Pacific Northwest National Laboratory

Operated by Battelle for the

U.S. Department of Energy

\section{Limited Field Investigation Report for Uranium Contamination in the 300-FF-5 Operable Unit at the 300 Area, Hanford Site, Washington}

\author{
B. A. Williams \\ C. F. Brown \\ W. Um \\ M. J. Nimmons \\ R. E. Peterson \\ B. N. Bjornstad \\ D. C. Lanigan \\ R. J. Serne \\ F. A. Spane \\ M. L. Rockhold
}

November 2007 


\title{
DISCLAIMER
}

This report was prepared as an account of work sponsored by an agency of the United States Government. Neither the United States Government nor any agency thereof, nor Battelle Memorial Institute, nor any of their employees, makes any warranty, express or implied, or assumes any legal liability or responsibility for the accuracy, completeness, or usefulness of any information, apparatus, product, or process disclosed, or represents that its use would not infringe privately owned rights. Reference herein to any specific commercial product, process, or service by trade name, trademark, manufacturer, or otherwise does not necessarily constitute or imply its endorsement, recommendation, or favoring by the United States Government or any agency thereof, or Battelle Memorial Institute. The views and opinions of authors expressed herein do not necessarily state or reflect those of the United States Government or any agency thereof.

\author{
PACIFIC NORTHWEST NATIONAL LABORATORY \\ operated by \\ BATTELLE \\ for the \\ UNITED STATES DEPARTMENT OF ENERGY \\ under Contract DE-AC05-76RL01830
}

\author{
Printed in the United States of America \\ Available to DOE and DOE contractors from the \\ Office of Scientific and Technical Information, \\ P.O. Box 62, Oak Ridge, TN 37831-0062; \\ ph: (865) 576-8401 \\ fax: (865) 576-5728 \\ email: reports@adonis.osti.gov

\begin{abstract}
Available to the public from the National Technical Information Service, ph: (800) 553-6847 fax: (703) 605-6900

email: orders@ntis.fedworld.gov online ordering: http://www.ntis.gov/ordering.htm
\end{abstract} \\ U.S. Department of Commerce, 5285 Port Royal Rd., Springfield, VA 22161
}




\title{
Limited Field Investigation Report for Uranium Contamination in the 300-FF-5 Operable Unit at the 300 Area, Hanford Site, Washington
}

\author{
B. A. Williams \\ C. F. Brown \\ W. Um \\ M. J. Nimmons \\ R. E. Peterson \\ B. N. Bjornstad \\ D. C. Lanigan \\ R. J. Serne \\ F. A. Spane \\ M. L. Rockhold
}

November 2007

Prepared for

the U.S. Department of Energy

under Contract DE-AC05-76RL01830

Pacific Northwest National Laboratory

Richland, Washington 99352 


\section{Executive Summary}

Additional data needed for development of a Comprehensive Environmental Response, Compensation, and Liability Act (CERCLA) Phase III Feasibility Study to address a persistent uranium plume in 300 Area groundwater provided the stimulus for the limited field investigation (LFI) described in this report. The focus of the LFI was to determine the location and geochemical nature of the source for the uranium plume. These objectives were accomplished by drilling four new groundwater monitoring wells in the 300-FF-5 Operable Unit (OU) in fiscal year 2006 as defined in the Operable Unit Limited Field Investigation Plan (DOE 2006a). Wells 399-3-18 (C4999), 399-3-19 (C5001), 399-3-20 (C5002), and 399-1-23 (C5000) were drilled to characterize the uranium distribution in sediments in the vadose zone and the unconfined aquifer. In addition to uranium, the presence of other contaminants of concern were also evaluated.

Uranium contamination in groundwater beneath the Hanford Site's 300 Area has persisted longer than predicted by modeling that was conducted during the 1990s as part of the initial remedial investigation for the 300-FF-5 Operable Unit. Even though discharge of uranium-bearing effluent to infiltration ponds and trenches ended by the mid-1980s, and removal of contaminated soil from former waste sites was accomplished in the late 1990s, the groundwater plume today continues to occupy a relatively constant area, with concentrations remaining within a fairly fixed range. Because portions of the plume exceed the drinking water standard for uranium (30 $\mu \mathrm{g} / \mathrm{L})$, the U.S. Department of Energy is supporting renewed remedial investigation activities and remedial action feasibility studies. The goal of this renewed effort is to find a remedy that will reduce uranium concentrations in the aquifer such that the aquifer is restored to its maximum beneficial use, i.e., as a potential supplier of drinking water.

To provide the information necessary to proceed with the remedial action feasibility study and possible field treatability tests, a limited field investigation (LFI) has been conducted. The focus of the LFI was to determine the location and mobility characteristics for contaminant uranium that continues to re-supply the groundwater plume. Presumed sources include uranium remaining in the vadose zone and/or sequestered in the aquifer sediments, which interact with the fluctuating groundwater-river water. This information is fundamental for evaluating remedial action alternatives to reduce the concentration of uranium in groundwater to meet regulatory standards. New results provided by the LFI will be used in developing computer simulations of groundwater flow and uranium transport, in designing treatability field tests, and when implementing remedial action decisions.

The four LFI borehole locations were chosen to represent various combinations of proximity to former waste disposal sites, proximity to the Columbia River, and wide ranging hydrogeologic features. Highly detailed descriptions of geologic features encountered during drilling facilitated re-interpretation of descriptions from earlier drilling activities. Extensive analytical work was conducted on sediment samples collected from the continuous core recovered from each borehole, and on water samples collected from the saturated zone at depth discrete intervals during drilling. Hydrologic testing was conducted at multiple depth levels in each borehole to provide data on the ability of the sediment to transmit water. Geophysical logging of the entire borehole was conducted to provide additional details on stratigraphic features, and in an attempt to identify and quantify contaminant uranium concentrations. In addition to uranium, new information was obtained on the unexpected presence of other contaminants of concern (i.e., volatile organic compounds) at depths below those routinely monitored by the existing well network. 
The LFI produced abundant new observational data about conditions in the vadose zone and unconfined aquifer that are relevant to uranium contamination in the subsurface environment. The new information developed during the LFI pertains to stratigraphy and hydrologic units; the vertical distribution of uranium in the vadose zone and unconfined aquifer; and the potential usefulness of geophysical logging for mapping contaminant uranium in future boreholes. Principal findings relative to the objectives for the LFI include:

- The sonic drilling method was successfully used to recover abundant cored sections of the coarse, loosely consolidated gravel and sand units comprising the vadose zone and unconfined aquifer beneath the 300 Area. A portion of the core recovered has been archived and is available for future investigations.

- Geologic characterization activities performed during drilling have revealed significant new details on the stratigraphy at these sites. The new information allowed re-interpretation of drilling logs for previously installed wells, followed by a substantial update to the database for the hydrogeologic framework for the 300 Area. This update helps reduce uncertainty in computer simulation of groundwater flow and uranium transport through the aquifer.

- Lower than expected levels of contaminant uranium were encountered in the sediment samples from the vadose zone, and were too low to permit use of spectral gamma geophysical logging in the field to define the vertical distribution of contaminant uranium in boreholes. Because of this, the planned Phase II drilling was canceled, as it depended on using spectral gamma logging to map the distribution of contaminant uranium over a broad area.

- At three of the four borehole locations, there is no distinct evidence from laboratory geochemical analysis of samples collected during drilling and/or geophysical logging of relatively elevated levels of uranium in sediment immediately above the water table. At the fourth location, 399-1-23 (C5000), which is near the most recently active waste disposal site, somewhat elevated levels of uranium are indicated in the lower portion of the vadose zone. Elevated levels of contamination in this "smear zone" near the water table have been postulated as a source region that continues to supply uranium to the groundwater plume.

- Relatively high concentrations of uranium have been estimated for moisture associated with the unsaturated sediment above the water table in two of the four boreholes drilled (399-3-18 and 399-1-23). The estimates are based on the amount of uranium measured in 1:1 water extracts of sediment samples. These results are then adjusted so that they represent the concentrations present in the natural moisture associated with the sediment, as estimated using the lab sample. The implication of high uranium concentrations in vadose zone moisture with regard to re-supply of uranium to the groundwater plume is under investigation.

- Contaminant uranium extracted from aquifer sediment samples was also at relatively low levels and comparable to levels observed in samples from the vadose zone.

- Total uranium concentrations in depth-discrete groundwater samples collected during drilling are generally consistent with concentrations observed in historical groundwater monitoring results. 
- The discrete interval groundwater sampling, laboratory geochemical extracts of the sediments, and hydraulic conductivity measurements conducted during drilling confirmed that the groundwater uranium plume is constrained above the Hanford-Ringold contact boundary. These data are consistent with groundwater uranium concentrations obtained from the current 300 Area monitoring well network.

Additional discoveries not directly related to the initial objectives for the LFI include:

- Volatile organic compounds were discovered in many of the groundwater samples collected during drilling. Unexpectedly high concentrations of trichloroethene were encountered in some deep aquifer water samples from two of the boreholes. The samples were obtained from below the saturated Hanford formation in a relatively fine-grained (i.e., less transmissive) subunit within the Ringold Formation.

- Unexpectedly low values for the specific conductance of groundwater samples were measured at one location deep in the unconfined aquifer. The anomalously low values appear to be correlated with the relatively fine-grained subunit in the Ringold Formation, and the significance of this finding is not currently well understood.

This report includes a compilation of all geologic, hydrologic, geochemical, and geophysical data collected. Final monitoring well construction and development activities are described. The report is intended to be a reference document that provides updated descriptions of (a) the hydrogeologic framework for the uranium plume, (b) the vertical distribution of contaminant uranium, and (c) the geochemical features that control the fate and mobility of uranium. The new information provided by the LFI will lead to a refinement of the conceptual site model for uranium contamination in the 300 Area subsurface environment. When combined with the results from treatability tests and an updated conceptual site model, the Phase III Feasibility Study will lead to a future Proposed Plan for remedial action in the 300-FF-5 Operable Unit. 


\section{Acknowledgments}

The Pacific Northwest National Laboratory (PNNL) performed work to characterize the extent of uranium contamination in the vadose zone and unconfined aquifer within the 300-FF-5 Operable Unit of the Hanford Site, Washington. The successful completion of this project was largely due to an integrated network of PNNL staff from the Remediation and Closure Science Project, the Groundwater Performance Assessment Project, and the Environmental Sciences laboratory who contributed their collective and varied expertise to solve many of the environmental challenges that were part of this characterization effort.

Special thanks go to the field geologist, Jake Horner (Gram, Inc), for consistent, excellent work and tireless hours in the field during borehole drilling, characterization, and well construction. The project also thanks Rick McCain and supporting staff at Stoller, Inc., for borehole geophysical characterization and technical support. Thanks to PNNL's Rob Mackley, Brad Fritz, and Donny Mendoza for providing support to the characterization effort by supplying geologic sample data from the Columbia River and the hyporheic zone. The authors would also like to thank Steven Baum, Eric Clayton, Ray Clayton, Keith Geiszler, Cristian Iovin, Igor Kutnyakov, Michael Lindberg, Robert Orr, Rory Peterson, Kenton Rod, and Michelle Valenta (all of PNNL) for participating in planning the laboratory tests and completing analyses of the sediment and solution samples from the characterization studies.

Thanks also go to Paul Thorne (PNNL) for mapping support, Tyler Gilmore for providing PNNL technical reviews, and Tom Naymik and Ron Smith, PNNL project managers. Special thanks also go to Jane Borghese and Curt Kooiker at Fluor Hanford, Inc. for providing technical reviews of this document.

Finally, the authors wish to thank the PNNL text processing and editorial staff, Lila Andor and Rosalind Schrempf, for their excellent work and for meeting all deadlines ahead of schedule. 


\section{Contents}

Executive Summary .................................................................................................... iii

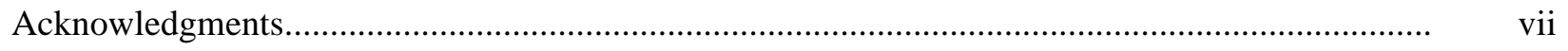

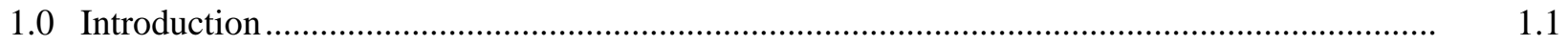

1.1 Regulatory Framework ........................................................................................

1.2 Persistence of the 300 Area Uranium Plume.................................................................... 1.3

1.3 Limited Field Investigation Objectives ......................................................................... 1.6

$1.4 \quad$ LFI Scope of Work: Overview …………………………………………………... 1.7

1.5 Background Information on the 300 Area.................................................................. 1.7

1.6 Organization of the Report ....................................................................................... 1.9

1.6.1 LFI Phase I - Borehole Drilling ..................................................................... 1.9

1.6.2 LFI Phase II - Geophysical Logging ............................................................ 1.10

1.6.3 Investigation Information and Data................................................................. 1.10

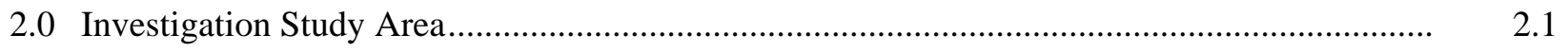

3.0 Updated Hydrogeologic Conceptual Model............................................................................... 3.1

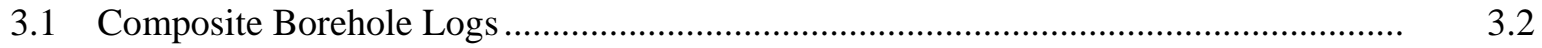

3.2 Borehole Lithology and Physical Properties ……………………………………….... 3.2

3.3 Sediment Core Photographic Log ………………………………………………... 3.2

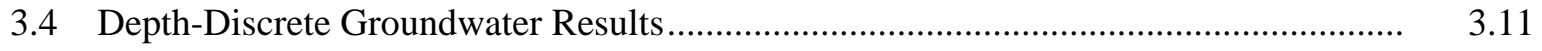

3.5 Depth-Discrete Aquifer Hydraulic Testing Results..................................................... 3.12

3.6 Spectral Gamma and Neutron Moisture Logging …………………………………... 3.18

3.7 Subsurface Characterization ......................................................................................... 3.18

4.0 Revised and Updated Contaminant Distribution Model ...........................................................

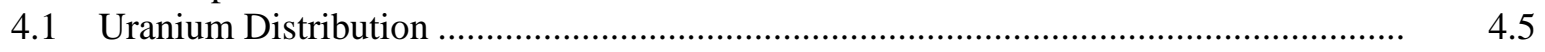

4.1.1 Uranium Contamination in the Aquifer........................................................... 4.5

4.1.2 Uranium Contamination in the Vadose Zone .................................................... 4.6

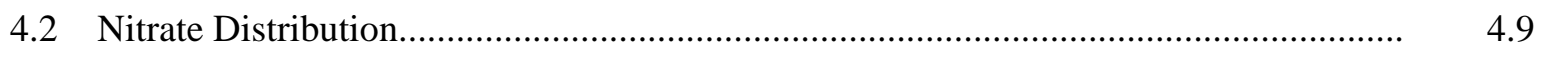

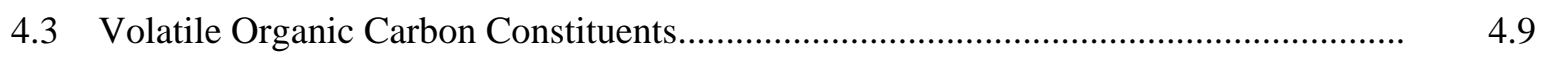

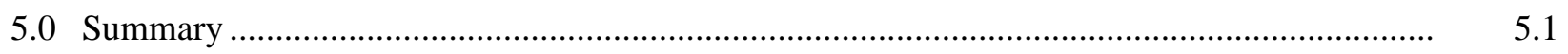

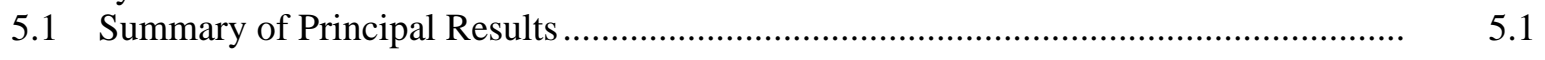

5.1.1 Drilling/Characterization Methodology ………………………………………. 5.1

5.1.2 Hydrogeologic Framework.............................................................................. 5.1

5.1.3 Contaminant Uranium in the Vadose Zone...................................................... 5.2

5.1.4 Contaminant Uranium in the Aquifer.............................................................. 5.3

5.1.5 Additional Discoveries and Observations ....................................................... 5.3

5.2 Phase II Drilling Activity …………………………………………………….... 5.4

5.3 Limitations and Caveats ........................................................................................... 5.4

6.0 LFI Phase I - Borehole Data ................................................................................................... 6.1

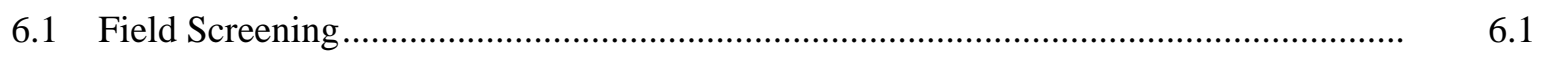

6.2 Well 399-3-18 (C4999) …………………………………………………….... 6.3

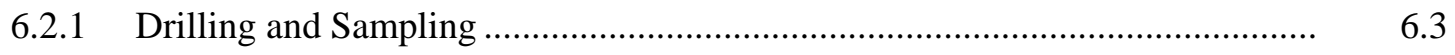

6.2.2 Well Completion ……………………………………………………..... 
6.2.3 Well Development and Pump Installation..................................................... 6.4

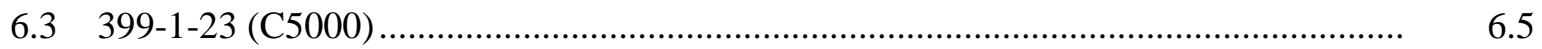

6.3.1 Drilling and Sampling .............................................................................. 6.5

6.3.2 Well Completion .................................................................................. 6.7

6.3.3 Well Development and Pump Installation..................................................... 6.7

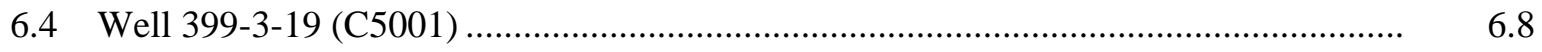

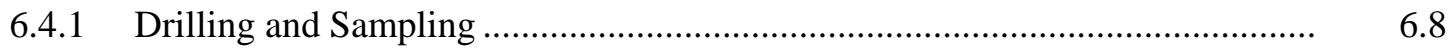

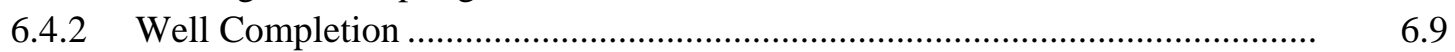

6.4.3 Well Development and Pump Installation....................................................... 6.9

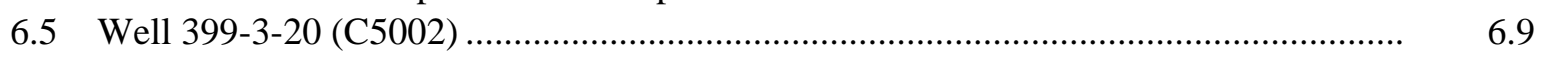

6.5.1 Drilling and Sampling .................................................................................. $\quad 6.10$

6.5.2 Well Completion ............................................................................... $\quad 6.10$

6.5.3 Well Development and Pump Installation................................................... 6.11

6.6 Field Characterization and Laboratory Activities Associated with the 300 Area

Limited Field Investigation ...................................................................................... $\quad 6.11$

6.6.1 Sediment Sampling and Analysis................................................................. 6.12

6.6.2 Depth-Discrete Groundwater Sampling and Analysis .................................... 6.44

6.6.3 Depth-Discrete Interval Aquifer Hydraulic Test Characterization.................... 6.47

6.6.4 Borehole Geophysical Logging .................................................................. 6.51

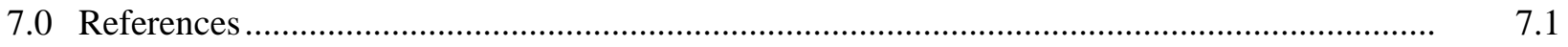

Appendix A - Well Summary Data .................................................................................... A.1

Appendix B - Sediment Core Data from Wells 399-3-18, 399-1-23, 399-3-19, and 399-3-20........ $\quad$ B.1

Appendix C - Borehole Geophysical Log Reports.................................................................. C.1

Appendix D - Laboratory Results of Groundwater and Sediment Analysis from

Wells 399-1-23, 399-3-18, 399-3-19, and 399-3-20 ............................................... D. D.

Appendix E - Selected Slug Test Analysis Plots for Discrete Depth Interval Testing .................... _ E.1

Appendix F - Groundwater Sampling Data ............................................................................. F.1

Appendix G - Well Installation Daily Field Activity Reports, C4999, C5000, C5001, and C5002.

G.1 


\section{Figures}

1.1 Limited Field Investigation Well Location Map - 300-FF-5 Operable

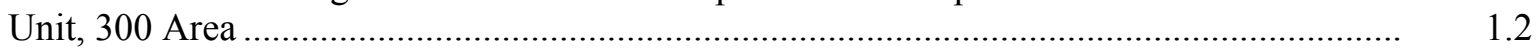

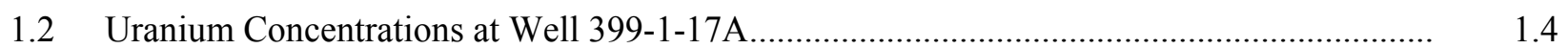

1.3 Uranium Concentrations and Water-Level Elevations at Wells 399-1-12 ............................ 1.5

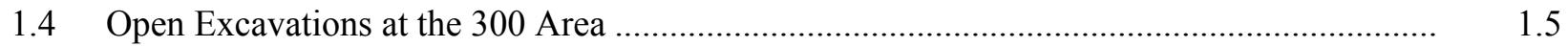

2.1 Location Map of New LFI Wells and Uranium Groundwater Contaminant Plume............... 2.2

3.1 Hydrogeologic Column Depicting the Hydrogeology of the 300 Area................................. 3.1

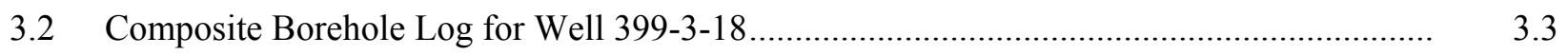

3.3 Composite Borehole Log for Well 399-1-23 .................................................................. 3.5

3.4 Composite Borehole Log for Well 399-3-19 .................................................................. 3.7

3.5 Composite Borehole Log for Well 399-3-20 ...............................................................

3.6 Vertical Distribution of Hydraulic Conductivity for Selected Depth Intervals at

3.7 Vertical Distribution of Hydraulic Conductivity for Selected Depth Intervals at Well 399-1-23, Based on Field Aquifer Hydraulic Test Characterization ............................. 3.14

3.8 Vertical Distribution of Hydraulic Conductivity for Selected Depth Intervals at Well 399-3-20, Based on Field Aquifer Hydraulic Test Characterization ............................. 3.17

3.9 Core Photograph Showing the Hanford Formation - Ringold Formation Contact Boundary in Well 399-3-18.

3.10 Core Photograph Showing the Ringold Formation Unit 5 and Unit 8 Contact Boundary in Well 399-1-23...

3.11 Schematic Cross Section Trending Southwest to Northeast Illustrating the Three Primary Hydrologic Units within the Unconfined Aquifer, 300-FF-5 Operable Unit

3.12 Elevation Contour Map of the Hanford/Ringold Contact Boundary, 300-FF-5 Operable Unit ....

3.13 Aerial Photograph Showing the 300 Area Under Construction …....................................... 3.24

3.14 Location Map Showing the Orientation of Hydrogeologic Cross Sections, 300-FF-5 Operable Unit

3.15 Hydrogeologic Cross Section 1-1' Illustrating the Unconfined Aquifer, H/R Contact and the Uranium Contaminant Distribution in Groundwater

3.16 Hydrogeologic Cross Section 2-2' Illustrating the Unconfined Aquifer, H/R Contact and the Uranium Contaminant Distribution in Groundwater .

3.17 Hydrogeologic Cross Section A-A’ Illustrating the Unconfined Aquifer, H/R Contact and the Uranium Contaminant Distribution in Groundwater ...

3.18 LFI Well Location Map Showing Locations of Ringold Formation Undesignated Fine-Grained Sand Samples Collected from the Columbia River Bottom and Shoreline.

3.19 Core Photograph Showing Open-Framework Gravel of the Hanford Formation in Well 399-3-20. 
3.20 Core Photograph Showing Reworked Sediments Within the Hanford Formation

Vadose Zone in Well 399-1-23

4.1 Stiff Chemistry Plots for Depth-Discrete Groundwater Samples in Well 399-3-18 _............ 4.2

4.2 Stiff Chemistry Plots for Depth-Discrete Groundwater Samples in Well 399-1-23 .............. 4.3

4.3 Stiff Chemistry Plots for Depth-Discrete Groundwater Samples in Borehole 399-3-19........ $\quad 4.4$

4.4 Stiff Chemistry Plots for Depth-Discrete Groundwater Samples in Borehole 399-3-20........ $\quad 4.4$

4.5 Soluble Uranium Concentrations in the Depth-Discrete Groundwater, Pore Water After Ultracentrifugation, and Calculated Pore Water Uranium Concentrations in the Sediments from Boreholes 399-3-18, 399-1-23, 399-3-19, and 399-3-20

6.1 Well Location Map for Limited Field Investigation Wells 399-3-18, 399-1-23, 399-3-19, and 399-3-20, 300-FF-5 Operable Unit

6.2 Six-Foot Splitspoon Core Barrel and Drive Shoe, and Opened Splitspoon Core Barrel During Recovery of Lexan Core Liners

6.3 Well 399-3-18 Core Photograph - Example of Preserved Structure Along the Hanford Formation/Ringold Formation Hydrogeologic Boundary

6.4 Moisture Content Data for Samples from Wells 399-3-18; 399-1-23; 399-3-19; and 399-3-20.

6.5 GEA Plots-Total vs. Natural Uranium Data in Sediments from Well 399-3-18 based on the Measurement of ${ }^{238} \mathrm{U}$ Daughter Products.

6.6 GEA Plot-Total vs. Natural Uranium Data in Sediments from Well 399-1-23 based on the Measurement of ${ }^{238} \mathrm{U}$ Daughter Products.

6.7 GEA Plot-Total vs. Natural Uranium Data in Sediments from Well 399-3-19 based on the Measurement of ${ }^{238} \mathrm{U}$ Daughter Products.

6.8 GEA Plot-Total vs. Natural Uranium Data in Sediments from Well 399-3-20 based on the Measurement of ${ }^{238} \mathrm{U}$ Daughter Products.

6.9 Water Extracts and Extractable Uranium by WE, AE, and MD with GEA Data in Sediments from Well 399-3-18.

6.10 Water Extracts and Extractable Uranium by WE, AE, and MD with GEA Data in Sediments from Well 399-1-23

6.11 Water Extracts and Extractable Uranium by WE, AE, and MD with GEA Data in Sediments from Well 399-3-19

6.12 Water Extracts and Extractable Uranium by WE, AE, and MD with GEA Data in Sediments from Well 399-3-20.

6.13 Grain-Size Distribution Data and Fitted Function for Sample C5001-74B from Well 399-3-19

6.14 Labile Uranium Leached from Well 399-3-18 Sediments Using Carbonate Extractant .........

6.15 Labile Uranium Leached from Well 399-1-23 Sediments Using Carbonate Extractant .........

6.16 Labile Uranium Leached from Well 399-3-19 Sediments Using Carbonate Extractant .........

6.17 Labile Uranium Leached from Well 399-3-20 Sediments Using Carbonate Extractant .........

6.18 Leachable Uranium Concentration vs. Reaction Times for Well 399-3-18 Sediments with Three Different Extract Solutions Pore Water; Groundwater; and River Water. 
6.19 Leachable Uranium Concentration vs. Reaction Times for Well 399-1-23 Sediments with Three Different Extract Solutions Pore Water; Groundwater; and River Water

6.20 Leachable Uranium Concentration vs. Reaction Times for Well 399-3-19 Sediments with Three Different Extract Solutions Pore Water; Groundwater; and River Water

6.21 Leachable Uranium Concentration vs. Reaction Times for Well 399-3-20

Sediments with Three Different Extract Solutions Pore Water; Groundwater; and River Water.

6.22 Comparison of Laboratory Sediment Gamma Energy Analysis KUT Results to the Borehole Geophysical Spectral Gamma KUT Results for Borehole 399-3-18

6.23 Comparison of PNNL Laboratory Sediment Gamma Energy Analysis KUT Results to Stoller Borehole Geophysical Spectral Gamma KUT Results for Borehole 399-1-23.

6.24 Comparison of PNNL Laboratory Sediment Gamma Energy Analysis KUT Results to Stoller Borehole Geophysical Spectral Gamma KUT Results for Borehole 399-3-19

6.25 Comparison of PNNL Laboratory Sediment Gamma Energy Analysis KUT Results to Stoller Borehole Geophysical Spectral Gamma KUT Results for Borehole 399-3-20

\section{Tables}

1.1 Published 300 Area Reports

3.1 Well 399-3-18 Aquifer Hydraulic Test Analysis Results

3.2 Well 399-3-18 Hydraulic Conductivity Distribution.

3.3 Well 399-1-23 Aquifer Hydraulic Test Analysis Results

3.4 Well 399-1-23 Hydraulic Conductivity Distribution.

3.5 Well 399-3-19 Test/Depth Interval Aquifer Hydraulic Test Analysis Results

3.6 Well 399-3-19 Test/Depth Hydraulic Conductivity Distribution...

3.7 Well 399-3-20 Aquifer Hydraulic Test Analysis Results

3.8 Well 399-3-20 Hydraulic Conductivity Distribution.

4.1 Volatile Organic Compounds in Water Samples Collected During Drilling at 300 Area Limited Field Investigation Sites....

6.1 Location and Elevation Data for New CERCLA Wells 399-3-18, 399-1-23, 399-3-19, and 399-3-20

6.2 Well Development Information for Wells 399-3-18, 399-1-23, 399-3-19, and 399-3-20.......

6.3 Characterization Analyses

6.4 300 Area LFI Sediment Core Inventory by Well

6.5 Physical Property Data for Bulk Sediment Samples from Wells 399-3-18, 399-1-23, 399-3-19, and 399-3-20 
6.6 Estimated Values of Ks for Bulk Sediment Samples from Wells 399-3-18, 399-1-23, 399-3-19, and 399-3-20 Based on Various Empirical Formulas.....

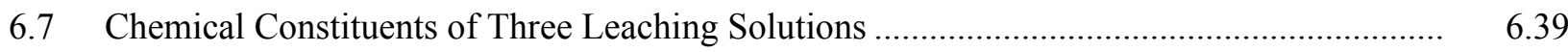

6.8 Summary of Depth-Discrete Groundwater Sampling in 300 LFI Boreholes ........................ 6.45

6.9 List of Selected Groundwater Constituents for Laboratory Analysis of Depth Discrete

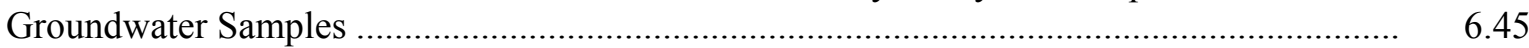

6.10 Uranium Concentrations in Depth Discrete Groundwater Samples ...................................... 6.47

6.11 Summary of Depth Discrete Aquifer Tests in 300 LFI Boreholes ........................................ 6.48

6.12 Aquifer Hydraulic Test Characteristics for Selected Test/Depth Intervals at

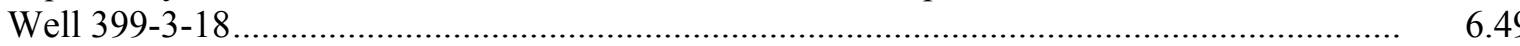

6.13 Aquifer Hydraulic Test Characteristics for Selected Test/Depth Intervals at Well 399-1-23

6.14 Aquifer Hydraulic Test Characteristics for Selected Test/Depth Intervals at Well 399-3-19

6.15 Aquifer Hydraulic Test Characteristics for Selected Test/Depth Intervals at Well 399-3-20 


\subsection{Introduction}

A limited field investigation (LFI) was undertaken in the Hanford Site 300 Area during 2006 to characterize the distribution and determine the processes that mobilize uranium in the vadose zone and aquifer at the 300 Area (TPA Milestone M-016-68, as updated February 25, 2005).

Detailed information on the geologic, hydrogeologic, and geochemical features that influence the mobility of uranium was collected from four boreholes drilled at four locations within the uranium plume (Figure 1.1). In addition to recovering nearly continuous core for each borehole, water samples were collected and aquifer testing was completed at frequent intervals in the saturated zone. Borehole geophysical logging was conducted to help define stratigraphic features and the presence of uranium originating from former nuclear reactor fuel production activities.

The LFI is part of a Comprehensive Environmental Response, Compensation, and Liability Act (CERCLA) Phase III Feasibility Study that focuses on the 300 Area uranium groundwater plume. Groundwater beneath the 300 Area is one of three geographic subregions of the 300-FF-5 Operable Unit (OU). Although other contaminants of potential concern (COPC) are present within the 300 Area subregion, only uranium has been deemed of sufficient concern to warrant additional study of remediation alternatives. The discovery of volatile organic carbon contaminants in this study warrants additional characterization beyond the LFI described herein. The results of this LFI will be used in the Phase III Feasibility Study which will lead to a future Proposed Plan for groundwater in the $300-\mathrm{FF}-5$ OU.

This report summarizes the findings from the LFI including the drilling, sampling, characterization, and well installation activities of this effort and provides a data compilation of those results. The report is intended to compile all available hydrogeologic, geochemical and well construction information obtained during the field investigation and associated groundwater, sediment, and geophysical analyses. Data presented in this report will be combined with previous characterization efforts to produce an integrated conceptual site model that will be documented in a separate report.

English units are used in this report in various locations to describe drilling and well completion and related activities because that is the system of units used by drillers and geologists to measure and report depths and well construction measurements. Metric units are used in other portions of this report.

Conversion to metric can be done by multiplying feet by 0.3048 to obtain meters or by multiplying inches by 2.54 to obtain centimeters.

\subsection{Regulatory Framework}

The LFI was conducted as part of a Phase III Feasibility Study for the 300-FF-5 Operable Unit (OU). The feasibility study is a partial consequence of the first 5-year review (EPA 2001) of the Record of Decision for the OU (EPA 1996). The review found that dissolved uranium plume predictions made during the initial remedial investigation/feasibility study (DOE-RL 1995b, p. 4-22) had not proven to be accurate. Subsequently, the Tri-Parties (U.S. Environmental Protection Agency [EPA], DOE, and Washington Department of Ecology [Ecology]) agreed to a new milestone (M-016-68, as updated February 25, 2005) calling for (a) a document providing updated conceptual models for the 300 Area uranium plume and 618-11 Burial Ground tritium plume, along with descriptions of the characteristics and trends for all previously identified contaminants of potential concern (COPC), (b) an evaluation of 


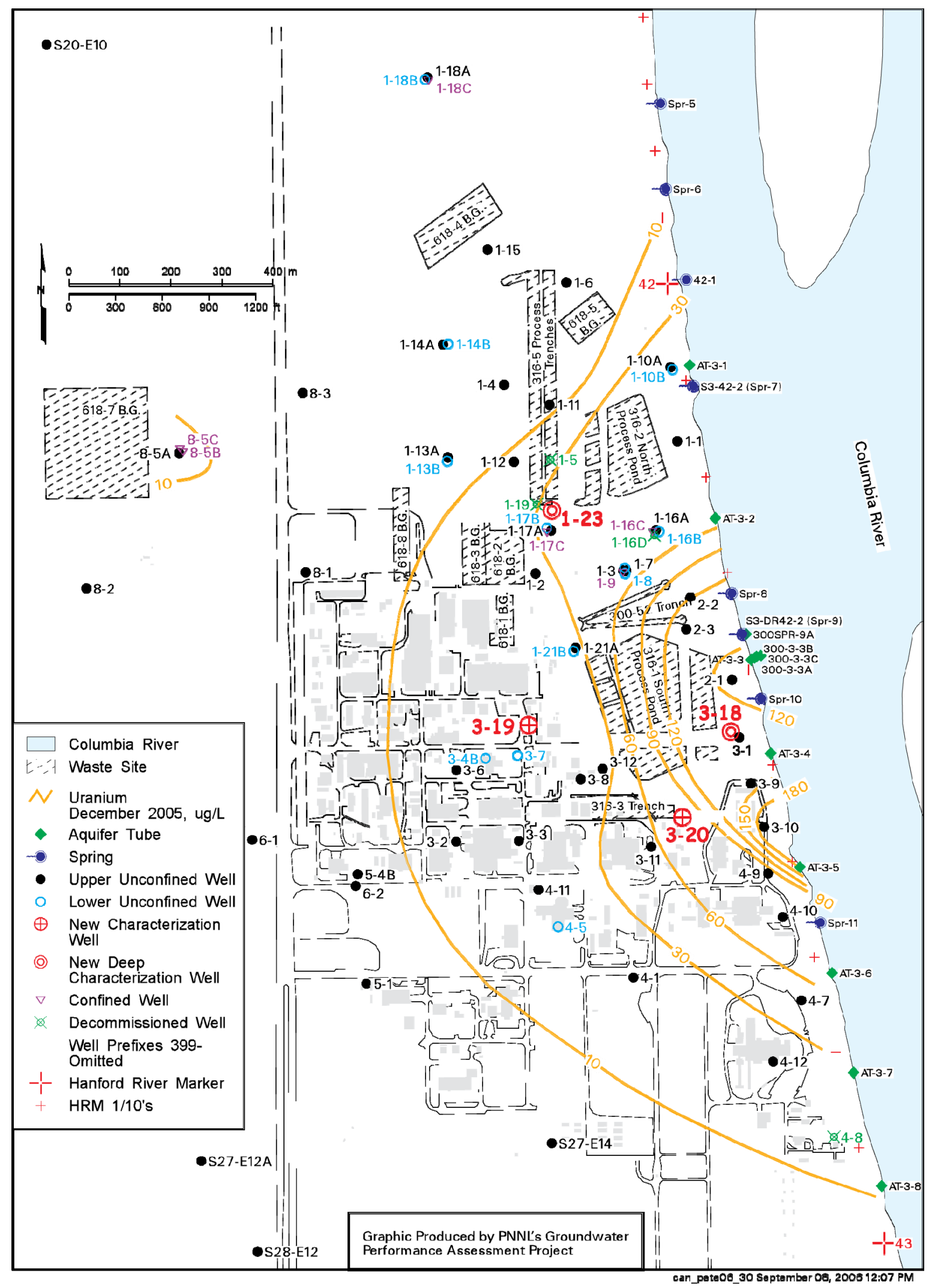

Figure 1.1. Limited Field Investigation Well Location Map - 300-FF-5 Operable Unit, 300 Area 
COPCs and updated list of those that should be retained for further evaluation, and (c) a work plan describing the scope and schedule for activities leading to a focused feasibility study report and proposed plan. Two documents were submitted to satisfy this March 31, 2005 milestone:

- Items (a) and (b):

- Contaminants of Potential Concern in the 300-FF-5 Operable Unit: Expanded Annual Groundwater Report for FY 2004 (Peterson et al. 2005).

- Item (c):

- Work Plan for Phase III Feasibility Study, 300-FF-5 Operable Unit (DOE 2005b).

- Following release of the Phase III Feasibility Study work plan, a LFI plan was developed and distributed in September 2005. That draft plan was subsequently revised and released in March 2006:

- 300-FF-5 Operable Unit Limited Field Investigation Plan (DOE 2006a).

The Record of Decision for the 300-FF-5 OU was developed in the mid-1990s (EPA 1996) and listed the following interim actions for groundwater:

- Continued monitoring of groundwater that is contaminated above health-based levels to make certain that concentrations continue to decrease.

- Institutional controls to make certain that groundwater use is restricted to prevent unacceptable exposures to groundwater contamination.

Although the first 5-year review of the Record of Decision found that these interim actions were still appropriate, it specified the need for additional monitoring and characterization activities. DOE decided to proceed with additional investigation of engineered remedial action alternatives (TPA Milestone M-016-68, Change Control M-016-04-05, August 9, 2004) to reduce the concentration of uranium in groundwater to levels below the U.S. Environmental Protection Agency's (EPA's) maximum contaminant level for drinking water supplies, i.e., $30 \mu \mathrm{g} / \mathrm{L}$ dissolved uranium in an unfiltered water sample.

A second 5-year review of this Record of Decision was conducted during 2006 and resulted in one action item (Action 19-1, due September 2008) that is specific to the 300 Area: "Complete focused feasibility study of 300-FF-5 OU to provide better characterization of the uranium contamination, develop a conceptual model, validate ecological consequences and evaluate treatment alternatives" (DOE 2006c, p. 3.16). The action item was developed in response to a review finding that the current interim remedy was not considered protective of human health or the environment. This LFI report documents the findings of the focused LFI and the data presented will be used in conjunction with all information available to update the conceptual site model for the 300 Area uranium plume. These data will then serve as the basis for the Phase III Feasibility Study and Proposed Plan for the 300-FF-5 OU.

\subsection{Persistence of the 300 Area Uranium Plume}

The persistence of the uranium plume in groundwater beneath the 300 Area after discharging of uranium-bearing liquid effluent to ground disposal facilities ended in 1985 represents a source of uncertainty as to the factors controlling contaminant migration within the area. Preliminary predictions made during the initial remedial investigation/feasibility study suggested that the plume would dissipate 
to meet regulatory requirements under natural conditions in 3 to 10 years from late 1993 (DOE 1995b). This contaminant plume dissipation has not occurred. Uranium concentrations in groundwater remain at relatively constant levels, though with distinct seasonal variations in concentration patterns; a portion of the uranium groundwater plume continues to exceed the current government regulatory standard for groundwater $(30 \mu \mathrm{g} / \mathrm{L})$. Several activities and events have occurred since the initial remedial investigation that prompts re-evaluation of the earlier conceptual model used to describe and simulate the uranium plume's behavior, including:

- Cessation of clean water discharge to the 300 Area process trenches (316-5 waste site). This clean water discharge occurred between 1991 and late 1994, and caused dilution of the uranium plume in the vicinity of the trenches. Uranium concentrations rebounded to earlier levels after 1994 (Figure 1.2).

- Unusually high water-table conditions during 1996 and 1997, caused by abnormally high Columbia River discharge. High water-table conditions have been suspected of remobilizing uranium contamination held in the lower vadose zone (Lindberg and Chou 2001, p. 4.12) (Figure 1.3).

- Extensive excavation of liquid waste disposal sites: Excavation of waste sites (process ponds) occurred during the mid-1990s, and backfilling did not occur until early 2004, thus exposing large portions of the 300 Area to potentially higher-than-normal rates of infiltration of moisture, which may have remobilized contamination held in the vadose zone (Figure 1.4).

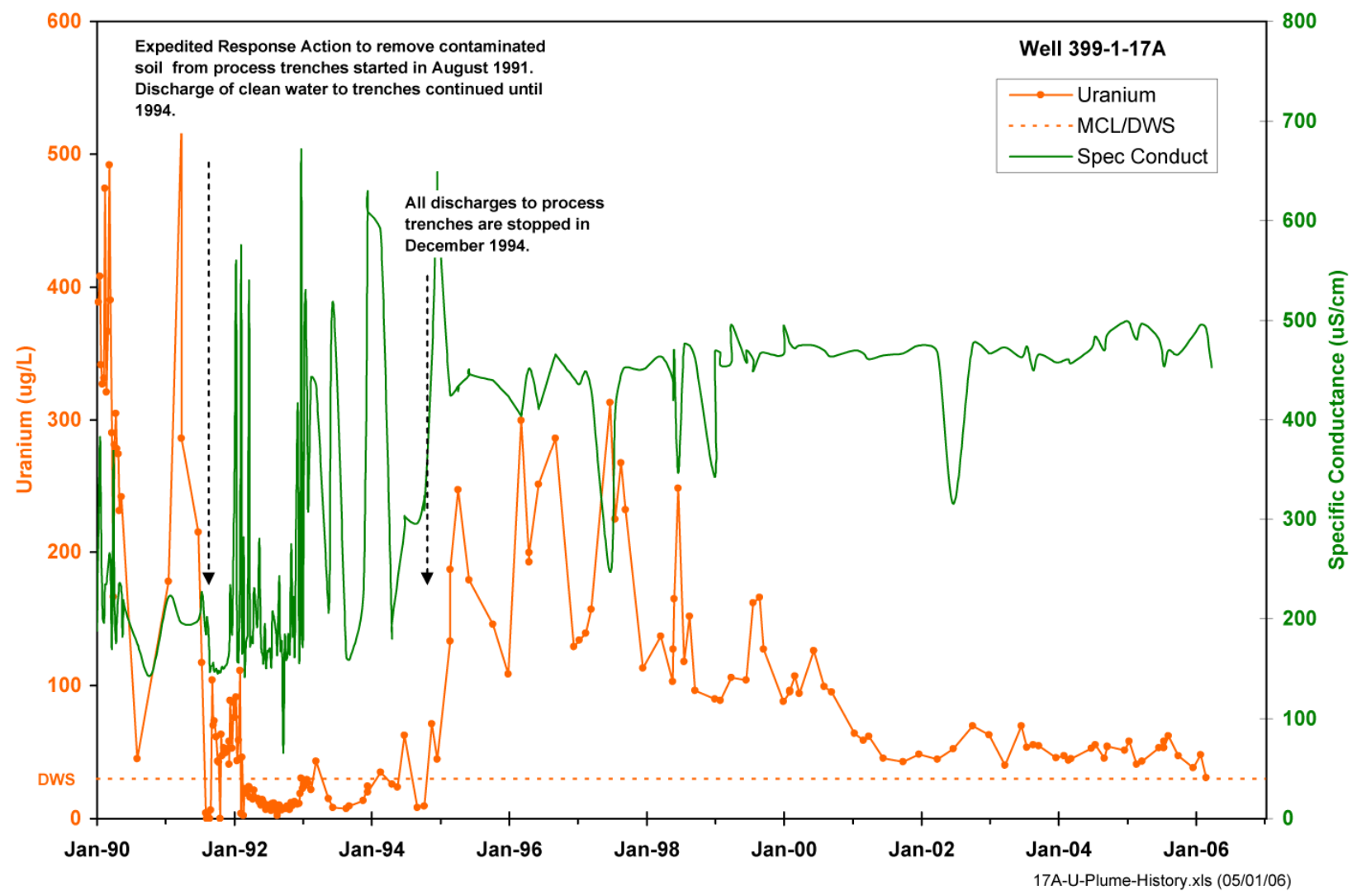

Figure 1.2. Uranium Concentrations at Well 399-1-17A 


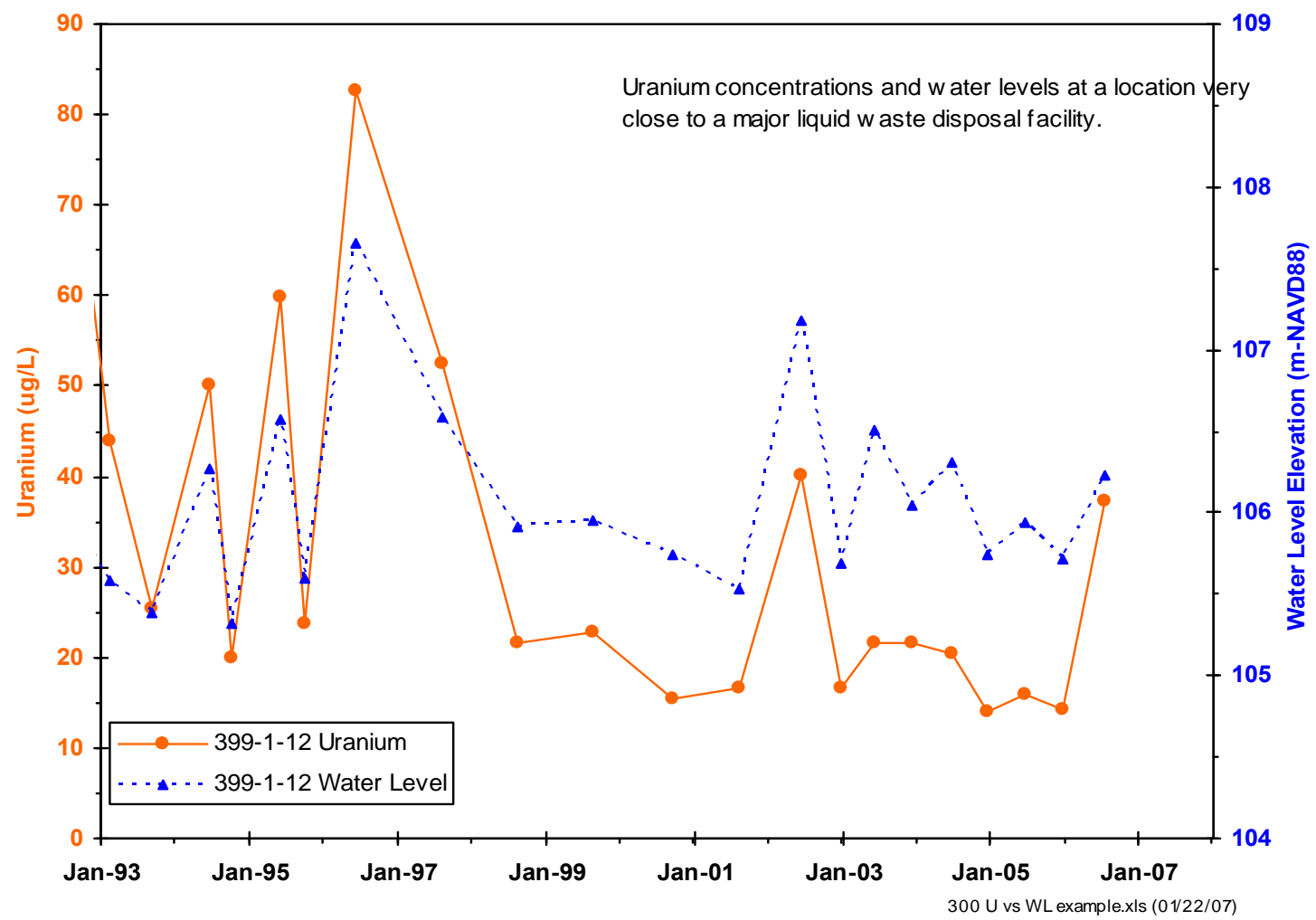

Figure 1.3. Uranium Concentrations and Water-Level Elevations at Wells 399-1-12

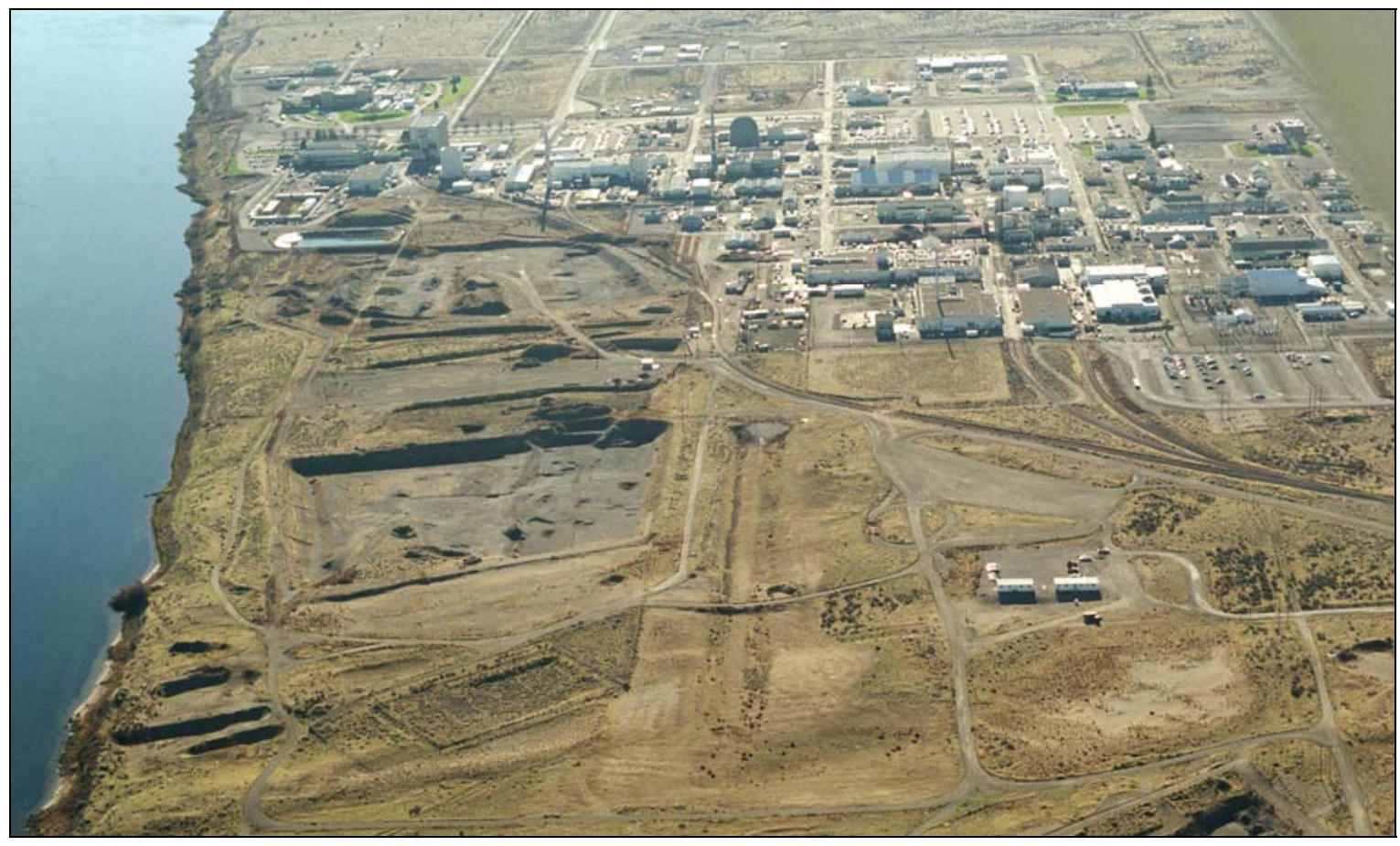

Figure 1.4. Open Excavations at the 300 Area 
These activities and events may partially explain why the plume has not dissipated as quickly as anticipated during the 1990 s, i.e., uranium continues to be supplied to groundwater at locations, and by processes, that are not yet fully understood. Without additional understanding, conducting a meaningful feasibility study to identify and evaluate remedies for the uranium in groundwater is not possible. Therefore, the U.S. Department of Energy (DOE) authorized this LFI to further characterize the distribution and processes that mobilize uranium in the vadose zone and aquifer at the 300 Area (TPA Milestone M-016-68, as updated February 25, 2005).

\subsection{Limited Field Investigation Objectives}

The LFI included a two-phased drilling, sampling, and test characterization campaign. Phase I utilized cored boreholes to characterize the vadose zone and uppermost aquifer at four representative locations. Phase II was to employ a widely distributed direct-push borehole network to gain access down to the water table for borehole geophysical logging characterization. The objectives for the LFI drilling phases are stated as information needs in the LFI work plan (DOE 2006a) as follows:

\section{Phase I - Characterization Boreholes}

- Determine the vertical distribution and concentrations for uranium in the lower vadose zone, the seasonally fluctuating zone between the low and high water table levels, and upper portion of the unconfined aquifer (uranium on aquifer solids and dissolved uranium).

- Evaluate the geochemical characteristics of sediment that influence uranium mobility in the environment (a) near the river, (b) near recently active waste sites, and (c) inland from river influence.

- Determine the hydraulic characteristics of sediment that influence movement of natural moisture, residual waste effluent that remains in the vadose zone and aquifer, and fluids injected as part of remedial action.

- Determine the relationship between spectral gamma logging data and laboratory analytical results for uranium.

- Determine the hydrogeologic framework and obtain subsurface geochemical data to better define preferential pathways for uranium transport along a postulated route(s) from waste site to the river (i.e., evidence for paleochannel).

\section{Phase II - Direct-Push Boreholes}

- Determine the vertical distribution of uranium in the vadose zone above the mapped groundwater plume.

- Determine the lateral/areal extent of zones where uranium is elevated in the vadose zone.

- Correlate concentration patterns that appear in the mapped plume with (a) waste sites, (b) proximity to the river, and (c) water-table elevation. 
During Phase I drilling of the characterization boreholes, it was determined that the high-resolution geophysical logging could not provide a low enough detection limit of contaminant uranium based on comparisons with laboratory analysis of sediment core samples, so the direct-push campaign, which does not obtain sediment samples and only provides a conduit to lower the high-resolution geophysical logging tools down into the vadose zone, was cancelled.

\subsection{LFI Scope of Work: Overview}

The characterization boreholes, Phase I, involved drilling four boreholes at locations representative of various hydrogeologic settings and proximity to liquid waste disposal sites. Two of the four boreholes were drilled through the entire unconfined aquifer; the remaining two extended into the upper part of the unconfined aquifer. Continuous core was recovered whenever possible from all four boreholes; water samples were collected at frequent intervals in the saturated zone; hydraulic tests were conducted at multiple intervals; and geophysical logging, including spectral gamma and neutron moisture logging, was completed for all four boreholes.

Select core were retained as archive material. Digital color photographs were taken, and a licensed geologist provided a description of each opened core section. The four boreholes were eventually completed as monitoring wells with screened intervals placed across the water table.

Analyses of sediment sub-samples from the recovered cores were divided into two tiers to accommodate the need for certain results immediately, and for other logistical considerations. As described in the LFI work plan (DOE 2006a), Tier 1 analyses of sediment included (1) moisture content and determination of total uranium concentration using gamma energy analysis (GEA), and (2) measurement of groundwater solution chemistry on the water samples. The uranium data were used to calibrate and confirm the geophysical spectral gamma logging results from the boreholes. Tier 2 analyses included particle-size distribution and solution chemistry of various extracts and leaching solutions from sediment samples. Core material was also made available to other investigators outside of the LFI who are working on various 300 Area research projects involving uranium.

Results from the LFI drilling and sample analysis activities are described in the following sections. These results and interpretations have provided new information and greater detail on existing information that forms the conceptual site model for uranium contamination in the 300 Area subsurface. Other investigations are underway in 2007 that will also contribute to that conceptual site model. These investigations include a drilling and sampling program focused on the discovery during the LFI of volatile organic compounds at depths greater than anticipated, and the DOE's Integrated Field-Scale Challenge initiative, which involves research directed at understanding the transport of uranium through the vadose zone and aquifer.

\subsection{Background Information on the 300 Area}

An extensive collection of reports is available with information on the 300 Area and its groundwater contamination issues. For readers not already familiar with the history of operations at the 300 Area, its hydrogeologic setting, contaminants of potential concern, and contaminant geochemistry, the reports listed in Table 1.1 are suggested for further information. A brief overview was prepared in 2004 (Peterson et al. 2005, pp. 1.2 to 1.4), from which the following paragraphs are extracted, with updates as appropriate. 
Table 1.1. Published 300 Area Reports

\begin{tabular}{||l||}
\hline History of Operations \\
\hline Data Compilation Task Report for the Source Investigation of the 300-FF-1 Operable Unit Phase I Remedial \\
Investigation (Young et al. 1990) \\
Addendum to Data Compilation Task Report for the Source Investigation of the 300-FF-1 Operable Unit Phase I \\
Remedial Investigations (Young and Fruchter 1991) \\
Past Practices Technical Characterization Study - 300 Area -Hanford Site (Gerber 1992) \\
300-FF-2 Operable Unit Technical Baseline Report (Deford et al. 1994) \\
\hline Hydrogeologic Setting \\
\hline Geohydrology and Groundwater Quality Beneath the 300 Area, Hanford Site, Washington (Lindberg and Bond \\
1979) \\
Interim Characterization Report for the 300 Areas Process Trenches (Schalla et al. 1988) \\
Phase I Hydrogeologic Summary of the 300-FF-5 Operable Unit, 300 Area (Swanson et al. 1992) \\
\hline Sampling and Hydrogeology of the Vadose Zone Beneath 300 Area Process Ponds (Bjornstad 2004) \\
\hline Contaminants of Potential Concern \\
\hline Contaminants of Potential Concern in the 300-FF-5 Operable Unit: Expanded Annual Groundwater Report for \\
FY 2004 (Peterson et al. 2005) \\
“300-FF-5 Operable Unit.” Chapter 2.12 in Hanford Site Groundwater Monitoring for Fiscal Year 2005 \\
(Lindberg and Peterson 2006) \\
\hline Contaminant Geochemistry \\
\hline The 300 Area Uranium Leach and Adsorption Project (Serne et al. 2002) \\
Uranium Geochemistry in Vadose Zone and Aquifer Sediments from the 300 Area Uranium Plume (Zachara \\
2005)
\end{tabular}

Facilities in the 300 Area of the Hanford Site were primarily involved with fabrication of nuclear fuel for plutonium production, which included some research and development activities, during the period spanning the startup of Hanford reactors in 1944 through the late 1980s (Young and Fruchter 1991). The range of activities produced a wide variety of waste streams that contained chemical and radiological constituents (Gerber 1992; Deford et al. 1994). Since the early 1990s, extensive remediation of inactive liquid waste disposal sites and solid waste burial grounds has taken place. As of December 2006, most liquid waste disposal sites, which are located in the northern half of the 300 Area, have been excavated, backfilled, and the ground surface contours restored. Some unknown amount of contamination likely remains in the vadose zone beneath the lower extent of the excavated areas. Additional contamination may also remain beneath buildings and facilities in the southern portion of the 300 Area, where decontamination and decommissioning activities are continuing, but where subsurface remedial action has not yet started.

The hydrogeologic intervals impacted by operations in the 300 Area consist of the Pliocene age Ringold Formation consisting of fluvial - lacustrine sediments deposited by the ancestral Columbia River (Lindsay 1995), and the Hanford formation which disconformably overlies an erosional surface in the Ringold Formation created during one or more Pleistocene cataclysmic floods (DOE 2002). 
Uranium is the most prominent waste constituent remaining in the environment beneath the 300 Area, and it has persisted in waste sites and groundwater during the years following the shutdown of most fuel fabrication activities and subsequent cessation of liquid effluent disposal to the ground. Uranium in soluble form is of concern for chemical toxicity and radiological exposure. The concentrations in groundwater for chemical toxicity are lower than those associated with radiological dose standards. Specific criteria on the toxicity to freshwater aquatic organisms are not been established, so by default, the criteria for the protection of aquatic organisms are the same as those applied for protection of human health. The EPA's maximum contaminant level for total uranium in groundwater for drinking water supplies is currently $30 \mu \mathrm{g} / \mathrm{L}$, measured as total uranium in an unfiltered water sample. Additional chemicals of concern present in groundwater beneath the 300 Area include the volatile organic compounds cis-1, 2-dichloroethene, trichloroethene, and tetrachloroethene. Also, groundwater monitoring confirms that tritium, nitrate, technetium-99, and trichloroethene migrate into the 300 Area from upgradient source areas (i.e., from the northwest and southwest).

\subsection{Organization of the Report}

This report documents: (a) an initial interpretation of the new geologic, hydrologic, and geochemical data obtained thus far; (b) all aspects of the drilling activities completed to date under the LFI (i.e., fulfills the requirement for a borehole completion report); (c) description of and results from analytical work performed on sediment core and water samples; and (d) results of hydrologic testing and geophysical logging. Additionally, selected information from other investigations or monitoring conducted contemporaneously is referenced to better interpret findings from the LFI. A summary and discussion section is included that identifies the major advances made toward an improved conceptual site model for uranium and the remaining uncertainties in achieving a credible technical baseline for evaluating remedial action alternatives for the 300 Area uranium plume.

\subsubsection{LFI Phase I - Borehole Drilling}

The LFI was divided into two main phases: Phase I - Borehole Drilling has been completed, and the results are provided in this report. The locations of the four new wells are shown on the location map in Figure 1.1. These new groundwater monitoring wells also fulfill requirements of the Hanford Federal Facility Agreement and Consent Order (Tri-Party Agreement; Ecology et al. 1989) Milestone M-24-57 ${ }^{1}$ during FY 2006. The new wells were constructed to the specifications and requirements described in Washington Administrative Code (WAC) 173-160, 300-FF-5 Operable Unit Field Investigation Plan (DOE 2005) and specifications provided by Fluor Hanford, Inc. (FHI), Richland, Washington. During drilling and construction of the wells, groundwater sampling and analysis activities were conducted to determine the distribution of radiological and chemical contaminants, collect continuous intact sediment core samples for hydrogeologic and geochemical characterization, and perform aquifer testing to determine aquifer flow conditions. Detailed geophysical logging was also performed to determine the distribution of manmade uranium in the subsurface.

\footnotetext{
${ }^{1}$ Letter from EJ Murphy-Fitch (Fluor Hanford, Inc., Richland, Washington) to Distribution, Tentative Agreement on Tri-Party Agreement Negotiations on the Overall Strategy and Approach for Hanford Groundwater Protection, Monitoring, and Remediation (M-024), dated September 22, 2003.
} 


\subsubsection{LFI Phase II - Geophysical Logging}

LFI Phase II - Geophysical logging, planned for 15 direct push (DPT) boreholes, was cancelled because sediment concentrations capable of producing the observed persistent uranium plume were at concentrations less than that detectable by geophysical logging and, in lieu of this scope, approval from regulators and DOE was received to perform additional analyses for uranium in sediment core samples collected from the Phase I boreholes. ${ }^{2}$ The results from that work are presented in this report. There are currently no plans to perform the LFI - Phase II scope.

\subsubsection{Investigation Information and Data}

All of the available and relevant information obtained during the LFI is contained in this report. Most of the supporting data and well information is located in the seven appendices at the end of this report.

Each appendix is organized to contain information about specific activities conducted during the LFI.

Appendix A contains the general well installation information such as the Well Summary Sheets, the field geologist's borehole logs, the well construction summary reports, well development and pump installation records, and the well survey results.

Appendix B contains the sediment core information including, core inventory forms, the geologists' core descriptions, photographs of the opened split spoon core, and core chain-of-custody forms.

Appendix C contains the complete geophysical log reports and data.

Appendix D contains the laboratory results of groundwater and sediment analysis and contains grainsize distribution data and metrics determined for whole (bulk) sediment samples from the four boreholes.

Appendix E contains aquifer testing information including selected slug test analysis plots and results.

Appendix F contains supporting information for the groundwater sampling activities which includes the depth-discrete groundwater sample location information and field sampling results, the groundwater sample analysis request reports, and the associated chain of custody forms.

Appendix G contains the drilling contractor's general well construction information including the contractor's borehole daily field activity reports, and the construction surveillance-acceptance report.

\footnotetext{
${ }^{2}$ Letter from Mr. Nick Ceto (Program Manager, U.S. Environmental Protection Agency, Region 10) to Matt McCormick (U.S. Department of Energy, Richland, Washington), Recommendation to Cancel 300-FF-5 Limited Field Investigation Direct Push Technology, dated November 15, 2006.
} 


\subsection{Investigation Study Area}

The LFI was completed at the 300 Area within the 300-FF-5 OU. As defined in the LFI work plan (DOE-RL 2006a), four characterization boreholes were drilled to collect subsurface data to define the vertical distribution of the uranium and obtain sediment and water samples for investigating their uranium sequestration and mobility characteristics (location map provided in Figure 2.1). Locations of new boreholes, principal liquid and solid waste sites, existing monitoring wells, and shoreline monitoring sites are shown in Figure 2.1. Criteria used to select locations for these boreholes included (a) within the 300 Area uranium plume as defined by the $10-\mu \mathrm{g} / \mathrm{L}$ contour, (b) proximity to a waste site that likely acted as a relatively recent supplier of uranium to groundwater, (c) one site influenced by river water infiltration, and (d) a second site inland of that influence and upgradient of the source areas. Consideration was given to drilling through former liquid waste disposal sites; however, the increased cost for drilling in potentially contaminated zones would have resulted in drilling at fewer locations. Future investigations are likely to include drilling through the footprints of former waste sites (e.g., DOE's Integrated Field-Scale Challenge initiative).

The first characterization borehole, 399-3-18 (C4999), is located in the central portion of the uranium plume, i.e., the area where concentrations exceed $60 \mu \mathrm{g} / \mathrm{L}$ near the Columbia River. This core area of the uranium plume intersects $\sim 800$ meters $(2,600$ feet) of the Columbia River shoreline and extends $\sim 300$ meters ( 980 feet) inland of the bank; it is generally downgradient of the primary 300 Area liquid waste disposal sources. Well 399-3-18 (C4999) is located 40 meters (130 feet) west of the riverbank and is adjacent to existing well 399-3-1 (see well location map in Figure 2.1).

This area of relatively high uranium concentrations also coincides with a topographically elevated Hanford/Ringold contact underlain by the erosional remnant of Ringold Formation fine-grained sediment. Drilling at this location was successful in confirming the presence of this fine-grained interval and recovering nearly continuous sediment core from this relatively low-permeability stratigraphic interval. The results will help to evaluate the hydraulic and geochemical influence that these fine-grained sediments have on uranium concentrations in the groundwater. This location also provided sediment core from the saturated to semi-saturated interval near the water table that is influenced by infiltrating Columbia River water.

The location for the second characterization borehole, 399-1-23 (C5000), was based on investigating the presence of a residual uranium source that may be located deep in the vadose zone, i.e., just above the present day water table and near a recently active waste site. Borehole 399-1-23 (C5000) is located near the liquid effluent discharge end of the decommissioned 300 Area process trenches (WIDS 316-5) (see Figure 2.1). Groundwater monitoring results dating back to the 1980 s indicate that these trenches were a primary source area for uranium that impacted the aquifer.

The first two boreholes spanned the vadose zone and the entire unconfined aquifer down to the Ringold Formation (Fm) lower mud confining unit, which was contacted between approximately 110 and 126 feet below ground surface (bgs). Thus, a complete vertical section through the upper unconfined aquifer was characterized for uranium and other COPC.

The third borehole, borehole 399-3-19 (C5001), was positioned to investigate the presence of residual uranium within the lower vadose zone and uppermost aquifer in an area that is outside of the plume migration path from the primary 300 Area liquid waste disposal sites (Figure 2.1). 


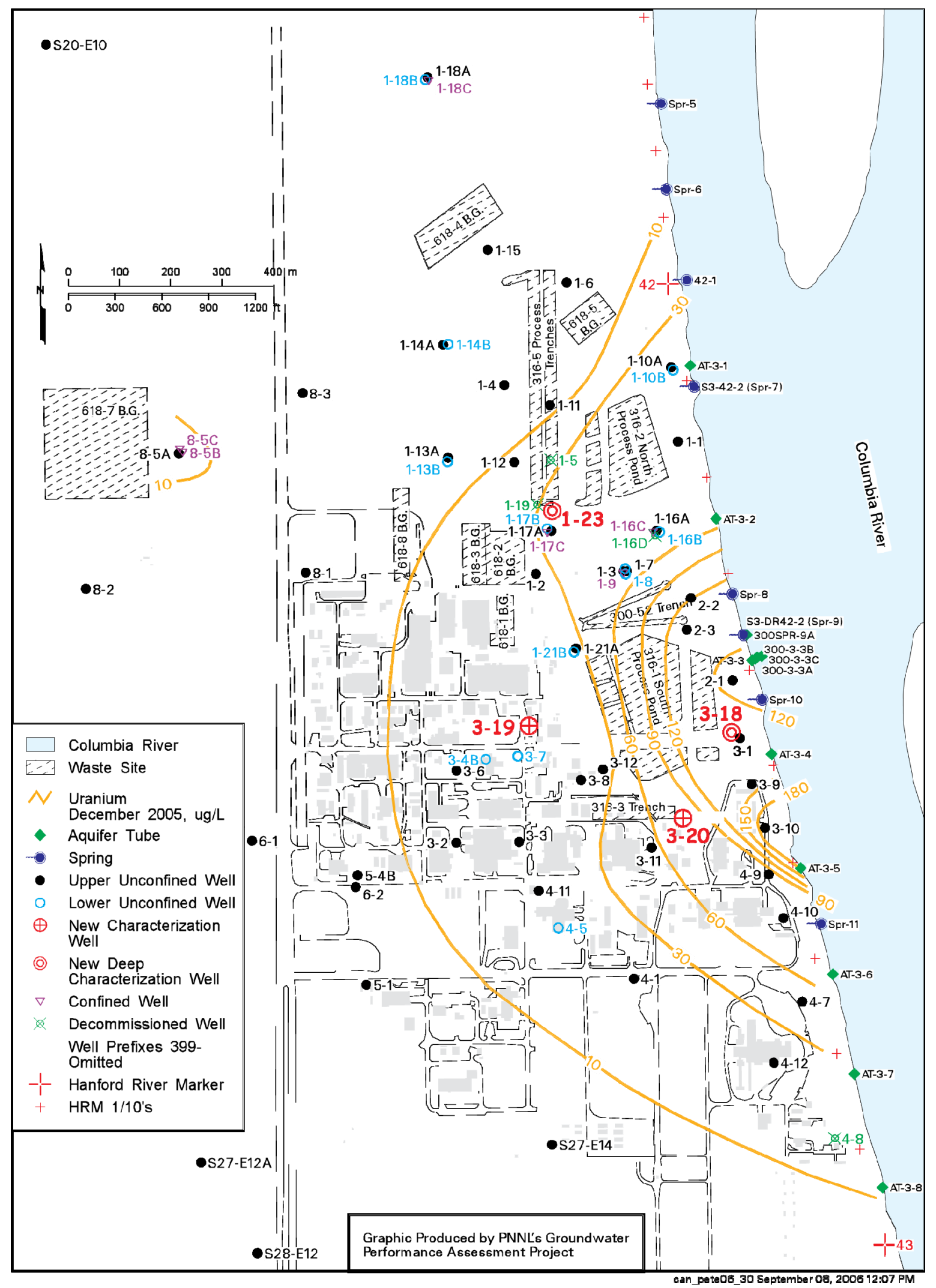

Figure 2.1. Location Map of New LFI Wells and Uranium Groundwater Contaminant Plume 
The location is also inland far enough that, under normal river flow conditions, it is not impacted by the infiltration of river water. However, the uranium plume is persistent in this region. This borehole provided access to the vadose zone and upper portion of the unconfined aquifer for the collection of sediment core and depth-discrete water samples and other geohydrologic data. This location also provided data for differentiating the saturated highly permeable Hanford formation sediment from the less permeable Ringold Formation sediment. The presence of Hanford formation sediment is presumed to control contaminant movement within the uppermost aquifer in this area. This well location improves uranium plume monitoring coverage in the area that is upgradient from most sources. Characterization well 399-3-19 (C5001) is located 150 meters (492 feet) directly west (hydraulically upgradient direction) of the South Process Pond (WIDS 316-1).

The fourth borehole, 399-3-20 (C5002), was drilled at a location immediately southeast (and presumably downgradient) of the 307 disposal trench (WIDS 316-3). The 307 trench is a known uranium source area and the presumed source of a nearby localized uranium hotspot in groundwater (Figure 2.1). This location was chosen to collect vadose and aquifer sediment from the vicinity of this waste site to determine whether residual uranium in the vadose zone sediment is a current contributor of uranium to groundwater. 


\subsection{Updated Hydrogeologic Conceptual Model}

This section updates the hydrogeologic interpretation for the unconfined aquifer system within the LFI study area of the 300 Area based on the new characterization results obtained during the drilling of four new boreholes. This interpretation adds to existing published knowledge and information reported previously by others (e.g., Lindberg and Bond 1979; Schalla et al. 1988; Swanson et al. 1992). Results from sediment sample analyses, geologic core descriptions, depth-discrete groundwater analysis, aquifer hydraulic test analyses, spectral gamma and neutron moisture logging, and well development data from the four wells are correlated to provide an interpretation of the hydrogeologic conditions at each borehole location.

The characterization data obtained from the four boreholes confirm and refine existing hydrogeologic interpretations, and provide new information about the hydrogeology of the 300 Area. This information was used to refine the 300 Area hydrogeologic conceptual models, update contaminant transport models, and support selection of remedial alternatives for uranium contamination in vadose zone sediments and groundwater. The hydrogeologic column for the 300 Area is illustrated in Figure 3.1.

Hanford Site - 300 Area

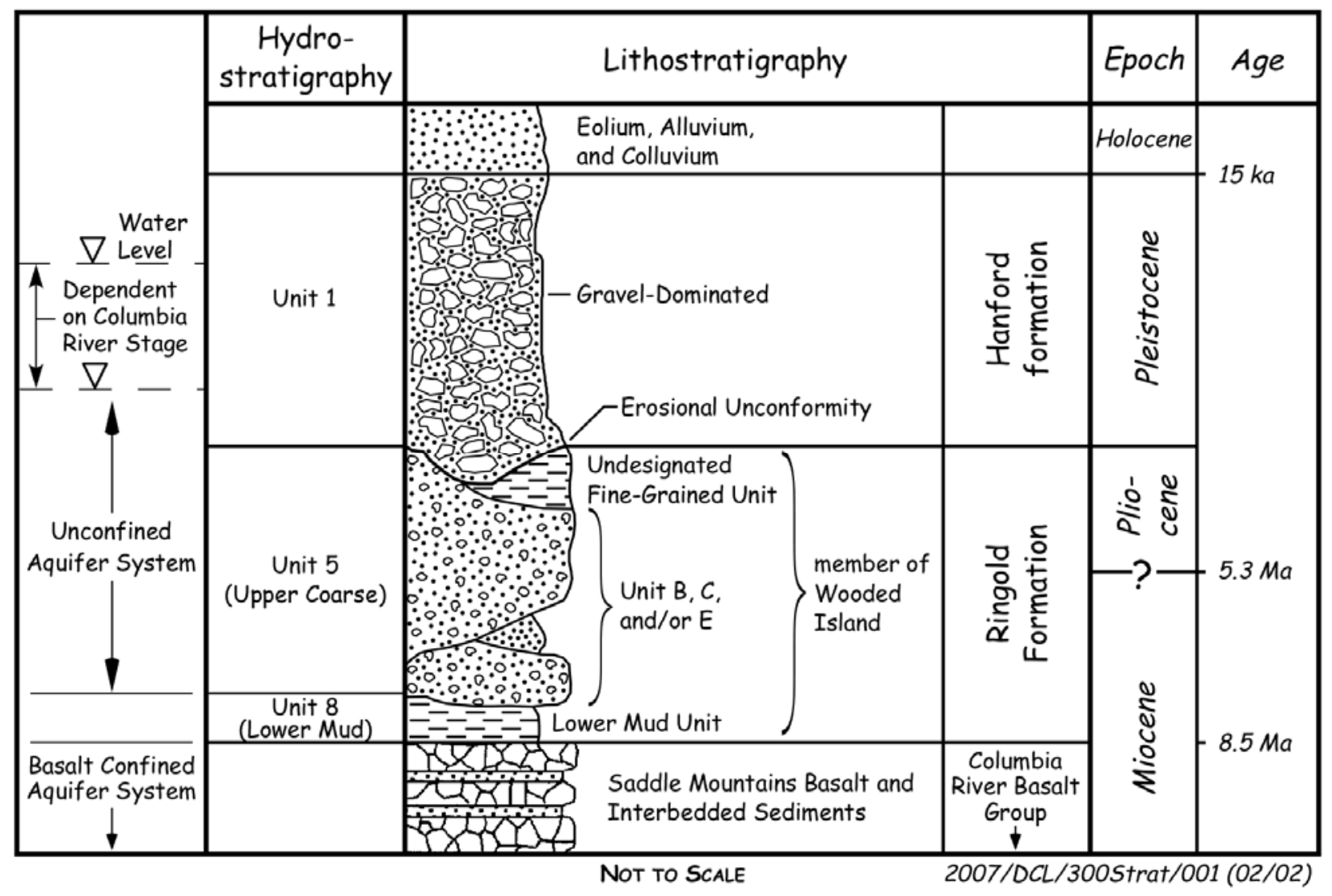

Modified for 300 Area after Reidel et. al. (1992), Thorne et al. (1993), Lindsey (1995), Williams et. al. (2000), DOE (2002)

Figure 3.1. Hydrogeologic Column Depicting the Hydrogeology of the 300 Area 
This section includes a discussion of the criteria used to evaluate and interpret these new data. Composite borehole logs illustrate the interpreted hydrogeology developed for each borehole (Figures 3.2 to 3.5). An accurate interpretation of the hydrogeology is prerequisite to understanding the nature and extent of contaminant movement within the aquifer system. Section 4 provides the interpretation of the sediment and groundwater hydrochemistry and contaminant results for the four new wells and establishes contaminant pathways as they relate to the hydrogeology of the 300 Area.

\subsection{Composite Borehole Logs}

A composite borehole log was assembled for each new borehole (Figures 3.2 to 3.5). These interpretive logs utilize multiple data sets and provide a graphic, easy-to-use compilation of pertinent data and a hydrogeologic profile representing each borehole. Stratigraphic contacts, key lithologic intervals, and hydrogeologic units within each borehole are identified based on the interpretation of the available data. Depth-specific data used to construct the composite logs include (1) the well as-built diagram; (2) characterization intervals illustrating the sampling, coring, and aquifer hydraulic testing intervals and frequency; (3) a graphic representation of the borehole lithology based on descriptions of sediment grab samples and core; (4) the uranium concentrations in groundwater and sediment samples along with select organic contaminants; (5) the geophysical and laboratory gamma energy analysis (GEA) uranium data included for comparison; and (6) the geophysical total gamma and moisture log correlations. In addition to these data, a table of depth-discrete aquifer testing results and a summary table containing groundwater sampling information are provided with each composite borehole log.

\subsection{Borehole Lithology and Physical Properties}

Grab samples collected from the core barrel drive shoe ( 6-feet-depth intervals) and from examination of the ends of the 1-foot-long core liners were used to describe the lithology in the boreholes. The field descriptions are recorded on the geologist's borehole log located in Appendix A. A more detailed geologic description of the opened core was also completed (Appendix B), and these descriptions are represented graphically on the composite logs for each well (Figures 3.2 to 3.5). The core data provide visual confirmation of the depths and zonation (changes in lithology) of Hanford and Ringold Formation lithologies and allow a precise lithologic description of individual units and determination of the hydrogeologic contact boundaries and unit thicknesses. The sample quality and formation representativeness of the core samples is generally very good where complete core recovery occurred (see also Section 6.6.1).

\subsection{Sediment Core Photographic Log}

A digital photograph of each opened sediment core from each well is included in Appendix B. These photos were used to confirm the lithologic descriptions and contacts recorded by the field geologist and to support the overall hydrogeologic interpretation. The interpretative value of these photographs is very good and provides a quick access to, and realistic view of, the borehole sediments. Where possible, key hydrogeologic contact boundaries have been defined on the core photos. The photographic file (Appendix B) provides a qualitative visual record of the cores in their original opened condition. These photos record the original structure, moisture content, and fabric of the cored intervals (i.e., grain size, grain orientation, color, and relative moisture). 


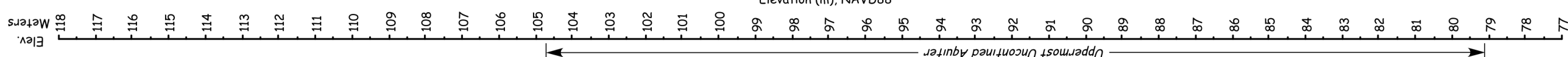

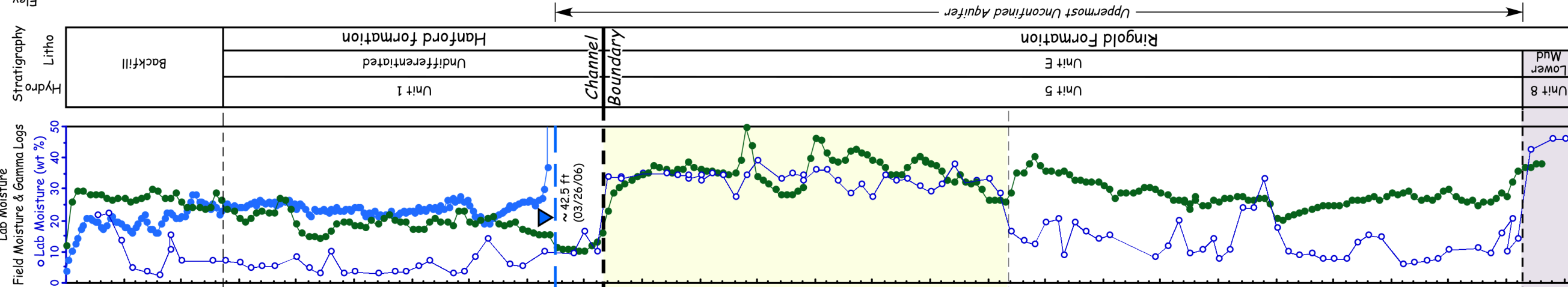

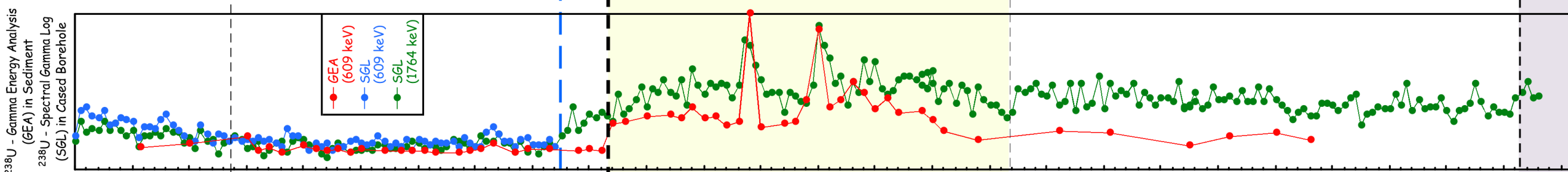
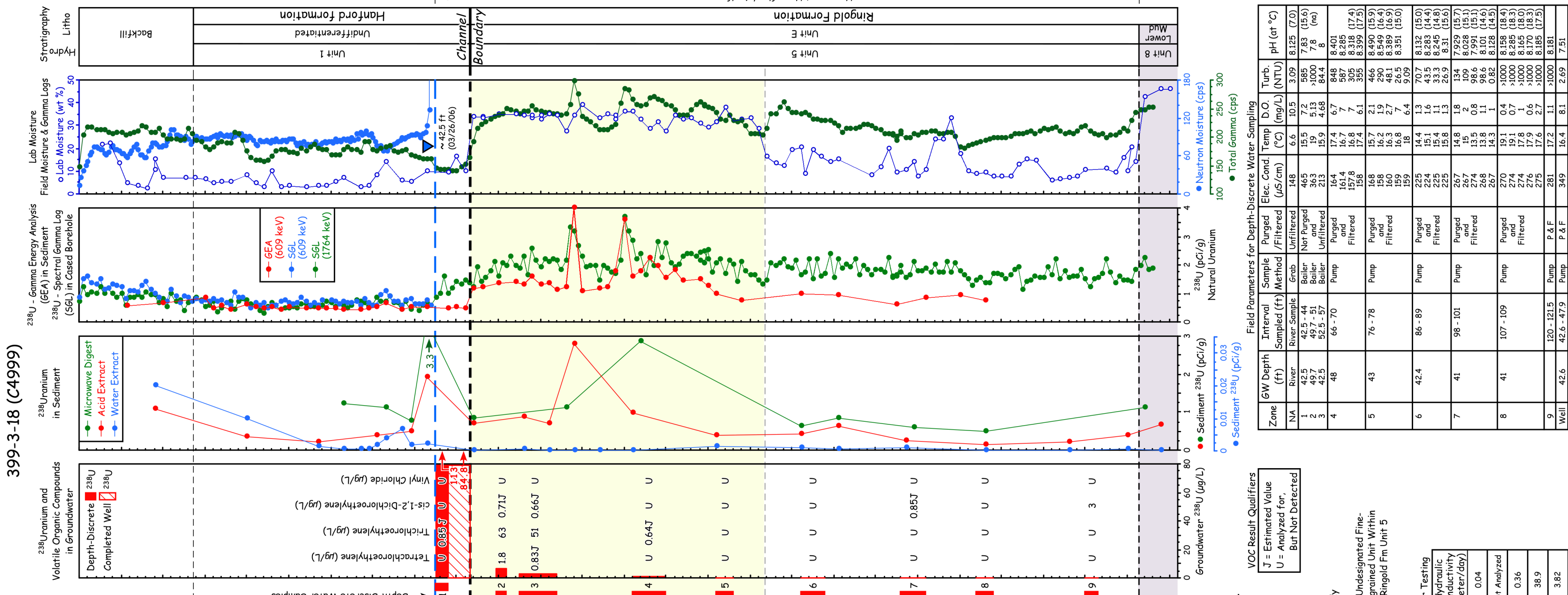

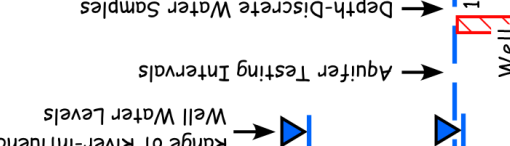
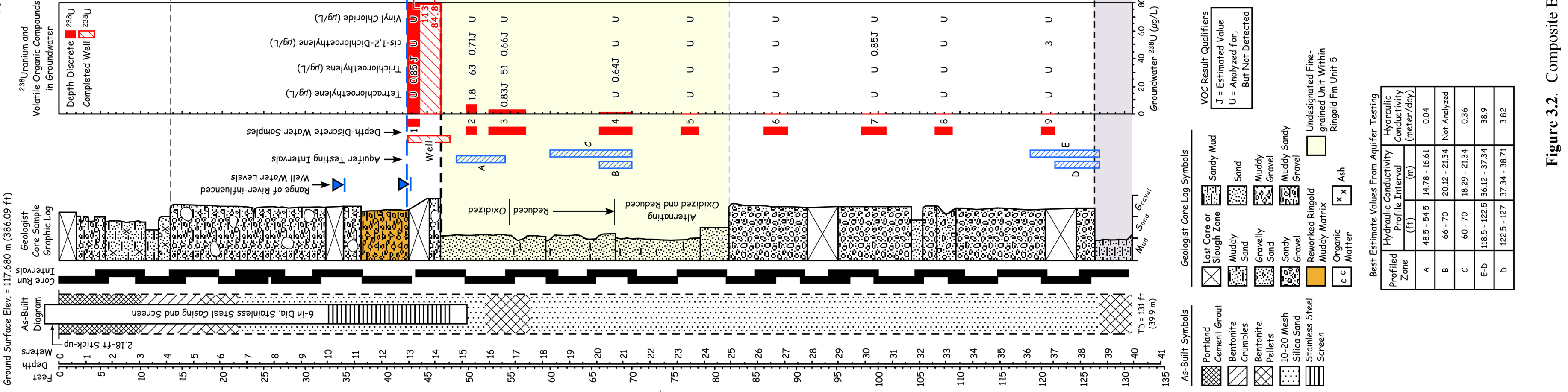


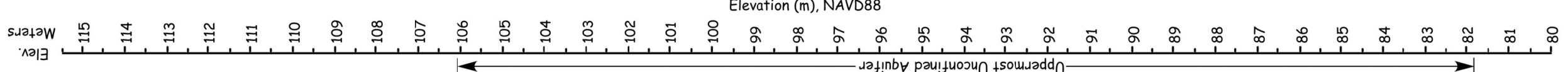

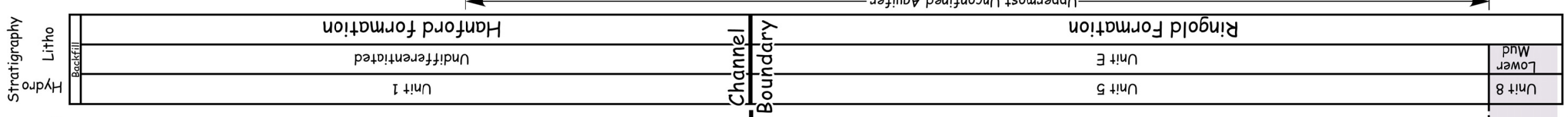
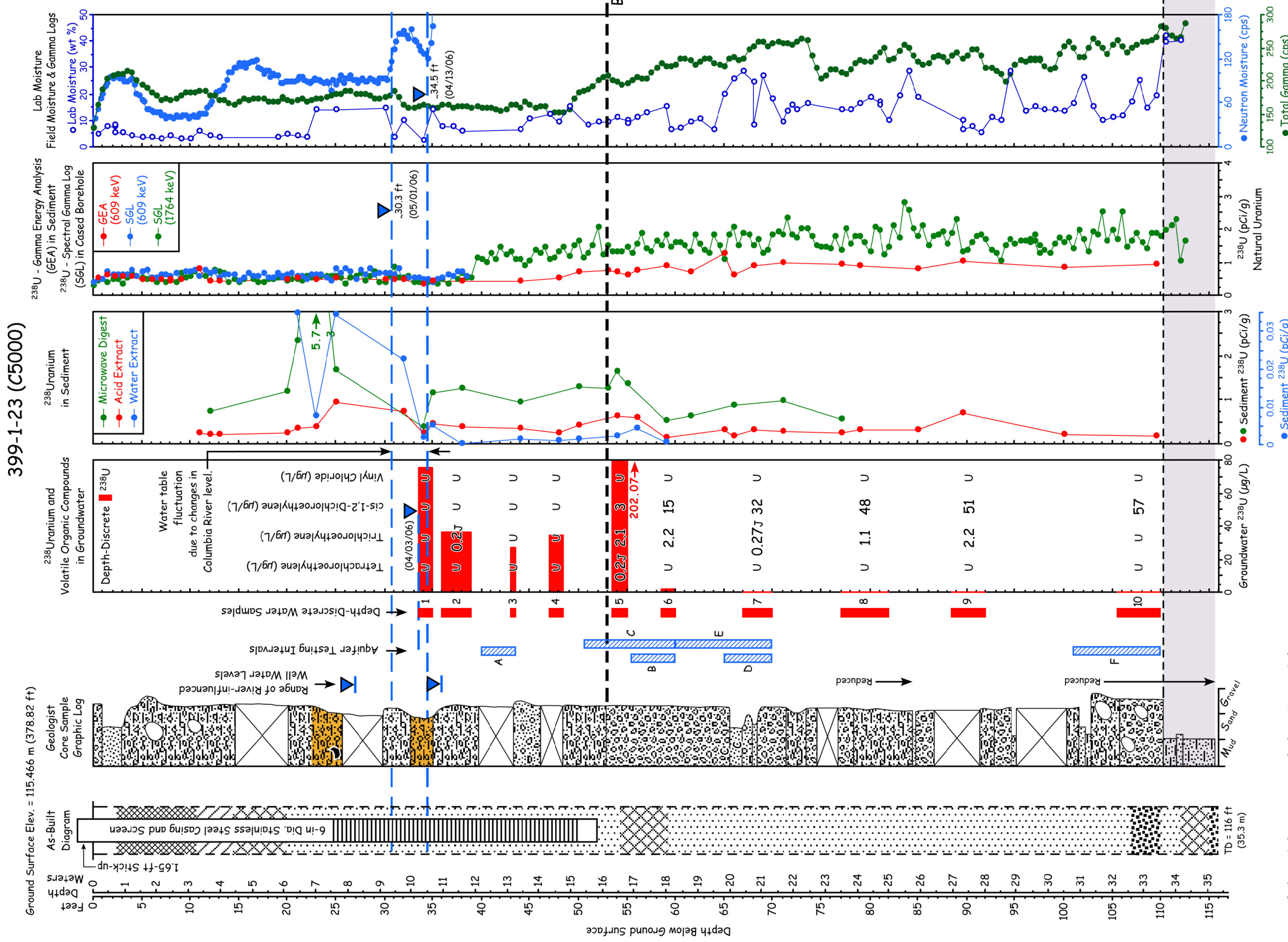

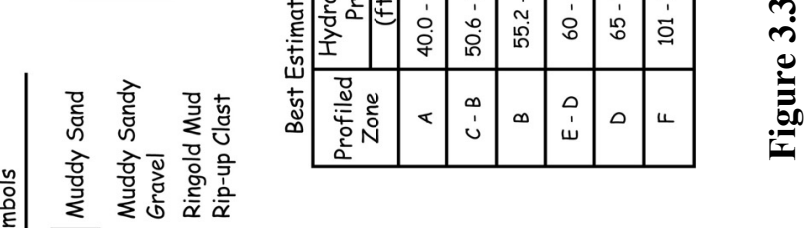

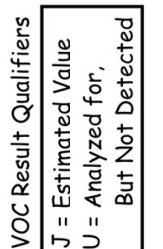

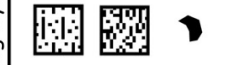

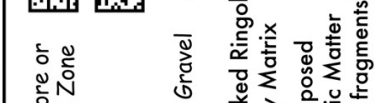

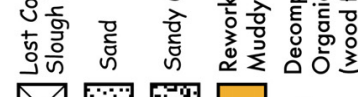

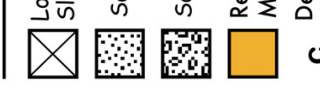

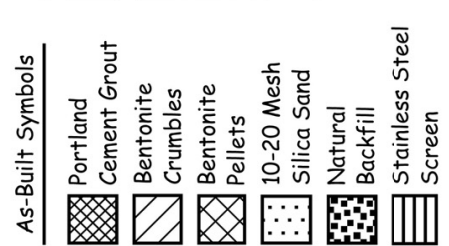




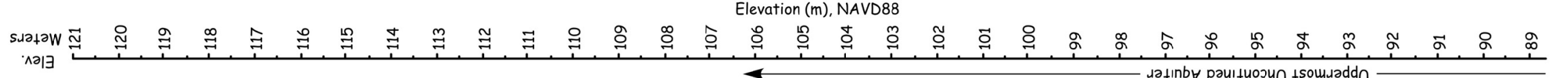
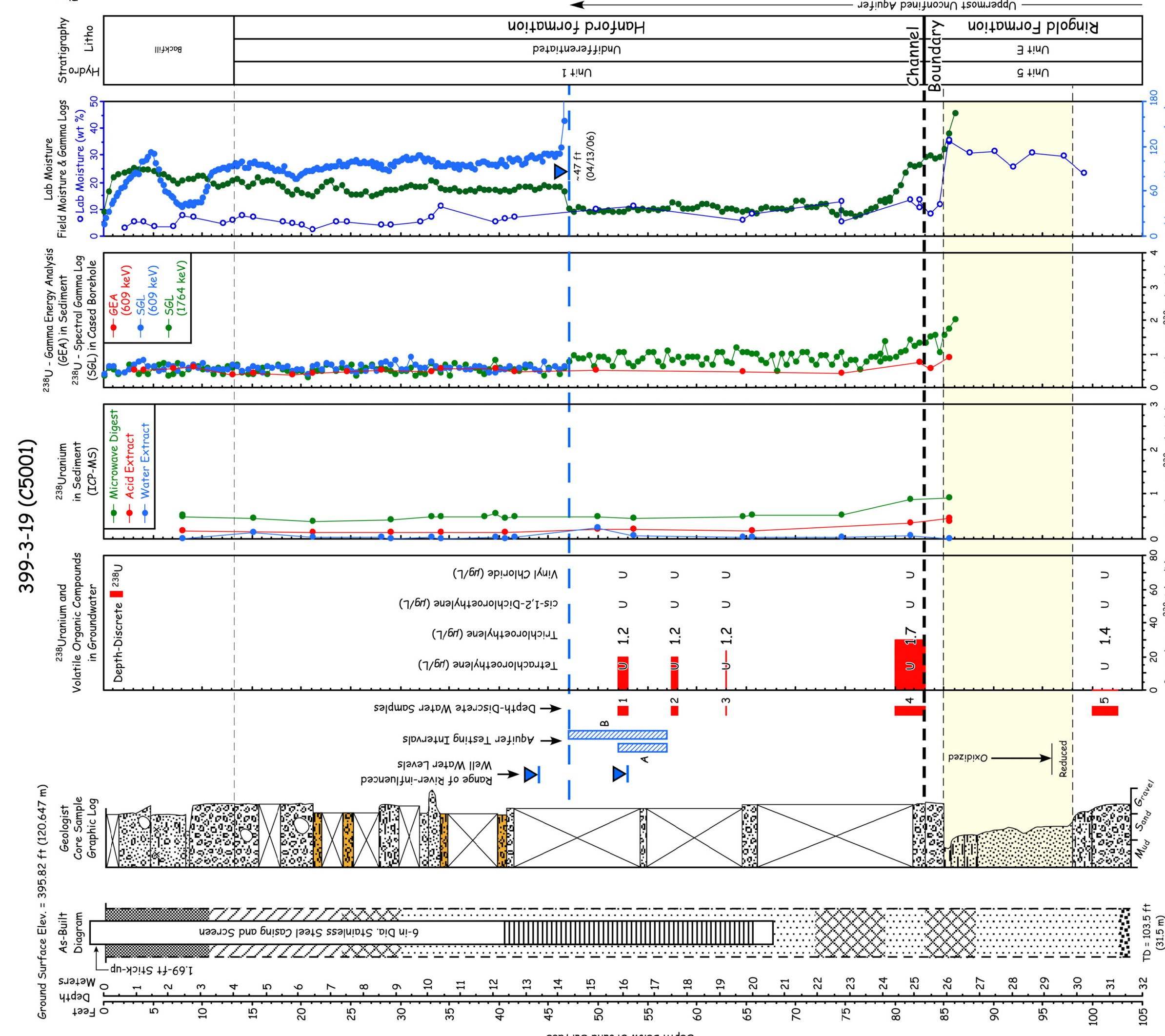

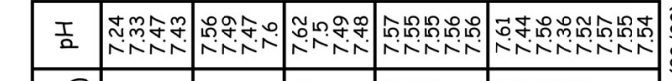
产全

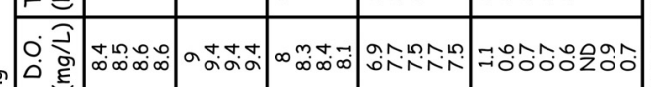

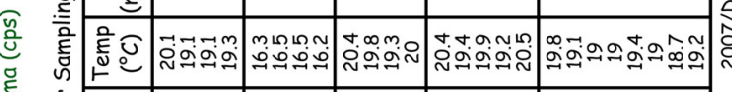

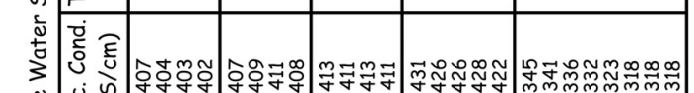

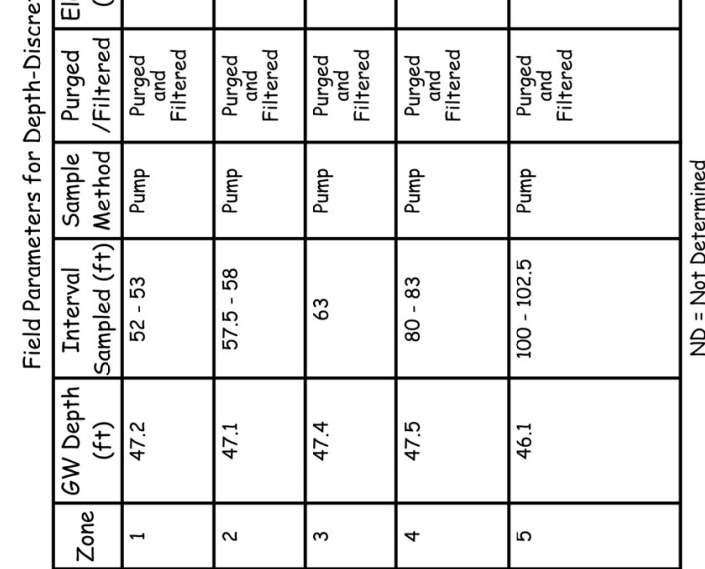

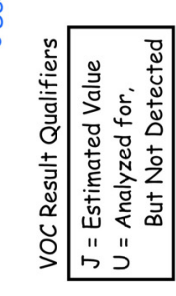
敦 旁

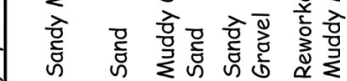

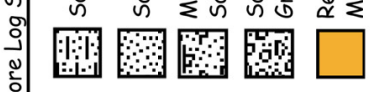
ํํำ

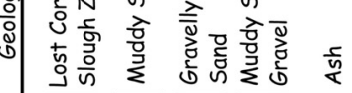
区18

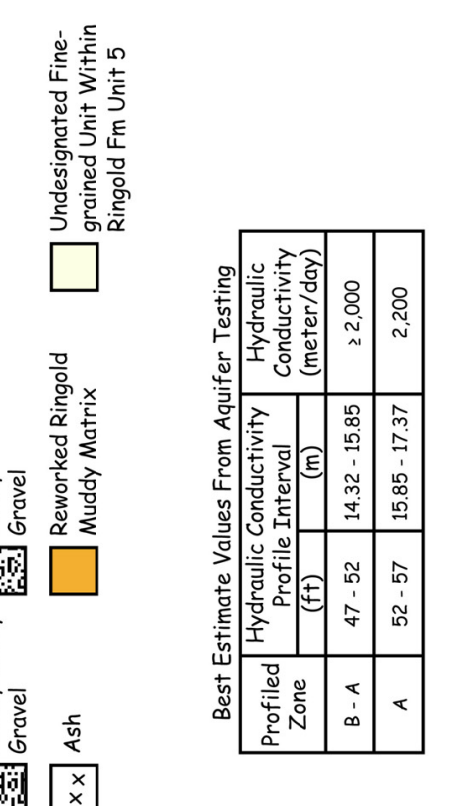

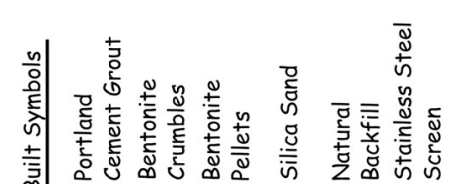

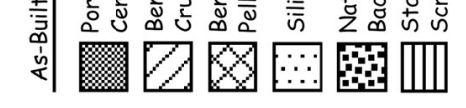




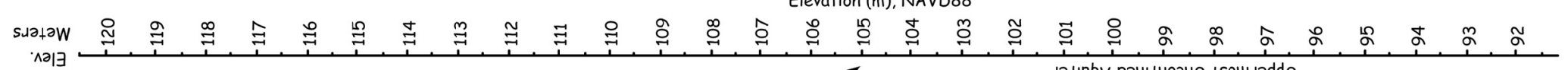
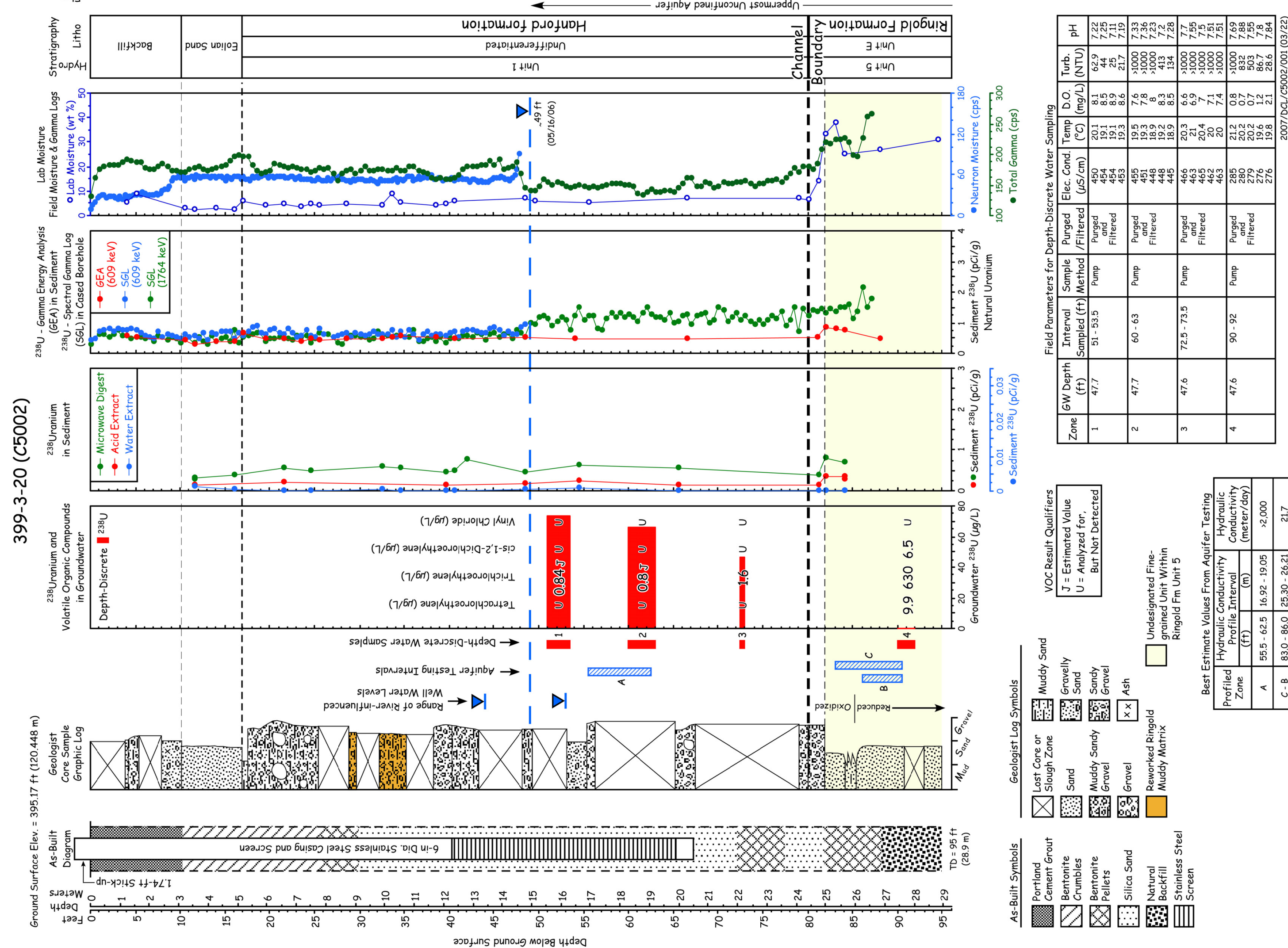


\subsection{Depth-Discrete Groundwater Results}

Groundwater data are used to better understand the relationship between contaminant concentrations, preferential groundwater flow, and aquifer boundaries in order to understand contaminant migration through the aquifer and to aid in developing the conceptual models. In addition to showing contaminant vertical depth distributions within the aquifer, discrete-depth groundwater sample data (see Section 6.6.2 for details on sampling and analysis results) aid in identifying and extrapolating hydrogeologic boundaries between characterization boreholes throughout the study area. Some groundwater flow conditions and variations in natural chemical concentrations were identified. Restrictions to groundwater movement in some zones and infiltration within the unconfined aquifer system were identified based on vertical changes in the field parameters for the groundwater such as specific conductance, dissolved oxygen, $\mathrm{pH}$, and temperature. In addition, the laboratory analytical data results also aided in defining vertical and spatial changes in the distribution of natural groundwater based on the chemical makeup of various constituents. These data are used to interpret which zones within the aquifer are more conducive to external influences or changes on the aquifer system, such as river elevation changes and resultant aquifer interaction, artificial recharge from surface disposal operations, and induced groundwater flow, etc.

The laboratory-measured $\mathrm{pH}$ of groundwater samples collected from the four boreholes were similar and ranged from 7.8 to 8.2 (see Table D.1 in Appendix D). The pH measured in the vadose zone sediment pore water, obtained by ultracentrifugation of aliquots of sediment and 1:1 sediment to water extracts (used on many samples that were not ultracentrifuged because of time constraints or for samples that did not contain adequate natural moisture to produce a useful volume), was between 7.2 and 9.0. The higher $\mathrm{pH}$ values $(\mathrm{pH}=\sim 9)$ were found in ultracentrifuged sediments from below the water table and can not be attributed to the presence of caustic waste disposed to near-surface facilities. The cause of the slightly elevated $\mathrm{pH}$ is not known at this time.

Field $\mathrm{pH}$ values for the groundwater obtained during the collection of the depth-discrete water samples ranged from 7.2 to 8.4 , a slightly larger range of values than the laboratory measured $\mathrm{pH}$ values, perhaps because of more variable temperature conditions in the field, and variable ability to purge the formation being sampled (Figures 3.2 through 3.5).

Specific conductance values measured in groundwater samples from well 399-3-18 (C4999) were lower, relatively, than those measured in groundwater samples from wells 399-1-23 (C5000), 399-3-19 (C5001), and 399-3-20 (C5002) undoubtedly caused by well 399-3-18 (C4999)'s proximity to the Columbia River. Higher specific conductance values in vadose zone sediment pore water samples for the four boreholes were attributed to higher concentrations of dissolved ions in pore water solution (Appendix D, Table D.1).

Alkalinity and calcium concentrations were measured for groundwater samples from the four boreholes, and the calculated calcite saturation index (SI) showed values greater than 0 (between 1.5 and 3.0), which is consistent with calcite-oversaturated conditions in groundwater (Appendix D, Table D.1 and D.3 through D.7). Alkalinity in borehole well 399-3-18 (C4999) groundwater samples was also lower, similar to the specific conductance data compared to those from the other three wells (399-1-23 [C5000], 399-3-19 [C5001], and 399-3-20 [C5002]). Low alkalinity values for groundwater and pore water samples from well 399-3-18 (C4999), collected at depths of 52.5-77.0 and 56-62 feet bgs, respectively, were associated with a fine-grained silty sand unit located at these depths. Finding the lowest groundwater alkalinity in the fine-grained silty sand likely is an indication that dilute river water 
makes up a greater portion of the water in this lower permeability material; that is, the more saline "inland" groundwater transports towards the Columbia River in the shallower and coarser more highly permeable materials without much mixing with waters in the pores of the lower silty sand sediments. The lowest alkalinity value $(94.2 \mathrm{mg} / \mathrm{L})$ of the well 399-1-23 (C5000) groundwater samples was measured at a depth of 68.5 feet bgs, where a thin fine-grained silty sand within the Ringold Formation was encountered. The specific conductance measured during purging prior to collection of the depth-discrete groundwater samples revealed similar values (Appendix F, Table F.1). Well 399-3-18 (C4999) had the lowest measured specific conductance of all the wells, and all of the wells measured decreasing specific conductance with depth. Proximity to the Columbia River and its river stage influences are the cause of the low specific conductance in well 399-3-18 (C4999) and may also partially explain the decrease in specific conductance with depth in all the wells.

There was no significant difference in geochemical data measured in the laboratory at the boundary between the Hanford and Ringold formations for samples from the four boreholes. However, dissolved oxygen, measured in field samples during collection of the depth-discrete groundwater samples, dropped significantly to levels below $2.7 \mathrm{mg} / \mathrm{L}$ in the Ringold Formation sediments in all of the wells (Appendix F, Table F.1). The dissolved oxygen data suggest that reducing conditions may predominate in the deeper portion of the unconfined aquifer. This apparent reducing geochemical trend with depth is also supported by the physical appearance (greenish/blue-grayish color) of the sediment samples collected from these deeper portions of the aquifer (Figures 3.2 through 3.5).

Cation and anion analyses were also measured on groundwater and pore water samples from the four boreholes (see Appendix D, Tables D.3 through D.7). After bicarbonate (alkalinity), nitrate and sulfate were found to be the next dominant anions, and the higher concentrations of most of the anions were distributed in the shallower depths of the aquifer. The most dominant cation in both groundwater and pore water from the four boreholes was calcium. This indicated that the waters were oversaturated with respect to calcite, based on calculated calcite saturation index values being consistently larger than zero. Other major cationic elements such as silicon, aluminum, iron, sulfur, magnesium, sodium, potassium and minor amounts of arsenic, lead, and titanium were also found in groundwater samples from the four boreholes. None of the groundwater or vadose zone sediment pore water from the four boreholes showed significant signs of the presence of enriched sodium nitrate waste, which is generally the most ubiquitous chemical species found in Hanford Site process waste.

\subsection{Depth-Discrete Aquifer Hydraulic Testing Results}

The information provided by multiple, depth-discrete aquifer hydraulic tests (performed in each borehole) allow the determination of groundwater conditions across varying hydrogeologic intervals. These results are used to identify the general permeability distribution of major hydrogeologic units within the aquifer system and to distinguish groundwater flow paths within the subsurface. See Figures 3.2 through 3.5 for the intervals analyzed in each well. A detailed description of the aquifer hydraulic testing performed at each characterization well site, and the associated analytical results are presented in Section 6.6.3. A brief summary of the analytical results for the respective characterization wells is provided in the following paragraphs.

Figure 3.6 shows the vertical depth distribution of hydraulic conductivity determined for the five Ringold Formation depth intervals in well 399-3-18 (C4999). The figure results are based on the test depth interval analysis results presented in Tables 3.1 and 3.2. 


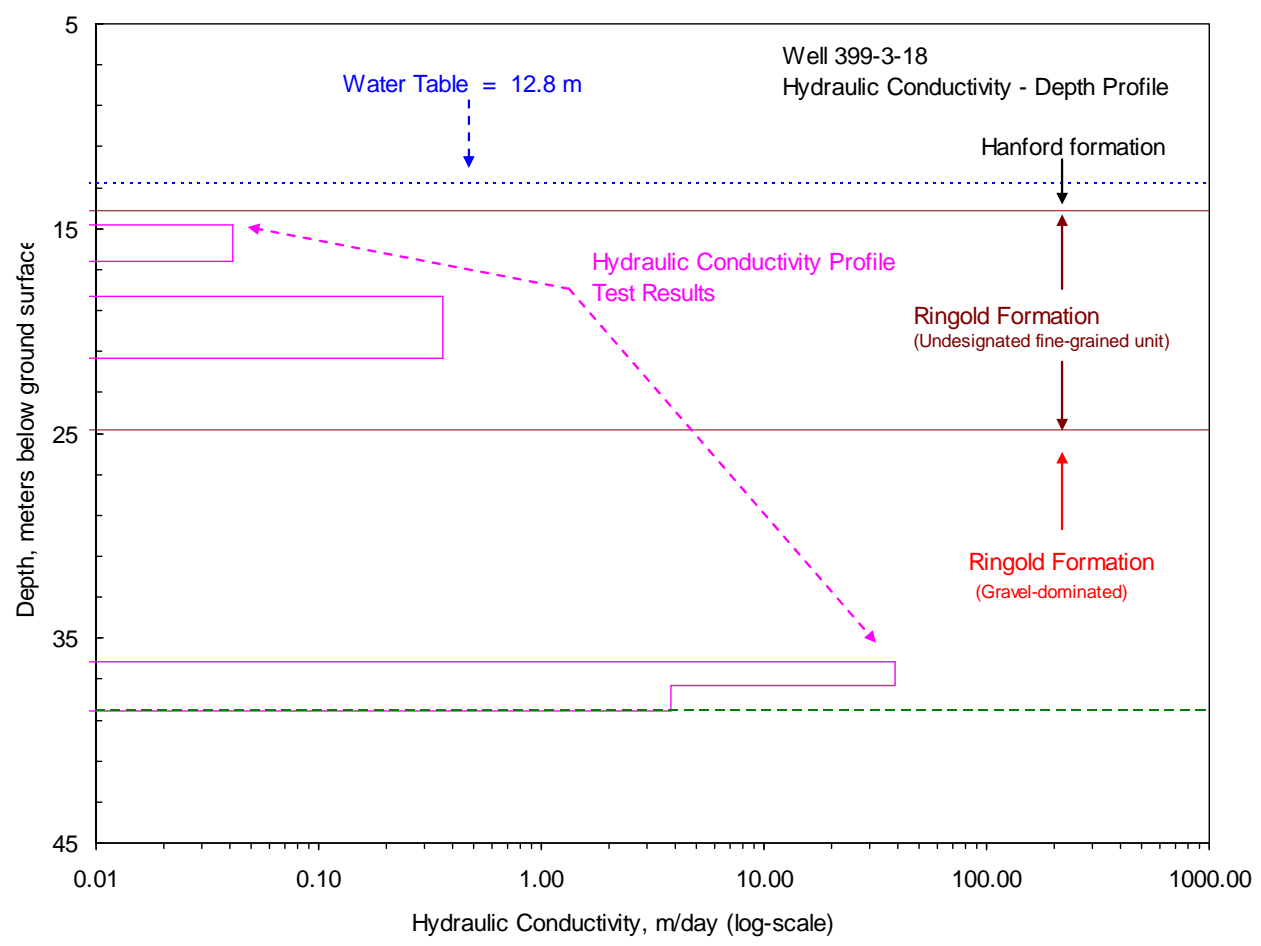

Figure 3.6. Vertical Distribution of Hydraulic Conductivity for Selected Depth Intervals at Well 399-3-18 (C4999), Based on Field Aquifer Hydraulic Test Characterization

Table 3.1. Well 399-3-18 (C4999) Aquifer Hydraulic Test Analysis Results

\begin{tabular}{|c|c|c|c|c|}
\hline \multirow[b]{2}{*}{$\begin{array}{c}\text { (Zone) } \\
\text { Test Interval (m, bgs) }\end{array}$} & \multicolumn{2}{|c|}{ Type-Curve Analysis Method } & \multicolumn{2}{|c|}{$\begin{array}{l}\text { Time-History Matching Analysis } \\
\text { Method }^{(a)}\end{array}$} \\
\hline & $\begin{array}{c}\text { Hydraulic Conductivity, } \\
\mathrm{K}_{\mathrm{h}}{ }^{(\mathrm{b})} \\
(\mathrm{m} / \text { day })\end{array}$ & $\begin{array}{c}\text { Specific Storage, } \\
\mathrm{S}_{\mathrm{s}} \\
\left(\mathrm{m}^{-1}\right)\end{array}$ & $\begin{array}{c}\text { Hydraulic Conductivity, } \\
\mathrm{K}_{\mathrm{h}}{ }^{(\mathrm{b})} \\
(\mathrm{m} / \text { day })\end{array}$ & $\begin{array}{c}\text { Specific Storage, } \\
\mathrm{S}_{\mathrm{s}} \\
\left(\mathrm{m}^{-1}\right)\end{array}$ \\
\hline (A) $14.78-16.61^{*}$ & "NA & $\overline{\mathrm{NA}}$ & $0.04 *$ & $5.5 \mathrm{E}-6^{(\mathrm{c})}$ \\
\hline (B) $20.12-21.34 * *$ & NA & NA & $* *$ & $* *$ \\
\hline (C) $18.29-21.34^{*}$ & NA & NA & 0.36 & $3.3 \mathrm{E}-6^{(\mathrm{c})}$ \\
\hline (D) $37.34-38.71$ & $\begin{array}{c}3.67-3.89 \\
(3.82)\end{array}$ & $1.0 \mathrm{E}-5$ & NA & NA \\
\hline (E) $36.12-38.71$ & $\begin{array}{c}19.0-24.2 \\
(21.6)\end{array}$ & $1.0 \mathrm{E}-4-5.0 \mathrm{E}-4$ & NA & NA \\
\hline $\begin{array}{l}\text { Note: Number in pare } \\
\text { (a) Standard type-cur } \\
\text { recovered test res } \\
\text { (b) Assumed to be un } \\
\text { (c) Based on an assig } \\
* \quad \text { Some of the a } \\
\text { permeability } \mathrm{f} \\
* * \quad \text { Most of the ac } \\
\text { NA }=\text { Not applicabl }\end{array}$ & $\begin{array}{l}\text { eses is the average value } \\
\text { analytical method is not } \\
\text { sses. Results based on a } \\
\text { rm within the well-screen } \\
\text { torativity value }(\mathrm{S}=1.0 \mathrm{E}- \\
\text { fer hydraulic test data lost } \\
\text { nation condition. Test ana } \\
\text { fer hydraulic test data lost } \\
\text { nation condition. Not eno } \\
\text { applied analytical methoc }\end{array}$ & $\begin{array}{l}\text { l tests. } \\
\text { letely applicable d } \\
\text { imposed, time-hist } \\
\text { section. } \\
\text { ng transfer from d } \\
\text { based on time-hi } \\
\text { ag transfer from da } \\
\text { data available for }\end{array}$ & $\begin{array}{l}\text { the incomplete test data } \\
\text { natch of all aquifer hydrau } \\
\text { gger system. Response in } \\
\text { match. } \\
\text { gger system. Response in } \\
\text { history match analysis. }\end{array}$ & $\begin{array}{l}\text { d and lack of fully } \\
\text { ests conducted. } \\
\text { tes low } \\
\text { es low }\end{array}$ \\
\hline
\end{tabular}


Table 3.2. Well 399-3-18 (C4999) Hydraulic Conductivity Distribution

\begin{tabular}{|c|c|c|c|c|}
\hline & \multirow[b]{2}{*}{$\begin{array}{l}\text { Profile Interval } \\
\quad(\mathrm{m}, \mathrm{bgs})\end{array}$} & \multicolumn{2}{|c|}{ Best Estimate Value } & \multirow[b]{2}{*}{ Basis/Comments } \\
\hline & & $\begin{array}{c}\text { Hydraulic Conductivity, } \\
\mathrm{K}_{\mathrm{h}}^{(\mathrm{a})} \\
(\mathrm{m} / \text { day })\end{array}$ & Specific Storage, $\mathrm{S}_{\mathrm{s}}\left(\mathrm{m}^{-1}\right)$ & \\
\hline & $14.78-16.61$ & 0.04 & $5.5 \mathrm{E}-6^{(\mathrm{b})}$ & Zone A \\
\hline & $20.12-21.34$ & $-(\mathrm{c})$ & $-(c)$ & Zone B \\
\hline & $18.29-21.34$ & 0.36 & $3.3 \mathrm{E}-6^{(\mathrm{b})}$ & Zone $\mathrm{C}$ \\
\hline & $36.12-37.34$ & 38.9 & $3.0 \mathrm{E}-4$ & Zone E - Zone D \\
\hline & $37.34-38.71$ & 3.82 & $1.0 \mathrm{E}-5$ & Zone D \\
\hline $\begin{array}{l}\text { (a) } \\
\text { (b) } \\
\text { (c) }\end{array}$ & $\begin{array}{l}\text { Assumed to be } \\
\text { Based on an ass } \\
\text { Most of the Zor } \\
\text { permeability for }\end{array}$ & \multicolumn{3}{|c|}{$\begin{array}{l}\text { Most of the Zone B aquifer hydraulic test data lost during transfer from datalogger system. Response indicates low } \\
\text { permeability formation condition. Not enough data available for quantitative analysis. }\end{array}$} \\
\hline
\end{tabular}

As indicated in Table 3.2, hydraulic conductivity for the lower permeability Ringold Formation fine-grained unit ranged between 0.04 and $0.36 \mathrm{~m} /$ day, while the two underlying higher permeability middle Ringold Formation test intervals ranged more widely between 3.82 and $38.9 \mathrm{~m} /$ day. Selected analysis figures for the respective test depth zones are presented in Appendix E.

Figure 3.7 shows the vertical depth distribution of hydraulic conductivity determined for the four successful Ringold Formation interval tests and one Hanford formation interval test conducted at well 399-1-23 (C5000).

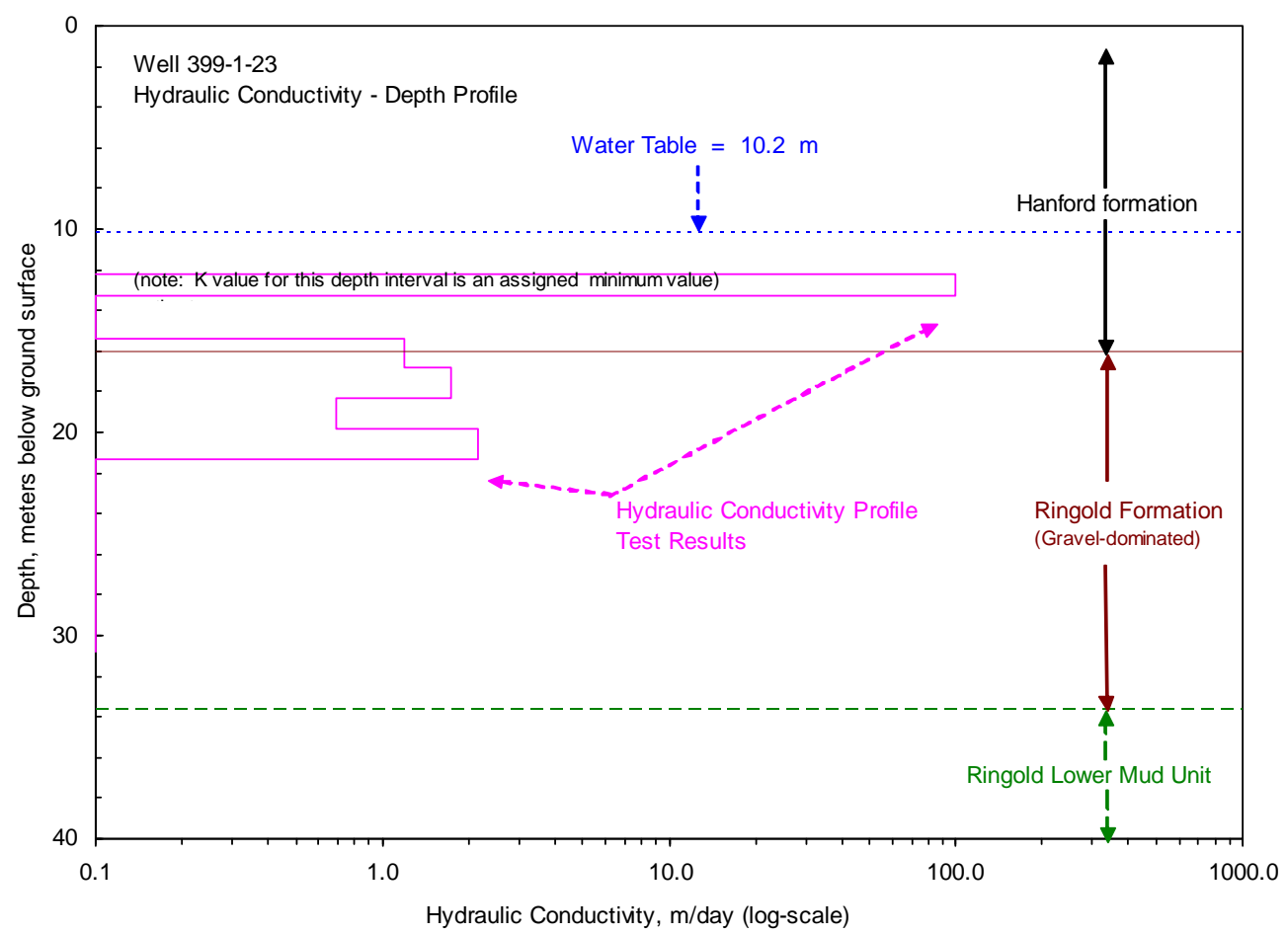

Figure 3.7. Vertical Distribution of Hydraulic Conductivity for Selected Depth Intervals at Well 399-1-23 (C5000), Based on Field Aquifer Hydraulic Test Characterization 
Figure 3.7 illustrates the distribution of hydraulic conductivity $\left(\mathrm{K}_{\mathrm{h}}\right)$ with depth within the various hydrogeologic units. As shown in the figure, the $\mathrm{K}_{\mathrm{h}}$ in the Hanford formation is at least two orders of magnitude higher than the $\mathrm{K}_{\mathrm{h}}$ within the underlying Ringold Formation sediment. The results are based on the test depth interval analysis results presented in Tables 3.3 and 3.4.

Table 3.3. Well 399-1-23 (C5000) Aquifer Hydraulic Test Analysis Results

\begin{tabular}{|c|c|c|c|c|}
\hline \multirow[b]{2}{*}{$\begin{array}{l}\text { (Zone) Test Interval } \\
(\mathrm{m} \text { bgs })\end{array}$} & \multicolumn{2}{|c|}{ Type-Curve Analysis Method } & \multicolumn{2}{|c|}{ High-K Analysis Method $^{(a)}$} \\
\hline & $\begin{array}{c}\text { Hydraulic } \\
\text { Conductivity, } \mathrm{K}_{\mathrm{h}}{ }^{(\mathrm{b})} \\
(\mathrm{m} / \text { day })\end{array}$ & $\begin{array}{c}\text { Specific Storage, } \\
\mathrm{S}_{\mathrm{s}}\left(\mathrm{m}^{-1}\right)\end{array}$ & $\begin{array}{c}\text { Hydraulic } \\
\text { Conductivity, } \mathrm{K}_{\mathrm{h}}{ }^{(\mathrm{b})} \\
(\mathrm{m} / \text { day })\end{array}$ & $\begin{array}{c}\text { Dimensionless } \\
\text { Damping Parameter, } \\
\mathrm{C}_{\mathrm{D}}\end{array}$ \\
\hline (A) $12.19-13.26^{(\mathrm{c})}$ & NA & NA & $>100^{(\mathrm{c})}$ & - \\
\hline (B) $16.82-18.29$ & $\begin{array}{c}1.60-1.86 \\
(1.73)\end{array}$ & $1.0 \mathrm{E}-5-3.0 \mathrm{E}-5$ & NA & NA \\
\hline (C) $15.42-18.29$ & 1.47 & $1.0 \mathrm{E}-5$ & NA & NA \\
\hline (D) $19.81-21.34$ & 2.16 & $5.0 \mathrm{E}-5-1.0 \mathrm{E}-4$ & NA & NA \\
\hline (E) $18.29-21.34$ & 1.43 & $1.0 \mathrm{E}-4$ & NA & NA \\
\hline (F) $30.78-33.53^{*}$ & NA & NA & NA & NA \\
\hline \multicolumn{5}{|c|}{$\begin{array}{l}\text { Note: Number in parentheses is the average value for all tests. } \\
\text { (a) Standard type-curve analytical method is not valid for aquifer hydraulic tests exhibiting either critically or } \\
\text { under-damped behavior. Results based on high K analysis method (Butler and Garnett 2000). } \\
\text { (b) Assumed to be uniform within the well-screen test section. } \\
\text { (c) No quantitative analysis of test is possible, due to pressure probe location during testing. Test response } \\
\text { indicates a very high K condition. Value listed should be considered to be an assigned, lowest possible } \\
\text { value. } \\
\text { * All aquifer hydraulic test responses for this zone adversely affected by packer by-pass (leakage). } \\
\mathrm{NA}=\text { Not applicable or applied analytical method. }\end{array}$} \\
\hline
\end{tabular}

Table 3.4. Well 399-1-23 (C5000) Hydraulic Conductivity Distribution

\begin{tabular}{|c|c|c|c|c|}
\hline & \multirow[b]{2}{*}{$\begin{array}{l}\text { Profile Interval } \\
\quad(\mathrm{m}, \mathrm{bgs})\end{array}$} & \multicolumn{2}{|c|}{ Best Estimate Value } & \multirow[b]{2}{*}{ Basis/Comments } \\
\hline & & $\begin{array}{l}\text { Hydraulic Conductivity, } \\
\mathrm{K}_{\mathrm{h}}^{\text {(a) }} \\
(\mathrm{m} / \text { day })\end{array}$ & $\begin{array}{c}\text { Specific Storage, } \\
\mathrm{S}_{\mathrm{s}}\left(\mathrm{m}^{-1}\right)\end{array}$ & \\
\hline & $12.19-13.26^{(\mathrm{b})}$ & $>100$ & - & Zone $\mathrm{A}^{(\mathrm{b})}$ \\
\hline & $15.42-16.83$ & 1.20 & $2.0 \mathrm{E}-5$ & Zone C - Zone B \\
\hline & $16.83-18.29$ & 1.73 & $1.0 \mathrm{E}-5$ & Zone B \\
\hline & $18.29-19.81$ & 0.69 & $7.5 \mathrm{E}-5$ & Zone E - Zone D \\
\hline & $19.81-21.33$ & 2.16 & $1.0 \mathrm{E}-4$ & Zone D \\
\hline & $30.78-33.53^{(\mathrm{c})}$ & - & - & Zone $\mathrm{F}^{(\mathrm{c})}$ \\
\hline $\begin{array}{l}\text { (a) } \\
\text { (b) } \\
\text { (c) }\end{array}$ & \multicolumn{4}{|c|}{$\begin{array}{l}\text { Assumed to be uniform within the test/depth interval. } \\
\text { No quantitative analysis of test is possible, due to pressure probe location during test. Test response } \\
\text { indicates a very high K condition. Value listed is an assigned, lowest possible value. } \\
\text { All aquifer hydraulic test responses for this zone adversely affected by packer by-pass (leakage). }\end{array}$} \\
\hline
\end{tabular}


As indicated in Table 3.4, hydraulic conductivities for Ringold Formation test intervals ranged narrowly between 0.69 and $2.16 \mathrm{~m} /$ day, suggesting rather uniform formation conditions with depth at this location. The hydraulic conductivity value for the top depth interval (Zone A), which is reflective of the Hanford formation, represents an assigned value (i.e., $\geq 100 \mathrm{~m} /$ day). As noted in Table 3.3, because of test limitations for this depth interval, no quantitative test analysis for this depth interval was possible, but the test response indicates a high permeability condition. The actual hydraulic conductivity value for this zone, therefore, is likely to be significantly higher than this assigned minimum value. Selected analysis figures for the respective test zones are presented in Appendix E.

There is no vertical depth distribution of hydraulic conductivity figure provided for well 399-3-19 (C5001) because only two test depth-interval characterizations were conducted at this well site. Both test depth intervals were located within the Hanford formation and indicated high-permeability conditions with $K_{h}$ values $>2,000 \mathrm{~m} /$ day. The results for test depth interval analysis results are presented in Tables 3.5 and 3.6.

Table 3.5. Well 399-3-19 (C5001) Test/Depth Interval Aquifer Hydraulic Test Analysis Results

\begin{tabular}{|c|c|c|c|c|}
\hline \multirow[b]{2}{*}{$\begin{array}{l}\text { Test/Depth } \\
\text { Interval }\end{array}$} & \multicolumn{2}{|c|}{ Type-Curve Analysis Method } & \multicolumn{2}{|c|}{ High-K Analysis Method $^{(b)}$} \\
\hline & $\begin{array}{c}\text { Hydraulic Conductivity, } \\
\mathrm{K}_{\mathrm{h},} \text { (a) } \\
\text { (m/day) }\end{array}$ & $\begin{array}{l}\text { Specific Storage, } \\
\mathrm{S}_{\mathrm{s}}\left(\mathrm{m}^{-1}\right)\end{array}$ & $\begin{array}{c}\text { Hydraulic Conductivity, } \\
\mathrm{K}_{\mathrm{h}} \text {, } \\
(\mathrm{m} / \text { day })\end{array}$ & $\begin{array}{c}\text { Dimensionless } \\
\text { Damping Parameter, } C_{D}\end{array}$ \\
\hline Zone A & NA & NA & $\begin{array}{c}2,100-2,300 \\
(2,200)\end{array}$ & \begin{tabular}{|c|}
0.11 \\
\end{tabular} \\
\hline Zone $\mathrm{B}^{(\mathrm{c})}$ & NA & NA & $\geq 2,000^{(\mathrm{c})}$ & $-(\mathrm{c})$ \\
\hline
\end{tabular}

NA Not applicable or applied analytical method.

Note: Number in parentheses is the average value for all tests.

(a) Assumed to be uniform within the well-screen test section.

(b) Standard type-curve analytical method are not valid for aquifer hydraulic tests exhibiting under-damped behavior.

Results based on High-K analysis method (Butler and Garnett 2000).

(c) No quantitative analysis of test is possible, due to the minor test response and rapid recovery. Test response indicates a very high $\mathrm{K}$ condition. Estimate listed should be considered to be an assigned, lowest possible value

Table 3.6. Well 399-3-19 (C5001) Test/Depth Hydraulic Conductivity Distribution

\begin{tabular}{|c|c|c|c|}
\hline \multirow[b]{2}{*}{$\begin{array}{l}\text { Test/Depth } \\
\text { Interval m, bgs }\end{array}$} & \multicolumn{2}{|c|}{ Best Estimate Value } & \multirow[b]{2}{*}{ Basis/Comments } \\
\hline & $\begin{array}{c}\text { Hydraulic Conductivity, } \\
\mathrm{K}_{\mathrm{h}}{ }^{(\mathrm{a})}(\mathrm{m} / \text { day })\end{array}$ & $\begin{array}{c}\text { Specific Storage, } \\
\mathrm{S}_{\mathrm{s}}\left(\mathrm{m}^{-1}\right)\end{array}$ & \\
\hline $14.32-15.85^{(\mathrm{b})}$ & $\geq 2,000^{(\mathrm{b})}$ & - & Z Zone B - Zone A \\
\hline $15.85-17.37$ & 2,200 & - & Zone A \\
\hline
\end{tabular}

Figure 3.8 shows the vertical depth distribution of hydraulic conductivity determined for the three depth interval tests for well 399-3-20 (C5002). The results are based on the test depth interval analysis results presented in Tables 3.7 and 3.8. This figure illustrates the distribution of hydraulic conductivity $\left(\mathrm{K}_{\mathrm{h}}\right)$ within the various hydrogeologic units. 


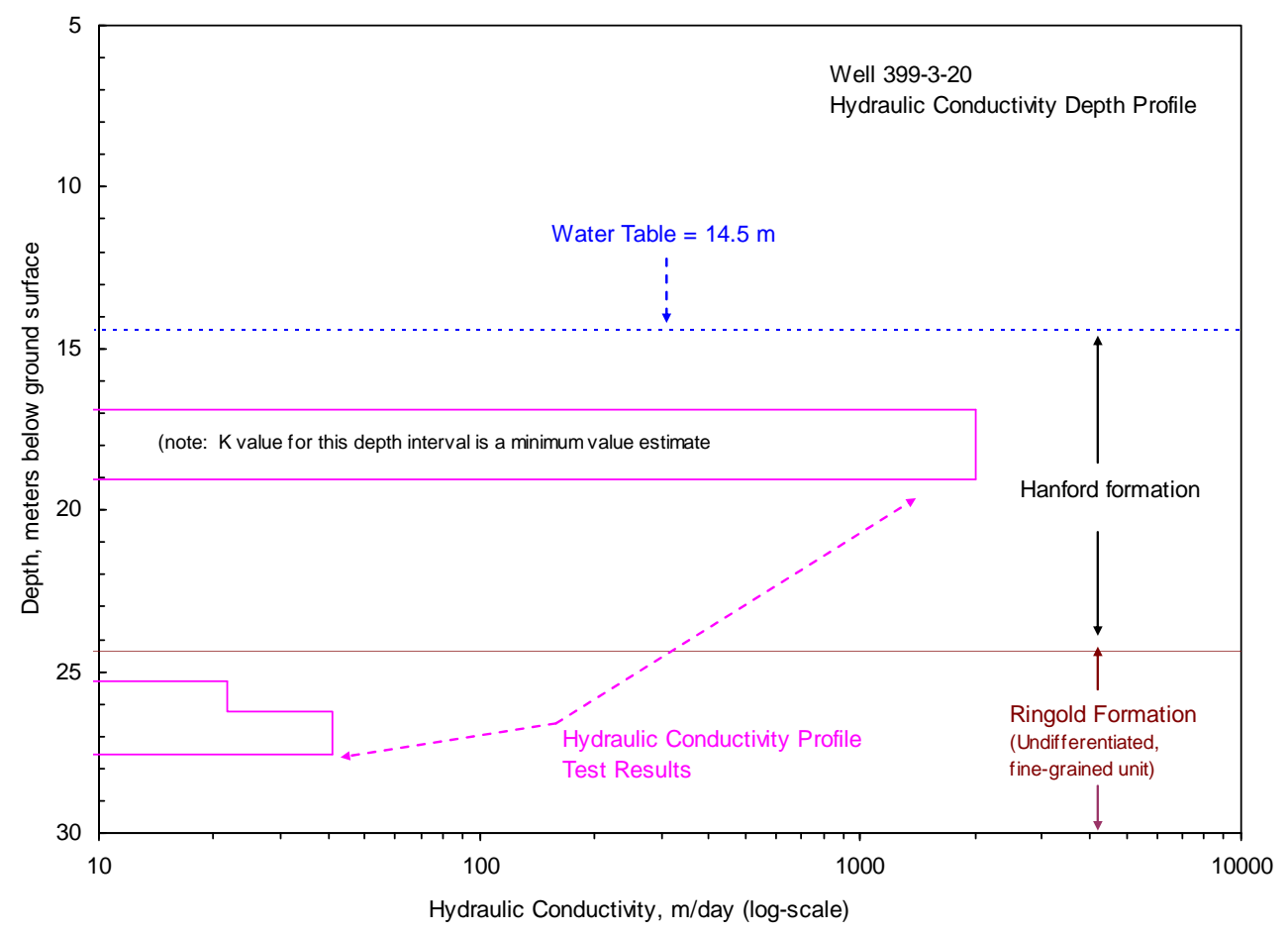

Figure 3.8. Vertical Distribution of Hydraulic Conductivity for Selected Depth Intervals at Well 399-3-20 (C5002), Based on Field Aquifer Hydraulic Test Characterization

Table 3.7. Well 399-3-20 (C5002) Aquifer Hydraulic Test Analysis Results

\begin{tabular}{|c|c|c|c|c|}
\hline \multirow[b]{2}{*}{$\begin{array}{c}\text { (Zone) Test } \\
\text { Interval (m bgs) }\end{array}$} & \multicolumn{2}{|c|}{ Type-Curve Analysis Method } & \multicolumn{2}{|c|}{$\begin{array}{l}\text { High-K Analysis } \\
\text { Method }^{(\mathrm{a})}\end{array}$} \\
\hline & $\begin{array}{c}\text { Hydraulic } \\
\text { Conductivity, } \mathrm{K}_{\mathrm{h}}^{(\mathrm{b})} \\
(\mathrm{m} / \text { day })\end{array}$ & $\begin{array}{l}\text { Specific Storage, } \\
\qquad \mathrm{S}_{\mathrm{s}}\left(\mathrm{m}^{-1}\right)\end{array}$ & $\begin{array}{c}\text { Hydraulic Conductivity, } \\
\mathrm{K}_{\mathrm{h}}^{(\mathrm{b})} \\
(\mathrm{m} / \text { day })\end{array}$ & $\begin{array}{c}\text { Dimensionless } \\
\text { Damping Parameter, } \\
\mathrm{C}_{\mathrm{D}}\end{array}$ \\
\hline (A) $16.92-19.05$ & NA & NA & $\geq 2,000^{(\mathrm{c})}$ & 0.06 \\
\hline (B) $26.21-27.58$ & NA & NA & 41.2 & 1.5 \\
\hline (C) $25.30-27.58$ & NA & NA & 33.4 & 1.5 \\
\hline \multicolumn{5}{|c|}{$\begin{array}{l}\text { (a) Standard type-curve analytical method is not valid for aquifer hydraulic tests exhibiting either critically or } \\
\text { under-damped behavior. Results based on High-K analysis method (Butler and Garnett 2000). } \\
\text { (b) Assumed to be uniform within the well-screen test section. } \\
\text { (c) Analysis of Zone A aquifer hydraulic tests provided non-consistent results all with K values }>2,000 \mathrm{~m} / \text { day. } \\
\text { Test responses indicate a very high K condition. Value listed should be considered to be an assigned, lowest } \\
\text { possible value. }\end{array}$} \\
\hline
\end{tabular}


Table 3.8. Well 399-3-20 (C5002) Hydraulic Conductivity Distribution

\begin{tabular}{||c|c|c|c||}
\hline \multirow{2}{*}{$\begin{array}{c}\text { Profile Interval } \\
(\mathrm{m}, \mathrm{bgs})\end{array}$} & $\begin{array}{c}\text { Hydraulic Conductivity, } \\
\mathrm{K}_{\mathrm{h}}{ }^{(\mathrm{a})} \\
(\mathrm{m} / \mathrm{day})\end{array}$ & $\begin{array}{c}\text { Specific Storage, } \\
\mathrm{S}_{\mathrm{s}} \\
\left(\mathrm{m}^{-1}\right)\end{array}$ & Basis/Comments \\
\cline { 2 - 4 } & $\geq 2,000$ & - & Zone A \\
\hline \hline $16.92-19.05$ & 21.7 & - & Zone C - Zone B \\
\hline $25.30-26.21$ & 41.2 & - & Zone B \\
\hline $26.21-27.58$ & \multicolumn{2}{|c||}{} \\
\hline (a) Assumed to be uniform within the test/depth interval.
\end{tabular}

As indicated in Table 3.6, a hydraulic conductivity for the Hanford formation test interval is assigned as $\geq 2,000 \mathrm{~m} /$ day. This assigned value is a result of a lack of uniformity of analysis results for tests conducted for this depth interval. This represents a minimum estimate and interval conditions may be significantly higher (i.e., by a factor of 2 or 3 greater) than this assigned value. Hydraulic conductivity values for the underlying two Ringold Formation depth intervals ranged between 21.7 and $41.2 \mathrm{~m} /$ day (Table 3.6). Selected analysis figures for the respective test zones are presented in Appendix E.

Overall, the $\mathrm{K}_{\mathrm{h}}$ distribution in the four wells show a very high permeability condition for the Hanford formation gravel-dominated facies compared to a very low-to-moderate permeability within the various Ringold Formation sediments. These data indicate that groundwater and associated dissolved or suspended contamination can be displaced very quickly and moves laterally more rapidly within the Hanford formation in comparison to groundwater within the underlying Ringold Formation. It also suggests that contaminants migrating into the unconfined aquifer from the overlying vadose zone likely would be removed from the aquifer system more rapidly through this more permeable unit and are less likely to migrate deeper into the Ringold Formation portion of the aquifer even though the saturated portion of the Hanford formation is much thinner than the saturated Ringold Formation.

\subsection{Spectral Gamma and Neutron Moisture Logging}

The geophysical spectral gamma log data are used qualitatively to refine the lithologic/hydrogeologic interpretations. The inflections recorded on the geophysical logs were used to corroborate and precisely define changes in lithology, i.e., sand versus silt/clay or gravel intervals, to more precisely locate contact boundaries, the water table, and gamma emitting contaminants. The composite logs (Figures 3.2 through 3.5) provide the geophysical log correlations relevant to the hydrogeologic interpretation at each borehole. Based on interpretations by Stoller Inc., there were no manmade gamma-emitting contaminants detected above the minimum detectable level (MDL) in these wells. The detailed geophysical reports are presented in Appendix C. Section 6.6.4 also provides details of the geophysical well logging process.

\subsection{Subsurface Characterization}

The entire uppermost unconfined aquifer system was characterized in detail in new wells 399-3-18 (C4999) and 399-1-23 (C5000). The variable thickness of the permeable Hanford formation, which disconformably overlies the older and less permeable Ringold Formation sediments, was accurately defined in all four wells. The distinct lithologic contrast across the Hanford - Ringold erosional boundary was documented and verified via core samples (e.g., Figure 3.9). 


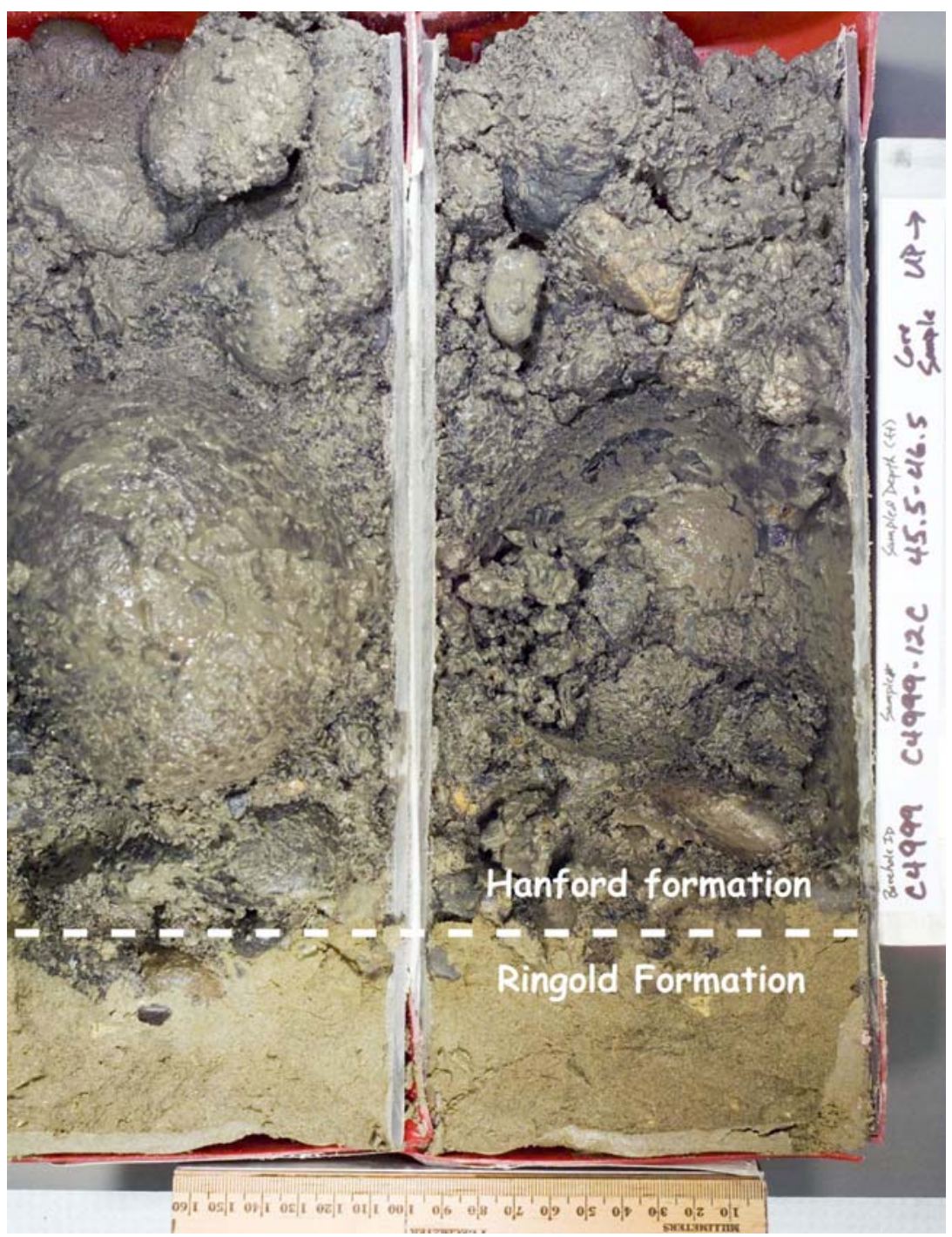

Figure 3.9. Core Photograph Showing the Hanford Formation - Ringold Formation Contact Boundary in Well 399-3-18 (C4999)

The lower confining unit (Ringold Lower Mud Unit 8) was also defined, and samples were collected in core obtained across the contact between the Unit 8 and the overlying Ringold Formation Unit 5 (e.g., Figure 3.10). Based on these results, the uppermost unconfined aquifer system, defined as the saturated interval from the water table to the top of the Ringold Formation lower mud unit (Unit 8), ranges from approximately 23 meters ( 75 feet) to 27.4 meters (90 feet) thick depending on the water-table elevation recorded in each well, which constantly changes due to changes in river level. Drilling in the two deep wells terminated in the Ringold lower mud unit, and no new information was obtained below those depths. 


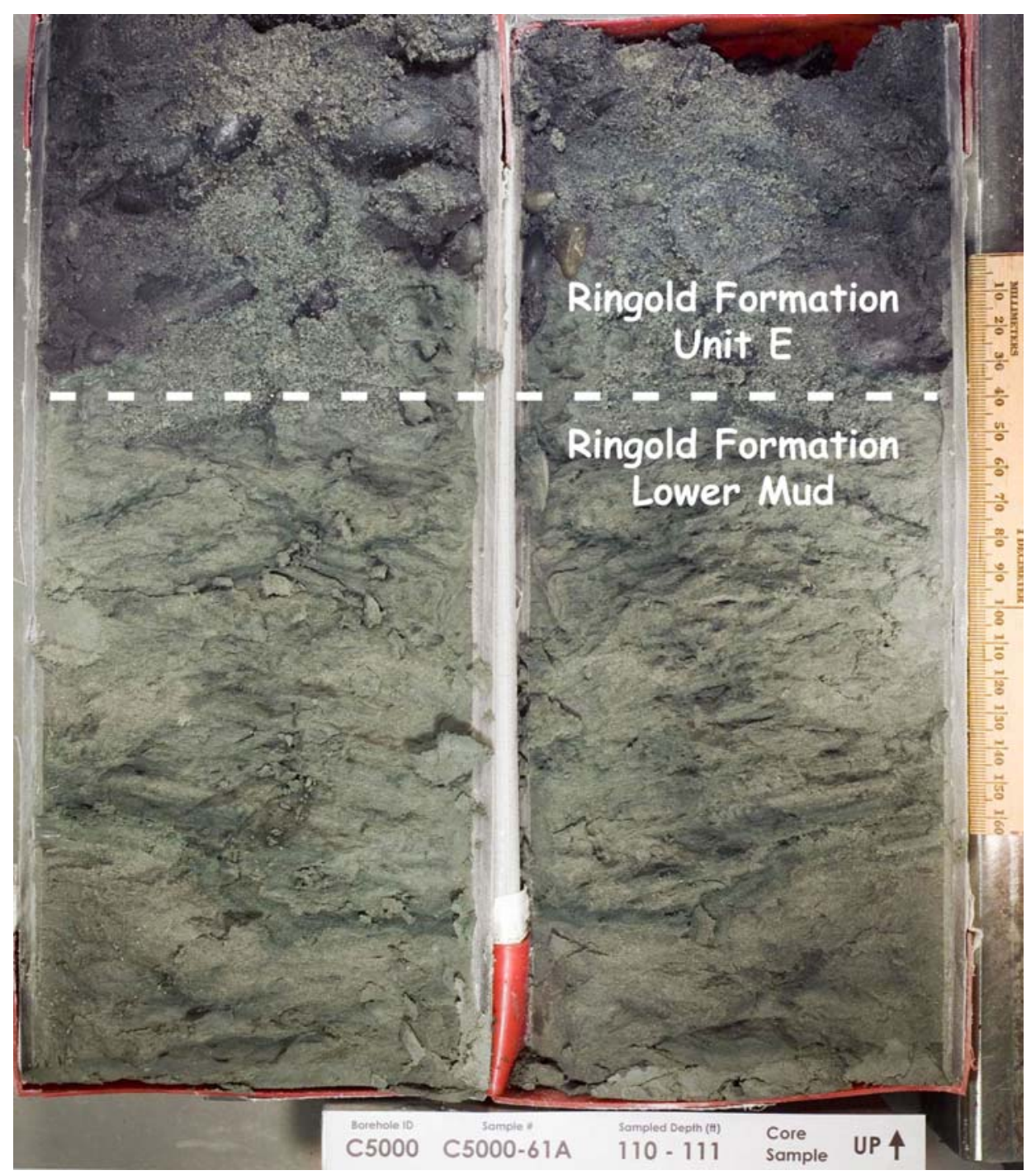

Figure 3.10. Core Photograph Showing the Ringold Formation Unit 5 and Unit 8 Contact Boundary in Well 399-1-23 (C5000)

Depth-discrete hydraulic flow parameters and groundwater results were compared to depth-equivalent lithologic intervals and used to differentiate preferential flow paths within the unconfined aquifer system. Three primary hydrologic units or flow zones were identified within the unconfined aquifer system in this area (Figure 3.11): (1) the highly-transmissive Hanford formation gravel-dominated facies as the uppermost hydrologic unit, (2) a less-transmissive sandy unit (Ringold Formation undesignated fine-grained unit) in the middle, and (3) a moderately transmissive silty, sandy, gravel sequence (Ringold Formation Unit $\mathrm{E}$ ) in the lower portion. The bottom of the unconfined aquifer is at the contact between the base of Ringold Formation Unit E (Unit 5) and the underlying aquitard, the Ringold lower mud (Unit 8). 


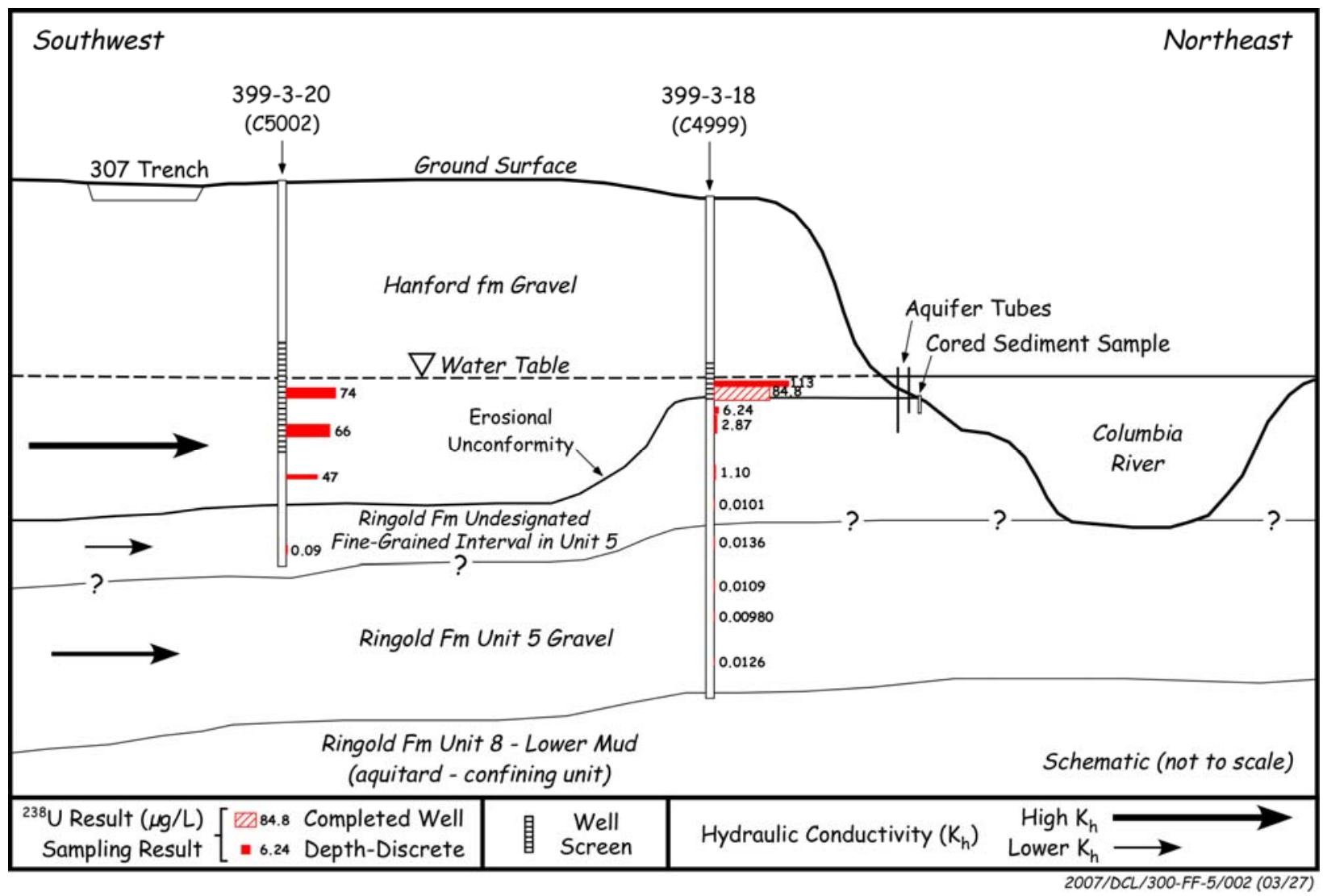

Figure 3.11. Schematic Cross Section Trending Southwest to Northeast Illustrating the Three Primary Hydrologic Units within the Unconfined Aquifer, 300-FF-5 Operable Unit

Combining the sediment core descriptions with the aquifer testing results facilitated the subdivision of the aquifer into mapable hydrogeologic units based on varying hydraulic properties (Figure 3.11). The hydraulic conductivity data and the well development information confirm that the Hanford formation Unit 1 gravel-dominated facies is significantly more permeable then the underlying, older Ringold Formation Unit 5 sediments. The Ringold Formation sediment is more compacted, variably cemented, and geochemically altered resulting in a lower overall permeability. The measured Hanford formation hydraulic conductivity ranges greater than 2,000 meters per day compared to a measured high value in the Ringold Formation of only 41.2 meters per day.

The Hanford/Ringold contact, which lies below the water table in most of the LFI study area, reflects an erosional paleo-surface believed to have been created by Pleistocene ice age catastrophic flooding across the area. The contrast in permeabilities across this Hanford/Ringold contact creates an effective groundwater flow boundary (e.g., Figure 3.9). Where saturated, the more permeable Hanford formation gravel-dominated facies, deposited directly onto this eroded Ringold surface, creates a preferential groundwater flow path that only exists within the very uppermost portion of the unconfined aquifer system. Characterization data used to define the contact include changes noted by the driller and in the wellsite geologist borehole log, sediment core descriptions, the borehole geophysical logs, and the integrated depth-discrete aquifer hydraulic testing and groundwater sample results. These data have been 
correlated and used to support the reinterpretation of the Hanford/Ringold contact (top of Ringold Formation) in the existing well records and to update and revise the relief map of the top of the Ringold Formation for the 300 Area (Figure 3.12).

The revised relief map confirms a major topographic trough, or channel, eroded into the Ringold Formation that trends northwest to southeast across the 300 study area. This northwest-southeast trending channel is paralleled by a Ringold Formation high, erosional remnant ridge on the east side of the study area near the river. The subsurface topographic relief across the channel-ridge area ranges up to $\sim 14$ meters. This prominent Hanford filled Ringold channel was first discovered in an excavated trench in 1958 (Figure 3.13) during installation of a water supply pipeline for serving the Plutonium Recycle Test Reactor (Lindberg and Bond 1979). This channel, and others like it, is eroded into the underlying Ringold Formation and filled with more permeable Hanford formation gravel-dominated sediments. These highly permeable channel deposits provide pathways for groundwater contaminants to migrate more rapidly and to discharge ultimately to the Columbia River. This channel and other features of the subsurface are conceptually illustrated using the new borehole data in hydrogeologic cross sections (Figure 3.14). Figures 3.15 to 3.17 illustrate the revised hydrogeology perpendicular and parallel to the Columbia River, including the well locations, the primary hydrogeologic units and the vertical distribution and extent of uranium contamination in the unconfined aquifer system.

Within the Ringold Formation, new subsurface data have lead to the discovery of a locally continuous and thick fine-grained silty sand interval near the top of the Ringold Formation in the LFI study area. These new data suggest that prior to the post-Ringold erosional episode, a fairly extensive Ringold finegrained interval (as yet undesignated) was present across portions of the 300 Area. This is based on a relatively thick ( $\sim 12$ to 35 feet), well sorted, fine-grained sand and silt interval that was characterized in three of the four boreholes (Figures 3.2 through 3.5). In addition, a review of older existing well data and geophysical logs suggests that this fine-grained interval is present and more widespread then previously thought. Preliminary mapping indicates that portions of or the entire fine-grained unit may have been removed in some deeply eroded areas. These areas could be misinterpreted as non-depositional areas giving the appearance that the fine-grained unit is not as continuous as we now believe.

To investigate the lateral extent of this fine-grained unit, additional sediment sampling and coring was completed by the Remediation Task of the Science and Technology Project (S\&T Project). Sediment sampling at an underwater outcrop located offshore in the Columbia River, and from two core locations at the shoreline recovered fine-grained sand and silt samples very similar to the fine-grained sediment cored in the new wells (Figure 3.18). The addition of the river and shoreline core samples supports the hypothesis that this fine-grained unit is relatively continuous, extending out beneath the river (Figure 3.15). River shore aquifer tube water sample results also suggest a vertical hydraulic barrier to groundwater movement through or across this fine-grained interval. Hydraulic conductivity measurements $(0.04$ and 0.36 meters per day) from well 399-3-18 (C4999) across this fine-grained interval indicate that this zone has very low permeability compared to shallower Hanford formation and deeper Ringold Formation sediments. Additional work is needed to confirm the extent and significance of this unit to groundwater and contaminant flow within the 300 Area.

Finally, geophysical log data were used to confirm and precisely determine contact depths and identify changes in lithology. Together, the integrated data sets represented in the composite logs provide accurate and comprehensive interpretations of the hydrogeology of the area. 


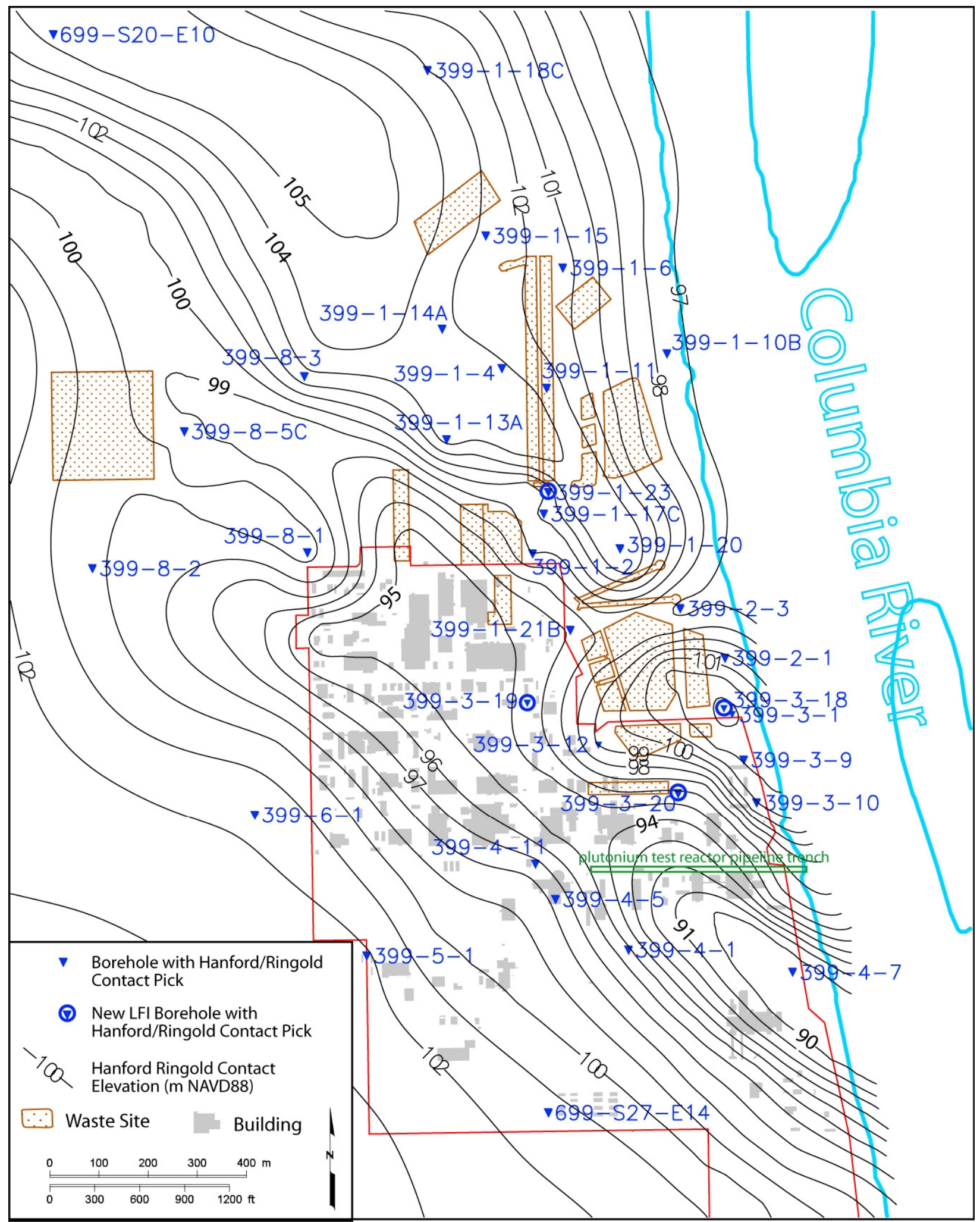

Figure 3.12. Elevation Contour (Relief) Map of the Hanford/Ringold Contact Boundary, 300-FF-5 Operable Unit 


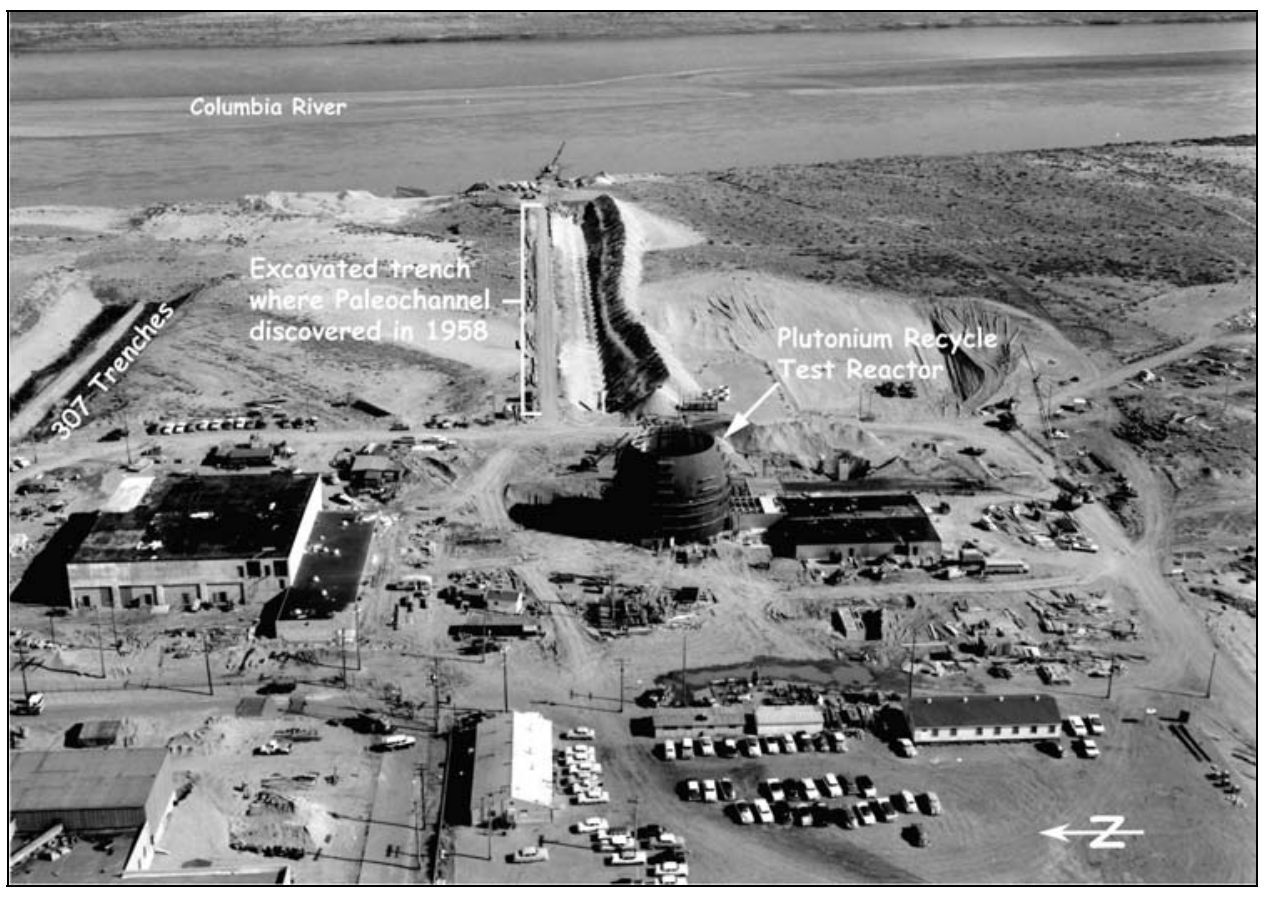

Figure 3.13. Aerial Photograph (1958) Showing the 300 Area Under Construction. Visible in this photograph are the 307 trenches and excavated plutonium recycle test reactor pipeline trench.

Hydrogeologic units (Figure 3.1) encountered in the boreholes, from youngest (shallowest) to oldest (deepest) as illustrated in the composite borehole logs (Figures 3.2 to 3.5) include:

1. Recent surficial sediments (Holocene) and/or backfill material composed of reworked Hanford sandy gravel and eolian silt and sand deposits, or coal plant ash waste. These deposits overlie the area and range in thickness from 0.3 meter ( 1 foot) up to approximately 5.2 meters ( 17 feet) bgs in the new wells.

2. Hanford formation Unit 1 gravel-dominated sediments comprise the rest of the vadose zone and the upper, most permeable portion of the unconfined aquifer in all the new wells. This unit is composed of unconsolidated sediment ranging in grain size from boulder to pebble gravel and includes coarse to fine sand with minor amounts of silt. Most often, these sediments exhibit a clastsupport structure; matrix between clasts is normally a poorly sorted mixture of sand and silt. Occasionally, matrix is missing, which produces an open-framework fabric (Figure 3.19). There were no distinguishable or mapable hydrogeologic changes within the vadose zone between these wells, but there are isolated occurrences of older, reworked Ringold Formation sediment distinguished by their more cohesive sediment structure, color and/or degree of sorting (Figure 3.20). These Ringold Formation sediments may also contain zones with higher clay/silt content. There are also zones where reworked Ringold Formation mud was deposited along with the Hanford formation cataclysmic flood gravel (Bjornstad 2004). Large boulder-size clasts of consolidated, cohesive Ringold Formation clay/silt were observed as rip-up clasts and lenses within the Hanford formation in the 300 Area (see Bjornstad 2004). These Ringold Formation sediments, randomly deposited, may create localized restrictions to the vertical movement of liquid and moisture in the vadose zone. Overall, Unit 1 ranges in thickness from $~ 9.8$ meters (32 feet) in well 399-3-18 
(C4999) to 21.3 meters (70 feet) in well 399-3-19 (C5001). The saturated portion of Unit 1 ranges in thickness from $\sim 1$ meter (3 feet) in well 399-3-18 (C4999) near the river to 10.7 meters (35 feet) thick in the paleo-erosional channel encountered in well 399-3-19 (C5001). These saturated thicknesses decrease and increase depending on river induced changes occurring at the water table.

3. Ringold Formation Unit 5 (Figure 3.1) unconformably underlies the Hanford formation Unit 1 and is composed predominantly of (a) a fluvial fine-grained silt to sand interval, and (b) a fluvial gravel to silty sandy gravel unit (DOE 2006a). The fine-grained silt to sand interval (undesignated) (Figure 3.1) was confirmed by coring in three of the four boreholes and overlies the variably indurated, fluvial silty sandy gravel Ringold Formation Unit 5 sequence (Figure 3.1). The finegrained interval was encountered (Figures 3.2 to 3.5) near the Hanford/Ringold contact and ranges in thickness from $\sim 0$ meters in well 399-1-23 (C5000) to $\sim 11$ meters (36 feet) in well 399-3-18 (C4999). The fluvial gravel facies ranges in thickness from $\sim 13.4$ meters (44 feet) in well 399-3-18 (C4999) to 17.4 meters (57 feet) in well 399-1-23 (C5000). Combined, these two units comprise the lower, and significantly less permeable, portion of the unconfined aquifer beneath the $300-\mathrm{FF}-5$ OU. The contact with the overlying Hanford formation is determined based on a distinct change in basalt content, color, decreasing grain size and better sorting in the Ringold sediments (Appendix B). This interpretation is also supported by changes in the hydraulic properties exhibited by aquifer tests conducted in the two formations and increasing total gamma activity (e.g., increases in natural potassium-40).

4. Ringold Formation Unit 8 (lower mud unit) underlies the Ringold Formation Unit 5 and forms the lower boundary of the unconfined aquifer system (Figure 3.1). This confining unit separates the basalt confined aquifer system from the overlying unconfined aquifer system. The lower mud unit is comprised of silty clay to silty sand and forms a sharp well defined contact boundary with the overlying Unit 5 fluvial gravel (Figure 3.10). Only two of the four wells, 399-3-18 (C4999) and 399-1-23 (C5000) (Figures 3.2 to 3.5), were drilled deep enough to encounter the lower mud unit; there are several older existing wells that have penetrated or tagged this interval. The two wells were drilled approximately 1.5 meters ( 5 feet) into the top of this unit to confirm the boundary and collect intact core samples.

5. Ice Harbor Member (lava flows) of the Saddle Mountains Basalt underlies the Ringold lower mud Unit 8. Drilling did not penetrate to the depth of the Ice Harbor Member during the LFI characterization.

6. Additional information about the hydrogeology of the 300 Area is available in DOE (2006a). 


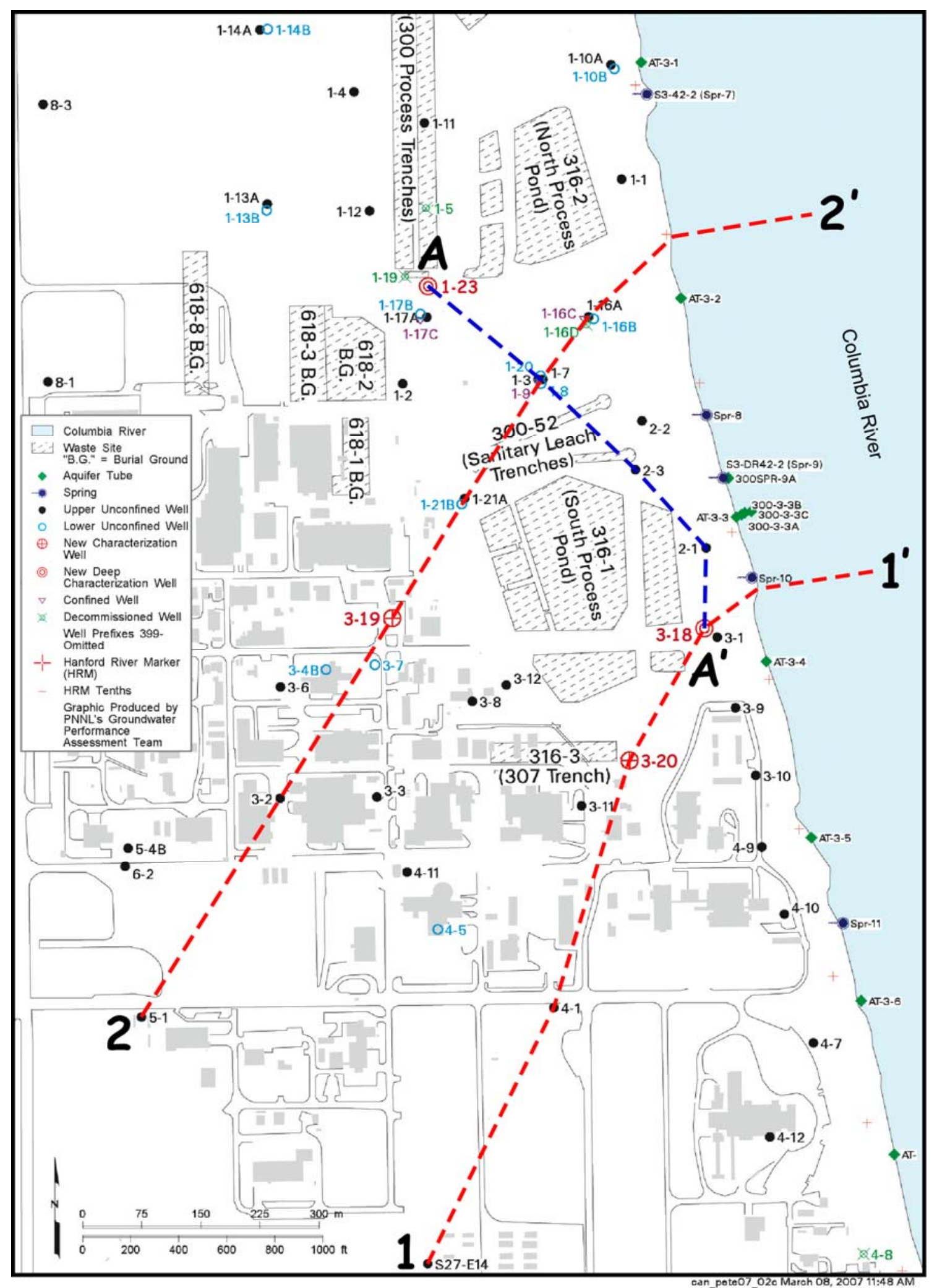

Figure 3.14. Location Map Showing the Orientation of Hydrogeologic Cross Sections, 300-FF-5 Operable Unit 


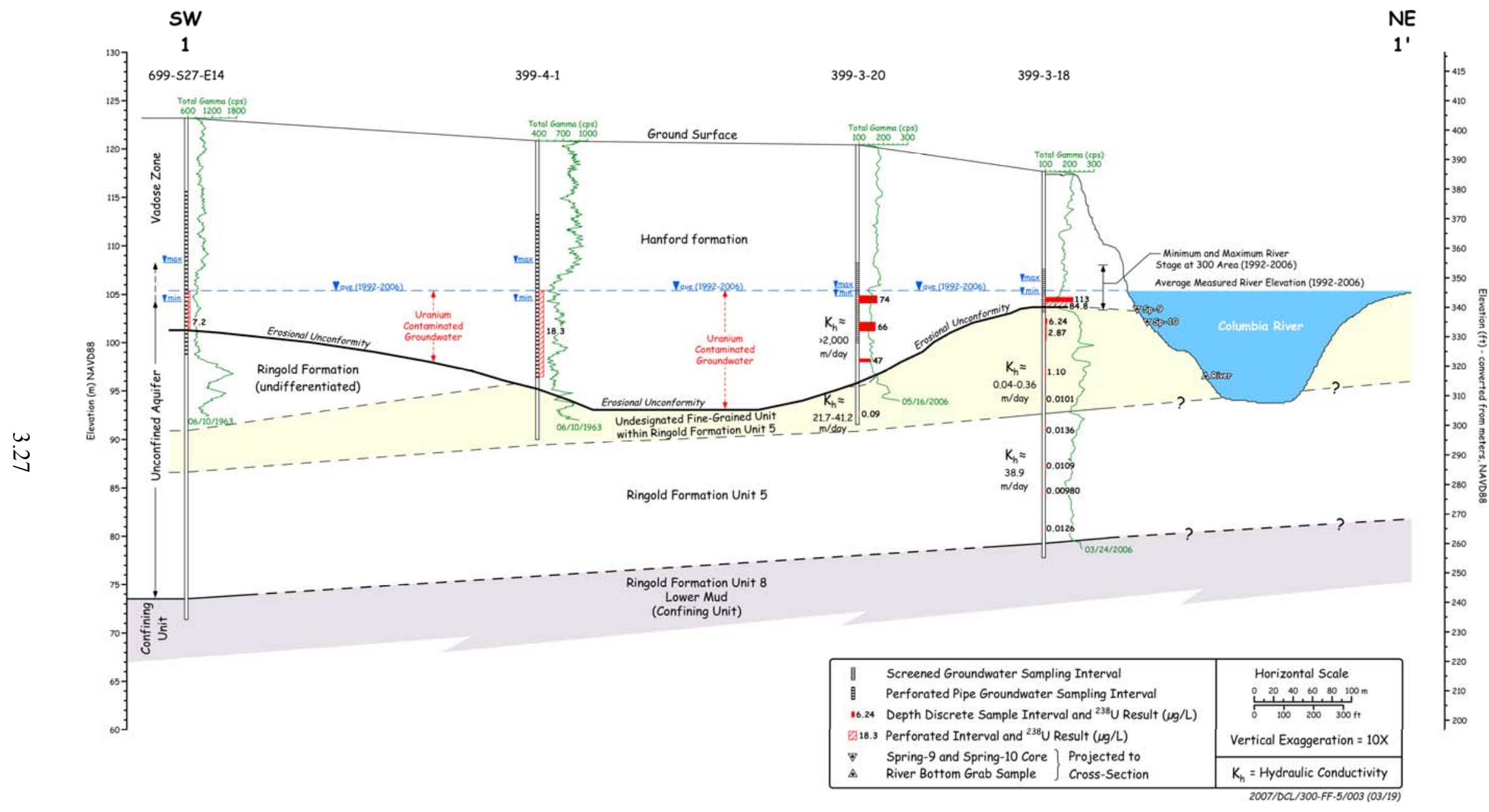

Figure 3.15. Hydrogeologic Cross Section 1-1' (SW to NE) Illustrating the Unconfined Aquifer, H/R Contact and the Uranium Contaminant Distribution in Groundwater 


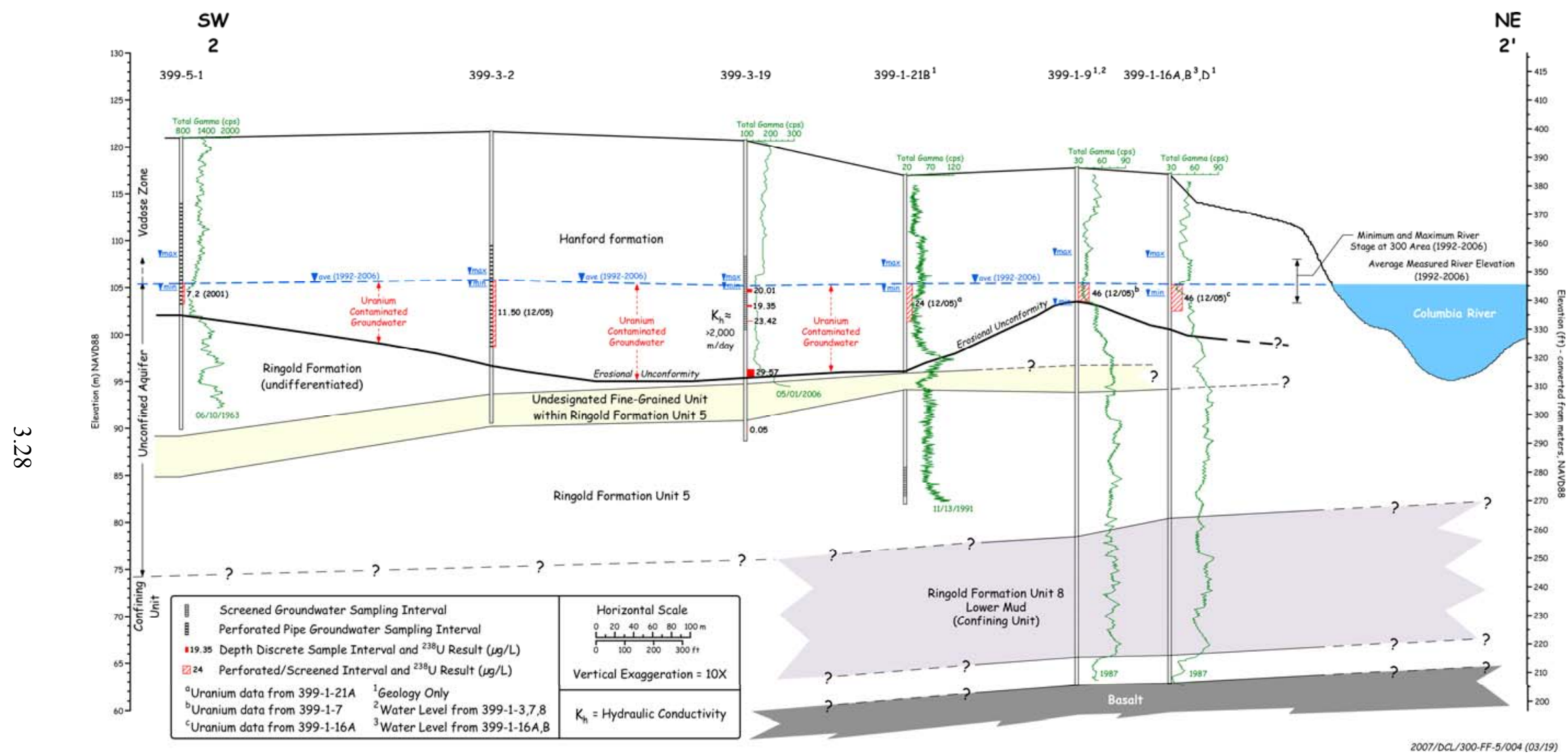

Figure 3.16. Hydrogeologic Cross Section 2-2' (SW to NE) Illustrating the Unconfined Aquifer, H/R Contact and the Uranium Contaminant Distribution in Groundwater 


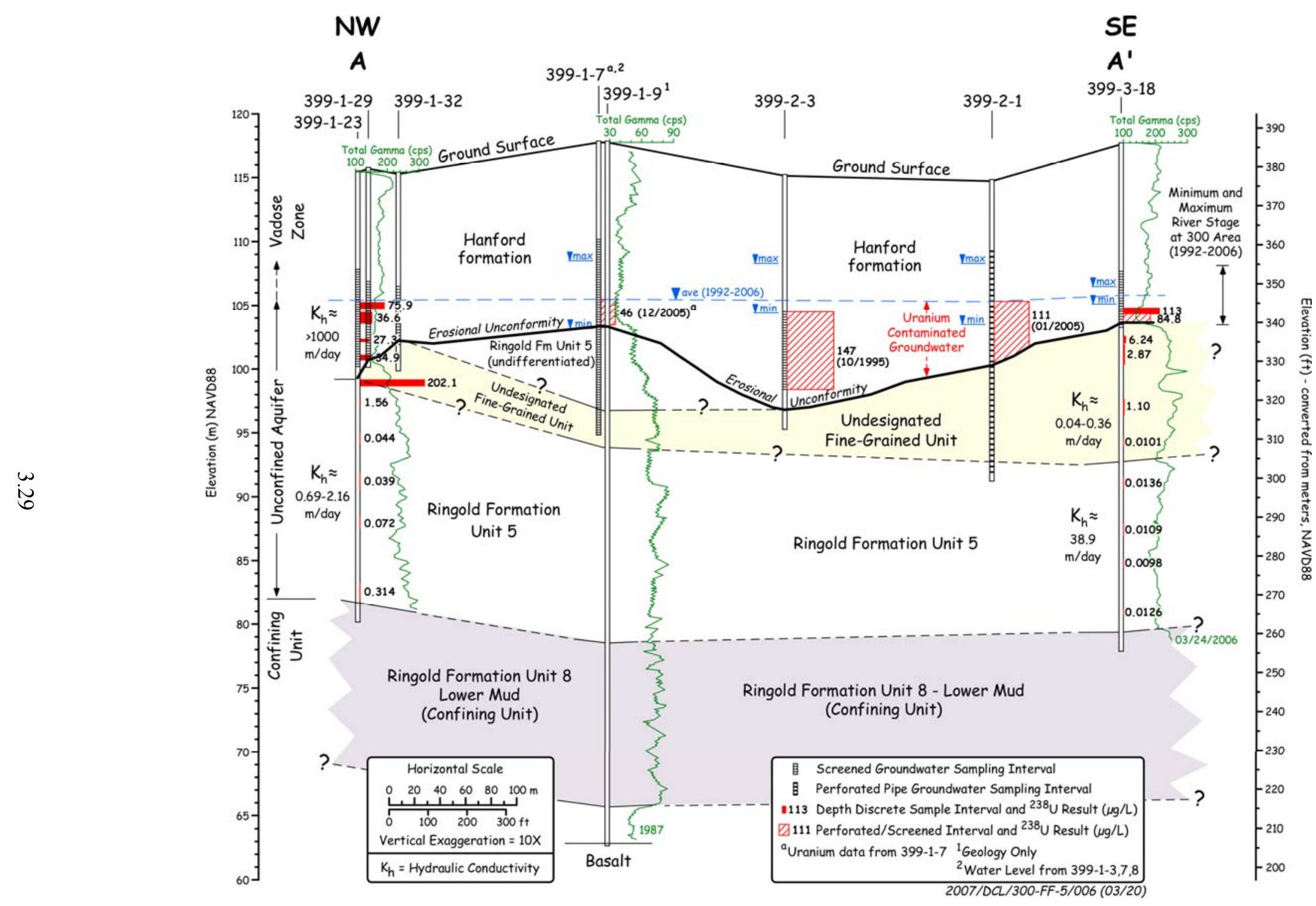

Figure 3.17. Hydrogeologic Cross Section A-A' (NW to SE) Illustrating the Unconfined Aquifer, H/R Contact and the Uranium Contaminant Distribution in Groundwater 


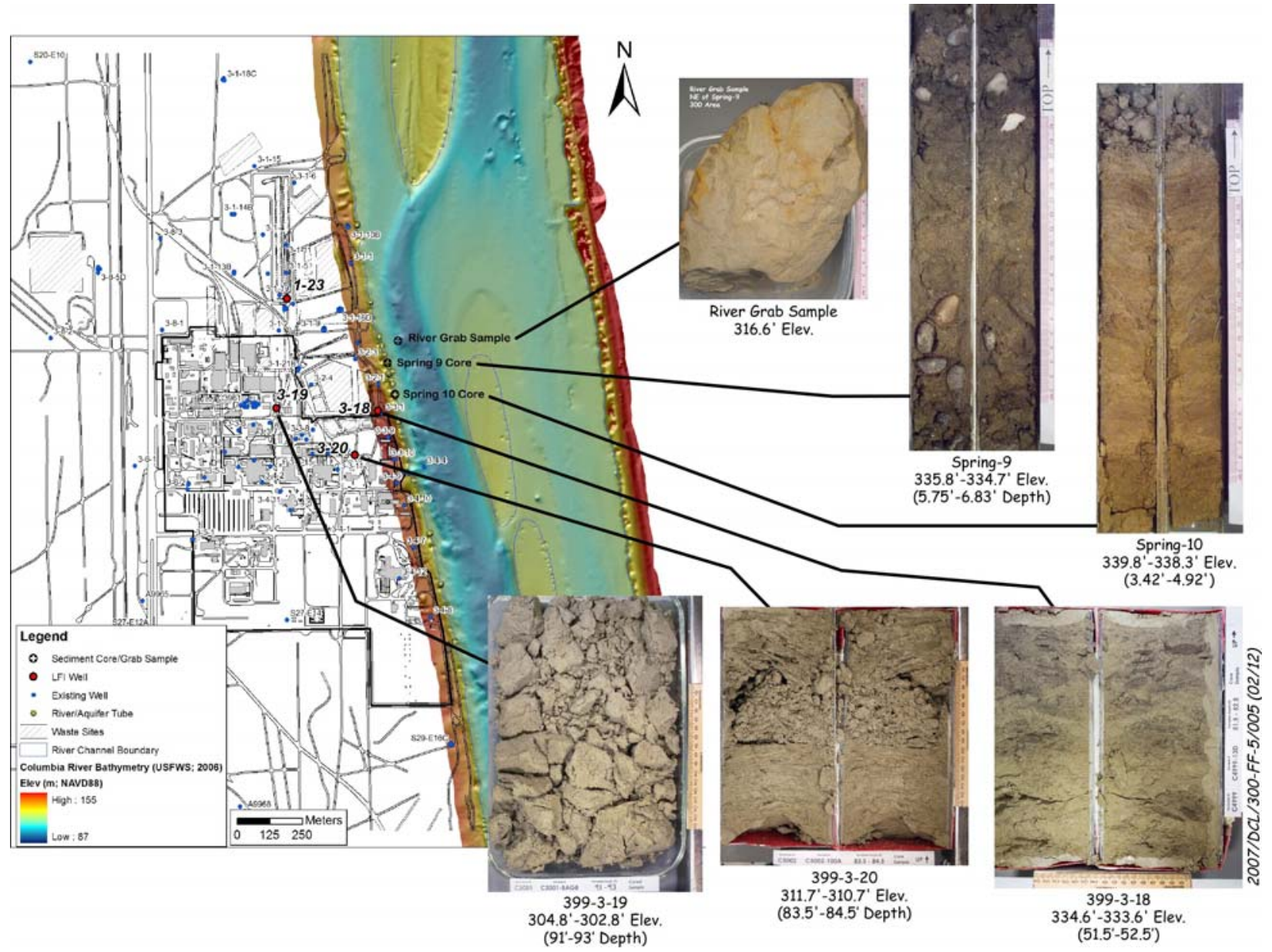

Figure 3.18. LFI Well Location Map Showing Locations of Ringold Formation Undesignated FineGrained Sand Samples Collected from the Columbia River Bottom and Shoreline 


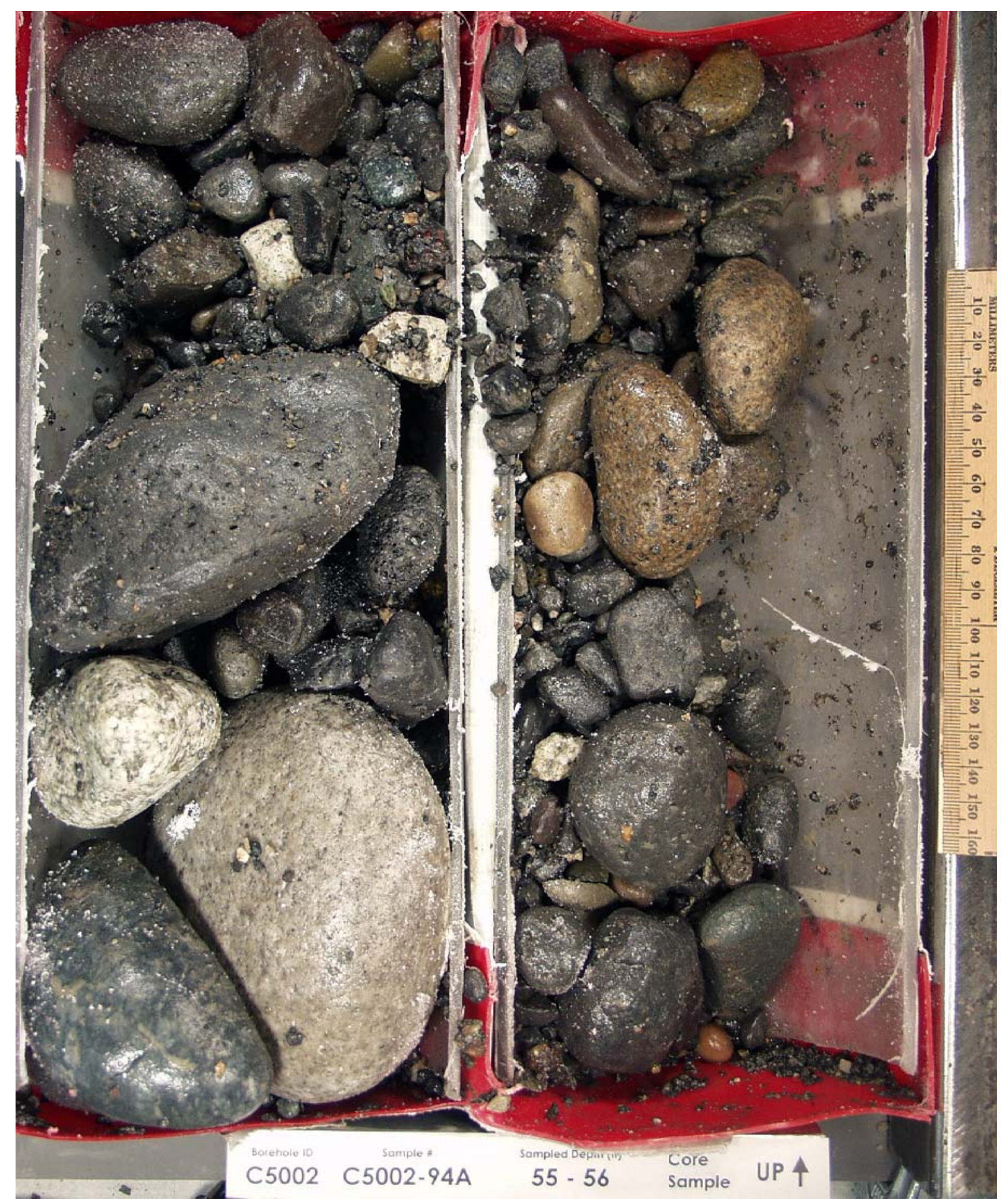

Figure 3.19. Core Photograph Showing Open-Framework Gravel of the Hanford Formation in Well 399-3-20 (C5002) 


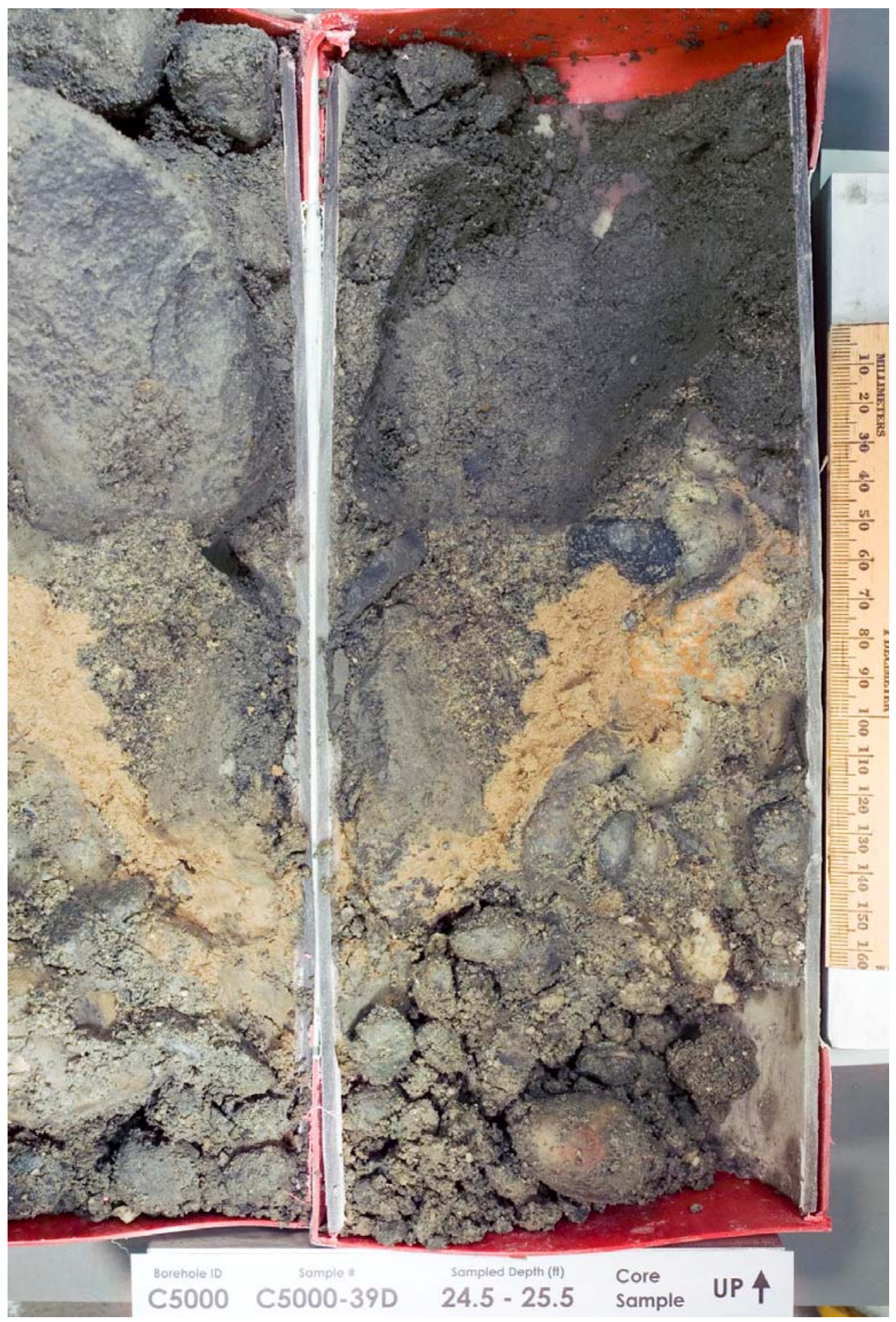

Figure 3.20. Core Photograph Showing Reworked Sediments Within the Hanford Formation Vadose Zone in Well 399-1-23 (C5000) 


\subsection{Revised and Updated Contaminant Distribution Model}

Section 4 provides the interpretation of the sediment and groundwater hydrochemistry and contaminant results for the four new wells and establishes contaminant pathways as they relate to the hydrogeology of the 300 Area.

The ultimate goal of the 300 Area LFI was to determine the distribution and concentration of Hanford process uranium in the lower vadose zone and unconfined aquifer (DOE 2006a). This section describes the distribution of the primary contaminants uranium, nitrate, and volatile organic carbon compounds associated with trichloroethene (TCE) detected during characterization of the four new boreholes. These contaminant distributions are incorporated into the updated hydrogeologic interpretations for the boreholes and will be used to develop vadose zone and groundwater contaminant conceptual models (Figures 3.2 through 3.5).

Depth-discrete groundwater sample data and analytical results (see Section 6.6.2 for details on sampling and analysis), besides showing where the contamination is and how it is distributed, aid in determining hydrologic conditions and flow boundaries within the aquifer system. The laboratory analytical data directly provide the identification, concentration, and distribution of contaminants and other constituents within the aquifer system. In addition to these data, groundwater flow conditions and aquifer variations can also, indirectly, be determined based on vertical changes in the groundwater indicator parameters collected in the field during drilling and sampling (such as specific conductance, dissolved oxygen, $\mathrm{pH}$, and temperature). Combined, these data are used to interpret which zones within the aquifer are contaminated and to better understand the relationship between contaminant concentration, groundwater flow zones, and aquifer boundaries as needed for developing the conceptual models.

Field parameters indicate an interval with redox-reducing conditions and low specific conductance within the lower to middle Ringold Formation that suggests that the lower portion of the unconfined aquifer has been less prone to infiltration by younger water sources (Figures 4.1 to 4.4). Aquifer testing (Section 3.4) and visual inspection of sediment core results also support this interpretation. These data are corroborated by the depth-discrete uranium/nitrate results, two of the primary mobile dissolved contaminants in the 300 Area whose concentrations drop off significantly at or just below the Hanford/ Ringold contact. Other constituent concentrations, such as sulfate and calcium, also drop off significantly below this contact. The lack of these constituents in the deeper intervals below the Hanford/Ringold contact also support the presence of a geochemical reducing trend with depth within the lower unconfined aquifer. Data from the four wells all confirm that the Hanford/Ringold contact is the primary flow boundary within the upper unconfined aquifer (Figures 3.2 through 3.5) that controls the vertical movement of groundwater and dissolved contaminants.

Geochemical stiff diagrams (Figures 4.1 through 4.4) illustrate the major cation and anion composition for groundwater samples from the discrete sample depths in each of the four new boreholes. All of the shallow groundwater samples are dominated by calcium and bicarbonate, which is the natural condition of groundwater (uncontaminated or slightly contaminated). There is a subtle shift in the cation makeup of the groundwater with depth wherein the mono-valent cations sodium and potassium increase and calcium decreases, especially in the low dissolved oxygen/reducing redox interval below the Hanford/Ringold contact. 
Selected Results for Depth Discrete Water Sampling from Borehole C4999 (399-3-18)

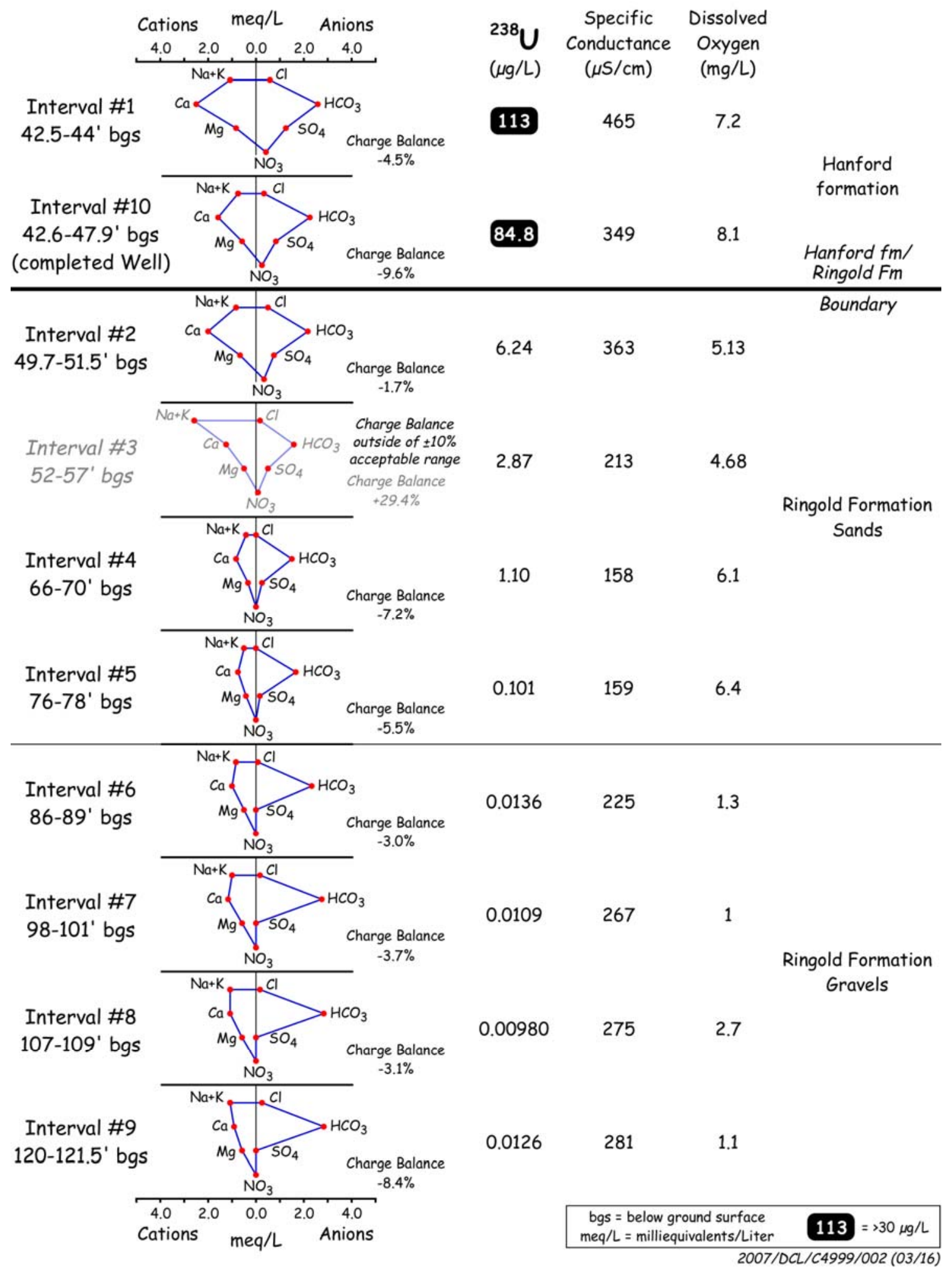

Figure 4.1. Stiff Chemistry Plots for Depth-Discrete Groundwater Samples in Well 399-3-18 (C4999) 
Selected Results for Depth Discrete Water Sampling from Borehole C5000 (399-1-23)

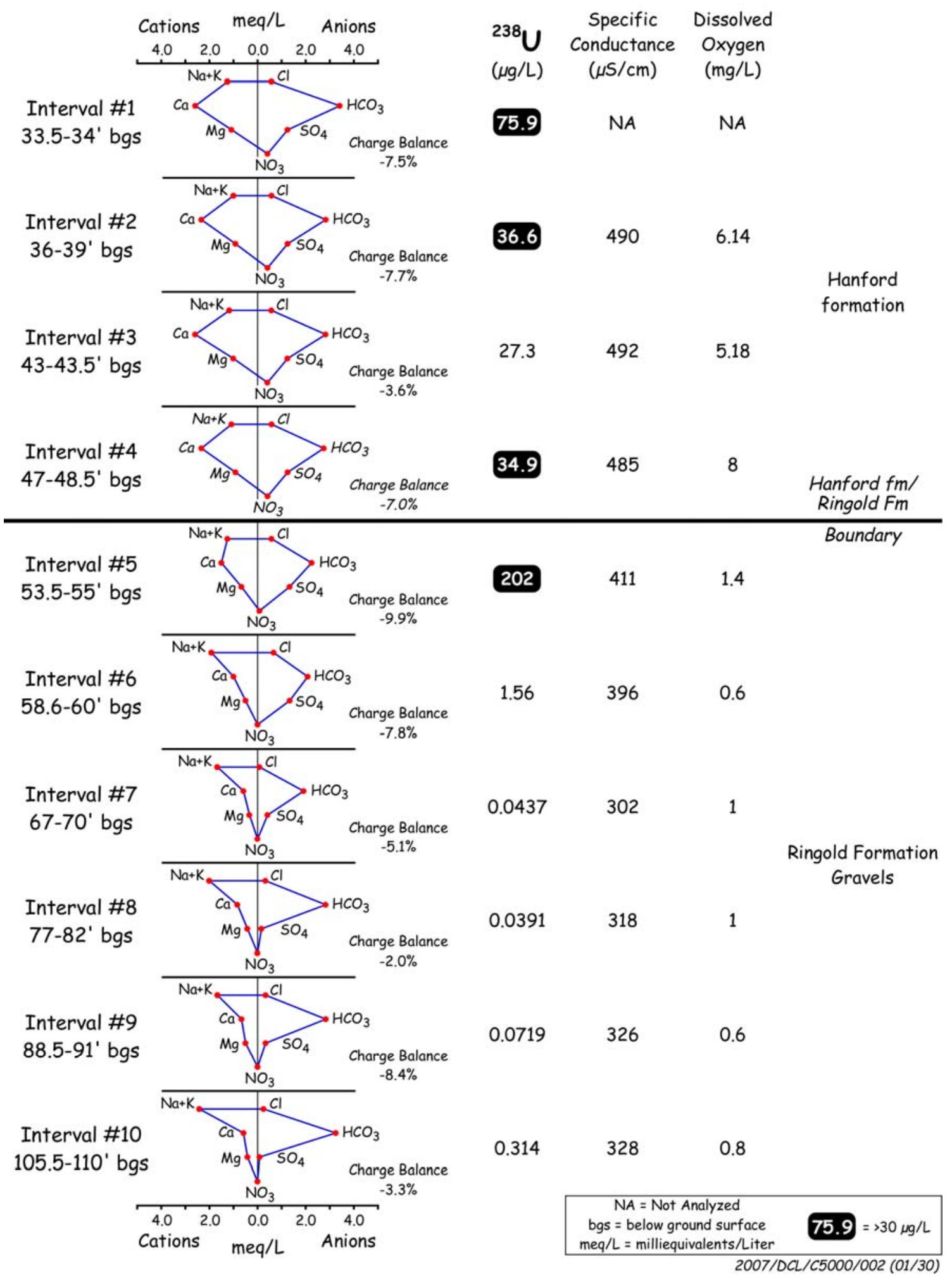

Figure 4.2. Stiff Chemistry Plots for Depth-Discrete Groundwater Samples in Well 399-1-23 (C5000) 
Selected Results for Depth Discrete Water Sampling from Borehole C5001 (399-3-19)

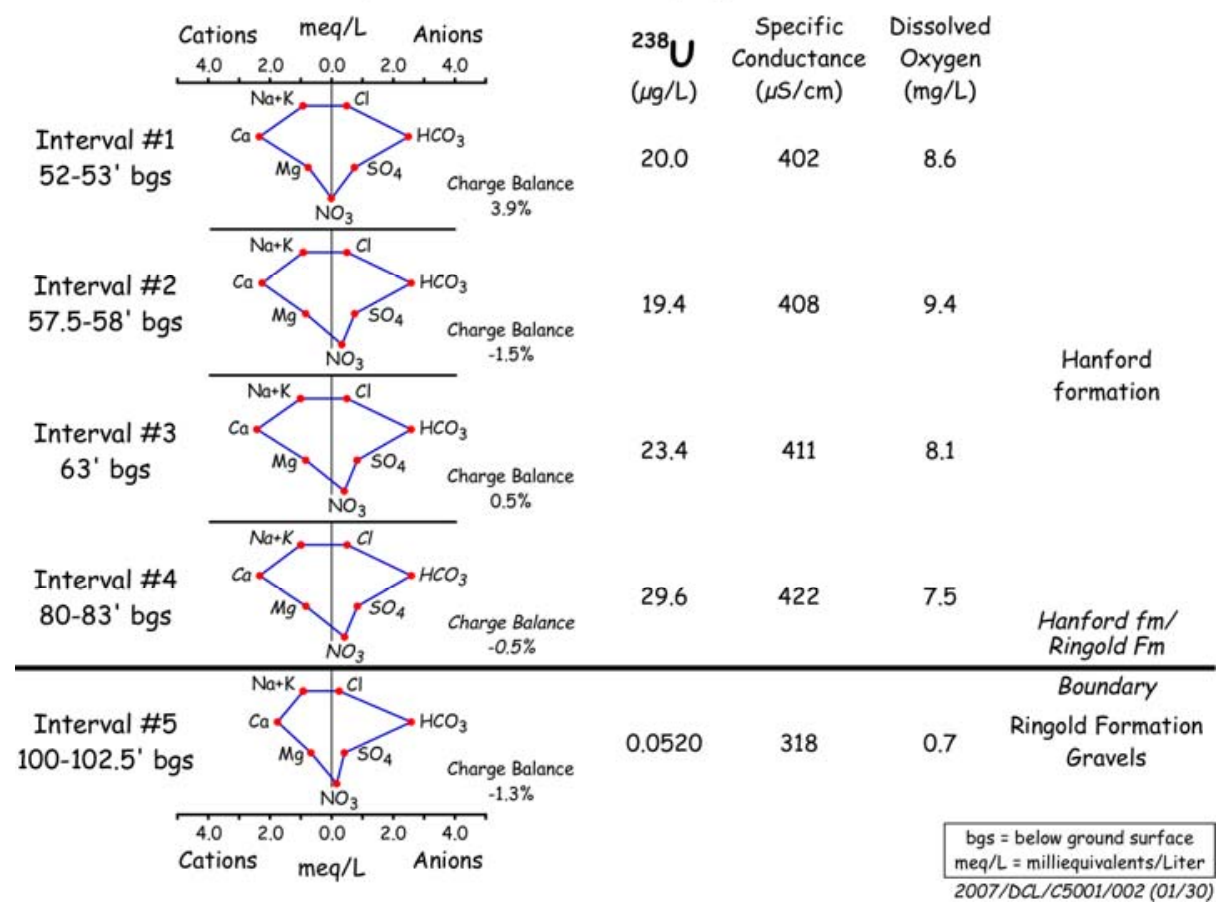

Figure 4.3. Stiff Chemistry Plots for Depth-Discrete Groundwater Samples in Borehole 399-3-19 (C5001)

Selected Results for Depth Discrete Water Sampling from Borehole C5002 (399-3-20)

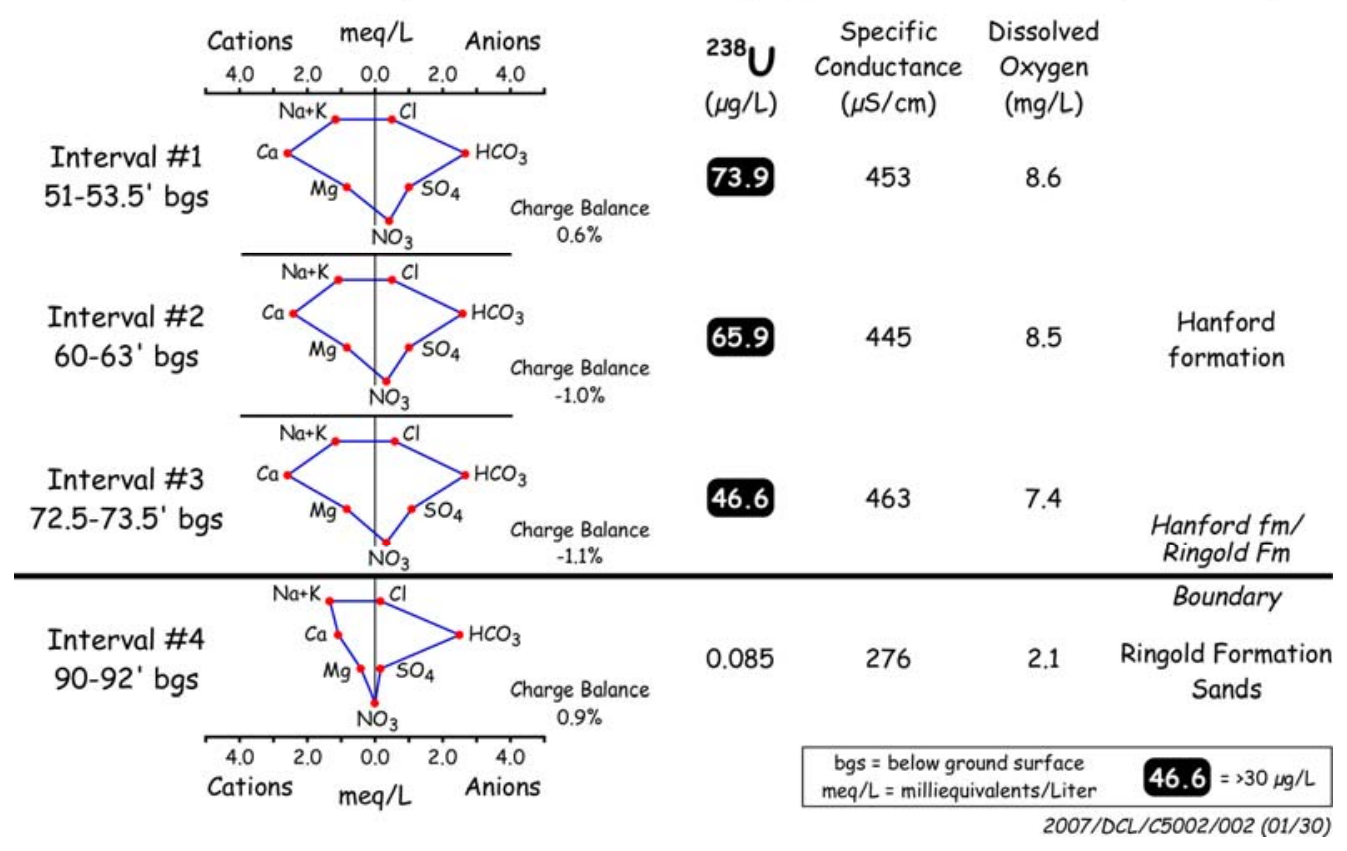

Figure 4.4. Stiff Chemistry Plots for Depth-Discrete Groundwater Samples in Borehole 399-3-20 (C5002) 


\subsection{Uranium Distribution}

\subsubsection{Uranium Contamination in the Aquifer}

Based on depth-discrete groundwater data (Appendix D, Table D.22), as illustrated on the four composite borehole logs (Figures 3.2 to 3.5 ) and groundwater chemistry plots (Figures 4.1 to 4.4), elevated (above natural background) concentrations of dissolved uranium in groundwater is restricted to the upper portion of the unconfined aquifer primarily above the Hanford/Ringold contact boundary. The lack of detectable levels of Hanford process uranium in the borehole geophysical logging results (Section 6.6.4) and the laboratory GEA results (Section 6.6.1.3) also support this observation.

Elevated uranium concentrations in groundwater, ranging up to $202 \mu \mathrm{g} / \mathrm{L}$, occur in the groundwater throughout the saturated Hanford formation gravel and only slightly penetrate into the upper Ringold Formation in all four of the new boreholes. With the exception of samples that were collected near, or that bridged, the Hanford/Ringold contact, groundwater uranium results are essentially below detection at all sample depths below the Hanford/Ringold contact in all of the new wells.

The highest dissolved uranium in groundwater, $\sim 202 \mu \mathrm{g} / \mathrm{L}$, was detected in well 399-1-23 (C5000) at the Hanford/Ringold contact (see Figures 3.3 and 4.2). EPA's maximum contaminant level for uranium in drinking water supplies is $30 \mu \mathrm{g} / \mathrm{L}$. Values for four other shallower groundwater samples within the $\sim 6$-meter-thick Hanford formation had dissolved uranium concentrations that ranged between $\sim 35$ and $80 \mu \mathrm{g} / \mathrm{L}$, and the highest concentration was at the water table. This well is located at the disposal end of the now decommissioned 316-5 Process Trenches that are a known past source of process uranium.

Well 399-3-18 (C4999), located downgradient of the 316-South Process Pond, had the second highest groundwater uranium concentration, $\sim 113 \mu \mathrm{g} / \mathrm{L}$, from a sample collected at the water table (Figures 3.2 and 4.1). The saturated Hanford formation interval is significantly thinner than the other three new wells ( $\sim 1$ meter when sampled). The uranium concentration of the next deeper groundwater sample was $<10 \mu \mathrm{g} / \mathrm{L}$. This deeper groundwater uranium concentration is lower because the sample interval bridged or was located just below the H/R contact and may reflect dilution of the high uranium concentration groundwater in the Hanford formation from the deeper groundwater within the lower permeability Ringold Formation (which contains lower uranium concentrations). Several of the older existing wells in this area have long screen or perforated intervals that are open across the H/R contact which implies that the resulting groundwater samples may be diluted and that the measured uranium concentrations are not representative of the true uranium concentrations within the thin saturated Hanford formation portion of the aquifer that has high permeability (i.e., transports water readily to the Columbia River).

New well 399-3-19 (C5001), located upgradient (generally) of all of the known waste disposal ponds and trenches, had the lowest uranium concentrations in the groundwater of all the new wells (Figures 3.4 and 4.3). This location intersects a thick, saturated Hanford formation gravel-dominated interval ( $\sim 11$ meters) within the prominent channel eroded into the Ringold Formation. The average groundwater uranium concentration from four independent depth samples collected from the Hanford formation was less then the $30-\mu \mathrm{g} / \mathrm{L}$ EPA drinking water standard. Uranium concentrations in the groundwater in the fourth well, 399-3-20 (C5002), ranged between $\sim 50$ and $75 \mu \mathrm{g} / \mathrm{L}$ (Figures 3.5 and 4.4). The highest value 
was near the water table. This well is located at the southeastern corner of the 307 Trench, a suspected source of uranium contamination to groundwater. The saturated Hanford formation is $\sim 9.5 \mathrm{~m}$ thick at this location.

The groundwater uranium concentration results from the depth-discrete samples from the four new boreholes are generally consistent with regional uranium plume concentrations as determined through the routine 300-FF-5 OU sampling program; these results reflect dissolved uranium concentrations in the shallow, unconfined aquifer within the permeable gravel-dominated deposits of the Hanford formation (Figure 2.1).

Based on the new characterization data obtained during the LFI, it is probable that most of the dissolved uranium contamination within the 300-FF-5 OU moving through groundwater is constrained to the saturated, variably thick Hanford formation sediment above the Hanford/Ringold boundary. The lack of detectable uranium below the Hanford/Ringold contact is also consistent with the hydrogeologic interpretation. Aquifer test results, groundwater analytical data, and field indicator parameters (specific conductance and dissolved oxygen) suggest that the groundwater below the Hanford/Ringold is older water that has not been significantly altered or displaced by the more recent liquid waste effluent disposal activities.

\subsubsection{Uranium Contamination in the Vadose Zone}

The analysis for uranium on sediments or in pore fluid within the vadose zone has been completed (Section 6.6.1.4). Overall, there is a general trend in which samples from the lower vadose zone and the uppermost aquifer contain Hanford process uranium (i.e., the total uranium is higher than the natural uranium), especially in the 399-3-18 (C4999) and 399-1-23 (C5000) borehole sediment samples. However, there were no "hot spots" (high uranium concentration) of process uranium detected in the vadose zone or saturated sediments during characterization of these four boreholes. Both borehole geophysical and laboratory GEA results support this observation.

In addition to obtaining the directly measured pore water from a few selected sediment samples using ultracentrifugation, 1:1 sediment to water extracts were performed, and the water extract data were recalculated (dilution corrected) to derive uranium concentrations in pore water of the sediments. Actual chemical composition, including uranium concentration of the native pore water in the sediments, was estimated from the 1:1 water extract analyses after correcting for dilution based on knowledge of the moisture content of the sediment samples. A comparison of the uranium concentrations measured in groundwater samples, directly measured pore water samples after ultracentrifuge, and calculated pore water from the 1:1 sediment-water extracts from the four wells is shown in Figure 4.5. The same figure, with a different scale to show more detail, is included in Appendix D (Figure D.21).

Uranium concentrations in the pore waters measured directly after ultracentrifugation for wells 399-3-18 (C4999) and 399-1-23 (C5000) sediments were similar to those from the estimated pore waters based on 1:1 water extracts after moisture content correction. Uranium concentrations in the calculated pore waters ranged up to $3,650 \mu \mathrm{g} / \mathrm{L}$ and showed relatively higher concentrations in well 399-3-18 (C4999) and well 399-1-23 (C5000) sediments. Both well 399-3-19 (C5001) and well 399-3-20 (C5002) groundwater and estimated vadose zone sediment pore waters showed relatively low uranium concentrations compared to samples from well 399-3-18 (C4999) or well 399-1-23 (C5000). The borehole sediment uranium concentration profiles (Figure 4.5) suggest that near the water table, vadose 

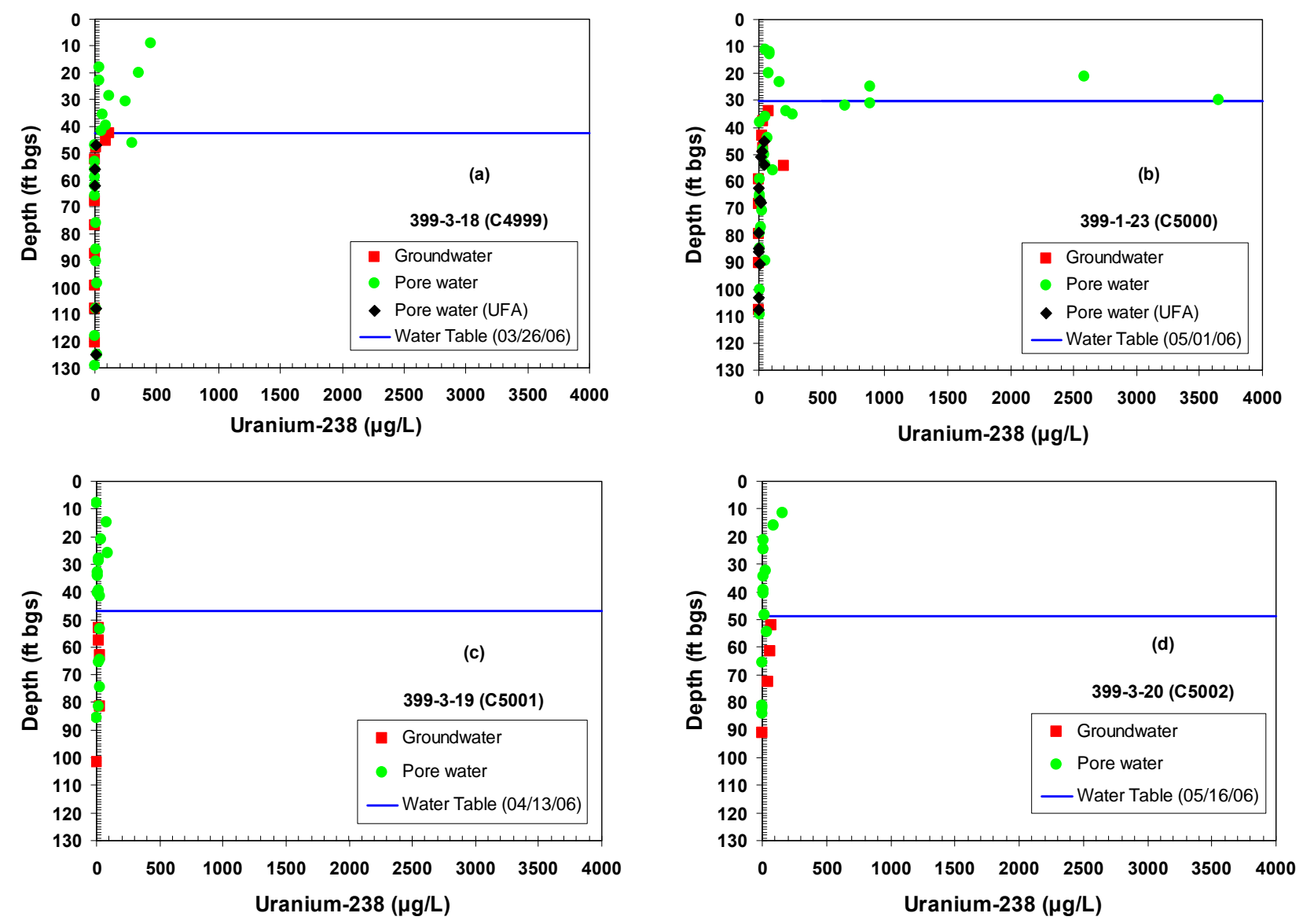

Figure 4.5. Soluble Uranium Concentrations in the Depth-Discrete Groundwater, Pore Water After Ultracentrifugation, and Calculated Pore Water Uranium Concentrations in the Sediments from Boreholes (a) 399-3-18 (C4999), (b) 399-1-23 (C5000), (c) 399-3-19 (C5001), and (d) 399-3-20 (C5002)

sediment pore water contains elevated uranium concentrations that are equivalent to, or slightly higher than, the elevated concentrations in the shallow groundwater. The elevated vadose sediment uranium concentrations could indicate a nearby source or a remnant of lateral spreading due to groundwater fluctuations. These results support a conceptual model wherein the uranium is more evenly distributed as a low concentration vadose zone source spread over a large footprint. An alternative conceptual model assumes one or more residual uranium source "hot spots" in the vadose zone or upper aquifer sediments might be controlling the groundwater contamination. Based on the data from these four new boreholes, only well 399-1-23 (C5000) and possibly well 399-3-18 (C4999) contain any significant concentrations of uranium within the vadose zone pore fluids and sediments. The vadose zone surrounding wells 399-1-23 (C5000) and 399-3-18 (C4999) may be a slow bleeding source of uranium to the upper unconfined aquifer by both natural recharge and as caused by the seasonal river stage water table fluctuations.

It is probable that residual uranium contamination exists in the lower vadose zone beneath the southern portion of the 316-5 process trenches based on data from well 399-1-23 (C5000). The well 399-1-23 (C5000) borehole has the highest vadose pore water uranium concentrations and analysis of vadose sediments indicates above background levels of uranium are present at depths 6 meters bgs down 
to the water table ( $\sim 10.5$ meters). In addition, based on large differences between microwave-assisted sediment digestion uranium extracts and uranium leaching results using carbonate extractant (see Section 6.6.1.4 for details), high concentrations of recalcitrant uranium contamination were also found in the well 399-1-23 (C5000) borehole vadose zone sediments. Because carbonate-leachable uranium is considered to be labile uranium, the difference between the carbonate-leached uranium and the microwave-assisted digested uranium (total leachable uranium) indicates the presence of a more strongly bound uranium phase, perhaps found as mineral coprecipitates or within mineral structures. The carbonate-leachable strongly bound uranium contamination, detected in the vadose zone sediments close to the water table, could be a continuous source of uranium that slowly bleeds into the groundwater through a saturation-de-saturation mechanism that is controlled by river level fluctuations.

The highest inorganic carbon content $\left(3.42 \mathrm{mg} / \mathrm{g}\right.$ or $2.85 \mathrm{wt} . \%$ as $\left.\mathrm{CaCO}_{3}\right)$ was found at a depth of $7 \mathrm{~m}$ (23 feet) bgs where the highest uranium concentration $(5 \mathrm{pCi} / \mathrm{g})$ was detected via the microwave-assisted digestion method (well 399-1-23 [C5000]). These results suggest that uranium is present in this sample due to co-precipitation with calcite. Similar results suggesting possible uranium co-precipitation with calcite in 300 Area sediments have been found by others (Wang et al. 2005; Zachara et al. 2005). We speculate that the higher inorganic carbon content in the sediments from well 399-1-23 (C5000) may be related to reactions of alkaline waste with atmospheric carbon dioxide and the native vadose zone pore waters during the active disposal period into the 300 Area process trenches. However, it may be possible that the higher inorganic carbon contents in the well 399-1-23 (C5000) sediments are detrital (transported and deposited by the ice-age floods) from subtle differences in sediment mineralogy. More detailed microscale characterization techniques would need to be applied to these sediments to potentially determine the origin of the carbonates in the sediments.

Co-precipitation of uranium with calcite in vadose zone sediments might have significant implications for the fate and transport of uranium in groundwater, especially in the capillary fringe region where the water table tends to fluctuate due to Columbia River level changes. The total carbon content measured in sediments from boreholes 399-3-19 (C5001) and 399-3-20 (C5002) was relatively low, and inorganic carbon content varied from 0.0 to 0.96 and to $0.93 \mathrm{mg} / \mathrm{g}\left(<1 \mathrm{wt} . \%\right.$ as $\left.\mathrm{CaCO}_{3}\right)$, respectively, similar to those values found in sediments from borehole 399-3-18 (C4999). The highest inorganic carbon content $(0.93 \mathrm{mg} / \mathrm{g})$ measured in sediments from borehole 399-3-20 (C5002) at a depth of 24.7 meters ( 81.1 feet) bgs might result from calcium carbonate present as cementing materials at the boundary between the Hanford and Ringold formation sediments.

Work conducted on sediment samples collected by backhoe at locations within the footprints of the former North and South Process Ponds (two sites each) concluded that the vadose zone beneath each of these former disposal sites could continue to be potential sources for supplying uranium to the underlying groundwater plume (Zachara et al. 2005). The vertical profiles at each of the four locations produced results that were different at each location; the profiles showed no marked trend in hexavalent uranium concentrations with depth. The samples did reveal fundamental information on the geochemical nature of the residual uranium contamination, particularly with respect to mobility characteristics. 


\subsection{Nitrate Distribution}

The analysis of nitrate concentration in groundwater samples and 1:1 water extracts from the sediments from the four boreholes was conducted, and the results are shown in Appendix D. Detectable nitrate concentrations in the groundwater were only found in the shallower depths of the aquifer (within 5, 17, 34, and 23 feet of the water table in boreholes 399-3-18 (C4999), 399-1-23 (C5000), 399-3-19 (C5001), and 399-3-20 (C5002), respectively). The groundwater nitrate concentrations ranged from 13 to 21, 26 to 27,37 to 39 and 22 to $23 \mathrm{mg} / \mathrm{L}$ in the shallow zones of the aquifer at boreholes 399-3-18 (C4999), 399-1-23 (C5000), 399-3-19 (C5001), and 399-3-20 (C5002), respectively. These concentrations are below the drinking water MCL and not noteworthy compared to nitrate plumes on the 200 Area Central Plateau. There are a few high nitrate concentrations detected in the lower depths of the vadose zone pore water (upper 35 feet in borehole 399-3-18 (C4999) at concentrations of 4,460 down to $110 \mathrm{mg} / \mathrm{L}$ and upper 20 feet in borehole 399-1-23 (C5000) pore water at concentrations from 60 to $33 \mathrm{mg} / \mathrm{L}$. At borehole 399-3-19 (C5001), there was one pore water sample at 39.5 feet bgs that contained $36 \mathrm{mg} / \mathrm{L}$ nitrate, and at borehole 399-3-20 (C5002) the pore water nitrate was $140 \mathrm{mg} / \mathrm{L}$ at 16 feet bgs and the nitrate pore water concentration dropped below the detection limit $<10 \mathrm{mg} / \mathrm{L}$ at 25 feet bgs. All the aquifer sediments showed low nitrate concentration from 1:1 water extracts. Most nitrate concentrations in the aquifer significantly drop below detection limits at the Hanford/Ringold contact. As can be seen in Figures 4.1 to 4.4 , nitrate is never a dominant anion in the groundwater.

The new data from the recently installed boreholes 399-3-18 (C4999), 399-1-23 (C5000), 399-3-19 (C5001), and 399-3-20 (C5002) suggest that the source of the nitrate in the groundwater today is likely not the vadose zone sediments at the $300-\mathrm{FF}-5$ OU. There is no indication that the deep vadose zone sediments or aquifer sediments contain elevated nitrate concentrations that could be supplying the low concentrations of nitrate found in the groundwater at the 300-FF-5 OU. A more likely source is upgradient groundwater that is impacted by other Hanford activities, the Central Plateau fuel reprocessing facilities, and/or irrigation water that recharges the aquifer from nearby agricultural and industrial facilities. At boreholes 399-3-18 (C4999) and to a limited extent 399-1-23 (C5000) in the near-surface vadose zone, there is elevated nitrate that could be a future source of groundwater nitrate if a water driving force (including slow natural recharge) pushes the soluble nitrate to the water table. However, these pools of nitrate do not appear to be the cause of the current groundwater nitrate distribution.

\subsection{Volatile Organic Carbon Constituents}

As part of the LFI characterization, the groundwater samples were also analyzed for volatile organic compounds (VOC). Several organic carbon compounds were detected in all four of the boreholes at depths well below the water table and below those typically monitored by the 300 Area well network (Table 4.1).

At the northern location (well 399-1-23 [C5000]), cis-1,2-dichloroethene (DCE) was detected at multiple depth horizons in the deeper portion of the aquifer below the Hanford/Ringold contact, with concentrations increasing with increased depth (Figure 3.3). This occurrence is consistent with other monitoring data from nearby wells that reveal the presence of DCE in the lower portion of the unconfined aquifer. The source for the DCE is presumed to be disposal of liquid effluent to the 300 Area Process Trenches (316-5 waste site) during the 1970s and 1980s. 
At two of the southern locations, wells 399-3-18 (C4999) and 399-3-20 (C5002), results for TCE were well above the drinking water standard, again at depths below the Hanford/Ringold contact (Figures 3.2 and 3.5). Re-analysis of those samples confirmed the initial results, and there is no evidence to indicate that TCE may have been inadvertently introduced into the boreholes during drilling activities. Consequently, the elevated concentrations are presumed to represent aquifer conditions. These occurrences were unexpected and have opened new questions regarding the extent of VOC contamination in the subsurface at the 300 Area.

The area of concern is centered on LFI well 399-3-20 (C5002) and extends to include the southern portion of the South Process Pond (316-1 waste site) and 307 Trench (316-3 waste site) (see Figure 2.1). A water sample collected during drilling at well 399-3-20 (C5002) from the Ringold Formation undesignated fine-grained unit contained TCE at a concentration of $630 \mu \mathrm{g} / \mathrm{L}$. This unit is below the Hanford formation unit 1 monitored by the completed monitoring well (see Table 4.1) and other wells in the area. LFI well 399-3-18 (C4999), located 200 meters to the northeast of well 399-3-20 (C5002), also revealed elevated TCE concentrations $(63$ and $51 \mu \mathrm{g} / \mathrm{L})$ in drilling samples collected from the upper portion of the same hydrologic unit as in well 399-3-20 (C5002).

TCE concentrations in drilling samples from the uppermost Hanford formation hydrogeologic unit, i.e., above the Hanford/Ringold contact, are consistent with those indicated by long-term groundwater monitoring. Concentrations in the Hanford gravels have been lower than the $5-\mu \mathrm{g} / \mathrm{L}$ drinking water standard for at least the last decade in the area of concern (Peterson et al. 2005). The TCE has been presumed to have migrated into the 300 Area from sources to the southwest, i.e., it is not associated with 300 Area waste sites (Lindberg and Peterson 2006). However, the presence of TCE and other volatile organic compounds at depths in the aquifer greater than those monitored by existing wells poses new questions as to the origin and nature of VOC contamination in the unconfined aquifer.

DOE has elected to go forward with characterizing the VOC occurrence at depth in the unconfined aquifer at the southern locations in the 300-FF-5 OU because of these questions. This new VOC investigation is not part of this LFI. 
Table 4.1. Volatile Organic Compounds in Water Samples Collected During Drilling at 300 Area Limited Field Investigation Sites

\begin{tabular}{|c|c|c|c|c|c|c|c|c|}
\hline $\begin{array}{c}\text { Drilling sample } \\
\text { location designator }\end{array}$ & $\begin{array}{c}\text { Elevation at } \\
\text { top of } \\
\text { sample } \\
\text { interval } \\
\text { (m-NAVD88) }\end{array}$ & $\begin{array}{c}\text { Elevation at } \\
\text { bottom of } \\
\text { sample } \\
\text { interval } \\
\text { (m-NAVD88) }\end{array}$ & $\begin{array}{l}\text { Drilling } \\
\text { sample } \\
\text { relative to } \\
\text { final } \\
\text { screened } \\
\text { interval } \\
\end{array}$ & $\begin{array}{c}\text { Sample } \\
\text { Collect } \\
\text { Date/Time }\end{array}$ & 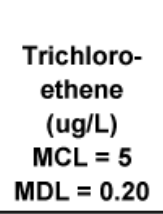 & $\begin{array}{c}\text { Tetrachloro- } \\
\text { ethene } \\
\text { (ug/L) } \\
M C L=5 \\
M D L=0.19 \\
\end{array}$ & $\begin{array}{c}\text { Cis-1,2- } \\
\text { dichloro- } \\
\text { ethene } \\
\text { (ug/L) } \\
M C L=70 \\
M D L=0.19\end{array}$ & $\begin{array}{c}\text { Vinyl } \\
\text { chloride } \\
\text { (ug/L) } \\
M C L=2 \\
M D L=0.23 \\
\end{array}$ \\
\hline \multicolumn{9}{|c|}{ 399-1-23: Near southern end of former 300 Area Process Trenches (316-5 waste site) } \\
\hline C5000,399-1-23(1) & 105.2 & 105.1 & Within & $4 / 3 / 2006$ & $\mathrm{U}$ & $\mathrm{U}$ & $\bar{U}$ & $\mathrm{U}$ \\
\hline C5000,399-1-23 (2) & 104.5 & 103.6 & Within & $4 / 4 / 2006$ & 0.20 & $\mathrm{U}$ & U & U \\
\hline C5000,399-1-23 (3) & 102.3 & 102.2 & Within & $4 / 4 / 2006$ & U & $U$ & U & U \\
\hline C5000,399-1-23 (4) & 101.1 & 100.7 & Within & $4 / 5 / 2006$ & U & $\mathrm{U}$ & $\mathrm{U}$ & U \\
\hline (completed well) & 107.8 & 100.2 & Screen & $7 / 6 / 2006$ & 0.22 & U & U & $U$ \\
\hline C5000,399-1-23 (5) & 99.1 & 98.7 & Below & $4 / 5 / 2006$ & 2.10 & 0.20 & 3.00 & $U$ \\
\hline C5000,399-1-23 (6) & 97.6 & 97.2 & Below & $4 / 6 / 2006$ & 2.20 & U & 15.00 & U \\
\hline C5000,399-1-23 (7) & 95.0 & 94.1 & Below & $4 / 7 / 2006$ & 0.27 & U & 32.00 & U \\
\hline C5000,399-1-23 (8) & 92.0 & 90.5 & Below & $4 / 10 / 2006$ & 1.10 & U & 48.00 & $U$ \\
\hline C5000,399-1-23 (9) & 88.5 & 87.4 & Below & $4 / 11 / 2006$ & 2.20 & U & 51.00 & U \\
\hline $\mathrm{C} 5000,399-1-23(10)$ & 83.3 & 81.9 & Below & $4 / 17 / 2006$ & U & $\mathrm{U}$ & 57.00 & U \\
\hline \multicolumn{9}{|c|}{ 399-3-18: Near Columbia River, downgradient of former South Process Ponds (316-1 waste site) } \\
\hline C4999,399-3-18(1) & 104.7 & 104.7 & Within & $3 / 14 / 2006$ & 0.85 & $\mathrm{U}$ & $\mathrm{U}$ & $\mathrm{U}$ \\
\hline C4999,399-3-18 (10) & 104.7 & 103.1 & Within & $4 / 13 / 2006$ & 0.78 & $\mathrm{U}$ & U & U \\
\hline (completed well) & 107.6 & 103.0 & Screen & $6 / 27 / 2006$ & 1.40 & U & U & U \\
\hline C4999,399-3-18 (2) & 103.7 & 102.5 & At bottom & $3 / 14 / 2006$ & 63.00 & 1.80 & 0.71 & $U$ \\
\hline C4999,399-3-18 (3) & 101.7 & 101.7 & Below & $3 / 15 / 2006$ & 51.00 & 0.83 & 0.66 & U \\
\hline C4999,399-3-18 (4) & 97.6 & 96.3 & Below & $3 / 16 / 2006$ & 0.64 & U & U & U \\
\hline C4999,399-3-18 (5) & 94.5 & 93.9 & Below & $3 / 20 / 2006$ & U & U & U & $U$ \\
\hline C4999,399-3-18 (6) & 91.5 & 90.6 & Below & $3 / 21 / 2006$ & U & U & U & U \\
\hline C4999,399-3-18 (7) & 87.8 & 86.9 & Below & $3 / 22 / 2006$ & U & U & 0.85 & U \\
\hline C4999,399-3-18 (8) & 85.1 & 84.5 & Below & $3 / 22 / 2006$ & U & U & U & $U$ \\
\hline C4999,399-3-18 (9) & 81.1 & 80.6 & Below & $3 / 23 / 2006$ & U & $\mathrm{U}$ & 3.00 & U \\
\hline \multicolumn{9}{|c|}{ 399-3-19: Inland, upgradient from principal liquid waste disposal sites } \\
\hline C5001 399-3-19(1) & 104.5 & 104.5 & Within & $4 / 26 / 2006$ & 1.20 & $\mathrm{U}$ & $\bar{U}$ & $\mathrm{U}$ \\
\hline C5001 399-3-19 (2) & 103.1 & 103.0 & Within & $4 / 27 / 2006$ & 1.20 & $\mathrm{U}$ & $U$ & U \\
\hline C5001 399-3-19 (3) & 101.4 & 101.4 & Within & $4 / 27 / 2006$ & 1.20 & $\mathrm{U}$ & U & U \\
\hline (completed well) & 108.5 & 100.8 & Screen & $7 / 6 / 2006$ & 0.77 & U & U & $U$ \\
\hline C5001 399-3-19 (4) & 96.3 & 93.8 & Below & $4 / 28 / 2006$ & 1.70 & $\mathrm{U}$ & U & U \\
\hline C5001 399-3-19 (5) & 90.2 & 89.4 & Below & $5 / 3 / 2006$ & 1.40 & U & $U$ & U \\
\hline C5001 399-3-19 (6) & no sample & no sample & Below & & & $\mathrm{U}$ & U & U \\
\hline \multicolumn{9}{|c|}{ 399-3-20: Adjacent to downgradient side of 307 Process Trench (316-3 waste site) } \\
\hline C5002 399-3-20 (1) & 104.9 & 104.1 & Within & $5 / 12 / 2006$ & 0.84 & $\mathrm{U}$ & $\mathrm{U}$ & $\mathrm{U}$ \\
\hline C5002 399-3-20 (2) & 102.2 & 101.2 & Within & $5 / 12 / 2006$ & 0.80 & U & U & U \\
\hline (completed well) & 108.3 & 100.6 & Screen & $7 / 6 / 2006$ & 1.50 & U & $U$ & $U$ \\
\hline C5002 399-3-20 (3) & 98.5 & 98.2 & Below & $5 / 15 / 2006$ & 1.60 & U & U & U \\
\hline C5002 399-3-20 (4) & 93.0 & 92.4 & Below & $5 / 16 / 2006$ & 630.00 & 9.90 & 6.50 & U \\
\hline C5002 399-3-20 (5) & no sample & no sample & Below & & & & & \\
\hline C5002 399-3-20 (6) & no sample & no sample & Below & & & & & \\
\hline
\end{tabular}




\subsection{Summary}

The Limited Field Investigation produced abundant new observational data about conditions in the vadose zone and unconfined aquifer in the 300 Area that are relevant to uranium contamination in the subsurface environment. Each of the four characterization borehole drilling sites represented a different combination of hydrologic settings, proximity to waste disposal sites, and proximity to the Columbia River. The sites were chosen to provide the widest assortment of subsurface conditions relative to contaminant uranium, given the resources available, such that the conceptual site model for uranium can be developed as comprehensively as possible. The new information obtained by the LFI pertains to (a) stratigraphy and hydrologic units, (b) the vertical distribution of uranium in the vadose zone and unconfined aquifer from laboratory geochemical analyses and field measurements, and (c) the potential usefulness of geophysical logging for mapping contaminant uranium in future 300 Area boreholes.

\subsection{Summary of Principal Results}

Objectives for the Phase I characterization boreholes are described in Section 1.2. The following presents a summary of results that are relevant toward meeting those objectives, along with additional general information on what was achieved during this investigation:

\subsubsection{Drilling/Characterization Methodology}

The sonic drilling method was successfully used at four representative locations to recover continuous core throughout the vadose zone and unconfined aquifer. The drilling activity also facilitated the collection of groundwater samples from the saturated zone, hydraulic testing at multiple depth horizons, and geophysical logging using a variety of tools. A portion of the core recovered has been archived and is available for future investigations.

The four characterization boreholes were completed as monitoring wells, with screened intervals positioned in the upper portion of the unconfined aquifer. Each well screen was strategically placed, based on laboratory analyses, to capture the peak vertical zone of uranium contaminated groundwater in the unconfined aquifer at each well location. The four new monitoring wells and their well identifiers are: 399-3-18 (C4999), 399-1-23 (C5000), 399-3-19 (C5001), and 399-3-20 (C5002). All four wells have been added to the groundwater monitoring schedule.

\subsubsection{Hydrogeologic Framework}

Geologic characterization activities during drilling have revealed significant new details on the subsurface stratigraphy at these sites. The new information has permitted re-interpretation of the drilling logs from previously installed wells, which has been followed by a substantial update of the database for the 300 Area hydrogeologic framework. Significant products include a newly defined structure contour surface for the contact between the gravel dominated Hanford formation Unit 1 and the underlying Ringold Formation Unit 5. The saturated portion of the Hanford gravels appears to contain the bulk of contaminant uranium, and the relief on the contact likely influences the movement pattern of that plume.

The Hanford formation Unit 1, composed predominantly of unconsolidated sandy gravel, is significantly more permeable than the underlying and older Ringold Formation, which includes more 
compacted and variably cemented fine-grained to gravelly sediment. The principal subunits of Ringold Formation Unit 5 include a) an undesignated fine-grained unit composed of silt and fine sand, and b) the silty sandy gravel interval.

The hydraulic conductivity $\left(\mathrm{K}_{\mathrm{h}}\right)$ of the Hanford formation Unit 1 gravel is very high $(\geq 2,000$ meters per day) compared to the low-to-moderate conductivity in Ringold Formation Unit 5 subunit (0.04 to 41.2 meters per day). Because of these differences, the Hanford-Ringold contact represents an effective barrier to downward migration of groundwater and contaminants.

The Ringold Formation Unit 5 undesignated fine-grained subunit is composed of low permeability silty sand to sandy sediment, and is present at three of the four characterization borehole locations (it is not present at the northernmost location, 399-1-23). The subunit is characterized by alternating layers of oxidized and reduced fine-grained sediment, and by relatively low groundwater specific conductance values. Previous drilling had indicated the occasional presence of a similar fine-grained subunit in Ringold Unit 5. However, the LFI results have revealed that this subunit is more continuous than previously thought and has significance relative to contamination at depth. The undesignated fine-grained subunit does not contain elevated levels of uranium contamination, but has revealed evidence for contamination by VOC.

\subsubsection{Contaminant Uranium in the Vadose Zone}

The amount of uranium contamination (i.e., activity per unit mass of sediment) in vadose zone samples was determined by laboratory geochemical analysis of various extracts of the bulk sediments, including a 1:1 water extract, acid extract, and microwave-assisted digestion of the sample. GEA was also used to measure uranium activity in the laboratory samples. For nearly all measurements, the activity of uranium in the sediment is in the less than $4 \mathrm{pCi} / \mathrm{g}$ (based on dry weight). The uranium measured by GEA is presumed to be consistent with background levels of natural uranium in the sediment.

At three of the four borehole locations, there is no distinct evidence for elevated levels of uranium in sediment immediately above the water table. However, at one of the boreholes (399-1-23, near the former 300 Area Process Trenches), uranium is shown to be somewhat elevated in a zone positioned approximately one meter above the normal high water level at the borehole site, with values ranging up to $5.7 \mathrm{pCi} / \mathrm{g}$. The highest activities of uranium are for analyses done using microwave assisted digestion, which is the most aggressive "extraction" method for preparing the sample, and thus would be the most likely extraction method for total uranium concentration including less mobile forms of uranium. The microwave-assisted digestions were performed on small masses of sediment from which gravel particles $(>2 \mathrm{~mm}$ ) were removed. Thus the microwave-assisted uranium concentration values were often larger than the GEA concentration values for the same bulk sediment that contained gravel. This is common because the larger gravel particles contain lower concentrations of trace constituents, such as uranium, than the smaller particles based on mass.

The relatively low levels of uranium, i.e., lower than expected, that were encountered in sediment samples from the vadose zone were too low to allow use of spectral gamma geophysical logging and GEA results measured in the field to define the vertical distribution of contaminant uranium in the boreholes. Geophysical logging analysts for this investigation have estimated that the lower detection limit for that logging effort was $\sim 10 \mathrm{pCi}$ of total uranium/g. 
While most measurements for contaminant uranium in sediment from the vadose zone do not reveal distinctly elevated levels on a unit sediment mass basis, estimates for the concentration of uranium in the moisture associated with the sample (i.e., activity per pore water volume in the sediment) do reveal significantly elevated values in two of the four new wells. These estimates are based on the analyses of water extracts from the sediment, with the results then interpreted relative to the natural moisture content of the sample. The highest estimated values for uranium in pore water range up to $\sim 3,650 \mathrm{pCi} / \mathrm{L}$ and were found in borehole 399-1-23. This borehole location is adjacent to the former 300 Area Process Trenches, which were the last infiltration trenches to receive uranium-bearing effluent. Elevated concentrations ( $\sim 500 \mathrm{pCi} / \mathrm{L})$ were also estimated for vadose zone pore water from borehole 399-3-18, which is located within the central portion of the mapped groundwater uranium plume. The significance of these high uranium concentrations estimated for vadose zone pore waters with respect to their influence on maintaining the groundwater plume remains under investigation.

\subsubsection{Contaminant Uranium in the Aquifer}

Uranium extracted from aquifer sediment samples was also at relatively low levels and comparable to levels observed in sediment from the vadose zone. There is the suggestion of a reduced zone containing elevated amounts of natural uranium in samples from the fine-grained aquifer sediments encountered at 399-3-18; it appears that this zone has been acting as a "sink" for natural uranium. Based on uranium leaching using different solutions, the uranium present in the aquifer sediments can slowly desorb from the contaminated sediments located near the capillary fringe region, where water chemistry is frequently changed by river water infiltration. Due to the sensitivity of uranium release to the chemistry of the contacting water, the river water influx and mixing in the capillary fringe zone could be a continuous source of slowly bleeding uranium into the 300 Area aquifer.

Uranium concentrations in depth-discrete groundwater samples collected during drilling are generally consistent with concentrations observed in historical groundwater monitoring samples. The highest groundwater uranium concentrations in the water obtained during borehole drilling ranged up to $\sim 200 \mu \mathrm{g} / \mathrm{L}$ and were found at the location near the former 300 Area Process Trenches (399-1-23). At all four locations, the highest groundwater uranium concentrations were observed in samples from the saturated Hanford gravels. Samples collected from the underlying Ringold Formation showed very low concentrations of uranium that are consistent with natural background levels.

The depth-discrete interval groundwater sampling conducted during drilling confirmed that interpretations regarding the distribution and concentrations of the uranium plume are adequately represented by sampling and analysis activities in the current monitoring well network.

\subsubsection{Additional Discoveries and Observations}

Determining the characteristics of contaminant uranium was the primary focus for the LFI characterization activities. Additional measurements were made to provide supporting information relevant to uranium mobility, and to take advantage of the opportunity to screen for other 300 Area COPC.

VOCs were detected in many of the groundwater samples collected during drilling. Samples from depth intervals equivalent to those monitored by the established well network show concentrations that are consistent with those revealed by routine monitoring. However, unexpectedly high levels of 
trichloroethene were encountered in deeper groundwater samples from boreholes 399-3-18 and 399-3-20. These groundwater samples were obtained within the Ringold Formation undesignated fine grained unit (i.e., less transmissive). This discovery has led to planning for an additional investigation of VOCs in the 300 Area.

At borehole 399-3-18, unexpectedly low values for the specific conductance of groundwater samples collected during drilling were measured. The anomalously low values also appeared to be correlated with the relatively low permeability fine-grained subunit in the Ringold Formation. The significance of this finding is not currently well understood.

\subsection{Phase II Drilling Activity}

As initially conceived, the LFI would proceed with two phases of drilling: the first would involve coring and extensive characterization at representative locations (Phase I), and the second was to be a widespread distribution of direct-push boreholes to provide access for high resolution spectral gamma logging (Phase II). Because the levels of uranium encountered during the Phase I drilling were too low for detection by the spectra gamma logging equipment, the second phase was cancelled.

There are several consequences of this development, although none are expected to be critical to achieving sufficient information to proceed with the feasibility study. However, without a field method to map differences in the levels of uranium in the capillary fringe ("smear") zone throughout the area occupied by the uranium plume, there is no new information on the nature of those differences (i.e., large or small variations) and on correlations with proximity to waste sites, process sewer lines, the Columbia River, and water table fluctuations.

\subsection{Limitations and Caveats}

This LFI was planned and conducted in accordance with the purpose of providing better characterization of the sediment and uppermost aquifer beneath the 300-FF-5 OU. It was designed to provide an outline level of information of the vertical, stratigraphic occurrence and distribution of the primary constituent of concern, uranium, at four locations. These four locations were pre-selected based upon proximity to source(s), historic groundwater residual concentrations, and a simplified conceptual model that hypothesized the potential of a widespread occurrence of uranium at or near a fluctuating water table. The intent of this initial phase of characterization was to provide a rigorous basis for extrapolation with a second phase of investigation at 15 Direct Push Technology (DPT) locations spread across the site. With the technical inability to quantitatively correlate radioactivity from uranium in these DPT holes based on laboratory-analyzed uranium concentrations from sediments collected in the first phase, our ability to map the lateral extent of uranium deposits associated with sediments has been precluded. Consequently, this investigation is limited in its lateral resolution of a non-uniform, spatially variable contaminated site. With the exception of some limited pit samples collected in the two former pond areas prior to backfilling in 2004, there is minimal additional information concerning uranium residuals in or near known waste disposal units at the site. This deficiency increases the uncertainty of the resulting conceptual model. However, the ongoing treatability investigation near the south end of the 316-trench and future borings that will accompany phased implementation of future remediation deployments will provide opportunities for confirmation of the geochemical and uranium depositional patterns indicated by this investigation. 
Indications of other contaminants, notably TCE, in two of the southern boreholes of this investigation were not delineated sufficiently by this investigation to define the source, extent, and magnitude of the chlorinated solvent(s). Follow-up characterization efforts have been planned and will be conducted to better address the chlorinated solvents detected in this study.

The 300-FF-5 OU is an extensive area with multiple historic release locations into a spatially variable subsurface vadose zone with a dynamic and temporally changing hydrogeology. An understanding of the contaminant distribution and mechanism developed from the information herein should be viewed within the broad context as presenting a larger scale conceptual model of uranium contamination as affecting dissolved uranium in the groundwater. It provides a sound fundamental beginning for developing a remediation strategy for the site. Further site resolution and particulars of implementing remedial actions will develop as the remediation effort proceeds. 


\subsection{LFI Phase I - Borehole Data}

This section summarizes the drilling, characterization activities, and construction of the four Phase I groundwater monitoring wells. Groundwater monitoring wells 399-3-18 (C4999), 399-1-23 (C5000), 399-3-19 (C5001), and 399-3-20 (C5002) were installed in the four new boreholes between May and July 2006. The location of these wells is shown in Figure 6.1. These new groundwater monitoring wells also fulfill requirements of the Hanford Federal Facility Agreement and Consent Order (Ecology et al. 1989) Milestone M-24-57 (Murphy-Fitch 2003) ${ }^{3}$ during FY 2006. The new wells were constructed to the specifications and requirements described in Washington Administrative Code (WAC) 173-160, Sampling and Analysis Plan for CERCLA Well Drilling at 300-FF-5 OU, FY05 (DOE 2005a), and specifications provided by Fluor Hanford, Inc. (FHI), Richland, Washington.

Additional well construction documentation is on file with FHI. The Hanford Well Information System (HWIS) (http://apweb02.rl.gov/cfroot/rapidweb/phmc/cp/hwisapp/) contains electronic drilling and construction records for these wells (Note: this link is password protected, contact FHI or DOE for access approval).

The four boreholes were drilled with the resonant sonic drill method using 9-5/8 inch outside diameter (0.5-inch-thick) carbon steel casing and cored using a 6-feet long by 5-inch inside diameter split spoon core barrel. The boreholes were completed with nominal 6-inch-diameter stainless steel casings and screens as groundwater monitoring wells.

Two of the four characterization boreholes (399-3-18 [C4999] and 399-1-23 [C5000]) were drilled through the entire uppermost unconfined aquifer to the top of the Ringold Formation lower mud confining unit that separates and isolates the lower confined Ringold/basalt aquifer system. The purpose of the deep drilling was to provide access for characterization of the entire upper unconfined aquifer. The third and fourth characterization boreholes (399-3-19 [C5001] and 399-3-20 [C5002]) were only drilled to depths that extend midway into the unconfined aquifer because existing data and monitoring results suggested that the uranium contamination was mainly constrained to the very upper portion of the unconfined aquifer. All of these boreholes provided access to the vadose zone and upper portion of the unconfined aquifer for the collection of continuous sediment core and depth-discrete water samples for aquifer testing and borehole geophysical logging.

\subsection{Field Screening}

Field screening for radiological and chemical contaminants was completed at each well during drilling and sampling to fulfill site safety and worker health requirements. During drilling of the four new boreholes, drill cuttings and select core samples were screened in the field for VOCs and beta-gamma activity by radiation control technicians and site safety staff. Subsurface spectral gamma logs were also evaluated for gamma-emitting contaminants (details are discussed in Section 6.6.4).

\footnotetext{
${ }^{3}$ Letter from EJ Murphy-Fitch (Fluor Hanford, Inc., Richland, Washington) to Distribution, “Tentative Agreement on Tri-Party Agreement Negotiations on the Overall Strategy and Approach for Hanford Groundwater Protection, Monitoring, and Remediation (M-024),” dated September 22, 2003.
} 


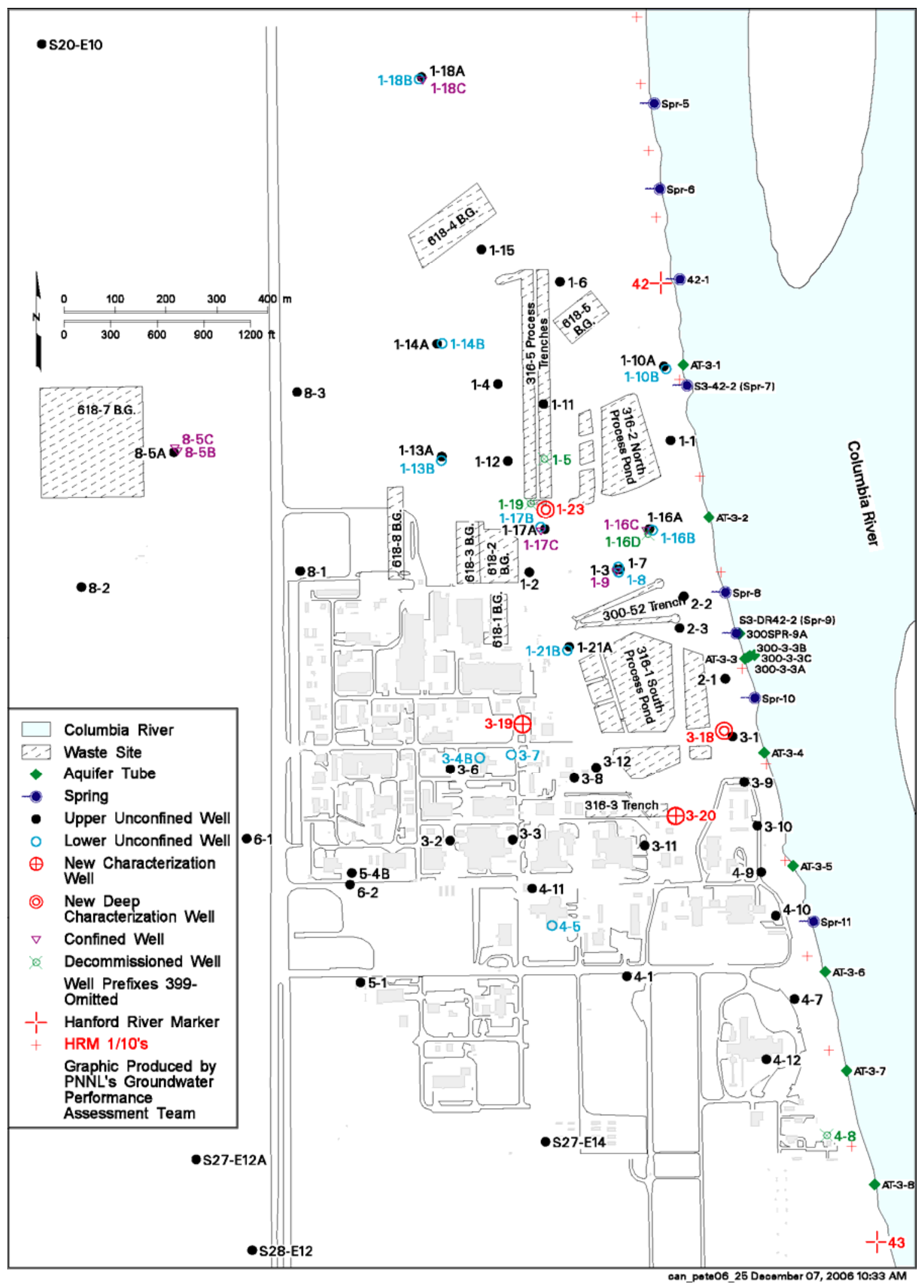

Figure 6.1. Well Location Map for Limited Field Investigation Wells 399-3-18 (C4999), 399-1-23 (C5000), 399-3-19 (C5001), and 399-3-20 (C5002), 300-FF-5 Operable Unit 
Radiation screening of cuttings revealed only natural background levels. Results of field screening for radiation and gases during drilling are indicated on the daily drilling reports, which are on file with the drilling contractor (FHI).

\subsection{Well 399-3-18 (C4999)}

Well 399-3-18 (C4999) is located approximately 200 feet west of the Columbia River in the 300 Area (Figure 6.1), downgradient of the former 316-1 South Process Ponds and slightly west of existing well 399-1-3. The new well monitors the uppermost unconfined aquifer and is screened across lower Hanford formation sediments.

\subsubsection{Drilling and Sampling}

Well 399-3-18 (C4999) was drilled with a rotosonic drill rig from surface to a total depth of 131 feet bgs. Temporary 9-5/8-inch outside diameter casing was used during drilling to total depth. Drilling began on March 9, 2006, and total depth was reached on March 23, 2006.

Continuous coring was attempted during drilling from the surface to 130.5 feet bgs. Representative core was obtained from approximately $71 \%$ of the borehole. The water table was encountered at approximately 42.5 feet bgs. The borehole log in Appendix A provides the lithologic description of sediments encountered in the field during drilling. The composite log in Figure 3.2 is a compilation of all geologic, hydrologic, geophysical, and uranium data collected from the well. High-resolution digital photographs of the sediment core are provided in Appendix B.

Ten depth-discrete water samples were collected, and four depth-discrete aquifer hydraulic tests were performed during drilling through the unconfined aquifer. The groundwater samples were analyzed as described in Section 6.6.2. Select results from the vadose zone and groundwater analysis are plotted on the composite log (Figure 3.2) to illustrate the vertical contaminant distribution and the relationship to the various hydrogeologic units.

Sediments encountered during drilling were composed of approximately 13 feet of coal ash and other backfill sediment near the surface followed by predominantly unconsolidated cataclysmic flood deposits composed of mostly the gravel-dominated facies of the hydrologic Unit 1 (Hanford formation) from approximately 13 feet to a depth of 46.3 feet bgs.

The Hanford/Ringold contact at this location is marked by a very abrupt and sharp change in lithology. Beneath the Hanford formation gravel-dominated facies lay fluvial deposits belonging to an undesignated fine-grained unit of the Ringold Formation (Unit 5), which is composed of a thick, well sorted sequence of compact silty, very fine sand from approximately 46.3 feet to a depth of 81.5 feet bgs. A silty sandy gravel to gravelly sand sequence of the Ringold Formation Unit 5 was encountered from 81.5 feet to a depth of approximately 126.4 feet bgs. The Ringold Formation lower mud unit, which is considered the lower boundary of the upper unconfined aquifer was contacted at 126.4 feet bgs and extends to at least the total depth at approximately 130.5 feet bgs. The lower mud unit is composed of clayey silt to silty sand. The field geologist's borehole log, along with the well construction summary report, as-built diagram, well development and pump installation records, and well survey results are 
included in Appendix A. Appendix B contains the core chain-of-custody forms, the core photographs, and the detailed geologic description of the sediment core. A more detailed hydrogeologic interpretation of the borehole sediments is included in Section 3.0.

The borehole and drill cuttings were monitored regularly for organic vapors and radionuclide contaminants (i.e., gamma). Radioisotope monitoring revealed no detectable contamination was present. Spectral gamma and neutron moisture geophysical logs were run in the temporary borehole in March 2006 by Stoller Corporation (Appendix C). Section 6.6.4 provides more details of this logging.

\subsubsection{Well Completion}

The permanent casing and screen were installed in well 399-3-18 (C4999) on March 28, 2006. A 15-feet long, 6-inch inside diameter, stainless steel, continuous wire-wrap 20 slot (0.02-inch slot) screen was set from 32.86 to 47.86 feet bgs (Figure 3.2). A 2-feet long, 6-inch inside diameter stainless steel sump is attached to the bottom of the screen and extends from 47.86 to 49.86 feet bgs. The permanent well casing is 6-inch ID, stainless steel from 32.86 feet bgs to 2.18 feet above ground surface.

The screen filter pack is composed of 10-20 mesh silica sand placed from 22 to 52 feet bgs, which was developed with a dual surge block to settle the sand pack. The annular seal is composed of 3/8-inch bentonite pellets from 17.2 to 22 feet bgs and granular bentonite crumbles from 17.2 to 10.1 feet bgs. The surface seal is composed of Portland cement grout from 10.1 feet bgs to ground surface. A 4-feet by 4-feet by 6-inch concrete pad was placed around the well at the surface. A protective well head casing with locking cap, four protective steel posts, and a brass marker stamped with the well identification number and Hanford well number were set into the concrete pad.

A borehole straightness test was completed. The vertical and horizontal coordinates of the well were surveyed by Fluor Federal Services on August 3, 2006. The horizontal position of the well was referenced to horizontal control stations established by the U.S. Army Corps of Engineers (USACE). The coordinates horizontal datum is NAD83(91). Vertical datum is NAVD88 and is based on existing USACE bench marks. The coordinates are Washington Coordinate System, South Zone. Survey data are included in Table 6.1 and Appendix A. The static water level was 39.5 feet bgs on April 13, 2006.

\subsubsection{Well Development and Pump Installation}

Well 399-3-18 (C4999) was developed on April 13, 2006, at the bottom of the screen at approximately 50.5 feet below top of casing (btc) using a temporary submersible pump. The depth to water was measured at 42.6 feet below btc prior to development. A pressure transducer was installed above the pump and connected to a Hermit datalogger to monitor water level during development. A total of 1,485 gallons of water was pumped. Table 6.2 contains the well development results, including pump intake depth, pump rate, pump run time, drawdown, final turbidity (NTU), $\mathrm{pH}$, and temperature readings. Water samples were collected following well development and submitted to the labs for analysis.

A dedicated 0.5-horsepower Grundfos ${ }^{\mathrm{TM}}$ submersible sampling pump (model 5SO5-13) was installed in well 399-3-18 (C4999) on May 23, 2006. The sampling pump intake was set at 43.53 feet bgs, and connected to the surface with 3/4-inch diameter stainless steel riser pipe. 
Table 6.1. Location and Elevation Data for New CERCLA Wells 399-3-18 (C4999), 399-1-23 (C5000), 399-3-19 (C5001), and 399-3-20 (C5002)

\begin{tabular}{|c|c|c|c|c|}
\hline $\begin{array}{l}\text { Well Name } \\
\text { (Well ID) }\end{array}$ & $\begin{array}{c}\text { Easting } \\
\text { (meters) }\end{array}$ & $\begin{array}{l}\text { Northing } \\
\text { (meters) }\end{array}$ & $\begin{array}{c}\text { Elevation } \\
\text { (meters) }\end{array}$ & Comments \\
\hline \multirow{4}{*}{$\begin{array}{l}399-3-18 \\
\text { (C4999) }\end{array}$} & 594464.71 & 116019.98 & & Center of casing \\
\hline & & & 118.615 & Top of casing, N. edge \\
\hline & & & 117.680 & Brass survey marker \\
\hline & & & 118.620 & Top pump base plate, N. edge \\
\hline \multirow{4}{*}{$\begin{array}{l}399-1-23 \\
(\mathrm{C} 5000)\end{array}$} & 594113.52 & 116453.04 & & Center of casing \\
\hline & & & 116.307 & Top of casing, N. edge \\
\hline & & & 115.446 & Brass survey marker \\
\hline & & & 116.312 & Top pump base plate, N. edge \\
\hline \multirow{4}{*}{$\begin{array}{l}\text { 399-23-19 } \\
(\mathrm{C} 5001)\end{array}$} & 594071.94 & 116030.22 & & Center of casing \\
\hline & & & 121.447 & Top of casing, N. edge \\
\hline & & & 120.647 & Brass survey marker \\
\hline & & & 121.452 & Top pump base plate, N. edge \\
\hline \multirow{4}{*}{$\begin{array}{l}399-3-20 \\
(\mathrm{C} 5002)\end{array}$} & 594375.42 & 115849.70 & & Center of casing \\
\hline & & & 121.76 & Top of casing, N. edge \\
\hline & & & 120.448 & Brass survey marker \\
\hline & & & 121.281 & Top pump base plate, $N$. edge \\
\hline
\end{tabular}

\section{$6.3 \quad 399-1-23(\mathrm{C} 5000)$}

Well 399-1-23 (C5000) is located approximately 60 feet from the south end (effluent disposal end) of the 316-5 Process Trenches (Figure 6.1) and is slightly northeast of existing wells 399-1-17A, B, and C. The new well monitors the uppermost unconfined aquifer and is screened across lower Hanford formation sediments (Figure 3.3).

\subsubsection{Drilling and Sampling}

Well 399-1-23 (C5000) was drilled with a rotosonic drill rig from surface to a total depth of 116 feet bgs. Temporary $95 / 8$-inch outside diameter casing was used during drilling to total depth. Drilling began on March 30, 2006, and total depth was reached on April 12, 2006.

Continuous coring was attempted during drilling from the surface to 112.5 feet bgs. Representative core was obtained from approximately $63 \%$ of the borehole. The water table was encountered at approximately 33.5 feet bgs. The borehole log in Appendix A provides the lithologic description of sediments encountered during drilling. The composite log (Figure 3.3) summarizes the core sample intervals, and provides the lithology and graphic log based on a detailed description of the core samples. Digital photographs of the sediment core are provided in Appendix B. 
Table 6.2. Well Development Information for Wells 399-3-18 (C4999), 399-1-23 (C5000), 399-3-19 (C5001), and 399-3-20 (C5002)

\begin{tabular}{|c|c|c|c|c|c|c|}
\hline $\begin{array}{l}\text { Well } \\
\text { Number }\end{array}$ & $\begin{array}{l}\text { Pump Rate } \\
\text { (gpm) }\end{array}$ & $\begin{array}{l}\text { Pump Intake } \\
\text { Depth (ft btc) }\end{array}$ & $\begin{array}{l}\text { Pumping } \\
\text { Run Time } \\
\text { (min) }\end{array}$ & $\begin{array}{c}\text { Drawdown } \\
(\mathrm{ft})\end{array}$ & Final Field Readings & $\begin{array}{l}\text { Recovery Test } \\
\text { Time }\end{array}$ \\
\hline \multirow{2}{*}{$\begin{array}{l}399-3-18 \\
(\mathrm{C} 4999)\end{array}$} & 15 & 50.5 & 30 & 0 & $\begin{array}{l}10.3 \mathrm{NTU}, 345 \mu \mathrm{s} / \mathrm{cm}, 15.5^{\circ} \mathrm{C}, \\
\mathrm{pH}=7.43, \mathrm{DO}=8.3\end{array}$ & N/A \\
\hline & 15 & 50.5 & 69 & 0 & $\begin{array}{l}2.69 \mathrm{NTU}, 349 \mu \mathrm{s} / \mathrm{cm}, 16.4^{\circ} \mathrm{C} \\
\mathrm{pH}=7.51, \mathrm{DO}=8.1\end{array}$ & N/A \\
\hline \multirow{2}{*}{$\begin{array}{l}399-1-23 \\
\text { (C5000) }\end{array}$} & 16 & 48 & 29 & N/A & $1.88 \mathrm{NTU}$ & N/A \\
\hline & 16 & 36 & 31 & N/A & 2.82 NTU & N/A \\
\hline \multirow{2}{*}{$\begin{array}{l}399-3-19 \\
(\mathrm{C} 5001)\end{array}$} & 15 & 68.6 & 48 & 0.2 & $\begin{array}{l}0.83 \mathrm{NTU}, 480 \mu \mathrm{c} / \mathrm{cm}, 17.2^{\circ} \mathrm{C} \\
\mathrm{pH}=7.23\end{array}$ & $\mathrm{~N} / \mathrm{A}$ \\
\hline & 15 & 53.6 & 27 & 0.001 & $\begin{array}{l}0.43 \mathrm{NTU}, 477 \mu \mathrm{s} / \mathrm{cm}, 17.2^{\circ} \mathrm{C} \\
\mathrm{pH}=7.42\end{array}$ & N/A \\
\hline \multirow{2}{*}{$\begin{array}{l}399-3-20 \\
(\mathrm{C} 5002)\end{array}$} & 15 & 68 & 42 & 0.09 & $\begin{array}{l}0.81 \mathrm{NTU}, 416 \mu \mathrm{c} / \mathrm{cm}, 17.2^{\circ} \mathrm{C}, \\
\mathrm{pH}=7.4\end{array}$ & N/A \\
\hline & 15 & 53 & 36 & 0.1 & $\begin{array}{l}0.67 \mathrm{NTU}, 414 \mu \mathrm{c} / \mathrm{cm}, 18.5^{\circ} \mathrm{C}, \\
\mathrm{pH}=7.43\end{array}$ & $\mathrm{~N} / \mathrm{A}$ \\
\hline \multicolumn{7}{|c|}{$\begin{array}{l}\mathrm{ft} \text { btc }=\text { Feet below } \\
\text { gpm }=\text { Gallons pe } \\
\text { N/A }=\text { Not availal } \\
\text { NTU }=\text { Nephelom } \\
\mu \mathrm{s} / \mathrm{cm}=\text { Micro sien } \\
\text { DO }=\text { Dissolved }\end{array}$} \\
\hline
\end{tabular}

Ten depth-discrete water samples were collected and seven depth-discrete aquifer hydraulic tests were performed during drilling through the unconfined aquifer. The groundwater samples were analyzed as described in Section 6.6.2. Select results from the vadose zone and groundwater analysis are plotted on the composite log to illustrate the vertical contaminant distribution and the relationship to the various hydrogeologic units.

Sediments encountered during drilling were comprised of approximately 51 feet of predominantly unconsolidated silty sandy gravel of the Hanford formation (hydrologic Unit 1) from approximately 1.5 feet to a depth of 52.5 feet bgs. Backfill and/or recent Holocene deposits make up the upper 1.5 feet of the borehole.

The exact Hanford/Ringold contact ( $\sim 52.5$ feet bgs) at this location is difficult to identify and data suggest a gradational contact consisting of a mixture of similarly textured Hanford formation silty sandy gravel and Ringold Formation silty sandy gravel. However, the transition from grey poorly sorted gravel to brown, better sorted gravel at approximately 52.5 feet suggest that the contact is near this depth. The Ringold Formation Unit 5 consists predominantly of a silty sandy gravel to sandy gravel with minor silty to sandy intervals from 52.5 feet to a depth of approximately 110.3 feet bgs. The Ringold Formation Lower Mud Unit, which is considered the lower boundary of the upper unconfined aquifer was contacted at 110.3 feet bgs and extends deeper than the borehole total depth at approximately 116 feet bgs. The 
Lower Mud Unit is composed of silt to silty fine sand. The field geologist's borehole log, along with the well construction summary report, as-built diagram, well development and pump installation records, and well survey results are included in Appendix A. Appendix B contains the core chain-of-custody forms and the core photographs. A more detailed hydrogeologic interpretation of the borehole sediments is included in Section 3.0.

The borehole and drill cuttings were monitored regularly for organic vapors and radioisotope contaminants (i.e., gamma). Radioisotope monitoring revealed no detectable contamination was present. Spectral gamma and neutron moisture geophysical logs were run in the temporary borehole in April 2006 by Stoller Corporation (Appendix C). Section 6.6 provides more details of this logging.

\subsubsection{Well Completion}

The permanent casing and screen were installed in well 399-1-23 (C5000) on April 19, 2006. A 25-feet long, 6-inch inside diameter, stainless steel, continuous wire-wrap 20 slot (0.02-inch slot) screen was set from 24.94 to 49.95 feet bgs (Figure 3.3). A 2-feet long, 6-inch inside diameter stainless steel sump is attached to the bottom of the screen and extends from 49.95 to 51.98 feet bgs. The permanent well casing is 6-inch inside diameter, stainless steel from 24.94 bgs to 1.65 feet above ground surface.

The screen filter pack is composed of 10-20 mesh silica sand placed from 20 to 54.4 feet bgs, which was developed with a dual surge block to settle the sand pack. The annular seal is composed of 3/8-inch bentonite pellets from 14.4 to 20 feet bgs and granular bentonite crumbles from 14.4 to 10.8 feet bgs. The surface seal is composed of Portland cement grout from 10.8 feet bgs to ground surface. A 4-foot by 4-foot by 6-inch concrete pad was placed around the well at the surface. A protective well head casing with locking cap, four protective steel posts, and a brass marker stamped with the well identification number and Hanford well number were set into the concrete pad.

The vertical and horizontal coordinates of the well were surveyed by Fluor Federal Services on August 3, 2006. The horizontal position of the well was referenced to horizontal control stations established by the USACE. The horizontal datum is NAD83(91). Vertical datum is NAVD88 and is based on existing USACE bench marks. The coordinates are Washington Coordinate System, South Zone. Survey data are included in Table 6.1 and Appendix A. The static water level was 30.3 feet bgs on May 1, 2006.

\subsubsection{Well Development and Pump Installation}

Well 399-1-23 (C5000) was developed on May 1, 2006. Two intervals, 48 feet and at 38 feet below top of casing (btc), were pumped using a temporary submersible pump. The depth to water was measured at 33.0 feet btc prior to development. A pressure transducer was installed above the pump and connected to a Hermit datalogger to monitor water level during development. A total of 930 gallons of water was pumped. Table 6.2 contains the well development results, including pump intake depth, pump rate, pump run time, drawdown, and final turbidity (NTU).

A dedicated $0.5 \mathrm{hp}$ Grundfos ${ }^{\mathrm{TM}}$ submersible sampling pump (model 5SO5-13) was installed in well 399-1-23 (C5000) on May 23, 2006. The sampling pump intake was set at 43.88 feet bgs, and connected to the surface with 3/4-inch diameter stainless steel riser pipe. Depth to water was measured at 33.4 feet btc. 


\subsection{Well 399-3-19 (C5001)}

Well 399-3-19 (C5001) is located upgradient approximately 450 feet west of the 316-1 South Process Ponds within the 300 Area (Figure 6.1). The new well monitors the uppermost unconfined aquifer and is screened across lower Hanford formation sediments (Figure 3.4).

\subsubsection{Drilling and Sampling}

Well 399-3-19 (C5001) was drilled with a rotosonic drill rig from surface to a total depth of 103.5 feet below ground surface (bgs). Temporary 9 5/8-inch outside diameter casing was used during drilling to total depth. Drilling began on April 24, 2006, and total depth was reached on May 3, 2006.

Continuous coring was attempted during drilling from the surface to approximately 100 feet bgs. However, core recovery was poor $(<50 \%)$ in the saturated Hanford formation because of the loose, unconsolidated nature of the gravel. The water table was encountered at approximately 47.2 feet bgs on April 26, 2006. The borehole log in Appendix A provides the lithologic description of sediments encountered during drilling. The composite log (Figure 3.4) summarizes the core sample intervals, and provides the lithology and graphic log based on a detailed description of the core samples. Digital photographs and detailed geologic description of the core are in Appendix B.

Five depth-discrete water samples were collected and two depth-discrete aquifer hydraulic tests were performed during drilling through the unconfined aquifer. The groundwater samples were analyzed as described in Section 6.6.2. Select results from the vadose zone and groundwater analysis are plotted on the composite log (Figure 3.4) to illustrate the vertical contaminant distribution and the relationship to the various hydrogeologic units.

Sediments encountered during drilling were comprised of approximately 13 feet of backfill sediments at the surface, followed by predominantly unconsolidated sand to sandy gravel and gravel of the hydrologic Unit 1 (Hanford formation) from approximately 13 feet to a depth of 83 feet bgs.

The Hanford/Ringold contact at this location is at approximately 83 feet bgs and distinguished by changes in lithology and color. There is only approximately 1.5 feet of Ringold Formation Unit 5 sandy gravel before the lithology changes abruptly into a clayey silt to sand interval located from approximately 84.7 feet bgs to 98 feet bgs. The borehole reached a total depth of 103.5 feet bgs within the Unit 5 sandy gravel. The field geologist's borehole log, along with the well construction summary report, as-built diagram, well development and pump installation records, and well survey results are included in Appendix A. Appendix B contains the core chain-of-custody forms, the core photographs, and the detailed geologic description of the sediment core. A more detailed hydrogeologic interpretation of the borehole sediments is included in Section 3.0.

The borehole and drill cuttings were monitored regularly for organic vapors and radioisotope contaminants (i.e., gamma). Radioisotope monitoring revealed no detectable contamination was present. Spectral gamma and neutron moisture geophysical logs were run in the temporary borehole in May 2006 by Stoller Corporation (Appendix C). Section 6.6.4 provides more details of this logging. 


\subsubsection{Well Completion}

The permanent casing and screen were installed in well 399-3-19 (C5001) on May 5, 2006. A 25-foot long, 6-inch inside diameter, stainless steel, continuous wire-wrap 20 slot (0.02-inch slot) screen was set from 40.29 to 65.42 feet bgs (Figure 3.4). A 2-feet long, 6-inch inside diameter stainless steel sump is attached to the bottom of the screen and extends from 65.42 to 67.45 feet bgs. The permanent well casing is 6-inch inside diameter, stainless steel from $40.29 \mathrm{bgs}$ to 1.69 feet above ground surface.

The screen filter pack is composed of 6-9 mesh silica sand placed from 29.9 to 71.9 feet bgs, and was developed with a dual surge block to settle the sand pack. The annular seal is composed of $3 / 8$-inch bentonite pellets from 23.9 to 29.9 feet bgs and granular bentonite crumbles from 10.5 to 23.9 feet bgs. The surface seal is composed of Portland cement grout from 10.5 feet bgs to ground surface. A 4-foot by 4-foot by 6-inch concrete pad was placed around the well at the surface. A protective well head casing with locking cap, four protective steel posts, and a brass marker stamped with the well identification number and Hanford well number were set into the concrete pad.

The vertical and horizontal coordinates of the well were surveyed by Fluor Federal Services on August 3, 2006. The horizontal position of the well was referenced to horizontal control stations established by the USACE. The horizontal datum is NAD83(91). Vertical datum is NAVD88 and is based on existing USACE bench marks. The coordinates are Washington Coordinate System, South Zone. Survey data are included in Table 6.1 and Appendix A. The static water level was 47.7 feet bgs on May 22, 2006.

\subsubsection{Well Development and Pump Installation}

Well 399-3-19 (C5001) was developed on May 22, 2006, at two locations within the screen at approximately 68.3 and 53.6 feet btc using a temporary submersible pump. The depth to water was measured at 50.34 feet btc prior to development. A pressure transducer was installed above the pump and connected to a Hermit datalogger to monitor water level during development. A total of 1,125 gallons of water was pumped. Table 6.2 contains the well development results, including pump intake depth, pump rate, pump run time, drawdown, final turbidity (NTU), specific conductivity, $\mathrm{pH}$, dissolved oxygen, and temperature readings.

A dedicated 0.5-horsepower Grundfos ${ }^{\mathrm{TM}}$ submersible sampling pump (model 5SO5-13) was installed in well 399-3-19 (C5001) on May 23, 2006. The sampling pump intake was set at 59.10 feet bgs, and connected to the surface with $3 / 4$-inch diameter stainless steel riser pipe.

\subsection{Well 399-3-20 (C5002)}

Well 399-3-20 (C5002) is located immediately downgradient, and adjacent to the southeast side of the 307 Trench within the 300 Area (Figure 6.1). The new well monitors the uppermost unconfined aquifer and is screened across lower Hanford formation sediments (Figure 3.5). 


\subsubsection{Drilling and Sampling}

Well 399-3-20 (C5002) was drilled with a rotosonic drill rig from surface to a total depth of 95 feet bgs. Temporary $95 / 8$-inch outside diameter casing was used during drilling to total depth. Drilling began on May 11, 2006, and total depth was reached on May 16, 2006. A borehole straightness test was successfully completed.

Continuous coring was attempted during drilling from the surface to approximately 95 feet bgs. However, core recovery was poor $(<50 \%)$ in the saturated Hanford formation because of the loose, unconsolidated nature of the gravel. The water table was encountered at approximately 47.7 feet bgs on May 12, 2006. The borehole log in Appendix A provides the lithologic description of sediments encountered during drilling. The composite log (Figure 3.5) summarizes the core sample intervals and provides the lithology and graphic log based on a detailed description of the core samples. Digital photographs of the sediment core are provided in Appendix B.

Four depth-discrete water samples were collected, and four depth-discrete aquifer hydraulic tests were performed during drilling through the unconfined aquifer. The groundwater samples were analyzed as described in Section 6.6.2. Select results from the vadose zone and groundwater analysis are plotted on the composite log (Figure 3.5) to illustrate the vertical contaminant distribution and the relationship to the various hydrogeologic units.

Sediments encountered during drilling include approximately 10 feet of backfill overlaying 6.5 feet of eolian (Holocene) sand from approximately 10 to 16.5 feet bgs. The Hanford formation Unit 1 is composed of unconsolidated silty sandy gravel to gravel from approximately 6.5 feet to a depth of 80 feet bgs.

The Hanford/Ringold contact at this location is at approximately 80 feet bgs and distinguished by changes in lithology and color. The Ringold Formation Unit 5 sandy gravel is less then 2 feet thick and changes abruptly into sand that extends from approximately 81.8 feet bgs to 95 feet bgs (total depth). The borehole reached a total depth of 95 feet bgs within the Unit 5 fine-to coarse-grained sand. The field geologist's borehole log, along with the well construction summary report, as-built diagram, well development and pump installation records, and well survey results are included in Appendix A. Appendix B contains the core chain-of-custody forms, the core photographs, and a detailed geologic description of the core. A more detailed hydrogeologic interpretation of the borehole sediments is included in Section 3.0.

The borehole and drill cuttings were monitored regularly for organic vapors and radioisotope contaminants (i.e., gamma). Radioisotope monitoring revealed no detectable contamination was present. Spectral gamma and neutron moisture geophysical logs were run in the temporary borehole in May 2006 by Stoller Corporation (Appendix C). Section 6.6.4 provides more details of this logging.

\subsubsection{Well Completion}

The permanent casing and screen were installed in well 399-3-20 (C5002) on May 18, 2006. A 25-foot long, 6-inch inside diameter, stainless steel, continuous wire-wrap 20 slot (0.02-inch slot) screen was set from 40.24 to 65.26 feet bgs (Figure 3.5). A 2-foot long, 6-inch inside diameter stainless steel 
sump is attached to the bottom of the screen and extends from 65.26 to 67.28 feet bgs. The permanent well casing is 6-inch inside diameter, stainless steel from 40.24 feet bgs to 1.74 feet above ground surface.

The screen filter pack is composed of 6-9 mesh silica sand placed from 29.9 to 72.1 feet bgs, and was developed with a dual surge block to settle the sand pack. The annular seal is composed of 3/8-inch bentonite pellets from 25.5 to 29.9 feet bgs and granular bentonite crumbles from 10.2 to 25.5 feet bgs. The surface seal is composed of Portland cement grout from 10.2 feet bgs to ground surface. A 4-foot by 4-foot by 6-inch concrete pad was placed around the well at the surface. A protective well head casing with locking cap, four protective steel posts, and a brass marker stamped with the well identification number and Hanford well number were set into the concrete pad.

The vertical and horizontal coordinates of the well were surveyed by Fluor Federal Services on August 3, 2006. The horizontal position of the well was referenced to horizontal control stations established by the USACE. The horizontal datum is NAD83(91). Vertical datum is NAVD88 and is based on existing USACE bench marks. The coordinates are Washington Coordinate System, South Zone. Survey data are included in Table 6.1 and Appendix A. The static water level was 46.4 feet bgs on May 22, 2006.

\subsubsection{Well Development and Pump Installation}

Well 399-3-20 (C5002) was developed on May 27, 2006, at two locations within the screen at approximately 68 and 66 feet btc using a temporary submersible pump. The depth to water was measured at 49.07 feet btc prior to development. A pressure transducer was installed above the pump and connected to a Hermit datalogger to monitor water level during development. A total of 1,170 gallons of water was pumped. Table 6.2 contains the well development results, including pump intake depth, pump rate, pump run time, drawdown, final turbidity (NTU), specific conductivity, $\mathrm{pH}$, and temperature readings.

A dedicated 0.5-horsepower Grundfos ${ }^{\mathrm{TM}}$ submersible sampling pump (model 5SO5-13) was installed in well 399-3-20 (C5002) on May 23, 2006. The sampling pump intake was set at 58.94 feet bgs, and connected to the surface with 3/4-inch diameter stainless steel riser pipe.

\subsection{Field Characterization and Laboratory Activities Associated with the 300 Area Limited Field Investigation}

This section details the characterization activities conducted during drilling of the four new boreholes. It also provides the sampling and analysis results from sediment, groundwater, and other testing methods used in the hydrogeologic and geochemical investigation of the vadose zone and uppermost unconfined aquifer. Section 3.0 provides an updated hydrogeologic interpretation based on these LFI results. Section 4.0 incorporates the contaminant concentration data results from sediment and groundwater analysis into the updated hydrogeology conceptual model and provides an interpretation of contaminant distribution within the vadose zone and uppermost unconfined aquifer within the LFI area of the 300 Area.

Characterization activities, i.e., sampling and testing, conducted in association with drilling the four boreholes include the following: 
- Collection of sediment grab samples and continuous intact sediment core returned to the surface during drilling

- Geochemical characterization of sediments

- Collection and analysis of depth-discrete groundwater samples during drilling

- Depth-discrete aquifer testing during and after drilling

- Water-level measurements

- High-resolution borehole geophysical logging at the completion of drilling and prior to well construction (i.e., packing the outside annulus of the permanent casing with sand, bentonite, and concrete at selected depths)

- Well development parameters (groundwater field parameters and drawdown during pumping and recovery).

\subsubsection{Sediment Sampling and Analysis}

This section describes the sediment sampling methods used during Phase I Well Drilling, and the sediment analysis and data results. Continuous and minimally disturbed (intact) sediment cores were required from surface to total depth in each borehole (DOE 2006a). The purposes of the core samples were to provide (1) intact sediment samples for more detailed and representative descriptions of the borehole lithology and to improve and refine the hydrogeologic conceptual model, (2) intact, depthdiscrete samples for evaluation of physical and chemical properties associated with uranium contamination and sequestration, and (3) intact, whole-core samples for treatability testing to develop chemical treatment techniques that can be used to reduce uranium contamination to groundwater. Actual core recovery varied depending on the type of sediments being cored. A high percentage of the saturated Hanford formation core was not recovered intact due to loose, unconsolidated coarse sand and gravel, and in many instances, those intervals had to be cored a second time to recover sediment. Core recovery did improve in the Ringold Formation because it is composed of more consolidated sediments.

The detailed geologic descriptions of the opened core are contained in Appendix B and graphically displayed on the composite logs (Figures 3.2 through 3.5). The composite logs (Section 3.0) also contain the cored depths and intervals for each borehole. Appendix B also provides a digital photograph of each core opened. After opening and sub-sampling, the remaining core material was retained in 1-2 liter plastic containers, labeled with depth and well number. These moisture-proof containers are archived at the Environmental Sciences Laboratory (ESL) located in the 300 Area.

At the sediment characterization laboratory, the core samples were subdivided and analyzed based on the protocol and procedures defined in the sampling and analysis plan (DOE 2006a). Table 6.3 provides a summary of analysis performed on the sediment samples.

The wellsite geologist's borehole logs in Appendix A contain a general description of the cored and drilled interval for each well. The borehole logs include descriptions of the following: 
- Drilling conditions and changes in drilling conditions (e.g., drilling method, drill rate, addition of water, heaving sand)

- Depths of all collected samples and tests

- Lithologic descriptions of sediment (e.g., grain size classification, color, mineralogy/lithology, sorting, etc.).

A total of 420 feet of core was recovered from the four Phase I boreholes. Approximately $58 \%$ of the cored intervals were considered representative of subsurface lithology. Table 6.4 provides the total depth drilled in each borehole, the total cored interval in each borehole, and the number and percentage of those core that were determined to be representative of subsurface conditions. The composite Logs (Figures 3.2 through 3.5) illustrate the core intervals in each borehole

Table 6.3. Characterization Analyses

\begin{tabular}{|c|c|}
\hline Tier 1 Characterization Analyses & Tier 2 Characterization Analyses \\
\hline $\begin{array}{l}\text { - Core opening, including visual inspection, } \\
\text { geological characterization, and photographing } \\
\text { of the cores } \\
\text { - } \quad \text { Moisture content measurement } \\
\text { - GEA }\end{array}$ & 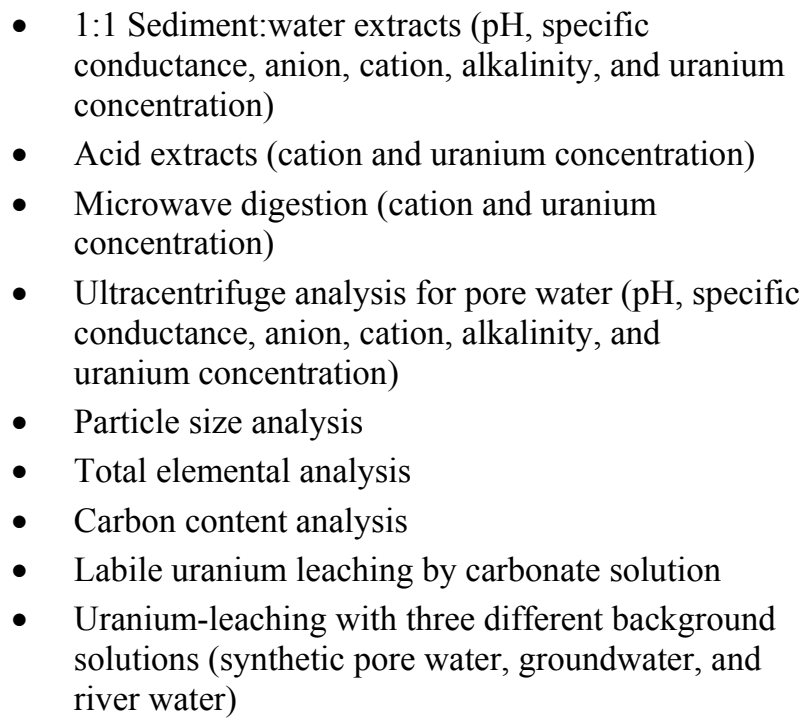 \\
\hline
\end{tabular}


Table 6.4. 300 Area LFI Sediment Core Inventory by Well

\begin{tabular}{|c|c|c|c|c|c|}
\hline Well ID & $\begin{array}{l}\text { Total Drill } \\
\text { Depth } \\
\text { (feet bgs) }\end{array}$ & $\begin{array}{l}\text { Total Cored } \\
\text { Interval } \\
\text { (feet bgs) }\end{array}$ & $\begin{array}{l}\text { Intact Core } \\
\text { Recovered }^{(a)} \\
\quad \text { (feet) }\end{array}$ & $\begin{array}{c}\% \text { Recovery of } \\
\text { Representative Core } \\
(\%)\end{array}$ & Comments \\
\hline $\begin{array}{l}399-3-18 \\
(\mathrm{C} 4999)\end{array}$ & 131 & $0-130.5$ & 93 & 71.0 & $\begin{array}{l}\text { Opened core moved to } \\
\text { containers for storage at ESL } \\
\text { after opening }\end{array}$ \\
\hline $\begin{array}{l}399-1-23 \\
(\mathrm{C} 5000)\end{array}$ & 116 & $0-113$ & 70.8 & 62.7 & $\begin{array}{l}\text { Opened core moved to } \\
\text { containers for storage at ESL } \\
\text { after opening }\end{array}$ \\
\hline $\begin{array}{l}399-3-19 \\
(\mathrm{C} 5001)\end{array}$ & 103.5 & $1-89$ & 41.2 & 46.8 & $\begin{array}{l}11 \text { feet of core was bagged } \\
(\sim 89 \text { to } 100 \text { feet bgs })\end{array}$ \\
\hline $\begin{array}{l}399-3-20 \\
(\mathrm{C} 5002)\end{array}$ & 95 & $3.5-91$ & 39.3 & 44.9 & $\begin{array}{l}7 \text { feet of core was bagged } \\
(\sim 85 \text { to } 91 \text {, and } 95 \text { feet bgs) }\end{array}$ \\
\hline Total & 445.5 & 419.5 & 244.3 & 58.2 & \\
\hline
\end{tabular}

The core samples were obtained by utilizing sonic energy from the drill string to drive a 6-feet-long by 6-inch-diameter splitspoon core barrel ahead of the drilled portion of the borehole into undisturbed sediment (Figure 6.2). After retrieval of the core barrel, the borehole was over-drilled, using a larger diameter drive casing, to the depth reached by the core barrel ( 4-6 feet interval) and the borehole was cleaned out to the bottom of the casing to remove cuttings and slough in preparation for the next core barrel run. The depth to the bottom of the borehole was confirmed with a steel tape prior to each core barrel run. The core barrel assembly contains six 1-foot-long, 5-inch inside diameter Lexan (plastic) liners stacked end to end and is fitted with a 6-inch-long drive shoe attached at the front end. Slough in the bottom of the borehole could not always be kept cleaned out so portions of the upper core liners occasionally contained slough. These slough liners were identified based on (1) knowledge of the re-cored depth intervals, and/or (2) direct examination of core ends, and/or (3) confirmed through examination when opened in the laboratory. Where possible, the slough material was not used for sample analysis.

Upon retrieval, the 6-feet-long core barrels were immediately opened at the drill site and the individual 1-foot-long liners were labeled with top and bottom depths, directional arrow, sequential liner number, and well ID. All liners were sealed with plastic end caps and sealing tape and placed in coolers for temporary storage until they could be transferred offsite to the PNNL ESL in the 325 Building in the 300 Area.

The sequential numbering of each 1-foot long core section was recorded for each well to assure proper depth placement and location of the core (Appendix B). Chain-of-custody forms were used to inventory and track the transfer of the core from the drill site to the laboratory (Appendix B). 


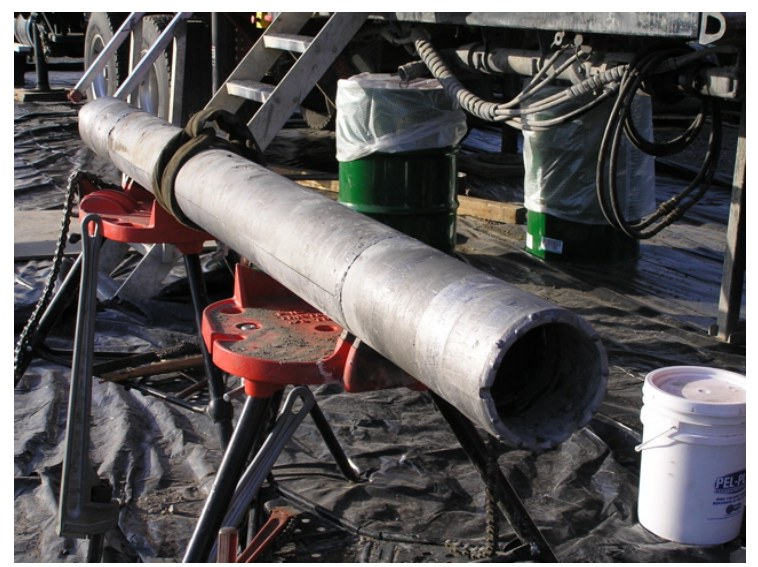

(a)

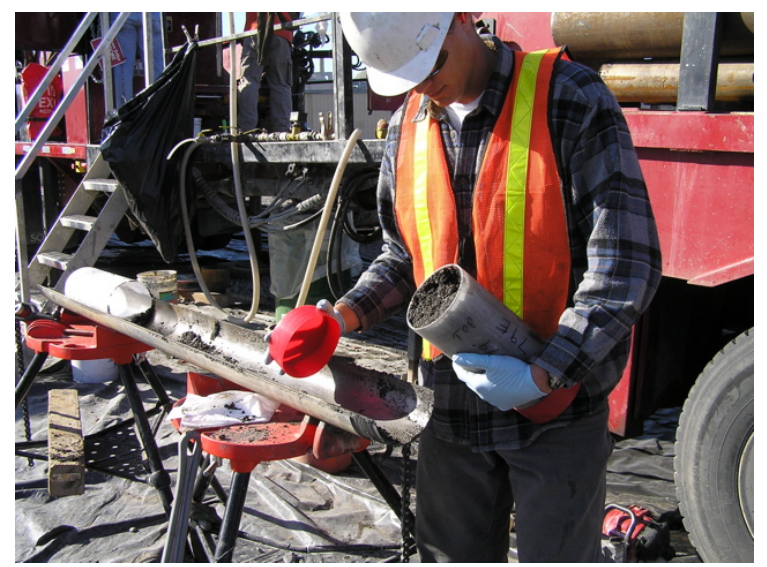

(b)

Figure 6.2. a) Six-Foot Splitspoon Core Barrel and Drive Shoe, and b) Opened Splitspoon Core Barrel During Recovery of Lexan Core Liners

An integrated sampling approach was used to select which core samples were opened for physical and geochemical analysis and which core sections were retained intact for treatability testing and/or archived for future testing. Core that was designated for physical and geochemical analysis was placed horizontally on a lighted table jig, cut lengthwise in half, and laid open for sub-sampling. A high-resolution digital photograph of each opened core section was taken to record the intact sediment structure, lithology, grain size distribution and orientation, and color (Appendix B). A licensed geologist observed the split core to determine the most representative intervals for sampling (and to identify and remove slough intervals). Sub-sampling was accomplished by scooping sediment, typically from the center of the opened core, and sealing the sample in labeled airtight containers. The geologist examined each opened core and prepared a detailed lithologic description of the sediment before the core material was transferred into labeled containers for storage and archival. Cores that were not opened were retained intact and placed in cold storage.

The core descriptions from each well revealed similar occurrences and trends related to drilling and changes in lithology (i.e., geologic formation). Most of the 6-feet-long core runs in the Ringold Formation had nearly complete recovery. Recovery was poorer in the Hanford formation, where most of the core runs had slough in the uppermost (shallowest) liner(s). The quality of the core sediments for all but the coarsest material was good, i.e., the preservation of textural, stratigraphic, and large clast orientations (Appendix B). The lowest core recovery rates occurred when coring in the saturated lower Hanford formation gravel, which is composed of nearly $100 \%$ gravel to sandy gravel with minimal amounts of silt, and/or clay material to hold or bind the sediment particles together and keep them from falling out during retrieval. Note: various attempts were made to keep these gravel sediments from falling out of the core barrel during retrieval, including using retention baskets, welded nuts and bolts inside the core barrel drive shoe, etc. It was not surprising that these gravel-dominated intervals also had the highest apparent permeability based on aquifer hydraulic testing and other (water sampling) measurements. The highest percentage of core recovery was within the compacted fine-grained Ringold Formation sediments. 
Overall, the quality of the LFI coring operation was greatly improved versus conventional splitspoon coring by utilizing larger diameter (5-inch-diameter versus 4-inch-diameter) liners and a longer splitspoon core barrel (6-feet versus 2-feet). The larger diameter core allowed a more complete recovery of the predominantly pebbly to cobble gravel sections without plugging, breaking, pulverizing, or rotating/ moving the larger clasts (Figure 6.3). The longer core barrels allowed a longer, more continuous recovery process with less depth interval disruption (e.g., sloughing and measurement error) between core runs.

\subsubsection{Characterization of Sediments}

Physical and geochemical characterizations of the 300-FF-5 OU sediments from the four LFI boreholes were conducted at PNNL in the ESL. These activities included Tier 1 and Tier 2 characterization and analyses. A summary of the methods used for Tier 1 and 2 sediment characterization and analysis performed is provided in Table 6.3. One of the primary goals of the Tier 1 work was to "ground truth" the field geophysical logging results, with a specific emphasis on comparing the field-derived uranium measurements versus that uranium content of the field-moist sediments (including pore water) acquired in a controlled laboratory setting. The Tier 1 work included opening and photographing the cores, a geologist performing detailed visual inspection of the core material, determining the gravimetric water content of the samples, and measuring total uranium in the as-received sediment using GEA. Tier 2 sediment analyses were performed to better determine where to place the screen intervals in the wells and to better delineate the uranium concentration profile in the vadose zone and aquifer sediments and groundwater. More details for each specific method can be found in the 300-FF-5 OU LFI plan (DOE 2005b). Results from all of the analyses performed on the 300-FF-5 OU samples are summarized below according to individual analysis.

\subsubsection{Moisture Content}

This section describes the results, by well, of the moisture analysis performed on the sediment core samples. Overall, these moisture results reveal reasonable vadose moisture levels, averaging between 4.7 to $5.4 \mathrm{wt} . \%$, which would be expected for this type of Hanford formation gravel-dominated environment (Horton et al. 2003; Serne et al. 2002). The core liners from below the water table often showed moisture contents below values expected for fully saturated sediments, which reflects moisture loss out of the bottom of the splitspoon core sampler while traveling back up the casing. The gravimetric moisture results obtained in the laboratory are also plotted by depth on the borehole composite logs for each well (Figures 3.2 through 3.5) along with the qualitative field neutron moisture logs (see Table D.13 in Appendix D).

Well 399-1-23 (C5000) appears to be the only borehole to have elevated moisture levels in the vadose zone beginning at approximately 23 feet bgs that also coincides with elevated uranium concentrations found in the sediment samples from the same interval (Figure 6.4). The field neutron moisture log does not show elevated moisture in this zone, and based on the fact that this interval is described as reworked mixed Ringold mud and flood deposits, it cannot be stated conclusively that the elevated moisture in this zone is residual fluid from past liquid disposals at the 316-5 Process Trenches. That is, the elevated moisture contents in these vadose zone sediment samples are likely just a reflection of the fine-grained nature of the sediments and not residual waste fluids. 


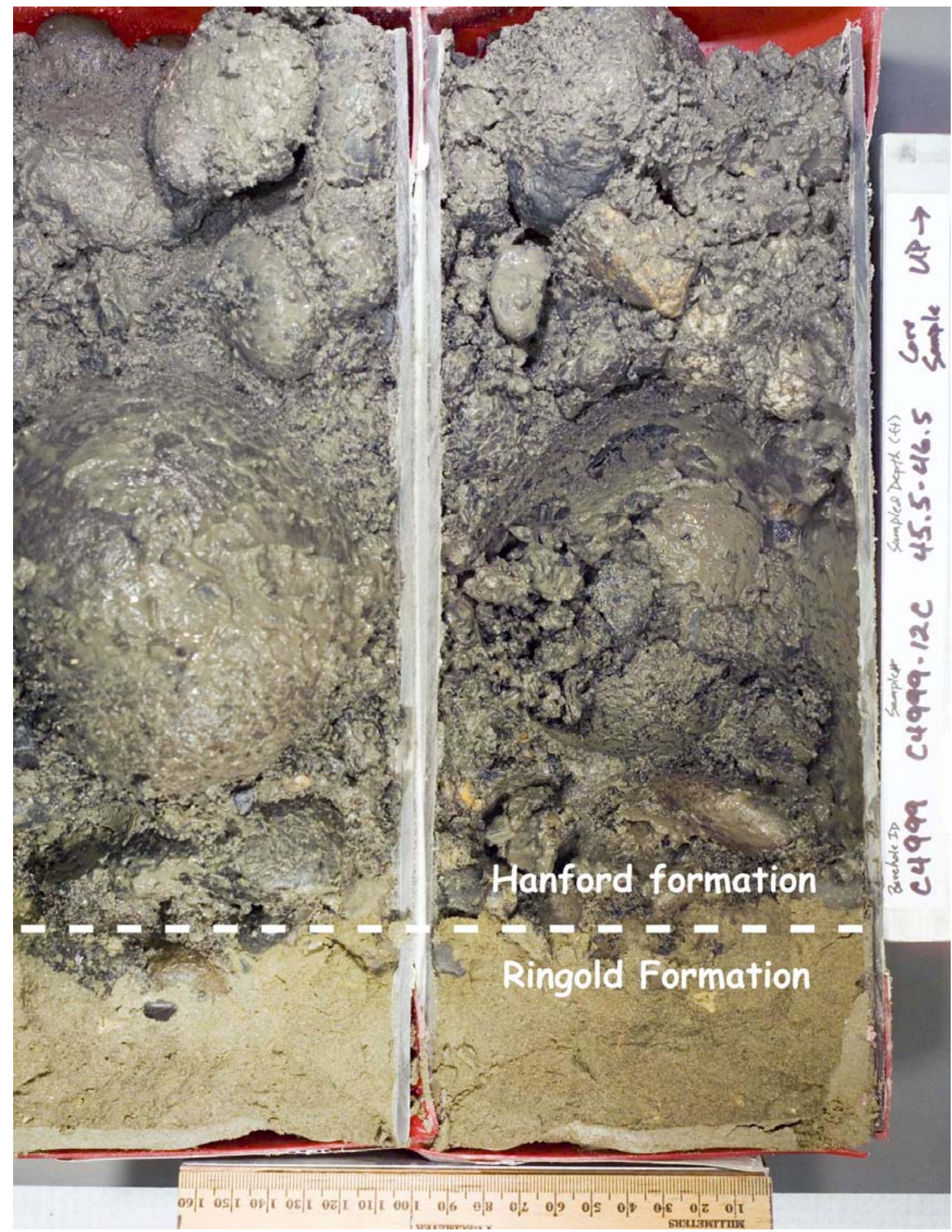

Figure 6.3. Well 399-3-18 (C4999) Core Photograph - Example of Preserved Structure Along the Hanford Formation/Ringold Formation Hydrogeologic Boundary. Coarse, poorly sorted basaltic gravel, sand, and silt of the Hanford formation overlies brown, well sorted, arkosic fine sand of the Ringold Formation. 

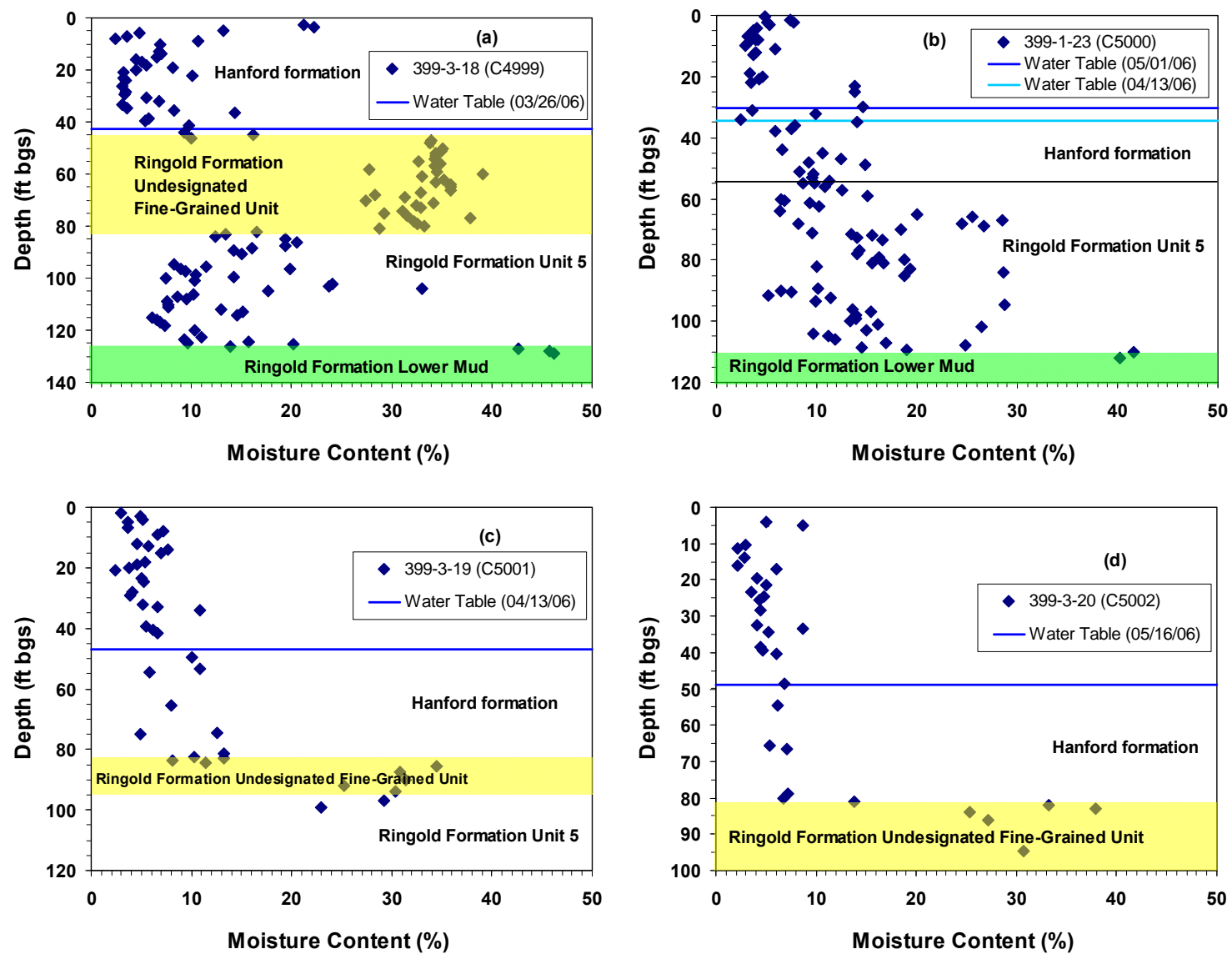

Figure 6.4. Moisture Content (\%) Data for Samples from Wells (a) 399-3-18 (C4999); (b) 399-1-23 (C5000); (c) 399-3-19 (C5001); and (d) 399-3-20 (C5002)

There do not appear to be any significant zones of elevated or anomalously high moisture in the vadose zone in any of the other three wells above the high water table elevation that might be attributed to residual waste liquids or migrating contaminants. A more detailed borehole by borehole discussion of moisture content follows.

Borehole sediment moisture profiles (see Figure 6.4a-d) illustrate the relative distribution of moisture throughout the four boreholes. All values below the water table are elevated because these samples had been recently saturated by Columbia River or groundwater during fluctuating river stage variations and only partially drained, depending on the relative permeability of the sample, at the time of analysis.

Well 399-3-18 (C4999): A total of 133 sediment samples extending from the ground surface to 131 feet below ground surface (bgs) were collected from borehole 399-3-18 (C4999). Gravimetric moisture contents of the samples collected from the vadose zone varied from a low of 2.4 weight percent (wt.\%) to a high of $22.3 \mathrm{wt} . \%$ (Figure $6.4 \mathrm{a}$ ). The two vadose zone samples with the highest moisture contents $(21.2$ and 22.3 wt.\%) were collected at the shallowest depth (2.7-3.7 feet bgs). The relatively high moisture contents found at shallow depth were attributed to the presence of fine-grained coal ash and other finegrained backfill sediments at the surface and possible recent rain events. The average moisture content in the Hanford formation sediments located from 13 feet bgs to the water table (42.5 feet) was $5.6 \mathrm{wt} . \%$, which is consistent to the known range of moisture contents for uncontaminated Hanford formation 
vadose zone sediment. Three possible thin lenses of increased moisture were observed at approximately 9, 23, and 36 feet bgs, respectively, in the vadose zone. These elevated moisture intervals are associated with Ringold rip-up clasts or Hanford formation stringers containing greater concentrations of silt and/or clay. The Ringold Formation undesignated fine-grained unit and Ringold lower mud intervals, located at 46-82 feet and 126-131 feet, respectively, also contain higher moisture contents (30-40 and 43-48 wt.\%) compared to those measured in Ringold Unit E sediments between 82-125 feet bgs. These higher moisture values are due to higher moisture retention that naturally occurs in finer-grained sediment. Relative moisture values in the Ringold formation samples were collected from the saturated zone (i.e., below the water table), and thus are higher than the range of moisture contents for Hanford formation vadose zone sediments.

Well 399-1-23 (C5000): a total of 110 sediment samples extending from the ground surface to 116 feet bgs were collected. Gravimetric moisture contents from the samples collected from the vadose zone to the bottom of the unconfined aquifer are shown in Figure 6.4b. Moisture contents in the vadose zone varied between a low of $2.9 \mathrm{wt} . \%$ and a high of $13.8 \mathrm{wt} . \%$ with an average of $4.9 \mathrm{wt} . \%$. The highest moisture content (13.8 wt.\%) was measured at approximately 23 feet bgs, above the high water table, and may be attributed to water table fluctuations due to seasonal changes in the stage of the Columbia River or to post-operational residual moisture moving down through the vadose zone or trapped in silty deposits within the Hanford formation. Results from uranium analysis of sediment samples from the same depth interval reveals slightly elevated uranium concentrations at these same depths but we cannot say that the coincident elevated moisture content and uranium content reflect residual liquid waste disposed into the 316-5 process trenches. Sediments in the Ringold Formation lower mud unit, located below 110 feet, showed high water contents (40-41 wt.\%), which are due to the fine-grained, low-permeability (highmoisture retention) nature of this interval.

Well 399-13-19 (C5001): A total of 49 core samples from the ground surface to 89 feet bgs and an additional 5 bagged grab samples between 89 and 100 feet bgs were collected. Gravimetric moisture contents of the samples collected from the vadose zone to the bottom of the unconfined aquifer are shown in Figure 6.4c. Moisture contents in the vadose zone were variable from a low of 2.9 wt. $\%$ to a high of 10.8 wt.\%. The average moisture content of all the vadose zone samples was 5.4 wt.\%. A higher moisture content range (4.9-35.0 wt.\%) was found in aquifer sediments and the highest water content (24$35 \mathrm{wt} . \%$ ) was found in the Ringold fine-grained silty sand unit at depths between 85 and 100 feet bgs.

Well 399-3-20 (C5002): A total of 50 core samples from the ground surface to 85 feet bgs and an additional 4 bagged samples between 85 and 95 feet bgs were collected. Gravimetric moisture contents of the samples collected from the vadose zone to the bottom of the unconfined aquifer are shown in Figure $6.4 \mathrm{~d}$. Moisture contents in the vadose zone showed a relatively narrow range between 2.2 and 8.7 wt. $\%$ and an average moisture content in vadose zone sediments was $4.7 \mathrm{wt} . \%$. The higher moisture contents (25-38 wt.\%) found in the deeper aquifer sediments are attributed to finer-grained sediment in the Ringold Formation located below 82 feet bgs.

\subsubsection{Gamma Energy Analysis (GEA)}

GEA was performed on sediment samples to measure the amount of process uranium detectable in the boreholes for comparison to geophysical borehole gamma logging uranium results. This was one of the most important steps of the LFI (Phase II) because if the uranium was detectable, and confirmed using the 
geophysical borehole logging technique, it would greatly enhance the ability to quickly and costeffectively screen for uranium distribution in the vadose beneath the 300-FF-5 OU LFI study area.

To complete the GEA measurements in the laboratory, aliquots of sediment from the core samples were placed in 1-L marinellis containers and counted for 2 hours on a $60 \%$ efficient intrinsic-germanium gamma detector. Spectral analysis was conducted using a library containing key energies associated with the decay of uranium and thorium isotopes and their daughters. Control samples were run throughout the analysis to ensure correct operation of the detectors. The controls contained isotopes with photo peaks spanning the full detector range and were monitored for peak position, counting rate, and full-width halfmaximum.

The laboratory GEA results were compared with those measured by the borehole geophysical spectral gamma system in the field (Section 6.6.4). The results for the ${ }^{40} \mathrm{~K},{ }^{232} \mathrm{Th}$, and ${ }^{238} \mathrm{U}$ all agreed exceptionally well for the vadose zone samples, but discrepancies began to arise once samples from below the water table were compared. Overall, comparison of the laboratory results versus the borehole geophysical GEA performed in the field was reasonable (Section 6.6.4 and Figures 3.2 through 3.5).

The GEA data from borehole samples were further refined in an attempt to discern Hanford-produced (process) uranium from natural background uranium. This was accomplished by comparing the activities of various uranium decay products. Specifically, ${ }^{214} \mathrm{Bi}$ at $609 \mathrm{keV}$ was used to quantitate natural ${ }^{238} \mathrm{U}$. Conversely, ${ }^{234 \mathrm{~m}} \mathrm{~Pa}$ at $1,001 \mathrm{keV},{ }^{234} \mathrm{Th}$ at $63.3 \mathrm{keV}$, and the ${ }^{234} \mathrm{Th}$ doublet at $92.5 \mathrm{keV}$ were monitored and used to measure total ${ }^{238} \mathrm{U}$; the difference between the uranium measured at these energies and that measured at $609 \mathrm{keV}$ (total ${ }^{238} \mathrm{U}$ - natural ${ }^{238} \mathrm{U}$ ) is being labeled as Hanford-process uranium. If the uranium was processed into fuel rods at Hanford over the time period 1943 to $1990 \mathrm{~s}$, the first two ${ }^{238} \mathrm{U}$ daughter products, ${ }^{234} \mathrm{Th}\left(\mathrm{t}_{1 / 2}=24\right.$ days $)$ and ${ }^{234 \mathrm{~m}} \mathrm{~Pa}\left(\mathrm{t}_{1 / 2}=1.17\right.$ minutes $)$, would be in secular equilibrium with the parent ${ }^{238} \mathrm{U}$ in the sediments and pore waters. However, sufficient time would not have elapsed for any ${ }^{238} \mathrm{U}$ daughters below ${ }^{234} \mathrm{U}$ (e.g., ${ }^{214} \mathrm{Bi}$ ) to be present at measurable activities. Thus, this strategy should differentiate natural background ${ }^{238} \mathrm{U}$ and Hanford-processed ${ }^{238} \mathrm{U}$ within the sediments. Further, it is assumed that the uranium contained in these samples is present at natural relative abundances (i.e., $99.3 \%{ }^{238} \mathrm{U}$ with little to no ${ }^{235} \mathrm{U}$ enrichment); so that any ${ }^{238} \mathrm{U}$ measured using the aforementioned isotopes could be further simplified as either "total uranium" and/or "natural uranium." The error bars contained within Figures 6.5 through 6.8 represent the one-sigma counting uncertainties associated with each measured isotope for the masses of sediment used and live count times chosen after background radiation subtraction.

The highest natural uranium concentration in the sediments from the four boreholes measured by GEA was approximately $4 \mathrm{pCi} / \mathrm{g}$, as found in borehole 399-3-18 (C4999) (Figure 6.5). This value is coincident with a thin silt interval that was deposited naturally within the thick Ringold Formation fine sand unit (Figure 3.2). Overall, the natural uranium background concentrations in the four boreholes averaged around $1 \mathrm{pCi} / \mathrm{g}$ or less (Figure 6.6). By comparison, the natural uranium concentrations measure by GEA for these intervals are similar to the laboratory-derived total uranium values (microwave and acid digest methods) measured for the same sample intervals and therefore indicate that these intervals are probably reflecting higher levels of natural uranium deposited with the fine-grained Ringold Formation. The highest GEA-measured total uranium, based on the ${ }^{234} \mathrm{Th}$ doublet at $92.5 \mathrm{keV}$, was approximately 13 and $11 \mathrm{pCi} / \mathrm{g}$ measured in sediment samples from boreholes 399-3-18 (C4999) and 399-1-23 (C5000) (Figures 6.5 and 6.6). These samples were collected from depths of approximately 65 and 70 feet bgs respectively, within the Ringold Formation undesignated fine grained unit and Ringold Formation Unit 5 


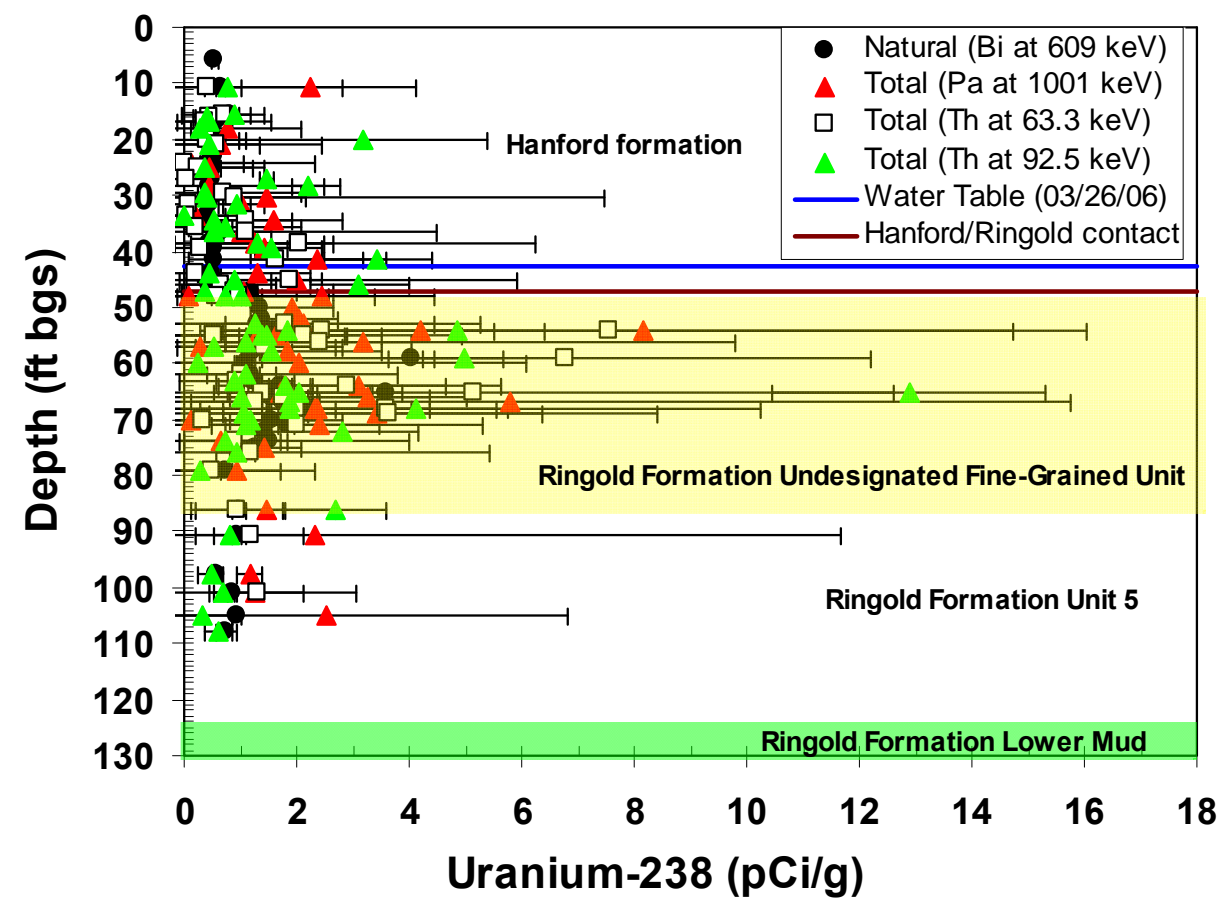

Figure 6.5. GEA Plots-Total vs. Natural Uranium Data in Sediments from Well 399-3-18 (C4999) based on the Measurement of ${ }^{238} \mathrm{U}$ Daughter Products

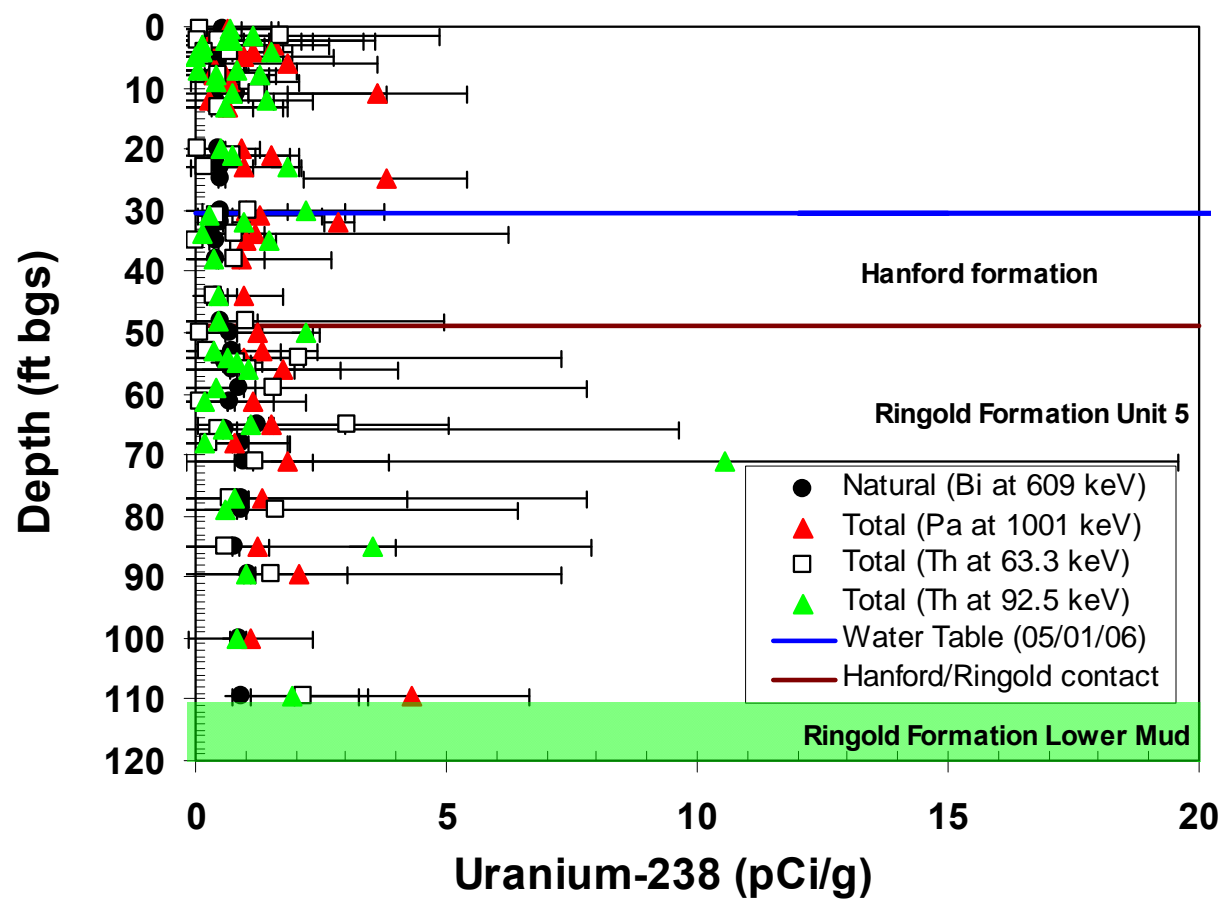

Figure 6.6. GEA Plot-Total vs. Natural Uranium Data in Sediments from Well 399-1-23 (C5000) based on the Measurement of ${ }^{238} \mathrm{U}$ Daughter Products 
below the water table in wells 399-3-18 (C4999) and 399-1-23 (C5000). These high total uranium values are not very precise because of the very large error bars associated with these values.

The data in Figure 6.5 show a trend of increased total uranium concentration in sediment below the water table to a depth of about 80 feet bgs in well 399-3-18 (C4999). This increase in uranium concentration coincides with the Ringold Formation undesignated fine grained unit located from approximately 46 to 82 feet bgs. Data from well 399-1-23 (C5000) (Figure 6.6) are more random, with few high uranium concentration values near the water table, and otherwise do not reveal continuous high values or trends.

The total and natural uranium in the sediments from wells 399-3-19 (C5001) and 399-3-20 (C5002) are all less than $3 \mathrm{pCi} / \mathrm{g}$, which is well within the range of uncontaminated background uranium concentrations in sediments at the Hanford Site (Figures 6.7 and 6.8). There is no statistical difference between the total and natural activities measured suggesting that there is no significant occurrence of Hanfordprocess uranium in the sediments at these two locations.

Overall, there is a general trend in which samples from the lower vadose zone and shallow aquifer contain Hanford process uranium (i.e., the total uranium is higher than the natural uranium), especially in the wells 399-3-18 (C4999) and 399-1-23 (C5000) samples. However, there were no "hot spots" (high uranium concentration) of Hanford-process uranium detected in the vadose zone or saturated sediments during characterization of these four wells. In addition, given the relatively large error bars associated with the data (which represent $1-\sigma$ ); it is difficult to quantitatively state that a significant amount of Hanford-process uranium is present in any of these samples.

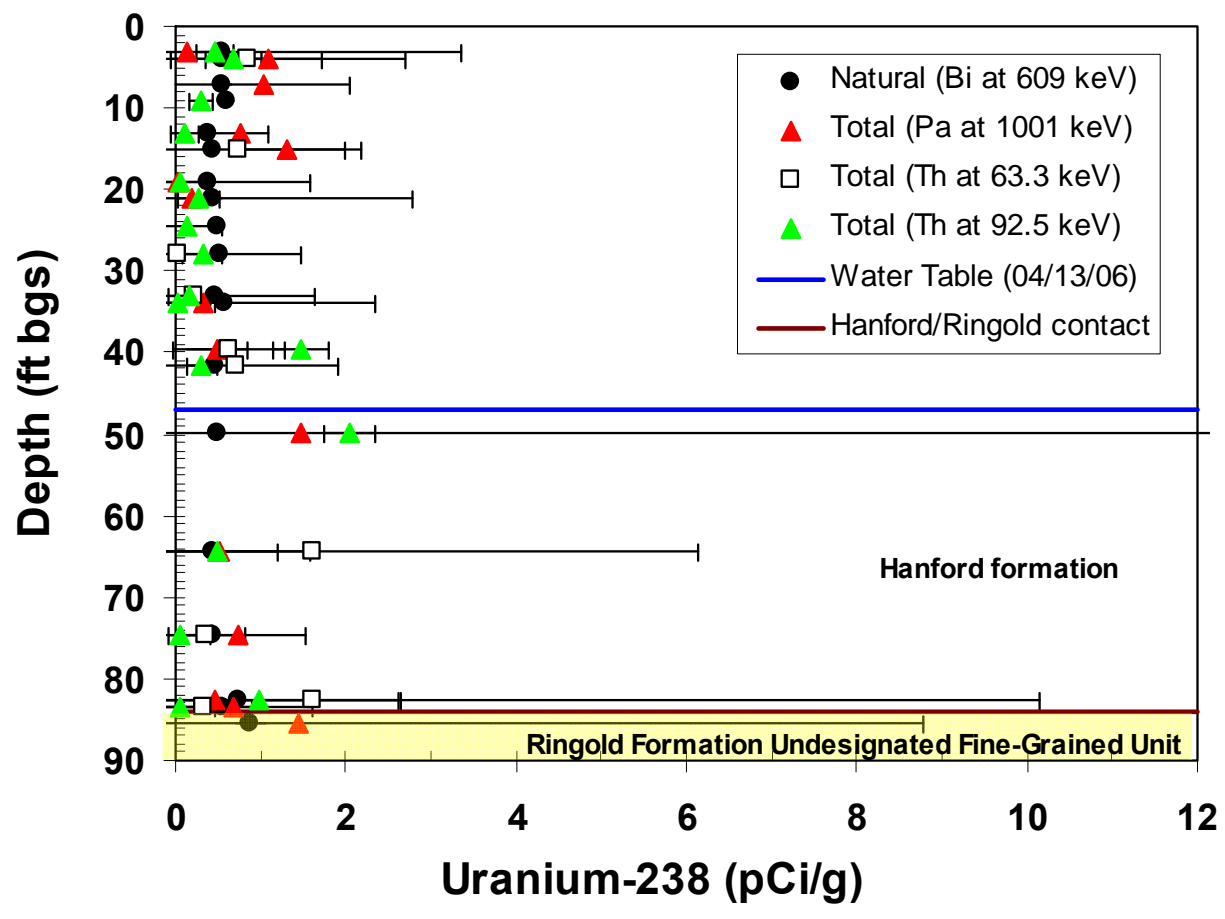

Figure 6.7. GEA Plot-Total vs. Natural Uranium Data in Sediments from Well 399-3-19 (C5001) based on the Measurement of ${ }^{238} \mathrm{U}$ Daughter Products 


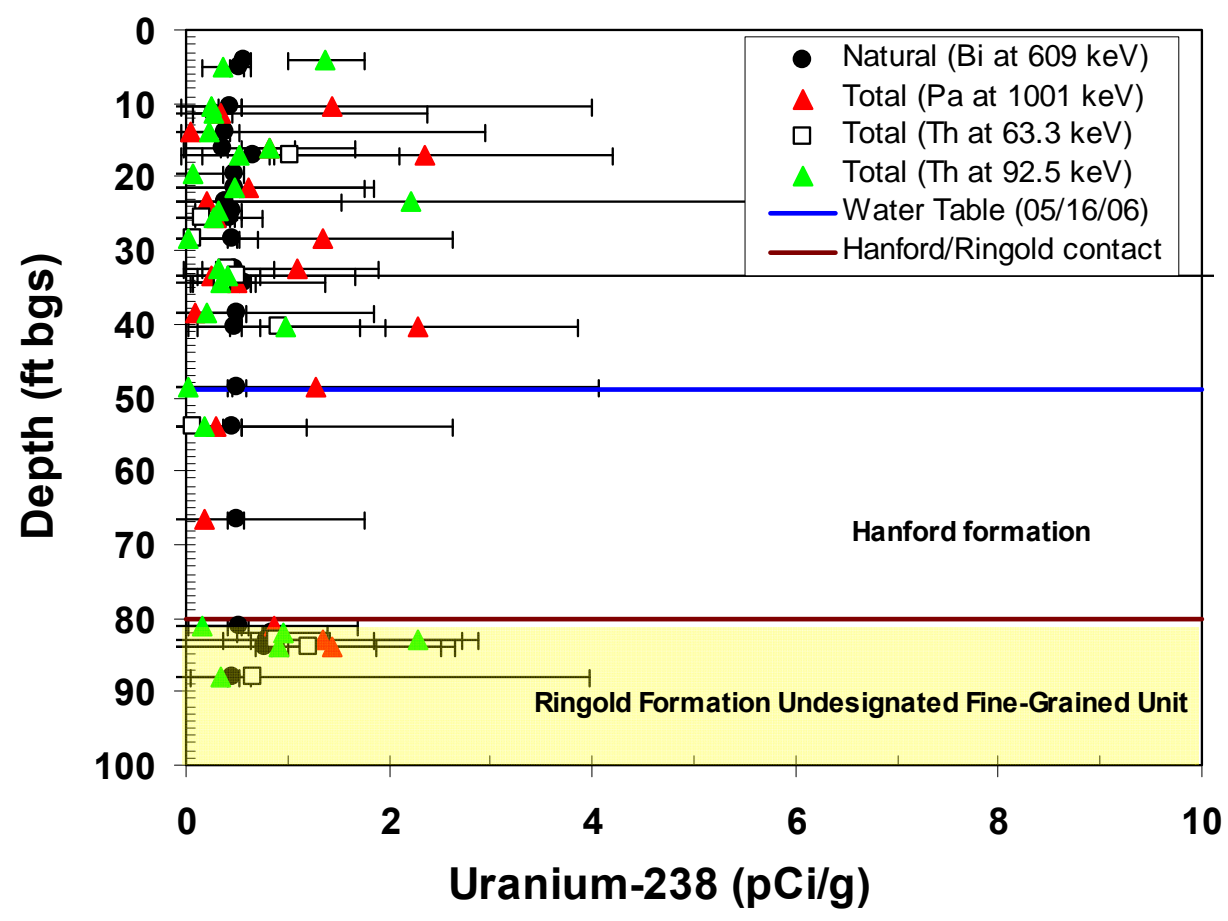

Figure 6.8. GEA Plot-Total vs. Natural Uranium Data in Sediments from Well 399-3-20 (C5002) based on the Measurement of ${ }^{238} \mathrm{U}$ Daughter Products

Because only very low quantities of Hanford-process uranium were found in two of the four wells, the planned correlation of the GEA results with the field geophysical results was not possible. Therefore, Phase II of the LFI plan was cancelled, and more detailed laboratory analysis to evaluate the fate of the uranium in the sediment samples was performed and is described in Section 6.6.1.4.

\subsubsection{Geochemical Extracts (Water Extracts, Acid Extracts, and Microwave Digests)}

In addition to GEA and moisture content calculations of sediment samples, Tier II sediment:water (1:1) extracts (WE), acid extracts (AE), and microwave assisted digestions (MD) were performed on selected samples from the four boreholes. Naturally occurring uranium is typically present in a form that is recalcitrant to water leaching; therefore, elevated concentrations of uranium in the sediment:water (1:1) extracts is generally indicative of contaminant (Hanford-process) uranium. A subset of samples was also extracted via either 8 Molar hot nitric acid extraction (AE) or MD, which are both more effective extraction methods than water extracts. The MD solution consists of $16 \mathrm{M} \mathrm{HNO}_{3}(17 \%), 12 \mathrm{M} \mathrm{HCl}(7 \%)$, $32 \mathrm{M} \mathrm{HF}(3.3 \%), 0.5 \mathrm{~g}$ of $\mathrm{H}_{3} \mathrm{BO}_{3}(1.5 \%)$, and deionized water. The resulting solutions were analyzed for dissolved uranium via inductively coupled plasma mass spectrometry (ICP-MS). Unlike the GEA data, which were composed of the bulk sample material and included gravels and cobbles, the WE, AE and MD procedures used finer-grained material (only material with a diameter $<2 \mathrm{~mm}$ ). Of the two methods (AE and MD), only the MD procedure resulted in total sample dissolution; therefore, it is the most representative technique for quantifying total uranium in the $<2$-mm sediment-size fraction. The distribution of natural uranium, calculated using GEA, is compared to the various extract and digested uranium values (Figures 6.9 to 6.12). 

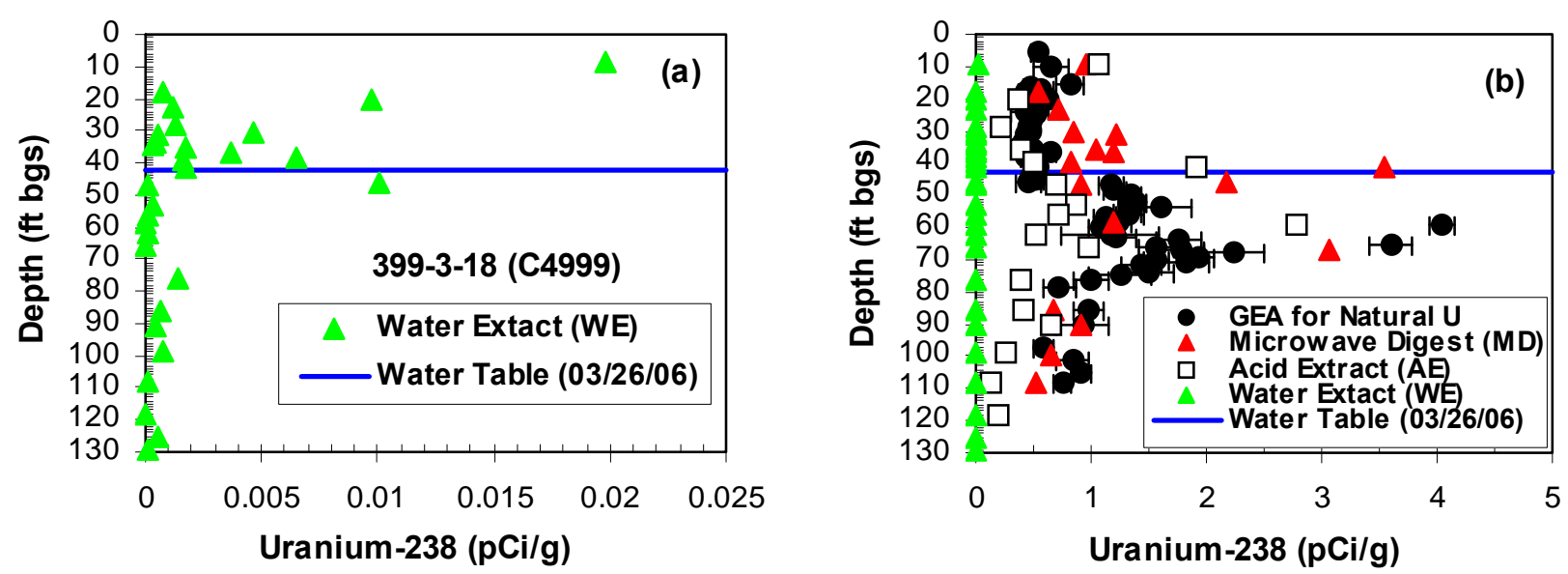

Figure 6.9. Water Extracts (a) and Extractable Uranium by WE, AE, and MD with GEA Data (b) in Sediments from Well 399-3-18 (C4999)
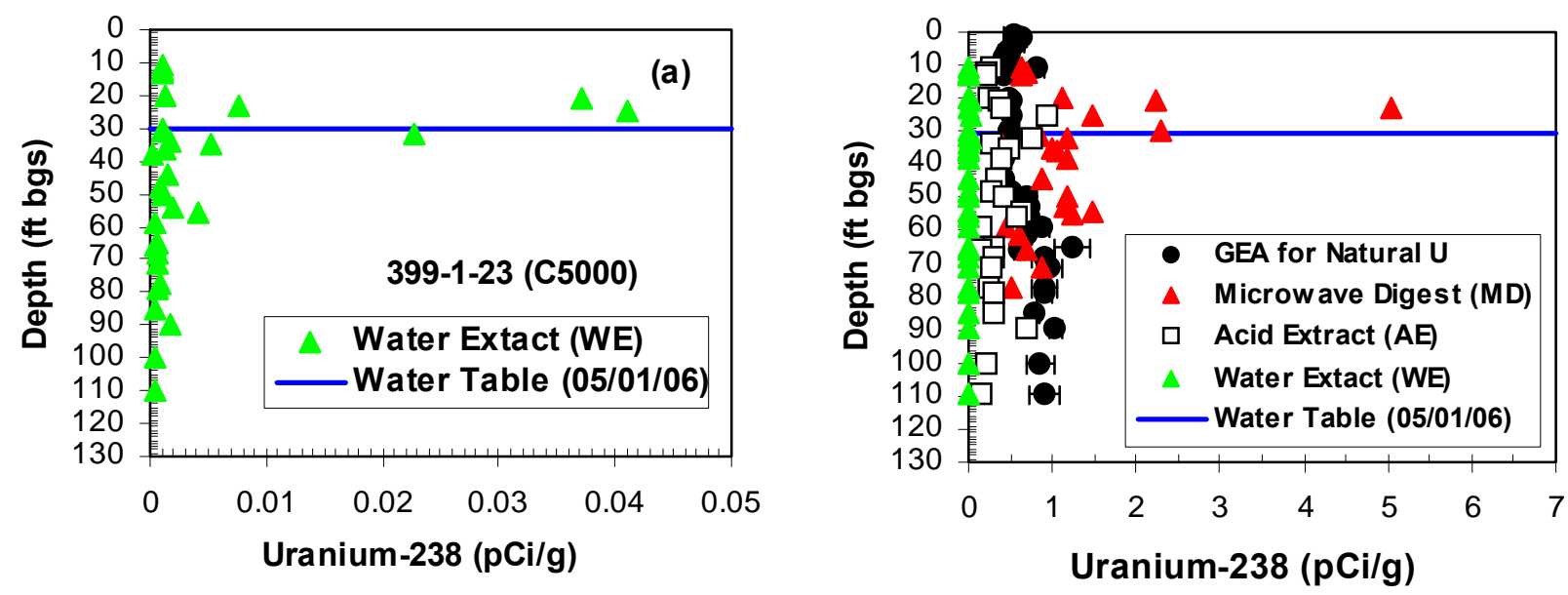

Figure 6.10. Water Extracts (a) and Extractable Uranium by WE, AE, and MD with GEA Data (b) in Sediments from Well 399-1-23 (C5000)

The WE were prepared by adding an exact weight of de-ionized water to approximately 60 grams of sediment sub-sampled $(<2 \mathrm{~mm})$ from each liner. The weight of de-ionized water needed was calculated based on the weight of the field-moist samples and their previously determined moisture contents. The sum of the existing moisture (pore water) and the de-ionized water was fixed at the mass of the oven-dry sediment. An appropriate amount of de-ionized water was added to screw-cap jars containing the fieldmoist sediment samples. The jars were sealed and briefly shaken by hand, then placed on a mechanical orbital shaker for 1 hour. The samples were allowed to settle until the supernatant liquid was fairly clear, usually overnight. The supernatant was carefully decanted and filtered aliquots (passed through $0.45-\mu \mathrm{m}$ membranes) were separated for specific conductance, $\mathrm{pH}$, anion, cation, alkalinity, carbon, and radionuclide analyses for the dissolved uranium content of the water extracts (results are provided in Appendix D). 

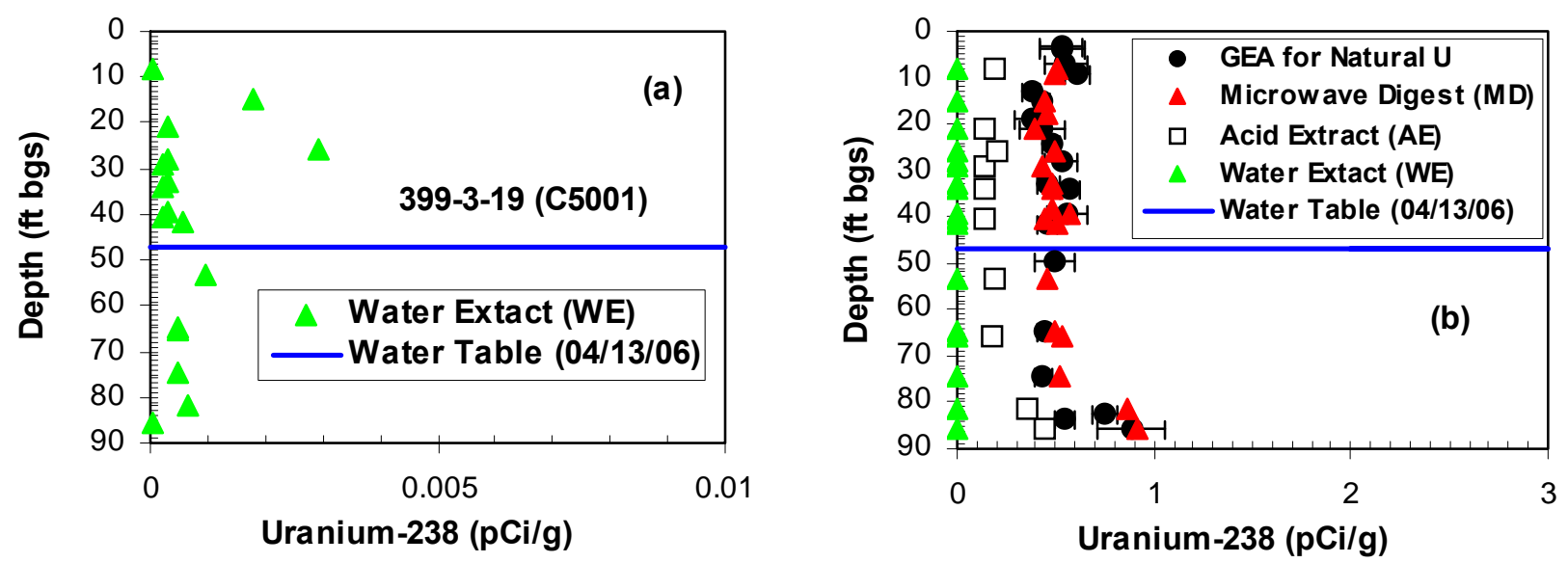

Figure 6.11. Water Extracts (a) and Extractable Uranium by WE, AE, and MD with GEA Data (b) in Sediments from Well 399-3-19 (C5001)
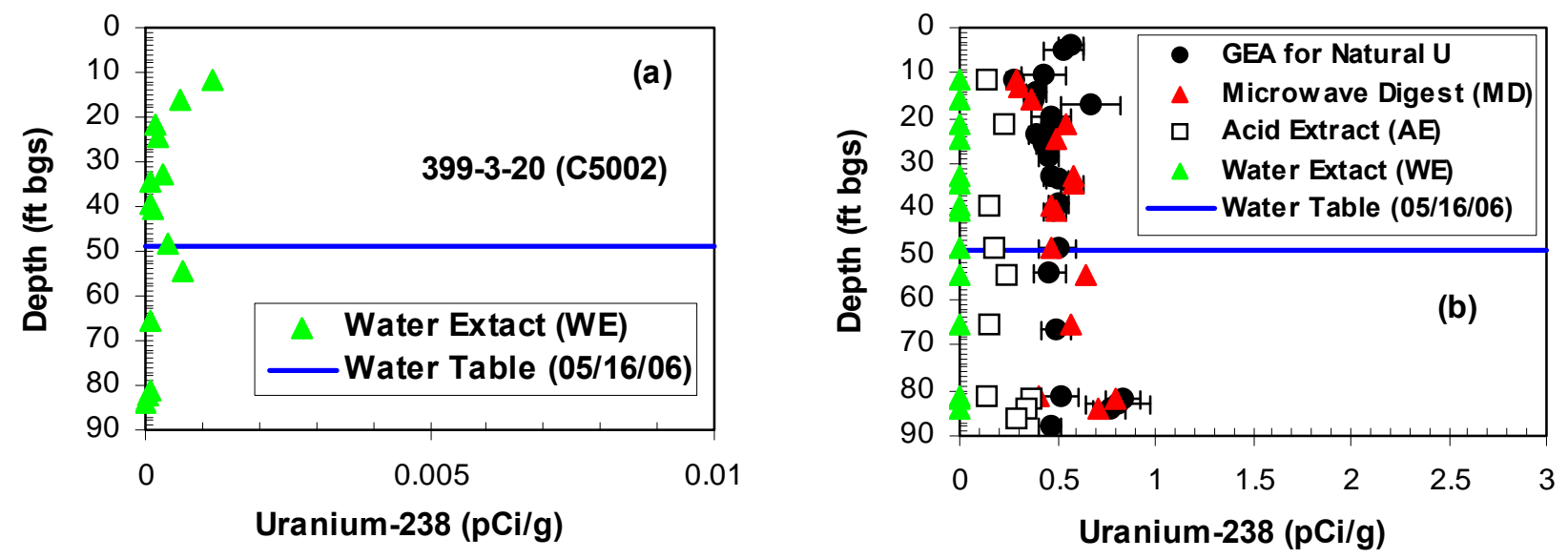

Figure 6.12. Water Extracts (a) and Extractable Uranium by WE, AE, and MD with GEA Data (b) in Sediments from Well 399-3-20 (C5002)

For the sediment samples from well 399-3-18 (C4999), the baseline or background water-extractable uranium concentration in the sediment was approximately $3 \mathrm{E}-04 \mathrm{pCi} / \mathrm{g}$. However, the shallowest sample in the vadose zone from well 399-3-18 (C4999) analyzed via a sediment:water (1:1) extract contained nearly two orders of magnitude more water extractable uranium than the background value. Additionally, there appears to be evidence of elevated uranium in well 399-3-18 (C4999) sediment samples collected just below the water table based on the $\mathrm{AE}$ and MD methods. It should be noted that a sediment:water extract does not adequately assess the total amount of labile (amount available for leaching/transport) uranium present in the sediment. Based on the data measured via GEA in Figure 6.9, the background natural uranium concentration in the sediment from well 399-3-18 (C4999) varied between approximately 0.5 and $4.0 \mathrm{pCi} / \mathrm{g}$. Generally, the MD samples contain more uranium than the measured uranium concentration via any other extraction/analytical technique. This is likely because the uranium present in the MD samples is associated with the finer-grained material that was targeted via the MD technique. In addition, most of the samples containing higher uranium concentrations measured in extracts by various 
methods were located near and just below the water table down to 80 feet bgs. We attribute this zone of elevated uranium to be caused by the presence of the Ringold Formation undesignated fine grained unit between 40-80 feet bgs (see composite Figure 3.2). Although the total uranium concentrations in the borehole 399-3-18 (C4999) sediments were still relatively low (less than $4 \mathrm{pCi} / \mathrm{g}$ based on MD) and there was no significantly high concentration of process uranium detected in the 399-3-18 (C4999) vadose zone or saturated sediments during the drilling and characterization, there appear to be regions of mildly elevated Hanford-process uranium, up to about $3 \mathrm{pCi} / \mathrm{g}$, in the vadose zone sediments close to the water table (based on the difference between total uranium and natural uranium in the laboratory-generated uranium extracts and GEA results).

For the sediments from well 399-1-23 (C5000), the highest water-extractable uranium concentration, which is approximately two times higher than the highest water-extractable uranium concentration found in 399-3-18 (C4999) sediments, was found in vadose zone sediments close to the water table (Figure 6.10). Most of the high water-extractable uranium concentrations in well 399-1-23 (C5000) sediments were found in either deep vadose zone sediments or shallow aquifer sediments, consistent with previous results for well 399-3-18 (C4999) that Hanford-process uranium is located close to the water table.

Based on the data measured via GEA in Figure $6.10 \mathrm{~b}$, the background natural uranium concentration in the sediment from well 399-1-23 (C5000) varied between approximately 0.4 and $1.2 \mathrm{pCi} / \mathrm{g}$. Assuming that the MD results indicate total uranium concentration and the difference between total uranium and natural uranium in the laboratory extract results is considered as the contribution from Hanford-process (contaminant) uranium, the highest Hanford-process uranium measured in the well 399-1-23 (C5000) sediments was about $5 \mathrm{pCi} / \mathrm{g}$ for sediments located in the deep vadose zone close to the water table. Well 399-1-23 (C5000) shows the highest concentration of Hanford-process uranium both in the vadose zone sediment and shallow aquifer sediments analyzed among sediments from all four wells. It is also located just feet from the effluent disposal end of the 316-5 Process Trench.

For the sediment samples from wells 399-3-19 (C5001) and 399-3-20 (C5002), the highest waterextractable uranium was less than 0.003 and $0.002 \mathrm{pCi} / \mathrm{g}$, respectively (Figures 6.11 and 6.12). Even though slightly higher water-extractable uranium concentrations, versus the $<0.001 \mathrm{pCi} / \mathrm{g}$ average for all the water extracts in these two wells, were found in shallow vadose zone sediments (near 20 feet bgs) from these two wells, Hanford-process uranium was not detected in sediments from wells 399-3-19 (C5001) and 399-3-20 (C5002) based on the MD extract uranium values coinciding with the natural background uranium values using GEA. Stated differently, the comparable uranium concentrations with depth between natural uranium (quantified by GEA) and the total uranium (quantified by MD for both vadose zone and aquifer sediments from the 399-3-19 (C5001) and 399-3-20 (C5002) boreholes indicate negligible Hanford-process uranium is present in these sediments.

The highest concentration of water-extractable process uranium measured in the laboratory for sediments from the four wells was around 0.02 and $0.041 \mathrm{pCi} / \mathrm{g}$ for a few vadose sediments above the water table in wells 399-3-18 (C4999) and 399-1-23 (C5000), respectively. These process uranium values equate to pore water concentrations of approximately 450 and 2,590 $\mu \mathrm{g} / \mathrm{L}$, respectively, for the two boreholes. These concentrations are higher than the total uranium concentrations measured in the 300-FF-5 OU groundwater (Section 6.6.2), suggesting that uranium in the vadose zone sediments at boreholes 399-3-18 (C4999) and 399-1-23 (C5000) could be a continuing and slowly bleeding source of the uranium contamination in the aquifer. 
Uranium concentration data from the water extracts, ultracentrifuged pore water and groundwater described above are found in Appendix D (Table D.2). Other information such as water extract pH, alkalinity, specific conductance, major cations and anions analyses for these fluids are provided in Appendix D (Tables D.1 and D.3-D.7). Higher values for $\mathrm{pH}$, specific conductance, alkalinity, and dilution corrected cation/anion analysis were found in water extract samples compared to those from groundwater and pore water samples due to the dissolution of some soluble solids during the water extract process. More detailed discussions for groundwater and pore water samples from the four boreholes are provided in Section 6.6.2.

\subsubsection{Total Elemental Analysis}

The total elemental composition of the sediments from the four wells were determined by MD with subsequent analysis of the dissolved material by inductively coupled plasma-optical emission spectrometry (ICP-OES) and inductively coupled plasma/mass spectrometry (ICP-MS). The dominant major elements in the sediments from the four LFI boreholes are shown in Appendix D (Table D.8). The bulk chemical composition showed that $\mathrm{Si}, \mathrm{Al}$, and Fe were the most dominant elements in most of the sediments from the four boreholes due to the abundance of quartz and aluminosilicate minerals. Other major elements were $\mathrm{Ca}, \mathrm{Na}, \mathrm{Mg}, \mathrm{K}, \mathrm{Ti}, \mathrm{S}, \mathrm{Mn}, \mathrm{P}$, and $\mathrm{Sr}$, which are similarly distributed in all the sediments analyzed from the four boreholes. Similar concentrations of minor elements (As, Ba, Be, Bi, $\mathrm{Cd}, \mathrm{Co}, \mathrm{Cr}, \mathrm{Cu}, \mathrm{Li}, \mathrm{Mo}, \mathrm{Ni}, \mathrm{Pb}, \mathrm{Se}, \mathrm{V}, \mathrm{Zn}, \mathrm{Zr}, \mathrm{Ag}, \mathrm{Re}$, and $\mathrm{Sb}$ ) were found in the sediments from all four boreholes. Because most of the selected sediment samples for total elemental analysis were from the Hanford formation with some designated as the Ringold Formation undesignated fine grained unit above Ringold Formation Unit 5, the major and minor elements concentrations are similar for the selected sediment samples from the four borehole sediments. However, different elemental concentrations are expected between the Hanford formation and Ringold Formation as reported by Bjornstad (1990) because of different proportions of the major minerals and some differences in minor mineral occurrences in these two formations. Even though no specific mineralogy study has been conducted at this time on these four borehole sediments, the major and minor elements are considered to result from quartz, feldspar, and clays (smectite, chlorite, and mica).

\subsubsection{Particle-Size and Physical Properties Analysis}

Particle size analysis using 1) bulk sediments including gravels and 2) for size fractions less than

$2 \mathrm{~mm}$ was conducted using a combination of sieve and hydrometer methods (Gee and Or 2002). Particle size analysis results for sediments less than $2 \mathrm{~mm}$ are shown in Appendix D (Table D.9). For sediments from borehole 399-3-18 (C4999), higher clay contents were found at depths of 23 and 36.5 feet bgs, consistent with the high moisture contents measured in these fine-grained samples. The highest silt/clay content (64.24\%) was found in a sample from borehole 399-3-18 (C4999) at a depth of 127 feet bgs, where the Ringold Formation lower mud unit is located.

Over $90 \%$ of the sediments from borehole 399-1-23 (C5000) were dominated by gravel and sand sized particles. Higher silt/clay contents (29.7-31.6\%) were found at a depth between 21 and 25 feet bgs at 399-1-23 (C5000), which is consistent with the high moisture contents measured over this depth zone (Figure 3.3). For sediments from borehole 399-3-19 (C5001), over 95\% of the samples were dominated by gravel- and sand-sized particles. The higher silt/clay content (34.4\%) found at depth of 34 feet bgs was consistent with the highest moisture content measured in the vadose zone sediments from 399-3-19 
(C5001) (Figure 3.4). The highest silt/clay content (50.6\%) in a sample at a depth of 85.5 feet bgs was consistent with the presence of the Ringold Formation undesignated fine grained unit highlighted in yellow color in the composite figure (Figure 3.4).

Particle-size analysis results for sediments from borehole 399-3-20 (C5002) showed that over 90\% of the samples were dominated by gravel and sand. Higher silt/clay contents, about $29 \%$, were found at depths of 21.5 and 39.5 feet bgs in vadose zone. At borehole 399-3-20 (C5002), the Hanford formation below the water table showed low silt/clay contents $(<15 \%)$, but relatively higher silt/clay contents were found in the Ringold Formation undesignated fine grained unit below a depth of 82 feet bgs.

For most of the samples, particle-size distribution data were generated for only the $<2 \mathrm{~mm}$ size fraction. Almost all of the bulk samples analyzed for grain-size distribution are from the graveldominated Hanford formation. However, particle-size analyses were also performed on the whole (bulk) sediment for 20 samples, five from each of the four boreholes (see Appendix D). Continuous functions were fit to the discrete grain-size distribution data for these 20 samples using an Excel-Visual Basic Applications program to generate various metrics, reported in Appendix D; Figures D.1-D.20).

A summary of physical and hydraulic property data for the 20 selected samples for which particlesize distributions were measured on the whole (bulk) sample is presented in Table 6.5. The selected samples listed in Table 6.5 were collected from the immediate vicinity of the water table (elevation $~ 105-$ $106 \mathrm{~m}$ ), and from overlying and underlying locations in the vadose and saturated zones, respectively. The interpreted hydrogeologic unit designations (e.g., Hanford formation or Ringold Formation) are listed for each sample, and the gravel, sand, silt, and clay percentages are given in Table 6.5. The complete sets of grain-size distribution data and various metrics for these samples are presented in Appendix D.

Grain size metrics reported in Appendix D were computed using both $\mathrm{mm}$ and $\phi$ scales, where $\phi$ is defined as (Folk 1980)

$$
\phi=-\log _{2}(\mathrm{~mm})
$$

One of the reported metrics is the inclusive graphic standard deviation, $\sigma_{I G}$, defined as

$$
\sigma_{I G}=\frac{d_{16}-d_{84}}{4}+\frac{d_{5}-d_{95}}{6.6}
$$

where $d$ is the grain diameter (in $\phi$ units), and the subscripts (e.g., 16, 84, etc.) refer to the weight percent of the bulk sample with grain sizes smaller than the given diameter. The inclusive graphic standard deviation is a measure of the uniformity or sorting of the grain-size distribution.

Also reported in Appendix D are the geometric mean diameter, $d_{\text {geom }}$, and the geometric standard deviation, $\sigma_{\text {geom }}$, (both in units of $\mathrm{mm}$ ) which were computed as follows (Campbell 1985)

$$
d_{\text {geom }}=\exp \left\{\sum m_{i} \ln d_{i}\right\}
$$


Table 6.5. Physical Property Data for Bulk Sediment Samples from Wells 399-3-18 (C4999), 399-1-23 (C5000), 399-3-19 (C5001), and 399-3-20 (C5002)

\begin{tabular}{|c|c|c|c|c|c|c|c|c|c|c|c|c|c|}
\hline \multirow[b]{2}{*}{ Well ID } & \multirow[b]{2}{*}{ Sample } & \multicolumn{4}{|c|}{ Depths } & \multirow{2}{*}{$\begin{array}{c}\text { Elevation } \\
\text { Mid-pt } \\
\text { (m) }\end{array}$} & \multirow[b]{2}{*}{ Unit } & \multirow{2}{*}{$\begin{array}{c}\text { Bulk } \\
\text { Density } \\
\left(\mathrm{g} / \mathrm{cm}^{3}\right)\end{array}$} & \multirow{2}{*}{$\begin{array}{c}\text { Total } \\
\text { Porosity } \\
\dagger\end{array}$} & \multirow[b]{2}{*}{$\%$ Grav } & \multirow[b]{2}{*}{$\%$ Sand } & \multirow[b]{2}{*}{$\%$ Silt } & \multirow[b]{2}{*}{$\%$ Clay } \\
\hline & & $\begin{array}{l}\text { Top } \\
\text { (ft) }\end{array}$ & $\begin{array}{l}\text { Bot } \\
(\mathrm{ft})\end{array}$ & $\begin{array}{l}\text { Mid-pt } \\
(\mathrm{ft})\end{array}$ & $\begin{array}{l}\text { Mid-pt } \\
\text { (m) }\end{array}$ & & & & & & & & \\
\hline 399-3-18 & C4999-6D & 22.5 & 23.5 & 23 & 7.01 & 110.67 & $\overline{\mathrm{H}}$ & 2.17 & 0.212 & 93.28 & 3.98 & 1.11 & 1.63 \\
\hline $399-3-18$ & C4999-9C & 31 & 32 & 31.5 & 9.60 & 108.08 & $\mathrm{H}$ & 2.28 & 0.175 & 86.94 & 9.61 & 2.37 & 1.08 \\
\hline $399-3-18$ & C4999-10C & 35 & 36 & 35.5 & 10.82 & 106.86 & $\mathrm{H}$ & 2.30 & 0.168 & 82.75 & 11.39 & 4.47 & 1.39 \\
\hline $399-3-18$ & C4999-10C & 36 & 37 & 36.5 & 11.13 & 106.55 & $\mathrm{H}$ & 2.18 & 0.211 & 71.48 & 16.35 & 8.71 & 3.45 \\
\hline $399-3-18$ & C4999-11D & 41 & 42 & 41.5 & 12.65 & 105.03 & $\mathrm{H}$ & 2.11 & 0.237 & 93.31 & 4.42 & 1.73 & 0.55 \\
\hline & & & & & & & & & & & & & \\
\hline $399-1-23$ & C5000-39D & 24.5 & 25.5 & 25 & 7.62 & 107.83 & $\mathrm{H}$ & 1.95 & 0.293 & 71.78 & 21.15 & 4.16 & 2.92 \\
\hline $399-1-23$ & $\mathrm{C} 5000-40 \mathrm{C}$ & 31.5 & 32.5 & 32 & 9.75 & 105.69 & $\mathrm{H}$ & 2.34 & 0.152 & 76.18 & 19.43 & 3.02 & 1.37 \\
\hline $399-1-23$ & C5000-40E & 33.5 & 34.5 & 34 & 10.36 & 105.08 & $\mathrm{H}$ & 2.31 & 0.165 & 70.59 & 22.12 & 5.34 & 1.95 \\
\hline $399-1-23$ & C5000-41C & 35.5 & 36.5 & 36 & 10.97 & 104.47 & $\mathrm{H}$ & 2.34 & 0.153 & 76.45 & 19.73 & 2.55 & 1.26 \\
\hline $399-1-23$ & C5000-45C & 53.5 & 54.5 & 54 & 16.46 & 98.99 & $\mathrm{R}$ & 2.26 & 0.182 & 82.77 & 13.18 & 3.03 & 1.02 \\
\hline $399-3-19$ & C5001-66A & 20.5 & 21.5 & 21 & 6.40 & 114.25 & $\mathrm{H}$ & 2.30 & 0.167 & 62.57 & 33.50 & 2.19 & 1.73 \\
\hline 399-3-19 & C5001-69D & 33.5 & 34.5 & 34 & 10.36 & 110.28 & $\mathrm{H}$ & 1.90 & 0.310 & 93.53 & 4.64 & 1.05 & 0.78 \\
\hline 399-3-19 & C5001-70E & 40 & 41 & 40.5 & 12.34 & 108.30 & $\mathrm{H}$ & 2.28 & 0.172 & 83.20 & 14.21 & 1.89 & 0.70 \\
\hline 399-3-19 & C5001-73B & 46.5 & 47.5 & 47 & 14.33 & 106.32 & $\mathrm{H}$ & 1.95 & 0.295 & 80.36 & 18.16 & 1.05 & 0.42 \\
\hline 399-3-19 & C5001-74B & 53 & 54 & 53.5 & 16.31 & 104.34 & $\mathrm{H}$ & 2.04 & 0.263 & 83.46 & 15.60 & 0.63 & 0.31 \\
\hline $399-3-20$ & C5002-86E & 21 & 22 & 21.5 & 6.55 & 113.89 & $\mathrm{H}$ & 1.99 & 0.279 & 80.15 & 15.96 & 3.13 & 0.76 \\
\hline $399-3-20$ & C5002-91C & 39 & 40 & 39.5 & 12.04 & 108.41 & $\mathrm{H}$ & 2.31 & 0.165 & 80.35 & 14.31 & 2.92 & 2.43 \\
\hline $399-3-20$ & C5002-92D & 48 & 49 & 48.5 & 14.78 & 105.67 & $\mathrm{H}$ & 2.45 & 0.113 & 85.69 & 12.19 & 1.47 & 0.65 \\
\hline $399-3-20$ & C5002-93E & 54 & 55 & 54.5 & 16.61 & 103.84 & $\mathrm{H}$ & 2.17 & 0.214 & 86.56 & 12.72 & 0.51 & 0.21 \\
\hline $399-3-20$ & C5002-98E & 80.5 & 81.7 & 81.1 & 24.72 & 95.73 & $\mathrm{H} / \mathrm{R}$ & 2.19 & 0.205 & 80.84 & 16.93 & 1.91 & 0.32 \\
\hline & & & & & & Arithmeti & verages & 2.19 & 0.207 & 81.11 & 14.98 & 2.66 & 1.25 \\
\hline
\end{tabular}


and

$$
\sigma_{\text {geom }}=\exp \left\{\left[\sum m_{i}\left(\ln d_{i}\right)^{2}-\left(\sum m_{i} \ln d_{i}\right)^{2}\right]^{1 / 2}\right\}
$$

and where $m_{i}$ is the mass fraction of size class $i$, and $d_{i}$ is the arithmetic mean diameter $(\mathrm{mm})$ of size class $i$. The metrics $d_{\text {geom }}$ and $\sigma_{\text {geom }}$ were used by Campbell (1985) to predict moisture retention characteristics of soils from texture data. The ratio of $d_{\text {geom }} / \sigma_{\text {geom }}$ has also been used recently by Ward et al. (2006) to develop pedotransfer functions (PTFs) that relate physical and hydraulic properties of soils to their texture.

The grain-size metrics reported in Appendix D were generated by fitting a continuous analytic function to each set of discrete grain size data. An example is depicted in Figure 6.13. The analytic functions were evaluated at 500 different values of the fraction passing a given size (fraction<), over a range from 0.0001 to 0.999 , to generate the discrete size classes used to calculate $d_{\text {geom }}$ and $\sigma_{\text {geom }}$ from Equations (6.3) and (6.4).

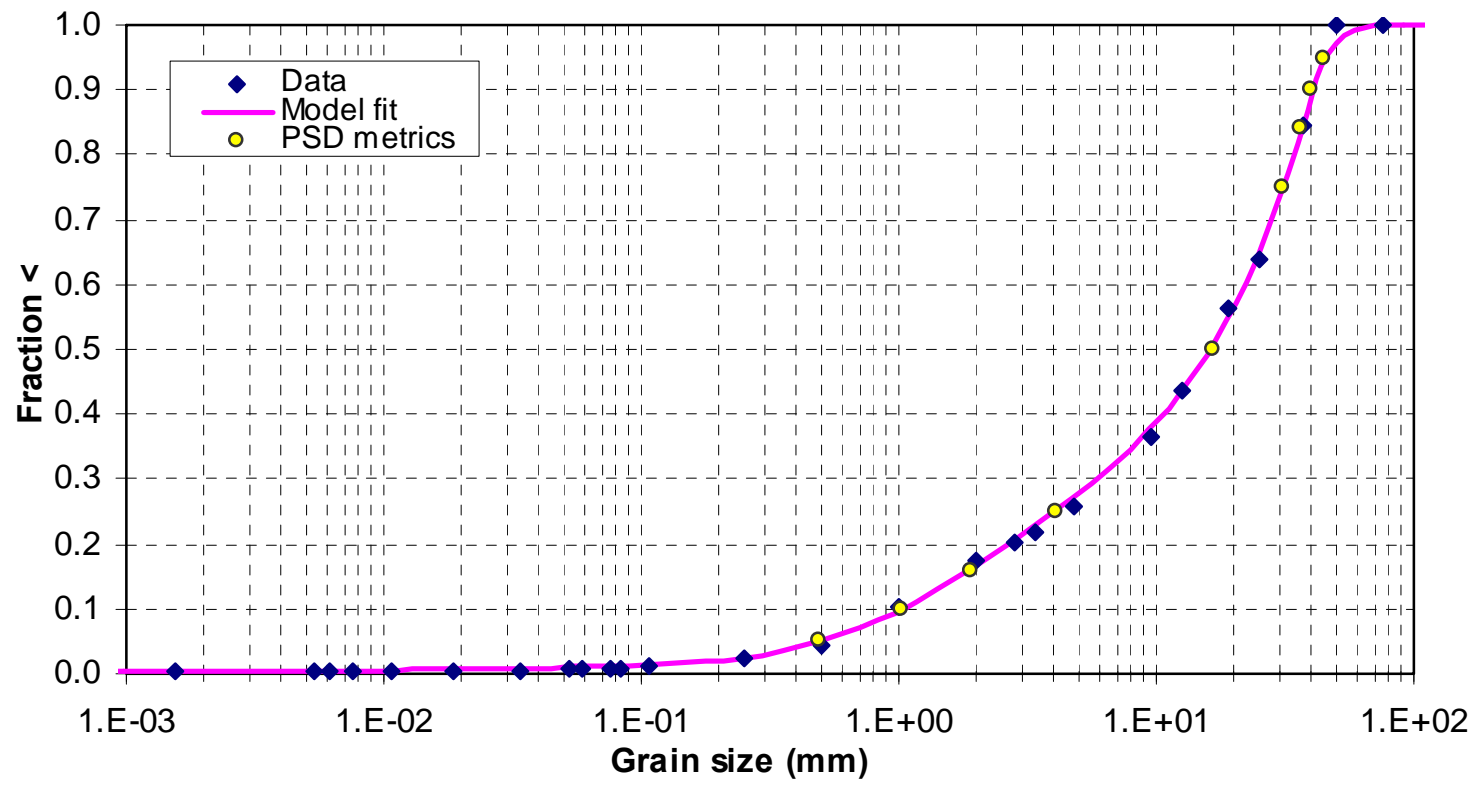

Figure 6.13. Grain-Size Distribution Data and Fitted Function for Sample C5001-74B from Well 399-3-19

Based on the grain-size distribution metrics (Appendix D), an estimate of saturated hydraulic conductivity $\left(\mathrm{K}_{\mathrm{s}}\right)$ was calculated using several methods. The simplest formula is due to Hazen (1911)

$$
K_{s}=C d_{10}^{2}
$$

where $K_{s}$ is the saturated hydraulic conductivity $(\mathrm{cm} / \mathrm{s}), C$ is a constant (taken here to be 1$)$, and $d_{10}$ is the effective grain size (mm) for which $10 \%$ (by weight) of the particles in the sample are finer (Freeze and Cherry 1979, p. 350). Hydraulic conductivities were also computed using the well-known KozenyCarmen equation (Bear 1972, p. 166) 


$$
K_{s}=\left(\frac{\rho_{w} g}{\mu}\right)\left[\frac{n^{3}}{(1-n)^{2}}\right]\left(\frac{d_{m}^{2}}{180}\right)
$$

where $\rho_{\mathrm{w}}$ and $\mu$ are the density and viscosity of water, respectively, $g$ is the gravitational constant, $n$ is the porosity, and $d_{m}$ is a representative grain size, taken here to be either $d_{50}(\mathrm{~mm})$ or $d_{\text {geom }}(\mathrm{mm})$. Porosity was calculated from

$$
n=1-\frac{\rho_{b}}{\rho_{p}}
$$

where $\rho_{b}$ and $\rho_{p}$ are the bulk and particle densities, respectively. Particle densities were not measured, so an average particle density of $2.76 \mathrm{~g} / \mathrm{cm}^{3}$ (Williams et al. 2006) was used to compute the porosities reported in Table 6.5 .

The Hazen formula uses a single grain-size metric, $d_{10}$, while the Kozeny-Carmen equation uses a measure of the median grain diameter, $d_{50}$ or $d_{\text {geom }}$, and the porosity of the porous medium. Masch and Denny (1966) analyzed 12 sets of grain size data and showed that the permeability of unconsolidated sands was related to both the median grain diameter, $d_{50}$, and the inclusive graphic standard deviation, $\sigma_{\mathrm{IG}}$. However they did not develop any predictive formulas for these relationships.

The Masch and Denny (1966) data set was reanalyzed by Mark Rockhold (PNNL) who developed the following regression relationship which coalesces the data from their 12 samples into a single curve (see Figure 4 of Williams et al. 2006)

$$
\mathrm{K}_{\mathrm{s}}(\mathrm{cm} / \mathrm{s})=4.744 \mathrm{e}-4 *\left[\mathrm{~d}_{50}(\mathrm{~mm}) /{\sigma_{I G}}^{1 / 2}\right]^{1.519}, \mathrm{R}^{2}=0.9813
$$

In the soils literature, this type of regression relationship is referred to as a pedotransfer function (PTF) (Guber et al. 2006). Ward et al. (2006) used the ratio $d_{\text {geom }} / \sigma_{\text {geom }}$ to generate the following PTF for $\mathrm{K}_{\mathrm{s}}$ based on average sand, silt, and clay percentages for eleven soil types in the USDA textural classification system

$$
\mathrm{K}_{\mathrm{s}}(\mathrm{cm} / \mathrm{hr})=385.97 *\left(d_{\text {geom }} / \sigma_{\text {geom }}\right)^{0.9318}, \mathrm{R}^{2}=0.9733
$$

It should be noted that Ward et al. (2006) referred to the ratio $d_{\text {geom }} / \sigma_{\text {geom }}$ as the "Fredle index." However, the Fredle index, F.I., was defined by Lotspeich and Everest (1981) as

$$
\text { F.I. }=\frac{d_{\text {geom }}}{S_{o}}
$$

where So is another type of sorting index 


$$
S_{o}=\sqrt{\frac{d_{75}}{d_{25}}}
$$

and where $d_{75}$ and $d_{25}$ are the grain diameters (in $\mathrm{mm}$ ) at the 75th and 25th percentiles of the distribution. The ratios $d_{\text {geom }} / \sigma_{\text {geom }}$ and $d_{\text {geom }} / S_{o}$ do not yield the same values. Therefore, strictly speaking, it is incorrect to refer to the ratio of $d_{\text {geom }} / \sigma_{\text {geom }}$ as the Fredle index.

The Masch and Denny (1966) data set and the sand, silt, and clay percentages used by Ward et al. (2006) represent relatively fine-textured sediments $(<2 \mathrm{~mm}$ size fraction) relative to those that are found in the 300 Area. Another PTF was developed to predict $\mathrm{K}_{\mathrm{s}}$ from texture data using $>50$ samples of mostly Hanford sediments, which ranged in texture from silt loam to pea gravel. This PTF is given by (see Figure 5 of Williams et al. 2006).

$$
\mathrm{K}_{\mathrm{s}}(\mathrm{cm} / \mathrm{s})=0.0481 *\left(\mathrm{~d}_{50}(\mathrm{~mm}) / \sigma_{I G}^{2}\right)^{0.9369}, \mathrm{R}^{2}=0.7665
$$

Equations (6.10), (6.11), and (6.12) will be referred to as $\mathrm{K}_{\mathrm{s}}$ PTF-3, PTF-2, and PTF-1, respectively. Although the $\mathrm{R}^{2}$ value for PTF-1 (Equation [6.12]) is considerably lower than the other PTFs, it was developed using more than four times as many samples, and extends into a coarser range of textures.

Values of $\mathrm{K}_{\mathrm{s}}$ were estimated from the various empirical formula (described in Appendix D) and are listed in Table 6.6. For any given sample, the five empirical formulas yield estimates of $\mathrm{K}_{\mathrm{s}}$ that range over 4 orders of magnitude. Estimates of $\mathrm{K}_{\mathrm{s}}$ using the $\mathrm{d}_{50}$-based Kozeny-Carmen equation are consistently the highest for all the samples, while estimates of $\mathrm{K}_{\mathrm{s}}$ using PTF-3 (from the Masch and Denny data set) are the lowest for most of the samples.

These empirical $\mathrm{K}_{\mathrm{s}}$ calculations were compared to aquifer hydraulic test analysis results from the same borehole depth intervals. Aquifer hydraulic test results from the 15.85-17.37 $\mathrm{m}$ depth interval were calculated for well 399-3-19 (C5001). This aquifer hydraulic test analysis yielded a value of $\mathrm{K}_{\mathrm{s}}=$ 2,300 m/d. A sediment sample, C5001-74B, from the 16.3-16.46 m depth interval of well 399-3-19 (C5001), is within the aquifer hydraulic test interval. Table 6.6 indicates that the estimated $\mathrm{K}_{\mathrm{s}}$ values for this sample ranges from 923 and 14,000 m/d, respectively, which are approximately 2.5 times less than, and 6 times greater than, the $\mathrm{K}_{\mathrm{s}}$ value estimated from the aquifer hydraulic test. Based on the comparisons in Table 6.6, the Hazen formula provides an estimate of $\mathrm{K}_{\mathrm{s}}$ that is closest to the pump test value for this location.

On average (all 20 samples in Table 6.5), the values of $\mathrm{K}_{\mathrm{s}}$ estimated using PTF-1 are only $\sim 30 \%$ greater than those estimated using PTF-2, despite the fact that these two PTFs were generated using completely different and independent data sets and different grain-size distribution metrics. These two PTFs were also generated using $\mathrm{K}_{\mathrm{s}}$ data that were collected on vertically oriented core samples, whereas aquifer hydraulic tests measure the horizontal $\mathrm{K}_{\mathrm{s}}$. Therefore, it is reasonable to assume that the PTF values are representative of $\mathrm{K}_{\mathrm{s}}$ in the vertical direction. If this is assumed, and if a horizontal to vertical anisotropy ratio of 10:1 is also assumed, PTF-1 and PTF-2 yield horizontal $\mathrm{K}_{\mathrm{s}}$ estimates of $10^{*} 150=$ $1,500 \mathrm{~m} / \mathrm{d}$, and $10 * 171=1,710 \mathrm{~m} / \mathrm{d}$, respectively, for Sample C5001-74B. These values are both within a factor of approximately 1.5 of the aquifer hydraulic test estimate of $K_{\mathrm{s}}$ from the 15.85 - to $17.37-\mathrm{m}$-depth interval in well 399-3-19 (C5001). 
Table 6.6. Estimated Values of $\mathrm{K}_{\mathrm{s}}$ for Bulk Sediment Samples from Wells 399-3-18 (C4999), 399-1-23 (C5000), 399-3-19 (C5001), and 399-3-20 (C5002) Based on Various Empirical Formulas

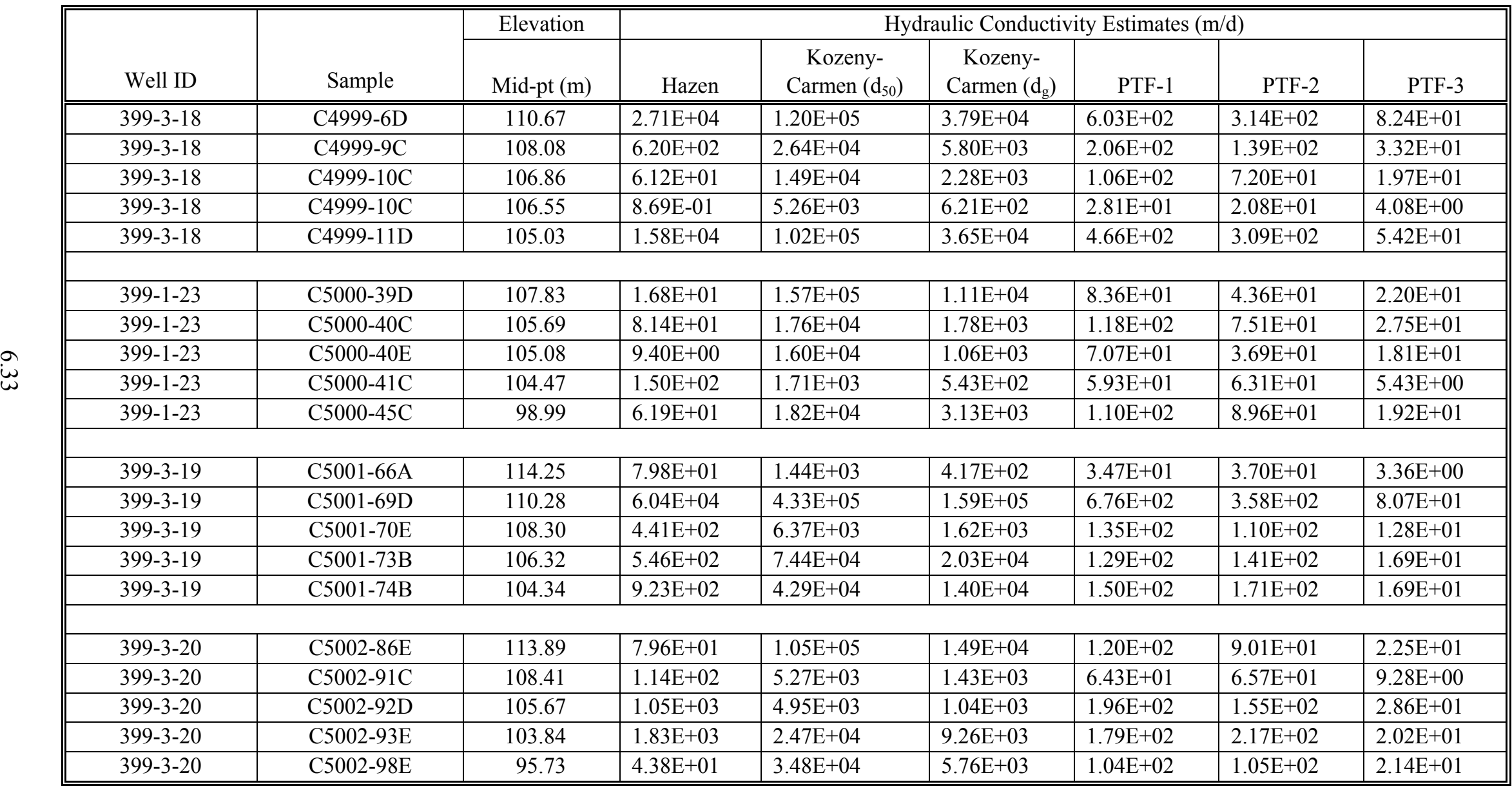


An aquifer hydraulic test was also performed over the 55.5-62.5 feet depth interval in well 399-3-20 (C5002). Analysis of this aquifer hydraulic test yielded a value of $\mathrm{K}_{\mathrm{s}}>2,000 \mathrm{~m} / \mathrm{d}$. Sample C5002-93E was collected from the 54-55 feet depth interval in this well (Table 6.6), just above the aquifer hydraulic test interval. The Hazen formula and both the $\mathrm{d}_{50^{-}}$and $\mathrm{d}_{\mathrm{g}}$-based Kozeny-Carmen equations yield $\mathrm{K}_{\mathrm{s}}$ estimates $>1,000 \mathrm{~m} / \mathrm{d}$ (Table 6.6). Also, if the $\mathrm{K}_{\mathrm{s}}$ estimates from PTF-1 and PTF-2 are increased to account for an assumed horizontal to vertical anisotropy ratio of 10 , they both yield horizontal $\mathrm{K}_{\mathrm{s}}$ estimates $>1,000 \mathrm{~m} / \mathrm{d}$.

No other aquifer hydraulic tests were performed in the intervals where the whole sediment grain-size distribution data were generated, so no further comparisons can be made at this time between grain sizebased and aquifer hydraulic test $\mathrm{K}_{\mathrm{s}}$ estimates. Based on this very limited comparison, we tentatively recommend that where no aquifer hydraulic or pump test data are available, but reliable, whole sediment grain-size distribution data are, then the Hazen formula should be used to estimate $\mathrm{K}_{\mathrm{s}}$. Alternatively, the horizontal $\mathrm{K}_{\mathrm{s}}$ can be estimated by multiplying the $\mathrm{K}_{\mathrm{s}}$ (vertical) estimates generated using either PTF-1 or PTF-2 by a factor of 10 . Note, however, that for the gravel-dominated 300 Area Hanford formation, we recommend that whole sediment grain-size distribution data be generated from larger diameter (5 inches or more) cores obtained by sonic drilling, such as those collected for this LFI, rather than from smaller (4 inches) diameter cores that are typically obtained using the more standard cable-tool drilling method (Williams et al. 2006). The larger-diameter, sonic-drilled core samples are clearly more representative of the in situ sediments at this site.

As a final comment regarding the use of PTFs or other empirical formulas for estimating $\mathrm{K}_{\mathrm{s}}$ (or any other hydraulic parameters) from grain-size data alone, it should be emphasized that these estimates do not account for structure (e.g., layering, stratification, or laminations), grain shape and orientation (e.g., spherical versus plate-like grains), or physicochemical properties (e.g., calcite cementation) of the in situ sediments. All of these factors may affect the pore-size distributions and connectivity of the pores leading to significantly different hydraulic properties for sediment samples that might have similar grainsize distributions but different structure. Although the Hazen formula, $\mathrm{d}_{\mathrm{g}}$-based Kozeny-Carmen equation, and scaled PTFs all yield reasonable $\mathrm{K}_{\mathrm{s}}$ estimates for Hanford formation sediments in the 300 Area, they do not appear to work well for the Ringold Formation sediments. New and improved empirical formulas or PTFs for estimating Ringold Formation $\mathrm{K}_{\mathrm{s}}$ values could potentially be developed by combining grain-size distribution data and chemical property information (Davis et al. 2006; Lu 2007).

\subsubsection{Carbon Content Analysis}

The sediment total carbon (TC) and inorganic carbon (IC) contents in each core were measured with a Shimadzu TOC-V CSN instrument, and organic carbon content was determined by the difference between the measured TC and IC contents. Measured carbon contents results for selected sediments from the four boreholes are shown in Appendix D (Table D.11). Carbon contents in sediments from borehole 399-3-18 (C4999) were low, and inorganic carbon contents varied from 0.0 to $0.96 \mathrm{mg} / \mathrm{g}$, which on average equates to less than $1 \mathrm{wt} . \%$ of inorganic carbon as $\mathrm{CaCO}_{3}$ being present in these sediments. Most of the relatively high IC contents $(0.34-0.96 \mathrm{mg} / \mathrm{g})$ indicative of discrete carbonate minerals or coatings were found in the shallow vadose zone borehole 399-3-18 (C4999) sediments between ground surface and 39.5 feet bgs. The inorganic carbon content (IC) in sediments from borehole 399-1-23 (C5000) varied from 0.0 to $3.42 \mathrm{mg} / \mathrm{g}$, indicating much higher inorganic carbon content than those found in sediments from borehole 399-3-18 (C4999). The highest inorganic carbon content (3.42 mg/g or $2.85 \mathrm{wt} . \%$ as $\mathrm{CaCO}_{3}$ ) in 399-1-23 
(C5000) was found at a depth of 23 feet bgs, where the highest uranium concentration ( $5 \mathrm{pCi} / \mathrm{g}$ ) was detected via the MD method (See Figure 6.10). These results suggest that uranium is present in this sample due to co-precipitation with calcite. Similar results suggesting possible uranium co-precipitation with calcite in 300 Area sediments have been found by others (Wang et al. 2005; Zachara et al. 2005). We speculate that the higher inorganic carbon content in the sediments from 399-1-23 (C5000) may be related to reactions of alkaline waste with atmospheric carbon dioxide and the native vadose zone pore waters during the active disposal period into the 300 Area process trenches.

Co-precipitation of uranium with calcite in vadose zone sediments might have significant implications for the fate and transport of uranium in groundwater, especially at the capillary fringe region where the water table tends to fluctuate due to Columbia River level changes. The total carbon contents measured in sediments from boreholes 399-3-19 (C5001) and 399-3-20 (C5002) were relatively low, and inorganic carbon content varied 0.0 to 0.96 and to $0.93 \mathrm{mg} / \mathrm{g}\left(<1 \mathrm{wt} . \%\right.$ as $\left.\mathrm{CaCO}_{3}\right)$, respectively, similar to those values found in sediments from borehole 399-3-18 (C4999). The highest inorganic carbon content $(0.93 \mathrm{mg} / \mathrm{g})$ measured in sediments from borehole 399-3-20 (C5002) at a depth of 81.1 feet bgs might result from calcium carbonate present as cementing materials at the boundary between the Hanford and Ringold Formation sediments.

\subsubsection{Labile Uranium Leaching Using Carbonate Solution}

Water extracts are used to investigate the chemical composition of pore fluids within the sediment; however, they do not provide an accurate indication of the total amount of labile uranium in the sediments. Therefore, a carbonate leaching method was used to determine the total amount of uranium capable of being removed from the sediment under realistic environmental conditions. A carbonate

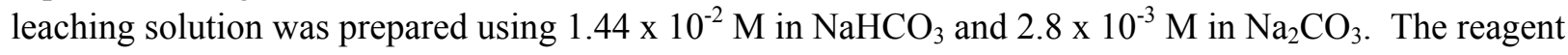
$\mathrm{pH}$ was 9.3, and a solid-to-solution ratio of 3 grams sediment to $35 \mathrm{~mL}$ of carbonate extractant was used for the tests. The leached uranium concentration was determined as a function of time, with total reaction times ranging from 1 to 21 days. Carbonate extract solutions were filtered using $0.45-\mu \mathrm{m}$ syringe filters and analyzed for dissolved uranium using ICP-MS, for $\mathrm{pH}$ using a solid state electrode, and for dissolved calcium using ICP. Duplicate aliquots of the carbonate extract were measured, and data were calculated as an average concentration value with an error of one standard deviation. Sample information and the measured $\mathrm{pH}$, alkalinity, and $\mathrm{Ca}$ concentration in each sample extract are shown in Appendix D (Table D.11).

Labile uranium leaching results for the sediments from borehole 399-3-18 (C4999) showed variable concentrations ( 0.1 to $3.3 \mu \mathrm{g} / \mathrm{g}$ ) of leachable uranium depending on reaction times and the selected sediments used (Figure 6.14). However, most of the sediments had leachable uranium concentration less than $1.0 \mu \mathrm{g} / \mathrm{g}$, even though a total of 21 days of reaction time was permitted. The highest leachable uranium was found in the sample (C4999-11D) collected at a depth of 41.5 feet bgs, which was close to the water table. This result agreed well with previous geochemical extraction data (Figure 6.9). The amount of leached uranium by the carbonate solution in sample C4999-11D increased rapidly for the first 7 days of reaction time, and then leveled off after 14 days of reaction, indicating steady-state leaching was approached. Since there was no significant change in the amount of uranium leached after a 21-day reaction, the maximum leachable uranium concentration in this sediment sample was estimated to be $3.3 \mu \mathrm{g} / \mathrm{g}$. Based on the previously determined total uranium concentration $(10.5 \mu \mathrm{g} / \mathrm{g})$ for this sediment sample (C4999-11D) measured via microwave digestion, approximately $7.2 \mu \mathrm{g} / \mathrm{g}$ of uranium was considered to exist as a recalcitrant phase that might potentially be co-precipitated with calcite or present as trace components in aluminosilicate mineral structures. 


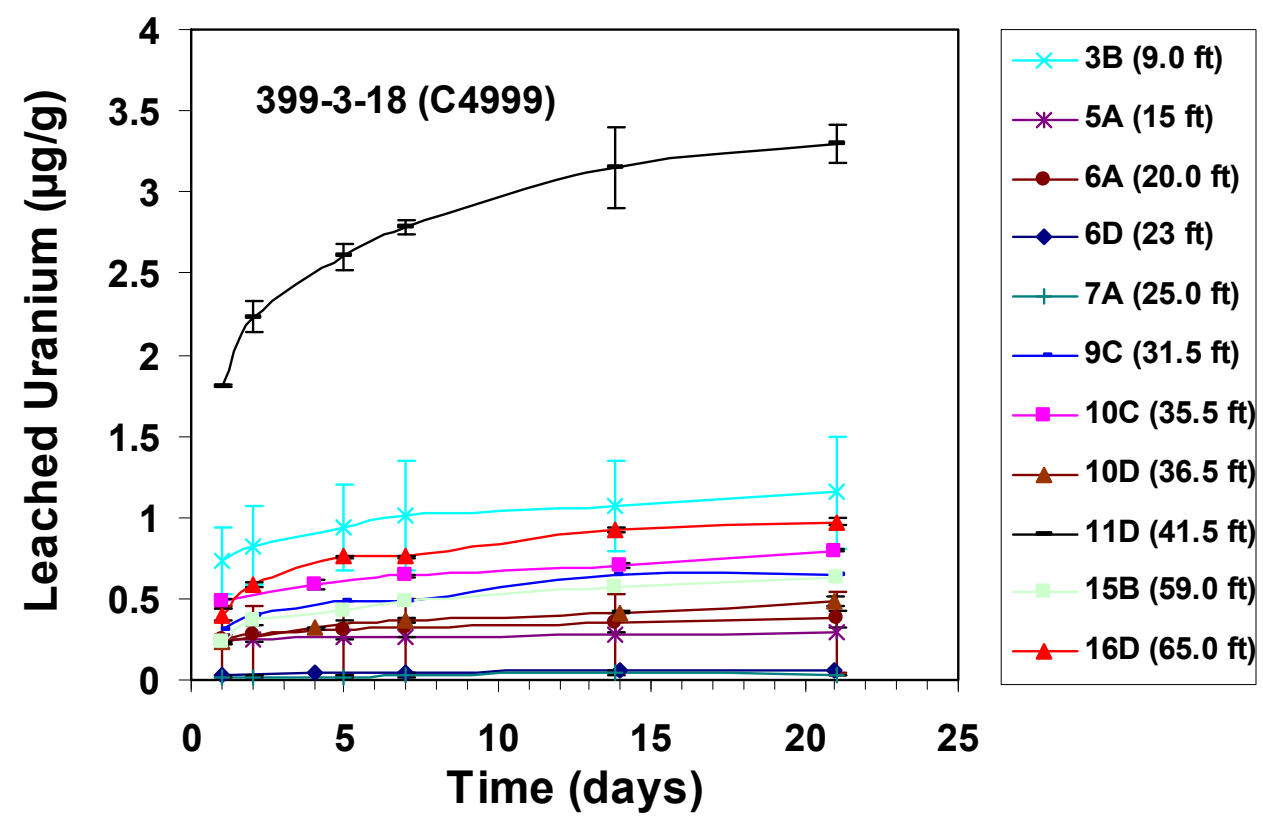

Figure 6.14. Labile Uranium Leached from Well 399-3-18 (C4999) Sediments Using Carbonate Extractant

The dissolved $\mathrm{Ca}$ concentration and the $\mathrm{pH}$ in the carbonate leachates decreased slightly with increasing reaction time, indicating a minor amount of calcite precipitation might have occurred over time during the carbonate leaching tests (Table D.11 in Appendix D).

The highest concentration of uranium leached from sediments from borehole 399-1-23 (C5000) was $3.2 \mu \mathrm{g} / \mathrm{g}$ in sample C5000-39D, which was collected at a depth of 25.0 feet bgs (Figure 6.15). This sample reached a steady-state condition with respect to uranium solution concentration after 14 days of reaction, showing a slow and steady increase of leachable uranium between days 3 and 14. Previously reported MD results for this sample revealed that it contained a total uranium concentration of $4.4 \mu \mathrm{g} / \mathrm{g}$; therefore, the carbonate leach results indicate that a small amount of uranium (about $1.2 \mu \mathrm{g} / \mathrm{g}$ ) present in this sample existed as more strongly bound forms. Although the highest uranium containing sample in the borehole 399-1-23 (C5000) was C5000-39B collected at a depth of 23 feet bgs, this sample was not selected for carbonate leaching. It was selected for uranium leaching with three different solutions discussed in the next section. Most of the samples, except C5000-39D, showed low carbonate-leachable uranium concentrations $(<1 \mu \mathrm{g} / \mathrm{g})$, even after 21 days reaction.

Leachable uranium (via carbonate extraction) from selected sediments from boreholes 399-3-19 (C5001) and 399-3-20 (C5002) was negligible $(<0.2 \mu \mathrm{g} / \mathrm{g})$ when compared to those from boreholes 399-3-18 (C4999) and 399-1-23 (C5000). Most of the sediments from boreholes 399-3-19 (C5001) and 399-3-20 (C5002) had steady state dissolved uranium concentrations after 14 days of reaction (Figures 6.16 and 6.17). The carbonate leaching results for boreholes 399-3-19 (C5001) and 399-3-20 (C5002) were consistent with previous GEA results and various geochemical extraction data indicating that these sediments contained little if any Hanford process (contaminant) uranium. 


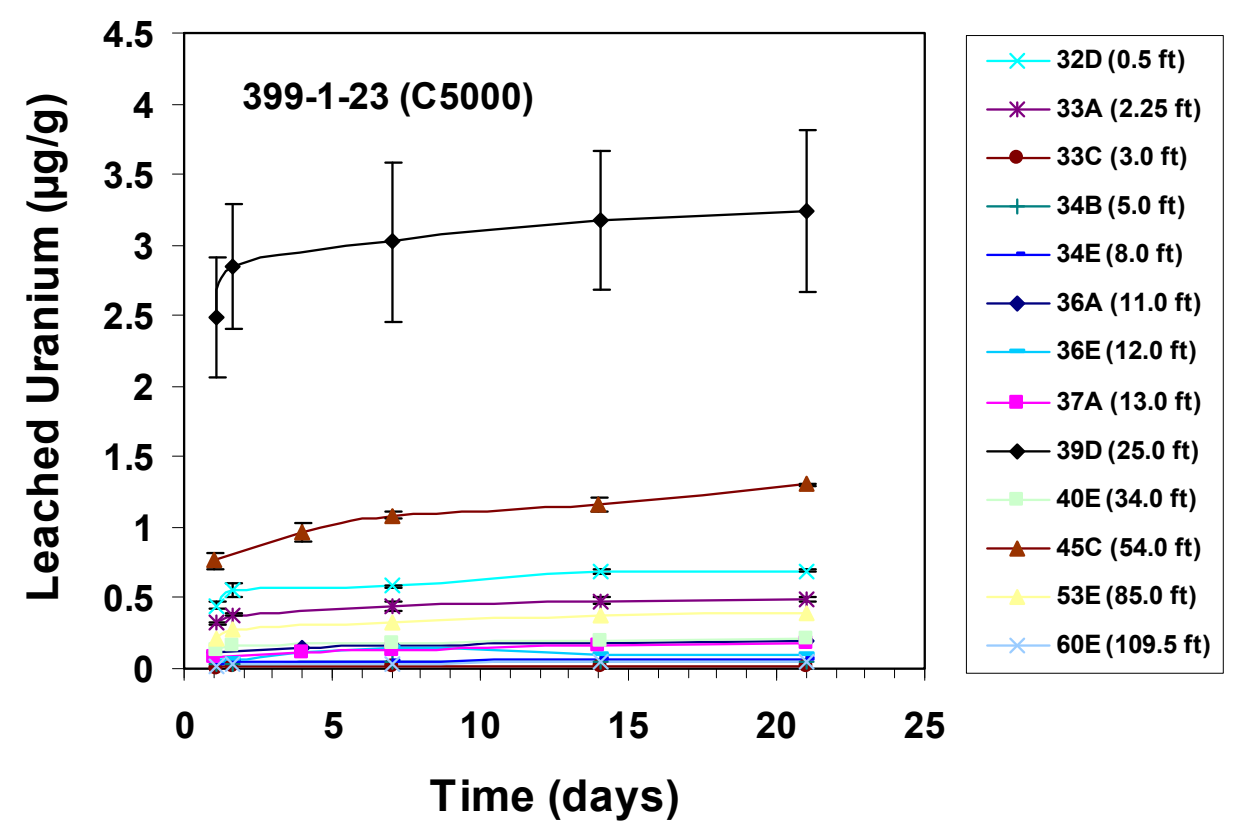

Figure 6.15. Labile Uranium Leached from Well 399-1-23 (C5000) Sediments Using Carbonate Extractant

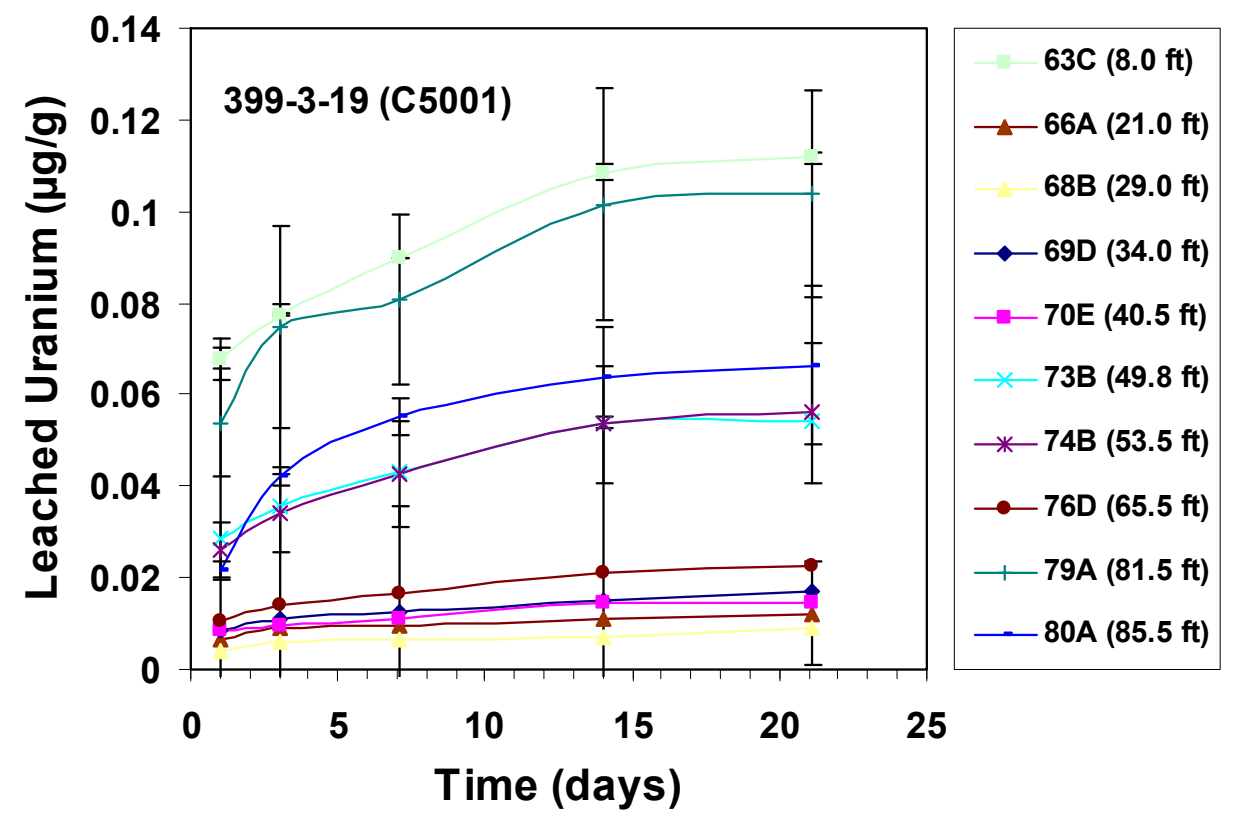

Figure 6.16. Labile Uranium Leached from Well 399-3-19 (C5001) Sediments Using Carbonate Extractant 


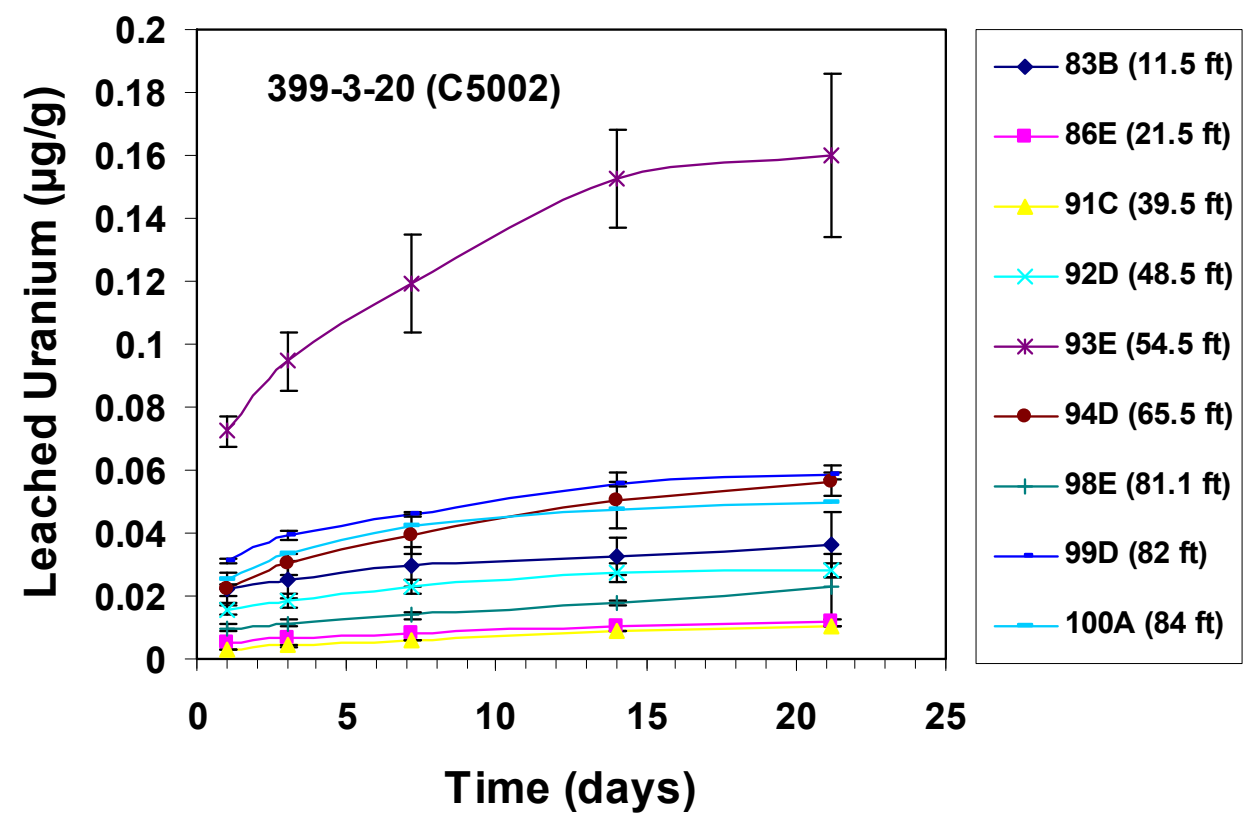

Figure 6.17. Labile Uranium Leached from Well 399-3-20 (C5002) Sediments Using Carbonate Extractant

\subsubsection{Uranium Leaching with Different Solutions (Synthetic Pore Water, Groundwater, and River Water)}

Uranium batch leaching experiments were also conducted to determine the total amount of uranium likely to be released under field-relevant conditions using three different synthetic leaching solutions (pore water, groundwater, and river water). The synthetic leaching solutions were prepared based on the measured chemical compositions of 300 Area vadose zone pore water, 300 Area groundwater, and Columbia River water. Three solutions consisting of different ionic strengths, carbonate concentrations, and $\mathrm{pHs}$ were used to measure the kinetics and total mass of uranium that could be leached from sediments under geochemical environments germane to the varying mixture of groundwater and river water found in the smear zone. Total ionic strength was controlled by $\mathrm{NaNO}_{3}$ to avoid any potential $\mathrm{CaCO}_{3}$ precipitate during the leaching experiments. Chemical compositions of each leaching solution are shown in Table 6.7. Several sediments from each borehole were selected to be contacted with the various solutions using a solid-to-solution ratio of 1:10 and reaction timed from 1 to 28 days. The batch test reactors were gently agitated on a platform shaker and sparged with air every few days to keep the test containers in equilibrium with air containing atmospheric concentrations of oxygen and carbon dioxide. Extract solutions were filtered using $0.45-\mu \mathrm{m}$ syringe filters and analyzed for dissolved uranium concentrations using ICP-MS. The solid to solution ratio was kept constant at 1:10 by adding fresh reagent to replace the small aliquot $(1-2 \mathrm{~mL})$ removed at each sampling time. Selected sample results for leached uranium, as well as the measured $\mathrm{pH}$, alkalinity, and $\mathrm{Ca}$ concentrations in leachates, are presented in Appendix D (Table D.12).

Leachable-uranium concentrations in selected sediments from the four boreholes as a function of reaction time using the three different leaching solutions (pore water, groundwater, and river water) are shown in Figures 6.18 to 6.21 . As found in the previously reported carbonate leaching tests, sample C4999-11D had the highest leachable-uranium concentration in all three solutions among all borehole 
Table 6.7. Chemical Constituents of Three Leaching Solutions

\begin{tabular}{||l|c|c|c||}
\hline \multirow{2}{*}{\multicolumn{1}{|c|}{ Constituents }} & \multicolumn{3}{|c||}{ Concentrations (M) } \\
\cline { 2 - 4 } & Pore Water & Groundwater & River Water \\
\hline \hline $\mathrm{Na}^{+}$ & $2.17 \times 10^{-2}$ & $2.17 \times 10^{-3}$ & $3.04 \times 10^{-4}$ \\
\hline $\mathrm{Ca}^{2+}$ & $5.00 \times 10^{-3}$ & $5.00 \times 10^{-4}$ & $2.50 \times 10^{-4}$ \\
\hline $\mathrm{K}^{+}$ & $6.41 \times 10^{-3}$ & $6.41 \times 10^{-4}$ & $5.13 \times 10^{-5}$ \\
\hline $\mathrm{Mg}^{2+}$ & $1.67 \times 10^{-3}$ & $1.67 \times 10^{-4}$ & $1.65 \times 10^{-4}$ \\
\hline $\mathrm{NO}_{3}{ }^{-}$ & $4.35 \times 10^{-2}$ & $4.35 \times 10^{-3}$ & $1.61 \times 10^{-5}$ \\
\hline $\mathrm{Cl}^{-}$ & $5.63 \times 10^{-3}$ & $5.63 \times 10^{-4}$ & $5.63 \times 10^{-5}$ \\
\hline $\mathrm{SO}_{4}{ }^{2-}$ & $1.87 \times 10^{-3}$ & $1.87 \times 10^{-4}$ & $1.04 \times 10^{-4}$ \\
\hline $\mathrm{HCO}_{3}{ }^{-}$ & $9.17 \times 10^{-3}$ & $9.17 \times 10^{-4}$ & $6.56 \times 10^{-4}$ \\
\hline $\mathrm{I}$ (calculated) & $\mathrm{I}=0.075 \mathrm{M}$ & $\mathrm{I}=0.0075 \mathrm{M}$ & $\mathrm{I}=0.0013 \mathrm{M}$ \\
\hline $\mathrm{pH}$ (measured) & $\mathrm{pH}=7.91$ & $\mathrm{pH}=7.39$ & $\mathrm{pH}=7.13$ \\
\hline
\end{tabular}

399-3-18 (C4999) sediments tested. The high dissolved carbonate concentration in the synthetic pore water leaching solution resulted in higher leachable-uranium concentrations than those found in the groundwater and river water extracts. Enriched carbonate solutions are known promoters for leaching uranium from geologic solids and have been used for many decades to extract (via in situ processes) uranium from low-grade ore bodies (see for example see Deutsch et al. (1983, 1984, and 1985 and references therein). River water leached the least amount of uranium from the 399-3-18 (C4999-11D) sample. However, because river water was undersaturated with respect to carbonate minerals, some uranium did leach but the resultant leachate did not reach a steady-state condition, even after 21 days of reaction. This slow and gradual release of uranium into the river water was especially noticeable in other sediments from boreholes 399-1-23 (C5000), 399-3-19 (C5001), and 399-3-20 (C5002).

If the release of uranium from contaminated sediment in the 300 Area capillary fringe and aquifer sediments was controlled solely by adsorption-desorption processes for typical clays, silicates, aluminosilicates and hydrous oxides, one might expect little desorption to occur in Columbia River water because it has lower dissolved carbonate concentrations and overall ionic strength and slightly lower $\mathrm{pH}$ values than the groundwater. It is well known that uranium desorption is promoted by increasing carbonate, increasing $\mathrm{pH}$, and increasing ionic strength as long as calcite precipitation is not occurring (see discussion in Zachara (2005) and references therein). Thus, it is somewhat counter-intuitive to find some uranium leaching into the dilute simulated river water in the tests described herein. Another uranium release process such as dissolution of co-precipitated uranium rich carbonate minerals could explain the laboratory results. Even though a small amount of leachable-uranium was measured in the river-water extract laboratory tests, it is not certain that the infiltration of river water into the 300 Area groundwater system, caused by fluctuations in the river stage, will lead to significant leaching of uranium in the field.

On the other hand, in support of the laboratory results, the mixing of Columbia River water with existing groundwater does change the chemical composition of water sampled in the monitoring wells. There does appear to be a positive correlation between the water table elevation, observed uranium concentration in the water samples obtained from the monitoring well network (see discussions in 

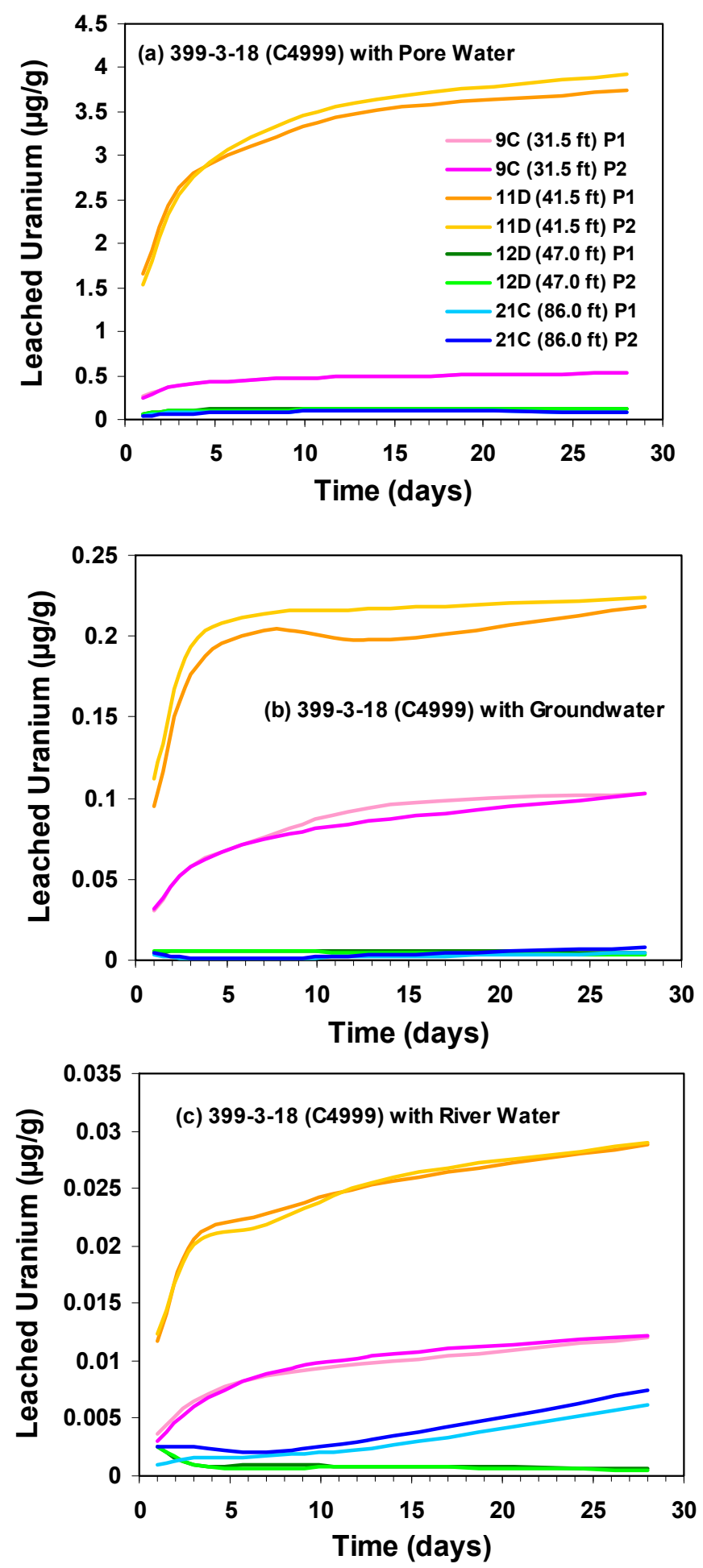

Figure 6.18. Leachable Uranium Concentration vs. Reaction Times for Well 399-3-18 (C4999) Sediments with Three Different Extract Solutions (a) Pore Water; (b) Groundwater; and (c) River Water. The legend for all three plots is the same; duplicate results are shown in similar colors. 

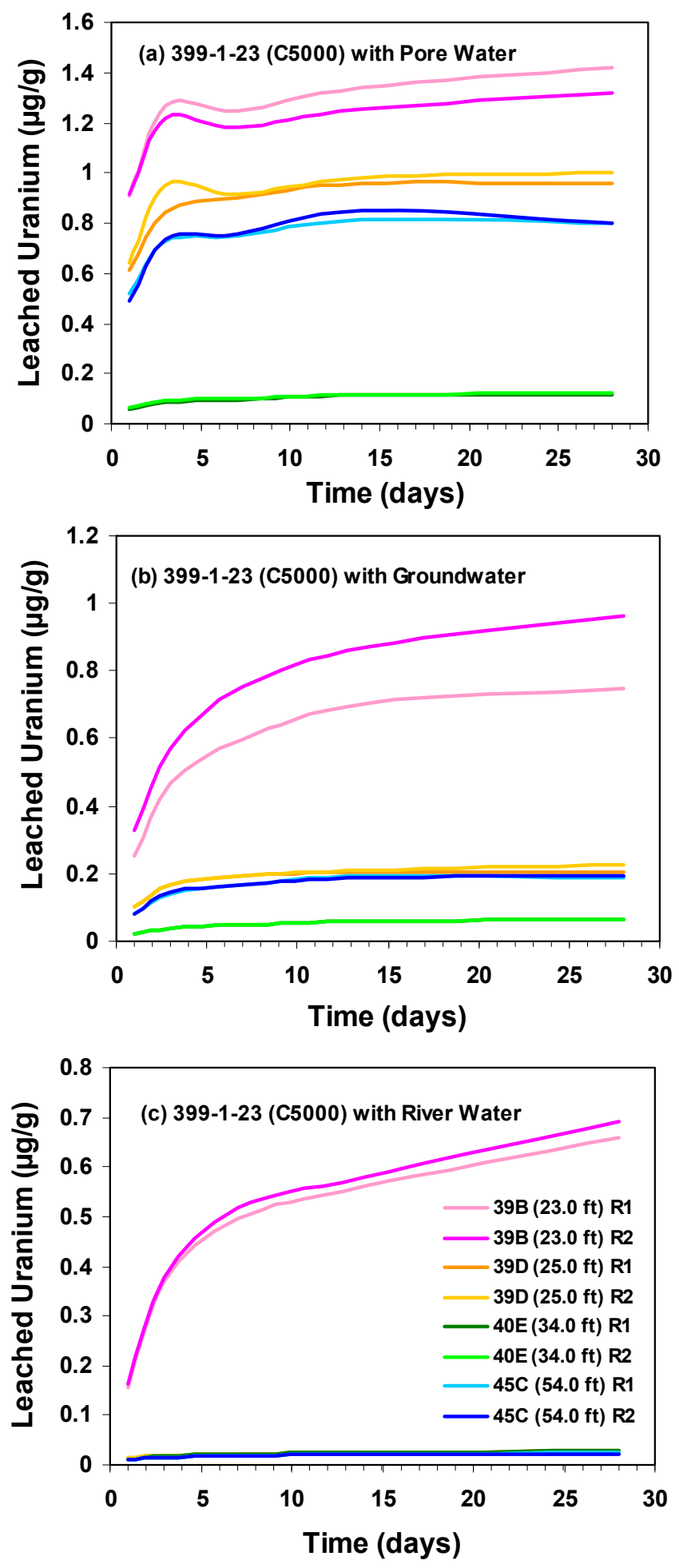

Figure 6.19. Leachable Uranium Concentration vs. Reaction Times for Well 399-1-23 (C5000) Sediments with Three Different Extract Solutions (a) Pore Water; (b) Groundwater; and (c) River Water. The legend for all three plots is the same; duplicate results are shown in similar colors. 

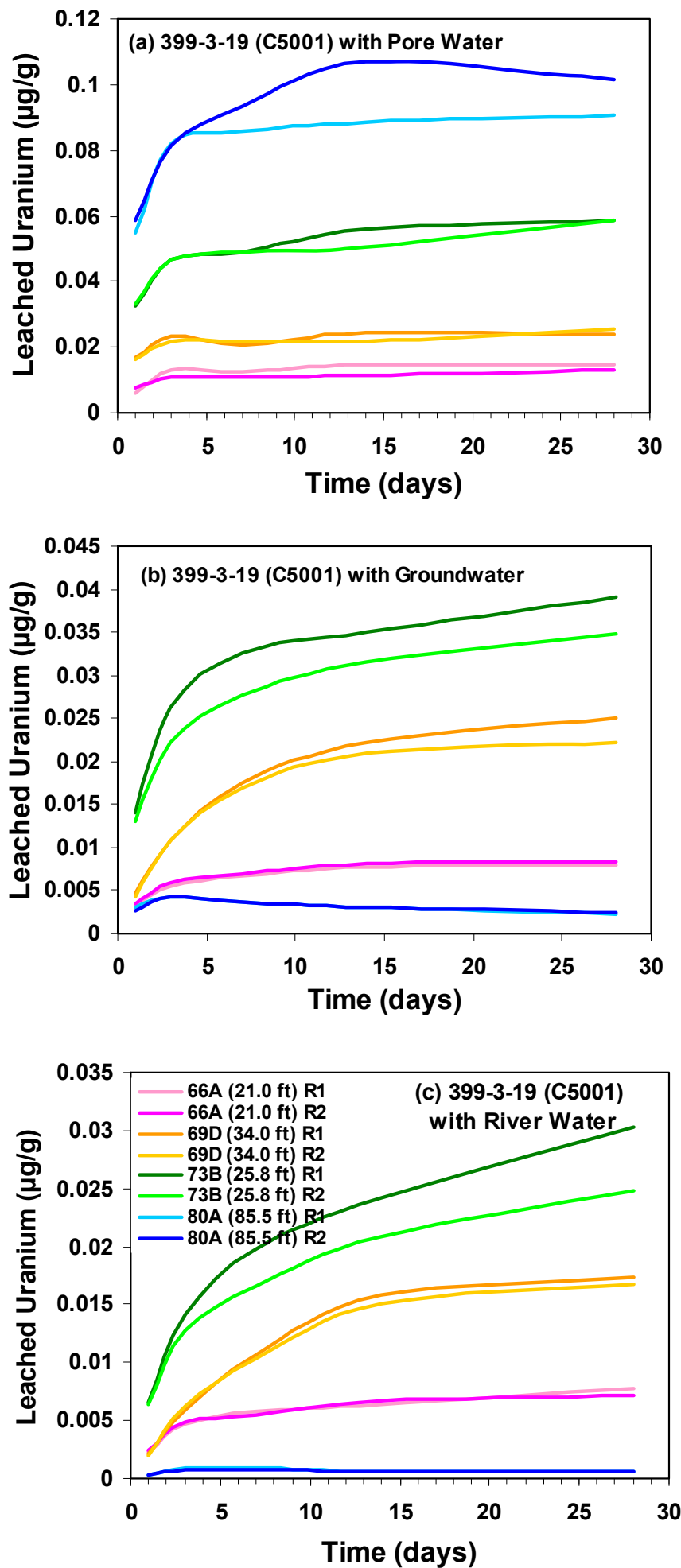

Figure 6.20. Leachable Uranium Concentration vs. Reaction Times for Well 399-3-19 (C5001) Sediments with Three Different Extract Solutions (a) Pore Water; (b) Groundwater; and (c) River Water. The legend for all three plots is the same; duplicate results are shown in similar colors. 

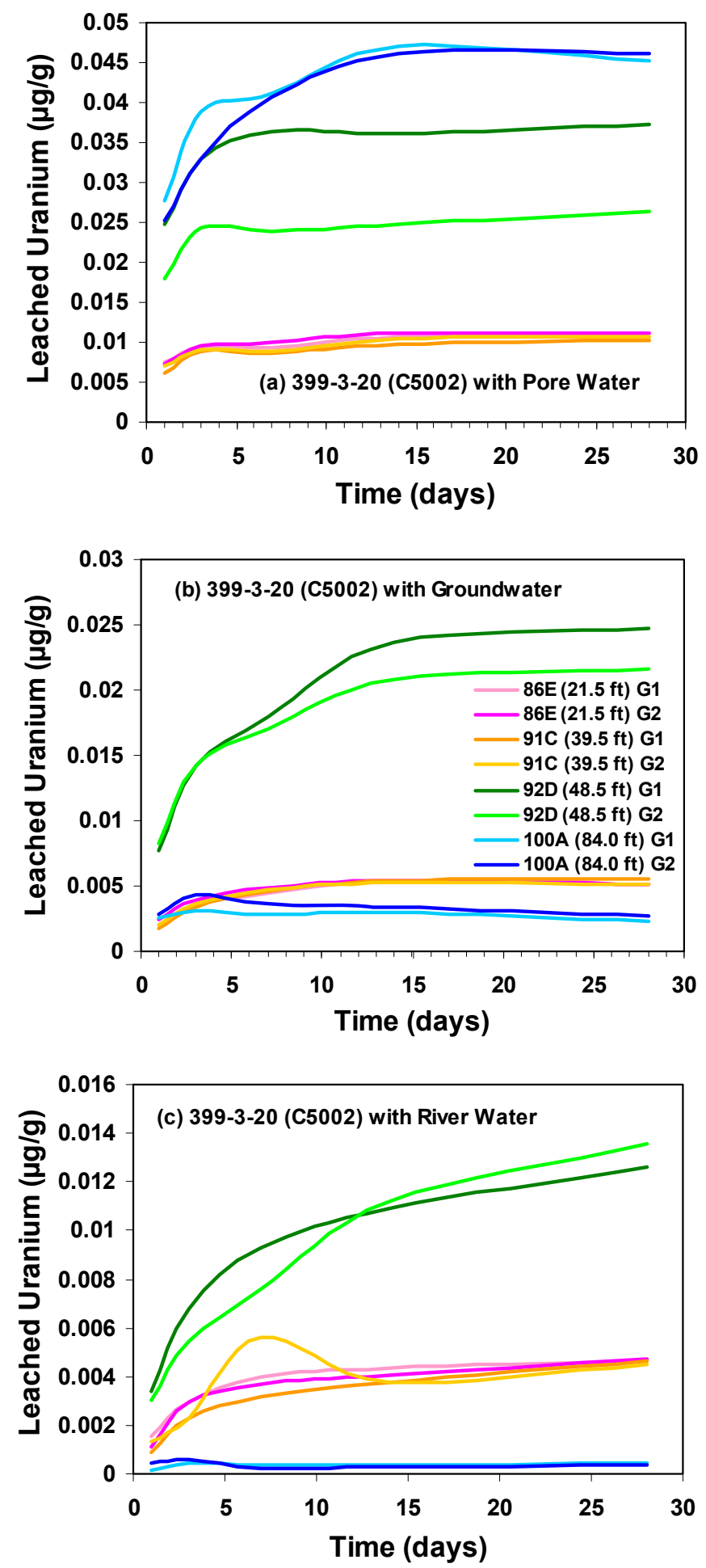

Figure 6.21. Leachable Uranium Concentration vs. Reaction Times for Well 399-3-20 (C5002) Sediments with Three Different Extract Solutions (a) Pore Water; (b) Groundwater; and (c) River Water. The legend for all three plots is the same; duplicate results are shown in similar colors. 
Lindberg and Chou (2001) and Figure 1.3 in this report), and the annual groundwater monitoring reports (e.g., Hartman et al. 2006). Mixing amongst vadose zone pore water and aquifer groundwater with the more dilute river water could increase calcite dissolution from the surrounding sediments and allow co-precipitated uranium to slowly desorb from uranium enriched-calcite or calcite coated aluminosilicates. For the sediments from borehole 399-1-23 (C5000), the highest leachable-uranium concentration was found in sample C5000-39B, which was collected at a depth of 23.0 feet bgs; this result was consistent with the high total uranium content in this sediment as determined by microwave assisted digestion. The sample containing the second highest pore water leachable-uranium concentration was C5000-39D; this sample also had the highest uranium solution concentration in the carbonate leach tests.

The decrease in uranium concentrations in the leachate for borehole 399-1-23 (C5000) sediments, especially 39B which contacted with the simulated pore water solution after 3 days of reaction, was attributed to co-precipitation or re-adsorption of uranium with/onto freshly precipitated calcite. The reduced calcium concentrations measured at 7 days of reaction time support the hypothesis that the uranium in this leach test may have co-precipitated with freshly precipitated calcite in this sample (see Table D.12 in Appendix D). Because C5000-39B sediment showed the highest inorganic carbon content, calcite precipitation-dissolution reactions were plausible with small variations in pore water temperature, $\mathrm{pH}$, calcium, and alkalinity during this period of the leach test. However, subsequently increasing uranium concentration in the leaching samples after 7 days' reaction resulted from a kinetic-controlled uranium leaching process as shown by different sediment samples, which showed continuously increasing uranium leaching concentration even after 28 days reaction. The uranium kinetic leaching was controlled by diffusion from interior grains or less easily accessible locations within the sediments. Slow uranium release kinetics can be a main source of recurring uranium contamination in groundwater.

The sediments from boreholes 399-3-19 (C5001) and 399-3-20 (C5002) had the lowest leachableuranium concentrations in all three leachant tests due to the lack of significant uranium contamination in these sediments. However, uranium solution concentrations in these laboratory leach tests slowly increased in the river water leaching solution (which was the most dilute solution), for the tested sediments from all the boreholes suggesting that uranium can slowly desorb/dissolve from the contaminated sediments located near the capillary fringe region, where water chemistry is frequently changed by river water infiltration. The river water influx and mixing in the capillary fringe zone that borders the river might be a continuous source of uranium slowly bleeding into the 300 Area groundwater system.

\subsubsection{Depth-Discrete Groundwater Sampling and Analysis}

This section describes the depth-discrete groundwater sampling method used during Phase I Well Drilling and provides the groundwater chemical composition results. Depth discrete groundwater samples were required in each borehole (DOE/RL-2005-47, Rev. 1). The purposes of the groundwater samples were to (1) provide depth-discrete groundwater samples for the evaluation of radiological and chemical contaminants of concern, (2) obtain depth-discrete groundwater results to improve understanding of the distribution of contaminants in the unconfined aquifer system, and (3) compare depth variations in groundwater chemistry with respect to vertical and lateral changes in the hydrogeology.

The wellsite geologist's borehole logs, contained in Appendix A, provide a general description and locations of the depth-discrete groundwater sample intervals for each well. The composite borehole logs (Figures 3.2 to 3.5) show the depth-discrete groundwater sample intervals and summarize key radiochemical and VOC results. In addition, Figures 4.1 through 4.4 show macro constituent chemical results 
illustrated as Stiff diagrams, and concentration values; superimposed on these figures is the hydrogeologic unit boundaries. Table 6.8 provides a list of the depth-discrete samples collected per borehole and the thickness of the saturated interval drilled (water table to total depth). The list of constituents that were analyzed (Table 6.9) was developed based on COPC as defined in the operations and maintenance plan (DOE 2002b) and based on other geochemical data needs (i.e., modeling and groundwater chemistry). Groundwater sample analysis and quality assurance procedures are provided in the sampling and analysis plan in the LFI plan (DOE 2006a).

Table 6.8. Summary of Depth-Discrete Groundwater Sampling in 300 LFI Boreholes

\begin{tabular}{||l|c|c|c|l||}
\hline Well ID & $\begin{array}{c}\text { Total Drill } \\
\text { Depth } \\
(\mathrm{ft} \text { bgs })\end{array}$ & $\begin{array}{c}\text { Saturated } \\
\text { Interval } \\
\text { Drilled (ft) }\end{array}$ & $\begin{array}{c}\text { Number of } \\
\text { Depth Discrete } \\
\text { GW Samples }\end{array}$ & \multicolumn{1}{||}{ Comments } \\
\hline $\begin{array}{l}399-3-18 \\
(\mathrm{C} 4999)\end{array}$ & 131 & 83.5 & 10 & 3 samples bailed, 7 pumped \\
\hline $\begin{array}{l}399-1-23 \\
(\mathrm{C} 5000)\end{array}$ & 116 & 75.5 & 10 & 1 sample bailed, 9 samples pumped \\
$\begin{array}{l}399-3-19 \\
(\mathrm{C} 5001)\end{array}$ & 103.5 & 56.5 & 5 & All samples pumped \\
\hline $\begin{array}{l}399-3-20 \\
(\mathrm{C} 5002)\end{array}$ & 95 & 46 & 4 & All samples pumped \\
\hline
\end{tabular}

Table 6.9. List of Selected Groundwater Constituents for Laboratory Analysis of Depth Discrete Groundwater Samples

\begin{tabular}{|c|c|c|c|}
\hline Sample Type & Planned Sample Interval & Planned Constituents & Analytical Laboratory \\
\hline \multirow[t]{7}{*}{ Depth-discrete groundwater } & \multirow{7}{*}{ 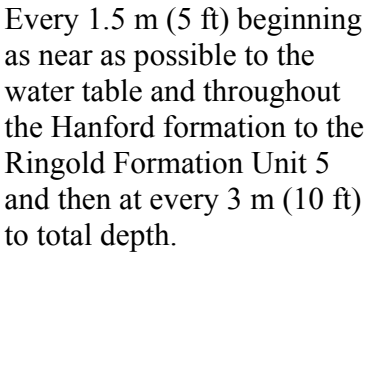 } & Alkalinity & ESL at 325 Building \\
\hline & & Anions & ESL at 325 Building \\
\hline & & Dissolved inorganic carbon & ESL at 325 Building \\
\hline & & $\begin{array}{l}\text { Field Parameters (temp, } \mathrm{pH} \text {, } \\
\text { spec. cond., DO, and redox) }\end{array}$ & Field measurement \\
\hline & & ICP metals (filtered) & ESL at 325 Building \\
\hline & & $\begin{array}{l}\text { Volatile Organic Analysis } \\
\text { (8260 GCMS) }\end{array}$ & PNNL's Contract Laboratory \\
\hline & & Uranium-238 & ESL at 325 Building \\
\hline
\end{tabular}

Depth-discrete groundwater sample collection began in each borehole at the water table and continued at approximately 5-feet-depth intervals until the Ringold Formation was confirmed, and then the sampling interval was increased to approximately 10- to 15-feet intervals until borehole total depth was reached. The sample interval spacing was increased in the last two boreholes (399-3-19 [C5001] and 399-3-20 [C5002]) to account for a thicker saturated Hanford formation gravel sequence that exhibited very high permeability. The samples are considered representative, to the extent practicable, of the aquifer at the depth that the samples were collected.

The sample collection method required the driller to stop drilling at the target sample depth and clean out the borehole to remove all cuttings and slough. An approximately 10-feet-long, 20-slot temporary well screen and inflatable packer was then inserted at the bottom of the borehole, and the drill casing was 
back pulled approximately 1 to 5 feet to expose the screen to the borehole and surrounding formation. The packer was inflated to seal the inner casing annulus from the aquifer and surrounding formation, and a submersible pump was installed inside the screen and used to first purge and then pump the groundwater sample. The sample intervals were purged until groundwater parameters (temperature, $\mathrm{pH}$, specific conductance, and dissolved oxygen) stabilized. These field parameters are tabulated by sample interval in the composite diagrams (Figures 3.2 to 3.5). In some instances, such as very near the water table or in low-permeability intervals, the water sample was collected without purging using a bailer to retrieve the sample. The bailed or pumped water samples were captured and filtered through a $0.45-\mu \mathrm{m}$ filter using a peristaltic pump into the required sample containers. The samples were stored onsite in coolers until they could be delivered to the ESL and/or the PNNL offsite contract laboratory for analysis. All depth-discrete groundwater samples were collected according to the sampling plan (see DOE 2006b) and documented procedures. Chain-of-custody forms were required for all samples (Appendix E). The field parameters, measured during borehole purging and used to determine when groundwater conditions had stabilized for sampling, were documented in field logs (Appendix E). Instrumentation used during the collection of all the groundwater samples was calibrated according to the manufacturer's procedures.

The depth-discrete groundwater samples, collected from the four LFI wells, were analyzed to determine the total dissolved uranium-238 concentration using ICP-MS. In addition, residual pore water that remained in the sediment samples from boreholes 399-3-18 (C4999) and 399-1-23 (C5000) after core opening and initial sample collection was captured using an ultracentrifuge and also analyzed for uranium concentrations. Because of the low uranium concentration in the groundwater samples from 399-3-19 (C5001) and 399-3-20 (C5002), the ultracentrifuge was not applied to the sediments from these two wells.

The measured groundwater uranium concentrations exceeded natural background concentration $(\sim 10 \mu \mathrm{g} / \mathrm{L})$ in the uppermost aquifer in all four wells (Table 6.10). The uranium concentrations in groundwater samples ranged up to a high of $202 \mu \mathrm{g} / \mathrm{L}$. The highest uranium groundwater concentration was found in borehole 399-1-23 (C5000) collected at a depth (54.3 feet bgs) close to boundary between the Hanford formation and Ringold Formation (Figure 3.3). Well 399-3-19 (C5001) also showed its highest uranium concentration $(29.6 \mu \mathrm{g} / \mathrm{L})$ at a depth of 81.5 feet bgs close to the boundary between Hanford and Ringold formation (see Figure 3.4). Although most of the high uranium concentrations in depth-discrete groundwater samples were measured in the uppermost aquifer samples (Figures 3.2 to 3.5) of the four wells (see Figure E.1 in Appendix E for details), other elevated uranium concentrations were also found close to the contact between the Hanford and Ringold formations. These high concentrations might be attributed to the chemical differences or change of sediment texture and permeability between these two formations.

Uranium concentrations in the pore waters measured directly after ultracentrifugation were similar to those from the estimated pore waters based on 1:1 water extracts after moisture content correction. As discussed in Section 4.0 (Figure 4.4), uranium concentrations in the calculated pore waters ranged up to $3,650 \mu \mathrm{g} / \mathrm{L}$ and showed relatively higher concentrations in wells 399-3-18 (C4999) and 399-1-23 (C5000) vadose zone sediments. Both wells 399-3-19 (C5001) and 399-3-20 (C5002) groundwater and estimated pore waters showed relatively low uranium concentrations compared to samples from well 399-3-18 (C4999) or well 399-1-23 (C5000). 
Table 6.10. Uranium Concentrations in Depth Discrete Groundwater Samples

\begin{tabular}{|c|c|c|c|}
\hline Wells & Sample ID & Depth (feet bgs) & 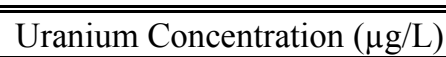 \\
\hline \multirow{10}{*}{$\begin{array}{c}399-3-18 \\
\text { (C4999) }\end{array}$} & B1FR99 & 42.5 & $1.13 \mathrm{E}+02$ \\
\hline & B1FR76 & 45.3 & $8.48 \mathrm{E}+01$ \\
\hline & B1FR91 & 49.7 & $6.24 \mathrm{E}+00$ \\
\hline & B1FRB3 & 52 & $2.87 \mathrm{E}+00$ \\
\hline & B1FR87 & 68.0 & $1.10 \mathrm{E}+00$ \\
\hline & B1FRB7 & 77.0 & $1.01 \mathrm{E}-01$ \\
\hline & B1FR83 & 87.5 & $1.36 \mathrm{E}-02$ \\
\hline & B1FR95 & 99.5 & $1.09 \mathrm{E}-02$ \\
\hline & B1FR79 & 108.0 & $9.80 \mathrm{E}-03$ \\
\hline & B1FR31 & 120.8 & $1.26 \mathrm{E}-02$ \\
\hline \multirow{10}{*}{$\begin{array}{r}399-1-23 \\
\text { (C5000) }\end{array}$} & B1FR35 & 33.8 & $7.59 \mathrm{E}+01$ \\
\hline & B1FR39 & 37.5 & $3.66 \mathrm{E}+01$ \\
\hline & B1FR43 & 43.3 & $2.73 \mathrm{E}+01$ \\
\hline & B1FR47 & 47.8 & $3.49 \mathrm{E}+01$ \\
\hline & B1FR51 & 54.3 & $2.02 \mathrm{E}+02$ \\
\hline & B1FR55 & 59.3 & $1.56 \mathrm{E}+00$ \\
\hline & B1FR59 & 68.5 & 4.37E-02 \\
\hline & B1FR63 & 79.5 & $3.91 \mathrm{E}-02$ \\
\hline & B1FR67 & 90.3 & 7.19E-02 \\
\hline & B1FR71 & 107.8 & $3.14 \mathrm{E}-01$ \\
\hline \multirow{5}{*}{$\begin{array}{c}399-3-19 \\
\text { (C5001) }\end{array}$} & B1HRW9 & 53.0 & $2.00 \mathrm{E}+01$ \\
\hline & B1HRX3 & 57.8 & $1.94 \mathrm{E}+01$ \\
\hline & B1HRX7 & 63.0 & $2.34 \mathrm{E}+01$ \\
\hline & B1HRY1 & 81.5 & $2.96 \mathrm{E}+01$ \\
\hline & B1HRY5 & 101.8 & $5.20 \mathrm{E}-02$ \\
\hline \multirow{4}{*}{$\begin{array}{l}399-3-20 \\
\text { (C5002) }\end{array}$} & B1HT03 & 52.3 & $7.39 \mathrm{E}+01$ \\
\hline & В1HT07 & 61.5 & $6.59 \mathrm{E}+01$ \\
\hline & B1HT11 & 72.5 & $4.66 \mathrm{E}+01$ \\
\hline & B1HT15 & 91.0 & $8.51 \mathrm{E}-02$ \\
\hline
\end{tabular}

\subsubsection{Depth-Discrete Interval Aquifer Hydraulic Test Characterization}

Depth-discrete interval aquifer hydraulic test characterization was conducted at the four borehole sites during drilling of the monitoring wells to provide an assessment of the variation and vertical distribution of hydraulic conductivity with depth within the unconfined aquifer at these specific locations. This type of characterization information is important for predicting/simulating contaminant migration (i.e., numerical flow/transport modeling), designing remedial actions, and developing proper monitoring well strategies for the respective locations. Because of the importance of this characterization information, depth-discrete interval aquifer hydraulic testing was required and identified for each borehole (DOE 2006a). The specific objective of the aquifer hydraulic test characterization was to provide depth distributed hydraulic property information that may be correlated with observed physical changes in the subsurface hydrogeology (see Section 3.0). 
Table 6.11 summarizes the number of depth-discrete interval tests performed at each well during borehole drilling/advancement. Aquifer hydraulic testing was generally planned to coincide with selective depth-discrete water sampling, which could then utilize a common, temporary well-screen installation during the sampling/characterization process. Following collection of the water sample, the temporary casing was pulled back to expose approximately 5 feet of screen, and the packer that was attached to the top of the well-screen assembly was then inflated to isolate the test interval. The aquifer hydraulic tests were initiated mechanically by rapidly removing a slugging rod of known volume from the well-screen section. In most instances, two different size slugging rods were used during the testing program at each well to impose different stress levels on the test section. The stress levels for the two slugging rods were calculated to impose an aquifer hydraulic-withdrawal test response of $0.676 \mathrm{~m}$ (lowstress tests) and $1.431 \mathrm{~m}$ (high-stress tests) within a 0.1016-m inside diameter well. As noted in Butler $(1996 ; 1997)$ and discussed in Spane and Newcomer (2004), differences exhibited between aquifer hydraulic tests conducted at different stress levels can be used to evaluate stress-dependent, non-linear test well effects (e.g., dynamic skin, turbulent head loss), which are unrelated to aquifer characteristics.

Table 6.11. Summary of Depth Discrete Aquifer Tests in 300 LFI Boreholes

\begin{tabular}{||c|c|c|c||}
\hline Well ID & $\begin{array}{c}\text { Total Drill Depth } \\
(\mathrm{ft} \mathrm{bgs})\end{array}$ & $\begin{array}{c}\text { Saturated Interval } \\
\text { Drilled (ft) }\end{array}$ & $\begin{array}{c}\text { Depth Discrete } \\
\text { Test Intervals\# }\end{array}$ \\
\hline \hline $399-3-18(\mathrm{C} 4999)$ & 131 & 83.5 & 5 \\
\hline $399-1-23(\mathrm{C} 5000)$ & 116 & 75.5 & 6 \\
\hline $399-3-19(\mathrm{C} 5001)$ & 103.5 & 56.5 & 2 \\
\hline $399-3-20(\mathrm{C} 5002)$ & 95 & 46 & 3 \\
\hline
\end{tabular}

Analytical methods used to analyze the aquifer hydraulic test results follow the methods described in Spane and Newcomer (2004). Briefly stated, standard type-curve methods were used to analyze tests exhibiting over-damped (exponential decay) response, while the high-K analysis type-curve matching method was used to analyze tests displaying either under-damped (oscillatory) or critically damped (transitional) response characteristics. A description of the performance and analysis of aquifer hydraulic tests conducted at each of the four well sites is provided below.

\subsubsection{Well 399-3-18 (C4999) Aquifer Hydraulic Testing Characterization}

Five specific test/depth intervals were characterized at well 399-3-18 (C4999) between March 15 and 27, 2006 by aquifer hydraulic testing as the borehole was advanced to its final depth $39.9 \mathrm{~m} \mathrm{bgs.}$ Pertinent test information for the individual discrete test/depth intervals is presented in Table 6.12. Diagnostic analysis of aquifer hydraulic tests conducted for the various test/depth intervals indicate that all of the test zones exhibited over-damped (exponential decay) conditions. The top three test intervals (Zones A, B, and B1) were within the lower permeability Ringold Formation upper fine-grained unit (Unit 5). Aquifer hydraulic tests conducted in lower permeability formations require long test times to monitor full recovery. For most of the tests conducted in the top three intervals, full recovery was not attained before initiating subsequent aquifer hydraulic tests. In addition, due to a loss of test data during transfer downloading from the datalogger system, only a portion of the total test data was available for the top three test intervals for analysis. To account for the lack of full test data recovery and the lack of a complete test data record, "time-history matching" was applied to the test data sequence for these three 
Table 6.12. Aquifer Hydraulic Test Characteristics for Selected Test/Depth Intervals at Well 399-3-18 (C4999)

\begin{tabular}{|c|c|c|c|c|c|c|}
\hline \multirow[b]{2}{*}{ Test Zone } & \multicolumn{4}{|c|}{ Test Parameters } & \multirow[b]{2}{*}{$\begin{array}{c}\text { Diagnostic Aquifer } \\
\text { Hydraulic Test } \\
\text { Response Model }\end{array}$} & \multirow[b]{2}{*}{ Hydrogeologic Unit Tested ${ }^{(a)}$} \\
\hline & $\begin{array}{l}\text { Test } \\
\text { Date }\end{array}$ & $\begin{array}{l}\text { \# Aquifer } \\
\text { Hydraulic } \\
\text { Tests }\end{array}$ & $\begin{array}{l}\text { Depth to } \\
\text { Water, } \\
\text { m bgs }\end{array}$ & $\begin{array}{l}\text { Test/Depth } \\
\text { Interval, } \mathrm{m} \text { bgs }\end{array}$ & & \\
\hline Zone A* & $3 / 15 / 06$ & 2 & 12.95 & $\begin{array}{c}14.78-16.61 \\
(1.83)\end{array}$ & $\begin{array}{l}\text { Over-Damped* } \\
\text { (exponential-decay) }\end{array}$ & $\begin{array}{l}\text { Ringold Formation - Upper Mud } \\
\text { (Unit 5) }\end{array}$ \\
\hline Zone $\mathrm{B}^{* *}$ & $3 / 17 / 06$ & 4 & 12.80 & $\begin{array}{c}20.12-21.34 \\
(1.22)\end{array}$ & $\begin{array}{l}\text { Over-Damped** } \\
\text { (exponential-decay) }\end{array}$ & $\begin{array}{l}\text { Ringold Formation - Upper Mud } \\
\text { (Unit 5) }\end{array}$ \\
\hline Zone C & $3 / 17 / 06$ & 4 & 12.80 & $\begin{array}{c}18.29-21.34 \\
(3.05)\end{array}$ & $\begin{array}{l}\text { Over-Damped* } \\
\text { (exponential-decay) }\end{array}$ & $\begin{array}{l}\text { Ringold Formation - Upper Mud } \\
\text { (Unit 5) }\end{array}$ \\
\hline Zone D & $3 / 27 / 06$ & 8 & 12.71 & $\begin{array}{c}37.34-38.71 \\
(1.19) \\
\end{array}$ & $\begin{array}{l}\text { Over-Damped } \\
\text { (exponential-decay) }\end{array}$ & Ringold Formation (Unit 5) \\
\hline Zone E & $3 / 27 / 06$ & 4 & 12.71 & $\begin{array}{c}36.12-38.71 \\
(2.41)\end{array}$ & $\begin{array}{l}\text { Over-Damped } \\
\text { (exponential-decay/ } \\
\text { elastic response) }\end{array}$ & Ringold Formation (Unit 5) \\
\hline \multicolumn{7}{|c|}{$\begin{array}{l}\text { Note: For all test/depth zones, } r_{c}=0.051 \text { meters; } r_{w}=0.1222 \text { meters } \\
\text { (a) Hydrogeologic unit number in parentheses indicates the relevant groundwater-flow model layer, as described in } \\
\text { Thorne et al. } 1993 \text {. } \\
\text { (b) Value listed in parentheses is the effective well-screen test length; for Zones C and D, the value is reflective of the top } \\
\text { of the Lower Mud unit located at a depth of } 38.53 \mathrm{~m} \text { bgs. } \\
\text { Some of the aquifer hydraulic test data lost during transfer from datalogger system. Response indicates low permeability } \\
\text { formation condition. Test analysis based on time-history match. } \\
\text { ** Most of the aquifer hydraulic test data lost during transfer from datalogger system. Response indicates low permeability } \\
\text { formation condition. No quantitative test analysis possible. }\end{array}$} \\
\hline
\end{tabular}

low-permeability test depth intervals. Time-history matching approaches rely on superposition of preceding test activities as the basis of the composite analysis method. This contrasts with standard analytical methods that focus on analyzing individual hydrologic tests.

The bottom two test intervals were within the higher permeability sand and gravel of the middle Ringold Formation (Unit 5). Standard type-curve analysis methods were used to quantify hydraulic property conditions for tests conducted within these two depth intervals.

\subsubsection{Well 399-1-23 (C5000) Aquifer Hydraulic Testing Characterization}

In all, at well 399-1-23 (C5000) six specific test/depth intervals were characterized between April 4 and 18, 2006 by aquifer hydraulic testing as the borehole was advanced to its final depth $35.4 \mathrm{~m}$ bgs. Pertinent test information for the individual discrete test/depth intervals is presented in Table 6.13. Diagnostic analysis of aquifer hydraulic tests conducted for the various test/depth intervals indicates that most of the test zones (i.e., Zones B-E) exhibited exponential decay (over-damped) conditions. The top test interval (Zone A) exhibited under-damped (oscillatory) response behavior, which is expected for test zones within the highly permeable Hanford formation. Aquifer hydraulic tests conducted in highly permeable formations require positioning of the pressure sensor near the top of the well water-column for quantitative test analysis. This was not done for this test interval; consequently, only a "greater-than" value can be assigned for the test interval. Additionally, hydrologic communication occurred around the packer used to isolate the lowest test/depth interval (Zone F/G); and therefore, no characterization results are possible for this test interval. Results from depth-discrete intervals Zones B-E are representative of the middle Ringold Formation (Unit 5). 
Table 6.13. Aquifer Hydraulic Test Characteristics for Selected Test/Depth Intervals at Well 399-1-23 (C5000)

\begin{tabular}{|c|c|c|c|c|c|c|}
\hline \multirow[b]{2}{*}{ Test Zone } & \multicolumn{4}{|c|}{ Test Parameters } & \multirow[b]{2}{*}{$\begin{array}{c}\text { Diagnostic Aquifer } \\
\text { Hydraulic Test } \\
\text { Response Model }\end{array}$} & \multirow[b]{2}{*}{ Hydrogeologic Unit Tested ${ }^{(a)}$} \\
\hline & $\begin{array}{l}\text { Test } \\
\text { Date }\end{array}$ & $\begin{array}{l}\text { \# Aquifer } \\
\text { Hydraulic } \\
\text { Tests }\end{array}$ & $\begin{array}{l}\text { Depth to } \\
\text { Water, } \\
\text { m bgs }\end{array}$ & $\begin{array}{l}\text { Test/Depth } \\
\text { Interval, } \mathrm{m} \text { bgs }\end{array}$ & & \\
\hline Zone A & $4 / 4 / 06$ & 4 & 10.20 & $\begin{array}{c}12.19-13.26 \\
(1.07)\end{array}$ & $\begin{array}{l}\text { Under-Damped } \\
\text { (oscillatory response) }\end{array}$ & Hanford formation (Unit 1) \\
\hline Zone B & $4 / 6 / 06$ & 8 & 10.18 & $\begin{array}{c}16.83-18.29 \\
\quad(1.46)\end{array}$ & $\begin{array}{l}\text { Over-Damped } \\
\text { (exponential-decay) }\end{array}$ & Ringold Formation (Unit 5) \\
\hline Zone $\mathrm{C}^{*}$ & $4 / 6 / 06$ & 6 & 10.18 & $\begin{array}{c}15.42-18.29 \\
(2.87)\end{array}$ & $\begin{array}{l}\text { Over-Damped* } \\
\text { (exponential-decay) }\end{array}$ & $\begin{array}{l}\text { Hanford and Ringold Formations } \\
\text { (Unit } 1 \text { and Unit 5) }\end{array}$ \\
\hline Zone D & $4 / 7 / 06$ & 8 & 10.21 & $\begin{array}{c}19.81-21.33 \\
(1.52)\end{array}$ & $\begin{array}{l}\text { Over-Damped } \\
\text { (exponential-decay) }\end{array}$ & Ringold Formation (Unit 5) \\
\hline Zone E & $4 / 7 / 06$ & 2 & 10.21 & $\begin{array}{c}18.29-21.33 \\
(3.04)\end{array}$ & $\begin{array}{l}\text { Over-Damped } \\
\text { (exponential-decay) }\end{array}$ & Ringold Formation (Unit 5) \\
\hline Zone $\mathrm{F}^{* *}$ & $4 / 18 / 06$ & 12 & $9.33^{*}$ & $\begin{array}{l}30.78-33.53 \\
\quad(2.75)\end{array}$ & $\begin{array}{l}\text { Critically-Damped** } \\
\text { (transitional } \\
\text { response) }\end{array}$ & Ringold Formation (Unit 5) \\
\hline \multicolumn{7}{|c|}{$\begin{array}{l}\text { Note: For all test/depth zones, } \mathrm{r}_{\mathrm{c}}=0.051 \text { meters; } \mathrm{r}_{\mathrm{w}}=0.1222 \text { meters. } \\
\text { (a) Hydrogeologic unit number in parentheses indicates the relevant groundwater-flow model layer, as described in } \\
\text { Thorne et al. } 1993 \text {. } \\
\text { Aquifer hydraulic test characterization adversely affected by packer by-pass (leakage) during the last four aquifer hydraulic } \\
\text { tests; only first aquifer hydraulic } \\
\text { withdrawal test results considered to be representative. } \\
\text { ** Aquifer hydraulic test characterization adversely affected by packer by-pass (leakage); all test results are highly } \\
\text { questionable. }\end{array}$} \\
\hline
\end{tabular}

\subsubsection{Well 399-3-19 (C5001) Aquifer Hydraulic Testing Characterization}

Two specific test/depth intervals for well 399-3-19 (C5001) were characterized on April 27, 2006 by aquifer hydraulic testing as the borehole was advanced to its final depth 31.5 meters bgs. Pertinent test information for the individual discrete test/depth intervals is presented in Table 6.14. Diagnostic analysis of aquifer hydraulic tests conducted for the two test/depth intervals indicate that both of the test zones exhibited under-damped (oscillatory) conditions. The two test intervals were within the highly permeable Hanford formation (Unit 1). Under-damped aquifer hydraulic tests require use of High-K analysis typecurve matching methods. No quantitative analysis of the longer test interval (3.05 meters) Zone B test was possible due to the extremely low test response and rapid recovery. Test responses indicate a very high $\mathrm{K}$ condition.

A selected analysis figure for test interval Zone A is contained in Appendix E. 
Table 6.14. Aquifer Hydraulic Test Characteristics for Selected Test/Depth Intervals at Well 399-3-19 (C5001)

\begin{tabular}{|c|c|c|c|c|c|c|}
\hline \multirow[b]{2}{*}{ Test Zone } & \multicolumn{4}{|c|}{ Test Parameters } & \multirow[b]{2}{*}{$\begin{array}{l}\text { Diagnostic Aquifer } \\
\text { Hydraulic Test } \\
\text { Response Model }\end{array}$} & \multirow[b]{2}{*}{ Hydrogeologic Unit Tested } \\
\hline & $\begin{array}{l}\text { Test } \\
\text { Date }\end{array}$ & $\begin{array}{l}\text { \# Aquifer } \\
\text { Hydraulic } \\
\text { Tests }\end{array}$ & $\begin{array}{l}\text { Depth to } \\
\text { Water, } \\
\text { m bgs }\end{array}$ & $\begin{array}{c}\text { Test/Depth } \\
\text { Interval, m bgs }\end{array}$ & & \\
\hline Zone A & $4 / 27 / 06$ & 4 & 14.36 & $\begin{array}{c}15.85-17.37 \\
(1.52)\end{array}$ & $\begin{array}{l}\text { Under-Damped } \\
\text { (oscillatory response) }\end{array}$ & Hanford formation (Unit 1) \\
\hline Zone B & $4 / 27 / 06$ & 4 & 14.36 & $\begin{array}{c}14.32-17.37 \\
(3.05)\end{array}$ & $\begin{array}{l}\text { Under-Damped } \\
\text { (oscillatory response) }\end{array}$ & Hanford formation (Unit 1) \\
\hline \multicolumn{7}{|c|}{$\begin{array}{l}\text { Note: For all test } / \text { depth zones, } r_{c}=0.051 \text { meters; } r_{w}=0.1222 \text { meters. } \\
\text { (a) Hydrogeologic unit number in parentheses indicates the relevant groundwater-flow model layer, as described in } \\
\text { Thorne et al. } 1993 \text {. }\end{array}$} \\
\hline
\end{tabular}

\subsubsection{Well 399-3-20 (C5002) Aquifer Hydraulic Testing Characterization}

Three specific test/depth intervals in well 399-3-20 (C5002) were characterized between May 15 and 17,2006 by aquifer hydraulic testing as the borehole was advanced to its final depth of $29.0 \mathrm{~m}$ bgs. Pertinent test information for the individual discrete test/depth intervals is presented in Table 6.15. Diagnostic analysis of depth-discrete interval aquifer hydraulic tests conducted indicate that the top Hanford formation test zone (A) exhibited under-damped (oscillatory) conditions while the two underlying Ringold Formation test intervals (Zones C and D) exhibited critically damped test behavior. Tests exhibiting either critically damped or under-damped aquifer hydraulic test response require use of High-K analysis type-curve matching methods.

Table 6.15. Aquifer Hydraulic Test Characteristics for Selected Test/Depth Intervals at Well 399-3-20 (C5002)

\begin{tabular}{|c|c|c|c|c|c|c|}
\hline \multirow[b]{2}{*}{ Test Zone } & \multicolumn{4}{|c|}{ Test Parameters } & \multirow[b]{2}{*}{$\begin{array}{l}\text { Diagnostic Aquifer } \\
\text { Hydraulic Test } \\
\text { Response Model }\end{array}$} & \multirow[b]{2}{*}{ Hydrogeologic Unit Tested ${ }^{(a)}$} \\
\hline & $\begin{array}{l}\text { Test } \\
\text { Date }\end{array}$ & $\begin{array}{l}\text { \# Aquifer } \\
\text { Hydraulic } \\
\text { Tests }\end{array}$ & $\begin{array}{l}\text { Depth to } \\
\text { Water, } \\
\text { m bgs }\end{array}$ & $\begin{array}{c}\text { Test/Depth } \\
\text { Interval, m bgs }\end{array}$ & & \\
\hline Zone A, B & $5 / 15 / 06$ & 8 & 14.51 & $\begin{array}{c}16.92-19.05 \\
(2.13)\end{array}$ & $\begin{array}{l}\text { Under-Damped } \\
\text { (oscillatory response) }\end{array}$ & Hanford formation (Unit 1) \\
\hline Zone C & $5 / 17 / 06$ & 4 & 14.78 & $\begin{array}{c}26.21-27.58 \\
(1.37)\end{array}$ & $\begin{array}{l}\text { Critically Damped } \\
\text { (transitional } \\
\text { response) }\end{array}$ & Ringold Formation (Unit 5) \\
\hline Zone D & $5 / 17 / 06$ & 4 & 14.78 & $\begin{array}{c}25.30-27.58 \\
(2.28)\end{array}$ & $\begin{array}{l}\text { Critically Damped } \\
\text { (transitional } \\
\text { response) }\end{array}$ & Ringold Formations (Unit 5) \\
\hline \multicolumn{7}{|c|}{$\begin{array}{l}\text { Note: For all test } / \text { depth zones, } r_{c}=0.051 \text { meters; } r_{w}=0.1222 \text { meters. } \\
\text { (a) Hydrogeologic unit number in parentheses indicates the relevant groundwater-flow model layer, as described in } \\
\text { Thorne et al. } 1993 \text {. }\end{array}$} \\
\hline
\end{tabular}

\subsubsection{Borehole Geophysical Logging}

High-resolution spectral gamma surveys and neutron moisture surveys were conducted in each borehole using borehole geophysical logging tools operated by Stoller Corporation. The main objective of the borehole logging was to determine the presence, distribution, and quantity of manmade 
(contaminant) uranium in the subsurface at each location (DOE/RL-2005-47-Rev. 1). Secondary objectives include (1) calibrating the planned Phase II DPT borehole geophysical logging system, (2) using the system as a correlation tool for identifying borehole lithology, and (3) determining the variations in moisture content in the vadose zone at each location.

The geophysical logs obtained in Phase I, including the detailed log data reports, are provided in Appendix C. The log reports describe calibration requirements, data processing, and contain the data results and interpretation including the borehole log plots for manmade radionuclides, natural gamma and neutron moisture logs. Table 6.16 provides a summary of geophysical logging activities performed at each borehole. The specific gamma isotopes that were analyzed by Stoller (Appendix C) were selected based on gamma emitting COPC, and also included known natural occurring radio-elements. All geophysical logging followed quality assurance procedures provided in Stoller's Quality Assurance Project Plan (Stoller 2006).

Table 6.16. Summary of Geophysical Borehole Logging in 300 LFI Boreholes

\begin{tabular}{||l|l|c|c|c|c|c||}
\hline Well ID & Date Logged & $\begin{array}{c}\text { Total Drill } \\
\text { Depth } \\
\text { (feet bgs) }\end{array}$ & $\begin{array}{c}\text { Spectral Gamma } \\
\text { Logged Interval } \\
\text { (feet)/count rate (sec) }\end{array}$ & $\begin{array}{c}\text { Repeat Interval } \\
\text { (feet)/count rate } \\
\text { (sec) }\end{array}$ & $\begin{array}{c}\text { Neutron Logged } \\
\text { Interval (feet)/count } \\
\text { rate (sec) }\end{array}$ & $\begin{array}{c}\text { Temporary Casing } \\
\text { Outside Diameter } \\
\text { (in.) }\end{array}$ \\
\hline $\begin{array}{l}399-3-18 \\
\text { (C4999) }\end{array}$ & $\begin{array}{l}\text { March 24 - } \\
25,2006\end{array}$ & 131 & $128-0 / 200$ & $45-32 / 400$ & $42.25-0 / 15$ & $95 / 8$ \\
\hline $\begin{array}{l}399-1-23 \\
\text { (C5000) }\end{array}$ & $\begin{array}{l}\text { April 12-18, } \\
2006\end{array}$ & 116 & $112.5-0 / 200$ & $50-19 / 200-400$ & $35.5-0 / 15$ & $95 / 8$ \\
\hline $\begin{array}{l}399-3-19 \\
\text { (C5001) }\end{array}$ & $\begin{array}{l}\text { May 1-2, } \\
2006\end{array}$ & 103.5 & $86.2-0 / 200$ & $60-35 / 400$ & $46.75-0 / 15$ & $95 / 8$ \\
\hline $\begin{array}{l}399-3-20 \\
(\mathrm{C} 5002)\end{array}$ & $\begin{array}{l}\text { May 16-17, } \\
2006\end{array}$ & 95 & $87-0 / 200$ & $85-78,50-42 / 400$ & $47.5-0 / 15$ & $95 / 8$ \\
\hline
\end{tabular}

Each borehole was logged from total depth to the surface inside the temporary drill casing prior to well completion. Spectral gamma measurements, collected at the designated 200 to 400 second count rate, using the "move-stop-acquire" technique every 0.5 feet along the borehole was employed to obtain the most optimal spectral gamma signal emitted from each borehole. Based on data processing by Stoller Corporation, no manmade (contaminant) gamma-emitting radionuclides were detected above the MDL (of $\sim 1 \mathrm{pCi} / \mathrm{g}\left[\right.$ for $\mathrm{U}^{235}$ ] and $\sim 12 \mathrm{pCi} / \mathrm{g}\left[\right.$ for $\left.\mathrm{U}^{238}\right]$ ) in any of the boreholes (details are provided in Appendix C). These data indicate that if manmade uranium exists at these locations, it is at very low concentration levels below the MDLs.

The geophysical log data have been evaluated and correlated to the hydrogeology and uranium and moisture data results from the laboratory analysis of sediment samples for each borehole. These results and comparisons are presented in the composite logs (Figures 3.2 to 3.5).

Laboratory-measured GEA results obtained from the sediment core samples from each well were compared to the borehole geophysical gamma energy results from the four new wells to determine if the data are quantitatively consistent and comparable and to determine data trends (Figures 6.22 to 6.25). 

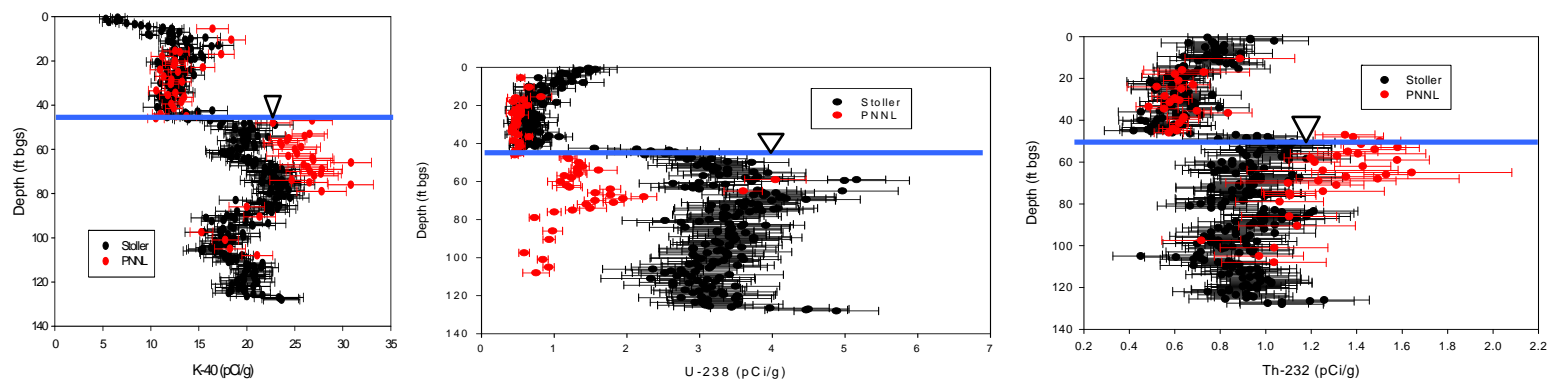

Figure 6.22. Comparison of Laboratory Sediment Gamma Energy Analysis KUT Results (PNNL) to the Borehole Geophysical Spectral Gamma KUT Results (Stoller) for Borehole 399-3-18 (C4999)
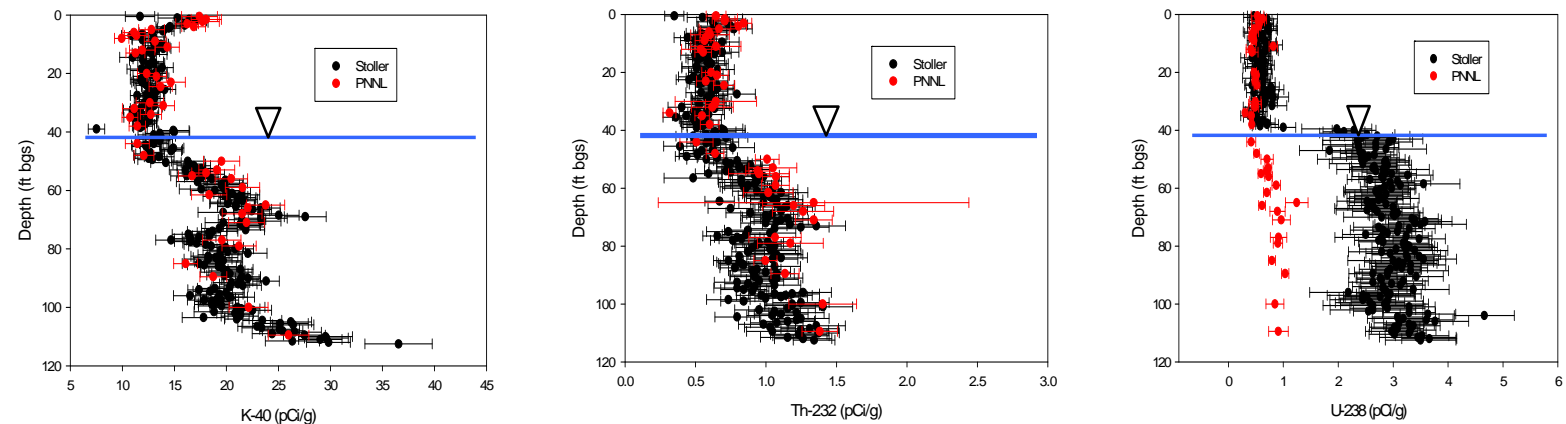

Figure 6.23. Comparison of PNNL Laboratory Sediment Gamma Energy Analysis KUT Results to Stoller Borehole Geophysical Spectral Gamma KUT Results for Borehole 399-1-23 (C5000)
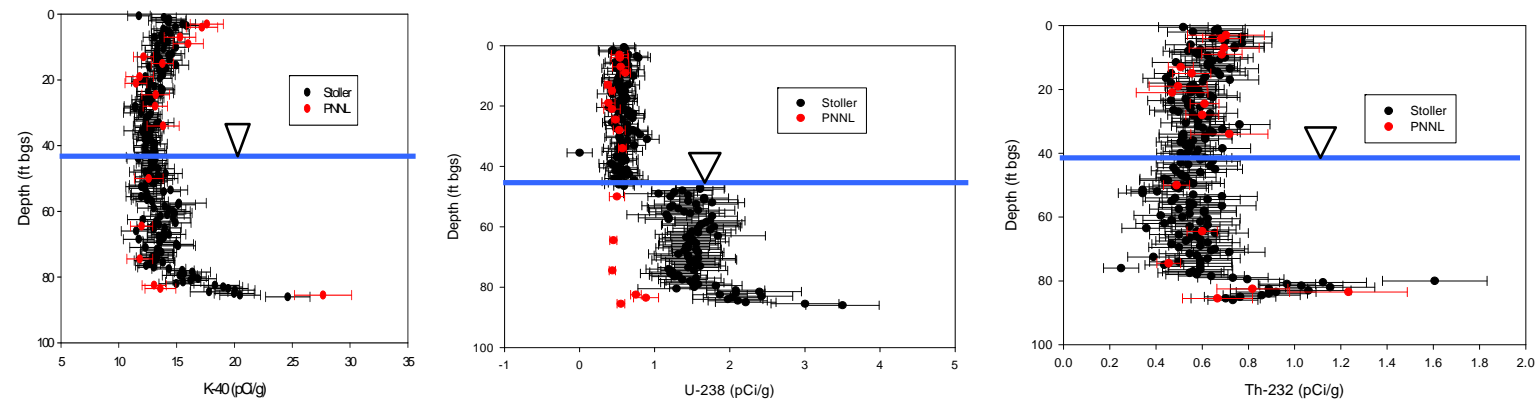

Figure 6.24. Comparison of PNNL Laboratory Sediment Gamma Energy Analysis KUT Results to Stoller Borehole Geophysical Spectral Gamma KUT Results for Borehole 399-3-19 (C5001) 

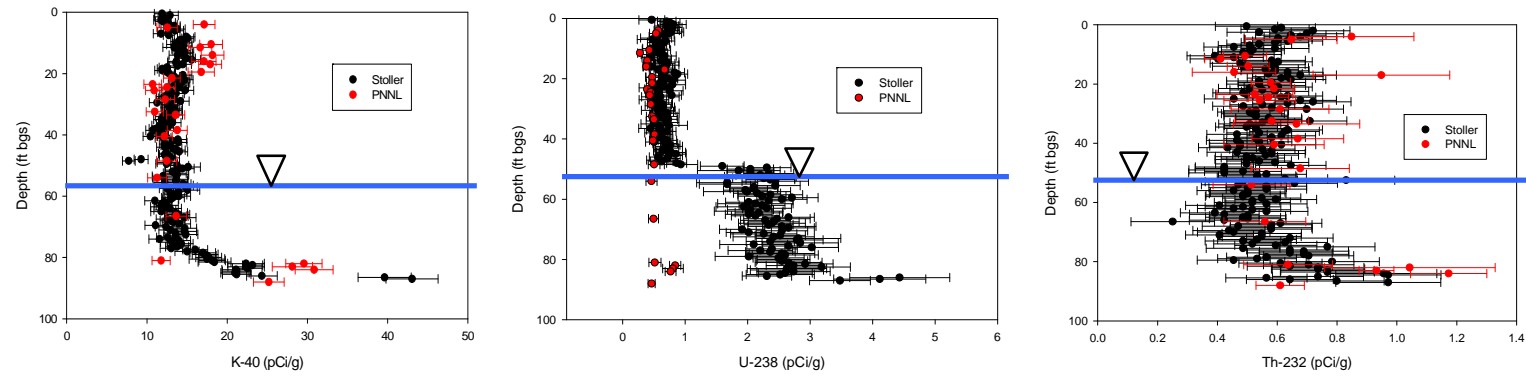

Figure 6.25. Comparison of PNNL Laboratory Sediment Gamma Energy Analysis KUT Results to Stoller Borehole Geophysical Spectral Gamma KUT Results for Borehole 399-3-20 (C5002)

Because no manmade uranium was detected in the borehole geophysical data, only select natural radio-element activity (potassium-40 $\left[{ }^{40} \mathrm{~K}\right]$, uranium-238 $\left[{ }^{238} \mathrm{U}\right]$, and thorium-232 $\left[{ }^{232} \mathrm{Th}\right]$ [KUT]) from the laboratory GEA data and the borehole geophysical data were compared. These natural uranium results, from the laboratory and borehole geophysical data are also plotted on the composite logs (Figures 3.2 to 3.5). The data plots (Figures 6.22 to 6.25) illustrate the differences between the major natural occurring energy peaks (KUT) between the laboratory versus the field geophysical logging results. The laboratory GEA results have a higher precision because the sediment samples were analyzed in a controlled laboratory environment that was free from background interferences, and the samples were analyzed in 1-L marinelli containers that completely surround the detector to improve counting efficiency. Therefore, detection of low-energy gamma emitters (such as thorium-234) was practical (detection of low-energy gamma emitters was not possible in the field because their signals were blocked by the steel drill casing), and the samples were counted for 600 seconds per sample (67\% longer then geophysical results). As illustrated in Figures 6.22 to 6.25, there is good agreement between the two KUT data sets, laboratory (PNNL) versus geophysical (Stoller), throughout the vadose zone (i.e., above the water table). The uranium data agreement, however, deteriorates below the water table; the increase in the Stoller geophysical results is attributed to radon in the water inside the casing and within the saturated sediments outside the casing (sees Stoller log reports in Appendix C). Other slight differences in the data for ${ }^{40} \mathrm{~K}$ and ${ }^{232} \mathrm{Th}$ maybe due to over-corrections applied for casing thickness and water saturation. Note that radon is a daughter product of uranium decay and is not an indication of manmade uranium.

Borehole geophysical neutron moisture data were also collected from the vadose zone in each well (Appendix C). Neutron moisture measurements were collected at a rate of 15 second per 0.25 -foot (Table 6.18.). These moisture data represent, at best, qualitative changes in moisture throughout the vadose zone because the drill casing diameter is too large to correctly quantify moisture values. Moisture data from laboratory analysis of select sediment core samples are also plotted by depth on the composite logs (Figures 3.2 through 3.5) along with the geophysical neutron moisture (and total gamma) data. As illustrated on the composite logs, there is a significant difference in the vadose moisture data between the two sets of results. Both data sets are suspect for several reasons. The laboratory moisture samples may have been altered due to (1) drainage of liquids from the core barrel during retrieval, (2) reduction in moisture due to the heat generated during drilling, and (3) aeration (drying) of the sediment as the core liner is opened. However, the laboratory-measured moisture samples are probably more representative of vadose moisture conditions than the geophysical neutron moisture data because the drill casing was too large in diameter for the effective field measurement of moisture by neutron logging. 
Sediment moisture analysis was also completed on samples collected from the saturated zone. While not representative of the saturated zone because most of the free water drained off during core retrieval, they do qualitatively reveal changes in lithology based on grain-size differences. For example, in well 399-3-18 (C4999) (composite Figure 3.2), apparent moisture values increase across the interval of fine sand and most likely reflect an increase in retained moisture due to the decrease in relative grain size (permeability) of the fine-grained interval as compared to the coarser-grained (saturated) Ringold sediments.

The very low uranium MDLs that were achieved using longer count rates, larger, more sensitive germanium crystals $(60-70 \%)$ combined with the laboratory GEA system confirm that there are no highconcentration hot spots or zones of concentrated process uranium within the vadose zone or saturated interval at any of the four boreholes. However, the four boreholes represent a miniscule area of coverage for the entire 300-FF-5 OU sediments above and within the existing groundwater uranium plume so it can not be stated that no hot spots of uranium are present at locations not measurable by the field spectral gamma logging system (SGLS) or within the sediments from the four boreholes that were obtained. 


\subsection{References}

Bear J. 1972. Dynamics of Fluids in Porous Media. Dover Publications Inc., New York.

Bjornstad, BN. 1990. Geohydrology of the 218-W-5 Burial Ground. PNL-7336, Pacific Northwest Laboratory, Richland, Washington.

Bjornstad BN. 2004. Sampling and Hydrogeology of the Vadose Zone Beneath the 300 Area Process

Ponds. PNNL-14834, Pacific Northwest National Laboratory, Richland, Washington.

Butler JJ, Jr. 1996. "Slug Tests in Site Characterization: Some Practical Considerations."

Environmental Geosciences 3(3):154-163.

Butler JJ, Jr. 1997. The Design, Performance, and Analysis of Slug Tests. Lewis Publishers, CRC Press, Boca Raton, Florida.

Butler JJ, Jr. and EJ Garnett. 2000. Simple Procedures for Analysis of Slug Tests in Formations of High Hydraulic Conductivity using Spreadsheet and Scientific Graphics Software. Open-file Report 2000-40, Kansas Geological Survey, Lawrence, Kansas.

Campbell GS. 1985. Soil Physics with Basic. Elsevier, New York.

CERCLA - Comprehensive Environmental Response, Compensation, and Liability Act of 1980, as amended, Public Law 96-510, 94 Statute 2767, 42 USC 9601 et seq.

Davis JM, ND Roy, PS Mozley, and JS Hall. 2006. “The Effect of Carbonate Cementation on Permeability Heterogeneity in Fluvial Aquifers: An Outcrop Analog Study. Sedimentary Geol. 184:267280.

Deford DH, RW Carpenter, and MW Einan. 1994. 300-FF-2 Operable Unit Technical Baseline Report. BHI-00012, Rev. 00, Bechtel Hanford, Inc., Richland, Washington.

Deutsch WJ, WJ Martin, LE Eary, and RJ Serne. 1985. Methods of Minimizing Ground-Water Contamination from In-Situ Leach Uranium Mining - Final Report. NUREG/CR-3709, Nuclear Regulatory Commission, Washington D.C. now available from National Technical Information Center, Springfield, Virginia.

Deutsch WJ, NE Bell, BW Mercer, RJ Serne, JS Shade and DR Tweeton. 1984. Aquifer Restoration Techniques for In-Situ Leach Uranium Mines. NUREG/CR-3104, Nuclear Regulatory Commission, Washington D.C. now available from National Technical Information Center, Springfield, Virginia.

Deutsch WJ, RJ Serne, NE Bell, and WJ Martin. 1983. Aquifer Restoration at In-Situ Leach Uranium Mines: Evidence for Natural Restoration Processes. NUREG/CR-3136, Nuclear Regulatory Commission, Washington, D.C. now available from National Technical Information Center, Springfield, Virginia. 
DOE. 1995a. Proposed Plan for the 300-FF-1 and 300-FF-5 Operable Units. DOE/RL-95-88, Rev. 0, U.S. Department of Energy, Richland, Washington.

DOE. 1995b. Remedial Investigation/Feasibility Study Report for the 300-FF-5 Operable Unit. DOE/RL-94-85, Rev. 0, U.S. Department of Energy, Richland, Washington.

DOE. 2002a. 300-FF-5 Operable Unit Sampling and Analysis Plan. DOE/RL-2002-11, Rev. 0, Prepared by CH2M HILL Hanford, Inc. for U.S. Department of Energy, Richland, Washington.

DOE. 2002b. Operation and Maintenance Plan for the 300-FF-5 Operable Unit. DOE/RL-95-73, Rev. 1. Prepared by CH2M HILL Hanford, Inc. for U.S. Department of Energy, Richland, Washington.

DOE-RL. 2002. Standardized Stratigraphic Nomenclature for Post-Ringold-Formation Sediments Within the Central Pasco Basin. DOE/RL-2002-39, Rev. 0, June 2002. U.S. Department of Energy, Richland, Washington. (Author: BN Bjornstad; prepared by Pacific Northwest National Laboratory).

DOE. 2005a. Sampling-Analysis Plan for CERCLA Well Drilling at 300-FF-5 04, FY05. DOE/RL2005-47, Rev. 1, Prepared by Pacific Northwest National Laboratory for the U.S. Department of Energy, Richland, Washington.

DOE. 2005b. Work Plan for Phase III Feasibility Study, 300-FF-5 Operable Unit. DOE/RL-2005-41, Rev. 0, Prepared by Pacific Northwest National Laboratory for the U.S. Department of Energy, Richland, Washington.

DOE. 2006a. 300-FF-5 Operable Unit Limited Field Investigation Plan. DOE/RL-2005-47, Rev. 1, Prepared by Pacific Northwest National Laboratory for the U.S. Department of Energy, Richland, Washington. (authors: BA Williams, CF Brown, RE Peterson, EC Thornton, MJ Nimmons, SB Yabusaki, TG Naymik, JW Lindberg, ML Rockhold, and MD Williams).

DOE. 2006b. 300-FF-5 Operable Unit Sampling and Analysis Plan. DOE/RL-2002-11, Rev. 1, Prepared by Pacific Northwest National Laboratory for the U.S. Department of Energy, Richland, Washington.

DOE. 2006c. CERCLA Five-Year Review Report for the Hanford Site. DOE/RL-2006-20, Rev. 0, U.S. Department of Energy, Richland, Washington. (Copy for Public Review)

Ecology - Washington State Department of Ecology, U.S. Environmental Protection Agency, and U.S. Department of Energy. 1989. Hanford Federal Facility Agreement and Consent Order. Document No. 89-10, as amended, (The Tri-Party Agreement), Olympia, Washington.

EPA. 1996. Record of Decision for U.S. DOE Hanford 300-FF-1 and 300-FF-5 Operable Units Remedial Actions. Agreement Between U.S. Department of Energy and U.S. Environmental Protection Agency, with Concurrence by the Washington State Department of Ecology, July 17, 1996.

EPA. 2001. U.S. DOE Hanford Site: First Five Year Review Report. April 2001. Prepared by U.S. Environmental Protection Agency, Region 10, Hanford Project Office, Richland, Washington.

Folk RL. 1980. Petrology of Sedimentary Rocks. Hemphill Publishing Co., Austin, Texas. 
Freeze RA and JA Cherry. 1979. Groundwater. Prentice-Hall, Inc., Englewood Cliffs, New Jersey.

Gee GW and D Orr. 2002. "Particle-Size Analysis." In JH Dane and GC Topp (eds.), Methods of Soil Analysis, Part 4 - Physical Methods. Soil Sci. Am. Book Series: 5.

Gerber MS. 1992. Past Practices Technical Characterization Study-300 Area -Hanford Site. WHC-MR-0388, Westinghouse Hanford Company, Richland, Washington.

Guber AK, YA Pachepsky, MTh Van Genuchten, WJ Rawls, J Simunek, D Jacques, TJ Nicholson, and RE Cady. 2006. "Field-Scale Water Flow Simulations Using Ensembles of Pedotransfer Functions for Soil Water Retention." Vadose Zone J 5:234-247.

Hartman MJ, LF Morasch, and WD Webber (eds.). 2006. Hanford Site Groundwater Monitoring for Fiscal Year 2005. PNNL-15670, Pacific Northwest National Laboratory, Richland, Washington.

Hazen A. 1911. "Discussion - Dams on Sand Foundations.” Trans. Am. Soc. Civil Engineers 73:199.

Horton DG, HT Schaef, RJ Serne, CF Brown, MM Valenta, TS Vickerman, IV Kutnyakov, SR Baum, KN Geiszler, and KE Parker. 2003. Geochemistry of Samples from Borehole C3117 (299-E24-21). PNNL-14289, Pacific Northwest National Laboratory, Richland, Washington.

Lindberg JW and FW Bond. 1979. Geohydrology and Groundwater Quality Beneath the 300 Area, Hanford Site, Washington. PNL-2949, Pacific Northwest Laboratory, Richland, Washington.

Lindberg JW and CJ Chou. 2001. 300 Area Process Trenches Groundwater Monitoring Plan. PNNL-13645, Pacific Northwest National Laboratory, Richland, Washington.

Lindberg JW and RE Peterson. 2006. "300-FF-5 Operable Unit." Chapter 2.12 in Hanford Site Groundwater Monitoring for Fiscal Year 2005, eds. MJ Hartman, LF Morasch, and WD Webber. PNNL-15670, Pacific Northwest National Laboratory, Richland, Washington.

Lindsey KA. 1995. Miocene- to Pliocene-Aged Suprabasalt Sediments of the Hanford Site, SouthCentral Washington. BHI-00184, Rev. 00, July 1995, Bechtel Hanford, Inc., Richland, Washington.

Lotspeich FB and FH Everest. 1981. "A new method for reporting and interpreting textural composition of spawning gravel." Research note. Pacific Northwest Forest and Range Experiment Station, Forest Service, U.S. Dept of Agriculture. Lu H-Y. 2007. "A Method to Estimate Hydraulic Conductivity from Bulk Geochemical Compositions.” Environ Geol. 51:1029-1041.

Masch FD and KJ Denny. 1966. "Grain-Size Distribution and Its Effect on the Permeability of Unconsolidated Sands.” Water Resour. Res. 2:665-677.

Peterson, RE (editor). 2005. Contaminants of Potential Concern in the 300-FF-5 Operable Unit: Expanded Annual Groundwater Report for FY 2004. PNNL-15127, Pacific Northwest National Laboratory, Richland, Washington. (Contributors: EJ Freeman, CJ Murray, RE Peterson, PD Thorne, MJ Truex, VR Vermeul, MD Williams, SB Yabusaki, JM Zachara, JL Lindberg, and JP McDonald). 
Poeter E and DR Gaylord. 1990. "Influence of Aquifer Heterogeneity on Contaminant Transport at the Hanford Site.” Ground Water, Vol. 28, No. 6, November-December 1990, pp. 900-909.

Schalla R, RW Wallace, RL Aaberg, SP Airhart, DJ Bates, JVM Carlile, DS Cline, DI Dennison, MD Freshley, PR Heller, EJ Jensen, KB Olsen, RG Parkhurst, JT Rieger, and EJ Westergard. 1988. Interim Characterization Report for the 300 Areas Process Trenches. PNL-6716, September 1988. Pacific Northwest Laboratory, Richland, Washington. (RW Wallace, RL Aaberg, SP Airhart, DJ Bates, JVM Carlile, CS Cline, DI Dennison, MD Freshley, PR Heller, EJ Jensen, KB Olsen, RG Parkhurst, JT Rieger, and EJ Westergard).

Serne RJ, CF Brown, HT Schaef, EM Pierce, JW Lindberg, Z Wang, PL Gassman, and JG Catalano. 2002. The 300 Area Uranium Leach and Adsorption Project. PNNL-14022, Pacific Northwest National Laboratory, Richland, Washington.

Spane FA and DR Newcomer. 2004. Results of Detailed Hydrologic Characterization Tests - FY 2003. PNNL-14186, Pacific Northwest National Laboratory, Richland, Washington.

Stoller 2006. Quality Assurance Project Plan. HGLP-002, S.M. Stoller Corporation, Richland, Washington.

Swanson LC, GG Kelty, KA Lindsey, KR Simpson, RK Price, and SD Consort. 1992. Phase I Hydrogeologic Summary of the 300-FF-5 Operable Unit, 300 Area. WHC-SD-EN-TI-052, Rev. 0, Westinghouse Hanford Company, Richland, Washington.

Thorne PD, MA Chamness, FA Spane, Jr., VR Vermeul, and WD Webber. 1993. Three-Dimensional Conceptual Model for the Hanford Site Unconfined Aquifer System, FY 93 Status Report. PNL-8971, Pacific Northwest Laboratory, Richland, Washington.

WAC 173-160. Minimum Standards for Construction and Maintenance of Wells. Washington Administrative Code, Olympia, Washington.

Vermeul VR, JS Fruchter, DM Wellman, BA Williams, and MD Williams. 2006. Site Characterization Plan: Uranium Stabilization through Polyphosphate Injection. PNNL-16008, Pacific Northwest National Laboratory, Richland, Washington.

Waichler SR and SB Yabusaki. 2005. Flow and Transport in the Hanford 300 Area Vadose ZoneAquifer-River System. PNNL-15125, Pacific Northwest National Laboratory, Richland, Washington.

Wang Z, JM Zachara, JP McKinley, and SC Smith. 2005. "Cryogenic Laser Induced U(VI) Fluorescence Studies of a U(VI) Substituted Natural Calcite: Implications to U(VI) Speciation in Contaminated Hanford Sediments.” Environmental Science and Technology 39, 2651-2659.

Ward AL, ME Conrad, WD Daily, JB Fink, VL Freedman, GW Gee, GM Hoverston, MJ Keller, EL Majer, CJ Murray, MD Whote, SB Yabusaki, and ZF Zhang. 2006. Vadose Zone Transport Study Summary Report. PNNL-15443, Pacific Northwest National Laboratory, Richland, Washington. 
Williams BA, BN Bjornstad, DC Lanigan, JM Keller, and ML Rockhold. 2006. Borehole Data Package for One CY 2005 CERCLA Well 699-S20-E10, 300-FF-5 Operable Unit, Hanford Site, Washington.

PNNL-15417, Pacific Northwest National Laboratory, Richland, Washington.

Young JS, RM Fruland, and JS Fruchter. 1990. Data Compilation Task Report for the Source Investigations of the 300-FF-1 Operable Unit Phase I Remedial Investigation. PNL-7241, Pacific Northwest Laboratory, Richland, Washington.

Young JS and JS Fruchter. 1991. Addendum to Data Compilation Task Report for the Source Investigation of the 300-FF-1 Operable Unit Phase I Remedial Investigations. EMO-1026, Prepared by Environmental Management Operations for the U.S. Department of Energy, Richland, Washington.

Zachara JM (editor). 2005. Uranium Geochemistry in Vadose Zone and Aquifer Sediments from the 300 Area Uranium Plume. PNNL-15121, March 2005, Pacific Northwest National Laboratory, Richland, Washington. (Collaborators: JA Davis, C Liu, JP McKinley, N Qafoku, DM Wellman, and SB Yabusaki). 


\section{Appendix A}

\section{Well Summary Data}




\section{Well Summary Sheet (as-Built)}

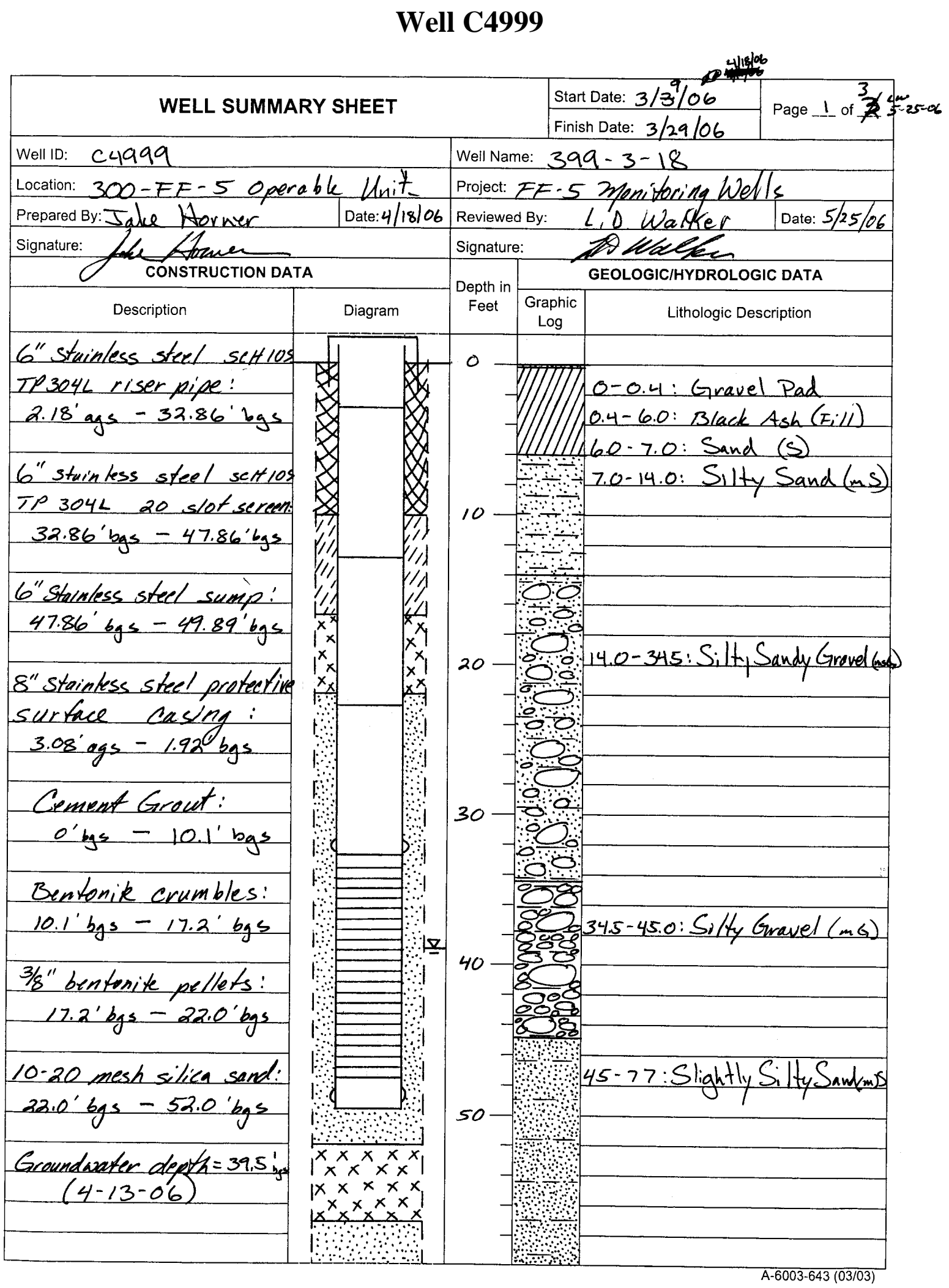




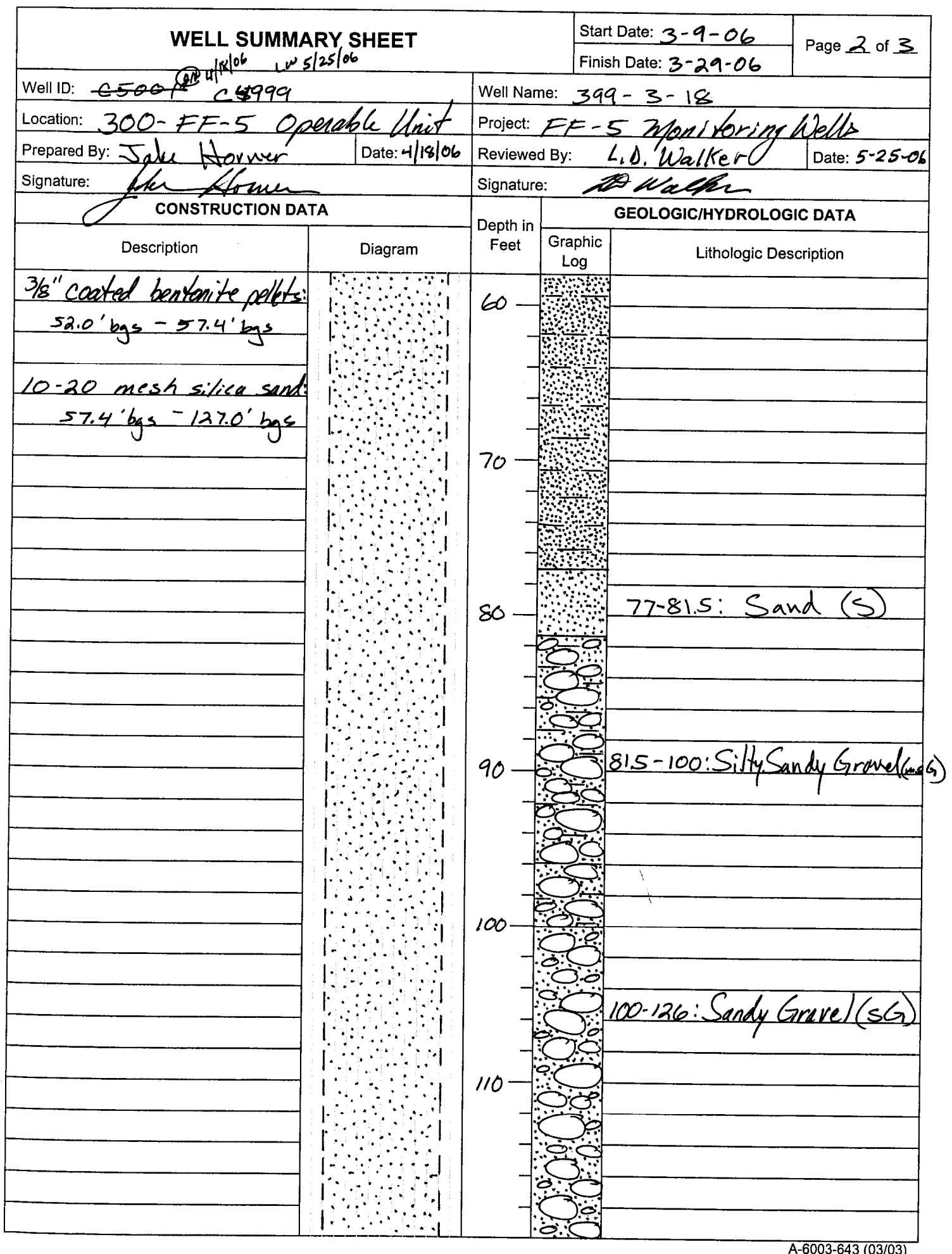

A-6003-643 (03/03) 


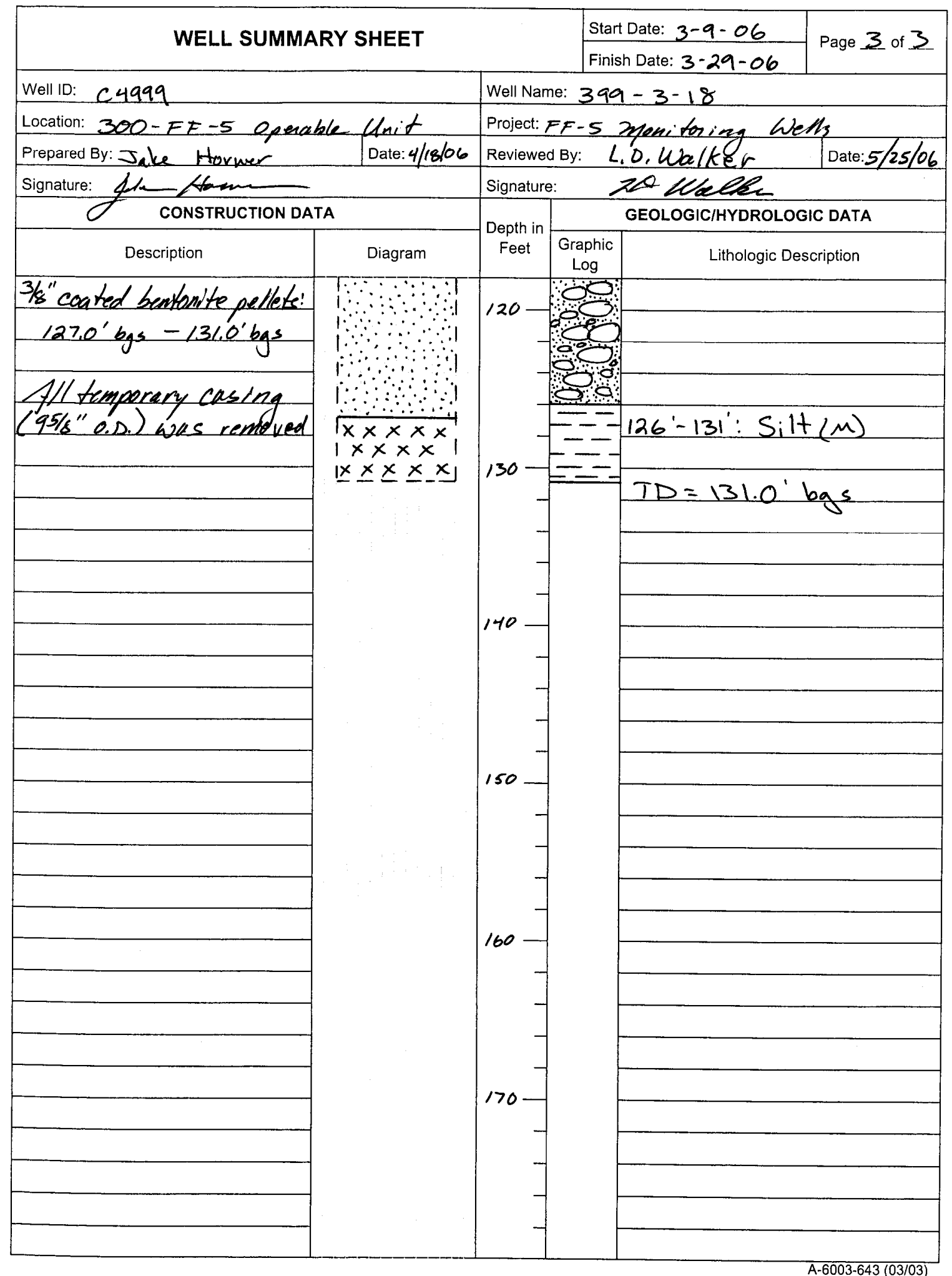




\section{Well C5000}

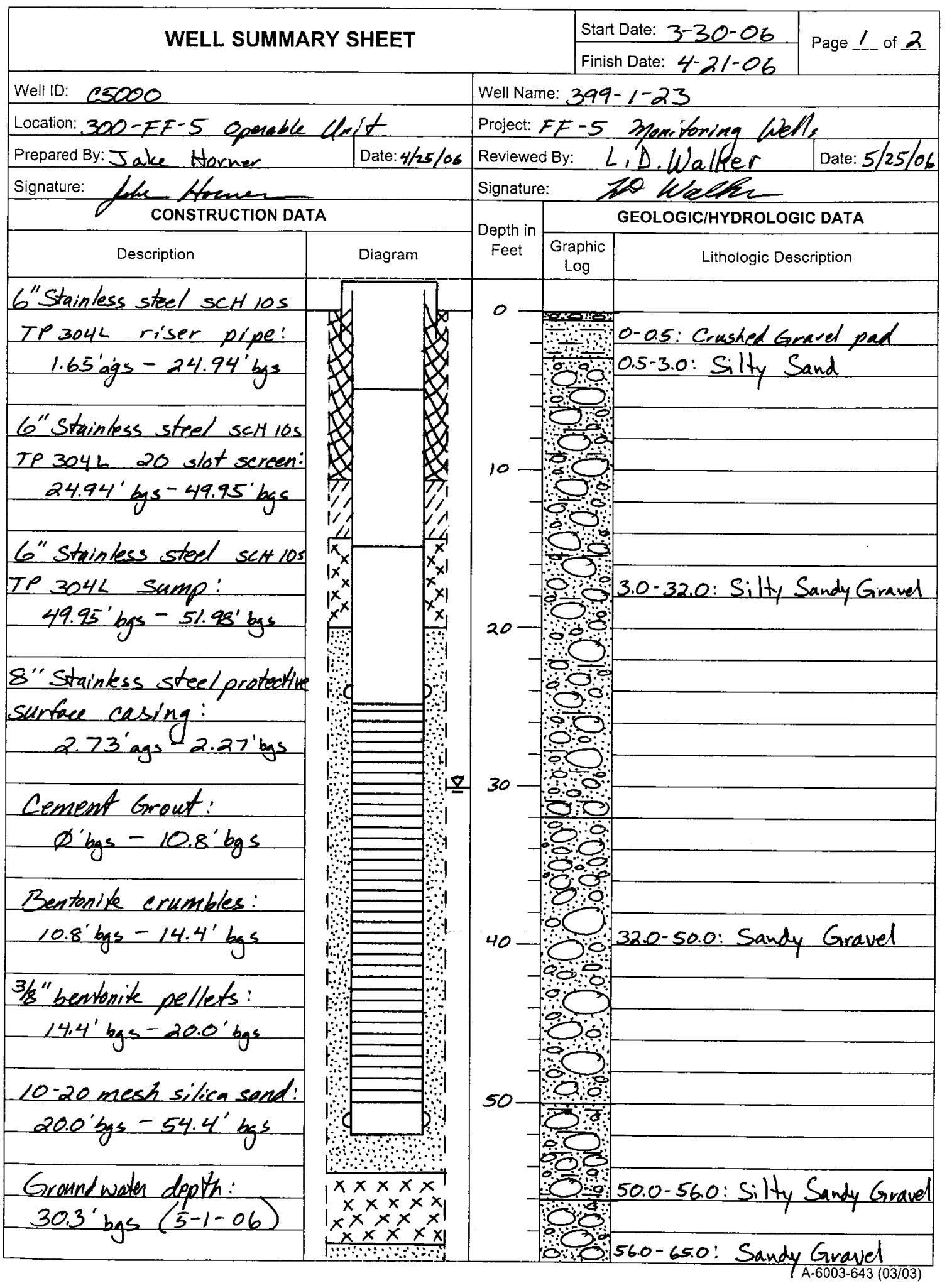




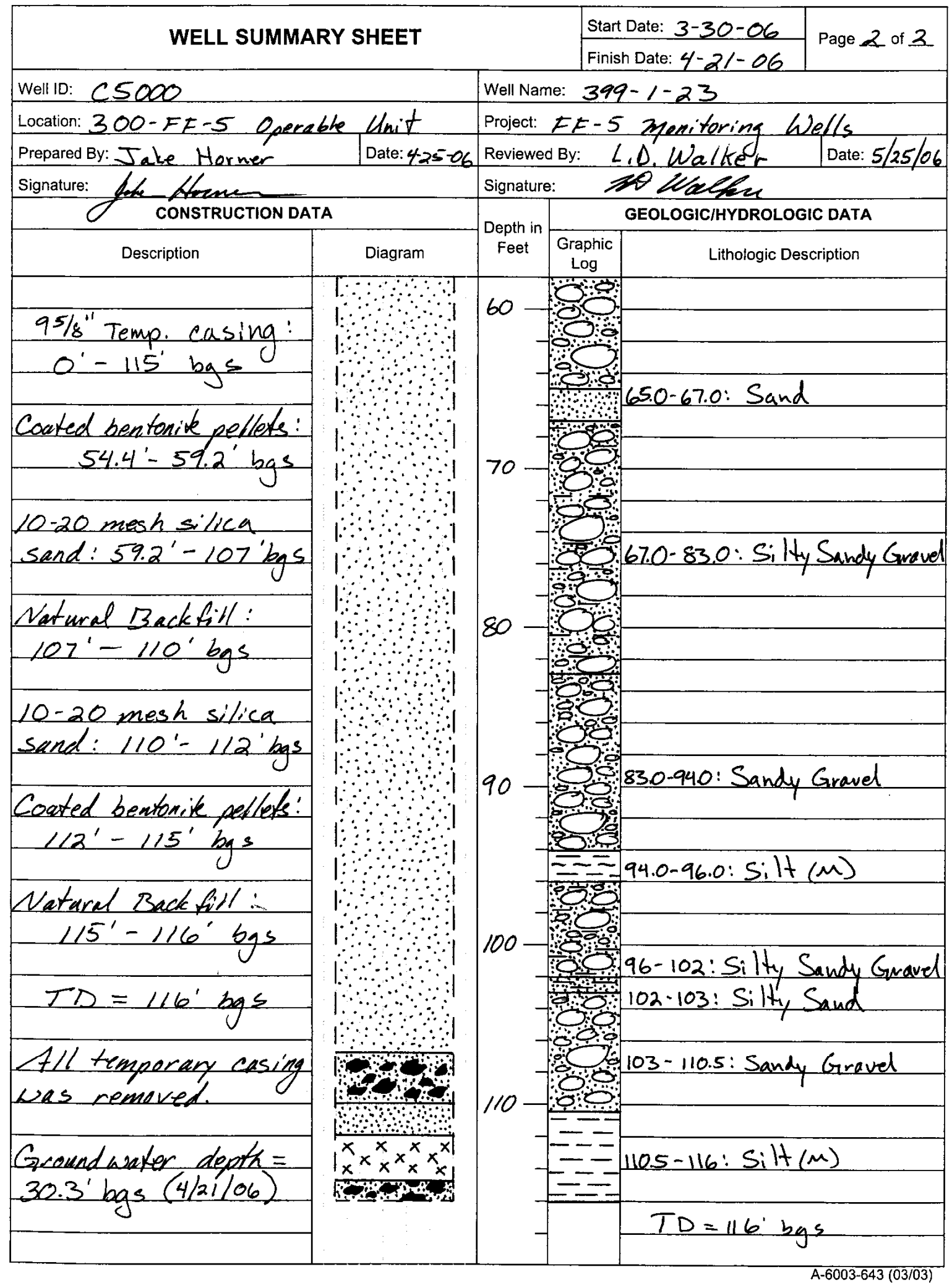




\section{Well C5001}

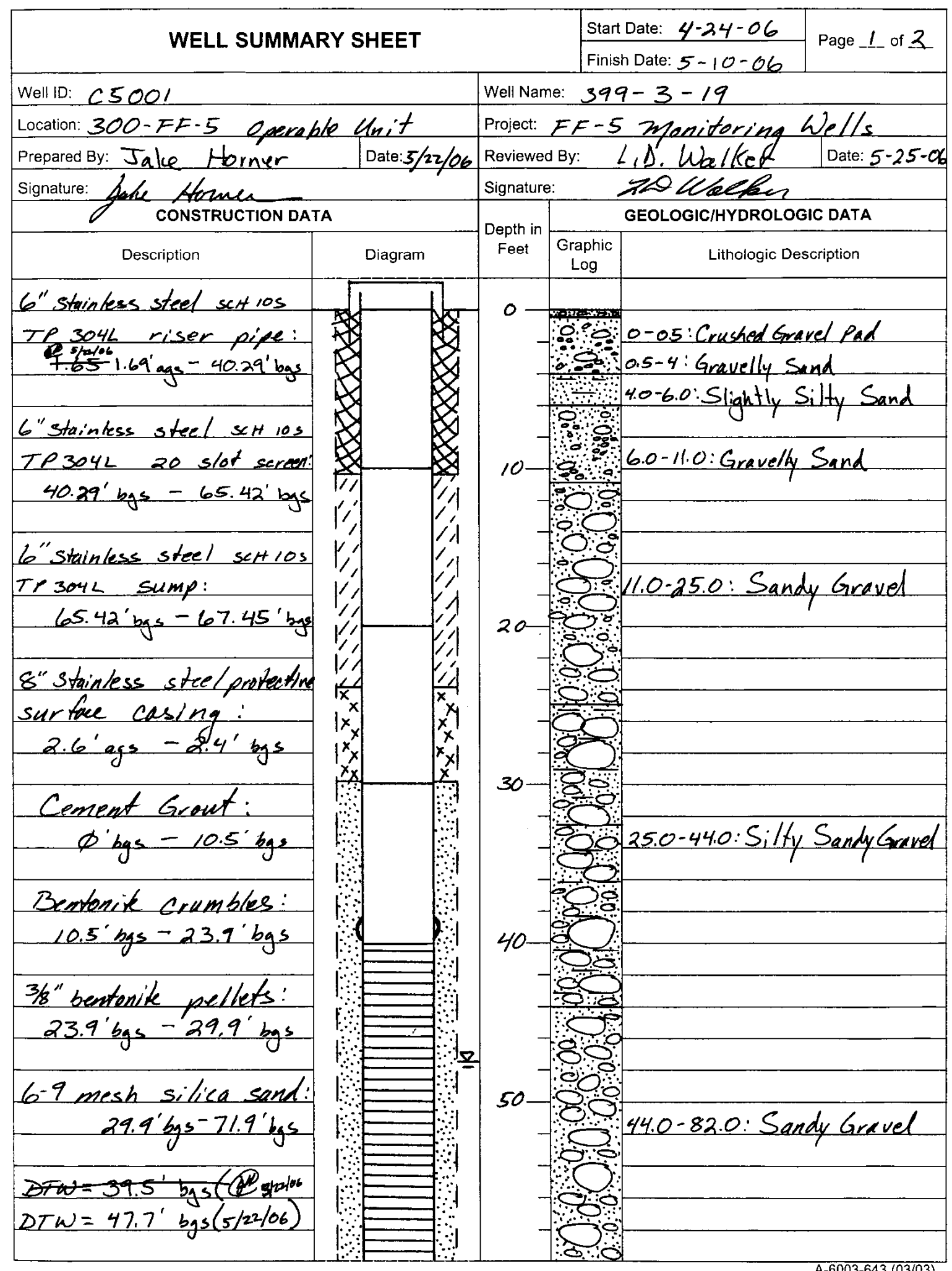




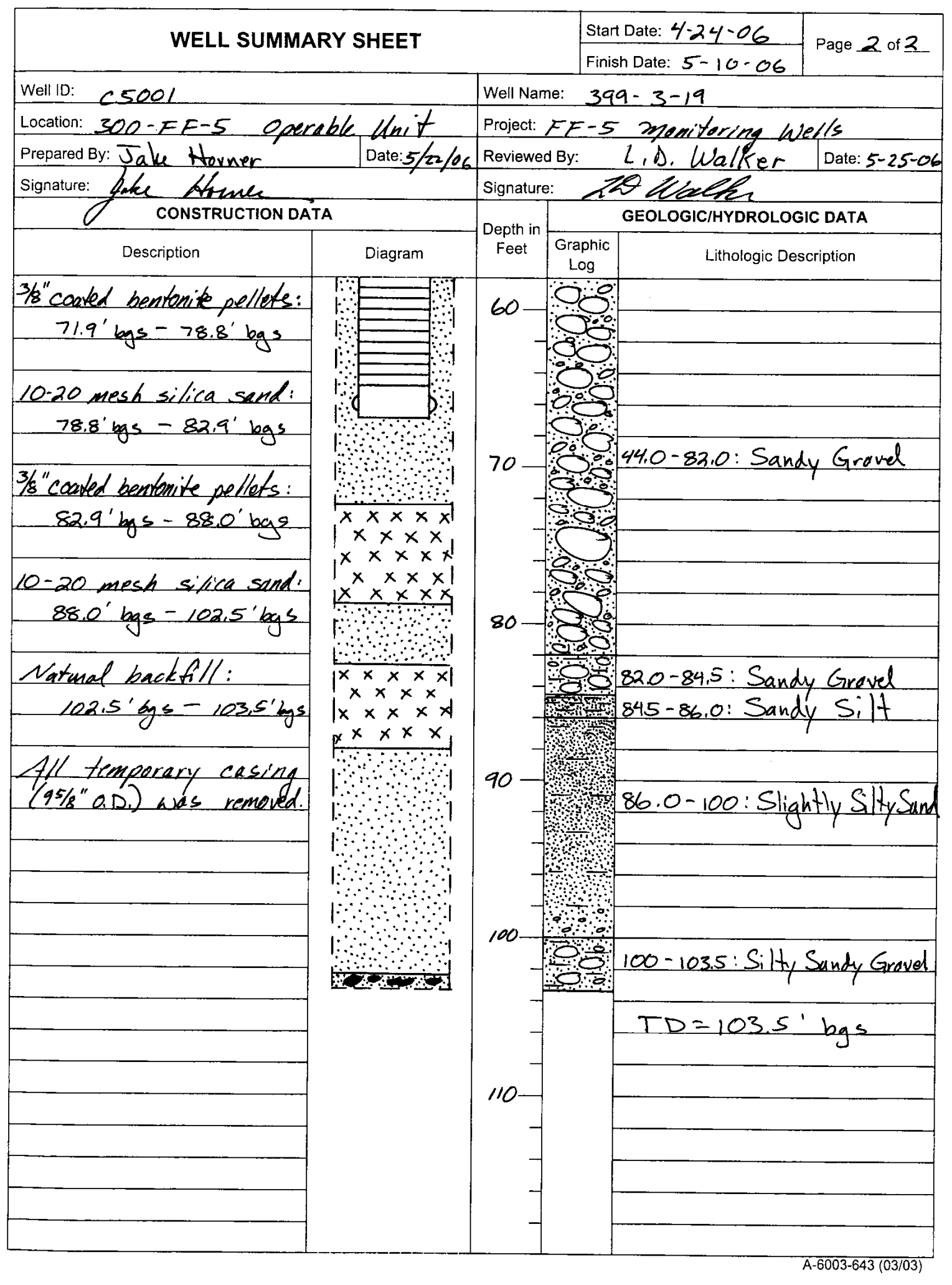




\section{Well C5002}

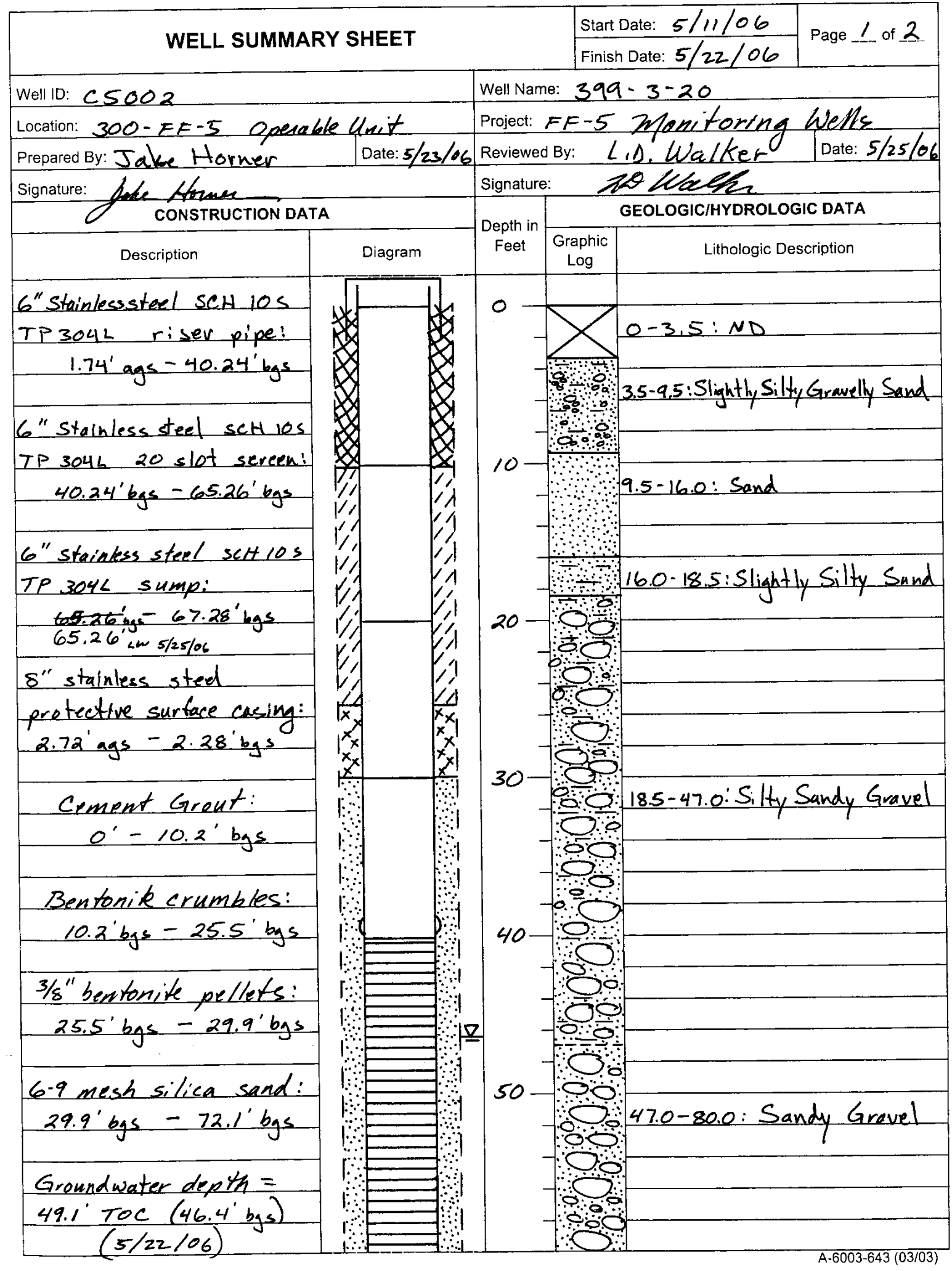




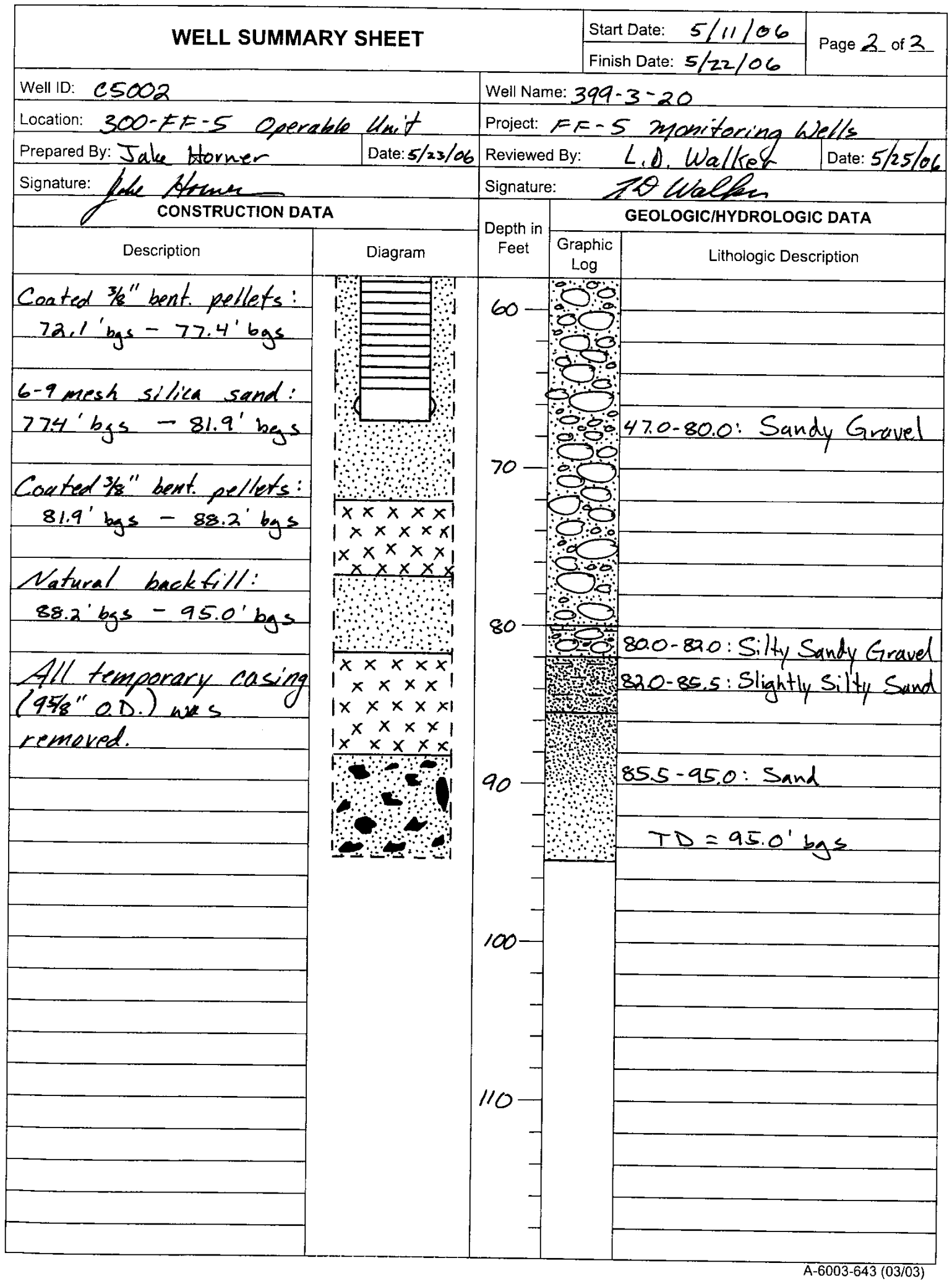




\section{Borehole Log}

\section{Well C4999}

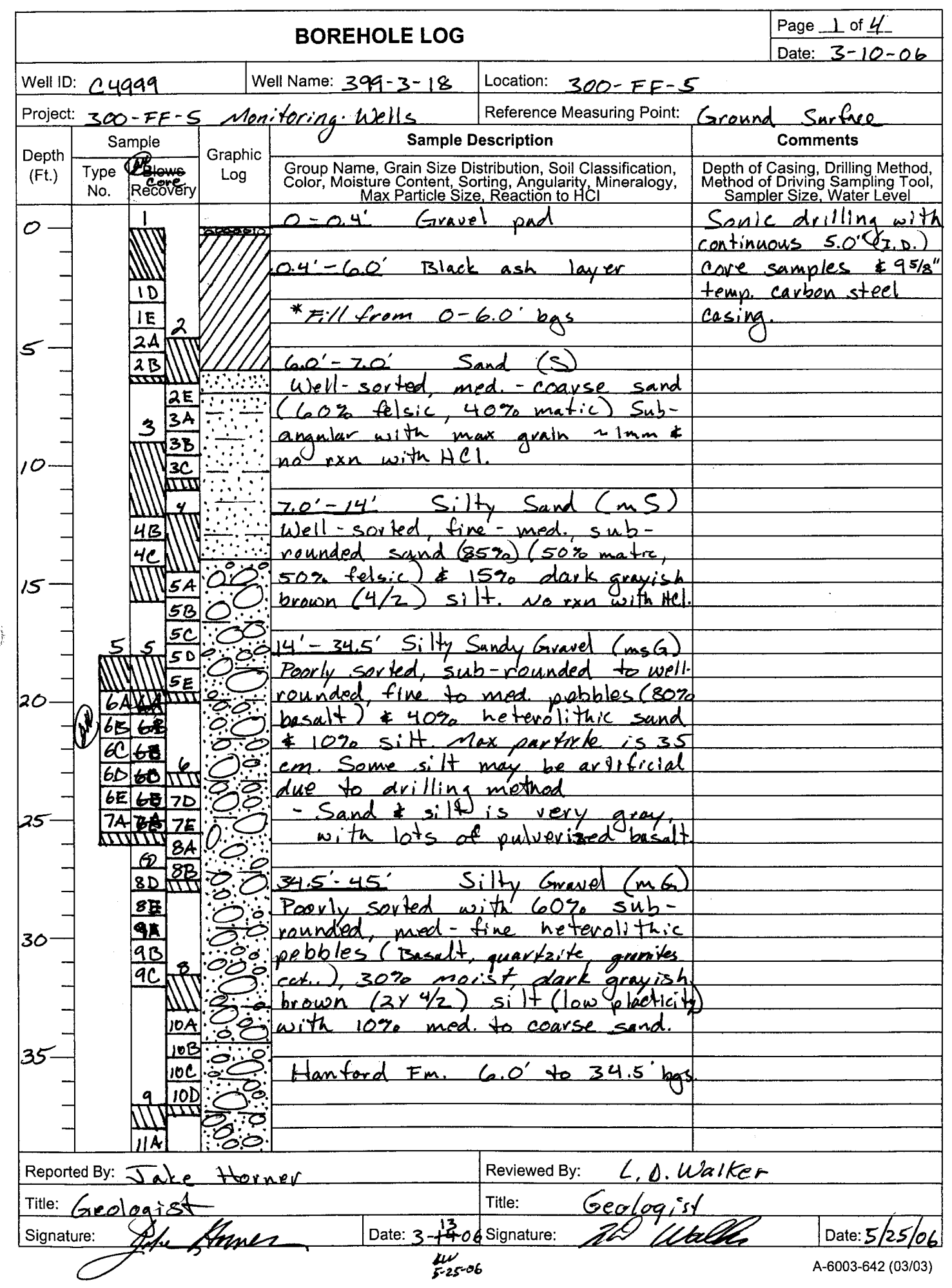




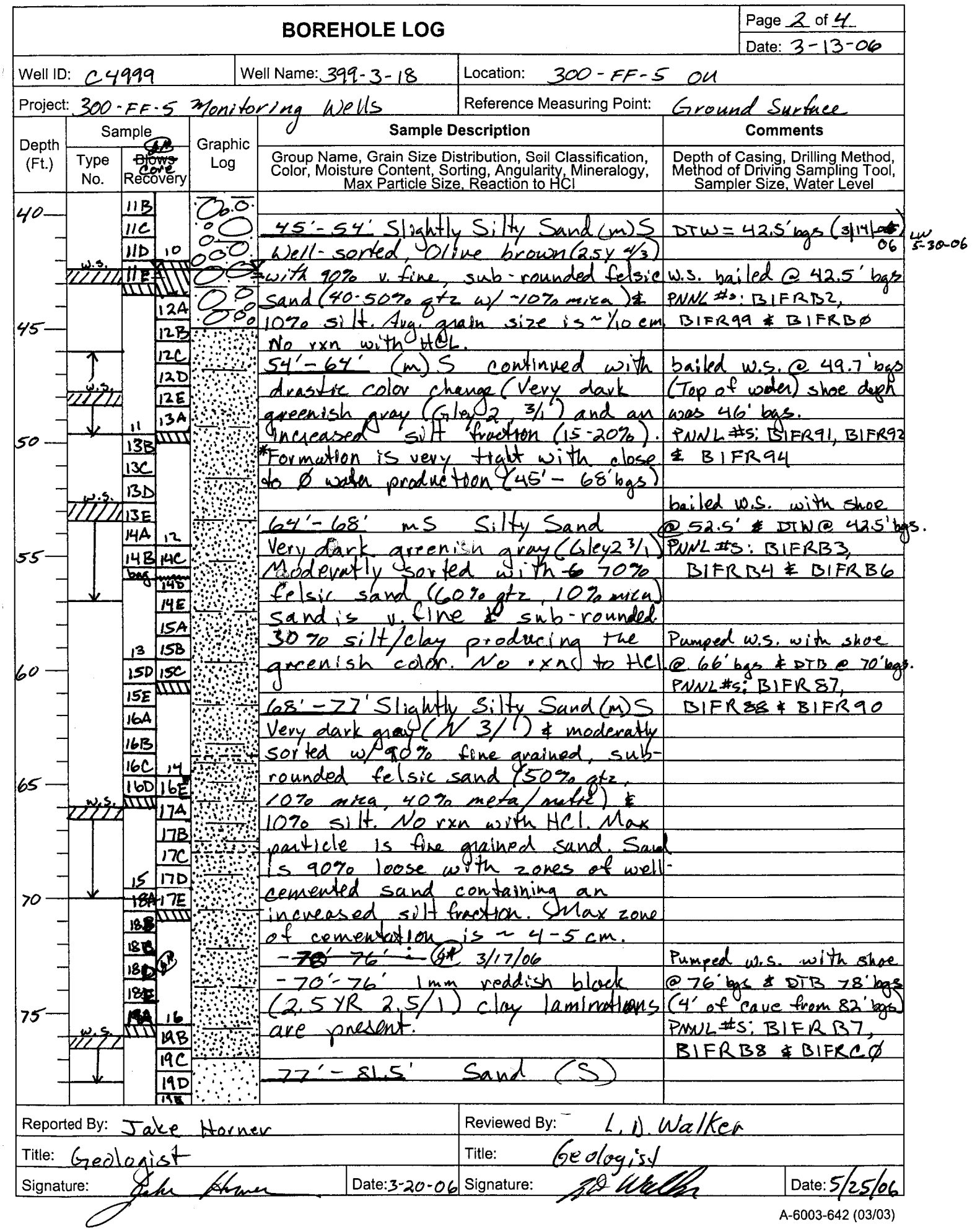




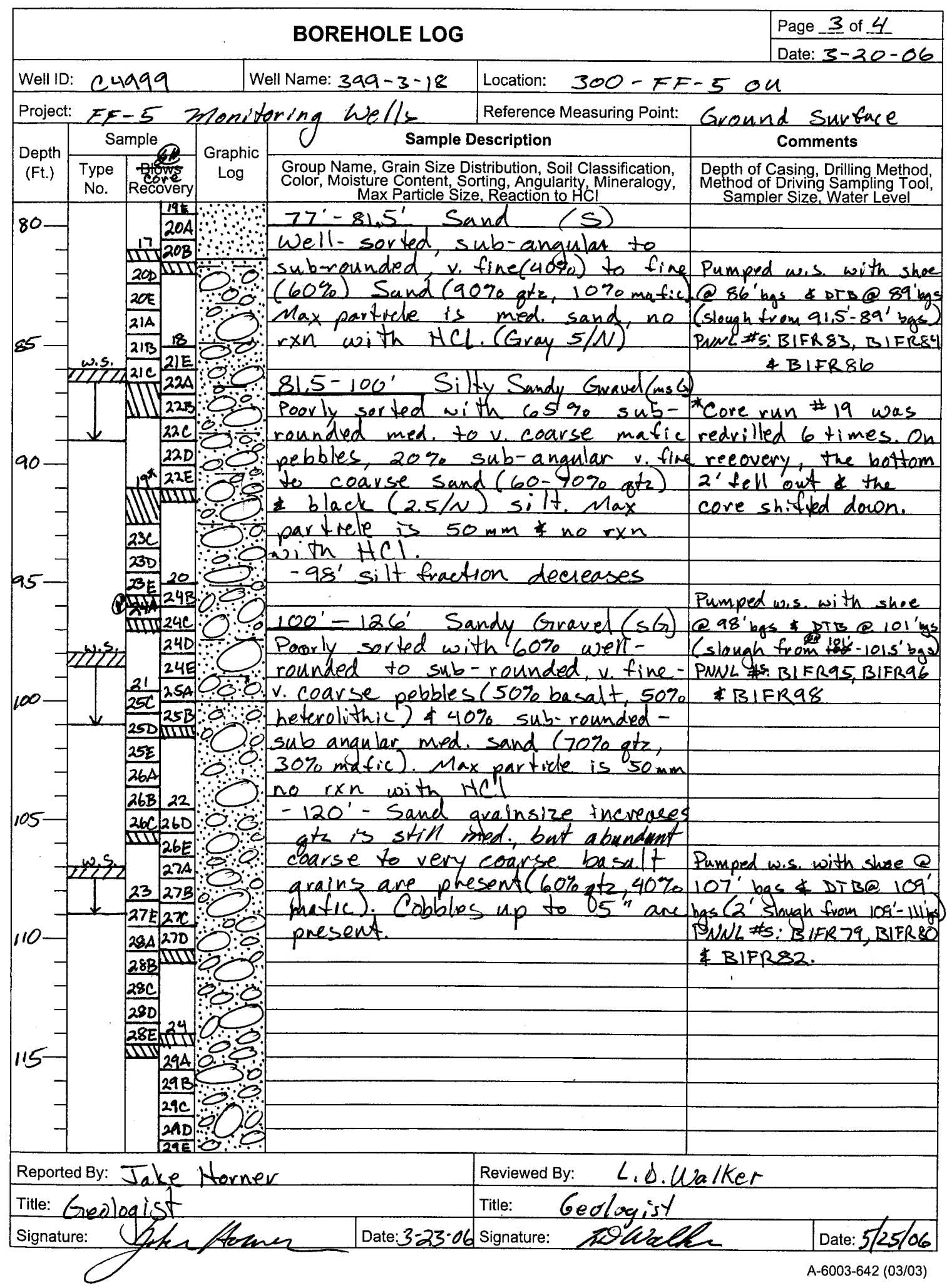




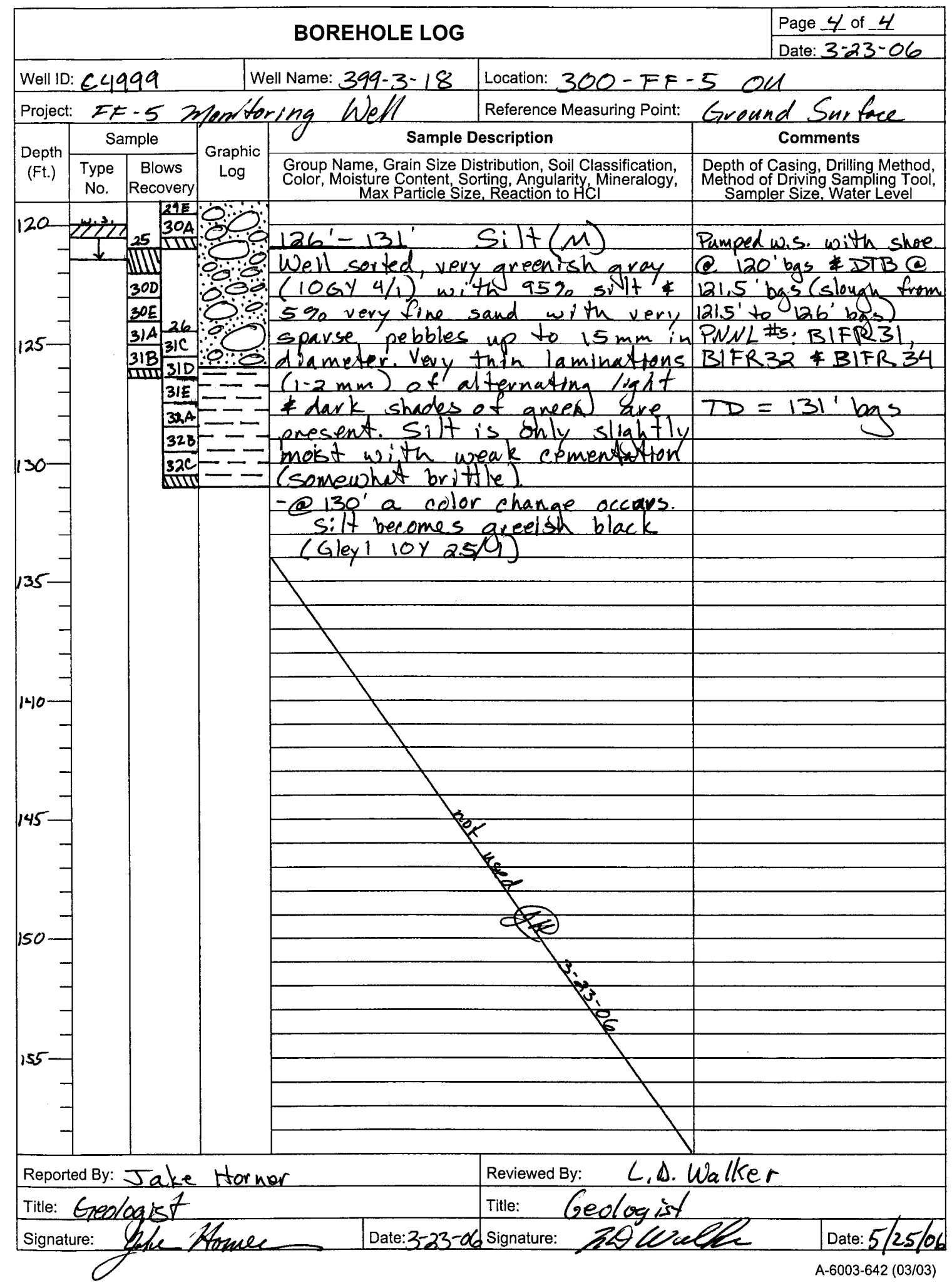




\section{Well C5000}

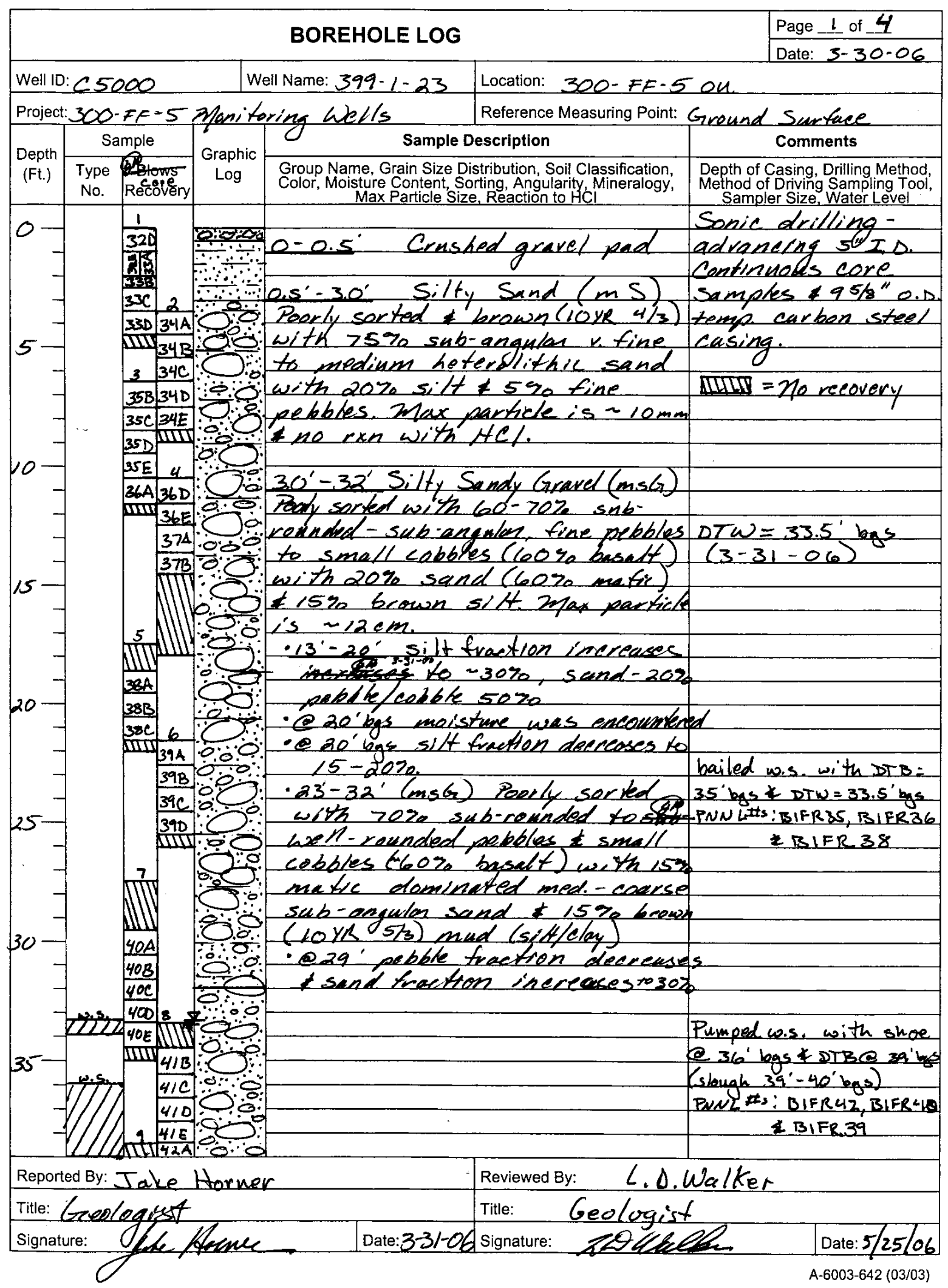




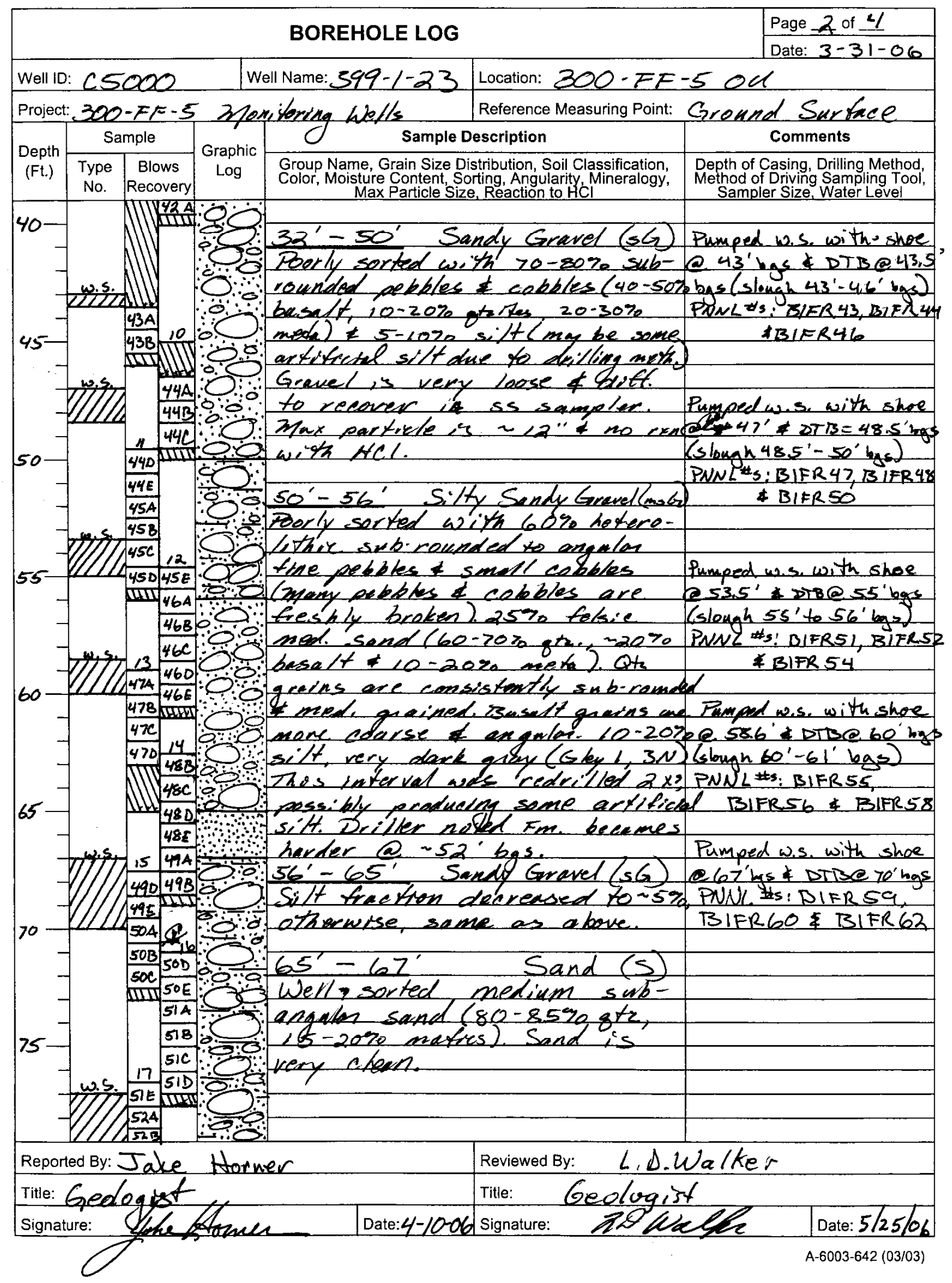




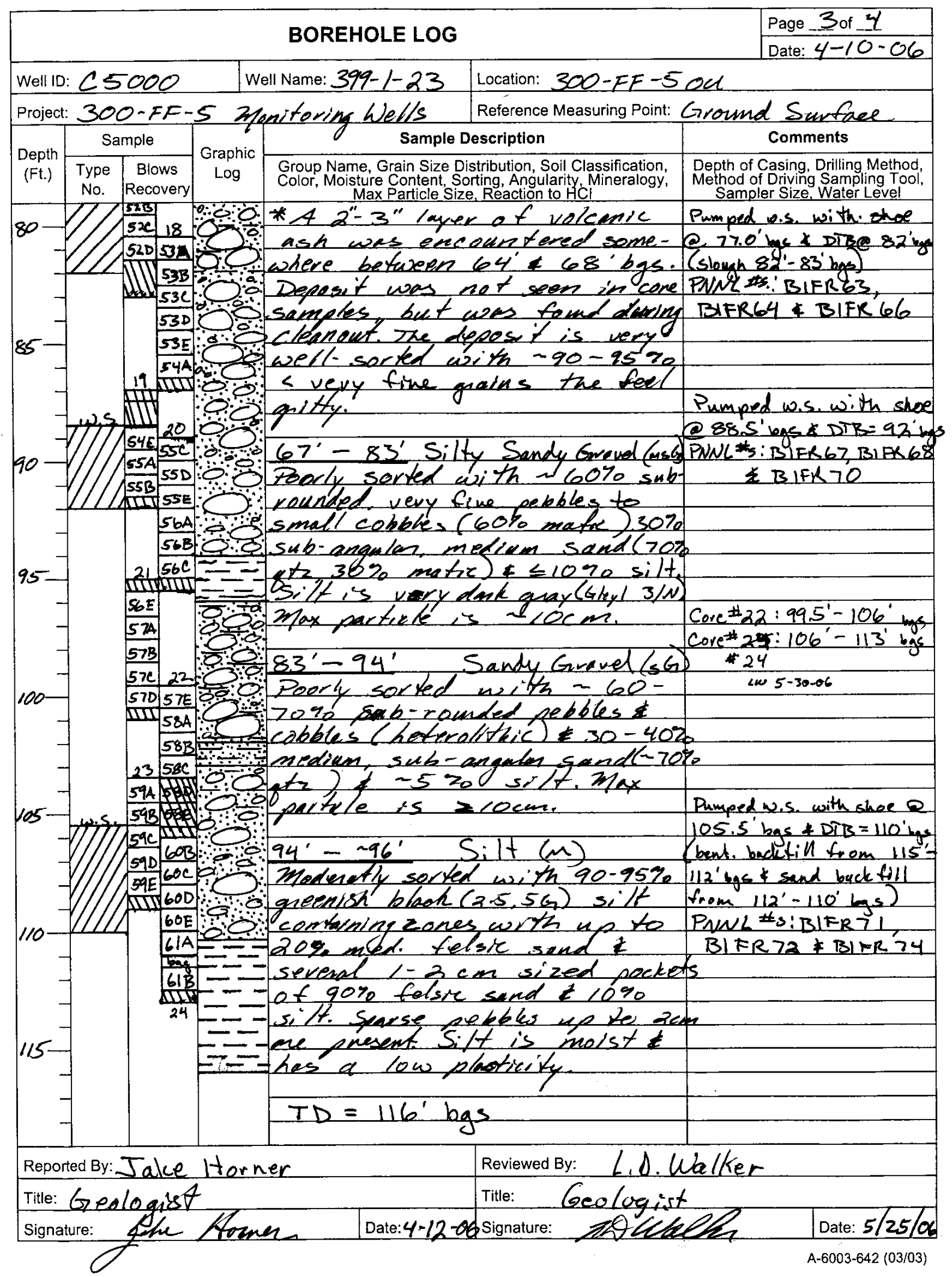




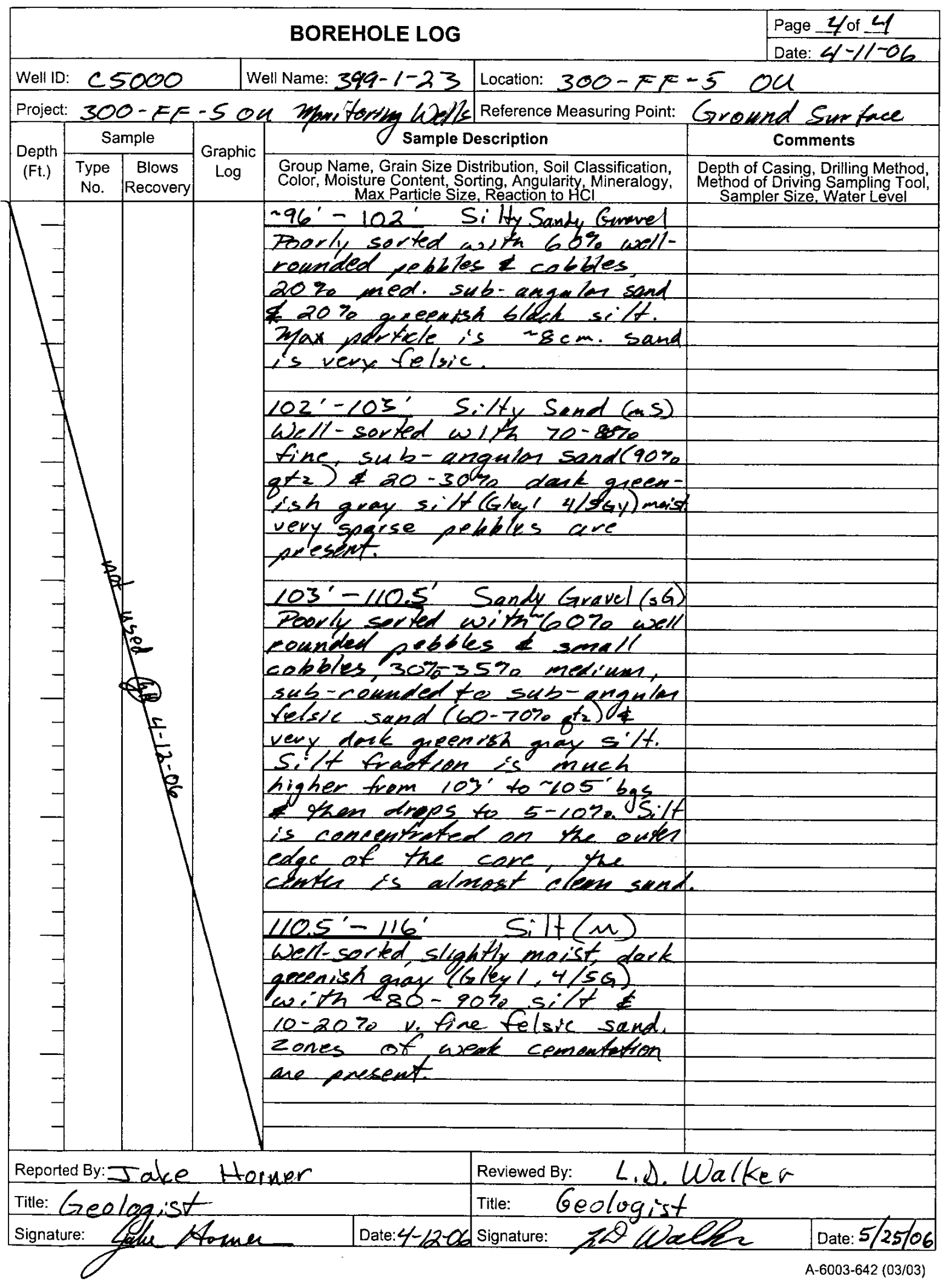




\section{Well C5001}

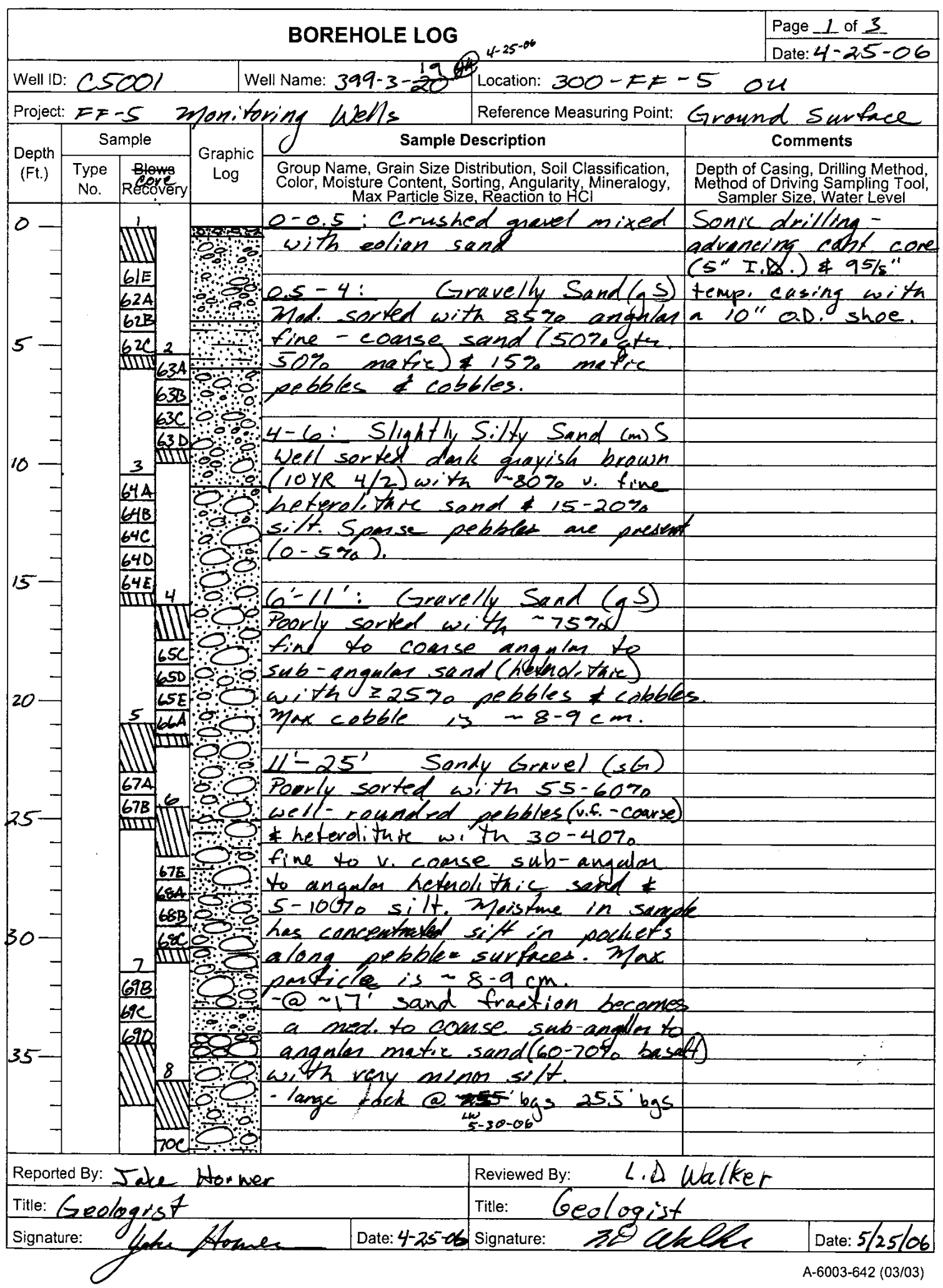




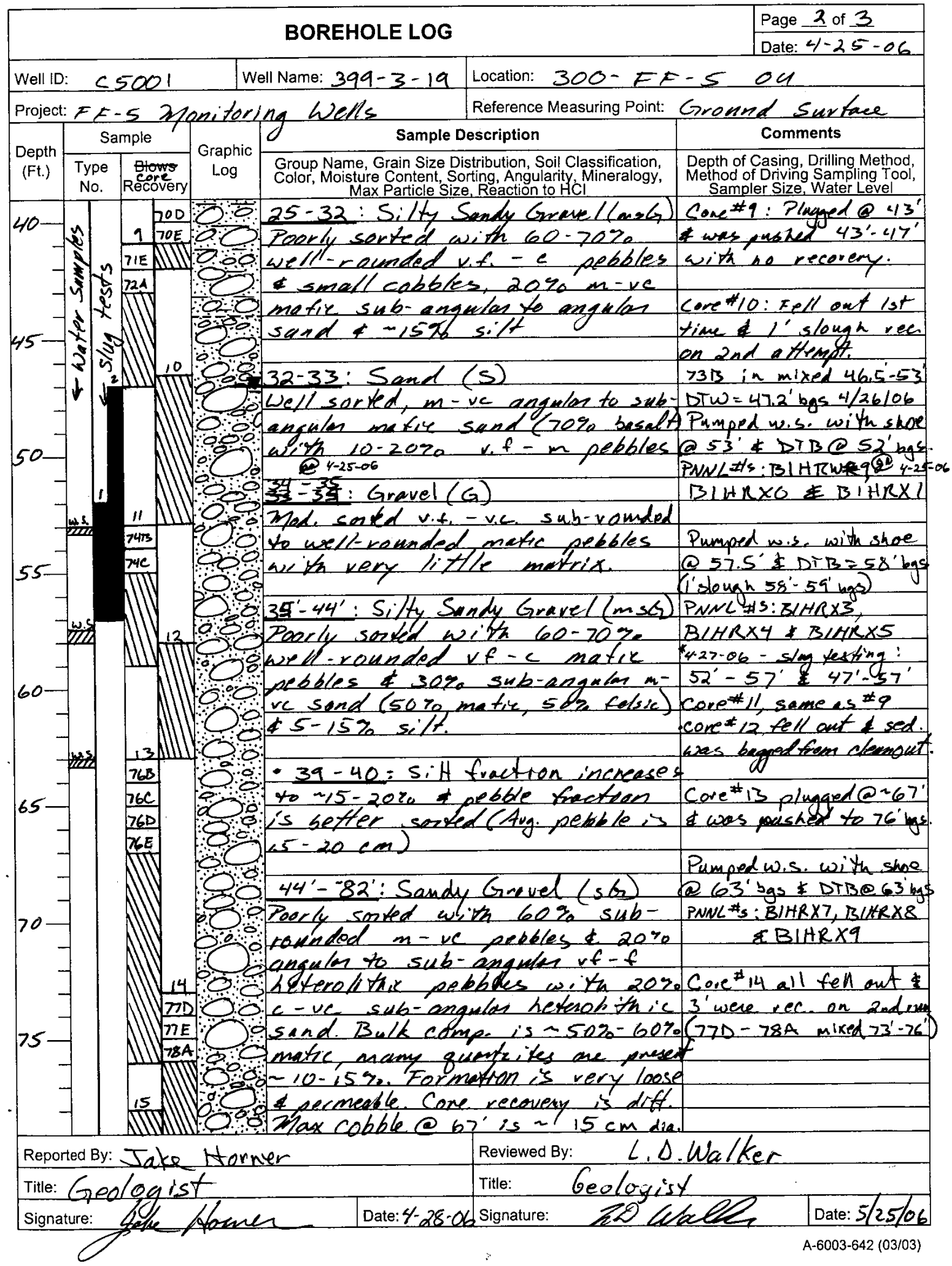




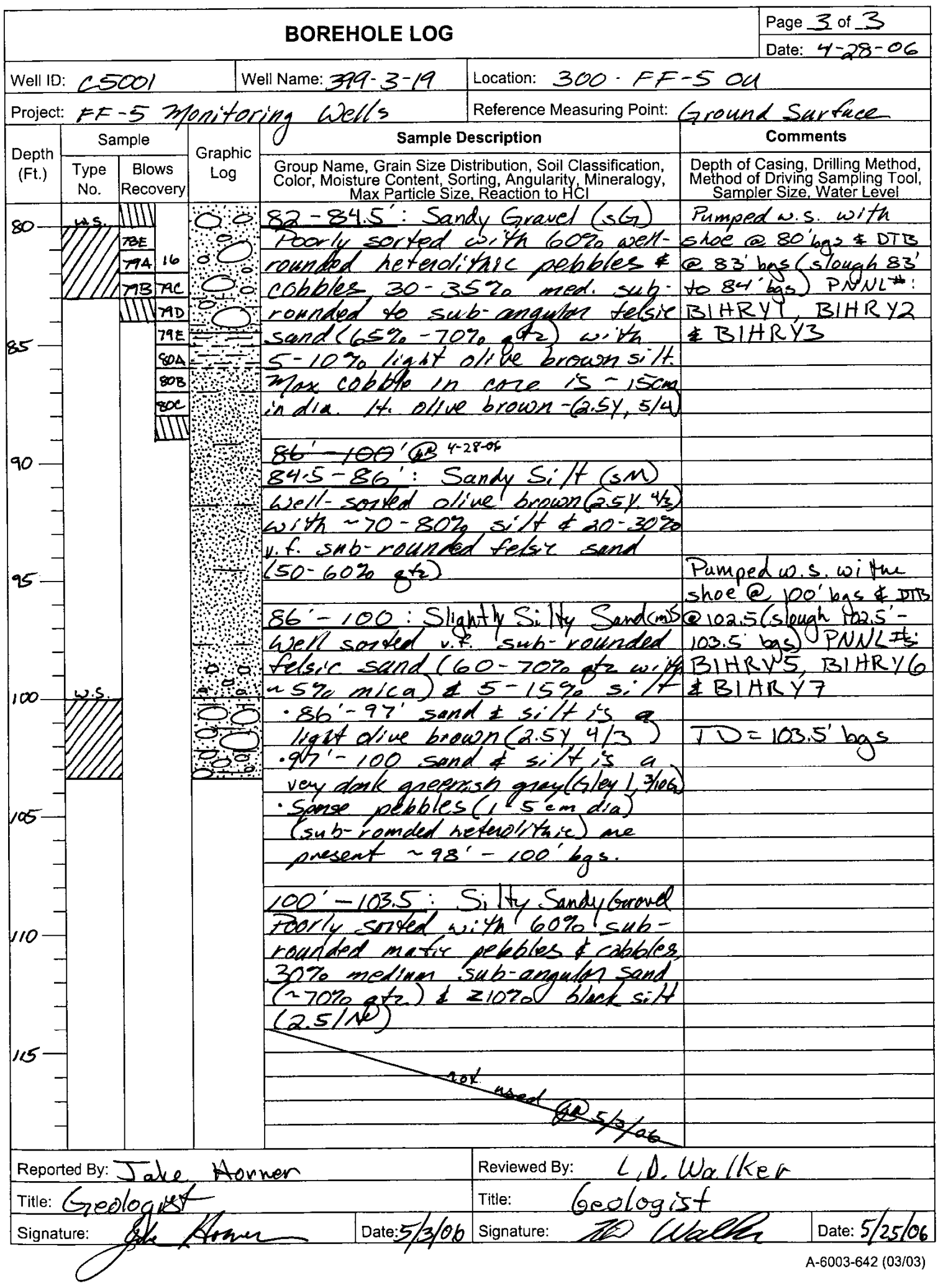




\section{Well C5002}

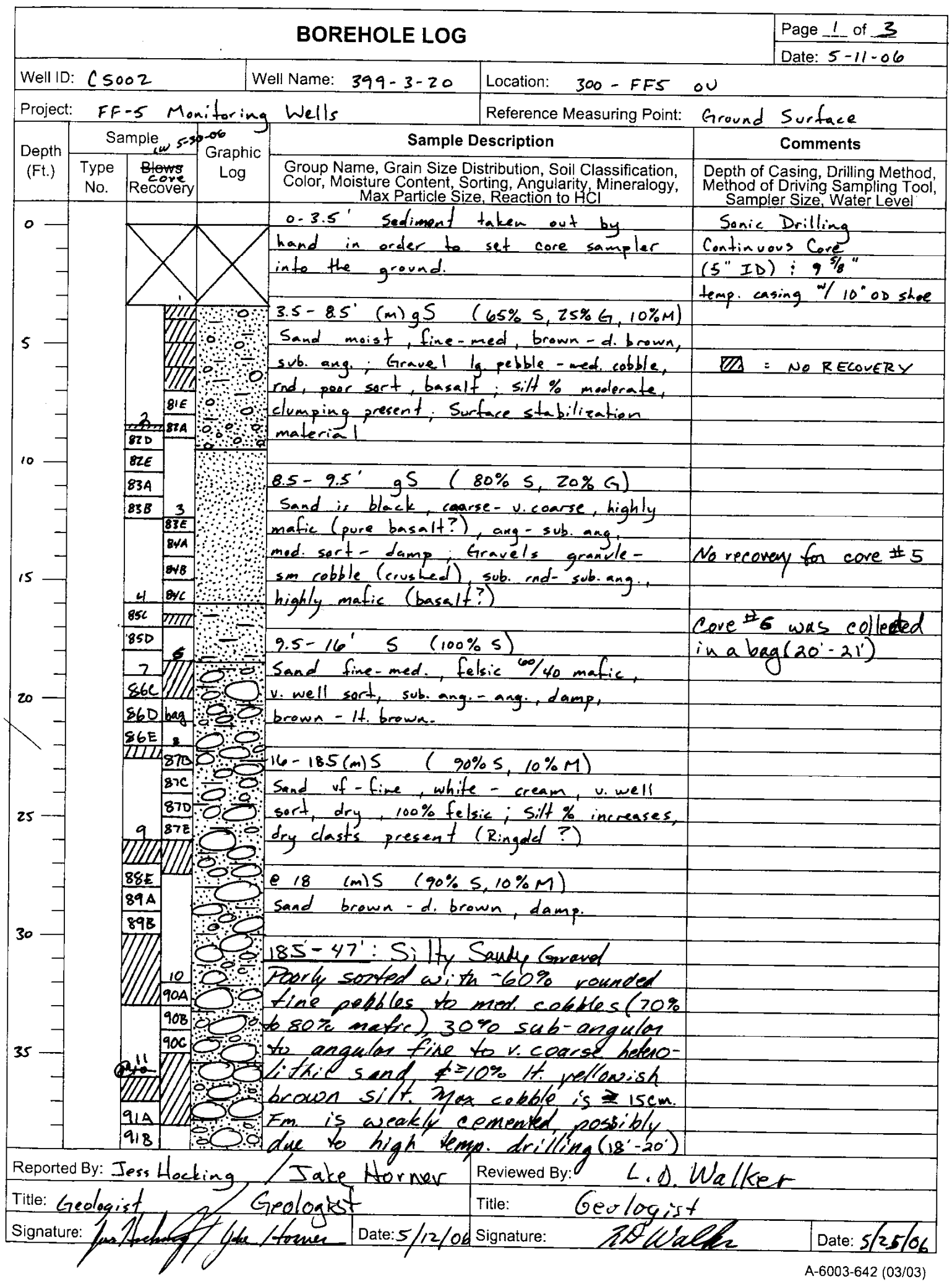




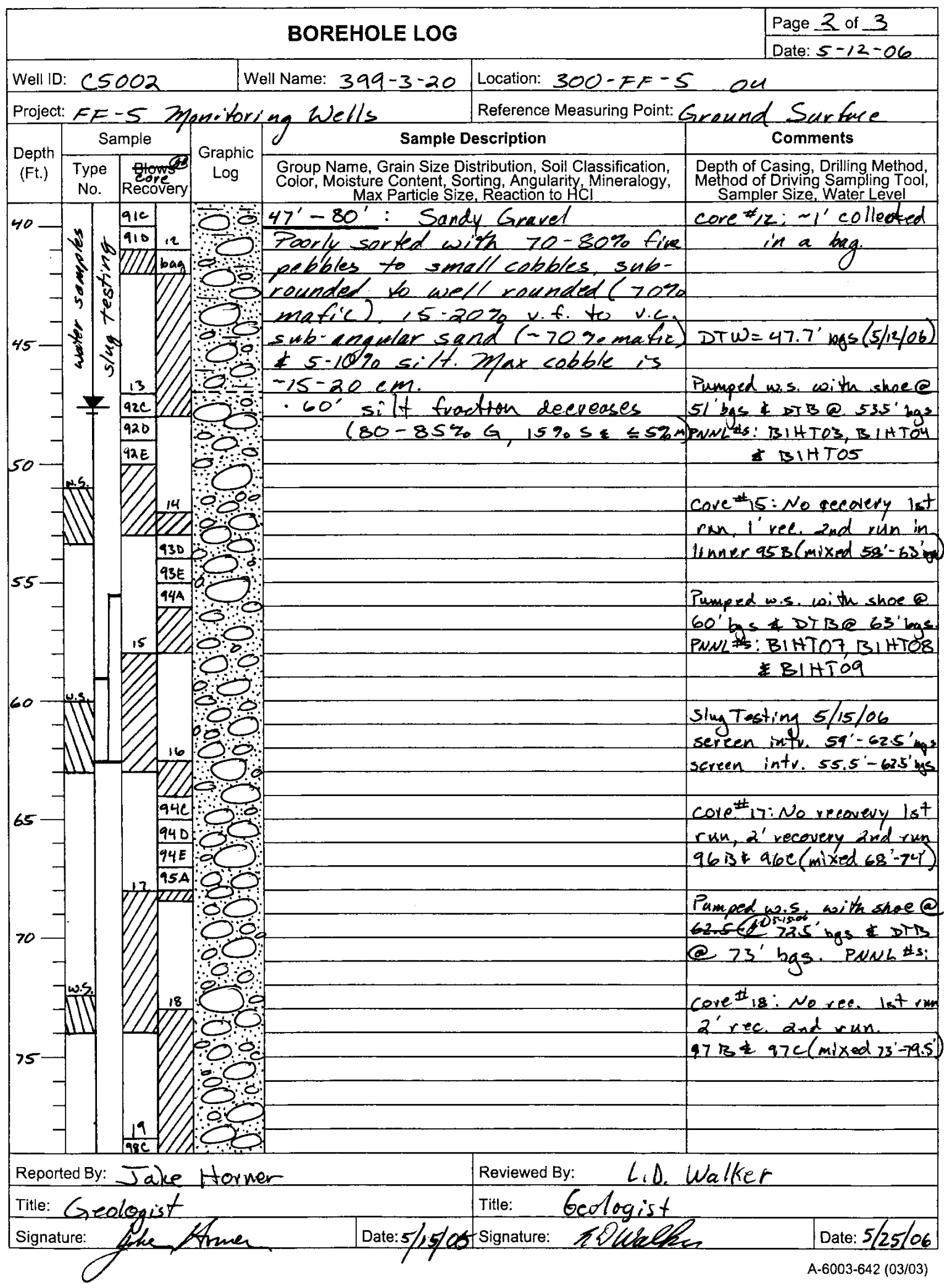




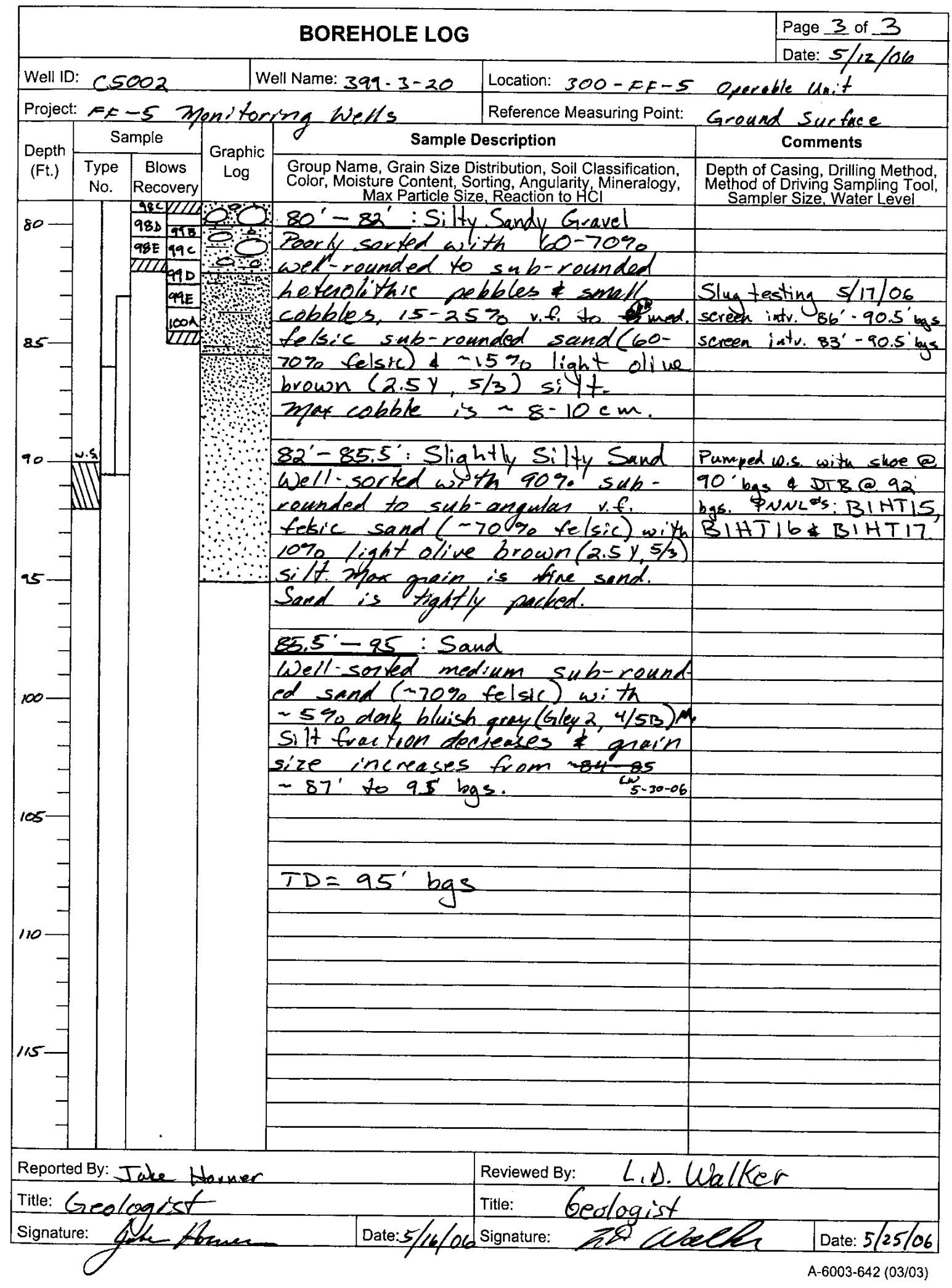




\title{
Well Survey Data Report
}

\author{
Well C4999
}

\begin{tabular}{|c|c|c|c|c|c|c|}
\hline \multicolumn{7}{|c|}{ WELL SURVEY DATA REPORT } \\
\hline \multicolumn{3}{|l|}{ Project: } & \multicolumn{4}{|c|}{$\begin{array}{l}\text { Prepared By: S. Wray } \\
\text { Company: }\end{array}$} \\
\hline \multicolumn{3}{|c|}{ Date Requested: $7 / 31 / 06$} & \multicolumn{4}{|c|}{ Requestor: Scott Worley (FGG) } \\
\hline \multicolumn{3}{|c|}{ Date of Survey: $8 / 03 / 06$} & \multicolumn{4}{|c|}{ Surveyor: S. Wray FGG Survey Dept. } \\
\hline \multicolumn{3}{|c|}{ ERC Point of Contact: } & \multicolumn{4}{|c|}{$\begin{array}{c}\text { Survey Co. Point of Contact: } \\
\text { L. A. Henke, P.L.S. }\end{array}$} \\
\hline \multirow{4}{*}{\multicolumn{3}{|c|}{$\begin{array}{l}\text { Description of Work: } \\
\text { Civil Survey of Groundwater Monitoring } \\
\text { Well \#C4999 (399-3-18) }\end{array}$}} & \multicolumn{4}{|c|}{ Horizontal Datum: NAD83(91) } \\
\hline & & & \multicolumn{4}{|c|}{ Vertical Datum: NAVD88 } \\
\hline & & & \multicolumn{4}{|c|}{ Units: $\quad$ METERS } \\
\hline & & & \multicolumn{4}{|c|}{ Hanford Area Designation: $300 \mathrm{~A}$} \\
\hline \multicolumn{7}{|c|}{ Coordinate Systom: Washington State Plane Coordinates (South Zone) } \\
\hline \multicolumn{7}{|c|}{ Horizontal Control Monuments; N323 (USC\&GS), 300-70 (FGG) } \\
\hline \multicolumn{7}{|c|}{ Vertical Control Monuments: $300-28$ (FGG), $300-60$ (FGG) } \\
\hline Well ID & Well Name & Easting & & Northing & Elevation & \\
\hline C4999 & $399-3-18$ & 594464.7 & & 116019.98 & & Center of Casing \\
\hline & & & & & 118.620 & $\begin{array}{l}\text { Top Pump Baseplate. } \\
\text { N. Edge }\end{array}$ \\
\hline & & & & & 118.615 & Top Casing, N. Edge \\
\hline & & & & & 117.680 & Brass Survey Marker \\
\hline \multicolumn{7}{|c|}{$\begin{array}{l}\text { Notes: } \\
\begin{array}{l}\text { EQUIPMENT USED: TRIMBLE GPS } 5800 \text { RTK } \\
\text { TRIMBLE DiNi } 12 \text { LEVEL }\end{array}\end{array}$} \\
\hline \multicolumn{7}{|c|}{$\begin{array}{l}\text { Surveyor Statement: } \\
\text { I, Larry A. Henke, a Professional Land Surveyor registered } \\
\text { in the State of Washington (Registration No. } 38975 \text { ), hereby } \\
\text { certify that this report is based on a fieid survey performed in } \\
\text { August, } 2006 \text { under my direct supervision, and that the data } \\
\text { contained here is true and correct. }\end{array}$} \\
\hline
\end{tabular}

Original to:

Distribution by DIS: 
Well C5000

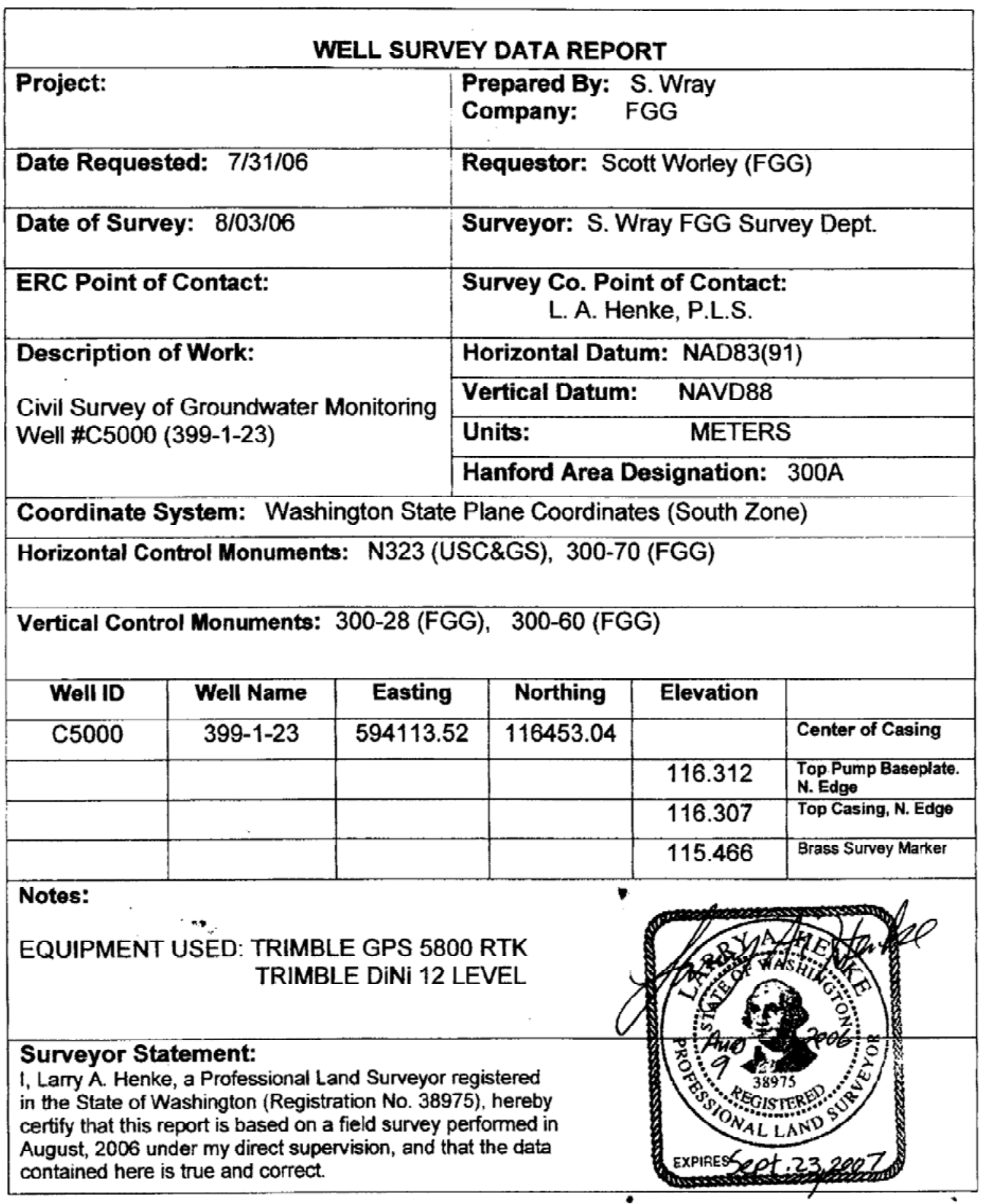

Original to:

Distribution by DIS: 
Well C5001

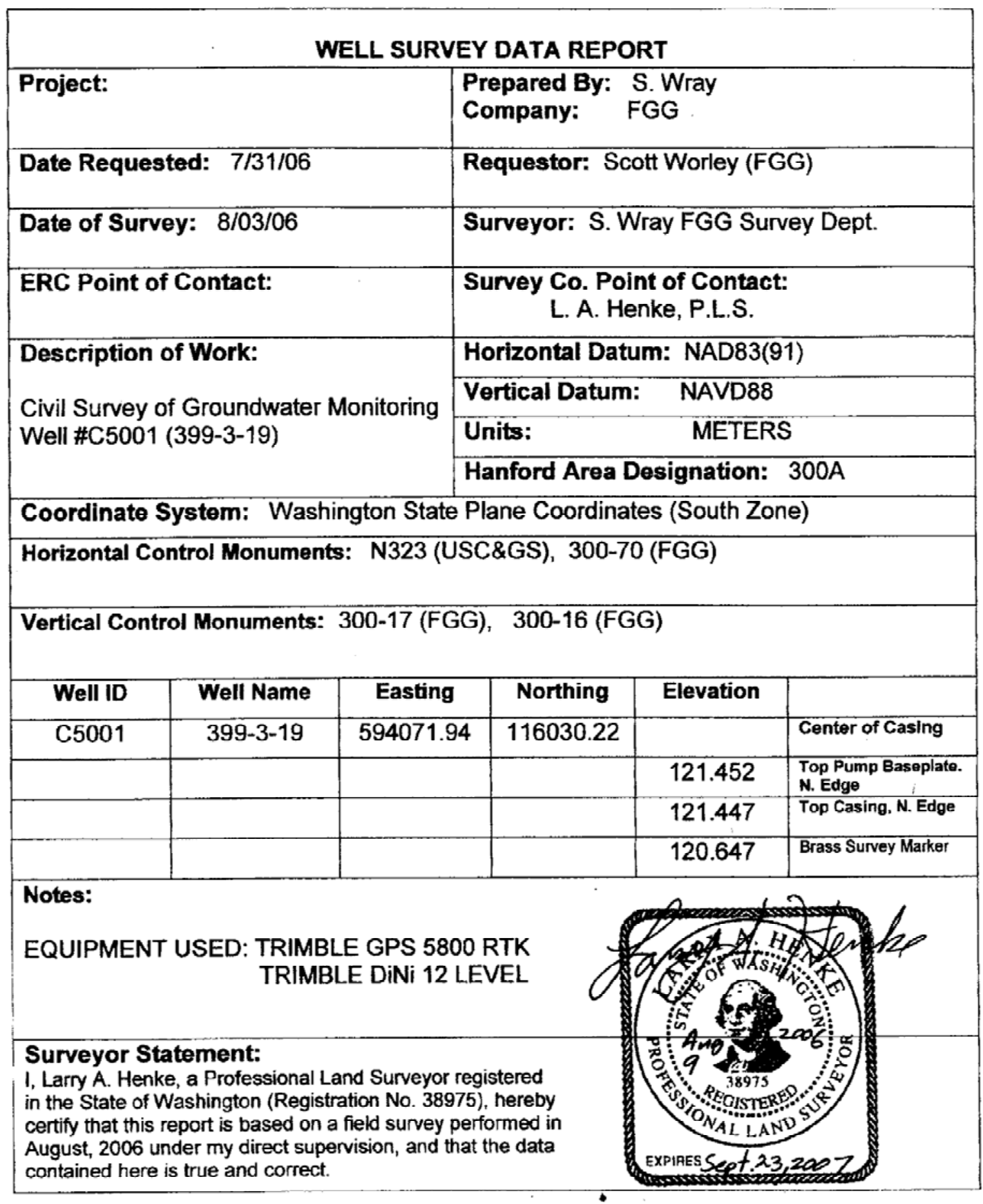

Original to:

Distribution by DIS: 
Well C5002

\begin{tabular}{|c|c|c|c|c|c|c|}
\hline \multicolumn{7}{|c|}{ WELL SURVEY DATA REPORT } \\
\hline \multicolumn{3}{|l|}{ Project: } & \multicolumn{4}{|c|}{$\begin{array}{l}\text { Prepared By: S. Wray } \\
\text { Company: }\end{array}$} \\
\hline \multicolumn{3}{|c|}{ Date Requested: $7 / 31 / 06$} & \multicolumn{4}{|c|}{ Requestor: Scott Worley (FGG) } \\
\hline \multicolumn{3}{|c|}{ Date of Survey: $8 / 03 / 06$} & \multicolumn{4}{|c|}{ Surveyor: S. Wray FGG Survey Dept. } \\
\hline \multicolumn{3}{|c|}{ ERC Point of Contact: } & \multicolumn{4}{|c|}{$\begin{array}{c}\text { Survey Co. Point of Contact: } \\
\text { L. A. Henke, P.L.S. }\end{array}$} \\
\hline \multirow{4}{*}{\multicolumn{3}{|c|}{$\begin{array}{l}\text { Description of Work: } \\
\text { Civil Survey of Groundwater Monitoring } \\
\text { Well \#C5002 (399-3-20) }\end{array}$}} & \multicolumn{4}{|c|}{ Horizontal Datum: NAD83(91) } \\
\hline & & & \multicolumn{4}{|c|}{\begin{tabular}{|l} 
Vertical Datum: $\quad$ NAVD88 \\
\end{tabular}} \\
\hline & & & \multicolumn{4}{|c|}{\begin{tabular}{|l} 
Units: $\quad$ METERS \\
\end{tabular}} \\
\hline & & & \multicolumn{4}{|c|}{ Hanford Area Designation: $300 \mathrm{~A}$} \\
\hline \multicolumn{7}{|c|}{ Coordinate System: Washington State Plane Coordinates (South Zone) } \\
\hline \multicolumn{7}{|c|}{ Horizontal Control Monuments: N323 (USC\&GS), 300-70 (FGG) } \\
\hline \multicolumn{7}{|c|}{ Vertical Control Monuments: $300-28$ (FGG), $300-60$ (FGG) } \\
\hline Well ID & Well Name & Easting & & Northing & Elevation & \\
\hline C5002 & $399-3-20$ & 594375. & & 115849.70 & & Center of Casing \\
\hline & & & & & 121.281 & $\begin{array}{l}\text { Top Pump Baseplate. } \\
\text { N. Edge }\end{array}$ \\
\hline & & & & & 121.276 & Top Casing, N. Edge \\
\hline & & & & & 120.448 & Brass Survey Marker \\
\hline \multicolumn{7}{|c|}{$\begin{array}{l}\text { Notes: } \\
\text { EQUIPMENT USED: TRIMBLE GPS } 5800 \text { RTK } \\
\text { TRIMBLE DiNi } 12 \text { LEVEL }\end{array}$} \\
\hline \multicolumn{7}{|c|}{$\begin{array}{l}\text { Surveyor Statement: } \\
\text { I, Larry A. Henke, a Professional Land Surveyor registered } \\
\text { in the State of Washington (Registration No. 38975), hereby } \\
\text { certify that this report is based on a field survey performed in } \\
\text { August, } 2006 \text { under my direct supervision, and that the data } \\
\text { contained here is true and correct. }\end{array}$} \\
\hline
\end{tabular}

Original to:

Distribution by DIS: 


\section{Well Construction Summary Report}

\section{Well C4999}

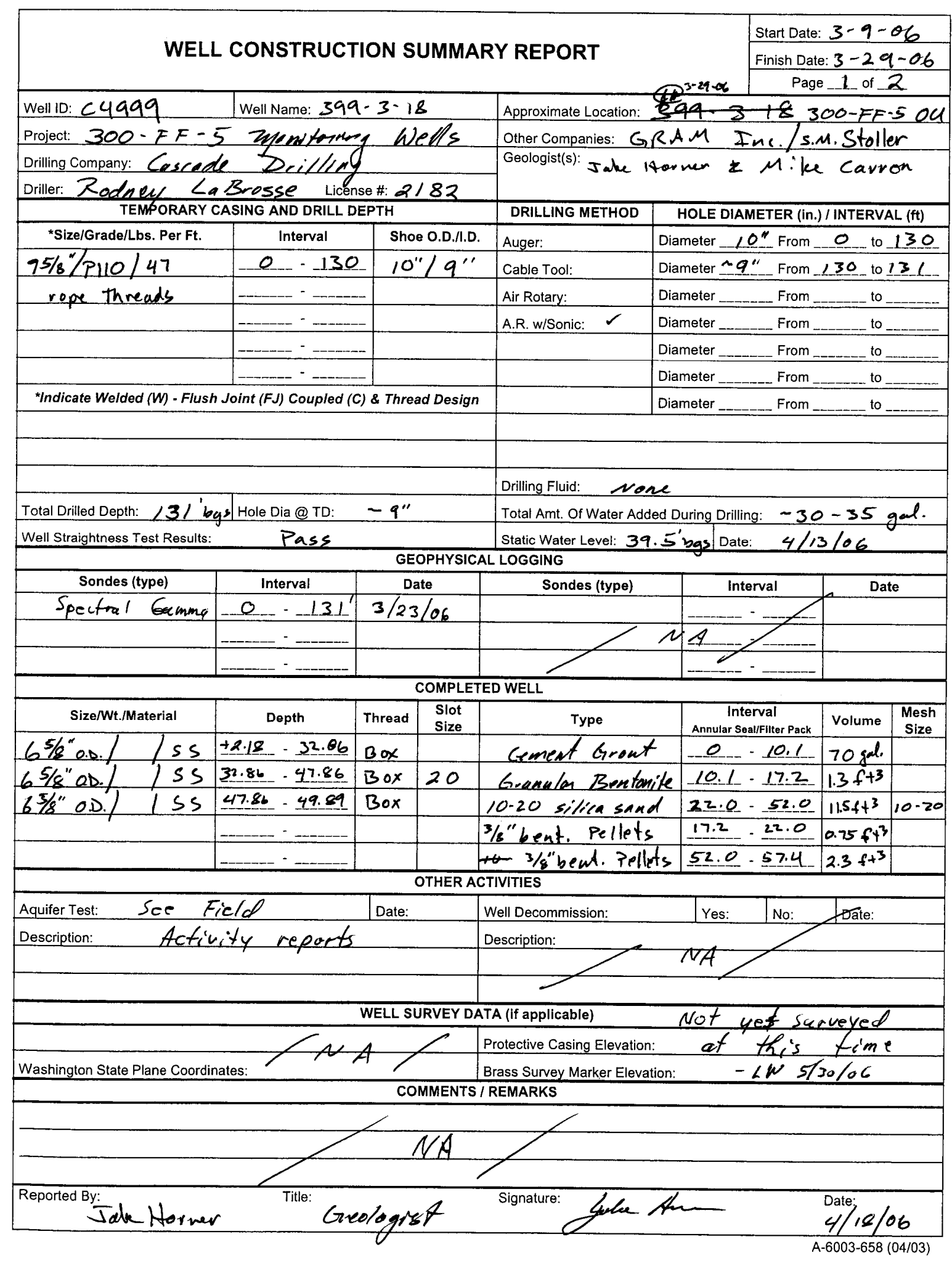


WELL CONSTRUCTION SUMMARY REPORT

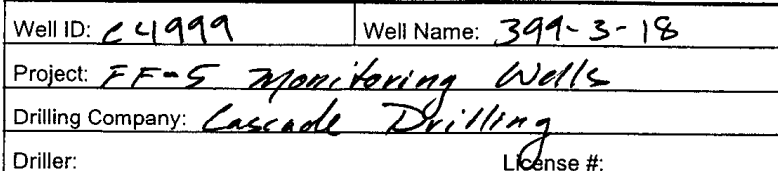

TEMPORARY CASING AND DRILL DEPTH
Approximate Location: $300-F F-504$ Other Companies: GRAM ImC Geologist(s):

Jake Horner \& Mike Carron

\begin{tabular}{|c|c|c|c|c|c|c|}
\hline \multicolumn{3}{|c|}{ TEMPORARY CASING AND DRILL DEPTH } & DRILLING METHOD & \multicolumn{3}{|c|}{ HOLE DIAMETER (in.) / INTERVAL (ft) } \\
\hline \multirow[t]{6}{*}{ "Size/Grade/Lbs. Per Ft. } & Interval & Shoe O.D.I.D. & Auger: & \multicolumn{3}{|c|}{ Diameter_____ From ______ to } \\
\hline & er. - & & Cable Tool: & \multicolumn{3}{|c|}{ Diameter ___ From $\_$to } \\
\hline & $-\ldots$ & & Air Rotary: & \multicolumn{3}{|c|}{ Diameter ___ From _____. to } \\
\hline & - & & A,R. w/Sonic: & \multicolumn{3}{|c|}{ Diameter From _____ to } \\
\hline & - & & & \multicolumn{3}{|c|}{ Eiameter _______ From _______ to } \\
\hline & - & & & \multicolumn{3}{|c|}{ Diameter______ From ________ to ________ } \\
\hline \multicolumn{3}{|c|}{${ }^{*}$ Indicate Welded (W) - Flush Joint (FJ) Coupled (C) \& Thread Design } & & \multicolumn{3}{|c|}{ Diameter_____ From _____ to } \\
\hline \multicolumn{7}{|c|}{$\mu$} \\
\hline & & & \multicolumn{4}{|l|}{ Drilling Fluid: } \\
\hline Total Drilled Depth: & Hole Dia @ JO: & & \multicolumn{4}{|c|}{ Total Amt. Of Water Added During Drilling: } \\
\hline \multicolumn{3}{|l|}{ Well Straightness Test Results: } & \multirow{2}{*}{ Static Water Lovel: } & \multicolumn{3}{|l|}{\begin{tabular}{l|l|} 
& Date: \\
\end{tabular}} \\
\hline \multicolumn{6}{|c|}{ GEOPHYSICAL LOGGING } & \\
\hline \multirow[t]{4}{*}{ Sondes (type) } & Interval & Date & \multirow[t]{2}{*}{ Sondes (type) } & Interval & \multicolumn{2}{|c|}{ Date } \\
\hline & 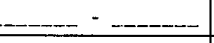 & & & - & & \\
\hline & - - & & & - - - - - & & \\
\hline & $+\ldots$ & & & 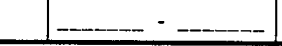 & & \\
\hline \multicolumn{7}{|c|}{ COMPLETED WELL } \\
\hline \multirow[t]{6}{*}{ Size/Wt./Material } & Depth & \begin{tabular}{l|} 
Slot \\
Size
\end{tabular} & Type & $\begin{array}{c}\text { Interval } \\
\text { Annular SealfFilter Pack }\end{array}$ & Volume & $\begin{array}{l}\text { Mesh } \\
\text { Size }\end{array}$ \\
\hline & 드._- & & silica send & $57.4-127.0$ & $498+3$ & $10-20$ \\
\hline & 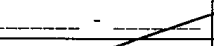 & & $3 / \Omega^{\prime \prime}$ caated bent pe & 1 tet $1220-131.0$ & 5or & \\
\hline & $24-1$ & & & - & $0.5 \mathrm{ft}^{3}$ & \\
\hline & $a_{-}$ & & & - & & \\
\hline & - & & & - & & \\
\hline
\end{tabular}

\begin{tabular}{|l|l|l|l|l|l|}
\hline Aquifer Test: & Date: & Well Decommission: & Yes: & No: & Date: \\
\hline Description: & & Description: & \\
\hline & & & \\
\hline
\end{tabular}

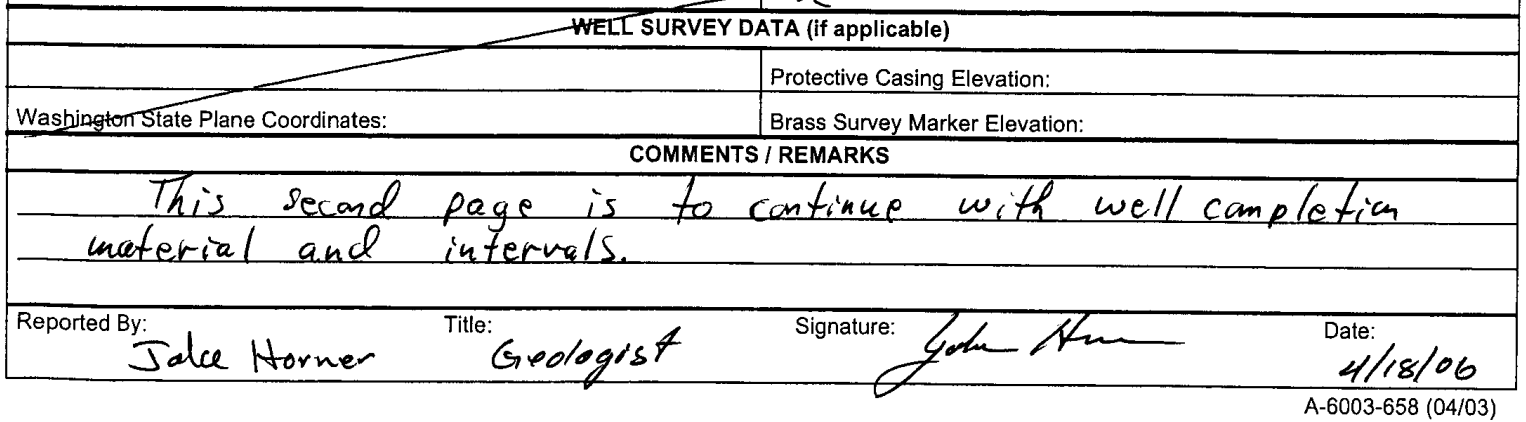


WELL ATTRIBUTES REPORT

FIELD ORDER NO

WELL ID

WELL NAME

HOST WELL ID

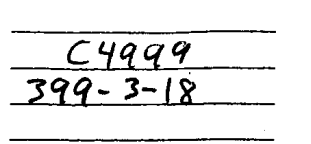

DRILL DATE
CONST.DATE
CONST DEPTH

$\frac{\frac{3-9-06}{3-29-06}}{49.89^{\prime} \text { bys }}$

LAST INSPECTION

NORTHING.

EASTING

ELEVATION

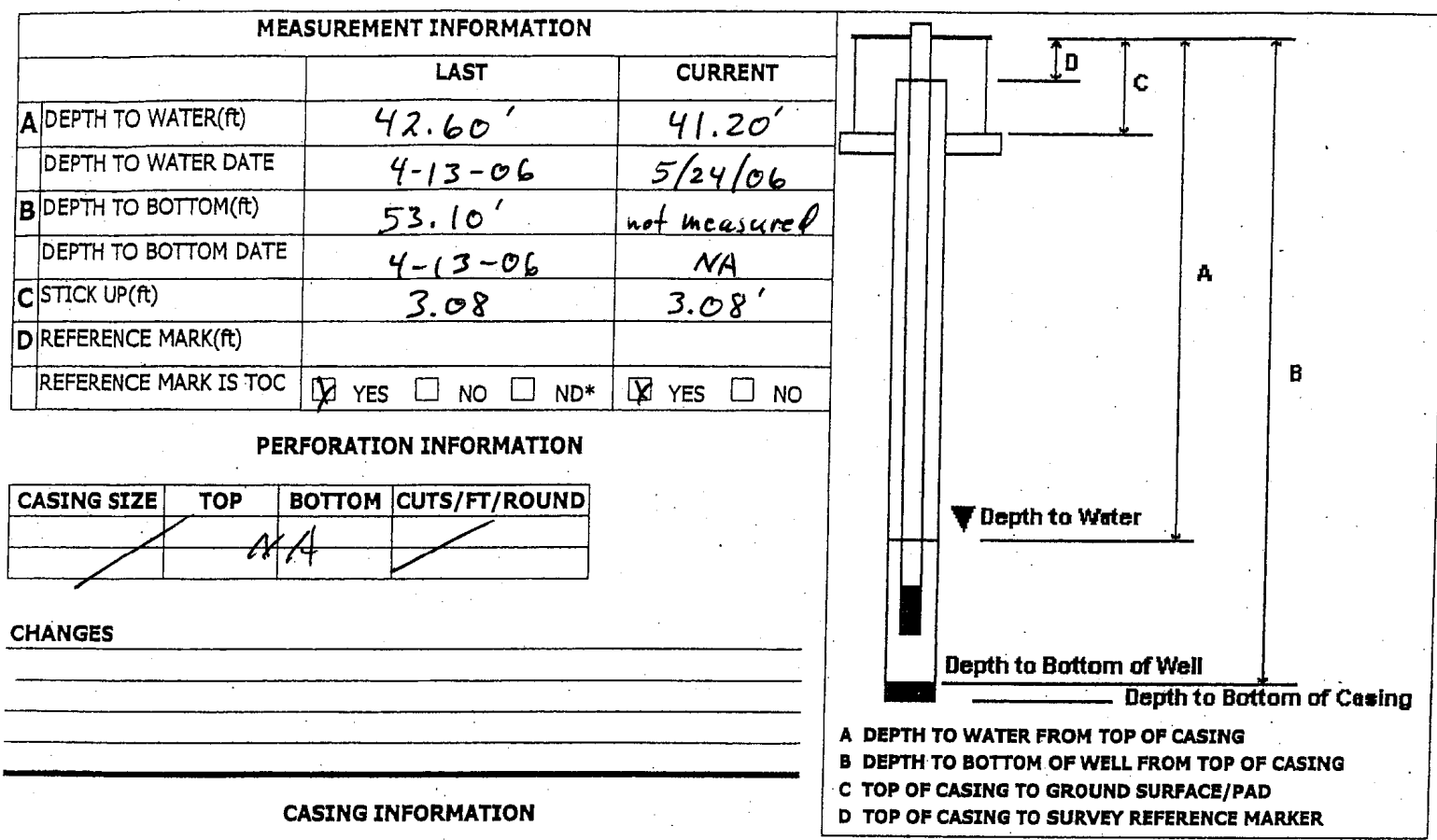

\begin{tabular}{|c|c|c|c|c|c|c|}
\hline SIZE & TOP & BOTTOM & MATERIAL & TYPE & CONNECTION & THICKNESS \\
\hline $6^{\prime \prime} I D$ & 2.18 & 32.86 & 55 & $304 L$ & $F 480$ & $5 \mathrm{Ch} .10$ \\
\hline & & & & & & \\
\hline
\end{tabular}

\section{CHANGES}

SCREEN INFORMATION

\begin{tabular}{|c|c|c|c|c|c|}
\hline SIZE & TOP & BOTTOM & MATERIAL & TYPE & SLOT SIZE \\
\hline $6^{\prime \prime} \Omega D$ & 32.86 & 47.86 & SS & $304 \mathrm{~L}$ & $0.020-\mathrm{in}$ \\
\hline
\end{tabular}

\section{CHANGES}




\section{WELL ATTRIBUTES REPORT}

FIELD ORDER NO

WELL ID

WELL NAME

HOST WELL ID

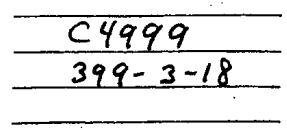

$\begin{array}{ll}\text { DRILL DATE } & \frac{3-9-06}{3-29-06} \\ \text { CONST DATE } & \frac{39.896 \mathrm{bg}}{49.89^{\prime}}\end{array}$

LAST INSPECTION

NORTHING

EASTING

ELEVATION

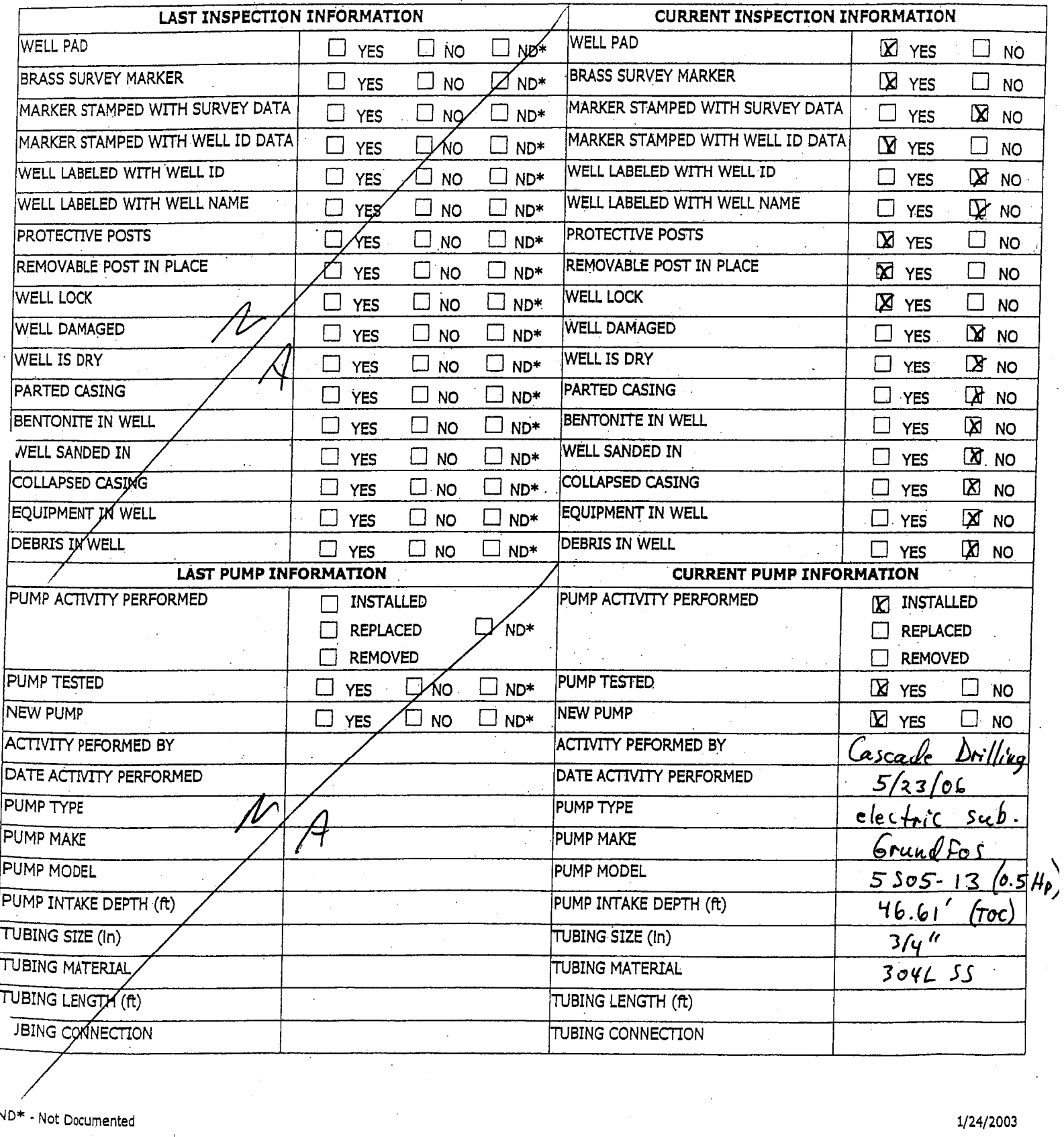




\section{Well C5000}

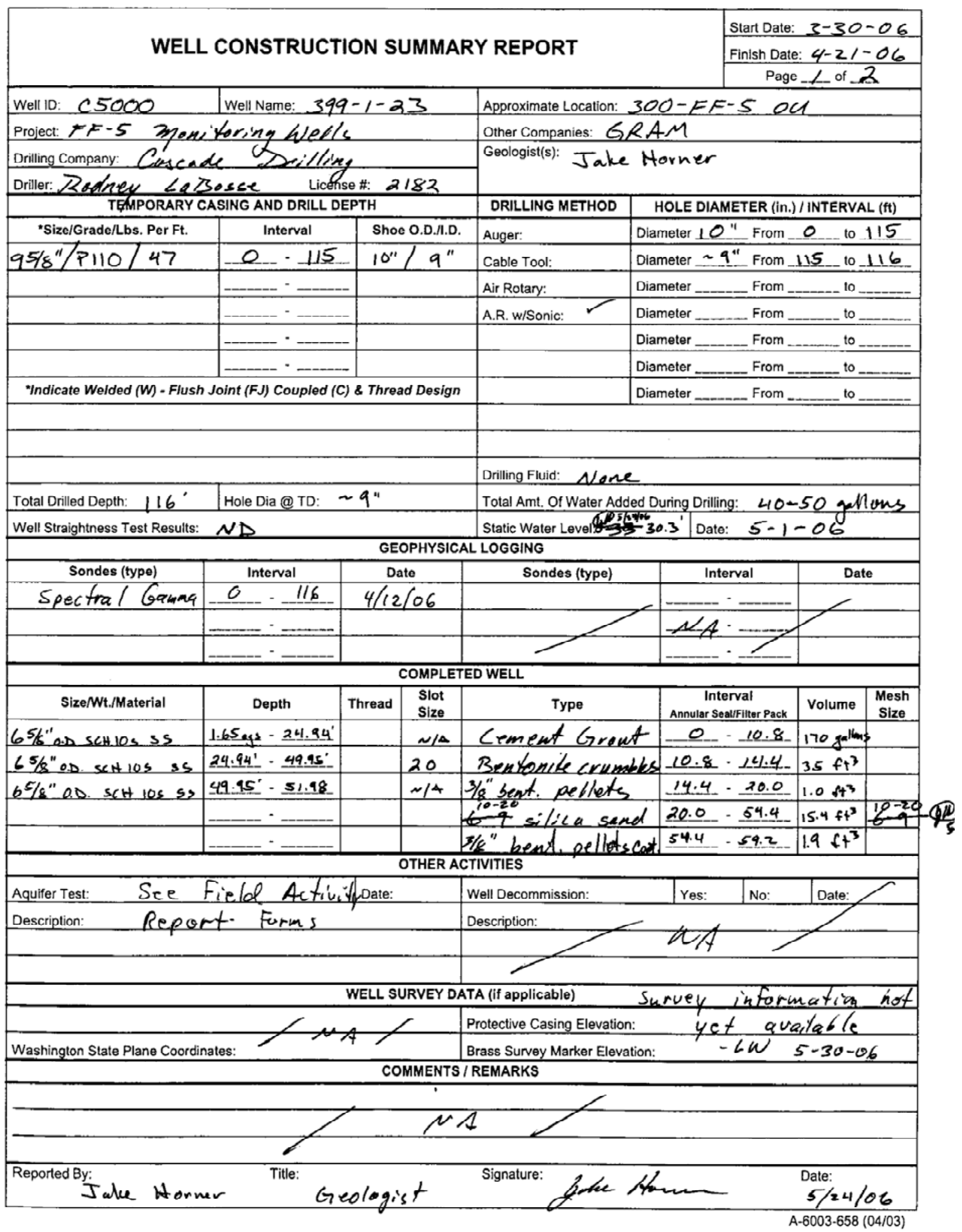




\section{WELL CONSTRUCTION SUMMARY REPORT}

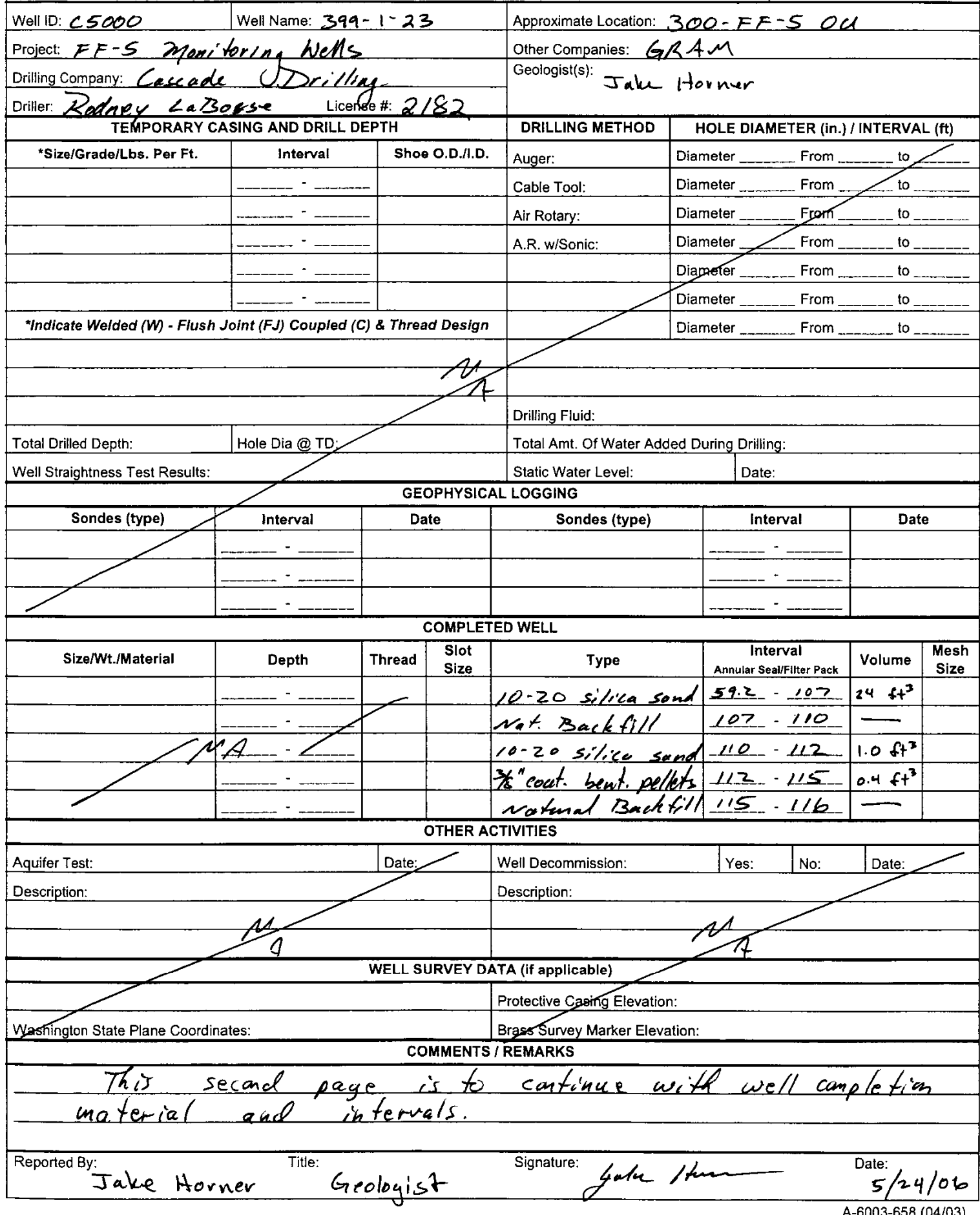


WELL ATTRIBUTES REPORT

(1) FIELD ORDER NO

WELL ID

WELL NAME

HOST WELL ID

\begin{tabular}{ll}
$\frac{C 5000}{399-1-23}$ & $\begin{array}{l}\text { DRILL DATE } \\
\text { CONST DATE }\end{array}$ \\
CONST DEPTH & $\frac{3-30-06}{4-21-06}$ \\
\hline
\end{tabular}

LAST INSPECTION

NORTHING

EASTING

ELEVATION

\begin{tabular}{|c|c|c|}
\hline \multicolumn{3}{|c|}{ MEASUREMENT INFORMATION } \\
\hline & LAST & CURRENT \\
\hline A DEPTH TO WATER( $\mathrm{f}$ ) & $33.0^{\prime}$ & $33.34^{\prime}$ \\
\hline DEPTH TO WATER DATE & $5 / 1 / 06$ & $5 / 24 / 06$ \\
\hline 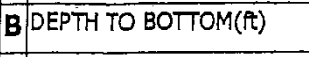 & $53.8^{\prime}$ & not meas. \\
\hline DEPTH TO BOTTOM DATE & $5 / 1 / 06$ & $N A$ \\
\hline C STICK UP(f) & 2.73 & $2.73^{\prime}$ \\
\hline \begin{tabular}{l|l|l}
$D$ & REFERENCE MARK(ft) \\
\end{tabular} & & \\
\hline REFERENCE MARK IS TOC & $\square$ YES $\square$ NO $\square$ ND* & $\square$ YES $\square$ NO \\
\hline
\end{tabular}

PERFORATION INFORMATION

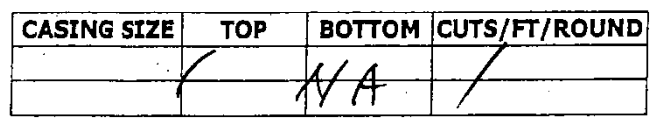

\section{CHANGES}

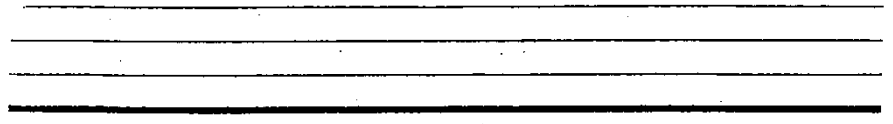

CASING INFORMATION

\begin{tabular}{|c|c|c|c|c|c|c|}
\hline SIZE & TOP & BOTTOM & MATERIAL & TYPE & CONNECTION & THICKNESS \\
\hline $6^{\prime \prime} I D$ & $1.65^{\prime}$ & $24.95^{\prime}$ & SS & $304 \mathrm{~L}$ & F480 & $5 \mathrm{C} .10$ \\
\hline
\end{tabular}

\section{CHANGES}

\section{SCREEN INFORMATION}

\begin{tabular}{|c|c|c|c|c|c|}
\hline SIZE & TOP & BOTTOM & MATERIAL & TYPE & SLOT SIZE \\
\hline $6^{\text {I }}$ TD & 24.95 & 49.95 & SS & $304 \mathrm{~L}$, wire wrap & $0.020-$ qh. $^{-0}$ \\
\hline
\end{tabular}

\section{CHANGES}




\section{WELL ATTRIBUTES REPORT}

\begin{tabular}{|c|c|c|c|c|}
\hline \multirow[b]{2}{*}{$\begin{array}{l}\text { FIELD ORDER NO } \\
\text { WELL ID } \\
\text { WELL NAME } \\
\text { HOST WELL ID }\end{array}$} & \multirow[b]{2}{*}{$\frac{C 5000}{399-1-23}$} & \multirow[b]{2}{*}{$\begin{array}{l}\text { DRILL DATE } \\
\text { CONST DATE } \\
\text { CONST DEPTH }\end{array}$} & \multirow[b]{2}{*}{$\frac{\frac{3-30-06}{4-21-06}}{51.98^{\prime} 695}$} & \multirow{2}{*}{ W } \\
\hline & & & & \\
\hline \multicolumn{3}{|c|}{ LAST INSPECTION INFORMATION } & \multicolumn{2}{|c|}{ CURRENT INSPECTION INFORMATION } \\
\hline WELL PAD & $\square$ YES & $\square$ No $\square$ ND* & \begin{tabular}{|l|l} 
WELL PAD \\
\end{tabular} & $\triangle$ YES $\square$ NO \\
\hline BRASS SURVEY MARKER & $\square$ YES & $\square$ No $\mathrm{ND}^{*}$ & BRASS SURVEY MARKER & $\nabla$ YES \\
\hline MARKER STAMPED WITH SURVEY DATA & $\square$ YES & $\square \mathrm{NO} \square \mathrm{ND}^{*}$ & MARKER STAMPED WITH SURVEY DATA & $\square$ YES \\
\hline MARKER STAMPED WTTH WELL ID DATA & $\square$ YES & $\square$ No $\square$ ND* & MARKER STAMPED WITH WELL ID DATA & YES \\
\hline WELL LABELED WITH WELL ID & $\square$ YES & $\square$ ND* & WELL LABELED WTTH WELL ID & $\square$ YES \\
\hline WELL LABELED WTTH WELL NAME & $\square$ YES & $\square$ NO $\square$ ND* & WELL LABELED WITH WELL NAME & $\square$ YES $\quad \square$ NO \\
\hline PROTECTIVE POSTS & Q Y YES & $\square$ NO $\square$ ND* & PROTECTIVE POSTS & $\bar{\square}$ YES \\
\hline REMOVABLE POST IN PLACE & $\square$ YES & $\square \mathrm{ND}^{*}$ & REMOVABLE POST IN PLACE & $\triangle$ YES \\
\hline WELL LOCK & $\square$ YES & $\square \mathrm{ND*}$ & WELL LOCK & $\mathbb{Q}$ YES \\
\hline WELL DAMAGED & $\square$ YES & $\square N D^{*}$ & WEL DAMAGED & $\square$ YES $\quad \square$ NO \\
\hline WELL IS DRY & $\square$ YES & $\square \mathrm{ND}^{*}$ & WELL IS DRY & $\square$ YES $\quad$ NO \\
\hline PARTED CASING & $\square$ YES & $\square$ ND* & PARTED CASING & $\square$ YES T NO \\
\hline BENTONITE IN WELL & $\square$ YES & $\square$ NO $\square$ ND* & BENTONITE IN WELL & $\square$ YES \\
\hline WELL SANDED IN & $\square$ YES & $\square$ ND* & WELL SANDED IN & YES \\
\hline COLLAPSED CASIISt & $\square$ YES & $\square$ NO $\square$ ND*, & COLLAPSED CASING & $\square$ YES $\quad$ NO \\
\hline EQUIPMENT IN WELL & $\square$ YES & $\square \mathrm{ND}^{*}$ & EQUIPMENT IN WELL & No \\
\hline DEBRIS IN WVELL & $\square$ YES & $\square \mathrm{ND}^{*}$ & DEBRIS IN WELL & $\square$ YES \\
\hline \multicolumn{3}{|c|}{ LAST PUMP INFORMATION } & \multicolumn{2}{|c|}{ CURRENT PUMP INFORMATION } \\
\hline \begin{tabular}{|l|l|} 
PUMP ACTVITY PERFORMED & \\
\end{tabular} & $\begin{array}{l}\square \text { INSTA } \\
\square \text { REPLA } \\
\square \text { REMO }\end{array}$ & & PUMP ACTIVITY PERFORMED & \begin{tabular}{|l} 
INSTALED \\
$\square$ REPLACED \\
$\square$ REMOVED \\
\end{tabular} \\
\hline PUMP TESTED & $\square$ YES & $\square \mathrm{Ng} . \square \mathrm{ND}^{*}$ & PUMP TESTED & $\square$ YES $\square$ NO \\
\hline NEW PUMP & $\square$ YES & $\square / \mathrm{NO} \square \mathrm{ND}^{*}$ & NEW PUMP & $\triangle$ YES $\square$ NO \\
\hline ACTTVITY PEFORMED BY & & & ACTIVITY PEFORMED BY & Cascade Drillans \\
\hline DATE ACTIVTY PERFORMED & & & DATE ACTIVTYY PERFORMED & $5 / 23 / 06$ \\
\hline PUMP TYPE & 1 & & PUMP TYPE & electric sub \\
\hline PUMP MAKE & A & & PUMP MAKE & Grundfos \\
\hline PUMP MODEL & & & PUMP MODEL & $5505-13(0.5 \mathrm{H}$ \\
\hline DUMP INTAKE DEPTH ( $(\mathrm{t})$ & & & PUMP INTAKE DEPTH (tt) & $46.6^{\circ}(\mathrm{Toc})$ \\
\hline TUBING SIZE (In) & & & TUBING SIZE (In) & $3 / 4^{\prime \prime}$ \\
\hline UUING MRTERIAL & & & TUBING MATERIAL & SS $304 \mathrm{C}$ \\
\hline TUEING LENGTH (f) & & & TUBING LENGTH (f̂t) & \\
\hline JBING CONNGETION & & & TUBING CONNECTION & \\
\hline
\end{tabular}




\section{Well C5001}

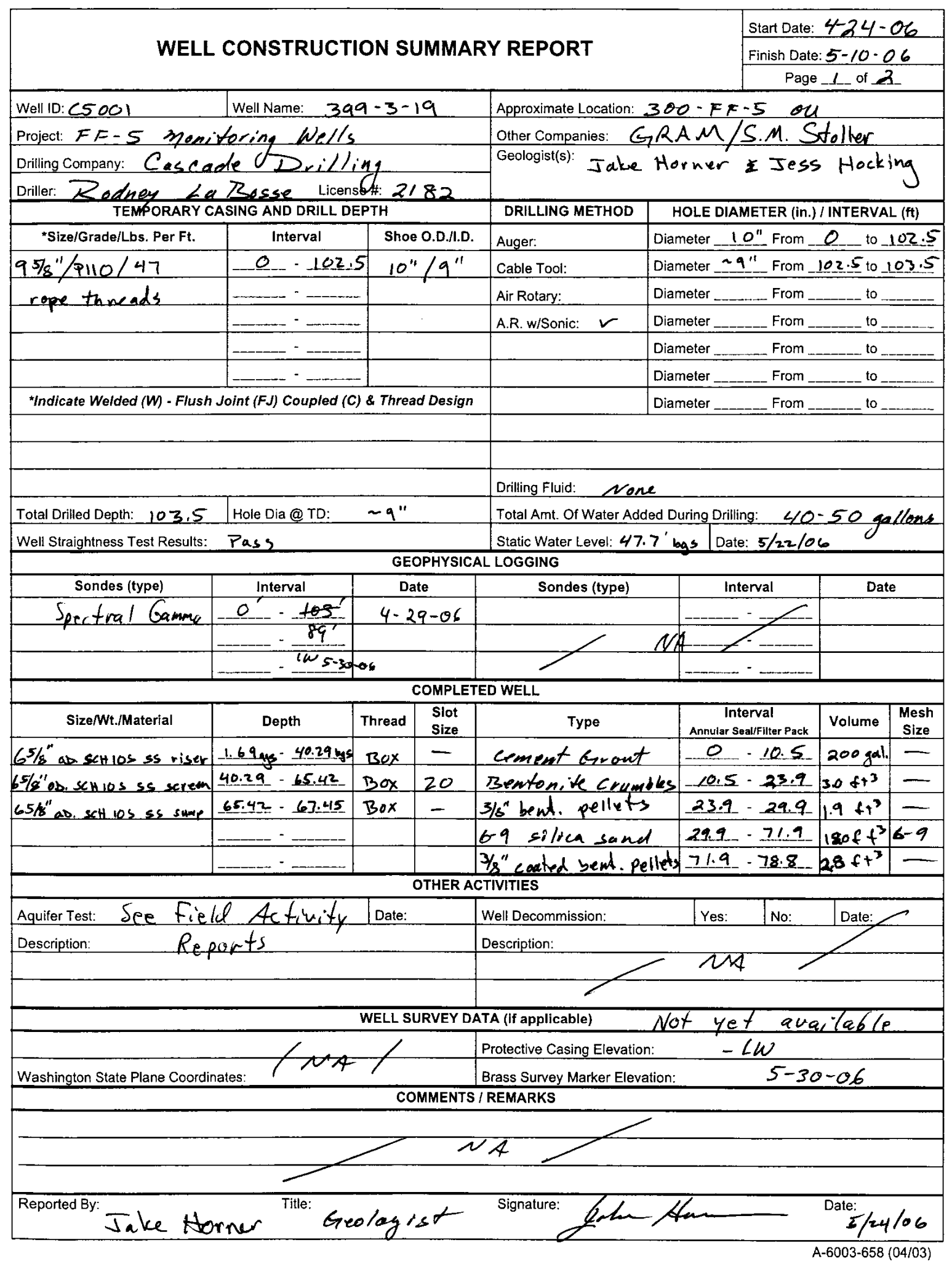




\section{WELL CONSTRUCTION SUMMARY REPORT}

Page 2 of 23

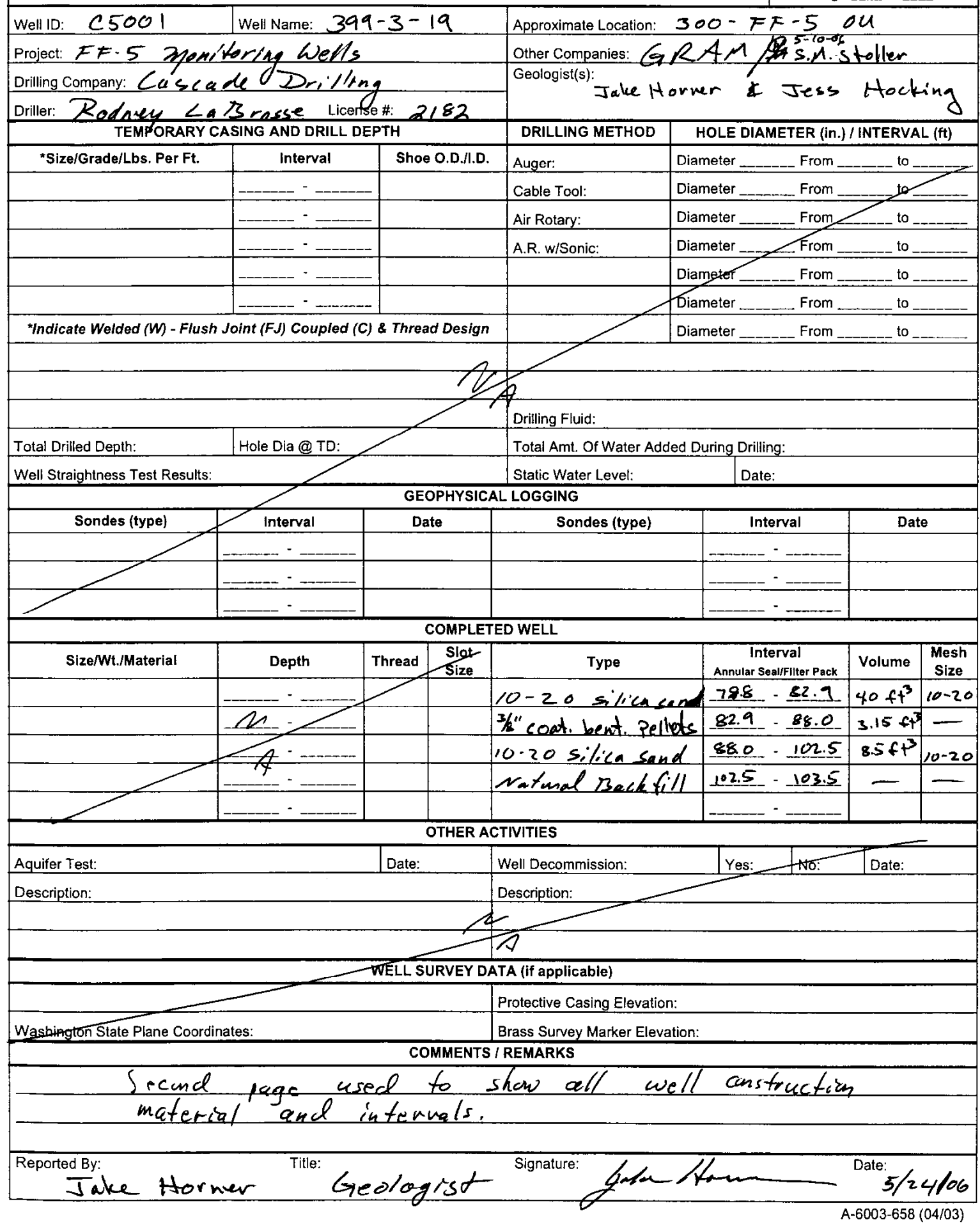


WELL ATTRIBUTES REPORT

FIELLD ORDER NO

WELL ID

WELL NAME

HOST WELL ID

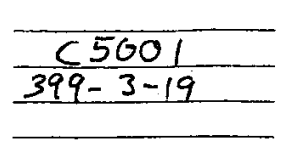

DRILL DATE
CONST DATE
CONST DEPTH

$4-24-06$

LAST INSPECTION

NORTHING

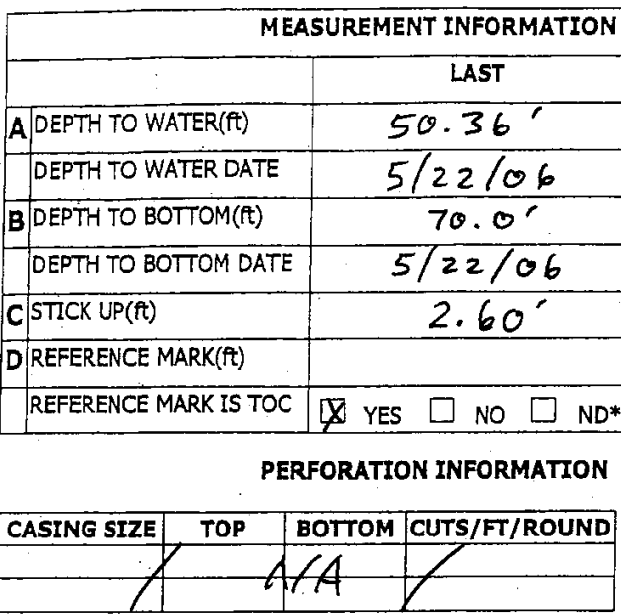

\section{CHANGES}

(2)

\begin{tabular}{|c|c|}
\hline CURRENT \\
\hline 50.33 \\
\hline $5 / 24 / 06$ \\
\hline nof meas \\
\hline$N A$ \\
\hline 2.60 \\
\hline$X$ YES $\square$ NO \\
\hline
\end{tabular}

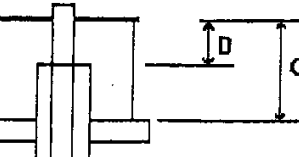

$\longrightarrow$

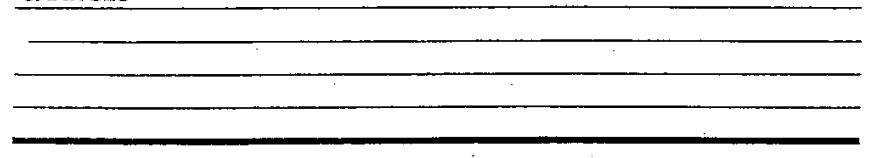

CASING INFORMATION

Depth to Woter

Deph to wher.

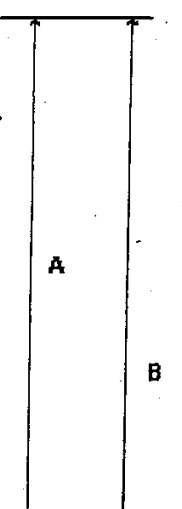

BOTTOM MATERIAL

\begin{tabular}{|c|c|c|c|c|c|c|}
\hline SIZE & TOP & BOTTOM & MATERIAL & TYPE & CONNECTION & THICKNESS \\
\hline $6^{\prime \prime} I D$ & $1.69^{\prime}$ & $40.29^{\prime}$ & 55 & $304 L$ & 5480 & $5 C h .10$ \\
\hline
\end{tabular}

\section{CHANGES}

\section{SCREEN INFORMATION}

\begin{tabular}{|c|c|c|c|c|c|}
\hline SIZE & TOP & BOTTOM & MATERIAL & TYPE & SLOT SIZE \\
\hline $6^{\prime \prime}$ ID & 40.29 & 65.42 & SS & $3046 /$ wire wrSP & $0.020-i 4$ \\
\hline & & & & & \\
\hline
\end{tabular}

\section{Changes}




\section{WELL ATTRIBUTES REPORT}

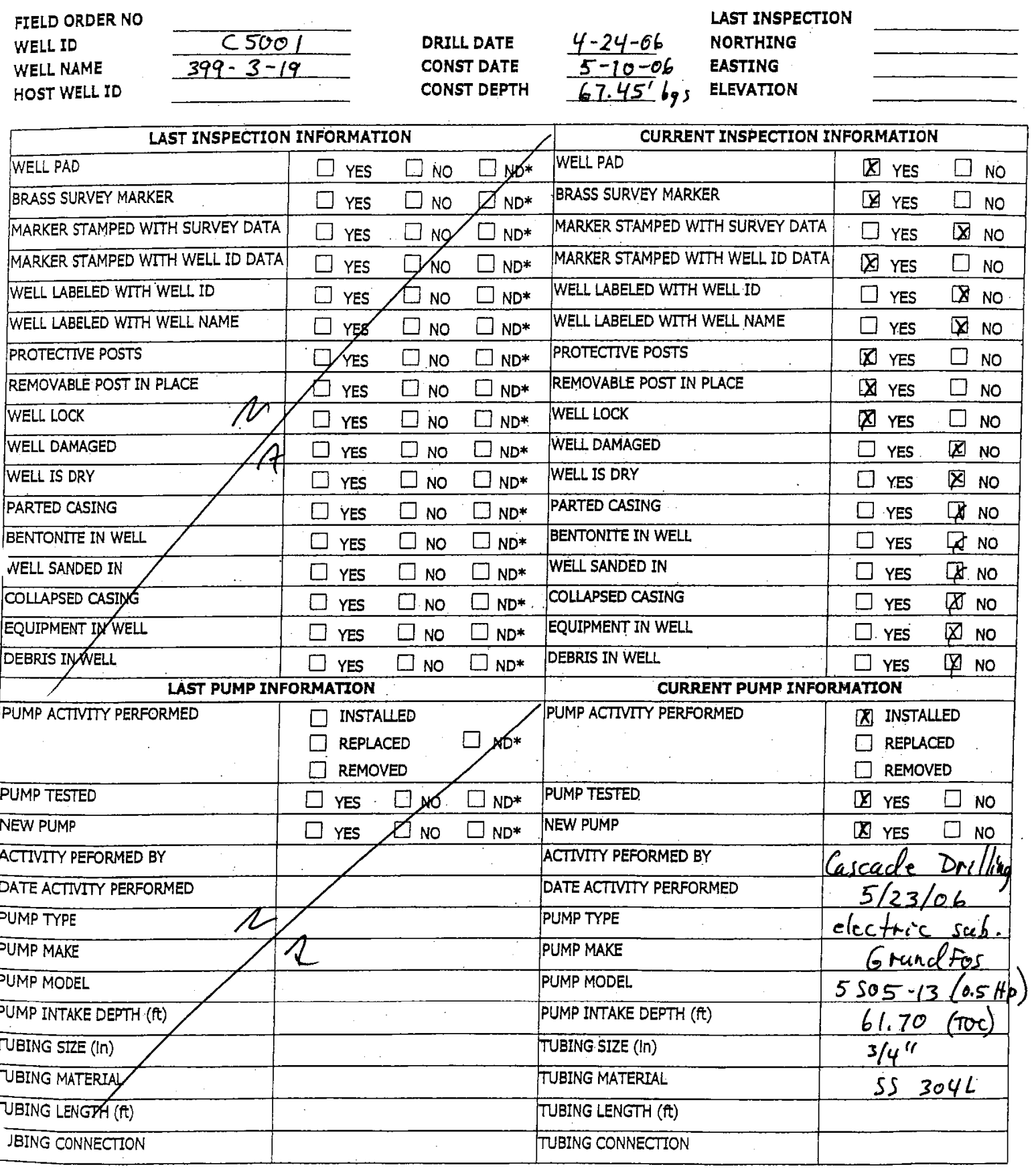




\section{Well C5002}

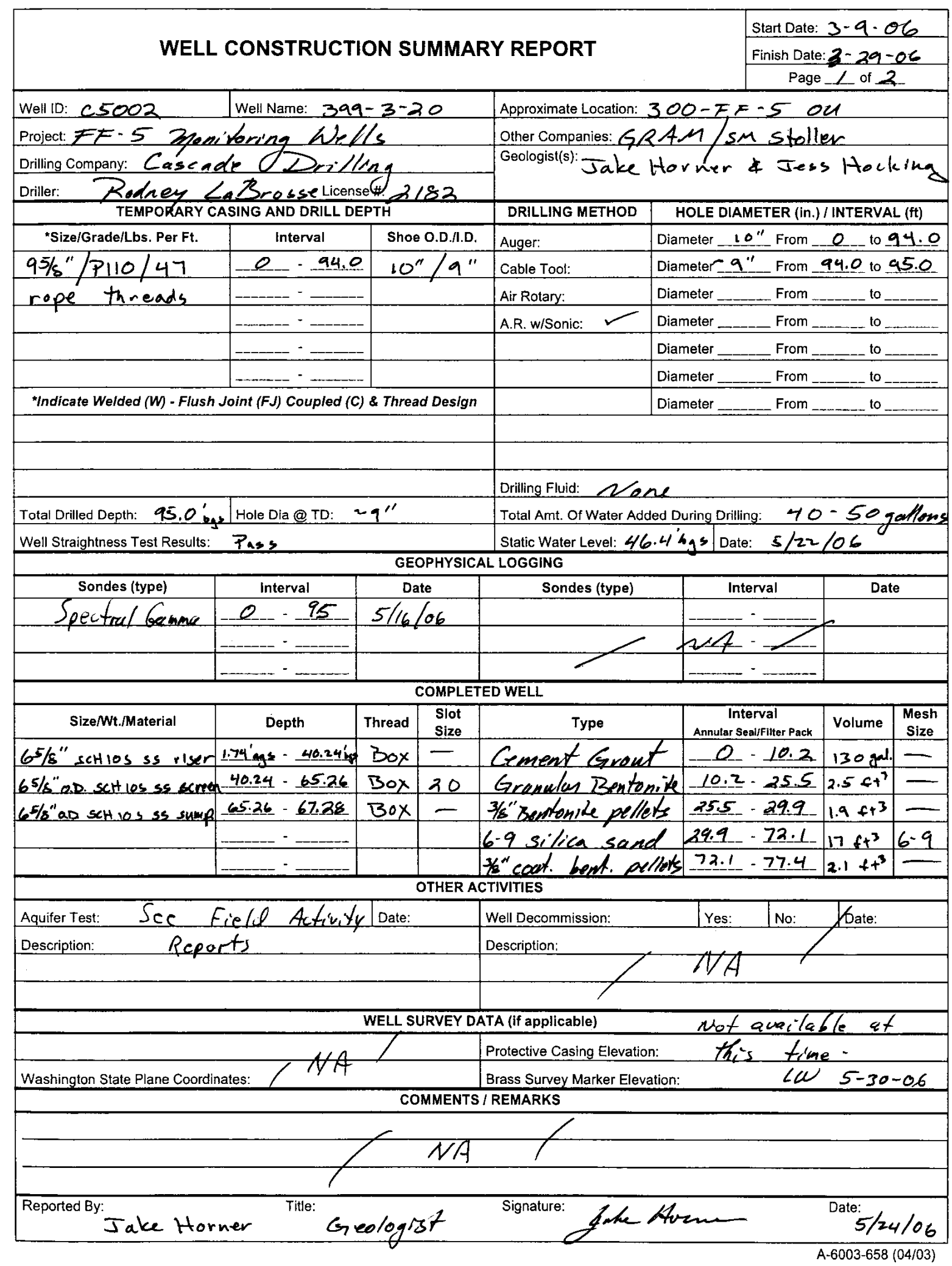


WELL CONSTRUCTION SUMMARY REPORT

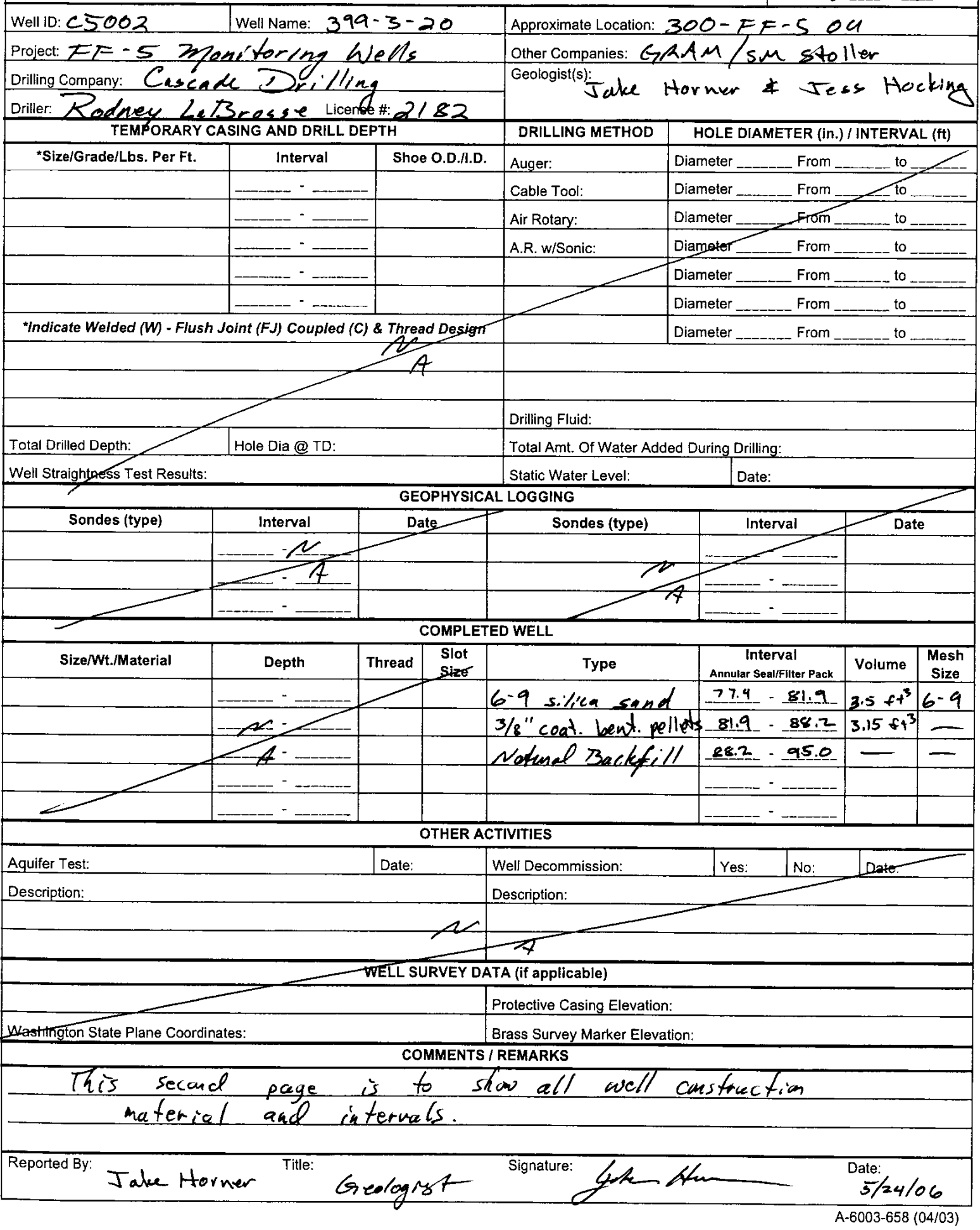




\section{WELL ATTRIBUTES REPORT}

FIELD ORDER NO

WELL ID

WELL NAME

HOST WELL ID

$\frac{65002}{399-3-20}$

$\begin{array}{ll}\text { DRILL DATE } & \frac{3-9-06}{3-29-06} \\ \text { CONST DATE } & \frac{3-29}{67.28^{\prime} 6 g s}\end{array}$

LAST INSPECTION

NORTHING

EASTING

ELEVATION

\begin{tabular}{|c|c|c|}
\hline \multicolumn{3}{|c|}{ MEASUREMENT INFORMATION } \\
\hline & LAST & CURRENT \\
\hline $\begin{array}{l}\text { A DEPTH TO WATER( } \mathrm{f}) \\
\end{array}$ & $49.05^{\prime}$ & $49.95^{\prime}$ \\
\hline DEPTH TO WATER DATE & $5-22-06$ & $5-24-06$ \\
\hline B DEPTH TO BOTTOM(t) & $70.0^{\prime}$ & not measured \\
\hline DEPTH TO BOTTOM DATE & $5.22-06$ & $N A$ \\
\hline 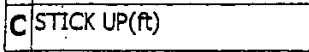 & 2.72 & $2.72^{\prime}$ \\
\hline D REFERENCE MARK(ft) & & \\
\hline REFERENCE MARK IS TOC & $\square$ YES $\square$ NO $\square$ ND* & $\square$ YES $\square$ NO \\
\hline
\end{tabular}

PERFORATION INFORMATION

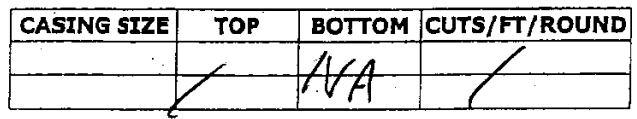

\section{CHANGES}

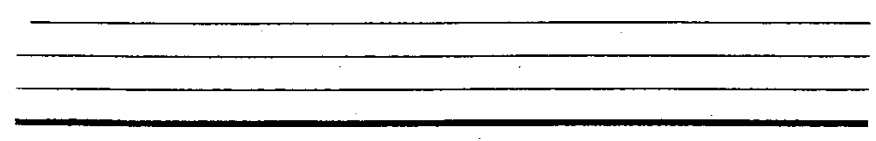

CASING INFORMATION

bgs bgs

\begin{tabular}{|c|c|c|c|c|c|c|}
\hline SIZE & TOP & BOTTOM & MATERIAL & TYPE & CONNECTION & THICKNESS \\
\hline $6 "$ ID & 1.74 & 40.24 & 55 & 3044 & $F 480$ & $5 \mathrm{C} h .10$ \\
\hline
\end{tabular}

\section{CHANGES}

bgs
SCREEN INFORMATION
\begin{tabular}{|c|c|c|c|c|c|}
\hline SIZE & TOP & BOTTOM & MATERIAL & TYPE & SLOT SIZE \\
\hline $6^{\prime \prime I D}$ & 40.24 & 65.26 & SS & $304 / /$ wire wrap & $0.020-$ ih \\
\hline
\end{tabular}

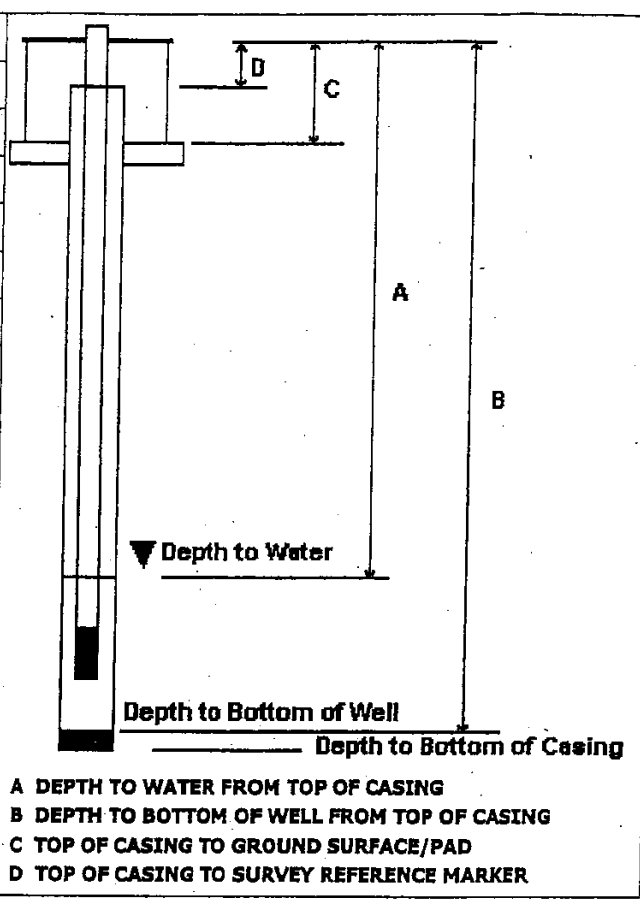

A DEPTH TO WATER FROM TOP OF CASING

B DEPTH TO BOTTOM OF WELL FROM TOP OF CASINO

C TOP OF CASING TO GROUND SURFACE/PAD

CONNECTION

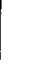

CHANGES 


\section{WELL ATTRIBUTES REPORT}

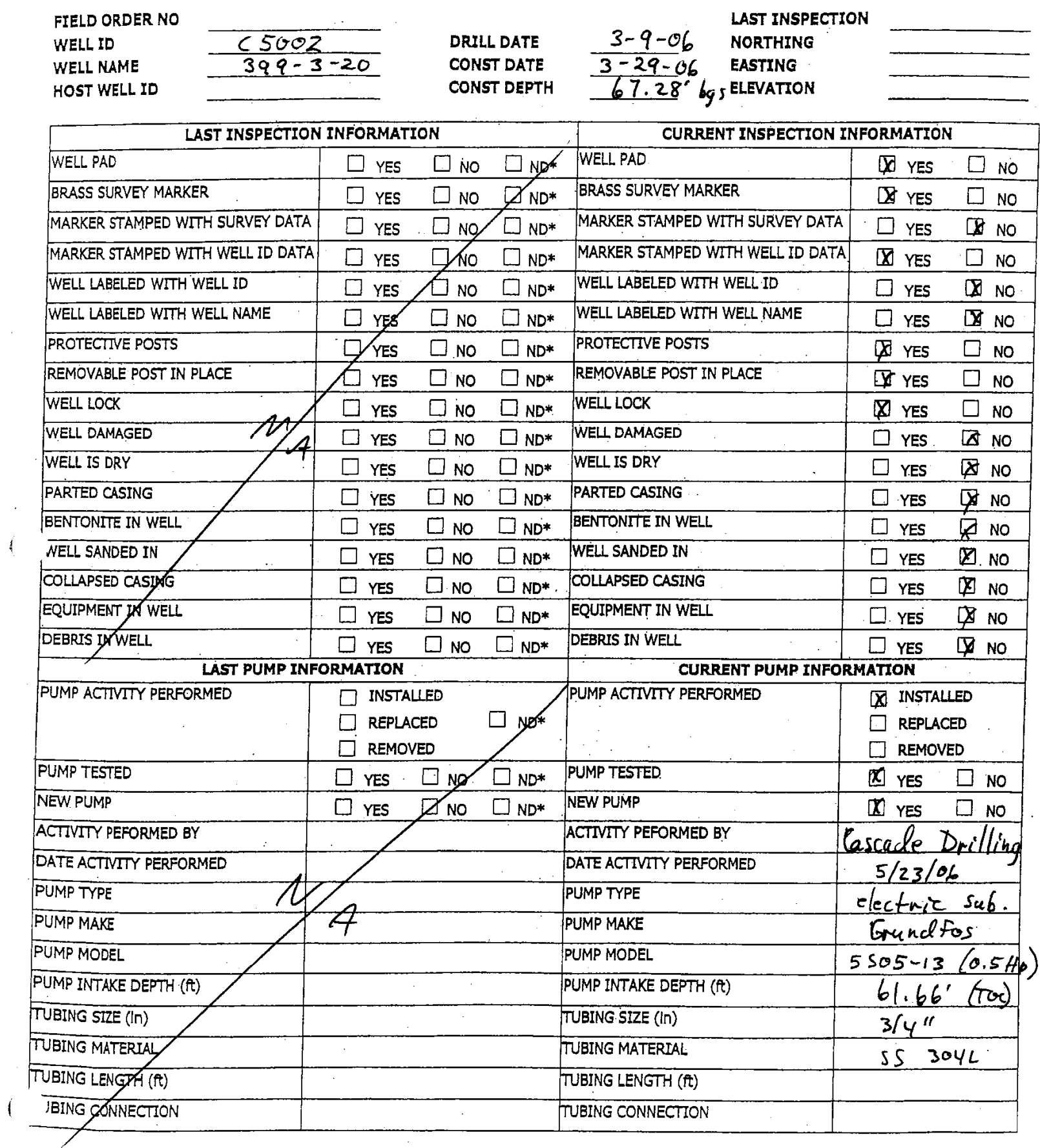




\section{Well Development and Pump Installation Report}

\section{Well C4999}

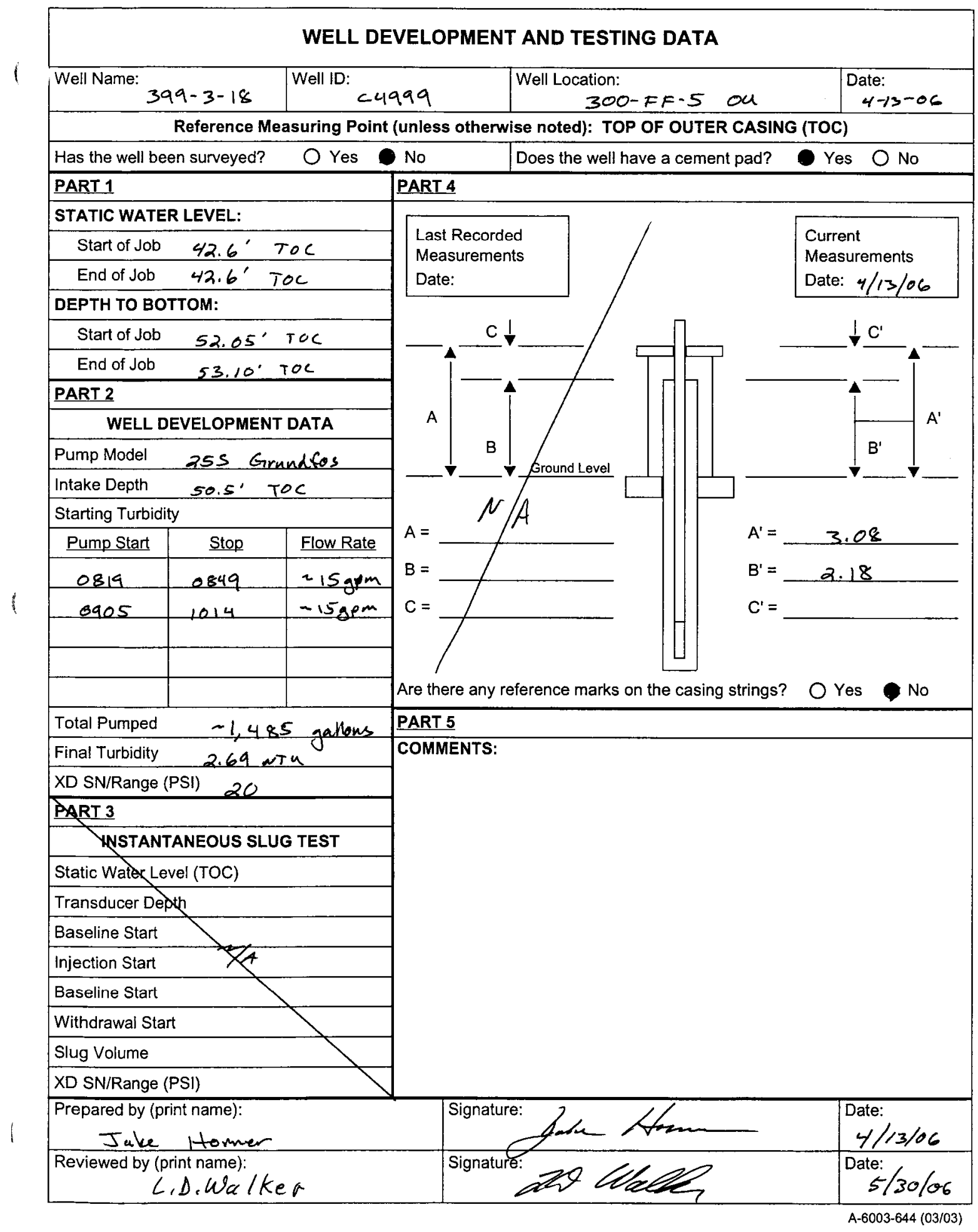




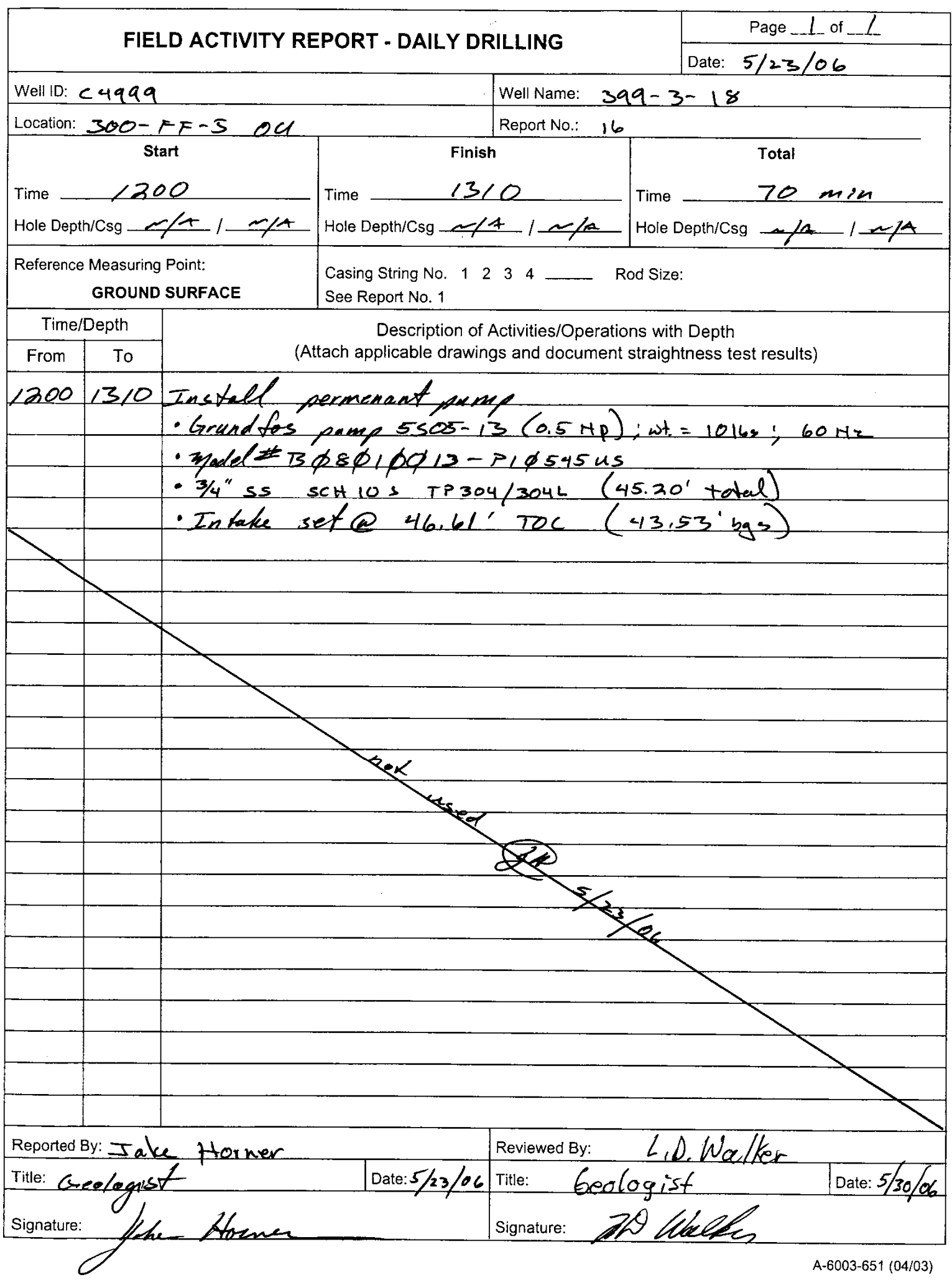




\section{Well C5000}

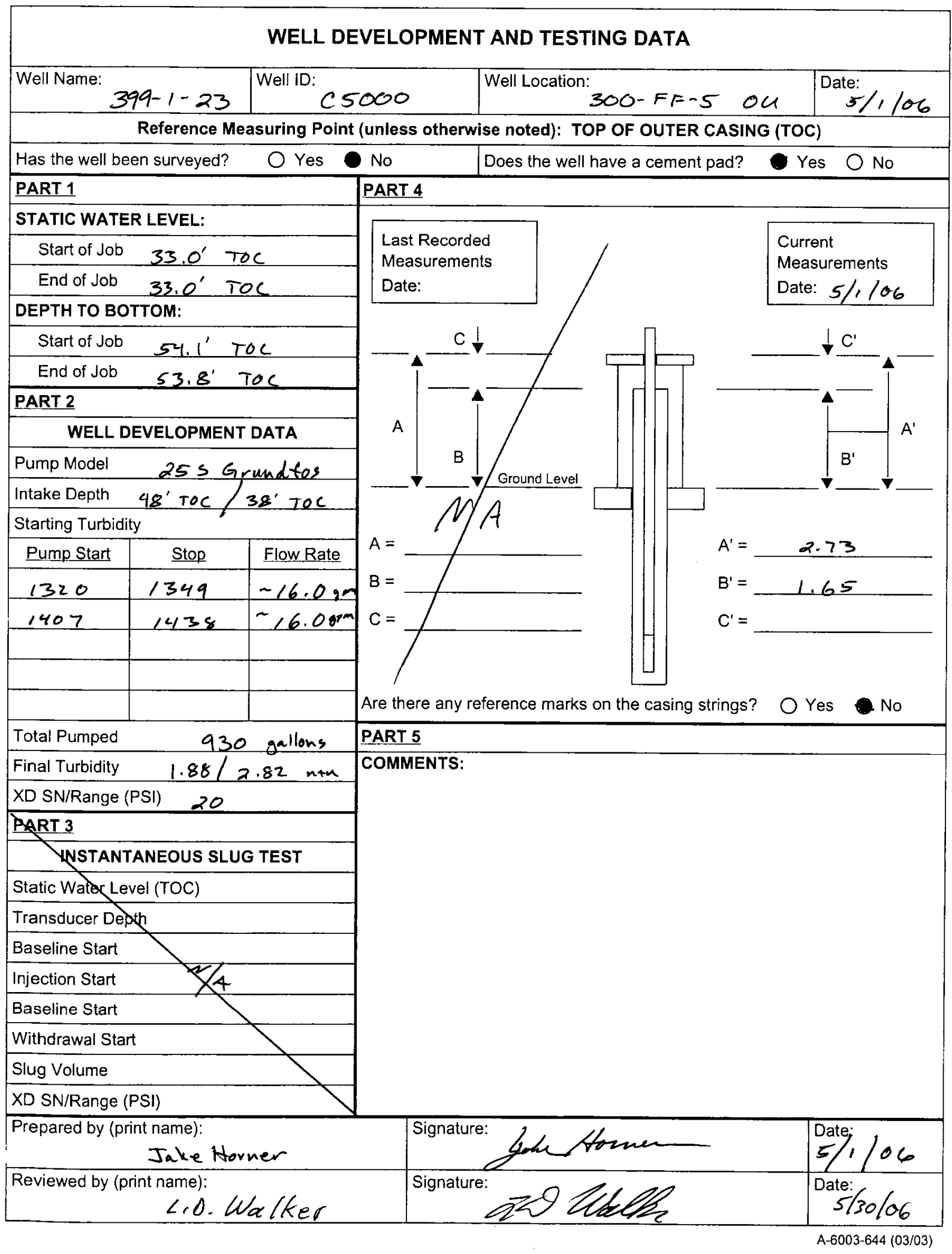




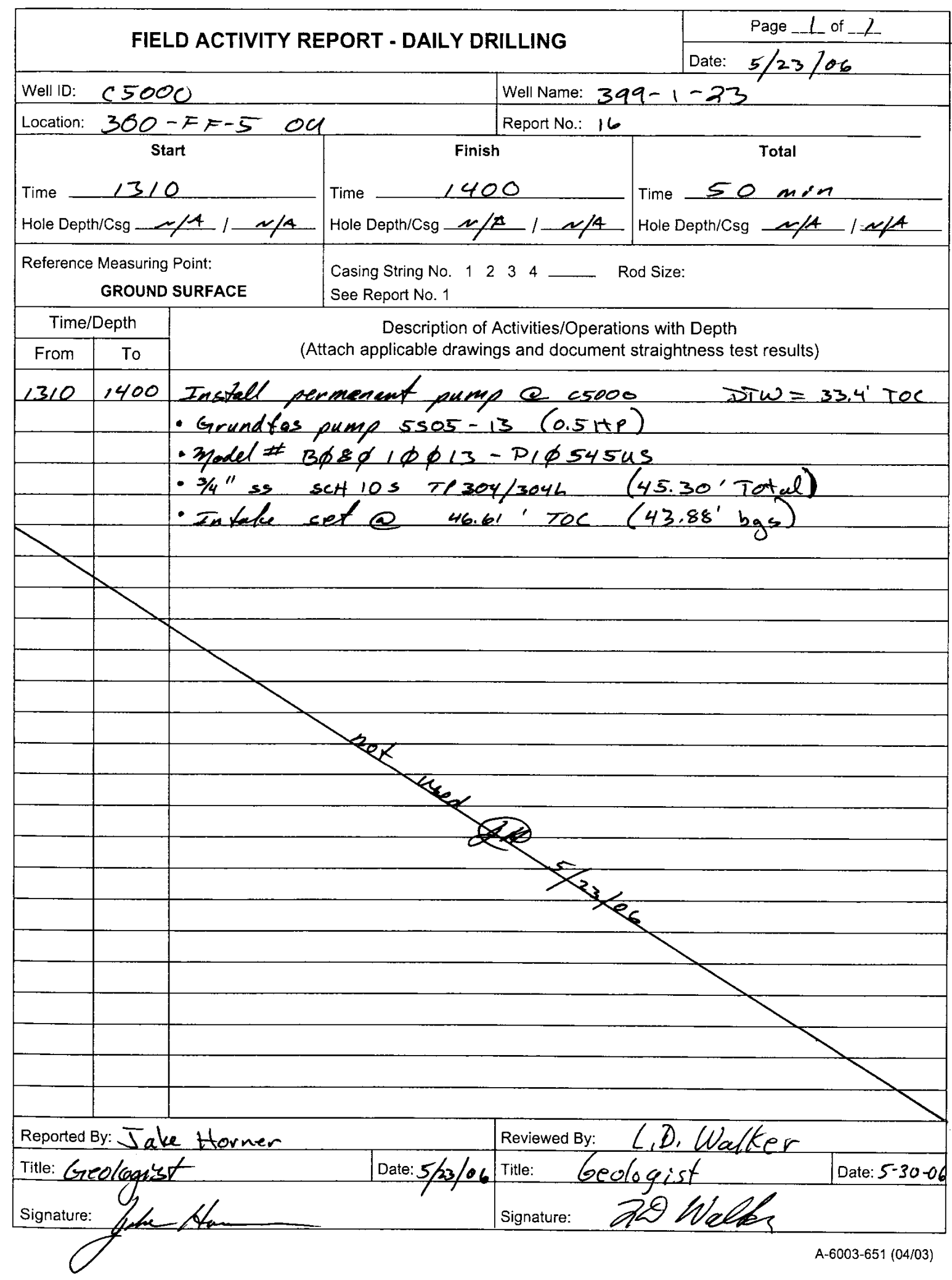




\section{Well C5001}

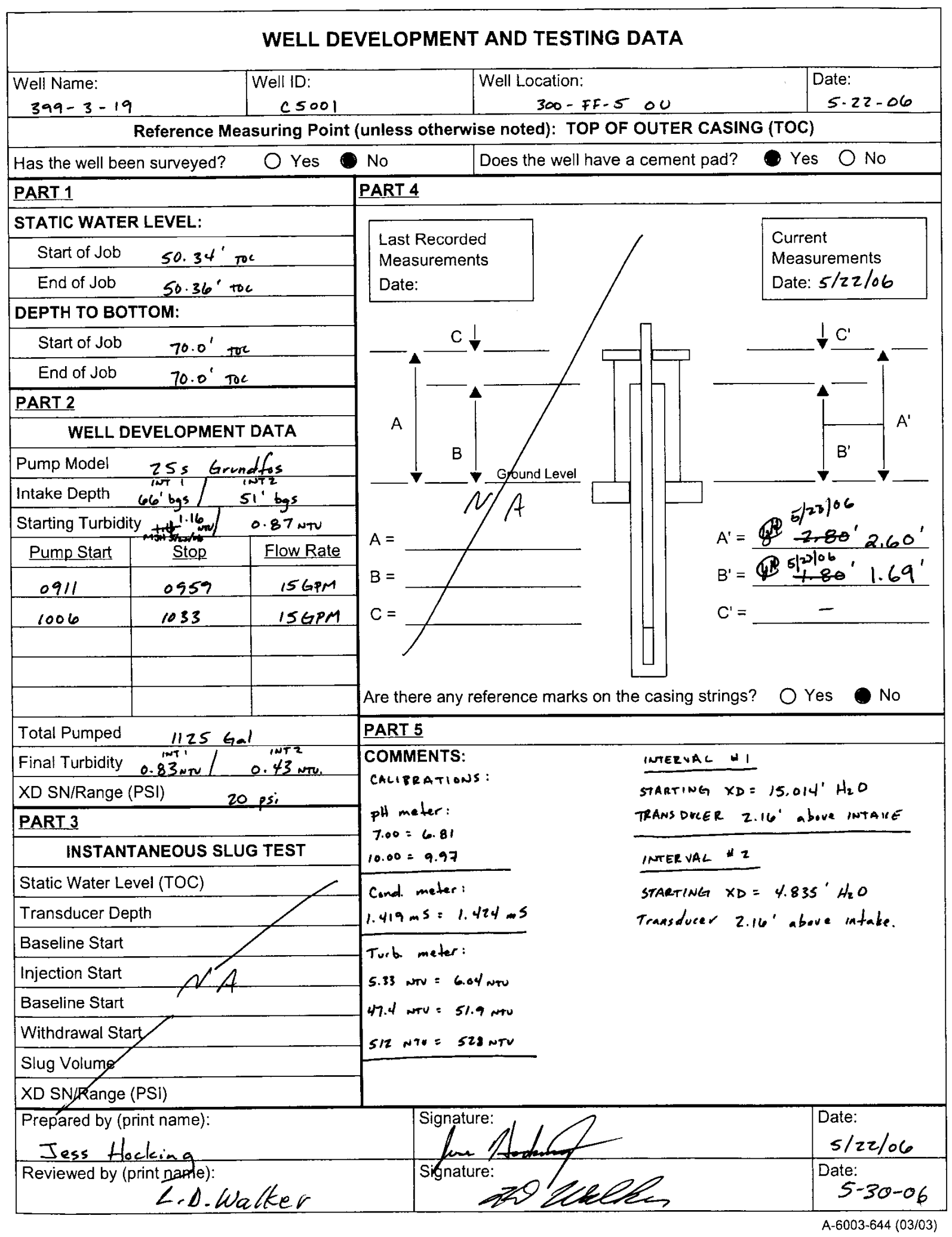




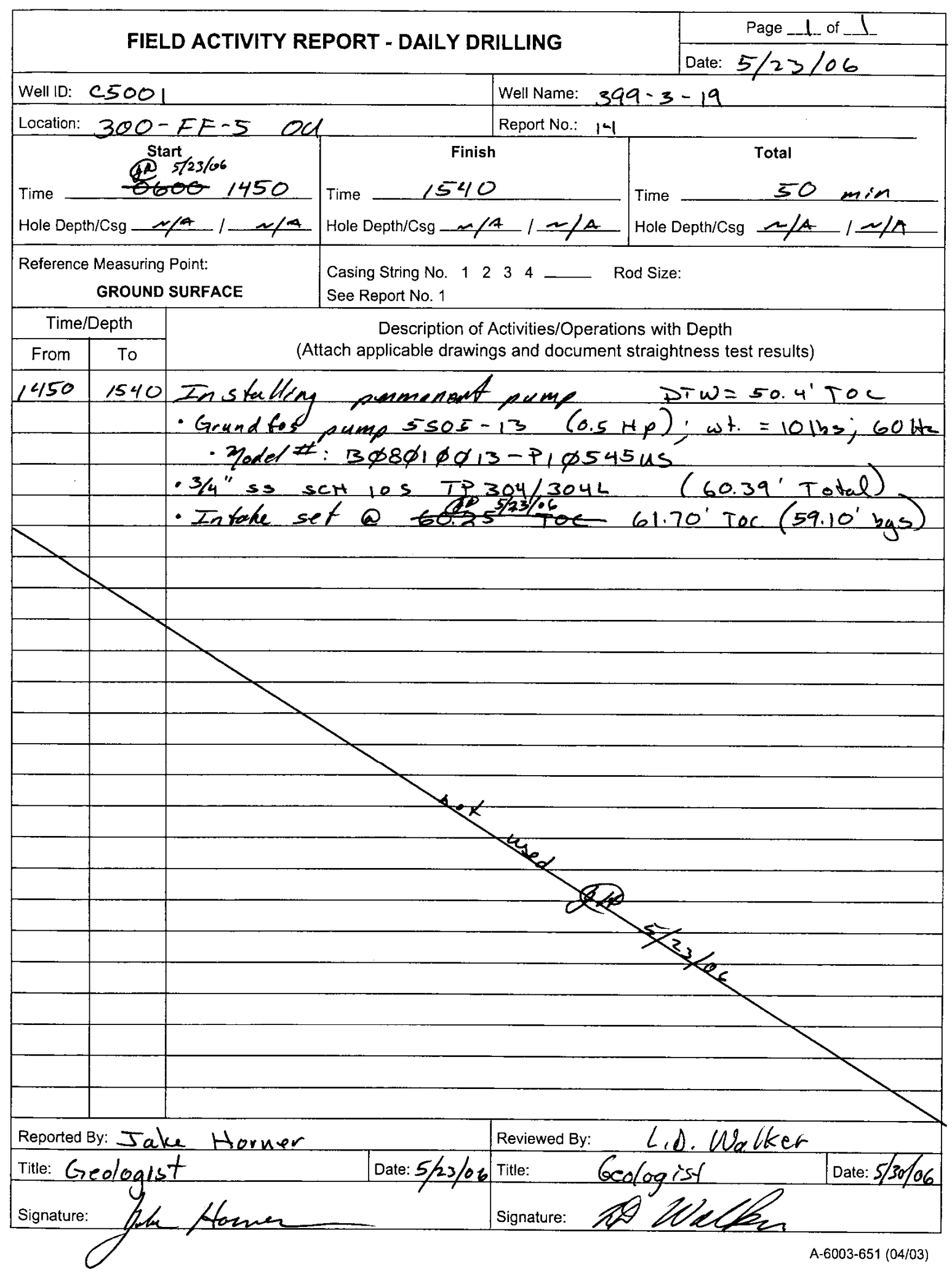




\section{Well C5002}

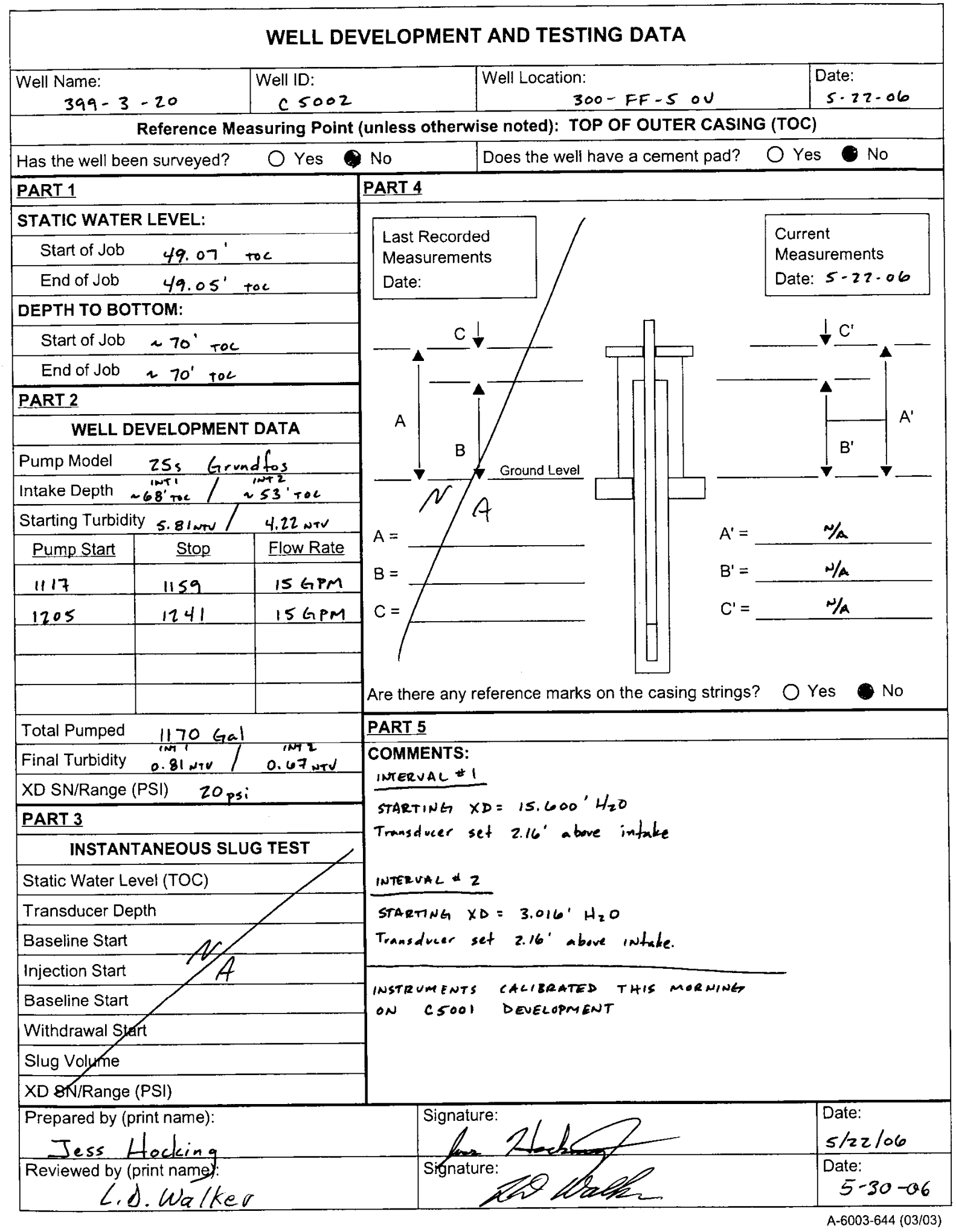




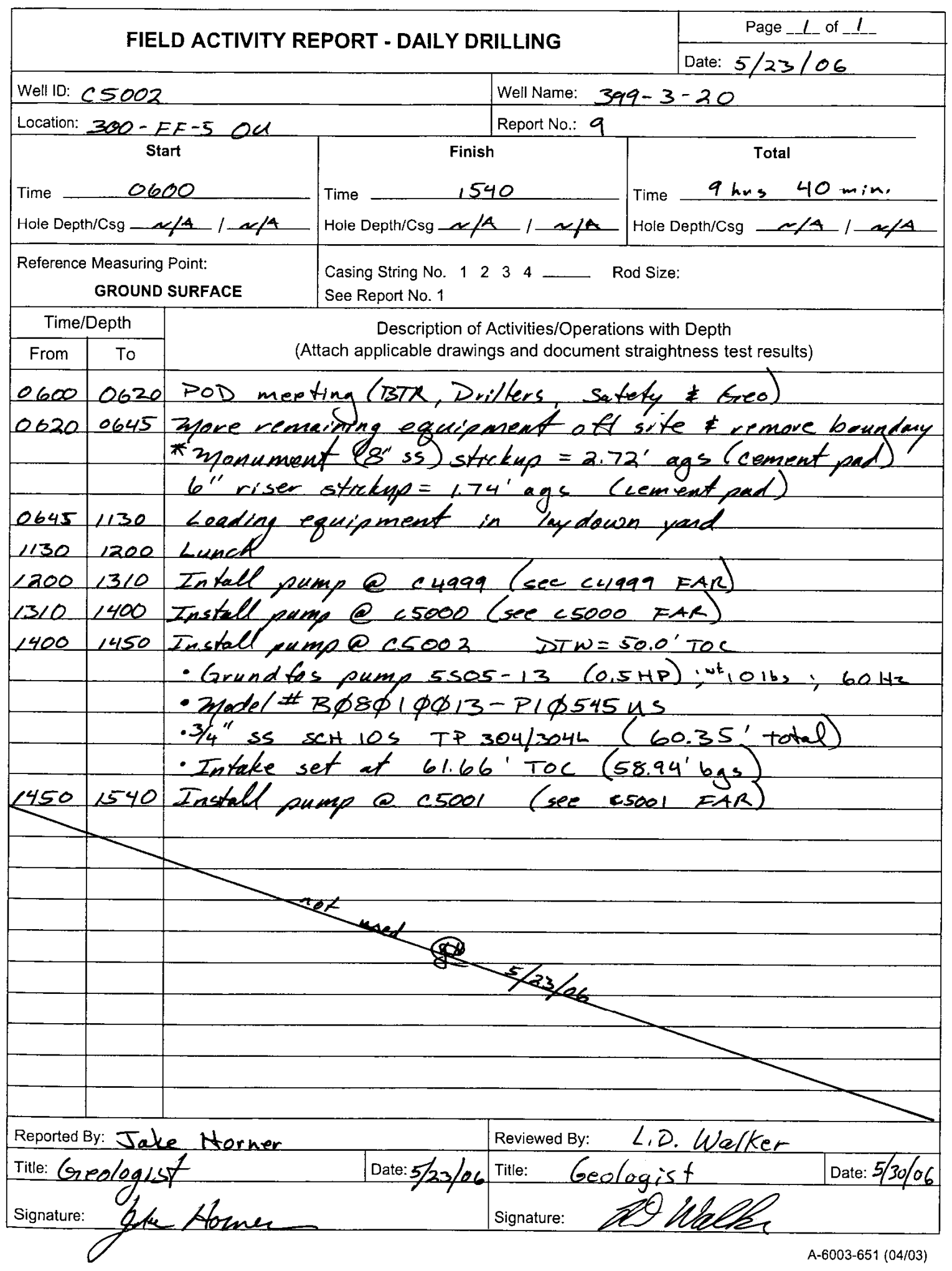




\section{Appendix B}

Sediment Core Data from Wells 399-3-18, 399-1-23, 399-3-19, and 399-3-20 
300 LFI LEXAN Core Linı 399-3-18

\begin{tabular}{|c|c|c|c|c|c|c|c|c|}
\hline \multirow{9}{*}{$\frac{\text { Box }}{\text { Box \#1 }}$} & \multicolumn{2}{|c|}{ mark sequential order } & \multirow{2}{*}{$\begin{array}{r}\text { weight (g) } \\
474\end{array}$} & \multirow{2}{*}{$\frac{\text { Core Run \# }}{1}$} & \multirow{2}{*}{$\frac{\text { Interval Depth }}{2 "-0}$} & \multirow{2}{*}{$\frac{\% \text { Recovery }}{0}$} & \multirow{2}{*}{\begin{tabular}{|c|} 
Date collected \\
$3 / 10 / 2006$ \\
\end{tabular}} & \multirow[t]{2}{*}{ Comments } \\
\hline & 1 & $1 \mathrm{~A}$ & & & & & & \\
\hline & 2 & 1B & 472 & 1 & $1 ' 2 "-2 "$ & 0 & $3 / 10 / 2006$ & \multirow[b]{2}{*}{ drill pad aravel } \\
\hline & 3 & $1 \mathrm{C}$ & 473 & 1 & $2^{\prime} 2^{\prime}-1 ' 2^{\prime \prime}$ & 20. & $3 / 10 / 2006$ & \\
\hline & 4 & 1D & 472 & 1 & $3^{\prime} 2^{\prime \prime}-2 ' 2^{\prime \prime}$ & 100 & $3 / 10 / 2006$ & ash \\
\hline & 5 & $1 \mathrm{E}$ & 471 & 1 & $4^{\prime} 2^{\prime \prime}-3^{\prime} 2^{\prime \prime}$ & 100 & $3 / 10 / 2006$ & ash \\
\hline & 6 & $2 A$ & 476 & 1 & 5'2"-4'2" & 100 & $3 / 10 / 2006$ & ash \\
\hline & 7 & $2 B$ & 474 & 1 & $6^{\prime} 2^{\prime \prime}-5^{\prime} 2^{\prime \prime}$ & 100 & $3 / 10 / 2006$ & \multirow[t]{2}{*}{ ash and sand } \\
\hline & 8 & $2 \mathrm{C}$ & 402 & 2 & $5.5-4.5$ & 0 & $3 / 10 / 2006$ & \\
\hline \multirow[t]{8}{*}{ Box \#2 } & 1 & $2 \mathrm{D}$ & 472 & 2 & $6.5^{\prime}-5.5^{\prime}$ & 0 & 3/10/2006 & \multirow{3}{*}{ probably slough } \\
\hline & 2 & $2 \mathrm{E}$ & 474 & 2 & $7.5^{\prime}-6.5^{\prime}$ & 50 & $3 / 10 / 2006$ & \\
\hline & 3 & $3 \mathrm{~A}$ & 470 & 2 & $8.5^{\prime}-7.5^{\prime}$ & 100 & $3 / 10 / 2006$ & \\
\hline & 4 & 3B & 471 & 2 & $9.5^{\prime}-8.5^{\prime}$ & 100 & $3 / 10 / 2006$ & \\
\hline & 5 & $3 C$ & 470 & 2 & $10.5^{\prime}-9.5^{\prime}$ & 100 & $3 / 10 / 2006$ & \\
\hline & 6 & $3 D$ & 476 & 3 & $10^{\prime 2} 2 "-9 ' 2 "$ & 0 & $3 / 10 / 2006$ & \\
\hline & 7 & $3 \mathrm{E}$ & 473 & 3 & 11'2"-10'2" & 0 & $3 / 10 / 2006$ & \\
\hline & 8 & $4 \mathrm{~A}$ & 403 & 3 & $12^{\prime 2} 2^{\prime \prime}-11 ' 2 "$ & 0 & $3 / 10 / 2006$ & \\
\hline \multirow[t]{8}{*}{ Box \# 3} & 1 & 4B & 472 & 3 & $13^{\prime} 2^{\prime \prime}-12^{\prime} 2^{\prime \prime}$ & 75 & $3 / 10 / 2006$ & \multirow{4}{*}{ sample fell out of shoe and $1 \mathrm{st}$ liner } \\
\hline & 2 & $4 \mathrm{C}$ & 469 & 3 & 14'2"-13'2" & 100 & $3 / 10 / 2006$ & \\
\hline & 3 & 4D & 470 & 3 & $15^{\prime} 2 "-14^{\prime} 2^{\prime \prime}$ & 0 & $3 / 10 / 2006$ & \\
\hline & 4 & $4 \mathrm{E}$ & 472 & 4 & $14.5-13.5$ & 0 & $3 / 10 / 2006$ & \\
\hline & 5 & $5 \mathrm{~A}$ & 468 & 4 & $15.5-14.5$ & 30 & $3 / 10 / 2006$ & \multirow[t]{4}{*}{ probably slough } \\
\hline & 6 & $5 B$ & 468 & 4 & $16.5-15.5$ & 100 & $3 / 10 / 2006$ & \\
\hline & 7 & $5 C$ & 472 & 4 & $17.5-16.5$ & 100 & $3 / 10 / 2006$ & \\
\hline & 8 & $5 \mathrm{D}$ & 422 & 4 & $18.5-17.5$ & 100 & $3 / 10 / 2006$ & \\
\hline \multirow[t]{8}{*}{ Box\# 4} & 1 & $5 \mathrm{E}$ & 474 & 4 & $19.5-18.5$ & 100 & $3 / 10 / 2006$ & \multirow{8}{*}{ lost some sample out of shoe } \\
\hline & 2 & $6 \mathrm{~A}$ & 468 & 5 & $20.5-19.5$ & 55 & $3 / 10 / 2006$ & \\
\hline & 3 & $6 \mathrm{~B}$ & 471 & 5 & $21.5-20.5$ & 100 & $3 / 10 / 2006$ & \\
\hline & 4 & $6 \mathrm{C}$ & 471 & 5 & $22.5-21.5$ & 100 & $3 / 10 / 2006$ & \\
\hline & 5 & $6 \mathrm{D}$ & 470 & 5 & $23.5-22.5$ & 100 & $3 / 10 / 2006$ & \\
\hline & 6 & $6 \mathrm{E}$ & 464 & 5 & $24.5-23.5$ & 100 & $3 / 10 / 2006$ & \\
\hline & 7 & $7 \mathrm{~A}$ & 471 & 5 & $25.5-24.5$ & 90 & $3 / 10 / 2006$ & \\
\hline & 8 & $7 \mathrm{~B}$ & 415 & 6 & $22.5-21.5$ & 0 & $3 / 10 / 2006$ & \\
\hline \multirow[t]{2}{*}{ Box \# 5} & 1 & $7 \mathrm{C}$ & 469 & 6 & $23.5-22.5$ & 10 & $3 / 10 / 2006$ & \multirow{2}{*}{$\begin{array}{l}\text { probably slough } \\
\text { probably slough }\end{array}$} \\
\hline & 2 & 7D & 475 & 6 & $24.5-23.5$ & 100 & $3 / 10 / 2006$ & \\
\hline
\end{tabular}




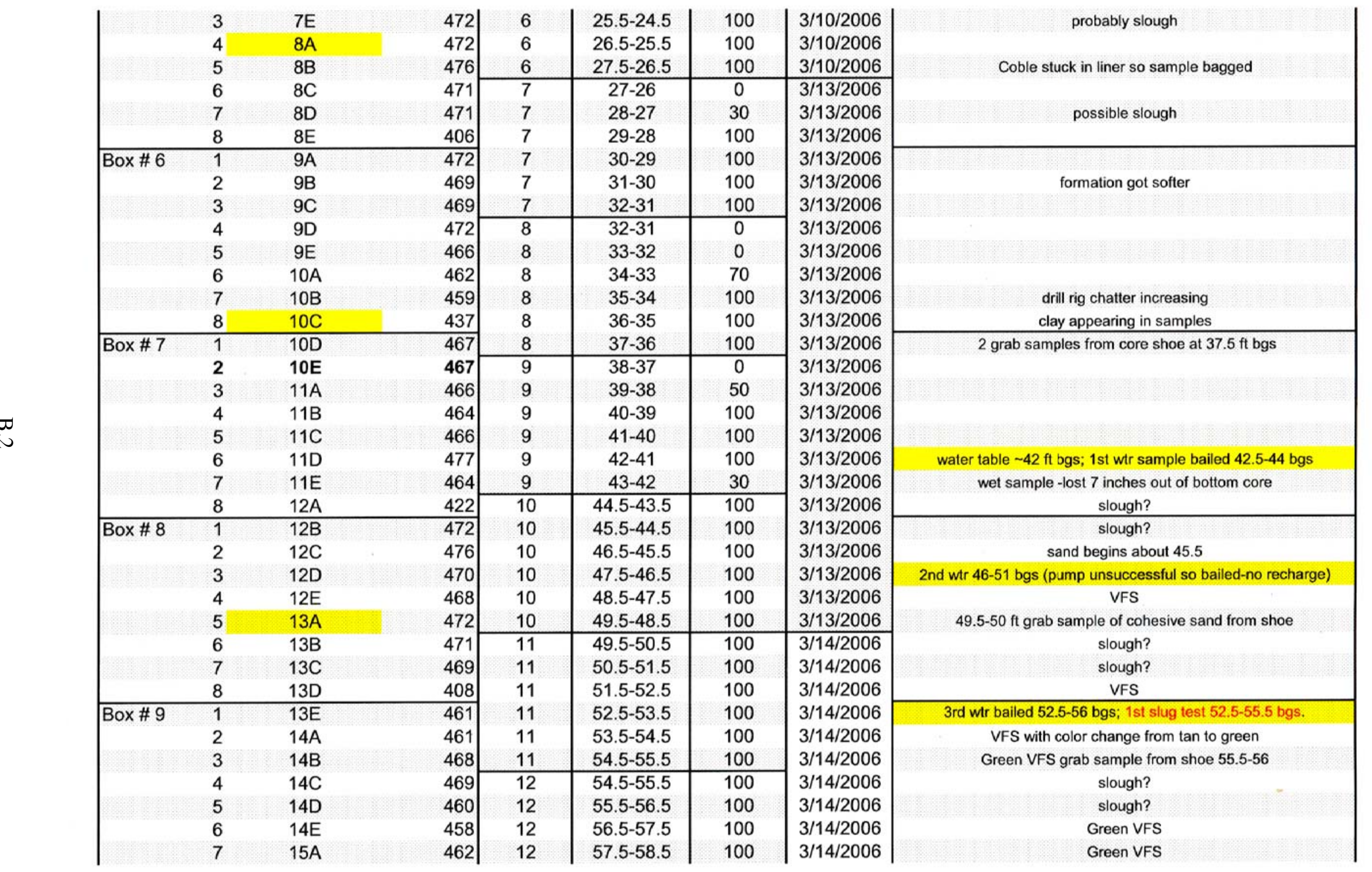




\begin{tabular}{|c|c|c|c|c|c|c|c|c|}
\hline I & 8 & 15B & 461 & 12 & $58.5-59.5$ & \multirow{2}{*}{$\mid \begin{array}{c}100 \\
\text { melted liner }\end{array}$} & \multirow{2}{*}{$\begin{array}{l}3 / 14 / 2006 \\
3 / 14 / 2006\end{array}$} & Green VFS to silt \\
\hline Box \#10 & 1 & $15 \mathrm{C}$ & 464 & 12 & $59.5-61$ & & & This sample was bagged \\
\hline & 2 & $15 \mathrm{D}$ & 465 & 13 & $59.5-60.5$ & \begin{tabular}{l|}
100 \\
\end{tabular} & $3 / 16 / 2006$ & slough? \\
\hline & 3 & $15 \mathrm{E}$ & 471 & 13 & $60.5-61.5$ & 100 & $3 / 16 / 2006$ & slough? \\
\hline & 4 & $16 \mathrm{~A}$ & 468 & 13 & $61.5-62.5$ & 100 & $3 / 16 / 2006$ & green vfs \\
\hline & 5 & $16 \mathrm{~B}$ & 472 & 13 & $62.5-63.5$ & 100 & $3 / 16 / 2006$ & \\
\hline & 6 & $16 \mathrm{C}$ & 467 & 13 & $63.5-64.5$ & 100 & $3 / 16 / 2006$ & \\
\hline & 7 & $16 \mathrm{D}$ & 476 & 13 & $64.5-65.5$ & 100 & $3 / 16 / 2006$ & Shoe grab sample at $65.6-66.0$ \\
\hline & 8 & $16 \mathrm{E}$ & 413 & 14 & $64.5-65.5$ & 100 & $3 / 16 / 2006$ & slough? \\
\hline Box\#11 & 1 & $17 \mathrm{~A}$ & 473 & 14 & $65.5-66.5$ & 100 & $3 / 16 / 2006$ & 4th water sample pumped $\sim 66-70 \mathrm{ft}$ bgs \\
\hline & 2 & $17 \mathrm{~B}$ & 470 & 14 & $66.5-67.5$ & 100 & $3 / 16 / 2006$ & 2nd slug test $\sim 66-70$ and $\sim 61.5-70$ bgs \\
\hline & 3 & $17 \mathrm{C}$ & 473 & 14 & $67.5-68.5$ & 100 & $3 / 16 / 2006$ & \\
\hline & 4 & 17D & 476 & 14 & $68.5-69.5$ & 100 & $3 / 16 / 2006$ & sand grain size increasing \\
\hline & 5 & 17E & 474 & 14 & $69.5-70.5$ & 100 & $3 / 16 / 2006$ & lost shoe sample at $71^{\circ}$ \\
\hline & 6 & $18 \mathrm{~A}$ & 470 & 15 & $70.5-69.5$ & 100 & $3 / 17 / 2006$ & $100 \%$ sluff discarded sample and liner \\
\hline & 7 & $18 \mathrm{~B}$ & 472 & 15 & $71.5-70.5$ & 100 & $3 / 17 / 2006$ & $-50 \%$ sluff in top of liner \\
\hline & 8 & $18 \mathrm{C}$ & 393 & 15 & $72.5-71.5$ & 100 & $3 / 17 / 2006$ & \\
\hline Box\#12 & 1 & $18 \mathrm{D}$ & 461 & 15 & $73.5-72.5$ & 100 & $3 / 17 / 2006$ & \\
\hline & 2 & $18 \mathrm{E}$ & 464 & 15 & $74.5-73.5$ & 100 & $3 / 17 / 2006$ & \\
\hline & 3 & $19 \mathrm{~A}$ & 464 & 15 & $75.5-74.5$ & 100 & $3 / 17 / 2006$ & Lost sample in shoe at 76 bgs \\
\hline & 4 & $19 B$ & 466 & 16 & $76.5-75.5$ & 100 & $3 / 17 / 2006$ & 5 th wtr sample pumped from $\sim 76-78$ bgs \\
\hline & 5 & $19 \mathrm{C}$ & 467 & 16 & $77.5-76.5$ & 100 & $3 / 17 / 2006$ & \\
\hline & 6 & $19 D$ & 468 & 16 & $78.5-77.5$ & 100 & $3 / 17 / 2006$ & \\
\hline & 7 & $19 \mathrm{E}$ & 467 & 16 & $79.5-78.5$ & 100 & $3 / 17 / 2006$ & \\
\hline & 8 & $20 \mathrm{~A}$ & 450 & 16 & $80.5-79.5$ & 100 & $3 / 17 / 2006$ & \\
\hline Box \#13 & 1 & $20 \mathrm{~B}$ & 472 & 16 & $81.5-80.5$ & 100 & $3 / 17 / 2006$ & \\
\hline & $z$ & 206 & 469 & 17 & liner distroyed & 0 & $3 / 20 / 2006$ & Stuck in core barrel (cut out before sampling) \\
\hline & 3 & $20 D$ & 466 & 17 & $82.5-81.5$ & 100 & $3 / 20 / 2006$ & \\
\hline & 4 & $20 E$ & 472 & 17 & $83.5-82.5$ & 100 & $3 / 20 / 2006$ & Silty sandy gravel \\
\hline & 5 & $21 \mathrm{~A}$ & 473 & 17 & $84.5-83.5$ & 100 & $3 / 20 / 2006$ & Silty sandy gravel \\
\hline & 6 & 21B & 472 & 17 & $85.5-84.5$ & 100 & $3 / 20 / 2006$ & Silty sandy gravel \\
\hline & 7 & $21 \mathrm{C}$ & 470 & 17 & $86.5-85.5$ & 100 & $3 / 20 / 2006$ & Silty sandy gravel \\
\hline & 8 & 21D & 403 & $18-17$ & $87.5-86.5$ & 100 & $3 / 20 / 2006$ & 6 th wtr sample pumped $\sim 86-89$ bgs \\
\hline Box \# 14 & 1 & $21 \mathrm{E}$ & 464 & 18 & $86-85$ & 100 & $3 / 20 / 2006$ & slough? \\
\hline & 2 & $22 \mathrm{~A}$ & 453 & 18 & $87-86$ & 100 & $3 / 20 / 2006$ & slough? \\
\hline & 3 & $22 B$ & 469 & 18 & $88-87$ & 100 & $3 / 20 / 2006$ & Silty sandy gravel \\
\hline & 4 & $22 \mathrm{C}$ & 469 & 18 & $89-88$ & 100 & $3 / 20 / 2006$ & Silty sandy gravel \\
\hline
\end{tabular}




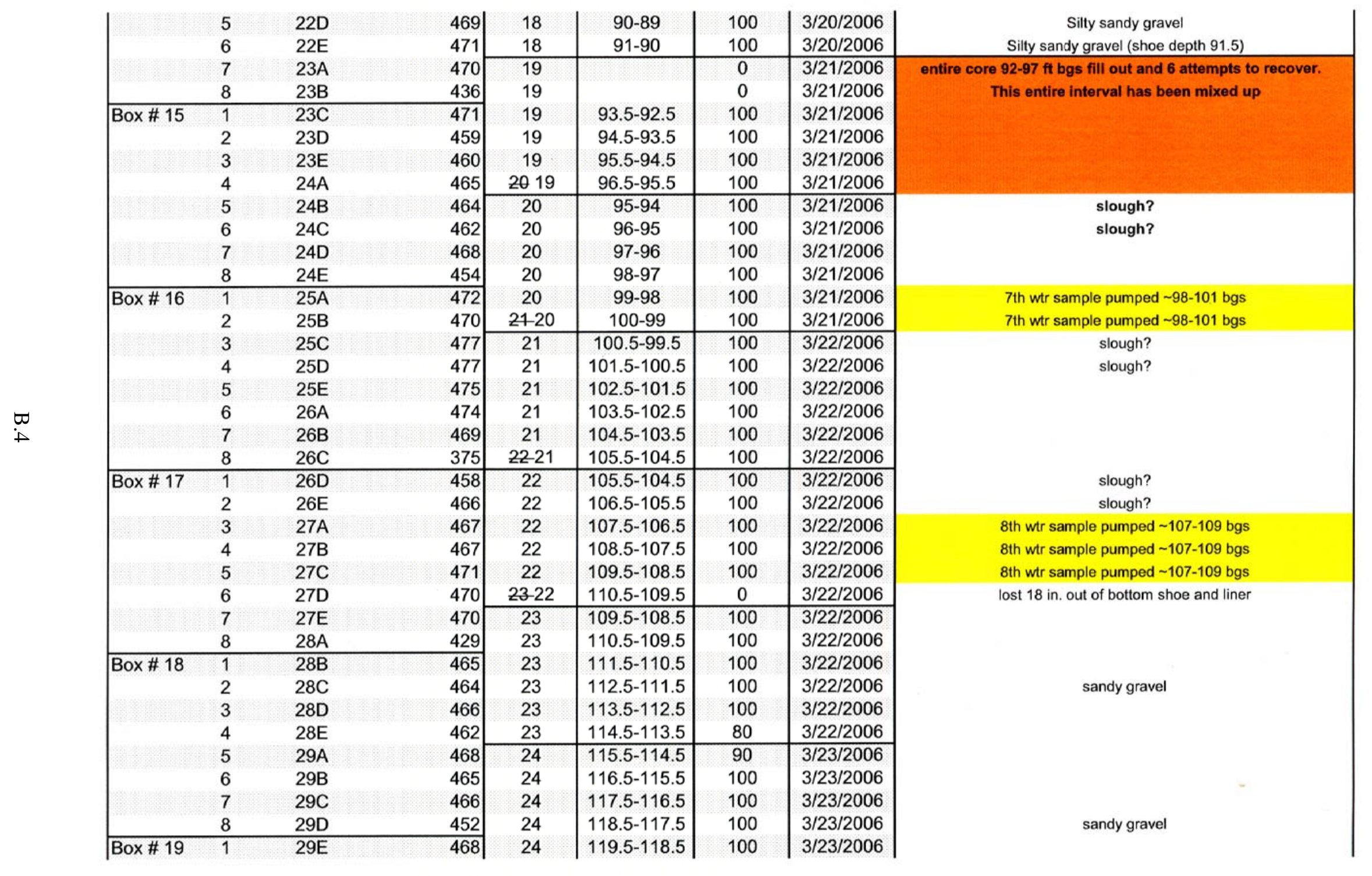




\begin{tabular}{|c|c|c|c|c|c|c|c|c|}
\hline & 2 & $30 \mathrm{~A}$ & 468 & 24 & $120.5-119.5$ & 70 & $3 / 23 / 2006$ & \\
\hline & 3 & $30 \mathrm{~B}$ & 464 & 25 & $121-120$ & 0 & $3 / 23 / 2006$ & \multirow{3}{*}{$\begin{array}{l}\text { 9th wtr sample pumped } \sim 120-121.5 \text { bgs } \\
\text { all slough, dumped liner and sample }\end{array}$} \\
\hline & 4 & $30 \mathrm{C}$ & 464 & 25 & $122-121$ & 50 & $3 / 23 / 2006$ & \\
\hline & 5 & $30 \mathrm{D}$ & 462 & 25 & $123-122$ & 100 & $3 / 23 / 2006$ & \\
\hline & 6 & $30 \mathrm{E}$ & 466 & 25 & $124-123$ & 100 & $3 / 23 / 2006$ & sandy gravel \\
\hline & 7 & $31 \mathrm{~A}$ & 466 & 25 & $125-124$ & 100 & $3 / 23 / 2006$ & Proposed 3rd slug test $~ 126-116$ bgs \\
\hline & 8 & $31 \mathrm{~B}$ & 453 & 25 & 126-125 & 50 & $3 / 23 / 2006$ & \multirow{2}{*}{$\begin{array}{l}\text { Lost } 1 / 2 \text { of sample } \\
\text { sandy gravel }\end{array}$} \\
\hline Box \# 20 & 1 & $31 \mathrm{C}$ & 470 & 26 & $125.5-124.5$ & 100 & $3 / 23 / 2006$ & \\
\hline & 2 & 310 & 464 & 26 & $126.5-125.5$ & 100 & $3 / 23 / 2006$ & Lower Mud contact 126 bgs \\
\hline & 4 & $32 \mathrm{~A}$ & 463 & 26 & $128.5-127.5$ & 100 & $3 / 23 / 2006$ & LMU \\
\hline & 5 & $32 \mathrm{~B}$ & 467 & 26 & $129.5-128.5$ & 100 & $3 / 23 / 2006$ & \multirow{2}{*}{$\begin{array}{l}\text { LMU } \\
\text { LMU }\end{array}$} \\
\hline & 6 & $32 \mathrm{C}$ & 465 & 26 & $130.5-129.5$ & 100 & $3 / 23 / 2006$ & \\
\hline
\end{tabular}

Column E - Core Run \# provides the core run sequence during drilling.

Each core run consists of a $6.5 \mathrm{ft}$ long core barrel consisting of $6 \sim 1$-ft-long lexan liners plus a $0.5 \mathrm{ft}$ core shoe

Column F - Interval Depth provides the $\sim 1 \mathrm{ft}$-long Lexan core depth interval

Column G - \% Recovery provides the percentage of the $\sim 1$-ft-long Liner that is full of sediment

Column A, B, C, and D provide tracking and weight information for the Lexan liners

Column C -sequential order provides the lab liner identifiers. Yellow highlighted numbers are retained core intact for treatability and future lab testing. 
300 LFI LEXAN Core Liners

399-1-23

Well C5000

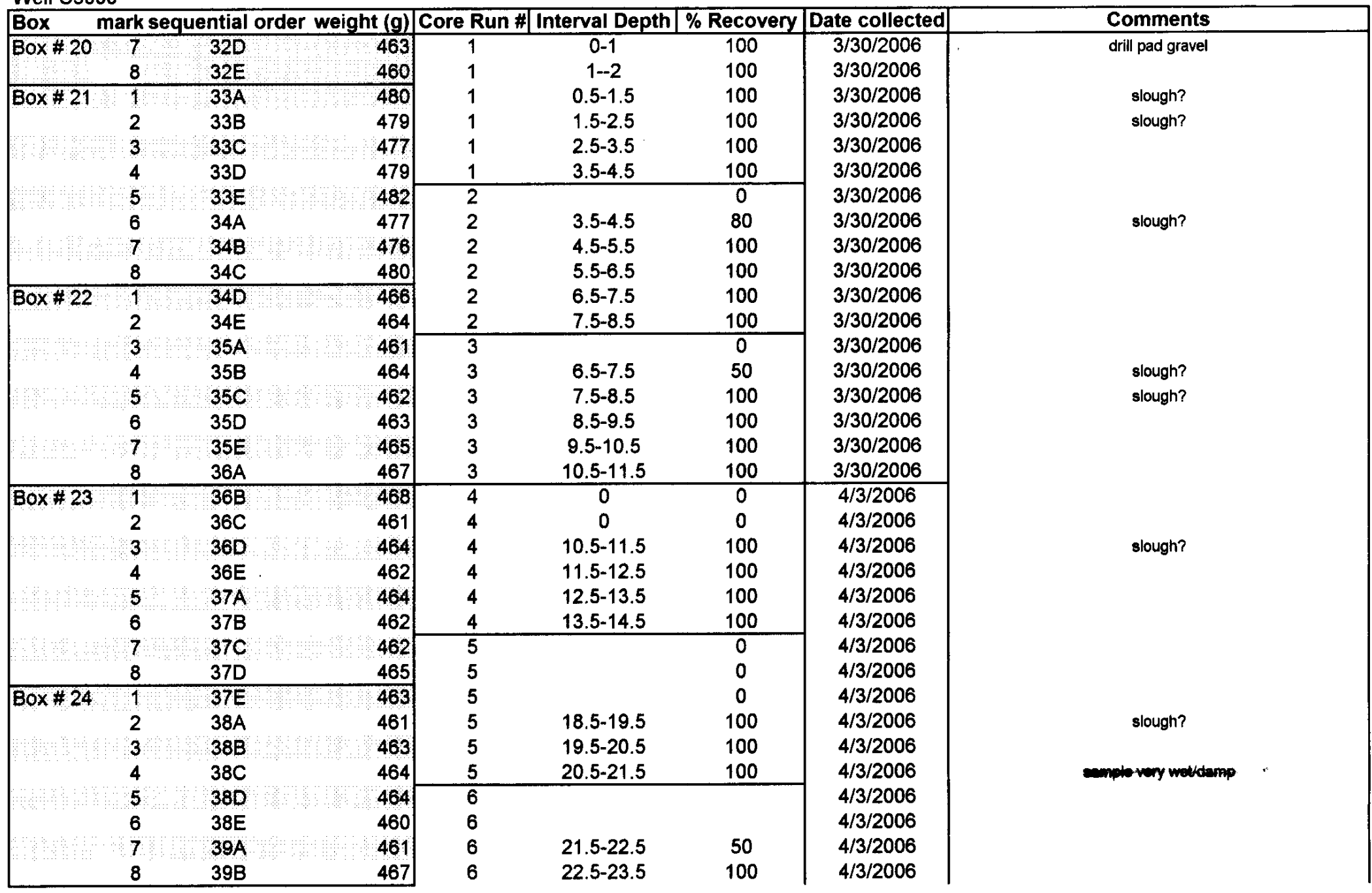




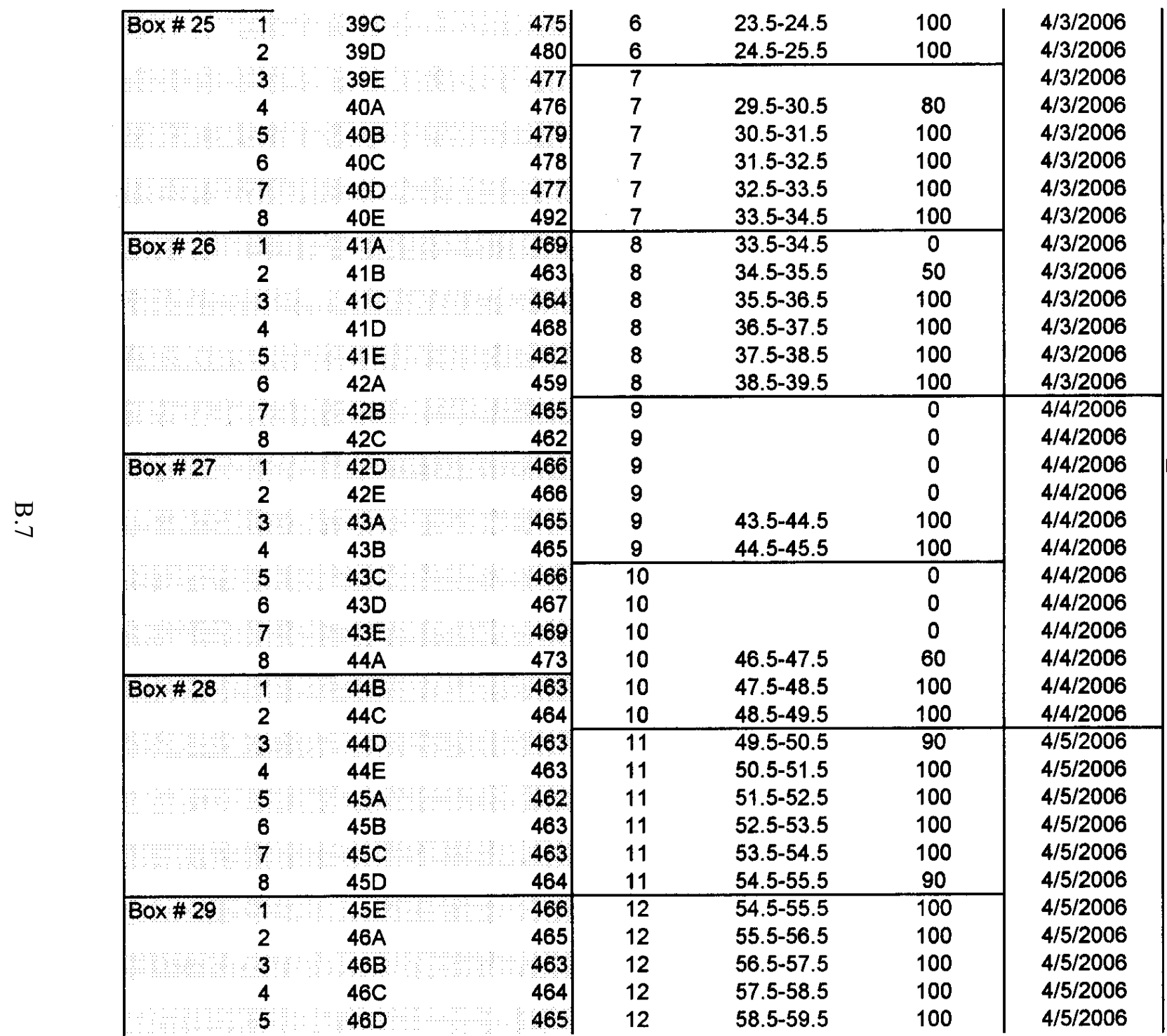

Entire core interval (9) fell out of core barrel.

Several attempts made to retrieve cuttings

Entire interval mixed and now graded due to multiple attempts

material is highly permeable sandy gravel

Drilled $45^{\prime}$ to $50^{\prime}$ ' bgs only 3 ' recovered

loose perm. sandy gravel just pushed aside during coring

slough?

Core run \#11 fell out and was redrilled

Interval cored was $49.5-56 \mathrm{ft}$ bgs

slough?

$100 \%$ core run (12) recovery

similar sand as in 399-3-18 w/ gravel, and sit 


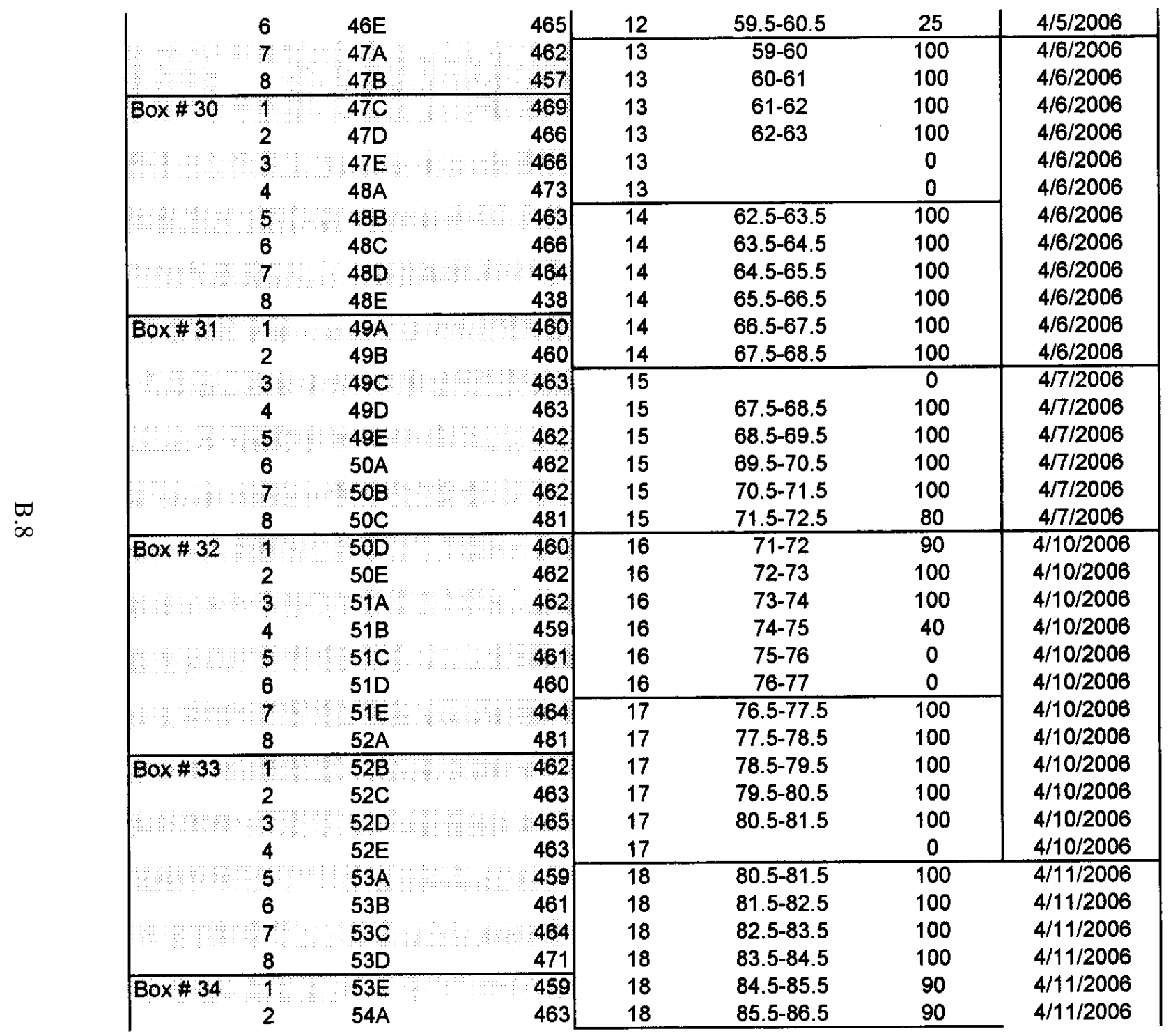

\section{lost bottom $1 \mathrm{ft}$ \\ slough? \\ slough? \\ core fell out \\ core fell out \\ slough? \\ silty sandy gravel \\ silty sandy gravel}

very fine grained qtz sand, well sorted very fine grained qtz sand, well sorted shoe to 70 "bgs

$$
\begin{aligned}
& \text { slough? } \\
& \text { slough? }
\end{aligned}
$$

slough?

slough?

slough?

Core run\#16 73-77.5 interval

core fell out

core fell out

Core run \#17 73-83 interval

$$
\begin{aligned}
& 1.5 \mathrm{ft} \text { fell out } \\
& \text { slough? } \\
& \text { slough? } \\
& \text { slough? }
\end{aligned}
$$




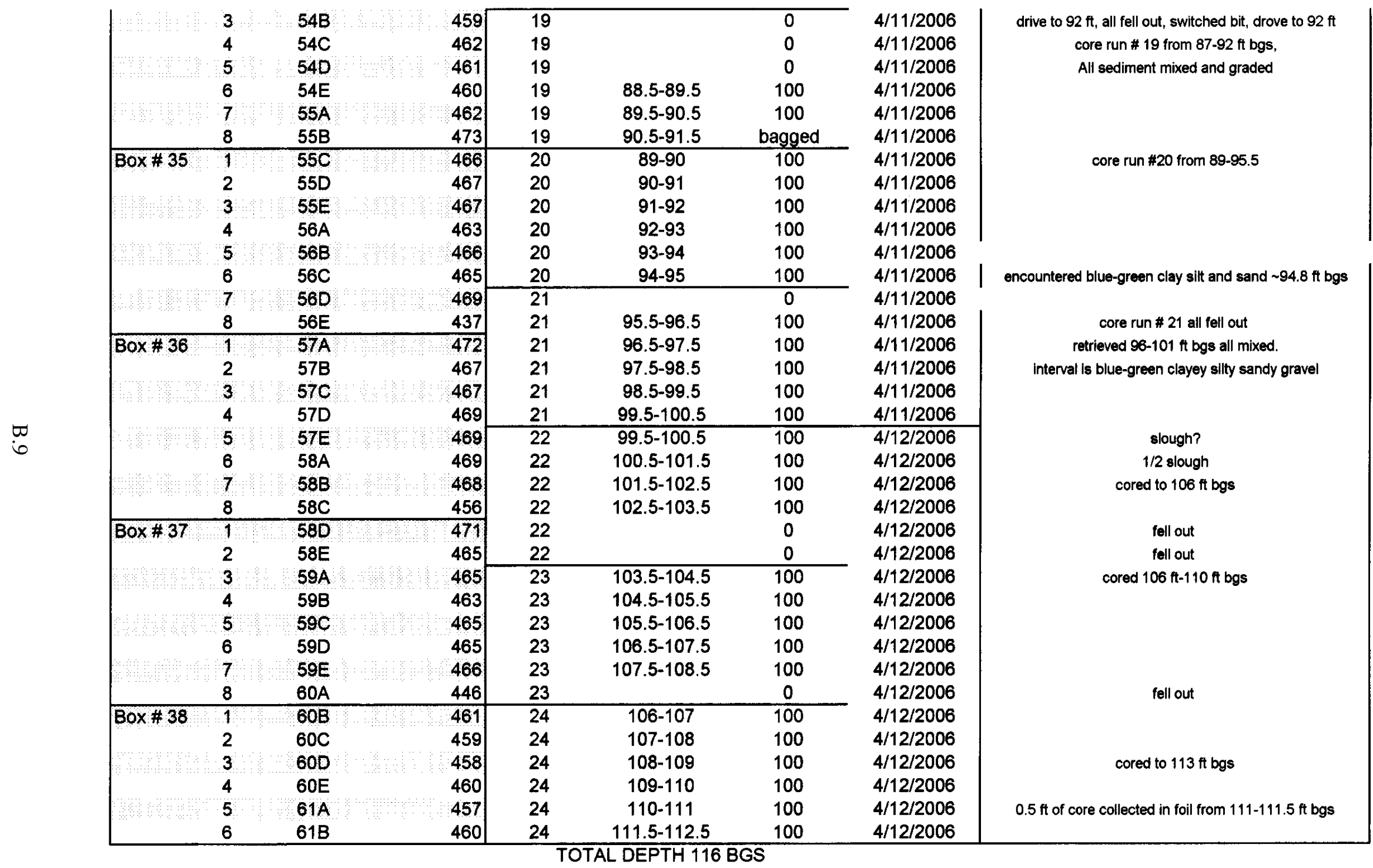


300 LFI LEXAN Core Liners

$399-3-19$

Well C5001

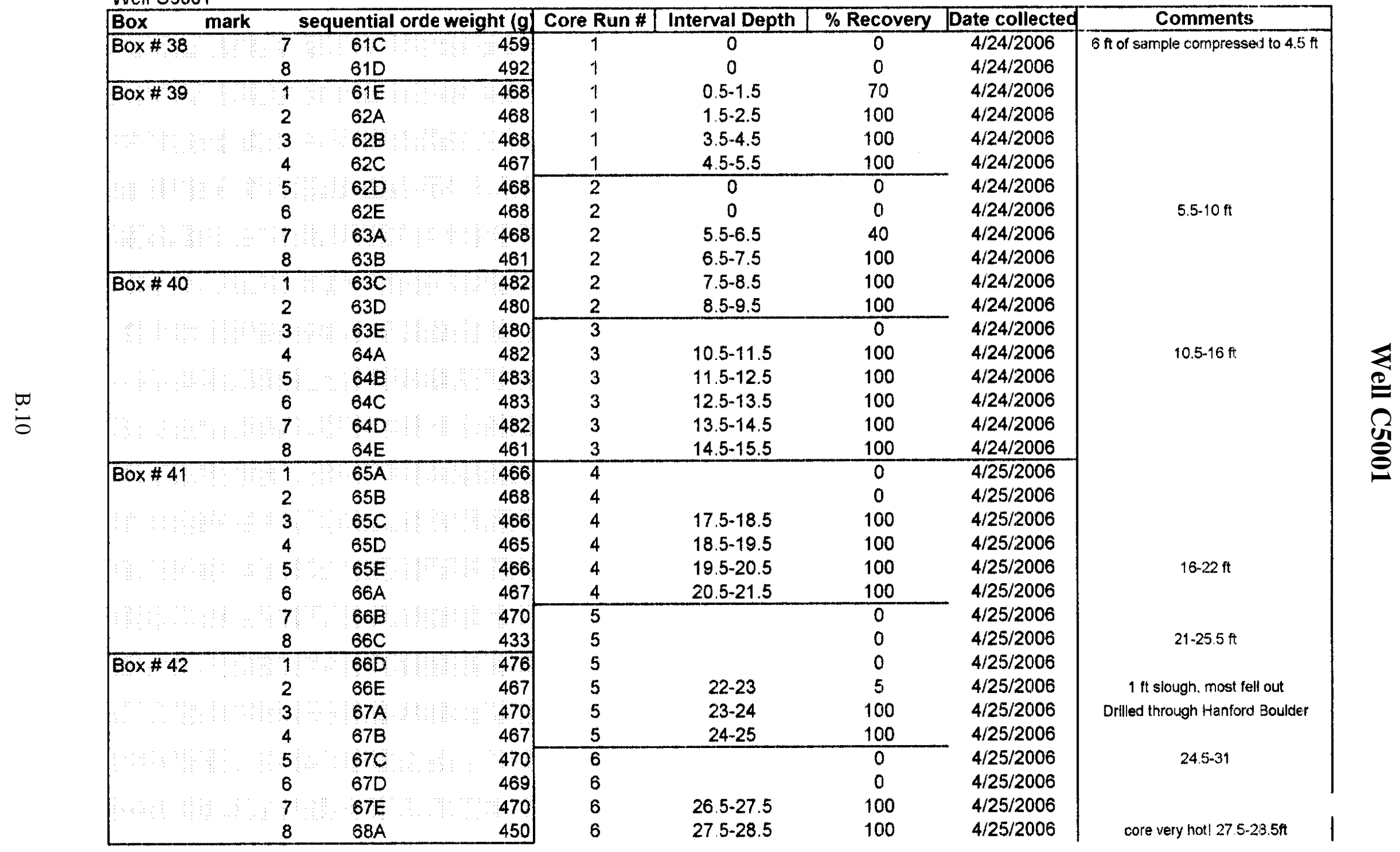




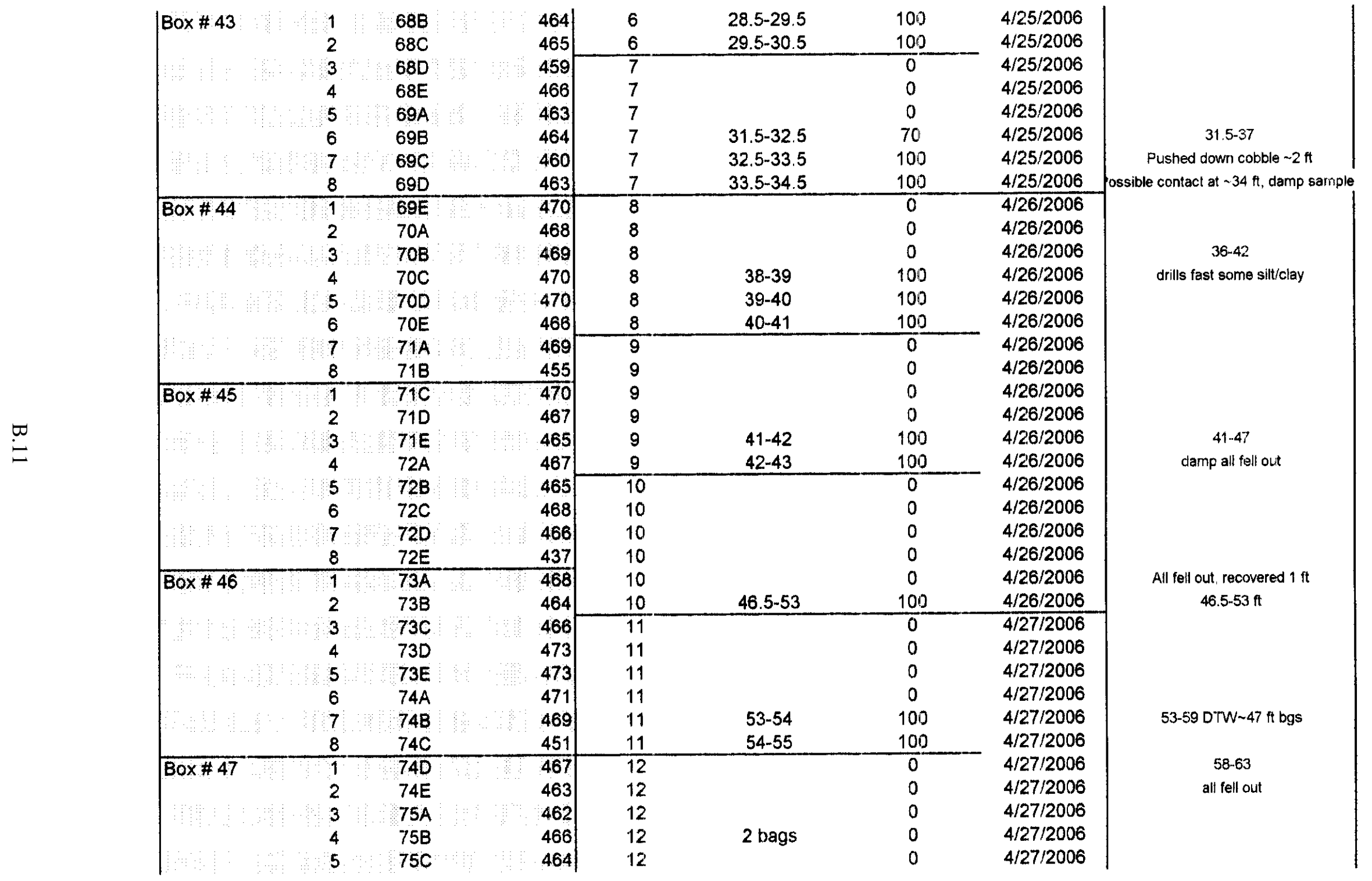




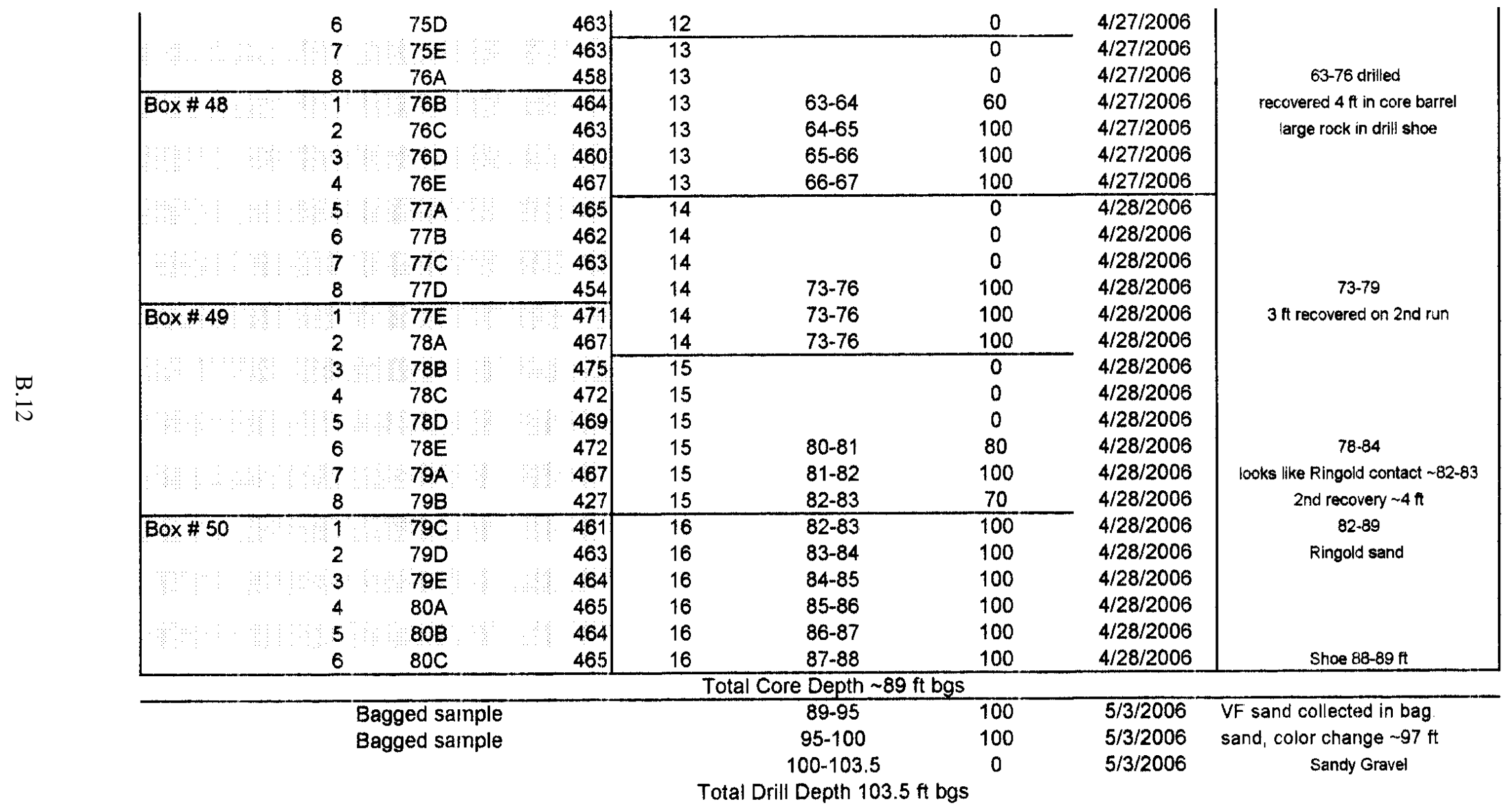


300 LFI LEXAN Core Liners

$399-3-20$

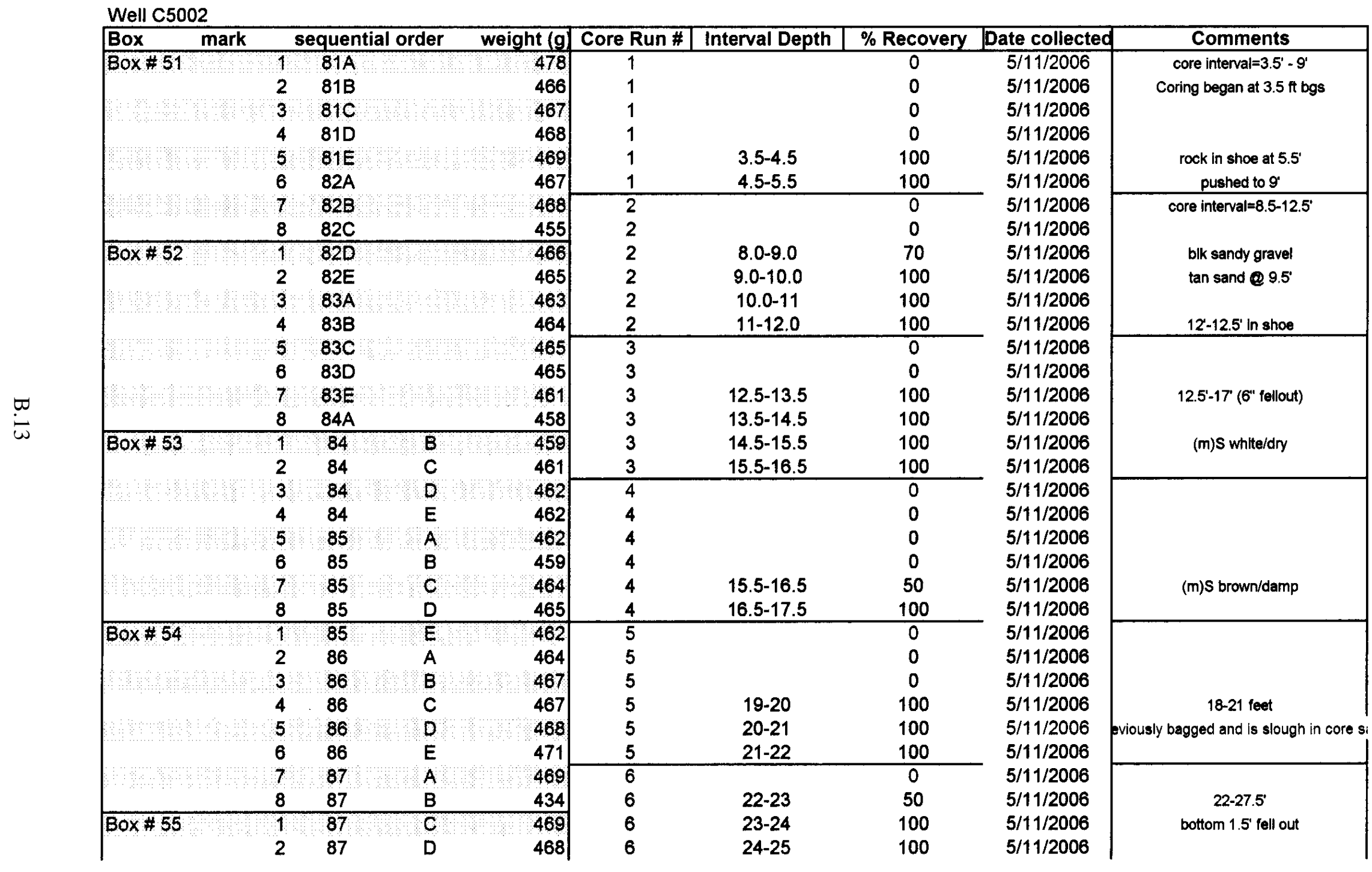




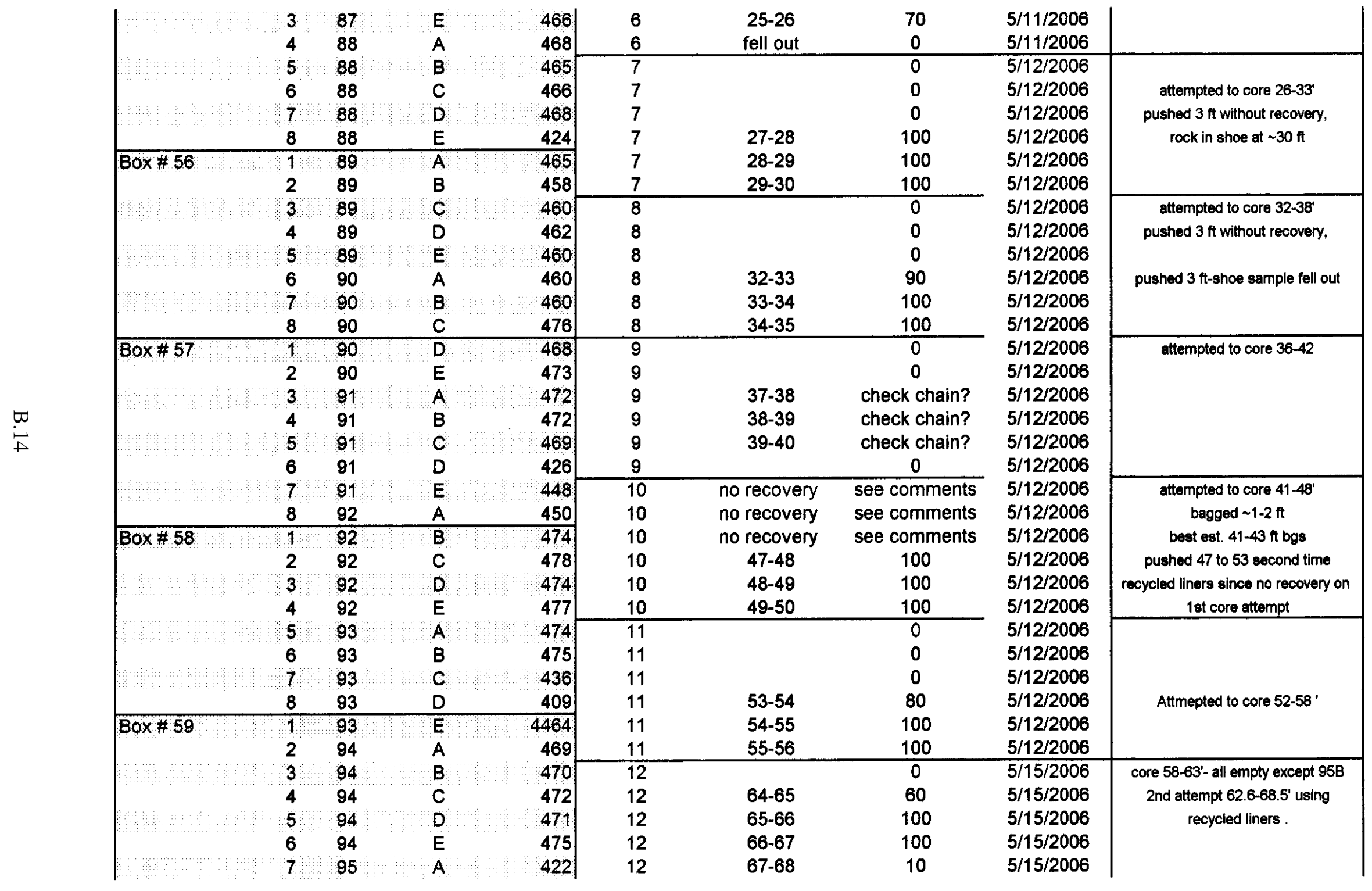




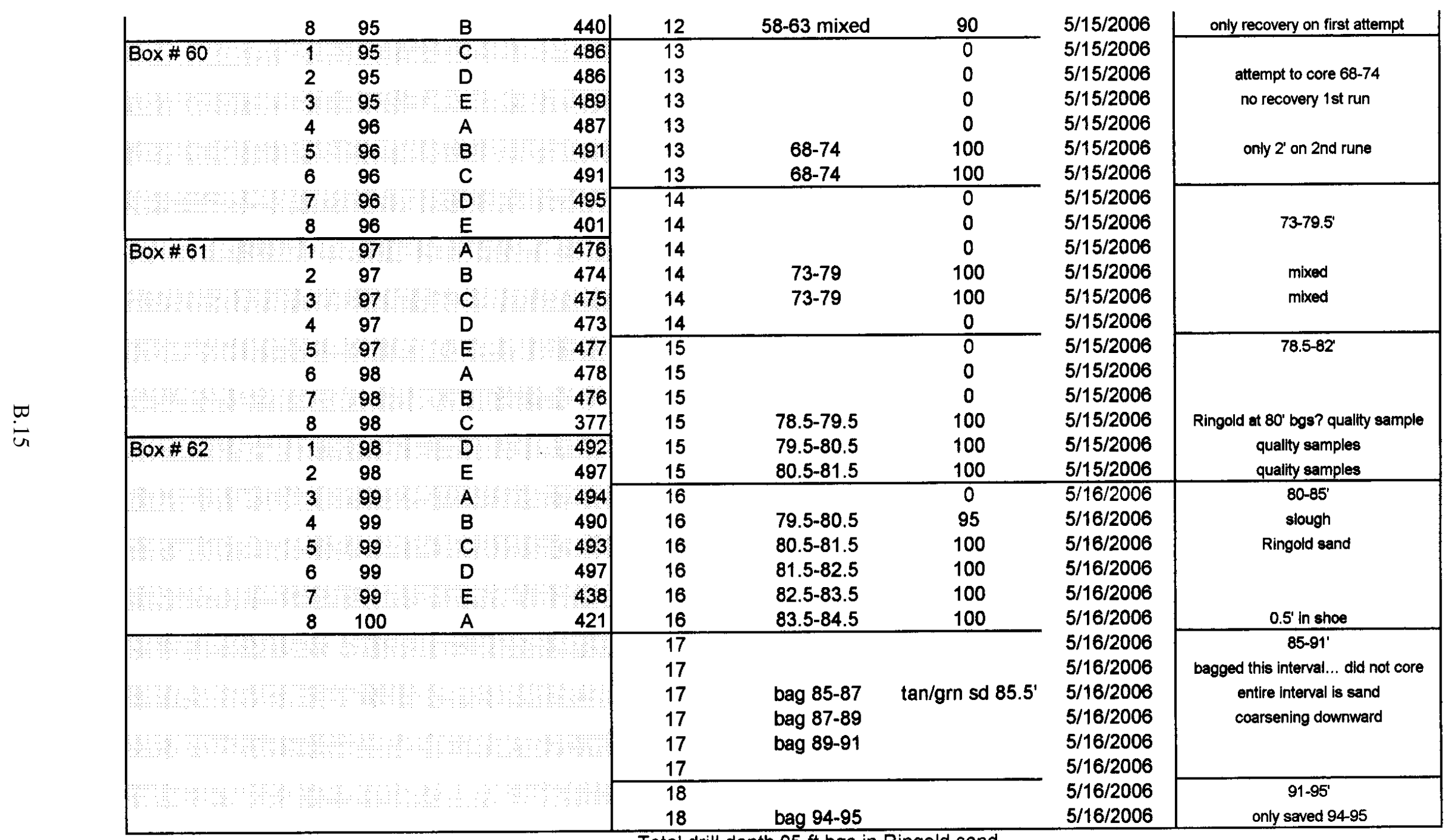

Total drill depth $95 \mathrm{ft}$ bgs in Ringold sand 


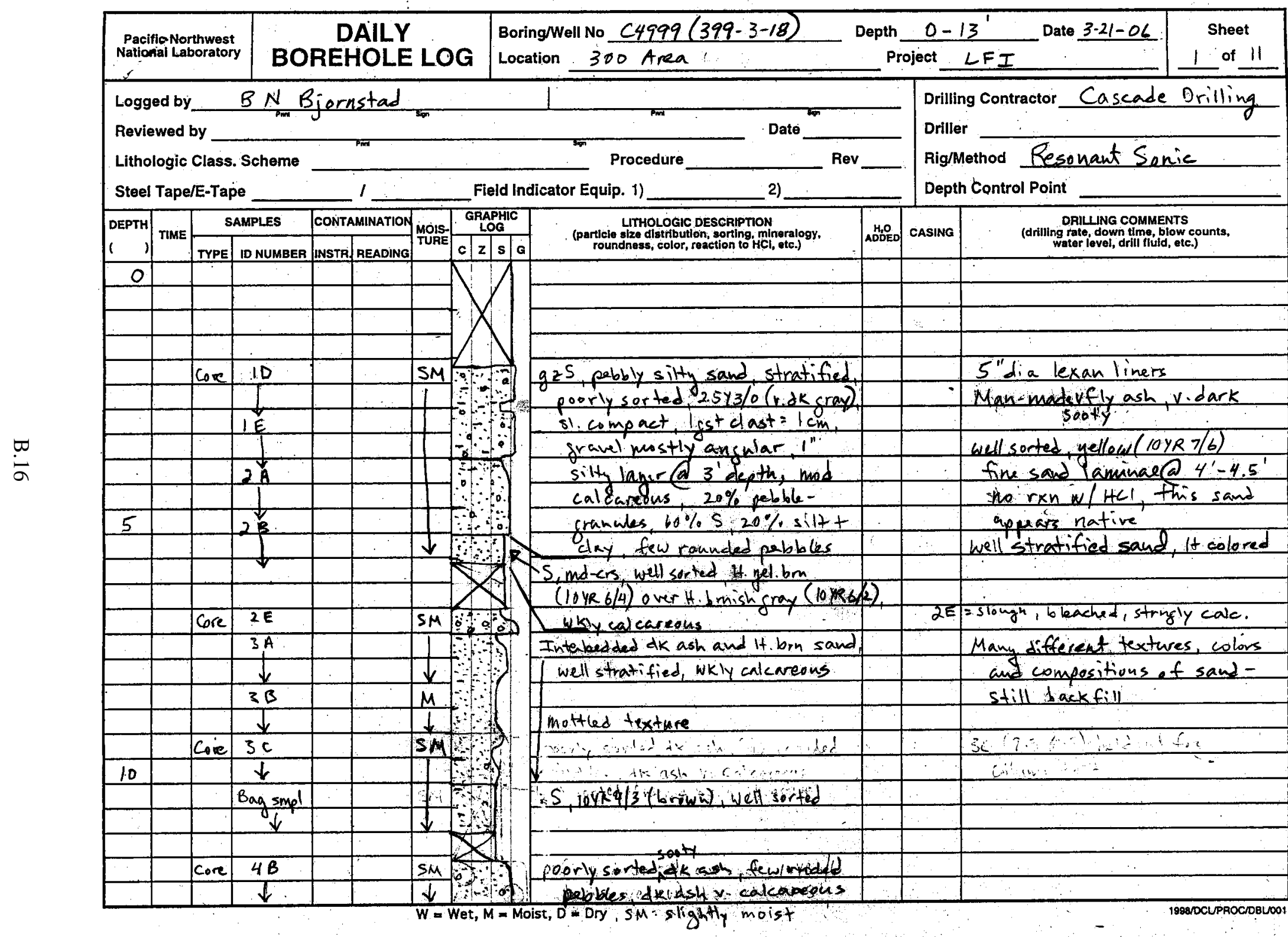




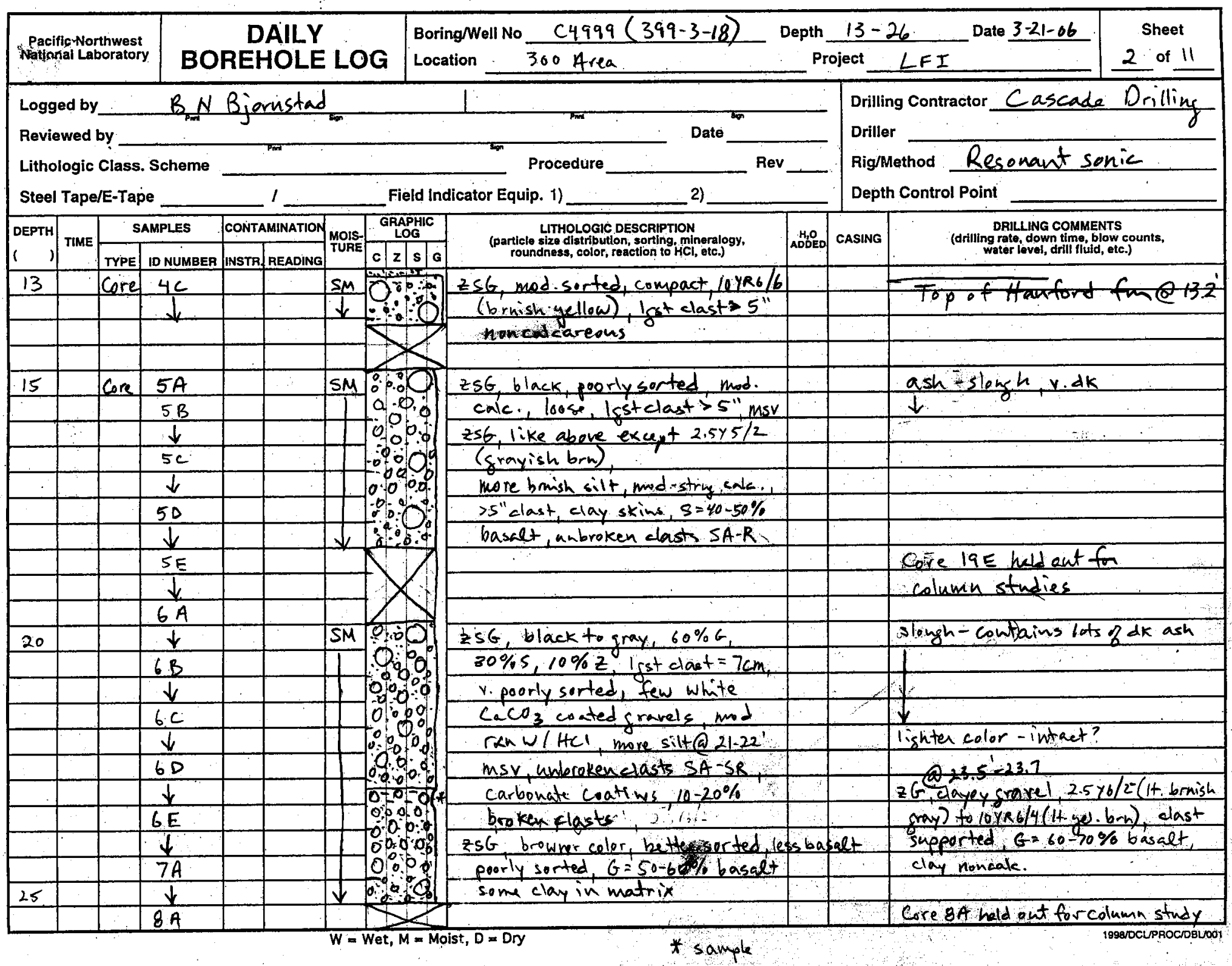




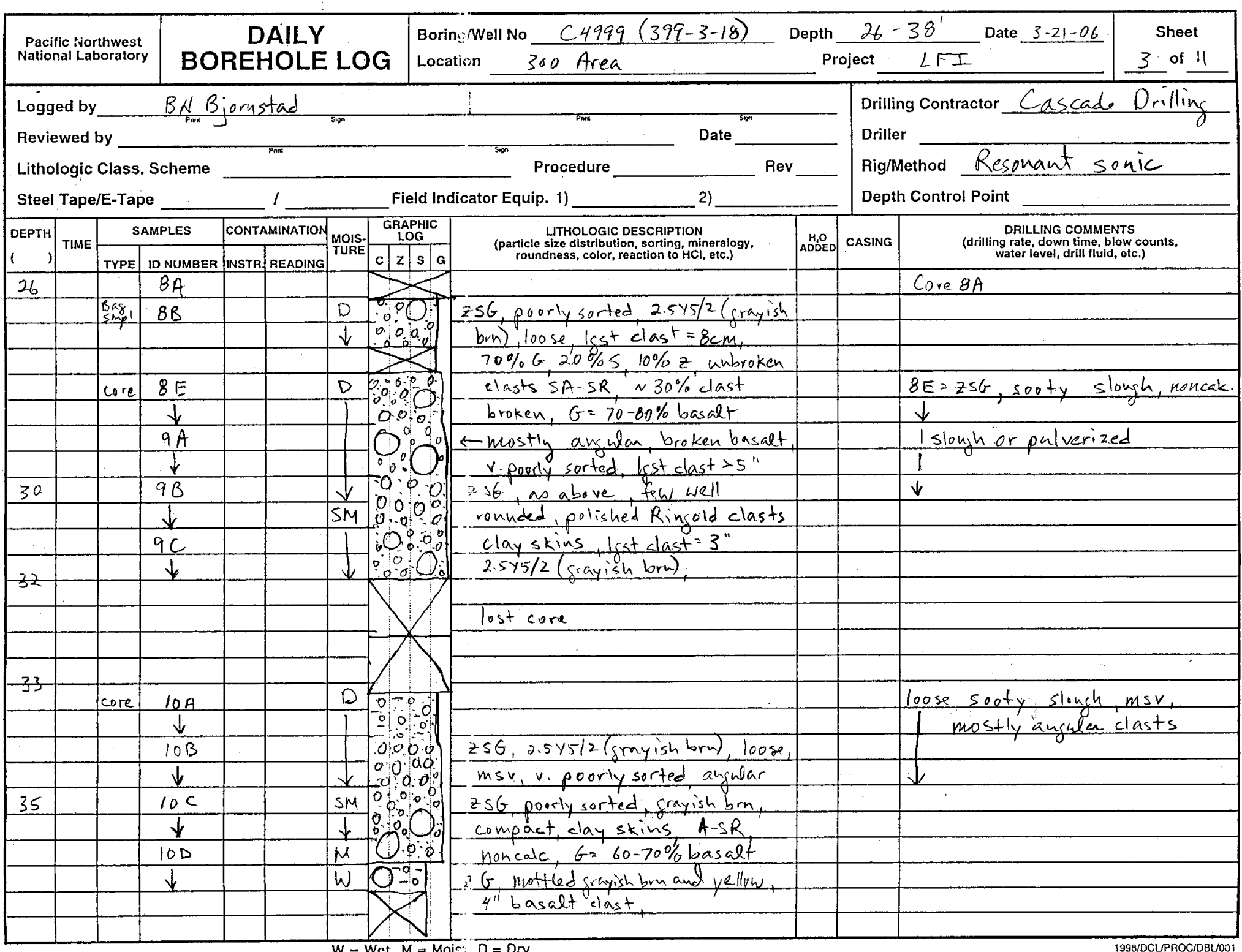




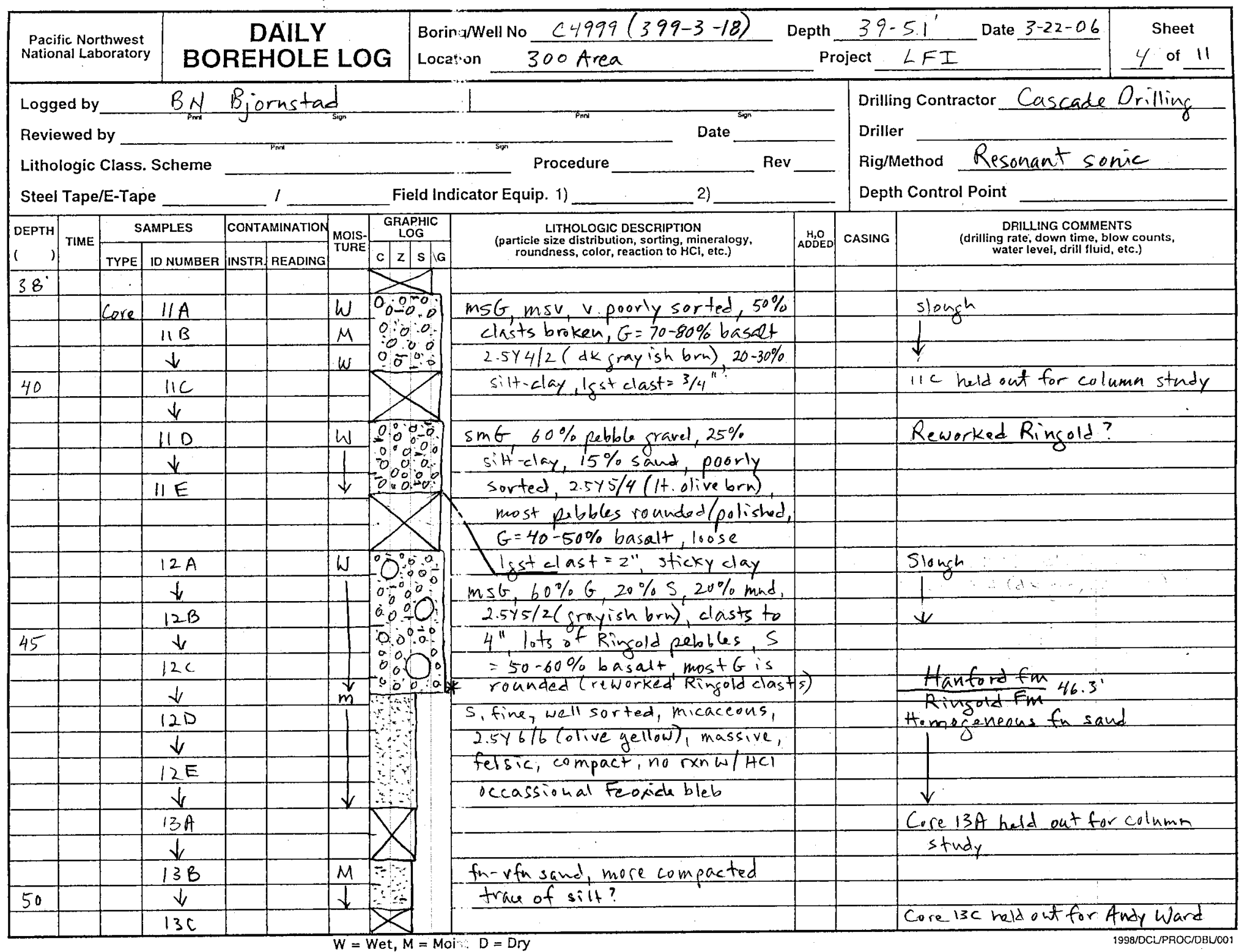




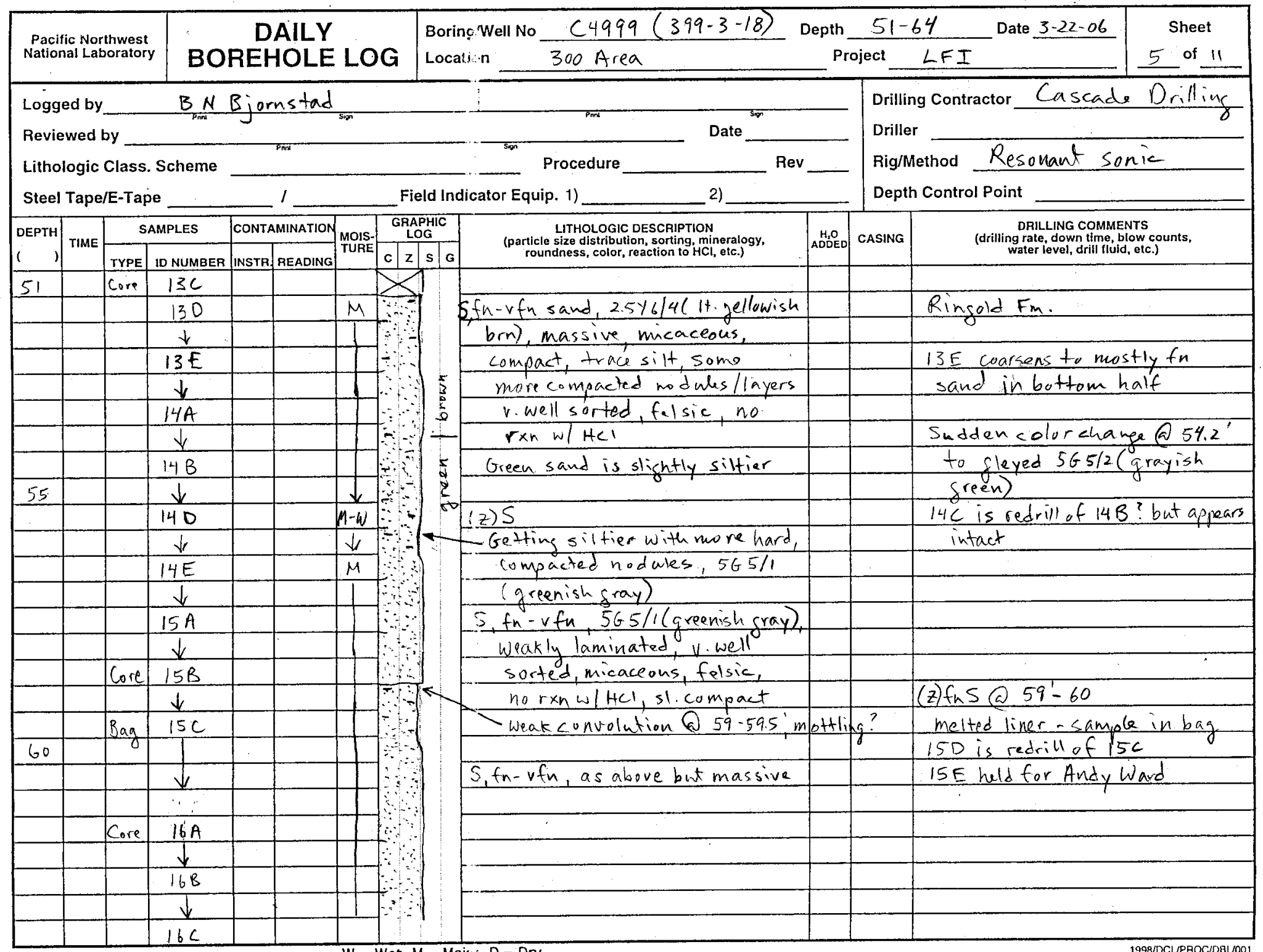




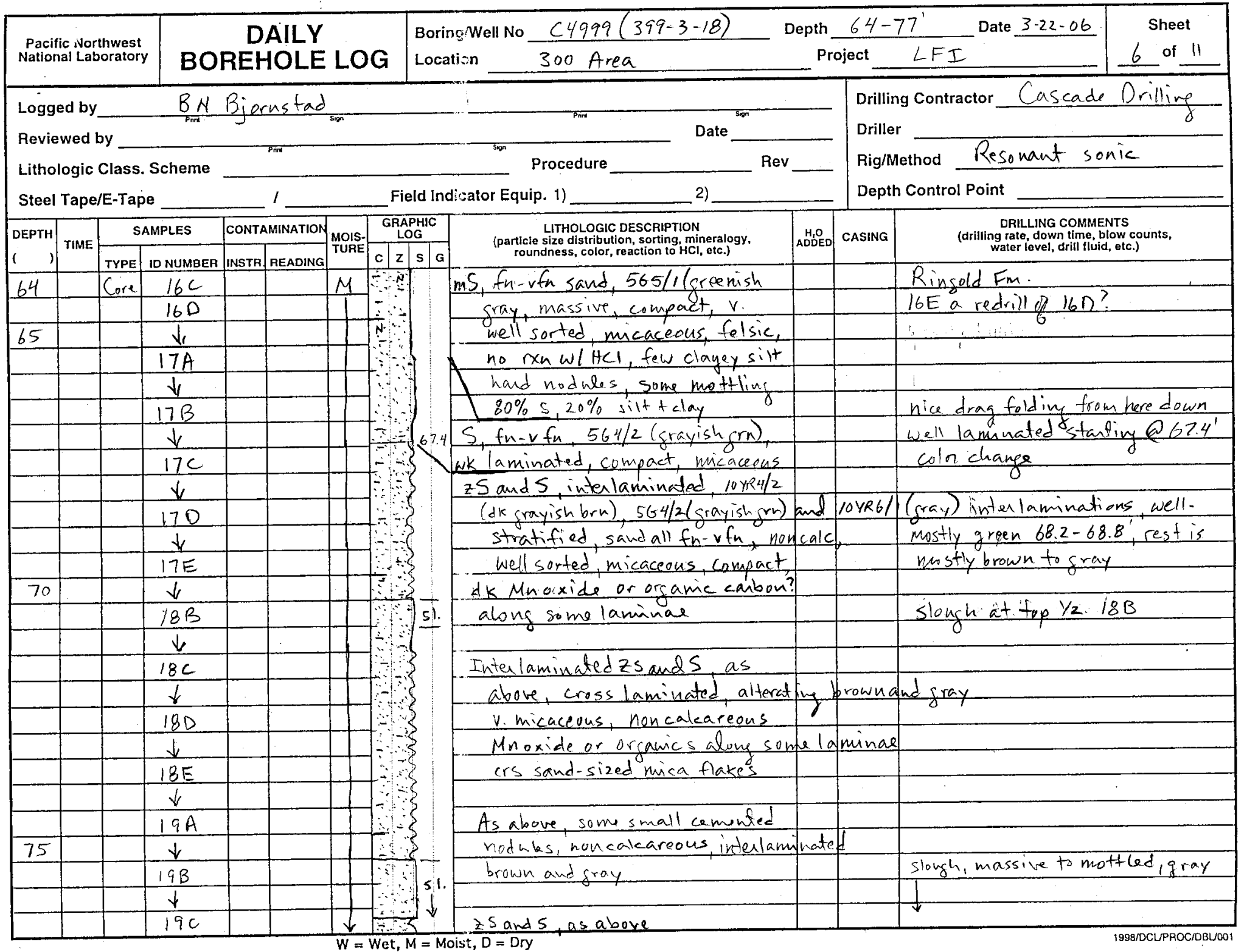




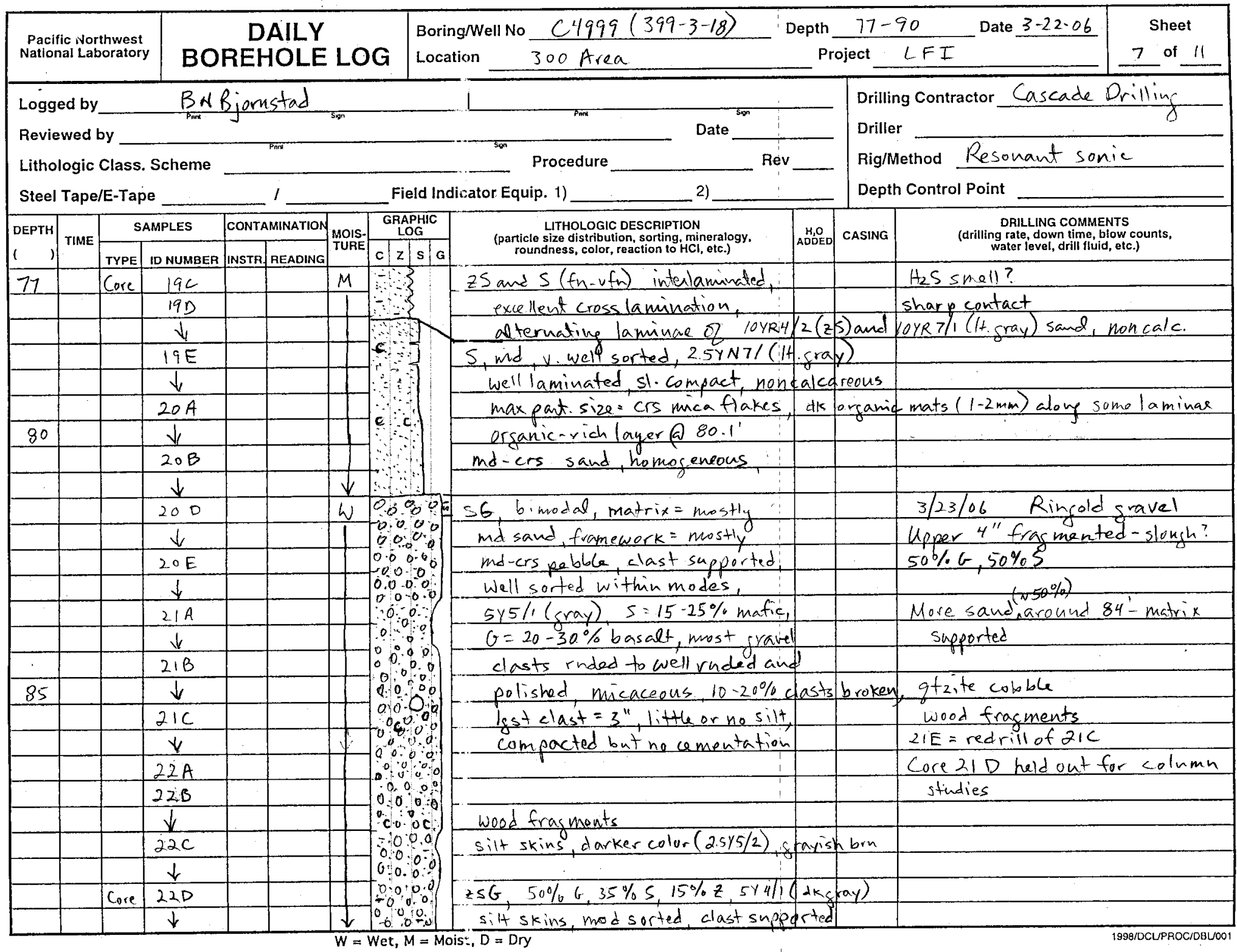




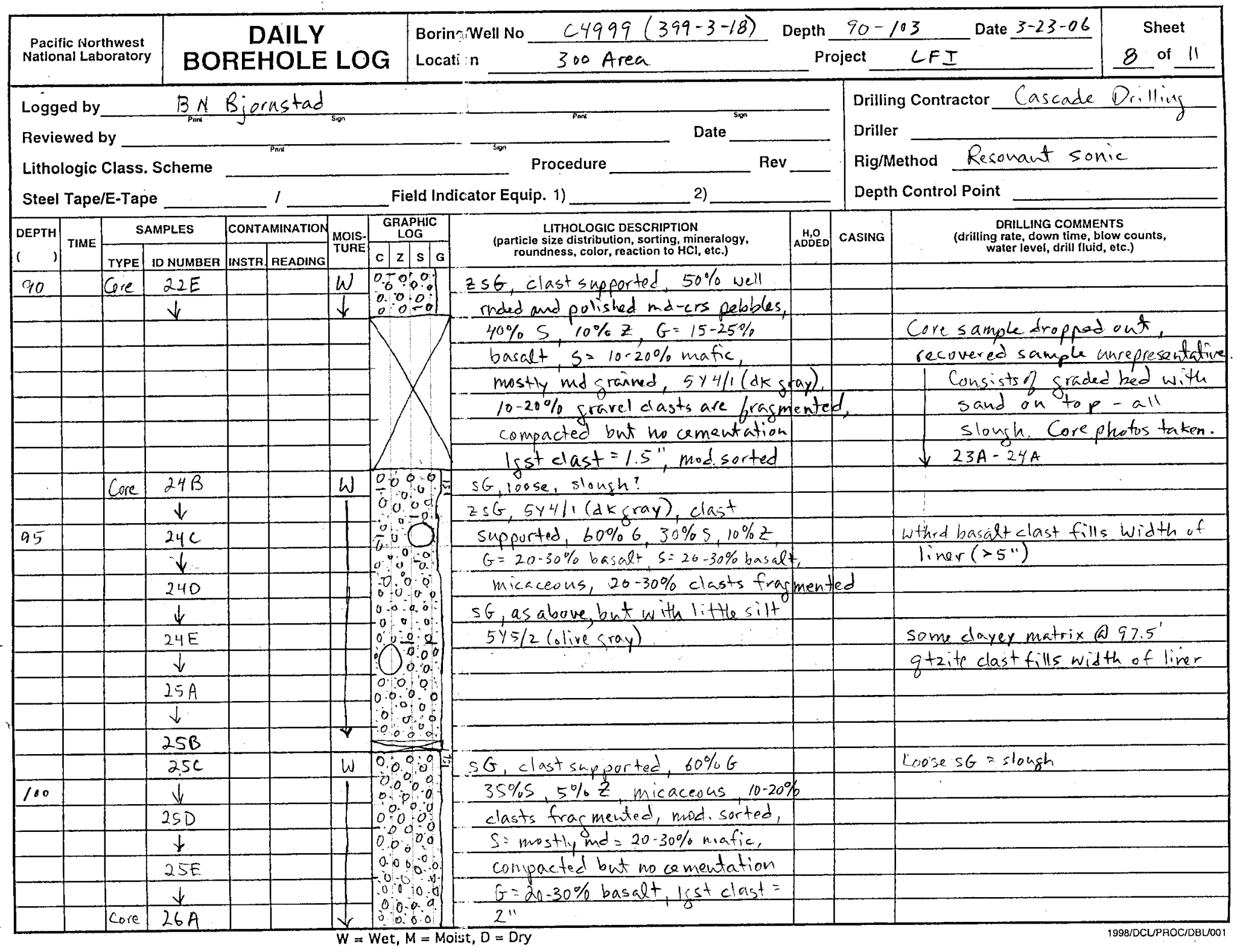




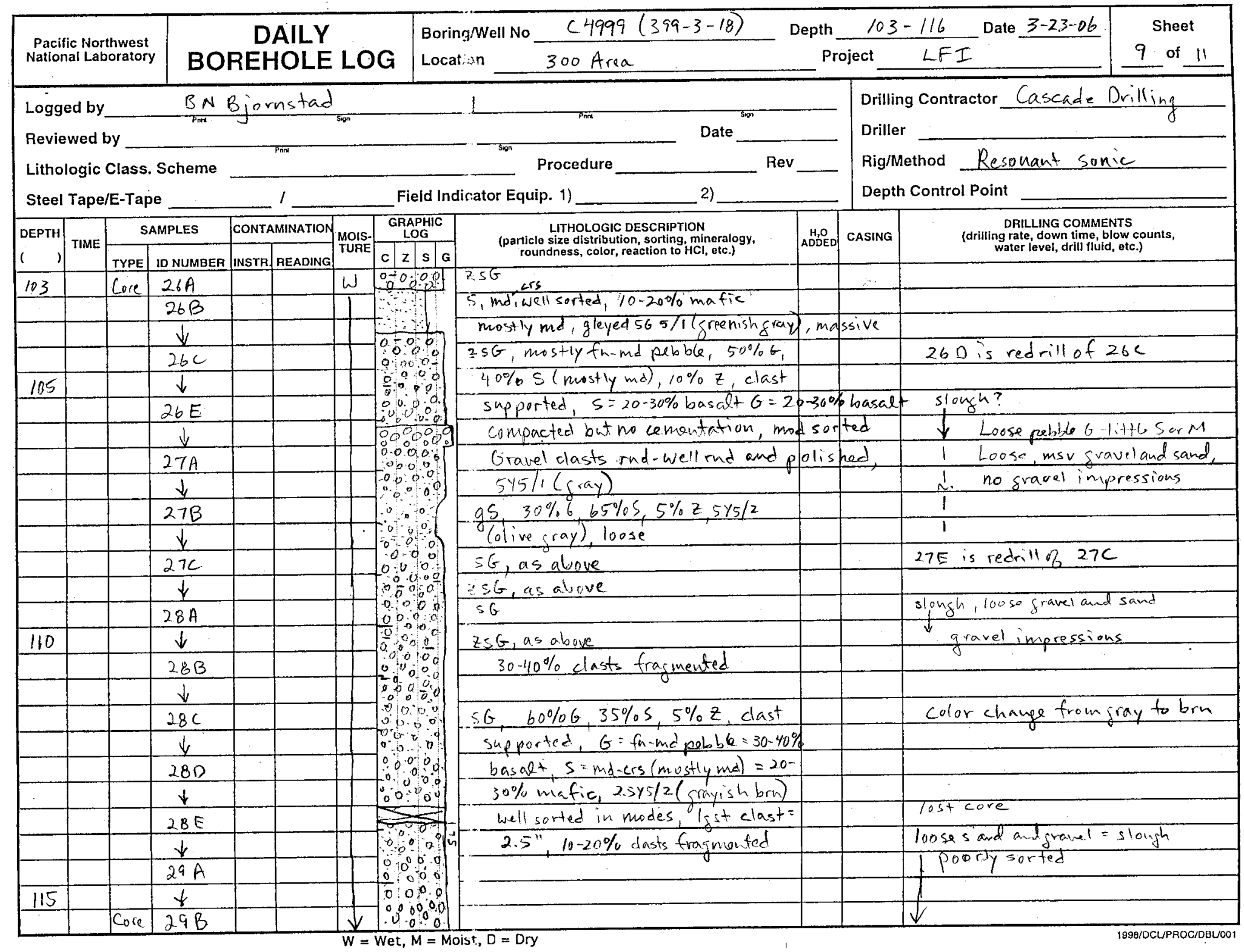




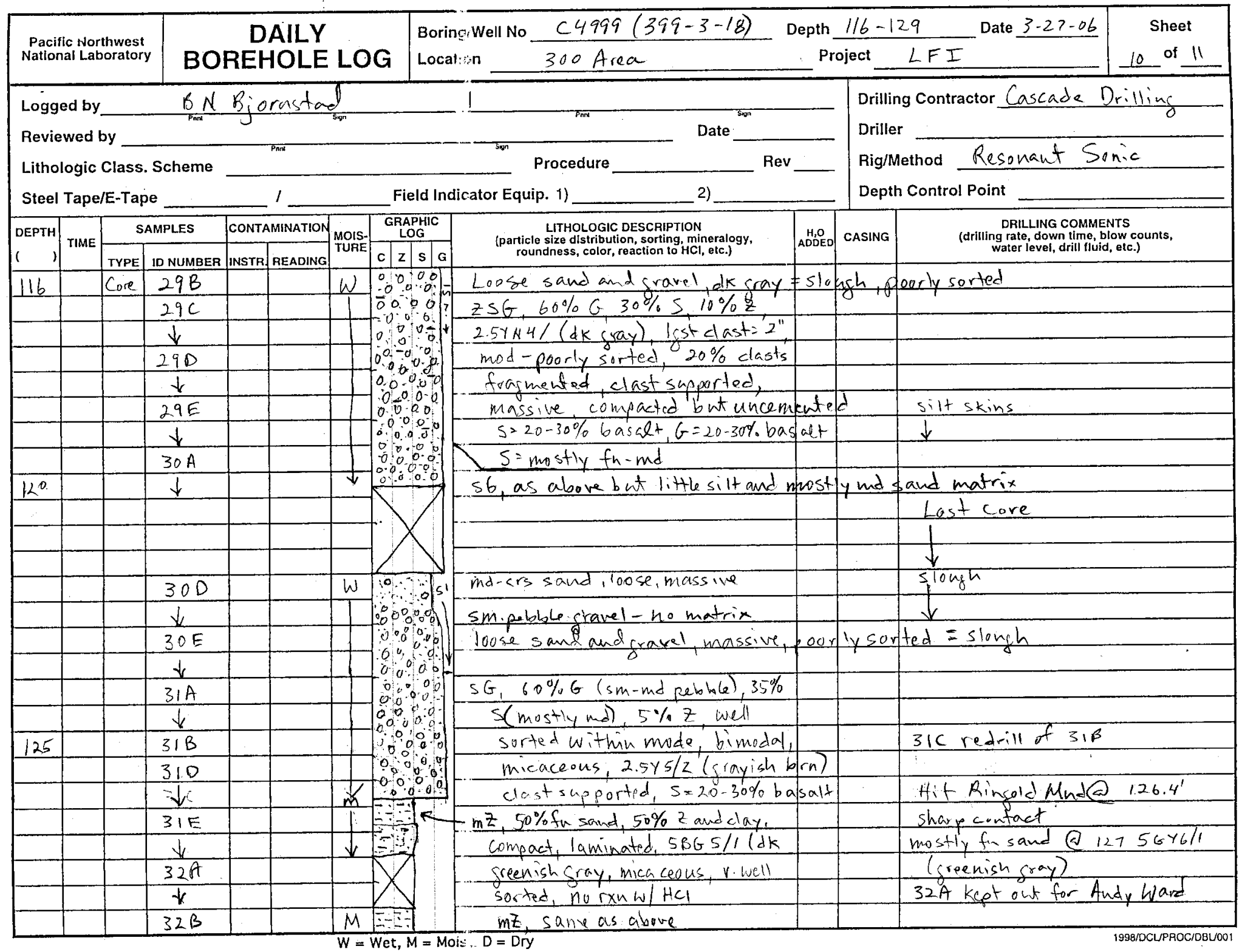




\begin{tabular}{|c|c|c|c|c|c|c|c|c|c|c|c|c|}
\hline \multicolumn{3}{|c|}{$\begin{array}{l}\text { Pacific Northwest } \\
\text { National Laboratory }\end{array}$} & \multicolumn{5}{|c|}{$\begin{array}{l}\text { DAILY } \\
\text { BOREHOLE LOG }\end{array}$} & \multicolumn{5}{|c|}{$\begin{array}{l}\text { Borir : Well No } \frac{(4999(399-3-18)}{300 \text { Area }} \text { Depth } \frac{129-130.5}{\text { Project LFI }} \text { Date } 3-27-06 \\
\text { Location }\end{array}$} \\
\hline \multicolumn{11}{|c|}{ Logged by $\quad B N$ Bjornstad } & \\
\hline \multirow{2}{*}{\multicolumn{11}{|c|}{ Reviewed by ___ }} & & \\
\hline \multirow{2}{*}{\multicolumn{4}{|c|}{$\begin{array}{l}\text { Lithologic Class. Scheme } \\
\text { Steel Tape/E-Tape }\end{array}$}} & & & & & & \multirow{2}{*}{\multicolumn{2}{|c|}{ Procedure $\quad$ Qquip. 1) 2 Rev }} & \multirow{2}{*}{\multicolumn{2}{|c|}{$\begin{array}{l}\text { Driller } \\
\text { Rig/Method Resonant Sonic } \\
\text { Depth Control Point }\end{array}$}} \\
\hline & & & & 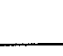 & -1 & & & & & & & \\
\hline \multirow{2}{*}{$\begin{array}{ll}\text { DEPTH } \\
i \quad 1\end{array}$} & \multirow{2}{*}{ TIME } & \multicolumn{2}{|c|}{ SAMPLES } & \multicolumn{2}{|c|}{ CONTAMINATION } & \multicolumn{3}{|c|}{$\begin{array}{c}\text { GRAPHIC } \\
\text { LOG }\end{array}$} & \multirow{2}{*}{ 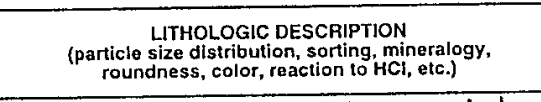 } & \multirow{2}{*}{ ADODED } & \multirow{2}{*}{ CASING } & \multirow{2}{*}{ 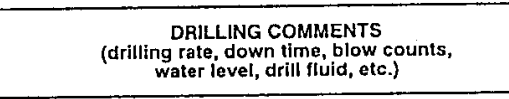 } \\
\hline & & TYPE & IO NUMBER & INSTF & READING & TURE & $\begin{array}{lll}c \mid & z \\
\end{array}$ & s. $\mathrm{G}_{\mathrm{B}}$ & & & & \\
\hline 129 & & Care & $32 B$ & & & $M$ & 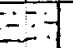 & & $m z$ as above well laminated, & & & \\
\hline & & & $32 c$ & & & 1 & 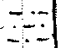 & & few hard laminal of darker clay & & & \\
\hline 130 & & & $\downarrow$ & & & $\downarrow$ & +9 & & ffns, well laminated, srayish & & & $\begin{array}{l}\text { distinct colar change to } 10 y k 5 / 2 \\
\text { (graysh bom)@ } 130.2 \text { whare }\end{array}$ \\
\hline & & & & & & & & & bro, compact, norxn $\omega / \mathrm{HCl}$ & & & $\frac{\text { (graysh bom } 130.2 \text { where }}{\text { changes to } z \text { fnsand }}$ \\
\hline & & & & & & & & & well sorted, $60 \%$ fn-rfn sand, & & & \\
\hline & & & & & & & & & $40 \%$ silt & & & \\
\hline & & & & & & & & & & & & \\
\hline & & & & & & & & & & & & \\
\hline & & & & & & & & & & & & \\
\hline & & & & & & & & & & & & \\
\hline & & & & & & & & & & & & \\
\hline & & & & & & & & & & & & \\
\hline & & & & & & & & & & & & \\
\hline & & & & & & & & & & & & \\
\hline & & & & & & & & & & & & \\
\hline & & & & & & & & & & & & \\
\hline & & & & & & & & & & & & \\
\hline & & & & & & & & & & & & \\
\hline & & & & & & & & & & & & \\
\hline & & & & & & & & & & & & \\
\hline & & & & & & & & & & & & \\
\hline & & & & & & & & & & & & \\
\hline & & & & & & & & & & & & \\
\hline & & & & & & & & & & & & \\
\hline & & & & & & & & & & & & \\
\hline
\end{tabular}




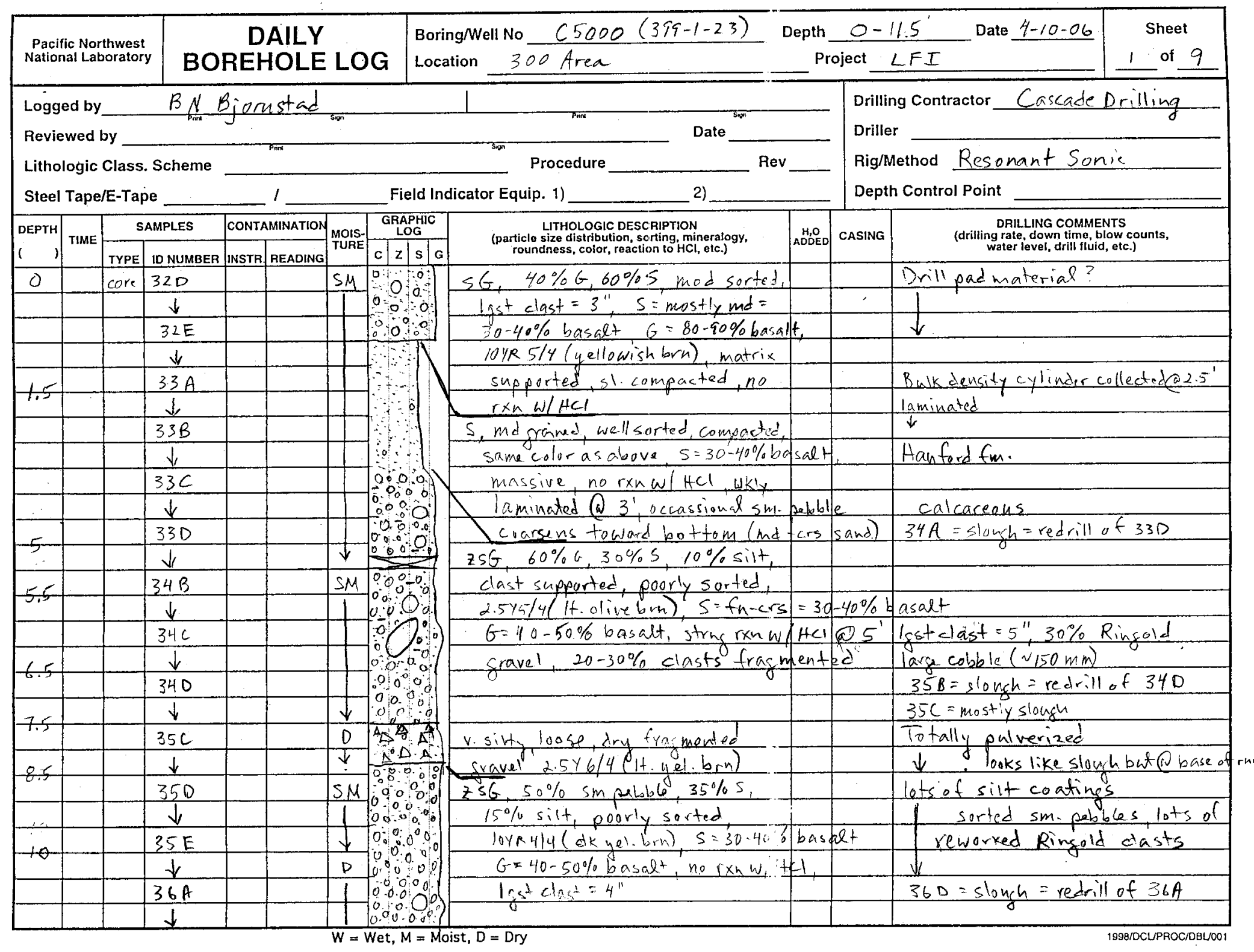




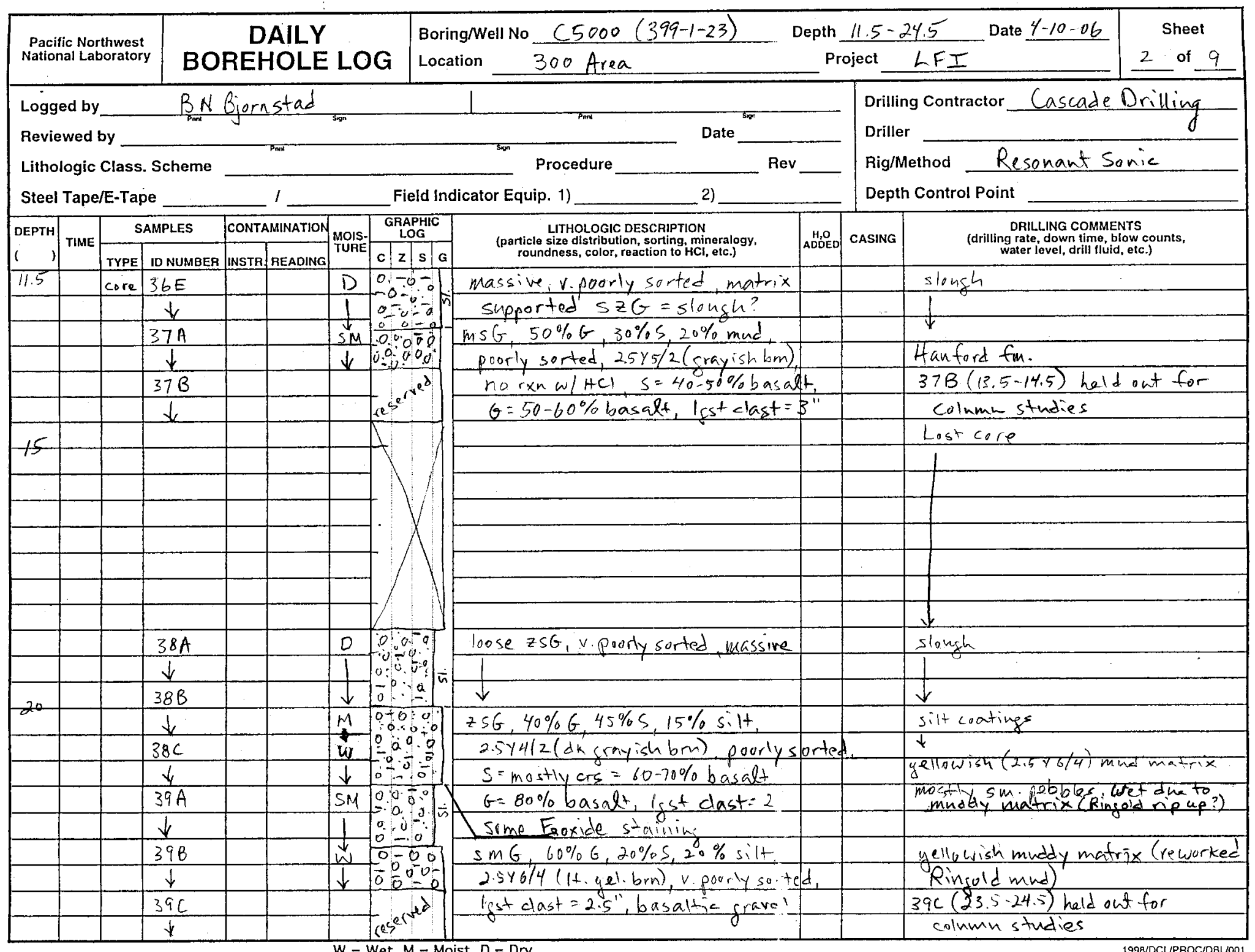




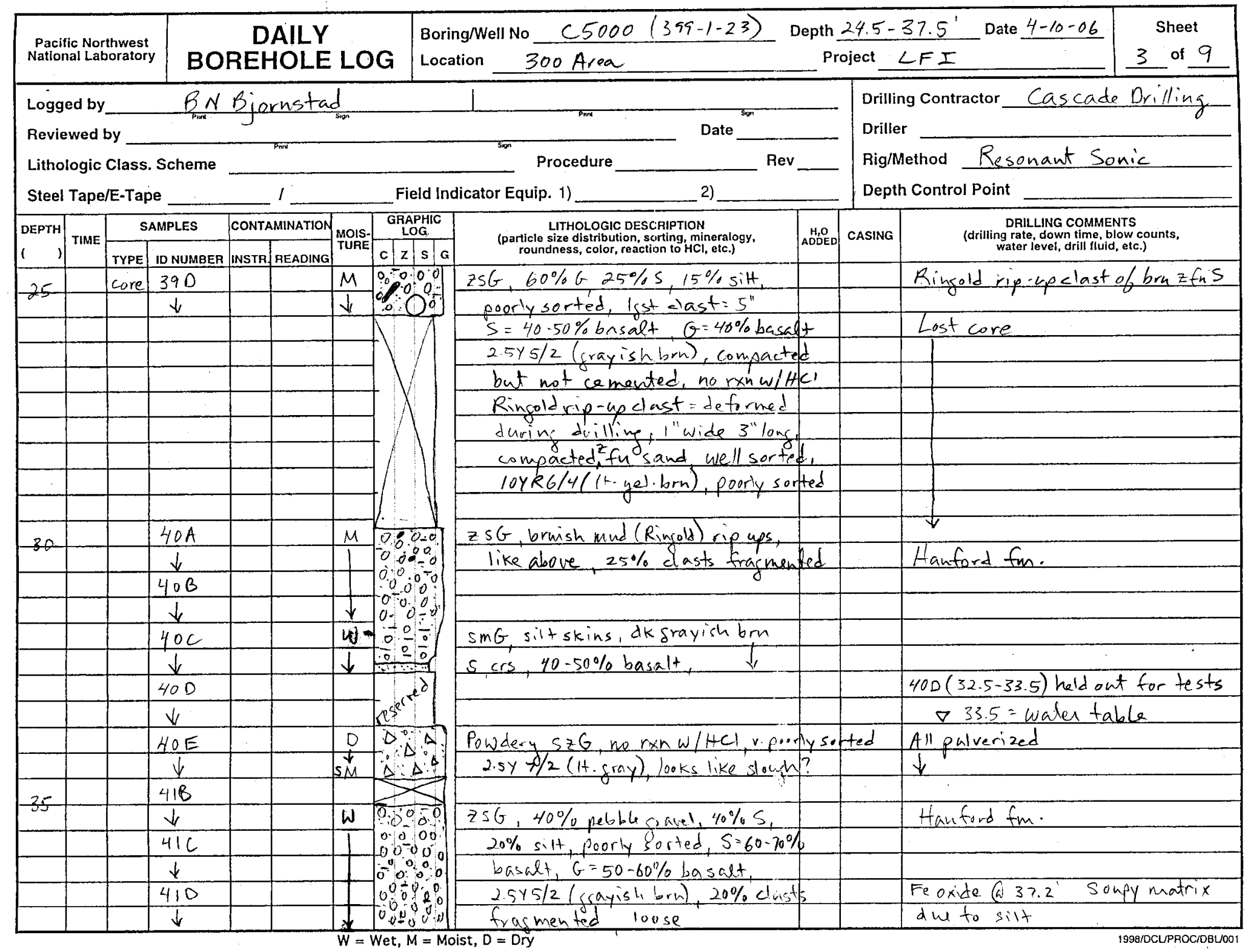




\begin{tabular}{|c|c|c|c|c|c|c|c|c|c|c|c|c|}
\hline \multicolumn{3}{|c|}{$\begin{array}{l}\text { Pacific Northwest } \\
\text { National Laboratory }\end{array}$} & \multicolumn{4}{|c|}{$\begin{array}{l}\text { DAILY } \\
\text { BOREHOLE LOG }\end{array}$} & $\begin{array}{l}\text { Borin } \\
\text { Loca }\end{array}$ & ing/Well No $\frac{C 5000(399-1-23)}{300 \text { Area }}$ & \multicolumn{3}{|c|}{$\begin{array}{l}\text { Depth } \frac{37.5-50.5}{\text { Project LFI }} \text { Date } 4-10-06 \\
\end{array}$} & 4 of 9 \\
\hline \multicolumn{3}{|c|}{ Logged by } & \multicolumn{4}{|c|}{ BN Biornstad } & & & & \\
\hline \multicolumn{10}{|c|}{ Reviewed by } & & & \\
\hline \multirow{2}{*}{\multicolumn{4}{|c|}{$\begin{array}{l}\text { Lithologic Class. Scheme } \\
\text { Steel Tape/E-Tape }\end{array}$}} & & & & & Procedure & \multirow[t]{2}{*}{$R \in V$} & \multirow{2}{*}{\multicolumn{3}{|c|}{$\begin{array}{l}\text { Driller } \\
\text { Rig/Method Resonant sonic } \\
\text { Depth Control Point }\end{array}$}} \\
\hline & & & & & 1 & & Field Ind & dicator Equip. 1) _____ ${ }^{2)}$ & & & & \\
\hline \multirow{6}{*}{\begin{tabular}{l|l|} 
DEPTH \\
\\
37.5 \\
37
\end{tabular}} & \multirow{3}{*}{ TIME } & \multicolumn{2}{|c|}{ SAMPLES } & \multicolumn{2}{|c|}{ CONTAMINATION } & \multirow{2}{*}{\begin{tabular}{|l|} 
MOIS- \\
TURE
\end{tabular}} & $\begin{array}{c}\text { GRAPHIC } \\
\text { LOG }\end{array}$ & \multirow{2}{*}{$\begin{array}{l}\text { LITHOLOGII DESCRIPTION } \\
\text { (particle size distribution, sorting, mineralogy. } \\
\text { roundness, color, reaction to HCl, etc.) }\end{array}$} & \multirow{2}{*}{$\begin{array}{c}\text { H,O } \\
\text { ADOED }\end{array}$} & \multirow{2}{*}{ CASING } & \multirow{2}{*}{\multicolumn{2}{|c|}{$\begin{array}{l}\text { DRILLING COMMENTS } \\
\text { (driiling rate, down time blow counts, } \\
\text { water ievel, drilit fluidic, etc.) }\end{array}$}} \\
\hline & & TYPE & ID NUMBER & INSTR & READING & & 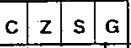 & & & & & \\
\hline & & core & $41 E$ & & & $w$ & $\begin{array}{ll}0+0.0 \\
0,0.0\end{array}$ & zSG $50 \%, \mathrm{G}, 30 \% \mathrm{~S}, 20 \% \mathrm{silt}$ & & & Soupy mud matrix & \\
\hline & & & $\downarrow_{1}$ & & & $\downarrow$ & $\begin{array}{lll}0 & 0 \\
0 & 0 & 0 \\
0\end{array}$ & poorly sorted, loose, $s=$ mosty & & & $\downarrow$ & \\
\hline & & & $42 A$ & & & & & Crs $=50-60 \%$ basalt, $G=50 \%$ & & & $42 \mathrm{~A}$ held out for $\mathrm{C}$ & lamn studies \\
\hline & & & $x$ & & & & $e^{2 e^{6}}$ & basalt $2.575 / 2$ (jrayish bre) & & & & \\
\hline \multirow[t]{9}{*}{-40} & & & & & & & & Isst clast $=2 "$ & & & llost core $\ldots$ & $\ldots$ \\
\hline & & & & & & & & 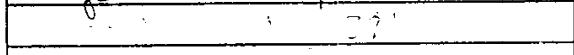 & & & $1 \ldots$ & \\
\hline & & & & & & & & & & & & \\
\hline & & & & & & & & & & & & \\
\hline & & & & & & & & & & & & \\
\hline & & & & & & & & & & & & \\
\hline & & & & & & & & & & & $t$ & \\
\hline & & & $43 A$ & & & 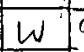 & & $5 G, 60 \%$ pebble gravel $40 \%$ md- & & & Fanford fm Fell ont & of Core barrel \\
\hline & & & $\downarrow$ & & & 1 & 000.0 & crs sand mod sorted & & & & \\
\hline \multirow{10}{*}{45} & & & $43 B$ & & & & & $2.5 y 5 / 2$ (stayish brh) loose & & & $\downarrow$ & \\
\hline & & & $\downarrow$ & & & $\downarrow$ & $=0.0$ & $S=70-80 \% \%$ basalt, $G=50-60 \%$ & & & browner color due to $A$ & Ringold silt \\
\hline & & & a & & & & & basalt isstclast $=2 "$ & & & in matrix & \\
\hline & & & & & & & & $25 G \quad 10 Y R 5 / 2$ (irgyish brh) & & & & \\
\hline & & & $44 A$ & & & W & & $50 \% \mathrm{G}, 25 \% \mathrm{~S}, 25 \% \mathrm{z}$, lots of & & & & \\
\hline & & & 4 & & & 1 & 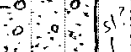 & silt poorly sorted $S=40-50 \%$ & & & $g S, 1005 e$, poorly so & ted, basaltic \\
\hline & & & $44 B$ & & & & 0 & basalt loose & & & & \\
\hline & & & $\downarrow$ & & & & $0=0.0 .0$ & $z s G$, loose, soney $s=50-60 \%$ & falt & & & \\
\hline & & & $44 \mathrm{C}$ & & & & -0.00 & loYRs/2 (grayishbin) poorly & orted & & & \\
\hline & & & $v$ & & & & 0.0. & $S=40-50 \%$ bas lest clast $=5, G=6$ & $0-70^{\circ}$ & lobasa & Qt Hanford $\mathrm{fm}_{\mathrm{m}}$. & \\
\hline \multirow{2}{*}{$50-1$} & & & 440 & & & & $0 \quad 0 J_{\mathrm{s}}$ & $795-6$, craded & & & slough & \\
\hline & & & $\downarrow$ & & & $\downarrow$ & $0_{00} 00_{0}^{\circ}$ & & & & & \\
\hline
\end{tabular}




\begin{tabular}{|c|c|c|c|c|c|c|c|c|c|c|c|c|}
\hline \multicolumn{3}{|c|}{$\begin{array}{l}\text { Pacific Northwest } \\
\text { National Laboratory }\end{array}$} & \multicolumn{4}{|c|}{$\begin{array}{c}\text { DAILY } \\
\text { BOREHOLE LOG }\end{array}$} & \multicolumn{5}{|c|}{$\begin{array}{l}\text { Boring/Well No } \frac{C 5000(399-1-23)}{300 \text { Area }} \\
\text { Location }\end{array}$} & $\begin{array}{c}\text { Sheet } \\
5 \text { of } 9\end{array}$ \\
\hline \multicolumn{10}{|c|}{ Logged by $\quad B N$ Bjornstad } & \\
\hline \multirow{2}{*}{\multicolumn{10}{|c|}{ Reviewed by }} & & & \\
\hline & & & & & & & & & & \multirow{2}{*}{\multicolumn{3}{|c|}{$\begin{array}{l}\text { Driller } \\
\text { Rig/Method Resonant Some } \\
\text { Depth Control Point }\end{array}$}} \\
\hline \multicolumn{10}{|c|}{ Steel Tape/E-Tape ___ } & & & \\
\hline \multirow{2}{*}{\multicolumn{2}{|c|}{\begin{tabular}{|l|l|} 
DEPTH & TIME \\
$(\quad 1$ & \\
\end{tabular}}} & \multicolumn{2}{|c|}{ SAMPLES } & \multicolumn{2}{|c|}{ CONTAMINATION } & \multirow{2}{*}{ MOIS- } & $\begin{array}{l}\text { GRAPHIC } \\
\text { LOG } \\
\end{array}$ & \multirow{2}{*}{ 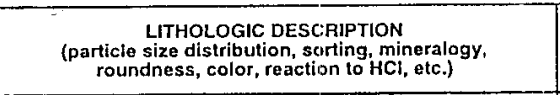 } & \multirow{2}{*}{ 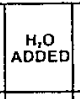 } & \multirow{2}{*}{ CASING } & \multirow{2}{*}{\multicolumn{2}{|c|}{$\begin{array}{l}\text { DRILLING COMMENTS } \\
\text { (drilling rate, down timo, blow counts, } \\
\text { water ievel, driil fluldo, etc.) }\end{array}$}} \\
\hline & & YPE & ID NUMBER & INSTR & READING & & 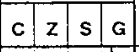 & & & & & \\
\hline \multirow[t]{8}{*}{50.5} & & ore & $44 E$ & & & $w$ & $0=0.1$ & \multicolumn{2}{|l|}{ ZSG, poorly sorted, massive, louse } & & \multicolumn{2}{|c|}{ Slungh or highly reduced (dk gray) } \\
\hline & & & $\frac{44 E}{\downarrow}$ & & & 1 & $0: 0-0.90$ & homoseneous, $2.5 y / v^{4} /(d k \delta$ fray $)$ & & & & \\
\hline & & & $45 A$ & & & & $\begin{array}{ccc}0 & 0 & 0 \\
-0 & 0 & 0 \\
-0 & 0\end{array}$ & & & & $\forall$ & \\
\hline & & & $\downarrow$ & & & & 00.00 & & & & & \\
\hline & & & $45 B$ & & & & 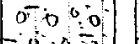 & mose compact, micaceous & & & Rincold Fm stants o & dbout here? \\
\hline & & & $\sqrt{t}$ & & & & $=0.000 .0$ & $5=20-30 \%$ basalt, sand grains stain & nned & dank & & \\
\hline & & & $45 c$ & & & & 00000 & $S G$ bimedal $60 \%, \quad 30 \% s, 40 \%$ & & & & \\
\hline & & & $\psi$ & & & & $00 \div 0$ & clast supported, s' compact. & & & & \\
\hline 55 & & & $45 D$ & & & & ${ }_{0}^{0} 0.0$ & micaceous, $s=m d=10-20 \% \mathrm{maf}$ & fic & & $45 E=$ slough $=$ redrill & of 450 \\
\hline & & & $\downarrow$ & & & & 0.00 & $G=30-40 \%$ basalt, $2.5 \% 5 / 2$ & & & silt skins & \\
\hline & & & $46 \mathrm{~A}$ & & & & 0.000 & (grayishbrh), Igst clast $=2.5^{\prime \prime}$, & & & & \\
\hline & & & $\downarrow$ & & & & 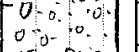 & $10-20 \%$ clasts frasmented & & & & \\
\hline & & & $46 B$ & & & & 0.0 .0 .0 & hust clasts well inded and polis he & & & & \\
\hline & & & $\downarrow$ & & & $\downarrow$ & $\begin{array}{llll}0 & 0 & 0 & 0 \\
0 & 0 & 0 & 0 \\
\end{array}$ & & & & lighter groy $(2.546 / 2)$ at 1 & bottom \\
\hline & & & $46 C$ & & & & & & & & $46 \mathrm{C}$ held out for coll & umn studies \\
\hline & & & $\downarrow$ & & & & {$\left[e^{\operatorname{ses} e}\right]^{\circ}$} & & & & & \\
\hline & & & 460 & & & $\omega$ & 0.090 & same as above still reduced & & & $4 / 11 / 06$ & \\
\hline & & & $x_{1}$ & & & $L$ & 00.00 & $(2.5 \times 5 / 2$ - srayish brn), clean & & & & \\
\hline to & & & $46 E$ & & & & $0.0: 01-$ & mo-crs sand matrix bimoda! & & & $47 A=$ slongh-basalti & c.loose \\
\hline 60 & & & $47 B$ & & & & 0.0 .0 .1 & micaceous & & & & \\
\hline & & & $\downarrow$ & & & & $\begin{array}{lllll}0 & 0 & 0 & 0 & 0 \\
0 & 0 & 0 & 0\end{array}$ & & & & & \\
\hline & & & $47 c$ & & & & $0 \begin{array}{llll}0 & 0 & 0 & 0 \\
0 & 0 & 0 & 0\end{array}$ & $10-20 \%$ elasts fragmented & & & & \\
\hline & & & $\downarrow$ & & & & 00.000 & & & & & \\
\hline & & & 470 & & & & 0.00 & Igst clast $=4 " G=40 \%$ basalt & & & $48 B$ redrill of 470 & \\
\hline & & & $y$ & & & $\downarrow$ & $=0.0$ & $S=10-15 \%$ mafic & & & & \\
\hline & & & $47 E$ & & & & $\sum$ & & & & Lust core & \\
\hline
\end{tabular}




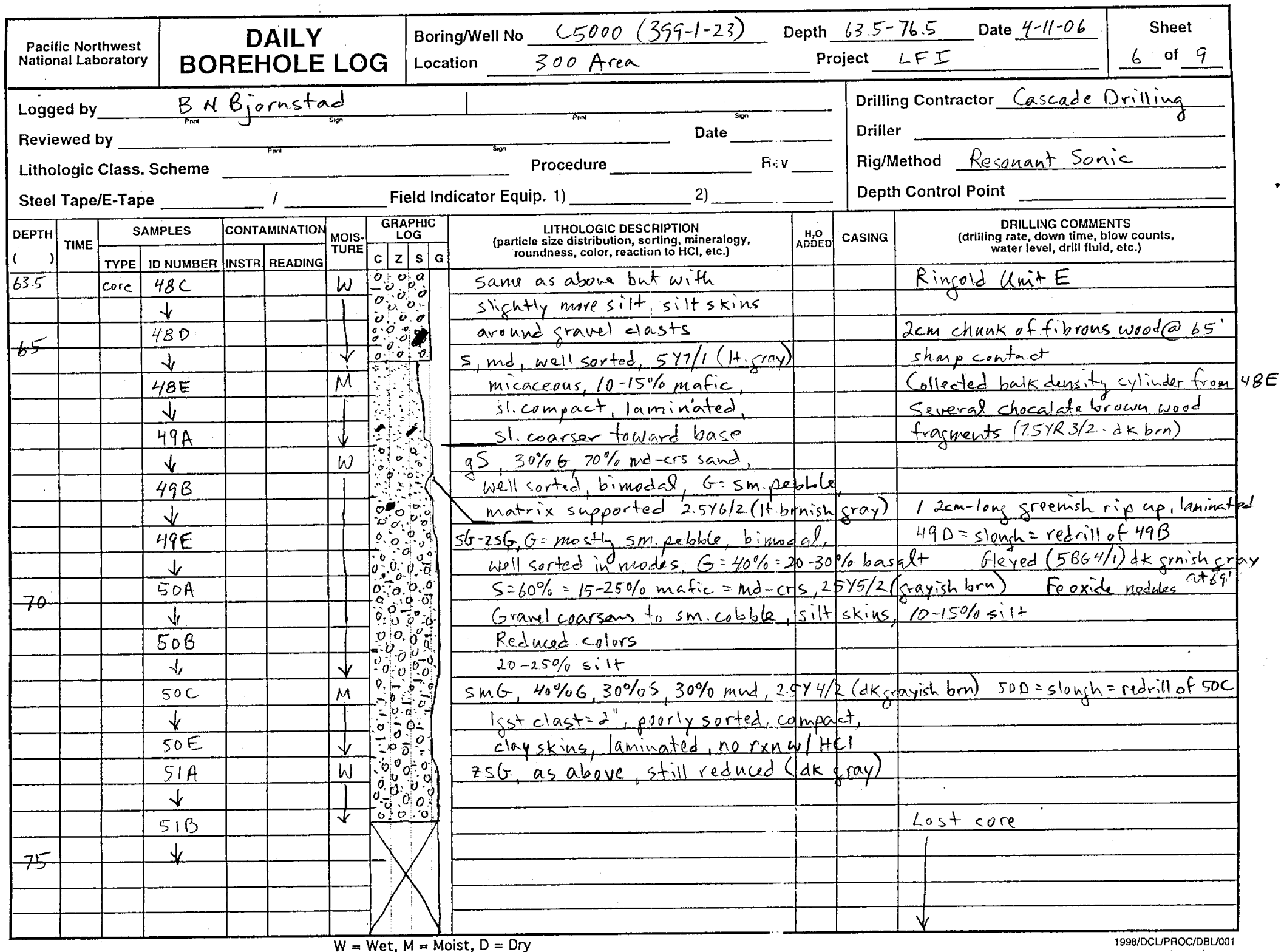




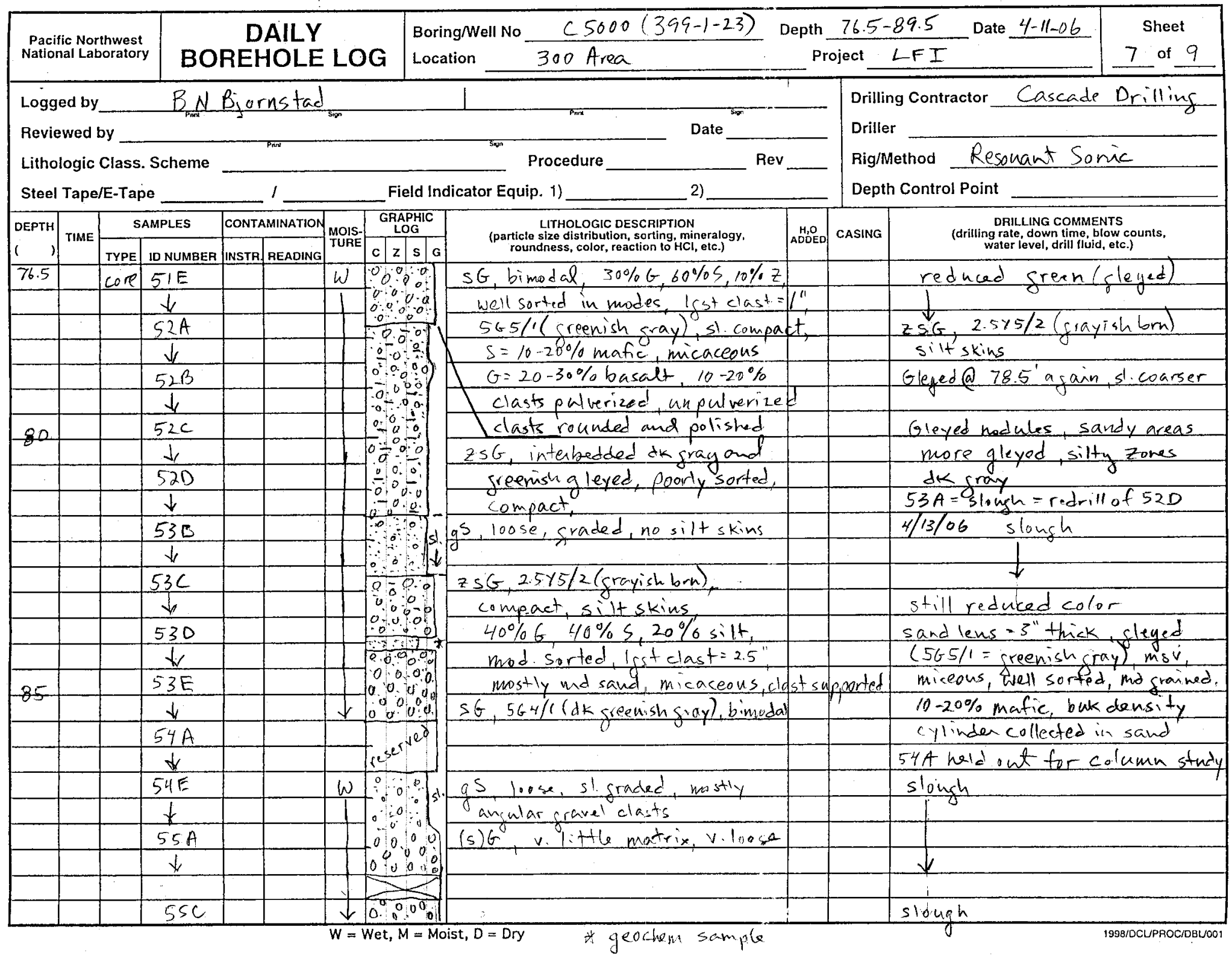




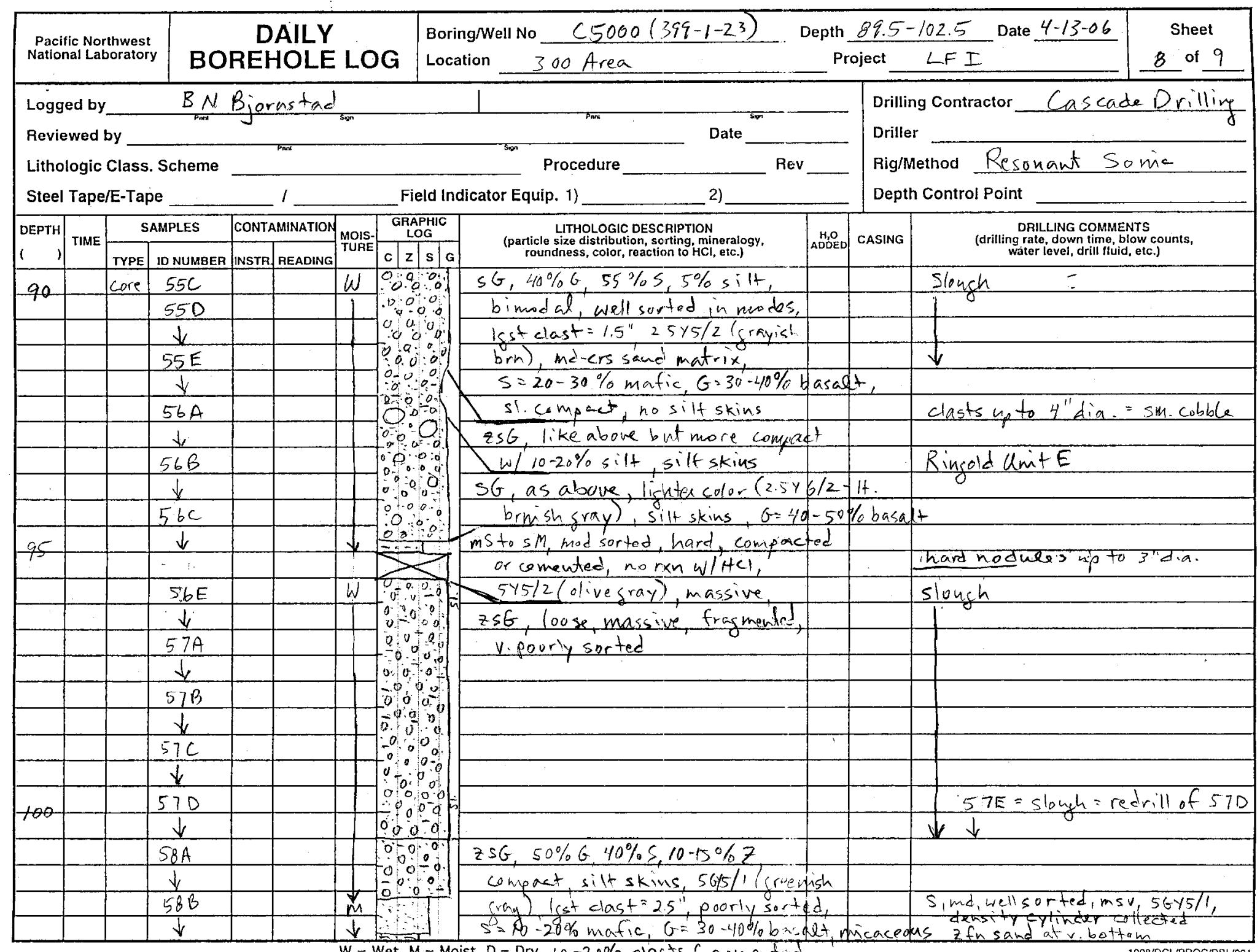

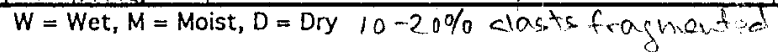




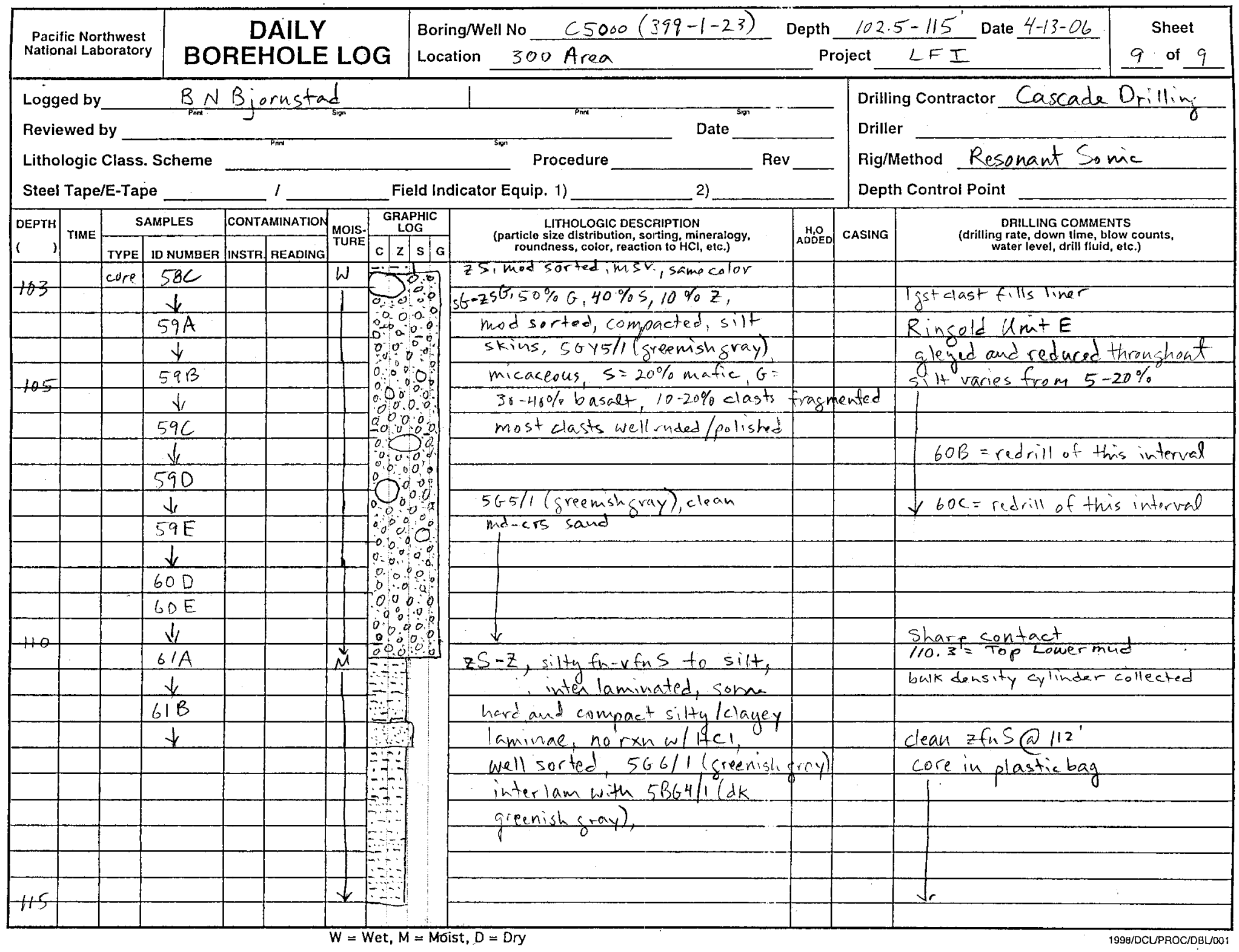




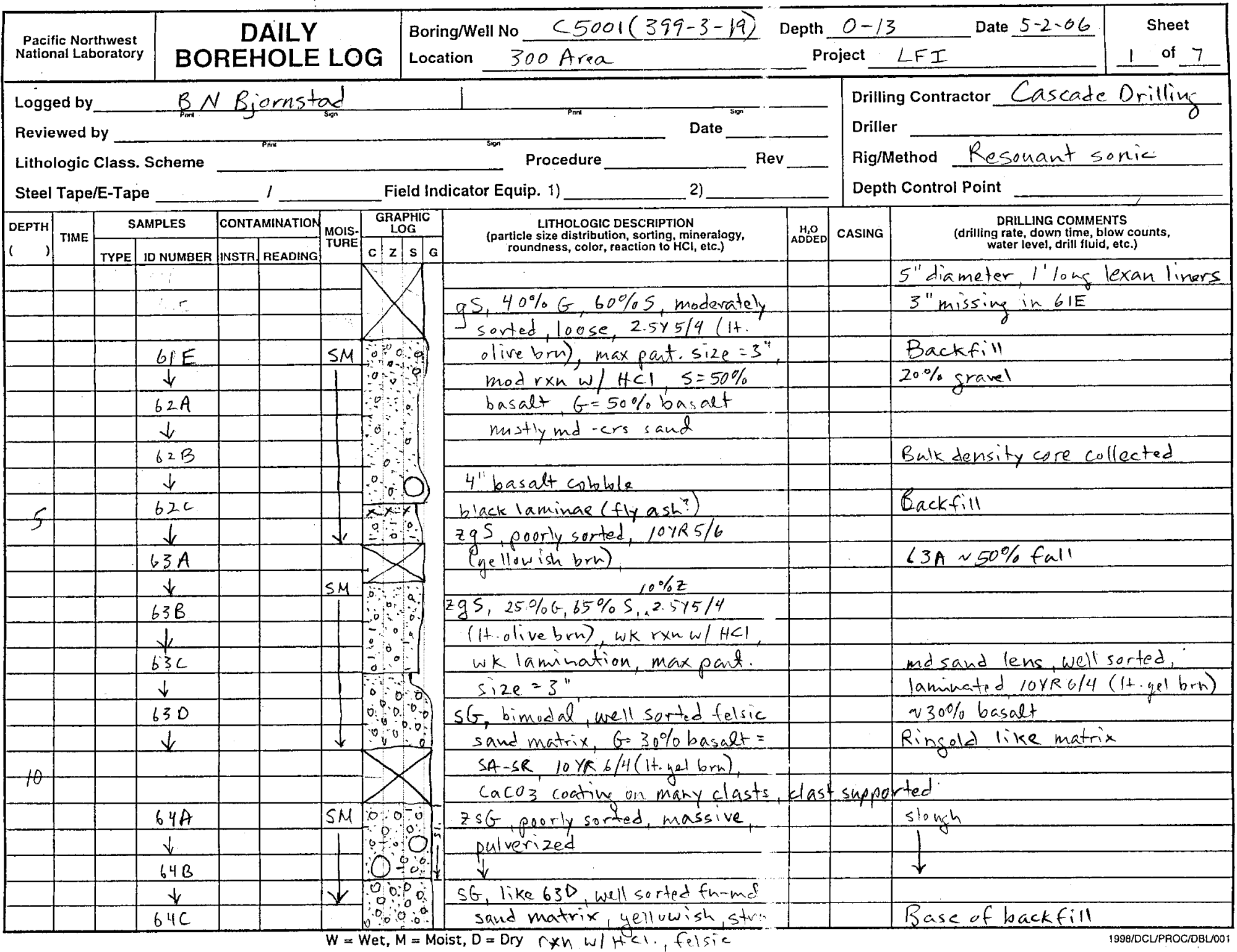




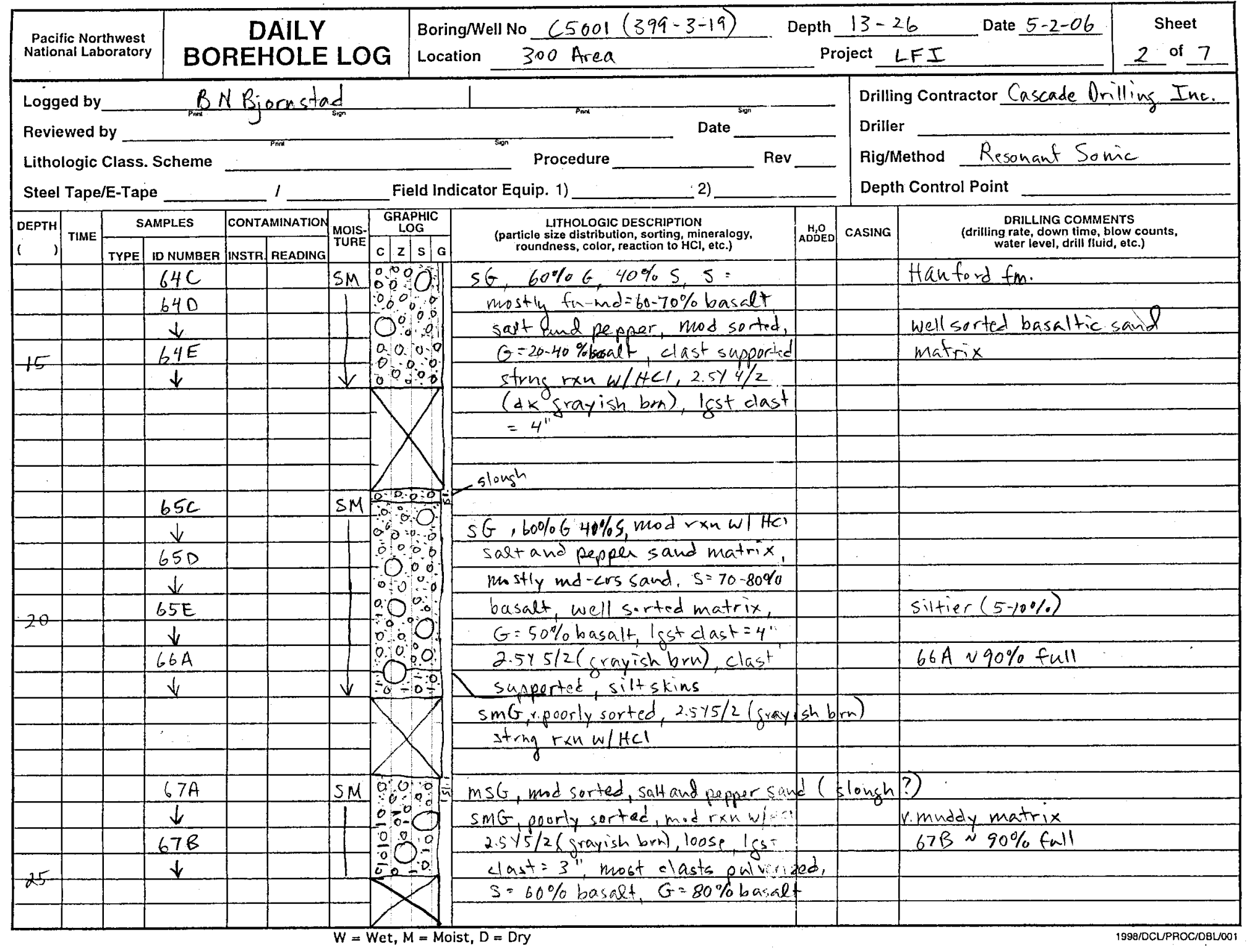




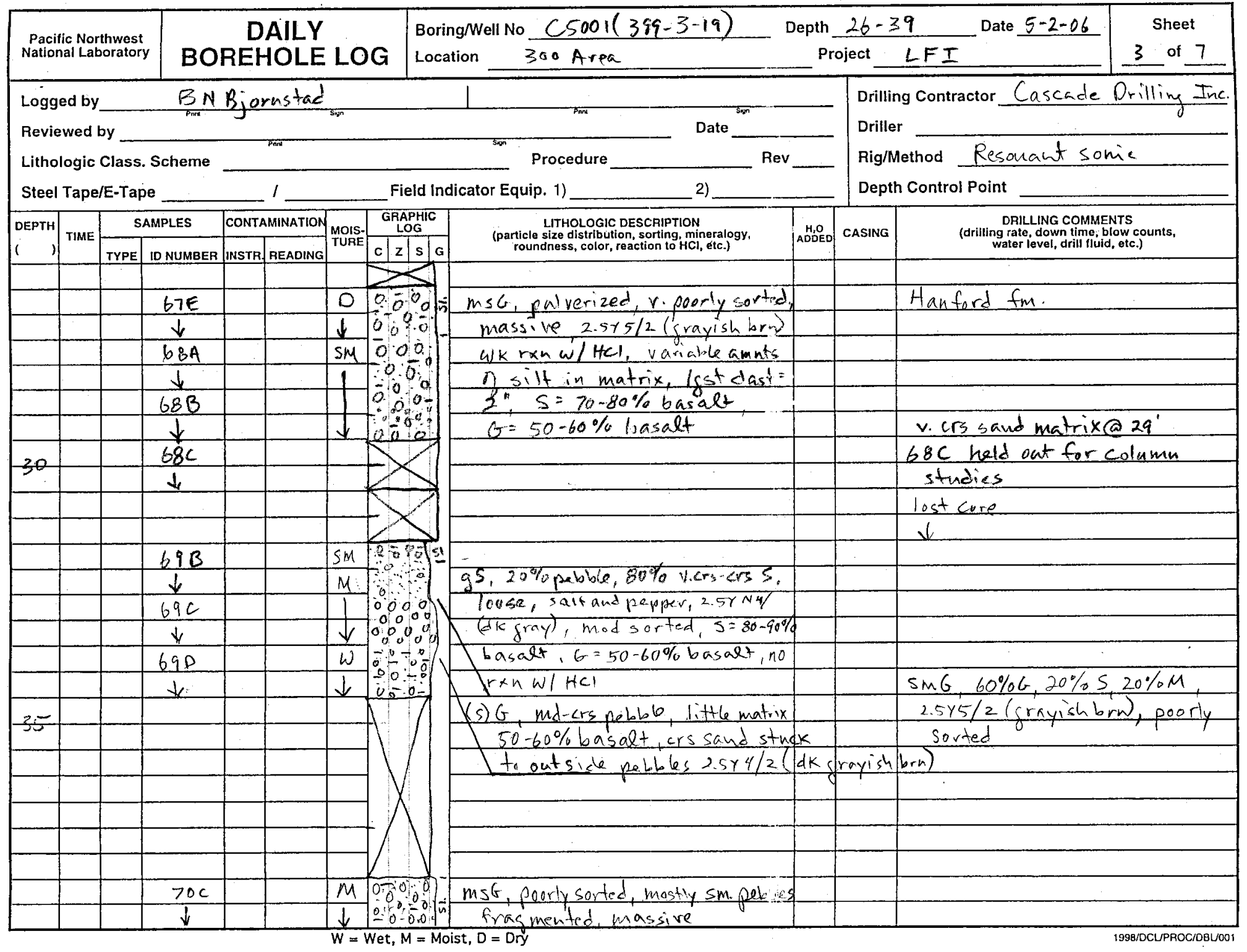




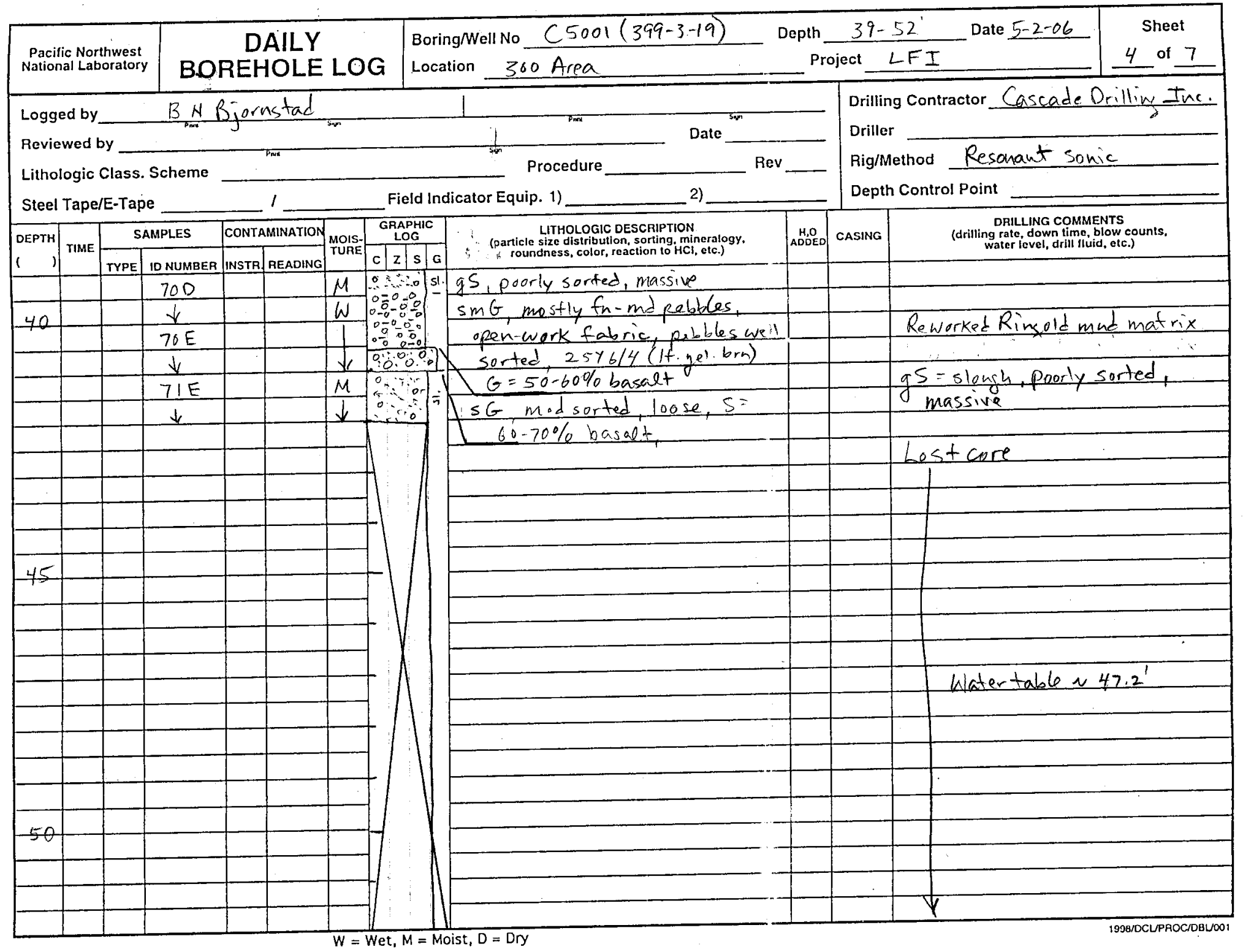




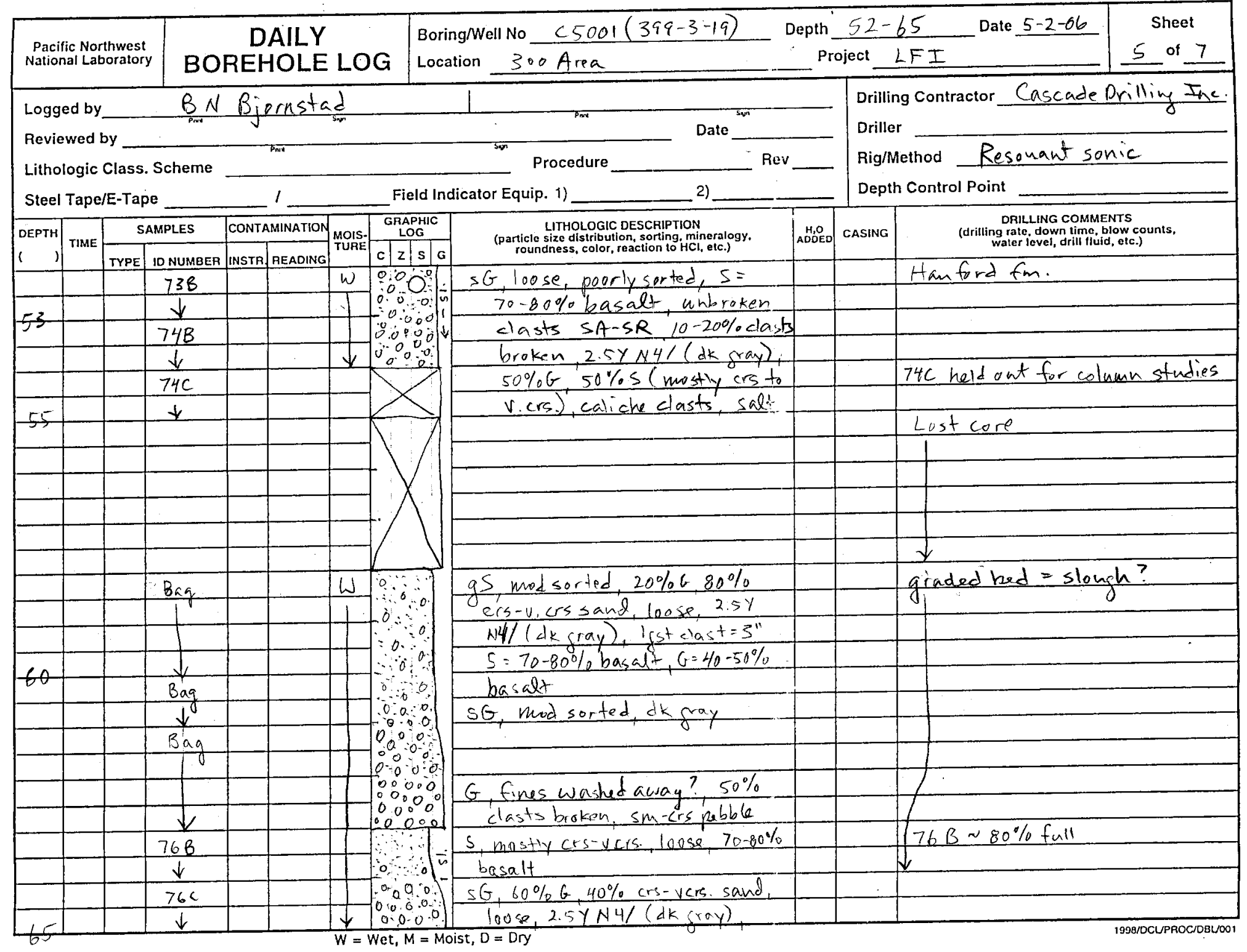




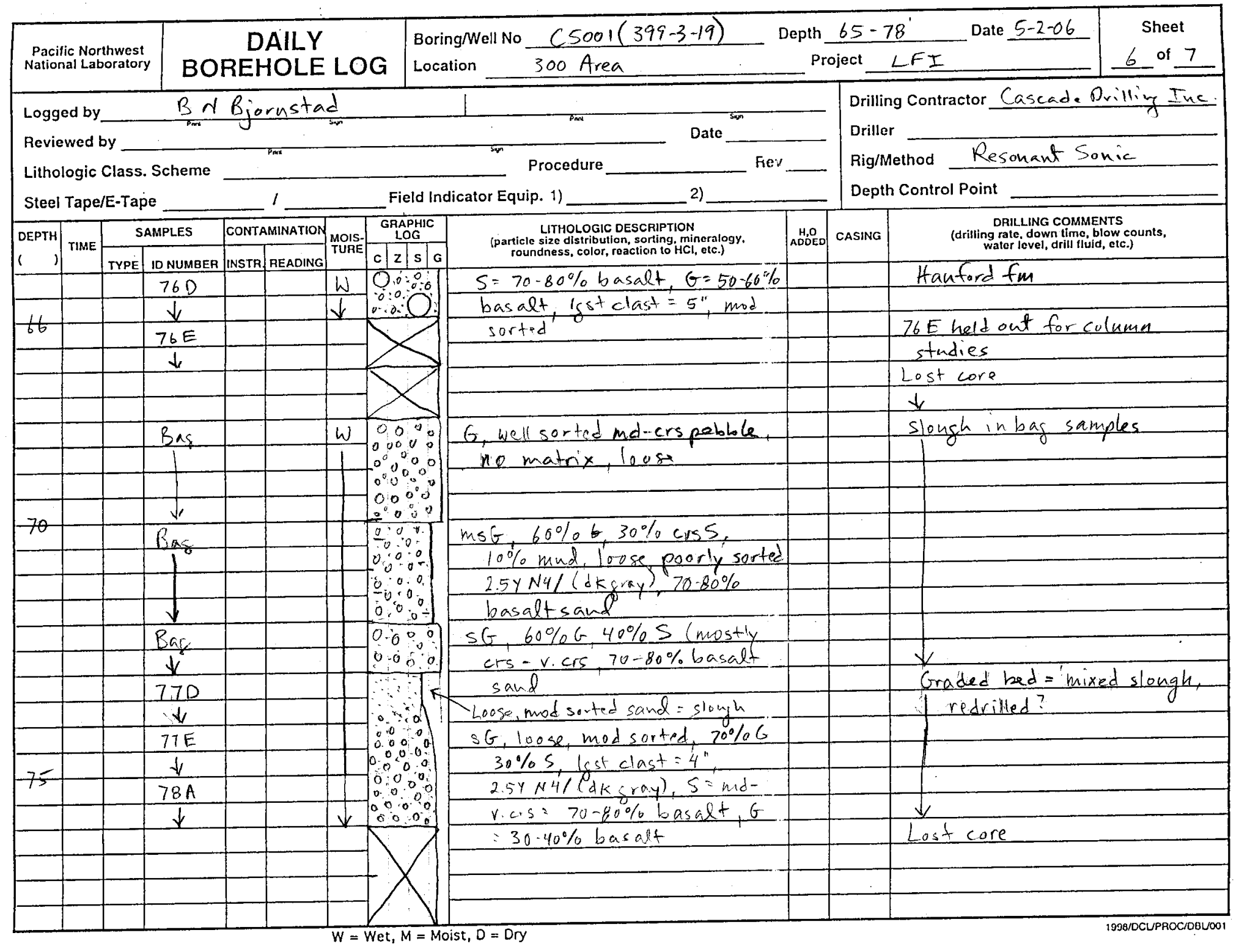




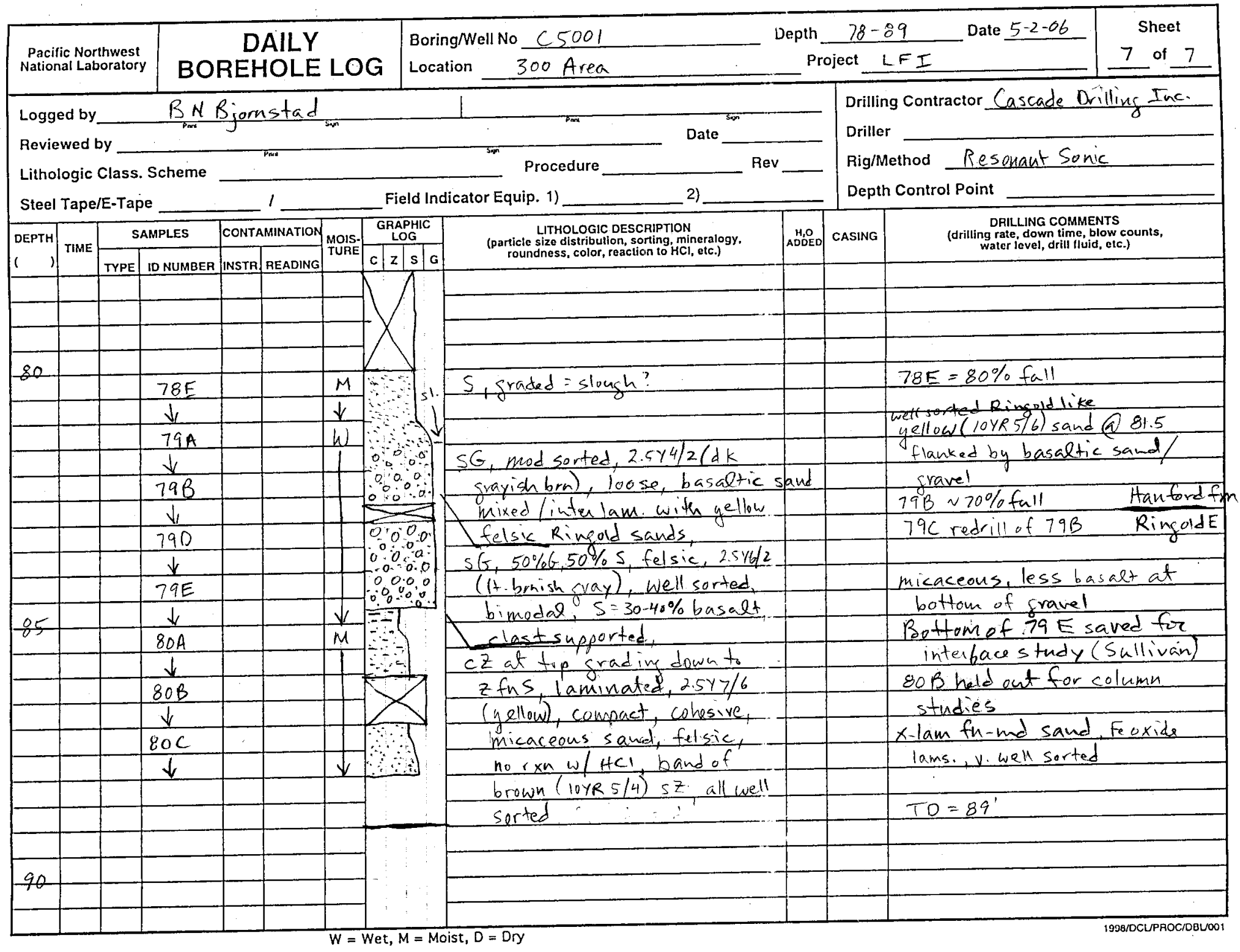




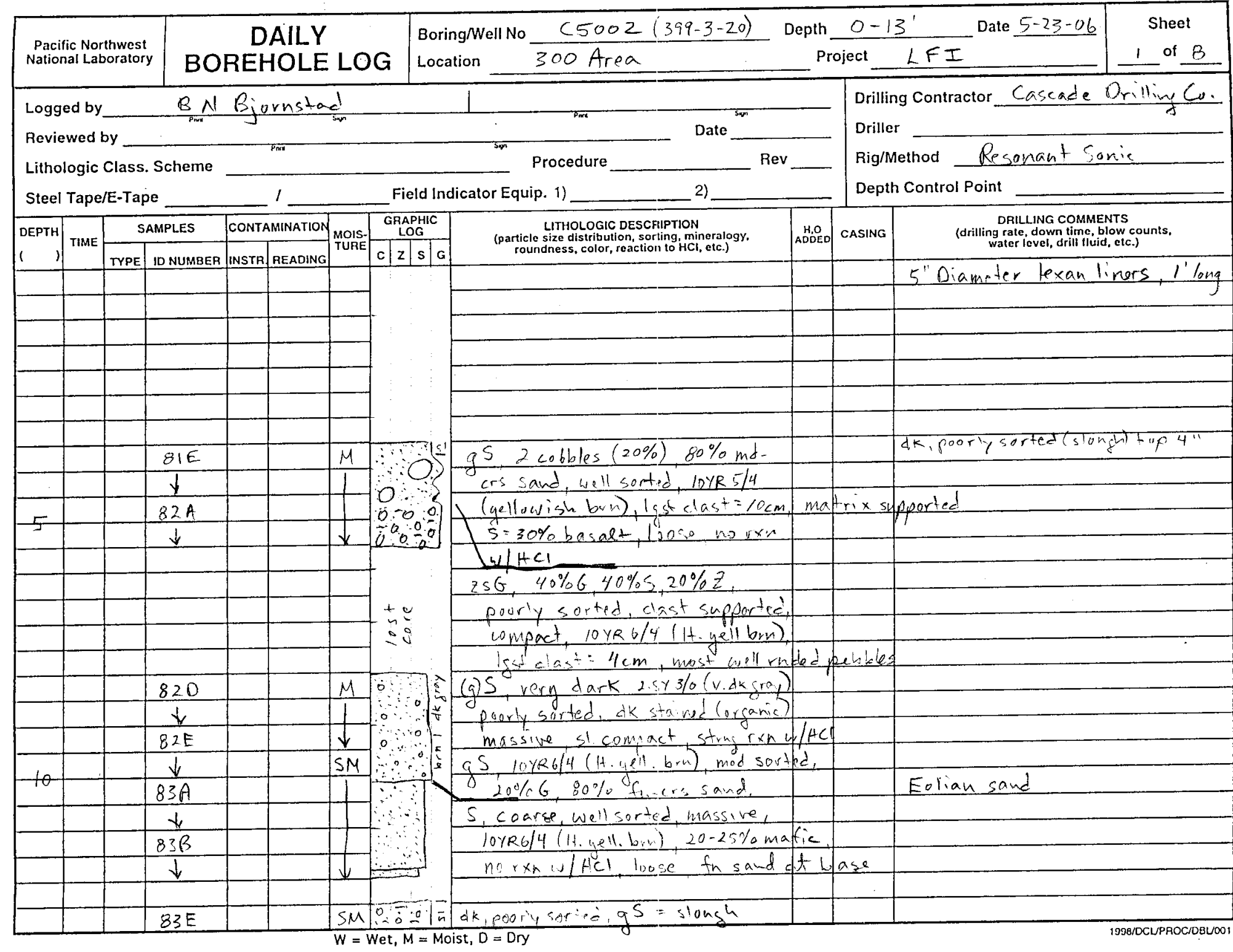




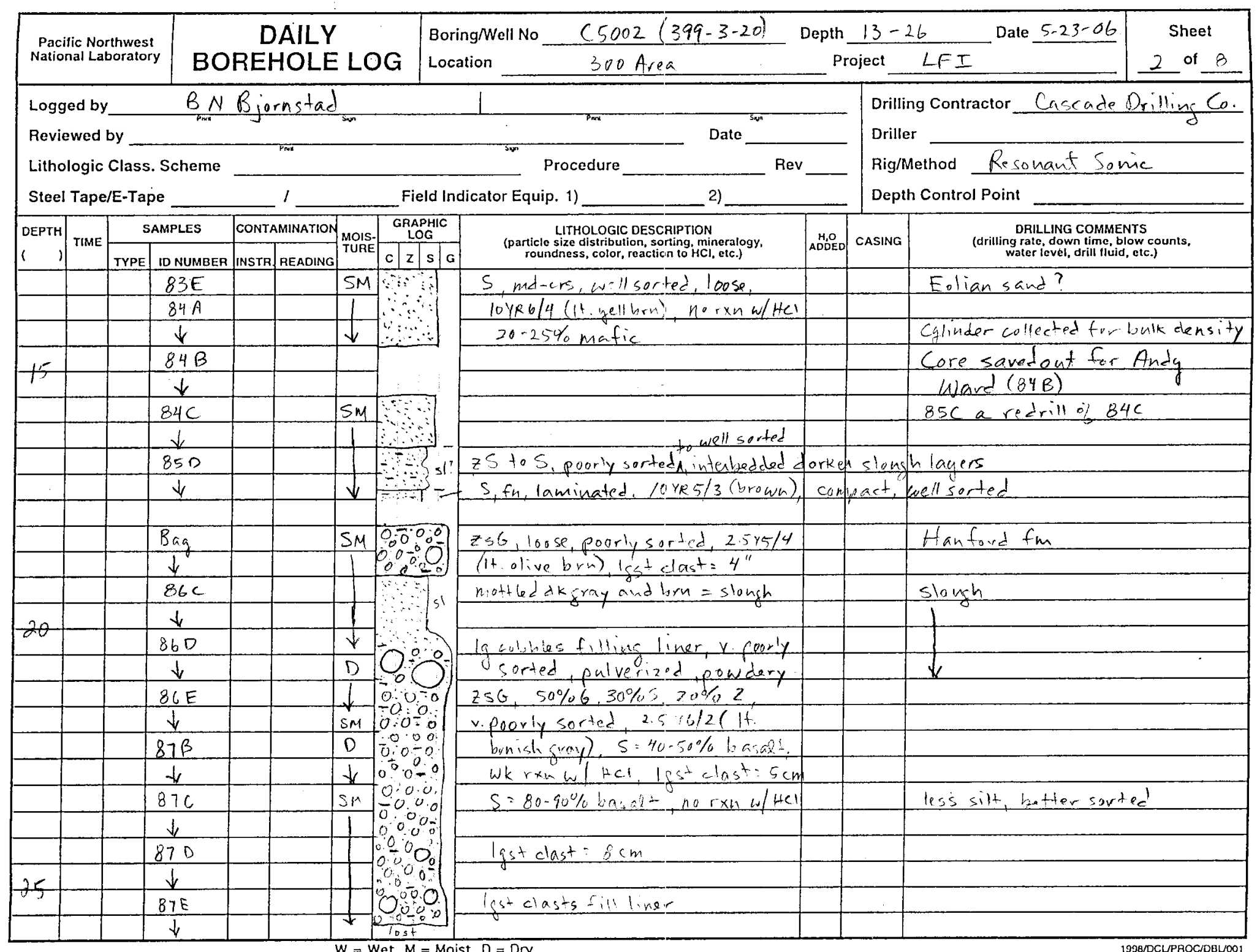




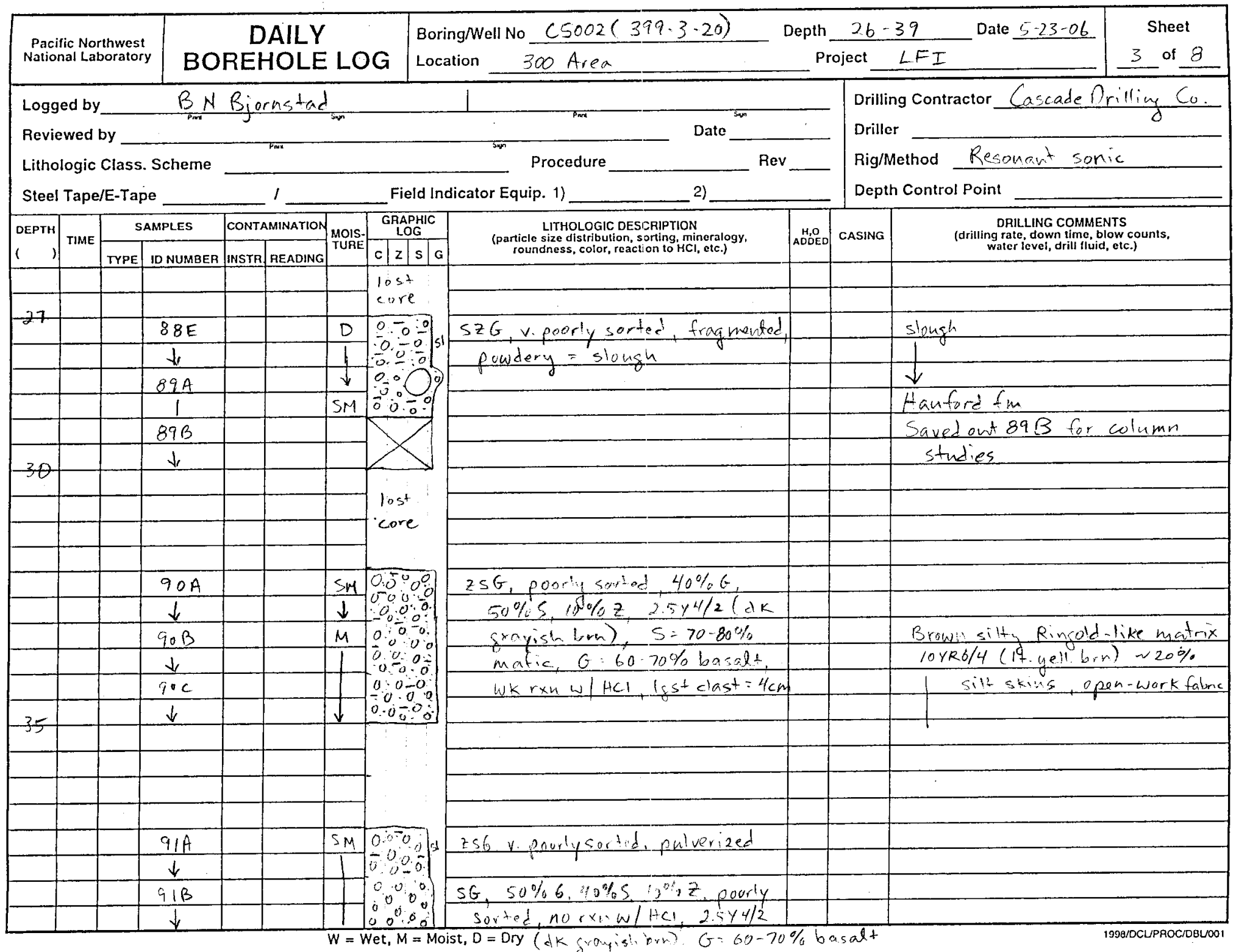




\begin{tabular}{|c|c|c|c|c|c|c|c|c|c|c|c|c|}
\hline \multicolumn{3}{|c|}{$\begin{array}{l}\text { Pacific Northwest } \\
\text { National Laboratory }\end{array}$} & \multicolumn{5}{|c|}{$\begin{array}{l}\text { DAILY } \\
\text { BOREHOLE LOG }\end{array}$} & $\begin{array}{l}\text { Boring/Well No } \frac{(5002(399-3-20)}{300 \text { Area }} \\
\text { Location }\end{array}$ & \multicolumn{3}{|c|}{ Depth $\frac{39-52}{\text { Project } L F I}$ Date $5-23 \cdot 06$} & $\begin{array}{l}\text { Sheet } \\
4 \text { of } 8 \\
\end{array}$ \\
\hline \multicolumn{10}{|c|}{ Logged by _ $\quad B_{p_{m e}} B_{j}$ jornstad $\quad L$} & \multirow{2}{*}{\multicolumn{3}{|c|}{$\begin{array}{l}\text { Drilling Contractor Co.,cade Drillin. } C_{0} \text {. } \\
\text { Driller }\end{array}$}} \\
\hline \multirow{2}{*}{\multicolumn{10}{|c|}{$\begin{array}{lll}\text { Reviewed by } \\
\text { Lithologic Class. Scheme } \quad \text { Procedure }\end{array}$}} & & & \\
\hline & & & & & & & & & & \\
\hline \multicolumn{10}{|c|}{$\begin{array}{l}\text { Lithologic Class. Scheme } \\
\text { Steel Tape/E-Tape }\end{array}$} & \multicolumn{3}{|c|}{ Depth Control Point } \\
\hline \multirow{3}{*}{\begin{tabular}{r|r} 
DEPTH \\
$(\quad, 1$ \\
\end{tabular}} & \multirow{2}{*}{ TIME } & \multicolumn{2}{|c|}{ SAMPLES } & \multicolumn{2}{|c|}{ CONTAMINATION } & \multirow{2}{*}{ MOIS- } & $\begin{array}{c}\text { GRAPHIC } \\
\text { LOG }\end{array}$ & \multirow{2}{*}{$\begin{array}{l}\text { LITHOLOGIC DESCRIPTION } \\
\text { (particle size distribution, sorting mineratogy, } \\
\text { roundness, color, reaction to HCl, etc.) }\end{array}$} & \multirow{2}{*}{$\left|\begin{array}{c}\mathrm{H}, \mathrm{O} \\
\mathrm{ADOED}\end{array}\right|$} & \multirow{2}{*}{ CASING } & \multirow{2}{*}{\multicolumn{2}{|c|}{$\begin{array}{c}\text { DRILLING COMMENTS } \\
\text { (drilling rate, down time, blow counts, } \\
\text { water level, drill fluid, etc.) }\end{array}$}} \\
\hline & & TYPE & ID NUMBER & INSTR: & READING & & \begin{tabular}{l|l|l|l}
$\mathrm{c}$ & $\mathrm{z}$ & $\mathrm{s}$ & $\mathrm{G}$ \\
\end{tabular} & & & & & \\
\hline & & & $91 \mathrm{c}$ & & & $S M$ & \multirow{2}{*}{$\left|\begin{array}{ccc}0 & 0 & 0 \\
0 & 0 & 0 \\
0 & 0 & 0 \\
0 ; 0 & 0\end{array}\right|$} & $Z S G, 50 \% G, 30 \%, 20 \% z$ & & & \multicolumn{2}{|l|}{ Haw ford $f_{x}$} \\
\hline \multirow[t]{7}{*}{40} & & & + & & & & & poorly sorted, $250 \% / 2$ (dk & & & \multirow{2}{*}{\multicolumn{2}{|c|}{ siltsking }} \\
\hline & & & 910 & & & & \multirow{2}{*}[\begin{array}{ccc}{0.0}&{0}\\
{0}&{0}&{0}\\
{0}&{0}&{0}\\
{0}&{0}&{0}\end{array}]{} & Crayish hrol, 15 st clas $=4 \mathrm{~cm}$ & & & & \\
\hline & & & $y$ & & & & & as v cur cand mad sorted & & & & \\
\hline & & & Bag & & & & 0.00 .00 & $z \leq G$, as above & & & mixed in bag & \\
\hline & & & 10 & & & & 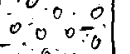 & & & & 18 & \\
\hline & & & & & & & {$\left[\begin{array}{cccc}0 & 0 & 0 & 0 \\
0 & 0 & 0 & 0\end{array}\right]$} & & & & & \\
\hline & & & $\checkmark$ & & & $\downarrow$ & $0.0 \div 0$ & & & & $\sqrt{ }$ & \\
\hline & & & & & & & & & & & & \\
\hline & & & & & & & & & & & & \\
\hline & & & & & & & I & & & & & \\
\hline-45 & & & & & & & 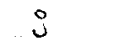 & & & & & \\
\hline & & & & & & & & & & & & \\
\hline & & & & & & & & & & & & \\
\hline & & & & & & & $\therefore$ & & & & & \\
\hline & & & & & & & & & & & & \\
\hline & & & $92 \mathrm{C}$ & & & W & $\because \because s$ & 9S, araded & & & & \\
\hline & & & $\downarrow$ & & & 1 & & $8+8+1$ & & & -847.7 & \\
\hline & & & 920 & & & & 0.0 .00 & 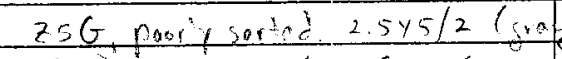 & gish & & & \\
\hline & & & $\downarrow$ & & & $\downarrow$ & 0000 & bru s: $80-90 \%$ maric $G=$ & & & & \\
\hline & & & $92 E$ & & & & & $50-60 \% 60000 \quad 1+c 00 t=6<4$ & & & $72 E$ saved out for & Cotwm \\
\hline 50 & & & $\downarrow$ & & & & & & & & studies & \\
\hline 30 & & & & & & & & & & & & \\
\hline & & & & & & & & & & & & \\
\hline & & & & & & & : & & & & & \\
\hline & & & & & & & & & & & & \\
\hline
\end{tabular}




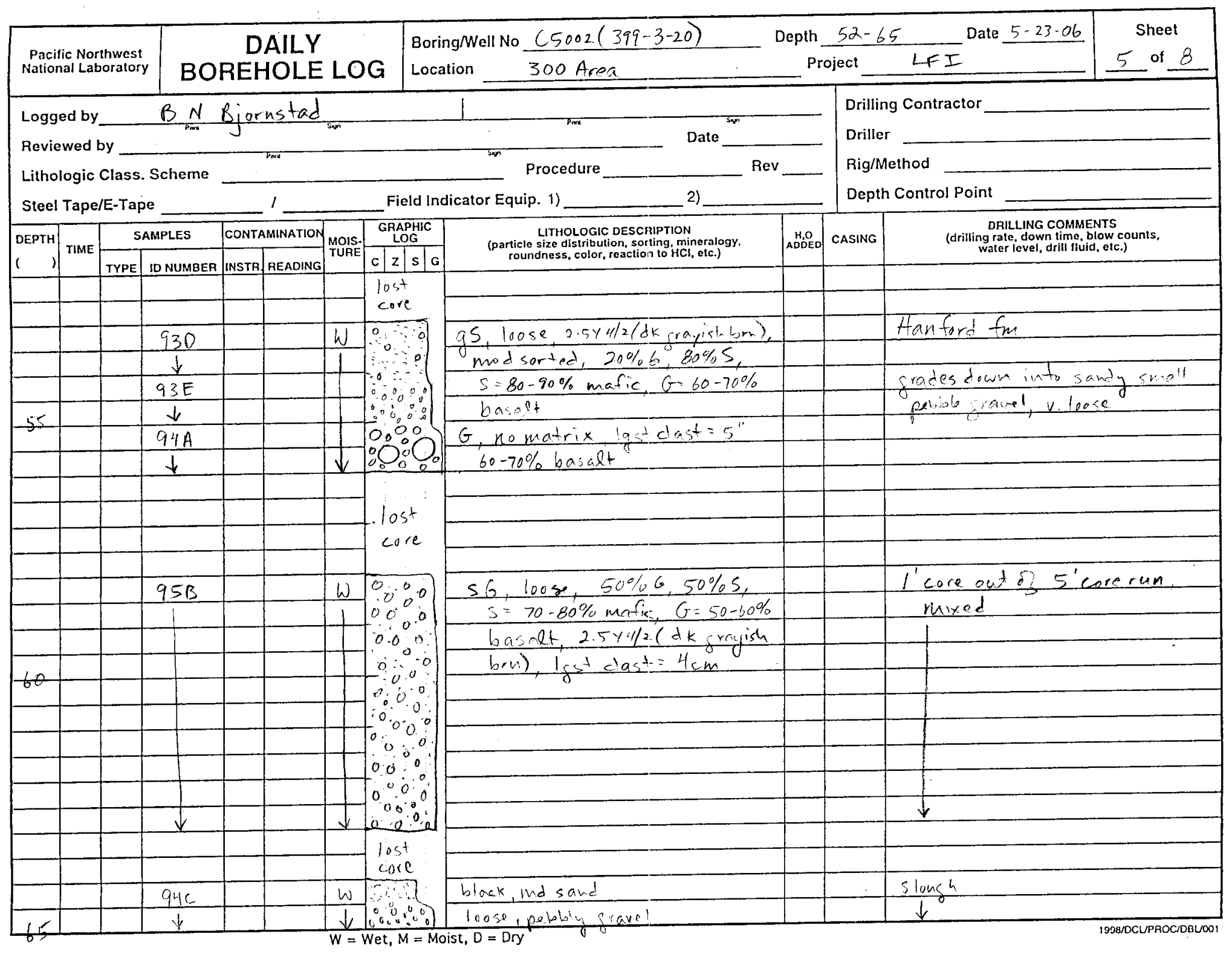




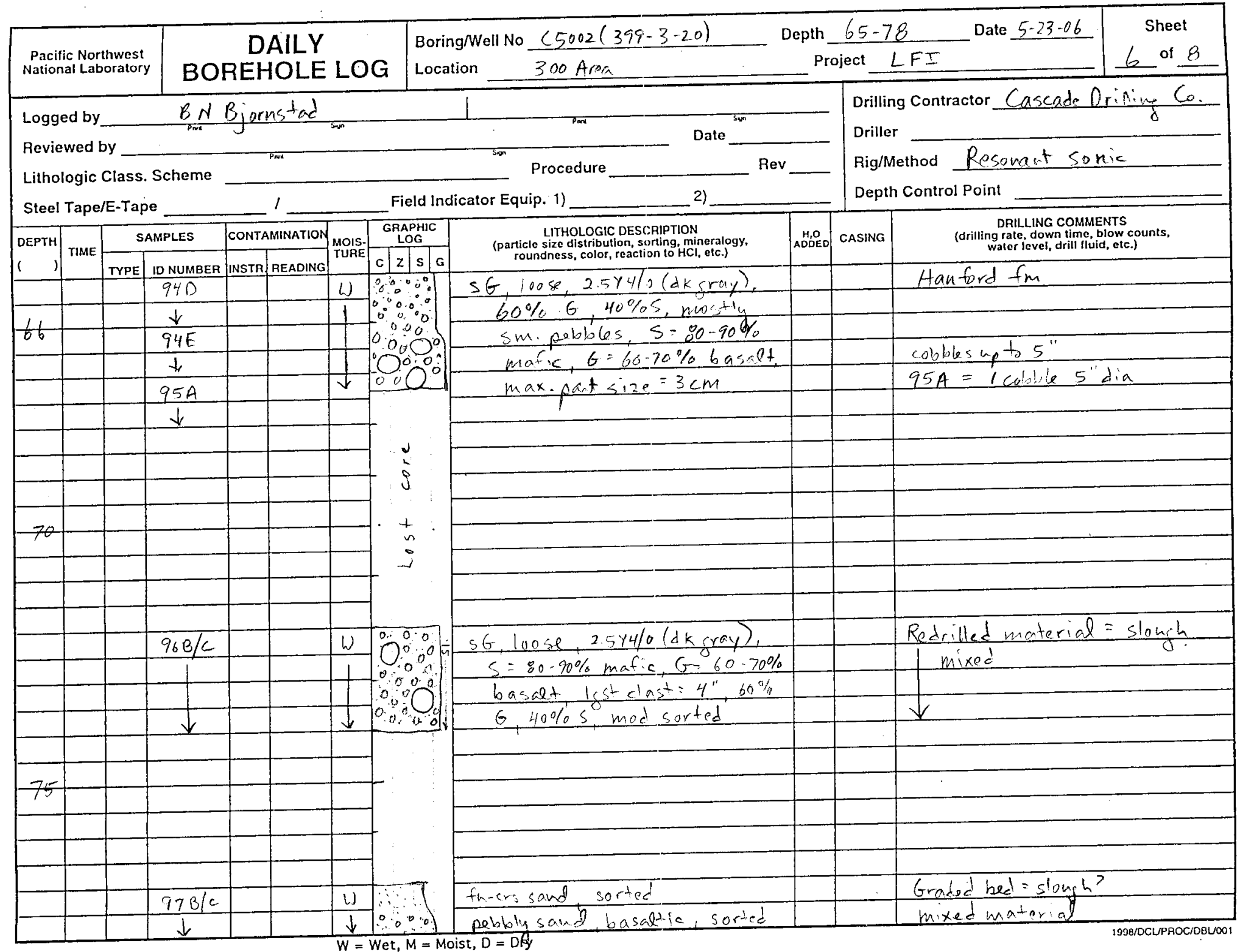




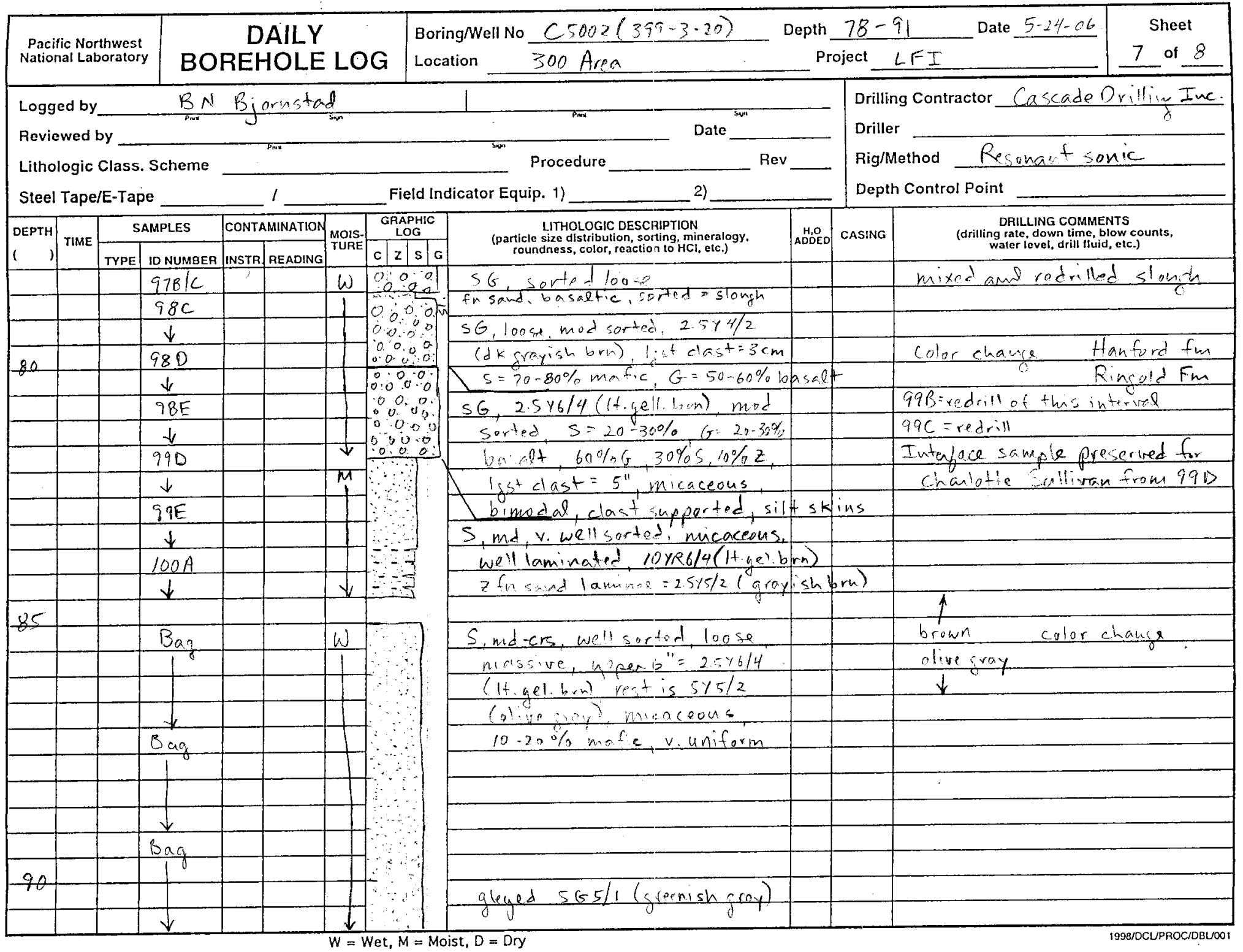




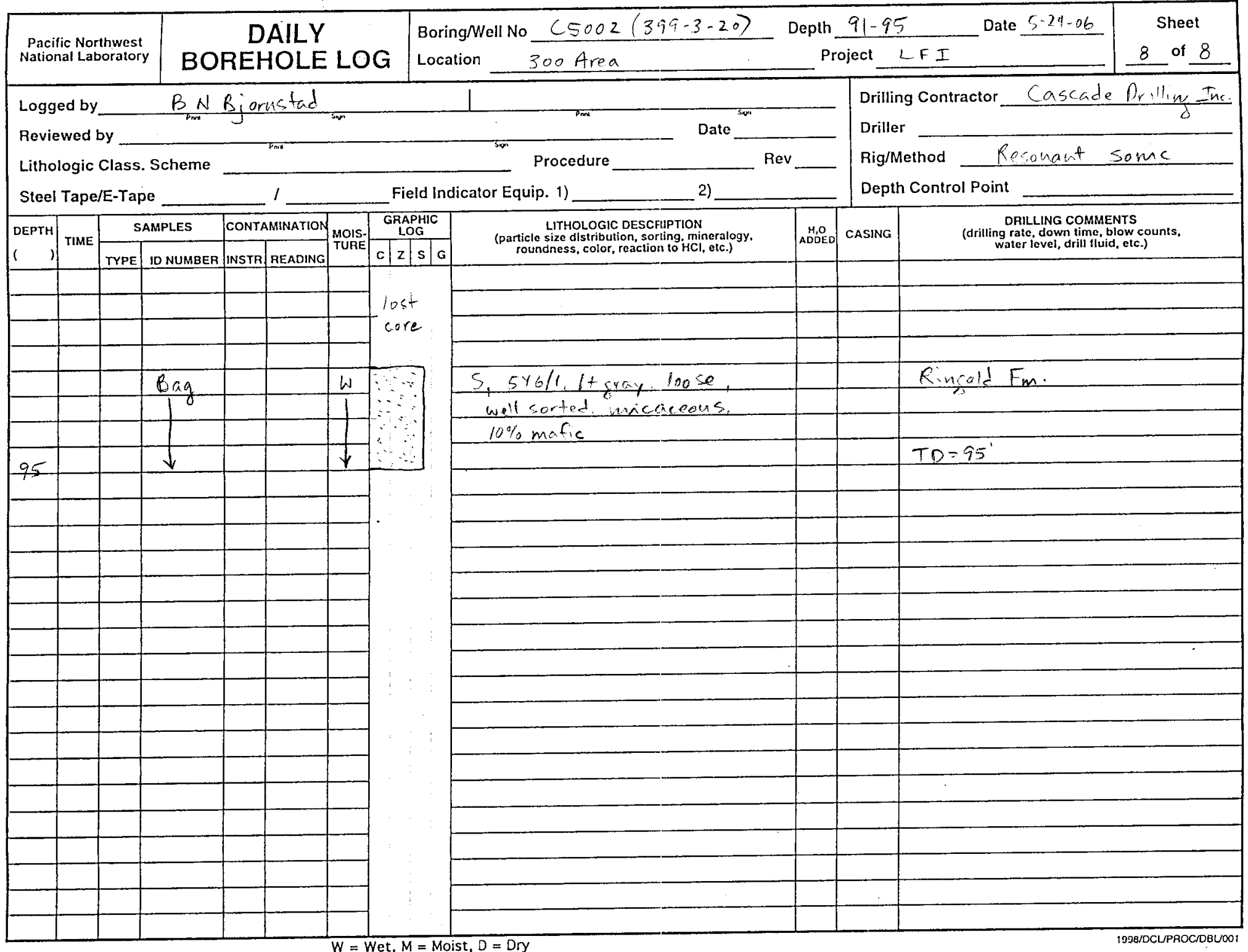




\section{Digital Core Photographs}

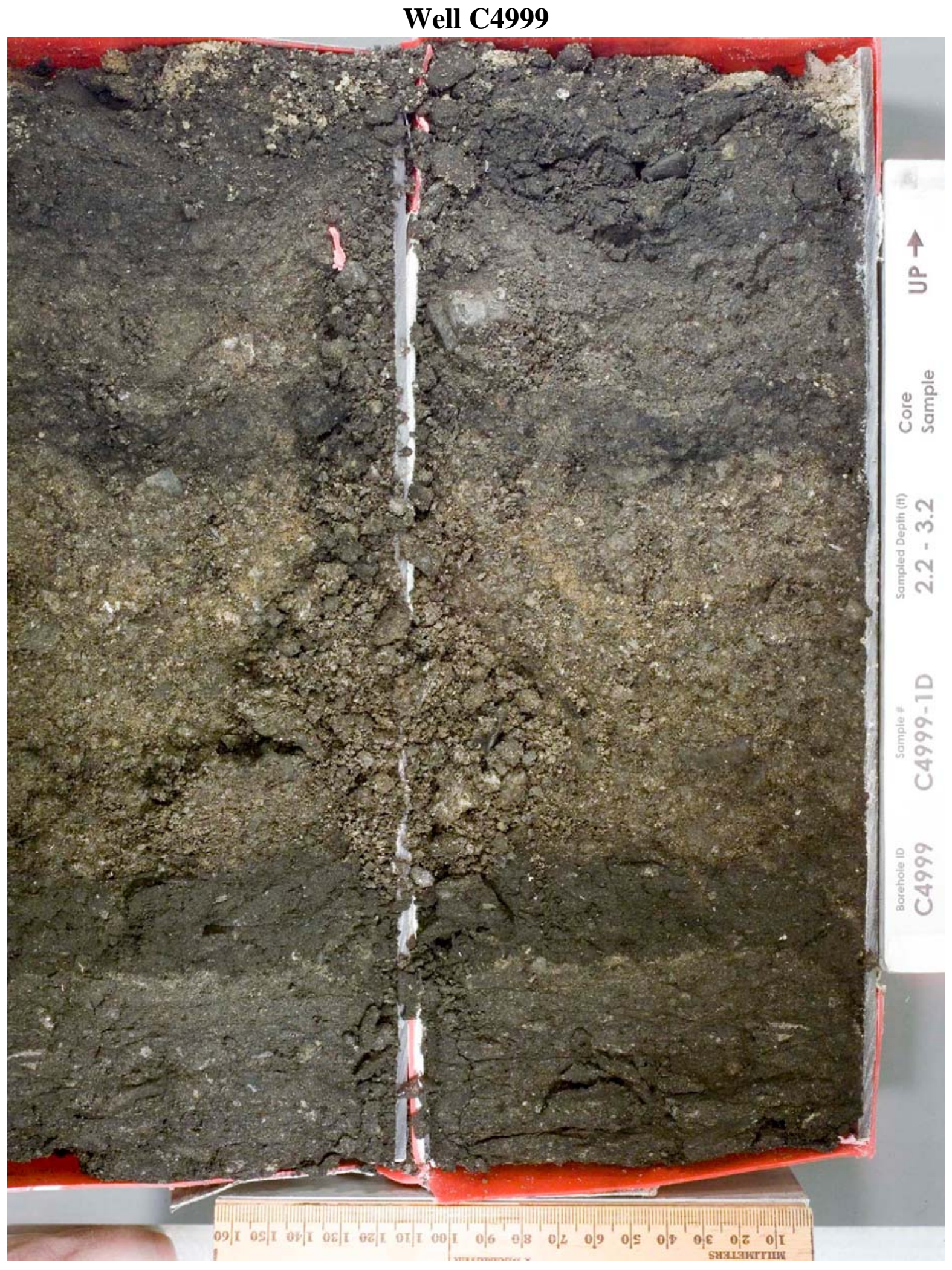




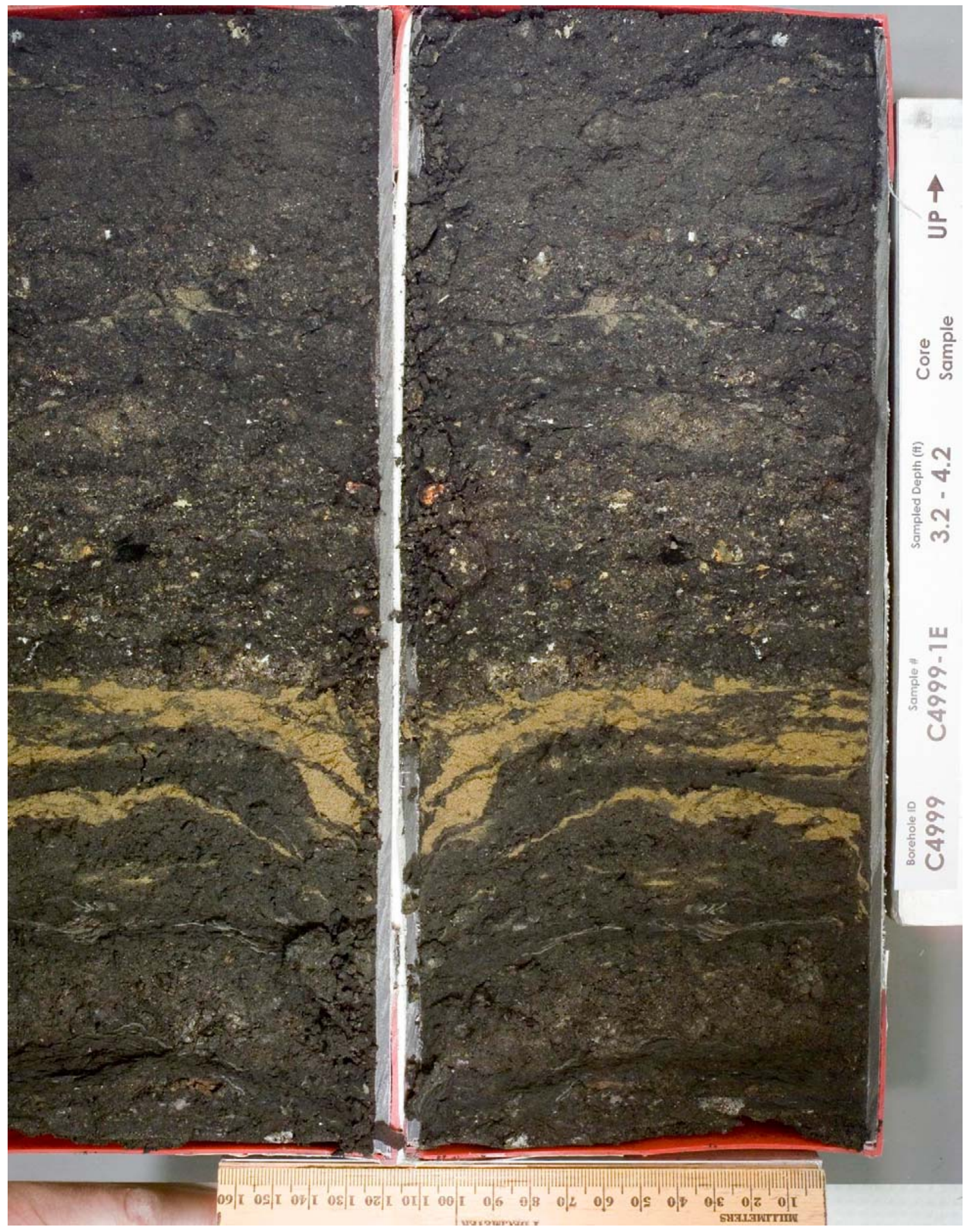




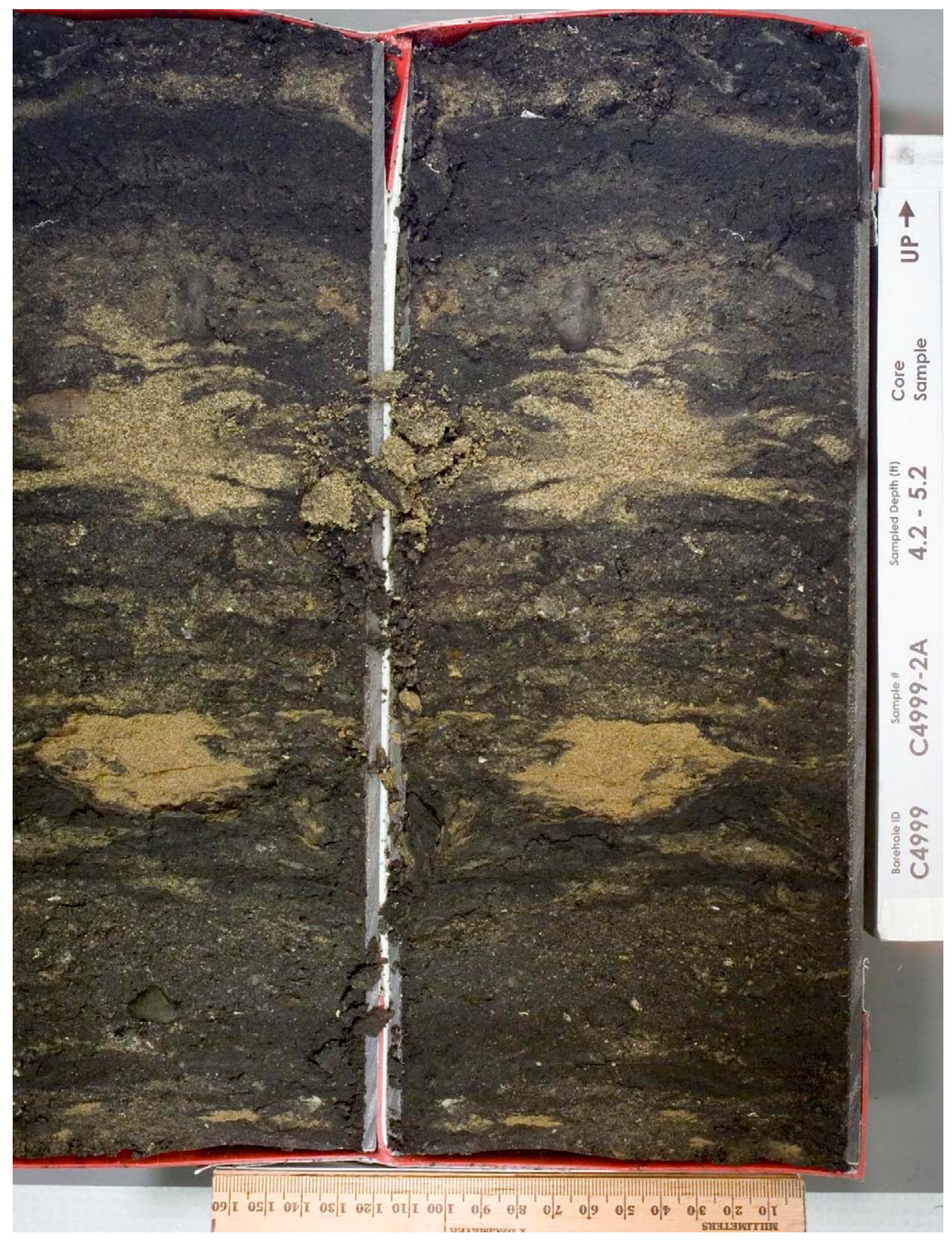




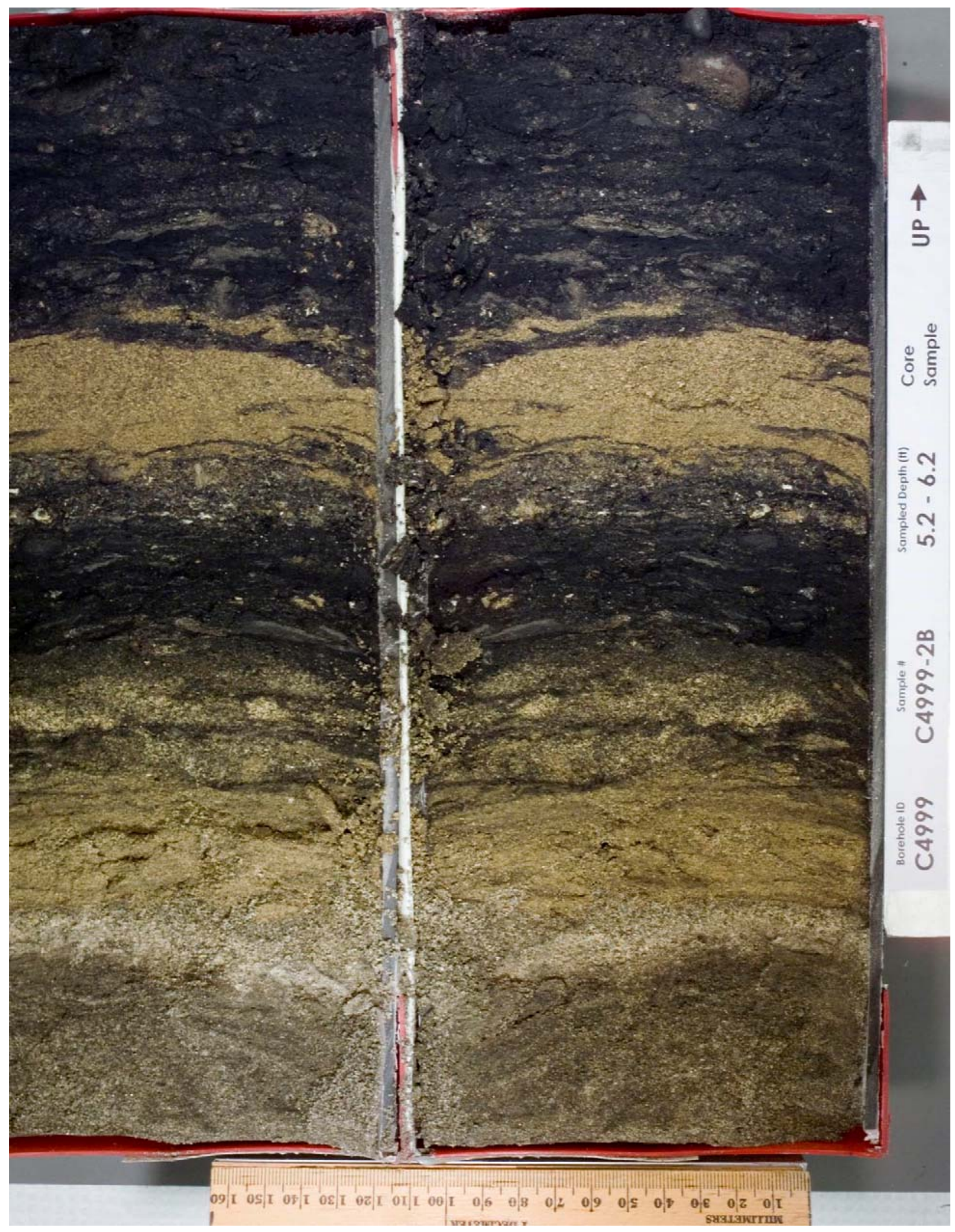




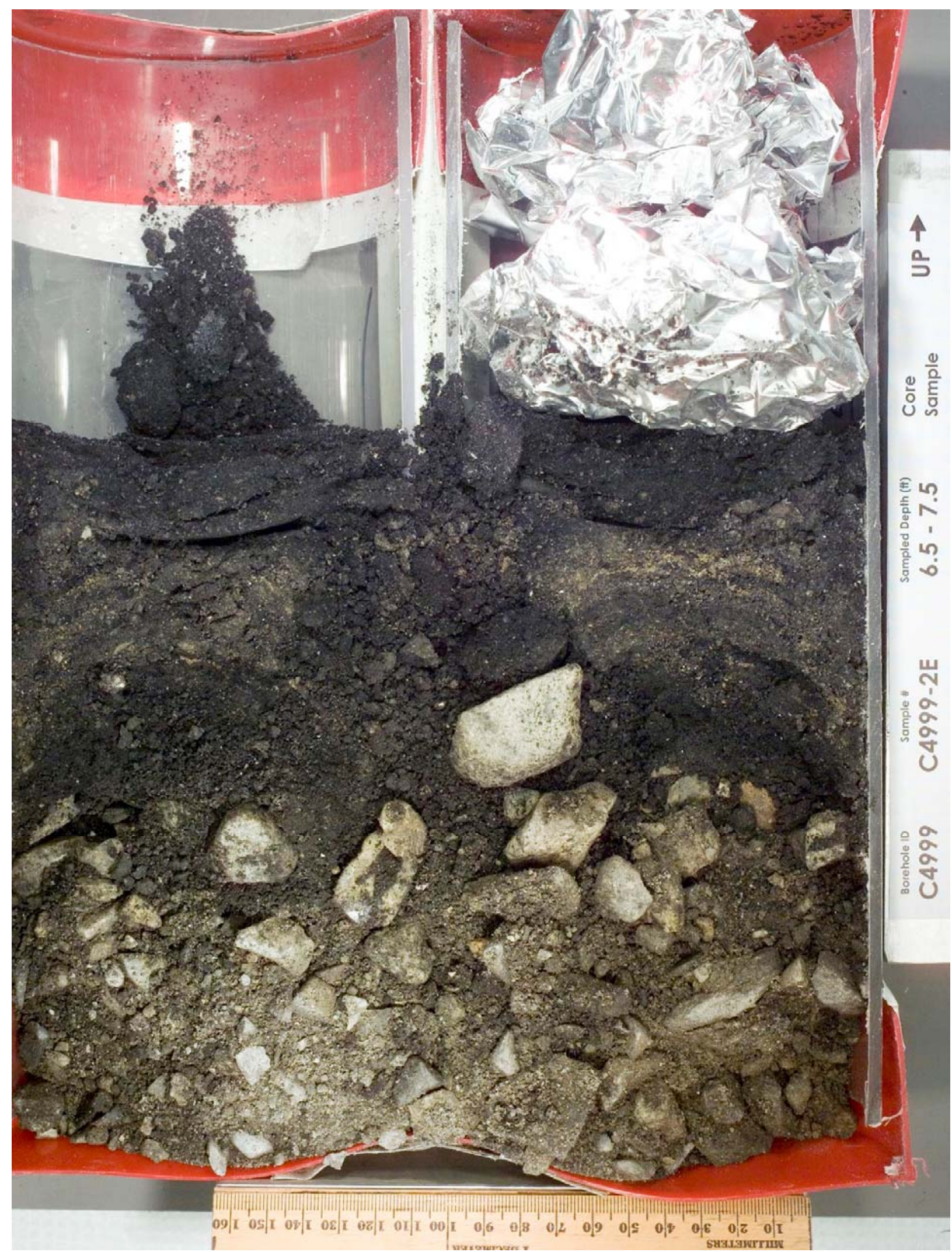




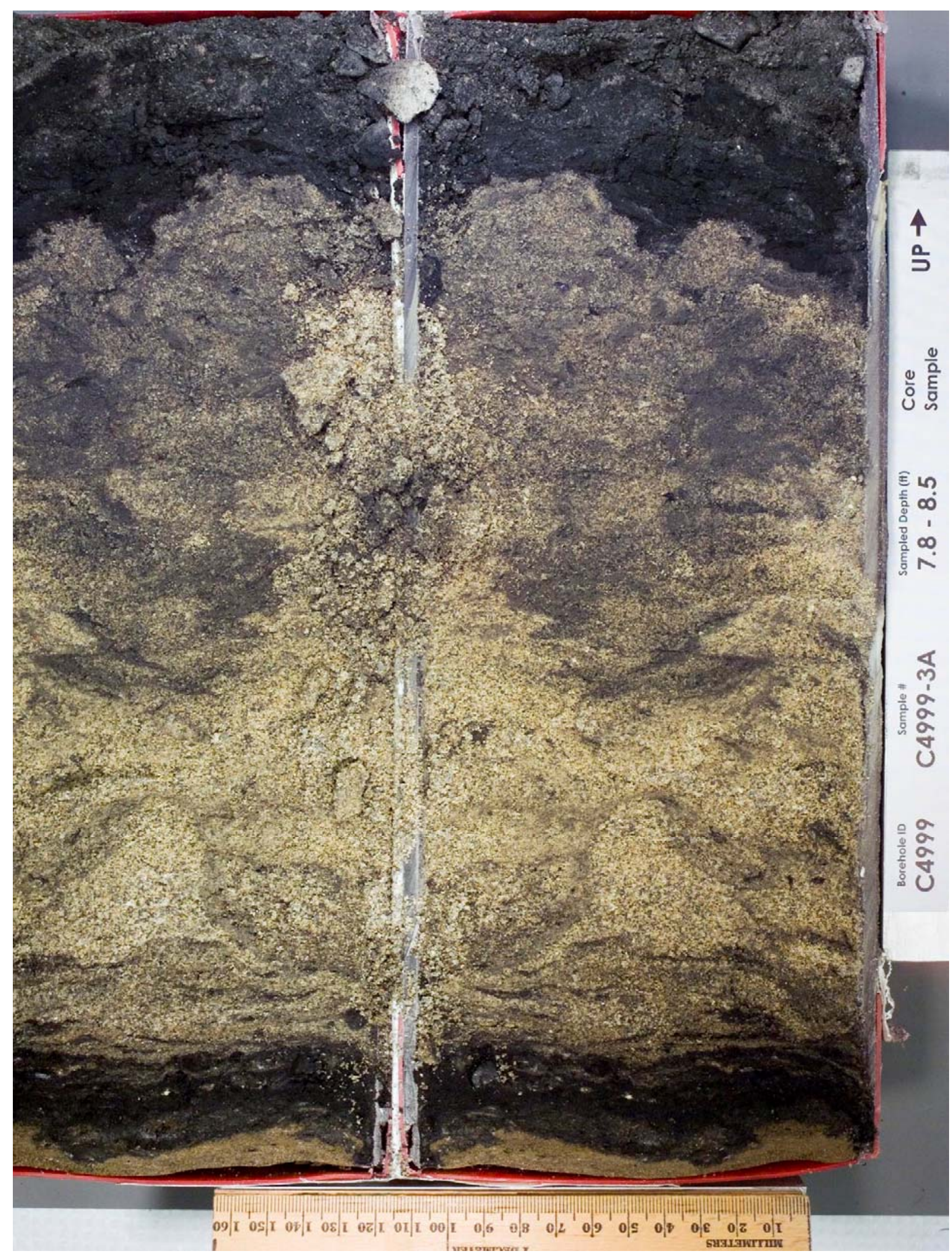




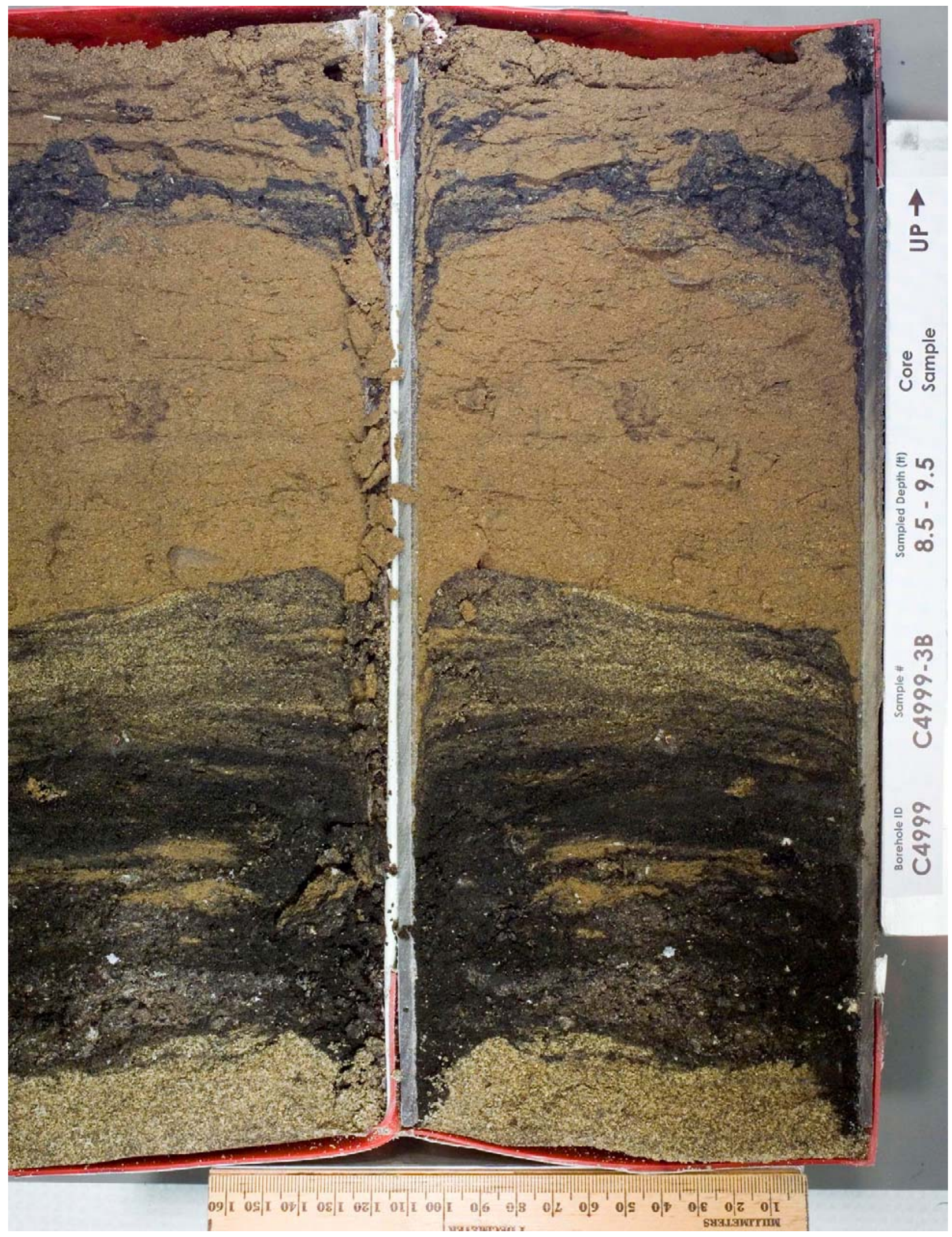




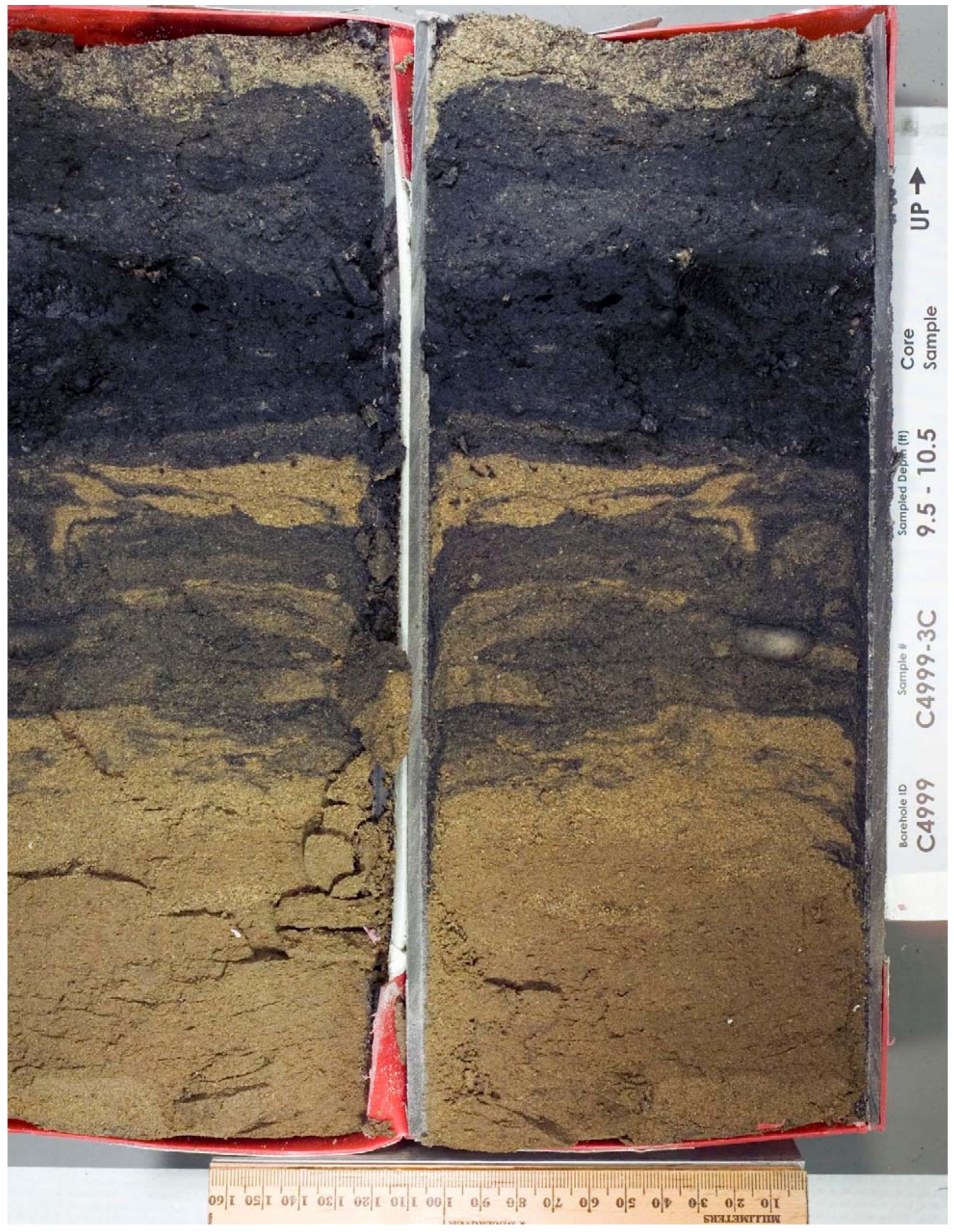




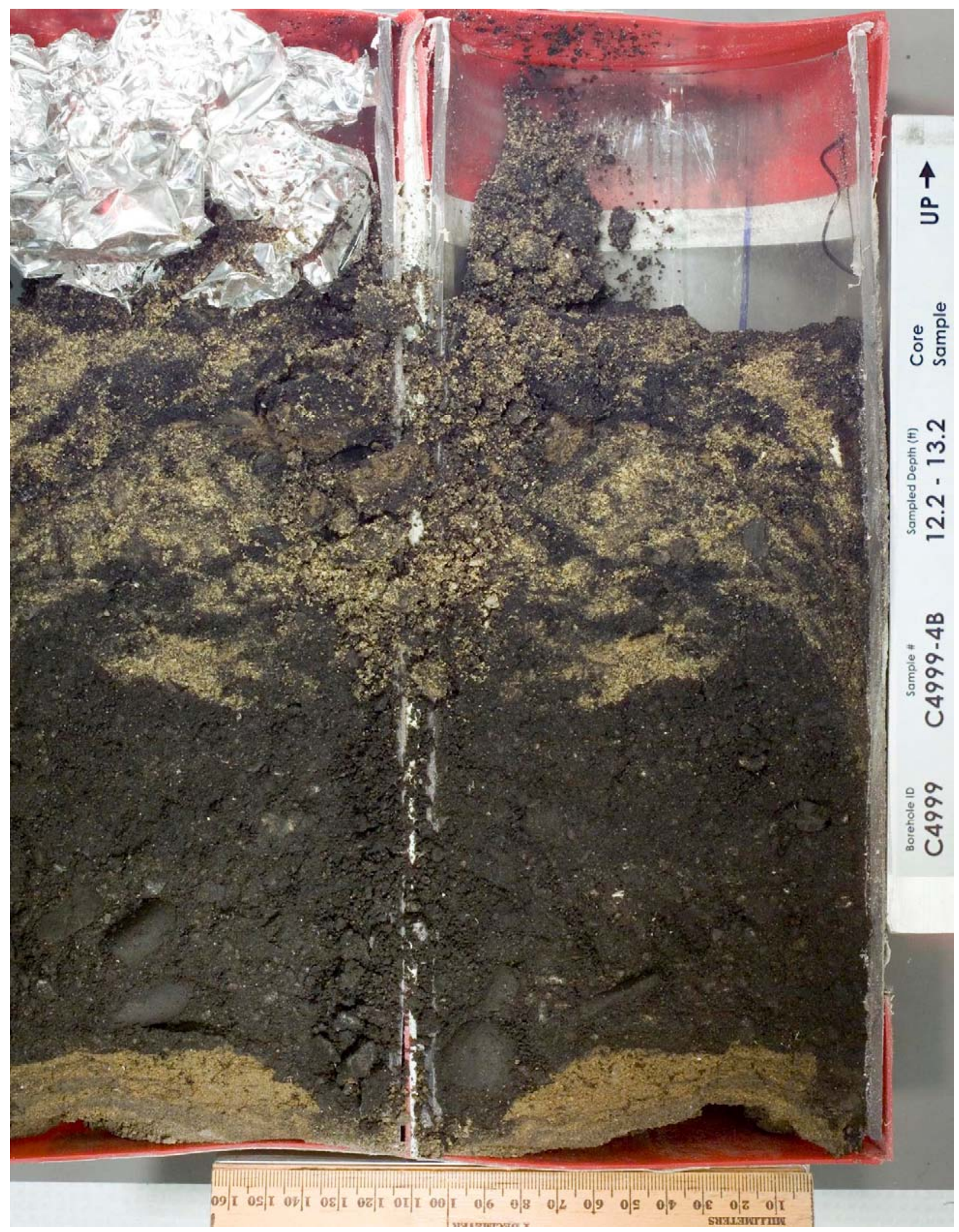




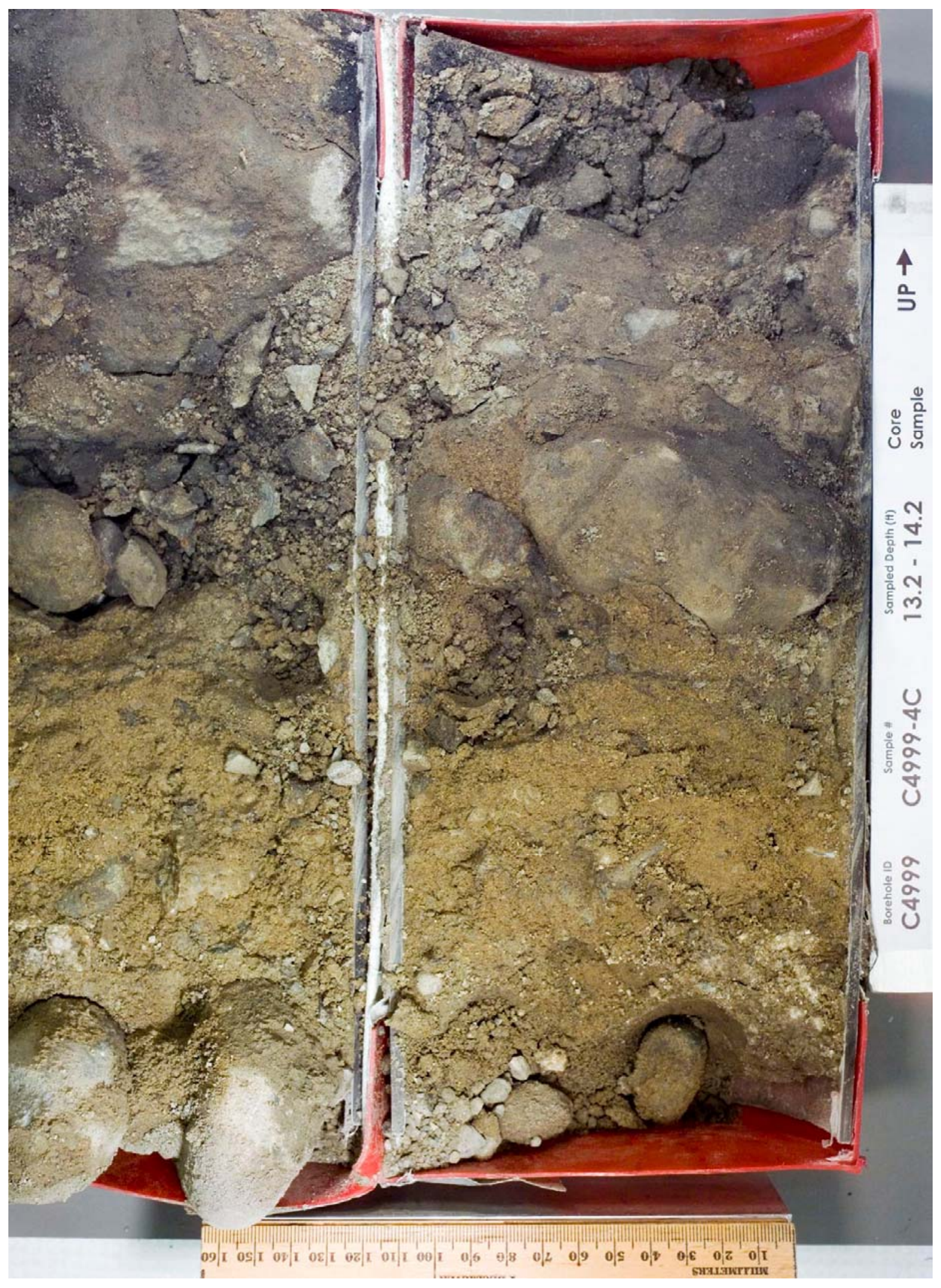




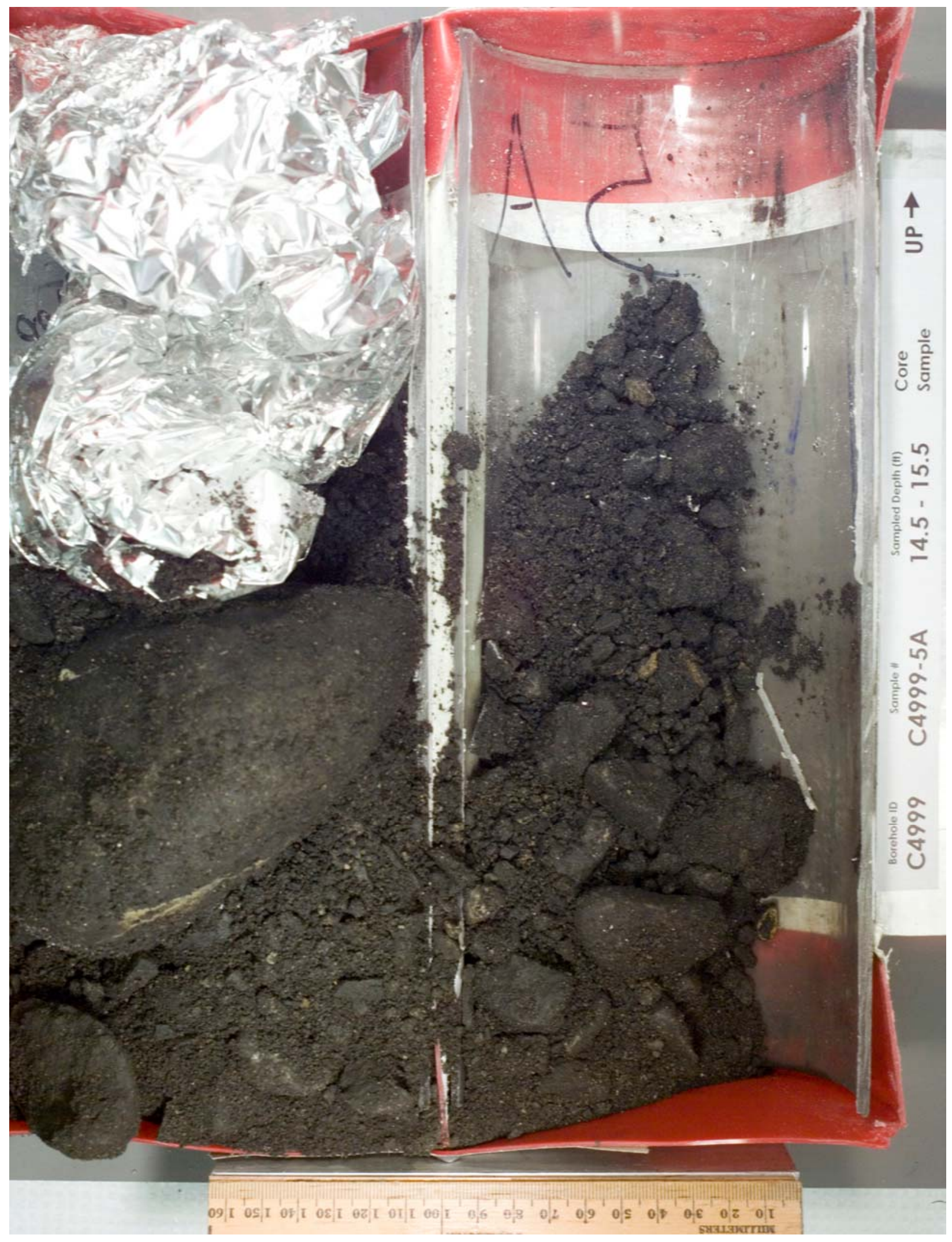




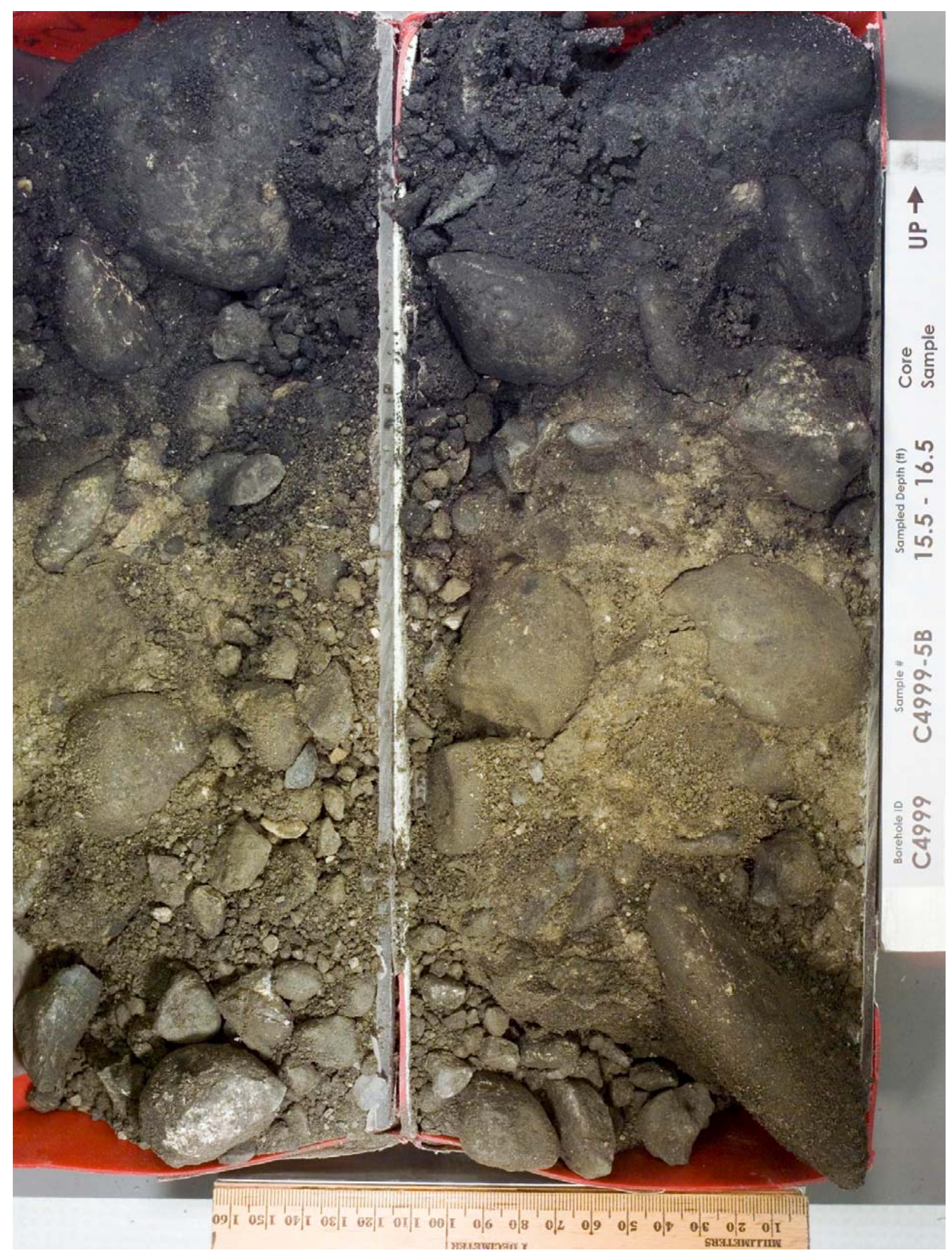




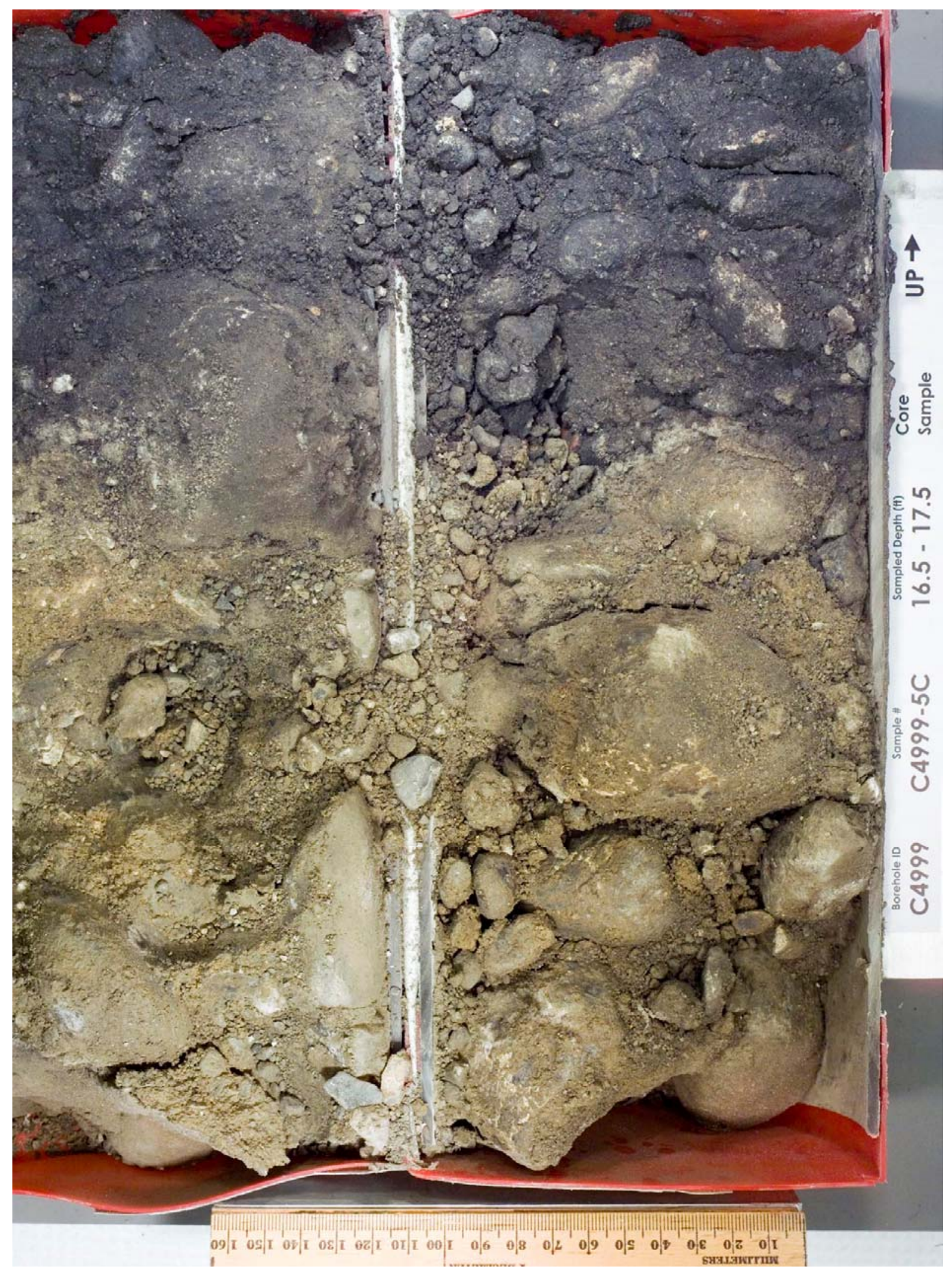




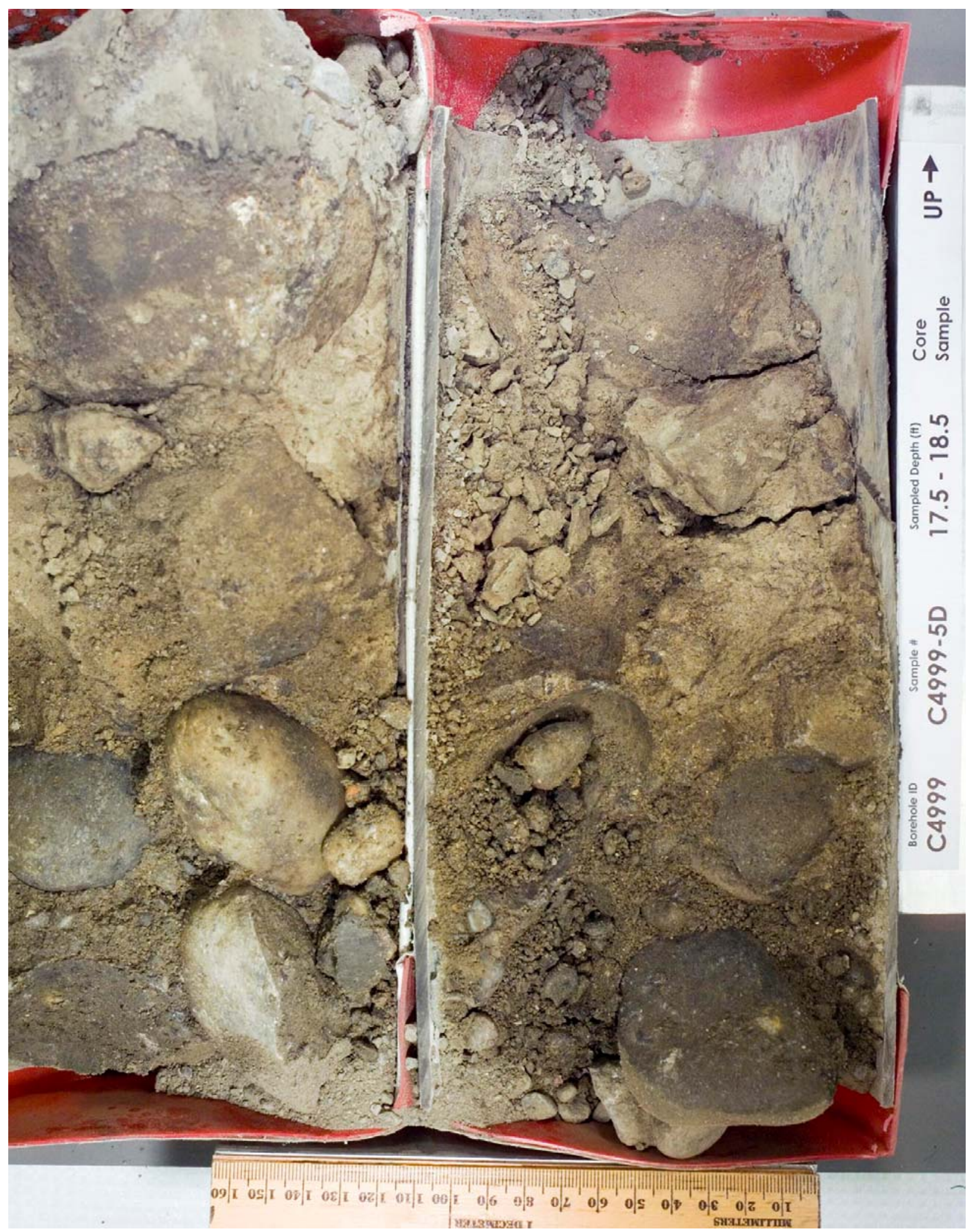




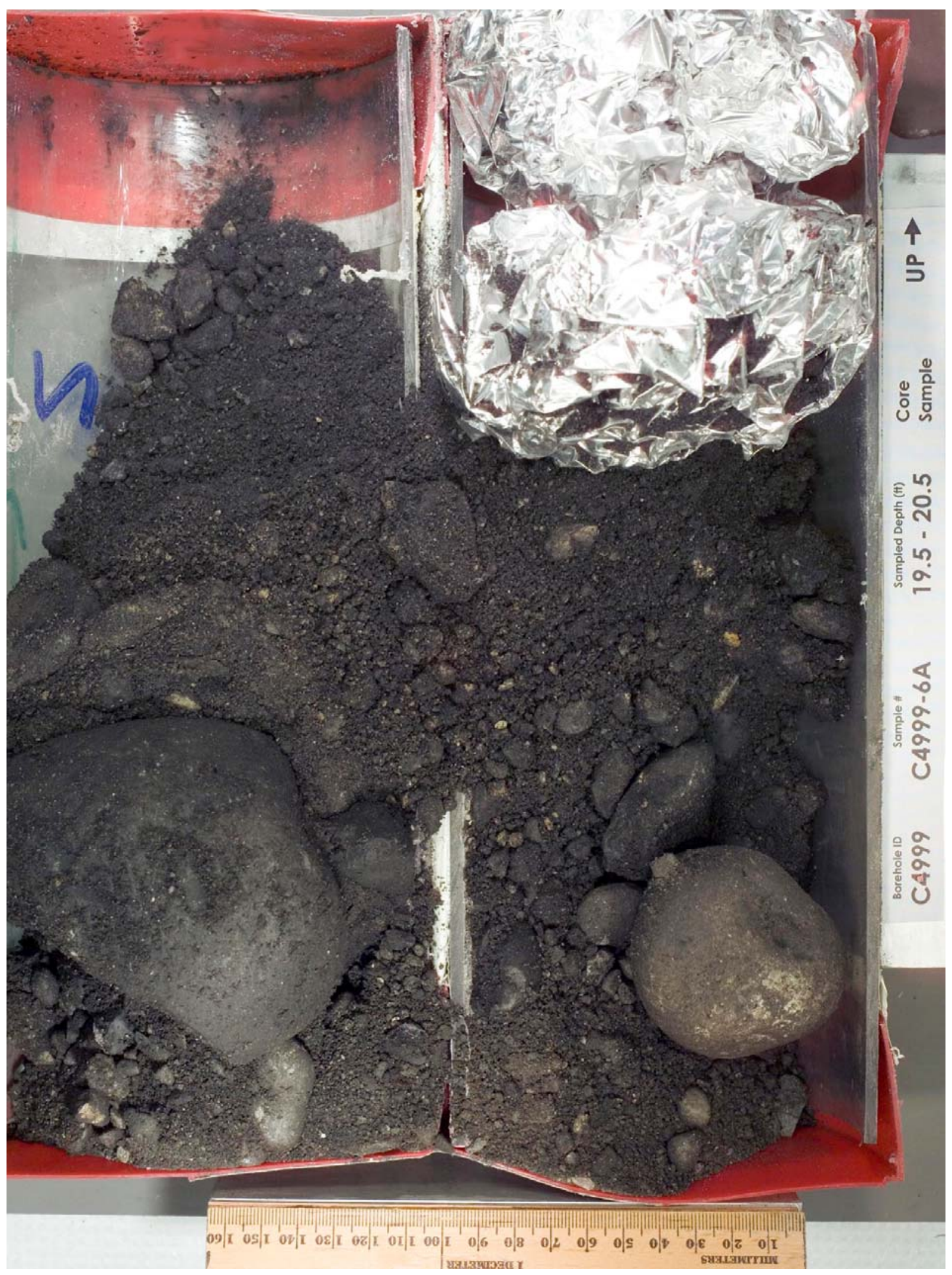




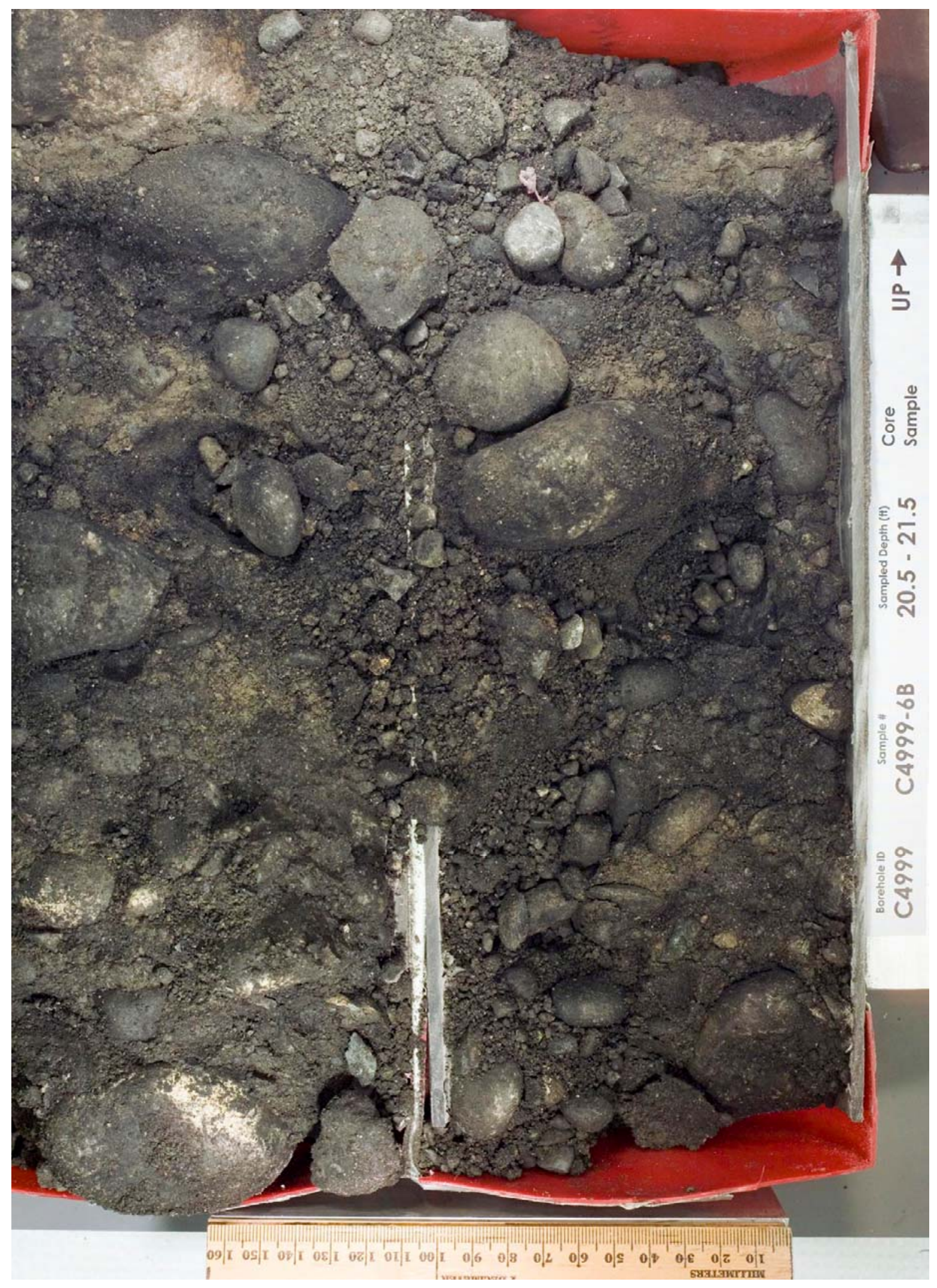




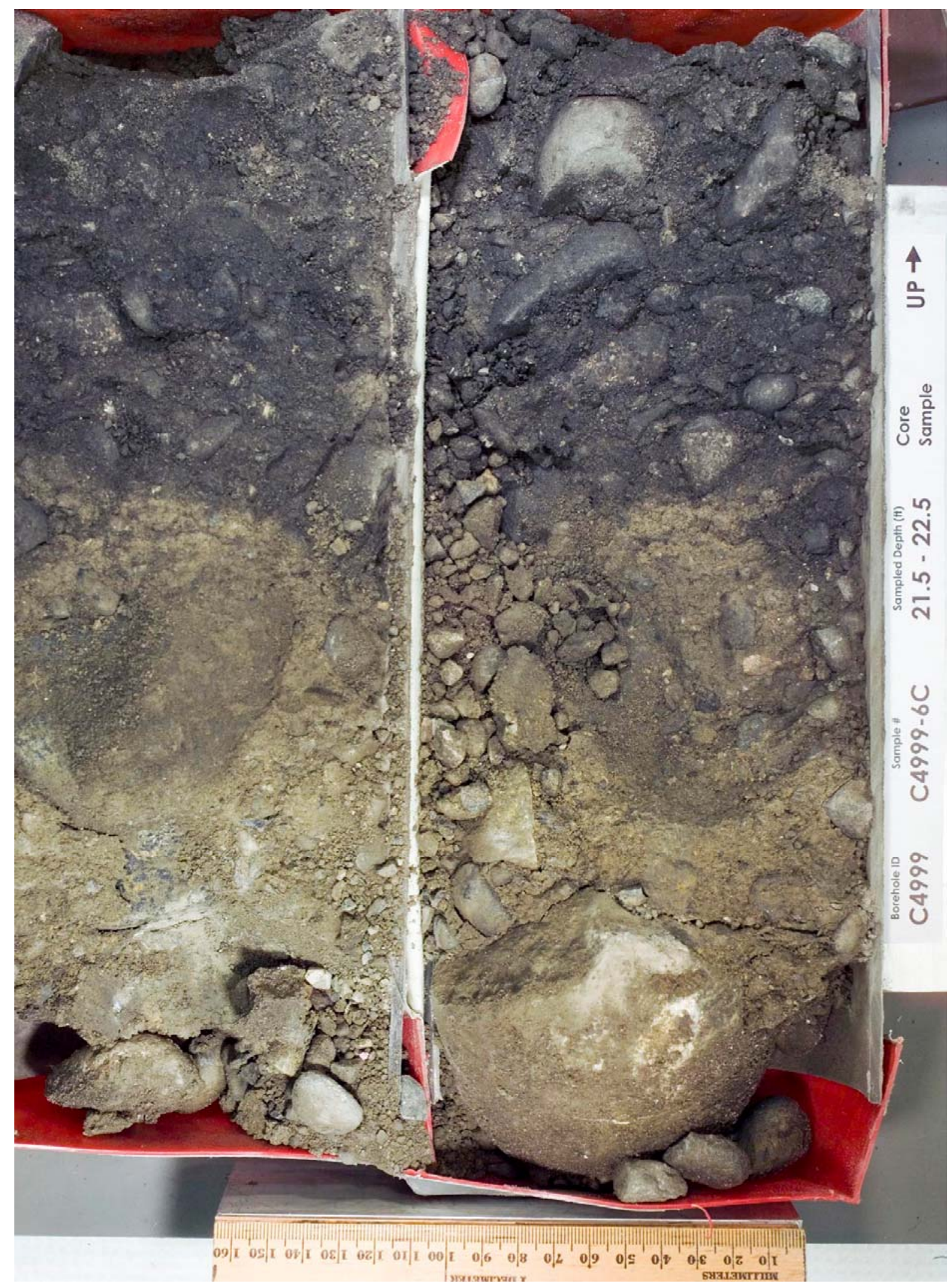




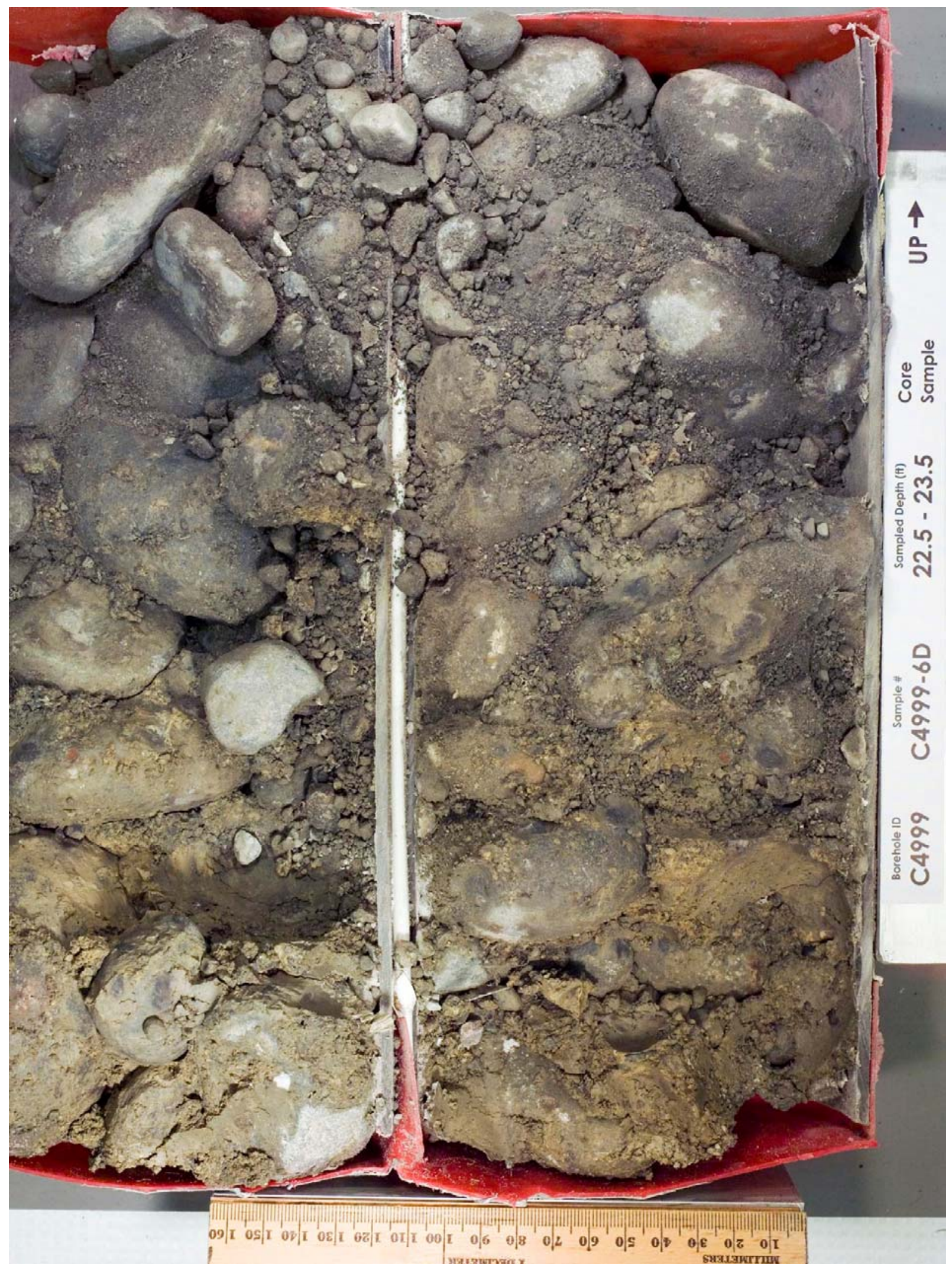




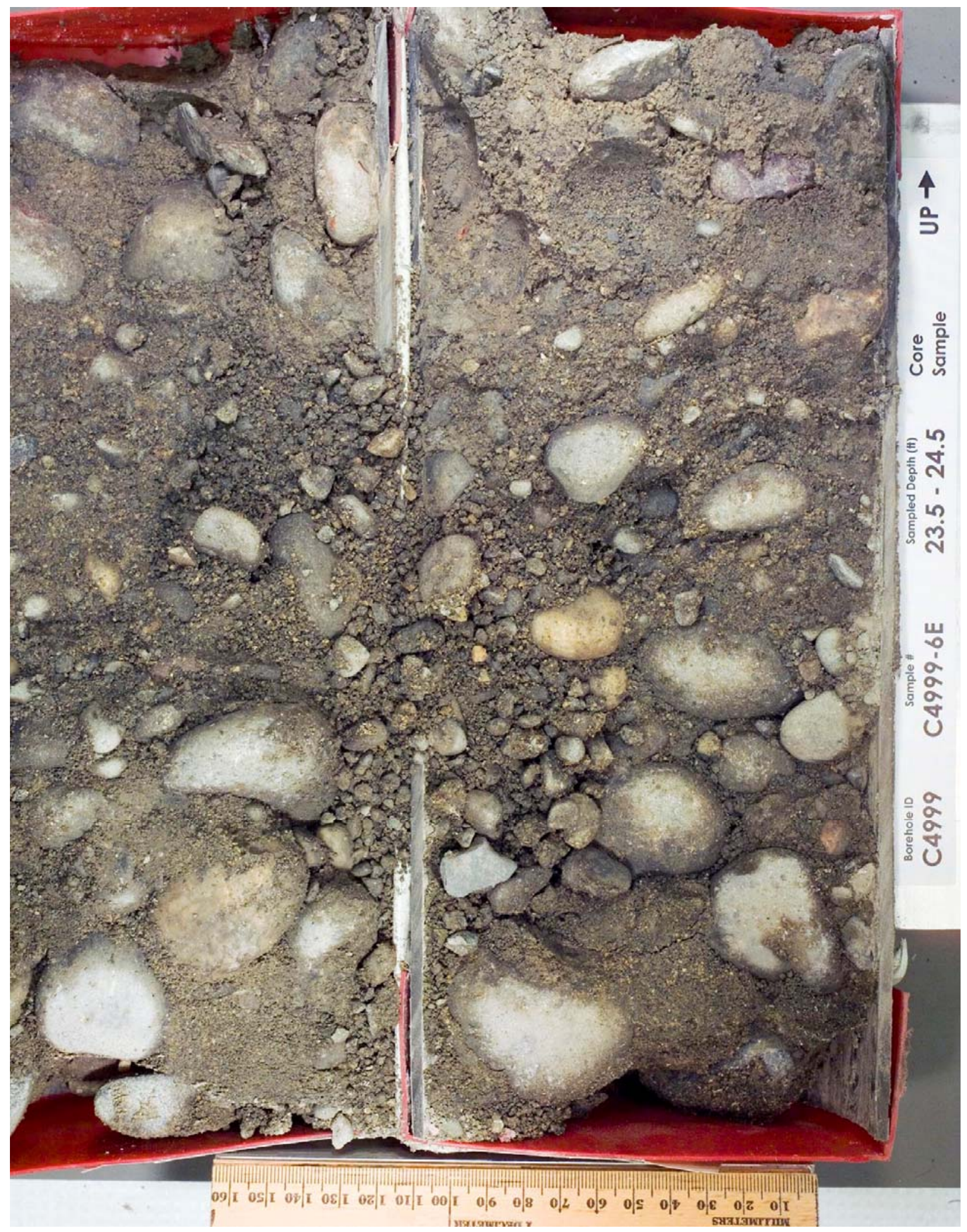




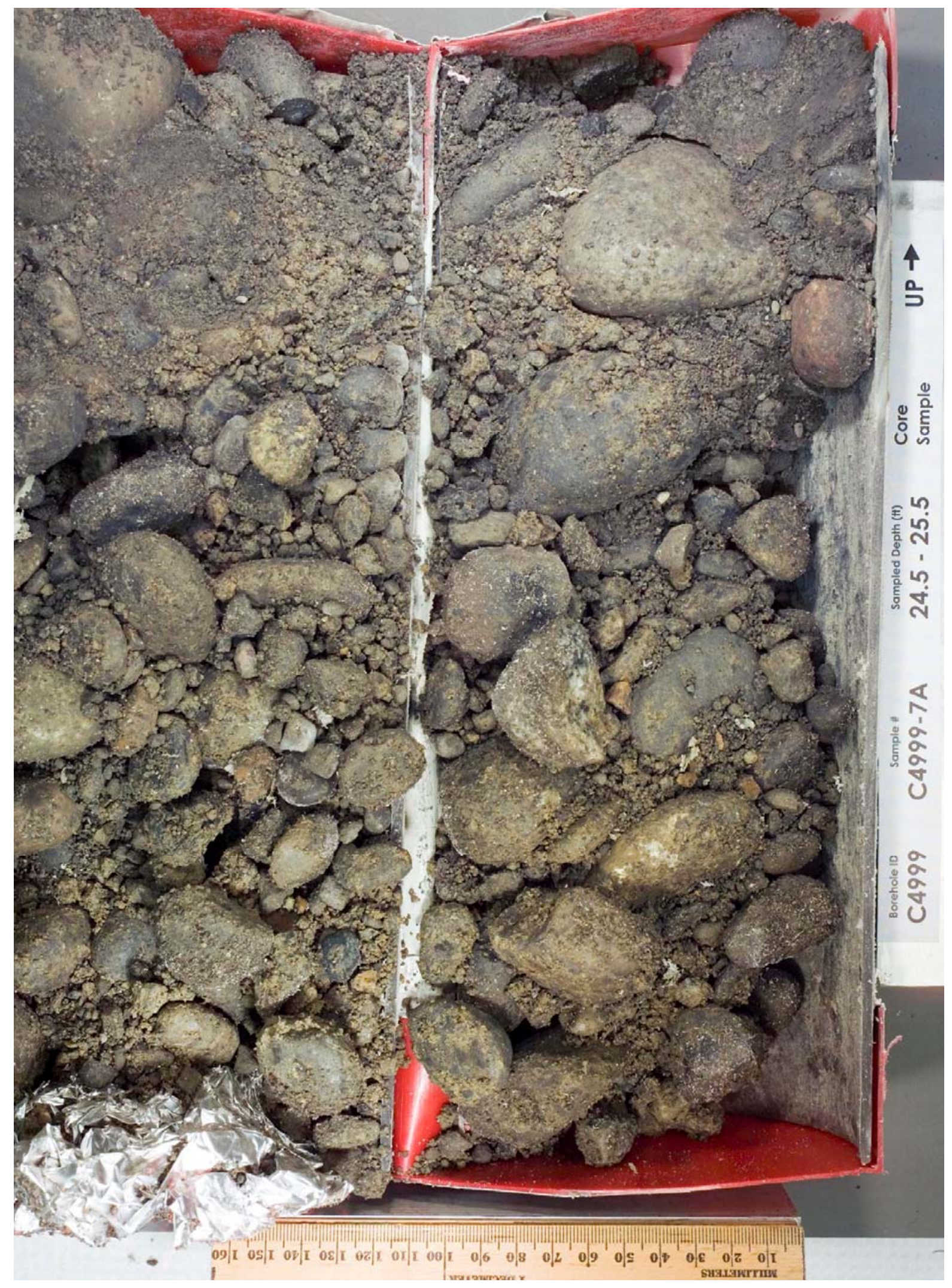




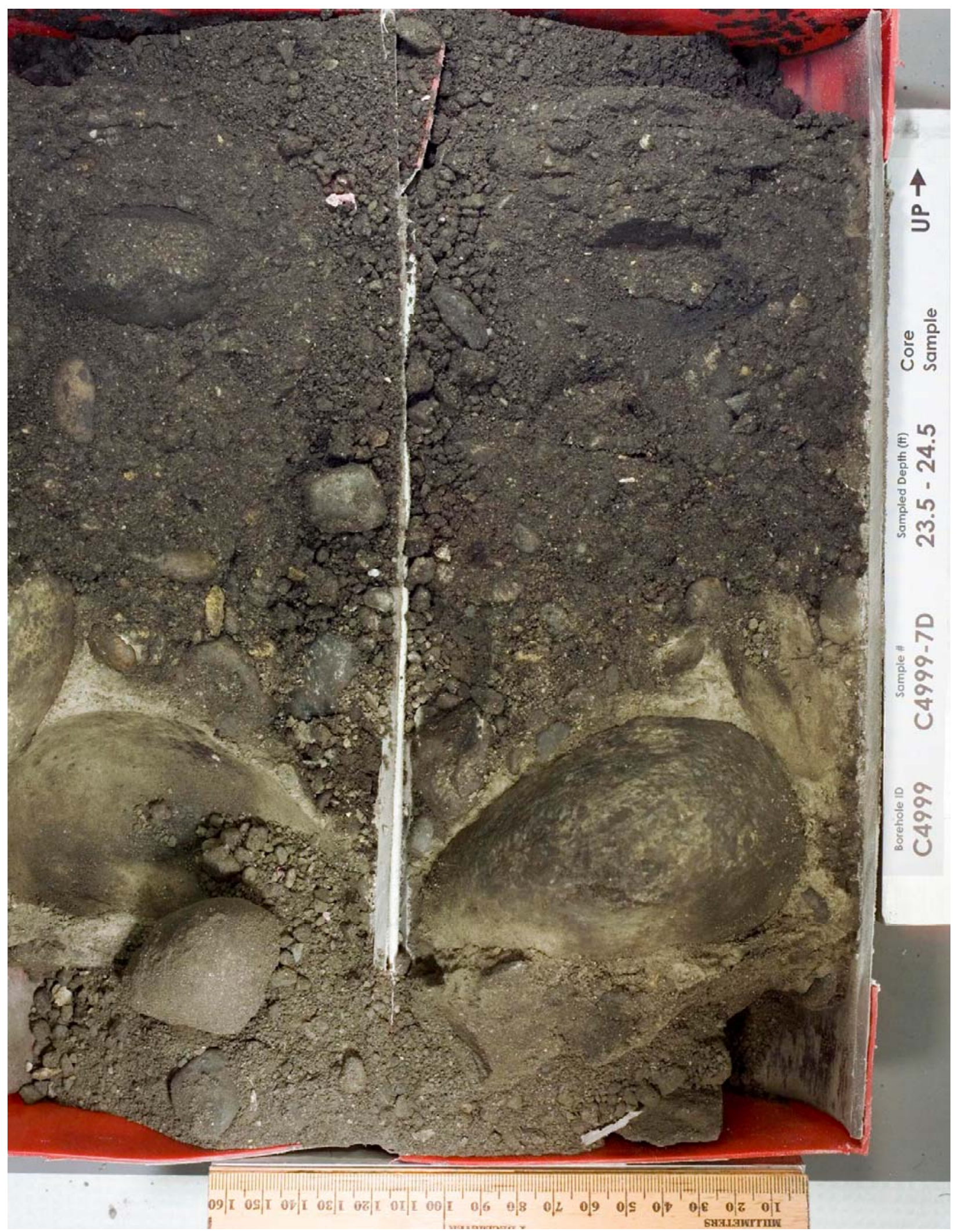




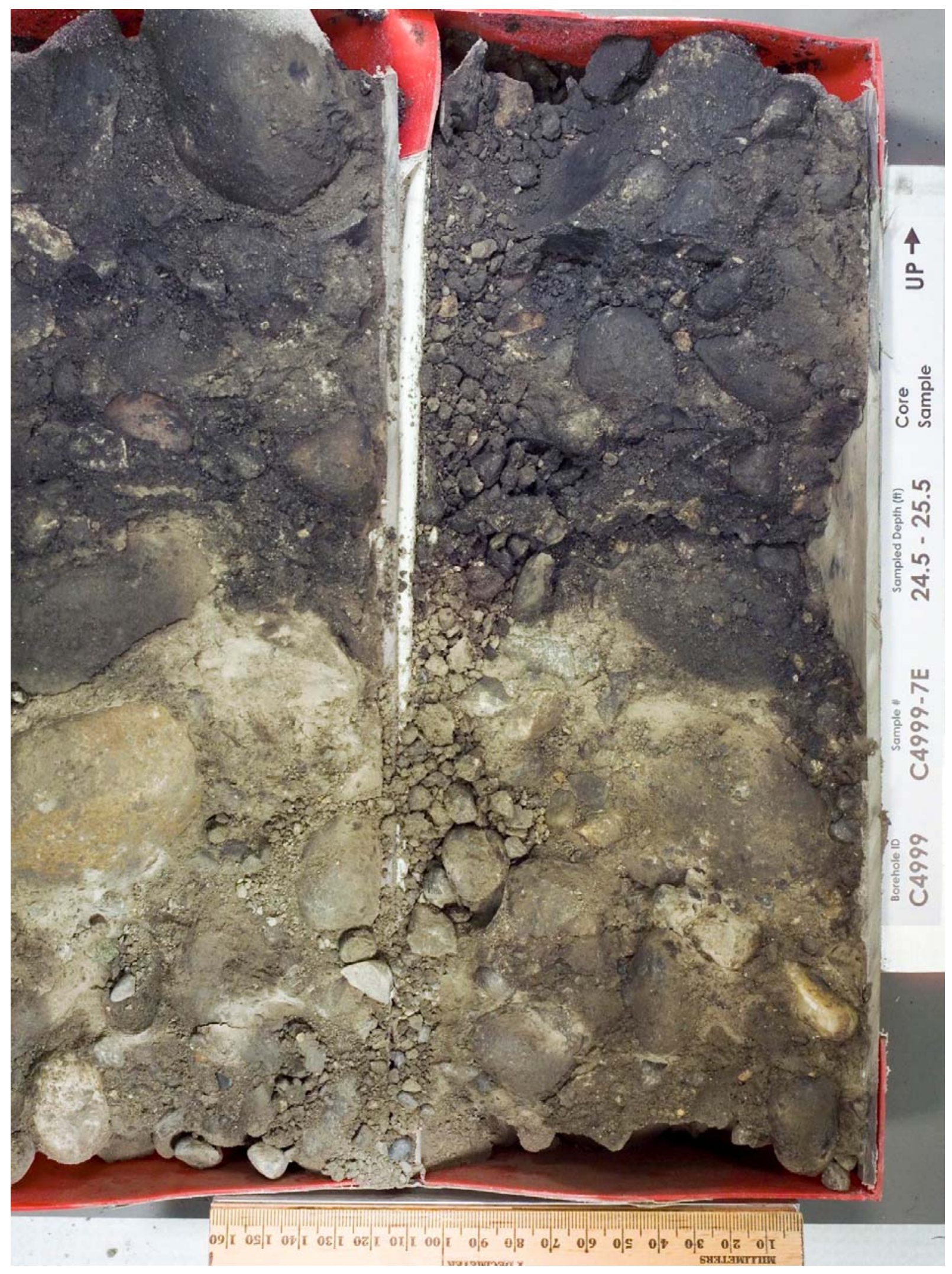




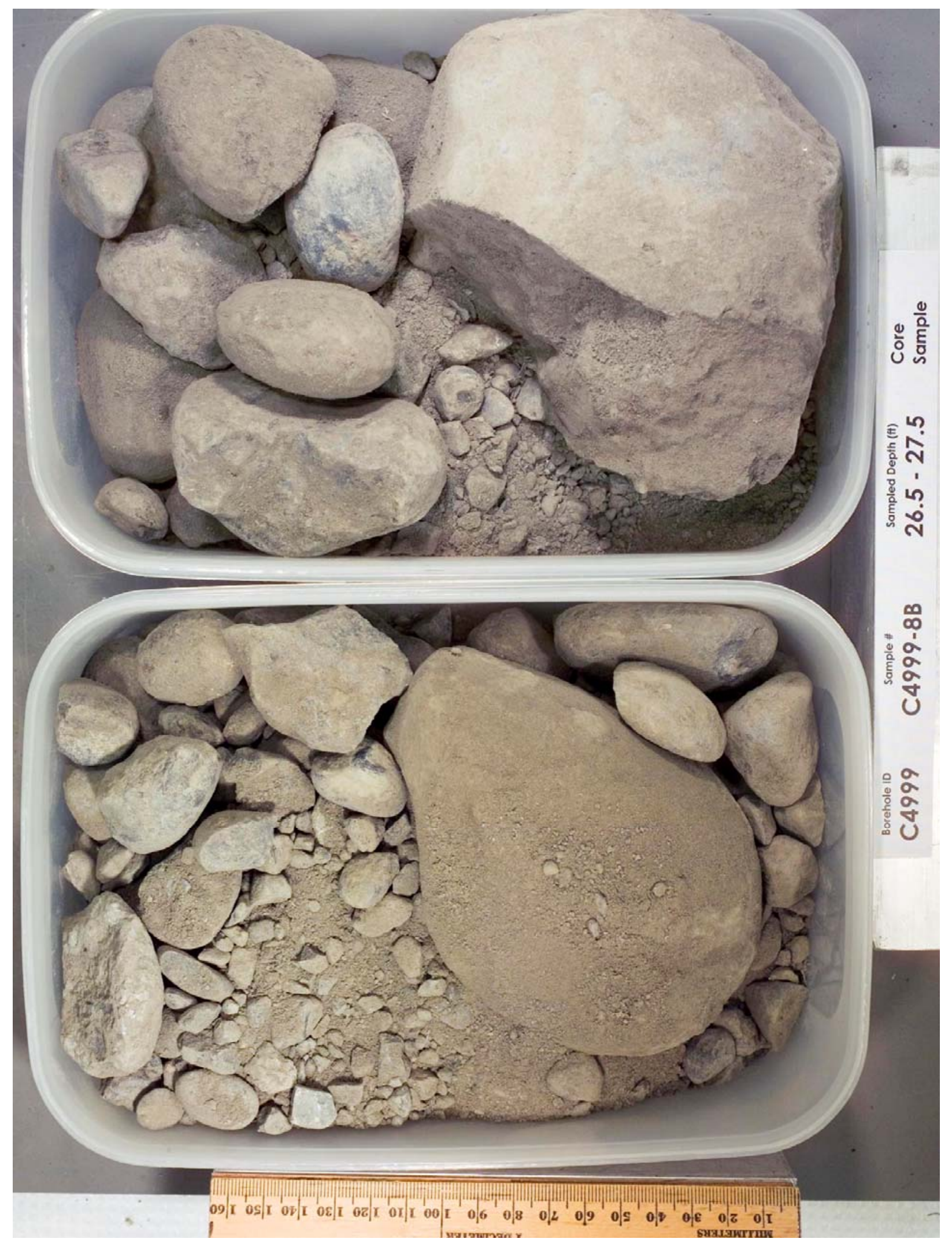




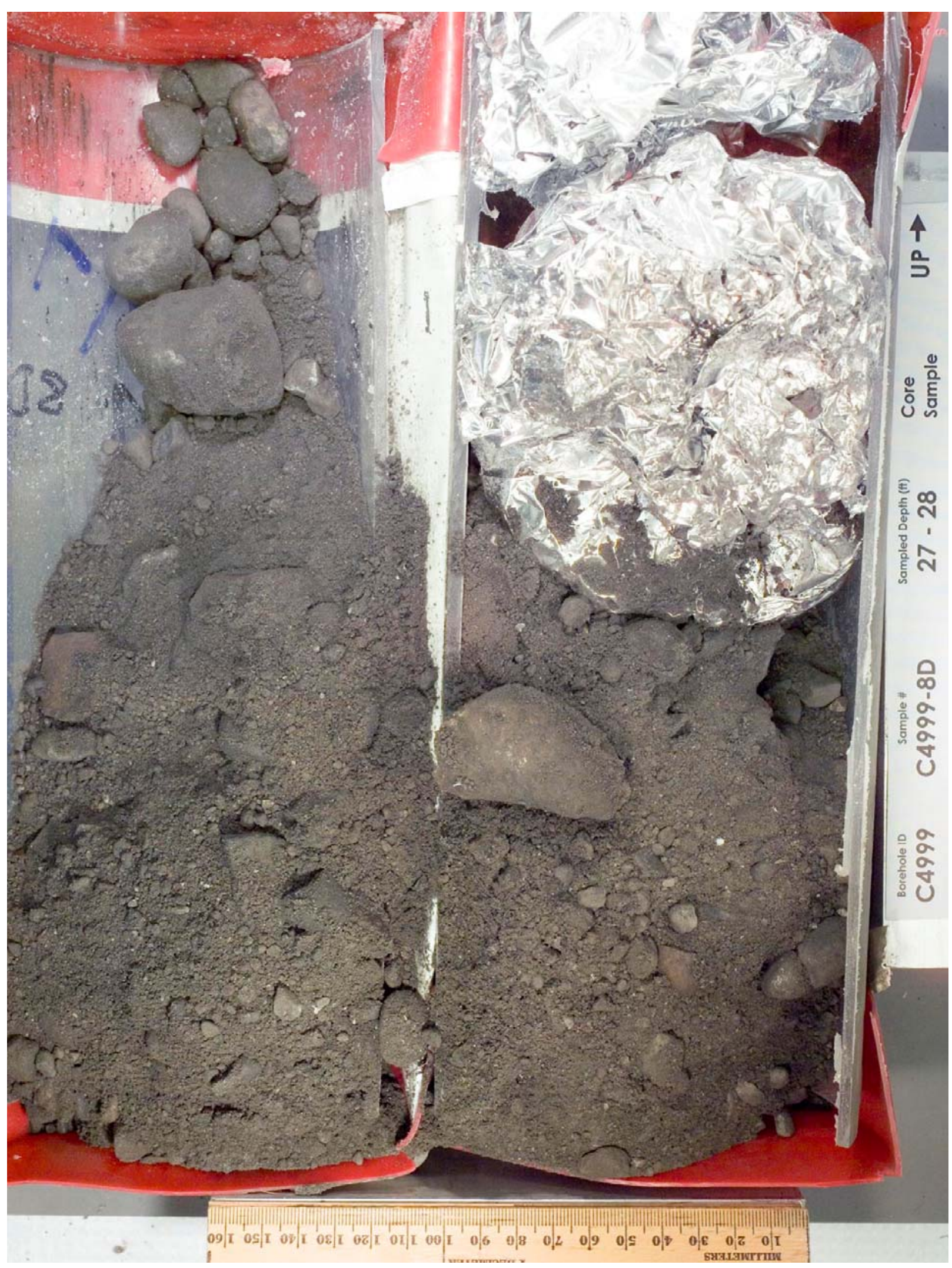




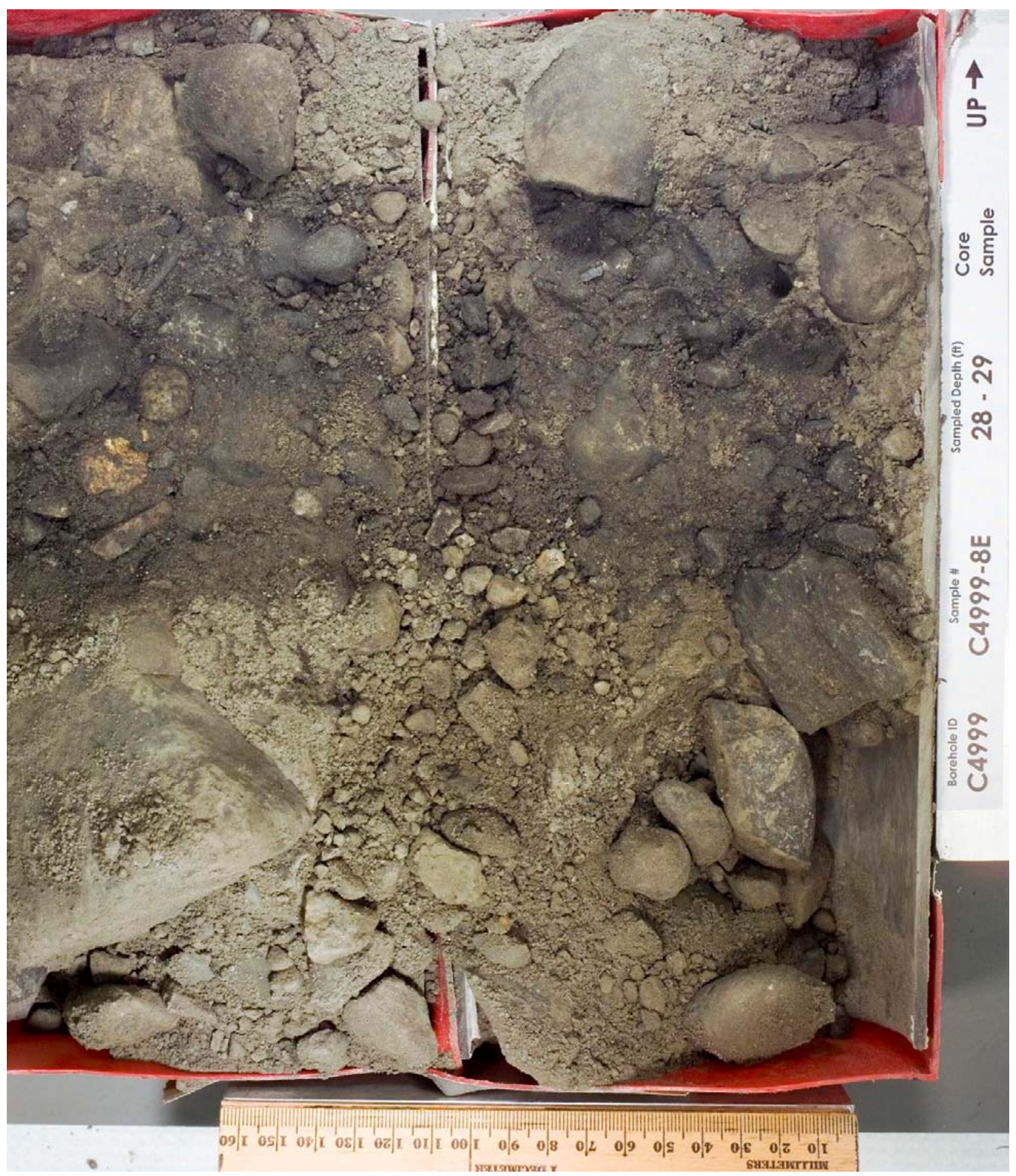




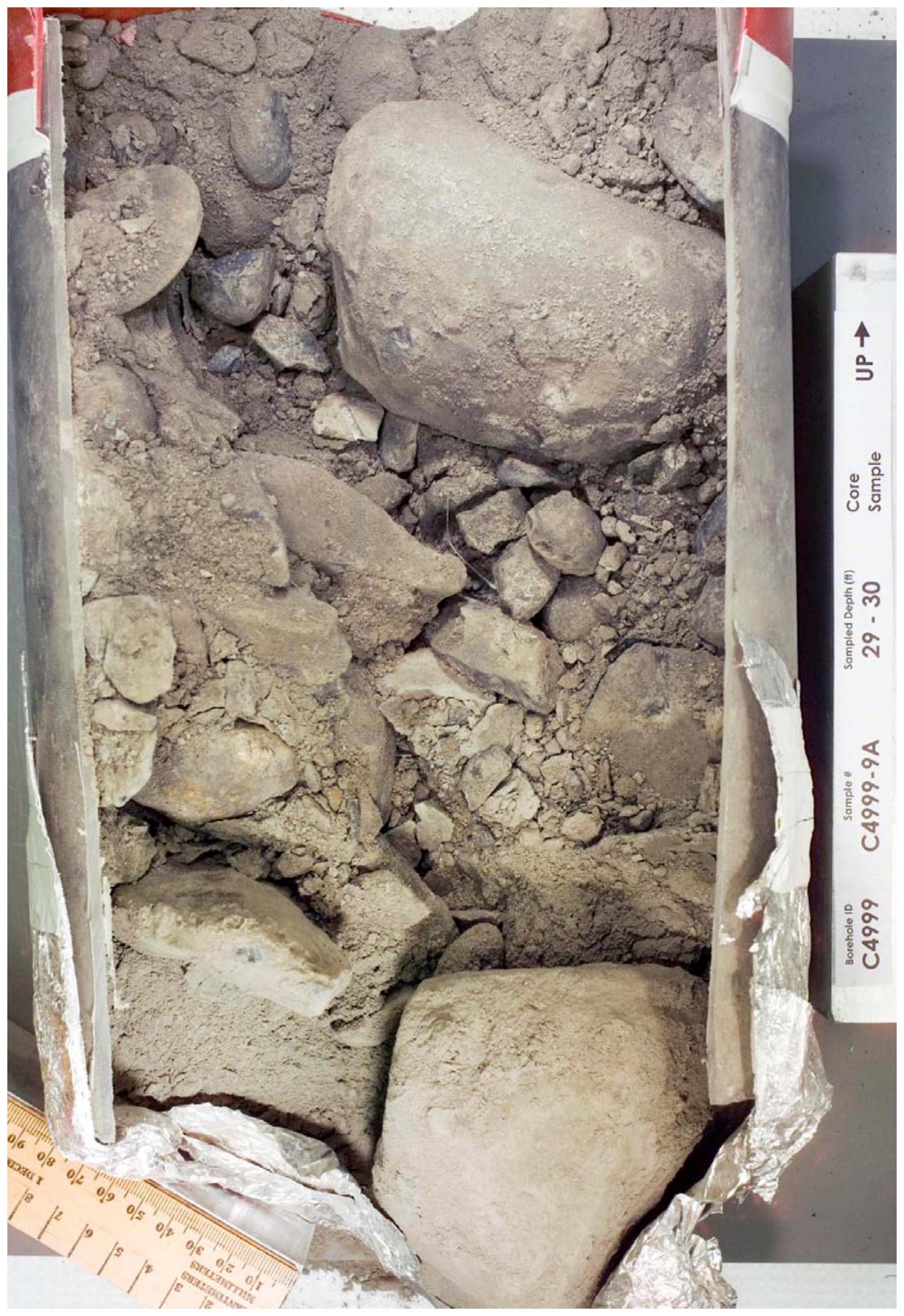




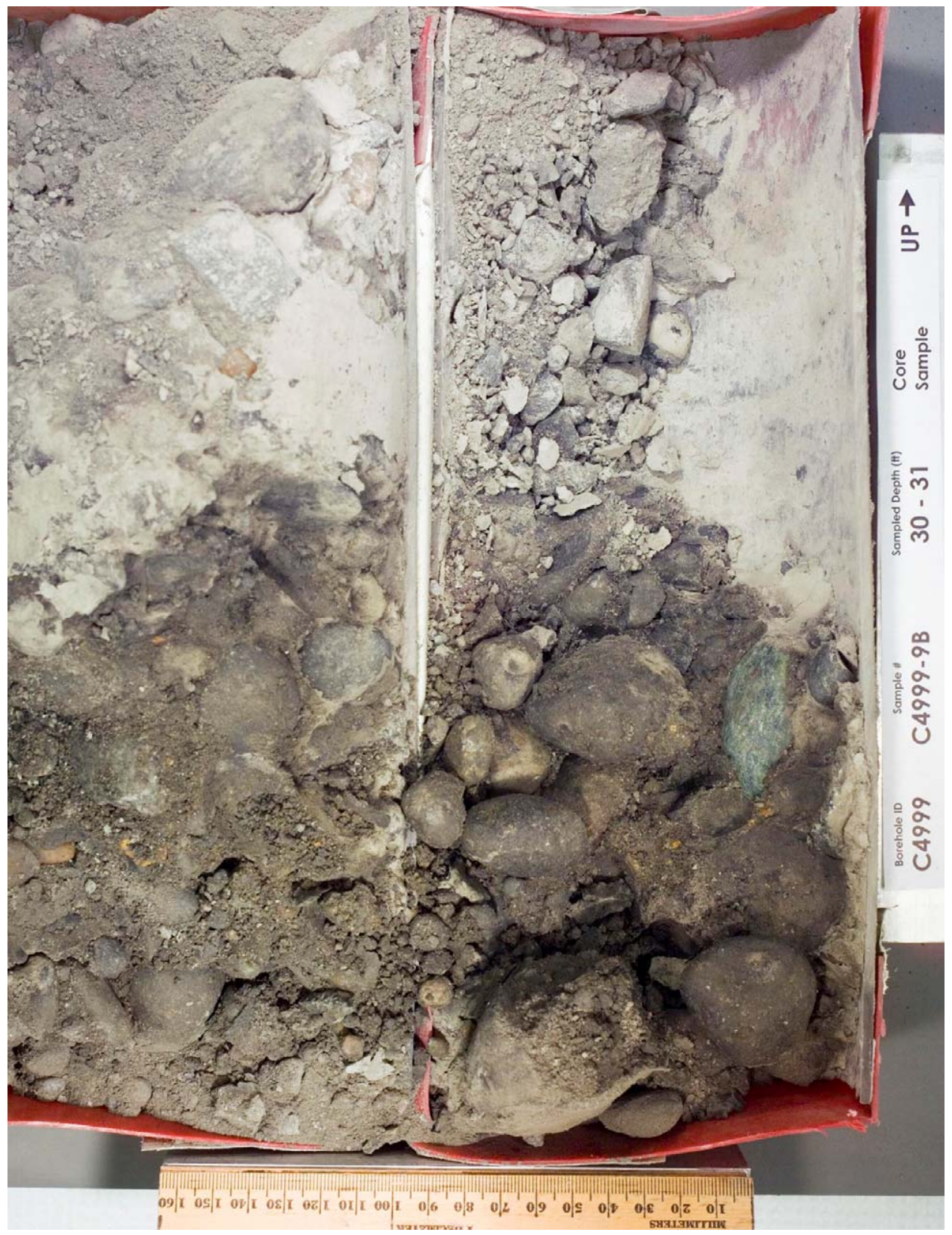




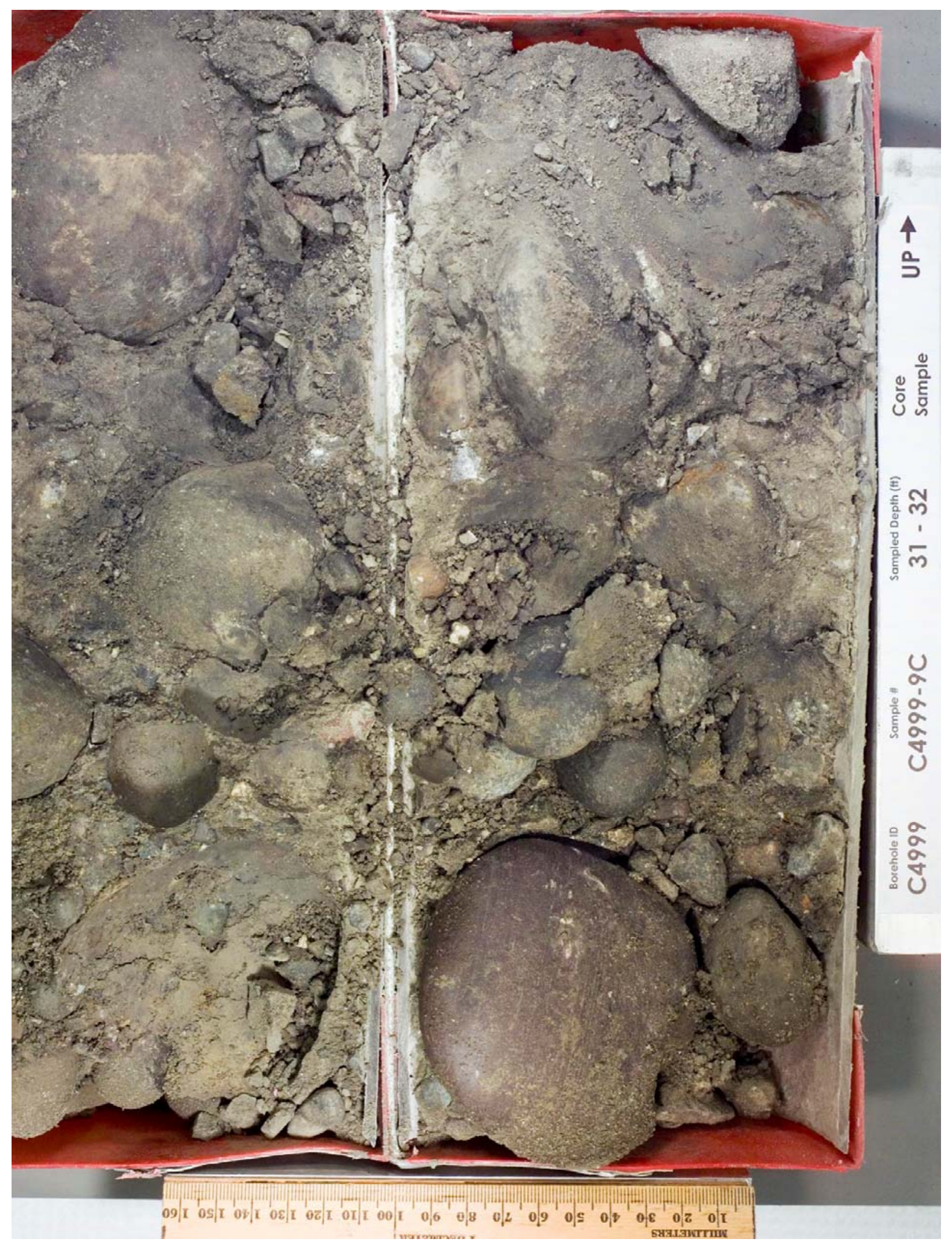




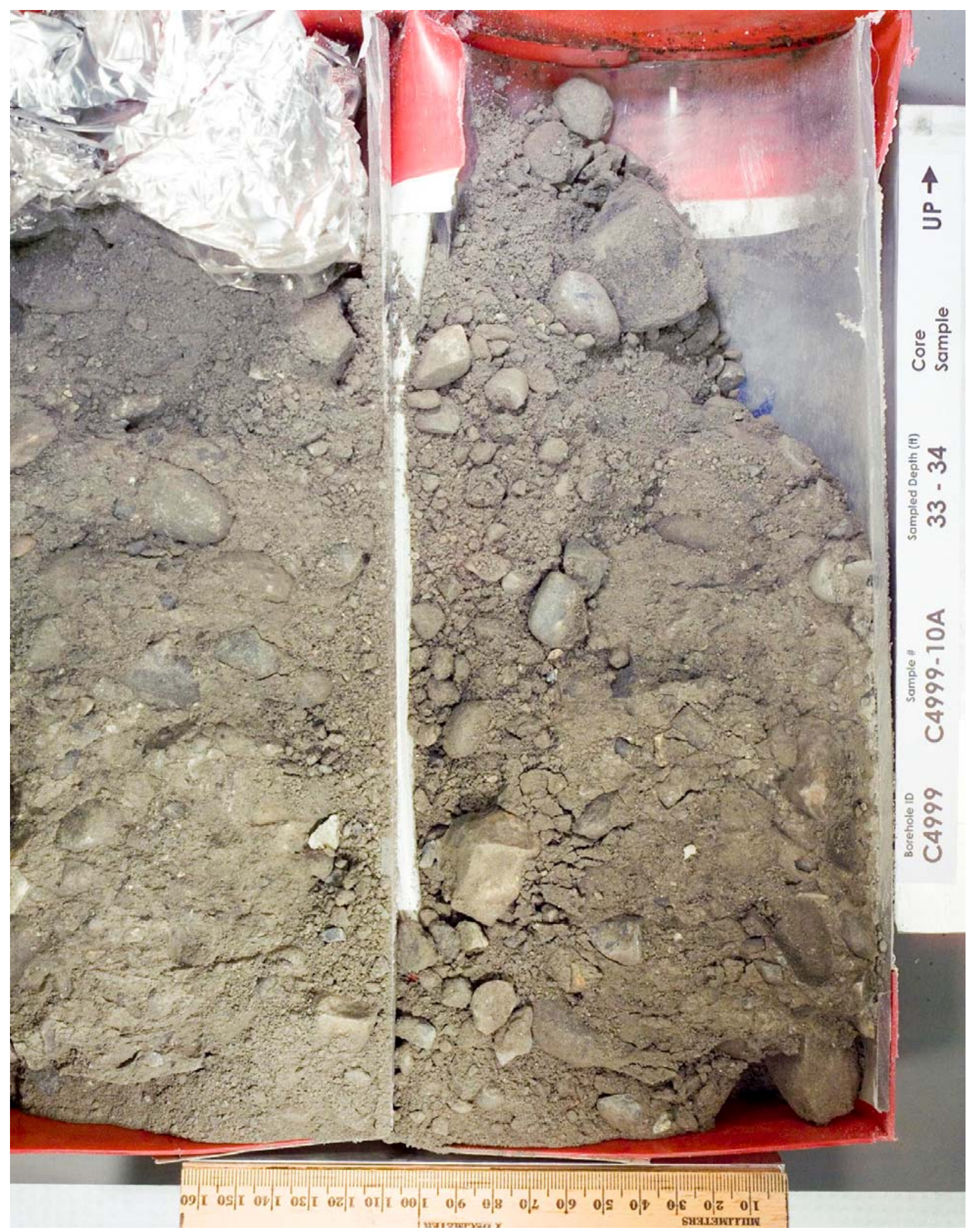




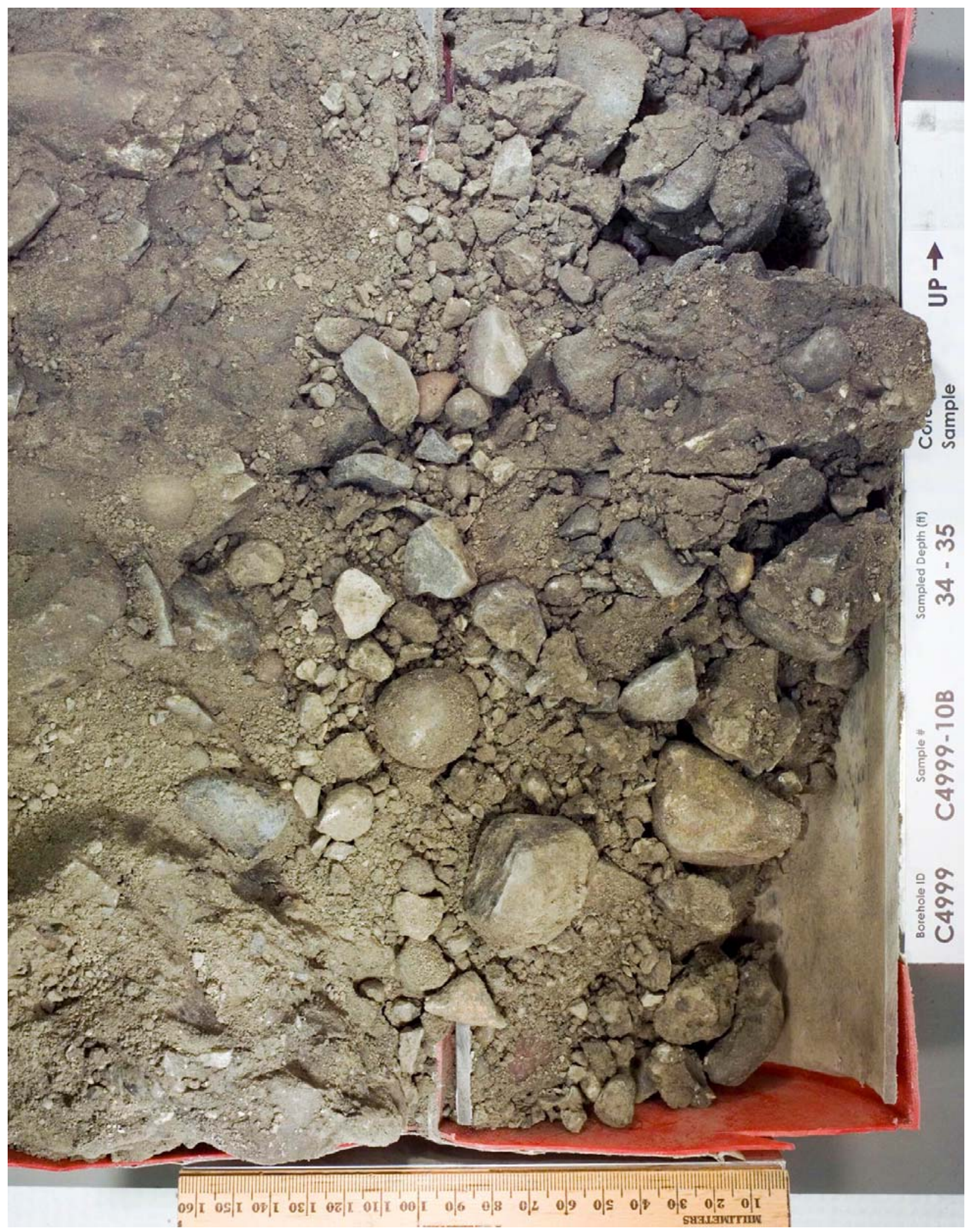




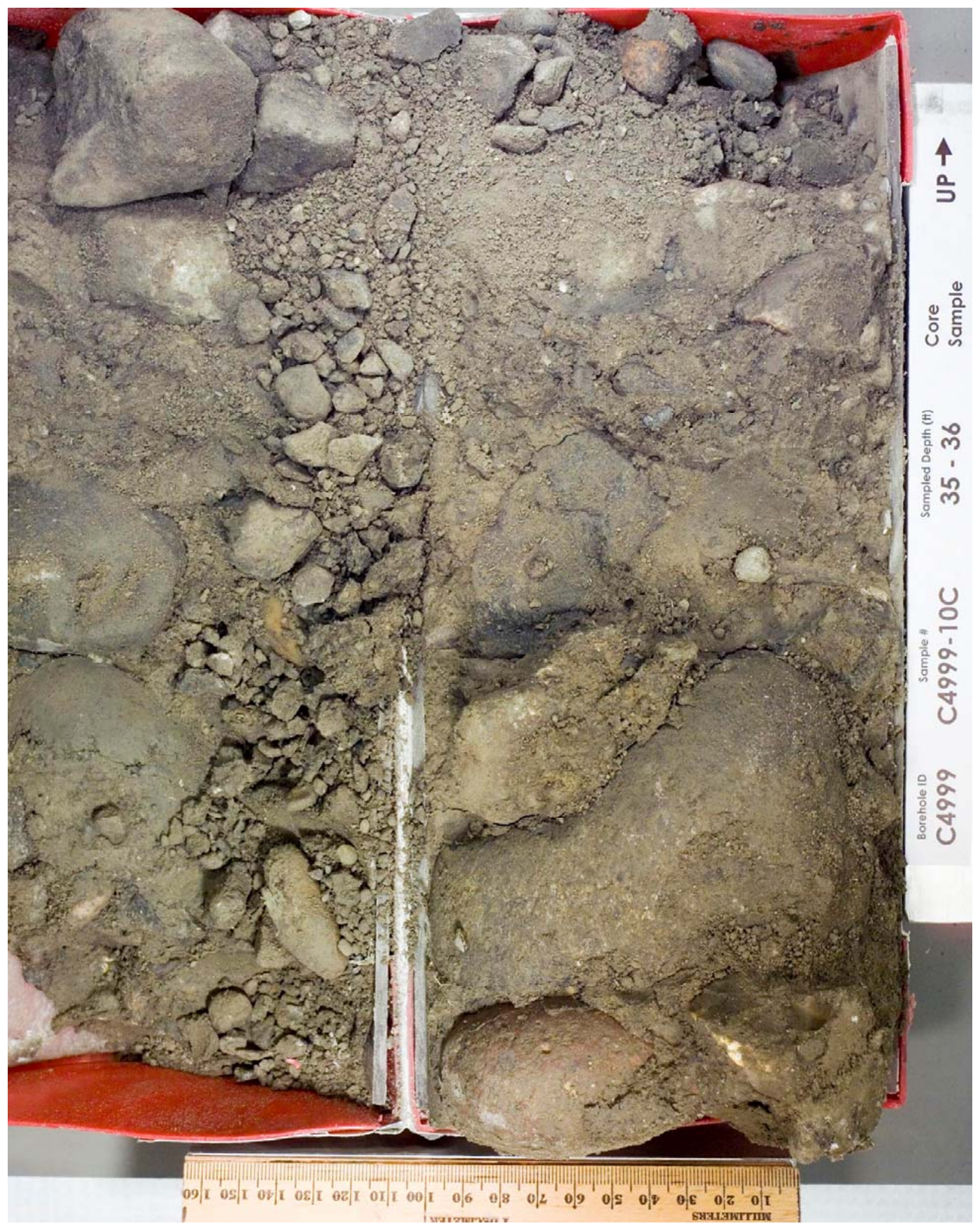




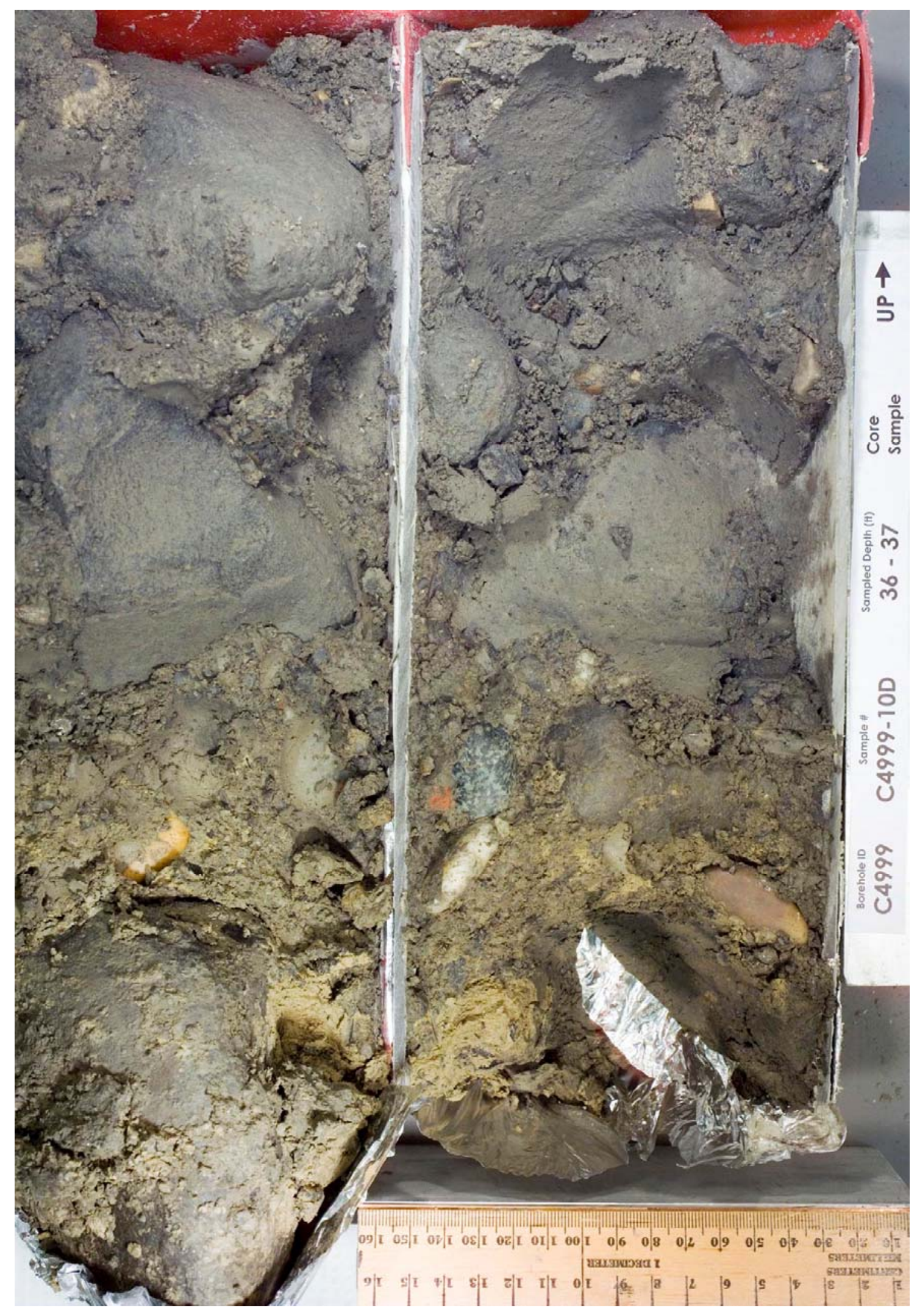




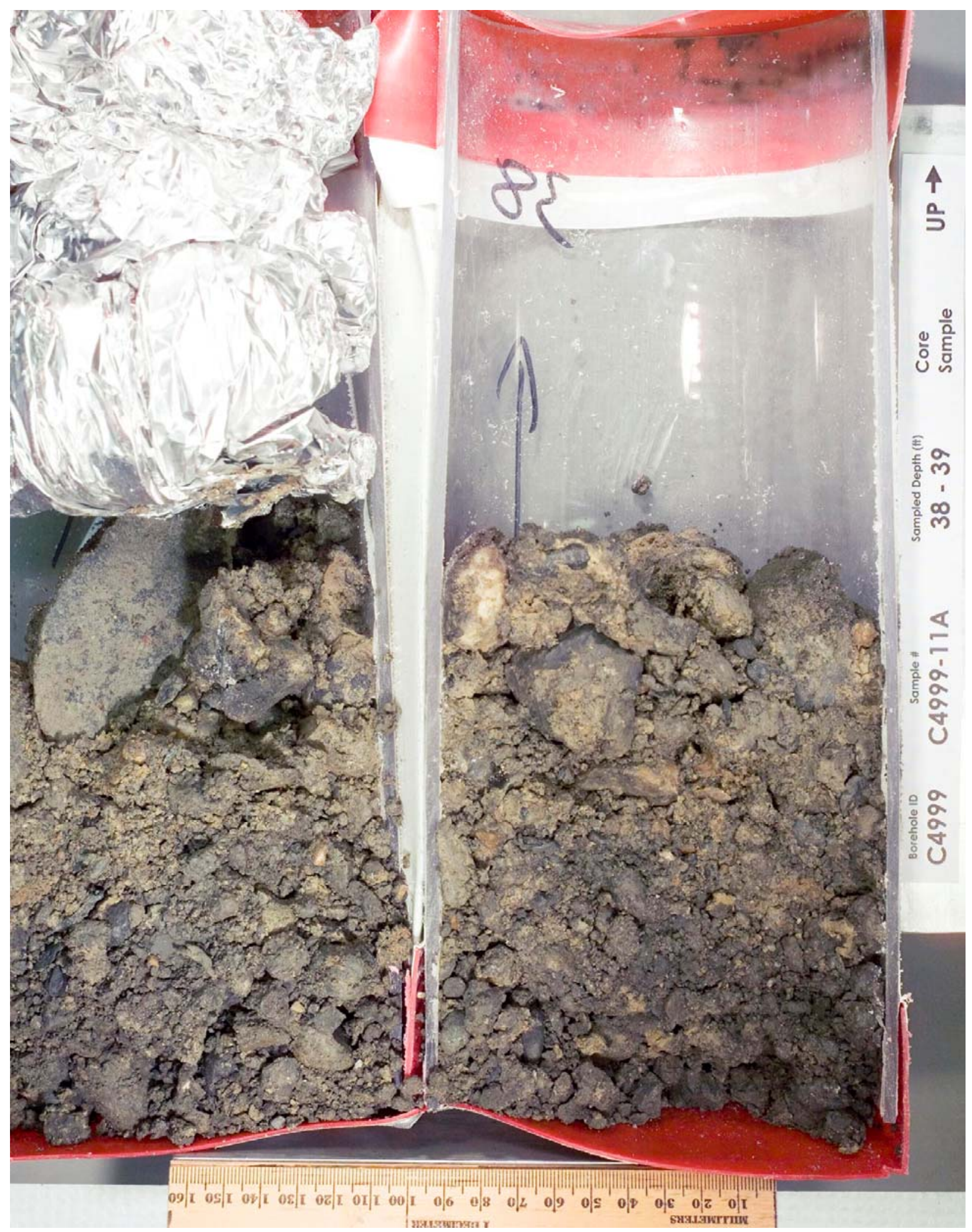




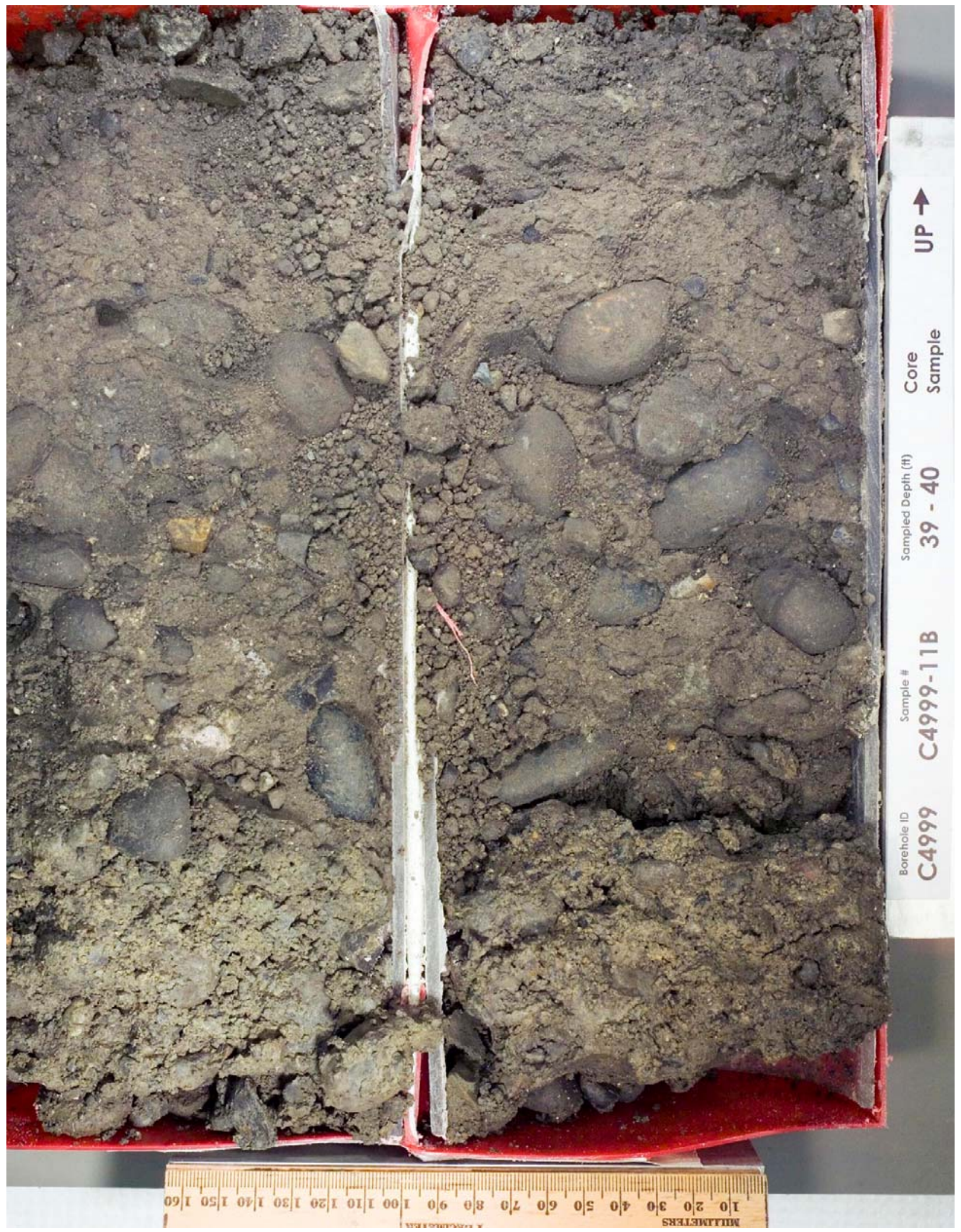




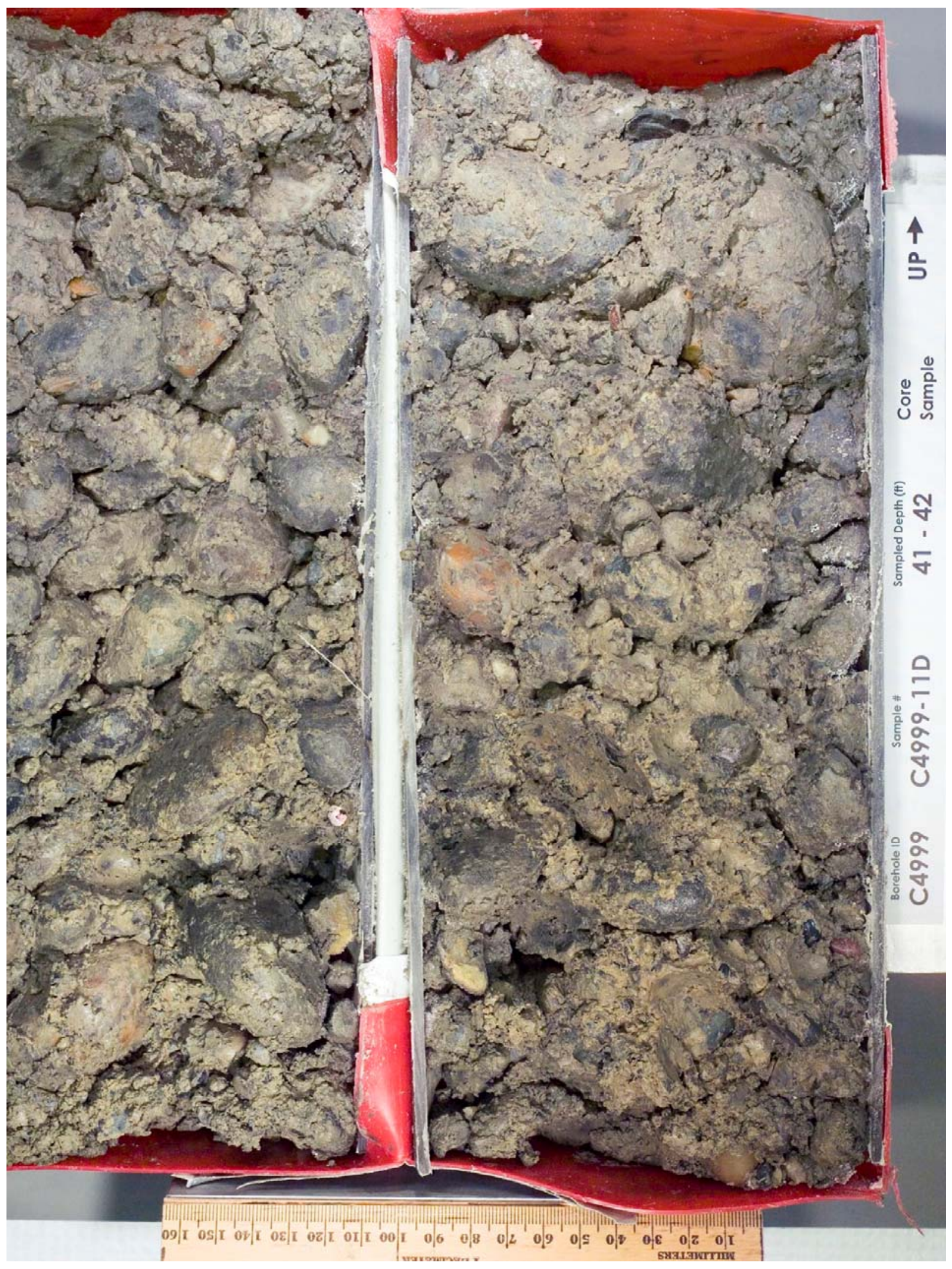




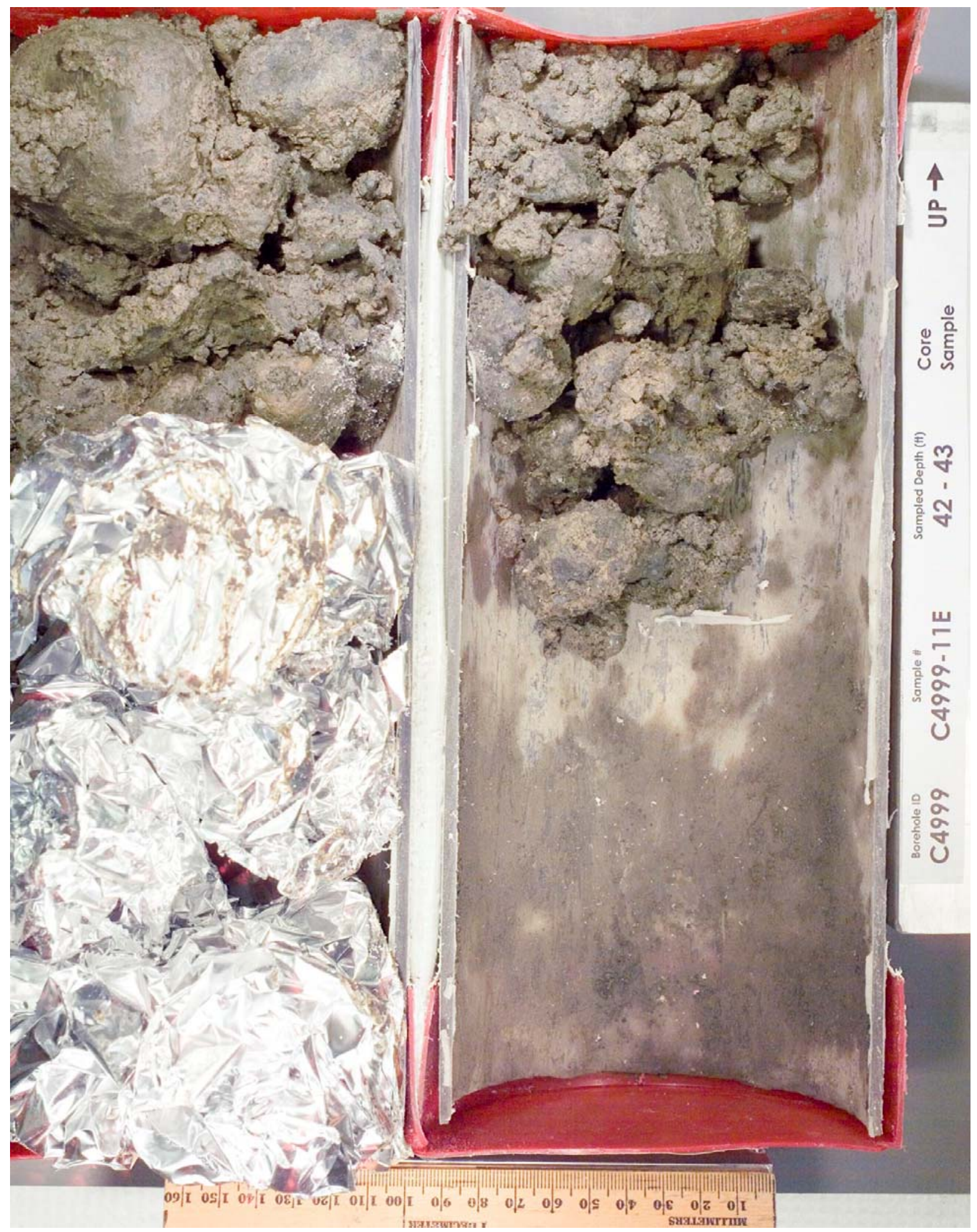




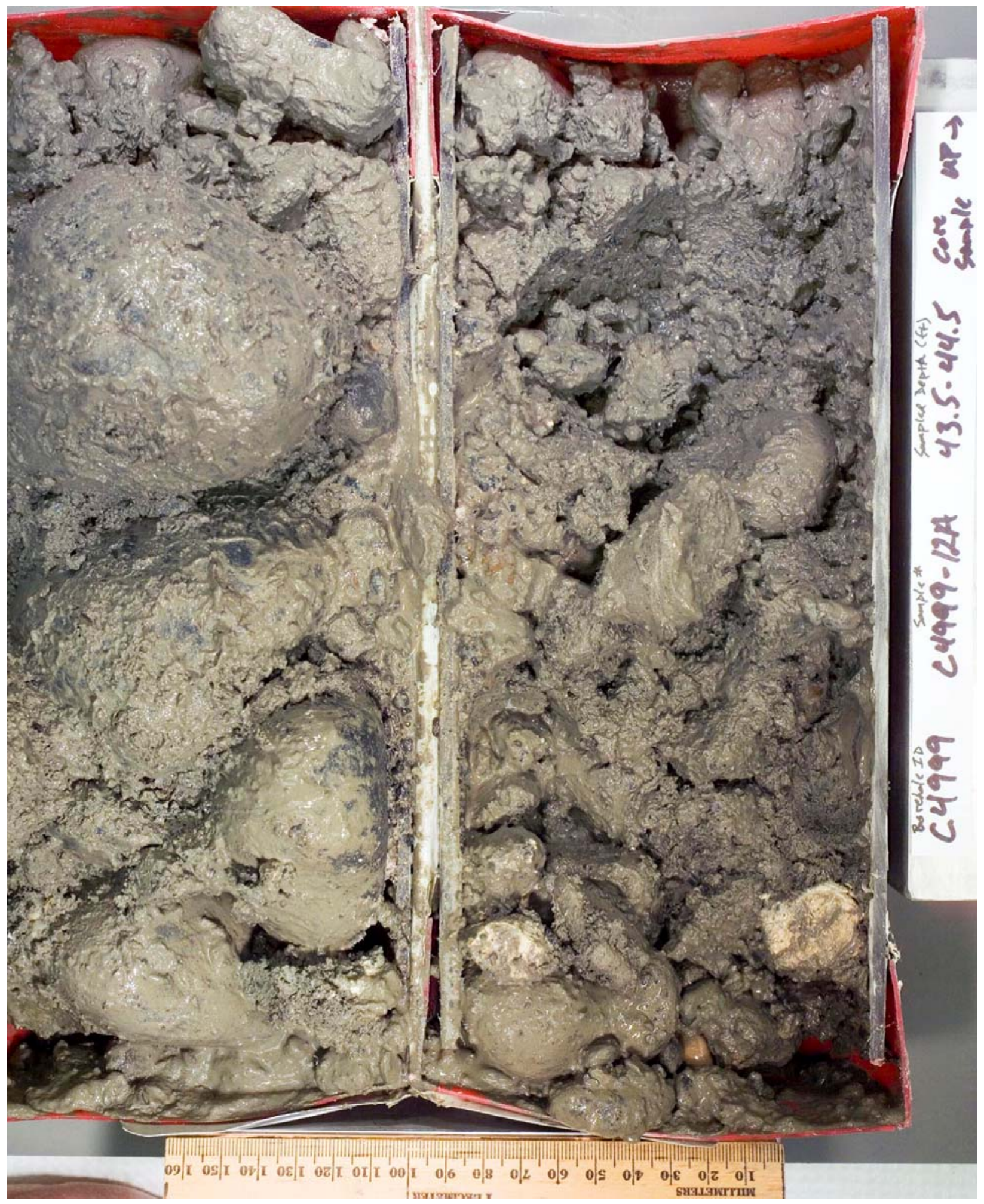




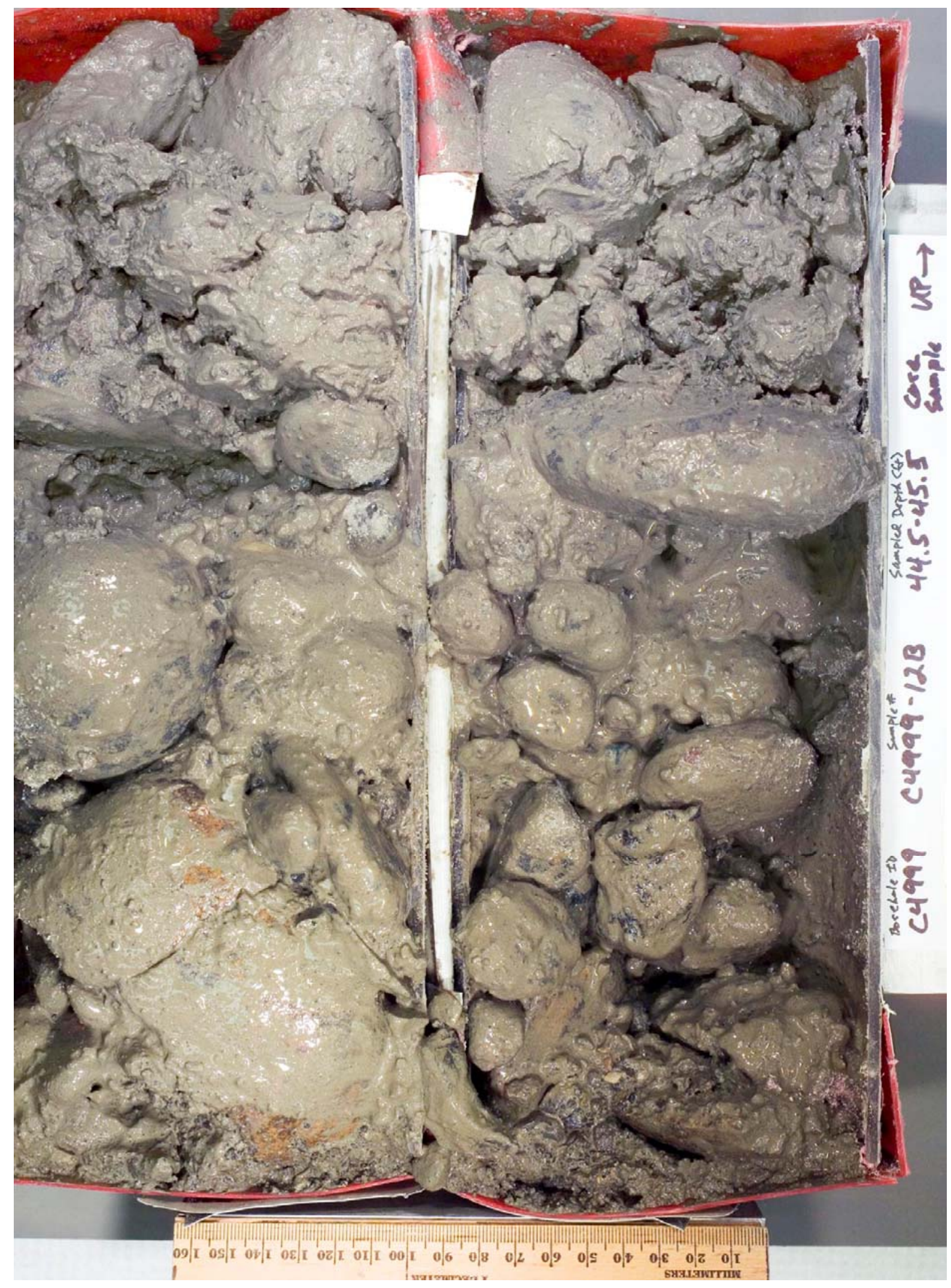




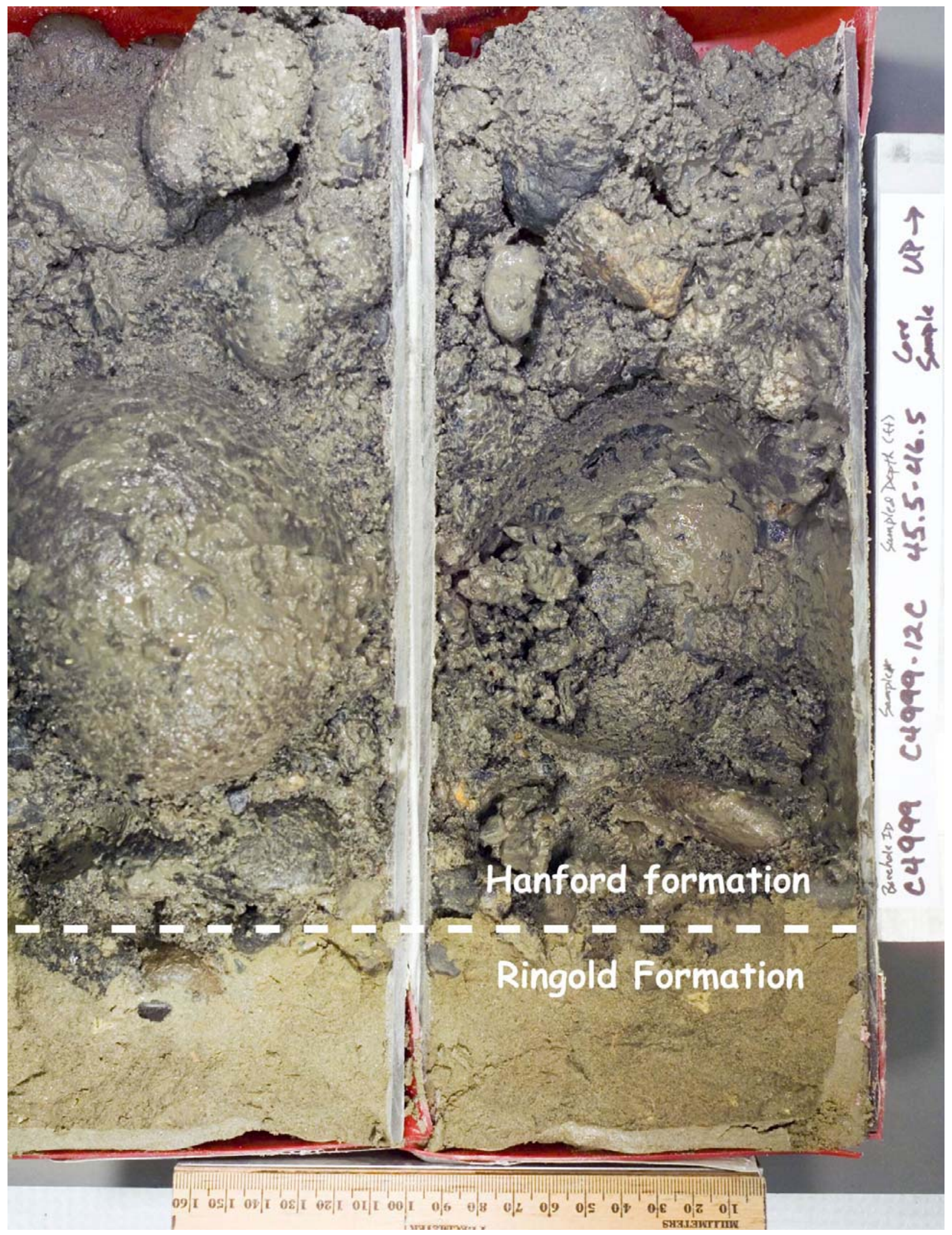




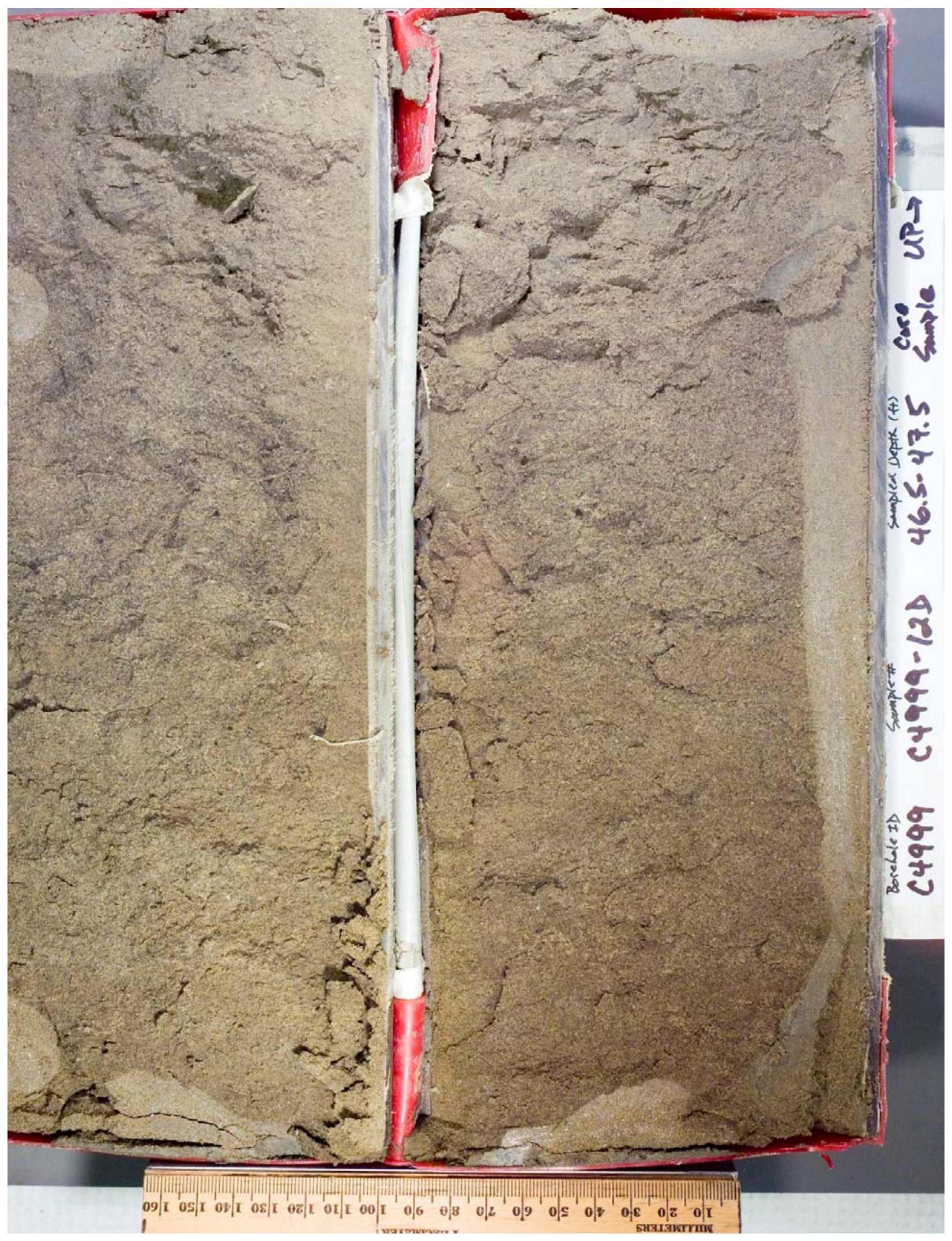




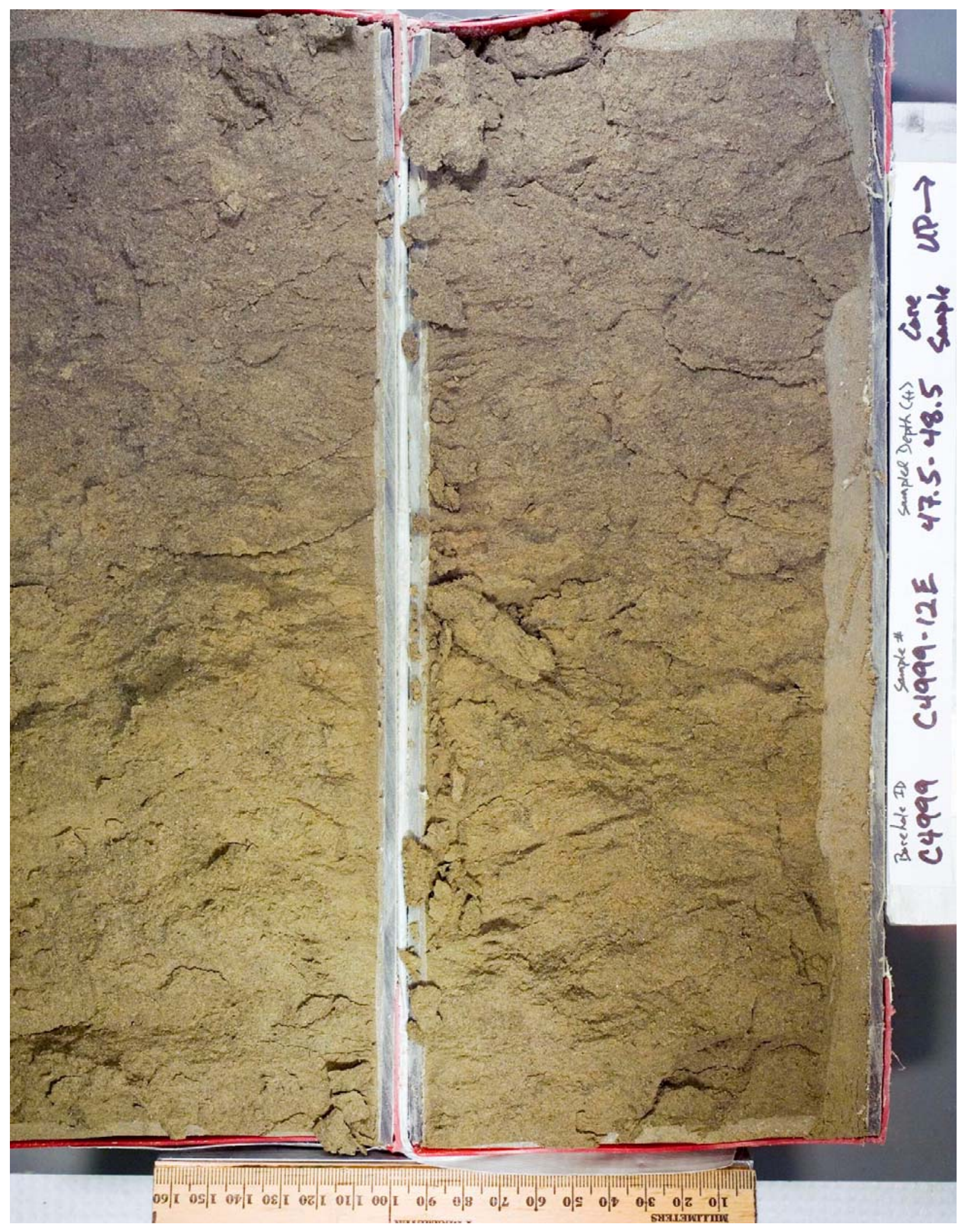




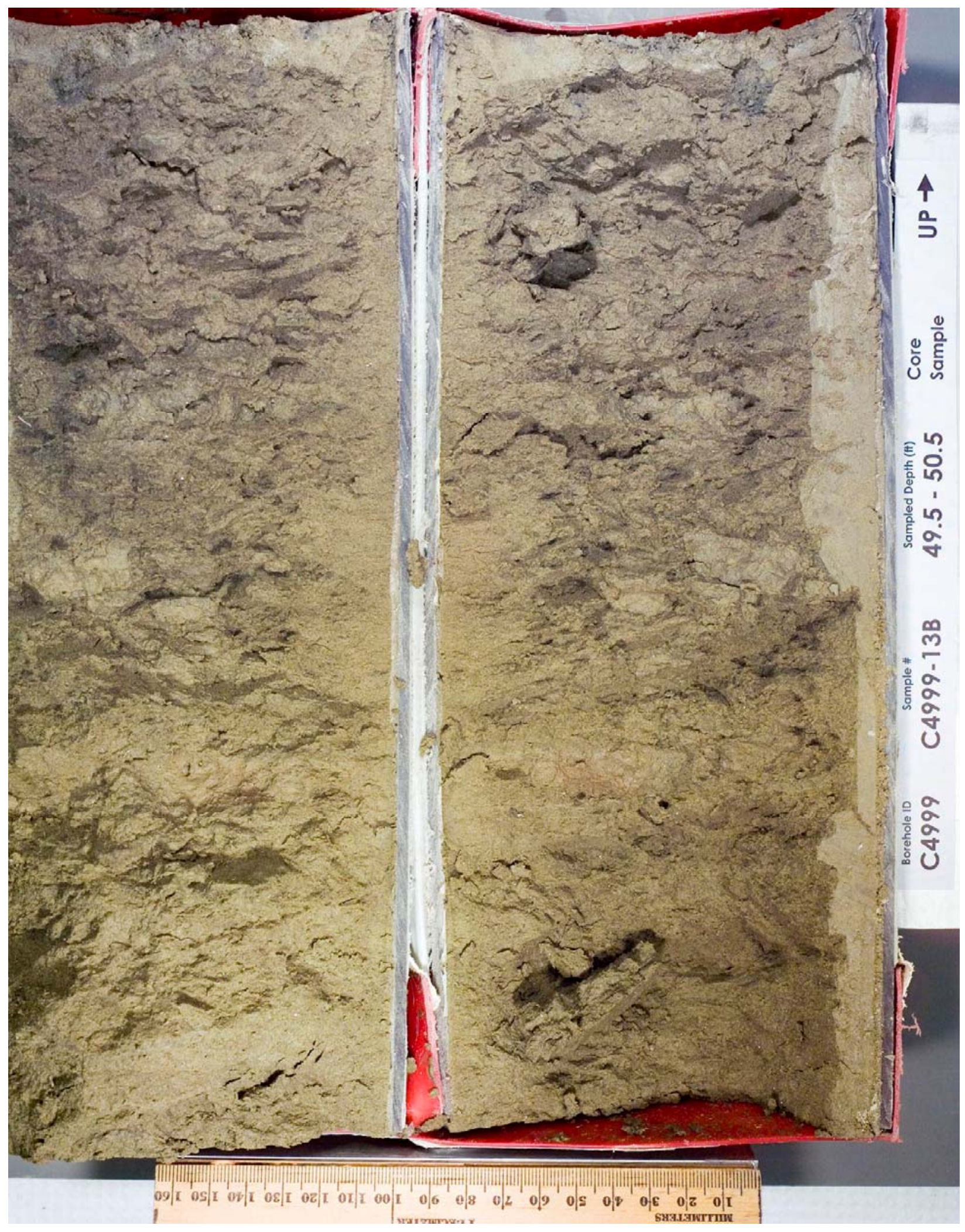




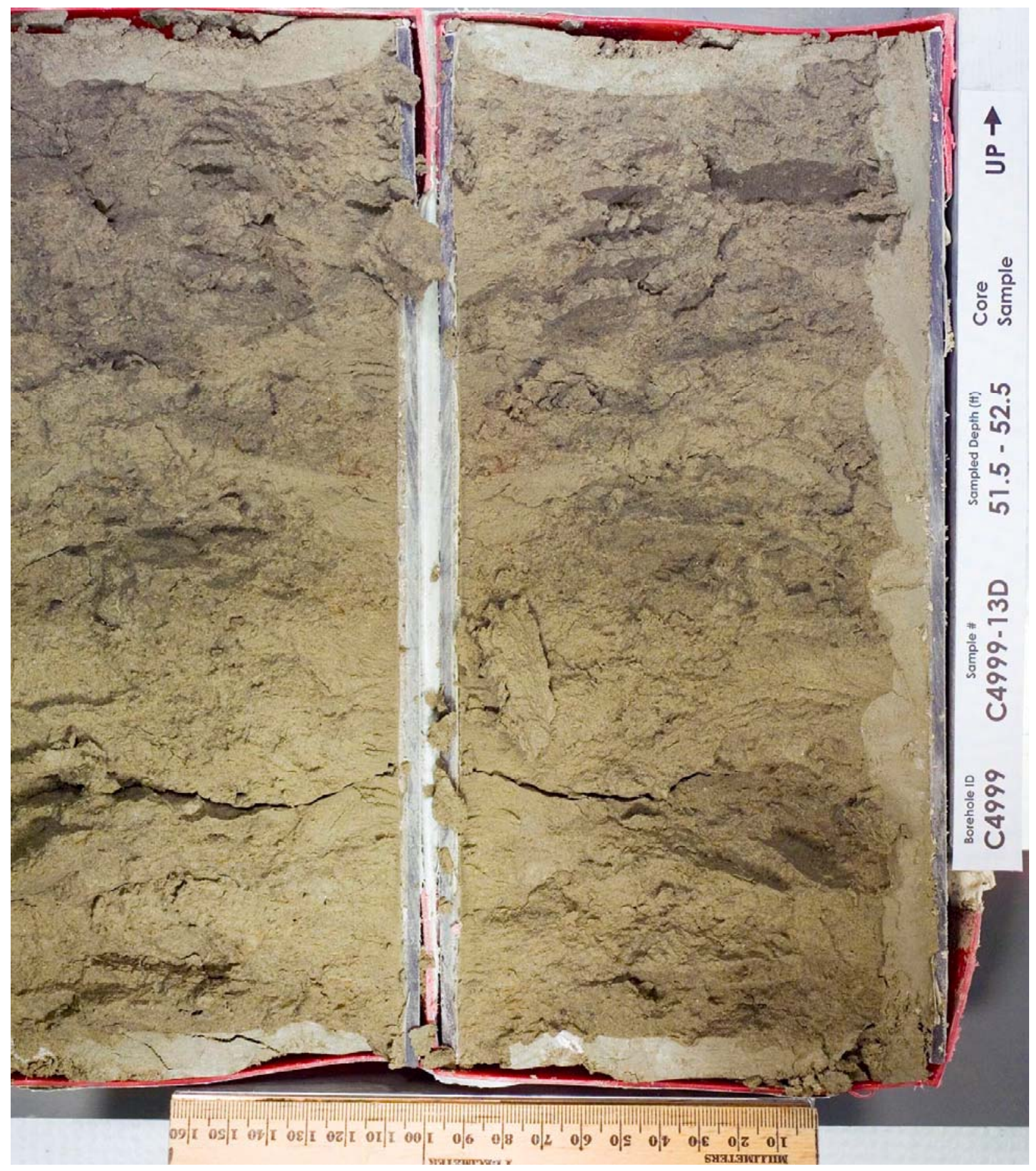




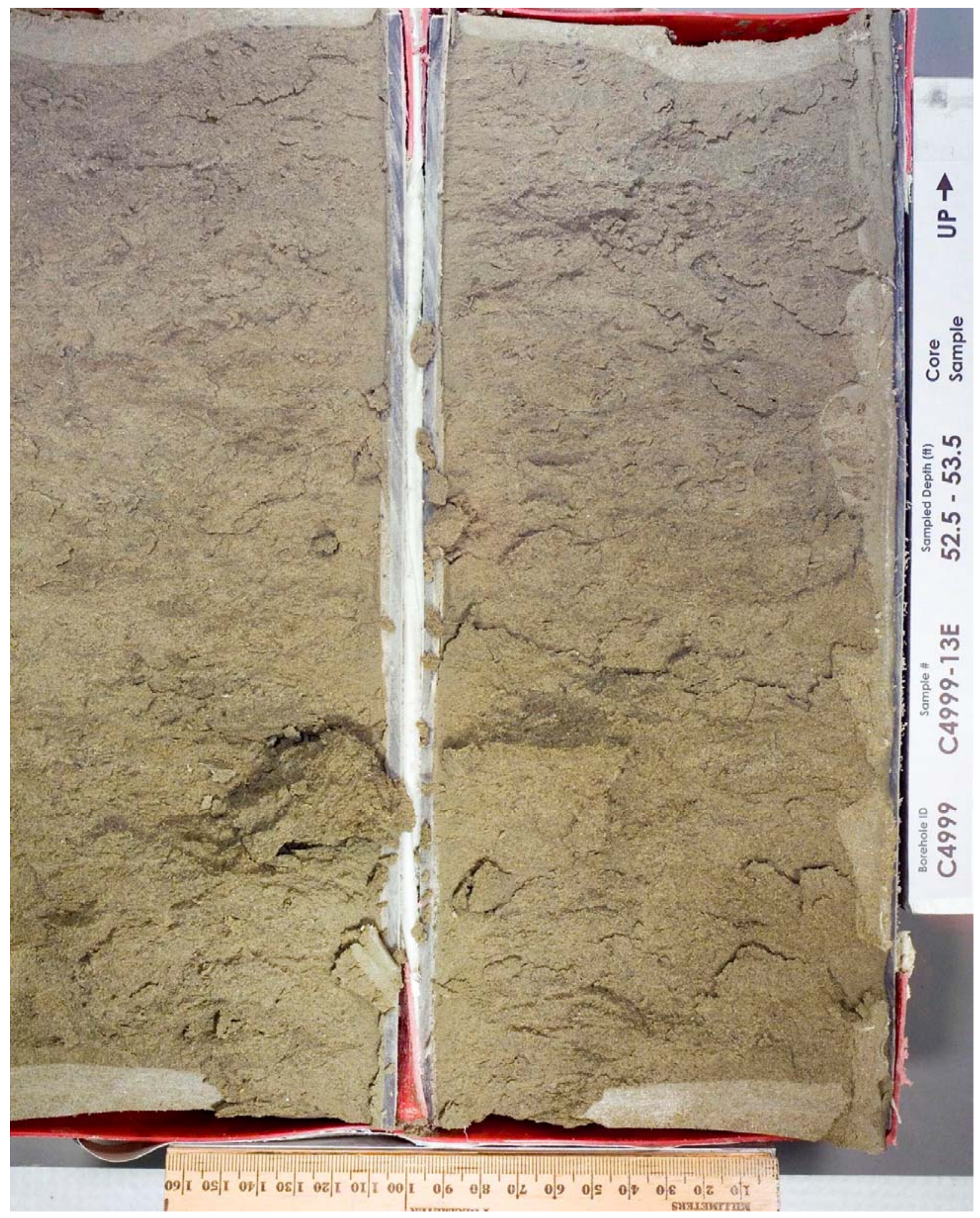




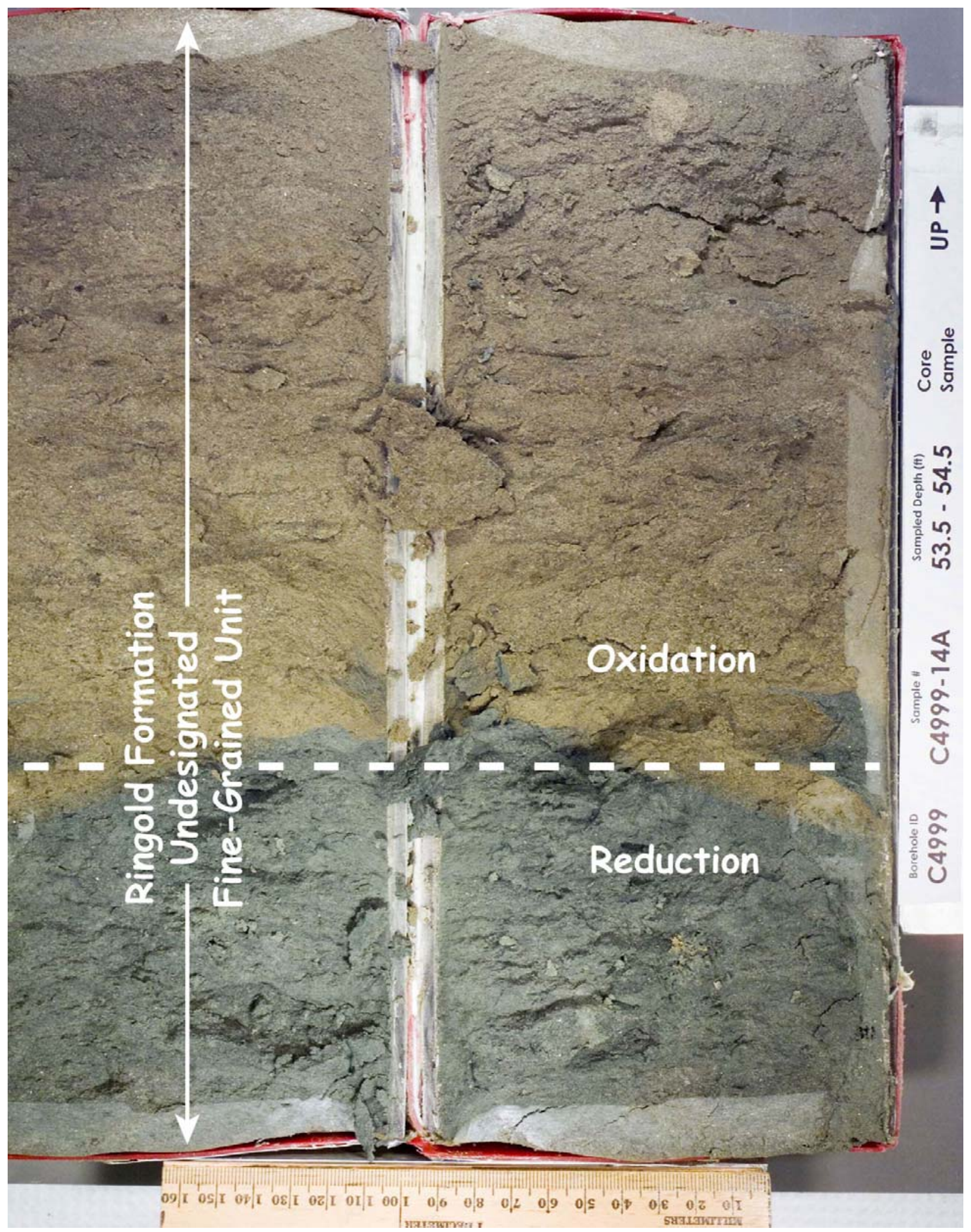




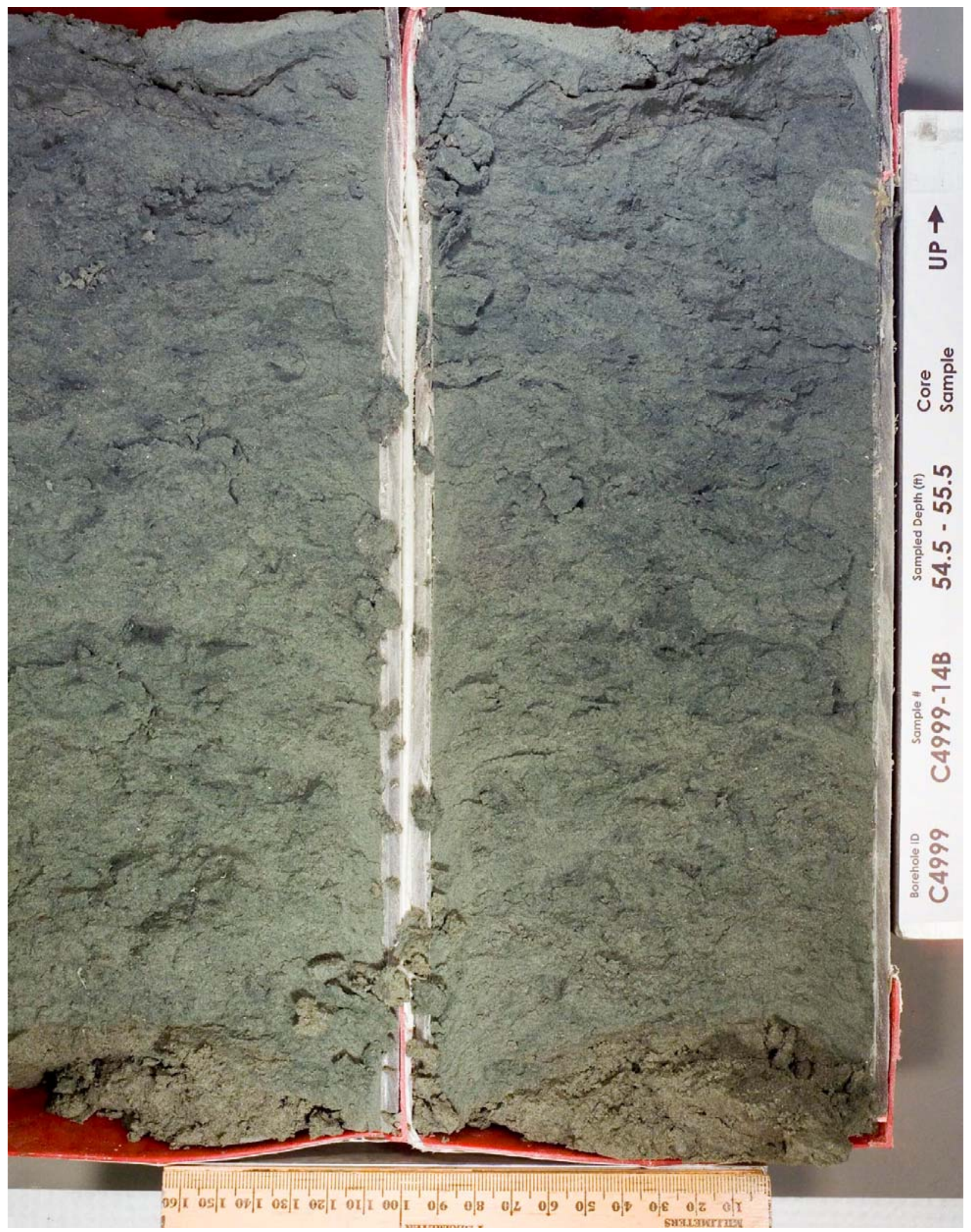




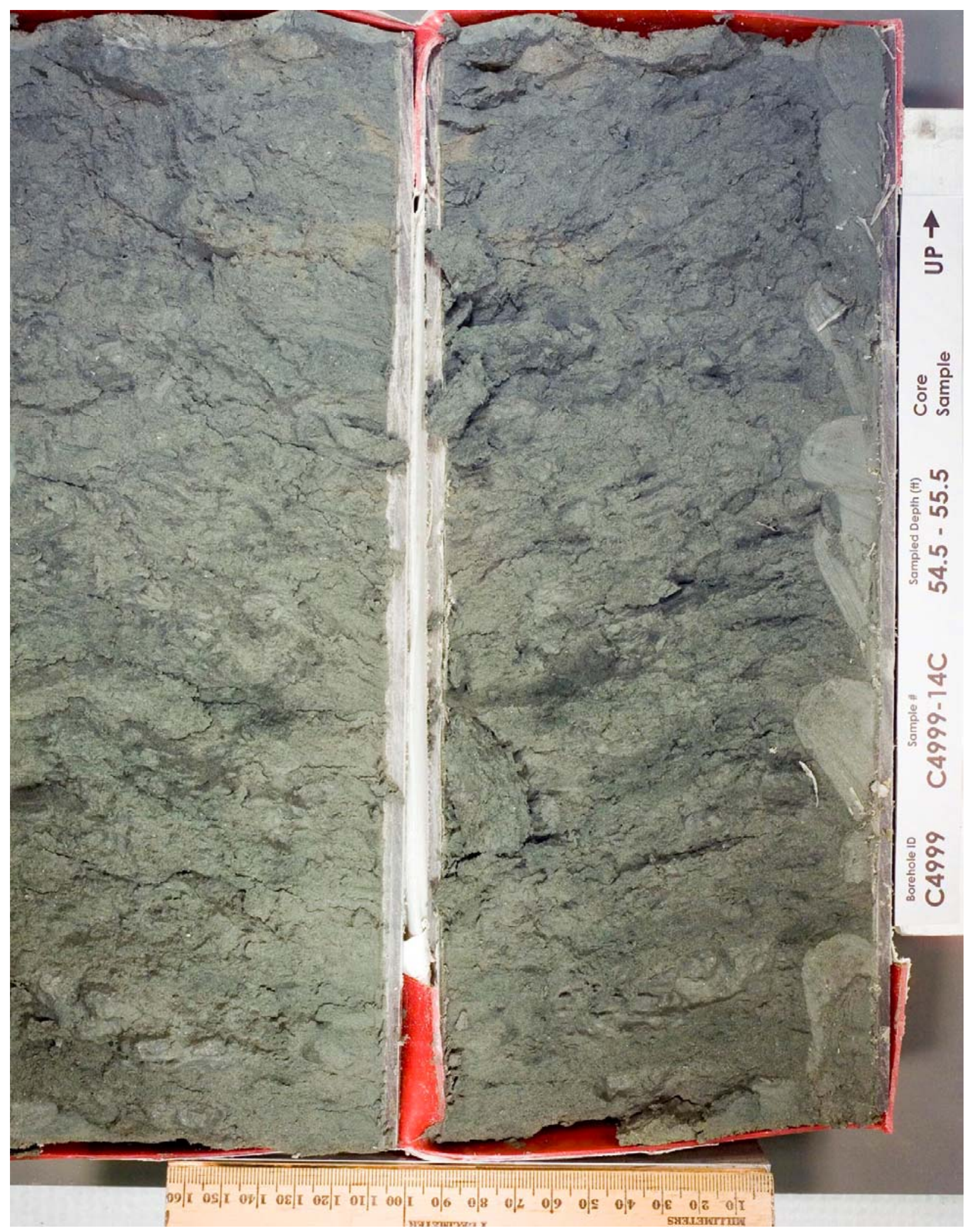




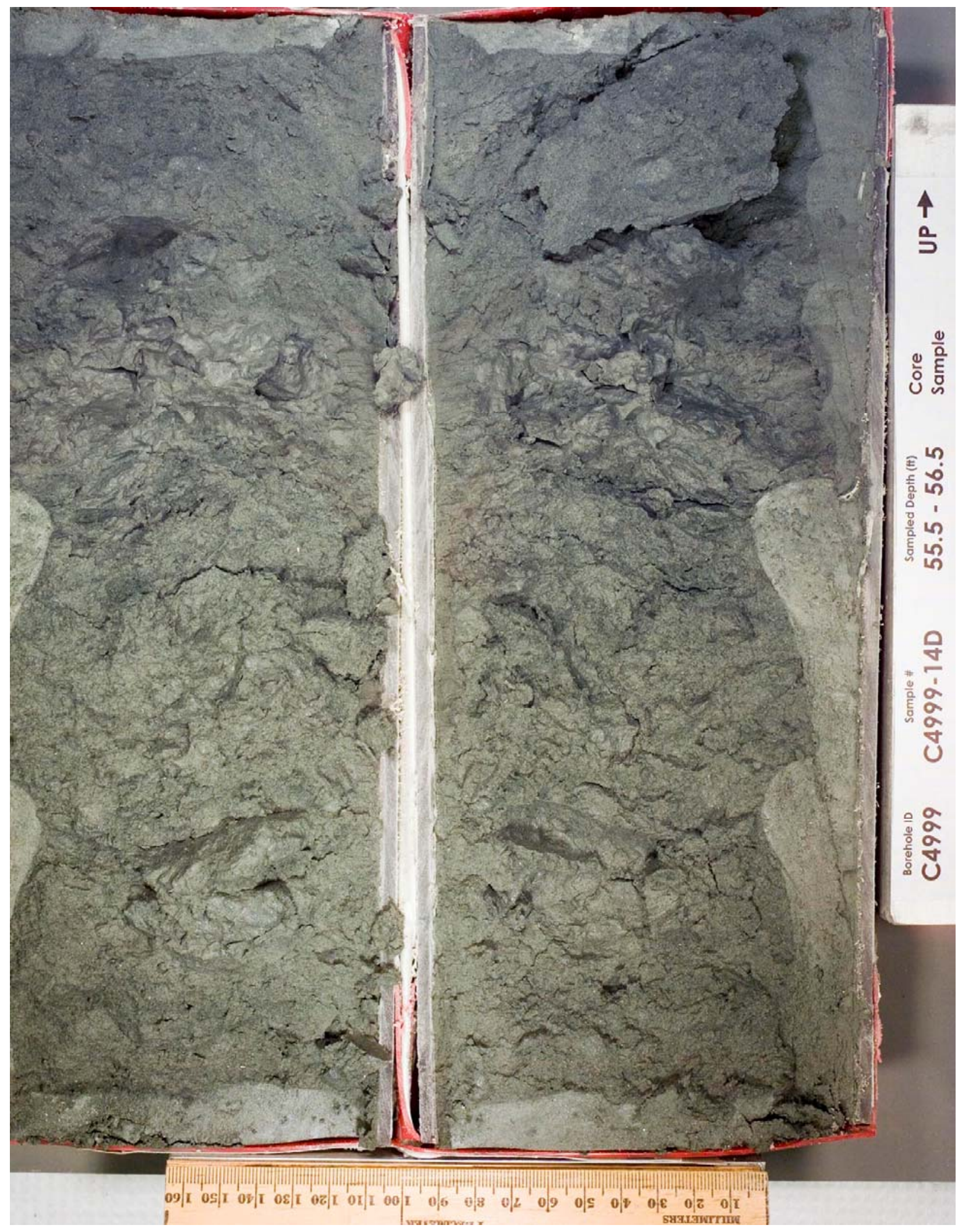




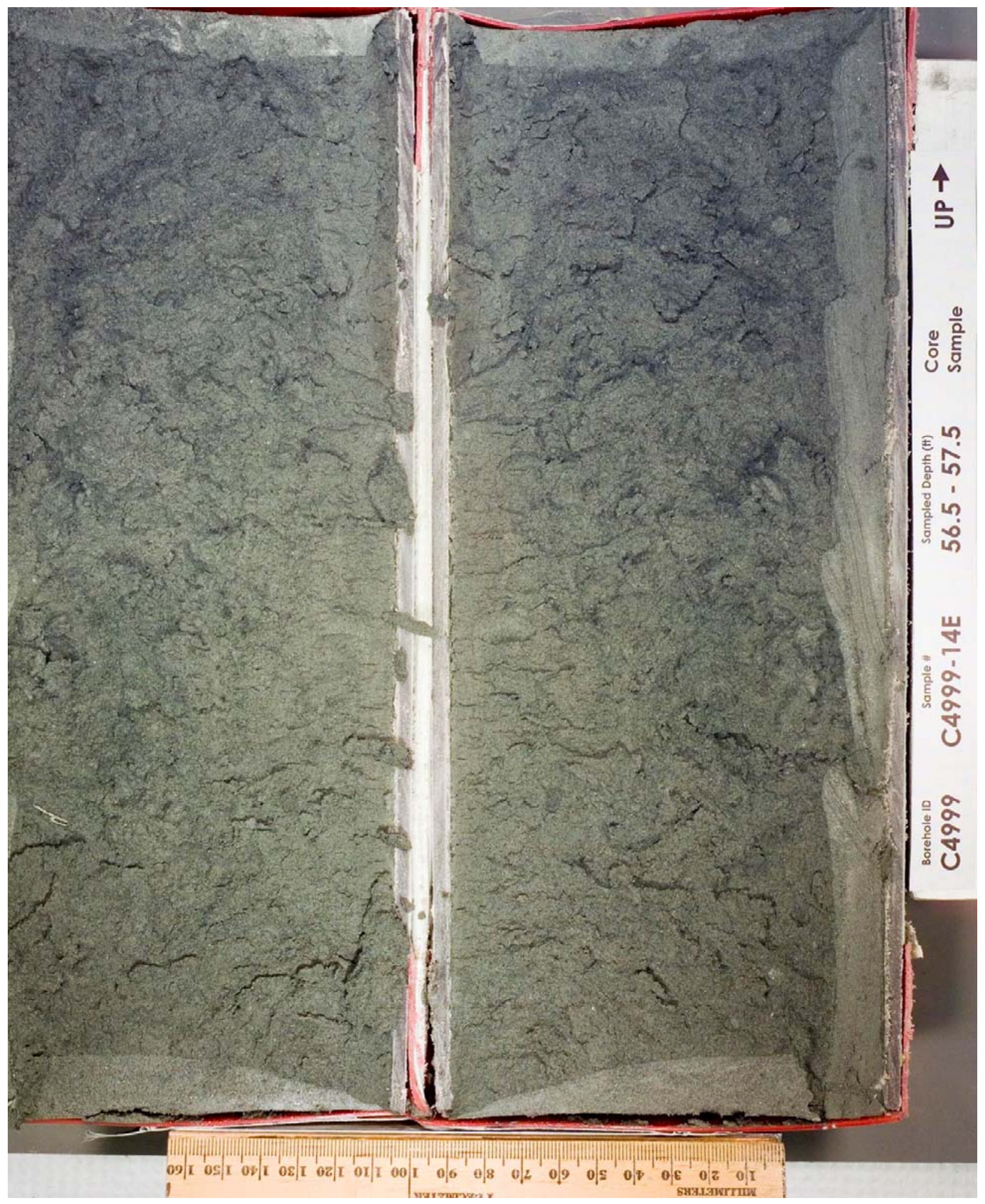




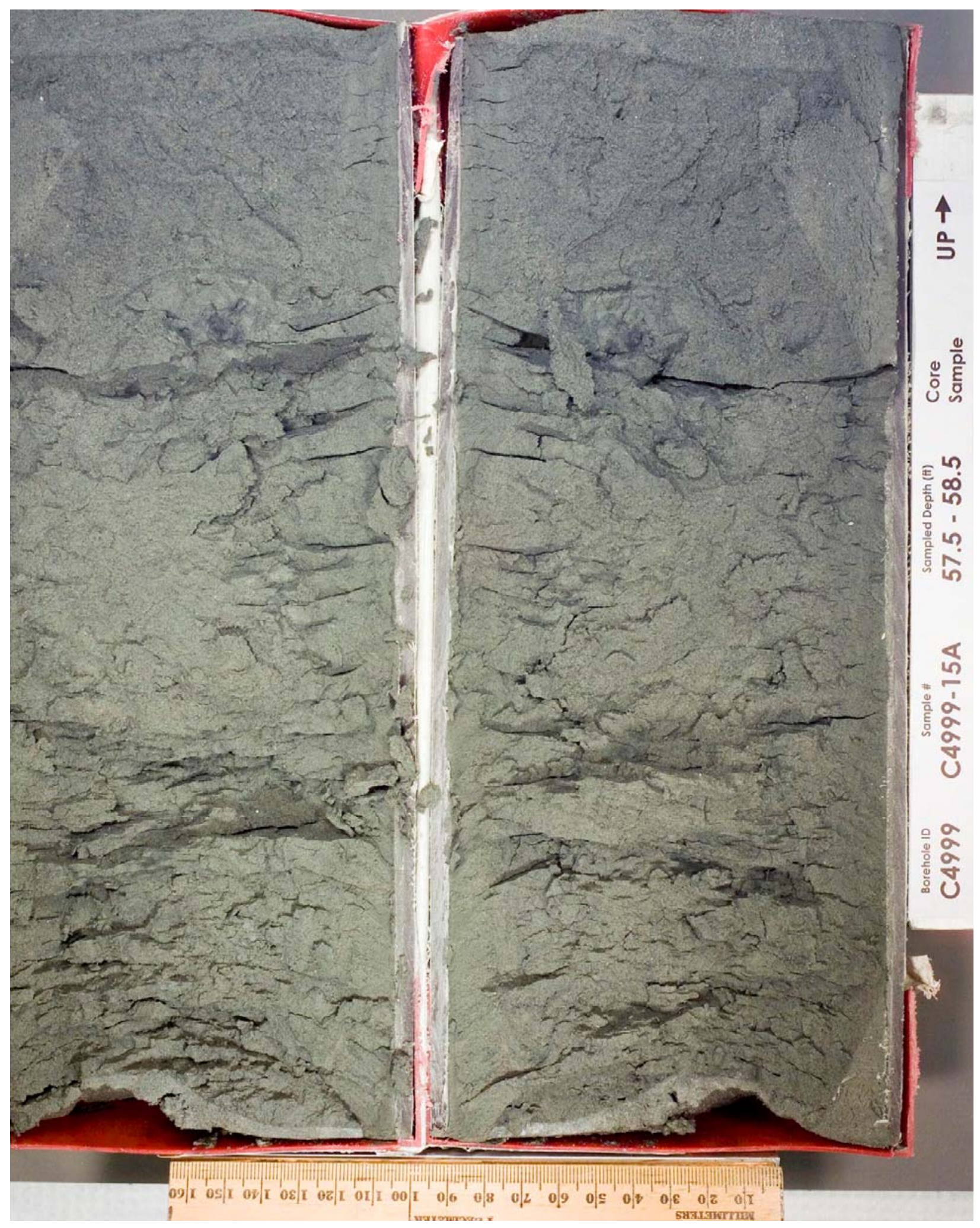




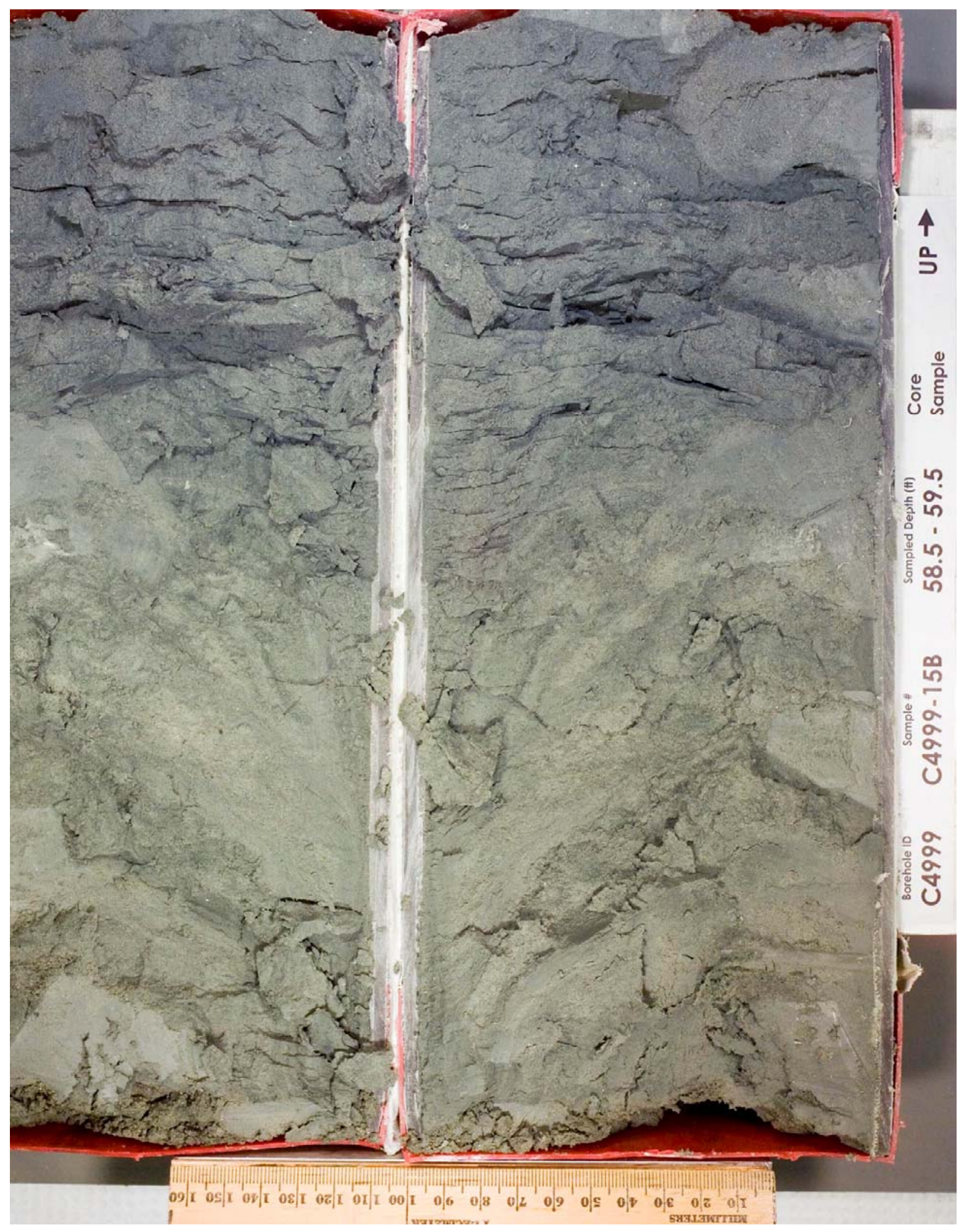




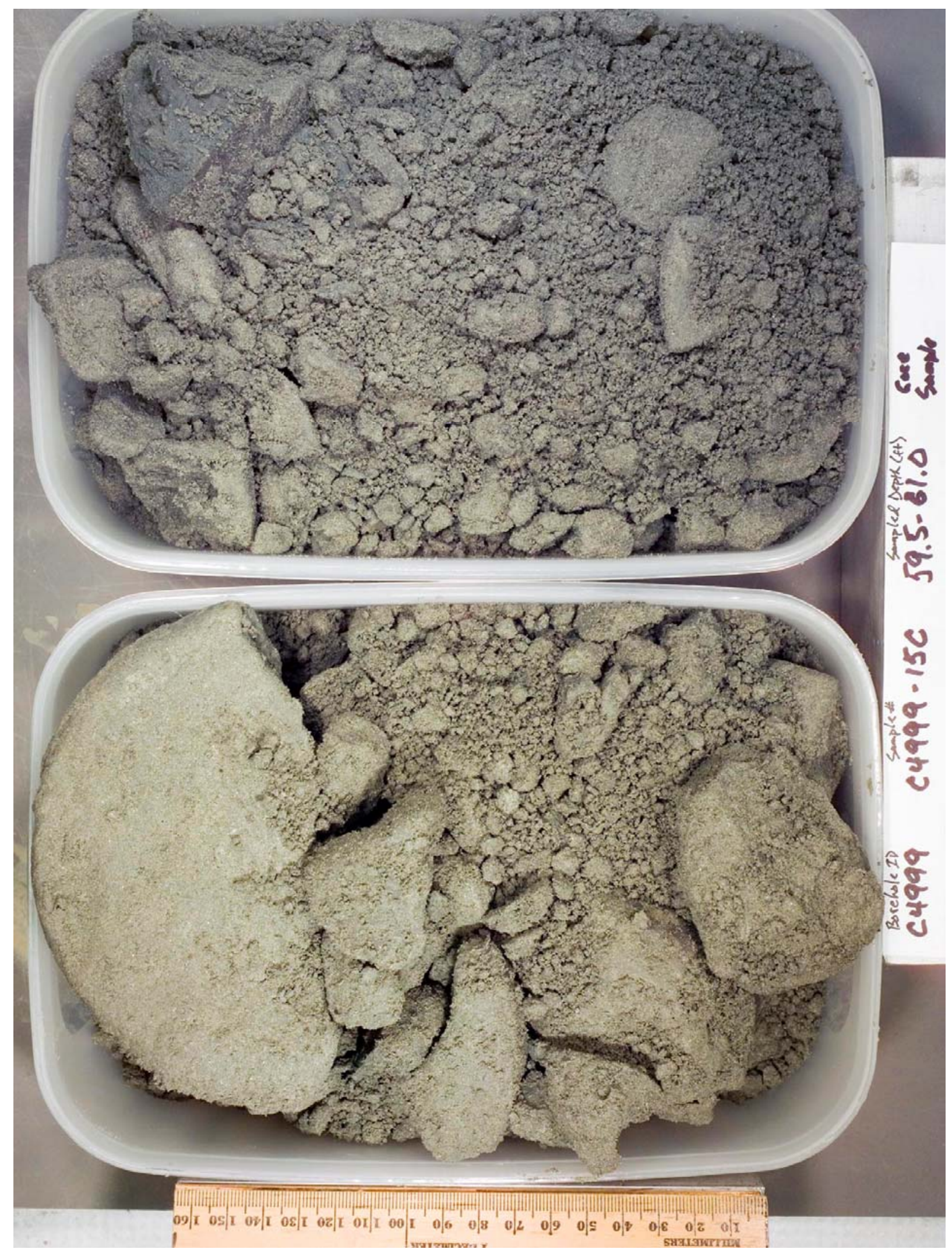




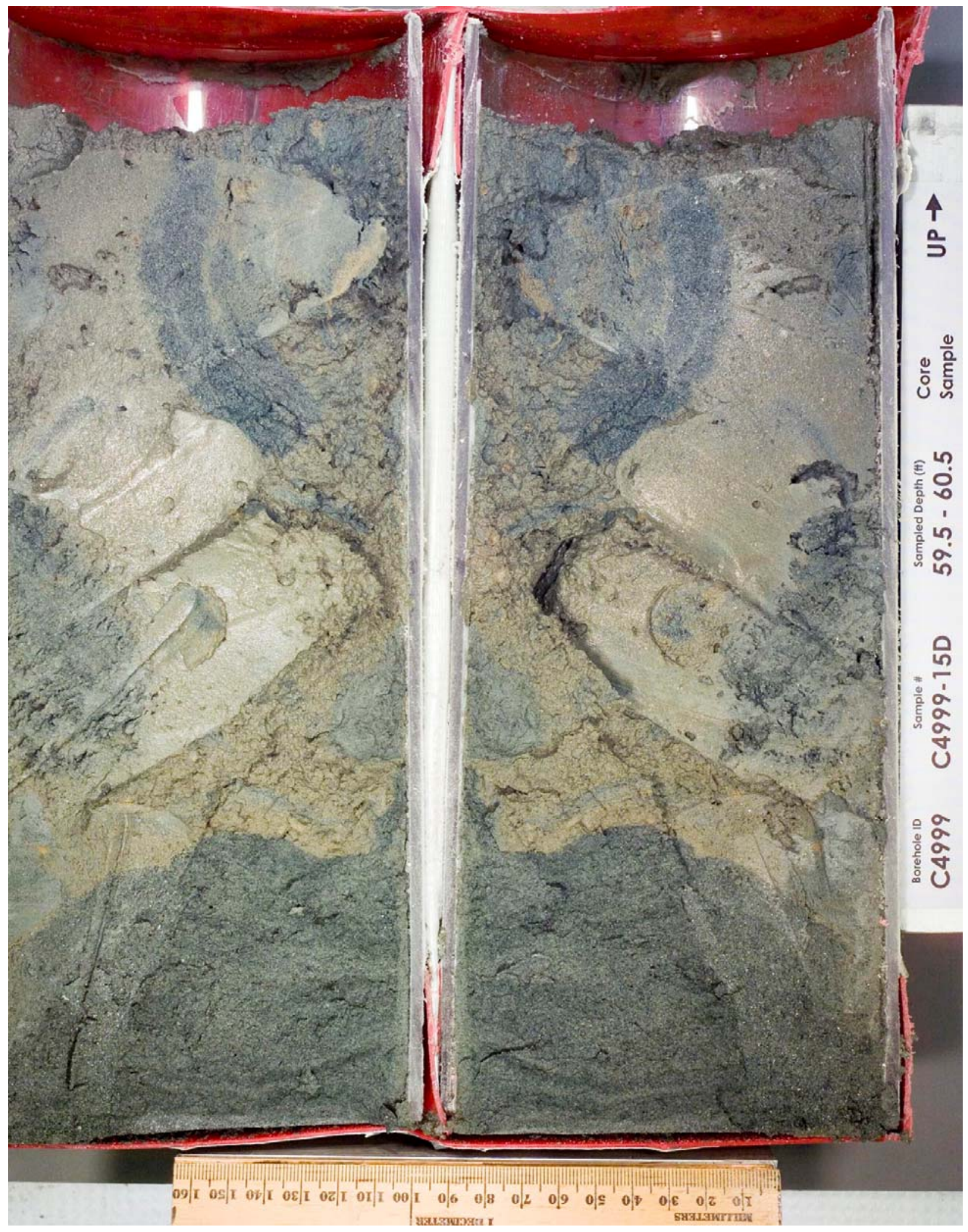




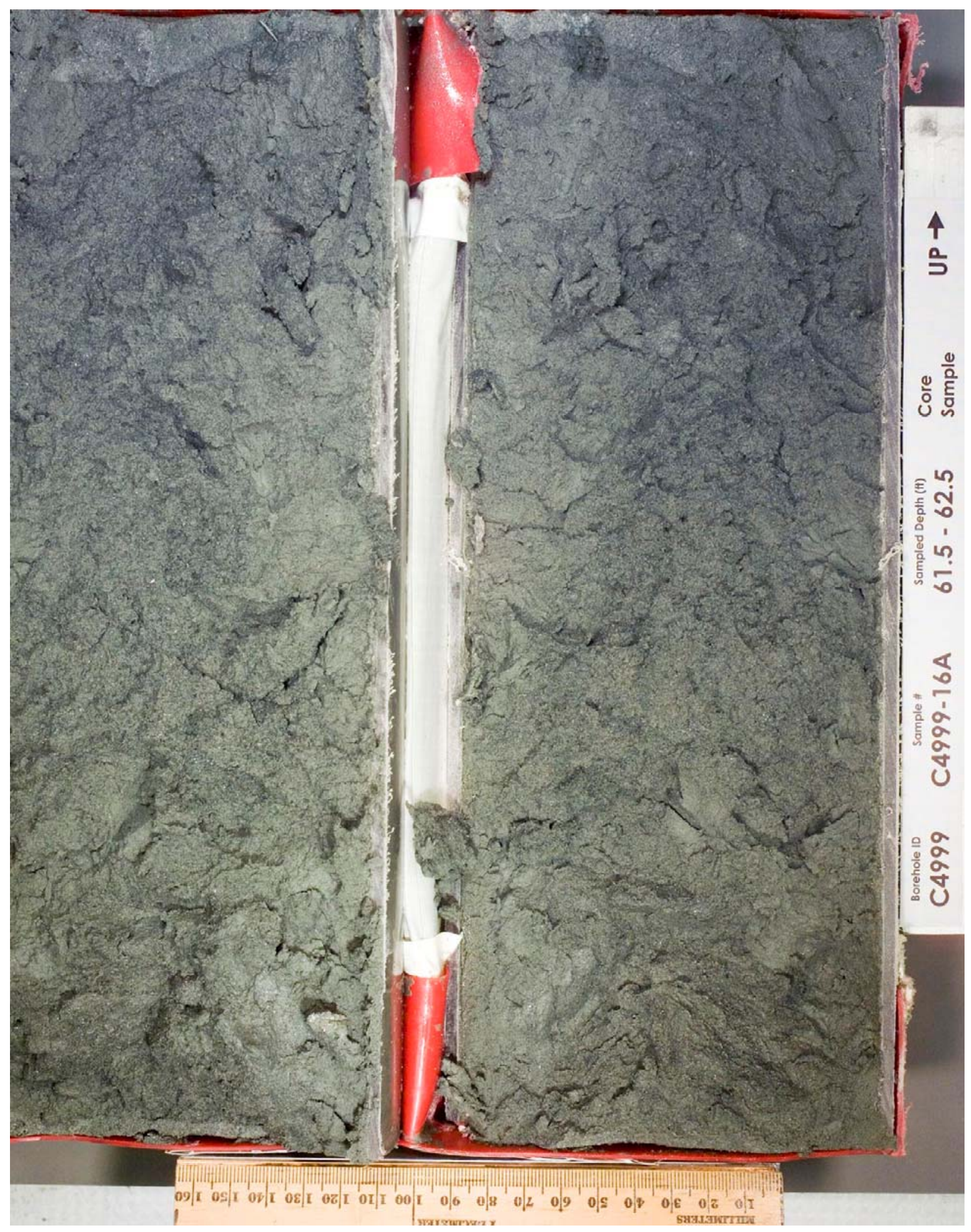




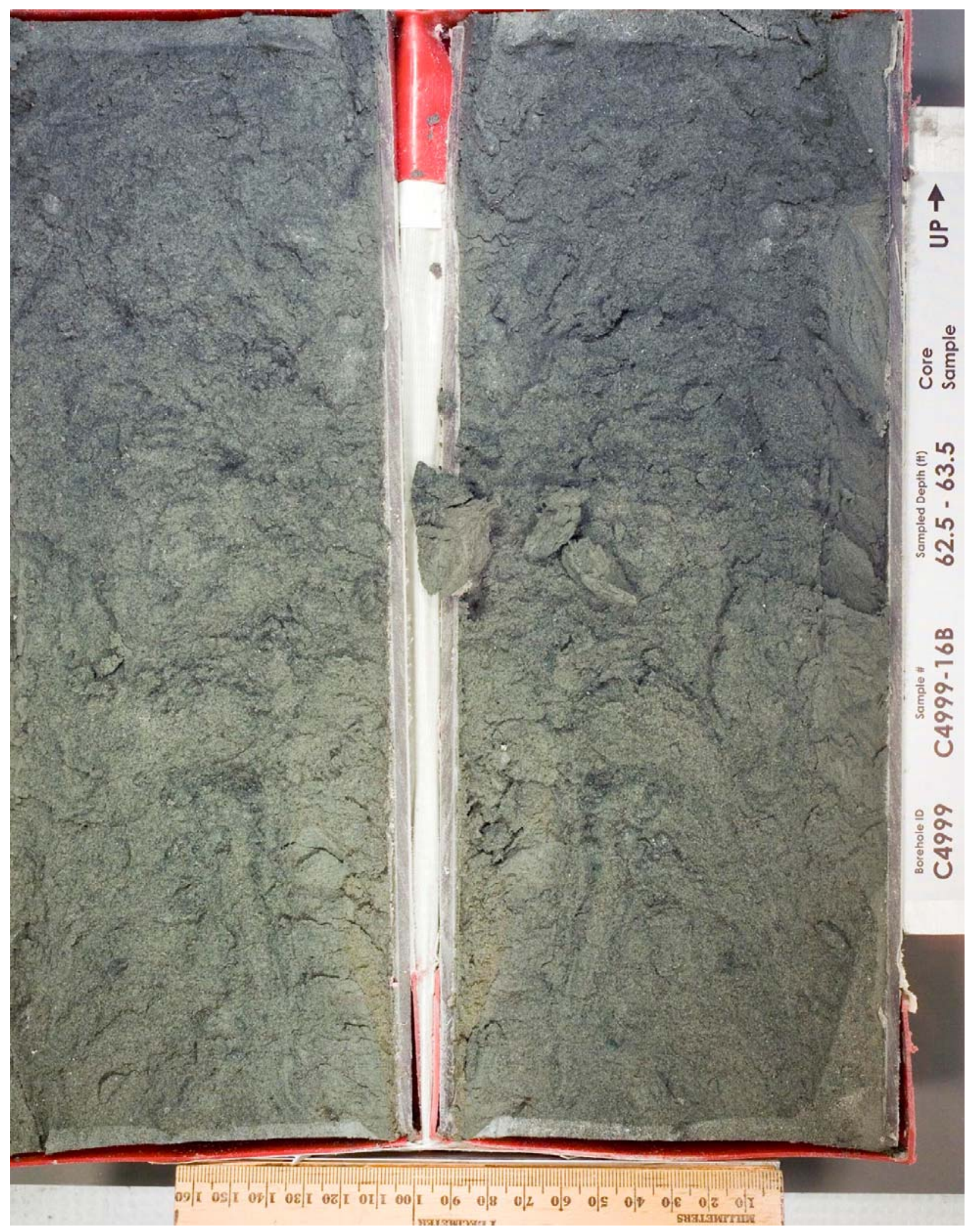




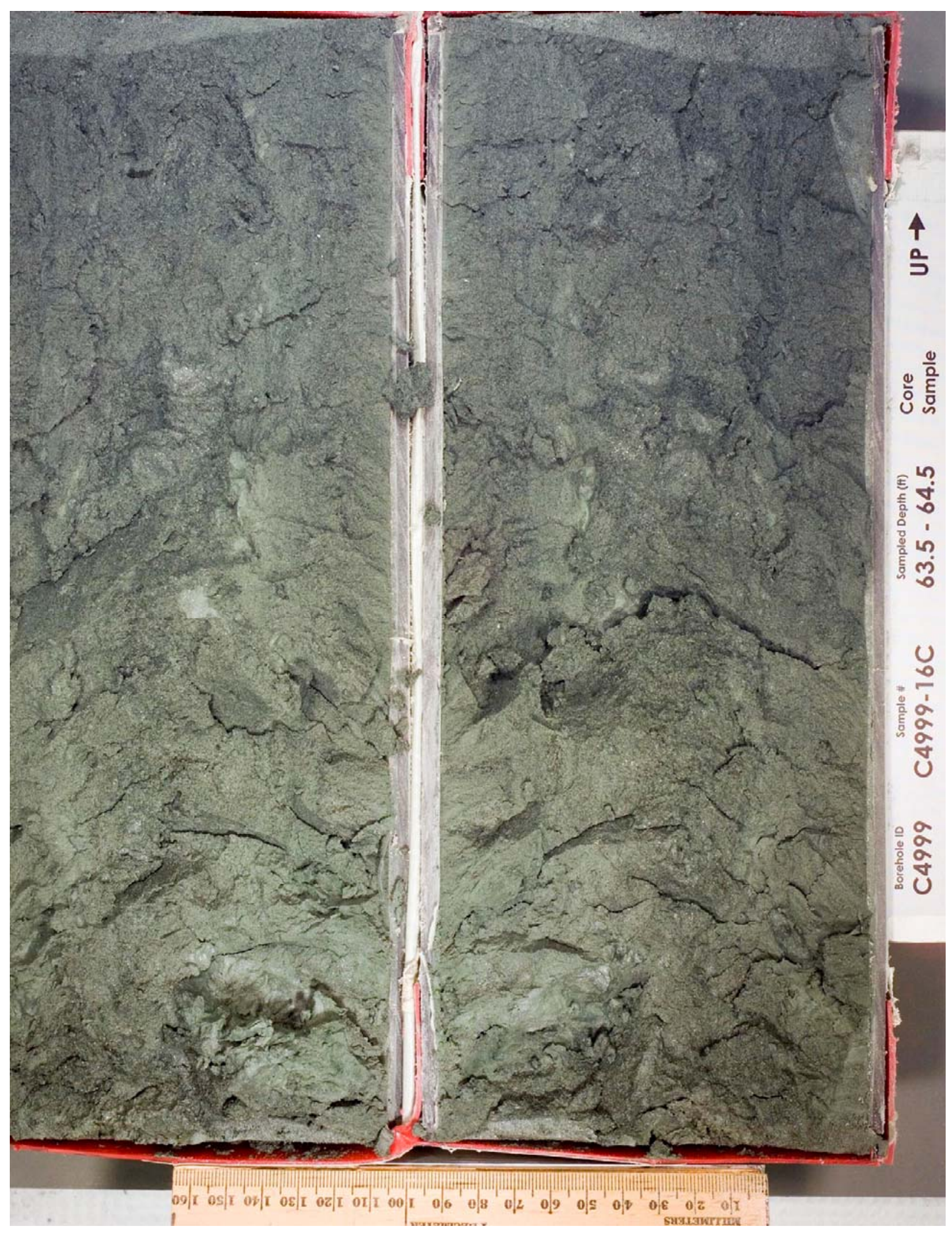




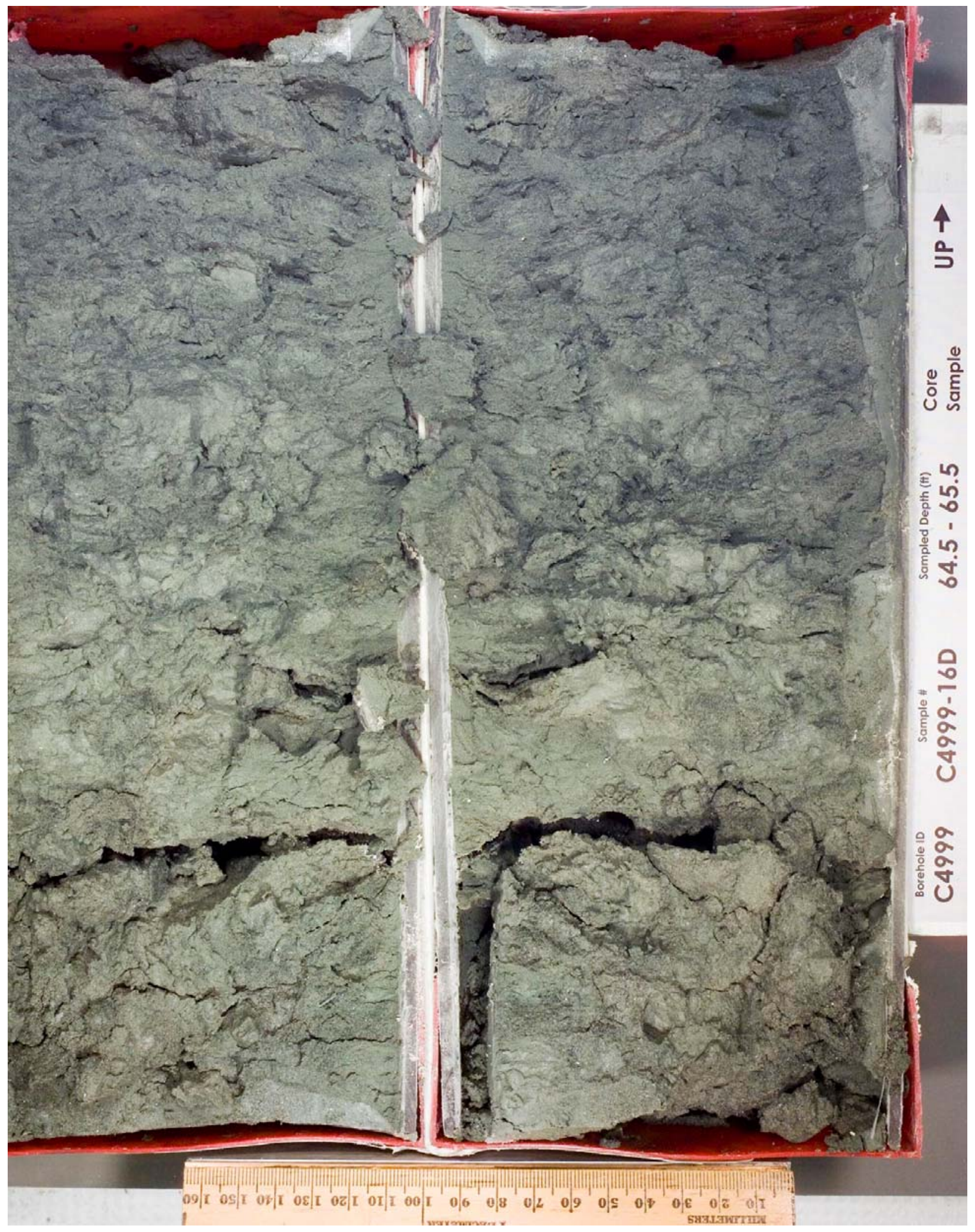




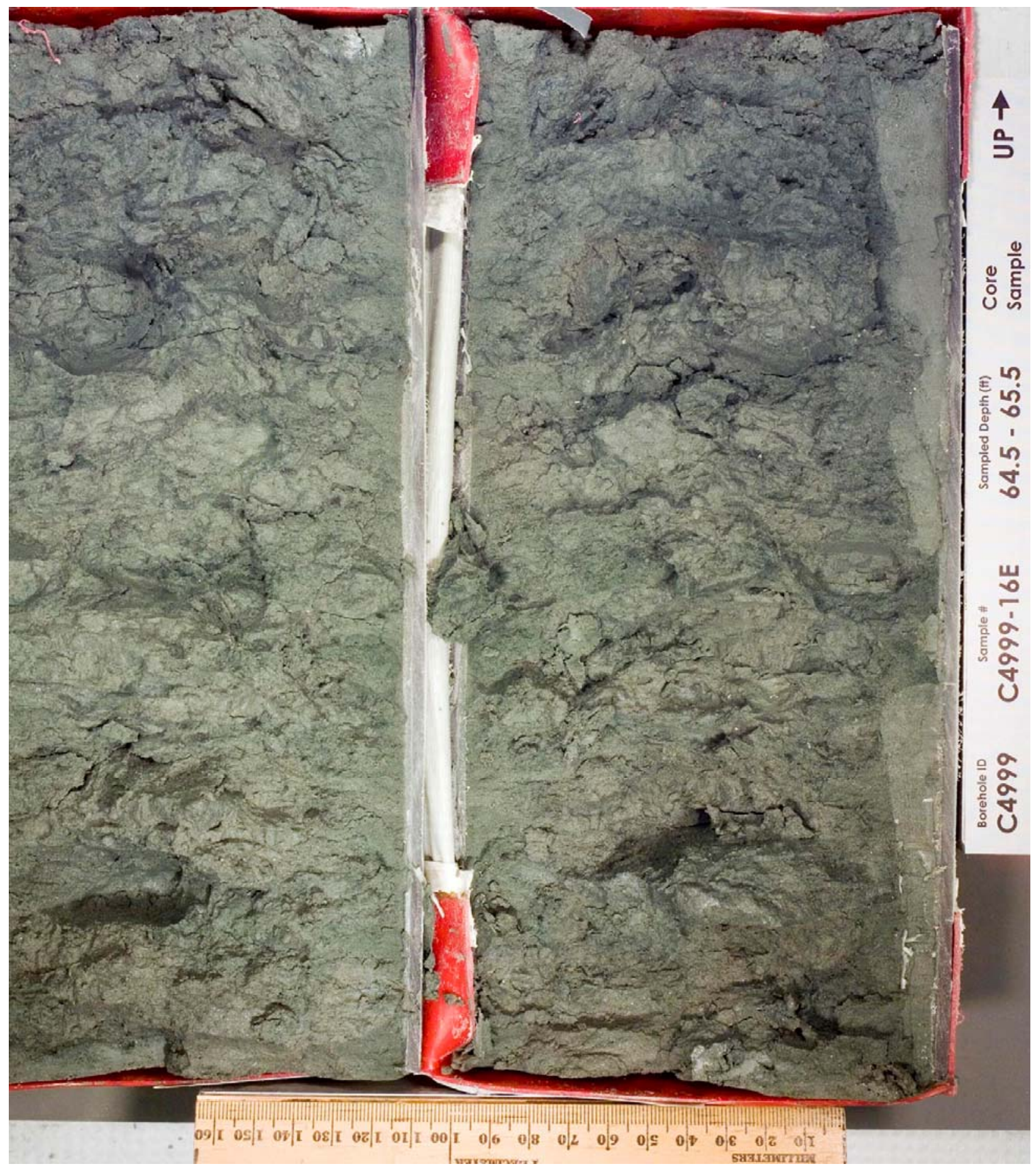




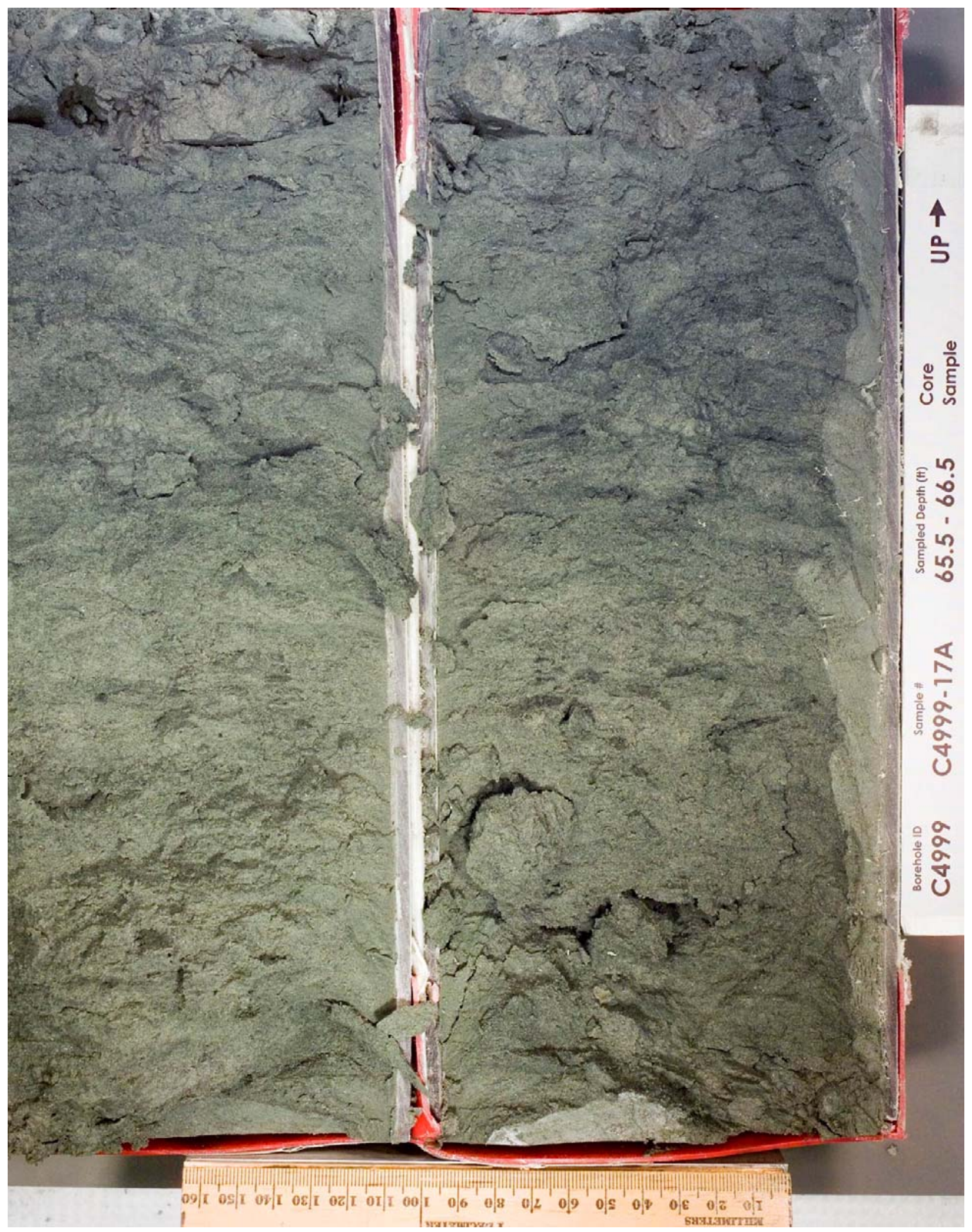




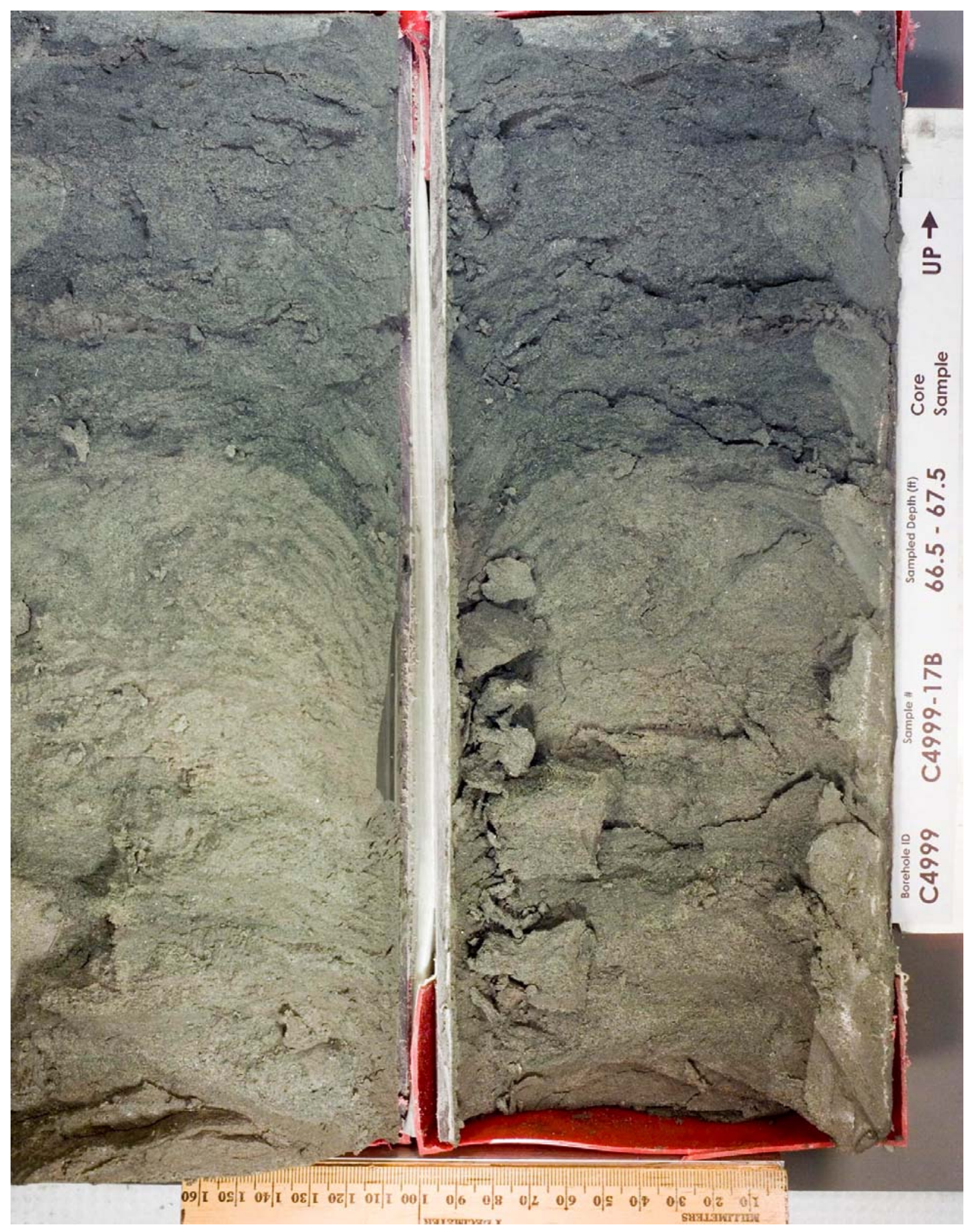

B.110 


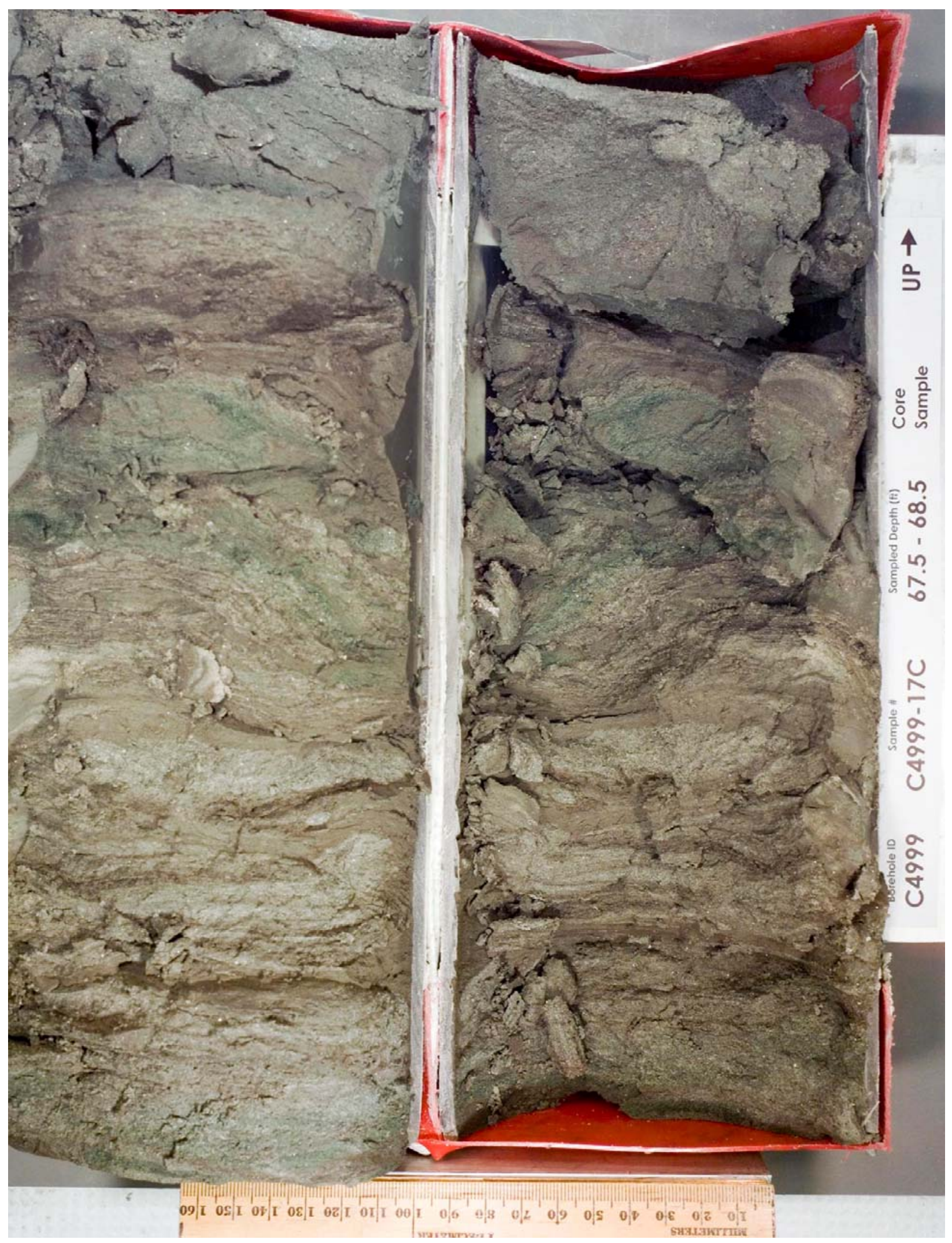

B.111 


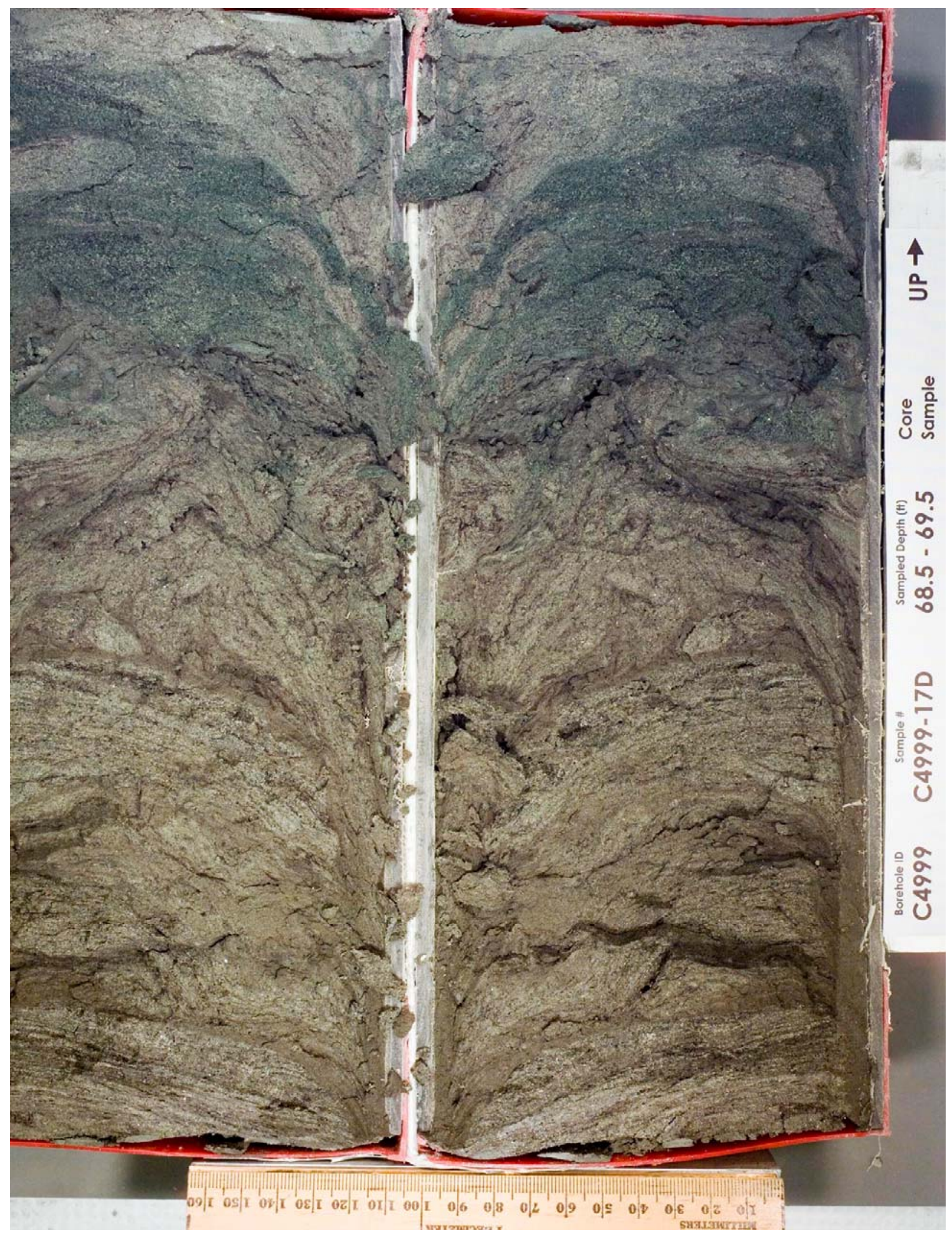

B.112 


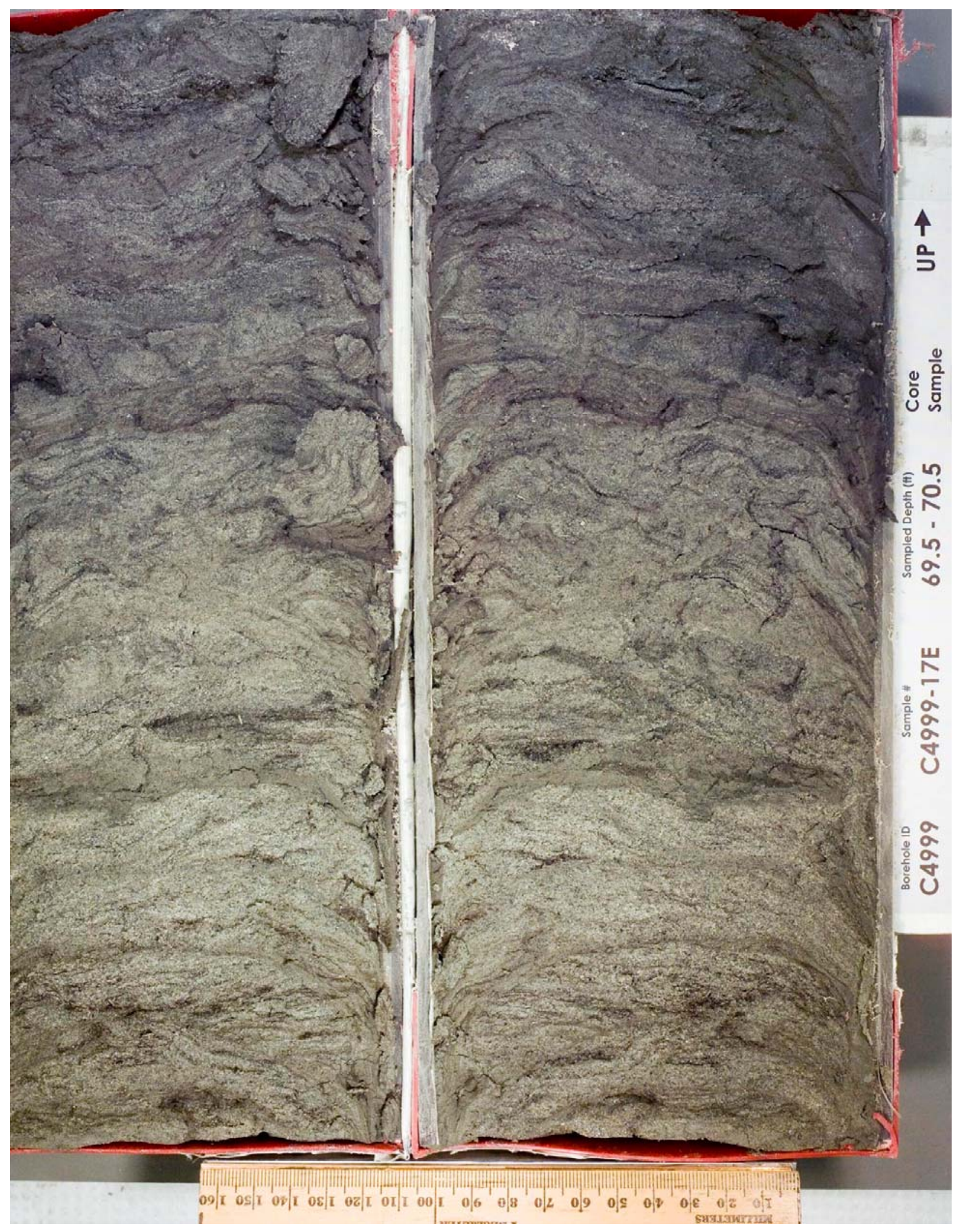

B.113 


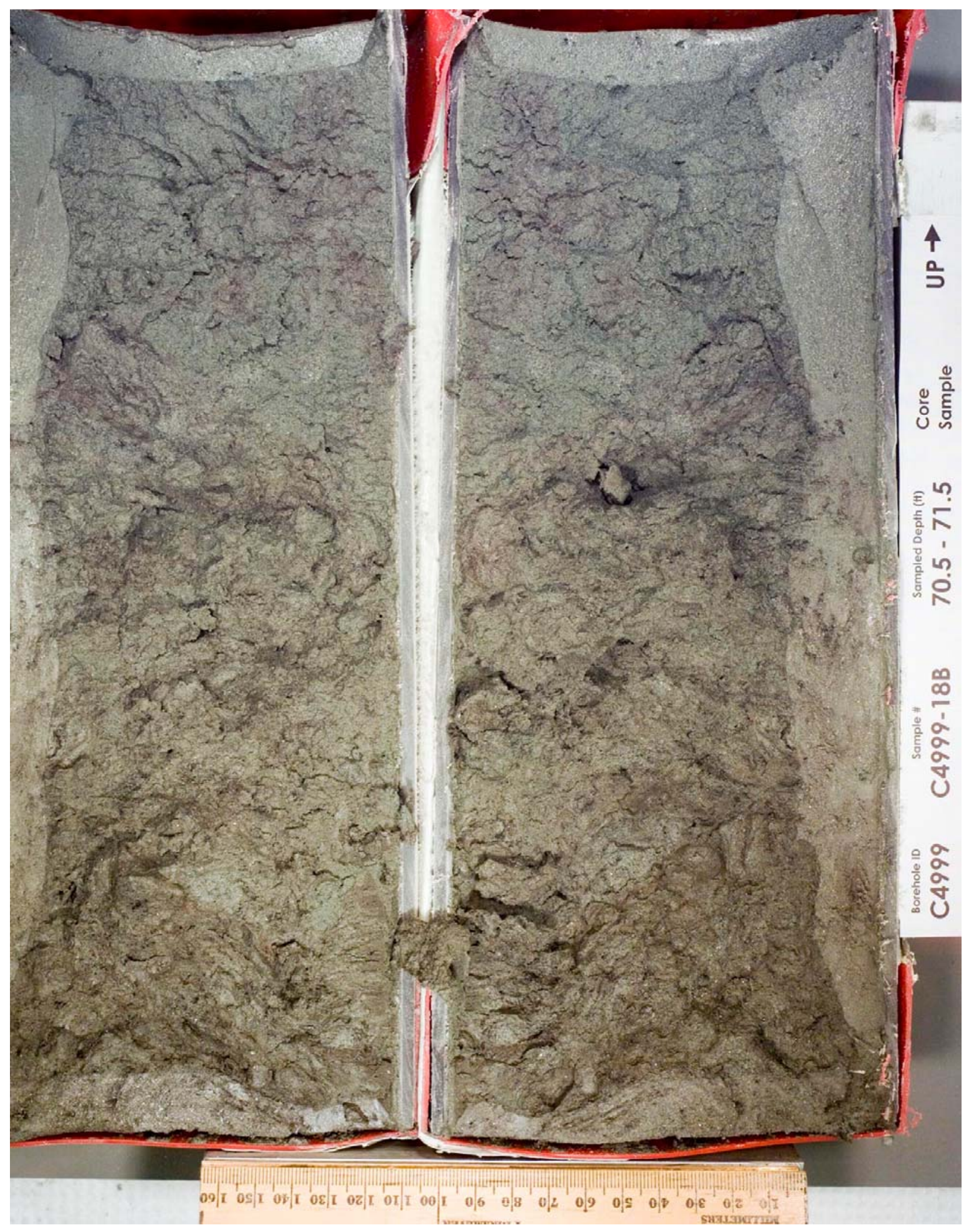

B.114 


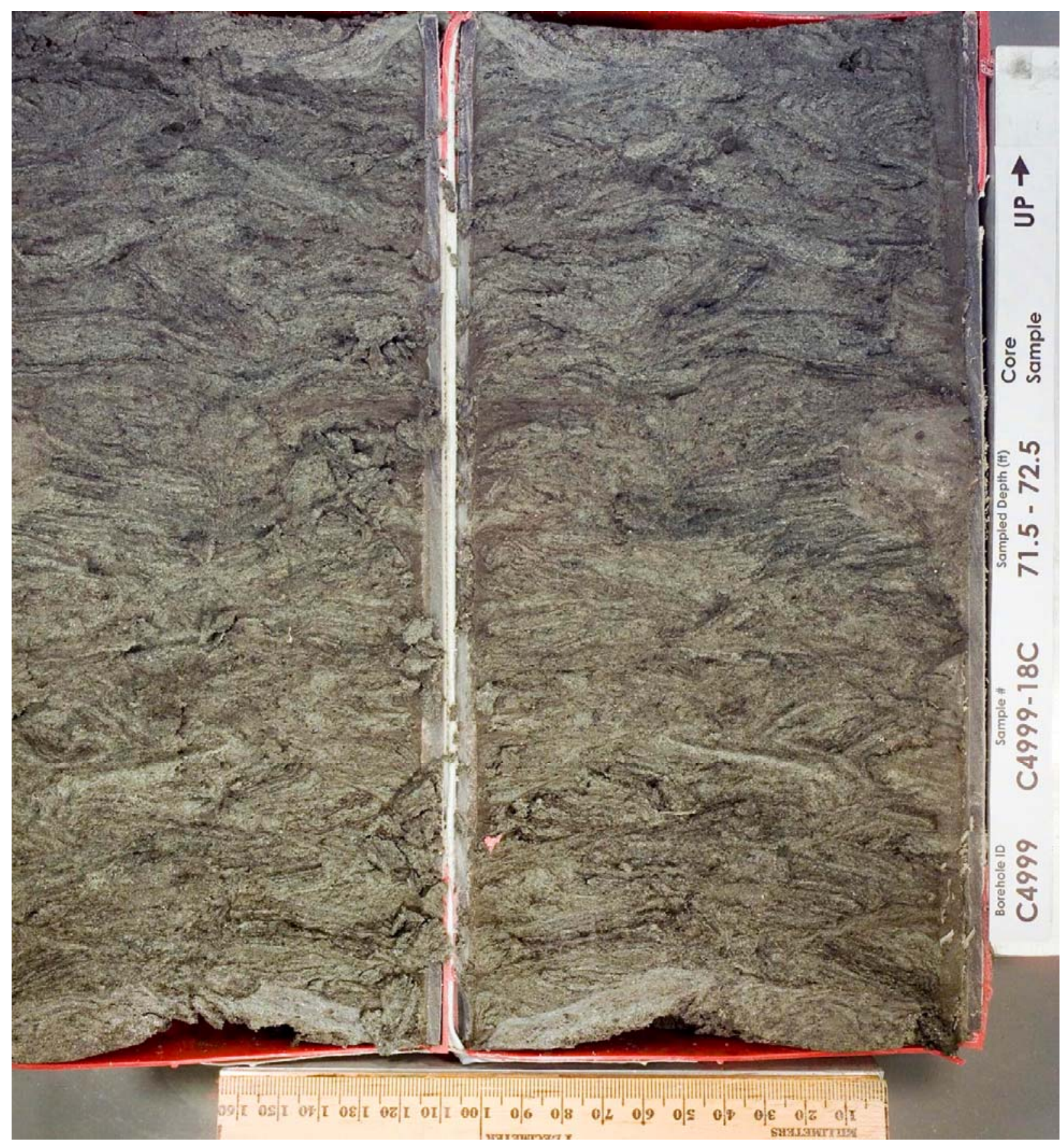

B.115 


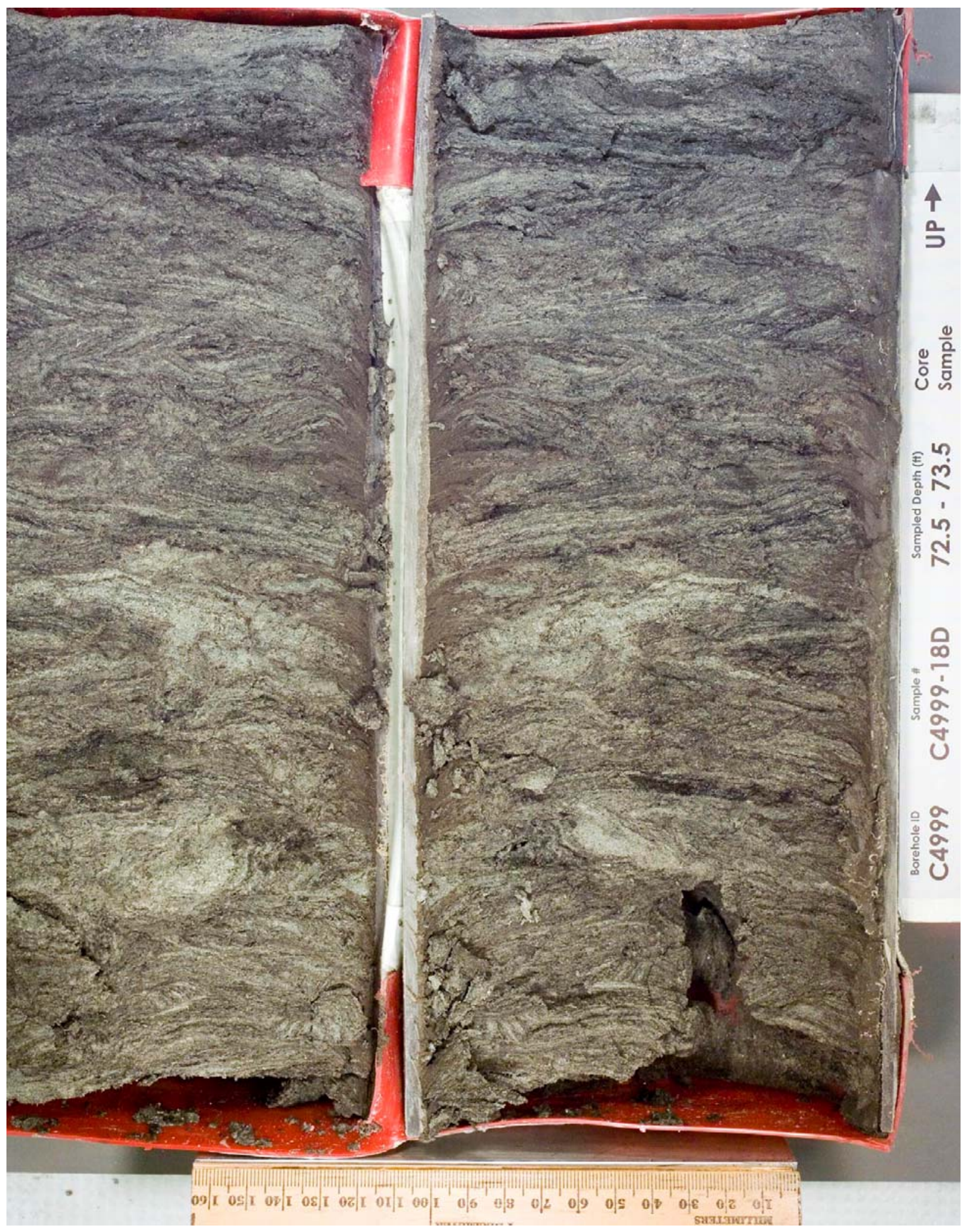




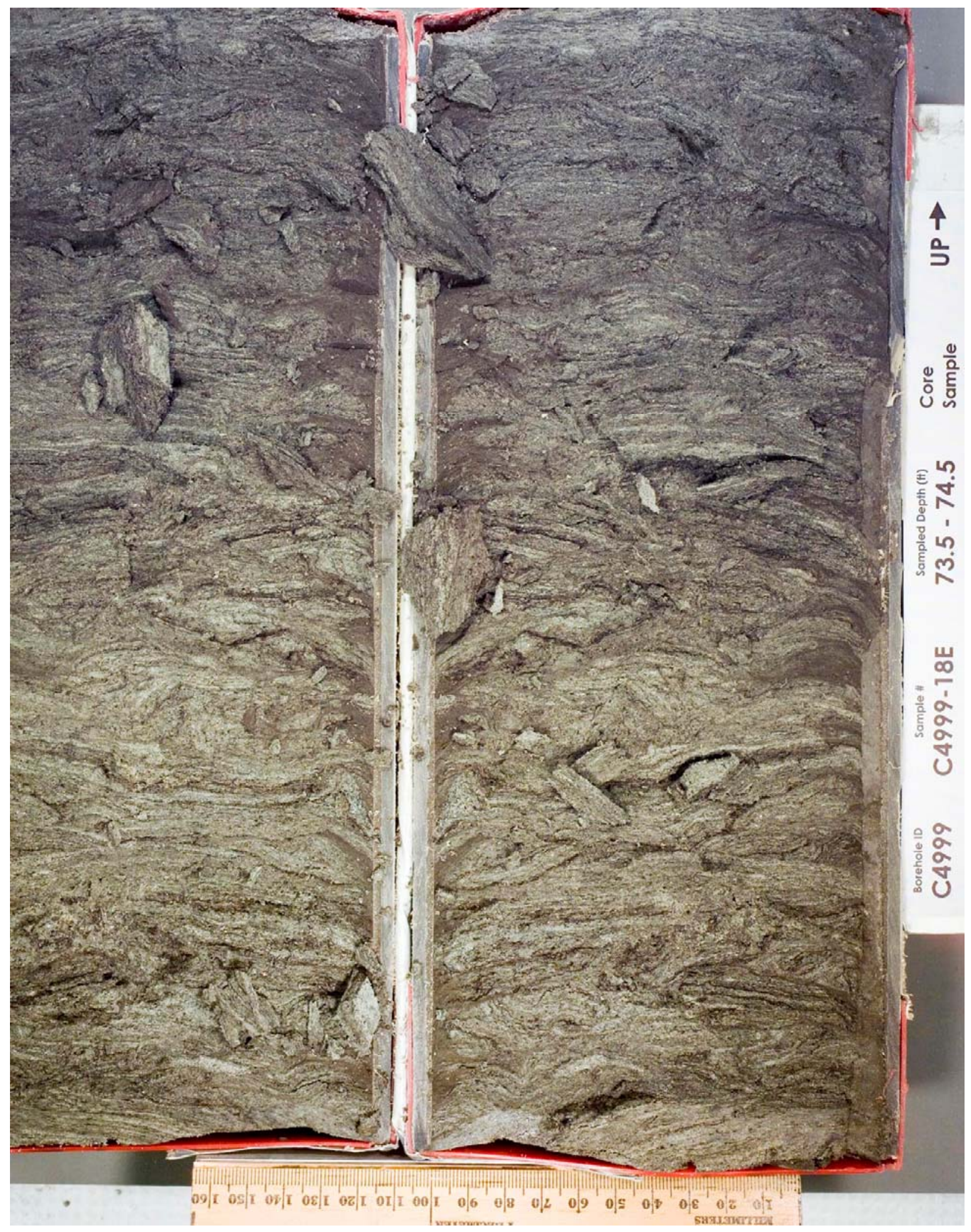




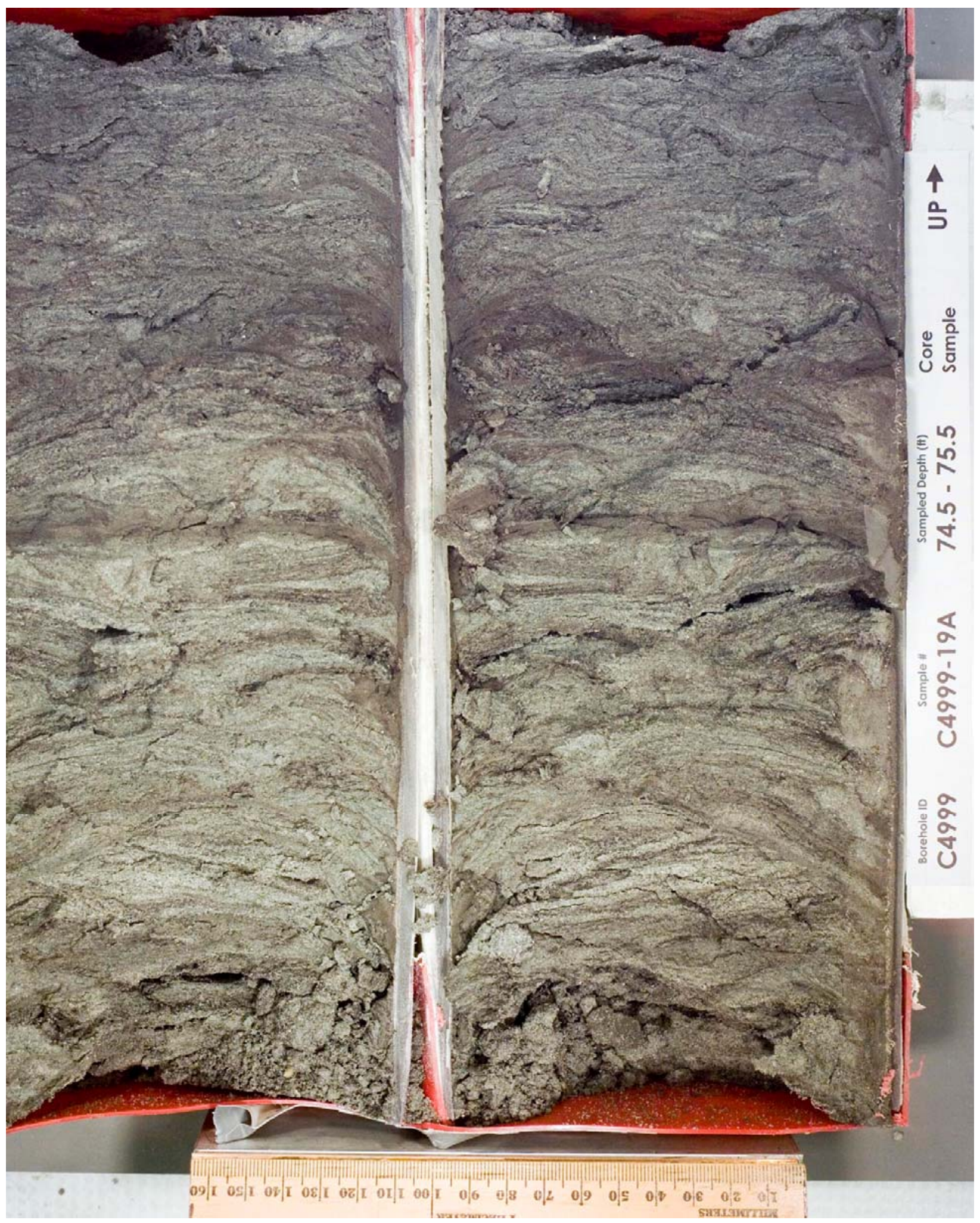




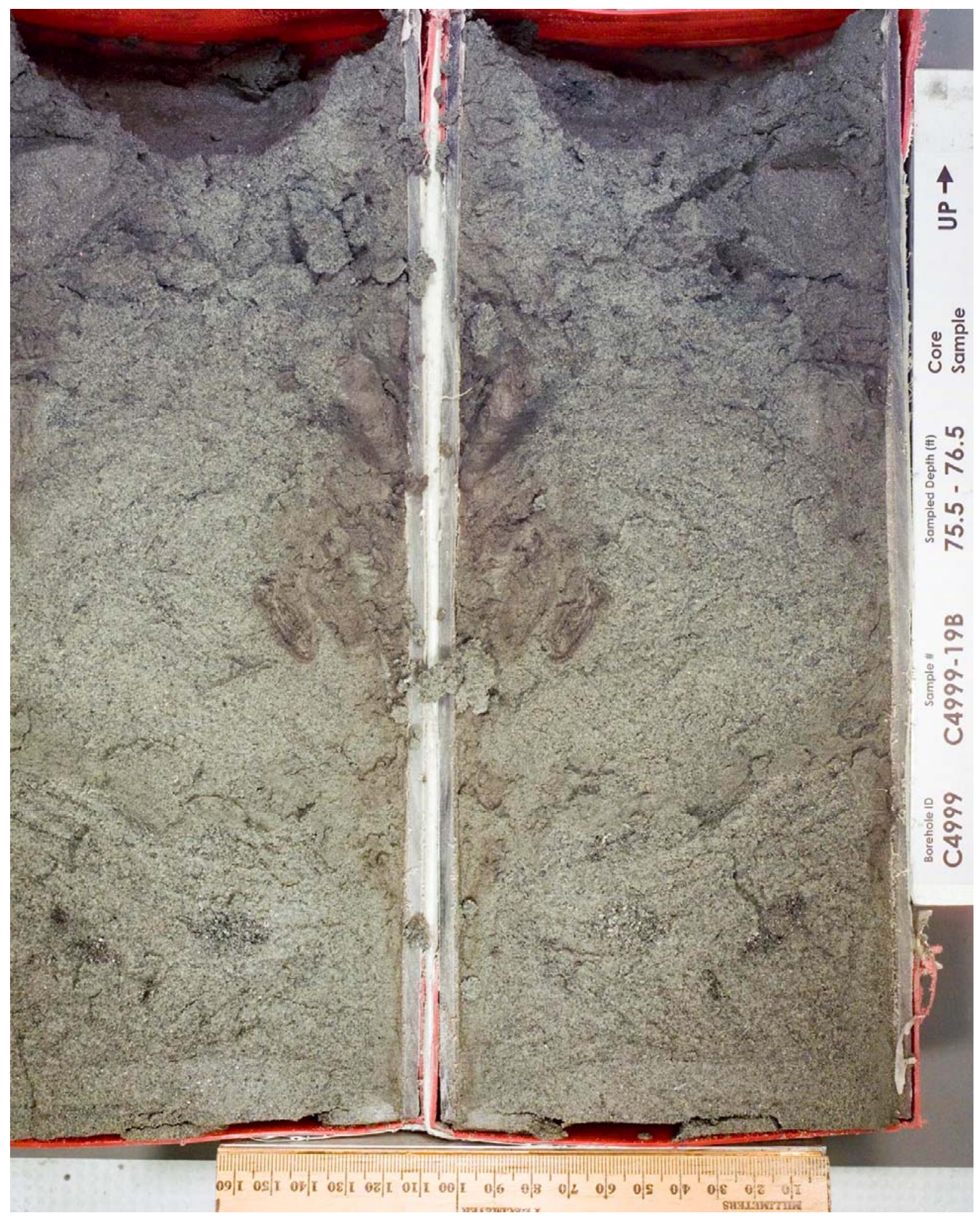




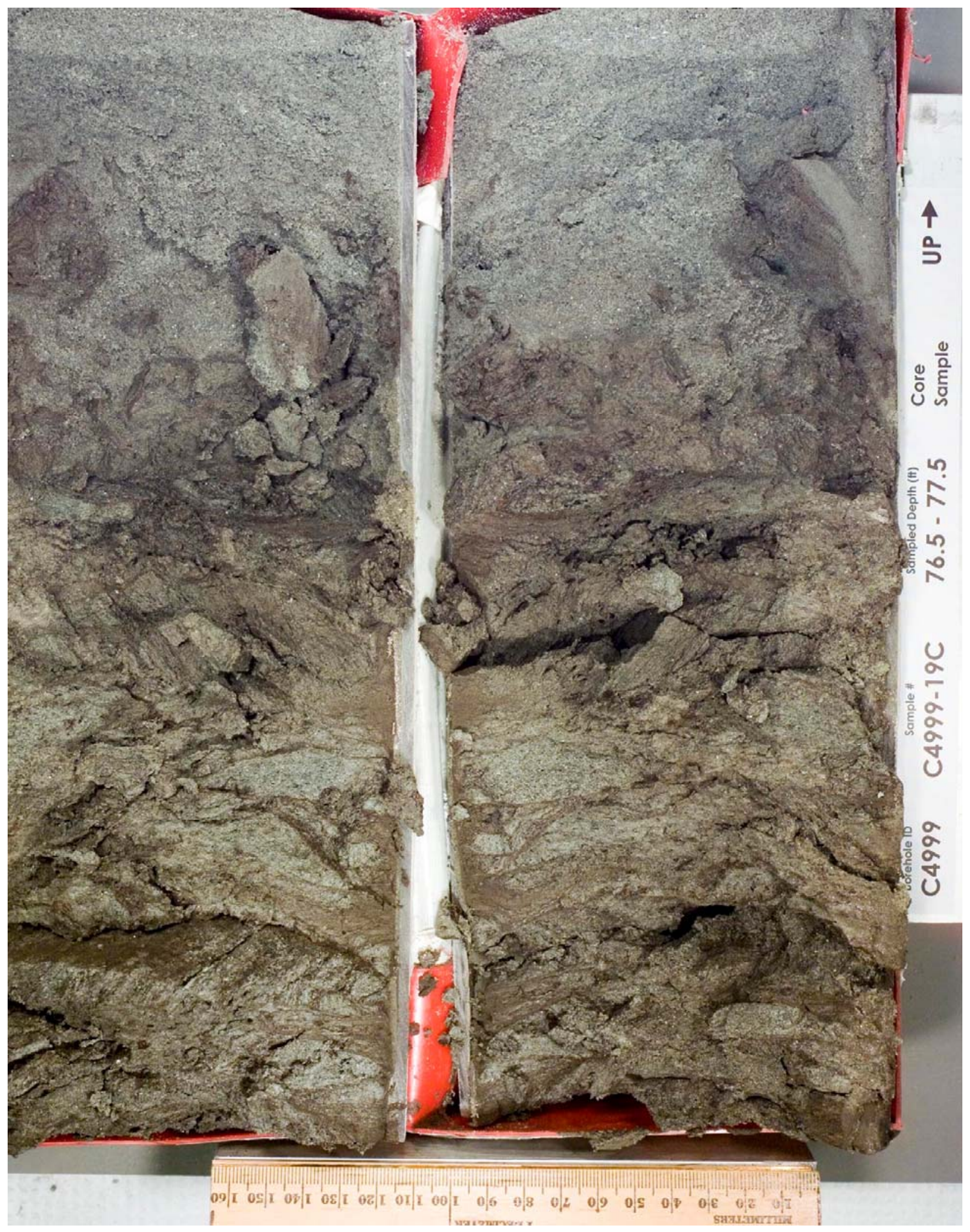




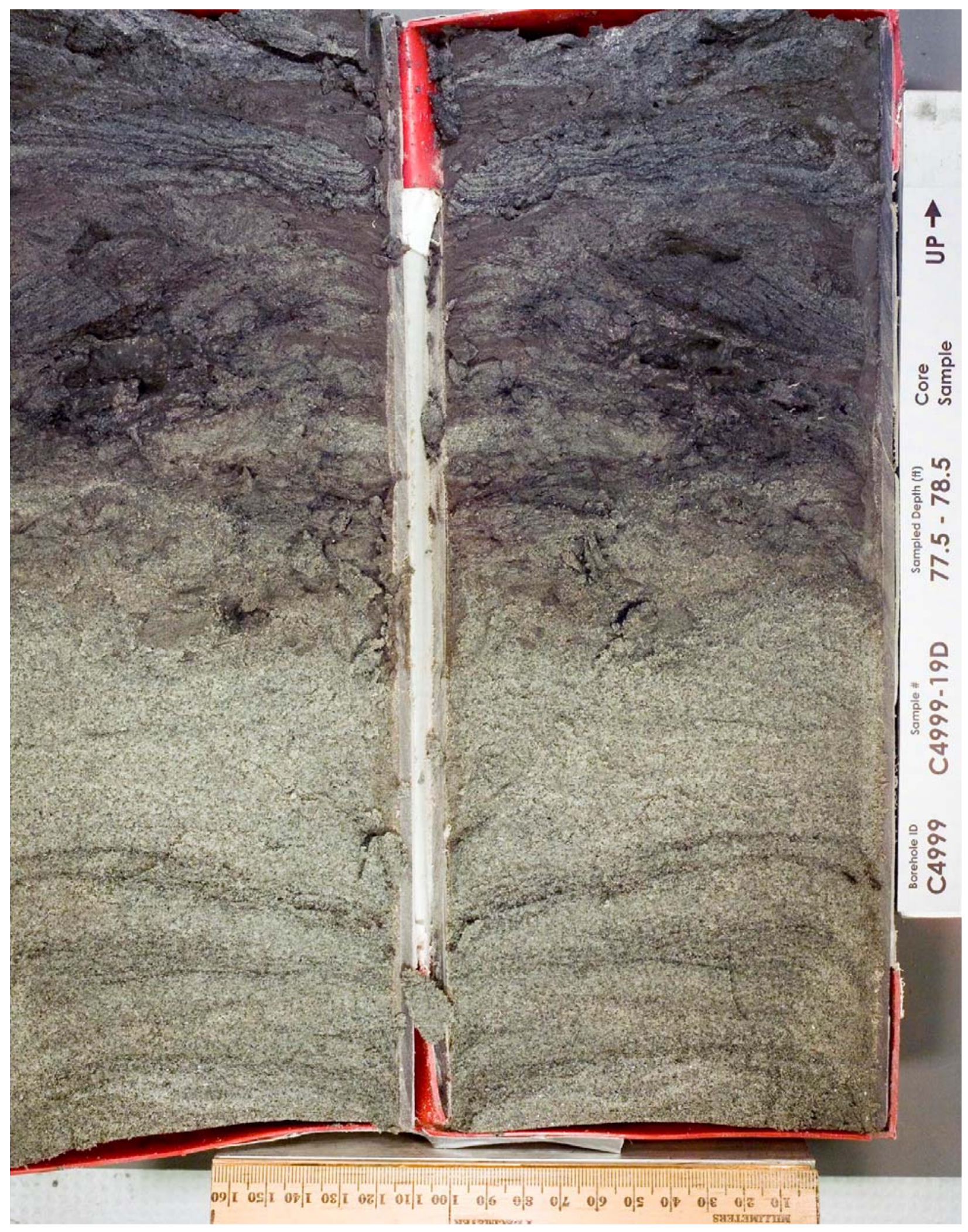




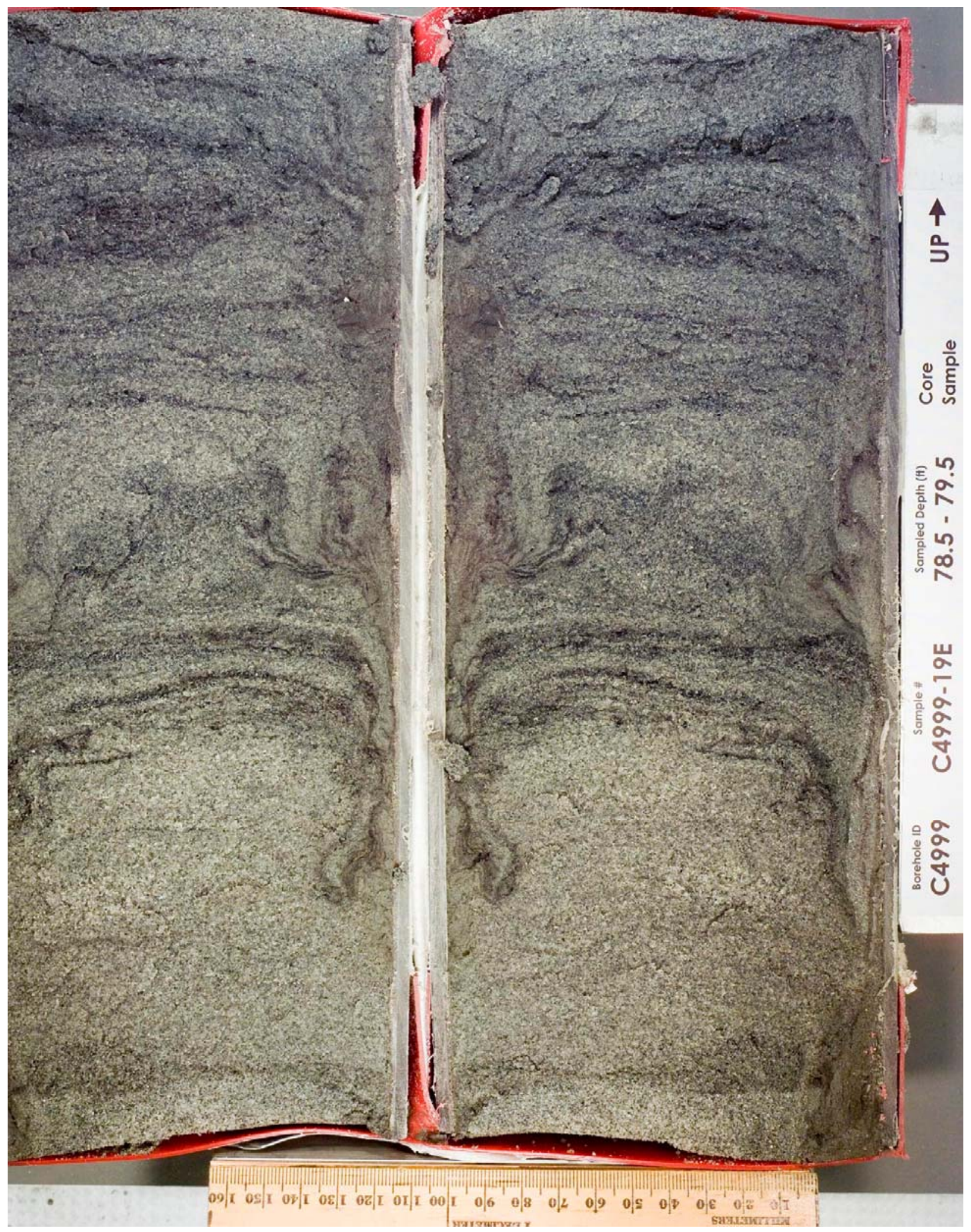




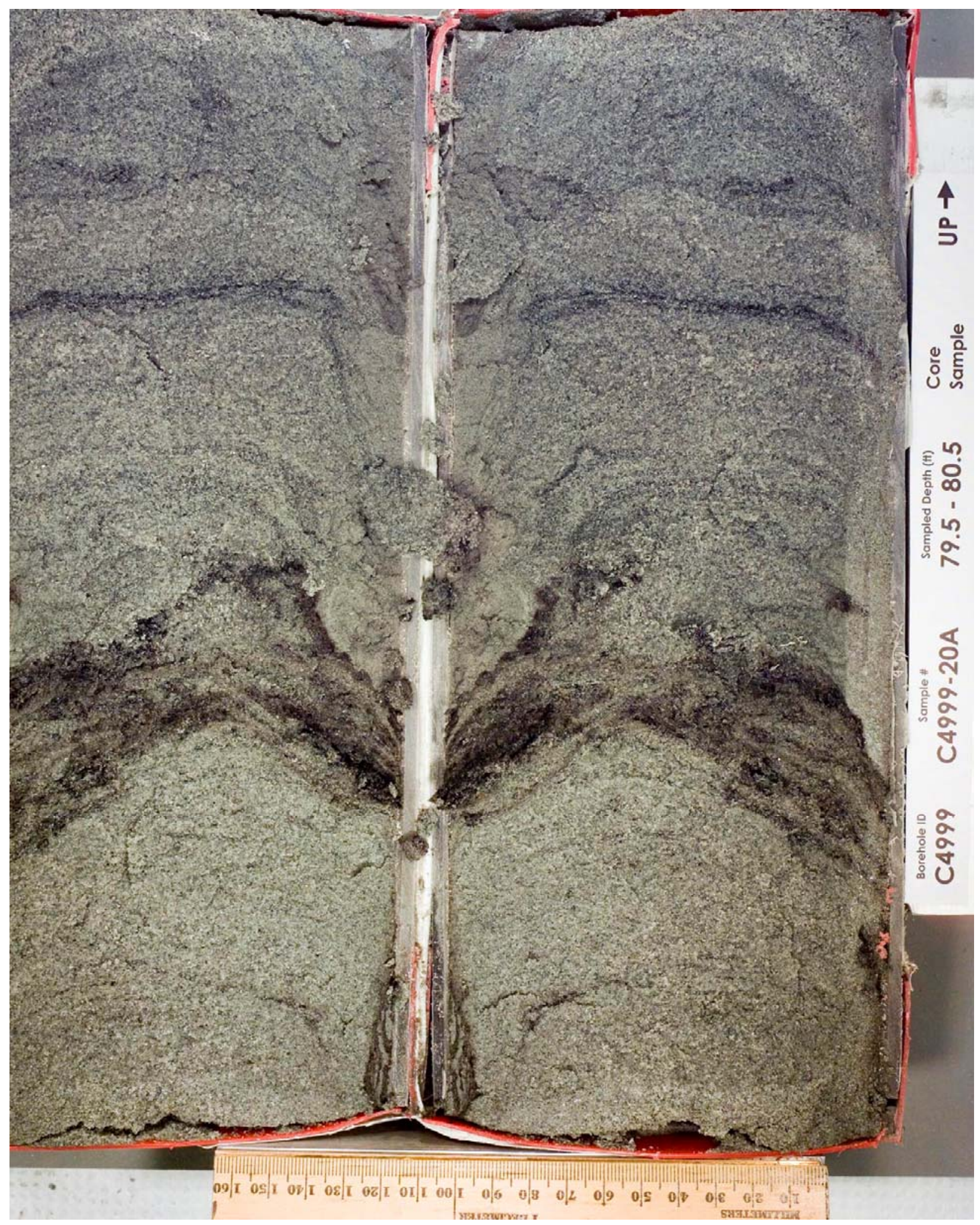




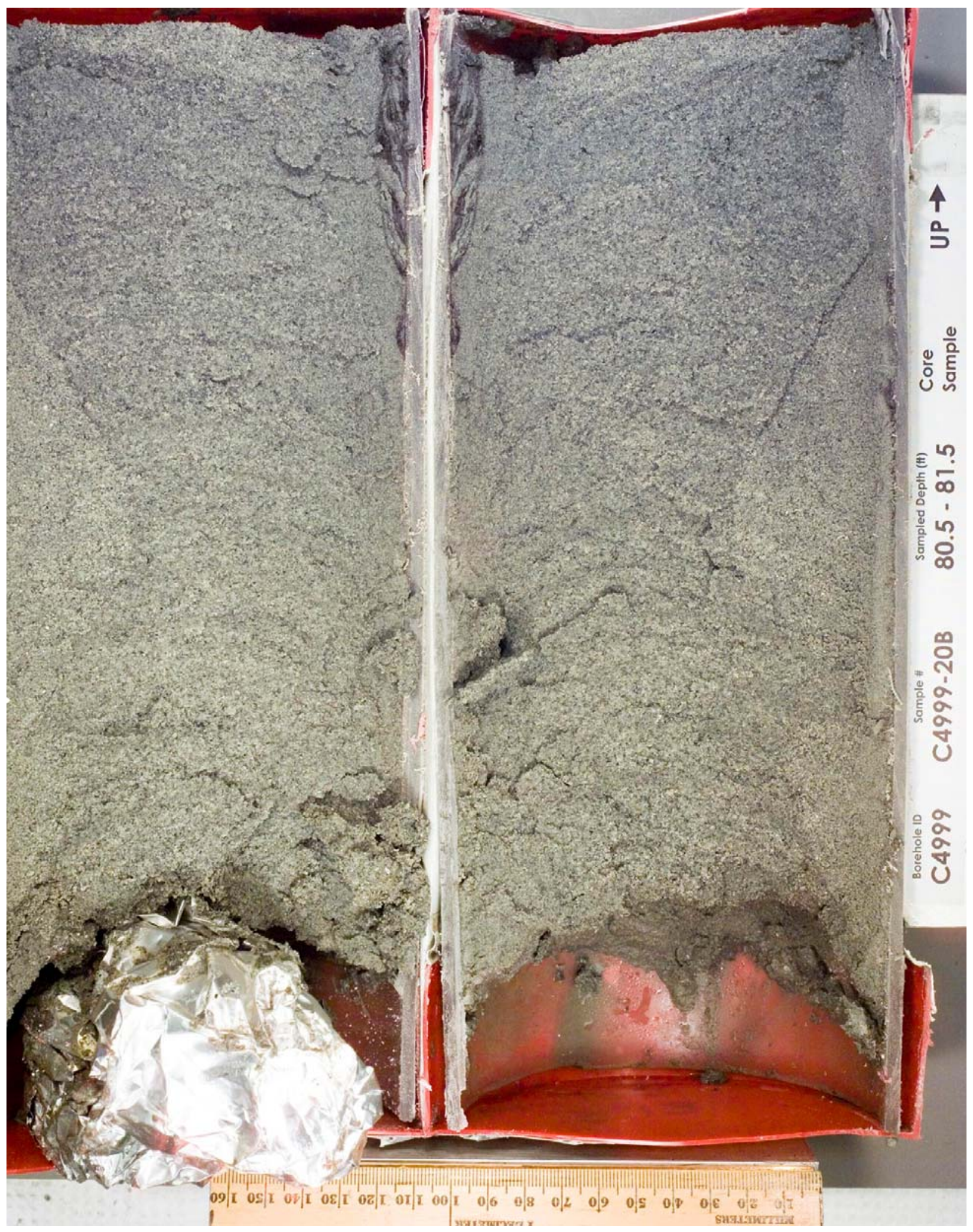




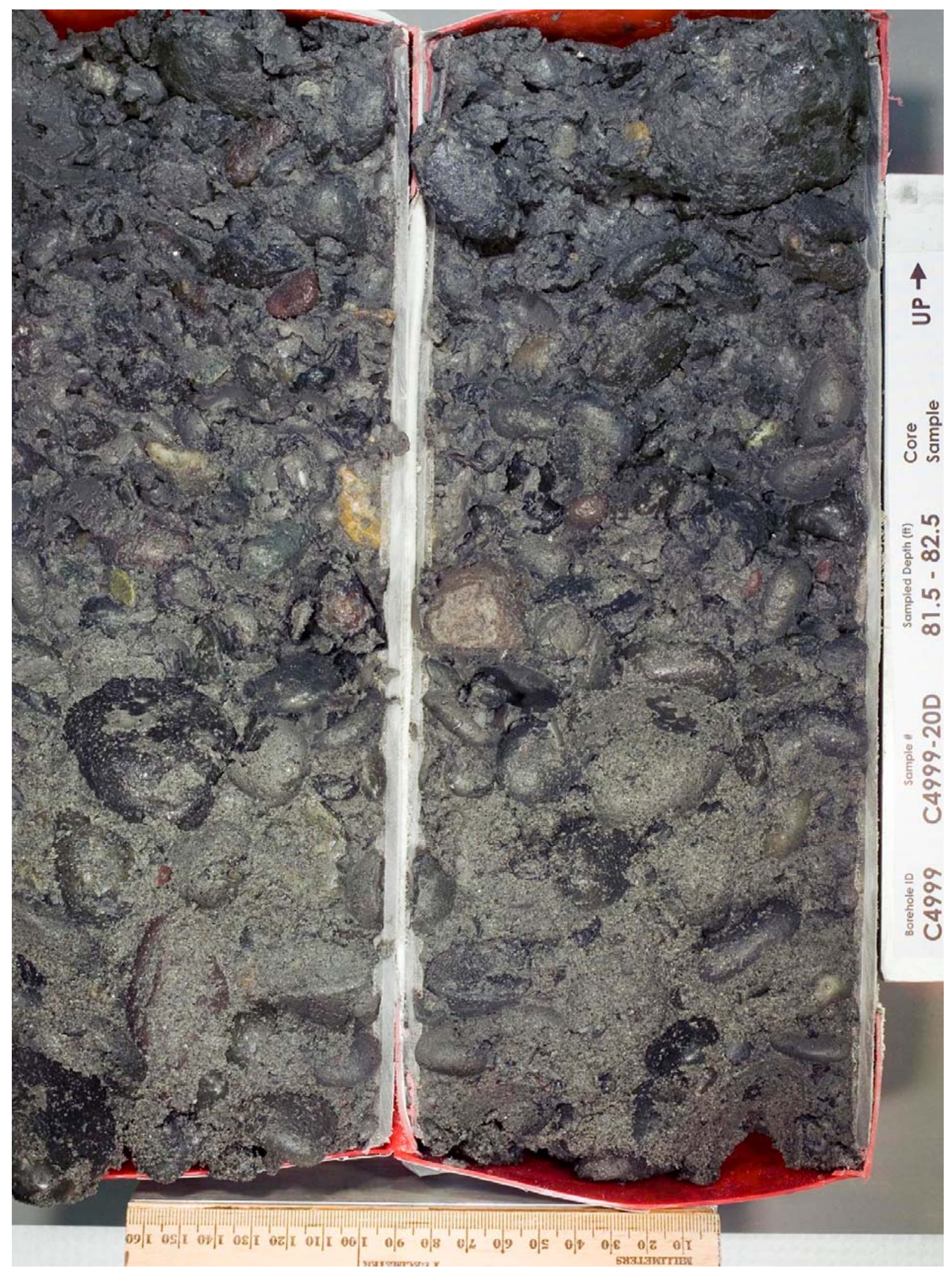




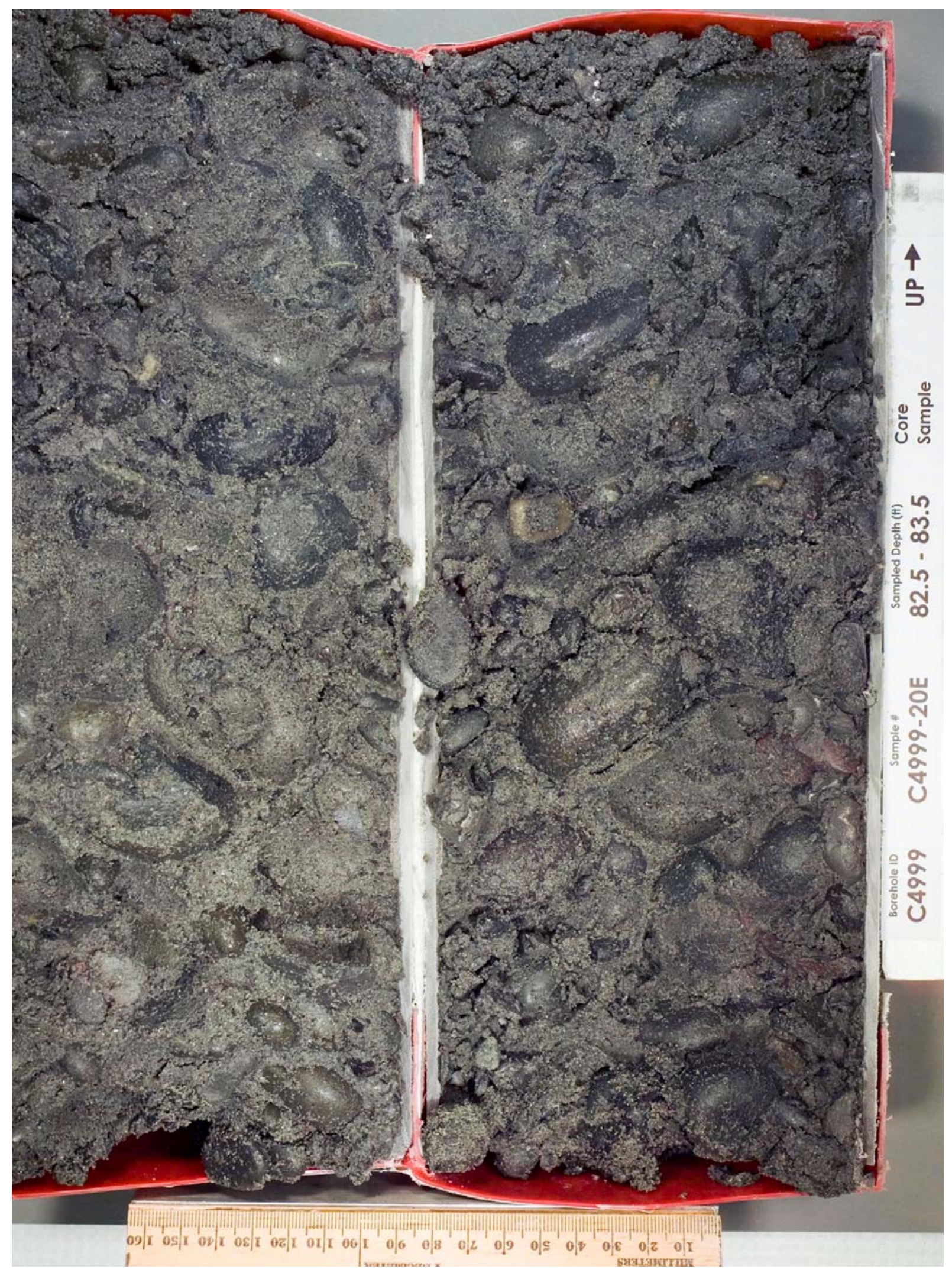




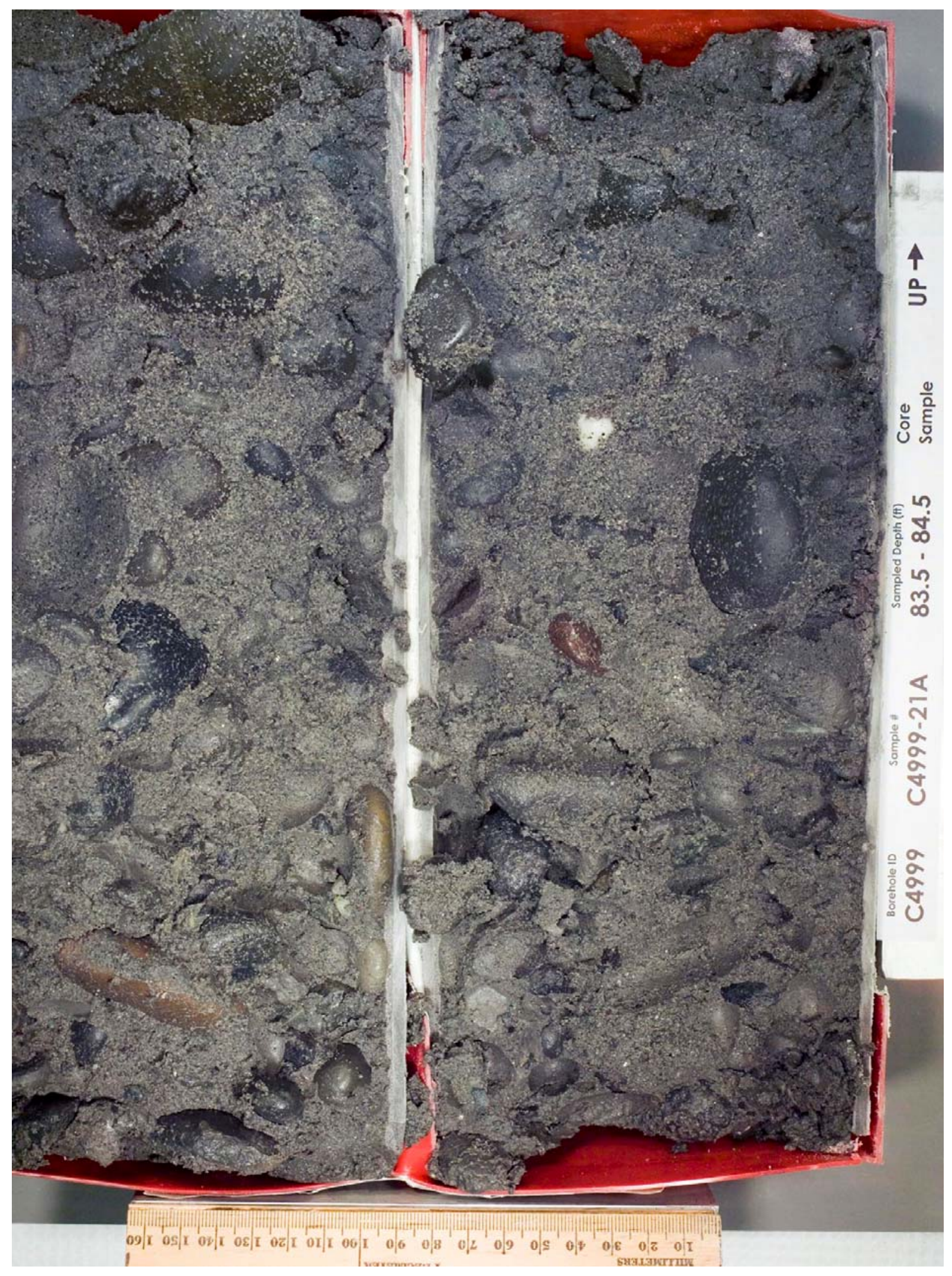




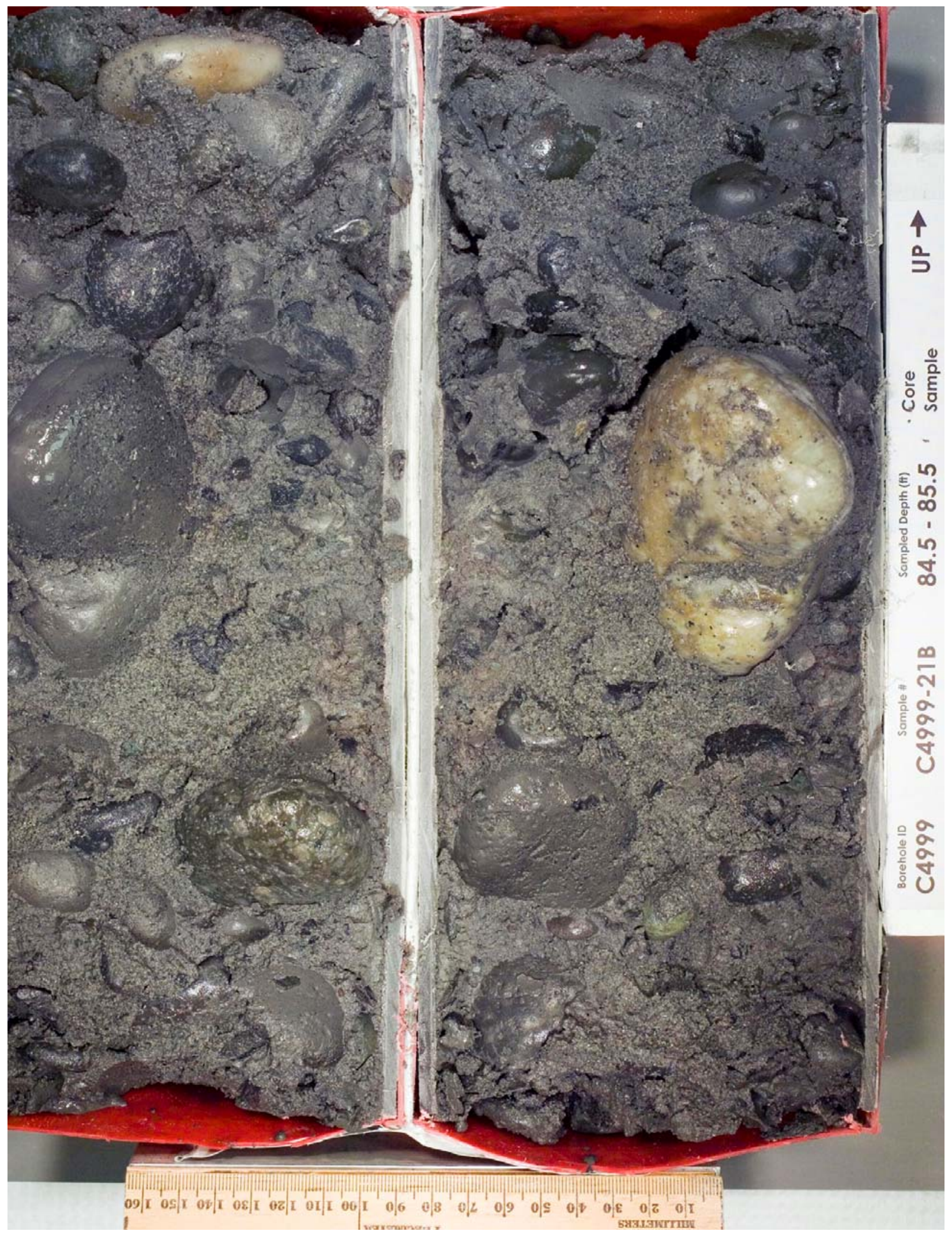




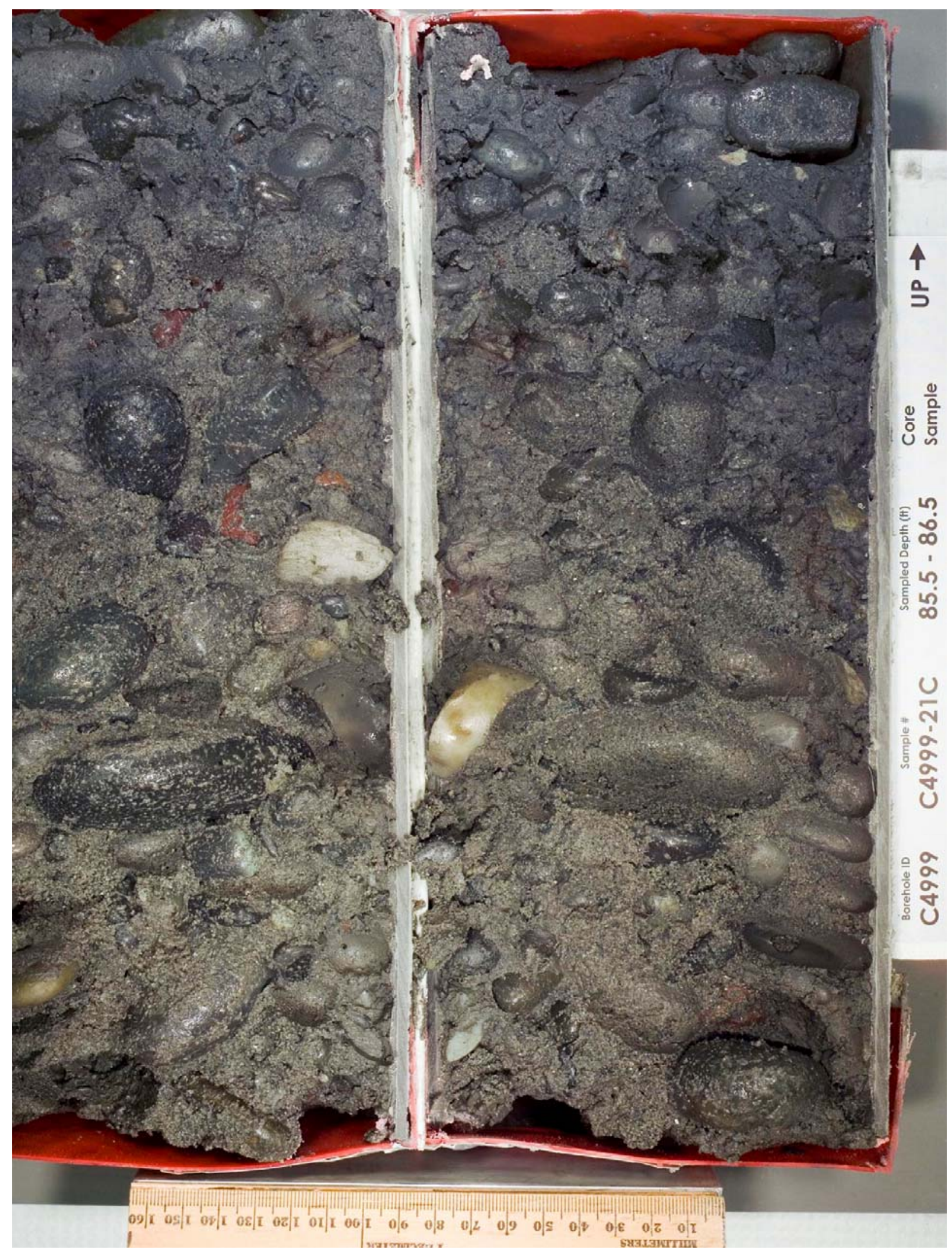




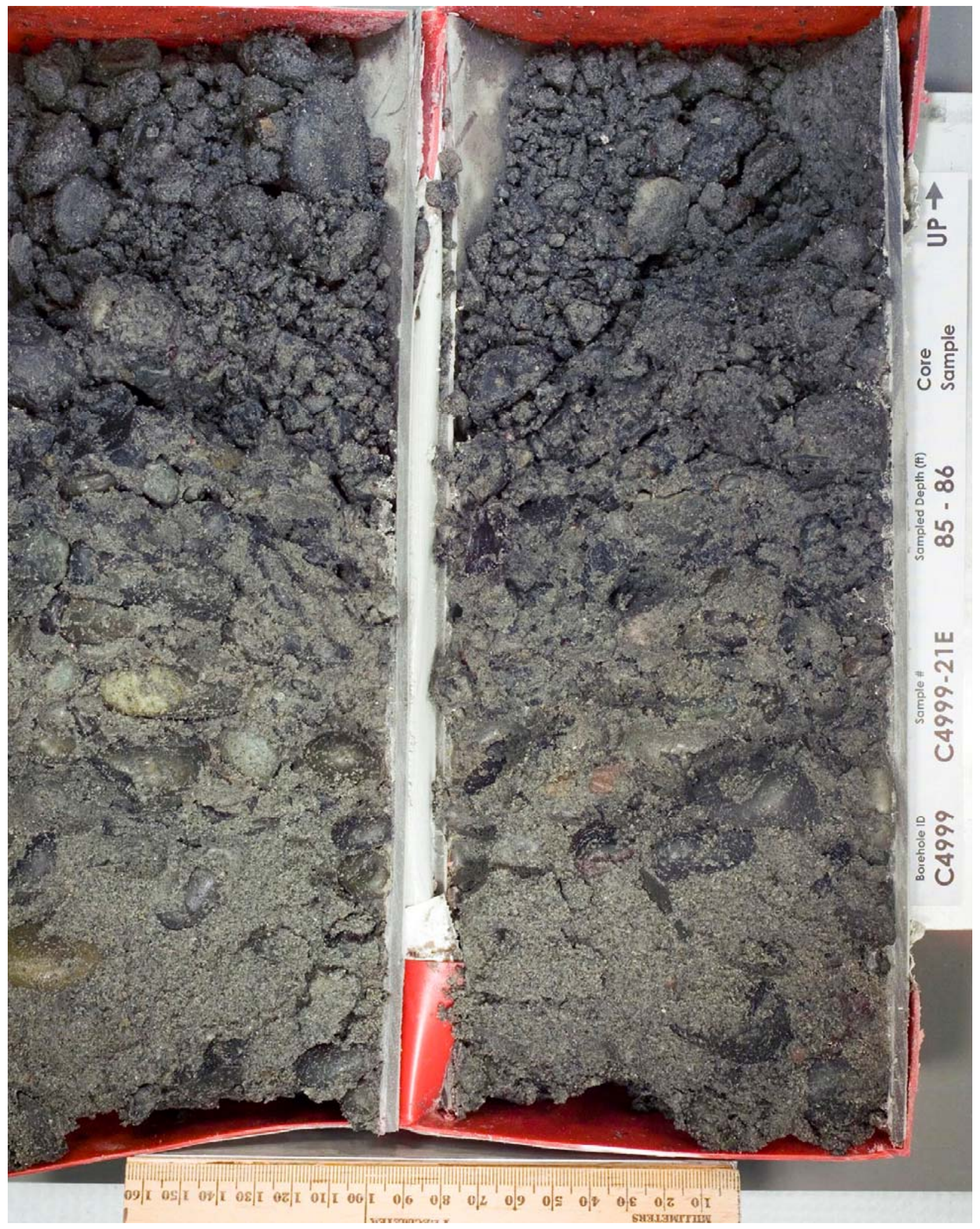




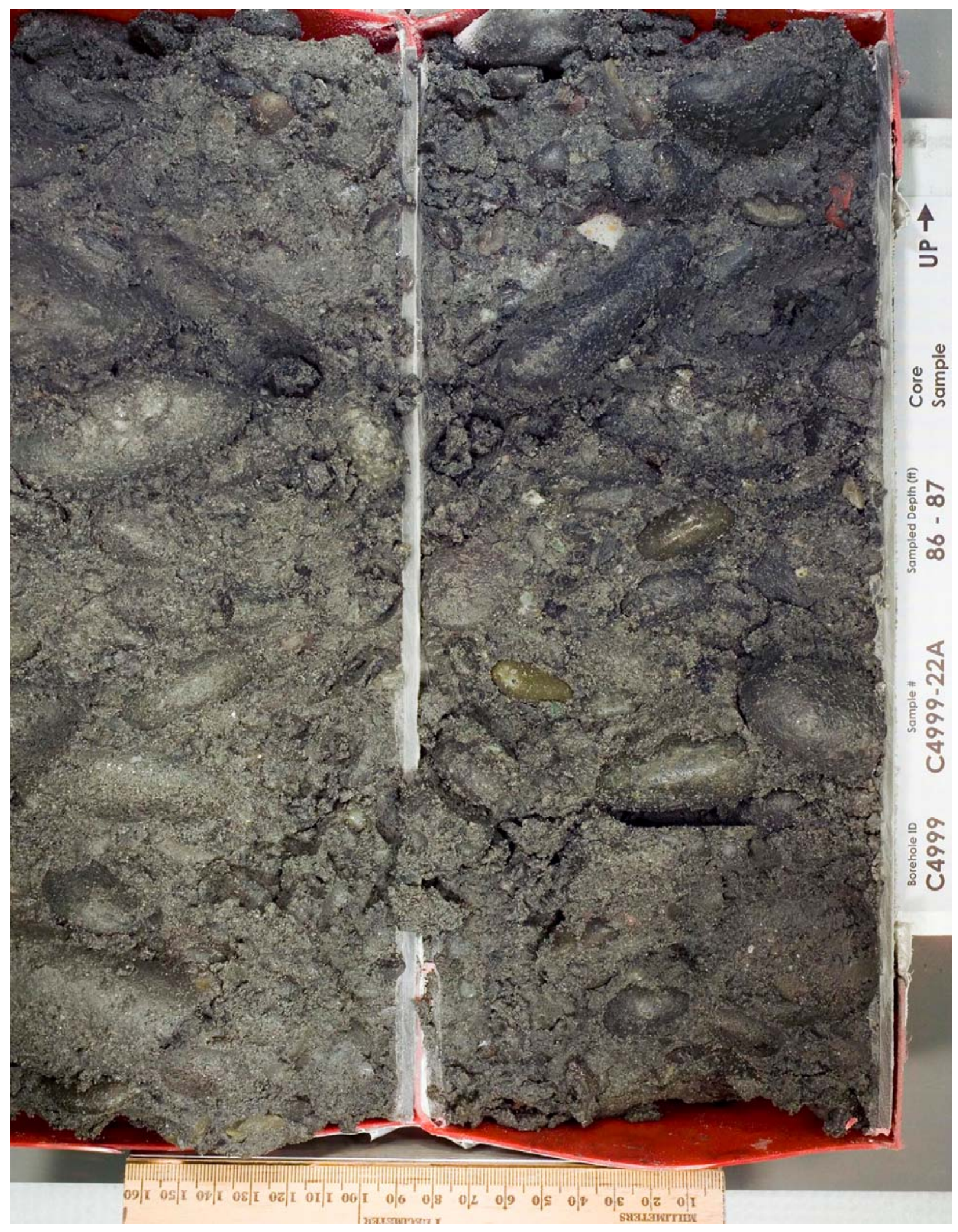




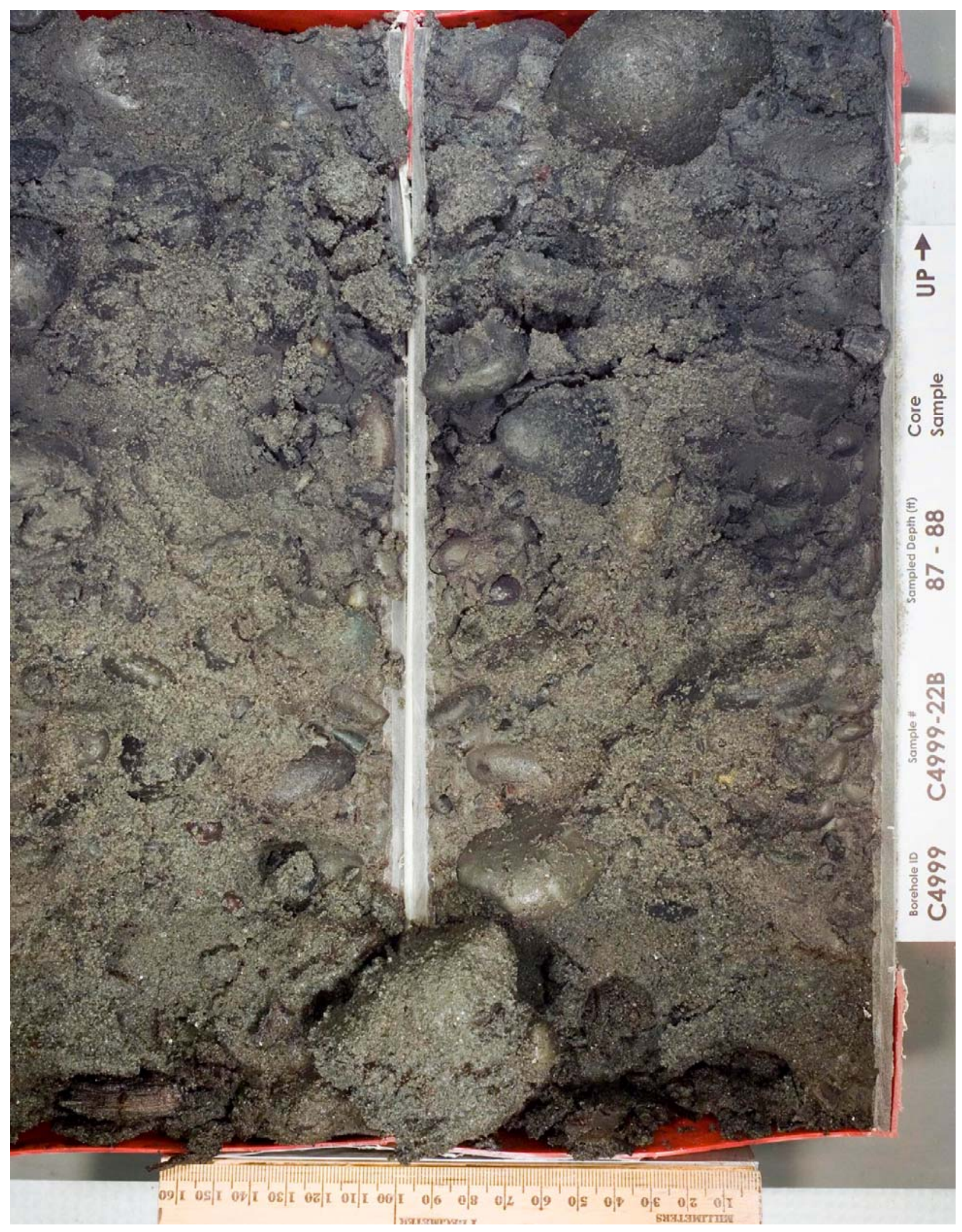




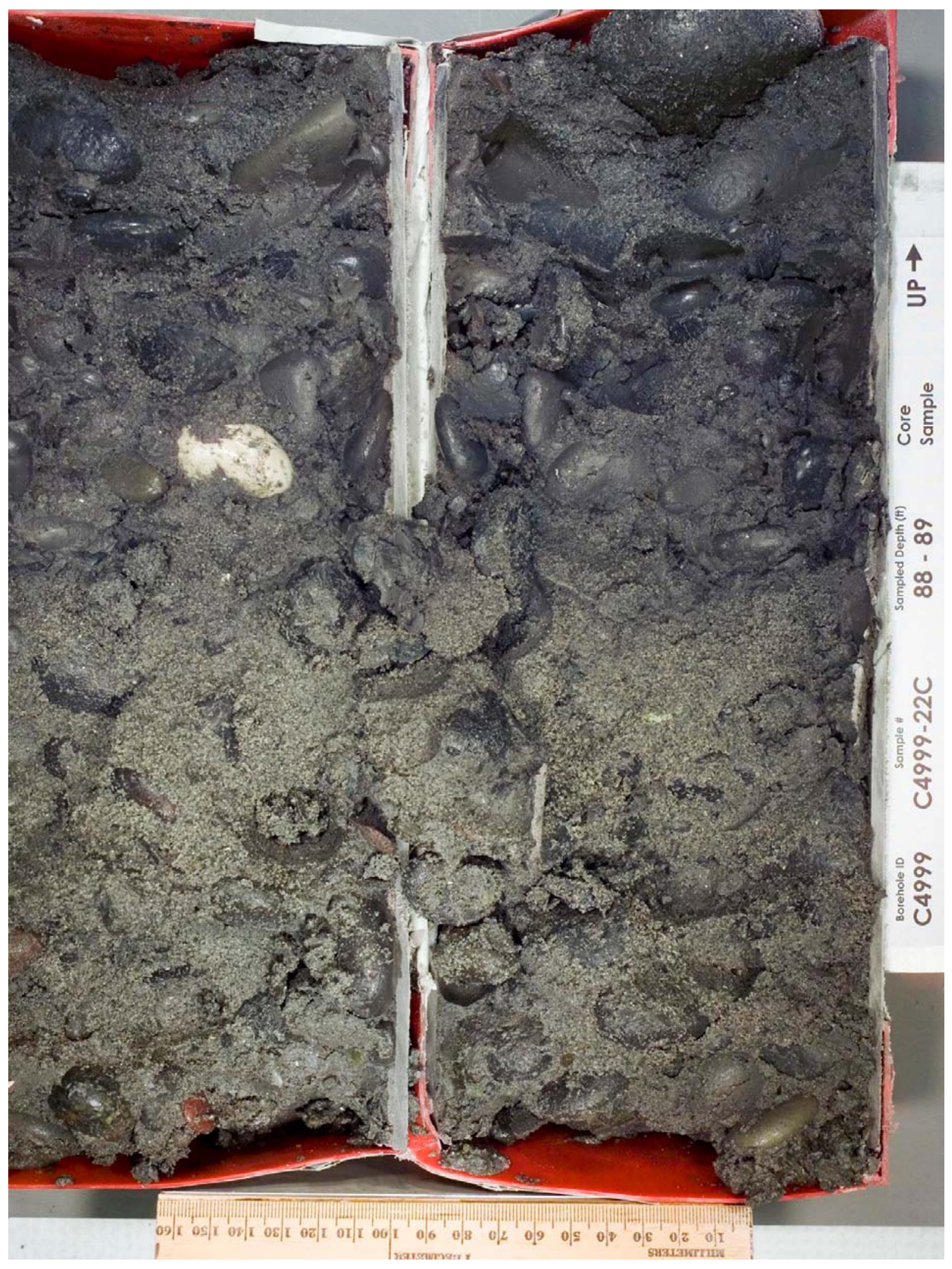




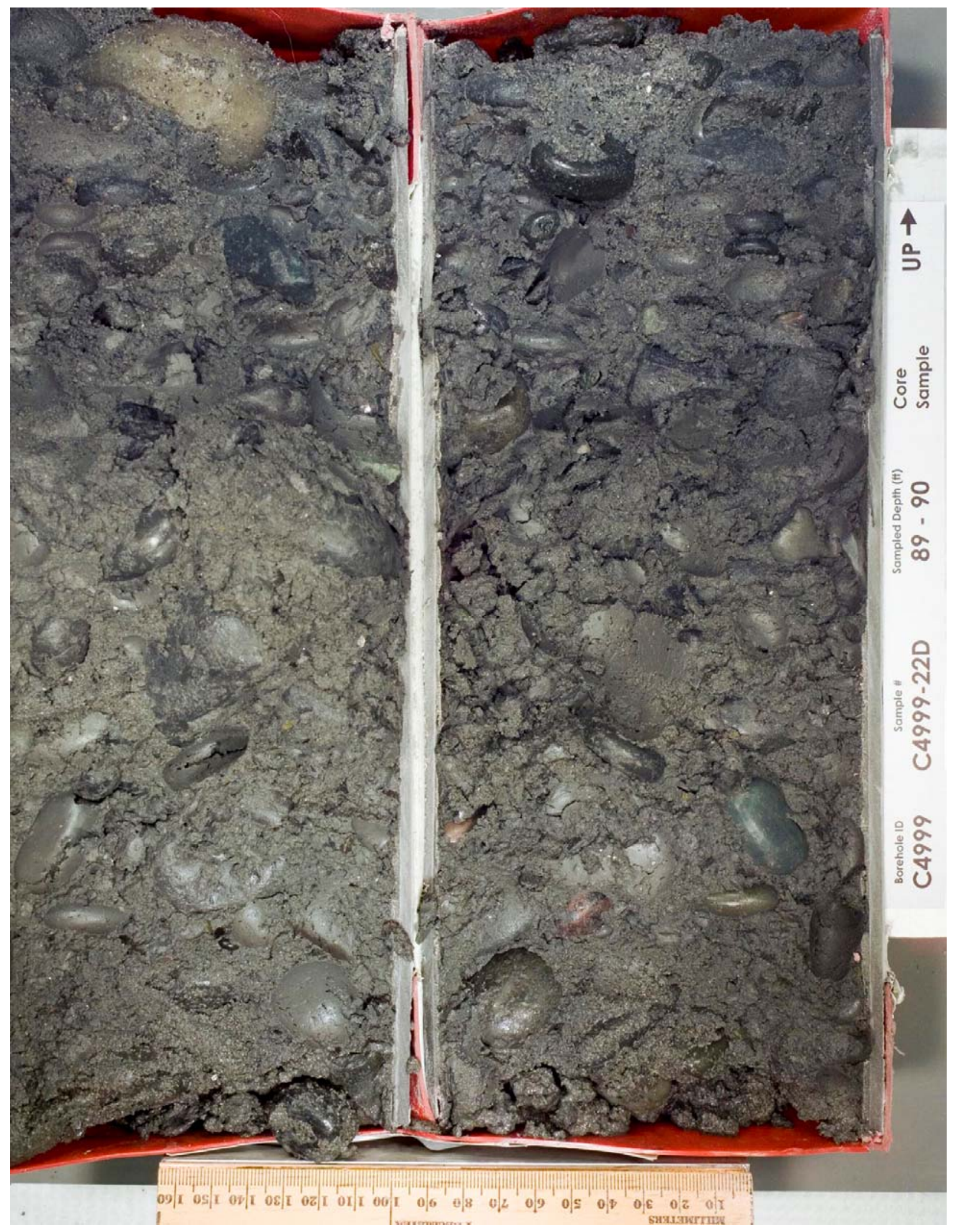




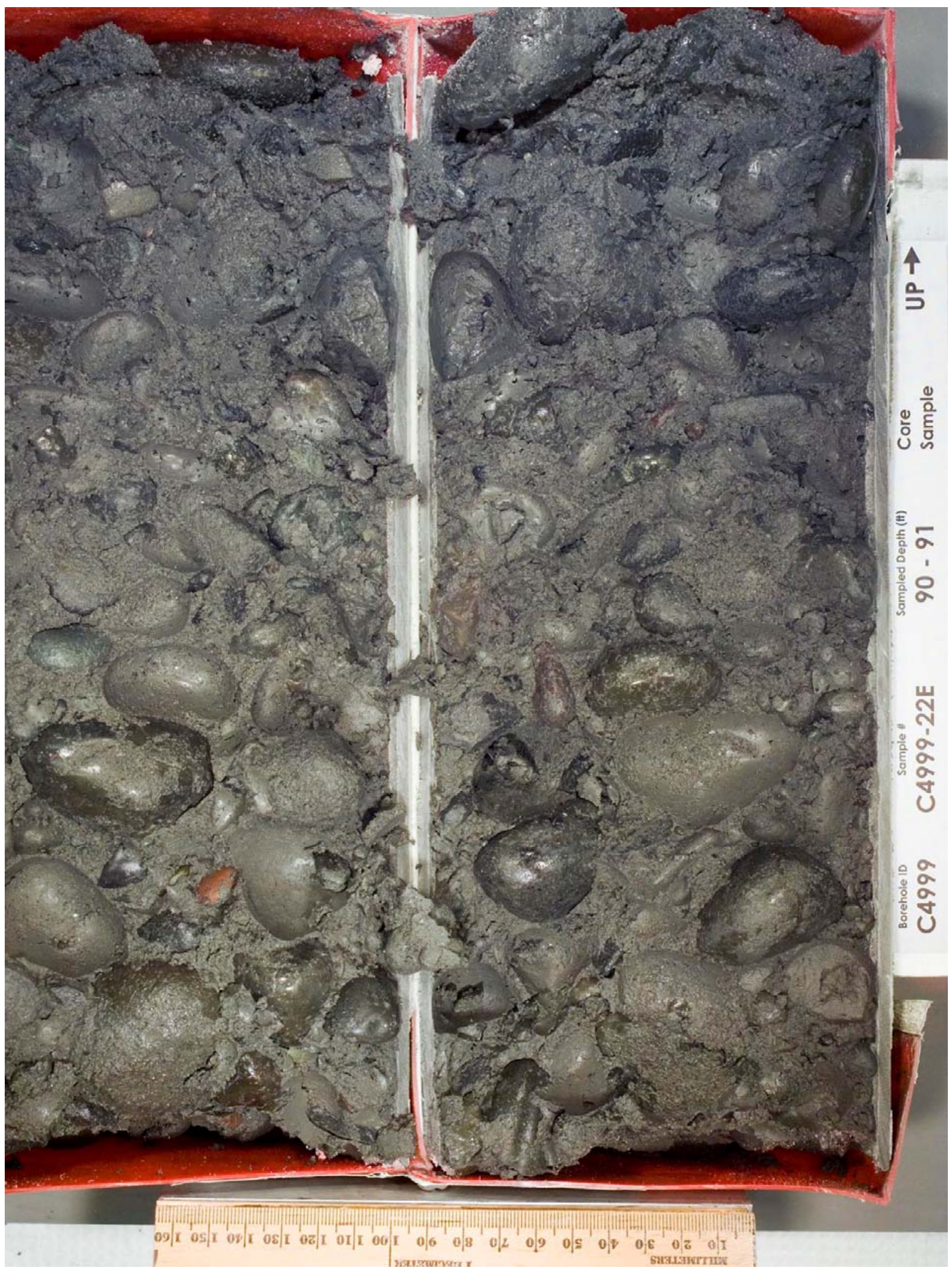




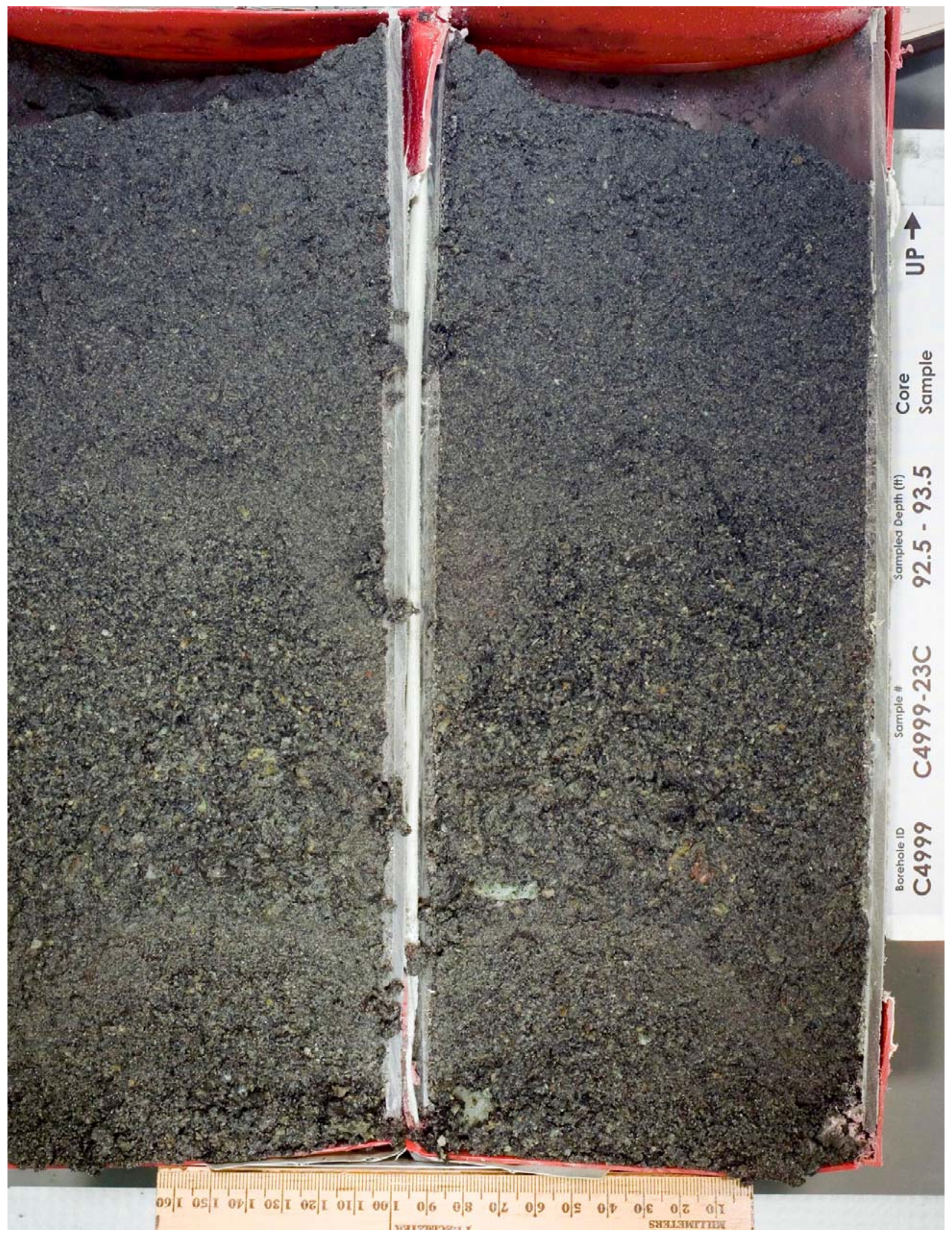




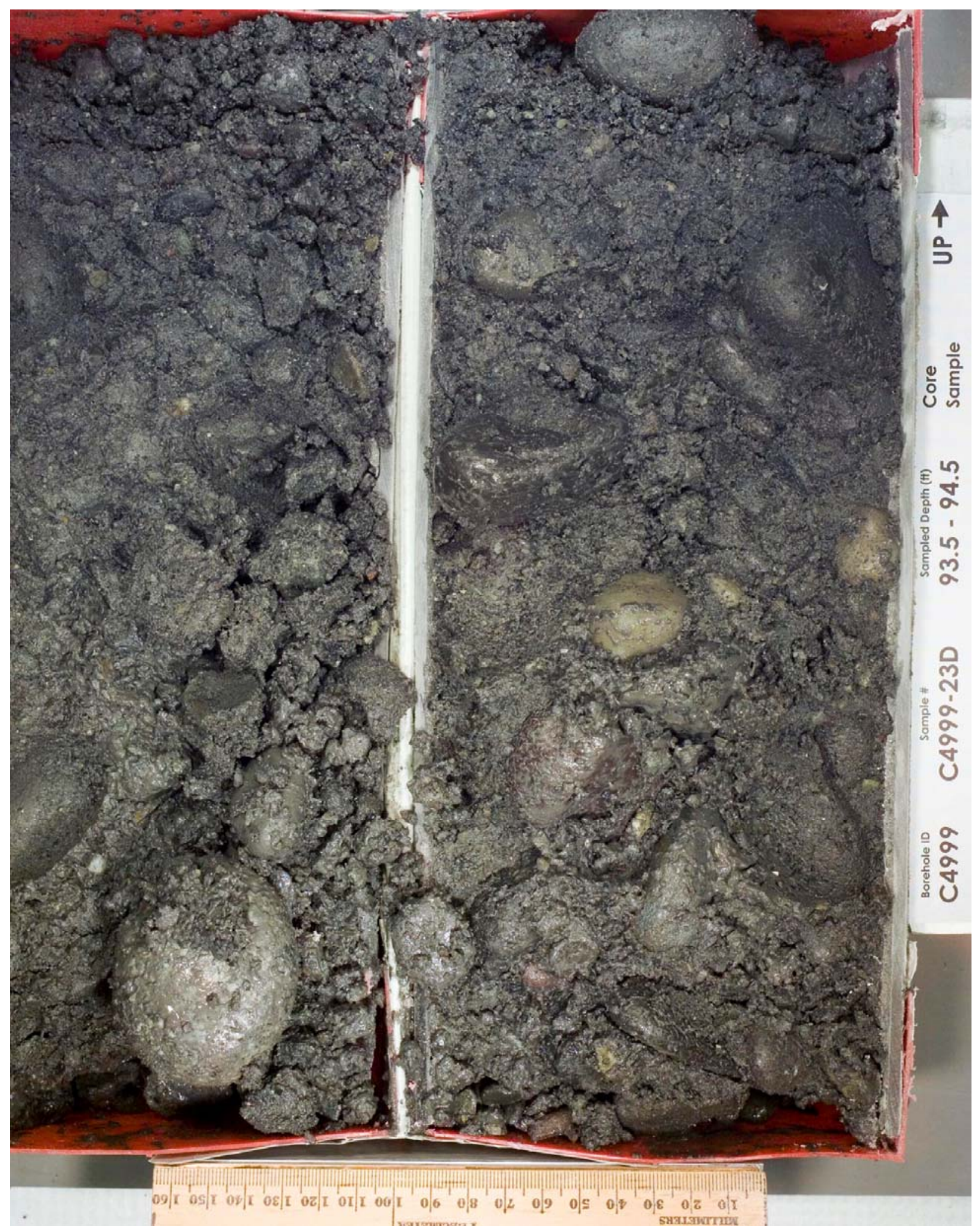




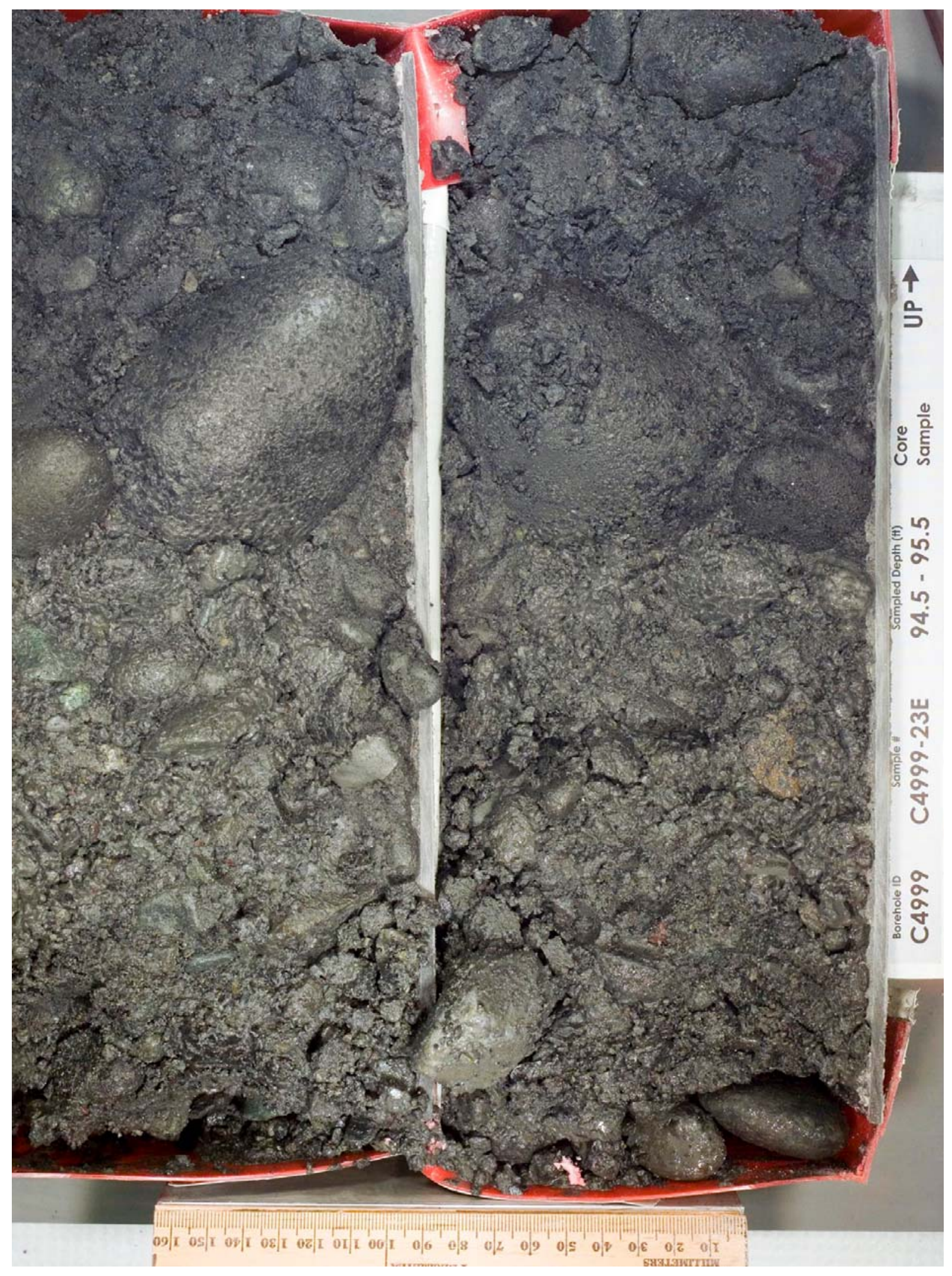




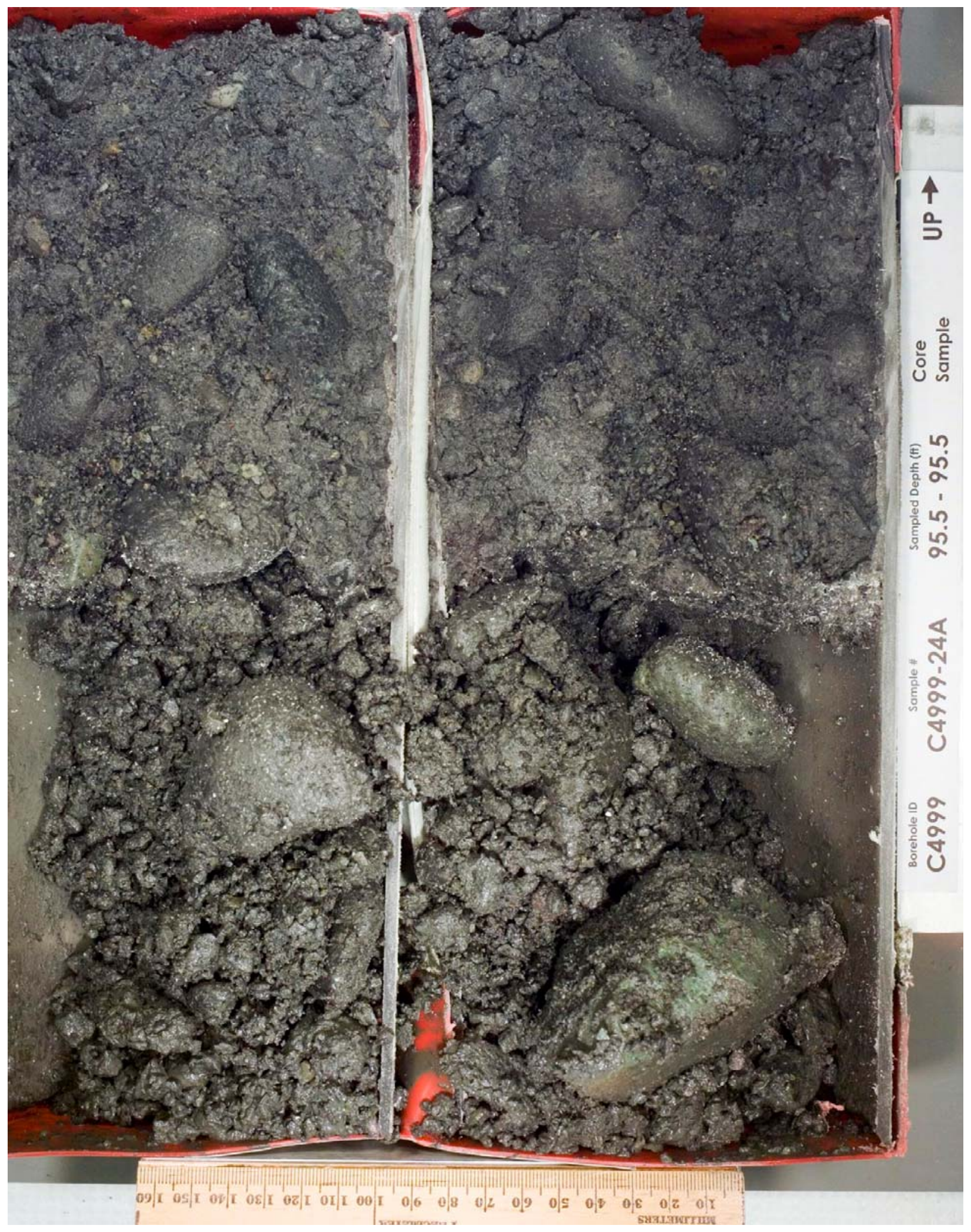




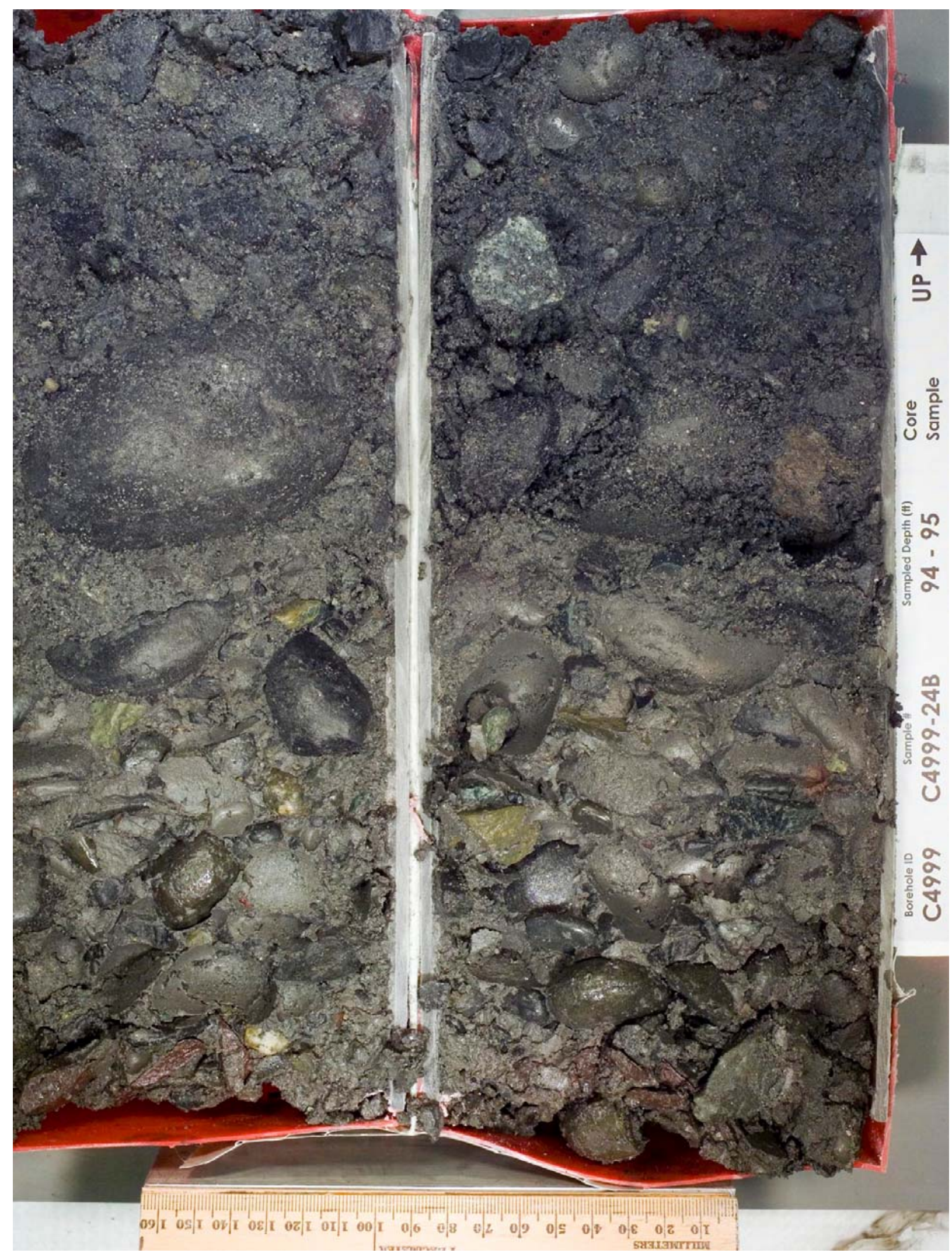




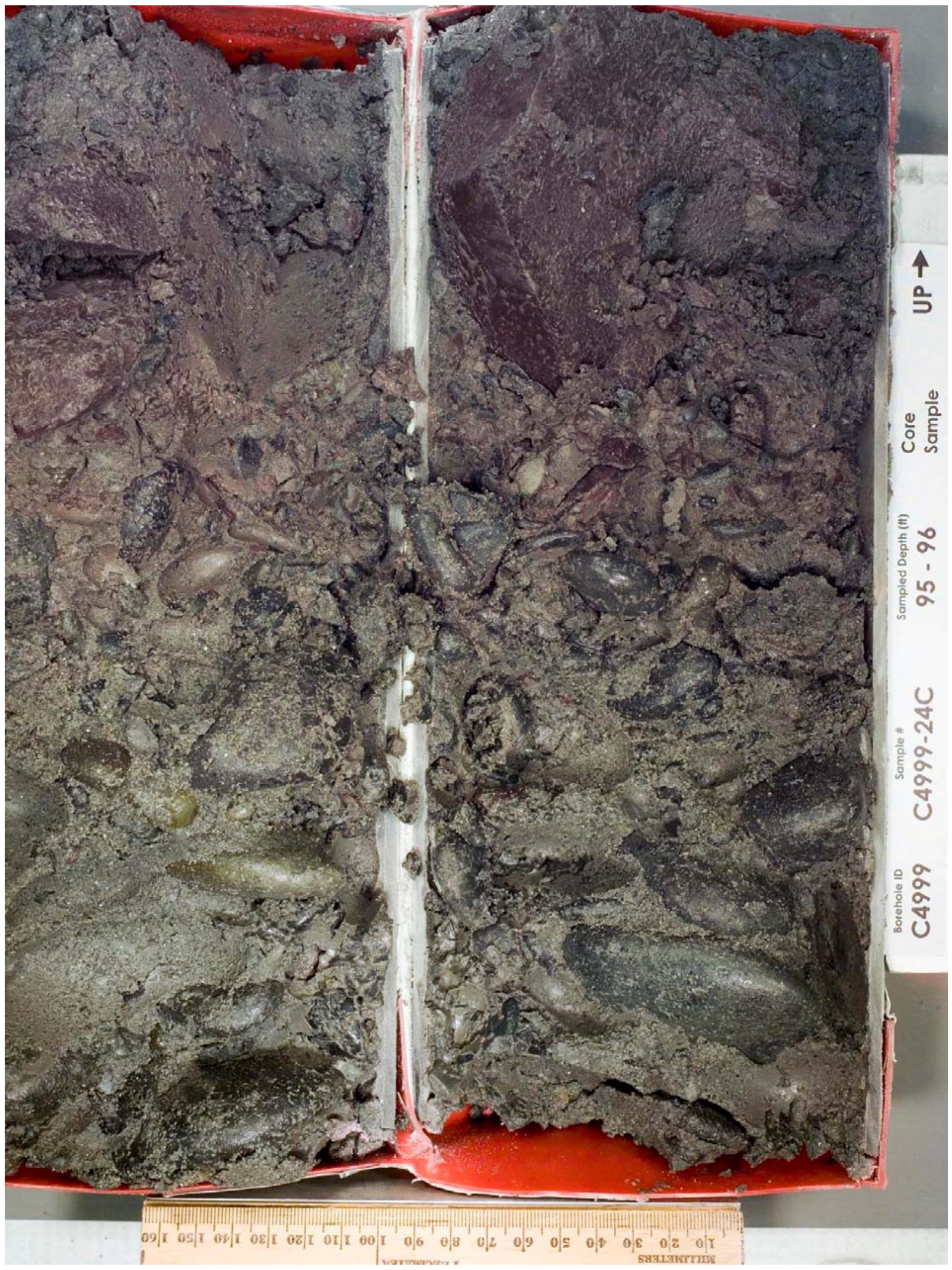




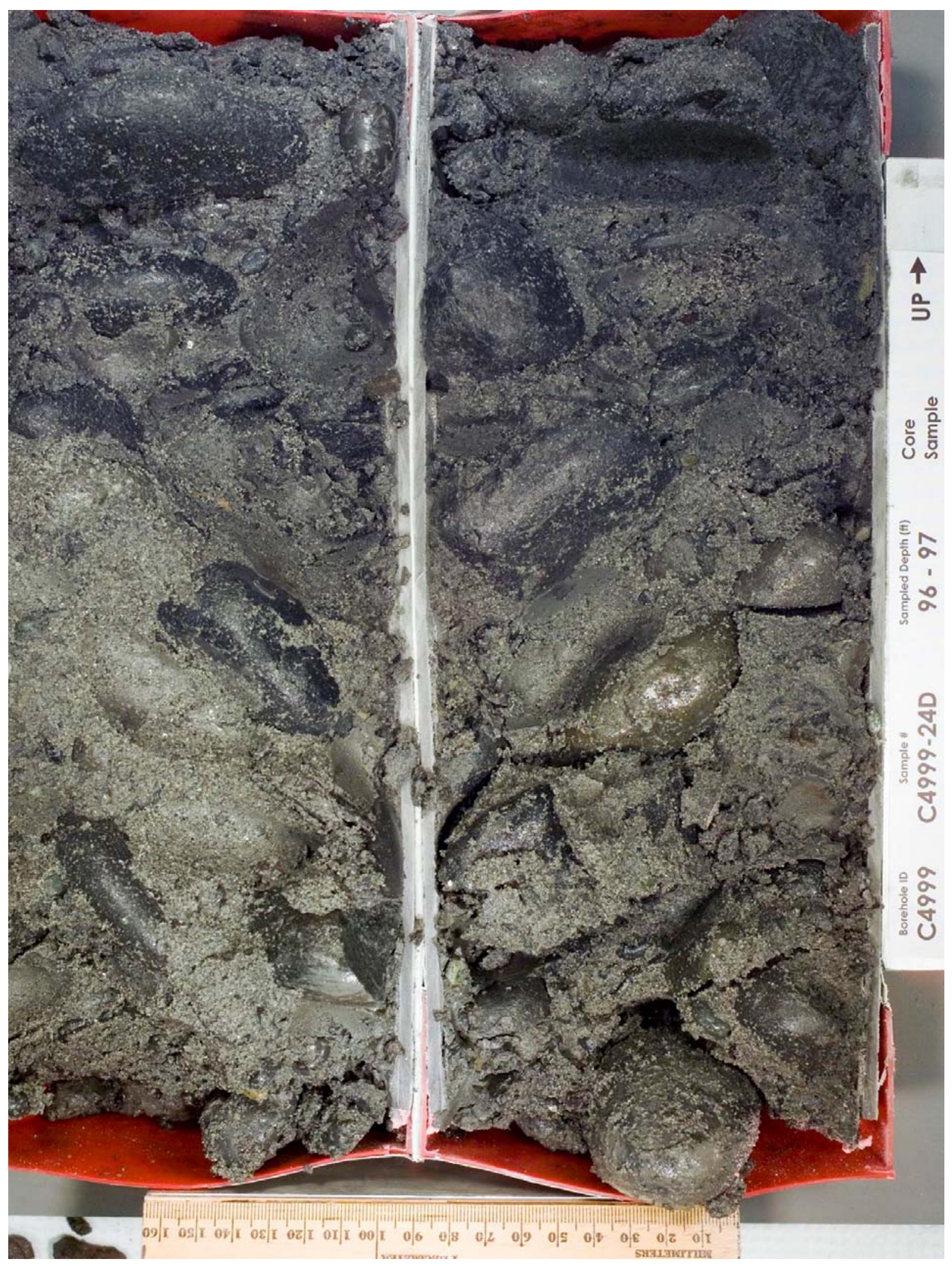




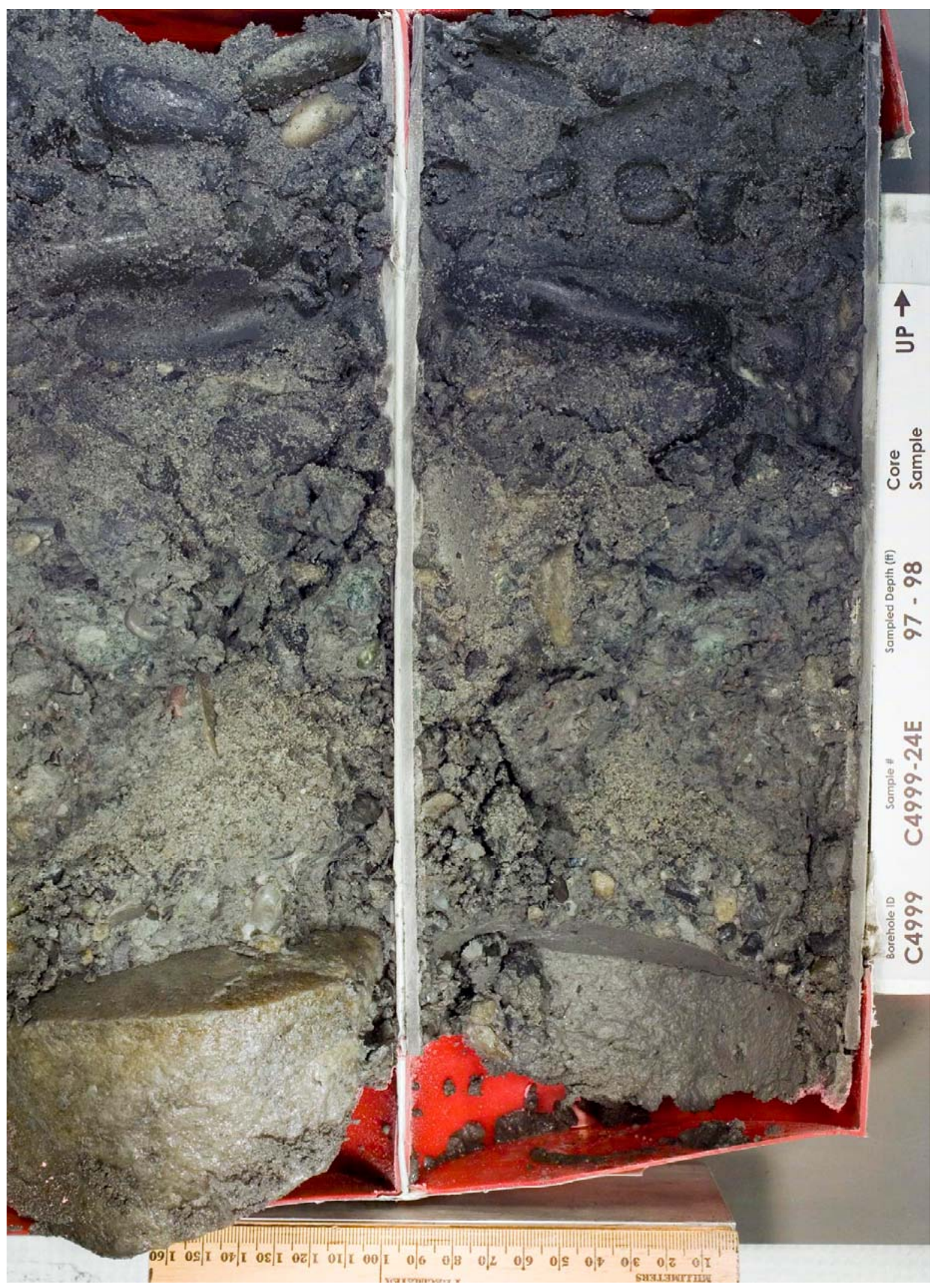




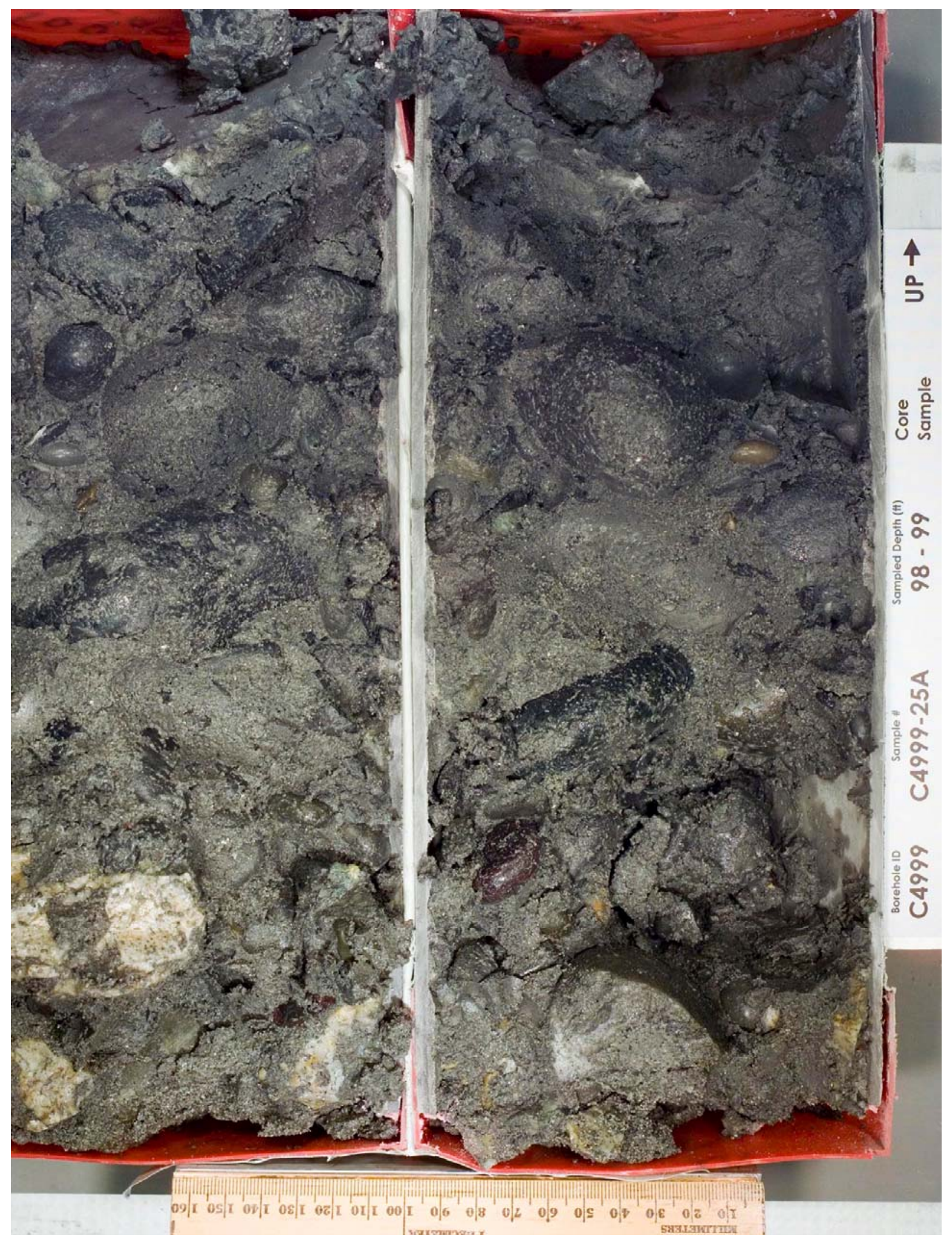




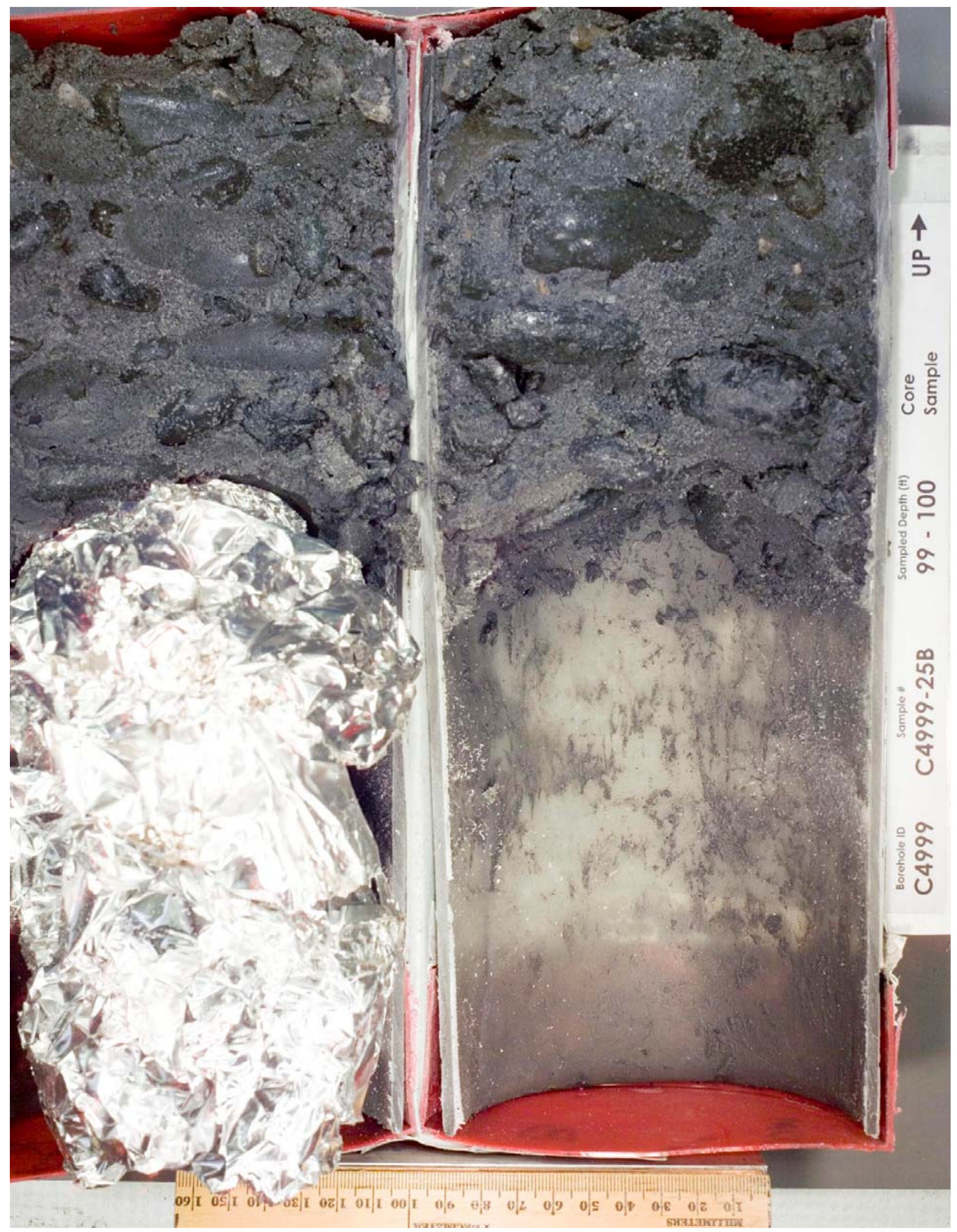




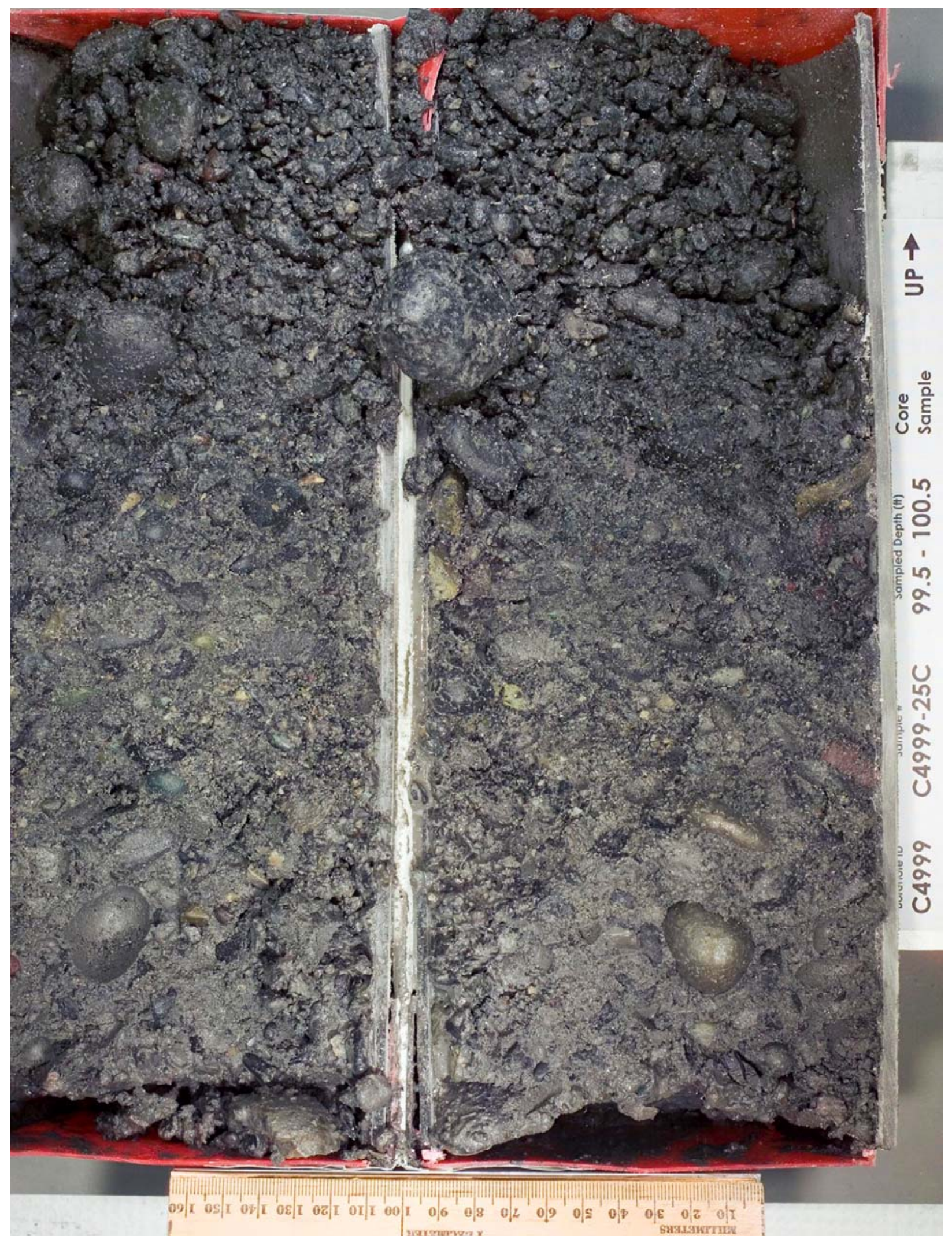




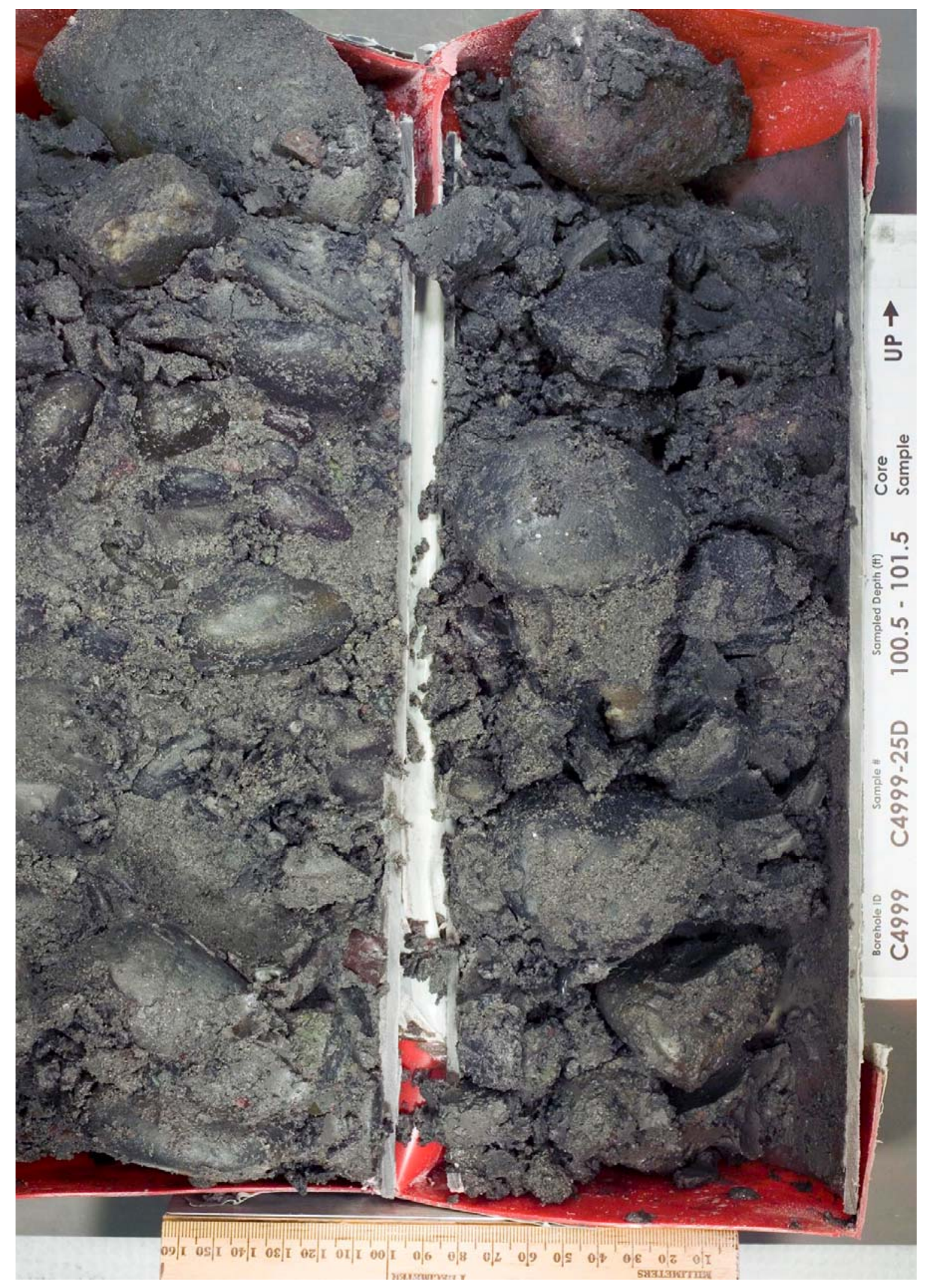




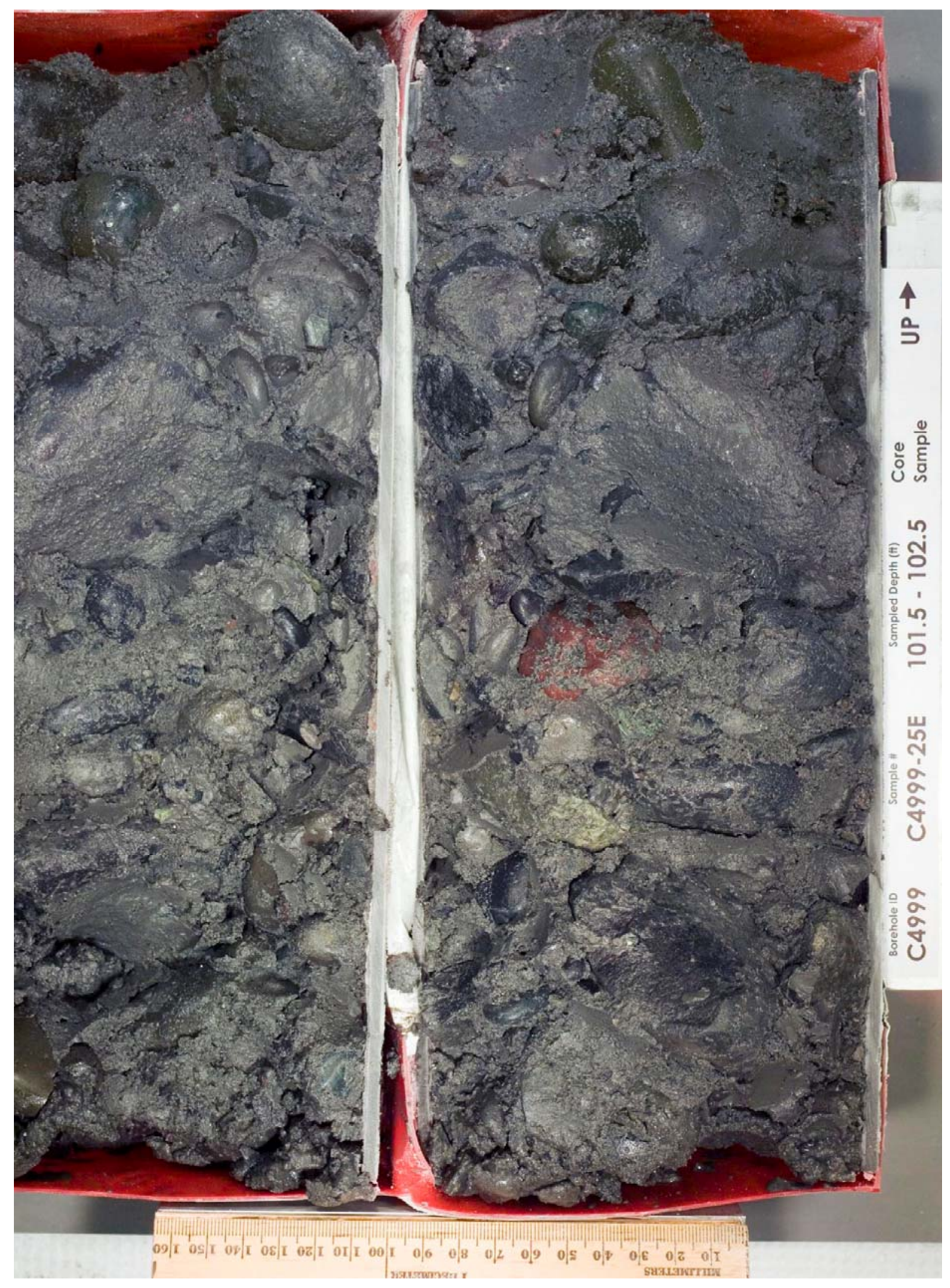




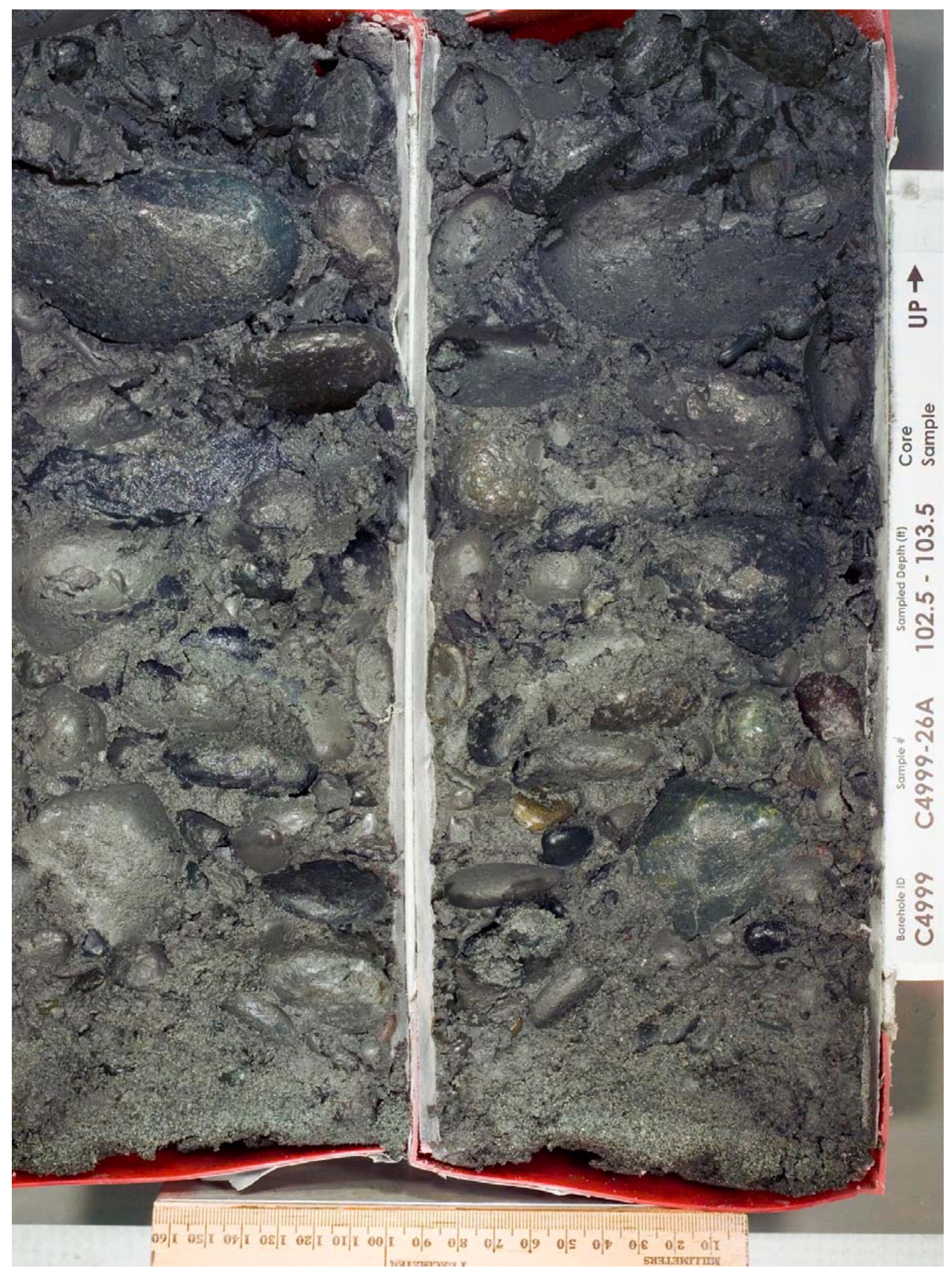




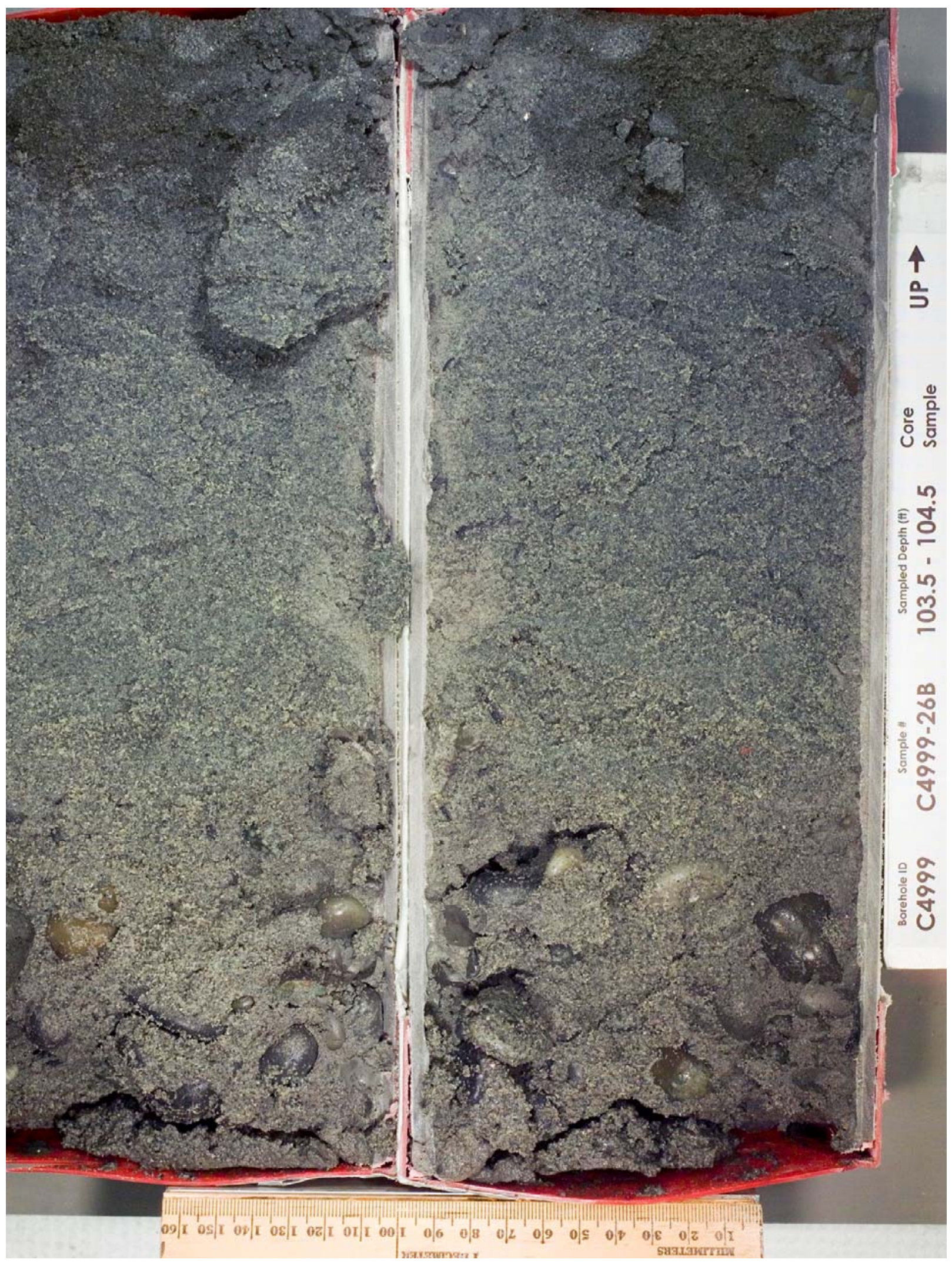




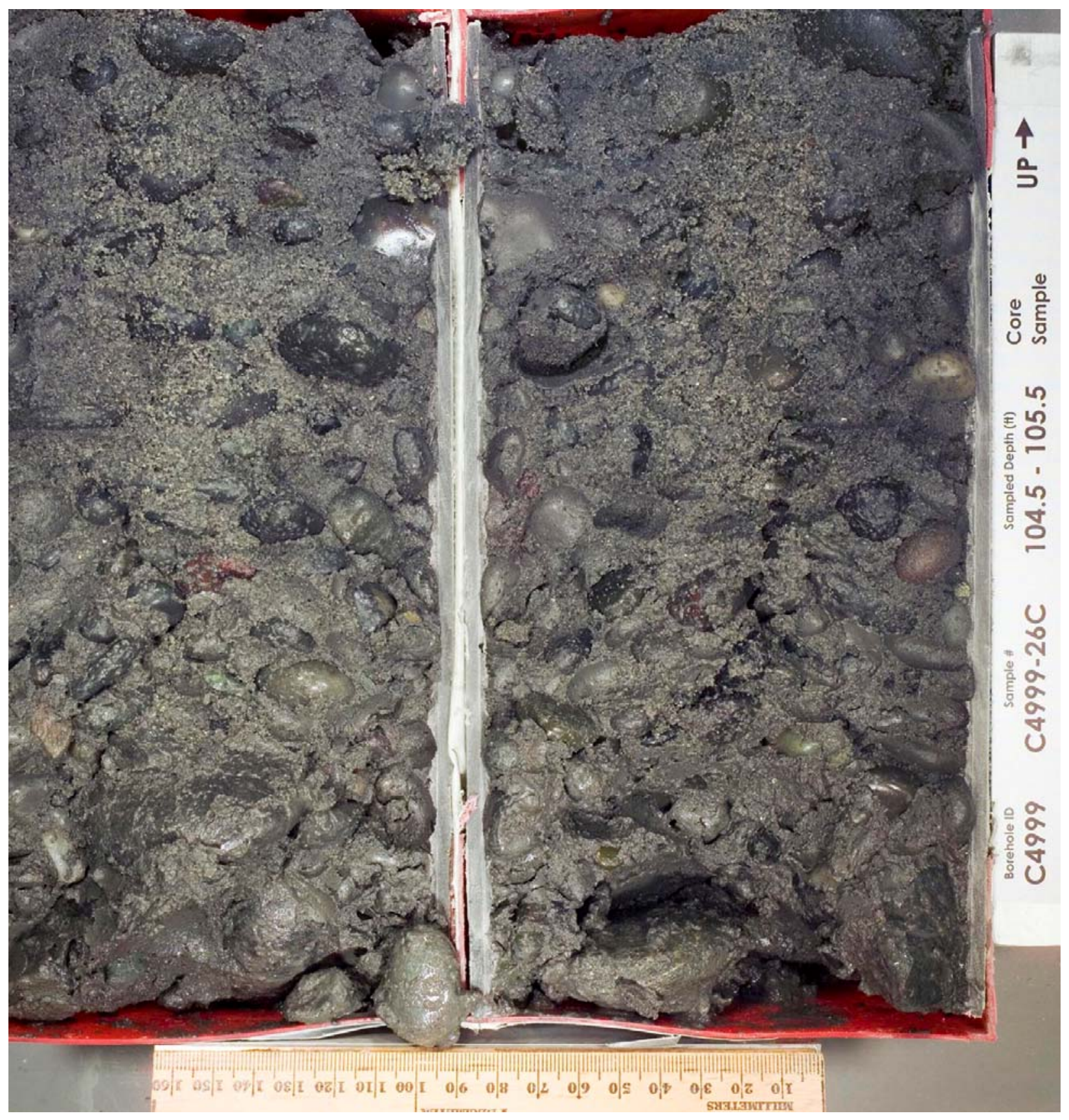

B.151 


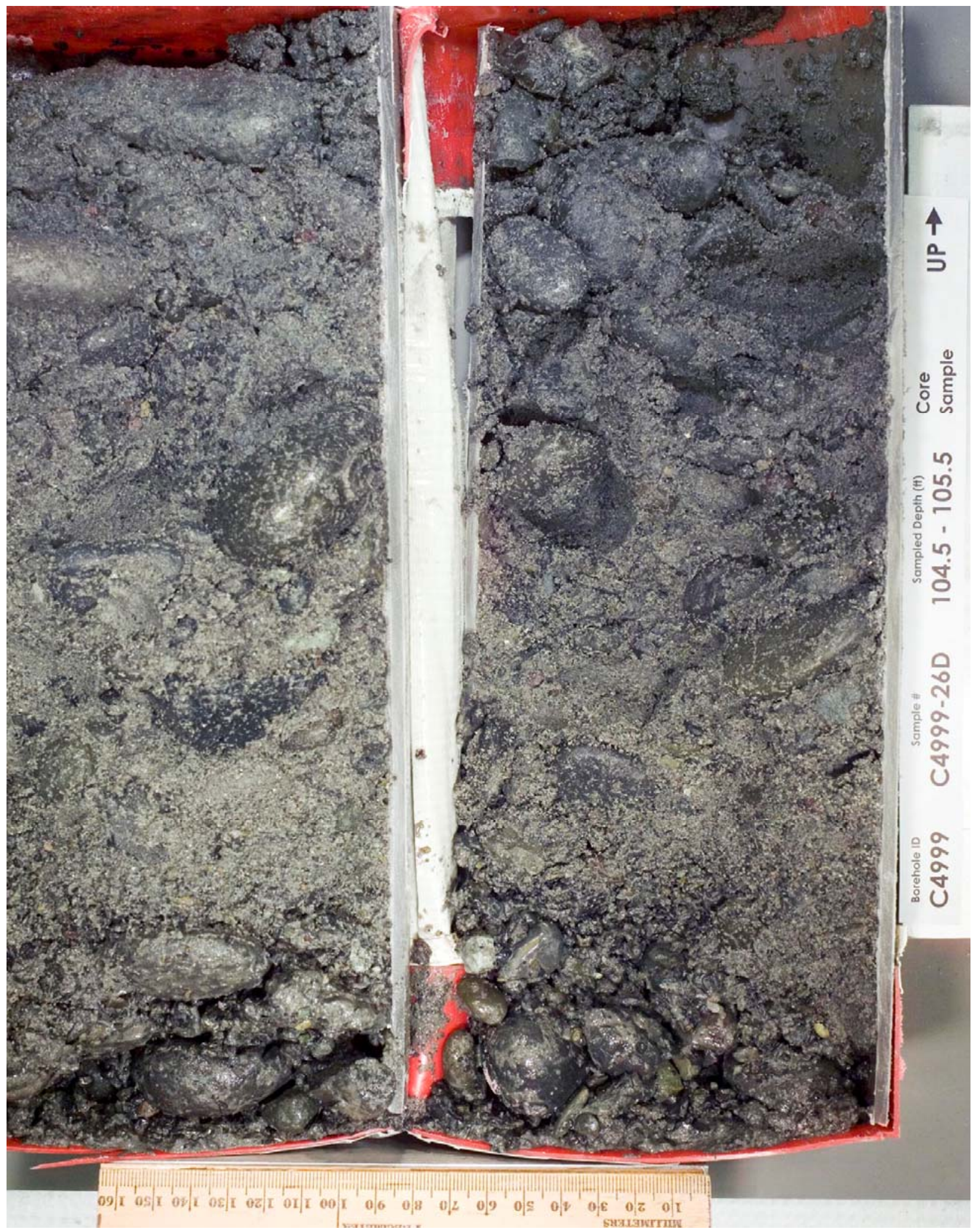




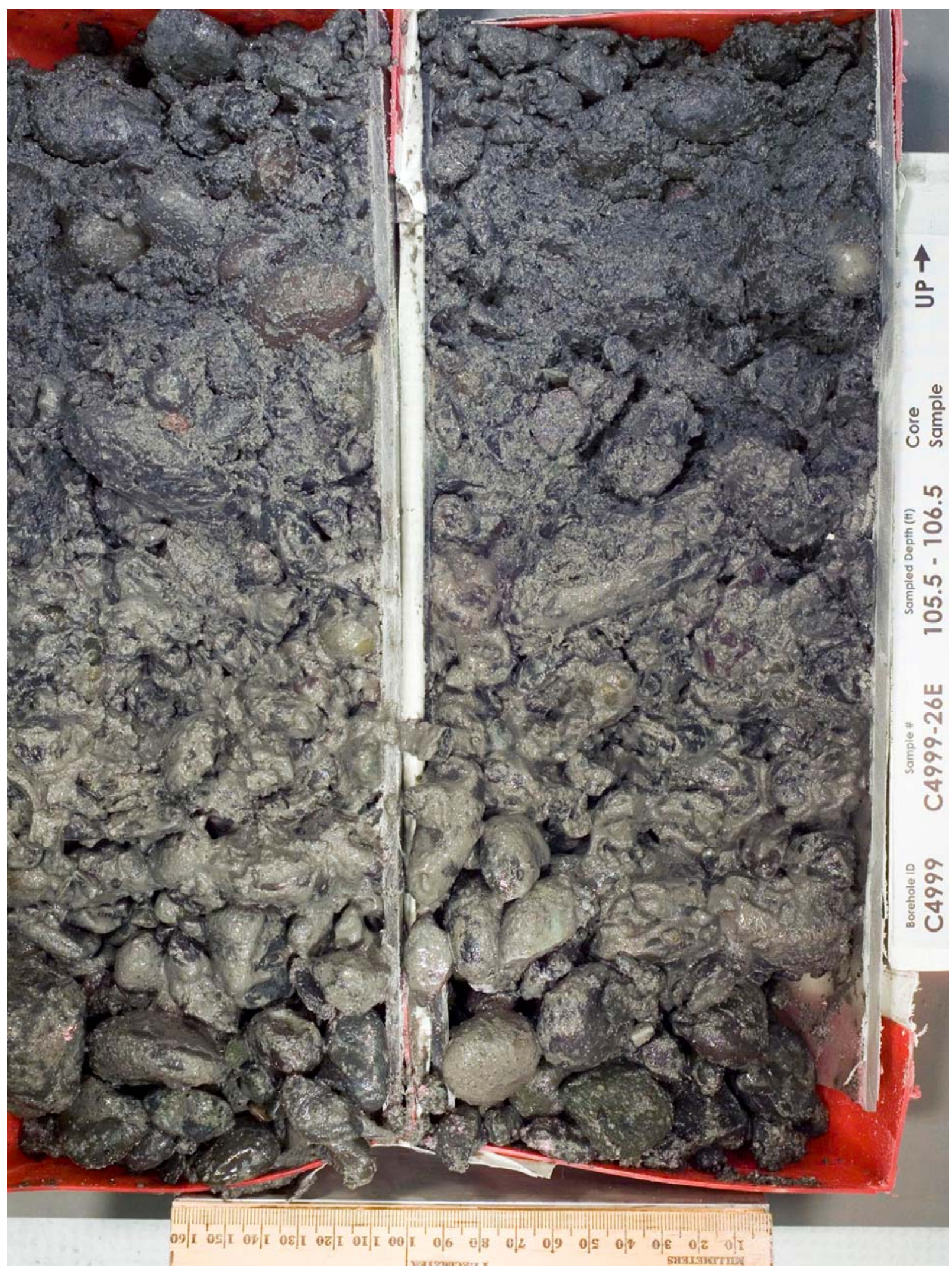




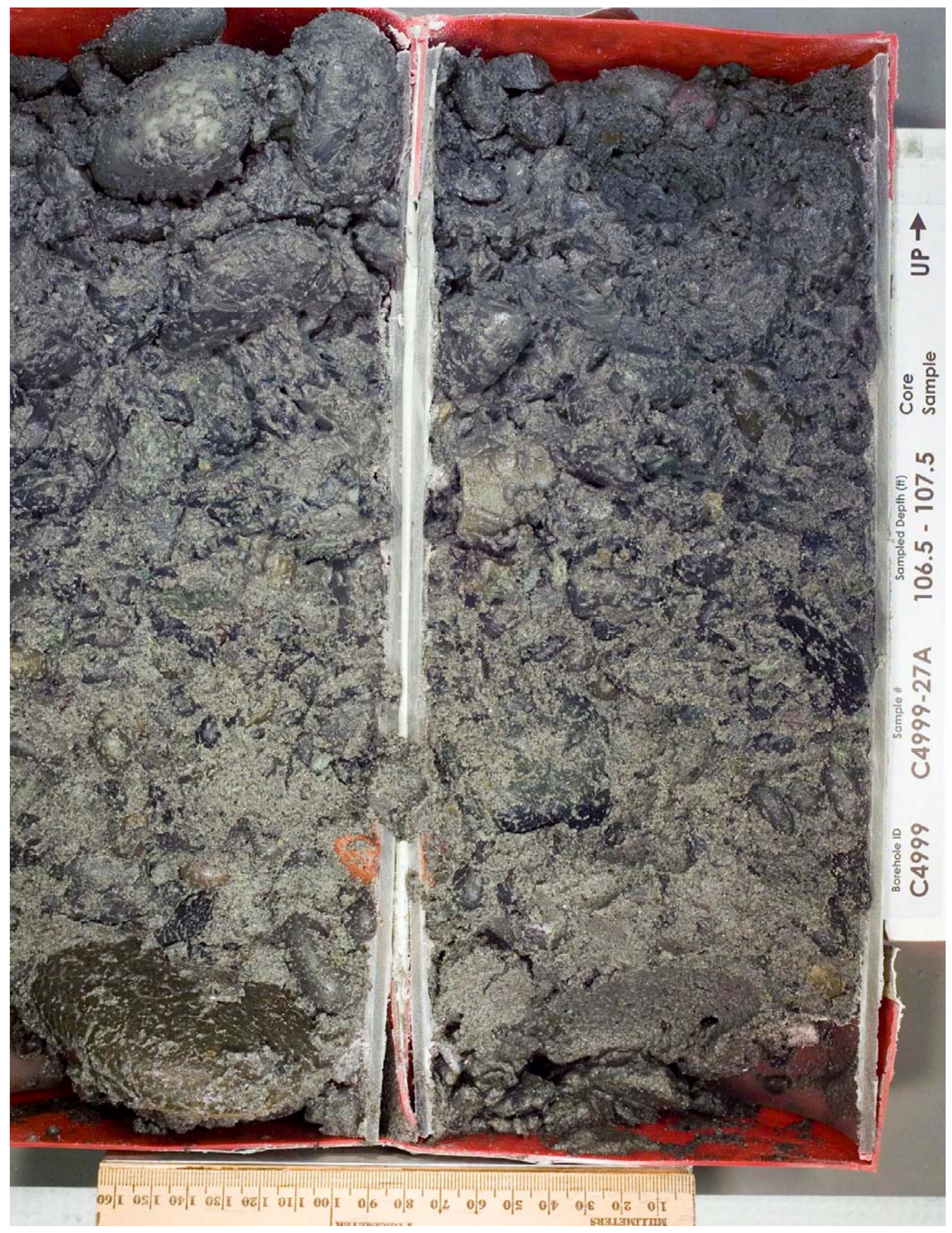




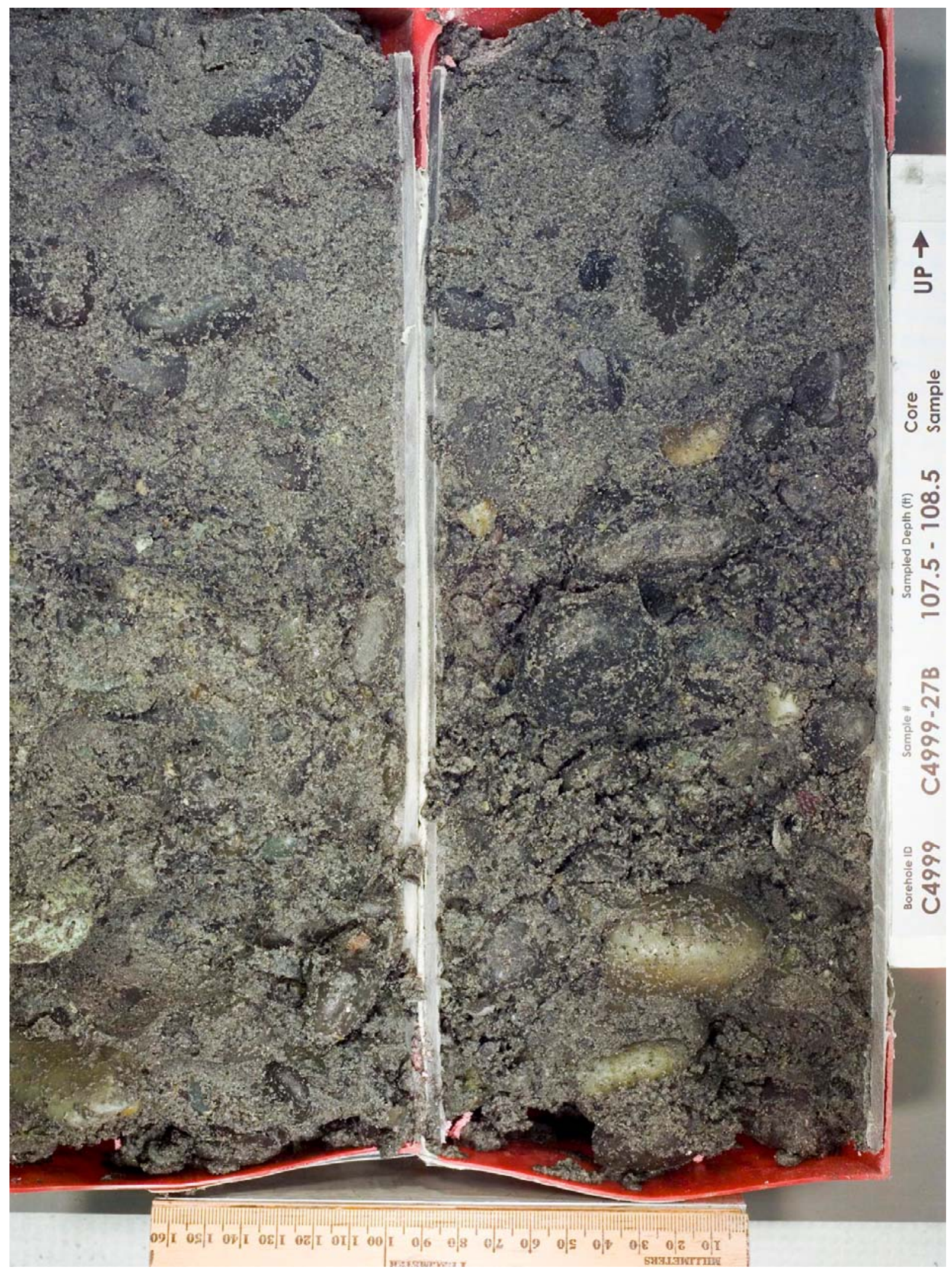




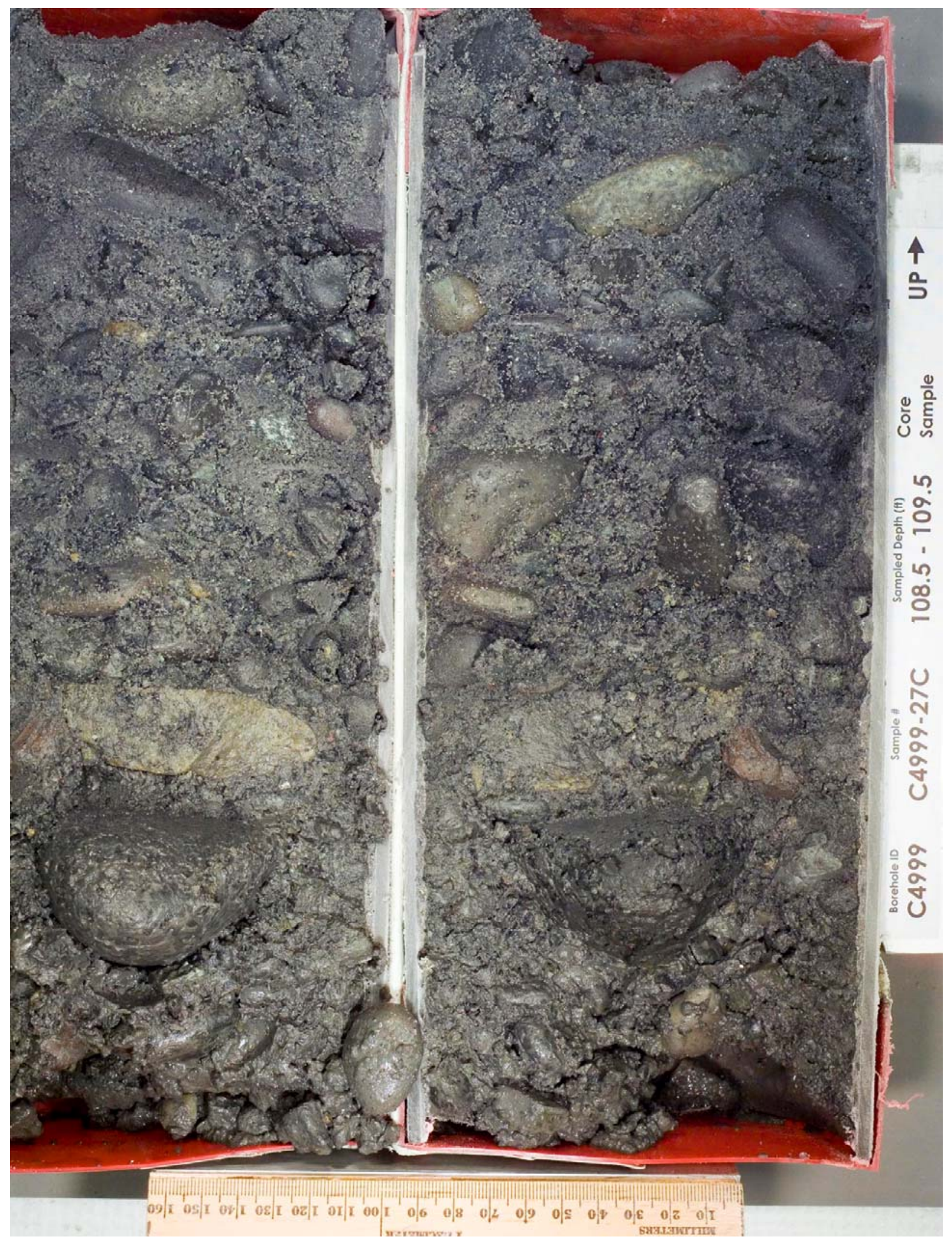




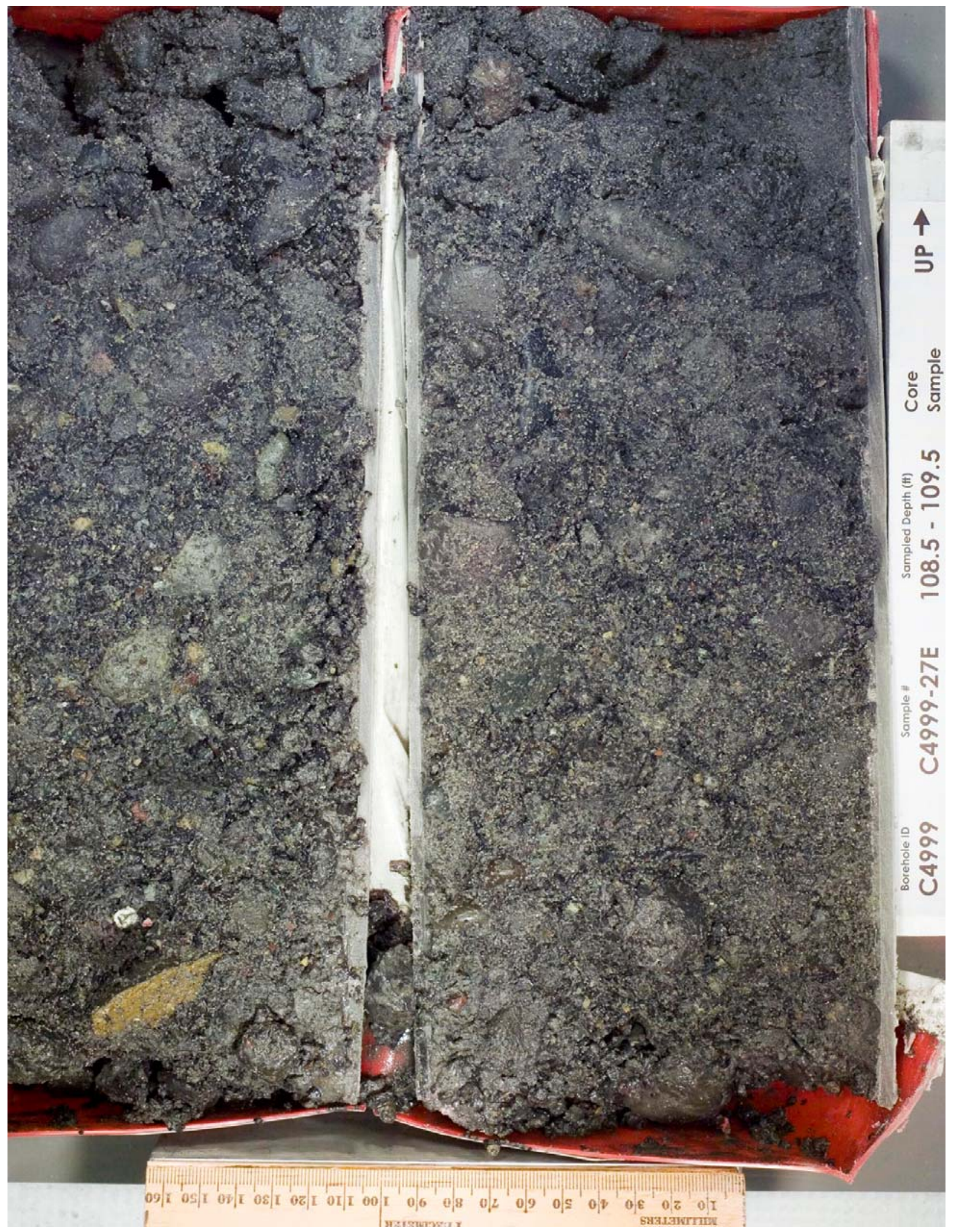




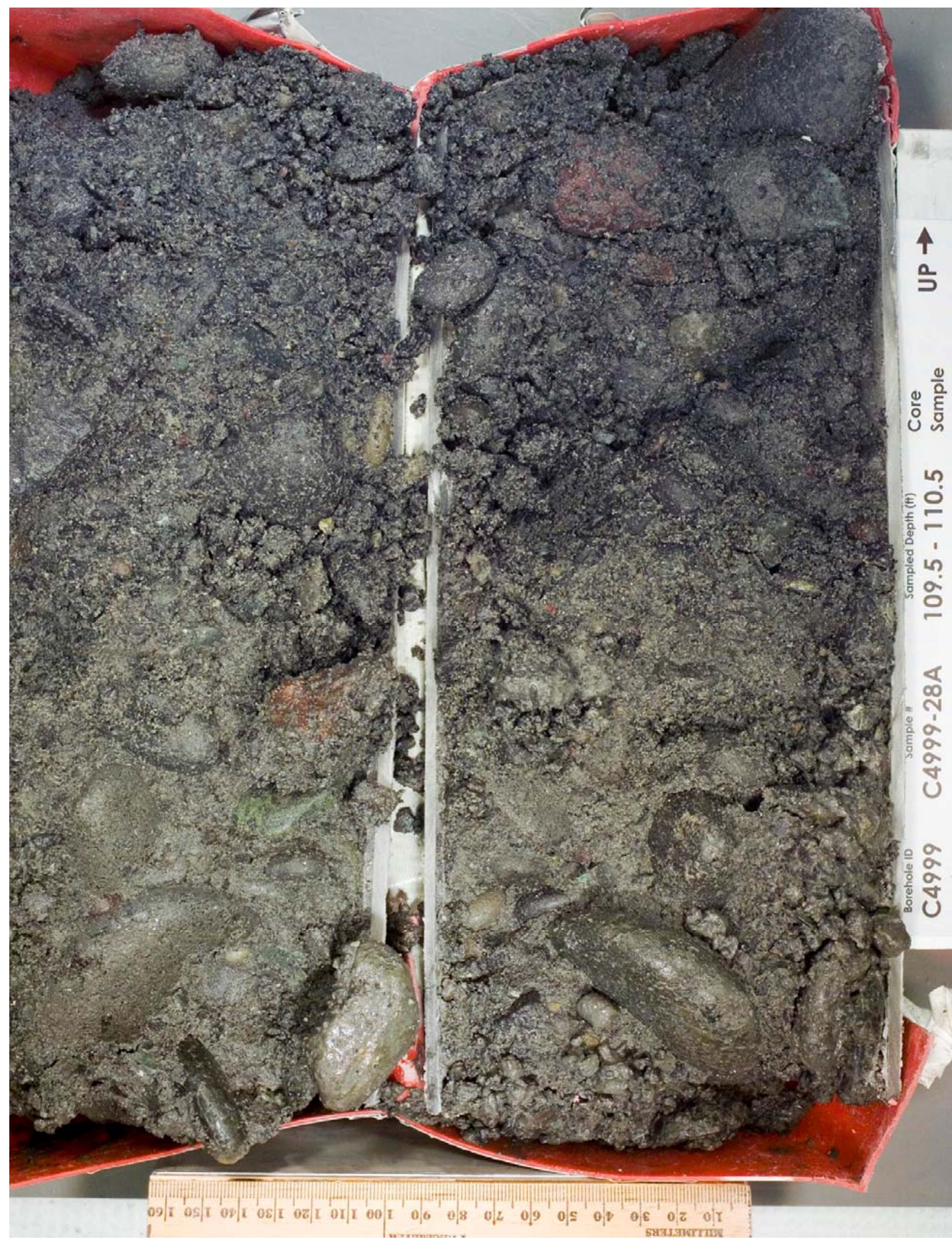




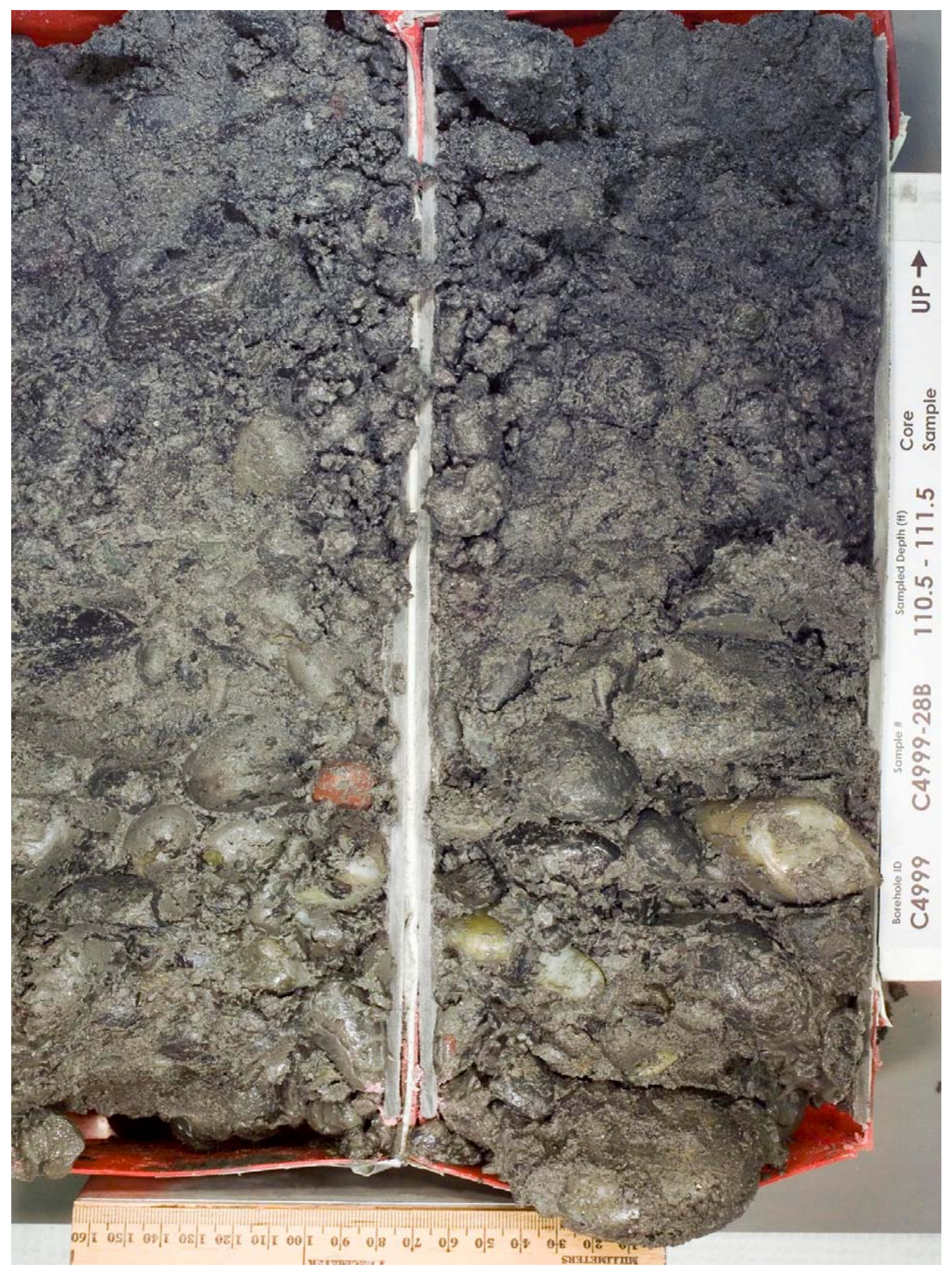




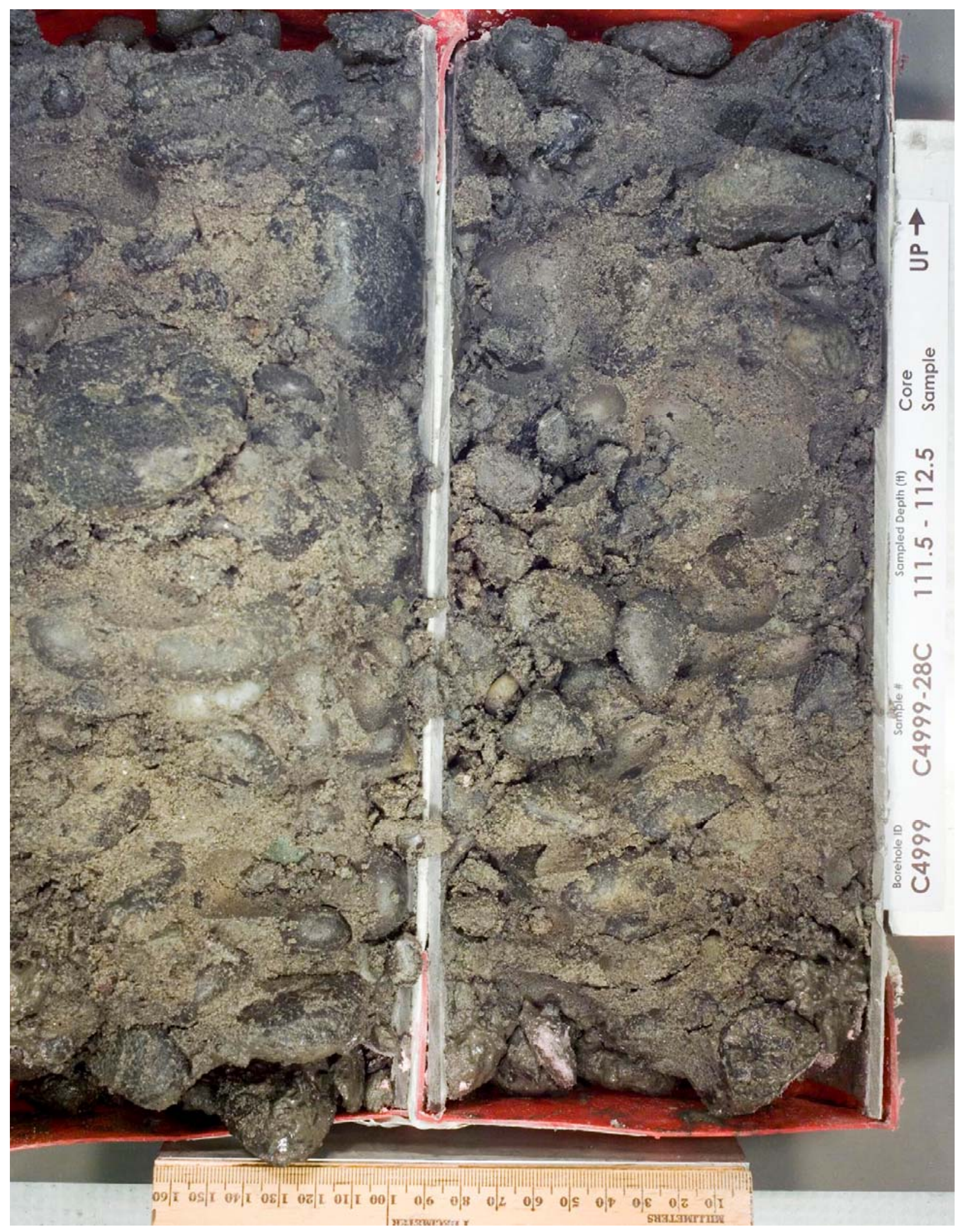




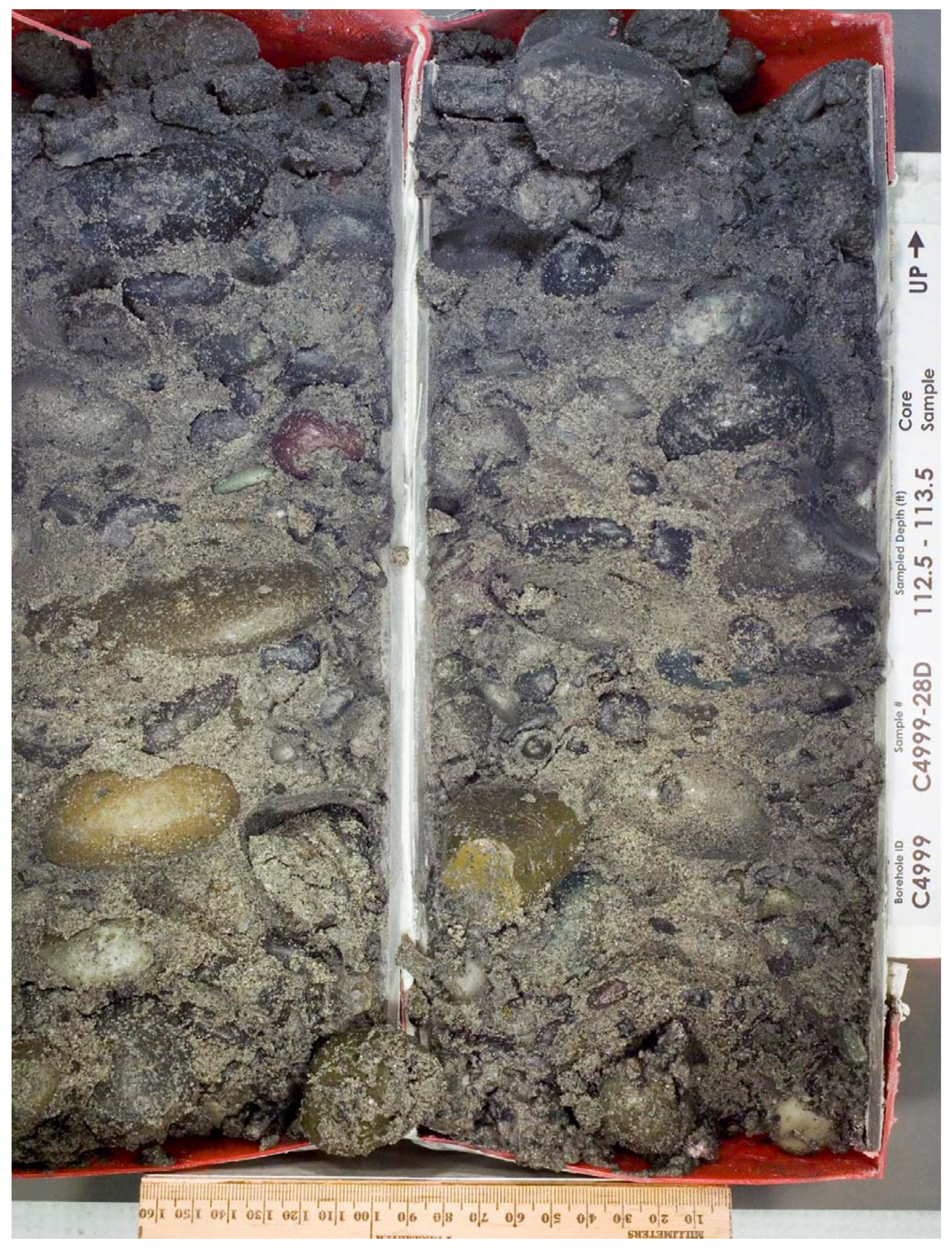




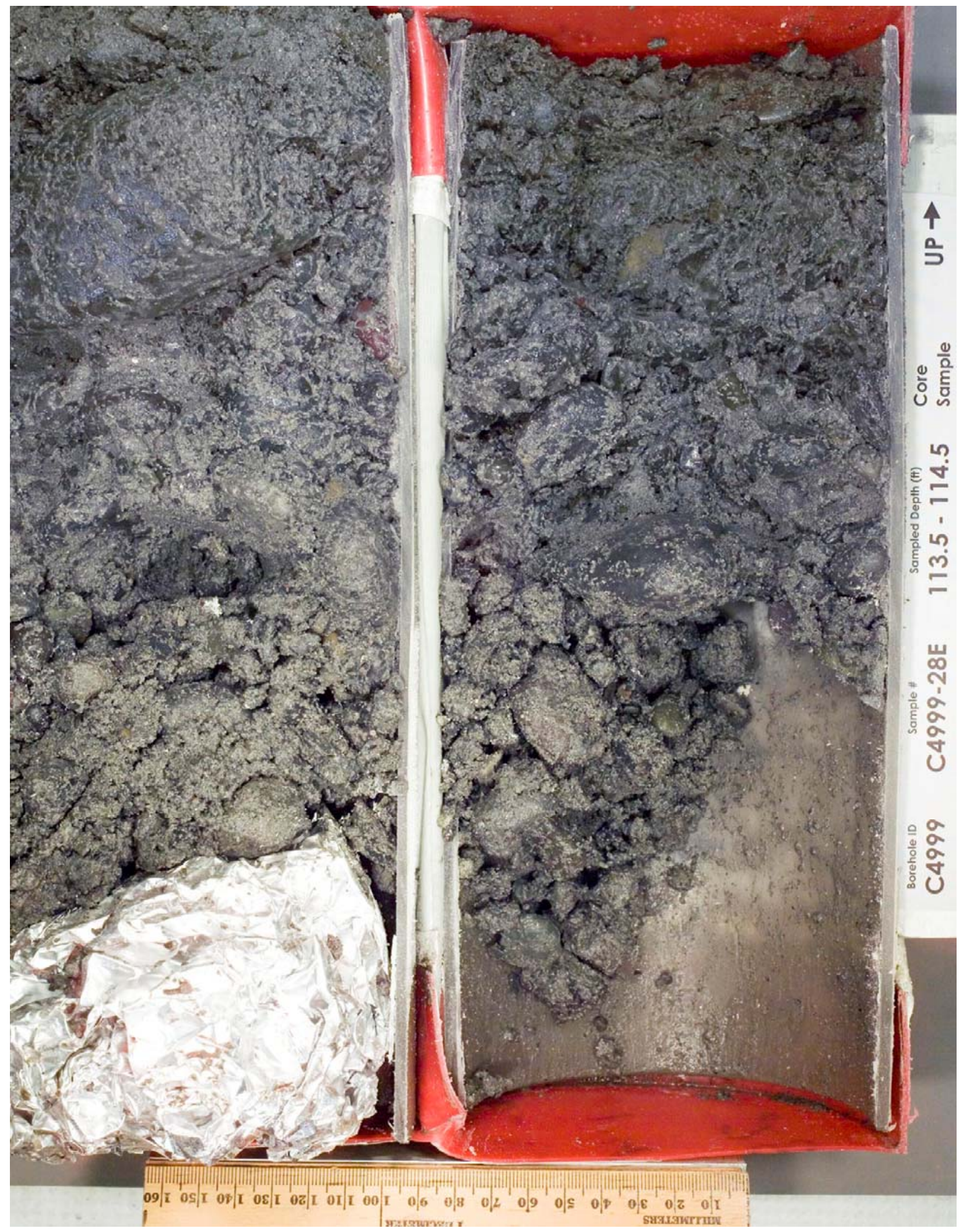




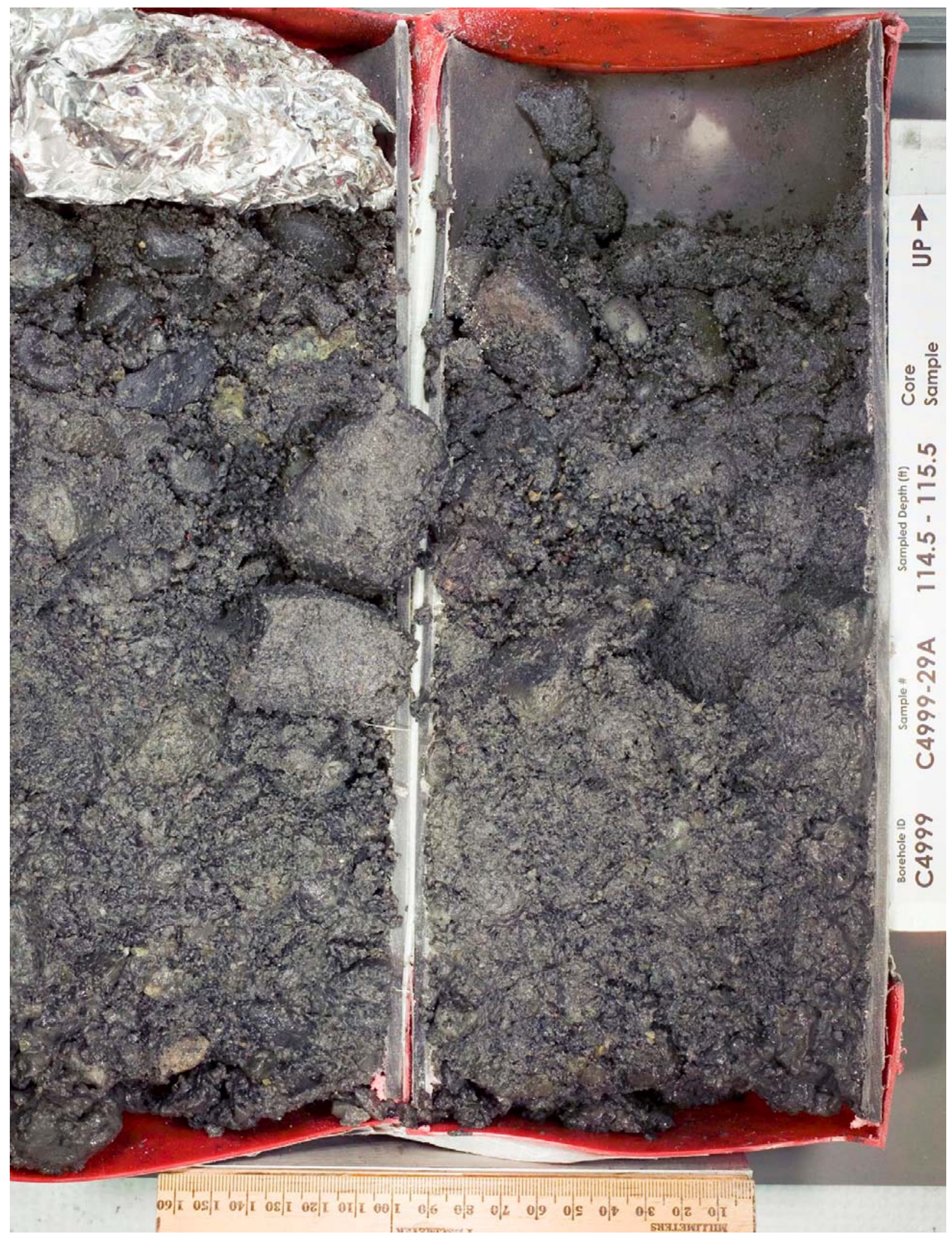




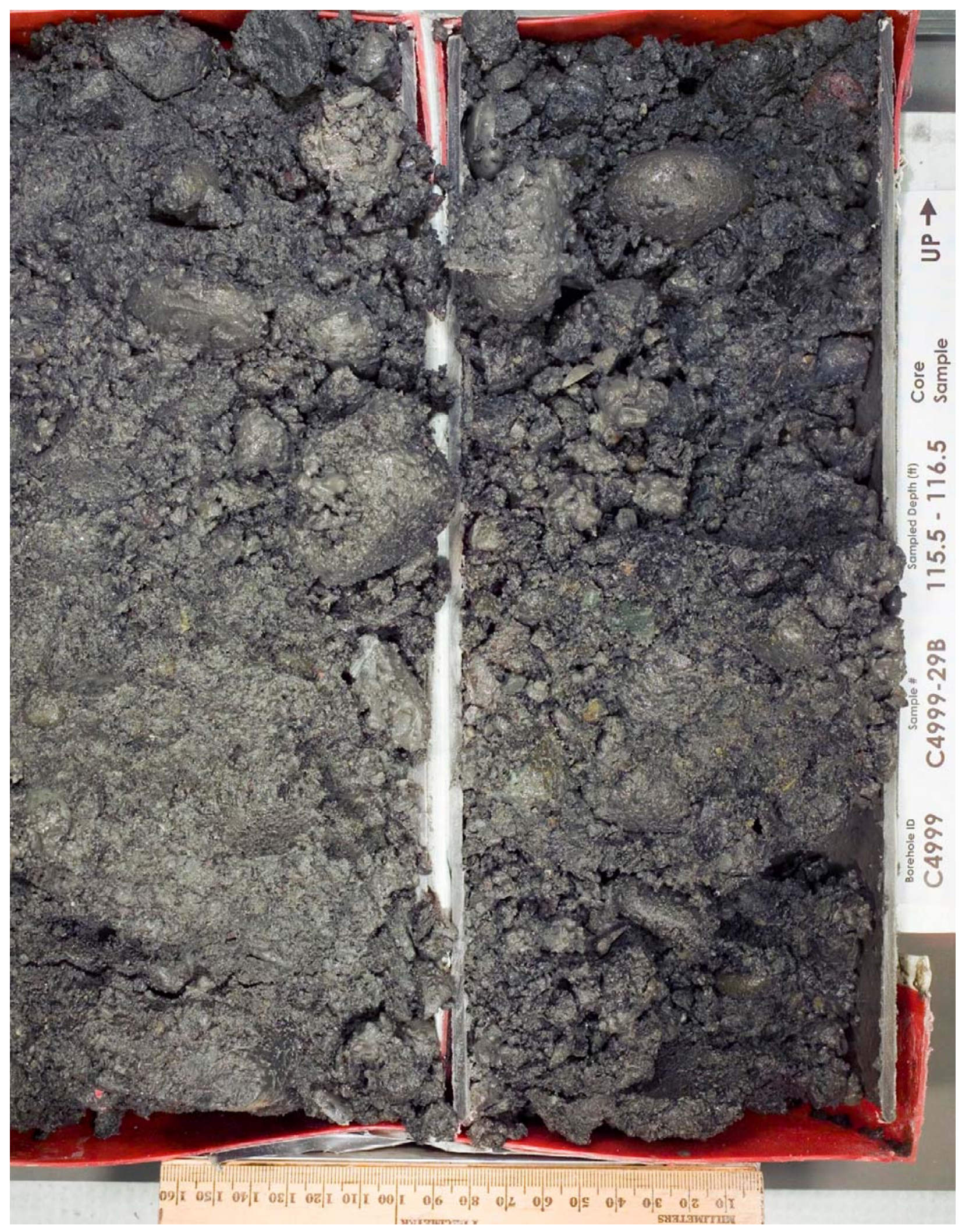




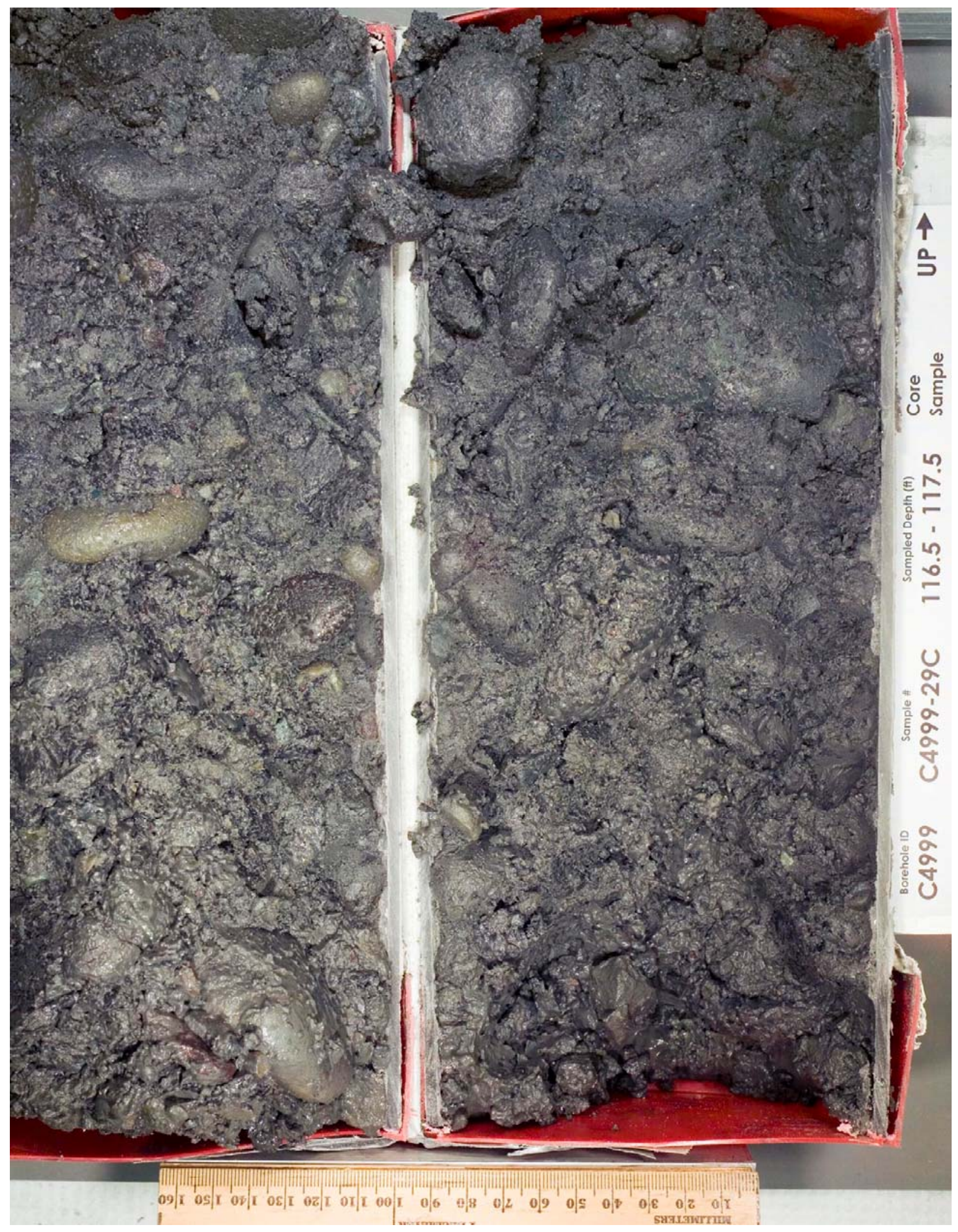




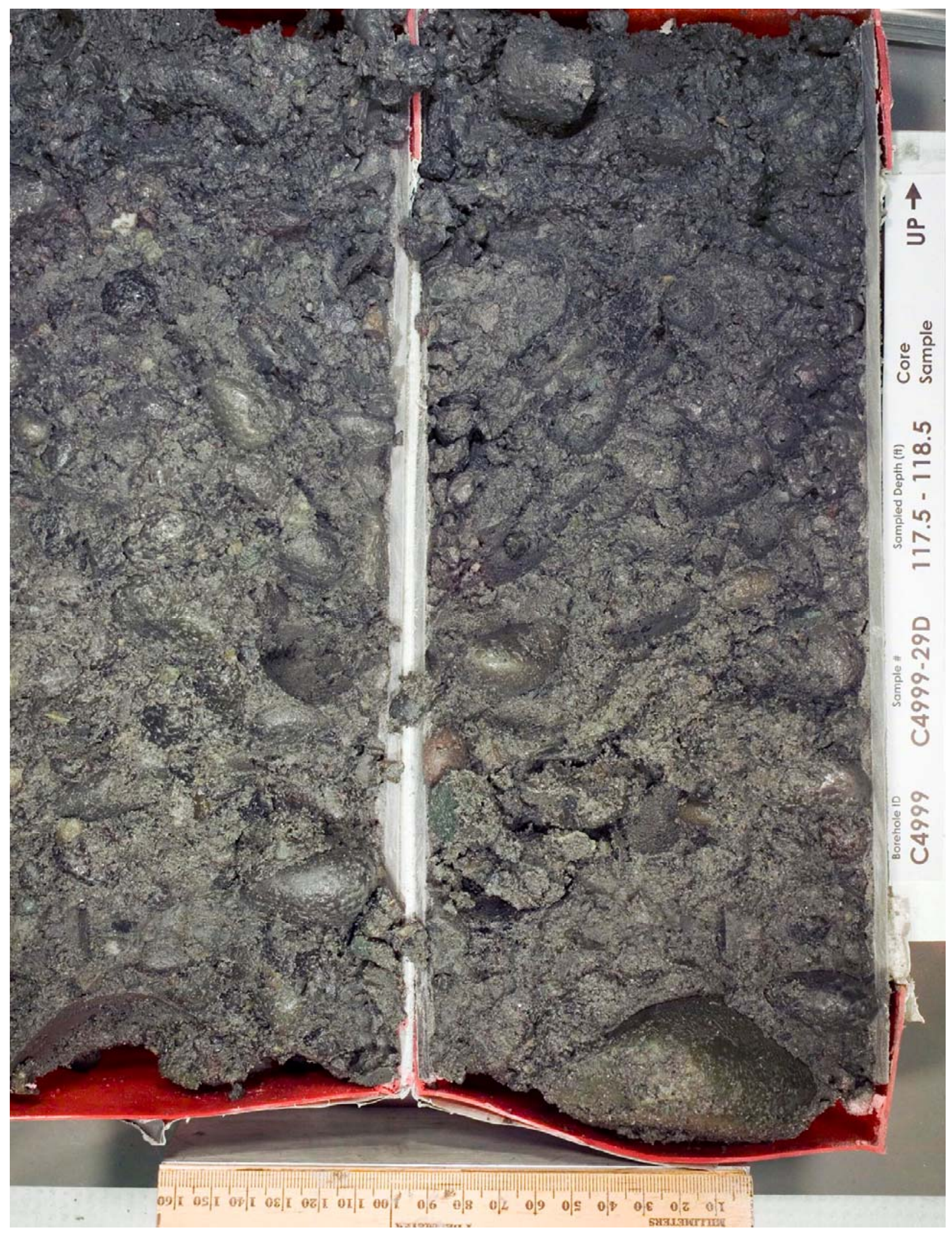




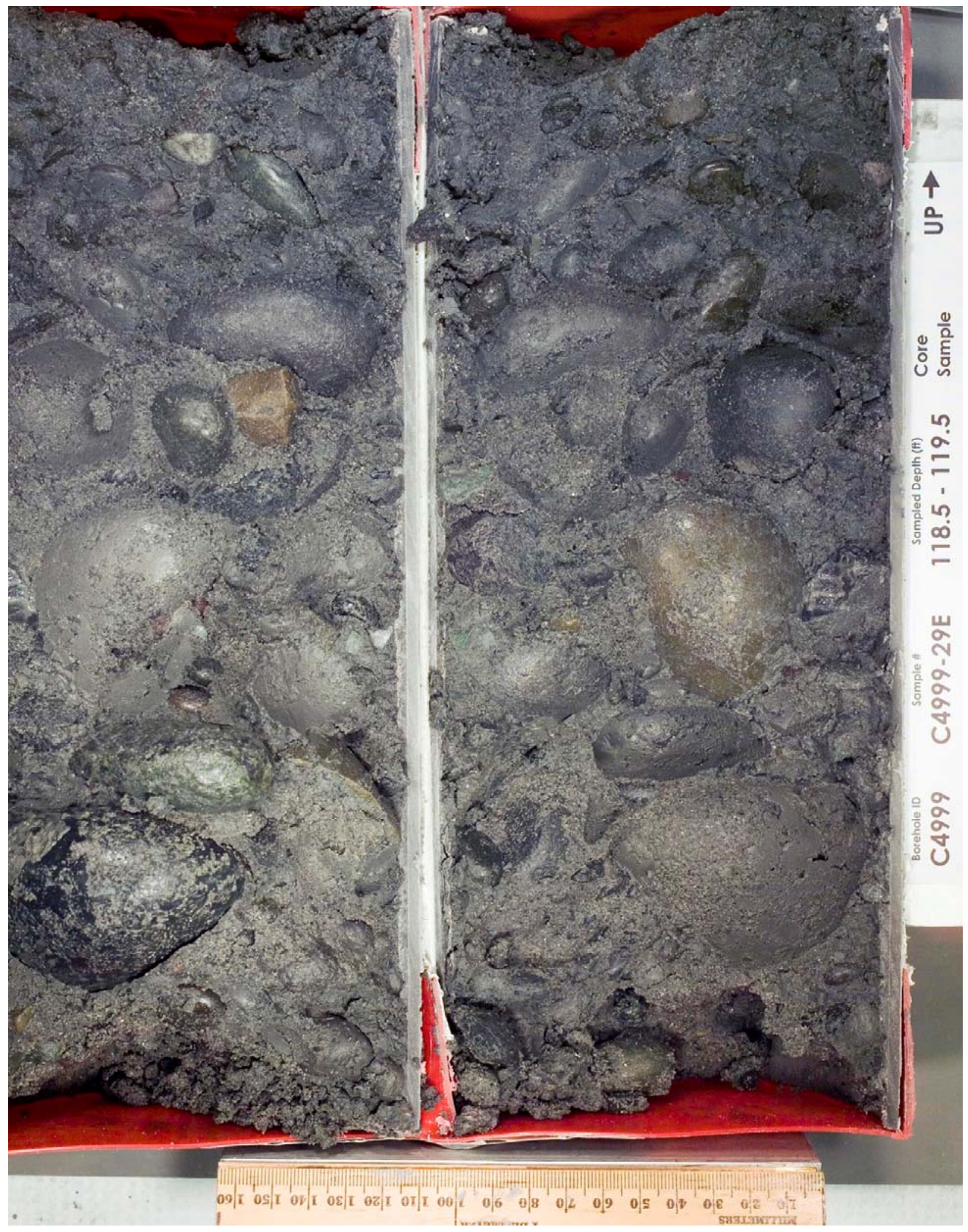




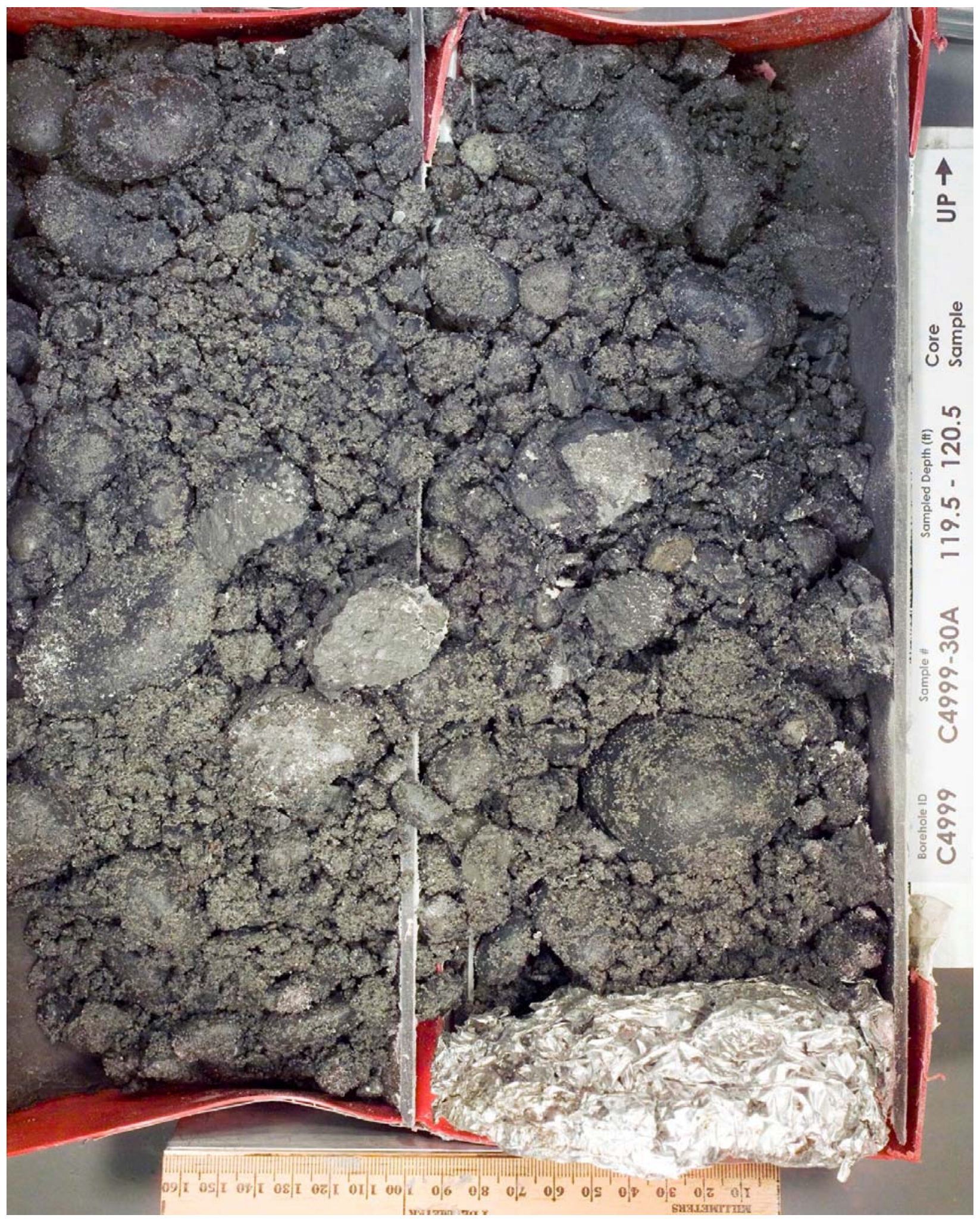




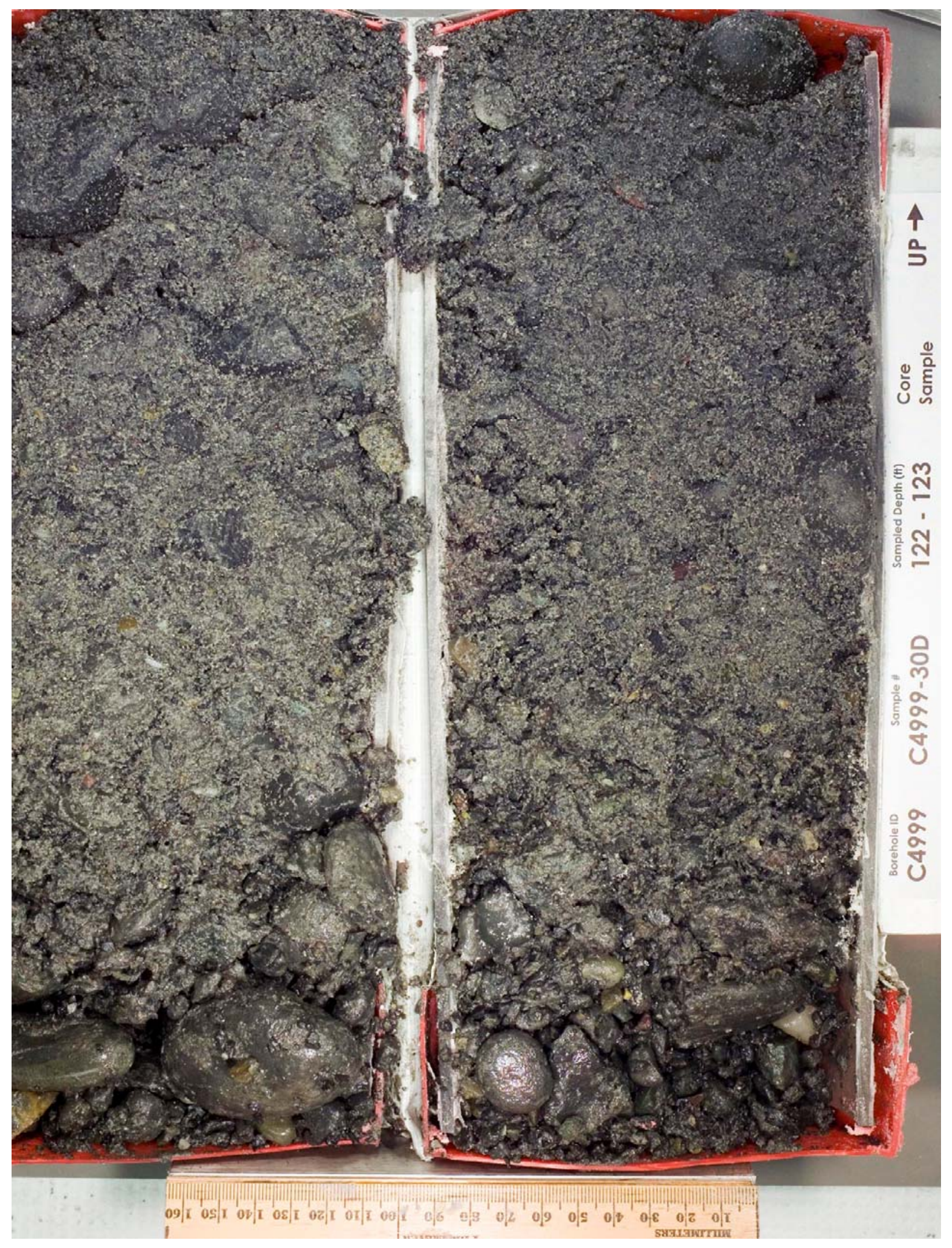




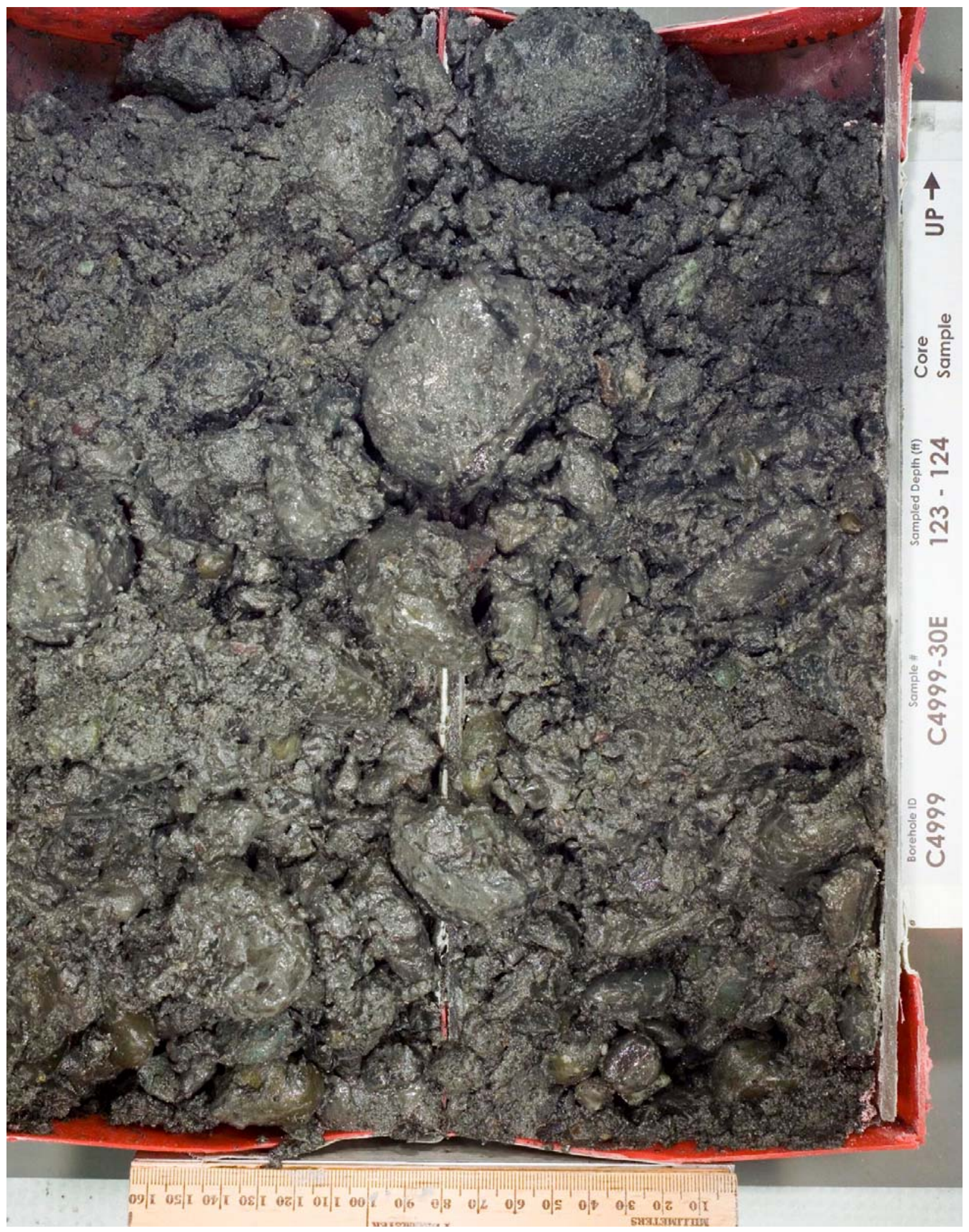




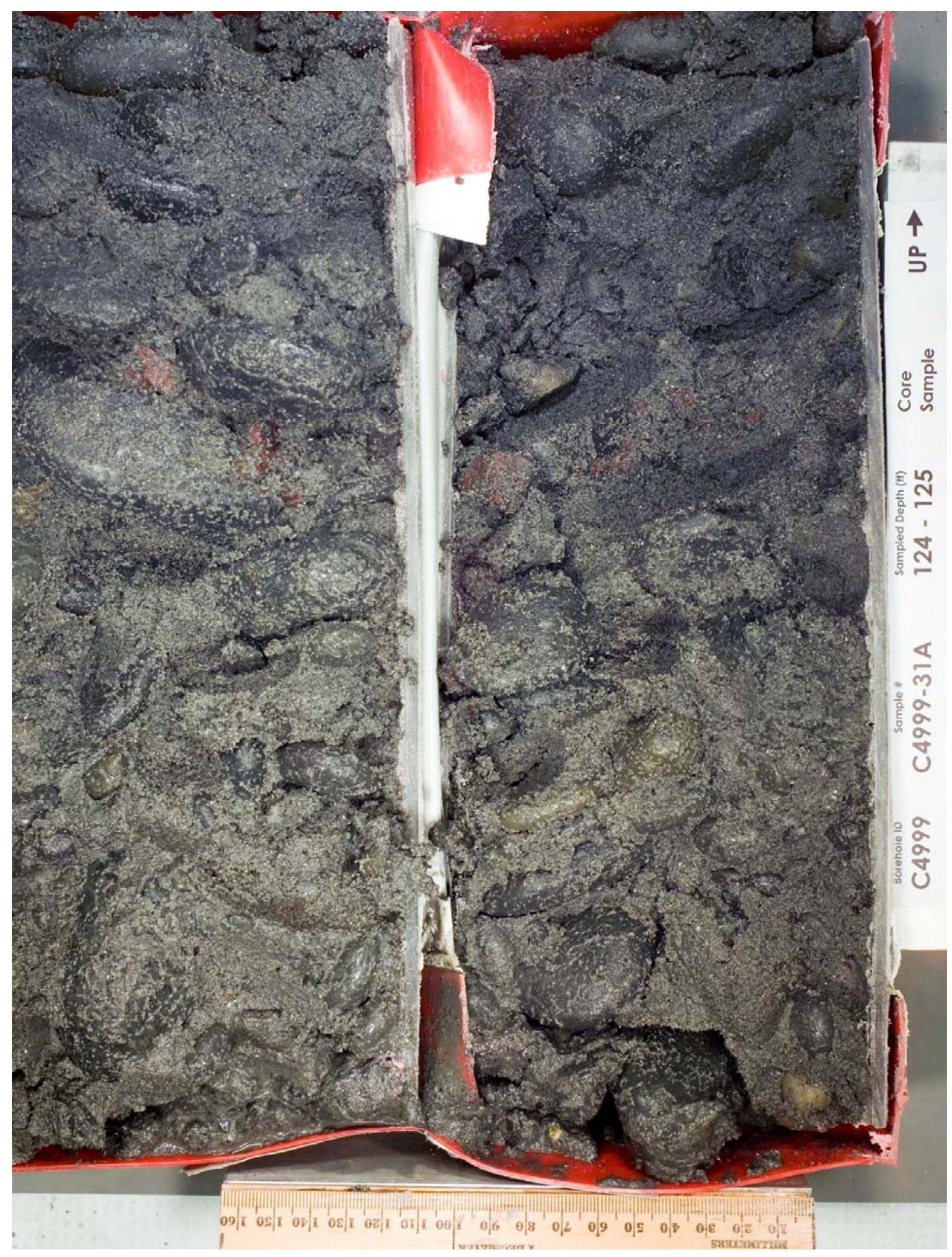




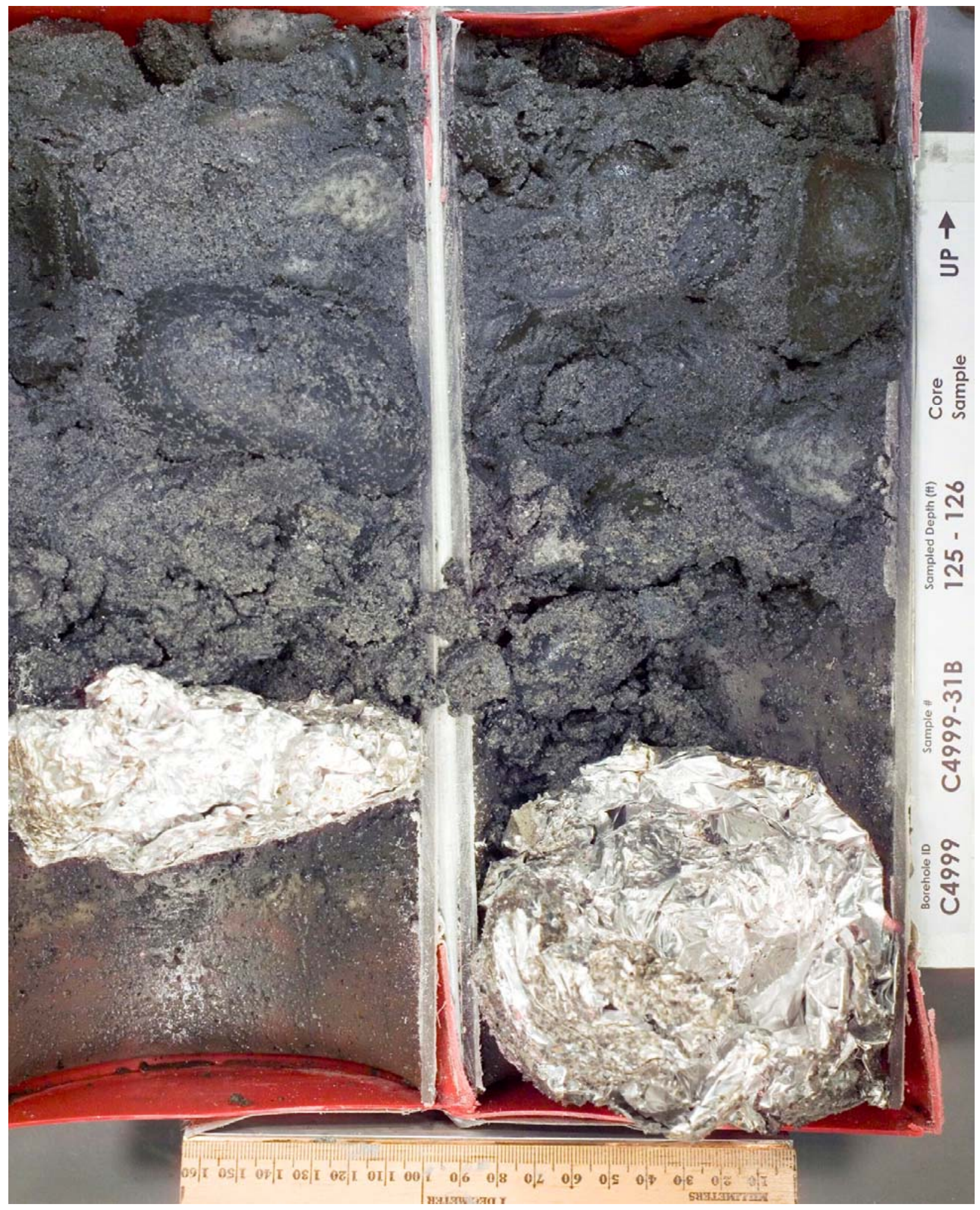




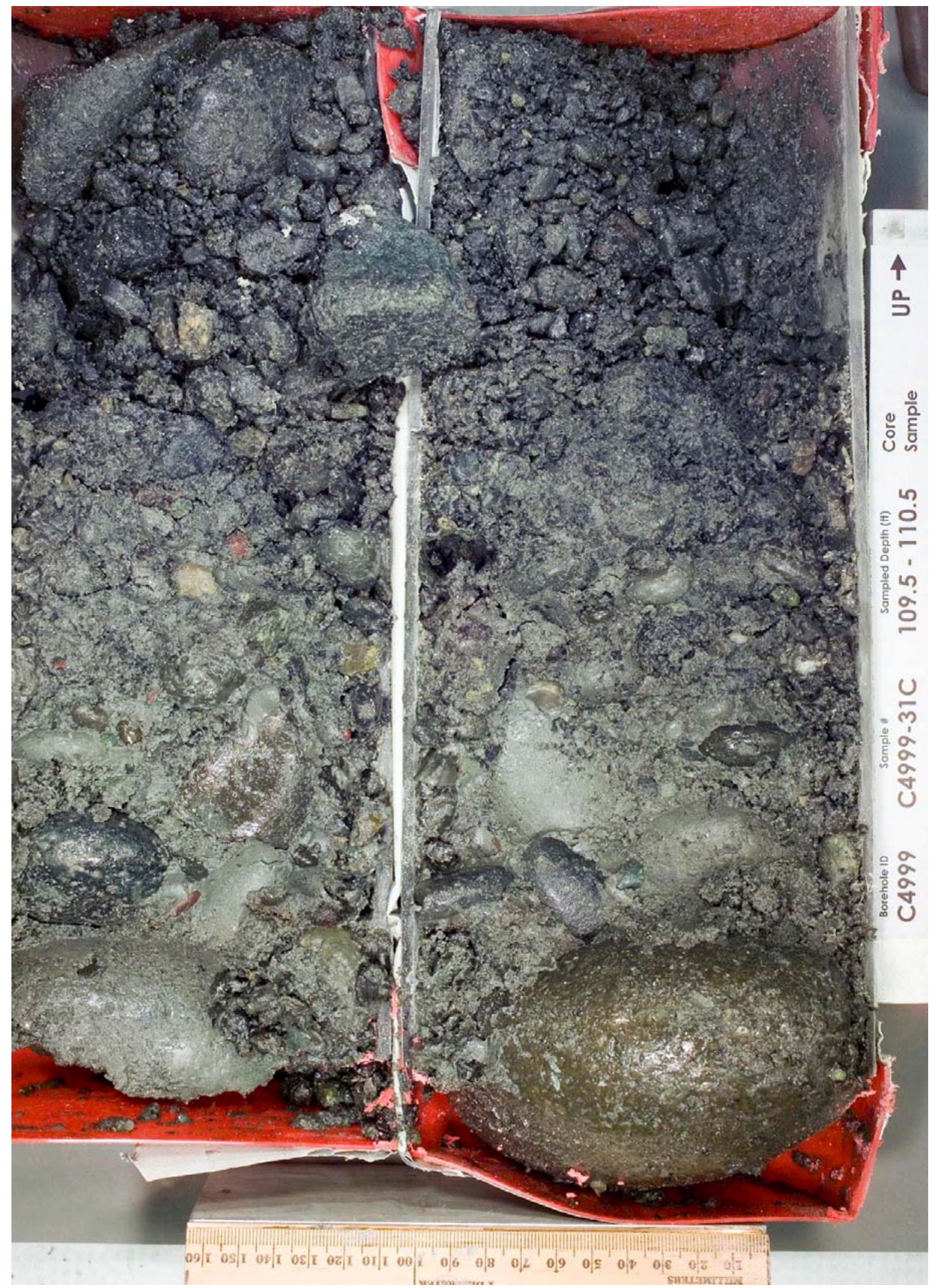




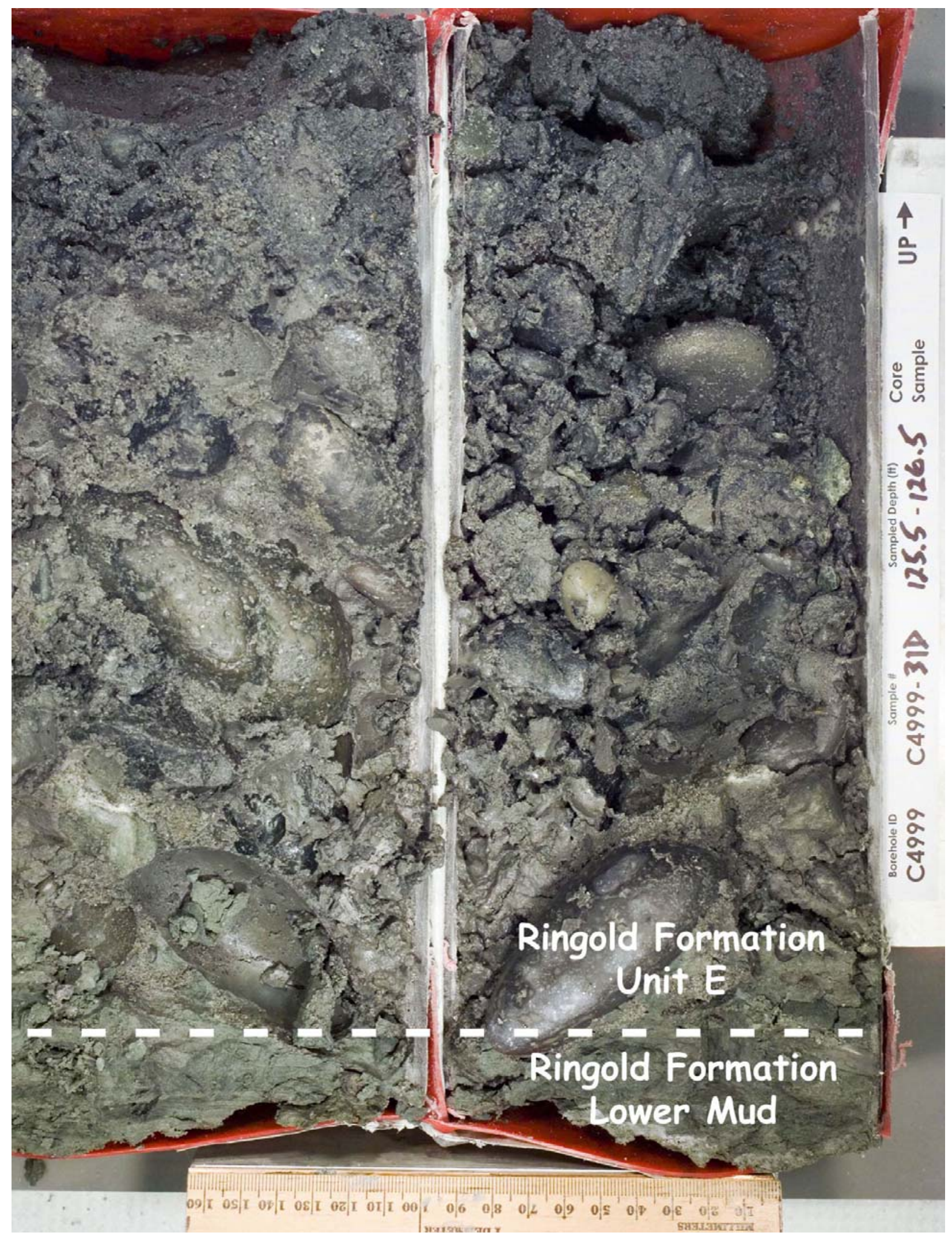




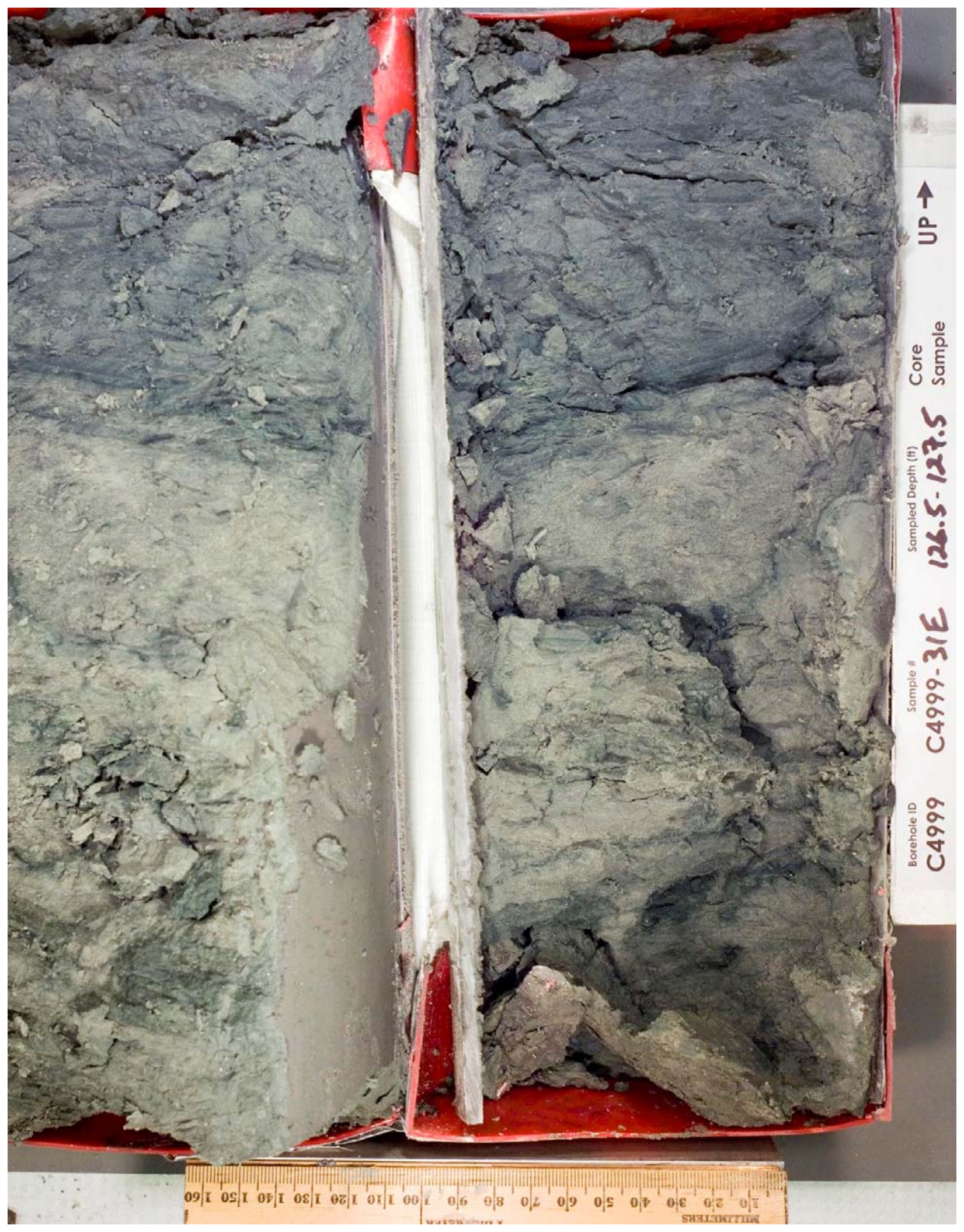




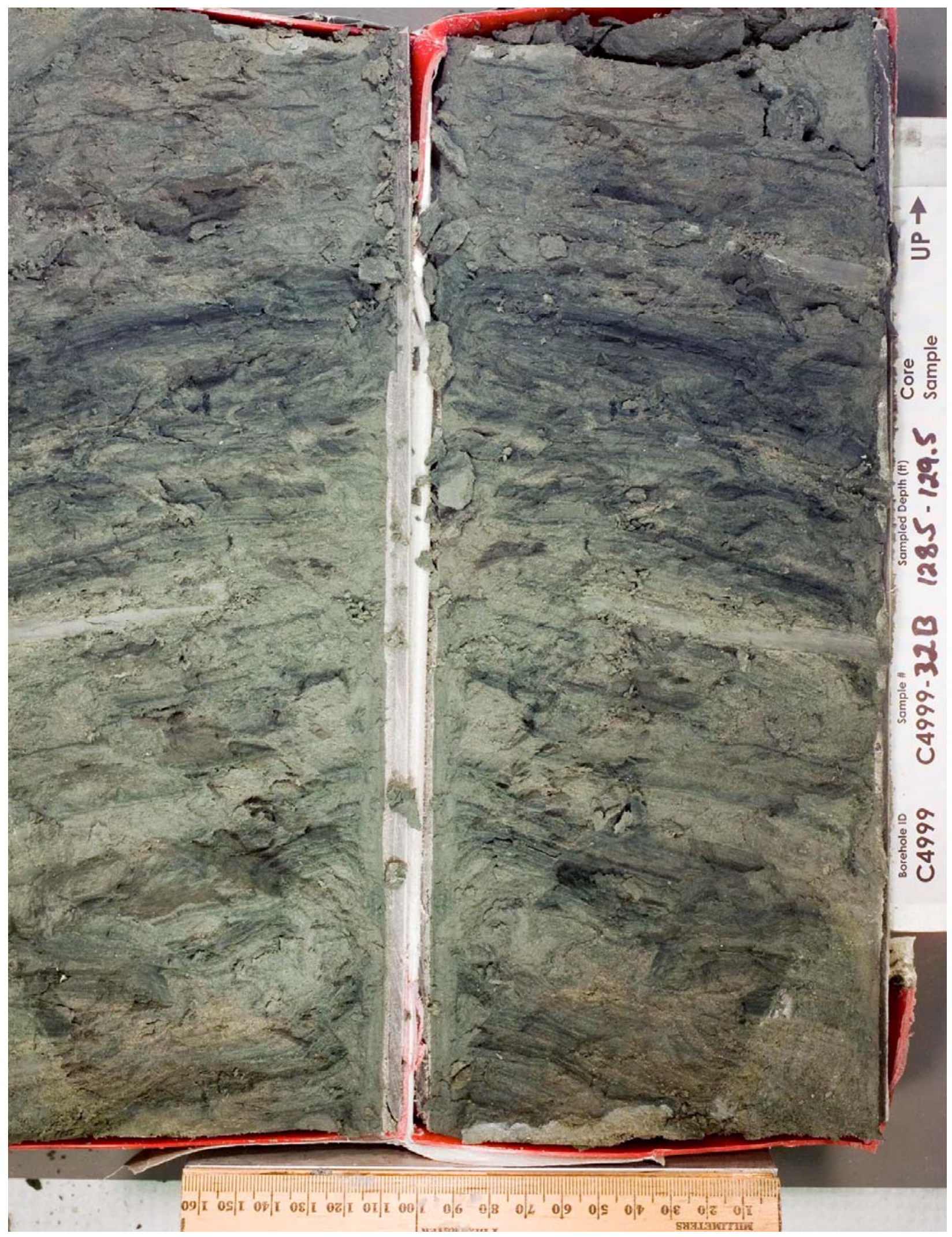




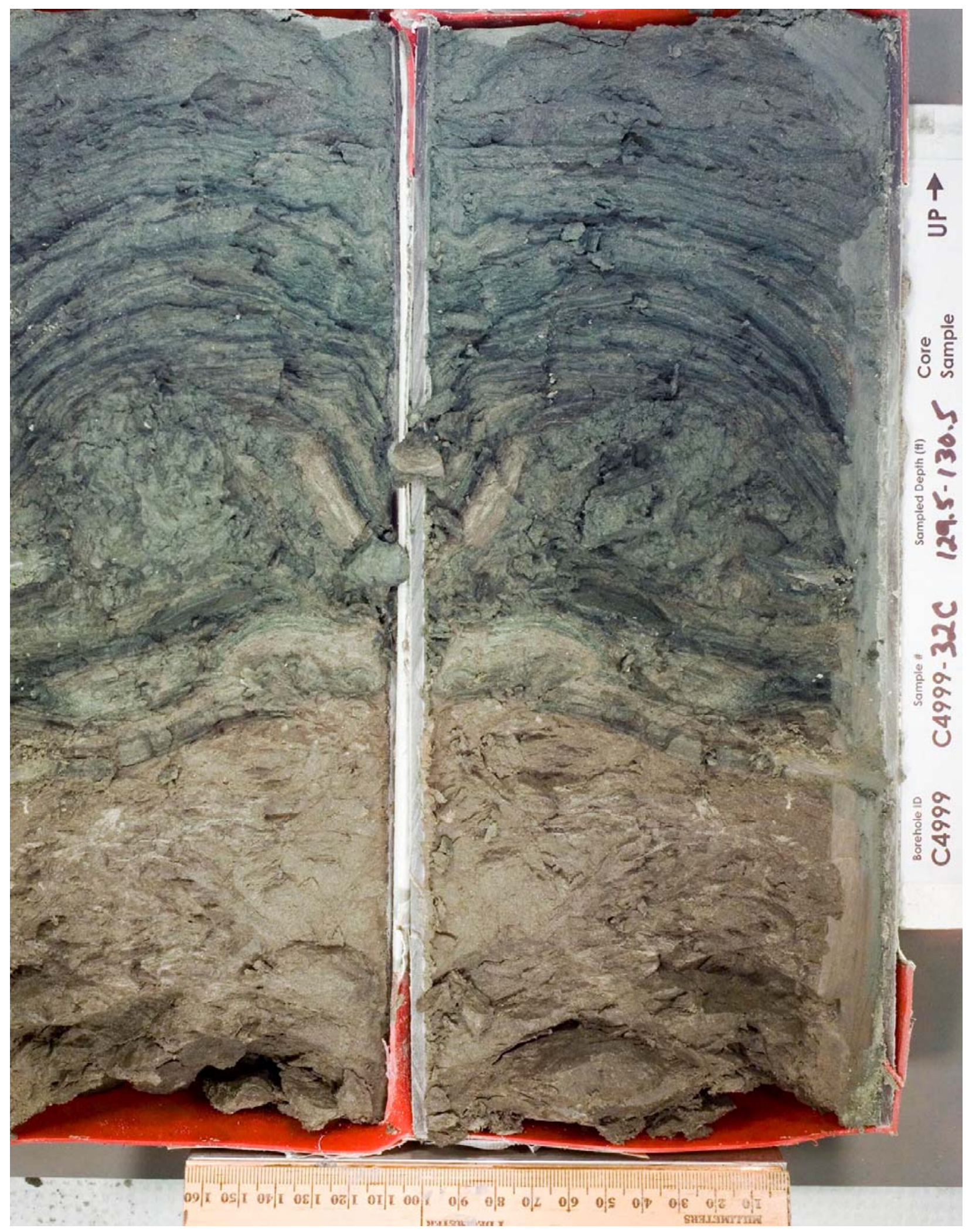




\section{Well C5000}

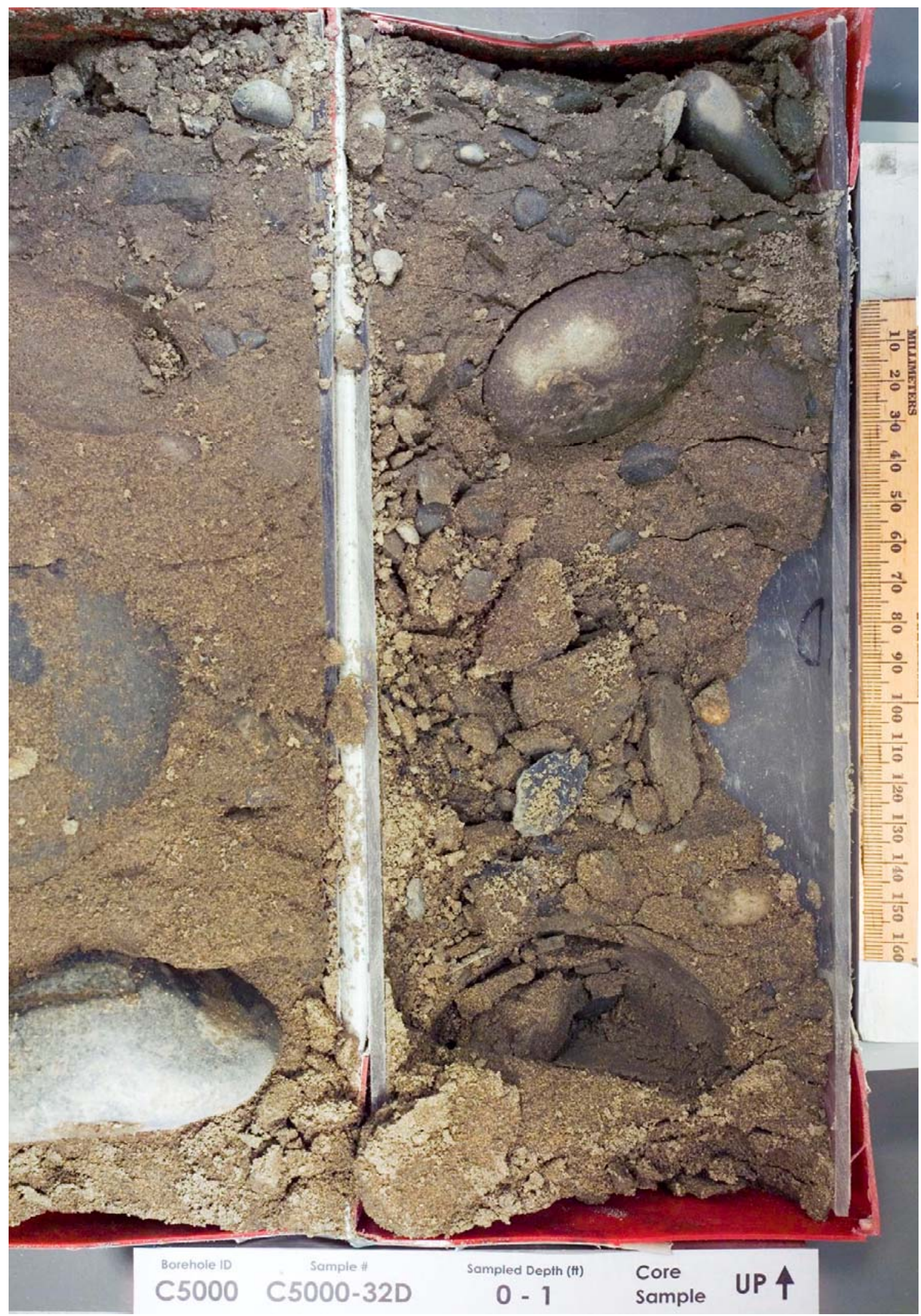




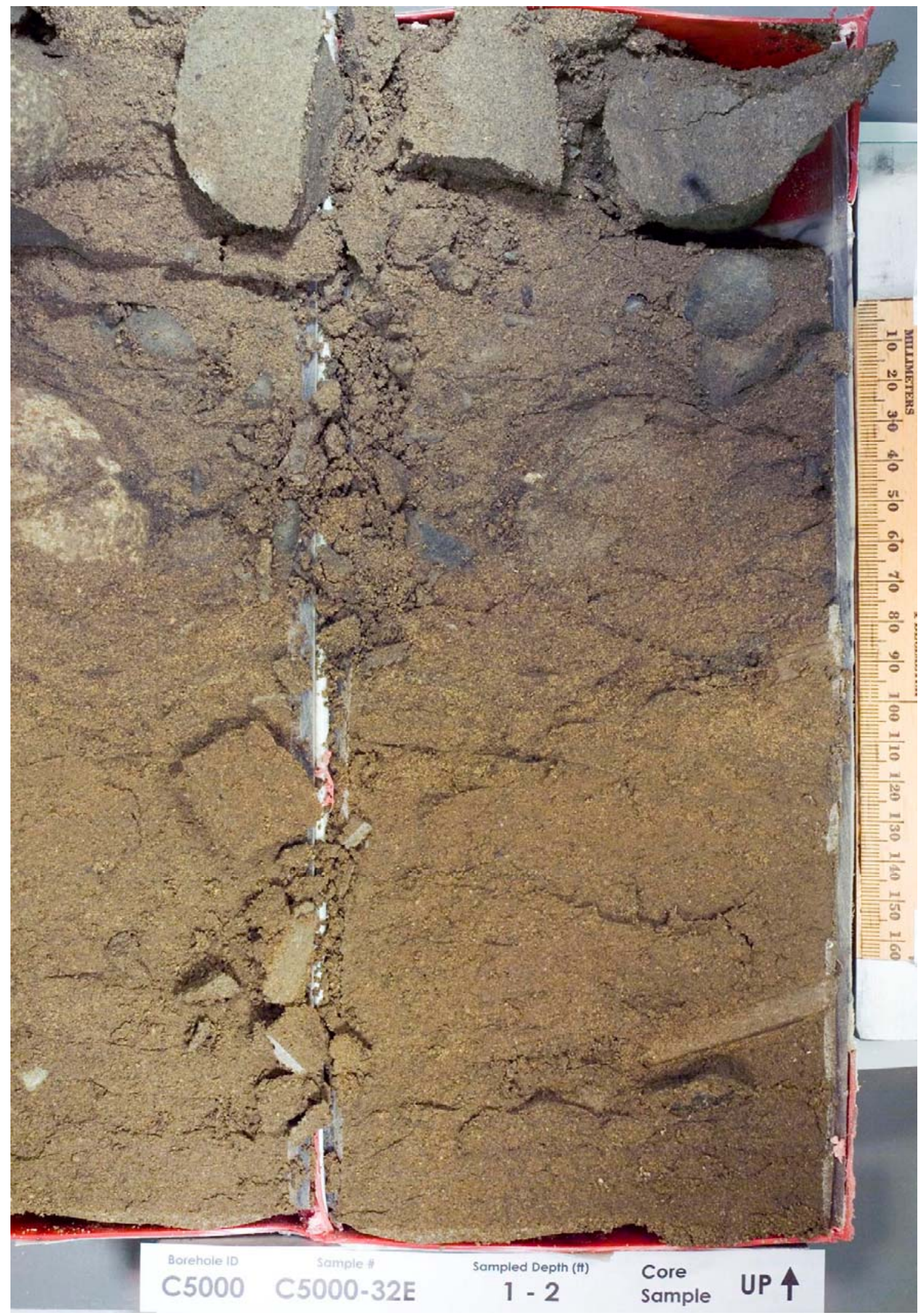

B.179 


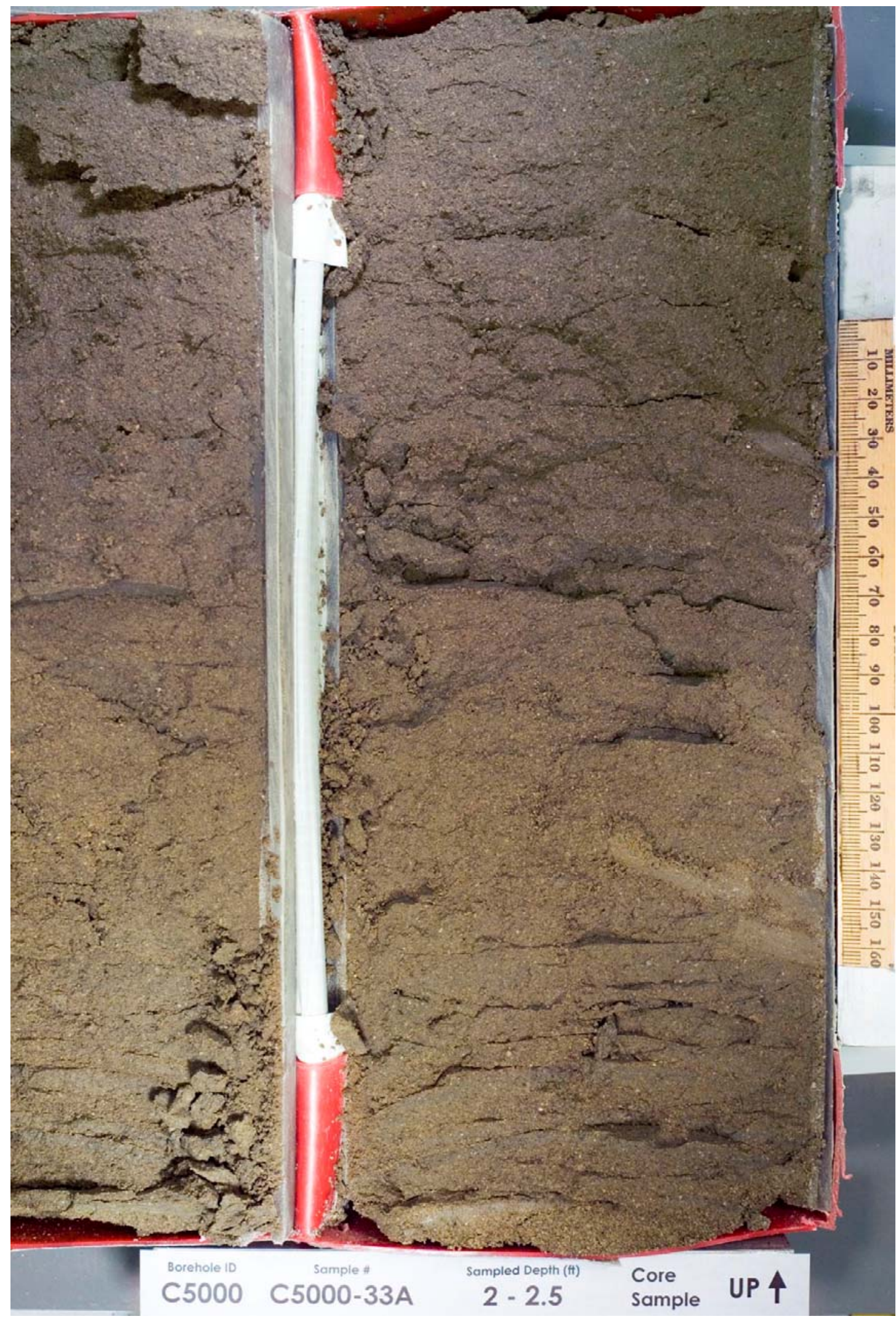

B.180 


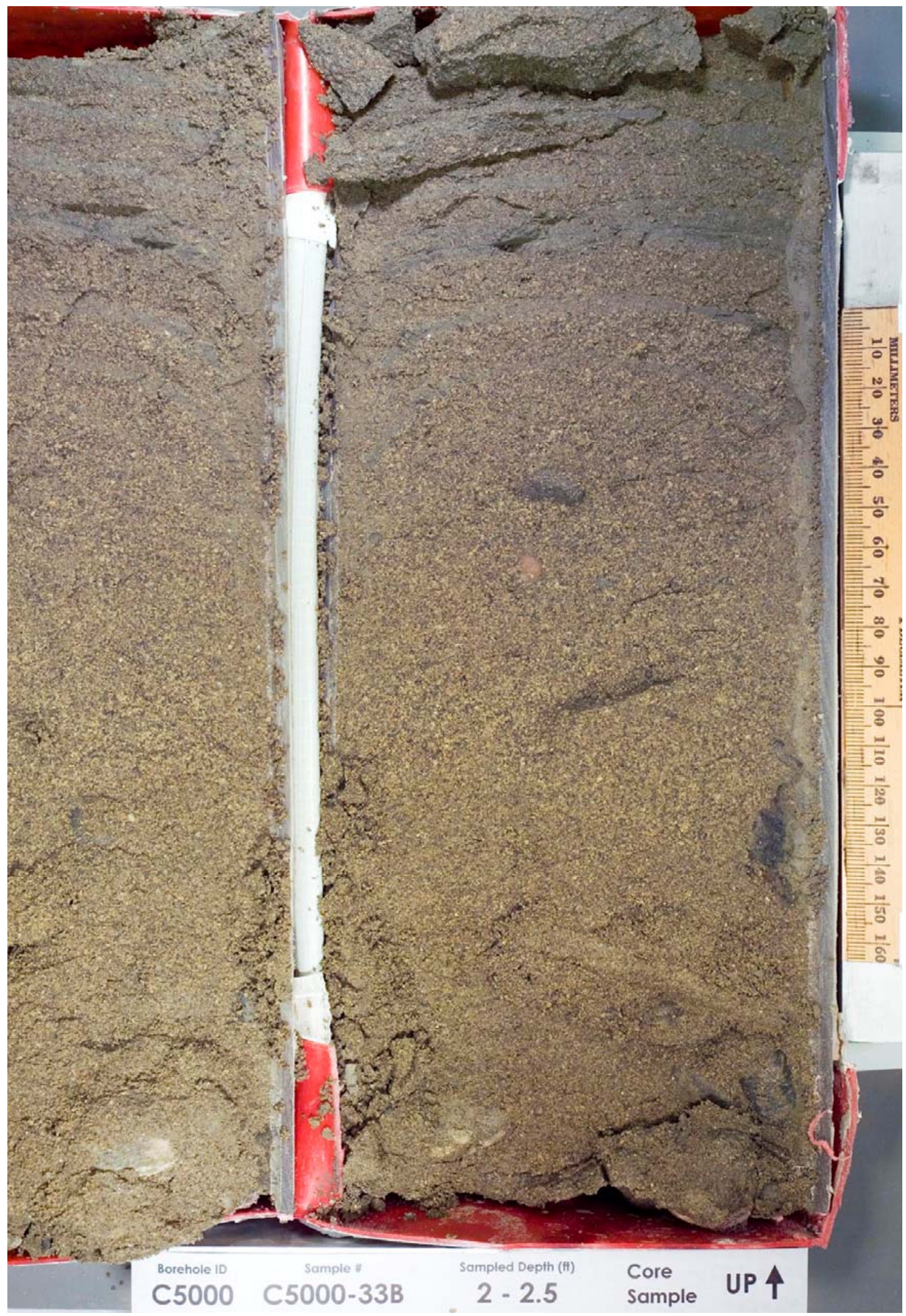

B.181 


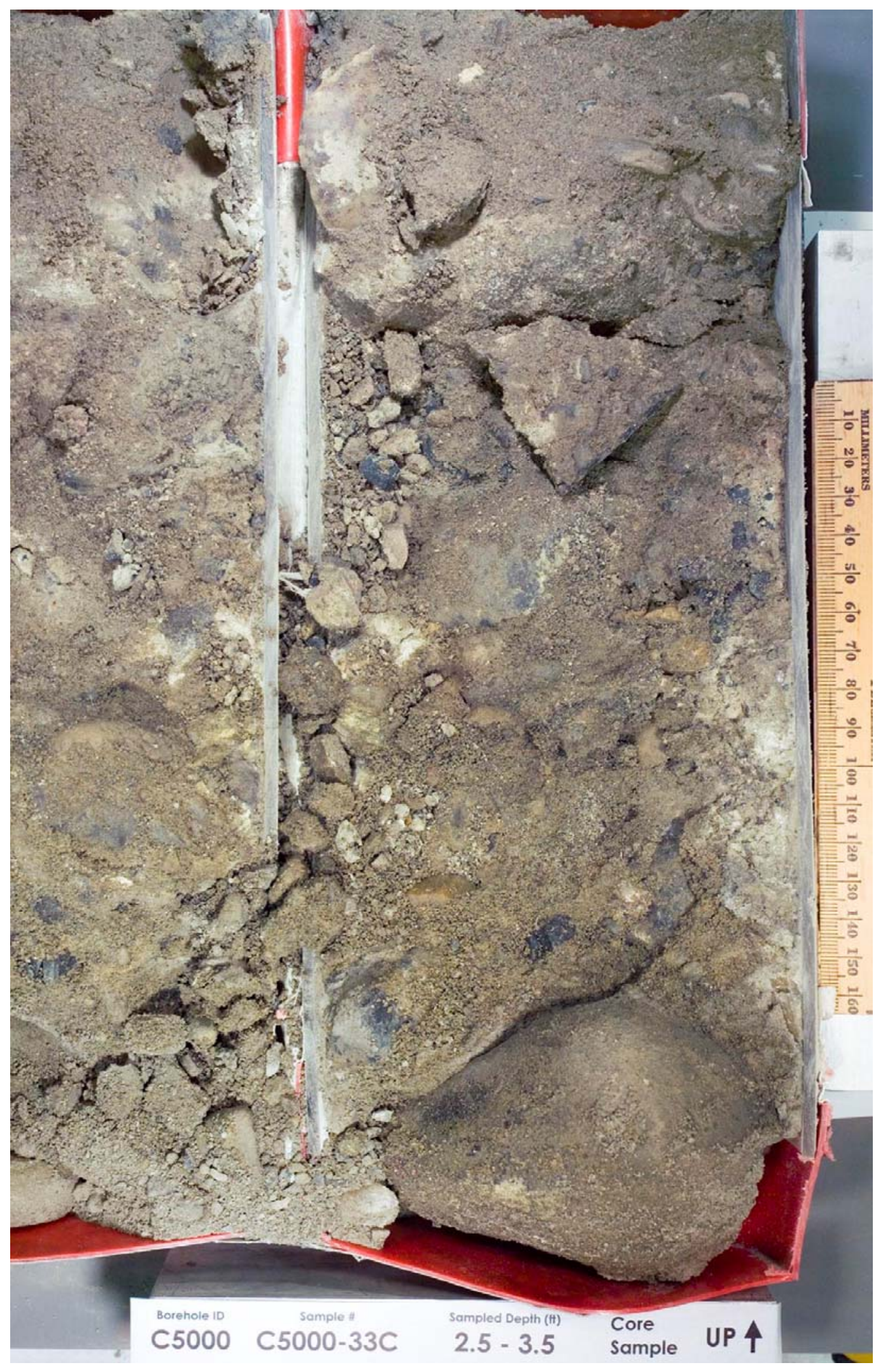

B.182 


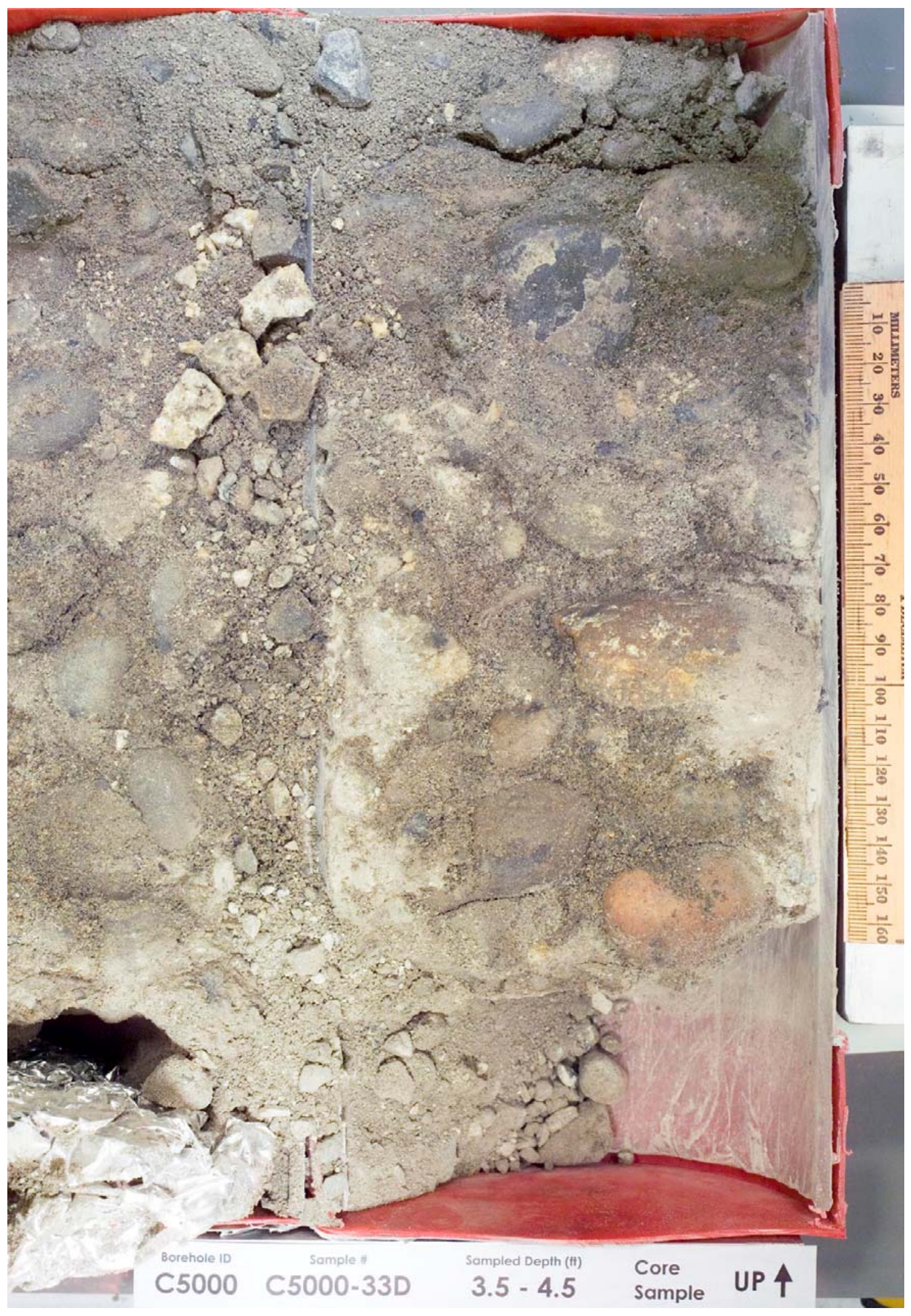

B.183 


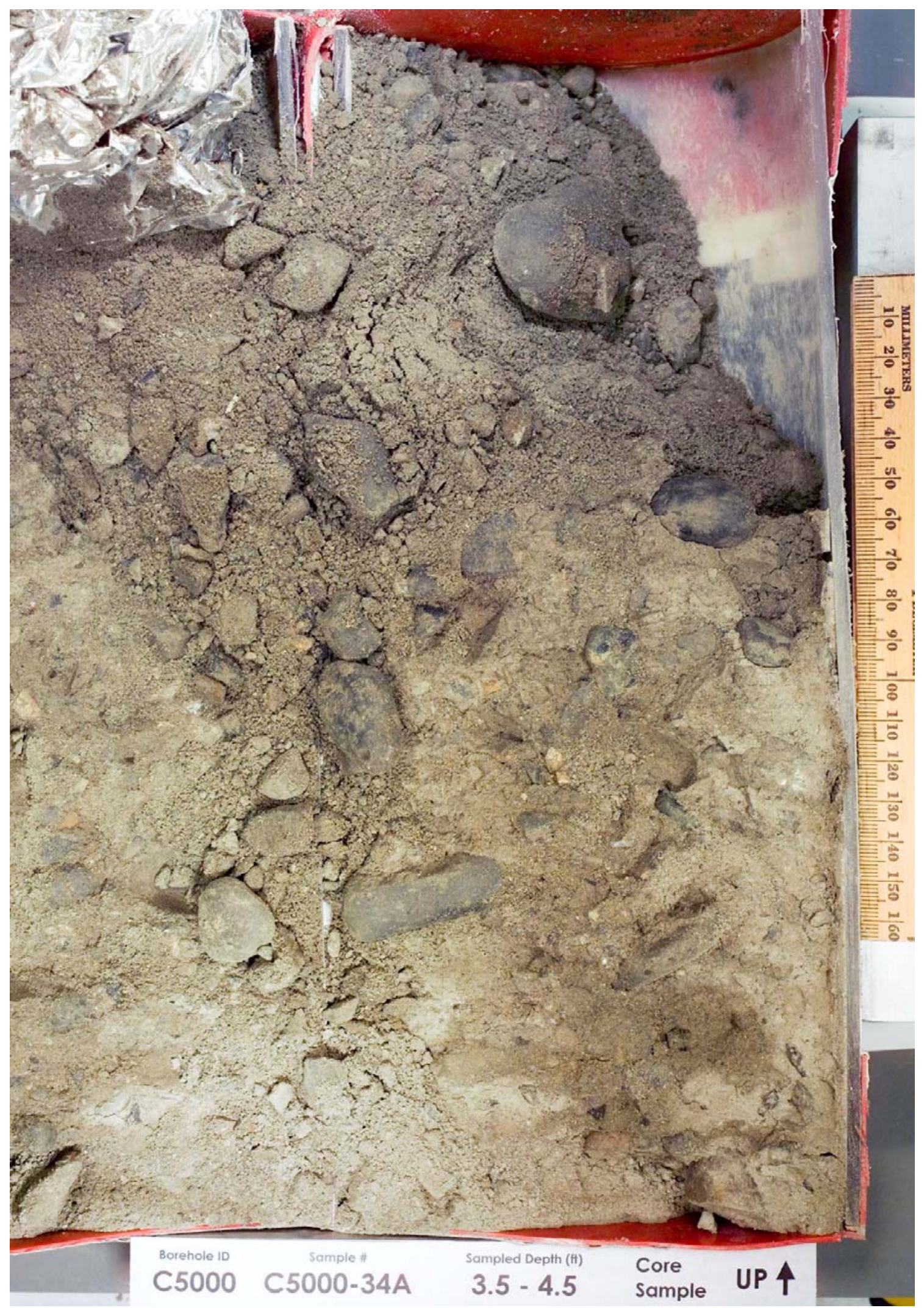




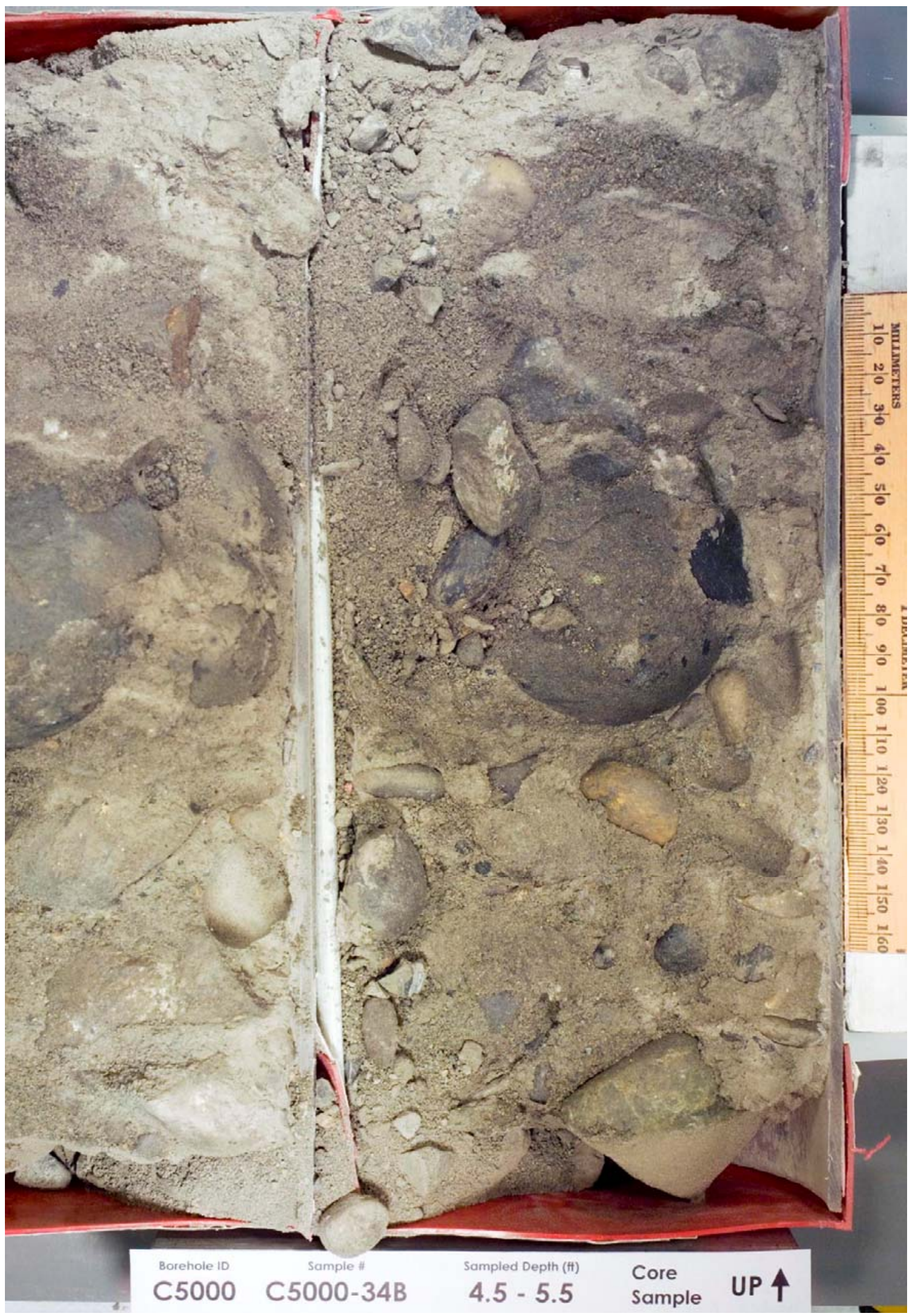




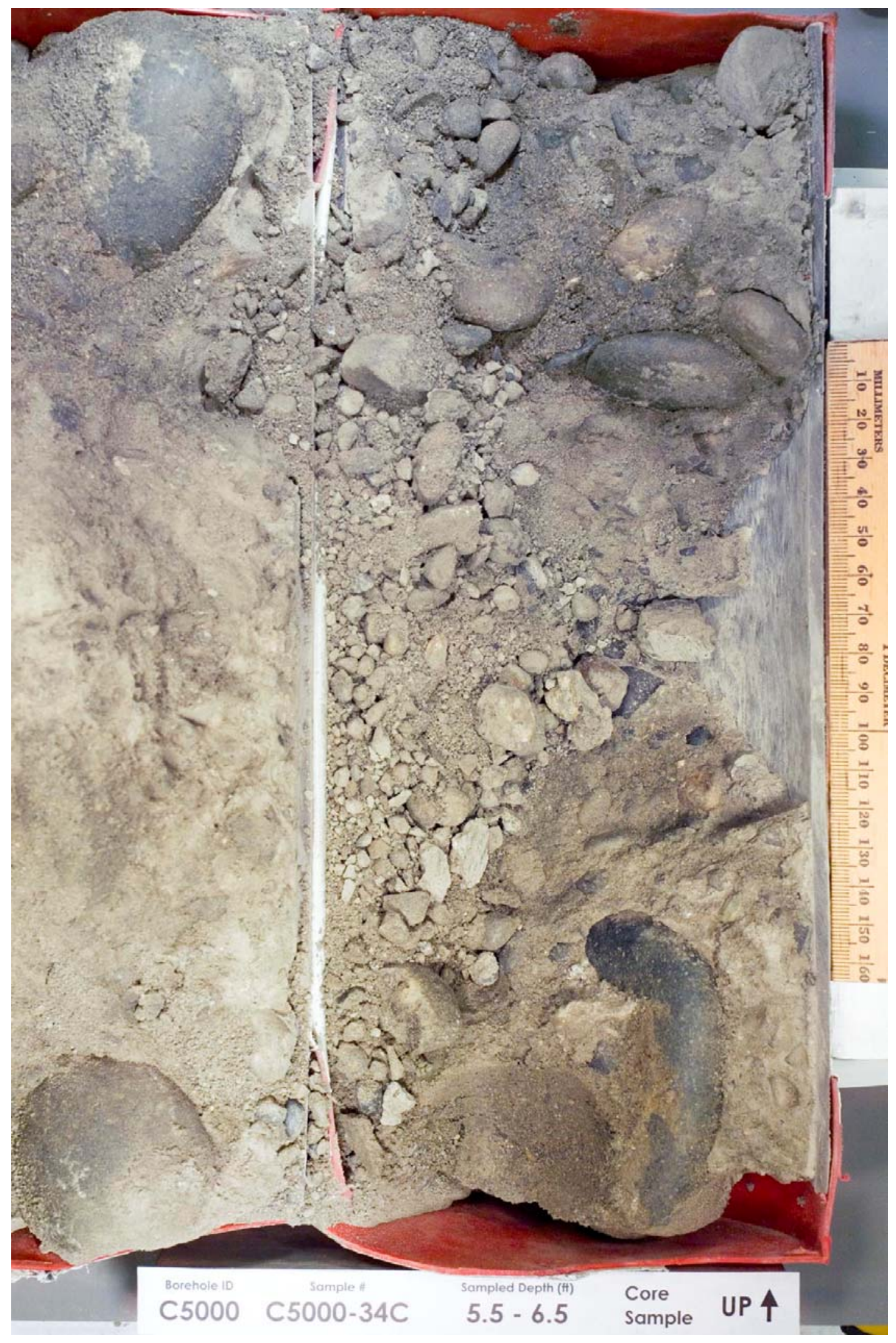




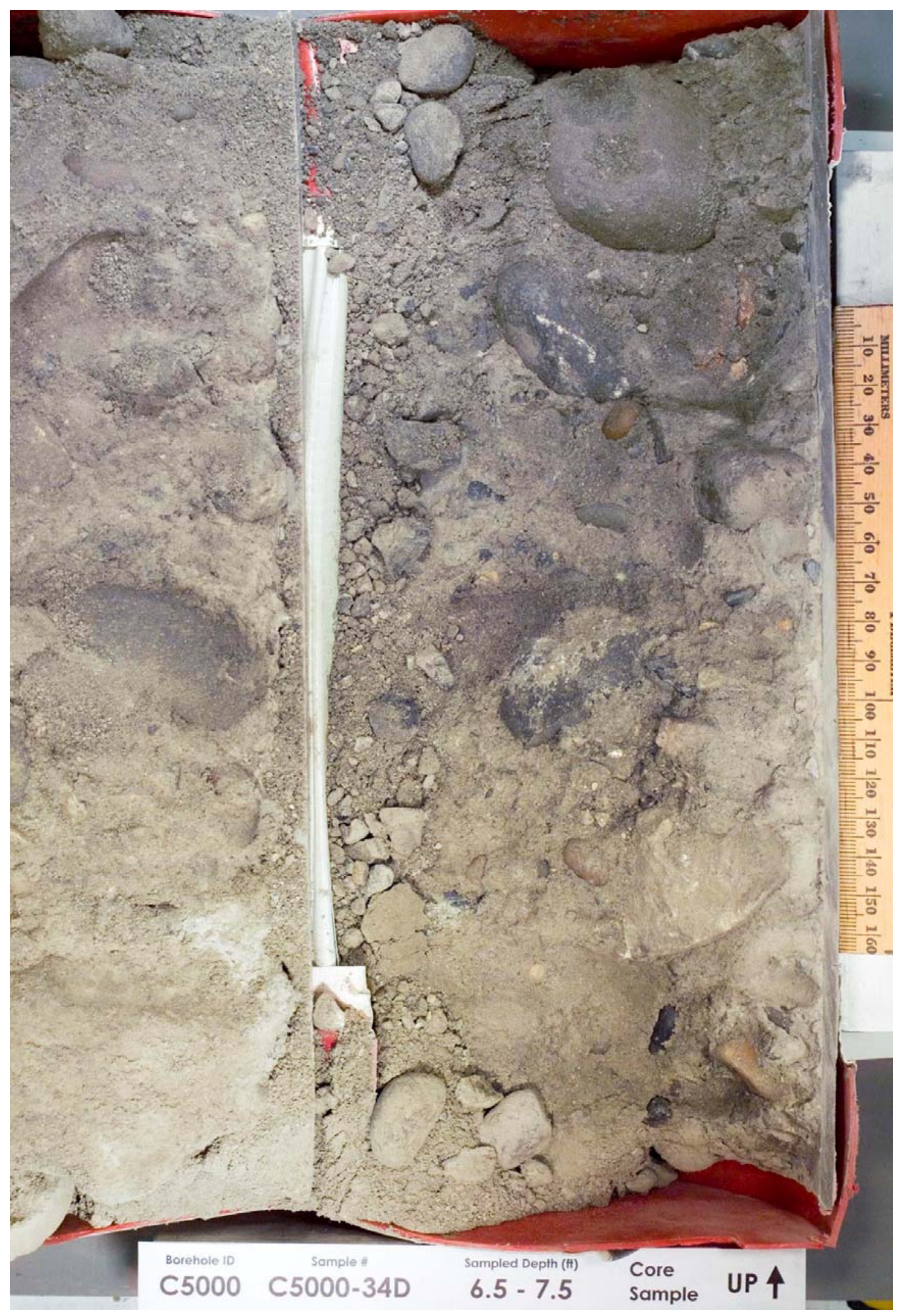

B.187 


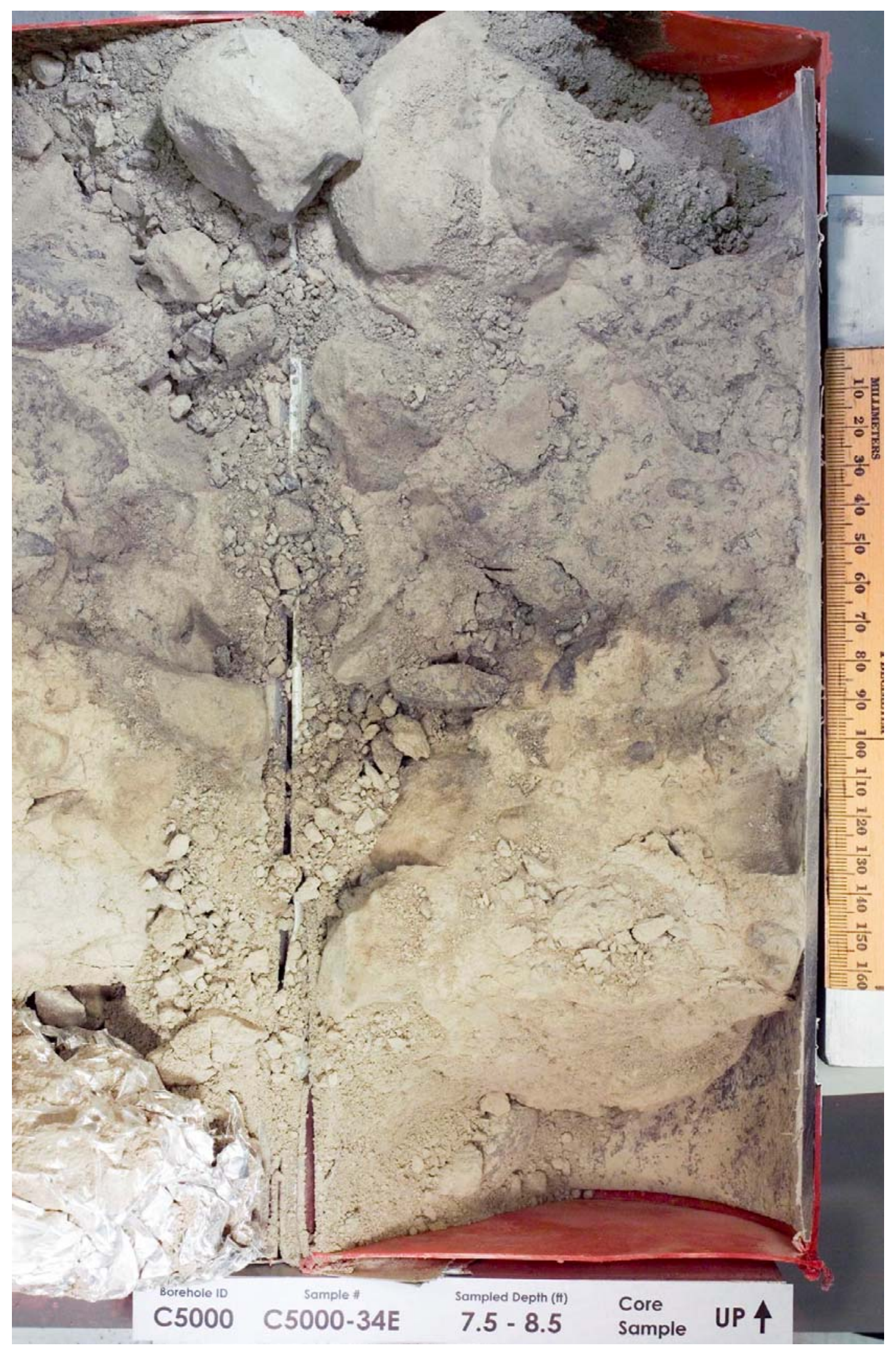




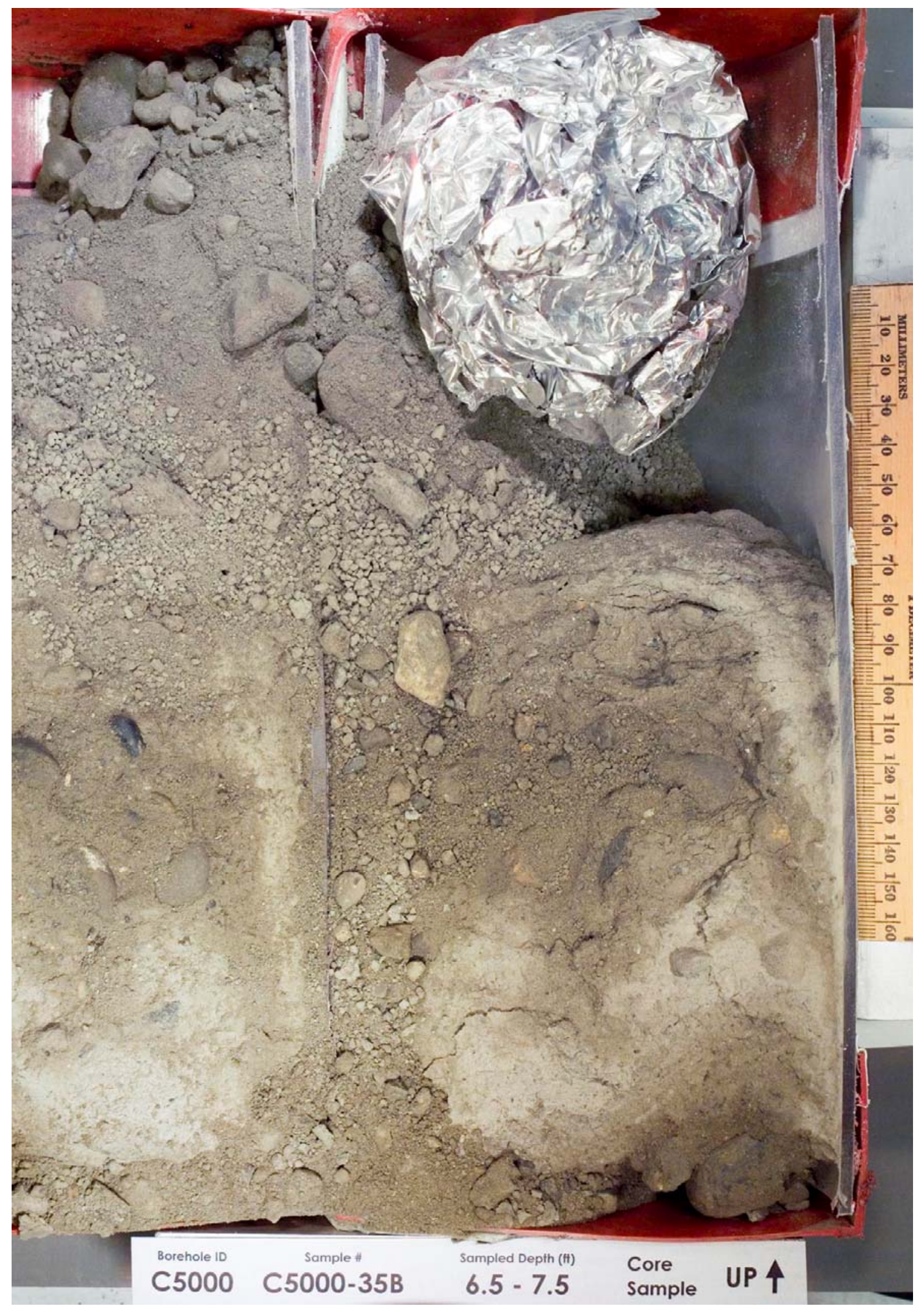




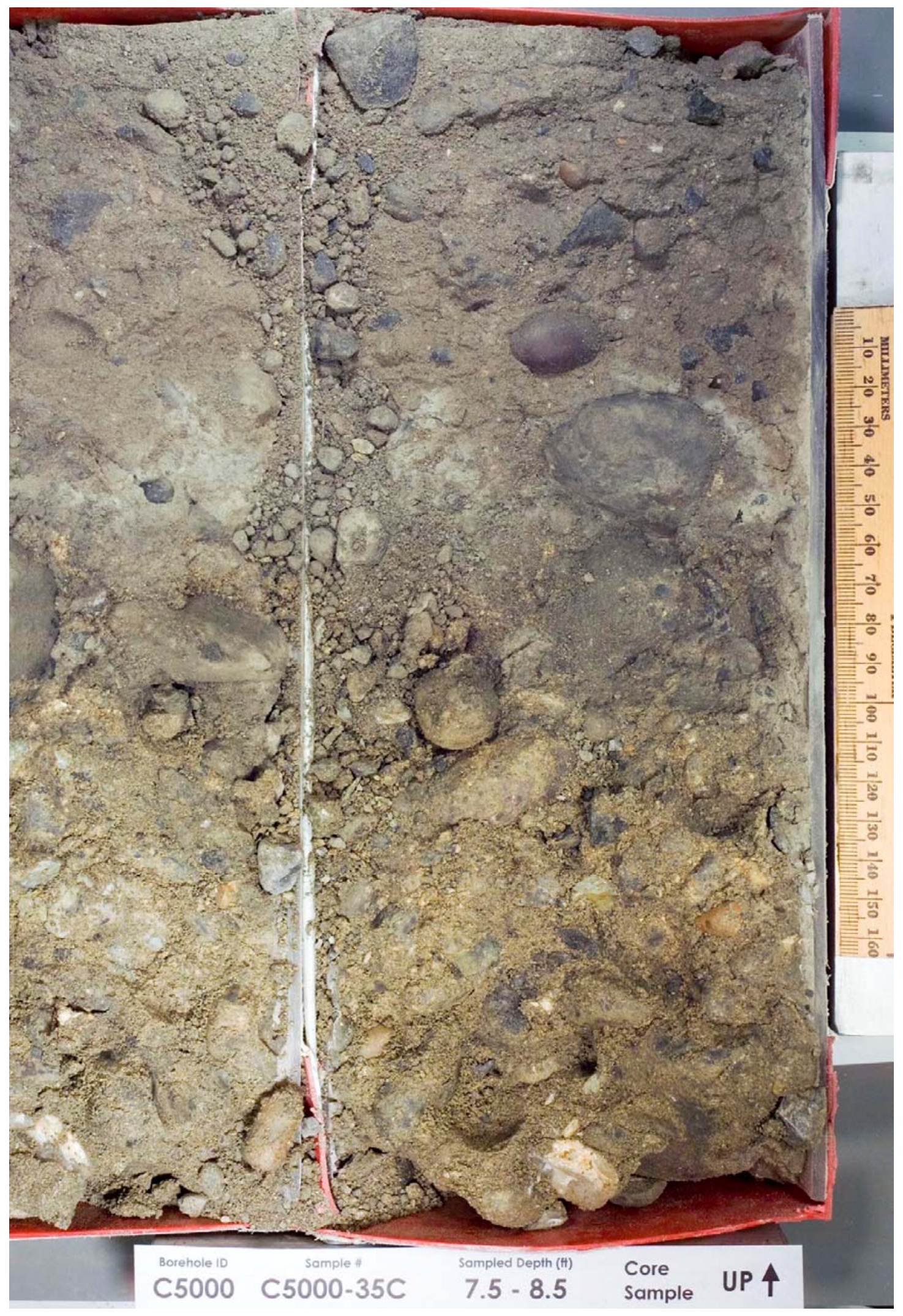




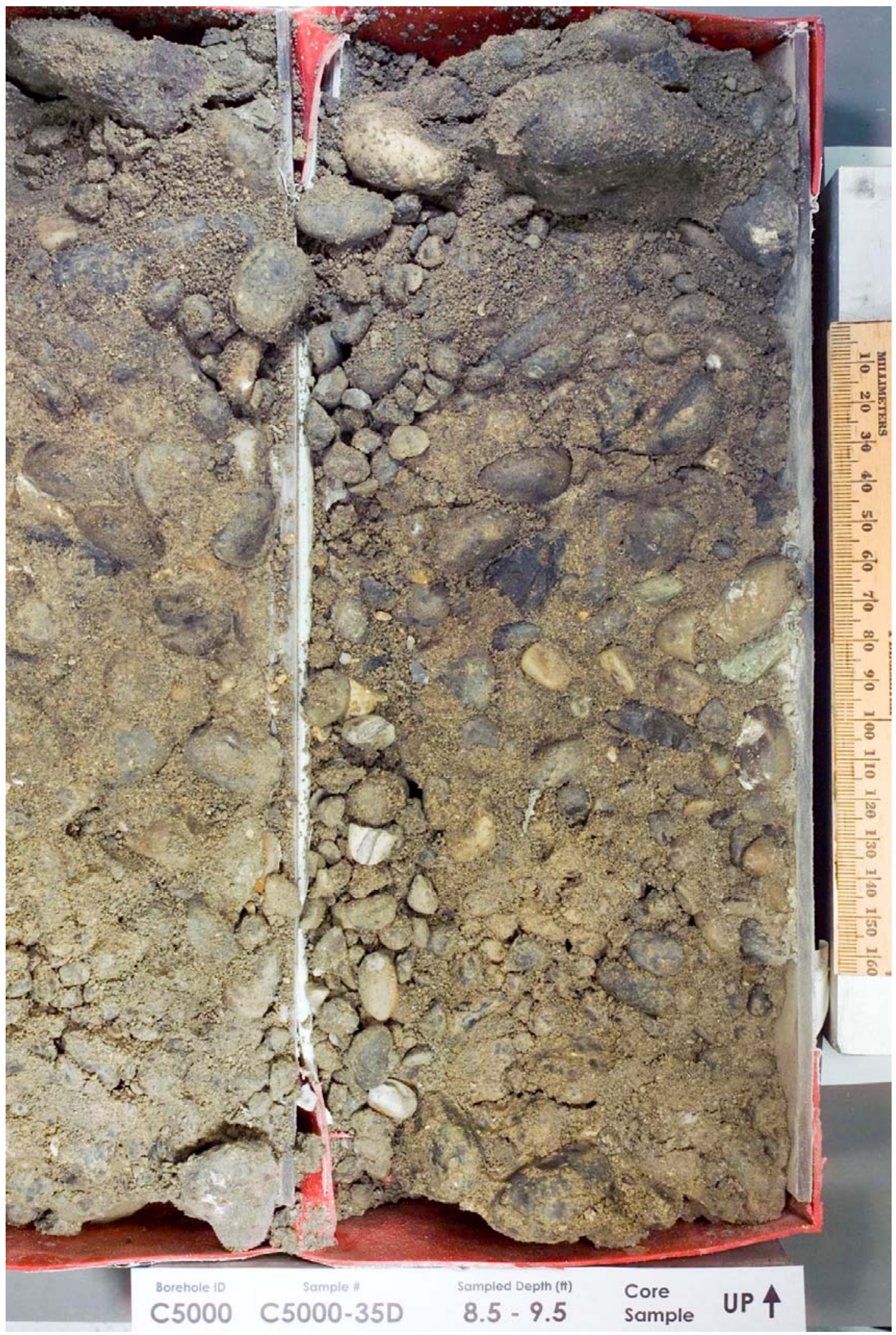

B.191 


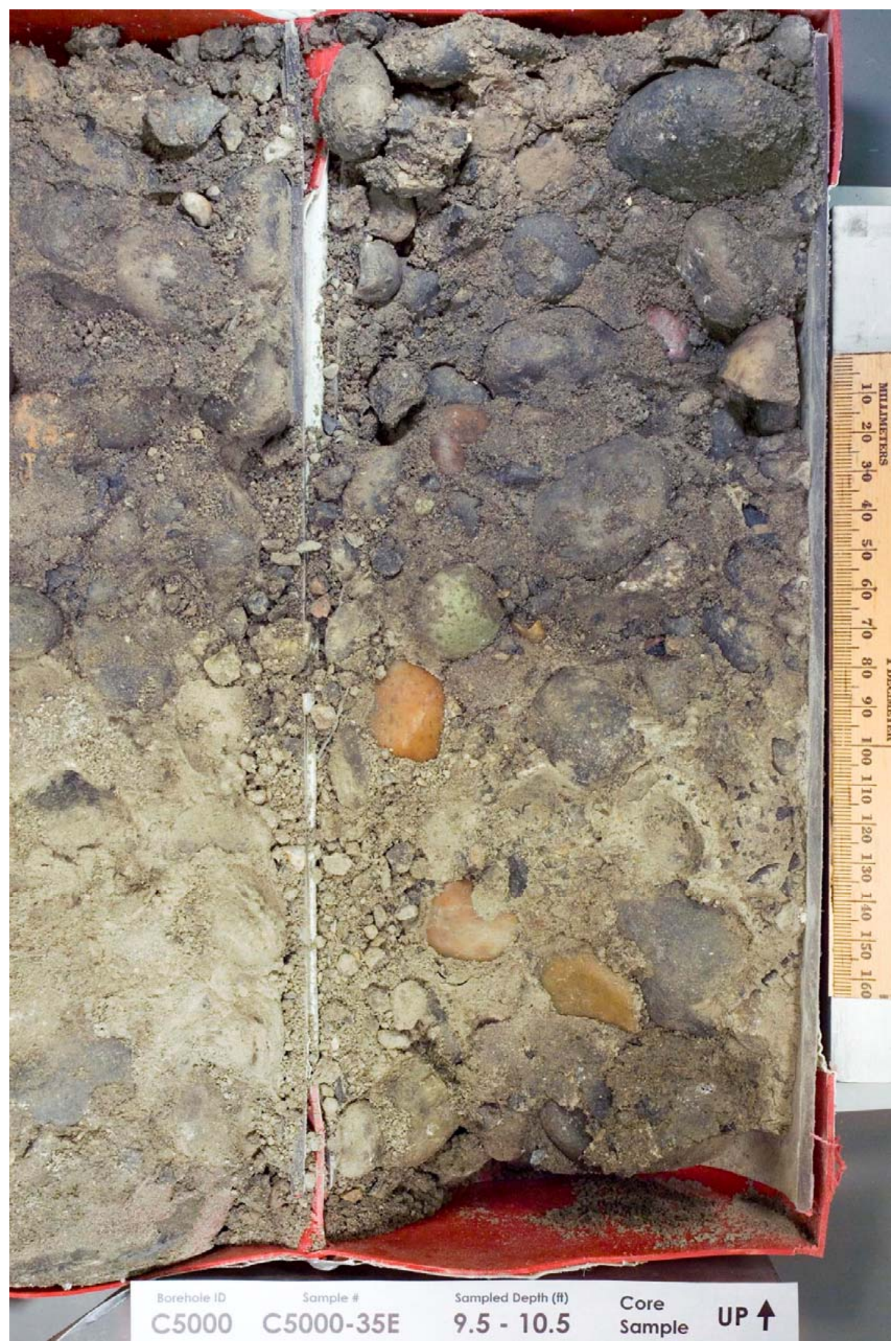

B.192 


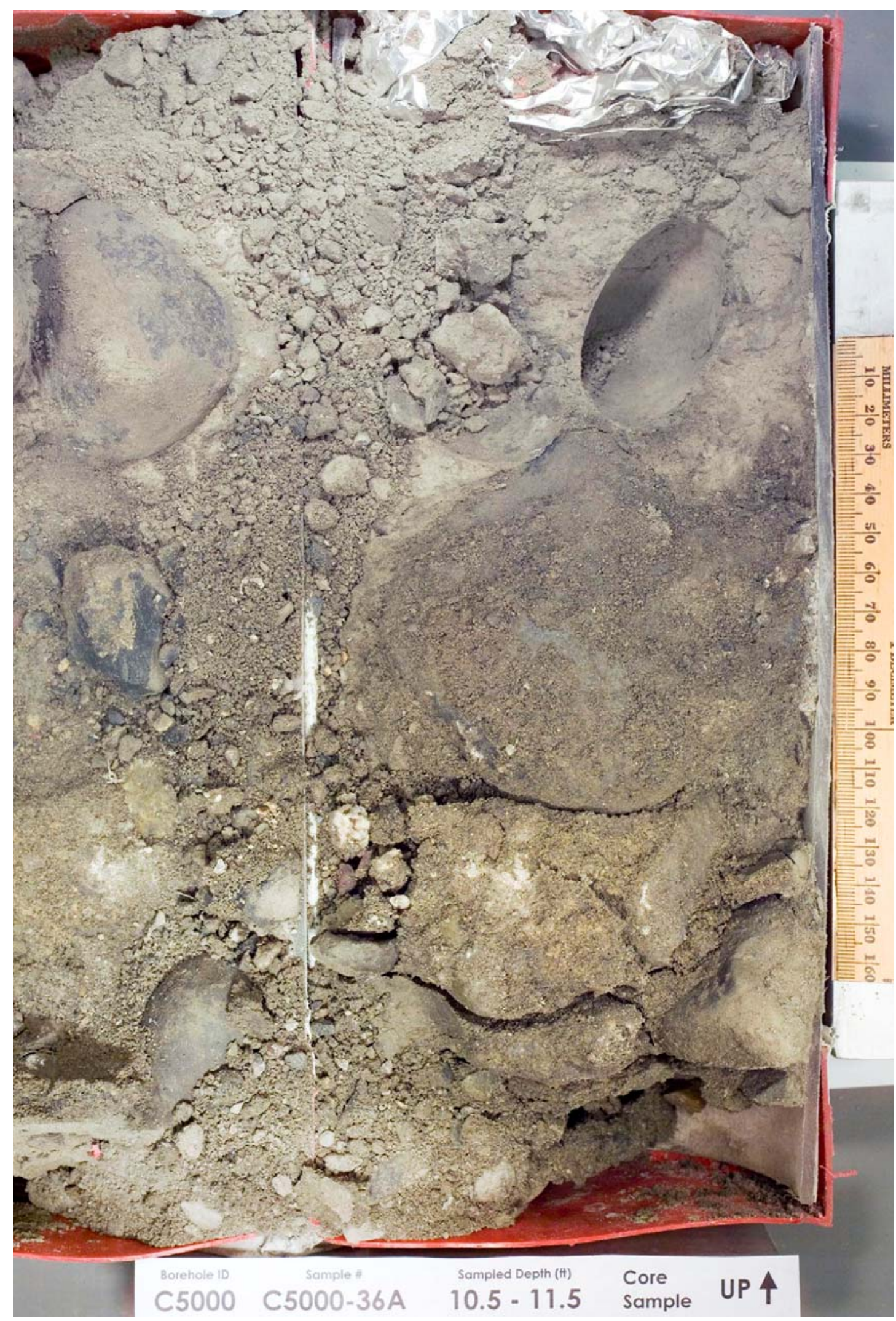

B.193 


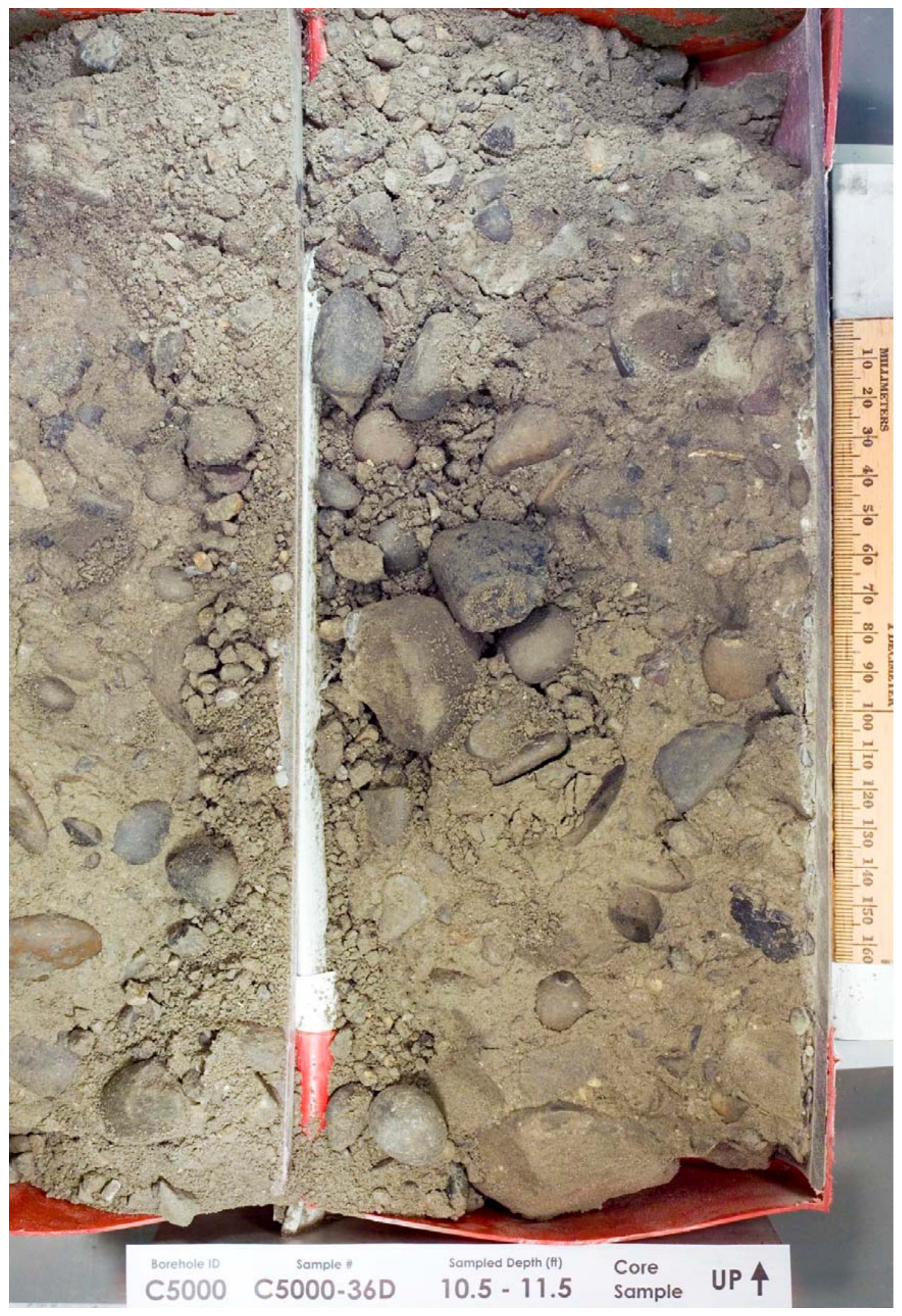

B.194 


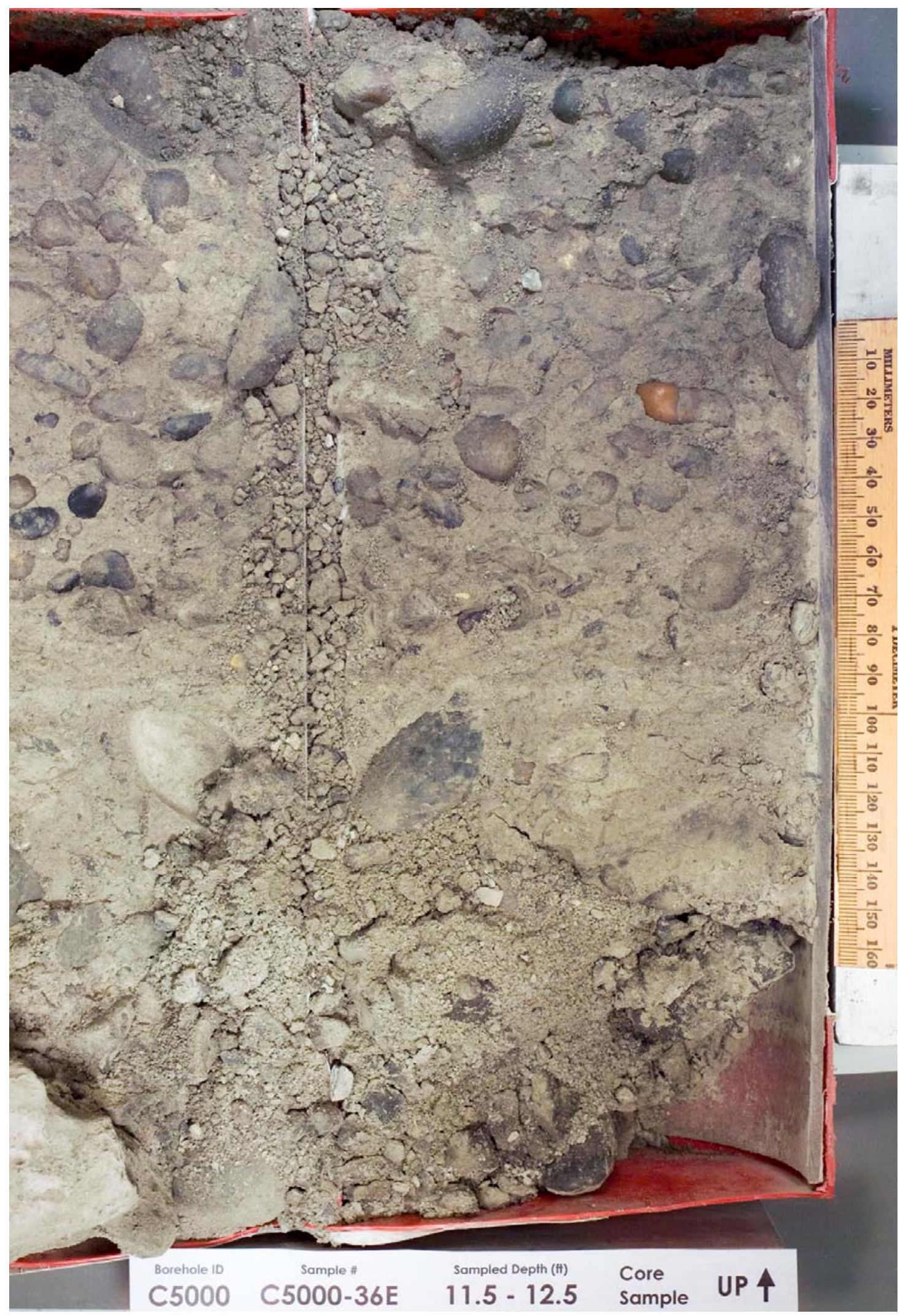




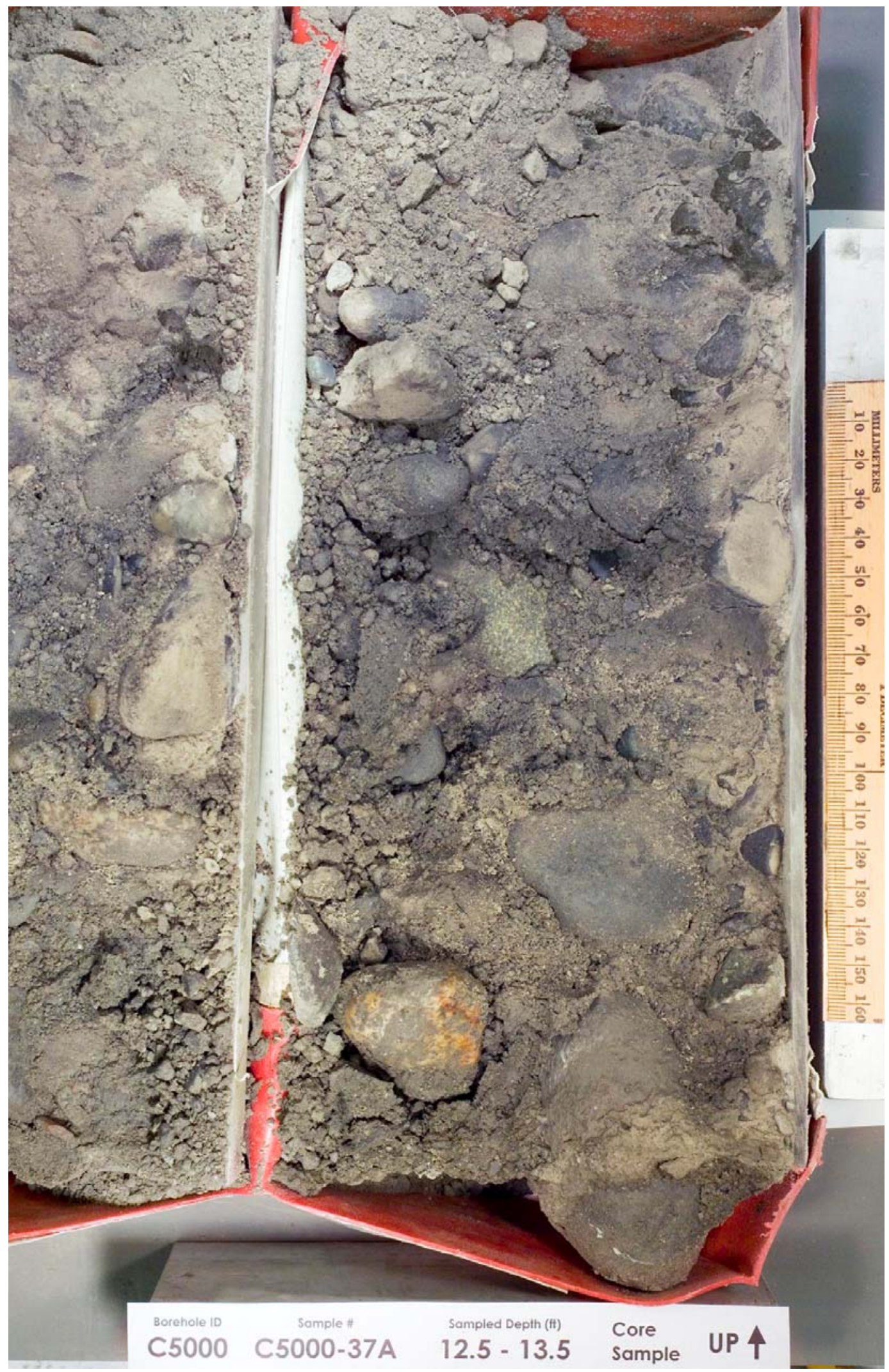




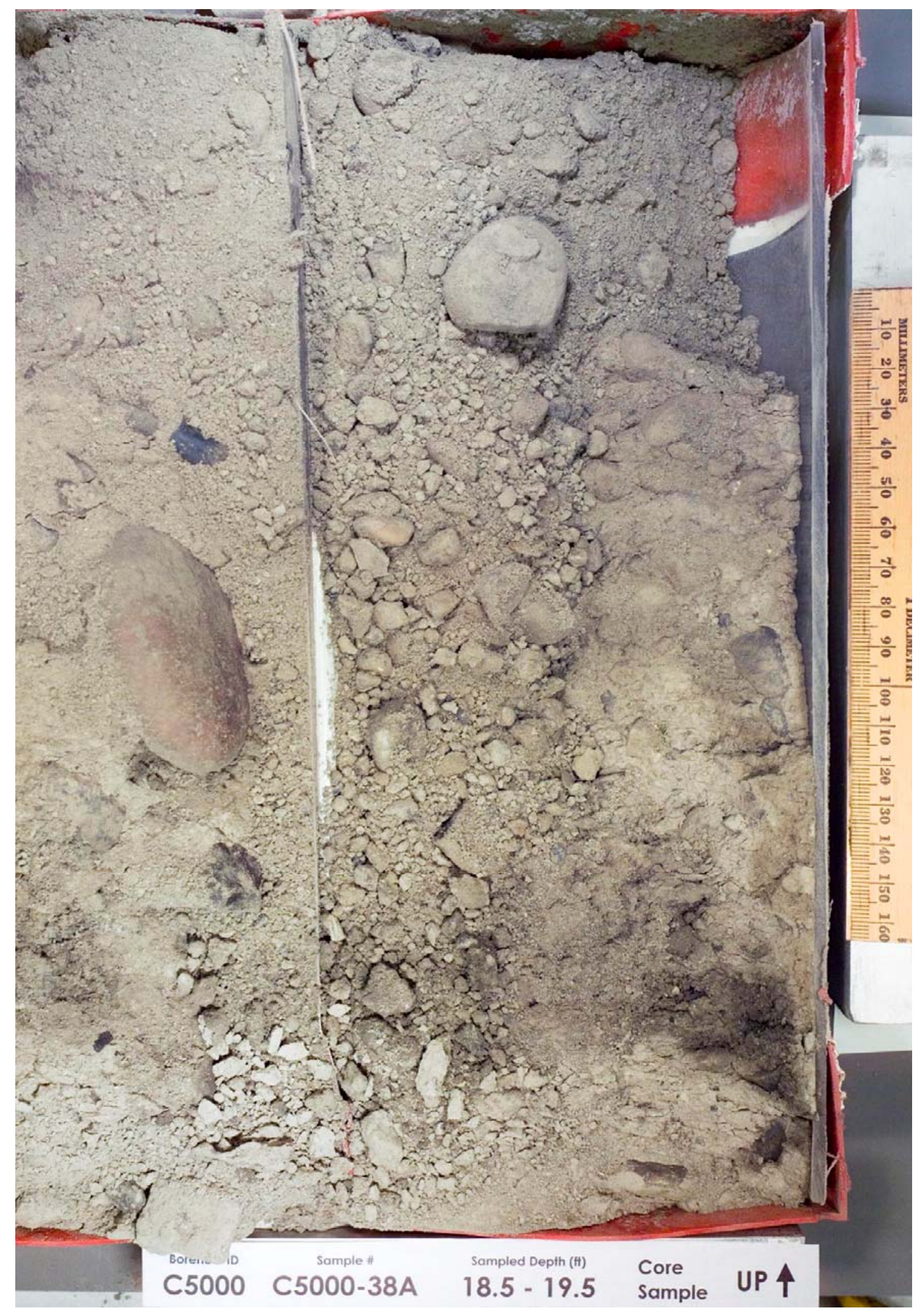

B.197 


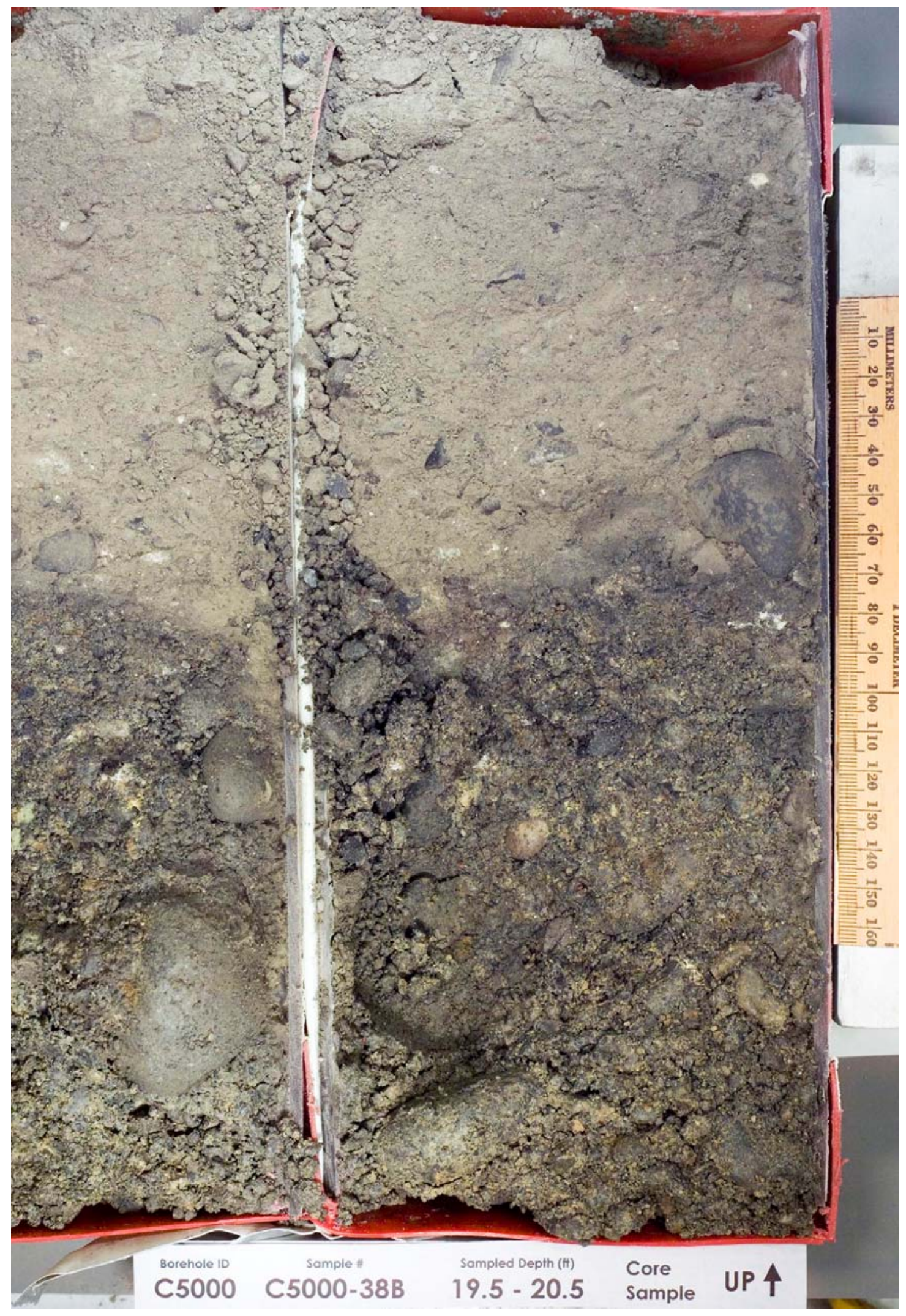

B.198 


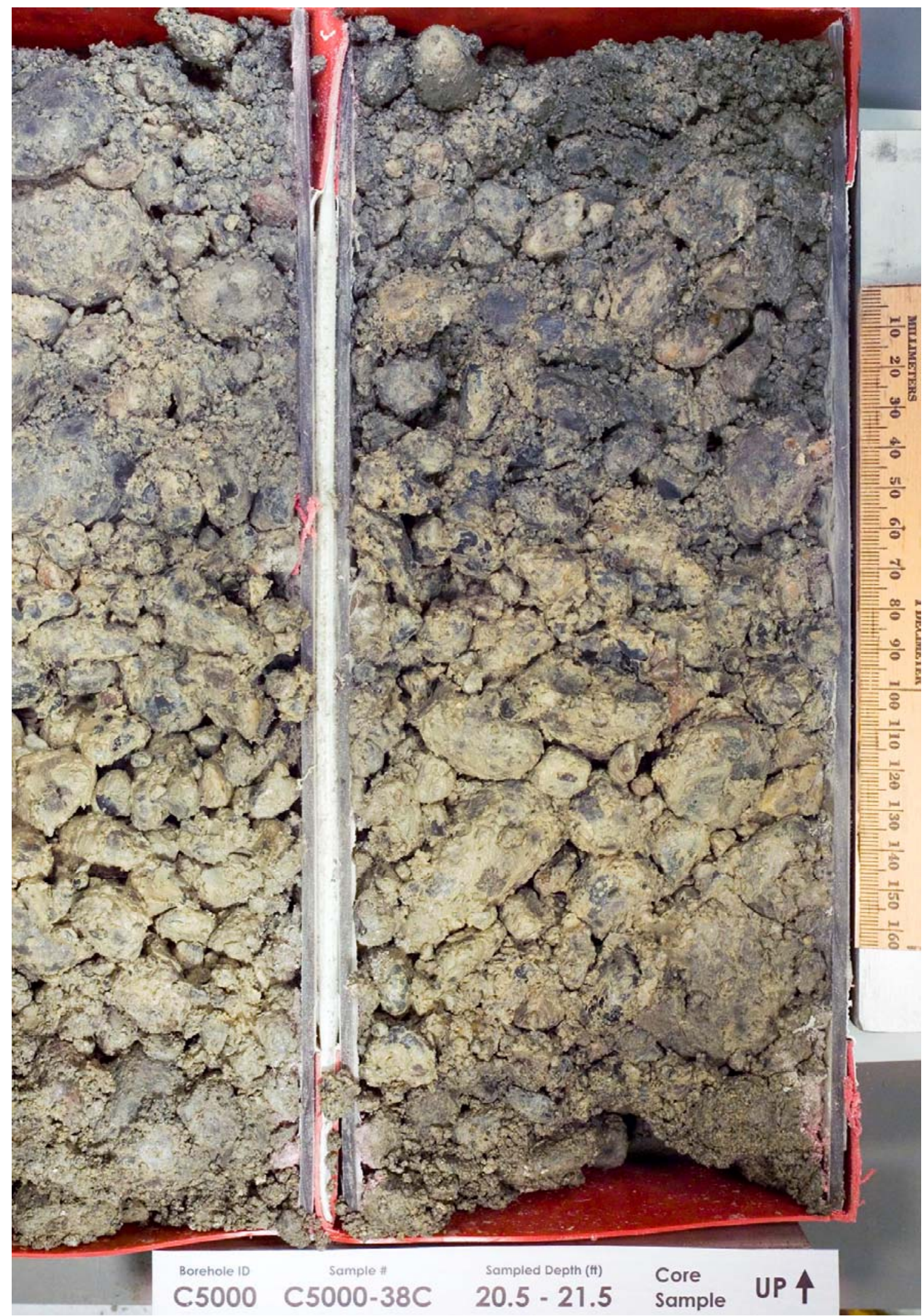




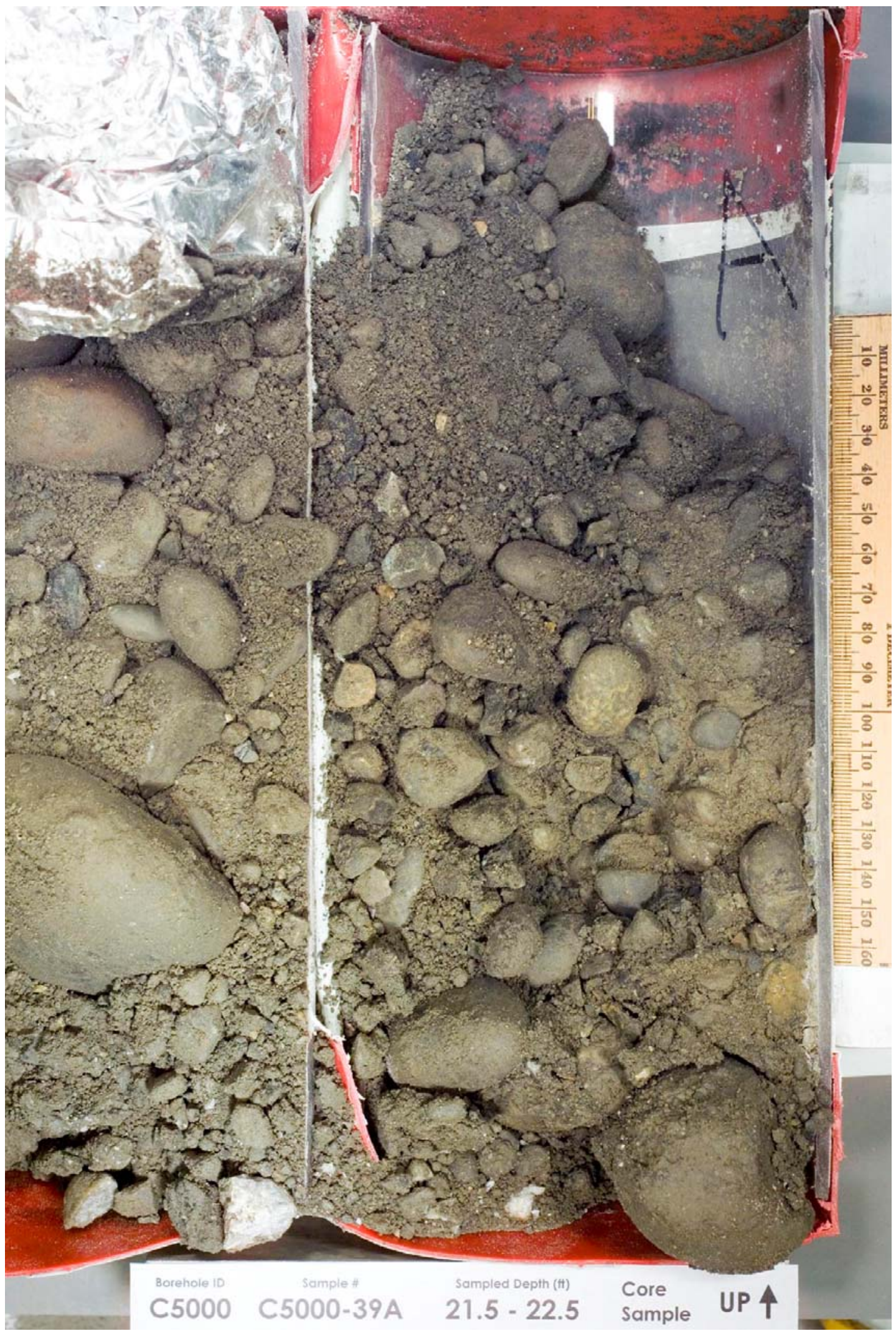




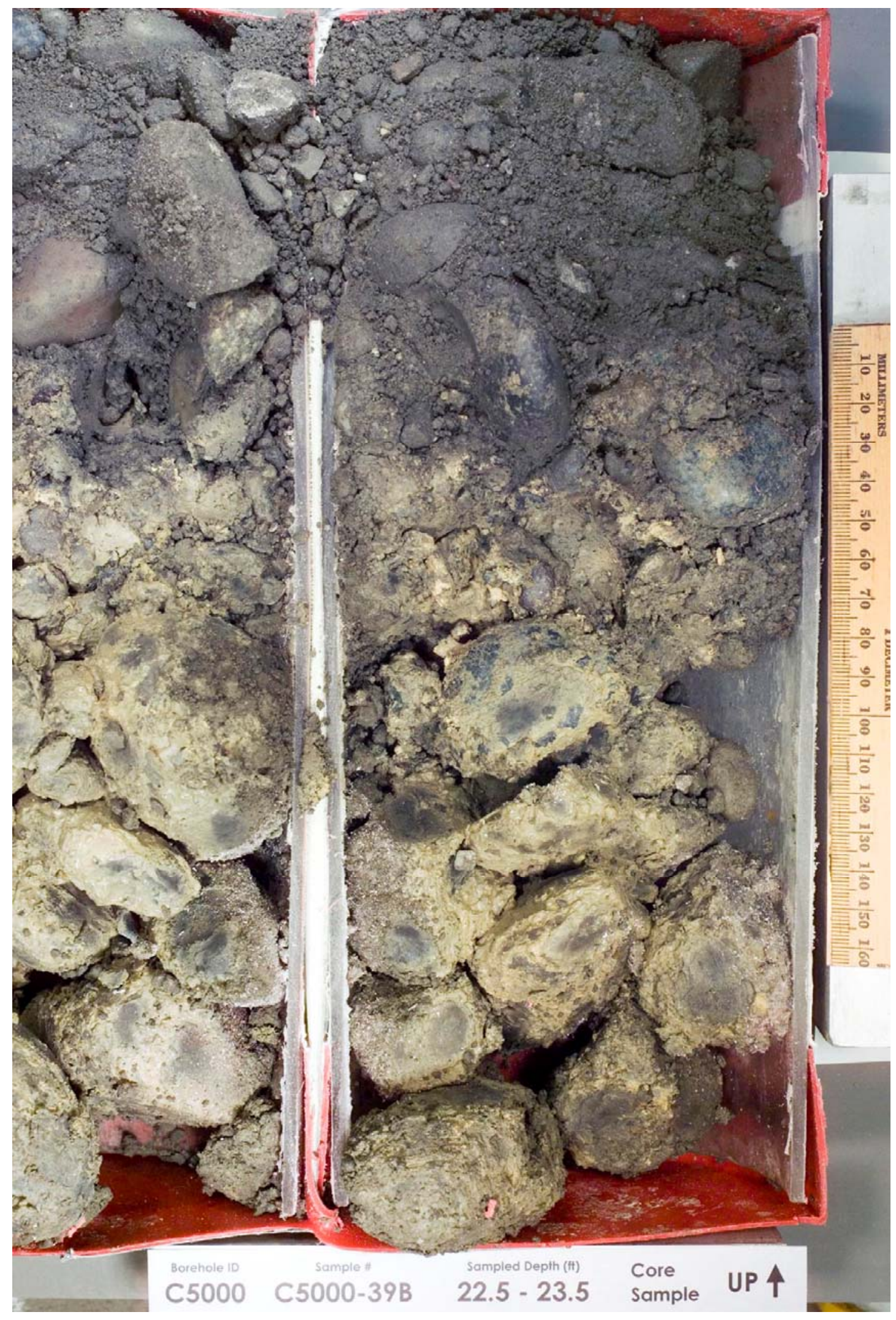




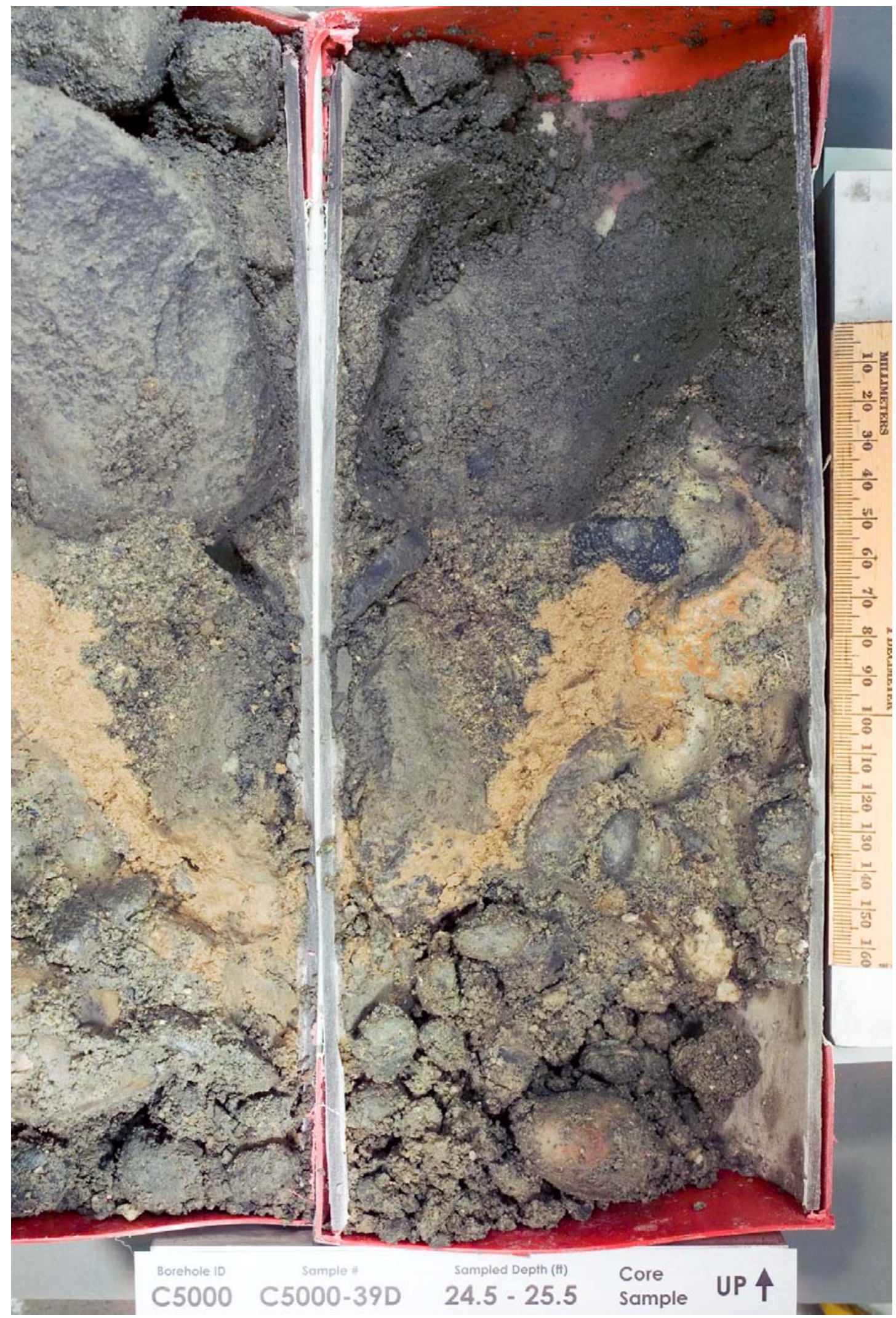




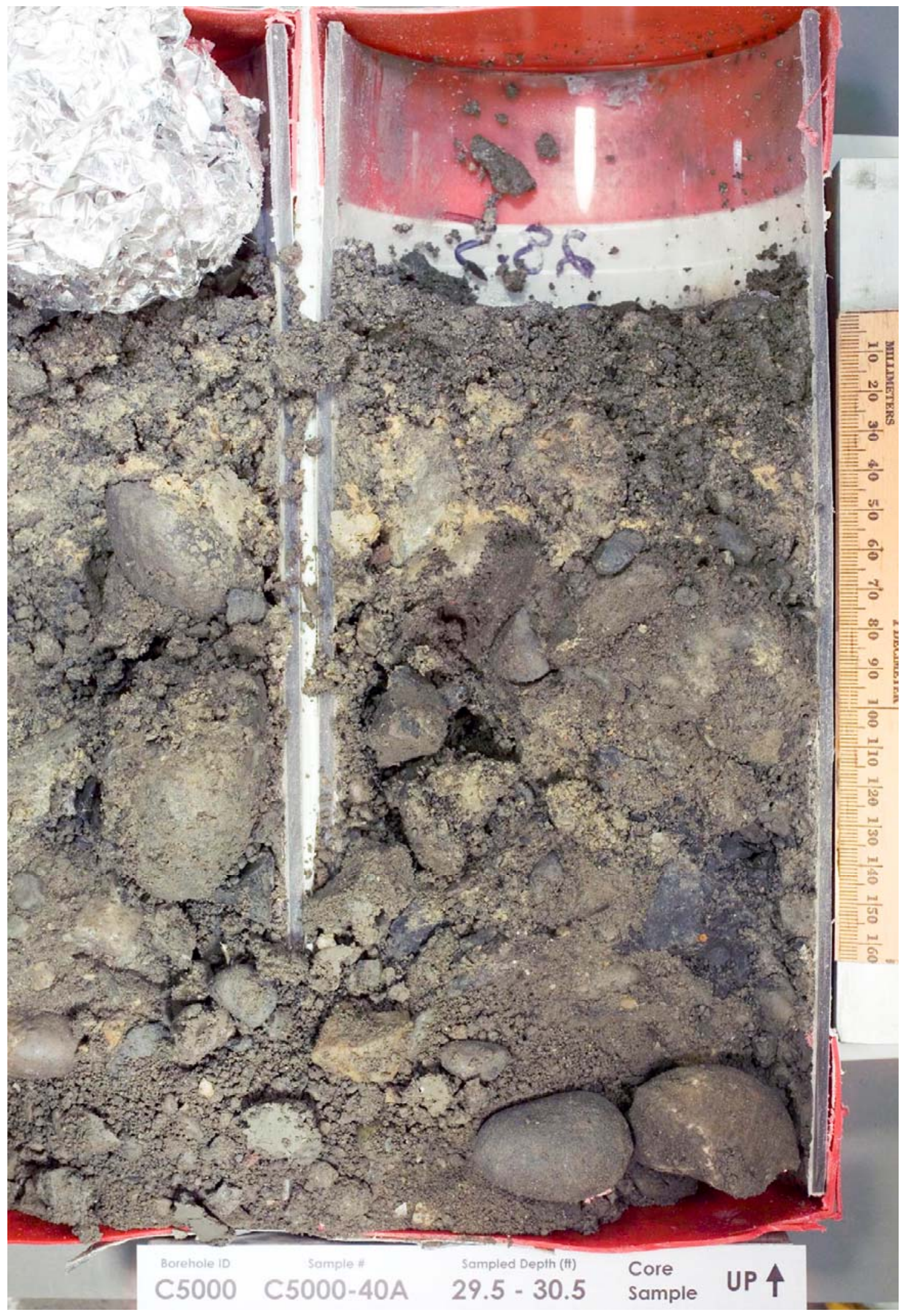




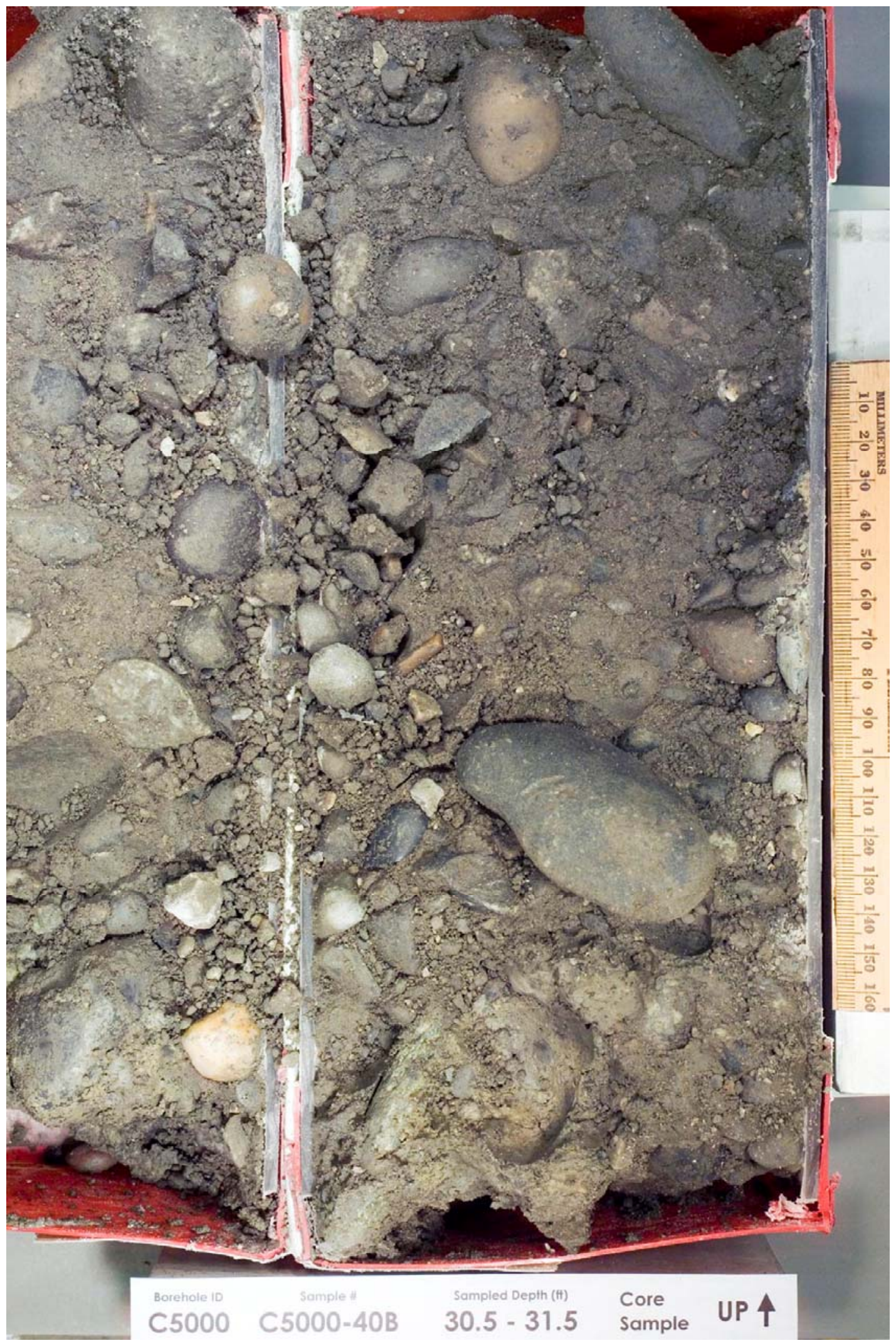




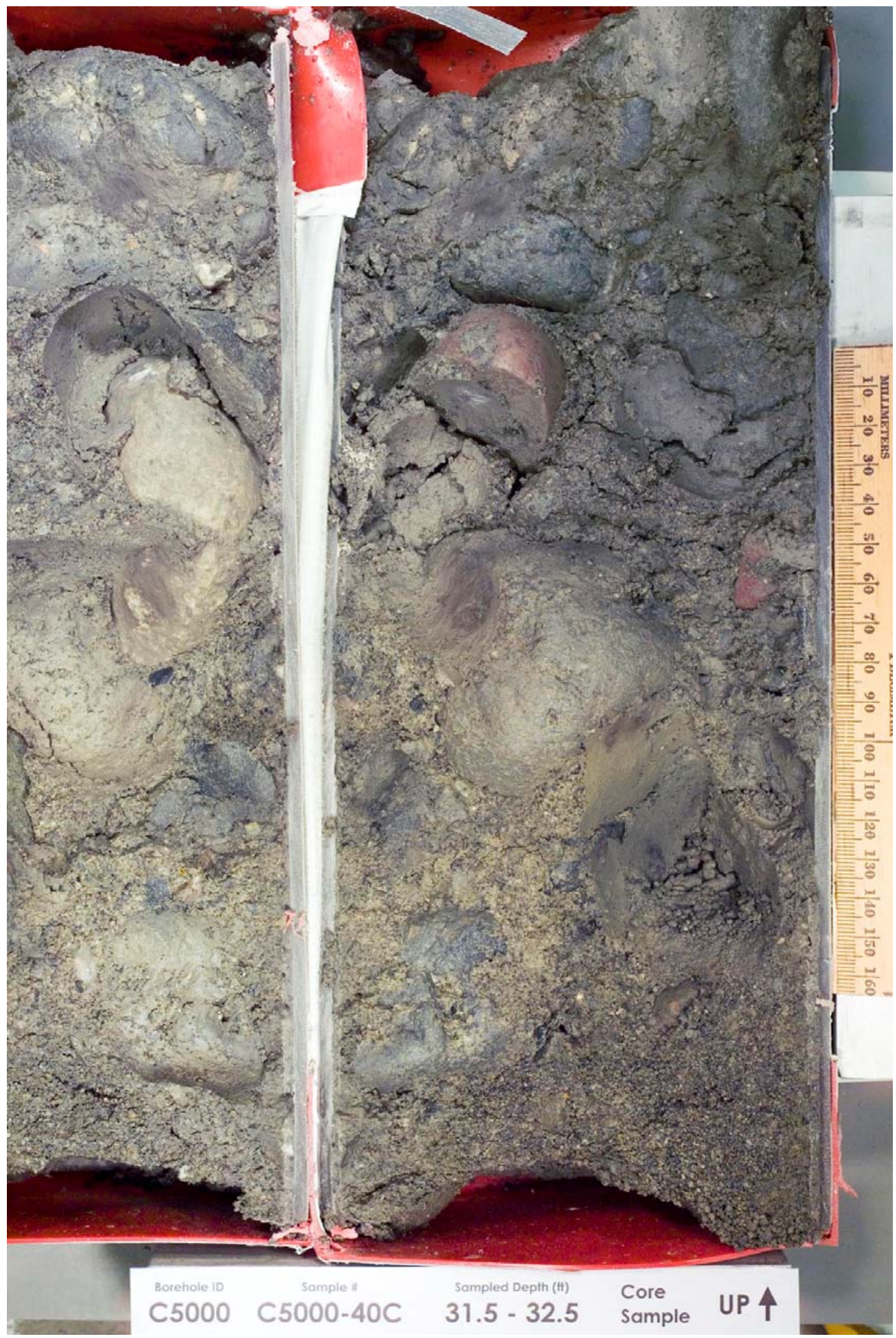




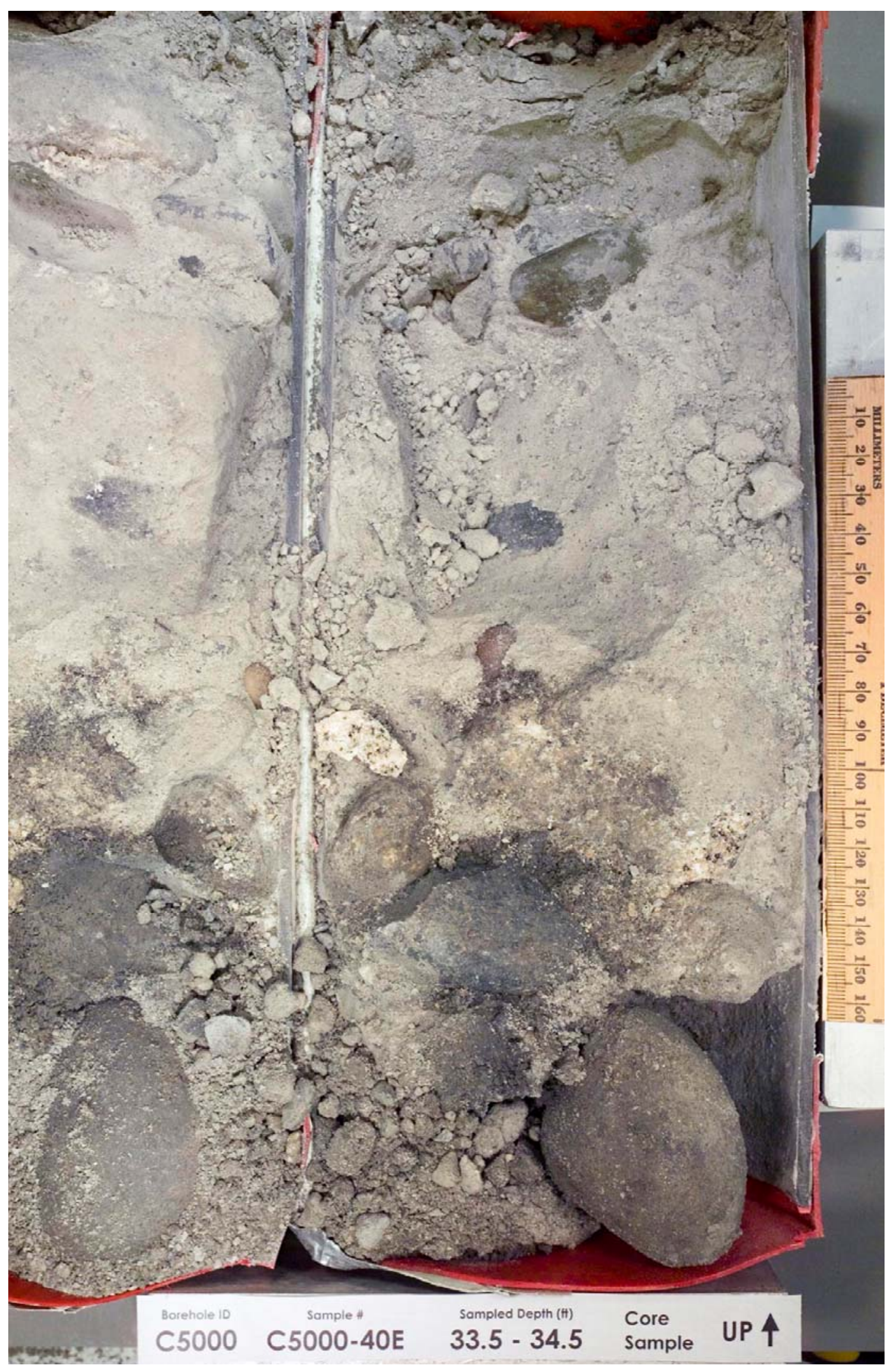




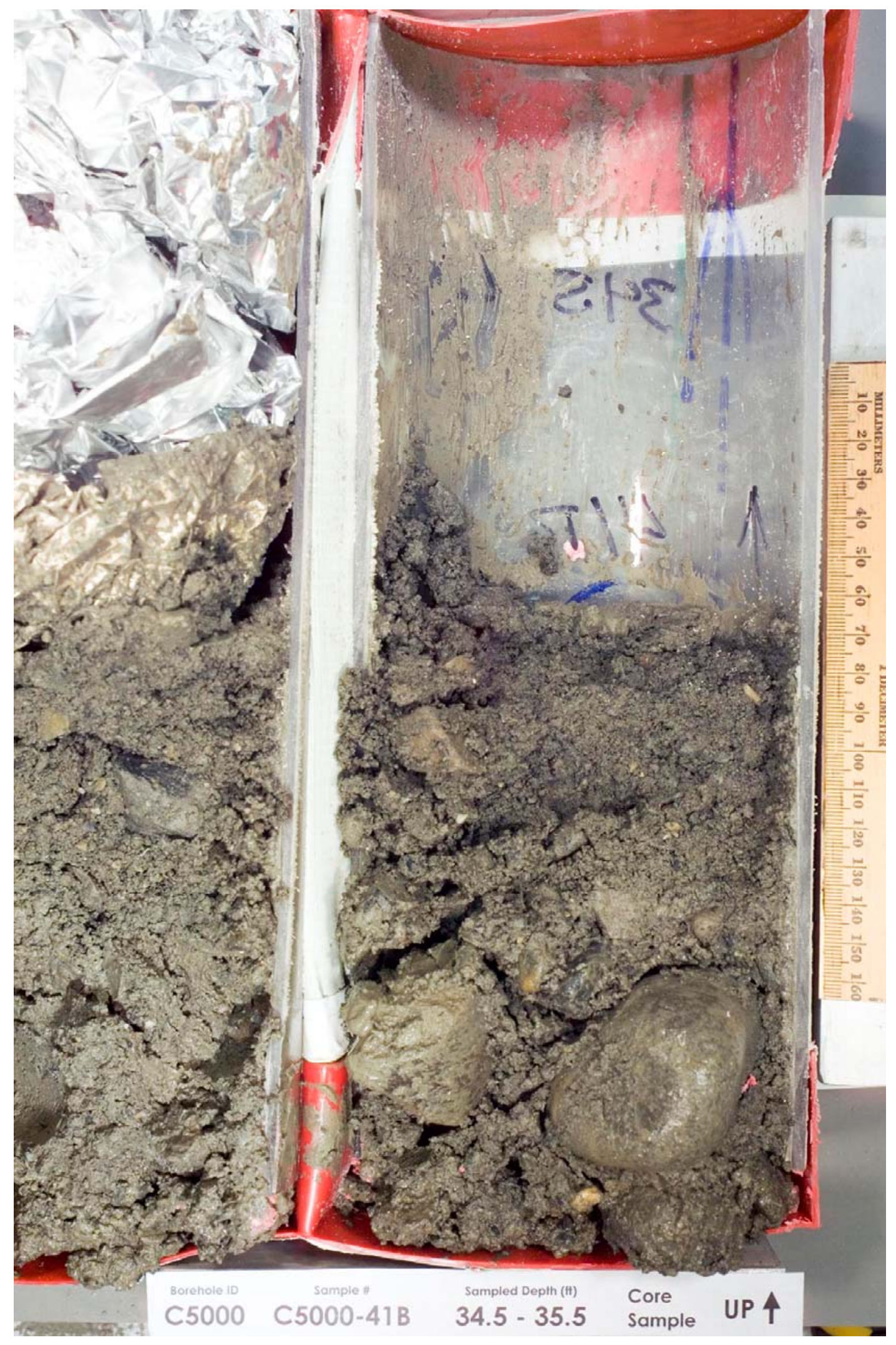




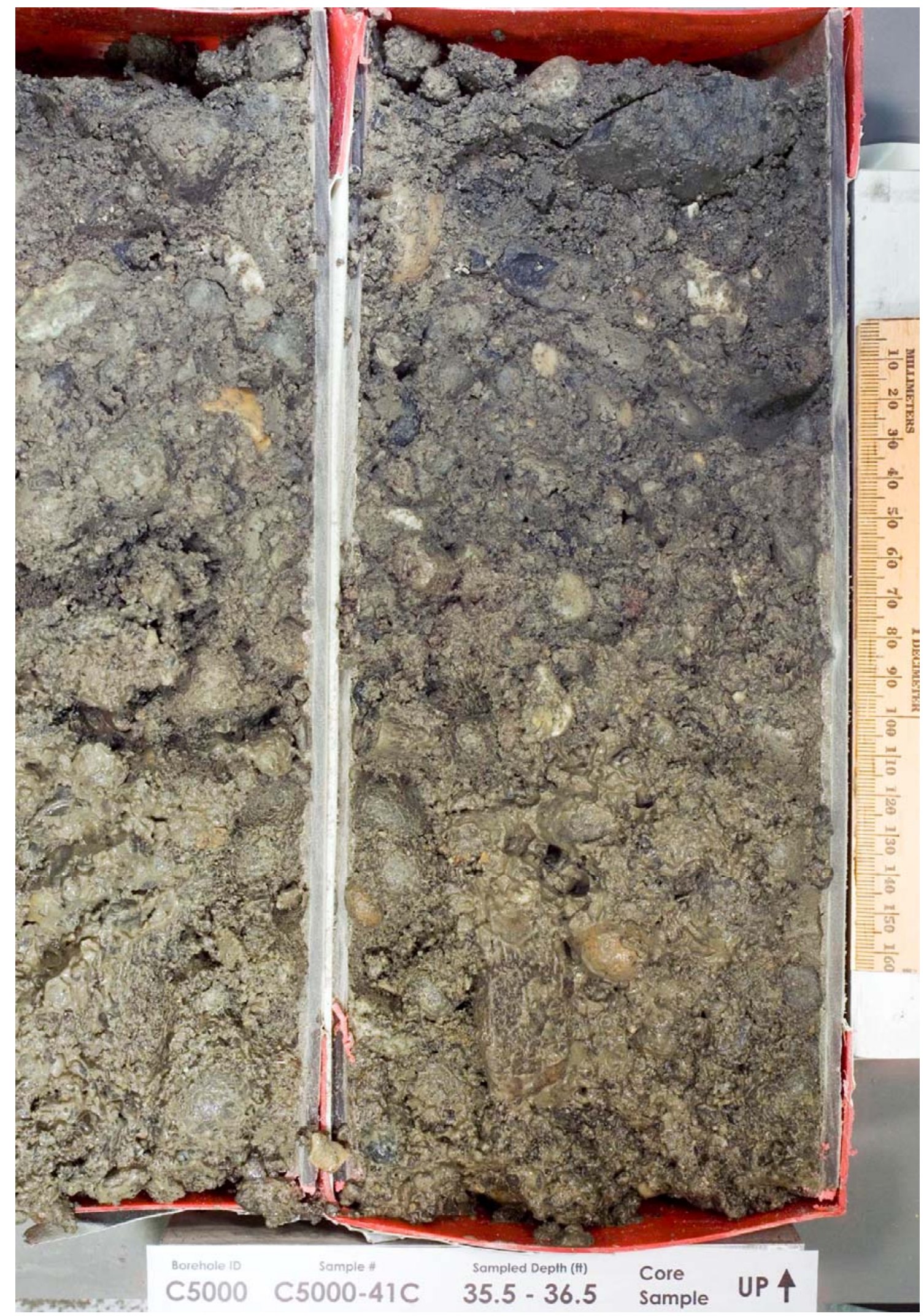




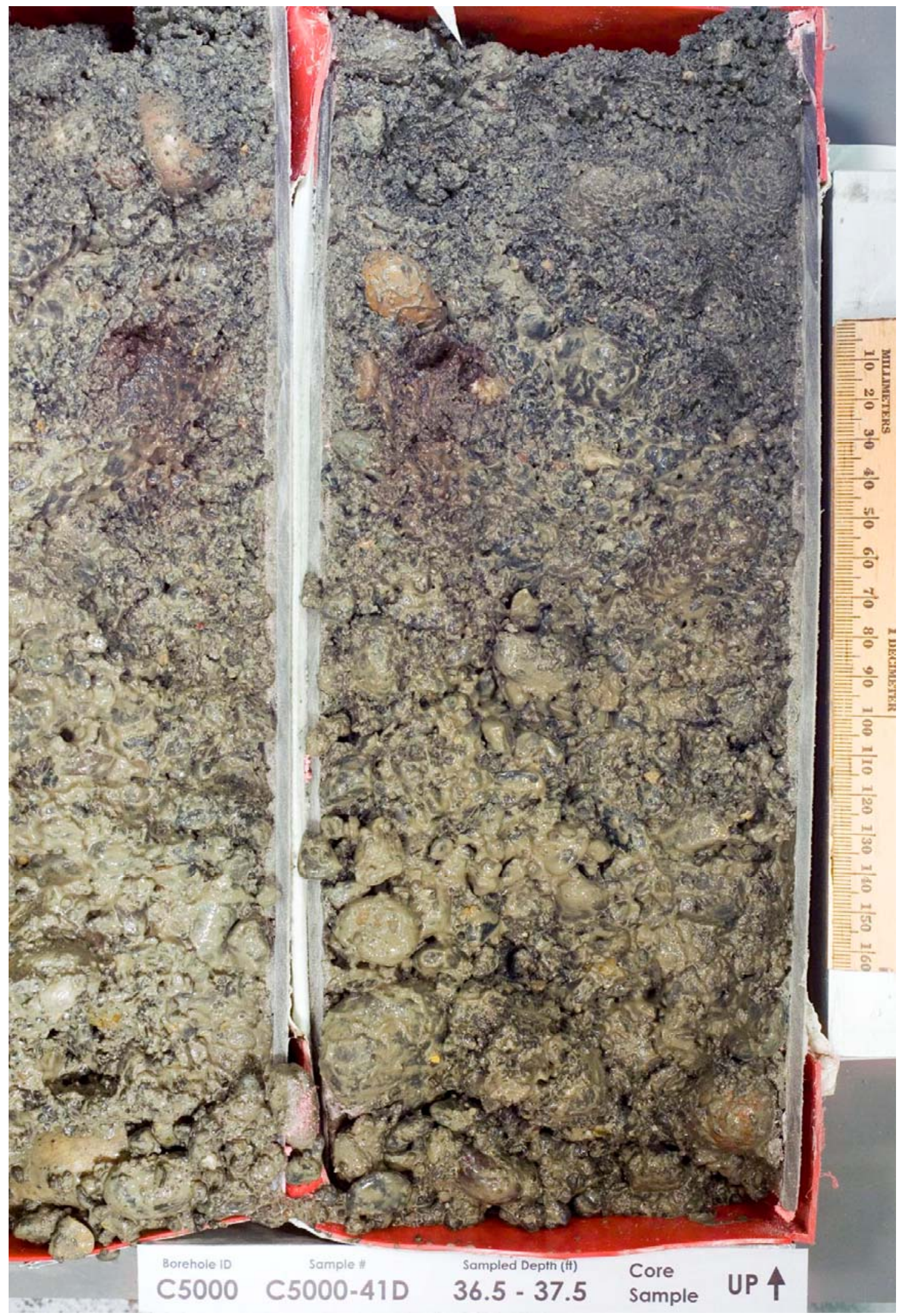




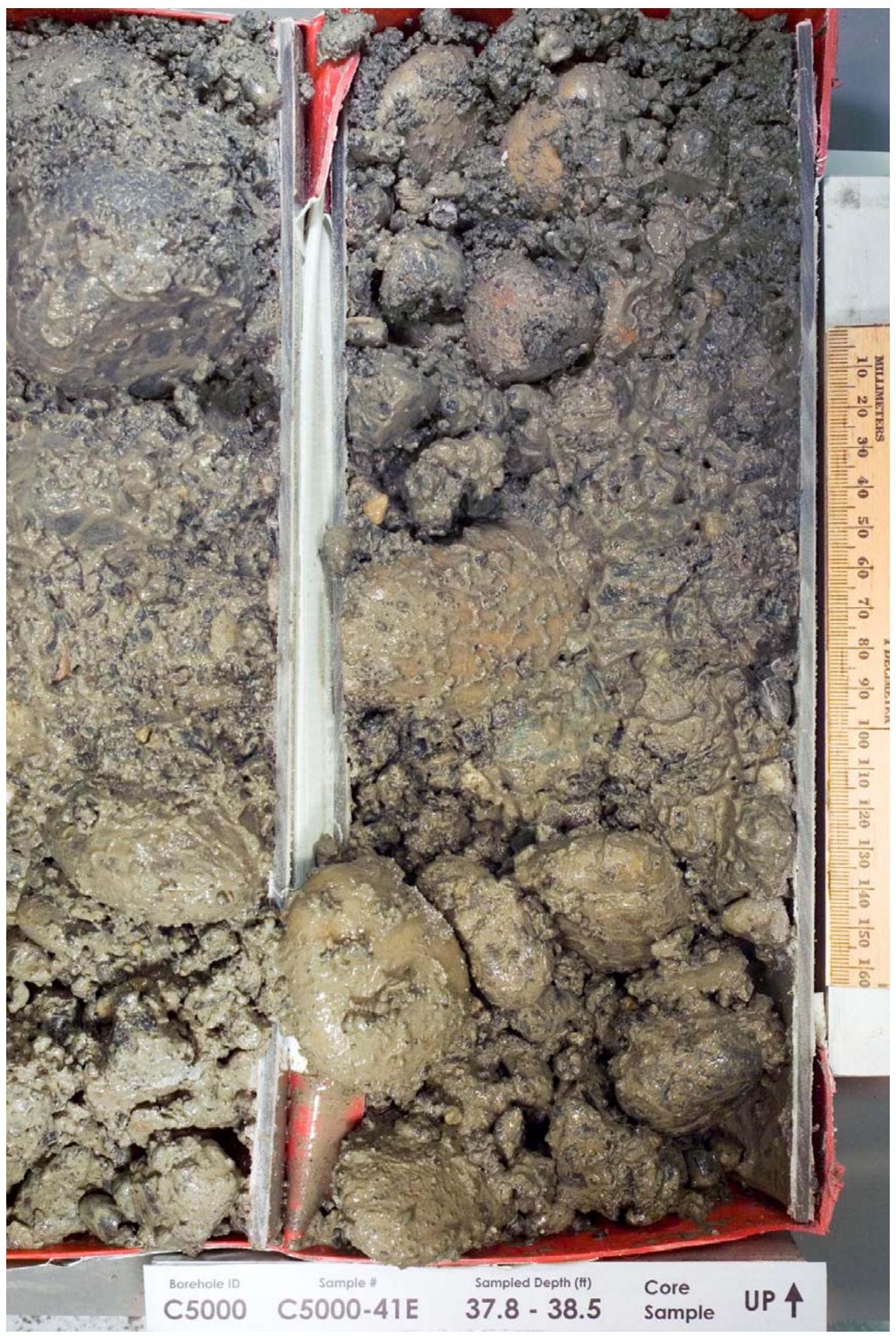




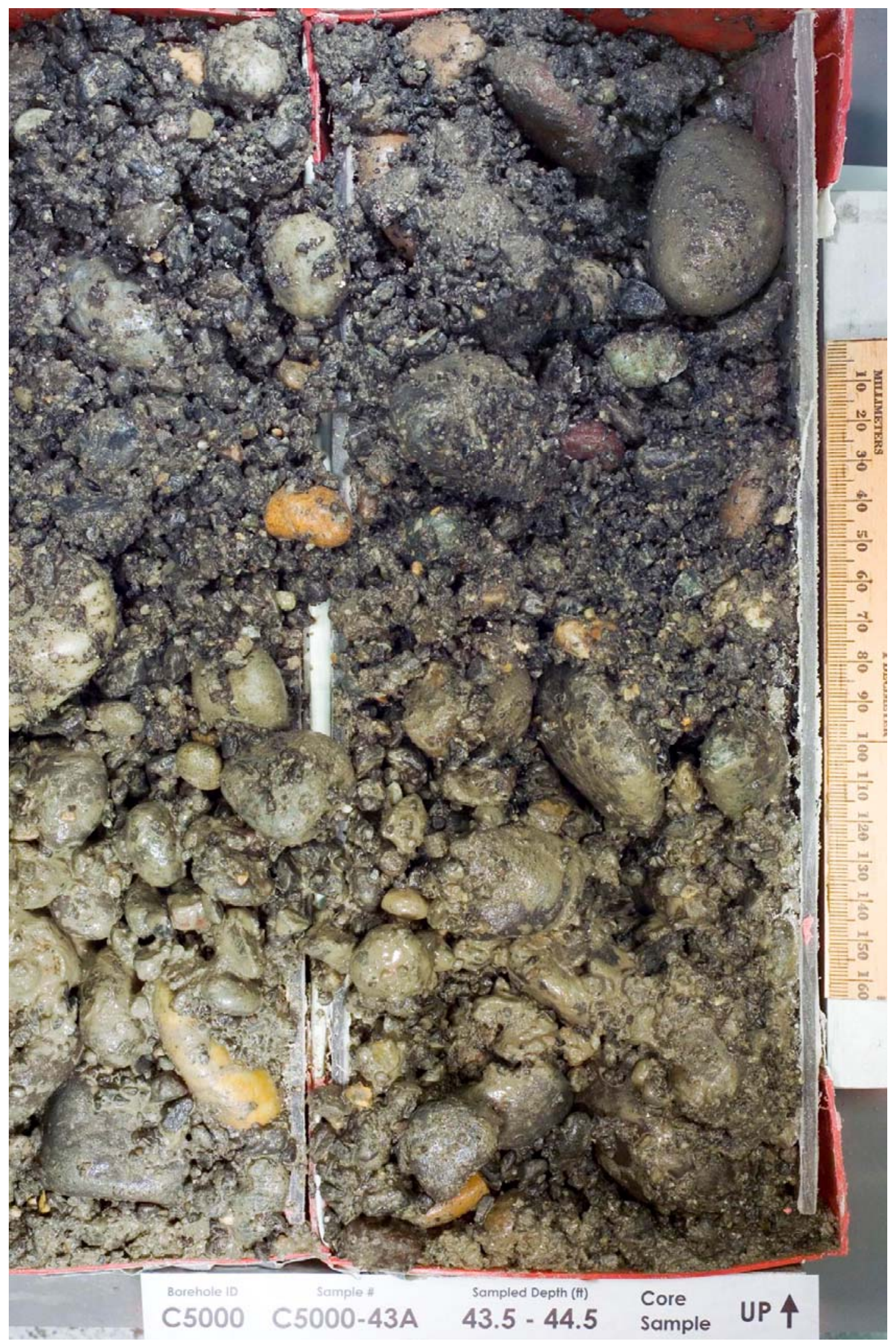




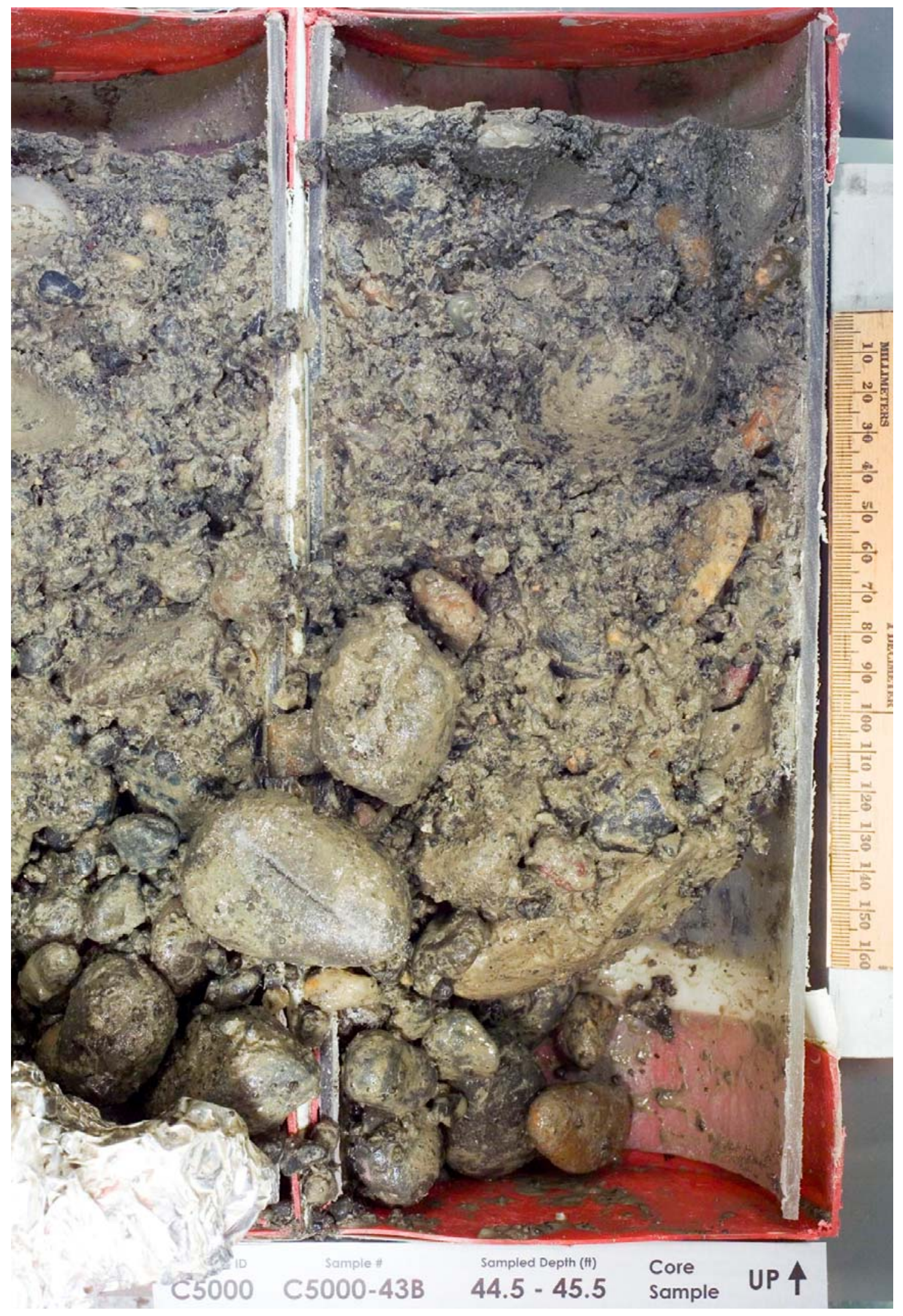




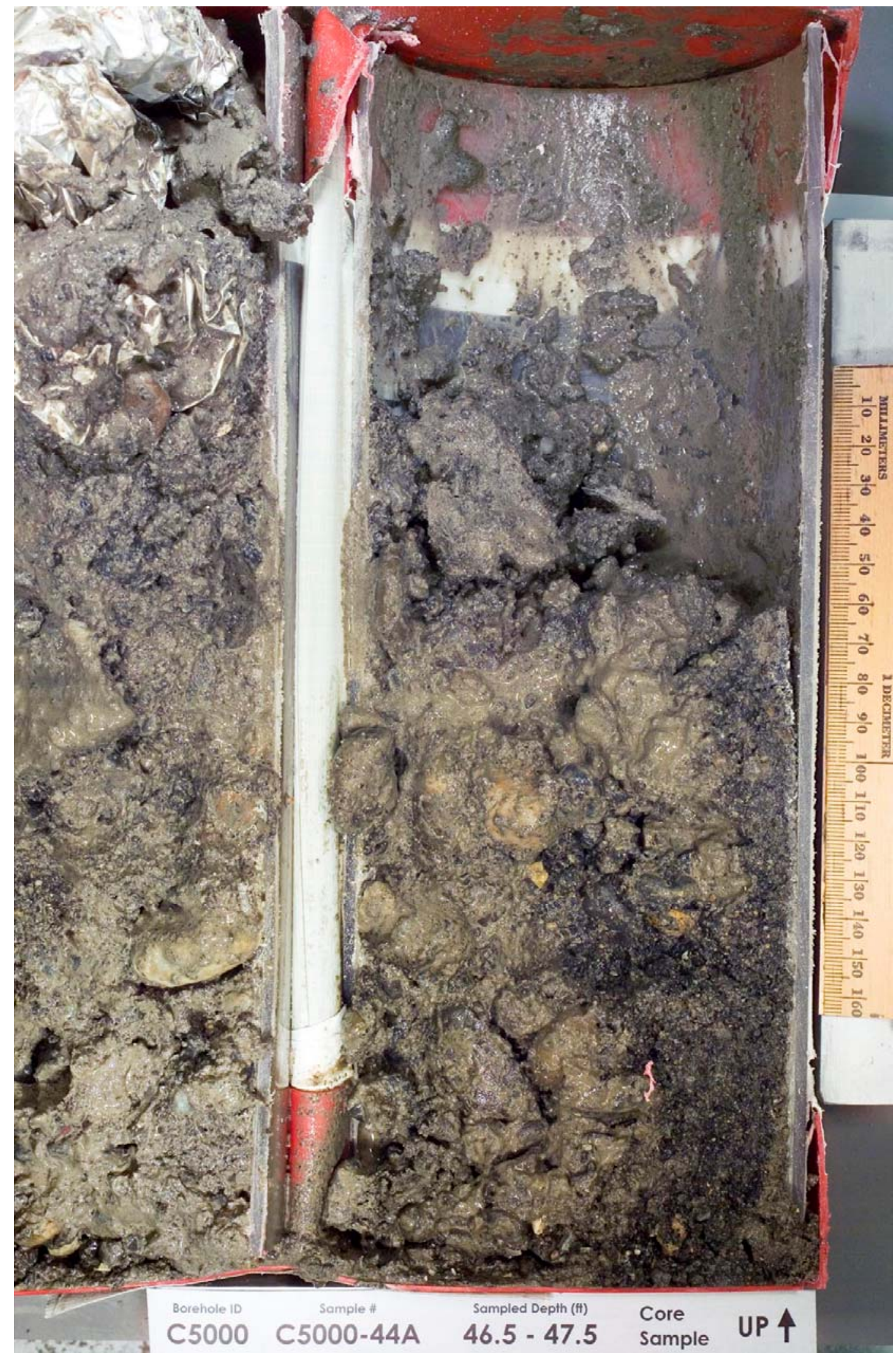




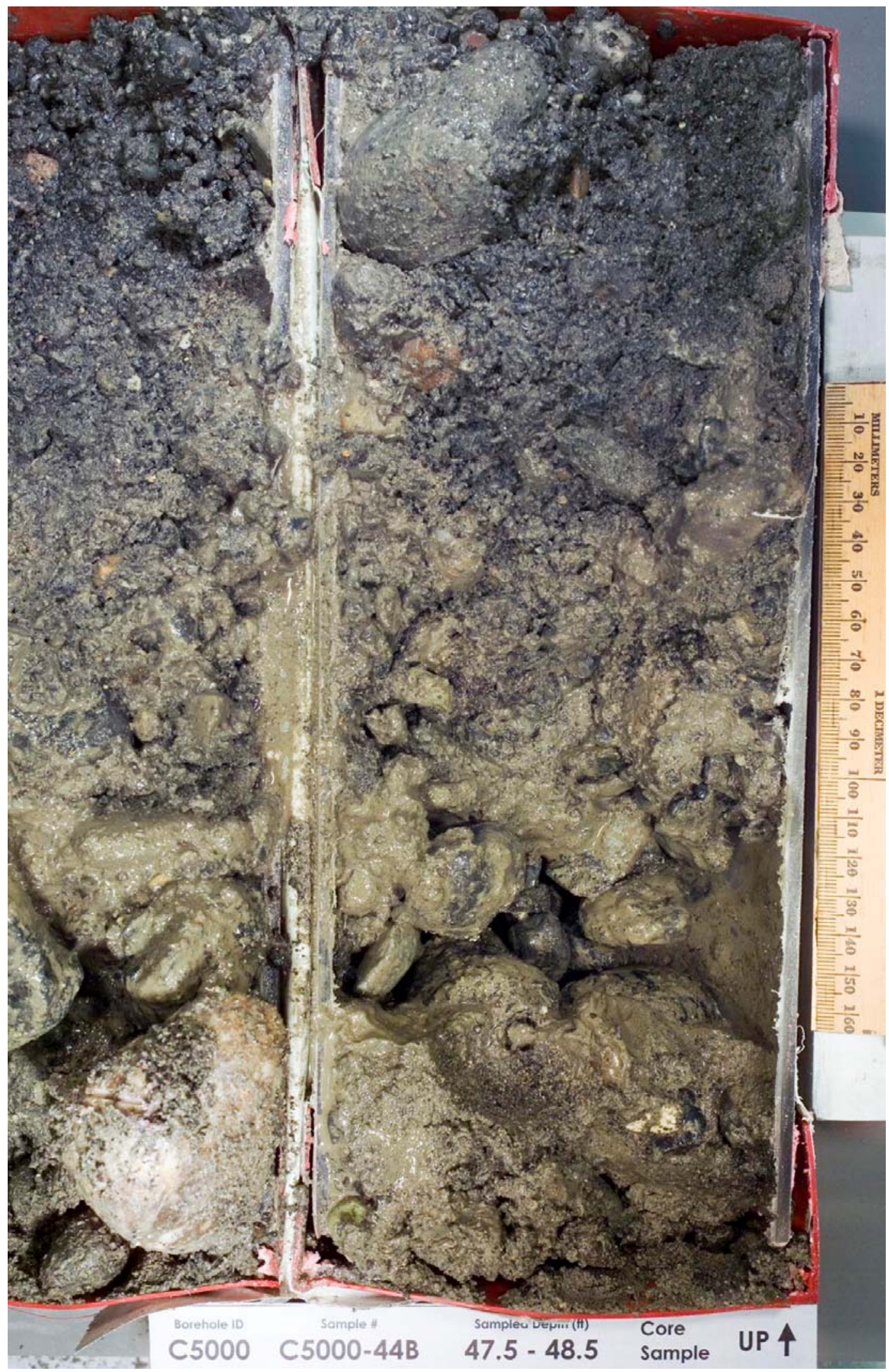




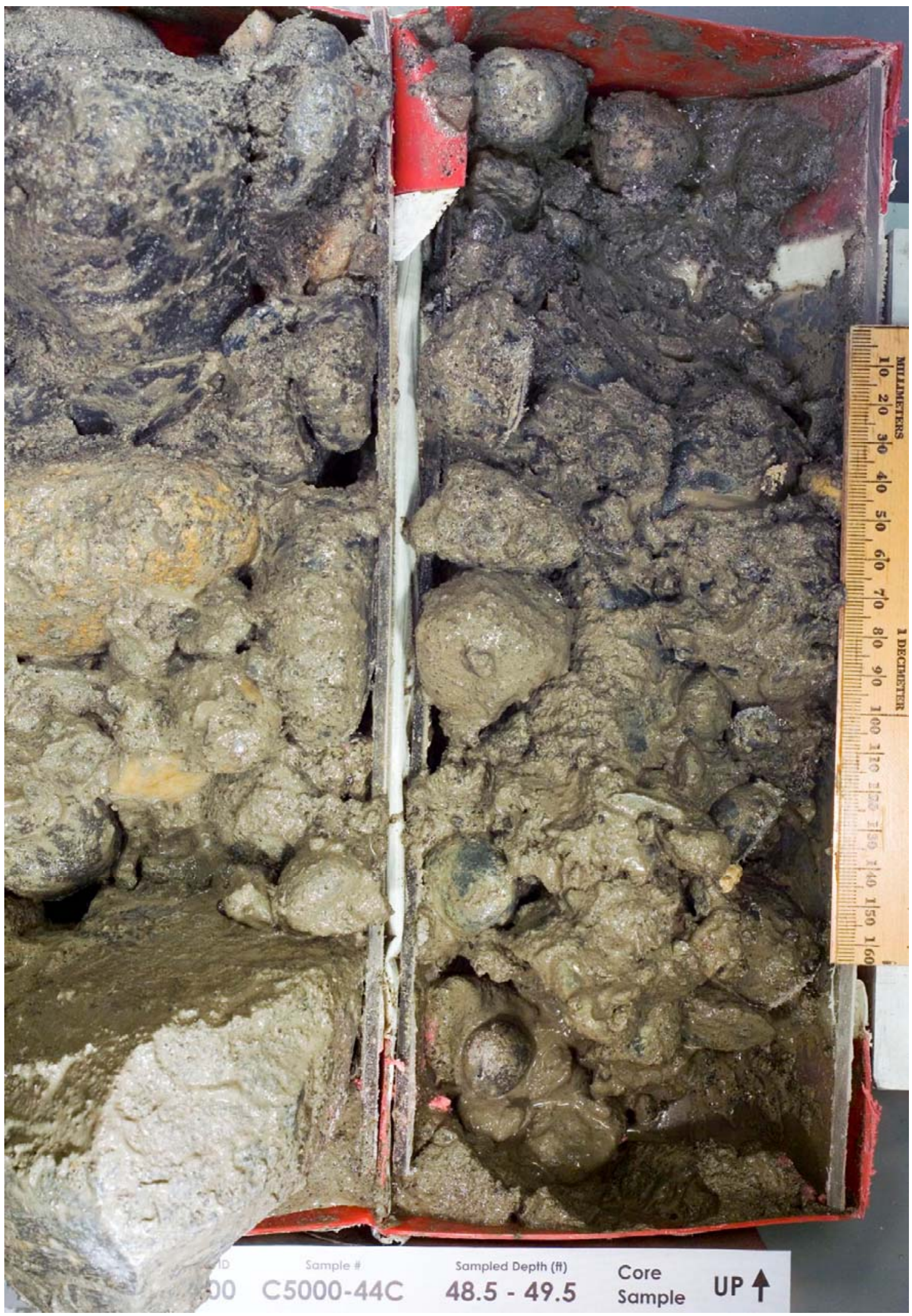




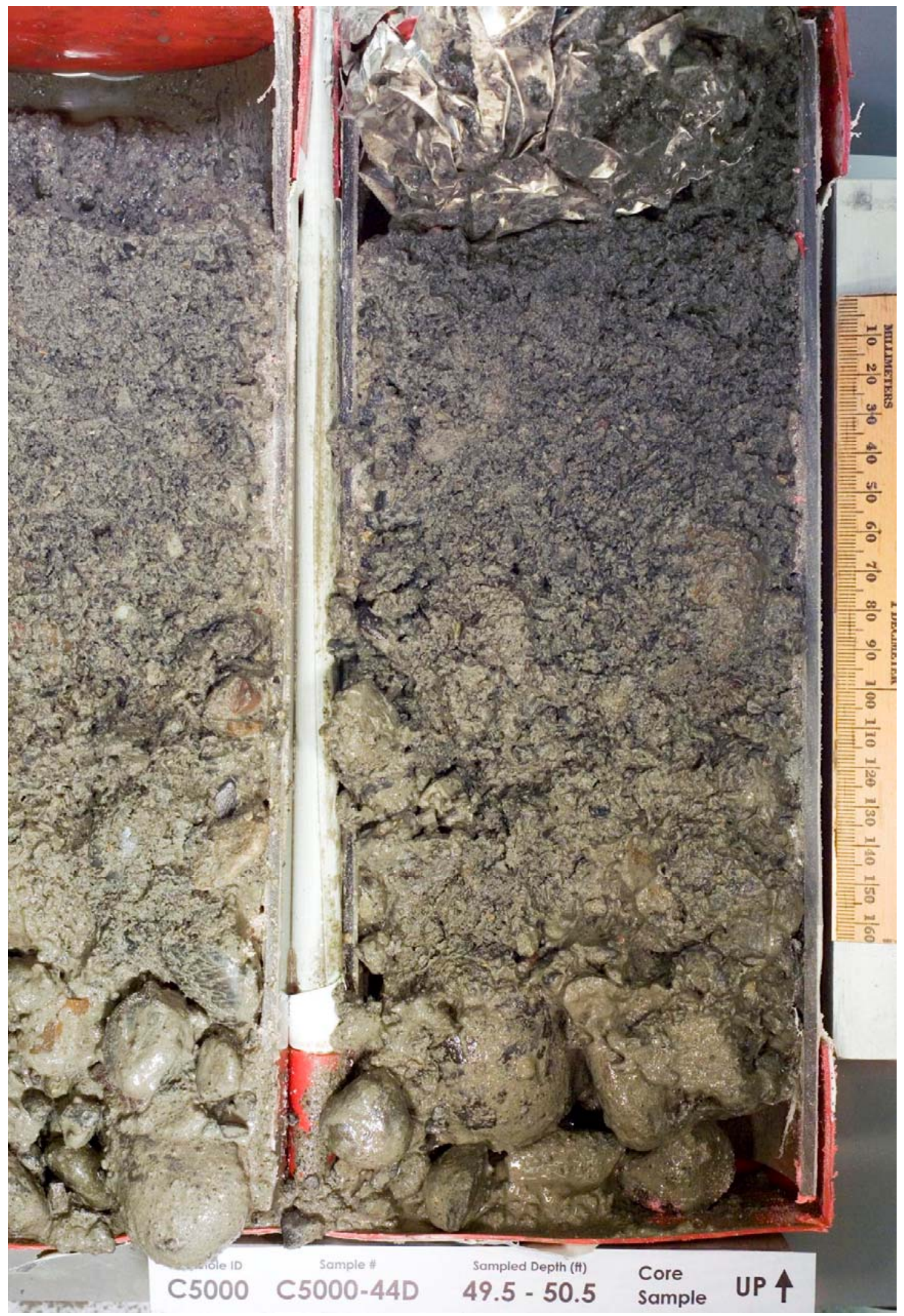




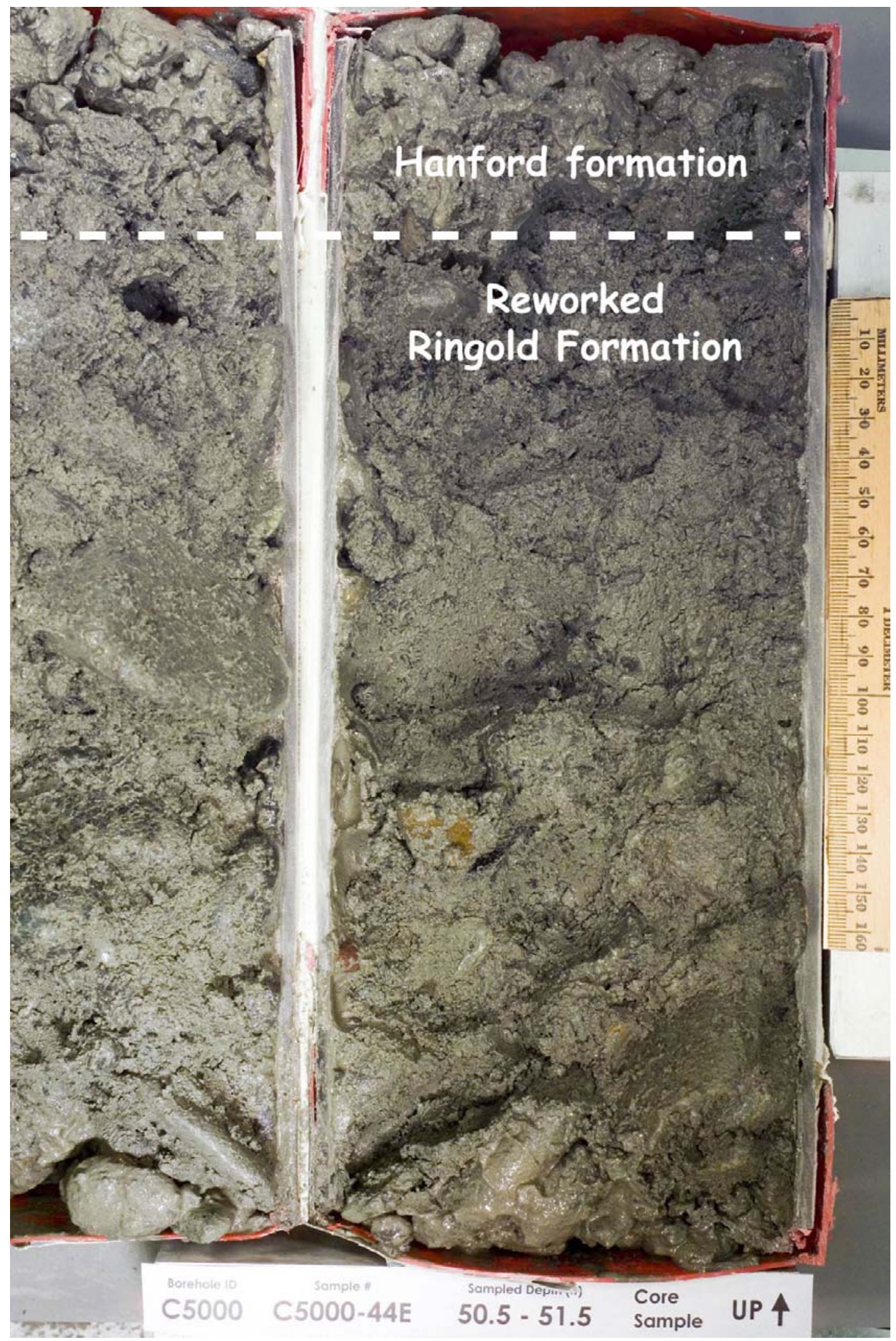




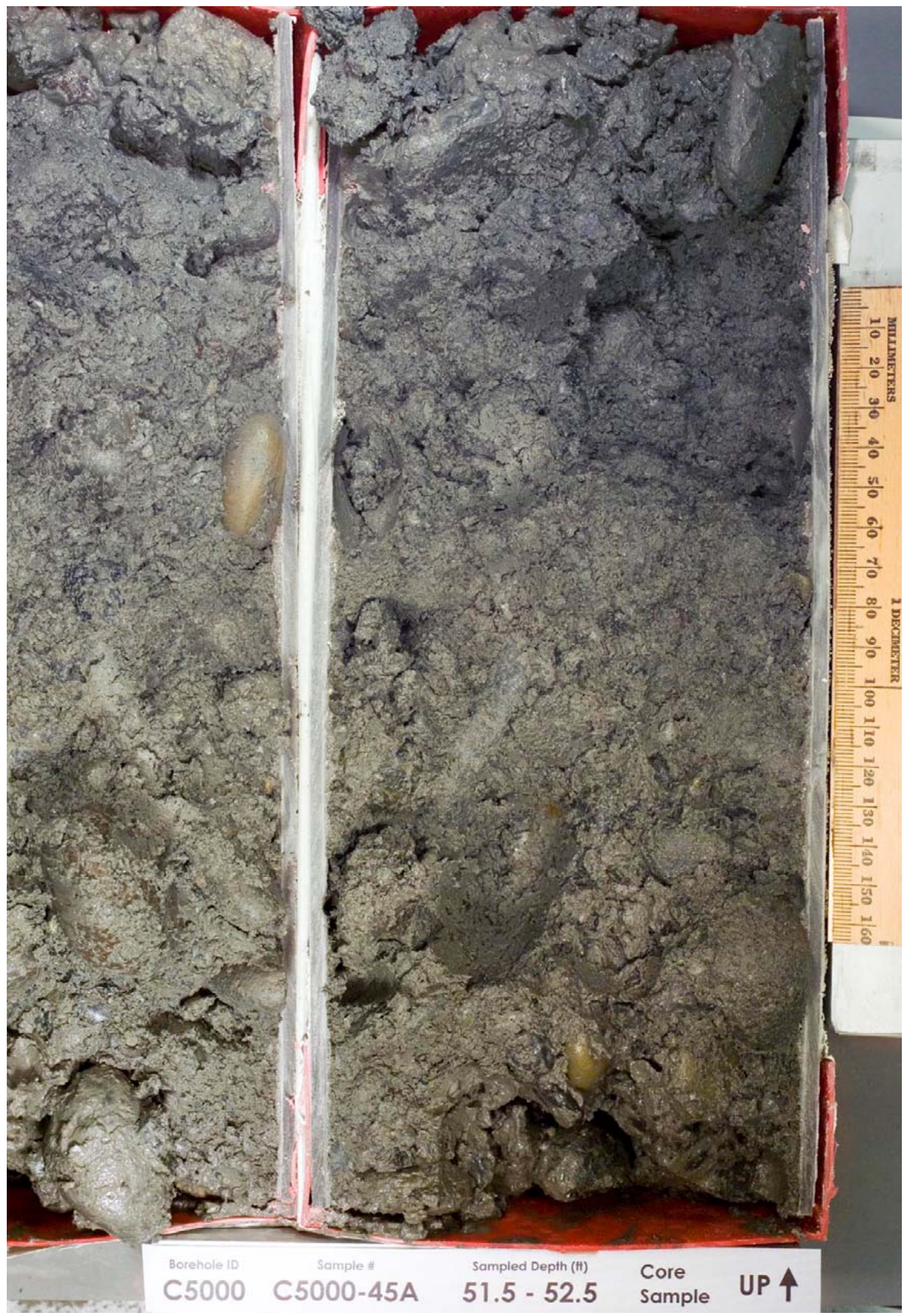




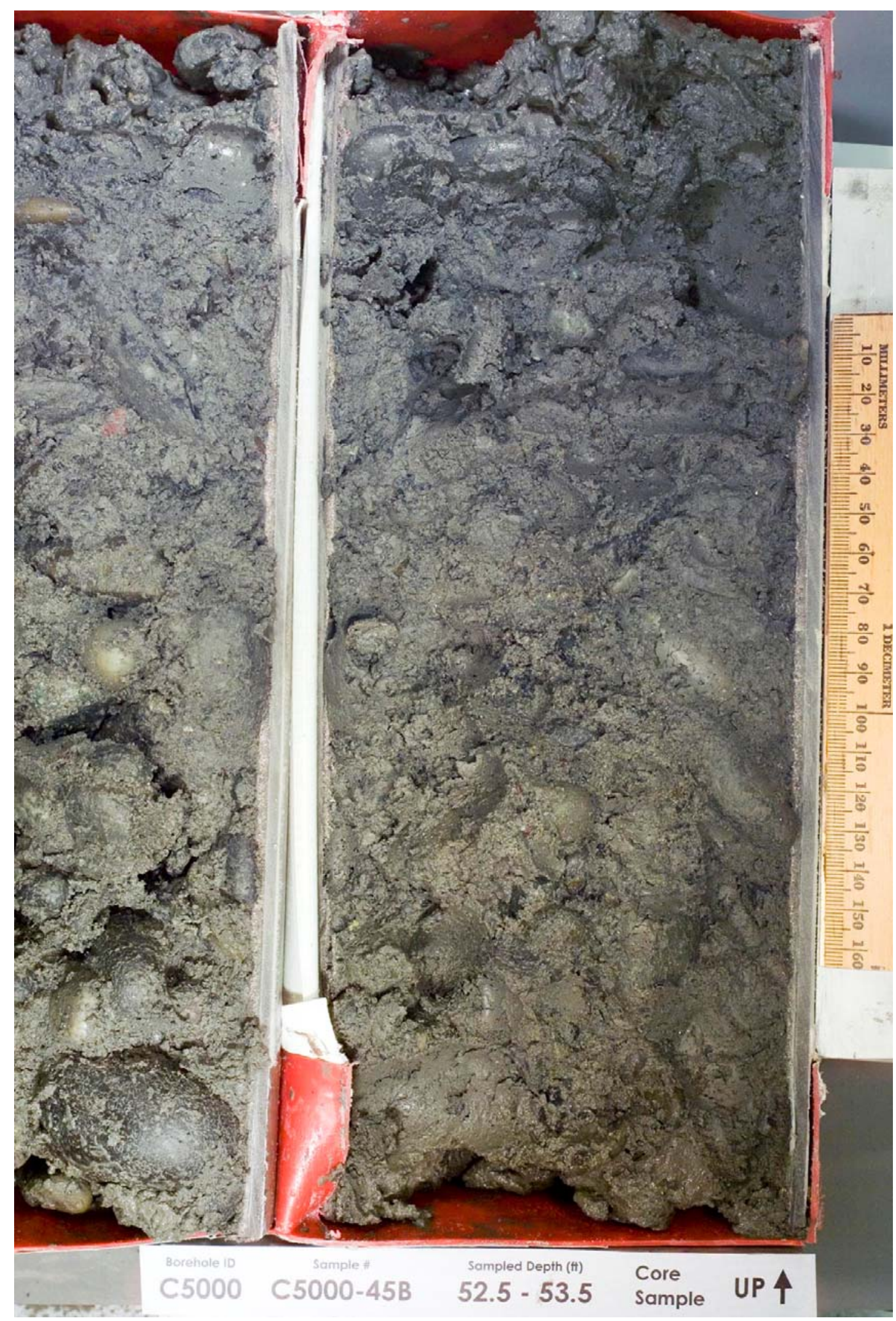




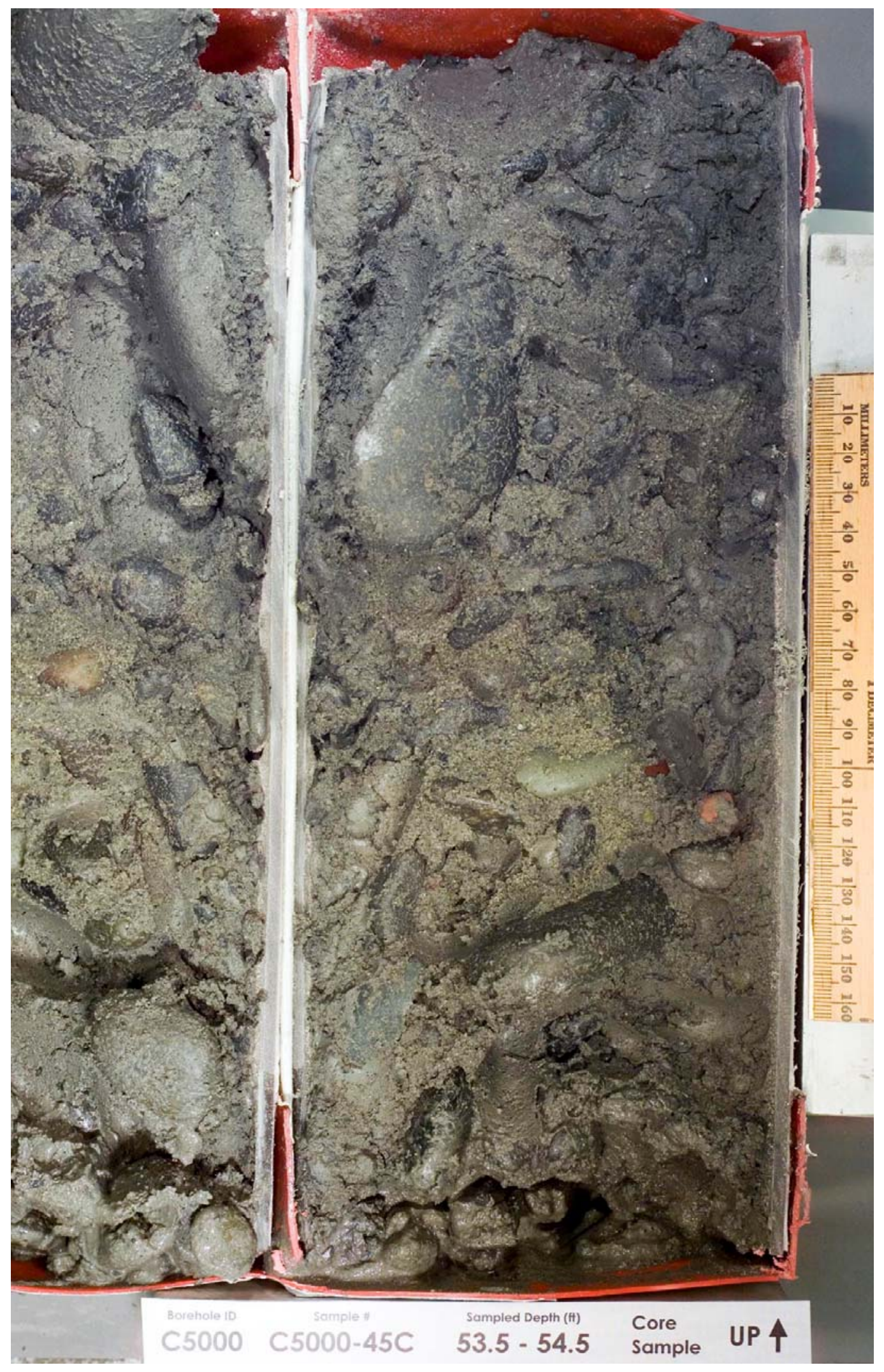




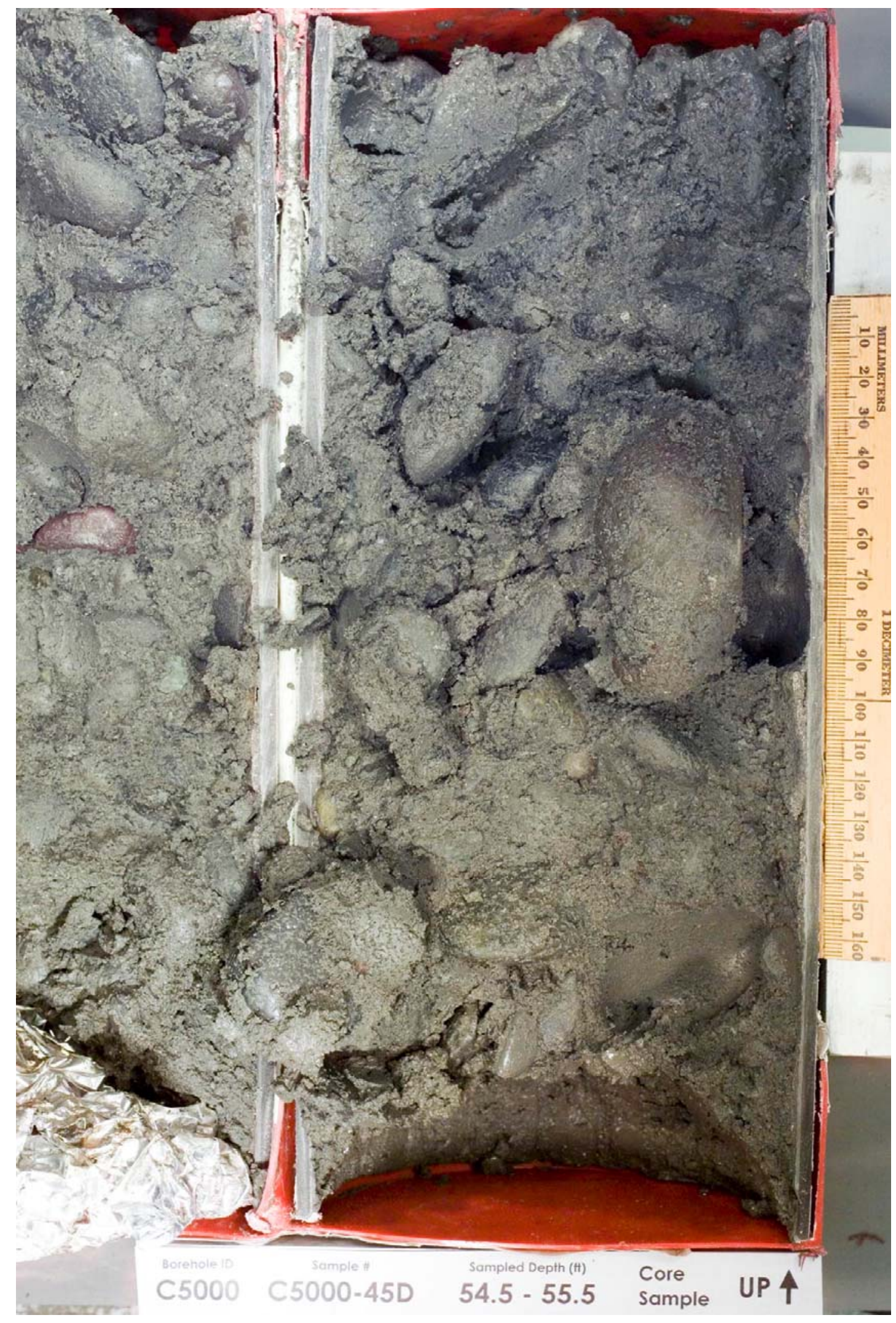




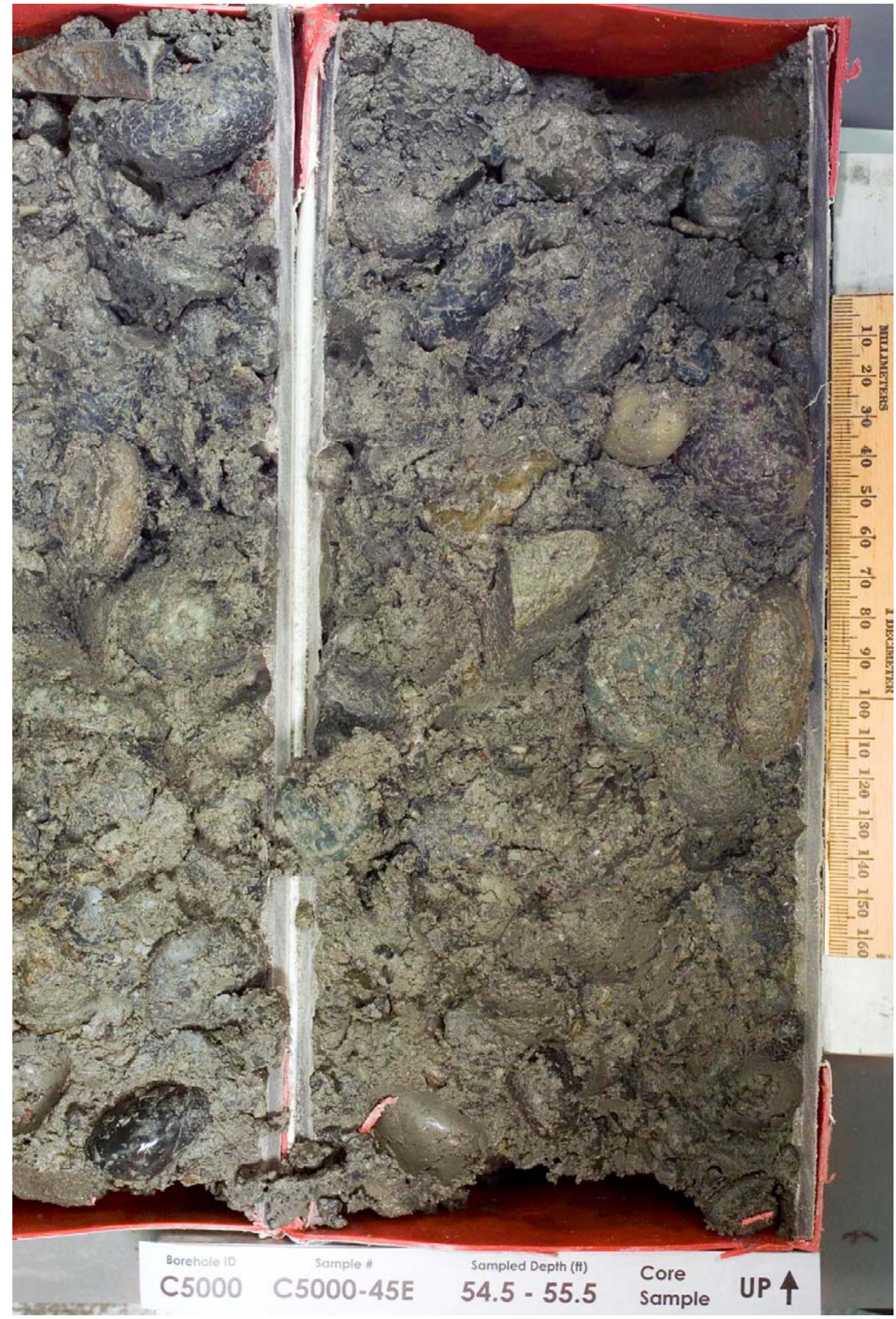




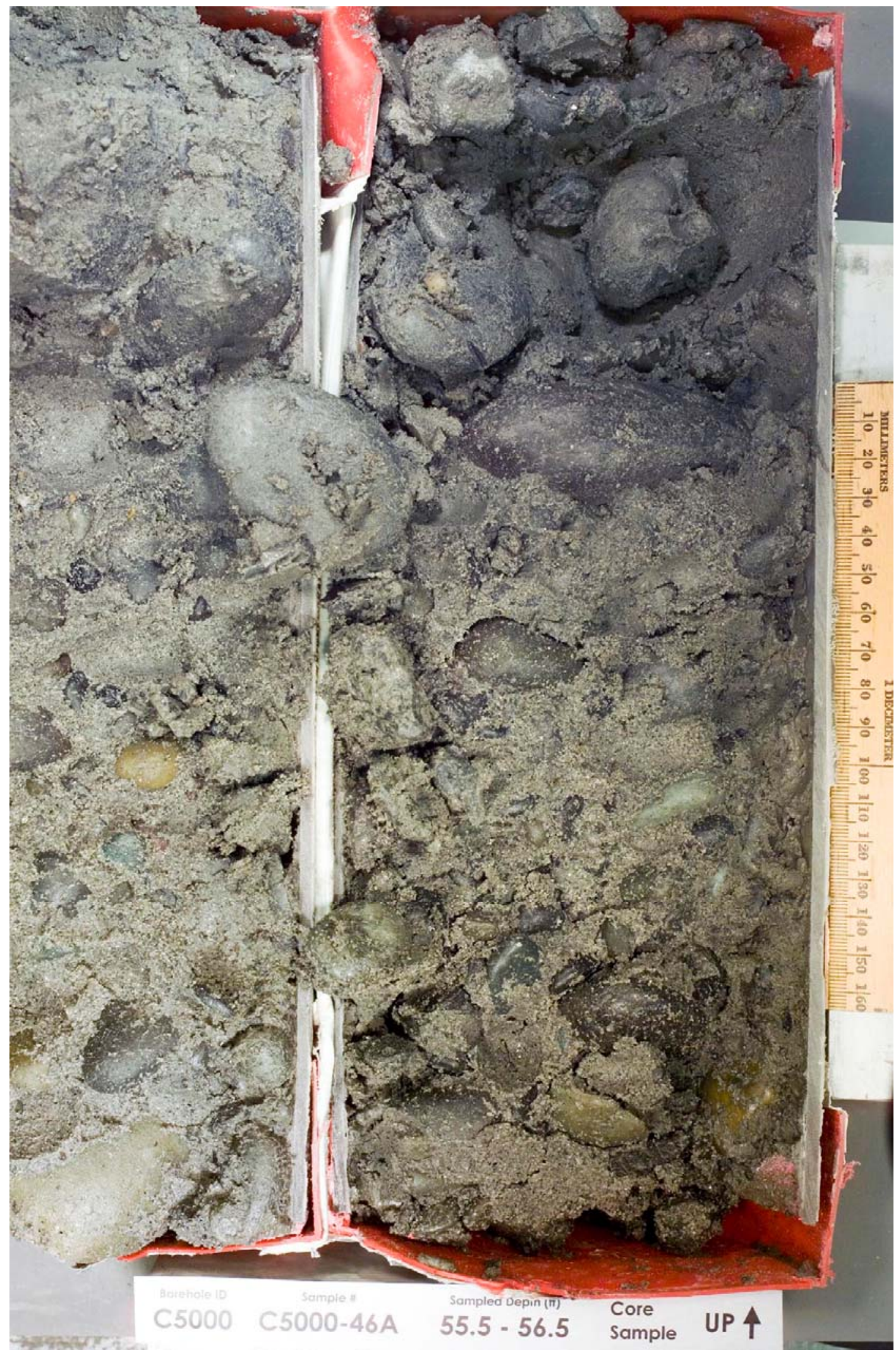




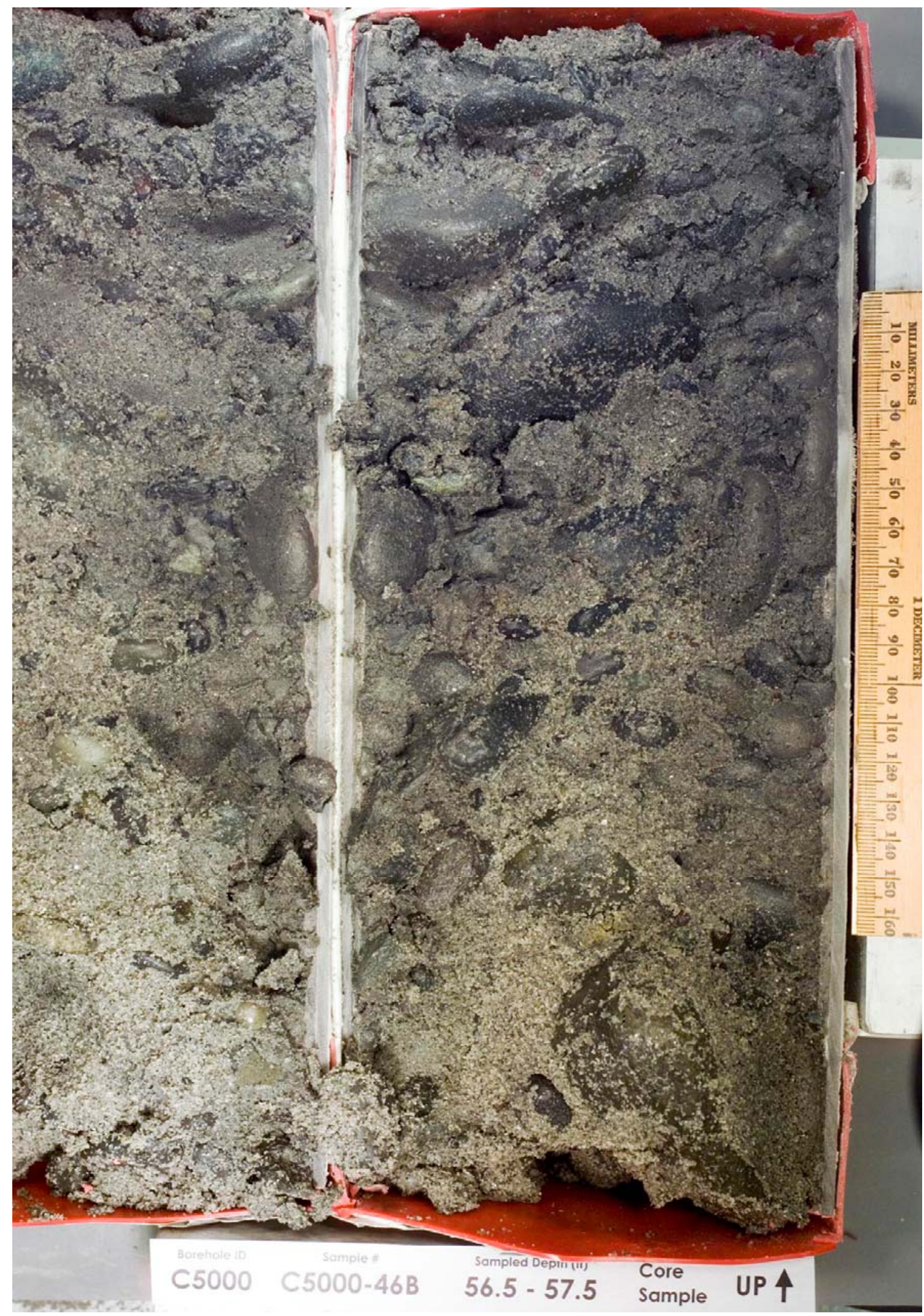




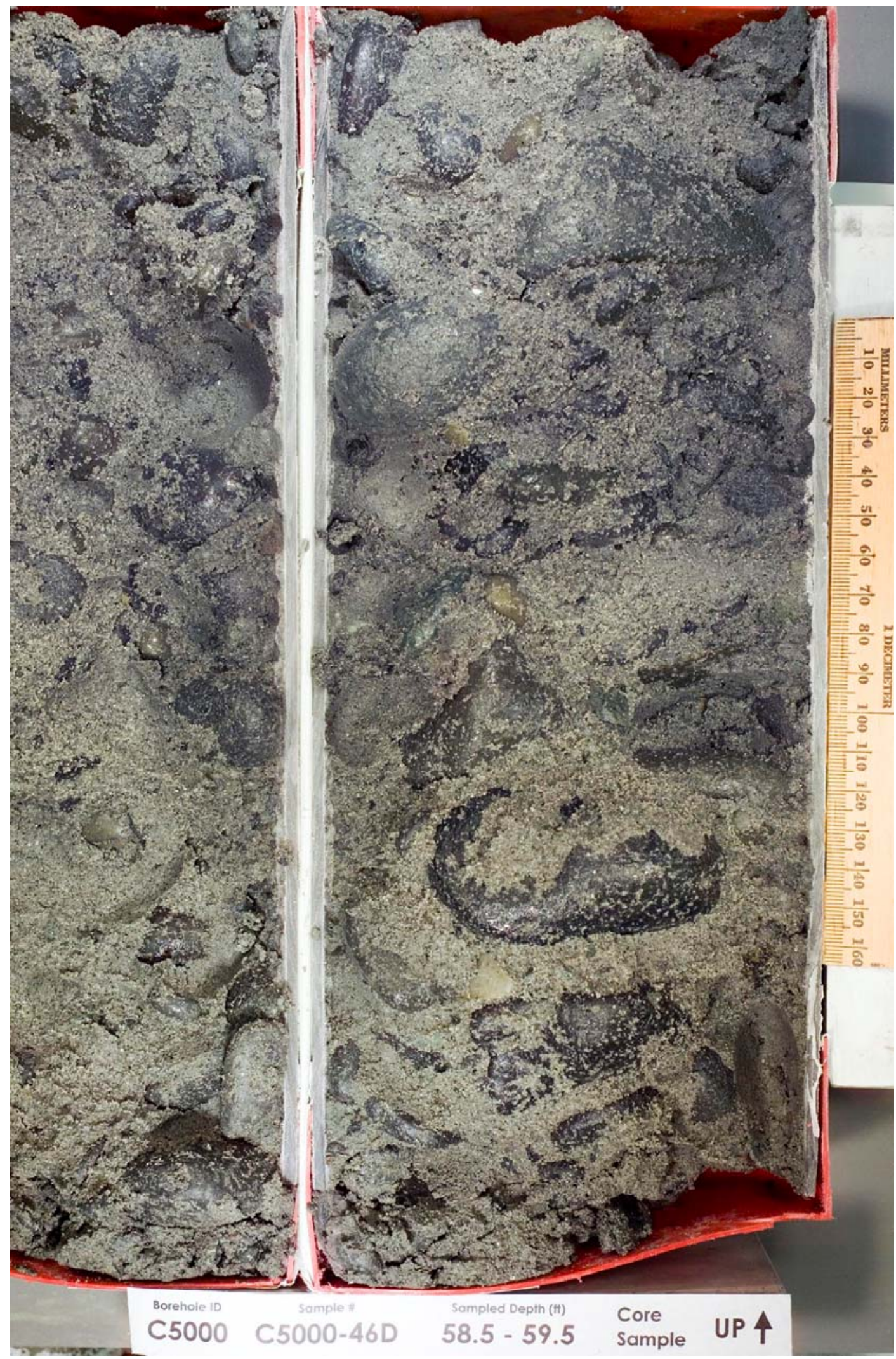




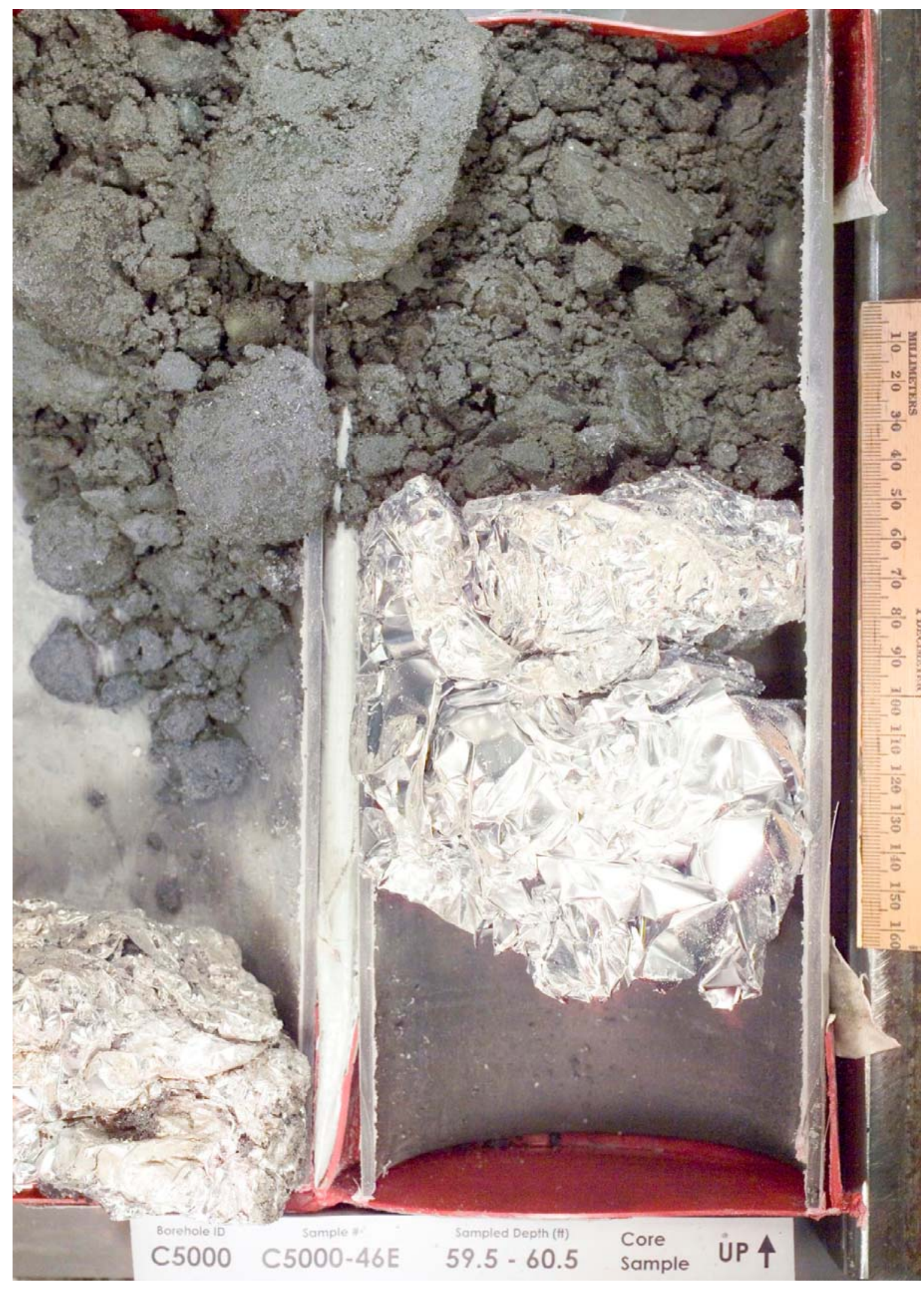




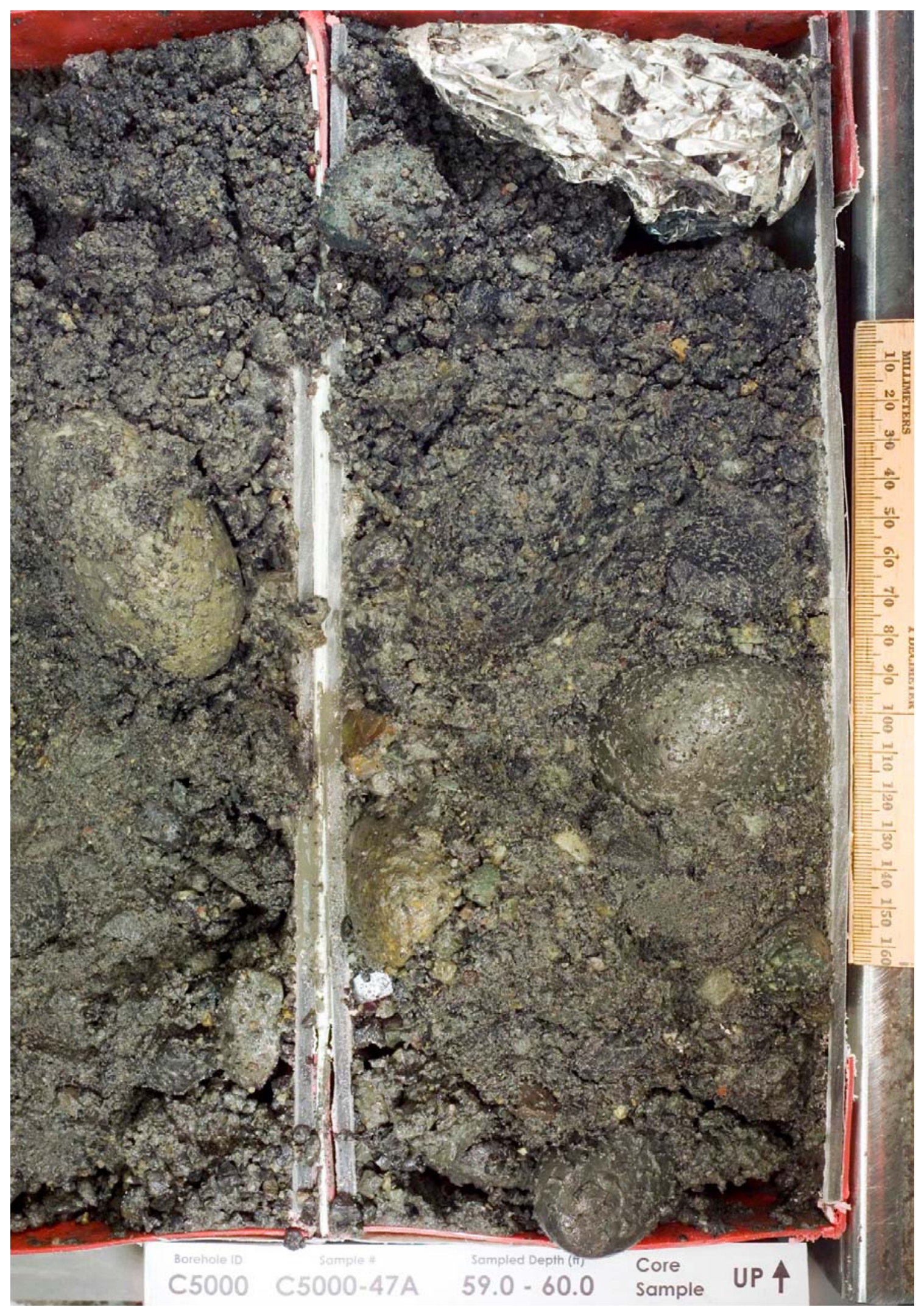




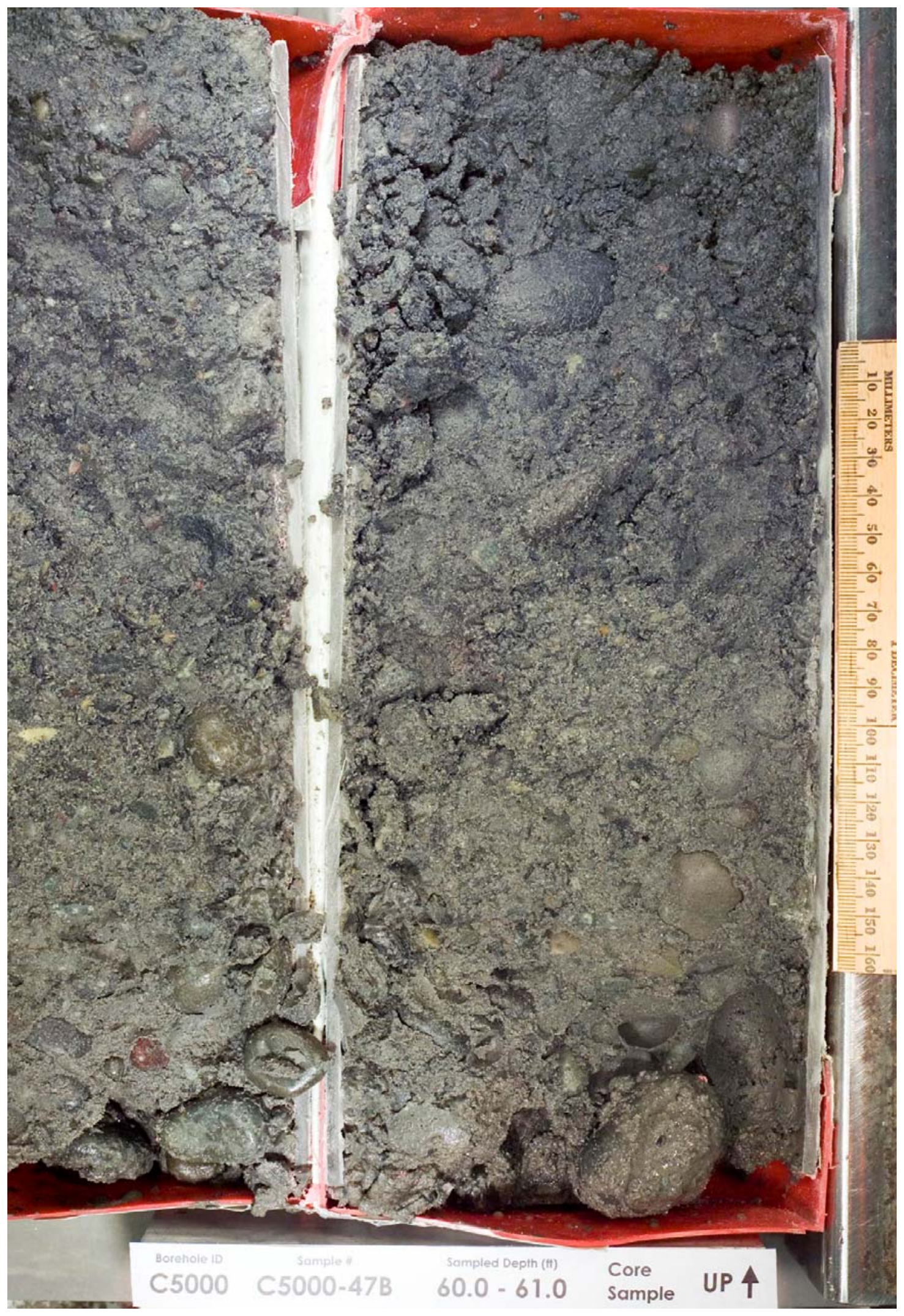




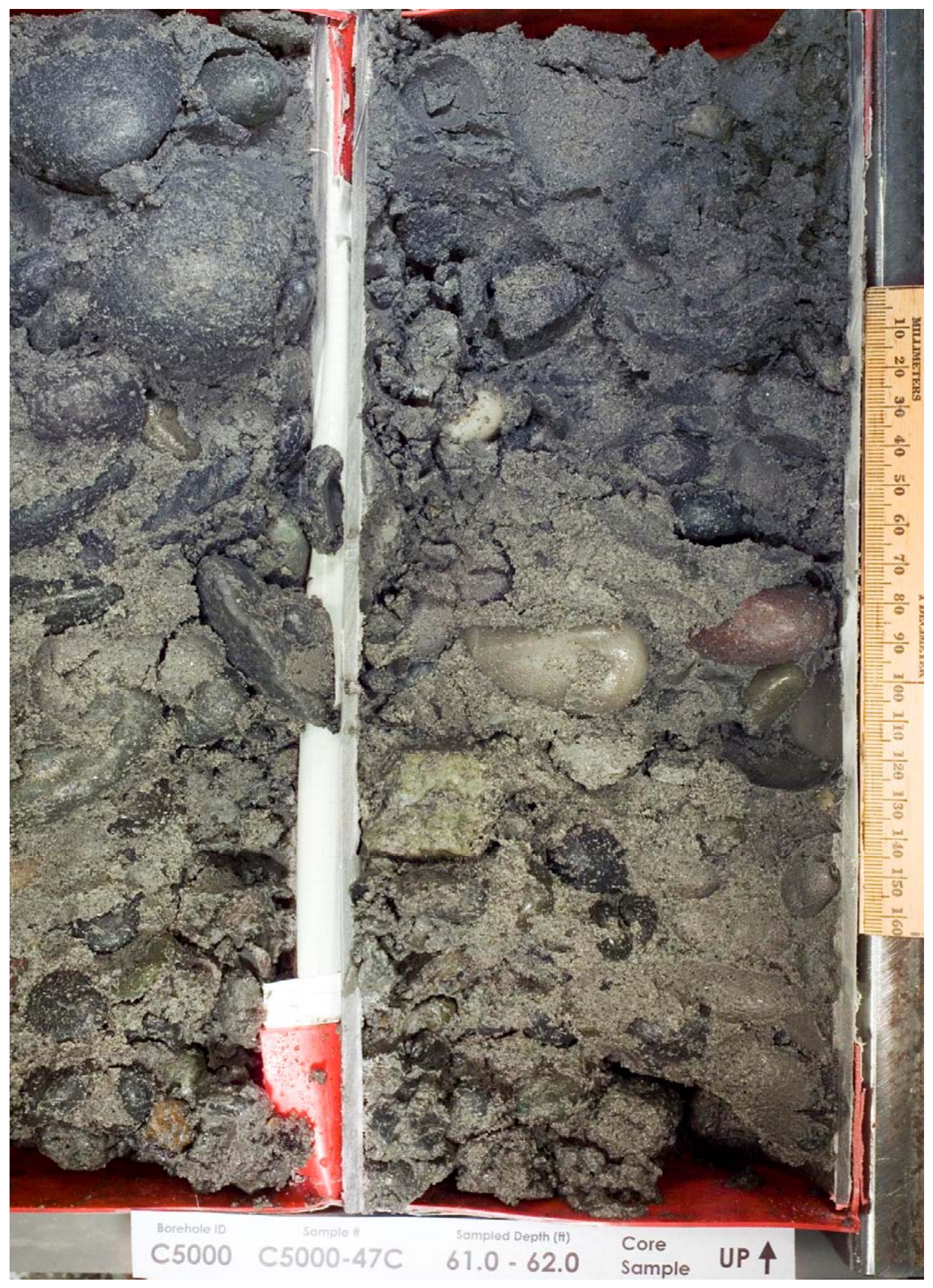




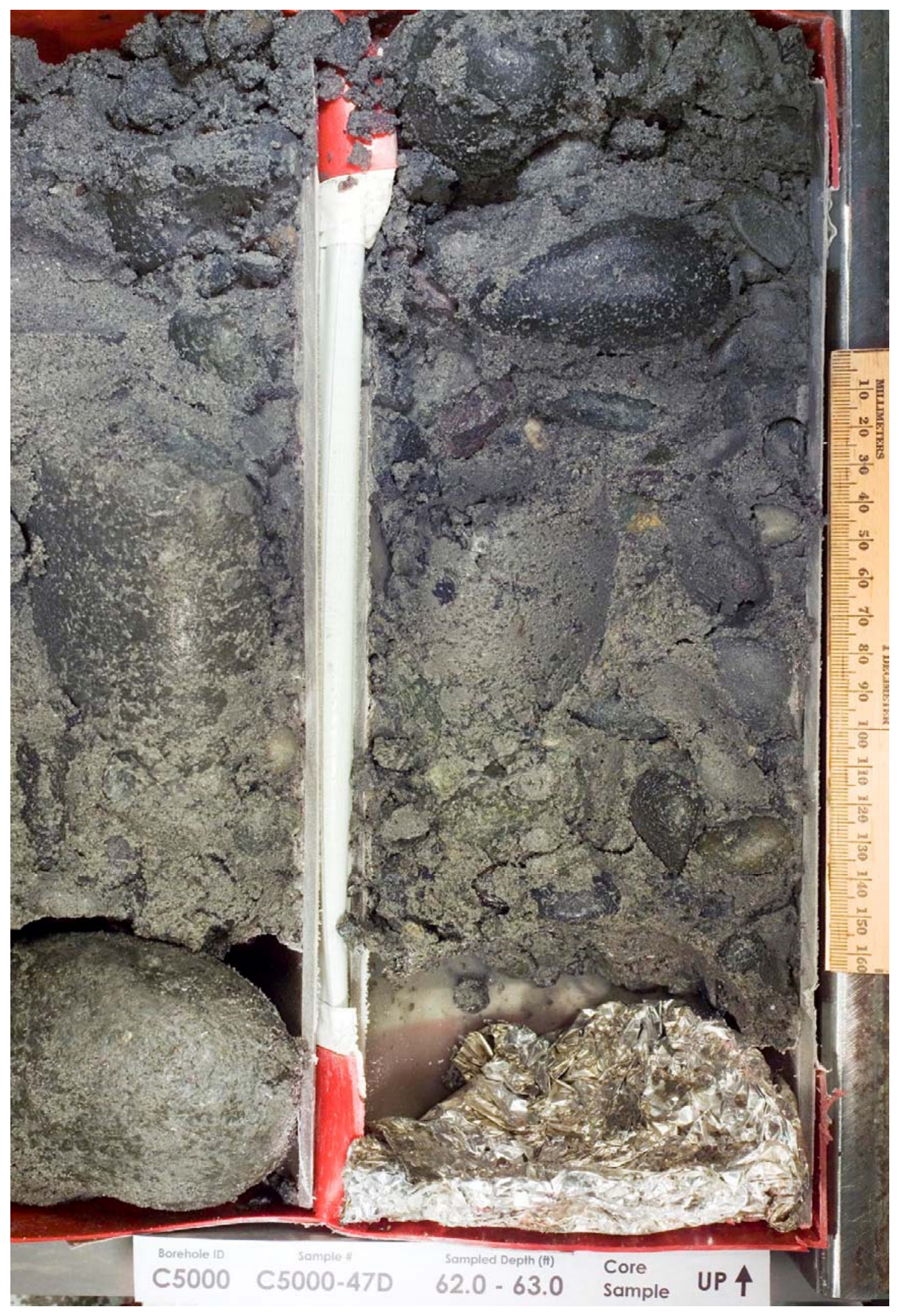




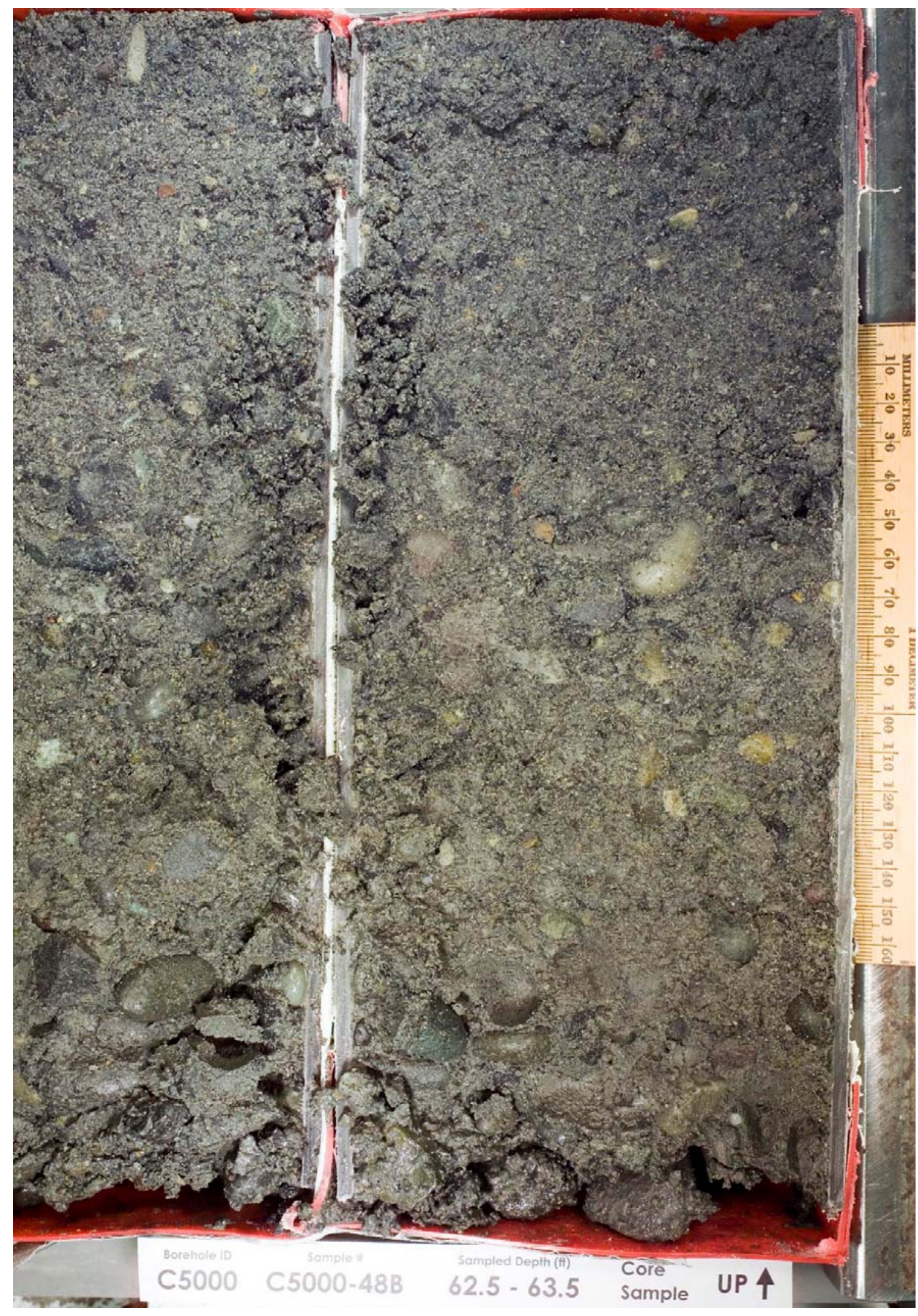




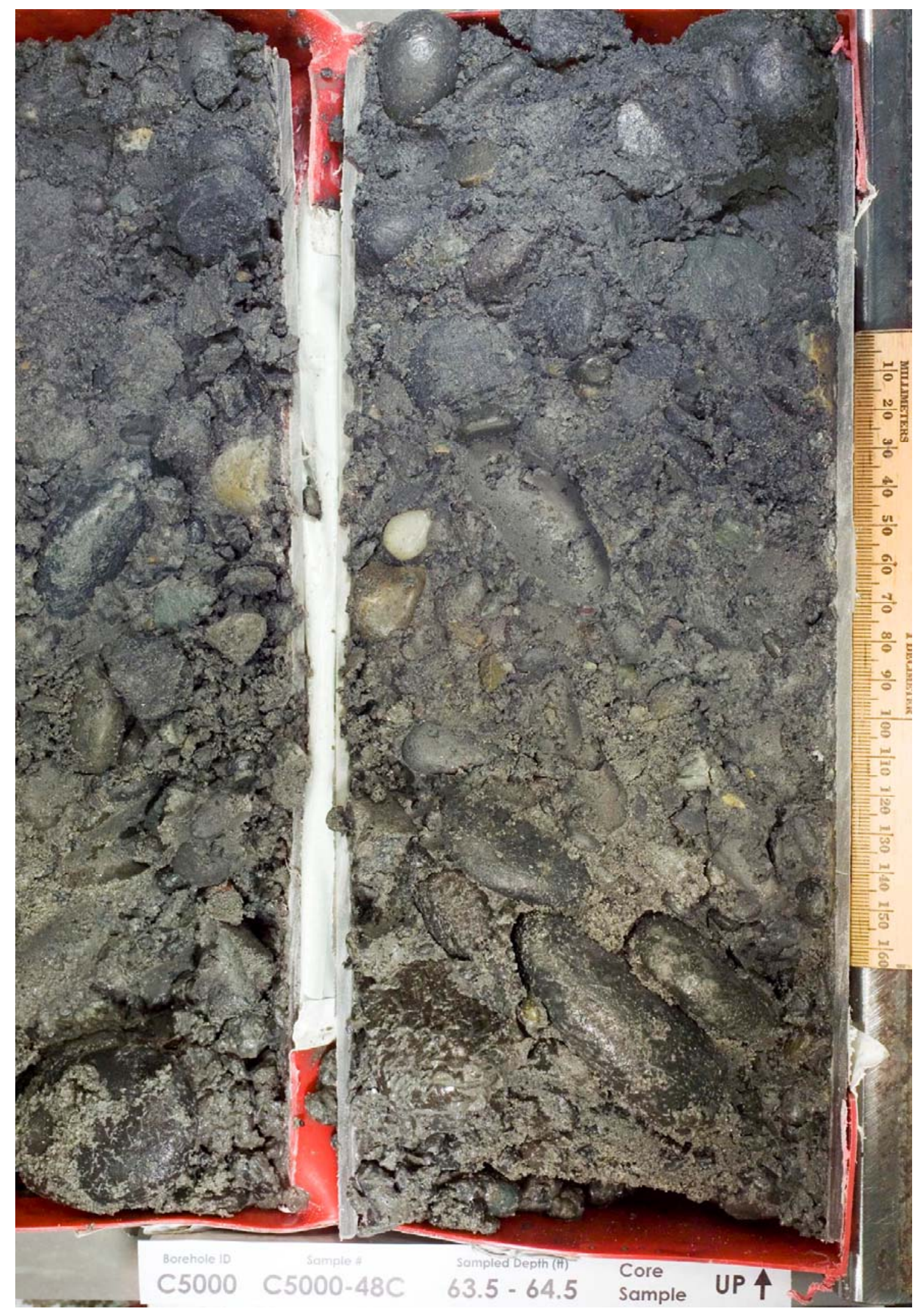




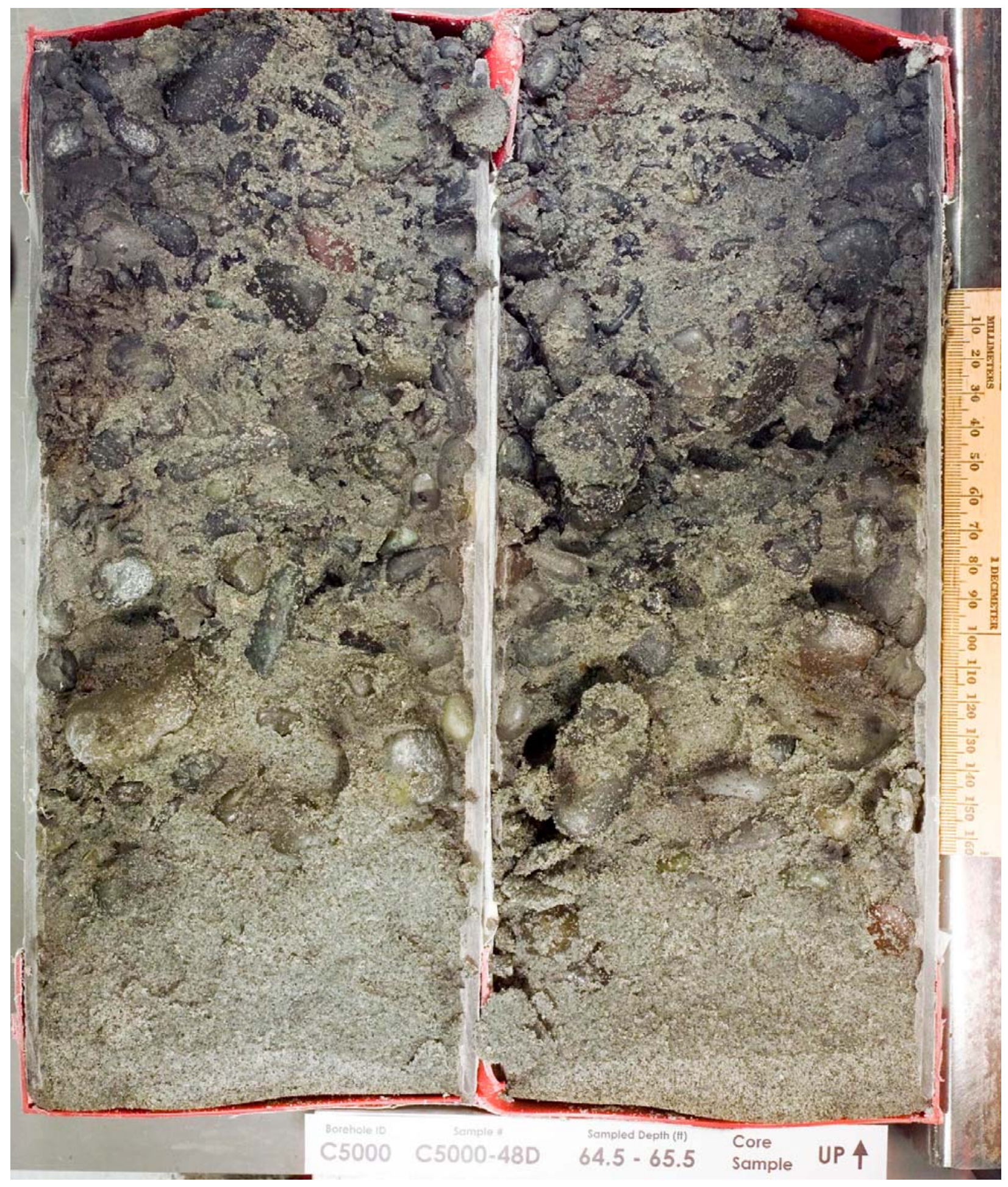




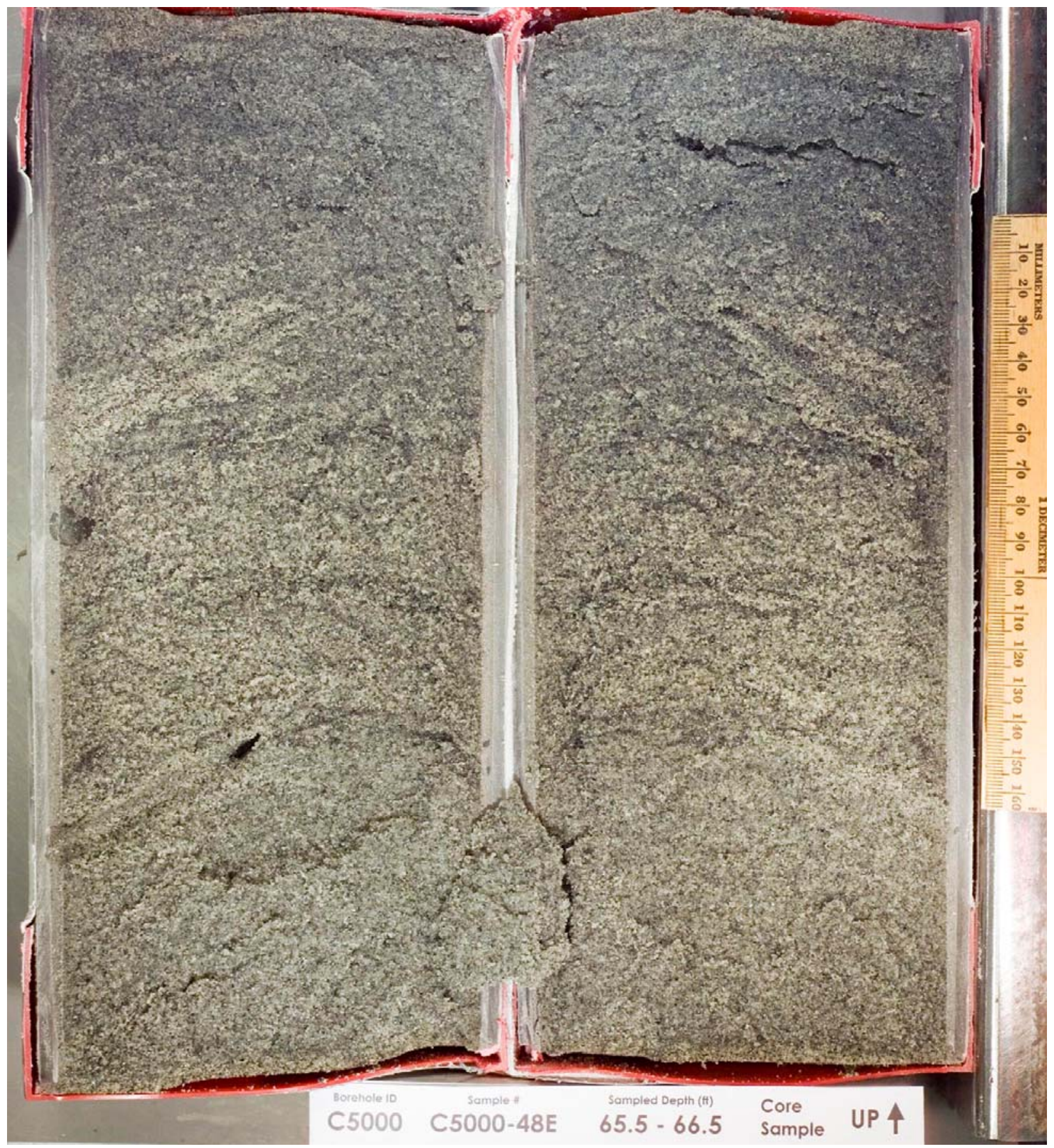




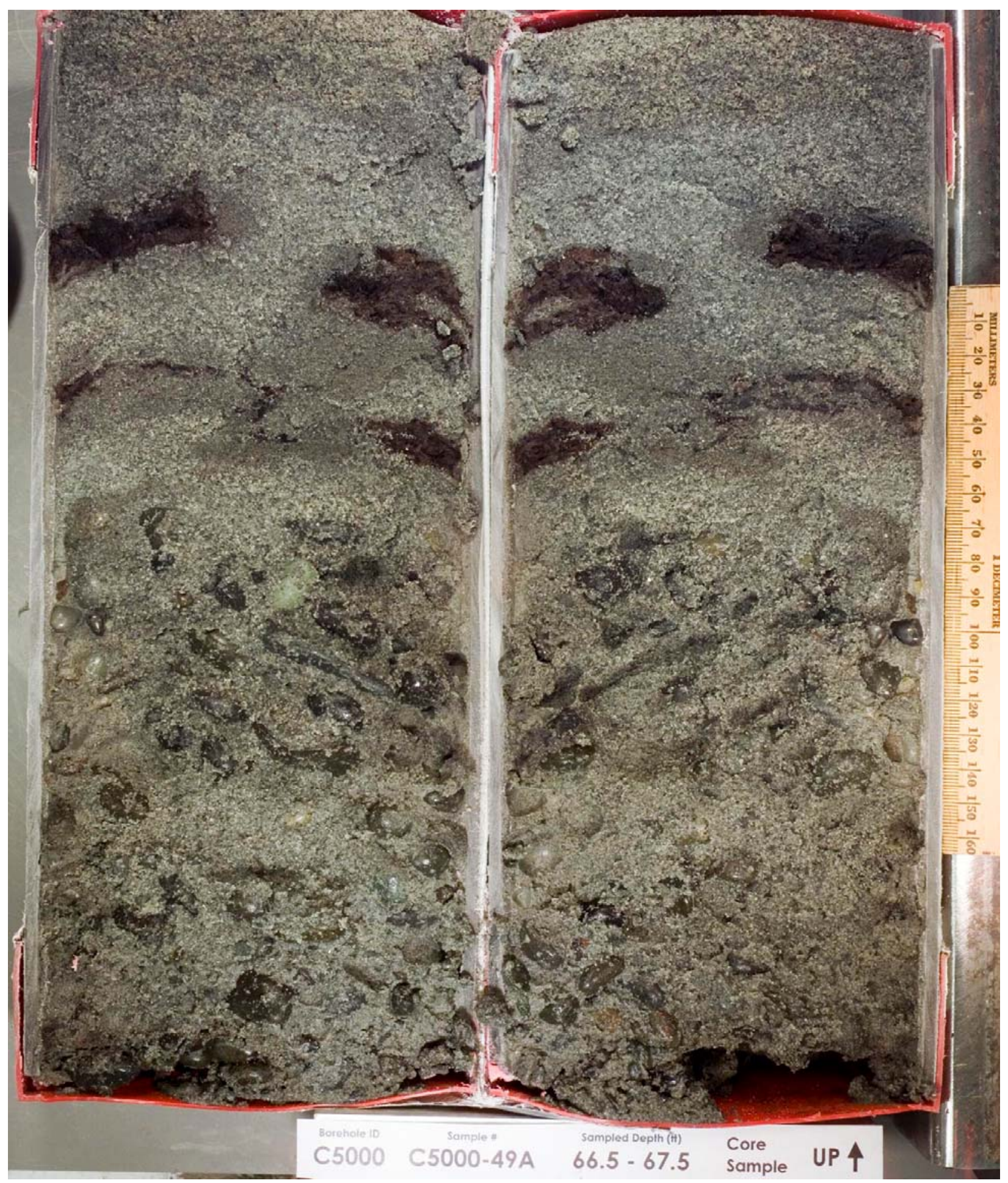




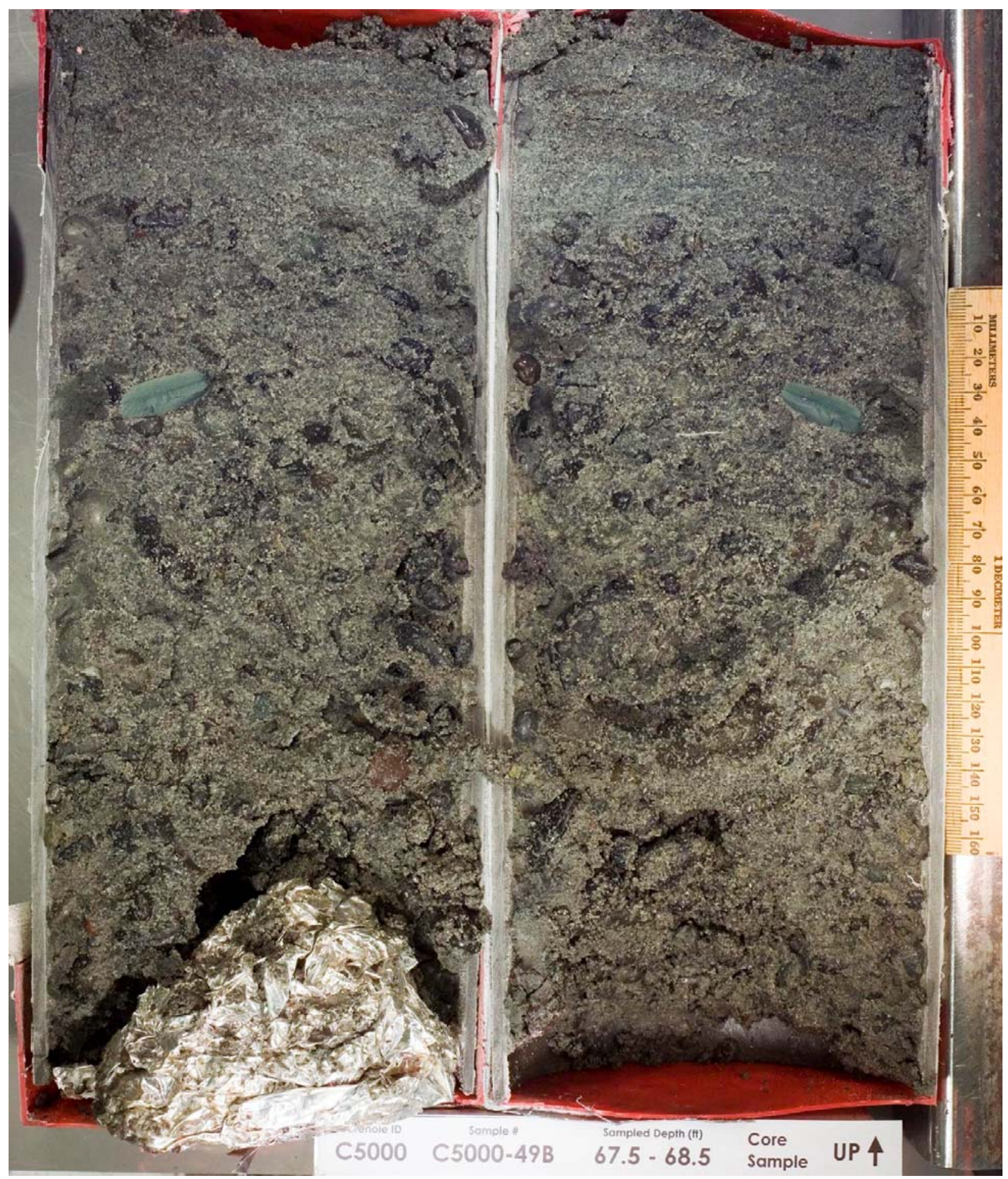




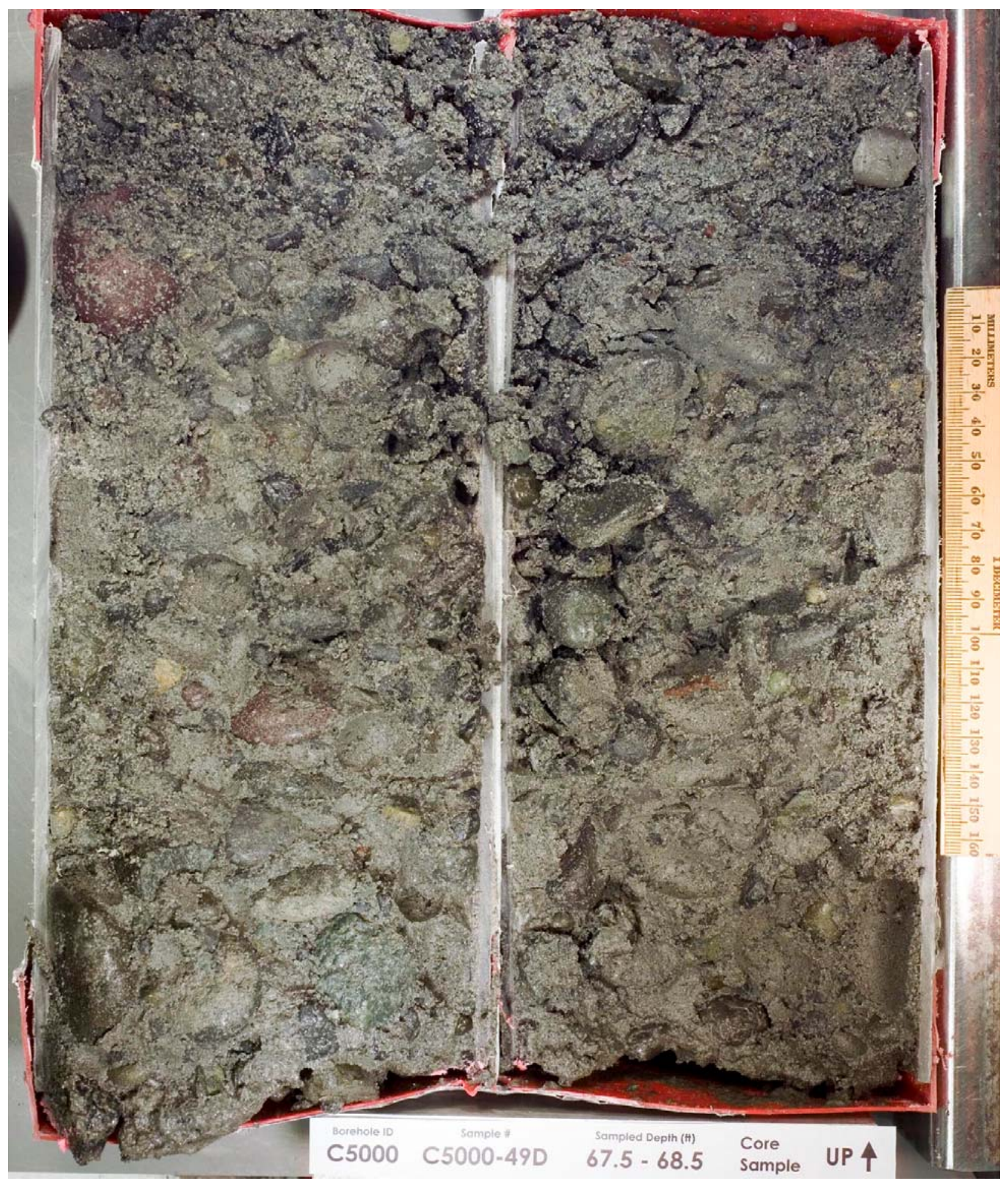




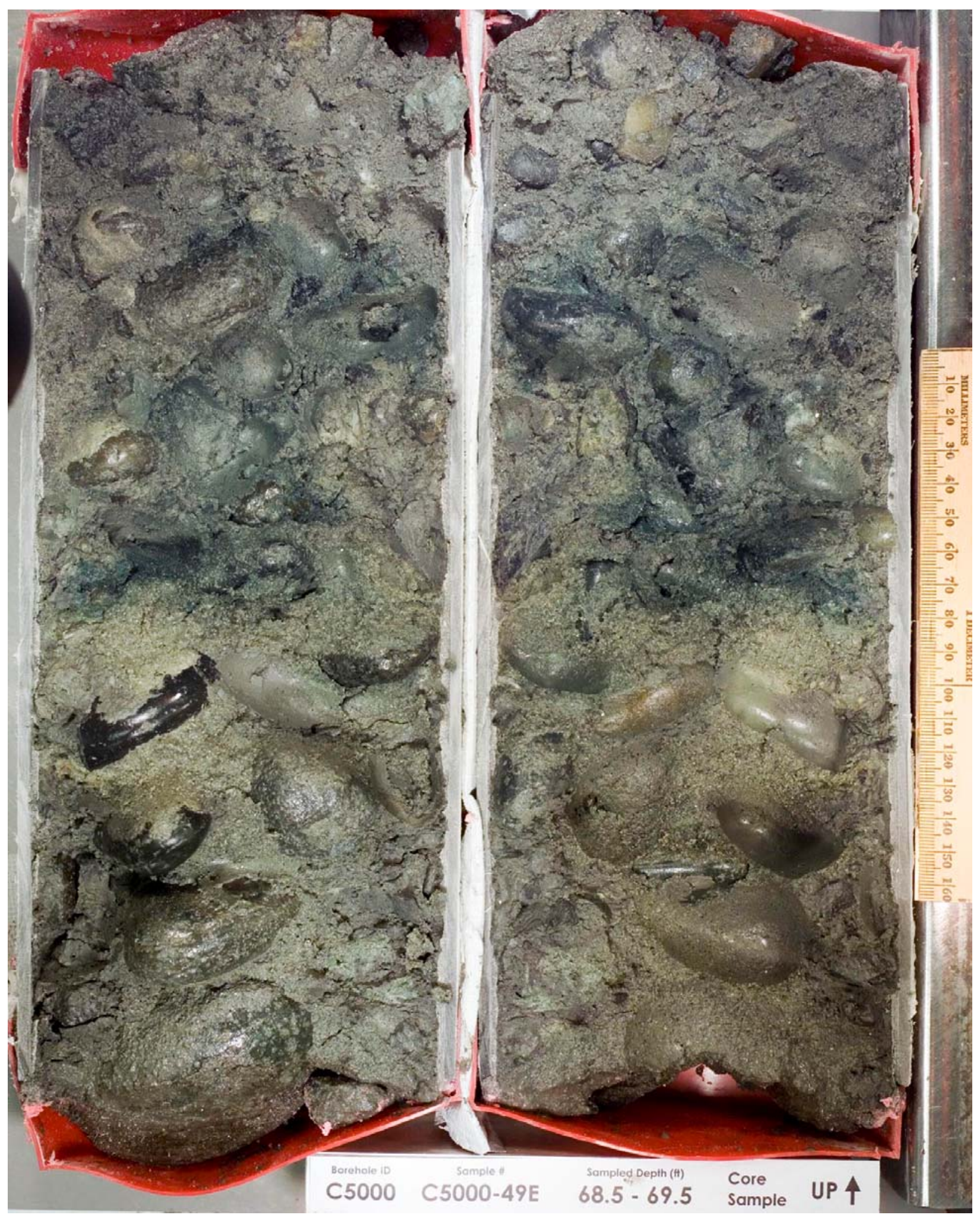




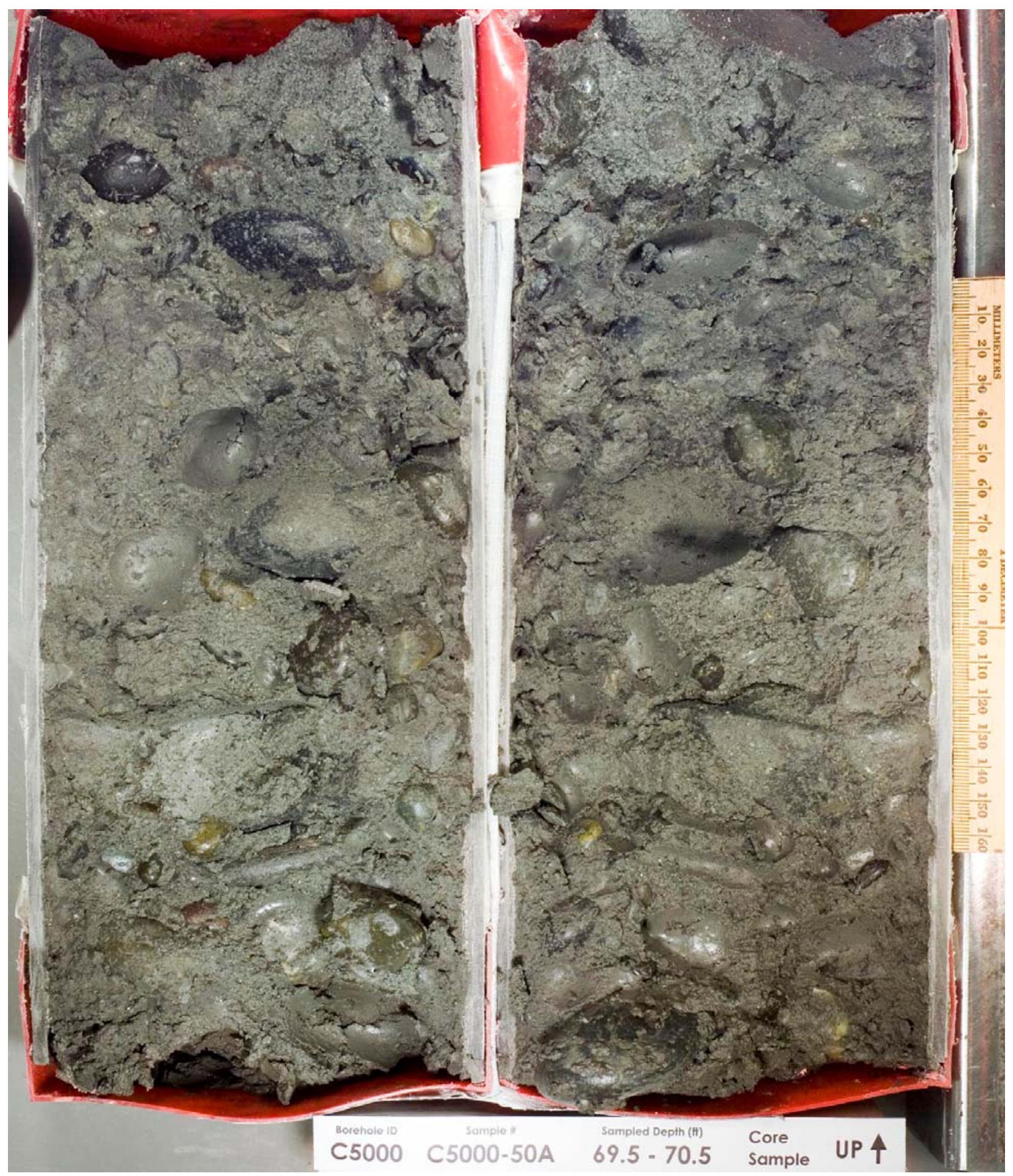




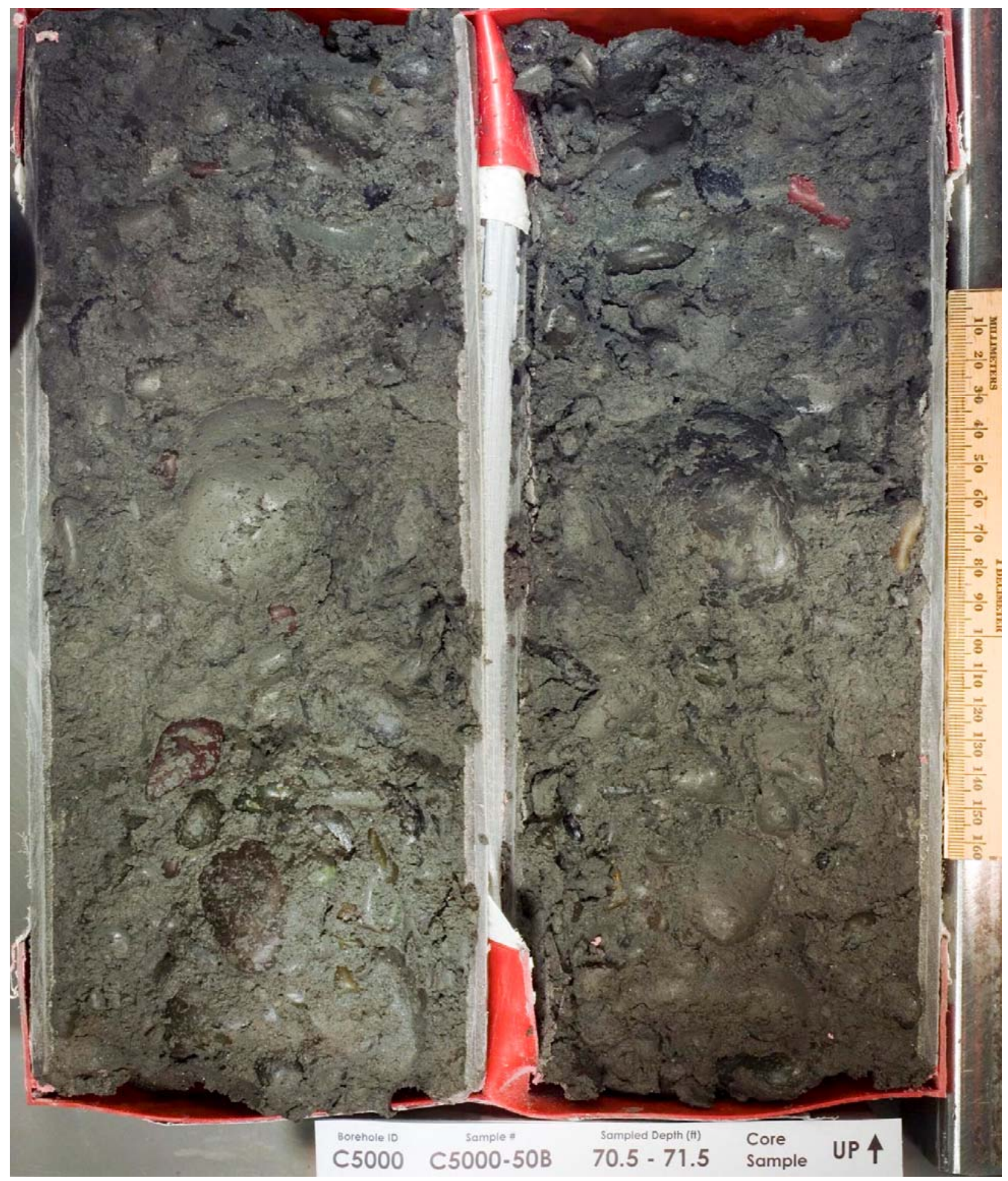




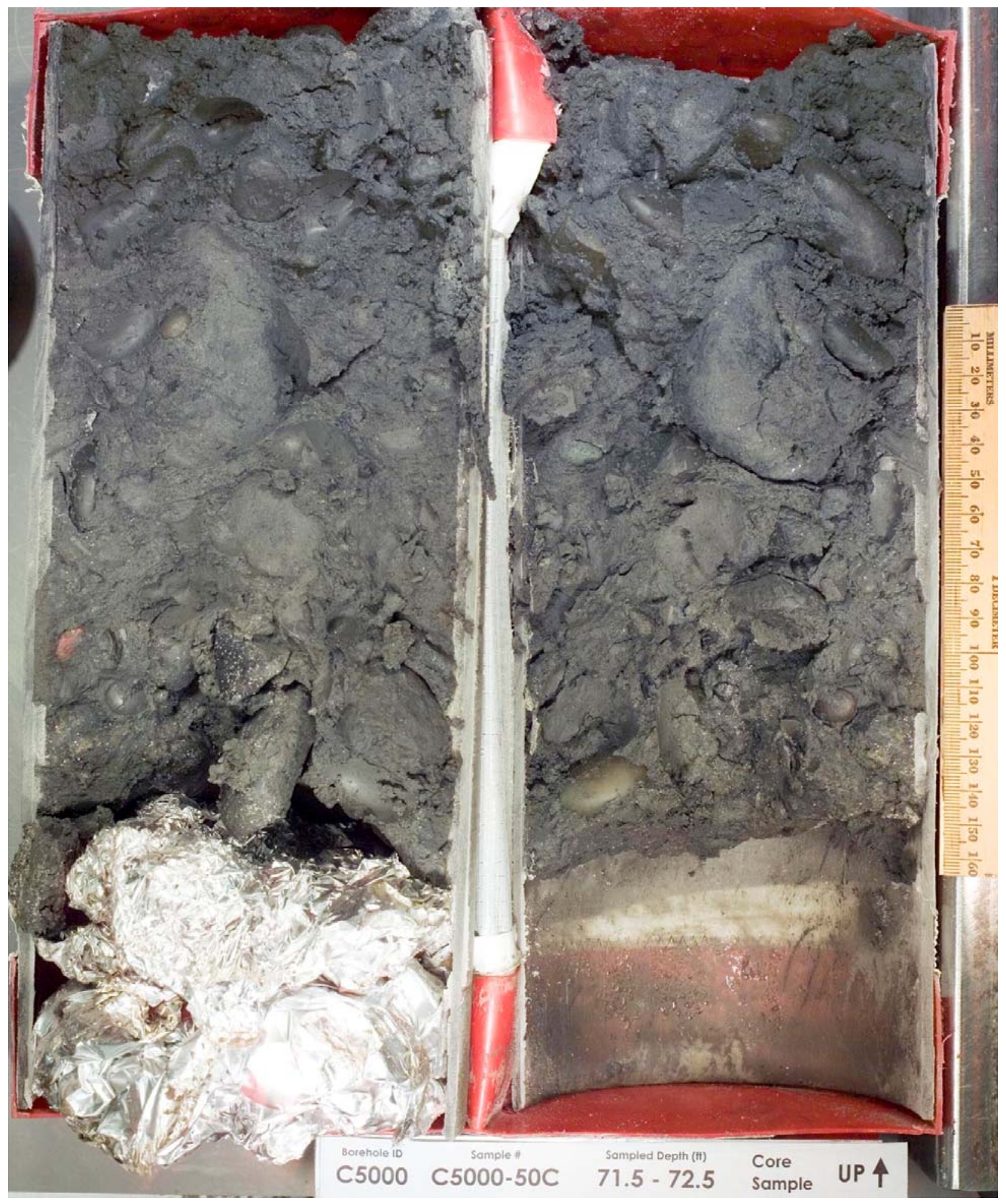




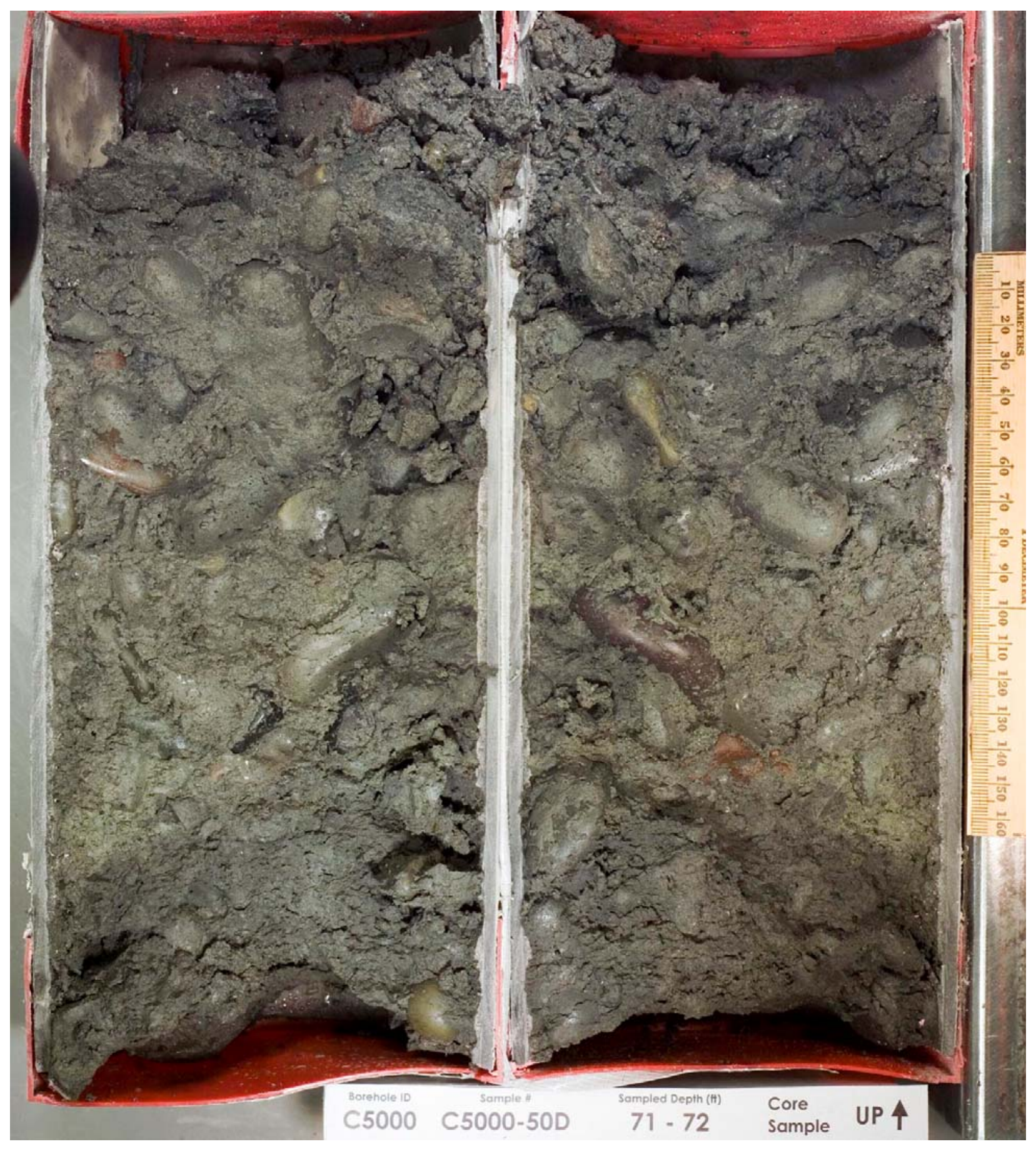




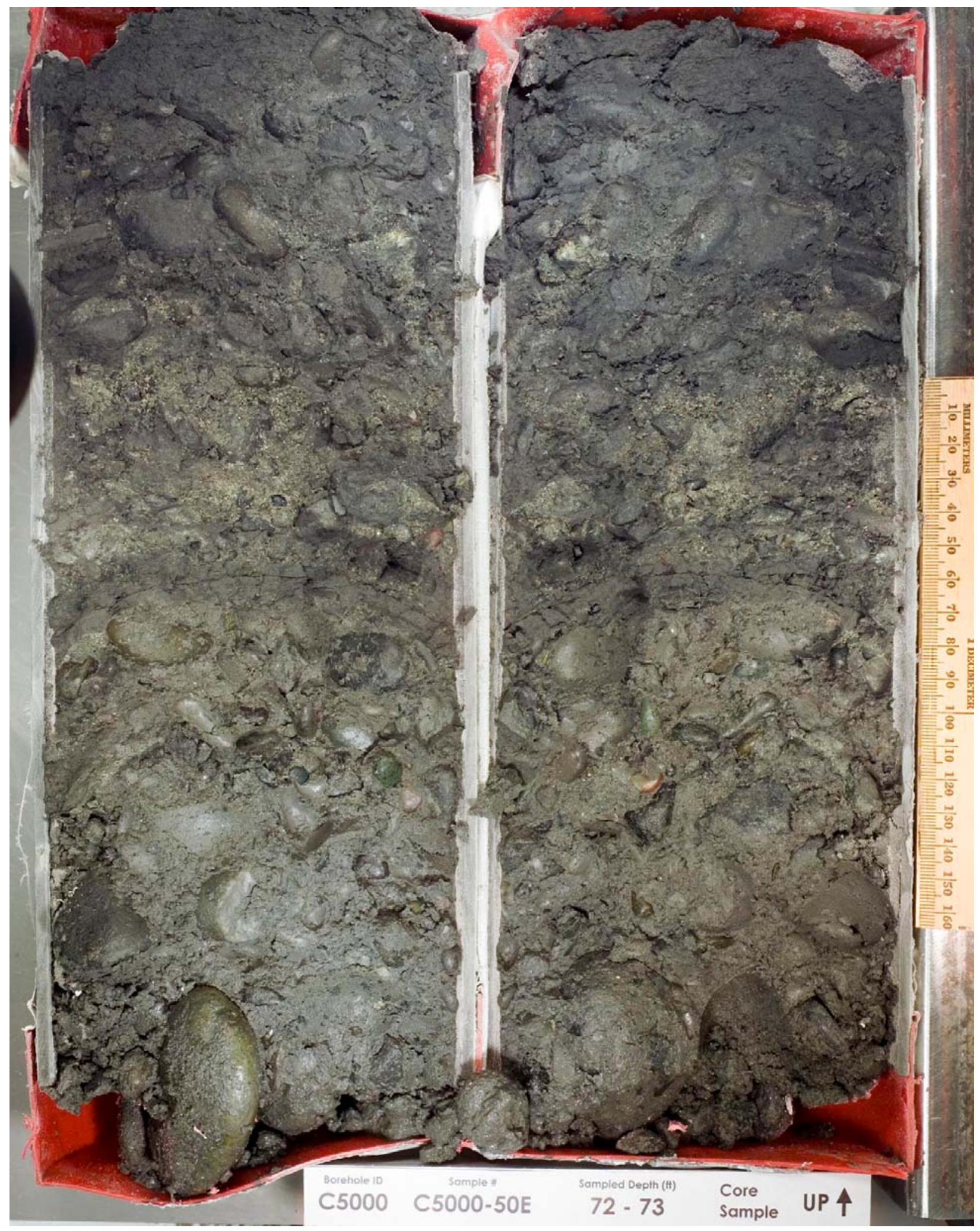




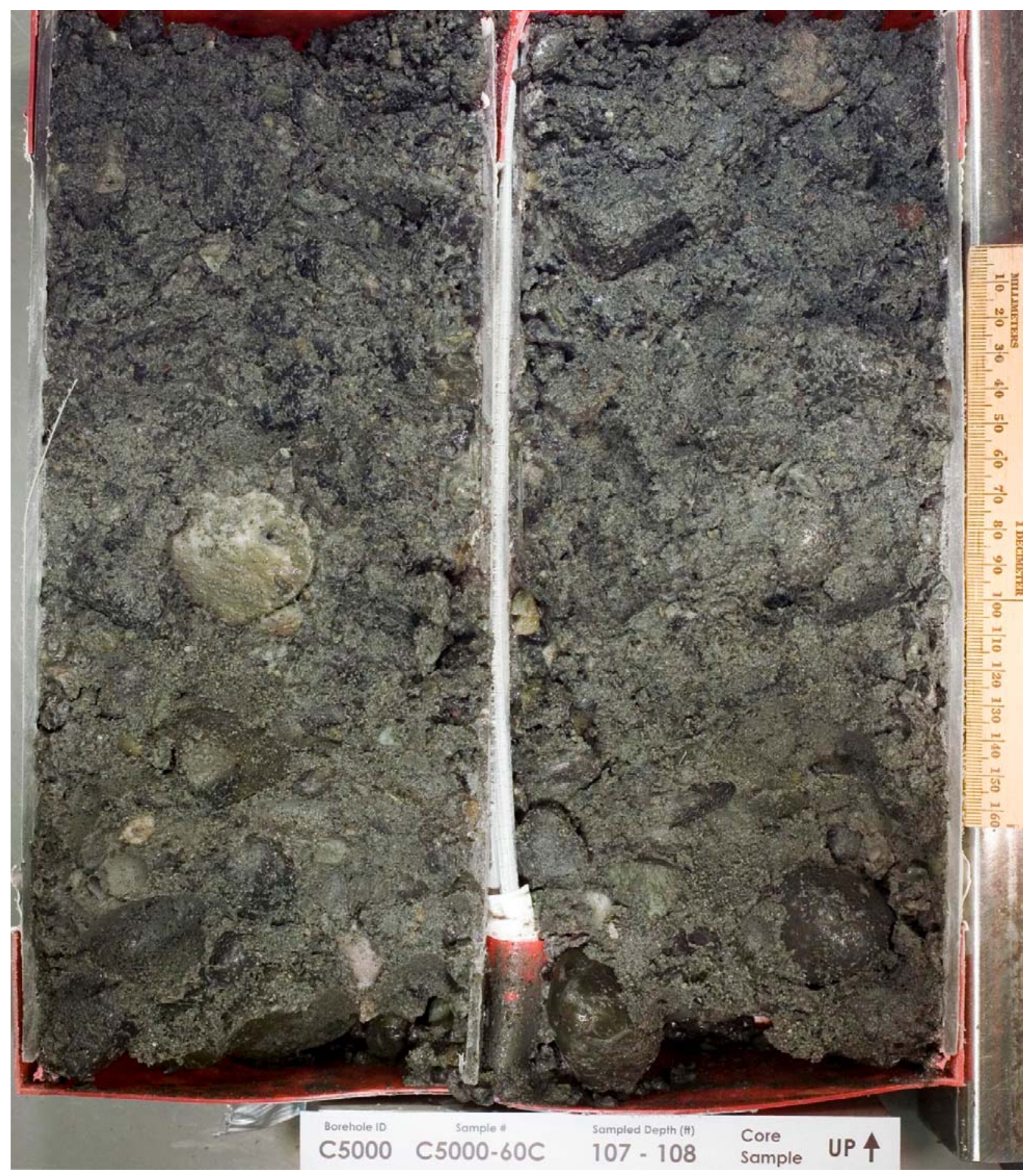




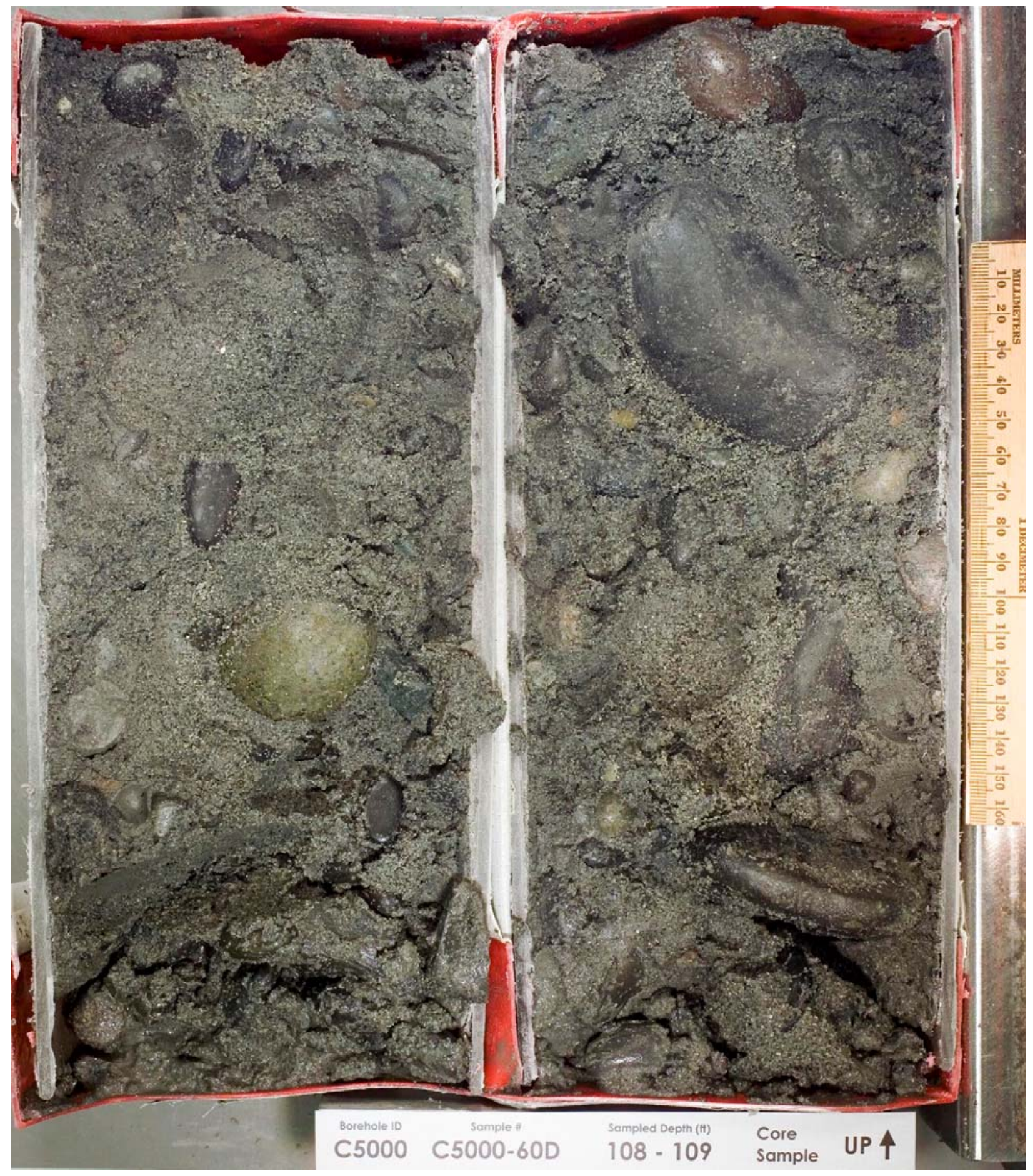




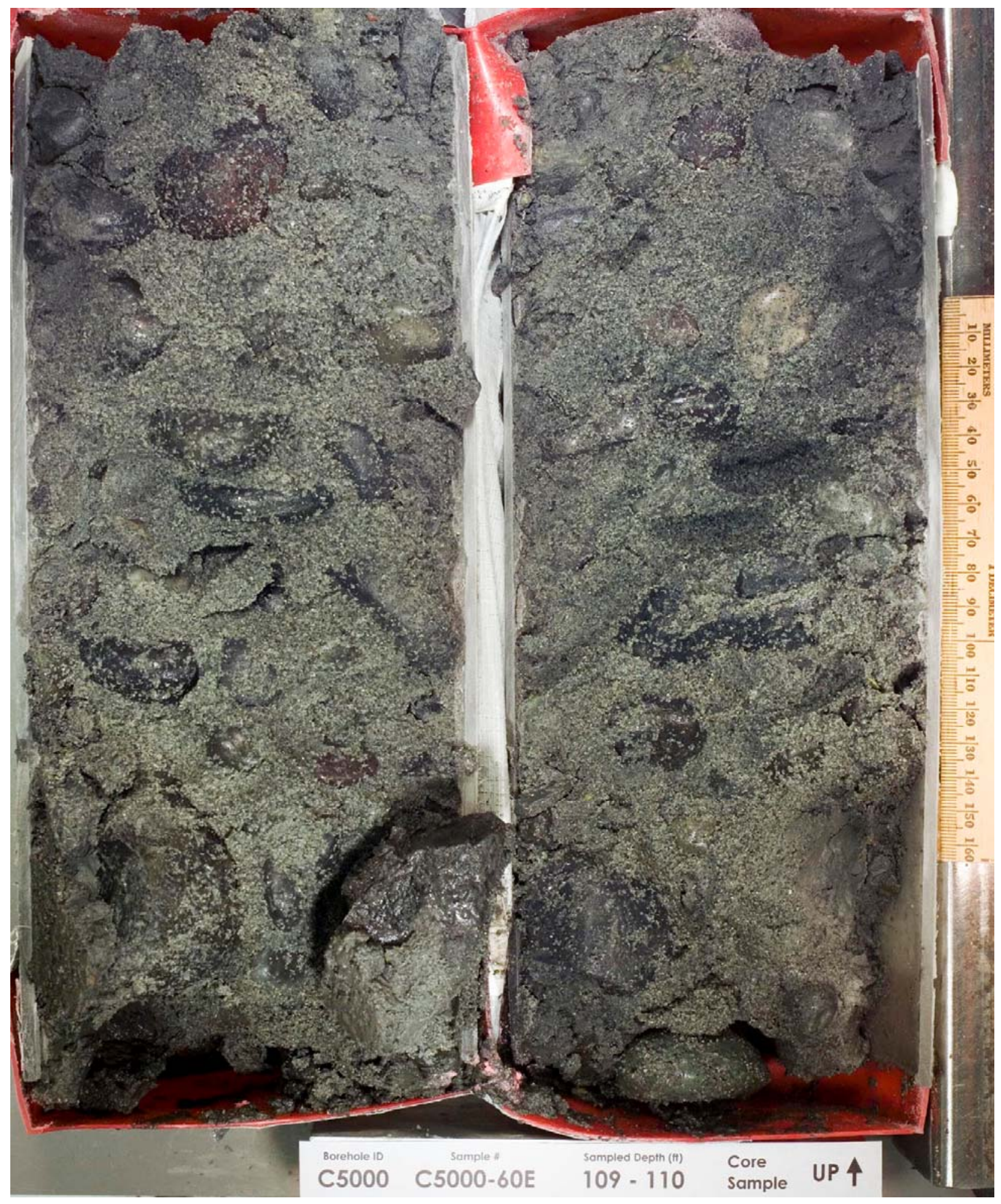




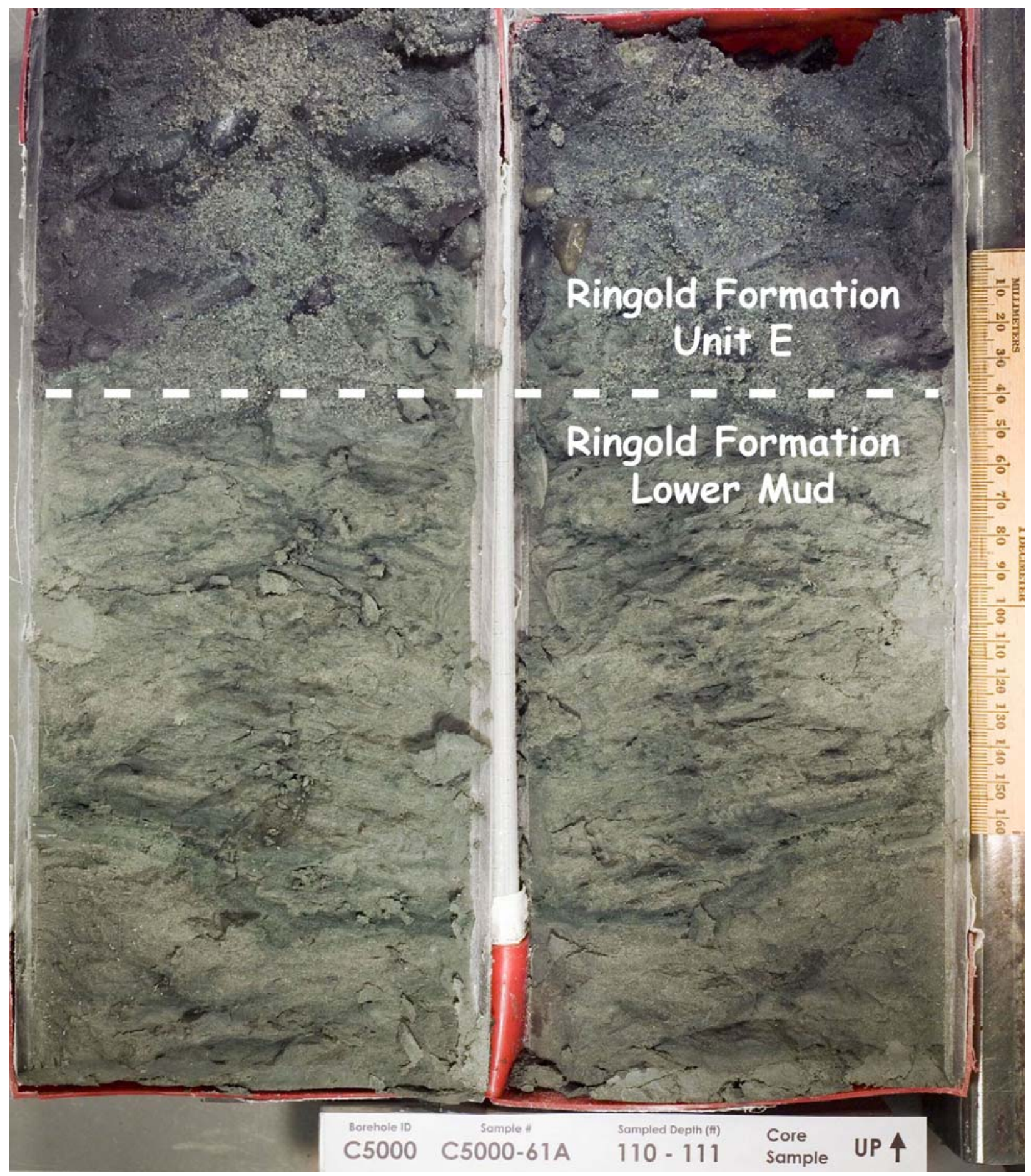




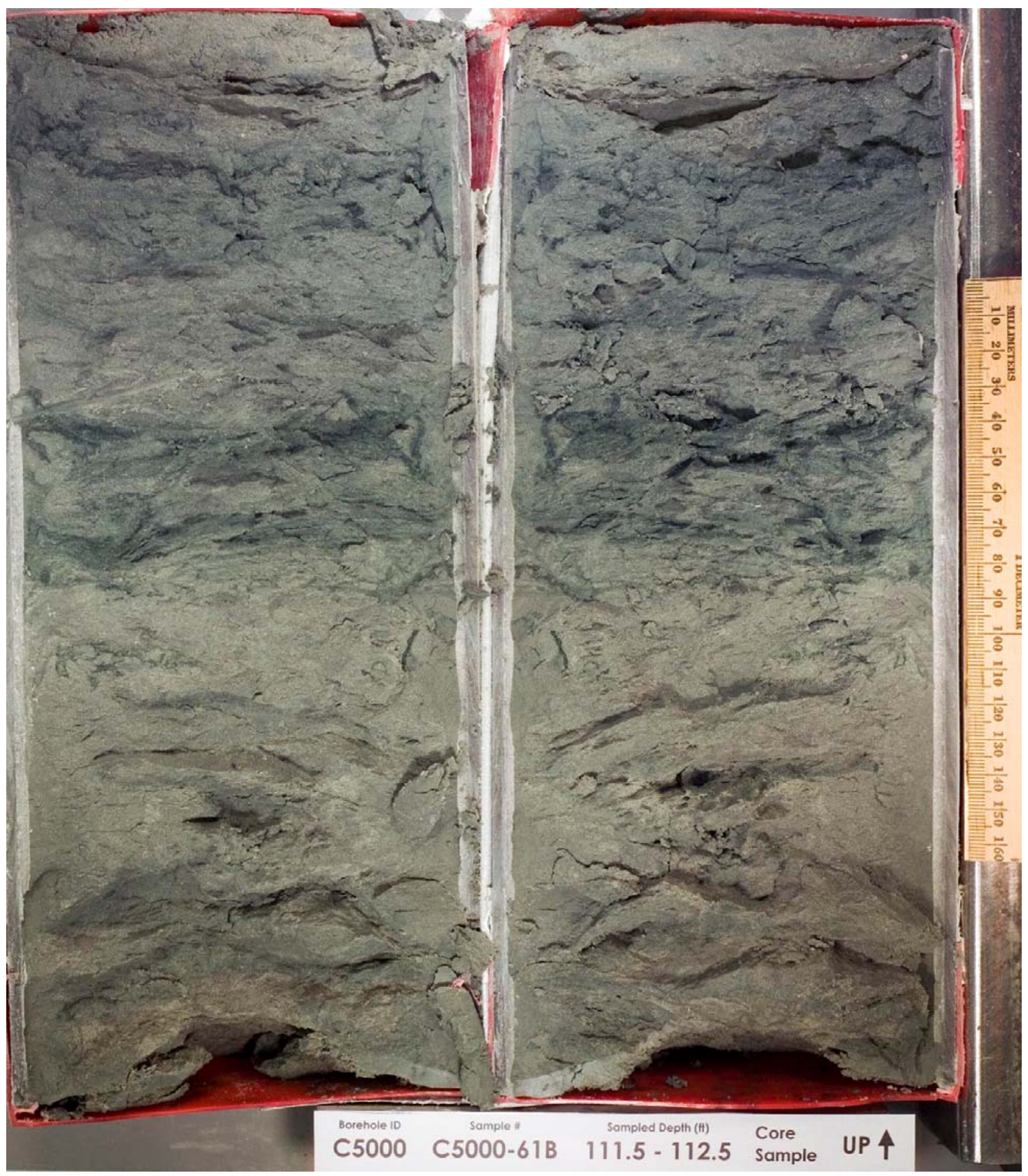


Well C5001

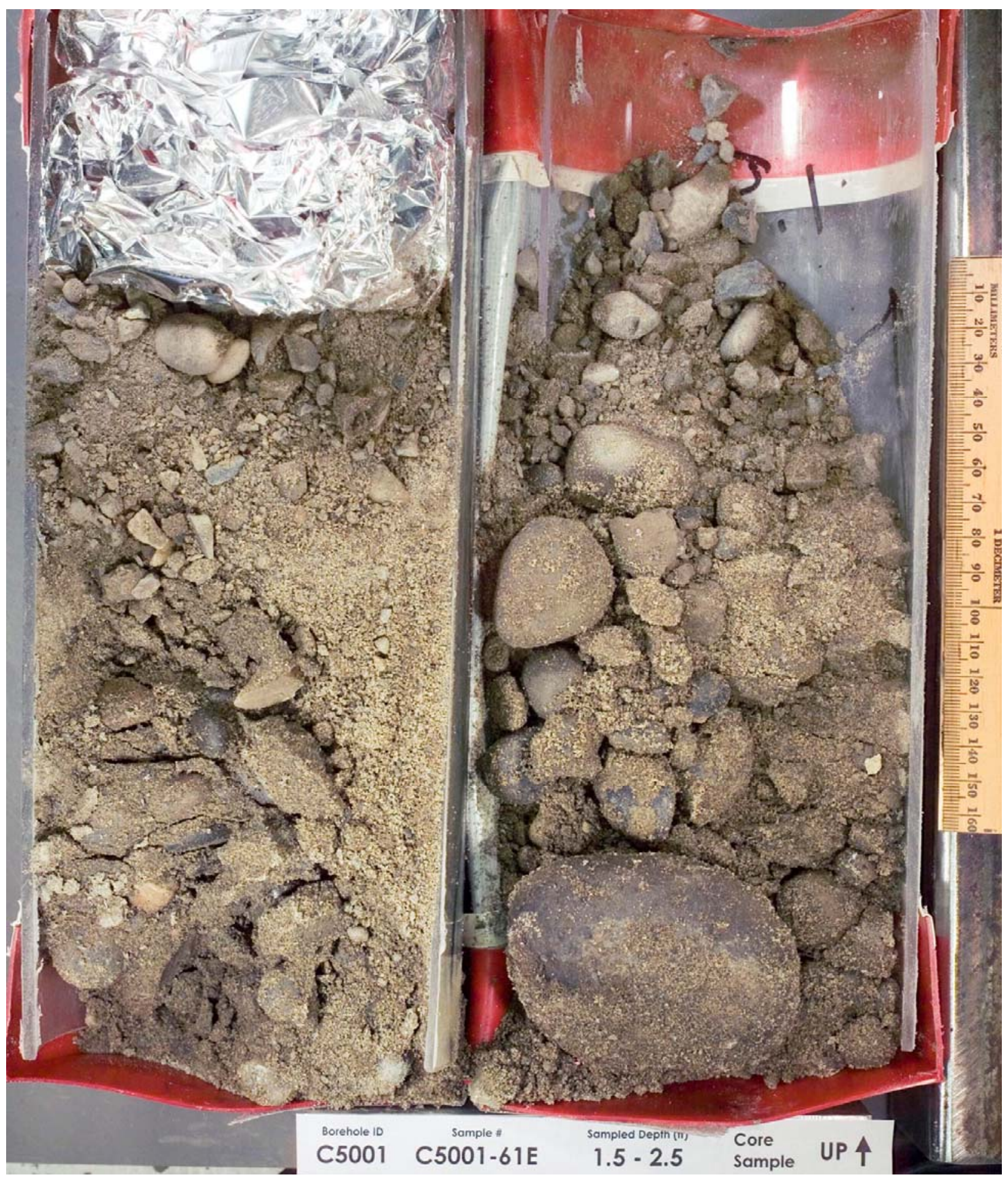




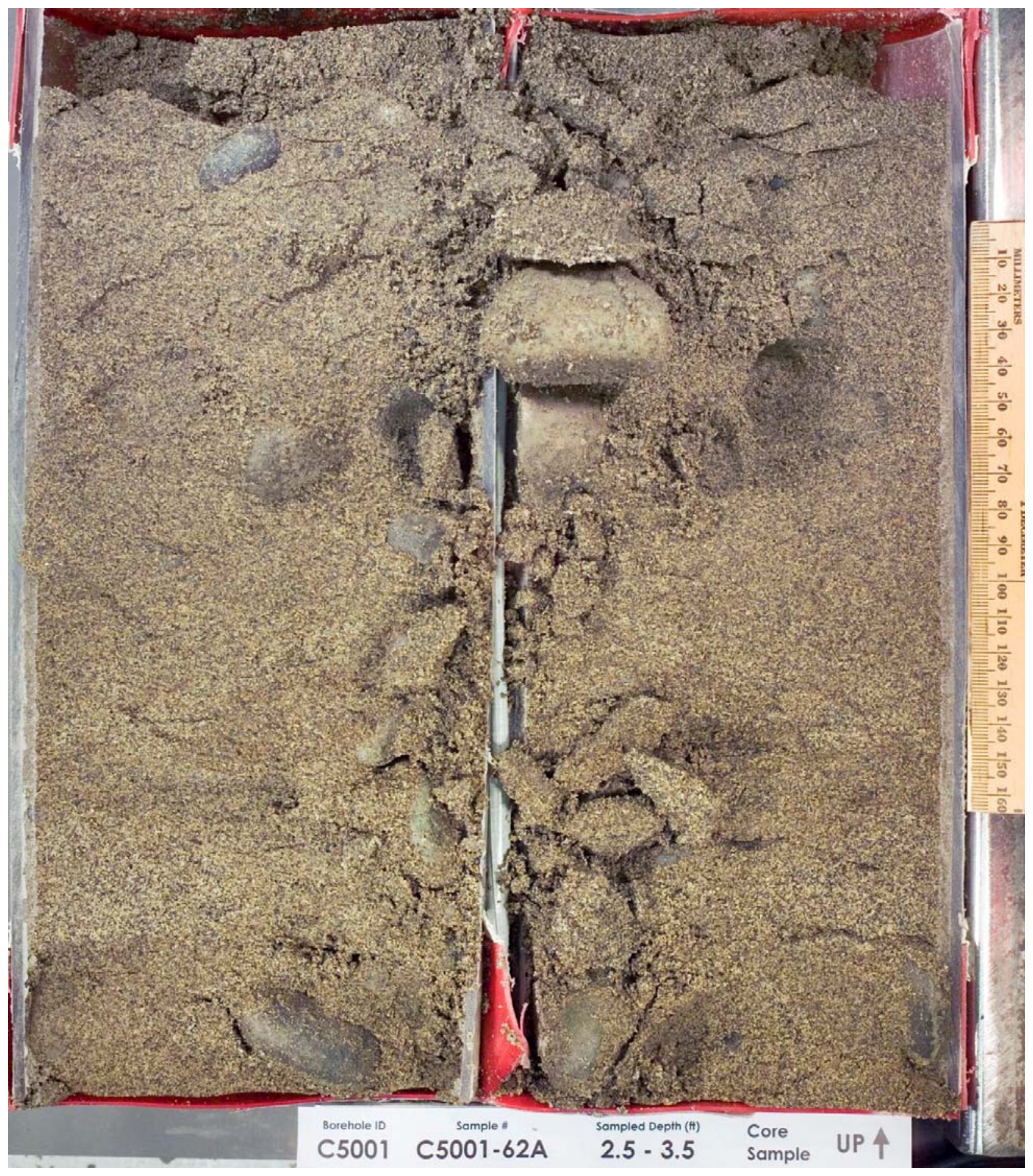




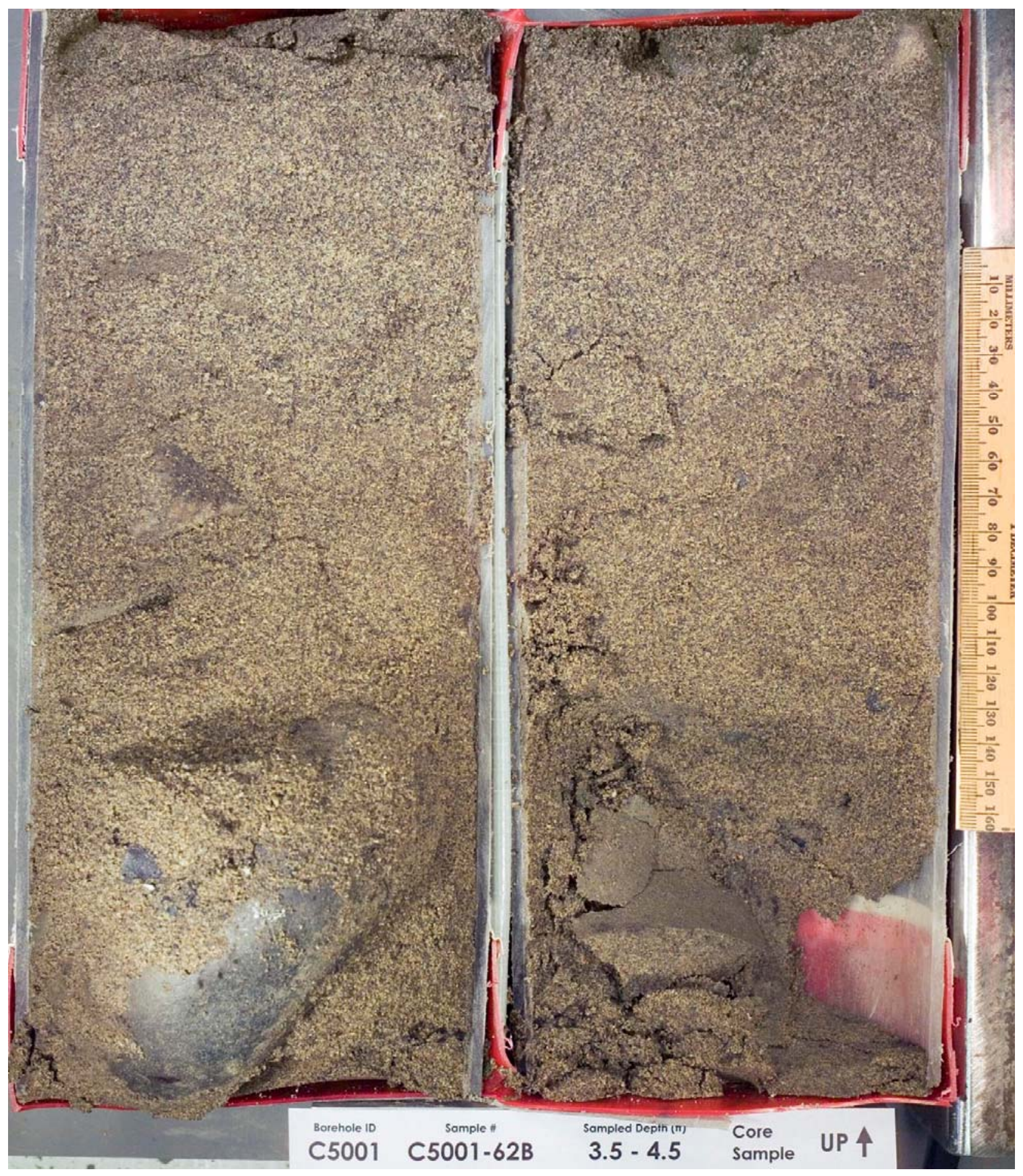




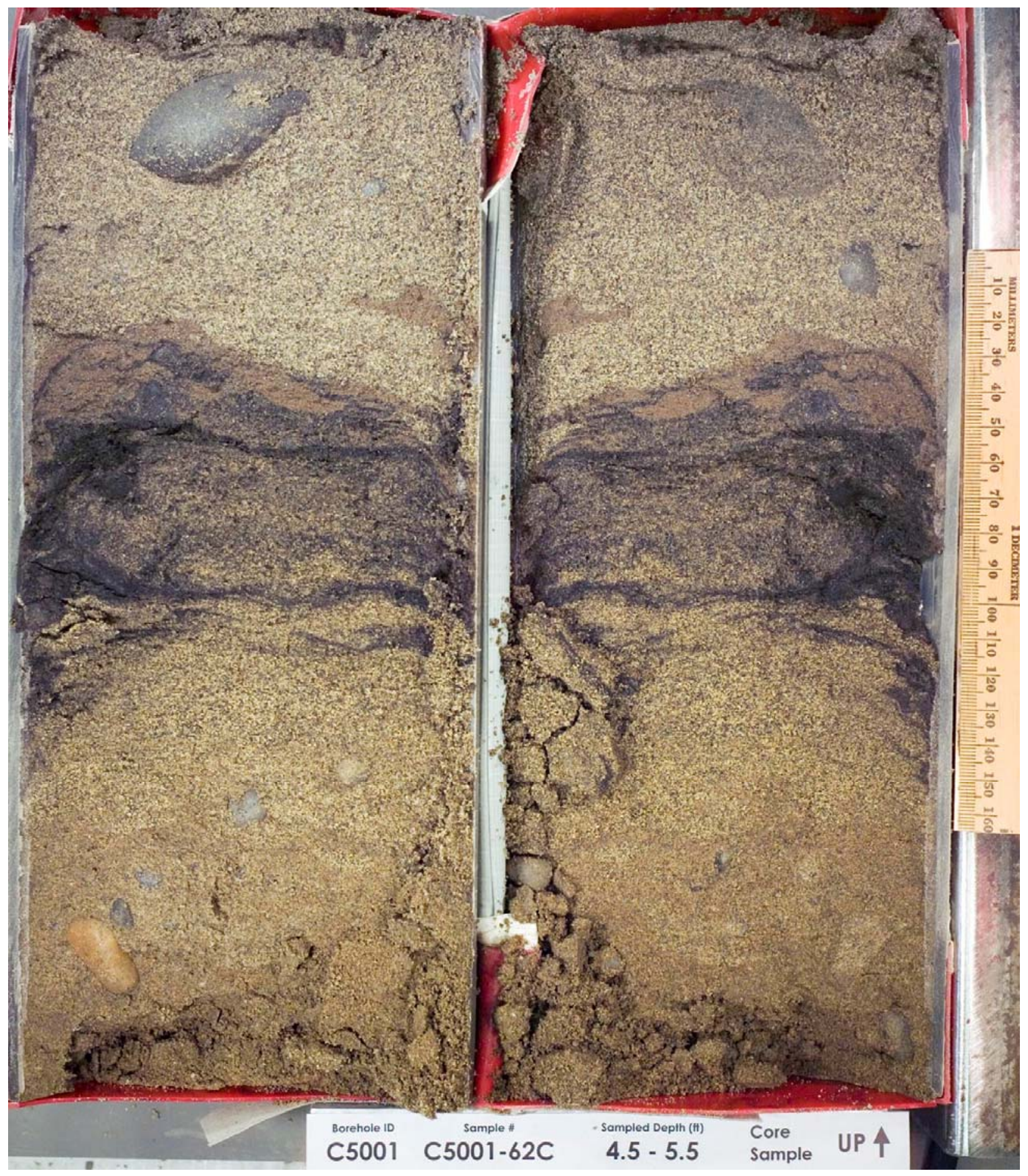




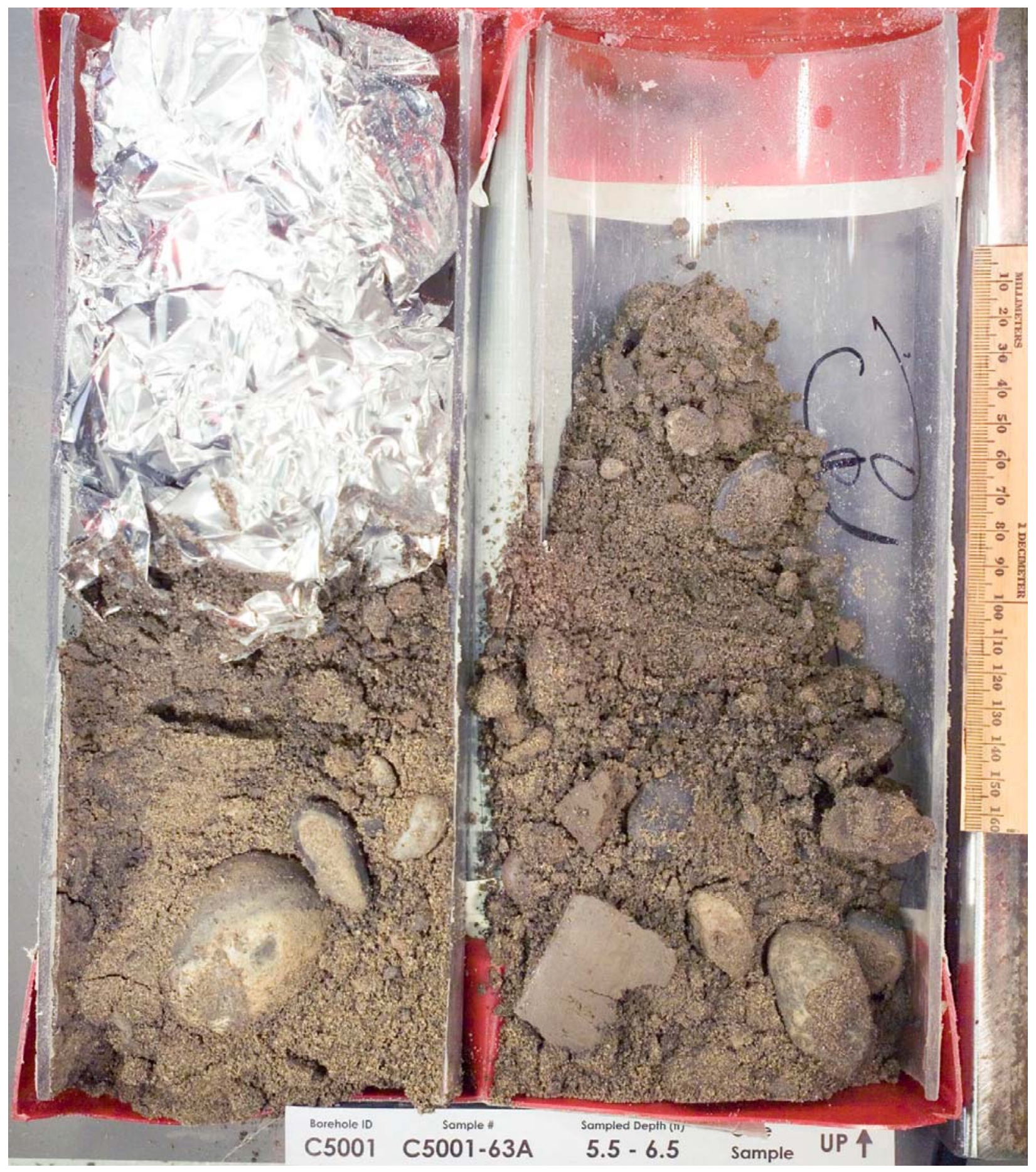




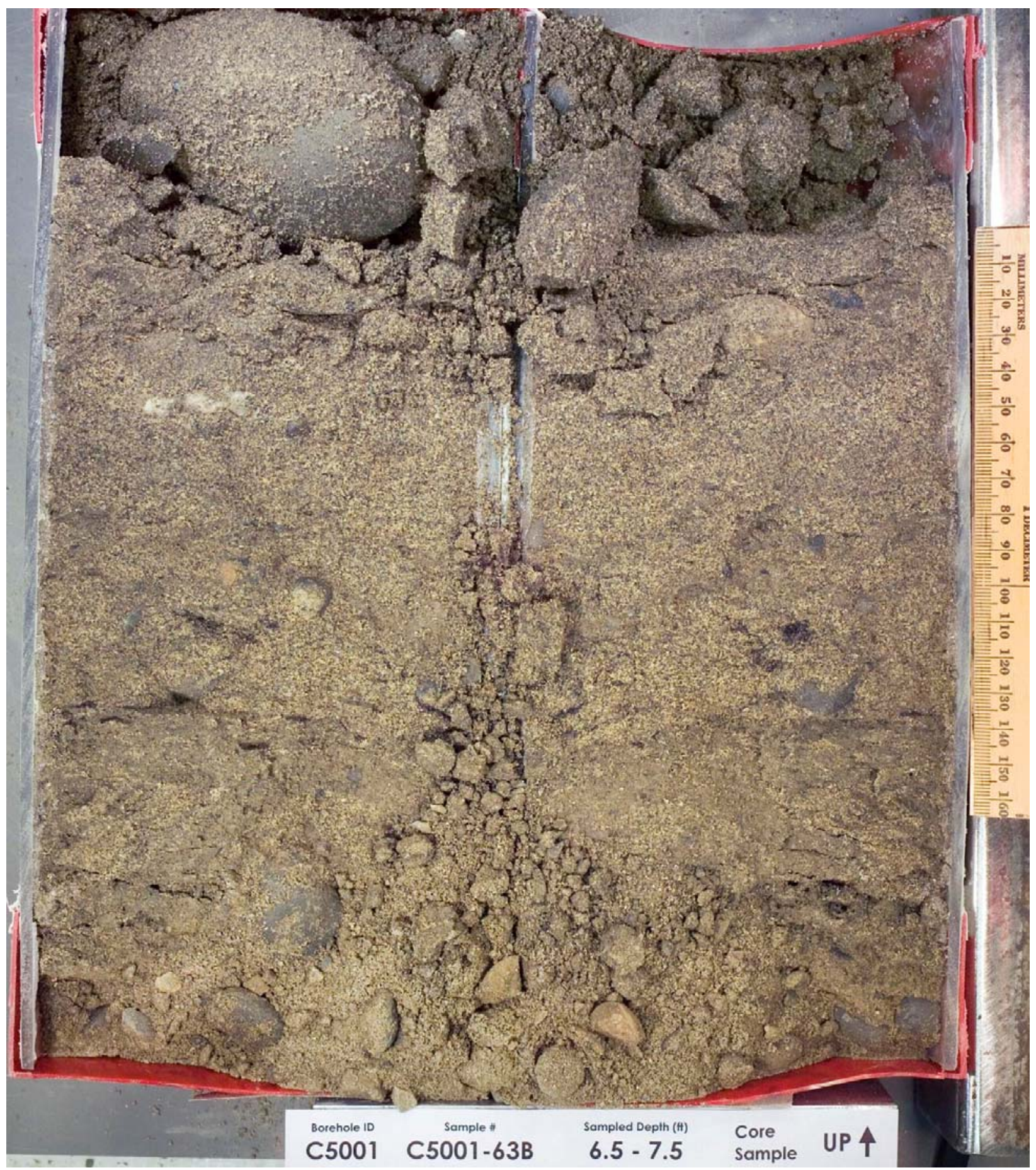




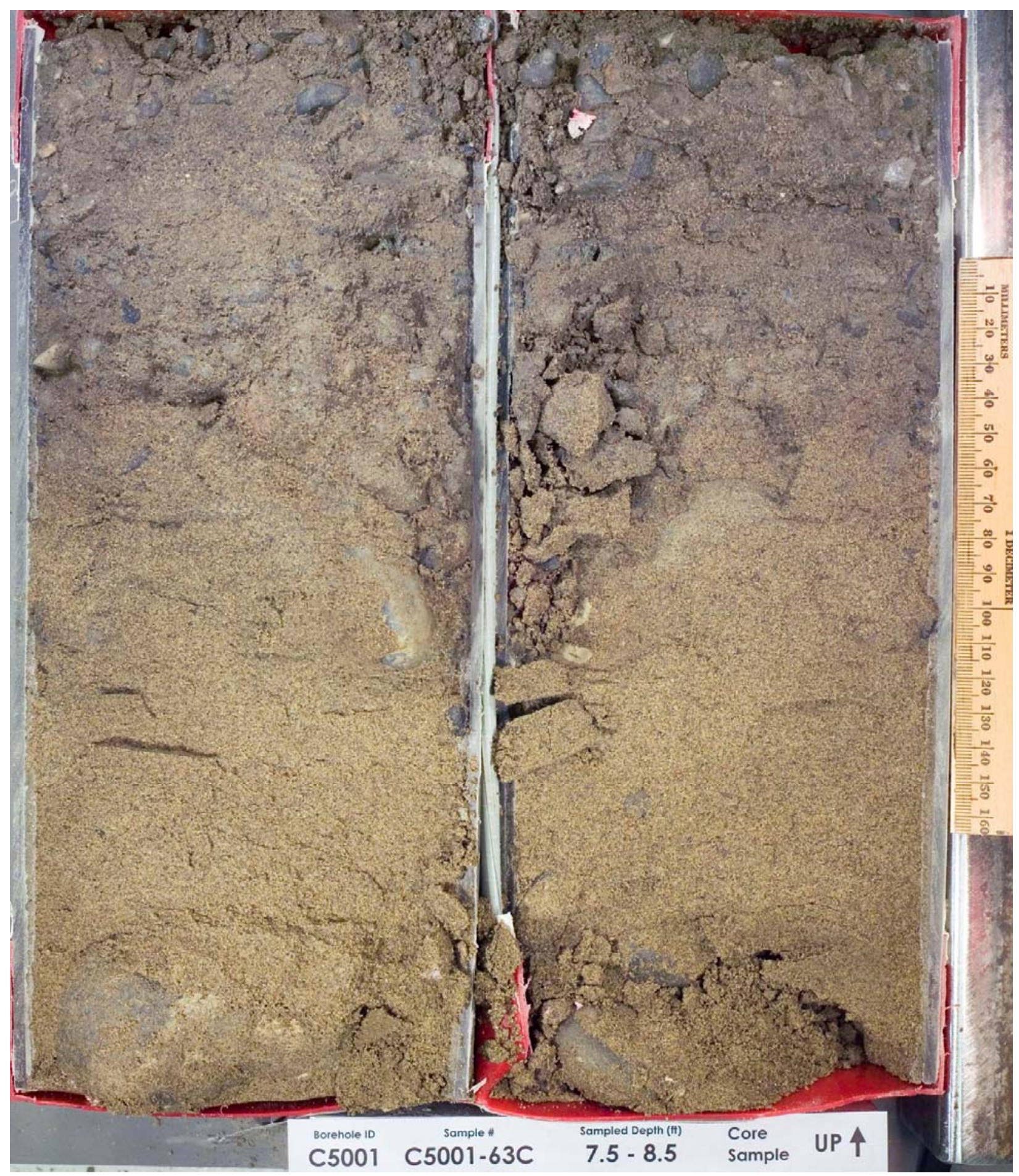




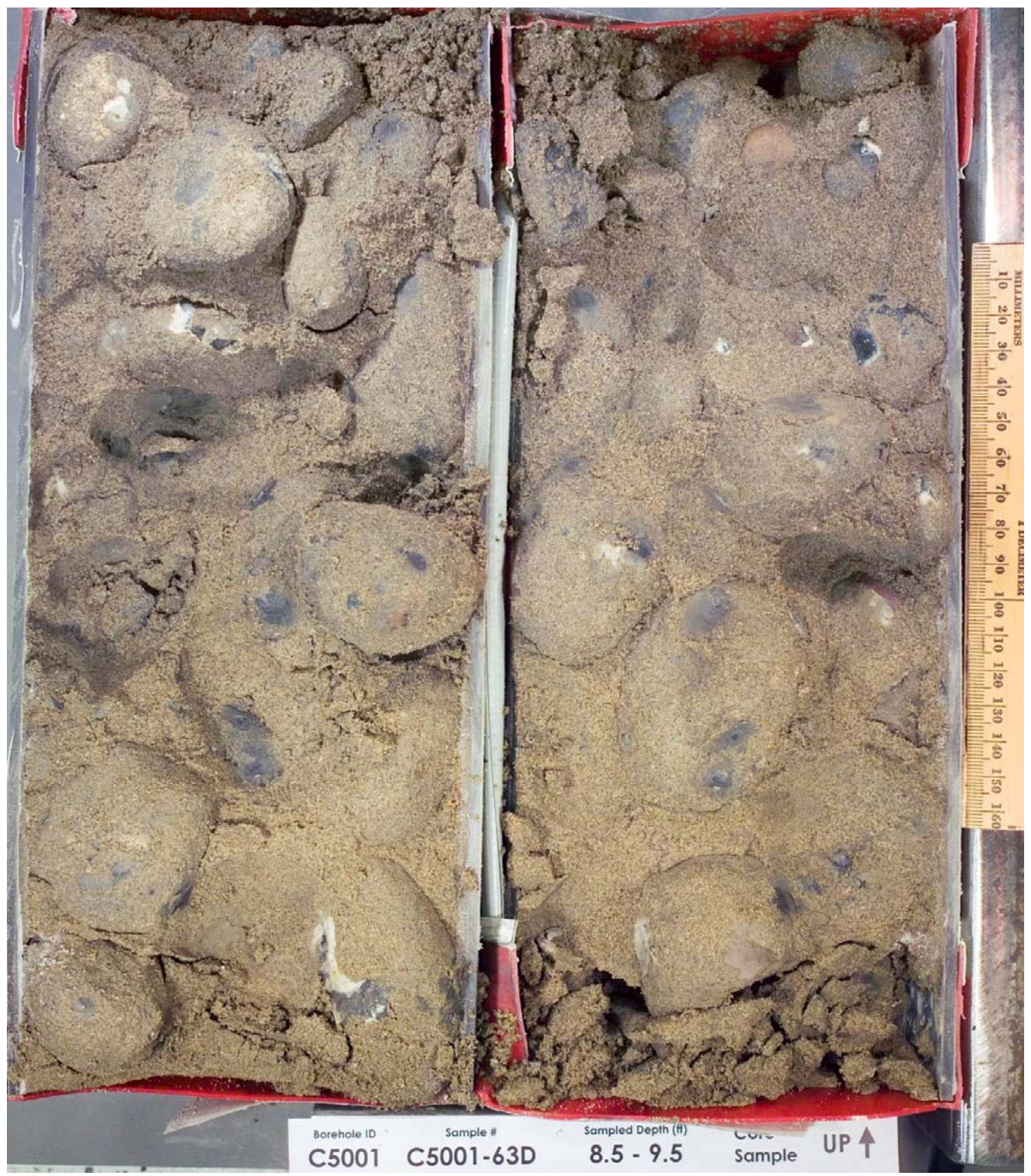




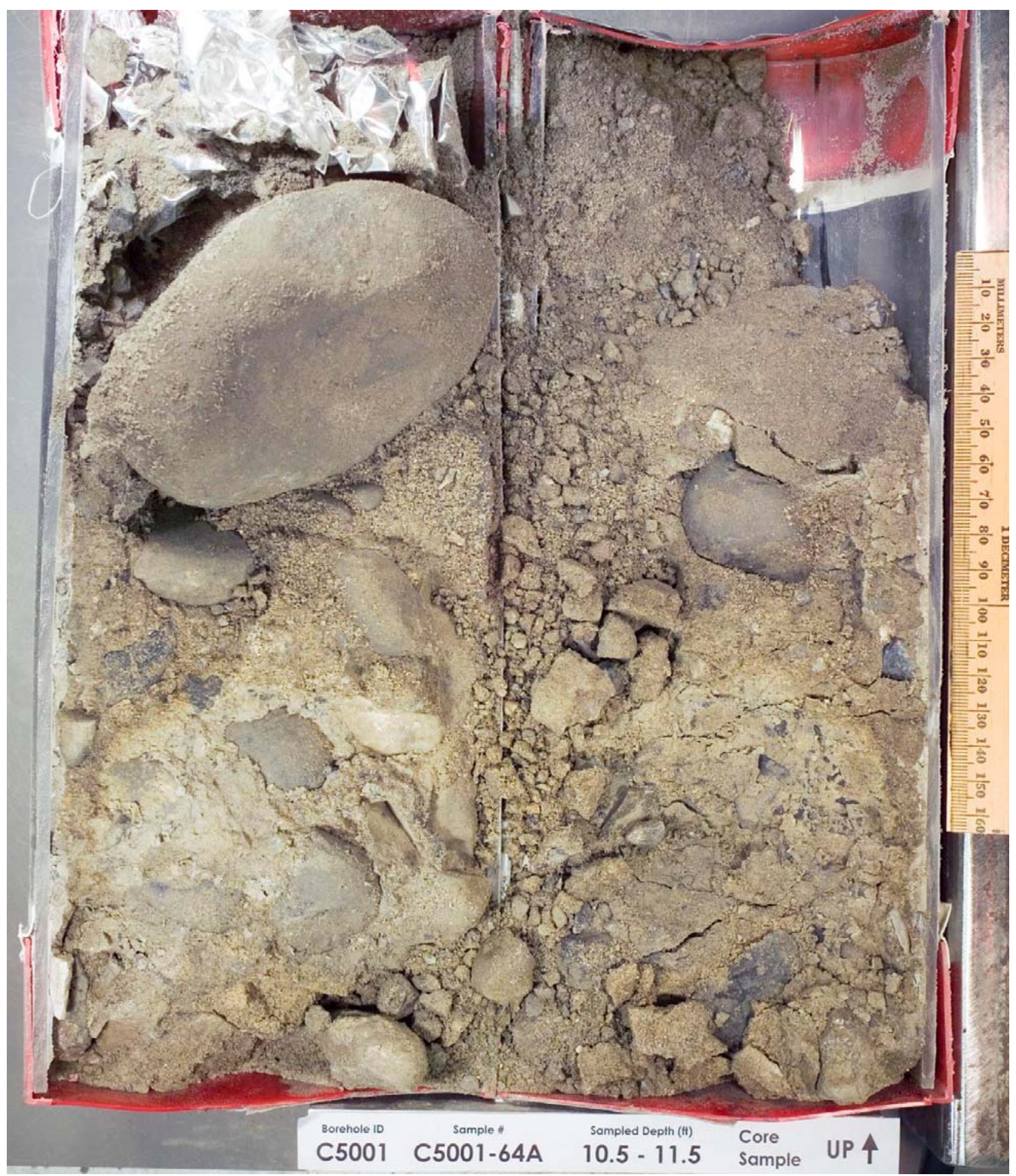




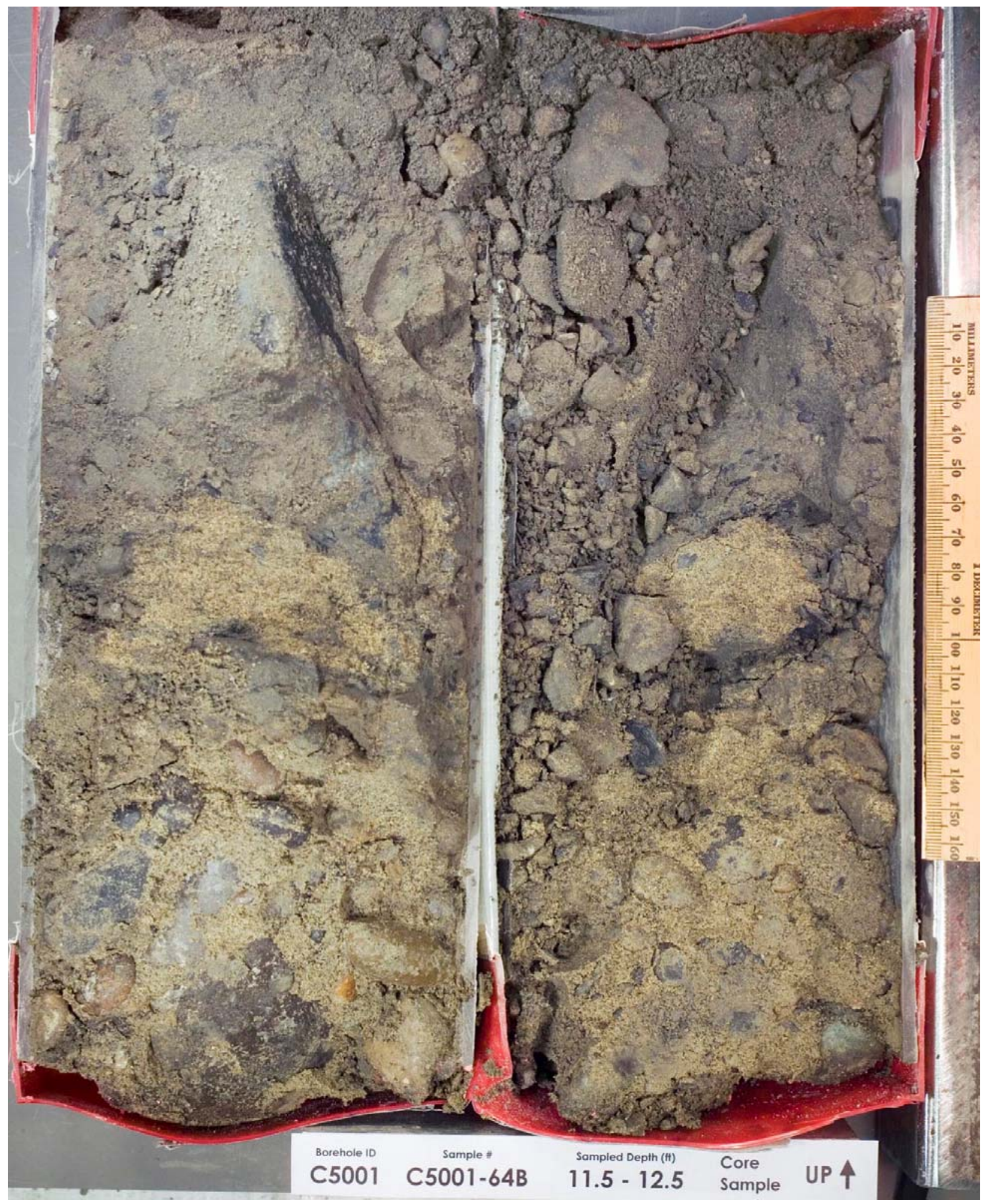




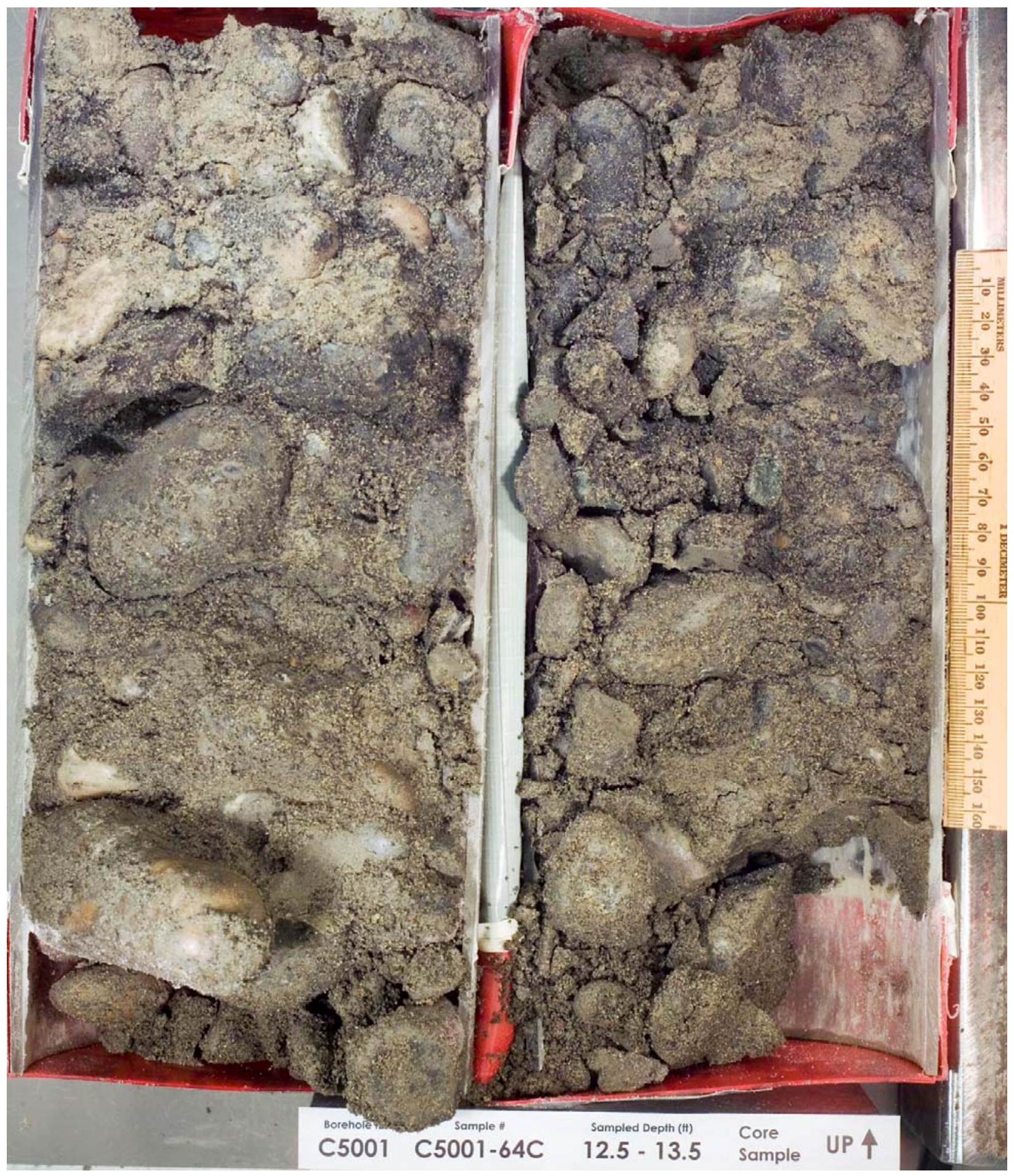




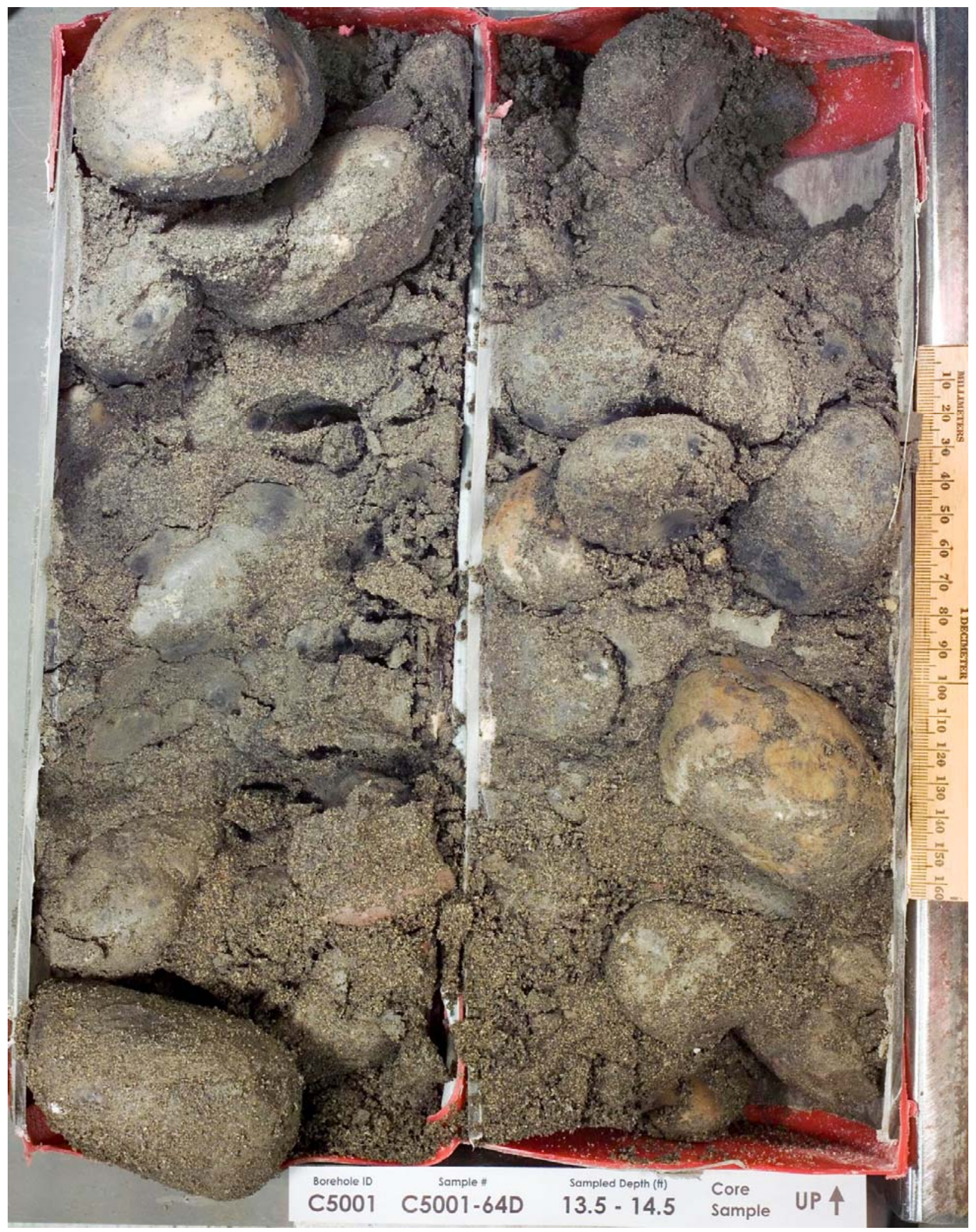




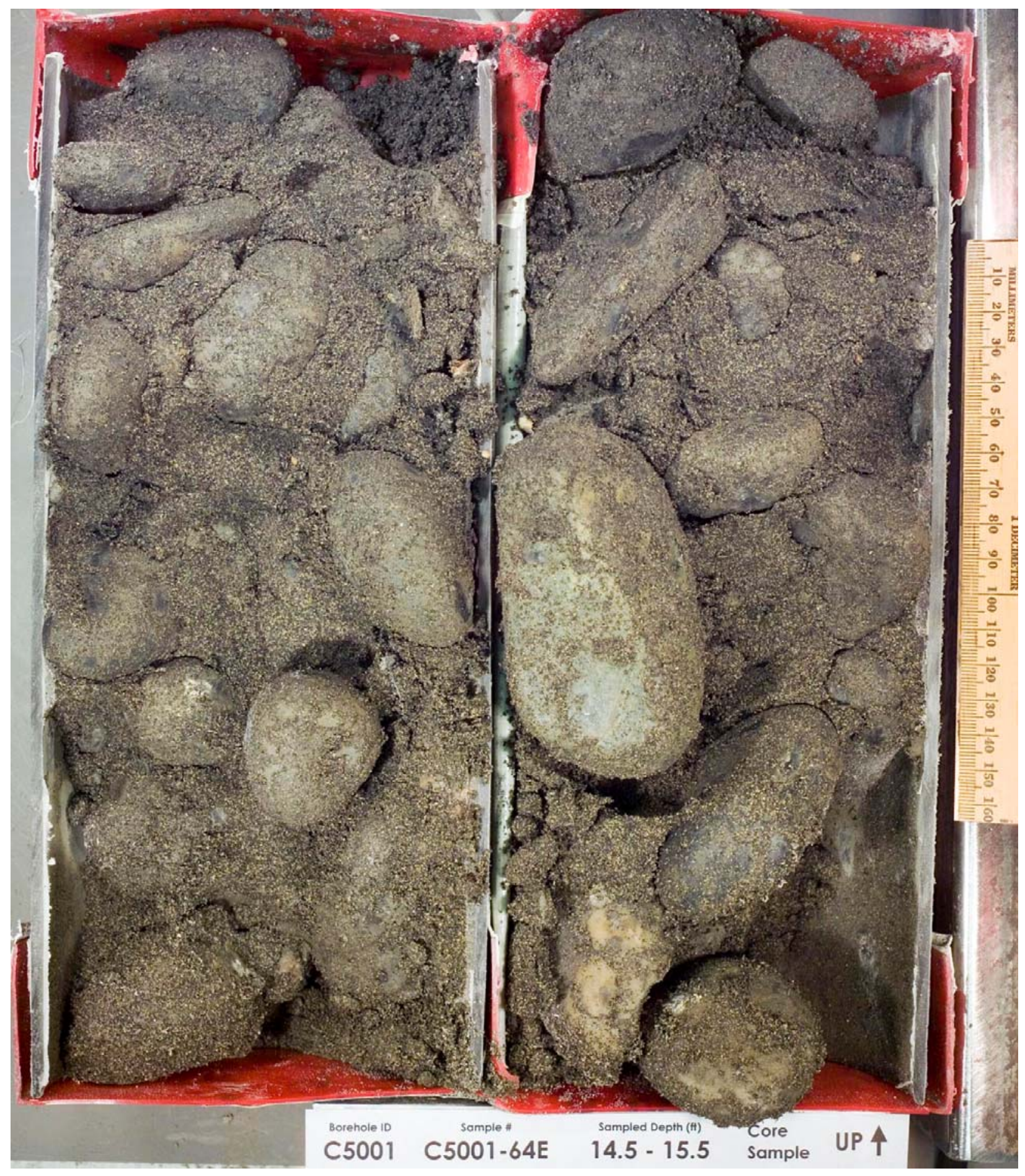




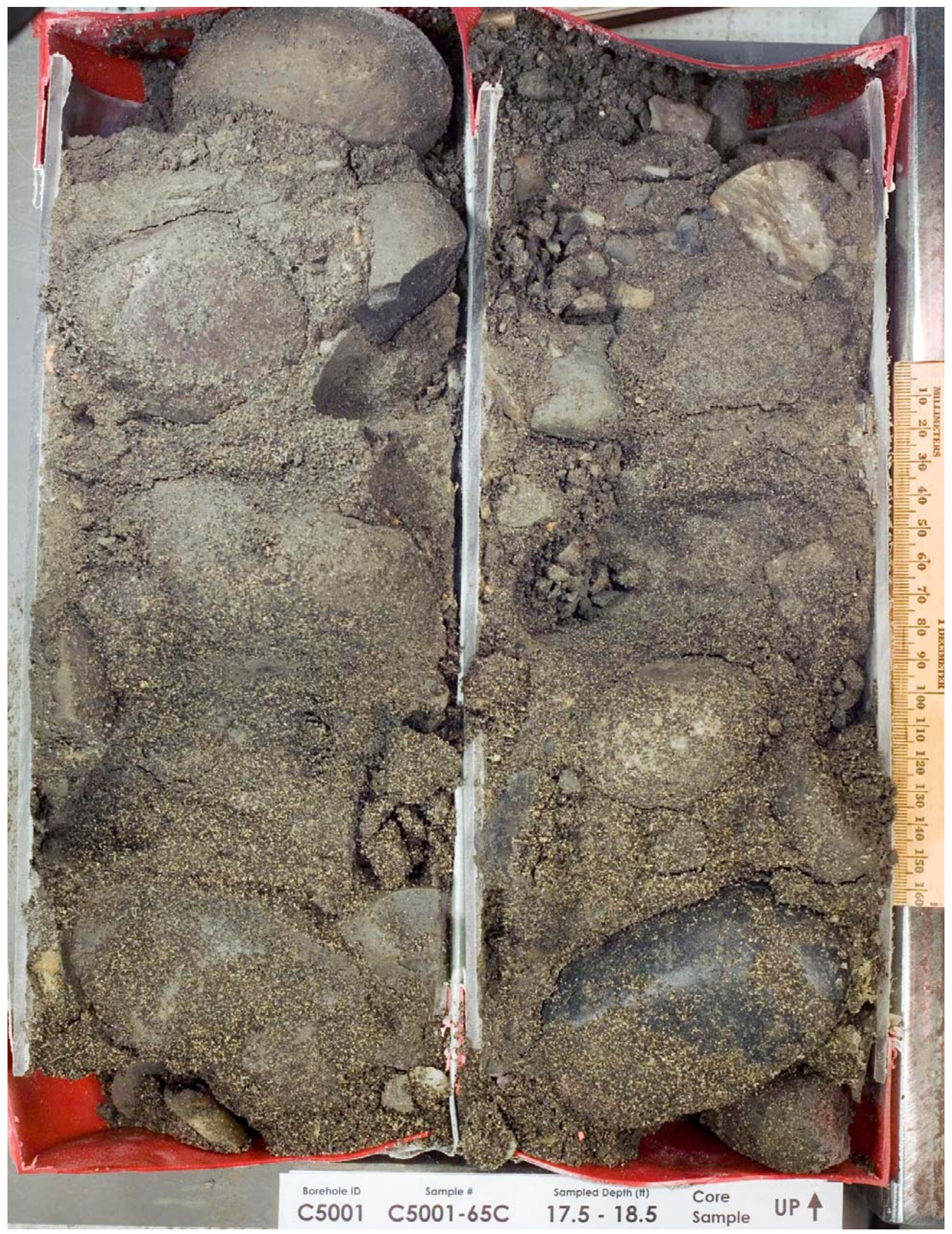




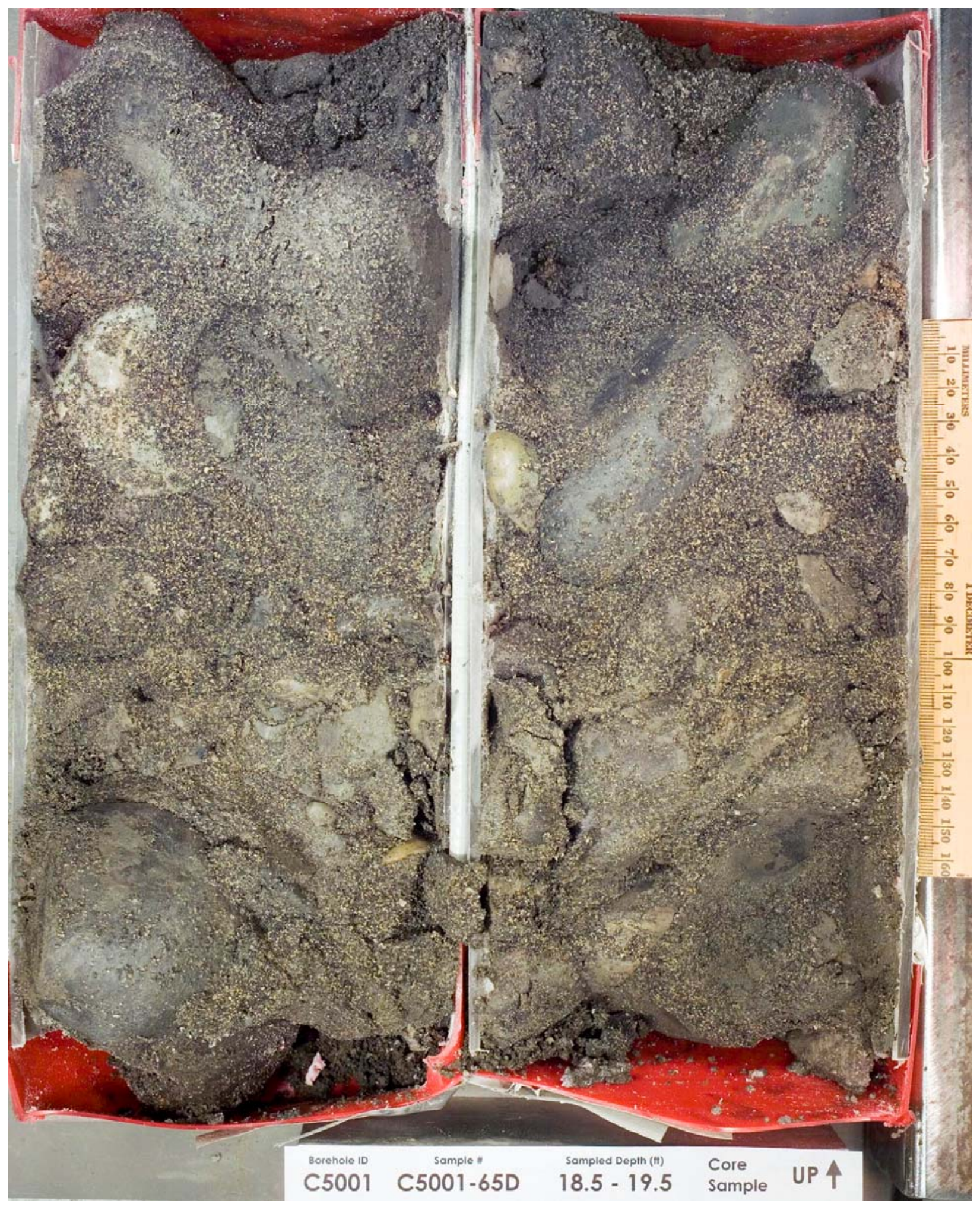




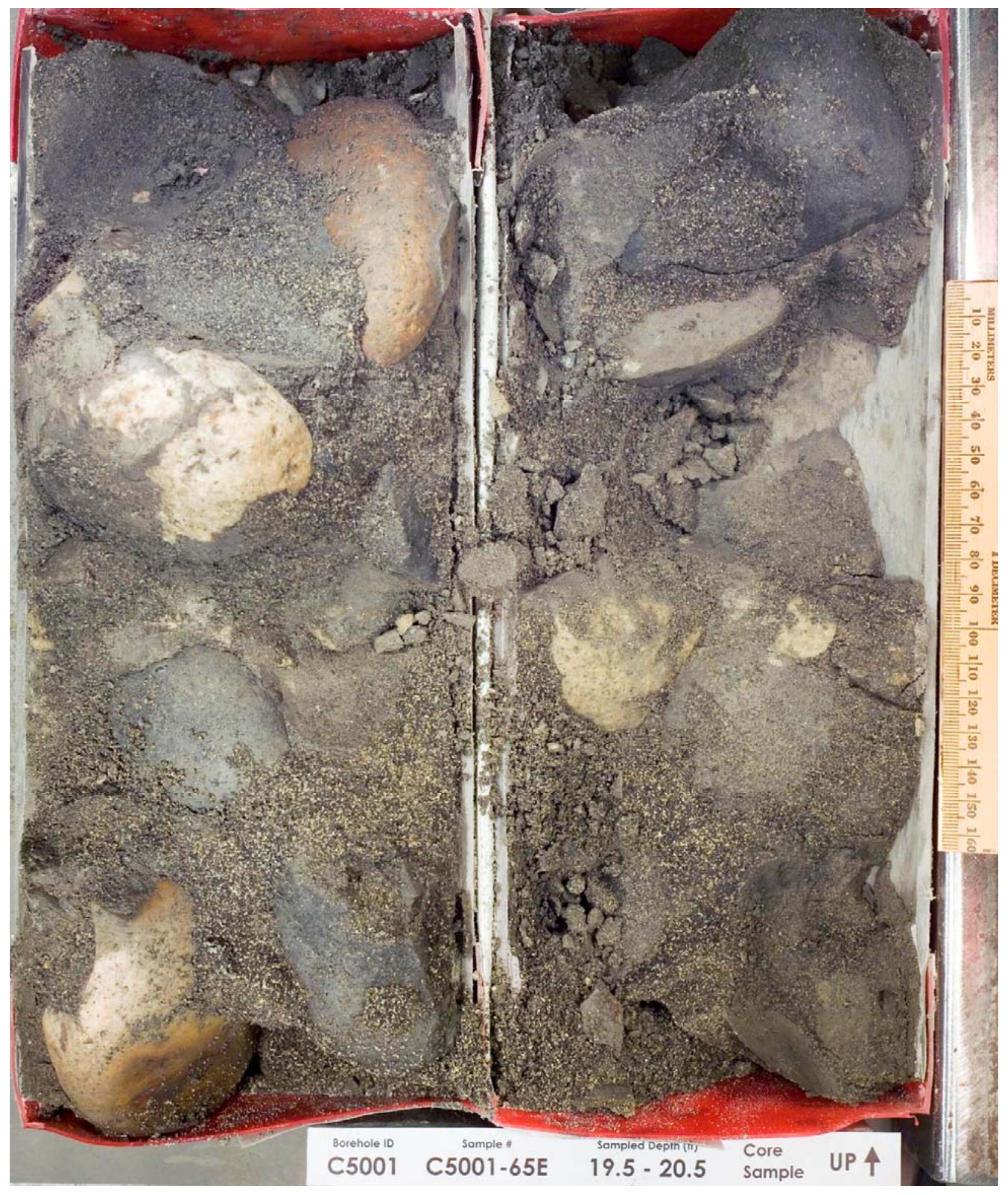




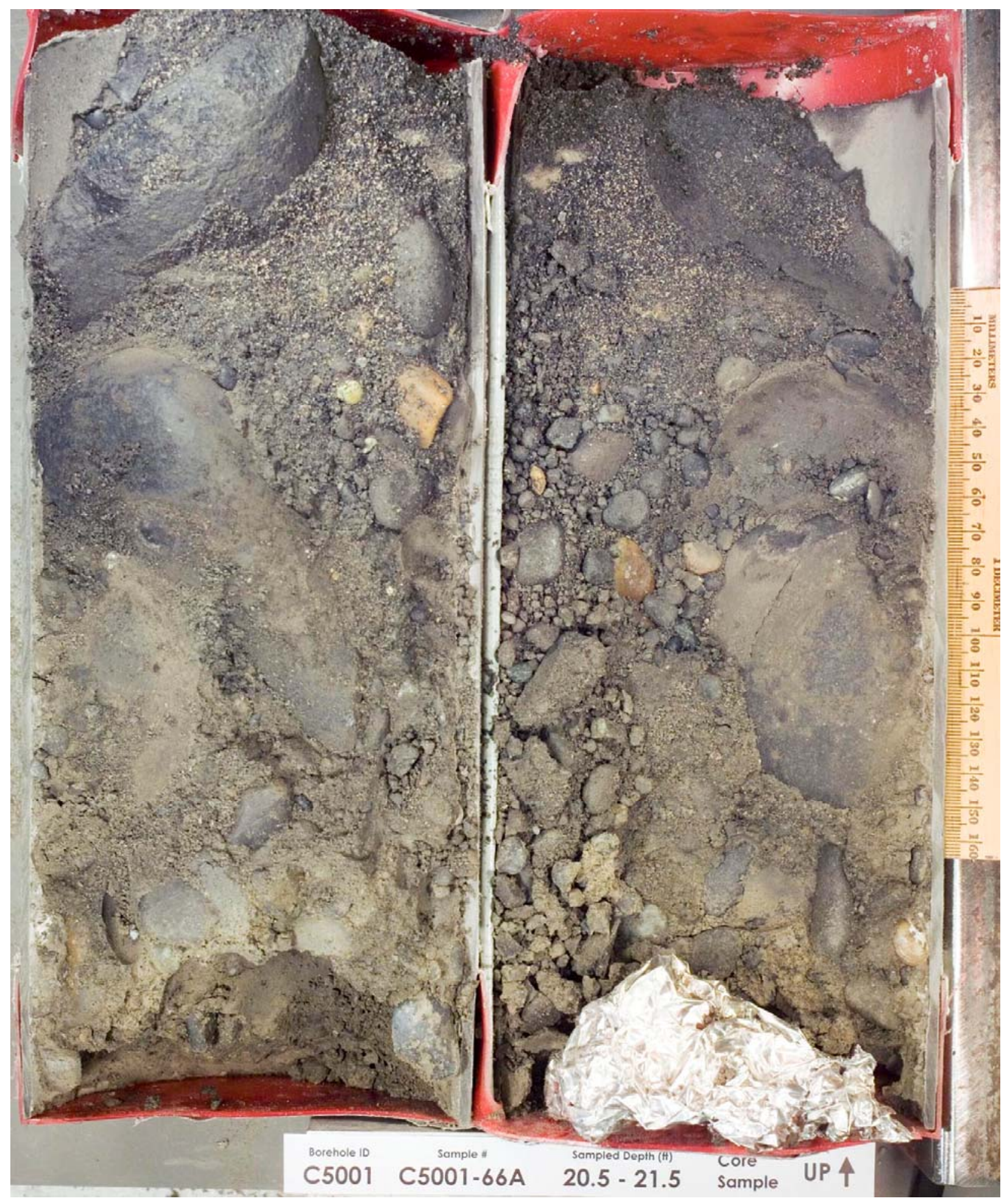




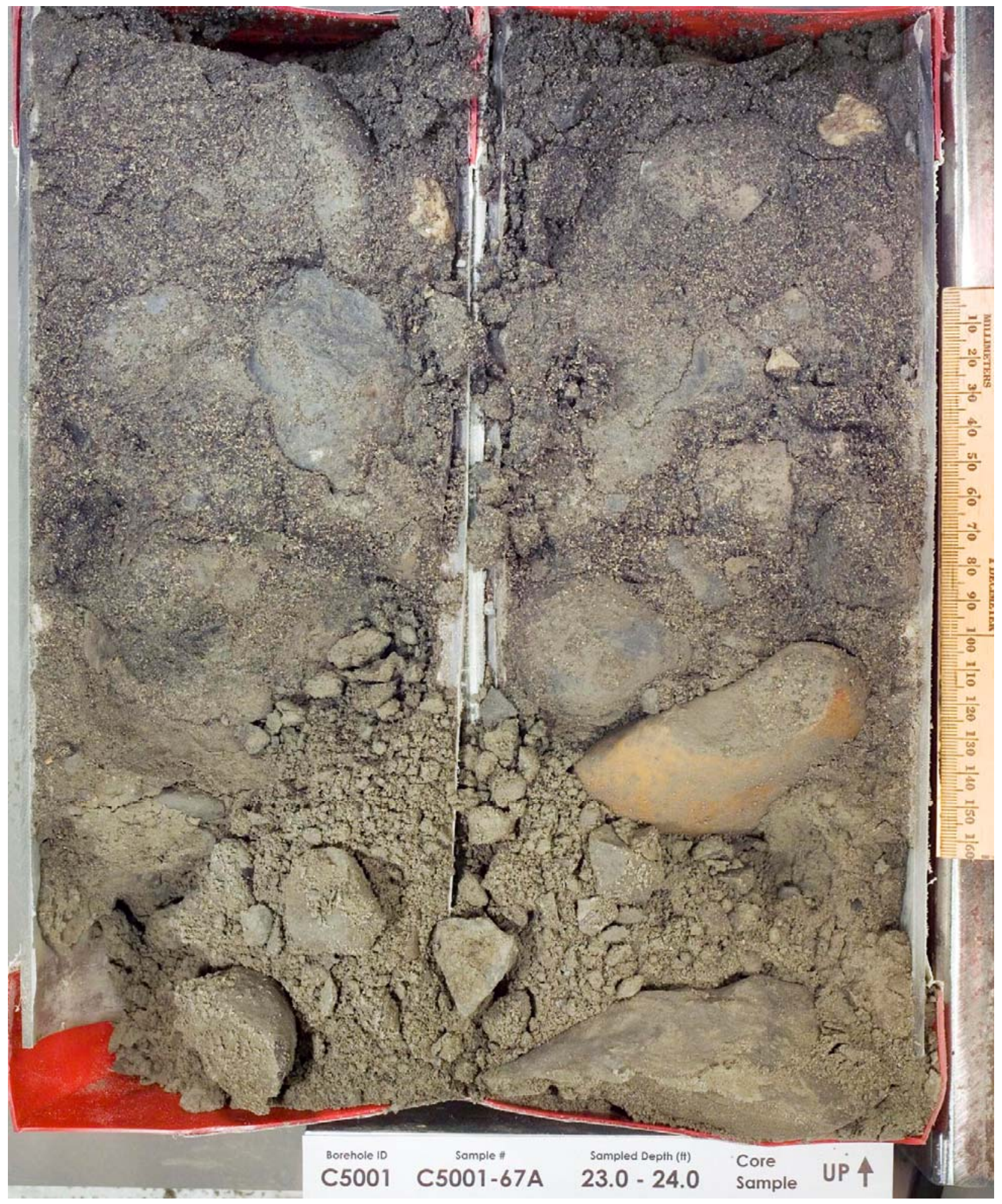




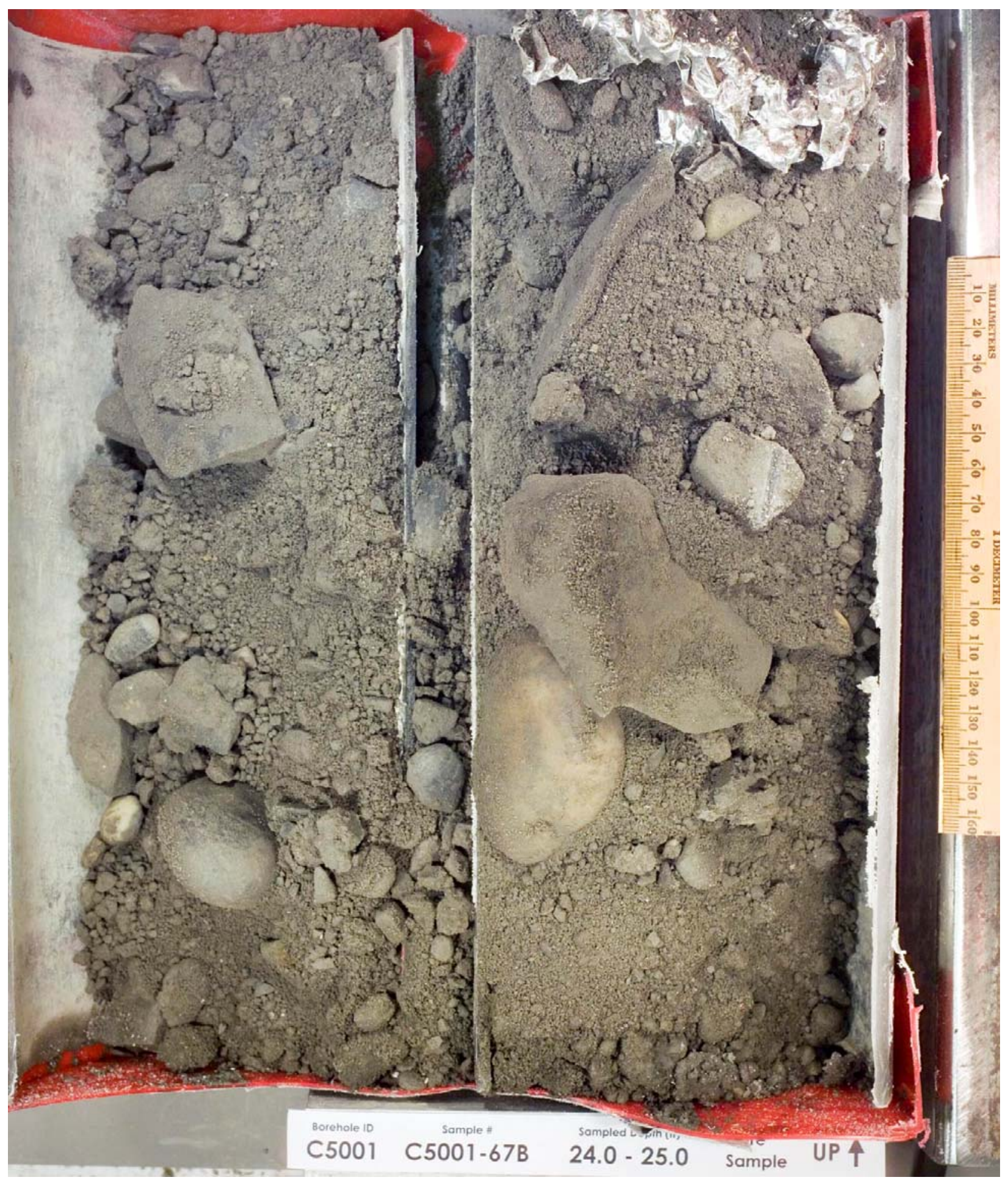




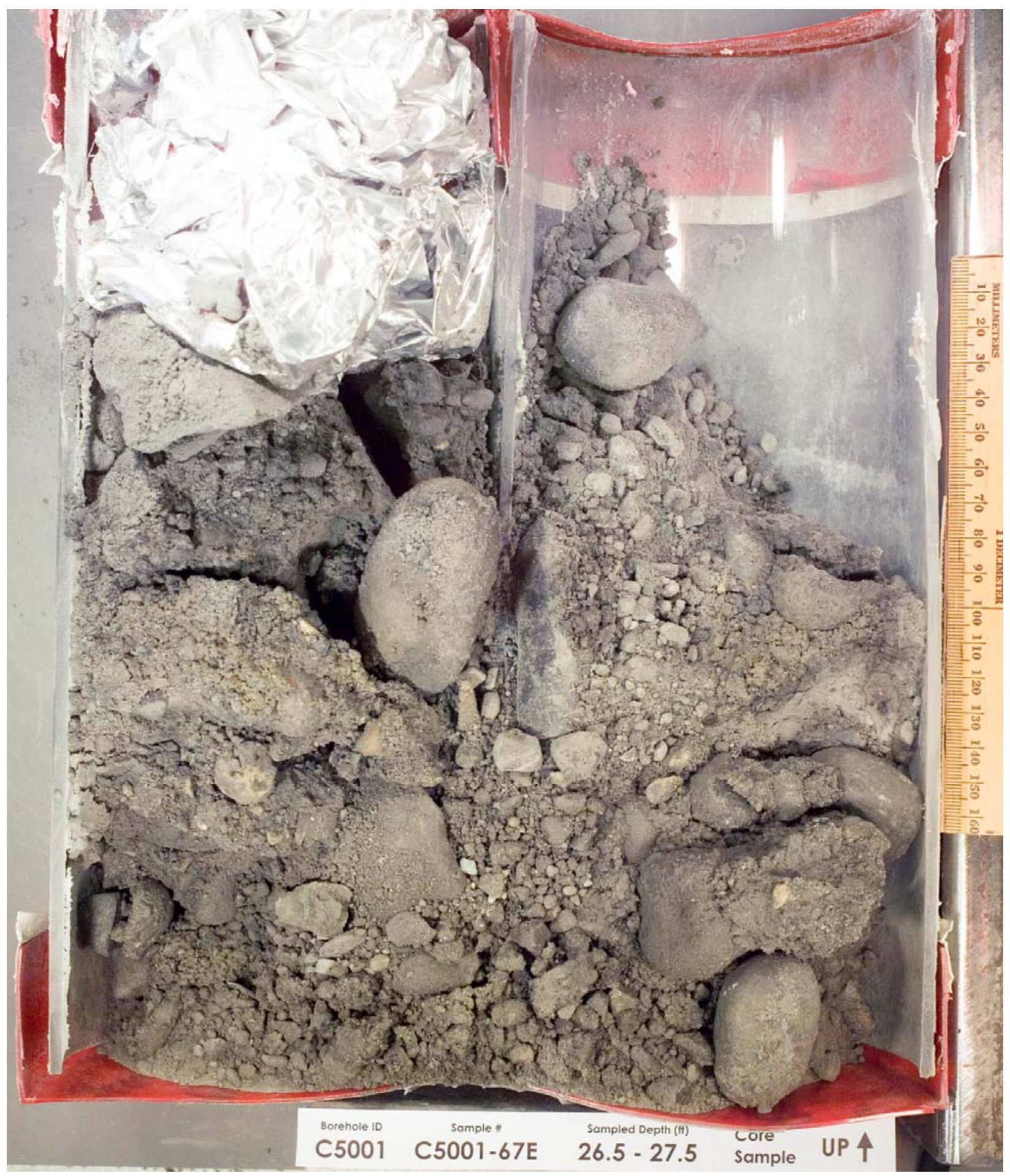




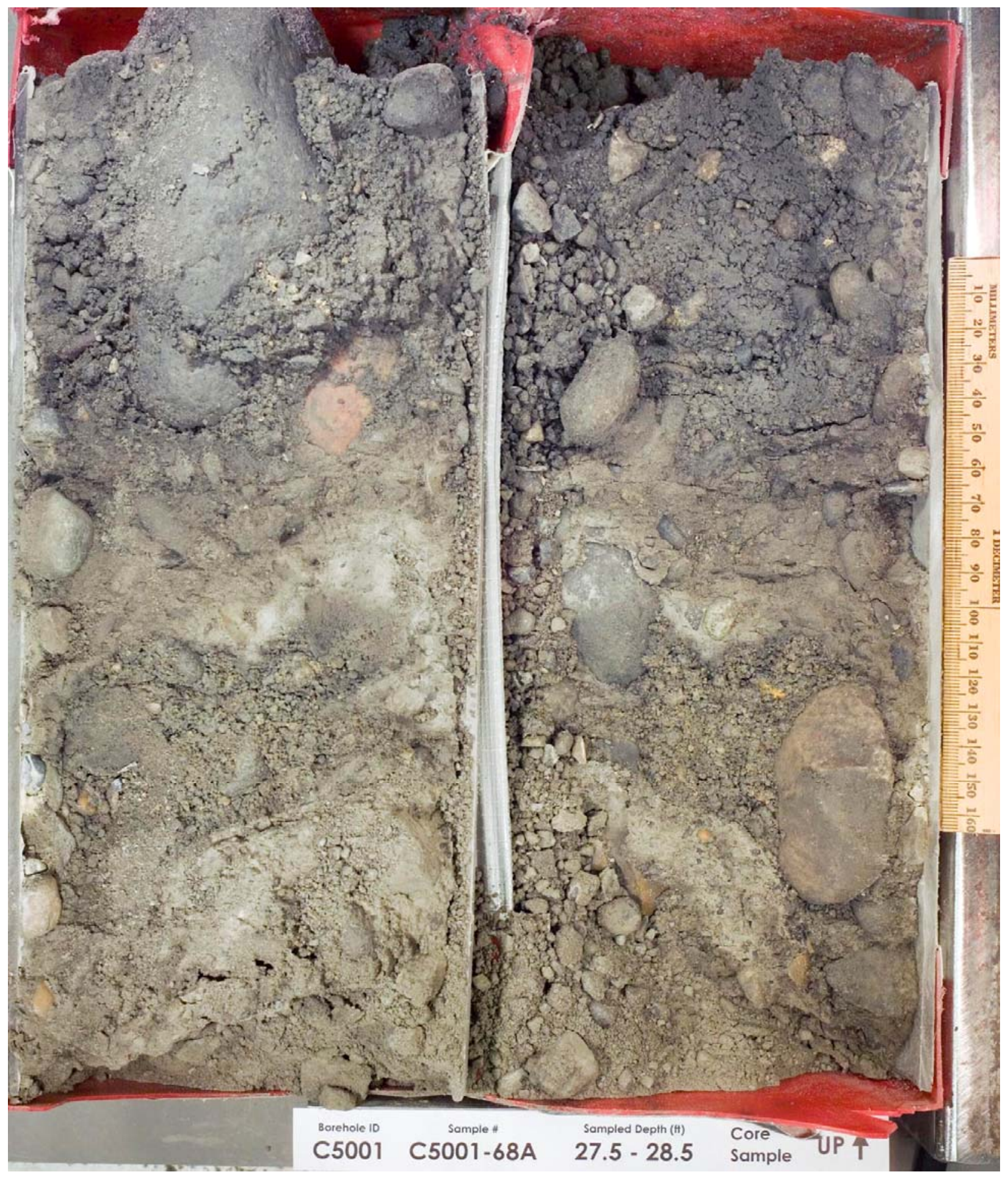




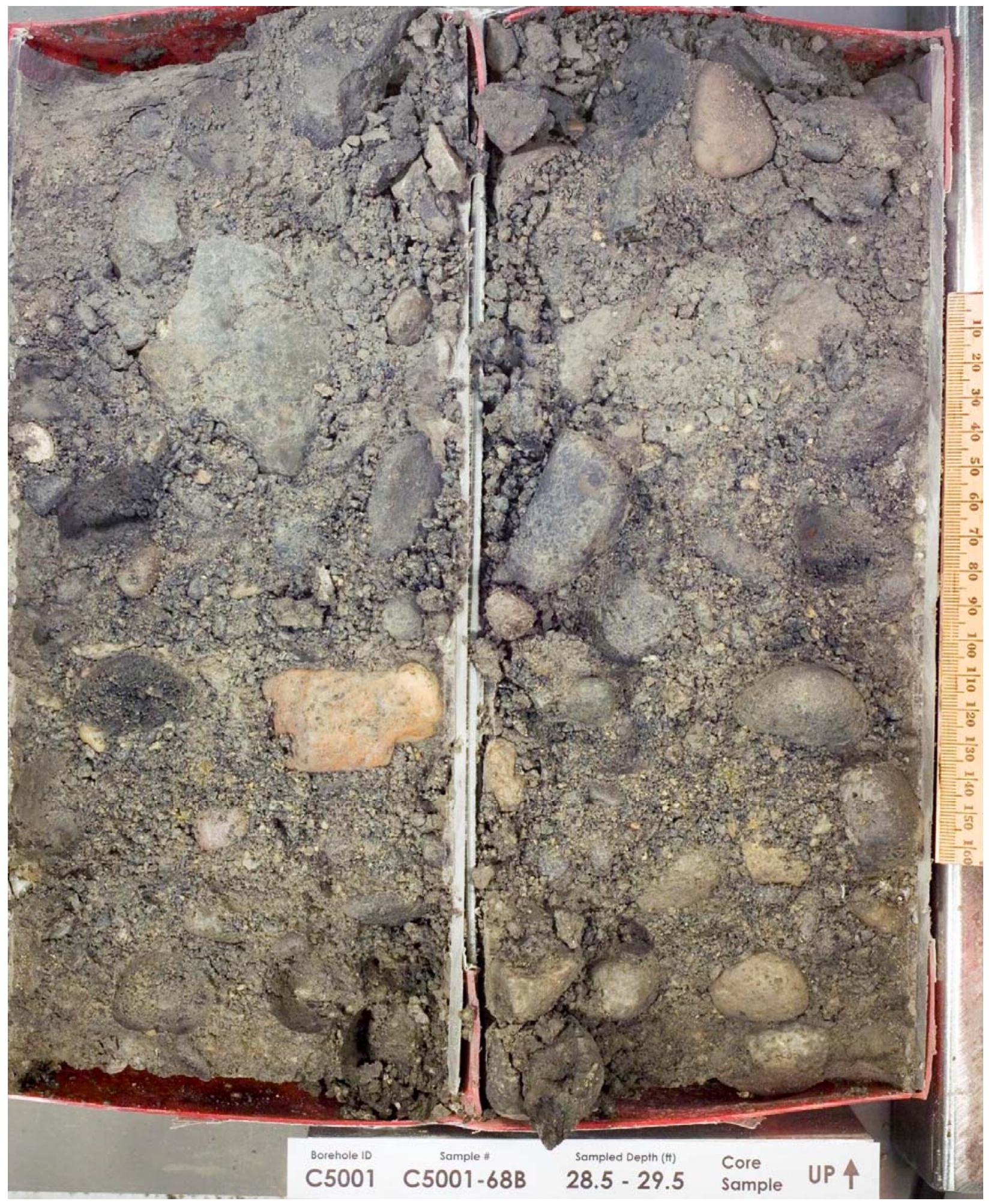




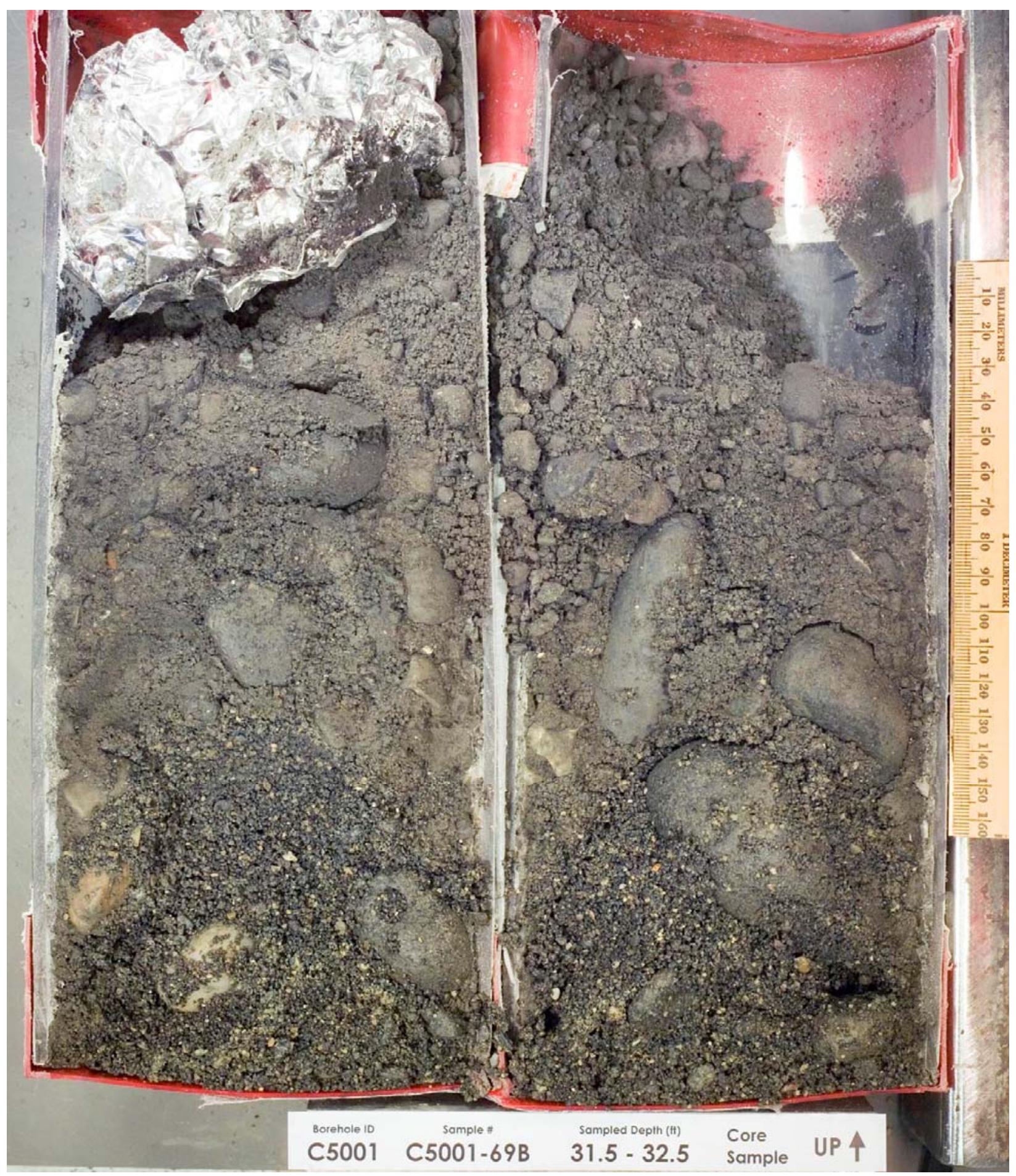




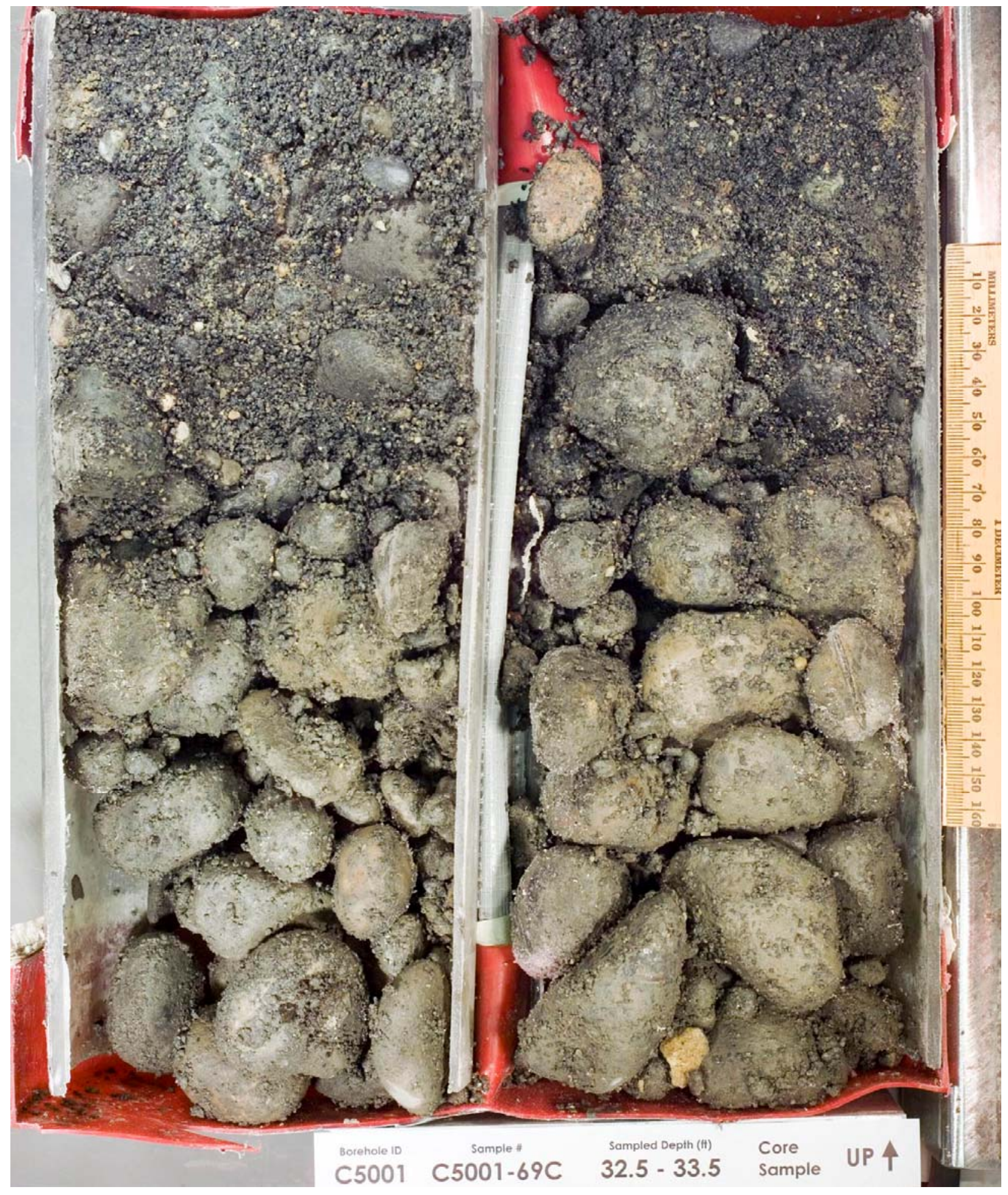




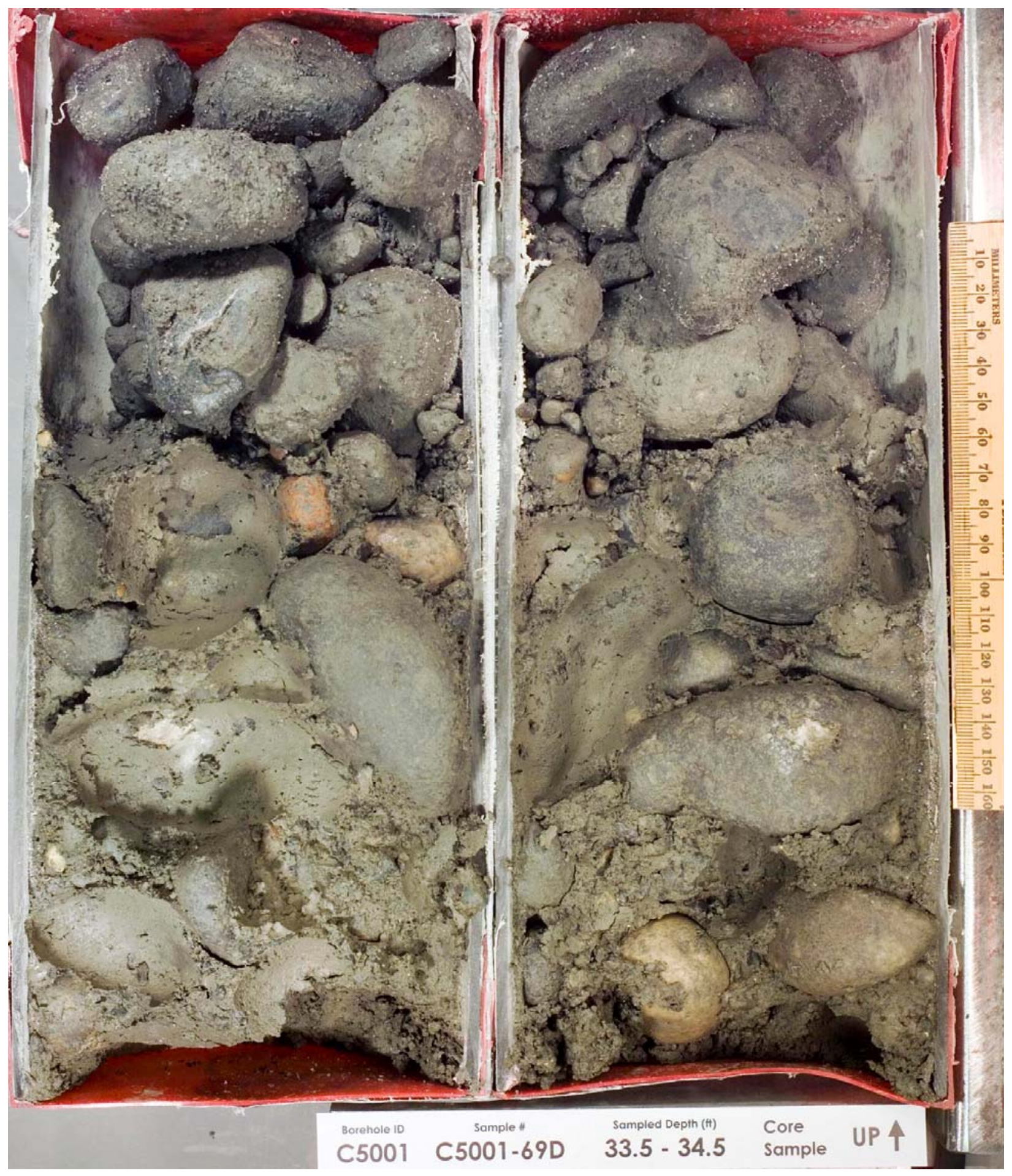




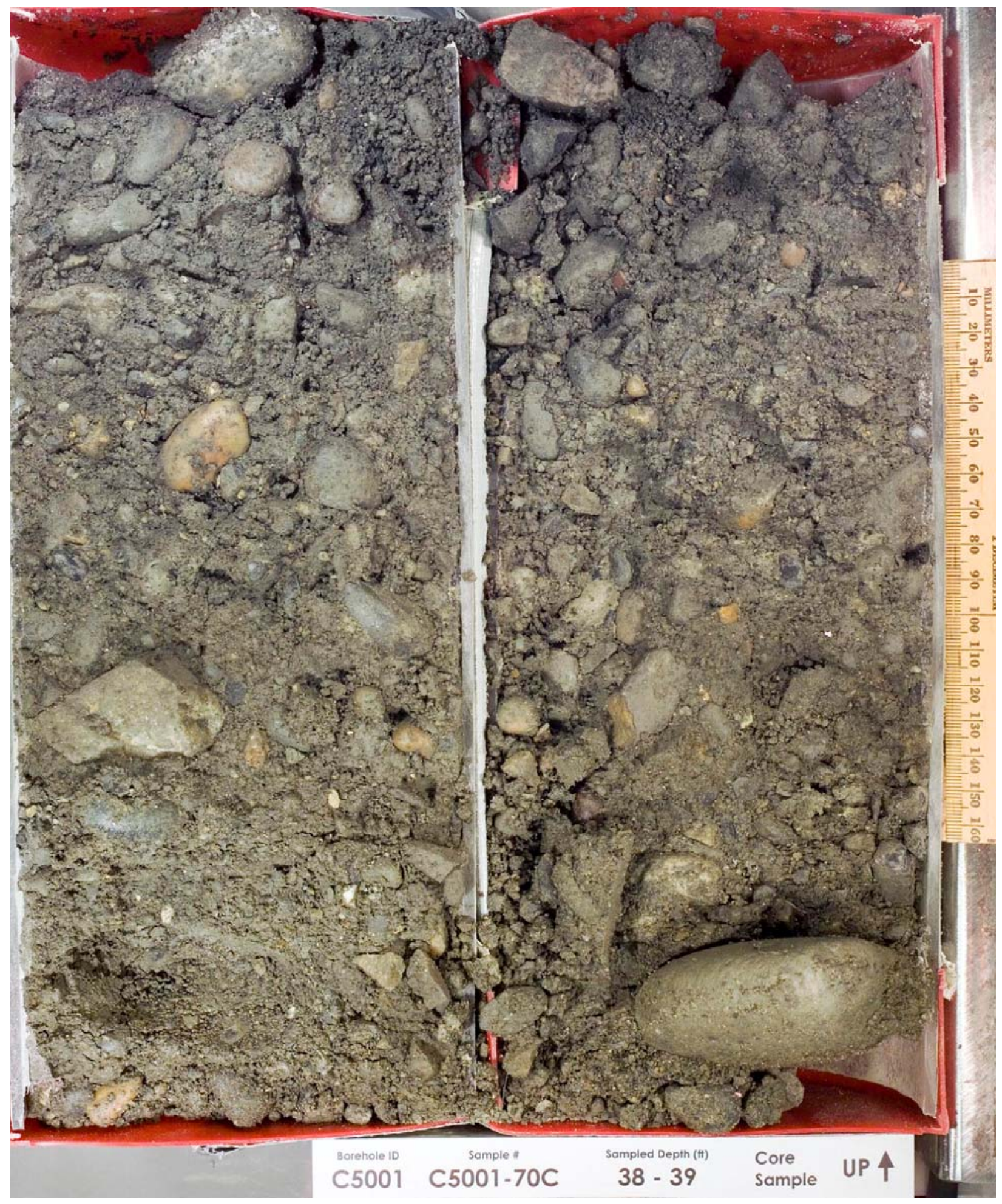




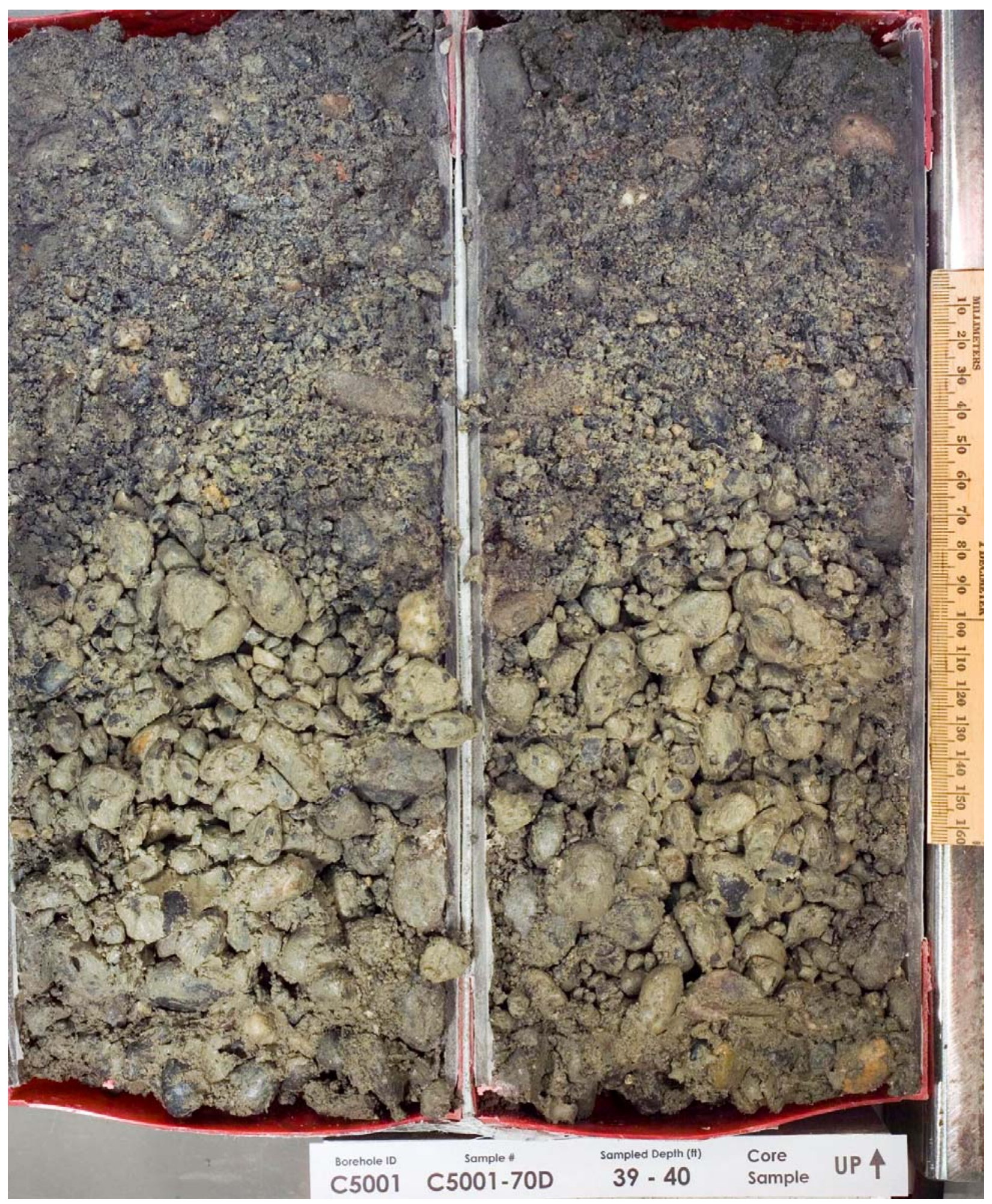




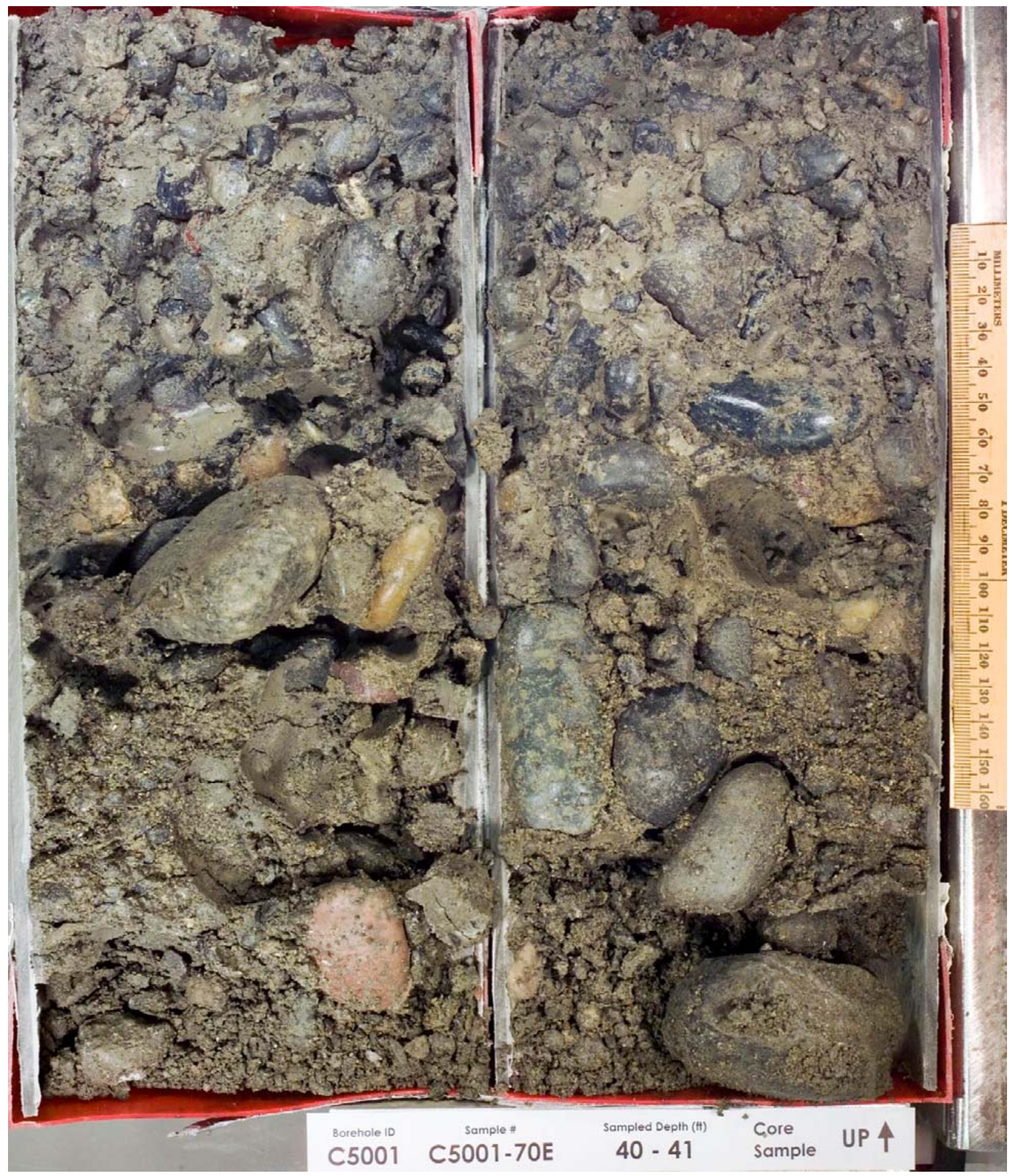




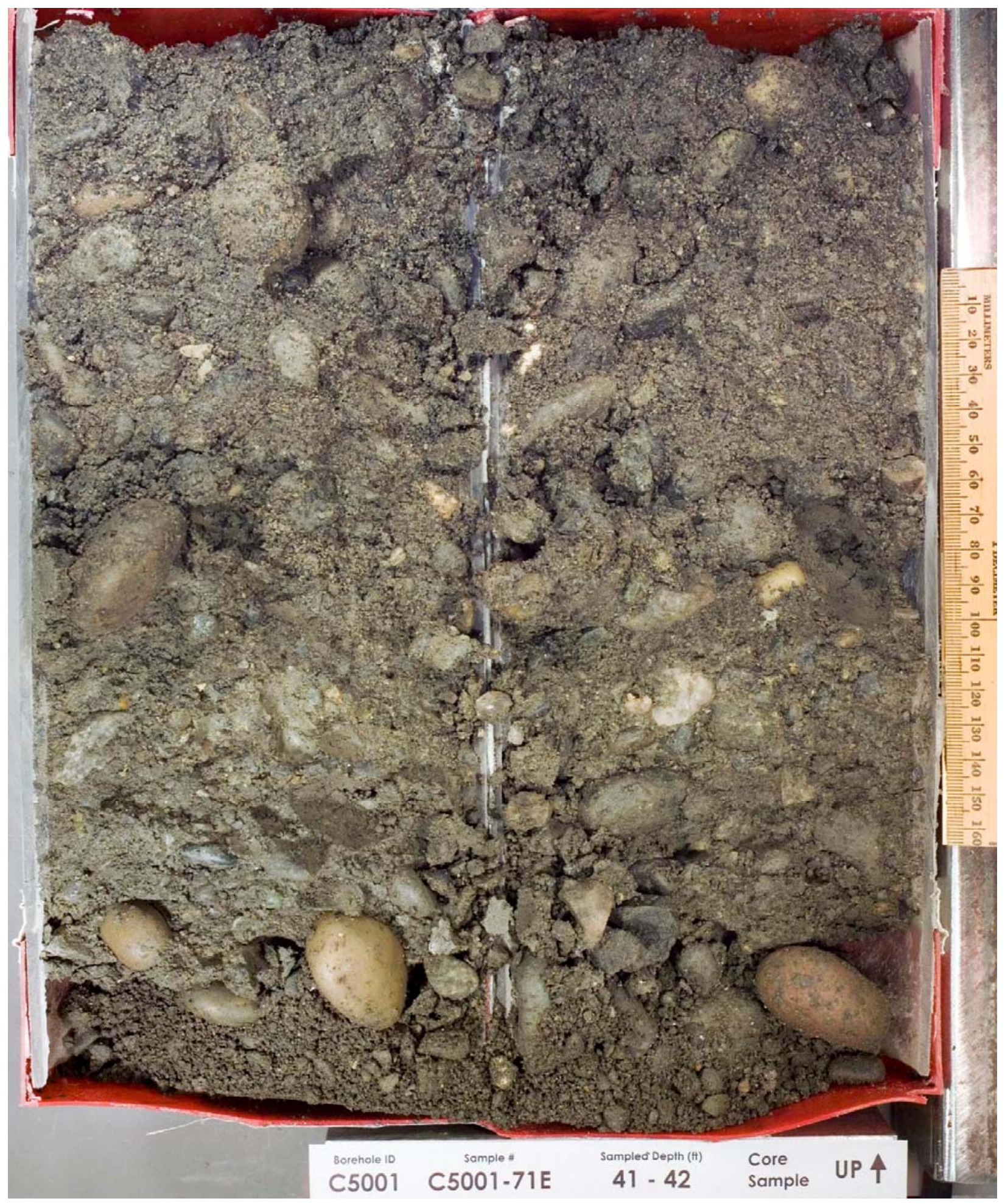




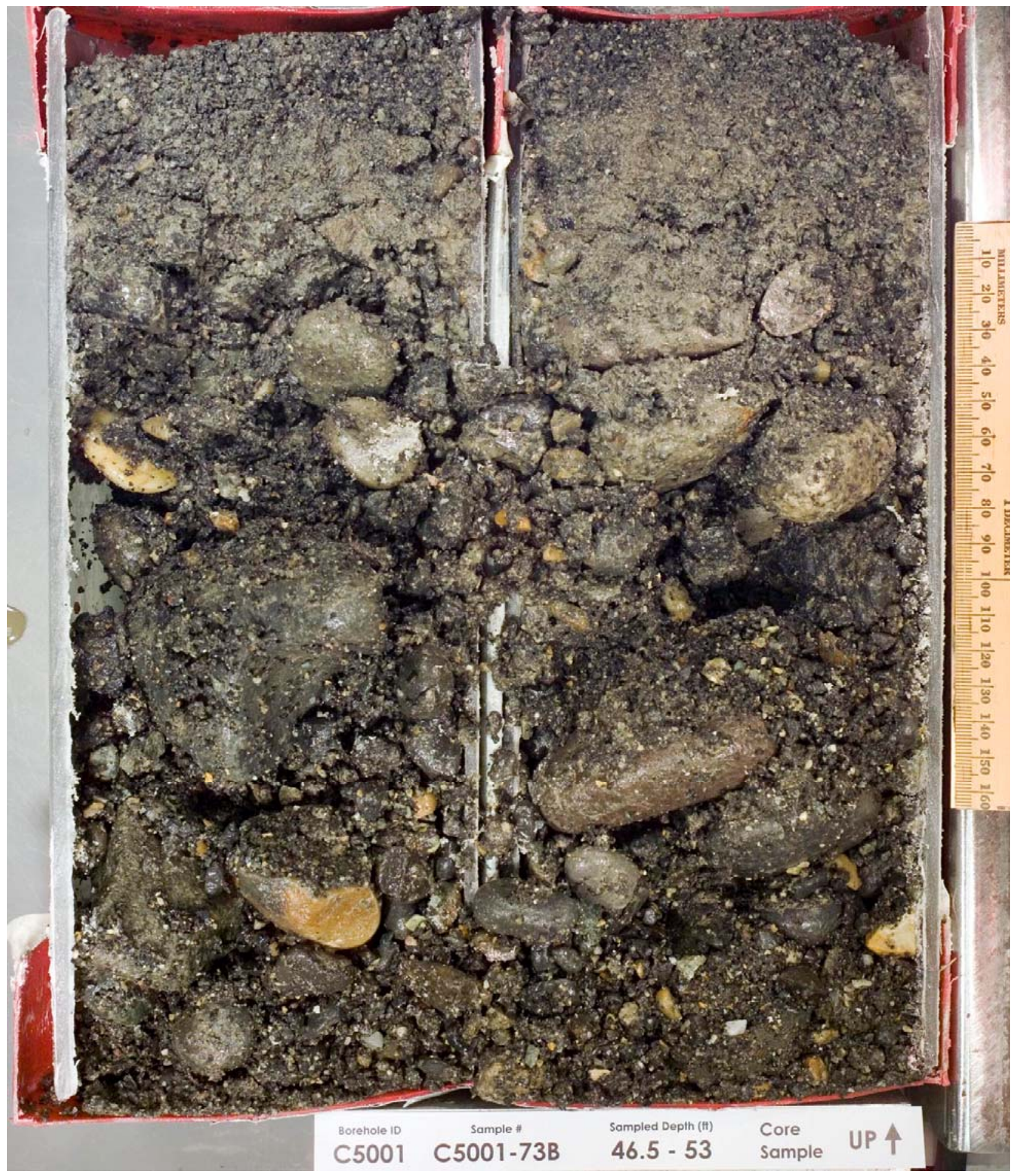




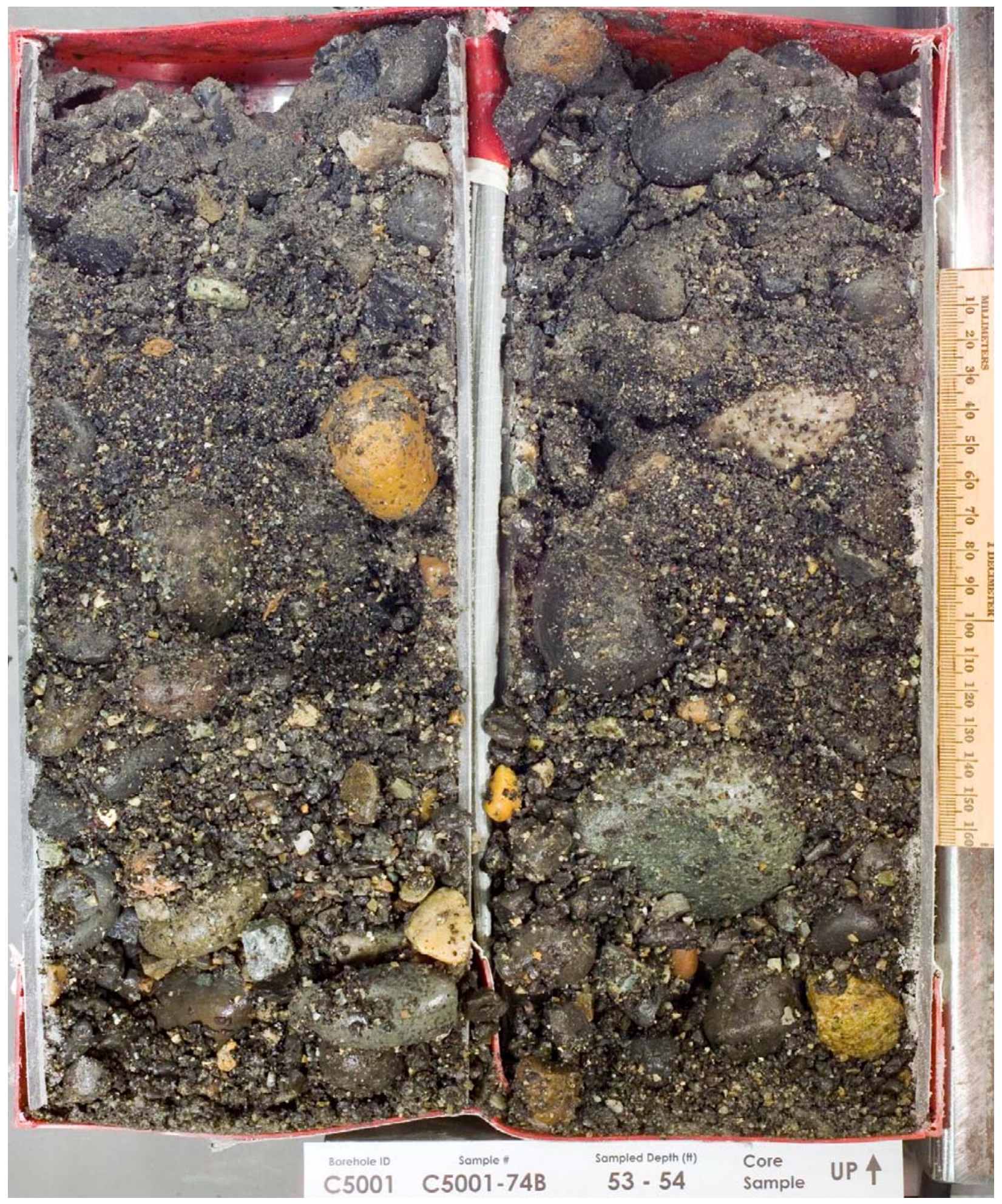




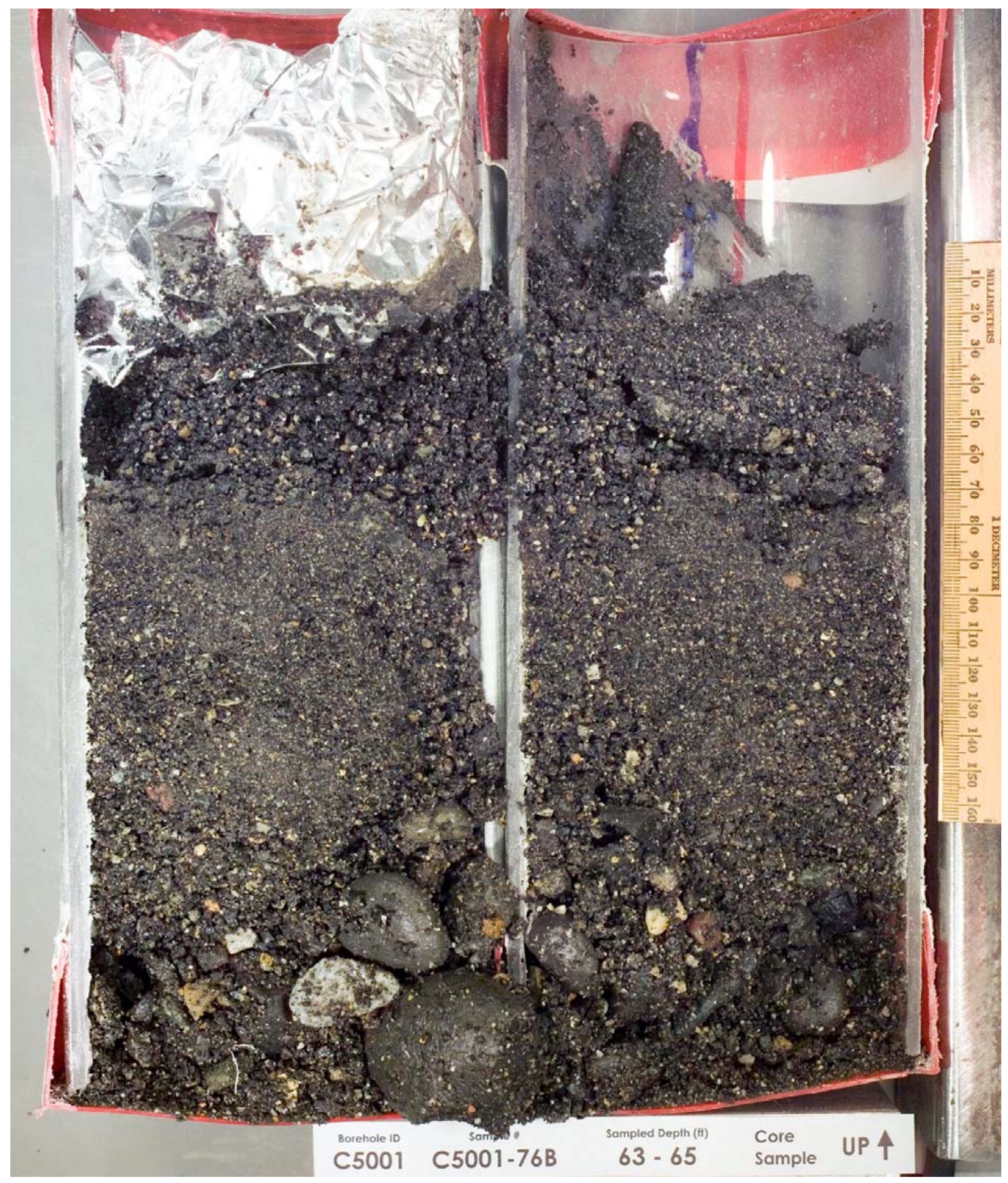




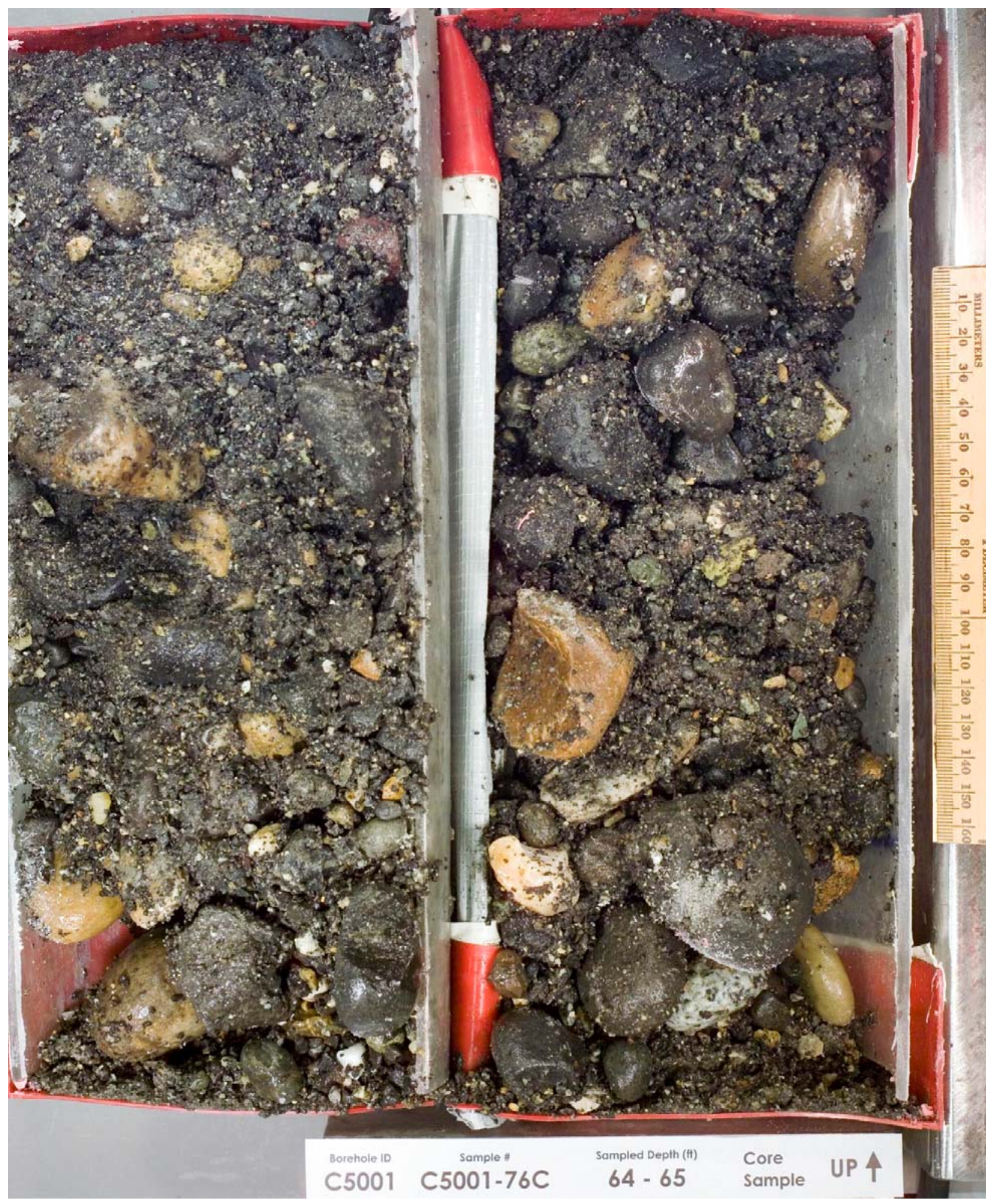




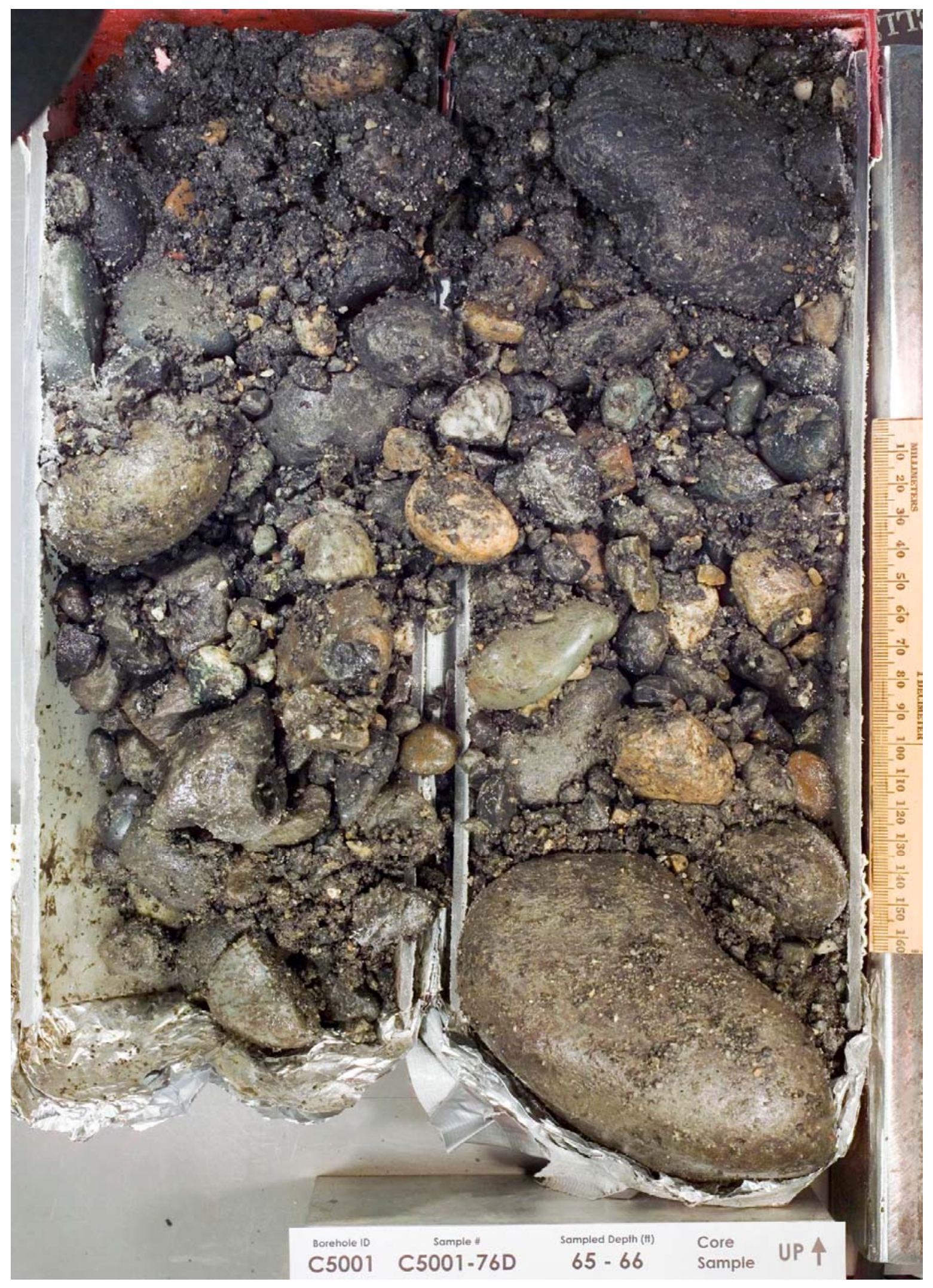




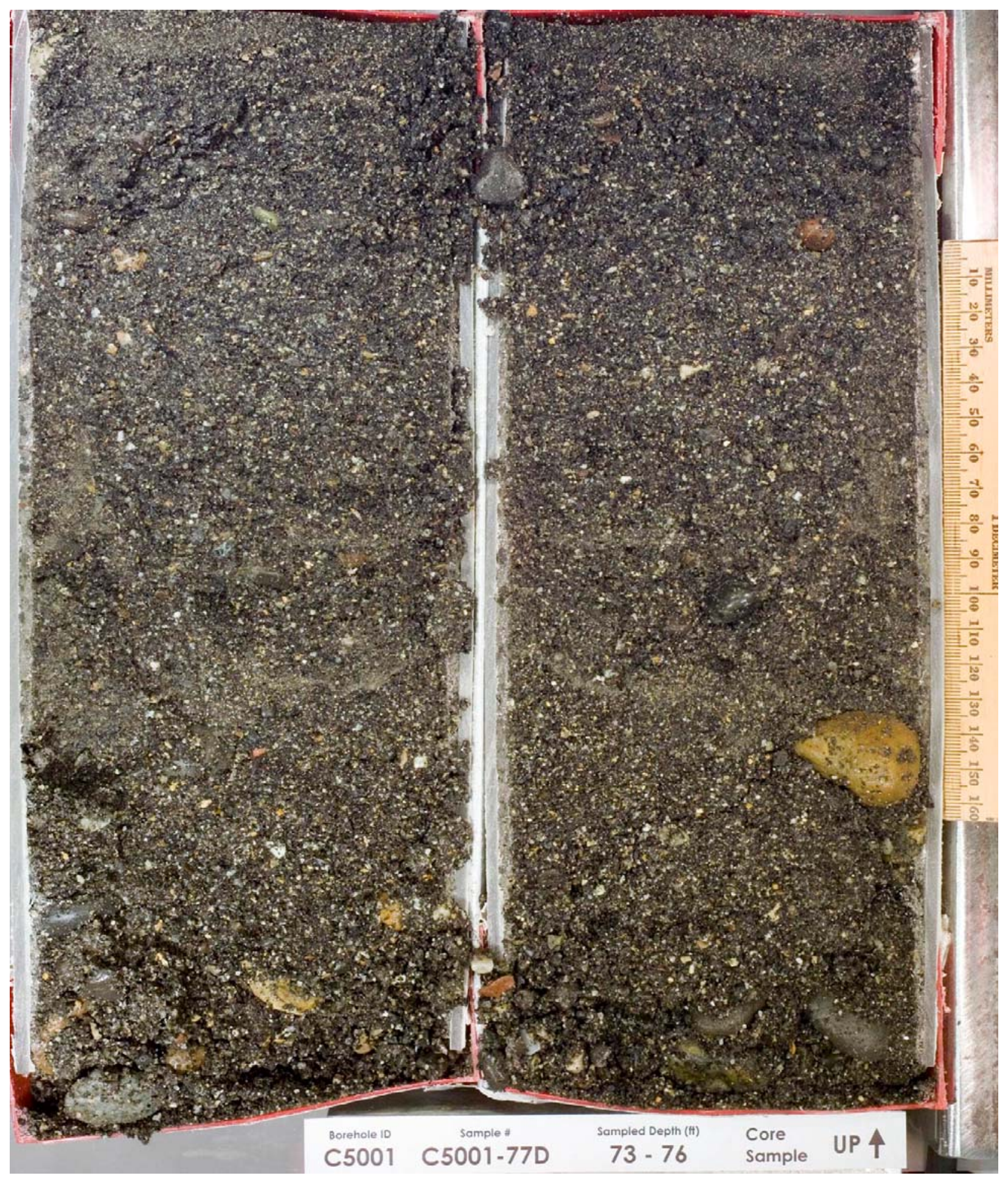




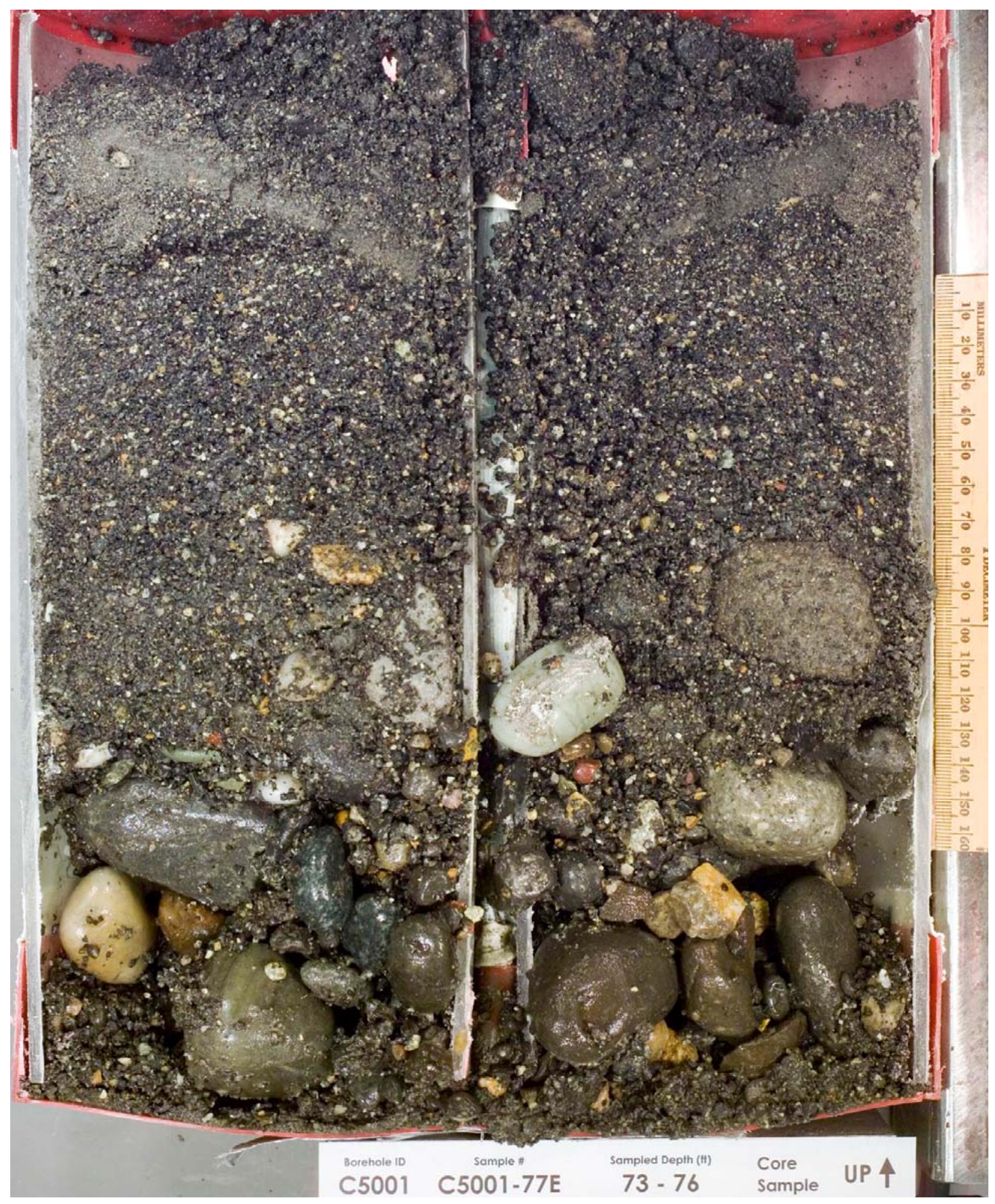




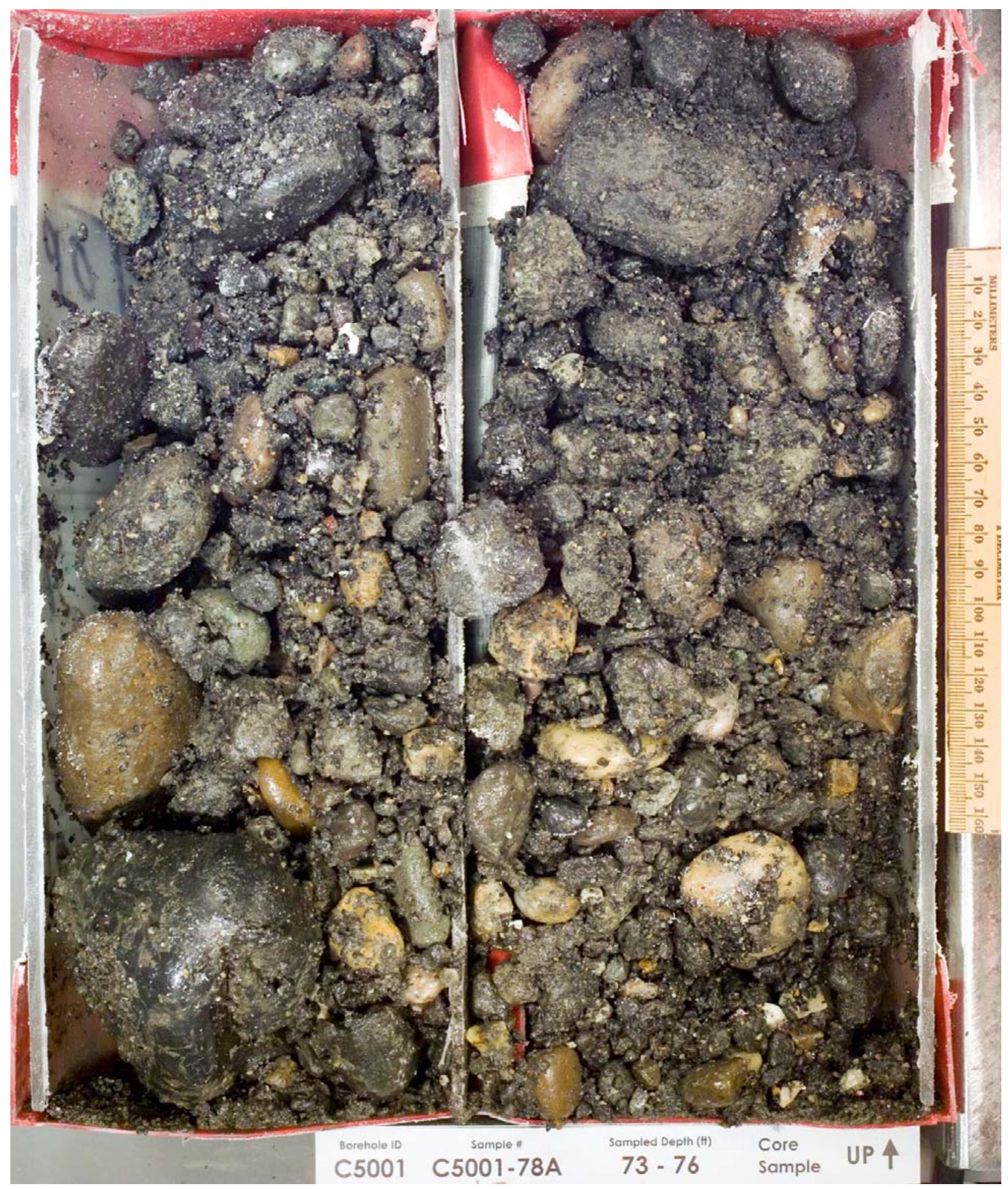




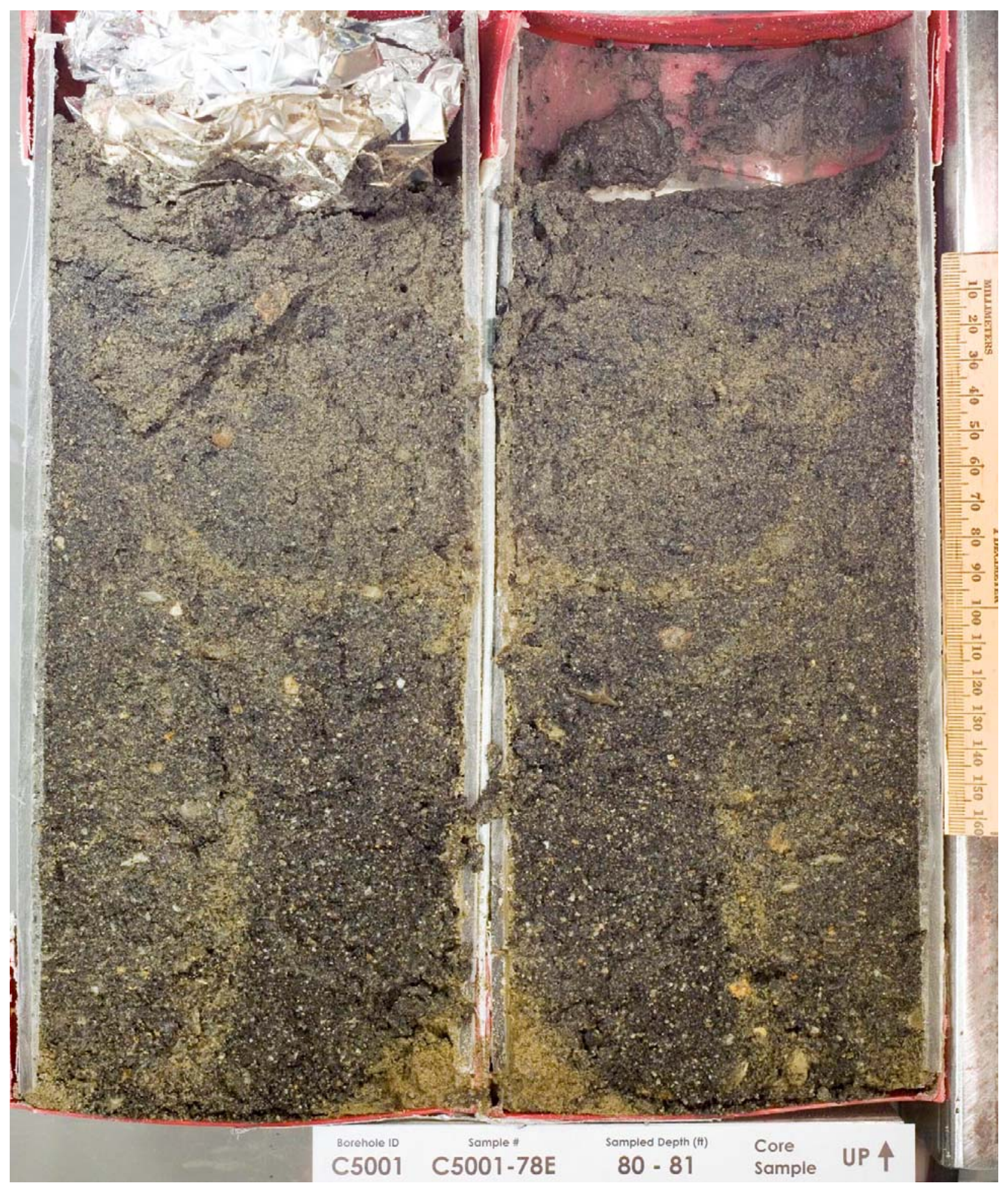




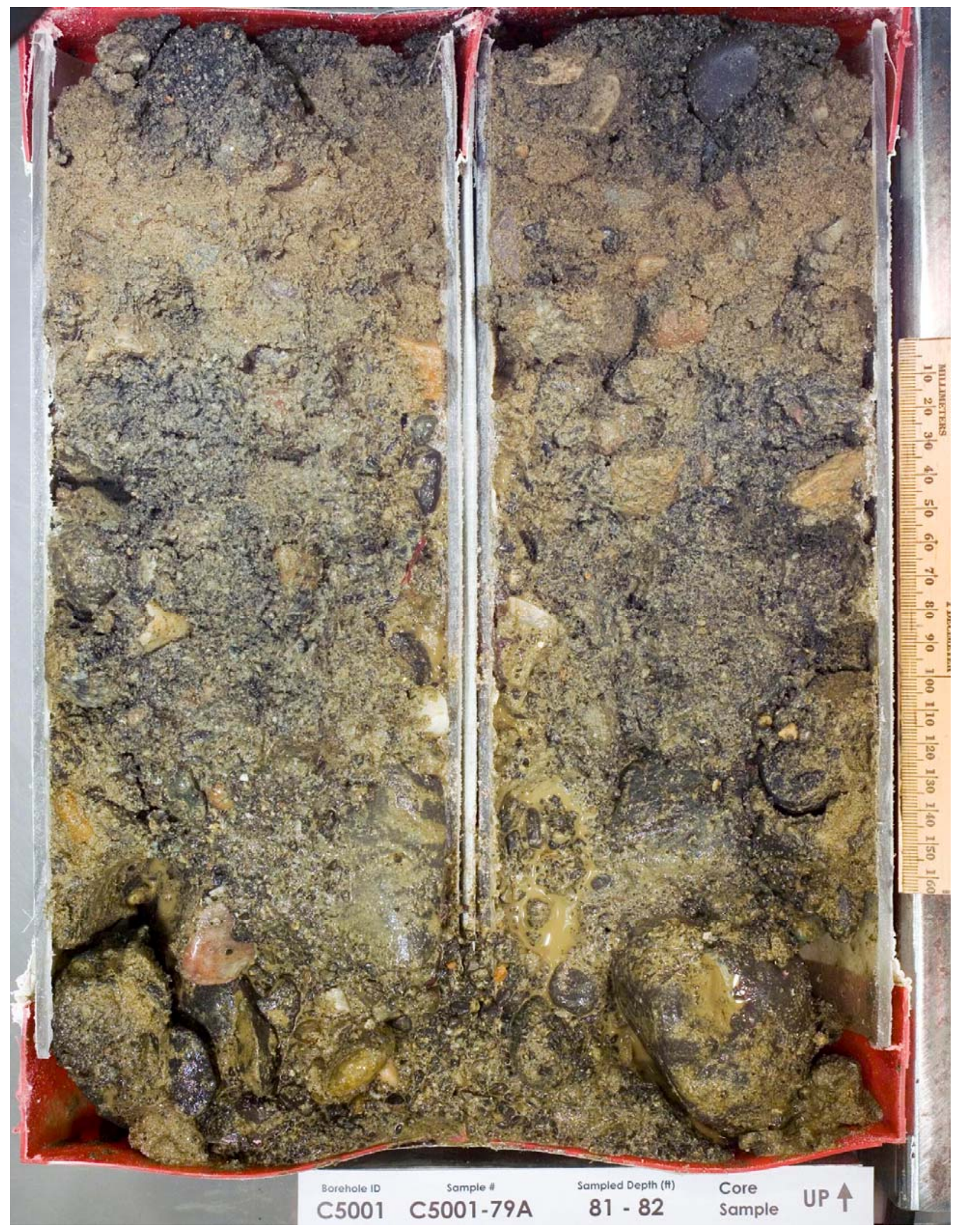




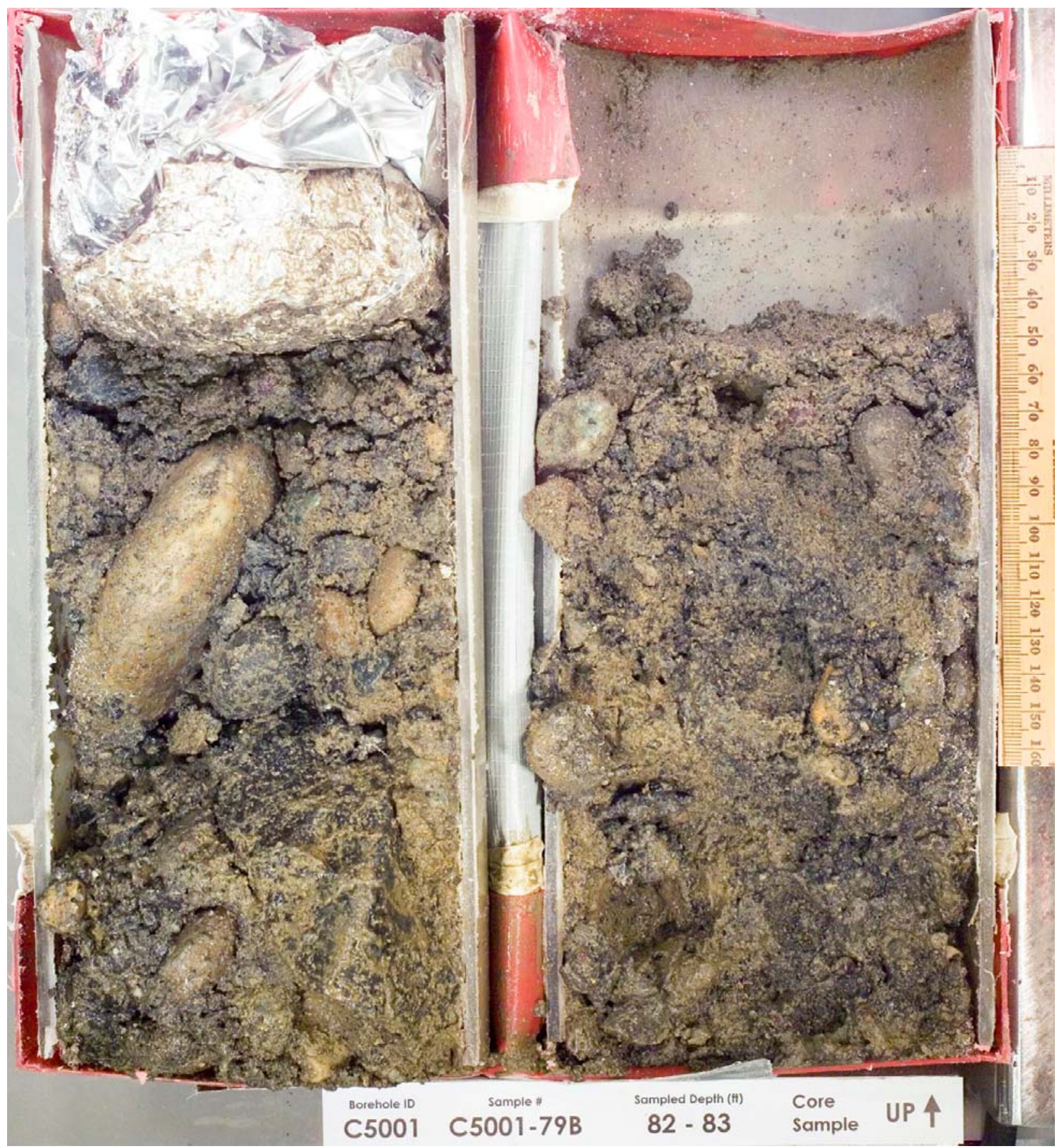




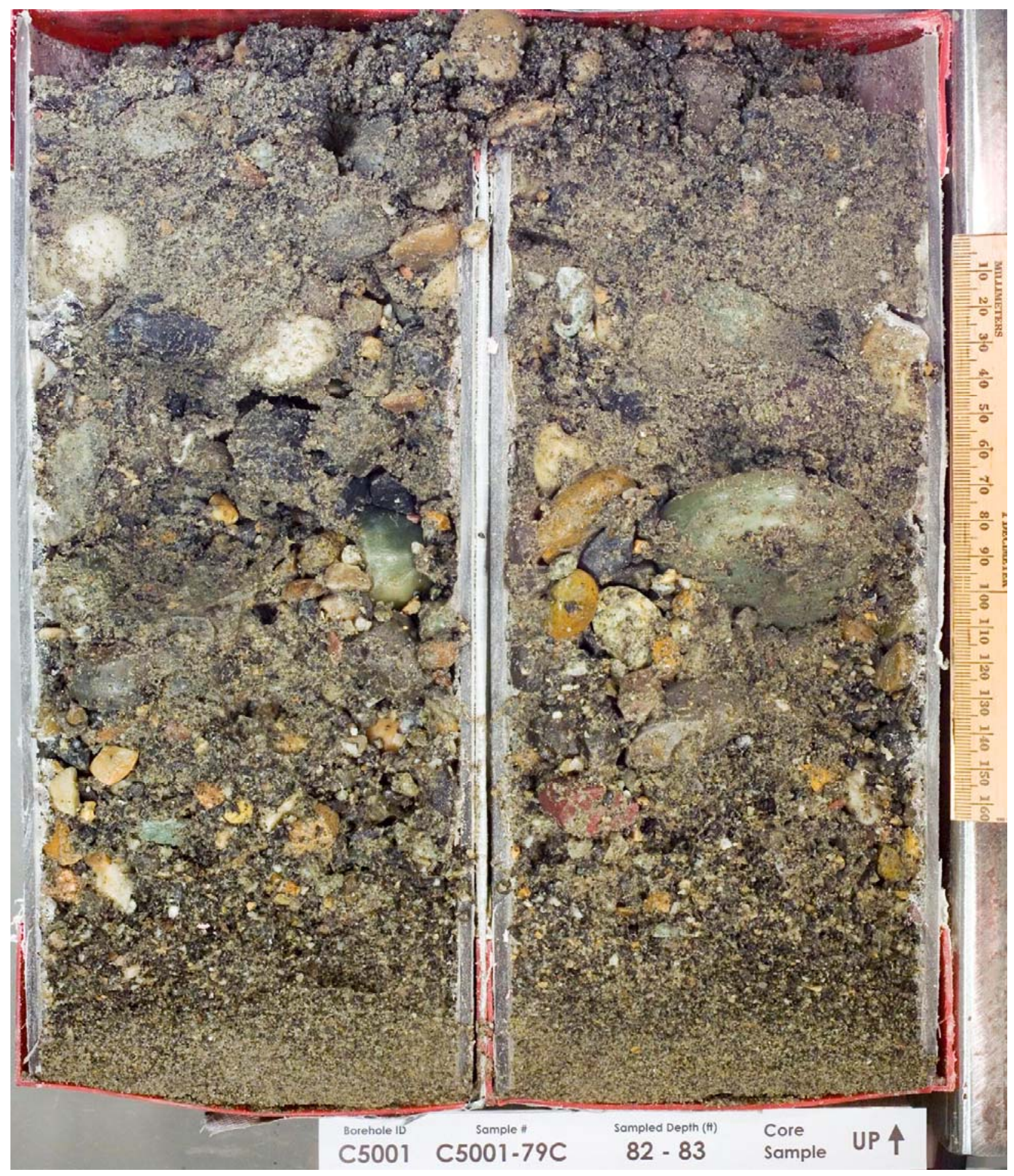




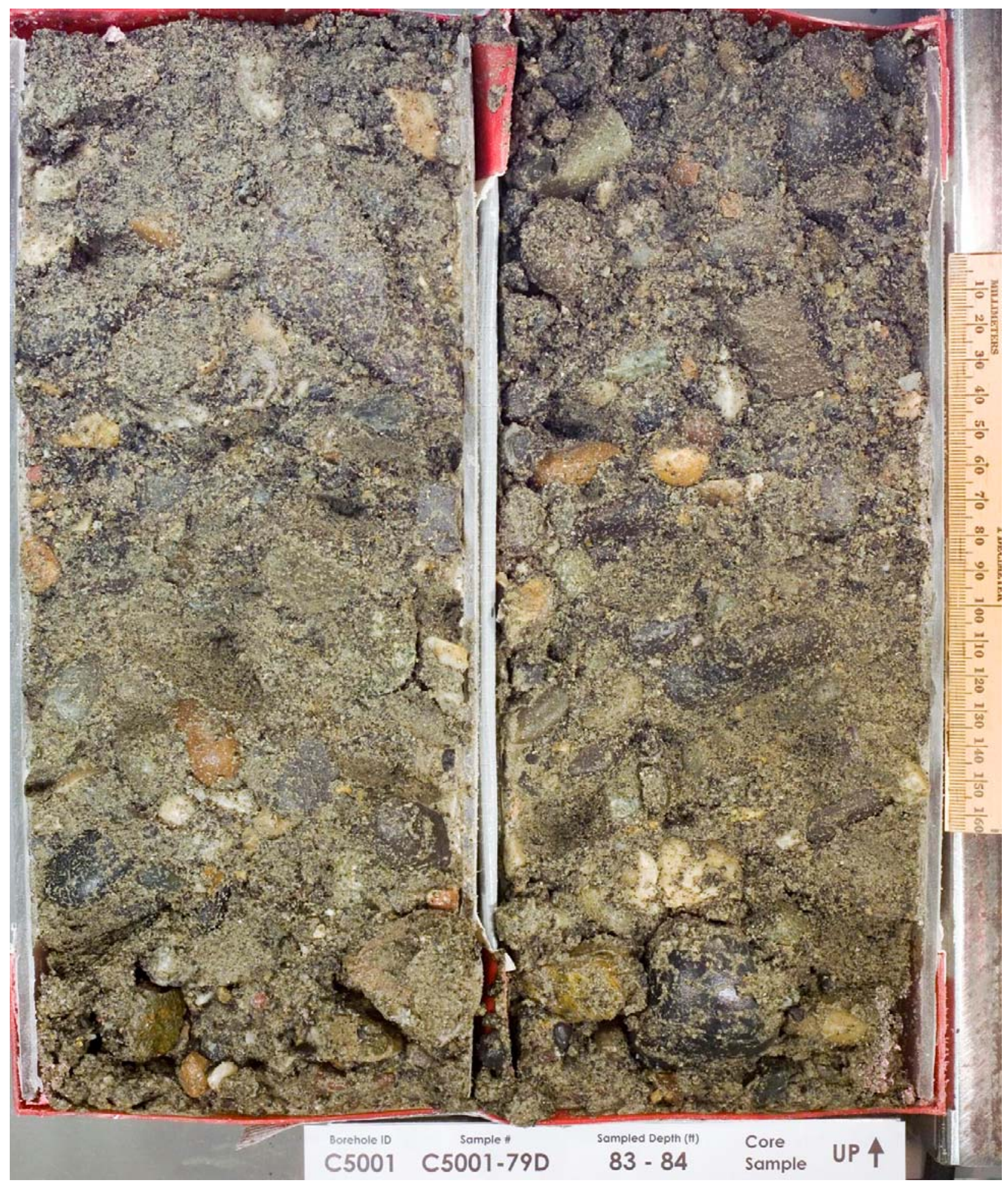




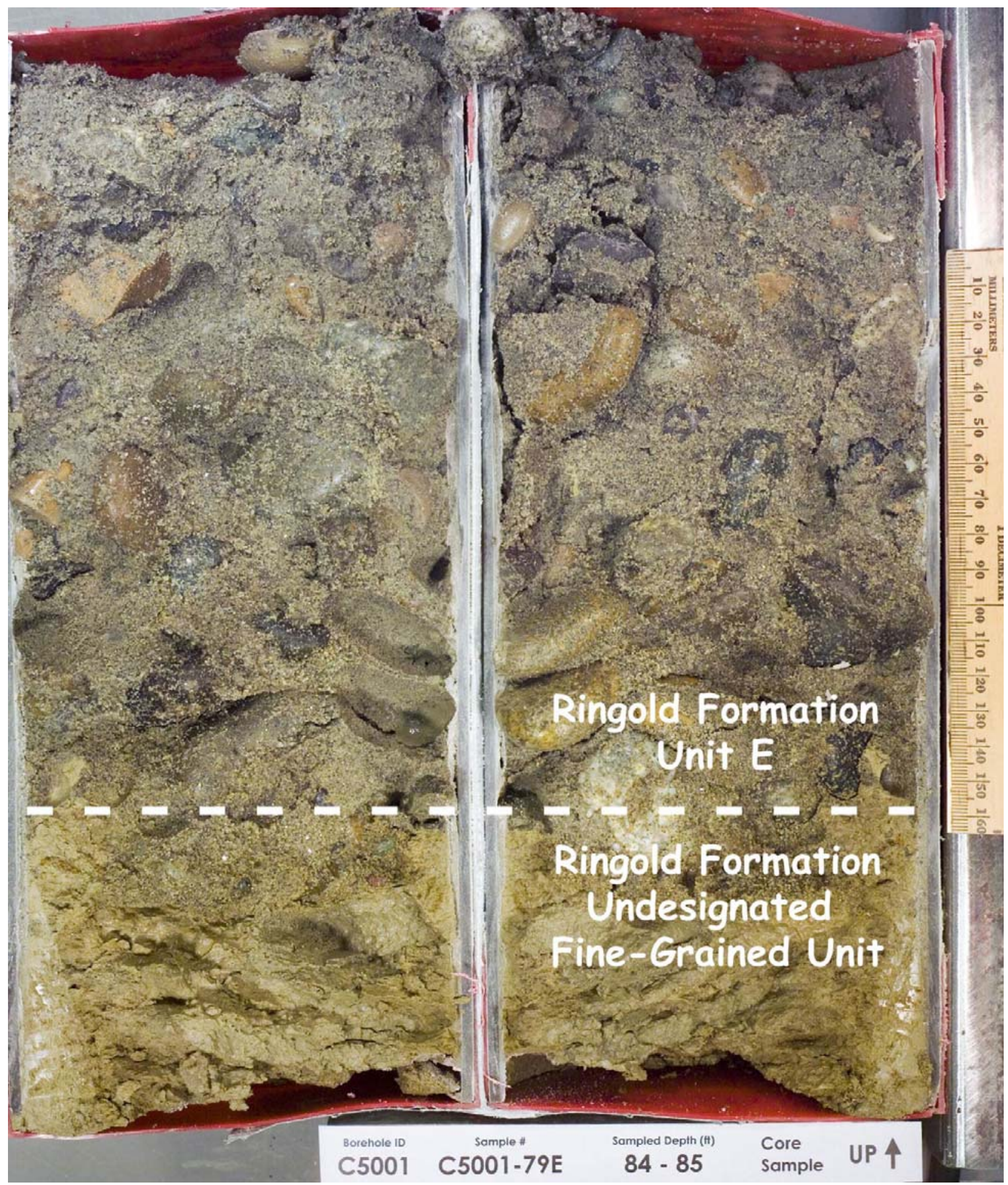




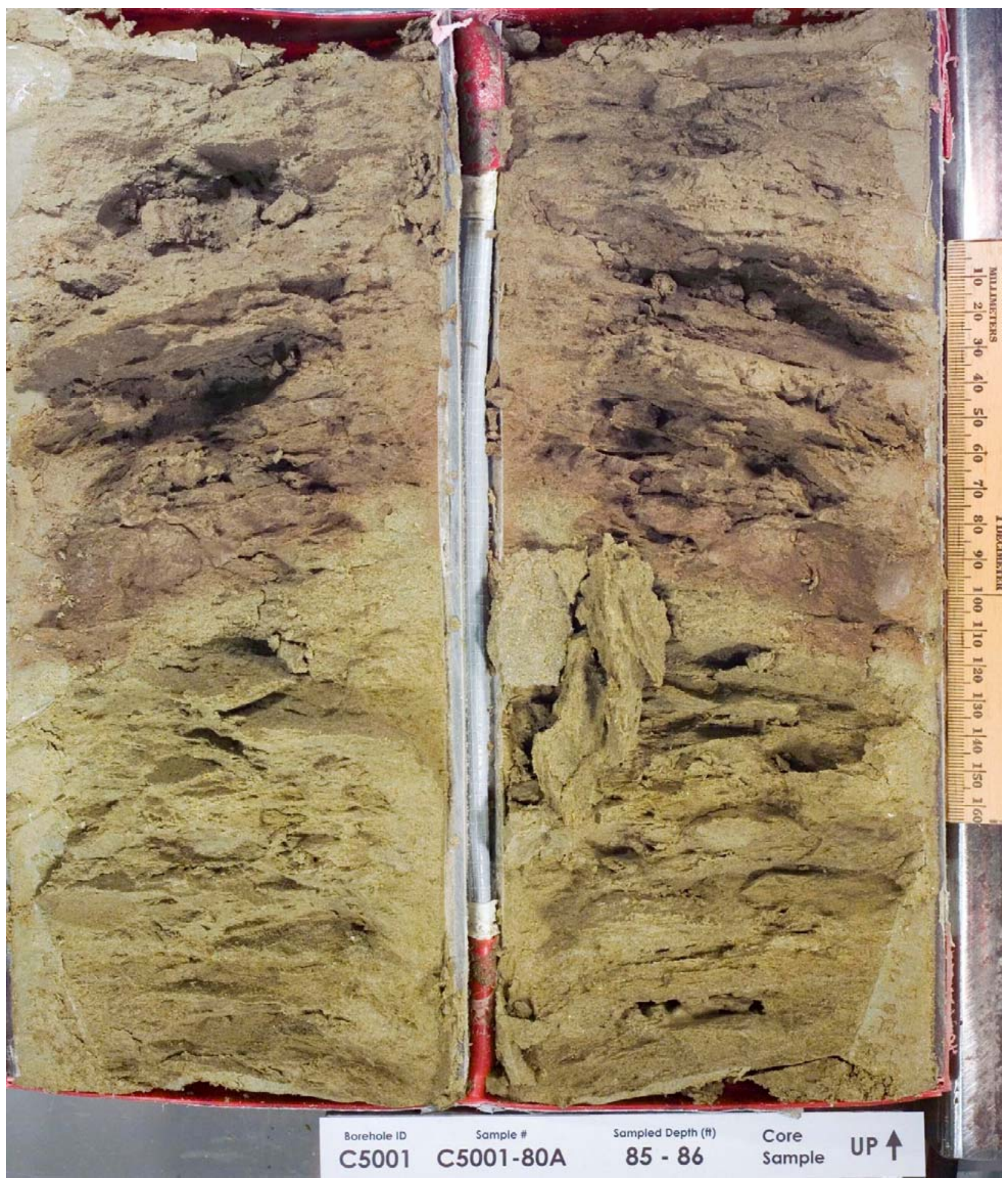




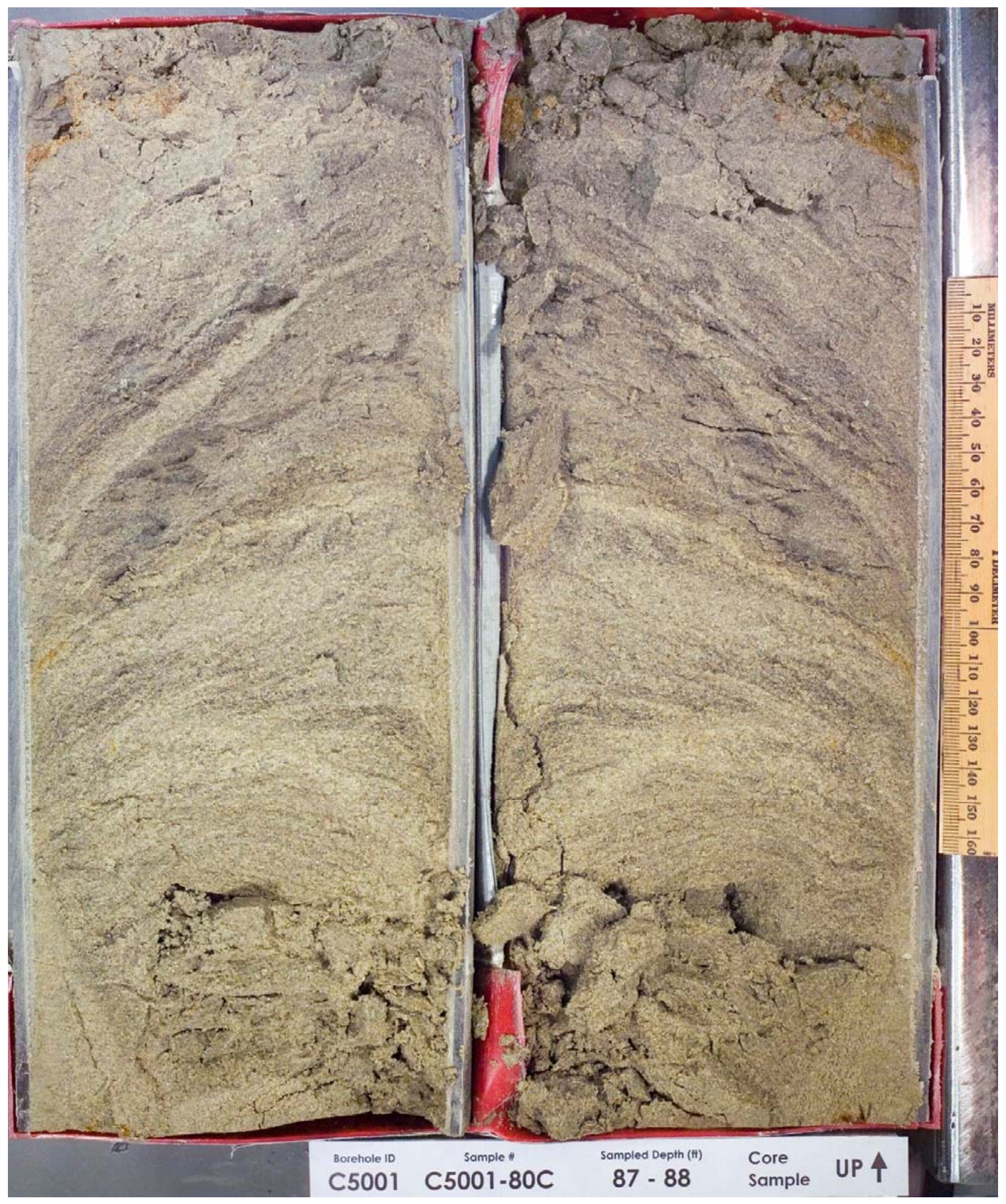




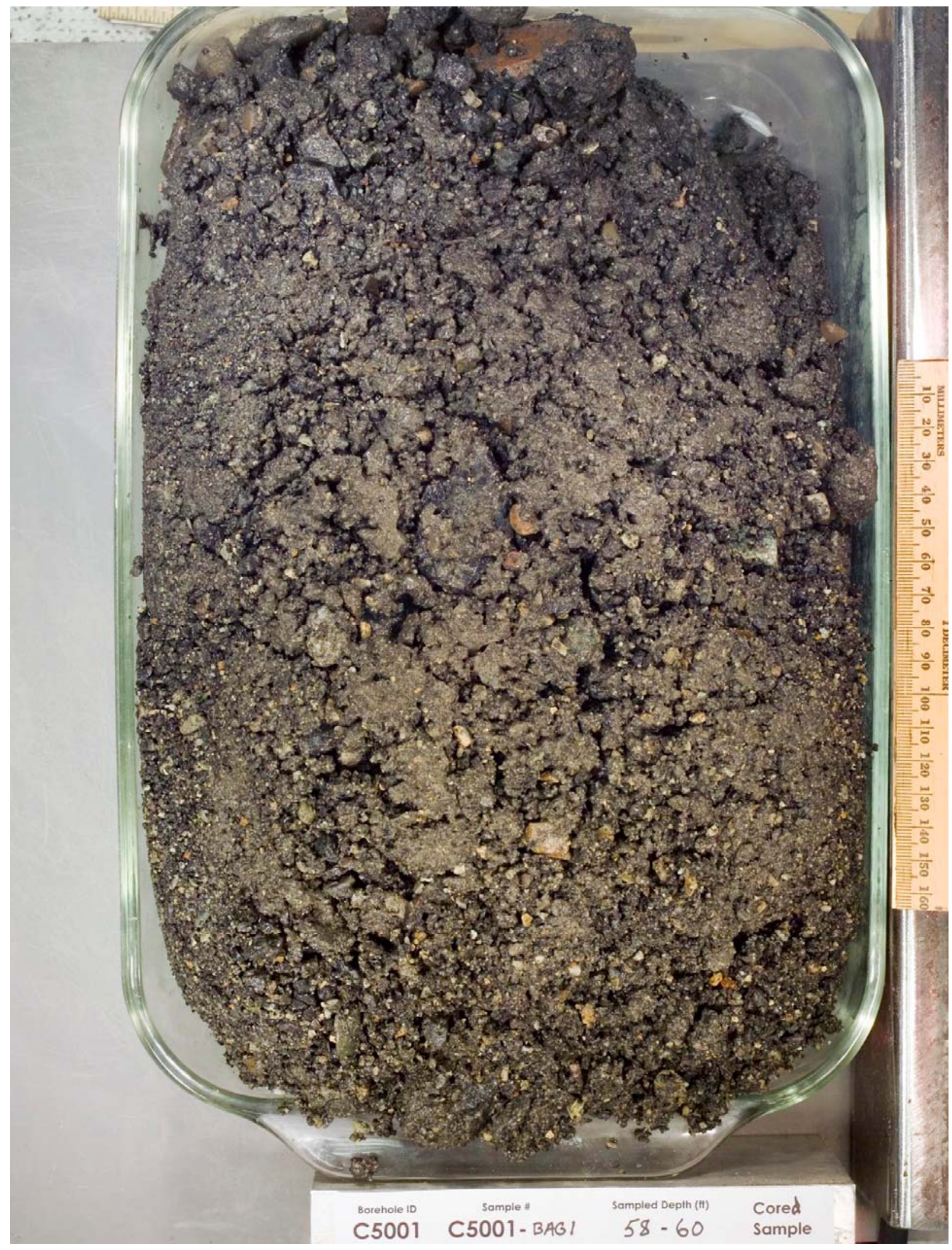




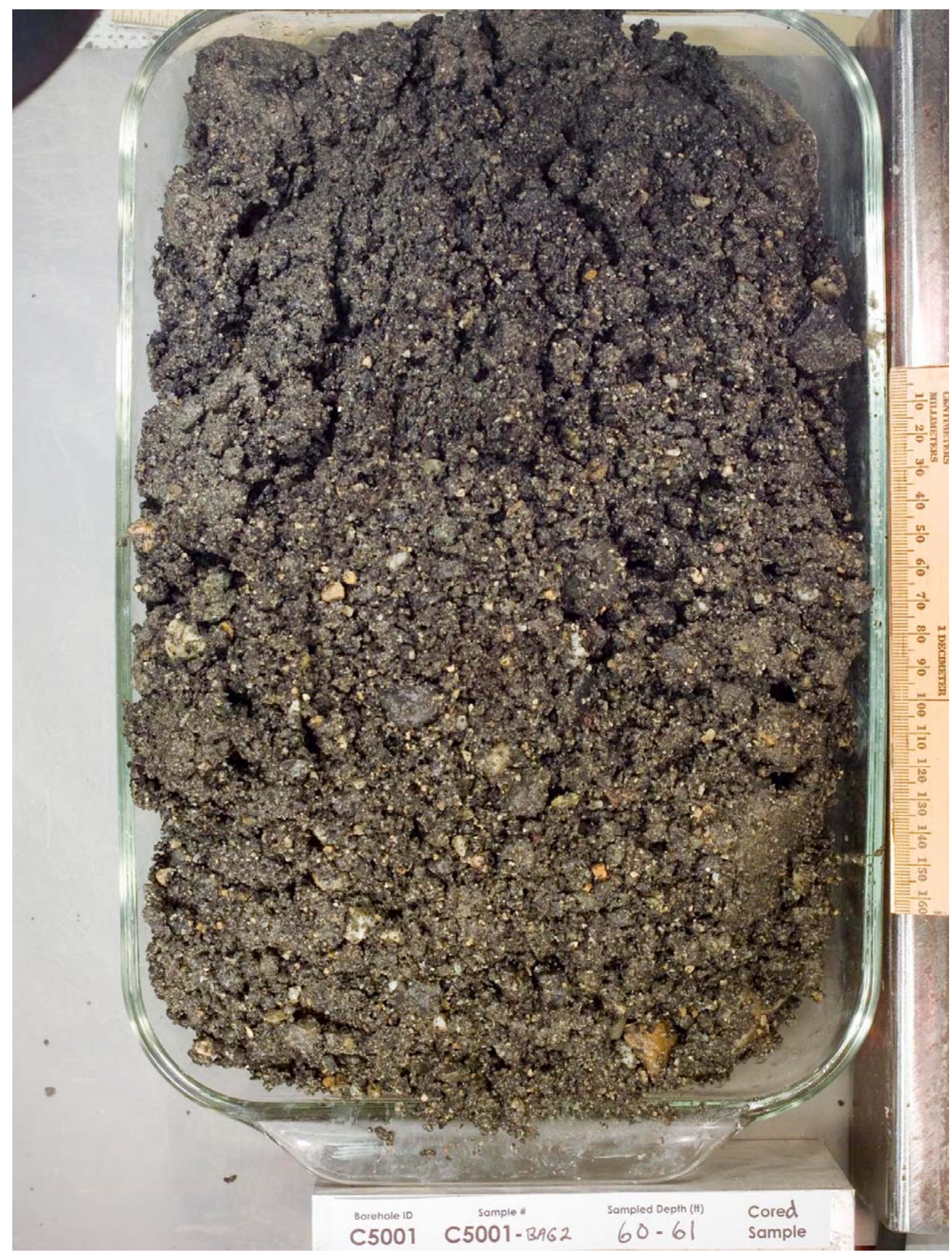




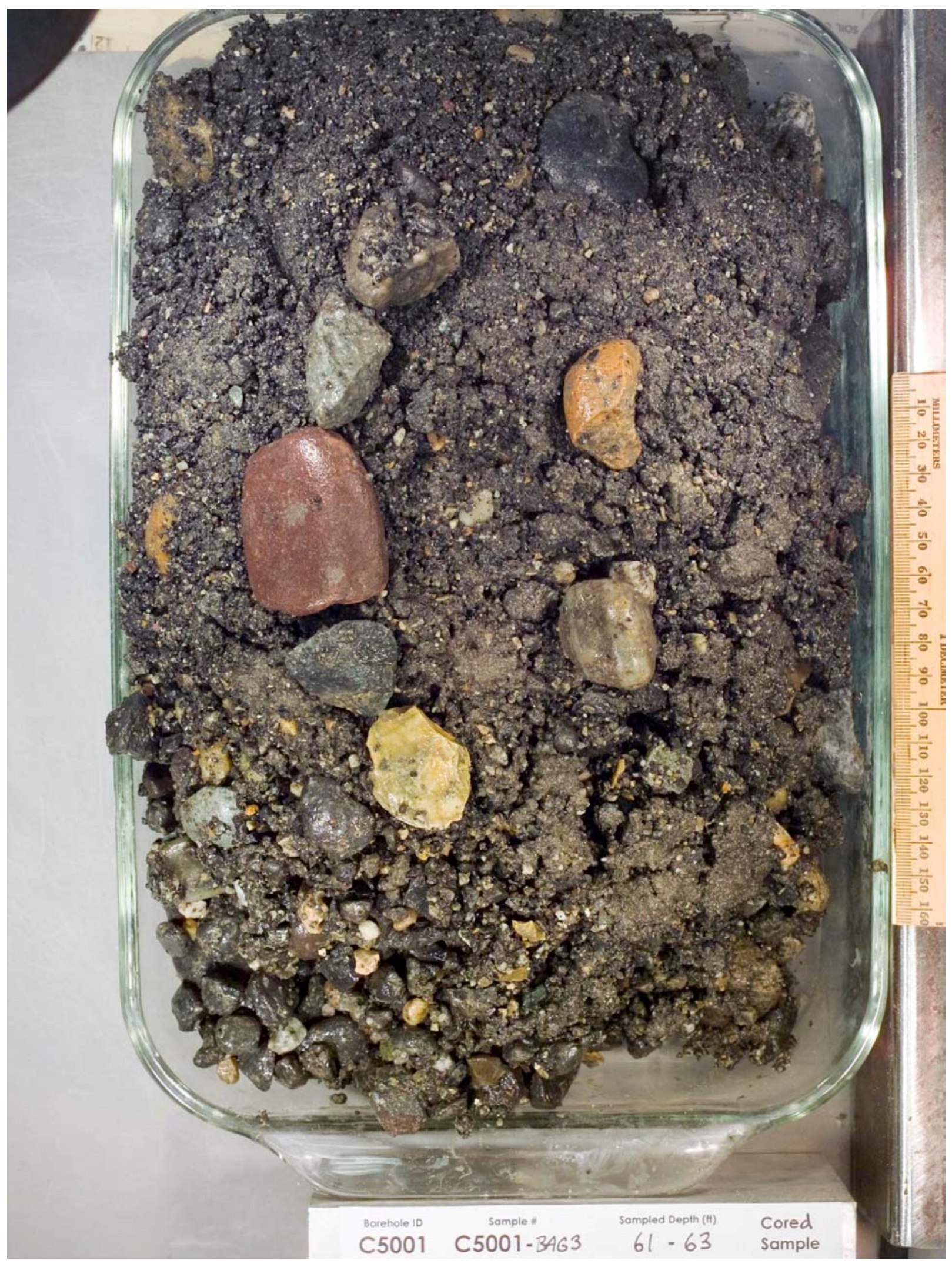




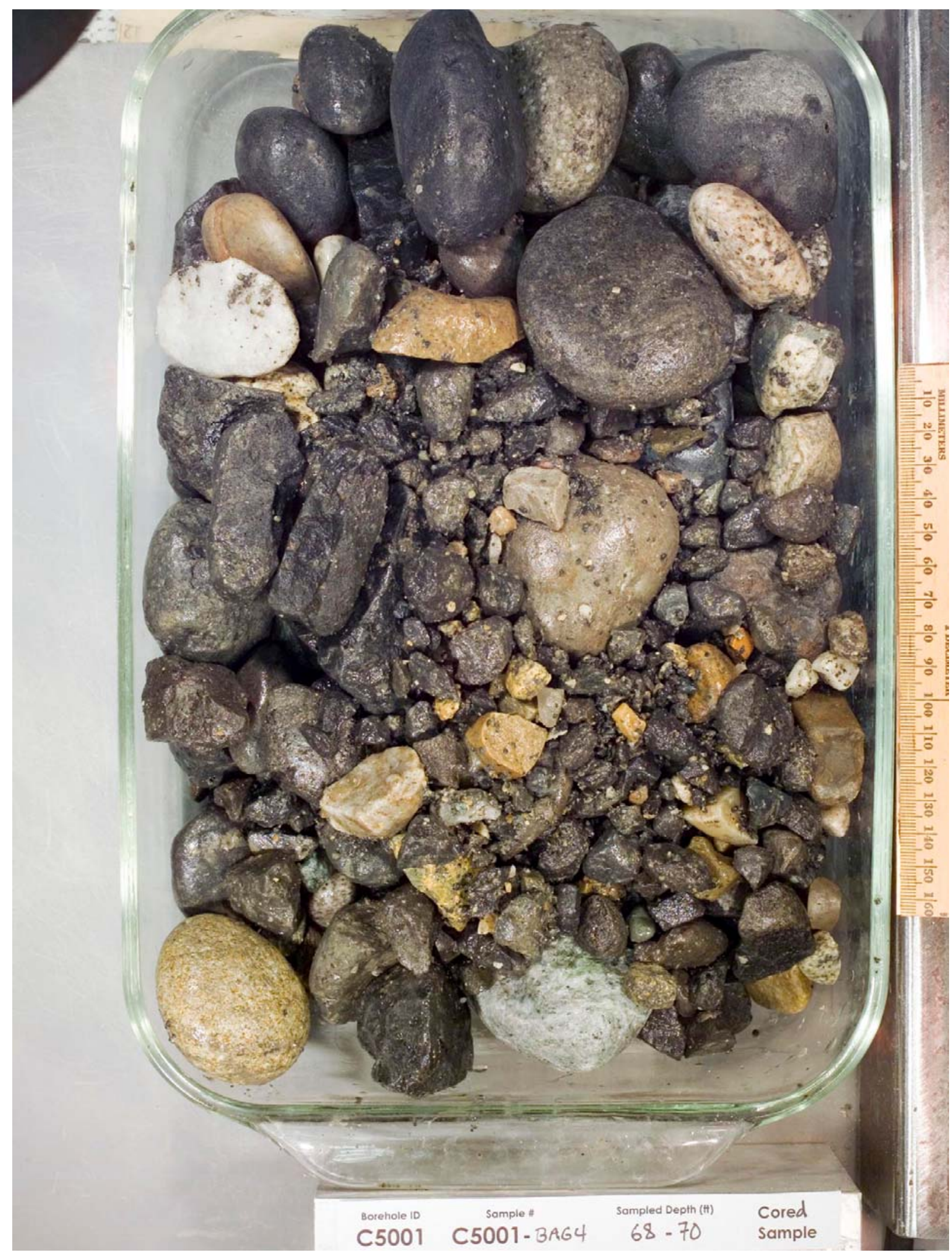




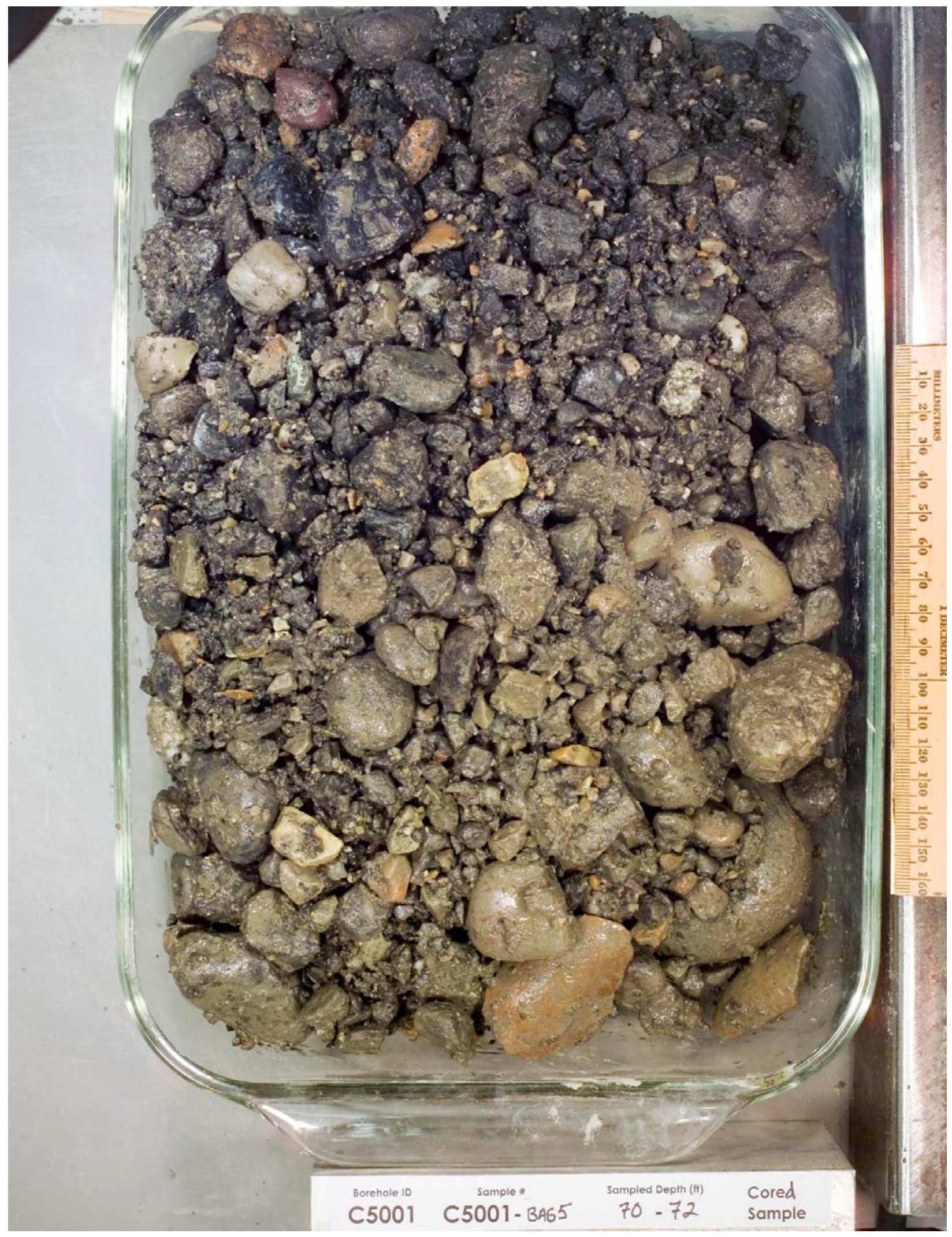




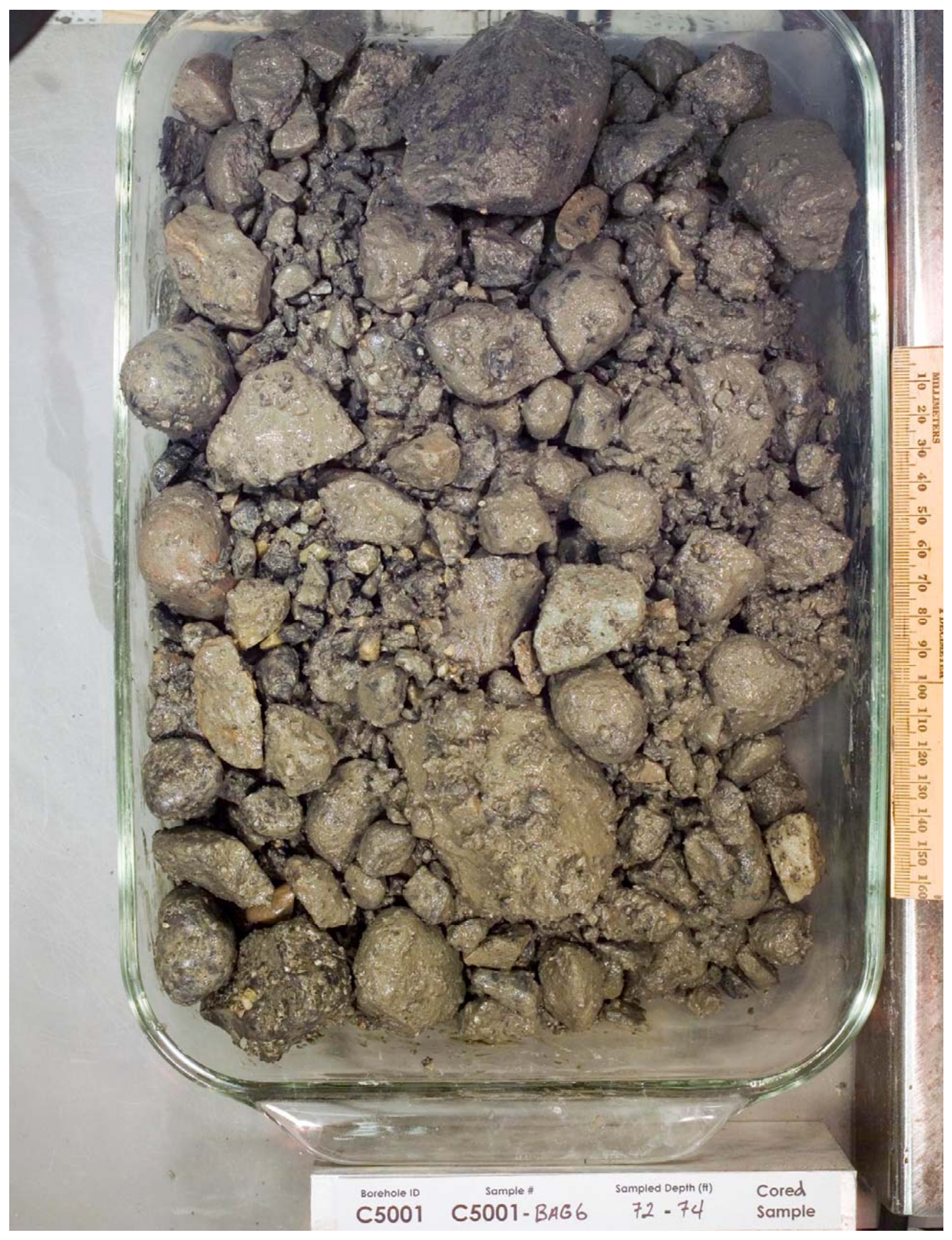




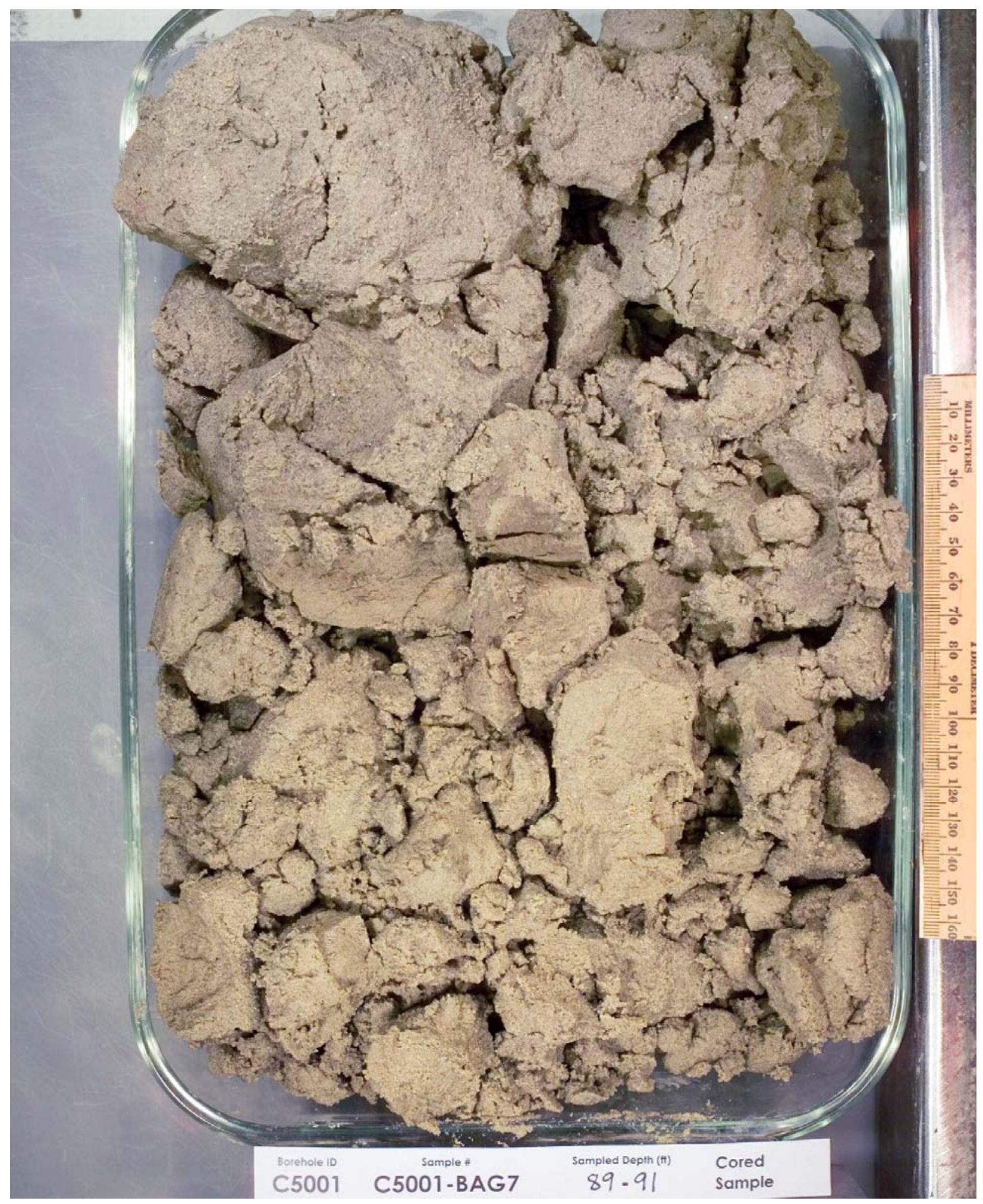




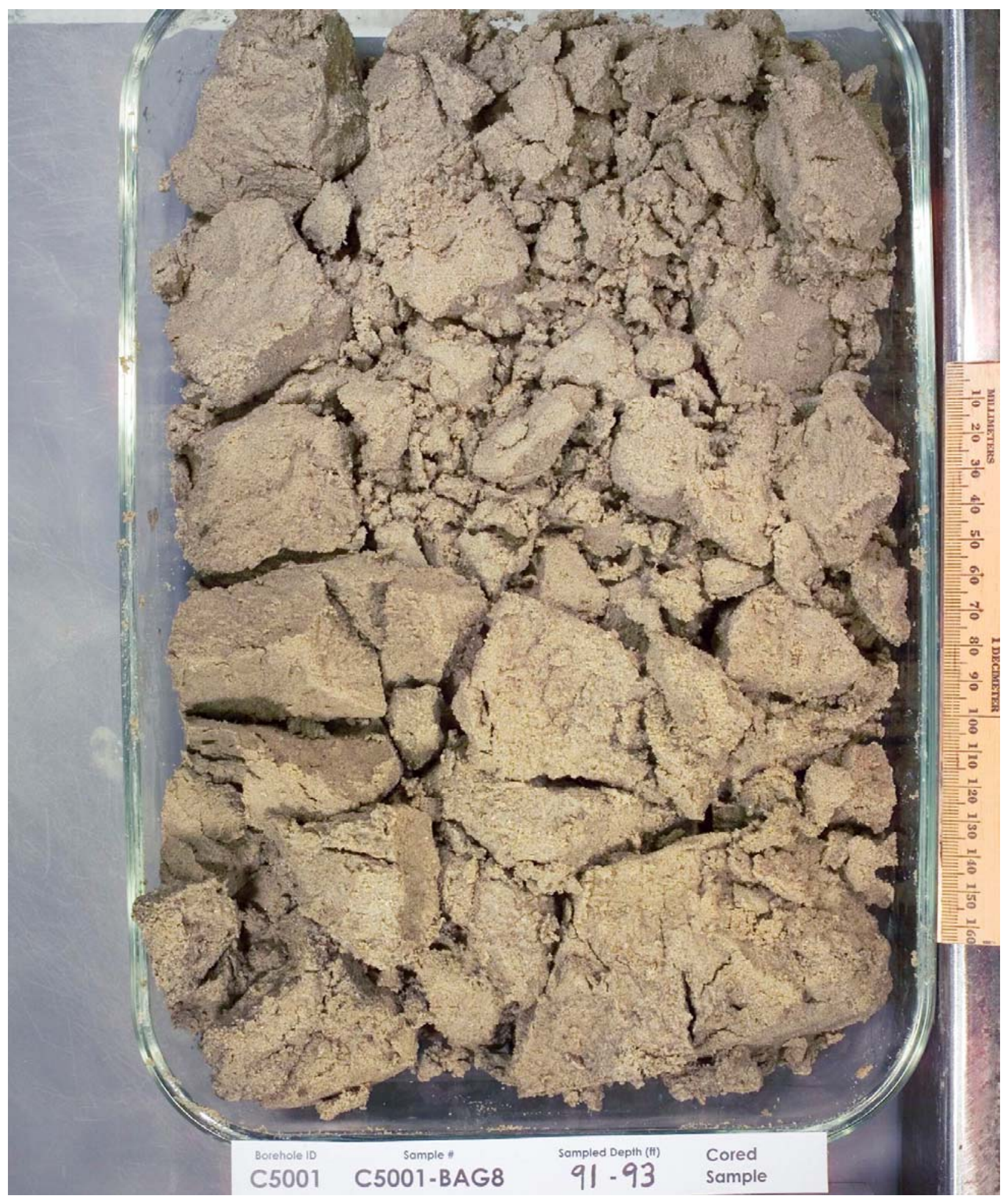




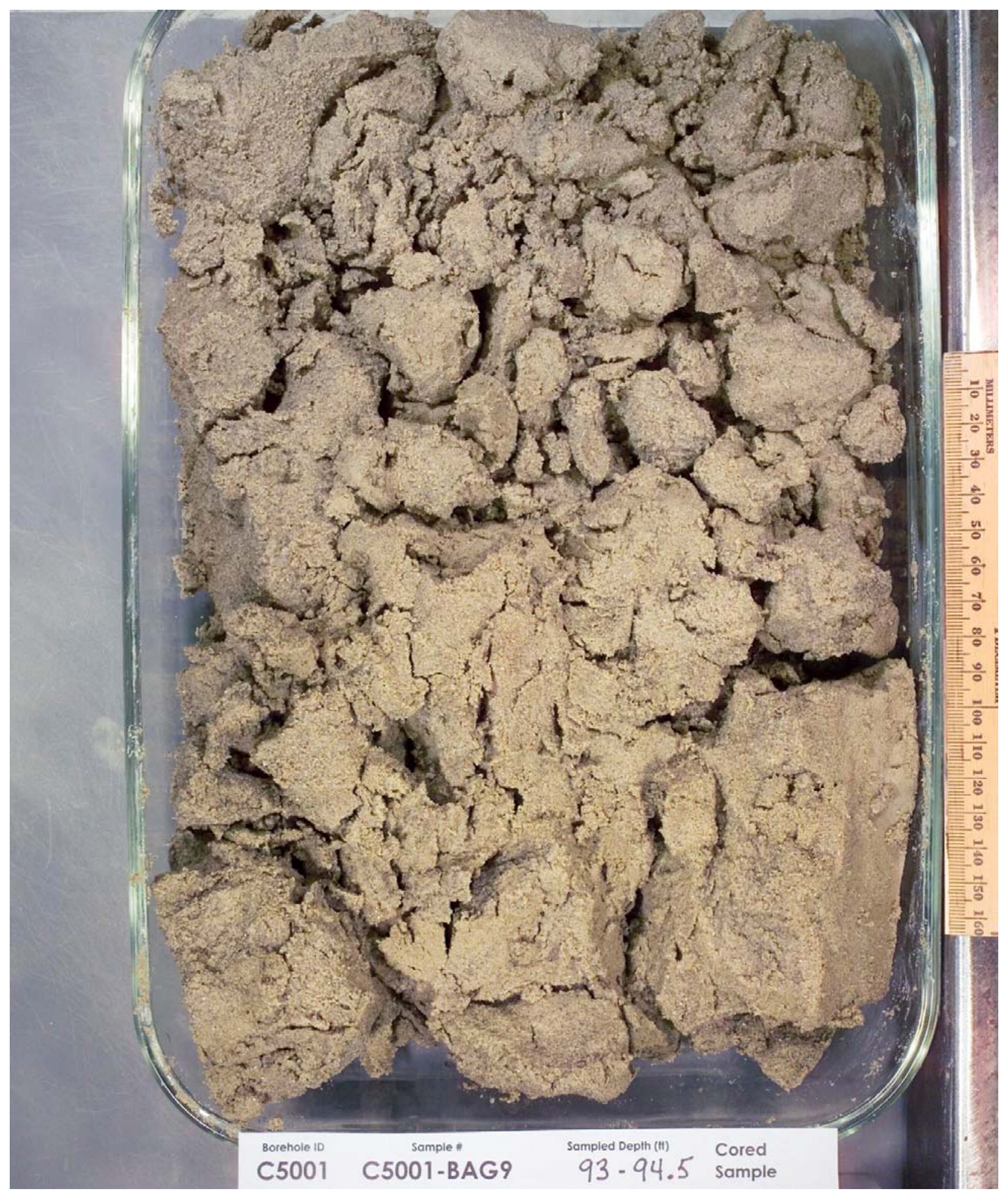




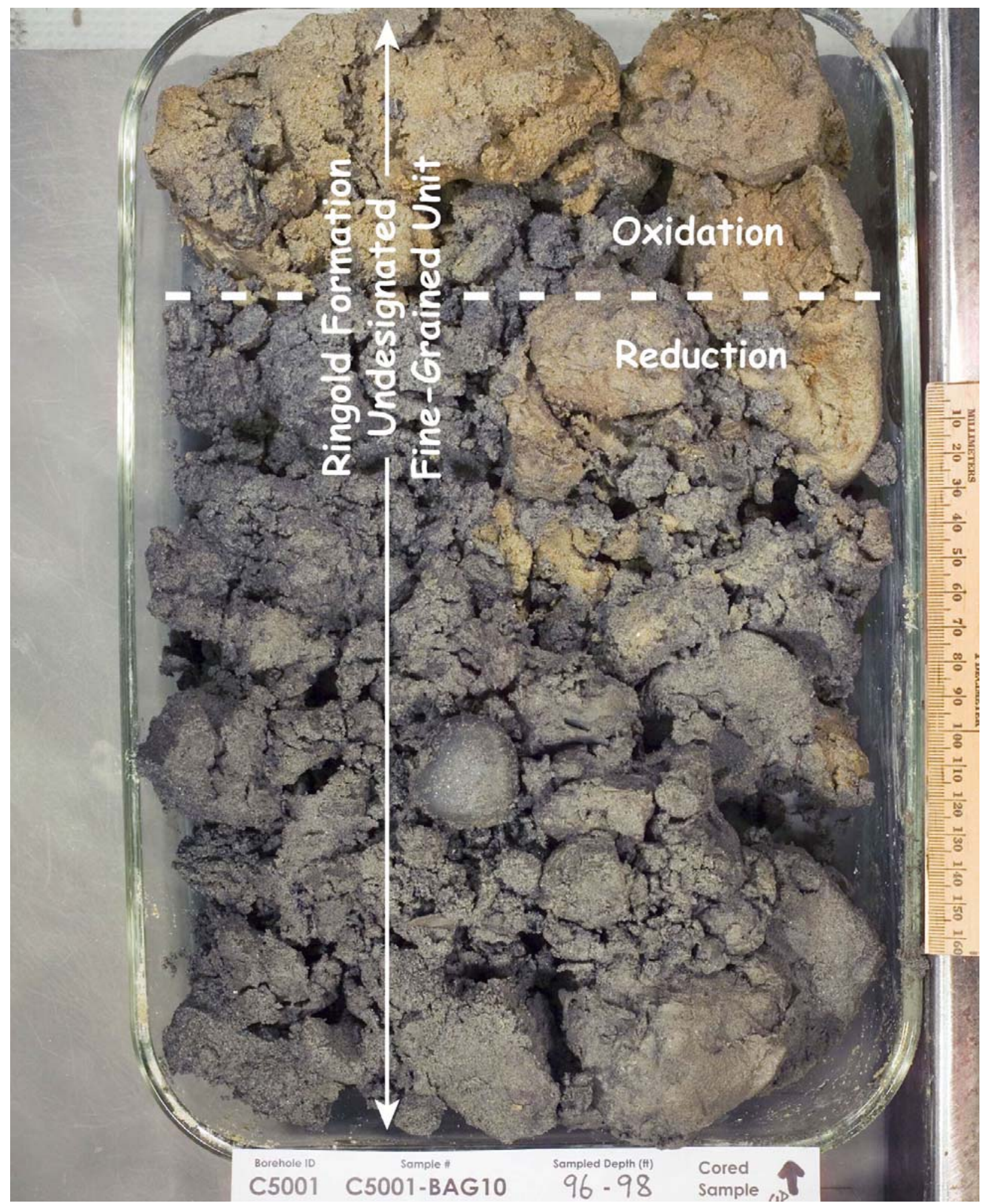




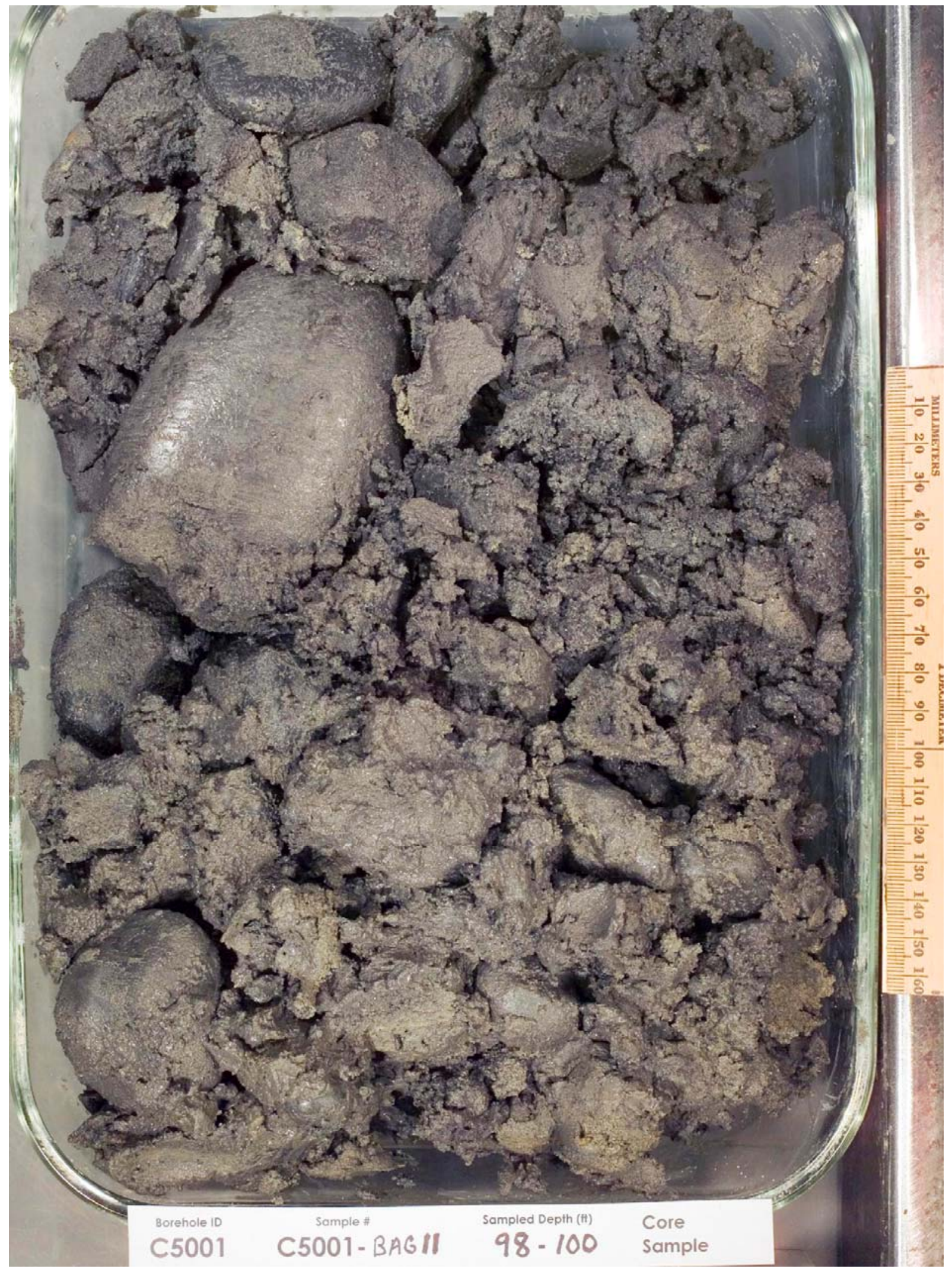




\section{Well C5002}

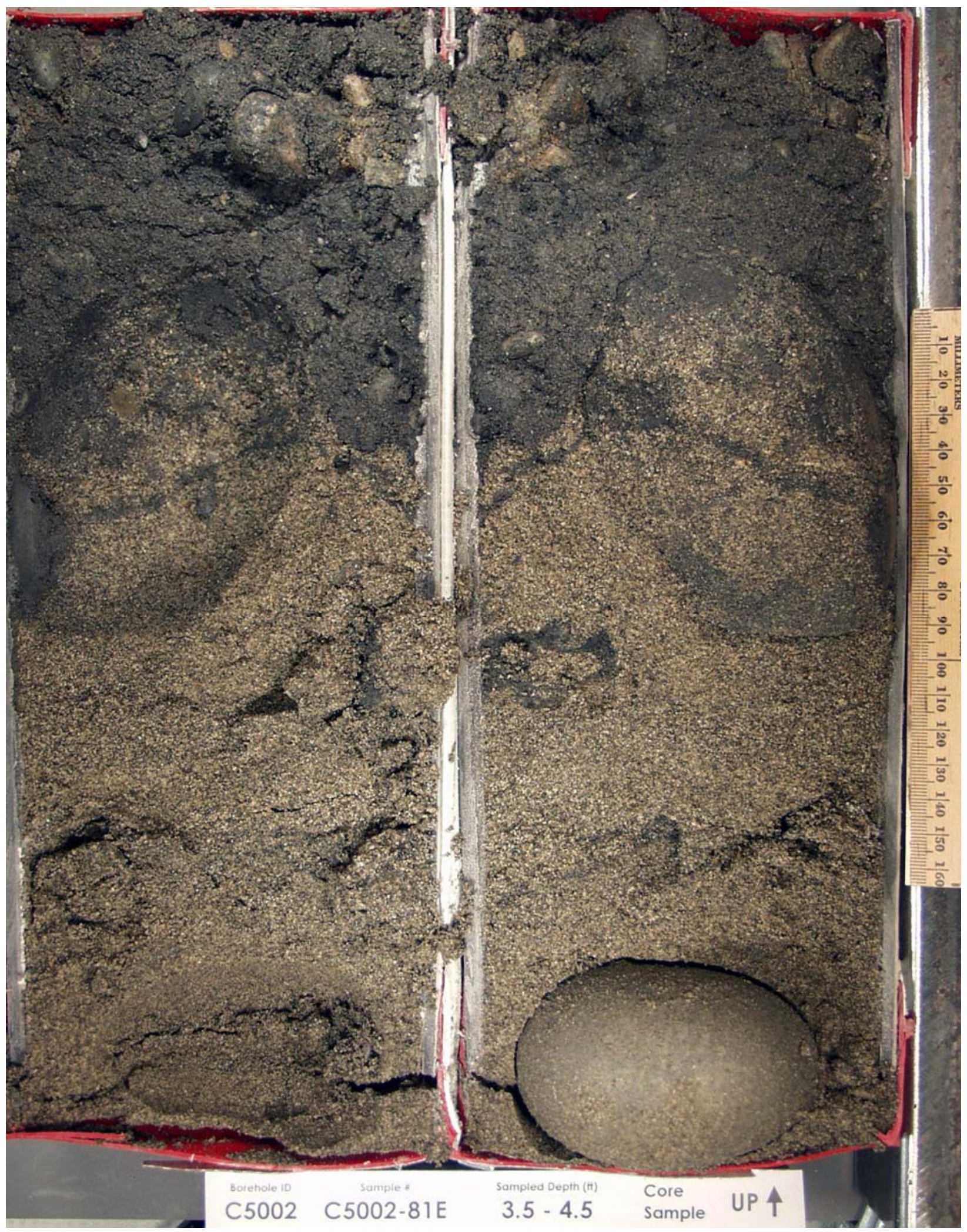




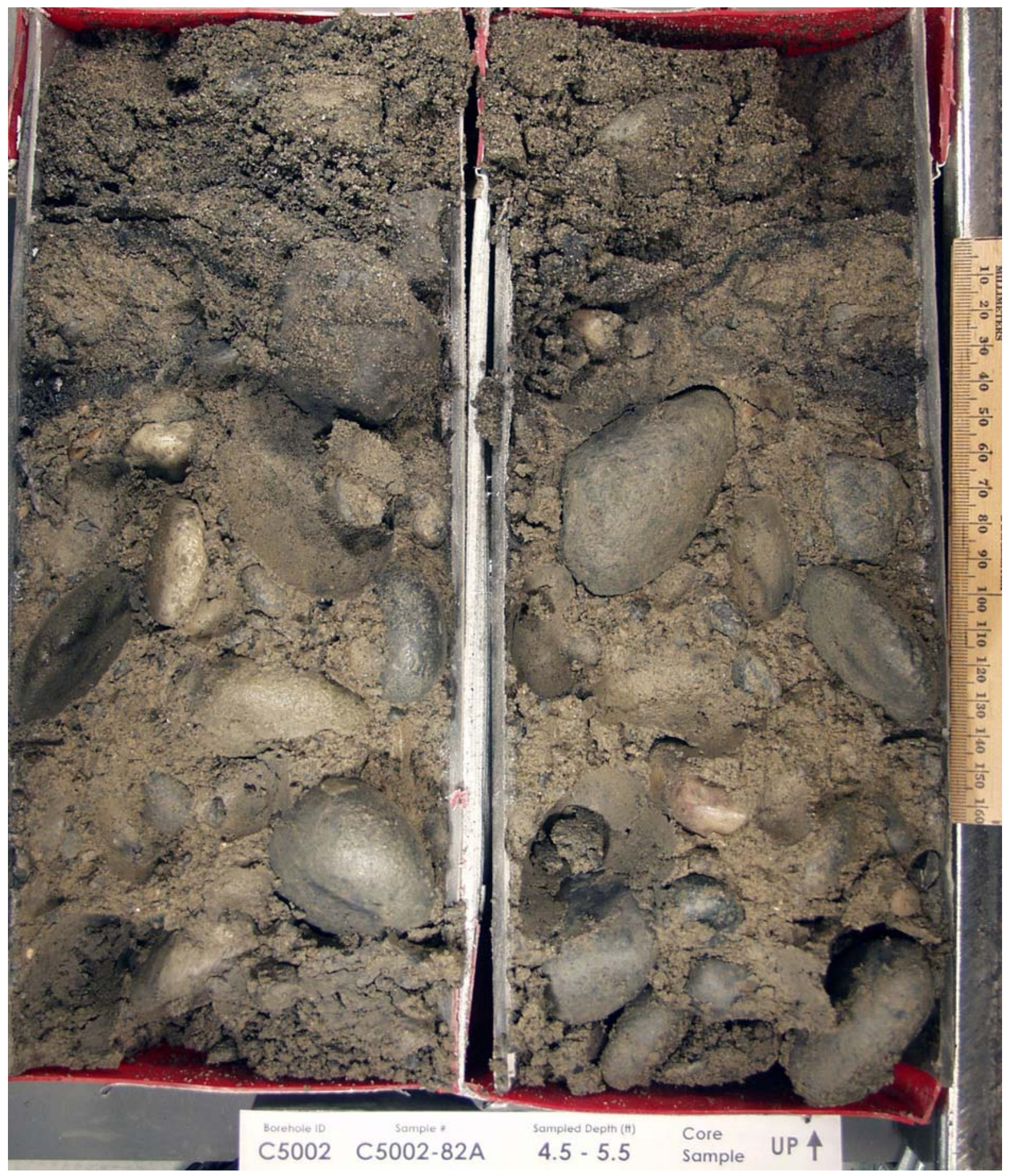




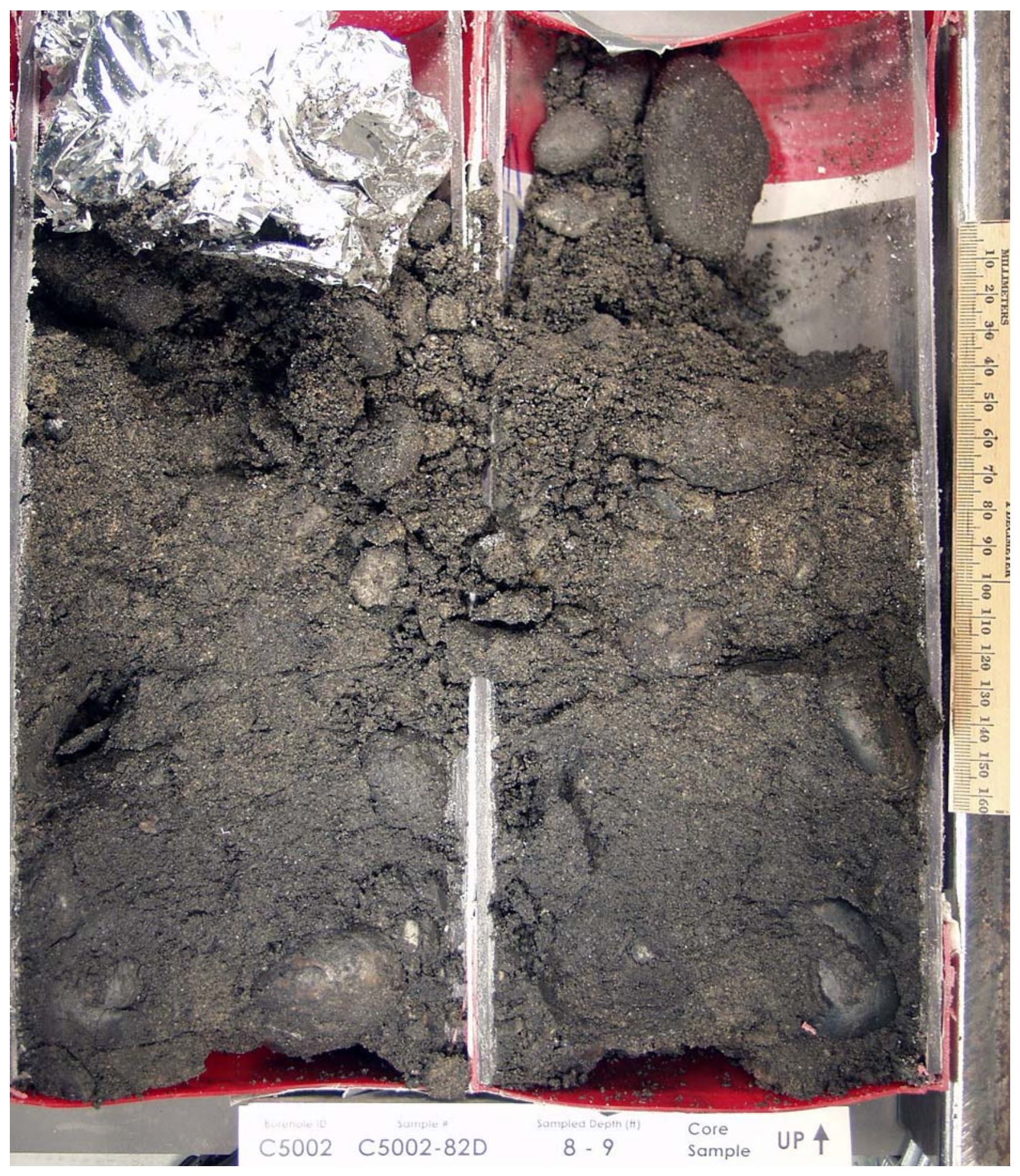




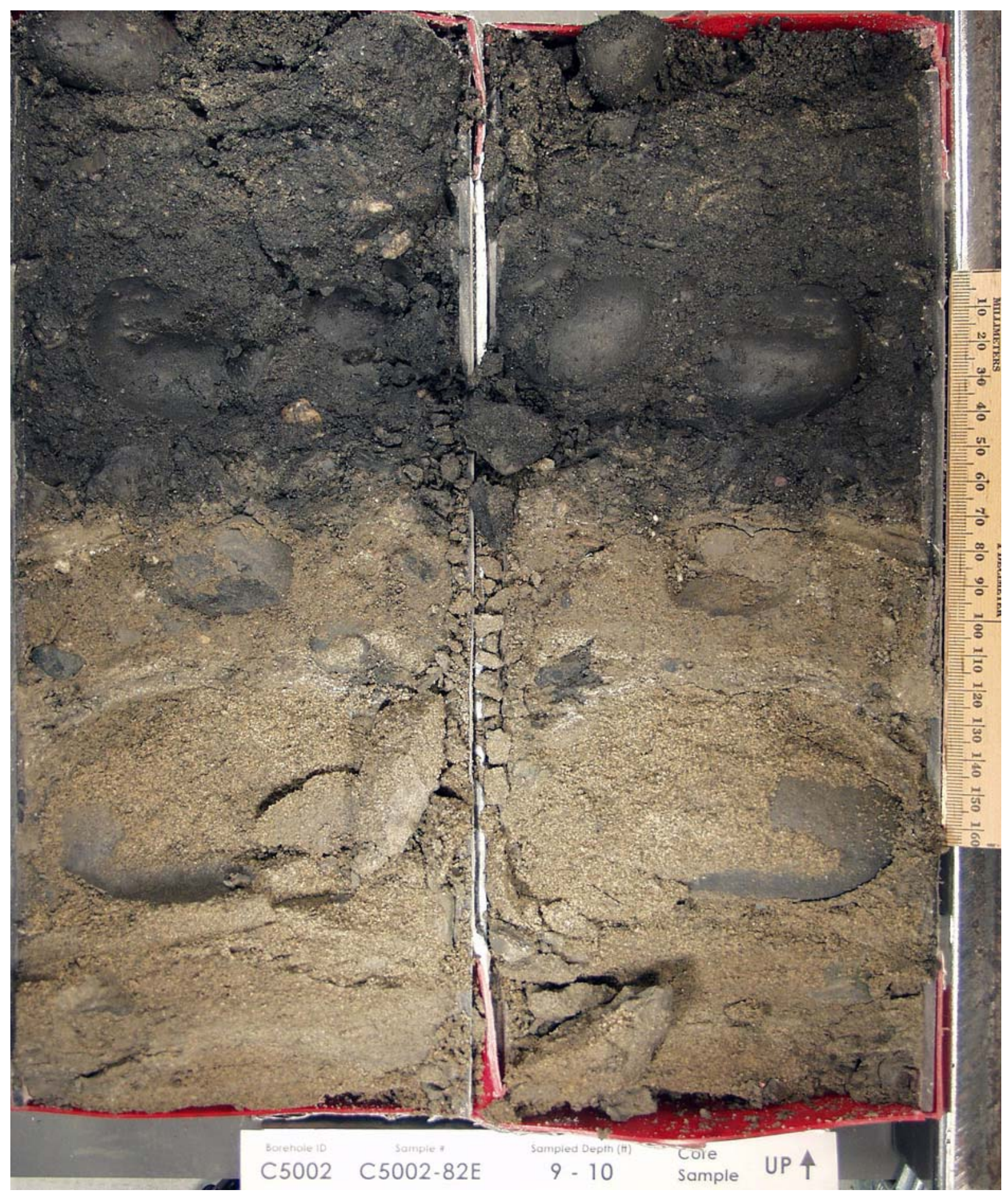




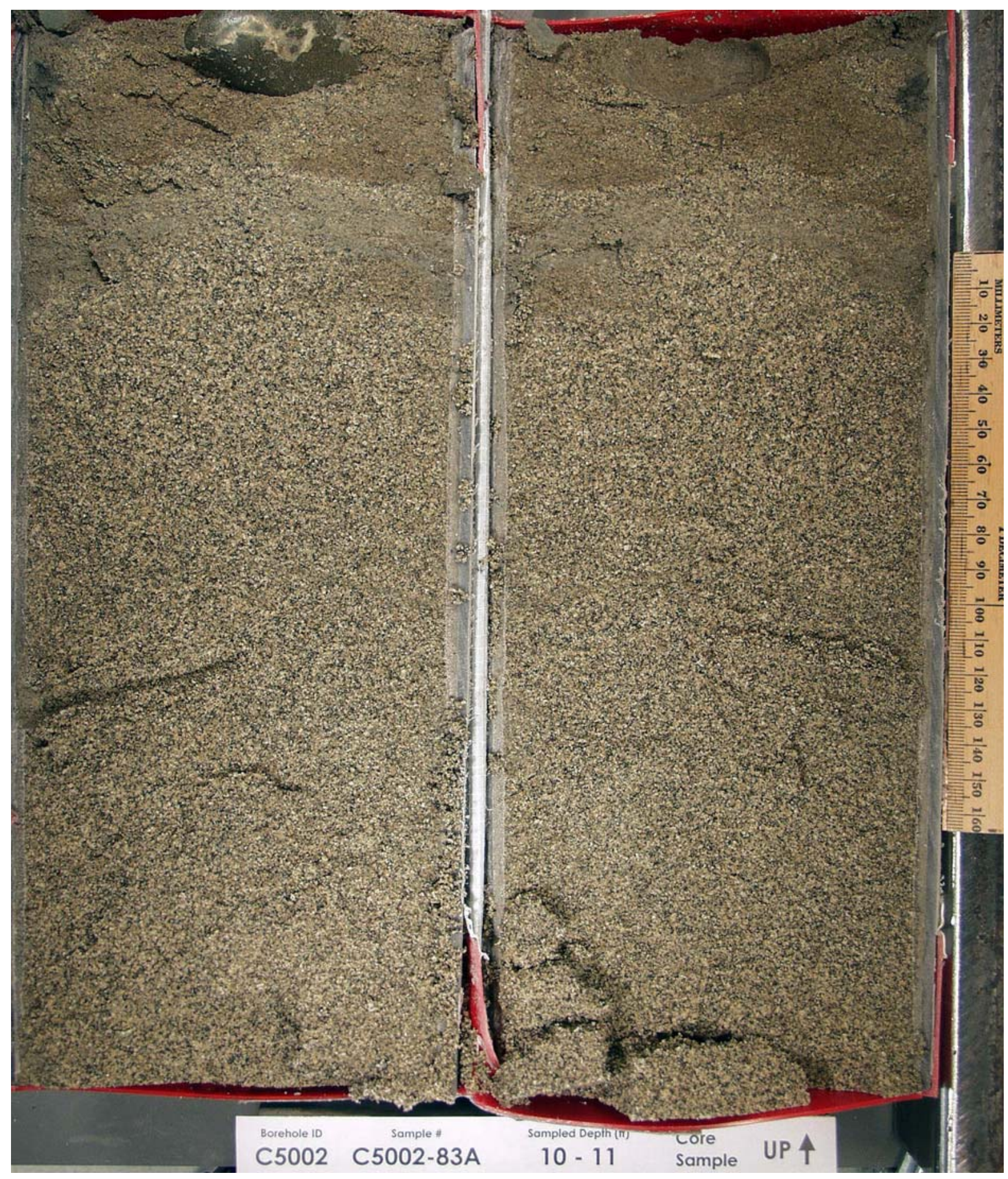




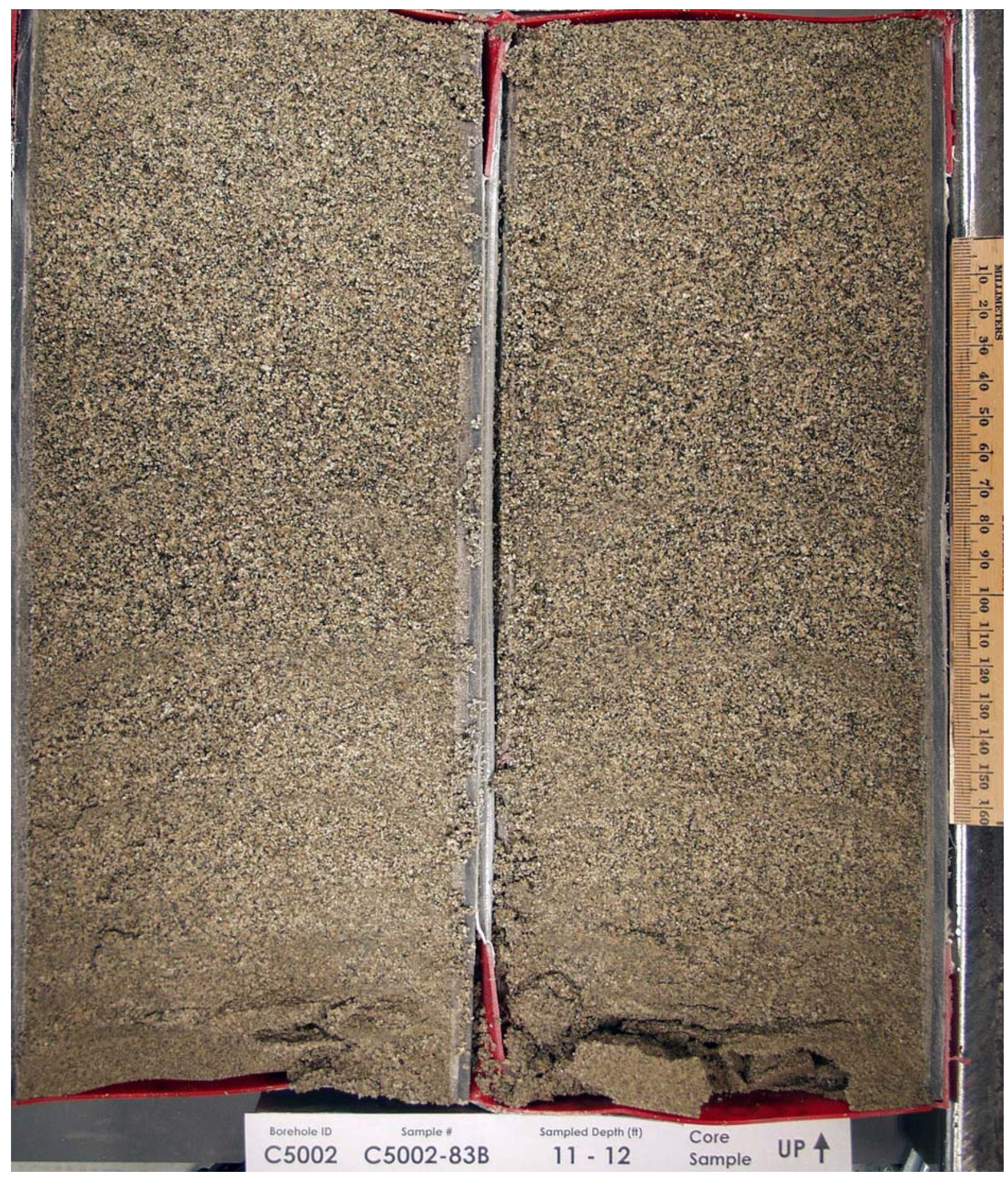




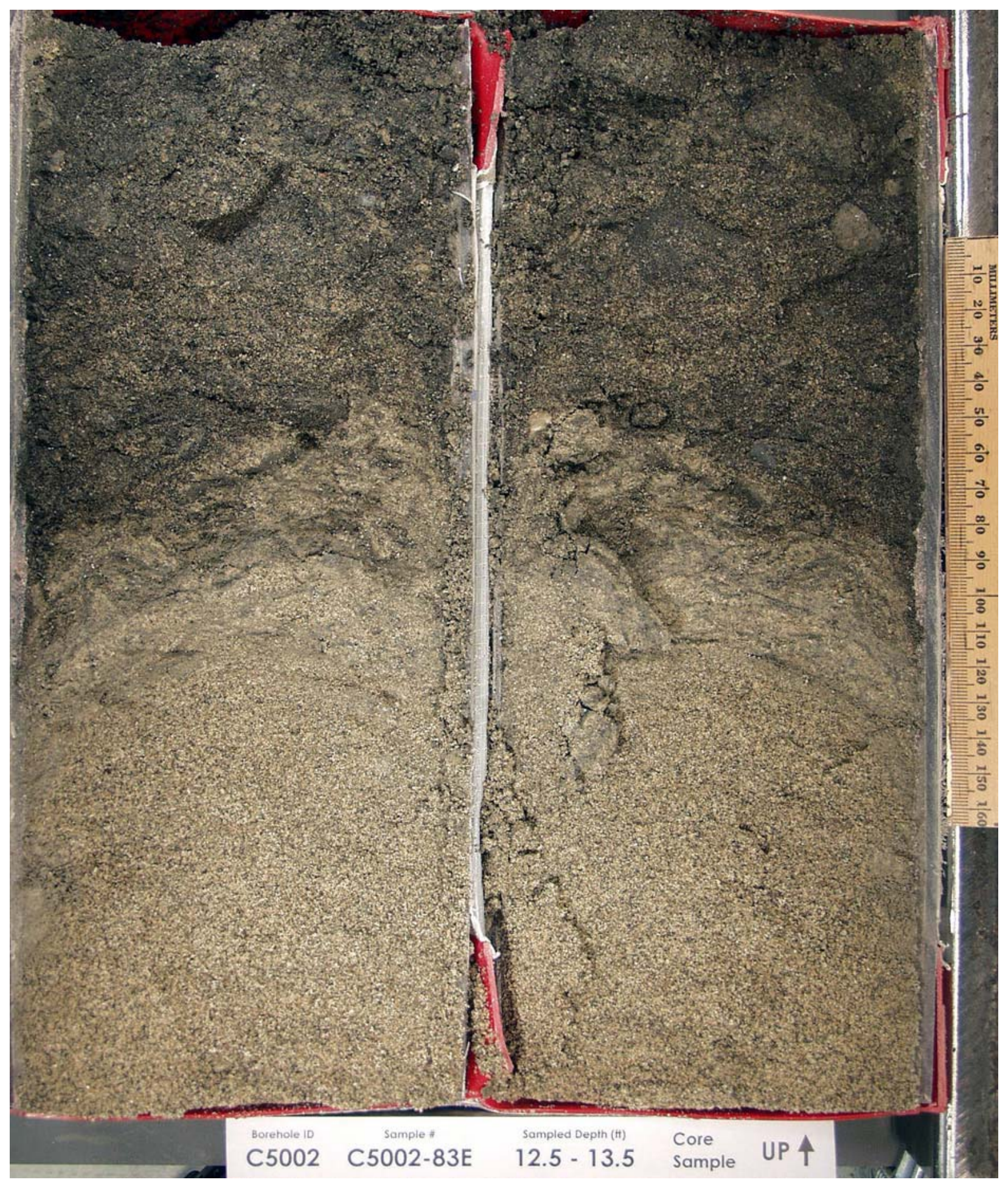




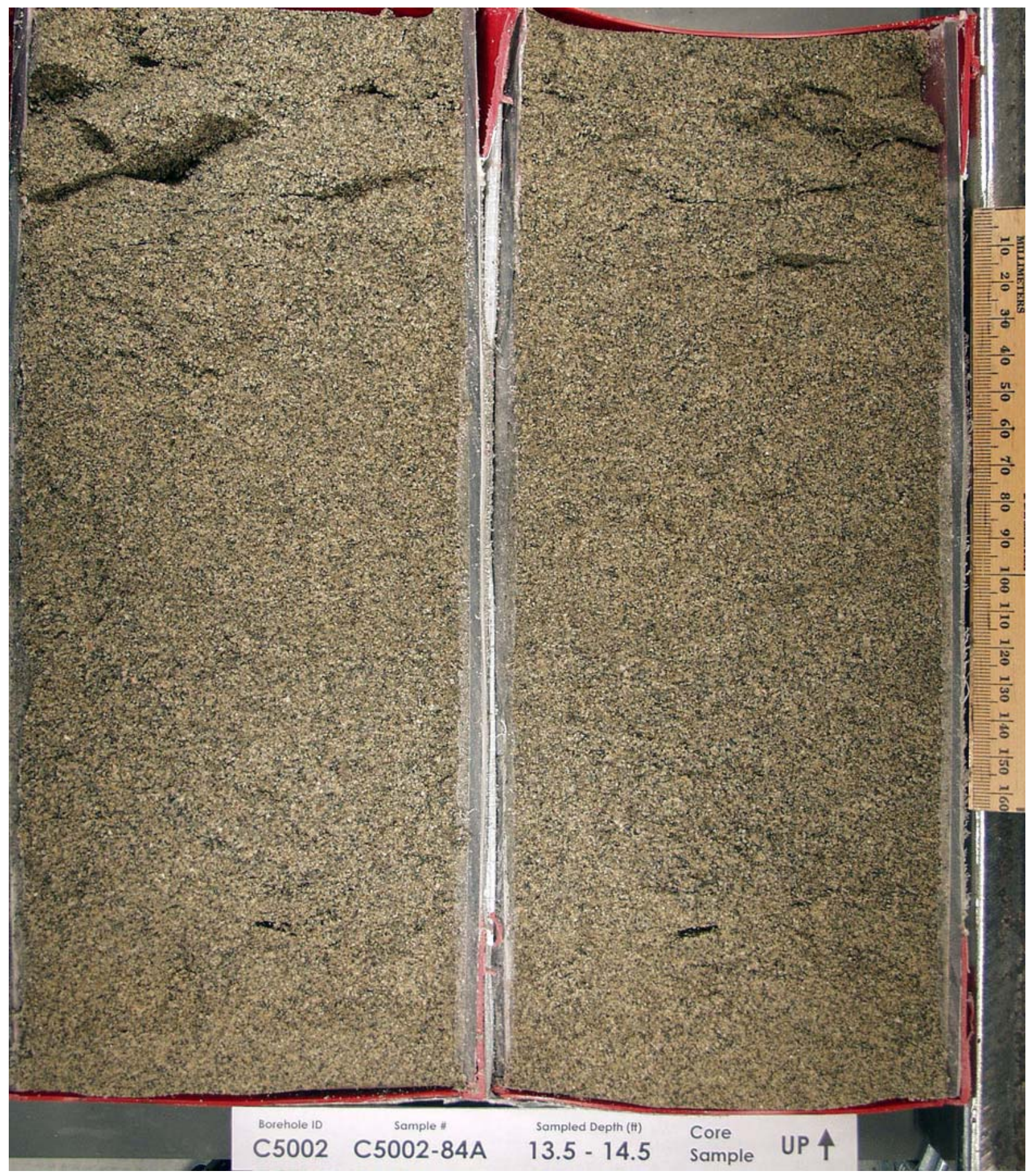




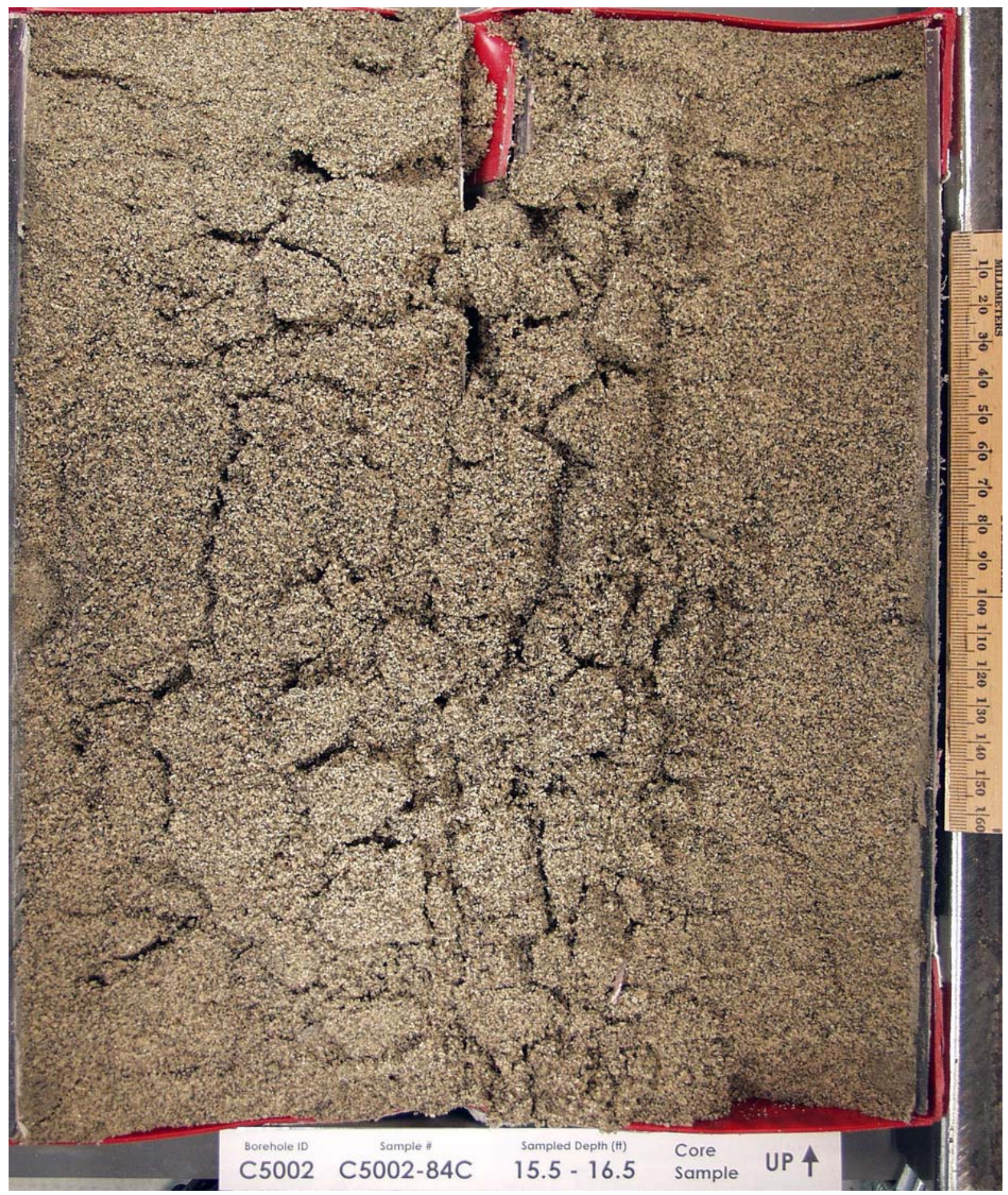




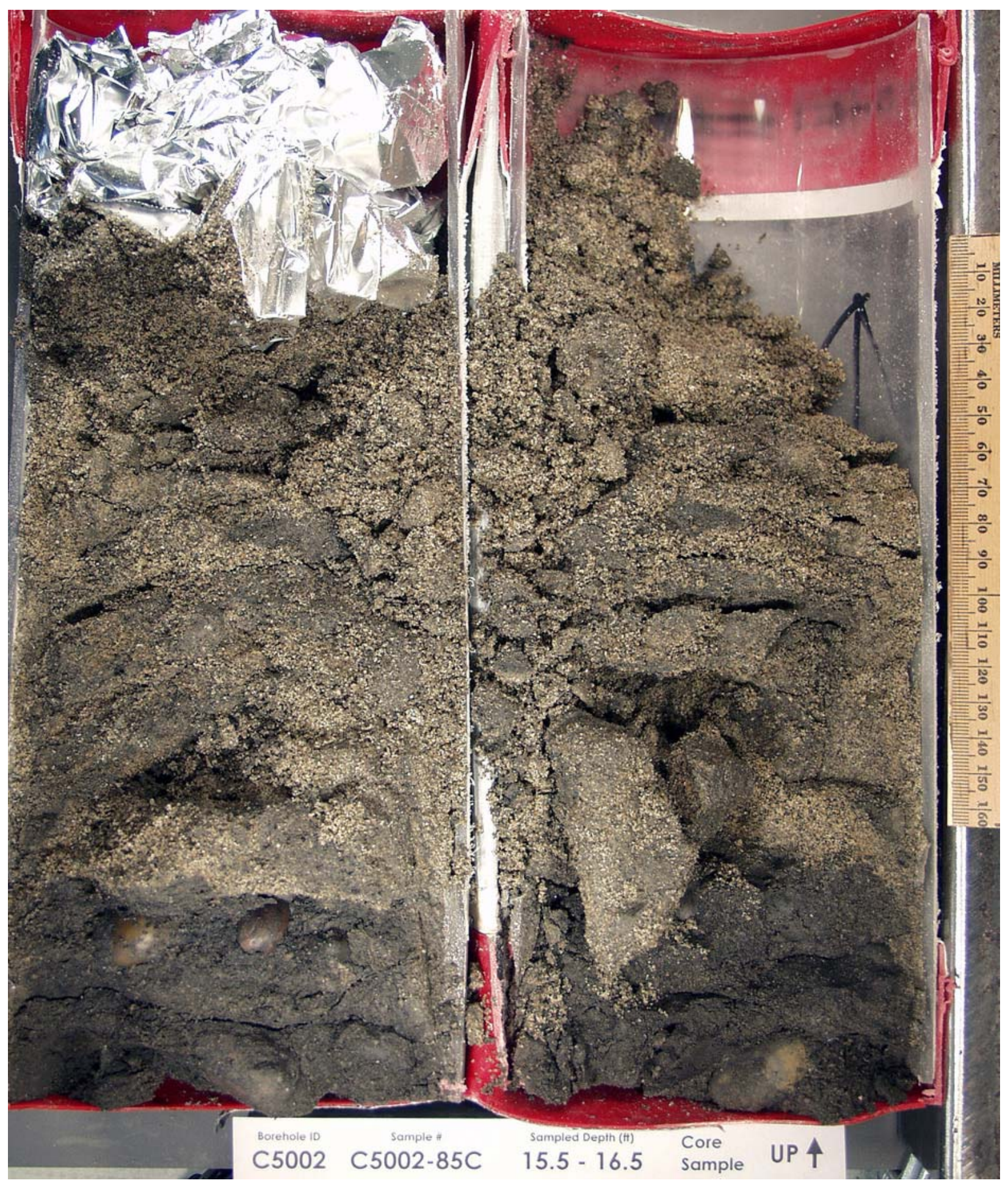




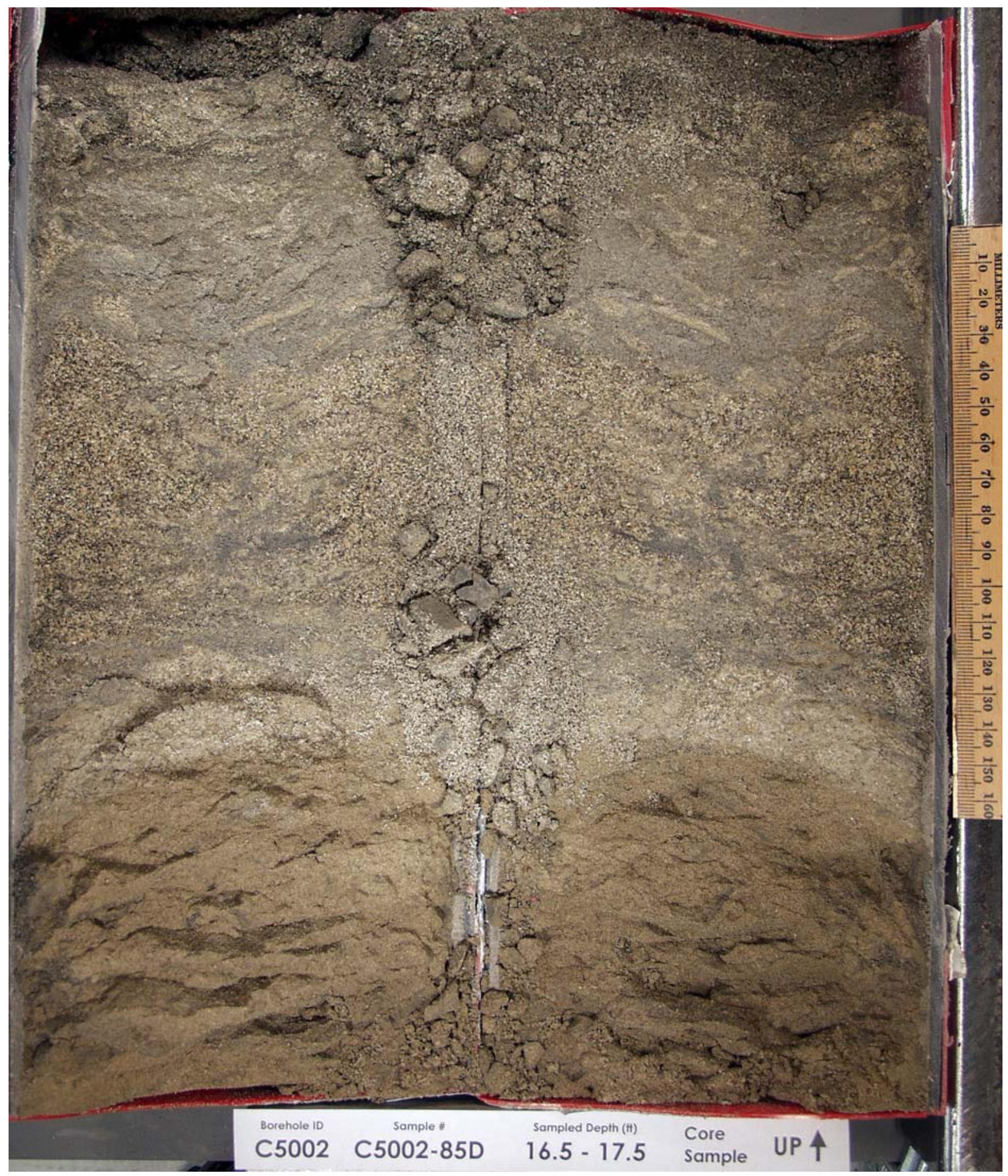




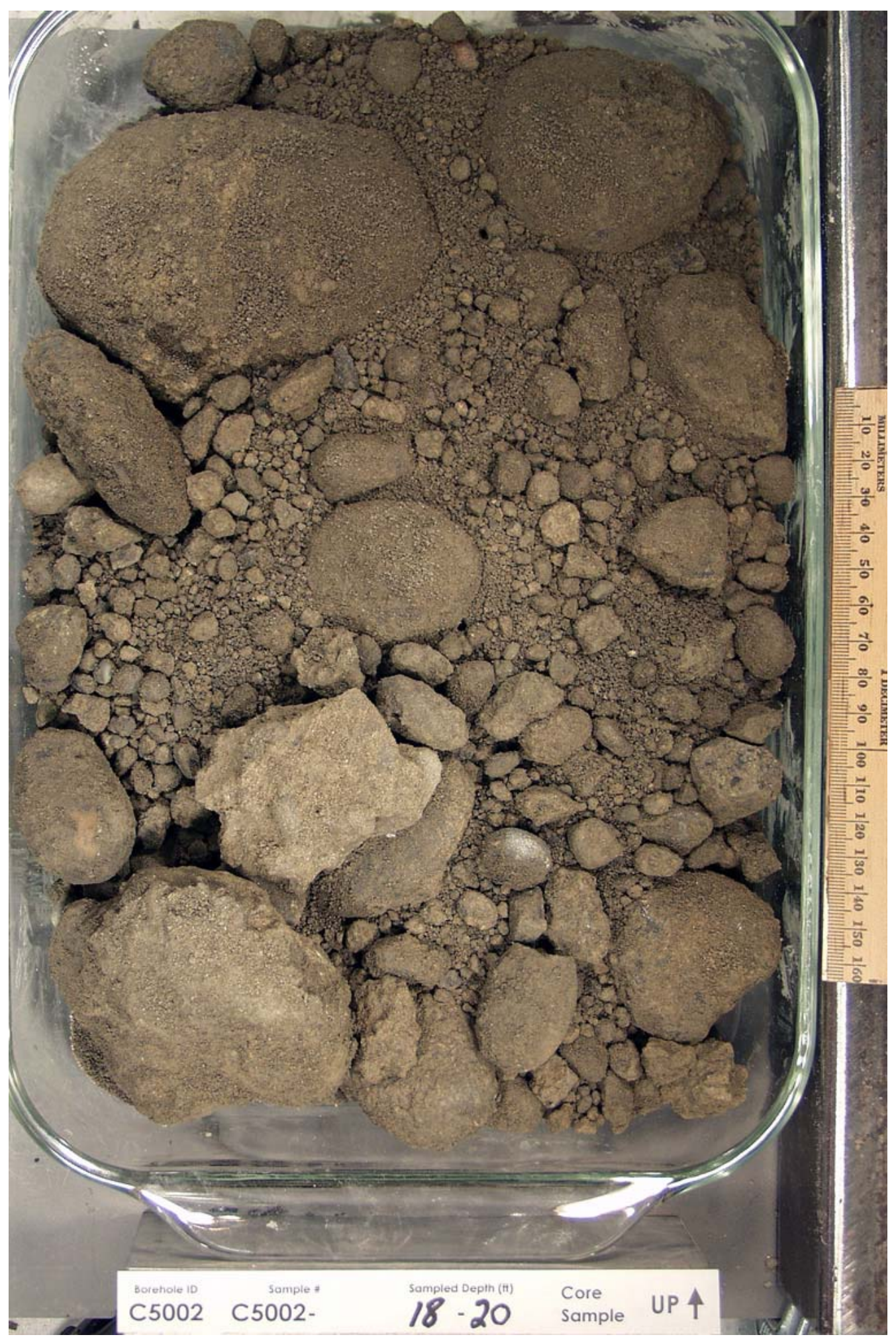

B.316 


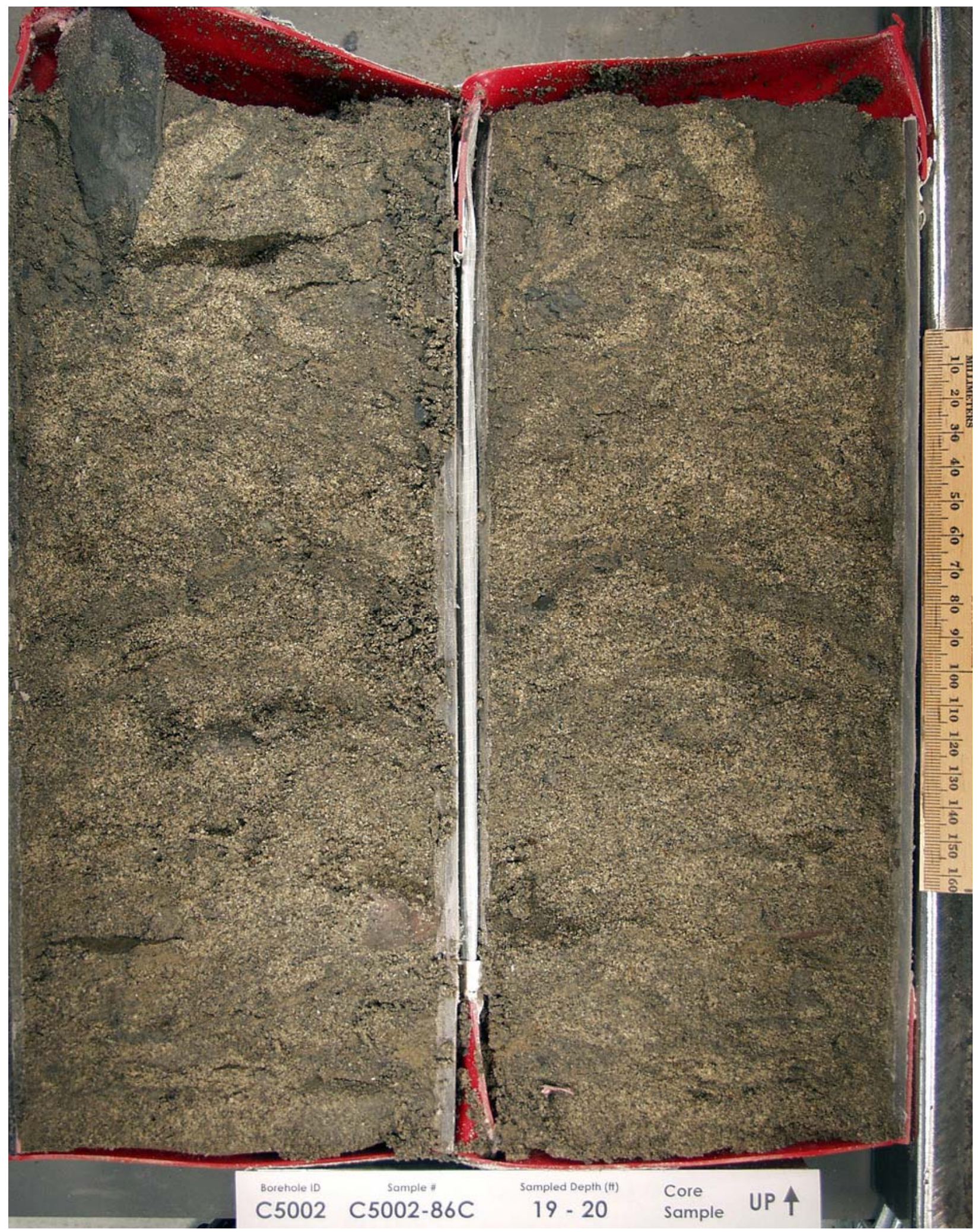




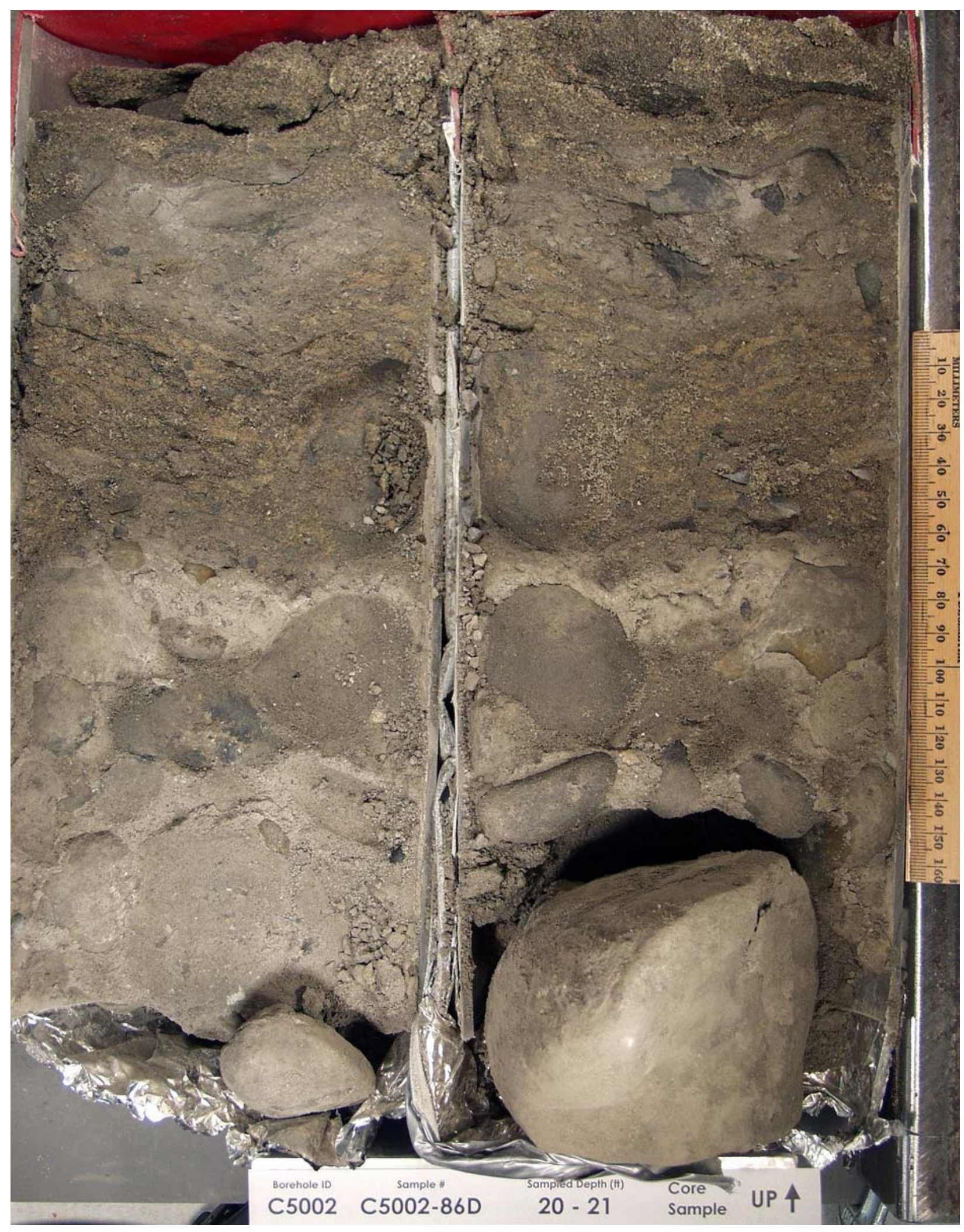




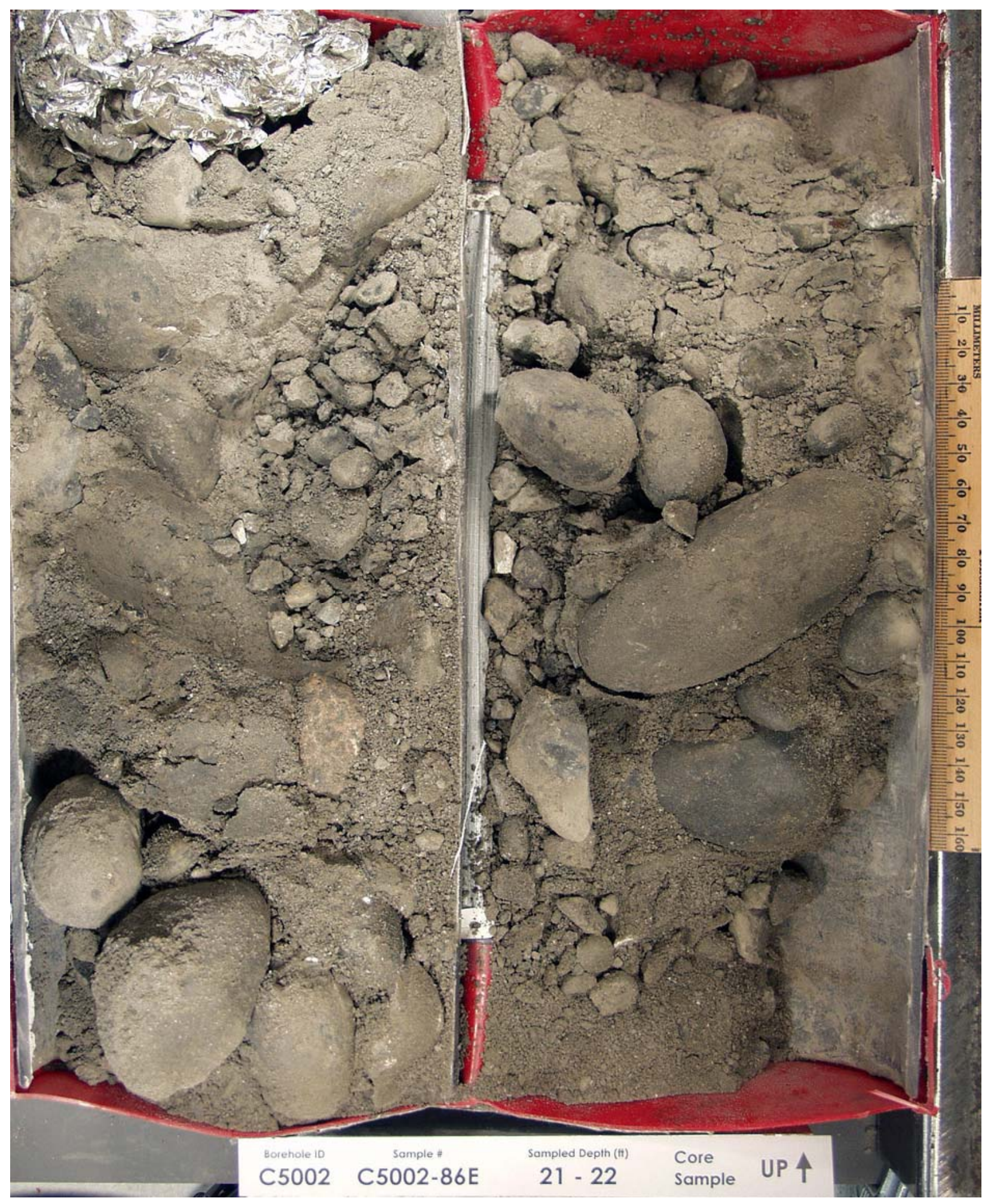




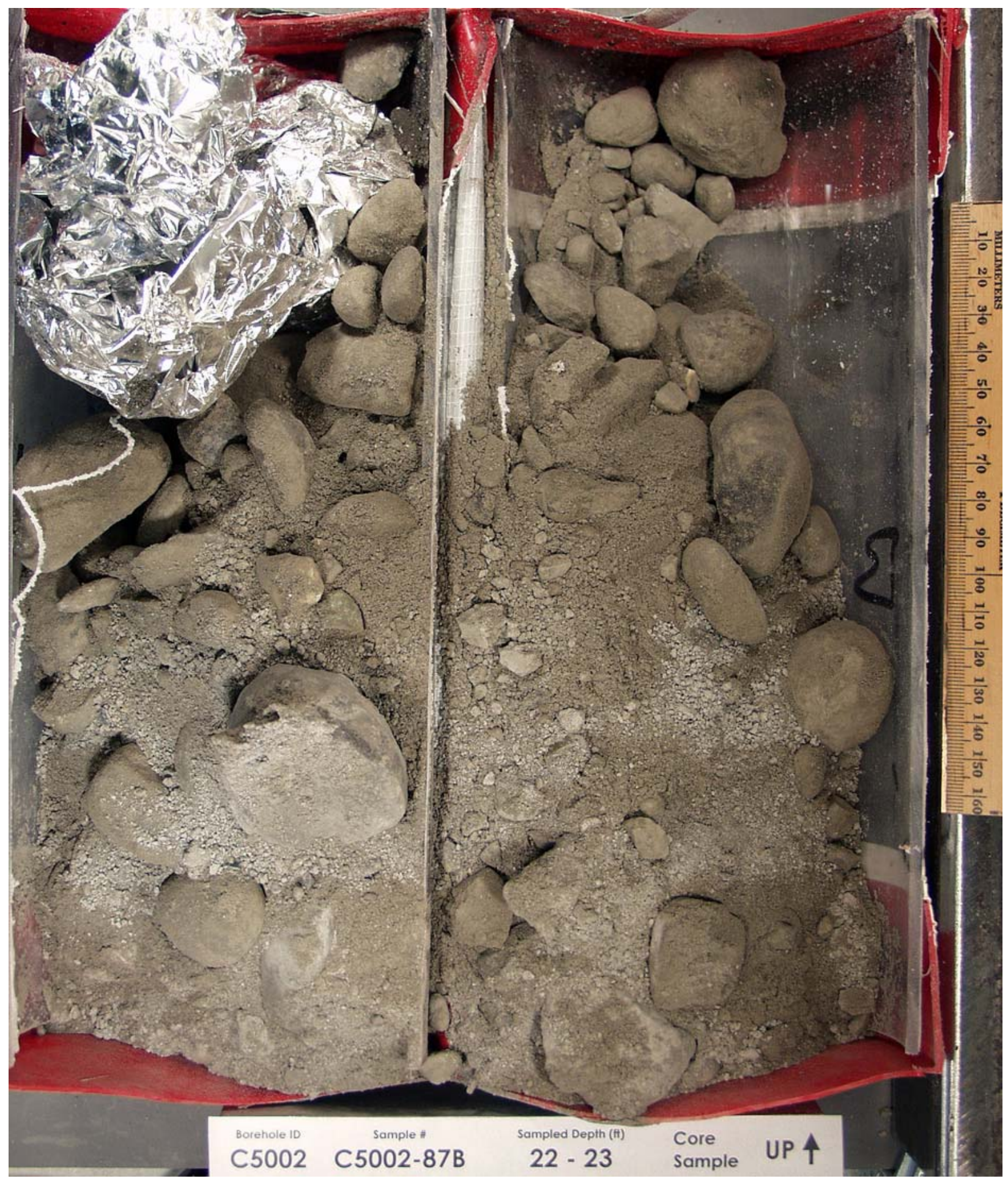




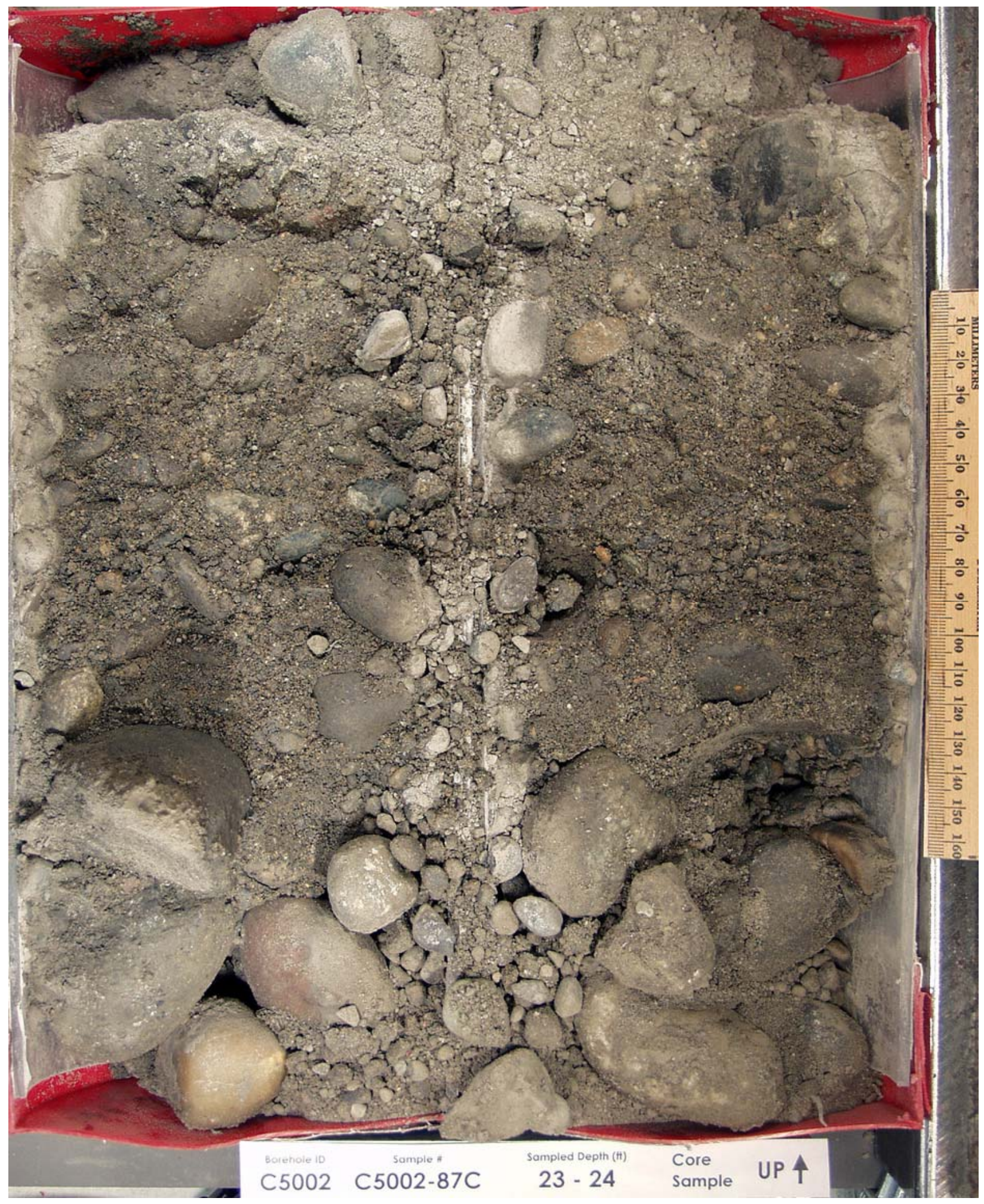




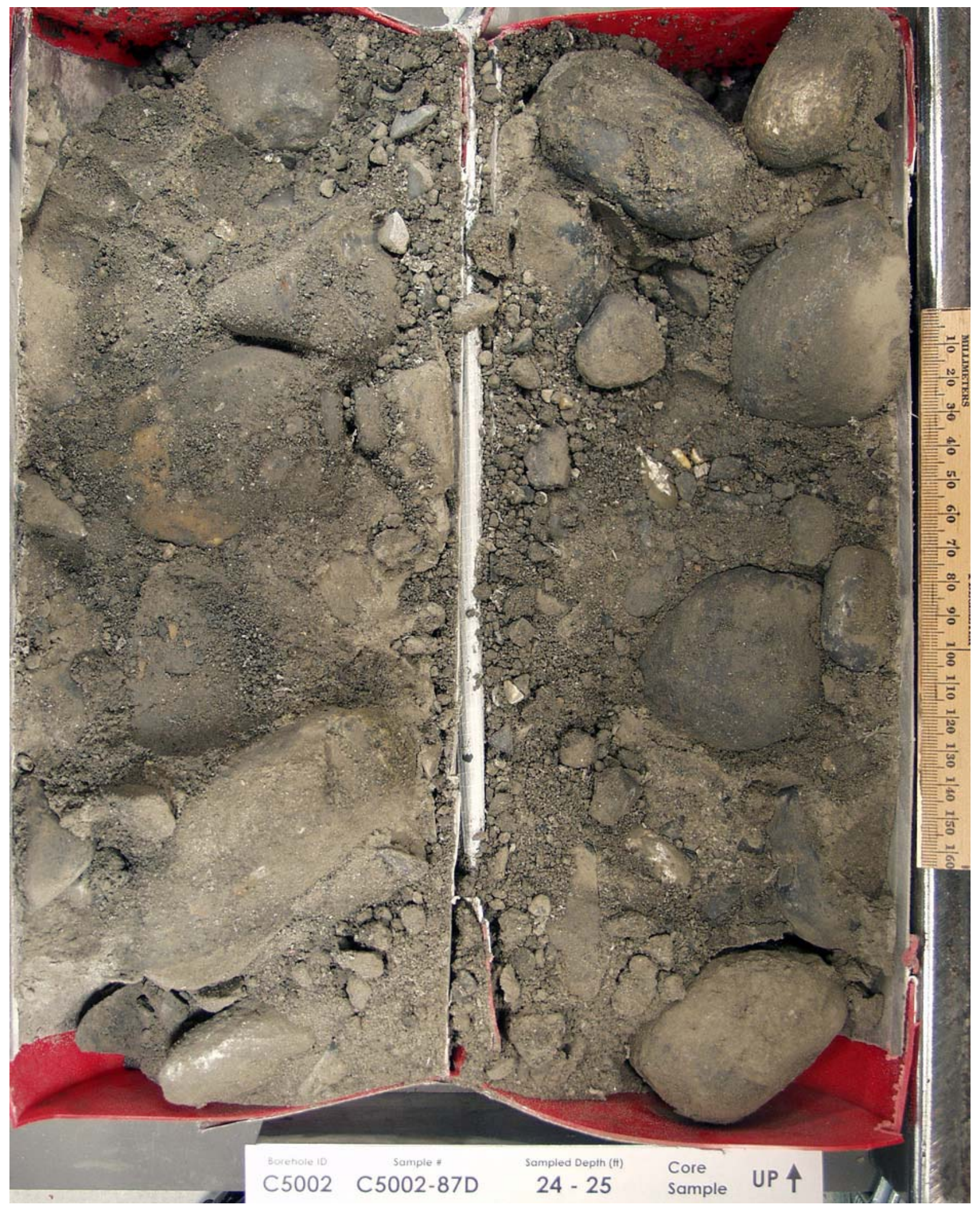




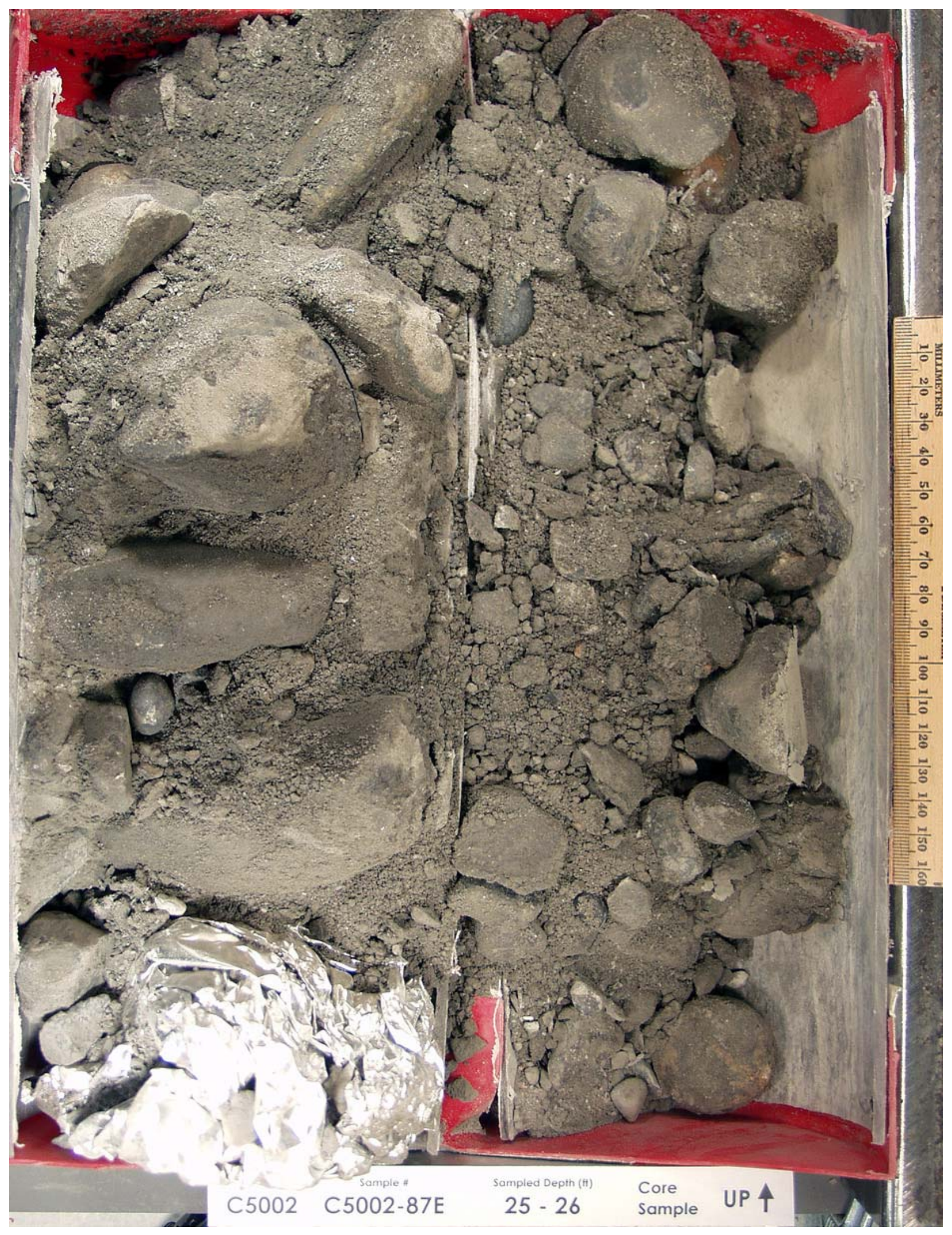




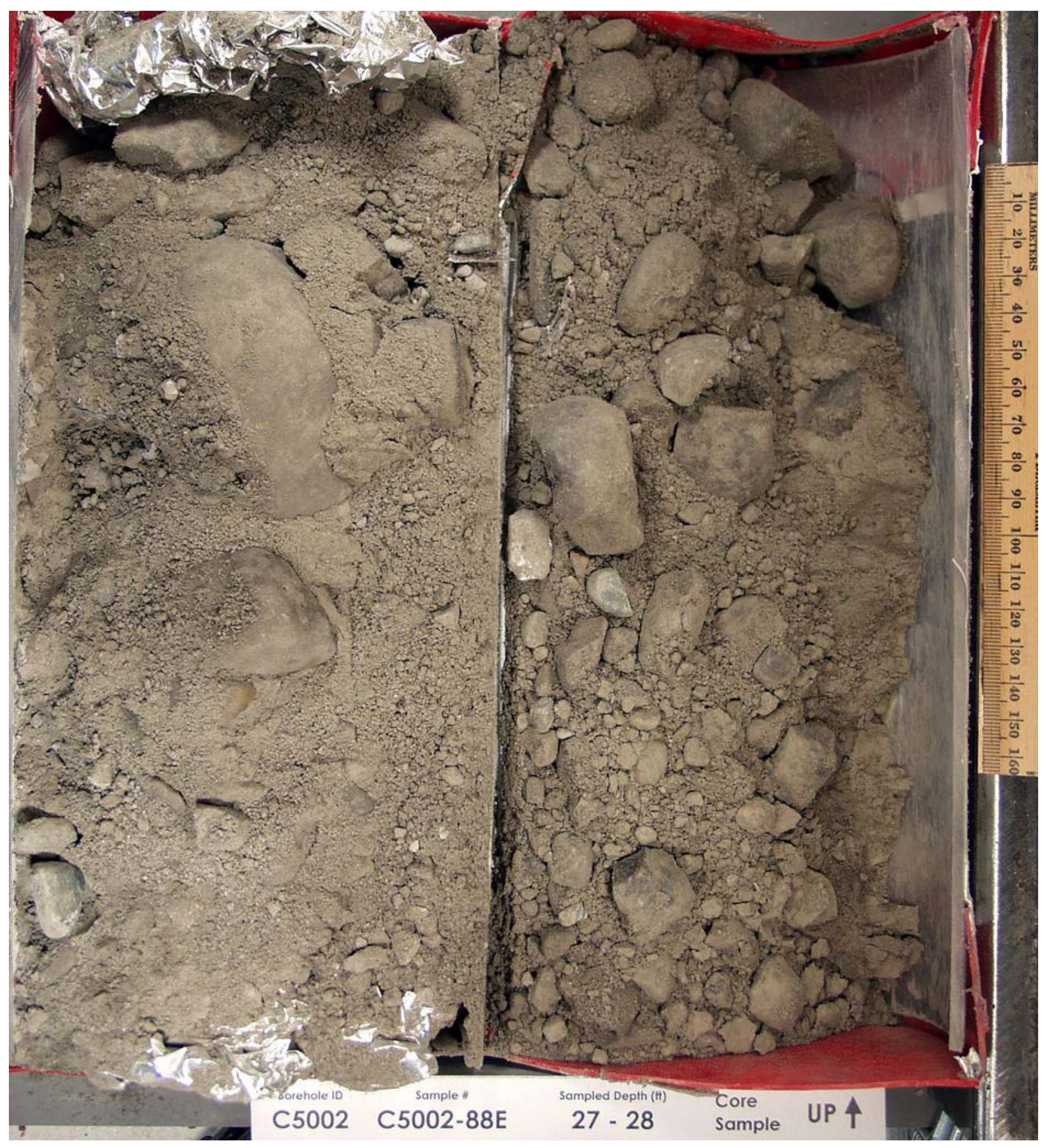




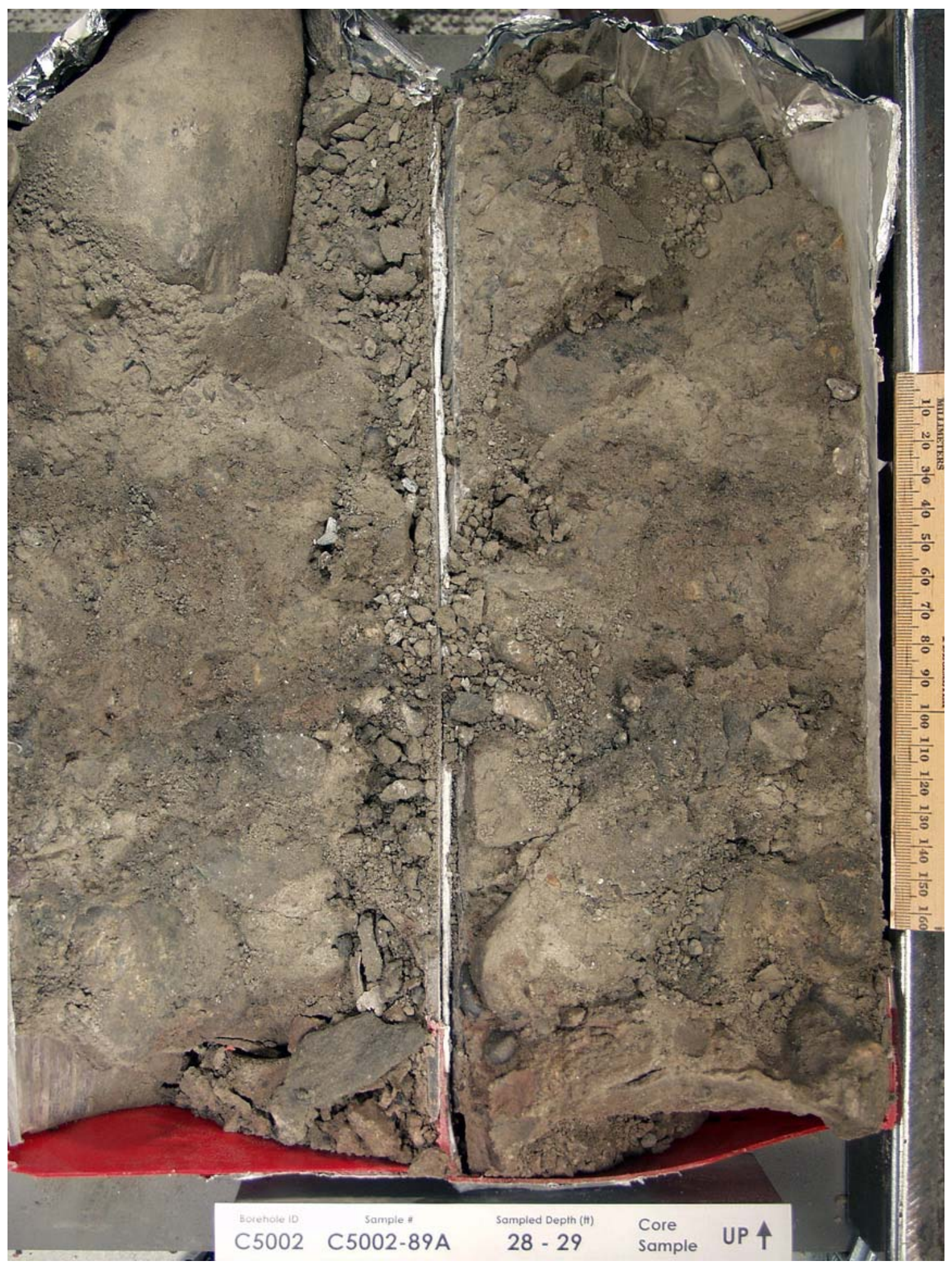




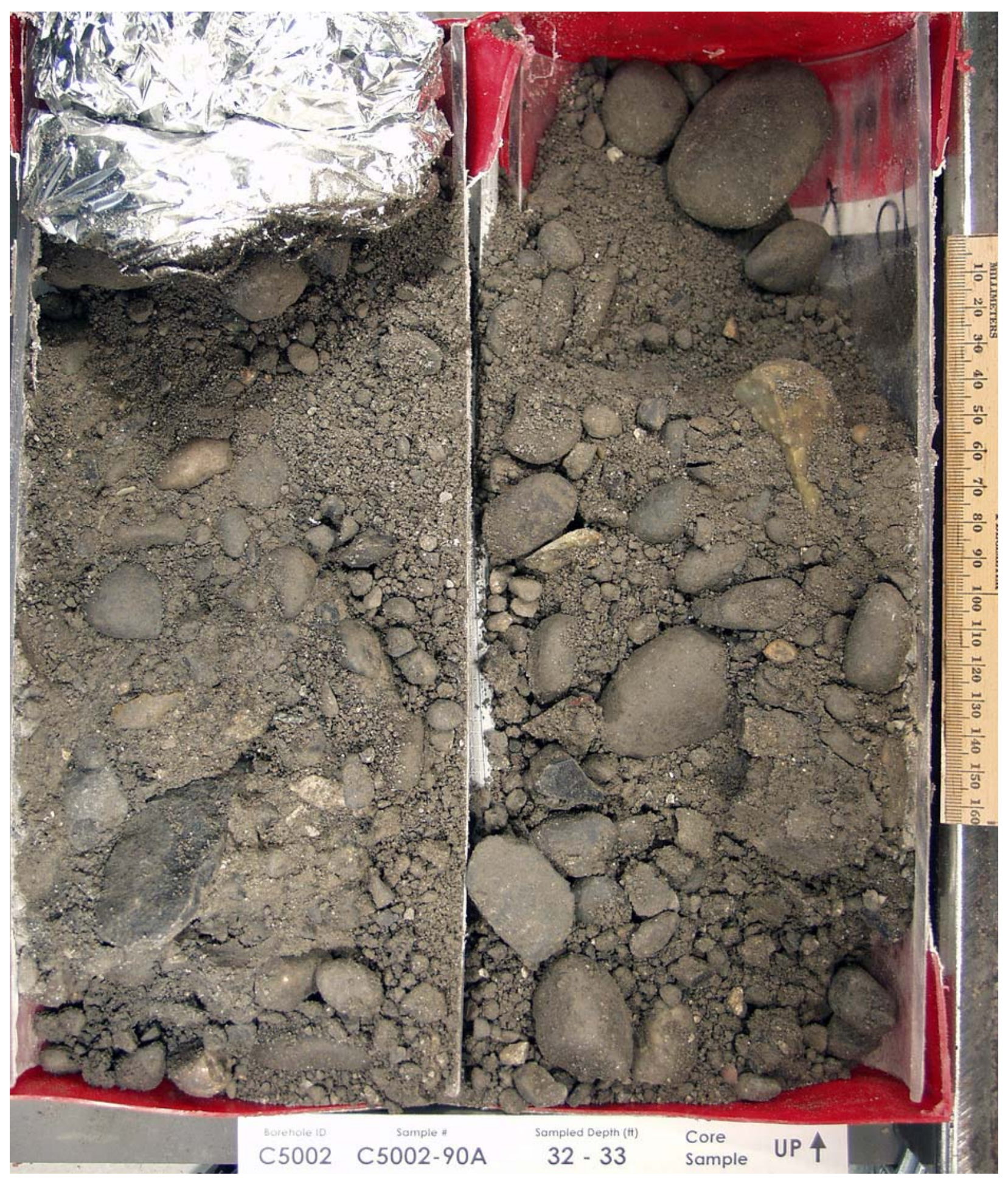




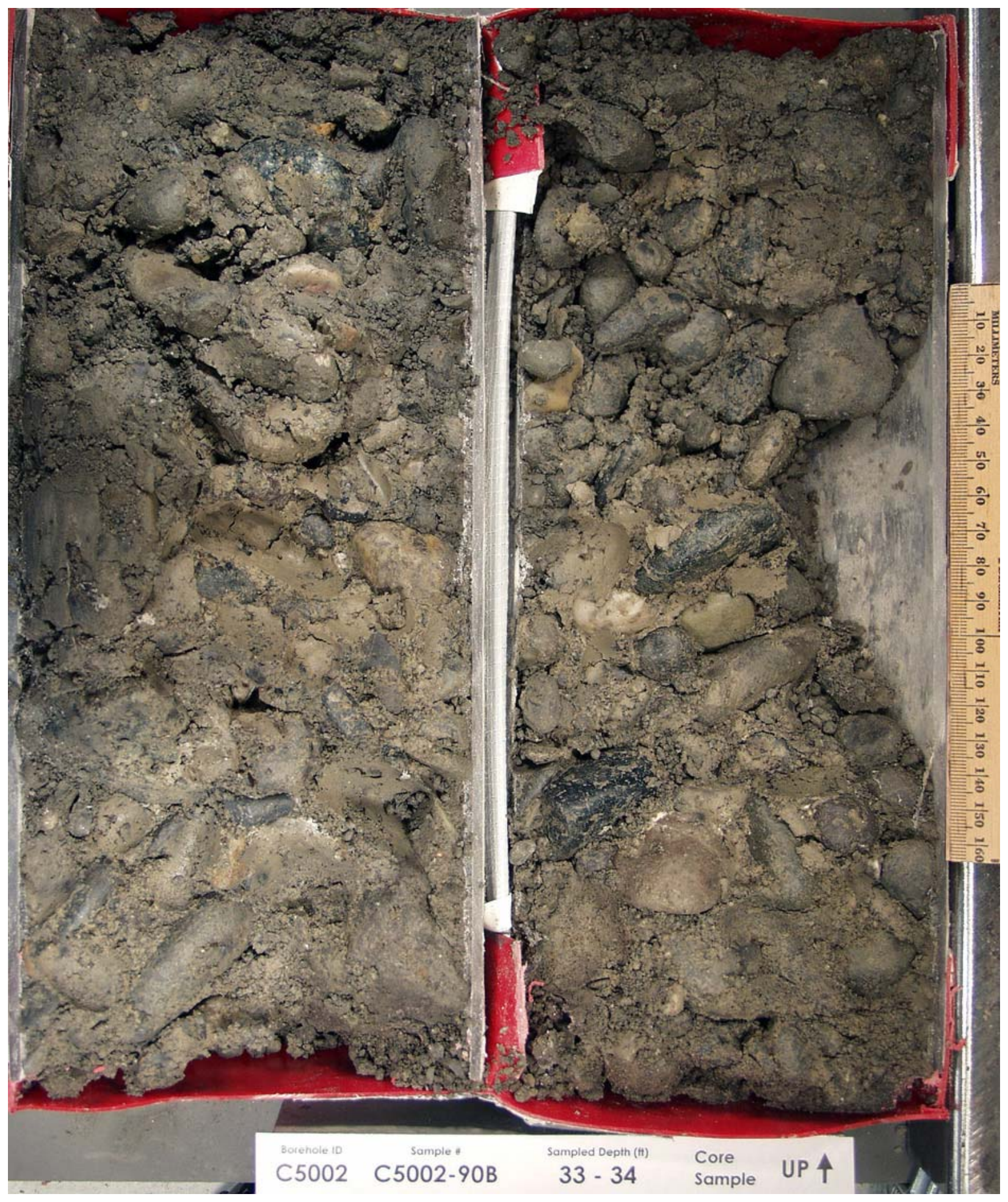




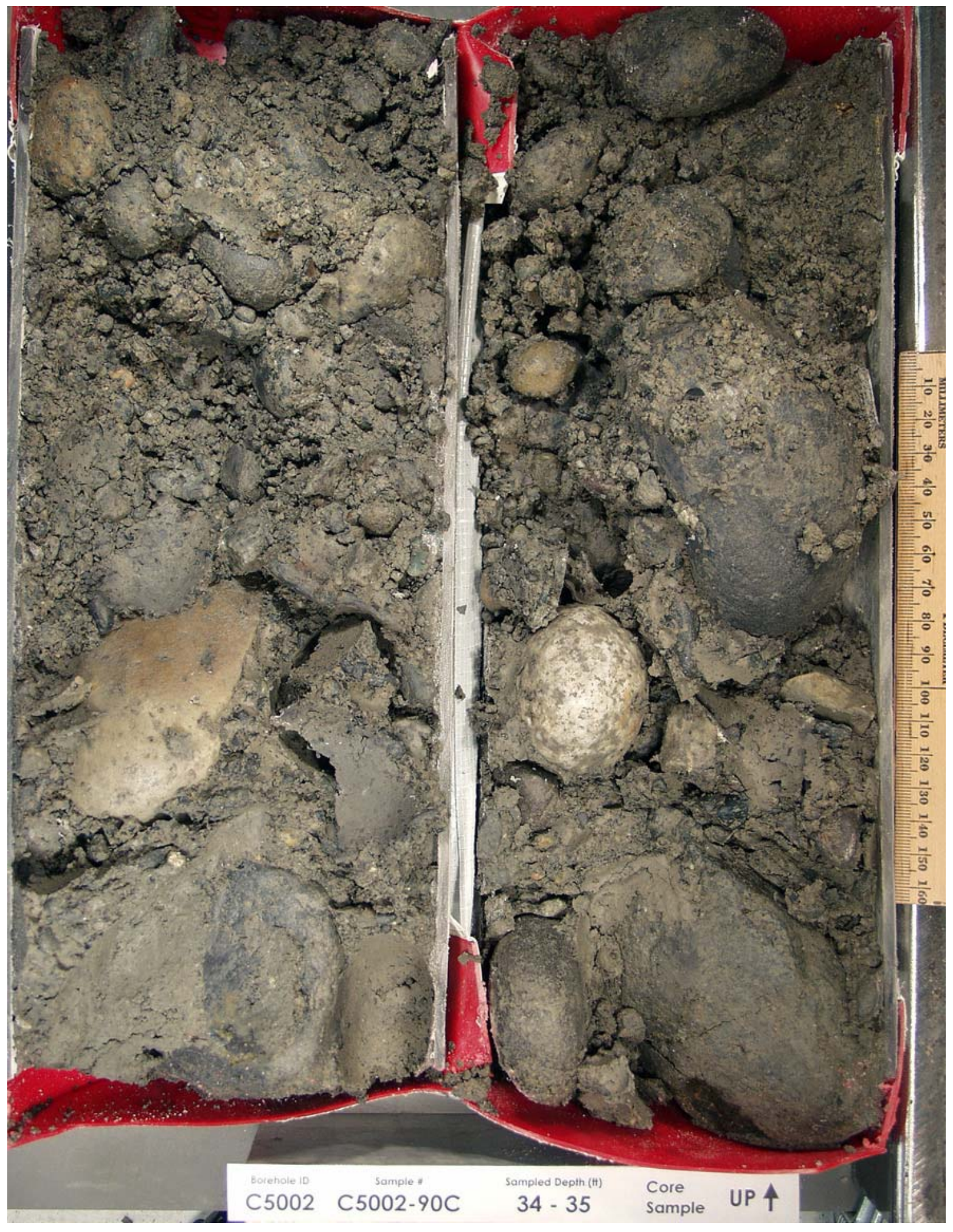




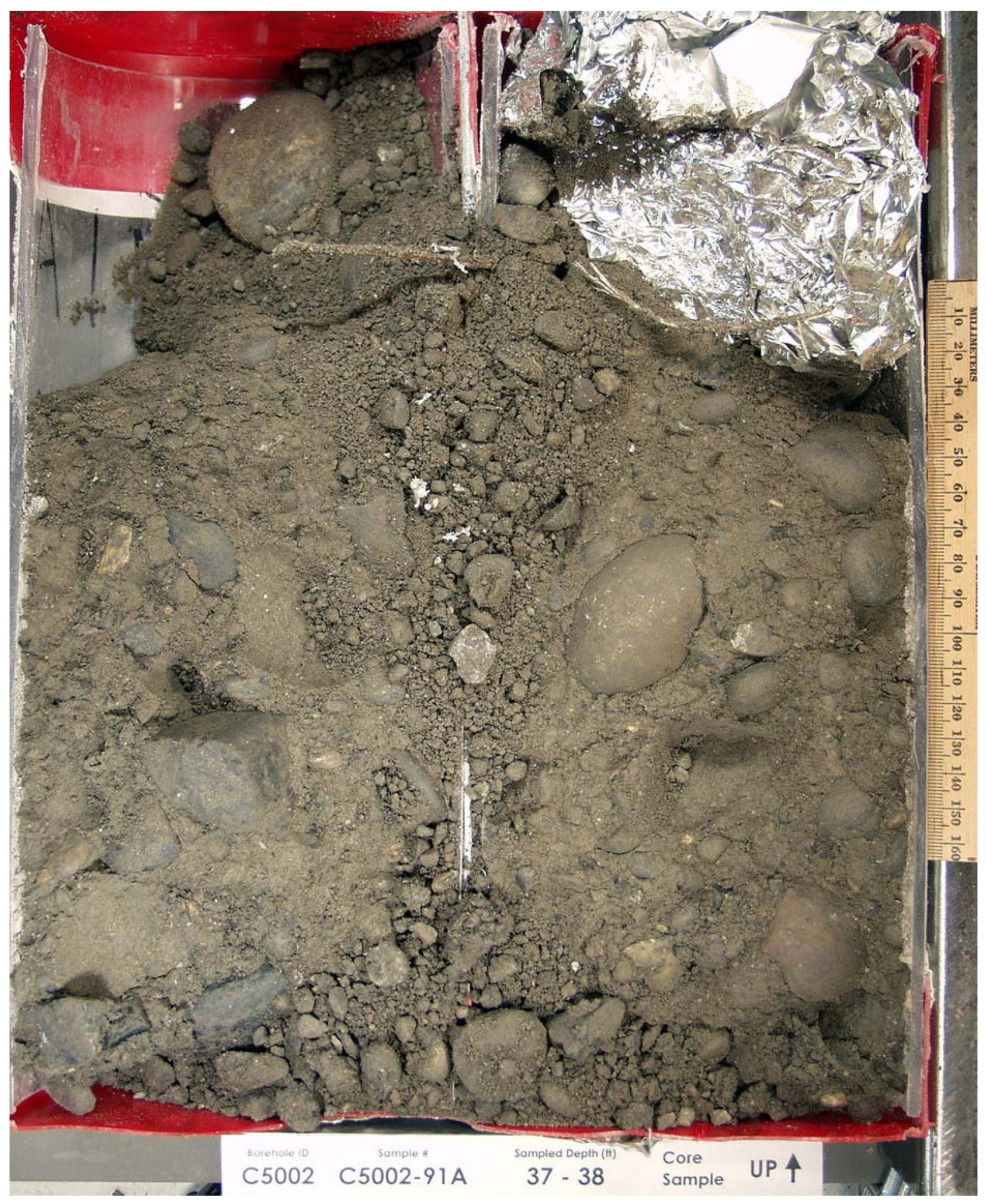




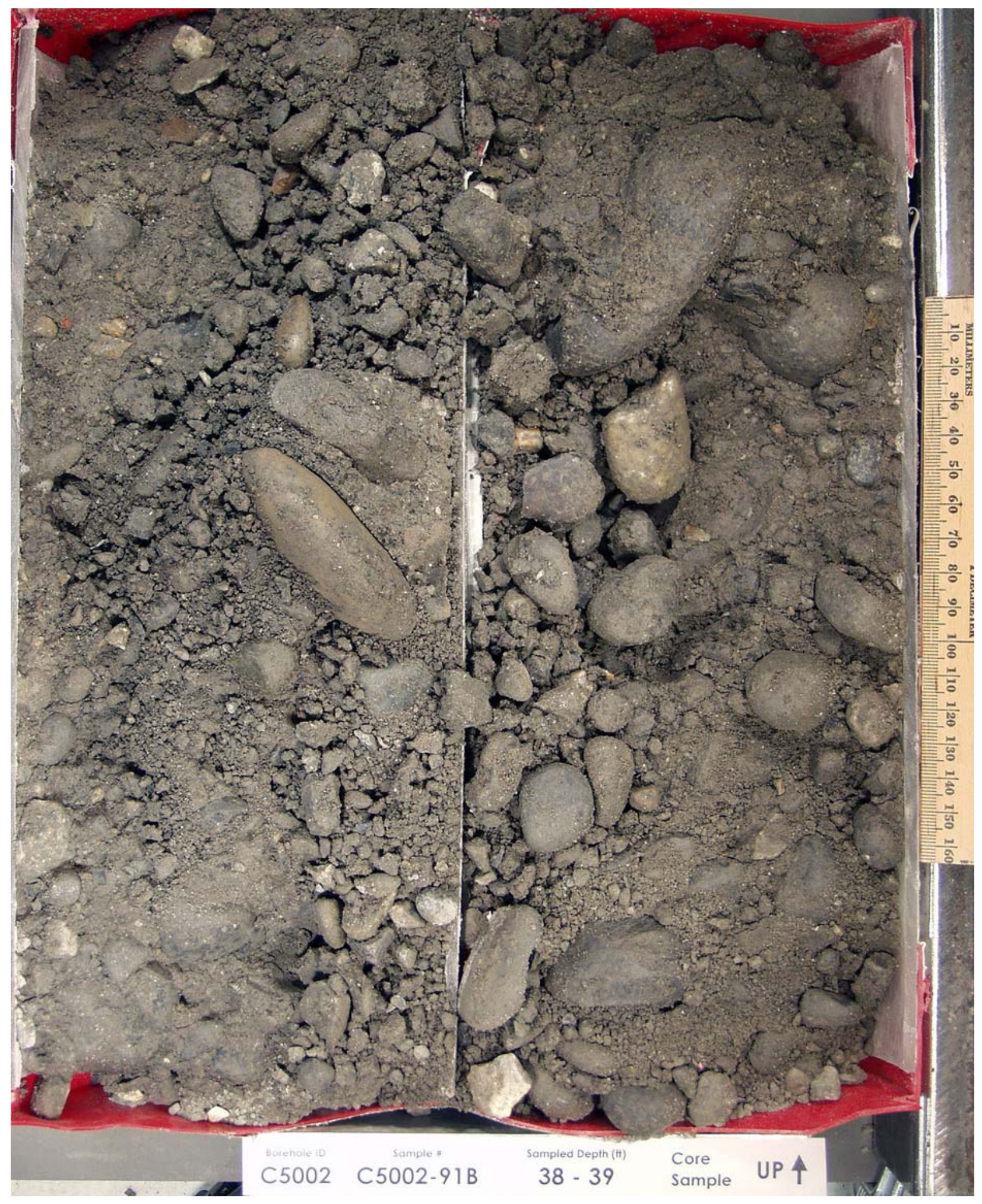




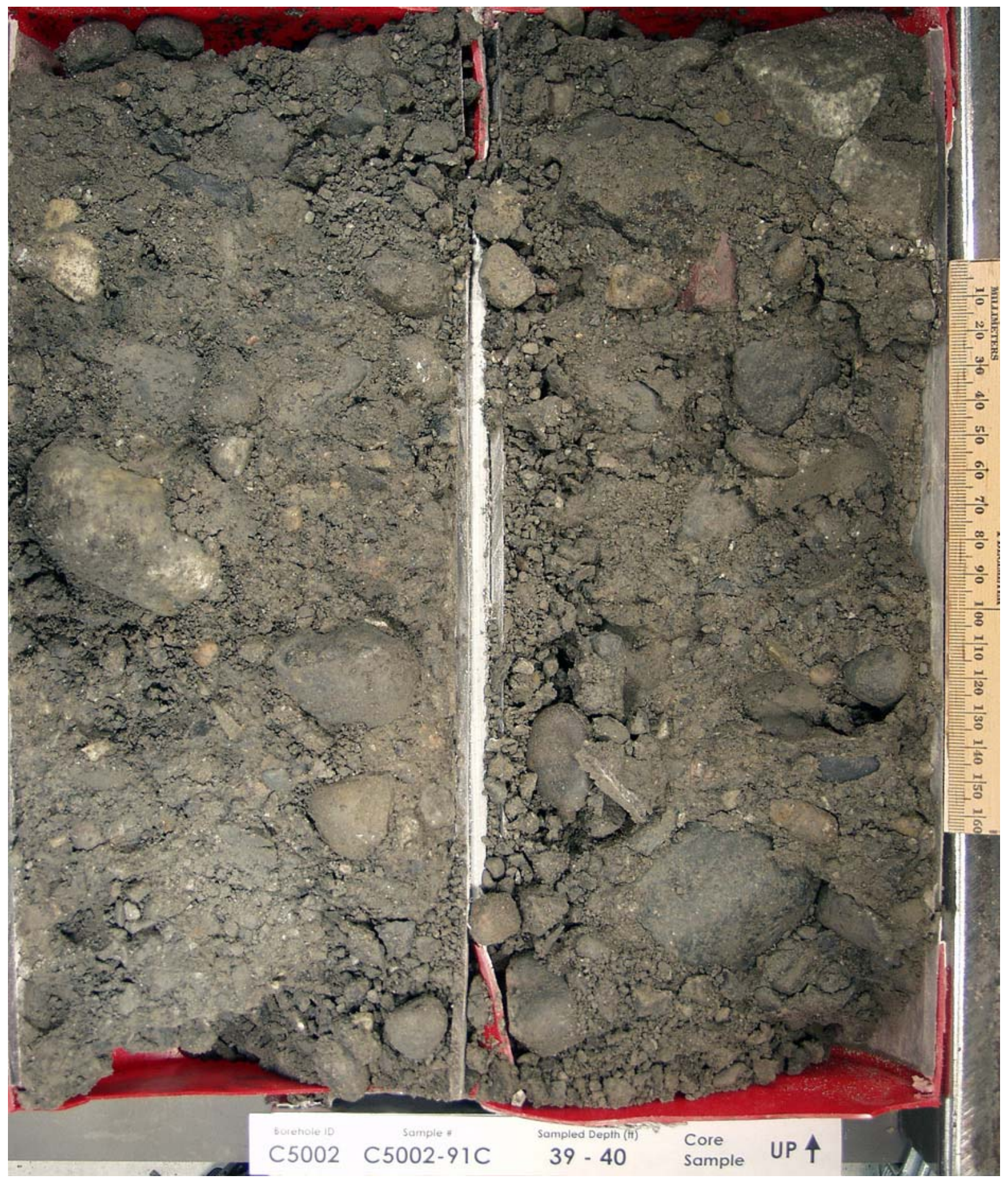




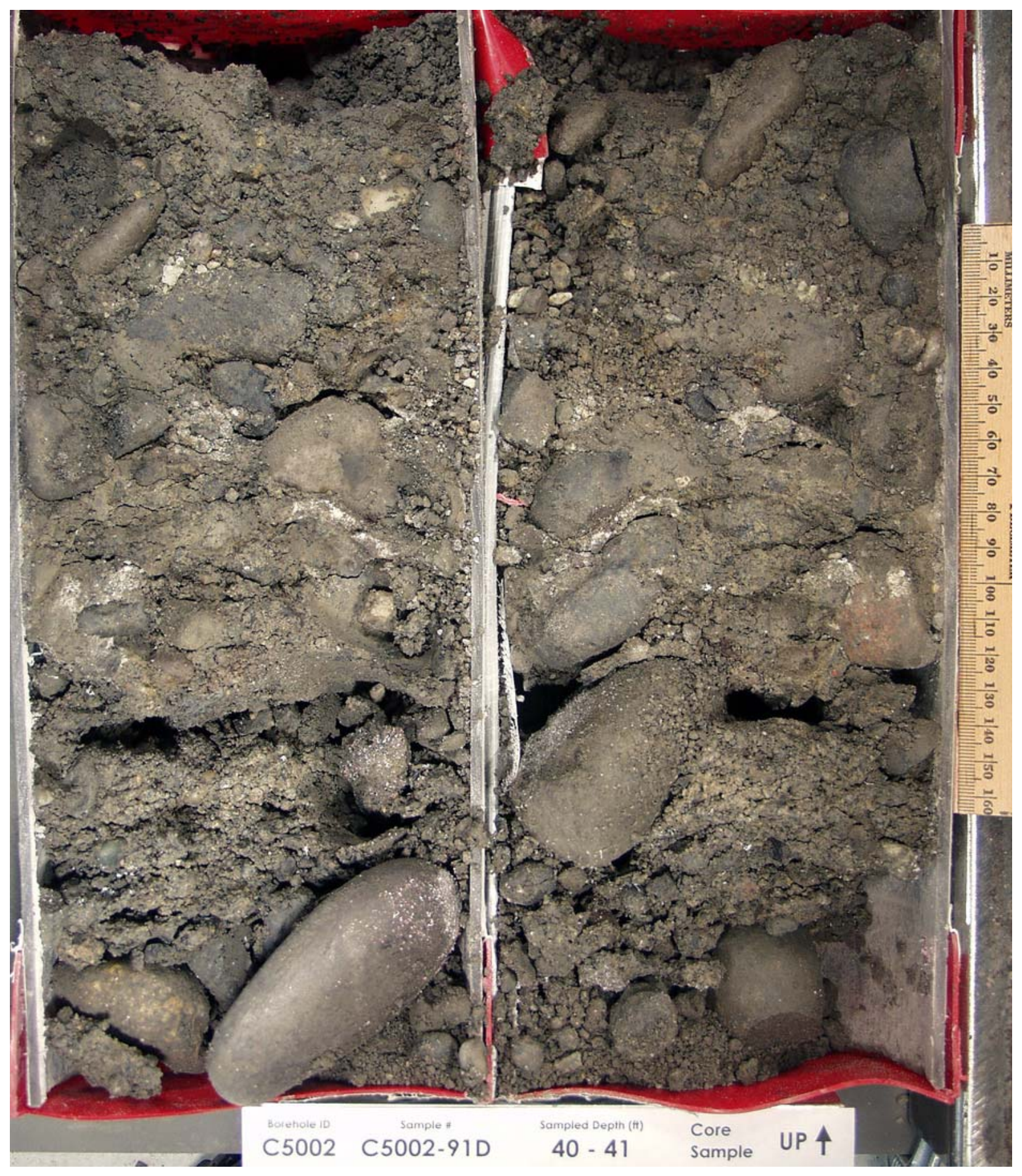




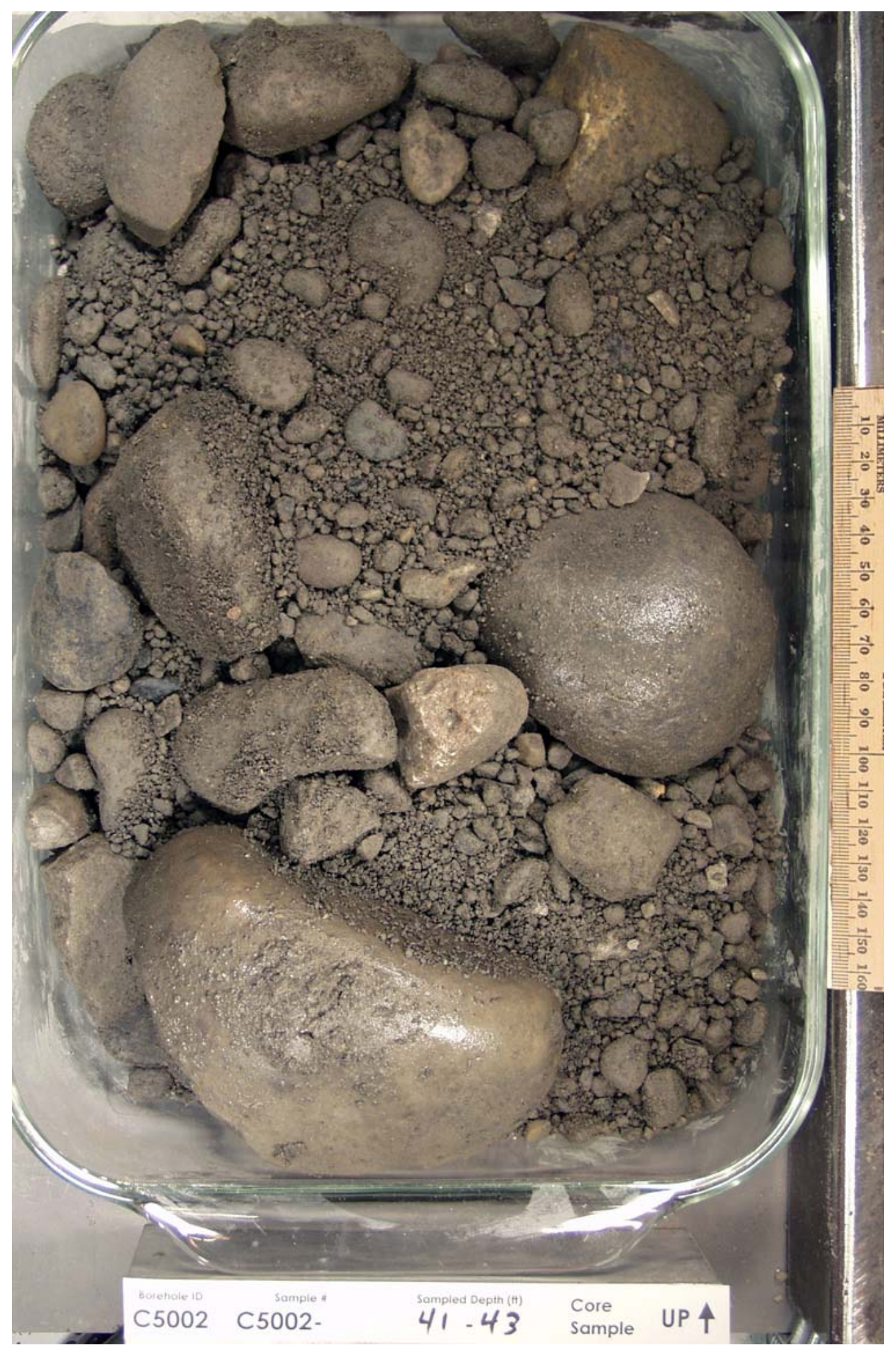




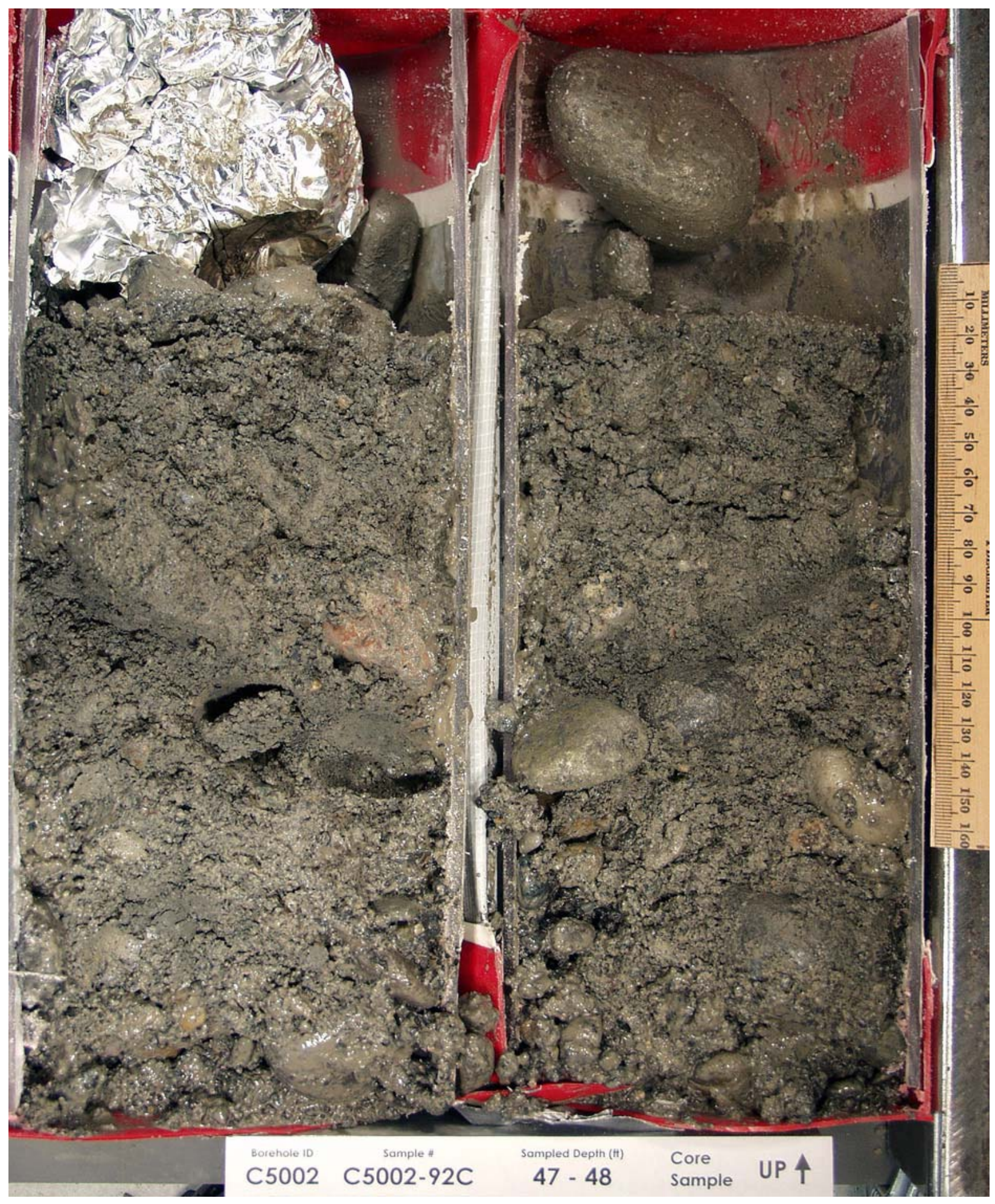




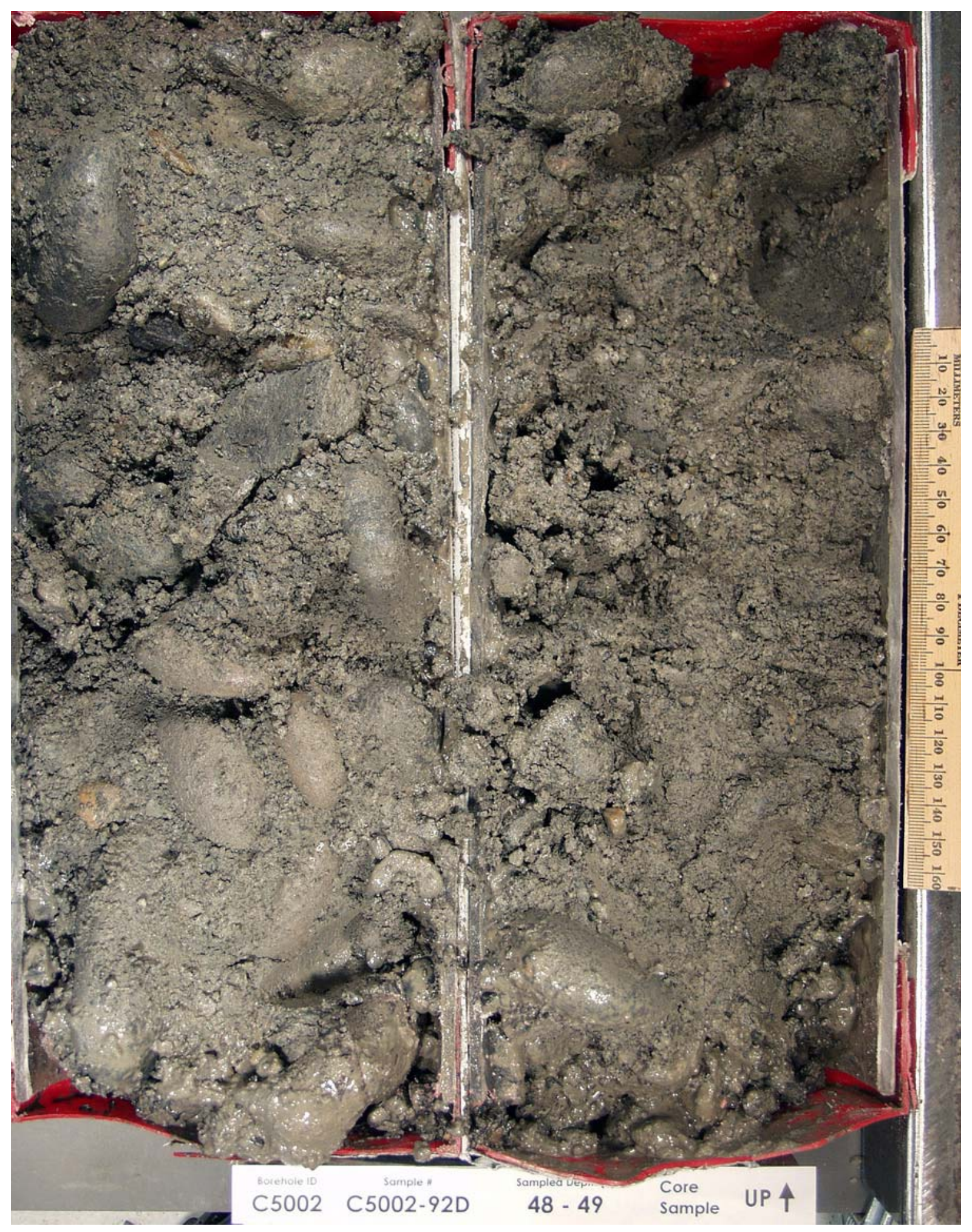




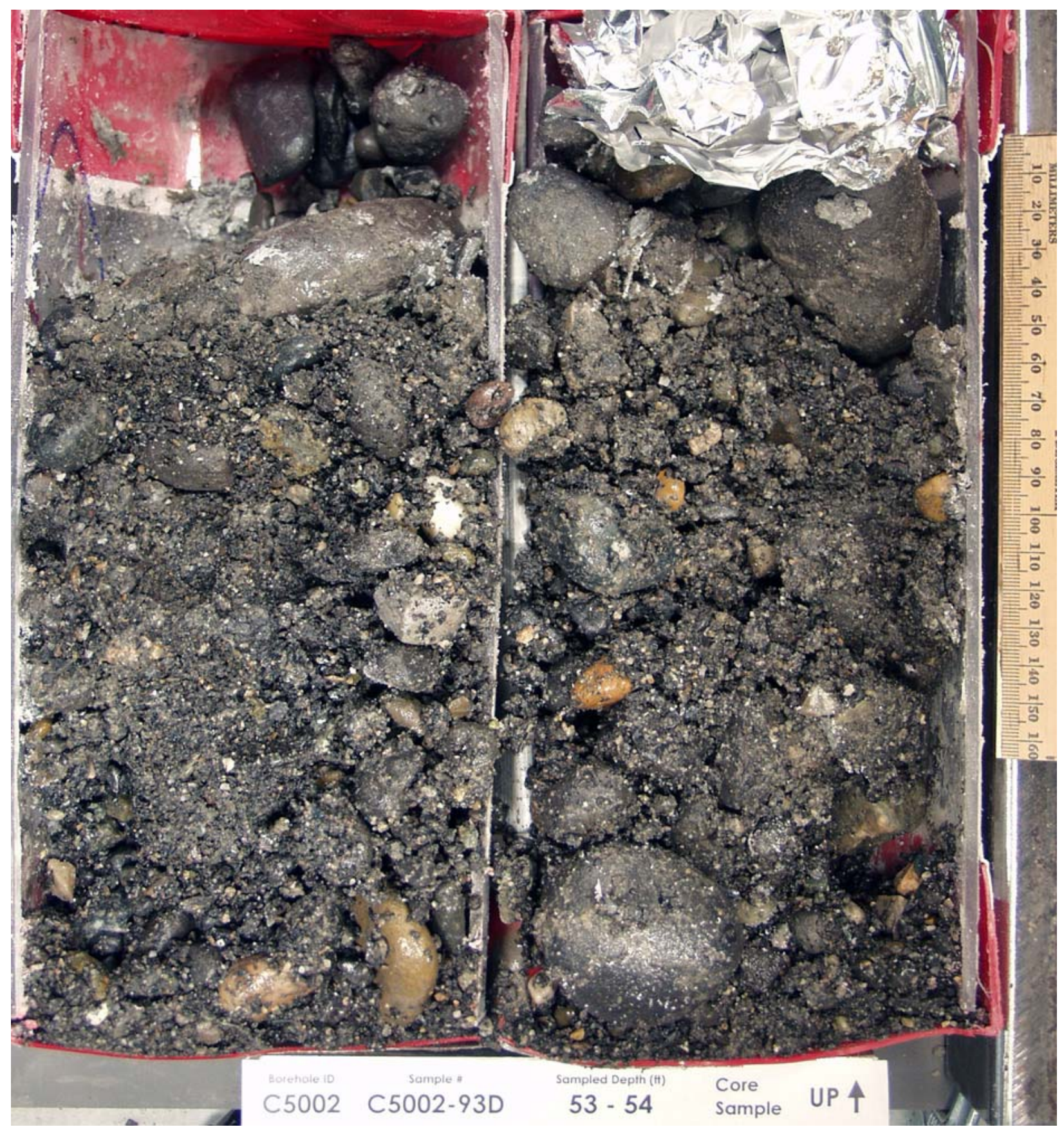




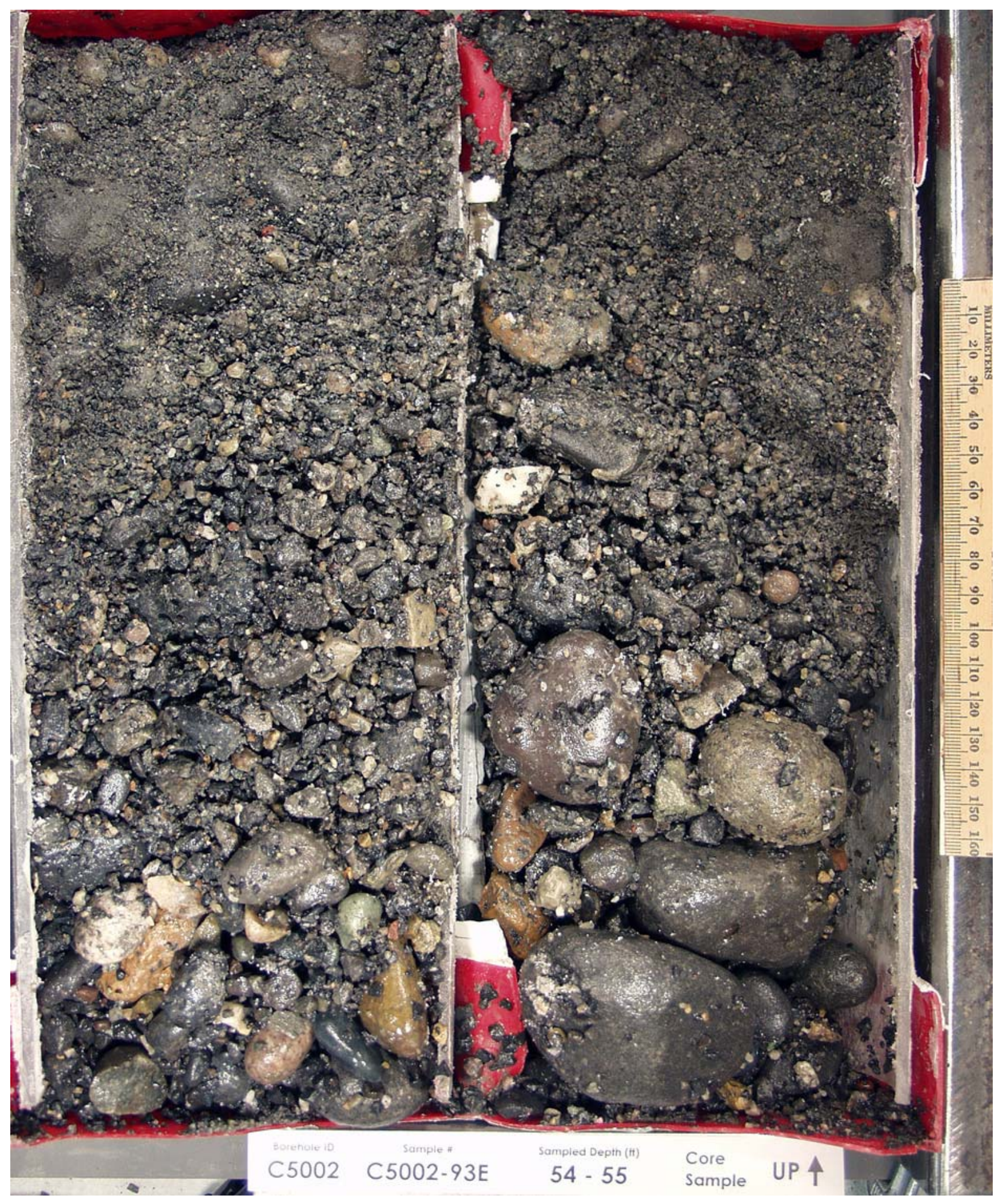




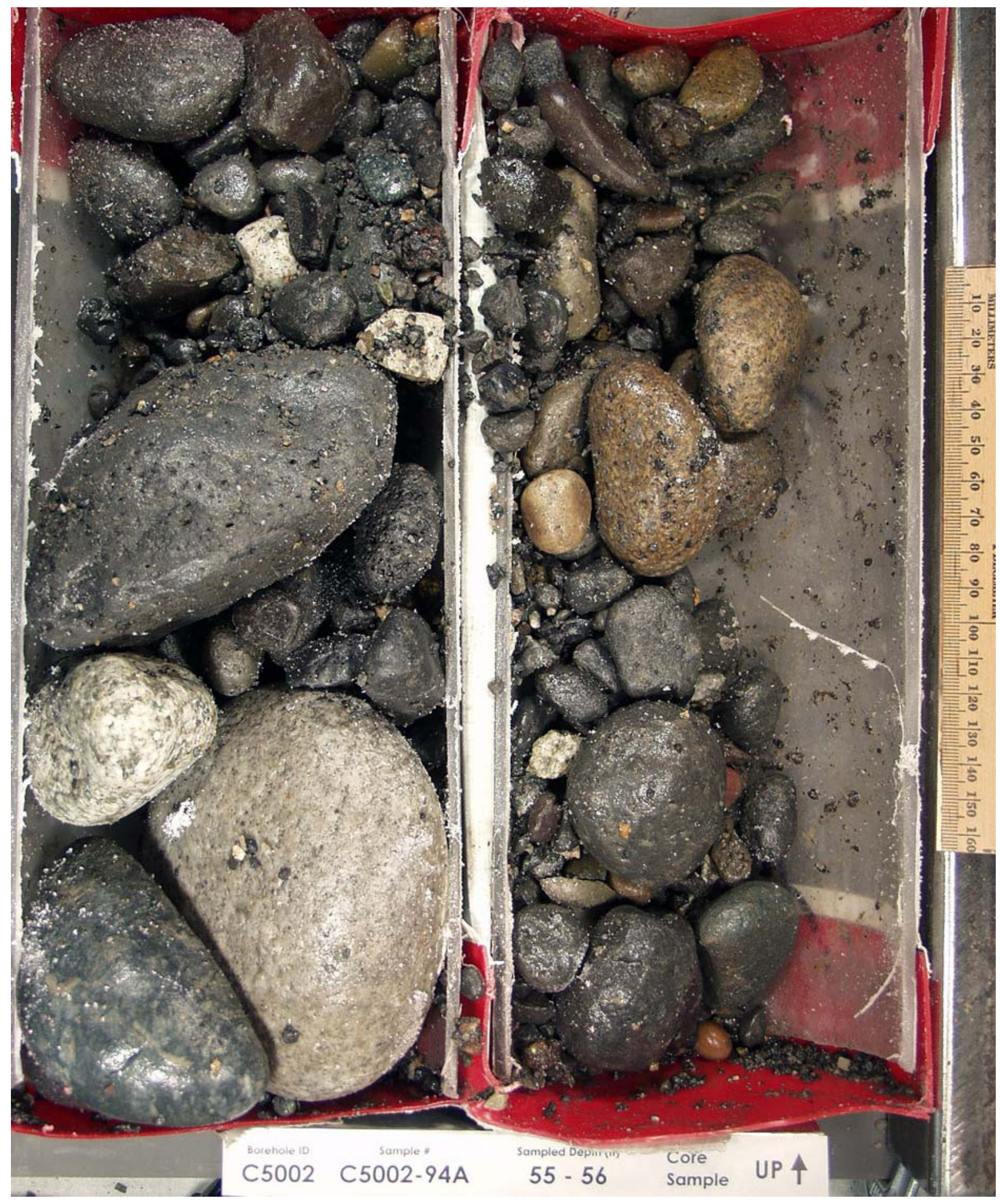




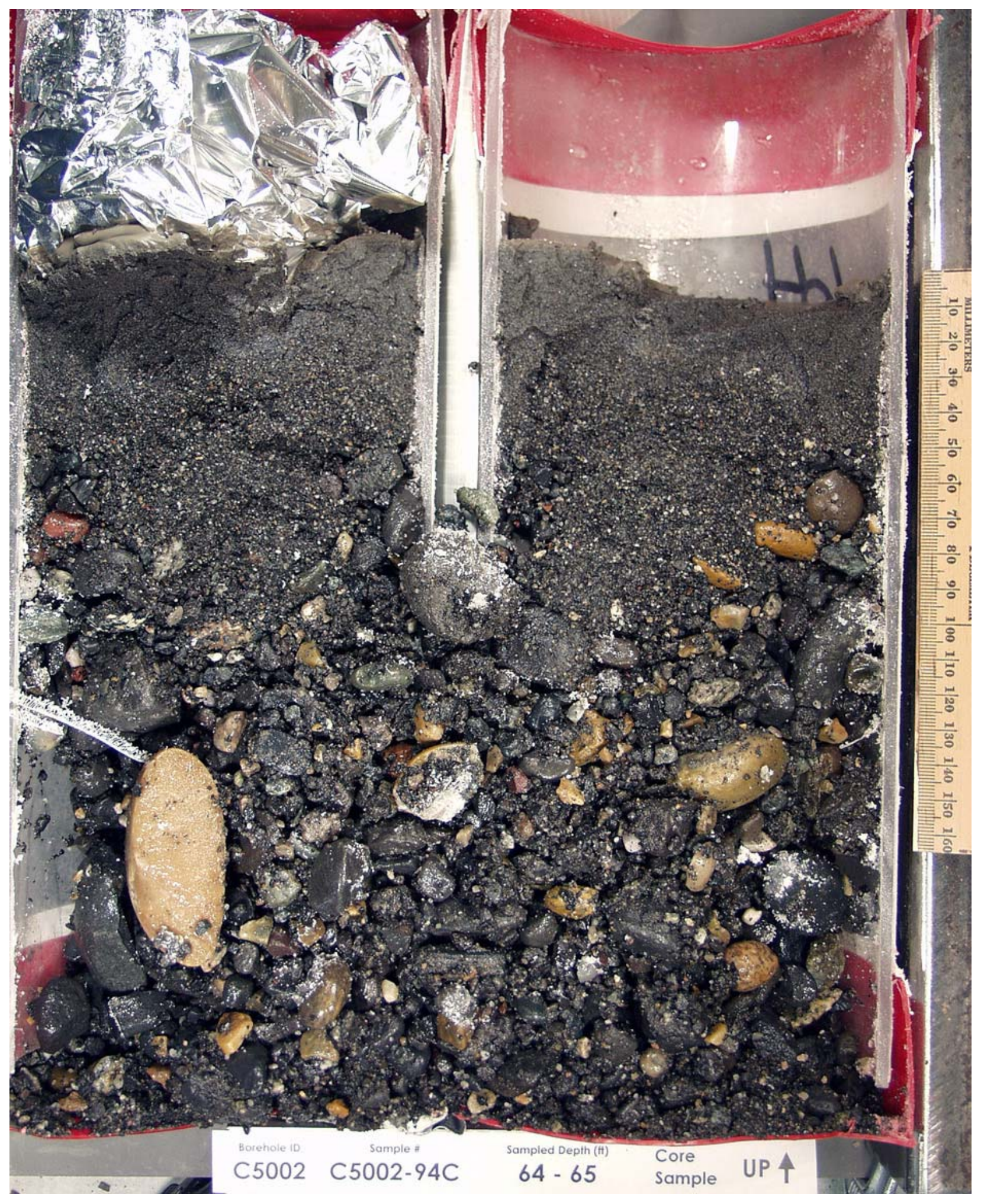




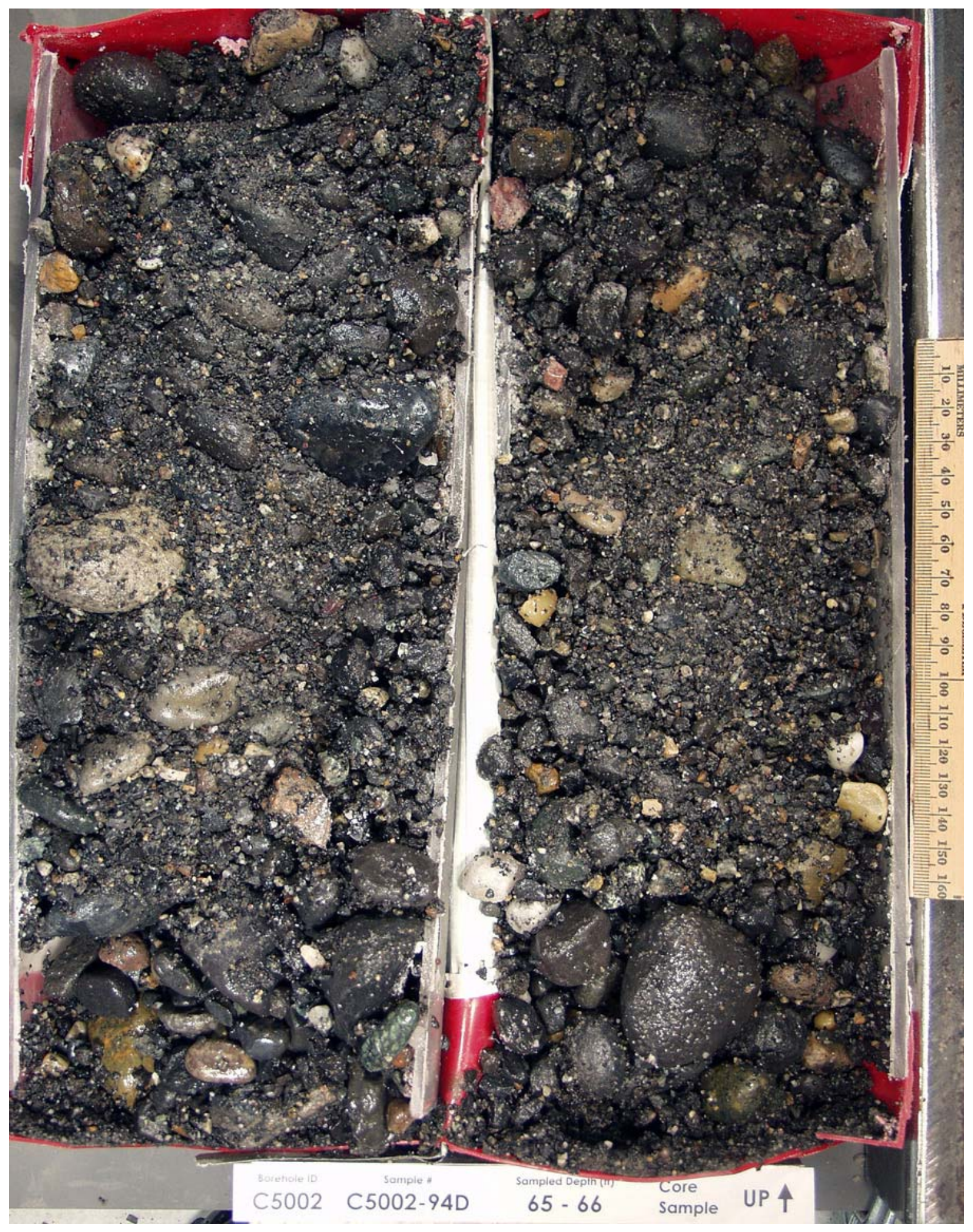




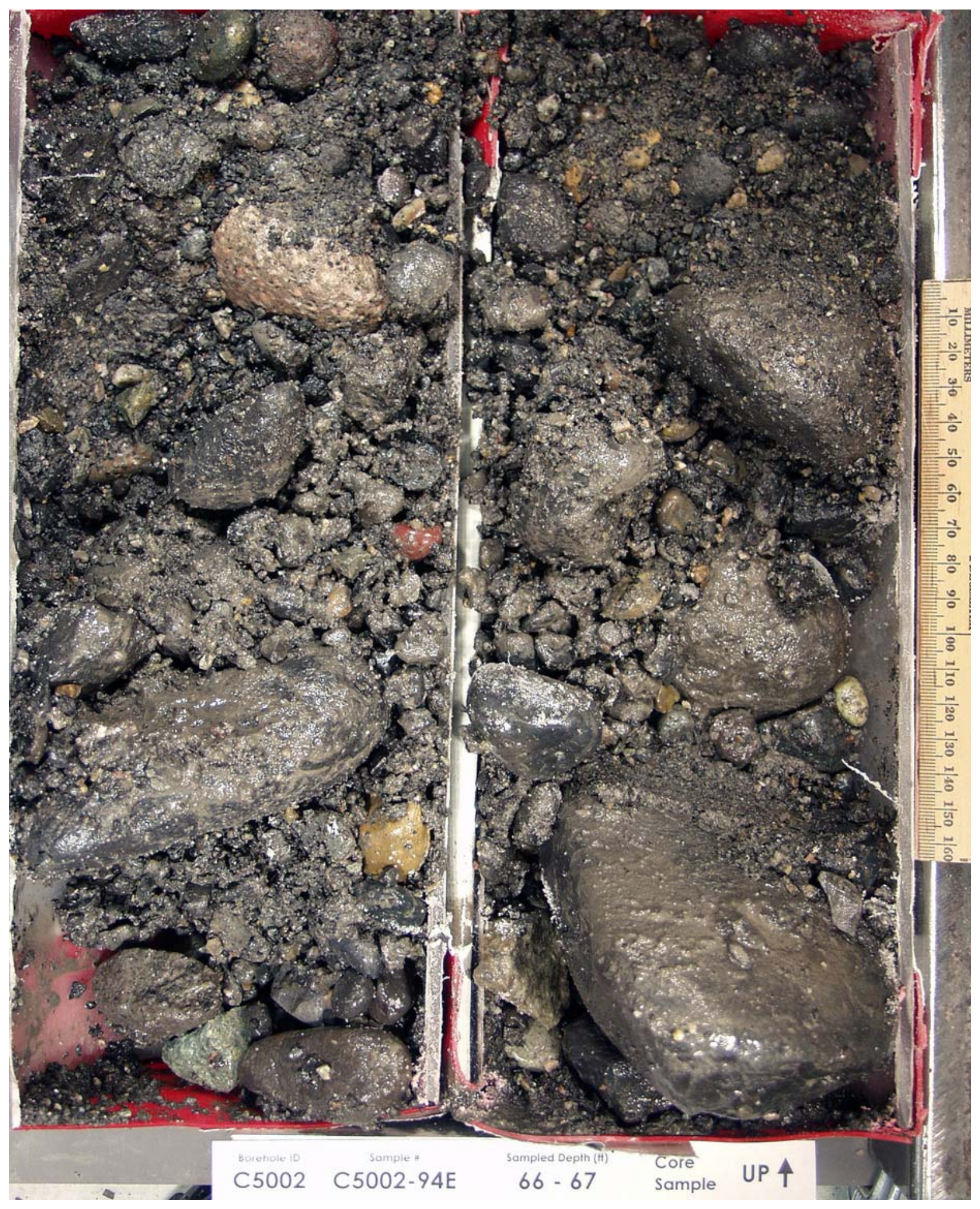




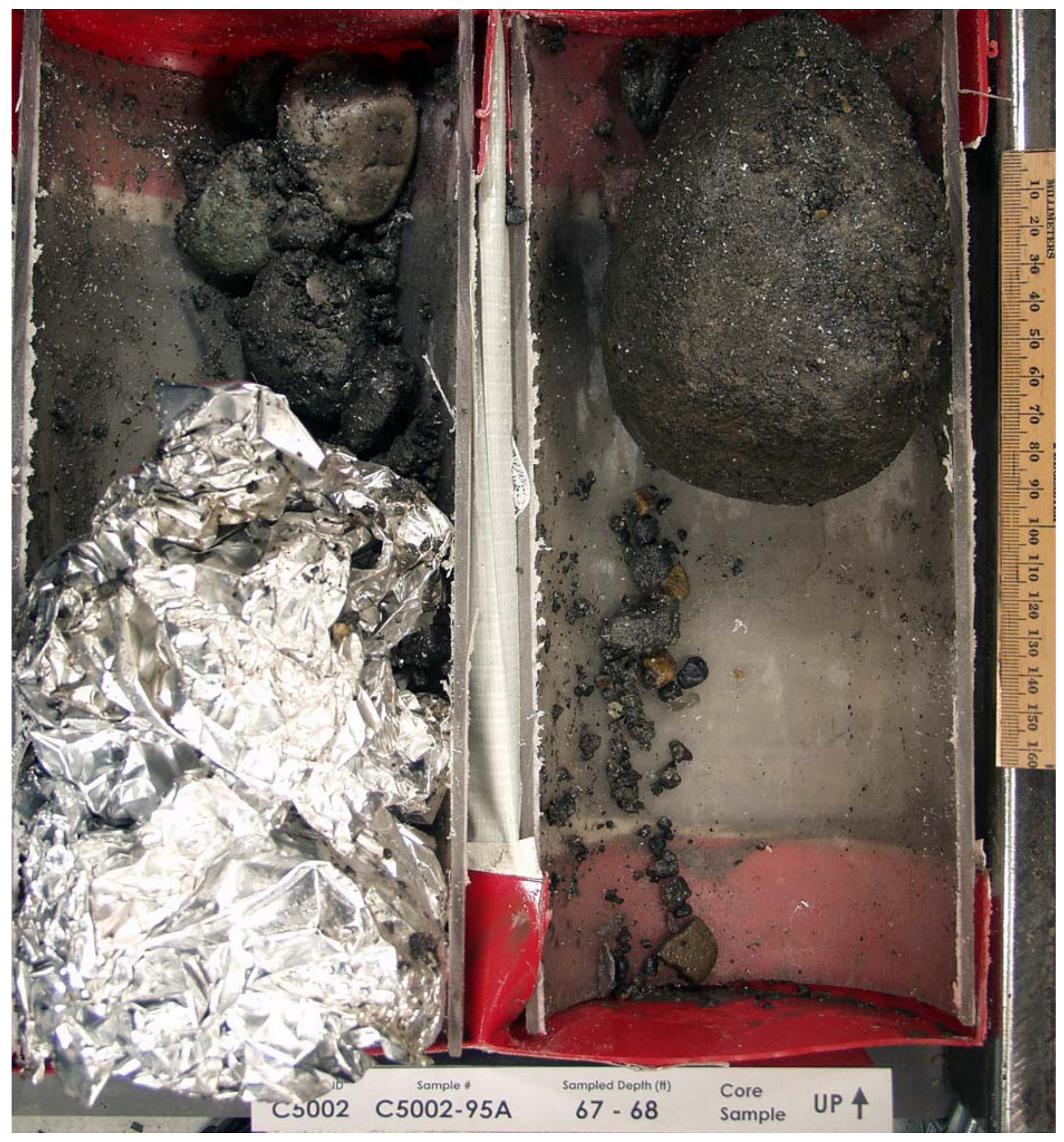




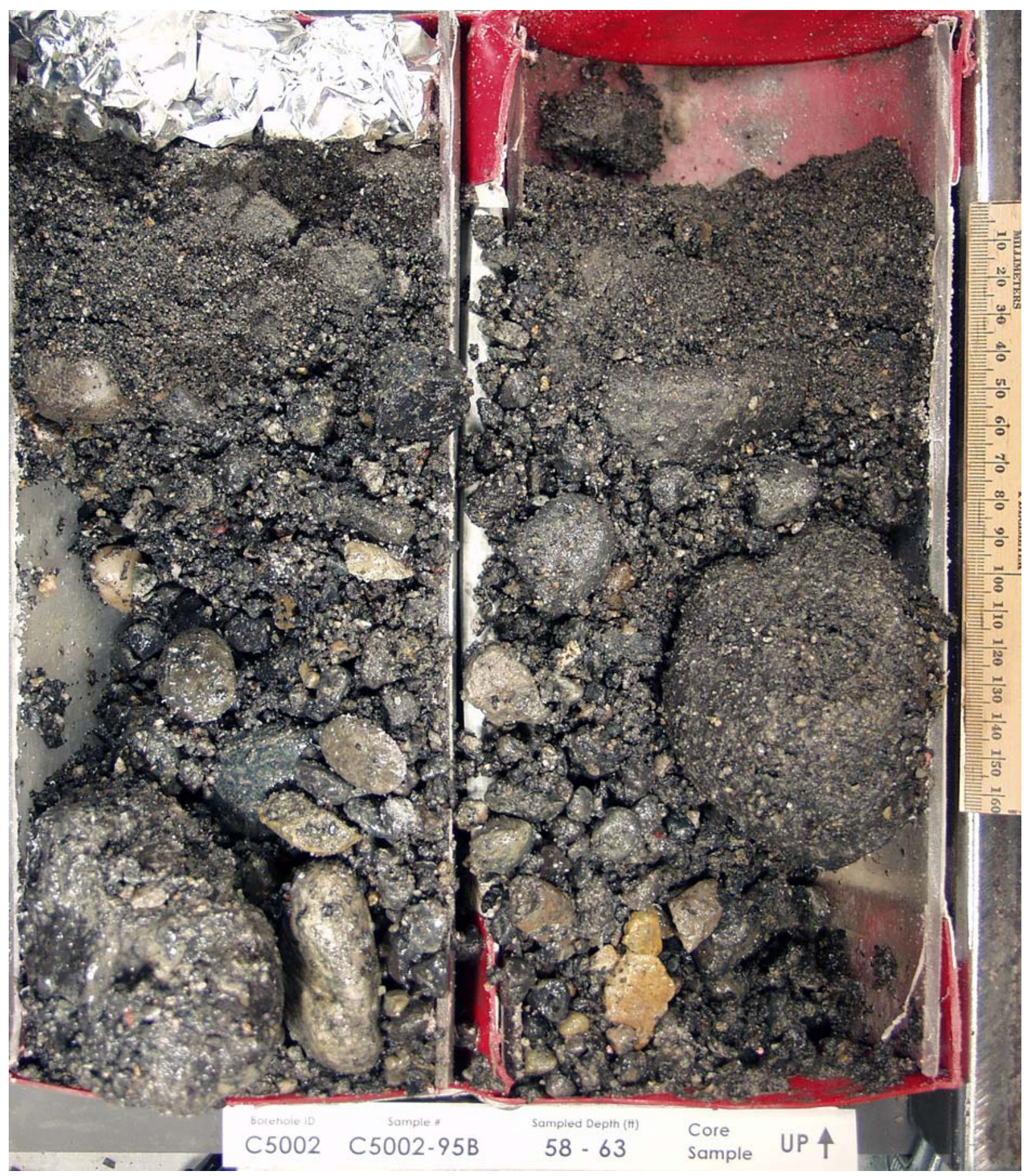




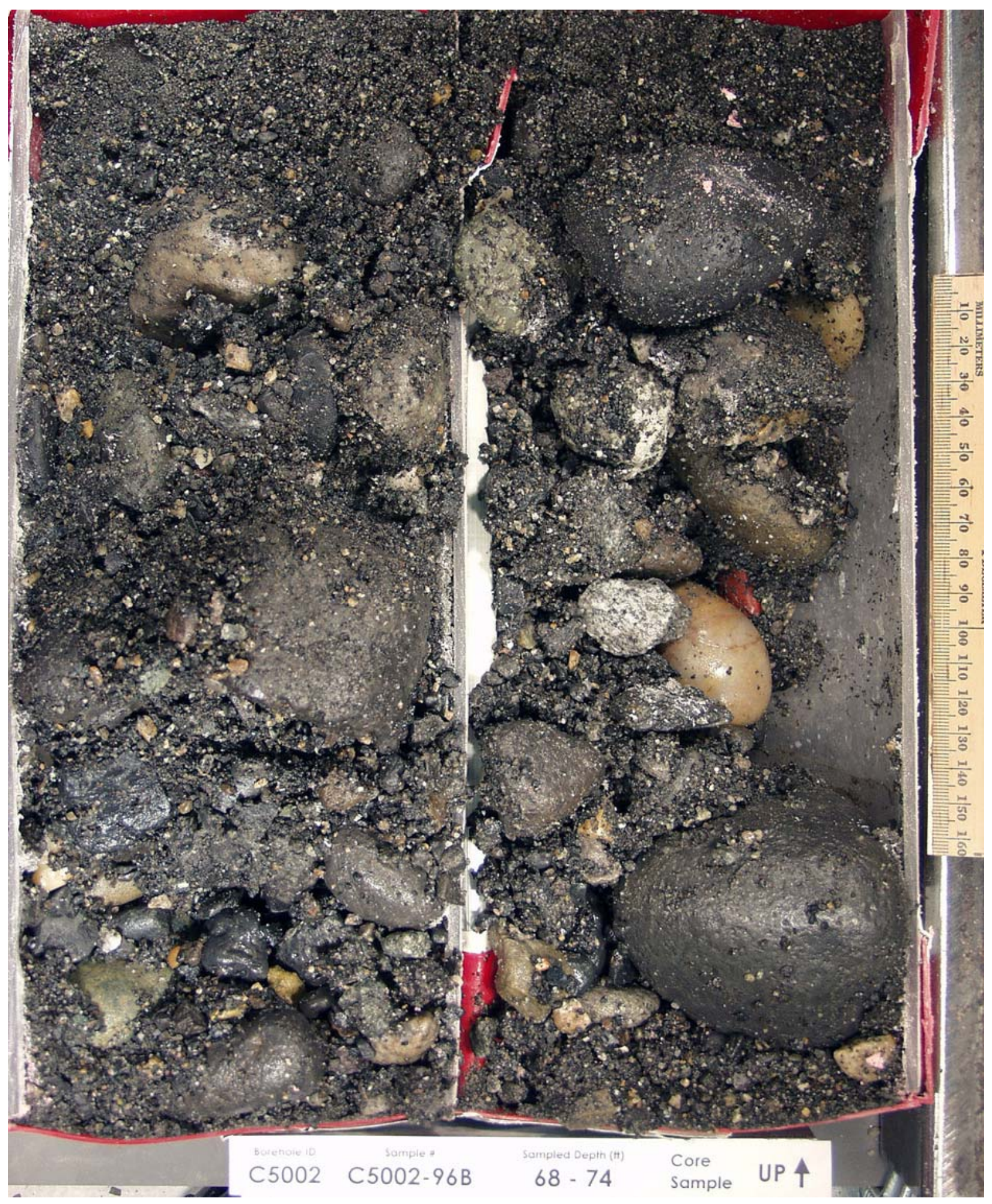




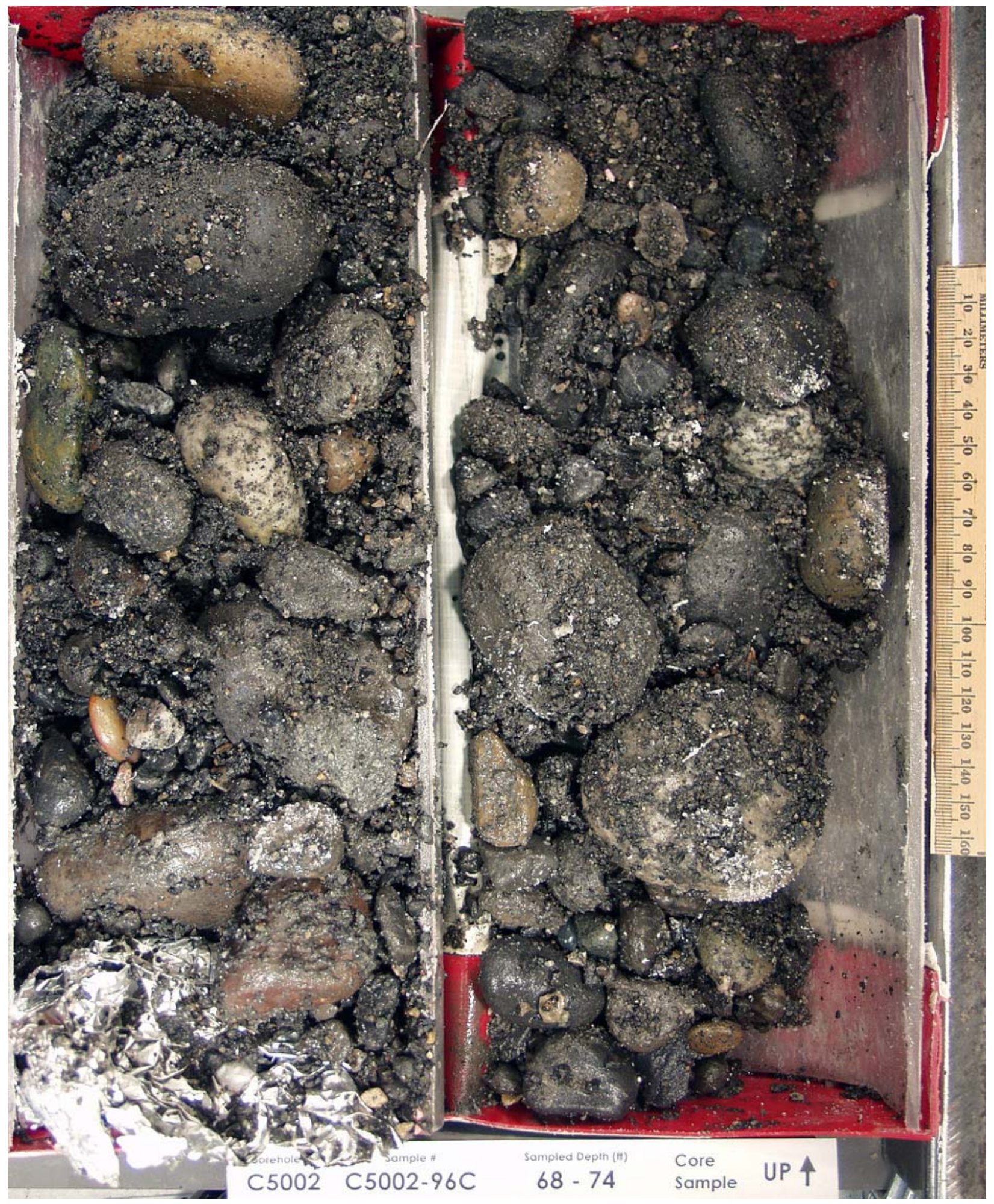




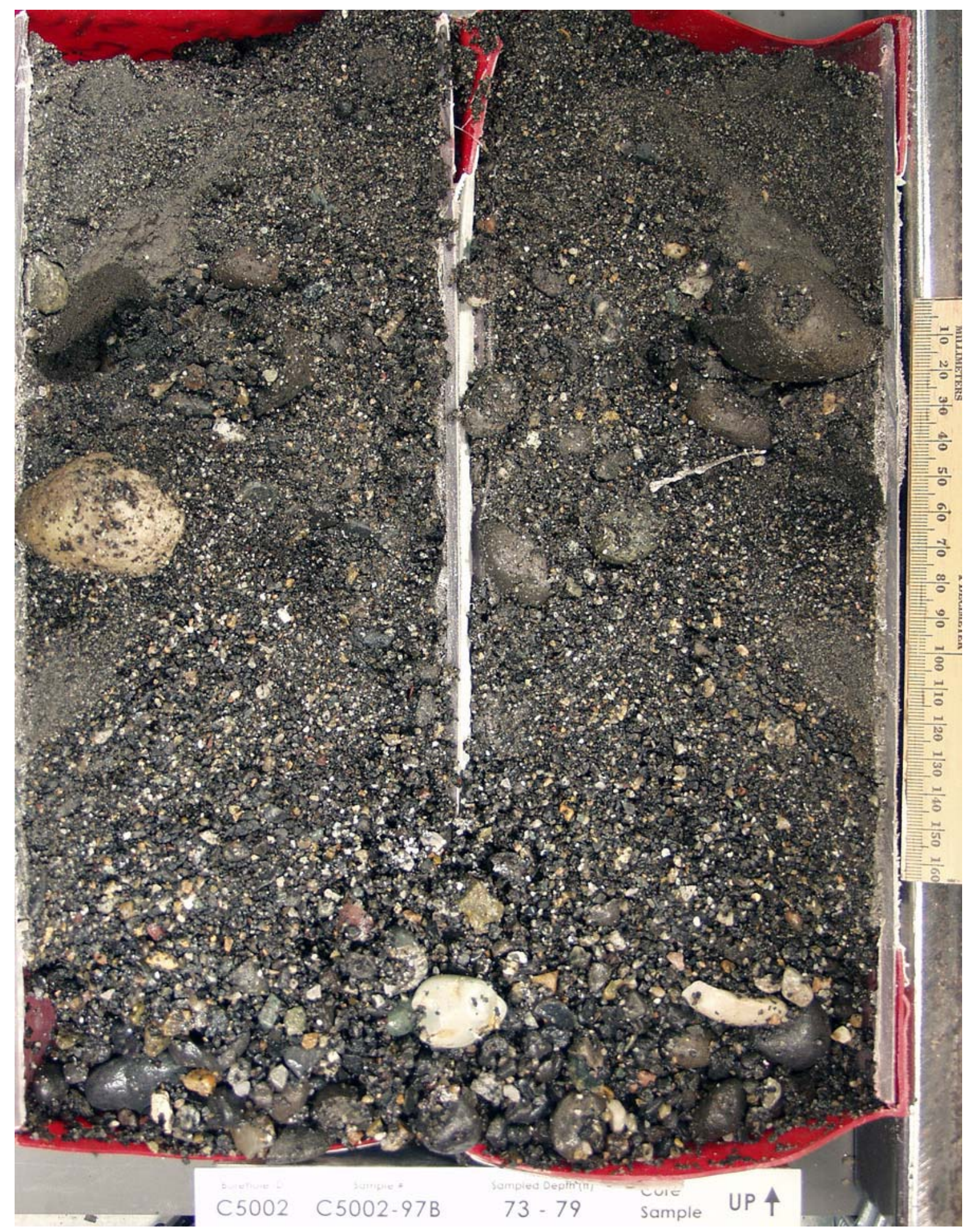




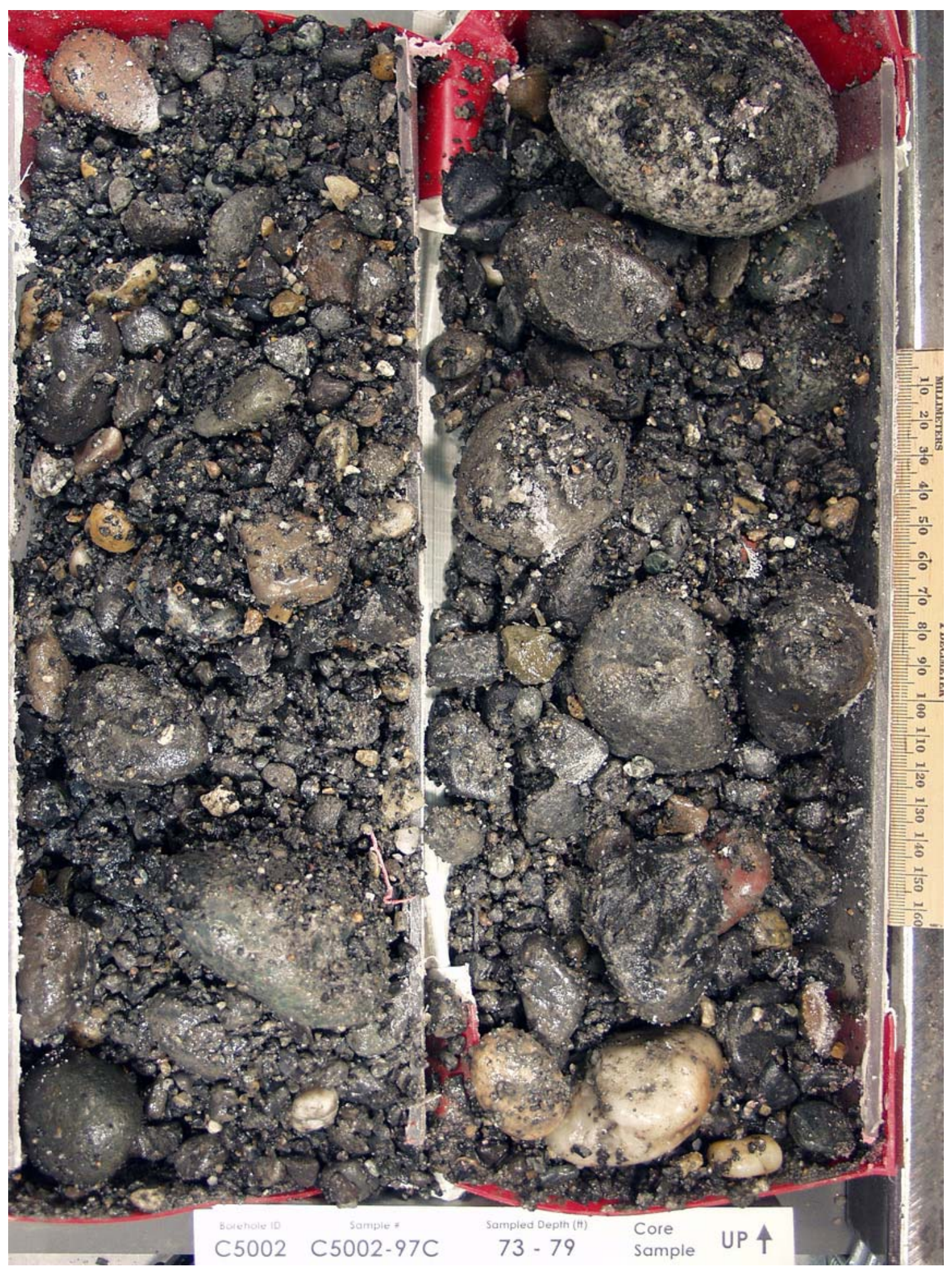




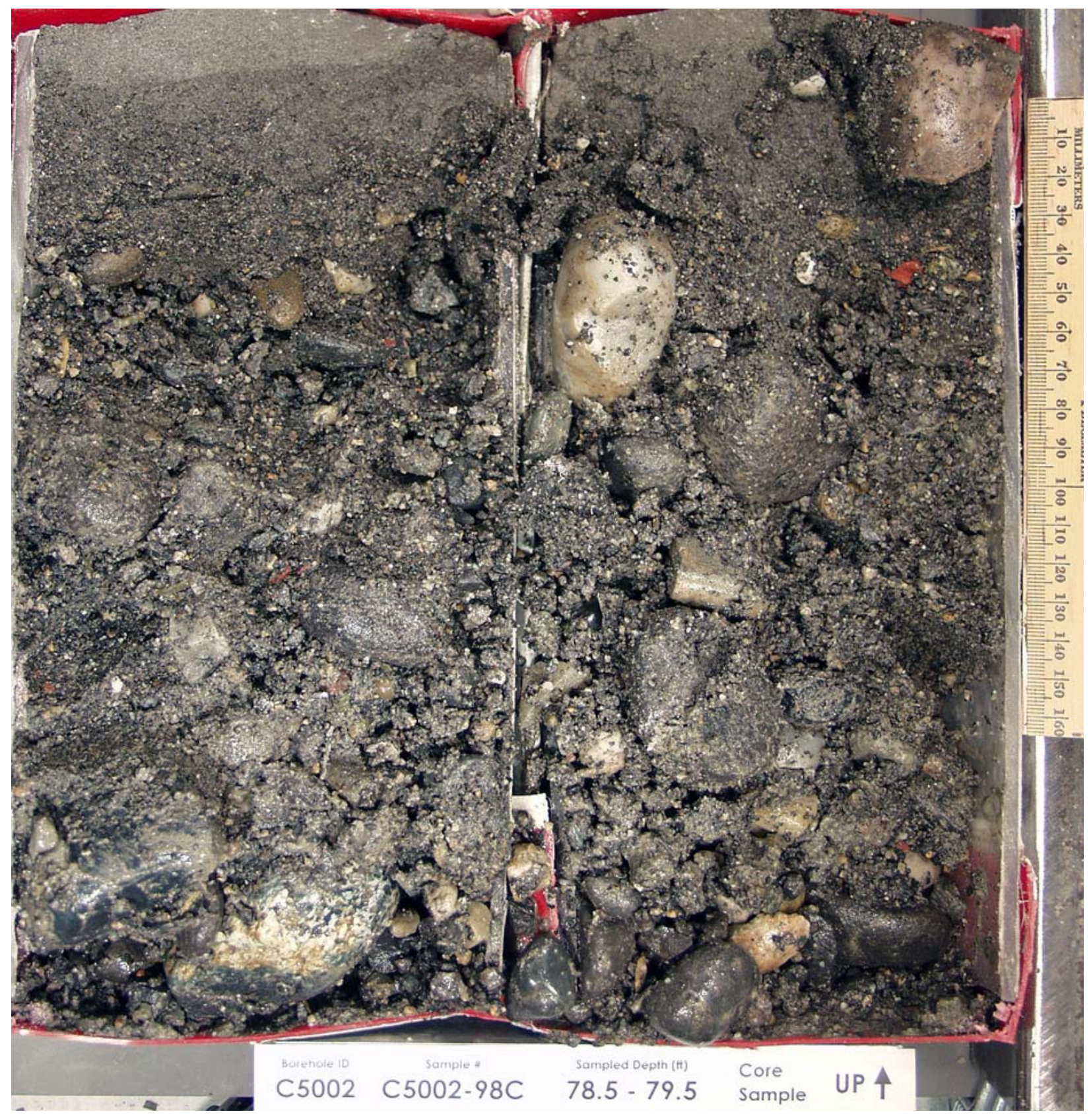




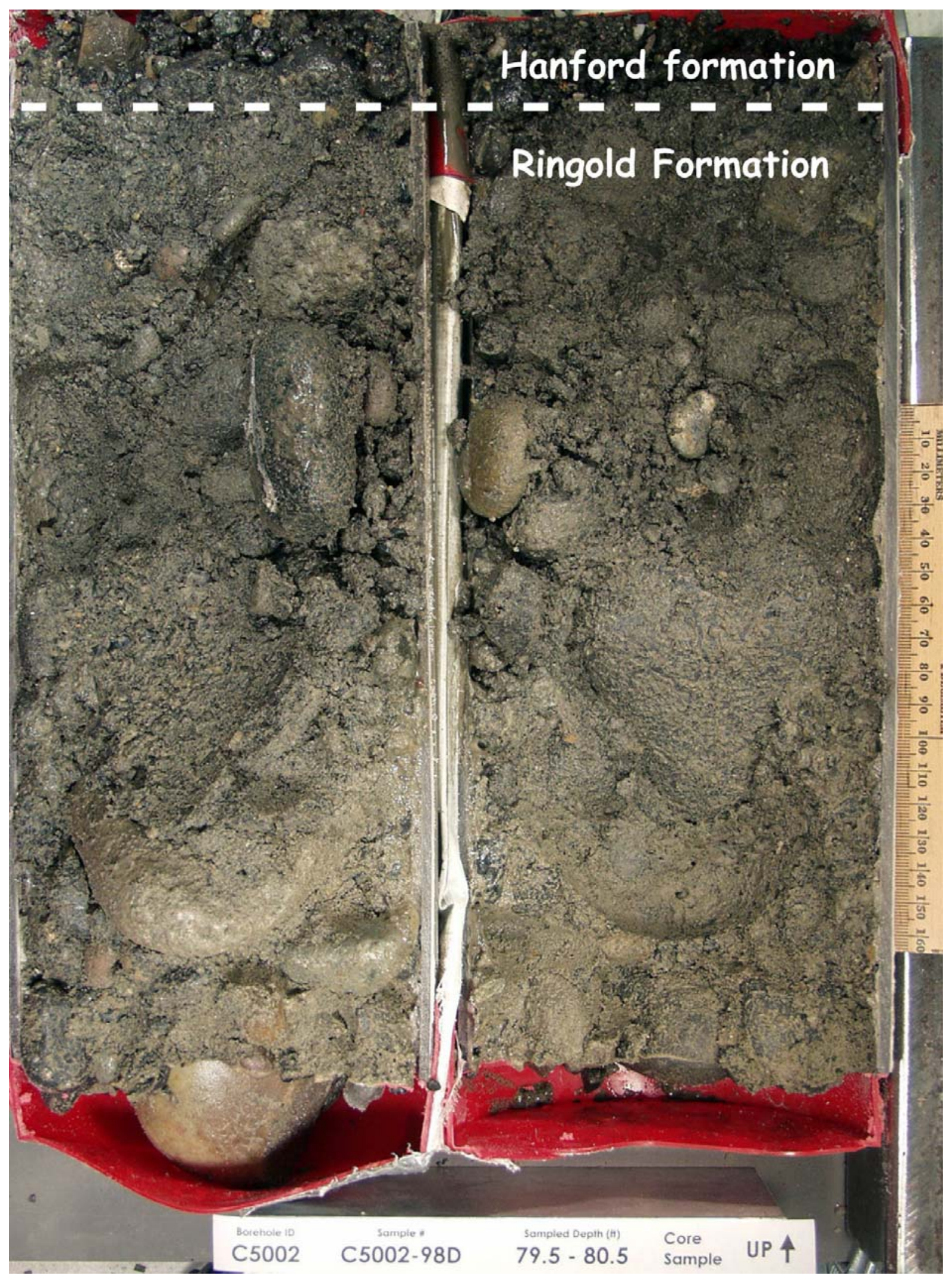




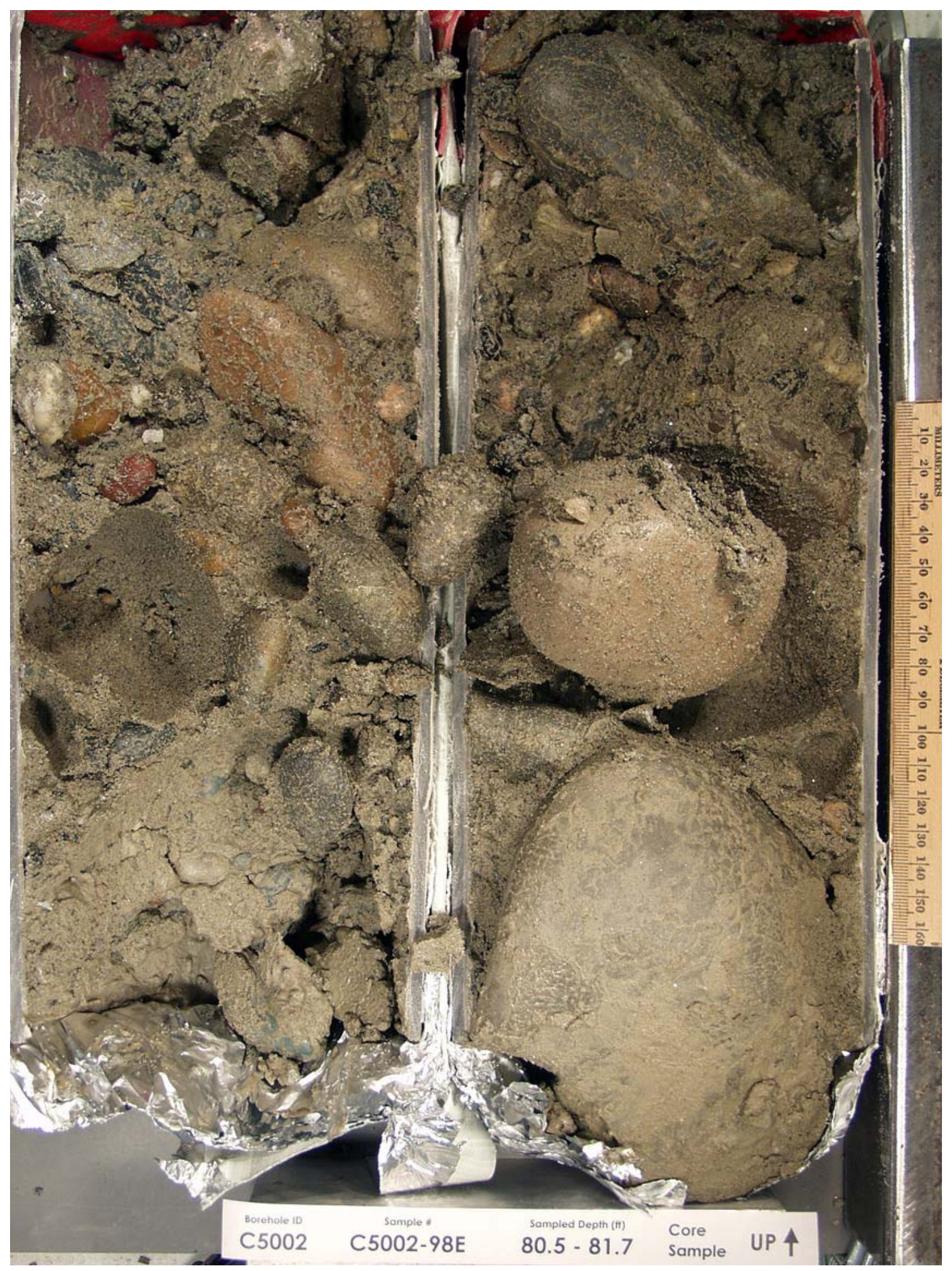




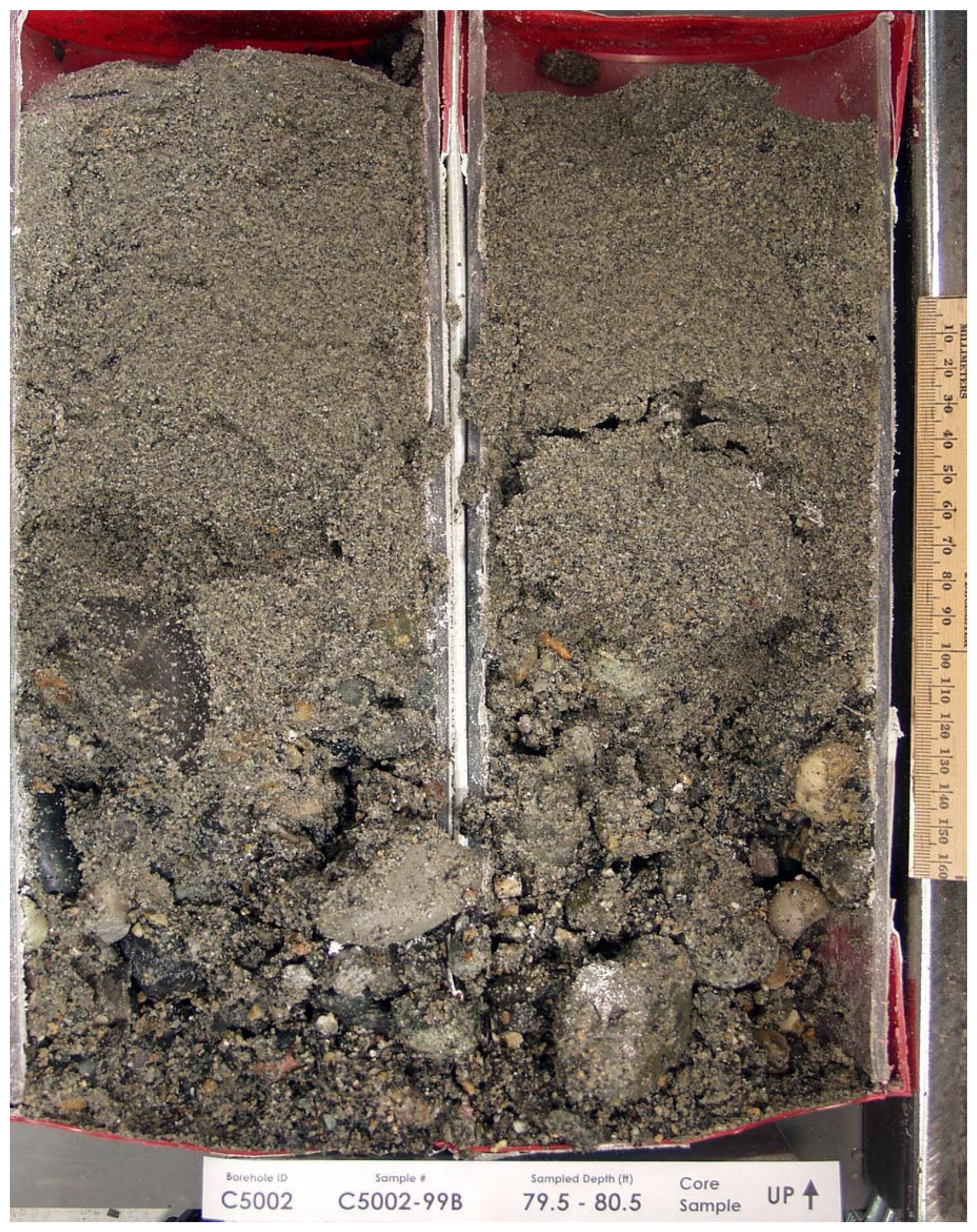




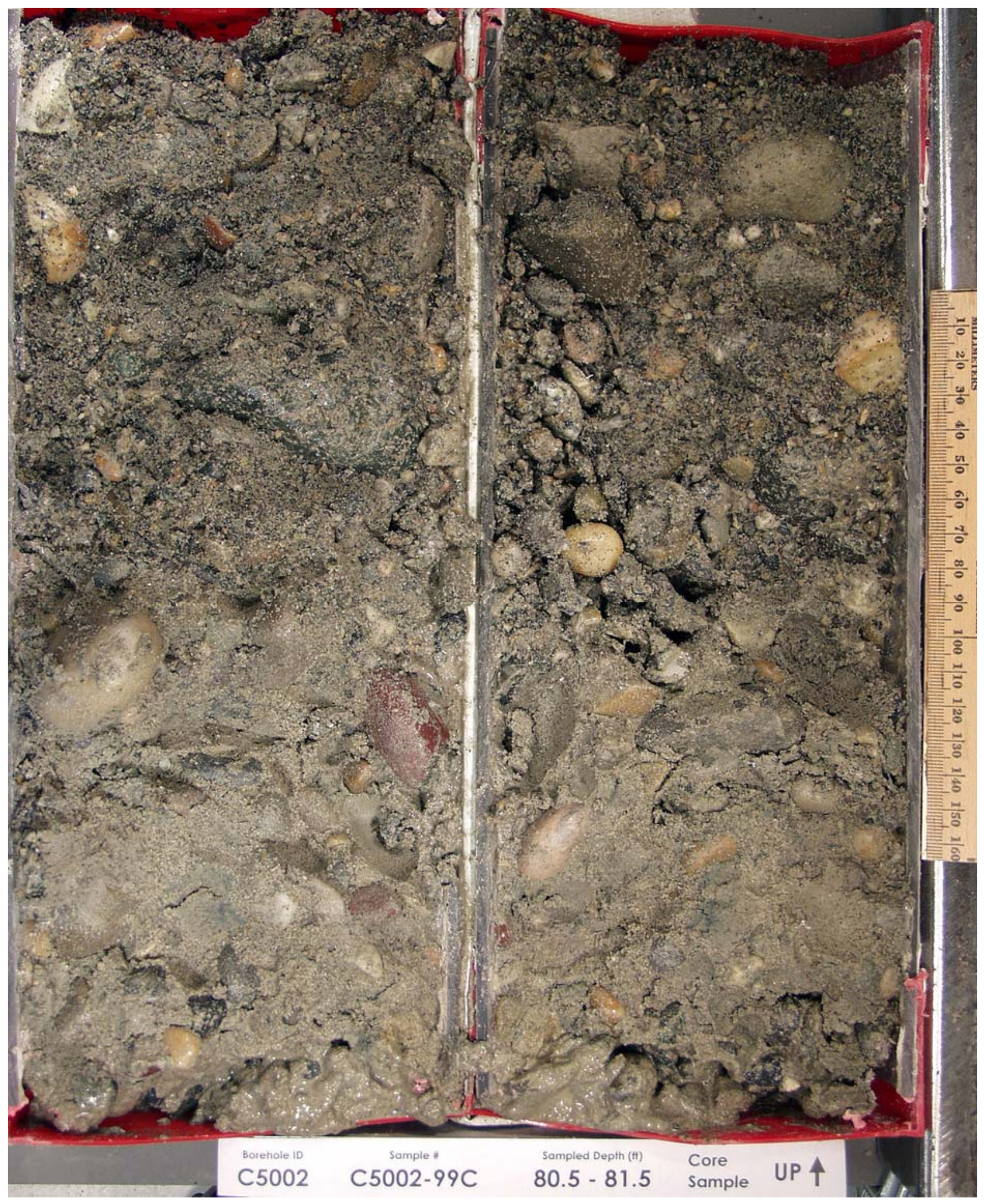




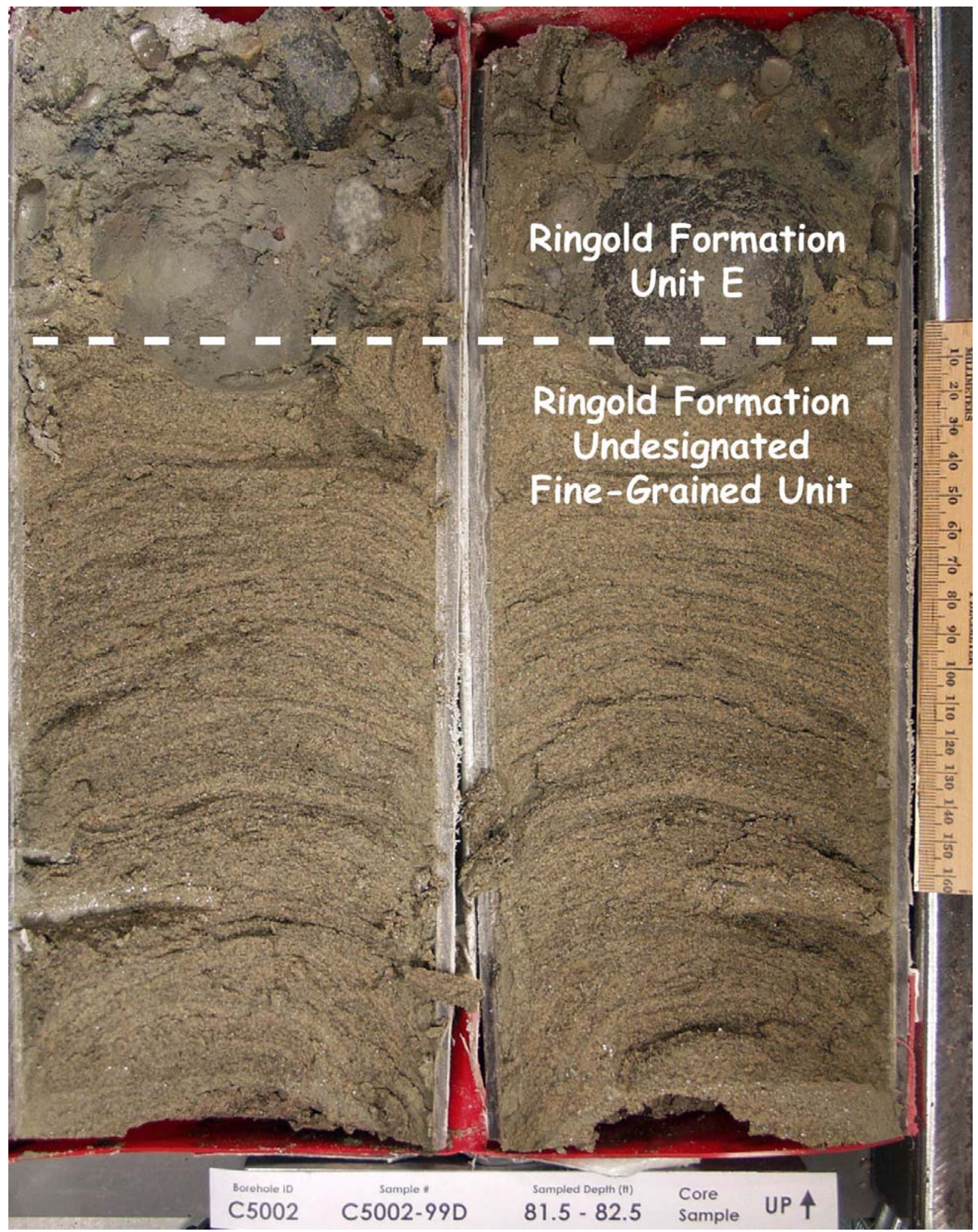




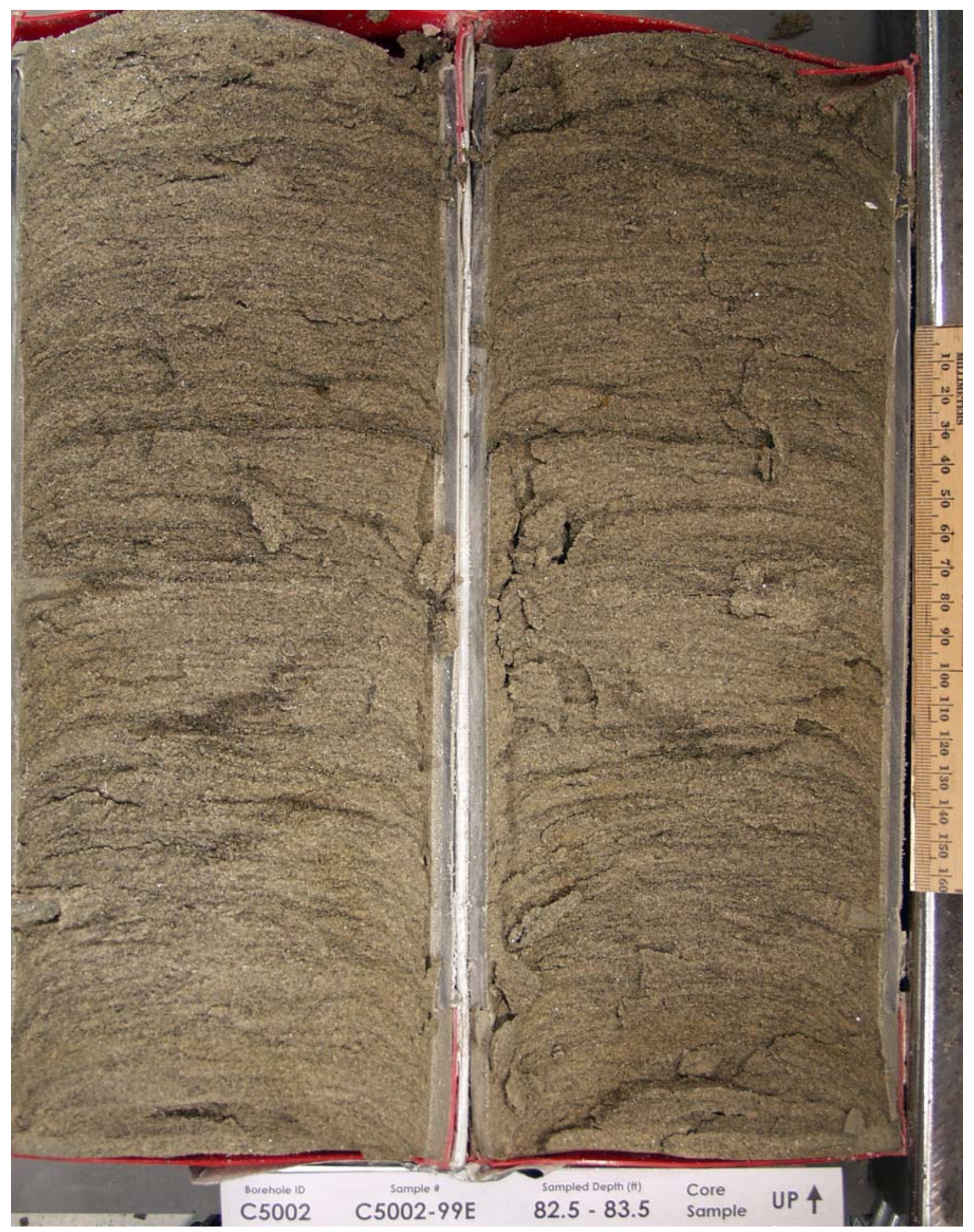




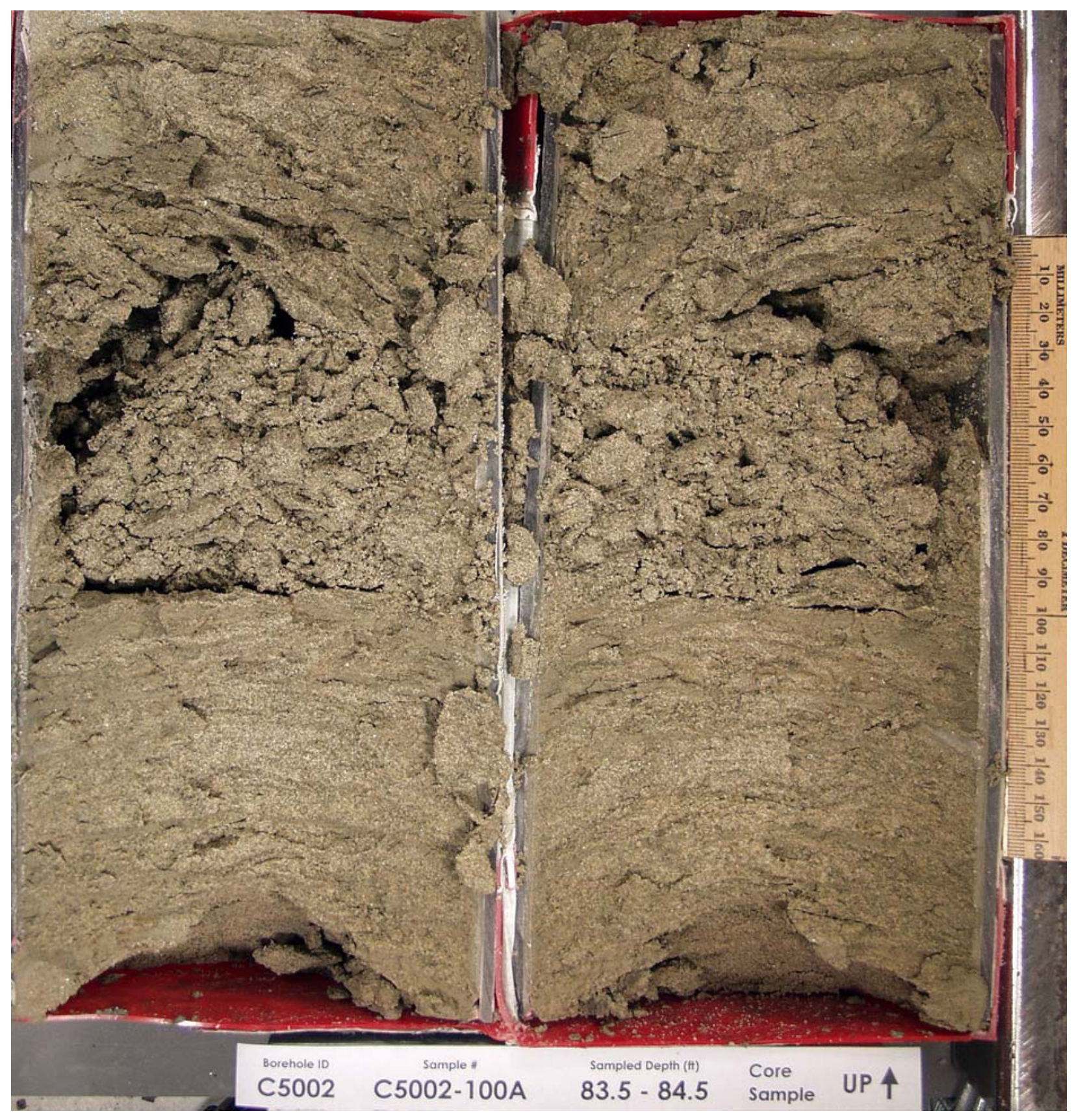




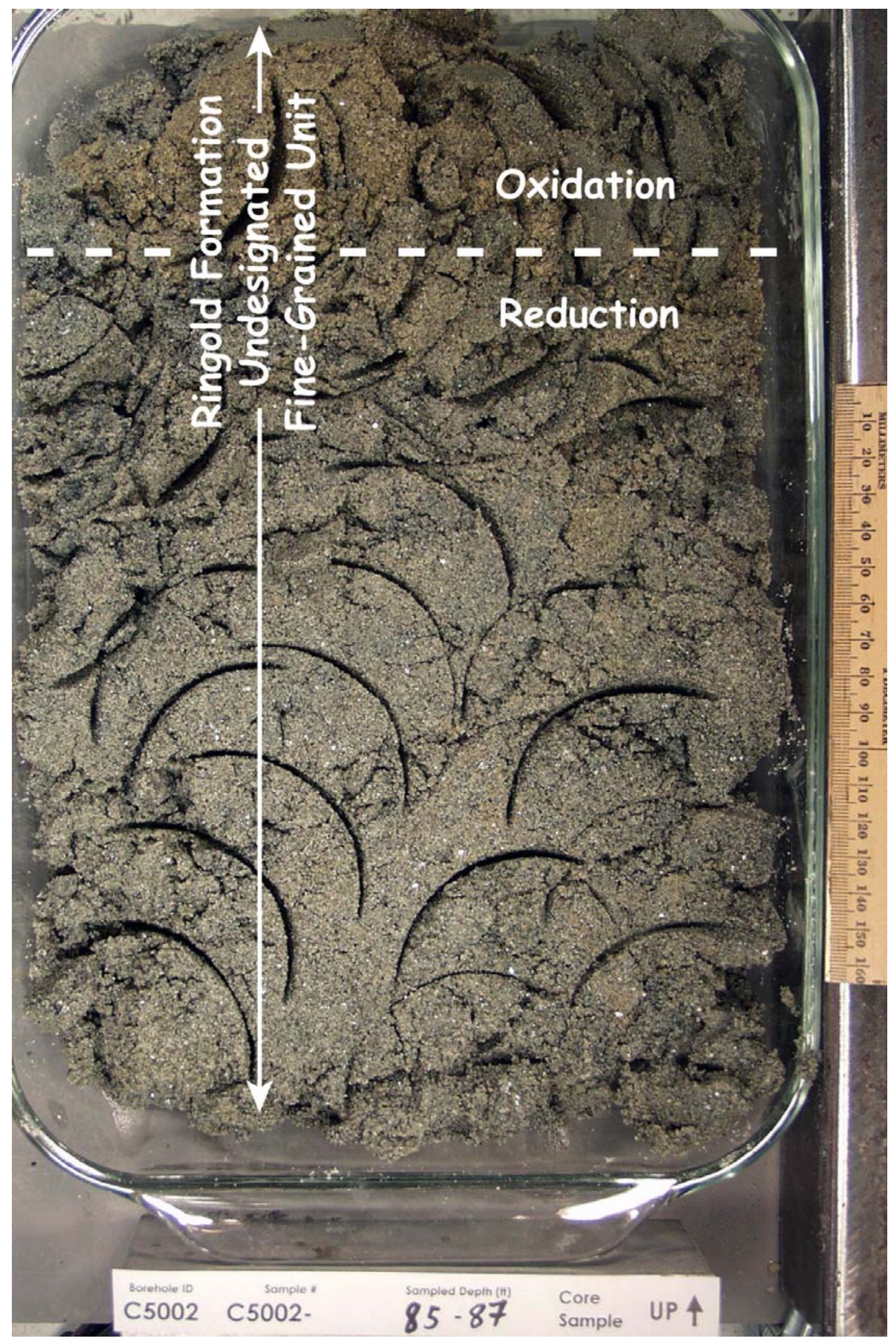




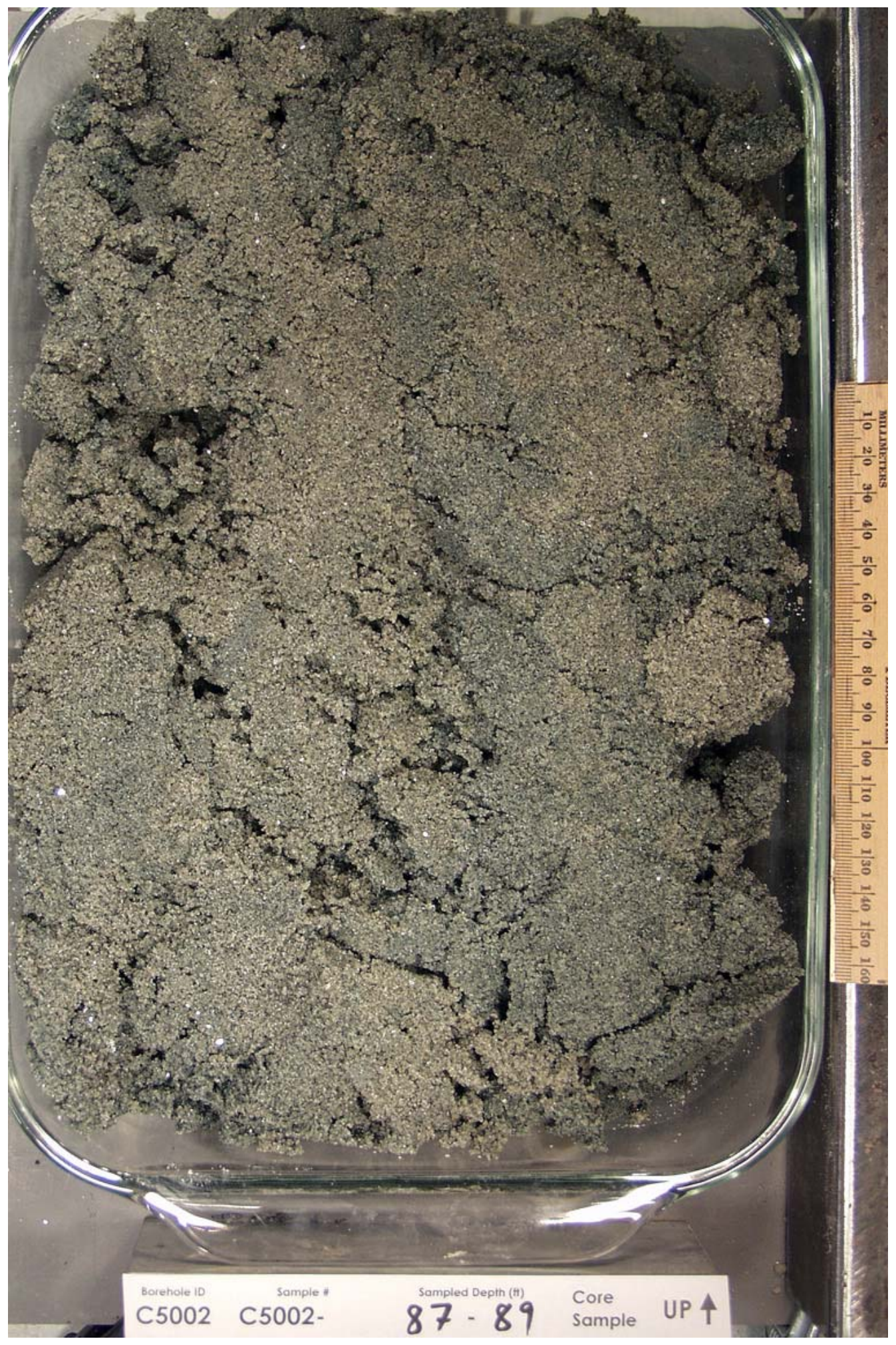




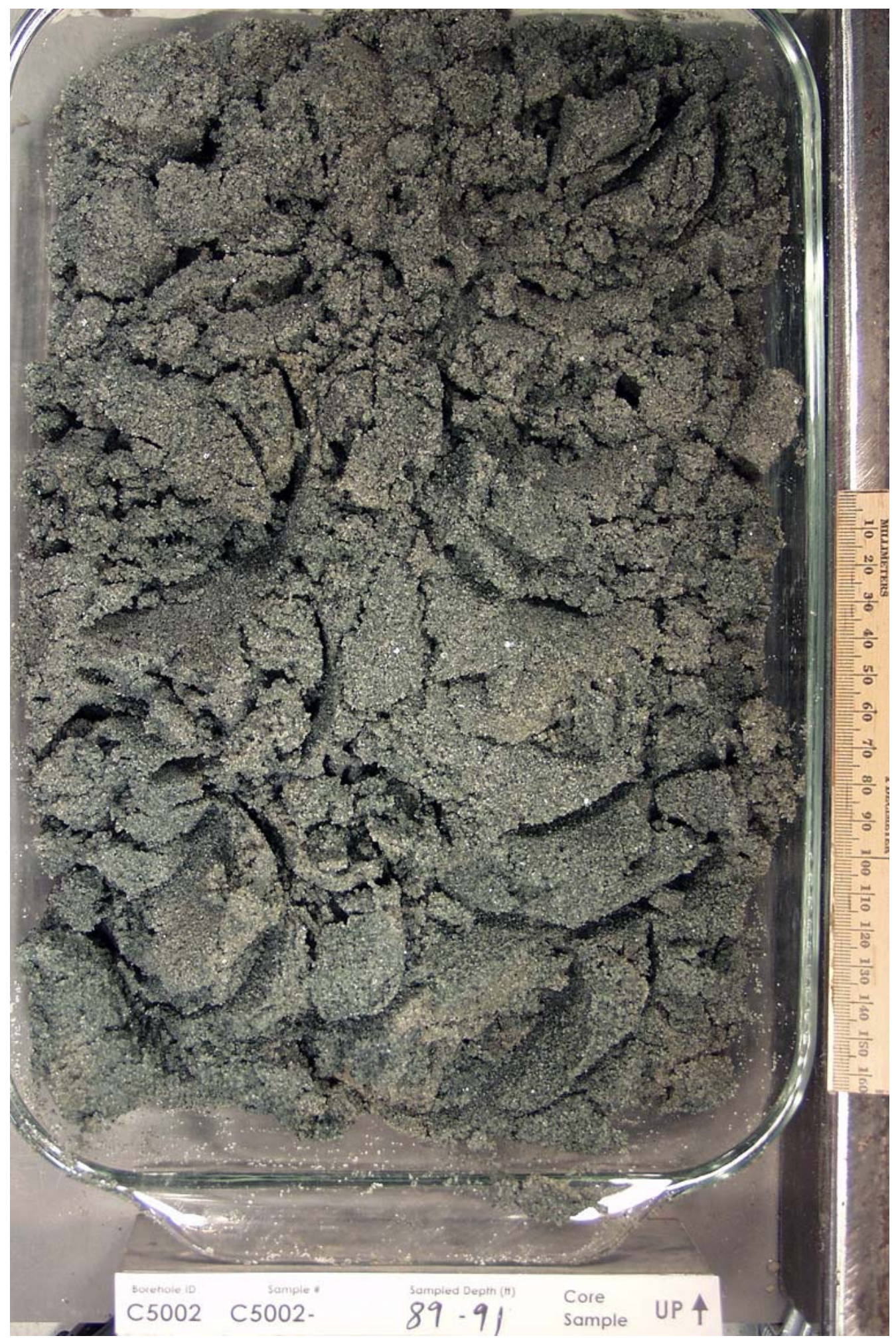




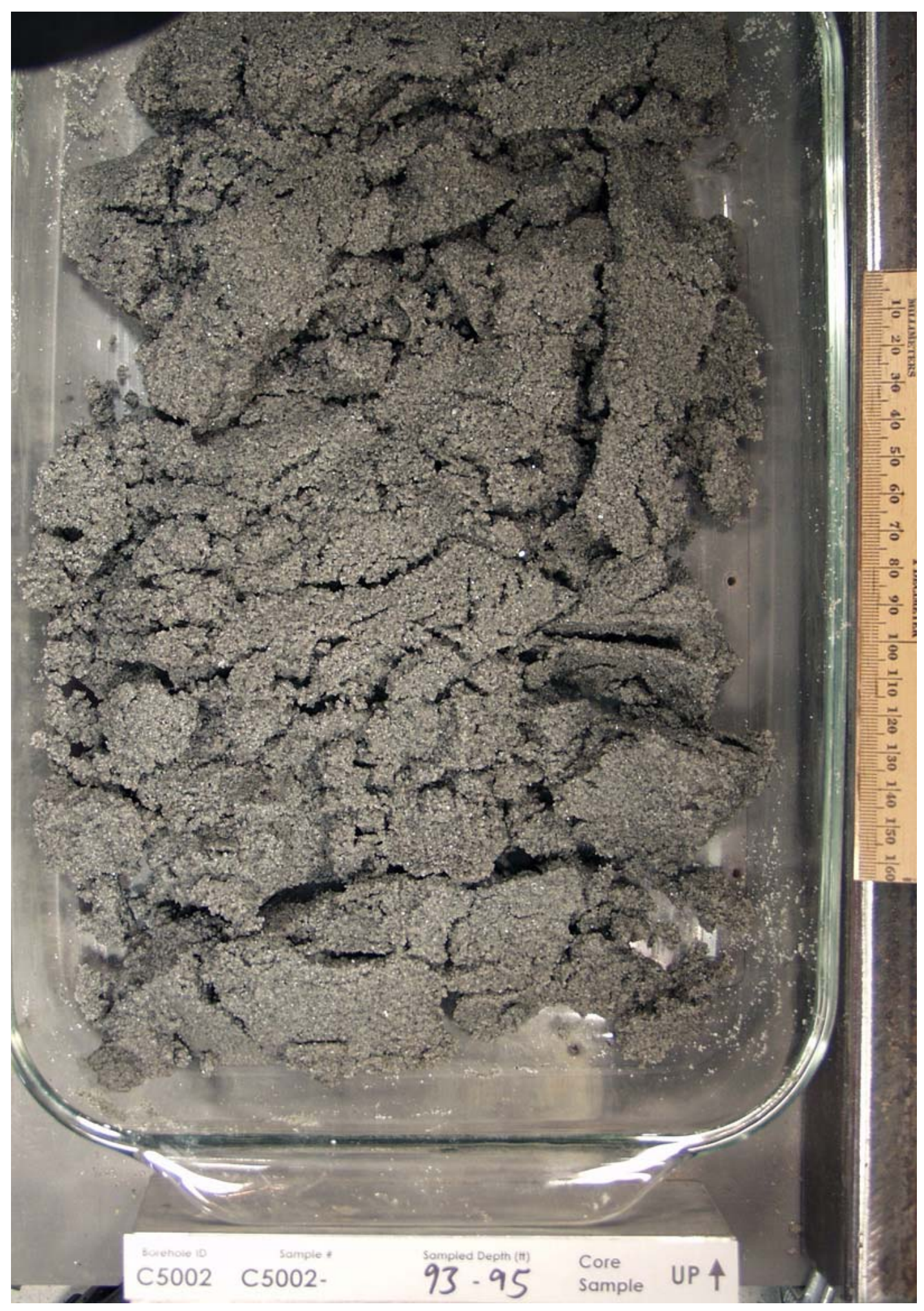




\section{Core Chain of Custody Forms}

\section{Well C4999}

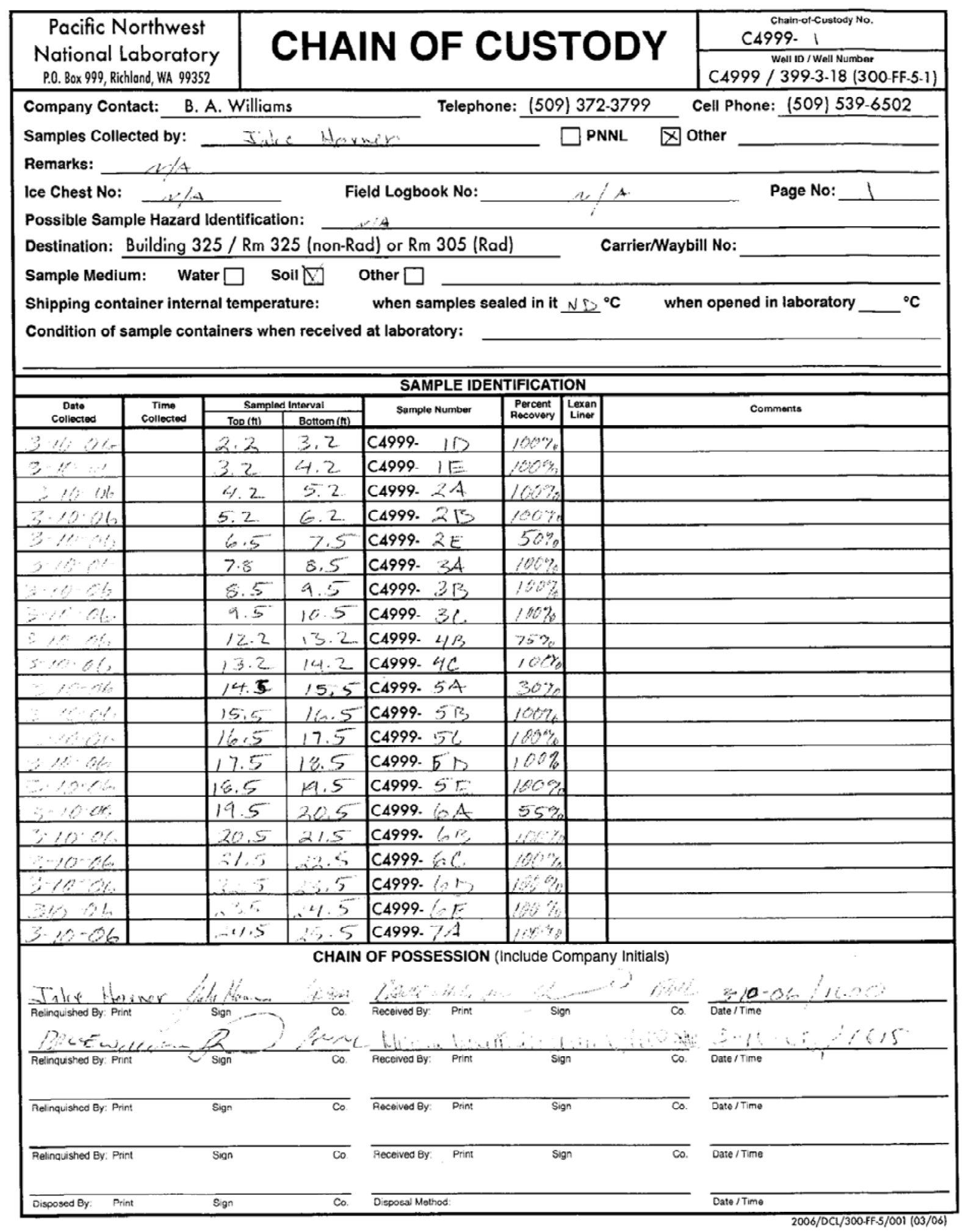




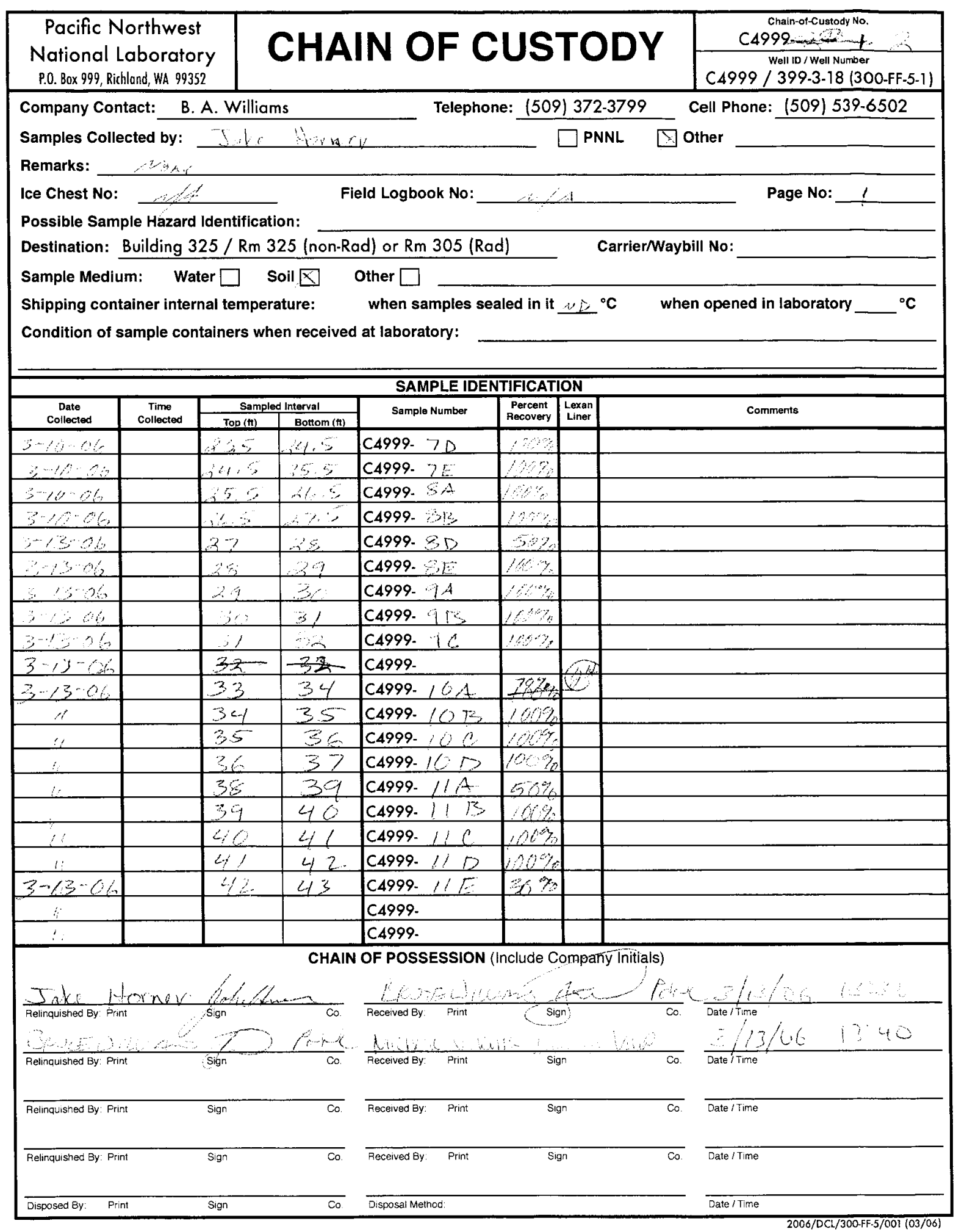




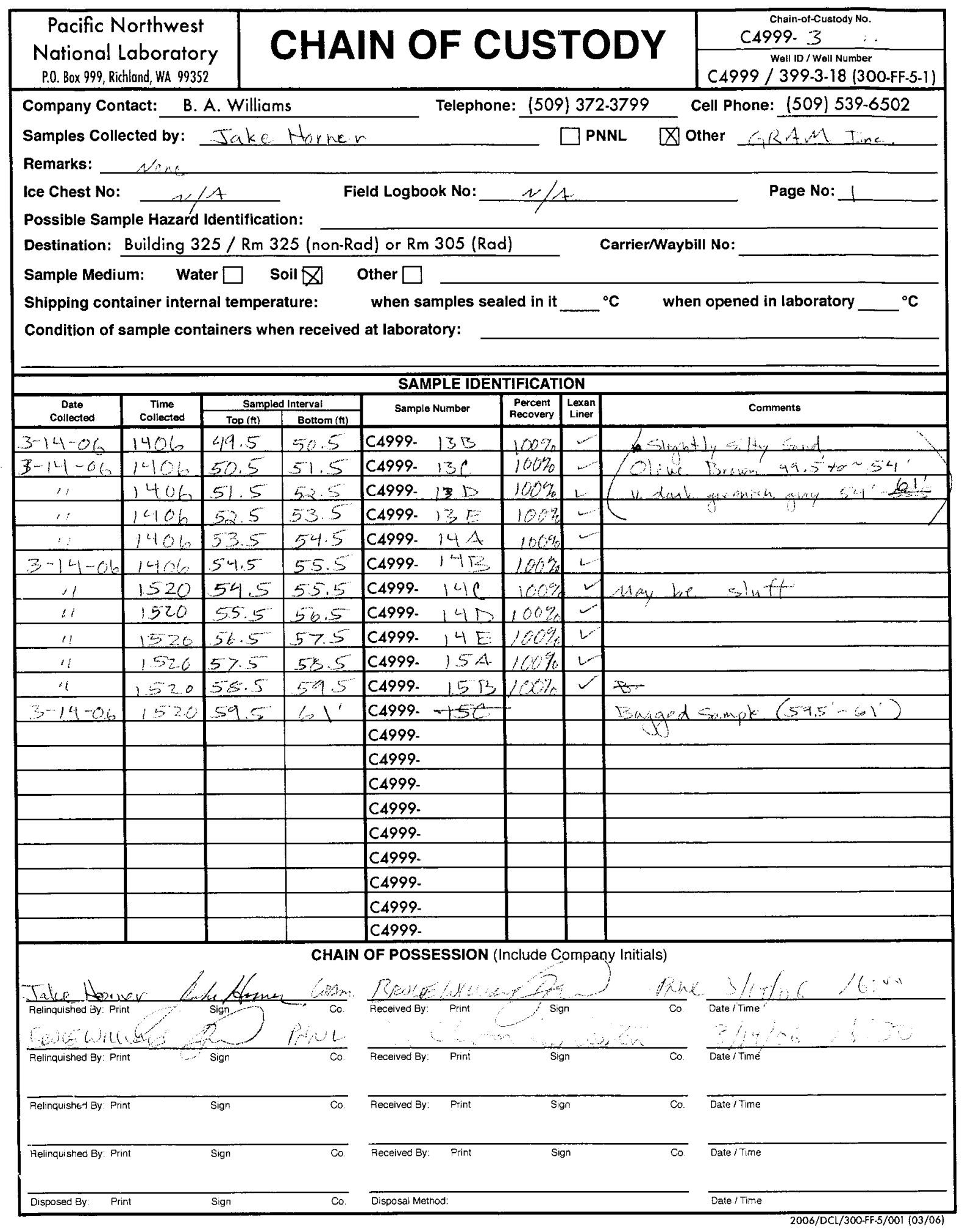




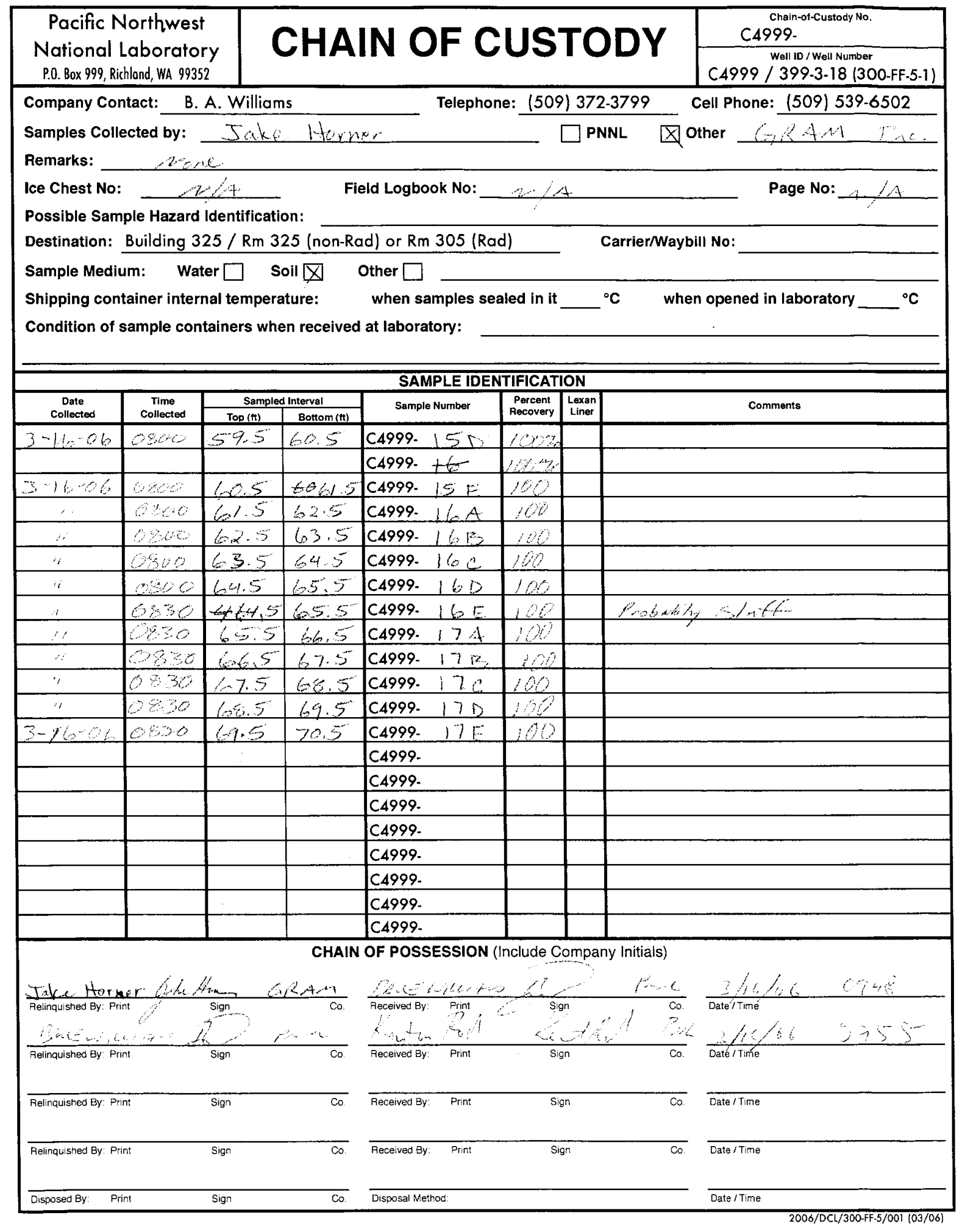




\begin{tabular}{|c|c|c|c|c|c|c|c|c|}
\hline \multicolumn{2}{|c|}{$\begin{array}{l}\text { Pacific Northwest } \\
\text { National Laboratory } \\
\text { P.0. Box } 999 \text {, Richland, WA } 99352\end{array}$} & & & & & & 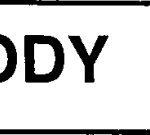 & $\begin{array}{c}\text { Chain-of-Custody No. } \\
\text { C4999- } \\
\text { Well ID/Well Number } \\
\text { C4999/399-3-18 (300-FF-5-1) }\end{array}$ \\
\hline \multicolumn{8}{|c|}{ Company Contact: $\quad$ B. A. Williams } & Cell Phone: (509) 539-6502 \\
\hline \multirow{2}{*}{\multicolumn{9}{|c|}{$\begin{array}{l}\text { Samples Collected by: Tale Hurner } \\
\text { Remarks: }\end{array}$}} \\
\hline & & & & & & & & \\
\hline \multirow{2}{*}{\multicolumn{6}{|c|}{$\begin{array}{l}\text { Ice Chest No: } \frac{1}{4} \text { Field Logbook No: } \\
\text { Possible Sample Hazard Identification: }\end{array}$}} & & & Page No: $,-1,1$ \\
\hline & & & & & & & & \\
\hline \multicolumn{6}{|c|}{ Destination: Building 325 / Rm 325 (non-Rad) or Rm 305 (Rad) } & & CarrierWayb & ill No: \\
\hline \multicolumn{6}{|c|}{ Sample Medium: : Water $\square \quad$ Soil $\square \quad$ Other $\square$} & & & \\
\hline \multicolumn{4}{|c|}{ Shipping container internal temperature: } & \multicolumn{4}{|c|}{ Condition of sample containers when received at laboratory: } & n opened in laboratory ___ ${ }^{\circ} \mathrm{C}$ \\
\hline \multicolumn{9}{|c|}{ SAMPLE IDENTIFICATION } \\
\hline $\begin{array}{c}\text { Date } \\
\text { Collected } \\
\end{array}$ & $\begin{array}{c}\text { Time } \\
\text { collected }\end{array}$ & \multicolumn{2}{|c|}{$\begin{array}{l}\text { Sampled Interval } \\
\text { Top (tt) } 1 \text { Botom (ti) } \\
\end{array}$} & Sample Number & 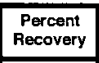 & \begin{tabular}{|c|} 
Lexan \\
Liner \\
\end{tabular} & \multicolumn{2}{|r|}{ Comments } \\
\hline \multirow{2}{*}{$3-17 \cdot 06$} & 1400 & 70.5 & 71.5 & C4999. 1813 & $100 \%$ & & \multicolumn{2}{|c|}{$50 \% \quad 504 \pi h$} \\
\hline & 1400 & 71.5 & 725 & C4999- $18 C$ & 100 & & \multicolumn{2}{|c|}{ i } \\
\hline \multirow{2}{*}{ 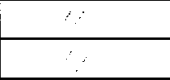 } & 1400 & $7 \ldots \cdot 5$ & $7 \% 3$ & C4999- I\& & 100 & & \multicolumn{2}{|c|}{ 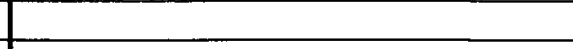 } \\
\hline & 1400 & 78,9 & -1.1 .5 & C4999- $18 E$ & 100 & & \multirow{2}{*}{\multicolumn{2}{|c|}{-2}} \\
\hline \multirow{2}{*}{ 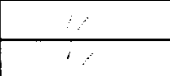 } & 1400 & 74.5 & $\cdots 5$ & C4999. $19 \mathrm{~A}$ & 100 & & & \\
\hline & 1900 & 75.5 & 76.5 & C4999. $19 \mathrm{TS}$ & .00 & & & \\
\hline+1 & 1500 & 760 & 775 & C4999. 19. & 100 & & & \\
\hline$\because$ & 1500 & 77.6 & 76.5 & C4999-19S & 10 & & & \\
\hline$\because$ & 1500 & 72.5 & 79.5 & C4999. $19 \mathrm{E}$ & 102 & & & \\
\hline$\because$ & 1.50 & $7+5$ & 80.5 & C4999- $20 A$ & 10 & & & \\
\hline $3-17-06$ & 1500 & 30.5 & 81.5 & C4999. 20B & 100 & & & \\
\hline $3-20-26$ & 1220 & 21.5 & $8 \cdot 5$ & C4999. 200 & 10 & & & \\
\hline$\therefore$ & 2.29 & 82.5 & 83.5 & C4999-20E & 00 & & & \\
\hline$\because$ & $\therefore=0$ & 93.5 & 54.5 & C4999. $21 A$ & 10 & & & \\
\hline$\because$ & 2.2 & 84.5 & 55.5 & C4999- का & 6 & & & \\
\hline$\therefore$ & 120 & 25,5 & 86.5 & C4999-2:C & $\Leftrightarrow$ & & & \\
\hline $3 \cdots 20,06$ & 120 & 25 & 87.5 & C4999. 21 D & 10 & & & \\
\hline & 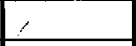 & & & C4999. & & & & \\
\hline & & & & C4999. & & & & \\
\hline & & & & C4999. & & & & \\
\hline & & & & C4999. & & & & \\
\hline & & & CHAIN & OF POSSESSION & nclude Ge & empan & y Initials) & \\
\hline Sake Hor & & Actane & $-G \angle A M$ & Satew & 12 & & int L & 3,306 \\
\hline Reiinquished By: Prin & & Sign & & $\begin{array}{ll}\text { Received By. } & \text { Print }\end{array}$ & Sigr & & & Date /Tríne \\
\hline you all & Lots $T$ & $\ldots$ & 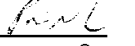 & Lond uldo & 1. & & nan & 32066 \\
\hline Relinquished By: Prin & & Sign & $c_{0}$ & Feceived By: Print & Sigr & & co. & Date/Time \\
\hline Relinquished By: Prin & & Sign & $\mathrm{co}_{\mathrm{L}}$ & Received By: Print & sigi & & $\overline{C o}$ & $\overline{\text { Date } / \text { Time }}$ \\
\hline Relinquished By: Prin & & Sign & $\overline{c o}$ & Received By: Print & & & Co & Date/Time \\
\hline Disposed By: & & Sign & Co. & Disposal Method: & & & & Date/Time \\
\hline
\end{tabular}




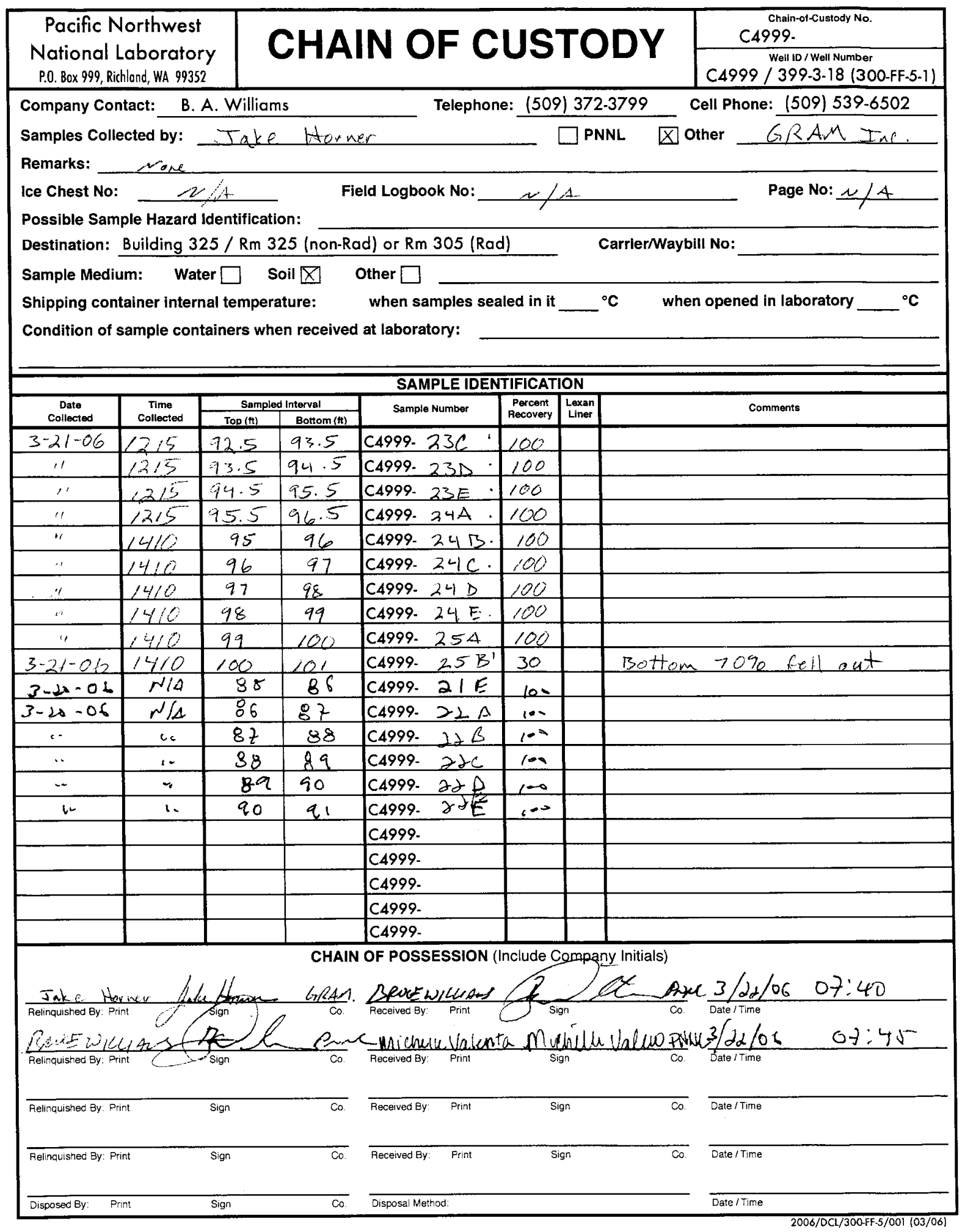




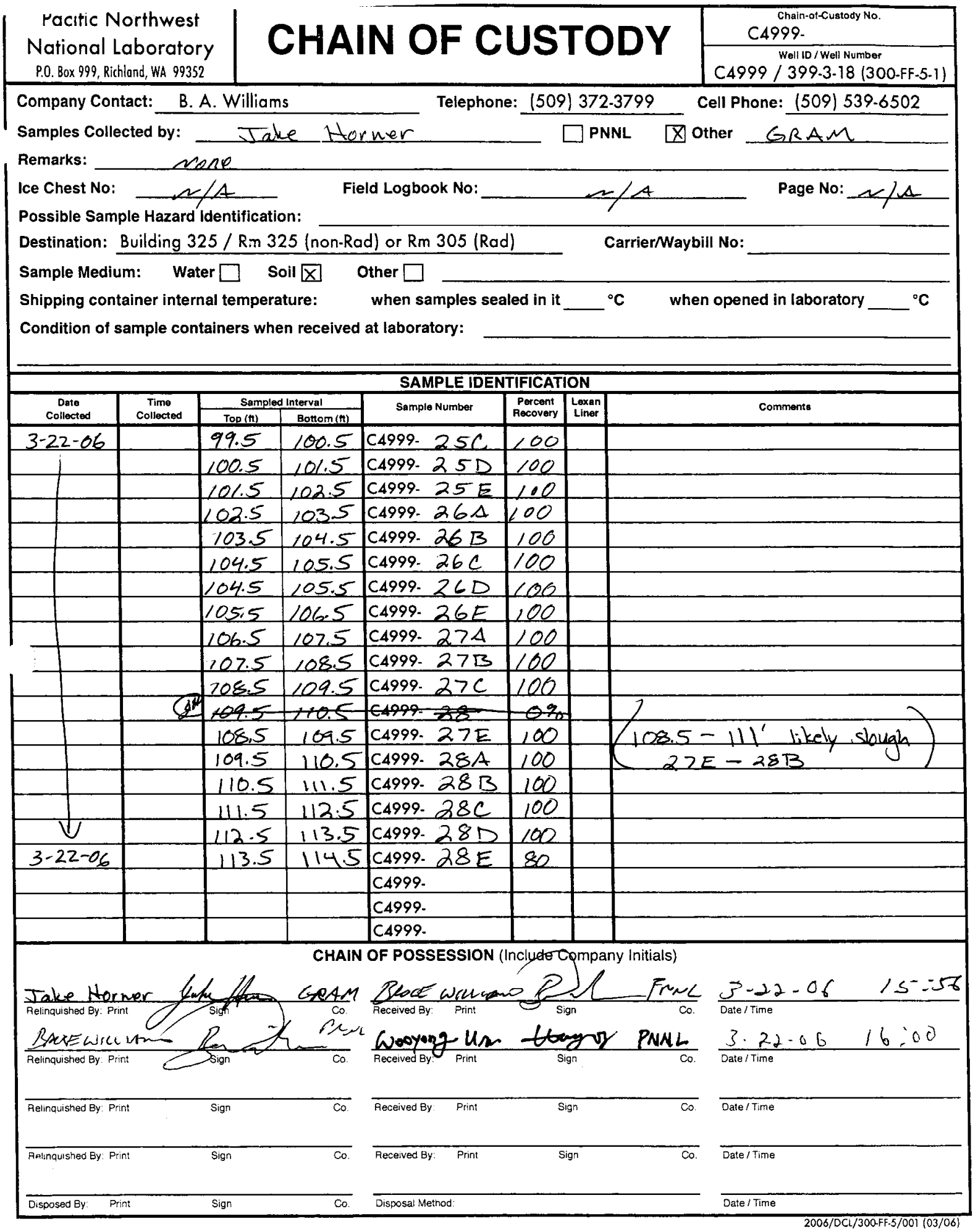




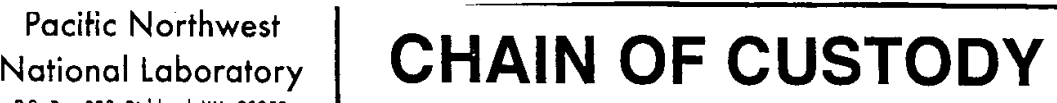 \\ P.0. Box 999, Richland, WA 99352}

Company Contact: B. A. Williams

Telephone: (509) 372-3799

Cell Phone: (509) 539-6502

Samples Collected by: Jake Horner

$\square$ PNNL 冈 Other GRAMInc.

Remarks:

Ice Chest No: rone

Possible Sample Hazard Identification:

Field Logbook No:

ฯ $/ 4$

Page No:

C4999.

Well ID / Well Number

C4999 / 399-3-18 (300-FF-5-1)

Destination: Building 325 / Rm 325 (non-Rad) or Rm 305 (Rad) Carrier/Waybill No:

Sample Medium: Water $\square \quad$ Soil $\varnothing \quad$ Other $\square$

Shipping container internal temperature:

when samples sealed in it

${ }^{\circ} \mathrm{C}$

when opened in laboratory

${ }^{\circ} \mathrm{C}$

Condition of sample containers when received at laboratory:

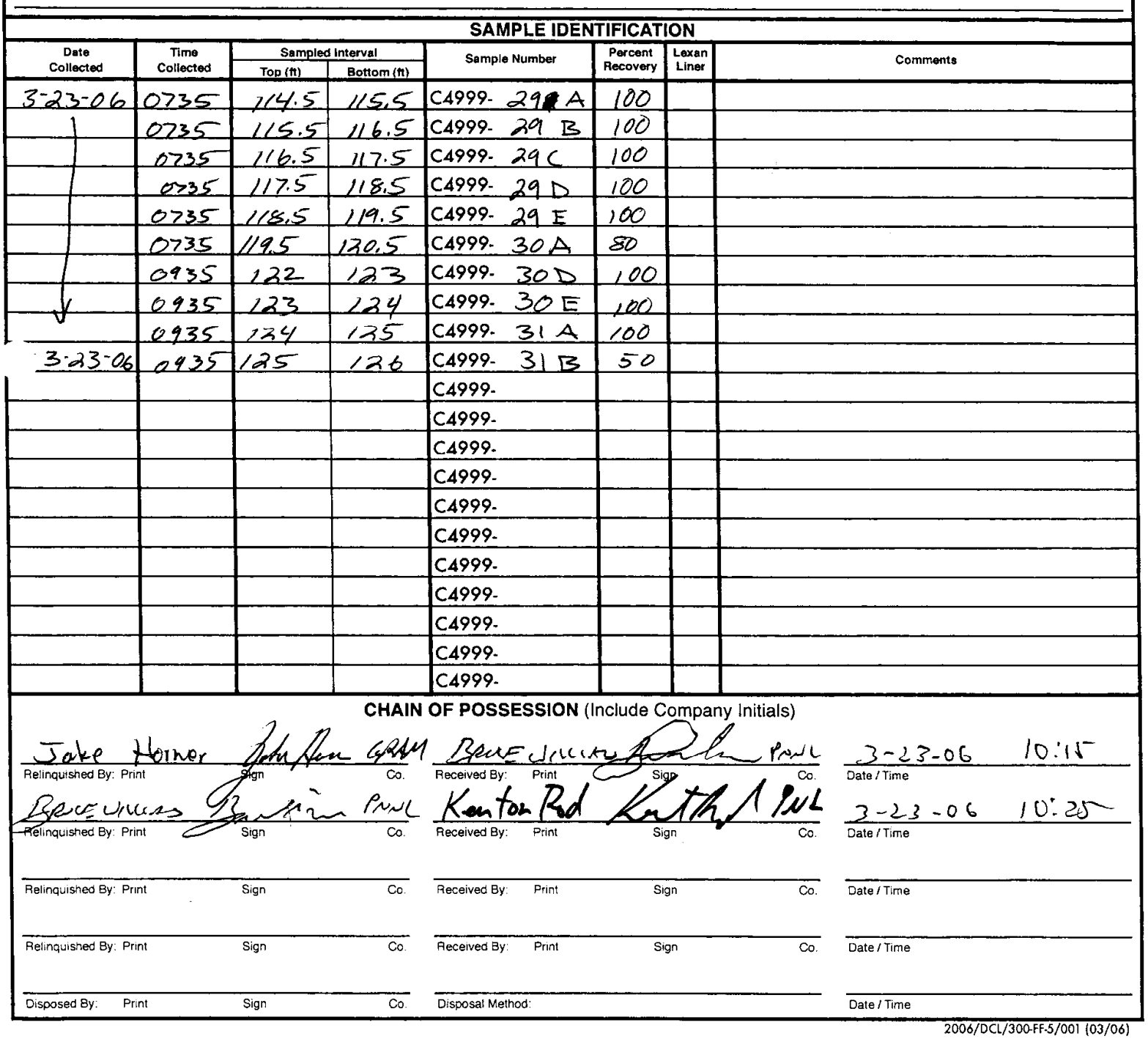




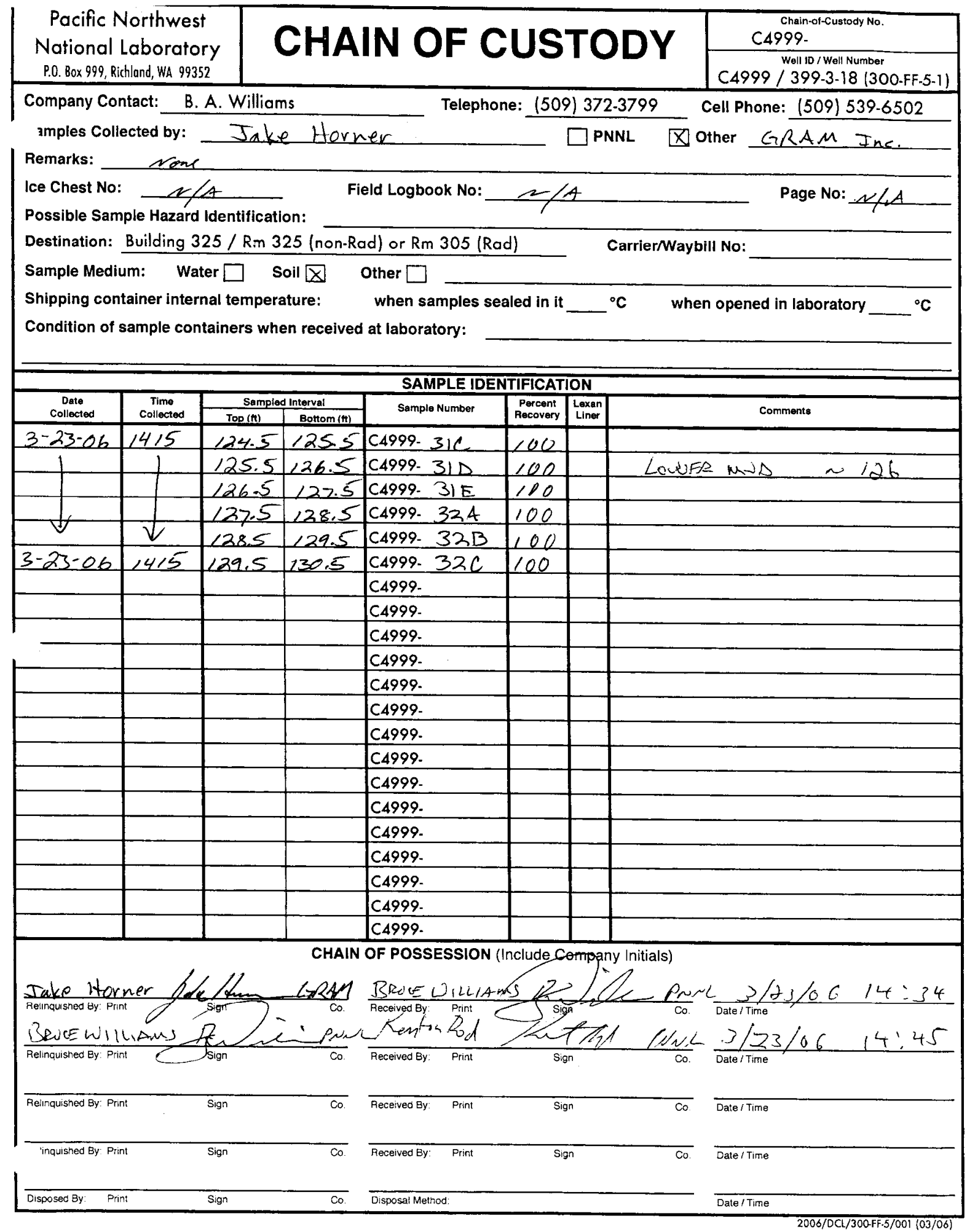




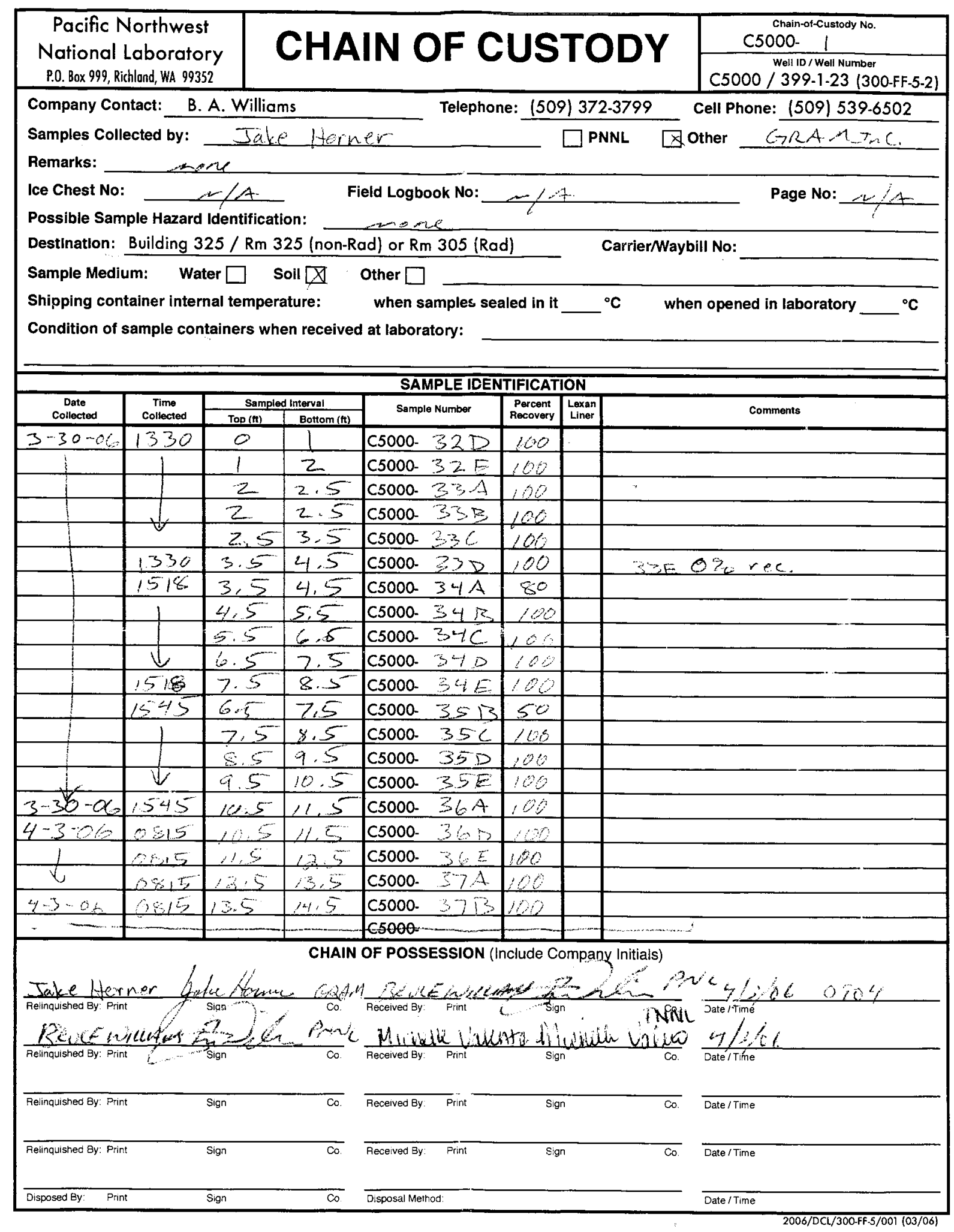




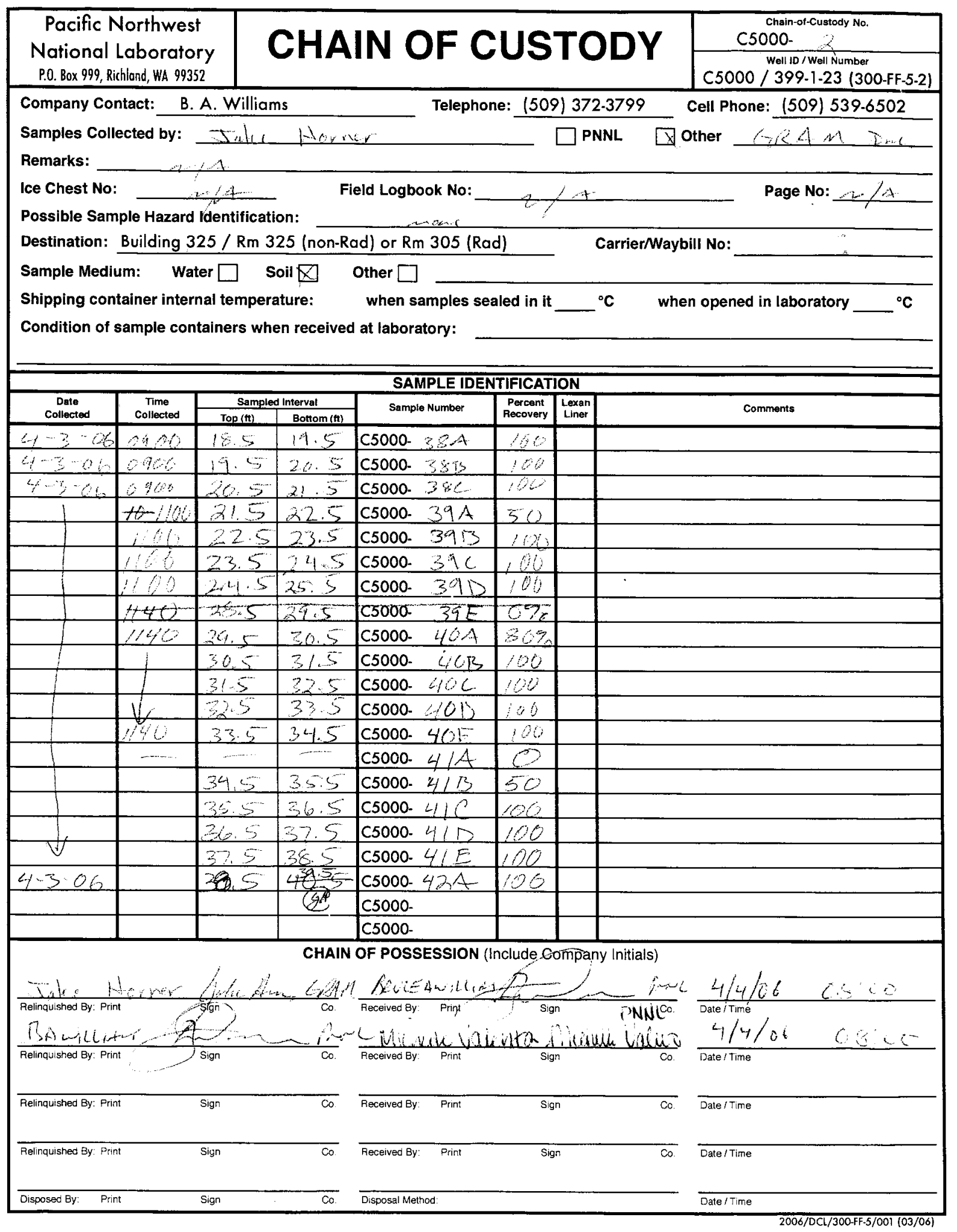




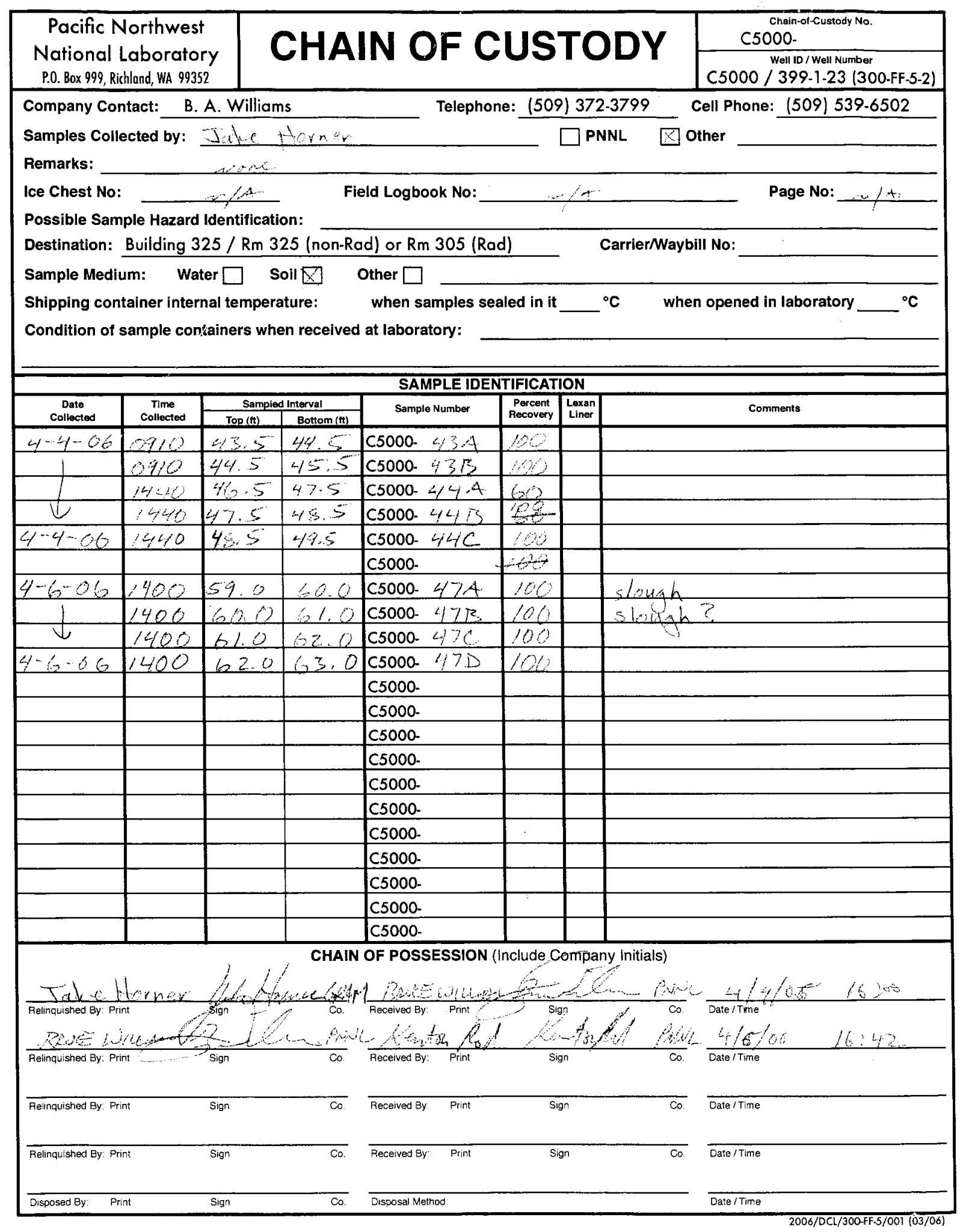




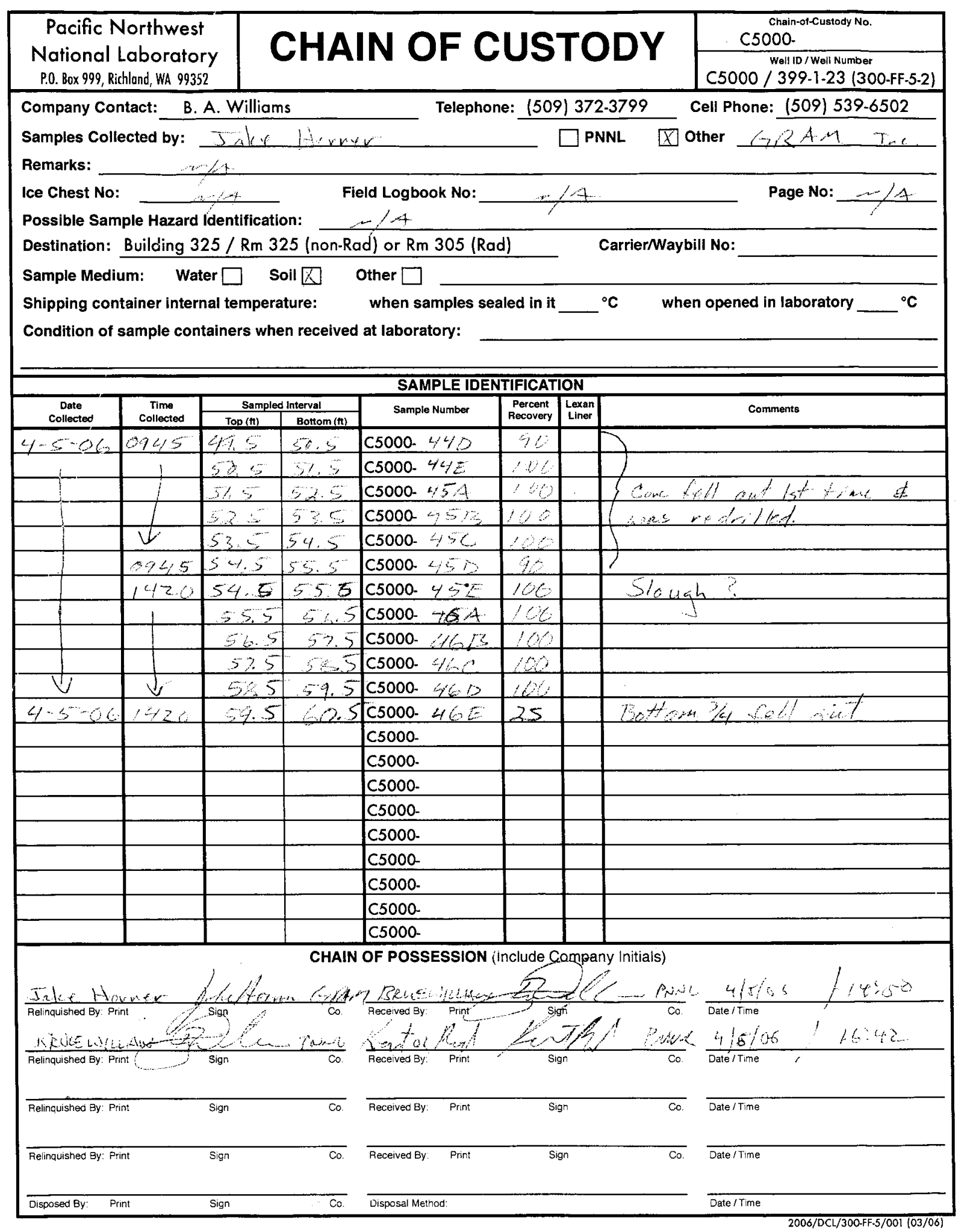




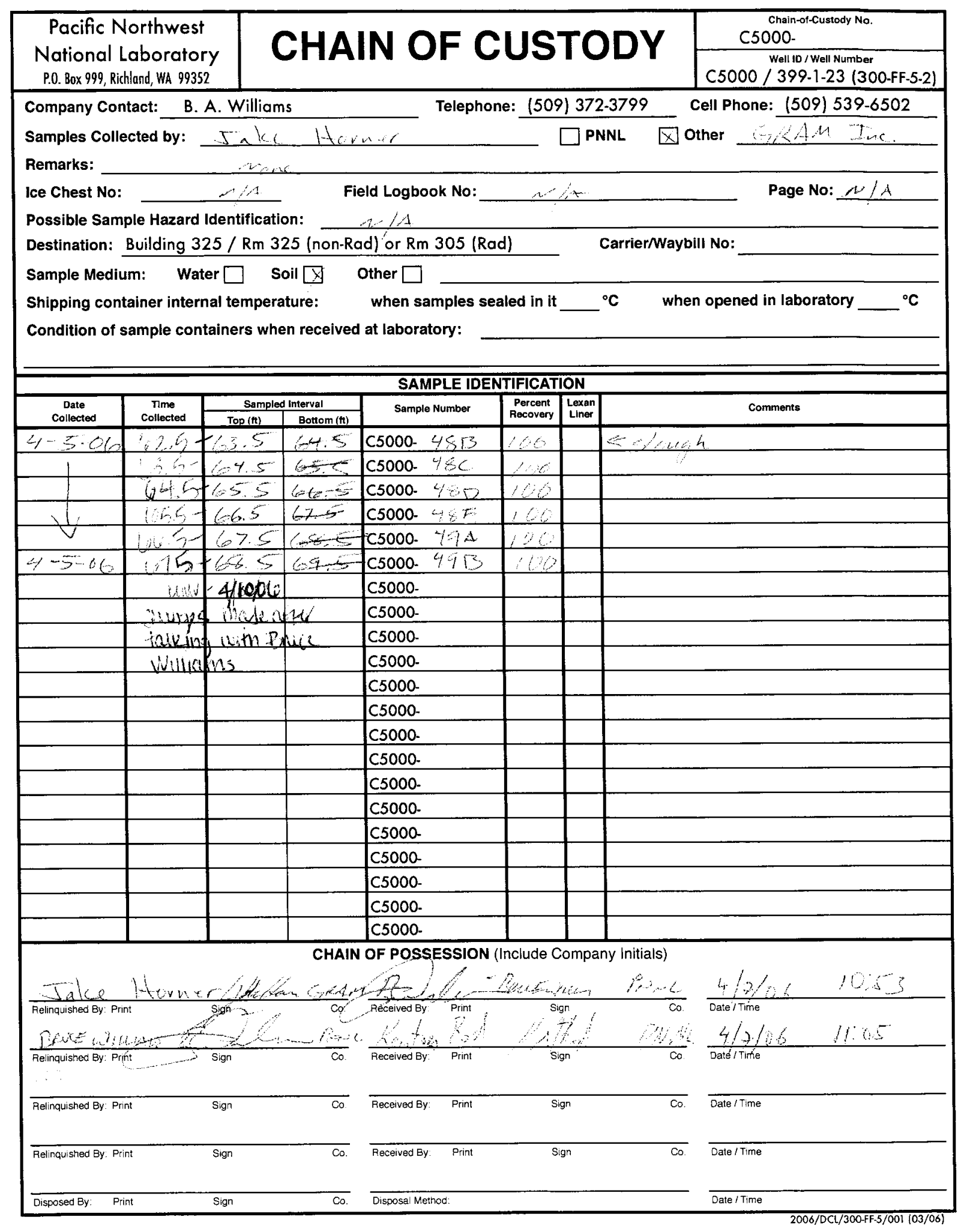




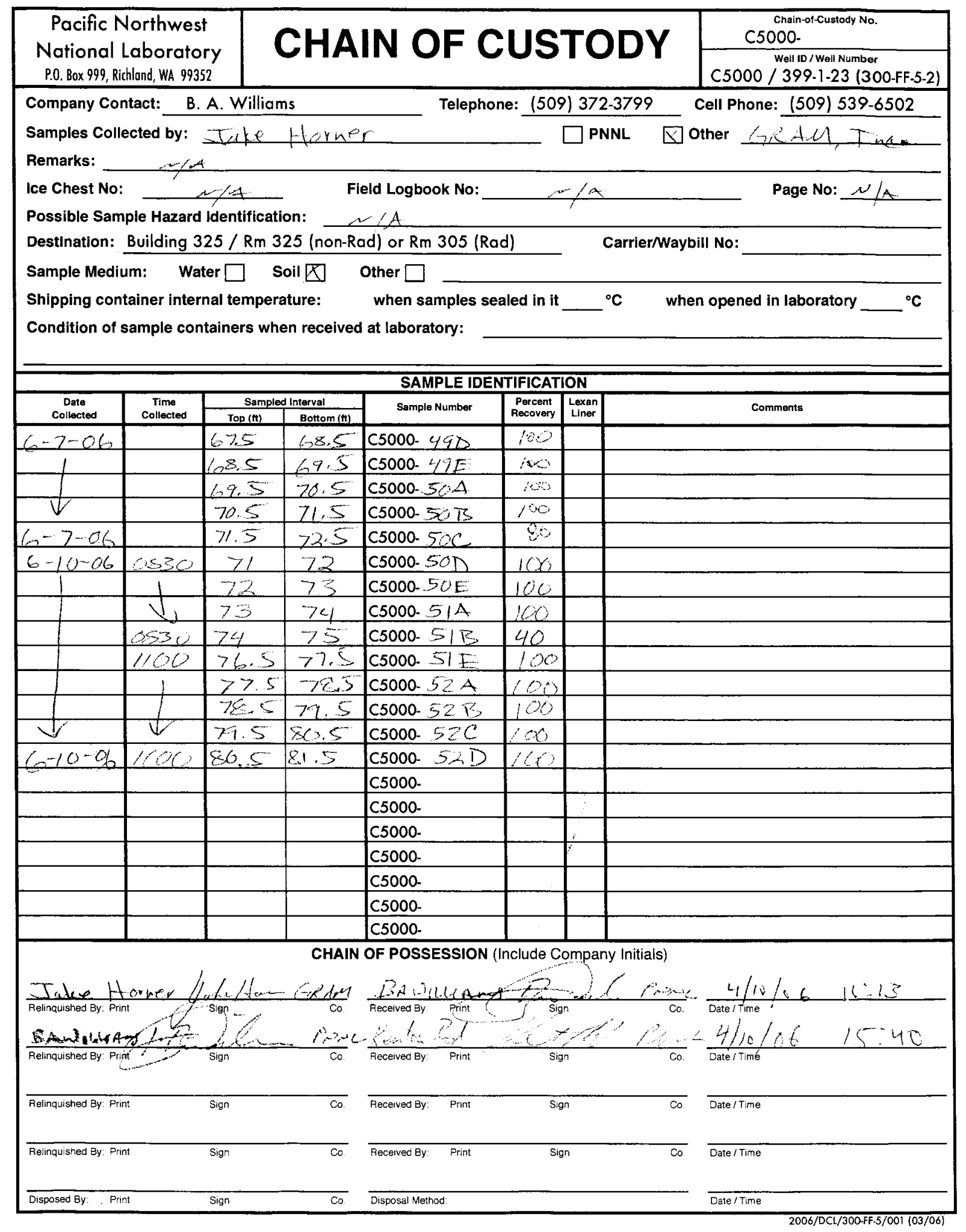




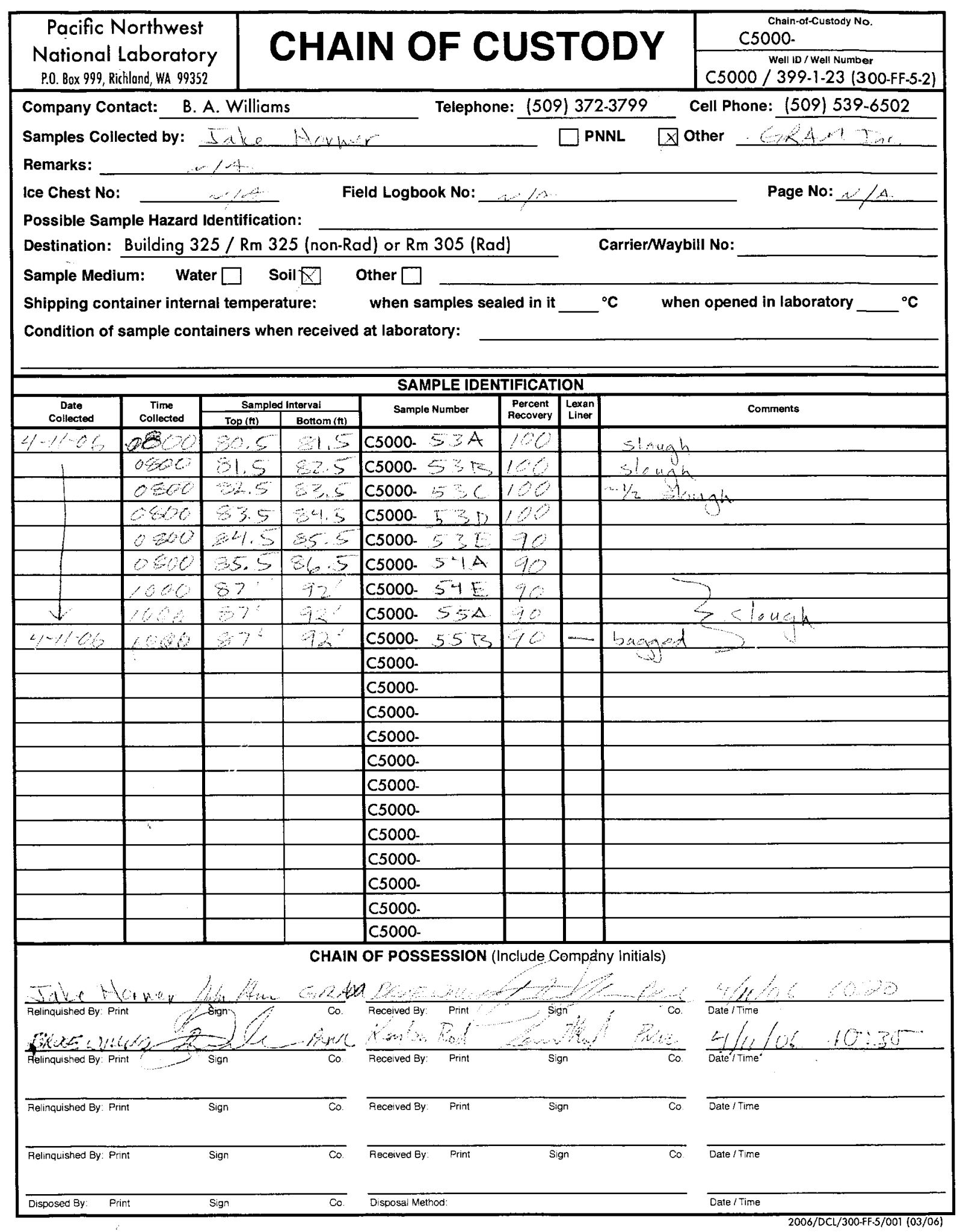




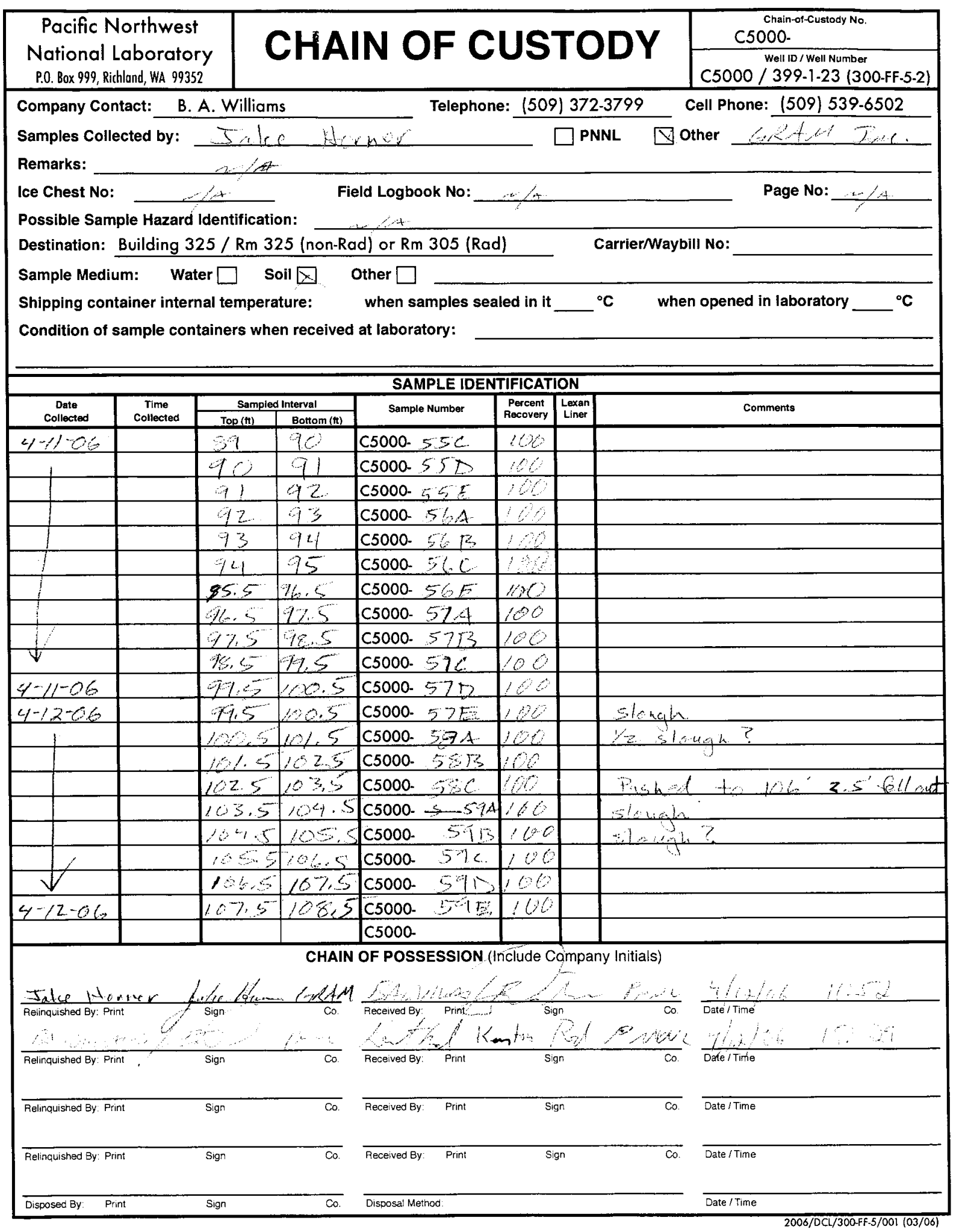




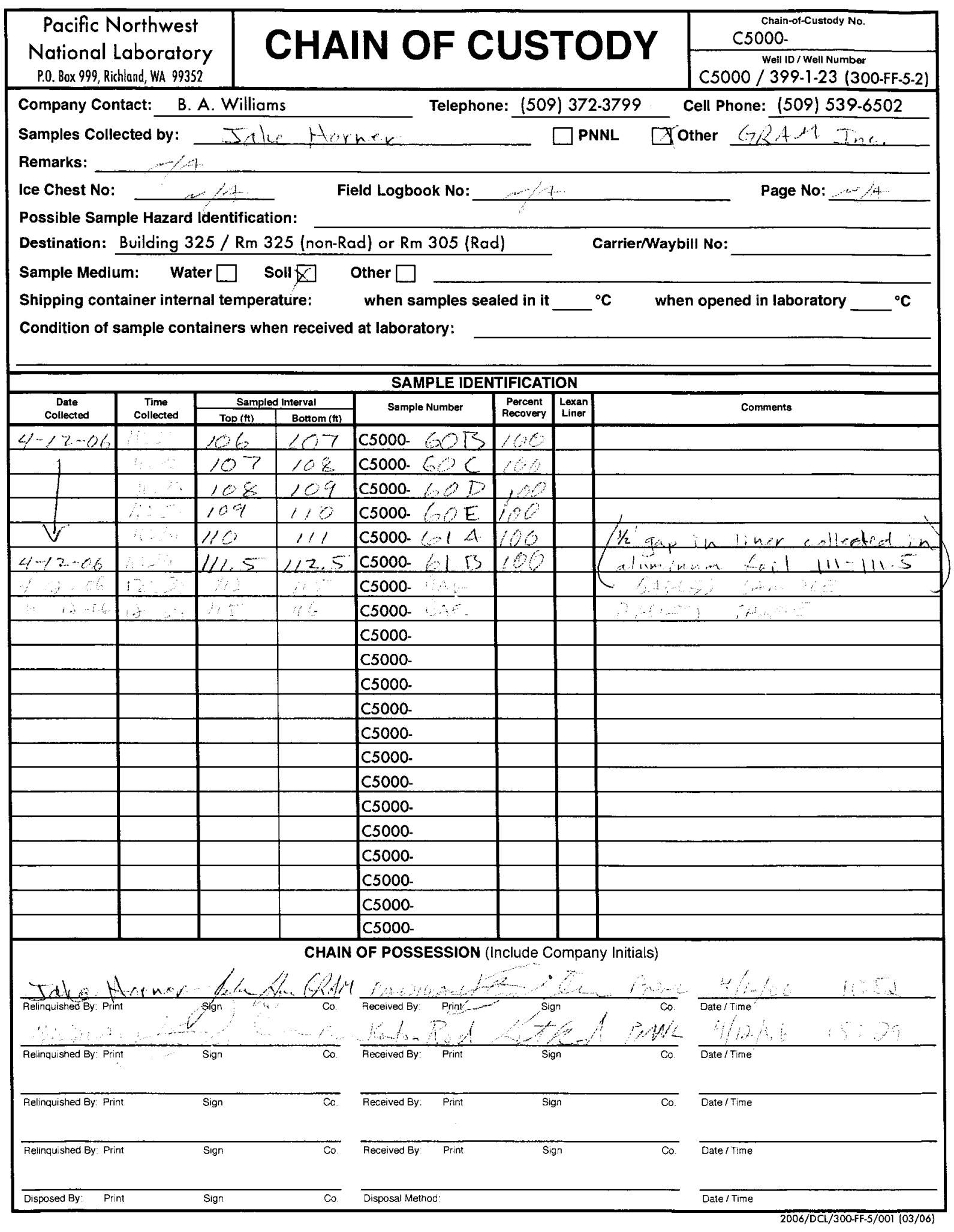




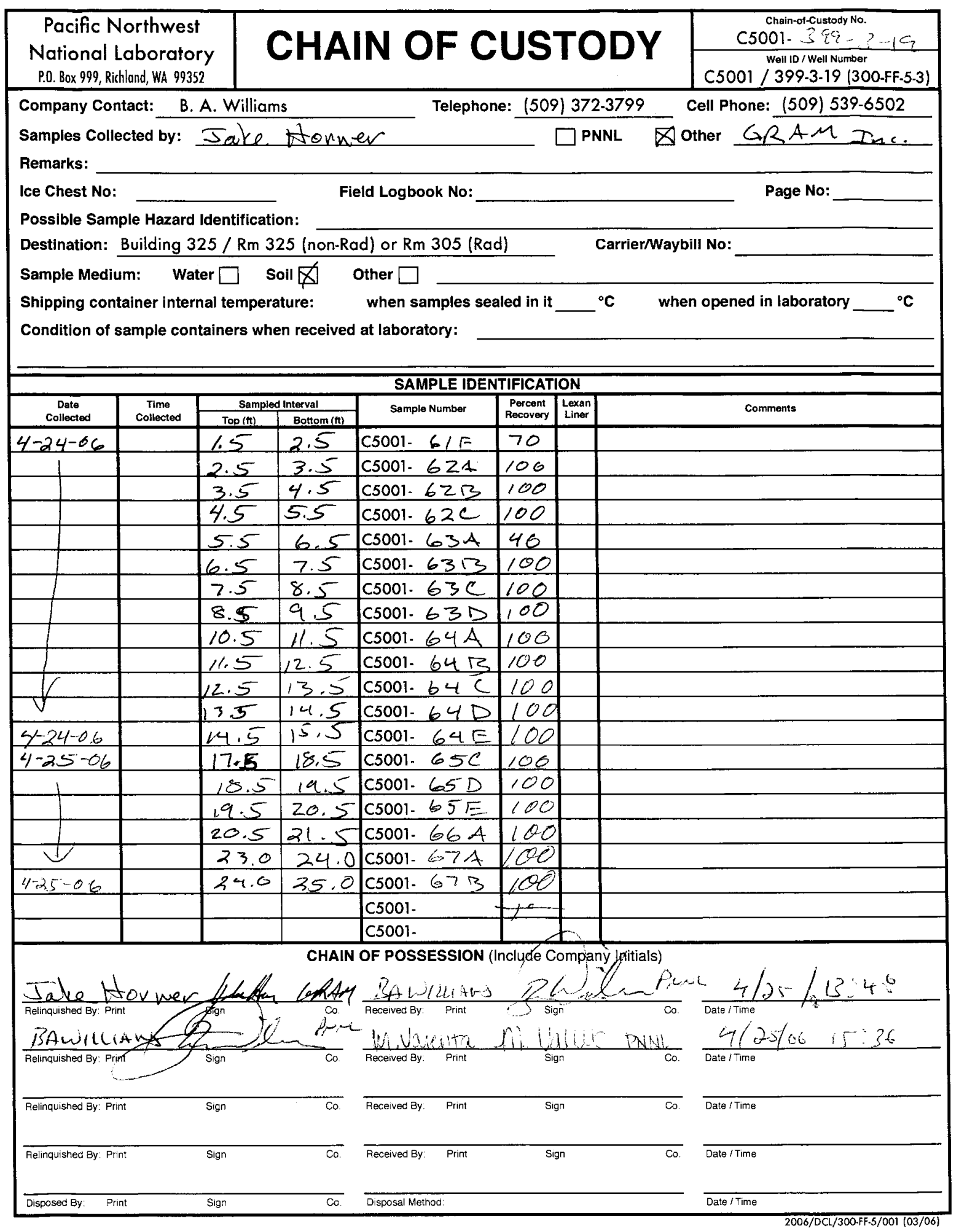




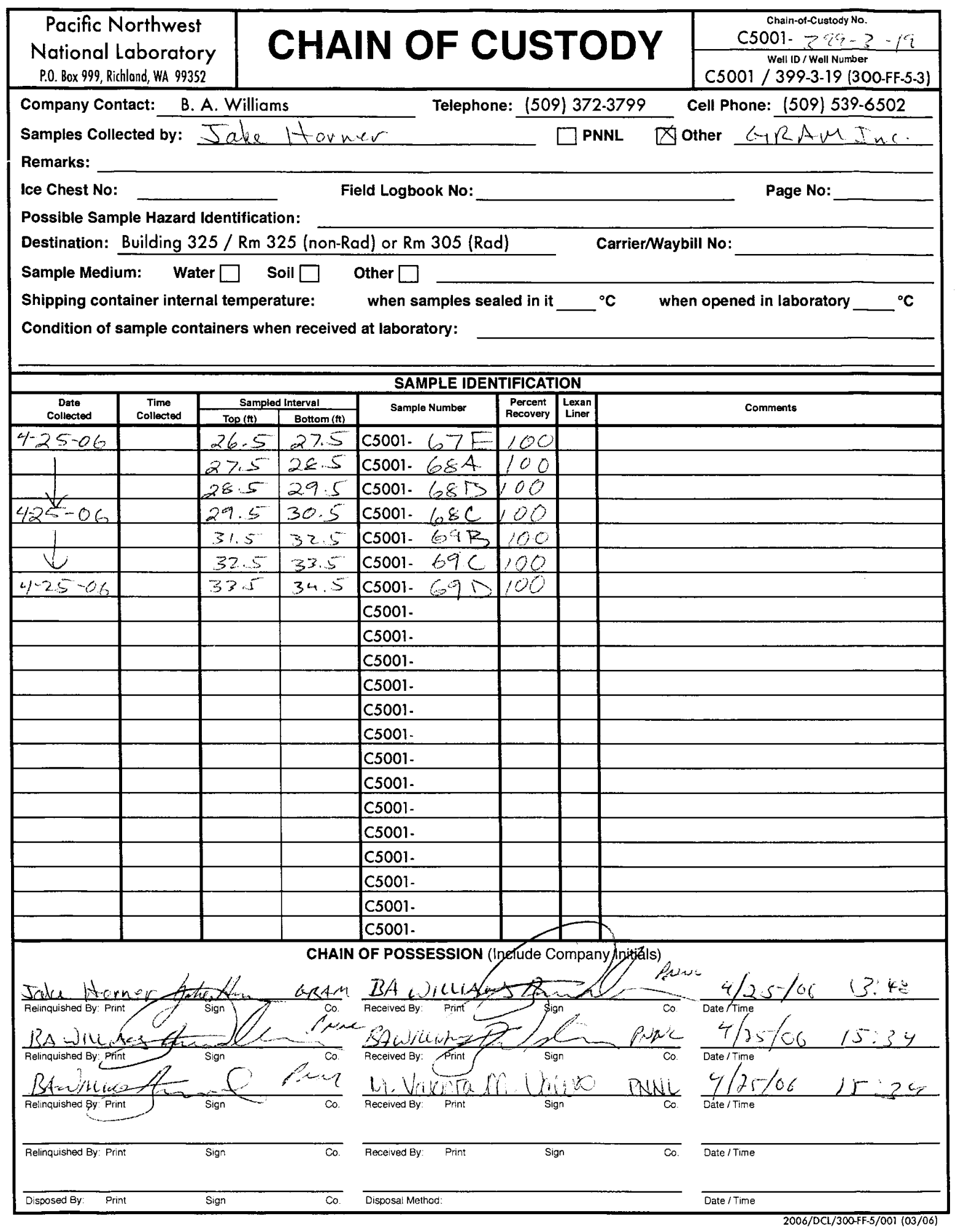




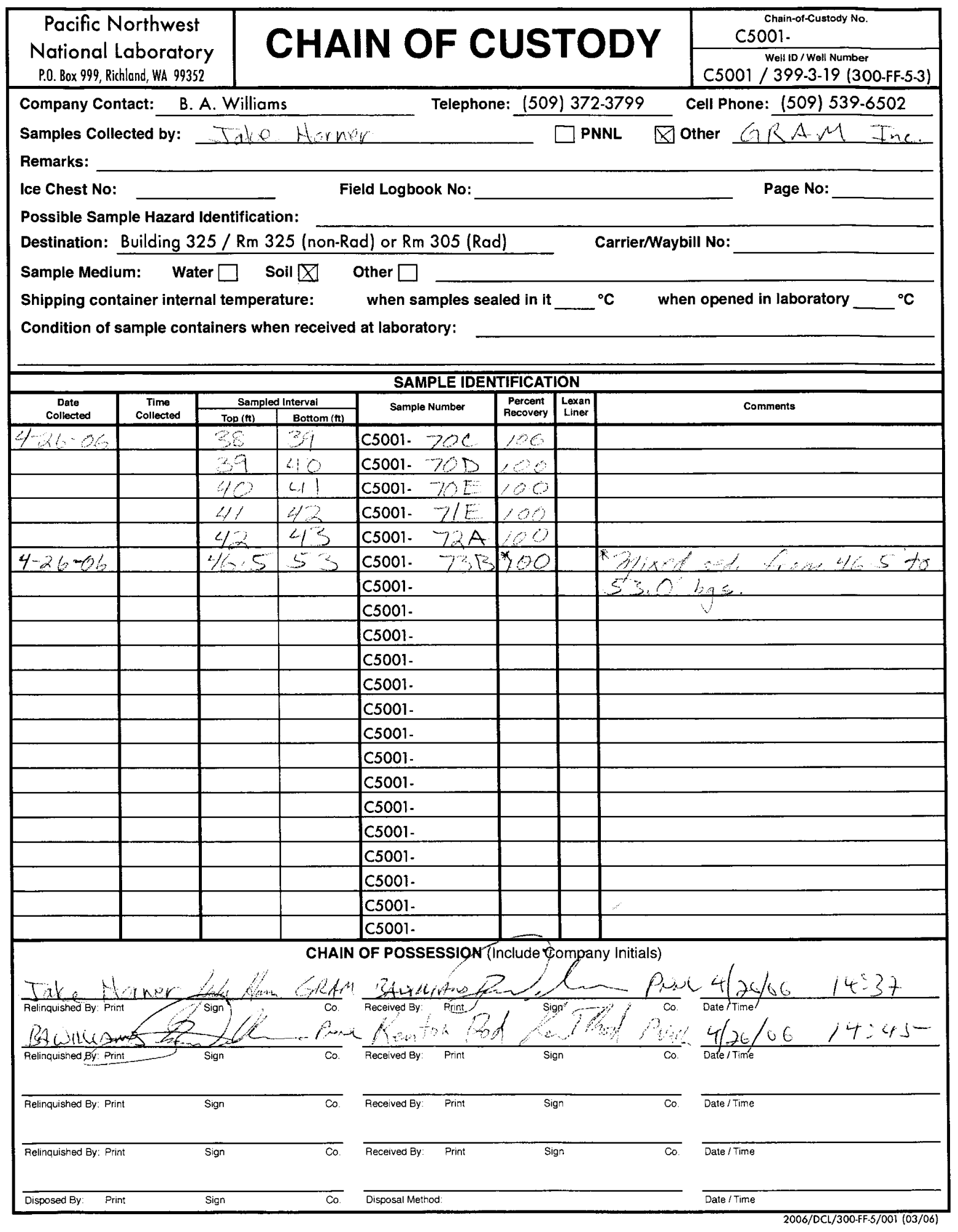




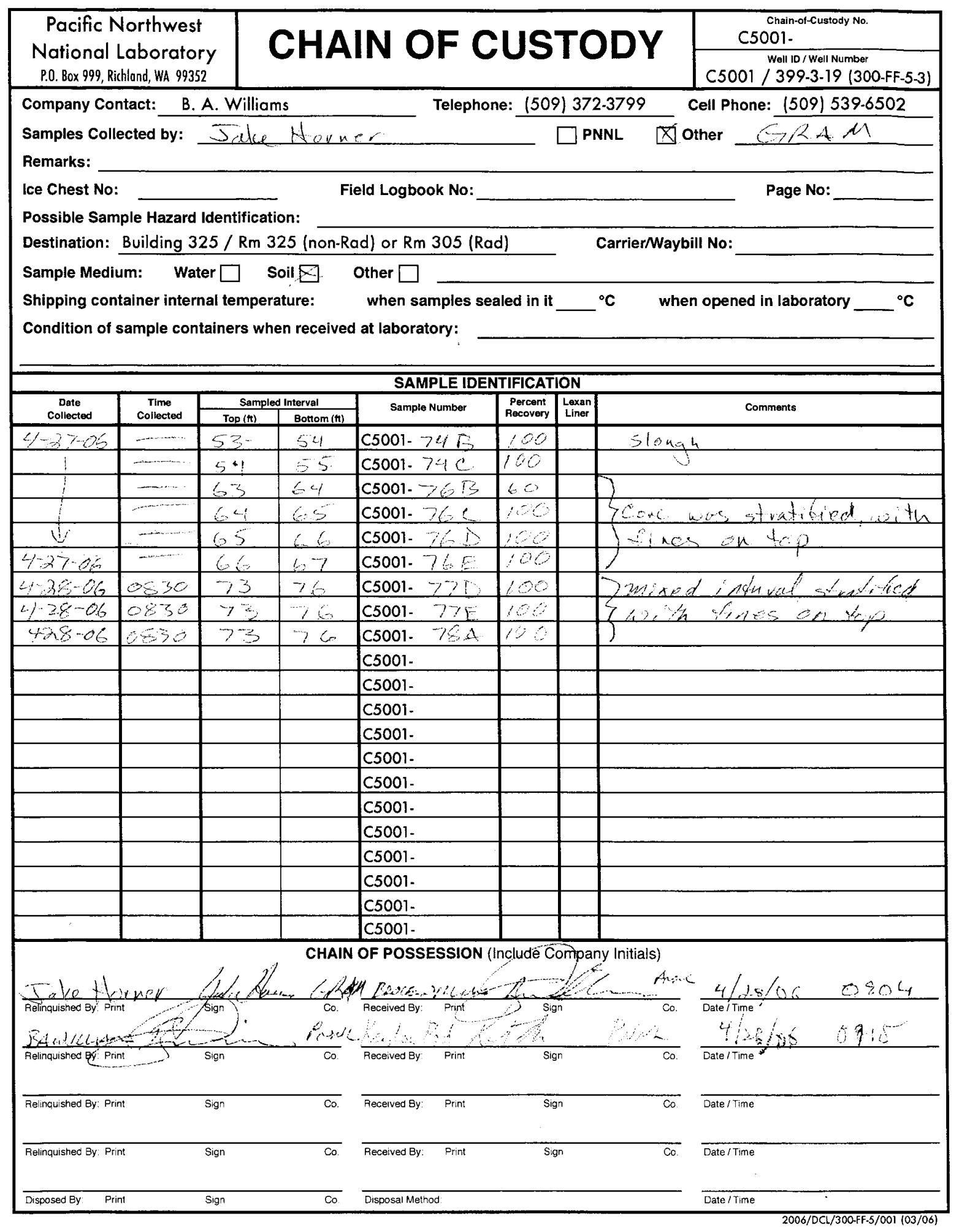




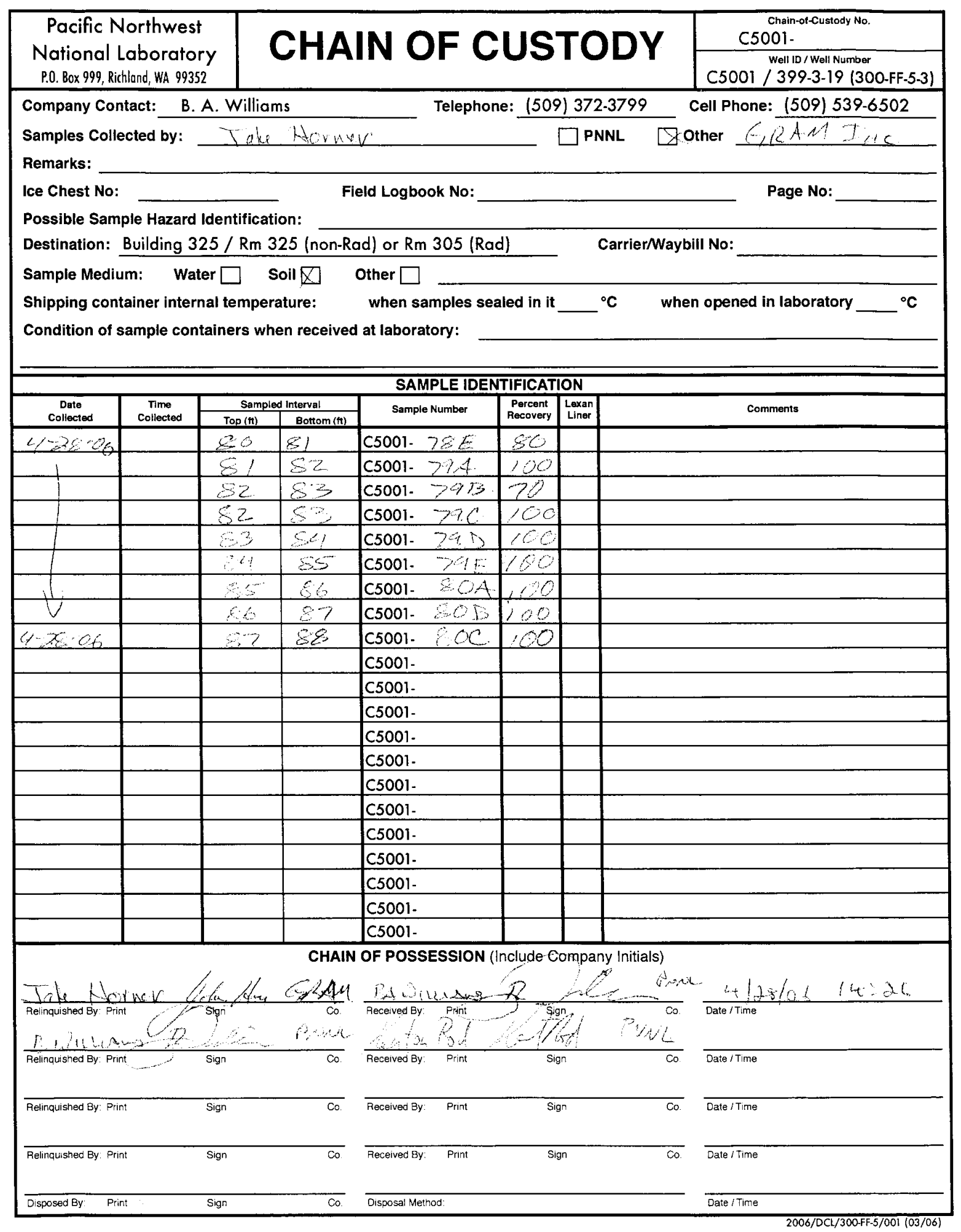




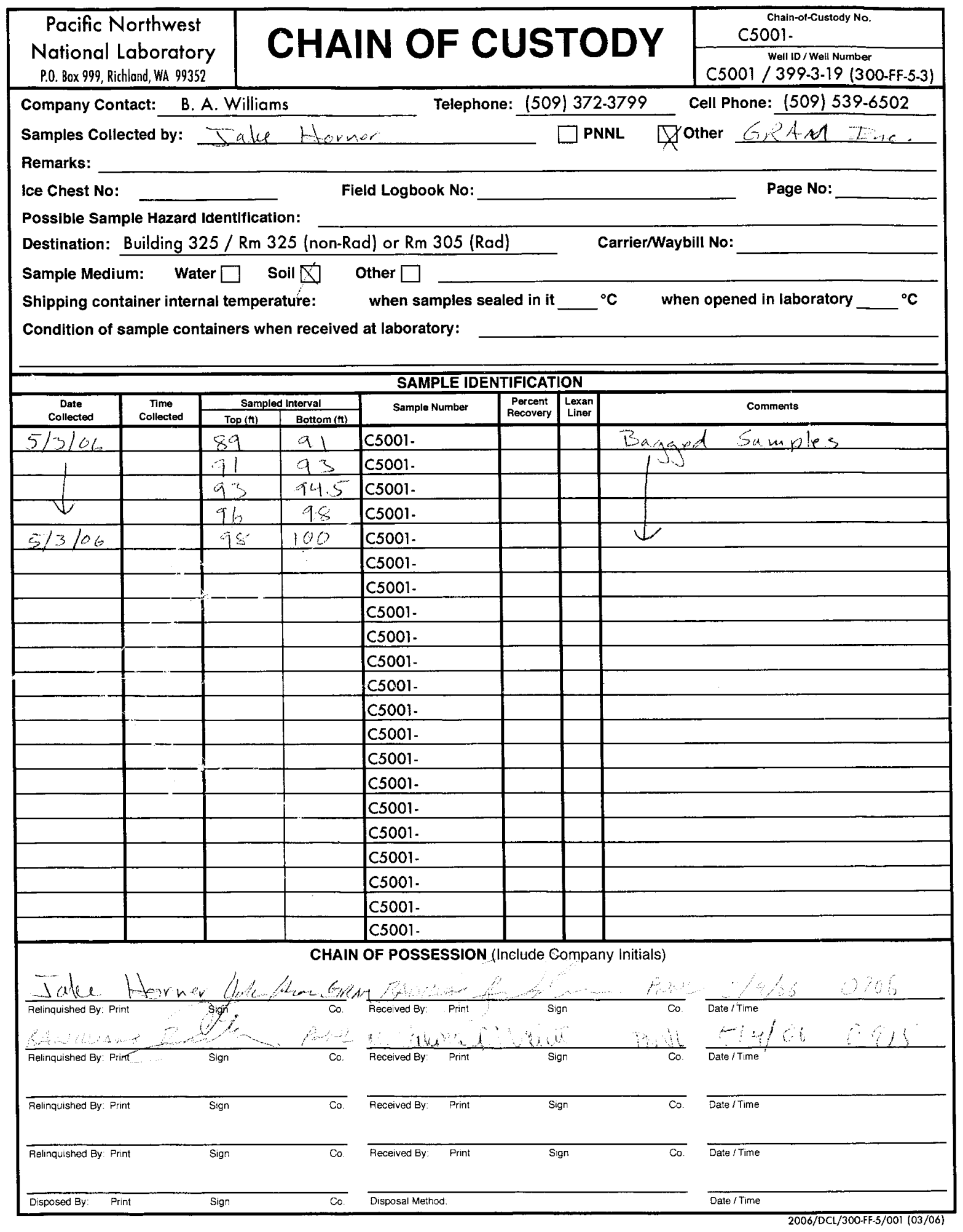




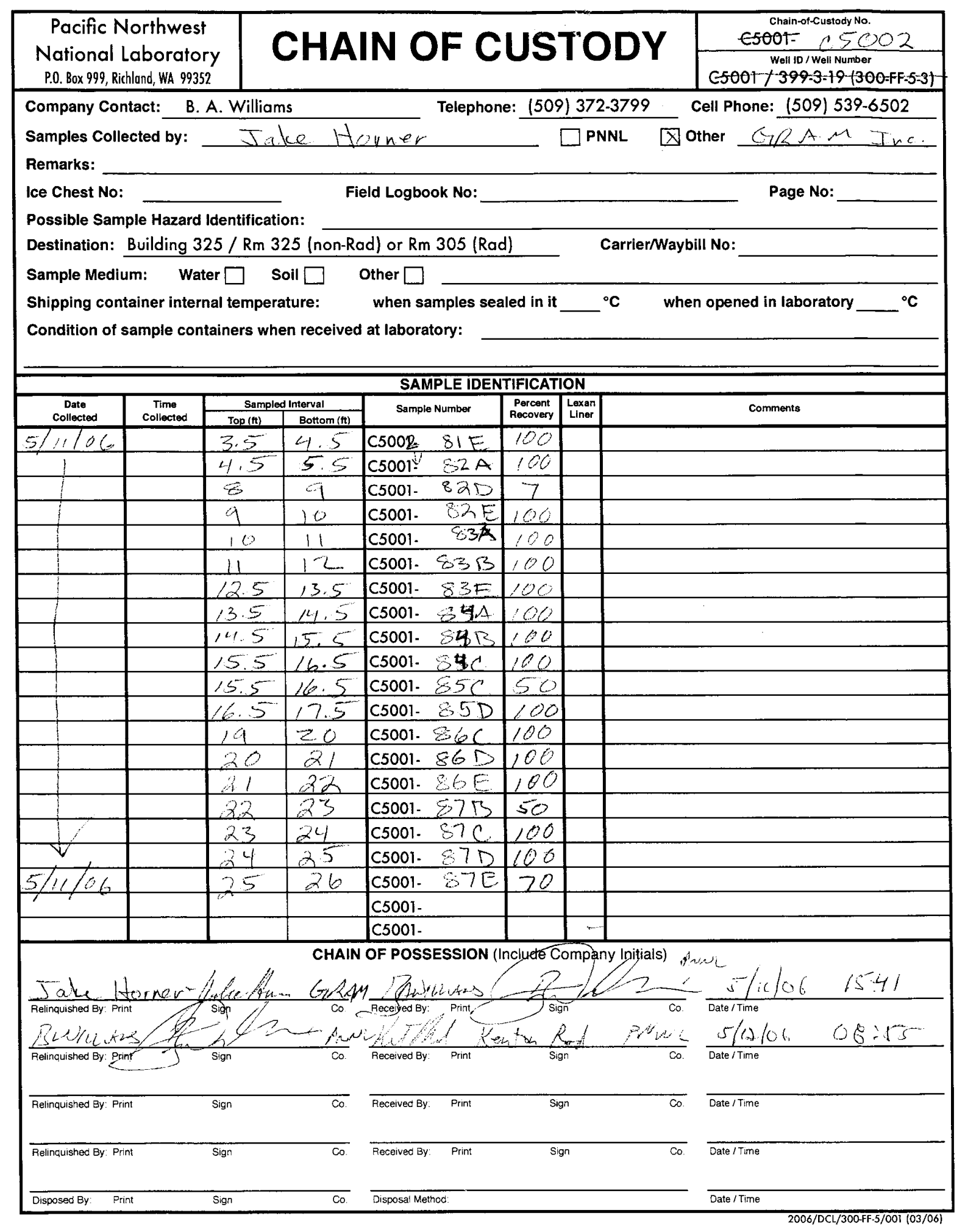




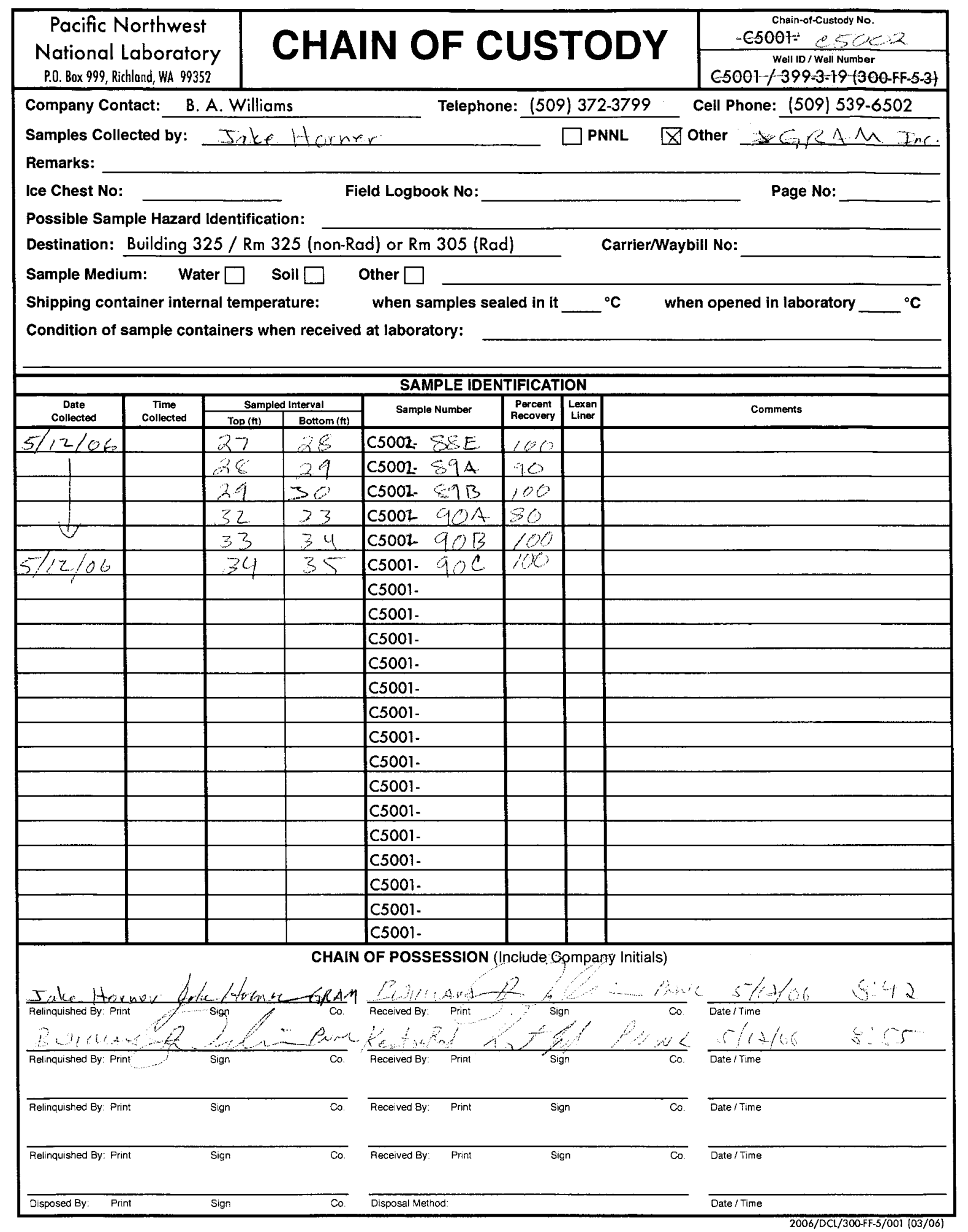




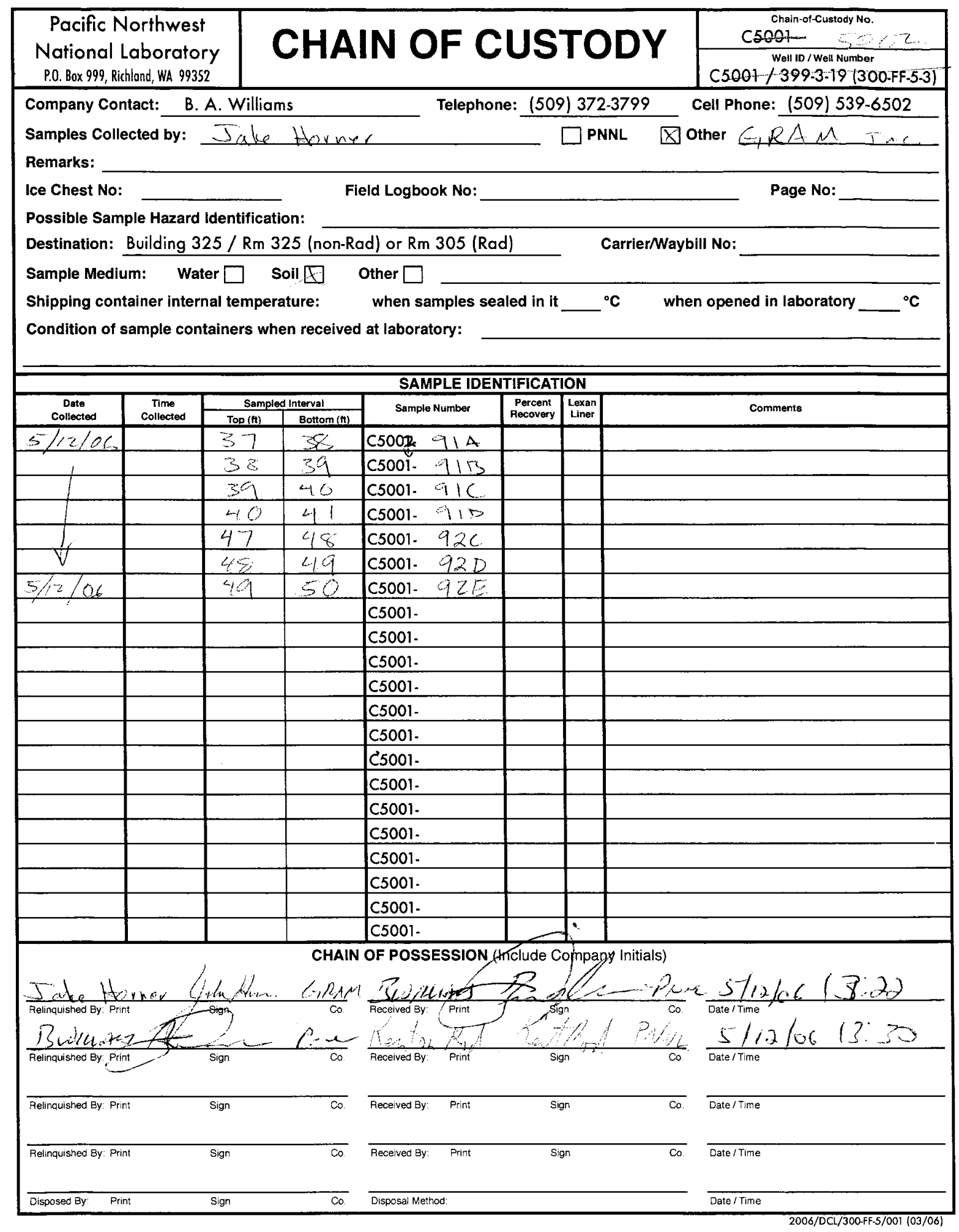




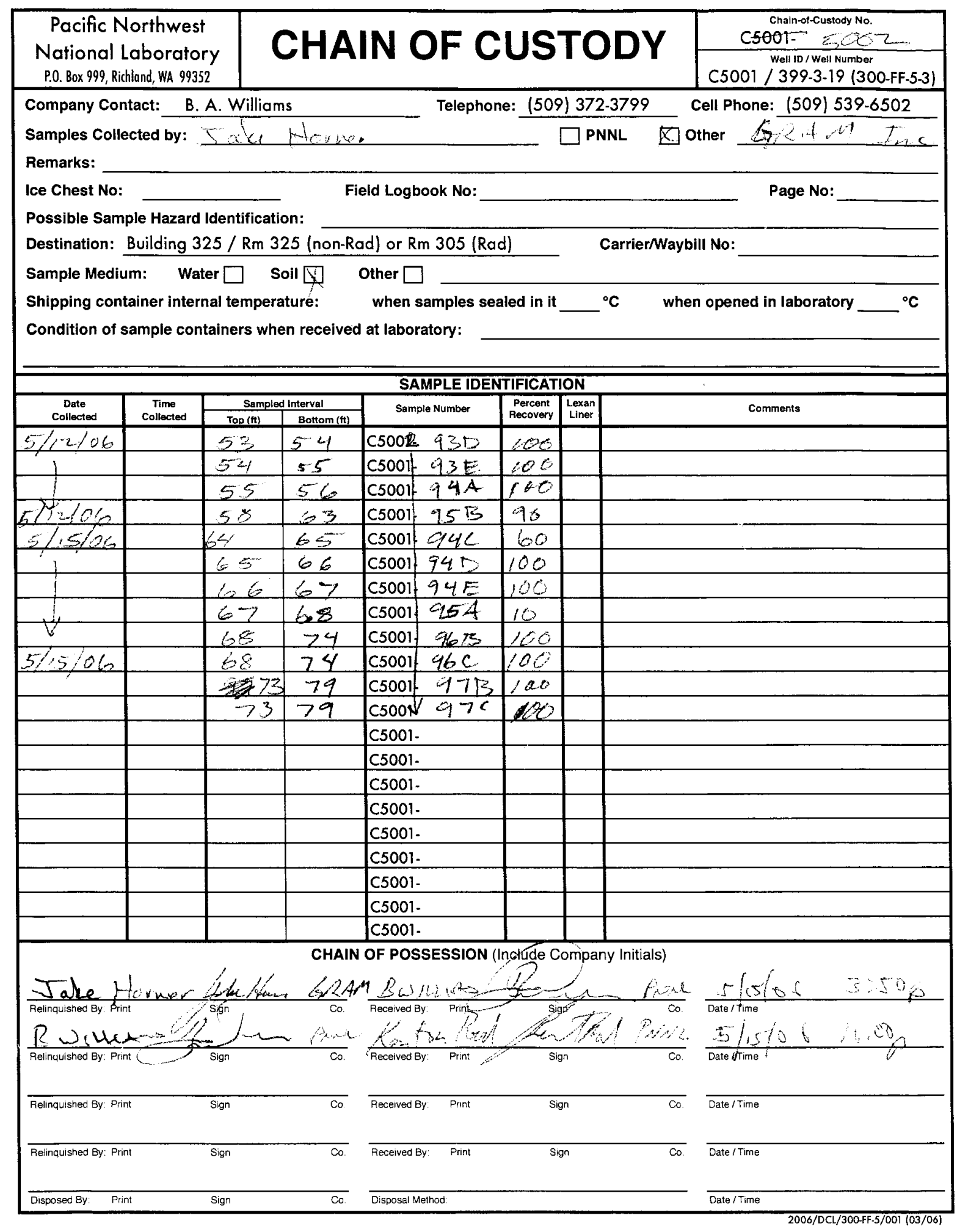




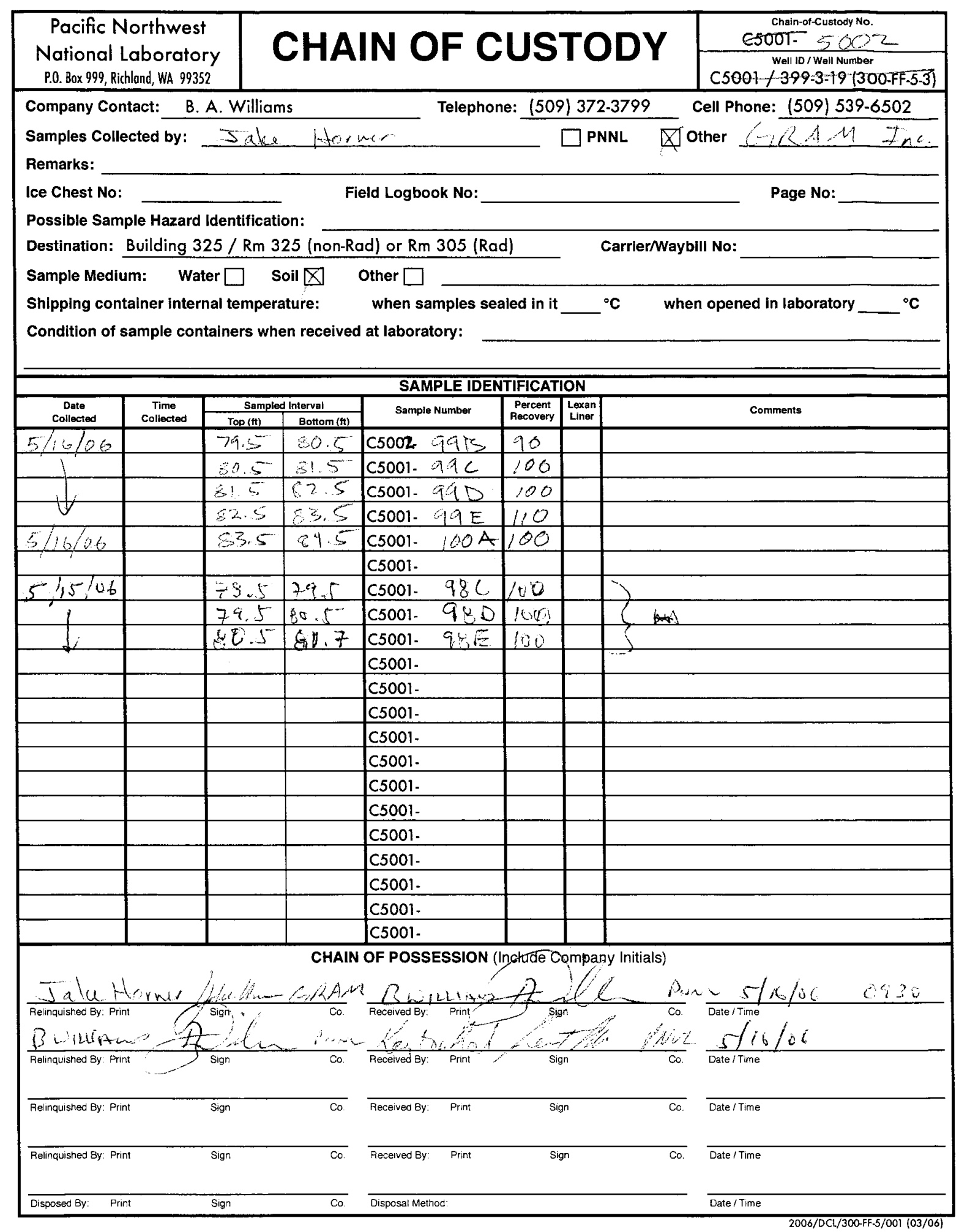




\section{Appendix C}

\section{Borehole Geophysical Log Reports}




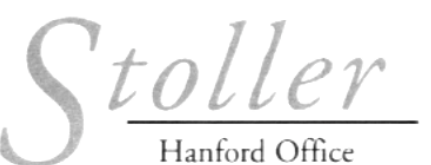

DOE-EM/GJ1182-2006

\section{9-3-18 (C4999) \\ Log Data Report}

\section{Borehole Information:}

\begin{tabular}{|c|c|c|c|c|c|}
\hline \multicolumn{3}{|c|}{ Borehole: $\quad 399-3-18(C 4999)$} & \multirow[b]{2}{*}{42.5 (apprc } & \multicolumn{2}{|c|}{$\begin{array}{l}\text { East from } 316-1 \text { South } \\
\text { Process Pond }\end{array}$} \\
\hline \multicolumn{2}{|c|}{ Coordinates (WA St Plane) } & $\mathrm{GWL}^{1}(\mathrm{ft}):$ & & GWL Date: & $03 / 26 / 06$ \\
\hline $\begin{array}{c}\text { North } \\
(\mathbf{m}) \\
\text { Not available }\end{array}$ & $\begin{array}{c}\text { East } \\
(\mathrm{m}) \\
\text { Not available }\end{array}$ & $\begin{array}{l}\text { Drill Date } \\
03 / 23 / 06\end{array}$ & $\begin{array}{l}\text { TOC } \\
\text { Elevation (ft) } \\
\text { Not available }\end{array}$ & $\begin{array}{l}\text { Total Depth }(\mathrm{ft}) \\
130\end{array}$ & $\begin{array}{l}\text { Type } \\
\text { Sonic }\end{array}$ \\
\hline
\end{tabular}

\section{Casing Information:}

\begin{tabular}{|c|c|c|c|c|c|c|}
\hline & \multicolumn{2}{c}{$\begin{array}{c}\text { Stickup } \\
\text { (ft) }\end{array}$} & $\begin{array}{c}\text { Outer } \\
\text { Diameter } \\
\text { (in.) }\end{array}$ & $\begin{array}{c}\text { Inside } \\
\text { Diameter } \\
\text { (in.) }\end{array}$ & $\begin{array}{c}\text { Thickness } \\
\text { (in.) }\end{array}$ & \multicolumn{2}{c|}{ Top (ft) } & Bottom (ft) \\
\hline Threaded Carbon Steel & 0.7 & $93 / 4$ & $85 / 8$ & $9 / 16$ & 0.7 & 130 \\
\hline
\end{tabular}

\section{Borehole Notes:}

The logging engineer measured the 8 -in. casing and stickup using a steel tape. Measurements were rounded to the nearest $1 / 16$ in. The onsite geologist reported the depth to groundwater.

\section{Logging Equipment Information:}

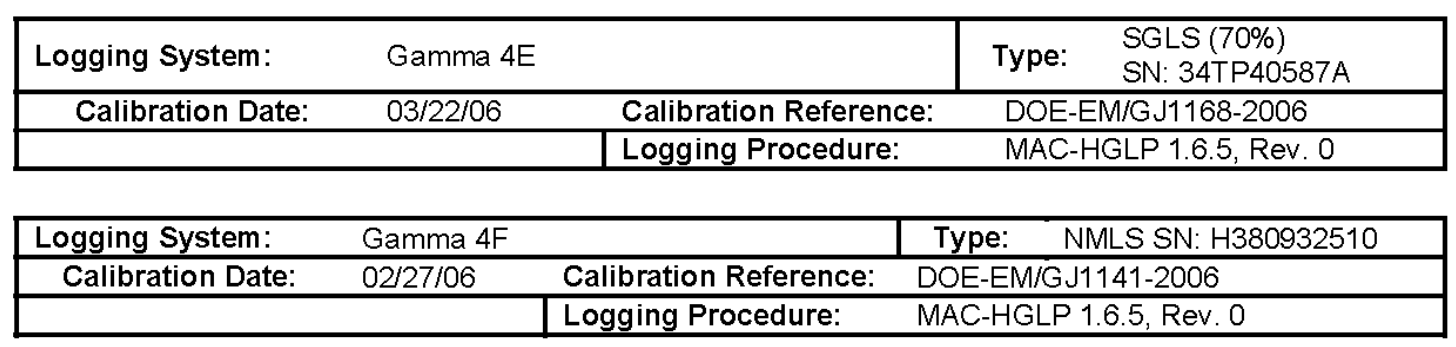

\section{Spectral Gamma Logging System (SGLS) Log Run Information:}

\begin{tabular}{|l|c|c|c|c|c|}
\hline Log Run & $\mathbf{1}$ & $\mathbf{2}$ & $\mathbf{3}$ & 4 Repeat & \\
\hline Date & $03 / 24 / 06$ & $03 / 24 / 06$ & $03 / 25 / 06$ & $03 / 25 / 06$ & \\
\hline Logging Engineer & Spatz & Spatz & Spatz & Spatz & \\
\hline Start Depth (ft) & 0.0 & 74.0 & 128.0 & 32.0 & \\
\hline Finish Depth (ft) & 75.0 & 98.0 & 97.0 & 45.0 & \\
\hline Count Time (sec) & 200 & 200 & 200 & 400 & \\
\hline Live/Real & $\mathrm{R}$ & $\mathrm{R}$ & $\mathrm{R}$ & $\mathrm{R}$ & \\
\hline Shield $\mathrm{Y} / \mathrm{N})$ & $\mathrm{N}$ & $\mathrm{N}$ & $\mathrm{N}$ & $\mathrm{N}$ & \\
\hline MSA Interval (ft) & 0.5 & 0.5 & 0.5 & 0.5 & \\
\hline $\mathrm{ft} /$ min & $\mathrm{N} / \mathrm{A}^{2}$ & $\mathrm{~N} / \mathrm{A}$ & $\mathrm{N} / \mathrm{A}$ & $\mathrm{N} / \mathrm{A}$ & \\
\hline
\end{tabular}




\begin{tabular}{|l|c|c|c|c|c|}
\hline Log Run & $\mathbf{1}$ & $\mathbf{2}$ & $\mathbf{3}$ & 4 Repeat & \\
\hline Pre-Verification & DEB61CAB & DEB61CAB & DEB71CAB & DEB71CAB & \\
\hline Start File & DEB61000 & DEB61151 & DEB71000 & DEB71063 & \\
\hline Finish File & DEB61150 & DEB61199 & DEB71062 & DEB71089 & \\
\hline Post-Verification & DEB61CAA & DEB61CAA & DEB71CAA & DEB71CAA & $-1 / 2$ \\
\hline $\begin{array}{l}\text { Depth Return Error } \\
\text { (in.) }\end{array}$ & $-1 / 4$ & +1 & +1 & $\begin{array}{l}\text { No fine gain } \\
\text { adjustment }\end{array}$ & \\
\hline Comments & $\begin{array}{l}\text { Fine gain } \\
\text { adjustment } \\
\text { after files - } \\
128 \&-140 .\end{array}$ & $\begin{array}{l}\text { No fine gain } \\
\text { adjustment }\end{array}$ & $\begin{array}{l}\text { No fine gain } \\
\text { adjustment }\end{array}$ & & \\
\hline
\end{tabular}

\section{Neutron Moisture Logging System (NMLS) Log Run Information:}

\begin{tabular}{|l|c|c|l|l|l|}
\hline Log Run & $\mathbf{5}$ & $\mathbf{6}$ Repeat & & \\
\hline Date & $03 / 25 / 06$ & $03 / 25 / 06$ & & & \\
\hline Logging Engineer & Pearson & Pearson & & & \\
\hline Start Depth (ft) & 0.0 & 30.0 & & & \\
\hline Finish Depth (ft) & 42.25 & 35.0 & & & \\
\hline Count Time (sec) & 15 & 15 & & & \\
\hline Live/Real & $\mathrm{R}$ & $\mathrm{R}$ & & & \\
\hline Shield (Y/N) & $\mathrm{N}$ & $\mathrm{N}$ & & & \\
\hline MSA Interval (ft) & 0.25 & 0.25 & & & \\
\hline ft/min & $\mathrm{N} / \mathrm{A}$ & $\mathrm{N} / \mathrm{A}$ & & \\
\hline Pre-Verification & DF162CAB & DF162CAB & & \\
\hline Start File & DF162178 & DF162348 & & & \\
\hline Finish File & DF162347 & DF162368 & & & \\
\hline Post-Verification & DF162CAA & DF162CAA & & & \\
\hline $\begin{array}{l}\text { Depth Return Error } \\
\text { (in.) }\end{array}$ & N/A & $-1 / 2$ & & & \\
\hline Comments & $\begin{array}{l}\text { No fine gain } \\
\text { adjustment }\end{array}$ & $\begin{array}{l}\text { No fine gain } \\
\text { adjustment }\end{array}$ & & & \\
\hline
\end{tabular}

\section{Logging Operation Notes:}

Logging was conducted with a centralizer on the sondes. Logging data acquisition is referenced to ground level. The maximum logging depth achieved was $128.33 \mathrm{ft}$. Repeat sections were collected in this borehole to evaluate each system's performance.

\section{Analysis Notes:}

\begin{tabular}{|l|l|l|l|l|l|}
\hline Analyst: & Henwood & Date: & $04 / 20 / 06$ & Reference: & GJO-HGLP 1.6.3, Rev. 0 \\
\hline
\end{tabular}

Pre-run and post-run verifications for the SGLS were acquired in the Amersham verifier, serial number 115 , which is enhanced in the naturally occurring radionculides ${ }^{40} \mathrm{~K},{ }^{238} \mathrm{U}$, and ${ }^{232} \mathrm{Th}$ (KUT). The net counts for the ${ }^{40} \mathrm{~K}$ (1460 keV energy peak) fell slightly below the lower control limits for efficiency. The sonde is usually placed in the verifier on the ground surface during verification measurements where naturally occurring KUT in the ground also contribute to the spectra. At this borehole, the verification measurements were acquired on the drilling deck, approximately $4 \mathrm{ft}$ above the ground surface. The observed deficiency in net counts for ${ }^{40} \mathrm{~K}$ is attributed to the location of the verification measurement and the data are accepted.

A casing correction for 9/16-in.-thick casing was applied to the SGLS log data.

SGLS spectra were processed in batch mode using APTEC SUPERVISOR to identify individual energy peaks and determine count rates. Concentrations were calculated with an EXCEL worksheet template 
identified as G4Emar06.xls using efficiency functions and corrections for casing, water, and dead time as determined from annual calibrations. Dead time corrections are applied where dead times exceed 4.7 percent. No correction for dead time was necessary. A correction for water was applied to data below $42.5 \mathrm{ft}$.

The NMLS data are presented as counts per second. A calibration for casing inside diameters greater than 8 -in. is not available.

\section{$\underline{\text { Results and Interpretations: }}$}

A plot of manmade radionuclides are included for ${ }^{137} \mathrm{Cs}$ and processed uranium $\left({ }^{235} \mathrm{U}\right.$ and $\left.{ }^{238} \mathrm{U}\right)$. The plot indicates all detections based on the routine processing software. All of the detections were at or near the respective MDLs. The approximate MDLs for ${ }^{137} \mathrm{Cs},{ }^{233} \mathrm{U}$, and ${ }^{238} \mathrm{U}$ in and out of water are: 0.4 and $0.2 \mathrm{pCi} / \mathrm{g} ; 4$ and $1 \mathrm{pCi} / \mathrm{g}$; and 20 and $12 \mathrm{pCi} / \mathrm{g}$. Inspection of each spectrum where a detection was indicated revealed no full energy peaks. Therefore, the detections are considered to be statistical fluctuations and are not considered valid. No other man-made radionuclides were indicated.

There is a strong indication of radon in the groundwater. Comparison of the $1764 \mathrm{keV}$ and $609 \mathrm{keV}^{214} \mathrm{Bi}$ gamma rays shows differing concentrations after corrections for water and casing. The casing and water correction factors decrease with increasing energy. Gamma rays originating inside the casing are not attenuated by the steel casing, and the net effect of applying the correction factors is to amplify results from low-energy gamma rays. The fact that the $609 \mathrm{keV}$ gamma ray results in a higher apparent concentration than the $1764 \mathrm{keV}$ gamma line suggests that radon is present in the groundwater. Normal formation concentrations of naturally occurring ${ }^{238} \mathrm{U}$ are between approximately 0.5 and $1.5 \mathrm{pCi} / \mathrm{g}$. The concentrations above the groundwater level are consistent with these values for the assays of both the 609 and $1764 \mathrm{keV}$ peaks. Note that enhanced radon is not related to the existence of man-made uranium.

The neutron moisture results are reported in counts per second because no valid calibration is available for borehole inside diameters greater than 8 in. Some variation is noted. The logging engineer reported a "void" in the formation near the surface of unknown depth extent. This void may be the cause of a very low count rate between the ground surface and $10 \mathrm{ft}$.

The repeat section indicates good agreement of the naturally occurring KUT.

\section{Log Plots:}

Man-made Radionuclides Natural Gamma Logs

Combination Plot

Total Gamma \& Moisture

Total Gamma \& Dead Time

Repeat Section of Natural Gamma Logs

\footnotetext{
${ }^{1} \mathrm{GWL}$ - groundwater level

${ }^{2} \mathrm{~N} / \mathrm{A}$ - not applicable
} 


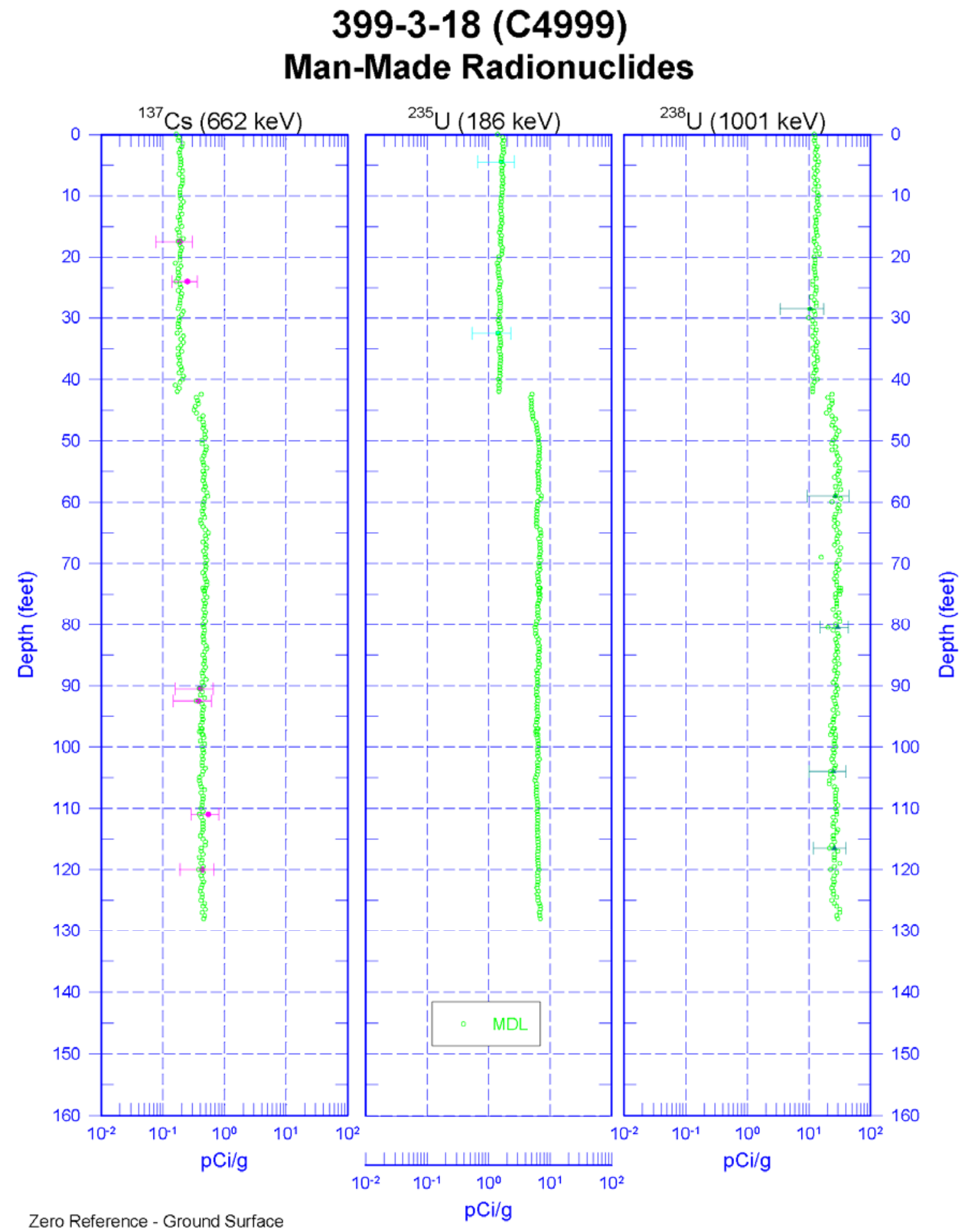


399-3-18 (C4999)

Natural Gamma Logs
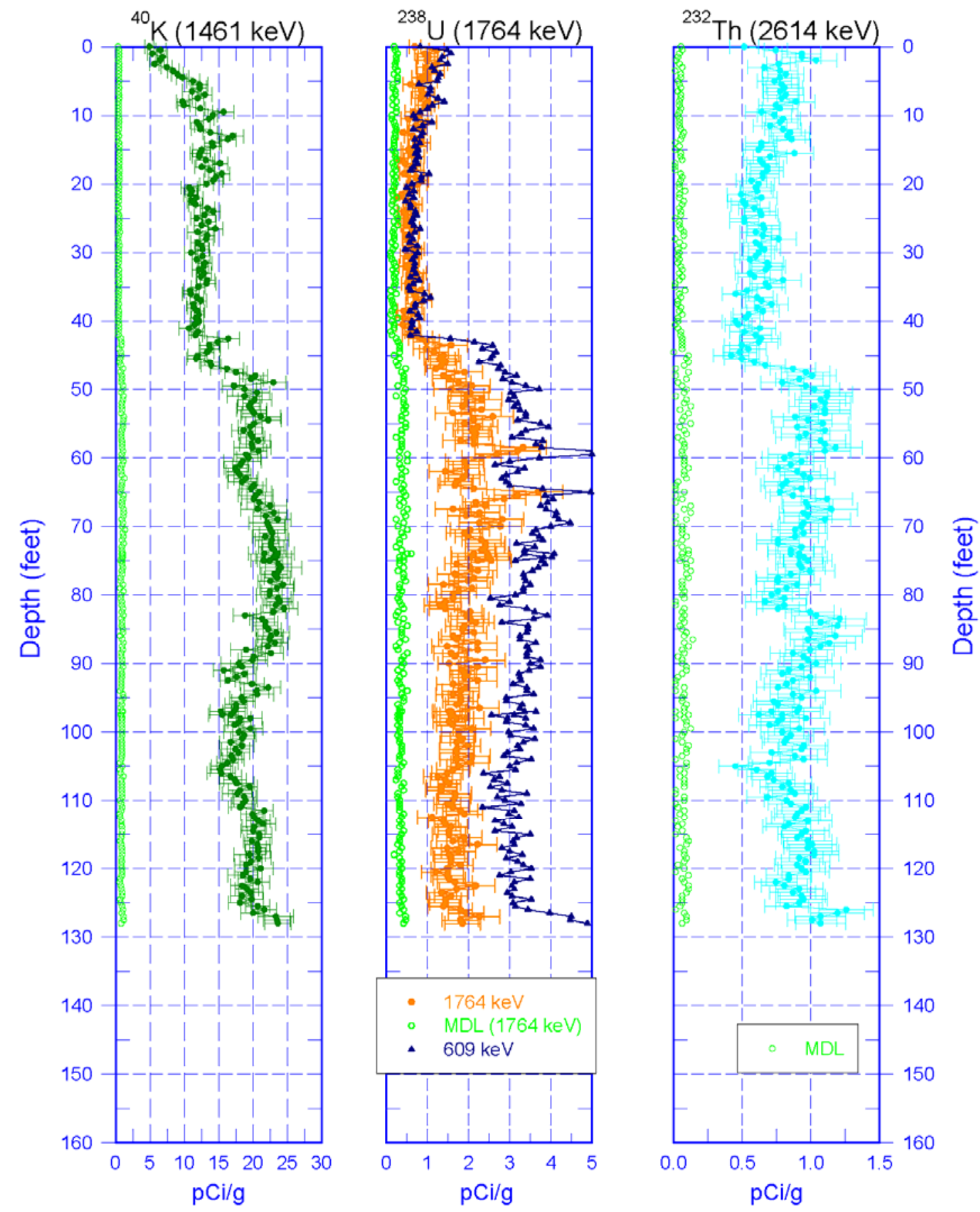

Zero Reference - Ground Surface 

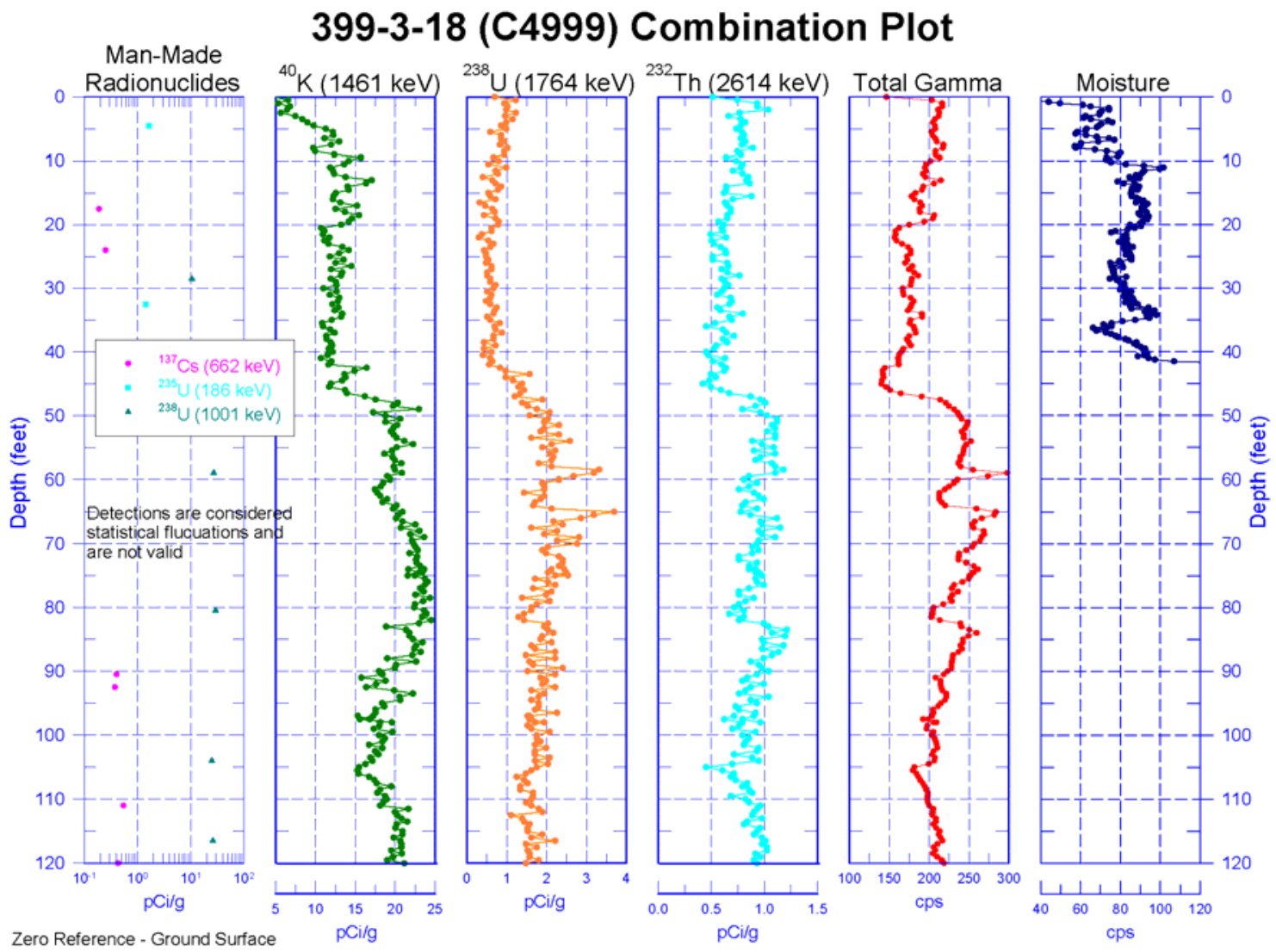


\section{9-3-18 (C4999) \\ Total Gamma \& Moisture}
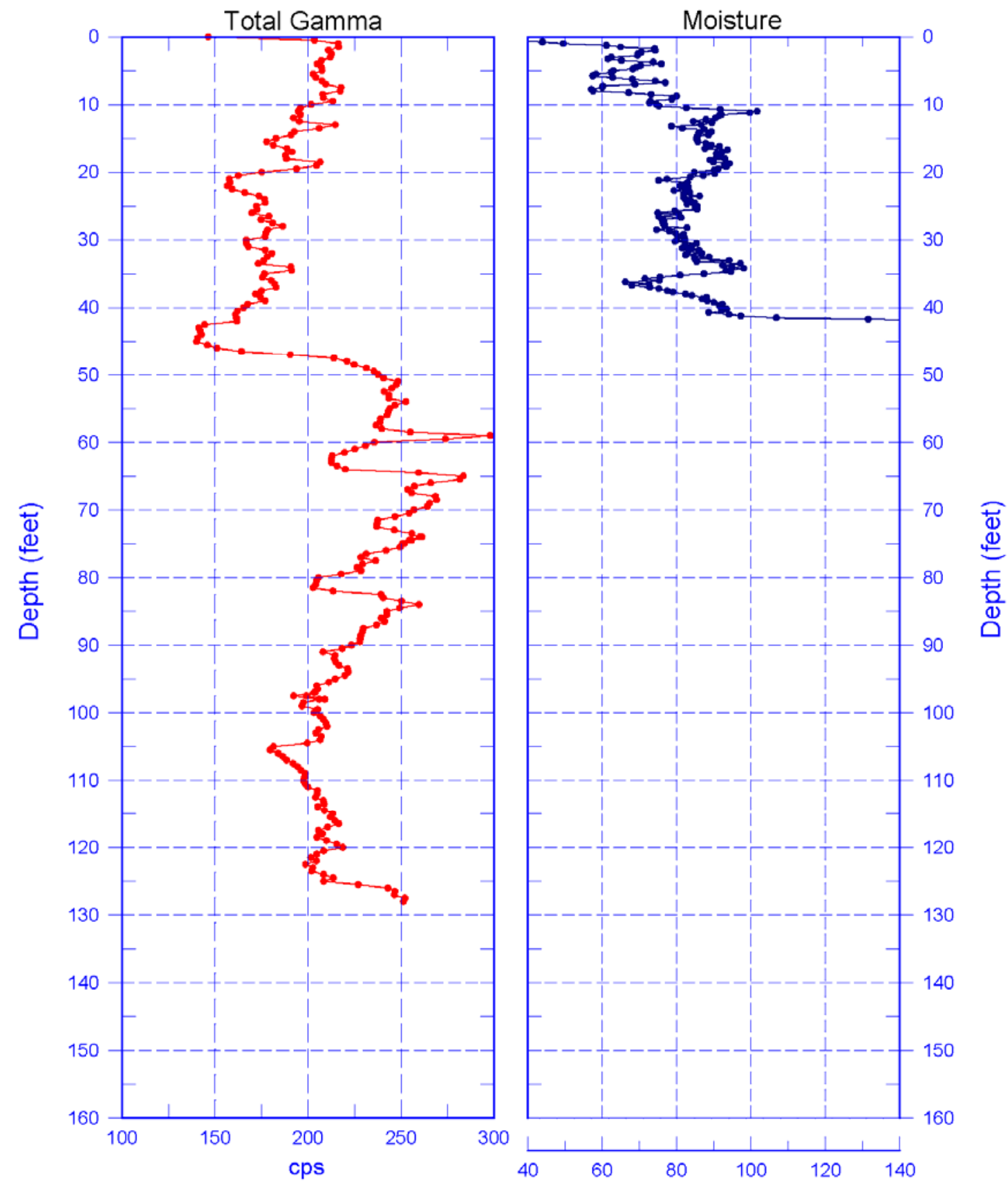

Reference - Ground Surface 


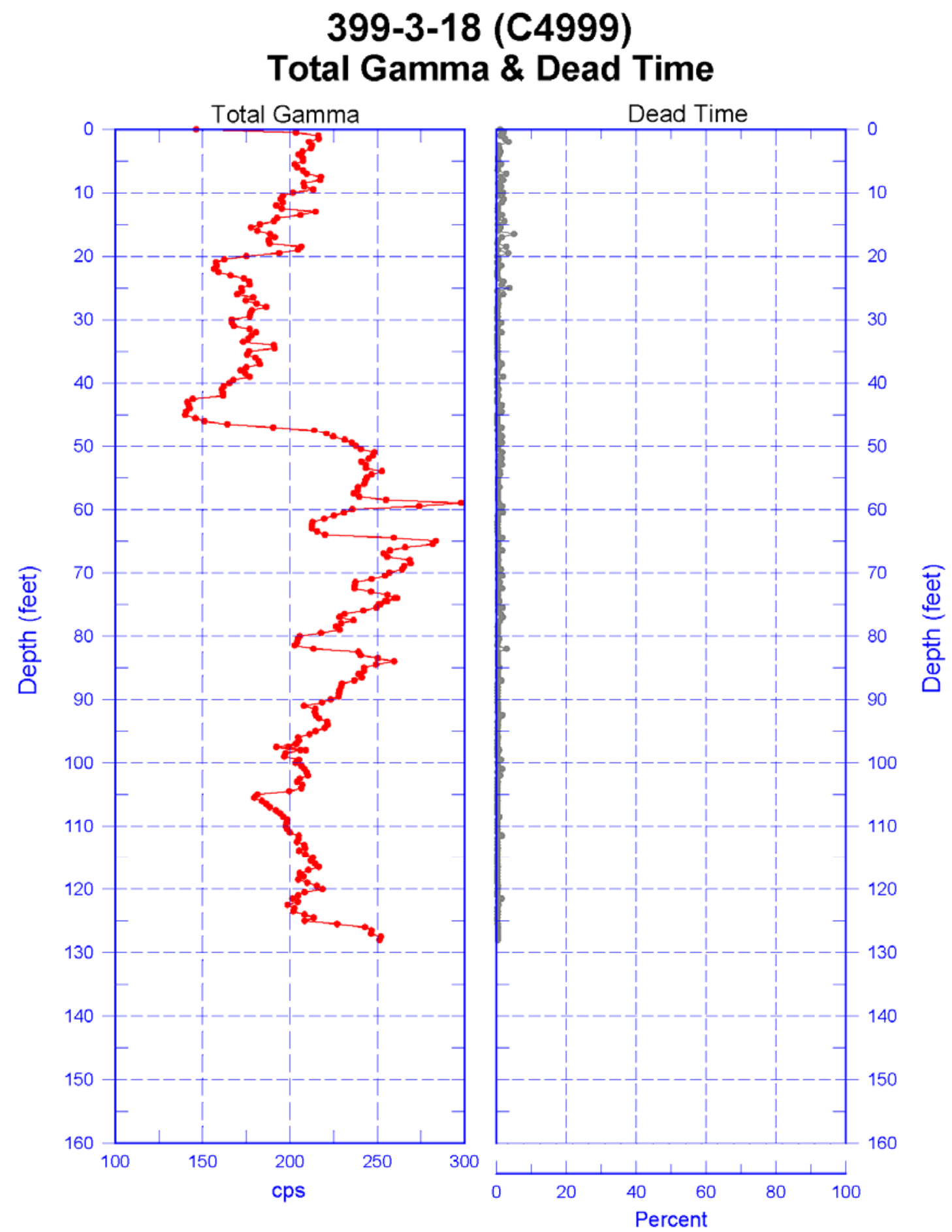

Reference - Ground Surface 


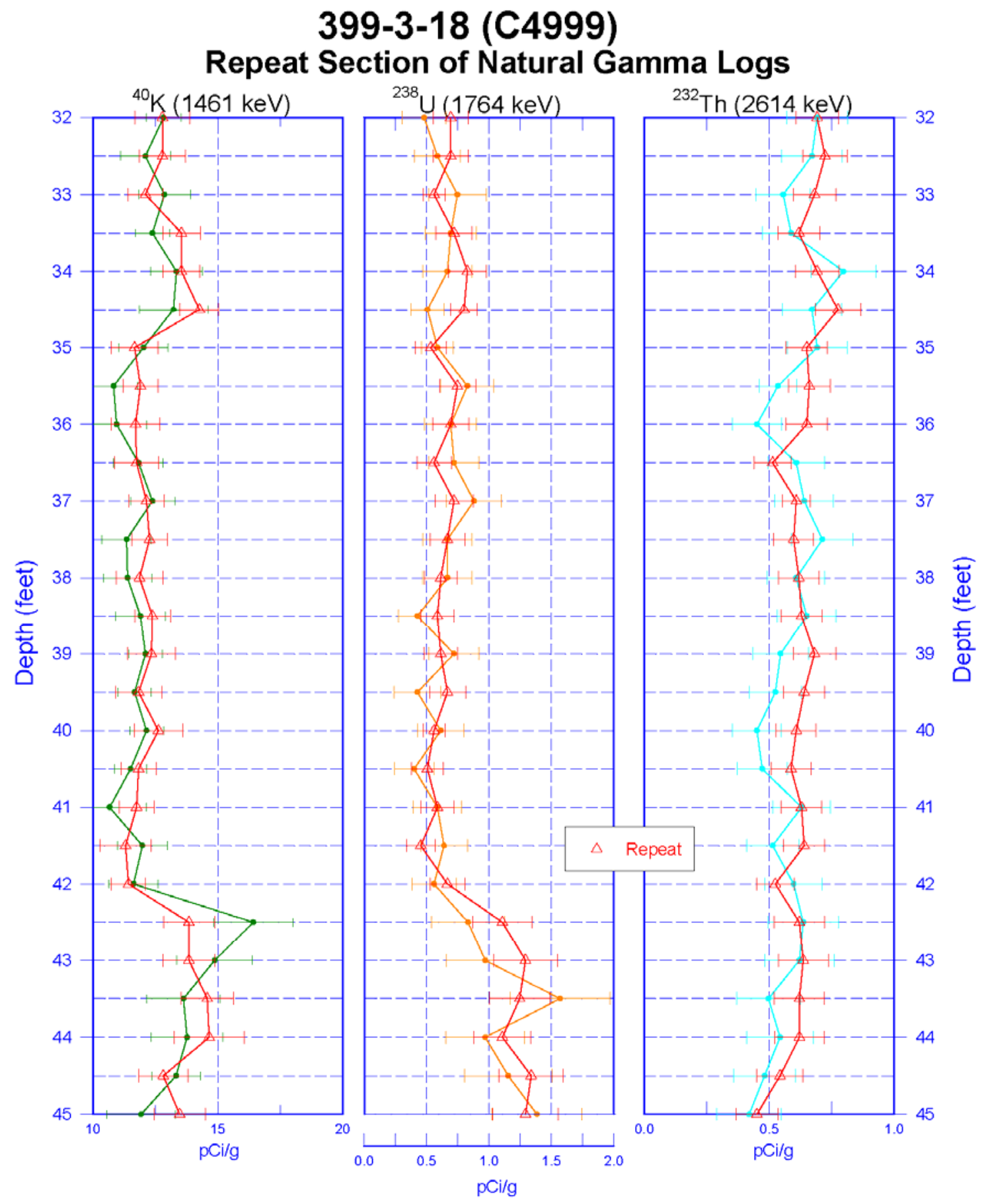

Zero Reference - Ground Surface 


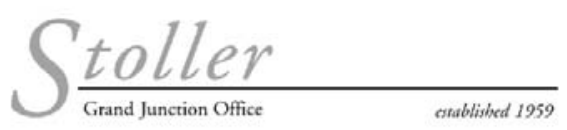

\section{9-1-23 (C5000) \\ Log Data Report}

Borehole Information:

\begin{tabular}{|c|c|c|c|c|c|}
\hline \multicolumn{3}{|c|}{ Borehole: $\quad 399-1-23(\mathrm{C} 5000)$} & \multirow[t]{2}{*}{ Site: } & \multicolumn{2}{|c|}{$\begin{array}{l}\text { South from 316-5 Process } \\
\text { Trenches }\end{array}$} \\
\hline \multicolumn{2}{|c|}{ Coordinates (WA St Plane) } & $\mathrm{GWL}^{\prime}(\mathrm{ft}):$ & & GWL Date: & $04 / 13 / 06$ \\
\hline $\begin{array}{c}\text { North } \\
(\mathbf{m}) \\
\text { not available }\end{array}$ & $\begin{array}{c}\text { East } \\
(\mathbf{m}) \\
\text { not available }\end{array}$ & $\begin{array}{l}\text { Drill Date } \\
04 / 12 / 06\end{array}$ & $\begin{array}{l}\text { TOC } \\
\text { Elevation (ft) } \\
\text { not available }\end{array}$ & $\begin{array}{l}\text { Total Depth }(\mathrm{ft}) \\
115\end{array}$ & $\begin{array}{l}\text { Type } \\
\text { Sonic }\end{array}$ \\
\hline
\end{tabular}

\section{Casing Information:}

\begin{tabular}{|c|c|c|c|c|c|c|}
\hline & \multicolumn{2}{c}{$\begin{array}{c}\text { Stickup } \\
\text { (ft) }\end{array}$} & $\begin{array}{c}\text { Outer } \\
\text { Diameter } \\
\text { (in.) }\end{array}$ & $\begin{array}{c}\text { Inside } \\
\text { Diameter } \\
\text { (in.) }\end{array}$ & $\begin{array}{c}\text { Thickness } \\
\text { (in.) }\end{array}$ & \multicolumn{2}{c|}{ Top (ft) } & Bottom (ft) \\
\hline Threaded Carbon Steel & 3.65 & $93 / 4$ & $85 / 8$ & $9 / 16$ & 3.65 & 115 \\
\hline
\end{tabular}

\section{Borehole Notes:}

The logging engineer measured the 8-in. casing and stickup using a steel tape. Measurements were rounded to the nearest $1 / 16 \mathrm{in}$. The onsite geologist reported the depth to bottom and depth to groundwater. Depth to water, inside the casing, was measured by the logging engineer at $39.1,37.75$, and $35.6 \mathrm{ft}$ on $04 / 13,04 / 14$, and $04 / 17$, respectively. The geologist stated the water inside the casing had not yet equilibrated with the groundwater outside the casing. The true static level of groundwater is $34.5 \mathrm{ft}$.

\section{Logging Equipment Information:}

\begin{tabular}{|c|c|c|c|}
\hline Logging System: & Gamma 4N & & $\begin{array}{ll}\text { Type: } & \text { SGLS (60\%) SN: } \\
& \text { 45TP22010A }\end{array}$ \\
\hline Calibration Date: & $04 / 06 / 06$ & Calibration Reference: & DOE-EM/GJ1177-2006 \\
\hline & & Logging Procedure: & MAC-HGLP 1.6.5, Rev. 0 \\
\hline
\end{tabular}

\begin{tabular}{|c|c|c|c|}
\hline Logging System: & Gamma $1 \mathrm{~N}$ & & $\begin{array}{ll}\text { Type: } & \text { SGLS (60\%) SN: } \\
& \text { 45TP22010A }\end{array}$ \\
\hline Calibration Date: & 04/05/06 & Calibration Reference: & DOE-EM/GJ1183-2006 \\
\hline & & Logging Procedure: & MAC-HGLP 1.6.5, Rev. 0 \\
\hline
\end{tabular}

\begin{tabular}{|cll|l|}
\hline Logging System: & Gamma 4F & Type: & NMLS SN: H380932510 \\
\hline Calibration Date: & $02 / 27 / 06$ & Calibration Reference: & DOE-EM/GJ1141-2006 \\
\hline & & Logging Procedure: & MAC-HGLP 1.6.5, ReV. 0 \\
\hline
\end{tabular}

\section{Spectral Gamma Logging System (SGLS) Log Run Information:}




\begin{tabular}{|c|c|c|c|c|c|}
\hline Log Run & 1 & 2 & 3 & 4 Repeat & 7 Repeat \\
\hline Date & $04 / 12 / 06$ & $04 / 13 / 06$ & $04 / 14 / 06$ & $04 / 14 / 06$ & $04 / 18 / 06$ \\
\hline Logging Engineer & Spatz & Spatz & Spatz & Spatz & Spatz \\
\hline Start Depth (ft) & 0.0 & 19.0 & 96.5 & 20.0 & 19.0 \\
\hline Finish Depth (ft) & 20.0 & 97.5 & 112.5 & 50.0 & 22.0 \\
\hline Count Time (sec) & 200 & 200 & 200 & 400 & 1000 \\
\hline Live/Real & $\mathrm{R}$ & $\mathrm{R}$ & $\mathrm{R}$ & $\mathrm{R}$ & $\mathrm{R}$ \\
\hline Shield $(\mathrm{Y} / \mathrm{N})$ & $N$ & $N$ & $N$ & $N$ & $N$ \\
\hline MSA Interval (ft) & 0.5 & 0.5 & 0.5 & 0.5 & 0.5 \\
\hline $\mathrm{ft} / \mathrm{min}$ & $N / A^{2}$ & $\mathrm{~N} / \mathrm{A}$ & $\mathrm{N} / \mathrm{A}$ & $\mathrm{N} / \mathrm{A}$ & $\mathrm{N} / \mathrm{A}$ \\
\hline Pre-Verification & DN271CAB & DN281CAB & DN291CAB & DN291CAB & AN012CAB \\
\hline Start File & DN271000 & DN281000 & DN291000 & DN291033 & AN012000 \\
\hline Finish File & DN271040 & DN281157 & DN291032 & DN291093 & AN012006 \\
\hline Post-Verification & DN271CAA & DN281CAA & DN291CAA & DN291CAA & AN012CAA \\
\hline $\begin{array}{l}\text { Depth Return Error } \\
\text { (in.) }\end{array}$ & 0 & 0 & $N / A$ & 0 & 0 \\
\hline Comments & $\begin{array}{l}\text { Fine gain } \\
\text { adjustment } \\
\text { after file- } 1030 \text {. }\end{array}$ & $\begin{array}{l}\text { No fine gain } \\
\text { adjustment }\end{array}$ & $\begin{array}{l}\text { No fine gain } \\
\text { adjustment }\end{array}$ & $\begin{array}{l}\text { No fine gain } \\
\text { adjustment }\end{array}$ & $\begin{array}{l}\text { No fine gain } \\
\text { adjustment }\end{array}$ \\
\hline
\end{tabular}

\section{Neutron Moisture Logging System (NMLS) Log Run Information:}

\begin{tabular}{|l|c|c|l|l|l|}
\hline Log Run & $\mathbf{5}$ & $\mathbf{6}$ Repeat & & & \\
\hline Date & $04 / 17 / 06$ & $04 / 17 / 06$ & & & \\
\hline Logging Engineer & Spatz & Spatz & & & \\
\hline Start Depth (ft) & 0.0 & 30.0 & & & \\
\hline Finish Depth (ft) & 35.5 & 35.0 & & & \\
\hline Count Time (sec) & 15 & 15 & & & \\
\hline Live/Real & $\mathrm{R}$ & $\mathrm{R}$ & & & \\
\hline Shield (Y/N) & $\mathrm{N}$ & $\mathrm{N}$ & & & \\
\hline MSA Interval (ft) & 0.25 & 0.25 & & & \\
\hline tt/min & $\mathrm{N} / \mathrm{A}$ & $\mathrm{N} / \mathrm{A}$ & & & \\
\hline Pre-Verification & DF172CAB & DF172CAB & & & \\
\hline Start File & DF172000 & DF172143 & & & \\
\hline Finish File & DF172142 & DF172163 & & & \\
\hline Post-Verification & DF172CAA & DF172CAA & & & \\
\hline $\begin{array}{l}\text { Depth Return Error } \\
\text { (in.) }\end{array}$ & N/A & 0 & & & \\
\hline Comments & $\begin{array}{l}\text { No fine gain } \\
\text { adjustment }\end{array}$ & $\begin{array}{l}\text { No fine gain } \\
\text { adjustment }\end{array}$ & & & \\
\hline
\end{tabular}

\section{Logging Operation Notes:}

Logging was conducted with a centralizer on the sondes. Logging data acquisition is referenced to ground level. The maximum logging depth achieved was $112.9 \mathrm{ft}$. Repeat sections were collected in this borehole to evaluate each system's performance and to acquire more detailed information at selected depths. The SGLS repeat sections were acquired at 400 seconds ( 20 to $50 \mathrm{ft}$ ) and 1000 seconds ( 19 to $22 \mathrm{ft}$ ) relative to the main $\log$ at a 200 second counting time.

\section{Analysis Notes:}

\begin{tabular}{|l|l|l|l|l|l|}
\hline Analyst: & Henwood & Date: & $05 / 01 / 06$ & Reference: & GJO-HGLP 1.6.3, Rev. 0 \\
\hline
\end{tabular}

Pre-run and post-run verifications for the SGLS (G4N) were acquired in the Amersham verifier, serial number 115 which is enhanced in the naturally occurring radionuclides ${ }^{40} \mathrm{~K},{ }^{238} \mathrm{U}$, and ${ }^{232} \mathrm{Th}$ (KUT). The 
resolution (FWHM) for the 609 and $1461 \mathrm{keV}$ energy peaks fell slightly below the lower control limits for pre-run verification data acquired on 04/13/06; the HASQUARD criteria were met. The control limits were not exceeded for the other five verification spectra. Therefore, the data are accepted.

Pre-run and post-run verifications for the SGLS (G1N) were acquired in the Amersham verifier, serial number 118 . The criteria were met.

A casing correction for 9/16-in.-thick casing was applied to the SGLS log data.

SGLS spectra were processed in batch mode using APTEC SUPERVISOR to identify individual energy peaks and determine count rates. Concentrations were calculated with EXCEL worksheet templates identified as G4NApr06.xls and G1NApr06.xls for logging systems G4N and G1N, respectively, using efficiency functions and corrections for casing, water, and dead time as determined from annual calibrations. Dead time corrections are applied where dead times exceed 8 and 10 percent for G4N and G1N, respectively. No correction for dead time was necessary. A correction for water was applied to data acquired on $04 / 13$ below $39.1 \mathrm{ft}$ in depth. For repeat data acquired $04 / 14$, the water correction was applied to data below $37.5 \mathrm{ft}$.

The NMLS data are presented as counts per second. A calibration for casing inside diameters greater than 8 -in. is not available.

\section{$\underline{\text { Results and Interpretations: }}$}

A plot of manmade radionuclides is included for ${ }^{137} \mathrm{Cs}$ and processed uranium $\left({ }^{235} \mathrm{U}\right.$ and $\left.{ }^{238} \mathrm{U}\right)$. The plot indicates all detections based on the routine processing software. All of the detections were at or near the respective MDLs. Inspection of each spectrum where detection was indicated revealed no full energy peaks. Therefore, the detections are considered to be statistical fluctuations and are not considered valid. No other manmade radionuclides were indicated.

There is a strong indication of radon in the groundwater. Comparison of the $1764 \mathrm{keV}$ and $609 \mathrm{keV}{ }^{214} \mathrm{Bi}$ gamma rays show differing concentrations after corrections for water and casing. The casing and water correction factors decrease with increasing energy. Gamma rays originating inside the casing are not attenuated by the steel casing, and the net effect of applying the correction factors is to amplify results from low-energy gamma rays. The fact that the $609 \mathrm{keV}$ gamma ray results in a higher apparent concentration than the $1764 \mathrm{keV}$ gamma line suggests that radon is present in the groundwater. Typical formation concentrations of naturally occurring ${ }^{238} \mathrm{U}$ are between approximately 0.5 and $1.5 \mathrm{pCi} / \mathrm{g}$. The concentrations above the groundwater level are consistent with these values for the assays of both the 609 and $1764 \mathrm{keV}$ peaks. Note that enhanced radon is not related to the existence of manmade uranium.

The neutron moisture results are reported in counts per second because no valid calibration is available for borehole inside diameters greater than 8 inches. Some variation is noted in the moisture profile.

The repeat sections generally indicate good agreement of the naturally occurring KUT. The repeat data were acquired at 400 ( 20 to $50 \mathrm{ft}$ ) and 1000 second ( 19 to $22 \mathrm{ft}$ ) counting times relative to the 200 second counting time for the main $\log$ data. The $\log$ data, especially for ${ }^{40} \mathrm{~K}$ do not repeat between 36 and $39 \mathrm{ft}$. The water level in the borehole before logging this interval on $04 / 13$ was $39.1 \mathrm{ft}$. When the repeat data were acquired on $04 / 14$, the depth to water was measured before logging at $37.5 \mathrm{ft}$. Corrections used for water in the borehole are applied accordingly. The static water level (i.e., formation water is at the same level as water inside the borehole) was not realized until after the SGLS logging was complete. The lack of repeatability in this $\log$ interval is apparently due to incorrect water corrections because of changing depth to water that occurred during logging and between the separate log events.

\section{Log Plots:}

Manmade Radionuclides 
Natural Gamma Logs

Combination Plot

Total Gamma \& Moisture

Total Gamma \& Dead Time

Repeat Section of Natural Gamma Logs (20 to $50 \mathrm{ft}$ )

Repeat Section of Natural Gamma Logs (19 to $22 \mathrm{ft}$ )

${ }^{1}$ GWL - groundwater level

${ }^{2} \mathrm{~N} / \mathrm{A}$ - not applicable 


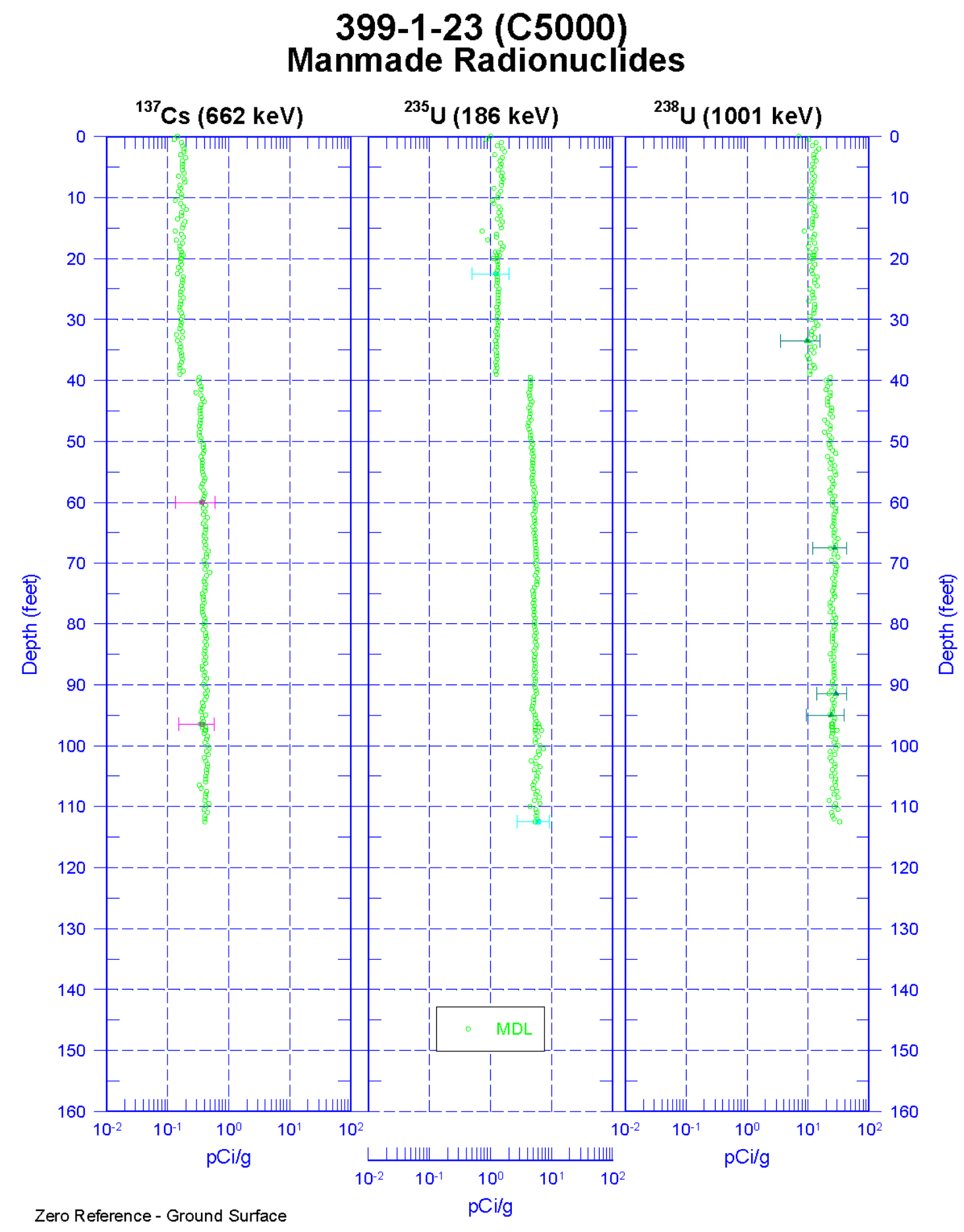




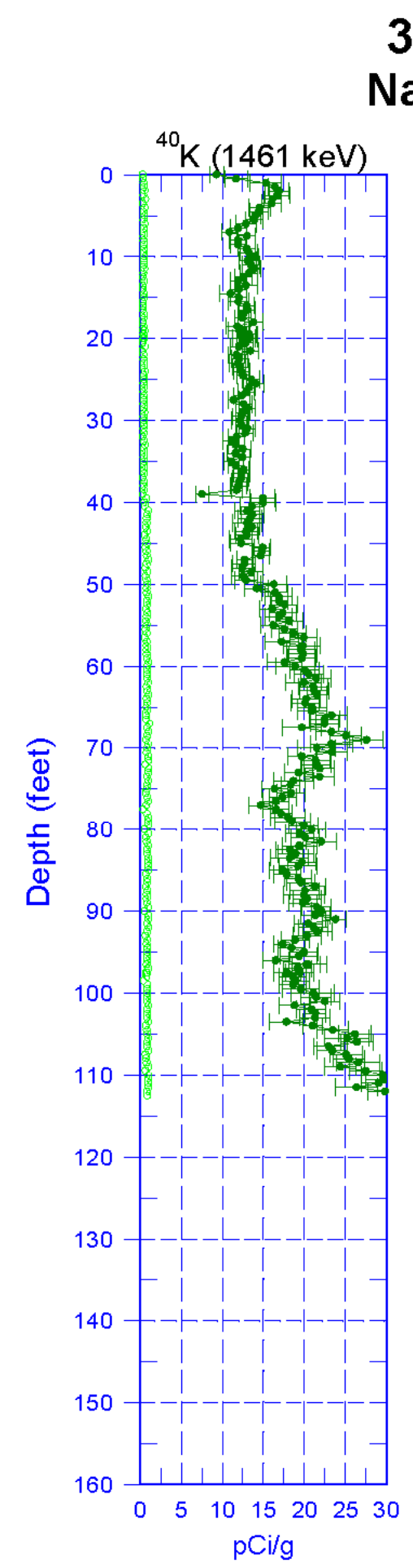

\section{9-1-23 (C5000) Natural Gamma Logs}
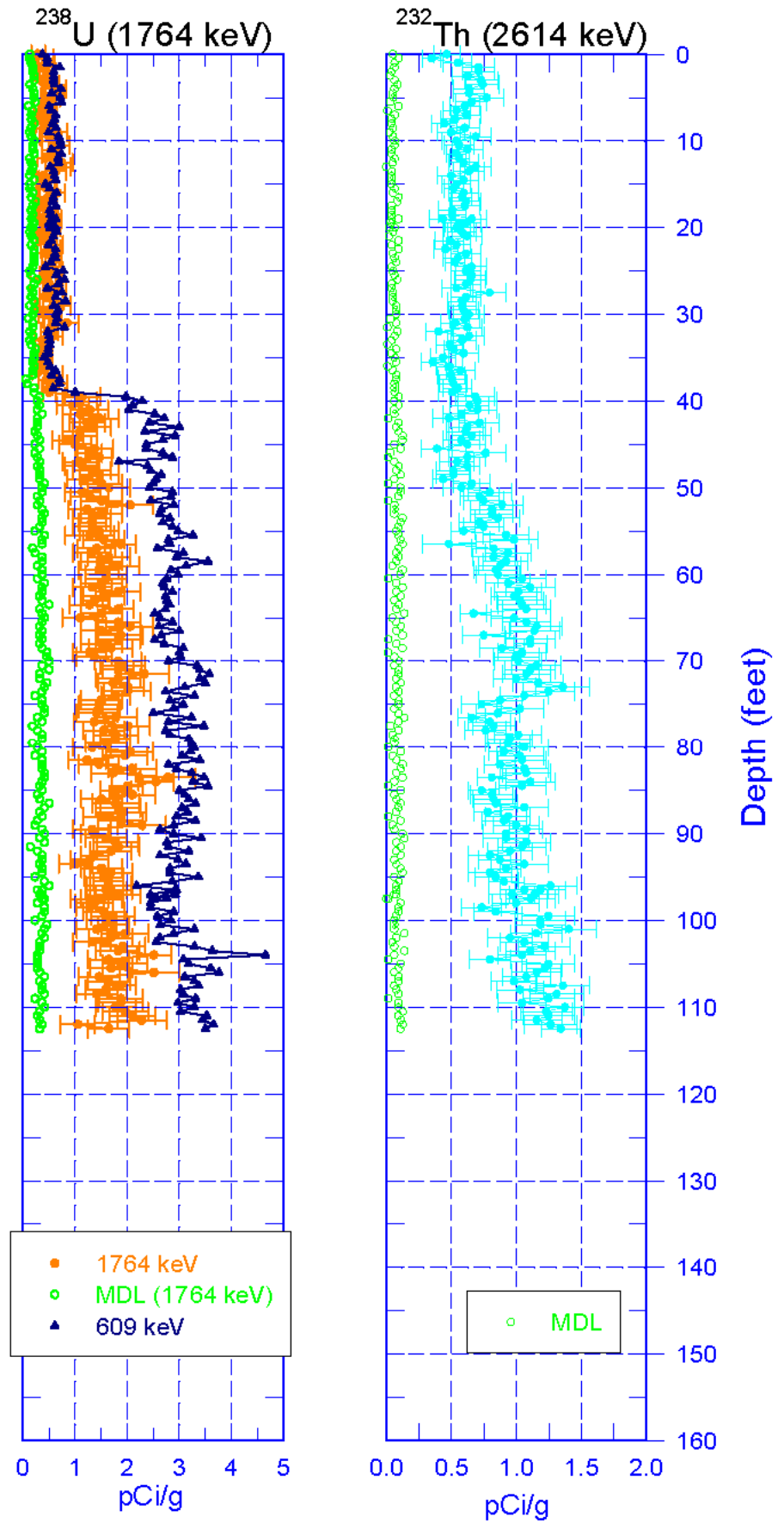

Zero Reference - Ground Surface 


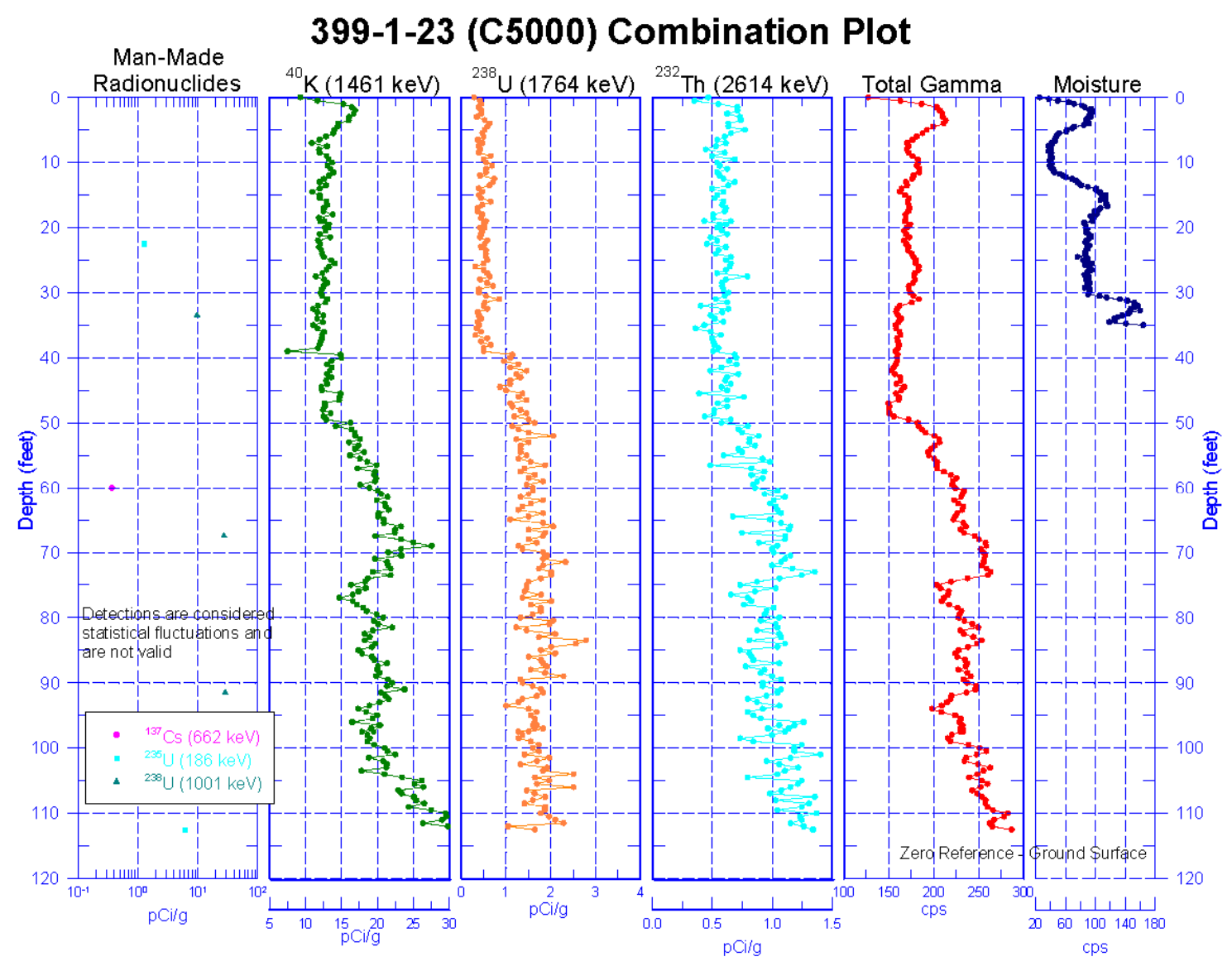




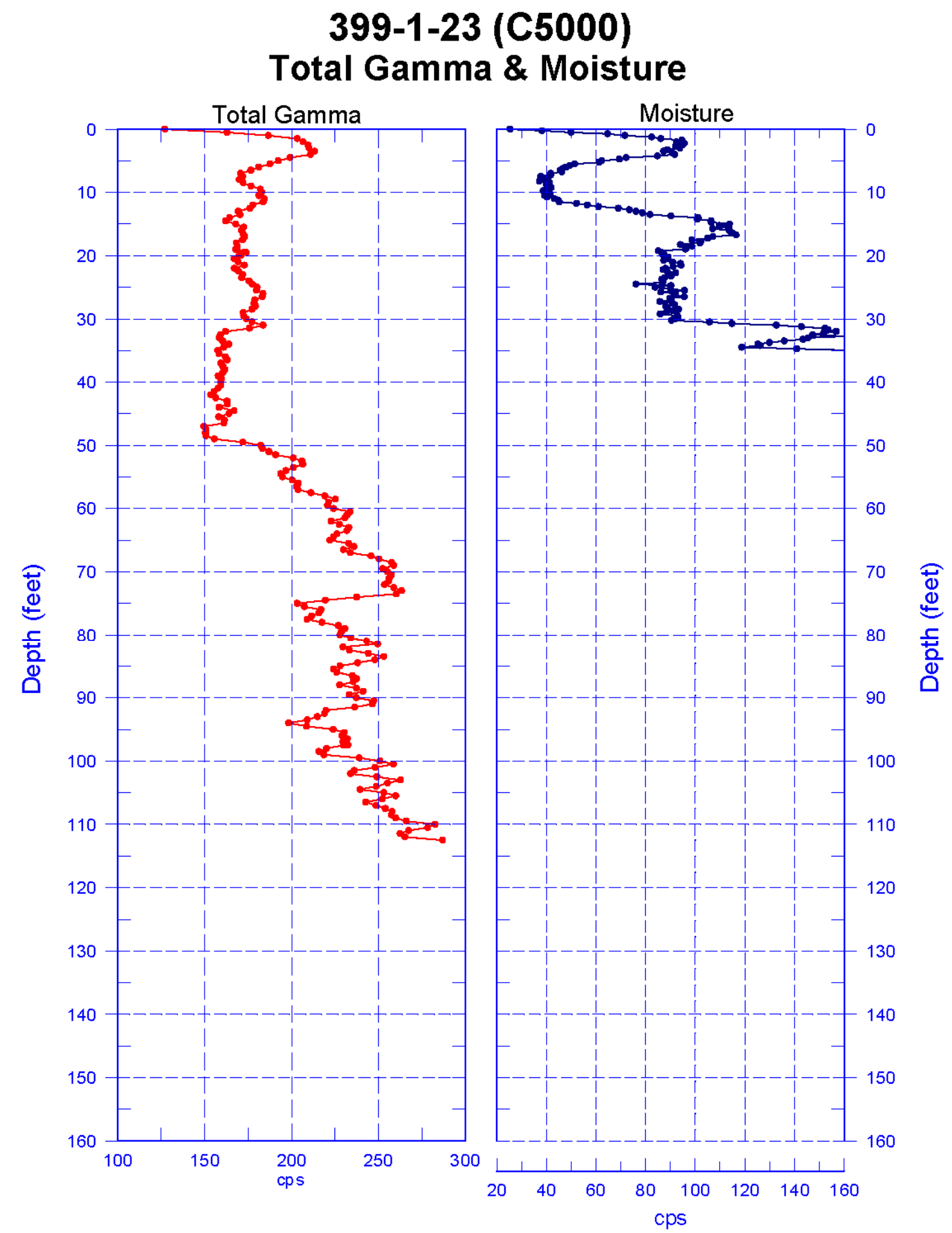

Reference - Ground Surface 


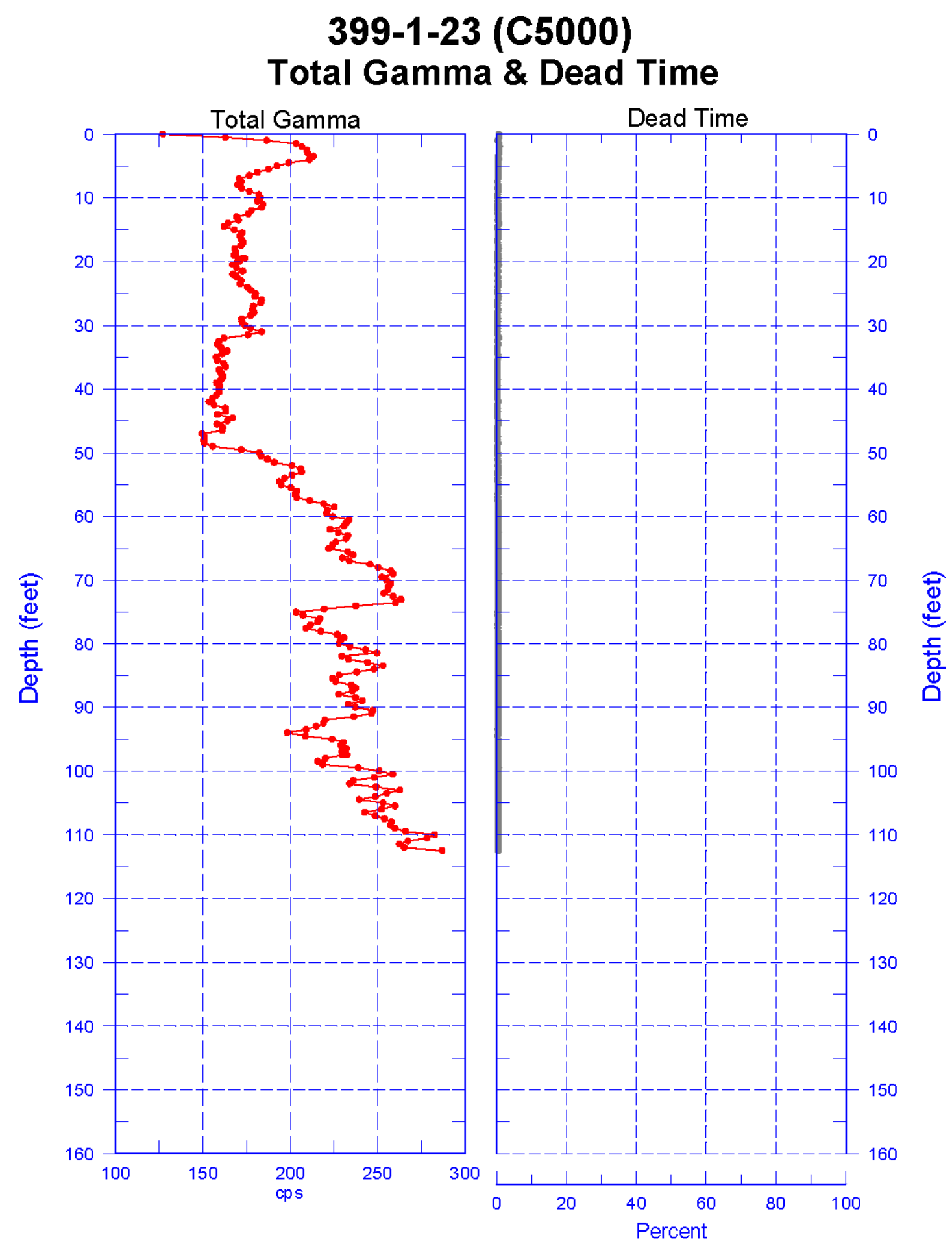

Reference - Ground Surface 


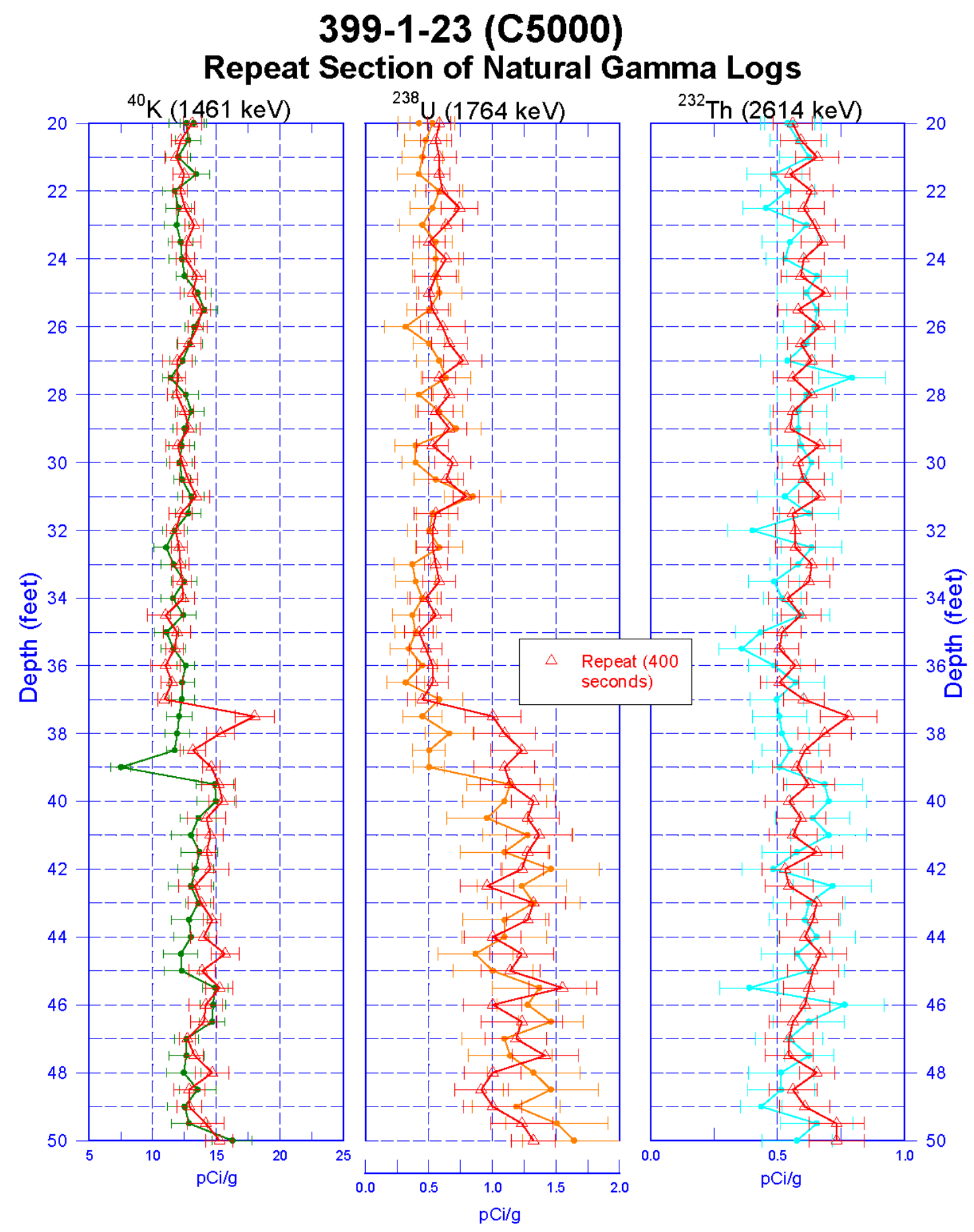

Zero Reference - Ground Surface 


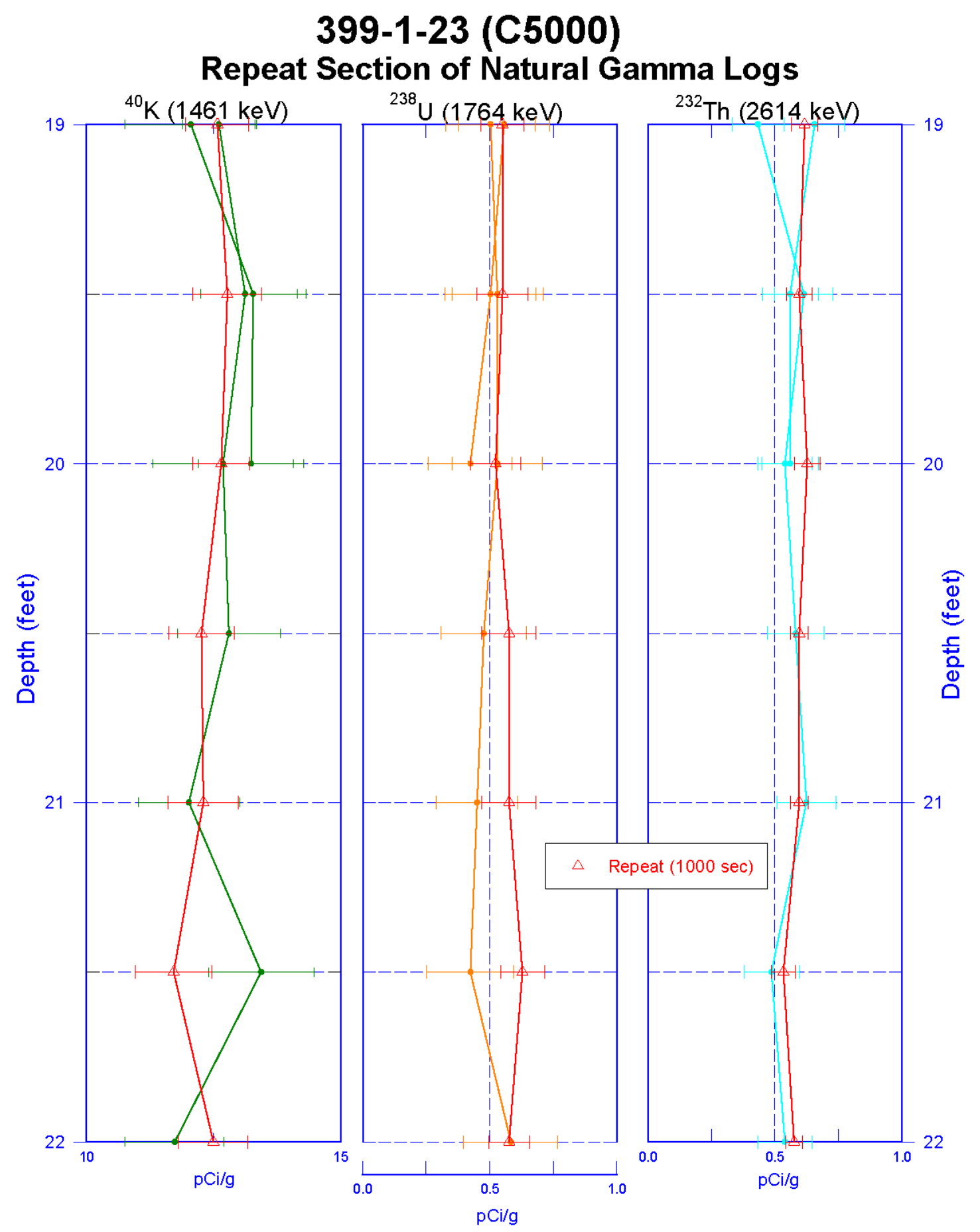

Zero Reference - Ground Surface 
Stoller

\section{9-3-19 (C5001) \\ Log Data Report}

\section{Borehole Information:}

\begin{tabular}{|c|c|c|c|c|c|}
\hline \multicolumn{3}{|c|}{ Borehole: $\quad 399-3-19(\mathrm{C} 5001)$} & \multirow[b]{2}{*}{47 (aporoximate) } & \multicolumn{2}{|c|}{$\begin{array}{l}\text { South from } 316-5 \text { Process } \\
\text { Trenches }\end{array}$} \\
\hline \multicolumn{2}{|c|}{ Coordinates (WA St Plane) } & $\mathrm{GWL}^{1}(\mathrm{ft}):$ & & GWL Date: & $04 / 13 / 06$ \\
\hline $\begin{array}{c}\text { North } \\
\text { (m) } \\
\text { not available }\end{array}$ & $\begin{array}{c}\text { East } \\
(\mathbf{m}) \\
\text { not available }\end{array}$ & $\begin{array}{l}\text { Drill Date } \\
05 / 01 / 06\end{array}$ & $\begin{array}{l}\text { TOC } \\
\text { Elevation (ft) } \\
\text { not available }\end{array}$ & $\begin{array}{l}\text { Total Depth (ft) } \\
86\end{array}$ & $\begin{array}{l}\text { Type } \\
\text { Sonic }\end{array}$ \\
\hline
\end{tabular}

\section{Casing Information:}

\begin{tabular}{|c|c|c|c|c|c|c|}
\hline Casing Type & $\begin{array}{c}\text { Stickup } \\
\text { (ft) }\end{array}$ & $\begin{array}{c}\text { Outer } \\
\text { Diameter } \\
\text { (in.) }\end{array}$ & $\begin{array}{c}\text { Inside } \\
\text { Diameter } \\
\text { (in.) }\end{array}$ & $\begin{array}{c}\text { Thickness } \\
\text { (in.) }\end{array}$ & Top (ft) & Bottom (ft) \\
\hline Threaded Carbon Steel & 2.0 & $93 / 4$ & $85 / 8$ & $9 / 16$ & 2.0 & 86 \\
\hline
\end{tabular}

\section{Borehole Notes:}

The logging engineer measured the 8-in. casing and stickup using a steel tape. Measurements were rounded to the nearest $1 / 16 \mathrm{in}$. The onsite geologist reported the depth to bottom and depth to groundwater.

\section{Logging Equipment Information:}

\begin{tabular}{|c|c|c|c|}
\hline Logging System: & Gamma 4N & & $\begin{array}{ll}\text { Type: } & \begin{array}{l}\text { SGLS (60\%) SN } \\
\text { 45TP22010A }\end{array}\end{array}$ \\
\hline Calibration Date: & $04 / 06 / 06$ & Calibration Reference: & DOE-EM/GJ1177-2006 \\
\hline & & Logging Procedure: & MAC-HGLP 1.6.5, Rev. 0 \\
\hline
\end{tabular}

\begin{tabular}{|clll|}
\hline Logging System: & Gamma 4F & Type: & NMLS SN: H380932510 \\
\hline Calibration Date: & $04 / 28 / 06$ & Calibration Reference: & TBD \\
\hline & & Logging Procedure: & MAC-HGLP 1.6.5, Rev. 0 \\
\hline
\end{tabular}

\section{Spectral Gamma Logging System (SGLS) Log Run Information:}

\begin{tabular}{|l|c|c|c|l|l|}
\hline Log Run & $\mathbf{3}$ & $\mathbf{4}$ & 5 Repeat & & \\
\hline Date & $05 / 01 / 06$ & $05 / 02 / 06$ & $05 / 02 / 06$ & & \\
\hline Logging Engineer & Spatz & Spatz & Spatz & & \\
\hline Start Depth (ft) & 0.0 & 0.0 & 35.0 & & \\
\hline Finish Depth (ft) & 79.5 & 78.5 & 60.0 & & \\
\hline Count Time (sec) & 200 & 200 & 400 & & \\
\hline Live/Real & $\mathrm{R}$ & $\mathrm{R}$ & $\mathrm{R}$ & & \\
\hline Shield (Y/N) & $\mathrm{N}$ & $\mathrm{N}$ & $\mathrm{N}$ & & \\
\hline MSA Interval (ft) & 0.5 & 0.5 & 0.5 & & \\
\hline
\end{tabular}




\begin{tabular}{|l|l|l|l|l|l|}
\hline Log Run & $\mathbf{3}$ & $\mathbf{4}$ & $\mathbf{5}$ Repeat & & \\
\hline tt/min & \multicolumn{1}{|c|}{$\mathrm{N}^{2} \mathrm{~A}^{2}$} & N/A & N/A & & \\
\hline Pre-Verification & DN301CAB & DN301CAB & DN301CAB & & \\
\hline Start File & DN301000 & DN301160 & DN301176 & & \\
\hline Finish File & DN301159 & DN301175 & DN301226 & & \\
\hline Post-Verification & DN301CAA & DN301CAA & DN301CAA & & \\
\hline $\begin{array}{l}\text { Depth Return Error } \\
\text { in.) }\end{array}$ & -0.5 & N/A & 0 & & \\
\hline Comments & $\begin{array}{l}\text { Fine gain } \\
\text { adjustment } \\
\text { after files-020, } \\
057 .\end{array}$ & $\begin{array}{l}\text { No fine gain } \\
\text { adjustment }\end{array}$ & $\begin{array}{l}\text { No fine gain } \\
\text { adjustment }\end{array}$ & & \\
\hline
\end{tabular}

\section{Neutron Moisture Logging System (NMLS) Log Run Information:}

\begin{tabular}{|l|c|c|l|l|l|}
\hline Log Run & $\mathbf{1}$ & $\mathbf{2}$ Repeat & & & \\
\hline Date & $05 / 01 / 06$ & $05 / 01 / 06$ & & & \\
\hline Logging Engineer & Spatz & Spatz & & & \\
\hline Start Depth (ft) & 0.0 & 25.0 & & & \\
\hline Finish Depth (ft) & 46.75 & 30.0 & & & \\
\hline Count Time (sec) & 15 & 15 & & & \\
\hline Live/Real & $\mathrm{R}$ & $\mathrm{R}$ & & & \\
\hline Shield (Y/N) & $\mathrm{N}$ & $\mathrm{N}$ & & & \\
\hline MSA Interval (ft) & 0.25 & N/A & N/A & & \\
\hline ft/min & DF202CAB & DF202CAB & & & \\
\hline Pre-Verification & DF202000 & DF202188 & & & \\
\hline Start File & DF202187 & DF202208 & & & \\
\hline Finish File & DF202CAA & DF202CAA & & & \\
\hline Post-Verification & N/A & 0 & & & \\
\hline $\begin{array}{l}\text { Depth Return Error } \\
\text { (in.) }\end{array}$ & $\begin{array}{l}\text { No fine gain } \\
\text { adjustment }\end{array}$ & $\begin{array}{l}\text { No fine gain } \\
\text { adjustment }\end{array}$ & & & \\
\hline Comments & & & & \\
\hline
\end{tabular}

\section{Logging Operation Notes:}

Logging was conducted with a centralizer on the sondes. Logging data acquisition is referenced to ground level. The maximum logging depth achieved was $86.2 \mathrm{ft}$. Repeat sections were collected in this borehole to evaluate each system's performance and to acquire more detailed information at selected depths. The SGLS repeat section was acquired between 35 and $60 \mathrm{ft}$ ( 400 seconds) and between 25 and $30 \mathrm{ft}$ for the NMLS.

\section{Analysis Notes:}

\begin{tabular}{|l|l|l|l|l|l|}
\hline Analyst: & Henwood & Date: & 05/09/06 & Reference: & GJO-HGLP 1.6.3, Rev. 0 \\
\hline
\end{tabular}

Pre-run and post-run verifications for the SGLS (G4N) were acquired in the Amersham verifier, serial number 115 which is enhanced in the naturally occurring radionuclides ${ }^{40} \mathrm{~K},{ }^{238} \mathrm{U}$, and ${ }^{232} \mathrm{Th}$ (KUT). The verification criteria were met.

A casing correction for $9 / 16$-in.-thick casing was applied to the SGLS log data.

SGLS spectra were processed in batch mode using APTEC SUPERVISOR to identify individual energy peaks and determine count rates. Concentrations were calculated with EXCEL worksheet template 
identified as G4NApr06.xls using efficiency functions and corrections for casing, water, and dead time as determined from annual calibrations. No correction for dead time was necessary. A correction for water was applied to data acquired below $47 \mathrm{ft}$ in depth.

The NMLS data are presented as counts per second. A calibration for casing inside diameters greater than 8 -in. is not available.

\section{$\underline{\text { Results and Interpretations: }}$}

A plot of manmade radionuclides is included for ${ }^{137} \mathrm{Cs}$ and processed uranium $\left({ }^{235} \mathrm{U}\right.$ and $\left.{ }^{238} \mathrm{U}\right)$. The plot indicates all detections based on the routine processing software. All of the detections were at or near the respective MDLs. Inspection of each spectrum where detection was indicated revealed no full energy peaks. Therefore, the detections are considered to be statistical fluctuations and are not considered valid. No other manmade radionuclides were indicated.

There is a strong indication of radon in the groundwater. Comparison of the $1764 \mathrm{keV}$ and $609 \mathrm{keV}{ }^{214} \mathrm{Bi}$ gamma rays show differing concentrations after corrections for water and casing. The casing and water correction factors decrease with increasing energy. Gamma rays originating inside the casing are not attenuated by the steel casing, and the net effect of applying the correction factors is to amplify results from low-energy gamma rays. The fact that the $609 \mathrm{keV}$ gamma ray results in a higher apparent concentration than the $1764 \mathrm{keV}$ gamma line suggests that radon is present in the groundwater. Typical formation concentrations of naturally occurring ${ }^{238} \mathrm{U}$ are between approximately 0.5 and $1.5 \mathrm{pCi} / \mathrm{g}$. The concentrations above the groundwater level are consistent with these values for the assays of both the 609 and $1764 \mathrm{keV}$ peaks. Note that enhanced radon is not related to the existence of manmade uranium.

The neutron moisture results are reported in counts per second because no valid calibration is available for borehole inside diameters greater than 8 inches. Some variation is noted in the moisture profile.

The repeat sections generally indicate good agreement of the naturally occurring KUT and moisture. No manmade radionuclides were detected at the 400 second counting time.

\section{Log Plots:}

Manmade Radionuclides

Natural Gamma Logs

Combination Plot

Total Gamma \& Moisture

Total Gamma \& Dead Time

Repeat Section of Natural Gamma Logs

Moisture Repeat Section

${ }^{1} \mathrm{GWL}$ - groundwater level

${ }^{2} \mathrm{~N} / \mathrm{A}-$ not applicable 


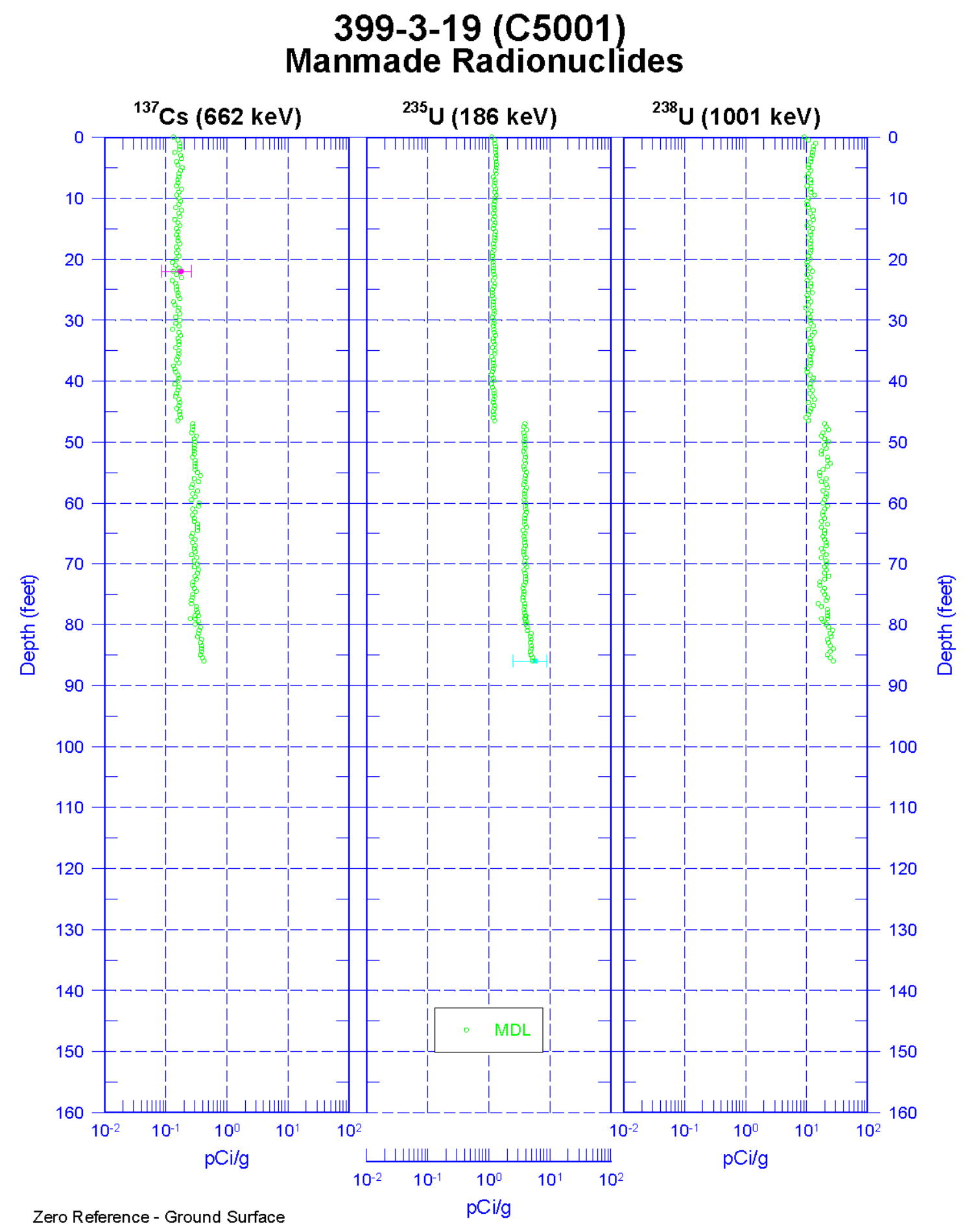




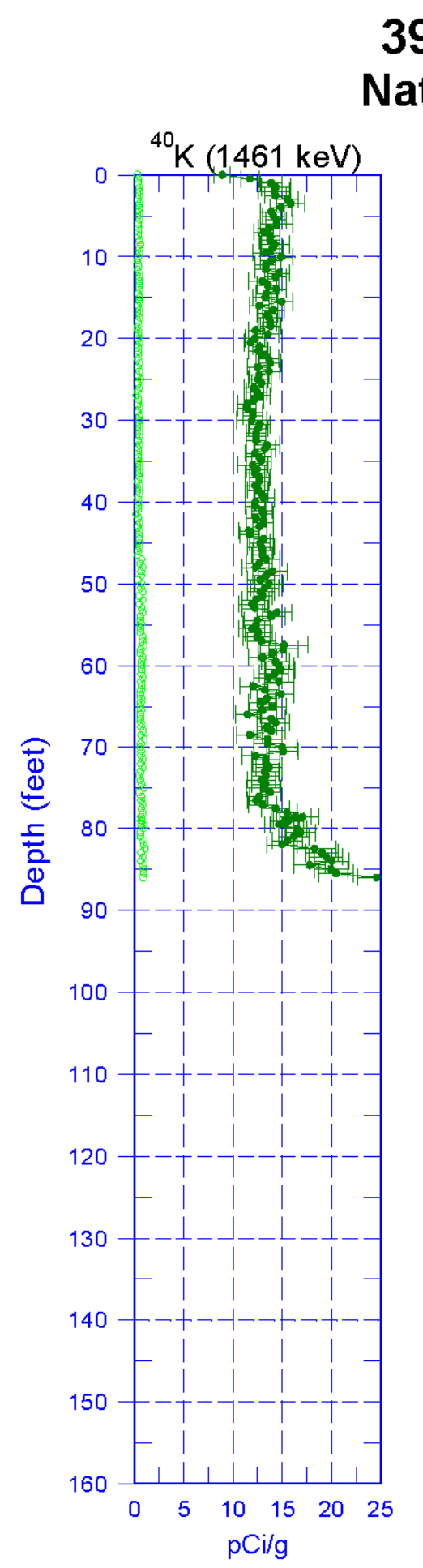

399-3-19 (C5001) Natural Gamma Logs
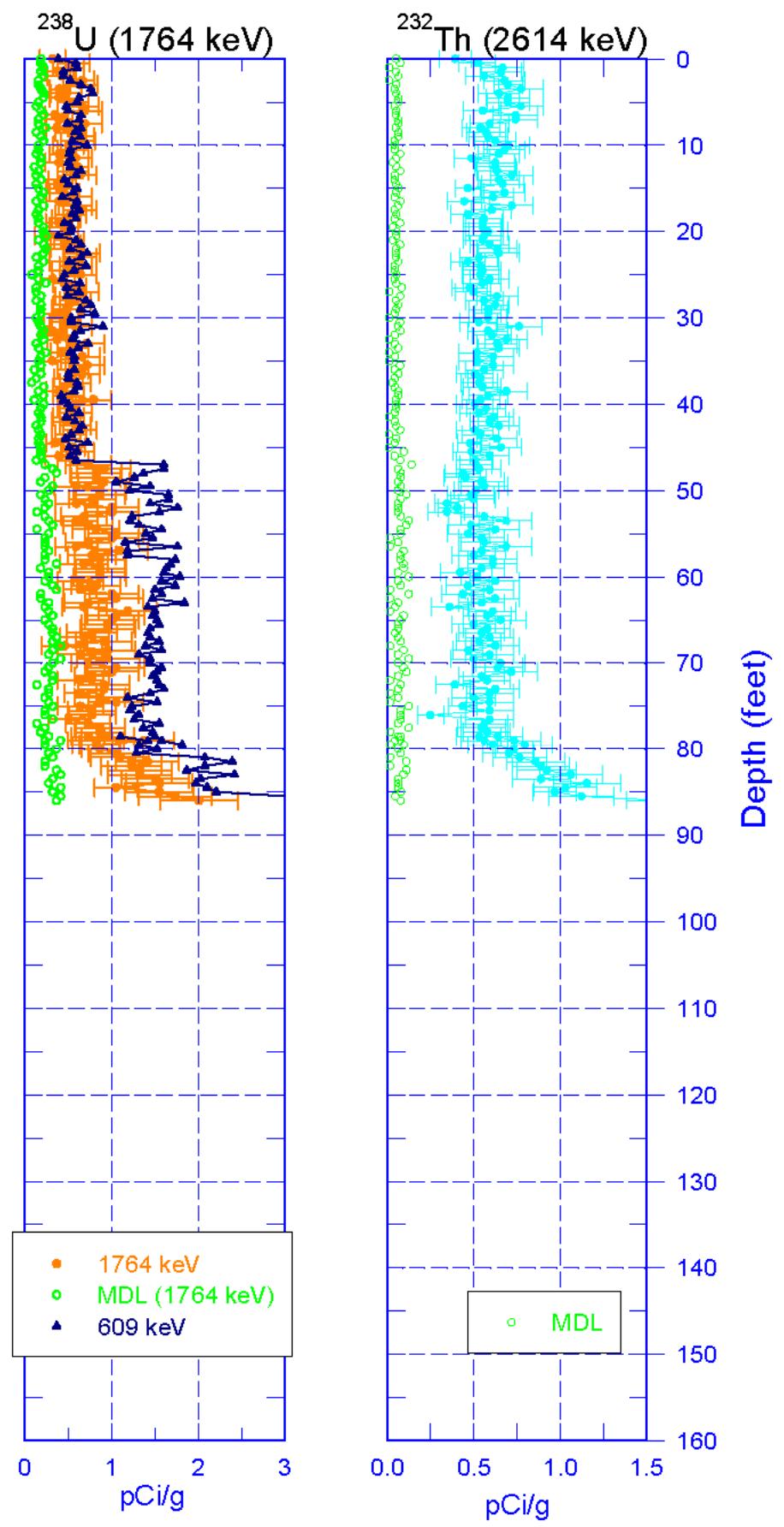

Zero Reference - Ground Surface 


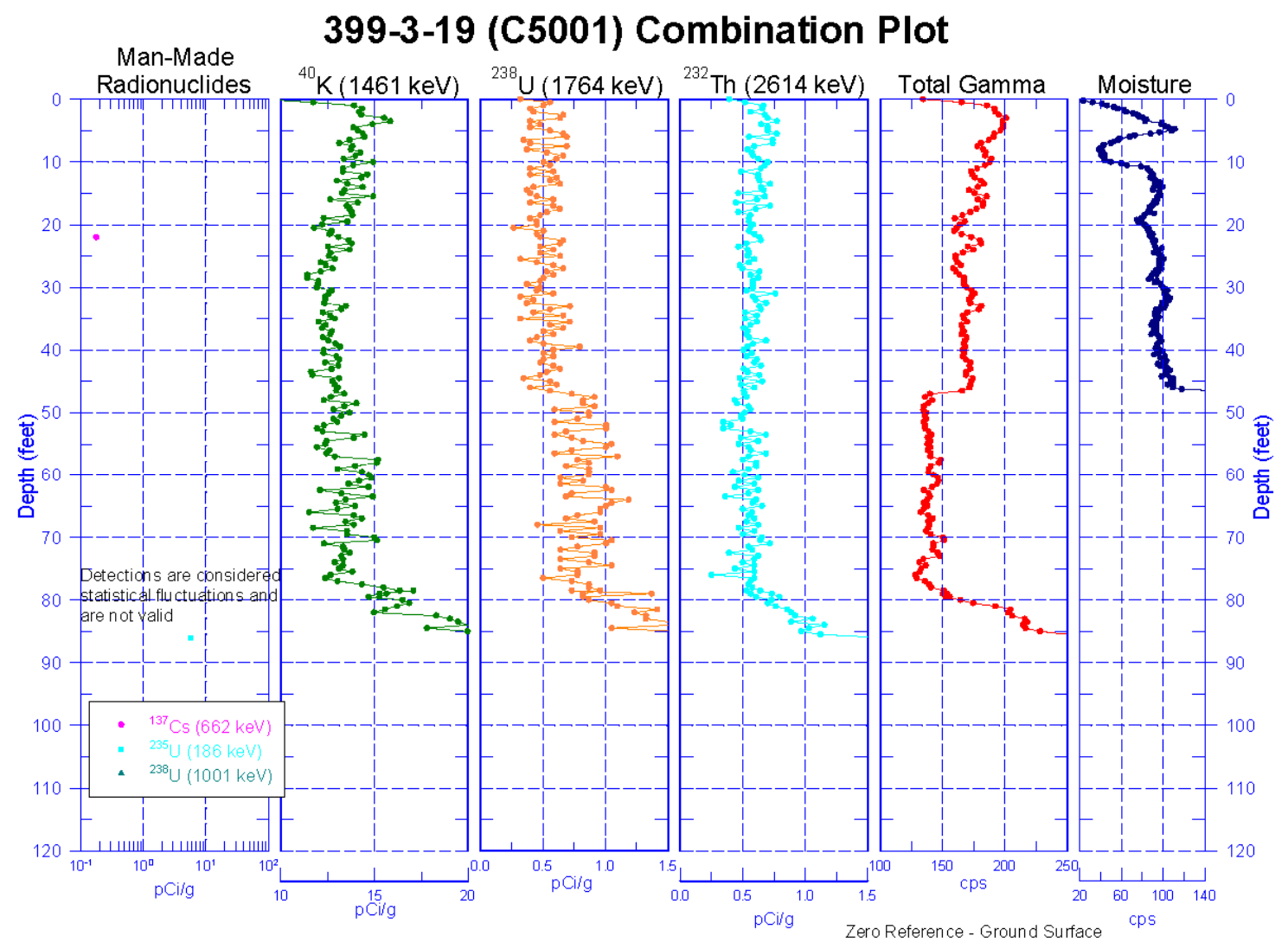



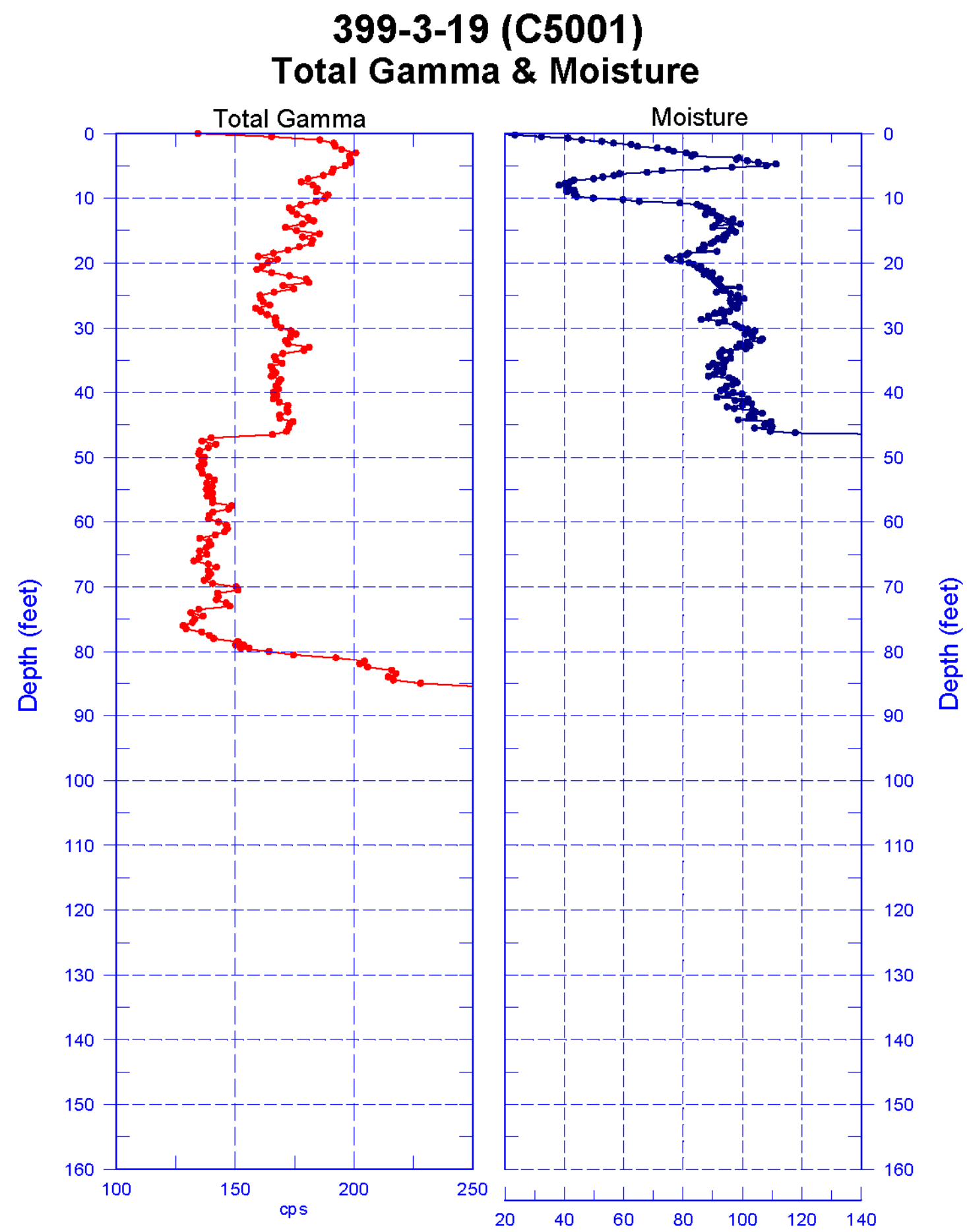

Reference - Ground Surface 


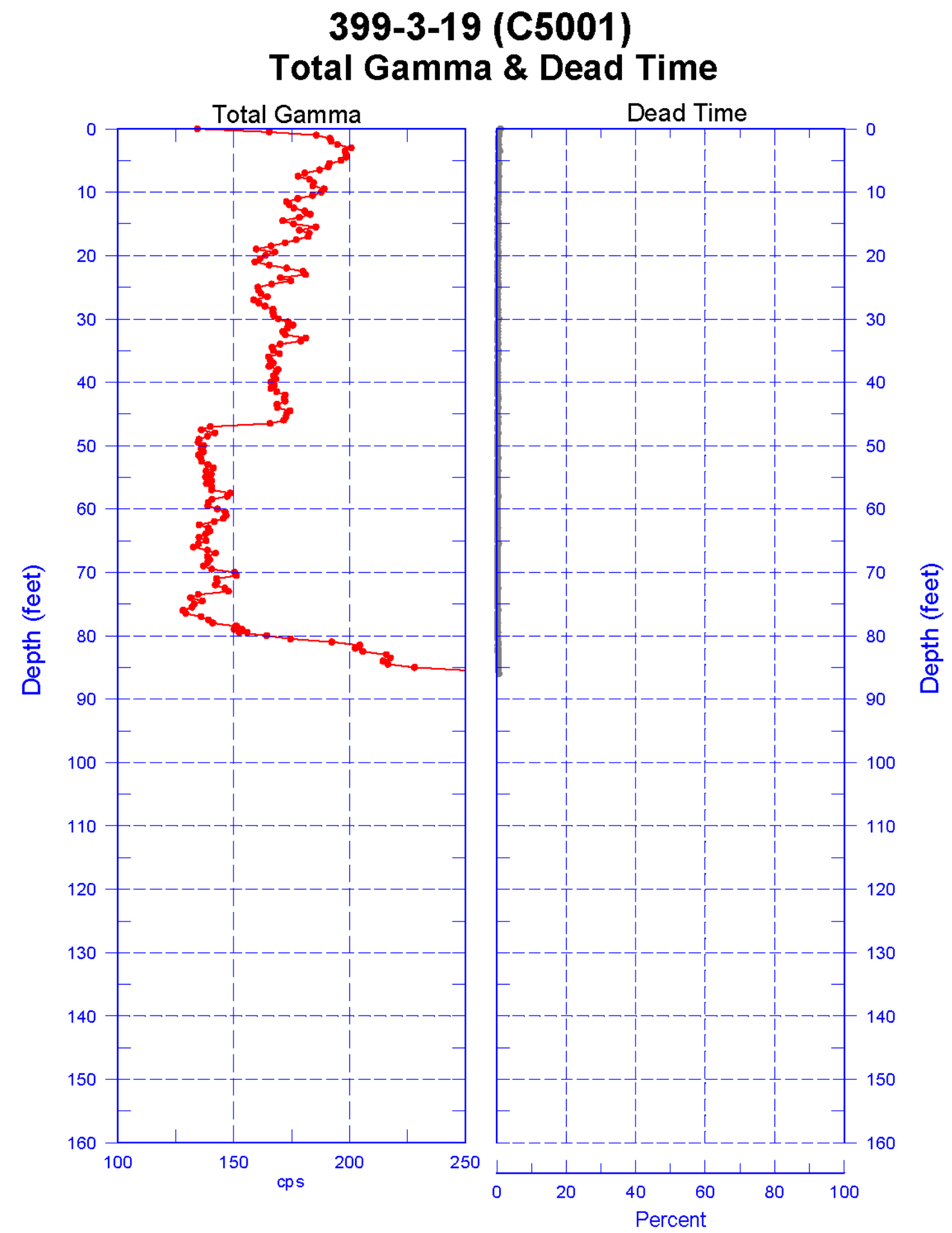

Reference - Ground Surface 


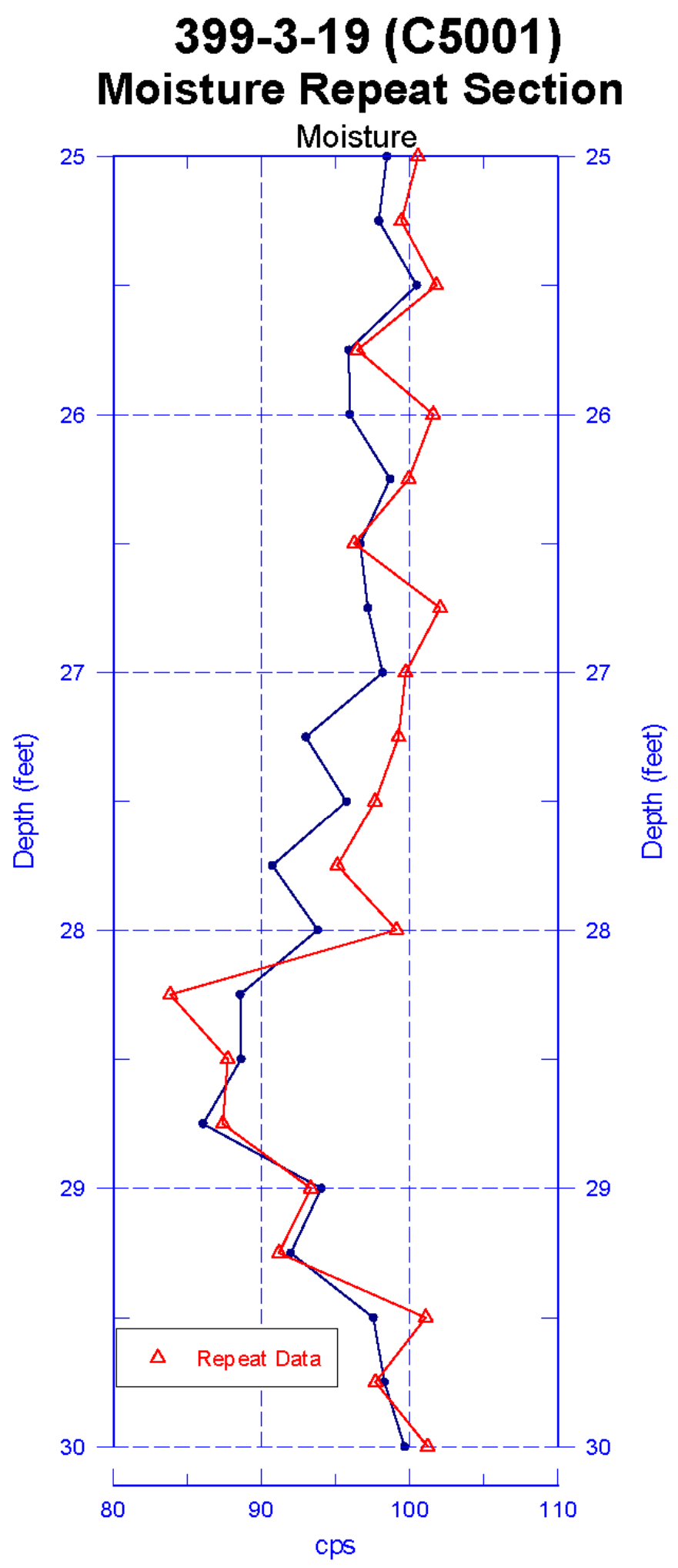

Reference - Ground Surface 
$\int \frac{201 / e r}{\text { Grand Junction Office }}$

\section{9-3-20 (C5002) \\ Log Data Report}

DOE-EM/GJ1203-2006

\section{Borehole Information:}

\begin{tabular}{|c|c|c|c|c|c|}
\hline \multicolumn{2}{|c|}{ Borehole: $\quad 399-3-$} & $5002)$ & \multirow{2}{*}{$\frac{\text { Site: }}{49 \text { (approximate) }}$} & \multicolumn{2}{|c|}{$\begin{array}{c}\text { East of } 307 \text { Disposal } \\
\text { Trenches (WIDS Site } 316-3\end{array}$} \\
\hline \multicolumn{2}{|c|}{ Coordinates (WA St Plane) } & $\mathrm{GWL}^{\prime}(\mathrm{ft}):$ & & GWL Date: & $05 / 16 / 06$ \\
\hline $\begin{array}{c}\text { North } \\
\text { (m) } \\
\text { not available }\end{array}$ & $\begin{array}{c}\text { East } \\
\text { (m) } \\
\text { not available }\end{array}$ & $\begin{array}{l}\text { Drill Date } \\
05 / 01 / 06\end{array}$ & \begin{tabular}{l}
\multicolumn{1}{c}{ TOC } \\
Elevation (ft) \\
not available
\end{tabular} & $\begin{array}{c}\text { Total Depth (ft) } \\
90\end{array}$ & $\begin{array}{l}\text { Type } \\
\text { Sonic }\end{array}$ \\
\hline
\end{tabular}

\section{Casing Information:}

\begin{tabular}{|c|c|c|c|c|c|c|}
\hline Casing Type & $\begin{array}{c}\text { Stickup } \\
\text { (ft) }\end{array}$ & $\begin{array}{c}\text { Outer } \\
\text { Diameter } \\
\text { (in.) }\end{array}$ & $\begin{array}{c}\text { Inside } \\
\text { Diameter } \\
\text { (in.) }\end{array}$ & $\begin{array}{l}\text { Thickness } \\
\text { (in.) }\end{array}$ & Top (ft) & Bottom (ft) \\
\hline Threaded Carbon Steel & 4.5 & $93 / 4$ & $85 / 8$ & $9 / 16$ & 4.5 & 90 \\
\hline
\end{tabular}

\section{Borehole Notes:}

The logging engineer measured the 8-in. casing and stickup using a steel tape. Measurements were rounded to the nearest $1 / 16$ in. The onsite geologist reported the depth to bottom and depth to groundwater.

\section{Logging Equipment Information:}

\begin{tabular}{|c|c|c|c|}
\hline Logging System: & & Gamma 4N & $\begin{array}{c}\text { SGLS (60\%) SN } \\
\text { 45TP22010A } \\
\end{array}$ \\
\hline Calibration Date: & 04/06/06 & Calibration Reference: & DOE-EM/GJ1177-2006 \\
\hline & & Logging Procedure: & MAC-HGLP 1.6.5, Rev. 0 \\
\hline
\end{tabular}

\begin{tabular}{|c|c|c|c|}
\hline Logging System: & & Gamma 4H & NMLS SN: H310700352 \\
\hline Calibration Date: & 03/06/06 & Calibration Reference: & DOE-EM/GJ1154-2006 \\
\hline & & Logging Procedure: & MAC-HGLP 1.6.5, Rev. 0 \\
\hline
\end{tabular}

\section{Spectral Gamma Logging System (SGLS) Log Run Information:}

\begin{tabular}{|l|c|c|c|c|c|}
\hline Log Run & $\mathbf{1}$ & $\mathbf{2}$ & 3 Repeat & 4 Repeat & \\
\hline Date & $05 / 16 / 06$ & $05 / 16 / 06$ & $05 / 17 / 06$ & $05 / 17 / 06$ & \\
\hline Logging Engineer & Spatz & Spatz & Spatz & Spatz & \\
\hline Start Depth (ft) & 0.0 & 66.0 & 85.0 & 50.0 & \\
\hline Finish Depth (ft) & 65.5 & 87.0 & 78.0 & 42.0 & \\
\hline Count Time (sec) & 200 & 200 & 400 & 400 & \\
\hline Live/Real & $\mathrm{R}$ & $\mathrm{R}$ & $\mathrm{R}$ & $\mathrm{R}$ & \\
\hline Shield (Y/N) & $\mathrm{N}$ & $\mathrm{N}$ & $\mathrm{N}$ & $\mathrm{N}$ & \\
\hline MSA Interval (ft) & 0.5 & 0.5 & 0.5 & 0.5 & \\
\hline
\end{tabular}




\begin{tabular}{|c|c|c|c|c|}
\hline Log Run & 1 & 2 & 3 Repeat & 4 Repeat \\
\hline $\mathrm{ft} / \mathrm{min}$ & $N / A^{2}$ & N/A & N/A & N/A \\
\hline Pre-Verification & DN311CAB & DN311CAB & DN311CAB & DN311CAB \\
\hline Start File & DN311000 & DN311133 & DN311175 & DN311190 \\
\hline Finish File & DN311132 & DN311174 & DN311189 & DN311206 \\
\hline Post-Verification & DN311CAA & DN311CAA & DN311CAA & DN311CAA \\
\hline $\begin{array}{l}\text { Depth Return Error } \\
\text { (in.) }\end{array}$ & 0 & N/A & $N / A$ & $N / A$ \\
\hline Comments & $\begin{array}{l}\text { Fine gain } \\
\text { adjustment } \\
\text { after files-020, } \\
-50 \text {, and }-083 \text {. }\end{array}$ & $\begin{array}{l}\text { No fine gain } \\
\text { adjustments. }\end{array}$ & $\begin{array}{l}\text { No fine gain } \\
\text { adjustments. }\end{array}$ & $\begin{array}{l}\text { No fine gain } \\
\text { adjustments. }\end{array}$ \\
\hline
\end{tabular}

\section{Neutron Moisture Logging System (NMLS) Log Rum Information:}

\begin{tabular}{|l|c|c|l|l|l|}
\hline Log Run & $\mathbf{5}$ & $\mathbf{6}$ Repeat & & & \\
\hline Date & $05 / 01 / 06$ & $05 / 01 / 06$ & & & \\
\hline Logging Engineer & Spatz & Spatz & & & \\
\hline Start Depth (ft) & 0.0 & 42.0 & & & \\
\hline Finish Depth (ft) & 47.75 & 47.75 & & & \\
\hline Count Time (sec) & 15 & 15 & & & \\
\hline Live/Real & $\mathrm{R}$ & $\mathrm{R}$ & & \\
\hline Shield (Y/N) & $\mathrm{N}$ & $\mathrm{N}$ & & \\
\hline MSA Interval (ft) & 0.25 & 0.25 & & \\
\hline ft/min & $\mathrm{N} / \mathrm{A}$ & $\mathrm{N} / \mathrm{A}$ & & \\
\hline Pre-Verification & DH052CAB & DH052CAB & & \\
\hline Start File & DH052000 & DH052192 & & \\
\hline Finish File & DH052191 & DH052215 & & & \\
\hline Post-Verification & DH052CAA & DH052CAA & & & \\
\hline $\begin{array}{l}\text { Depth Return Error } \\
\text { (in.) }\end{array}$ & N/A & 0 & & & \\
\hline Comments & $\begin{array}{l}\text { No fine gain } \\
\text { adjustment }\end{array}$ & $\begin{array}{l}\text { No fine gain } \\
\text { adjustment }\end{array}$ & & & \\
\hline
\end{tabular}

\section{Logging Operation Notes:}

Logging was conducted with a centralizer on the sondes. Logging data acquisition is referenced to ground level. The maximum logging depth achieved was $87.2 \mathrm{ft}$. Repeat sections were collected in this borehole to evaluate each system's performance and to acquire more detailed information at selected depths. The SGLS repeat sections were acquired at 400 second counting time relative to 200 seconds for the main $\log$.

\section{Analysis Notes:}

\begin{tabular}{|l|l|l|l|l|l|}
\hline Analyst: & Henwood & Date: & $05 / 18 / 06$ & Reference: & G.JO-HGLP 1.6.3, Rev. 0 \\
\hline
\end{tabular}

Pre-run and post-run verifications for the SGLS (G4N) were acquired in the Amersham verifier, serial number 115 which is enhanced in the naturally occurring radionuclides ${ }^{40} \mathrm{~K},{ }^{238} \mathrm{U}$, and ${ }^{232} \mathrm{Th}$ (KUT). The verification criteria were met.

A casing correction for 9/16-in.-thick casing was applied to the SGLS log data.

SGLS spectra were processed in batch mode using APTEC SUPERVISOR to identify individual energy peaks and determine count rates. Concentrations were calculated with EXCEL worksheet template identified as G4NApr06.xls using efficiency functions and corrections for casing, water, and dead time as determined from annual calibrations. No correction for dead time was necessary. A correction for water was applied to data acquired below $49 \mathrm{ft}$ in depth. 
The NMLS data are presented as counts per second. A calibration for casing inside diameters greater than 8 -in. is not available.

\section{$\underline{\text { Results and Interpretations: }}$}

A plot of manmade radionuclides is included for ${ }^{137} \mathrm{Cs}$ and processed uranium $\left({ }^{235} \mathrm{U}\right.$ and $\left.{ }^{238} \mathrm{U}\right)$. The plot indicates all detections based on the routine processing software. All of the detections were at or near the respective MDLs. Inspection of each spectrum where a detection was indicated revealed no full energy peaks. Therefore, the detections are considered to be statistical fluctuations and are not considered valid. No other manmade radionuclides were indicated.

There is a strong indication of radon in the groundwater. Comparison of the $1764 \mathrm{keV}$ and $609 \mathrm{keV}{ }^{214} \mathrm{Bi}$ gamma rays show differing concentrations after corrections for water and casing. The casing and water correction factors decrease with increasing energy. Gamma rays originating inside the casing are not attenuated by the steel casing, and the net effect of applying the correction factors is to amplify results from low-energy gamma rays. The fact that the $609 \mathrm{keV}$ gamma ray results in a higher apparent concentration than the $1764 \mathrm{keV}$ gamma line suggests that radon is present in the groundwater. Typical formation concentrations of naturally occurring ${ }^{238} \mathrm{U}$ are between approximately 0.5 and $1.5 \mathrm{pCi} / \mathrm{g}$. The concentrations above the groundwater level are consistent with these values for the assays of both the 609 and $1764 \mathrm{keV}$ peaks. Note that enhanced radon is not related to the existence of manmade uranium.

The neutron moisture results are reported in counts per second because no valid calibration is available for borehole inside diameters greater than 8 inches. Some variation is noted in the moisture profile

The repeat sections generally indicate good agreement of the naturally occurring KUT and moisture. No manmade radionuclides were detected at the 400 second counting time.

\section{Log Plots:}

Manmade Radionuclides

Natural Gamma Logs

Combination Plot

Total Gamma \& Moisture

Total Gamma \& Dead Time

Repeat Section of Natural Gamma Logs (42-50 ft)

Repeat Section of Natural Gamma Logs $(78-85 \mathrm{ft})$

Moisture Repeat Section

${ }^{1}$ GWL - groundwater level

${ }^{2} \mathrm{~N} / \mathrm{A}$ - not applicable 


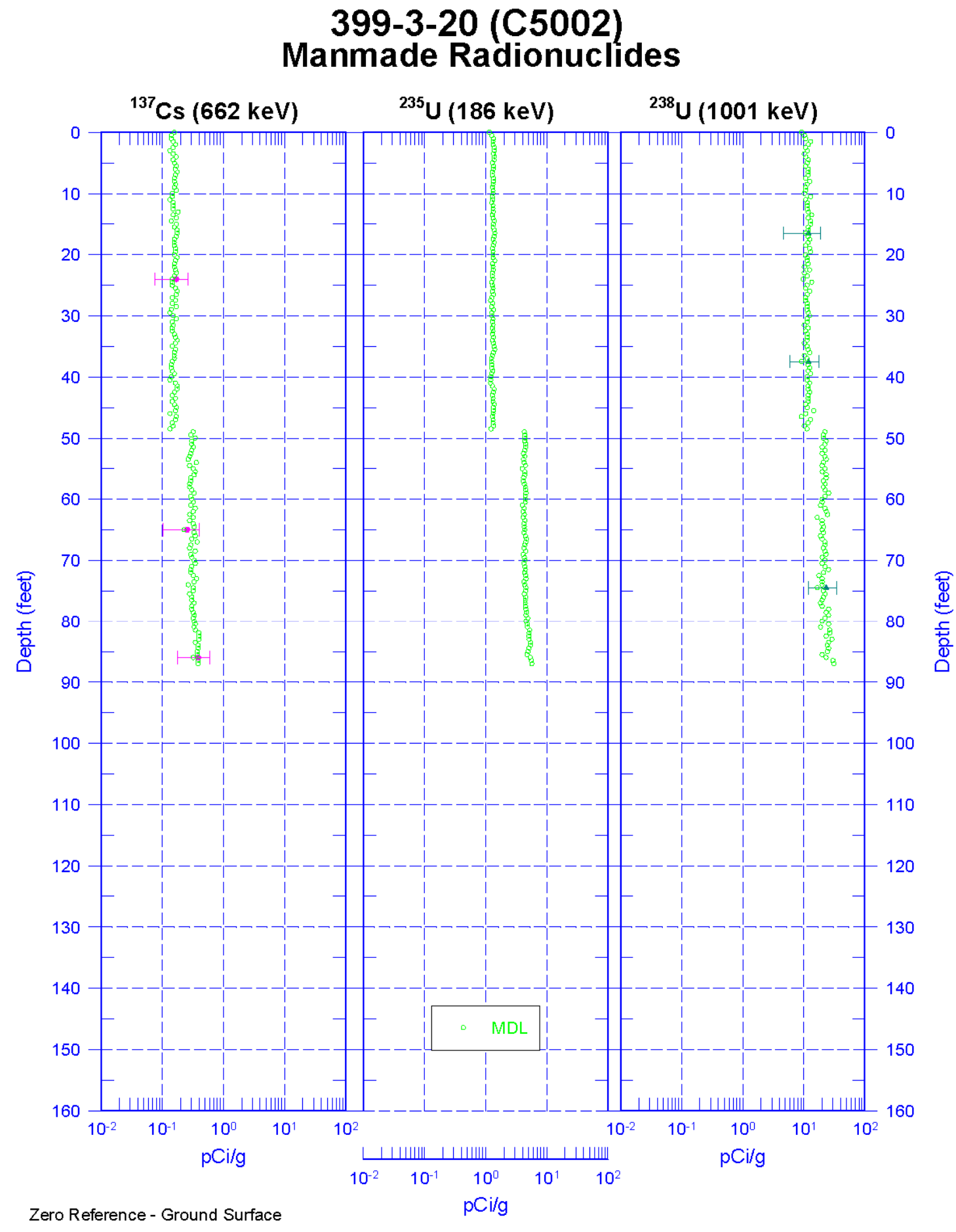




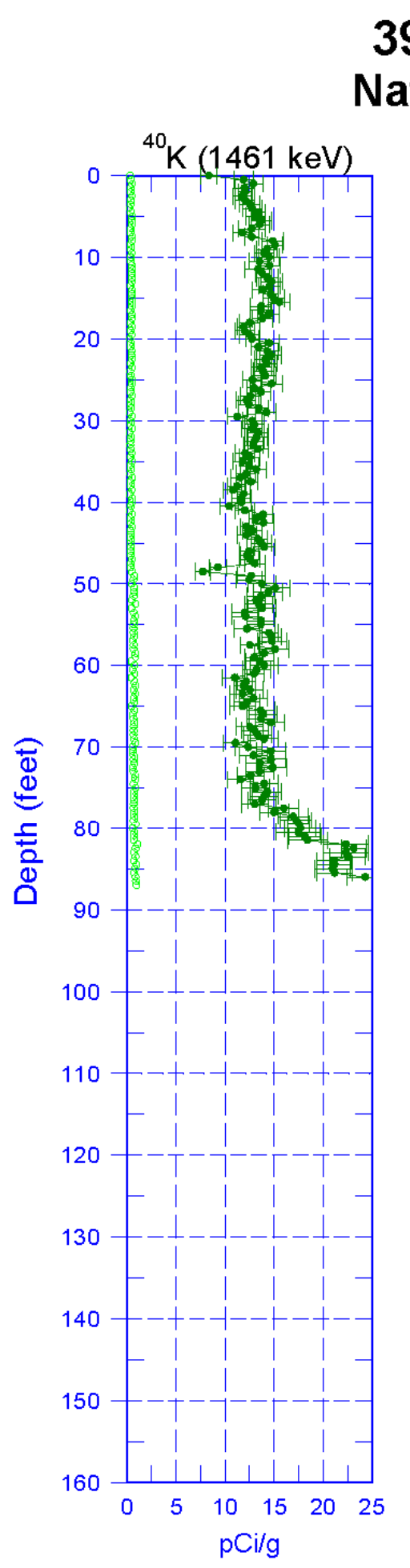

399-3-20 (C5002)

Natural Gamma Logs
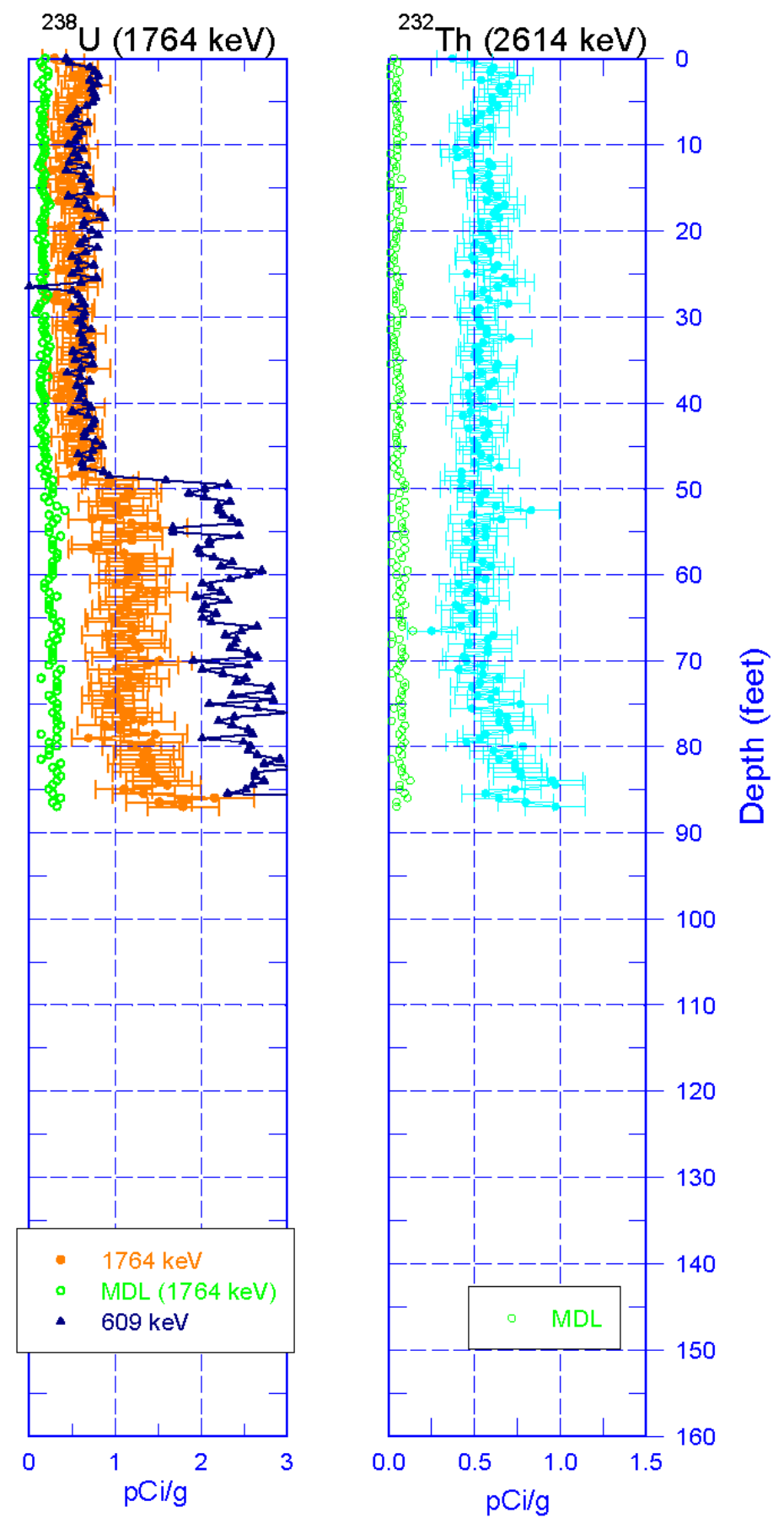

Zero Reference - Ground Surface 


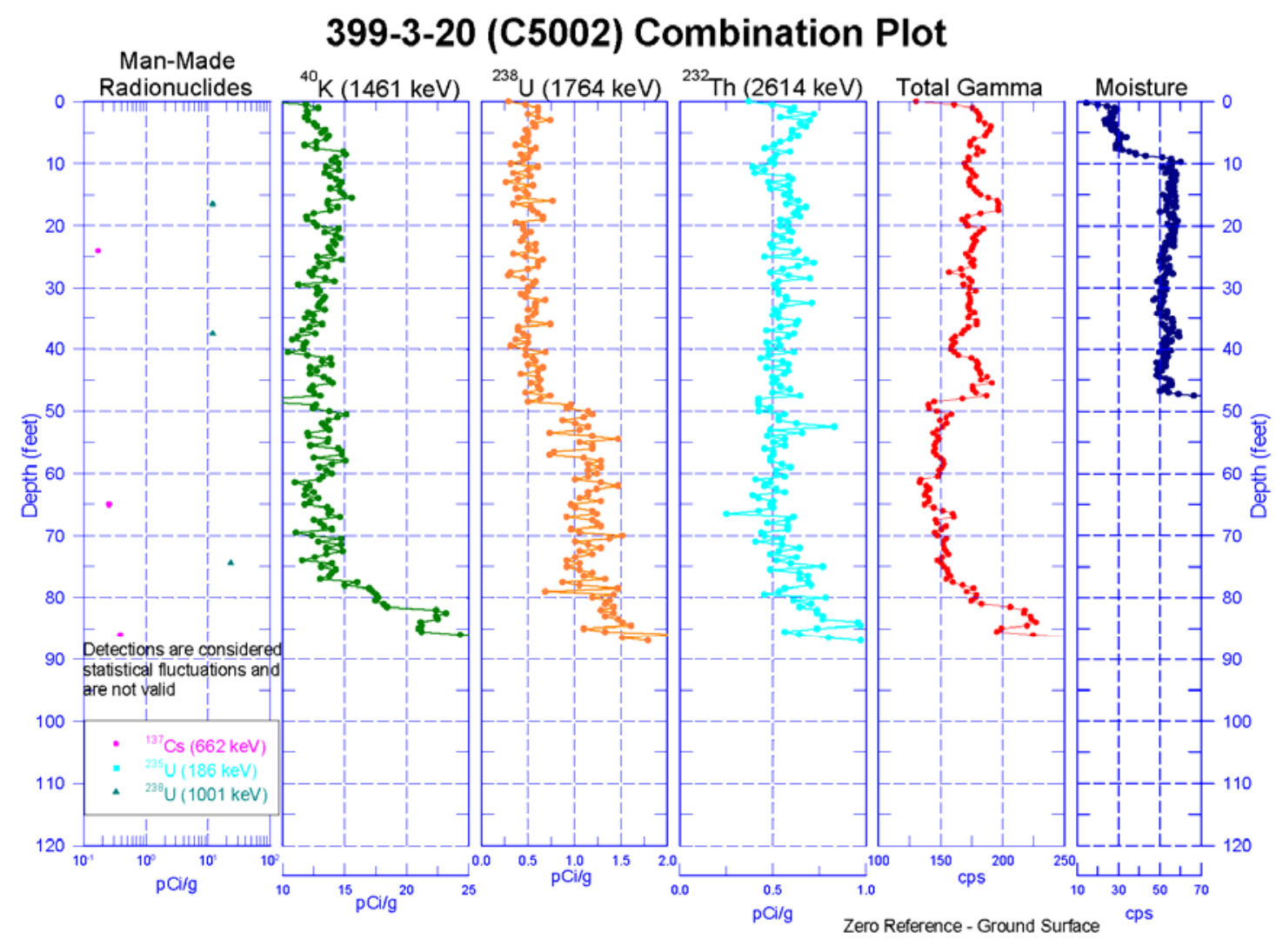



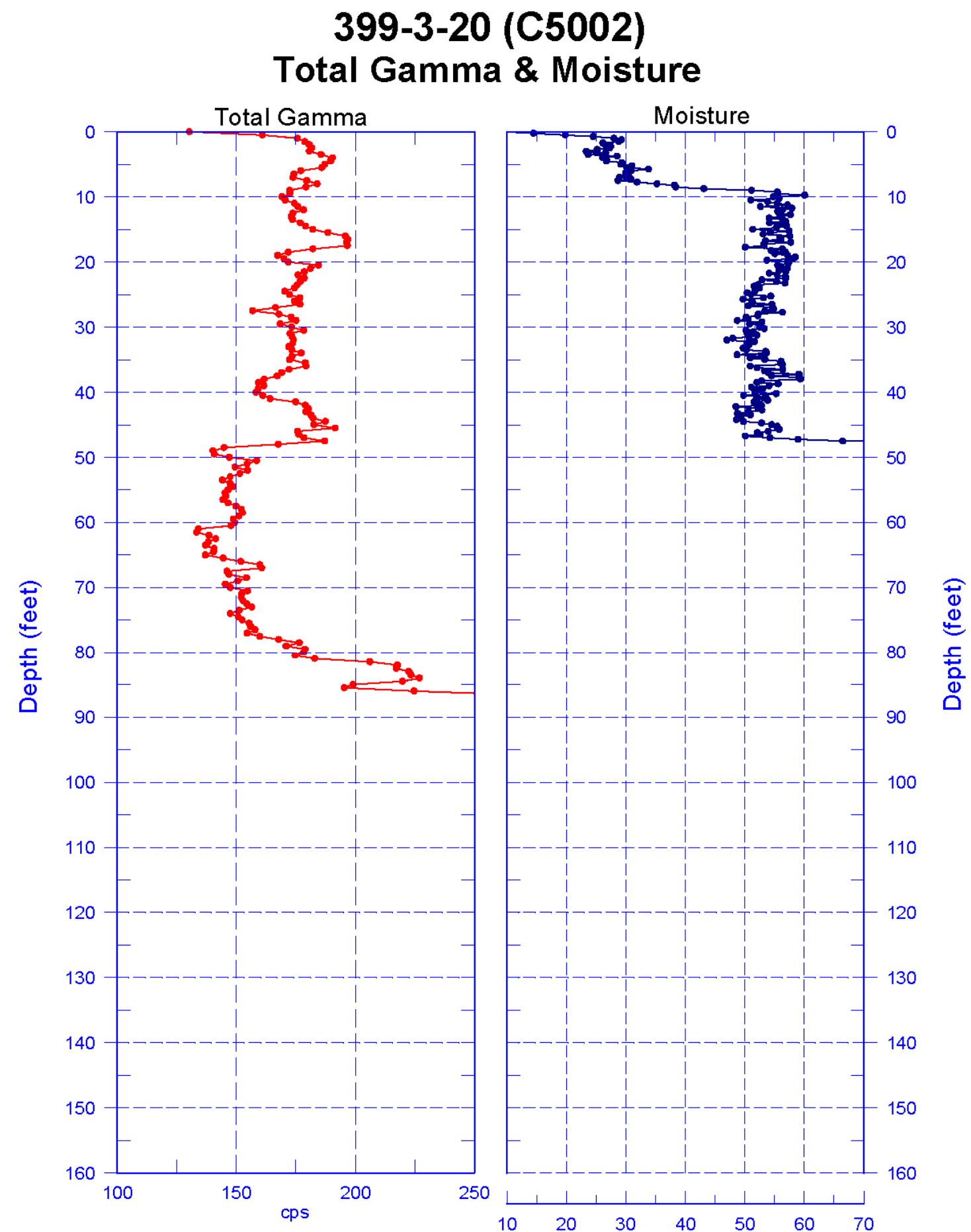

Reference - Ground Surface 


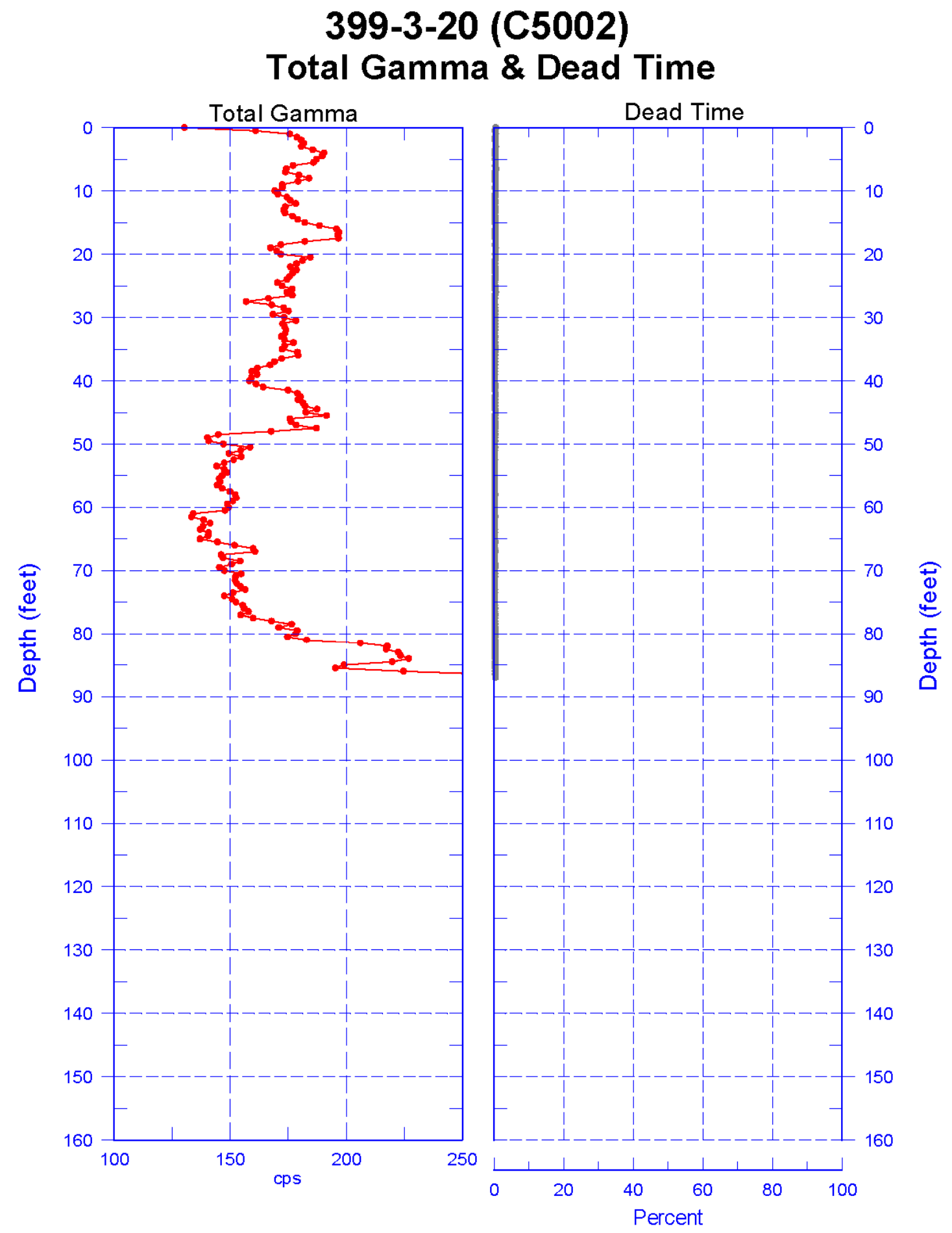

Reference - Ground Surface 


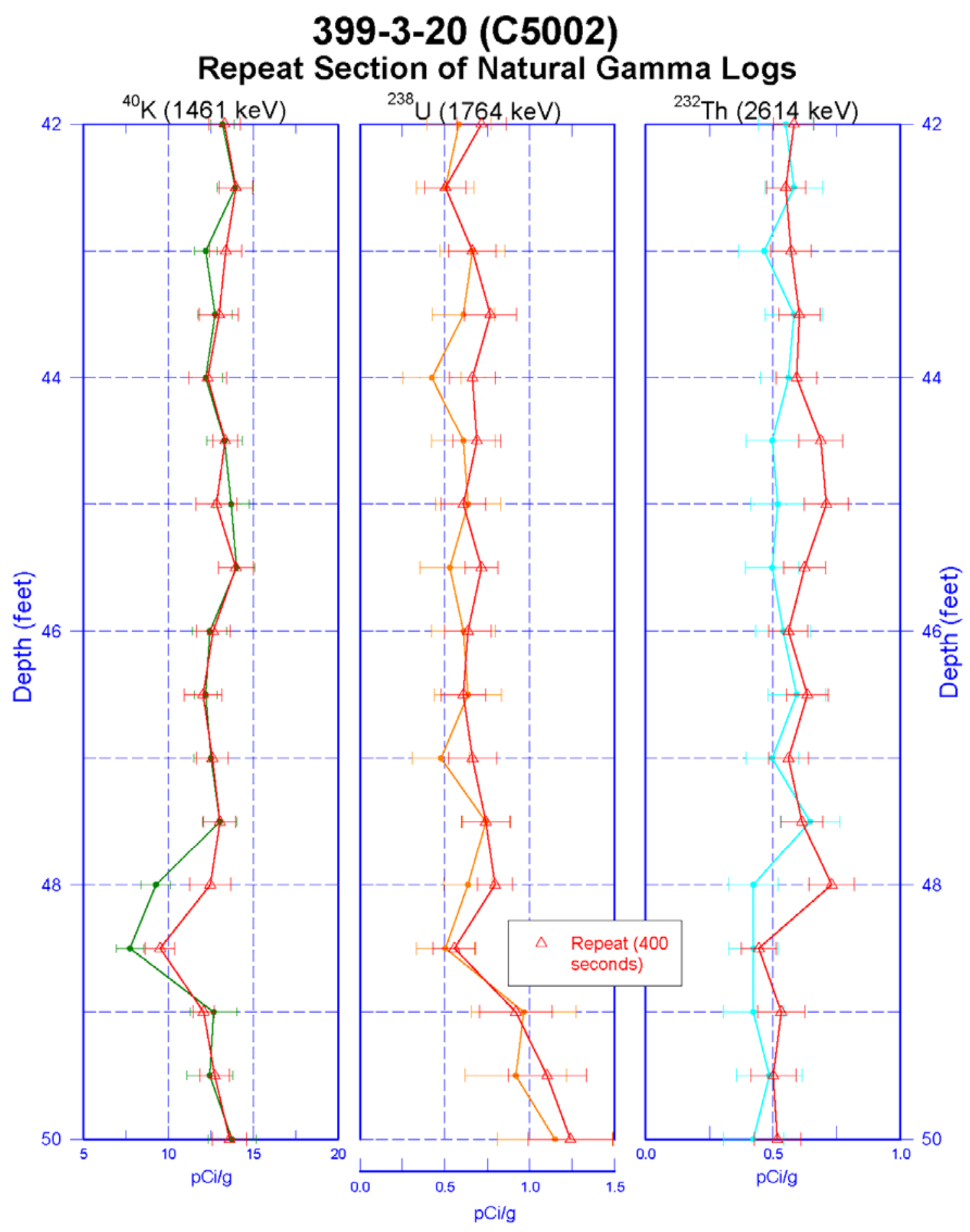

Zero Reference - Ground Surface 


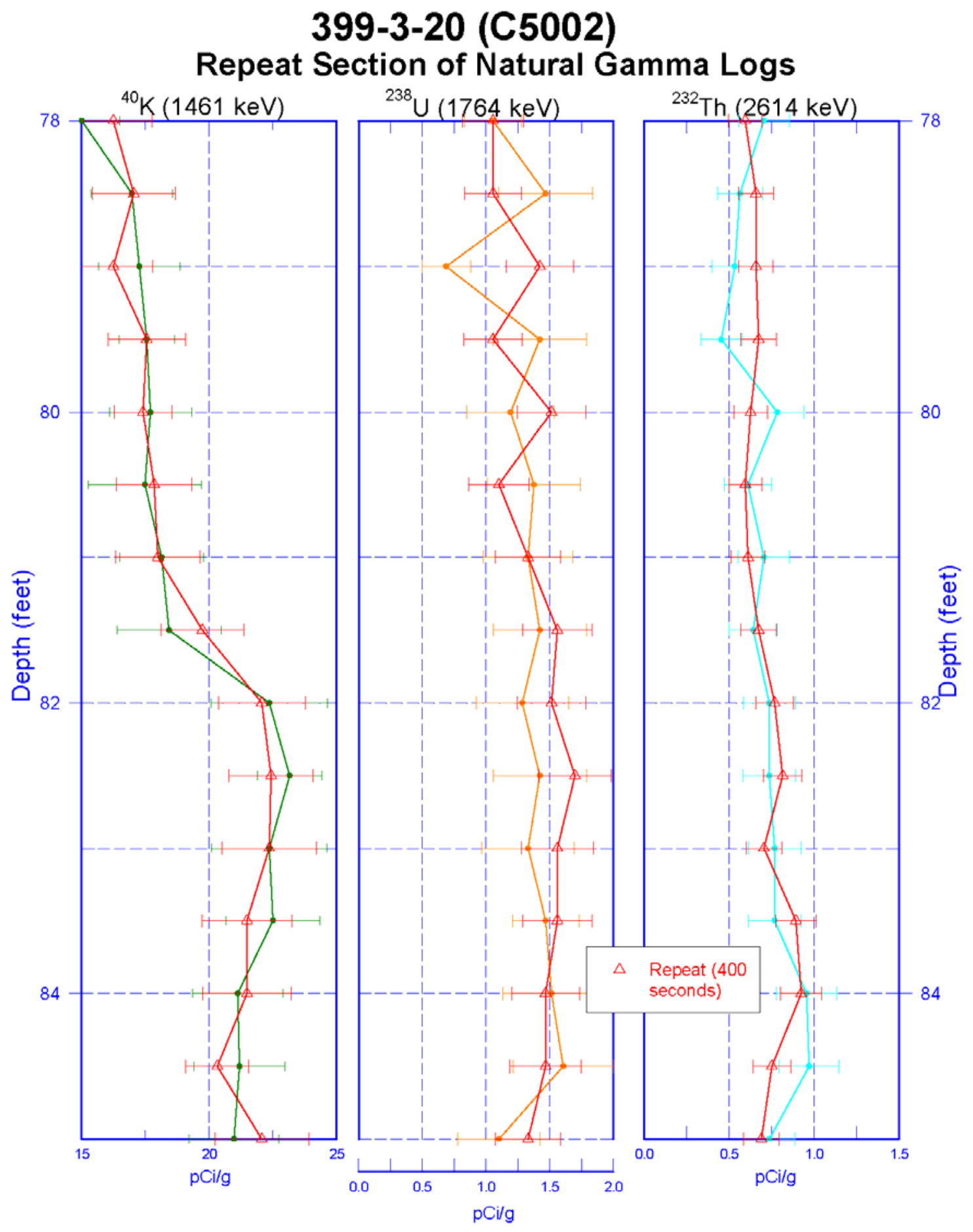

Zero Reference - Ground Surface 


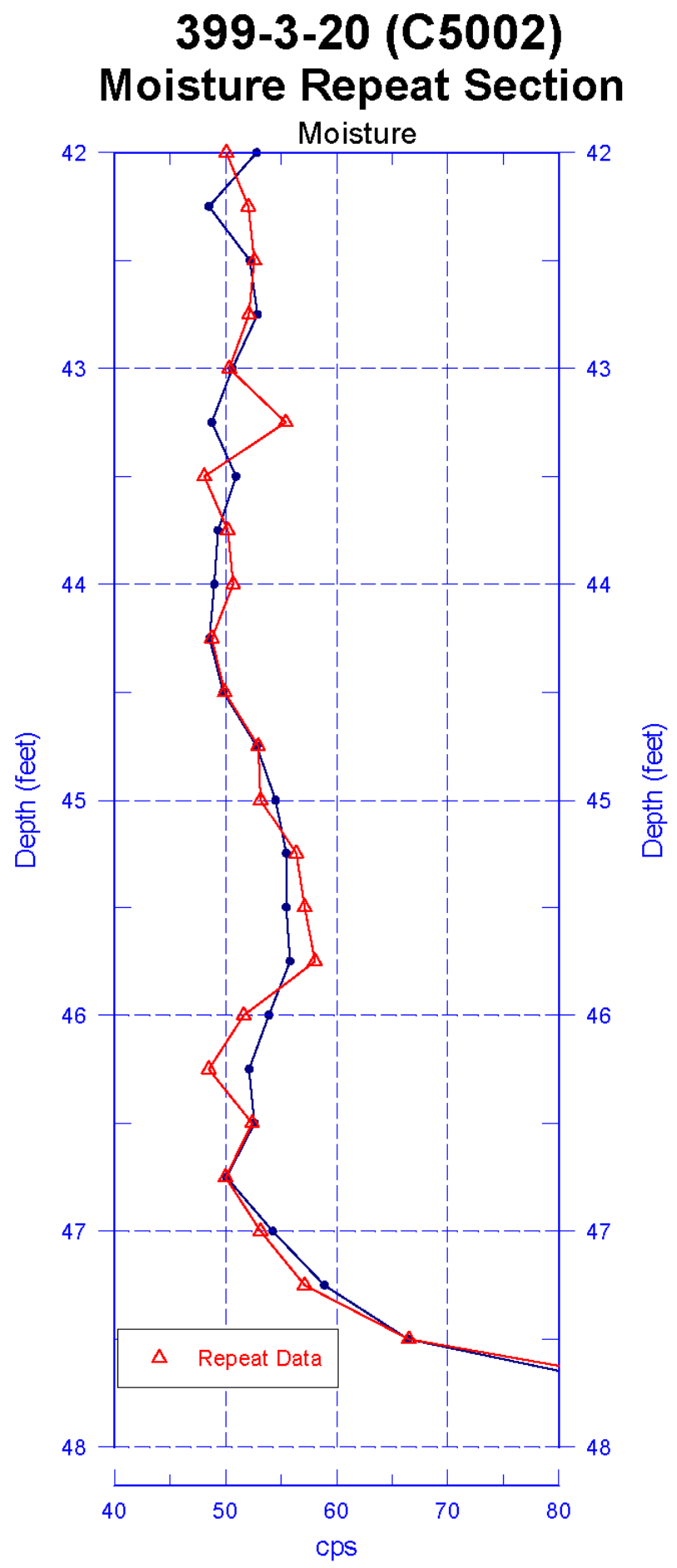

Reference - Ground Surface 


\section{Appendix D}

Laboratory Results of Groundwater and Sediment Analysis from Wells 399-1-23, 399-3-18, 399-3-19, and 399-3-20 


\section{Appendix D}

\section{Laboratory Results of Groundwater and Sediment Analysis from Wells 399-1-23, 399-3-18, 399-3-19, and 399-3-20}

Table D.1. $\quad$ pH, Alkalinity, and Electrical Conductivity of Groundwater, Water Extracts, and Pore Water After Centrifugation from 399-3-18 (C4999), 399-1-23 (C5000), 399-3-19 (C5001), and 399-3-20 (C5002) (NA indicates “Not Analyzed” because of not enough sample volume)

\begin{tabular}{|c|c|c|c|c|c|}
\hline Well & Sample ID & $\begin{array}{l}\text { Depth } \\
\text { (ft bgs) }\end{array}$ & $\mathrm{pH}$ & $\begin{array}{l}\text { Electrical Conductivity } \\
(\mathrm{mS} / \mathrm{cm})\end{array}$ & $\begin{array}{c}\text { Alkalinity } \\
\left(\mathrm{mg} / \mathrm{L} \text { as } \mathrm{CaCO}_{3}\right)\end{array}$ \\
\hline \multirow{34}{*}{ C4999 } & \multicolumn{5}{|c|}{ Groundwater $\left(T=21.7 \pm 0.1^{\circ} \mathrm{C}\right)$} \\
\hline & B1FR92 & 47.9 & 7.95 & 0.351 & 107.3 \\
\hline & B1FRB4 & 52.5 & 7.96 & 0.234 & 81.06 \\
\hline & B1FR88 & 68.0 & 8.00 & 0.179 & 76.43 \\
\hline & B1FRB8 & 77.0 & 8.06 & 0.199 & 84.15 \\
\hline & B1FR84 & 87.5 & 8.13 & 0.249 & 117.3 \\
\hline & B1FR96 & 99.5 & 8.20 & 0.275 & 139.0 \\
\hline & B1FR80 & 108.0 & 8.18 & 0.275 & 142.0 \\
\hline & B1FR32 & 120.8 & 8.04 & 0.281 & 140.5 \\
\hline & \multicolumn{5}{|c|}{ Water Extracts (Alkalinity and EC Values Were Dilution Corrected. $T=23.2 \pm 0.4^{\circ} \mathrm{C}$ ) } \\
\hline & C4999-3B & 9.00 & 7.70 & 12.72 & 584.5 \\
\hline & C4999-5D & 18.0 & 7.74 & 5.170 & 1370.0 \\
\hline & C4999-6A & 20.0 & 7.99 & 11.90 & 1308.0 \\
\hline & C4999-6D & 23.0 & 7.73 & 2.801 & 710.6 \\
\hline & C4999-8E & 28.5 & 7.77 & 9.609 & 1849.0 \\
\hline & C4999-9B & 30.5 & 7.56 & 3.126 & 869.8 \\
\hline & C4999-10C & 35.5 & 7.74 & 2.860 & 660.5 \\
\hline & C4999-11B & 39.5 & 7.85 & 4.560 & 1164.0 \\
\hline & C4999-11D & 41.5 & 7.44 & 0.877 & NA \\
\hline & C4999-12C & 46.0 & 7.55 & 1.224 & 425.9 \\
\hline & C4999-12D & 47.0 & 7.33 & 0.353 & 66.48 \\
\hline & C4999-13E & 53.0 & 7.56 & 0.318 & 103.7 \\
\hline & C4999-14D & 56.0 & 7.12 & 1.014 & 51.44 \\
\hline & C4999-15B & 59.0 & 7.18 & 0.892 & 52.60 \\
\hline & C4999-16A & 62.0 & 7.52 & 0.598 & 60.97 \\
\hline & C4999-17A & 66.0 & 7.20 & 0.482 & 42.19 \\
\hline & C4999-19B & 76.0 & 7.34 & 1.354 & 73.78 \\
\hline & C4999-21C & 86.0 & 7.39 & 1.851 & 59.99 \\
\hline & C4999-22E & 90.5 & 7.44 & 2.255 & 154.1 \\
\hline & C4999-25A & 98.5 & 7.29 & 2.172 & 140.4 \\
\hline & C4999-27B & 108.0 & 7.30 & 2.385 & 285.2 \\
\hline & C4999-29D & 118.0 & 7.12 & 2.644 & 181.5 \\
\hline & C4999-31C & 125.0 & 7.36 & 1.957 & 313.4 \\
\hline & C4999-32B & 129.0 & 7.50 & 0.349 & 74.56 \\
\hline
\end{tabular}


Table D.1. (contd)

\begin{tabular}{|c|c|c|c|c|c|}
\hline Well & Sample ID & $\begin{array}{c}\text { Depth } \\
\text { (ft bgs) }\end{array}$ & $\mathrm{pH}$ & $\begin{array}{c}\text { Electrical Conductivity } \\
(\mathrm{mS} / \mathrm{cm})\end{array}$ & $\begin{array}{c}\text { Alkalinity } \\
\left(\mathrm{mg} / \mathrm{L} \text { as } \mathrm{CaCO}_{3}\right)\end{array}$ \\
\hline \multirow{18}{*}{ C5000 } & \multicolumn{5}{|c|}{ Pore Water After Ultracentrifugation $\left(T=22.5 \pm 0.2^{\circ} \mathrm{C}\right)$} \\
\hline & C4999-12D & 47.0 & 8.84 & 0.399 & 120.8 \\
\hline & C4999-14D & 56.0 & 7.22 & 1.050 & 23.56 \\
\hline & C4999-16A & 62.0 & 7.61 & 0.582 & 34.96 \\
\hline & C4999-31C & 125.0 & 8.04 & 0.267 & 96.50 \\
\hline & C4999-31E & 127.0 & 8.10 & 0.617 & 72.20 \\
\hline & \multicolumn{5}{|c|}{ Groundwater $\left(T=21.9 \pm 0.1^{\circ} \mathrm{C}\right)$} \\
\hline & B1FR36 & 33.8 & 7.84 & 0.451 & 171.4 \\
\hline & B1FR40 & 37.5 & 7.57 & 0.424 & 139.7 \\
\hline & B1FR44 & 43.3 & 7.56 & 0.457 & 139.7 \\
\hline & B1FR48 & 47.8 & 7.83 & 0.466 & 139.0 \\
\hline & B1FR52 & 54.3 & 8.13 & 0.405 & 112.7 \\
\hline & B1FR56 & 59.3 & 8.02 & 0.395 & 104.2 \\
\hline & B1FR60 & 68.5 & 8.04 & 0.304 & 94.18 \\
\hline & B1FR64 & 79.5 & 8.10 & 0.326 & 142.0 \\
\hline & B1FR68 & 90.3 & 8.13 & 0.318 & 140.5 \\
\hline & B1FR72 & 107.8 & 8.10 & 0.327 & 162.1 \\
\hline & B1FR32 & 120.8 & 8.04 & 0.281 & 140.5 \\
\hline \multirow{29}{*}{ C5000 } & \multicolumn{5}{|c|}{ Water Extracts (Alkalinity and EC Values Were Dilution Corrected. $T=21.8 \pm 0.2^{\circ} \mathrm{C}$ ) } \\
\hline & C5000-36A & 11.0 & 7.49 & 2.95 & 992.8 \\
\hline & C5000-36E & 12.0 & 7.58 & 5.49 & 1861.0 \\
\hline & C5000-37A & 13.0 & 7.47 & 4.50 & 1313.0 \\
\hline & C5000-38B & 20.0 & 7.62 & 4.54 & 1479.0 \\
\hline & C5000-38C & 21.0 & 7.62 & 2.39 & 993.7 \\
\hline & C5000-39B & 23.0 & 7.82 & 1.53 & 613.6 \\
\hline & C5000-39D & 25.0 & 7.92 & 1.32 & 508.8 \\
\hline & C5000-40A & 30.0 & 7.84 & 1.48 & 600.9 \\
\hline & C5000-40B & 31.0 & 7.80 & 4.02 & 1756.0 \\
\hline & C5000-40C & 32.0 & 7.80 & 1.73 & 406.9 \\
\hline & C5000-40E & 34.0 & 7.52 & 6.38 & 1962.0 \\
\hline & C5000-41B & 35.0 & 7.69 & 2.76 & 1007.0 \\
\hline & C5000-41C & 36.0 & 7.40 & 1.05 & 406.9 \\
\hline & C5000-41E & 38.0 & 7.30 & 1.21 & 409.1 \\
\hline & C5000-43A & 44.0 & 7.54 & 1.85 & 762.7 \\
\hline & C5000-44B & 48.0 & 7.65 & 1.34 & 499.3 \\
\hline & C5000-44E & 50.0 & 7.54 & 1.33 & 438.5 \\
\hline & C5000-45C & 54.0 & 7.52 & 1.32 & 309.2 \\
\hline & C5000-46A & 56.0 & 7.43 & 1.32 & 320.4 \\
\hline & C5000-46D & 59.0 & 7.27 & 1.05 & 185.6 \\
\hline & C5000-48D & 65.0 & 7.20 & 0.81 & 128.9 \\
\hline & C5000-48E & 66.0 & 7.19 & 0.59 & 91.24 \\
\hline & C5000-49D & 68.0 & 7.50 & 1.87 & 415.3 \\
\hline & C5000-50B & 71.0 & 7.64 & 2.11 & 538.2 \\
\hline & C5000-51E & 77.0 & 7.59 & 1.00 & 315.5 \\
\hline & C5000-52B & 79.0 & 7.61 & 0.99 & 280.3 \\
\hline & C5000-53E & 85.0 & 7.62 & 0.95 & 164.8 \\
\hline & C5000-54E & 89.5 & 7.54 & 1.29 & 382.9 \\
\hline
\end{tabular}


Table D.1. (contd)

\begin{tabular}{|c|c|c|c|c|c|}
\hline Well & Sample ID & $\begin{array}{c}\text { Depth } \\
\text { (ft bgs) }\end{array}$ & $\mathrm{pH}$ & $\begin{array}{c}\text { Electrical Conductivity } \\
(\mathrm{mS} / \mathrm{cm})\end{array}$ & $\begin{array}{c}\text { Alkalinity } \\
\left(\mathrm{mg} / \mathrm{L} \text { as } \mathrm{CaCO}_{3}\right)\end{array}$ \\
\hline \multirow{15}{*}{$\begin{array}{l}\text { C5000 } \\
\text { (contd) }\end{array}$} & C5000-57D & 100.0 & 7.39 & 1.11 & 366.2 \\
\hline & C5000-60E & 109.5 & 7.49 & 0.93 & 243.7 \\
\hline & \multicolumn{5}{|c|}{ Pore Water After Ultracentrifugation $\left(T=22.2 \pm 0.1^{\circ} \mathrm{C}\right)$} \\
\hline & C5000-43B & 45.0 & 7.66 & 0.44 & 162.1 \\
\hline & C5000-44C & 49.0 & 7.62 & NA & 162.1 \\
\hline & C5000-45C & 54.0 & 7.99 & NA & 119.7 \\
\hline & C5000-48B & 62.5 & 7.72 & NA & 247.0 \\
\hline & C5000-49A & 67.0 & 8.45 & NA & 154.4 \\
\hline & C5000-49D & 68.0 & 8.01 & 0.44 & 223.9 \\
\hline & C5000-52B & 79.0 & 8.26 & NA & 223.9 \\
\hline & C5000-54A & 85.0 & 8.29 & NA & 324.2 \\
\hline & C5000-53E & 86.0 & 9.04 & NA & 193.0 \\
\hline & C5000-55D & 90.5 & 8.36 & NA & 223.9 \\
\hline & C5000-58C & 103.0 & 8.36 & NA & NA \\
\hline & C5000-60C & 107.5 & 9.01 & 0.34 & 193.0 \\
\hline \multirow{14}{*}{ C5001 } & \multicolumn{5}{|c|}{ Groundwater $\left(T=22.0 \pm 0.1^{\circ} \mathrm{C}\right)$} \\
\hline & B1HRX0 & 53 & 7.78 & 0.40 & 124.3 \\
\hline & B1HRX4 & 57.8 & 7.79 & 0.38 & 126.6 \\
\hline & B1HRX8 & 63.0 & 7.97 & 0.41 & 126.6 \\
\hline & B1HRY2 & 81.5 & 7.98 & 0.42 & 128.9 \\
\hline & B1HRY6 & 101.8 & 7.89 & 0.32 & 127.4 \\
\hline & \multicolumn{5}{|c|}{ Water Extracts (Alkalinity and EC values Were Dilution Corrected. $T=22.5 \pm 0.1^{\circ} \mathrm{C}$ ) } \\
\hline & C5001-64E & 15.0 & 7.76 & 1.82 & 834.6 \\
\hline & C5001-68A & 28.0 & 7.86 & 4.18 & 1584.4 \\
\hline & C5001-69C & 33.0 & 7.74 & 2.05 & 804.3 \\
\hline & C5001-70D & 39.5 & 7.28 & 1.94 & 763.8 \\
\hline & C5001-71E & 41.5 & 7.60 & 2.64 & 1161.0 \\
\hline & C5001-76C & 64.5 & 7.31 & 1.43 & 624.6 \\
\hline & C5001-78A & 74.5 & 7.36 & 1.81 & 778.3 \\
\hline \multirow{11}{*}{ C5002 } & \multicolumn{5}{|c|}{ Groundwater $\left(T=22.2 \pm 0.1^{\circ} \mathrm{C}\right)$} \\
\hline & B1HT04 & 52.3 & 7.97 & 0.44 & 132.8 \\
\hline & B1HT08 & 61.5 & 7.85 & 0.43 & 128.2 \\
\hline & B1HT12 & 72.5 & 7.95 & 0.45 & 133.6 \\
\hline & B1HT16 & 91.0 & 8.10 & 0.28 & 125.8 \\
\hline & \multicolumn{5}{|c|}{ Water Extracts (Alkalinity and EC Values Were Dilution Corrected. $T=22.6 \pm 0.1^{\circ} \mathrm{C}$ ) } \\
\hline & C5002-84C & 16.0 & 7.50 & 4.83 & 1901.0 \\
\hline & C5002-87D & 24.5 & 7.78 & 3.72 & 1498.0 \\
\hline & C5002-90A & 32.5 & 7.67 & 4.84 & 1680.0 \\
\hline & C5002-90C & 34.5 & 7.60 & 2.43 & 915.5 \\
\hline & C5002-91D & 40.5 & 7.40 & 2.13 & 669.4 \\
\hline
\end{tabular}


Table D.2. Uranium Concentration Data from GEA, WE, AE, and MD for Sediments in 399-3-18 (C4999), 399-1-23 (C5000), 399-3-19 (C5001), and 399-3-20 (C5002)

\begin{tabular}{|c|c|c|c|c|c|c|}
\hline Wells & Sample ID & $\begin{array}{c}\text { Depth } \\
\text { (ft bgs) }\end{array}$ & GEA (U-238 at 609) (pCi/g) & $\begin{array}{c}\text { WE } \\
(\mathrm{pCi} / \mathrm{g})\end{array}$ & $\begin{array}{c}\mathrm{AE} \\
(\mathrm{pCi} / \mathrm{g})\end{array}$ & $\begin{array}{c}\text { MD } \\
(\mathrm{pCi} / \mathrm{g})\end{array}$ \\
\hline \multirow{45}{*}{$\begin{array}{l}\text { C4999 } \\
(399-3-18)\end{array}$} & C4999-2B & 5.7 & 5.43E-01 & & & \\
\hline & C4999-3B & 9.0 & & $1.98 \mathrm{E}-02$ & $1.07 \mathrm{E}+00$ & $9.56 \mathrm{E}-01$ \\
\hline & C4999-3C & 10.5 & $6.54 \mathrm{E}-01$ & & & \\
\hline & C4999-5A & 15.5 & 8.20E-01 & & & \\
\hline & C4999-5B & 16.00 & $4.72 \mathrm{E}-01$ & & & \\
\hline & C4999-5C & 17.00 & $5.74 \mathrm{E}-01$ & & & \\
\hline & C4999-5D & 18.00 & 4.35E-01 & $7.16 \mathrm{E}-04$ & & 5.39E-01 \\
\hline & C4999-6A & 20.00 & $6.28 \mathrm{E}-01$ & $9.72 \mathrm{E}-03$ & 3.64E-01 & \\
\hline & C4999-6B & 21.00 & 5.32E-01 & & & \\
\hline & C4999-6C & 22.00 & 4.74E-01 & & & \\
\hline & C4999-6D & 23.00 & 5.33E-01 & 1.23E-03 & & 7.09E-01 \\
\hline & C4999-6E & 24.00 & 4.29E-01 & & & \\
\hline & C4999-7A & 25.00 & 5.29E-01 & & & \\
\hline & C4999-8B & 27.00 & $4.88 \mathrm{E}-01$ & & & \\
\hline & C4999-8E & 28.50 & 4.66E-01 & 1.30E-03 & 2.23E-01 & \\
\hline & C4999-9A & 29.50 & 4.87E-01 & & & \\
\hline & C4999-9B & 30.50 & 4.75E-01 & 4.69E-03 & & $8.45 \mathrm{E}-01$ \\
\hline & C4999-9C & 31.50 & 4.36E-01 & 4.98E-04 & & $1.23 \mathrm{E}+00$ \\
\hline & C4999-10A & 33.50 & 4.23E-01 & $4.14 \mathrm{E}-04$ & & \\
\hline & C4999-10B & 34.50 & 4.58E-01 & $3.10 \mathrm{E}-04$ & & \\
\hline & C4999-10C & 35.50 & 5.01E-01 & 1.72E-03 & 3.93E-01 & $1.04 \mathrm{E}+00$ \\
\hline & C4999-10D & 36.50 & $6.54 \mathrm{E}-01$ & $3.70 \mathrm{E}-03$ & & $1.20 \mathrm{E}+00$ \\
\hline & C4999-11A & 38.50 & $4.40 \mathrm{E}-01$ & 6.49E-03 & & \\
\hline & C4999-11B & 39.50 & 5.19E-01 & $1.61 \mathrm{E}-03$ & 4.97E-01 & 8.23E-01 \\
\hline & C4999-11D & 41.50 & 5.33E-01 & $1.71 \mathrm{E}-03$ & $1.91 \mathrm{E}+00$ & $3.54 \mathrm{E}+00$ \\
\hline & C4999-12A & 44.00 & $4.70 \mathrm{E}-01$ & & & \\
\hline & C4999-12B & 45.00 & 5.30E-01 & & & \\
\hline & C4999-12C & 46.00 & $4.58 \mathrm{E}-01$ & $1.01 \mathrm{E}-02$ & & $2.18 \mathrm{E}+00$ \\
\hline & C4999-12D & 47.00 & $1.18 \mathrm{E}+00$ & $1.59 \mathrm{E}-04$ & 6.88E-01 & $9.07 \mathrm{E}-01$ \\
\hline & C4999-12E & 48.15 & $1.20 \mathrm{E}+00$ & & & \\
\hline & C4999-13B & 50.00 & $1.34 \mathrm{E}+00$ & & & \\
\hline & C4999-13D & 52.00 & $1.39 \mathrm{E}+00$ & & & \\
\hline & C4999-13E & 53.00 & $1.32 \mathrm{E}+00$ & $3.36 \mathrm{E}-04$ & 8.77E-01 & \\
\hline & C4999-14B & 55.00 & $1.32 \mathrm{E}+00$ & & & \\
\hline & C4999-14D & 56.00 & $1.34 \mathrm{E}+00$ & 6.70E-05 & 7.17E-01 & \\
\hline & C4999-14E & 57.00 & $1.14 \mathrm{E}+00$ & & & \\
\hline & C4999-15A & 58.00 & $1.24 \mathrm{E}+00$ & & & $1.19 \mathrm{E}+00$ \\
\hline & C4999-15B & 59.00 & $4.04 \mathrm{E}+00$ & $4.66 \mathrm{E}-05$ & $2.78 \mathrm{E}+00$ & \\
\hline & C4999-15D & 60.00 & $1.08 \mathrm{E}+00$ & & & \\
\hline & C4999-16A & 62.00 & $1.17 \mathrm{E}+00$ & 6.03E-05 & 5.26E-01 & \\
\hline & C4999-16B & 63.00 & $1.21 \mathrm{E}+00$ & & & \\
\hline & C4999-16C & 64.00 & $1.77 \mathrm{E}+00$ & & & \\
\hline & C4999-16D & 65.00 & $3.60 \mathrm{E}+00$ & & & \\
\hline & C4999-17A & 66.00 & $1.57 \mathrm{E}+00$ & 3.22E-05 & $9.80 \mathrm{E}-01$ & \\
\hline & C4999-17B & 67.00 & $1.77 \mathrm{E}+00$ & & & $3.06 \mathrm{E}+00$ \\
\hline
\end{tabular}


Table D.2. (contd)

\begin{tabular}{|c|c|c|c|c|c|c|}
\hline Wells & Sample ID & $\begin{array}{c}\text { Depth } \\
\text { (ft bgs) } \\
\end{array}$ & GEA(U-238 at 609) (pCi/g) & $\begin{array}{c}\text { WE } \\
\text { (pCi/g) } \\
\end{array}$ & $\begin{array}{c}\mathrm{AE} \\
(\mathrm{pCi} / \mathrm{g}) \\
\end{array}$ & $\begin{array}{c}\mathrm{MD} \\
(\mathrm{pCi} / \mathrm{g}) \\
\end{array}$ \\
\hline \multirow{21}{*}{$\begin{array}{l}\text { C4999 } \\
(399-3-18) \\
\text { (contd) }\end{array}$} & C4999-17C & 68.00 & $2.23 \mathrm{E}+00$ & & & \\
\hline & C4999-17D & 69.00 & $1.95 \mathrm{E}+00$ & & & \\
\hline & C4999-17E & 70.00 & $1.56 \mathrm{E}+00$ & & & \\
\hline & C4999-18B & 71.00 & $1.82 \mathrm{E}+00$ & & & \\
\hline & C4999-18C & 72.00 & $1.44 \mathrm{E}+00$ & & & \\
\hline & C4999-18E & 74.00 & $1.49 \mathrm{E}+00$ & & & \\
\hline & C4999-19A & 75.00 & $1.25 \mathrm{E}+00$ & & & \\
\hline & C4999-19B & 76.00 & $1.00 \mathrm{E}+00$ & 1.37E-03 & 3.97E-01 & \\
\hline & C4999-19E & 79.00 & $7.28 \mathrm{E}-01$ & & & \\
\hline & C4999-21C & 86.00 & 9.79E-01 & 6.59E-04 & 4.18E-01 & $6.81 \mathrm{E}-01$ \\
\hline & C4999-22E & 90.50 & 9.31E-01 & 4.72E-04 & 6.42E-01 & 9.08E-01 \\
\hline & C4999-24E & 97.50 & 5.87E-01 & & & \\
\hline & C4999-25A & 98.50 & & 7.72E-04 & $2.52 \mathrm{E}-01$ & \\
\hline & C4999-25B & 99.50 & & & & 6.42E-01 \\
\hline & C4999-25D & 101.00 & 8.43E-01 & & & \\
\hline & C4999-26C & 105.00 & 9.23E-01 & & & \\
\hline & C4999-27B & 108.00 & 7.50E-01 & 1.43E-04 & 1.32E-01 & 5.28E-01 \\
\hline & C4999-29D & 118.00 & & 2.29E-05 & 2.01E-01 & \\
\hline & C4999-31C & 125.00 & & 5.34E-04 & 3.80E-01 & \\
\hline & C4999-31E & 127.00 & & & & $1.19 \mathrm{E}+00$ \\
\hline & C4999-32B & 129.00 & & 5.79E-05 & $6.50 \mathrm{E}-01$ & \\
\hline \multirow{26}{*}{$\begin{array}{l}\text { C5000 } \\
(399-1-23)\end{array}$} & C5000-32D & 0.50 & 5.31E-01 & & & \\
\hline & C5000-32E & 1.50 & 6.26E-01 & & & \\
\hline & C5000-33A & 2.25 & 5.44E-01 & & & \\
\hline & C5000-33B & 2.25 & 5.64E-01 & & & \\
\hline & C5000-33C & 3.00 & 5.54E-01 & & & \\
\hline & C5000-33D & 4.00 & 5.48E-01 & & & \\
\hline & C5000-34B & 5.00 & 4.74E-01 & & & \\
\hline & C5000-34C & 6.00 & 4.64E-01 & & & \\
\hline & C5000-34D & 7.00 & 4.48E-01 & & & \\
\hline & C5000-34E & 8.00 & 4.21E-01 & & & \\
\hline & C5000-35B & 7.00 & 4.74E-01 & & & \\
\hline & C5000-35C & 8.00 & 4.70E-01 & & & \\
\hline & C5000-35D & 9.00 & 4.65E-01 & & & \\
\hline & C5000-36A & 11.00 & 8.19E-01 & 1.04E-03 & 2.57E-01 & 6.45E-01 \\
\hline & C5000-36E & 12.00 & 4.12E-01 & 1.15E-03 & 2.25E-01 & 6.96E-01 \\
\hline & C5000-37A & 13.00 & 4.31E-01 & 1.09E-03 & 2.14E-01 & 6.34E-01 \\
\hline & C5000-38B & 20.00 & 4.71E-01 & $1.26 \mathrm{E}-03$ & $2.40 \mathrm{E}-01$ & $1.12 \mathrm{E}+00$ \\
\hline & C5000-38C & 21.00 & 5.13E-01 & 3.72E-02 & 3.60E-01 & $2.24 \mathrm{E}+00$ \\
\hline & C5000-39B & 23.00 & 4.86E-01 & 7.56E-03 & 3.79E-01 & $5.03 E+00$ \\
\hline & C5000-39D & 25.00 & 5.21E-01 & 4.11E-02 & 9.36E-01 & $1.48 \mathrm{E}+00$ \\
\hline & C5000-40A & 30.00 & 4.90E-01 & 1.15E-03 & & $2.31 \mathrm{E}+00$ \\
\hline & C5000-40B & 31.00 & 4.87E-01 & 1.09E-03 & & 8.33E-01 \\
\hline & C5000-40C & 32.00 & 4.83E-01 & 2.28E-02 & 7.47E-01 & $1.19 \mathrm{E}+00$ \\
\hline & C5000-40E & 34.00 & 3.07E-01 & $1.78 \mathrm{E}-03$ & 2.59E-01 & 3.80E-01 \\
\hline & C5000-41B & 35.00 & 4.19E-01 & 5.22E-03 & 4.72E-01 & 9.99E-01 \\
\hline & C5000-41C & 36 & & 1.23E-03 & & $1.05 \mathrm{E}+00$ \\
\hline
\end{tabular}


Table D.2. (contd)

\begin{tabular}{|c|c|c|c|c|c|c|}
\hline Wells & Sample ID & $\begin{array}{l}\text { Depth } \\
\text { (ft bgs) }\end{array}$ & GEA(U-238 at 609) (pCi/g) & $\begin{array}{c}\text { WE } \\
(p C i / g)\end{array}$ & $\begin{array}{c}\mathrm{AE} \\
(\mathrm{pCi} / \mathrm{g})\end{array}$ & $\begin{array}{c}\text { MD } \\
(\mathrm{pCi} / \mathrm{g})\end{array}$ \\
\hline \multirow{20}{*}{$\begin{array}{l}\text { C5000 } \\
\text { (399-1-23) } \\
\text { (contd) }\end{array}$} & C5000-41E & 38.00 & 4.29E-01 & $1.60 \mathrm{E}-04$ & 3.82E-01 & $1.18 \mathrm{E}+00$ \\
\hline & C5000-43A & 44.00 & 4.17E-01 & $1.44 \mathrm{E}-03$ & 3.47E-01 & 8.90E-01 \\
\hline & C5000-44B & 48.00 & 5.14E-01 & 9.70E-04 & 2.59E-01 & \\
\hline & C5000-44E & 50.00 & 7.05E-01 & $1.16 \mathrm{E}-03$ & 4.17E-01 & $1.19 \mathrm{E}+00$ \\
\hline & C5000-45B & 53.00 & $7.28 \mathrm{E}-01$ & & & $1.15 \mathrm{E}+00$ \\
\hline & C5000-45C & 54.00 & 7.01E-01 & $1.94 \mathrm{E}-03$ & 6.19E-01 & $1.47 \mathrm{E}+00$ \\
\hline & C5000-45D & 55.00 & 5.97E-01 & & & $1.23 \mathrm{E}+00$ \\
\hline & C5000-46A & 56.00 & 7.35E-01 & 4.24E-03 & 5.82E-01 & \\
\hline & C5000-46D & 59.00 & 8.73E-01 & 4.29E-04 & 1.52E-01 & 4.64E-01 \\
\hline & C5000-47C & 61.50 & 7.03E-01 & & & 5.91E-01 \\
\hline & C5000-48D & 65.00 & $1.25 \mathrm{E}+00$ & $5.98 \mathrm{E}-04$ & $3.14 \mathrm{E}-01$ & \\
\hline & C5000-48E & 66.00 & 6.14E-01 & 5.11E-04 & 1.64E-01 & 7.02E-01 \\
\hline & C5000-49D & 68.00 & 8.95E-01 & 5.82E-04 & 3.01E-01 & \\
\hline & C5000-50B & 71.00 & 9.64E-01 & 7.02E-04 & $2.68 \mathrm{E}-01$ & 8.83E-01 \\
\hline & C5000-51E & 77.00 & 9.14E-01 & 7.76E-04 & 2.31E-01 & $5.05 \mathrm{E}-01$ \\
\hline & C5000-52B & 79.00 & 9.02E-01 & 6.31E-04 & 3.16E-01 & \\
\hline & C5000-53E & 85.00 & 7.94E-01 & 3.66E-04 & 3.09E-01 & \\
\hline & C5000-54E & 89.50 & $1.04 \mathrm{E}+00$ & $1.77 \mathrm{E}-03$ & 6.87E-01 & \\
\hline & C5000-57D & 100.00 & 8.49E-01 & 3.61E-04 & $2.01 \mathrm{E}-01$ & \\
\hline & C5000-60E & 109.50 & 9.12E-01 & 5.05E-04 & 1.62E-01 & \\
\hline \multirow{27}{*}{$\begin{array}{l}\text { C5001 } \\
(399-3-19)\end{array}$} & C5001-62A & 3.0 & 5.32E-01 & & & \\
\hline & C5001-62C & 4.0 & 5.36E-01 & & & \\
\hline & C5001-63B & 7.0 & $5.48 \mathrm{E}-01$ & & & \\
\hline & C5001-63C & 8.0 & & 4.12E-05 & 1.93E-01 & 5.14E-01 \\
\hline & C5001-63D & 9.0 & 6.08E-01 & & & \\
\hline & C5001-64C & 13.0 & 3.77E-01 & & & \\
\hline & C5001-64E & 15.0 & 4.32E-01 & 1.80E-03 & & 4.42E-01 \\
\hline & C5001-65D & 19.0 & 3.85E-01 & & & \\
\hline & C5001-66A & 21.0 & 4.32E-01 & 3.03E-04 & $1.34 \mathrm{E}-01$ & 3.99E-01 \\
\hline & C5001-67B & 24.5 & 4.77E-01 & & & \\
\hline & C5001-68A & 28.0 & 5.28E-01 & 2.91E-04 & & \\
\hline & C5001-68B & 29.0 & & $2.12 \mathrm{E}-04$ & 1.35E-01 & 4.31E-01 \\
\hline & C5001-69C & 33.0 & 4.63E-01 & 2.99E-04 & & 4.81E-01 \\
\hline & C5001-69D & 34.0 & 5.70E-01 & 2.05E-04 & $1.42 \mathrm{E}-01$ & 4.84E-01 \\
\hline & C5001-70C & 38.5 & & & & 4.89E-01 \\
\hline & C5001-70D & 39.5 & 5.60E-01 & 2.92E-04 & & 5.71E-01 \\
\hline & C5001-70E & 40.5 & & 2.31E-04 & 1.35E-01 & 4.43E-01 \\
\hline & C5001-71E & 41.5 & 4.58E-01 & 5.54E-04 & & 5.03E-01 \\
\hline & C5001-73B & 49.8 & 4.98E-01 & 2.91E-03 & 1.99E-01 & 4.96E-01 \\
\hline & C5001-74B & 53.5 & & 9.77E-04 & 1.96E-01 & 4.60E-01 \\
\hline & C5001-76C & 64.5 & 4.50E-01 & 5.00E-04 & & 4.94E-01 \\
\hline & C5001-76D & 65.5 & & 4.93E-04 & $1.74 \mathrm{E}-01$ & 5.38E-01 \\
\hline & C5001-78A & 74.5 & 4.35E-01 & 4.72E-04 & & $5.25 \mathrm{E}-01$ \\
\hline & C5001-79A & 81.5 & & 6.62E-04 & 3.57E-01 & 8.62E-01 \\
\hline & C5001-79B & 82.5 & $7.50 \mathrm{E}-01$ & & & \\
\hline & C5501-79D & 83.5 & 5.51E-01 & & & \\
\hline & C5001-80A & 85.5 & 8.84E-01 & 5.99E-05 & 4.49E-01 & $9.16 \mathrm{E}-01$ \\
\hline
\end{tabular}


Table D.2. (contd)

\begin{tabular}{|c|c|c|c|c|c|c|}
\hline Wells & Sample ID & $\begin{array}{c}\text { Depth } \\
\text { (ft bgs) }\end{array}$ & GEA(U-238 at 609) (pCi/g) & $\begin{array}{c}\text { WE } \\
(\mathrm{pCi} / \mathrm{g})\end{array}$ & $\begin{array}{c}\mathrm{AE} \\
(\mathrm{pCi} / \mathrm{g})\end{array}$ & $\begin{array}{c}\mathrm{MD} \\
(\mathrm{pCi} / \mathrm{g})\end{array}$ \\
\hline \multirow{27}{*}{$\begin{array}{l}\text { C5002 } \\
(399-3-20)\end{array}$} & C5002-81E & 4.0 & $5.66 \mathrm{E}-01$ & & & \\
\hline & C5002-82A & 5.0 & 5.33E-01 & & & \\
\hline & C5002-83A & 10.5 & $4.28 \mathrm{E}-01$ & & & \\
\hline & C5002-83B & 11.5 & $2.76 \mathrm{E}-01$ & 1.17E-03 & 1.39E-01 & 2.93E-01 \\
\hline & C5002-84A & 14.0 & 3.93E-01 & & & \\
\hline & C5002-84C & 16.0 & 3.77E-01 & 6.17E-04 & & 3.70E-01 \\
\hline & C5002-85D & 17.0 & 6.71E-01 & & & \\
\hline & C5002-86C & 19.5 & 4.72E-01 & & & \\
\hline & C5002-86E & 21.5 & $4.72 \mathrm{E}-01$ & $1.58 \mathrm{E}-04$ & $2.26 \mathrm{E}-01$ & 5.47E-01 \\
\hline & C5002-87C & 23.5 & 3.92E-01 & & & \\
\hline & C5002-87D & 24.5 & $4.51 \mathrm{E}-01$ & 2.00E-04 & & 4.97E-01 \\
\hline & C5002-87E & 25.5 & 4.32E-01 & & & \\
\hline & C5002-89A & 28.5 & 4.51E-01 & & & \\
\hline & C5002-90A & 32.5 & 4.73E-01 & 3.07E-04 & & 5.87E-01 \\
\hline & C5002-90B & 33.5 & 5.01E-01 & & & \\
\hline & C5002-90C & 34.5 & 5.75E-01 & 7.87E-05 & & 5.78E-01 \\
\hline & C5002-91B & 38.5 & 5.10E-01 & & & \\
\hline & C5002-91C & 39.5 & & 7.11E-05 & $1.56 \mathrm{E}-01$ & 4.70E-01 \\
\hline & C5002-91D & 40.5 & 4.84E-01 & $1.14 \mathrm{E}-04$ & & 4.91E-01 \\
\hline & C5002-92D & 48.5 & 5.03E-01 & 4.13E-04 & $1.74 \mathrm{E}-01$ & 4.67E-01 \\
\hline & C5002-93E & 54.0 & 4.61E-01 & $6.76 \mathrm{E}-04$ & 2.47E-01 & $6.48 \mathrm{E}-01$ \\
\hline & C5002-94D & 65.5 & & 7.22E-05 & $1.46 \mathrm{E}-01$ & 5.66E-01 \\
\hline & C5002-94E & 66.5 & 4.93E-01 & & & \\
\hline & C5002-98D & 81.0 & 5.15E-01 & & & \\
\hline & C5002-98E & 81.1 & & 1.07E-04 & $1.44 \mathrm{E}-01$ & 4.02E-01 \\
\hline & C5002-99D & 82.0 & & $3.84 \mathrm{E}-05$ & 3.64E-01 & 7.99E-01 \\
\hline & C5002-100A & 84.0 & & $6.59 \mathrm{E}-06$ & 3.42E-01 & 7.11E-01 \\
\hline
\end{tabular}


Table D.3. IC Anion Analysis Results for 300-FF5 Samples

\begin{tabular}{|c|c|c|c|c|c|c|c|c|c|}
\hline Well & Sample ID & $\begin{array}{c}\text { Depth } \\
\text { (ft bgs) } \\
\end{array}$ & $\begin{array}{c}\mathrm{F}^{-} \\
(\mathrm{mg} / \mathrm{L}) \\
\end{array}$ & $\begin{array}{c}\begin{array}{c}\mathrm{Cl}- \\
(\mathrm{mg} / \mathrm{L})\end{array} \\
\end{array}$ & $\begin{array}{c}\mathrm{NO}_{2}^{-} \\
(\mathrm{mg} / \mathrm{L}) \\
\end{array}$ & $\begin{array}{c}\mathrm{Br}^{-} \\
(\mathrm{mg} / \mathrm{L}) \\
\end{array}$ & $\begin{array}{c}\mathrm{NO}_{3^{-}} \\
(\mathrm{mg} / \mathrm{L}) \\
\end{array}$ & $\begin{array}{c}\mathrm{SO}_{4}{ }^{2-} \\
(\mathrm{mg} / \mathrm{L}) \\
\end{array}$ & $\begin{array}{c}\mathrm{PO}_{4}^{3-} \\
(\mathrm{mg} / \mathrm{L}) \\
\end{array}$ \\
\hline \multirow{33}{*}{ C4999 } & \multicolumn{9}{|c|}{ Groundwater } \\
\hline & B1FR76 & 45.3 & 0.44 & 11.17 & $<0.397$ & $<0.388$ & 13.02 & 38.57 & 0.97 \\
\hline & B1FR92 & 47.9 & 0.39 & 16.75 & $<0.397$ & $<0.388$ & 21.26 & 34.63 & $<0.860$ \\
\hline & B1FRB4 & 52.5 & 0.18 & 5.58 & $<0.397$ & $<0.388$ & 4.82 & 25.15 & $<0.860$ \\
\hline & B1FR88 & 68.0 & 0.27 & 0.86 & $<0.397$ & $<0.388$ & $<0.430$ & 13.06 & $<0.860$ \\
\hline & B1FRB8 & 77.0 & 0.33 & 1.34 & $<0.397$ & $<0.388$ & $<0.430$ & 9.40 & $<0.860$ \\
\hline & B1FR84 & 87.5 & 0.41 & 3.51 & $<0.397$ & $<0.388$ & $<0.430$ & $<0.734$ & $<0.860$ \\
\hline & B1FR96 & 99.5 & 0.42 & 5.95 & $<0.397$ & $<0.388$ & $<0.430$ & $<0.734$ & $<0.860$ \\
\hline & B1FR80 & 108.0 & 0.43 & 6.21 & $<0.397$ & $<0.388$ & $<0.430$ & $<0.734$ & $<0.860$ \\
\hline & B1FR32 & 120.80 & 0.47 & 8.06 & $<0.397$ & $<0.388$ & $<0.430$ & $<0.734$ & $<0.860$ \\
\hline & \multicolumn{9}{|c|}{ Water Extracts (Concentration Values Were Dilution Corrected) } \\
\hline & C4999-3B & 9.0 & 4.39 & 29.07 & $<3.099$ & $<3.029$ & 4463.2 & 3252.5 & $<6.713$ \\
\hline & C4999-6A & 20.0 & 8.04 & 42.13 & $<4.911$ & $<4.800$ & 2952.5 & 2698.5 & $<10.64$ \\
\hline & C4999-8E & 28.5 & 29.40 & 245.95 & $<11.60$ & $<11.33$ & 865.11 & 1469.3 & $<25.12$ \\
\hline & C4999-10C & 35.5 & 17.40 & 81.11 & $<4.852$ & $<4.742$ & 108.84 & 429.32 & $<10.51$ \\
\hline & C4999-11B & 39.5 & 39.39 & 245.32 & $<7.481$ & $<7.311$ & 8.20 & 527.29 & $<16.21$ \\
\hline & C4999-11D & 41.5 & 11.08 & 11.26 & $<4.094$ & $<4.001$ & 16.44 & 77.32 & $<8.868$ \\
\hline & C4999-12D & 47.0 & 1.23 & 14.03 & $<1.179$ & $<1.152$ & 18.83 & 42.11 & $<2.554$ \\
\hline & C4999-13E & 53.0 & 0.40 & 4.92 & $<1.159$ & $<1.133$ & 2.44 & 26.40 & $<2.512$ \\
\hline & C4999-14D & 56.0 & 0.71 & 2.87 & $<1.150$ & $<1.124$ & $<1.246$ & 375.62 & $<2.492$ \\
\hline & C4999-15B & 59.0 & 0.89 & 2.68 & $<1.176$ & $<1.149$ & $<1.274$ & 304.76 & $<2.548$ \\
\hline & C4999-16A & 62.0 & 1.00 & 1.92 & $<1.206$ & $<1.178$ & $<1.306$ & 177.61 & $<2.612$ \\
\hline & C4999-17A & 66.0 & 0.96 & 1.06 & $<1.276$ & $<1.247$ & $<1.382$ & 121.52 & $<2.765$ \\
\hline & C4999-19B & 76.0 & 0.86 & 2.38 & $<1.265$ & $<1.236$ & $<1.370$ & 512.93 & $<2.740$ \\
\hline & C4999-21C & 86.0 & 2.58 & 8.73 & $<1.928$ & $<1.885$ & $<2.089$ & 572.40 & $<4.177$ \\
\hline & C4999-22E & 90.5 & 3.59 & 8.59 & $<2.641$ & $<2.581$ & $<2.861$ & 750.28 & $<5.722$ \\
\hline & C4999-25A & 98.5 & 2.97 & 7.51 & $<3.799$ & $<3.713$ & $<4.115$ & 629.86 & $<8.230$ \\
\hline & C4999-27B & 108.0 & 2.33 & 9.29 & $<4.190$ & $<4.095$ & $<4.538$ & 738.22 & $<9.077$ \\
\hline & C4999-29D & 118.0 & 4.00 & 12.56 & $<5.832$ & $<5.700$ & $<6.317$ & 677.87 & $<12.64$ \\
\hline & C4999-31C & 125.0 & 3.18 & 6.26 & $<4.132$ & $<4.039$ & $<4.476$ & 399.24 & $<8.952$ \\
\hline & C4999-32B & 129.0 & 3.20 & 6.69 & $<0.871$ & $<0.852$ & 1.28 & 67.54 & $<1.888$ \\
\hline & \multicolumn{9}{|c|}{ Pore Water After Ultracentrifugation } \\
\hline & C4999-31C & 125.0 & $<1.49$ & 9.00 & $<3.97$ & $<3.88$ & $<4.30$ & 9.53 & $<8.60$ \\
\hline \multirow{14}{*}{ C5000 } & \multicolumn{9}{|c|}{ Groundwater } \\
\hline & B1FR36 & 33.8 & 0.44 & 19.98 & $<0.397$ & $<0.388$ & 26.86 & 61.51 & $<0.860$ \\
\hline & B1FR40 & 38.5 & 0.31 & 19.39 & $<0.397$ & $<0.388$ & 26.48 & 60.08 & $<0.860$ \\
\hline & B1FR44 & 43.3 & 0.32 & 19.83 & $<0.397$ & $<0.388$ & 26.68 & 60.30 & $<0.860$ \\
\hline & B1FR48 & 47.3 & 0.38 & 19.34 & $<0.397$ & $<0.388$ & 26.30 & 60.07 & $<0.860$ \\
\hline & B1FR52 & 54.3 & 0.35 & 20.83 & $<0.397$ & $<0.388$ & 5.35 & 64.09 & $<0.860$ \\
\hline & B1FR56 & 59.3 & 0.60 & 22.57 & $<0.397$ & $<0.388$ & $<0.430$ & 62.18 & $<0.860$ \\
\hline & B1FR60 & 68.5 & 1.40 & 26.69 & $<0.397$ & $<0.388$ & $<0.430$ & 19.64 & $<0.860$ \\
\hline & B1FR64 & 79.5 & 1.18 & 13.13 & $<0.397$ & $<0.388$ & $<0.430$ & 8.17 & $<0.860$ \\
\hline & B1FR68 & 90.3 & 1.02 & 10.26 & $<0.397$ & $<0.388$ & $<0.430$ & 15.70 & $<0.860$ \\
\hline & B1FR72 & 107.8 & 1.21 & 9.30 & $<0.397$ & $<0.388$ & $<0.430$ & 3.49 & $<0.860$ \\
\hline & \multicolumn{9}{|c|}{ Water Extracts (Concentration Values Were Dilution Corrected) } \\
\hline & C5000-36A & 11.0 & 28.35 & 25.68 & $<6.807$ & $<6.653$ & 51.04 & 208.95 & $<14.75$ \\
\hline & C5000-36E & 12.0 & 38.72 & 38.20 & $<10.18$ & $<9.953$ & 59.75 & 584.17 & $<22.06$ \\
\hline
\end{tabular}


Table D.3. (contd)

\begin{tabular}{|c|c|c|c|c|c|c|c|c|c|}
\hline Well & Sample ID & $\begin{array}{c}\text { Depth } \\
\text { (ft bgs) }\end{array}$ & $\begin{array}{c}F^{-} \\
(\mathrm{mg} / \mathrm{L})\end{array}$ & $\begin{array}{c}\mathrm{Cl}- \\
(\mathrm{mg} / \mathrm{L})\end{array}$ & $\begin{array}{c}\mathrm{NO}_{2}{ }^{-} \\
(\mathrm{mg} / \mathrm{L})\end{array}$ & $\begin{array}{c}\mathrm{Br}^{-} \\
(\mathrm{mg} / \mathrm{L})\end{array}$ & $\begin{array}{c}\mathrm{NO}_{3^{-}} \\
(\mathrm{mg} / \mathrm{L})\end{array}$ & $\begin{array}{l}\mathrm{SO}_{4}{ }^{2-} \\
(\mathrm{mg} / \mathrm{L})\end{array}$ & $\begin{array}{c}\mathrm{PO}_{4}^{3-} \\
(\mathrm{mg} / \mathrm{L})\end{array}$ \\
\hline & C5000-37A & 13.0 & 26.13 & 15.01 & $<10.89$ & $<10.64$ & 47.61 & 643.79 & $<23.50$ \\
\hline & C5000-38B & 20.0 & 48.20 & 32.19 & $<8.741$ & $<8.543$ & $<9.467$ & 491.14 & $<18.94$ \\
\hline & C5000-38C & 21.0 & 7.21 & $<6.365$ & $<9.291$ & $<9.080$ & 33.37 & 51.74 & $<20.13$ \\
\hline & C5000-39B & 23.0 & 10.28 & 7.87 & $<2.869$ & $<2.804$ & $<3.107$ & 100.85 & $<6.214$ \\
\hline & C5000-39D & 25.0 & 22.31 & 6.53 & $<2.875$ & $<2.810$ & 20.10 & 50.74 & $<6.228$ \\
\hline & C5000-40C & 32.0 & 27.16 & 9.52 & $<4.026$ & $<3.935$ & 17.93 & 83.19 & $<8.722$ \\
\hline & C5000-40E & 34.0 & 56.25 & 47.02 & $<17.10$ & $<16.72$ & 31.63 & 712.26 & $<37.05$ \\
\hline & C5000-41B & 35.0 & 19.65 & 34.46 & $<6.902$ & $<6.745$ & $<7.475$ & 215.66 & $<14.95$ \\
\hline & C5000-41E & 38.0 & 8.57 & 19.89 & $<6.786$ & $<6.632$ & $<7.350$ & 83.35 & $<14.70$ \\
\hline & C5000-43A & 44.0 & 15.08 & 20.14 & $<6.128$ & $<5.989$ & $<6.637$ & 77.86 & $<13.28$ \\
\hline & C5000-44B & 48.0 & 5.49 & 22.55 & $<4.352$ & $<4.253$ & $<4.713$ & 87.81 & $<9.427$ \\
\hline & C5000-44E & 50.0 & 5.87 & 28.65 & $<4.902$ & $<4.791$ & $<5.310$ & 139.42 & $<10.62$ \\
\hline & C5000-45C & 54.0 & 7.08 & 31.15 & $<3.533$ & $<3.453$ & $<3.827$ & 195.25 & $<7.654$ \\
\hline & C5000-46A & 56.0 & 4.03 & 20.03 & $<3.745$ & $<3.660$ & $<4.056$ & 232.52 & $<8.112$ \\
\hline & C5000-46D & 59.0 & 3.17 & 17.72 & $<2.651$ & $<2.591$ & $<2.871$ & 194.30 & $<5.742$ \\
\hline & C5000-48D & 65.0 & 2.43 & 13.42 & $<2.008$ & $<1.962$ & $<2.175$ & 206.29 & $<4.350$ \\
\hline & C5000-48E & 66.0 & 2.70 & 22.19 & $<1.564$ & $<1.528$ & $<1.694$ & 56.81 & $<3.388$ \\
\hline & C5000-49D & 68.0 & 5.27 & 21.21 & $<4.854$ & $<4.744$ & $<5.258$ & 369.98 & $<10.52$ \\
\hline & C5000-50B & 71.0 & 14.37 & 28.85 & $<4.131$ & $<4.037$ & $<4.474$ & 329.15 & $<8.949$ \\
\hline & C5000-51E & 77.0 & 4.09 & 9.67 & $<2.847$ & $<2.782$ & $<3.083$ & 135.72 & $<6.167$ \\
\hline & C5000-52B & 79.0 & 4.86 & 8.62 & $<2.529$ & $<2.471$ & $<2.739$ & 111.69 & $<5.478$ \\
\hline & C5000-53E & 85.0 & 2.89 & 6.78 & $<2.118$ & $<2.070$ & $<2.294$ & 194.25 & $<4.589$ \\
\hline & C5000-54E & 89.5 & 4.11 & 7.94 & $<3.938$ & $<3.849$ & $<4.266$ & 180.14 & $<8.531$ \\
\hline & C5000-57D & 100.0 & 6.47 & 9.19 & $<3.037$ & $<2.968$ & $<3.290$ & 72.74 & $<6.579$ \\
\hline & C5000-60E & 109.5 & 4.42 & 8.54 & $<2.089$ & $<2.042$ & $<2.263$ & 126.95 & $<4.525$ \\
\hline & \multicolumn{9}{|c|}{ Pore water After Ultracentrifugation } \\
\hline & C5000-43B & 45.0 & $<1.49$ & 18.95 & $<3.97$ & $<3.88$ & 19.13 & 64.00 & $<8.60$ \\
\hline & C5000-44C & 49.0 & $<1.49$ & 19.11 & $<3.97$ & $<3.88$ & 8.93 & 60.24 & $<8.60$ \\
\hline & C5000-44E & 51.0 & 1.15 & 22.30 & $<3.97$ & $<3.88$ & $<4.30$ & 76.75 & $<8.60$ \\
\hline & C5000-45C & 54.0 & 1.34 & 23.86 & $<3.97$ & $<3.88$ & $<4.30$ & 79.41 & $<8.60$ \\
\hline & C5000-48B & 62.5 & 3.51 & 31.34 & $<3.97$ & $<3.88$ & $<4.30$ & 51.81 & $<8.60$ \\
\hline & C5000-49A & 67.0 & 2.62 & 33.62 & $<3.97$ & $<3.88$ & $<4.30$ & 30.39 & $<8.60$ \\
\hline & C5000-49D & 68.0 & 2.42 & 20.41 & $<3.97$ & $<3.88$ & $<4.30$ & 15.65 & $<8.60$ \\
\hline & C5000-52B & 79.0 & 4.09 & 24.57 & $<3.97$ & $<3.88$ & $<4.30$ & 16.81 & $<8.60$ \\
\hline & C5000-54A & 85.0 & 2.23 & 11.61 & $<3.97$ & $<3.88$ & $<4.30$ & 23.22 & $<8.60$ \\
\hline & C5000-53E & 86.0 & 1.50 & 10.99 & $<3.97$ & $<3.88$ & $<4.30$ & 24.98 & $<8.60$ \\
\hline & C5000-55D & 90.5 & 2.27 & 12.86 & $<3.97$ & $<3.88$ & $<4.30$ & 27.26 & $<8.60$ \\
\hline & C5000-58C & 103.0 & 3.34 & 16.26 & $<3.97$ & $<3.88$ & $<4.30$ & 17.27 & $<8.60$ \\
\hline & C5000-60C & 107.5 & 3.19 & 13.05 & $<3.97$ & $<3.88$ & $<4.30$ & 11.23 & $<8.60$ \\
\hline \multirow{6}{*}{ C5001 } & \multicolumn{9}{|c|}{ Groundwater } \\
\hline & B1HRX0 & 53.0 & 0.31 & 16.46 & $<0.097$ & 0.09 & 23.02 & 36.93 & $<0.206$ \\
\hline & B1HRX4 & 57.8 & 0.31 & 16.52 & $<0.097$ & 0.11 & 22.39 & 37.03 & $<0.206$ \\
\hline & B1HRX8 & 63.0 & 0.29 & 16.71 & $<0.097$ & 0.09 & 23.31 & 38.40 & $<0.206$ \\
\hline & B1HRY2 & 81.5 & 0.35 & 17.65 & $<0.097$ & $<0.072$ & 23.53 & 39.33 & $<0.206$ \\
\hline & B1HRY6 & 101.8 & $<0.208$ & 8.57 & $<0.097$ & $<0.072$ & 11.54 & 19.26 & 0.41 \\
\hline
\end{tabular}


Table D.3. (contd)

\begin{tabular}{|c|c|c|c|c|c|c|c|c|c|}
\hline Well & Sample ID & $\begin{array}{c}\text { Depth } \\
\text { (ft bgs) }\end{array}$ & $\begin{array}{c}\mathrm{F}^{-} \\
(\mathrm{mg} / \mathrm{L})\end{array}$ & $\begin{array}{c}\mathrm{Cl}- \\
(\mathrm{mg} / \mathrm{L})\end{array}$ & $\begin{array}{c}\mathrm{NO}_{2}{ }^{-} \\
(\mathrm{mg} / \mathrm{L})\end{array}$ & $\begin{array}{c}\mathrm{Br}^{-} \\
(\mathrm{mg} / \mathrm{L})\end{array}$ & $\begin{array}{c}\mathrm{NO}_{3^{-}} \\
(\mathrm{mg} / \mathrm{L})\end{array}$ & $\begin{array}{c}\mathrm{SO}_{4}{ }^{2-} \\
(\mathrm{mg} / \mathrm{L})\end{array}$ & $\begin{array}{c}\mathrm{PO}_{4}{ }^{3-} \\
(\mathrm{mg} / \mathrm{L})\end{array}$ \\
\hline & \multicolumn{9}{|c|}{ Water Extracts } \\
\hline & C5001-64E & 15.0 & 11.94 & 4.77 & $<6.50$ & $<6.93$ & $<6.24$ & 39.54 & $<7.28$ \\
\hline & C5001-68A & 28.0 & 29.87 & 30.08 & $<10.64$ & $<11.35$ & $<10.21$ & 256.26 & $<11.91$ \\
\hline & C5001-69C & 33.0 & 6.92 & 4.37 & $<6.91$ & $<7.37$ & $<6.63$ & 45.81 & $<7.74$ \\
\hline & C5001-70D & 39.5 & 7.67 & $<4.40$ & $<8.26$ & $<8.81$ & 36.12 & 107.13 & $<9.25$ \\
\hline & C5001-71E & 41.5 & 10.78 & 6.02 & $<6.72$ & $<7.16$ & $<6.45$ & 107.34 & $<7.52$ \\
\hline & C5001-76C & 64.5 & 8.70 & 16.66 & $<7.60$ & $<8.11$ & $<7.30$ & 59.39 & $<8.51$ \\
\hline & C5001-78A & 74.5 & 8.13 & 16.29 & $<9.47$ & $<10.10$ & $<9.09$ & 71.97 & $<10.61$ \\
\hline \multirow{11}{*}{ C5002 } & \multicolumn{9}{|c|}{ Groundwater } \\
\hline & B1HT04 & 52.3 & 0.35 & 17.73 & $<0.097$ & $<0.072$ & 23.70 & 49.78 & 0.23 \\
\hline & B1HT08 & 61.5 & 0.32 & 17.47 & $<0.097$ & 0.09 & 22.21 & 49.02 & 0.24 \\
\hline & B1HT12 & 72.5 & 0.35 & 20.12 & $<0.097$ & 0.10 & 22.32 & 50.76 & $<0.206$ \\
\hline & B1HT16 & 91.0 & 0.51 & 6.94 & $<0.097$ & $<0.072$ & $<0.090$ & 5.98 & $<0.206$ \\
\hline & \multicolumn{9}{|c|}{ Water Extracts } \\
\hline & C5002-84C & 16.0 & 7.07 & $<11.15$ & $<20.95$ & $<22.35$ & 138.77 & 210.96 & $<23.46$ \\
\hline & C5002-87D & 24.5 & 22.19 & 8.85 & $<10.06$ & $<10.73$ & 58.53 & 266.88 & $<11.26$ \\
\hline & C5002-90A & 32.5 & 22.27 & 18.56 & $<11.55$ & $<12.31$ & $<11.09$ & 458.04 & $<12.93$ \\
\hline & C5002-90C & 34.5 & 14.81 & $<4.67$ & $<8.77$ & $<9.35$ & $<8.42$ & 195.26 & $<9.82$ \\
\hline & C5002-91D & 40.5 & 11.33 & 5.21 & $<7.82$ & $<8.34$ & $<7.51$ & 294.47 & $<8.76$ \\
\hline
\end{tabular}


Table D.4. ICP-OEP for Cations Analysis of C4999 Samples

\begin{tabular}{|c|c|c|c|c|c|c|c|c|c|c|c|c|c|c|}
\hline Sample ID & $\begin{array}{c}\text { Depth } \\
\text { (ft bgs) }\end{array}$ & $\begin{array}{c}\mathrm{Al} \\
(\mu \mathrm{g} / \mathrm{L})\end{array}$ & $\begin{array}{c}\text { As } \\
(\mu \mathrm{g} / \mathrm{L})\end{array}$ & $\begin{array}{c}\mathrm{B} \\
(\mu \mathrm{g} / \mathrm{L})\end{array}$ & $\begin{array}{c}\mathrm{Ba} \\
(\mu \mathrm{g} / \mathrm{L})\end{array}$ & $\begin{array}{c}\mathrm{Be} \\
(\mu \mathrm{g} / \mathrm{L})\end{array}$ & $\begin{array}{c}\mathrm{Bi} \\
(\mu \mathrm{g} / \mathrm{L})\end{array}$ & $\begin{array}{c}\text { Ca } \\
(\mu \mathrm{g} / \mathrm{L})\end{array}$ & $\begin{array}{c}\mathrm{Cd} \\
(\mu \mathrm{g} / \mathrm{L})\end{array}$ & $\begin{array}{c}\text { Co } \\
(\mu \mathrm{g} / \mathrm{L})\end{array}$ & $\begin{array}{c}\mathrm{Cr} \\
(\mu \mathrm{g} / \mathrm{L})\end{array}$ & $\begin{array}{c}\mathrm{Cu} \\
(\mu \mathrm{g} / \mathrm{L})\end{array}$ & $\mathrm{Fe}(\mu \mathrm{g} / \mathrm{L})$ & $\begin{array}{c}\mathrm{K} \\
(\mu \mathrm{g} / \mathrm{L})\end{array}$ \\
\hline \multicolumn{15}{|c|}{ Groundwater } \\
\hline B1FR99 & 42.5 & $4.0 \mathrm{E}+02$ & $2.0 \mathrm{E}+03$ & $8.5 \mathrm{E}+01$ & $6.1 \mathrm{E}+01$ & $5.5 \mathrm{E}-01$ & $2.0 \mathrm{E}+02$ & $5.0 \mathrm{E}+04$ & 7.3E-01 & $3.3 \mathrm{E}+00$ & $5.0 \mathrm{E}+01$ & $8.5 \mathrm{E}+00$ & $1.2 \mathrm{E}+01$ & $4.2 \mathrm{E}+03$ \\
\hline B1FR76 & 45.3 & $4.0 \mathrm{E}+02$ & $9.9 \mathrm{E}+00$ & $5.5 \mathrm{E}+01$ & $4.6 \mathrm{E}+01$ & $3.8 \mathrm{E}-01$ & $2.0 \mathrm{E}+03$ & $3.2 \mathrm{E}+04$ & $1.0 \mathrm{E}+01$ & $3.3 \mathrm{E}+00$ & $2.0 \mathrm{E}+00$ & $1.2 \mathrm{E}+01$ & $4.3 \mathrm{E}+01$ & $2.9 \mathrm{E}+03$ \\
\hline B1FR92 & 47.9 & $4.0 \mathrm{E}+02$ & $2.0 \mathrm{E}+03$ & $9.4 \mathrm{E}+01$ & $3.9 \mathrm{E}+01$ & 9.3E-01 & $1.6 \mathrm{E}+01$ & $4.0 \mathrm{E}+04$ & $1.0 \mathrm{E}-02$ & $5.7 \mathrm{E}+00$ & $5.0 \mathrm{E}+01$ & $1.0 \mathrm{E}+01$ & $8.5 \mathrm{E}+00$ & $6.3 \mathrm{E}+03$ \\
\hline B1FRB4 & 52.5 & $4.0 \mathrm{E}+02$ & $2.0 \mathrm{E}+03$ & $9.5 \mathrm{E}+01$ & $1.9 \mathrm{E}+01$ & $1.7 \mathrm{E}+00$ & $8.1 \mathrm{E}+00$ & $2.6 \mathrm{E}+04$ & 6.3E-01 & $5.0 \mathrm{E}+00$ & $5.0 \mathrm{E}+01$ & $1.8 \mathrm{E}+01$ & $4.0 \mathrm{E}+01$ & $4.4 \mathrm{E}+03$ \\
\hline B1FR88 & 68.0 & $5.0 \mathrm{E}+01$ & $2.0 \mathrm{E}+03$ & $9.9 \mathrm{E}+01$ & $1.0 \mathrm{E}+01$ & $1.7 \mathrm{E}+00$ & $1.5 \mathrm{E}+01$ & $1.7 \mathrm{E}+04$ & $1.1 \mathrm{E}-02$ & $2.8 \mathrm{E}+00$ & $5.0 \mathrm{E}+01$ & $1.2 \mathrm{E}+01$ & $5.8 \mathrm{E}+01$ & $4.5 \mathrm{E}+03$ \\
\hline B1FRB8 & 77.0 & $3.7 \mathrm{E}+01$ & $2.0 \mathrm{E}+03$ & $8.2 \mathrm{E}+01$ & $1.1 \mathrm{E}+01$ & $1.4 \mathrm{E}+00$ & $2.0 \mathrm{E}+02$ & $1.6 \mathrm{E}+04$ & $1.5 \mathrm{E}-01$ & $1.7 \mathrm{E}+00$ & $5.0 \mathrm{E}+01$ & $1.3 \mathrm{E}+01$ & $4.3 \mathrm{E}+01$ & $4.7 \mathrm{E}+03$ \\
\hline B1FR84 & 87.5 & $2.6 \mathrm{E}+01$ & $2.0 \mathrm{E}+03$ & $7.7 \mathrm{E}+01$ & $2.4 \mathrm{E}+01$ & $9.1 \mathrm{E}-01$ & $6.9 \mathrm{E}+00$ & $2.0 \mathrm{E}+04$ & $2.0 \mathrm{E}+01$ & $3.6 \mathrm{E}+00$ & $5.0 \mathrm{E}+01$ & $1.2 \mathrm{E}+01$ & $8.5 \mathrm{E}+01$ & $4.9 \mathrm{E}+03$ \\
\hline B1FR96 & 99.5 & $3.6 \mathrm{E}+01$ & $2.0 \mathrm{E}+03$ & $7.5 \mathrm{E}+01$ & $3.5 \mathrm{E}+01$ & 7.4E-01 & $2.0 \mathrm{E}+02$ & $2.3 \mathrm{E}+04$ & $2.0 \mathrm{E}+01$ & $3.3 \mathrm{E}+00$ & $5.0 \mathrm{E}+01$ & $7.6 \mathrm{E}+00$ & $1.6 \mathrm{E}+02$ & $5.0 \mathrm{E}+03$ \\
\hline B1FR80 & 108.0 & $6.5 \mathrm{E}+00$ & $1.0 \mathrm{E}+02$ & $4.0 \mathrm{E}+01$ & $4.3 \mathrm{E}+01$ & $3.2 \mathrm{E}-01$ & $2.0 \mathrm{E}+03$ & $2.3 \mathrm{E}+04$ & $1.0 \mathrm{E}+01$ & $1.0 \mathrm{E}+02$ & $1.0 \mathrm{E}+01$ & $1.1 \mathrm{E}+01$ & $1.8 \mathrm{E}+02$ & $5.0 \mathrm{E}+03$ \\
\hline B1FR32 & 120.80 & $5.6 \mathrm{E}+00$ & $2.9 \mathrm{E}+00$ & $4.9 \mathrm{E}+01$ & $3.3 \mathrm{E}+01$ & 5.1E-01 & $1.3 \mathrm{E}+01$ & $1.9 \mathrm{E}+04$ & $1.0 \mathrm{E}+01$ & $1.0 \mathrm{E}+02$ & $1.0 \mathrm{E}+01$ & $1.2 \mathrm{E}+01$ & $1.0 \mathrm{E}+02$ & $4.2 \mathrm{E}+03$ \\
\hline \multicolumn{15}{|c|}{ Water Extracts (Concentration Values Were Dilution Corrected) } \\
\hline C4999-3B & 9.0 & $7.8 \mathrm{E}+02$ & $6.5 \mathrm{E}+02$ & $7.1 \mathrm{E}+04$ & $3.5 \mathrm{E}+02$ & $2.1 \mathrm{E}+01$ & $3.9 \mathrm{E}+03$ & $1.2 \mathrm{E}+06$ & $3.9 \mathrm{E}+02$ & $1.5 \mathrm{E}+02$ & $3.8 \mathrm{E}+01$ & $6.1 \mathrm{E}+02$ & $1.2 \mathrm{E}+02$ & $1.7 \mathrm{E}+05$ \\
\hline C4999-5D & 18.0 & $2.0 \mathrm{E}+02$ & $1.1 \mathrm{E}+03$ & $8.0 \mathrm{E}+02$ & $1.7 \mathrm{E}+02$ & $4.8 \mathrm{E}+01$ & $4.5 \mathrm{E}+03$ & $1.5 \mathrm{E}+05$ & $1.7 \mathrm{E}+01$ & $4.5 \mathrm{E}+02$ & $1.5 \mathrm{E}+01$ & $1.9 \mathrm{E}+02$ & $1.9 \mathrm{E}+02$ & $1.7 \mathrm{E}+05$ \\
\hline C4999-6A & 20.0 & $1.2 \mathrm{E}+03$ & $3.7 \mathrm{E}+02$ & $4.6 \mathrm{E}+04$ & $6.8 \mathrm{E}+02$ & $3.0 \mathrm{E}+01$ & $5.4 \mathrm{E}+02$ & $1.0 \mathrm{E}+06$ & $6.2 \mathrm{E}+02$ & $2.1 \mathrm{E}+02$ & $4.4 \mathrm{E}+01$ & $9.2 \mathrm{E}+02$ & $4.4 \mathrm{E}+02$ & $1.9 \mathrm{E}+05$ \\
\hline C4999-6D & 23.0 & $3.4 \mathrm{E}+01$ & $5.0 \mathrm{E}+02$ & $6.6 \mathrm{E}+02$ & $1.1 \mathrm{E}+02$ & $1.7 \mathrm{E}+01$ & $9.4 \mathrm{E}+01$ & $9.3 \mathrm{E}+04$ & $1.2 \mathrm{E}+02$ & $2.5 \mathrm{E}+02$ & $3.1 \mathrm{E}+02$ & $8.9 \mathrm{E}+01$ & $4.3 \mathrm{E}+01$ & $7.6 \mathrm{E}+04$ \\
\hline C4999-8E & 28.5 & $1.7 \mathrm{E}+03$ & $6.2 \mathrm{E}+02$ & $1.3 \mathrm{E}+04$ & $8.8 \mathrm{E}+02$ & $2.6 \mathrm{E}+02$ & $7.6 \mathrm{E}+03$ & $4.9 \mathrm{E}+05$ & $5.8 \mathrm{E}+03$ & $1.9 \mathrm{E}+03$ & $3.2 \mathrm{E}+01$ & $8.8 \mathrm{E}+03$ & $1.7 \mathrm{E}+03$ & $3.4 \mathrm{E}+05$ \\
\hline C4999-9B & 30.5 & $3.3 \mathrm{E}+02$ & $3.0 \mathrm{E}+02$ & $1.5 \mathrm{E}+03$ & $3.6 \mathrm{E}+02$ & $1.0 \mathrm{E}+02$ & $9.9 \mathrm{E}+02$ & $1.7 \mathrm{E}+05$ & $2.8 \mathrm{E}+01$ & $7.9 \mathrm{E}+01$ & $5.7 \mathrm{E}+02$ & $4.6 \mathrm{E}+02$ & $2.9 \mathrm{E}+02$ & $5.7 \mathrm{E}+04$ \\
\hline C4999-10C & 35.5 & $4.6 \mathrm{E}+02$ & $1.1 \mathrm{E}+03$ & $1.2 \mathrm{E}+03$ & $2.4 \mathrm{E}+02$ & $2.3 \mathrm{E}+01$ & $7.6 \mathrm{E}+02$ & $1.3 \mathrm{E}+05$ & $6.1 \mathrm{E}+02$ & $1.9 \mathrm{E}+02$ & $1.2 \mathrm{E}+01$ & $7.9 \mathrm{E}+02$ & $1.6 \mathrm{E}+02$ & $7.1 \mathrm{E}+04$ \\
\hline C4999-11B & 39.5 & $6.0 \mathrm{E}+02$ & $1.1 \mathrm{E}+03$ & $1.1 \mathrm{E}+03$ & $3.4 \mathrm{E}+02$ & $3.4 \mathrm{E}+01$ & $1.9 \mathrm{E}+03$ & $2.4 \mathrm{E}+05$ & $9.4 \mathrm{E}+02$ & $3.0 \mathrm{E}+02$ & $6.2 \mathrm{E}+01$ & $1.1 \mathrm{E}+03$ & $1.9 \mathrm{E}+02$ & $1.2 \mathrm{E}+05$ \\
\hline C4999-11D & 41.5 & $1.1 \mathrm{E}+03$ & $1.9 \mathrm{E}+03$ & $1.3 \mathrm{E}+03$ & $1.2 \mathrm{E}+02$ & $6.6 \mathrm{E}+01$ & $2.7 \mathrm{E}+03$ & $4.1 \mathrm{E}+04$ & $2.1 \mathrm{E}+03$ & $4.4 \mathrm{E}+02$ & $1.1 \mathrm{E}+02$ & $2.4 \mathrm{E}+03$ & $2.3 \mathrm{E}+03$ & $3.4 \mathrm{E}+04$ \\
\hline C4999-12C & 46.0 & $3.7 \mathrm{E}+02$ & $8.9 \mathrm{E}+02$ & $3.5 \mathrm{E}+02$ & $1.6 \mathrm{E}+02$ & $2.8 \mathrm{E}+01$ & $3.9 \mathrm{E}+01$ & $9.1 \mathrm{E}+04$ & $1.4 \mathrm{E}+00$ & $3.7 \mathrm{E}+00$ & $3.1 \mathrm{E}+02$ & $1.3 \mathrm{E}+02$ & $1.3 \mathrm{E}+02$ & $2.1 \mathrm{E}+04$ \\
\hline C4999-12D & 47.0 & $8.1 \mathrm{E}+01$ & $3.1 \mathrm{E}+01$ & $1.3 \mathrm{E}+02$ & $2.9 \mathrm{E}+01$ & $4.8 \mathrm{E}+00$ & $2.5 \mathrm{E}+02$ & $2.0 \mathrm{E}+04$ & $1.5 \mathrm{E}+02$ & $3.6 \mathrm{E}+01$ & $7.9 \mathrm{E}+00$ & $1.5 \mathrm{E}+02$ & $9.4 \mathrm{E}+01$ & $1.0 \mathrm{E}+04$ \\
\hline C4999-13E & 53.0 & $1.6 \mathrm{E}+02$ & $2.4 \mathrm{E}+02$ & $3.2 \mathrm{E}+02$ & $1.5 \mathrm{E}+01$ & $1.7 \mathrm{E}+01$ & $1.1 \mathrm{E}+03$ & $2.5 \mathrm{E}+04$ & $5.8 \mathrm{E}+02$ & $1.7 \mathrm{E}+02$ & $4.9 \mathrm{E}+01$ & $5.9 \mathrm{E}+02$ & $1.1 \mathrm{E}+02$ & $1.5 \mathrm{E}+04$ \\
\hline C4999-14D & 56.0 & $1.3 \mathrm{E}+02$ & $3.0 \mathrm{E}+02$ & $6.5 \mathrm{E}+02$ & $1.0 \mathrm{E}+02$ & $4.0 \mathrm{E}+01$ & $9.2 \mathrm{E}+02$ & $1.2 \mathrm{E}+05$ & $6.0 \mathrm{E}+00$ & $1.4 \mathrm{E}+02$ & $6.8 \mathrm{E}+01$ & $3.9 \mathrm{E}+02$ & $1.9 \mathrm{E}+02$ & $4.4 \mathrm{E}+04$ \\
\hline C4999-15B & 59.0 & $1.0 \mathrm{E}+02$ & $5.9 \mathrm{E}+03$ & $4.4 \mathrm{E}+02$ & $8.6 \mathrm{E}+01$ & $3.4 \mathrm{E}+01$ & $9.5 \mathrm{E}+02$ & $8.5 \mathrm{E}+04$ & $5.9 \mathrm{E}+02$ & $1.1 \mathrm{E}+02$ & $1.6 \mathrm{E}+01$ & $3.8 \mathrm{E}+02$ & $1.1 \mathrm{E}+02$ & $3.5 \mathrm{E}+04$ \\
\hline C4999-16A & 62.0 & $2.4 \mathrm{E}+01$ & $1.5 \mathrm{E}+03$ & $5.6 \mathrm{E}+01$ & $4.9 \mathrm{E}+01$ & $6.9 \mathrm{E}+00$ & $2.0 \mathrm{E}+02$ & $4.8 \mathrm{E}+04$ & $1.5 \mathrm{E}+02$ & $2.6 \mathrm{E}+01$ & $1.2 \mathrm{E}+01$ & $8.7 \mathrm{E}+01$ & $2.6 \mathrm{E}+01$ & $2.5 \mathrm{E}+04$ \\
\hline C4999-17A & 66.0 & $3.5 \mathrm{E}+01$ & $1.4 \mathrm{E}+02$ & $9.5 \mathrm{E}+01$ & $3.7 \mathrm{E}+01$ & $6.5 \mathrm{E}+00$ & $7.3 \mathrm{E}+01$ & $3.2 \mathrm{E}+04$ & $6.8 \mathrm{E}-01$ & $2.5 \mathrm{E}+01$ & $5.9 \mathrm{E}+00$ & $8.3 \mathrm{E}+01$ & $3.9 \mathrm{E}+01$ & $2.5 \mathrm{E}+04$ \\
\hline C4999-19B & 76.0 & $3.2 \mathrm{E}+02$ & $4.4 \mathrm{E}+02$ & $8.2 \mathrm{E}+01$ & $1.9 \mathrm{E}+02$ & $4.9 \mathrm{E}+00$ & $2.9 \mathrm{E}+02$ & $1.3 \mathrm{E}+05$ & $1.6 \mathrm{E}+02$ & $1.2 \mathrm{E}+01$ & $1.5 \mathrm{E}+00$ & $8.8 \mathrm{E}+01$ & $2.8 \mathrm{E}+01$ & $3.4 \mathrm{E}+04$ \\
\hline C4999-21C & 86.0 & $1.1 \mathrm{E}+02$ & $2.4 \mathrm{E}+02$ & $8.6 \mathrm{E}+01$ & $2.0 \mathrm{E}+02$ & $6.5 \mathrm{E}+00$ & $3.5 \mathrm{E}+02$ & $1.2 \mathrm{E}+05$ & $2.4 \mathrm{E}+02$ & $3.9 \mathrm{E}+01$ & $2.9 \mathrm{E}+00$ & $1.3 \mathrm{E}+02$ & $2.8 \mathrm{E}+02$ & $5.4 \mathrm{E}+04$ \\
\hline C4999-22E & 90.5 & $8.0 \mathrm{E}+01$ & $3.3 \mathrm{E}+03$ & $6.3 \mathrm{E}+01$ & $2.3 \mathrm{E}+02$ & $1.0 \mathrm{E}+01$ & $3.5 \mathrm{E}+02$ & $1.5 \mathrm{E}+05$ & $3.3 \mathrm{E}+02$ & $4.8 \mathrm{E}+01$ & $2.7 \mathrm{E}+01$ & $1.4 \mathrm{E}+02$ & $7.6 \mathrm{E}+01$ & $6.6 \mathrm{E}+04$ \\
\hline C4999-25A & 98.5 & $2.0 \mathrm{E}+02$ & $4.8 \mathrm{E}+03$ & $1.3 \mathrm{E}+02$ & $2.4 \mathrm{E}+02$ & $1.1 \mathrm{E}+01$ & $1.0 \mathrm{E}+03$ & $1.3 \mathrm{E}+05$ & $4.8 \mathrm{E}+02$ & $9.8 \mathrm{E}+01$ & $2.8 \mathrm{E}+01$ & $2.4 \mathrm{E}+02$ & $8.5 \mathrm{E}+01$ & $6.4 \mathrm{E}+04$ \\
\hline C4999-27B & 108.0 & $1.4 \mathrm{E}+02$ & $5.3 \mathrm{E}+03$ & $5.1 \mathrm{E}+01$ & $3.2 \mathrm{E}+02$ & $1.1 \mathrm{E}+01$ & $4.4 \mathrm{E}+02$ & $1.4 \mathrm{E}+05$ & $5.3 \mathrm{E}+02$ & $6.5 \mathrm{E}+01$ & $2.4 \mathrm{E}+01$ & $2.5 \mathrm{E}+02$ & $9.2 \mathrm{E}+01$ & $6.7 \mathrm{E}+04$ \\
\hline C4999-29D & 118.0 & $4.2 \mathrm{E}+02$ & $5.2 \mathrm{E}+02$ & $1.1 \mathrm{E}+03$ & $3.2 \mathrm{E}+02$ & $7.6 \mathrm{E}+01$ & $1.7 \mathrm{E}+03$ & $1.1 \mathrm{E}+05$ & $4.5 \mathrm{E}+00$ & $1.5 \mathrm{E}+02$ & $3.6 \mathrm{E}+01$ & $4.0 \mathrm{E}+02$ & $2.2 \mathrm{E}+02$ & $6.5 \mathrm{E}+04$ \\
\hline C4999-31C & 125.0 & $2.3 \mathrm{E}+02$ & $2.5 \mathrm{E}+02$ & $6.1 \mathrm{E}+02$ & $2.5 \mathrm{E}+02$ & $3.5 \mathrm{E}+01$ & $1.1 \mathrm{E}+03$ & $9.5 \mathrm{E}+04$ & $5.2 \mathrm{E}+02$ & $6.2 \mathrm{E}+01$ & $2.1 \mathrm{E}+01$ & $2.2 \mathrm{E}+02$ & $1.5 \mathrm{E}+02$ & $6.0 \mathrm{E}+04$ \\
\hline C4999-32B & 129.0 & $2.6 \mathrm{E}+01$ & $6.8 \mathrm{E}+01$ & $7.7 \mathrm{E}+01$ & $2.5 \mathrm{E}+01$ & $5.3 \mathrm{E}+00$ & $2.2 \mathrm{E}+02$ & $7.5 \mathrm{E}+03$ & $1.1 \mathrm{E}+02$ & $1.4 \mathrm{E}+01$ & 1.3E-01 & $4.5 \mathrm{E}+01$ & $4.8 \mathrm{E}+01$ & $1.2 \mathrm{E}+04$ \\
\hline \multicolumn{15}{|c|}{$\begin{array}{c}\text { Pore Water After Ultracentrifugation } \\
\end{array}$} \\
\hline C4999-31C & 125.0 & $1.1 \mathrm{E}+02$ & $1.5 \mathrm{E}+02$ & $3.5 \mathrm{E}+02$ & $4.7 \mathrm{E}+01$ & $5.2 \mathrm{E}+00$ & $5.3 \mathrm{E}+01$ & $1.7 \mathrm{E}+04$ & $8.7 \mathrm{E}+00$ & $1.5 \mathrm{E}+01$ & $6.3 \mathrm{E}+01$ & $1.0 \mathrm{E}+02$ & $9.5 \mathrm{E}+01$ & $6.0 \mathrm{E}+03$ \\
\hline
\end{tabular}


Table D.4. (contd)

\begin{tabular}{|c|c|c|c|c|c|c|c|c|c|c|c|c|c|c|}
\hline Sample ID & $\begin{array}{c}\text { Depth } \\
\text { (ft bgs) }\end{array}$ & $\begin{array}{c}\mathrm{Li} \\
(\mu \mathrm{g} / \mathrm{L})\end{array}$ & $\begin{array}{c}\mathrm{Mg} \\
(\mu \mathrm{g} / \mathrm{L})\end{array}$ & $\begin{array}{c}\text { Mn } \\
(\mu \mathrm{g} / \mathrm{L})\end{array}$ & $\begin{array}{c}\text { Mo } \\
(\mu \mathrm{g} / \mathrm{L})\end{array}$ & $\begin{array}{c}\mathrm{Ni} \\
(\mu \mathrm{g} / \mathrm{L})\end{array}$ & $\begin{array}{c}\mathrm{P} \\
(\mu \mathrm{g} / \mathrm{L})\end{array}$ & $\begin{array}{c}\mathrm{Pb} \\
(\mu \mathrm{g} / \mathrm{L})\end{array}$ & $\begin{array}{c}\text { Se } \\
(\mu \mathrm{g} / \mathrm{L})\end{array}$ & $\begin{array}{c}\mathrm{Sr} \\
(\mu \mathrm{g} / \mathrm{L})\end{array}$ & $\begin{array}{c}\mathrm{Ti} \\
(\mu \mathrm{g} / \mathrm{L})\end{array}$ & $\begin{array}{c}\mathrm{V} \\
(\mu \mathrm{g} / \mathrm{L})\end{array}$ & $\mathrm{Zn}(\mu \mathrm{g} / \mathrm{L})$ & $\begin{array}{c}\mathrm{Na} \\
(\mu \mathrm{g} / \mathrm{L})\end{array}$ \\
\hline \multicolumn{15}{|c|}{ Groundwater } \\
\hline B1FR99 & 42.5 & $3.1 \mathrm{E}+01$ & $1.1 \mathrm{E}+04$ & $9.6 \mathrm{E}+01$ & $4.0 \mathrm{E}+00$ & $9.8 \mathrm{E}+00$ & $1.8 \mathrm{E}+02$ & $1.0 \mathrm{E}+02$ & $1.1 \mathrm{E}+02$ & $2.1 \mathrm{E}+02$ & $2.0 \mathrm{E}+02$ & $2.0 \mathrm{E}+02$ & $2.7 \mathrm{E}+01$ & $2.2 \mathrm{E}+04$ \\
\hline B1FR76 & 45.3 & $2.0 \mathrm{E}+02$ & $7.6 \mathrm{E}+03$ & $1.1 \mathrm{E}+01$ & $1.0 \mathrm{E}+01$ & $2.9 \mathrm{E}+00$ & $2.7 \mathrm{E}+02$ & $1.0 \mathrm{E}+02$ & $2.0 \mathrm{E}+02$ & $1.4 \mathrm{E}+02$ & $2.0 \mathrm{E}+02$ & $8.8 \mathrm{E}-01$ & $1.6 \mathrm{E}-01$ & $1.7 \mathrm{E}+04$ \\
\hline B1FR92 & 47.9 & $4.1 \mathrm{E}+01$ & $8.3 \mathrm{E}+03$ & $1.0 \mathrm{E}+02$ & $3.3 \mathrm{E}+01$ & $1.2 \mathrm{E}+01$ & $4.1 \mathrm{E}+01$ & $1.0 \mathrm{E}+02$ & $1.1 \mathrm{E}+02$ & $1.8 \mathrm{E}+02$ & $3.0 \mathrm{E}+00$ & $6.5 \mathrm{E}+00$ & $2.1 \mathrm{E}+01$ & $1.6 \mathrm{E}+04$ \\
\hline B1FRB4 & 52.5 & $3.5 \mathrm{E}+01$ & $5.7 \mathrm{E}+03$ & $1.8 \mathrm{E}+02$ & $1.3 \mathrm{E}+01$ & $9.2 \mathrm{E}+00$ & $4.4 \mathrm{E}+01$ & $1.0 \mathrm{E}+02$ & $1.1 \mathrm{E}+02$ & $1.2 \mathrm{E}+02$ & 7.3E-01 & $1.3 \mathrm{E}+01$ & $2.1 \mathrm{E}+01$ & $5.7 \mathrm{E}+03$ \\
\hline B1FR88 & 68.0 & $4.0 \mathrm{E}+01$ & $4.2 \mathrm{E}+03$ & $2.1 \mathrm{E}+01$ & $4.0 \mathrm{E}+00$ & $9.2 \mathrm{E}+00$ & $2.6 \mathrm{E}+01$ & $1.0 \mathrm{E}+02$ & $3.7 \mathrm{E}+00$ & $8.1 \mathrm{E}+01$ & $3.1 \mathrm{E}+01$ & $2.1 \mathrm{E}+01$ & $2.4 \mathrm{E}+01$ & $6.2 \mathrm{E}+03$ \\
\hline B1FRB8 & 77.0 & $2.8 \mathrm{E}+01$ & $4.6 \mathrm{E}+03$ & $2.0 \mathrm{E}+01$ & $4.0 \mathrm{E}+01$ & $5.4 \mathrm{E}+00$ & $4.5 \mathrm{E}+01$ & $1.0 \mathrm{E}+02$ & $3.0 \mathrm{E}+01$ & $8.4 \mathrm{E}+01$ & $2.2 \mathrm{E}+01$ & $1.4 \mathrm{E}+01$ & $2.1 \mathrm{E}+01$ & $9.7 \mathrm{E}+03$ \\
\hline B1FR84 & 87.5 & $3.6 \mathrm{E}+01$ & $5.8 \mathrm{E}+03$ & $2.7 \mathrm{E}+01$ & $4.0 \mathrm{E}+01$ & $7.6 \mathrm{E}+00$ & $5.0 \mathrm{E}+01$ & $4.2 \mathrm{E}+00$ & $2.9 \mathrm{E}+01$ & $1.1 \mathrm{E}+02$ & $2.0 \mathrm{E}+02$ & $1.4 \mathrm{E}+01$ & $2.2 \mathrm{E}+01$ & $1.6 \mathrm{E}+04$ \\
\hline B1FR96 & 99.5 & $3.3 \mathrm{E}+01$ & $7.3 \mathrm{E}+03$ & $3.5 \mathrm{E}+01$ & $4.0 \mathrm{E}+01$ & $4.3 \mathrm{E}+00$ & $4.6 \mathrm{E}+01$ & $1.0 \mathrm{E}+02$ & $7.5 \mathrm{E}+01$ & $1.3 \mathrm{E}+02$ & $2.0 \mathrm{E}+02$ & $2.8 \mathrm{E}+00$ & $2.1 \mathrm{E}+01$ & $2.0 \mathrm{E}+04$ \\
\hline B1FR80 & 108.0 & $2.0 \mathrm{E}+02$ & $7.5 \mathrm{E}+03$ & $4.9 \mathrm{E}+01$ & $5.7 \mathrm{E}+00$ & $1.4 \mathrm{E}+00$ & $3.1 \mathrm{E}+01$ & $1.0 \mathrm{E}+02$ & $1.7 \mathrm{E}+02$ & $1.4 \mathrm{E}+02$ & $2.3 \mathrm{E}+01$ & $1.0 \mathrm{E}+02$ & $1.0 \mathrm{E}+02$ & $2.2 \mathrm{E}+04$ \\
\hline B1FR32 & 120.80 & $2.0 \mathrm{E}+02$ & $7.2 \mathrm{E}+03$ & $4.6 \mathrm{E}+01$ & $4.1 \mathrm{E}+00$ & $1.0 \mathrm{E}+02$ & $5.7 \mathrm{E}+01$ & $1.0 \mathrm{E}+02$ & $1.2 \mathrm{E}+02$ & $1.1 \mathrm{E}+02$ & $2.0 \mathrm{E}+02$ & $1.0 \mathrm{E}+02$ & $1.0 \mathrm{E}+02$ & $2.2 \mathrm{E}+04$ \\
\hline \multicolumn{15}{|c|}{ Water Extracts (Concentration Values Were Dilution Corrected) } \\
\hline C4999-3B & 9.0 & $1.4 \mathrm{E}+03$ & $7.5 \mathrm{E}+05$ & $6.6 \mathrm{E}+00$ & $1.9 \mathrm{E}+02$ & $4.1 \mathrm{E}+02$ & $1.9 \mathrm{E}+03$ & $3.9 \mathrm{E}+03$ & $6.5 \mathrm{E}+03$ & $7.5 \mathrm{E}+03$ & $3.9 \mathrm{E}+03$ & $9.8 \mathrm{E}+02$ & $9.3 \mathrm{E}+02$ & $3.0 \mathrm{E}+05$ \\
\hline C4999-5D & 18.0 & $1.2 \mathrm{E}+02$ & $3.6 \mathrm{E}+04$ & $7.0 \mathrm{E}+01$ & $4.7 \mathrm{E}+02$ & $1.4 \mathrm{E}+02$ & $2.1 \mathrm{E}+03$ & $4.5 \mathrm{E}+03$ & $1.7 \mathrm{E}+03$ & $8.6 \mathrm{E}+02$ & $2.3 \mathrm{E}+03$ & $4.8 \mathrm{E}+02$ & $9.6 \mathrm{E}+02$ & $7.2 \mathrm{E}+05$ \\
\hline C4999-6A & 20.0 & $1.6 \mathrm{E}+03$ & $5.2 \mathrm{E}+05$ & $1.7 \mathrm{E}+01$ & $4.1 \mathrm{E}+02$ & $5.4 \mathrm{E}+02$ & $2.5 \mathrm{E}+03$ & $6.2 \mathrm{E}+03$ & $5.4 \mathrm{E}+03$ & $6.9 \mathrm{E}+03$ & $3.7 \mathrm{E}+02$ & $1.5 \mathrm{E}+03$ & $1.5 \mathrm{E}+03$ & $4.7 \mathrm{E}+05$ \\
\hline C4999-6D & 23.0 & $8.4 \mathrm{E}+01$ & $2.7 \mathrm{E}+04$ & $5.5 \mathrm{E}+01$ & $4.4 \mathrm{E}+02$ & $6.0 \mathrm{E}+01$ & $9.9 \mathrm{E}+02$ & $1.1 \mathrm{E}+01$ & $1.9 \mathrm{E}+03$ & $6.1 \mathrm{E}+02$ & $1.2 \mathrm{E}+03$ & $1.7 \mathrm{E}+02$ & $6.3 \mathrm{E}+02$ & $3.7 \mathrm{E}+05$ \\
\hline C4999-8E & 28.5 & $1.7 \mathrm{E}+04$ & $1.4 \mathrm{E}+05$ & $8.4 \mathrm{E}+02$ & $1.4 \mathrm{E}+03$ & $4.6 \mathrm{E}+03$ & $6.5 \mathrm{E}+03$ & $3.0 \mathrm{E}+03$ & $1.8 \mathrm{E}+04$ & $2.5 \mathrm{E}+03$ & $5.8 \mathrm{E}+04$ & $1.5 \mathrm{E}+04$ & $2.3 \mathrm{E}+03$ & $9.2 \mathrm{E}+05$ \\
\hline C4999-9B & 30.5 & $4.2 \mathrm{E}+02$ & $4.2 \mathrm{E}+04$ & $2.8 \mathrm{E}+02$ & $7.4 \mathrm{E}+02$ & $1.7 \mathrm{E}+02$ & $1.5 \mathrm{E}+03$ & $4.5 \mathrm{E}+03$ & $3.4 \mathrm{E}+03$ & $8.6 \mathrm{E}+02$ & $2.3 \mathrm{E}+03$ & $2.8 \mathrm{E}+02$ & $9.2 \mathrm{E}+02$ & $2.9 \mathrm{E}+05$ \\
\hline C4999-10C & 35.5 & $1.7 \mathrm{E}+03$ & $3.4 \mathrm{E}+04$ & $1.5 \mathrm{E}+02$ & $5.2 \mathrm{E}+02$ & $4.1 \mathrm{E}+02$ & $3.8 \mathrm{E}+02$ & $9.9 \mathrm{E}+01$ & $3.7 \mathrm{E}+03$ & $6.7 \mathrm{E}+02$ & $2.7 \mathrm{E}+01$ & $1.5 \mathrm{E}+03$ & $1.7 \mathrm{E}+03$ & $2.8 \mathrm{E}+05$ \\
\hline C4999-11B & 39.5 & $2.3 \mathrm{E}+03$ & $5.8 \mathrm{E}+04$ & $4.8 \mathrm{E}+02$ & $1.2 \mathrm{E}+03$ & $4.9 \mathrm{E}+02$ & $2.1 \mathrm{E}+02$ & $1.9 \mathrm{E}+02$ & $4.0 \mathrm{E}+03$ & $1.1 \mathrm{E}+03$ & $9.4 \mathrm{E}+03$ & $2.4 \mathrm{E}+03$ & $2.7 \mathrm{E}+03$ & $4.3 \mathrm{E}+05$ \\
\hline C4999-11D & 41.5 & $6.5 \mathrm{E}+03$ & $9.9 \mathrm{E}+03$ & $4.4 \mathrm{E}+01$ & $1.0 \mathrm{E}+03$ & $1.5 \mathrm{E}+03$ & $3.1 \mathrm{E}+03$ & $2.1 \mathrm{E}+02$ & $7.0 \mathrm{E}+03$ & $2.8 \mathrm{E}+02$ & $2.1 \mathrm{E}+04$ & $5.2 \mathrm{E}+03$ & $1.6 \mathrm{E}+03$ & $7.3 \mathrm{E}+04$ \\
\hline C4999-12C & 46.0 & $9.0 \mathrm{E}+01$ & $2.0 \mathrm{E}+04$ & $9.7 \mathrm{E}+01$ & $1.6 \mathrm{E}+02$ & $1.1 \mathrm{E}+02$ & $2.2 \mathrm{E}+03$ & $1.5 \mathrm{E}+02$ & $2.1 \mathrm{E}+03$ & $3.8 \mathrm{E}+02$ & $1.3 \mathrm{E}+03$ & $3.9 \mathrm{E}+01$ & $5.2 \mathrm{E}+02$ & $7.1 \mathrm{E}+04$ \\
\hline C4999-12D & 47.0 & $3.5 \mathrm{E}+02$ & $4.6 \mathrm{E}+03$ & $2.0 \mathrm{E}+00$ & $6.8 \mathrm{E}+01$ & $8.3 \mathrm{E}+01$ & $2.4 \mathrm{E}+02$ & $4.8 \mathrm{E}+01$ & $8.8 \mathrm{E}+02$ & $9.5 \mathrm{E}+01$ & $1.5 \mathrm{E}+03$ & $3.7 \mathrm{E}+02$ & $5.1 \mathrm{E}+02$ & $2.3 \mathrm{E}+04$ \\
\hline C4999-13E & 53.0 & $1.5 \mathrm{E}+03$ & $5.9 \mathrm{E}+03$ & $2.0 \mathrm{E}+00$ & $3.6 \mathrm{E}+02$ & $3.4 \mathrm{E}+02$ & $1.0 \mathrm{E}+03$ & $8.3 \mathrm{E}+01$ & $2.2 \mathrm{E}+03$ & $1.1 \mathrm{E}+02$ & $5.8 \mathrm{E}+03$ & $6.0 \mathrm{E}+01$ & $2.6 \mathrm{E}+02$ & $7.5 \mathrm{E}+03$ \\
\hline C4999-14D & 56.0 & $1.1 \mathrm{E}+03$ & $1.6 \mathrm{E}+04$ & $9.7 \mathrm{E}+00$ & $3.6 \mathrm{E}+02$ & $2.7 \mathrm{E}+02$ & $2.8 \mathrm{E}+02$ & $3.3 \mathrm{E}+02$ & $1.2 \mathrm{E}+03$ & $5.5 \mathrm{E}+02$ & $5.8 \mathrm{E}+03$ & $1.4 \mathrm{E}+03$ & $5.7 \mathrm{E}+02$ & $1.5 \mathrm{E}+04$ \\
\hline C4999-15B & 59.0 & $1.5 \mathrm{E}+03$ & $1.3 \mathrm{E}+04$ & $8.9 \mathrm{E}+00$ & $7.2 \mathrm{E}+02$ & $2.1 \mathrm{E}+02$ & $7.2 \mathrm{E}+02$ & $1.2 \mathrm{E}+02$ & $4.4 \mathrm{E}+03$ & $4.1 \mathrm{E}+02$ & $5.9 \mathrm{E}+03$ & $1.5 \mathrm{E}+03$ & $3.4 \mathrm{E}+02$ & $1.7 \mathrm{E}+04$ \\
\hline C4999-16A & 62.0 & $2.8 \mathrm{E}+02$ & $8.0 \mathrm{E}+03$ & $3.8 \mathrm{E}+00$ & $2.3 \mathrm{E}+02$ & $2.3 \mathrm{E}+01$ & $2.8 \mathrm{E}+02$ & $4.4 \mathrm{E}+01$ & $6.5 \mathrm{E}+02$ & $2.3 \mathrm{E}+02$ & $1.5 \mathrm{E}+03$ & $9.1 \mathrm{E}+00$ & $2.2 \mathrm{E}+02$ & $1.6 \mathrm{E}+04$ \\
\hline C4999-17A & 66.0 & $3.4 \mathrm{E}+02$ & $5.0 \mathrm{E}+03$ & $1.2 \mathrm{E}+00$ & $1.5 \mathrm{E}+02$ & $4.5 \mathrm{E}+01$ & $1.4 \mathrm{E}+02$ & $1.6 \mathrm{E}+03$ & $1.1 \mathrm{E}+03$ & $1.5 \mathrm{E}+02$ & $1.6 \mathrm{E}+03$ & $4.0 \mathrm{E}+02$ & $3.2 \mathrm{E}+02$ & $1.6 \mathrm{E}+04$ \\
\hline C4999-19B & 76.0 & $4.7 \mathrm{E}+02$ & $3.5 \mathrm{E}+04$ & $5.9 \mathrm{E}+01$ & $7.0 \mathrm{E}+02$ & $4.6 \mathrm{E}+01$ & $2.3 \mathrm{E}+02$ & $7.4 \mathrm{E}+01$ & $9.3 \mathrm{E}+02$ & $8.1 \mathrm{E}+02$ & $1.6 \mathrm{E}+03$ & $9.1 \mathrm{E}+00$ & $3.4 \mathrm{E}+02$ & $4.3 \mathrm{E}+04$ \\
\hline C4999-21C & 86.0 & $5.5 \mathrm{E}+02$ & $3.5 \mathrm{E}+04$ & $1.1 \mathrm{E}+02$ & $4.0 \mathrm{E}+02$ & $9.1 \mathrm{E}+01$ & $8.5 \mathrm{E}+01$ & $3.4 \mathrm{E}+01$ & $1.1 \mathrm{E}+03$ & $6.3 \mathrm{E}+02$ & $2.4 \mathrm{E}+03$ & $6.1 \mathrm{E}+02$ & $5.1 \mathrm{E}+02$ & $1.2 \mathrm{E}+05$ \\
\hline C4999-22E & 90.5 & $8.3 \mathrm{E}+02$ & $4.2 \mathrm{E}+04$ & $9.3 \mathrm{E}+01$ & $7.1 \mathrm{E}+02$ & $1.0 \mathrm{E}+02$ & $4.0 \mathrm{E}+02$ & $8.1 \mathrm{E}+01$ & $1.4 \mathrm{E}+03$ & $7.5 \mathrm{E}+02$ & $3.3 \mathrm{E}+03$ & $8.3 \mathrm{E}+02$ & $5.0 \mathrm{E}+02$ & $1.4 \mathrm{E}+05$ \\
\hline C4999-25A & 98.5 & $1.1 \mathrm{E}+03$ & $3.8 \mathrm{E}+04$ & $7.7 \mathrm{E}+01$ & $3.6 \mathrm{E}+02$ & $6.2 \mathrm{E}+01$ & $8.6 \mathrm{E}+02$ & $3.1 \mathrm{E}+02$ & $1.6 \mathrm{E}+03$ & $6.7 \mathrm{E}+02$ & $4.8 \mathrm{E}+03$ & $1.0 \mathrm{E}+02$ & $8.5 \mathrm{E}+02$ & $1.2 \mathrm{E}+05$ \\
\hline C4999-27B & 108.0 & $1.1 \mathrm{E}+03$ & $4.9 \mathrm{E}+04$ & $3.8 \mathrm{E}+02$ & $2.3 \mathrm{E}+02$ & $2.0 \mathrm{E}+02$ & $7.7 \mathrm{E}+02$ & $1.3 \mathrm{E}+02$ & $2.6 \mathrm{E}+03$ & $7.7 \mathrm{E}+02$ & $5.3 \mathrm{E}+03$ & $1.3 \mathrm{E}+03$ & $9.1 \mathrm{E}+02$ & $1.2 \mathrm{E}+05$ \\
\hline C4999-29D & 118.0 & $1.5 \mathrm{E}+03$ & $3.8 \mathrm{E}+04$ & $2.5 \mathrm{E}+02$ & $7.7 \mathrm{E}+02$ & $4.2 \mathrm{E}+02$ & $8.7 \mathrm{E}+02$ & $7.3 \mathrm{E}+03$ & $1.8 \mathrm{E}+03$ & $6.4 \mathrm{E}+02$ & $7.3 \mathrm{E}+03$ & $1.8 \mathrm{E}+03$ & $1.4 \mathrm{E}+03$ & $1.4 \mathrm{E}+05$ \\
\hline C4999-31C & 125.0 & $1.3 \mathrm{E}+03$ & $3.2 \mathrm{E}+04$ & $1.2 \mathrm{E}+02$ & $3.8 \mathrm{E}+02$ & $1.9 \mathrm{E}+02$ & $3.8 \mathrm{E}+02$ & $7.3 \mathrm{E}+01$ & $5.2 \mathrm{E}+03$ & $5.5 \mathrm{E}+02$ & $5.2 \mathrm{E}+03$ & $1.3 \mathrm{E}+01$ & $5.5 \mathrm{E}+02$ & $1.3 \mathrm{E}+05$ \\
\hline C4999-32B & 129.0 & $2.5 \mathrm{E}+02$ & $2.0 \mathrm{E}+03$ & $1.4 \mathrm{E}+00$ & $1.1 \mathrm{E}+02$ & $2.3 \mathrm{E}+01$ & $6.3 \mathrm{E}+01$ & $7.2 \mathrm{E}+01$ & $3.0 \mathrm{E}+02$ & $4.8 \mathrm{E}+01$ & $1.1 \mathrm{E}+03$ & $1.7 \mathrm{E}+01$ & $2.1 \mathrm{E}+02$ & $3.9 \mathrm{E}+04$ \\
\hline \multicolumn{15}{|c|}{$\begin{array}{l}\text { Pore Water After Ultracentrifugation } \\
\end{array}$} \\
\hline C4999-31C & 125.0 & $1.3 \mathrm{E}+03$ & $5.8 \mathrm{E}+03$ & $1.2 \mathrm{E}+01$ & $7.8 \mathrm{E}+01$ & $1.7 \mathrm{E}+01$ & $2.9 \mathrm{E}+01$ & $2.7 \mathrm{E}+01$ & $2.4 \mathrm{E}+02$ & $1.1 \mathrm{E}+02$ & $1.3 \mathrm{E}+03$ & $1.4 \mathrm{E}+02$ & $6.6 \mathrm{E}+01$ & $2.6 \mathrm{E}+04$ \\
\hline
\end{tabular}


Table D.4. (contd)

\begin{tabular}{|c|c|c|c|c|c|c|c|c|}
\hline Sample ID & $\begin{array}{c}\text { Depth } \\
\text { (ft bgs) }\end{array}$ & $\begin{array}{c}\mathrm{Si} \\
(\mu \mathrm{g} / \mathrm{L})\end{array}$ & $\begin{array}{c}\mathrm{S} \\
(\mu \mathrm{g} / \mathrm{L})\end{array}$ & $\begin{array}{c}\mathrm{Ti} \\
(\mu \mathrm{g} / \mathrm{L})\end{array}$ & $\begin{array}{c}\mathrm{Zr} \\
(\mu \mathrm{g} / \mathrm{L})\end{array}$ & $\begin{array}{c}\mathrm{Ag} \\
(\mu \mathrm{g} / \mathrm{L})\end{array}$ & $\begin{array}{c}\mathrm{Re} \\
(\mu \mathrm{g} / \mathrm{L})\end{array}$ & $\begin{array}{c}\mathrm{Sb} \\
(\mu \mathrm{g} / \mathrm{L})\end{array}$ \\
\hline \multicolumn{9}{|c|}{$\begin{array}{ll}\text { Groundwater }\end{array}$} \\
\hline B1FR99 & 42.5 & $9.9 \mathrm{E}+03$ & $1.8 \mathrm{E}+04$ & $1.0 \mathrm{E}+01$ & $1.0 \mathrm{E}+02$ & $4.0 \mathrm{E}+02$ & $2.1 \mathrm{E}+00$ & $5.0 \mathrm{E}+03$ \\
\hline B1FR76 & 45.3 & $9.3 \mathrm{E}+03$ & $1.2 \mathrm{E}+04$ & $3.4 \mathrm{E}-01$ & $1.4 \mathrm{E}+00$ & $1.0 \mathrm{E}+02$ & $2.3 \mathrm{E}+01$ & $2.2 \mathrm{E}+01$ \\
\hline B1FR92 & 47.9 & $7.1 \mathrm{E}+03$ & $1.1 \mathrm{E}+04$ & $1.0 \mathrm{E}+01$ & $2.0 \mathrm{E}-01$ & $4.0 \mathrm{E}+02$ & $4.0 \mathrm{E}+01$ & $5.0 \mathrm{E}+03$ \\
\hline B1FRB4 & 52.5 & $8.8 \mathrm{E}+03$ & $7.8 \mathrm{E}+03$ & $3.7 \mathrm{E}-01$ & $1.0 \mathrm{E}+02$ & $4.0 \mathrm{E}+02$ & $1.7 \mathrm{E}+00$ & $5.0 \mathrm{E}+03$ \\
\hline B1FR88 & 68.0 & $1.4 \mathrm{E}+04$ & $4.0 \mathrm{E}+03$ & $6.5 \mathrm{E}+00$ & $4.3 \mathrm{E}-01$ & $4.0 \mathrm{E}+02$ & $3.9 \mathrm{E}+00$ & $5.0 \mathrm{E}+03$ \\
\hline B1FRB8 & 77.0 & $1.5 \mathrm{E}+04$ & $2.9 \mathrm{E}+03$ & $4.5 \mathrm{E}+00$ & $8.1 \mathrm{E}-02$ & $4.0 \mathrm{E}+02$ & $4.0 \mathrm{E}+01$ & $5.0 \mathrm{E}+03$ \\
\hline B1FR84 & 87.5 & $1.8 \mathrm{E}+04$ & $6.9 \mathrm{E}+01$ & $2.6 \mathrm{E}+00$ & $1.1 \mathrm{E}-01$ & $4.0 \mathrm{E}+02$ & 3.9E-01 & $5.0 \mathrm{E}+03$ \\
\hline B1FR96 & 99.5 & $1.8 \mathrm{E}+04$ & $8.0 \mathrm{E}+02$ & $2.9 \mathrm{E}+00$ & $4.6 \mathrm{E}-01$ & $4.0 \mathrm{E}+02$ & $3.1 \mathrm{E}+00$ & $5.0 \mathrm{E}+03$ \\
\hline B1FR80 & 108.0 & $1.9 \mathrm{E}+04$ & $1.1 \mathrm{E}+02$ & $1.4 \mathrm{E}+00$ & 3.9E-01 & $1.0 \mathrm{E}+02$ & $2.3 \mathrm{E}+01$ & $3.8 \mathrm{E}+01$ \\
\hline B1FR32 & 120.80 & $1.8 \mathrm{E}+04$ & $8.0 \mathrm{E}+02$ & $8.6 \mathrm{E}-01$ & 4.3E-01 & $1.0 \mathrm{E}+02$ & $2.8 \mathrm{E}+01$ & $4.4 \mathrm{E}+01$ \\
\hline \multicolumn{9}{|c|}{ Water Extracts (Concentration Values Were Dilution Corrected) } \\
\hline C4999-3B & 9.0 & $4.6 \mathrm{E}+04$ & $1.0 \mathrm{E}+06$ & $2.0 \mathrm{E}+02$ & $1.8 \mathrm{E}+01$ & $6.0 \mathrm{E}+01$ & $4.7 \mathrm{E}+02$ & $7.9 \mathrm{E}+02$ \\
\hline C4999-5D & 18.0 & $2.1 \mathrm{E}+05$ & $2.1 \mathrm{E}+05$ & $8.8 \mathrm{E}+00$ & $2.0 \mathrm{E}+01$ & $1.1 \mathrm{E}+01$ & $2.4 \mathrm{E}+02$ & $3.0 \mathrm{E}+02$ \\
\hline C4999-6A & 20.0 & $7.2 \mathrm{E}+04$ & $8.7 \mathrm{E}+05$ & $3.1 \mathrm{E}+02$ & $6.2 \mathrm{E}+02$ & $1.1 \mathrm{E}+02$ & $6.7 \mathrm{E}+02$ & $8.0 \mathrm{E}+02$ \\
\hline C4999-6D & 23.0 & $9.1 \mathrm{E}+04$ & $1.4 \mathrm{E}+05$ & $1.2 \mathrm{E}+02$ & $3.4 \mathrm{E}+00$ & $4.9 \mathrm{E}+02$ & $1.5 \mathrm{E}+02$ & $2.7 \mathrm{E}+02$ \\
\hline C4999-8E & 28.5 & $1.3 \mathrm{E}+05$ & $5.1 \mathrm{E}+05$ & $6.7 \mathrm{E}+01$ & $9.7 \mathrm{E}+00$ & $1.2 \mathrm{E}+03$ & $6.4 \mathrm{E}+03$ & $1.3 \mathrm{E}+04$ \\
\hline C4999-9B & 30.5 & $1.5 \mathrm{E}+05$ & $1.3 \mathrm{E}+05$ & $2.9 \mathrm{E}+01$ & $3.7 \mathrm{E}+01$ & $9.1 \mathrm{E}+02$ & $3.4 \mathrm{E}+02$ & $4.5 \mathrm{E}+03$ \\
\hline C4999-10C & 35.5 & $6.7 \mathrm{E}+04$ & $1.3 \mathrm{E}+05$ & $3.2 \mathrm{E}+00$ & $6.1 \mathrm{E}+02$ & $1.3 \mathrm{E}+02$ & $6.1 \mathrm{E}+02$ & $1.7 \mathrm{E}+03$ \\
\hline C4999-11B & 39.5 & $8.0 \mathrm{E}+04$ & $1.5 \mathrm{E}+05$ & $4.7 \mathrm{E}+02$ & $5.7 \mathrm{E}+00$ & $1.9 \mathrm{E}+02$ & $1.2 \mathrm{E}+03$ & $2.1 \mathrm{E}+03$ \\
\hline C4999-11D & 41.5 & $3.1 \mathrm{E}+04$ & $1.1 \mathrm{E}+04$ & $2.8 \mathrm{E}+01$ & $2.1 \mathrm{E}+03$ & $2.9 \mathrm{E}+02$ & $1.8 \mathrm{E}+03$ & $5.3 \mathrm{E}+03$ \\
\hline C4999-12C & 46.0 & $4.8 \mathrm{E}+04$ & $3.6 \mathrm{E}+04$ & $6.8 \mathrm{E}+00$ & $3.6 \mathrm{E}+00$ & $5.0 \mathrm{E}+02$ & $2.8 \mathrm{E}+02$ & $2.3 \mathrm{E}+02$ \\
\hline C4999-12D & 47.0 & $1.8 \mathrm{E}+04$ & $1.3 \mathrm{E}+04$ & $4.5 \mathrm{E}+01$ & $1.5 \mathrm{E}+02$ & $2.6 \mathrm{E}+01$ & $1.6 \mathrm{E}+02$ & $3.2 \mathrm{E}+02$ \\
\hline C4999-13E & 53.0 & $2.3 \mathrm{E}+04$ & $9.7 \mathrm{E}+03$ & $2.9 \mathrm{E}+02$ & $5.8 \mathrm{E}+02$ & $1.1 \mathrm{E}+02$ & $6.9 \mathrm{E}+02$ & $2.0 \mathrm{E}+03$ \\
\hline C4999-14D & 56.0 & $6.7 \mathrm{E}+03$ & $1.7 \mathrm{E}+05$ & $6.5 \mathrm{E}+00$ & $9.9 \mathrm{E}+00$ & $1.1 \mathrm{E}+02$ & $4.6 \mathrm{E}+02$ & $2.2 \mathrm{E}+03$ \\
\hline C4999-15B & 59.0 & $7.7 \mathrm{E}+03$ & $1.4 \mathrm{E}+05$ & $9.0 \mathrm{E}+00$ & $1.2 \mathrm{E}+01$ & $9.6 \mathrm{E}+01$ & $5.7 \mathrm{E}+02$ & $1.8 \mathrm{E}+03$ \\
\hline C4999-16A & 62.0 & $1.3 \mathrm{E}+04$ & $6.0 \mathrm{E}+04$ & $6.8 \mathrm{E}-01$ & $3.8 \mathrm{E}+00$ & $3.3 \mathrm{E}+01$ & $1.4 \mathrm{E}+02$ & $4.6 \mathrm{E}+02$ \\
\hline C4999-17A & 66.0 & $1.2 \mathrm{E}+04$ & $4.1 \mathrm{E}+04$ & $2.9 \mathrm{E}+00$ & $2.4 \mathrm{E}+00$ & $2.8 \mathrm{E}+01$ & $1.8 \mathrm{E}+02$ & $5.4 \mathrm{E}+02$ \\
\hline C4999-19B & 76.0 & $1.6 \mathrm{E}+04$ & $2.0 \mathrm{E}+05$ & $8.0 \mathrm{E}+01$ & $6.2 \mathrm{E}+00$ & $2.8 \mathrm{E}+01$ & $2.1 \mathrm{E}+02$ & $2.9 \mathrm{E}+02$ \\
\hline C4999-21C & 86.0 & $3.3 \mathrm{E}+04$ & $2.6 \mathrm{E}+05$ & $3.5 \mathrm{E}-01$ & $3.5 \mathrm{E}+00$ & $3.5 \mathrm{E}+01$ & $2.9 \mathrm{E}+02$ & $4.0 \mathrm{E}+02$ \\
\hline C4999-22E & 90.5 & $4.6 \mathrm{E}+04$ & $3.2 \mathrm{E}+05$ & $1.7 \mathrm{E}+02$ & $4.2 \mathrm{E}+00$ & $6.9 \mathrm{E}+01$ & $3.8 \mathrm{E}+02$ & $5.9 \mathrm{E}+02$ \\
\hline C4999-25A & 98.5 & $6.5 \mathrm{E}+04$ & $2.6 \mathrm{E}+05$ & $2.4 \mathrm{E}+02$ & $4.8 \mathrm{E}+02$ & $7.1 \mathrm{E}+01$ & $4.6 \mathrm{E}+02$ & $1.2 \mathrm{E}+03$ \\
\hline $\begin{array}{l}\text { C4999-27B } \\
\end{array}$ & 108.0 & $5.2 \mathrm{E}+04$ & $2.3 \mathrm{E}+05$ & $2.6 \mathrm{E}+02$ & $5.3 \mathrm{E}+02$ & $1.2 \mathrm{E}+02$ & $4.2 \mathrm{E}+02$ & $8.8 \mathrm{E}+02$ \\
\hline C4999-29D & 118.0 & $4.7 \mathrm{E}+04$ & $2.9 \mathrm{E}+05$ & $2.6 \mathrm{E}+01$ & $1.7 \mathrm{E}+01$ & $1.7 \mathrm{E}+02$ & $1.1 \mathrm{E}+03$ & $3.0 \mathrm{E}+03$ \\
\hline C4999-31C & 125.0 & $5.1 \mathrm{E}+04$ & $2.3 \mathrm{E}+05$ & $9.2 \mathrm{E}+00$ & $1.5 \mathrm{E}+01$ & $9.4 \mathrm{E}+01$ & $5.5 \mathrm{E}+02$ & $1.8 \mathrm{E}+03$ \\
\hline C4999-32B & 129.0 & $1.2 \mathrm{E}+04$ & $1.9 \mathrm{E}+04$ & $5.0 \mathrm{E}+00$ & $3.5 \mathrm{E}+00$ & $2.2 \mathrm{E}+01$ & $1.4 \mathrm{E}+02$ & $3.1 \mathrm{E}+02$ \\
\hline \multicolumn{9}{|c|}{$\begin{array}{l}\text { Pore Water After Ultracentrifugation } \\
\end{array}$} \\
\hline C4999-31C & 125.0 & $7.3 \mathrm{E}+03$ & $1.6 \mathrm{E}+04$ & $3.6 \mathrm{E}+00$ & $4.0 \mathrm{E}+00$ & $3.7 \mathrm{E}+01$ & $2.7 \mathrm{E}+02$ & $6.5 \mathrm{E}+02$ \\
\hline
\end{tabular}


Table D.5. ICP-OEP for Cations Analysis of C5000 Samples

\begin{tabular}{|c|c|c|c|c|c|c|c|c|c|c|c|c|c|c|}
\hline Sample ID & $\begin{array}{c}\text { Depth } \\
\text { (ft bgs) }\end{array}$ & $\begin{array}{c}\mathrm{Al} \\
(\mu \mathrm{g} / \mathrm{L})\end{array}$ & $\begin{array}{c}\text { As } \\
(\mu \mathrm{g} / \mathrm{L})\end{array}$ & $\begin{array}{c}\text { B } \\
(\mu \mathrm{g} / \mathrm{L})\end{array}$ & $\begin{array}{c}\mathrm{Ba} \\
(\mu \mathrm{g} / \mathrm{L})\end{array}$ & $\begin{array}{c}\mathrm{Be} \\
(\mu \mathrm{g} / \mathrm{L})\end{array}$ & $\begin{array}{c}\mathrm{Bi} \\
(\mu \mathrm{g} / \mathrm{L}) \\
\end{array}$ & $\begin{array}{c}\mathrm{Ca} \\
(\mu \mathrm{g} / \mathrm{L})\end{array}$ & $\begin{array}{c}\text { Cd } \\
(\mu \mathrm{g} / \mathrm{L})\end{array}$ & $\begin{array}{c}\text { Co } \\
(\mu \mathrm{g} / \mathrm{L}) \\
\end{array}$ & $\begin{array}{c}\mathrm{Cr} \\
(\mu \mathrm{g} / \mathrm{L})\end{array}$ & $\begin{array}{c}\mathrm{Cu} \\
(\mu \mathrm{g} / \mathrm{L})\end{array}$ & $\mathrm{Fe}(\mu \mathrm{g} / \mathrm{L})$ & $\begin{array}{c}\mathrm{K} \\
(\mu \mathrm{g} / \mathrm{L}) \\
\end{array}$ \\
\hline \multicolumn{15}{|c|}{ Groundwater } \\
\hline B1FR36 & 33.8 & $1.8 \mathrm{E}+01$ & $2.1 \mathrm{E}+01$ & $8.2 \mathrm{E}+01$ & $6.1 \mathrm{E}+01$ & $1.1 \mathrm{E}+00$ & $2.6 \mathrm{E}+01$ & $5.2 \mathrm{E}+04$ & $1.0 \mathrm{E}+01$ & $6.3 \mathrm{E}+00$ & $1.0 \mathrm{E}+01$ & $1.8 \mathrm{E}+01$ & $6.4 \mathrm{E}+01$ & $4.4 \mathrm{E}+03$ \\
\hline B1FR40 & 38.5 & $4.0 \mathrm{E}+02$ & $3.9 \mathrm{E}+01$ & $6.0 \mathrm{E}+01$ & $5.3 \mathrm{E}+01$ & 5.3E-01 & $4.0 \mathrm{E}+03$ & $4.7 \mathrm{E}+04$ & $1.0 \mathrm{E}+01$ & $1.7 \mathrm{E}+00$ & $3.3 \mathrm{E}+00$ & $1.6 \mathrm{E}+01$ & $6.6 \mathrm{E}+01$ & $4.1 \mathrm{E}+03$ \\
\hline B1FR44 & 43.3 & $4.0 \mathrm{E}+02$ & $2.2 \mathrm{E}+01$ & $5.1 \mathrm{E}+01$ & $5.4 \mathrm{E}+01$ & $4.7 \mathrm{E}-01$ & $4.0 \mathrm{E}+03$ & $5.1 \mathrm{E}+04$ & $1.0 \mathrm{E}+01$ & $1.0 \mathrm{E}+02$ & $2.1 \mathrm{E}+00$ & $1.5 \mathrm{E}+01$ & $9.1 \mathrm{E}+01$ & $4.7 \mathrm{E}+03$ \\
\hline B1FR48 & 47.3 & $4.0 \mathrm{E}+02$ & $3.3 \mathrm{E}+01$ & $4.7 \mathrm{E}+01$ & $4.7 \mathrm{E}+01$ & $2.4 \mathrm{E}-01$ & $3.1 \mathrm{E}+01$ & $4.7 \mathrm{E}+04$ & $1.0 \mathrm{E}+01$ & $1.7 \mathrm{E}+00$ & $1.0 \mathrm{E}+01$ & $1.5 \mathrm{E}+01$ & $1.1 \mathrm{E}+01$ & $3.9 \mathrm{E}+03$ \\
\hline B1FR52 & 54.3 & $1.1 \mathrm{E}+00$ & $7.2 \mathrm{E}+00$ & $4.2 \mathrm{E}+01$ & $2.8 \mathrm{E}+01$ & $8.4 \mathrm{E}-02$ & $5.1 \mathrm{E}+01$ & $3.0 \mathrm{E}+04$ & $1.0 \mathrm{E}+01$ & $2.4 \mathrm{E}+00$ & $1.0 \mathrm{E}+01$ & $1.5 \mathrm{E}+01$ & $5.0 \mathrm{E}+01$ & $7.1 \mathrm{E}+03$ \\
\hline B1FR56 & 59.3 & $5.1 \mathrm{E}+01$ & $1.0 \mathrm{E}+02$ & $5.1 \mathrm{E}+01$ & $3.4 \mathrm{E}+01$ & $1.1 \mathrm{E}-01$ & $5.2 \mathrm{E}+01$ & $1.9 \mathrm{E}+04$ & $8.2 \mathrm{E}-02$ & $1.0 \mathrm{E}+02$ & $1.0 \mathrm{E}+01$ & $1.7 \mathrm{E}+01$ & $2.4 \mathrm{E}+02$ & $5.7 \mathrm{E}+03$ \\
\hline B1FR60 & 68.5 & $6.8 \mathrm{E}+01$ & $1.0 \mathrm{E}+02$ & $4.8 \mathrm{E}+01$ & $2.0 \mathrm{E}+01$ & $4.8 \mathrm{E}-02$ & $4.1 \mathrm{E}+01$ & $1.2 \mathrm{E}+04$ & $1.0 \mathrm{E}+01$ & $2.6 \mathrm{E}+00$ & $1.0 \mathrm{E}+01$ & $1.7 \mathrm{E}+01$ & $1.7 \mathrm{E}+02$ & $4.7 \mathrm{E}+03$ \\
\hline B1FR64 & 79.5 & $4.6 \mathrm{E}+01$ & $1.0 \mathrm{E}+02$ & $5.0 \mathrm{E}+01$ & $2.5 \mathrm{E}+01$ & 2.3E-01 & $3.6 \mathrm{E}+01$ & $1.6 \mathrm{E}+04$ & $1.0 \mathrm{E}+01$ & $8.0 \mathrm{E}-01$ & 8.3E-01 & $1.5 \mathrm{E}+01$ & $2.1 \mathrm{E}+02$ & $5.8 \mathrm{E}+03$ \\
\hline B1FR68 & 90.3 & $1.0 \mathrm{E}+01$ & $1.0 \mathrm{E}+02$ & $4.2 \mathrm{E}+01$ & $4.0 \mathrm{E}+01$ & $3.6 \mathrm{E}-02$ & $3.7 \mathrm{E}+01$ & $1.4 \mathrm{E}+04$ & $1.0 \mathrm{E}+01$ & $1.5 \mathrm{E}+00$ & $1.0 \mathrm{E}+01$ & $1.6 \mathrm{E}+01$ & $1.6 \mathrm{E}+02$ & $5.1 \mathrm{E}+03$ \\
\hline B1FR72 & 107.8 & $1.8 \mathrm{E}+02$ & $1.0 \mathrm{E}+02$ & $4.6 \mathrm{E}+01$ & $3.6 \mathrm{E}+01$ & $2.7 \mathrm{E}-01$ & $3.7 \mathrm{E}+00$ & $1.1 \mathrm{E}+04$ & 6.8E-01 & $1.0 \mathrm{E}+02$ & $2.7 \mathrm{E}-02$ & $1.6 \mathrm{E}+01$ & $3.1 \mathrm{E}+02$ & $4.8 \mathrm{E}+03$ \\
\hline \multicolumn{15}{|c|}{ Water Extracts (Concentration Values Were Dilution Corrected) } \\
\hline C5000-36A & 11.0 & $1.8 \mathrm{E}+03$ & $5.6 \mathrm{E}+02$ & $6.7 \mathrm{E}+02$ & $1.5 \mathrm{E}+02$ & $1.6 \mathrm{E}+01$ & $5.1 \mathrm{E}+03$ & $6.8 \mathrm{E}+04$ & $1.3 \mathrm{E}+02$ & $9.0 \mathrm{E}+01$ & $3.4 \mathrm{E}+01$ & $2.5 \mathrm{E}+02$ & $1.9 \mathrm{E}+03$ & $6.9 \mathrm{E}+04$ \\
\hline C5000-36E & 12.0 & $2.8 \mathrm{E}+03$ & $4.2 \mathrm{E}+02$ & $8.6 \mathrm{E}+02$ & $5.2 \mathrm{E}+02$ & $2.3 \mathrm{E}+01$ & $7.7 \mathrm{E}+03$ & $2.3 \mathrm{E}+05$ & $7.6 \mathrm{E}+00$ & $1.3 \mathrm{E}+02$ & $2.3 \mathrm{E}+01$ & $3.0 \mathrm{E}+02$ & $3.9 \mathrm{E}+03$ & $1.3 \mathrm{E}+05$ \\
\hline C5000-37A & 13.0 & $1.9 \mathrm{E}+03$ & $6.1 \mathrm{E}+02$ & $7.7 \mathrm{E}+02$ & $6.8 \mathrm{E}+02$ & $2.3 \mathrm{E}+01$ & $8.2 \mathrm{E}+03$ & $1.7 \mathrm{E}+05$ & $7.9 \mathrm{E}+00$ & $1.1 \mathrm{E}+02$ & $2.4 \mathrm{E}+01$ & $3.5 \mathrm{E}+02$ & $1.8 \mathrm{E}+03$ & $9.8 \mathrm{E}+04$ \\
\hline C5000-38B & 20.0 & $1.2 \mathrm{E}+03$ & $3.5 \mathrm{E}+02$ & $5.6 \mathrm{E}+02$ & $3.9 \mathrm{E}+02$ & $1.6 \mathrm{E}+01$ & $6.6 \mathrm{E}+03$ & $1.6 \mathrm{E}+05$ & $1.7 \mathrm{E}+02$ & $4.9 \mathrm{E}+01$ & $1.2 \mathrm{E}+01$ & $2.4 \mathrm{E}+02$ & $7.3 \mathrm{E}+02$ & $1.1 \mathrm{E}+05$ \\
\hline C5000-40A & 30.0 & $7.4 \mathrm{E}+01$ & $9.8 \mathrm{E}+01$ & $1.8 \mathrm{E}+02$ & $1.2 \mathrm{E}+02$ & $1.2 \mathrm{E}+01$ & $1.7 \mathrm{E}+03$ & $8.2 \mathrm{E}+04$ & $1.5 \mathrm{E}+00$ & $1.7 \mathrm{E}+02$ & $1.2 \mathrm{E}+00$ & $1.2 \mathrm{E}+02$ & $5.0 \mathrm{E}+01$ & $2.1 \mathrm{E}+04$ \\
\hline C5000-40B & 31.0 & $5.7 \mathrm{E}+02$ & $8.0 \mathrm{E}+02$ & $1.1 \mathrm{E}+03$ & $3.7 \mathrm{E}+02$ & $8.0 \mathrm{E}+01$ & $1.9 \mathrm{E}+02$ & $2.0 \mathrm{E}+05$ & $9.1 \mathrm{E}+00$ & $7.0 \mathrm{E}+02$ & $8.8 \mathrm{E}+02$ & $2.5 \mathrm{E}+02$ & $2.8 \mathrm{E}+02$ & $9.6 \mathrm{E}+04$ \\
\hline C5000-41C & 36.0 & $3.7 \mathrm{E}+02$ & $1.2 \mathrm{E}+02$ & $1.2 \mathrm{E}+03$ & $1.7 \mathrm{E}+02$ & $9.3 \mathrm{E}+01$ & $2.2 \mathrm{E}+02$ & $5.6 \mathrm{E}+04$ & $2.9 \mathrm{E}+01$ & $2.7 \mathrm{E}+01$ & $4.0 \mathrm{E}+02$ & $3.4 \mathrm{E}+02$ & $2.3 \mathrm{E}+02$ & $2.1 \mathrm{E}+04$ \\
\hline C5000-48D & 65.0 & $8.4 \mathrm{E}+01$ & $3.5 \mathrm{E}+01$ & $1.0 \mathrm{E}+02$ & $5.5 \mathrm{E}+01$ & $2.9 \mathrm{E}+00$ & $1.5 \mathrm{E}+03$ & $2.7 \mathrm{E}+04$ & $3.8 \mathrm{E}+01$ & $1.7 \mathrm{E}+01$ & $2.5 \mathrm{E}+00$ & $6.2 \mathrm{E}+01$ & $7.6 \mathrm{E}+01$ & $2.3 \mathrm{E}+04$ \\
\hline C5000-48E & 66.0 & $1.1 \mathrm{E}+02$ & $1.6 \mathrm{E}+02$ & $8.4 \mathrm{E}+01$ & $3.5 \mathrm{E}+01$ & $2.3 \mathrm{E}+00$ & $1.2 \mathrm{E}+03$ & $1.2 \mathrm{E}+04$ & $2.3 \mathrm{E}+00$ & $6.6 \mathrm{E}+00$ & $3.0 \mathrm{E}+01$ & $3.9 \mathrm{E}+01$ & $1.9 \mathrm{E}+02$ & $1.9 \mathrm{E}+04$ \\
\hline C5000-49D & 68.0 & $2.8 \mathrm{E}+02$ & $2.1 \mathrm{E}+02$ & $1.4 \mathrm{E}+02$ & $1.5 \mathrm{E}+02$ & $7.2 \mathrm{E}+00$ & $3.7 \mathrm{E}+03$ & $7.2 \mathrm{E}+04$ & $2.7 \mathrm{E}-01$ & $5.3 \mathrm{E}+01$ & $4.3 \mathrm{E}+00$ & $8.0 \mathrm{E}+01$ & $1.2 \mathrm{E}+02$ & $6.1 \mathrm{E}+04$ \\
\hline C5000-50B & 71.0 & $6.0 \mathrm{E}+02$ & $2.4 \mathrm{E}+02$ & $3.3 \mathrm{E}+02$ & $1.2 \mathrm{E}+02$ & $5.6 \mathrm{E}+00$ & $3.1 \mathrm{E}+03$ & $4.0 \mathrm{E}+04$ & $7.8 \mathrm{E}+01$ & $2.5 \mathrm{E}+01$ & $1.4 \mathrm{E}+01$ & $9.9 \mathrm{E}+01$ & $6.8 \mathrm{E}+02$ & $7.8 \mathrm{E}+04$ \\
\hline C5000-51E & 77.0 & $2.1 \mathrm{E}+02$ & $3.0 \mathrm{E}+02$ & $2.0 \mathrm{E}+02$ & $1.3 \mathrm{E}+02$ & $1.4 \mathrm{E}+01$ & $5.5 \mathrm{E}+01$ & $2.8 \mathrm{E}+04$ & $1.4 \mathrm{E}+00$ & $2.2 \mathrm{E}+01$ & $1.0 \mathrm{E}+01$ & $3.3 \mathrm{E}+01$ & $1.8 \mathrm{E}+02$ & $3.4 \mathrm{E}+04$ \\
\hline C5000-52B & 79.0 & $4.6 \mathrm{E}+02$ & $1.0 \mathrm{E}+02$ & $1.3 \mathrm{E}+02$ & $5.4 \mathrm{E}+01$ & $9.2 \mathrm{E}+00$ & $1.9 \mathrm{E}+03$ & $2.0 \mathrm{E}+04$ & $4.8 \mathrm{E}+01$ & $1.5 \mathrm{E}+01$ & $2.2 \mathrm{E}+00$ & $4.0 \mathrm{E}+01$ & $7.0 \mathrm{E}+02$ & $3.4 \mathrm{E}+04$ \\
\hline C5000-53E & 85.0 & $8.8 \mathrm{E}+01$ & $1.5 \mathrm{E}+02$ & $7.8 \mathrm{E}+01$ & $1.1 \mathrm{E}+02$ & $5.9 \mathrm{E}+00$ & $1.6 \mathrm{E}+03$ & $3.0 \mathrm{E}+04$ & $7.4 \mathrm{E}-01$ & $1.2 \mathrm{E}+01$ & $6.1 \mathrm{E}+00$ & $2.9 \mathrm{E}+01$ & $5.5 \mathrm{E}+01$ & $3.1 \mathrm{E}+04$ \\
\hline C5000-54E & 89.5 & $3.0 \mathrm{E}+02$ & $1.5 \mathrm{E}+03$ & $1.7 \mathrm{E}+02$ & $1.1 \mathrm{E}+02$ & $9.5 \mathrm{E}+00$ & $3.0 \mathrm{E}+03$ & $4.0 \mathrm{E}+04$ & $7.4 \mathrm{E}+01$ & $2.0 \mathrm{E}+01$ & $4.0 \mathrm{E}+00$ & $2.3 \mathrm{E}+01$ & $1.8 \mathrm{E}+02$ & $3.9 \mathrm{E}+04$ \\
\hline C5000-57D & 100.0 & $3.2 \mathrm{E}+02$ & $2.7 \mathrm{E}+02$ & $9.0 \mathrm{E}+01$ & $6.4 \mathrm{E}+01$ & $6.9 \mathrm{E}+00$ & $2.3 \mathrm{E}+03$ & $2.1 \mathrm{E}+04$ & $5.6 \mathrm{E}+00$ & $1.0 \mathrm{E}+01$ & $6.5 \mathrm{E}+00$ & $2.4 \mathrm{E}+01$ & $3.0 \mathrm{E}+02$ & $3.6 \mathrm{E}+04$ \\
\hline C5000-60E & 109.5 & $2.1 \mathrm{E}+02$ & $2.1 \mathrm{E}+02$ & $5.2 \mathrm{E}+01$ & $1.3 \mathrm{E}+02$ & $4.4 \mathrm{E}+00$ & $1.6 \mathrm{E}+03$ & $2.2 \mathrm{E}+04$ & $3.9 \mathrm{E}+01$ & $5.7 \mathrm{E}+00$ & $2.7 \mathrm{E}+00$ & $5.7 \mathrm{E}+00$ & $2.1 \mathrm{E}+02$ & $2.9 \mathrm{E}+04$ \\
\hline \multicolumn{15}{|c|}{ Pore Water After Ultracentrifugation } \\
\hline C5000-43B & 45.0 & $1.0 \mathrm{E}+02$ & $5.9 \mathrm{E}+01$ & $2.0 \mathrm{E}+01$ & $5.2 \mathrm{E}+01$ & $1.3 \mathrm{E}+00$ & $5.7 \mathrm{E}+01$ & $4.9 \mathrm{E}+04$ & $5.0 \mathrm{E}+01$ & $9.5 \mathrm{E}+00$ & $2.8 \mathrm{E}+00$ & $1.8 \mathrm{E}+01$ & $1.1 \mathrm{E}+01$ & $4.3 \mathrm{E}+03$ \\
\hline C5000-44C & 49.0 & $2.9 \mathrm{E}+02$ & $5.0 \mathrm{E}+02$ & $6.9 \mathrm{E}+00$ & $4.5 \mathrm{E}+01$ & $1.1 \mathrm{E}+00$ & $7.4 \mathrm{E}+01$ & $5.1 \mathrm{E}+04$ & 8.5E-02 & $9.2 \mathrm{E}+00$ & $3.9 \mathrm{E}+00$ & $1.9 \mathrm{E}+01$ & $9.6 \mathrm{E}+00$ & $4.5 \mathrm{E}+03$ \\
\hline $\mathrm{C} 5000-44 \mathrm{E}$ & 51.0 & $9.6 \mathrm{E}+01$ & $4.0 \mathrm{E}+03$ & $7.7 \mathrm{E}+01$ & $2.5 \mathrm{E}+01$ & $8.0 \mathrm{E}+00$ & $6.6 \mathrm{E}+02$ & $2.6 \mathrm{E}+04$ & $4.0 \mathrm{E}+02$ & $4.9 \mathrm{E}+01$ & $1.9 \mathrm{E}+00$ & $1.5 \mathrm{E}+02$ & $4.6 \mathrm{E}+01$ & $1.5 \mathrm{E}+04$ \\
\hline C5000-45C & 54.0 & $1.0 \mathrm{E}+02$ & $4.0 \mathrm{E}+03$ & $2.3 \mathrm{E}+00$ & $2.9 \mathrm{E}+01$ & $8.1 \mathrm{E}+00$ & $7.3 \mathrm{E}+02$ & $2.8 \mathrm{E}+04$ & $4.0 \mathrm{E}+02$ & $6.1 \mathrm{E}+01$ & $2.5 \mathrm{E}+01$ & $1.5 \mathrm{E}+02$ & $6.5 \mathrm{E}+01$ & $2.4 \mathrm{E}+04$ \\
\hline C5000-48B & 62.5 & $4.5 \mathrm{E}+02$ & $1.5 \mathrm{E}+02$ & $1.1 \mathrm{E}+01$ & $1.0 \mathrm{E}+02$ & $8.1 \mathrm{E}+00$ & $6.1 \mathrm{E}+02$ & $1.4 \mathrm{E}+04$ & $4.0 \mathrm{E}+02$ & $4.2 \mathrm{E}+01$ & $4.4 \mathrm{E}+00$ & $1.5 \mathrm{E}+02$ & $6.7 \mathrm{E}+01$ & $1.3 \mathrm{E}+04$ \\
\hline C5000-49A & 67.0 & $2.1 \mathrm{E}+02$ & $2.6 \mathrm{E}+02$ & $2.0 \mathrm{E}+03$ & $2.8 \mathrm{E}+01$ & $4.1 \mathrm{E}+00$ & $4.9 \mathrm{E}+02$ & $1.1 \mathrm{E}+04$ & $6.2 \mathrm{E}-01$ & $2.0 \mathrm{E}+01$ & $7.3 \mathrm{E}+00$ & $6.6 \mathrm{E}+01$ & $1.8 \mathrm{E}+02$ & $1.0 \mathrm{E}+04$ \\
\hline C5000-49D & 68.0 & $8.5 \mathrm{E}+01$ & $5.1 \mathrm{E}+00$ & $2.9 \mathrm{E}+02$ & $3.4 \mathrm{E}+01$ & $1.9 \mathrm{E}+01$ & $2.4 \mathrm{E}+02$ & $1.2 \mathrm{E}+04$ & $4.6 \mathrm{E}+00$ & $3.2 \mathrm{E}+01$ & $1.0 \mathrm{E}+02$ & $7.5 \mathrm{E}+01$ & $6.3 \mathrm{E}+01$ & $1.0 \mathrm{E}+04$ \\
\hline C5000-52B & 79.0 & $4.7 \mathrm{E}+02$ & $2.0 \mathrm{E}+04$ & $2.0 \mathrm{E}+03$ & $7.3 \mathrm{E}+01$ & $1.1 \mathrm{E}+02$ & $2.9 \mathrm{E}+03$ & $5.4 \mathrm{E}+03$ & $2.0 \mathrm{E}+03$ & $4.1 \mathrm{E}+02$ & $9.6 \mathrm{E}+01$ & $7.5 \mathrm{E}+02$ & $3.5 \mathrm{E}+02$ & $1.9 \mathrm{E}+04$ \\
\hline C5000-53E & 86.0 & $3.0 \mathrm{E}+01$ & $6.3 \mathrm{E}+01$ & $8.5 \mathrm{E}+01$ & $6.1 \mathrm{E}+01$ & $4.2 \mathrm{E}+00$ & $1.7 \mathrm{E}+02$ & $1.2 \mathrm{E}+04$ & $1.0 \mathrm{E}+02$ & $1.9 \mathrm{E}+01$ & $4.3 \mathrm{E}+00$ & $3.7 \mathrm{E}+01$ & $1.8 \mathrm{E}+01$ & $9.9 \mathrm{E}+03$ \\
\hline C5000-54A & 85.0 & $2.1 \mathrm{E}+03$ & $7.1 \mathrm{E}+03$ & $5.2 \mathrm{E}+03$ & $4.4 \mathrm{E}+02$ & $3.4 \mathrm{E}+02$ & $2.0 \mathrm{E}+04$ & $1.6 \mathrm{E}+04$ & $1.0 \mathrm{E}+04$ & $8.3 \mathrm{E}+02$ & $8.3 \mathrm{E}+02$ & $3.5 E+03$ & $2.4 \mathrm{E}+03$ & $1.3 \mathrm{E}+05$ \\
\hline C5000-55D & 90.5 & $1.4 \mathrm{E}+02$ & $2.0 \mathrm{E}+03$ & $9.0 \mathrm{E}+01$ & $4.0 \mathrm{E}+01$ & $6.3 \mathrm{E}+00$ & $2.7 \mathrm{E}+02$ & $1.2 \mathrm{E}+04$ & $2.0 \mathrm{E}+02$ & $2.8 \mathrm{E}+01$ & $1.5 \mathrm{E}+01$ & $6.5 \mathrm{E}+01$ & $7.2 \mathrm{E}+01$ & $1.0 \mathrm{E}+04$ \\
\hline $\begin{array}{l}\mathrm{C} 5000-58 \mathrm{C} \\
\end{array}$ & 103.0 & $3.6 \mathrm{E}+02$ & $4.0 \mathrm{E}+03$ & $1.1 \mathrm{E}+02$ & $4.4 \mathrm{E}+01$ & $1.0 \mathrm{E}+01$ & $6.1 \mathrm{E}+02$ & $1.1 \mathrm{E}+04$ & $2.5 \mathrm{E}+00$ & $1.8 \mathrm{E}+01$ & $2.2 \mathrm{E}+01$ & $1.5 \mathrm{E}+02$ & $5.7 \mathrm{E}+01$ & $2.3 \mathrm{E}+04$ \\
\hline C5000-60C & 107.5 & $7.6 \mathrm{E}+01$ & $1.7 \mathrm{E}+02$ & $5.2 \mathrm{E}+01$ & $4.1 \mathrm{E}+01$ & $4.4 \mathrm{E}+00$ & $3.4 \mathrm{E}+02$ & $1.1 \mathrm{E}+04$ & $2.0 \mathrm{E}+02$ & $3.1 \mathrm{E}+01$ & $1.9 \mathrm{E}+01$ & $6.8 \mathrm{E}+01$ & $3.3 \mathrm{E}+01$ & $9.5 \mathrm{E}+03$ \\
\hline
\end{tabular}


Table D.5. (contd)

\begin{tabular}{|c|c|c|c|c|c|c|c|c|c|c|c|c|c|c|}
\hline Sample ID & $\begin{array}{c}\text { Depth } \\
\text { (ft bgs) }\end{array}$ & $\begin{array}{c}\mathrm{Li} \\
(\mu \mathrm{g} / \mathrm{L})\end{array}$ & $\begin{array}{c}\mathrm{Mg} \\
(\mu \mathrm{g} / \mathrm{L})\end{array}$ & $\begin{array}{c}\mathrm{Mn} \\
(\mu \mathrm{g} / \mathrm{L})\end{array}$ & $\begin{array}{c}\text { Mo } \\
(\mu \mathrm{g} / \mathrm{L})\end{array}$ & $\begin{array}{c}\mathrm{Ni} \\
(\mu \mathrm{g} / \mathrm{L})\end{array}$ & $\begin{array}{c}\mathrm{P} \\
(\mu \mathrm{g} / \mathrm{L}) \\
\end{array}$ & $\begin{array}{c}\mathrm{Pb} \\
(\mu \mathrm{g} / \mathrm{L})\end{array}$ & $\begin{array}{c}\text { Se } \\
(\mu \mathrm{g} / \mathrm{L})\end{array}$ & $\begin{array}{c}\mathrm{Sr} \\
(\mu \mathrm{g} / \mathrm{L})\end{array}$ & $\begin{array}{c}\mathrm{Ti} \\
(\mu \mathrm{g} / \mathrm{L})\end{array}$ & $\begin{array}{c}\mathrm{V} \\
(\mu \mathrm{g} / \mathrm{L})\end{array}$ & $\mathrm{Zn}(\mu \mathrm{g} / \mathrm{L})$ & $\begin{array}{c}\mathrm{Na} \\
(\mu \mathrm{g} / \mathrm{L})\end{array}$ \\
\hline \multicolumn{15}{|c|}{ Groundwater } \\
\hline B1FR36 & 33.8 & $4.2 \mathrm{E}+00$ & $1.3 \mathrm{E}+04$ & $4.2 \mathrm{E}+01$ & $2.7 \mathrm{E}+01$ & $4.8 \mathrm{E}+00$ & $7.6 \mathrm{E}+01$ & $1.0 \mathrm{E}+02$ & $2.3 \mathrm{E}+02$ & $2.4 \mathrm{E}+02$ & $2.0 \mathrm{E}+02$ & $1.2 \mathrm{E}+01$ & $1.0 \mathrm{E}+02$ & $2.7 \mathrm{E}+04$ \\
\hline B1FR40 & 38.5 & $3.1 \mathrm{E}+00$ & $1.2 \mathrm{E}+04$ & $8.0 \mathrm{E}+00$ & $1.0 \mathrm{E}+02$ & $3.6 \mathrm{E}-01$ & $1.3 \mathrm{E}+02$ & $1.0 \mathrm{E}+02$ & $1.2 \mathrm{E}+02$ & $2.2 \mathrm{E}+02$ & $6.1 \mathrm{E}+00$ & $1.2 \mathrm{E}+01$ & $5.1 \mathrm{E}+00$ & $2.1 \mathrm{E}+04$ \\
\hline B1FR44 & 43.3 & 8.7E-01 & $1.2 \mathrm{E}+04$ & $1.5 \mathrm{E}+01$ & $1.0 \mathrm{E}+02$ & $2.8 \mathrm{E}+00$ & $1.3 \mathrm{E}+02$ & $1.0 \mathrm{E}+02$ & $2.6 \mathrm{E}+02$ & $2.4 \mathrm{E}+02$ & $2.0 \mathrm{E}+02$ & $1.4 \mathrm{E}+01$ & $1.0 \mathrm{E}+02$ & $2.4 \mathrm{E}+04$ \\
\hline B1FR48 & 47.3 & $2.8 \mathrm{E}+00$ & $1.1 \mathrm{E}+04$ & $1.5 \mathrm{E}+02$ & $2.5 \mathrm{E}+01$ & $2.0 \mathrm{E}+00$ & $6.2 \mathrm{E}+01$ & $1.0 \mathrm{E}+02$ & $2.2 \mathrm{E}+02$ & $2.2 \mathrm{E}+02$ & $2.0 \mathrm{E}+02$ & $4.8 \mathrm{E}+00$ & 3.3E-01 & $2.2 \mathrm{E}+04$ \\
\hline B1FR52 & 54.3 & $1.1 \mathrm{E}+01$ & $8.5 \mathrm{E}+03$ & $4.1 \mathrm{E}+01$ & $8.4 \mathrm{E}+00$ & $3.3 \mathrm{E}+00$ & $2.8 \mathrm{E}+01$ & $1.0 \mathrm{E}+02$ & $1.7 \mathrm{E}+02$ & $1.5 \mathrm{E}+02$ & $6.0 \mathrm{E}-01$ & $1.0 \mathrm{E}+01$ & $1.0 \mathrm{E}+02$ & $2.5 \mathrm{E}+04$ \\
\hline B1FR56 & 59.3 & $1.0 \mathrm{E}+01$ & $6.2 \mathrm{E}+03$ & $4.1 \mathrm{E}+01$ & $3.5 \mathrm{E}+00$ & $3.7 \mathrm{E}+00$ & $2.5 \mathrm{E}+01$ & $1.0 \mathrm{E}+02$ & $9.6 \mathrm{E}+01$ & $1.0 \mathrm{E}+02$ & $2.1 \mathrm{E}+00$ & $1.2 \mathrm{E}+01$ & $1.0 \mathrm{E}+02$ & $4.2 \mathrm{E}+04$ \\
\hline B1FR60 & 68.5 & $8.1 \mathrm{E}+00$ & $3.9 \mathrm{E}+03$ & $2.9 \mathrm{E}+01$ & $7.0 \mathrm{E}+00$ & $4.0 \mathrm{E}+01$ & $9.4 \mathrm{E}+00$ & $1.0 \mathrm{E}+02$ & $1.2 \mathrm{E}+02$ & $6.1 \mathrm{E}+01$ & $2.2 \mathrm{E}+00$ & $9.2 \mathrm{E}+00$ & $1.0 \mathrm{E}+02$ & $3.7 \mathrm{E}+04$ \\
\hline B1FR64 & 79.5 & $3.5 \mathrm{E}+00$ & $5.2 \mathrm{E}+03$ & $3.0 \mathrm{E}+01$ & $1.0 \mathrm{E}+02$ & $4.0 \mathrm{E}+01$ & $2.1 \mathrm{E}+01$ & $2.0 \mathrm{E}+00$ & $1.1 \mathrm{E}+02$ & $8.5 \mathrm{E}+01$ & $2.0 \mathrm{E}+02$ & $2.0 \mathrm{E}+02$ & $1.0 \mathrm{E}+02$ & $4.3 \mathrm{E}+04$ \\
\hline B1FR68 & 90.3 & $9.1 \mathrm{E}+00$ & $5.8 \mathrm{E}+03$ & $4.4 \mathrm{E}+01$ & $4.9 \mathrm{E}+00$ & $4.0 \mathrm{E}+01$ & $1.8 \mathrm{E}+01$ & $1.0 \mathrm{E}+02$ & $1.1 \mathrm{E}+02$ & $8.5 \mathrm{E}+01$ & $2.0 \mathrm{E}+02$ & $8.4 \mathrm{E}+00$ & $1.0 \mathrm{E}+02$ & $3.6 \mathrm{E}+04$ \\
\hline B1FR72 & 107.8 & $1.1 \mathrm{E}+01$ & $4.8 \mathrm{E}+03$ & $4.3 \mathrm{E}+01$ & $8.5 \mathrm{E}+00$ & $4.0 \mathrm{E}+01$ & $5.0 \mathrm{E}+01$ & $1.0 \mathrm{E}+02$ & $7.6 \mathrm{E}+01$ & $7.6 \mathrm{E}+01$ & $3.3 \mathrm{E}+01$ & $8.8 \mathrm{E}+00$ & $1.0 \mathrm{E}+02$ & $5.2 \mathrm{E}+04$ \\
\hline \multicolumn{15}{|c|}{ Water Extracts (Concentration Values Were Dilution Corrected) } \\
\hline C5000-36A & 11.0 & $3.2 \mathrm{E}+01$ & $1.7 \mathrm{E}+04$ & $6.3 \mathrm{E}+01$ & $2.7 \mathrm{E}+02$ & $3.2 \mathrm{E}+02$ & $1.9 \mathrm{E}+03$ & $2.6 \mathrm{E}+03$ & $2.0 \mathrm{E}+03$ & $2.8 \mathrm{E}+02$ & $1.5 \mathrm{E}+02$ & $2.7 \mathrm{E}+02$ & $1.4 \mathrm{E}+03$ & $3.9 \mathrm{E}+05$ \\
\hline C5000-36E & 12.0 & $1.6 \mathrm{E}+02$ & $7.2 \mathrm{E}+04$ & $3.6 \mathrm{E}+02$ & $5.0 \mathrm{E}+02$ & $3.6 \mathrm{E}+02$ & $1.8 \mathrm{E}+03$ & $3.8 \mathrm{E}+03$ & $5.5 \mathrm{E}+03$ & $1.2 \mathrm{E}+03$ & $6.1 \mathrm{E}+01$ & $9.6 \mathrm{E}+02$ & $3.2 \mathrm{E}+03$ & $5.9 \mathrm{E}+05$ \\
\hline C5000-37A & 13.0 & $4.6 \mathrm{E}+01$ & $3.5 \mathrm{E}+04$ & $1.0 \mathrm{E}+02$ & $3.8 \mathrm{E}+02$ & $3.7 \mathrm{E}+02$ & $2.2 \mathrm{E}+03$ & $4.1 \mathrm{E}+03$ & $5.3 \mathrm{E}+03$ & $1.1 \mathrm{E}+03$ & $4.1 \mathrm{E}+03$ & $1.6 \mathrm{E}+02$ & $4.9 \mathrm{E}+03$ & $4.9 \mathrm{E}+05$ \\
\hline C5000-38B & 20.0 & $9.7 \mathrm{E}+01$ & $4.1 \mathrm{E}+04$ & $3.0 \mathrm{E}+02$ & $6.7 \mathrm{E}+02$ & $2.0 \mathrm{E}+02$ & $8.2 \mathrm{E}+02$ & $3.3 \mathrm{E}+03$ & $3.9 \mathrm{E}+03$ & $8.3 \mathrm{E}+02$ & $2.5 \mathrm{E}+02$ & $8.3 \mathrm{E}+02$ & $3.2 \mathrm{E}+03$ & $5.5 \mathrm{E}+05$ \\
\hline C5000-40A & 30.0 & $6.3 \mathrm{E}+01$ & $1.8 \mathrm{E}+04$ & $1.6 \mathrm{E}+02$ & $2.8 \mathrm{E}+02$ & $4.6 \mathrm{E}+01$ & $3.0 \mathrm{E}+02$ & $1.7 \mathrm{E}+03$ & $1.1 \mathrm{E}+03$ & $3.7 \mathrm{E}+02$ & $8.6 \mathrm{E}+02$ & $1.7 \mathrm{E}+03$ & $4.1 \mathrm{E}+02$ & $1.6 \mathrm{E}+05$ \\
\hline C5000-40B & 31.0 & $3.3 \mathrm{E}+02$ & $4.6 \mathrm{E}+04$ & $3.3 \mathrm{E}+02$ & $9.2 \mathrm{E}+02$ & $2.3 \mathrm{E}+02$ & $1.1 \mathrm{E}+03$ & $1.8 \mathrm{E}+02$ & $1.4 \mathrm{E}+03$ & $9.5 \mathrm{E}+02$ & $2.3 \mathrm{E}+02$ & $3.7 \mathrm{E}+02$ & $1.3 \mathrm{E}+03$ & $4.3 \mathrm{E}+05$ \\
\hline C5000-41C & 36.0 & $3.2 \mathrm{E}+02$ & $1.3 \mathrm{E}+04$ & $1.6 \mathrm{E}+02$ & $3.9 \mathrm{E}+02$ & $1.5 \mathrm{E}+02$ & $1.5 \mathrm{E}+03$ & $3.2 \mathrm{E}+03$ & $1.1 \mathrm{E}+03$ & $3.5 \mathrm{E}+02$ & $5.7 \mathrm{E}+01$ & $2.7 \mathrm{E}+02$ & $7.0 \mathrm{E}+02$ & $7.8 \mathrm{E}+04$ \\
\hline C5000-48D & 65.0 & $1.8 \mathrm{E}+01$ & $8.6 \mathrm{E}+03$ & $2.7 \mathrm{E}+01$ & $2.1 \mathrm{E}+02$ & $5.4 \mathrm{E}+01$ & $1.6 \mathrm{E}+02$ & $7.6 \mathrm{E}+02$ & $4.9 \mathrm{E}+02$ & $1.4 \mathrm{E}+02$ & $7.6 \mathrm{E}+02$ & $3.0 \mathrm{E}+02$ & $8.5 \mathrm{E}+02$ & $7.9 \mathrm{E}+04$ \\
\hline C5000-48E & 66.0 & $2.5 \mathrm{E}+01$ & $3.4 \mathrm{E}+03$ & $1.4 \mathrm{E}+00$ & $1.7 \mathrm{E}+02$ & $4.3 \mathrm{E}+01$ & $8.0 \mathrm{E}+01$ & $5.9 \mathrm{E}+02$ & $5.6 \mathrm{E}+02$ & $6.9 \mathrm{E}+01$ & $5.9 \mathrm{E}+02$ & $1.5 \mathrm{E}+02$ & $3.6 \mathrm{E}+02$ & $5.7 \mathrm{E}+04$ \\
\hline C5000-49D & 68.0 & $9.5 \mathrm{E}+01$ & $2.1 \mathrm{E}+04$ & $9.1 \mathrm{E}+01$ & $2.4 \mathrm{E}+02$ & $8.2 \mathrm{E}+01$ & $3.8 \mathrm{E}+02$ & $1.8 \mathrm{E}+03$ & $1.7 \mathrm{E}+03$ & $3.5 \mathrm{E}+02$ & $1.8 \mathrm{E}+03$ & $4.6 \mathrm{E}+02$ & $1.2 \mathrm{E}+03$ & $1.6 \mathrm{E}+05$ \\
\hline C5000-50B & 71.0 & $1.3 \mathrm{E}+02$ & $1.2 \mathrm{E}+04$ & $3.7 \mathrm{E}+01$ & $3.6 \mathrm{E}+03$ & $1.1 \mathrm{E}+02$ & $4.6 \mathrm{E}+02$ & $1.6 \mathrm{E}+03$ & $1.9 \mathrm{E}+03$ & $1.9 \mathrm{E}+02$ & $7.6 \mathrm{E}+01$ & $6.5 \mathrm{E}+01$ & $1.7 \mathrm{E}+03$ & $2.7 \mathrm{E}+05$ \\
\hline C5000-51E & 77.0 & $1.1 \mathrm{E}+01$ & $8.0 \mathrm{E}+03$ & $1.6 \mathrm{E}+01$ & $1.1 \mathrm{E}+02$ & $7.8 \mathrm{E}+01$ & $4.2 \mathrm{E}+02$ & $1.1 \mathrm{E}+03$ & $1.3 \mathrm{E}+03$ & $1.5 \mathrm{E}+02$ & $1.1 \mathrm{E}+03$ & $1.6 \mathrm{E}+01$ & $8.3 \mathrm{E}+02$ & $1.1 \mathrm{E}+05$ \\
\hline C5000-52B & 79.0 & $2.6 \mathrm{E}+01$ & $5.4 \mathrm{E}+03$ & $8.3 \mathrm{E}+00$ & $3.2 \mathrm{E}+02$ & $5.1 \mathrm{E}+01$ & $4.0 \mathrm{E}+02$ & $9.6 \mathrm{E}+02$ & $1.0 \mathrm{E}+03$ & $1.0 \mathrm{E}+02$ & $5.1 \mathrm{E}+00$ & $8.7 \mathrm{E}+01$ & $7.4 \mathrm{E}+02$ & $1.2 \mathrm{E}+05$ \\
\hline C5000-53E & 85.0 & $4.0 \mathrm{E}+01$ & $9.7 \mathrm{E}+03$ & $8.9 \mathrm{E}+00$ & $2.2 \mathrm{E}+02$ & $5.4 \mathrm{E}+01$ & $8.8 \mathrm{E}+01$ & $8.0 \mathrm{E}+02$ & $1.3 \mathrm{E}+03$ & $1.9 \mathrm{E}+02$ & $5.7 \mathrm{E}+01$ & $3.1 \mathrm{E}+02$ & $4.4 \mathrm{E}+02$ & $9.0 \mathrm{E}+04$ \\
\hline C5000-54E & 89.5 & $6.1 \mathrm{E}+01$ & $1.4 \mathrm{E}+04$ & $7.1 \mathrm{E}+01$ & $2.3 \mathrm{E}+02$ & $7.6 \mathrm{E}+01$ & $1.7 \mathrm{E}+02$ & $1.5 \mathrm{E}+03$ & $1.8 \mathrm{E}+03$ & $2.3 \mathrm{E}+02$ & $3.1 \mathrm{E}+01$ & $3.7 \mathrm{E}+02$ & $1.2 \mathrm{E}+03$ & $1.2 \mathrm{E}+05$ \\
\hline C5000-57D & 100.0 & $2.0 \mathrm{E}+01$ & $7.1 \mathrm{E}+03$ & $2.0 \mathrm{E}+01$ & $4.6 \mathrm{E}+02$ & $5.5 \mathrm{E}+01$ & $4.6 \mathrm{E}+02$ & $1.1 \mathrm{E}+03$ & $8.1 \mathrm{E}+02$ & $1.2 \mathrm{E}+02$ & $1.6 \mathrm{E}+01$ & $1.5 \mathrm{E}+02$ & $8.3 \mathrm{E}+02$ & $1.3 \mathrm{E}+05$ \\
\hline C5000-60E & 109.5 & $3.1 \mathrm{E}+01$ & $7.9 \mathrm{E}+03$ & $2.2 \mathrm{E}+01$ & $1.7 \mathrm{E}+02$ & $4.0 \mathrm{E}+01$ & $2.8 \mathrm{E}+02$ & $7.9 \mathrm{E}+02$ & $1.1 \mathrm{E}+03$ & $1.3 \mathrm{E}+02$ & $1.7 \mathrm{E}+01$ & $1.1 \mathrm{E}+02$ & $5.6 \mathrm{E}+02$ & $1.0 \mathrm{E}+05$ \\
\hline \multicolumn{15}{|c|}{ Pore Water After Ultracentrifugation } \\
\hline C5000-43B & 45.0 & $1.0 \mathrm{E}+02$ & $1.1 \mathrm{E}+04$ & $6.1 \mathrm{E}+01$ & $6.0 \mathrm{E}+01$ & $1.3 \mathrm{E}+01$ & $8.5 \mathrm{E}+01$ & $1.1 \mathrm{E}+01$ & $3.1 \mathrm{E}+02$ & $2.1 \mathrm{E}+02$ & $5.0 \mathrm{E}+02$ & $1.3 \mathrm{E}+02$ & $1.1 \mathrm{E}+02$ & $2.3 \mathrm{E}+04$ \\
\hline C5000-44C & 49.0 & $1.3 \mathrm{E}+02$ & $1.1 \mathrm{E}+04$ & $2.5 \mathrm{E}+01$ & $7.9 \mathrm{E}+01$ & $1.3 \mathrm{E}+01$ & $5.0 \mathrm{E}+01$ & $4.6 \mathrm{E}+00$ & $3.1 \mathrm{E}+02$ & $2.3 \mathrm{E}+02$ & $5.0 \mathrm{E}+02$ & $1.3 \mathrm{E}+02$ & $2.1 \mathrm{E}+02$ & $2.7 \mathrm{E}+04$ \\
\hline $\mathrm{C} 5000-44 \mathrm{E}$ & 51.0 & $8.3 \mathrm{E}+02$ & $6.4 \mathrm{E}+03$ & $9.2 \mathrm{E}+00$ & $2.5 \mathrm{E}+02$ & $5.4 \mathrm{E}+01$ & $8.2 \mathrm{E}+01$ & $1.2 \mathrm{E}+02$ & $9.5 \mathrm{E}+02$ & $1.2 \mathrm{E}+02$ & $4.0 \mathrm{E}+03$ & $5.1 \mathrm{E}+01$ & $3.9 \mathrm{E}+02$ & $3.3 \mathrm{E}+04$ \\
\hline C5000-45C & 54.0 & $7.1 \mathrm{E}+02$ & $7.2 \mathrm{E}+03$ & $4.0 \mathrm{E}+02$ & $2.3 \mathrm{E}+02$ & $2.6 \mathrm{E}+01$ & $1.3 \mathrm{E}+02$ & $1.3 \mathrm{E}+02$ & $1.6 \mathrm{E}+03$ & $1.3 \mathrm{E}+02$ & $4.0 \mathrm{E}+03$ & $1.4 \mathrm{E}+01$ & $4.4 \mathrm{E}+02$ & $3.6 \mathrm{E}+04$ \\
\hline C5000-48B & 62.5 & $1.0 \mathrm{E}+03$ & $4.1 \mathrm{E}+03$ & $8.1 \mathrm{E}+00$ & $3.8 \mathrm{E}+02$ & $9.8 \mathrm{E}+01$ & $5.0 \mathrm{E}+03$ & $1.1 \mathrm{E}+02$ & $2.3 \mathrm{E}+03$ & $7.3 \mathrm{E}+01$ & $4.0 \mathrm{E}+03$ & $1.0 \mathrm{E}+03$ & $9.3 \mathrm{E}+02$ & $4.7 \mathrm{E}+04$ \\
\hline C5000-49A & 67.0 & $3.0 \mathrm{E}+02$ & $3.5 \mathrm{E}+03$ & $4.0 \mathrm{E}+00$ & $1.8 \mathrm{E}+02$ & $4.1 \mathrm{E}+01$ & $9.9 \mathrm{E}+01$ & $7.3 \mathrm{E}+01$ & $1.8 \mathrm{E}+03$ & $5.3 \mathrm{E}+01$ & $1.2 \mathrm{E}+02$ & $1.8 \mathrm{E}+01$ & $1.4 \mathrm{E}+02$ & $3.7 \mathrm{E}+04$ \\
\hline C5000-49D & 68.0 & $4.7 \mathrm{E}+02$ & $3.9 \mathrm{E}+03$ & $1.6 \mathrm{E}+01$ & $2.5 \mathrm{E}+02$ & $7.3 \mathrm{E}+01$ & $7.6 \mathrm{E}+01$ & $5.8 \mathrm{E}+00$ & $7.7 \mathrm{E}+02$ & $6.7 \mathrm{E}+01$ & $2.0 \mathrm{E}+03$ & $5.0 \mathrm{E}+02$ & $2.0 \mathrm{E}+02$ & $4.5 \mathrm{E}+04$ \\
\hline C5000-52B & 79.0 & $4.8 \mathrm{E}+03$ & $4.1 \mathrm{E}+03$ & $6.1 \mathrm{E}+00$ & $1.1 \mathrm{E}+03$ & $6.7 \mathrm{E}+02$ & $2.5 \mathrm{E}+04$ & $2.9 \mathrm{E}+02$ & $1.2 \mathrm{E}+04$ & $1.7 \mathrm{E}+02$ & $2.0 \mathrm{E}+04$ & $1.4 \mathrm{E}+02$ & $8.4 \mathrm{E}+02$ & $4.6 \mathrm{E}+04$ \\
\hline C5000-53E & 86.0 & $2.3 \mathrm{E}+02$ & $3.7 \mathrm{E}+03$ & $5.5 \mathrm{E}+00$ & $6.0 \mathrm{E}+01$ & $1.7 \mathrm{E}+01$ & $1.9 \mathrm{E}+01$ & $1.0 \mathrm{E}+03$ & $3.4 \mathrm{E}+02$ & $5.9 \mathrm{E}+01$ & $1.0 \mathrm{E}+03$ & $1.4 \mathrm{E}+01$ & $4.2 \mathrm{E}+02$ & $3.8 \mathrm{E}+04$ \\
\hline C5000-54A & 85.0 & $2.3 \mathrm{E}+04$ & $7.0 \mathrm{E}+03$ & $4.0 \mathrm{E}+03$ & $3.3 \mathrm{E}+03$ & $1.5 \mathrm{E}+03$ & $1.3 \mathrm{E}+05$ & $2.0 \mathrm{E}+03$ & $7.1 \mathrm{E}+04$ & $3.4 \mathrm{E}+02$ & $1.0 \mathrm{E}+05$ & $3.3 \mathrm{E}+02$ & $4.1 \mathrm{E}+03$ & $5.5 \mathrm{E}+04$ \\
\hline C5000-55D & 90.5 & $4.5 \mathrm{E}+02$ & $4.8 \mathrm{E}+03$ & $1.4 \mathrm{E}+01$ & $1.9 \mathrm{E}+02$ & $2.1 \mathrm{E}+01$ & $2.5 \mathrm{E}+03$ & $1.0 \mathrm{E}+02$ & $7.4 \mathrm{E}+02$ & $6.9 \mathrm{E}+01$ & $2.0 \mathrm{E}+03$ & $5.0 \mathrm{E}+02$ & $1.6 \mathrm{E}+02$ & $4.5 \mathrm{E}+04$ \\
\hline C5000-58C & 103.0 & $8.1 \mathrm{E}+02$ & $4.3 \mathrm{E}+03$ & $6.6 \mathrm{E}+00$ & $3.4 \mathrm{E}+02$ & $3.2 \mathrm{E}+01$ & $3.6 \mathrm{E}+02$ & $8.8 \mathrm{E}+01$ & $2.7 \mathrm{E}+03$ & $7.9 \mathrm{E}+01$ & $4.0 \mathrm{E}+03$ & $1.0 \mathrm{E}+03$ & $7.5 \mathrm{E}+02$ & $4.9 \mathrm{E}+04$ \\
\hline C5000-60C & 107.5 & $3.9 \mathrm{E}+02$ & $4.4 \mathrm{E}+03$ & $6.4 \mathrm{E}+00$ & $1.4 \mathrm{E}+02$ & $4.9 \mathrm{E}+01$ & $2.4 \mathrm{E}+02$ & $3.9 \mathrm{E}+01$ & $1.7 \mathrm{E}+03$ & $6.1 \mathrm{E}+01$ & $2.0 \mathrm{E}+03$ & $1.4 \mathrm{E}+01$ & $1.1 \mathrm{E}+02$ & $4.8 \mathrm{E}+04$ \\
\hline
\end{tabular}


Table D.5. (contd)

\begin{tabular}{|c|c|c|c|c|c|c|c|c|}
\hline Sample ID & $\begin{array}{c}\text { Depth } \\
\text { (ft bgs) }\end{array}$ & $\begin{array}{c}\mathrm{Si} \\
(\mu \mathrm{g} / \mathrm{L})\end{array}$ & $\begin{array}{c}\mathrm{S} \\
(\mu \mathrm{g} / \mathrm{L})\end{array}$ & $\begin{array}{c}\mathrm{Ti} \\
(\mu \mathrm{g} / \mathrm{L})\end{array}$ & $\begin{array}{c}\mathrm{Zr} \\
(\mu \mathrm{g} / \mathrm{L})\end{array}$ & $\begin{array}{c}\mathrm{Ag} \\
(\mu \mathrm{g} / \mathrm{L})\end{array}$ & $\begin{array}{c}\mathrm{Re} \\
(\mu \mathrm{g} / \mathrm{L})\end{array}$ & $\begin{array}{c}\mathrm{Sb} \\
(\mu \mathrm{g} / \mathrm{L})\end{array}$ \\
\hline \multicolumn{9}{|l|}{ Groundwater } \\
\hline B1FR36 & 33.8 & $1.2 \mathrm{E}+04$ & $2.0 \mathrm{E}+04$ & $2.2 \mathrm{E}+00$ & $1.0 \mathrm{E}+00$ & $1.0 \mathrm{E}+02$ & $2.9 \mathrm{E}+01$ & $5.1 \mathrm{E}+01$ \\
\hline B1FR40 & 38.5 & $1.4 \mathrm{E}+04$ & $1.8 \mathrm{E}+04$ & $1.0 \mathrm{E}+01$ & $6.0 \mathrm{E}-01$ & $1.0 \mathrm{E}+02$ & $3.0 \mathrm{E}+01$ & $6.4 \mathrm{E}+01$ \\
\hline B1FR44 & 43.3 & $1.4 \mathrm{E}+04$ & $1.9 \mathrm{E}+04$ & $1.0 \mathrm{E}+01$ & $1.4 \mathrm{E}-01$ & $1.0 \mathrm{E}+02$ & $2.0 \mathrm{E}+01$ & $2.0 \mathrm{E}+01$ \\
\hline B1FR48 & 47.3 & $1.0 \mathrm{E}+04$ & $1.9 \mathrm{E}+04$ & $1.0 \mathrm{E}+01$ & $1.0 \mathrm{E}+00$ & $1.0 \mathrm{E}+02$ & $2.0 \mathrm{E}+01$ & $1.5 \mathrm{E}+01$ \\
\hline B1FR52 & 54.3 & $1.2 \mathrm{E}+04$ & $2.0 \mathrm{E}+04$ & $1.9 \mathrm{E}+00$ & 6.3E-02 & $1.0 \mathrm{E}+02$ & $2.7 \mathrm{E}+01$ & $2.8 \mathrm{E}+01$ \\
\hline B1FR56 & 59.3 & $1.8 \mathrm{E}+04$ & $1.9 \mathrm{E}+04$ & $8.3 \mathrm{E}+00$ & $8.7 \mathrm{E}-01$ & $1.0 \mathrm{E}+02$ & $2.9 \mathrm{E}+01$ & $1.7 \mathrm{E}+01$ \\
\hline B1FR60 & 68.5 & $2.0 \mathrm{E}+04$ & $6.3 \mathrm{E}+03$ & $7.1 \mathrm{E}+00$ & $5.0 \mathrm{E}-01$ & $1.0 \mathrm{E}+02$ & $3.1 \mathrm{E}+01$ & $1.1 \mathrm{E}+01$ \\
\hline B1FR64 & 79.5 & $2.1 \mathrm{E}+04$ & $2.9 \mathrm{E}+03$ & $6.5 \mathrm{E}+00$ & $4.7 \mathrm{E}-01$ & $1.0 \mathrm{E}+02$ & $2.7 \mathrm{E}+01$ & $4.3 \mathrm{E}+01$ \\
\hline B1FR68 & 90.3 & $2.1 \mathrm{E}+04$ & $5.1 \mathrm{E}+03$ & $1.4 \mathrm{E}+00$ & $2.5 \mathrm{E}-01$ & $1.0 \mathrm{E}+02$ & $3.1 \mathrm{E}+01$ & $3.1 \mathrm{E}+01$ \\
\hline B1FR72 & 107.8 & $2.1 \mathrm{E}+04$ & $1.3 \mathrm{E}+03$ & $1.3 \mathrm{E}+01$ & $1.3 \mathrm{E}+00$ & $1.0 \mathrm{E}+02$ & $2.5 \mathrm{E}+01$ & $3.5 \mathrm{E}+01$ \\
\hline \multicolumn{9}{|c|}{ Water Extracts (Concentration Values Were Dilution Corrected) } \\
\hline C5000-36A & 11.0 & $1.5 \mathrm{E}+05$ & $1.2 \mathrm{E}+05$ & $6.9 \mathrm{E}+01$ & $1.4 \mathrm{E}+01$ & $1.3 \mathrm{E}+03$ & $5.1 \mathrm{E}+02$ & $2.6 \mathrm{E}+03$ \\
\hline C5000-36E & 12.0 & $2.0 \mathrm{E}+05$ & $2.5 \mathrm{E}+05$ & $1.1 \mathrm{E}+02$ & $6.6 \mathrm{E}+00$ & $1.9 \mathrm{E}+03$ & $7.7 \mathrm{E}+02$ & $3.8 \mathrm{E}+03$ \\
\hline C5000-37A & 13.0 & $2.0 \mathrm{E}+05$ & $2.7 \mathrm{E}+05$ & $4.7 \mathrm{E}+01$ & $5.9 \mathrm{E}-01$ & $2.1 \mathrm{E}+03$ & $8.2 \mathrm{E}+02$ & $4.1 \mathrm{E}+03$ \\
\hline C5000-38B & 20.0 & $1.4 \mathrm{E}+05$ & $1.8 \mathrm{E}+05$ & $1.3 \mathrm{E}+01$ & $1.7 \mathrm{E}+02$ & $1.7 \mathrm{E}+03$ & $6.6 \mathrm{E}+02$ & $3.3 \mathrm{E}+03$ \\
\hline C5000-40A & 30.0 & $4.5 \mathrm{E}+04$ & $3.3 \mathrm{E}+04$ & $8.6 \mathrm{E}+01$ & $3.8 \mathrm{E}+00$ & $1.0 \mathrm{E}+00$ & $7.4 \mathrm{E}+01$ & $2.2 \mathrm{E}+02$ \\
\hline C5000-40B & 31.0 & $2.2 \mathrm{E}+05$ & $6.6 \mathrm{E}+04$ & $2.0 \mathrm{E}+01$ & $2.7 \mathrm{E}+01$ & $5.3 \mathrm{E}+01$ & $4.9 \mathrm{E}+02$ & $6.2 \mathrm{E}+02$ \\
\hline $\mathrm{C} 5000-41 \mathrm{C}$ & 36.0 & $6.9 \mathrm{E}+04$ & $2.6 \mathrm{E}+04$ & $4.4 \mathrm{E}+01$ & $4.2 \mathrm{E}+01$ & $6.4 \mathrm{E}+02$ & $3.2 \mathrm{E}+02$ & $4.5 \mathrm{E}+02$ \\
\hline C5000-48D & 65.0 & $3.6 \mathrm{E}+04$ & $7.2 \mathrm{E}+04$ & $4.1 \mathrm{E}+00$ & $3.8 \mathrm{E}+01$ & $3.8 \mathrm{E}+02$ & $1.5 \mathrm{E}+02$ & $7.6 \mathrm{E}+02$ \\
\hline C5000-48E & 66.0 & $2.4 \mathrm{E}+04$ & $3.5 \mathrm{E}+04$ & $2.5 \mathrm{E}+00$ & $3.0 \mathrm{E}+01$ & $3.0 \mathrm{E}+02$ & $1.2 \mathrm{E}+02$ & $5.9 \mathrm{E}+02$ \\
\hline C5000-49D & 68.0 & $5.9 \mathrm{E}+04$ & $1.2 \mathrm{E}+05$ & $1.8 \mathrm{E}+01$ & $9.2 \mathrm{E}+01$ & $9.2 \mathrm{E}+02$ & $3.7 \mathrm{E}+02$ & $1.8 \mathrm{E}+03$ \\
\hline C5000-50B & 71.0 & $7.0 \mathrm{E}+04$ & $1.1 \mathrm{E}+05$ & $2.8 \mathrm{E}+01$ & $1.6 \mathrm{E}-01$ & $7.8 \mathrm{E}+02$ & $3.1 \mathrm{E}+02$ & $4.5 \mathrm{E}+01$ \\
\hline C5000-51E & 77.0 & $5.8 \mathrm{E}+04$ & $4.4 \mathrm{E}+04$ & $3.7 \mathrm{E}+00$ & $5.4 \mathrm{E}+01$ & $4.0 \mathrm{E}-01$ & $2.0 \mathrm{E}+01$ & $1.1 \mathrm{E}+03$ \\
\hline C5000-52B & 79.0 & $5.4 \mathrm{E}+04$ & $7.1 \mathrm{E}+04$ & $3.2 \mathrm{E}+01$ & $2.6 \mathrm{E}+00$ & $4.8 \mathrm{E}+02$ & $1.9 \mathrm{E}+02$ & $9.6 \mathrm{E}+02$ \\
\hline C5000-53E & 85.0 & $3.5 \mathrm{E}+04$ & $1.0 \mathrm{E}+05$ & $8.0 \mathrm{E}+00$ & $2.0 \mathrm{E}+00$ & $4.0 \mathrm{E}+02$ & $2.8 \mathrm{E}+00$ & $8.0 \mathrm{E}+02$ \\
\hline C5000-54E & 89.5 & $4.6 \mathrm{E}+04$ & $5.9 \mathrm{E}+04$ & $2.1 \mathrm{E}+00$ & $9.2 \mathrm{E}-01$ & $7.4 \mathrm{E}+02$ & $1.2 \mathrm{E}+01$ & $1.5 \mathrm{E}+03$ \\
\hline C5000-57D & 100.0 & $6.7 \mathrm{E}+04$ & $5.2 \mathrm{E}+04$ & $1.3 \mathrm{E}+01$ & $3.6 \mathrm{E}+00$ & $5.7 \mathrm{E}+02$ & $6.4 \mathrm{E}+01$ & $1.1 \mathrm{E}+03$ \\
\hline C5000-60E & 109.5 & $4.8 \mathrm{E}+04$ & $6.9 \mathrm{E}+04$ & $8.6 \mathrm{E}+00$ & $1.2 \mathrm{E}+00$ & $3.9 \mathrm{E}+02$ & $1.6 \mathrm{E}+02$ & $7.9 \mathrm{E}+02$ \\
\hline \multicolumn{9}{|c|}{ Pore Water After Ultracentrifugation } \\
\hline C5000-43B & 45.0 & $6.0 \mathrm{E}+03$ & $2.1 \mathrm{E}+04$ & $2.5 \mathrm{E}+01$ & $1.8 \mathrm{E}+00$ & $9.6 \mathrm{E}+00$ & $5.7 \mathrm{E}+01$ & $2.7 \mathrm{E}+01$ \\
\hline C5000-44C & 49.0 & $7.0 \mathrm{E}+03$ & $2.0 \mathrm{E}+04$ & $2.5 \mathrm{E}+01$ & $5.0 \mathrm{E}+01$ & $9.5 \mathrm{E}+00$ & $4.0 \mathrm{E}+01$ & $1.2 \mathrm{E}+02$ \\
\hline C5000-44E & 51.0 & $2.8 \mathrm{E}+03$ & $2.5 \mathrm{E}+04$ & $2.0 \mathrm{E}+02$ & $4.0 \mathrm{E}+02$ & $7.1 \mathrm{E}+01$ & $5.9 \mathrm{E}+02$ & $7.1 \mathrm{E}+02$ \\
\hline C5000-45C & 54.0 & $3.5 \mathrm{E}+03$ & $4.0 \mathrm{E}+04$ & $1.8 \mathrm{E}-01$ & $2.8 \mathrm{E}+00$ & $8.0 \mathrm{E}+01$ & $4.5 \mathrm{E}+02$ & $4.6 \mathrm{E}+02$ \\
\hline C5000-48B & 62.5 & $3.6 \mathrm{E}+03$ & $2.8 \mathrm{E}+04$ & $5.1 \mathrm{E}+00$ & $4.0 \mathrm{E}+02$ & $6.1 \mathrm{E}+01$ & $4.9 \mathrm{E}+02$ & $1.1 \mathrm{E}+03$ \\
\hline C5000-49A & 67.0 & $8.2 \mathrm{E}+03$ & $1.6 \mathrm{E}+04$ & $4.2 \mathrm{E}+00$ & $2.0 \mathrm{E}+02$ & $2.9 \mathrm{E}+01$ & $2.5 \mathrm{E}+02$ & $4.7 \mathrm{E}+02$ \\
\hline C5000-49D & 68.0 & $5.8 \mathrm{E}+03$ & $1.6 \mathrm{E}+04$ & $8.4 \mathrm{E}+00$ & $1.4 \mathrm{E}+00$ & $3.3 \mathrm{E}+01$ & $2.3 \mathrm{E}+02$ & $6.6 \mathrm{E}+02$ \\
\hline C5000-52B & 79.0 & $4.0 \mathrm{E}+05$ & $4.0 \mathrm{E}+05$ & $4.1 \mathrm{E}+01$ & $2.9 \mathrm{E}+01$ & $3.7 \mathrm{E}+02$ & $2.0 \mathrm{E}+03$ & $3.7 \mathrm{E}+03$ \\
\hline C5000-53E & 86.0 & $8.8 \mathrm{E}+03$ & $1.5 \mathrm{E}+04$ & $9.9 \mathrm{E}-01$ & $3.0 \mathrm{E}+00$ & $1.1 \mathrm{E}+01$ & $9.1 \mathrm{E}+01$ & $2.7 \mathrm{E}+02$ \\
\hline C5000-54A & 85.0 & $2.0 \mathrm{E}+06$ & $2.0 \mathrm{E}+06$ & $1.9 \mathrm{E}+02$ & $1.3 \mathrm{E}+02$ & $2.1 \mathrm{E}+03$ & $1.3 \mathrm{E}+04$ & $2.5 \mathrm{E}+04$ \\
\hline C5000-55D & 90.5 & $5.2 \mathrm{E}+03$ & $2.3 \mathrm{E}+04$ & $4.6 \mathrm{E}+00$ & $1.1 \mathrm{E}+01$ & $2.2 \mathrm{E}+01$ & $2.5 \mathrm{E}+02$ & $4.6 \mathrm{E}+02$ \\
\hline C5000-58C & 103.0 & $4.5 \mathrm{E}+03$ & $6.7 \mathrm{E}+03$ & $5.0 \mathrm{E}+00$ & $2.5 \mathrm{E}+00$ & $6.4 \mathrm{E}+01$ & $5.2 \mathrm{E}+02$ & $1.3 \mathrm{E}+03$ \\
\hline C5000-60C & 107.5 & $6.8 \mathrm{E}+03$ & $4.3 \mathrm{E}+03$ & $3.1 \mathrm{E}+00$ & $4.4 \mathrm{E}+00$ & $3.6 \mathrm{E}+01$ & $2.5 \mathrm{E}+02$ & $6.1 \mathrm{E}+02$ \\
\hline
\end{tabular}


Table D.6. ICP-OEP for Cations Analysis of C5001 Samples

\begin{tabular}{|c|c|c|c|c|c|c|c|c|c|c|c|c|c|c|}
\hline Sample ID & $\begin{array}{l}\text { Depth } \\
\text { (ft bgs) }\end{array}$ & $\begin{array}{c}\mathrm{Al} \\
(\mu \mathrm{g} / \mathrm{L})\end{array}$ & $\begin{array}{c}\text { As } \\
(\mu \mathrm{g} / \mathrm{L})\end{array}$ & $\begin{array}{c}\text { B } \\
(\mu \mathrm{g} / \mathrm{L})\end{array}$ & $\begin{array}{c}\mathrm{Ba} \\
(\mu \mathrm{g} / \mathrm{L})\end{array}$ & $\begin{array}{c}\mathrm{Be} \\
(\mu \mathrm{g} / \mathrm{L})\end{array}$ & $\begin{array}{c}\mathrm{Bi} \\
(\mu \mathrm{g} / \mathrm{L})\end{array}$ & $\begin{array}{c}\mathrm{Ca} \\
(\mu \mathrm{g} / \mathrm{L})\end{array}$ & $\begin{array}{c}\mathrm{Cd} \\
(\mu \mathrm{g} / \mathrm{L})\end{array}$ & $\begin{array}{c}\text { Co } \\
(\mu \mathrm{g} / \mathrm{L})\end{array}$ & $\begin{array}{c}\mathrm{Cr} \\
(\mu \mathrm{g} / \mathrm{L})\end{array}$ & $\begin{array}{c}\mathrm{Cu} \\
(\mu \mathrm{g} / \mathrm{L})\end{array}$ & $\mathrm{Fe}(\mu \mathrm{g} / \mathrm{L})$ & $\begin{array}{c}\mathrm{K} \\
(\mu \mathrm{g} / \mathrm{L})\end{array}$ \\
\hline \multicolumn{15}{|c|}{ Groundwater } \\
\hline B1HRX0 & 53 & $7.5 \mathrm{E}+01$ & $2.2 \mathrm{E}-01$ & $7.2 \mathrm{E}+01$ & $4.7 \mathrm{E}+01$ & $1.1 \mathrm{E}+00$ & $1.5 \mathrm{E}+03$ & $4.7 \mathrm{E}+04$ & $7.5 \mathrm{E}+00$ & $5.9 \mathrm{E}+00$ & 9.3E-01 & $6.7 \mathrm{E}+00$ & $9.4 \mathrm{E}+01$ & $4.3 \mathrm{E}+03$ \\
\hline B1HRX4 & 57.8 & $7.5 \mathrm{E}+01$ & $3.0 \mathrm{E}+02$ & $6.6 \mathrm{E}+01$ & $4.6 \mathrm{E}+01$ & $1.1 \mathrm{E}+00$ & $1.5 \mathrm{E}+03$ & $4.6 \mathrm{E}+04$ & $7.5 \mathrm{E}+00$ & $6.0 \mathrm{E}+00$ & $3.1 \mathrm{E}+01$ & $5.9 \mathrm{E}+00$ & $3.4 \mathrm{E}+01$ & $4.1 \mathrm{E}+03$ \\
\hline B1HRX8 & 63.0 & $7.5 \mathrm{E}+01$ & $1.9 \mathrm{E}+01$ & $6.7 \mathrm{E}+01$ & $4.9 \mathrm{E}+01$ & $1.1 \mathrm{E}+00$ & $1.5 E+03$ & $4.8 \mathrm{E}+04$ & $7.5 \mathrm{E}+00$ & $5.9 \mathrm{E}+00$ & $1.5 \mathrm{E}+00$ & $3.4 \mathrm{E}+00$ & $7.7 \mathrm{E}+01$ & $4.5 \mathrm{E}+03$ \\
\hline B1HRY2 & 81.5 & $7.5 \mathrm{E}+01$ & $3.0 \mathrm{E}+02$ & $6.6 \mathrm{E}+01$ & $4.9 \mathrm{E}+01$ & 9.4E-01 & $1.5 \mathrm{E}+03$ & $4.7 \mathrm{E}+04$ & $7.5 \mathrm{E}+00$ & $4.6 \mathrm{E}+00$ & $1.9 \mathrm{E}+01$ & $1.3 \mathrm{E}+00$ & $4.4 \mathrm{E}+01$ & $4.8 \mathrm{E}+03$ \\
\hline B1HRY6 & 101.8 & $7.5 \mathrm{E}+01$ & $9.0 \mathrm{E}+00$ & $4.6 \mathrm{E}+01$ & $4.1 \mathrm{E}+01$ & 7.9E-01 & $1.5 \mathrm{E}+03$ & $3.5 \mathrm{E}+04$ & $7.5 \mathrm{E}+00$ & $6.1 \mathrm{E}+00$ & 7.2E-01 & $1.3 \mathrm{E}+00$ & $4.1 \mathrm{E}+02$ & $3.8 \mathrm{E}+03$ \\
\hline \multicolumn{15}{|c|}{ Water Extracts (Concentration Values Were Dilution Corrected) } \\
\hline C5001-63C & 8.0 & $1.1 \mathrm{E}+03$ & $2.1 \mathrm{E}+02$ & $7.7 \mathrm{E}+03$ & $6.0 \mathrm{E}+02$ & $1.8 \mathrm{E}+01$ & $1.1 \mathrm{E}+01$ & $4.6 \mathrm{E}+04$ & $7.8 \mathrm{E}+00$ & $2.0 \mathrm{E}+02$ & $4.0 \mathrm{E}+00$ & $2.2 \mathrm{E}+02$ & $1.5 \mathrm{E}+03$ & $2.0 \mathrm{E}+04$ \\
\hline C5001-64E & 15.0 & $9.8 \mathrm{E}+01$ & $7.2 \mathrm{E}+02$ & $6.8 \mathrm{E}+02$ & $2.1 \mathrm{E}+02$ & $4.8 \mathrm{E}+01$ & $1.6 \mathrm{E}+02$ & $1.6 \mathrm{E}+05$ & $1.2 \mathrm{E}+00$ & $3.6 \mathrm{E}+02$ & $4.5 \mathrm{E}+02$ & $2.4 \mathrm{E}+02$ & $1.1 \mathrm{E}+02$ & $2.4 \mathrm{E}+04$ \\
\hline C5001-66A & 21.0 & $2.2 \mathrm{E}+03$ & $2.5 \mathrm{E}+02$ & $1.8 \mathrm{E}+04$ & $5.0 \mathrm{E}+02$ & $2.8 \mathrm{E}+00$ & $5.1 \mathrm{E}+02$ & $2.5 \mathrm{E}+05$ & $1.8 \mathrm{E}+01$ & $5.9 \mathrm{E}+02$ & $1.5 \mathrm{E}+03$ & $4.7 \mathrm{E}+01$ & $3.3 \mathrm{E}+03$ & $1.4 \mathrm{E}+05$ \\
\hline C5001-68A & 28.0 & $3.0 \mathrm{E}+02$ & $2.2 \mathrm{E}+02$ & $9.4 \mathrm{E}+02$ & $3.2 \mathrm{E}+02$ & $4.8 \mathrm{E}+01$ & $1.0 \mathrm{E}+02$ & $2.6 \mathrm{E}+05$ & $1.5 \mathrm{E}+01$ & $5.9 \mathrm{E}+02$ & $7.4 \mathrm{E}+02$ & $3.2 \mathrm{E}+02$ & $2.0 \mathrm{E}+02$ & $1.1 \mathrm{E}+05$ \\
\hline C5001-68B & 29.0 & $1.5 \mathrm{E}+03$ & $1.2 \mathrm{E}+01$ & $1.2 \mathrm{E}+04$ & $3.0 \mathrm{E}+02$ & $1.9 \mathrm{E}+02$ & $4.7 \mathrm{E}+02$ & $1.6 \mathrm{E}+05$ & $8.4 \mathrm{E}+00$ & $3.8 \mathrm{E}+02$ & $9.4 \mathrm{E}+02$ & $7.9 \mathrm{E}+00$ & $1.5 \mathrm{E}+03$ & $7.5 \mathrm{E}+04$ \\
\hline C5001-69C & 33.0 & $2.3 \mathrm{E}+02$ & $4.3 \mathrm{E}+02$ & $8.8 \mathrm{E}+02$ & $4.6 \mathrm{E}+02$ & $1.9 \mathrm{E}+01$ & $2.6 \mathrm{E}+01$ & $1.6 \mathrm{E}+05$ & $1.9 \mathrm{E}+02$ & $3.2 \mathrm{E}+01$ & $4.8 \mathrm{E}+02$ & $1.3 \mathrm{E}+02$ & $5.1 \mathrm{E}+02$ & $4.1 \mathrm{E}+04$ \\
\hline C5001-69D & 34.0 & $3.8 \mathrm{E}+02$ & $1.4 \mathrm{E}+03$ & $4.2 \mathrm{E}+03$ & $1.8 \mathrm{E}+02$ & $6.8 \mathrm{E}+01$ & $2.1 \mathrm{E}+02$ & $8.2 \mathrm{E}+04$ & $3.8 \mathrm{E}+00$ & $1.4 \mathrm{E}+02$ & $3.4 \mathrm{E}+02$ & $6.8 \mathrm{E}+02$ & $1.8 \mathrm{E}+02$ & $3.2 \mathrm{E}+04$ \\
\hline C5001-70D & 39.5 & $2.7 \mathrm{E}+02$ & $5.3 \mathrm{E}+02$ & $2.3 \mathrm{E}+03$ & $2.4 \mathrm{E}+02$ & $1.2 \mathrm{E}+02$ & $1.1 \mathrm{E}+02$ & $1.6 \mathrm{E}+05$ & $2.6 \mathrm{E}+01$ & $4.6 \mathrm{E}+02$ & $5.7 \mathrm{E}+02$ & $4.9 \mathrm{E}+02$ & $1.8 \mathrm{E}+02$ & $5.5 \mathrm{E}+04$ \\
\hline C5001-70E & 40.5 & $3.0 \mathrm{E}+02$ & $2.4 \mathrm{E}+03$ & $7.4 \mathrm{E}+03$ & $3.4 \mathrm{E}+02$ & $1.2 \mathrm{E}+02$ & $2.5 \mathrm{E}+02$ & $1.6 \mathrm{E}+05$ & $7.4 \mathrm{E}+00$ & $2.4 \mathrm{E}+02$ & $5.9 \mathrm{E}+02$ & $1.2 \mathrm{E}+03$ & $3.1 \mathrm{E}+02$ & $5.1 \mathrm{E}+04$ \\
\hline C5001-71E & 41.5 & $3.4 \mathrm{E}+02$ & $8.0 \mathrm{E}+02$ & $1.1 \mathrm{E}+03$ & $3.5 \mathrm{E}+02$ & $4.5 \mathrm{E}+01$ & $5.1 \mathrm{E}+02$ & $2.2 \mathrm{E}+05$ & $1.6 \mathrm{E}+01$ & $3.7 \mathrm{E}+02$ & $4.7 \mathrm{E}+02$ & $2.2 \mathrm{E}+02$ & $3.1 \mathrm{E}+02$ & $7.2 \mathrm{E}+04$ \\
\hline C5001-73B & 25.8 & $2.4 \mathrm{E}+02$ & $1.5 \mathrm{E}+02$ & $4.5 \mathrm{E}+03$ & $1.2 \mathrm{E}+02$ & $7.5 \mathrm{E}+01$ & $4.2 \mathrm{E}+01$ & $7.3 \mathrm{E}+04$ & $2.5 \mathrm{E}+00$ & $1.5 \mathrm{E}+02$ & $3.7 \mathrm{E}+02$ & $1.1 \mathrm{E}+00$ & $1.6 \mathrm{E}+02$ & $2.6 \mathrm{E}+04$ \\
\hline C5001-74B & 53.5 & $2.6 \mathrm{E}+02$ & $1.4 \mathrm{E}+03$ & $3.7 \mathrm{E}+03$ & $2.4 \mathrm{E}+02$ & $6.8 \mathrm{E}+01$ & $2.7 \mathrm{E}+02$ & $6.9 \mathrm{E}+04$ & $2.7 \mathrm{E}+00$ & $1.4 \mathrm{E}+02$ & $3.4 \mathrm{E}+02$ & $6.8 \mathrm{E}+02$ & $2.2 \mathrm{E}+02$ & $2.1 \mathrm{E}+04$ \\
\hline C5001-76C & 64.5 & $7.9 \mathrm{E}+02$ & $5.9 \mathrm{E}+02$ & $7.3 \mathrm{E}+02$ & $4.0 \mathrm{E}+02$ & $5.2 \mathrm{E}+01$ & $2.6 \mathrm{E}+02$ & $9.8 \mathrm{E}+04$ & $2.1 \mathrm{E}+02$ & $5.2 \mathrm{E}+00$ & $5.3 \mathrm{E}+02$ & $1.4 \mathrm{E}+02$ & $7.4 \mathrm{E}+02$ & $3.8 \mathrm{E}+04$ \\
\hline C5001-76D & 65.5 & $5.1 \mathrm{E}+02$ & $1.8 \mathrm{E}+03$ & $4.8 \mathrm{E}+03$ & $2.9 \mathrm{E}+02$ & $9.2 \mathrm{E}+01$ & $1.9 \mathrm{E}+02$ & $9.3 \mathrm{E}+04$ & $6.1 \mathrm{E}+00$ & $8.9 \mathrm{E}+00$ & $4.6 \mathrm{E}+02$ & $9.2 \mathrm{E}+02$ & $3.7 \mathrm{E}+02$ & $3.0 \mathrm{E}+04$ \\
\hline C5001-78A & 74.5 & $6.9 \mathrm{E}+02$ & $5.5 \mathrm{E}+02$ & $5.4 \mathrm{E}+02$ & $5.5 \mathrm{E}+02$ & $3.8 \mathrm{E}+01$ & $4.3 \mathrm{E}+02$ & $1.4 \mathrm{E}+05$ & $2.2 \mathrm{E}+01$ & $5.3 \mathrm{E}+02$ & $6.6 \mathrm{E}+02$ & $1.2 \mathrm{E}+02$ & $4.3 \mathrm{E}+02$ & $5.7 \mathrm{E}+04$ \\
\hline C5001-79A & 81.5 & $2.0 \mathrm{E}+02$ & $1.1 \mathrm{E}+03$ & $3.0 \mathrm{E}+03$ & $1.2 \mathrm{E}+02$ & $5.6 \mathrm{E}+01$ & $1.5 \mathrm{E}+02$ & $5.7 \mathrm{E}+04$ & $1.7 \mathrm{E}+00$ & 9.5E-01 & $2.8 \mathrm{E}+02$ & $5.6 \mathrm{E}+02$ & $3.3 \mathrm{E}+02$ & $1.9 \mathrm{E}+04$ \\
\hline C5001-80A & 85.5 & $2.2 \mathrm{E}+02$ & 4.3E+01 & $1.3 \mathrm{E}+03$ & $6.3 \mathrm{E}+01$ & $3.5 \mathrm{E}+00$ & $4.3 \mathrm{E}+02$ & $3.4 \mathrm{E}+04$ & $6.8 \mathrm{E}-01$ & $4.3 \mathrm{E}+01$ & $6.4 \mathrm{E}+00$ & $2.2 \mathrm{E}+02$ & $3.4 \mathrm{E}+01$ & $8.6 \mathrm{E}+03$ \\
\hline
\end{tabular}


Table D.6. (contd)

\begin{tabular}{|c|c|c|c|c|c|c|c|c|c|c|c|c|c|c|}
\hline Sample ID & $\begin{array}{c}\text { Depth } \\
\text { (ft bgs) }\end{array}$ & $\begin{array}{c}\mathrm{Li} \\
(\mu \mathrm{g} / \mathrm{L})\end{array}$ & $\begin{array}{c}\mathrm{Mg} \\
(\mu \mathrm{g} / \mathrm{L})\end{array}$ & $\begin{array}{c}\mathrm{Mn} \\
(\mu \mathrm{g} / \mathrm{L})\end{array}$ & $\begin{array}{c}\text { Mo } \\
(\mu \mathrm{g} / \mathrm{L})\end{array}$ & $\begin{array}{c}\mathrm{Ni} \\
(\mu \mathrm{g} / \mathrm{L})\end{array}$ & $\begin{array}{c}\mathrm{P} \\
(\mu \mathrm{g} / \mathrm{L})\end{array}$ & $\begin{array}{c}\mathrm{Pb} \\
(\mu \mathrm{g} / \mathrm{L})\end{array}$ & $\begin{array}{c}\text { Se } \\
(\mu \mathrm{g} / \mathrm{L})\end{array}$ & $\begin{array}{c}\mathrm{Sr} \\
(\mu \mathrm{g} / \mathrm{L})\end{array}$ & $\begin{array}{c}\mathrm{Ti} \\
(\mu \mathrm{g} / \mathrm{L})\end{array}$ & $\begin{array}{c}\mathrm{V} \\
(\mu \mathrm{g} / \mathrm{L})\end{array}$ & $\mathrm{Zn}(\mu \mathrm{g} / \mathrm{L})$ & $\begin{array}{c}\mathrm{Na} \\
(\mu \mathrm{g} / \mathrm{L})\end{array}$ \\
\hline \multicolumn{15}{|c|}{ Groundwater } \\
\hline B1HRX0 & 53 & $3.0 \mathrm{E}+00$ & $9.6 \mathrm{E}+03$ & $1.1 \mathrm{E}+01$ & $2.3 \mathrm{E}+00$ & $2.2 \mathrm{E}+01$ & $1.0 \mathrm{E}+02$ & $3.0 \mathrm{E}+01$ & $1.6 \mathrm{E}+02$ & $2.0 \mathrm{E}+02$ & $3.0 \mathrm{E}+02$ & $7.5 \mathrm{E}+01$ & $8.5 \mathrm{E}+00$ & $1.9 \mathrm{E}+04$ \\
\hline B1HRX4 & 57.8 & $1.5 \mathrm{E}+01$ & $9.8 \mathrm{E}+03$ & $2.1 \mathrm{E}+01$ & $1.1 \mathrm{E}+01$ & $2.3 \mathrm{E}+01$ & $1.0 \mathrm{E}+02$ & $3.0 \mathrm{E}+01$ & $1.9 \mathrm{E}+02$ & $1.9 \mathrm{E}+02$ & $3.0 \mathrm{E}+02$ & $7.5 \mathrm{E}+01$ & $8.3 \mathrm{E}+00$ & $1.9 \mathrm{E}+04$ \\
\hline B1HRX8 & 63.0 & $5.3 \mathrm{E}+00$ & $1.0 \mathrm{E}+04$ & $2.2 \mathrm{E}+01$ & $6.2 \mathrm{E}+00$ & $1.9 \mathrm{E}+01$ & $9.0 \mathrm{E}+01$ & $3.0 \mathrm{E}+01$ & $2.3 \mathrm{E}+02$ & $2.0 \mathrm{E}+02$ & $3.0 \mathrm{E}+02$ & $7.5 \mathrm{E}+01$ & $8.5 \mathrm{E}+00$ & $2.0 \mathrm{E}+04$ \\
\hline B1HRY2 & 81.5 & $7.4 \mathrm{E}+00$ & $1.0 \mathrm{E}+04$ & $8.4 \mathrm{E}+01$ & $8.3 \mathrm{E}+00$ & $1.6 \mathrm{E}+01$ & $9.3 \mathrm{E}+01$ & $3.0 \mathrm{E}+01$ & $2.5 \mathrm{E}+02$ & $2.0 \mathrm{E}+02$ & $3.0 \mathrm{E}+02$ & $7.5 \mathrm{E}+01$ & $6.1 \mathrm{E}+00$ & $2.1 \mathrm{E}+04$ \\
\hline B1HRY6 & 101.8 & $6.8 \mathrm{E}+00$ & $7.8 \mathrm{E}+03$ & $9.5 \mathrm{E}+01$ & $4.6 \mathrm{E}+00$ & $1.5 \mathrm{E}+01$ & $8.6 \mathrm{E}+01$ & $3.0 \mathrm{E}+01$ & $1.4 \mathrm{E}+02$ & $1.6 \mathrm{E}+02$ & $5.8 \mathrm{E}+00$ & $7.5 \mathrm{E}+01$ & $1.4 \mathrm{E}+01$ & $1.8 \mathrm{E}+04$ \\
\hline \multicolumn{15}{|c|}{ Water Extracts (Concentration Values Were Dilution Corrected) } \\
\hline C5001-63C & 8.0 & $2.0 \mathrm{E}+04$ & $1.6 \mathrm{E}+04$ & $7.4 \mathrm{E}+01$ & $2.0 \mathrm{E}+03$ & $6.7 \mathrm{E}+01$ & $2.2 \mathrm{E}+03$ & $4.1 \mathrm{E}+02$ & $1.1 \mathrm{E}+03$ & $2.0 \mathrm{E}+02$ & $7.1 \mathrm{E}+01$ & $9.9 \mathrm{E}+01$ & $2.1 \mathrm{E}+03$ & $4.5 \mathrm{E}+04$ \\
\hline C5001-64E & 15.0 & $1.6 \mathrm{E}+02$ & $4.4 \mathrm{E}+04$ & $9.1 \mathrm{E}+01$ & $2.1 \mathrm{E}+02$ & $1.7 \mathrm{E}+02$ & $1.1 \mathrm{E}+03$ & $3.6 \mathrm{E}+03$ & $2.3 \mathrm{E}+03$ & $4.7 \mathrm{E}+02$ & $1.8 \mathrm{E}+03$ & $1.9 \mathrm{E}+02$ & $9.6 \mathrm{E}+02$ & $9.8 \mathrm{E}+04$ \\
\hline C5001-66A & 21.0 & $3.5 \mathrm{E}+02$ & $5.0 \mathrm{E}+04$ & $1.8 \mathrm{E}+02$ & $4.0 \mathrm{E}+01$ & $9.3 \mathrm{E}+01$ & $3.8 \mathrm{E}+03$ & $1.2 \mathrm{E}+03$ & $3.2 \mathrm{E}+03$ & $8.5 E+02$ & $1.2 \mathrm{E}+04$ & $1.1 \mathrm{E}+03$ & $4.1 \mathrm{E}+03$ & $4.3 \mathrm{E}+05$ \\
\hline C5001-68A & 28.0 & $4.1 \mathrm{E}+02$ & $6.6 \mathrm{E}+04$ & $3.1 \mathrm{E}+02$ & $1.0 \mathrm{E}+03$ & $1.2 \mathrm{E}+02$ & $1.6 \mathrm{E}+03$ & $5.9 \mathrm{E}+03$ & $4.8 \mathrm{E}+03$ & $1.1 \mathrm{E}+03$ & $2.9 \mathrm{E}+03$ & $2.5 \mathrm{E}+02$ & $1.2 \mathrm{E}+03$ & $3.6 \mathrm{E}+05$ \\
\hline C5001-68B & 29.0 & $2.5 \mathrm{E}+02$ & $3.4 \mathrm{E}+04$ & $9.3 \mathrm{E}+01$ & $3.8 \mathrm{E}+03$ & $6.6 \mathrm{E}+01$ & $1.5 \mathrm{E}+03$ & $7.5 \mathrm{E}+02$ & $1.2 \mathrm{E}+03$ & $6.1 \mathrm{E}+02$ & $7.5 \mathrm{E}+03$ & $7.8 \mathrm{E}+02$ & $2.1 \mathrm{E}+03$ & $2.2 \mathrm{E}+05$ \\
\hline C5001-69C & 33.0 & $1.3 \mathrm{E}+02$ & $3.2 \mathrm{E}+04$ & $3.8 \mathrm{E}+01$ & $1.4 \mathrm{E}+01$ & $8.9 \mathrm{E}+01$ & $6.0 \mathrm{E}+02$ & $3.8 \mathrm{E}+03$ & $4.9 \mathrm{E}+03$ & $6.8 \mathrm{E}+02$ & $1.9 \mathrm{E}+03$ & $2.3 \mathrm{E}+02$ & $8.1 \mathrm{E}+02$ & $1.1 \mathrm{E}+05$ \\
\hline C5001-69D & 34.0 & $9.3 \mathrm{E}+01$ & $1.5 \mathrm{E}+04$ & $1.6 \mathrm{E}+02$ & $2.8 \mathrm{E}+01$ & $2.9 \mathrm{E}+01$ & $1.3 \mathrm{E}+02$ & $2.7 \mathrm{E}+02$ & $5.8 \mathrm{E}+02$ & $3.4 \mathrm{E}+02$ & $2.7 \mathrm{E}+03$ & $1.8 \mathrm{E}+02$ & $1.1 \mathrm{E}+03$ & $1.3 \mathrm{E}+05$ \\
\hline C5001-70D & 39.5 & $3.5 \mathrm{E}+02$ & $2.8 \mathrm{E}+04$ & $9.8 \mathrm{E}+01$ & $4.2 \mathrm{E}+02$ & $2.2 \mathrm{E}+02$ & $7.1 \mathrm{E}+02$ & $4.6 \mathrm{E}+03$ & $5.0 \mathrm{E}+03$ & $6.7 \mathrm{E}+02$ & $2.3 \mathrm{E}+03$ & $3.9 \mathrm{E}+02$ & $8.0 \mathrm{E}+02$ & $1.1 \mathrm{E}+05$ \\
\hline C5001-70E & 40.5 & $1.1 \mathrm{E}+02$ & $3.0 \mathrm{E}+04$ & $5.4 \mathrm{E}+01$ & $2.4 \mathrm{E}+03$ & $3.8 \mathrm{E}+01$ & $5.7 \mathrm{E}+02$ & $4.7 \mathrm{E}+02$ & $4.7 \mathrm{E}+02$ & $6.7 \mathrm{E}+02$ & $4.7 \mathrm{E}+03$ & $3.1 \mathrm{E}+02$ & $2.4 \mathrm{E}+03$ & $1.3 \mathrm{E}+05$ \\
\hline C5001-71E & 41.5 & $2.0 \mathrm{E}+02$ & $4.6 \mathrm{E}+04$ & $3.1 \mathrm{E}+02$ & $2.8 \mathrm{E}+02$ & $1.0 \mathrm{E}+02$ & $1.8 \mathrm{E}+02$ & $3.7 \mathrm{E}+03$ & $1.7 \mathrm{E}+03$ & $9.8 \mathrm{E}+02$ & $1.9 \mathrm{E}+03$ & $1.0 \mathrm{E}+02$ & $6.5 \mathrm{E}+02$ & $1.6 \mathrm{E}+05$ \\
\hline C5001-73B & 25.8 & $8.2 \mathrm{E}+00$ & $1.3 \mathrm{E}+04$ & $3.1 \mathrm{E}+01$ & $1.5 \mathrm{E}+03$ & $2.4 \mathrm{E}+01$ & $1.6 \mathrm{E}+02$ & $3.0 \mathrm{E}+02$ & $5.5 \mathrm{E}+02$ & $2.4 \mathrm{E}+02$ & $3.0 \mathrm{E}+03$ & $1.2 \mathrm{E}+02$ & $9.2 \mathrm{E}+02$ & $8.3 \mathrm{E}+04$ \\
\hline C5001-74B & 53.5 & $8.4 \mathrm{E}+01$ & $1.2 \mathrm{E}+04$ & $8.2 \mathrm{E}+01$ & $3.5 E+00$ & $3.6 \mathrm{E}+01$ & $1.1 \mathrm{E}-01$ & $2.7 \mathrm{E}+02$ & $1.9 \mathrm{E}+02$ & $2.4 \mathrm{E}+02$ & $2.7 \mathrm{E}+03$ & $1.7 \mathrm{E}+02$ & $1.3 \mathrm{E}+03$ & $5.9 \mathrm{E}+04$ \\
\hline C5001-76C & 64.5 & $2.4 \mathrm{E}+02$ & $2.0 \mathrm{E}+04$ & $9.6 \mathrm{E}+01$ & $3.3 \mathrm{E}+02$ & $1.9 \mathrm{E}+02$ & $3.9 \mathrm{E}+02$ & $1.6 \mathrm{E}+02$ & $4.3 \mathrm{E}+03$ & $4.1 \mathrm{E}+02$ & $2.1 \mathrm{E}+03$ & $2.8 \mathrm{E}+02$ & $7.7 \mathrm{E}+02$ & $7.2 \mathrm{E}+04$ \\
\hline C5001-76D & 65.5 & $1.1 \mathrm{E}+02$ & $1.8 \mathrm{E}+04$ & $8.8 \mathrm{E}+01$ & $1.8 \mathrm{E}+03$ & $2.9 \mathrm{E}+01$ & $3.0 \mathrm{E}+01$ & $3.7 E+02$ & $3.7 E+03$ & $3.4 \mathrm{E}+02$ & $3.7 \mathrm{E}+03$ & $2.3 \mathrm{E}+02$ & $1.2 \mathrm{E}+03$ & $6.4 \mathrm{E}+04$ \\
\hline C5001-78A & 74.5 & $2.7 \mathrm{E}+02$ & $2.9 \mathrm{E}+04$ & $3.5 \mathrm{E}+01$ & $1.1 \mathrm{E}+01$ & $1.6 \mathrm{E}+02$ & $3.0 \mathrm{E}+02$ & $5.3 \mathrm{E}+03$ & $4.1 \mathrm{E}+03$ & $5.8 \mathrm{E}+02$ & $2.6 \mathrm{E}+03$ & $3.7 \mathrm{E}+02$ & $9.1 \mathrm{E}+02$ & $1.0 \mathrm{E}+05$ \\
\hline C5001-79A & 81.5 & $6.9 \mathrm{E}+01$ & $1.2 \mathrm{E}+04$ & $1.8 \mathrm{E}+02$ & $1.1 \mathrm{E}+03$ & $1.5 \mathrm{E}+01$ & $1.3 \mathrm{E}+01$ & $2.2 \mathrm{E}+02$ & $2.2 \mathrm{E}+03$ & $2.2 \mathrm{E}+02$ & $2.2 \mathrm{E}+03$ & $1.6 \mathrm{E}+02$ & $6.8 \mathrm{E}+02$ & $5.1 \mathrm{E}+04$ \\
\hline C5001-80A & 85.5 & $4.3 \mathrm{E}+03$ & $6.9 \mathrm{E}+03$ & $2.6 \mathrm{E}+00$ & $4.3 \mathrm{E}+02$ & $9.4 \mathrm{E}+00$ & $1.7 \mathrm{E}+02$ & $8.6 \mathrm{E}+01$ & $2.8 \mathrm{E}+02$ & $1.6 \mathrm{E}+02$ & $3.4 \mathrm{E}+01$ & $2.2 \mathrm{E}+02$ & $3.0 \mathrm{E}+02$ & $2.6 \mathrm{E}+04$ \\
\hline
\end{tabular}


Table D.6. (contd)

\begin{tabular}{|c|c|c|c|c|c|c|c|c|}
\hline Sample ID & $\begin{array}{c}\text { Depth } \\
\text { (ft bgs) }\end{array}$ & $\begin{array}{c}\mathrm{Si} \\
(\mu \mathrm{g} / \mathrm{L})\end{array}$ & $\begin{array}{c}\mathrm{S} \\
(\mu \mathrm{g} / \mathrm{L})\end{array}$ & $\begin{array}{c}\mathrm{Ti} \\
(\mu \mathrm{g} / \mathrm{L})\end{array}$ & $\begin{array}{c}\mathrm{Zr} \\
(\mu \mathrm{g} / \mathrm{L})\end{array}$ & $\begin{array}{c}\mathrm{Ag} \\
(\mu \mathrm{g} / \mathrm{L})\end{array}$ & $\begin{array}{c}\mathrm{Re} \\
(\mu \mathrm{g} / \mathrm{L})\end{array}$ & $\begin{array}{c}\mathrm{Sb} \\
(\mu \mathrm{g} / \mathrm{L})\end{array}$ \\
\hline \multicolumn{9}{|c|}{ Groundwater } \\
\hline B1HRX0 & 53 & $1.6 \mathrm{E}+04$ & $1.3 \mathrm{E}+04$ & $7.5 \mathrm{E}+00$ & 4.8E-01 & $7.5 \mathrm{E}+01$ & $5.1 \mathrm{E}+00$ & $2.4 \mathrm{E}+01$ \\
\hline B1HRX4 & 57.8 & $1.6 \mathrm{E}+04$ & $1.3 \mathrm{E}+04$ & $7.5 \mathrm{E}+00$ & 3.8E-01 & $7.5 \mathrm{E}+01$ & $6.9 \mathrm{E}+00$ & $1.2 \mathrm{E}+01$ \\
\hline B1HRX8 & 63.0 & $1.6 \mathrm{E}+04$ & $1.4 \mathrm{E}+04$ & $7.5 \mathrm{E}+00$ & $3.8 \mathrm{E}-01$ & $7.5 \mathrm{E}+01$ & $7.4 \mathrm{E}+00$ & $3.1 \mathrm{E}+01$ \\
\hline B1HRY2 & 81.5 & $1.5 \mathrm{E}+04$ & $1.5 \mathrm{E}+04$ & $7.5 \mathrm{E}+00$ & 5.2E-01 & $7.5 \mathrm{E}+01$ & $8.2 \mathrm{E}+00$ & $2.8 \mathrm{E}+01$ \\
\hline B1HRY6 & 101.8 & $1.5 \mathrm{E}+04$ & $1.0 \mathrm{E}+04$ & $1.0 \mathrm{E}+00$ & 6.8E-01 & $7.5 \mathrm{E}+01$ & $5.3 \mathrm{E}+00$ & $2.1 \mathrm{E}+01$ \\
\hline \multicolumn{9}{|c|}{ Water Extracts (Concentration Values Were Dilution Corrected) } \\
\hline C5001-63C & 8.0 & $7.8 \mathrm{E}+04$ & $4.7 \mathrm{E}+03$ & $6.6 \mathrm{E}+01$ & $2.1 \mathrm{E}+01$ & $2.0 \mathrm{E}+03$ & $2.0 \mathrm{E}+03$ & $2.0 \mathrm{E}+03$ \\
\hline C5001-64E & 15.0 & $1.4 \mathrm{E}+05$ & $1.4 \mathrm{E}+04$ & $1.8 \mathrm{E}+02$ & $1.7 \mathrm{E}+01$ & $8.4 \mathrm{E}+00$ & $2.9 \mathrm{E}+02$ & $1.7 \mathrm{E}+02$ \\
\hline C5001-66A & 21.0 & $2.3 \mathrm{E}+05$ & $8.0 \mathrm{E}+04$ & $9.6 \mathrm{E}+01$ & $1.2 \mathrm{E}+01$ & $5.9 \mathrm{E}+03$ & $5.9 \mathrm{E}+03$ & $5.9 \mathrm{E}+03$ \\
\hline C5001-68A & 28.0 & $1.8 \mathrm{E}+05$ & $1.3 \mathrm{E}+05$ & $2.9 \mathrm{E}+02$ & $1.7 \mathrm{E}+01$ & $1.2 \mathrm{E}+03$ & $2.7 \mathrm{E}+02$ & $5.9 \mathrm{E}+03$ \\
\hline C5001-68B & 29.0 & $1.6 \mathrm{E}+05$ & $2.2 \mathrm{E}+04$ & $6.9 \mathrm{E}+01$ & $3.8 \mathrm{E}+02$ & $3.8 \mathrm{E}+03$ & $3.8 \mathrm{E}+03$ & $3.8 \mathrm{E}+03$ \\
\hline C5001-69C & 33.0 & $1.5 \mathrm{E}+05$ & $2.1 \mathrm{E}+04$ & $4.1 \mathrm{E}+01$ & $3.8 \mathrm{E}+02$ & $1.5 \mathrm{E}+01$ & $4.6 \mathrm{E}+02$ & $5.6 \mathrm{E}+02$ \\
\hline C5001-69D & 34.0 & $5.0 \mathrm{E}+04$ & $3.9 \mathrm{E}+04$ & $5.3 \mathrm{E}+00$ & $1.4 \mathrm{E}+02$ & $1.4 \mathrm{E}+03$ & $1.4 \mathrm{E}+03$ & $1.4 \mathrm{E}+03$ \\
\hline C5001-70D & 39.5 & $1.4 \mathrm{E}+05$ & $3.8 \mathrm{E}+04$ & $3.7 \mathrm{E}+01$ & $3.7 \mathrm{E}+01$ & $9.2 \mathrm{E}+02$ & $3.0 \mathrm{E}+02$ & $2.5 \mathrm{E}+01$ \\
\hline C5001-70E & 40.5 & $9.5 \mathrm{E}+04$ & $6.0 \mathrm{E}+04$ & $1.5 \mathrm{E}+01$ & $2.4 \mathrm{E}+02$ & $2.4 \mathrm{E}+03$ & $2.4 \mathrm{E}+03$ & $2.4 \mathrm{E}+03$ \\
\hline C5001-71E & 41.5 & $1.1 \mathrm{E}+05$ & $4.1 \mathrm{E}+04$ & $6.4 \mathrm{E}+00$ & $1.3 \mathrm{E}+01$ & $7.4 \mathrm{E}+02$ & $2.4 \mathrm{E}+02$ & $3.3 \mathrm{E}+02$ \\
\hline C5001-73B & 25.8 & $3.3 \mathrm{E}+04$ & $1.9 \mathrm{E}+04$ & $5.1 \mathrm{E}+00$ & $1.5 \mathrm{E}+02$ & $1.5 \mathrm{E}+03$ & $1.5 \mathrm{E}+03$ & $1.5 \mathrm{E}+03$ \\
\hline C5001-74B & 53.5 & $2.6 \mathrm{E}+04$ & $1.8 \mathrm{E}+04$ & $5.6 \mathrm{E}+00$ & $1.4 \mathrm{E}+02$ & $1.4 \mathrm{E}+03$ & $1.4 \mathrm{E}+03$ & $1.4 \mathrm{E}+03$ \\
\hline C5001-76C & 64.5 & $7.5 \mathrm{E}+04$ & $2.4 \mathrm{E}+04$ & $3.1 \mathrm{E}+01$ & $3.4 \mathrm{E}+00$ & $1.6 \mathrm{E}+01$ & $1.5 \mathrm{E}+02$ & $2.6 \mathrm{E}+02$ \\
\hline C5001-76D & 65.5 & $3.4 \mathrm{E}+04$ & $1.7 \mathrm{E}+04$ & $1.0 \mathrm{E}+01$ & $1.8 \mathrm{E}+02$ & $1.8 \mathrm{E}+03$ & $1.8 \mathrm{E}+03$ & $1.8 \mathrm{E}+03$ \\
\hline C5001-78A & 74.5 & $1.0 \mathrm{E}+05$ & $2.6 \mathrm{E}+04$ & $1.6 \mathrm{E}+01$ & $1.6 \mathrm{E}+01$ & $1.1 \mathrm{E}+03$ & $5.1 \mathrm{E}+02$ & $2.4 \mathrm{E}+01$ \\
\hline C5001-79A & 81.5 & $2.7 \mathrm{E}+04$ & $1.6 \mathrm{E}+04$ & $5.3 \mathrm{E}+00$ & $1.1 \mathrm{E}+02$ & $1.1 \mathrm{E}+03$ & $1.1 \mathrm{E}+03$ & $1.1 \mathrm{E}+03$ \\
\hline C5001-80A & 85.5 & $2.6 \mathrm{E}+04$ & $1.5 \mathrm{E}+04$ & $1.6 \mathrm{E}+00$ & $3.5 \mathrm{E}+00$ & $4.3 \mathrm{E}+02$ & $4.3 \mathrm{E}+02$ & $4.3 \mathrm{E}+02$ \\
\hline
\end{tabular}


Table D.7. ICP-OEP for Cations Analysis of C5002 Samples

\begin{tabular}{|c|c|c|c|c|c|c|c|c|c|c|c|c|c|c|}
\hline Sample ID & $\begin{array}{c}\text { Depth } \\
\text { (ft bgs) }\end{array}$ & $\begin{array}{c}\mathrm{Al} \\
(\mu \mathrm{g} / \mathrm{L})\end{array}$ & $\begin{array}{c}\text { As } \\
(\mu \mathrm{g} / \mathrm{L})\end{array}$ & $\begin{array}{c}\text { B } \\
(\mu \mathrm{g} / \mathrm{L})\end{array}$ & $\begin{array}{c}\mathrm{Ba} \\
(\mu \mathrm{g} / \mathrm{L})\end{array}$ & $\begin{array}{c}\mathrm{Be} \\
(\mu \mathrm{g} / \mathrm{L})\end{array}$ & $\begin{array}{c}\mathrm{Bi} \\
(\mu \mathrm{g} / \mathrm{L})\end{array}$ & $\begin{array}{c}\text { Ca } \\
(\mu \mathrm{g} / \mathrm{L})\end{array}$ & $\begin{array}{c}\mathrm{Cd} \\
(\mu \mathrm{g} / \mathrm{L})\end{array}$ & $\begin{array}{c}\text { Co } \\
(\mu \mathrm{g} / \mathrm{L})\end{array}$ & $\begin{array}{c}\mathrm{Cr} \\
(\mu \mathrm{g} / \mathrm{L})\end{array}$ & $\begin{array}{c}\mathrm{Cu} \\
(\mu \mathrm{g} / \mathrm{L})\end{array}$ & $\mathrm{Fe}(\mu \mathrm{g} / \mathrm{L})$ & $\begin{array}{c}\mathrm{K} \\
(\mu \mathrm{g} / \mathrm{L})\end{array}$ \\
\hline \multicolumn{15}{|c|}{ Groundwater } \\
\hline B1HT04 & 52.3 & $7.5 \mathrm{E}+01$ & $3.0 \mathrm{E}+02$ & $7.2 \mathrm{E}+01$ & $6.3 \mathrm{E}+01$ & 7.6E-01 & $1.5 \mathrm{E}+03$ & $5.2 \mathrm{E}+04$ & $7.5 \mathrm{E}+00$ & $3.7 \mathrm{E}+00$ & $2.4 \mathrm{E}+00$ & $5.2 \mathrm{E}-02$ & $5.8 \mathrm{E}+01$ & $3.8 \mathrm{E}+03$ \\
\hline В1HT08 & 61.5 & $7.5 \mathrm{E}+01$ & $3.0 \mathrm{E}+02$ & $6.6 \mathrm{E}+01$ & $5.6 \mathrm{E}+01$ & $6.3 \mathrm{E}-01$ & $1.5 \mathrm{E}+03$ & $4.8 \mathrm{E}+04$ & $7.5 \mathrm{E}+00$ & $4.8 \mathrm{E}+00$ & $2.5 \mathrm{E}+00$ & $7.5 \mathrm{E}+01$ & $5.5 \mathrm{E}+01$ & $3.9 \mathrm{E}+03$ \\
\hline B1HT12 & 72.5 & $7.5 \mathrm{E}+01$ & $2.9 \mathrm{E}+01$ & $6.1 \mathrm{E}+01$ & $5.7 \mathrm{E}+01$ & $5.5 \mathrm{E}-01$ & $1.5 \mathrm{E}+03$ & $5.1 \mathrm{E}+04$ & $7.5 \mathrm{E}+00$ & $3.4 \mathrm{E}+00$ & $2.0 \mathrm{E}+00$ & $7.5 \mathrm{E}+01$ & $6.4 \mathrm{E}+01$ & $3.8 \mathrm{E}+03$ \\
\hline B1HT16 & 91.0 & $7.5 \mathrm{E}+01$ & $1.2 \mathrm{E}+00$ & $4.9 \mathrm{E}+01$ & $2.4 \mathrm{E}+01$ & 4.4E-01 & $1.5 \mathrm{E}+03$ & $2.2 \mathrm{E}+04$ & $7.5 \mathrm{E}+00$ & $2.7 \mathrm{E}+00$ & 4.2E-02 & $7.5 \mathrm{E}+01$ & $4.3 \mathrm{E}+01$ & $3.8 \mathrm{E}+03$ \\
\hline \multicolumn{15}{|c|}{ Water Extracts (Concentration Values Were Dilution Corrected) } \\
\hline C5002-83B & 11.5 & $1.4 \mathrm{E}+03$ & $6.9 \mathrm{E}+03$ & $7.3 \mathrm{E}+04$ & $6.1 \mathrm{E}+02$ & $1.7 \mathrm{E}+01$ & $7.2 \mathrm{E}+02$ & $4.8 \mathrm{E}+05$ & $2.3 \mathrm{E}+01$ & $3.2 \mathrm{E}+01$ & $1.7 \mathrm{E}+03$ & $1.0 \mathrm{E}+02$ & $1.4 \mathrm{E}+03$ & $2.5 \mathrm{E}+05$ \\
\hline C5002-84C & 16.0 & $1.6 \mathrm{E}+03$ & $2.3 \mathrm{E}+04$ & $3.8 \mathrm{E}+04$ & $9.7 \mathrm{E}+02$ & $4.9 \mathrm{E}+01$ & $8.2 \mathrm{E}+02$ & $3.6 \mathrm{E}+05$ & $7.1 \mathrm{E}+01$ & $2.1 \mathrm{E}+01$ & $1.5 \mathrm{E}+03$ & $4.9 \mathrm{E}+02$ & $1.7 \mathrm{E}+03$ & $2.0 \mathrm{E}+05$ \\
\hline C5002-86E & 21.5 & $2.5 \mathrm{E}+02$ & $7.5 \mathrm{E}+02$ & $1.9 \mathrm{E}+04$ & $3.0 \mathrm{E}+02$ & $1.2 \mathrm{E}+01$ & $2.6 \mathrm{E}+02$ & $2.6 \mathrm{E}+05$ & $1.5 \mathrm{E}+02$ & $3.0 \mathrm{E}+02$ & $7.5 \mathrm{E}+02$ & $1.5 \mathrm{E}+03$ & $2.8 \mathrm{E}+02$ & $7.3 \mathrm{E}+04$ \\
\hline C5002-87D & 24.5 & $7.4 \mathrm{E}+01$ & $1.2 \mathrm{E}+03$ & $5.5 \mathrm{E}+03$ & $2.3 \mathrm{E}+02$ & $2.3 \mathrm{E}+01$ & $5.6 \mathrm{E}+03$ & $2.5 \mathrm{E}+05$ & $2.8 \mathrm{E}+02$ & $5.6 \mathrm{E}+02$ & $7.0 \mathrm{E}+02$ & $2.4 \mathrm{E}+02$ & $1.1 \mathrm{E}+02$ & $6.6 \mathrm{E}+04$ \\
\hline C5002-90A & 32.5 & $1.3 \mathrm{E}+03$ & $2.1 \mathrm{E}+03$ & $2.9 \mathrm{E}+03$ & $6.1 \mathrm{E}+02$ & $1.6 \mathrm{E}+02$ & $1.2 \mathrm{E}+03$ & 4.3E+05 & $1.1 \mathrm{E}+01$ & $2.0 \mathrm{E}+00$ & $8.0 \mathrm{E}+02$ & $6.9 \mathrm{E}+02$ & $3.5 \mathrm{E}+02$ & $1.0 \mathrm{E}+05$ \\
\hline C5002-90C & 34.5 & $3.0 \mathrm{E}+02$ & $1.3 \mathrm{E}+03$ & $6.8 \mathrm{E}+02$ & $3.2 \mathrm{E}+02$ & $4.6 \mathrm{E}+01$ & $5.8 \mathrm{E}+02$ & $1.8 \mathrm{E}+05$ & $3.1 \mathrm{E}+00$ & $4.9 \mathrm{E}+02$ & $6.1 \mathrm{E}+02$ & $3.8 \mathrm{E}+02$ & $2.2 \mathrm{E}+02$ & $7.1 \mathrm{E}+04$ \\
\hline C5002-91C & 39.5 & $6.9 \mathrm{E}+02$ & $3.2 \mathrm{E}+03$ & $1.1 \mathrm{E}+04$ & $3.1 \mathrm{E}+02$ & $1.6 \mathrm{E}+02$ & $4.8 \mathrm{E}+02$ & $2.6 \mathrm{E}+05$ & $7.8 \mathrm{E}+00$ & $3.2 \mathrm{E}+02$ & $8.0 \mathrm{E}+02$ & $3.9 \mathrm{E}+01$ & $5.0 \mathrm{E}+02$ & $9.3 \mathrm{E}+04$ \\
\hline C5002-91D & 40.5 & $8.7 \mathrm{E}+02$ & $5.7 \mathrm{E}+02$ & $6.7 \mathrm{E}+02$ & $4.7 \mathrm{E}+02$ & $4.5 \mathrm{E}+01$ & $2.9 \mathrm{E}+02$ & $1.3 \mathrm{E}+05$ & $8.2 \mathrm{E}+00$ & $4.3 \mathrm{E}+02$ & $5.4 \mathrm{E}+02$ & $2.3 \mathrm{E}+02$ & $1.0 \mathrm{E}+03$ & $5.6 \mathrm{E}+04$ \\
\hline C5002-92D & 48.5 & $4.5 \mathrm{E}+02$ & $1.9 \mathrm{E}+02$ & $8.0 \mathrm{E}+03$ & $2.2 \mathrm{E}+02$ & $1.9 \mathrm{E}-01$ & $1.8 \mathrm{E}+02$ & $1.6 \mathrm{E}+05$ & $9.6 \mathrm{E}+00$ & $2.2 \mathrm{E}+02$ & $5.5 \mathrm{E}+02$ & $5.6 \mathrm{E}+00$ & $2.2 \mathrm{E}+02$ & $4.9 \mathrm{E}+04$ \\
\hline C5002-93E & 54.5 & $3.0 \mathrm{E}+02$ & $2.4 \mathrm{E}+02$ & $8.6 \mathrm{E}+03$ & $1.7 \mathrm{E}+02$ & $1.2 \mathrm{E}+02$ & $3.0 \mathrm{E}+02$ & $1.2 \mathrm{E}+05$ & $1.2 \mathrm{E}+02$ & $2.4 \mathrm{E}+02$ & $6.1 \mathrm{E}+02$ & $3.7 \mathrm{E}+00$ & $1.6 \mathrm{E}+02$ & $3.8 \mathrm{E}+04$ \\
\hline C5002-94D & 65.5 & $4.3 \mathrm{E}+02$ & $2.4 \mathrm{E}+03$ & $8.6 \mathrm{E}+03$ & $1.8 \mathrm{E}+02$ & $1.2 \mathrm{E}+02$ & $3.4 \mathrm{E}+02$ & $6.5 \mathrm{E}+04$ & $1.0 \mathrm{E}+01$ & $2.4 \mathrm{E}+02$ & $6.0 \mathrm{E}+02$ & $1.2 \mathrm{E}+03$ & $3.5 \mathrm{E}+02$ & $2.9 \mathrm{E}+04$ \\
\hline C5002-98E & 81.1 & $3.2 \mathrm{E}+02$ & $9.0 \mathrm{E}+01$ & $4.5 \mathrm{E}+03$ & $1.1 \mathrm{E}+02$ & $3.0 \mathrm{E}+00$ & $1.1 \mathrm{E}+03$ & $6.6 \mathrm{E}+04$ & $3.7 \mathrm{E}+00$ & $1.1 \mathrm{E}+02$ & $6.6 \mathrm{E}+00$ & $4.5 \mathrm{E}+02$ & $1.5 \mathrm{E}+02$ & $2.6 \mathrm{E}+04$ \\
\hline C5002-99D & 82.0 & 4.6E-02 & $1.4 \mathrm{E}+02$ & $1.9 \mathrm{E}+03$ & $6.1 \mathrm{E}+01$ & 9.2E-01 & $9.0 \mathrm{E}+00$ & $1.8 \mathrm{E}+04$ & $2.1 \mathrm{E}-01$ & $4.5 \mathrm{E}+01$ & $1.5 \mathrm{E}+00$ & $2.3 \mathrm{E}+02$ & $4.3 \mathrm{E}+01$ & $8.1 \mathrm{E}+03$ \\
\hline C5002-100A & 84.0 & $5.7 \mathrm{E}+01$ & $5.9 \mathrm{E}+02$ & $2.0 \mathrm{E}+03$ & $2.7 \mathrm{E}+01$ & $3.0 \mathrm{E}+01$ & $3.3 \mathrm{E}+01$ & $1.0 \mathrm{E}+04$ & $1.8 \mathrm{E}+00$ & 2.3E-01 & $1.5 \mathrm{E}+02$ & $5.4 \mathrm{E}-01$ & $1.1 \mathrm{E}+02$ & $8.0 \mathrm{E}+03$ \\
\hline
\end{tabular}


Table D.7. (contd)

\begin{tabular}{|c|c|c|c|c|c|c|c|c|c|c|c|c|c|c|}
\hline Sample ID & $\begin{array}{l}\text { Depth } \\
\text { (ft bgs) }\end{array}$ & $\begin{array}{c}\mathrm{Li} \\
(\mu \mathrm{g} / \mathrm{L})\end{array}$ & $\begin{array}{c}\mathrm{Mg} \\
(\mu \mathrm{g} / \mathrm{L})\end{array}$ & $\begin{array}{c}\mathrm{Mn} \\
(\mu \mathrm{g} / \mathrm{L})\end{array}$ & $\begin{array}{c}\text { Mo } \\
(\mu \mathrm{g} / \mathrm{L})\end{array}$ & $\begin{array}{c}\mathrm{Ni} \\
(\mu \mathrm{g} / \mathrm{L})\end{array}$ & $\begin{array}{c}P \\
(\mu \mathrm{g} / \mathrm{L})\end{array}$ & $\begin{array}{c}\mathrm{Pb} \\
(\mu \mathrm{g} / \mathrm{L})\end{array}$ & $\begin{array}{c}\text { Se } \\
(\mu \mathrm{g} / \mathrm{L})\end{array}$ & $\begin{array}{c}\mathrm{Sr} \\
(\mu \mathrm{g} / \mathrm{L})\end{array}$ & $\begin{array}{c}\mathrm{Ti} \\
(\mu \mathrm{g} / \mathrm{L})\end{array}$ & $\begin{array}{c}\mathrm{V} \\
(\mu \mathrm{g} / \mathrm{L})\end{array}$ & $\mathrm{Zn}(\mu \mathrm{g} / \mathrm{L})$ & $\begin{array}{c}\mathrm{Na} \\
(\mu \mathrm{g} / \mathrm{L})\end{array}$ \\
\hline \multicolumn{15}{|c|}{ Groundwater } \\
\hline B1HT04 & 52.3 & $6.2 \mathrm{E}+00$ & $1.0 \mathrm{E}+04$ & $7.4 \mathrm{E}+00$ & $5.4 \mathrm{E}+00$ & $1.1 \mathrm{E}+01$ & $1.8 \mathrm{E}+02$ & $3.0 \mathrm{E}+01$ & $2.6 \mathrm{E}+02$ & $2.4 \mathrm{E}+02$ & $1.4 \mathrm{E}+01$ & $7.5 \mathrm{E}+01$ & $1.5 \mathrm{E}+01$ & $2.4 \mathrm{E}+04$ \\
\hline B1HT08 & 61.5 & $1.1 \mathrm{E}+01$ & $1.0 \mathrm{E}+04$ & $3.0 \mathrm{E}+01$ & $5.0 \mathrm{E}+00$ & $1.2 \mathrm{E}+01$ & $1.6 \mathrm{E}+02$ & $3.0 \mathrm{E}+01$ & $2.6 \mathrm{E}+02$ & $2.1 \mathrm{E}+02$ & $3.0 \mathrm{E}+02$ & $7.5 \mathrm{E}+01$ & $1.1 \mathrm{E}+01$ & $2.3 \mathrm{E}+04$ \\
\hline B1HT12 & 72.5 & $3.0 \mathrm{E}+02$ & $1.0 \mathrm{E}+04$ & $7.4 \mathrm{E}+01$ & $6.1 \mathrm{E}+00$ & $1.1 \mathrm{E}+01$ & $1.2 \mathrm{E}+02$ & $3.0 \mathrm{E}+01$ & $2.5 \mathrm{E}+02$ & $2.3 \mathrm{E}+02$ & $2.7 \mathrm{E}+01$ & $7.5 \mathrm{E}+01$ & $8.0 \mathrm{E}+00$ & $2.4 \mathrm{E}+04$ \\
\hline B1HT16 & 91.0 & $1.9 \mathrm{E}+00$ & $5.4 \mathrm{E}+03$ & $7.2 \mathrm{E}+01$ & $4.9 \mathrm{E}+00$ & $1.0 \mathrm{E}+01$ & $1.1 \mathrm{E}+02$ & $3.0 \mathrm{E}+01$ & $1.4 \mathrm{E}+02$ & $1.1 \mathrm{E}+02$ & $5.7 \mathrm{E}+00$ & $7.5 \mathrm{E}+01$ & $2.9 \mathrm{E}+00$ & $2.9 \mathrm{E}+04$ \\
\hline \multicolumn{15}{|c|}{ Water Extracts (Concentration Values Were Dilution Corrected) } \\
\hline C5002-83B & 11.5 & $3.0 \mathrm{E}+02$ & $1.2 \mathrm{E}+05$ & $4.5 \mathrm{E}+01$ & $6.9 \mathrm{E}+03$ & $1.6 \mathrm{E}+02$ & $8.2 \mathrm{E}+03$ & $1.4 \mathrm{E}+03$ & $1.8 \mathrm{E}+03$ & $1.2 \mathrm{E}+03$ & $1.4 \mathrm{E}+04$ & $1.1 \mathrm{E}+03$ & $6.2 \mathrm{E}+03$ & $3.2 \mathrm{E}+05$ \\
\hline C5002-84C & 16.0 & $8.2 \mathrm{E}+02$ & $7.1 \mathrm{E}+04$ & $7.0 \mathrm{E}+01$ & $3.0 \mathrm{E}+02$ & $2.8 \mathrm{E}+02$ & $4.2 \mathrm{E}+03$ & $9.9 \mathrm{E}+01$ & $5.8 \mathrm{E}+03$ & $1.2 \mathrm{E}+03$ & $5.8 \mathrm{E}+03$ & $1.5 \mathrm{E}+03$ & $1.9 \mathrm{E}+03$ & $2.1 \mathrm{E}+05$ \\
\hline C5002-86E & 21.5 & $3.0 \mathrm{E}+04$ & $9.5 \mathrm{E}+04$ & $1.7 \mathrm{E}+02$ & $2.3 \mathrm{E}+02$ & 4.7E+01 & $1.7 \mathrm{E}+03$ & $6.0 \mathrm{E}+02$ & $1.9 \mathrm{E}+03$ & $1.2 \mathrm{E}+03$ & $6.0 \mathrm{E}+03$ & $2.8 \mathrm{E}+02$ & $2.5 \mathrm{E}+03$ & $3.3 \mathrm{E}+05$ \\
\hline C5002-87D & 24.5 & $2.7 \mathrm{E}+02$ & $8.8 \mathrm{E}+04$ & $3.1 \mathrm{E}+02$ & $2.8 \mathrm{E}+03$ & $9.3 \mathrm{E}+01$ & $1.2 \mathrm{E}+03$ & $3.2 \mathrm{E}+01$ & $3.8 \mathrm{E}+03$ & $1.0 \mathrm{E}+03$ & $2.8 \mathrm{E}+03$ & $4.2 \mathrm{E}+02$ & $9.8 \mathrm{E}+02$ & $2.6 \mathrm{E}+05$ \\
\hline C5002-90A & 32.5 & $6.0 \mathrm{E}+02$ & $9.9 \mathrm{E}+04$ & $1.7 \mathrm{E}+02$ & $1.0 \mathrm{E}+03$ & $3.2 \mathrm{E}+02$ & $9.8 \mathrm{E}+02$ & $6.4 \mathrm{E}+03$ & $6.3 \mathrm{E}+03$ & $2.2 \mathrm{E}+03$ & $3.2 \mathrm{E}+03$ & $3.2 \mathrm{E}+02$ & $1.3 \mathrm{E}+03$ & $2.6 \mathrm{E}+05$ \\
\hline C5002-90C & 34.5 & $4.5 \mathrm{E}+02$ & $3.5 \mathrm{E}+04$ & $3.3 \mathrm{E}+02$ & $3.2 \mathrm{E}+01$ & $1.6 \mathrm{E}+02$ & $4.4 \mathrm{E}+02$ & $4.9 \mathrm{E}+03$ & $3.5 \mathrm{E}+03$ & $8.4 \mathrm{E}+02$ & $2.4 \mathrm{E}+03$ & $4.9 \mathrm{E}+02$ & $9.1 \mathrm{E}+02$ & $1.4 \mathrm{E}+05$ \\
\hline C5002-91C & 39.5 & $2.9 \mathrm{E}+02$ & $5.1 \mathrm{E}+04$ & $2.4 \mathrm{E}+02$ & $6.8 \mathrm{E}+02$ & $7.7 \mathrm{E}+01$ & $7.3 \mathrm{E}+02$ & $6.4 \mathrm{E}+02$ & $2.9 \mathrm{E}+02$ & $1.2 \mathrm{E}+03$ & $6.4 \mathrm{E}+03$ & $4.5 \mathrm{E}+02$ & $2.8 \mathrm{E}+03$ & $2.6 \mathrm{E}+05$ \\
\hline C5002-91D & 40.5 & $3.7 \mathrm{E}+02$ & $2.9 \mathrm{E}+04$ & $1.2 \mathrm{E}+02$ & $2.6 \mathrm{E}+02$ & $1.7 \mathrm{E}+02$ & $1.1 \mathrm{E}+03$ & $1.6 \mathrm{E}+02$ & $3.4 \mathrm{E}+03$ & $6.3 \mathrm{E}+02$ & $2.2 \mathrm{E}+03$ & $4.6 \mathrm{E}+02$ & $8.3 \mathrm{E}+02$ & $1.5 \mathrm{E}+05$ \\
\hline C5002-92D & 48.5 & $8.8 \mathrm{E}+01$ & $3.1 \mathrm{E}+04$ & $6.4 \mathrm{E}+02$ & $1.5 \mathrm{E}+02$ & $6.2 \mathrm{E}+01$ & $3.0 \mathrm{E}+02$ & $4.4 \mathrm{E}+02$ & $1.1 \mathrm{E}+03$ & $6.7 \mathrm{E}+02$ & $4.4 \mathrm{E}+03$ & $2.0 \mathrm{E}+02$ & $1.8 \mathrm{E}+03$ & $1.2 \mathrm{E}+05$ \\
\hline C5002-93E & 54.5 & $1.2 \mathrm{E}+02$ & $2.4 \mathrm{E}+04$ & $2.0 \mathrm{E}+02$ & $8.5 \mathrm{E}+01$ & $4.3 \mathrm{E}+01$ & $4.5 E+02$ & $4.9 \mathrm{E}+02$ & $1.2 \mathrm{E}+03$ & $5.2 \mathrm{E}+02$ & $4.9 \mathrm{E}+03$ & $2.7 \mathrm{E}+02$ & $1.4 \mathrm{E}+03$ & $1.1 \mathrm{E}+05$ \\
\hline C5002-94D & 65.5 & $2.4 \mathrm{E}+04$ & $1.3 \mathrm{E}+04$ & $6.2 \mathrm{E}+01$ & $2.4 \mathrm{E}+03$ & $4.1 \mathrm{E}+01$ & $4.4 \mathrm{E}+02$ & $4.8 \mathrm{E}+02$ & $6.1 \mathrm{E}+02$ & $2.8 \mathrm{E}+02$ & $4.8 \mathrm{E}+03$ & $1.8 \mathrm{E}+02$ & $2.5 \mathrm{E}+03$ & $8.1 \mathrm{E}+04$ \\
\hline C5002-98E & 81.1 & $1.1 \mathrm{E}+04$ & $1.3 \mathrm{E}+04$ & $2.1 \mathrm{E}+02$ & $5.4 \mathrm{E}+01$ & $7.3 \mathrm{E}+00$ & $3.0 \mathrm{E}+02$ & $2.2 \mathrm{E}+02$ & $8.3 \mathrm{E}+02$ & $2.9 \mathrm{E}+02$ & $2.2 \mathrm{E}+03$ & $5.4 \mathrm{E}+02$ & $6.3 \mathrm{E}+02$ & $6.9 \mathrm{E}+04$ \\
\hline C5002-99D & 82.0 & $4.5 \mathrm{E}+03$ & $4.2 \mathrm{E}+03$ & $2.0 \mathrm{E}+01$ & $2.9 \mathrm{E}+01$ & 7.4E-01 & $8.1 \mathrm{E}+01$ & $9.0 \mathrm{E}+01$ & $3.6 \mathrm{E}+02$ & $9.4 \mathrm{E}+01$ & $2.5 \mathrm{E}+01$ & $2.4 \mathrm{E}+01$ & $5.1 \mathrm{E}+02$ & $2.9 \mathrm{E}+04$ \\
\hline C5002-100A & 84.0 & $3.5 \mathrm{E}+01$ & $2.4 \mathrm{E}+03$ & $2.9 \mathrm{E}+01$ & $7.4 \mathrm{E}+00$ & $4.8 \mathrm{E}+00$ & $3.2 \mathrm{E}+01$ & $1.2 \mathrm{E}+02$ & $1.2 \mathrm{E}+03$ & $5.6 \mathrm{E}+01$ & $1.2 \mathrm{E}+03$ & $1.1 \mathrm{E}+02$ & $9.0 \mathrm{E}+01$ & $2.9 \mathrm{E}+04$ \\
\hline
\end{tabular}


Table D.7. (contd)

\begin{tabular}{|c|c|c|c|c|c|c|c|c|}
\hline Sample ID & $\begin{array}{c}\text { Depth } \\
\text { (ft bgs) }\end{array}$ & $\begin{array}{c}\mathrm{Si} \\
(\mu \mathrm{g} / \mathrm{L})\end{array}$ & $\begin{array}{c}\mathrm{S} \\
(\mu \mathrm{g} / \mathrm{L})\end{array}$ & $\begin{array}{c}\mathrm{Ti} \\
(\mu \mathrm{g} / \mathrm{L})\end{array}$ & $\begin{array}{c}\mathrm{Zr} \\
(\mu \mathrm{g} / \mathrm{L})\end{array}$ & $\begin{array}{c}\mathrm{Ag} \\
(\mu \mathrm{g} / \mathrm{L})\end{array}$ & $\begin{array}{c}\mathrm{Re} \\
(\mu \mathrm{g} / \mathrm{L})\end{array}$ & $\begin{array}{c}\mathrm{Sb} \\
(\mu \mathrm{g} / \mathrm{L})\end{array}$ \\
\hline \multicolumn{9}{|c|}{ Groundwater } \\
\hline В1HT04 & 52.3 & $1.2 \mathrm{E}+04$ & $1.8 \mathrm{E}+04$ & $7.5 \mathrm{E}+00$ & 4.7E-01 & $7.5 \mathrm{E}+01$ & $6.9 \mathrm{E}+00$ & $2.7 \mathrm{E}+01$ \\
\hline В1НT08 & 61.5 & $1.3 \mathrm{E}+04$ & $1.8 \mathrm{E}+04$ & $7.5 \mathrm{E}+00$ & 2.3E-01 & $7.5 \mathrm{E}+01$ & $8.5 \mathrm{E}+00$ & $1.8 \mathrm{E}+01$ \\
\hline B1HT12 & 72.5 & $1.3 \mathrm{E}+04$ & $1.8 \mathrm{E}+04$ & $2.5 \mathrm{E}-01$ & 3.6E-01 & $7.5 \mathrm{E}+01$ & $4.5 \mathrm{E}+00$ & $1.1 \mathrm{E}+01$ \\
\hline B1HT16 & 91.0 & $1.7 \mathrm{E}+04$ & $2.3 \mathrm{E}+03$ & $7.5 \mathrm{E}+00$ & 2.3E-01 & $7.5 \mathrm{E}+01$ & $4.0 \mathrm{E}+00$ & $3.4 \mathrm{E}+01$ \\
\hline \multicolumn{9}{|c|}{ Water Extracts (Concentration Values Were Dilution Corrected) } \\
\hline C5002-83B & 11.5 & $4.7 \mathrm{E}+05$ & $1.7 \mathrm{E}+05$ & $3.6 \mathrm{E}+01$ & $6.9 \mathrm{E}+02$ & $6.9 \mathrm{E}+03$ & $6.9 \mathrm{E}+03$ & $6.9 \mathrm{E}+03$ \\
\hline C5002-84C & 16.0 & $4.1 \mathrm{E}+05$ & $7.4 \mathrm{E}+04$ & $7.2 \mathrm{E}+01$ & $3.9 \mathrm{E}+01$ & $2.3 \mathrm{E}+03$ & $1.0 \mathrm{E}+03$ & $1.3 \mathrm{E}+03$ \\
\hline C5002-86E & 21.5 & $2.3 \mathrm{E}+05$ & $1.1 \mathrm{E}+05$ & $8.2 \mathrm{E}-01$ & $1.6 \mathrm{E}+01$ & $3.0 \mathrm{E}+03$ & $3.0 \mathrm{E}+03$ & $3.0 \mathrm{E}+03$ \\
\hline C5002-87D & 24.5 & $2.1 \mathrm{E}+05$ & $1.0 \mathrm{E}+05$ & $2.8 \mathrm{E}+02$ & $2.2 \mathrm{E}+01$ & $1.1 \mathrm{E}+03$ & $1.7 \mathrm{E}+02$ & $1.9 \mathrm{E}+02$ \\
\hline C5002-90A & 32.5 & $2.3 \mathrm{E}+05$ & $2.0 \mathrm{E}+05$ & $2.9 \mathrm{E}+01$ & $5.6 \mathrm{E}+01$ & $1.3 \mathrm{E}+03$ & $5.5 \mathrm{E}+02$ & $2.9 \mathrm{E}+02$ \\
\hline C5002-90C & 34.5 & $1.6 \mathrm{E}+05$ & $7.3 \mathrm{E}+04$ & $4.8 \mathrm{E}+00$ & $1.3 \mathrm{E}+01$ & $9.7 \mathrm{E}+02$ & $3.3 \mathrm{E}+02$ & $4.9 \mathrm{E}+03$ \\
\hline C5002-91C & 39.5 & $1.7 \mathrm{E}+05$ & $1.5 \mathrm{E}+05$ & $1.1 \mathrm{E}+01$ & $3.2 \mathrm{E}+02$ & $3.2 \mathrm{E}+03$ & $3.2 \mathrm{E}+03$ & $3.2 \mathrm{E}+03$ \\
\hline C5002-91D & 40.5 & $1.4 \mathrm{E}+05$ & $1.1 \mathrm{E}+05$ & $6.5 \mathrm{E}+01$ & $1.7 \mathrm{E}+01$ & $3.6 \mathrm{E}+00$ & $4.8 \mathrm{E}+02$ & $1.3 \mathrm{E}+02$ \\
\hline C5002-92D & 48.5 & $8.7 \mathrm{E}+04$ & $5.3 \mathrm{E}+04$ & $2.1 \mathrm{E}+00$ & $2.2 \mathrm{E}+02$ & $2.2 \mathrm{E}+03$ & $2.2 \mathrm{E}+03$ & $2.2 \mathrm{E}+03$ \\
\hline C5002-93E & 54.5 & $9.0 \mathrm{E}+04$ & $4.3 \mathrm{E}+04$ & $2.5 \mathrm{E}+00$ & $2.4 \mathrm{E}+02$ & $2.4 \mathrm{E}+03$ & $2.4 \mathrm{E}+03$ & $2.4 \mathrm{E}+03$ \\
\hline C5002-94D & 65.5 & $6.6 \mathrm{E}+04$ & $3.1 \mathrm{E}+04$ & $9.3 \mathrm{E}+00$ & $2.4 \mathrm{E}+02$ & $2.4 \mathrm{E}+03$ & $2.4 \mathrm{E}+03$ & $2.4 \mathrm{E}+03$ \\
\hline C5002-98E & 81.1 & $3.9 \mathrm{E}+04$ & $1.8 \mathrm{E}+04$ & $2.2 \mathrm{E}+00$ & $3.3 \mathrm{E}+00$ & $1.1 \mathrm{E}+03$ & $1.1 \mathrm{E}+03$ & $1.1 \mathrm{E}+03$ \\
\hline C5002-99D & 82.0 & $3.3 \mathrm{E}+04$ & $1.1 \mathrm{E}+04$ & 2.9E-01 & 8.7E-01 & $4.5 \mathrm{E}+02$ & $4.5 \mathrm{E}+02$ & $4.5 \mathrm{E}+02$ \\
\hline C5002-100A & 84.0 & $4.3 \mathrm{E}+04$ & $9.7 \mathrm{E}+03$ & $3.2 \mathrm{E}+00$ & $5.9 \mathrm{E}+01$ & $5.9 \mathrm{E}+02$ & $5.9 \mathrm{E}+02$ & $5.9 \mathrm{E}+02$ \\
\hline
\end{tabular}


Table D.8. Major Elements of Sediment Samples Using Microwave Digestion/ICP-OES

\begin{tabular}{|c|c|c|c|c|c|c|c|c|c|c|c|c|c|c|}
\hline Wells & Sample ID & $\begin{array}{c}\text { Depth } \\
\text { (ft bgs) }\end{array}$ & $\begin{array}{c}\mathrm{Si} \\
(\mu \mathrm{g} / \mathrm{g})\end{array}$ & $\begin{array}{c}\mathrm{Al} \\
(\mu \mathrm{g} / \mathrm{g})\end{array}$ & $\begin{array}{c}\mathrm{Fe} \\
(\mu \mathrm{g} / \mathrm{g})\end{array}$ & $\begin{array}{c}\text { Ca } \\
(\mu \mathrm{g} / \mathrm{g})\end{array}$ & $\begin{array}{c}\mathrm{Na} \\
(\mu \mathrm{g} / \mathrm{g})\end{array}$ & $\begin{array}{c}\mathrm{Mg} \\
(\mu \mathrm{g} / \mathrm{g})\end{array}$ & $\begin{array}{c}\mathrm{K} \\
(\mu \mathrm{g} / \mathrm{g})\end{array}$ & $\begin{array}{c}\mathrm{Ti} \\
(\mu \mathrm{g} / \mathrm{g})\end{array}$ & $\begin{array}{c}\mathrm{S} \\
(\mu \mathrm{g} / \mathrm{g}\end{array}$ & $\begin{array}{c}\text { Mn } \\
(\mu \mathrm{g} / \mathrm{g})\end{array}$ & $\begin{array}{c}P \\
(\mu \mathrm{g} / \mathrm{g})\end{array}$ & $\begin{array}{c}\mathrm{Sr} \\
(\mu \mathrm{g} / \mathrm{g})\end{array}$ \\
\hline \multirow{6}{*}{ C4999 } & C4999-3B & 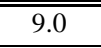 & $2.1 \mathrm{E}+05$ & $4.2 \mathrm{E}+04$ & $4.5 \mathrm{E}+04$ & $2.4 \mathrm{E}+04$ & $1.7 \mathrm{E}+04$ & $8.4 \mathrm{E}+03$ & $1.4 \mathrm{E}+04$ & $6.4 \mathrm{E}+03$ & $1.0 \mathrm{E}+04$ & $8.5 \mathrm{E}+02$ & $9.5 \mathrm{E}+02$ & $3.6 \mathrm{E}+02$ \\
\hline & C4999-5D & 18.0 & $2.0 \mathrm{E}+05$ & $3.3 \mathrm{E}+04$ & $7.5 \mathrm{E}+04$ & $4.5 \mathrm{E}+04$ & $1.5 \mathrm{E}+04$ & $1.1 \mathrm{E}+04$ & $9.0 \mathrm{E}+03$ & $1.2 \mathrm{E}+04$ & $9.6 \mathrm{E}+03$ & $1.3 \mathrm{E}+03$ & $1.5 \mathrm{E}+03$ & $3.1 \mathrm{E}+02$ \\
\hline & C4999-6D & 23.0 & $1.7 \mathrm{E}+05$ & $3.2 \mathrm{E}+04$ & $6.6 \mathrm{E}+04$ & $3.7 \mathrm{E}+04$ & $1.7 \mathrm{E}+04$ & $1.0 \mathrm{E}+04$ & $1.0 \mathrm{E}+04$ & $9.3 \mathrm{E}+03$ & $9.9 \mathrm{E}+03$ & $1.2 \mathrm{E}+03$ & $1.4 \mathrm{E}+03$ & $3.2 \mathrm{E}+02$ \\
\hline & C4999-9B & 30.5 & $2.2 \mathrm{E}+05$ & $3.3 \mathrm{E}+04$ & $7.8 \mathrm{E}+04$ & $4.2 \mathrm{E}+04$ & $1.7 \mathrm{E}+04$ & $1.0 \mathrm{E}+04$ & $9.3 \mathrm{E}+03$ & $1.2 \mathrm{E}+04$ & $9.6 \mathrm{E}+03$ & $1.4 \mathrm{E}+03$ & $1.6 \mathrm{E}+03$ & $2.9 \mathrm{E}+02$ \\
\hline & C4999-10C & 35.5 & $1.8 \mathrm{E}+05$ & $4.5 \mathrm{E}+04$ & $7.1 \mathrm{E}+04$ & $3.8 \mathrm{E}+04$ & $1.6 \mathrm{E}+04$ & $1.4 \mathrm{E}+04$ & $1.1 \mathrm{E}+04$ & $1.1 \mathrm{E}+04$ & $9.8 \mathrm{E}+03$ & $1.2 \mathrm{E}+03$ & $1.4 \mathrm{E}+03$ & $2.9 \mathrm{E}+02$ \\
\hline & C4999-12C & 46.0 & $1.7 \mathrm{E}+05$ & $3.0 \mathrm{E}+04$ & $7.1 \mathrm{E}+04$ & $4.0 \mathrm{E}+04$ & $1.7 \mathrm{E}+04$ & $9.3 \mathrm{E}+03$ & $8.0 \mathrm{E}+03$ & $1.1 \mathrm{E}+04$ & $9.5 \mathrm{E}+03$ & $1.2 \mathrm{E}+03$ & $1.5 \mathrm{E}+03$ & $3.1 \mathrm{E}+02$ \\
\hline \multirow{6}{*}{ C5000 } & C5000-36A & 11.0 & $1.8 \mathrm{E}+05$ & $2.9 \mathrm{E}+04$ & $7.2 \mathrm{E}+04$ & $3.9 \mathrm{E}+04$ & $1.9 \mathrm{E}+04$ & $8.5 \mathrm{E}+03$ & $8.7 \mathrm{E}+03$ & $1.1 \mathrm{E}+04$ & $9.8 \mathrm{E}+03$ & $1.3 \mathrm{E}+03$ & $1.6 \mathrm{E}+03$ & $3.3 \mathrm{E}+02$ \\
\hline & C5000-37A & 13.0 & $1.7 \mathrm{E}+05$ & $3.0 \mathrm{E}+04$ & $8.3 \mathrm{E}+04$ & $4.7 \mathrm{E}+04$ & $1.8 \mathrm{E}+04$ & $1.0 \mathrm{E}+04$ & $9.2 \mathrm{E}+03$ & $1.3 \mathrm{E}+04$ & $9.8 \mathrm{E}+03$ & $1.4 \mathrm{E}+03$ & $1.8 \mathrm{E}+03$ & $3.1 \mathrm{E}+02$ \\
\hline & C5000-40A & 30.0 & $1.8 \mathrm{E}+05$ & $3.1 \mathrm{E}+04$ & $7.2 \mathrm{E}+04$ & $4.1 \mathrm{E}+04$ & $1.7 \mathrm{E}+04$ & $9.7 \mathrm{E}+03$ & $9.6 \mathrm{E}+03$ & $1.1 \mathrm{E}+04$ & $9.5 \mathrm{E}+03$ & $1.3 \mathrm{E}+03$ & $1.6 \mathrm{E}+03$ & $3.2 \mathrm{E}+02$ \\
\hline & C5000-40B & 31.0 & $1.7 \mathrm{E}+05$ & $4.0 \mathrm{E}+04$ & $7.0 \mathrm{E}+04$ & $3.9 \mathrm{E}+04$ & $1.7 \mathrm{E}+04$ & $1.2 \mathrm{E}+04$ & $9.3 \mathrm{E}+03$ & $1.1 \mathrm{E}+04$ & $9.5 \mathrm{E}+03$ & $1.2 \mathrm{E}+03$ & $1.5 \mathrm{E}+03$ & $3.1 \mathrm{E}+02$ \\
\hline & C5000-40C & 32.0 & $1.8 \mathrm{E}+05$ & $4.7 \mathrm{E}+04$ & $7.4 \mathrm{E}+04$ & $4.2 \mathrm{E}+04$ & $1.7 \mathrm{E}+04$ & $1.4 \mathrm{E}+04$ & $9.9 \mathrm{E}+03$ & $1.2 \mathrm{E}+04$ & $9.5 \mathrm{E}+03$ & $1.3 \mathrm{E}+03$ & $1.7 \mathrm{E}+03$ & $3.1 \mathrm{E}+02$ \\
\hline & C5000-41C & 36.0 & $1.6 \mathrm{E}+05$ & $3.1 \mathrm{E}+04$ & $7.9 \mathrm{E}+04$ & $4.5 \mathrm{E}+04$ & $1.8 \mathrm{E}+04$ & $9.1 \mathrm{E}+03$ & $7.9 \mathrm{E}+03$ & $1.2 \mathrm{E}+04$ & $9.6 \mathrm{E}+03$ & $1.4 \mathrm{E}+03$ & $1.7 \mathrm{E}+03$ & $3.4 \mathrm{E}+02$ \\
\hline \multirow{10}{*}{ C5001 } & C5001-63C & 8.0 & $1.6 \mathrm{E}+05$ & $6.5 \mathrm{E}+04$ & $3.7 \mathrm{E}+04$ & $2.4 \mathrm{E}+04$ & $2.4 \mathrm{E}+04$ & $1.0 \mathrm{E}+04$ & $1.8 \mathrm{E}+04$ & $4.8 \mathrm{E}+03$ & $2.4 \mathrm{E}+01$ & $7.3 \mathrm{E}+02$ & $8.3 \mathrm{E}+02$ & $4.8 \mathrm{E}+02$ \\
\hline & C5001-66A & 21.0 & $1.6 \mathrm{E}+05$ & $4.7 \mathrm{E}+04$ & $8.1 \mathrm{E}+04$ & $4.7 \mathrm{E}+04$ & $2.1 \mathrm{E}+04$ & $1.5 \mathrm{E}+04$ & $9.5 \mathrm{E}+03$ & $1.3 \mathrm{E}+04$ & $8.6 \mathrm{E}+03$ & $1.4 \mathrm{E}+03$ & $1.8 \mathrm{E}+03$ & $3.6 \mathrm{E}+02$ \\
\hline & C5001-68B & 29.0 & $1.8 \mathrm{E}+05$ & $6.2 \mathrm{E}+04$ & $8.9 \mathrm{E}+04$ & $5.1 \mathrm{E}+04$ & $2.0 \mathrm{E}+04$ & $2.1 \mathrm{E}+04$ & $1.2 \mathrm{E}+04$ & $1.4 \mathrm{E}+04$ & $9.0 \mathrm{E}+03$ & $1.5 \mathrm{E}+03$ & $1.9 \mathrm{E}+03$ & $3.3 \mathrm{E}+02$ \\
\hline & C5001-69D & 34.0 & $1.7 \mathrm{E}+05$ & $5.2 \mathrm{E}+04$ & $7.8 \mathrm{E}+04$ & $5.0 \mathrm{E}+04$ & $1.9 \mathrm{E}+04$ & $1.7 \mathrm{E}+04$ & $1.2 \mathrm{E}+04$ & $1.2 \mathrm{E}+04$ & $9.2 \mathrm{E}+03$ & $1.4 \mathrm{E}+03$ & $1.7 \mathrm{E}+03$ & $3.1 \mathrm{E}+02$ \\
\hline & C5001-70E & 40.5 & $1.6 \mathrm{E}+05$ & $5.9 \mathrm{E}+04$ & $7.7 \mathrm{E}+04$ & $4.7 \mathrm{E}+04$ & $2.0 \mathrm{E}+04$ & $1.9 \mathrm{E}+04$ & $1.2 \mathrm{E}+04$ & $1.2 \mathrm{E}+04$ & $8.9 \mathrm{E}+03$ & $1.4 \mathrm{E}+03$ & $1.6 \mathrm{E}+03$ & $3.3 \mathrm{E}+02$ \\
\hline & $\begin{array}{l}\text { C5001-73B } \\
\end{array}$ & 25.8 & $1.8 \mathrm{E}+05$ & $5.8 \mathrm{E}+04$ & $7.4 \mathrm{E}+04$ & $4.4 \mathrm{E}+04$ & $1.9 \mathrm{E}+04$ & $1.7 \mathrm{E}+04$ & $1.2 \mathrm{E}+04$ & $1.2 \mathrm{E}+04$ & $9.1 \mathrm{E}+03$ & $1.3 \mathrm{E}+03$ & $1.6 \mathrm{E}+03$ & $3.2 \mathrm{E}+02$ \\
\hline & C5001-74B & 53.5 & $1.9 \mathrm{E}+05$ & $5.7 \mathrm{E}+04$ & $7.6 \mathrm{E}+04$ & $4.8 \mathrm{E}+04$ & $2.1 \mathrm{E}+04$ & $1.8 \mathrm{E}+04$ & $1.2 \mathrm{E}+04$ & $1.2 \mathrm{E}+04$ & $9.3 \mathrm{E}+03$ & $1.4 \mathrm{E}+03$ & $1.7 \mathrm{E}+03$ & $3.5 \mathrm{E}+02$ \\
\hline & C5001-76D & 65.5 & $1.5 \mathrm{E}+05$ & $5.8 \mathrm{E}+04$ & $7.7 \mathrm{E}+04$ & $4.6 \mathrm{E}+04$ & $2.1 \mathrm{E}+04$ & $1.8 \mathrm{E}+04$ & $1.2 \mathrm{E}+04$ & $1.2 \mathrm{E}+04$ & $9.0 \mathrm{E}+03$ & $1.4 \mathrm{E}+03$ & $1.6 \mathrm{E}+03$ & $3.3 \mathrm{E}+02$ \\
\hline & C5001-79A & 81.5 & $1.7 \mathrm{E}+05$ & $5.4 \mathrm{E}+04$ & $5.0 \mathrm{E}+04$ & $2.7 \mathrm{E}+04$ & $1.7 \mathrm{E}+04$ & $1.3 \mathrm{E}+04$ & $1.4 \mathrm{E}+04$ & $7.3 \mathrm{E}+03$ & $6.8 \mathrm{E}+01$ & $1.0 \mathrm{E}+03$ & $1.1 \mathrm{E}+03$ & $2.8 \mathrm{E}+02$ \\
\hline & C5001-80A & 85.5 & $1.6 \mathrm{E}+05$ & $7.1 \mathrm{E}+04$ & $3.2 \mathrm{E}+04$ & $1.2 \mathrm{E}+04$ & $1.6 \mathrm{E}+04$ & $8.4 \mathrm{E}+03$ & $2.4 \mathrm{E}+04$ & $3.5 \mathrm{E}+03$ & $4.0 \mathrm{E}+01$ & $2.3 \mathrm{E}+02$ & $4.0 \mathrm{E}+02$ & $3.4 \mathrm{E}+02$ \\
\hline \multirow{13}{*}{ C5002 } & C5002-84C & 16.0 & $2.2 \mathrm{E}+05$ & $6.7 \mathrm{E}+04$ & $2.8 \mathrm{E}+04$ & $3.0 \mathrm{E}+04$ & $2.8 \mathrm{E}+04$ & $8.4 \mathrm{E}+03$ & $2.3 \mathrm{E}+04$ & $4.0 \mathrm{E}+03$ & $1.0 \mathrm{E}+04$ & $5.1 \mathrm{E}+02$ & $7.6 \mathrm{E}+02$ & $6.1 \mathrm{E}+02$ \\
\hline & $\begin{array}{l}\mathrm{C} 5002-86 \mathrm{E} \\
\end{array}$ & 21.5 & $1.8 \mathrm{E}+05$ & $4.9 \mathrm{E}+04$ & $7.1 \mathrm{E}+04$ & $3.7 \mathrm{E}+04$ & $1.7 \mathrm{E}+04$ & $1.5 \mathrm{E}+04$ & $1.0 \mathrm{E}+04$ & $1.1 \mathrm{E}+04$ & $9.2 \mathrm{E}+03$ & $1.4 \mathrm{E}+03$ & $1.4 \mathrm{E}+03$ & $3.2 \mathrm{E}+02$ \\
\hline & C5002-87D & 24.5 & $2.1 \mathrm{E}+05$ & $3.8 \mathrm{E}+04$ & $7.6 \mathrm{E}+04$ & $4.4 \mathrm{E}+04$ & $1.8 \mathrm{E}+04$ & $1.1 \mathrm{E}+04$ & $1.1 \mathrm{E}+04$ & $1.2 \mathrm{E}+04$ & $1.0 \mathrm{E}+04$ & $1.3 \mathrm{E}+03$ & $1.6 \mathrm{E}+03$ & $3.5 \mathrm{E}+02$ \\
\hline & C5002-90A & 32.5 & $1.8 \mathrm{E}+05$ & $4.0 \mathrm{E}+04$ & $7.0 \mathrm{E}+04$ & $4.2 \mathrm{E}+04$ & $1.8 \mathrm{E}+04$ & $1.2 \mathrm{E}+04$ & $1.1 \mathrm{E}+04$ & $1.1 \mathrm{E}+04$ & $9.8 \mathrm{E}+03$ & $1.3 \mathrm{E}+03$ & $1.5 \mathrm{E}+03$ & $3.3 \mathrm{E}+02$ \\
\hline & C5002-90C & 34.5 & $2.4 \mathrm{E}+05$ & $4.6 \mathrm{E}+04$ & $7.3 \mathrm{E}+04$ & $3.9 \mathrm{E}+04$ & $1.6 \mathrm{E}+04$ & $1.3 \mathrm{E}+04$ & $1.3 \mathrm{E}+04$ & $1.1 \mathrm{E}+04$ & $1.0 \mathrm{E}+04$ & $1.3 \mathrm{E}+03$ & $1.6 \mathrm{E}+03$ & $3.0 \mathrm{E}+02$ \\
\hline & C5002-91C & 39.5 & $1.7 \mathrm{E}+05$ & $5.5 \mathrm{E}+04$ & $6.7 \mathrm{E}+04$ & $3.7 \mathrm{E}+04$ & $1.8 \mathrm{E}+04$ & $1.6 \mathrm{E}+04$ & $1.2 \mathrm{E}+04$ & $1.0 \mathrm{E}+04$ & $9.2 \mathrm{E}+03$ & $1.2 \mathrm{E}+03$ & $1.4 \mathrm{E}+03$ & $2.7 \mathrm{E}+02$ \\
\hline & C5002-91D & 40.5 & $1.8 \mathrm{E}+05$ & $4.3 \mathrm{E}+04$ & $7.1 \mathrm{E}+04$ & $3.9 \mathrm{E}+04$ & $1.6 \mathrm{E}+04$ & $1.3 \mathrm{E}+04$ & $1.0 \mathrm{E}+04$ & $1.1 \mathrm{E}+04$ & $9.6 \mathrm{E}+03$ & $1.3 \mathrm{E}+03$ & $1.6 \mathrm{E}+03$ & $3.0 \mathrm{E}+02$ \\
\hline & C5002-92D & 48.5 & $1.9 \mathrm{E}+05$ & $4.3 \mathrm{E}+04$ & $8.1 \mathrm{E}+04$ & $4.6 \mathrm{E}+04$ & $1.8 \mathrm{E}+04$ & $1.4 \mathrm{E}+04$ & $9.9 \mathrm{E}+03$ & $1.3 \mathrm{E}+04$ & $9.0 \mathrm{E}+03$ & $1.4 \mathrm{E}+03$ & $1.6 \mathrm{E}+03$ & $3.1 \mathrm{E}+02$ \\
\hline & C5002-93E & 54.5 & $1.7 \mathrm{E}+05$ & $6.2 \mathrm{E}+04$ & $7.7 \mathrm{E}+04$ & $4.6 \mathrm{E}+04$ & $2.1 \mathrm{E}+04$ & $2.0 \mathrm{E}+04$ & $1.2 \mathrm{E}+04$ & $1.2 \mathrm{E}+04$ & $9.0 \mathrm{E}+03$ & $1.4 \mathrm{E}+03$ & $1.6 \mathrm{E}+03$ & $3.3 \mathrm{E}+02$ \\
\hline & C5002-94D & 65.5 & $1.6 \mathrm{E}+05$ & $5.5 \mathrm{E}+04$ & $7.9 \mathrm{E}+04$ & $4.6 \mathrm{E}+04$ & $2.0 \mathrm{E}+04$ & $1.7 \mathrm{E}+04$ & $1.1 \mathrm{E}+04$ & $1.2 \mathrm{E}+04$ & $8.9 \mathrm{E}+03$ & $1.3 \mathrm{E}+03$ & $1.6 \mathrm{E}+03$ & $3.3 \mathrm{E}+02$ \\
\hline & C5002-98E & 81.1 & $1.8 \mathrm{E}+05$ & $6.2 \mathrm{E}+04$ & $2.4 \mathrm{E}+04$ & $2.1 \mathrm{E}+04$ & $2.1 \mathrm{E}+04$ & $8.0 \mathrm{E}+03$ & $1.8 \mathrm{E}+04$ & $2.5 \mathrm{E}+03$ & $1.9 \mathrm{E}+02$ & $5.5 \mathrm{E}+02$ & $5.3 \mathrm{E}+02$ & $4.1 \mathrm{E}+02$ \\
\hline & C5002-99D & 82.0 & $1.7 \mathrm{E}+05$ & $7.0 \mathrm{E}+04$ & $2.7 \mathrm{E}+04$ & $1.3 \mathrm{E}+04$ & $1.6 \mathrm{E}+04$ & $7.8 \mathrm{E}+03$ & $2.8 \mathrm{E}+04$ & $3.3 \mathrm{E}+03$ & $9.3 \mathrm{E}+03$ & $3.6 \mathrm{E}+02$ & $1.1 \mathrm{E}+03$ & $3.6 \mathrm{E}+02$ \\
\hline & C5002-100A & 84.0 & $1.6 \mathrm{E}+05$ & $6.4 \mathrm{E}+04$ & $2.3 \mathrm{E}+04$ & $1.2 \mathrm{E}+04$ & $1.6 \mathrm{E}+04$ & $6.4 \mathrm{E}+03$ & $2.7 \mathrm{E}+04$ & $3.1 \mathrm{E}+03$ & $9.3 \mathrm{E}+03$ & $2.9 \mathrm{E}+02$ & $6.7 \mathrm{E}+02$ & $3.5 \mathrm{E}+02$ \\
\hline
\end{tabular}


Table D.9. Particle Size Distribution for Sediments (<2 mm) in C4999, C5000, C5001, and C5002

\begin{tabular}{|c|c|c|c|c|c|}
\hline \multirow[b]{2}{*}{ Wells } & \multirow[b]{2}{*}{ Sample ID } & \multirow{2}{*}{$\begin{array}{c}\text { Depth } \\
\text { (ft bgs) }\end{array}$} & \multicolumn{3}{|c|}{ Particle Size Distribution (\%) ${ }^{(\mathrm{a})}$} \\
\hline & & & Clay & Silt & Sand \\
\hline \multirow{13}{*}{$\begin{array}{l}\text { C4999 } \\
(399-3-18)\end{array}$} & C4999-3B & 9 & 3.28 & 15.67 & 81.05 \\
\hline & C4999-6A & 20 & 10.21 & 6.80 & 82.99 \\
\hline & C4999-6D & 23 & 11.82 & 36.55 & 51.63 \\
\hline & C4999-9C & 31.5 & 7.26 & 25.08 & 67.66 \\
\hline & C4999-10C & 35.5 & 9.09 & 30.53 & 60.39 \\
\hline & C4999-10D & 36.5 & 11.82 & 37.76 & 50.42 \\
\hline & C4999-11D & 41.5 & 8.27 & 38.30 & 53.43 \\
\hline & C4999-13E & 53 & 4.60 & 29.03 & 66.37 \\
\hline & C4999-15A & 58 & 22.65 & 9.87 & 67.47 \\
\hline & C4999-17B & 67 & 3.34 & 12.52 & 84.14 \\
\hline & C4999-22E & 90.5 & 8.76 & 22.61 & 68.62 \\
\hline & C4999-25B & 99.5 & 4.67 & 10.35 & 84.98 \\
\hline & C4999-31E & 127 & 10.03 & 54.21 & 35.75 \\
\hline \multirow{12}{*}{$\begin{array}{l}\text { C5000 } \\
(399-1-23)\end{array}$} & C5000-38B & 20 & 3.62 & 10.70 & 85.69 \\
\hline & C5000-38C & 21 & 13.27 & 18.29 & 68.44 \\
\hline & C5000-39B & 23 & 9.12 & 21.14 & 69.74 \\
\hline & C5000-39D & 25 & 9.54 & 20.12 & 70.34 \\
\hline & C5000-40C & 32 & 4.44 & 17.70 & 77.86 \\
\hline & C5000-40E & 34 & 5.56 & 26.49 & 67.96 \\
\hline & C5000-41C & 36 & 4.06 & 16.47 & 79.46 \\
\hline & C5000-41E & 38 & 4.48 & 17.80 & 77.72 \\
\hline & C5000-44E & 51 & 3.50 & 21.09 & 75.41 \\
\hline & C5000-45B & 53 & 3.82 & 22.28 & 73.90 \\
\hline & C5000-45C & 54 & 5.68 & 20.06 & 74.27 \\
\hline & C5000-45D & 55 & 2.28 & 22.42 & 75.30 \\
\hline \multirow{10}{*}{$\begin{array}{l}\text { C5001 } \\
(399-3-19)\end{array}$} & C5001-63C & 8.0 & 2.28 & 8.01 & 89.71 \\
\hline & C5001-66A & 21.0 & 3.12 & 10.05 & 86.83 \\
\hline & C5001-68B & 29.0 & 4.55 & 12.23 & 83.23 \\
\hline & C5001-69D & 34.0 & 6.95 & 26.46 & 66.59 \\
\hline & C5001-70E & 40.5 & 4.60 & 12.13 & 83.26 \\
\hline & C5001-73B & 25.8 & 2.31 & 11.32 & 86.37 \\
\hline & C5001-74B & 53.5 & 1.93 & 2.50 & 95.58 \\
\hline & C5001-76D & 65.5 & 2.00 & 18.72 & 79.28 \\
\hline & C5001-79A & 81.5 & 2.54 & 9.65 & 87.81 \\
\hline & C5001-80A & 85.5 & 5.51 & 45.08 & 49.41 \\
\hline \multirow{9}{*}{$\begin{array}{l}\text { C5002 } \\
(399-3-20)\end{array}$} & C5002-83B & 11.5 & 1.22 & 1.95 & 96.83 \\
\hline & C5002-86E & 21.5 & 2.60 & 26.68 & 70.72 \\
\hline & C5002-91C & 39.5 & 6.95 & 23.60 & 69.45 \\
\hline & C5002-92D & 48.5 & 5.94 & 14.33 & 79.73 \\
\hline & C5002-93E & 54.5 & 0.83 & 5.73 & 93.44 \\
\hline & C5002-94D & 65.5 & 0.67 & 5.00 & 94.32 \\
\hline & C5002-98E & 81.1 & 3.26 & 10.67 & 86.07 \\
\hline & C5002-99D & 82 & 3.39 & 10.98 & 85.62 \\
\hline & C5002-100A & 84 & 3.16 & 15.02 & 81.82 \\
\hline
\end{tabular}


Table D.10. Carbon Content of Sediments ${ }^{(a)}$

\begin{tabular}{|c|c|c|c|c|c|c|c|}
\hline Well & ID & $\begin{array}{c}\text { Depth } \\
\text { (ft bgs) }\end{array}$ & $\begin{array}{l}\text { TC } \\
(\%)\end{array}$ & $\begin{array}{l}\text { IC } \\
(\%)\end{array}$ & $\begin{array}{l}\text { OC } \\
(\%)\end{array}$ & $\begin{array}{c}\mathrm{IC} \\
(\mathrm{mg} / \mathrm{g})\end{array}$ & $\begin{array}{c}\text { IC as } \mathrm{CaCO}_{3} \\
(\mathrm{~g} / \mathrm{g})\end{array}$ \\
\hline \multirow{20}{*}{ C4999 } & "C4999-3B & $\begin{array}{c}9.00 \\
\end{array}$ & $\bar{~} 1.72$ & "0.10 & 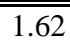 & 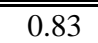 & $\begin{array}{c}0.00691 \\
\end{array}$ \\
\hline & C4999-6A & 20.0 & 2.48 & 0.11 & 2.37 & 0.96 & 0.00797 \\
\hline & C4999-8E & 28.5 & 0.40 & 0.04 & 0.36 & 0.31 & 0.00259 \\
\hline & C4999-10C & 35.5 & 0.28 & 0.01 & 0.27 & 0.09 & 0.00071 \\
\hline & C4999-11B & 39.5 & 0.12 & 0.04 & 0.08 & 0.34 & 0.00284 \\
\hline & C4999-11D & 41.5 & 0.05 & 0.00 & 0.05 & 0.00 & 0.00000 \\
\hline & C4999-12D & 47.0 & 0.02 & 0.00 & 0.02 & 0.00 & 0.00000 \\
\hline & C4999-13E & 53.0 & 0.02 & 0.00 & 0.02 & 0.00 & 0.00000 \\
\hline & C4999-14D & 56.0 & 0.04 & 0.00 & 0.04 & 0.00 & 0.00000 \\
\hline & C4999-15B & 59.0 & 0.17 & 0.01 & 0.16 & 0.07 & 0.00058 \\
\hline & C4999-16A & 62.0 & 0.03 & 0.00 & 0.03 & 0.00 & 0.00000 \\
\hline & C4999-17A & 66.0 & 0.04 & 0.01 & 0.04 & 0.05 & 0.00042 \\
\hline & C4999-19B & 76.0 & 0.08 & 0.00 & 0.08 & 0.00 & 0.00000 \\
\hline & C4999-21C & 86.0 & 0.20 & 0.00 & 0.20 & 0.03 & 0.00021 \\
\hline & C4999-22E & 90.5 & 0.13 & 0.00 & 0.13 & 0.02 & 0.00014 \\
\hline & C4999-25A & 98.5 & 0.06 & 0.00 & 0.06 & 0.00 & 0.00000 \\
\hline & C4999-27B & 108.0 & 0.14 & 0.02 & 0.12 & 0.16 & 0.00135 \\
\hline & C4999-29D & 118.0 & 0.16 & 0.01 & 0.15 & 0.06 & 0.00049 \\
\hline & C4999-31C & 125.0 & 0.08 & 0.00 & 0.08 & 0.02 & 0.00018 \\
\hline & C4999-32B & 129.0 & 0.07 & 0.00 & 0.07 & 0.00 & 0.00000 \\
\hline \multirow{27}{*}{ C5000 } & C5000-36A & 11.0 & 0.09 & 0.00 & 0.09 & 0.01 & 0.00005 \\
\hline & C5000-36E & 12.0 & 0.09 & 0.02 & 0.07 & 0.17 & 0.00138 \\
\hline & C5000-37A & 13.0 & 0.68 & 0.00 & 0.68 & 0.03 & 0.00025 \\
\hline & C5000-38B & 20.0 & 0.08 & 0.01 & 0.08 & 0.05 & 0.00038 \\
\hline & C5000-38C & 21.0 & 0.14 & 0.00 & 0.13 & 0.03 & 0.00021 \\
\hline & C5000-39B & 23.0 & 0.57 & 0.41 & 0.16 & 3.42 & 0.02850 \\
\hline & C5000-39D & 25.0 & 0.07 & 0.00 & 0.07 & 0.00 & 0.00000 \\
\hline & C5000-40C & 32.0 & 0.20 & 0.00 & 0.20 & 0.00 & 0.00000 \\
\hline & C5000-40E & 34.0 & 0.02 & 0.00 & 0.02 & 0.00 & 0.00000 \\
\hline & C5000-41B & 35.0 & 0.07 & 0.00 & 0.07 & 0.03 & 0.00025 \\
\hline & C5000-41E & 38.0 & 0.04 & 0.00 & 0.04 & 0.00 & 0.00000 \\
\hline & C5000-43A & 44.0 & 0.06 & 0.00 & 0.06 & 0.00 & 0.00000 \\
\hline & C5000-44B & 53.0 & 0.08 & 0.02 & 0.06 & 0.14 & 0.00119 \\
\hline & C5000-44E & 51.0 & 0.06 & 0.00 & 0.06 & 0.00 & 0.00000 \\
\hline & C5000-45C & 54.0 & 0.03 & 0.00 & 0.03 & 0.00 & 0.00000 \\
\hline & C5000-46A & 56.0 & 0.09 & 0.00 & 0.09 & 0.00 & 0.00000 \\
\hline & C5000-46D & 59.0 & 0.06 & 0.00 & 0.06 & 0.00 & 0.00000 \\
\hline & C5000-48D & 65.0 & 0.31 & 0.00 & 0.31 & 0.02 & 0.00017 \\
\hline & C5000-48E & 66.0 & 0.03 & 0.00 & 0.03 & 0.00 & 0.00000 \\
\hline & C5000-49D & 68.0 & 0.08 & 0.01 & 0.08 & 0.07 & 0.00057 \\
\hline & C5000-50B & 71.0 & 0.09 & 0.03 & 0.05 & 0.29 & 0.00240 \\
\hline & C5000-51E & 77.0 & 0.12 & 0.08 & 0.05 & 0.63 & 0.00525 \\
\hline & C5000-52B & 79.0 & 0.09 & 0.06 & 0.04 & 0.46 & 0.00385 \\
\hline & C5000-53E & 85.0 & 0.07 & 0.00 & 0.07 & 0.00 & 0.00000 \\
\hline & C5000-54E & 89.5 & 0.11 & 0.02 & 0.09 & 0.18 & 0.00153 \\
\hline & C5000-57D & 100.0 & 0.22 & 0.17 & 0.04 & 1.44 & 0.01196 \\
\hline & C5000-60E & 109.5 & 0.08 & 0.00 & 0.08 & 0.00 & 0.00000 \\
\hline
\end{tabular}


Table D.10. (contd)

\begin{tabular}{|c|c|c|c|c|c|c|c|}
\hline Well & ID & $\begin{array}{c}\text { Depth } \\
\text { (ft bgs) }\end{array}$ & $\begin{array}{l}\text { TC } \\
(\%) \\
\end{array}$ & $\begin{array}{l}\text { IC } \\
(\%) \\
\end{array}$ & $\begin{array}{l}\text { OC } \\
(\%) \\
\end{array}$ & $\begin{array}{c}\mathrm{IC} \\
(\mathrm{mg} / \mathrm{g}) \\
\end{array}$ & $\begin{array}{c}\text { IC as } \mathrm{CaCO}_{3} \\
(\mathrm{~g} / \mathrm{g})\end{array}$ \\
\hline \multirow{10}{*}{ C5001 } & C5001-63C & 8.0 & (20.05 & 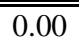 & 0.05 & 0.00 & 0.00000 \\
\hline & C5001-66A & 21.0 & 0.81 & 0.01 & 0.80 & 0.12 & 0.00099 \\
\hline & C5001-68B & 29.0 & 0.22 & 0.01 & 0.21 & 0.06 & 0.00049 \\
\hline & C5001-69D & 34.0 & 0.45 & 0.12 & 0.34 & 0.96 & 0.00802 \\
\hline & C5001-70E & 40.5 & 0.10 & 0.05 & 0.05 & 0.44 & 0.00364 \\
\hline & C5001-73B & 25.8 & 0.14 & 0.01 & 0.13 & 0.11 & 0.00092 \\
\hline & C5001-74B & 53.5 & 0.09 & 0.06 & 0.03 & 0.48 & 0.00403 \\
\hline & C5001-76D & 65.5 & 0.08 & 0.01 & 0.07 & 0.11 & 0.00090 \\
\hline & C5001-79A & 81.5 & 0.06 & 0.01 & 0.06 & 0.06 & 0.00047 \\
\hline & C5001-80A & 85.5 & 0.02 & 0.00 & 0.02 & 0.00 & 0.00000 \\
\hline \multirow{9}{*}{ C5002 } & C5002-83B & 11.5 & 0.12 & 0.07 & 0.05 & 0.61 & 0.00510 \\
\hline & C5002-86E & 13.0 & 0.64 & 0.09 & 0.54 & 0.78 & 0.00649 \\
\hline & C5002-91C & 39.5 & 0.13 & 0.01 & 0.12 & 0.07 & 0.00058 \\
\hline & C5002-92D & 48.5 & 0.07 & 0.00 & 0.06 & 0.03 & 0.00024 \\
\hline & C5002-93E & 54.5 & 0.06 & 0.01 & 0.05 & 0.07 & 0.00057 \\
\hline & C5002-94D & 65.5 & 0.02 & 0.00 & 0.02 & 0.00 & 0.00000 \\
\hline & C5002-98E & 81.1 & 0.17 & 0.11 & 0.05 & 0.93 & 0.00775 \\
\hline & C5002-99D & 82.0 & 0.02 & 0.00 & 0.02 & 0.00 & 0.00000 \\
\hline & C5002-100A & 84.0 & 0.01 & 0.00 & 0.01 & 0.00 & 0.00000 \\
\hline
\end{tabular}


Table D.11. Carbonate Leaching Results

\begin{tabular}{|c|c|c|c|c|c|c|c|c|}
\hline \multirow[b]{2}{*}{ Well } & \multirow[b]{2}{*}{ Sample ID } & \multirow{2}{*}{$\begin{array}{c}\text { Depth } \\
\text { (ft bgs) }\end{array}$} & \multicolumn{6}{|c|}{ Reactions Times (days) } \\
\hline & & & 1 & 4 & \multicolumn{2}{|l|}{7} & 14 & 21 \\
\hline \multirow{27}{*}{$\begin{array}{l}399-3-18 \\
(C 4999)\end{array}$} & \multicolumn{8}{|c|}{ pH } \\
\hline & C4999-6D & 23.0 & 8.63 & 8.65 & 8.63 & & 8.53 & 8.12 \\
\hline & C4999-10C & 35.5 & 8.69 & 8.72 & 8.69 & & 8.62 & 8.51 \\
\hline & C4999-10D & 36.5 & 8.45 & 8.49 & 8.39 & & 8.36 & 8.26 \\
\hline & \multicolumn{8}{|c|}{ Alkalinity (mg/L as $\left.\mathrm{CaCO}_{3}\right)$} \\
\hline & C4999-6D & 23.0 & 497.8 & 471.2 & 494.0 & & 467.4 & 486.4 \\
\hline & C4999-10C & 35.5 & 467.4 & 471.2 & 513. & & 524.4 & 524.4 \\
\hline & C4999-10D & 36.5 & 467.4 & 459.8 & 463. & & 452.2 & 433.2 \\
\hline & \multicolumn{8}{|c|}{ Ca Concentration (mg/L) } \\
\hline & C4999-6D & 23.0 & 2.97 & 2.68 & 2.59 & & 2.15 & 2.32 \\
\hline & C4999-10C & 35.5 & 3.26 & 3.00 & 2.80 & & 2.56 & 4.98 \\
\hline & C4999-10D & 36.5 & 4.70 & 4.79 & 5.01 & & 4.78 & 4.98 \\
\hline & & & Uranit & Concentra & ion $(\mu g / g)$ & & & \\
\hline & C4999-6D & 23.0 & 0.033 & 0.041 & 0.046 & & 0.054 & 0.060 \\
\hline & C4999-10C & 35.5 & 0.480 & 0.584 & 0.64 & & 0.704 & 0.797 \\
\hline & C4999-10D & 36.5 & 0.229 & 0.316 & 0.36 & & 0.417 & 0.480 \\
\hline & & & Uranit & Concentra & ion $(\mu \mathrm{g} / \mathrm{g})$ & & & \\
\hline & Reaction T & (days) & 1 & \begin{tabular}{l|}
2 \\
\end{tabular} & \begin{tabular}{l|l}
5 &
\end{tabular} & 7 & 14 & 21 \\
\hline & C4999-3B & 9.0 & 0.733 & 0.822 & 0.942 & 1.008 & 1.073 & 1.154 \\
\hline & C4999-5A & 15.0 & 0.232 & 0.245 & 0.258 & 0.266 & 0.285 & 0.290 \\
\hline & C4999-6A & 20.0 & 0.255 & 0.285 & 0.306 & 0.318 & 0.351 & 0.374 \\
\hline & C4999-7A & 25.0 & 0.021 & 0.020 & 0.017 & 0.034 & 0.041 & 0.034 \\
\hline & C4999-9C & 31.5 & 0.306 & 0.391 & 0.477 & 0.482 & 0.638 & 0.646 \\
\hline & C4999-11D & 41.5 & 1.809 & 2.234 & 2.606 & 2.786 & 3.151 & 3.295 \\
\hline & C4999-14A & 54.0 & 5.779 & 7.293 & 8.529 & 9.399 & 9.741 & 9.642 \\
\hline & C4999-15B & 59.0 & 0.237 & 0.359 & 0.430 & 0.478 & 0.578 & 0.626 \\
\hline & C4999-16D & 65.0 & 0.403 & 0.583 & 0.755 & 0.755 & 0.923 & 0.973 \\
\hline & & & & pH & & & & \\
\hline & C5000-36A & 11.0 & 8.73 & 8.77 & 8.72 & & 8.71 & 8.55 \\
\hline & C5000-37A & 13.0 & 8.75 & 8.80 & 8.74 & & 8.67 & 8.49 \\
\hline & C5000-45C & 54.0 & 8.77 & 8.85 & 8.83 & & 8.79 & 8.61 \\
\hline & & & Alkal & $y(\mathrm{mg} / \mathrm{L} \mathrm{a}$ & $\left.\mathrm{CaCO}_{3}\right)$ & & & \\
\hline & C5000-36A & 11.0 & 490.2 & 486.4 & \begin{tabular}{l|r} 
& 505.4 \\
\end{tabular} & & 543.4 & 516.8 \\
\hline & C5000-37A & 13.0 & 505.4 & 520.6 & 494. & & 501.6 & 532.0 \\
\hline & C5000-45C & 54.0 & 490.2 & 513.0 & 486. & & 501.6 & 463.6 \\
\hline & & & $\mathrm{Ca}$ & centration & $(\mathrm{mg} / \mathrm{L})$ & & & \\
\hline $399-1-23$ & C5000-36A & 11.0 & 2.86 & 2.58 & 2.31 & & 1.97 & 2.29 \\
\hline (C5000) & C5000-37A & 13.0 & 3.30 & 3.13 & 2.98 & & 2.40 & 2.96 \\
\hline & C5000-45C & 54.0 & 2.94 & 2.75 & 2.54 & & 2.32 & 2.36 \\
\hline & & & Uranit & Concentra & ion $(\mu \mathrm{g} / \mathrm{g})$ & & & \\
\hline & C5000-36A & 11.0 & 0.119 & 0.140 & 0.157 & 0. & 175 & 0.192 \\
\hline & C5000-37A & 13.0 & 0.088 & 0.118 & 0.138 & 0. & 163 & 0.179 \\
\hline & C5000-45C & 54.0 & 0.761 & 0.966 & 1.086 & 1. & 163 & 1.302 \\
\hline & & & Uranit & Concentra & ion $(\mu \mathrm{g} / \mathrm{g})$ & & & \\
\hline & Reaction T & (days) & 1 & 2 & 7 & & 14 & 21 \\
\hline & C5000-32D & 0.5 & 0.447 & 0.564 & 0.58 & & 0.686 & 0.695 \\
\hline & C5000-33A & 2.3 & 0.322 & 0.383 & 0.44 & & 0.478 & 0.489 \\
\hline
\end{tabular}


Table D.11. (contd)

\begin{tabular}{|c|c|c|c|c|c|c|c|}
\hline Well & Sample ID & $\begin{array}{r}\text { Depth } \\
\text { (ft bgs) } \\
\end{array}$ & $\begin{array}{c}\text { Reactions } \\
\text { Times } \\
\text { (days) } \\
\end{array}$ & Well & Sample ID & $\begin{array}{c}\text { Depth } \\
\text { (ft bgs) }\end{array}$ & $\begin{array}{c}\text { Reactions } \\
\text { Times } \\
\text { (days) } \\
\end{array}$ \\
\hline \multirow{8}{*}{$\begin{array}{l}\text { 399-1-23 } \\
\text { (C5000) } \\
\text { (contd) }\end{array}$} & C5000-33C & 3.0 & 0.004 & 0.010 & 0.018 & 0.015 & 0.023 \\
\hline & C5000-34B & 5.0 & 0.035 & 0.039 & 0.043 & 0.044 & 0.046 \\
\hline & C5000-34E & 8.0 & 0.033 & 0.046 & 0.056 & 0.066 & 0.069 \\
\hline & C5000-36E & 12.0 & 0.053 & 0.070 & 0.144 & 0.098 & 0.104 \\
\hline & C5000-39D & 25.0 & 2.486 & 2.847 & 3.021 & 3.178 & 3.241 \\
\hline & C5000-40E & 34.0 & 0.138 & 0.156 & 0.188 & 0.201 & 0.211 \\
\hline & C5000-53E & 85.0 & 0.218 & 0.285 & 0.326 & 0.377 & 0.393 \\
\hline & C5000-60E & 109.5 & 0.020 & 0.026 & 0.036 & 0.043 & 0.045 \\
\hline \multirow{12}{*}{$\begin{array}{l}\text { 399-3-19 } \\
\text { (C5001) }\end{array}$} & \multicolumn{7}{|c|}{ Uranium Concentration $(\mu \mathrm{g} / \mathrm{g})$} \\
\hline & \multicolumn{2}{|c|}{ Reaction Times (days) } & 1 & 3 & 7 & 14 & 21 \\
\hline & C5001-63C & 8.0 & 0.068 & 0.078 & 0.090 & 0.109 & 0.112 \\
\hline & C5001-66A & 21.0 & 0.006 & 0.009 & 0.010 & 0.011 & 0.012 \\
\hline & C5001-68B & 29.0 & 0.004 & 0.006 & 0.007 & 0.007 & 0.009 \\
\hline & C5001-69D & 34.0 & 0.009 & 0.011 & 0.013 & 0.015 & 0.017 \\
\hline & C5001-70E & 40.5 & 0.009 & 0.009 & 0.011 & 0.014 & 0.015 \\
\hline & C5001-73B & 49.8 & 0.029 & 0.036 & 0.043 & 0.054 & 0.054 \\
\hline & C5001-74B & 53.5 & 0.026 & 0.034 & 0.042 & 0.054 & 0.056 \\
\hline & C5001-76D & 65.5 & 0.010 & 0.014 & 0.017 & 0.021 & 0.023 \\
\hline & C5001-79A & 81.5 & 0.054 & 0.075 & 0.081 & 0.102 & 0.104 \\
\hline & C5001-80A & 85.5 & 0.022 & 0.042 & 0.055 & 0.064 & 0.066 \\
\hline \multirow{11}{*}{$\begin{array}{l}\text { 399-3-20 } \\
(\mathrm{C} 5002)\end{array}$} & \multicolumn{7}{|c|}{ Uranium Concentration ( $\mu \mathrm{g} / \mathrm{g})$} \\
\hline & \multicolumn{2}{|c|}{ Reaction Times (days) } & 1 & 3 & 7 & 14 & 21 \\
\hline & C5002-83B & 11.5 & 0.022 & 0.025 & 0.029 & 0.033 & 0.036 \\
\hline & C5002-86E & 21.5 & 0.005 & 0.006 & 0.008 & 0.010 & 0.012 \\
\hline & C5002-91C & 39.5 & 0.003 & 0.004 & 0.006 & 0.009 & 0.010 \\
\hline & C5002-92D & 48.5 & 0.016 & 0.019 & 0.023 & 0.027 & 0.028 \\
\hline & C5002-93E & 54.5 & 0.072 & 0.095 & 0.119 & 0.152 & 0.160 \\
\hline & C5002-94D & 65.5 & 0.022 & 0.030 & 0.039 & 0.050 & 0.057 \\
\hline & C5002-98E & 81.1 & 0.010 & 0.011 & 0.014 & 0.018 & 0.023 \\
\hline & C5002-99D & 82.0 & 0.031 & 0.039 & 0.046 & 0.056 & 0.058 \\
\hline & C5002-100A & 84.0 & 0.025 & 0.033 & 0.042 & 0.047 & 0.049 \\
\hline
\end{tabular}


Table D.12. Uranium Leaching Results with Three Different Solutions

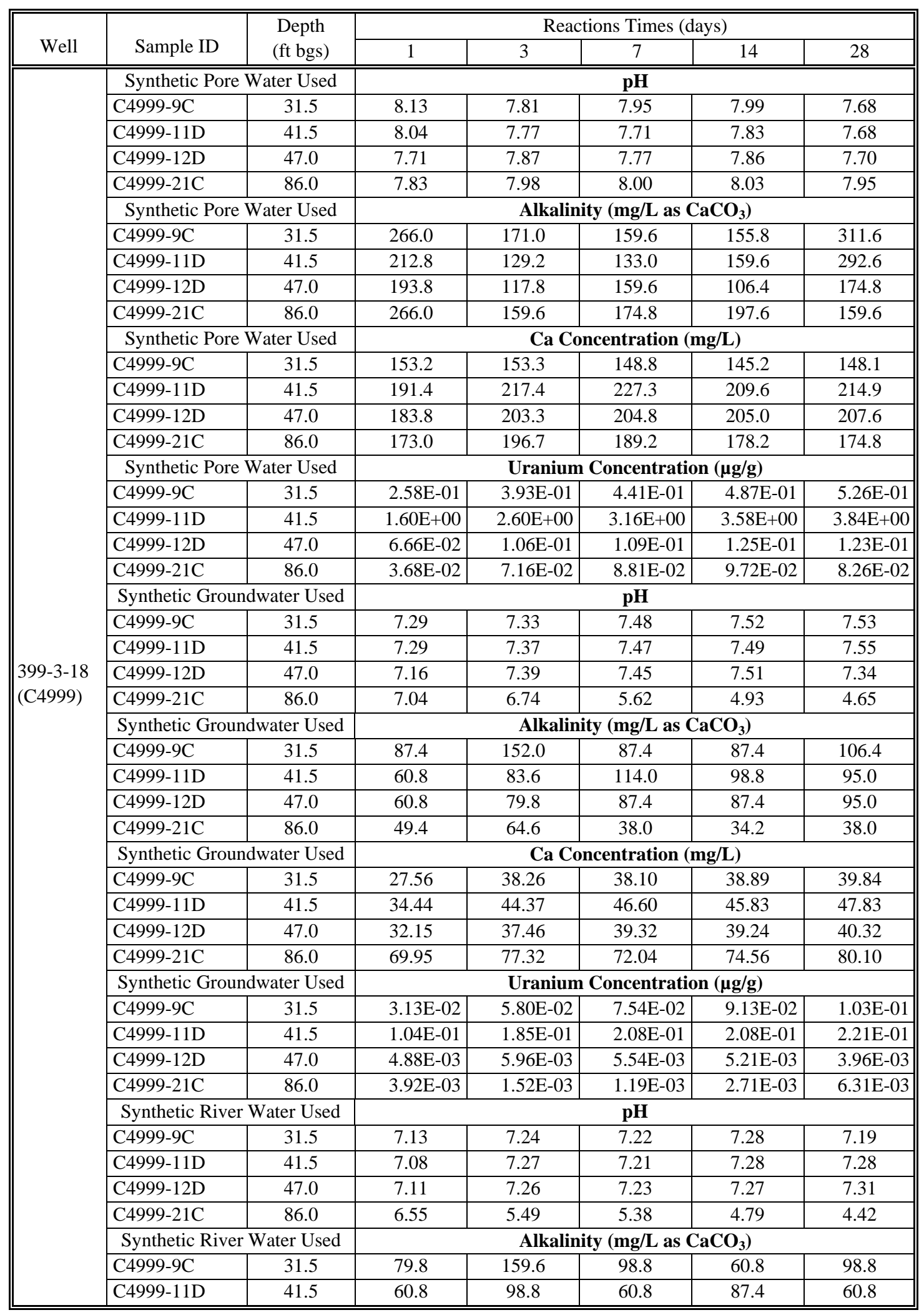


Table D.12. (contd)

\begin{tabular}{|c|c|c|c|c|c|c|c|}
\hline \multirow[b]{2}{*}{ Well } & \multirow[b]{2}{*}{ Sample ID } & \multirow{2}{*}{$\begin{array}{c}\text { Depth } \\
\text { (ft bgs) }\end{array}$} & \multicolumn{5}{|c|}{ Reactions Times (days) } \\
\hline & & & 1 & \begin{tabular}{|l|}
3 \\
\end{tabular} & 7 & 14 & 28 \\
\hline \multirow{12}{*}{$\begin{array}{l}\text { 399-3-18 } \\
\text { (C4999) } \\
\text { (contd) }\end{array}$} & C4999-12D & 477.0 & $\overline{76.0}$ & 102.6 & 57.0 & (64.6 & 76.0 \\
\hline & C4999-21C & 86.0 & 60.8 & 53.2 & 34.2 & 34.2 & 30.4 \\
\hline & \multicolumn{2}{|c|}{ Synthetic River Water Used } & \multicolumn{5}{|c|}{ Ca Concentration (mg/L) } \\
\hline & C4999-9C & 31.5 & 4.09 & 5.34 & 6.04 & 6.14 & 7.01 \\
\hline & C4999-11D & 41.5 & 4.04 & 5.31 & 6.06 & 6.31 & 7.21 \\
\hline & C4999-12D & 47.0 & 2.46 & 2.92 & 3.01 & 3.20 & 3.74 \\
\hline & C4999-21C & 86.0 & 49.1 & 56.4 & 53.5 & 52.9 & 60.6 \\
\hline & \multicolumn{2}{|c|}{\begin{tabular}{|l|} 
Synthetic River Water Used \\
\end{tabular}} & \multicolumn{5}{|c|}{ Uranium Concentration $(\mu \mathrm{g} / \mathrm{g})$} \\
\hline & C4999-9C & 31.5 & $3.32 \mathrm{E}-03$ & $6.25 \mathrm{E}-03$ & $8.80 \mathrm{E}-03$ & $1.03 \mathrm{E}-02$ & $1.21 \mathrm{E}-02$ \\
\hline & C4999-11D & 41.5 & $1.21 \mathrm{E}-02$ & $2.03 \mathrm{E}-02$ & $2.23 \mathrm{E}-02$ & $2.58 \mathrm{E}-02$ & $2.89 \mathrm{E}-02$ \\
\hline & C4999-12D & 47.0 & $2.46 \mathrm{E}-03$ & $9.39 \mathrm{E}-04$ & $7.98 \mathrm{E}-04$ & $8.18 \mathrm{E}-04$ & 5.97E-04 \\
\hline & C4999-21C & 86.0 & $1.71 \mathrm{E}-03$ & $2.08 \mathrm{E}-03$ & $1.88 \mathrm{E}-03$ & $3.11 \mathrm{E}-03$ & $6.85 \mathrm{E}-03$ \\
\hline \multirow{35}{*}{$\begin{array}{l}399-1-23 \\
\text { (C5000) }\end{array}$} & \multicolumn{2}{|c|}{\begin{tabular}{|l|} 
Synthetic Pore Water Used \\
\end{tabular}} & \multicolumn{5}{|c|}{ pH } \\
\hline & C5000-39B & 23.0 & 7.84 & 7.91 & 7.88 & 7.94 & 8.09 \\
\hline & C5000-39D & 25.0 & 7.68 & 7.95 & 7.88 & 7.93 & 7.73 \\
\hline & C5000-40E & 34.0 & 8.14 & 7.95 & 8.00 & 8.11 & 7.70 \\
\hline & C5000-45C & 54.0 & 8.20 & 7.95 & 7.93 & 8.08 & 7.80 \\
\hline & \multicolumn{2}{|c|}{ Synthetic Pore Water Used } & \multicolumn{5}{|c|}{ Alkalinity $\left(\mathrm{mg} / \mathrm{L}\right.$ as $\left.\mathrm{CaCO}_{3}\right)$} \\
\hline & C5000-39B & 23.0 & 235.6 & 197.6 & 155.8 & 125.4 & 133.0 \\
\hline & C5000-39D & 25.0 & 209.0 & 155.8 & 174.8 & 106.4 & 163.4 \\
\hline & C5000-40E & 34.0 & 273.6 & 212.8 & 212.8 & 178.6 & 258.4 \\
\hline & C5000-45C & 54.0 & 235.6 & 182.4 & 174.8 & 201.4 & 212.8 \\
\hline & \multicolumn{2}{|c|}{ Synthetic Pore Water Used } & \multicolumn{5}{|c|}{ Ca Concentration (mg/L) } \\
\hline & C5000-39B & 23.0 & 153.9 & \begin{tabular}{|l|}
166.7 \\
\end{tabular} & 166.0 & 160.3 & 158.7 \\
\hline & C5000-39D & 25.0 & 136.7 & 174.5 & 176.7 & 162.8 & 166.0 \\
\hline & C5000-40E & 34.0 & 118.0 & 104.3 & 102.2 & 96.8 & 96.8 \\
\hline & C5000-45C & 54.0 & 138.0 & 137.5 & 132.3 & 123.9 & 114.6 \\
\hline & \multicolumn{2}{|c|}{ Synthetic Pore Water Used } & \multicolumn{5}{|c|}{ Uranium Concentration $(\mu \mathrm{g} / \mathrm{g})$} \\
\hline & C5000-39B & 23.0 & $9.15 \mathrm{E}-01$ & $1.24 \mathrm{E}+00$ & $1.22 \mathrm{E}+00$ & $1.30 \mathrm{E}+00$ & $1.37 \mathrm{E}+00$ \\
\hline & C5000-39D & 25.0 & $6.28 \mathrm{E}-01$ & 8.99E-01 & $9.06 \mathrm{E}-01$ & $9.72 \mathrm{E}-01$ & $9.79 \mathrm{E}-01$ \\
\hline & C5000-40E & 34.0 & $6.28 \mathrm{E}-02$ & $9.05 \mathrm{E}-02$ & $9.71 \mathrm{E}-02$ & $1.13 \mathrm{E}-01$ & $1.18 \mathrm{E}-01$ \\
\hline & C5000-45C & 54.0 & 5.05E-01 & 7.32E-01 & $7.55 \mathrm{E}-01$ & $8.31 \mathrm{E}-01$ & $7.98 \mathrm{E}-01$ \\
\hline & \multicolumn{2}{|c|}{ Synthetic Groundwater Used } & \multicolumn{5}{|c|}{ pH } \\
\hline & C5000-39B & 23.0 & 7.34 & 7.59 & 7.58 & 7.56 & 7.59 \\
\hline & C5000-39D & 25.0 & 7.11 & 7.50 & 7.50 & 7.57 & 7.63 \\
\hline & C5000-40E & 34.0 & 7.26 & 7.54 & 7.51 & 7.42 & 7.43 \\
\hline & C5000-45C & 54.0 & 7.20 & 7.55 & 7.52 & 7.53 & 7.57 \\
\hline & \multicolumn{2}{|c|}{ Synthetic Groundwater Used } & & Alkalin & $\mathrm{y}(\mathrm{mg} / \mathrm{L}$ as $\mathrm{C}$ & $\left.\mathrm{COO}_{3}\right)$ & \\
\hline & C5000-39B & 23.0 & 83.6 & \begin{tabular}{l|l}
98.8 & \\
\end{tabular} & 98.8 & 87.4 & 125.4 \\
\hline & C5000-39D & 25.0 & 79.8 & 152.0 & 98.8 & 83.6 & 114.0 \\
\hline & C5000-40E & 34.0 & 60.8 & 95.0 & 95.0 & 83.6 & 98.8 \\
\hline & C5000-45C & 54.0 & 64.6 & 83.6 & 114.0 & 87.4 & 83.6 \\
\hline & Synthetic Gro & ater Used & & Ca Co & centration ( & $\mathrm{g} / \mathrm{L})$ & \\
\hline & C5000-39B & 23.0 & 33.23 & 44.07 & 47.23 & 46.12 & 49.74 \\
\hline & C5000-39D & 25.0 & 29.59 & 38.62 & 40.19 & 40.78 & 42.34 \\
\hline & C5000-40E & 34.0 & 20.18 & 25.35 & 27.07 & 28.39 & 29.39 \\
\hline & C5000-45C & 54.0 & 26.22 & 32.96 & 33.59 & 32.98 & 33.77 \\
\hline
\end{tabular}


Table D.12. (contd)

\begin{tabular}{|c|c|c|c|c|c|c|c|}
\hline \multirow[b]{2}{*}{ Well } & \multirow[b]{2}{*}{ Sample ID } & \multirow{2}{*}{$\begin{array}{c}\text { Depth } \\
\text { (ft bgs) }\end{array}$} & \multicolumn{5}{|c|}{ Reactions Times (days) } \\
\hline & & & 1 & 3 & 7 & 14 & 28 \\
\hline \multirow{25}{*}{$\begin{array}{l}399-1-23 \\
\text { (C5000) } \\
\text { (contd) }\end{array}$} & \multicolumn{2}{|c|}{$\begin{array}{c}\text { Synthetic Groundwater Used } \\
\end{array}$} & \multicolumn{5}{|c|}{ Uranium Concentration $(\mu \mathrm{g} / \mathrm{g})$} \\
\hline & C5000-39B & 23.0 & $2.90 \mathrm{E}-01$ & $5.18 \mathrm{E}-01$ & $6.74 \mathrm{E}-01$ & 7.89E-01 & $8.55 \mathrm{E}-01$ \\
\hline & C5000-39D & 25.0 & $1.02 \mathrm{E}-01$ & $1.67 \mathrm{E}-01$ & $1.94 \mathrm{E}-01$ & 2.06E-01 & 2.16E-01 \\
\hline & C5000-40E & 34.0 & $2.15 \mathrm{E}-02$ & $3.74 \mathrm{E}-02$ & $4.91 \mathrm{E}-02$ & $5.70 \mathrm{E}-02$ & $6.58 \mathrm{E}-02$ \\
\hline & C5000-45C & 54.0 & $8.20 \mathrm{E}-02$ & $1.40 \mathrm{E}-01$ & $1.67 \mathrm{E}-01$ & $1.90 \mathrm{E}-01$ & $1.91 \mathrm{E}-01$ \\
\hline & \multicolumn{2}{|c|}{\begin{tabular}{|l|} 
Synthetic River Water Used \\
\end{tabular}} & \multicolumn{5}{|c|}{ pH } \\
\hline & C5000-39B & 23.0 & 7.40 & 7.53 & 7.50 & 7.57 & 7.45 \\
\hline & C5000-39D & 25.0 & 6.88 & 7.52 & 7.36 & 7.40 & 7.37 \\
\hline & C5000-40E & 34.0 & 7.12 & 7.46 & 7.28 & 7.19 & 7.22 \\
\hline & C5000-45C & 54.0 & 7.10 & 7.37 & 7.25 & 7.29 & 7.13 \\
\hline & \multicolumn{2}{|c|}{ Synthetic River Water Used } & \multicolumn{5}{|c|}{ Alkalinity (mg/L as $\mathrm{CaCO}_{3}$ ) } \\
\hline & C5000-39B & 23.0 & 95.0 & 83.6 & 98.8 & 98.8 & 117.8 \\
\hline & C5000-39D & 25.0 & 64.6 & 83.6 & 79.8 & 95.0 & 64.6 \\
\hline & $\mathrm{C} 5000-40 \mathrm{E}$ & 34.0 & 79.8 & 129.2 & 79.8 & 79.8 & 117.8 \\
\hline & C5000-45C & 54.0 & 79.8 & 136.8 & 60.8 & 79.8 & 79.8 \\
\hline & \multicolumn{2}{|c|}{ Synthetic River Water Used } & \multicolumn{5}{|c|}{ Ca Concentration (mg/L) } \\
\hline & C5000-39B & 23.0 & 6.83 & 13.4 & 13.89 & 14.08 & 15.75 \\
\hline & C5000-39D & 25.0 & 2.46 & 3.23 & 3.63 & 3.92 & 4.34 \\
\hline & C5000-40E & 34.0 & 4.07 & 5.99 & 6.43 & 7.37 & 8.10 \\
\hline & C5000-45C & 54.0 & 6.25 & 7.54 & 7.42 & 7.97 & 8.35 \\
\hline & \multicolumn{2}{|c|}{ Synthetic River Water Used } & \multicolumn{5}{|c|}{ Uranium Concentration $(\mu \mathrm{g} / \mathrm{g})$} \\
\hline & C5000-39B & 23.0 & $1.59 \mathrm{E}-01$ & 3.73E-01 & 5.07E-01 & $5.70 \mathrm{E}-01$ & $6.74 \mathrm{E}-01$ \\
\hline & C5000-39D & 25.0 & $1.41 \mathrm{E}-02$ & $1.96 \mathrm{E}-02$ & $2.24 \mathrm{E}-02$ & $2.41 \mathrm{E}-02$ & $2.68 \mathrm{E}-02$ \\
\hline & C5000-40E & 34.0 & $1.02 \mathrm{E}-02$ & $1.62 \mathrm{E}-02$ & $1.99 \mathrm{E}-02$ & $2.46 \mathrm{E}-02$ & $2.74 \mathrm{E}-02$ \\
\hline & C5000-45C & 54.0 & 1.13E-02 & $1.62 \mathrm{E}-02$ & $1.88 \mathrm{E}-02$ & $2.21 \mathrm{E}-02$ & $2.45 \mathrm{E}-02$ \\
\hline \multirow{23}{*}{$\begin{array}{l}\text { 399-3-19 } \\
\text { (C5001) }\end{array}$} & \multicolumn{2}{|c|}{ Synthetic Pore Water Used } & \multicolumn{5}{|c|}{ pH } \\
\hline & C5001-66A & 21.0 & 8.00 & 7.99 & 8.04 & 8.07 & 7.85 \\
\hline & C5001-69D & 34.0 & 8.00 & 7.91 & 7.88 & 7.88 & 7.98 \\
\hline & C5001-73B & 25.8 & 7.89 & 7.96 & 7.91 & 8.06 & 8.09 \\
\hline & C5001-80A & 85.5 & 7.84 & 7.80 & 7.82 & 7.90 & 7.51 \\
\hline & \multicolumn{2}{|c|}{ Synthetic Pore Water Used } & \multicolumn{5}{|c|}{ Alkalinity (mg/L as $\left.\mathrm{CaCO}_{3}\right)$} \\
\hline & C5001-66A & 21.0 & 338.2 & 197.6 & 212.8 & 186.2 & 163.4 \\
\hline & C5001-69D & 34.0 & 220.4 & 159.6 & 155.8 & 125.4 & 235.6 \\
\hline & C5001-73B & 25.8 & 247.0 & 144.4 & 171.0 & 155.8 & 163.4 \\
\hline & C5001-80A & 85.5 & 182.4 & 277.4 & 155.8 & 129.2 & 155.8 \\
\hline & Synthetic Pol & ter Used & & Ca C & icentration & $\mathrm{g} / \mathrm{L})$ & \\
\hline & C5001-66A & 21.0 & 122.0 & 123.3 & 123.9 & 121.0 & 123.2 \\
\hline & C5001-69D & 34.0 & 169.2 & 173.5 & 175.6 & 167.4 & 168.7 \\
\hline & C5001-73B & 25.8 & 131.7 & 146.5 & 141.7 & 123.9 & 139.7 \\
\hline & C5001-80A & 85.5 & 205.3 & 232.2 & 240.9 & 238.7 & 240.1 \\
\hline & Synthetic Pol & ter Used & & Uraniu & Concentra & $(\mu \mathrm{g} / \mathrm{g})$ & \\
\hline & C5001-66A & 21.0 & $6.93 \mathrm{E}-03$ & $1.19 \mathrm{E}-02$ & $1.15 \mathrm{E}-02$ & $1.31 \mathrm{E}-02$ & $1.37 \mathrm{E}-02$ \\
\hline & C5001-69D & 34.0 & $1.65 \mathrm{E}-02$ & $2.24 \mathrm{E}-02$ & $2.11 \mathrm{E}-02$ & $2.31 \mathrm{E}-02$ & $2.47 \mathrm{E}-02$ \\
\hline & C5001-73B & 25.8 & $3.29 \mathrm{E}-02$ & $4.67 \mathrm{E}-02$ & $4.89 \mathrm{E}-02$ & 5.31E-02 & $5.88 \mathrm{E}-02$ \\
\hline & C5001-80A & 85.5 & 5.66E-02 & 8.17E-02 & $8.97 \mathrm{E}-02$ & $9.77 \mathrm{E}-02$ & $9.60 \mathrm{E}-02$ \\
\hline & Synthetic Gro & ater Used & & & pH & & \\
\hline & C5001-66A & 21.0 & 7.35 & 7.63 & 7.59 & 7.6 & 7.69 \\
\hline & \begin{tabular}{|l|} 
C5001-69D \\
\end{tabular} & 34.0 & 7.46 & 7.65 & 7.82 & 8.01 & 7.92 \\
\hline
\end{tabular}


Table D.12. (contd)

\begin{tabular}{|c|c|c|c|c|c|c|c|}
\hline \multirow[b]{2}{*}{ Well } & \multirow[b]{2}{*}{ Sample ID } & \multirow{2}{*}{$\begin{array}{l}\text { Depth } \\
\text { (ft bgs) }\end{array}$} & \multicolumn{5}{|c|}{ Reactions Times (days) } \\
\hline & & & 1 & 3 & 7 & 14 & 28 \\
\hline \multirow{37}{*}{$\begin{array}{l}\text { 399-3-19 } \\
\text { (C5001) } \\
\text { (contd) }\end{array}$} & C5001-73B & 25.8 & 7.32 & $\overline{7.59}$ & 7.63 & $\overline{c 7.78}$ & 7.78 \\
\hline & C5001-80A & 85.5 & 7.10 & 7.47 & 7.35 & 7.59 & 7.47 \\
\hline & \multicolumn{2}{|c|}{ Synthetic Groundwater Used } & \multicolumn{5}{|c|}{ Alkalinity $\left(\mathrm{mg} / \mathrm{L}\right.$ as $\left.\mathrm{CaCO}_{3}\right)$} \\
\hline & C5001-66A & 21.0 & 76.0 & 106.4 & 98.8 & 98.8 & 117.8 \\
\hline & C5001-69D & 34.0 & 79.8 & 117.8 & 159.6 & 174.8 & 174.8 \\
\hline & C5001-73B & 25.8 & 79.8 & 102.6 & 91.2 & 87.4 & 102.6 \\
\hline & C5001-80A & 85.5 & 79.8 & 79.8 & 60.8 & 79.8 & 95.0 \\
\hline & \multicolumn{2}{|c|}{ Synthetic Groundwater Used } & \multicolumn{5}{|c|}{ Ca Concentration (mg/L) } \\
\hline & C5001-66A & 21.0 & 26.25 & 35.07 & 37.68 & 38.60 & 39.02 \\
\hline & C5001-69D & 34.0 & 40.53 & 53.98 & 66.60 & 71.94 & 74.63 \\
\hline & C5001-73B & 25.8 & 30.60 & 41.99 & 44.06 & 45.88 & 46.42 \\
\hline & C5001-80A & 85.5 & 34.65 & 41.49 & 43.18 & 44.36 & 45.79 \\
\hline & \multicolumn{2}{|c|}{ Synthetic Groundwater Used } & \multicolumn{5}{|c|}{ Uranium Concentration $(\mu \mathrm{g} / \mathrm{g})$} \\
\hline & C5001-66A & 21.0 & $3.37 \mathrm{E}-03$ & $5.72 \mathrm{E}-03$ & $6.82 \mathrm{E}-03$ & 7.99E-03 & 8.09E-03 \\
\hline & C5001-69D & 34.0 & $4.55 \mathrm{E}-03$ & $1.08 \mathrm{E}-02$ & $1.72 \mathrm{E}-02$ & $2.16 \mathrm{E}-02$ & $2.37 \mathrm{E}-02$ \\
\hline & C5001-73B & 25.8 & $1.36 \mathrm{E}-02$ & $2.42 \mathrm{E}-02$ & $3.01 \mathrm{E}-02$ & $3.32 \mathrm{E}-02$ & $3.70 \mathrm{E}-02$ \\
\hline & C5001-80A & 85.5 & $2.87 \mathrm{E}-03$ & $4.23 \mathrm{E}-03$ & $3.72 \mathrm{E}-03$ & $3.08 \mathrm{E}-03$ & $2.38 \mathrm{E}-03$ \\
\hline & \multicolumn{2}{|c|}{ Synthetic River Water Used } & \multicolumn{5}{|c|}{ pH } \\
\hline & C5001-66A & 21.0 & 7.30 & 7.61 & 7.43 & 7.54 & 7.61 \\
\hline & C5001-69D & 34.0 & 7.23 & 7.79 & 7.72 & 7.93 & 7.64 \\
\hline & C5001-73B & 25.8 & 7.28 & 7.61 & 7.53 & 7.58 & 7.65 \\
\hline & C5001-80A & 85.5 & 7.11 & 7.40 & 7.28 & 7.37 & 7.36 \\
\hline & \multicolumn{2}{|c|}{ Synthetic River Water Used } & \multicolumn{5}{|c|}{ Alkalinity (mg/L as $\left.\mathrm{CaCO}_{3}\right)$} \\
\hline & C5001-66A & 21.0 & 152.0 & 79.8 & 83.6 & 79.8 & 117.8 \\
\hline & C5001-69D & 34.0 & 83.6 & 102.6 & 133.0 & 155.8 & 155.8 \\
\hline & C5001-73B & 25.8 & 95.0 & 102.6 & 83.6 & 114.0 & 98.8 \\
\hline & C5001-80A & 85.5 & 95.0 & 68.4 & 57.0 & 60.8 & 60.8 \\
\hline & \multicolumn{2}{|c|}{ Synthetic River Water Used } & \multicolumn{5}{|c|}{ Ca Concentration (mg/L) } \\
\hline & C5001-66A & 21.0 & 7.06 & 11.70 & 12.36 & 14.09 & 14.77 \\
\hline & C5001-69D & 34.0 & 11.91 & 21.92 & 28.13 & 34.42 & 37.38 \\
\hline & C5001-73B & 25.8 & 7.86 & 12.79 & 13.74 & 15.39 & 17.77 \\
\hline & C5001-80A & 85.5 & 3.28 & 3.81 & 4.10 & 4.25 & 4.90 \\
\hline & \multicolumn{2}{|c|}{ Synthetic River Water Used } & \multicolumn{5}{|c|}{ Uranium Concentration $(\mu \mathrm{g} / \mathrm{g})$} \\
\hline & C5001-66A & 21.0 & $2.38 \mathrm{E}-03$ & $4.78 \mathrm{E}-03$ & 5.63E-03 & $6.57 \mathrm{E}-03$ & $7.48 \mathrm{E}-03$ \\
\hline & C5001-69D & 34.0 & $2.04 \mathrm{E}-03$ & $6.11 \mathrm{E}-03$ & $1.05 \mathrm{E}-02$ & $1.55 \mathrm{E}-02$ & $1.70 \mathrm{E}-02$ \\
\hline & C5001-73B & 25.8 & $6.48 \mathrm{E}-03$ & $1.35 \mathrm{E}-02$ & $1.82 \mathrm{E}-02$ & $2.25 \mathrm{E}-02$ & $2.76 \mathrm{E}-02$ \\
\hline & C5001-80A & 85.5 & $2.72 \mathrm{E}-04$ & $8.14 \mathrm{E}-04$ & $8.29 \mathrm{E}-04$ & $6.07 \mathrm{E}-04$ & $5.92 \mathrm{E}-04$ \\
\hline \multirow{10}{*}{$\begin{array}{l}399-3-20 \\
(\mathrm{C} 5002)\end{array}$} & \multicolumn{2}{|c|}{ Synthetic Pore Water Used } & & & pH & & \\
\hline & C5002-86E & 21.5 & 7.96 & 8.04 & 8.00 & 8.03 & 8.03 \\
\hline & C5002-91C & 39.5 & 7.80 & 7.97 & 7.94 & 8.03 & 7.75 \\
\hline & C5002-92D & 48.5 & 7.85 & 7.93 & 7.89 & 7.92 & 7.91 \\
\hline & C5002-100A & 84.0 & 7.81 & 7.94 & 7.91 & 7.93 & 7.99 \\
\hline & Synthetic Pore & ter Used & & Alkal & $y(\mathrm{mg} / \mathrm{L} \mathrm{a}$ & $\left.\mathrm{CO}_{3}\right)$ & \\
\hline & C5002-86E & 21.5 & 231.8 & 167.2 & 163.4 & 171.0 & 193.8 \\
\hline & C5002-91C & 39.5 & 178.6 & 174.8 & 193.8 & 155.8 & 136.8 \\
\hline & C5002-92D & 48.5 & 178.6 & 148.2 & 155.8 & 167.2 & 171.0 \\
\hline & C5002-100A & 84.0 & 201.4 & 178.6 & 152.0 & 190.0 & 231.8 \\
\hline
\end{tabular}


Table D.12. (contd)

\begin{tabular}{|c|c|c|c|c|c|c|c|}
\hline \multirow[b]{2}{*}{ Well } & \multirow[b]{2}{*}{ Sample ID } & \multirow{2}{*}{$\begin{array}{c}\text { Depth } \\
\text { (ft bgs) }\end{array}$} & \multicolumn{5}{|c|}{ Reactions Times (days) } \\
\hline & & & 1 & 3 & 7 & 14 & 28 \\
\hline \multirow{50}{*}{$\begin{array}{l}\text { 399-3-20 } \\
\text { (C5002) } \\
\text { (contd) }\end{array}$} & \multicolumn{2}{|c|}{ Synthetic Pore Water Used } & \multicolumn{5}{|c|}{ Ca Concentration (mg/L) } \\
\hline & C5002-86E & 21.5 & 146.7 & 143.4 & 143.0 & 136.4 & 138.3 \\
\hline & C5002-91C & 39.5 & 135.9 & 148.1 & 145.8 & 144.7 & 142.7 \\
\hline & C5002-92D & 48.5 & 142.4 & 158.3 & 157.5 & 158.5 & 156.7 \\
\hline & C5002-100A & 84.0 & 164.1 & 169.6 & 167.0 & 159.7 & 162.4 \\
\hline & \multicolumn{2}{|c|}{ Synthetic Pore Water Used } & \multicolumn{5}{|c|}{ Uranium Concentration $(\mu \mathrm{g} / \mathrm{g})$} \\
\hline & C5002-86E & 21.5 & $7.41 \mathrm{E}-03$ & $9.53 \mathrm{E}-03$ & 9.60E-03 & $1.09 \mathrm{E}-02$ & $1.09 \mathrm{E}-02$ \\
\hline & C5002-91C & 39.5 & $6.56 \mathrm{E}-03$ & 8.96E-03 & 8.81E-03 & $1.01 \mathrm{E}-02$ & $1.04 \mathrm{E}-02$ \\
\hline & C5002-92D & 48.5 & $2.14 \mathrm{E}-02$ & 2.87E-02 & $3.01 \mathrm{E}-02$ & 3.05E-02 & $3.18 \mathrm{E}-02$ \\
\hline & C5002-100A & 84.0 & $2.66 \mathrm{E}-02$ & $3.59 \mathrm{E}-02$ & $4.08 \mathrm{E}-02$ & $4.66 \mathrm{E}-02$ & 4.57E-02 \\
\hline & \multicolumn{2}{|c|}{ Synthetic Groundwater Used } & \multicolumn{5}{|c|}{$\mathbf{p H}$} \\
\hline & C5002-86E & 21.5 & 7.26 & 7.59 & 7.60 & 7.65 & 7.66 \\
\hline & C5002-91C & 39.5 & 7.42 & 7.62 & 7.61 & 7.74 & 7.64 \\
\hline & C5002-92D & 48.5 & 7.31 & 7.71 & 7.68 & 7.91 & 7.88 \\
\hline & C5002-100A & 84.0 & 7.11 & 7.50 & 7.53 & 7.71 & 7.64 \\
\hline & \multicolumn{2}{|c|}{ Synthetic Groundwater Used } & \multicolumn{5}{|c|}{ Alkalinity (mg/L as $\left.\mathrm{CaCO}_{3}\right)$} \\
\hline & C5002-86E & 21.5 & 79.8 & 98.8 & 98.8 & 98.8 & 133.0 \\
\hline & C5002-91C & 39.5 & 79.8 & 125.4 & 159.6 & 102.6 & 91.2 \\
\hline & C5002-92D & 48.5 & 83.6 & 110.2 & 136.8 & 133.0 & 152.0 \\
\hline & C5002-100A & 84.0 & 83.6 & 98.8 & 87.4 & 83.6 & 83.6 \\
\hline & \multicolumn{2}{|c|}{ Synthetic Groundwater Used } & \multicolumn{5}{|c|}{ Ca Concentration (mg/L) } \\
\hline & C5002-86E & 21.5 & 33.33 & 42.69 & 45.13 & 44.05 & 45.78 \\
\hline & C5002-91C & 39.5 & 32.32 & 43.76 & 47.54 & 45.56 & 47.36 \\
\hline & C5002-92D & 48.5 & 34.21 & 44.62 & 50.49 & 51.76 & 54.54 \\
\hline & C5002-100A & 84.0 & 28.97 & 34.64 & 35.06 & 33.93 & 38.38 \\
\hline & \multicolumn{2}{|c|}{ Synthetic Groundwater Used } & \multicolumn{5}{|c|}{ Uranium Concentration $(\mu \mathrm{g} / \mathrm{g})$} \\
\hline & C5002-86E & 21.5 & $2.22 \mathrm{E}-03$ & $3.70 \mathrm{E}-03$ & 4.67E-03 & $5.40 \mathrm{E}-03$ & 5.15E-03 \\
\hline & C5002-91C & 39.5 & 1.89E-03 & 3.49E-03 & 4.65E-03 & 5.32E-03 & $5.38 \mathrm{E}-03$ \\
\hline & C5002-92D & 48.5 & 7.94E-03 & $1.42 \mathrm{E}-02$ & 1.75E-02 & 2.22E-02 & 2.32E-02 \\
\hline & C5002-100A & 84.0 & 2.71E-03 & 3.68E-03 & $3.25 \mathrm{E}-03$ & $3.21 \mathrm{E}-03$ & $2.50 \mathrm{E}-03$ \\
\hline & \multicolumn{2}{|c|}{ Synthetic River Water Used } & \multicolumn{5}{|c|}{$\mathrm{pH}$} \\
\hline & C5002-86E & 21.5 & 7.31 & 7.54 & 7.53 & 7.61 & 7.63 \\
\hline & C5002-91C & 39.5 & 7.28 & 7.58 & 7.46 & 7.57 & 7.68 \\
\hline & C5002-92D & 48.5 & 6.92 & 7.62 & 7.58 & 7.68 & 7.65 \\
\hline & C5002-100A & 84.0 & 6.61 & 7.44 & 7.36 & 7.39 & 7.44 \\
\hline & Synthetic Rive & ater Used & & Alkal & y (mg/L as & $\left.\mathrm{aCO}_{3}\right)$ & \\
\hline & C5002-86E & 21.5 & 91.2 & 98.8 & 98.8 & 83.6 & 98.8 \\
\hline & C5002-91C & 39.5 & 79.8 & 79.8 & 98.8 & 114.0 & 83.6 \\
\hline & C5002-92D & 48.5 & 64.6 & 83.6 & 87.4 & 98.8 & 117.8 \\
\hline & C5002-100A & 84.0 & 79.8 & ND & 57.0 & 68.4 & 98.8 \\
\hline & Synthetic Rive & ater Used & & Ca & centration & $\mathrm{g} / \mathrm{L})$ & \\
\hline & C5002-86E & 21.5 & 8.85 & 13.8 & 14.7 & 15.2 & 16.2 \\
\hline & C5002-91C & 39.5 & 7.96 & 12.0 & 20.3 & 14.6 & 16.4 \\
\hline & C5002-92D & 48.5 & 8.36 & 12.8 & 14.5 & 17.0 & 19.0 \\
\hline & C5002-100A & 84.0 & 2.24 & 2.85 & 3.20 & 3.41 & 3.73 \\
\hline & Synthetic Rive & Tater Used & & Uraniu & Concentra & $(\mu g / g)$ & \\
\hline & C5002-86E & 21.5 & $1.31 \mathrm{E}-03$ & 2.97E-03 & 3.82E-03 & $4.21 \mathrm{E}-03$ & 4.68E-03 \\
\hline & C5002-91C & 39.5 & $1.11 \mathrm{E}-03$ & $2.30 \mathrm{E}-03$ & $4.40 \mathrm{E}-03$ & $3.75 \mathrm{E}-03$ & $4.58 \mathrm{E}-03$ \\
\hline & C5002-92D & 48.5 & $3.22 \mathrm{E}-03$ & $6.11 \mathrm{E}-03$ & 8.43E-03 & $1.11 \mathrm{E}-02$ & $1.31 \mathrm{E}-02$ \\
\hline & C5002-100A & 84.0 & 3.13E-04 & 4.88E-04 & $3.24 \mathrm{E}-04$ & 3.31E-04 & $4.00 \mathrm{E}-04$ \\
\hline
\end{tabular}


Table D.13. Moisture Contents of Sediments Collected from Wells 399-3-18 (C4999), 399-1-23 (C5000), 399-3-19 (C5001), and 399-3-20 (C5002)

\begin{tabular}{|c|c|c|c|}
\hline Wells & Sample ID & Depth (ft bgs) & Moisture Contents (\%) \\
\hline \multirow{42}{*}{$\begin{array}{c}399-3-18 \\
\text { (C4999) }\end{array}$} & C4999-1D & 2.7 & 21.2 \\
\hline & C4999-1E & 3.7 & 22.3 \\
\hline & C4999-2A & 4.7 & 13.2 \\
\hline & C4999-2B & 5.7 & 4.85 \\
\hline & C4999-2E & 7.0 & 3.60 \\
\hline & C4999-3A & 8.0 & 2.44 \\
\hline & C4999-3B & 9.0 & 10.7 \\
\hline & C4999-3C & 10.0 & 6.93 \\
\hline & C4999-4B & 12.7 & 6.80 \\
\hline & C4999-4C & 13.7 & 7.02 \\
\hline & C4999-5A & 15.0 & 6.51 \\
\hline & C4999-5B & 16.0 & 4.53 \\
\hline & C4999-5C & 17.0 & 5.01 \\
\hline & C4999-5D & 18.0 & 5.54 \\
\hline & C4999-6A & 19.0 & 8.12 \\
\hline & C4999-6B & 20.0 & 4.49 \\
\hline & C4999-6C & 21.0 & 3.19 \\
\hline & C4999-6D & 22.0 & 10.1 \\
\hline & C4999-6E & 23.0 & 3.17 \\
\hline & C4999-7A & 24.0 & 3.43 \\
\hline & C4999-8B & 26.0 & 3.06 \\
\hline & C4999-8E & 28.5 & 3.46 \\
\hline & C4999-9A & 29.5 & 3.32 \\
\hline & C4999-9B & 30.5 & 5.53 \\
\hline & C4999-9C & 32.0 & 6.78 \\
\hline & C4999-10A & 33.5 & 3.13 \\
\hline & C4999-10B & 34.5 & 3.53 \\
\hline & C4999-10C & 35.5 & 8.20 \\
\hline & C4999-10D & 36.5 & 14.3 \\
\hline & C4999-11A & 38.5 & 5.74 \\
\hline & C4999-11B & 39.5 & 5.34 \\
\hline & C4999-11D & 41.5 & 9.73 \\
\hline & C4999-12A & 44.0 & 9.30 \\
\hline & C4999-12B & 45.0 & 16.2 \\
\hline & C4999-12C & 46.0 & 10.0 \\
\hline & C4999-12D & 47.0 & 34.0 \\
\hline & C4999-12E & 48.0 & 33.8 \\
\hline & C4999-13B & 50.0 & 35.1 \\
\hline & C4999-13D & 51.0 & 34.9 \\
\hline & C4999-13E & 52.0 & 34.4 \\
\hline & C4999-14A & 53.0 & 34.4 \\
\hline & C4999-14B & 54.0 & 34.3 \\
\hline
\end{tabular}


Table D.13. (contd)

\begin{tabular}{|c|c|c|c|}
\hline Wells & Sample ID & Depth (ft bgs) & Moisture Contents (\%) \\
\hline \multirow{46}{*}{$\begin{array}{c}\text { 399-3-18 } \\
\text { (C4999) }\end{array}$} & C4999-14C & 55.0 & 32.6 \\
\hline & C4999-14D & 56.0 & 34.8 \\
\hline & C4999-14E & 57.0 & 34.3 \\
\hline & C4999-15A & 58.0 & 27.7 \\
\hline & C4999-15B & 59.0 & 34.5 \\
\hline & C4999-15D & 60.0 & 39.1 \\
\hline & C4999-16A & 61.0 & 33.0 \\
\hline & C4999-16B & 62.0 & 35.2 \\
\hline & C4999-16C & 63.0 & 34.4 \\
\hline & C4999-16D & 64.0 & 35.9 \\
\hline & C4999-16E & 65.0 & 35.9 \\
\hline & C4999-17A & 66.0 & 35.9 \\
\hline & C4999-17B & 67.0 & 32.9 \\
\hline & C4999-17C & 68.0 & 28.4 \\
\hline & C4999-17D & 69.0 & 31.3 \\
\hline & C4999-17E & 70.0 & 27.5 \\
\hline & C4999-18B & 71.0 & 34.1 \\
\hline & C4999-18C & 72.0 & 32.4 \\
\hline & C4999-18D & 73.0 & 33.0 \\
\hline & C4999-18E & 74.0 & 31.1 \\
\hline & C4999-19A & 75.0 & 29.3 \\
\hline & C4999-19B & 76.0 & 31.5 \\
\hline & C4999-19C & 77.0 & 37.8 \\
\hline & C4999-19D & 78.0 & 32.3 \\
\hline & C4999-19E & 79.0 & 32.6 \\
\hline & C4999-20A & 80.0 & 33.2 \\
\hline & C4999-20B & 81.0 & 28.7 \\
\hline & C4999-20D & 82.0 & 16.5 \\
\hline & C4999-20E & 83.0 & 13.4 \\
\hline & C4999-21A & 84.0 & 12.4 \\
\hline & C4999-21B & 85.0 & 19.3 \\
\hline & C4999-21C & 86.0 & 20.6 \\
\hline & C4999-22A & 96.5 & 8.90 \\
\hline & C4999-22B & 87.5 & 19.4 \\
\hline & C4999-22C & 88.5 & 16.1 \\
\hline & C4999-22D & 89.5 & 14.2 \\
\hline & C4999-22E & 90.5 & 15.0 \\
\hline & C4999-24B & 94.5 & 8.21 \\
\hline & C4999-24C & 95.5 & 11.5 \\
\hline & C4999-24D & 96.5 & 19.9 \\
\hline & C4999-24E & 97.5 & 9.35 \\
\hline & C4999-25A & 98.5 & 10.5 \\
\hline & C4999-25B & 99.5 & 14.2 \\
\hline & C4999-25C & 100.0 & 7.48 \\
\hline & C4999-25D & 101.0 & 10.3 \\
\hline & C4999-25E & 102.0 & 24.1 \\
\hline
\end{tabular}


Table D.13. (contd)

\begin{tabular}{|c|c|c|c|}
\hline Wells & Sample ID & Depth (ft bgs) & Moisture Contents (\%) \\
\hline \multirow{26}{*}{$\begin{array}{c}399-3-18 \\
\text { (C4999) }\end{array}$} & C4999-26A & 103.0 & 23.8 \\
\hline & C4999-26B & 104.0 & 33.1 \\
\hline & C4999-26C & 105.0 & 17.7 \\
\hline & C4999-26E & 106.0 & 10.2 \\
\hline & C4999-27A & 107.0 & 8.55 \\
\hline & C4999-27B & 108.0 & 9.52 \\
\hline & C4999-27C & 109.0 & 7.61 \\
\hline & C4999-28A & 110.0 & 7.67 \\
\hline & C4999-28B & 111.0 & 7.63 \\
\hline & C4999-28C & 112.0 & 12.9 \\
\hline & C4999-28D & 113.0 & 15.1 \\
\hline & C4999-28E & 114.0 & 14.6 \\
\hline & C4999-29B & 115.0 & 6.05 \\
\hline & C4999-29C & 116.0 & 6.50 \\
\hline & C4999-29D & 117.0 & 6.91 \\
\hline & C4999-29E & 118.0 & 7.37 \\
\hline & C4999-30A & 120.0 & 10.3 \\
\hline & C4999-30D & 122.5 & 11.0 \\
\hline & C4999-30E & 123.5 & 9.30 \\
\hline & C4999-31A & 124.5 & 15.8 \\
\hline & C4999-31B & 125.5 & 20.2 \\
\hline & C4999-31C & 125.0 & 9.66 \\
\hline & C4999-31D & 126.0 & 13.9 \\
\hline & C4999-31E & 127.0 & 42.7 \\
\hline & C4999-32B & 128.0 & 45.7 \\
\hline & C4999-32C & 129.0 & 46.2 \\
\hline \multirow{20}{*}{$\begin{array}{c}399-1-23 \\
\text { (C5000) }\end{array}$} & C5000-32D & 0.5 & 4.87 \\
\hline & C5000-32E & 1.5 & 7.37 \\
\hline & C5000-33A & 2.25 & 7.71 \\
\hline & C5000-33B & 2.3 & 5.08 \\
\hline & C5000-33C & 3.0 & 5.26 \\
\hline & C5000-33D & 4.0 & 4.01 \\
\hline & C5000-34B & 5.0 & 3.73 \\
\hline & C5000-34C & 6.0 & 3.42 \\
\hline & C5000-34D & 7.0 & 3.24 \\
\hline & C5000-34E & 7.5 & 3.87 \\
\hline & C5000-35B & 8.0 & 3.12 \\
\hline & C5000-35C & 8.5 & 4.15 \\
\hline & C5000-35D & 9.0 & 3.10 \\
\hline & C5000-35E & 10.0 & 2.92 \\
\hline & C5000-36A & 11.0 & 5.85 \\
\hline & C5000-36E & 12.0 & 3.88 \\
\hline & C5000-37A & 13.0 & 3.69 \\
\hline & C5000-38A & 19.0 & 3.37 \\
\hline & C5000-38B & 20.0 & 4.64 \\
\hline & C5000-38C & 21.0 & 4.26 \\
\hline
\end{tabular}


Table D.13. (contd)

\begin{tabular}{|c|c|c|c|}
\hline Wells & Sample ID & Depth (ft bgs) & Moisture Contents (\%) \\
\hline \multirow{46}{*}{$\begin{array}{c}399-1-23 \\
(\mathrm{C} 5000)\end{array}$} & C5000-39A & 22.0 & 3.40 \\
\hline & C5000-39B & 23.0 & 13.8 \\
\hline & C5000-39D & 25.0 & 13.8 \\
\hline & C5000-40A & 30.0 & 14.6 \\
\hline & C5000-40B & 31.0 & 3.62 \\
\hline & C5000-40C & 32.0 & 9.86 \\
\hline & C5000-40E & 34.0 & 2.40 \\
\hline & C5000-41B & 35.0 & 14.0 \\
\hline & C5000-41C & 36.0 & 7.81 \\
\hline & C5000-41D & 37.0 & 7.48 \\
\hline & C5000-41E & 38.0 & 5.84 \\
\hline & C5000-43A & 44.0 & 6.54 \\
\hline & C5000-43B & 45.0 & 10.5 \\
\hline & C5000-44A & 47.0 & 12.4 \\
\hline & C5000-44B & 48.0 & 9.18 \\
\hline & C5000-44C & 49.0 & 14.9 \\
\hline & C5000-44E & 51.0 & 8.24 \\
\hline & C5000-45A & 52.0 & 9.63 \\
\hline & C5000-45B & 53.0 & 9.49 \\
\hline & C5000-45C & 54.0 & 11.3 \\
\hline & C5000-45D & 55.0 & 9.77 \\
\hline & C5000-45E & 55.0 & 8.57 \\
\hline & C5000-46A & 56.0 & 10.8 \\
\hline & C5000-46B & 57.0 & 12.6 \\
\hline & C5000-46D & 59.0 & 15.1 \\
\hline & C5000-47A & 60.0 & 6.39 \\
\hline & C5000-47B & 60.5 & 6.79 \\
\hline & C5000-47C & 61.5 & 9.35 \\
\hline & C5000-47D & 62.5 & 10.3 \\
\hline & C5000-48C & 64.0 & 6.31 \\
\hline & C5000-48D & 65.0 & 20.0 \\
\hline & C5000-48E & 66.0 & 25.6 \\
\hline & C5000-49A & 67.0 & 28.5 \\
\hline & C5000-49B & 68.0 & 24.4 \\
\hline & C5000-49D & 68.1 & 8.20 \\
\hline & C5000-49E & 69.0 & 26.7 \\
\hline & C5000-50A & 70.0 & 18.4 \\
\hline & C5000-50B & 71.0 & 9.59 \\
\hline & C5000-50C & 72.0 & 15.6 \\
\hline & C5000-50D & 71.5 & 13.4 \\
\hline & C5000-50E & 72.5 & 14.1 \\
\hline & C5000-51A & 73.5 & 16.6 \\
\hline & C5000-51E & 77.0 & 14.3 \\
\hline & C5000-52A & 78.0 & 14.0 \\
\hline & C5000-52B & 79.0 & 16.2 \\
\hline & C5000-52C & 80.0 & 18.8 \\
\hline
\end{tabular}


Table D.13. (contd)

\begin{tabular}{|c|c|c|c|}
\hline Wells & Sample ID & Depth (ft bgs) & Moisture Contents (\%) \\
\hline \multirow{30}{*}{$\begin{array}{c}399-1-23 \\
\text { (C5000) }\end{array}$} & C5000-52D & 81.0 & 16.7 \\
\hline & C5000-53A & 81.1 & 15.5 \\
\hline & C5000-53B & 82.0 & 9.99 \\
\hline & C5000-53C & 83.0 & 19.3 \\
\hline & C5000-53D & 84.0 & 28.7 \\
\hline & C5000-53E & 85.0 & 18.8 \\
\hline & C5000-54E & 89.5 & 10.1 \\
\hline & C5000-55C & 90.0 & 6.39 \\
\hline & C5000-55D & 90.5 & 7.45 \\
\hline & C5000-55E & 91.5 & 5.18 \\
\hline & C5000-56A & 92.5 & 11.4 \\
\hline & C5000-56B & 93.5 & 9.86 \\
\hline & C5000-56C & 94.5 & 28.7 \\
\hline & C5000-56E & 96.0 & 13.6 \\
\hline & C5000-57A & 97.0 & 15.5 \\
\hline & C5000-57B & 98.0 & 13.9 \\
\hline & C5000-57C & 99.0 & 13.9 \\
\hline & C5000-57D & 100.0 & 13.3 \\
\hline & C5000-58A & 101.0 & 16.0 \\
\hline & C5000-58B & 102.0 & 26.4 \\
\hline & C5000-58C & 103.0 & 14.9 \\
\hline & C5000-59A & 104.0 & 9.67 \\
\hline & C5000-59B & 105.0 & 11.1 \\
\hline & C5000-59C & 106.0 & 11.8 \\
\hline & C5000-59D & 107.0 & 16.9 \\
\hline & C5000-59E & 108.0 & 24.8 \\
\hline & C5000-60D & 108.5 & 14.5 \\
\hline & C5000-60E & 109.5 & 19.0 \\
\hline & C5000-61A & 110.1 & 41.6 \\
\hline & C5000-61B & 112.0 & 40.2 \\
\hline \multirow{16}{*}{$\begin{array}{c}399-1-19 \\
\text { (C5001) }\end{array}$} & C5001-61E & 2.0 & 2.94 \\
\hline & C5001-62A & 3.0 & 4.86 \\
\hline & C5001-62B & 4.0 & 5.08 \\
\hline & C5001-62C & 5.0 & 3.66 \\
\hline & C5001-63B & 7.0 & 3.67 \\
\hline & C5001-63C & 8.0 & 7.21 \\
\hline & C5001-63D & 9.0 & 6.59 \\
\hline & C5001-64B & 12.0 & 4.52 \\
\hline & C5001-64C & 13.0 & 5.72 \\
\hline & C5001-64D & 14.0 & 7.63 \\
\hline & C5001-64E & 15.0 & 6.92 \\
\hline & C5001-65C & 18.0 & 5.36 \\
\hline & C5001-65D & 19.0 & 4.62 \\
\hline & C5001-65E & 20.0 & 3.71 \\
\hline & C5001-66A & 21.0 & 2.43 \\
\hline & C5001-67A & 23.5 & 4.99 \\
\hline
\end{tabular}


Table D.13. (contd)

\begin{tabular}{|c|c|c|c|}
\hline Wells & Sample ID & Depth (ft bgs) & Moisture Contents (\%) \\
\hline \multirow{27}{*}{$\begin{array}{c}\text { 399-1-19 } \\
\text { (C5001) }\end{array}$} & C5001-67B & 24.5 & 5.27 \\
\hline & C5001-68A & 28.0 & 4.16 \\
\hline & C5001-68B & 29.0 & 3.86 \\
\hline & C5001-69B & 32.0 & 5.13 \\
\hline & C5001-69C & 33.0 & 6.61 \\
\hline & C5001-69D & 34.0 & 10.8 \\
\hline & C5001-70D & 39.5 & 5.46 \\
\hline & C5001-70E & 40.5 & 6.20 \\
\hline & C5001-71E & 41.5 & 6.63 \\
\hline & C5001-73B & 49.8 & 10.1 \\
\hline & C5001-74B & 53.5 & 10.9 \\
\hline & C5001-74C & 54.5 & 5.85 \\
\hline & C5001-76D & 65.5 & 8.00 \\
\hline & C5001-77D & 74.5 & 12.6 \\
\hline & C5001-78A & 75.0 & 4.96 \\
\hline & C5001-79A & 81.5 & 13.3 \\
\hline & C5001-79B & 82.5 & 10.3 \\
\hline & C5001-79C & 83.0 & 13.2 \\
\hline & C5001-79D & 83.5 & 8.05 \\
\hline & C5001-79E & 84.5 & 11.5 \\
\hline & C5001-80A & 85.5 & 34.5 \\
\hline & C5001-80C & 87.5 & 30.8 \\
\hline & C5001-89-91 & 90.0 & 31.4 \\
\hline & C5001-91-93 & 92.0 & 25.2 \\
\hline & C5001-93-94.5 & 93.8 & 30.3 \\
\hline & C5001-96-98 & 97.0 & 29.2 \\
\hline & C5001-98-100 & 99.0 & 23.0 \\
\hline \multirow{17}{*}{$\begin{array}{l}399-1-20 \\
(\mathrm{C} 5002)\end{array}$} & C5002-81E & 4.0 & 5.07 \\
\hline & C5002-82A & 5.0 & 8.68 \\
\hline & C5002-83A & 10.5 & 2.93 \\
\hline & C5002-83B & 11.5 & 2.22 \\
\hline & C5002-84A & 14.0 & 2.82 \\
\hline & C5002-84C & 16.0 & 2.19 \\
\hline & C5002-85D & 17.0 & 6.03 \\
\hline & C5002-86C & 19.5 & 4.14 \\
\hline & C5002-86E & 21.5 & 5.02 \\
\hline & C5002-87C & 23.5 & 3.50 \\
\hline & C5002-87D & 24.5 & 4.78 \\
\hline & C5002-87E & 25.5 & 4.36 \\
\hline & C5002-89A & 28.5 & 4.49 \\
\hline & C5002-90A & 32.5 & 4.14 \\
\hline & C5002-90B & 33.5 & 8.65 \\
\hline & C5002-90C & 34.5 & 5.22 \\
\hline & C5002-91B & 38.5 & 4.40 \\
\hline
\end{tabular}


Table D.13. (contd)

\begin{tabular}{||c|c|c|c||}
\hline Wells & Sample ID & Depth (ft bgs) & Moisture Contents (\%) \\
\hline \hline \multirow{3}{*}{$\begin{array}{c}\text { 399-1-20 } \\
\text { (C5002) }\end{array}$} & C5002-91C & 39.5 & 4.72 \\
\cline { 2 - 4 } & C5002-91D & 40.5 & 6.04 \\
\cline { 2 - 4 } & C5002-92D & 48.5 & 6.81 \\
\cline { 2 - 4 } & C5002-93E & 54.5 & 6.19 \\
\cline { 2 - 4 } & C5002-94D & 65.5 & 5.41 \\
\cline { 2 - 4 } & C5002-94E & 66.5 & 7.13 \\
\cline { 2 - 4 } & C5002-98C & 79.0 & 7.21 \\
\cline { 2 - 4 } & C5002-98D & 80.0 & 6.69 \\
\cline { 2 - 4 } & C5002-98E & 81.0 & 13.9 \\
\cline { 2 - 4 } & C5002-99D & 82.0 & 33.2 \\
\cline { 2 - 4 } & C5002-99E & 83.0 & 37.8 \\
\cline { 2 - 4 } & C5002-100A & 84.0 & 25.4 \\
\cline { 2 - 4 } & C5002-85-87 & 86.0 & 27.1 \\
\hline
\end{tabular}

Figures D.1 through D.20 represent grain-size distribution metrics for select samples in 399-3-18 (C4999), 399-1-23 (C5000), 399-3-19 (C5001), and 399-3-20 (C5002). 


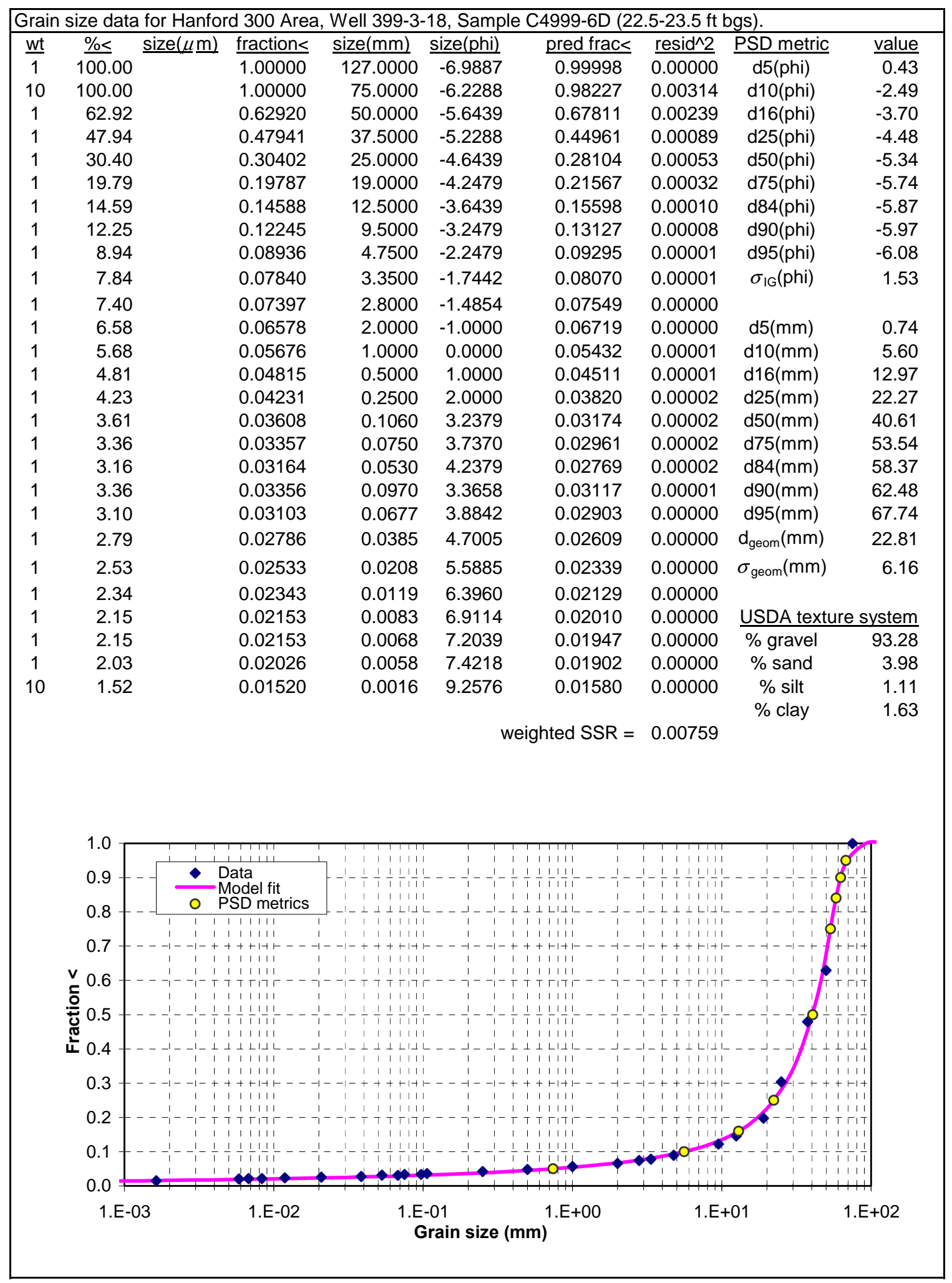

Figure D.1. Grain Size Data for Hanford 300 Area, Well 399-3-18, Sample C4999-6D (depth interval 22.5-23.5 feet) 


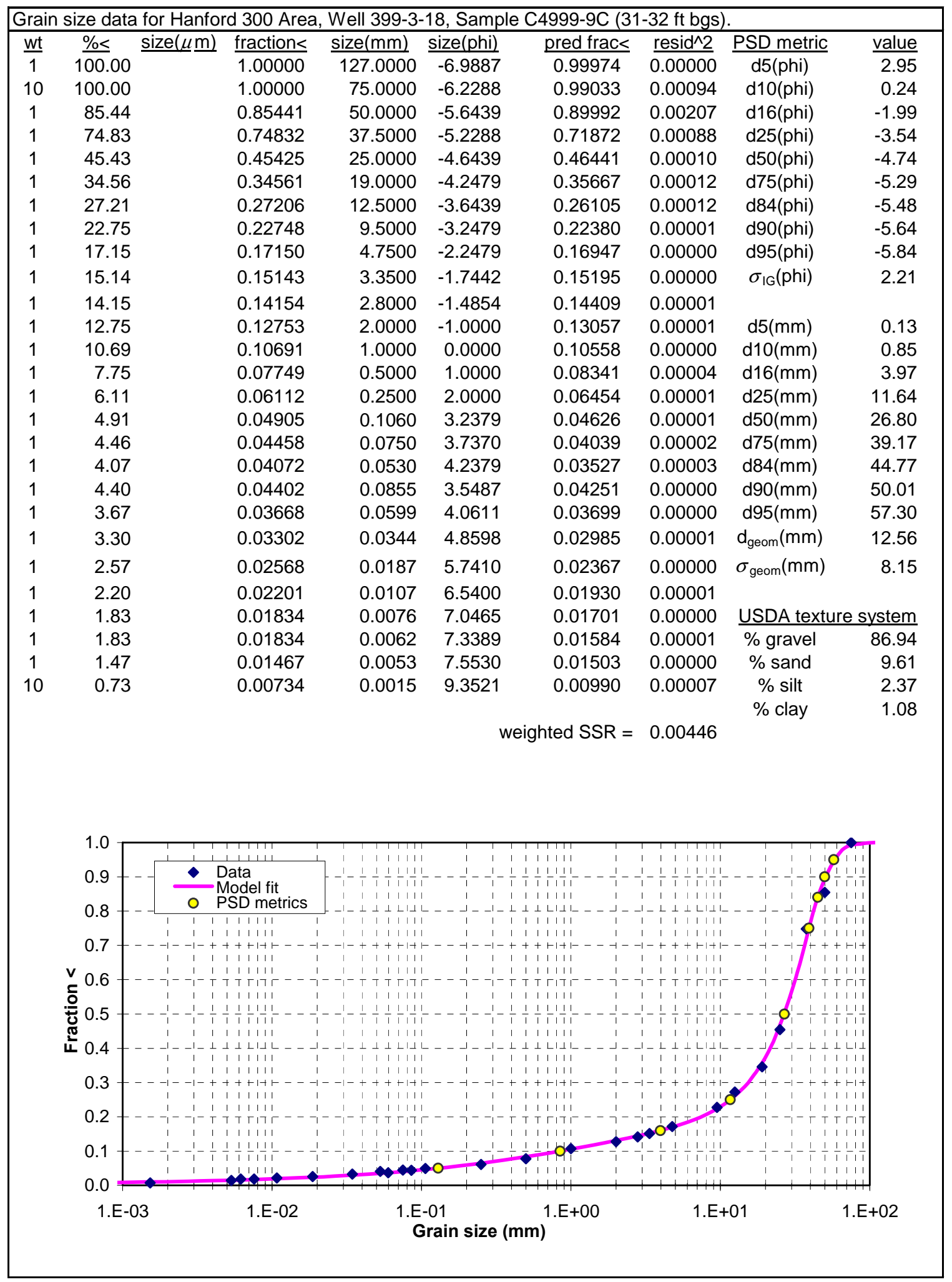

Figure D.2. Grain Size Data for Hanford 300 Area, Well 399-3-18, Sample C4999-9C (depth interval 31-32 feet) 


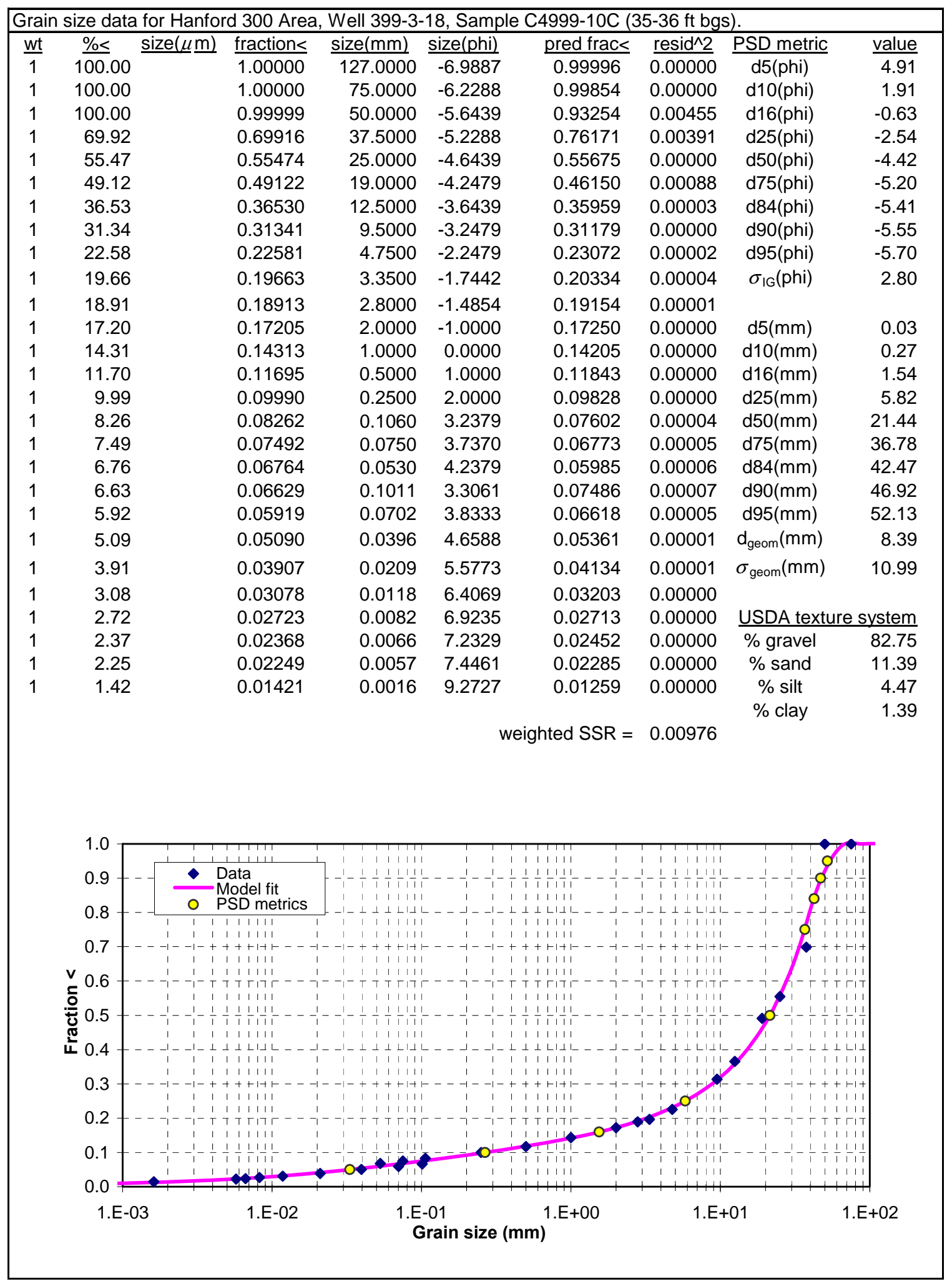

Figure D.3. Grain Size Data for Hanford 300 Area, Well 399-3-18, Sample C4999-10C (depth interval 35-36 feet) 


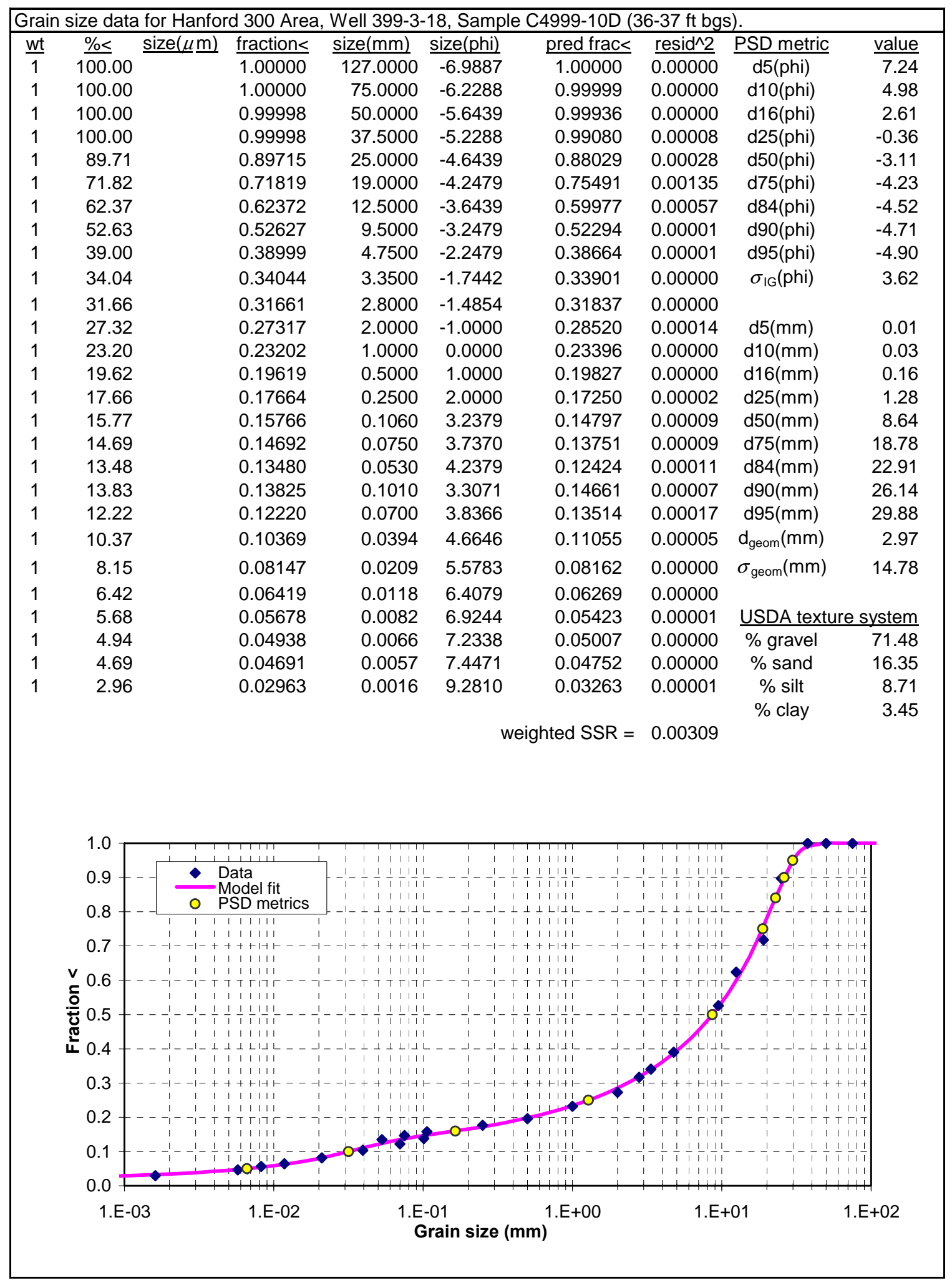

Figure D.4. Grain Size Data for Hanford 300 Area, Well 399-3-18, Sample C4999-10D (depth interval 36-37 feet) 


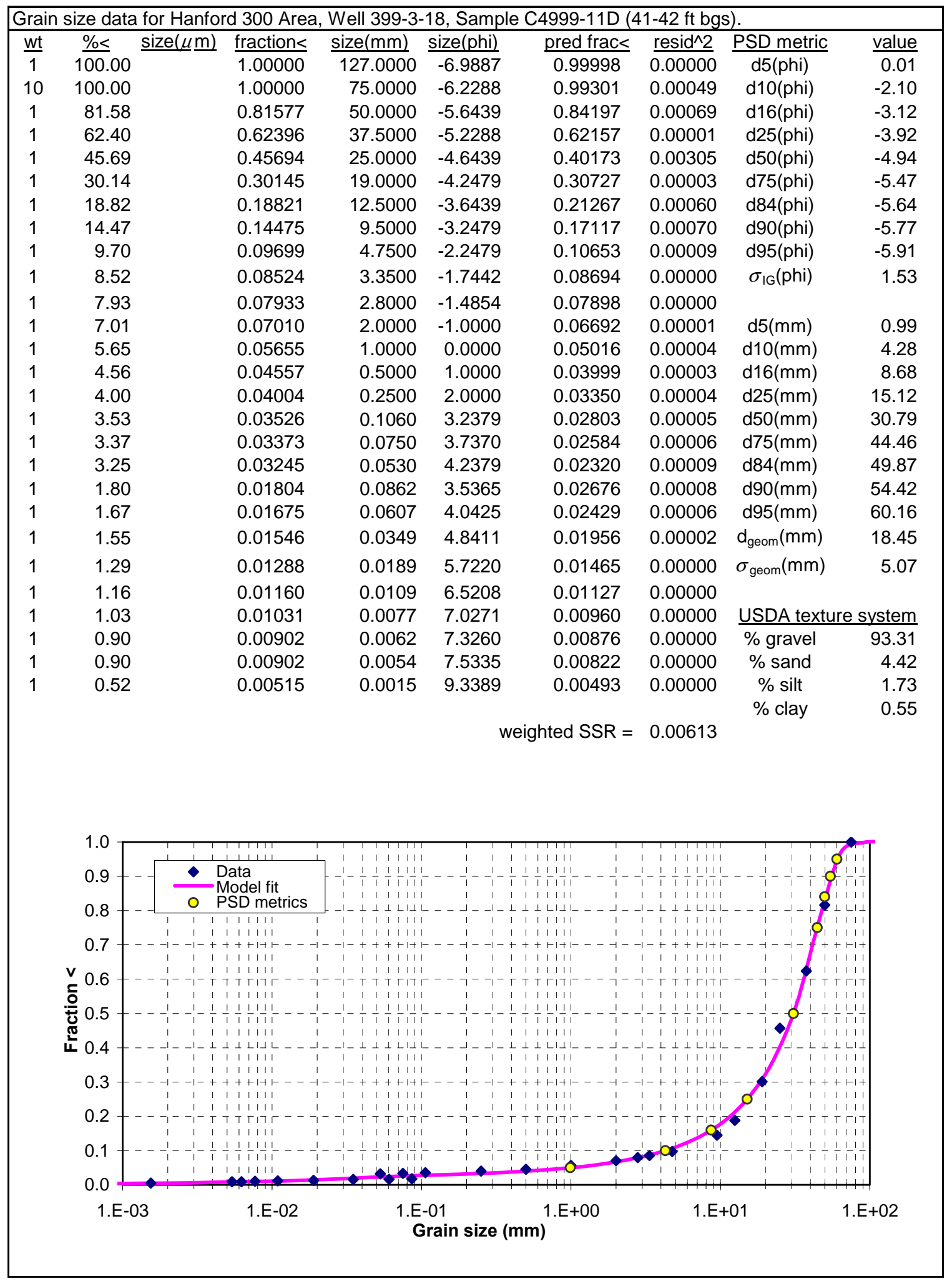

Figure D.5. Grain Size Data for Hanford 300 Area, Well 399-3-18, Sample C4999-11D (depth interval 41-42 feet) 


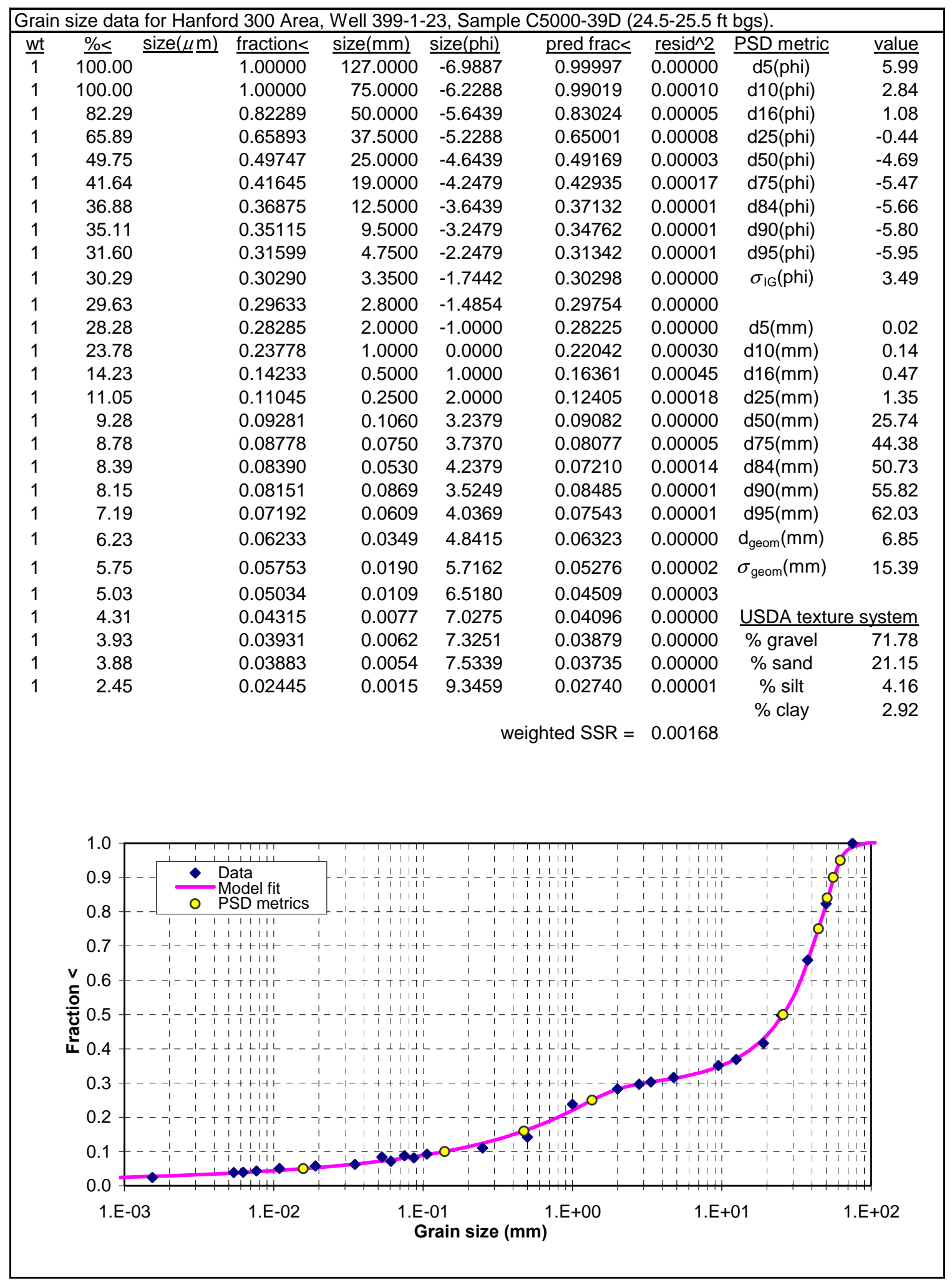

Figure D.6. Grain Size Data for Hanford 300 Area, Well 399-1-23, Sample C5000-39D (depth interval 24.5-25.5 feet) 


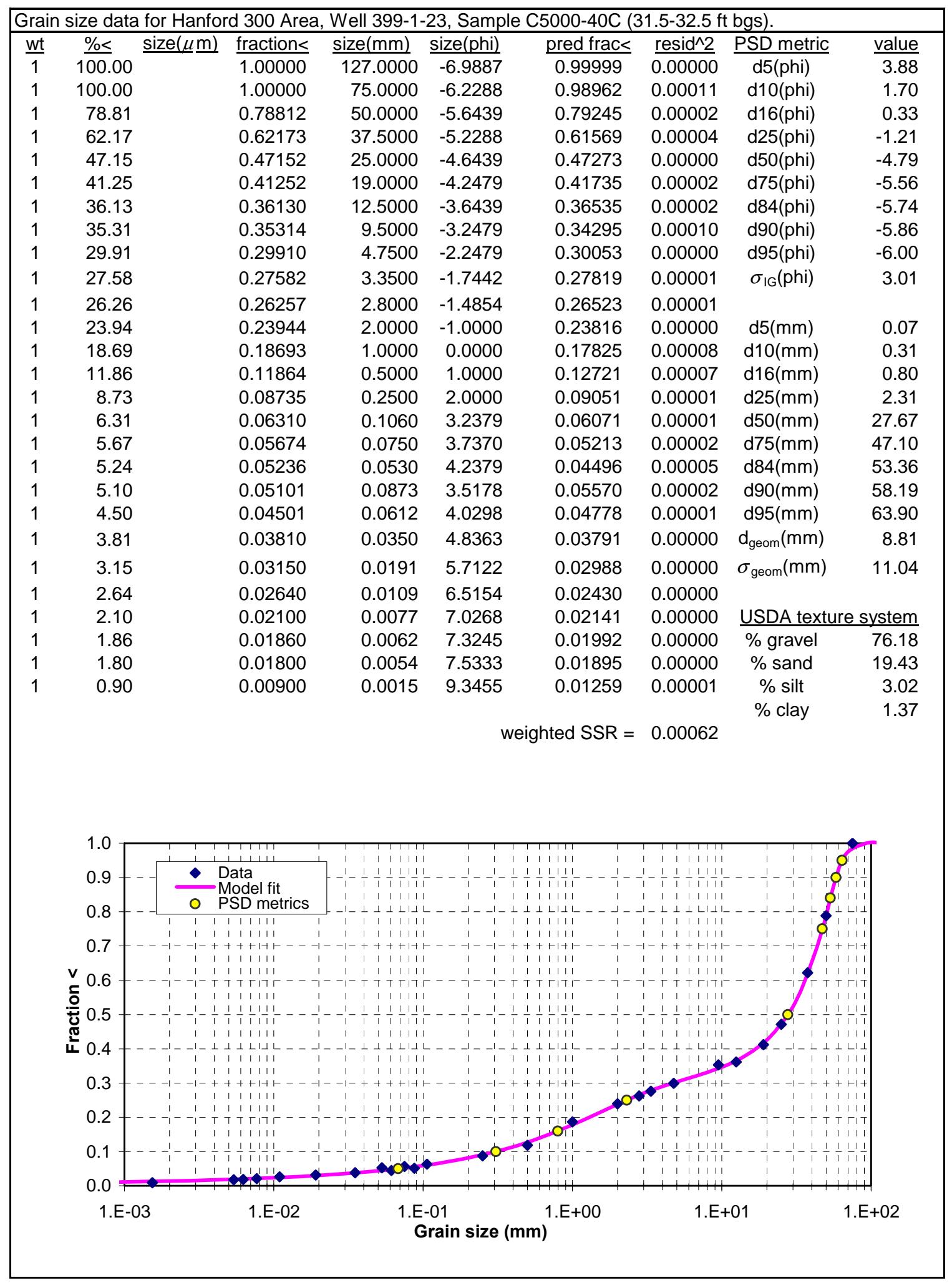

Figure D.7. Grain Size Data for Hanford 300 Area, Well 399-1-23, Sample C5000-40C (depth interval 31.5-32.5 feet) 


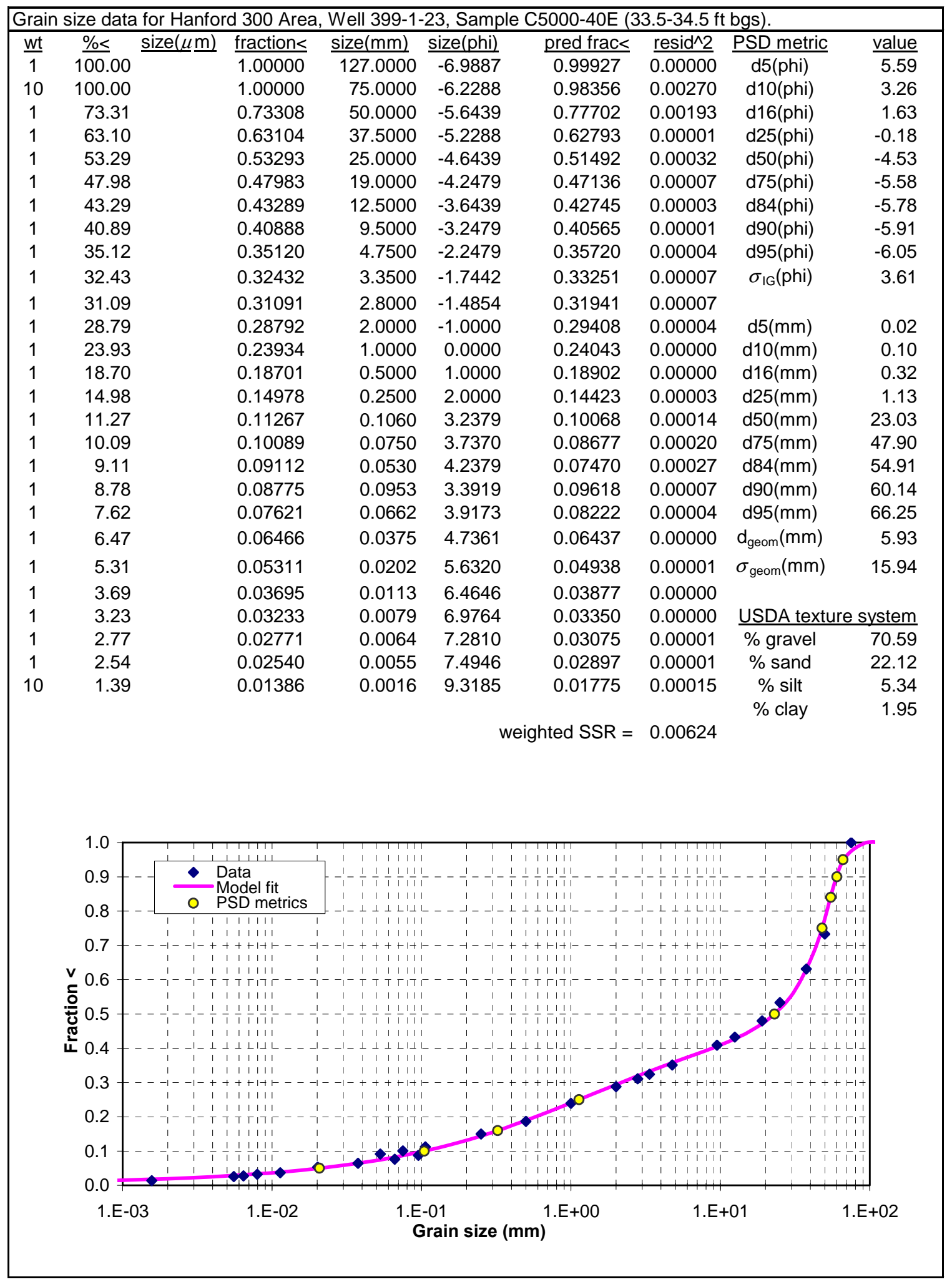

Figure D.8. Grain Size Data for Hanford 300 Area, Well 399-1-23, Sample C5000-40E (depth interval 33.5-34.5 feet) 


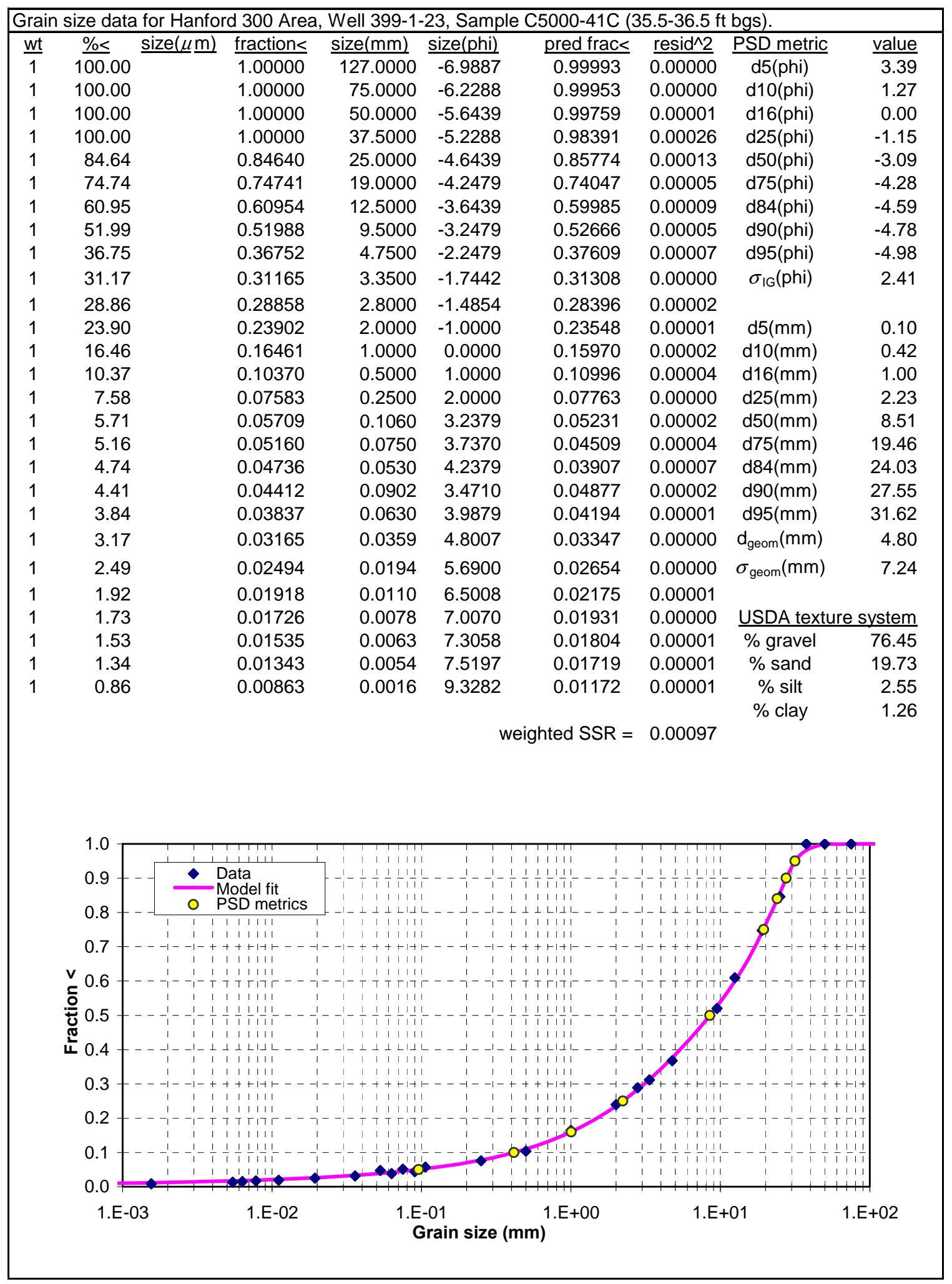

Figure D.9. Grain Size Data for Hanford 300 Area, Well 399-1-23, Sample C5000-41C (depth interval 35.5-36.5 feet) 


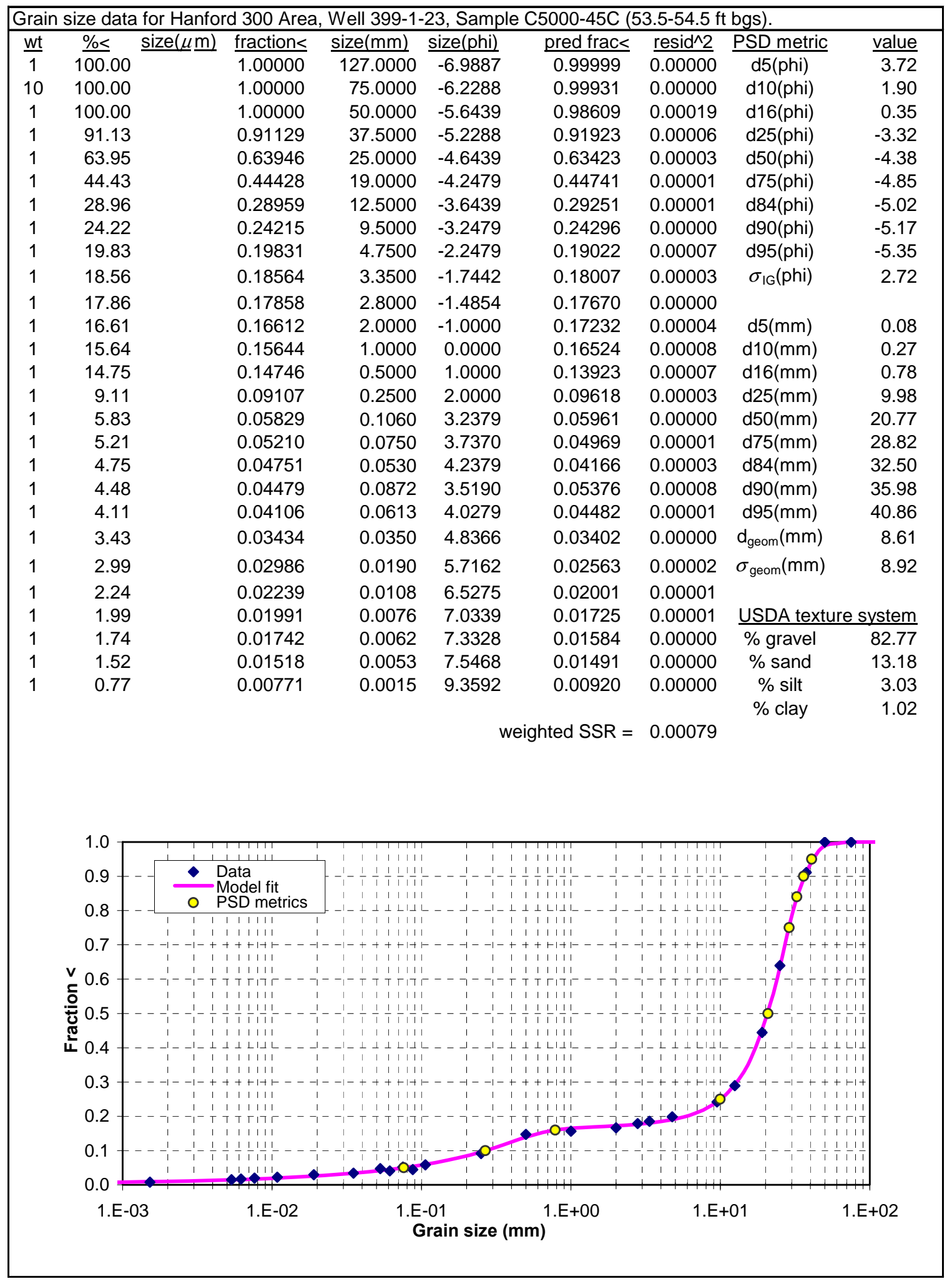

Figure D.10. Grain Size Data for Hanford 300 Area, Well 399-1-23, Sample C5000-45C (depth interval 53.5-54.5 feet) 


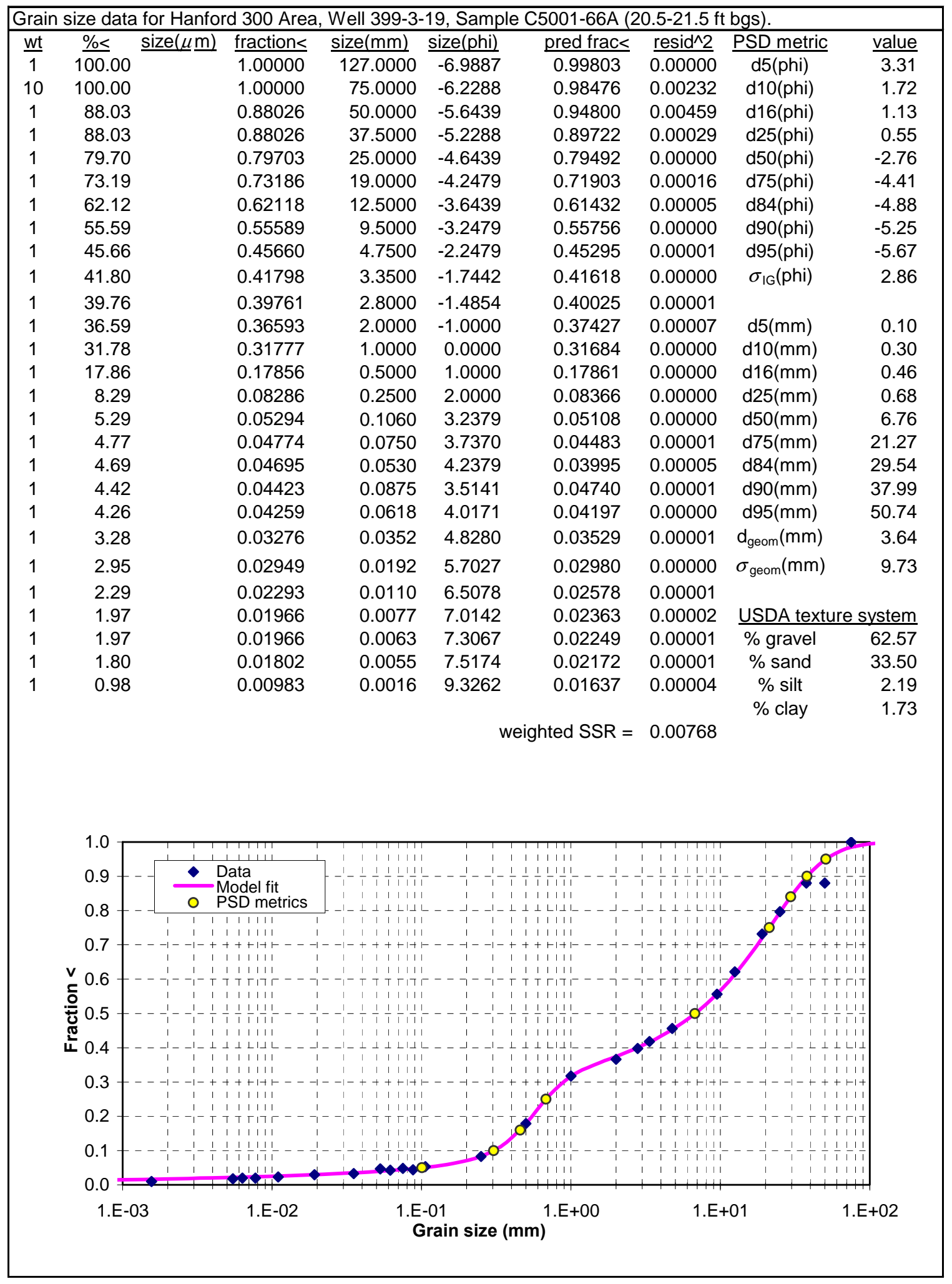

Figure D.11. Grain Size Data for Hanford 300 Area, Well 399-3-19, Sample C5001-66A (depth interval 20.5-21.5 feet) 


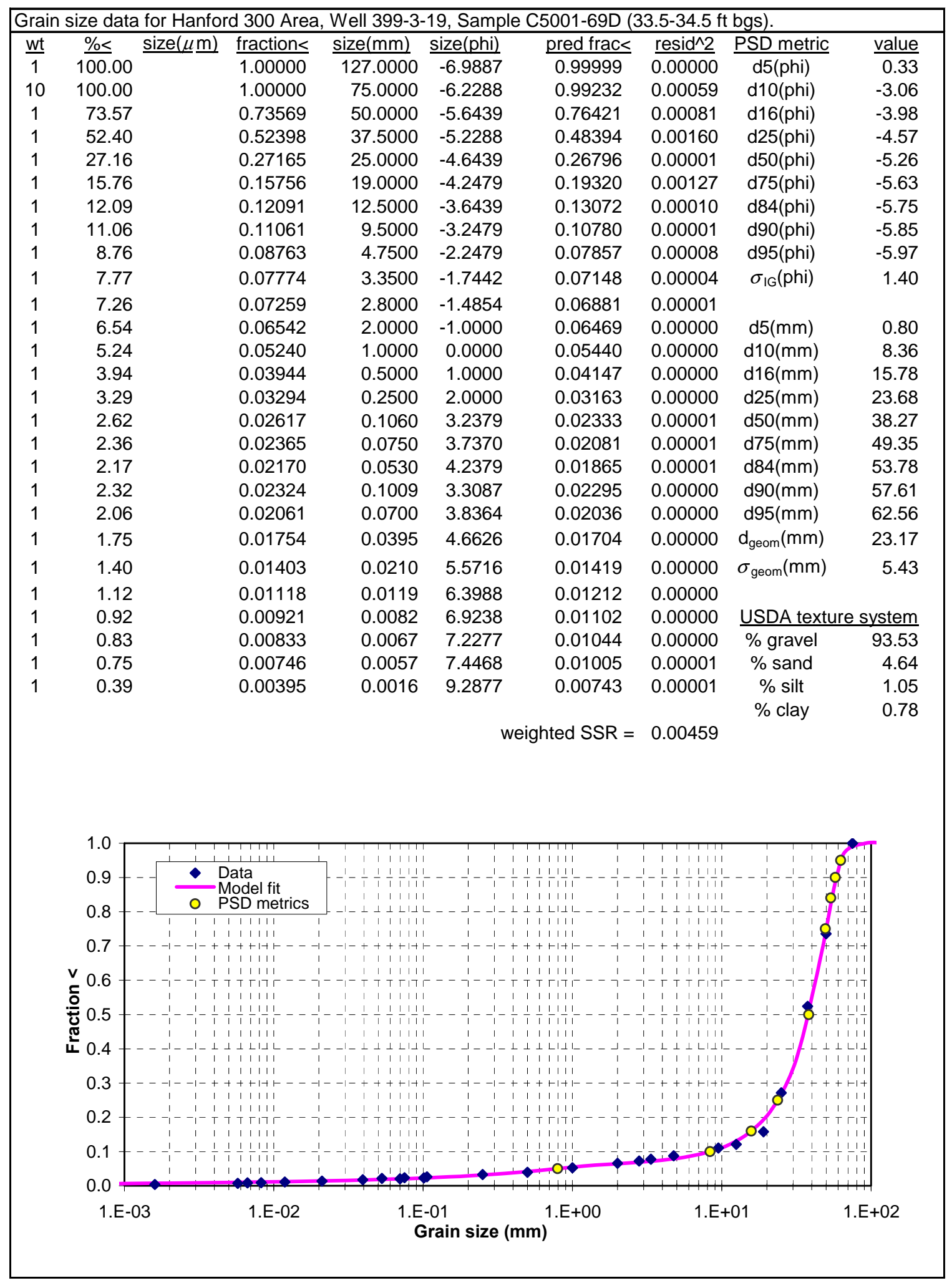

Figure D.12. Grain Size Data for Hanford 300 Area, Well 399-3-19, Sample C5001-69D (depth interval 33.5-34.5 feet) 


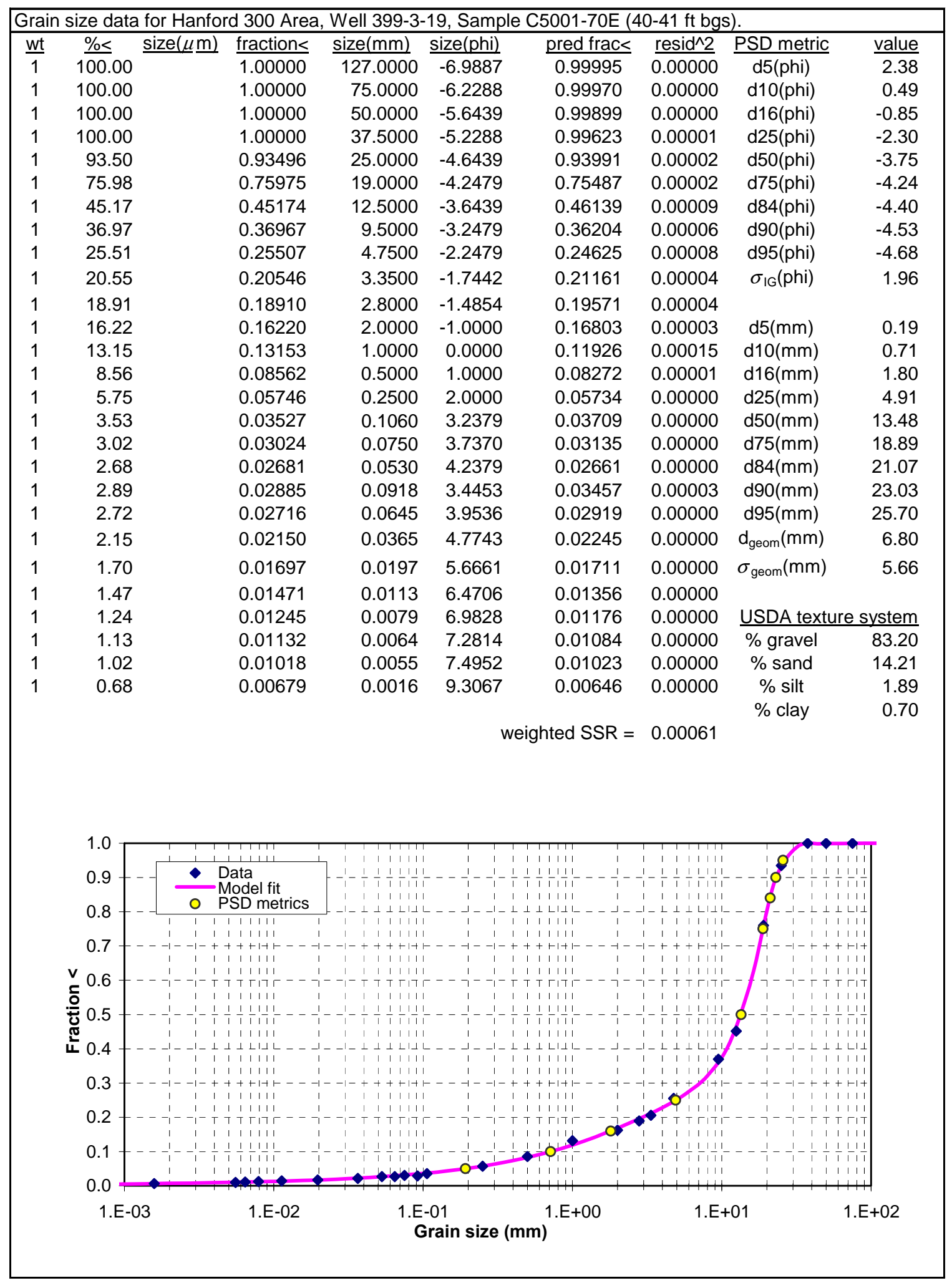

Figure D.13. Grain Size Data for Hanford 300 Area, Well 399-3-19, Sample C5001-70E (depth interval 40-41 feet) 


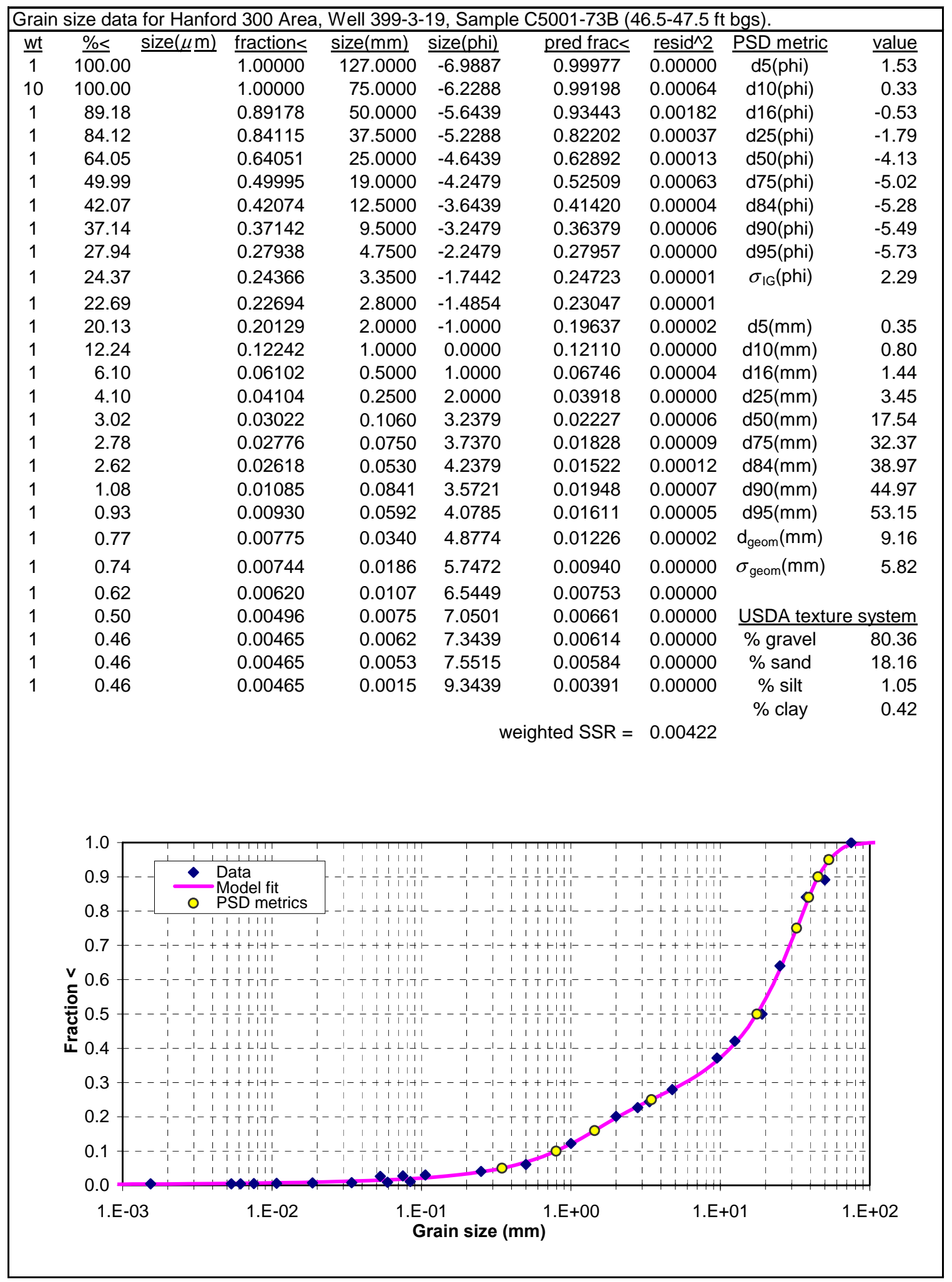

Figure D.14. Grain Size Data for Hanford 300 Area, Well 399-3-19, Sample C5001-73B (depth interval 46.5-47.5 feet) 


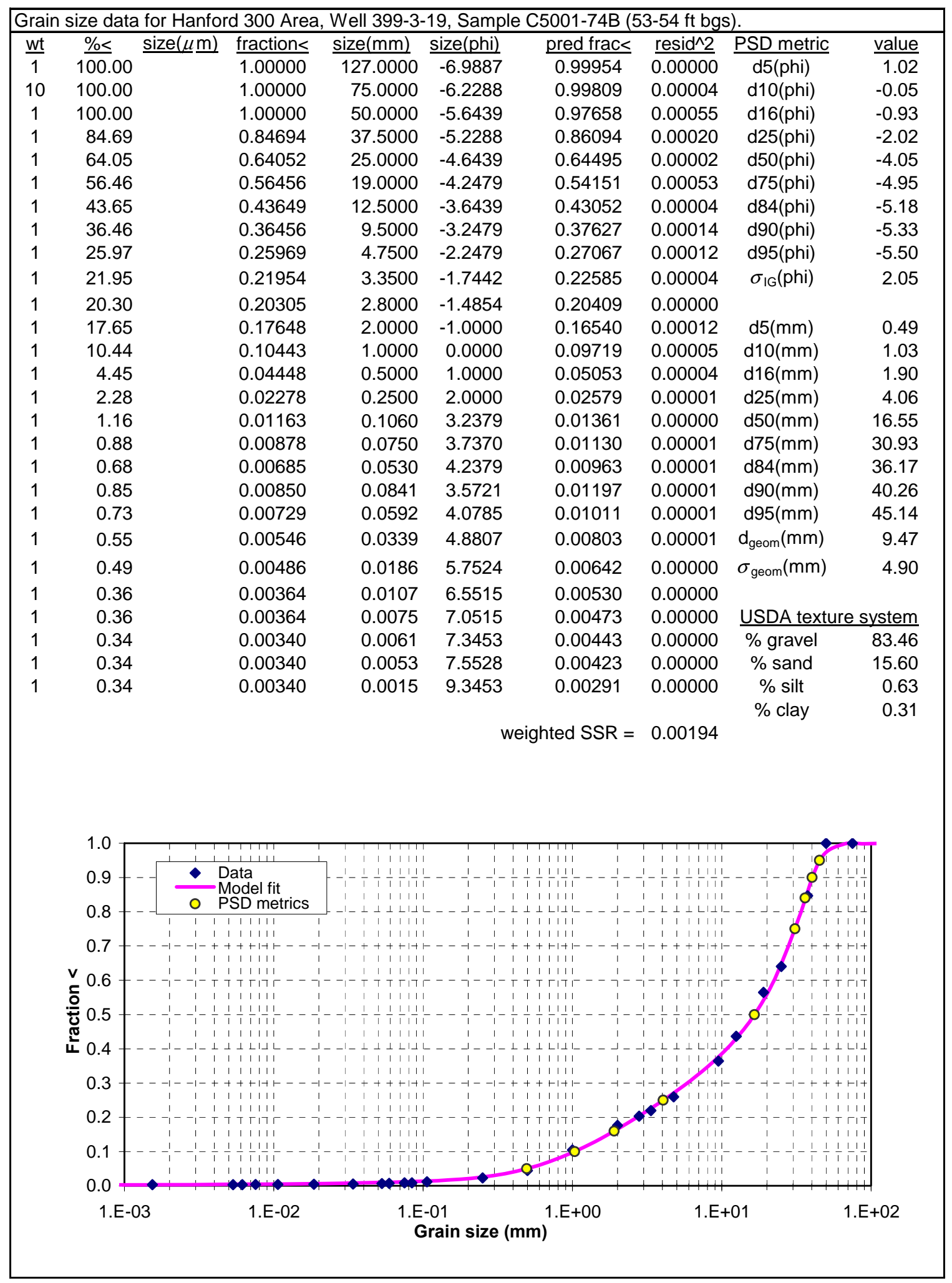

Figure D.15. Grain Size Data for Hanford 300 Area, Well 399-3-19, Sample C5001-74B (depth interval 53-54 feet) 


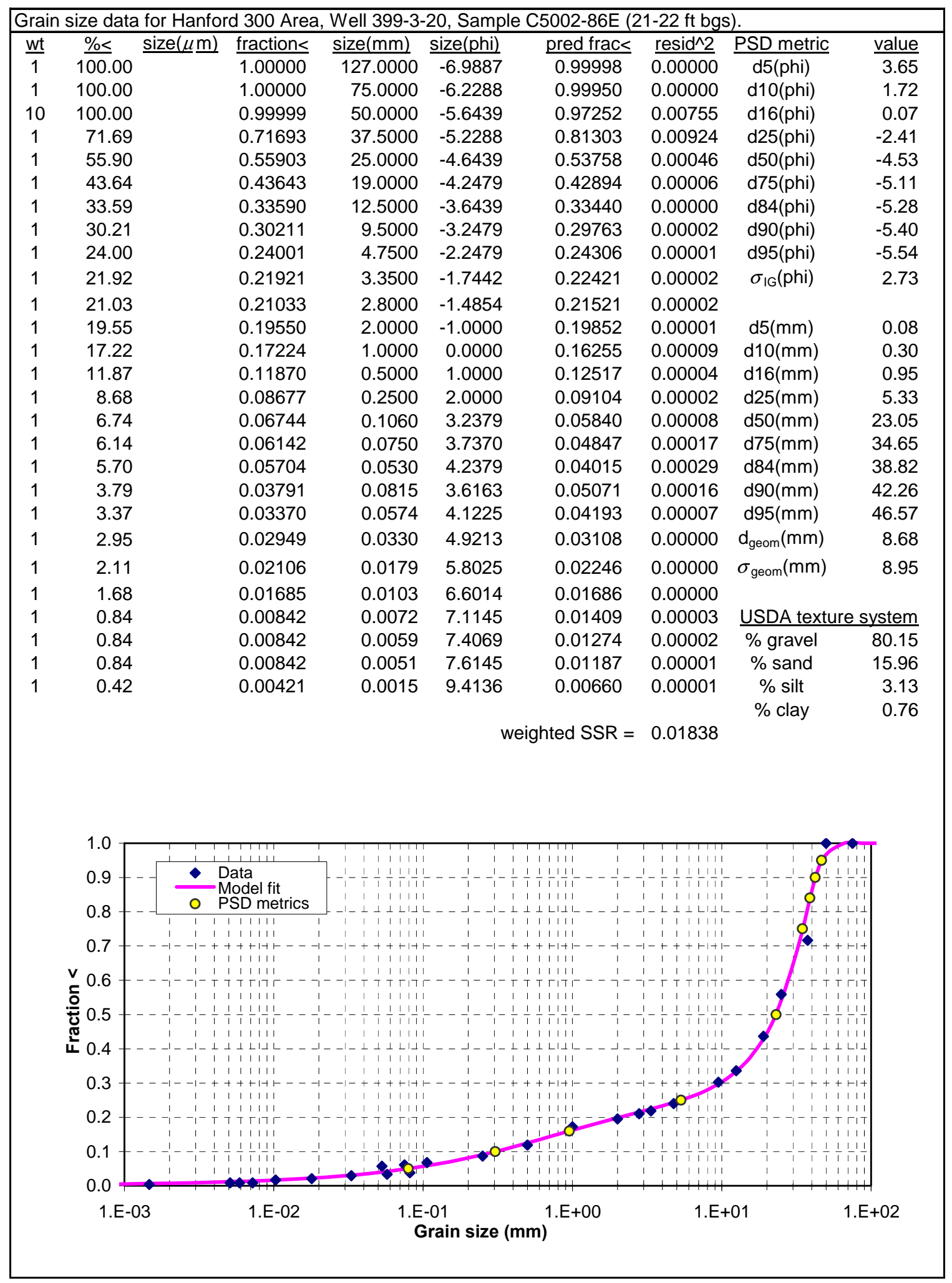

Figure D.16. Grain Size Data for Hanford 300 Area, Well 399-3-20, Sample C5002-86E (depth interval 21-22 feet) 


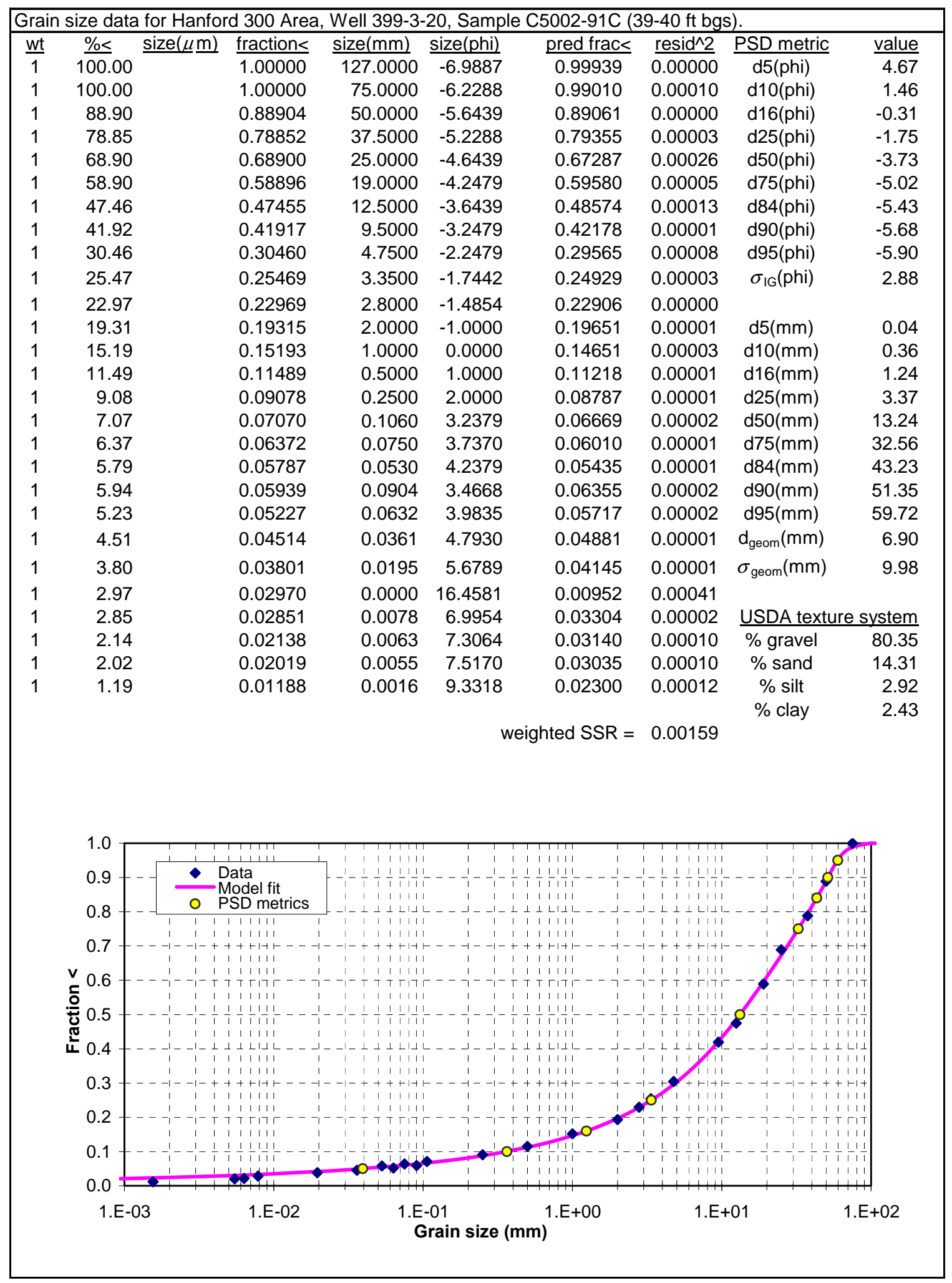

Figure D.17. Grain Size Data for Hanford 300 Area, Well 399-3-20, Sample C5002-91C (depth interval 39-40 feet) 


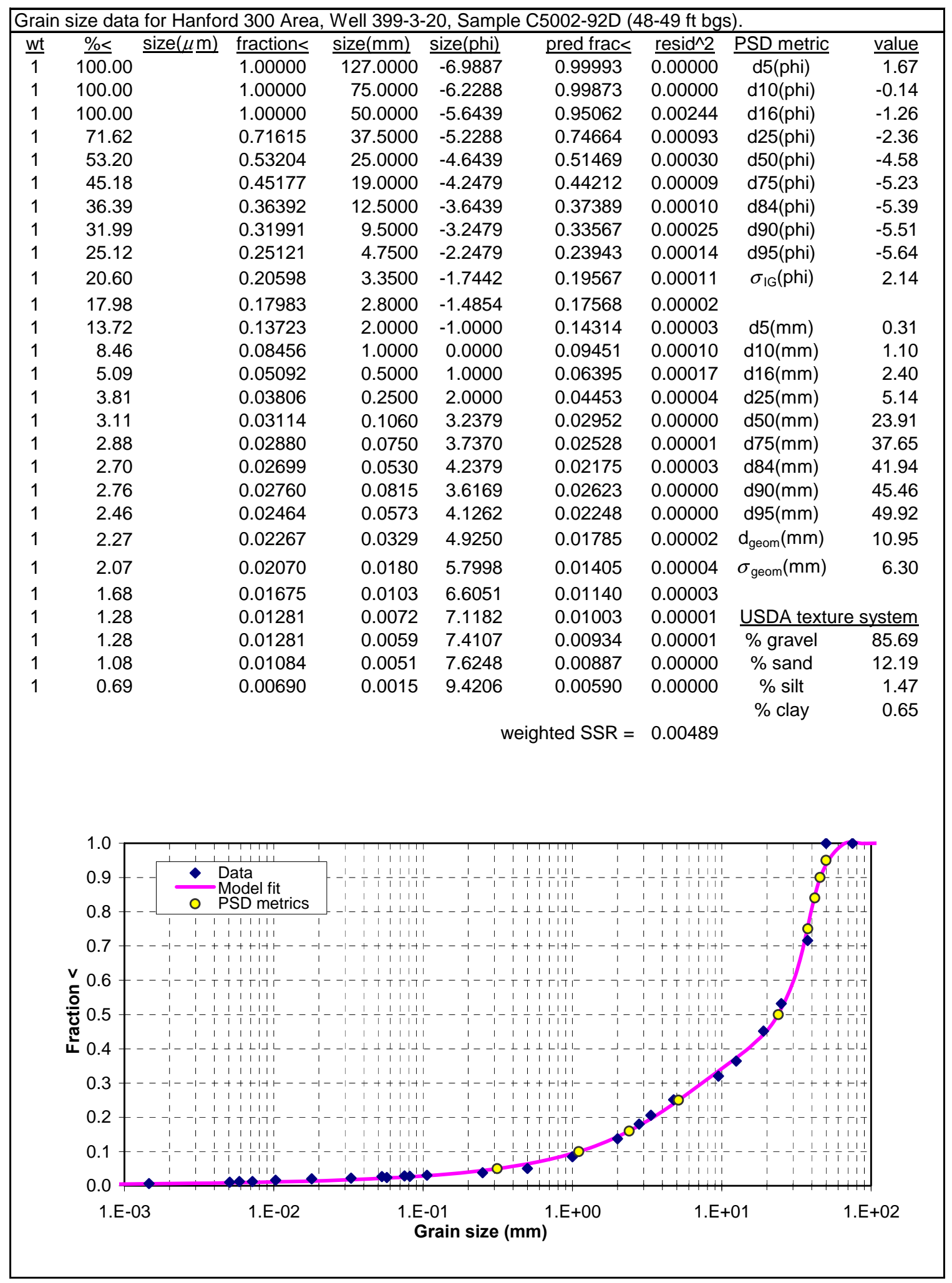

Figure D.18. Grain Size Data for Hanford 300 Area, Well 399-3-20, Sample C5002-92D (depth interval 48-49 feet) 


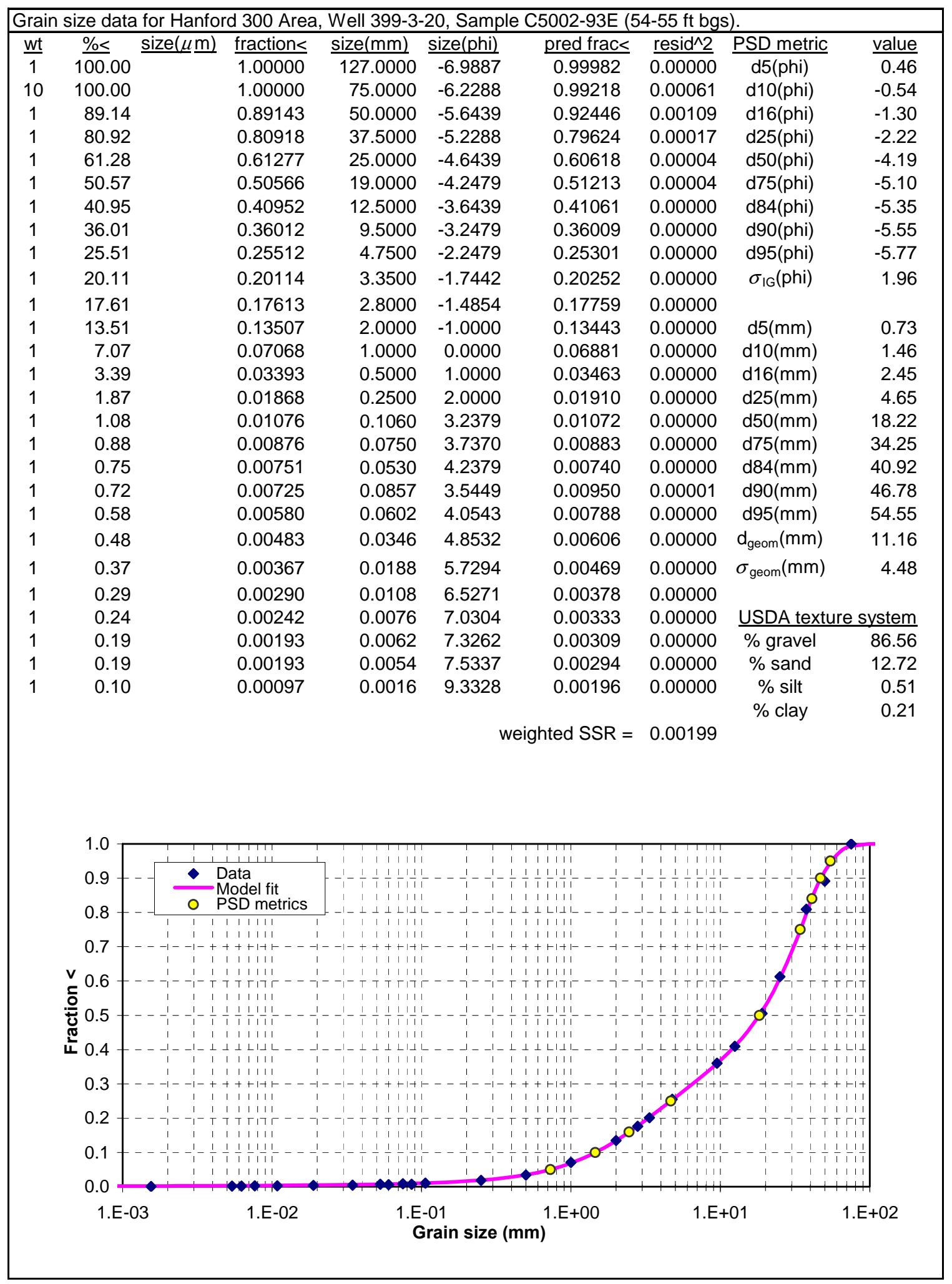

Figure D.19. Grain Size Data for Hanford 300 Area, Well 399-3-20, Sample C5002-93E (depth interval 54-55 feet) 


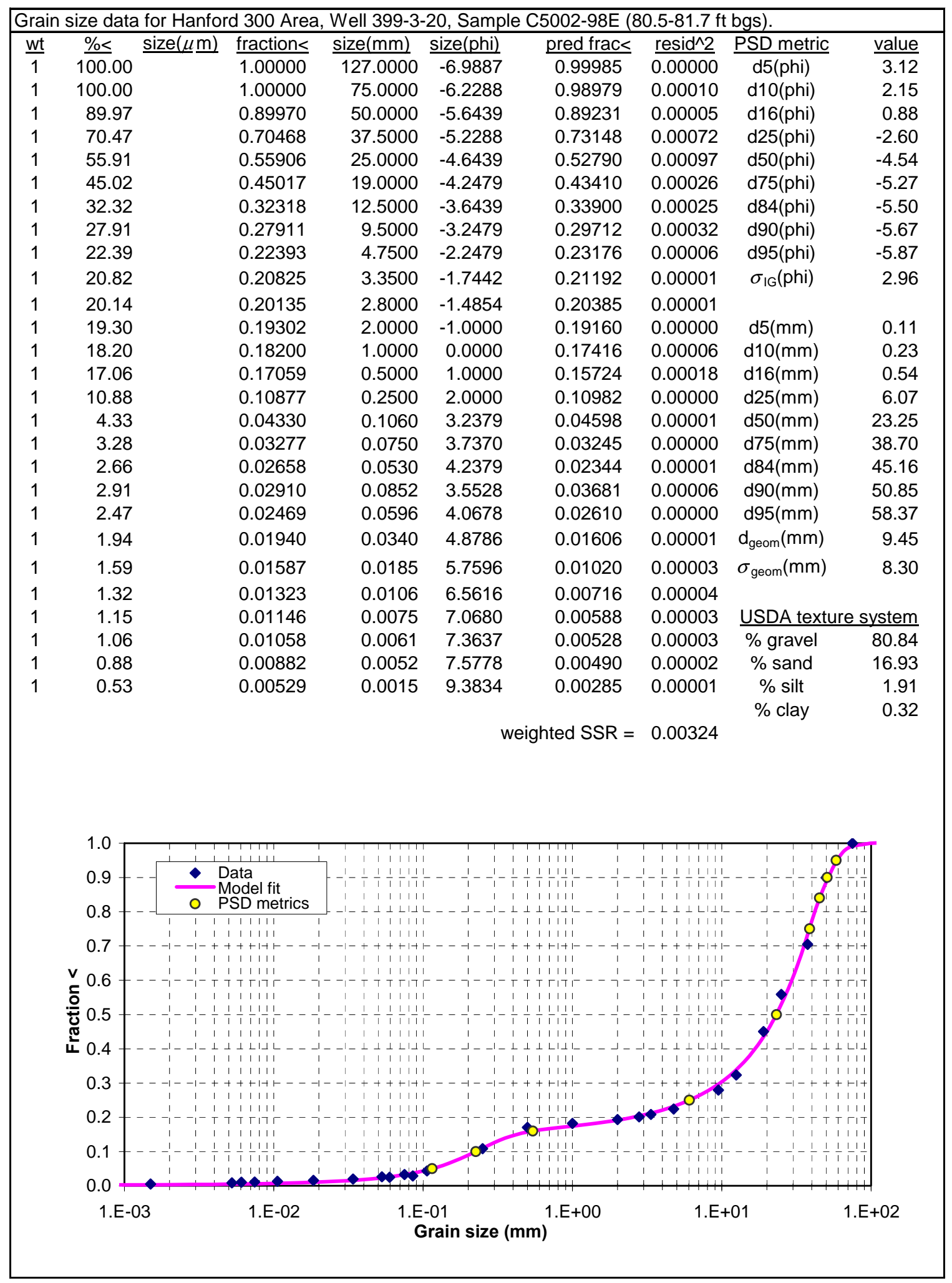

Figure D.20. Grain Size Data for Hanford 300 Area, Well 399-3-20, Sample C5002-98E (depth interval 80.5-81.7 feet) 

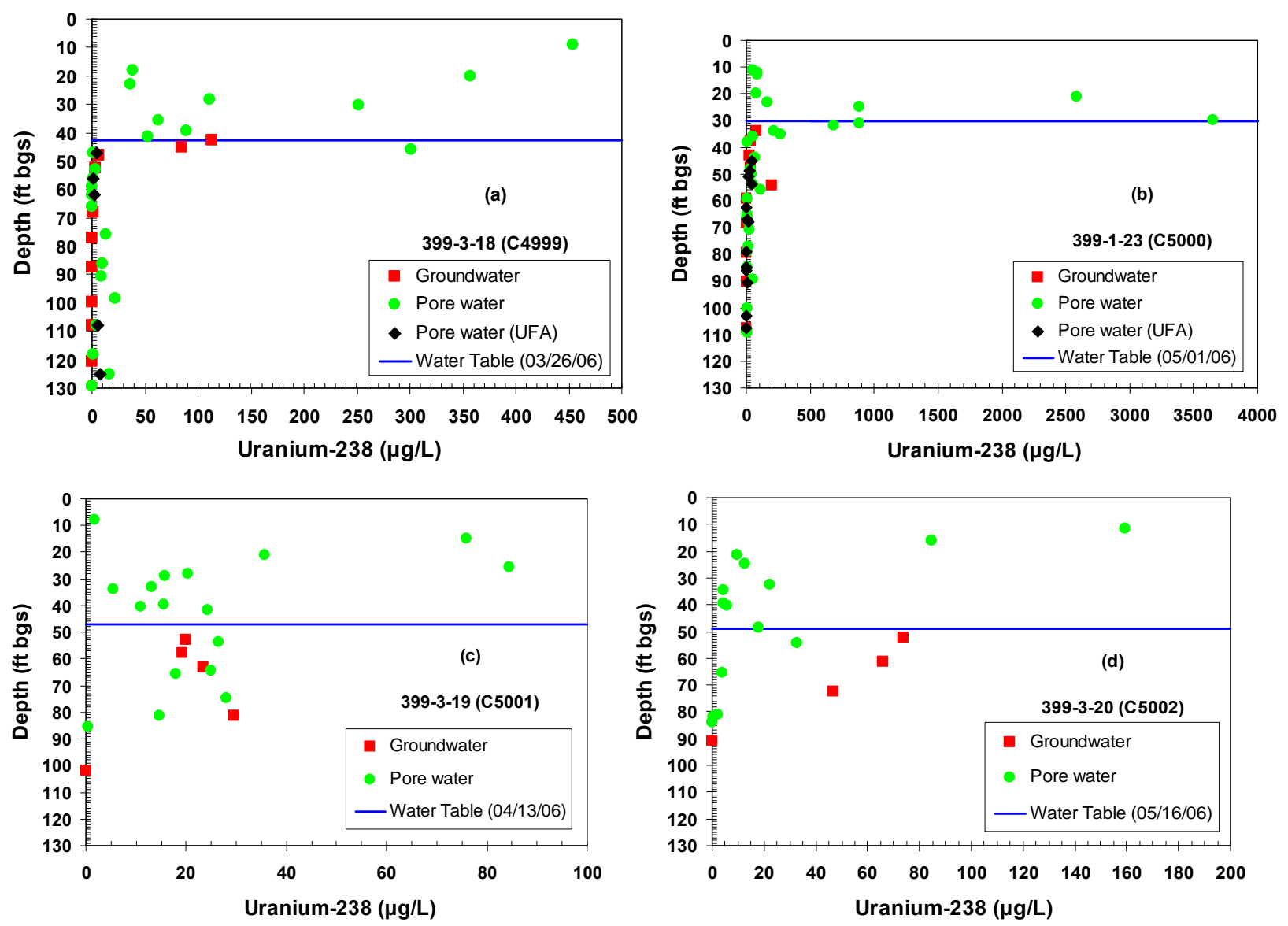

Figure D.21. Soluble Uranium Concentrations in the Depth-Discrete Groundwater, Pore Water after Ultracentrifugation (UFA), and Calculated Pore Water Uranium Concentrations in the Sediments from Boreholes (a) C4999; (b) C5000; (c) C5001; (d) C5002 


\section{Appendix E}

Selected Slug Test Analysis Plots for Discrete Depth Interval Testing 


\section{Appendix E}

\section{Selected Slug Test Analysis Plots for Discrete Depth Interval Testing}

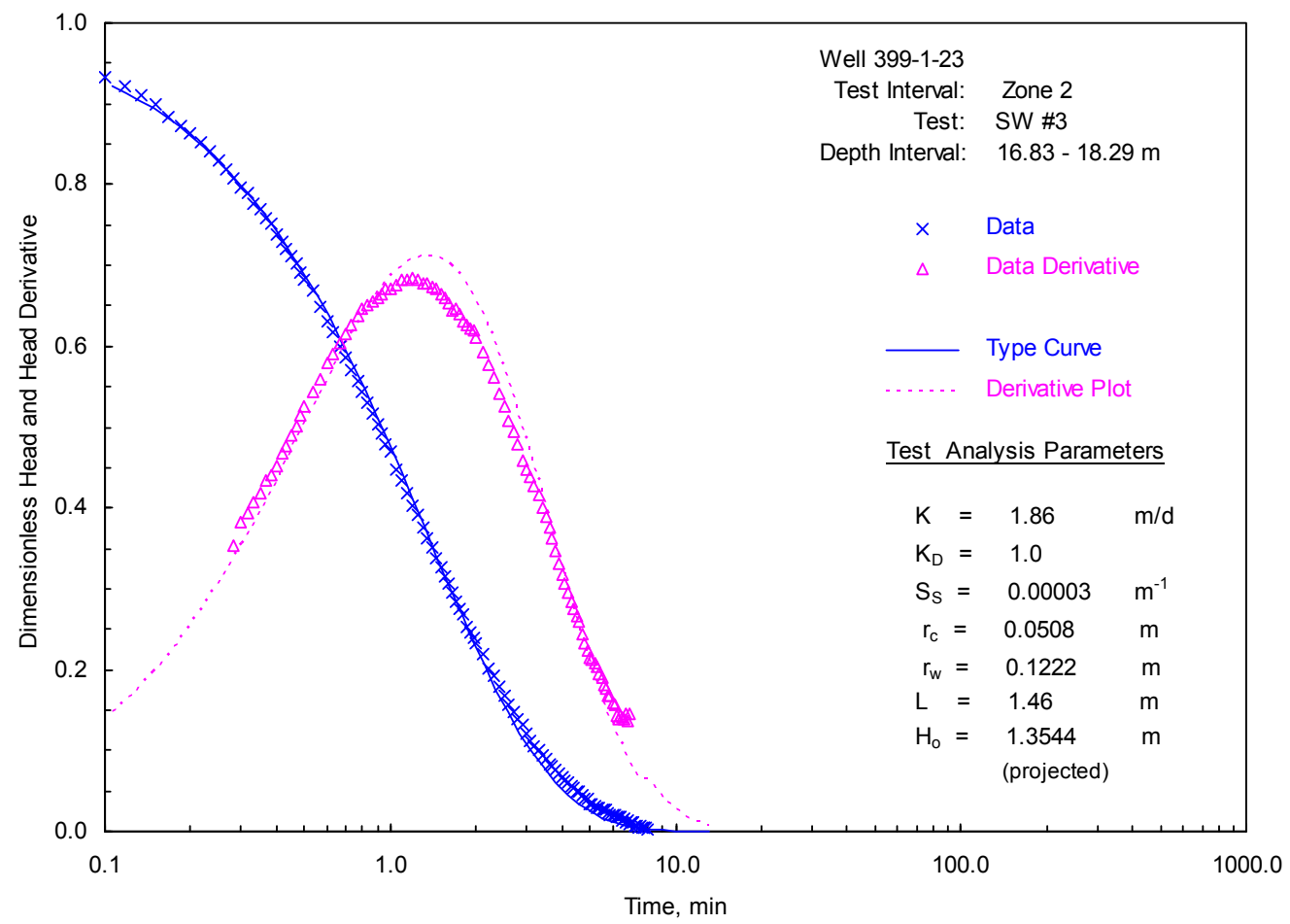

Figure E.1. Type-Curve Analysis Plot: Well 399-1-23; Depth Zone 2, Test SW \#3 


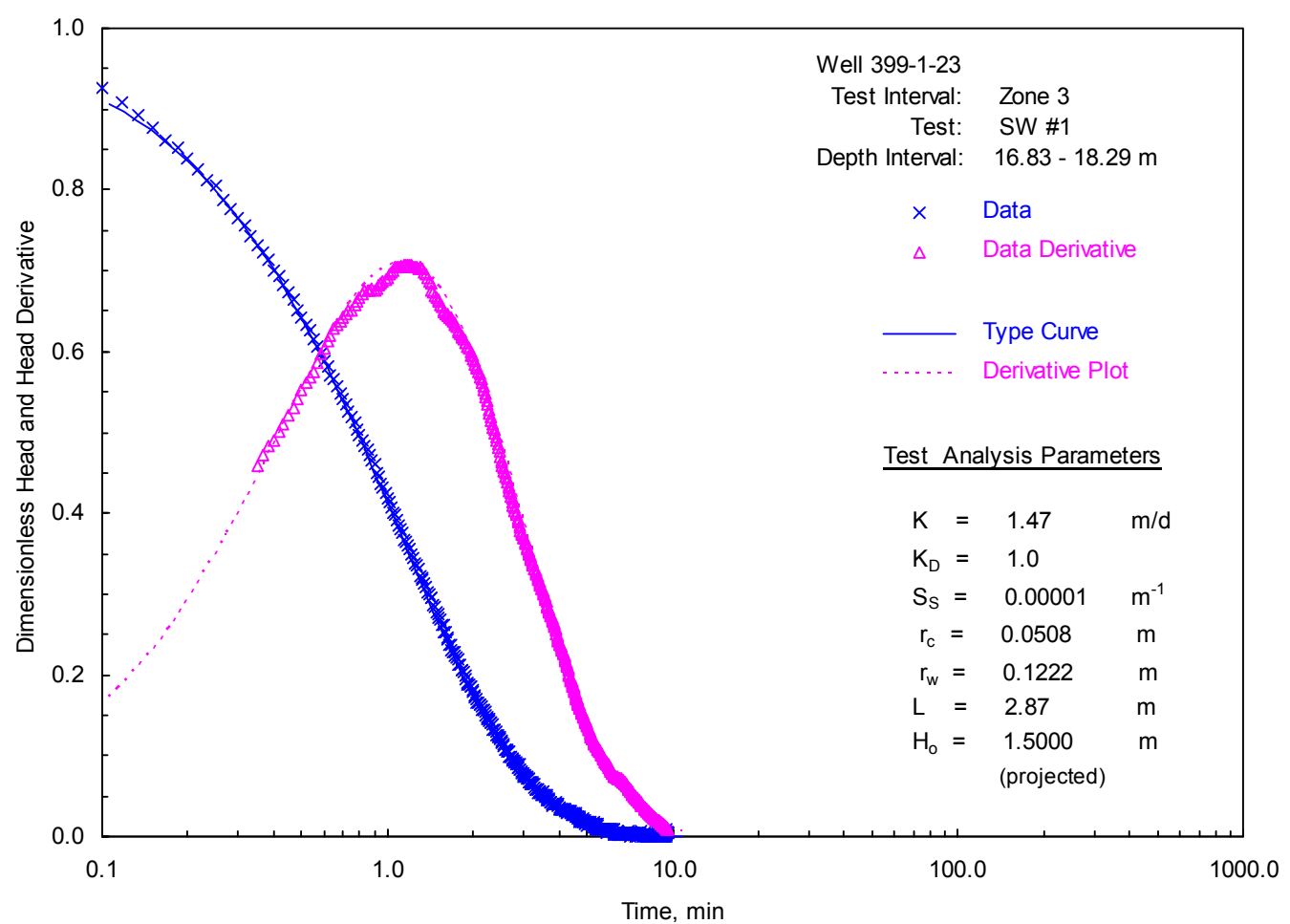

Figure E.2. Type-Curve Analysis Plot: Well 399-1-23; Depth Zone 3, Test SW \#1

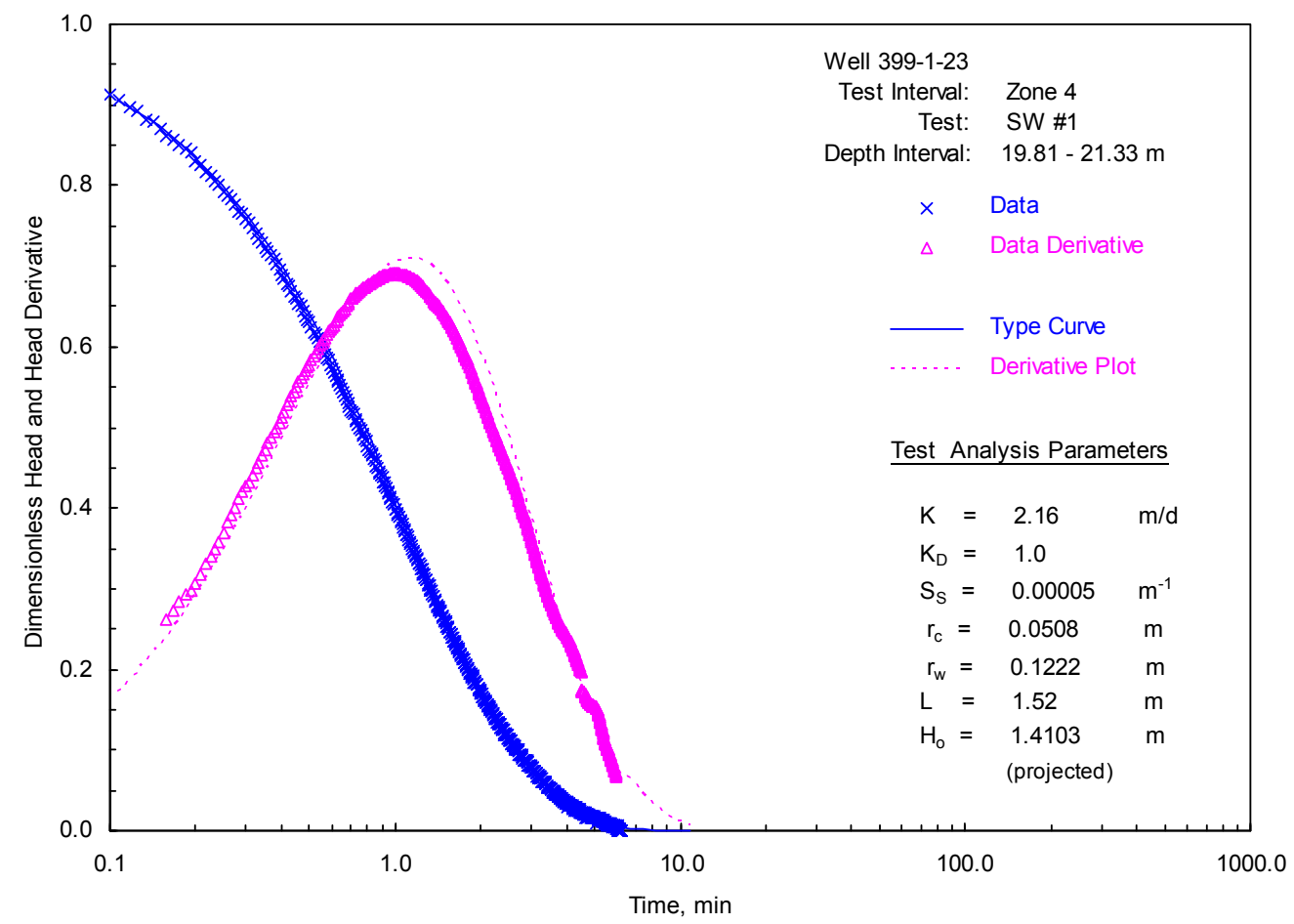

Figure E.3. Type-Curve Analysis Plot: Well 399-1-23; Depth Zone 4, Test SW \#1 


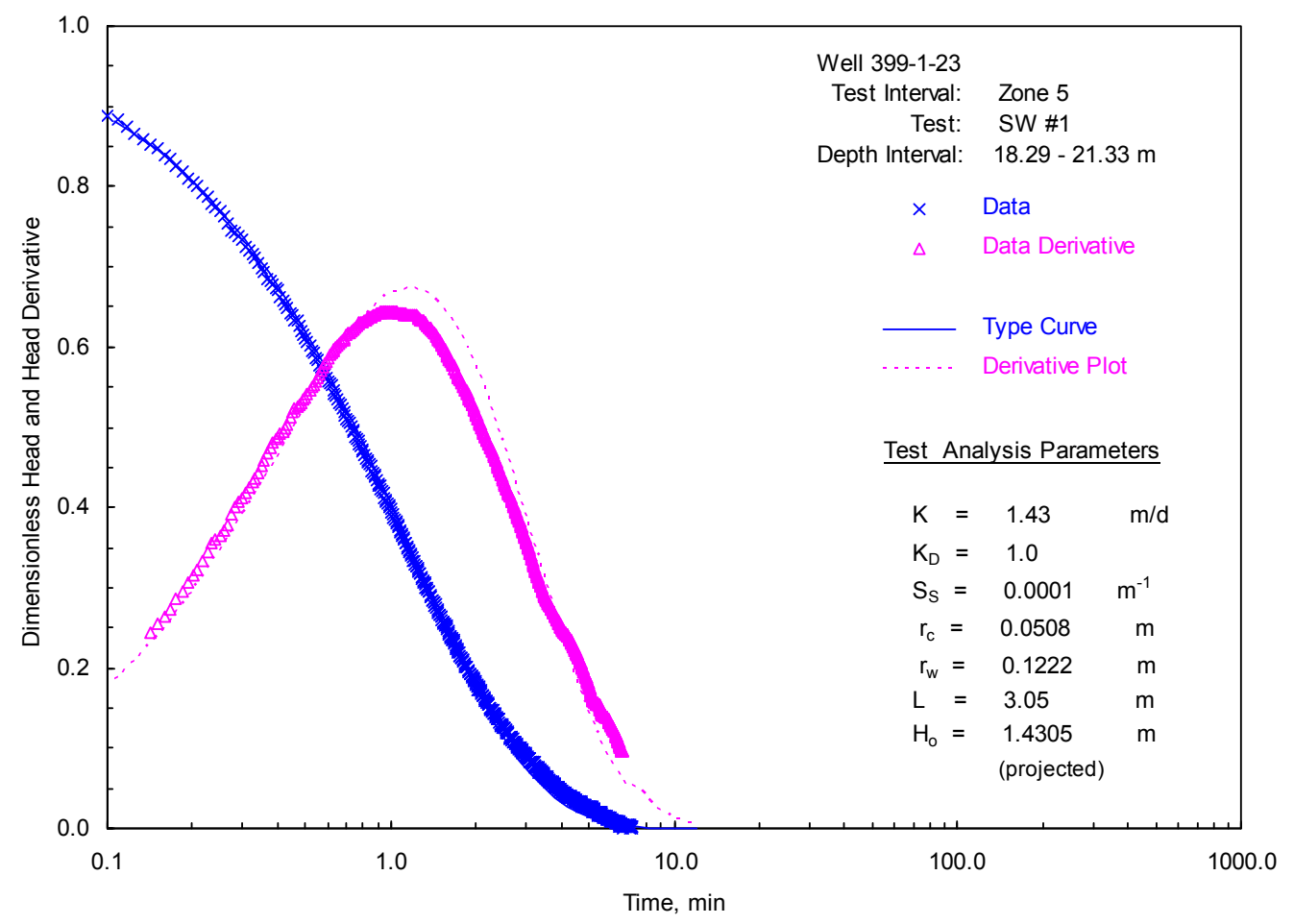

Figure E.4. Type-Curve Analysis Plot: Well 399-1-23; Depth Zone 5, Test SW \#1

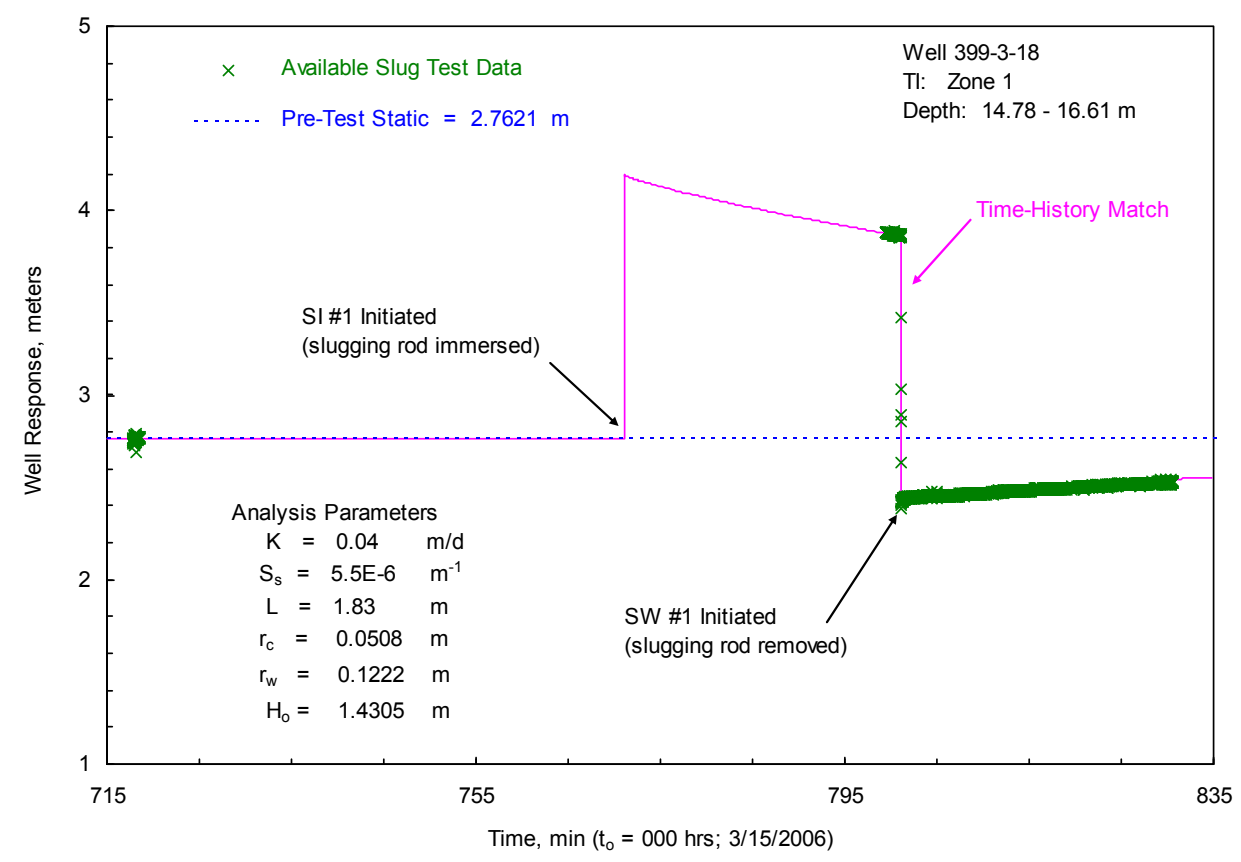

Figure E.5. Time-History Analysis Plot: Well 399-3-18; Depth Zone 1 


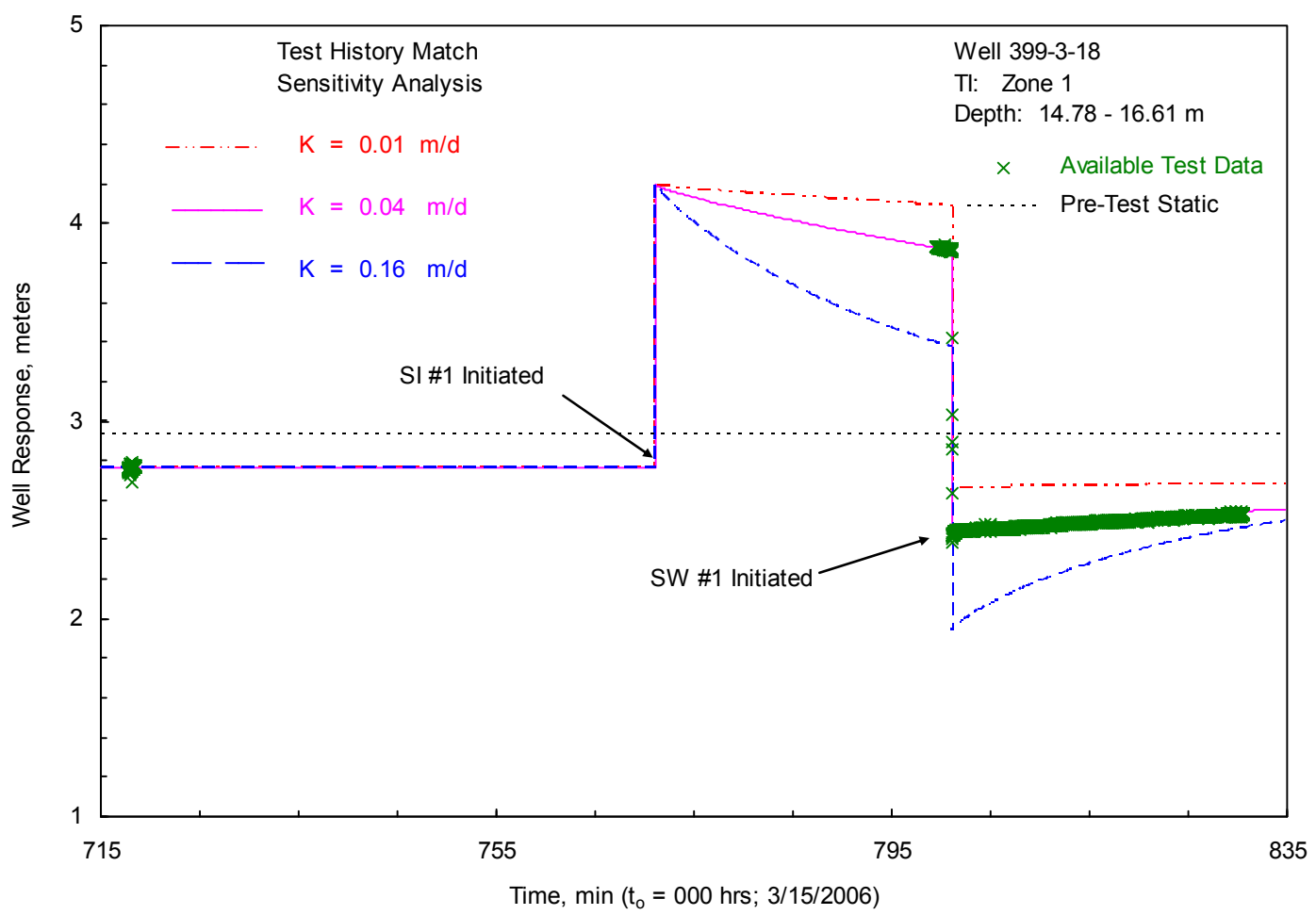

Figure E.6. Time-History Match - Sensitivity Analysis Plot: Well 399-3-18; Depth Zone 1

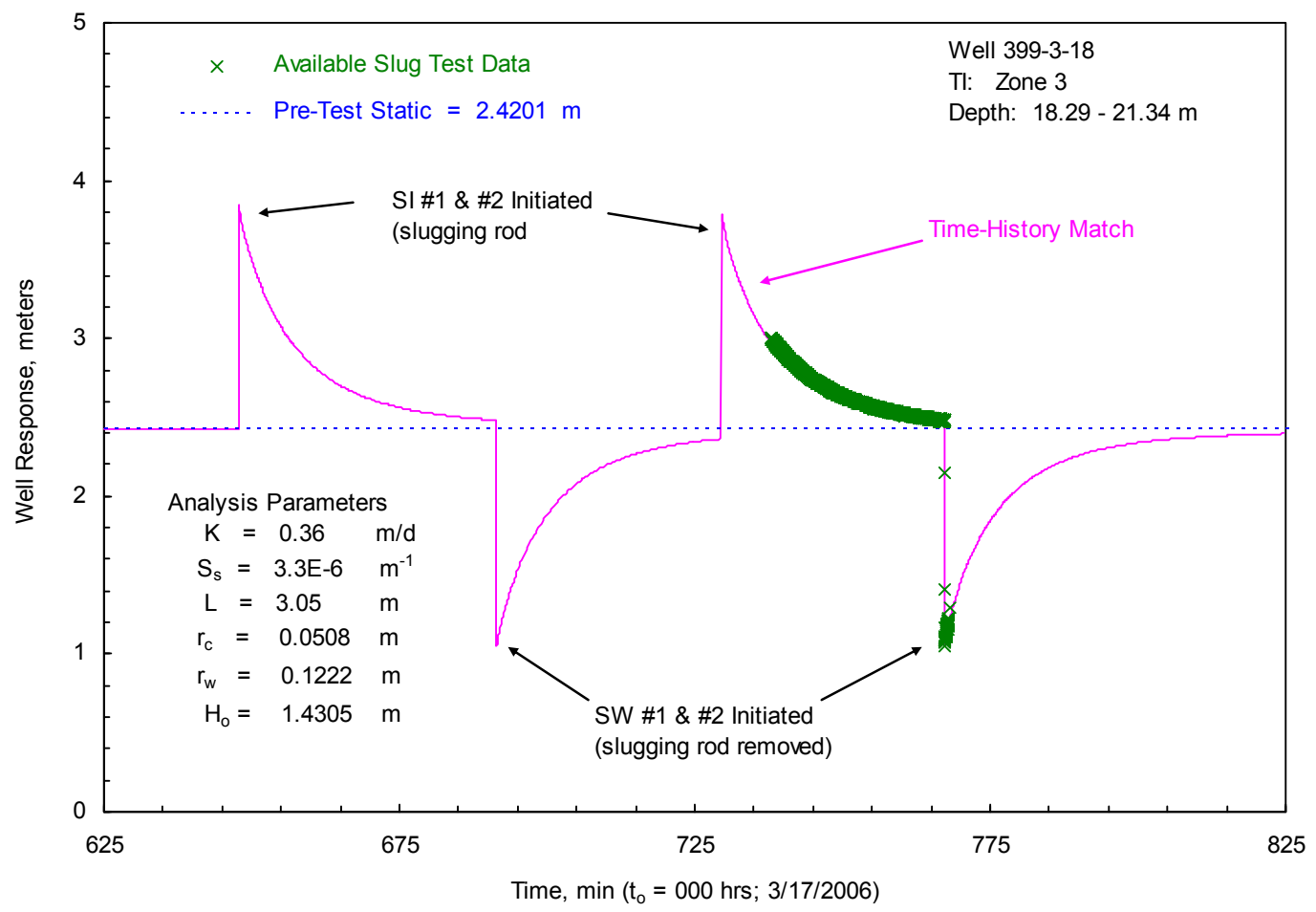

Figure E.7. Time-History Analysis Plot: Well 399-3-18; Depth Zone 3 


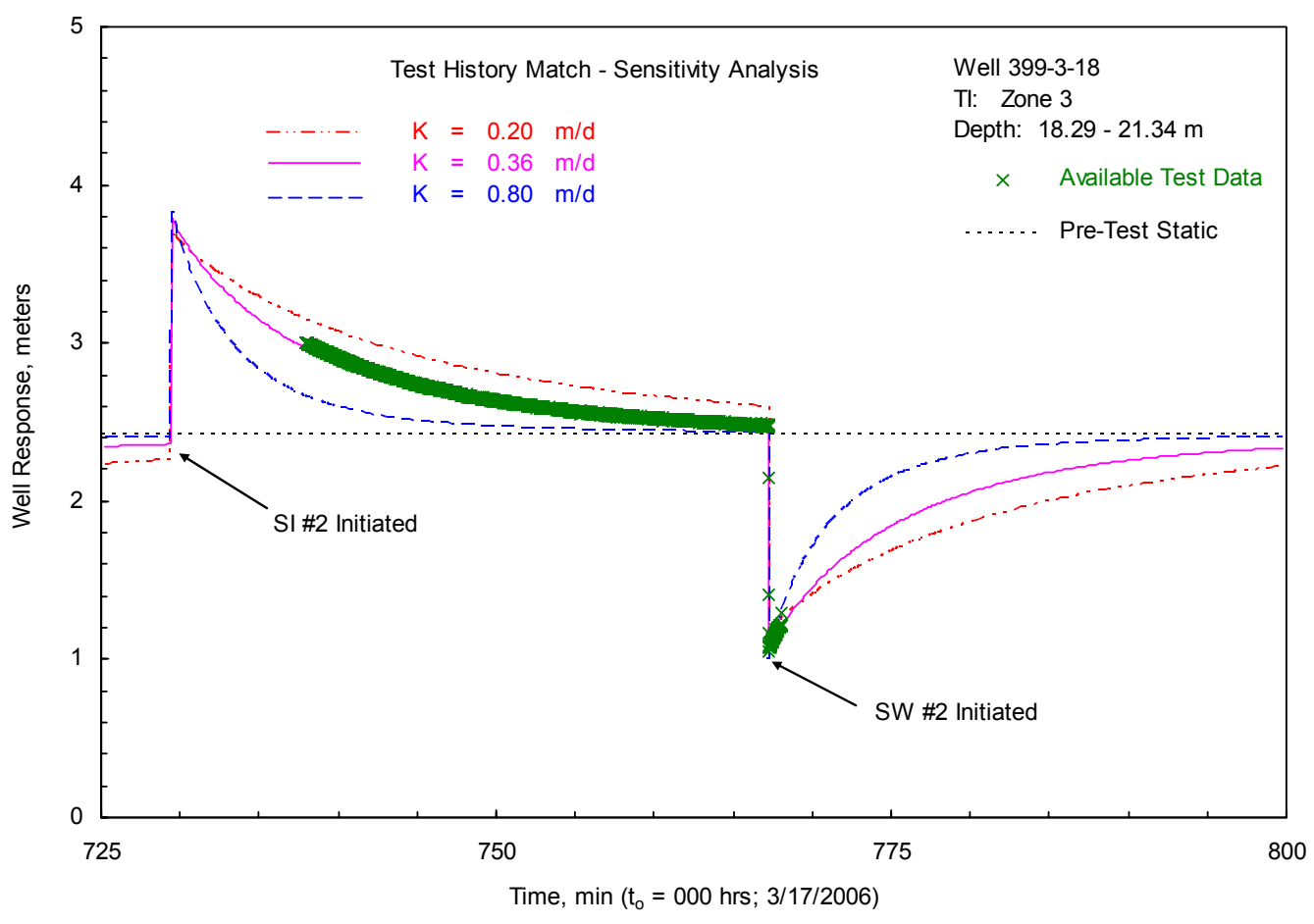

Figure E.8. Time-History Match - Sensitivity Analysis Plot: Well 399-3-18; Depth Zone 3

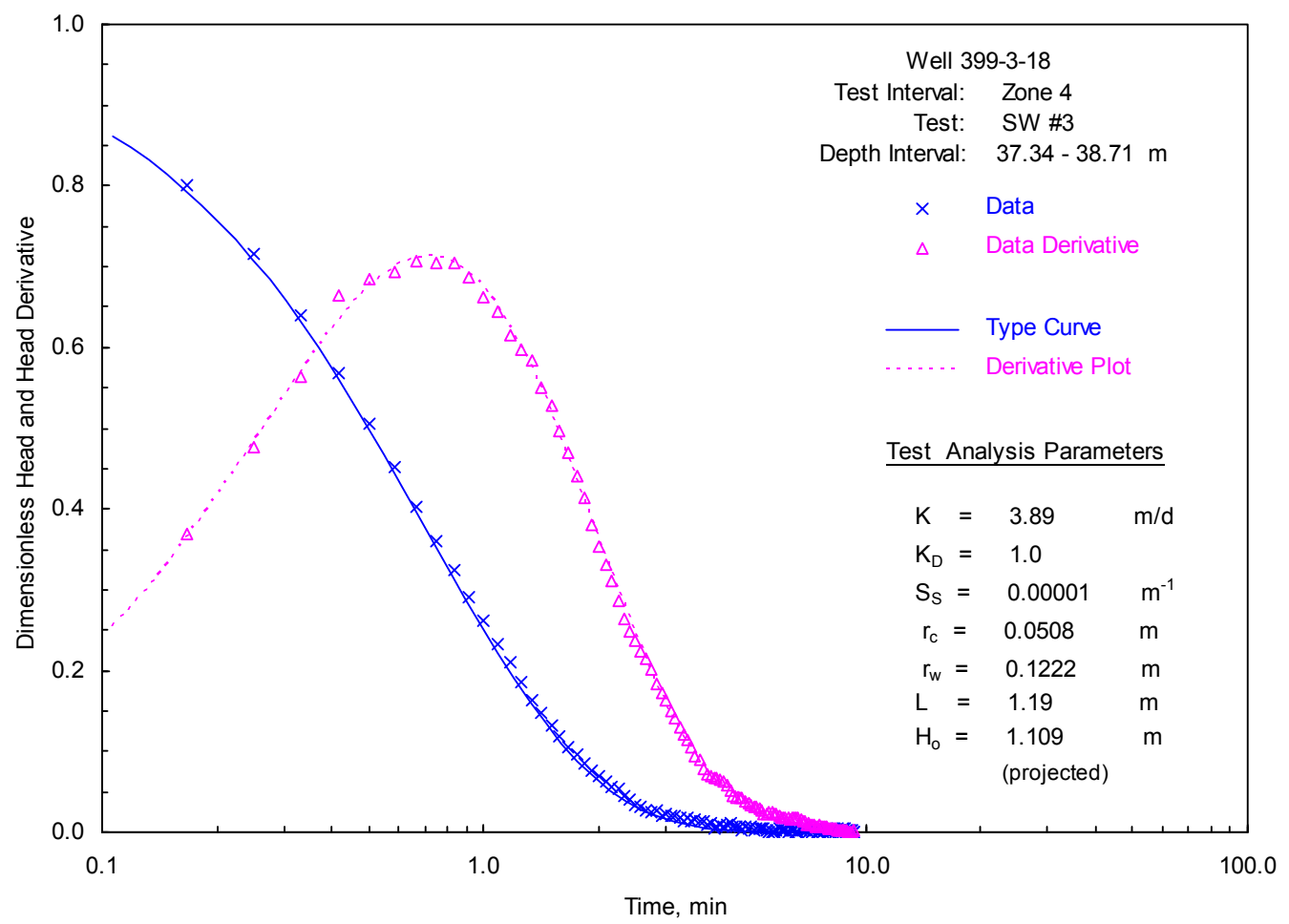

Figure E.9. Type-Curve Analysis Plot: Well 399-3-18; Depth Zone 4, Test SW \#3 


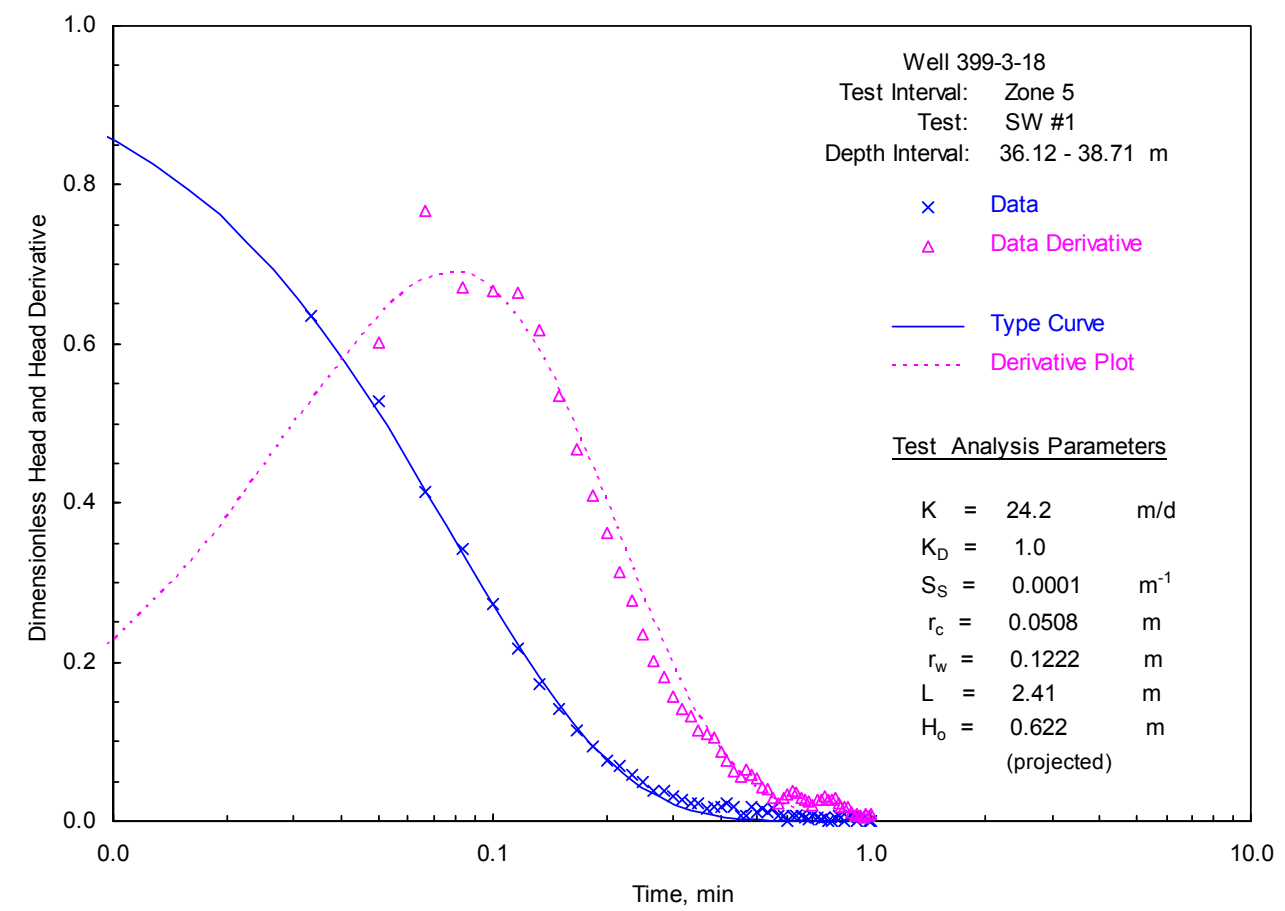

Figure E.10. Type-Curve Analysis Plot: Well 399-3-18; Depth Zone 5, Test SW \#1

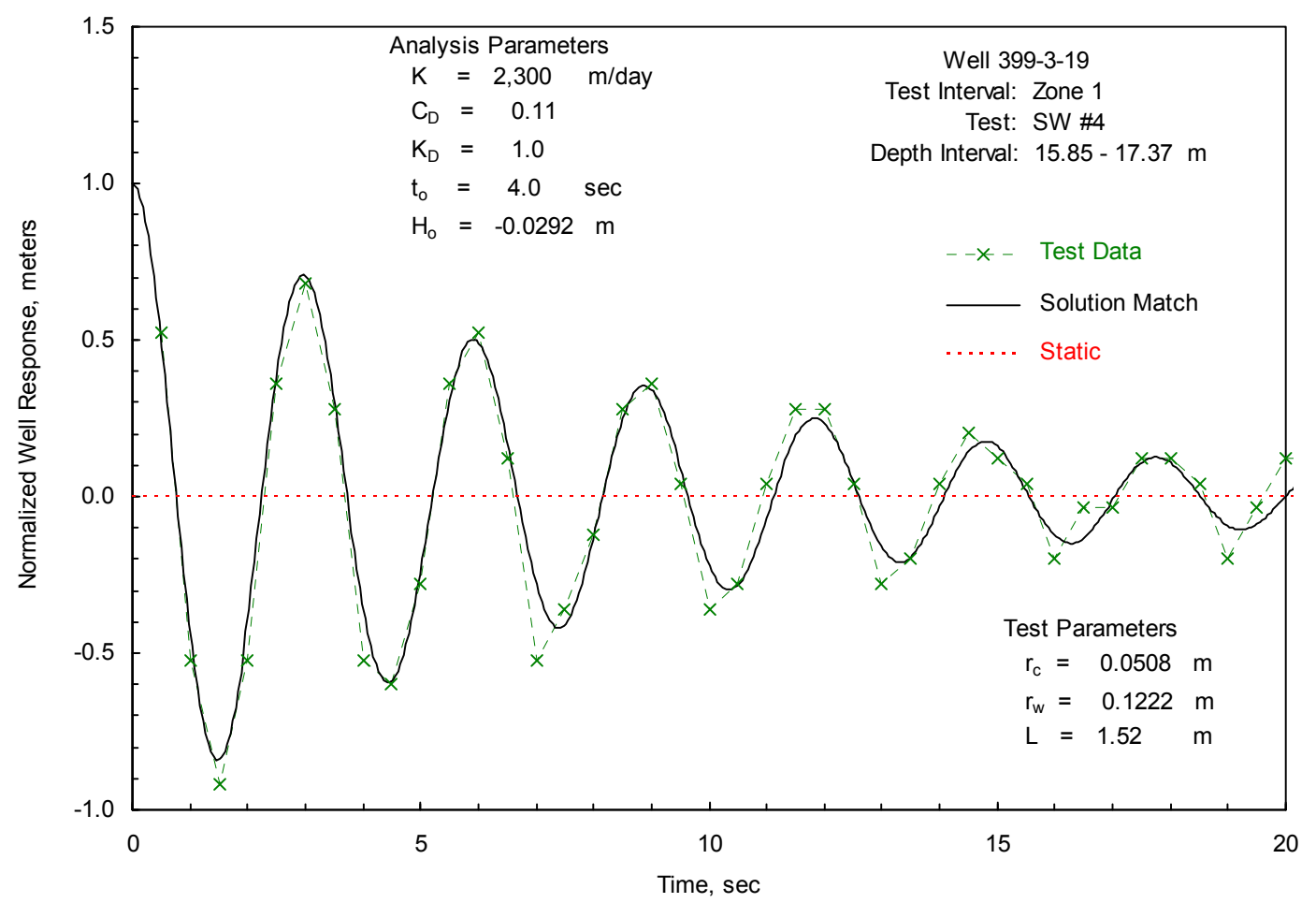

Figure E.11. High-K Analysis Plot: Well 399-3-19; Depth Zone 1, Test SW \#4 


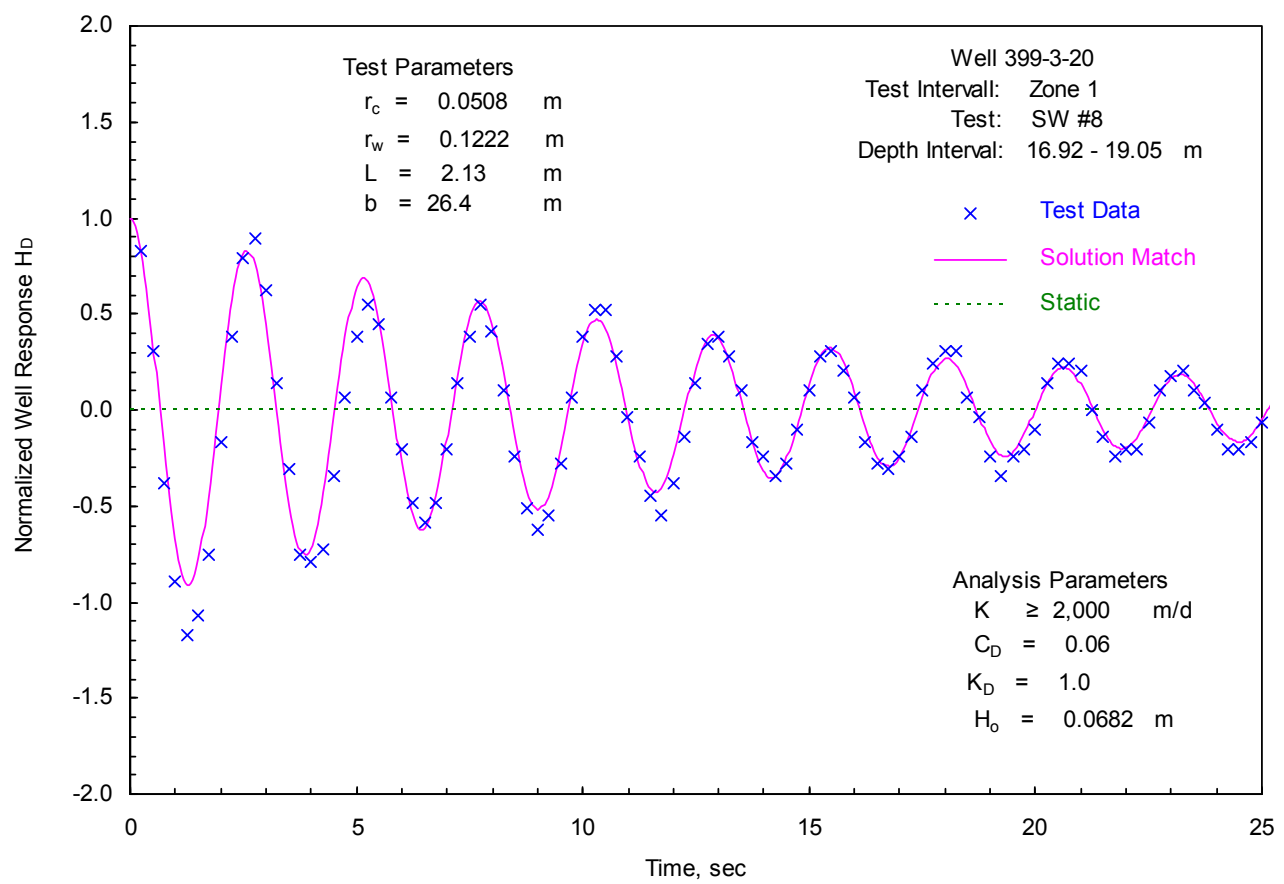

Figure E.12. High-K Analysis Plot: Well 399-3-20; Depth Zone 1, Test SW \#8

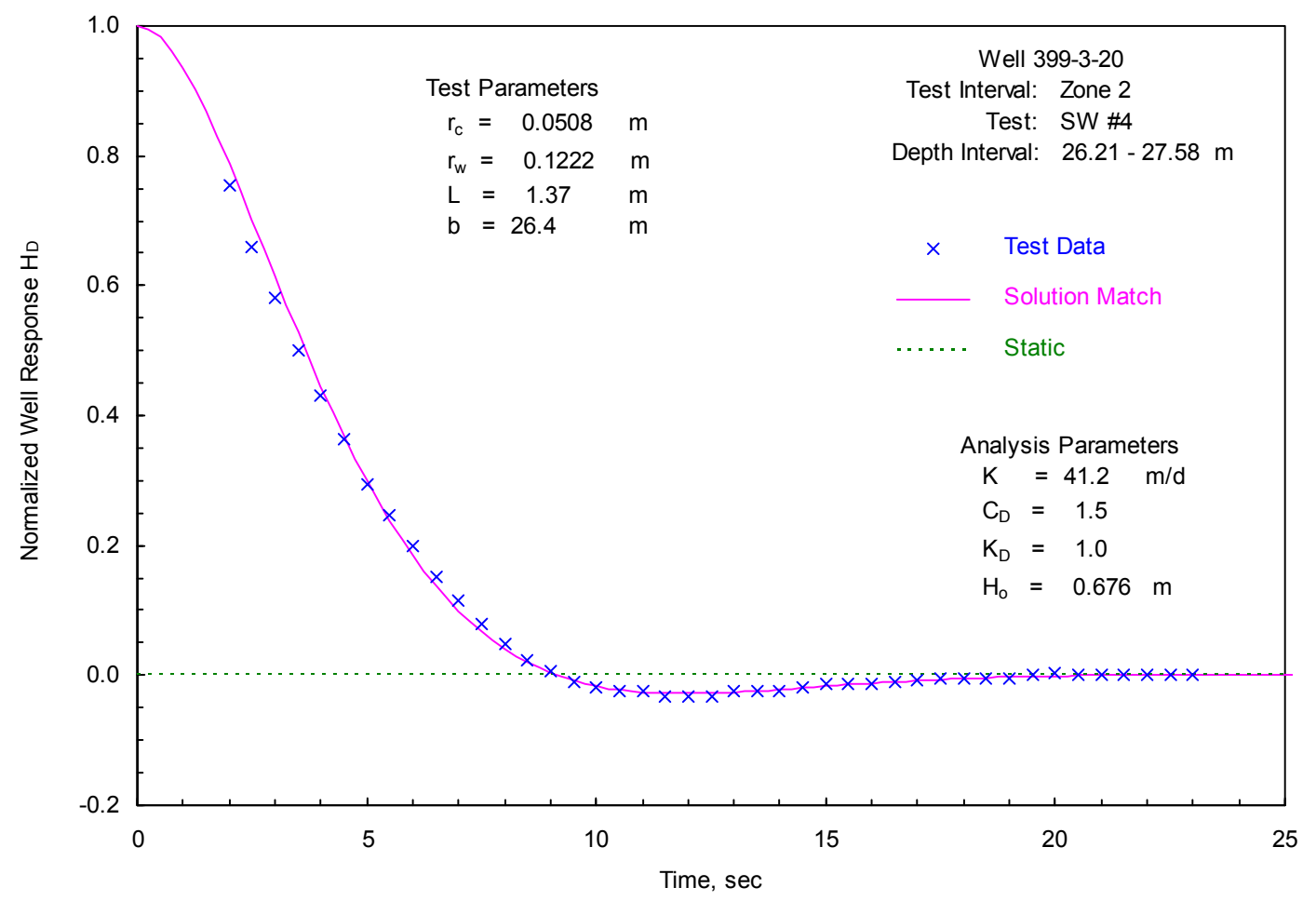

Figure E.13. High-K Analysis Plot: Well 399-3-20; Depth Zone 2, Test SW \#4 


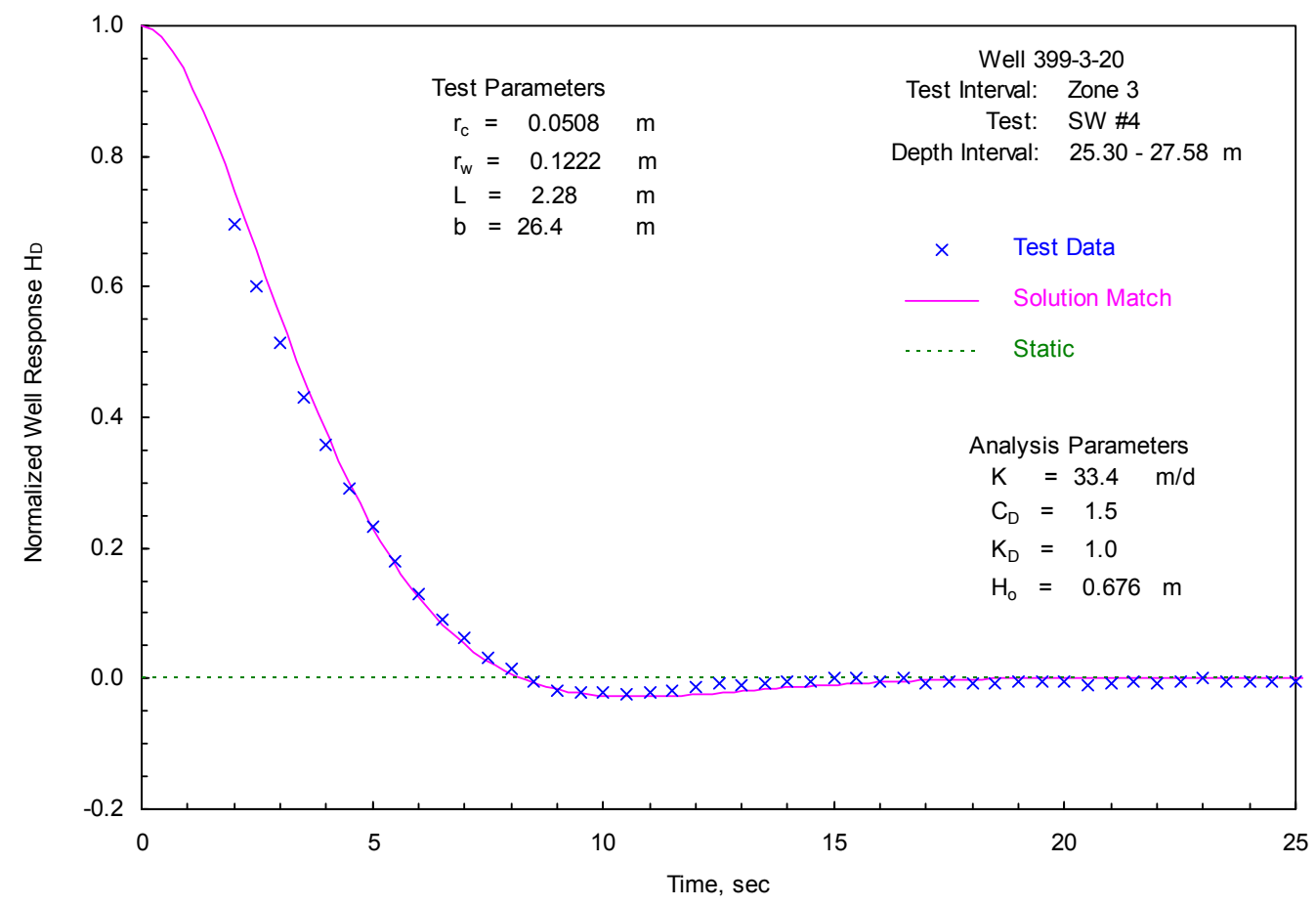

Figure E.14. High-K Analysis Plot: Well 399-3-20; Depth Zone 3, Test SW \#4 


\section{Appendix F}

\section{Groundwater Sampling Data}

This appendix contains a summary of the depth-discrete groundwater sampling locations and field parameters, the groundwater sample reports, and groundwater sample chain of custody forms 
Table F.1. Groundwater Data Sample Location Summary and Field Sampling Results

\begin{tabular}{|c|c|c|c|c|c|c|c|c|c|c|}
\hline \multicolumn{11}{|c|}{ Field Sampling Results for Depth Discrete Water Sampling at C4999 (399-3-18) } \\
\hline Sample \# & $\begin{array}{c}\text { Depth } \\
\text { Interval/Date }\end{array}$ & Pump/Bail & $\begin{array}{l}\text { GW Depth } \\
\text { (bgs) }\end{array}$ & $\begin{array}{l}\text { Turb } \\
\text { (NTU) }\end{array}$ & $\begin{array}{l}\text { Cond } \\
\text { (us) }\end{array}$ & $\begin{array}{l}\text { Temp } \\
\text { (c) }\end{array}$ & $\begin{array}{c}\mathrm{pH} \\
\text { (temp c) }\end{array}$ & $\begin{array}{l}\text { D.O. } \\
\text { (mg/L) }\end{array}$ & $\begin{array}{l}\text { Purged } \\
\text { (gal) }\end{array}$ & Comments \\
\hline (1) B1FRB1 & "42.5-44/3/14/06 & Bail & 42.5 & 2585 & 465 & 15.5 & $\begin{array}{c}7.83 \\
(15.6)\end{array}$ & 7.2 & 0 & $\begin{array}{l}\text { Unfiltered results, no } \\
\text { purge }\end{array}$ \\
\hline (2) B1FR93 & $49.7-51.5 / 3 / 14 / 06$ & Bail & 42.5 & $>1,000$ & 363 & 19 & 7.8(na) & 5.13 & 0 & $\begin{array}{l}\text { Unfiltered results, no } \\
\text { purge }\end{array}$ \\
\hline (3) B1FRB5 & $52-57 / 3 / 15 / 06$ & Bail & 42.5 & 84.4 & 213 & 15.9 & 8 & 4.68 & 0 & $\begin{array}{l}\text { Unfiltered results, no } \\
\text { purge }\end{array}$ \\
\hline \multirow[t]{4}{*}{ (4) B1FR89 } & $66-70 / 3 / 16 / 06$ & Pumped & 48 & 848 & 164 & 17.4 & 8.401 & 6.7 & NA & Purged and filtered \\
\hline & $66-70 / 3 / 16 / 06$ & Pumped & & 587 & 161.4 & 16.7 & 8.285 & 7 & NA & Purged and filtered \\
\hline & $66-70 / 3 / 16 / 06$ & Pumped & & 305 & 157.8 & 16.8 & $\begin{array}{l}8.318 \\
(17.4)\end{array}$ & 7 & NA & Purged and filtered \\
\hline & $66-70 / 3 / 16 / 06$ & Pumped & & 355 & 158 & 17.4 & $\begin{array}{l}8.399 \\
(17.5)\end{array}$ & 6.1 & NA & Purged and filtered \\
\hline \multirow[t]{5}{*}{ (5) B1FRB9 } & $76-78 / 3 / 20 / 06$ & Pumped & 43 & 466 & 168 & 15.7 & $\begin{array}{l}8.490 \\
(15.9)\end{array}$ & 2.1 & NA & Purged and filtered \\
\hline & 76-78/3/20/06 & Pumped & & 290 & 158 & 16.2 & $\begin{array}{l}8.549 \\
(16.4)\end{array}$ & 1.9 & NA & Purged and filtered \\
\hline & 76-78/3/20/06 & Pumped & & 48.1 & 160 & 16.3 & $\begin{array}{l}8.389 \\
(16.9) \\
\end{array}$ & 2.7 & NA & Purged and filtered \\
\hline & $76-78 / 3 / 20 / 06$ & Pumped & & 26.5 & 159 & 16.8 & $\begin{array}{l}8.351 \\
(15.0)\end{array}$ & 7 & NA & Purged and filtered \\
\hline & 76-78/3/20/06 & Pumped & & 9.09 & 159 & 18 & NA & 6.4 & NA & Purged and filtered \\
\hline \multirow[t]{4}{*}{ (6) B1FR85 } & $86-89 / 3 / 21 / 06$ & Pumped & 42.4 & 70.7 & 225 & 14.4 & $\begin{array}{l}8.132 \\
(15.0)\end{array}$ & 1.3 & NA & Purged and filtered \\
\hline & 86-89/3/21/06 & Pumped & & 43.5 & 224 & 15.1 & $\begin{array}{l}8.283 \\
(14.4)\end{array}$ & 1.6 & NA & Purged and filtered \\
\hline & 86-89/3/21/06 & Pumped & & 33.3 & 225 & 15.4 & $\begin{array}{l}8.245 \\
(14.8)\end{array}$ & 1.1 & NA & Purged and filtered \\
\hline & 86-89/3/21/06 & Pumped & & 26.9 & 225 & 15.8 & $\begin{array}{c}8.31 \\
(15.6)\end{array}$ & 1.3 & NA & Purged and filtered \\
\hline
\end{tabular}


Table F.1. (contd)

\begin{tabular}{|c|c|c|c|c|c|c|c|c|c|c|}
\hline \multicolumn{11}{|c|}{ Field Sampling Results for Depth Discrete Water Sampling at C4999 (399-3-18) } \\
\hline Sample \# & $\begin{array}{c}\text { Depth } \\
\text { Interval/Date }\end{array}$ & Pump/Bail & $\begin{array}{l}\text { GW Depth } \\
\text { (bgs) }\end{array}$ & $\begin{array}{c}\text { Turb } \\
\text { (NTU) }\end{array}$ & $\begin{array}{l}\text { Cond } \\
\text { (us) }\end{array}$ & $\begin{array}{l}\text { Temp } \\
\text { (c) }\end{array}$ & $\begin{array}{c}\mathrm{pH} \\
\text { (temp c) }\end{array}$ & $\begin{array}{c}\text { D.O. } \\
\text { (mg/L) }\end{array}$ & $\begin{array}{c}\text { Purged } \\
\text { (gal) }\end{array}$ & Comments \\
\hline \multirow[t]{5}{*}{$\begin{array}{l}\text { (7) B1FR97 } \\
\end{array}$} & 98-101/3/22/06 & Pumped & 41 & 10134 & 267 & $\begin{array}{l}14.8 \\
\end{array}$ & $\begin{array}{l}7.929 \\
(15.7)\end{array}$ & 1.8 & "NA & Purged and filtered \\
\hline & $98-101 / 3 / 22 / 06$ & Pumped & & 109 & 267 & 15 & $\begin{array}{l}8.028 \\
(15.1)\end{array}$ & 2 & NA & Purged and filtered \\
\hline & $98-101 / 3 / 22 / 06$ & Pumped & & 98.6 & 274 & 13.5 & $\begin{array}{l}7.991 \\
(15.1)\end{array}$ & 0.8 & NA & Purged and filtered \\
\hline & $98-101 / 3 / 22 / 06$ & Pumped & & 98.6 & 268 & 13.8 & $\begin{array}{l}8.101 \\
(14.6)\end{array}$ & 1.1 & NA & Purged and filtered \\
\hline & $98-101 / 3 / 22 / 06$ & Pumped & & 0.82 & 267 & 14.3 & $\begin{array}{l}8.128 \\
(14.5)\end{array}$ & 1 & NA & Purged and filtered \\
\hline NA & $\begin{array}{l}\text { River sample } \\
3 / 22 / 06\end{array}$ & grab & river & 3.09 & 148 & 6.6 & $\begin{array}{l}8.125 \\
(7.0)\end{array}$ & 10.5 & NA & River grab sample \\
\hline \multirow[t]{5}{*}{ (8) B1FR81 } & $107-109 / 3 / 22 / 06$ & Pumped & 41 & $>1,000$ & 270 & 19.1 & $\begin{array}{l}8.158 \\
(18.4)\end{array}$ & 0.4 & NA & Purged and filtered \\
\hline & 107-109/3/22/06 & Pumped & & $>1,000$ & 274 & 19.1 & $\begin{array}{l}8.285 \\
(18.3)\end{array}$ & 0.7 & NA & Purged and filtered \\
\hline & $107-109 / 3 / 22 / 06$ & Pumped & & $>1,000$ & 274 & 17.8 & $\begin{array}{l}8.165 \\
(18.0)\end{array}$ & 1 & NA & Purged and filtered \\
\hline & 107-109/3/22/06 & Pumped & & $>1,000$ & 276 & 17.9 & $\begin{array}{l}8.170 \\
(18.3) \\
\end{array}$ & 0.6 & NA & Purged and filtered \\
\hline & $107-109 / 3 / 22 / 06$ & Pumped & & $>1,000$ & 275 & 17.6 & $\begin{array}{l}8.185 \\
(17.5)\end{array}$ & 2.7 & NA & Purged and filtered \\
\hline (9) B1FR33 & $120-121.5 / 3 / 23 / 06$ & Pumped & & $>1,000$ & 281 & 17.2 & 8.181 & 1.1 & NA & Purged and filtered \\
\hline (10) B1FR77 & 42.6-47.9/4/13/06 & Pumped & 42.6 & 2.69 & 349 & 16.4 & 7.51 & 8.1 & 1485 & Purged and filtered \\
\hline
\end{tabular}


Table F.1. (contd)

\begin{tabular}{|c|c|c|c|c|c|c|c|c|c|c|}
\hline \multicolumn{11}{|c|}{ Field Sampling Results for Depth Discrete Water Sampling at C5000 (399-1-23) } \\
\hline Sample \# & $\begin{array}{c}\text { Depth } \\
\text { Interval/Date }\end{array}$ & Pump/Bail & $\begin{array}{l}\text { GW Depth } \\
\text { (bgs) }\end{array}$ & $\begin{array}{c}\text { Turb } \\
\text { (NTU) }\end{array}$ & $\begin{array}{c}\text { Cond } \\
\text { (us) }\end{array}$ & $\begin{array}{l}\text { Temp } \\
\text { (c) }\end{array}$ & $\begin{array}{c}\mathrm{pH} \\
\text { (temp c) }\end{array}$ & $\begin{array}{c}\mathrm{D} . \mathrm{O} . \\
(\mathrm{mg} / \mathrm{L})\end{array}$ & $\begin{array}{l}\text { Purged } \\
\text { (Gal) }\end{array}$ & Comments \\
\hline (1) B1FR37 & $33.5-34 / 4 / 03 / 06$ & Bail & 33 & NA & NA & NA & NA & NA & NA & $\begin{array}{l}\text { Unfiltered results, } \\
\sim 1 \text { gal. no purge }\end{array}$ \\
\hline (2) B1FR41 & 36-39/4/4/06 & Pumped & 33.5 & 5.3 & 490 & 15 & 7.47 & 6.14 & 200 & Purged and filtered \\
\hline (3) B1FR45 & $43-43.5 / 4 / 04 / 06$ & Pumped & 39.4 & 45.8 & 492 & 16.3 & 7.58 & 5.18 & 190 & Purged and filtered \\
\hline (4) B1FR49 & $47-48.5 / 4 / 05 / 06$ & Pumped & 39.2 & 65.9 & 485 & 13.9 & 7.8 & 8 & 200 & Purged and filtered \\
\hline (5) B1FR53 & $53.5-55 / 4 / 04 / 06$ & Pumped & 40.3 & 113 & 411 & 16.9 & 8.3 & 1.4 & $>300$ & Purged and filtered \\
\hline (6) B1FR57 & $58.6-60 / 4 / 06 / 06$ & Pumped & 39.4 & 196 & 396 & 14.8 & 8.2 & 0.6 & 240 & Purged and filtered \\
\hline (7) B1FR61 & 67-70/4/07/06 & Pumped & 39.4 & 561 & 302 & 15.6 & 8.26 & 1 & 345 & Purged and filtered \\
\hline (8) B1FR65 & $77-82 / 4 / 10 / 06$ & Pumped & 39.2 & 200 & 318 & 16.9 & 8.2 & 1 & 475 & Purged and filtered \\
\hline (9) B1FR69 & 88.5-91/4/11/06 & Pumped & 39.1 & 433 & 326 & 18 & 8.1 & 0.6 & 600 & Purged and filtered \\
\hline (10) B1FR73 & $105.5-110 / 4 / 17 / 06$ & Pumped & 34.8 & $>1,000$ & 328 & 18.5 & 8.2 & 0.8 & 270 & Purged and filtered \\
\hline
\end{tabular}


Table F.1. (contd)

\begin{tabular}{|c|c|c|c|c|c|c|c|c|c|c|}
\hline \multicolumn{11}{|c|}{ Field Sampling Results for Depth Discrete Water Sampling at C5001 (399-3-19) } \\
\hline Sample \# & $\begin{array}{c}\text { Depth } \\
\text { Interval/Date }\end{array}$ & Pump/Bail & $\begin{array}{c}\text { GW Depth } \\
\text { (bgs) }\end{array}$ & $\begin{array}{c}\text { Turb } \\
\text { (NTU) }\end{array}$ & $\begin{array}{c}\text { Cond } \\
\text { (us) }\end{array}$ & $\begin{array}{c}\text { Temp } \\
\text { (c) }\end{array}$ & $\begin{array}{c}\mathrm{pH} \\
\text { (temp c) }\end{array}$ & $\begin{array}{c}\text { D.O. } \\
\text { (mg/L) }\end{array}$ & $\begin{array}{c}\text { Purged } \\
\text { (gal) }\end{array}$ & Comments \\
\hline \multirow[t]{4}{*}{ (1) B1HRW8 } & $52-53 / 4 / 26 / 06$ & Pumped & 47.2 & 24.6 & 407 & 20.1 & 7.24 & 8.4 & 63 & Purged and filtered \\
\hline & $52-53 / 4 / 26 / 06$ & Pumped & 47.2 & 15 & 404 & 19.1 & 7.33 & 8.5 & 63.75 & Purged and filtered \\
\hline & $52-53 / 4 / 26 / 06$ & Pumped & 47.2 & 11.6 & 403 & 19.1 & 7.47 & 8.6 & 64.5 & Purged and filtered \\
\hline & $52-53 / 4 / 26 / 06$ & Pumped & 47.2 & 9.99 & 402 & 19.3 & 7.43 & 8.6 & 64.5 & Purged and filtered \\
\hline \multirow[t]{4}{*}{ (2) B1HRX2 } & $57.5-58 / 4 / 27 / 06$ & Pumped & 47.1 & 415 & 407 & 16.3 & 7.56 & 9 & 75 & Purged and filtered \\
\hline & $57.5-58 / 4 / 27 / 06$ & Pumped & 47.1 & 43.6 & 409 & 16.5 & 7.49 & 9.4 & 125 & Purged and filtered \\
\hline & $57.5-58 / 4 / 27 / 06$ & Pumped & 47.1 & 29.1 & 411 & 16.5 & 7.47 & 9.4 & 170 & Purged and filtered \\
\hline & $57.5-58 / 4 / 27 / 06$ & Pumped & 47.1 & 16 & 408 & 16.2 & 7.6 & 9.4 & 250 & Purged and filtered \\
\hline \multirow[t]{4}{*}{ (3) B1HRX7 } & $63 / 4 / 27 / 06$ & Pumped & 47.4 & $>1,000$ & 413 & 20.4 & 7.62 & 8 & 90 & Purged and filtered \\
\hline & 63/4/27/06 & Pumped & 47.4 & 598 & 411 & 19.8 & 7.5 & 8.3 & 130 & Purged and filtered \\
\hline & $63 / 4 / 27 / 06$ & Pumped & 47.4 & 294 & 413 & 19.3 & 7.49 & 8.4 & 178 & Purged and filtered \\
\hline & $63 / 4 / 27 / 06$ & Pumped & 47.4 & 67.4 & 411 & 20 & 7.48 & 8.1 & 250 & Purged and filtered \\
\hline \multirow[t]{5}{*}{ (4) B1HRY0 } & $80-83 / 4 / 28 / 06$ & Pumped & 47.5 & $>1,000$ & 431 & 20.4 & 7.57 & 6.9 & 150 & Purged and filtered \\
\hline & $80-83 / 4 / 28 / 06$ & Pumped & 47.5 & $>1,000$ & 426 & 19.4 & 7.55 & 7.7 & 200 & Purged and filtered \\
\hline & $80-83 / 4 / 28 / 06$ & Pumped & 47.5 & $>1,000$ & 426 & 19.9 & 7.55 & 7.5 & 250 & Purged and filtered \\
\hline & $80-83 / 4 / 28 / 06$ & Pumped & 47.5 & 639 & 428 & 19.2 & 7.56 & 7.7 & 300 & Purged and filtered \\
\hline & $80-83 / 4 / 28 / 06$ & Pumped & 47.5 & 392 & 422 & 20.5 & 7.56 & 7.5 & 360 & Purged and filtered \\
\hline \multirow[t]{8}{*}{ (5) B1HRY5 } & $100-103.5 / 5 / 03 / 06$ & Pumped & 46.1 & $>1,000$ & 345 & 19.8 & 7.61 & 1.1 & 140 & Purged and filtered \\
\hline & $100-103.5 / 5 / 03 / 06$ & Pumped & 46.1 & $>1,000$ & 341 & 19.1 & 7.44 & 0.6 & 182 & Purged and filtered \\
\hline & $100-103.5 / 5 / 03 / 06$ & Pumped & 46.1 & $>1,000$ & 336 & 19 & 7.56 & 0.7 & 202 & Purged and filtered \\
\hline & $100-103.5 / 5 / 03 / 06$ & Pumped & 46.1 & $>1,000$ & 332 & 19 & 7.36 & 0.7 & 226 & Purged and filtered \\
\hline & $100-103.5 / 5 / 03 / 06$ & Pumped & 46.1 & $>1,000$ & 323 & 19.4 & 7.52 & 0.6 & 260 & Purged and filtered \\
\hline & $100-103.5 / 5 / 03 / 06$ & Pumped & 46.1 & 528 & 318 & 19 & 7.57 & ND & 297 & Purged and filtered \\
\hline & $100-103.5 / 5 / 03 / 06$ & Pumped & 46.1 & 225 & 318 & 18.7 & 7.55 & 0.9 & 320 & Purged and filtered \\
\hline & $100-103.5 / 5 / 03 / 06$ & Pumped & 46.1 & 108 & 318 & 19.2 & 7.54 & 0.7 & 355 & Purged and filtered \\
\hline (6) B1HRY8 & DNS & DNS & DNS & DNS & DNS & DNS & DNS & DNS & DNS & DNS \\
\hline
\end{tabular}


Table F.1. (contd)

\begin{tabular}{|c|c|c|c|c|c|c|c|c|c|c|}
\hline \multicolumn{11}{|c|}{ Field Sampling Results for Depth Discrete Water Sampling at C5002 (399-3-20) } \\
\hline Sample \# & $\begin{array}{c}\text { Depth } \\
\text { Interval/Date } \\
\end{array}$ & Pump/Bail & $\begin{array}{c}\text { GW Depth } \\
\text { (bgs) }\end{array}$ & $\begin{array}{c}\text { Turb } \\
\text { (NTU) } \\
\end{array}$ & $\begin{array}{c}\text { Cond } \\
\text { (us) }\end{array}$ & $\begin{array}{l}\text { Temp } \\
\text { (c) } \\
\end{array}$ & $\begin{array}{c}\mathrm{pH} \\
\text { (temp c) } \\
\end{array}$ & $\begin{array}{c}\text { D.O. } \\
\text { (mg/L) }\end{array}$ & $\begin{array}{l}\text { Purged } \\
\text { (gal) }\end{array}$ & Comments \\
\hline \multirow[t]{4}{*}{ (1) B1HT03 } & 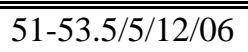 & Pumped & 47.7 & 262.9 & 2450 & 20.1 & 7.22 & 8.1 & 79 & Purged and filtered \\
\hline & $51-53.5 / 5 / 12 / 06$ & Pumped & 47.7 & 44 & 454 & 19.1 & 7.25 & 8.5 & 131 & Purged and filtered \\
\hline & $51-53.5 / 5 / 12 / 06$ & Pumped & 47.7 & 25 & 454 & 19.1 & 7.11 & 8.9 & 170 & Purged and filtered \\
\hline & $51-53.5 / 5 / 12 / 06$ & Pumped & 47.7 & 21.7 & 453 & 19.3 & 7.19 & 8.6 & 217 & Purged and filtered \\
\hline \multirow[t]{5}{*}{ (2) B1HT06 } & $60-63 / 5 / 12 / 06$ & Pumped & 47.7 & $>1,000$ & 455 & 19.5 & 7.33 & 7.6 & 50 & Purged and filtered \\
\hline & $60-63 / 5 / 12 / 06$ & Pumped & 47.7 & $>1,000$ & 451 & 19.3 & 7.36 & 7.8 & 85 & Purged and filtered \\
\hline & $60-63 / 5 / 12 / 06$ & Pumped & 47.7 & $>1,000$ & 448 & 18.9 & 7.23 & 8 & 135 & Purged and filtered \\
\hline & $60-63 / 5 / 12 / 06$ & Pumped & 47.7 & 413 & 448 & 19.2 & 7.2 & 8.3 & 170 & Purged and filtered \\
\hline & $60-63 / 5 / 12 / 06$ & Pumped & 47.7 & 134 & 445 & 18.9 & 7.28 & 8.5 & 230 & Purged and filtered \\
\hline \multirow[t]{5}{*}{ (3) B1HT10 } & 72.5-74/5/15/06 & Pumped & 47.6 & $>1,000$ & 466 & 20.3 & 7.7 & 6.6 & 100 & Purged and filtered \\
\hline & $72.5-74 / 5 / 15 / 06$ & Pumped & 47.6 & $>1,000$ & 463 & 21 & 7.55 & 6.9 & 150 & Purged and filtered \\
\hline & $72.5-74 / 5 / 15 / 06$ & Pumped & 47.6 & $>1,000$ & 465 & 20.4 & 7.5 & 7 & 200 & Purged and filtered \\
\hline & $72.5-74 / 5 / 15 / 06$ & Pumped & 47.6 & $>1,000$ & 462 & 20 & 7.51 & 7.1 & 250 & Purged and filtered \\
\hline & $72.5-74 / 5 / 15 / 06$ & Pumped & 47.6 & $>1,000$ & 463 & 20 & 7.51 & 7.4 & 310 & Purged and filtered \\
\hline \multirow[t]{5}{*}{ (4) B1HT14 } & $90-92 / 5 / 16 / 06$ & Pumped & 47.6 & $>1,000$ & 285 & 21.2 & 7.69 & 0.8 & 223 & Purged and filtered \\
\hline & $90-92 / 5 / 16 / 06$ & Pumped & 47.6 & 832 & 280 & 20.2 & 7.88 & 0.7 & 255 & Purged and filtered \\
\hline & $90-92 / 5 / 16 / 06$ & Pumped & 47.6 & 503 & 279 & 20.2 & 7.55 & 0.7 & 280 & Purged and filtered \\
\hline & $90-92 / 5 / 16 / 06$ & Pumped & 47.6 & 86.7 & 276 & 19.6 & 7.8 & 1.2 & 345 & Purged and filtered \\
\hline & $90-92 / 5 / 16 / 06$ & Pumped & 47.6 & 28.6 & 276 & 19.8 & 7.84 & 2.1 & 400 & Purged and filtered \\
\hline
\end{tabular}




\section{Groundwater Sample Reports}

\section{Well C4999}

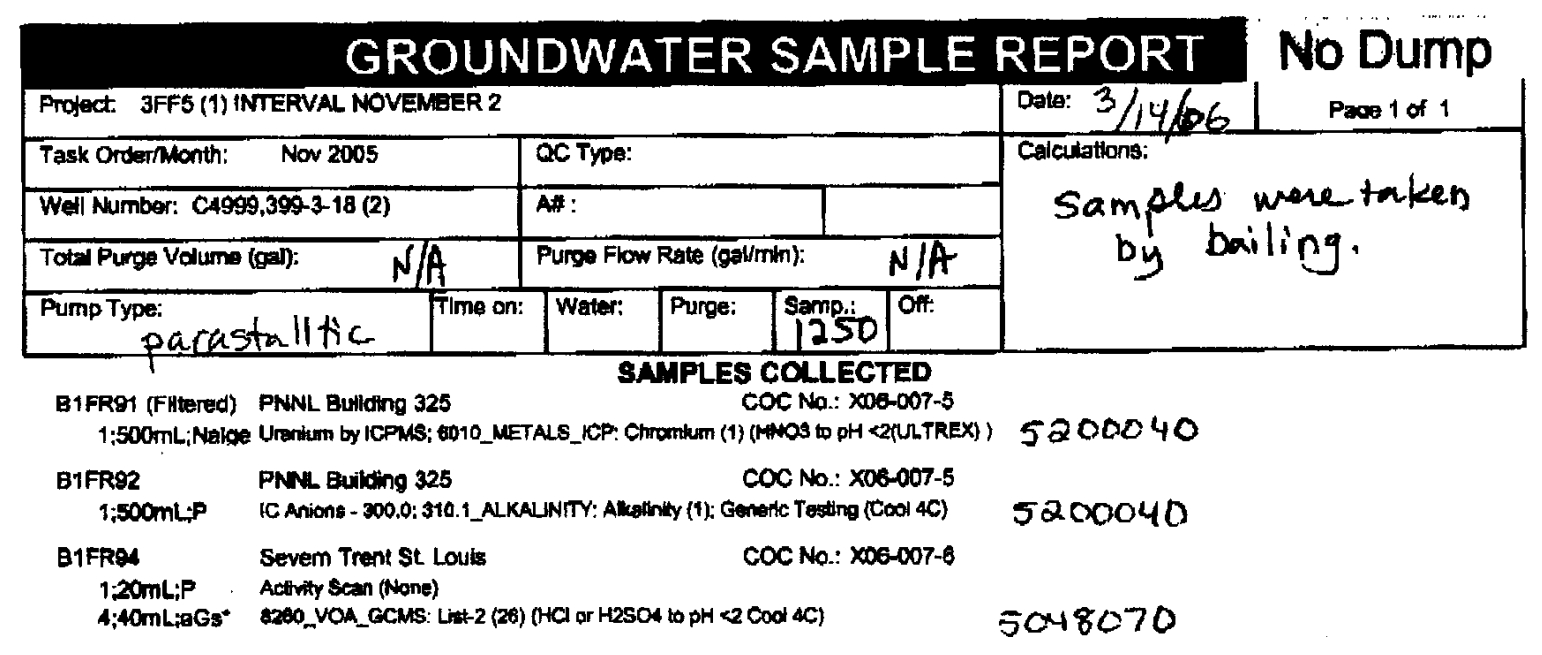

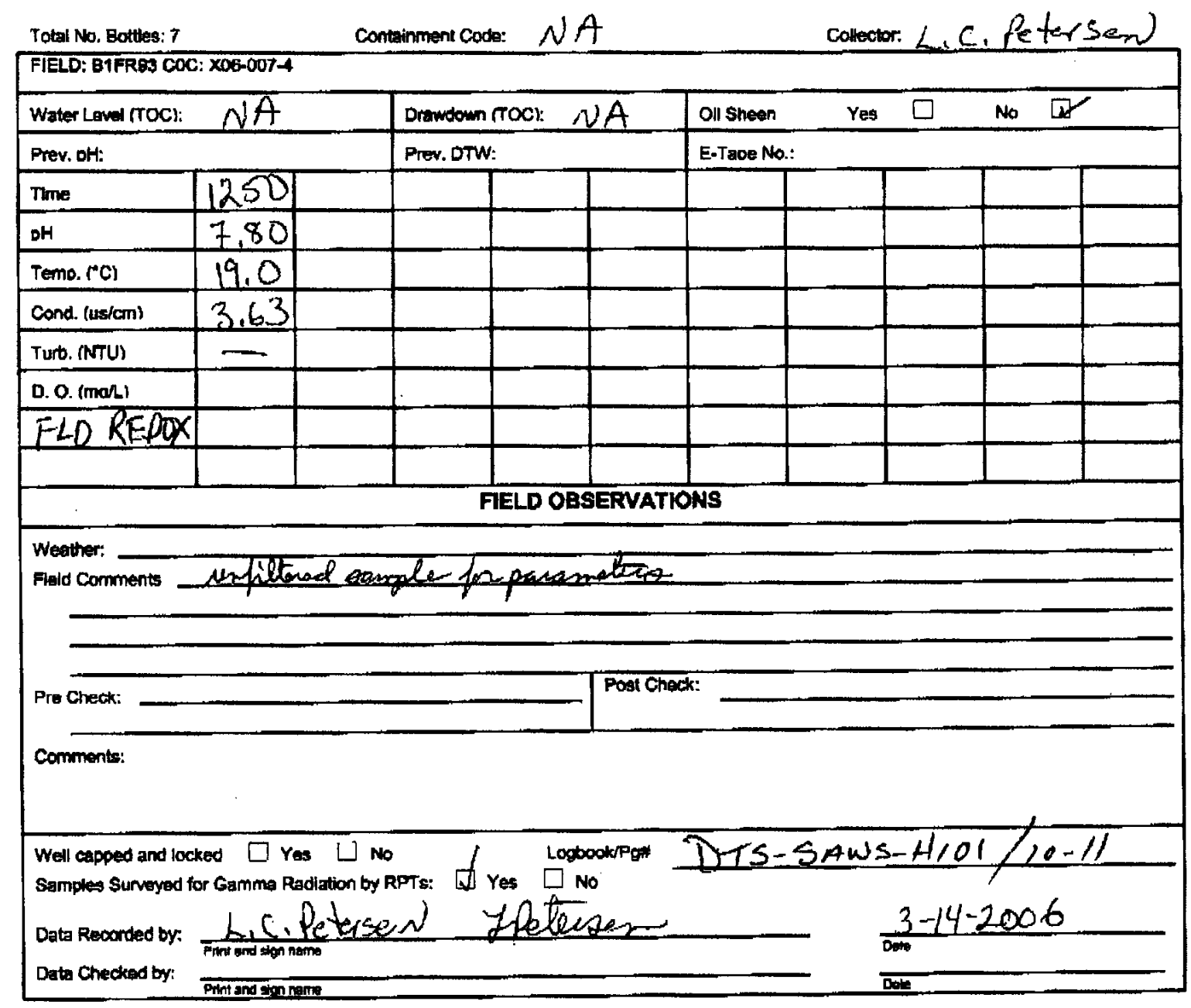




\begin{tabular}{|c|c|c|c|c|c|c|c|}
\hline \multicolumn{6}{|c|}{ Project: 3FF5 (1) INTERVAL NOVEMBER 2} & Date: $3 / 14 / 06$ & Page 1 of 1 \\
\hline Task Ordernkonth: & Nov 2005 & \multicolumn{4}{|l|}{ AC Type: } & \multirow[t]{4}{*}{ Calculations: } & \\
\hline \multicolumn{2}{|c|}{ Well Number: C4999,399-3-18 (1) } & \multicolumn{4}{|l|}{ Al: } & & \\
\hline \multicolumn{2}{|c|}{ Total Punge Volume (pal): } & \multicolumn{4}{|c|}{ Purge Flow Rota (gaimin): } & & \\
\hline \multicolumn{2}{|c|}{$\begin{array}{l}\text { Pump Type: } \\
\text { parastaltic }\end{array}$} & Water: & Purge: & Samp: & Off. & & \\
\hline \multicolumn{8}{|c|}{$\begin{array}{c}\text { SAMPLES COLLECTED } \\
\text { COC NO.: X06-007-2 } \\
\text { TALS_ICP: Chromium (1) (1HNO3 to pH CQUUTREX) }\end{array}$} \\
\hline $\begin{array}{l}\text { B1FRBO } \\
\quad 1 ; 600 \mathrm{~mL} ; P\end{array}$ & \multicolumn{5}{|c|}{ 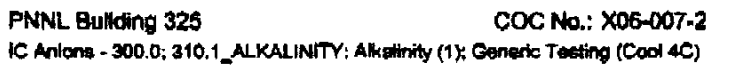 } & 5200040 & \\
\hline $\begin{array}{l}\text { B1FRB2 } \\
\text { 1:20mL;P } \\
\text { 4;40mL;:FGs }\end{array}$ & \multicolumn{5}{|c|}{ 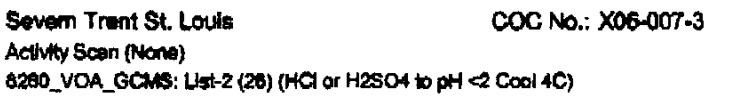 } & 5048070 & \\
\hline
\end{tabular}

Total No. Botues: 7 Contamment Coda: $N A$ collactor. L. CL Pe farser FIELD: BYFRBI COC: X06-007.1

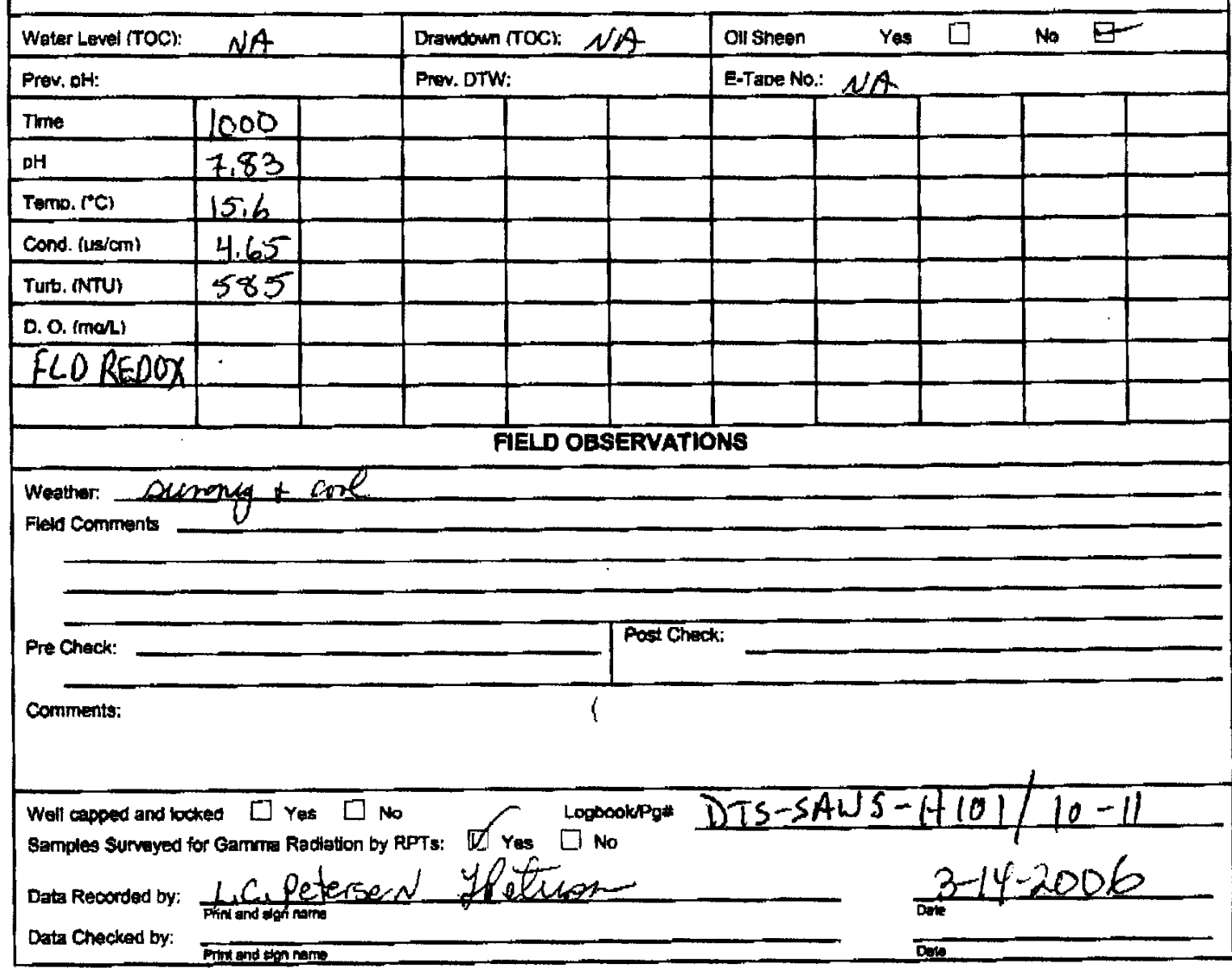




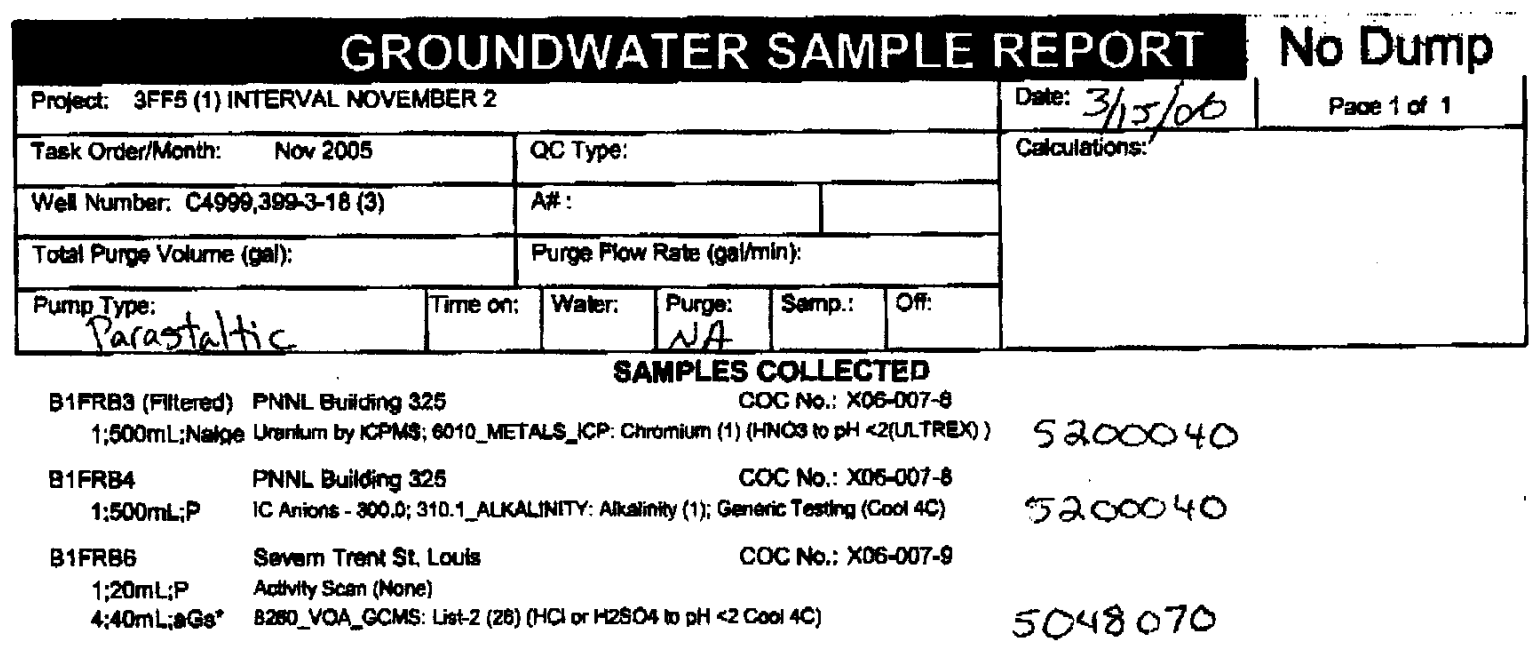

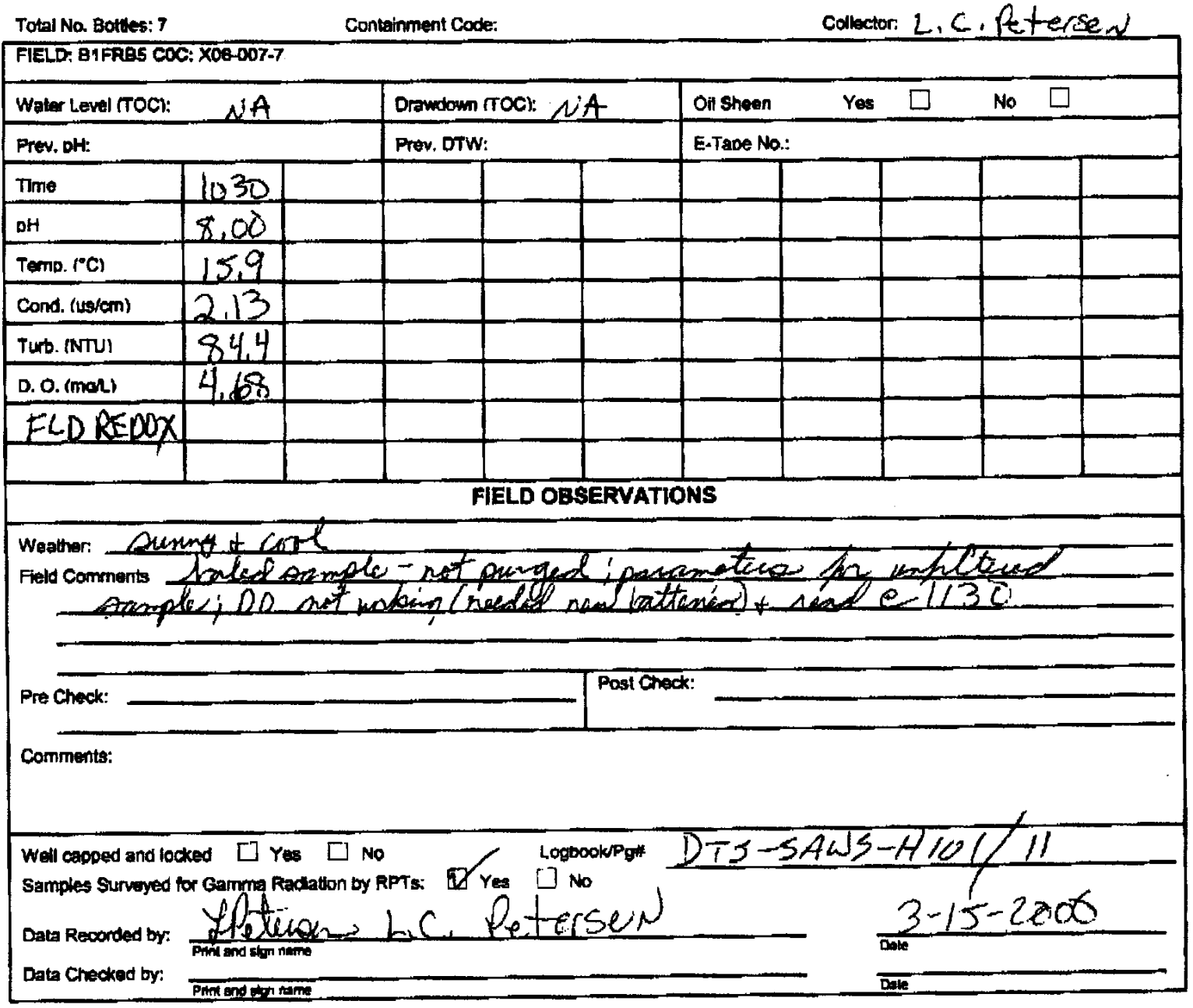




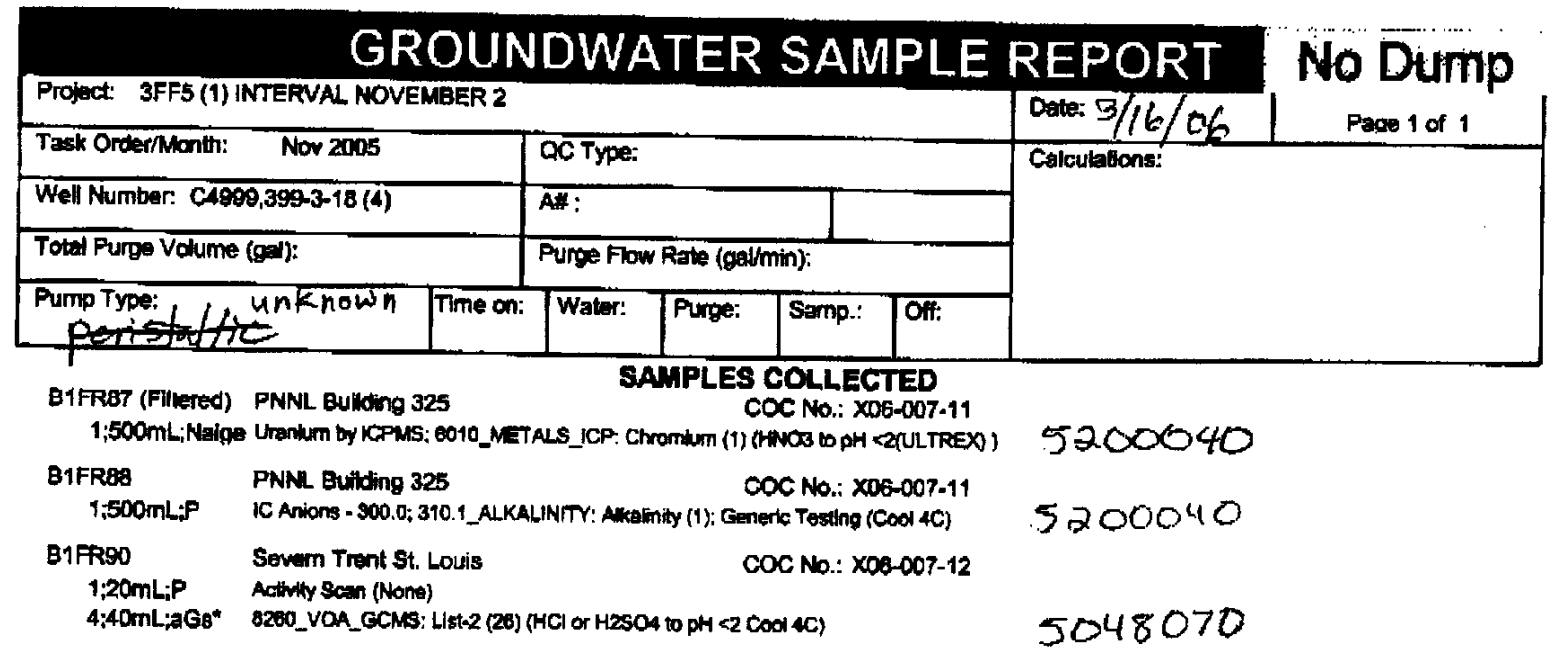

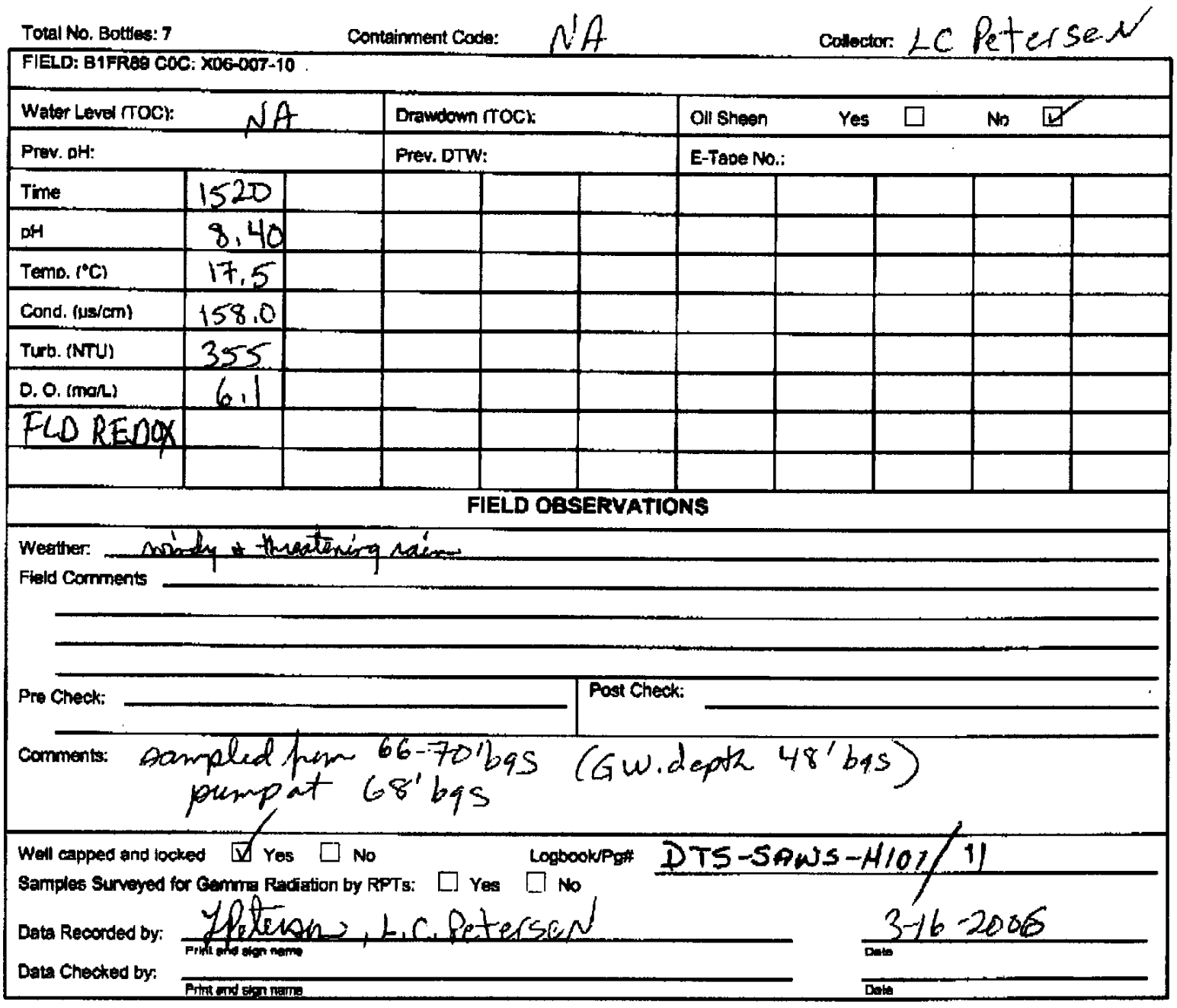




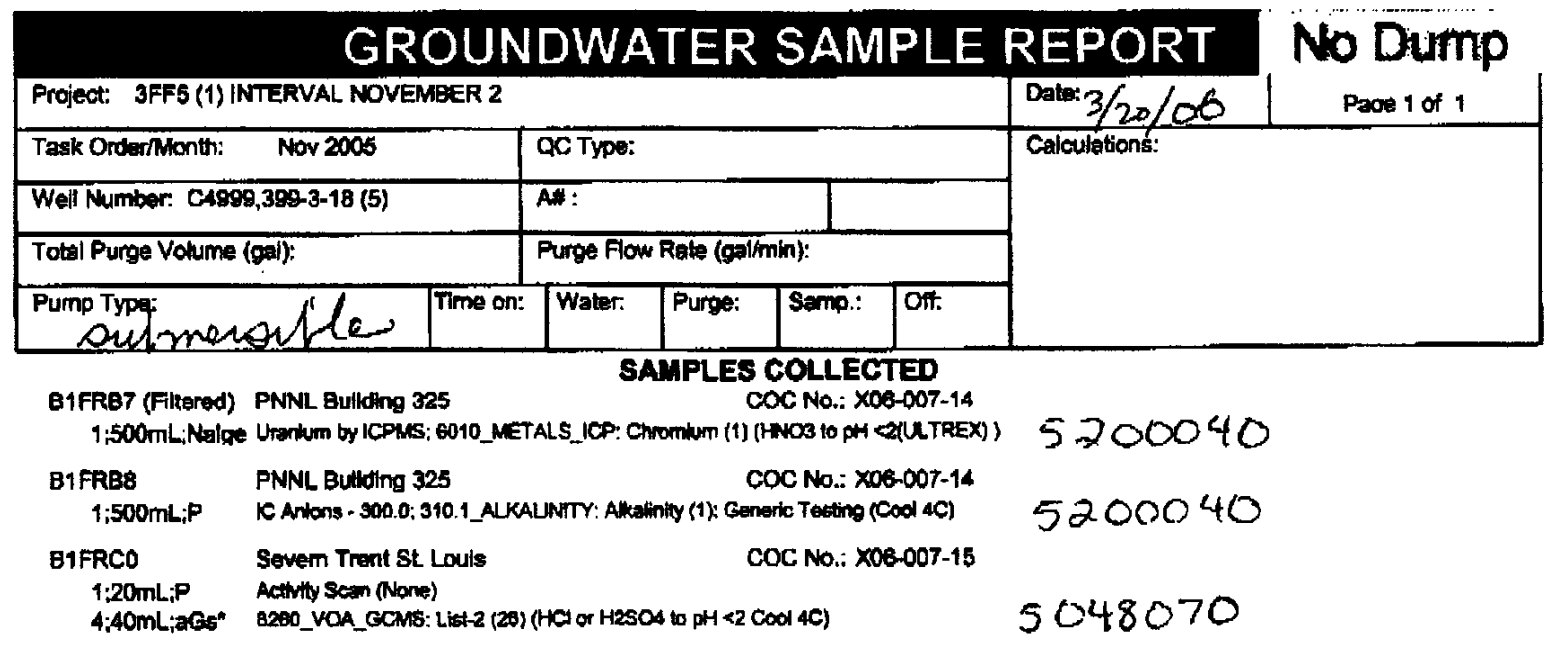

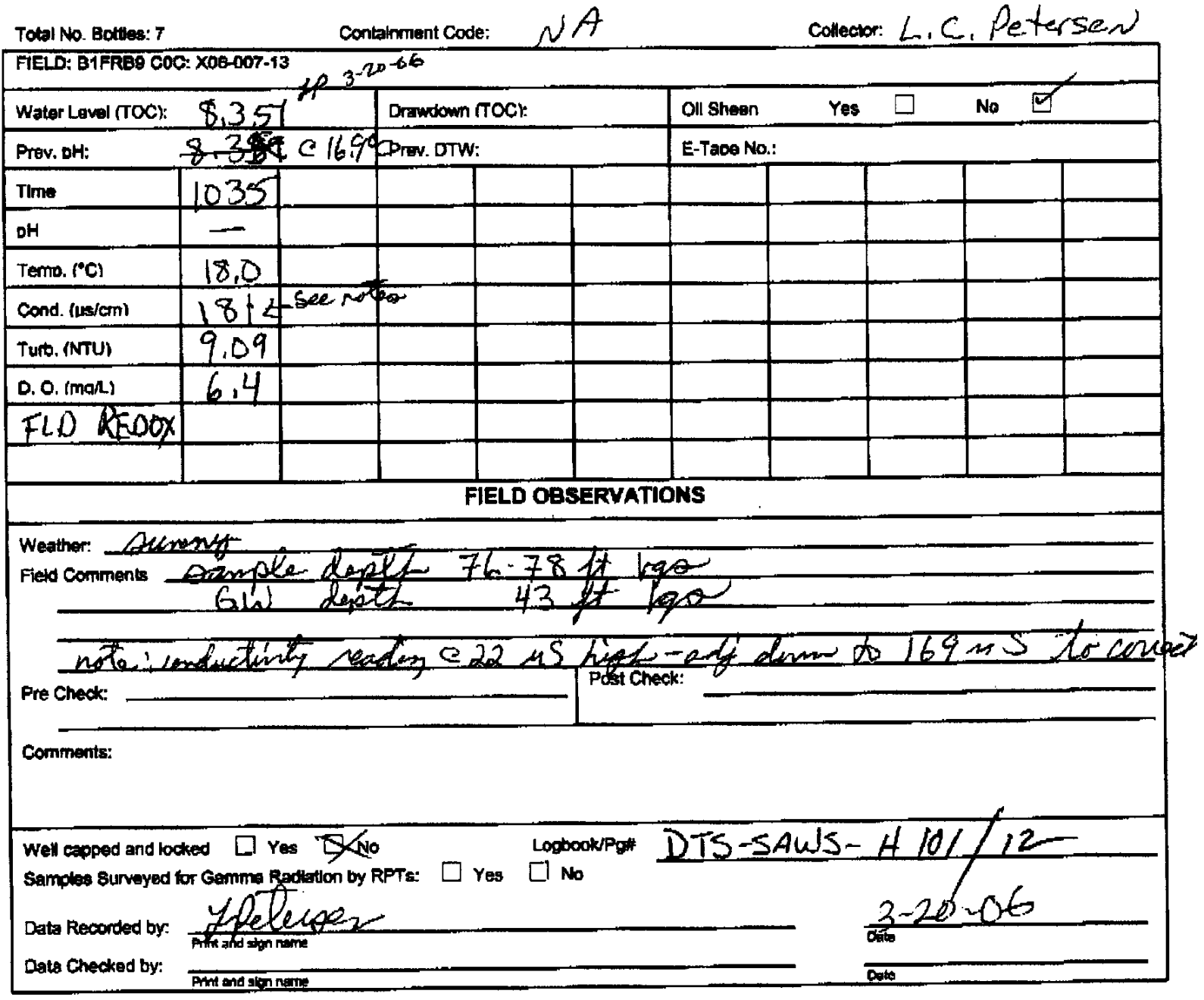




\section{GROUNDWATER SAMPLE REPORT No Dump}

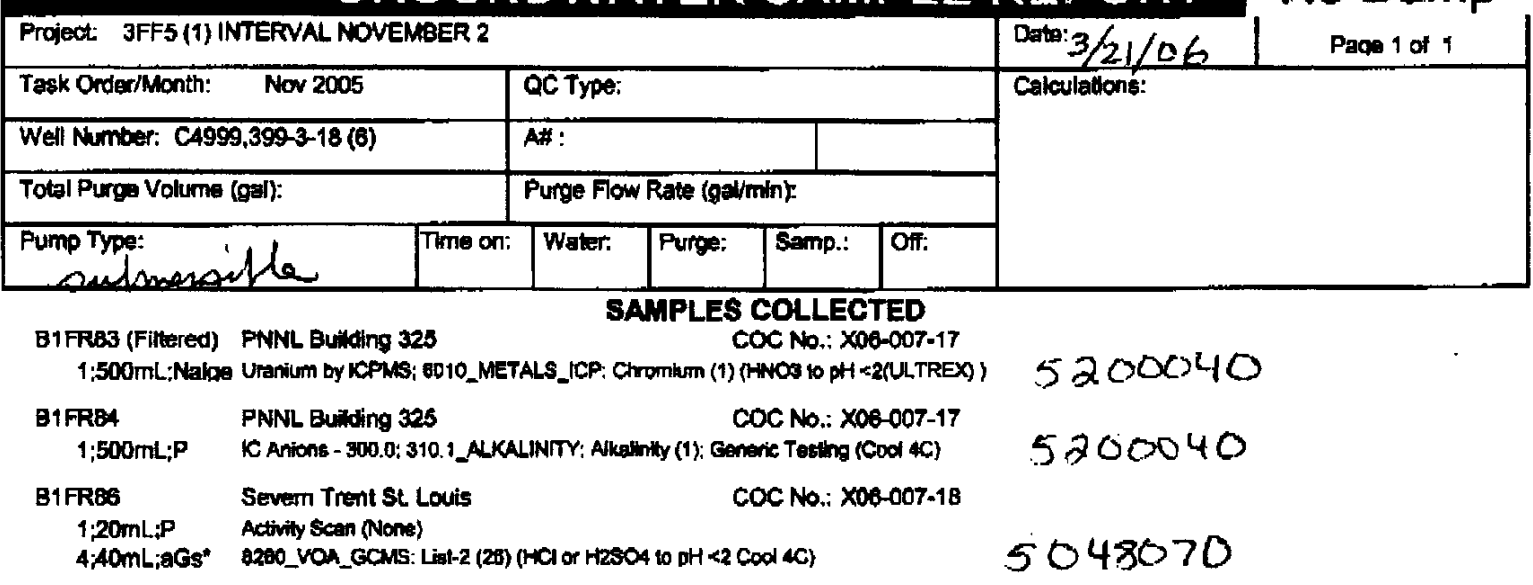

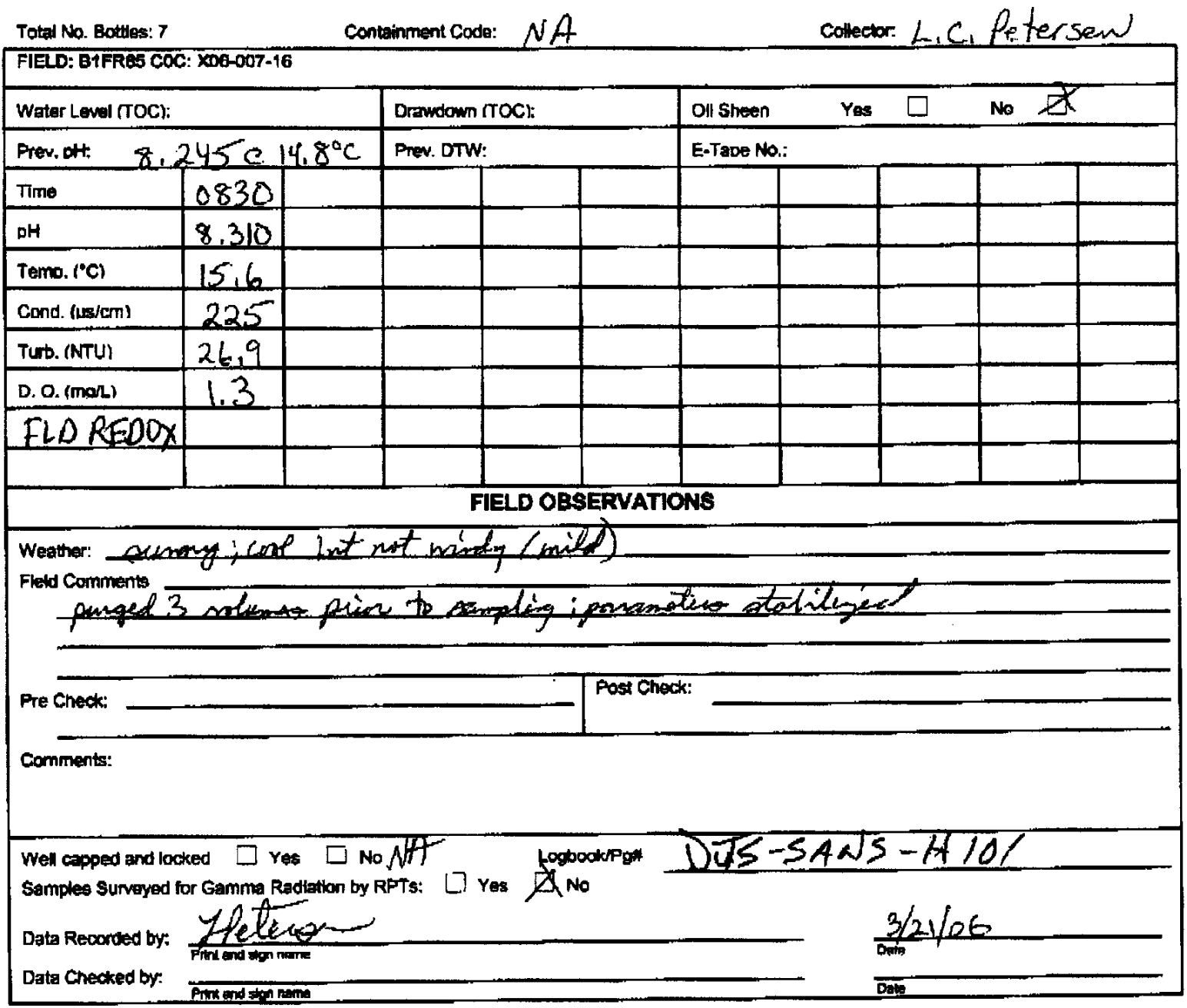




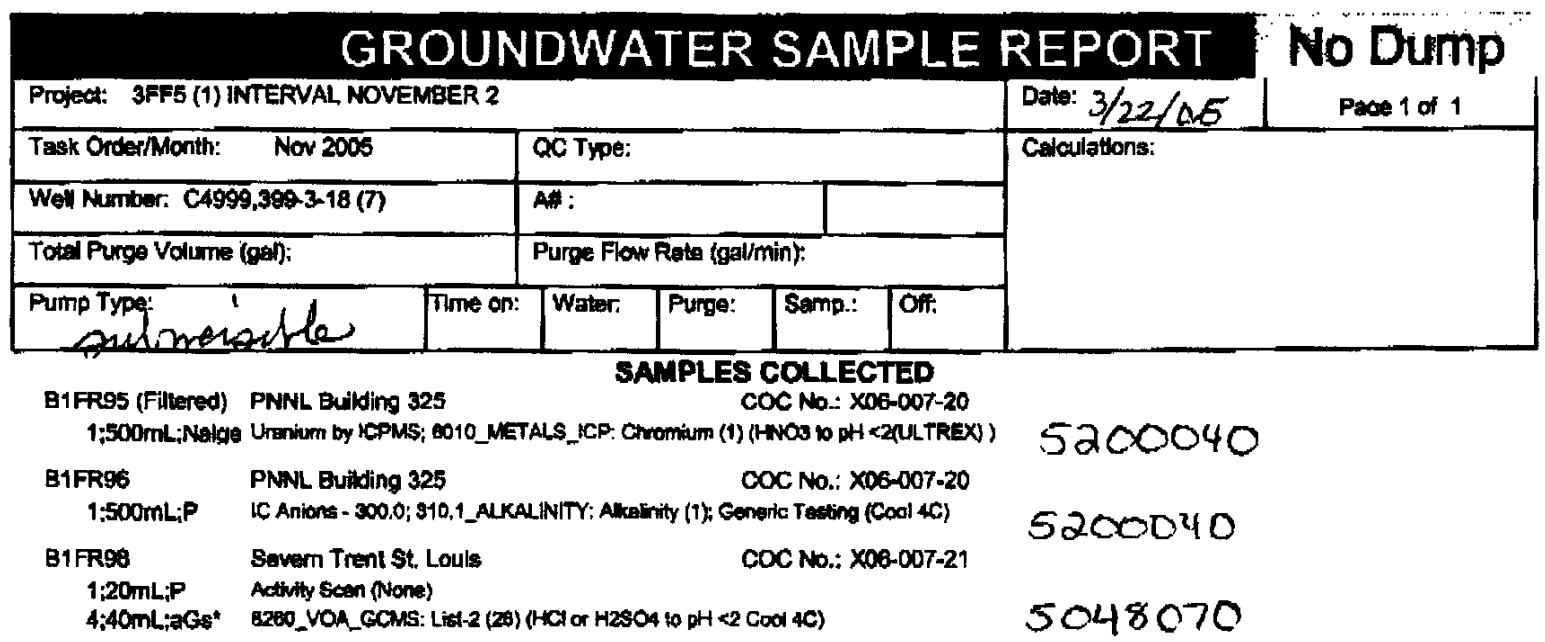

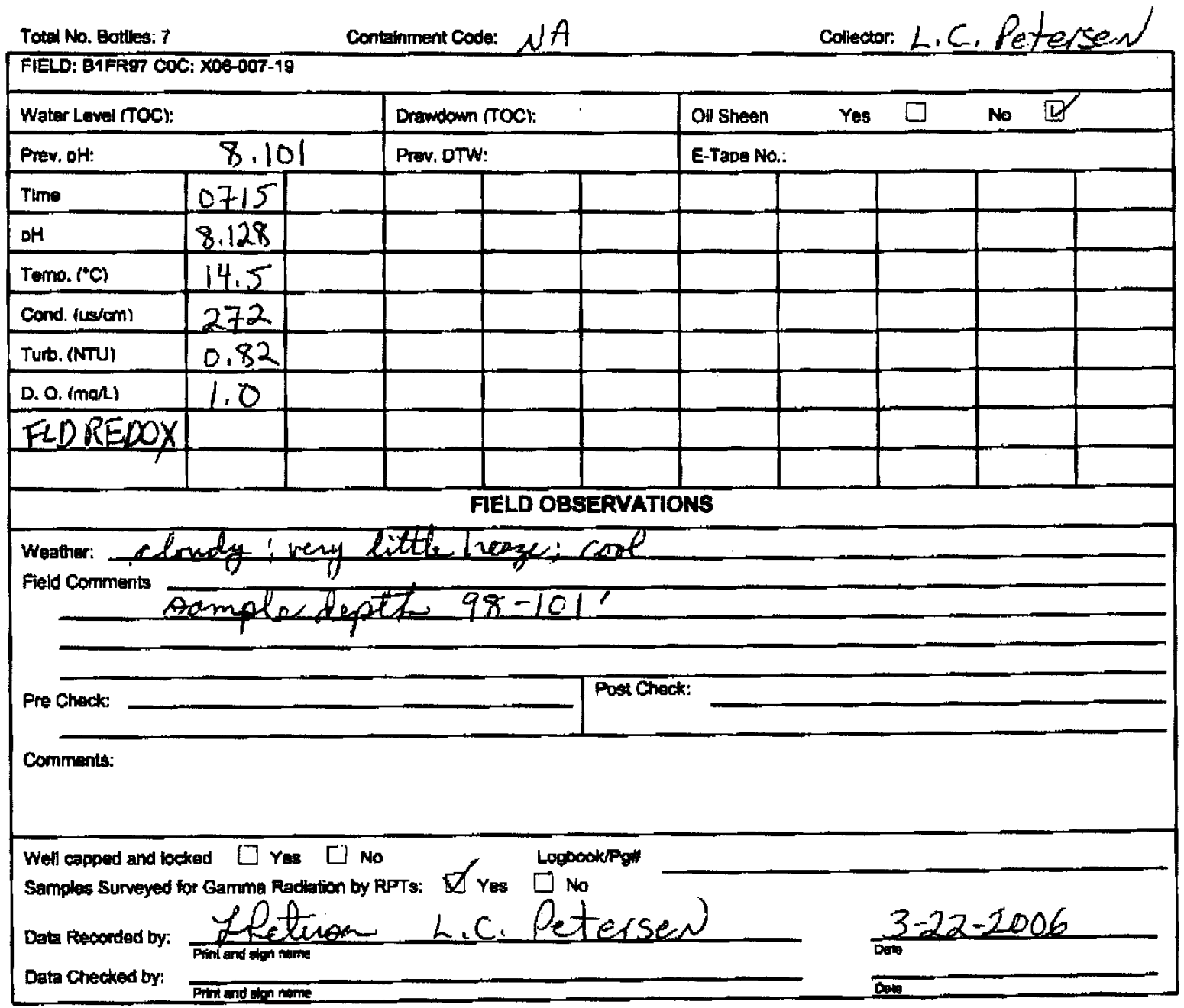




\begin{tabular}{|c|c|c|c|c|c|c|c|c|}
\hline & Data: $3 / 22 / 06$ & Paqa 1 of 1 \\
\hline \multicolumn{7}{|c|}{$\begin{array}{l}\text { GROUN } \\
\text { Project 3FF5 (1) INTERVAL NOVEMBER } 2\end{array}$} & \multirow{4}{*}{\multicolumn{2}{|c|}{ Calculations: }} \\
\hline \multicolumn{3}{|c|}{$\begin{array}{l}\text { Task Orderimonth: } \quad \text { Nov } 2005 \\
\text { Well Number: C4999,399-3-18 (8) }\end{array}$} & A\#: & & & & & \\
\hline \multicolumn{3}{|c|}{ Total Punge Volume (gal): } & \multicolumn{4}{|c|}{ Purge Fiow Rabe (gal/min): } & & \\
\hline \multicolumn{2}{|c|}{$\begin{array}{l}\text { Pump Type: } \\
\text { asulomenod le }\end{array}$} & Time on: & Water: & Purge: & Semp: & Of: & & \\
\hline \multicolumn{7}{|c|}{ 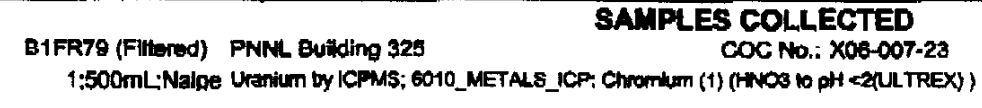 } & 5200040 & \\
\hline $\begin{array}{l}\text { B1FRBO } \\
1,500 \mathrm{~mL}: \mathrm{P}\end{array}$ & \multicolumn{6}{|c|}{ 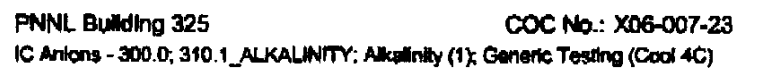 } & 5200040 & \\
\hline $\begin{array}{l}\text { B1FR82 } \\
\qquad \begin{array}{l}1 ; 20 \mathrm{~mL} ; \mathrm{P} \\
\text { 4;40mL;aG" }\end{array}\end{array}$ & \multicolumn{2}{|c|}{$\begin{array}{l}\text { Severn Trent St. Louis } \\
\text { Actiny SCom (None) } \\
\text { 8200_VOA_GCMS: Li 2 (28) }\end{array}$} & \multicolumn{4}{|c|}{$\operatorname{coc} N 0 .:$ X06-007-24 } & 50480 & \\
\hline
\end{tabular}

Totel No. Bottles: 7 Containnent code: $\quad \Delta A$ Collector: LCLfetenen

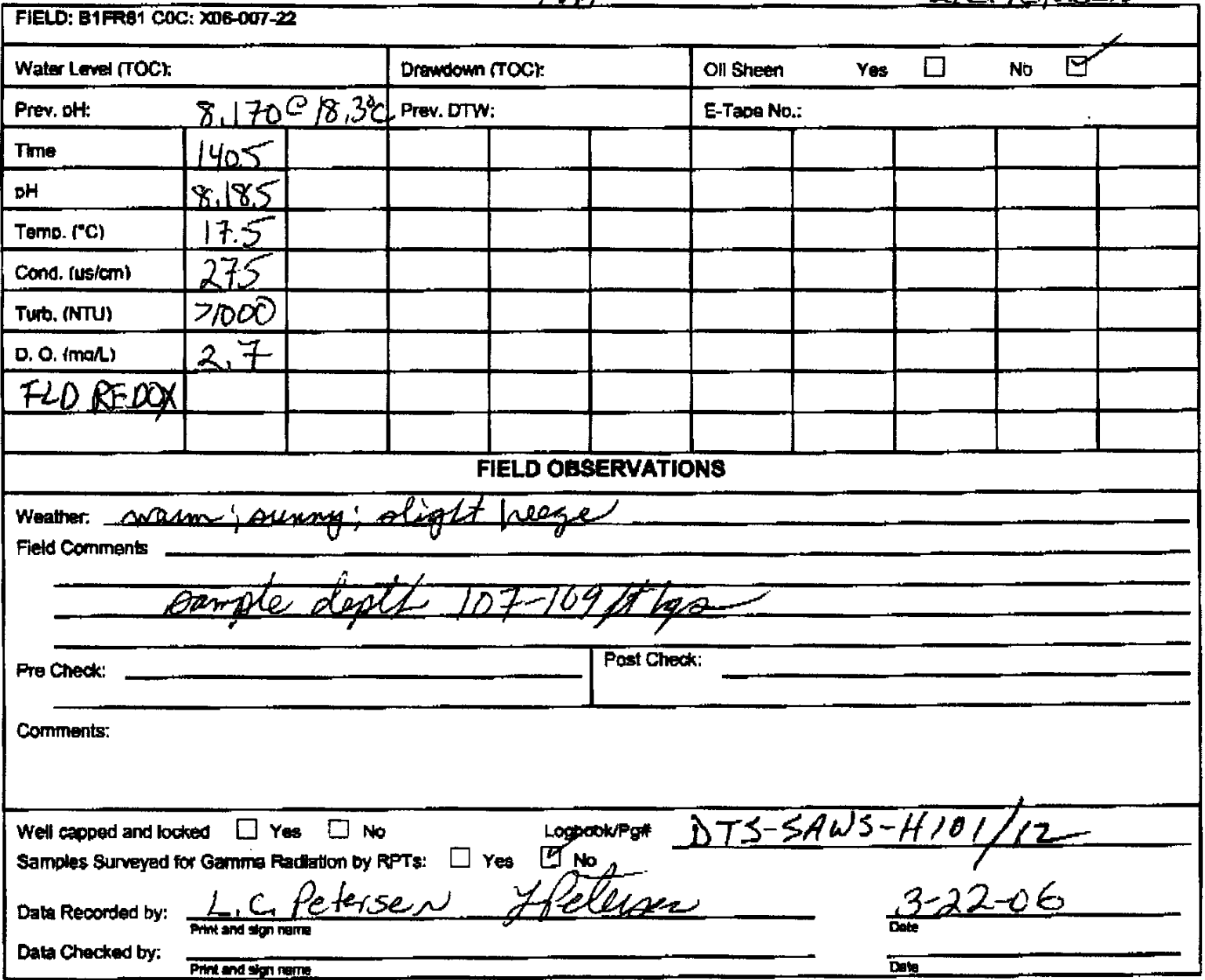


GROUNDWATER SAMPLE REPORT NO DUmp

Project: 3FF5 (1) INTERVAL NOVEMBER 2

\begin{tabular}{|c|c|c|c|c|c|}
\hline Task Order/Monthi & & \multicolumn{4}{|l|}{ OC Type: } \\
\hline \multicolumn{2}{|l|}{ Well Number: C4999,399-3-18 (9) } & \multicolumn{4}{|l|}{ A*: } \\
\hline \multicolumn{2}{|l|}{ Total Purge Volume (gel): } & \multicolumn{4}{|c|}{ Purge Flow Rate (gal/min); } \\
\hline $\begin{array}{l}\text { Pump Type: } \\
\text { Pulmengile }\end{array}$ & Time on: & Water: & Punge: & Samp.; & On: \\
\hline
\end{tabular}

B1FR31 (Filtered) PNNL Building 325 1;500 mLiNalge Urenium by ICPNS; 6010_METALS_LCP; Chromlum (1) 0

\section{SAMPLES COLLECTED}

$\operatorname{COC}$ No.: X06-007.26

B1FR32

PNNL Buinding 325

1:500mL;P

B1FR34

$1 ; 20 \mathrm{~mL} ; P$

4:40mLiags:

Sevem Trent St. Louls

Activty Scan (None)

8200_VOA_OCMS; LIFA-2 (26) (HCl or H2SO4 to pH $2 \mathrm{CoOl} 4 \mathrm{C})$
COC No.: $\times 06-007-26$

Ceneris Toling (Cool 4C)

$\operatorname{coc}$ No.: $\times 06-007-27$

Calculations:

5200040

5200040

5048070

Total No. Bottles: 7 Containment code: $N A$

collector: L.C.Petersen

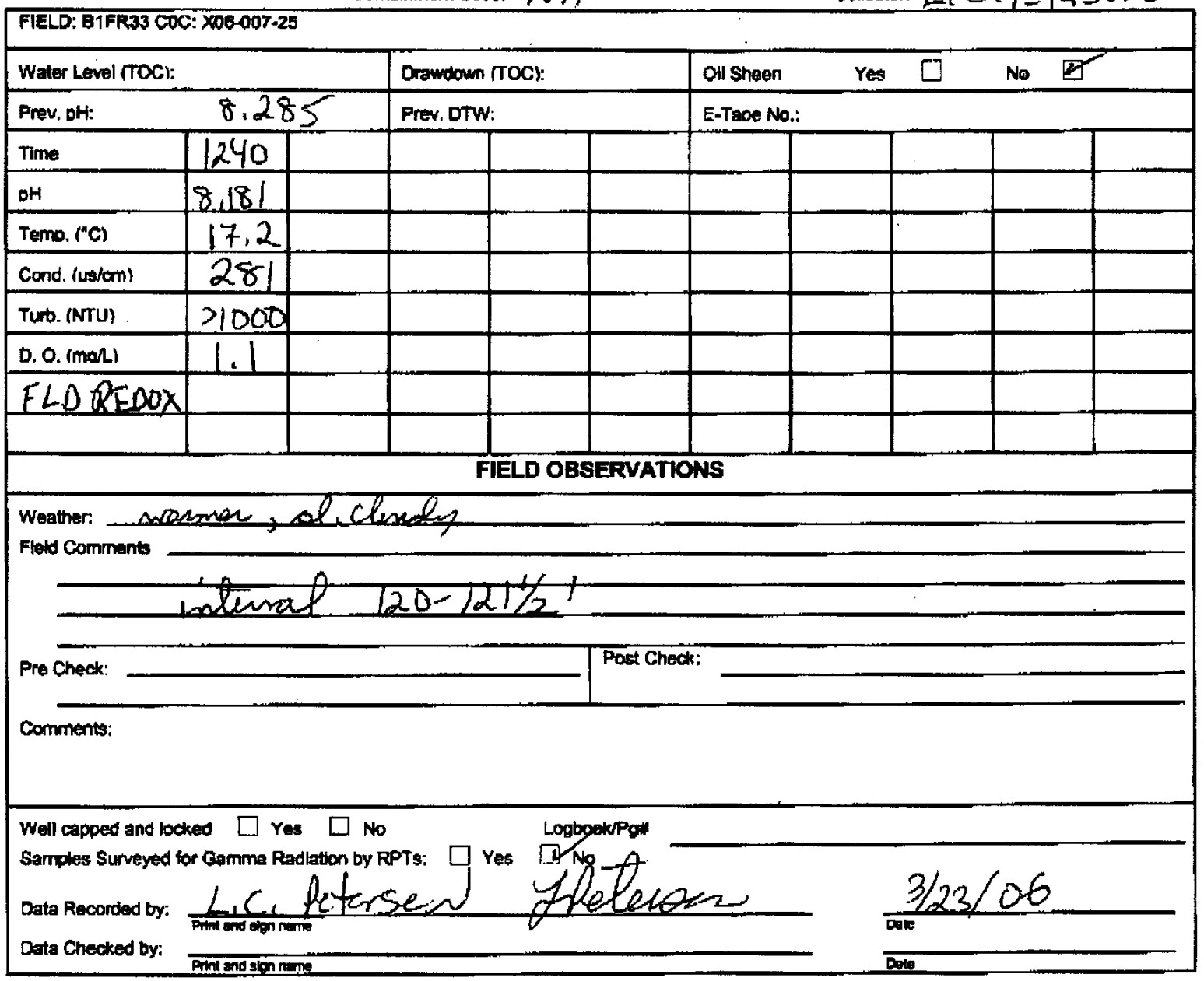




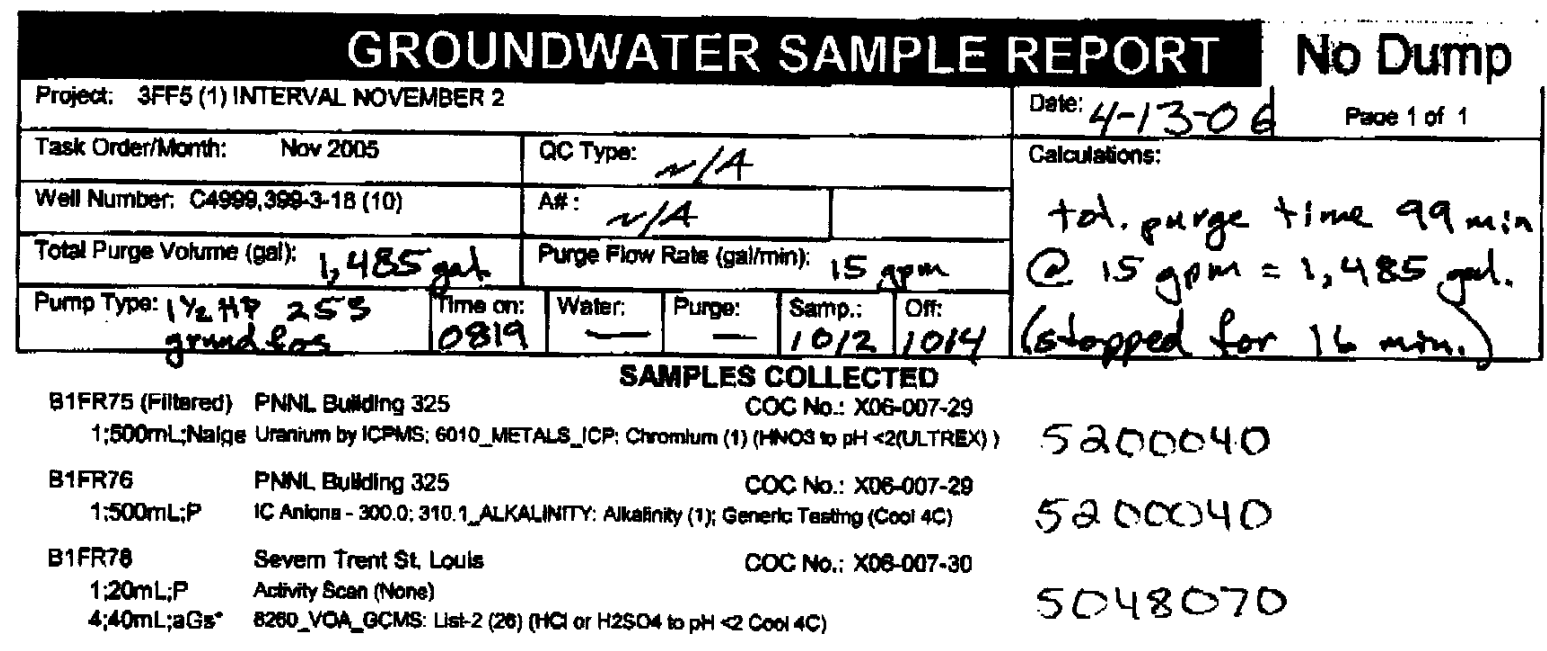

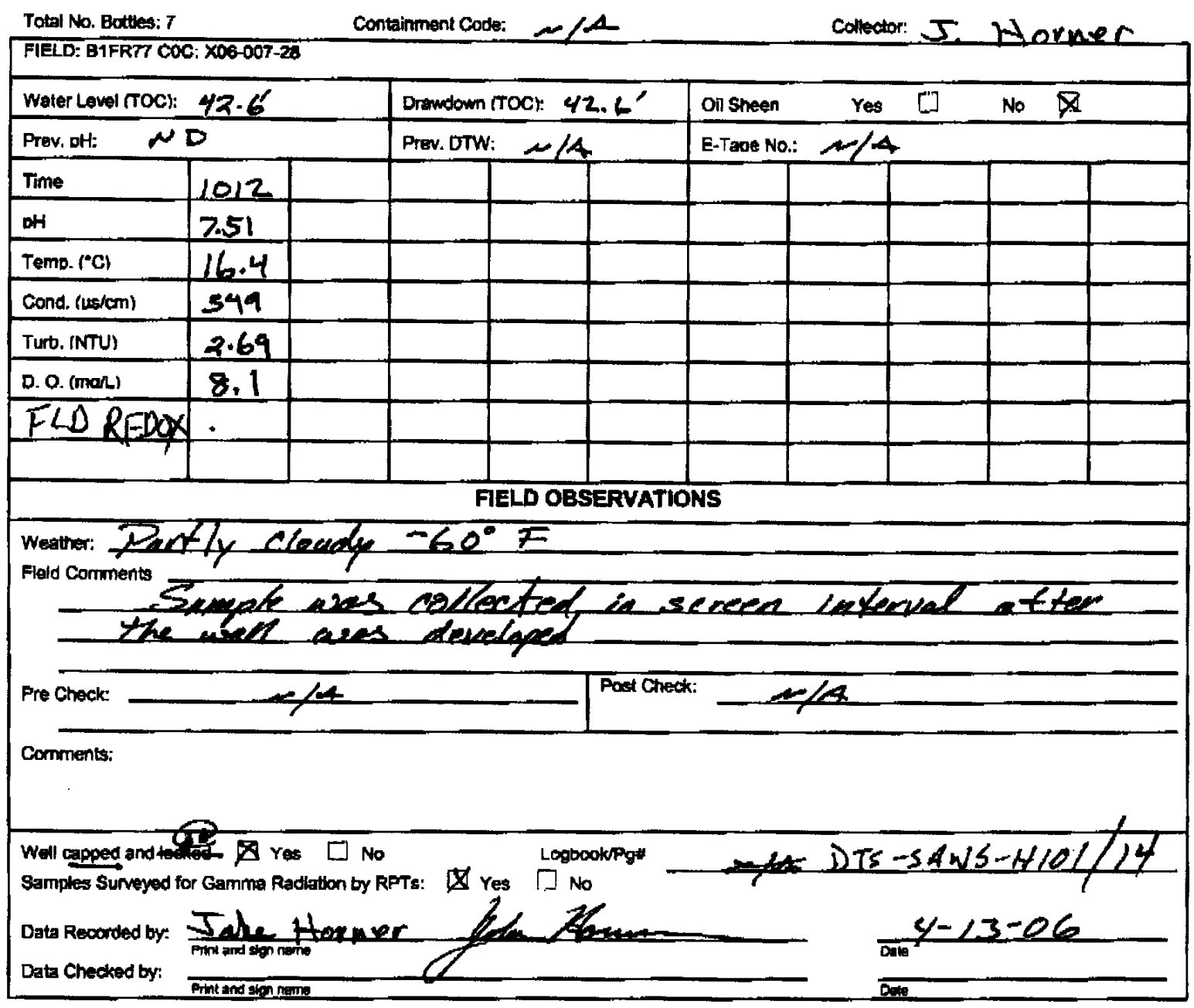




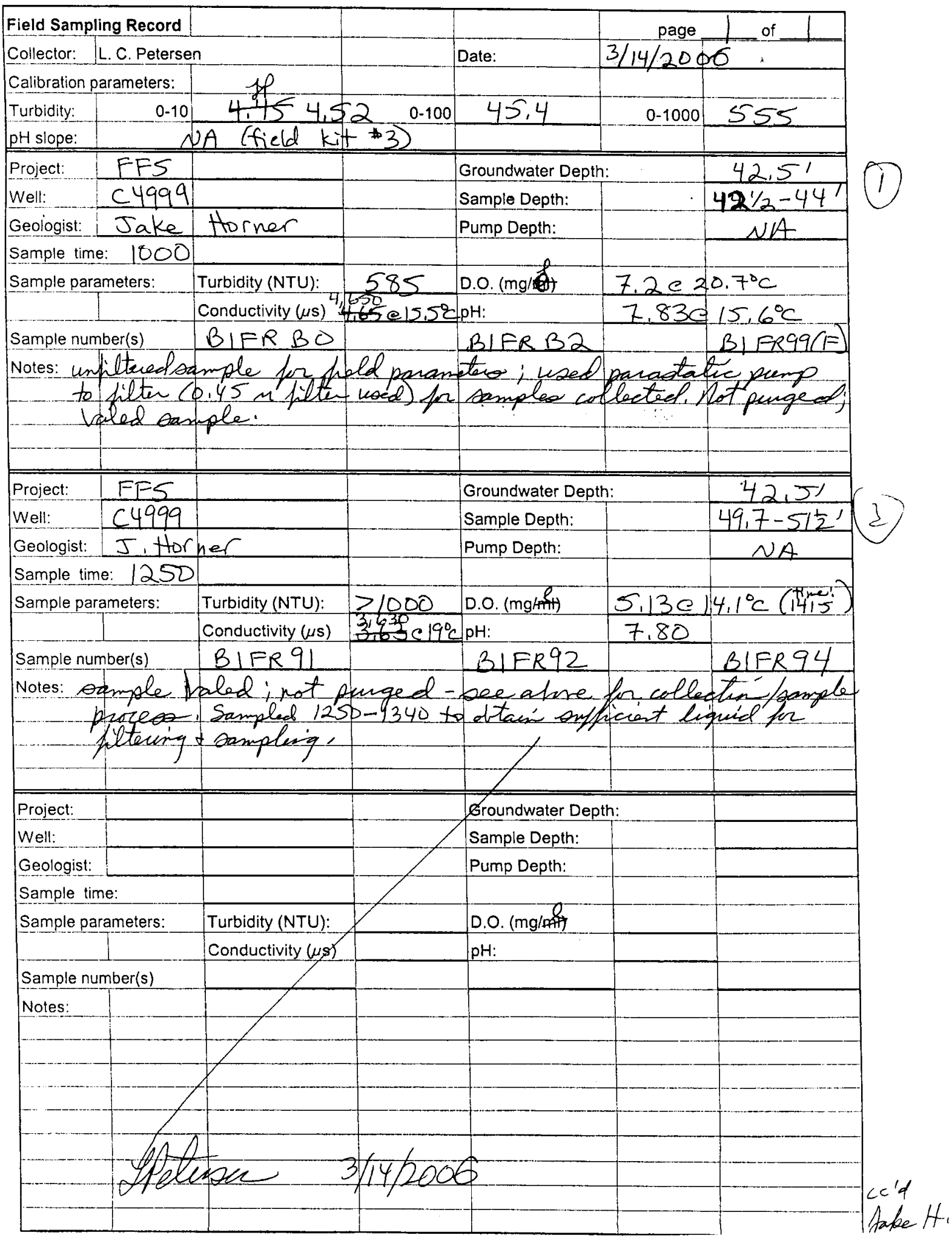




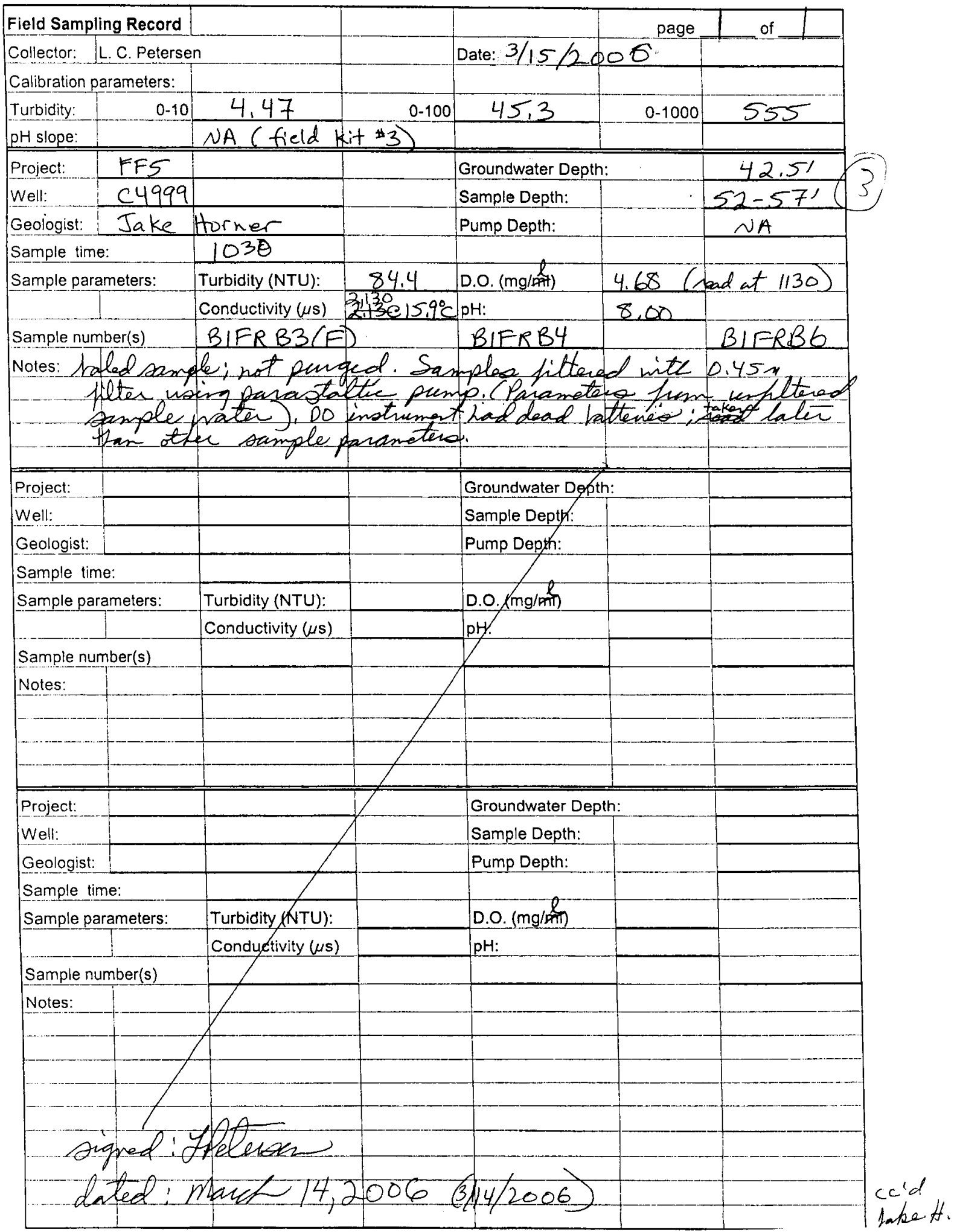




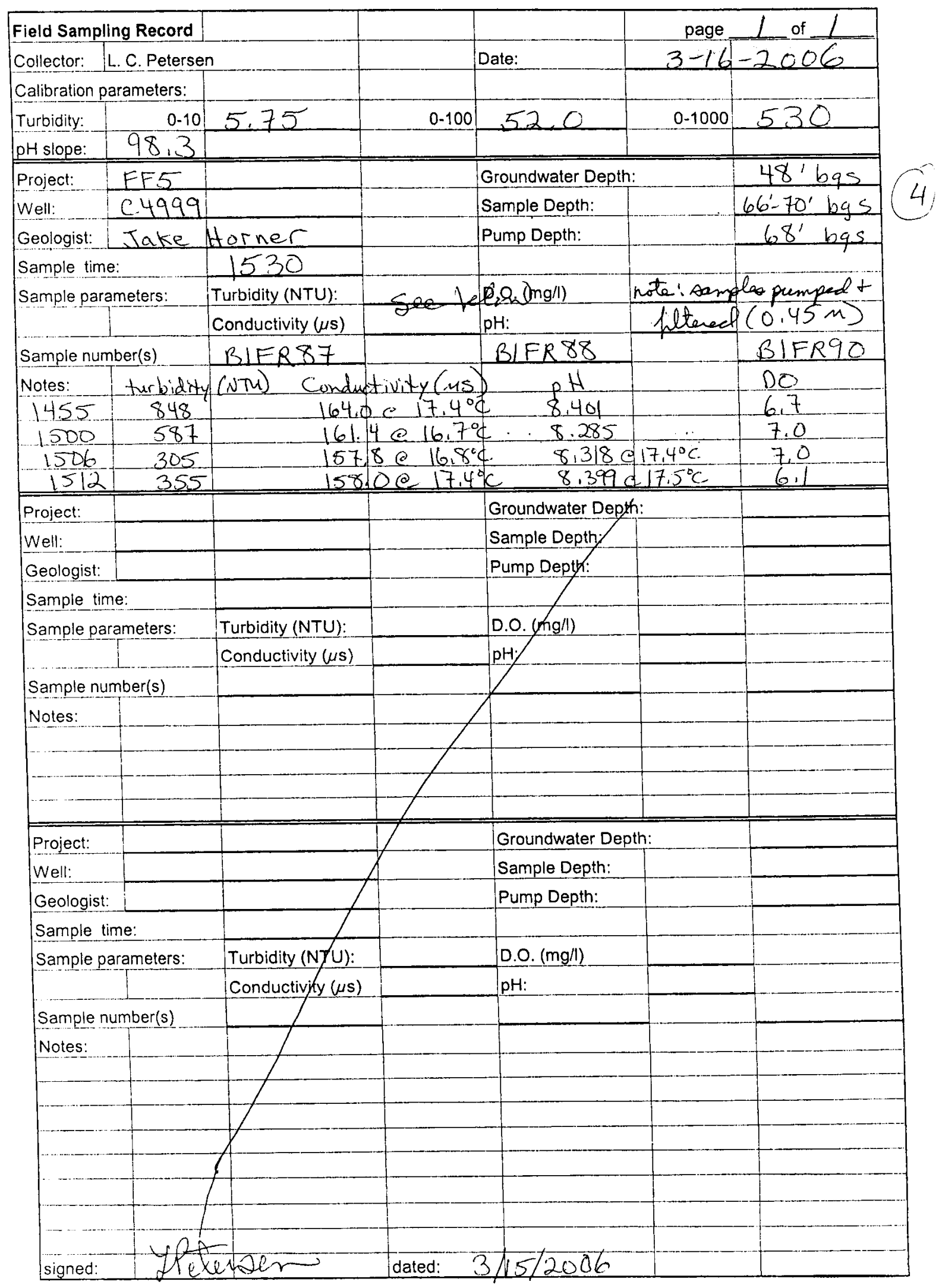




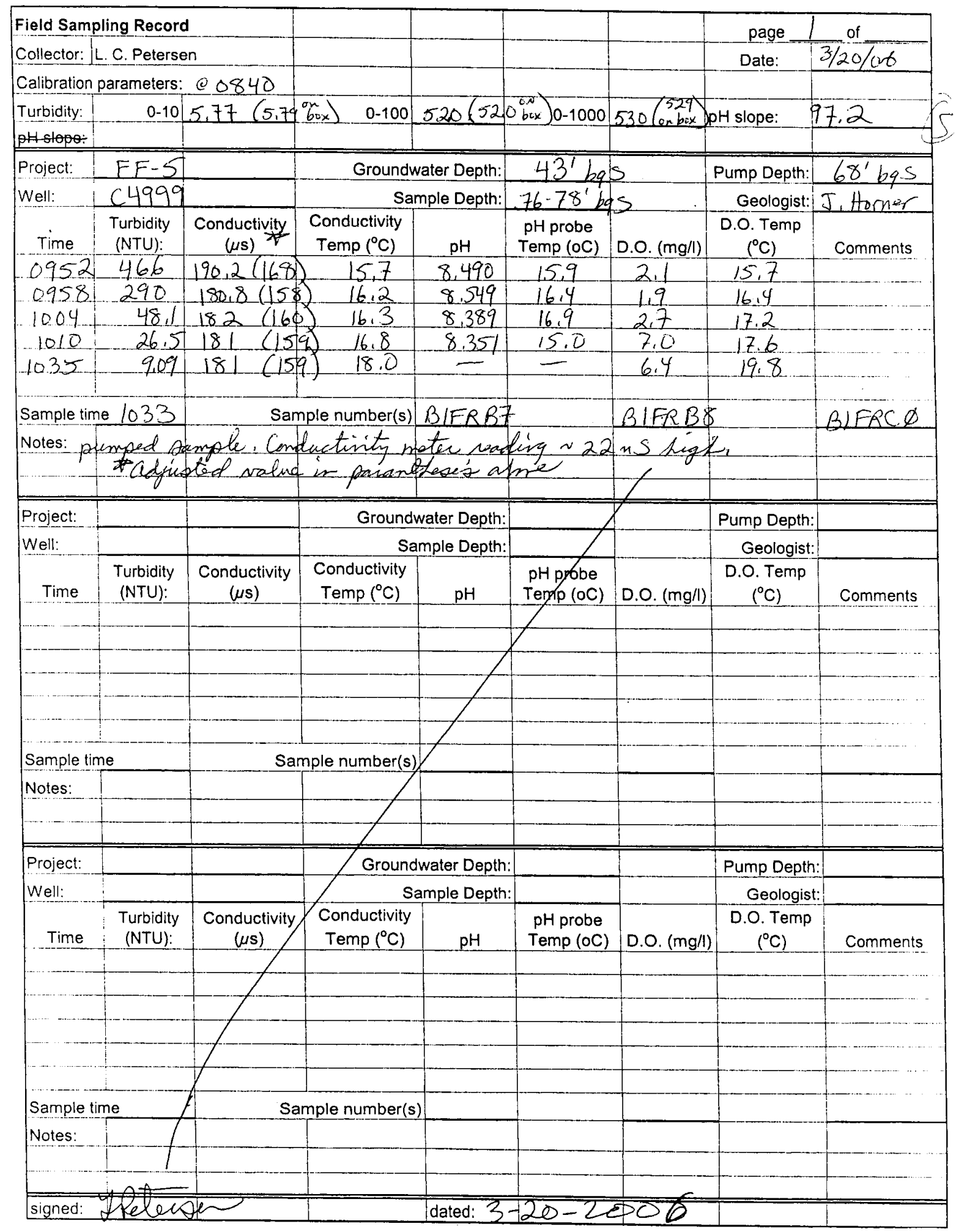




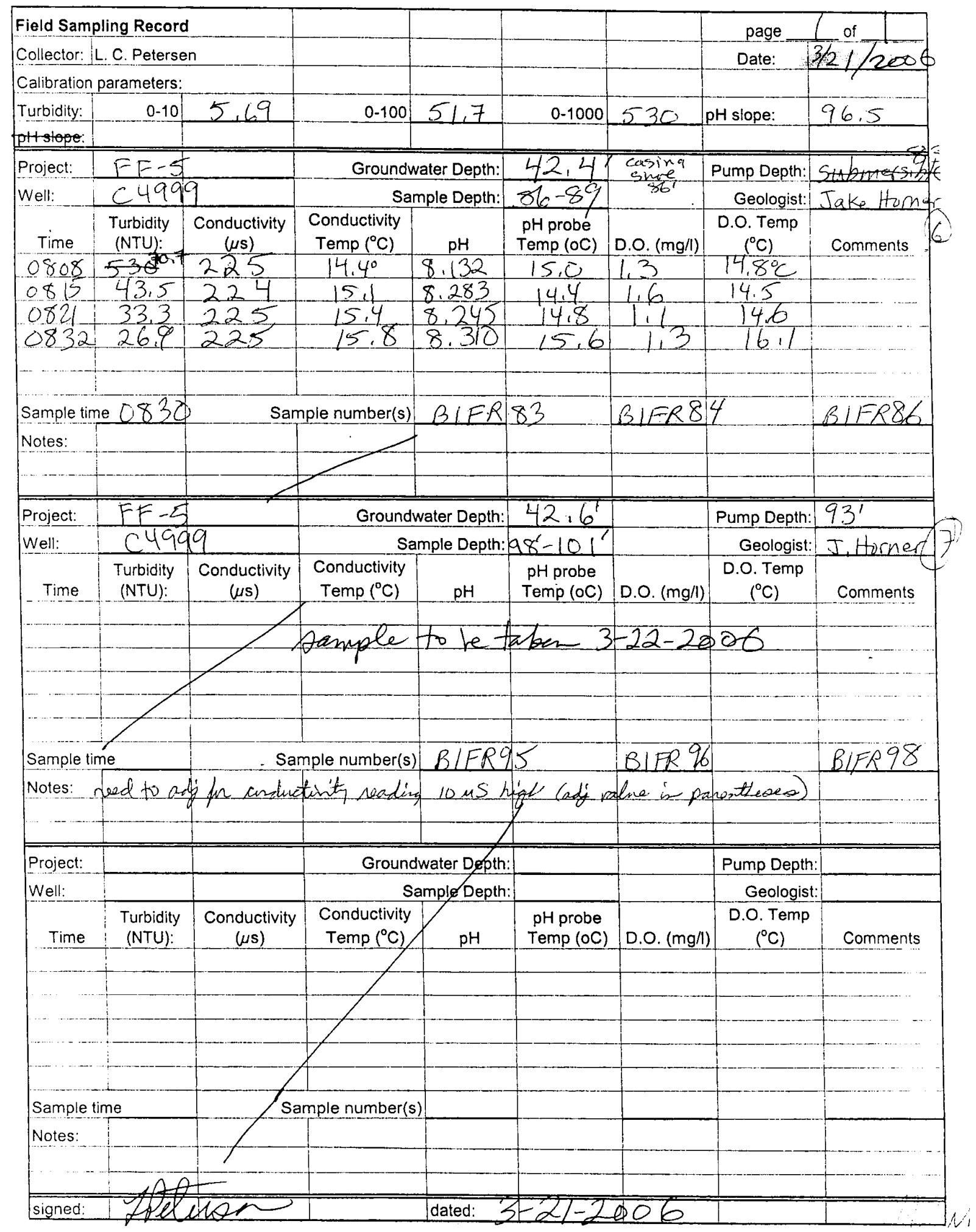




\begin{tabular}{|c|c|c|c|c|c|c|c|c|}
\hline \multirow{2}{*}{\multicolumn{3}{|c|}{ Field Sampling Record }} & & \multirow{2}{*}{\multicolumn{2}{|c|}{\begin{tabular}{l|l|l} 
page & of $/$
\end{tabular}}} \\
\hline & & & & & & & & \\
\hline Collector: : & C. Petersen & & & & & & \multicolumn{2}{|c|}{ page $\frac{1}{3 / 22 / 06}$ of $\frac{1}{\text { Date: }}$} \\
\hline \multicolumn{9}{|c|}{ Calibration parameters: } \\
\hline Turbidity: & 0-10 & $5,73(5,79$ & $0-100$ & $52,1(52$ & $2.0) 0-10005$ & $530\left(\begin{array}{c}5 \\
529\end{array}\right.$ & DH slope: & 96.1 \\
\hline Project: & \multicolumn{2}{|l|}{ EFS } & \multicolumn{2}{|c|}{ Groundwater Depth: } & 411 & & Pump Depth: & 931 \\
\hline Well: & \multicolumn{2}{|c|}{ c4999 } & \multicolumn{2}{|c|}{ Sample Depth: } & $98-1011$ & & Geologist: & Jake Horne \\
\hline Time & $\begin{array}{l}\text { Turbidity } \\
\text { (NTU): }\end{array}$ & $\begin{array}{c}\text { Conductivity } \\
(\mu \mathrm{s})\end{array}$ & \begin{tabular}{|c|} 
Conductivity \\
Temp $\left({ }^{\circ} \mathrm{C}\right)$ \\
\end{tabular} & $\mathrm{pH}$ & $\begin{array}{l}\text { pH probe } \\
\text { Temp (oC) }\end{array}$ & D.O. $(\mathrm{mg} / \mathrm{l})$ & $\begin{array}{c}\text { D.O. Temp } \\
\left({ }^{\circ} \mathrm{C}\right)\end{array}$ & Comments \\
\hline 0650 & 134 & $272(267)$ & 7) 14.8 & 7.929 & 15.7 & 1.8 & 14,3 & \\
\hline 0655 & 109 & $272(267)$ & 7) 15,0 & 8.028 & 15,1 & 2.0 & 14.4 & \\
\hline 0700 & 98,6 & $279(274$ & 14) 13.5 & 7.991 & $\mid S_{1}$ & 0.8 & 15,0 & \\
\hline 0.707 & 98.6 & $273(268$ & 68) 13,8 & 8.101 & 14,6 & 1.1 & 14,7 & \\
\hline 0719 & 0.82 & $272(267$ & 267) 14.3 & 8.128 & 14.5 & 1.0 & 14,5 & \\
\hline 0725 & 3.09 & 153114 & $1 4 8 \longdiv { 6 . 6 }$ & 8.125 & 7.0 & 10.5 & 8,3 & I Riverple \\
\hline \multicolumn{2}{|c|}{ Sample time 0715} & Samp & nple number(s) & BIFR95 & & BIFR96 & & BIFR98 \\
\hline \multirow[t]{2}{*}{ Notes: co } & nductivit & ty & $d$ by $\operatorname{Sm} \$$ & S...adj, to & tesults in & 4 parentle & bes & \\
\hline & & & & & & & & \\
\hline Project: & FFS & & \multicolumn{2}{|c|}{ Groundwater Depth: } & $41^{\prime}$ & & Pump Depth: & 1051 \\
\hline Well: & C4999 & & \multicolumn{2}{|c|}{ Sample Depth: } & $107-109 !$ & & Geologist: & t: Jitorner \\
\hline Time & $\begin{array}{l}\text { Turbidity } \\
\text { (NTU): }\end{array}$ & $\begin{array}{c}\text { Conductivity } \\
(\mu \mathrm{s})\end{array}$ & $\begin{array}{c}\text { Conductivity } \\
\text { Temp }\left({ }^{\circ} \mathrm{C}\right)\end{array}$ & $\mathrm{pH}$ & $\begin{array}{l}\text { pH probe } \\
\text { Temp (oC) }\end{array}$ & D.O. $(\mathrm{mg} / \mathrm{l})$ & $\begin{array}{l}\text { D.O. Temp } \\
\left({ }^{\circ} \mathrm{C}\right)\end{array}$ & Comments \\
\hline 1315 & $>1000$ & 270 & 19.1 & 8.158 & 18.4 & 0.4 & 20.9 & \\
\hline 1340 & $\geq 1000$ & 274 & 19.1 & 8.285 & 18.3 & 0.7 & 19.8 & \\
\hline 1350 & $>1000$ & 274 & 17.8 & 8.165 & 18.0 & 1.0 & 18.9 & \\
\hline 1355 & $>1000$ & 276 & 17.9 & 8.170 & 18.3 & 0.6 & 18.4 & \\
\hline 1406 & 71000 & 275 & 17.6 & 8.185 & 17.5 & 2.7 & 181 & \\
\hline \multicolumn{2}{|c|}{ Sample time 1405} & \multicolumn{2}{|c|}{ Sample number(s) } & BIFR 79 & & $B$ IFR 80 & & BIFR82 \\
\hline \multirow[t]{2}{*}{ Notes: } & & & ha $4 \mathrm{~ms}$ & Nowna & adjusted & resultsin & is parent & Heses \\
\hline & & & & & $>$ & & & \\
\hline Project: & & & \multicolumn{2}{|c|}{ Groundwater Depth: } & & & Pump Depth: & \\
\hline Well: & & & \multicolumn{2}{|c|}{ Sample Depth: } & & & Geologist: & \\
\hline Time & $\begin{array}{l}\text { Turbidity } \\
\text { (NTU): }\end{array}$ & $\begin{array}{c}\text { Conductivity } \\
(\mu \mathrm{s})\end{array}$ & $\begin{array}{c}\text { Conductivity } \\
\left.\text { Temp ( }{ }^{\circ} \mathrm{C}\right)\end{array}$ & $\mathrm{pH}$ & $\begin{array}{l}\text { pH probe } \\
\text { Temp (oC) }\end{array}$ & D.O. $(\mathrm{mg} / \mathrm{l})$ & \begin{tabular}{|c|} 
D.O. Temp \\
$\left({ }^{\circ} \mathrm{C}\right)$
\end{tabular} & Comments \\
\hline \multirow{2}{*}{\multicolumn{9}{|c|}{ 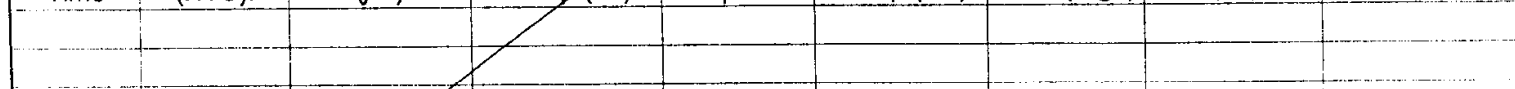 }} \\
\hline & & & & & & & & \\
\hline \multirow{2}{*}{\multicolumn{9}{|c|}{ … }} \\
\hline & & & & & & & & \\
\hline & & & & & & & & \\
\hline \multicolumn{2}{|c|}{ Sample time } & \multicolumn{3}{|c|}{ Sample number(s) } & & & & \\
\hline \multicolumn{9}{|c|}{ Notes: } \\
\hline & & & & & & & & \\
\hline & 10 & & & & & & & \\
\hline signed: & Deteros & ter & & & & dated: & $3-22-200$ & 006 \\
\hline
\end{tabular}




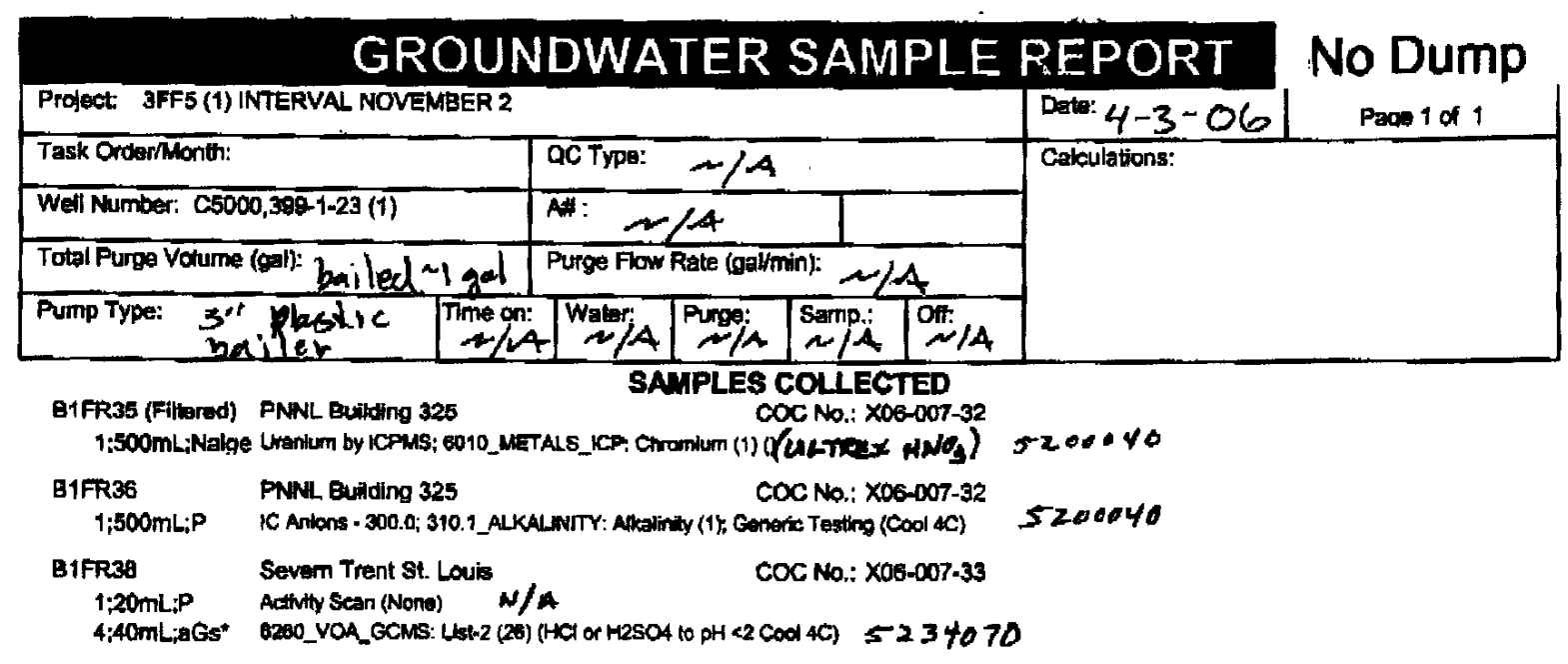

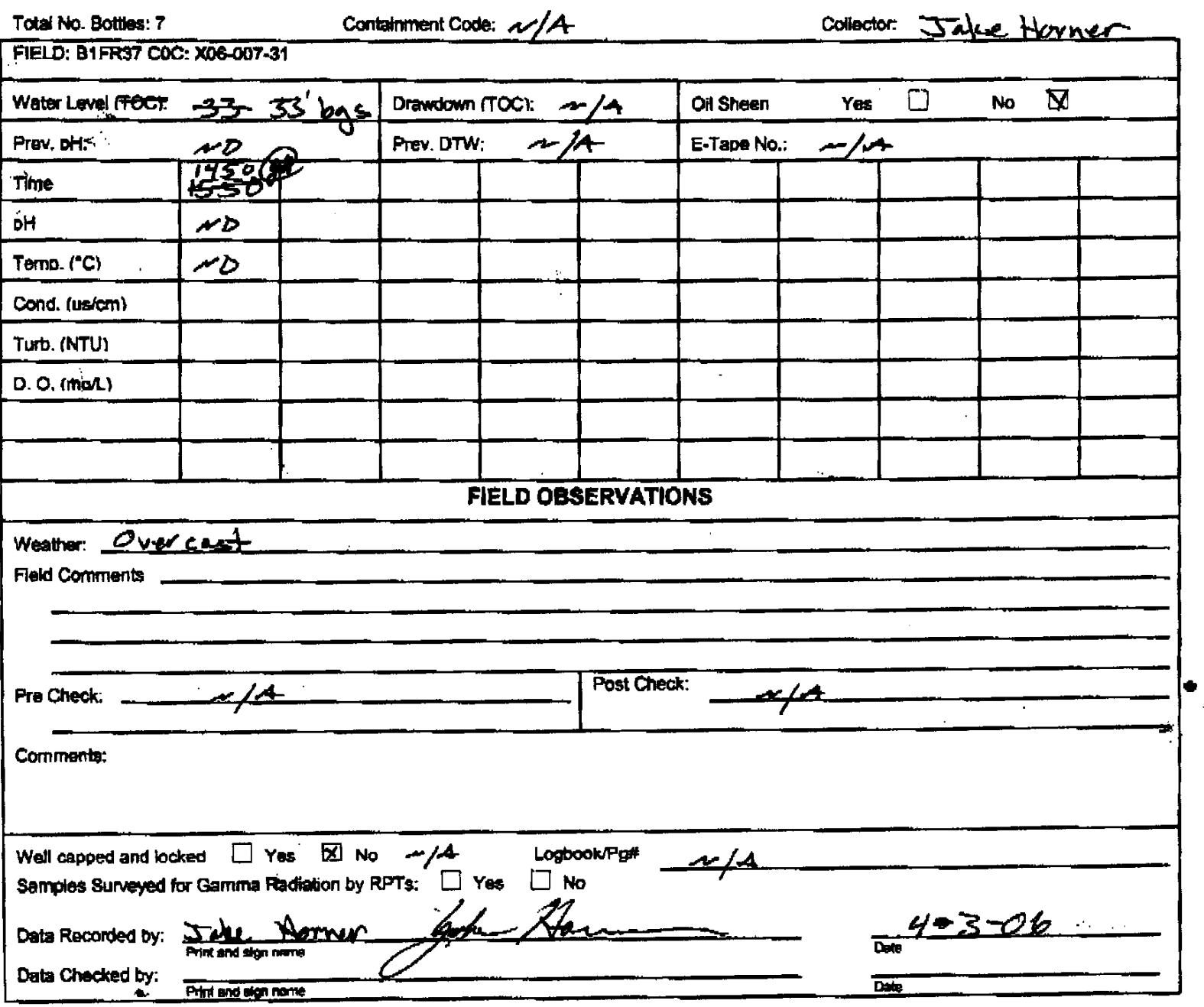




\section{GROUNDWATER SAMPLE REPORT No Dump}

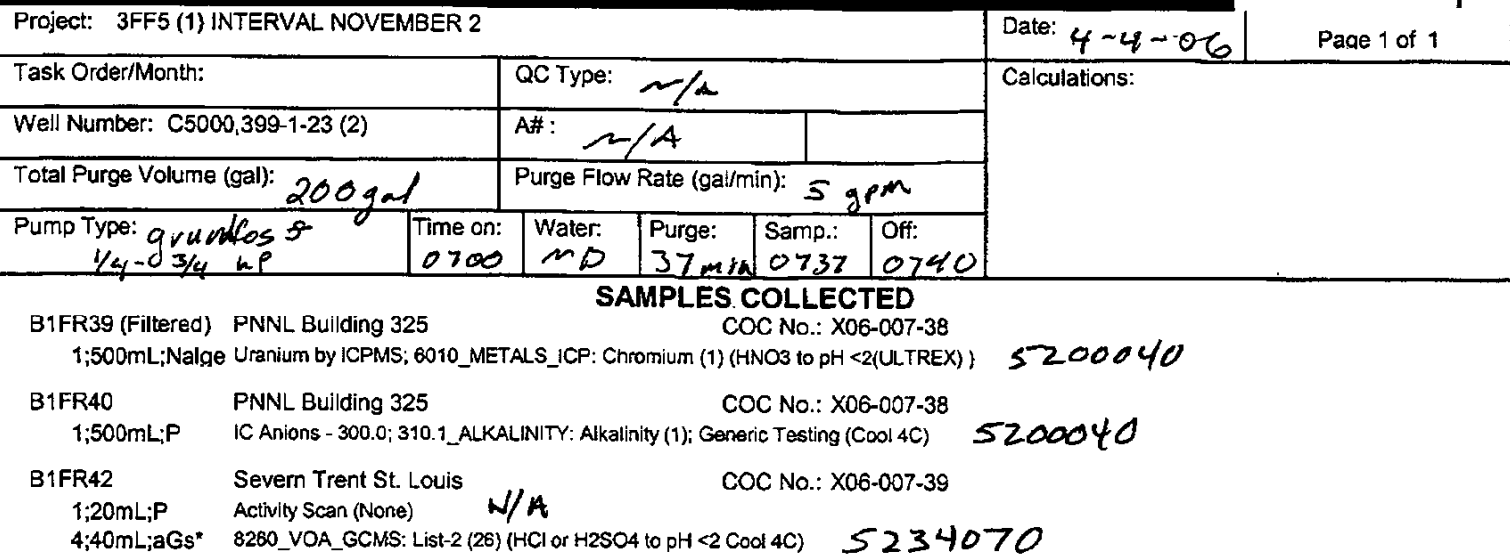

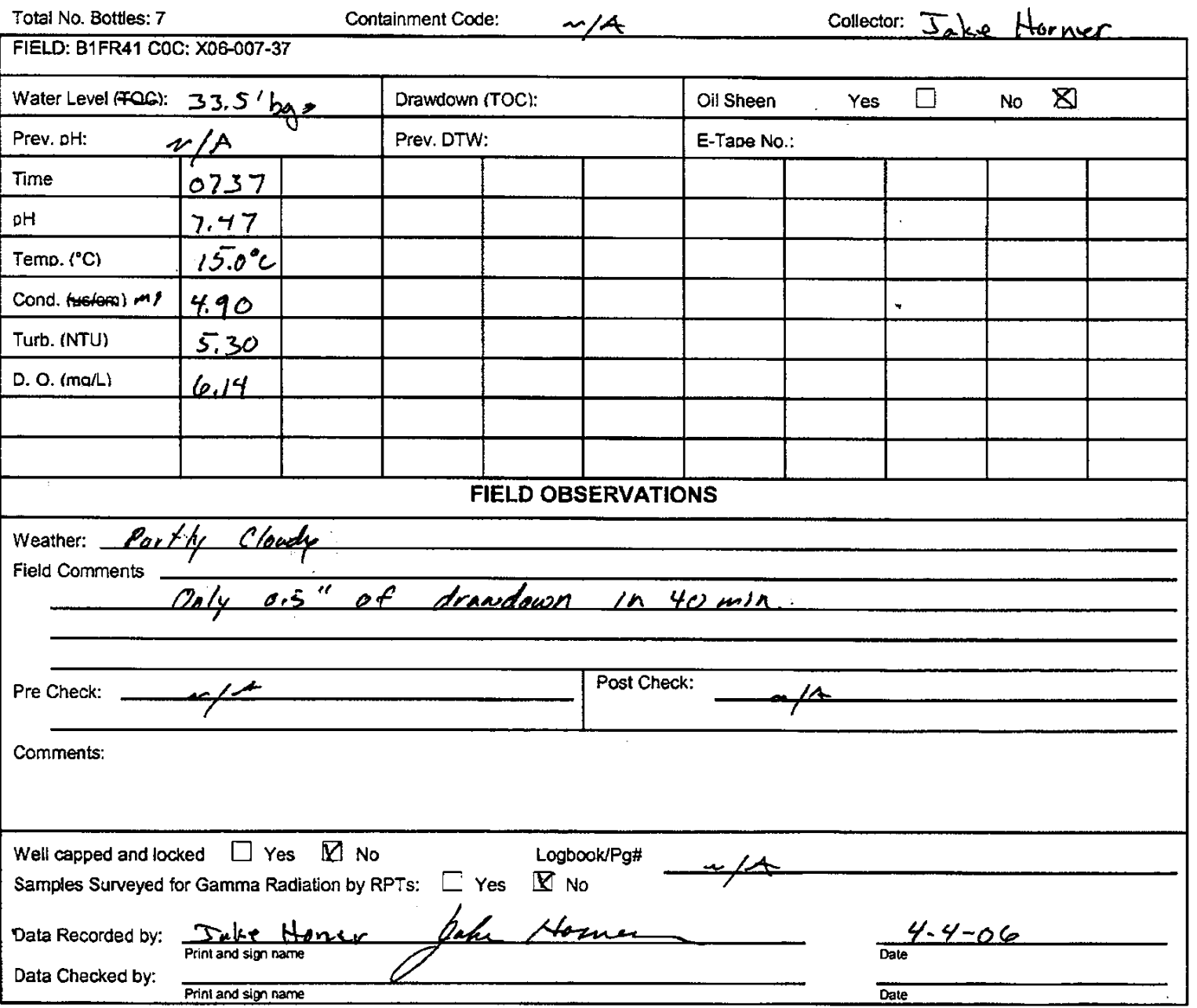




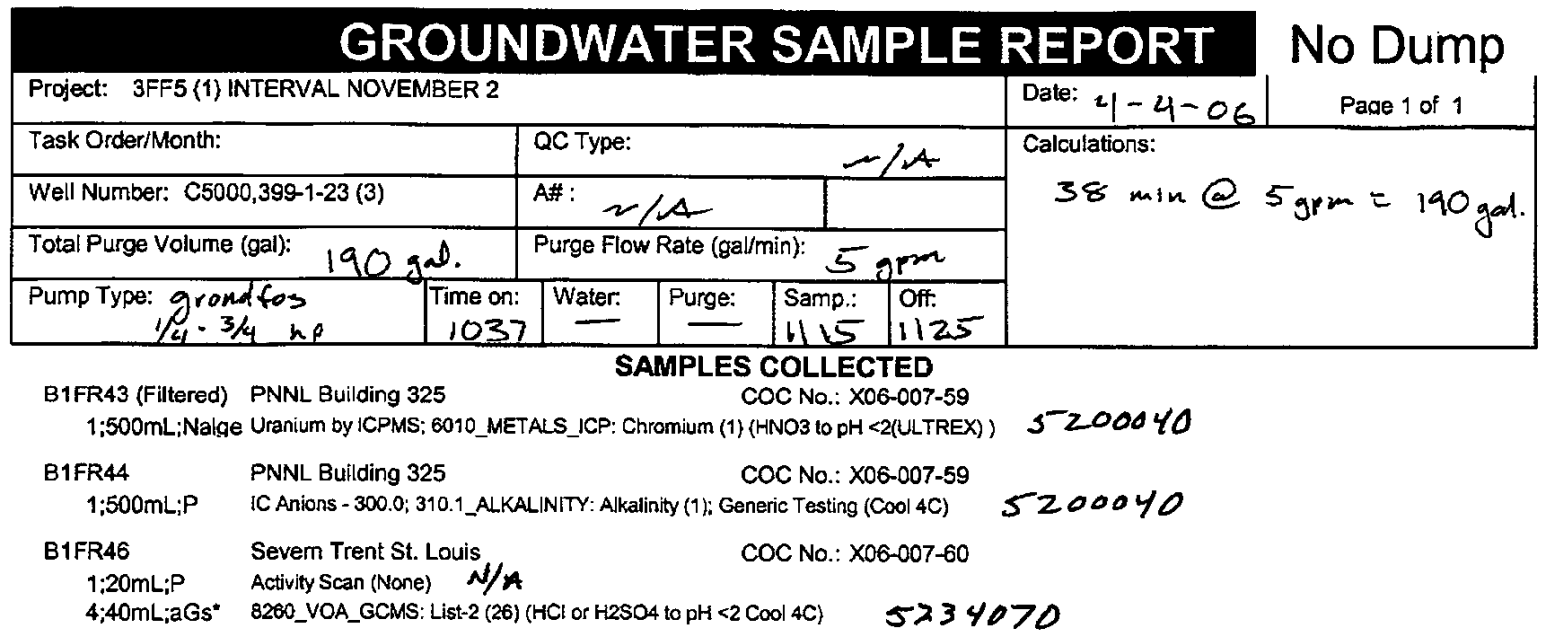

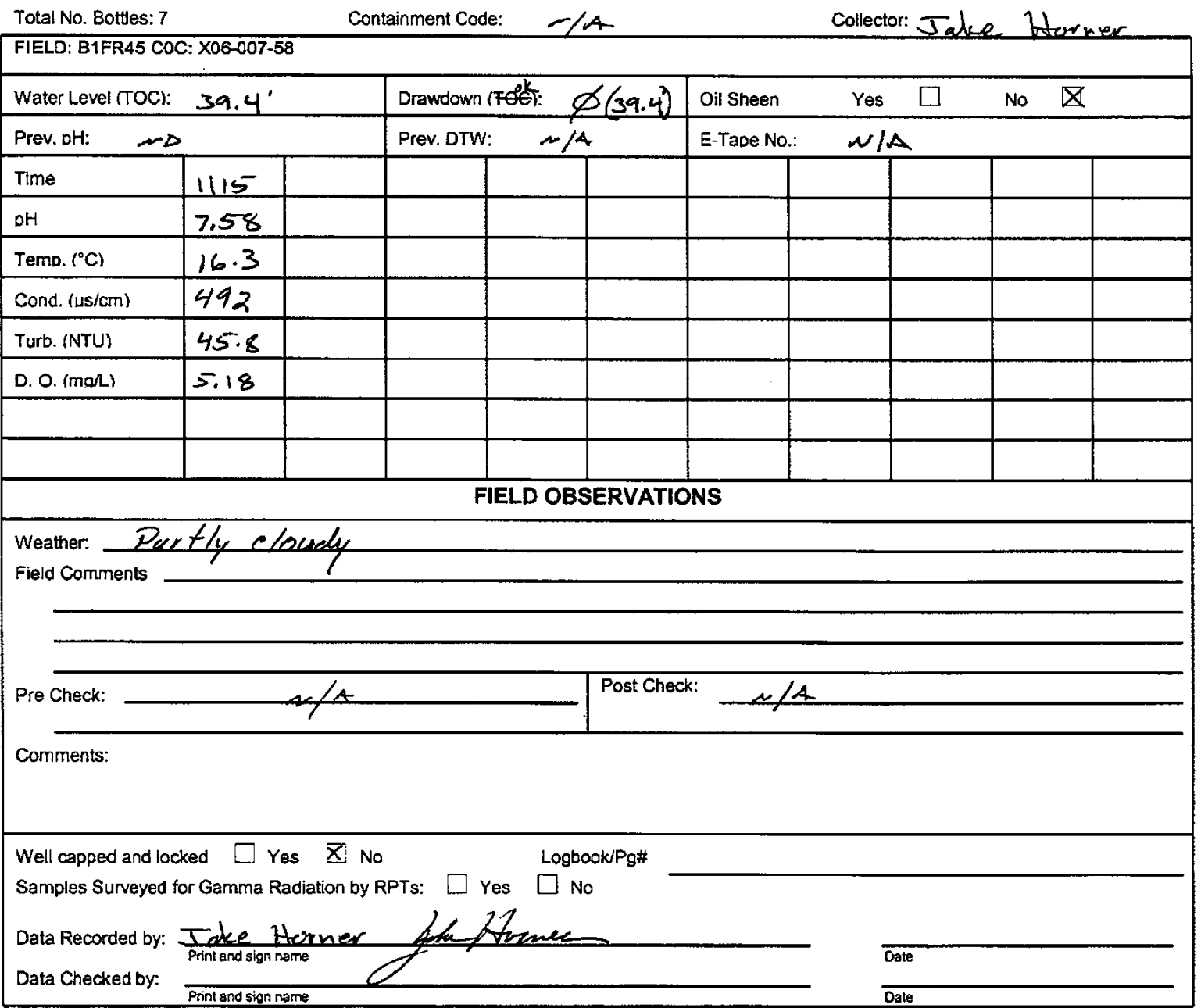




\section{GROUNDWATER SAMPLE REPORT No Dump}

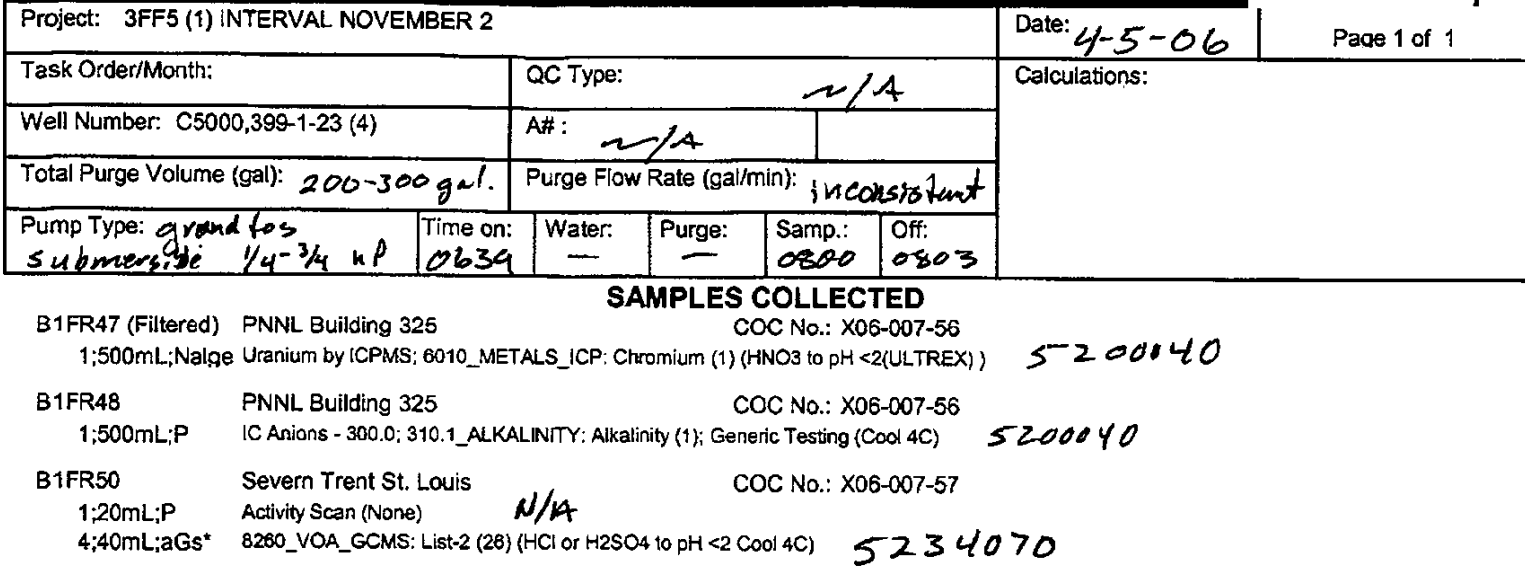

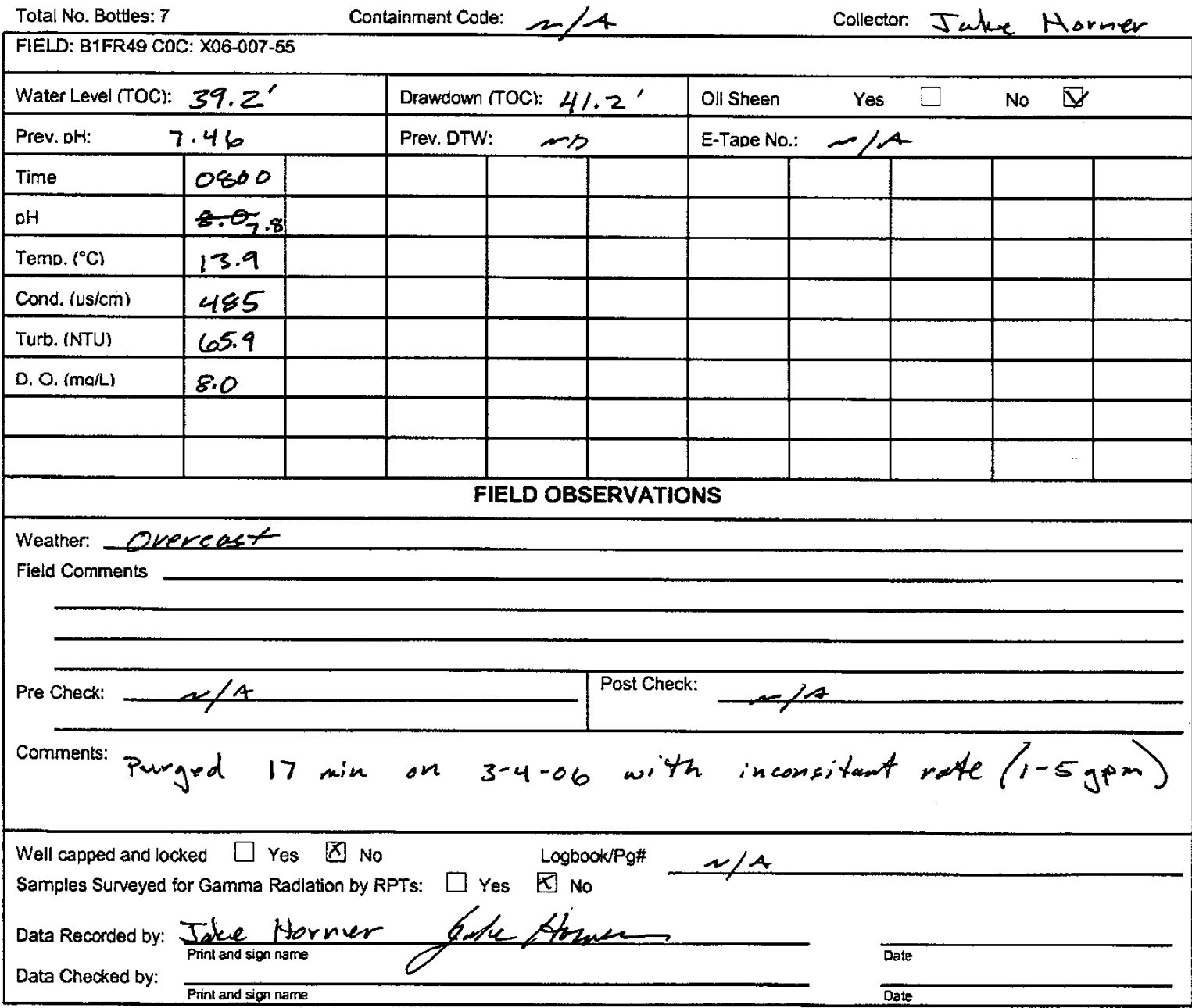




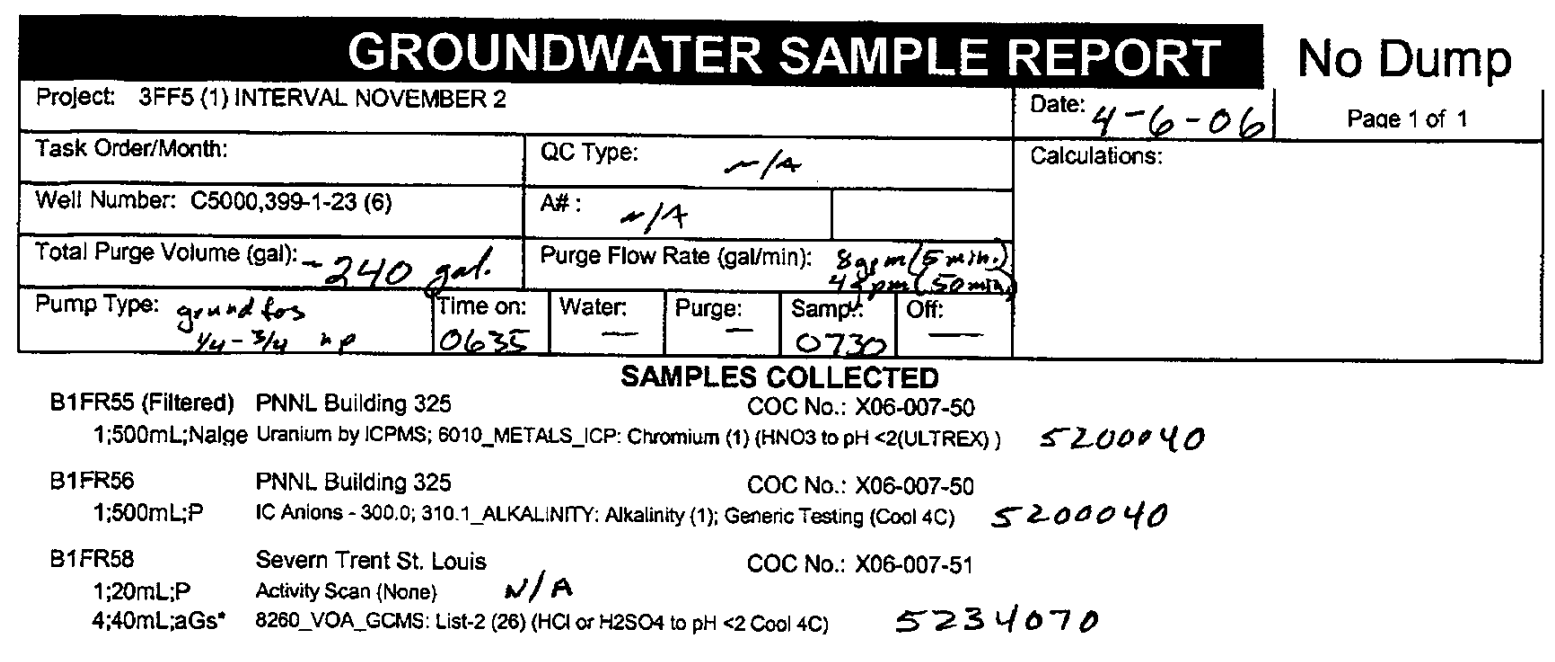

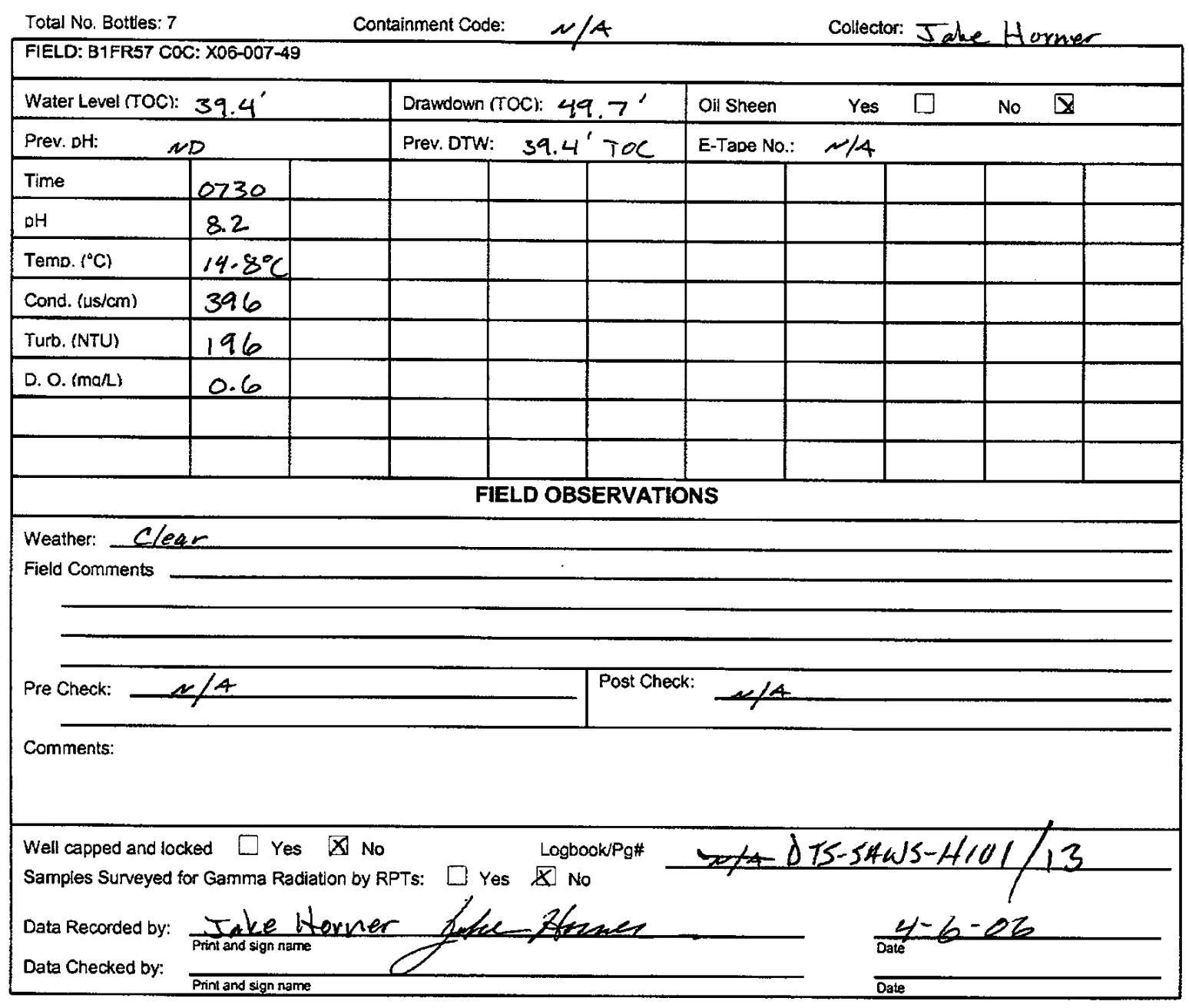




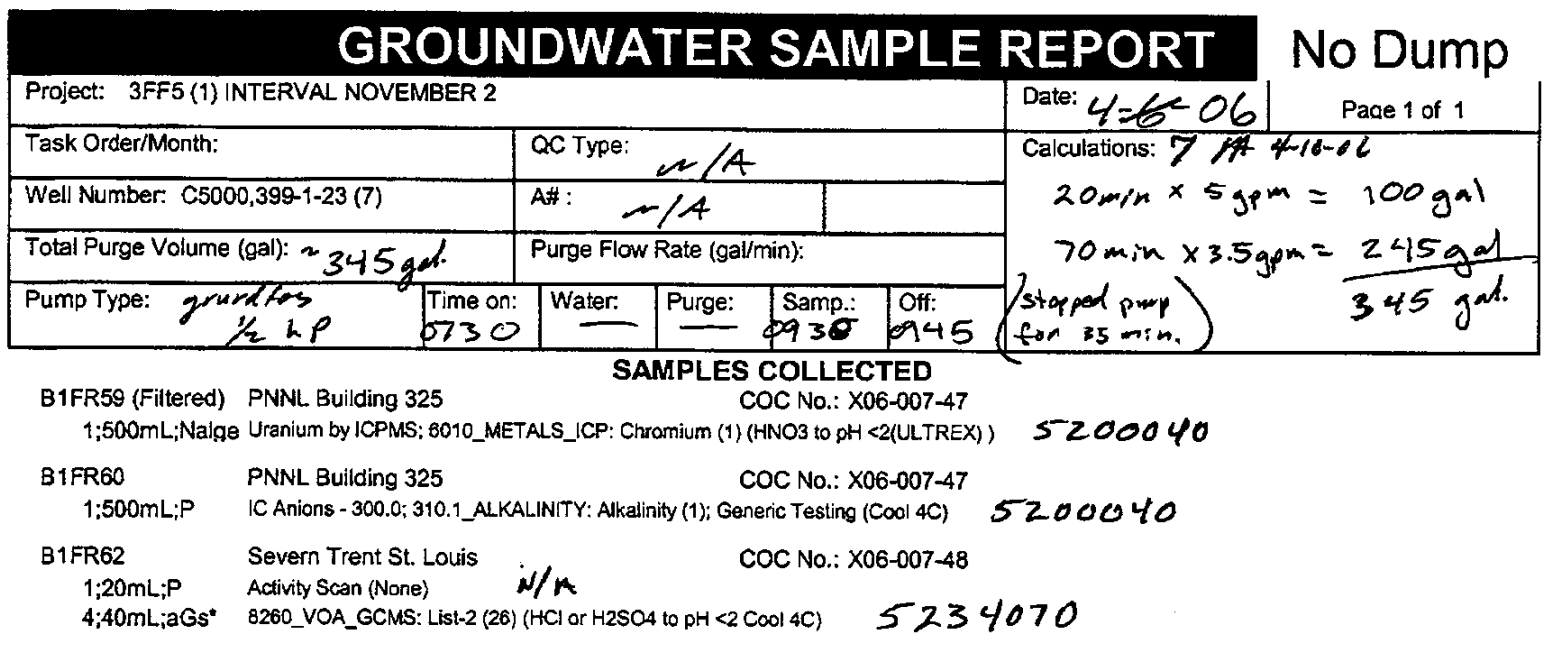

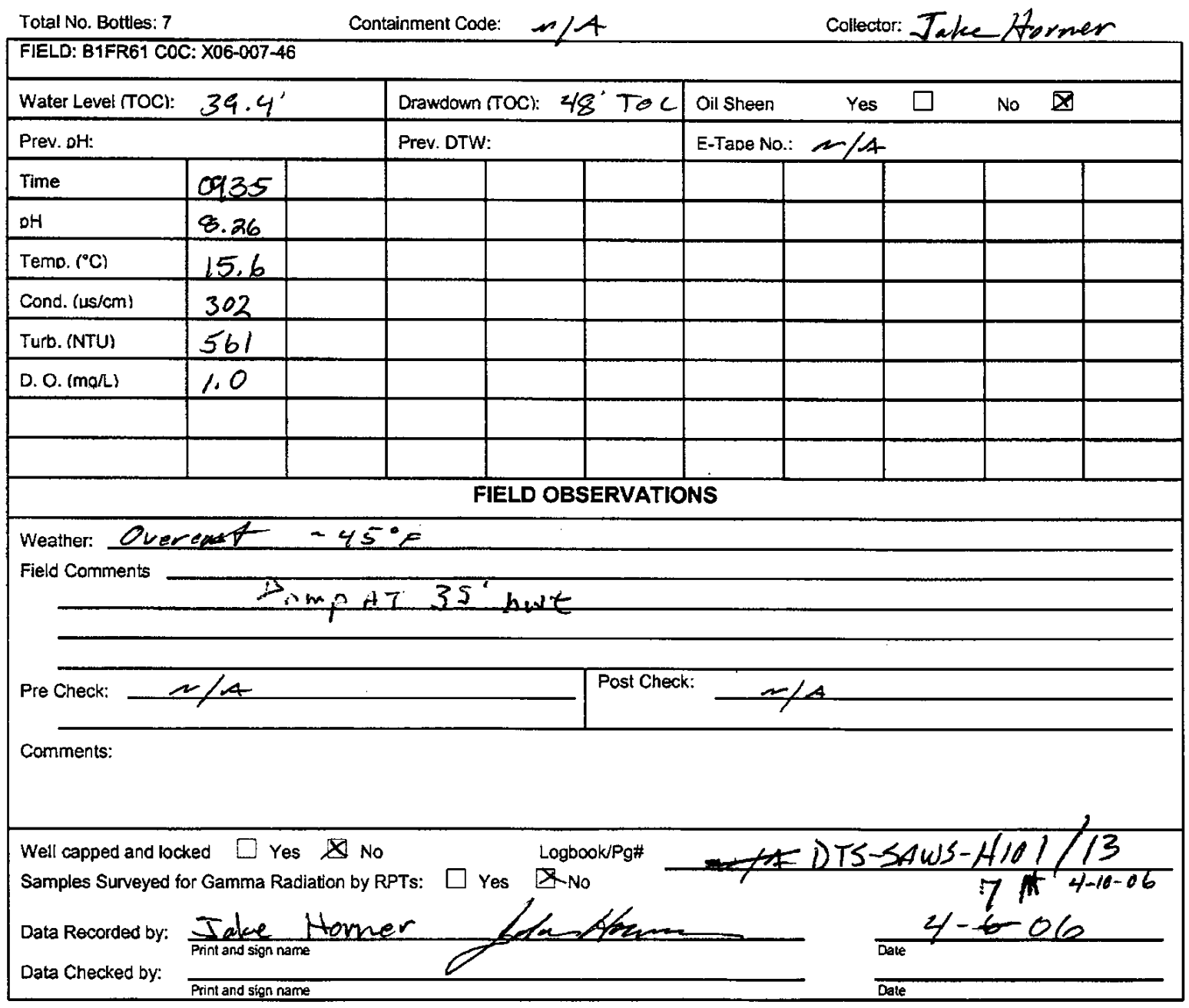




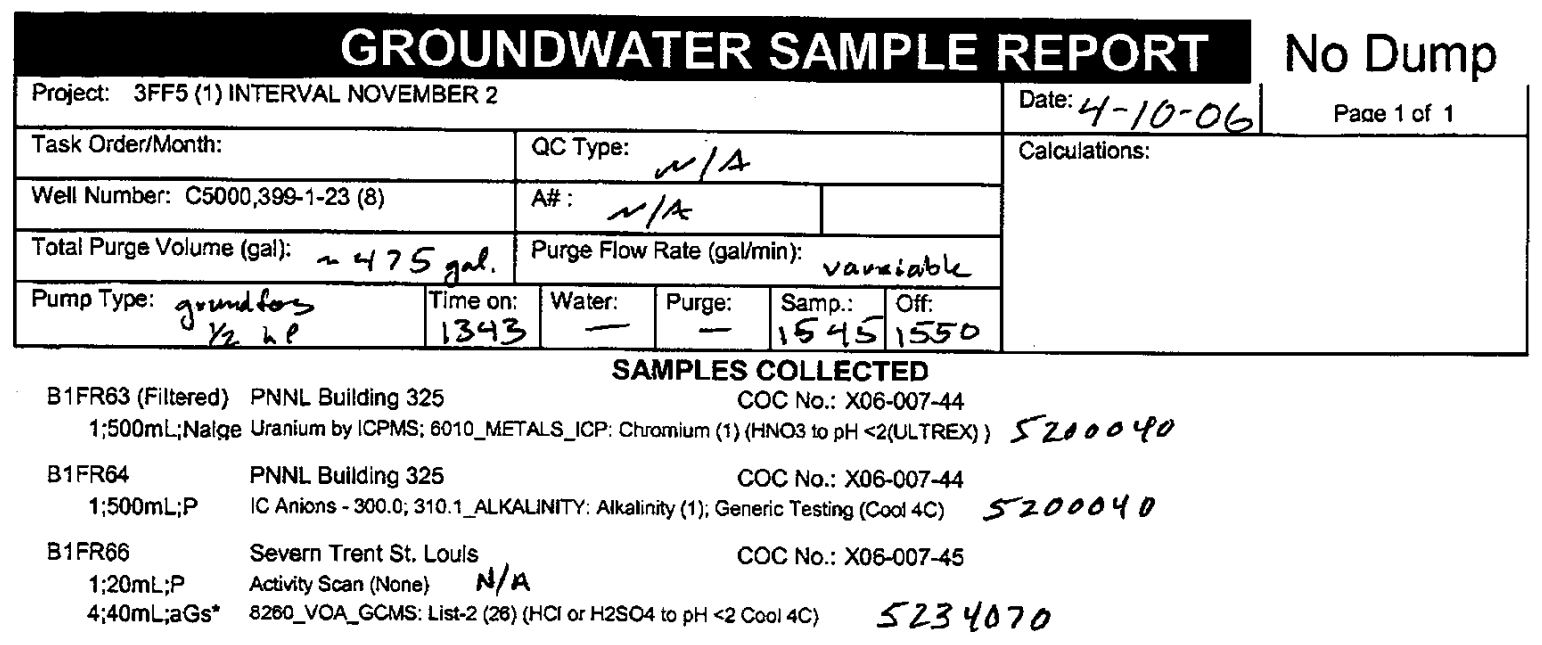

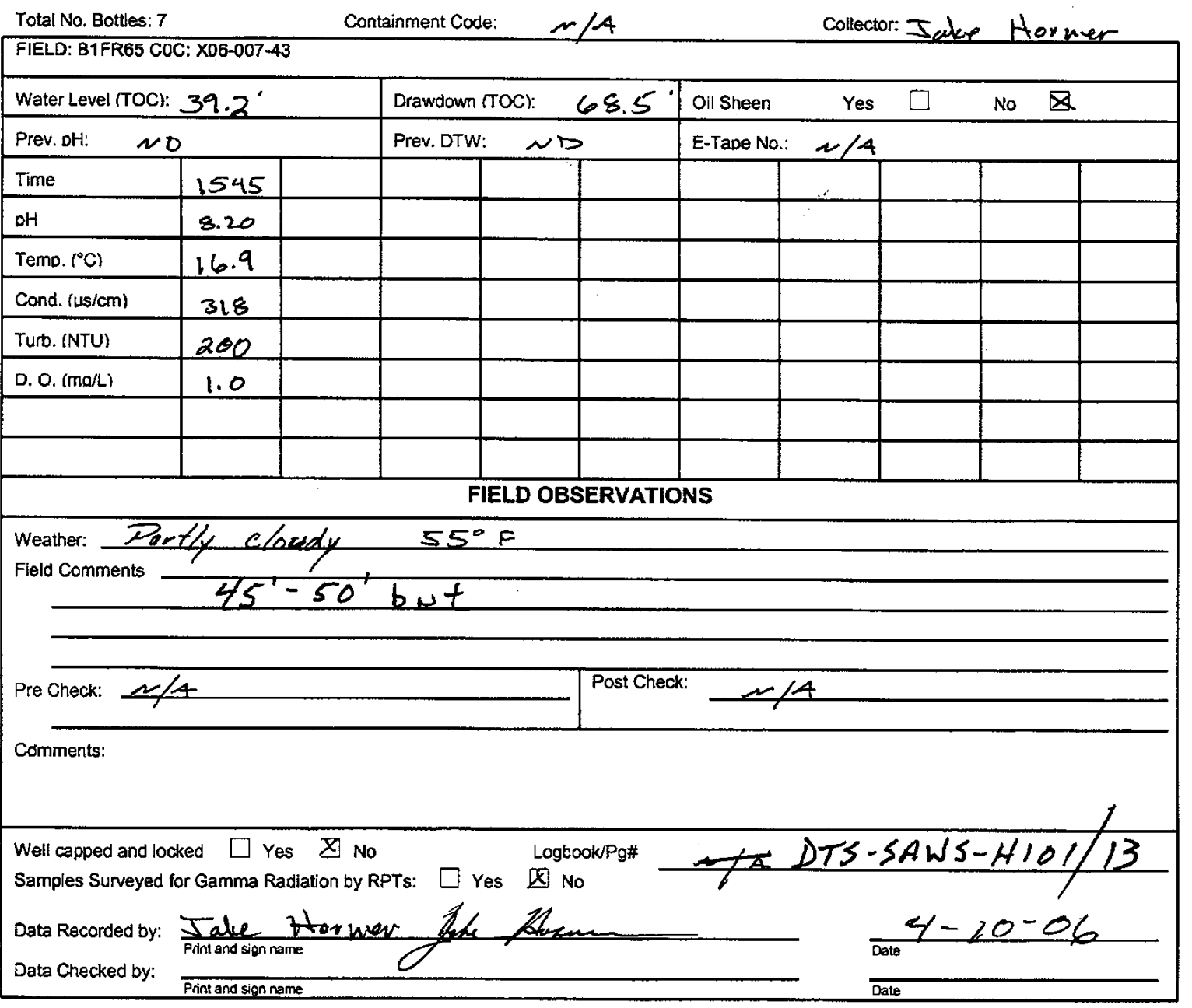




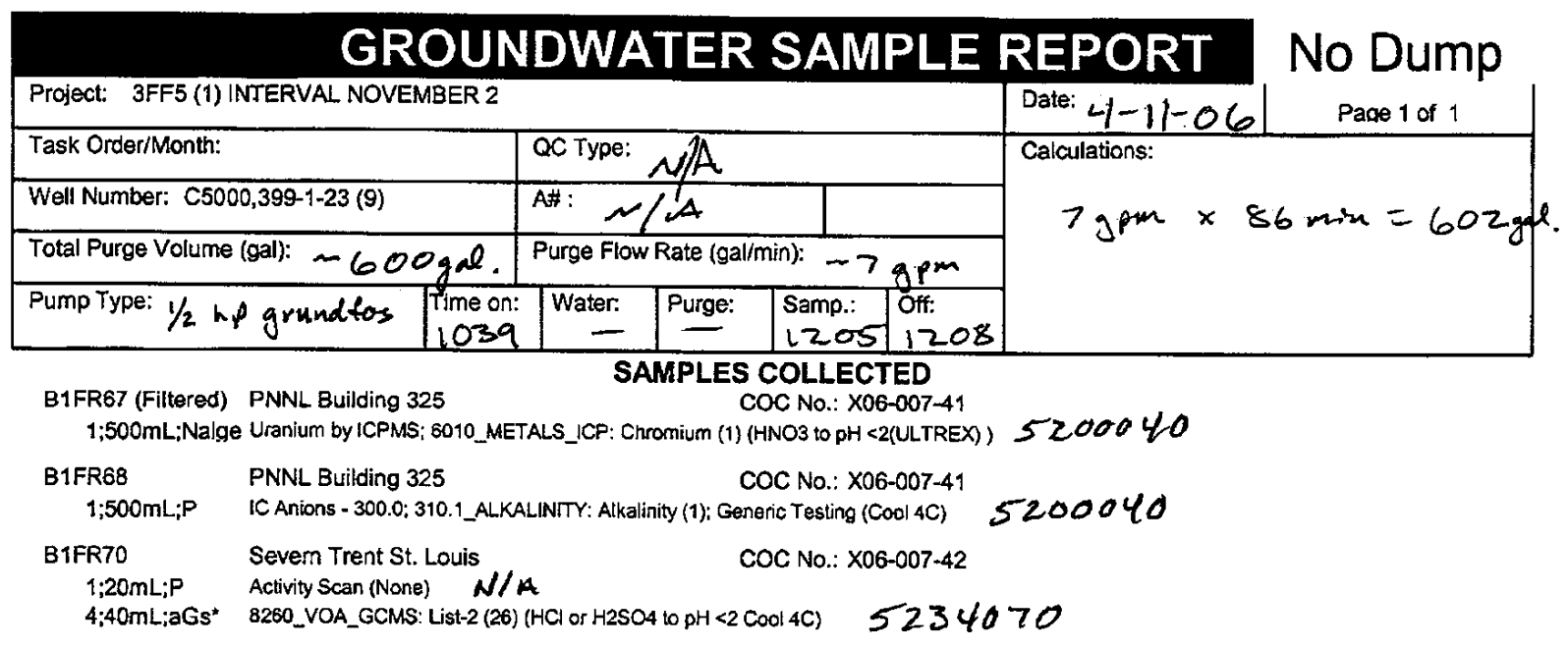

Total No. Bottles: 7

Containment Code: $N / 4$ Collector 5 ake Houner

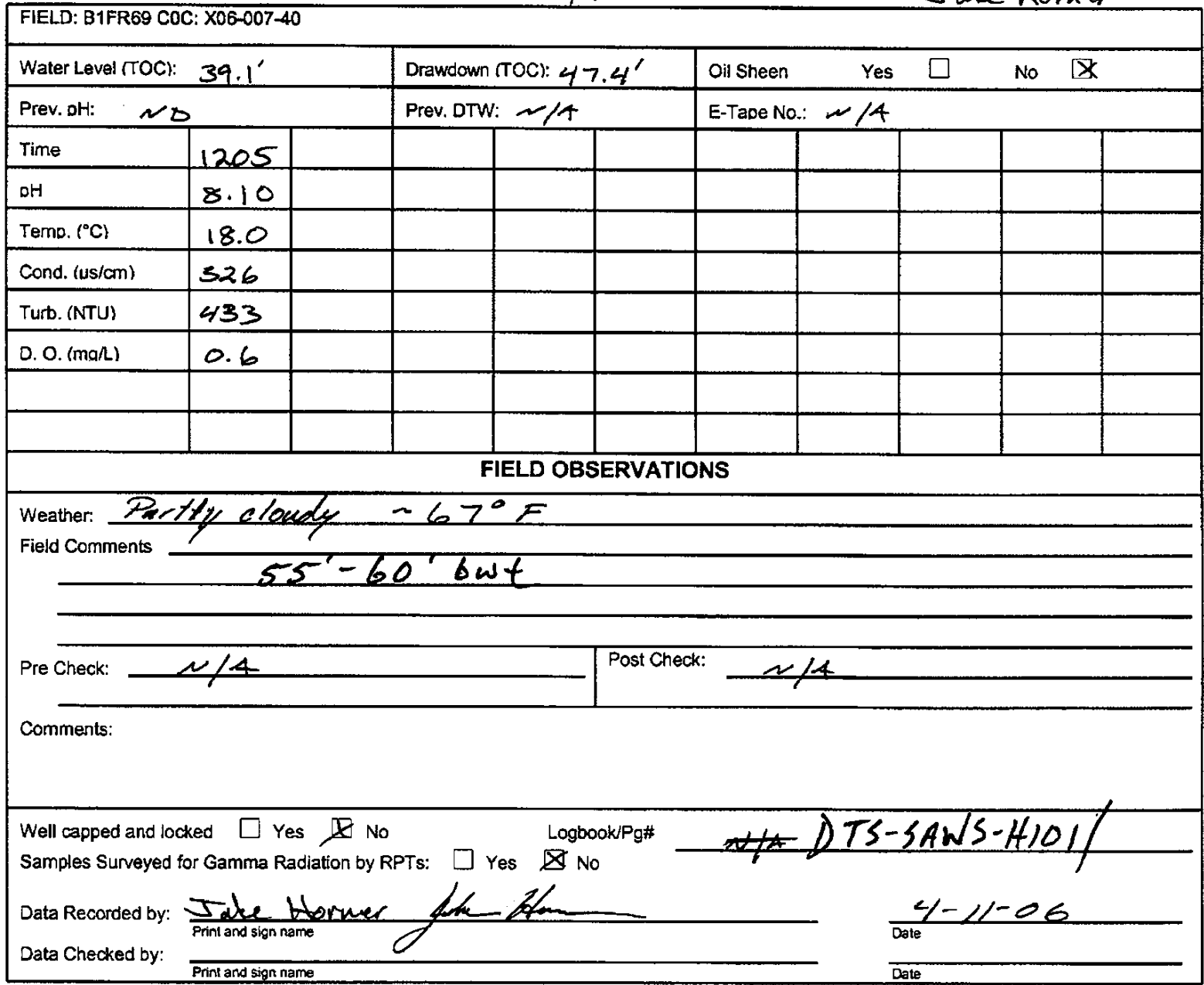




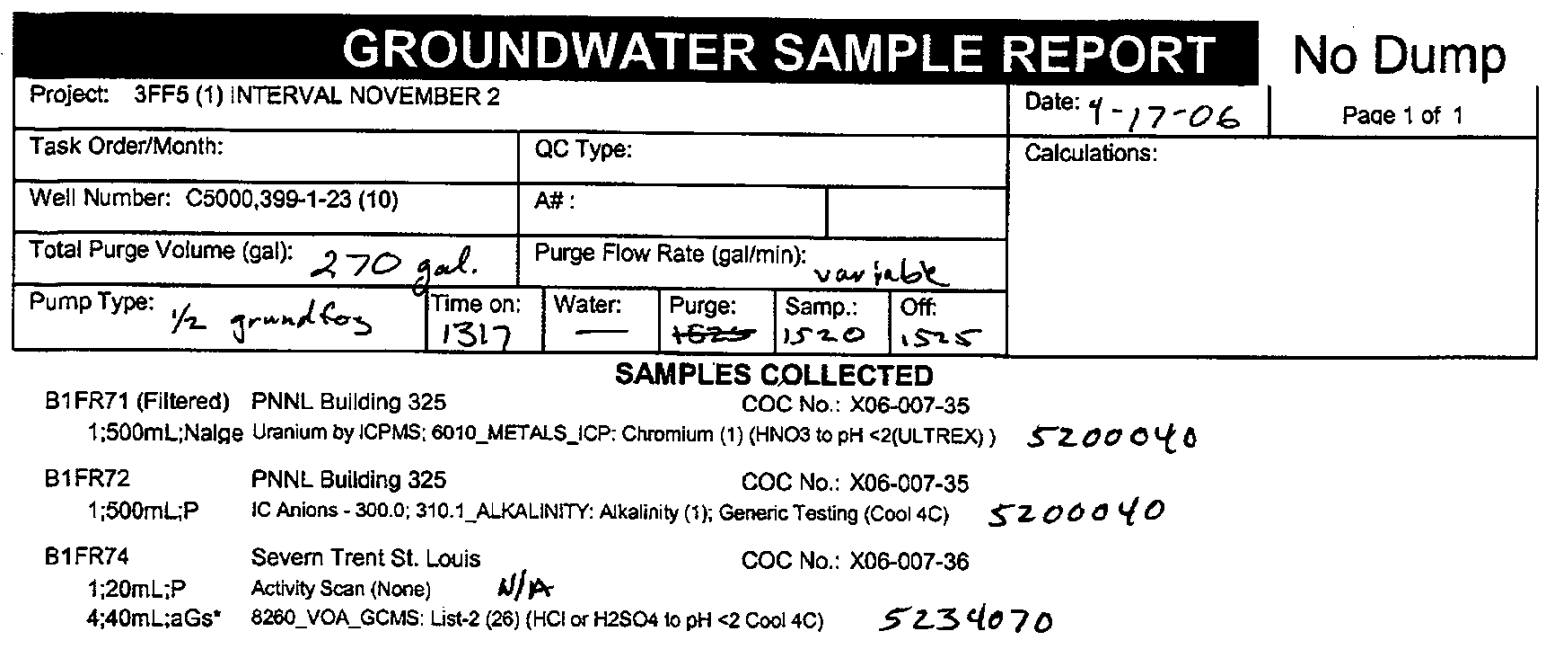

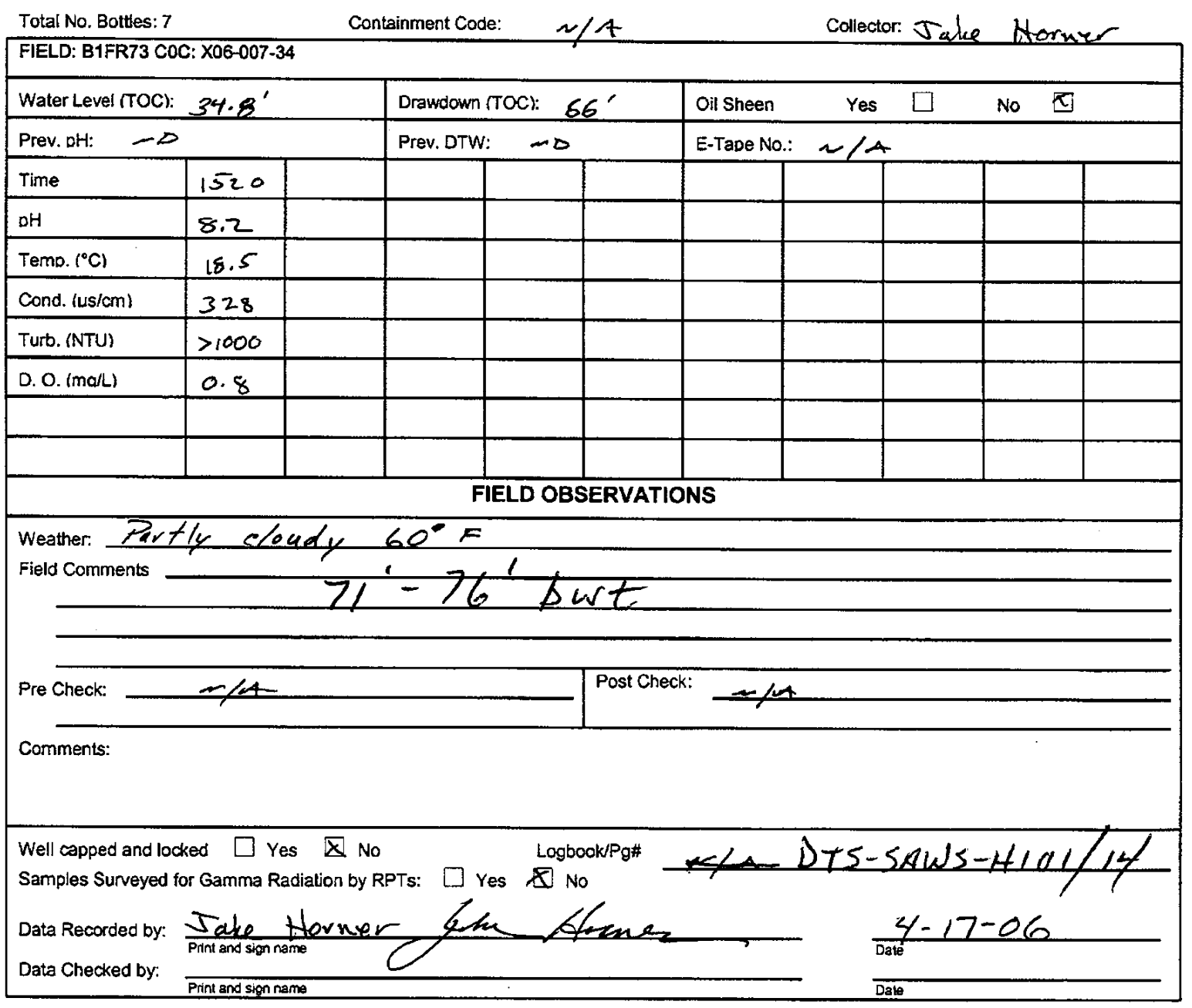




\section{Well C5001}

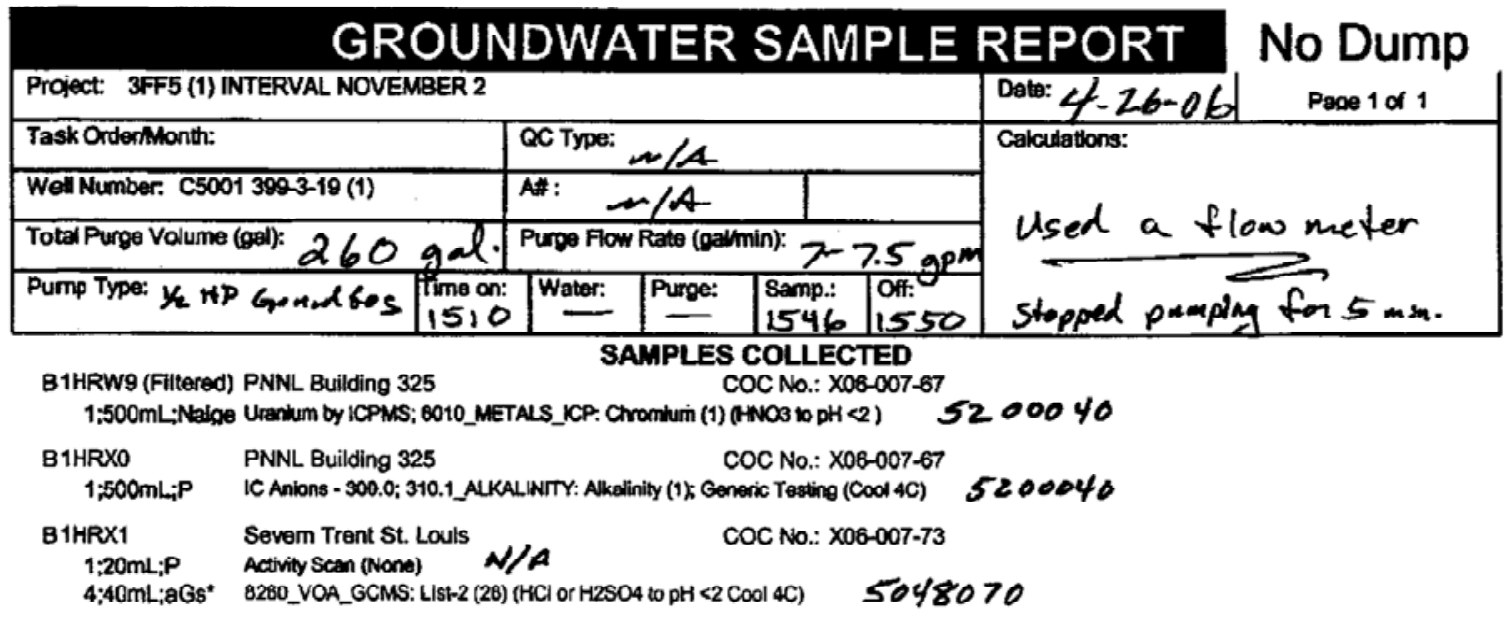

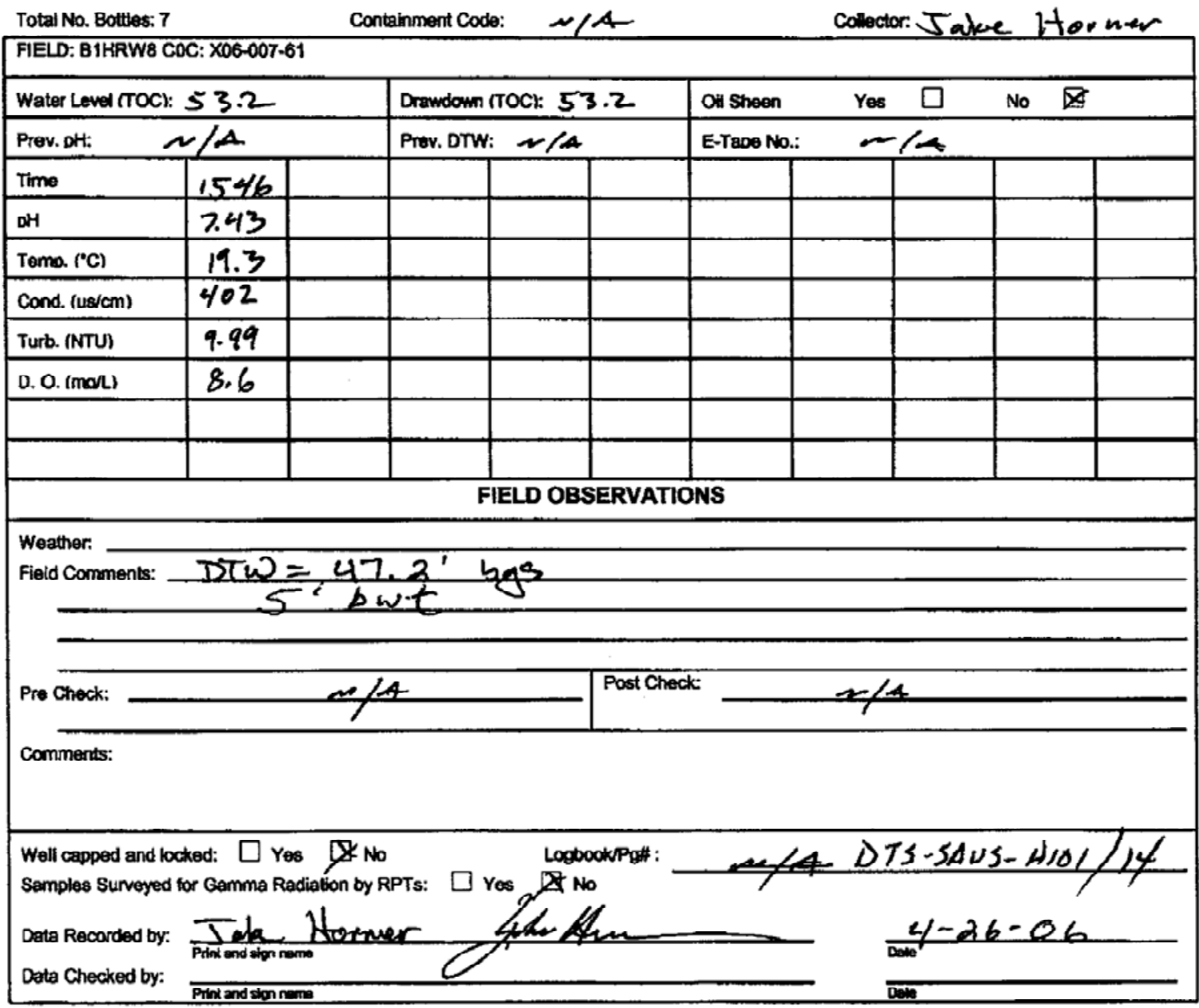




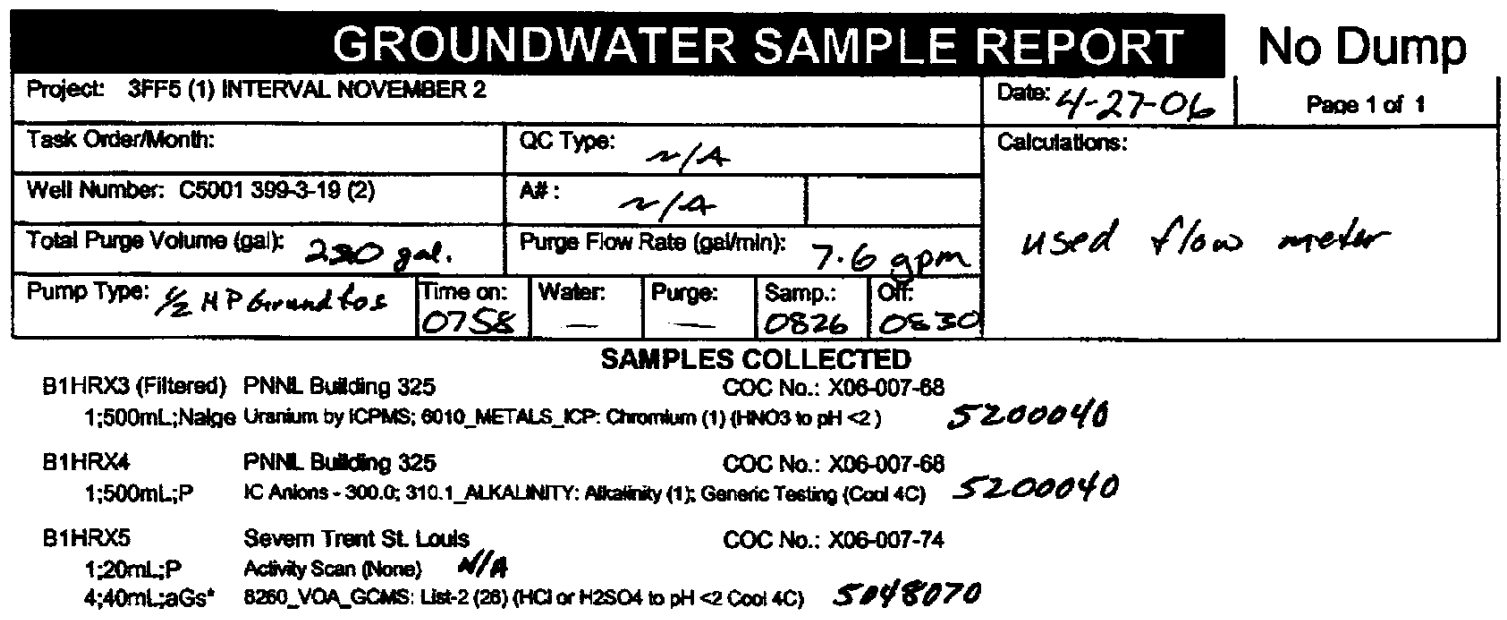

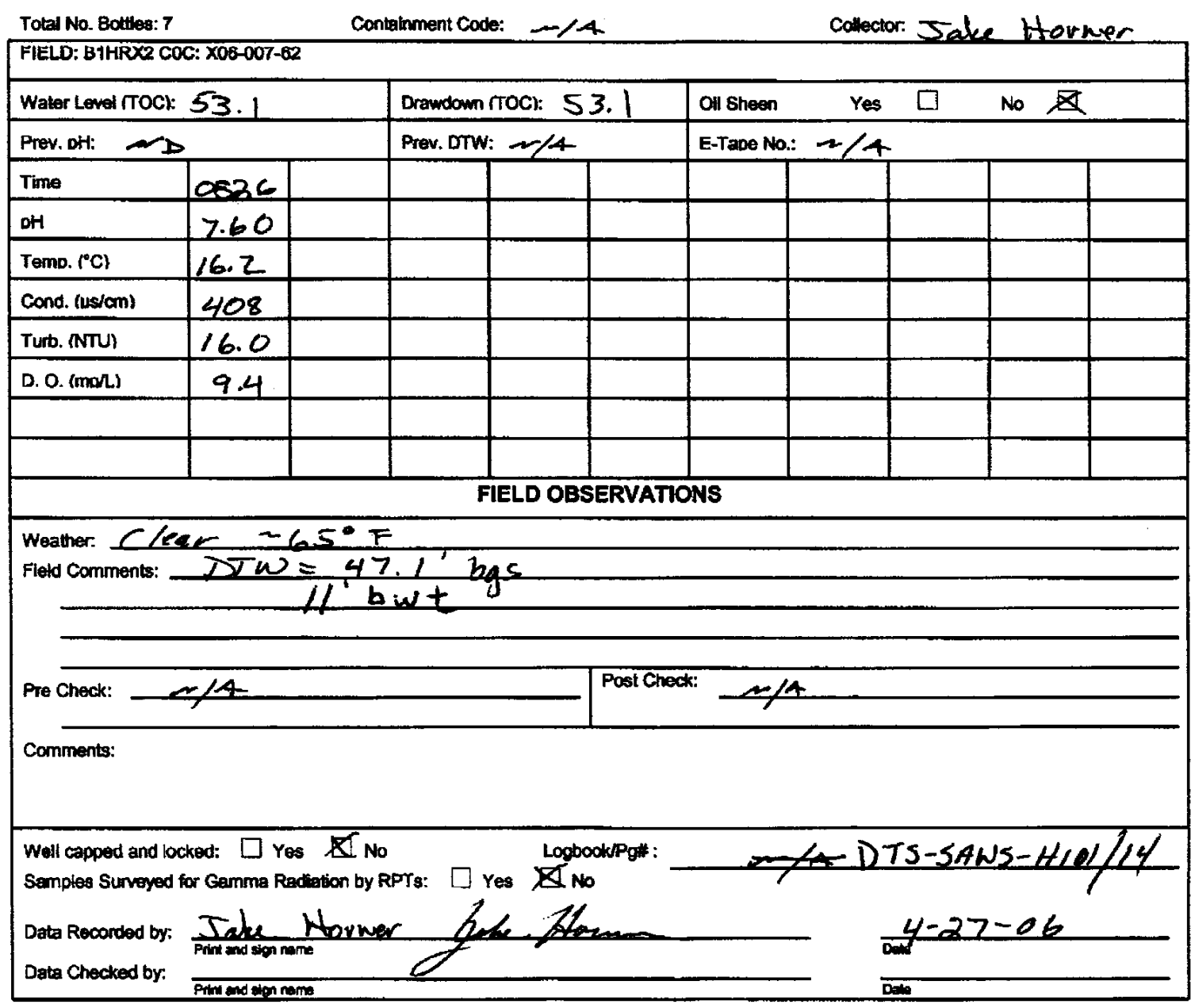




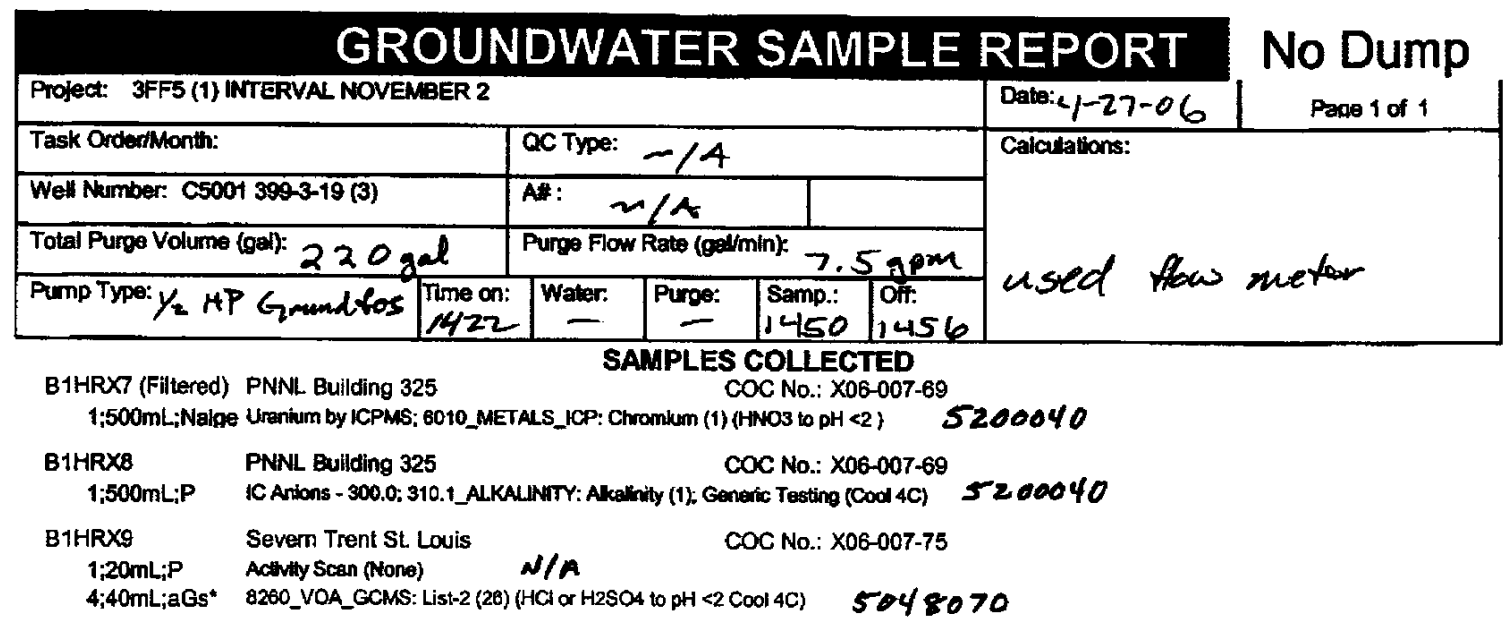

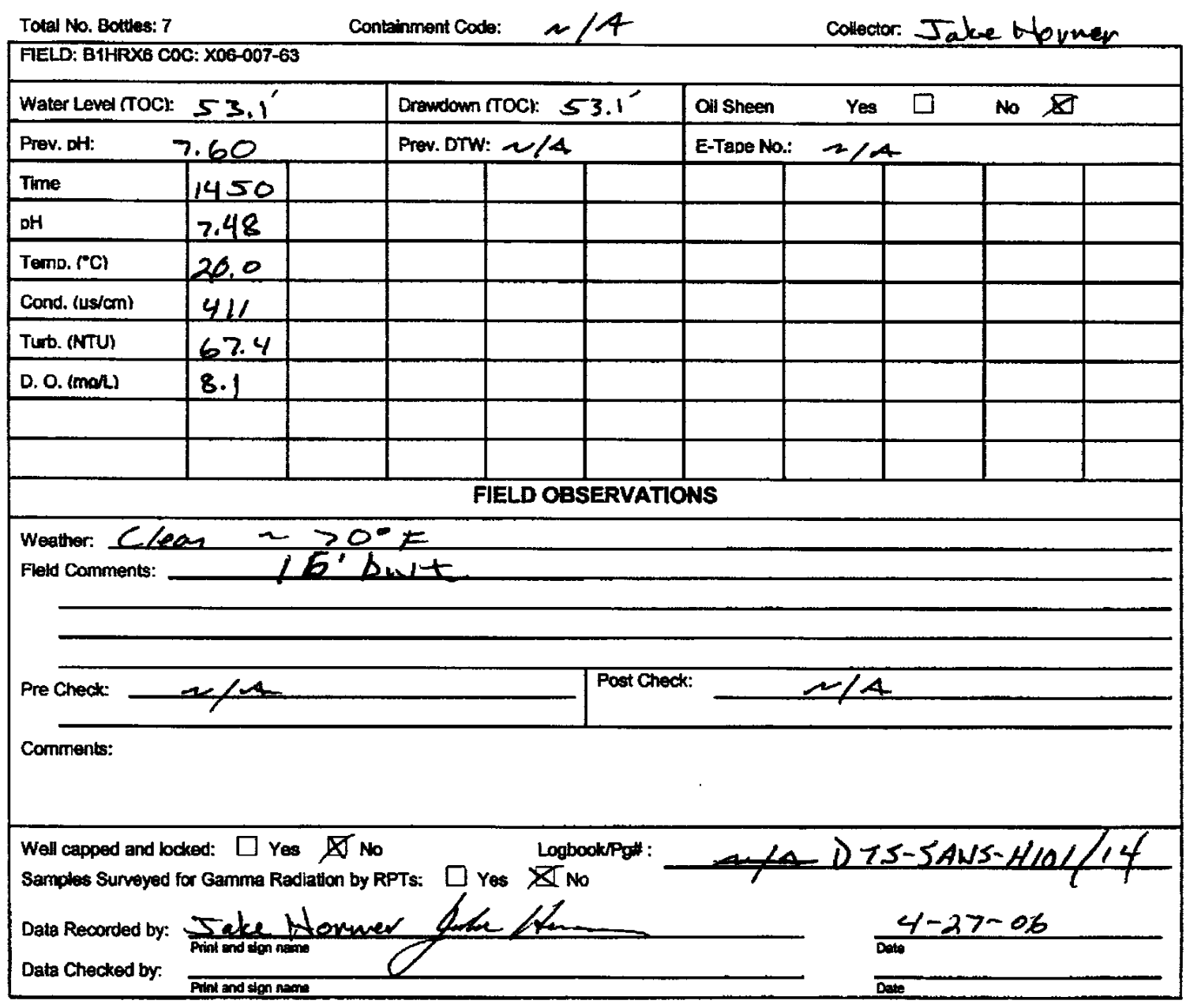




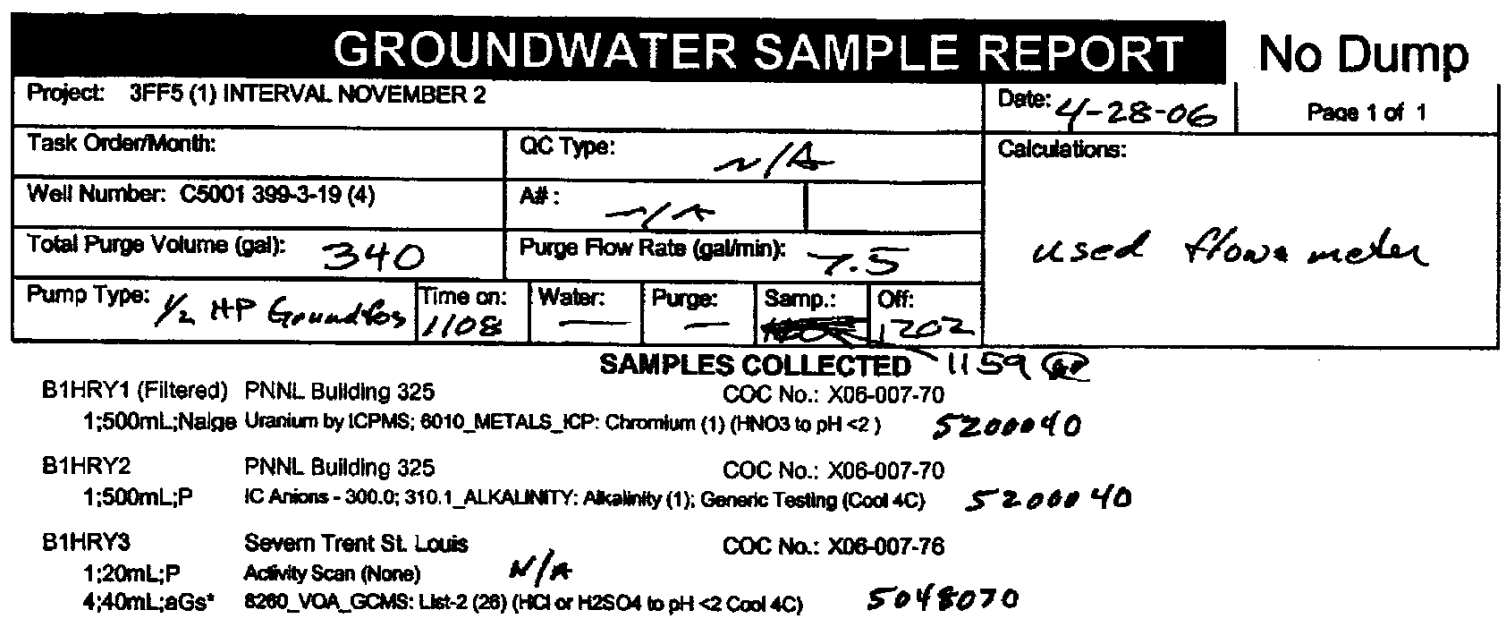

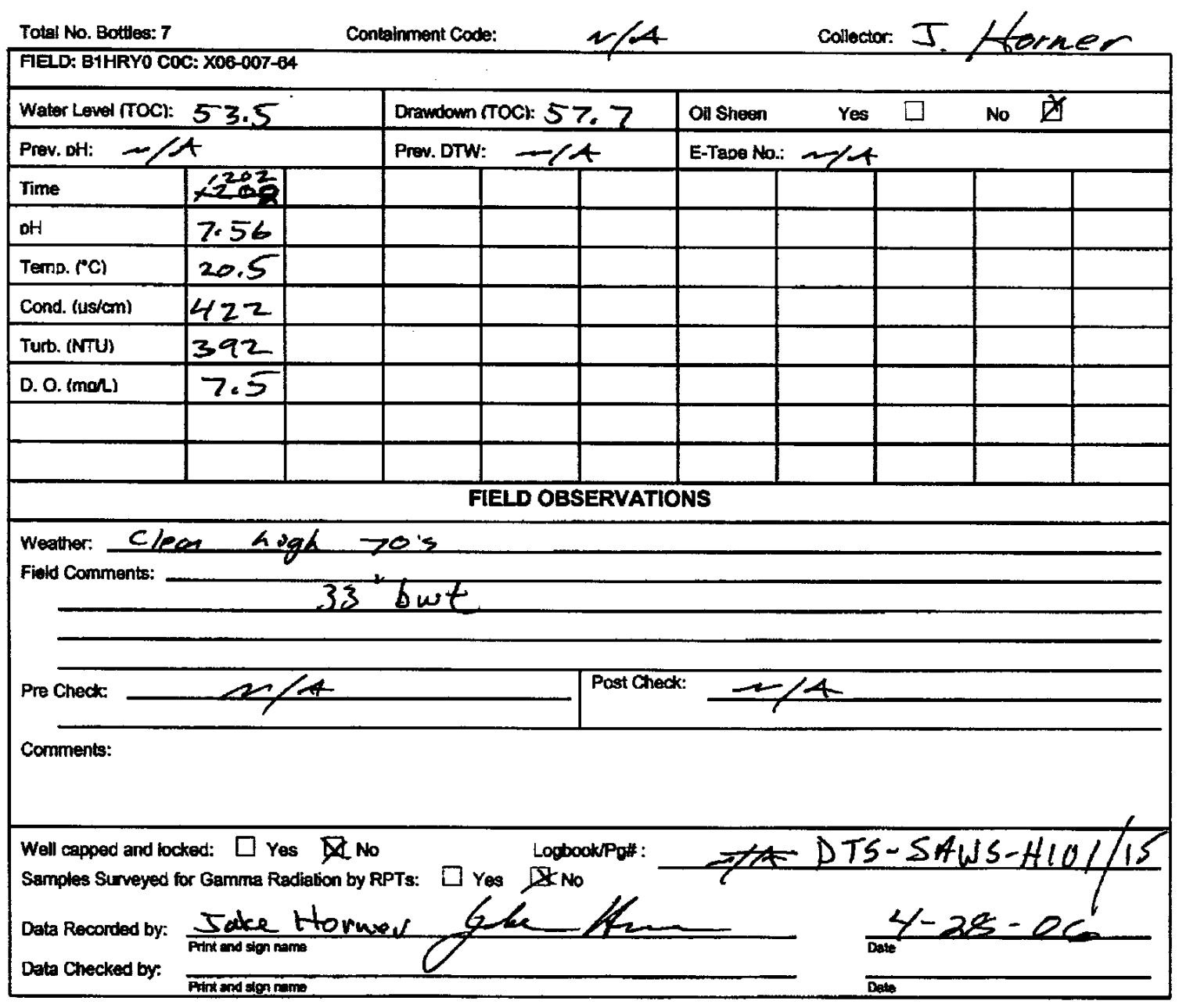




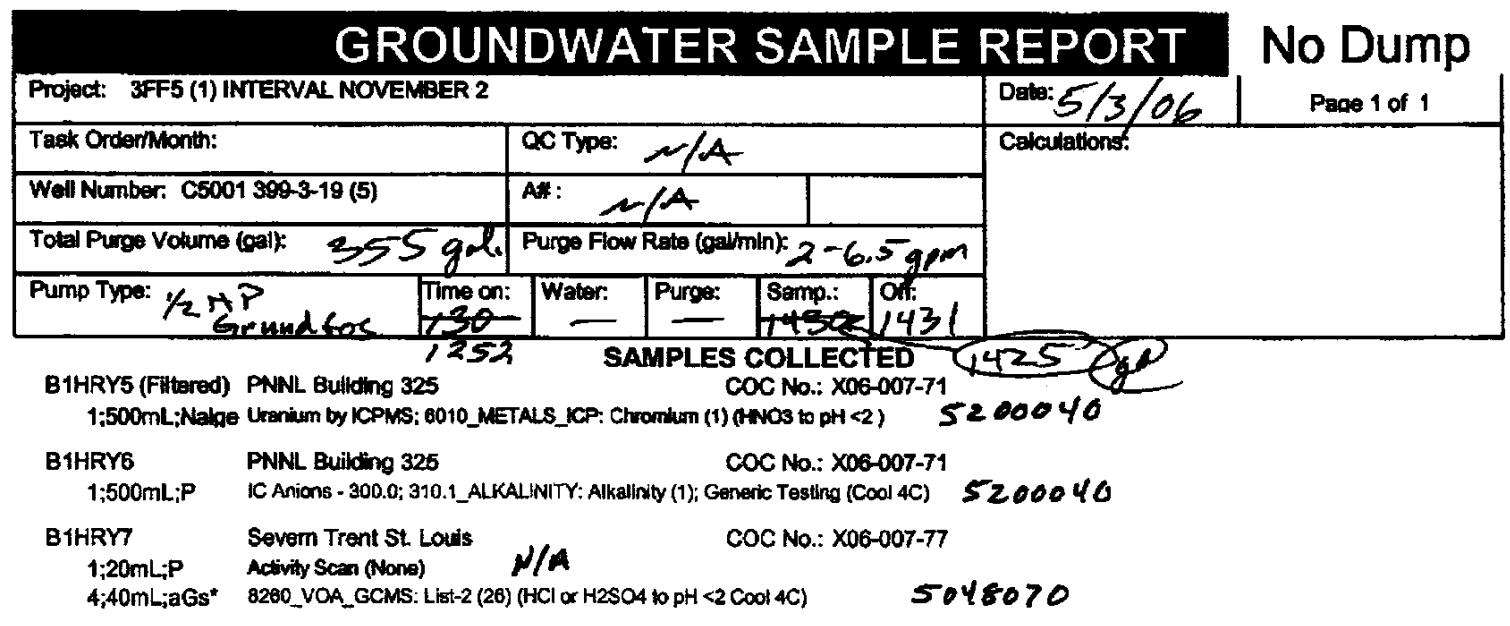

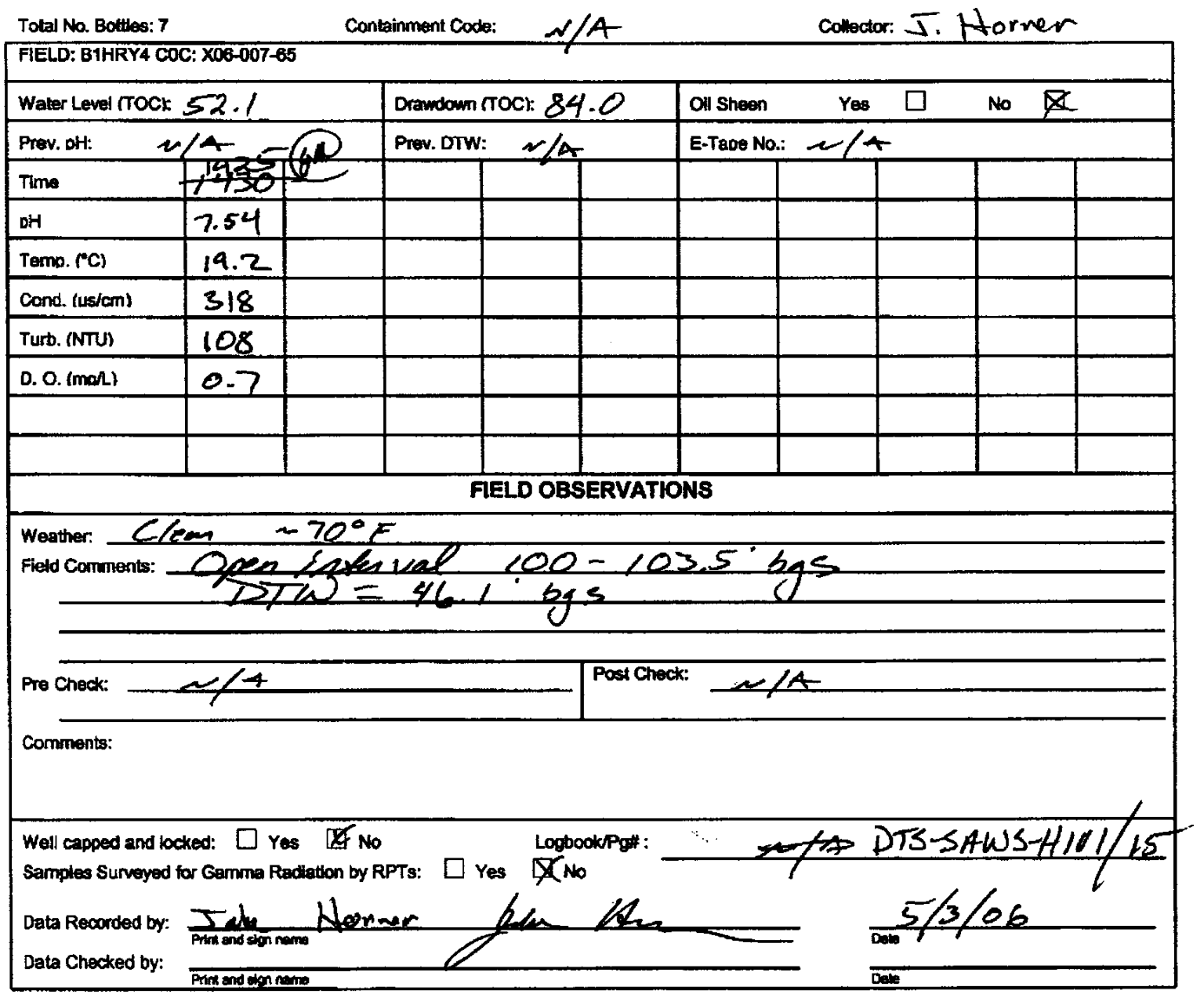




\section{Well C5002}

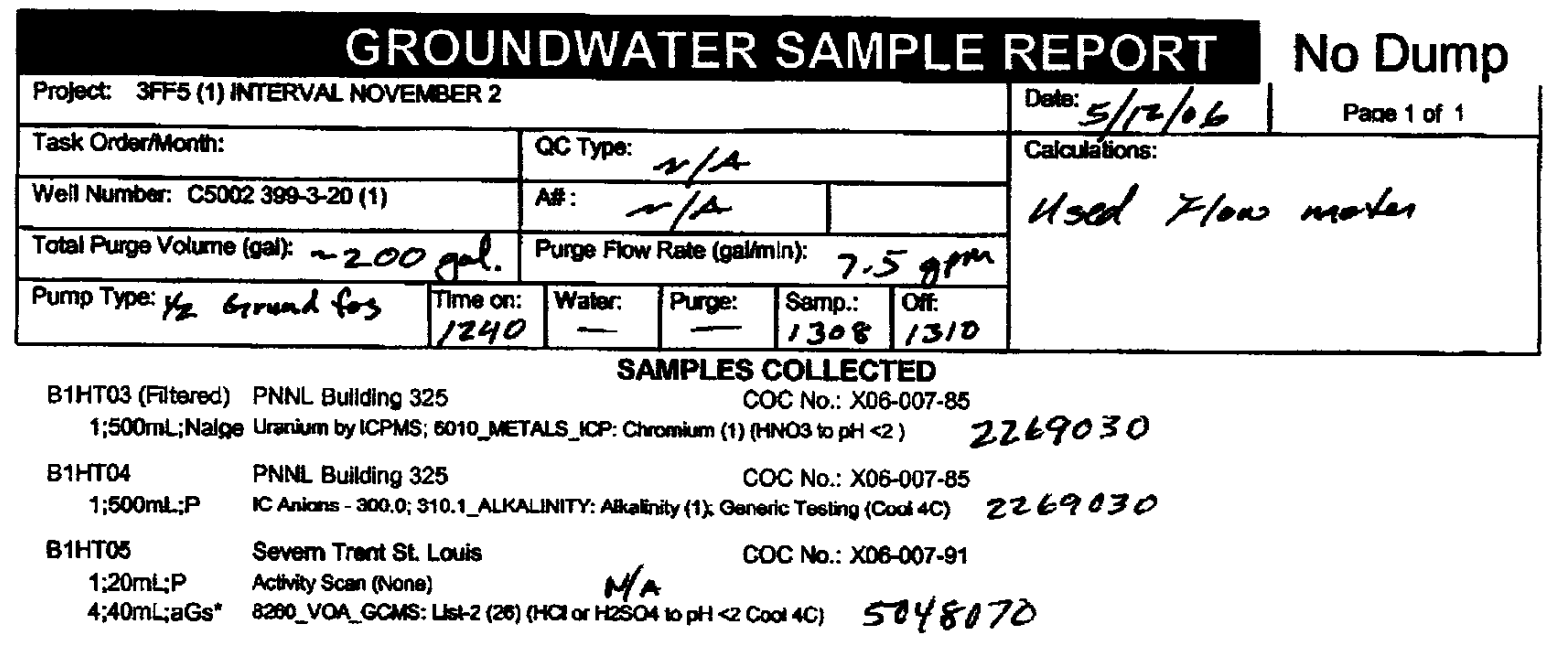

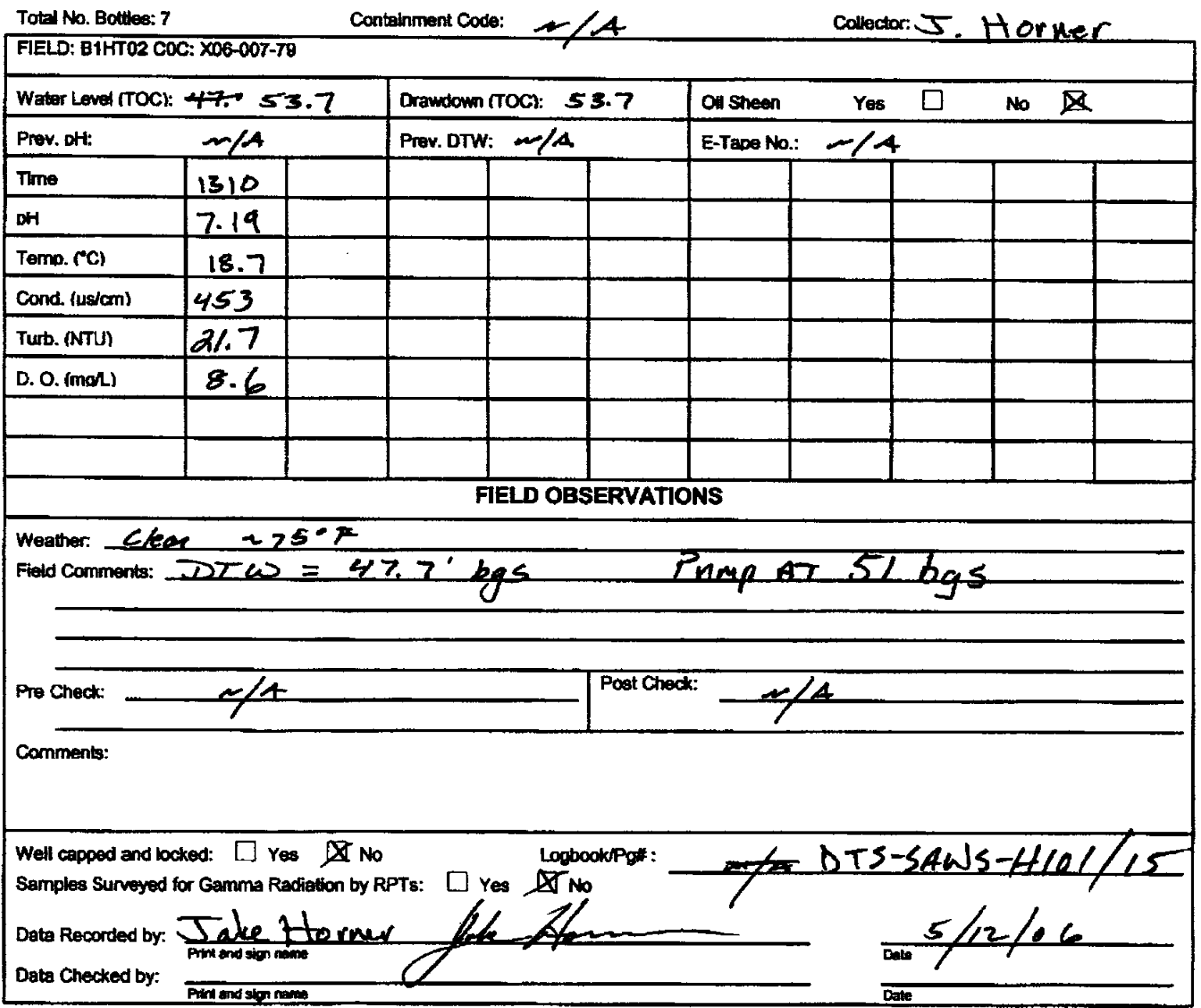




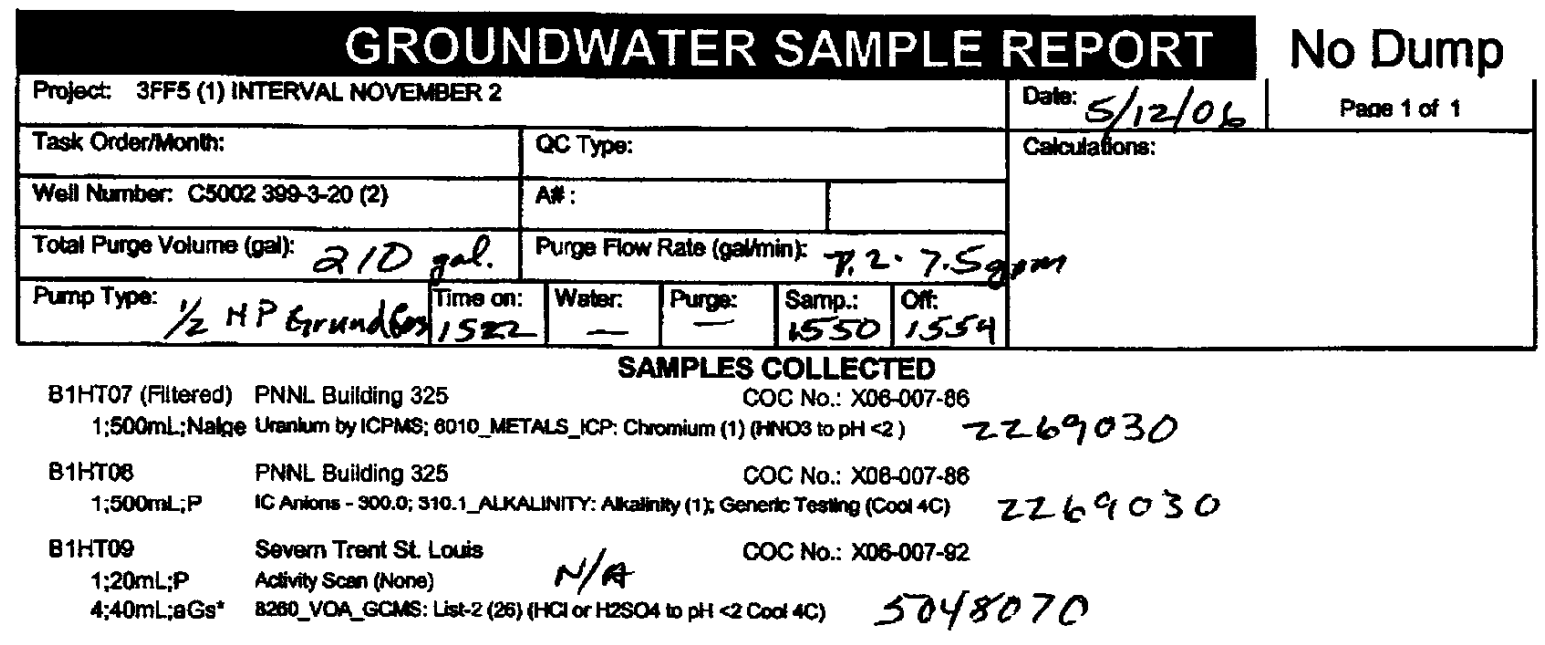

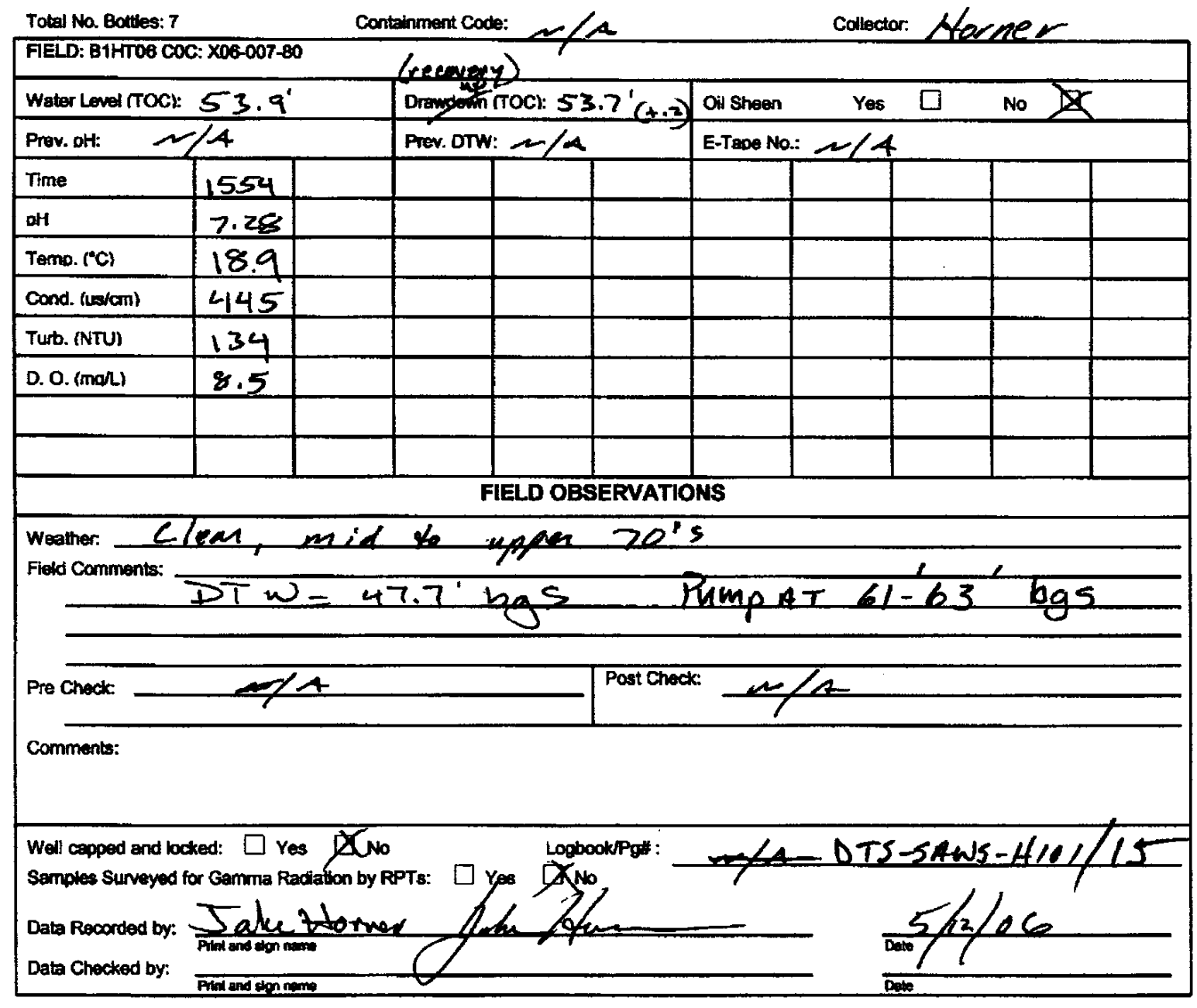




\begin{tabular}{|c|c|c|c|c|c|c|c|}
\hline \multicolumn{6}{|c|}{ Profect 3FFS (1) INTERVAL NOVEMBER 2} & Dato: $6 / \operatorname{les} 106$ & \\
\hline \multirow{2}{*}{\multicolumn{2}{|c|}{ 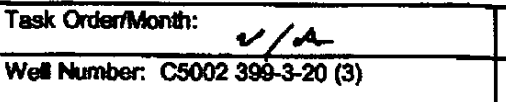 }} & \multicolumn{4}{|c|}{ OCType: $\pi / 4$} & \multirow{4}{*}{\multicolumn{2}{|c|}{ Catculations: }} \\
\hline & & A: : & 14 & & & & \\
\hline \multicolumn{2}{|c|}{ Total Punge Volume (gal): 300} & \multicolumn{4}{|c|}{ Purge Flow Rate (ga/min): $7.6 \mathrm{~g} / \mathrm{m}$} & & \\
\hline Pump Type: & $\begin{array}{l}\text { Thme an: } \\
1357\end{array}$ & Wat: & Puge: & $\begin{array}{l}\text { Samp:: } \\
1437\end{array}$ & $\begin{array}{l}\text { Oft: } \\
14 \times 5\end{array}$ & & \\
\hline $\begin{array}{l}\text { BiHT11 (Filtered) } \\
\text { 1;500mL:Nalgo }\end{array}$ & $\begin{array}{l}\text { PNML Building } 325 \\
\text { Uranium by ICPMS; } 6010 \text { MET }\end{array}$ & SA & MPLES & $\begin{array}{l}\text { OLLEC } \\
\text { C No.: } X \\
\text { NOS to pH }\end{array}$ & $\begin{array}{l}\text { TED } \\
6-007-87 \\
\text { 2) }\end{array}$ & $22810-30$ & \\
\hline $\begin{array}{l}\text { B1HT12 } \\
\quad 1 ; 500 \mathrm{~mL} ; P\end{array}$ & $\begin{array}{l}\text { PNNL Building } 325 \\
\text { IC ANions - 300.0; 310.1_ALKA }\end{array}$ & LINTrT: Aklatin & $\operatorname{tat}(1) ; \mathrm{Cen}$ & $\begin{array}{l}\text { C No: X } \\
\text { ric Testing }\end{array}$ & $\begin{array}{l}6-007-87 \\
0014 C)\end{array}$ & 4217060 & \\
\hline $\begin{array}{l}\text { B1HT13 } \\
\begin{array}{l}1 ; 20 \mathrm{~mL} ; P \\
4 ; 40 \mathrm{~mL} ; a \mathrm{as}^{*}\end{array}\end{array}$ & $\begin{array}{l}\text { Seven Trent St Louls } \\
\text { Activy Sean (Nono) } \\
\text { 82BO_VOA_GCMS: List-2 (20) }\end{array}$ & ( $\mathrm{ACl}$ or HesO & to $p H<2$ & C No.: $x$ & $\begin{array}{l}6-007-93 \\
504807\end{array}$ & & \\
\hline
\end{tabular}

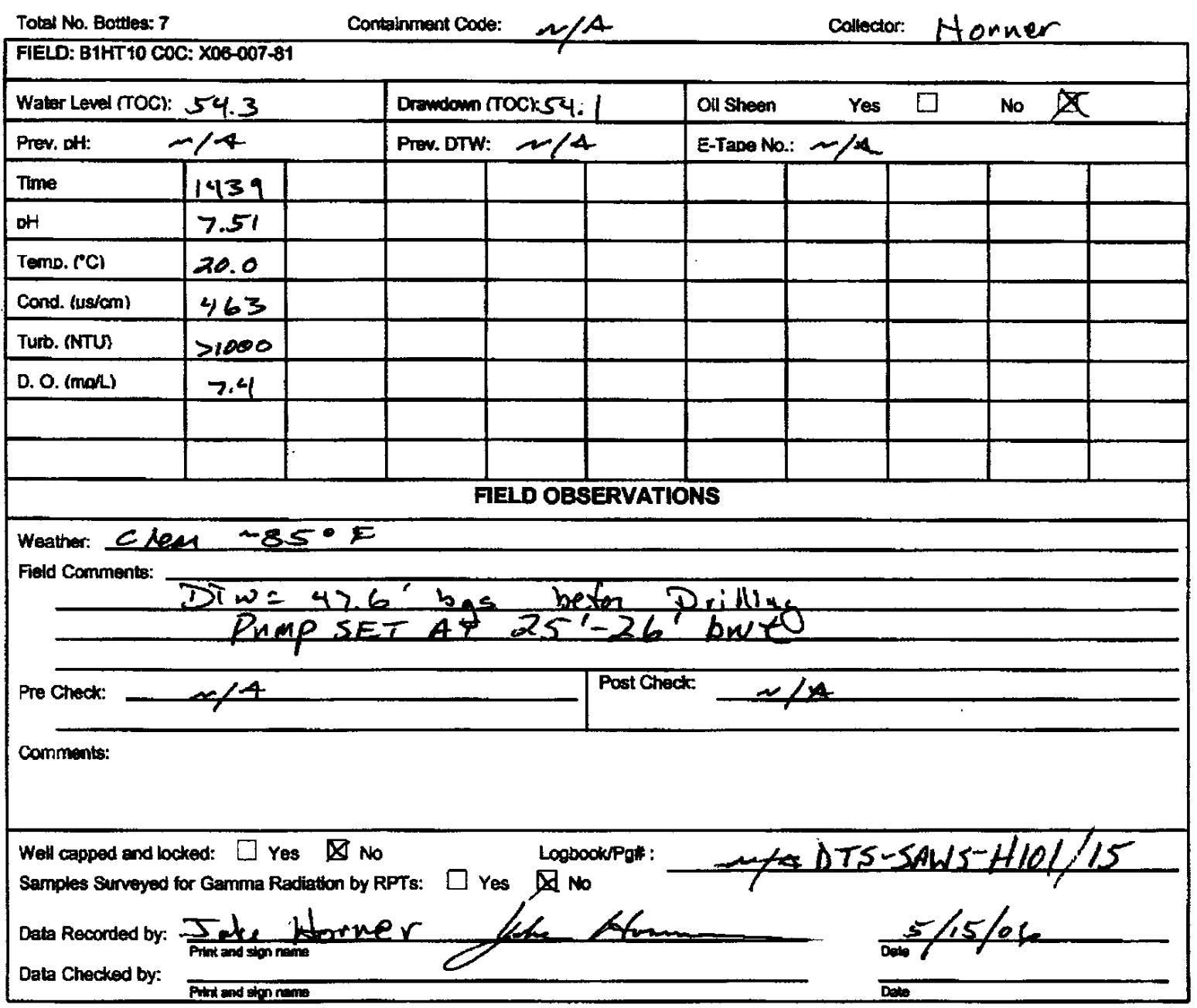




\begin{tabular}{|c|c|c|c|c|c|c|c|}
\hline \multicolumn{6}{|c|}{ Project SFF5 (1) INTERVAL NOVEMBER 2} & Date: $5 / 16 / 06$ & Page 1 of 1 \\
\hline \multicolumn{2}{|c|}{ Task Ordennonth: } & \multicolumn{4}{|c|}{ QC Type: $\mu / \mu$} & \multirow{3}{*}{\multicolumn{2}{|c|}{ Cakcukalions: }} \\
\hline \multicolumn{2}{|c|}{ Wel Number: C5002 399-320 (4) } & \multicolumn{4}{|c|}{\begin{tabular}{l|l}
$* 2 / 4$ & \\
\end{tabular}} & & \\
\hline \multicolumn{2}{|c|}{ Total Purge Volume (gel): 380 gallhes } & \multicolumn{4}{|c|}{ Purge Flow Rate (galmin): 7.6} & & \\
\hline \multicolumn{2}{|c|}{\begin{tabular}{l|l|l} 
Pump Type: $K$ AP Grendos & Time on: \\
\end{tabular}} & Water: & Puge: & $\begin{array}{l}\text { Samp.: } \\
12 / 2\end{array}$ & Off: 1218 & Tot. perap Val. & 426 godistes \\
\hline \multicolumn{2}{|c|}{$\begin{array}{l}\text { B1HT15 (Filtered) PNWh Bullding } 325 \\
\text { 1;500mLiNalgo Urantum by ICPWS; 6010_NET }\end{array}$} & \multicolumn{4}{|c|}{ 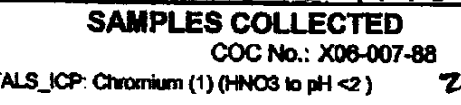 } & 269030 & \\
\hline $\begin{array}{l}\text { B1HT16 } \\
1 ; 500 \mathrm{~mL} ; \mathrm{P}\end{array}$ & \multicolumn{5}{|c|}{$\begin{array}{l}\text { PNNL Building 325 COC No.: X06-007-88 } \\
\text { KC ANIOns - 300.0; 310.1_ALKALINITY: Alkalinity (1); Generie Testing (Coof 4C) }\end{array}$} & 6,77060 & \\
\hline $\begin{array}{l}\text { B1HT17 } \\
\text { 1;20mL;P } \\
\text { 4;40mL;abs* }\end{array}$ & 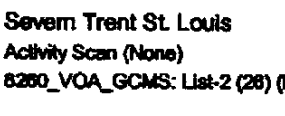 & \multicolumn{4}{|c|}{ COC No.: X08-007-94 } & 70 & \\
\hline
\end{tabular}

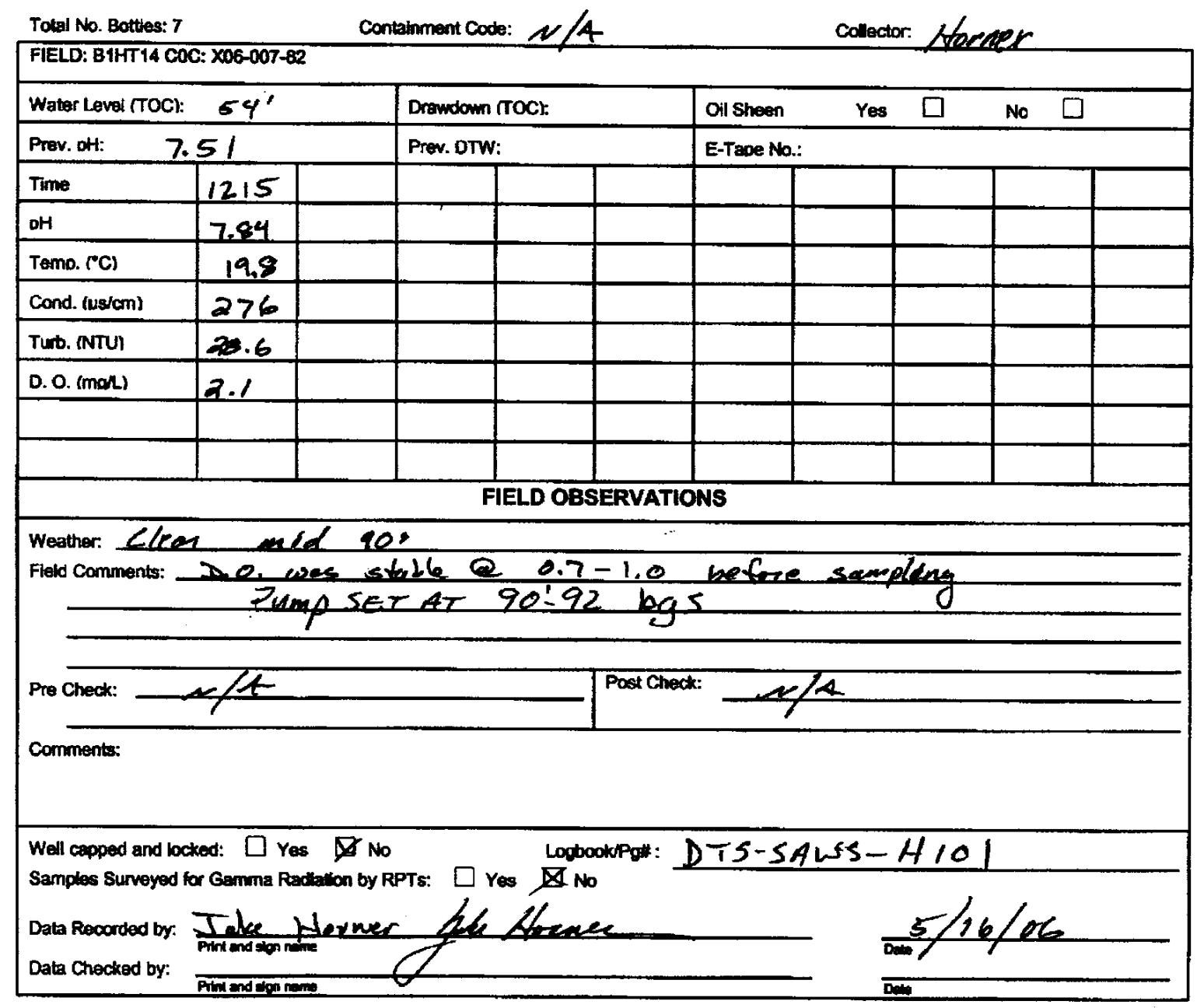




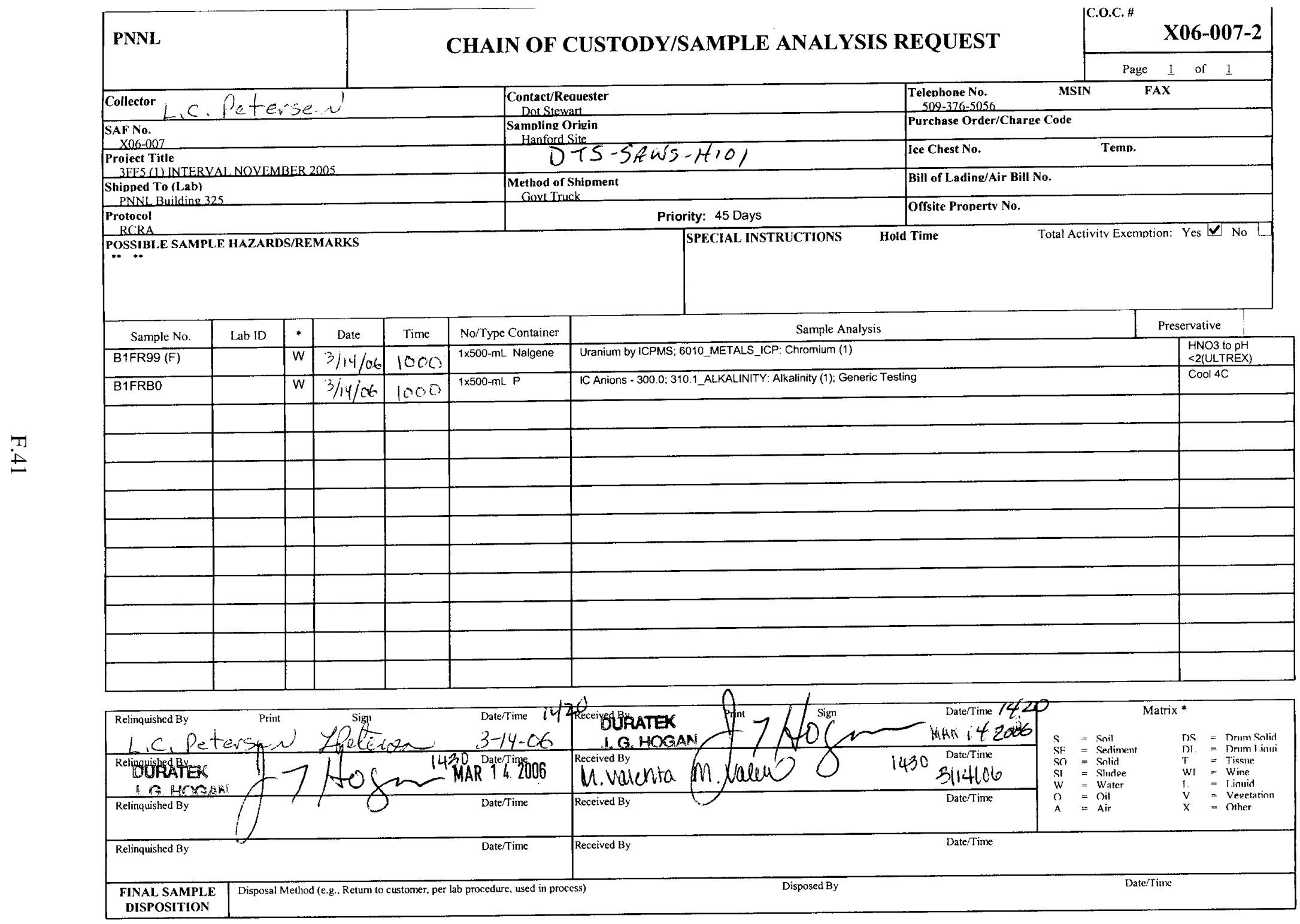




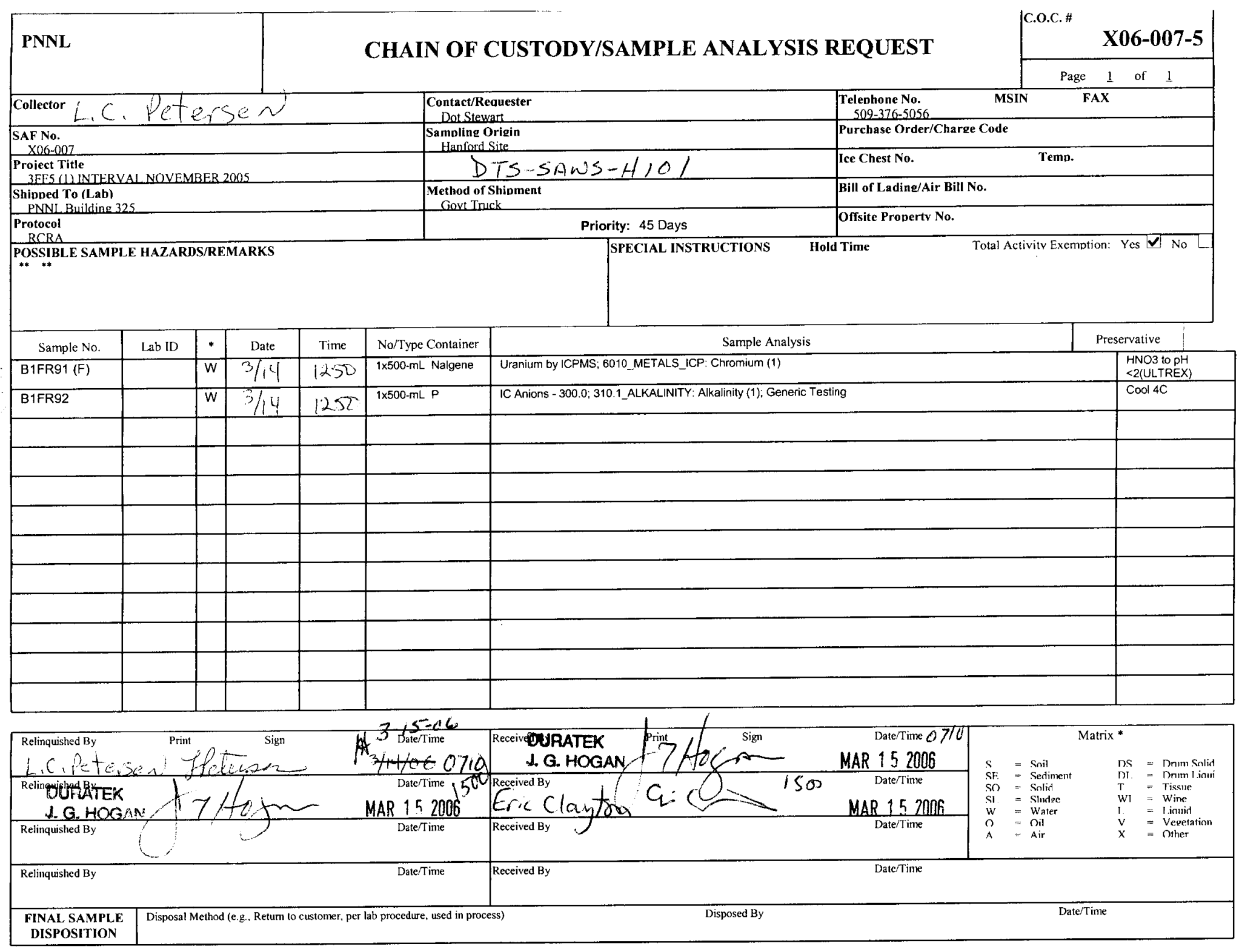




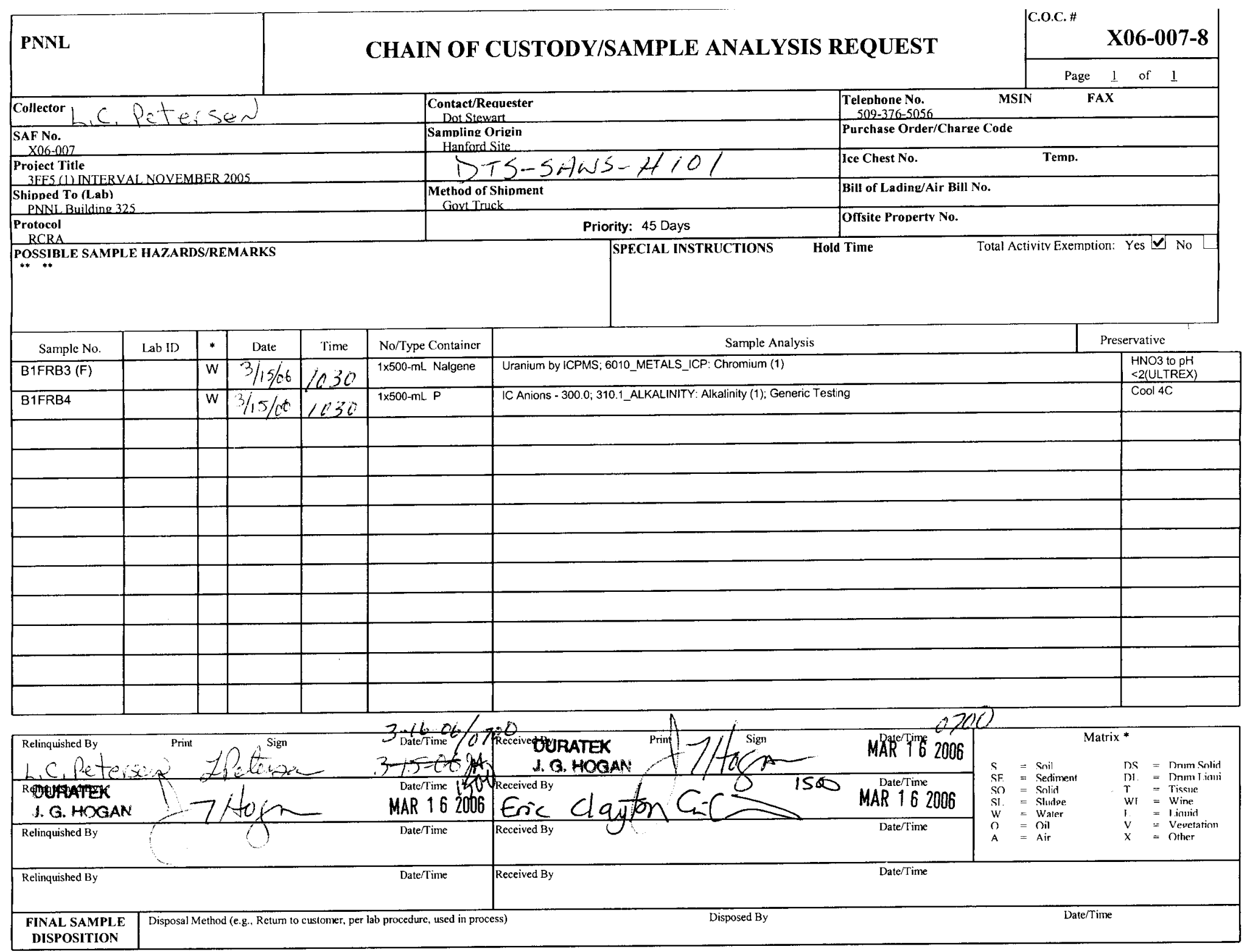




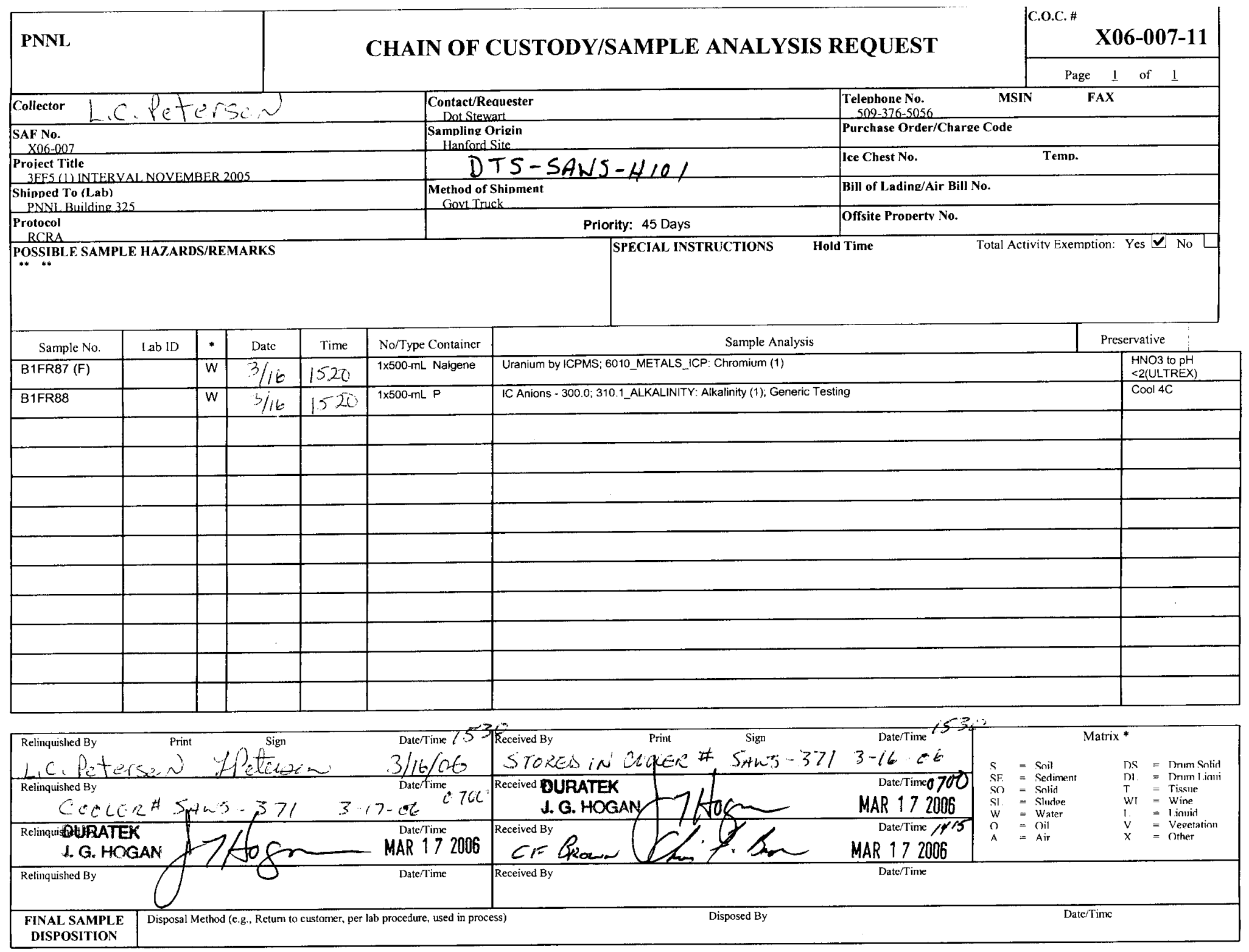




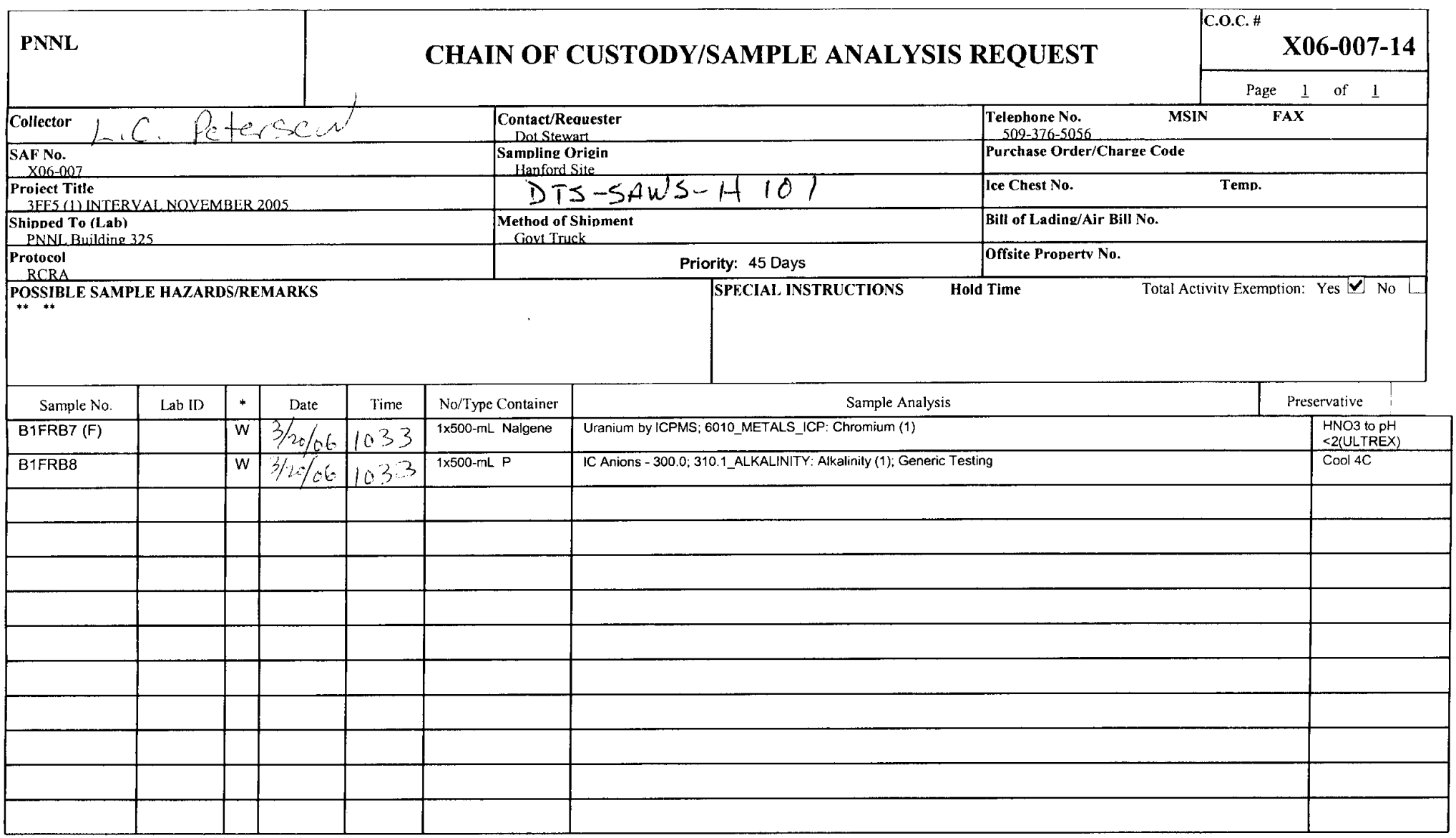

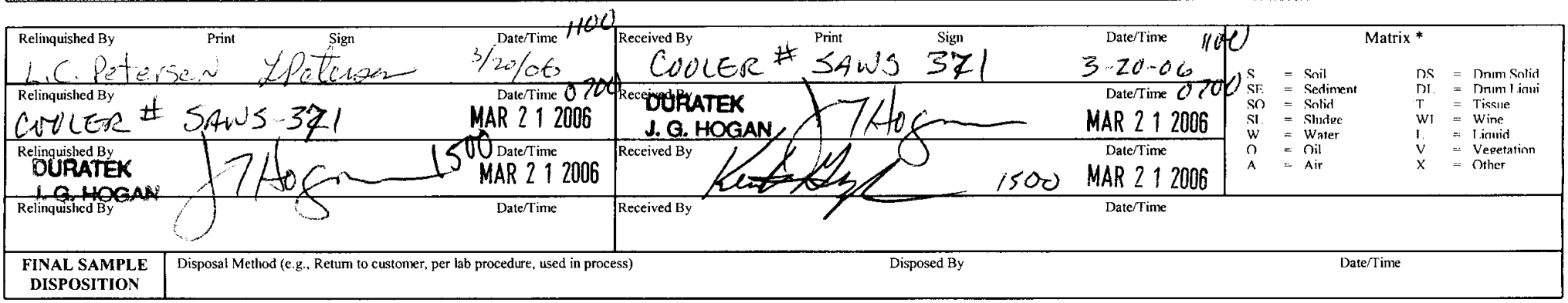




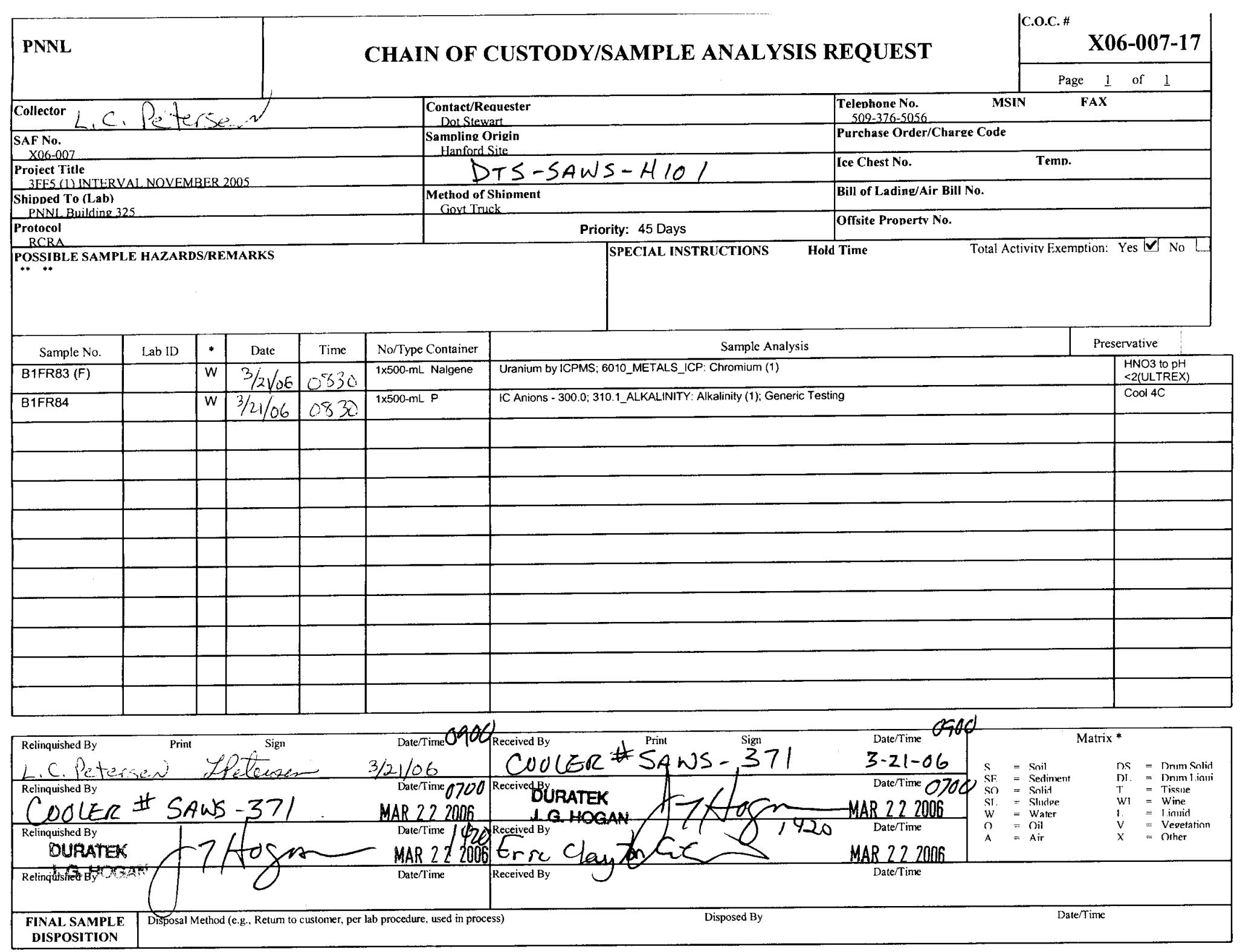




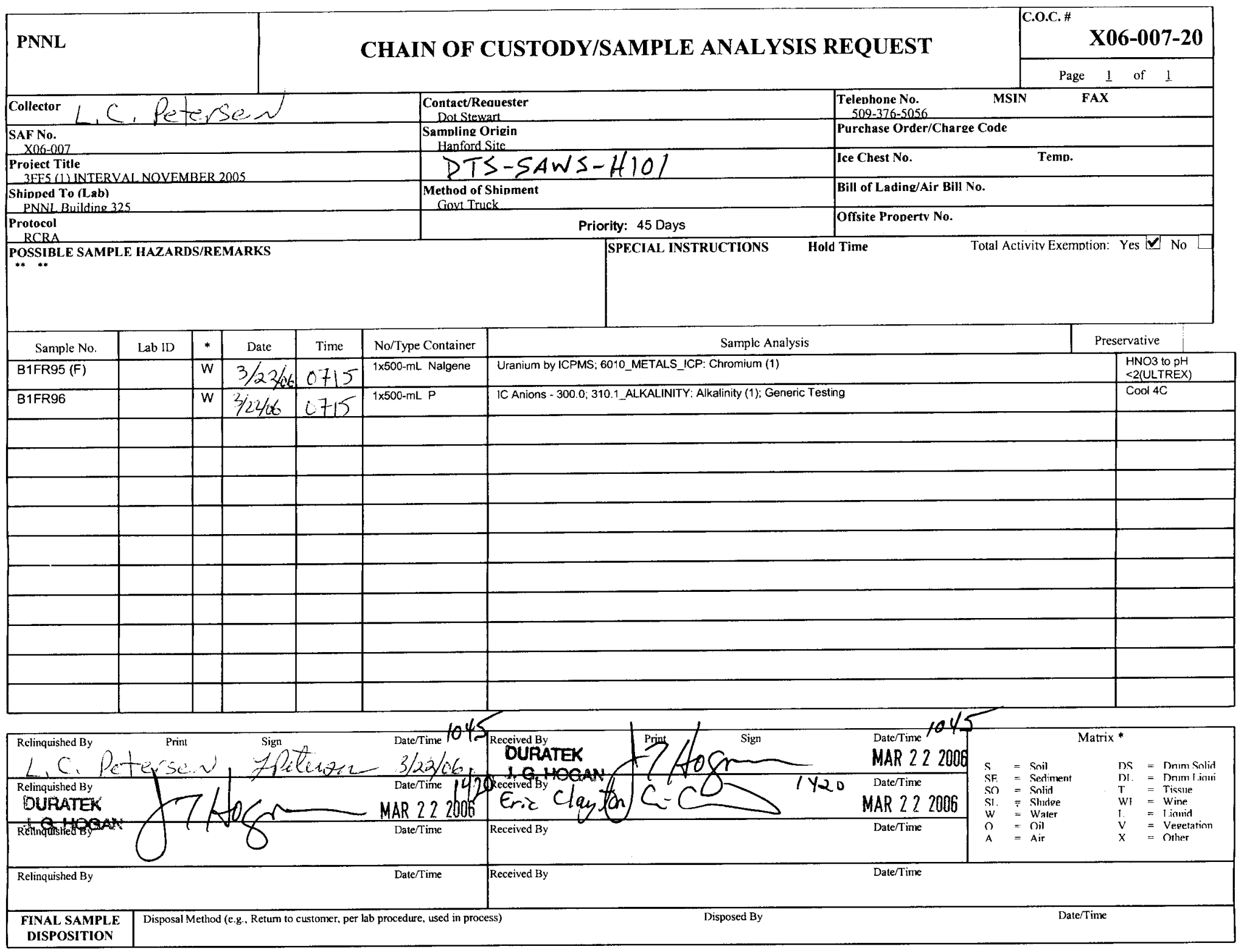




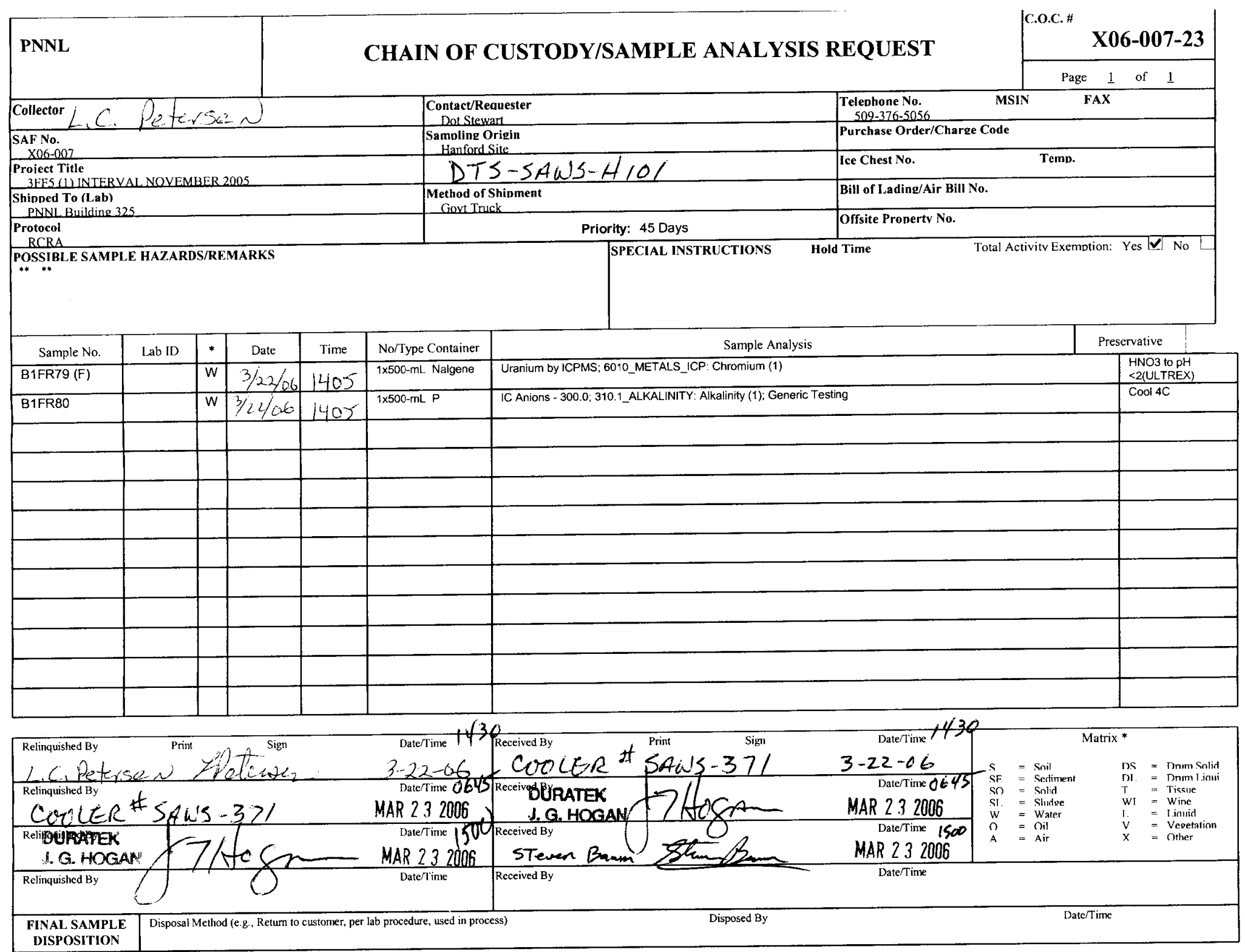




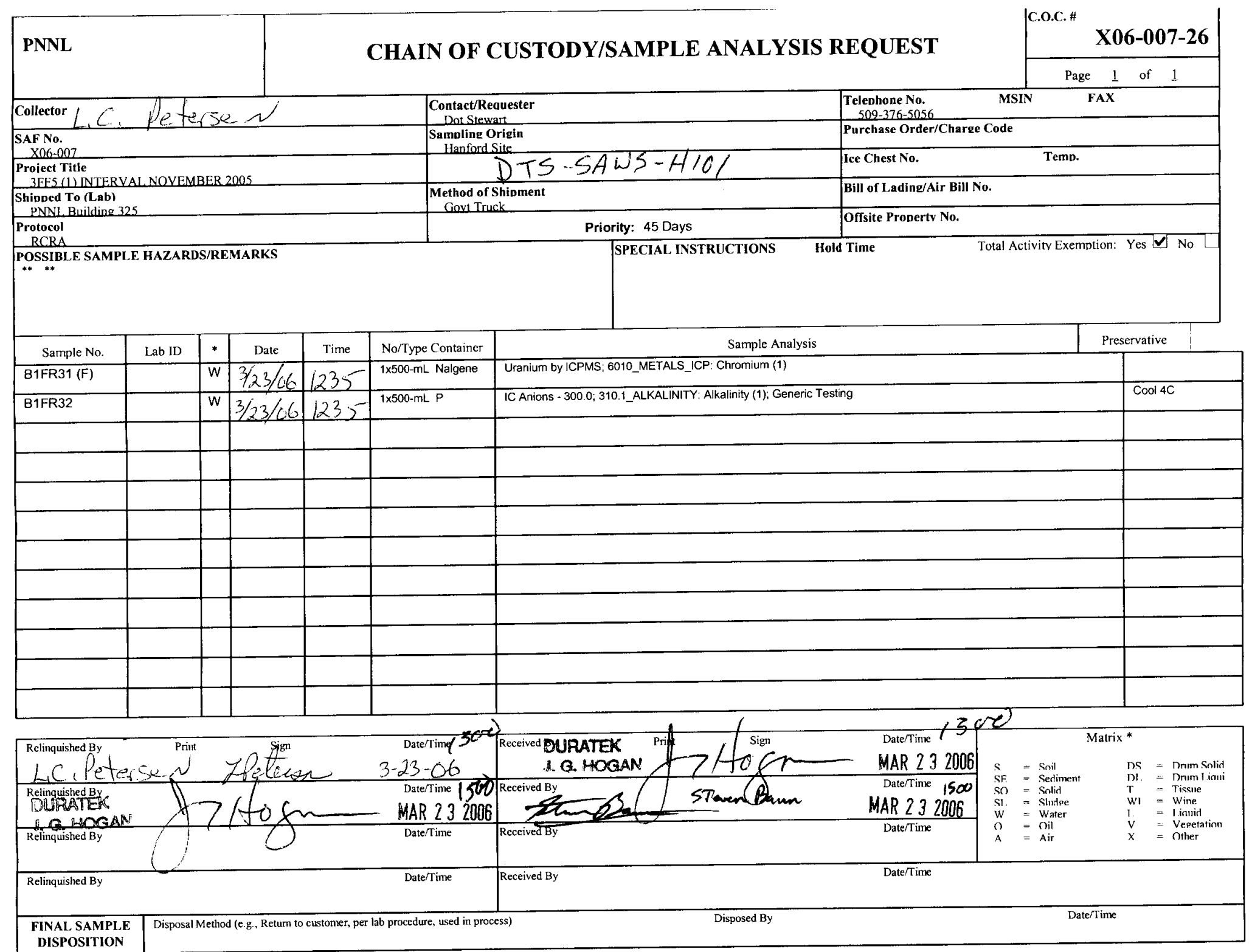




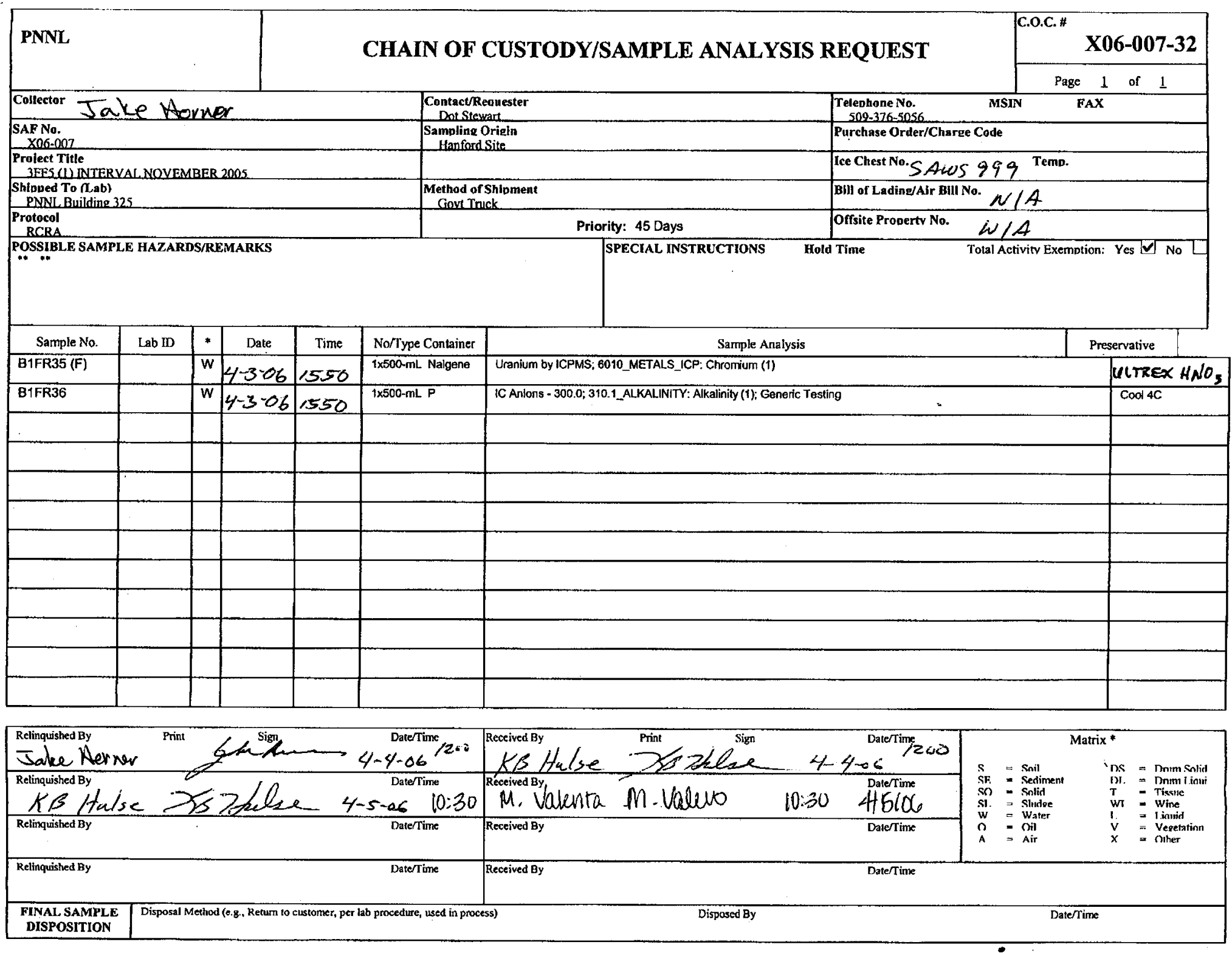




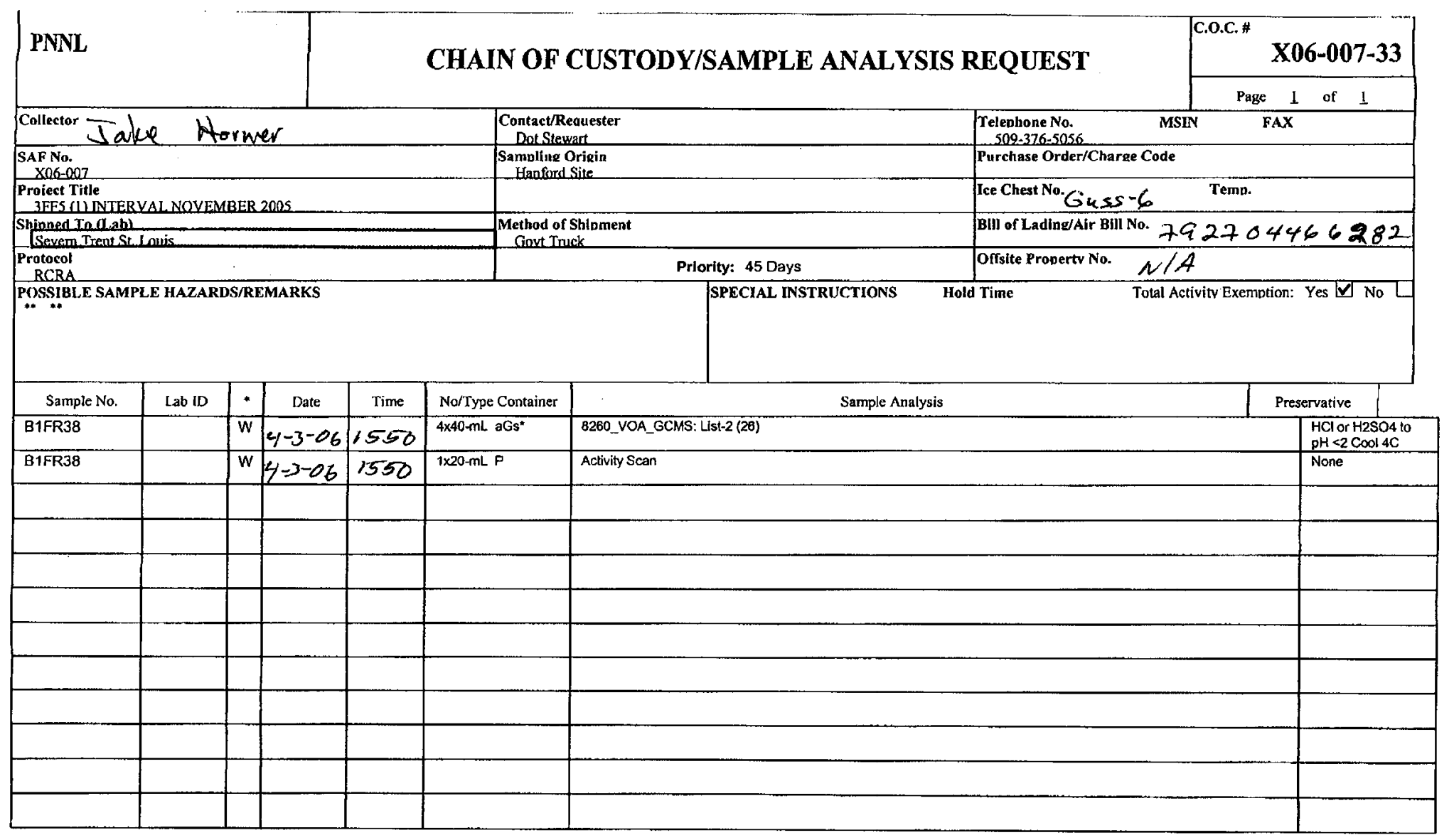

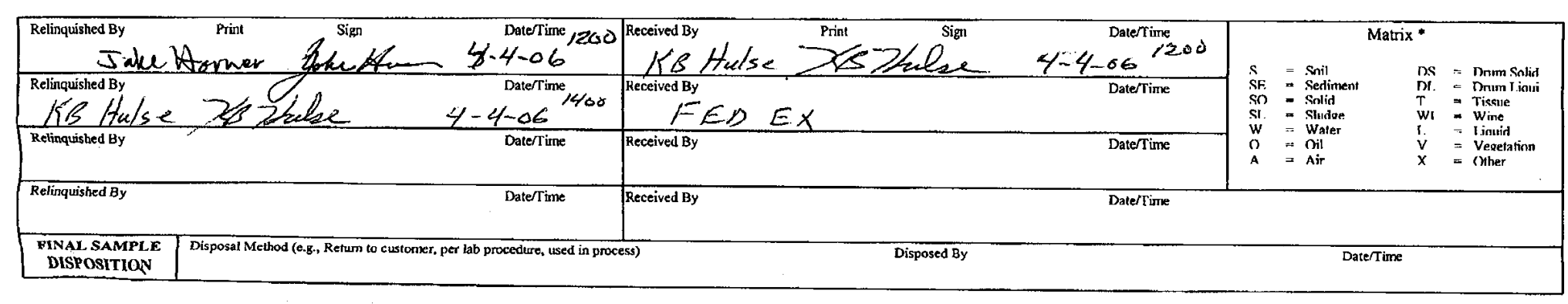




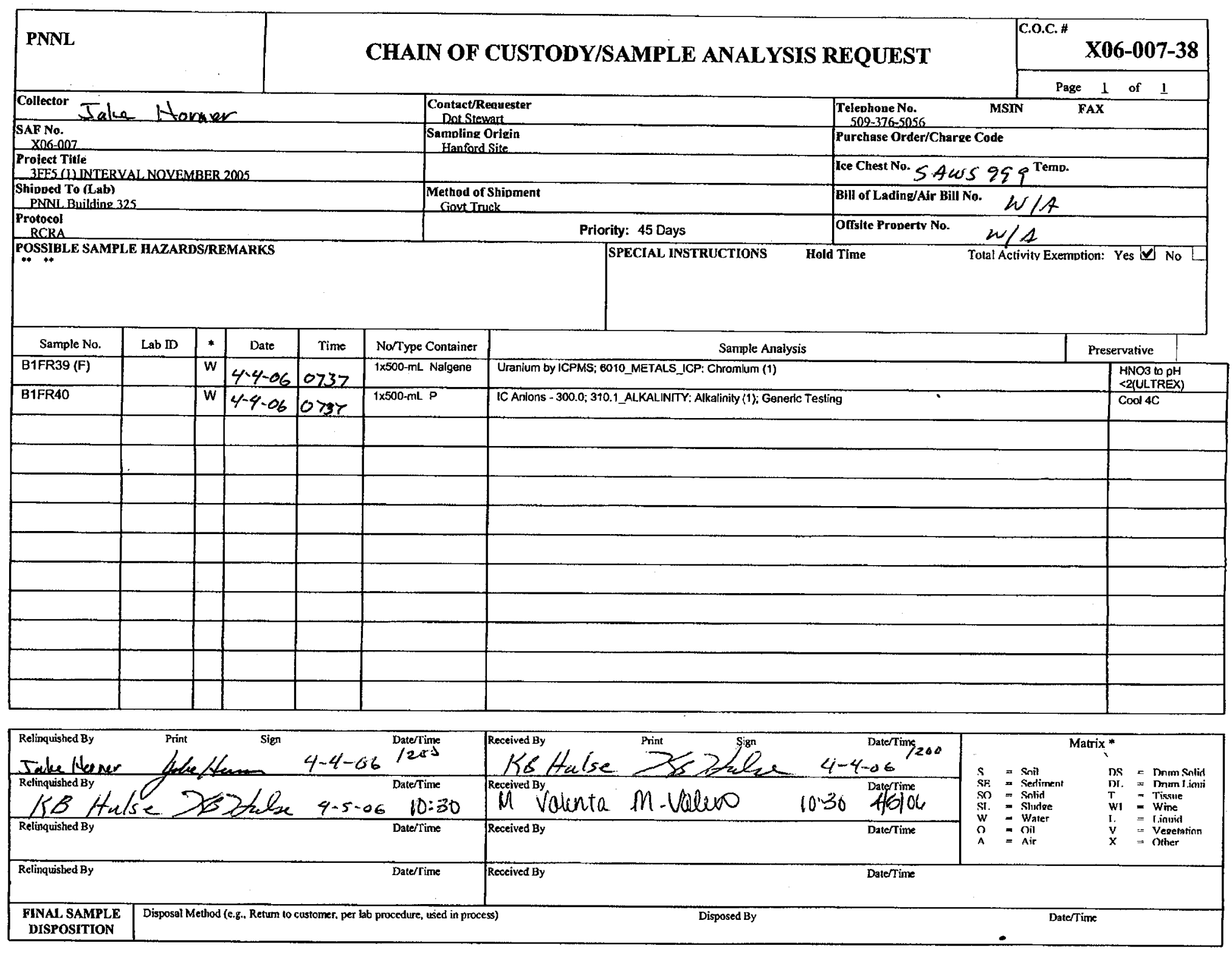




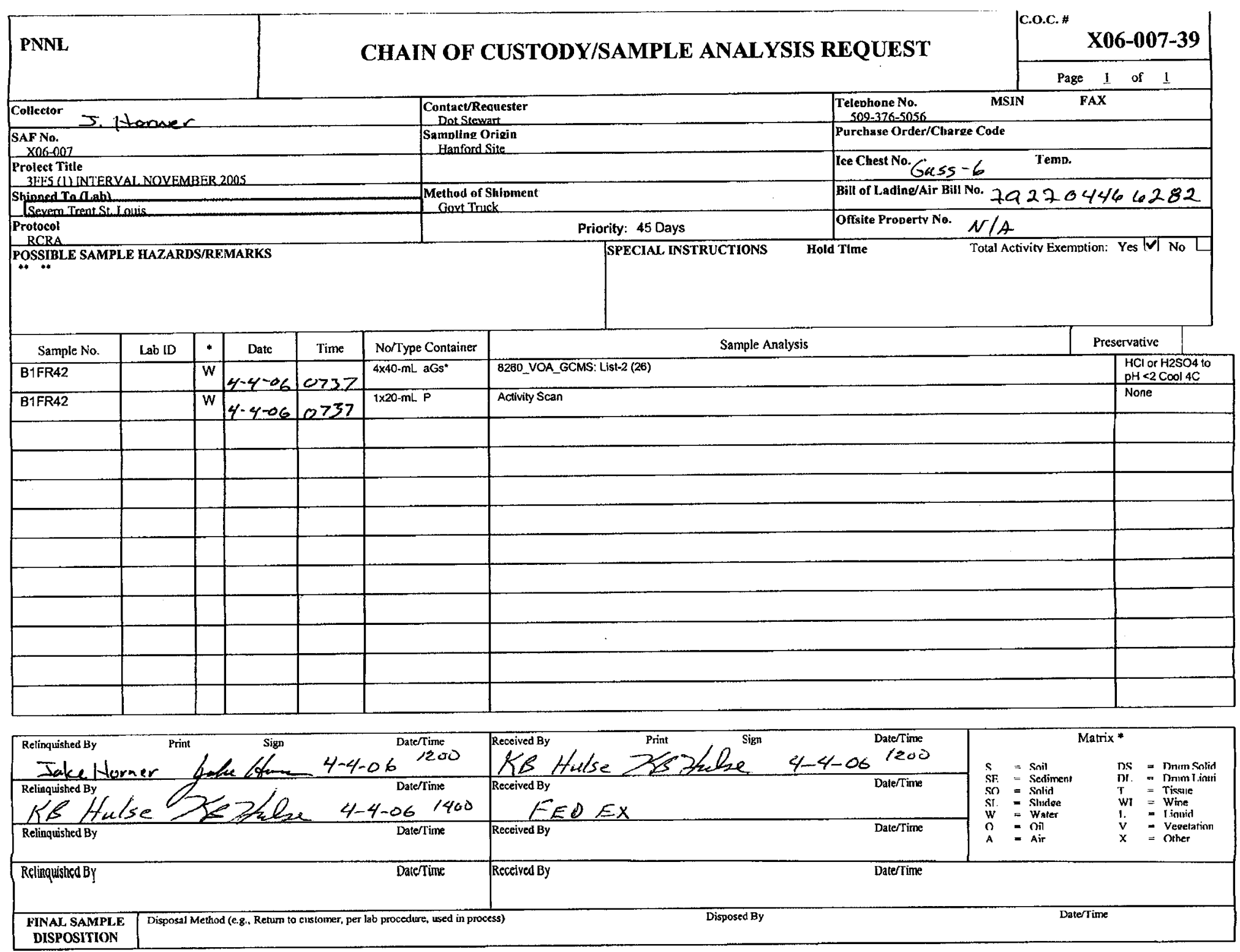




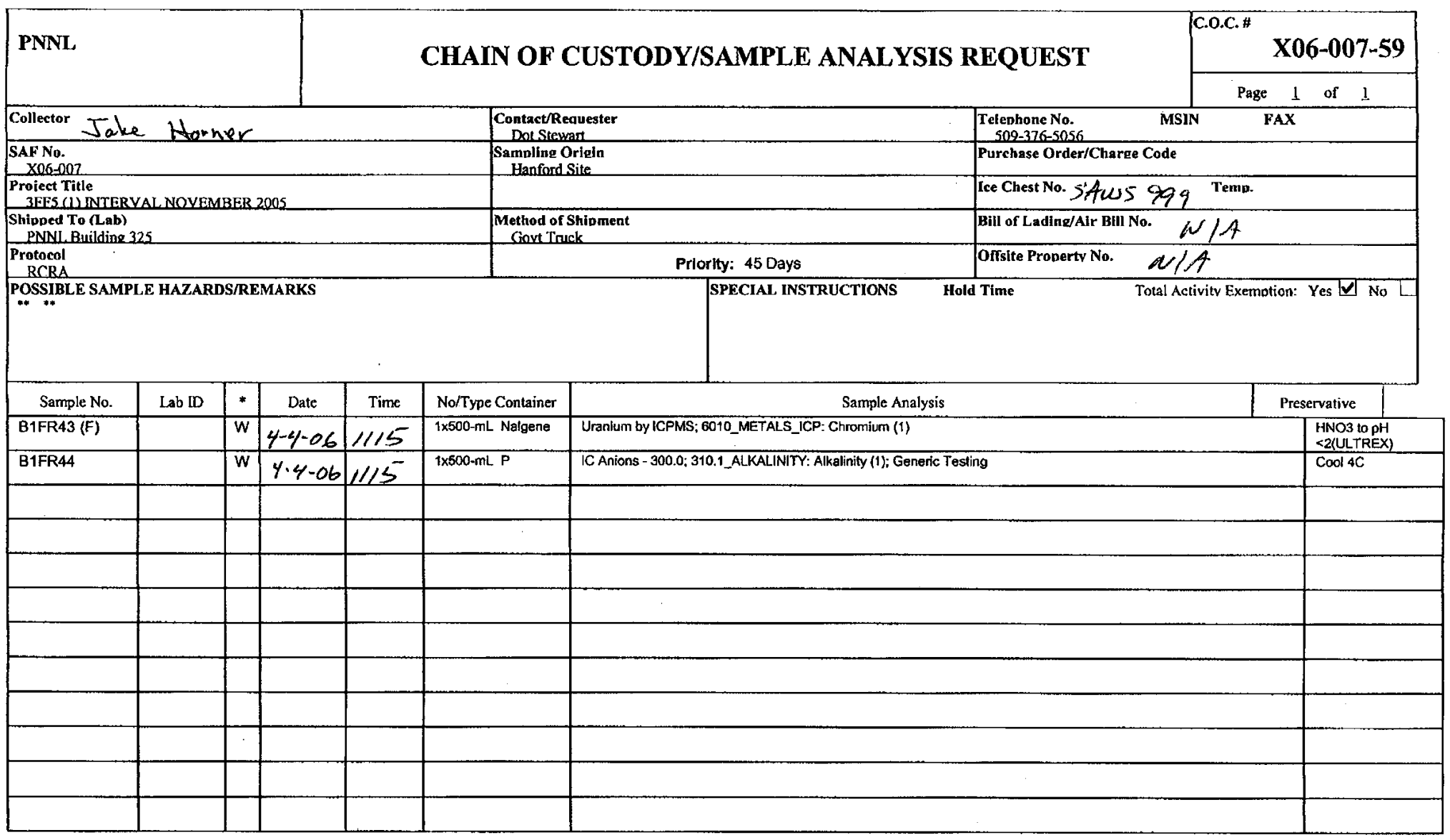

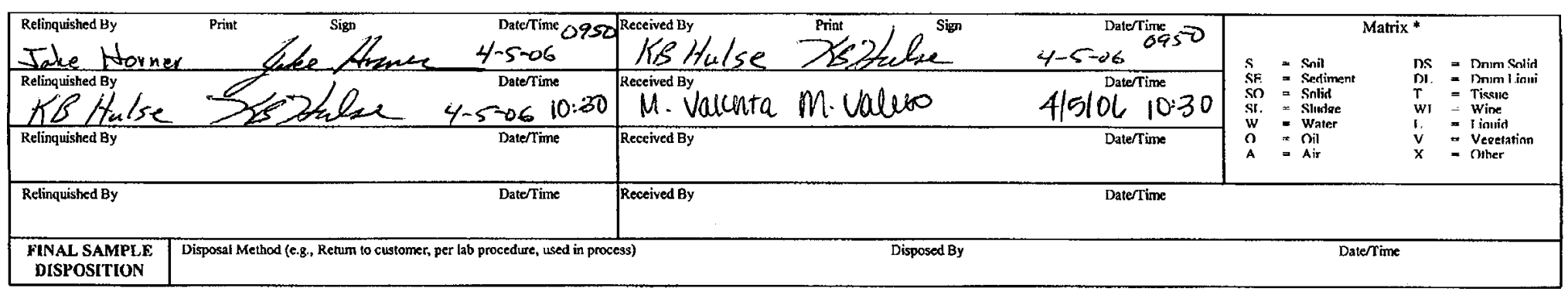




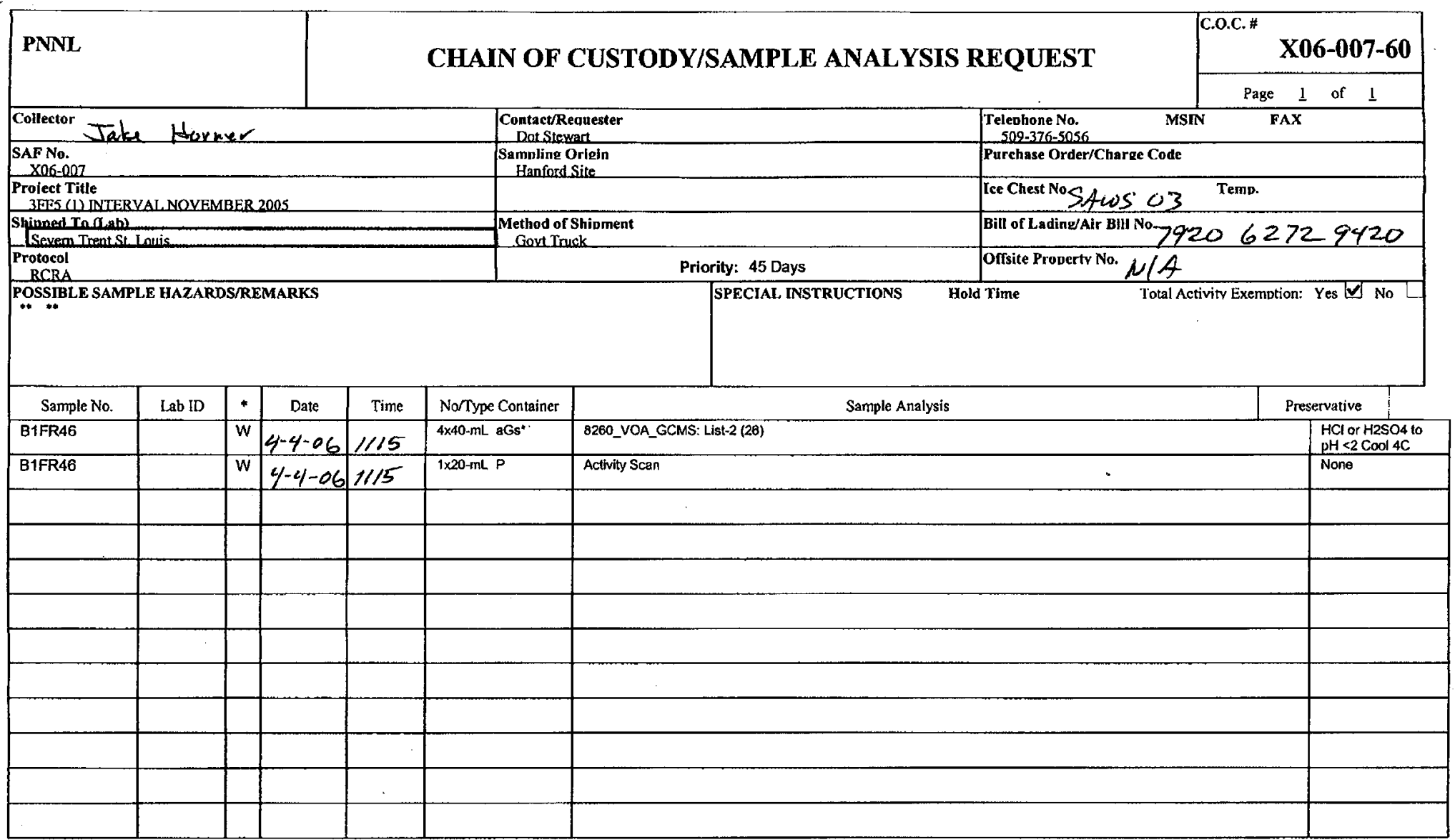

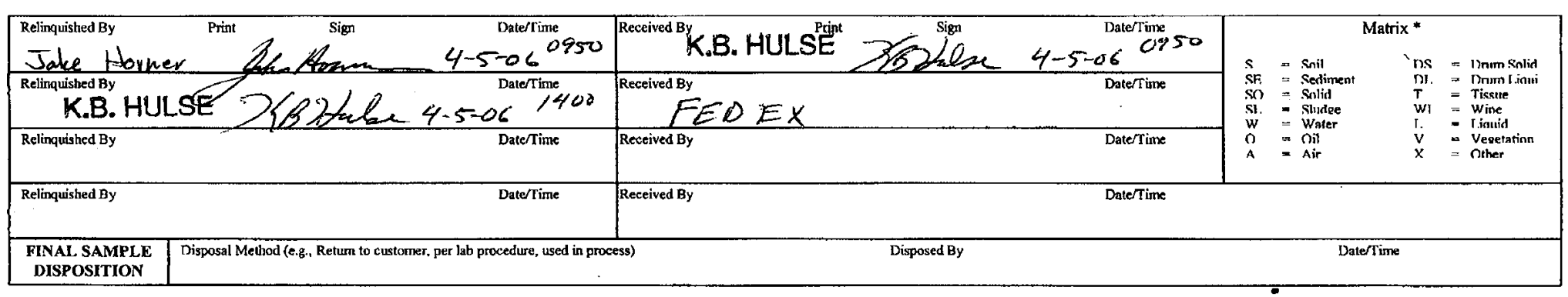




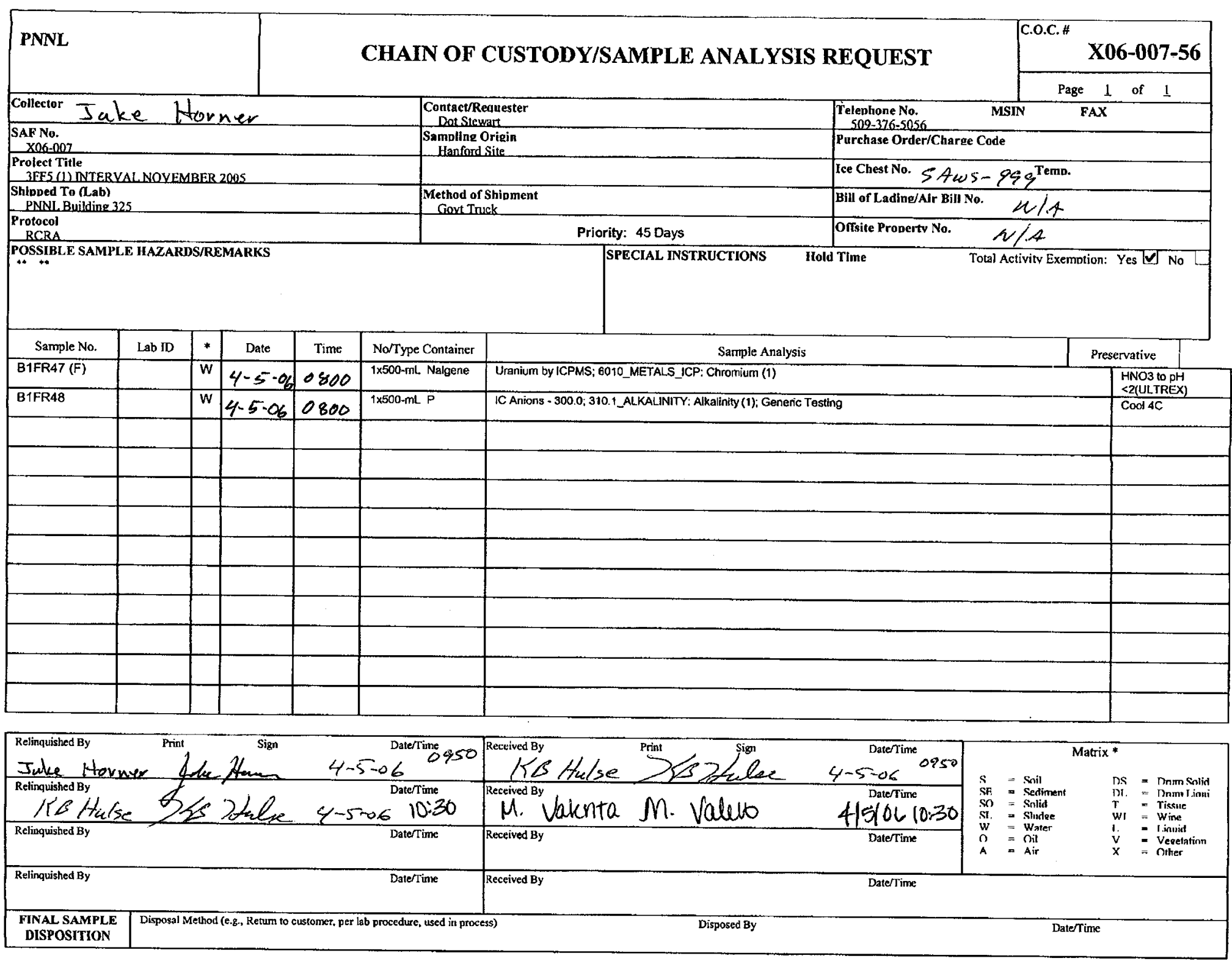




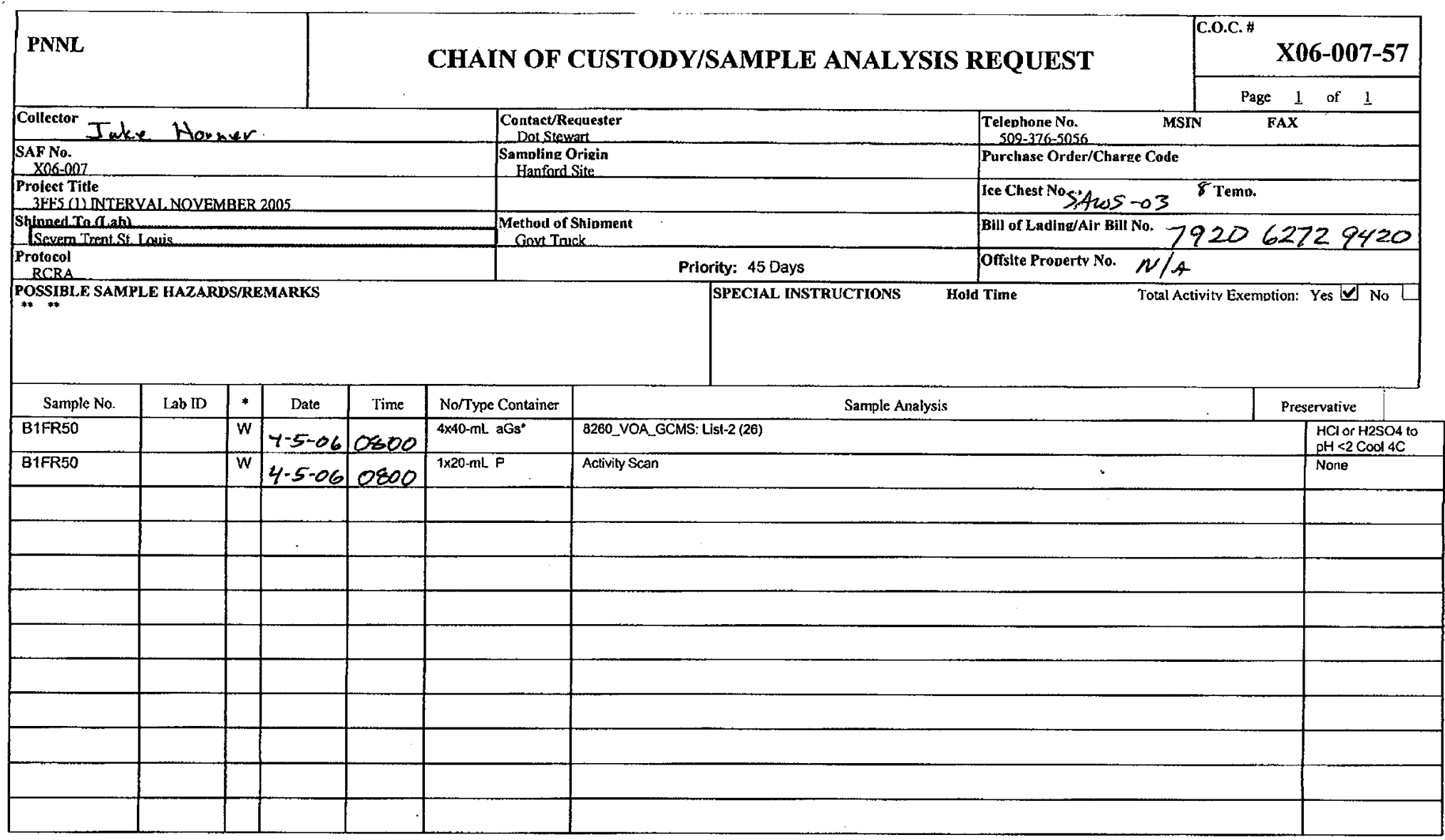

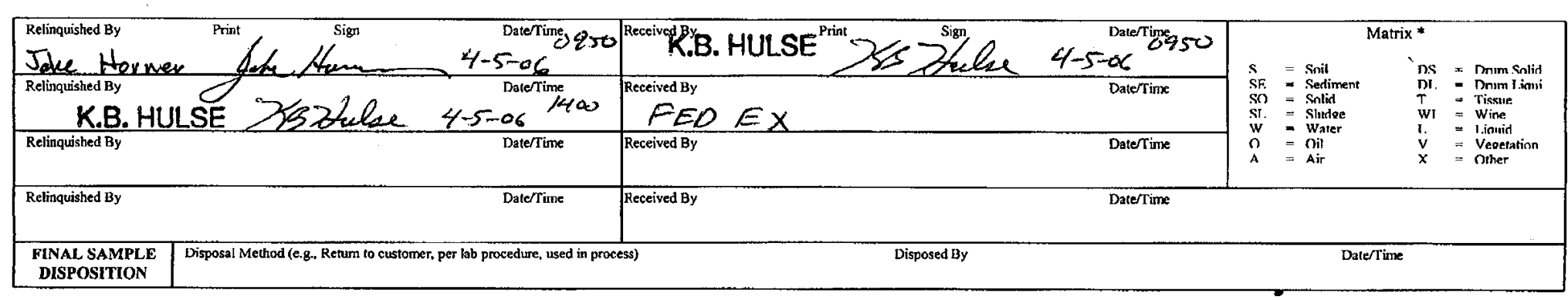




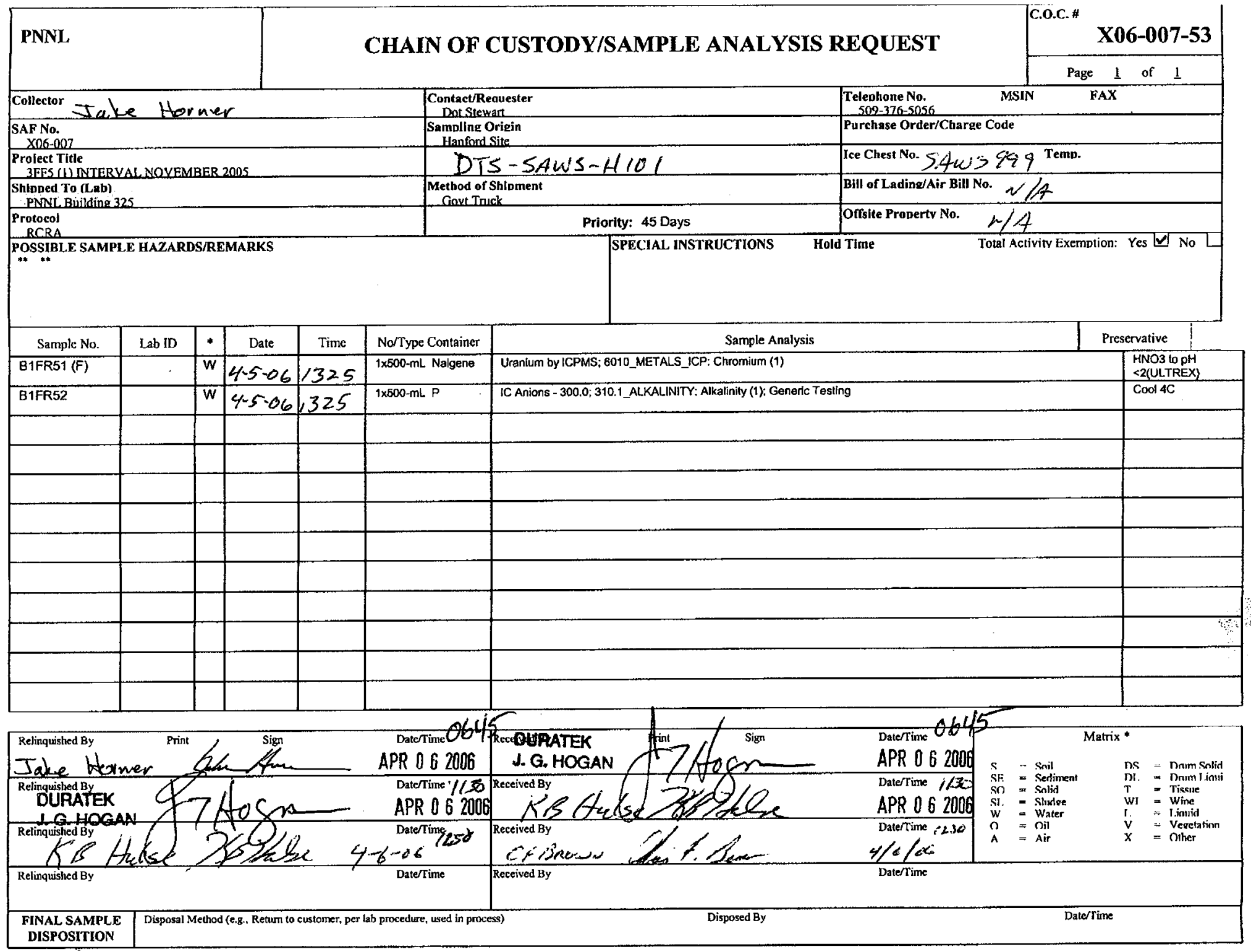




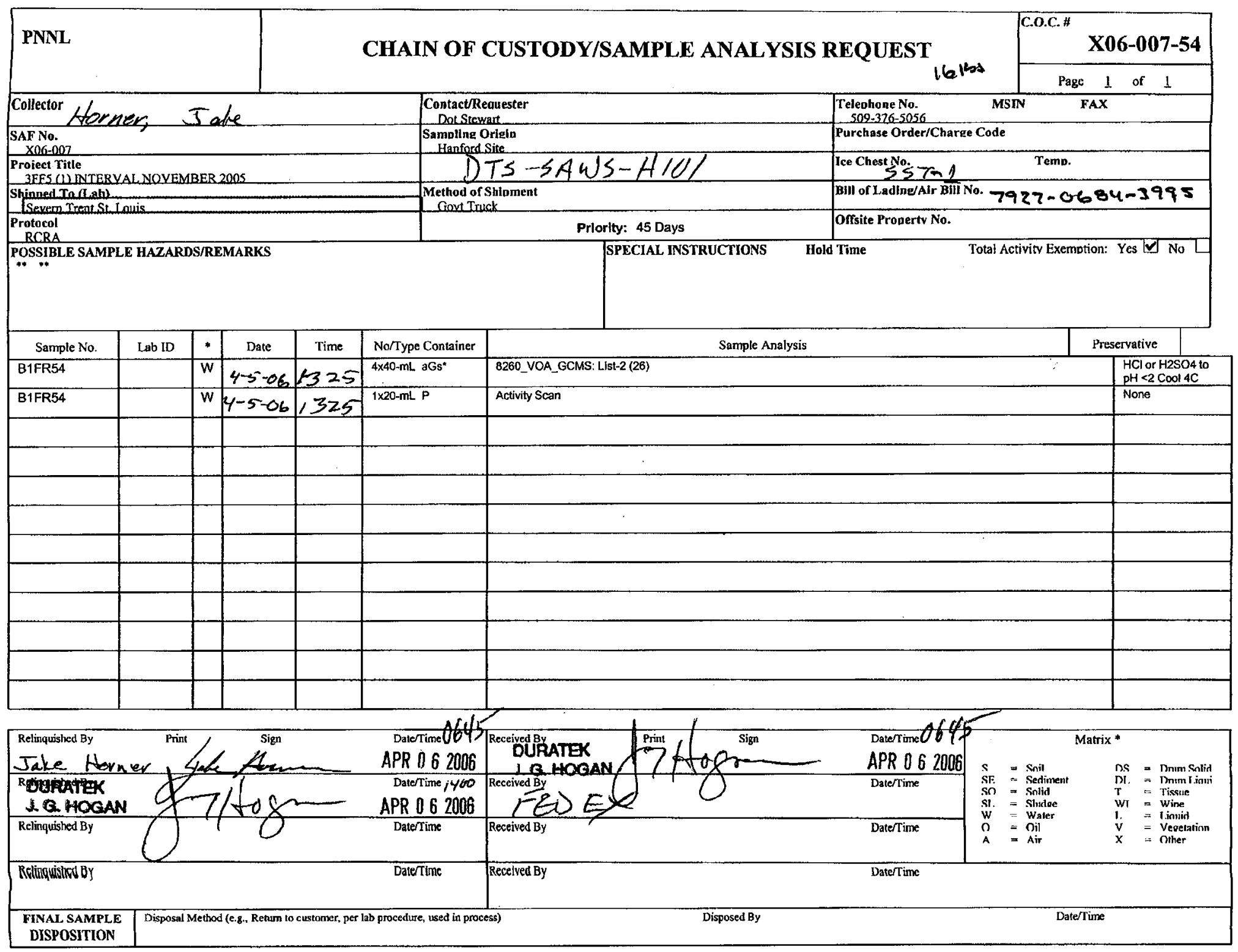




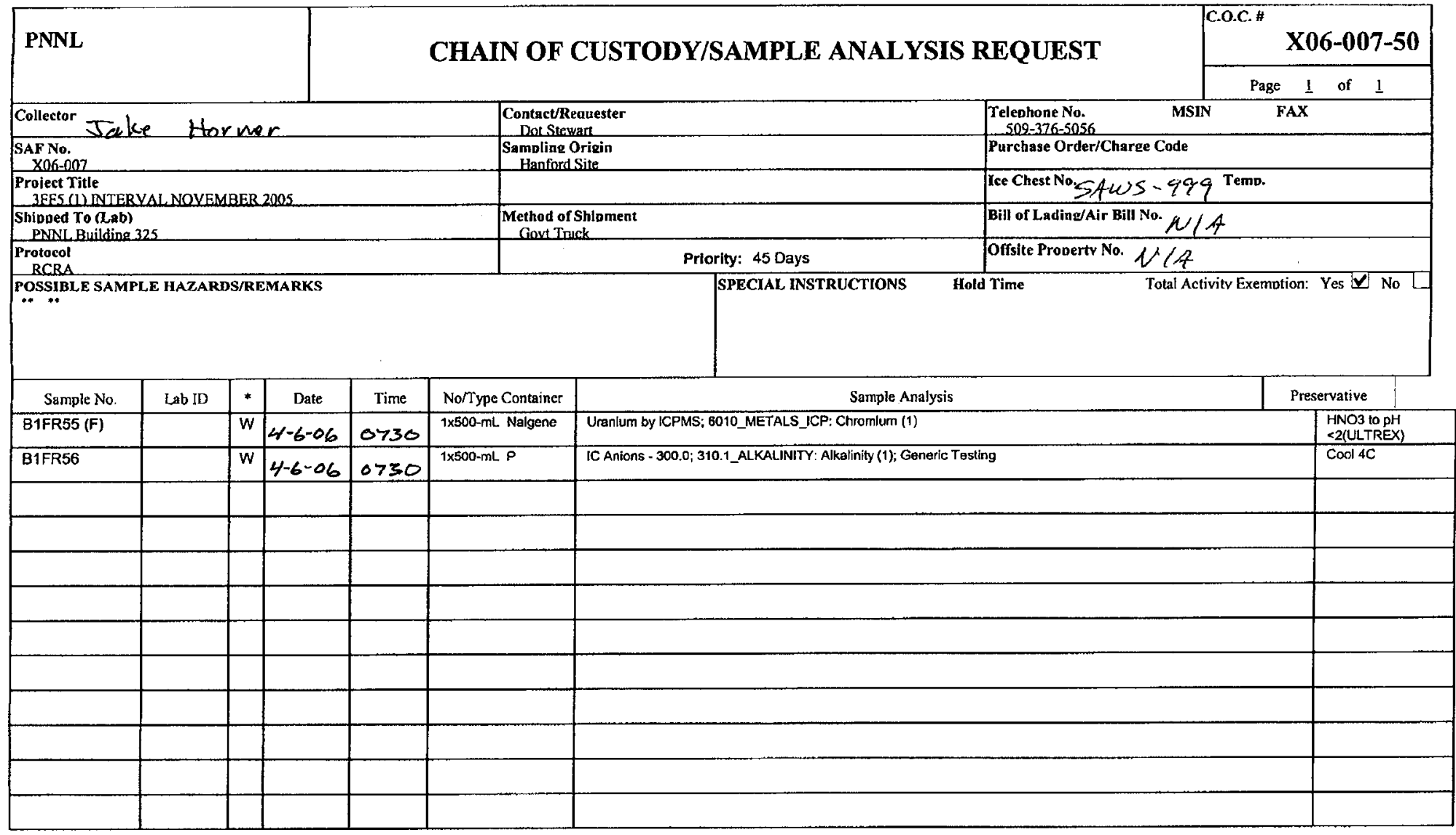

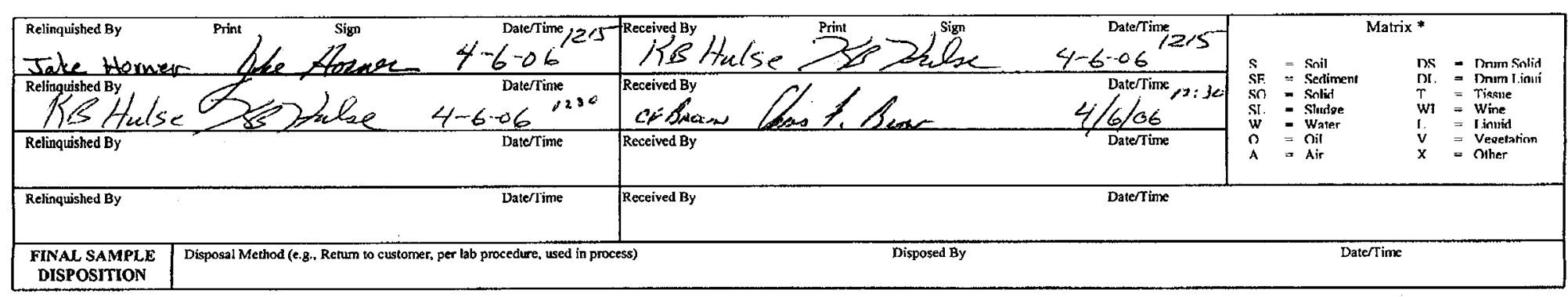




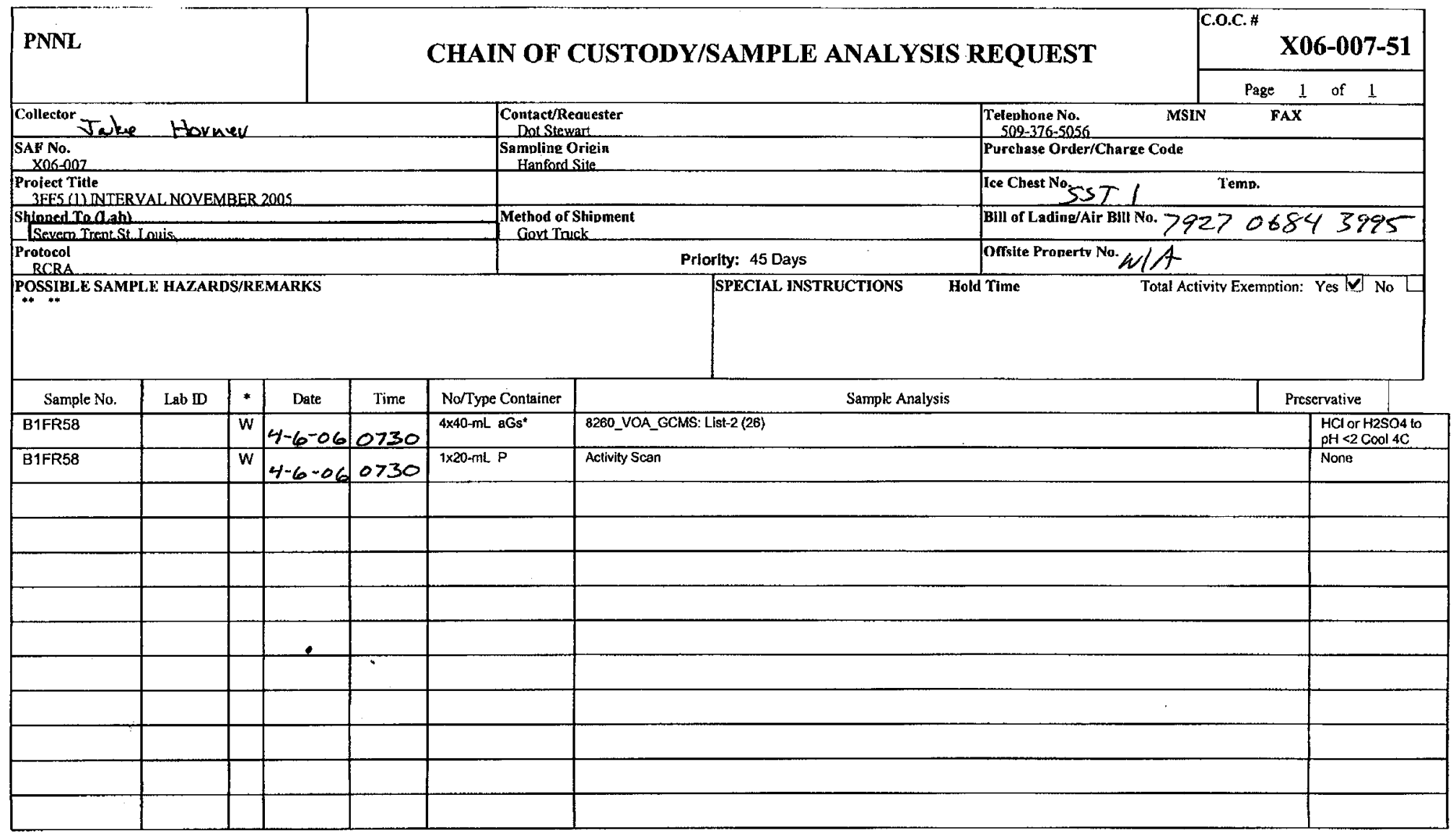

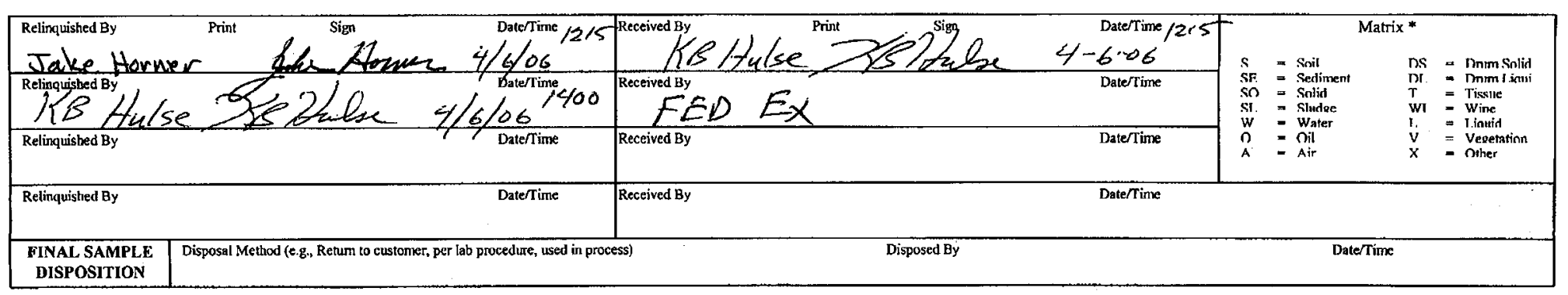




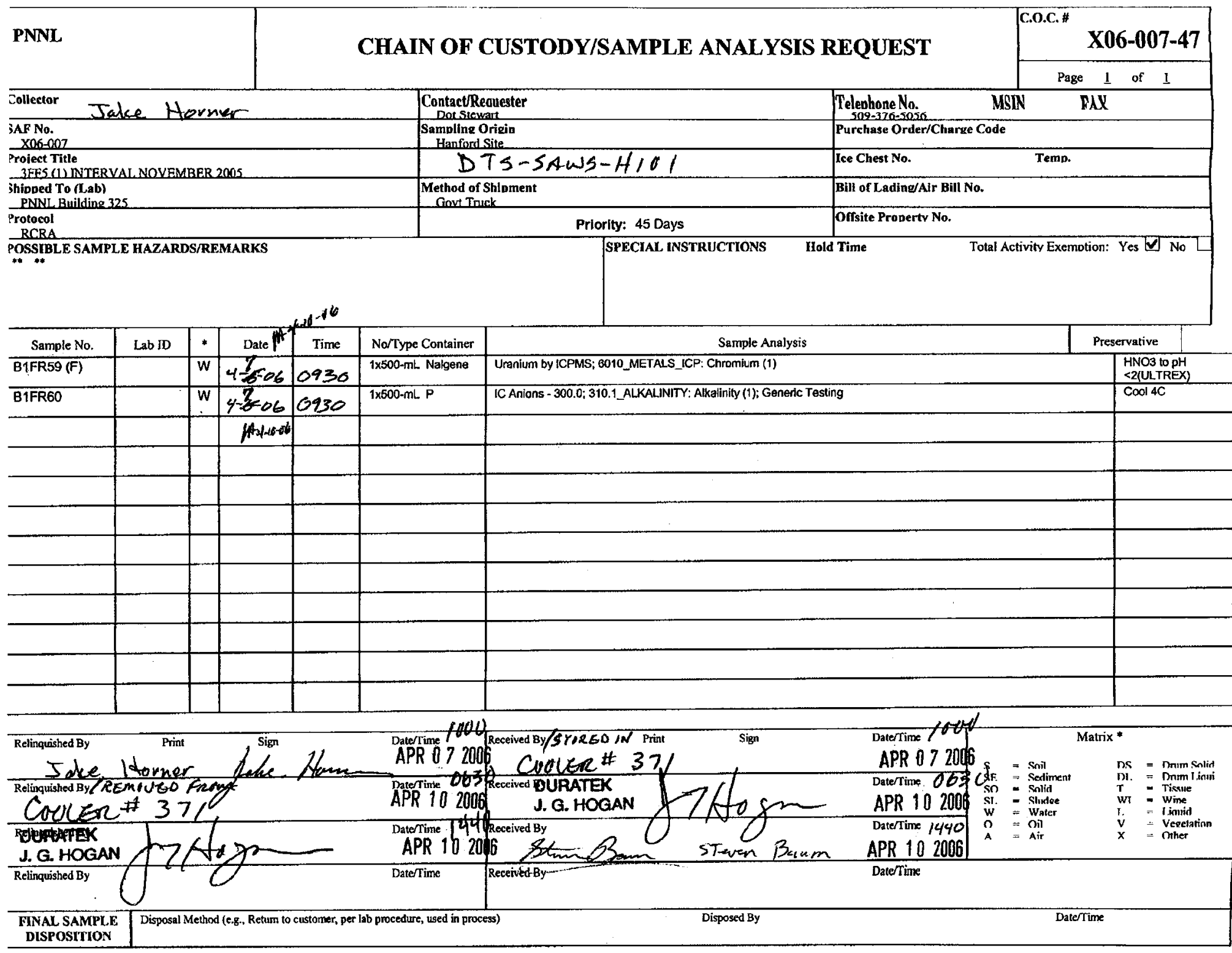




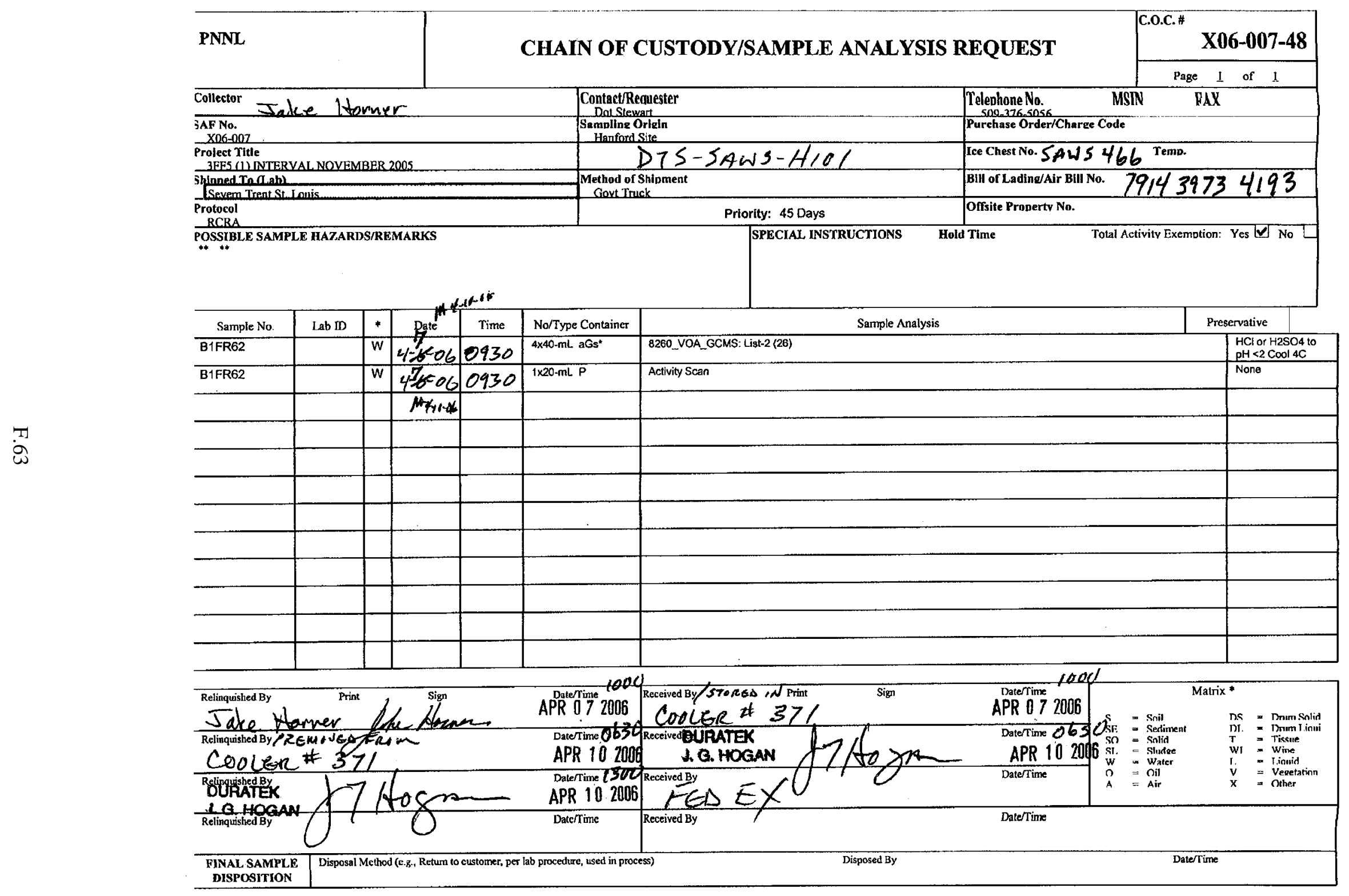




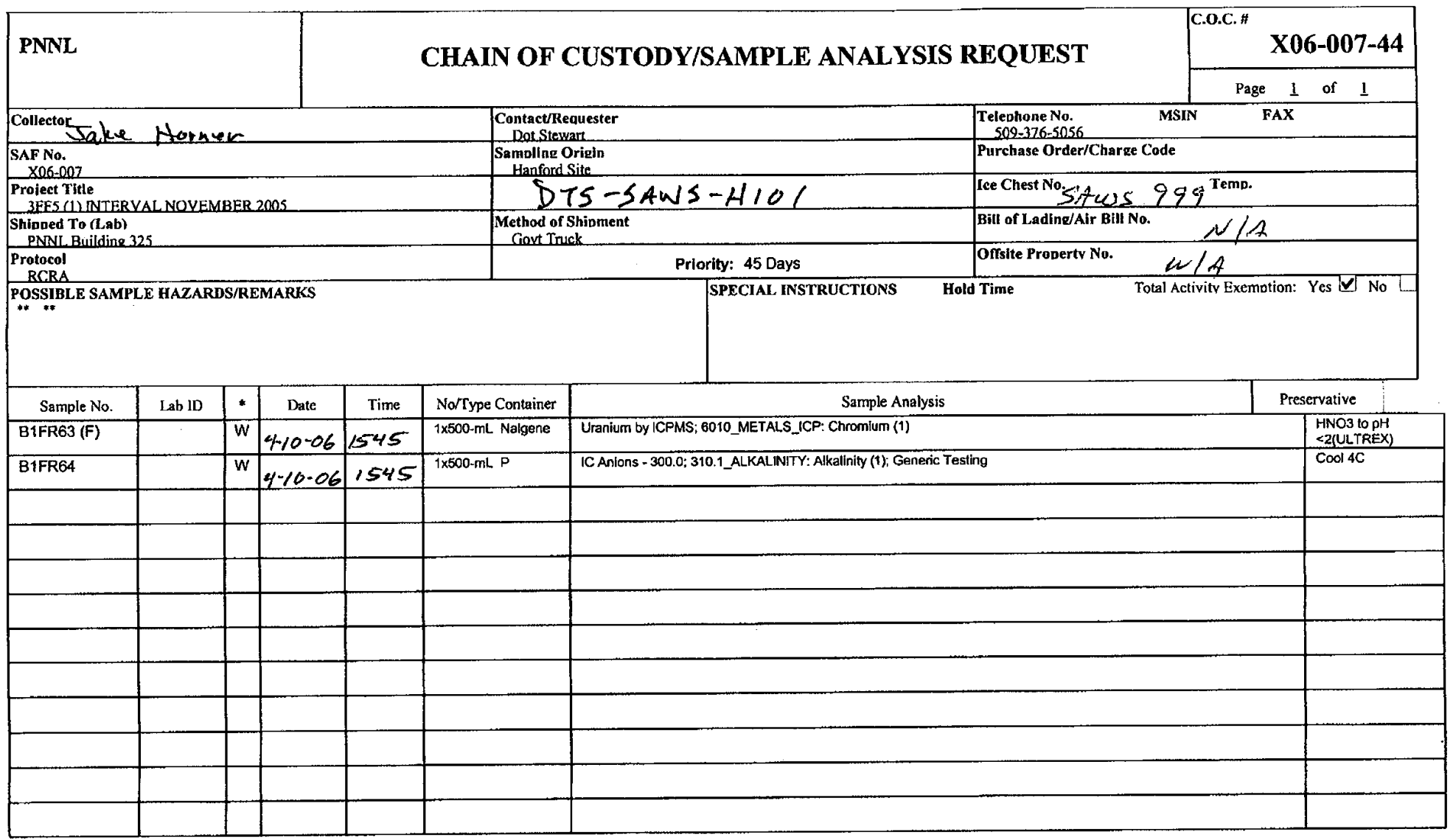

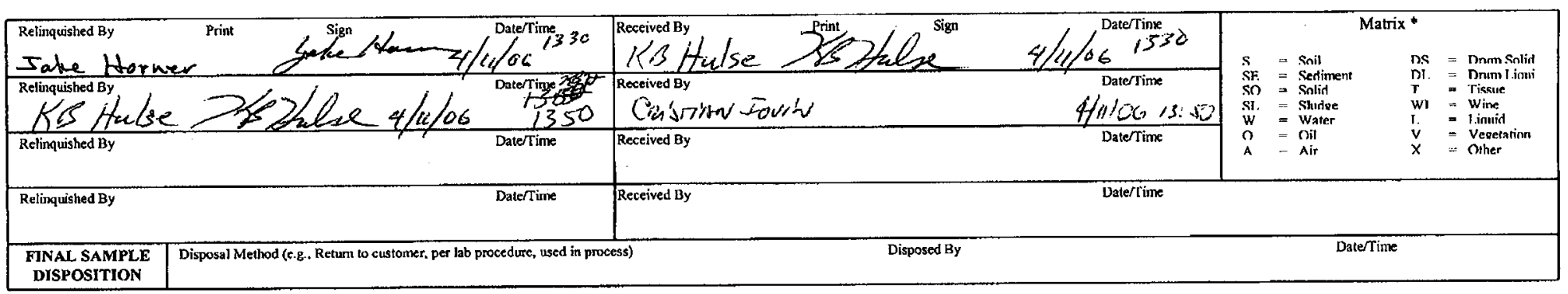




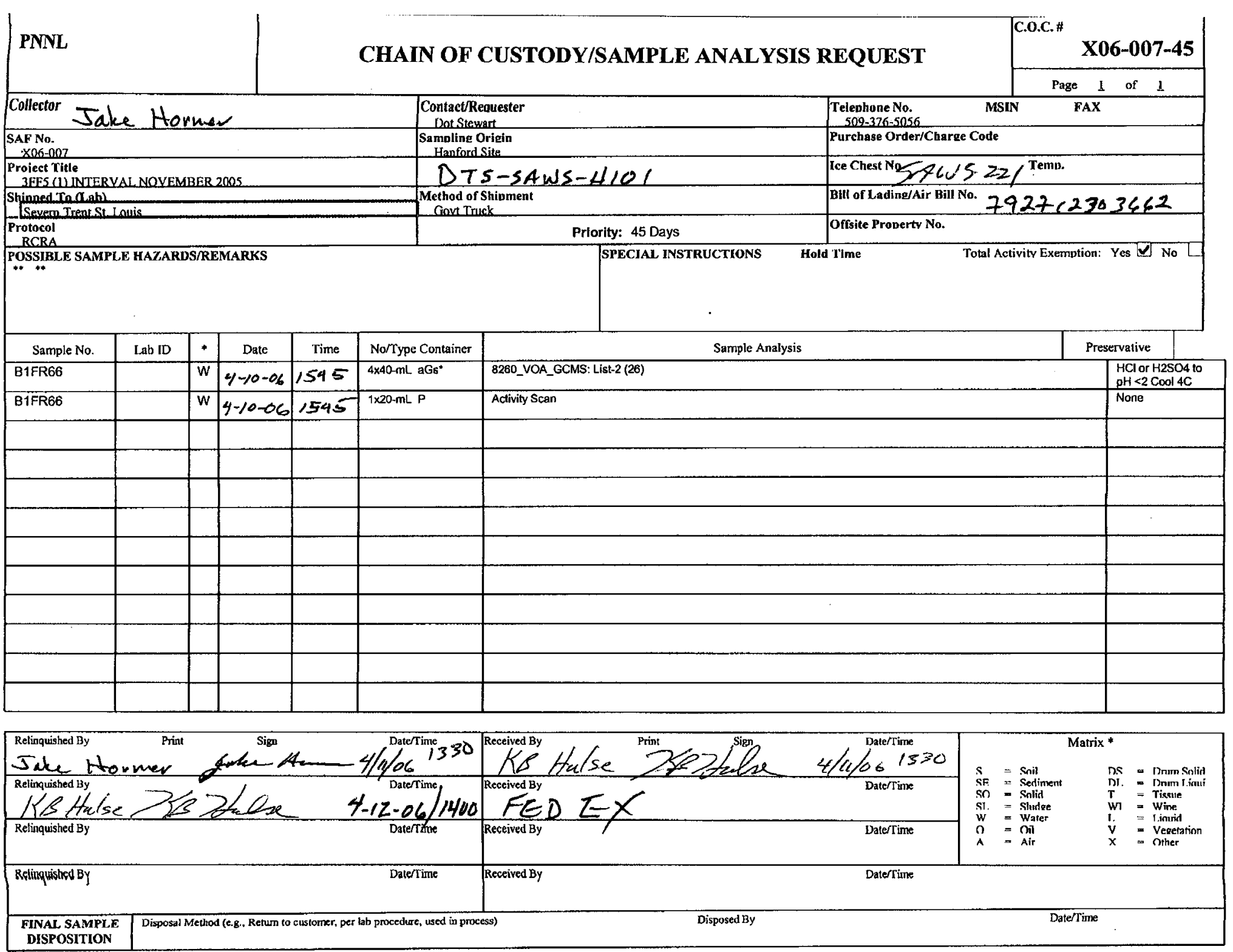




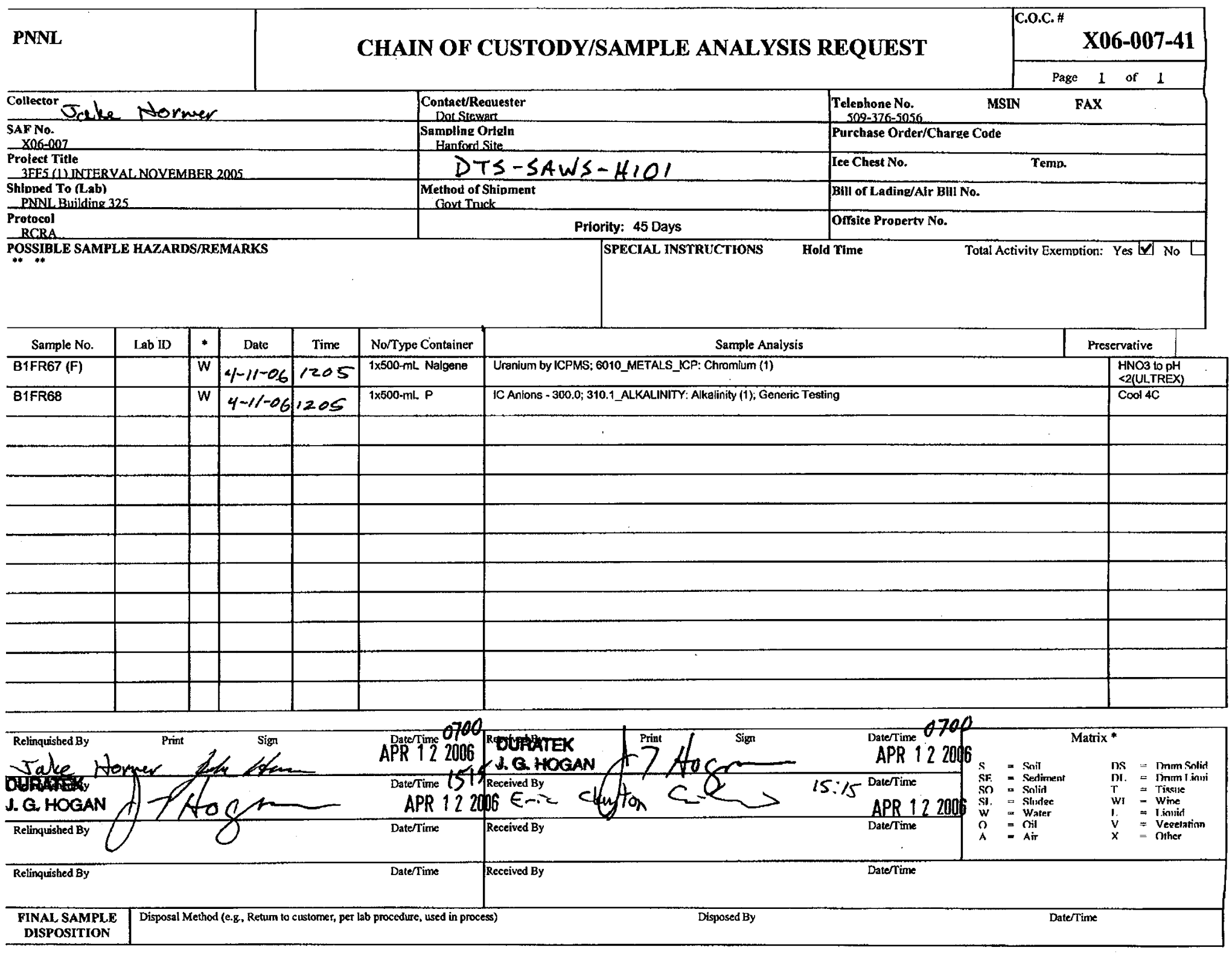




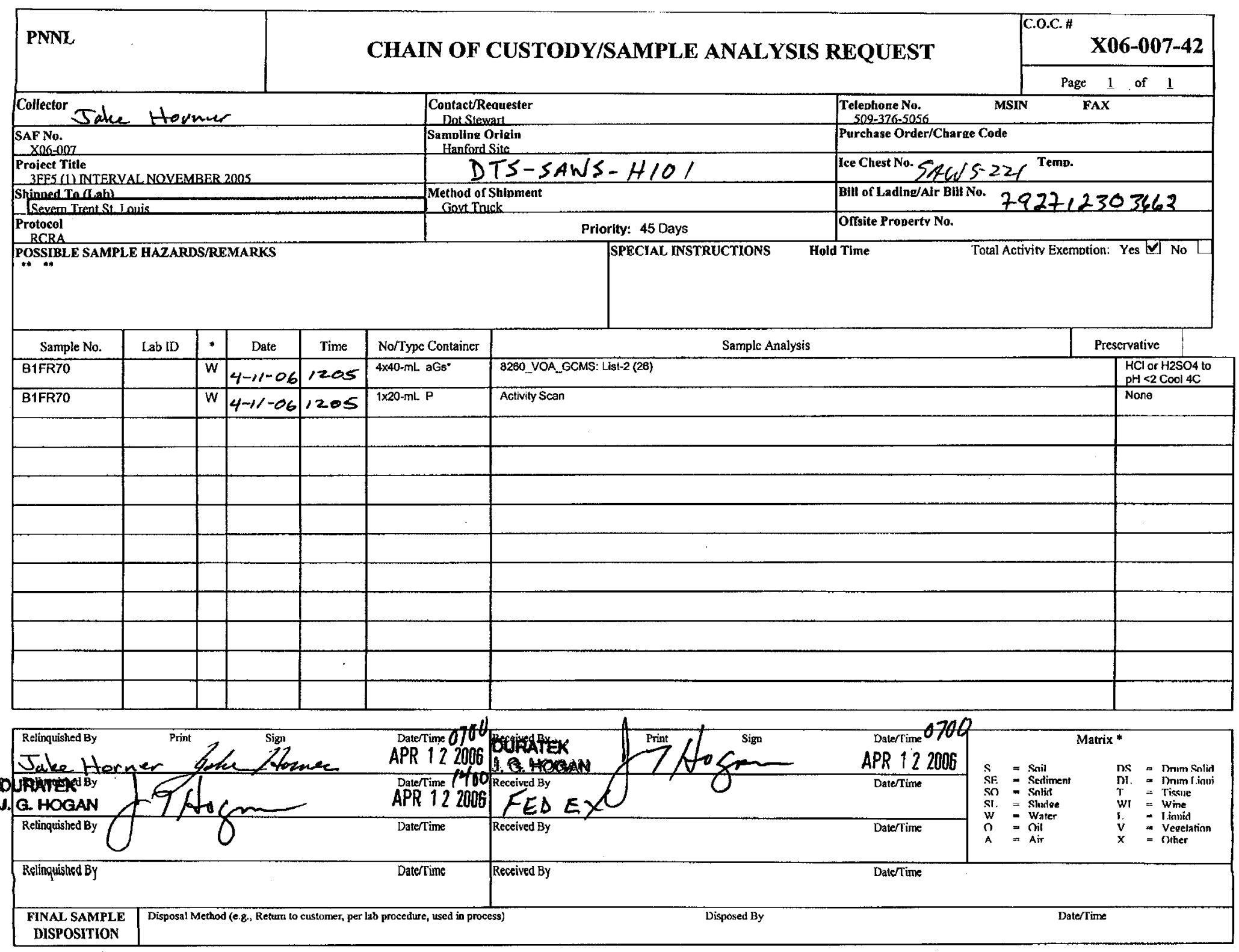




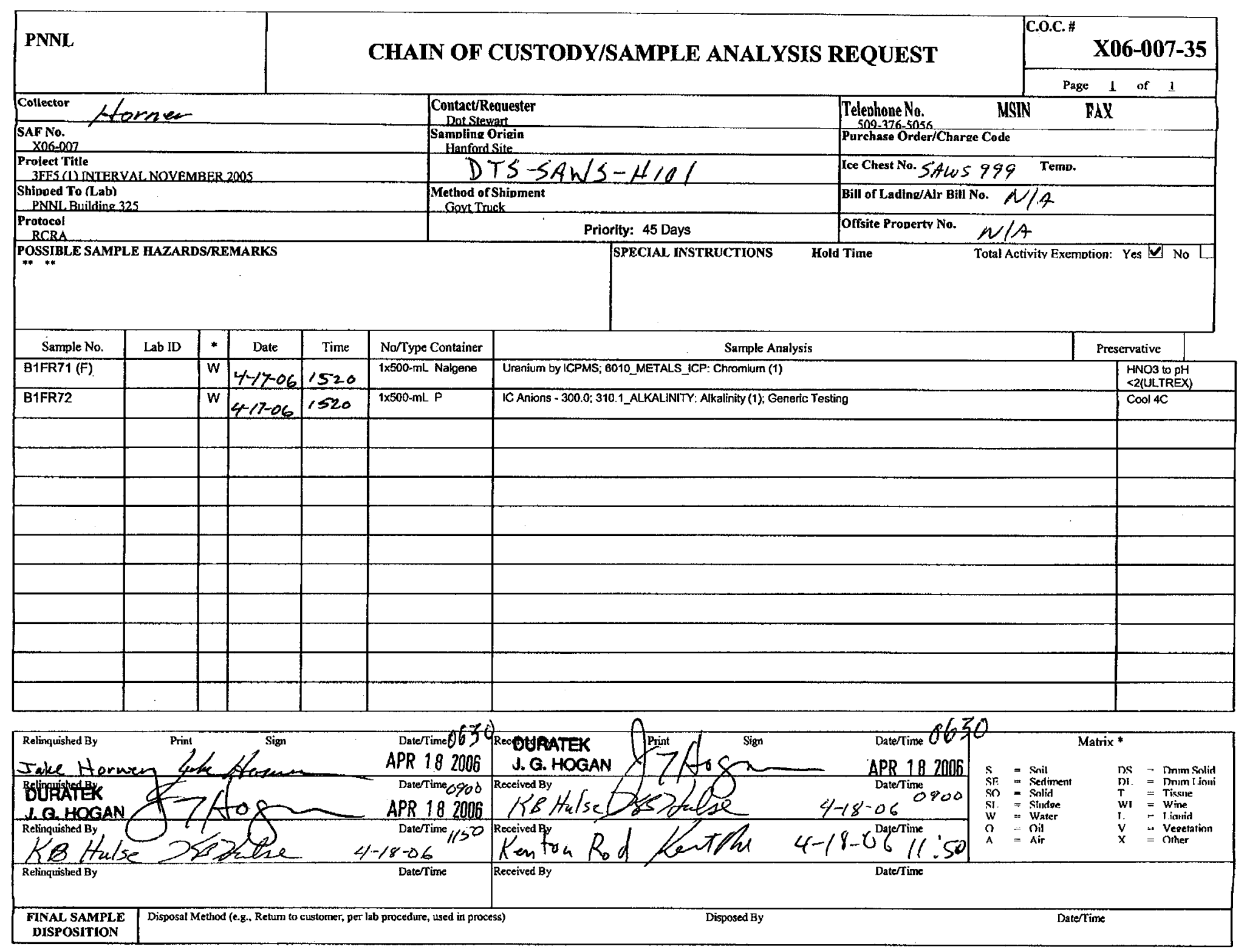




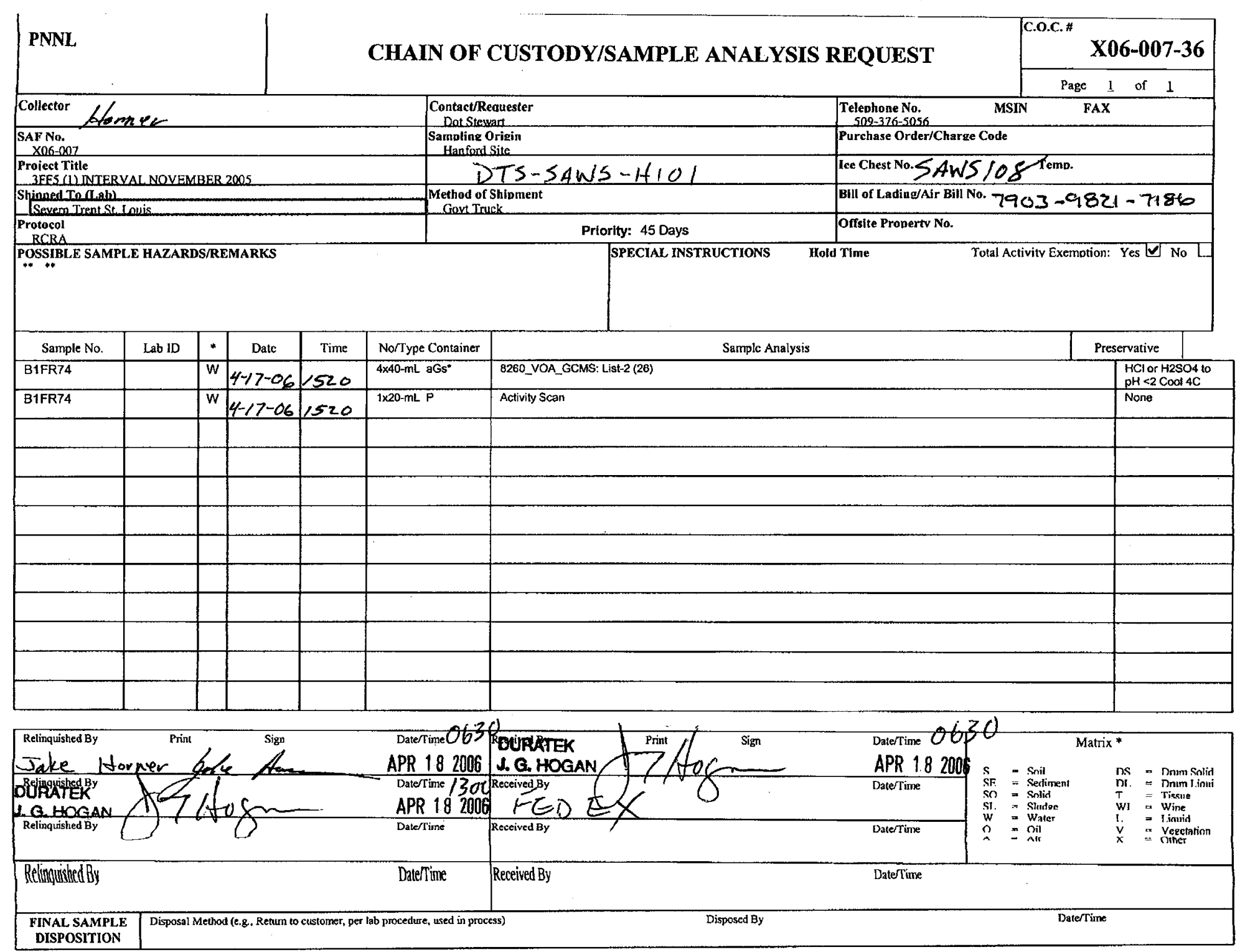




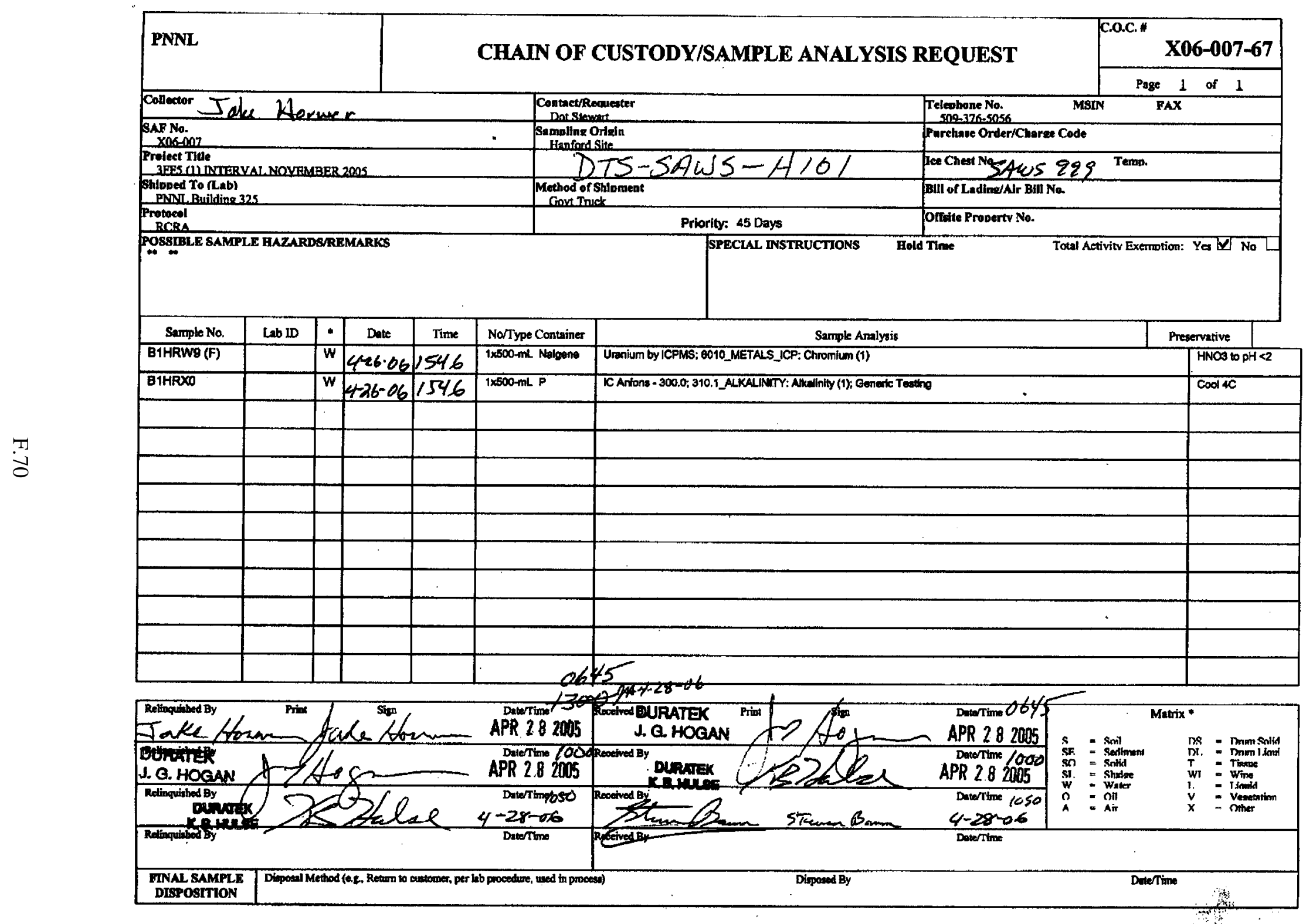




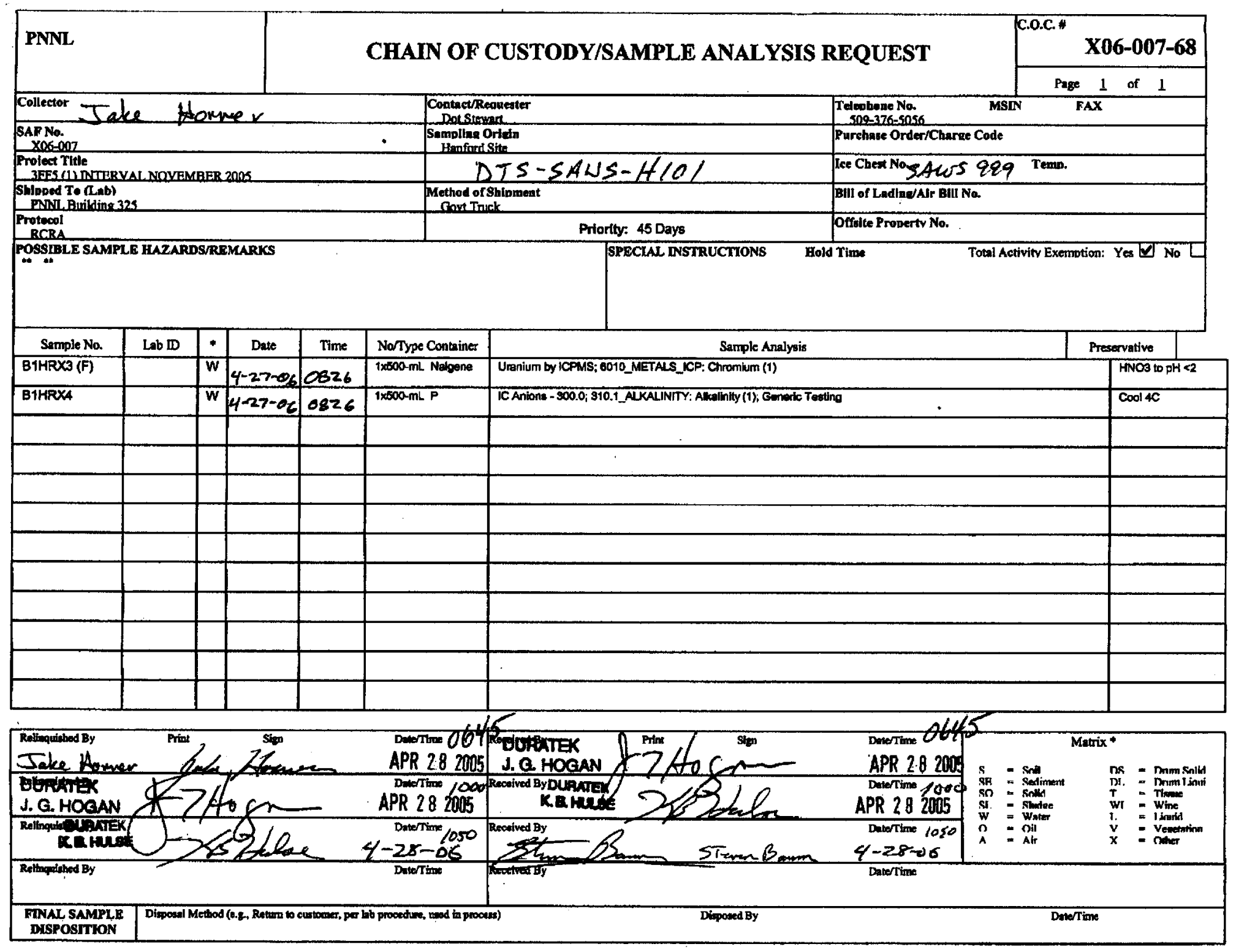




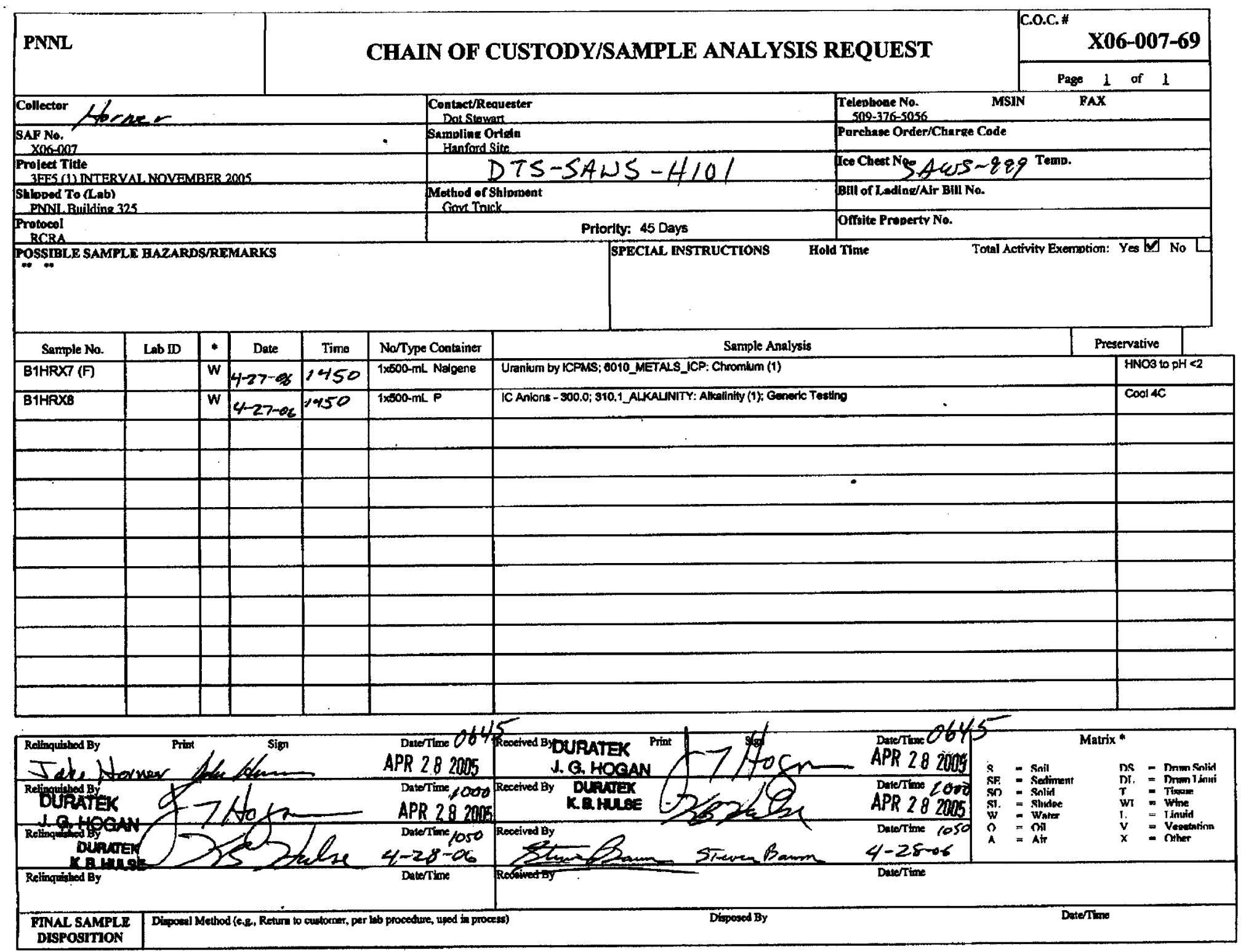




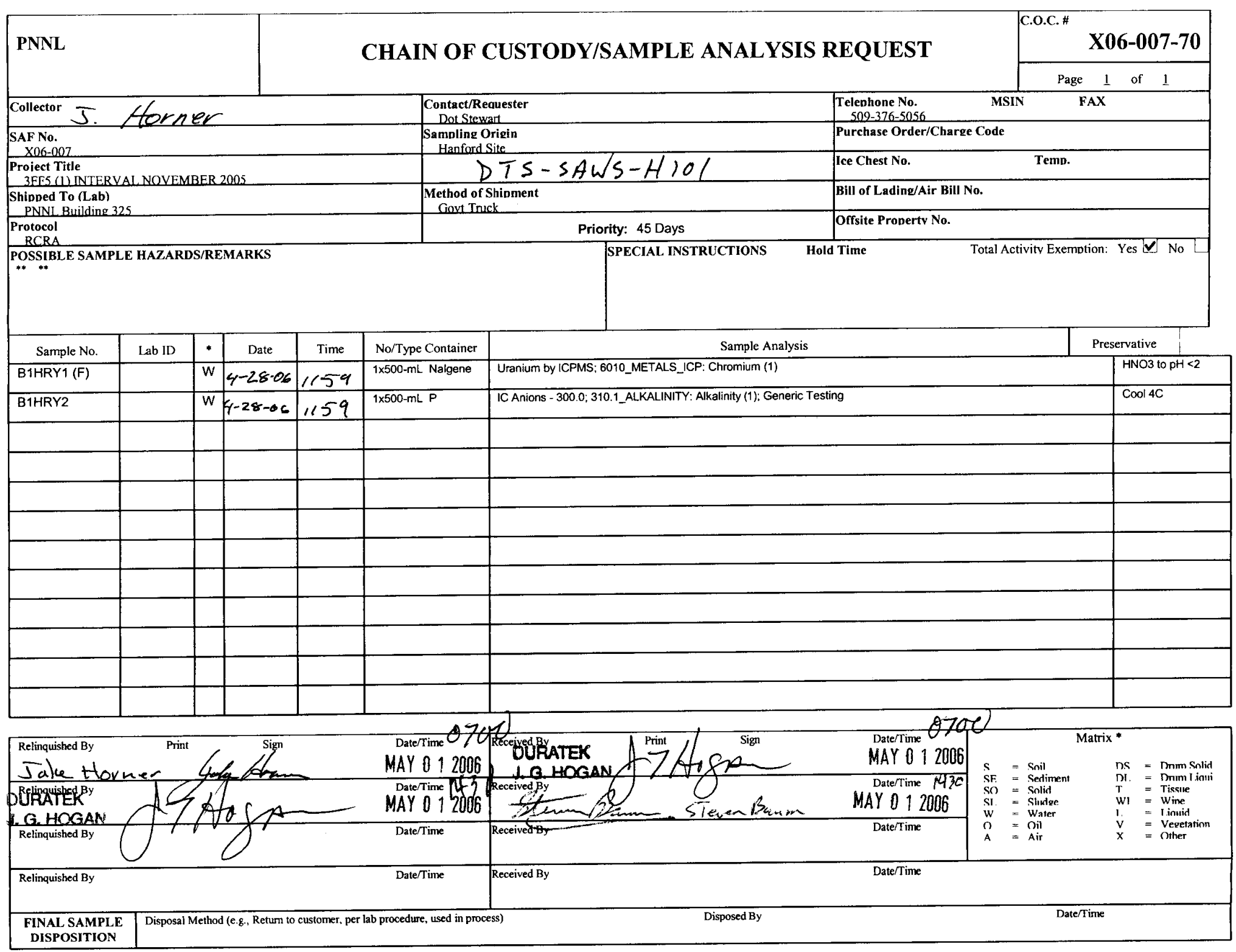




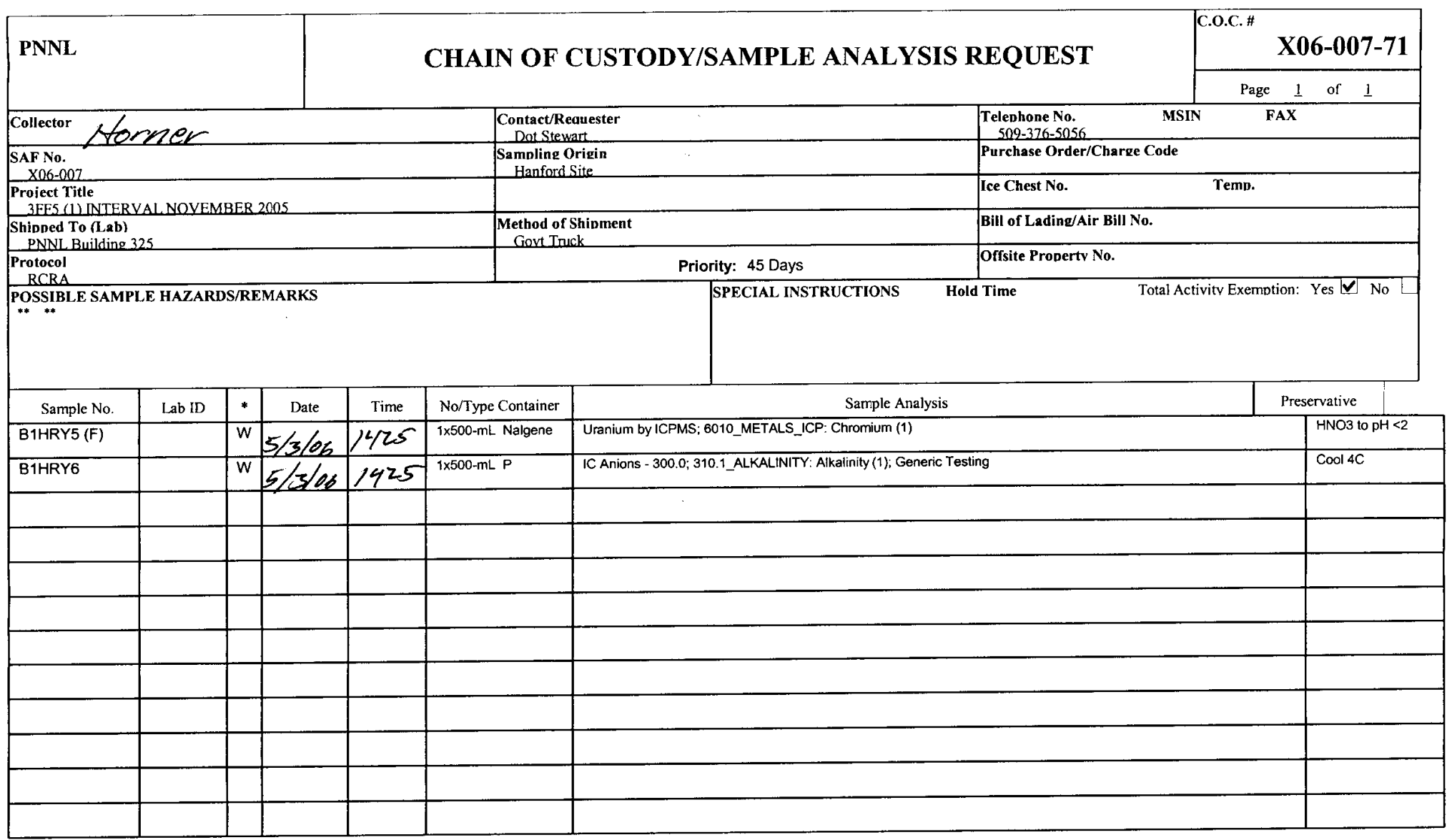

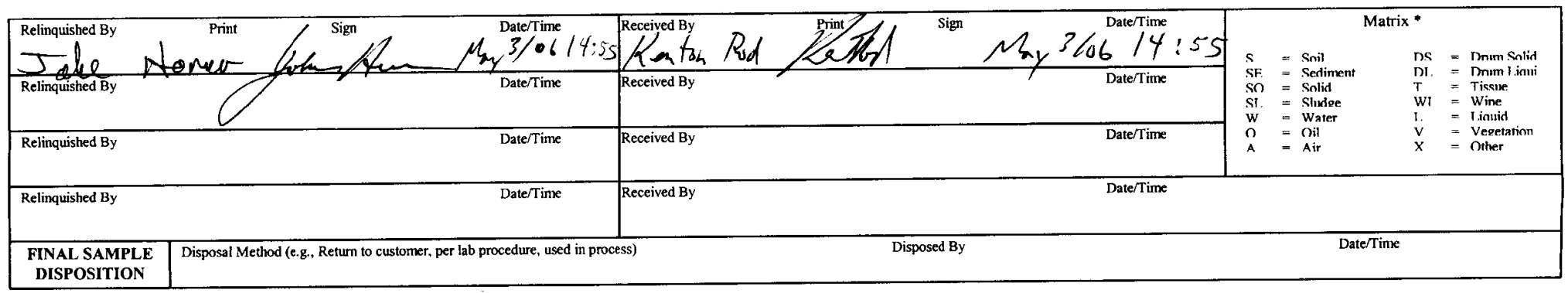




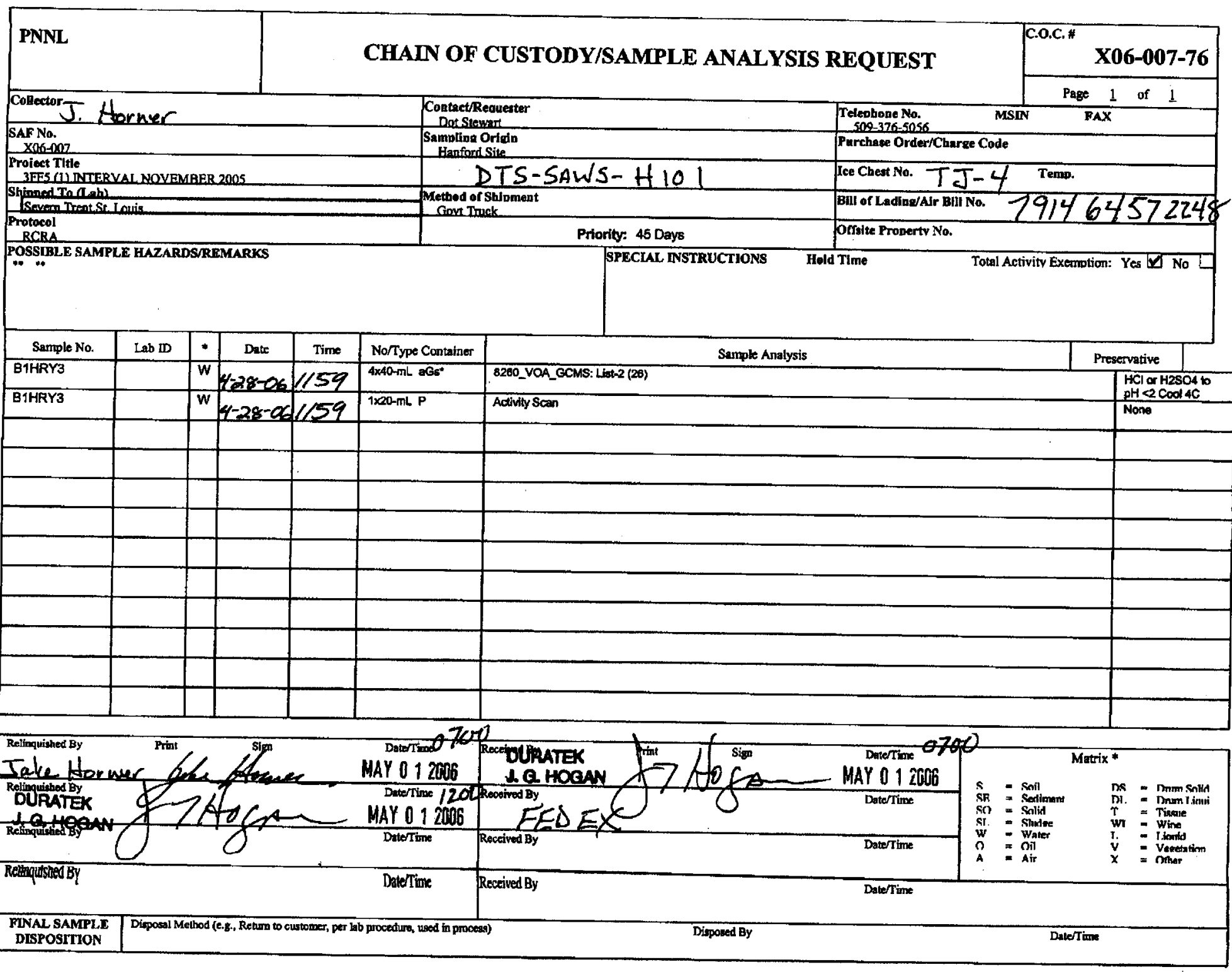




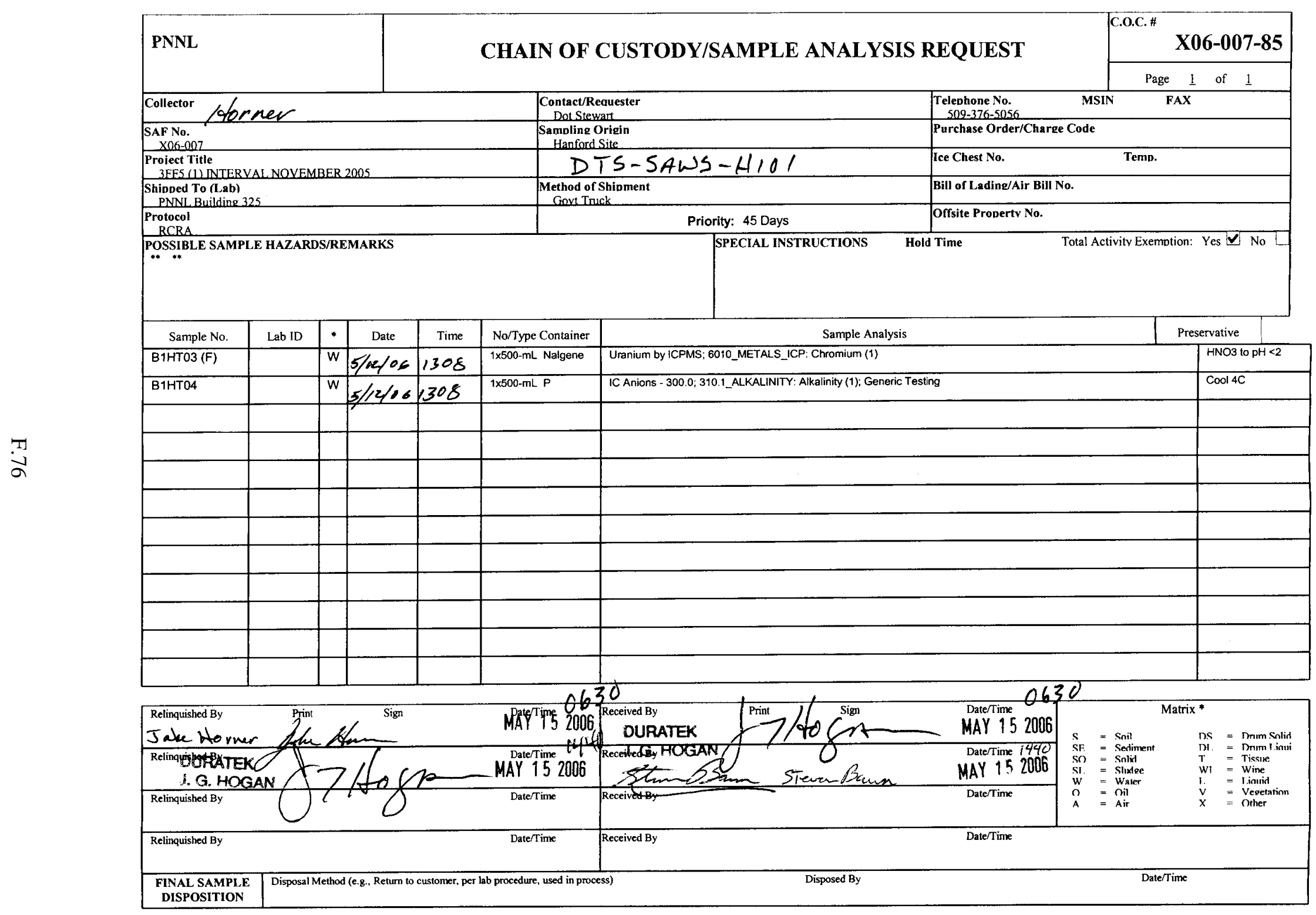




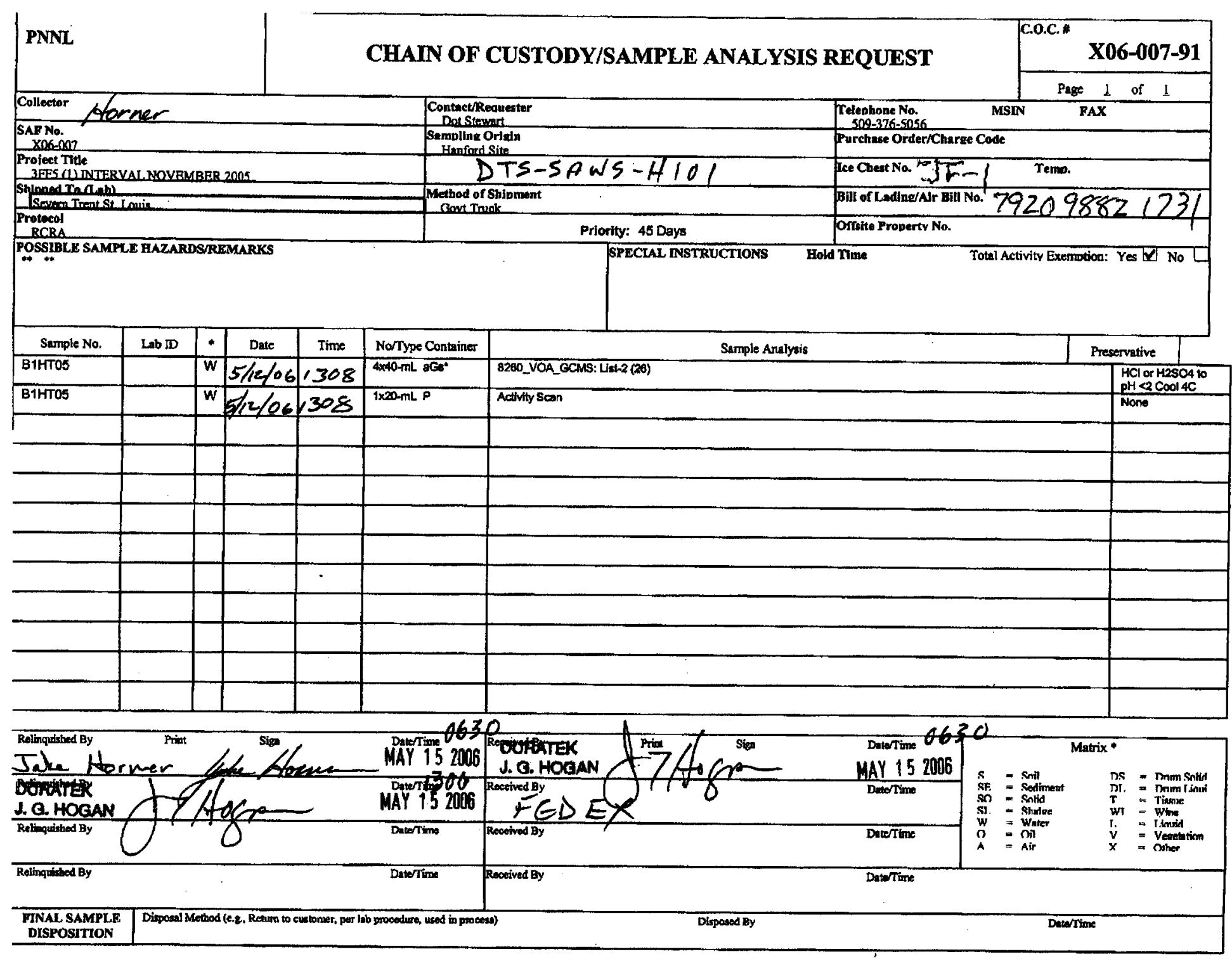




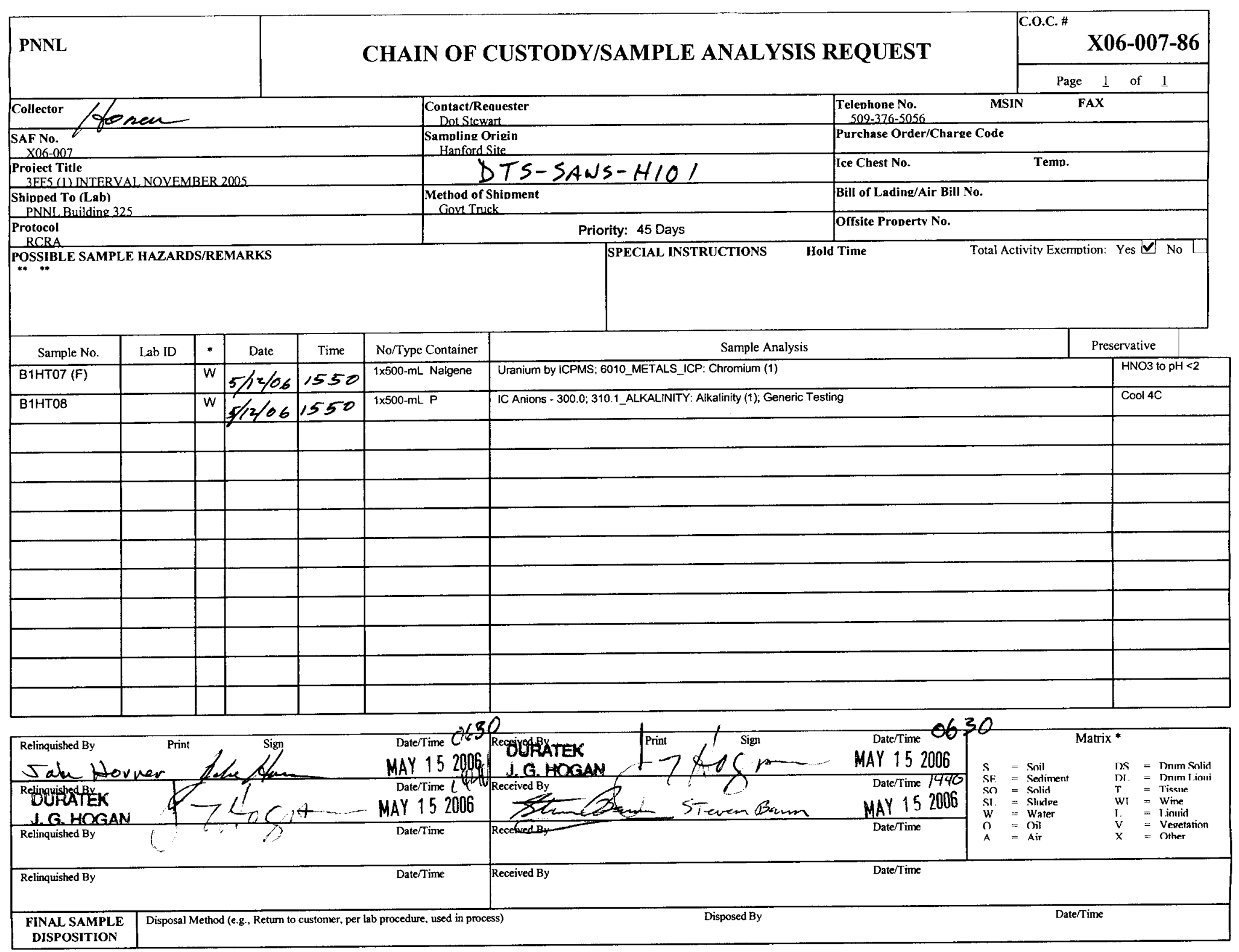




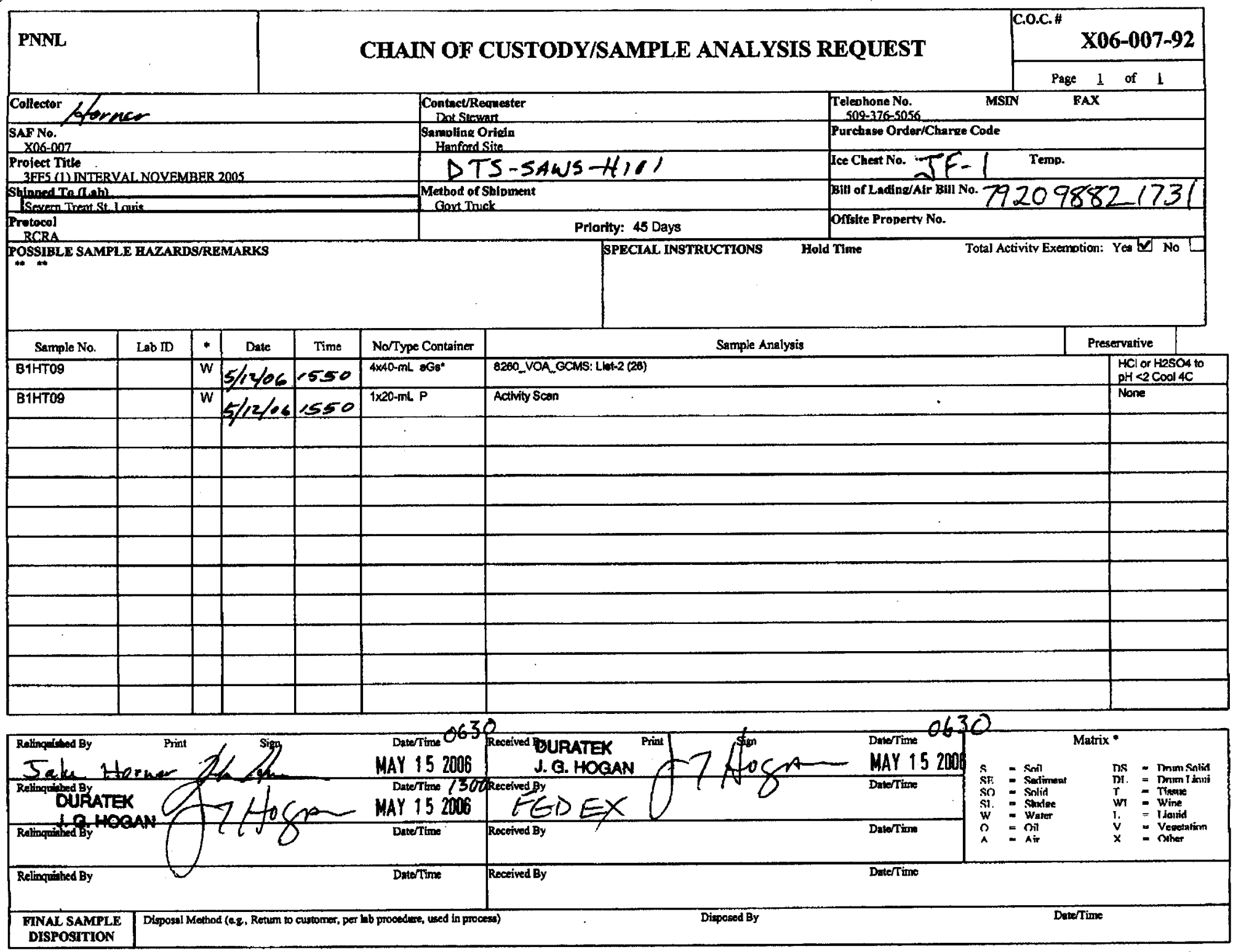




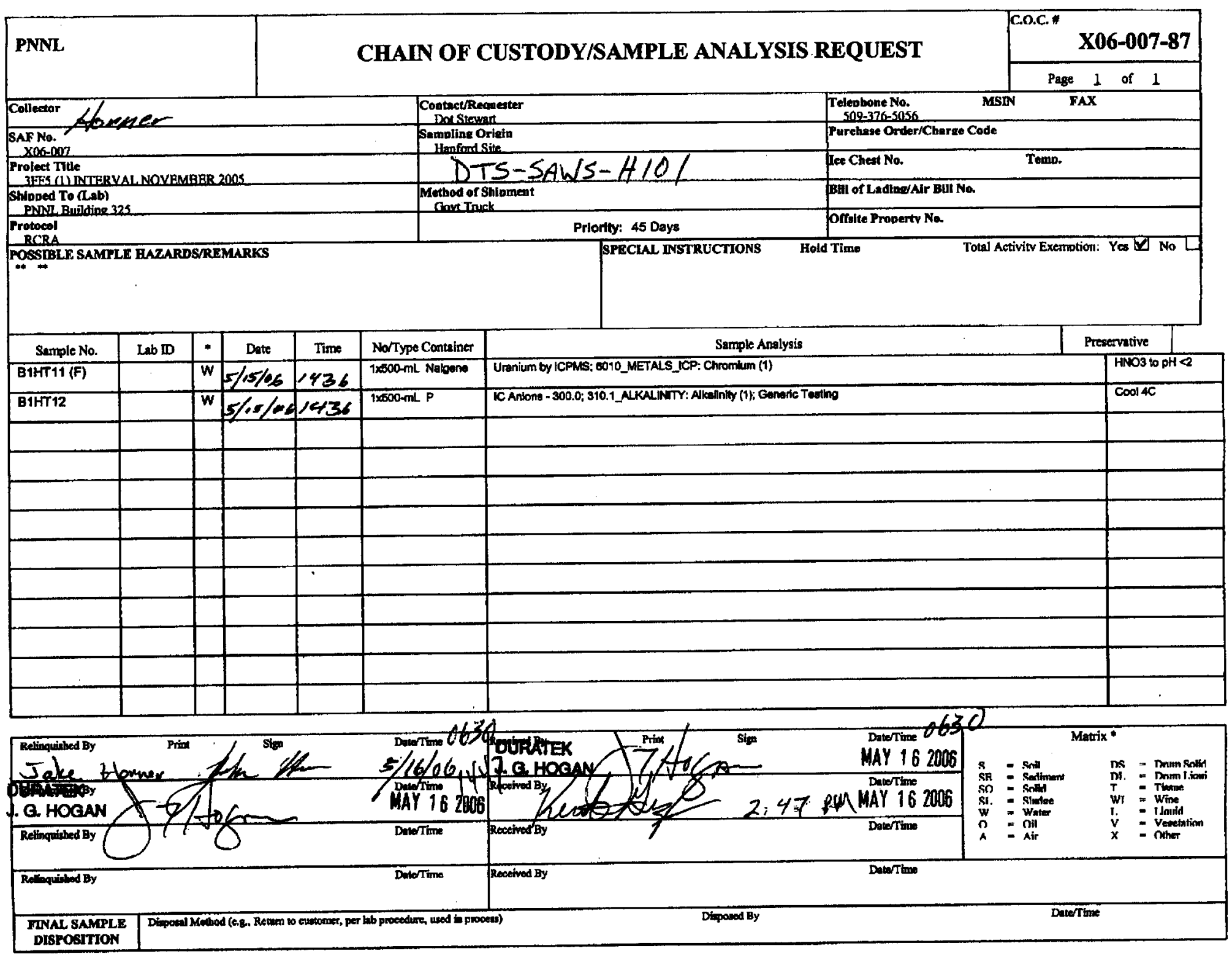




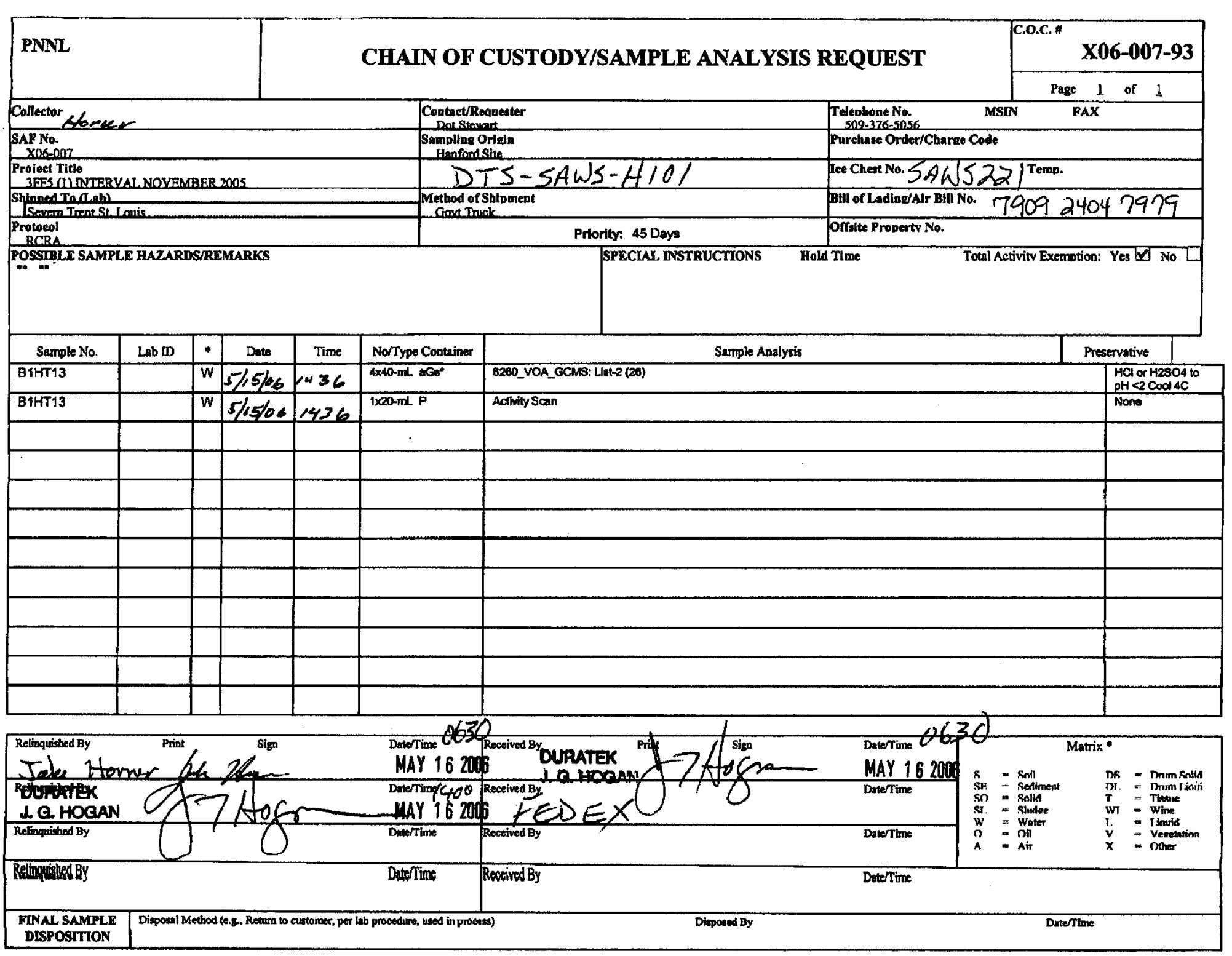




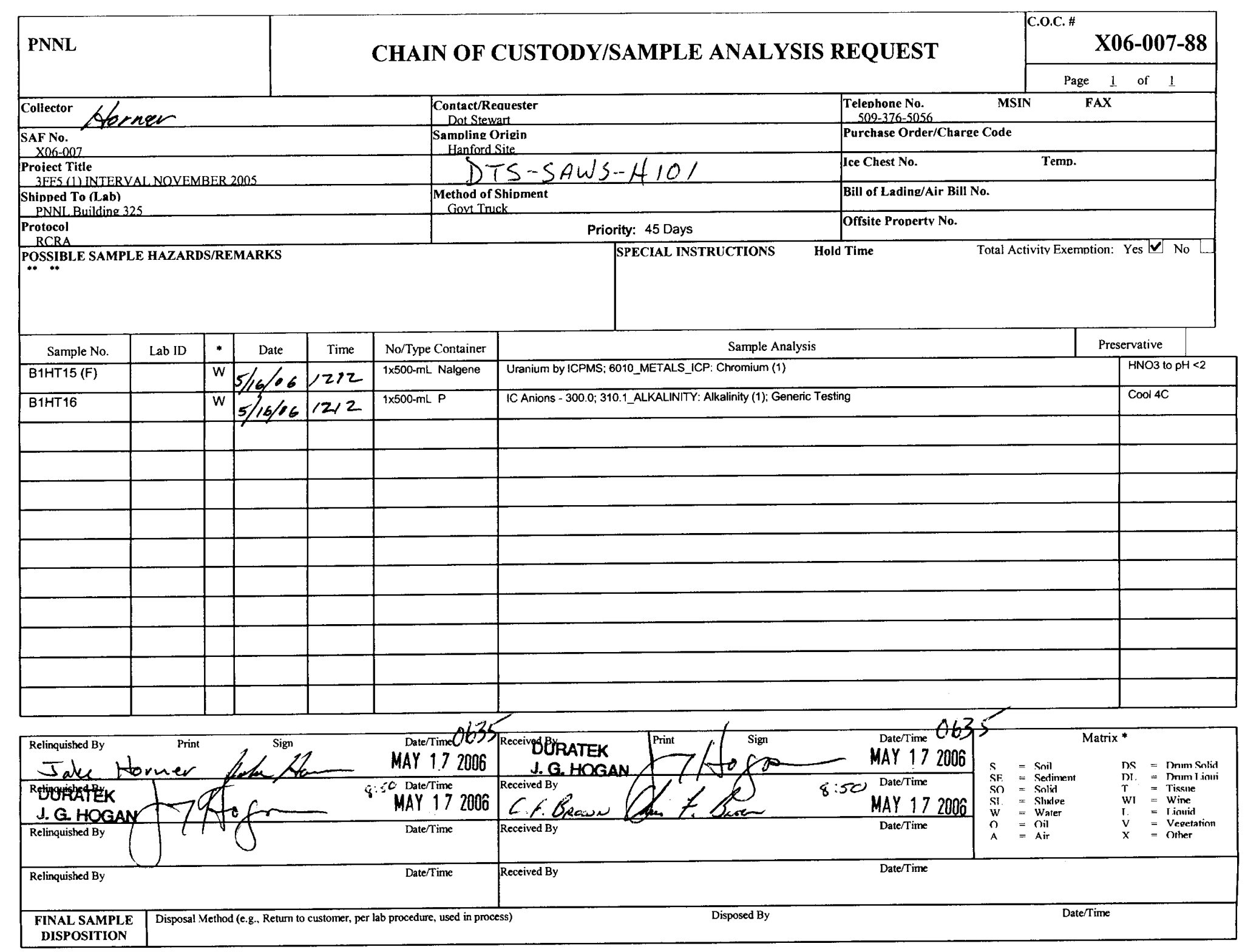




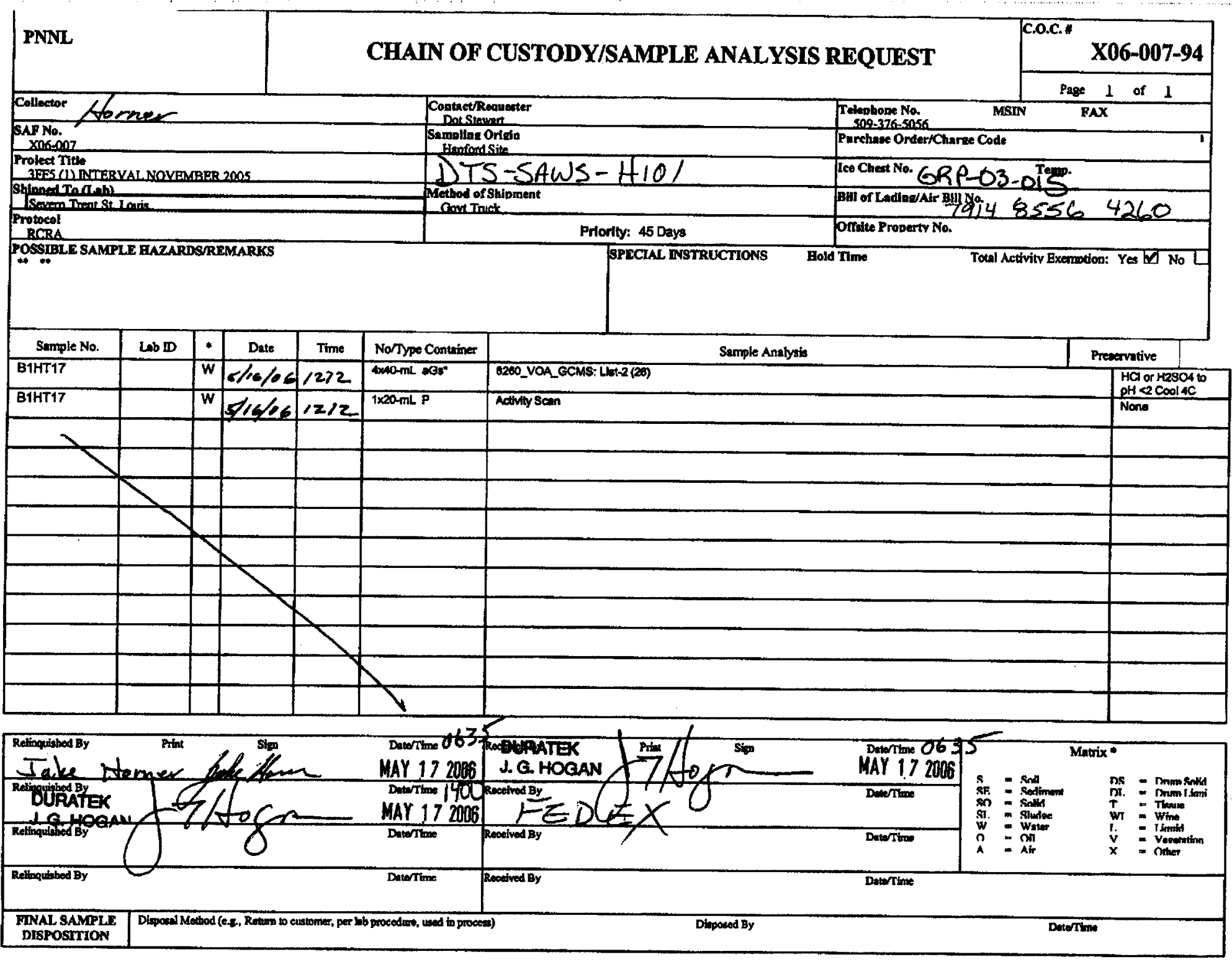




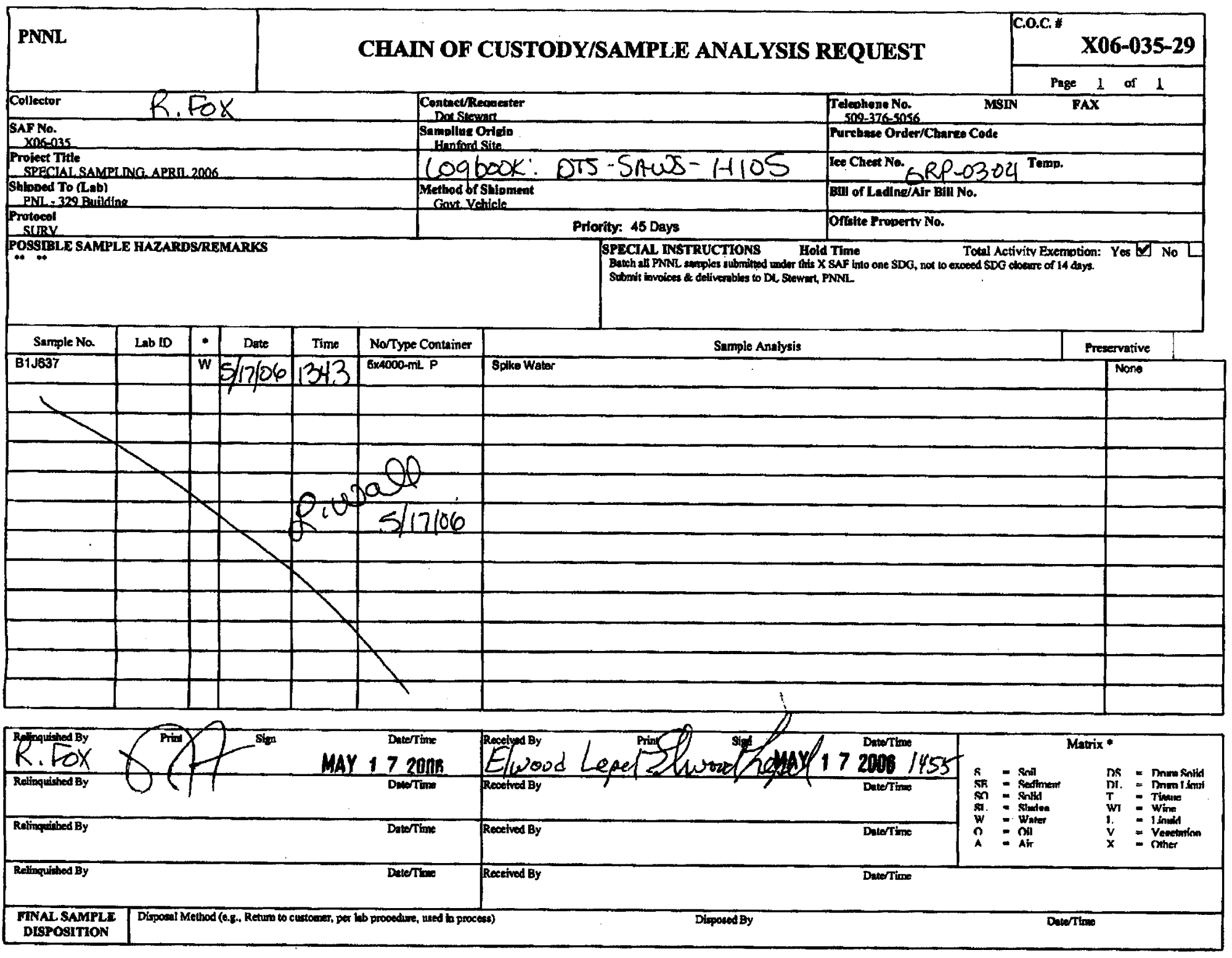




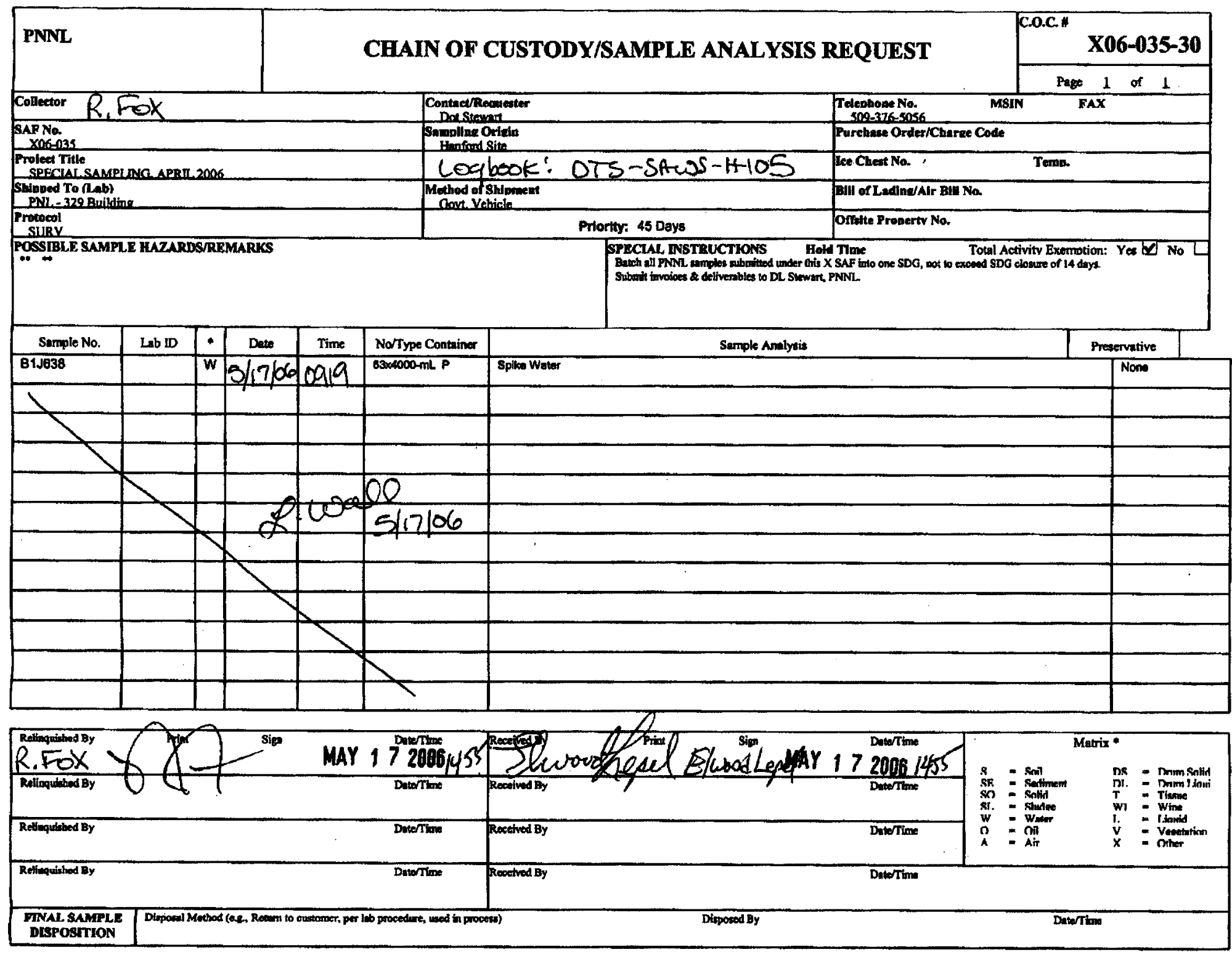




\section{Appendix G}

Well Installation Daily Field Activity Reports, C4999, C5000, C5001, and C5002 


\section{Drilling Field Activity Reports}

Well C4999

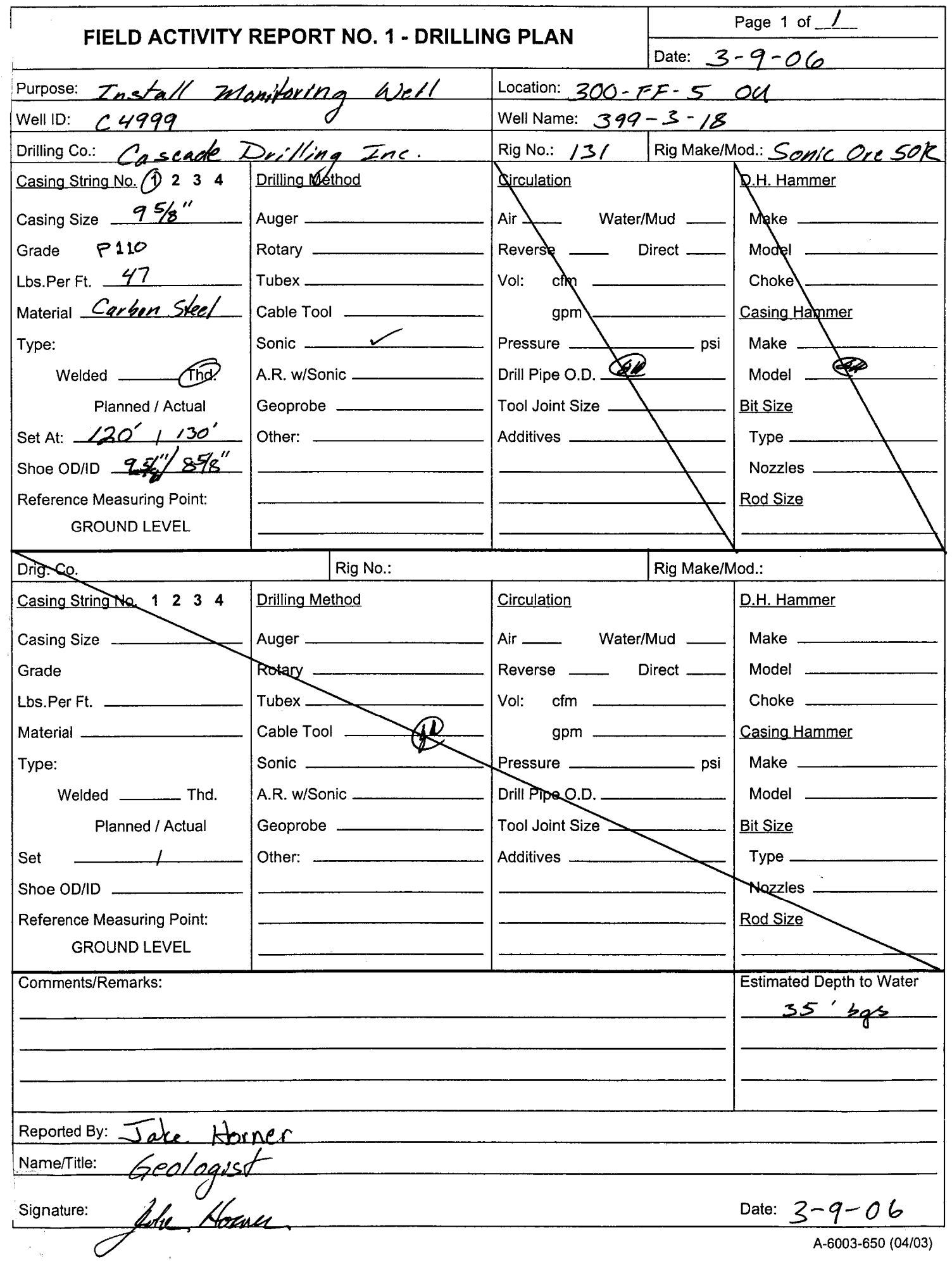

G.1 


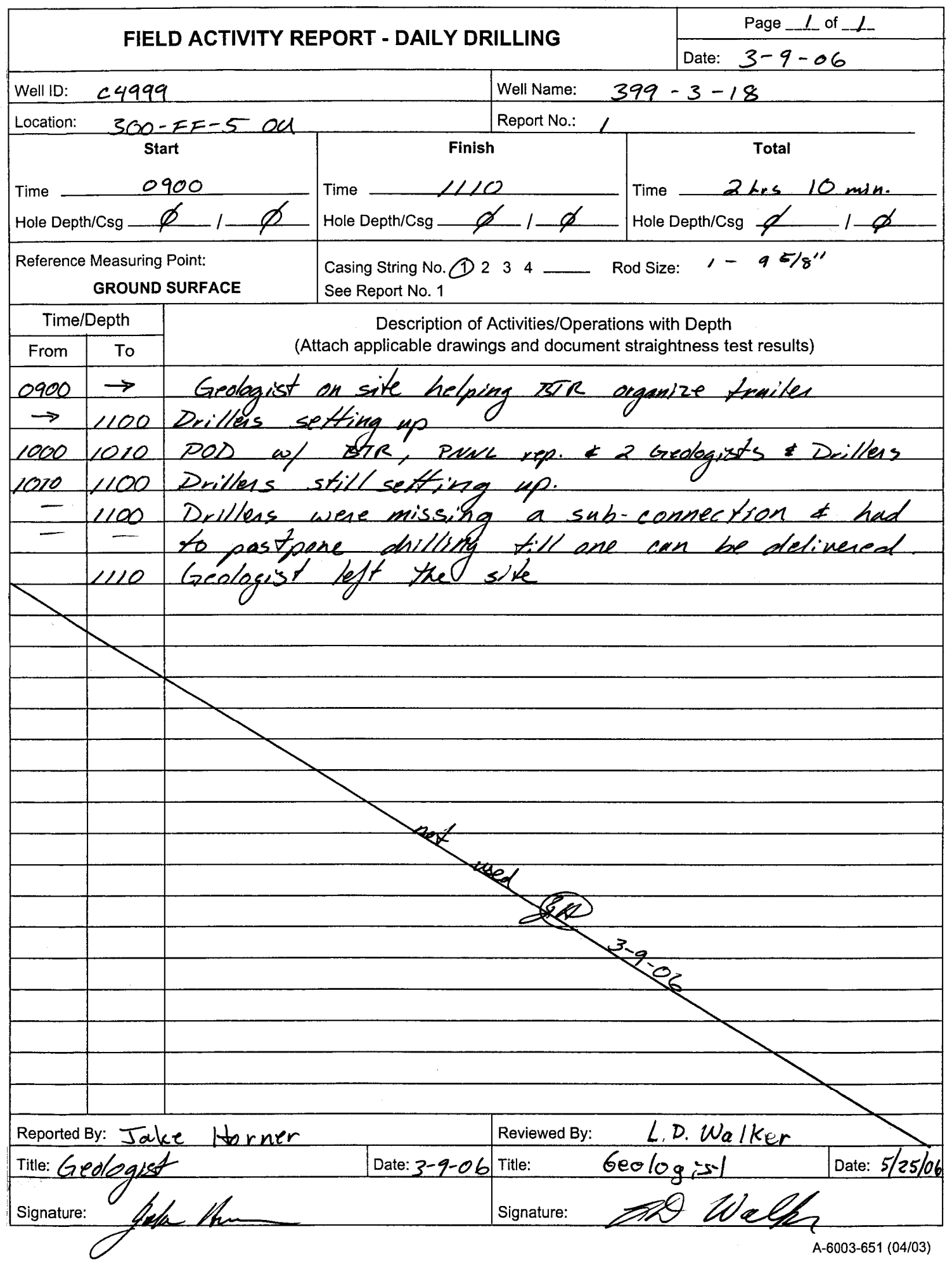




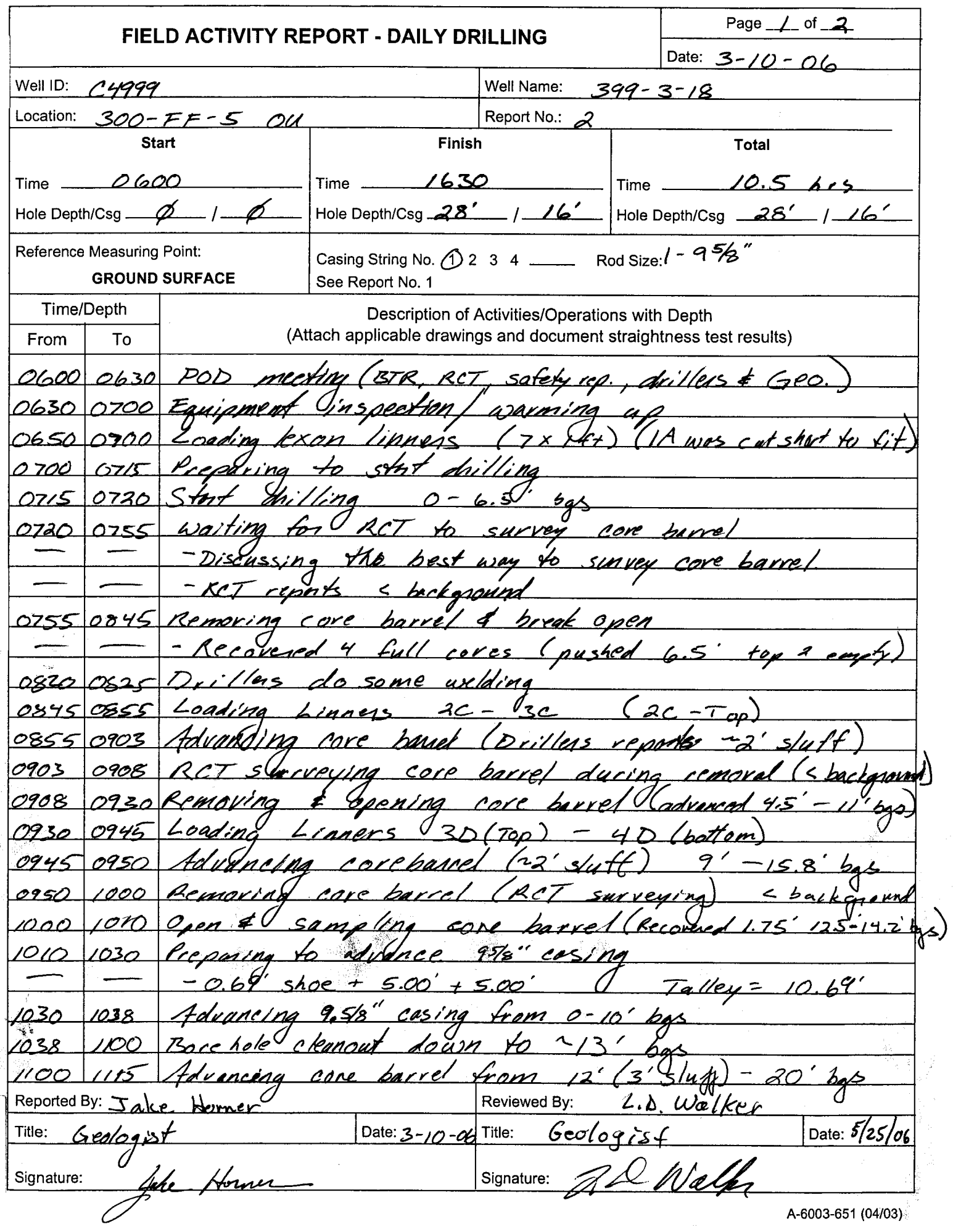




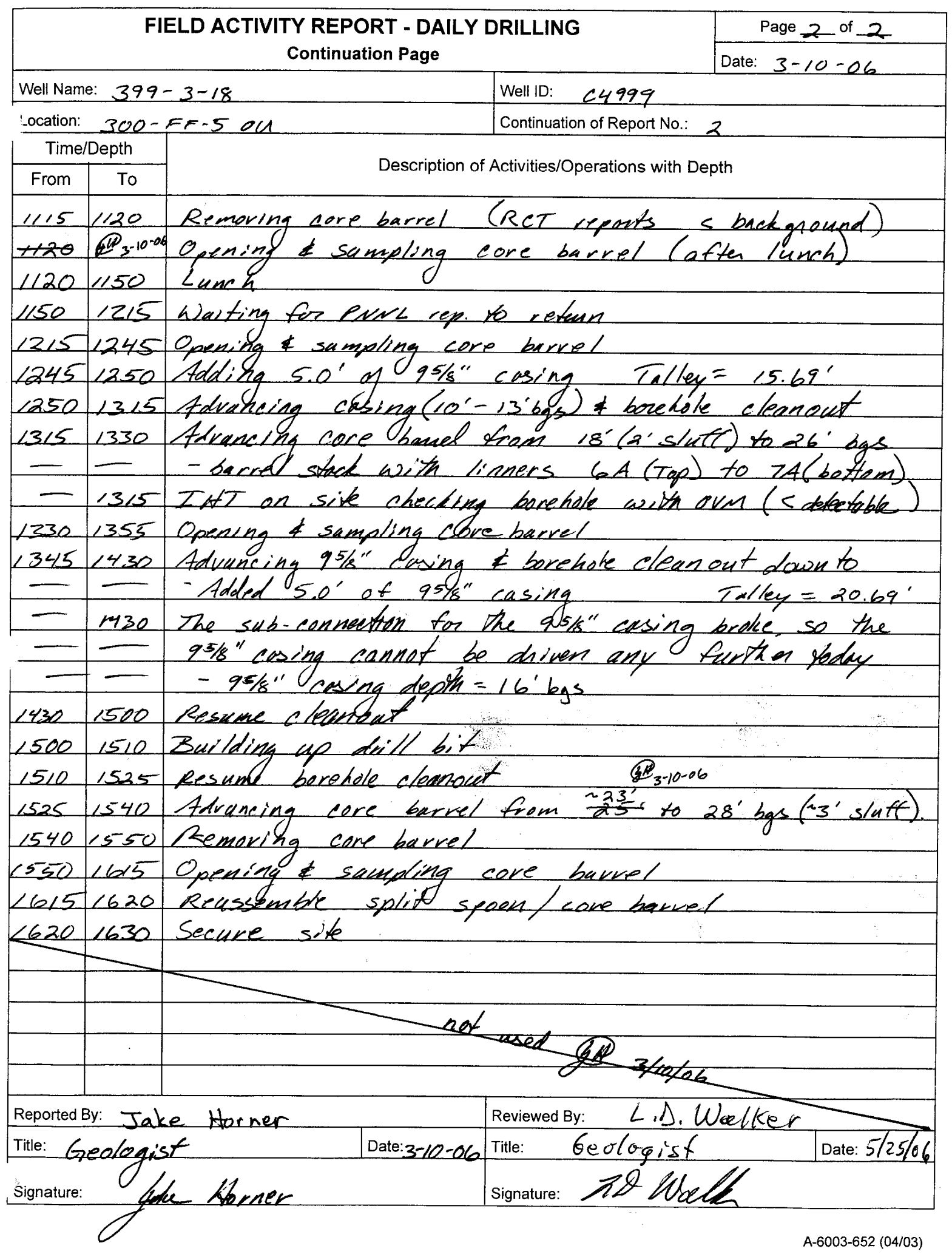




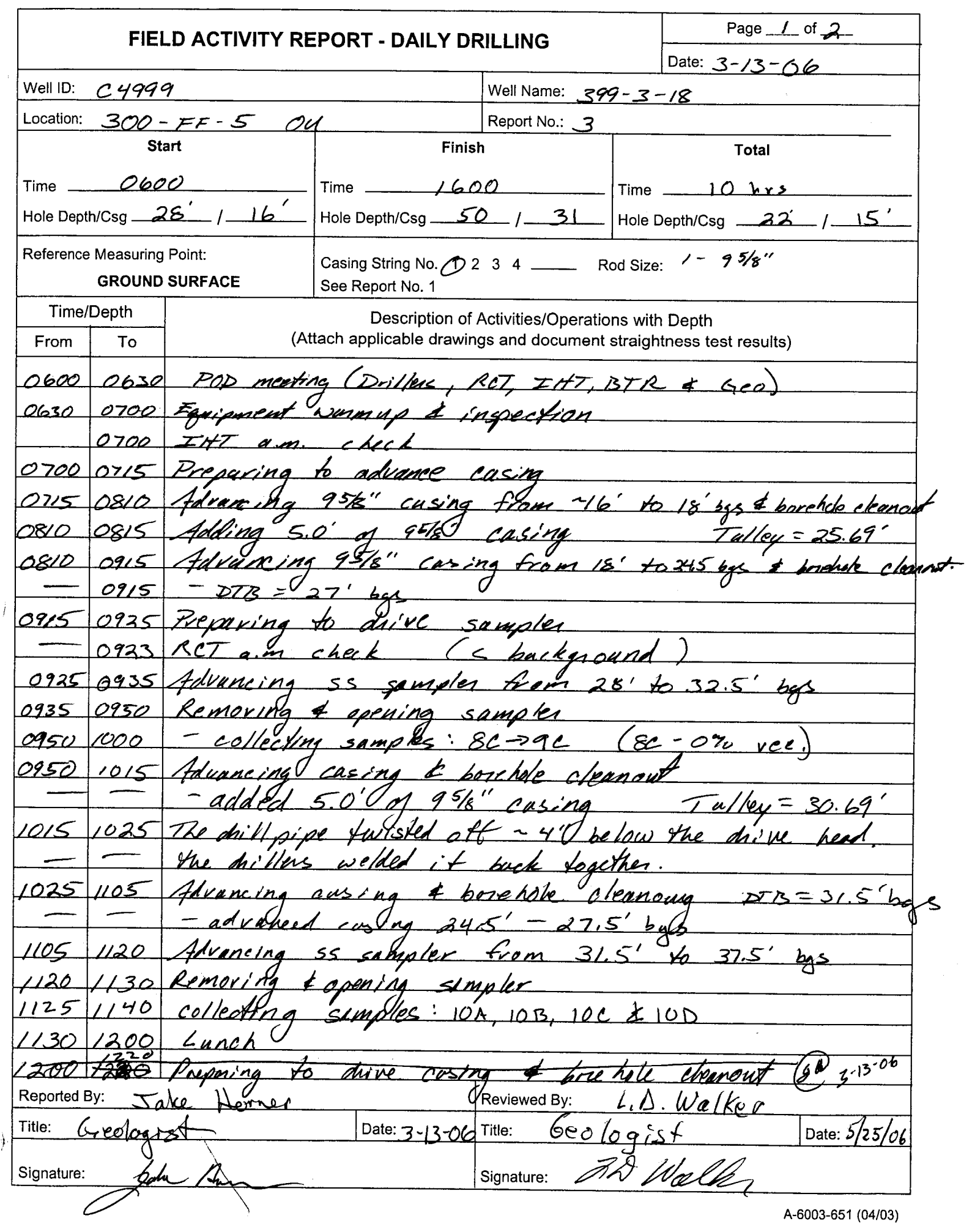




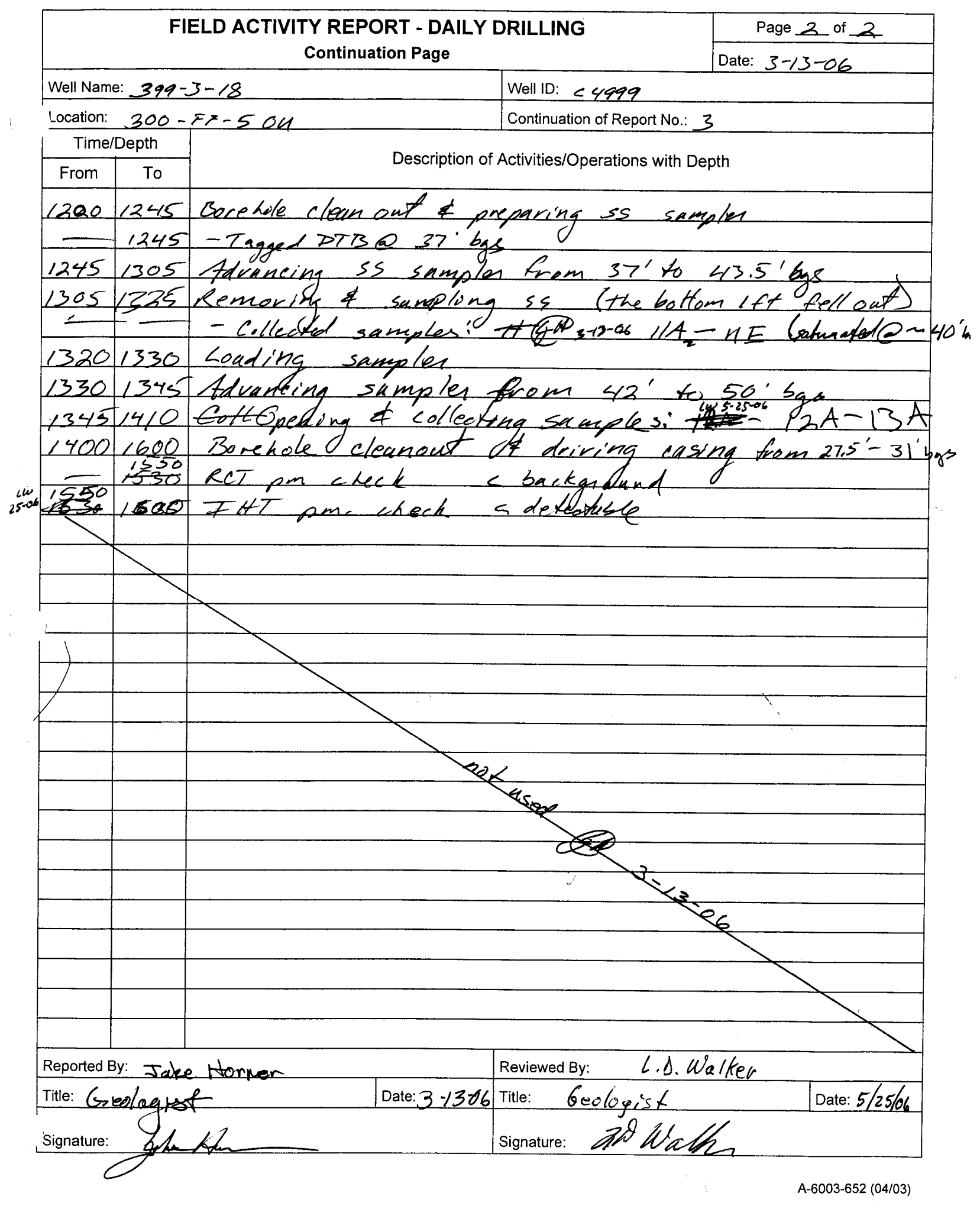

G.6 


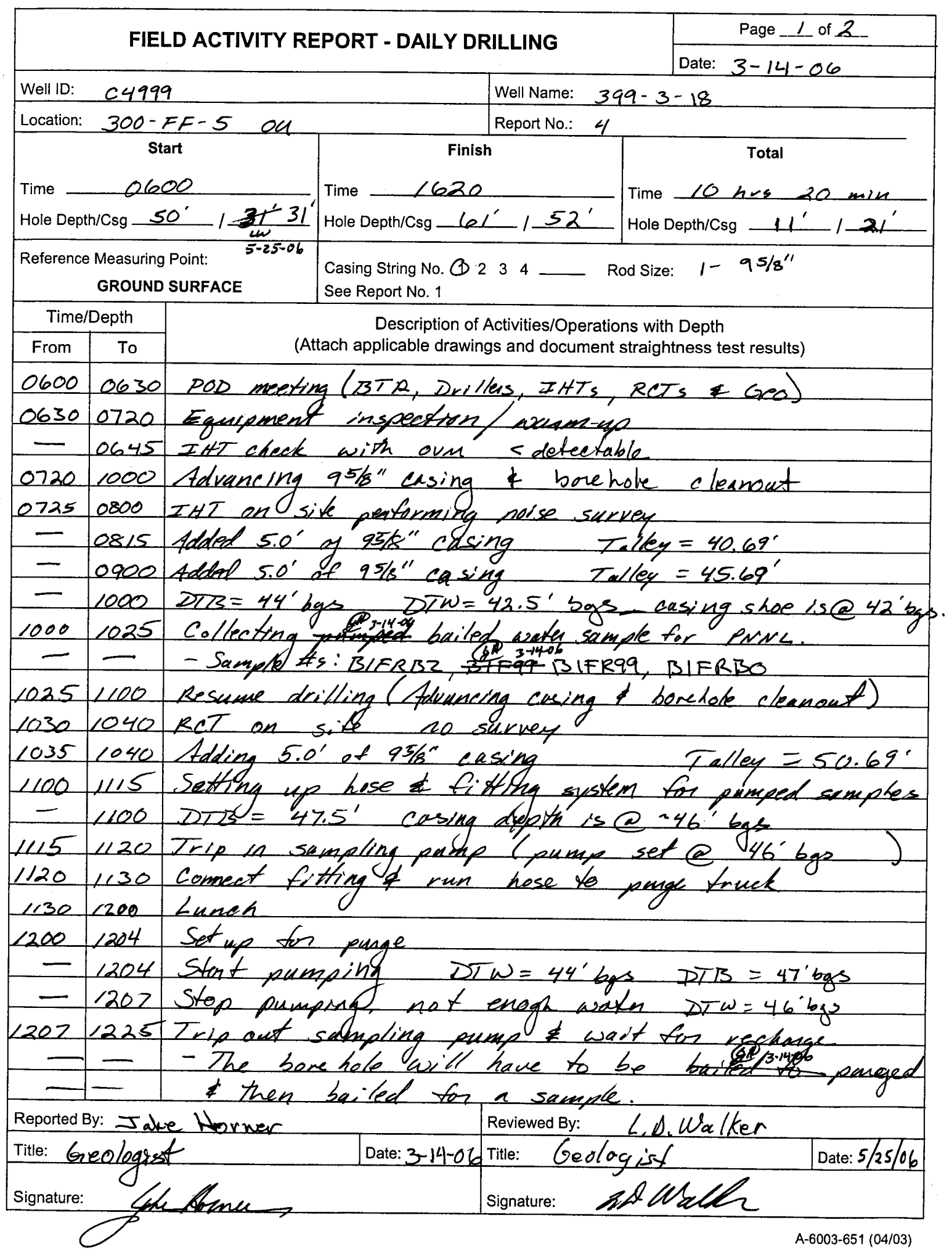




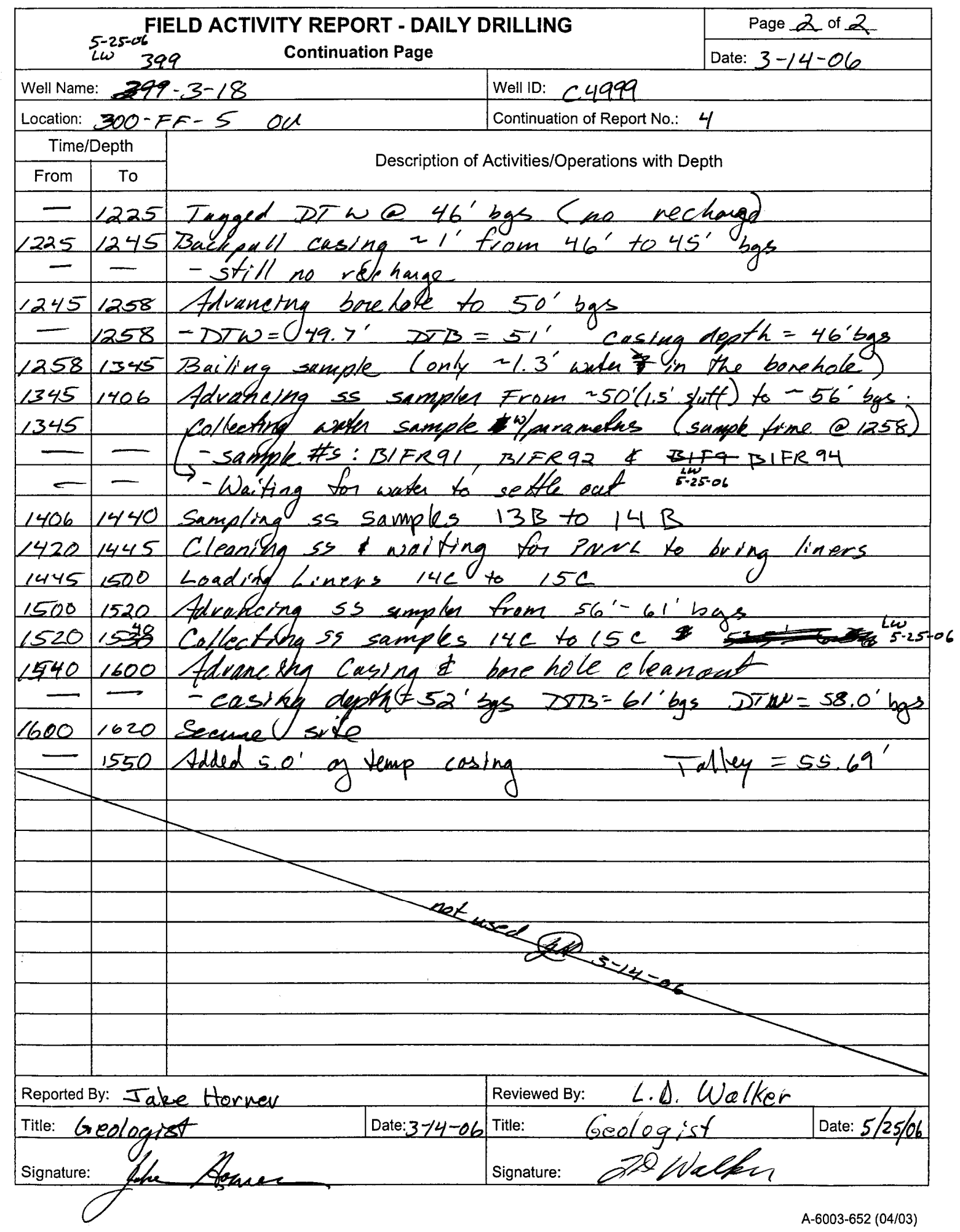




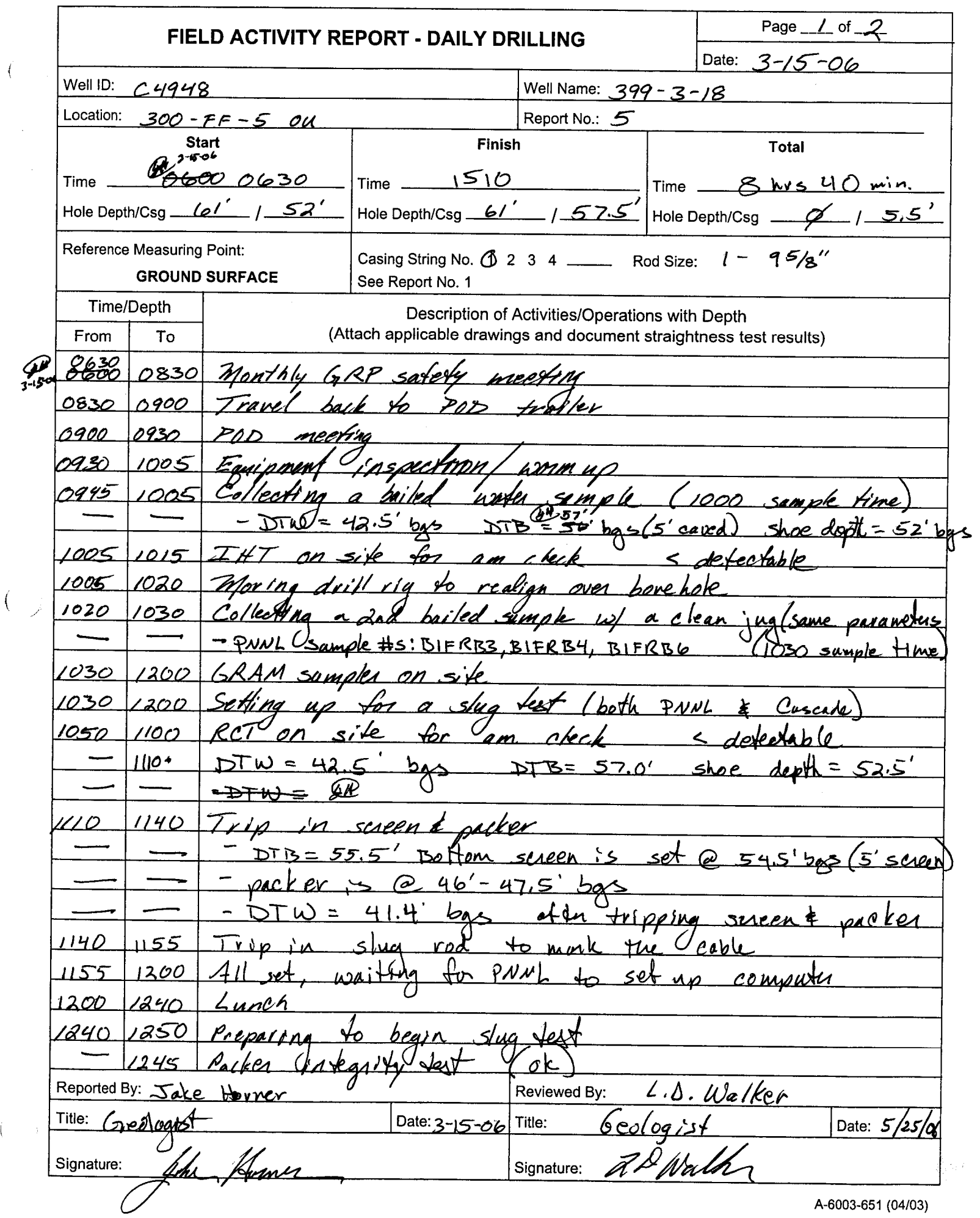




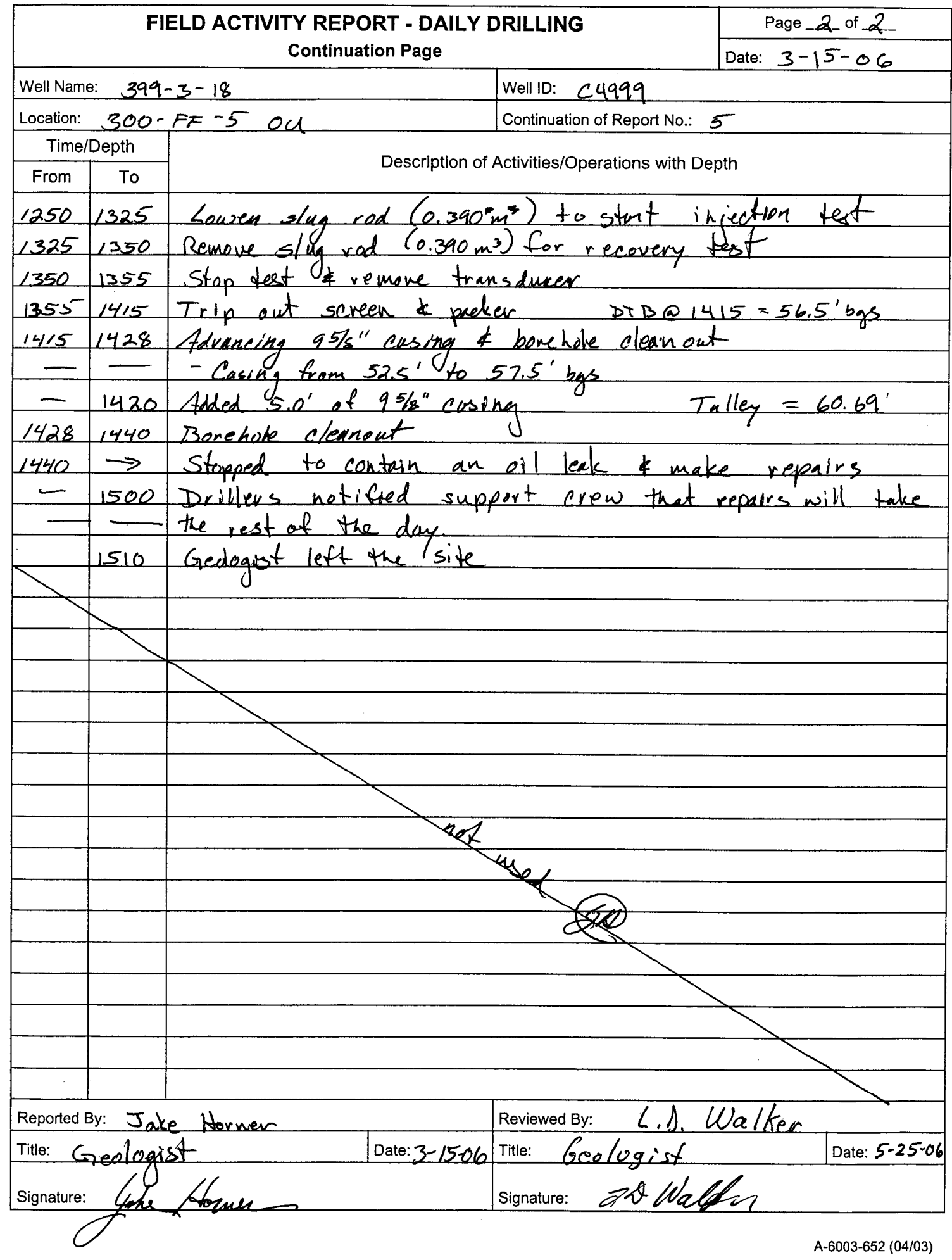




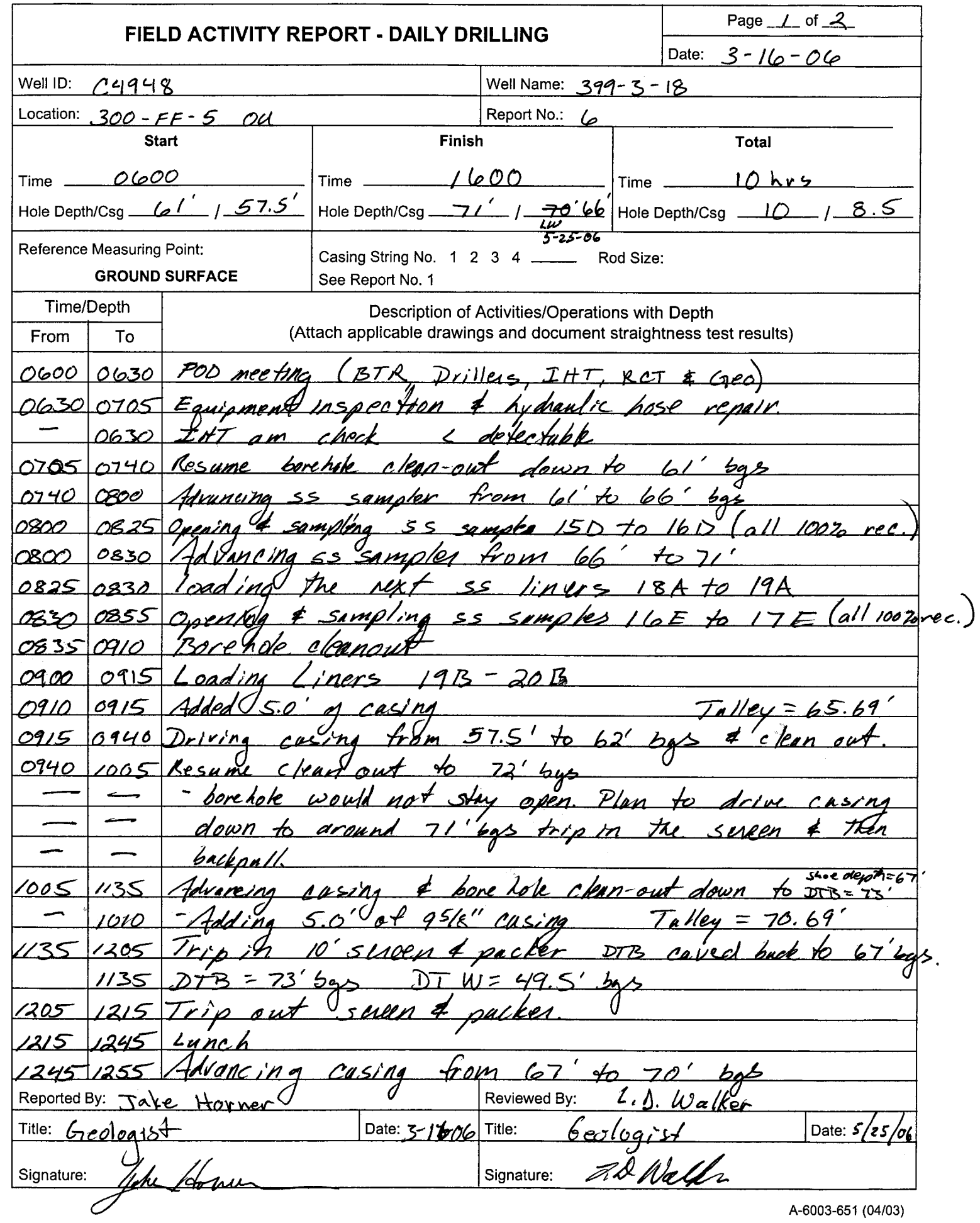




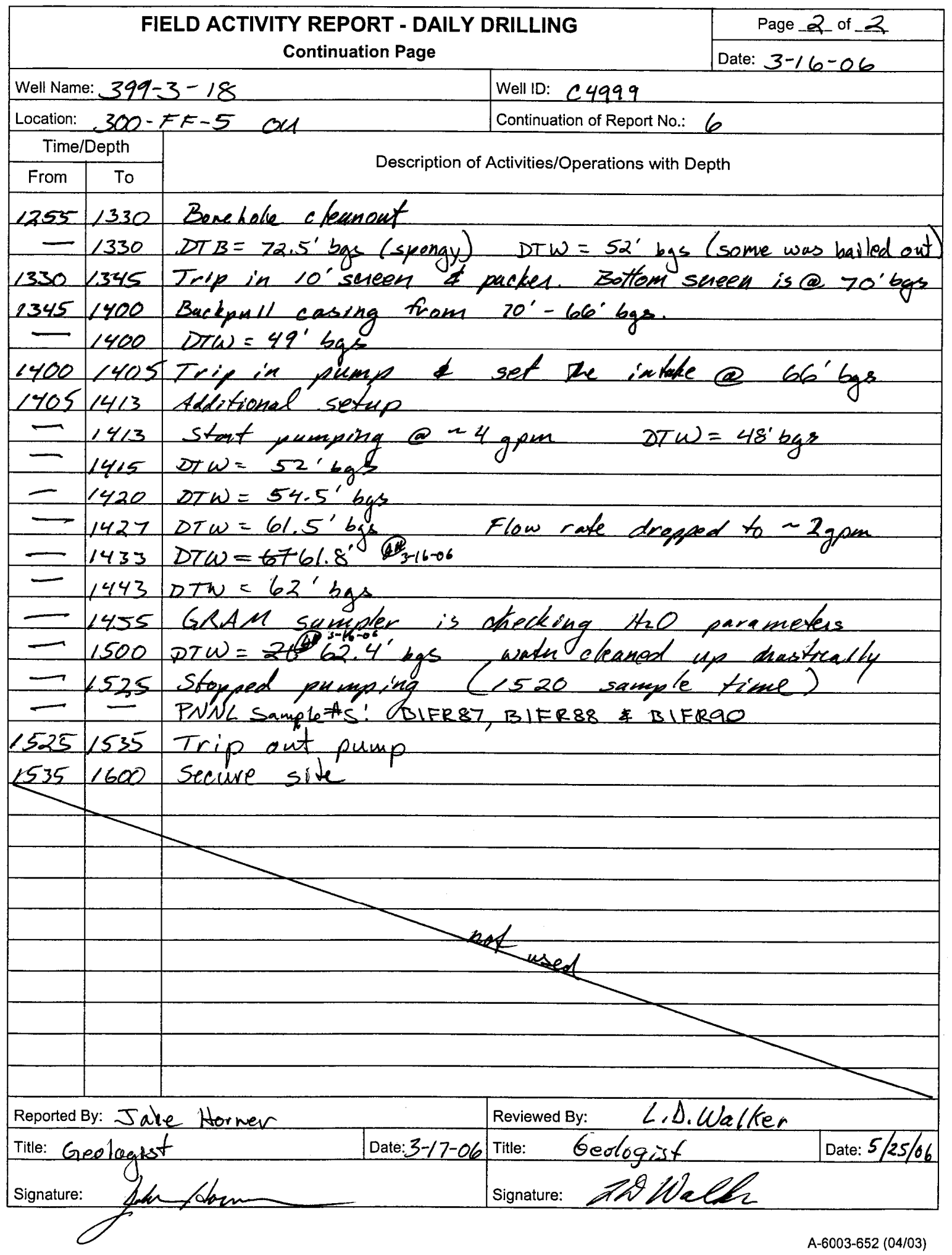




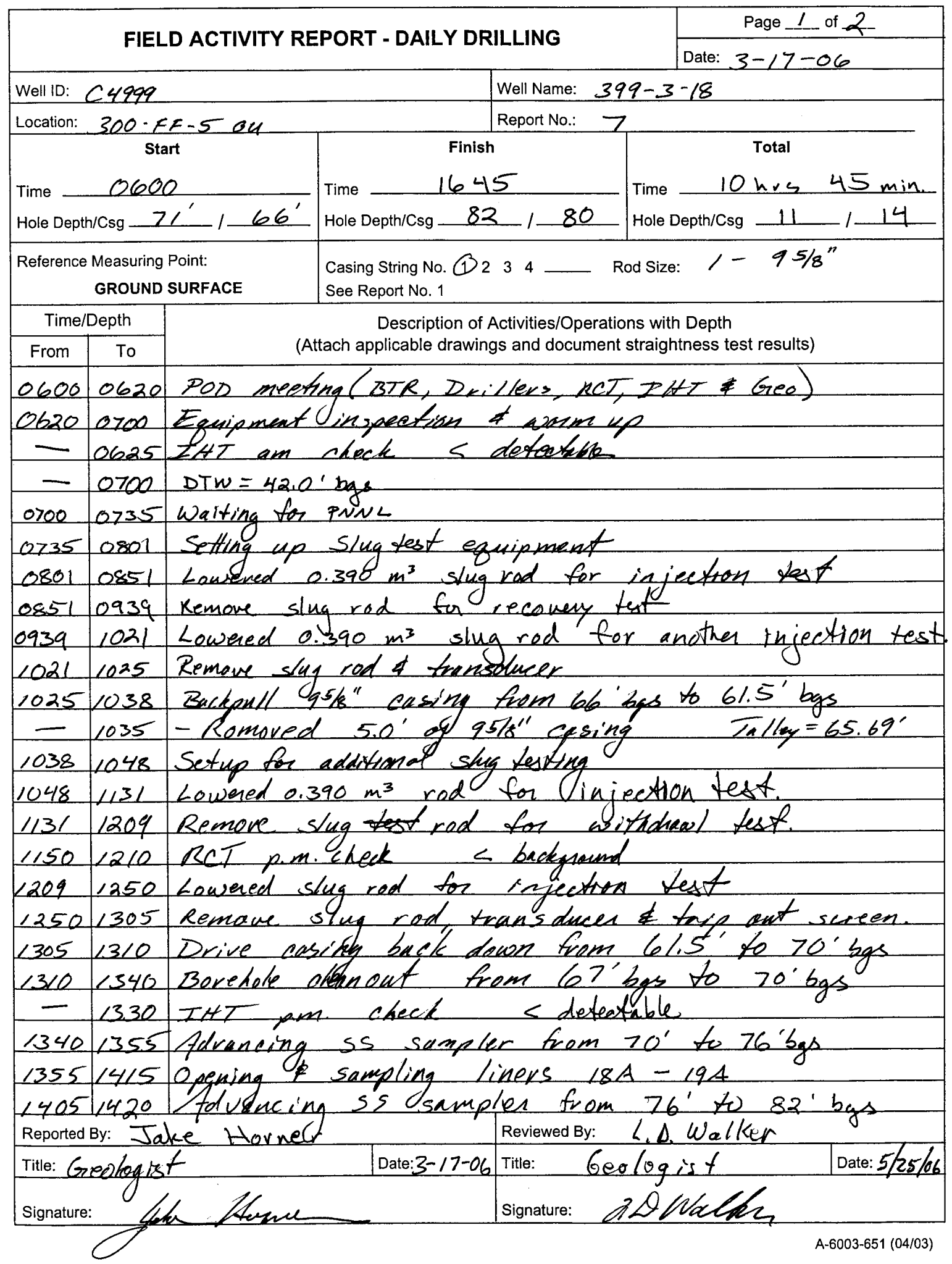




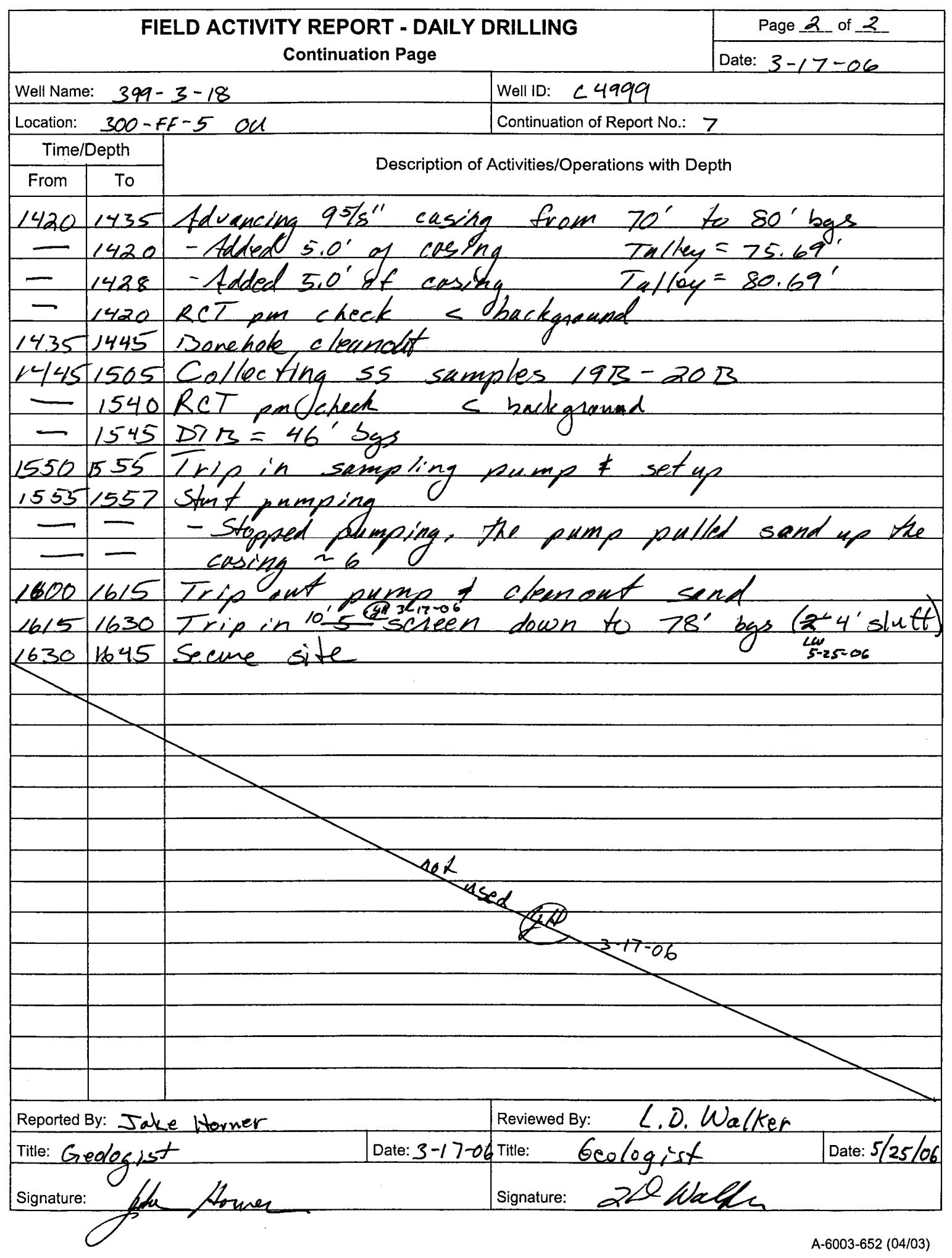




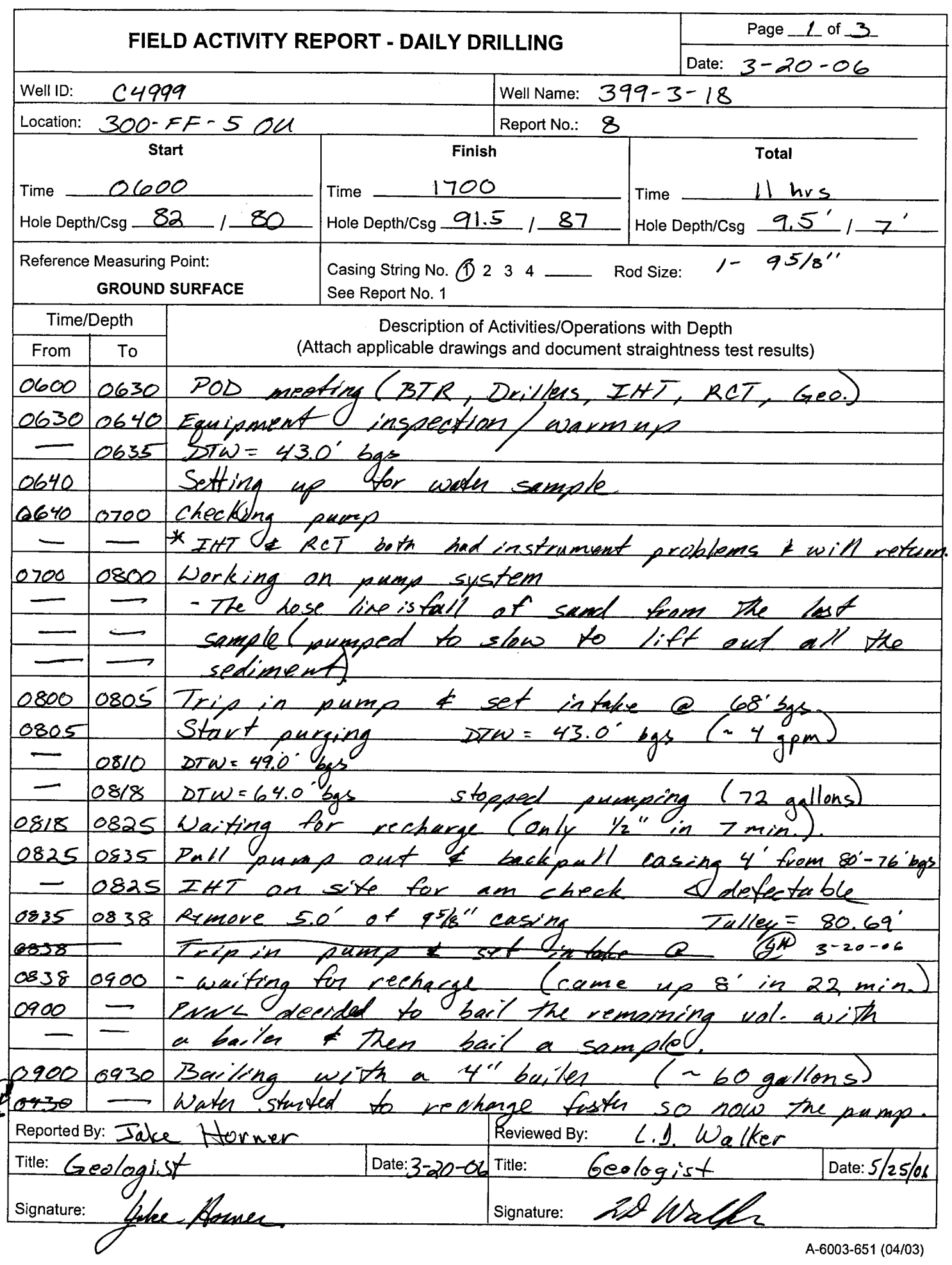




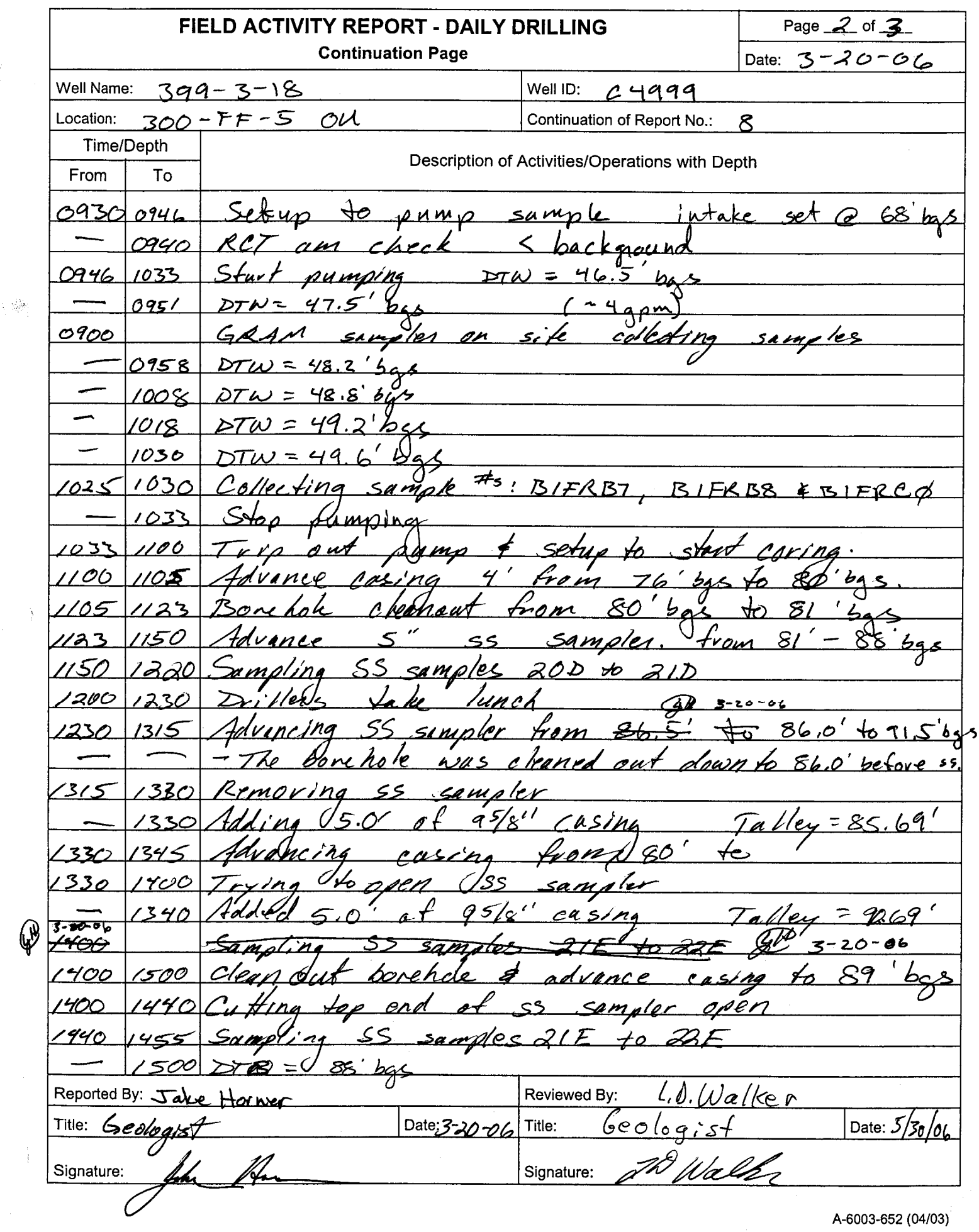




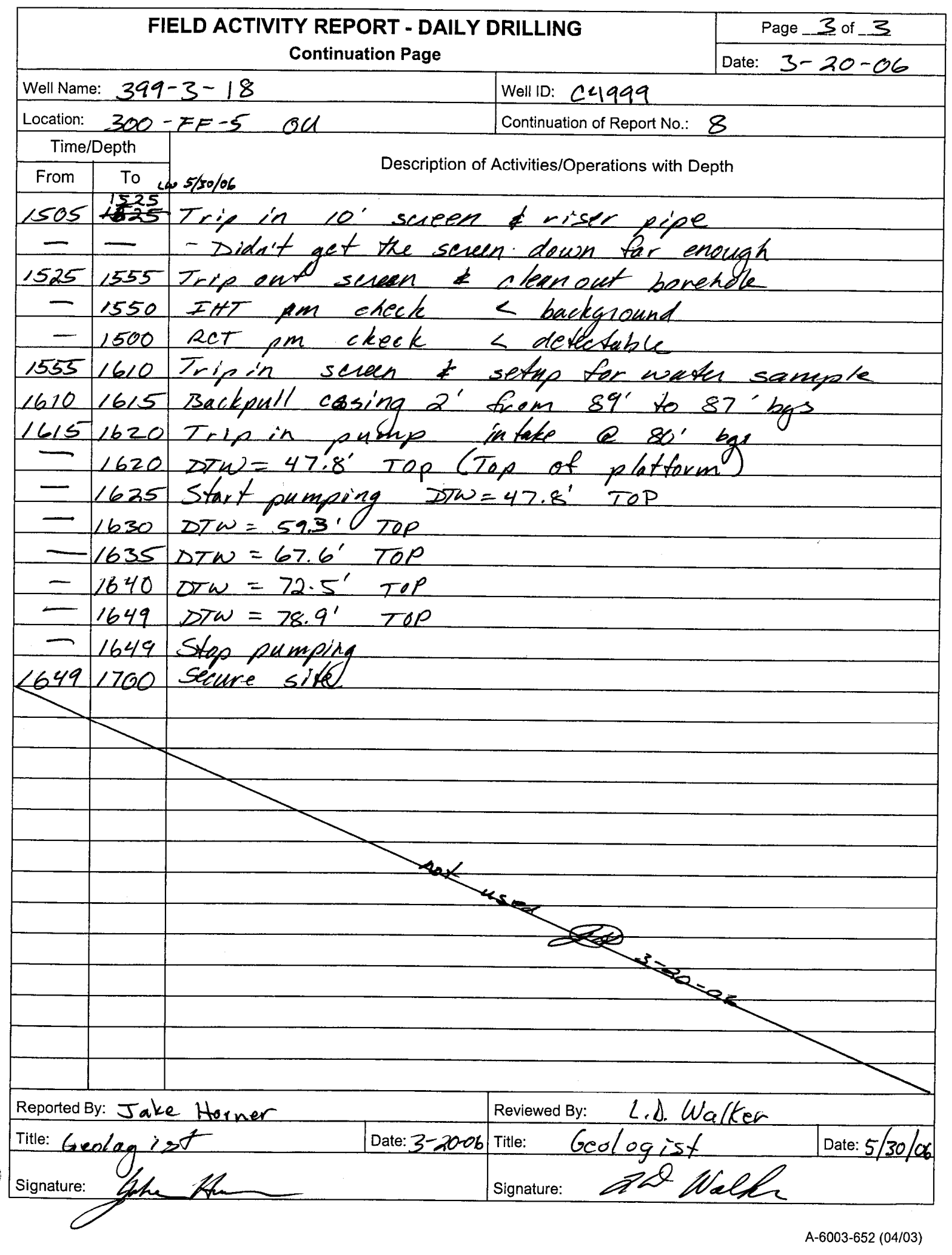




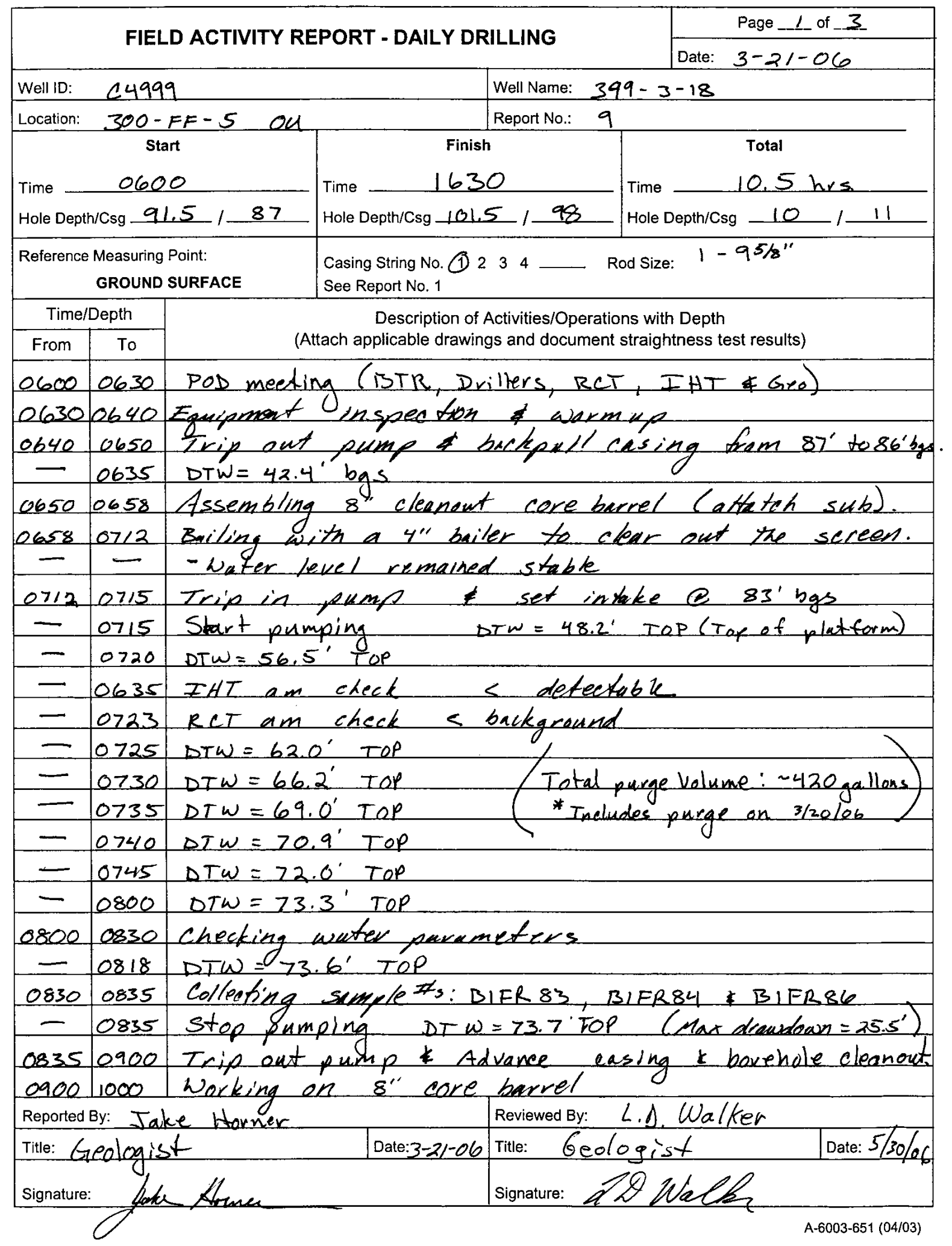




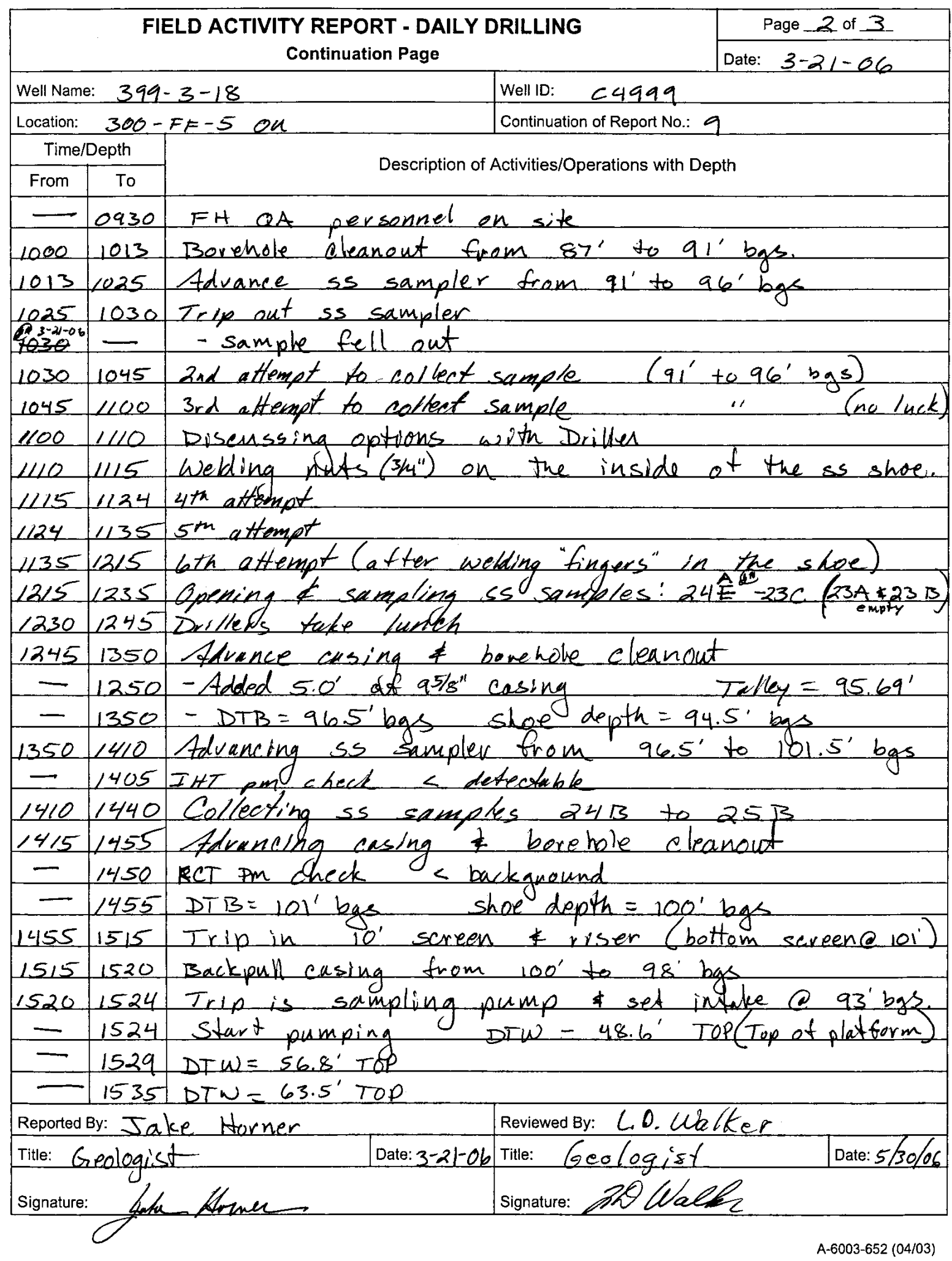




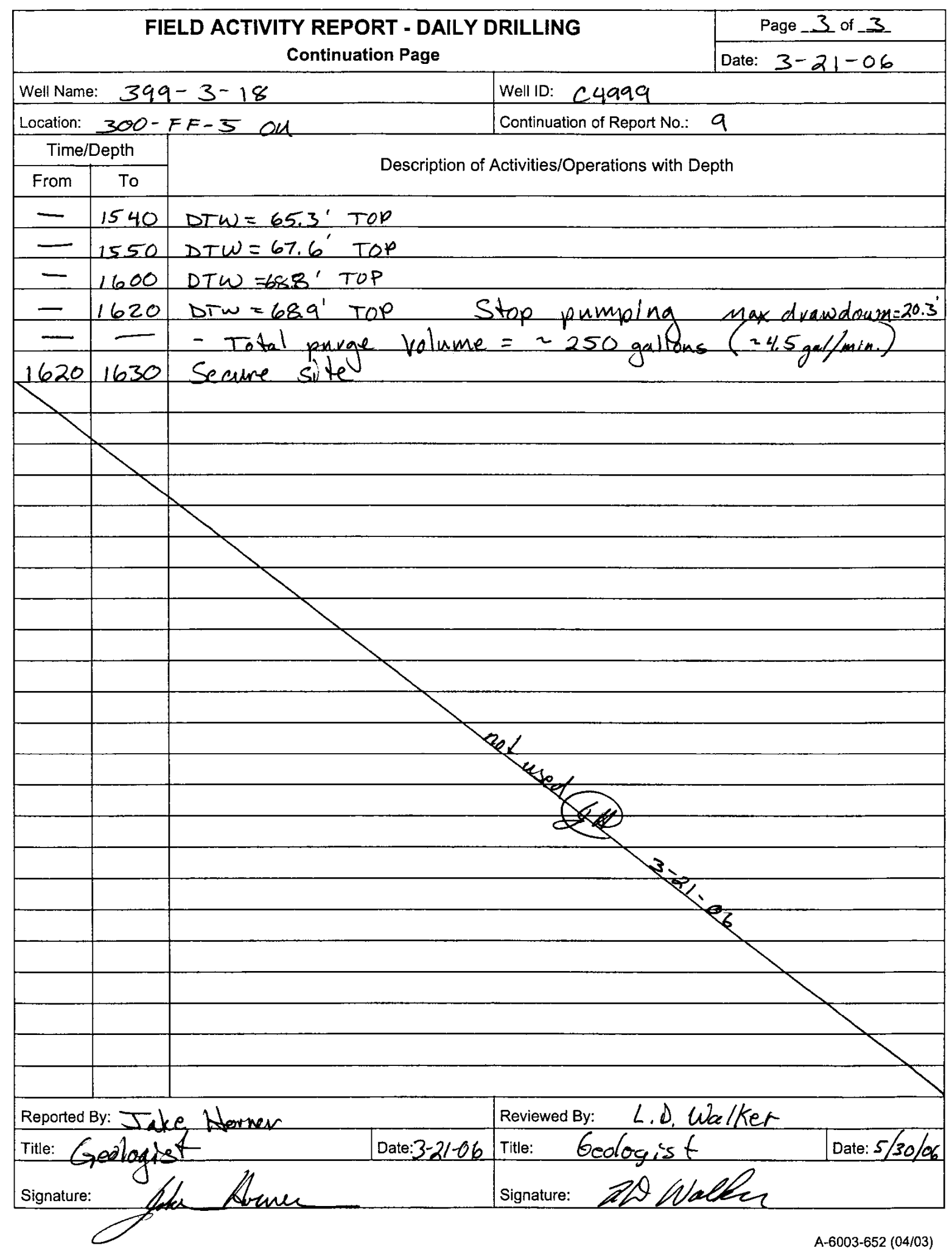




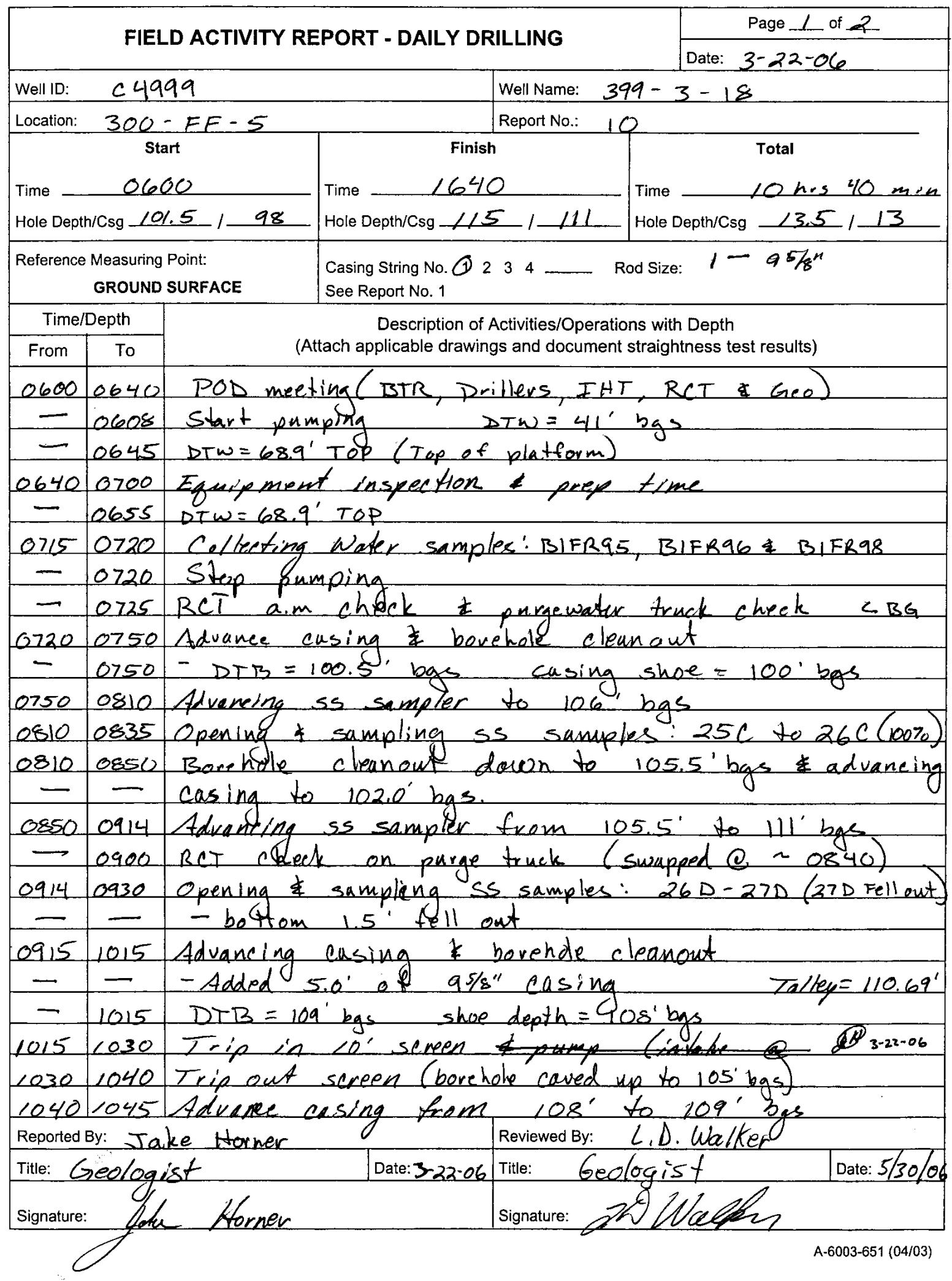




\begin{tabular}{|c|c|c|c|c|}
\hline \multirow{2}{*}{\multicolumn{4}{|c|}{$\begin{array}{l}\text { FIELD ACTIVITY REPORT - DAILY DRILLING } \\
\text { Continuation Page }\end{array}$}} & Page 2 of 2 \\
\hline & & & & Date: $3-22-06$ \\
\hline \multicolumn{3}{|c|}{ Well Name: $399-3-18$} & Well ID: & \\
\hline \multicolumn{3}{|c|}{ Location: $300-F E-5$ od } & Continuation & 10 \\
\hline \multicolumn{2}{|c|}{ Time/Depth } & \multirow{2}{*}{\multicolumn{3}{|c|}{ Description of Activities/Operations with Depth }} \\
\hline \multirow{2}{*}{$\begin{array}{l}\text { From } \\
1045\end{array}$} & \multirow{2}{*}{ To } & & & \\
\hline & & \multirow{2}{*}{\multicolumn{3}{|c|}{$\begin{array}{l}\text { Borehole cleanout down to } 109.3^{\prime} \mathrm{bg} \text { ' } \\
\text {-used a } 4^{\prime \prime} \text { sand pump from } 108^{\prime} \text { to } 109.3^{\prime} \text { bgs }\end{array}$}} \\
\hline- & $\longrightarrow$ & & & \\
\hline 1125 & 1135 & \multicolumn{3}{|c|}{ Trip in screen } \\
\hline $1 / 35$ & 1140 & \\
\hline 1140 & $1 / 48$ & \multicolumn{3}{|c|}{ Trip in sampling pump set intuke Q } \\
\hline- & 1149 & \multicolumn{3}{|c|}{ Start pumping DTw $=47.3^{\prime}$ TRP } \\
\hline 一 & 1154 & \multicolumn{3}{|c|}{ DT $\omega=55.5^{\circ}$ Top } \\
\hline - & 1300 & \multicolumn{3}{|l|}{$D T \omega=57.2^{\circ}$ TOP } \\
\hline- & 1205 & \multicolumn{3}{|l|}{$D T \omega=57.5^{\prime}$ TOP } \\
\hline - & 12.5 & \multicolumn{3}{|l|}{$D T \omega=57.7$ TOP } \\
\hline - & 1238 & \multicolumn{3}{|c|}{$D T \omega=58.2$ TOP } \\
\hline- & 1320 & \multicolumn{3}{|c|}{ IHI check < detectable } \\
\hline 1405 & 1410 & \multicolumn{3}{|c|}{ Collecting water samples: $B|F R>9, B| F R 80$ \&IFR82 } \\
\hline - & 1410 & \multicolumn{3}{|c|}{ Stop pumping $D T W=58.5^{\circ}$ TOP } \\
\hline 1410 & 1425 & \multicolumn{3}{|c|}{ Trip out pump \& screen } \\
\hline 1425 & 1440 & \multirow{3}{*}{\multicolumn{3}{|c|}{$\begin{array}{l}\text { Adrancing } 55 \text { sampler from } 109^{\prime} \text { to } 115^{\prime} \text { bges } \\
\text { Sampling sS samples: } 275 \text { to } 28 E \text { (28E on ly } 80 \%)\end{array}$}} \\
\hline 1440 & 1505 & & & \\
\hline 1445 & 1620 & & & \\
\hline 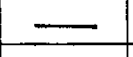 & 1920 & \multicolumn{3}{|c|}{$-D T B=114^{\prime}$ bgs shoe depth $=111^{\prime}$ bgs } \\
\hline 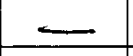 & 1540 & \multicolumn{3}{|c|}{ RCT pm check } \\
\hline 1620 & 1640 & \multirow{3}{*}{\multicolumn{3}{|c|}{$\begin{array}{l}\text { Advaneing is simpler from } 114^{\prime} \text { to } 118^{\prime} \text { bgs } \\
-3^{\prime} \text { fell out }\left(115^{\prime}-118^{\prime} \text { ing }\right) \text { (next attempt } 3 / 23 / 06 \\
\text { secure site }\end{array}$}} \\
\hline- & - & & & \\
\hline \multirow[t]{5}{*}{$\angle 640$} & 1650 & & & \\
\hline & & & & \\
\hline & & & & \\
\hline & & & & \\
\hline & & & & \\
\hline Reported $\mathrm{E}$ & 3y: Jo & e Horner & Reviewed B & Walker \\
\hline Title: Ge & edloges & Date: $3-22-06$ & & Date: $5 / 30 / 06$ \\
\hline & & & Signature: & ets \\
\hline
\end{tabular}




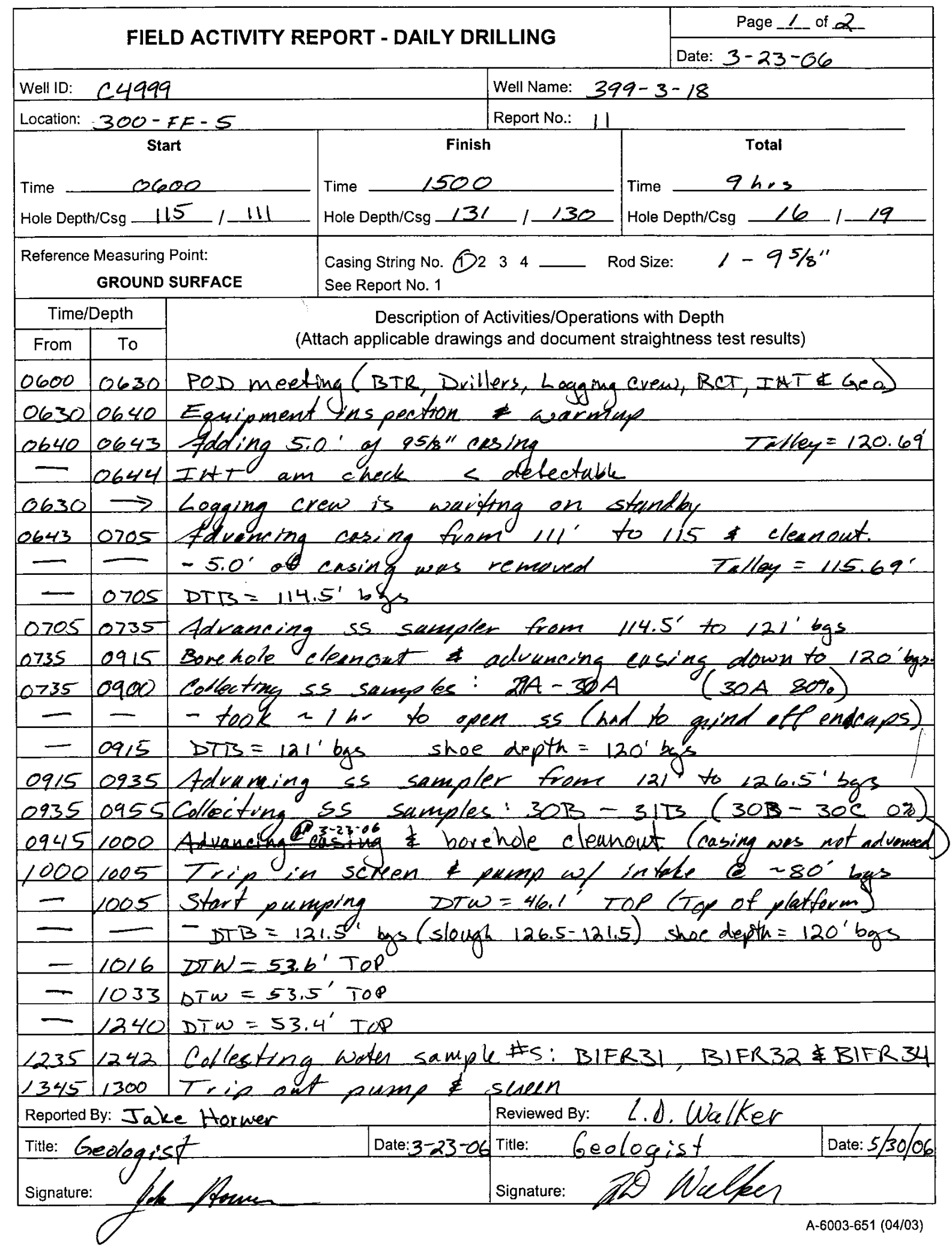




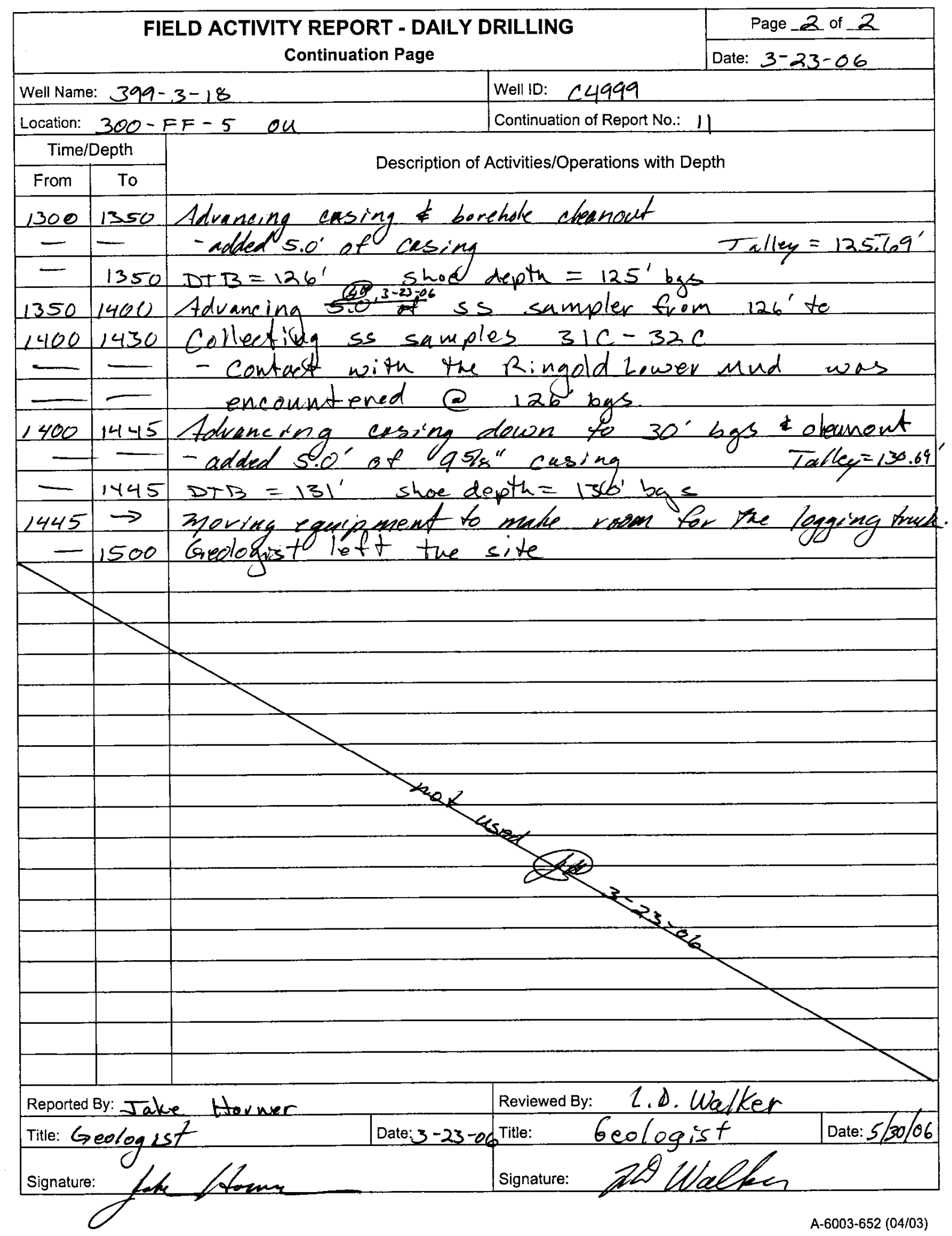




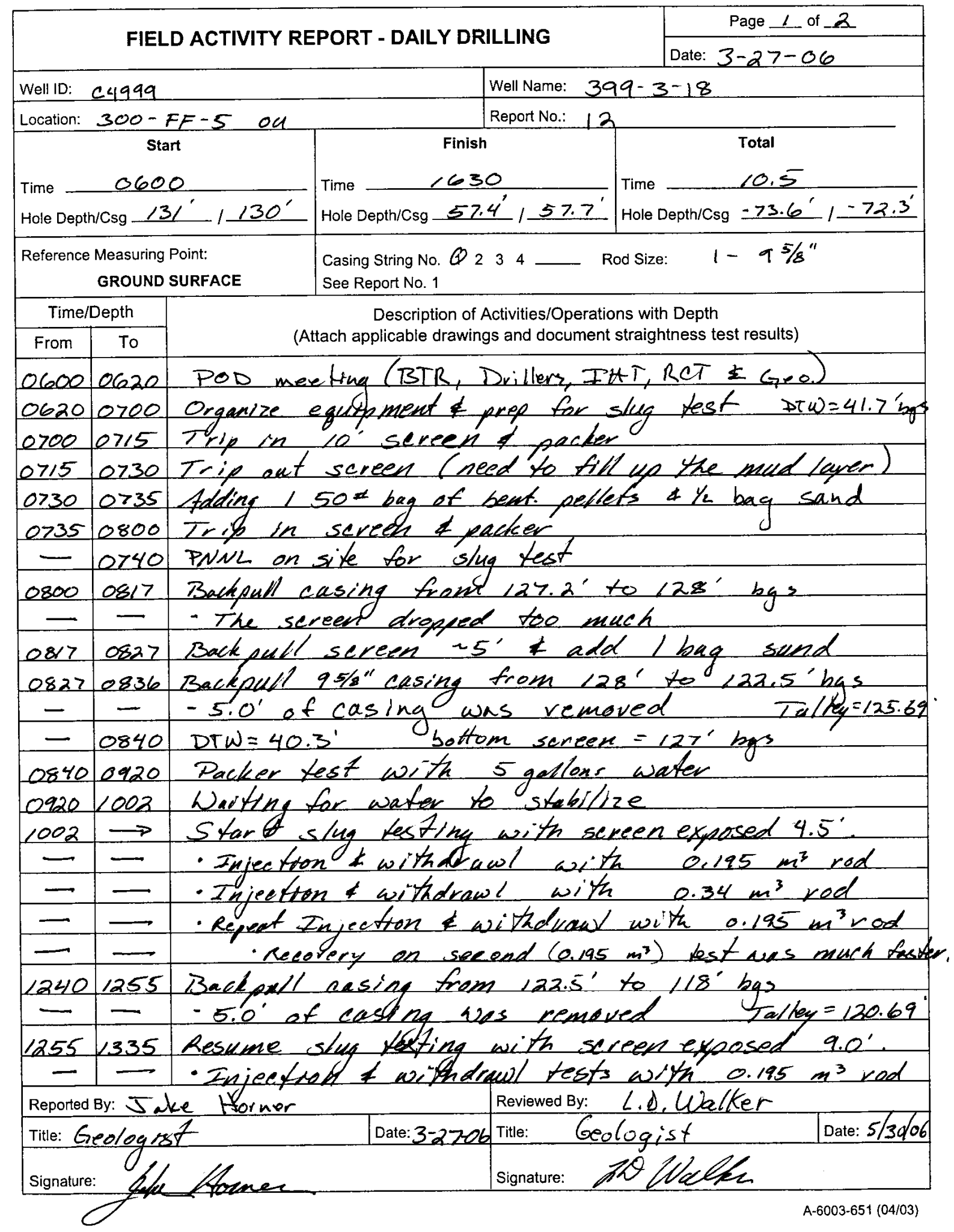




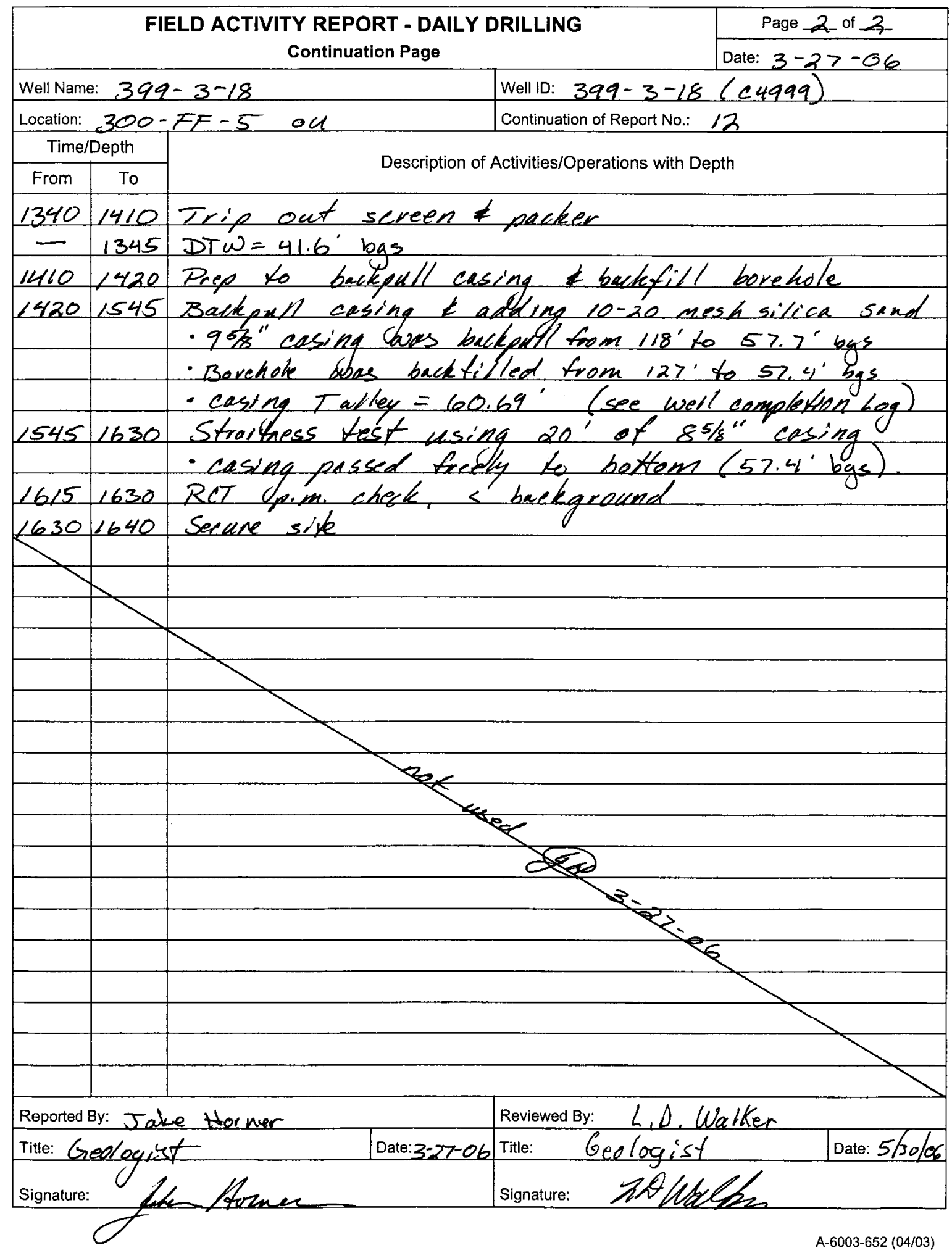




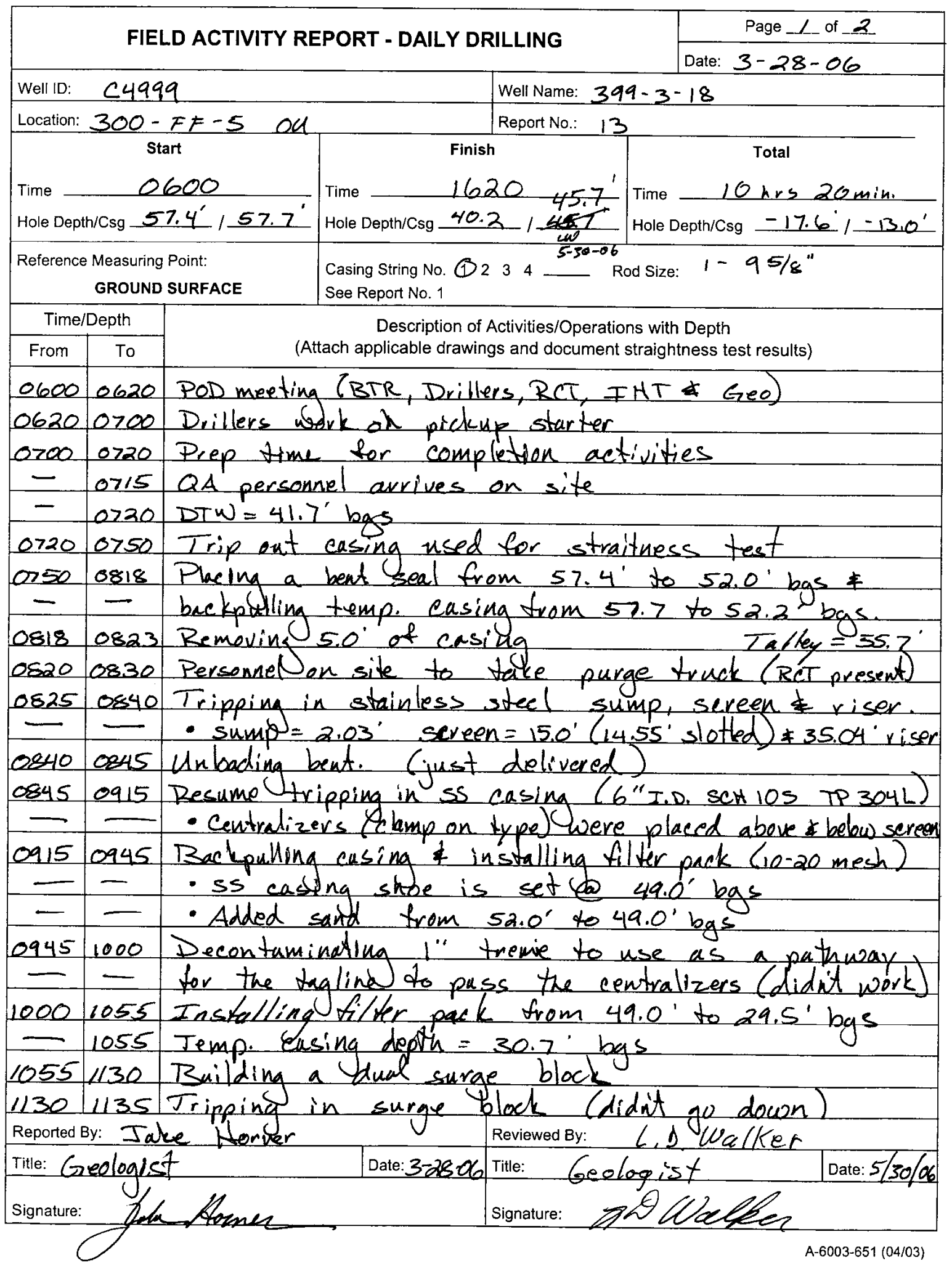




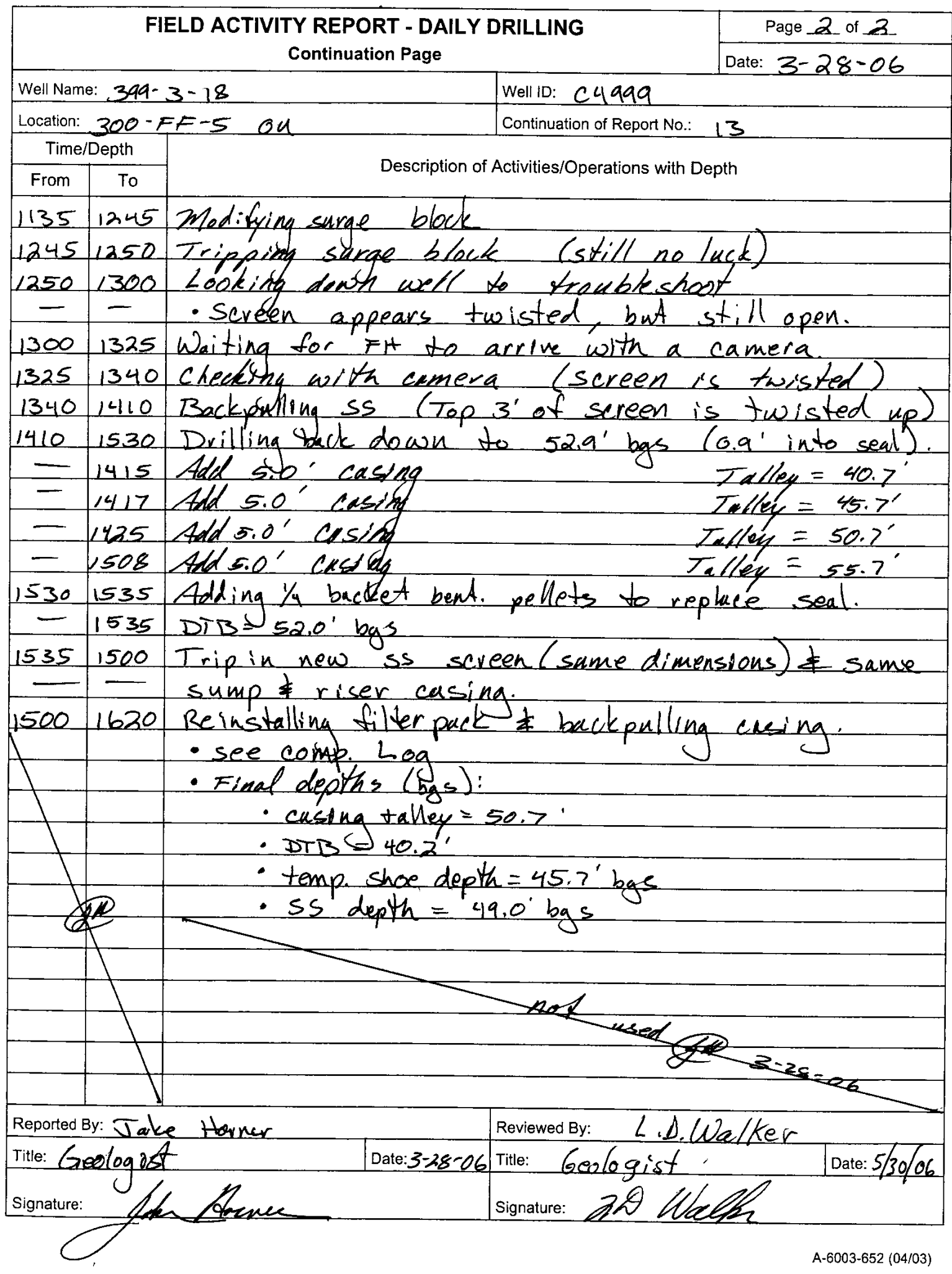




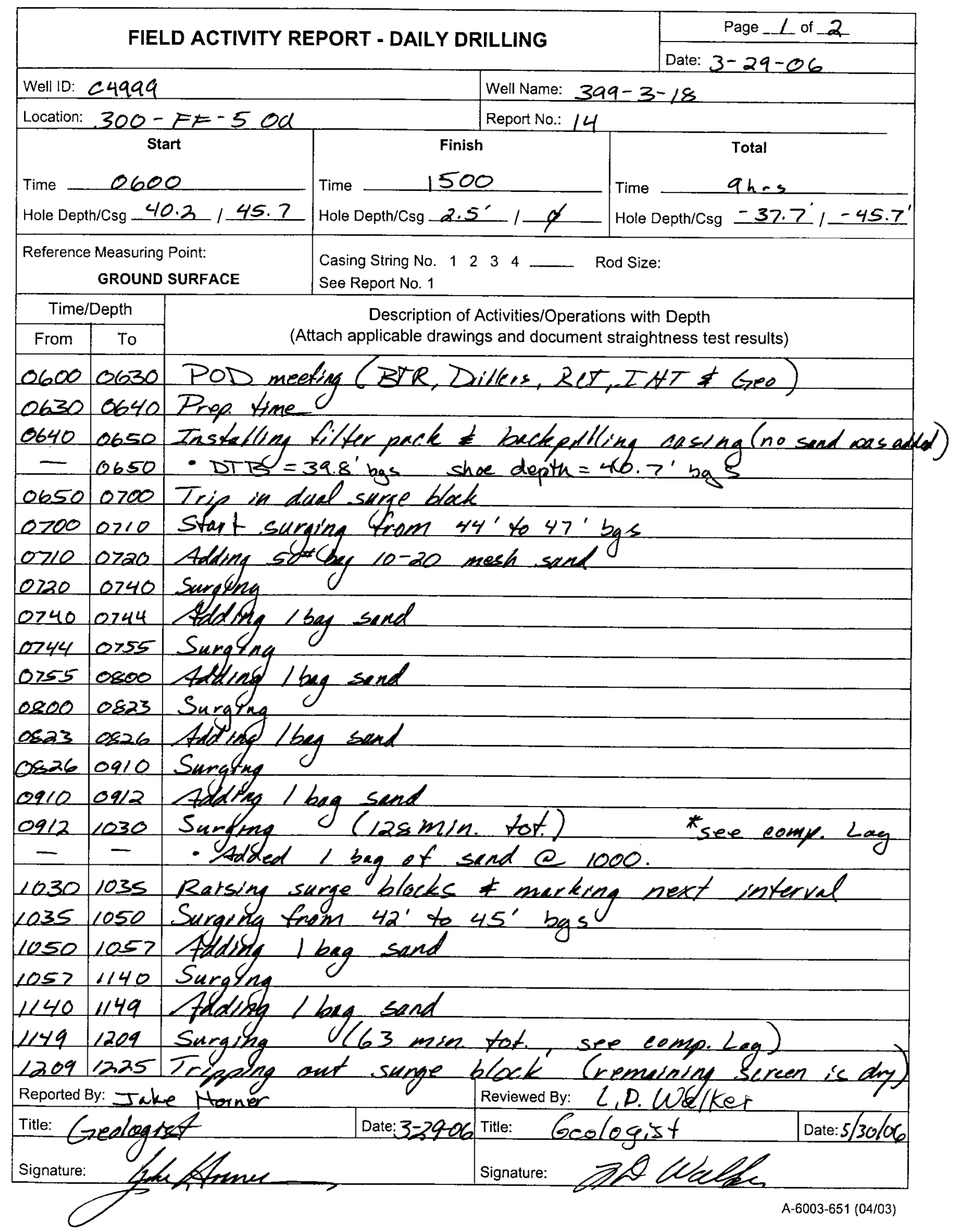




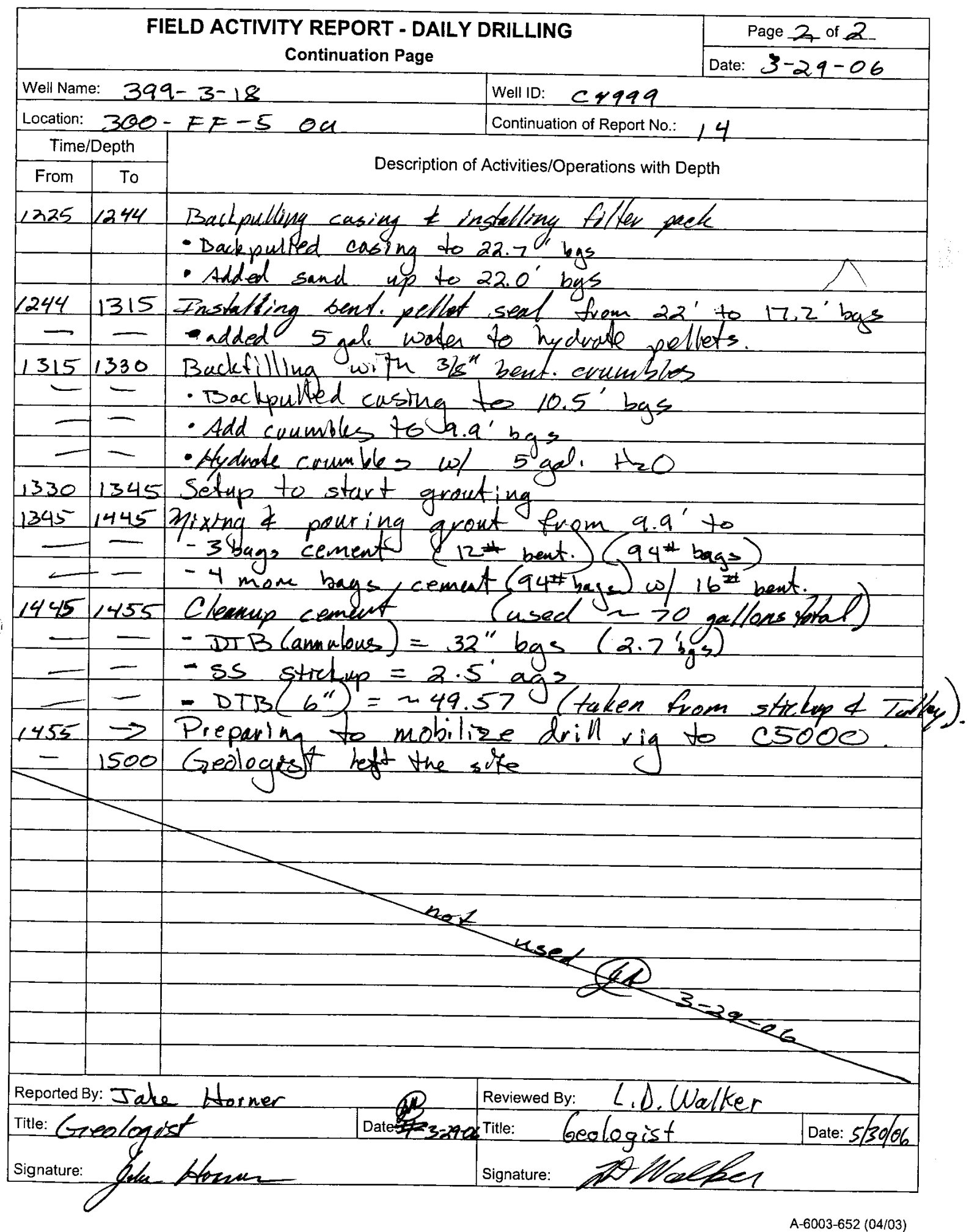




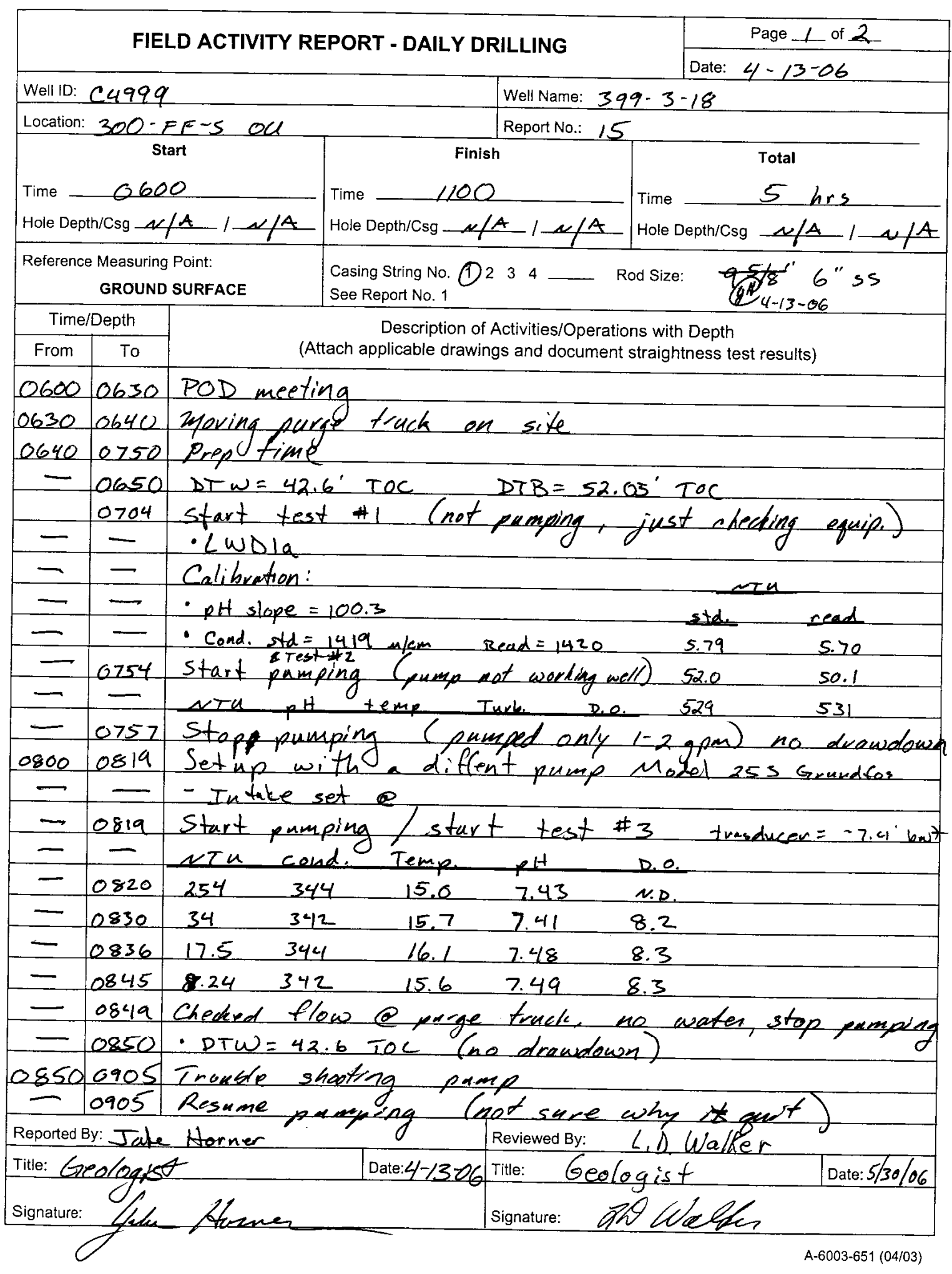




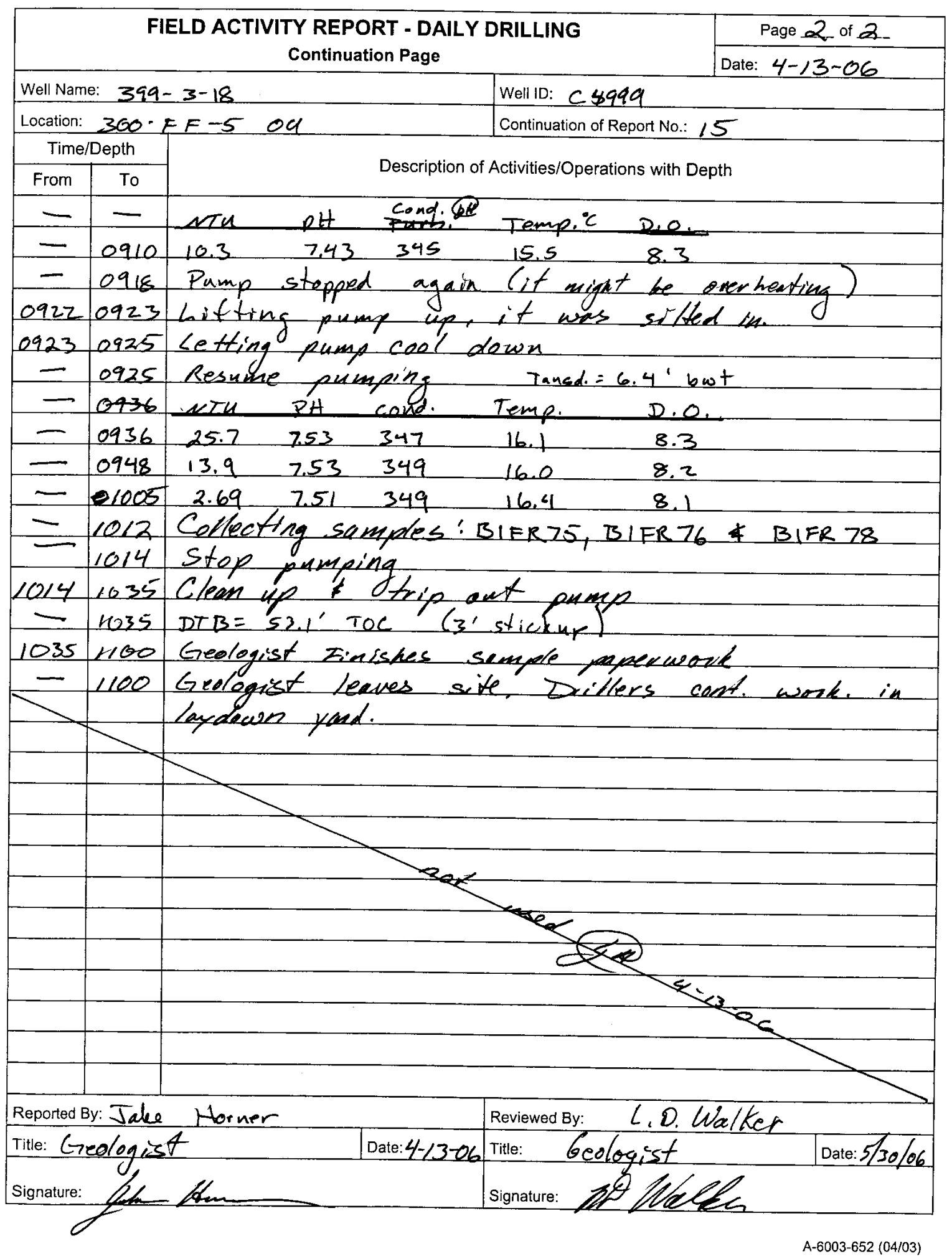




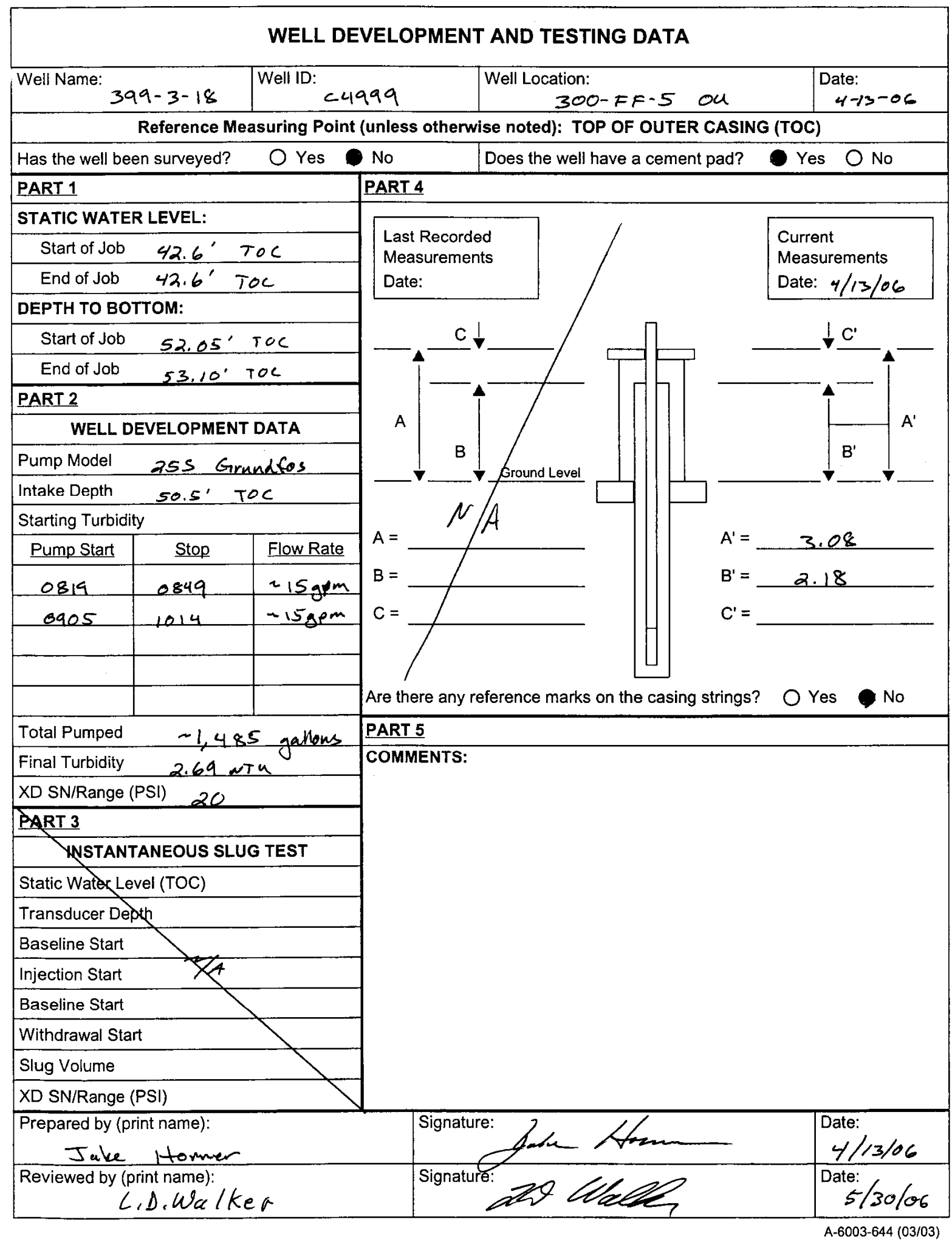




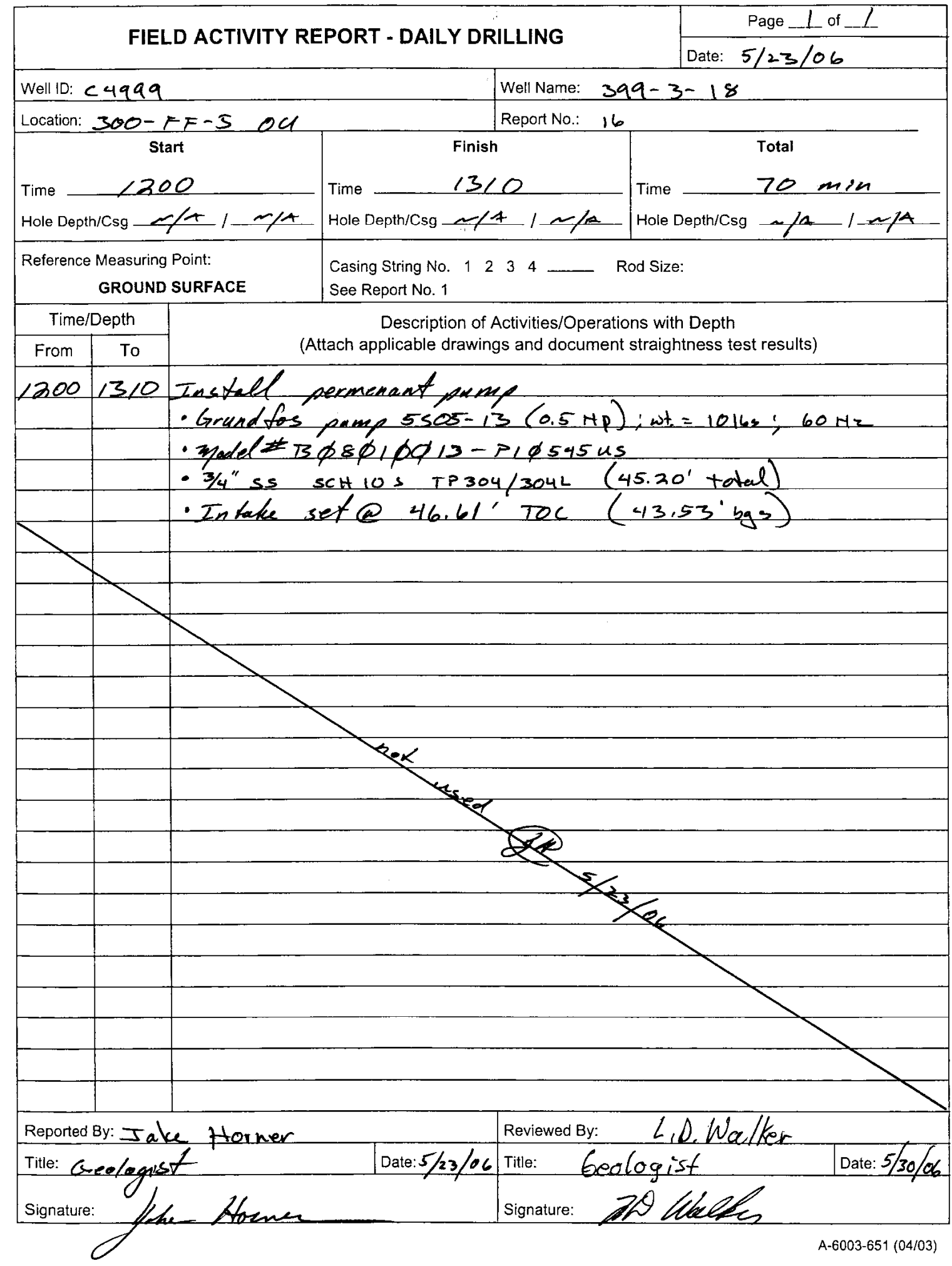




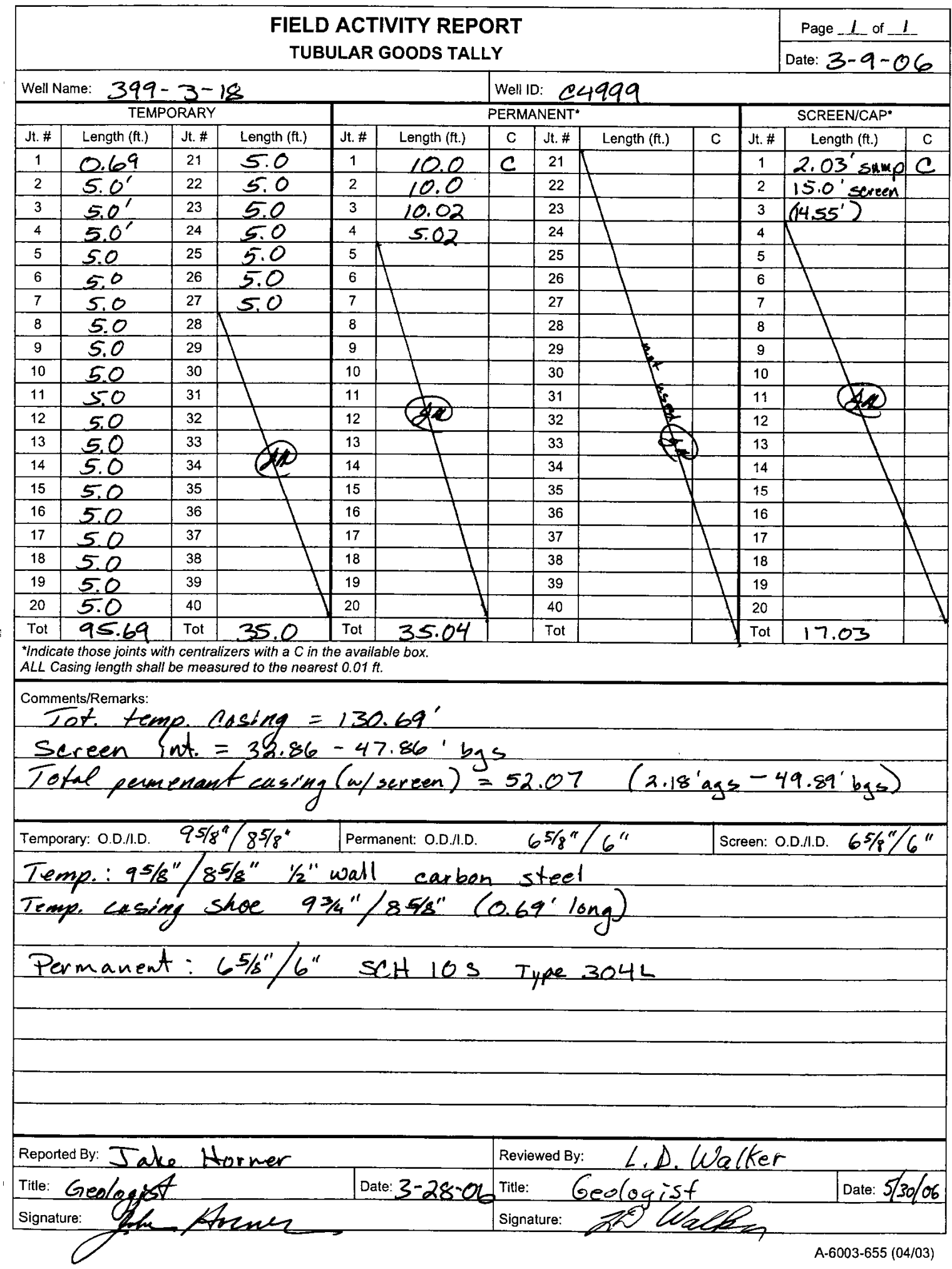




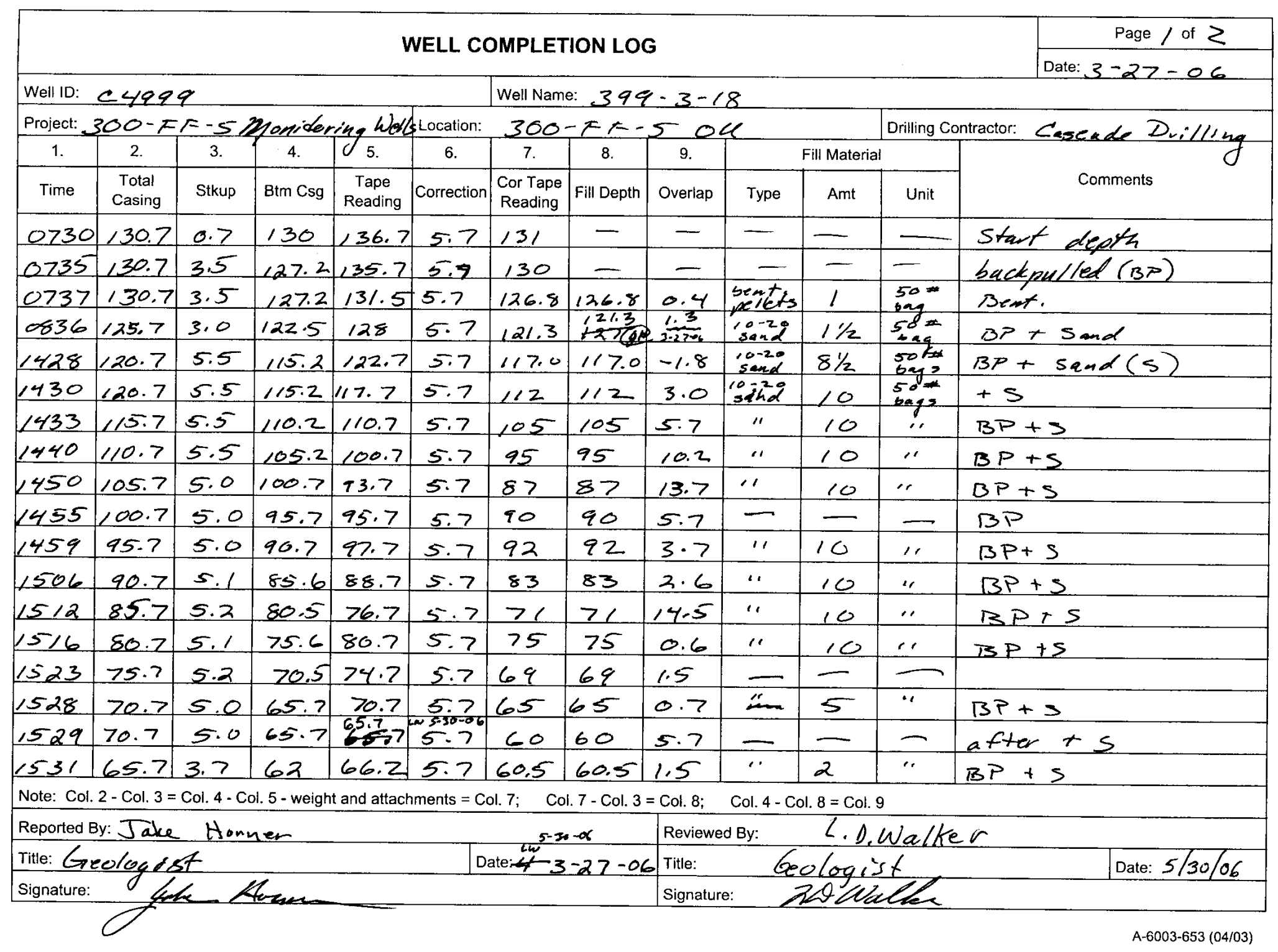




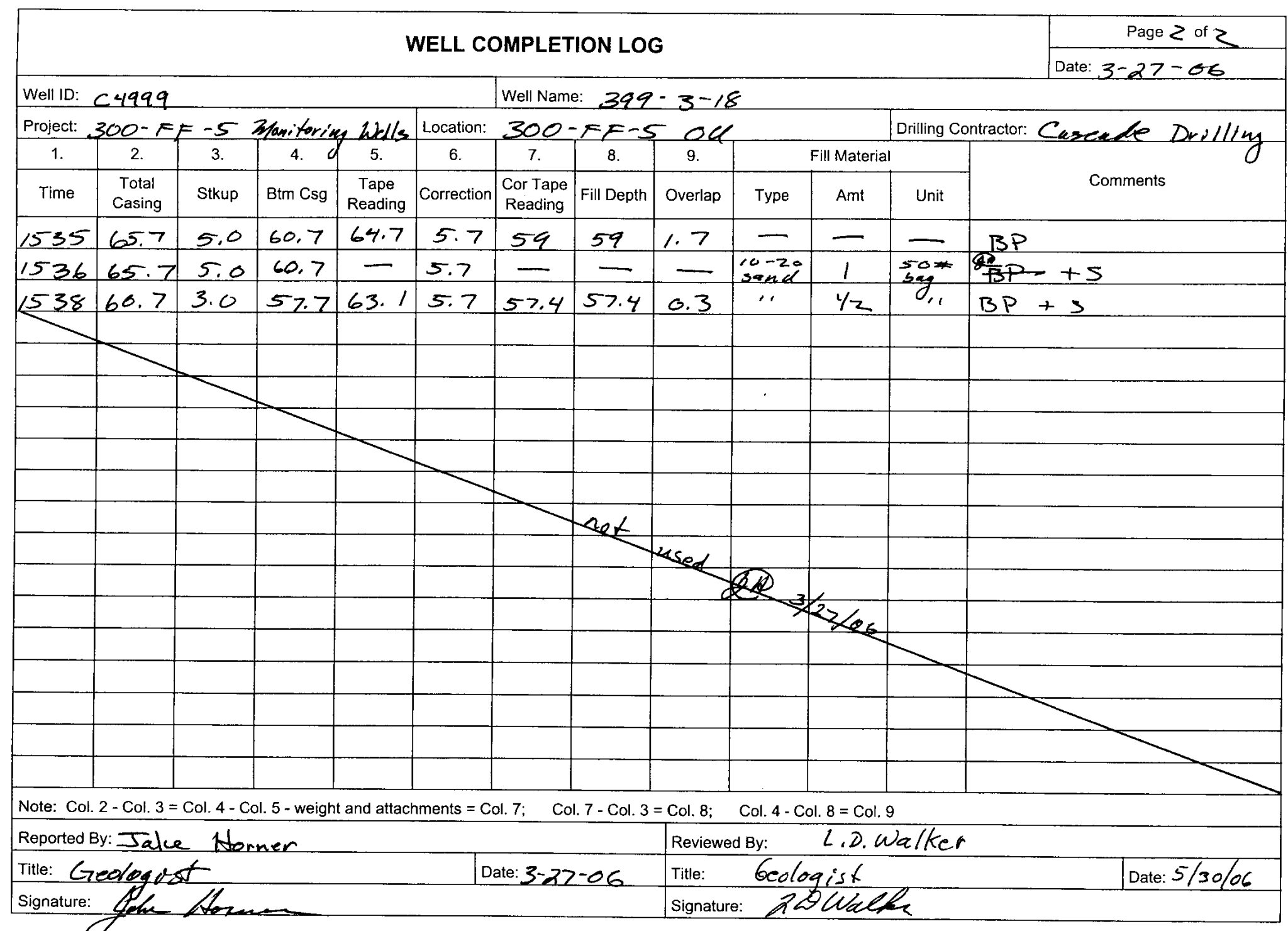


WELL COMPLETION LOG

Page 1 of 2 Date: $3-28-06$

\begin{tabular}{|c|c|c|c|c|c|c|c|c|c|c|c|c|}
\hline \multicolumn{6}{|c|}{ Well ID: C4999 } & \multicolumn{7}{|c|}{ Well Name: $\quad 399-3-18$} \\
\hline \multirow{2}{*}{$\frac{\text { Project: }}{1 .}$} & \multirow{2}{*}{$\frac{E=-5}{2 .}$} & \multicolumn{2}{|c|}{ Monitoring } & \multirow{2}{*}{$\frac{\text { wells }}{5 .}$} & \multirow{2}{*}{\begin{tabular}{|c} 
Location: \\
6.
\end{tabular}} & \multicolumn{3}{|c|}{$300-F F-S$} & \multicolumn{2}{|c|}{ or } & \multicolumn{2}{|c|}{ Drilling Contractor: Cascade Drillsug } \\
\hline & & 3. & 4 & & & 7. & 8. & 9. & \multicolumn{3}{|c|}{ Fill Material } & \multirow{2}{*}{ wescale suering } \\
\hline Time & \begin{tabular}{|c|} 
Total \\
Casing \\
\end{tabular} & Stkup & Btm Csg & \begin{tabular}{c|} 
Tape \\
Reading
\end{tabular} & Correction & $\begin{array}{l}\text { Cor Tape } \\
\text { Reading }\end{array}$ & Fill Depth & Overlap & Type & Amt & Unit & \\
\hline 0757 & 60.7 & 3.0 & 57.7 & 63,1 & 5.7 & 52.4 & 57.4 & 0.3 & - & $\longrightarrow$ & - & Start depths \\
\hline 0800 & 60.7 & 3.0 & 57.7 & 62.0 & 6.0 & 56.0 & 56.0 & 1.7 & bentifts & 1 & Sgathet & Tug a fter pellets (78" coated \\
\hline 0803 & 60.7 & 4.0 & 56,7 & 62.4 & 6.0 & 56,4 & 56.4 & 0.3 & - & $\longrightarrow$ & - & $B^{9}$ \\
\hline 0805 & 60.7 & 4.0 & 56.7 & 60.8 & 6.0 & $5 \% .8$ & $54 \cdot 8$ & 1.9 & $"$ & 1 & 11 & $+B$ \\
\hline 0807 & 60.7 & 5.3 & 55.4 & 60.9 & 6.0 & 54.9 & 54.9 & 0.5 & - & $\longrightarrow$ & - & \\
\hline 0809 & 60.7 & 5.3 & 55.4 & 60.0 & 6.0 & 54.0 & 54.0 & 1.4 & $\because$ & $1 / 2$ & $" 1$ & \\
\hline $08 / 0$ & 60.7 & 7.0 & $53 \cdot 7$ & 60.1 & 6.0 & 54.1 & 54.1 & -0.4 & - & $\longrightarrow$ & $=$ & \\
\hline 0811 & 60.7 & 7.0 & 53.7 & 59.5 & 6.0 & 53.5 & 53.5 & -6.2 & 11 & $1 / 2$ & 11 & \\
\hline 0813 & 60.7 & 8.5 & $52 \cdot 2$ & 59.9 & 6.0 & 53,9 & 53.9 & -1.7 & $=$ & - & - & \\
\hline 0814 & 60.7 & 8.5 & $52 \cdot 2$ & 59.9 & 6.0 & 53.9 & 53.9 & -1.7 & - & $\longrightarrow$ & $\longrightarrow$ & $?$ \\
\hline 0815 & 60.7 & 8.5 & 52.2 & 58.4 & 6.0 & 52.4 & 52.4 & -0.2 & a & $1 / 3$ & " & \\
\hline 0818 & 60.7 & 8.5 & 52.2 & 58.0 & 6.0 & 52.0 & 52.0 & 0.2 & " & $1 / 3$ & "I & \\
\hline 0925 & 55.7 & 3.5 & $52 \cdot 2$ & 55.0 & 6.0 & 49.0 & 49.0 & 3.0 & $\begin{array}{l}10-20 \\
\text { samel }\end{array}$ & 2.5 & $\begin{array}{l}507 \\
\text { Sugs }\end{array}$ & \\
\hline 1010 & 53,7 & 5.2 & 50.5 & 370 & 6.0 & 31.0 & 31.0 & 19.5 & 10 & 6 & $\phi$ & \\
\hline 1014 & 50.7 & 5.0 & 45.7 & 39.0 & 6.0 & 33.0 & 33.0 & 12.7 & - & $\longrightarrow$ & $\longrightarrow$ & \\
\hline 1017 & 50.7 & 5.0 & 45.7 & 35.0 & 6.0 & 29.0 & 29.0 & 16.7 & " & 4 & or & \\
\hline 1020 & 50.7 & 7.5 & 43.2 & 33.0 & 6.0 & 27.0 & 27.0 & $16 \cdot 2$ & 16 & 2 & $"$ & \\
\hline 1030 & 45.7 & 5.0 & 40.7 & 37.5 & 6.0 & 31.5 & $3 / .5$ & 9.2 & $\longrightarrow$ & 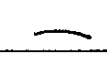 & $=$ & \\
\hline Note: Col. & $2-\mathrm{Col} .3$ & 1. $4-c$ & 5 -weigh & tt and attach & hments $=\mathrm{C}$ & Col. 7; Col & 1.7 - Col. 3 & $=$ Col. 8; & Col. 4 - & $8=\mathrm{Col}$. & & \\
\hline Reported & By: Jal & Ho & knee & & & & & Reviewe & d By: & 1.0 .6 & aller & \\
\hline Title: $G_{70}$ & & & & & & Date: $3-25$ & $8-36$ & Title: & Geolo & ist & & Date: $5 / 30 / 06$ \\
\hline Signature: & 4 he & & & & & & & & & & & \\
\hline
\end{tabular}




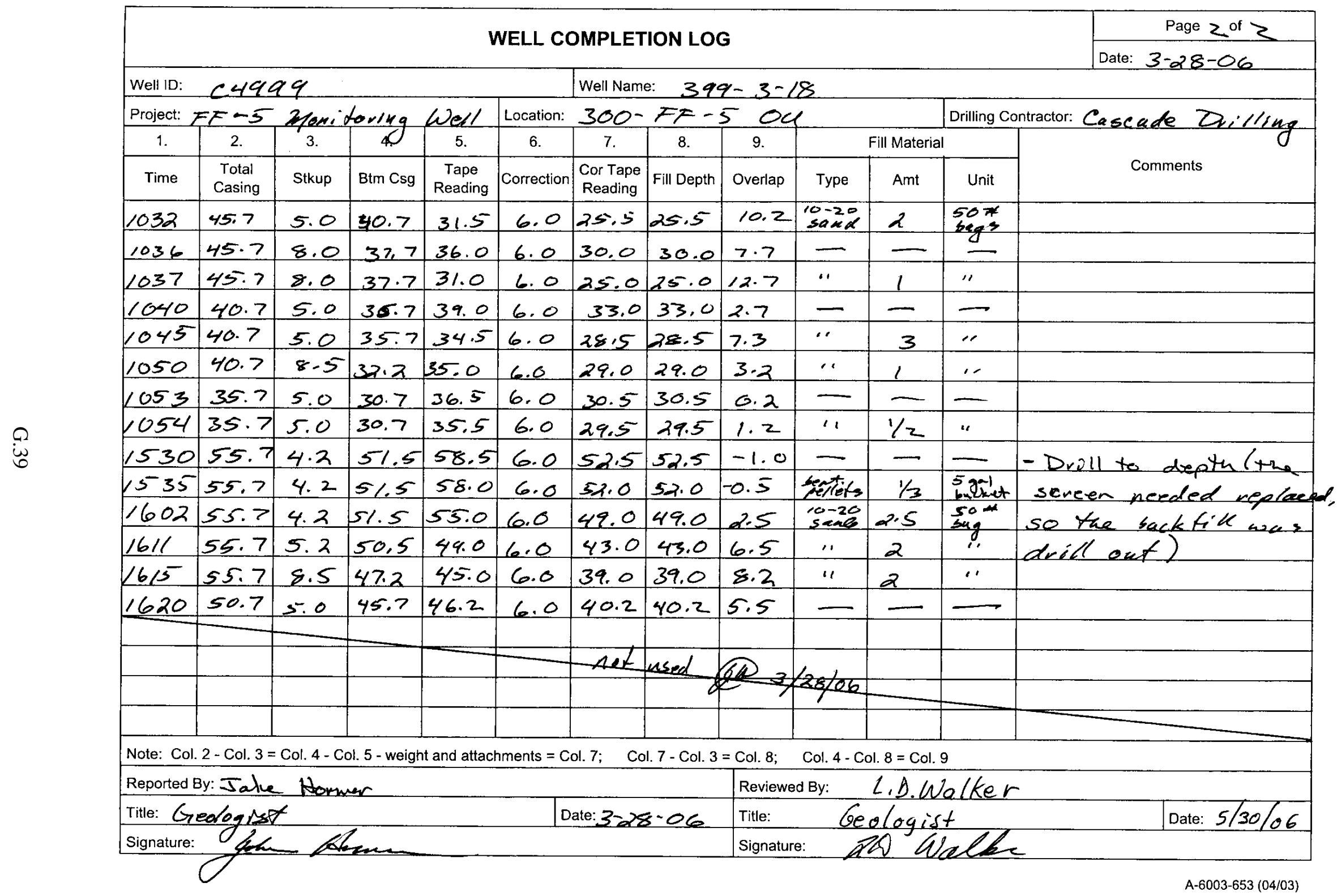




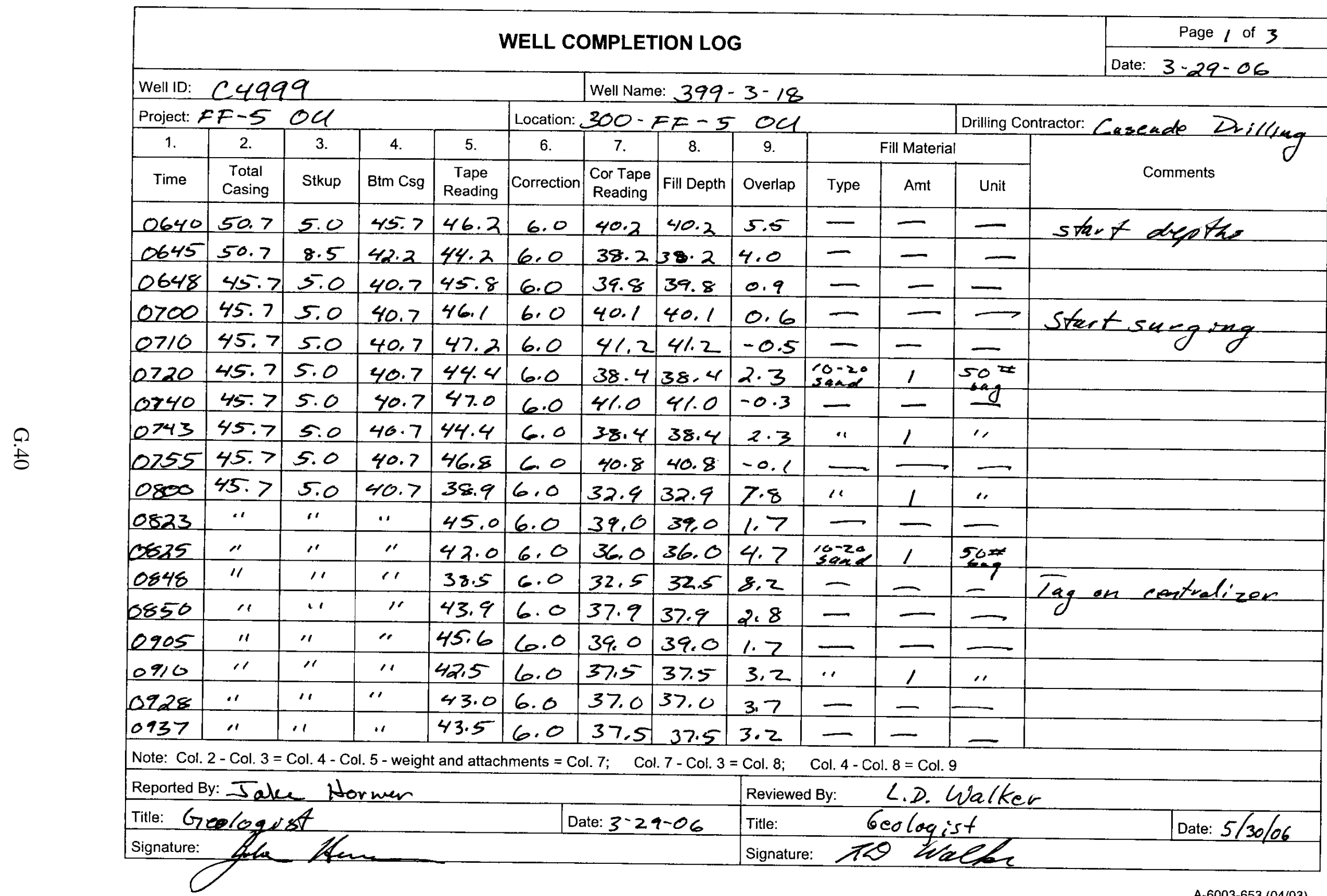




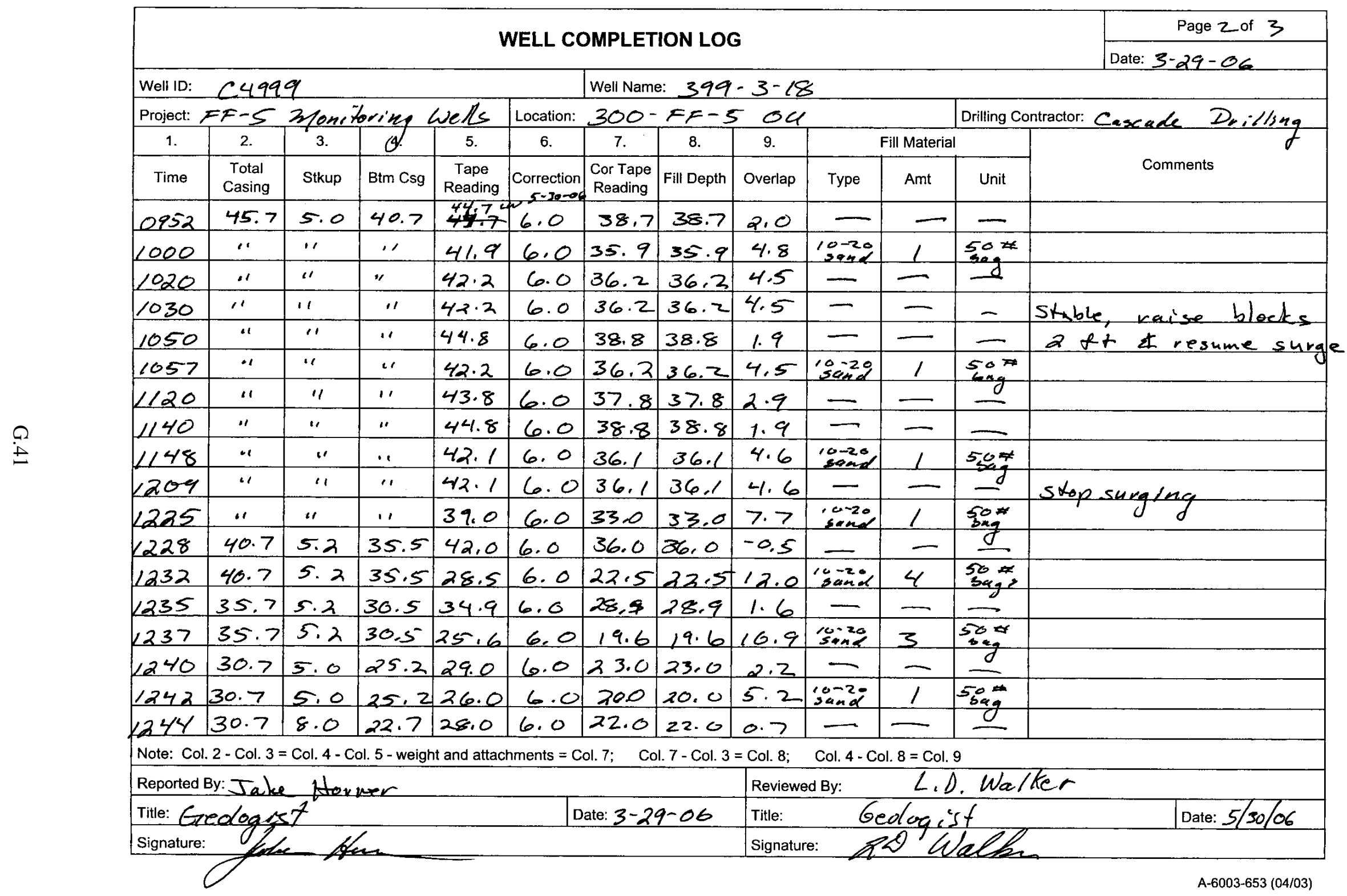




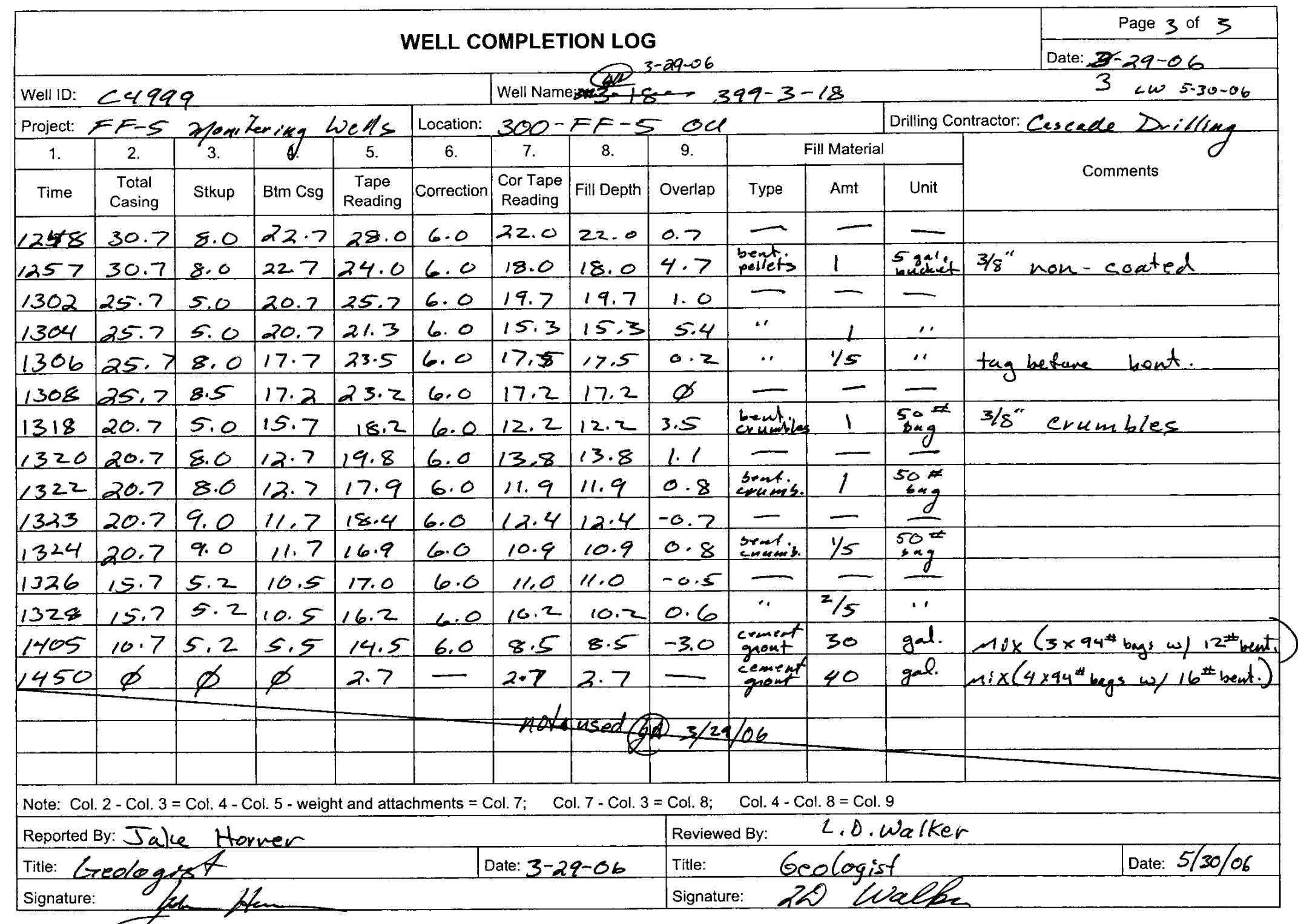


Well C5000

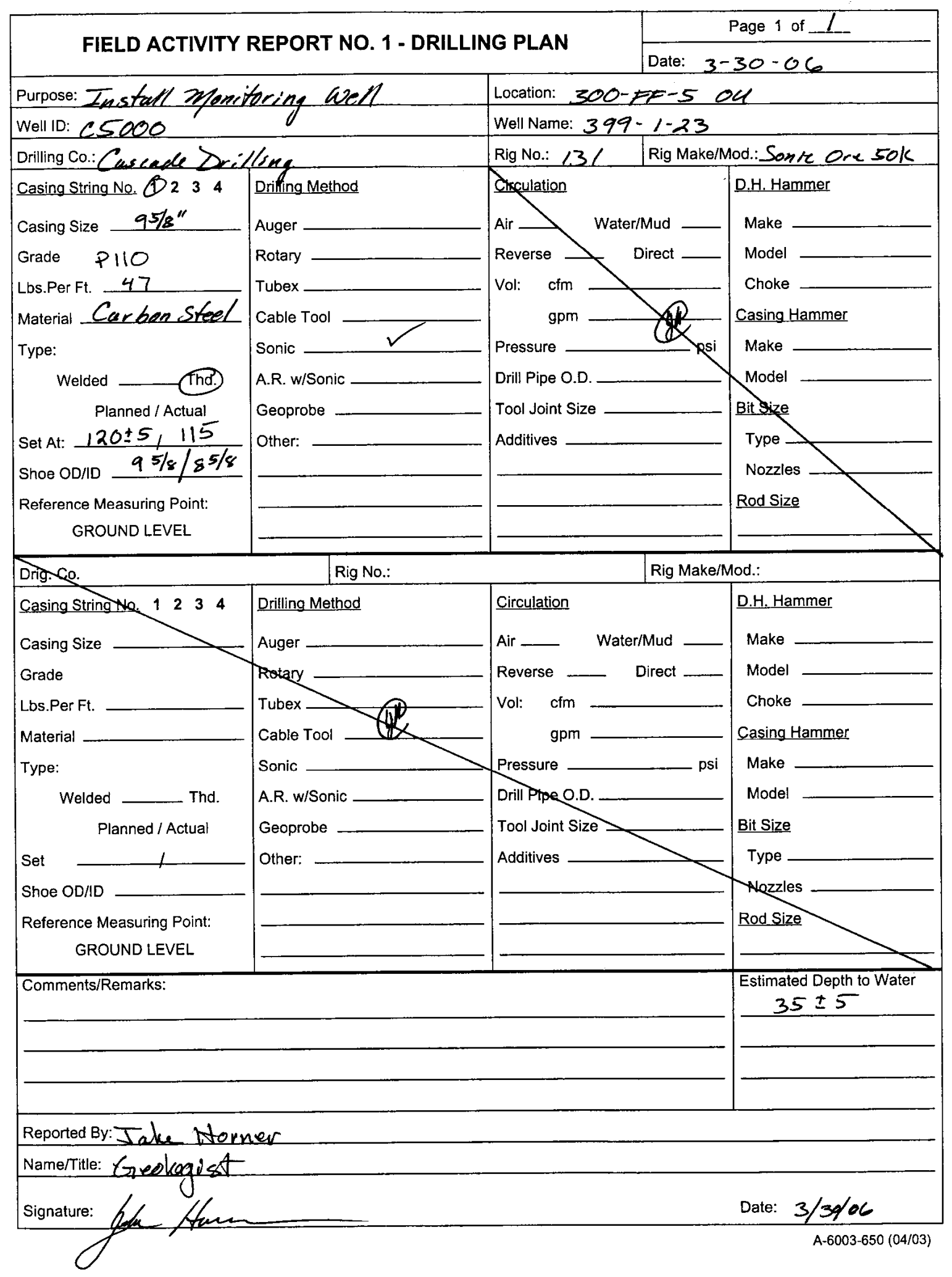




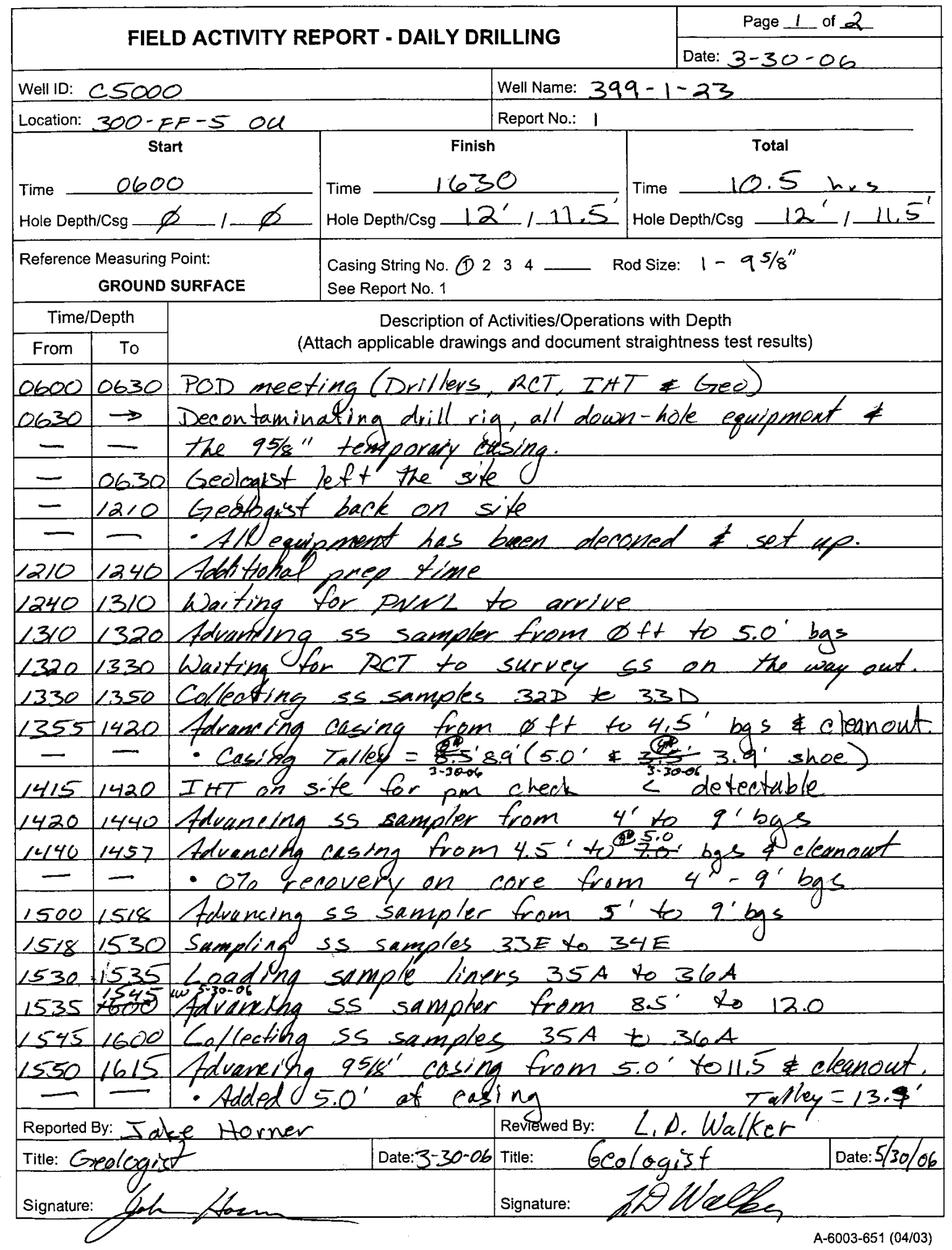




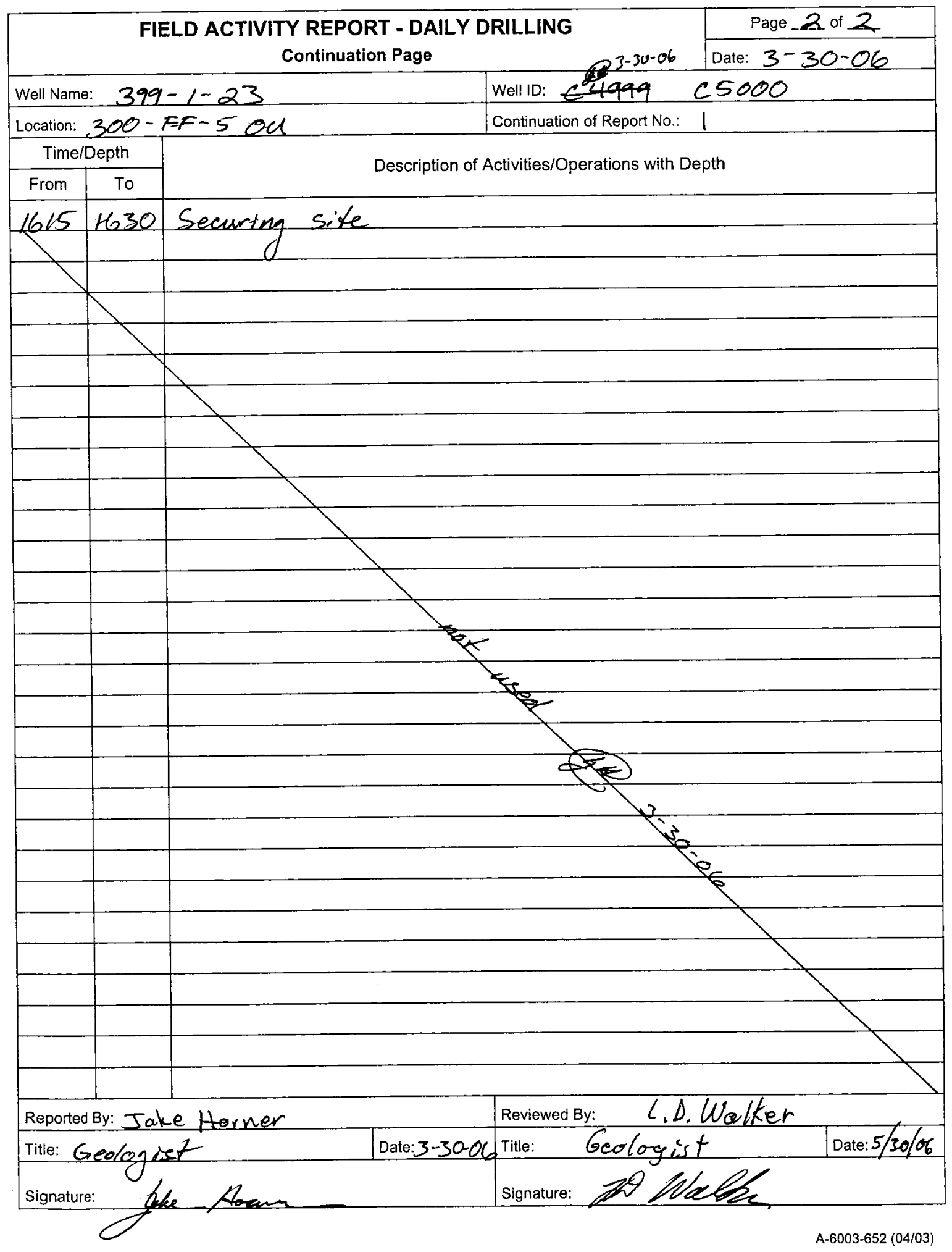




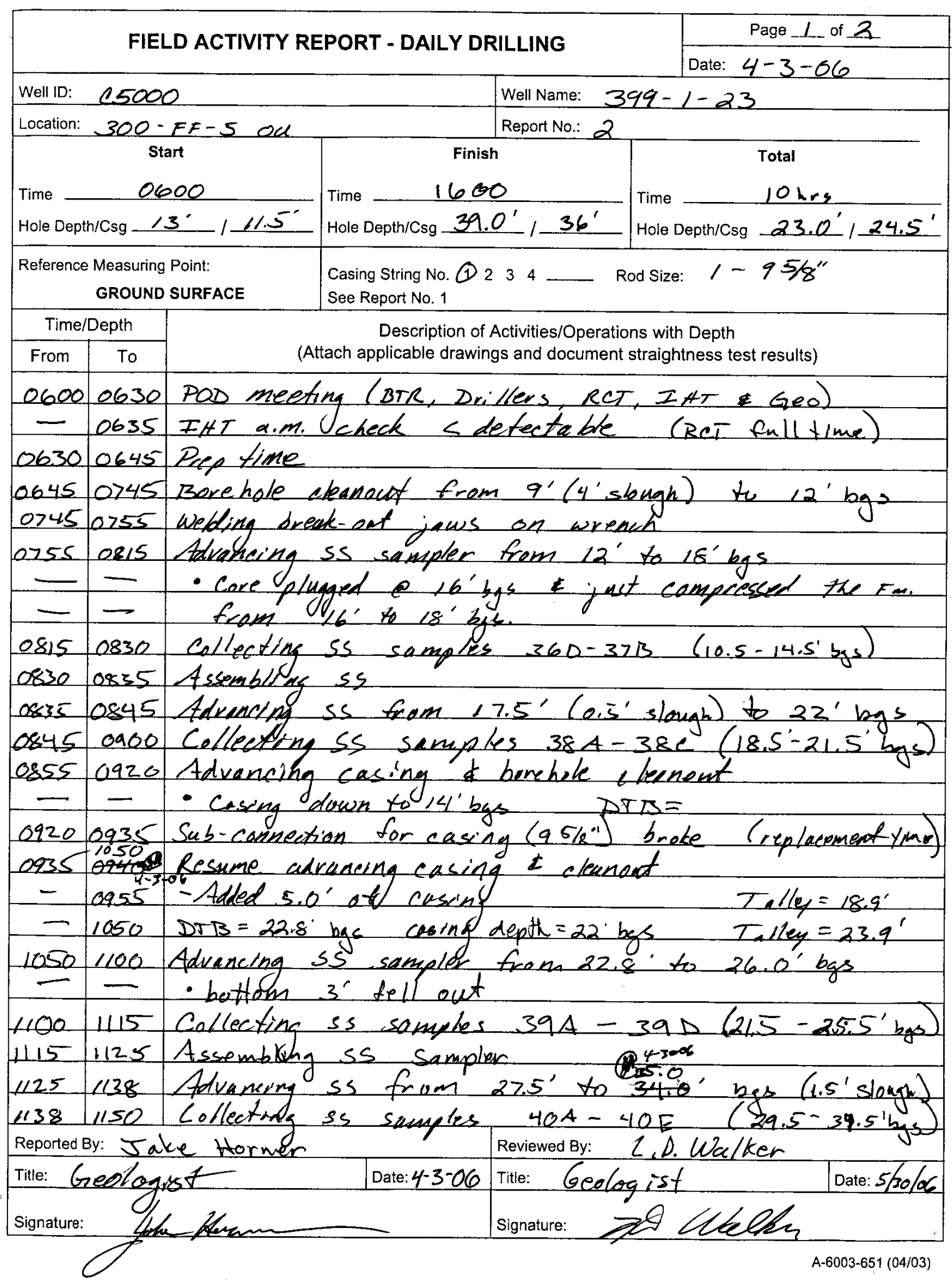




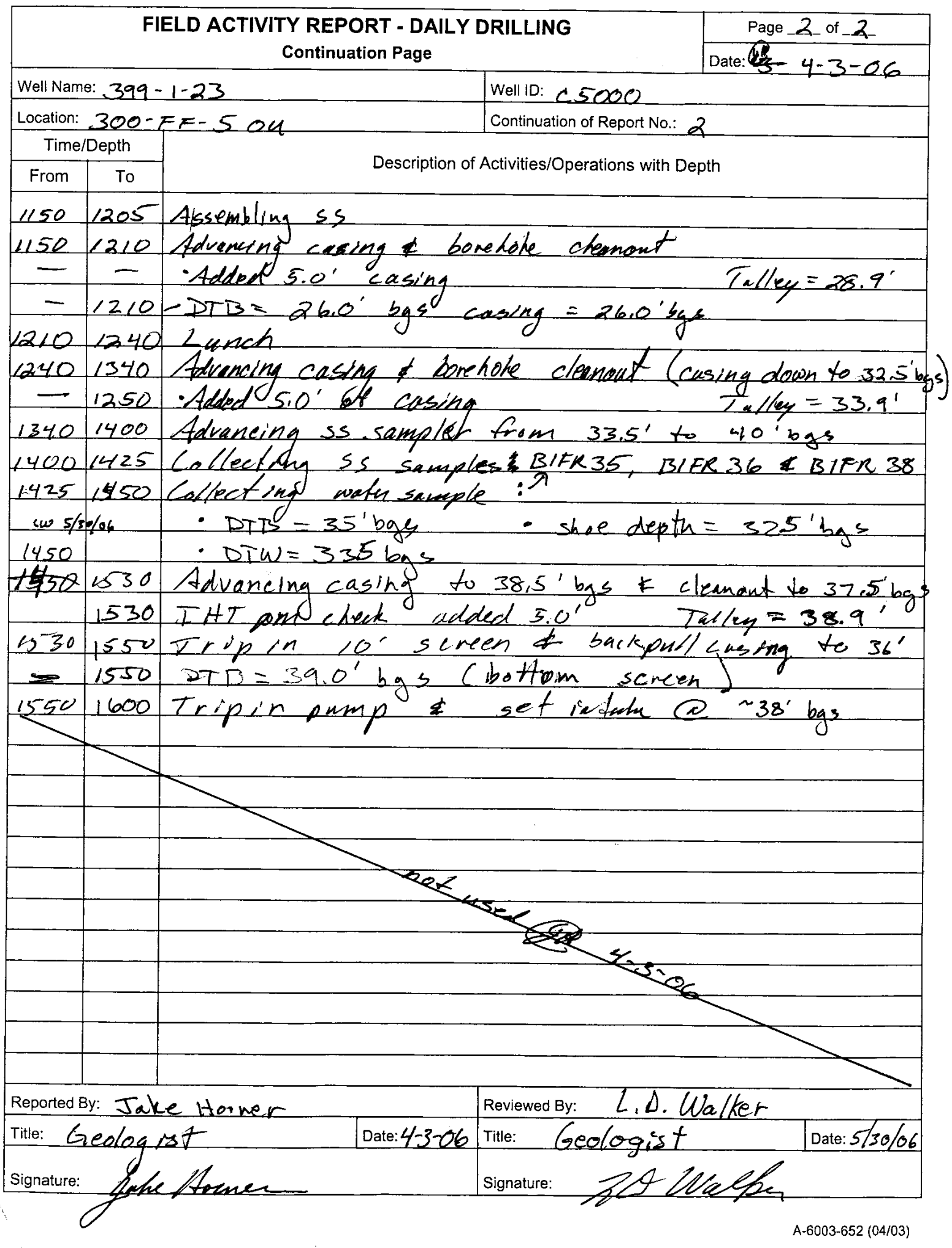




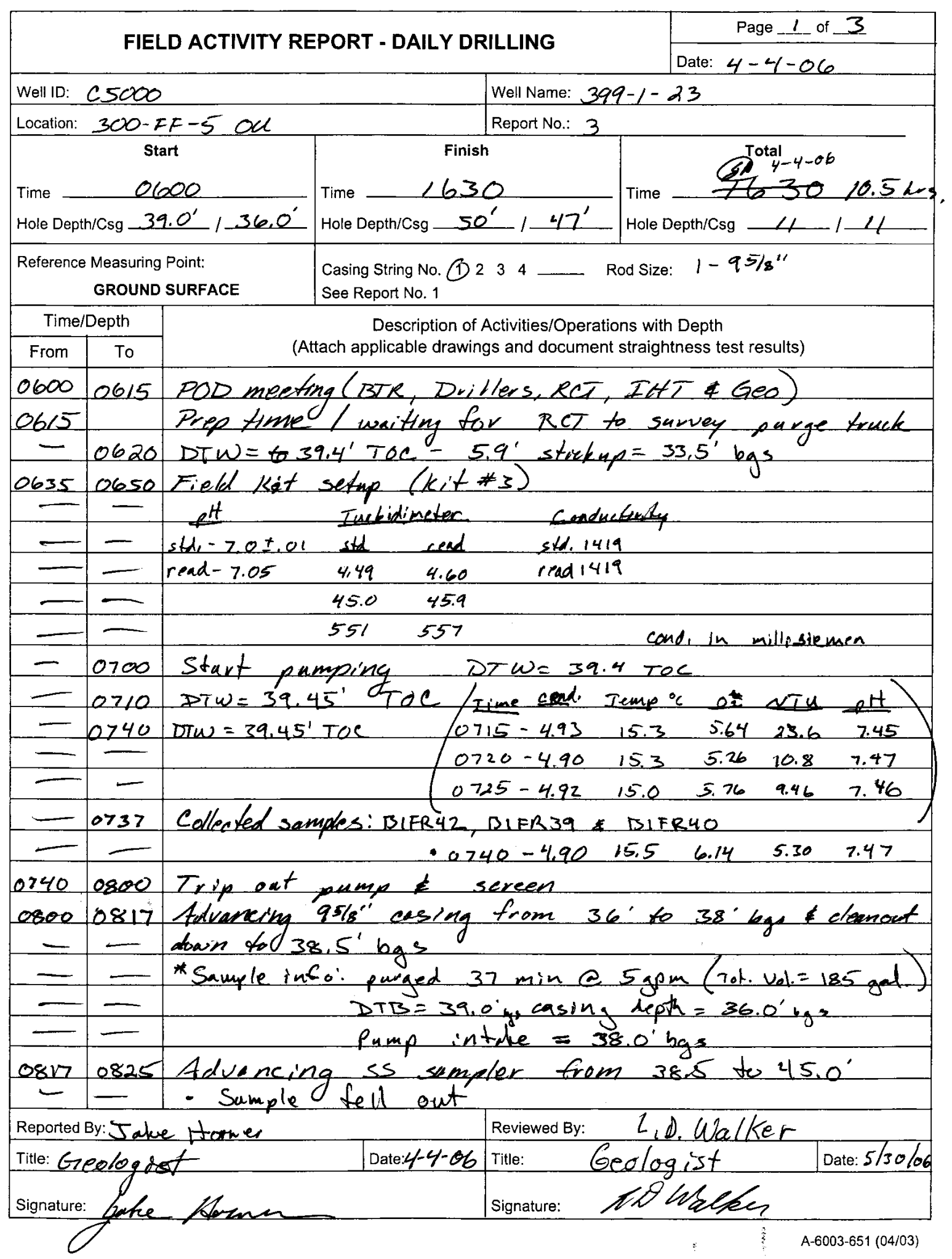




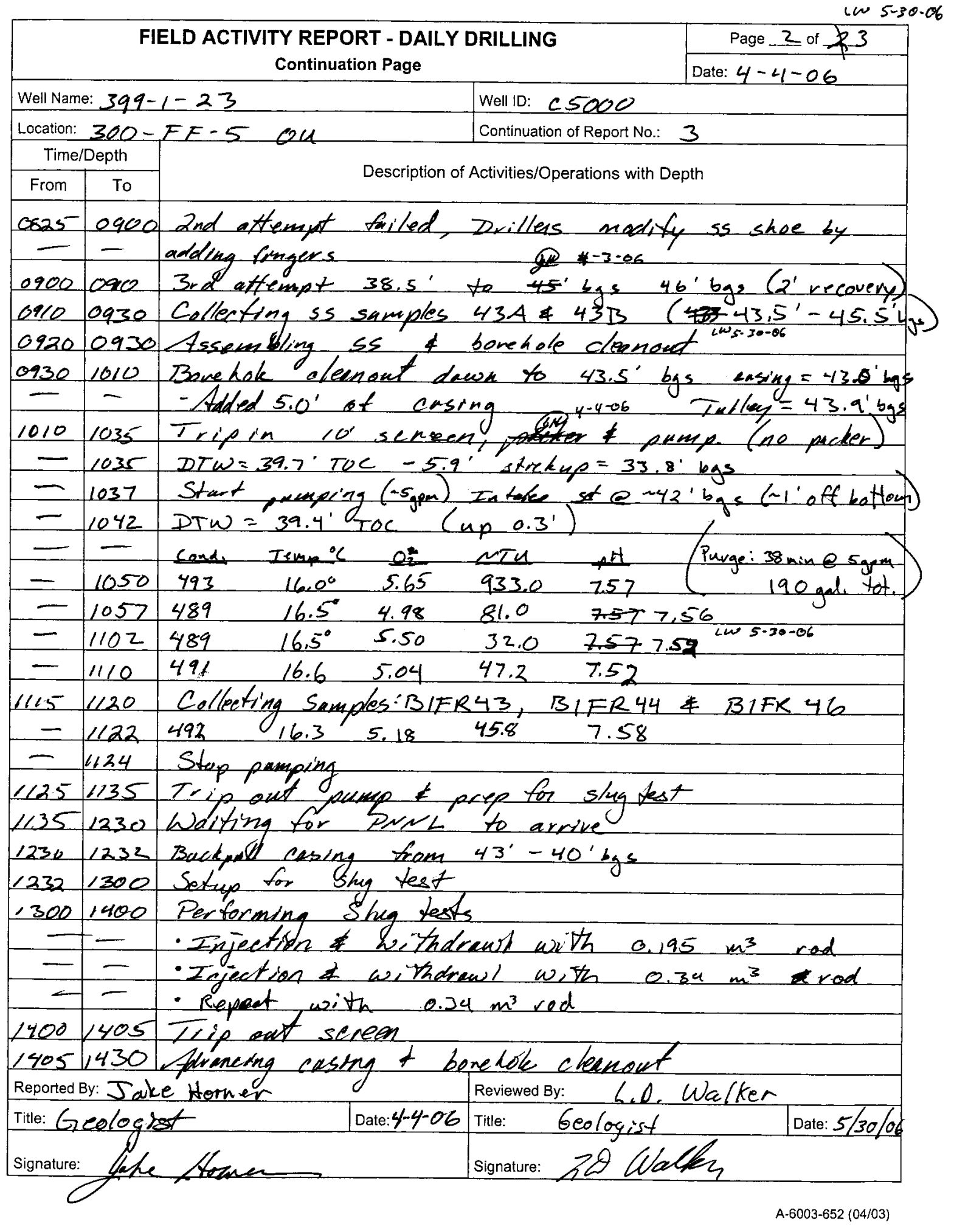




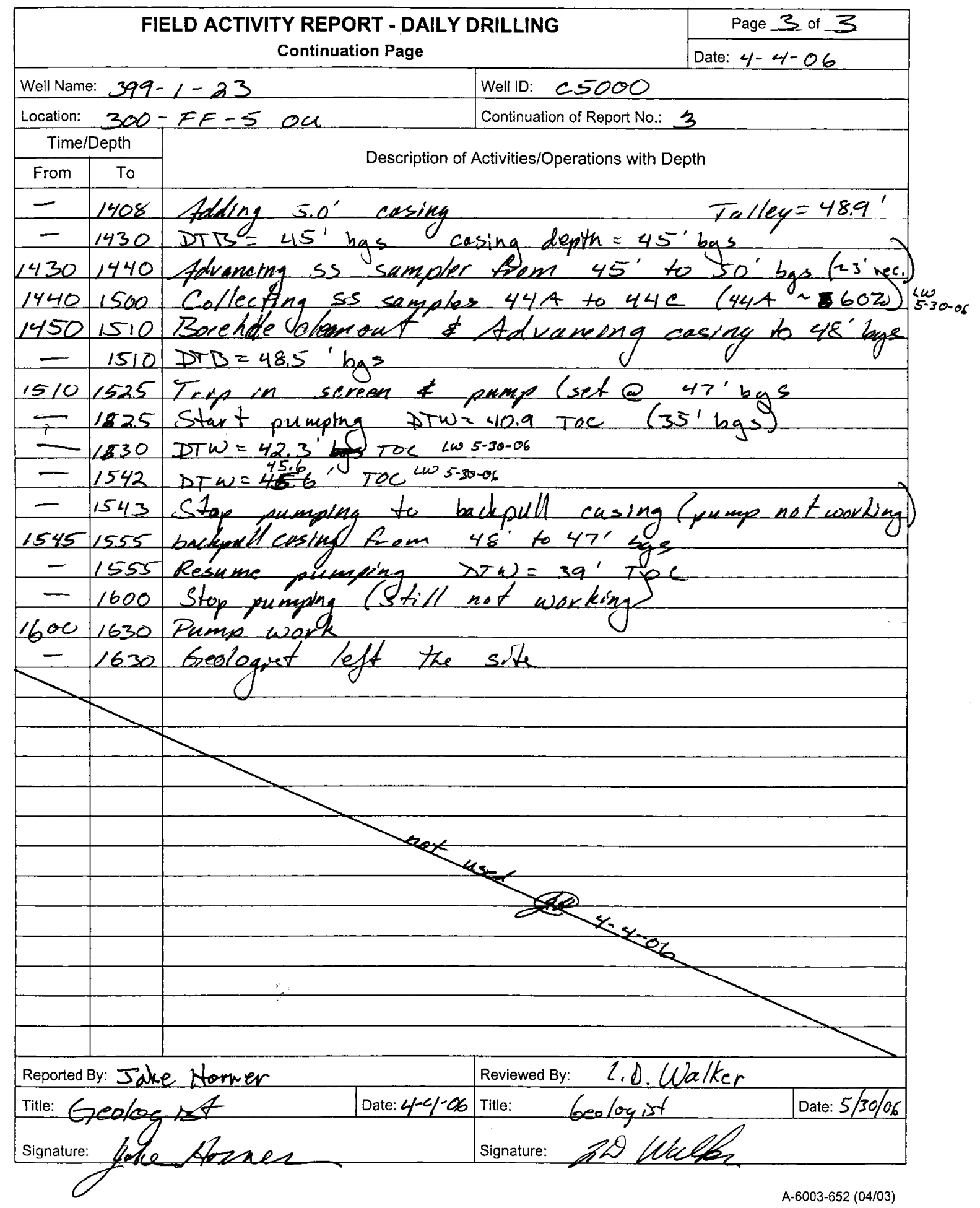




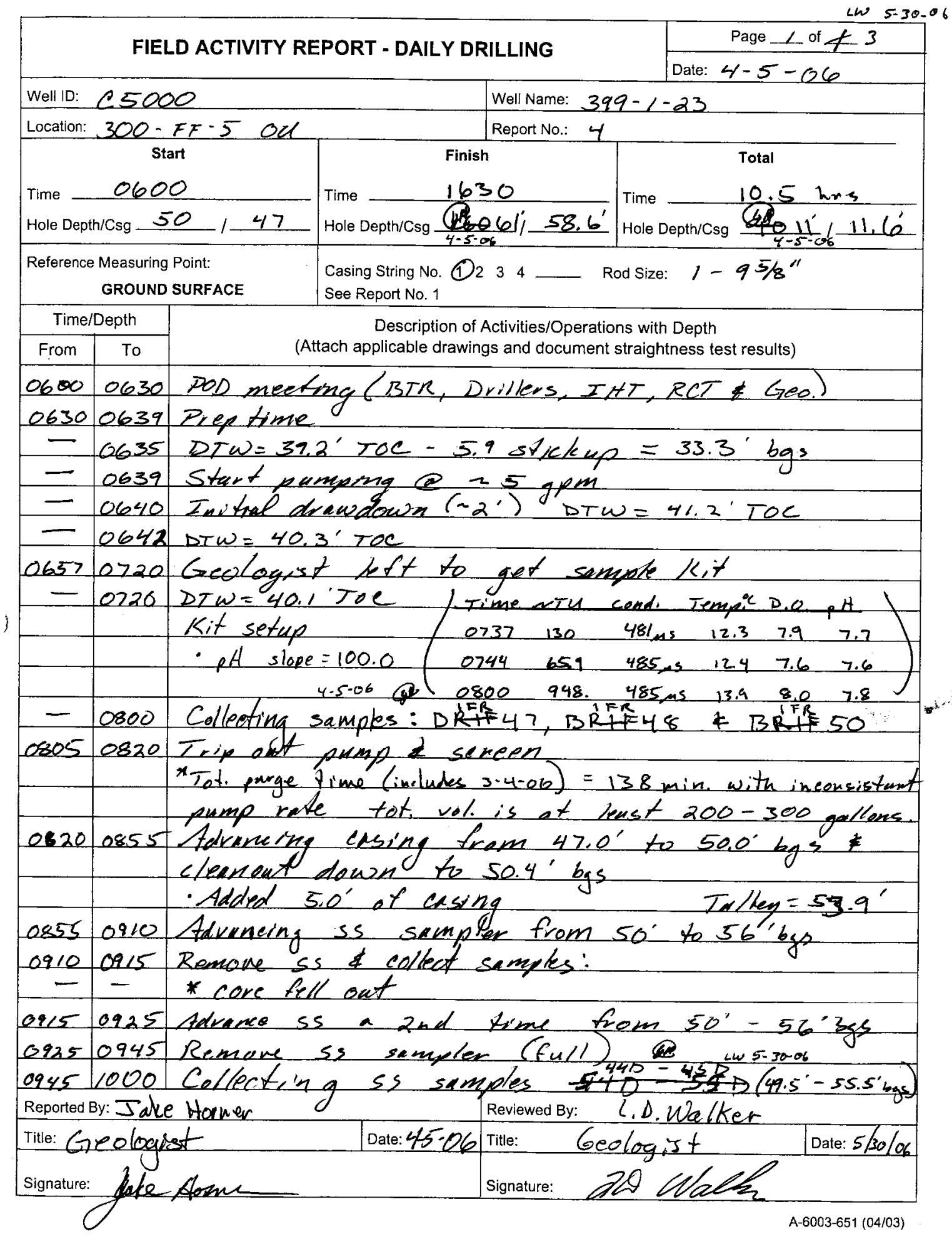




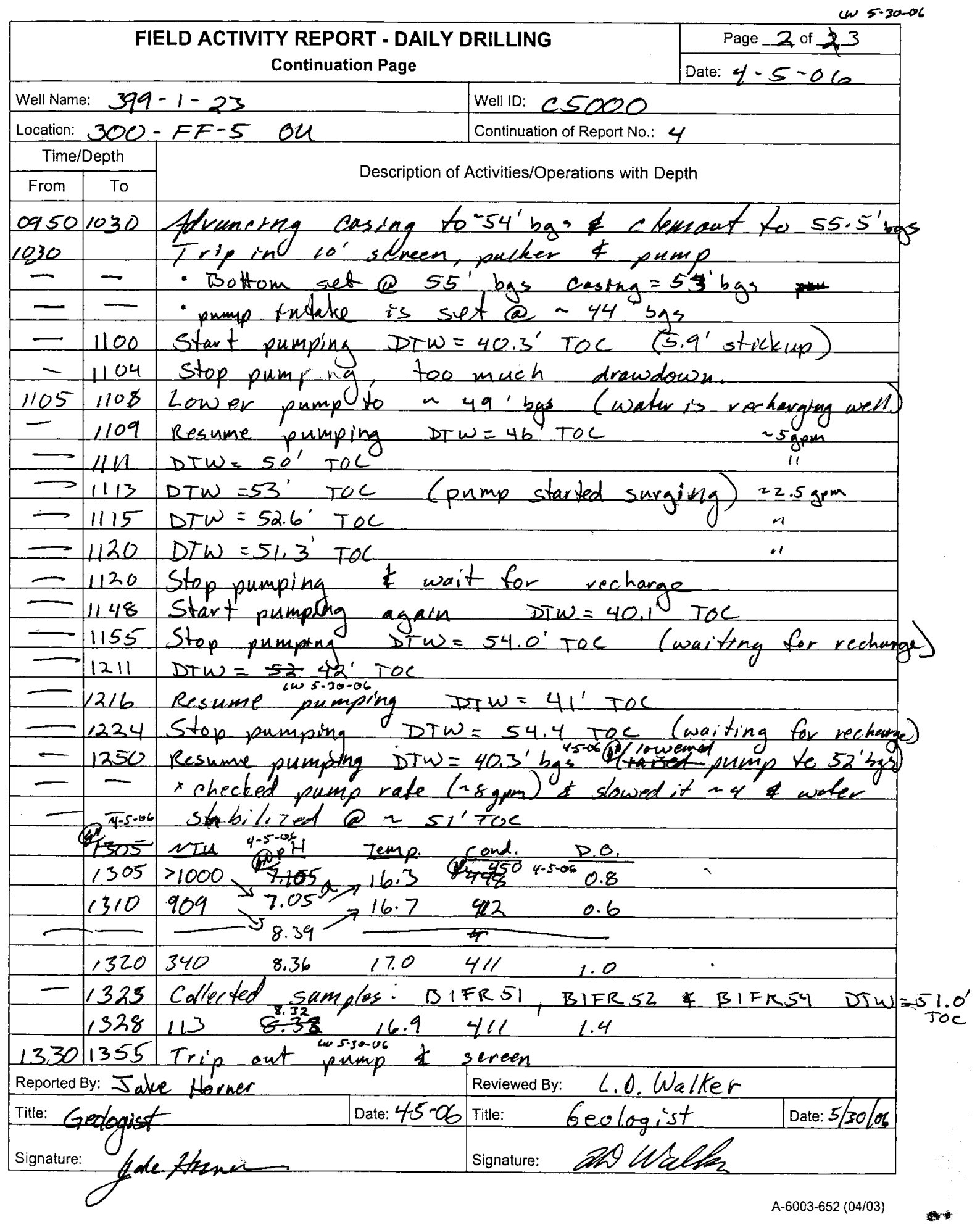




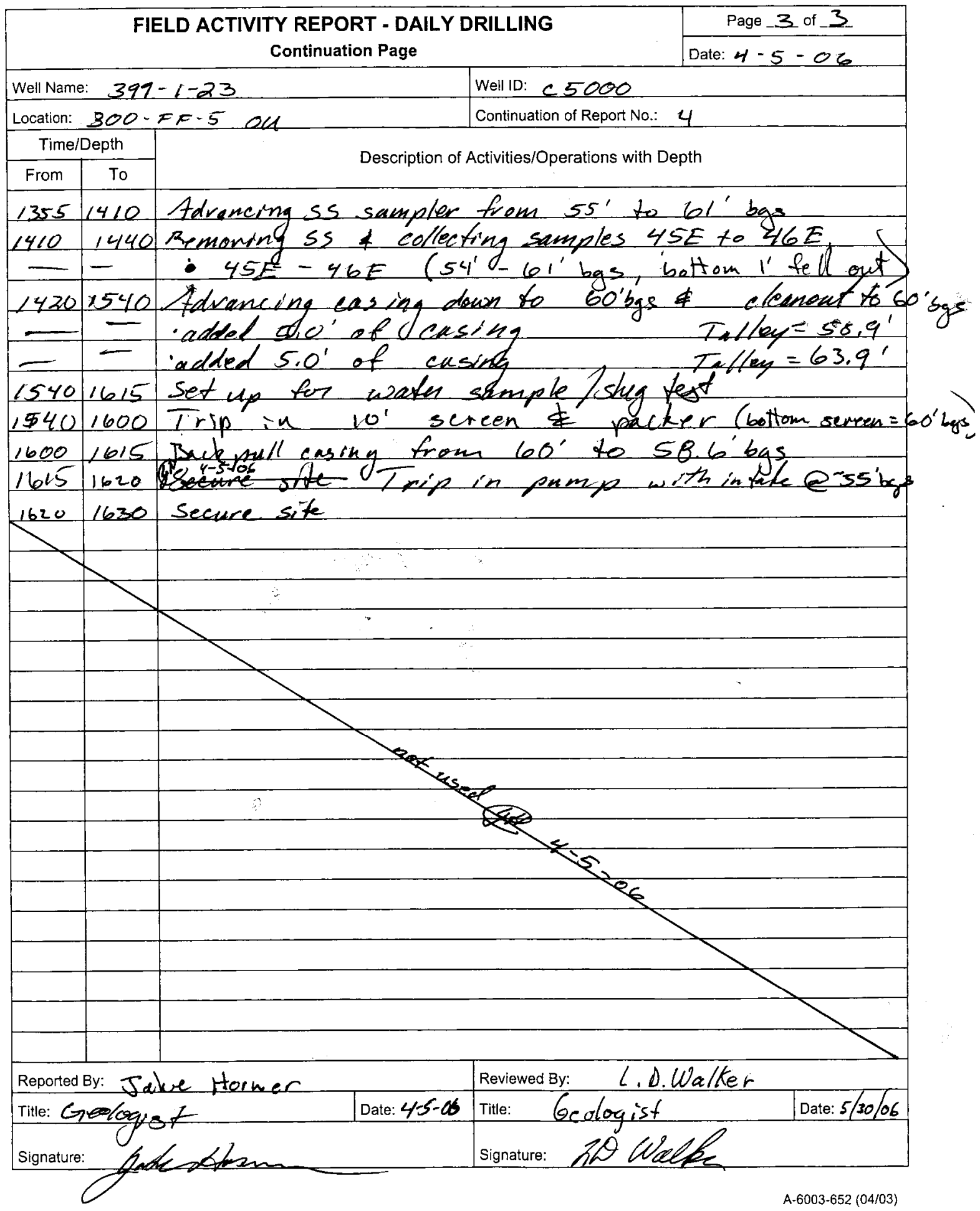




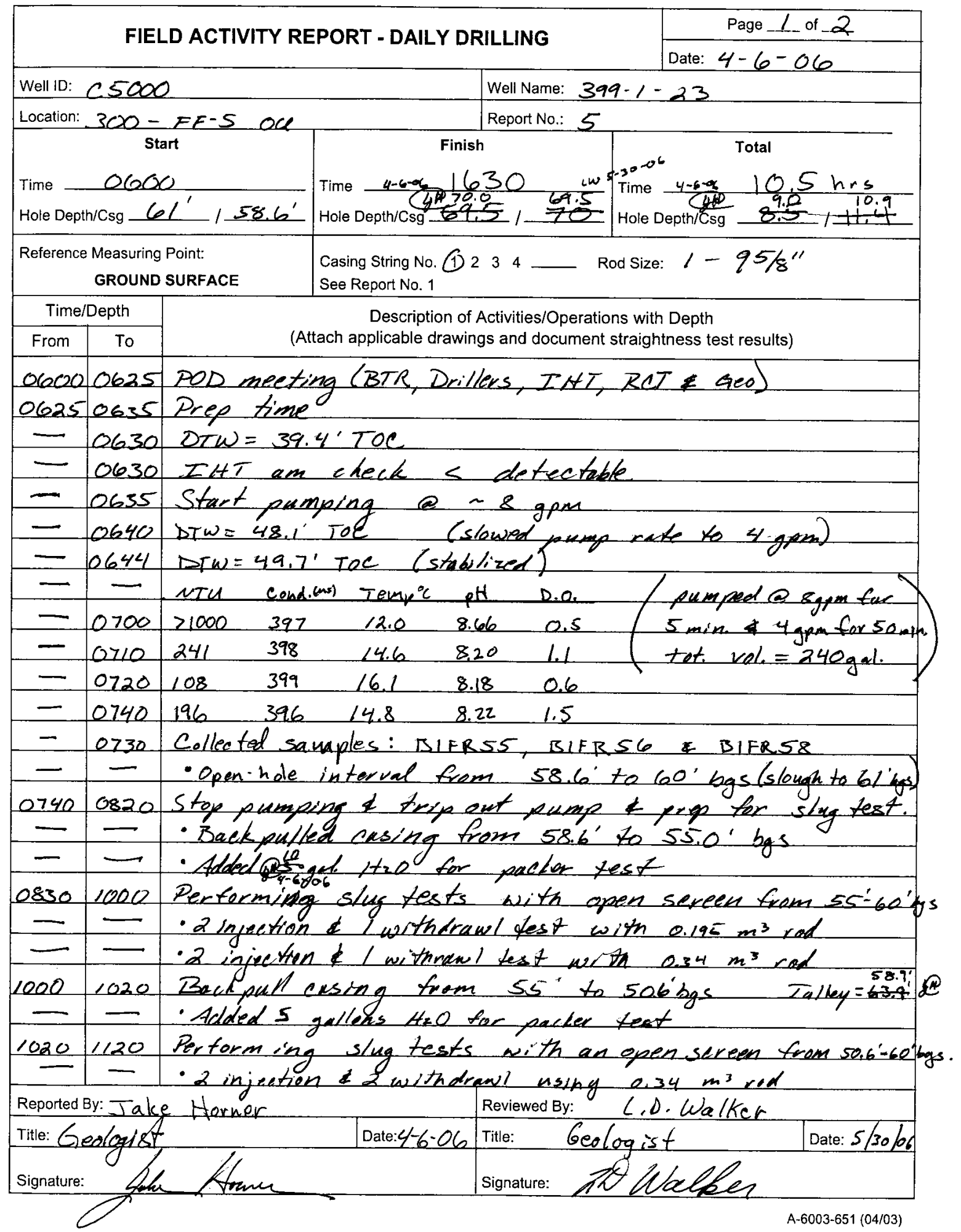




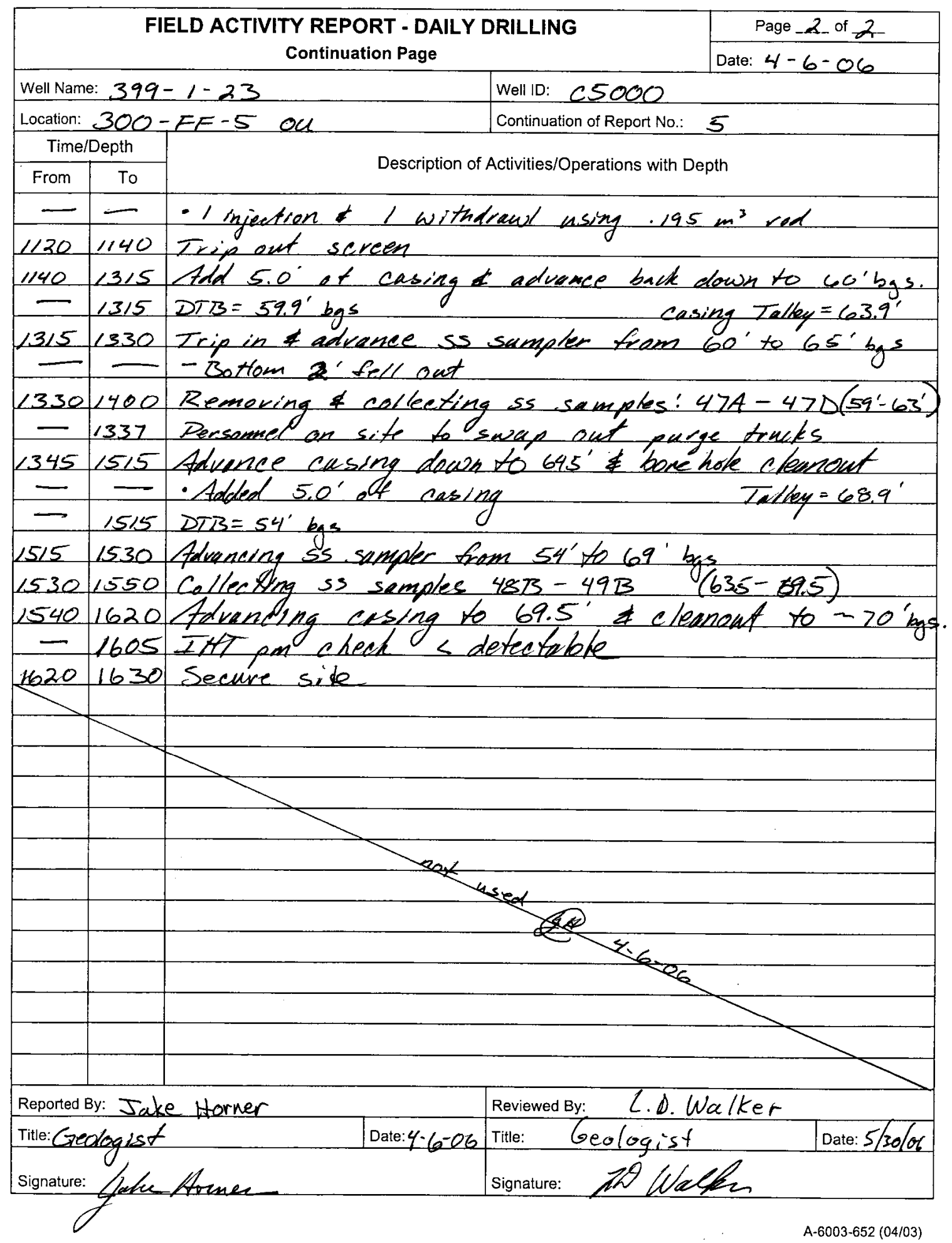




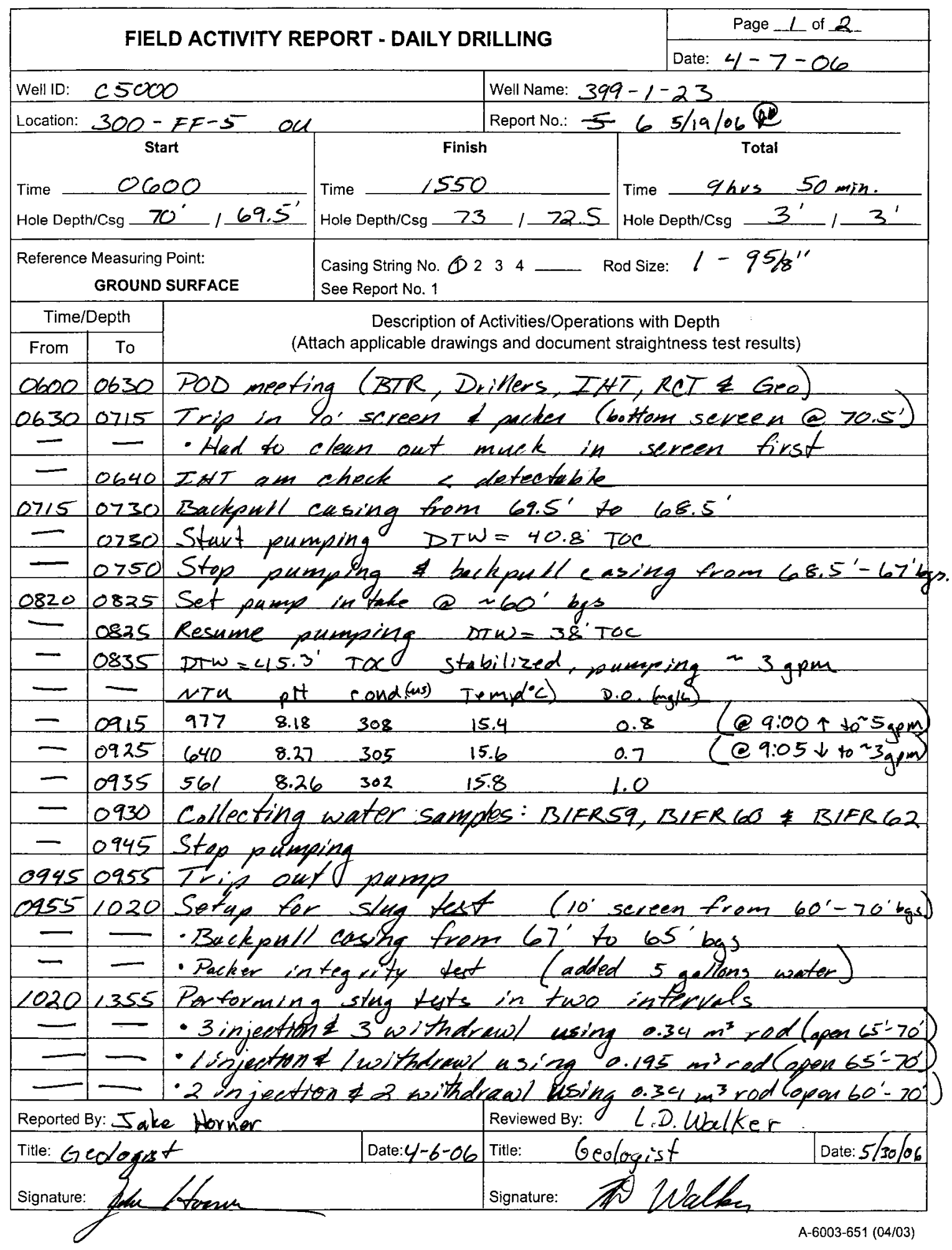




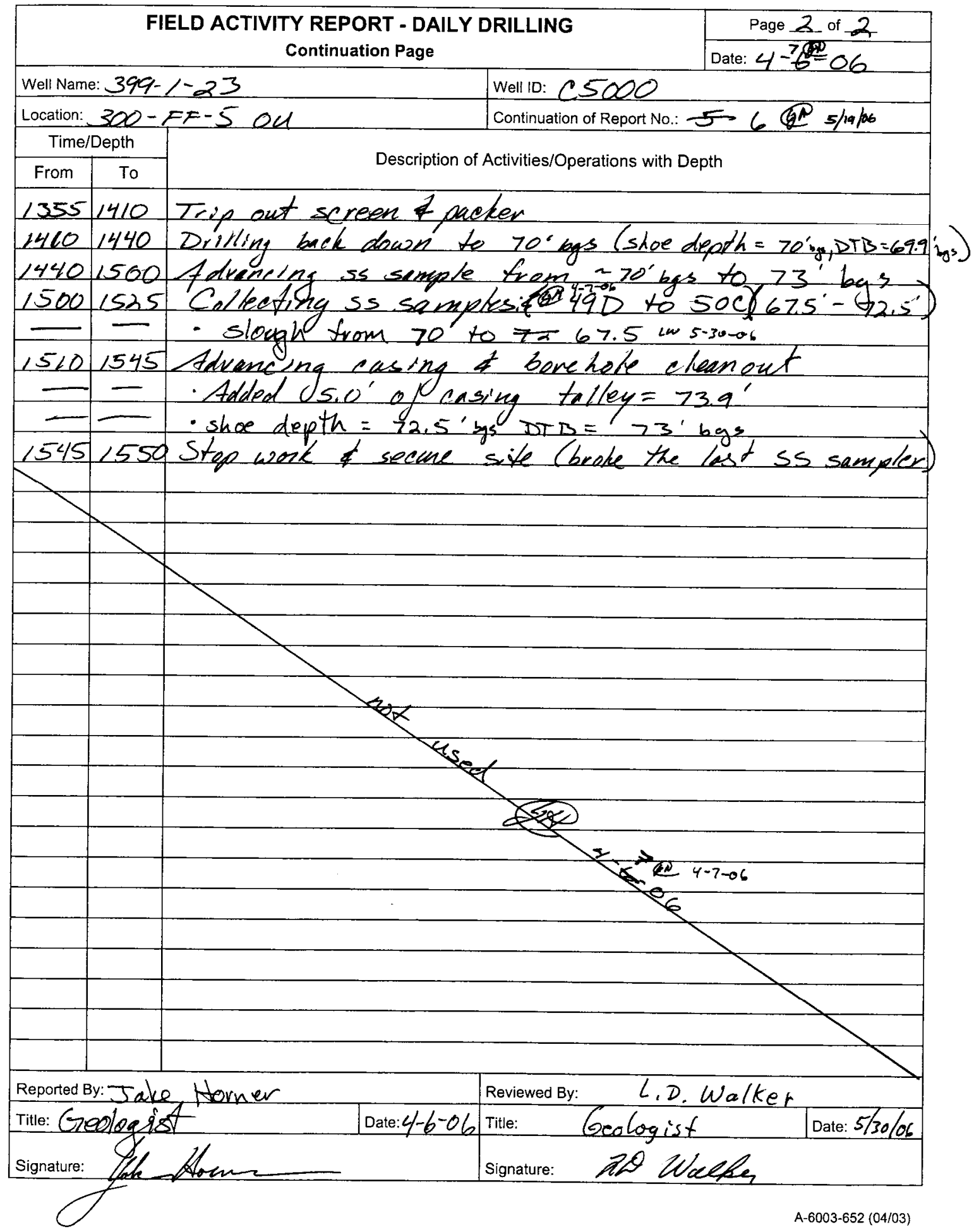




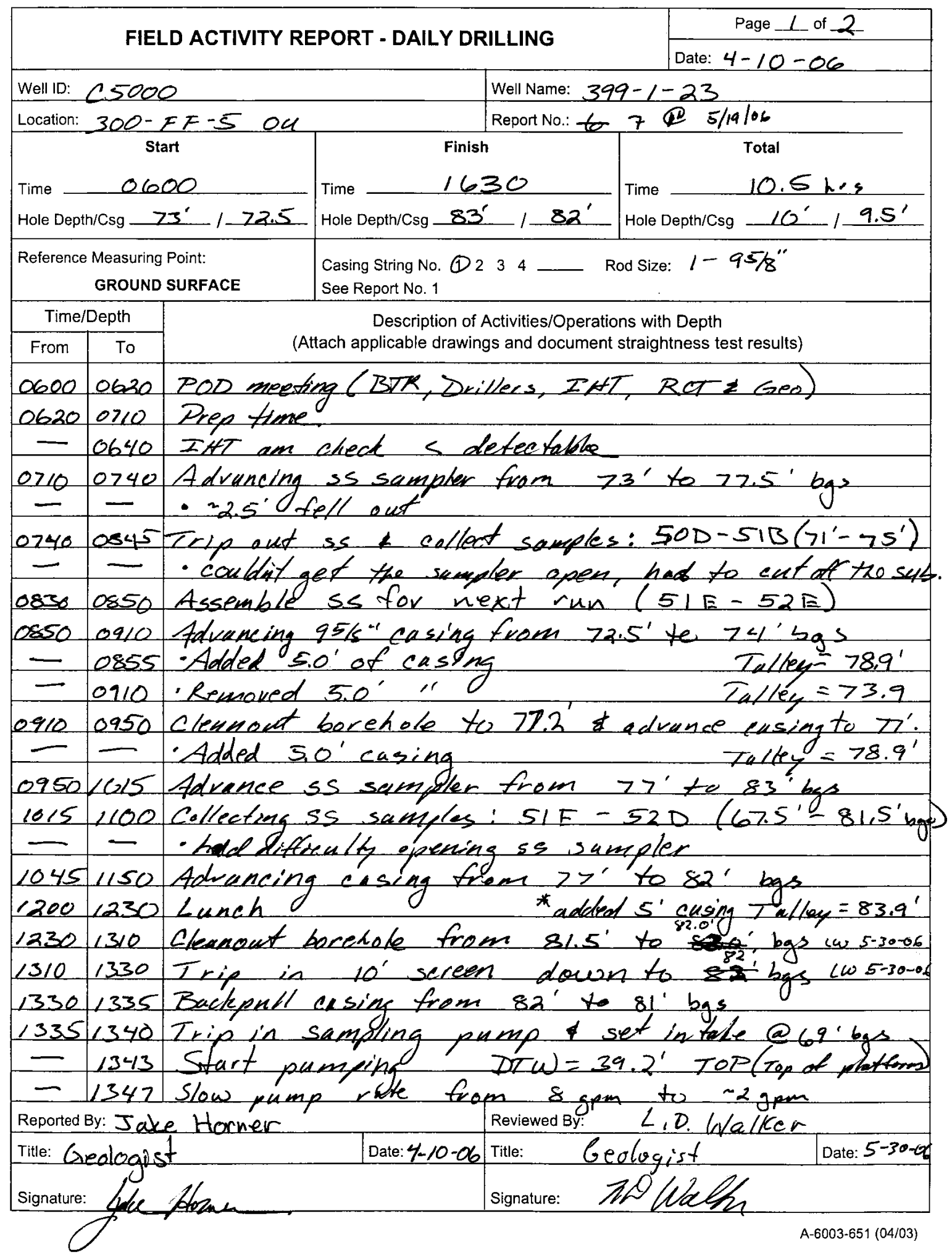




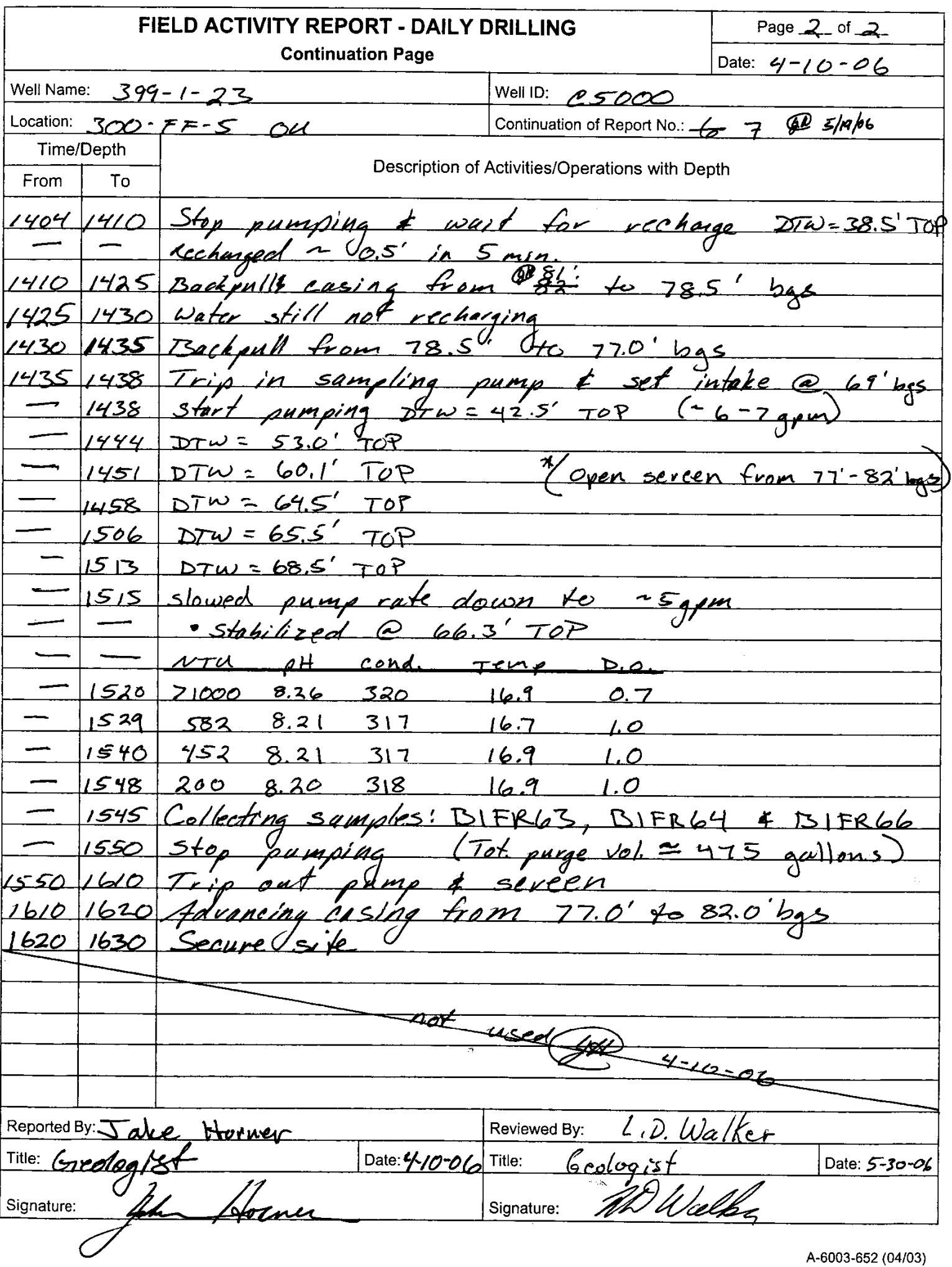




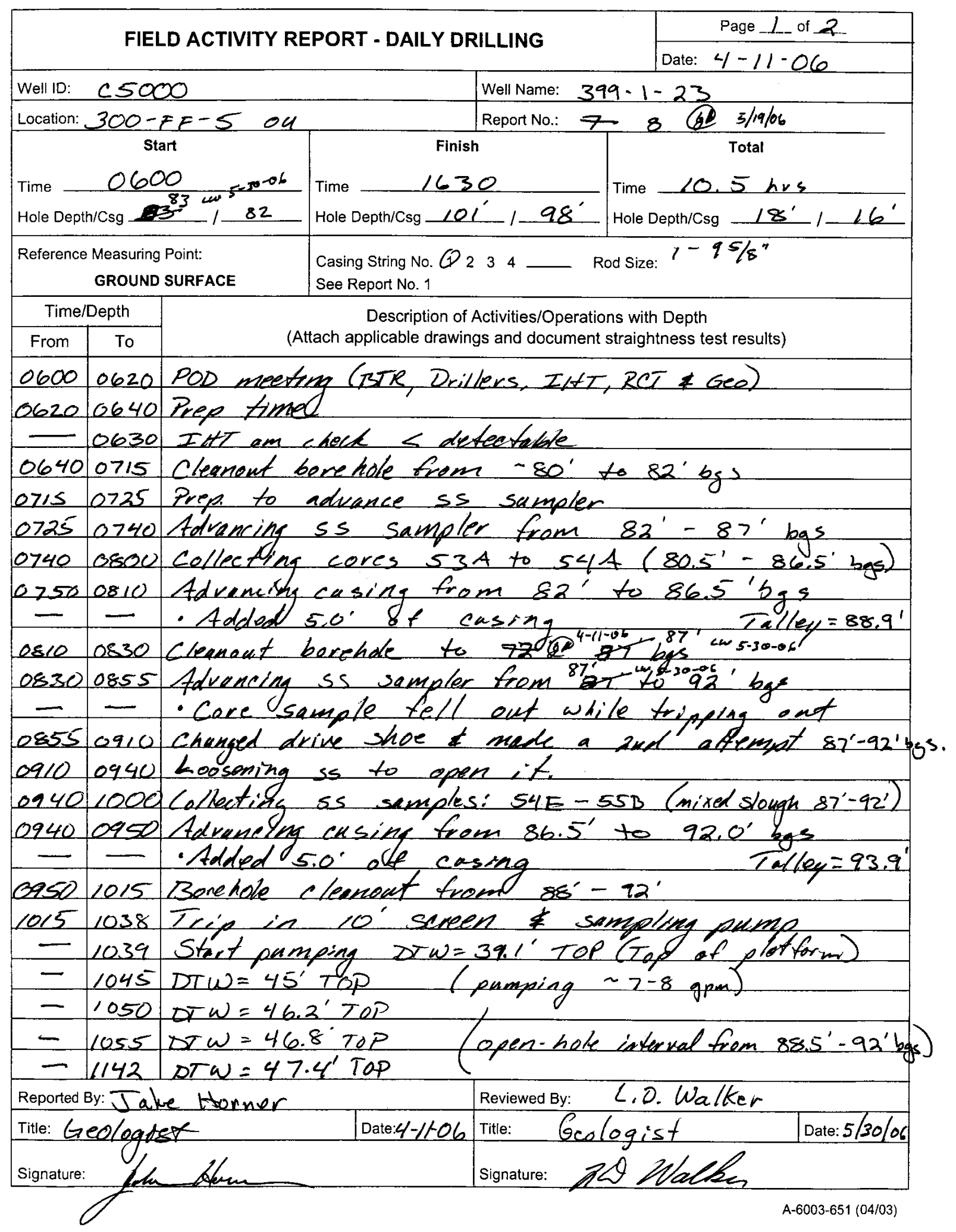




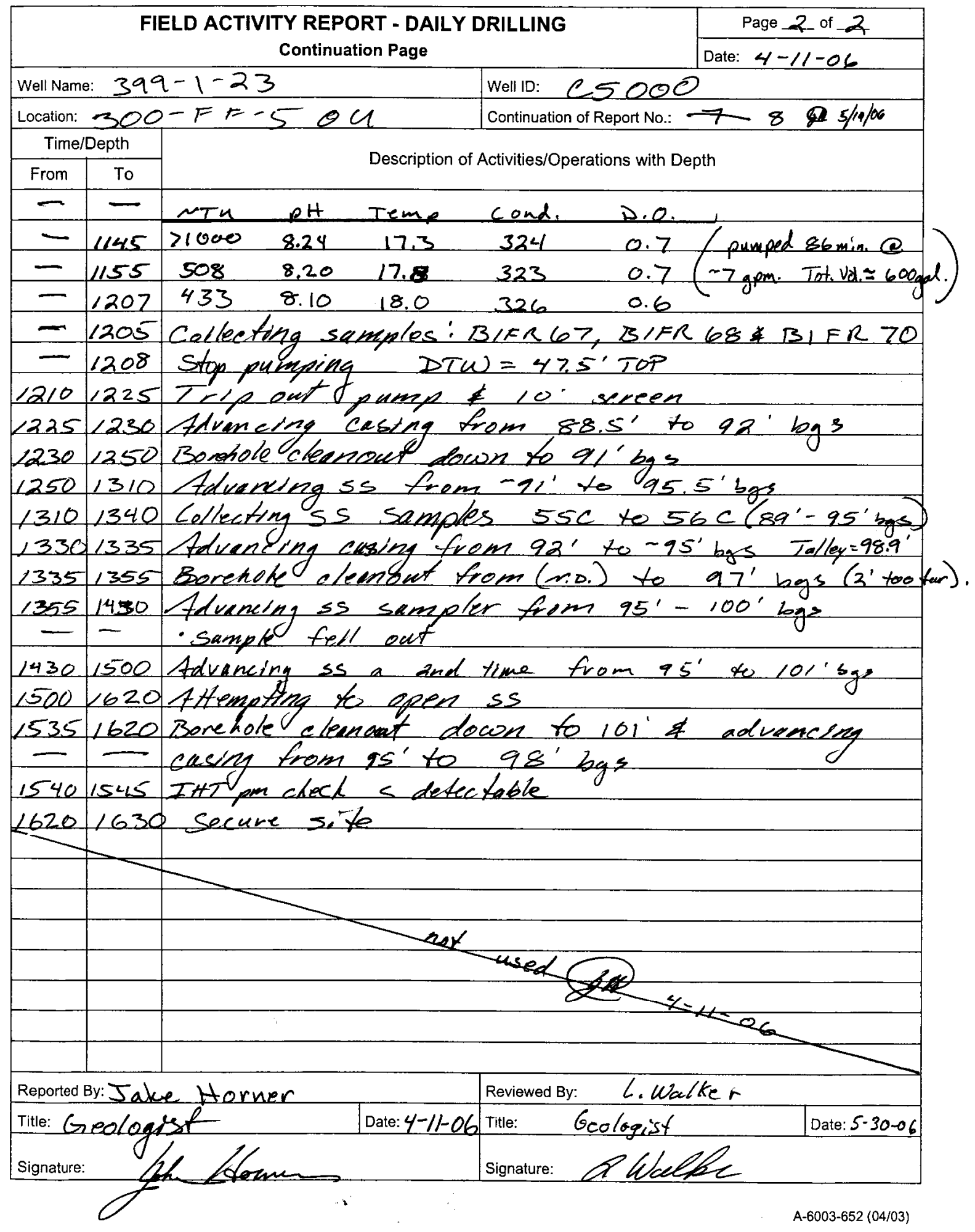


Lw 5.30-06

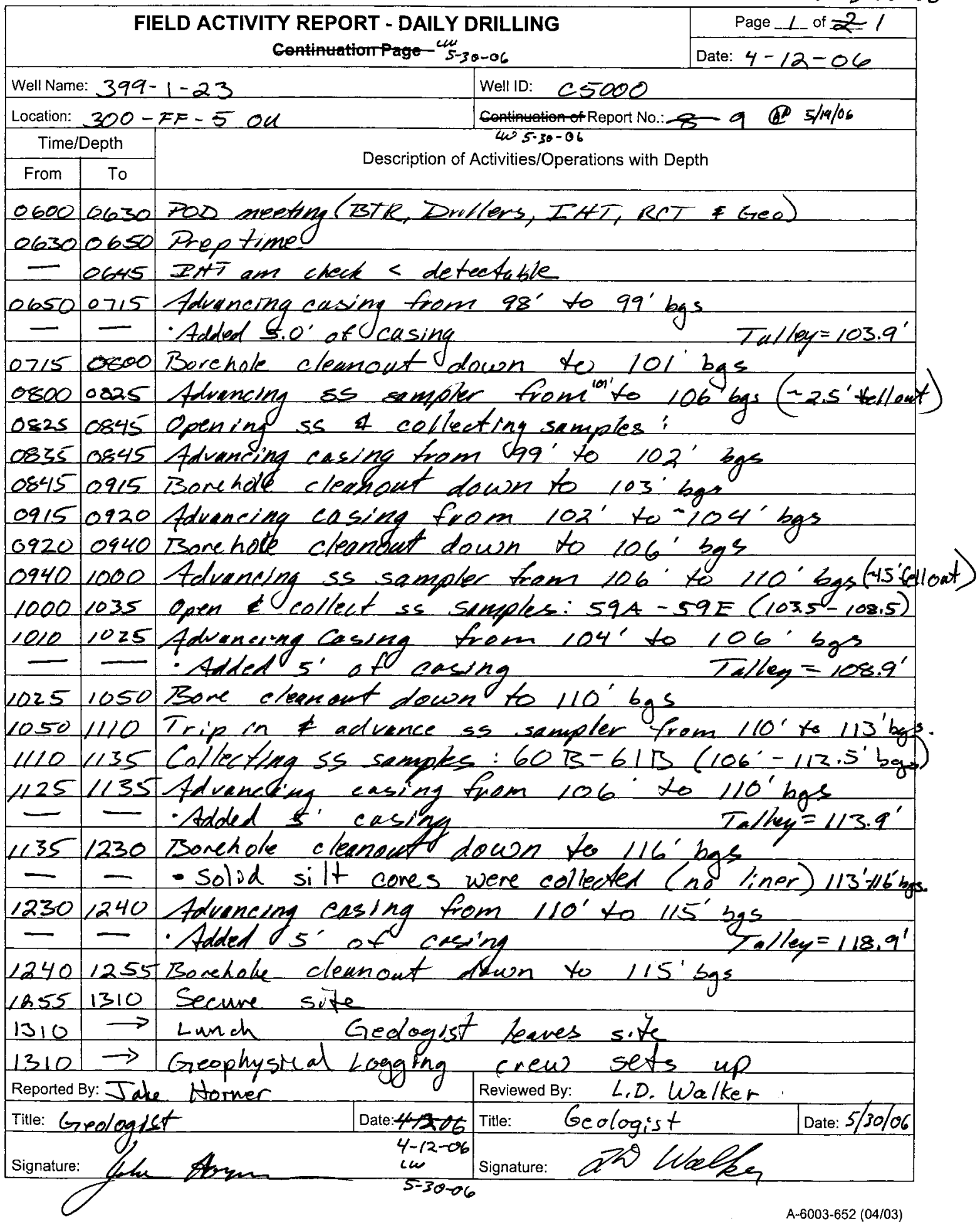




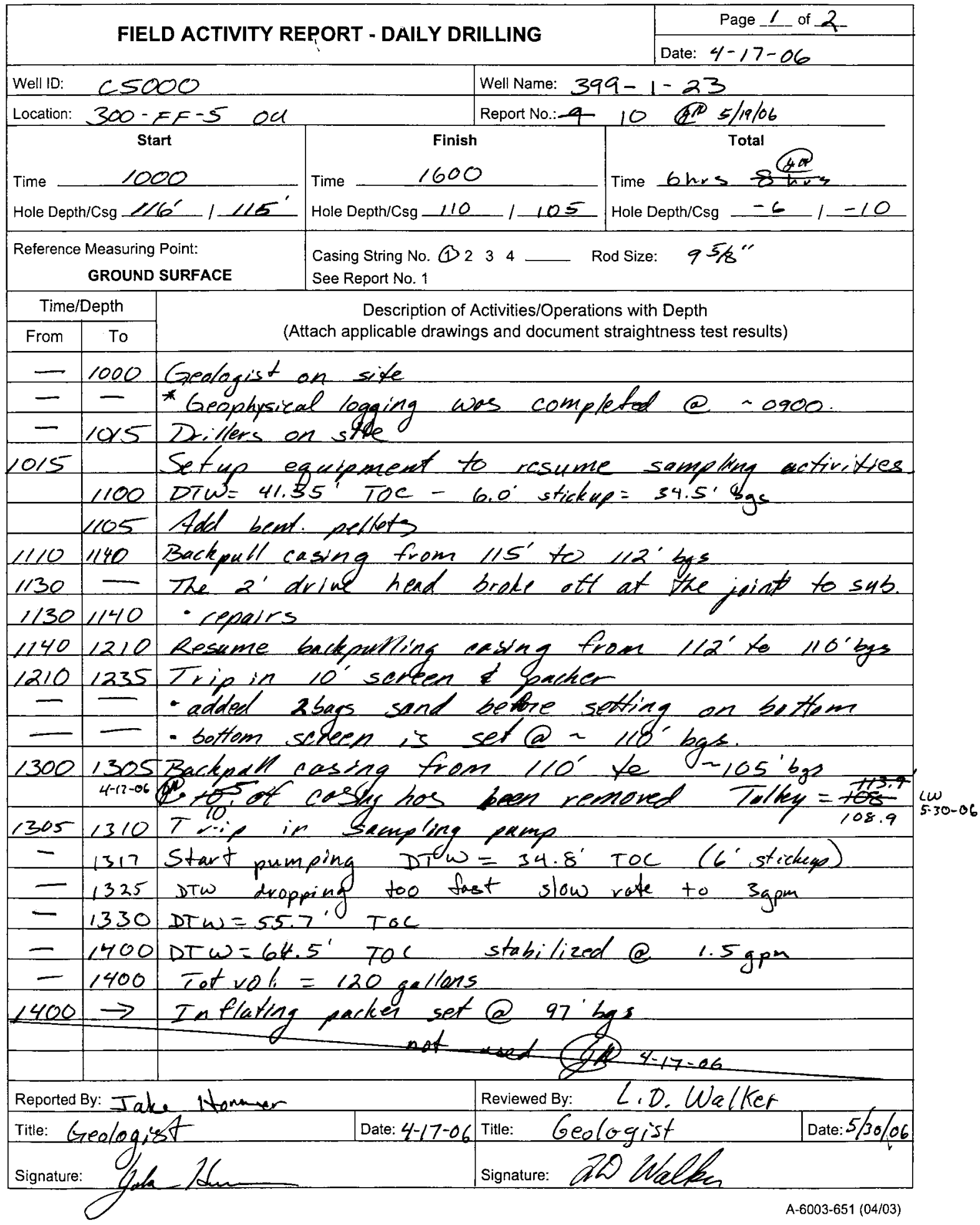




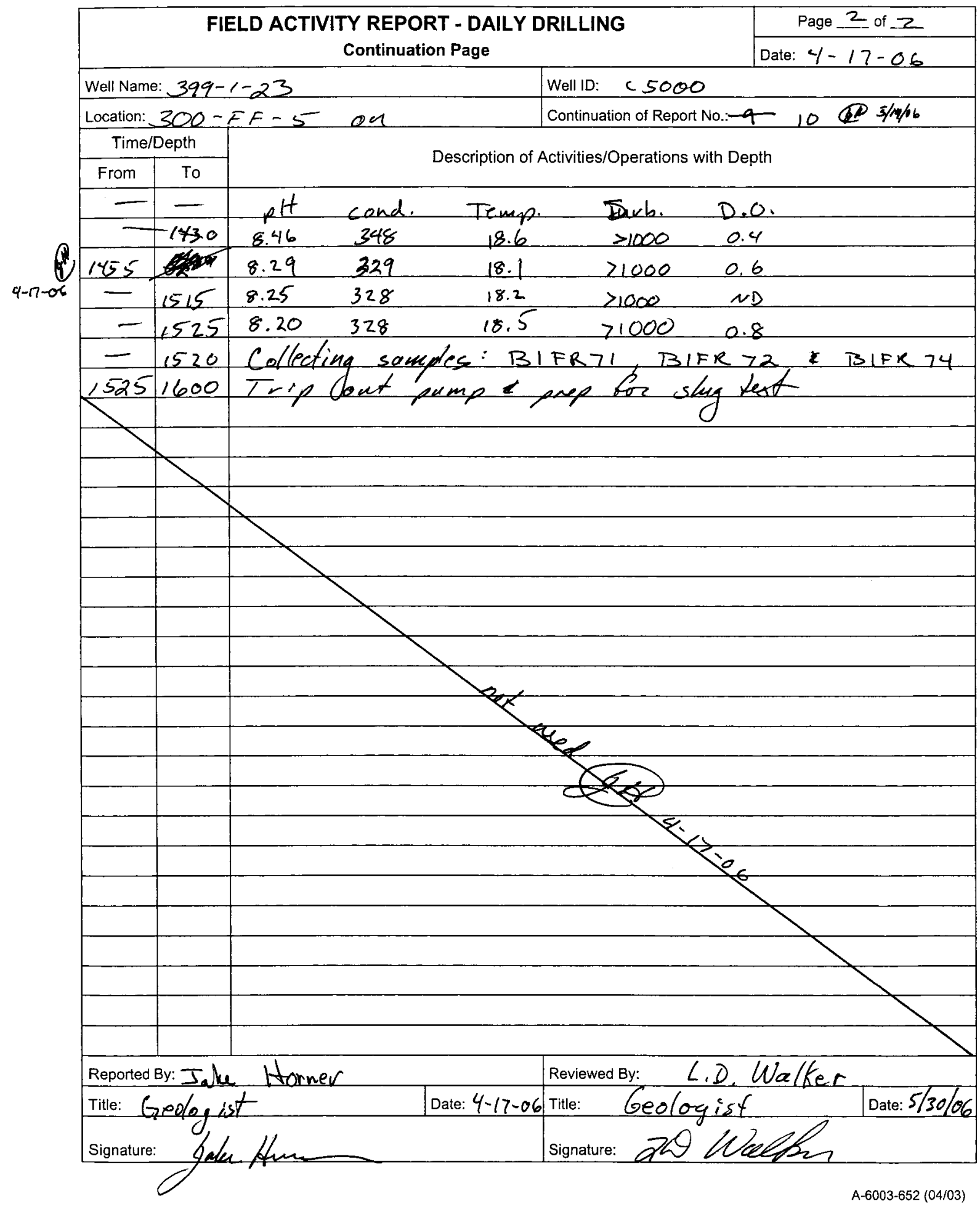




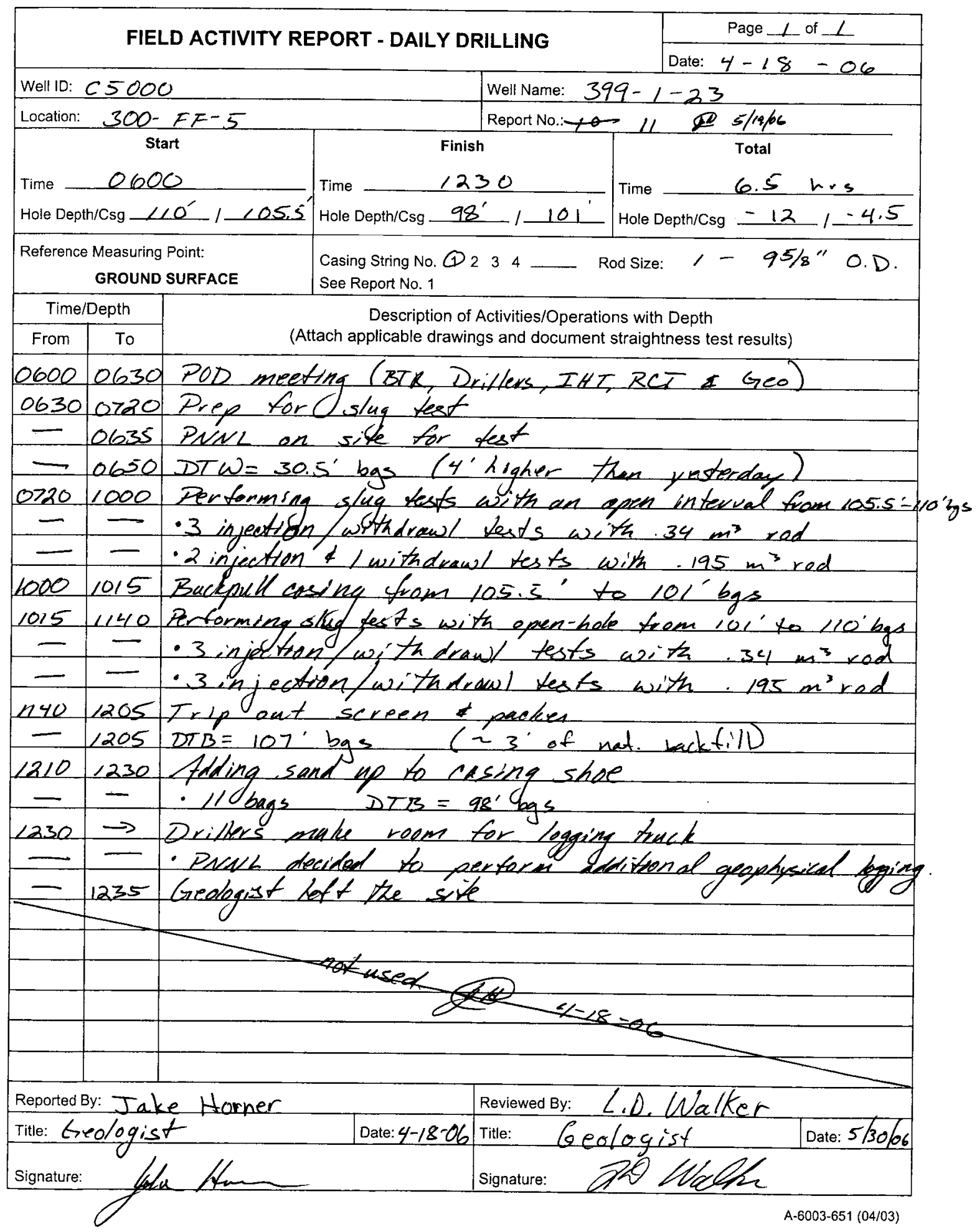




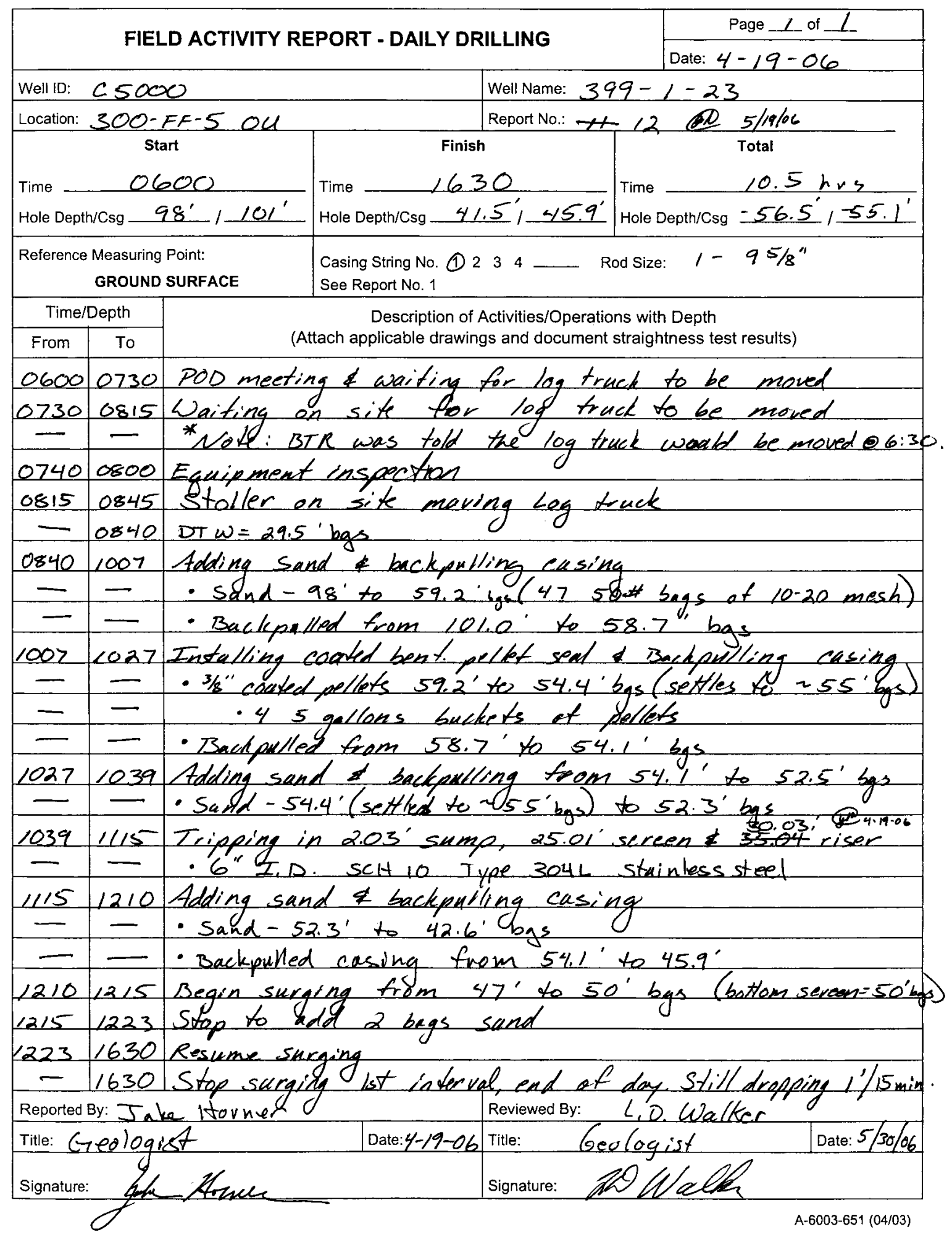




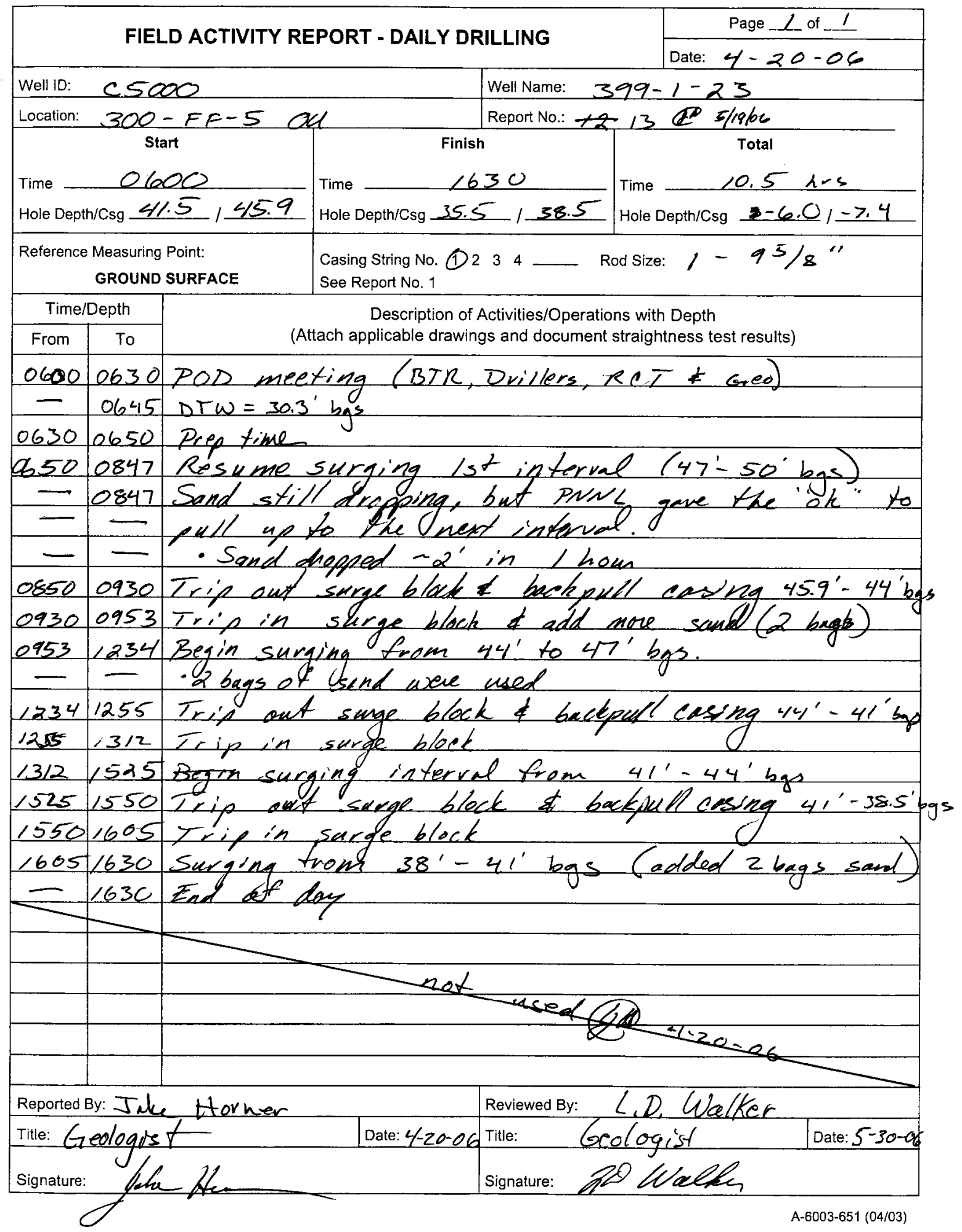




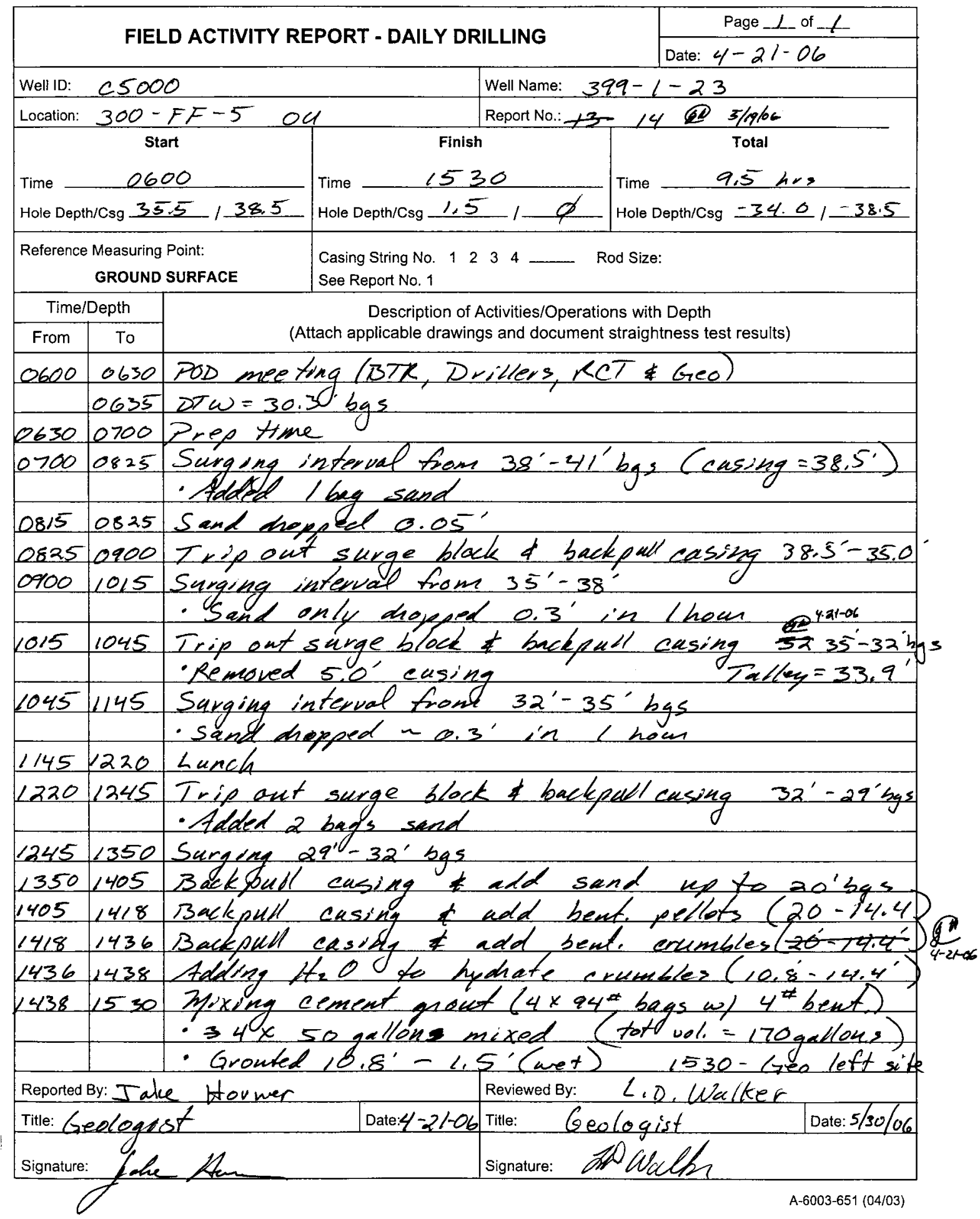




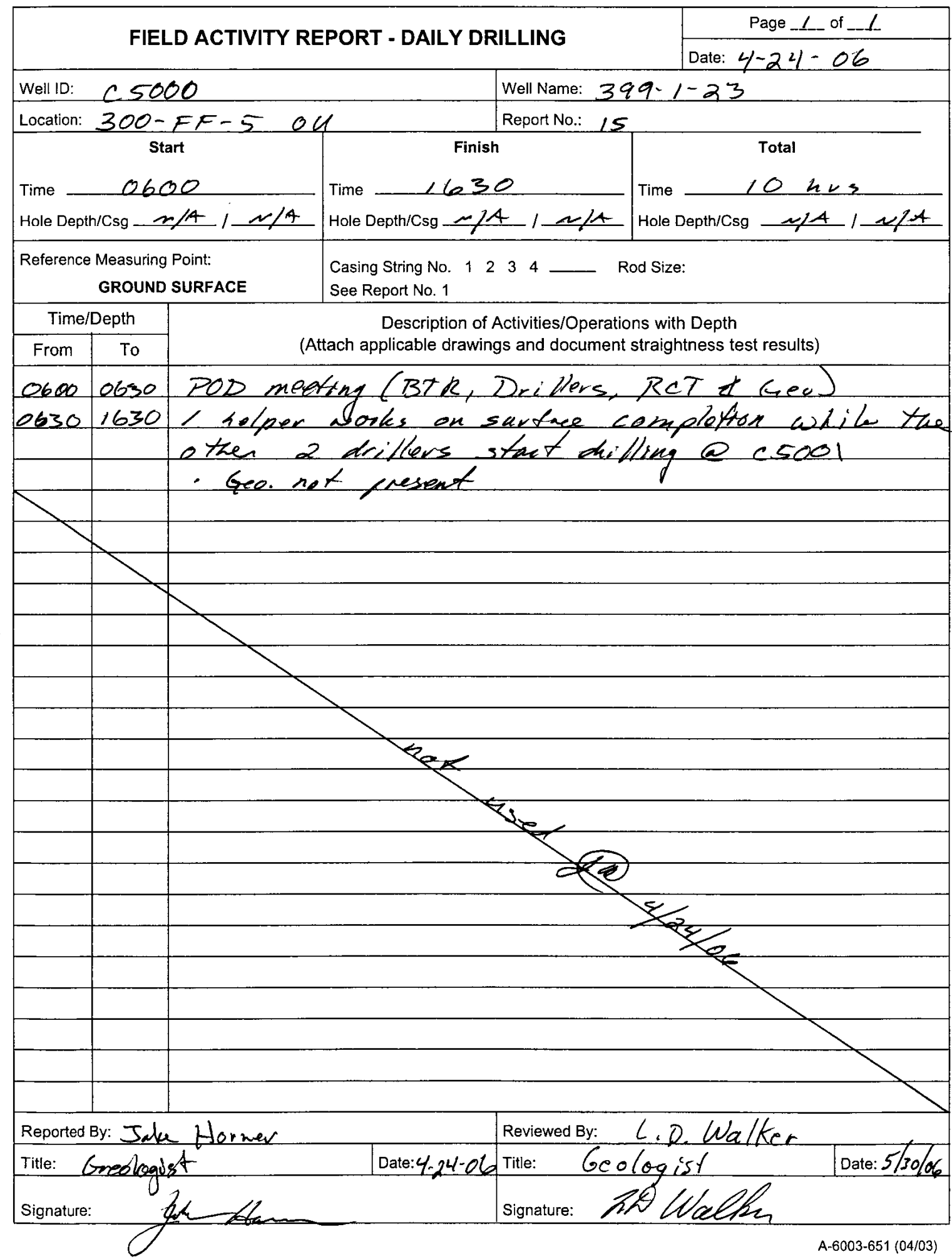




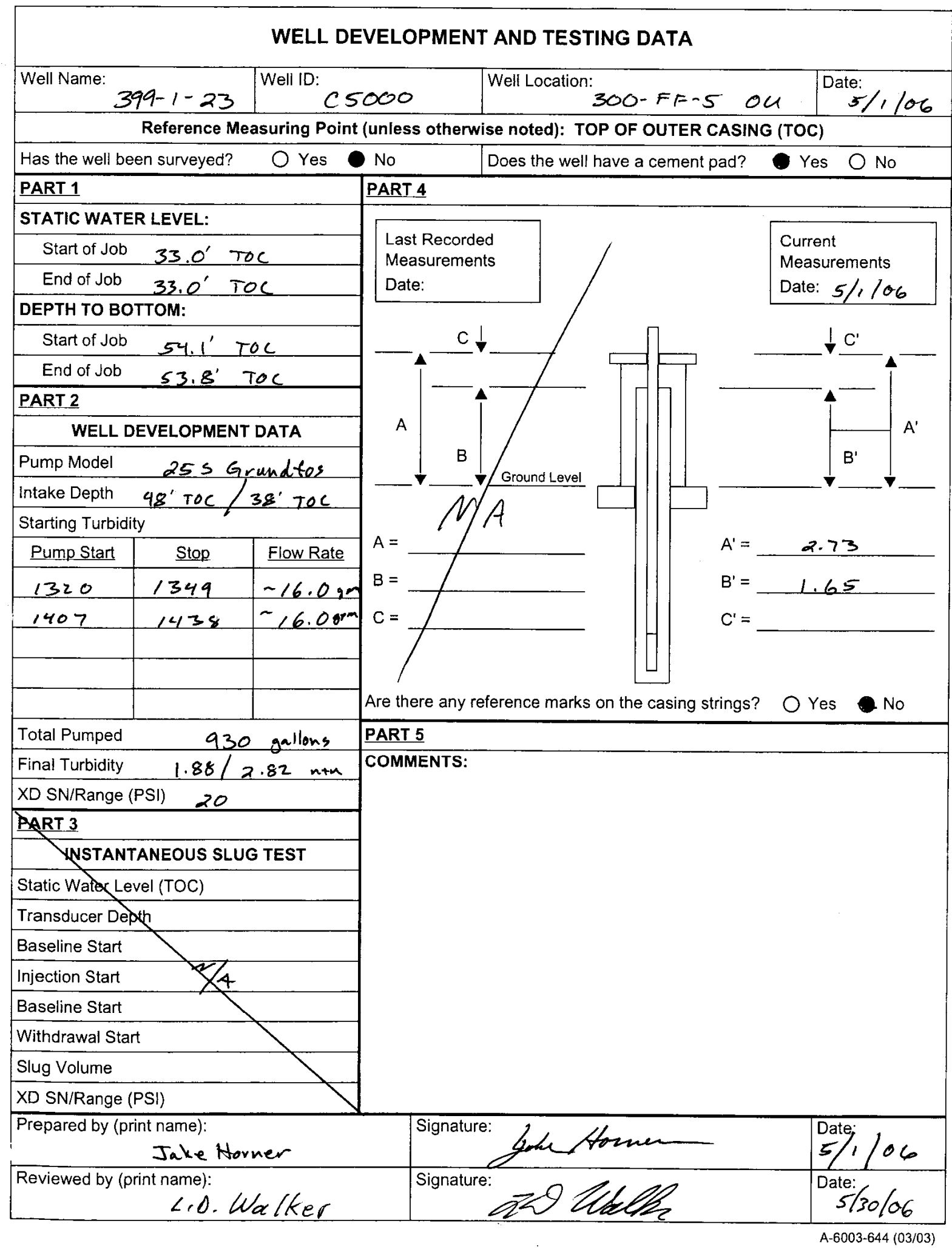




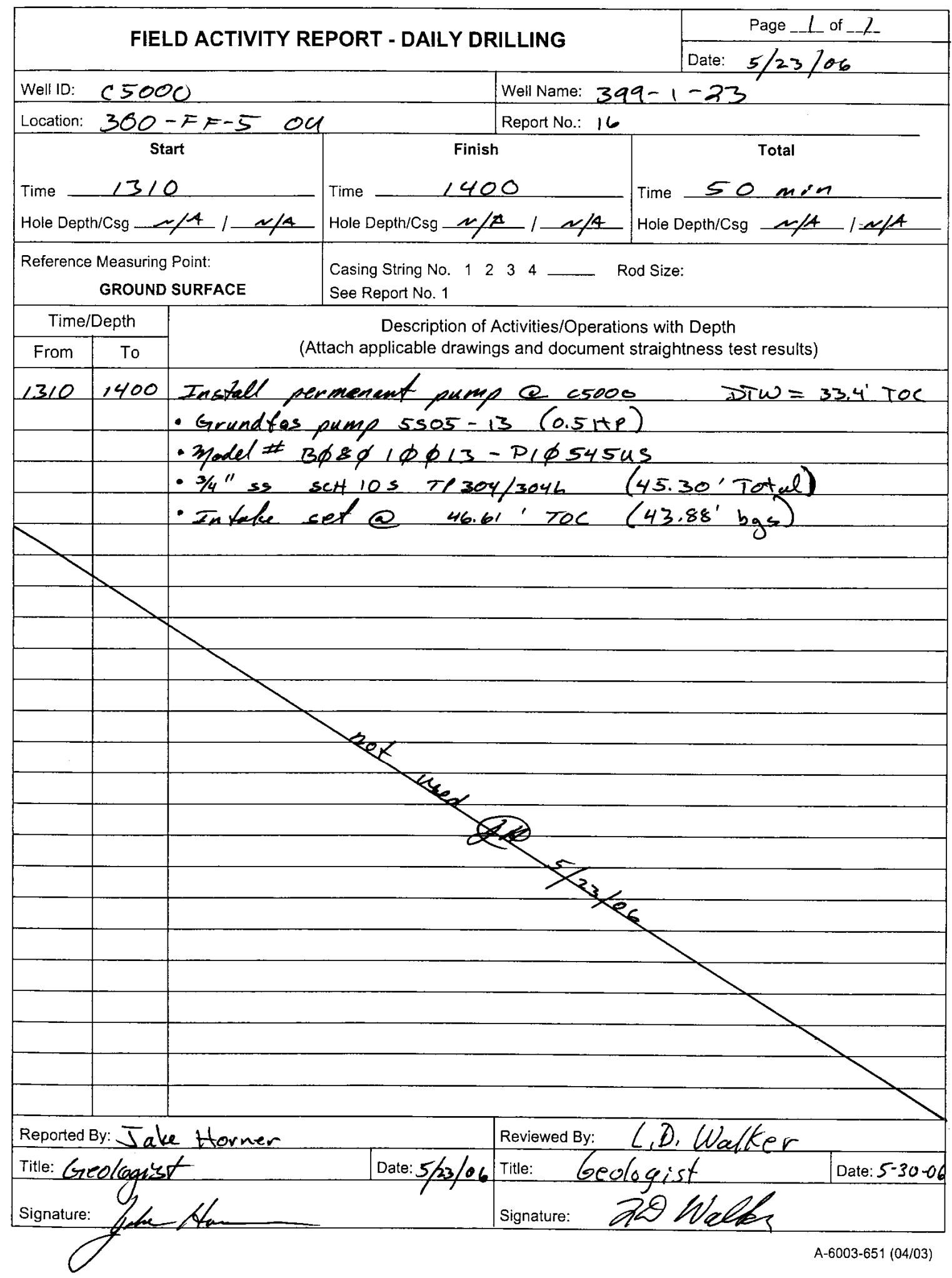




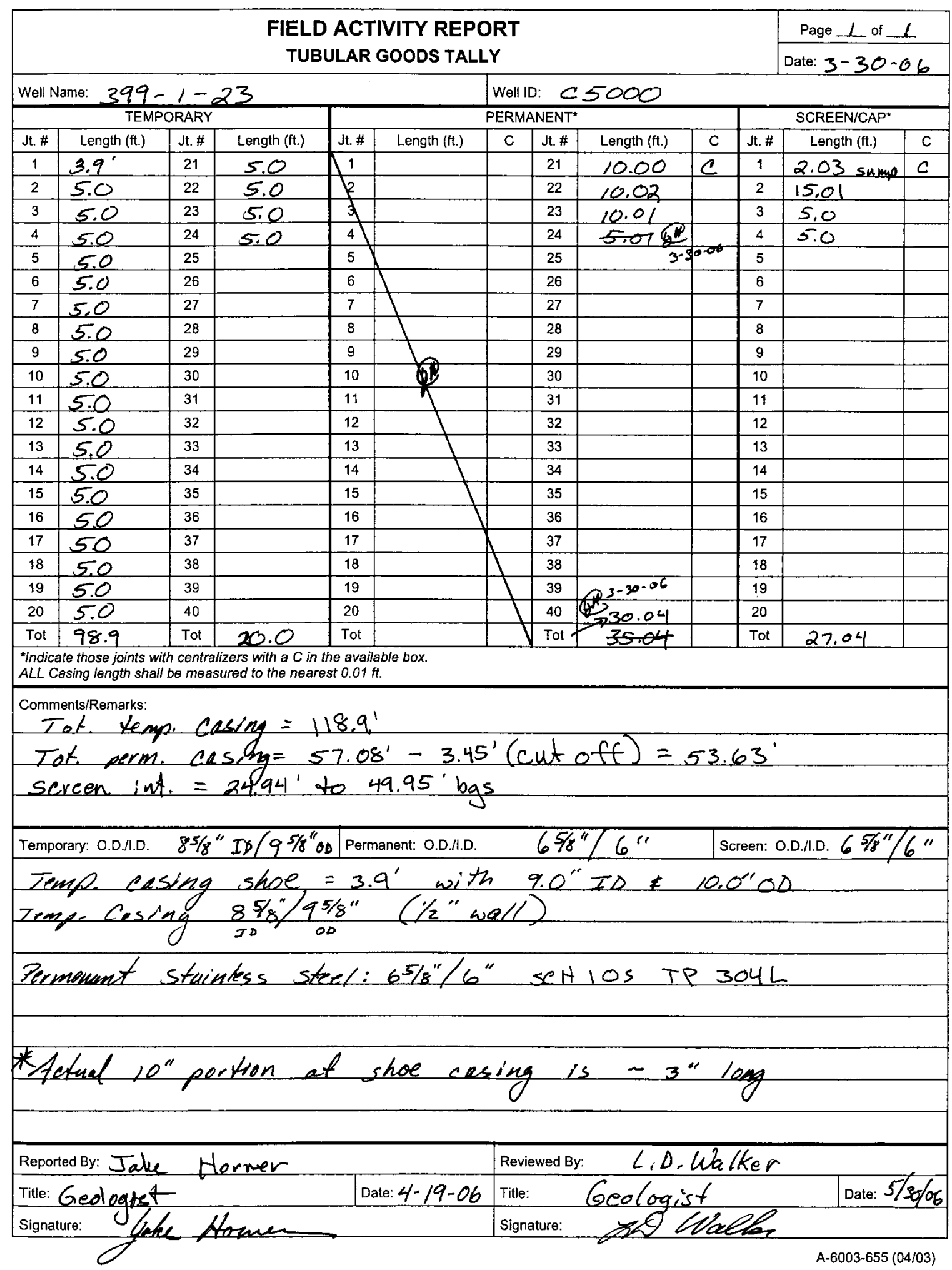




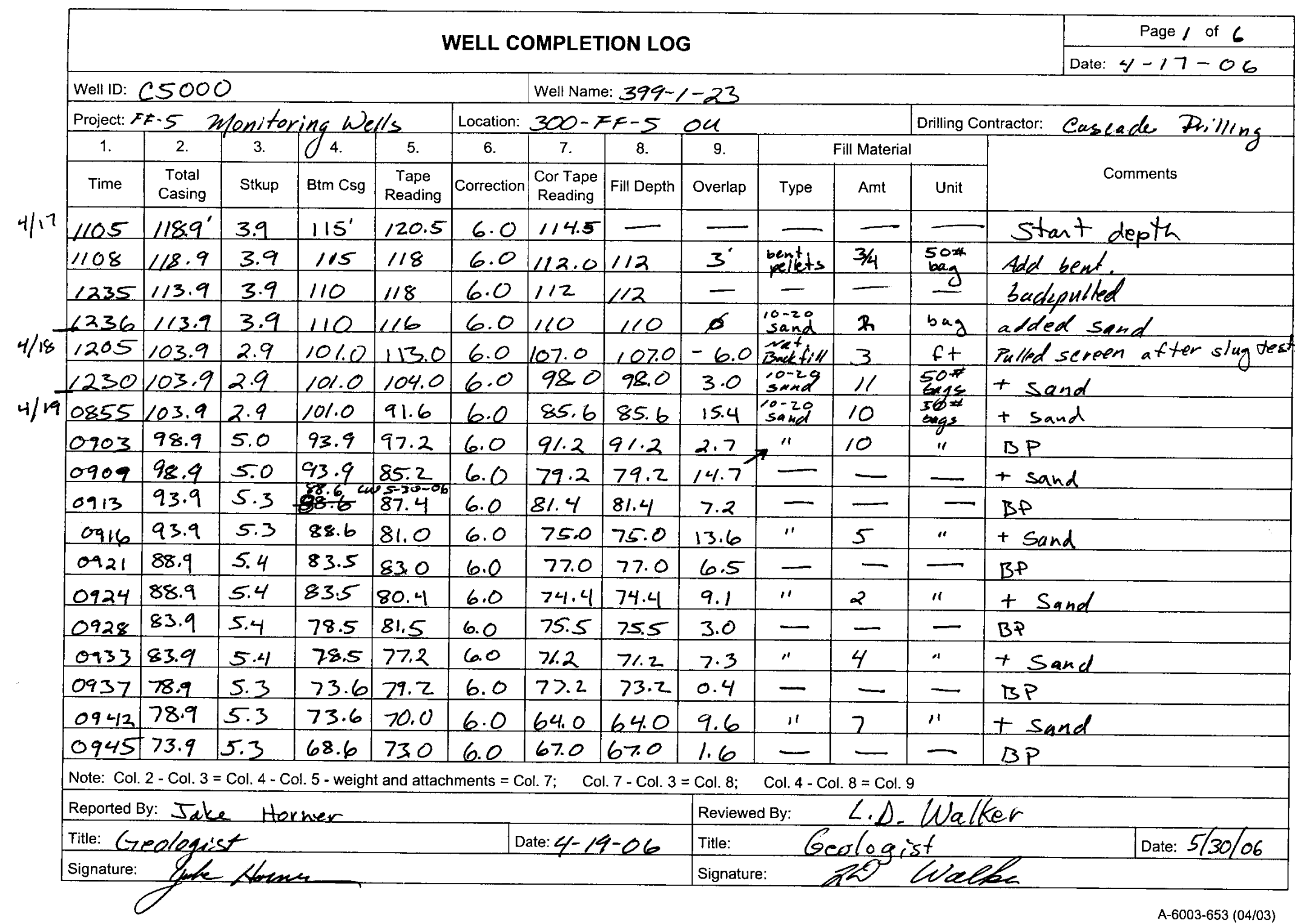


in 5-3006

\section{WELL COMPLETION LOG}

Page 2 of 6 Date: $4-19-06$

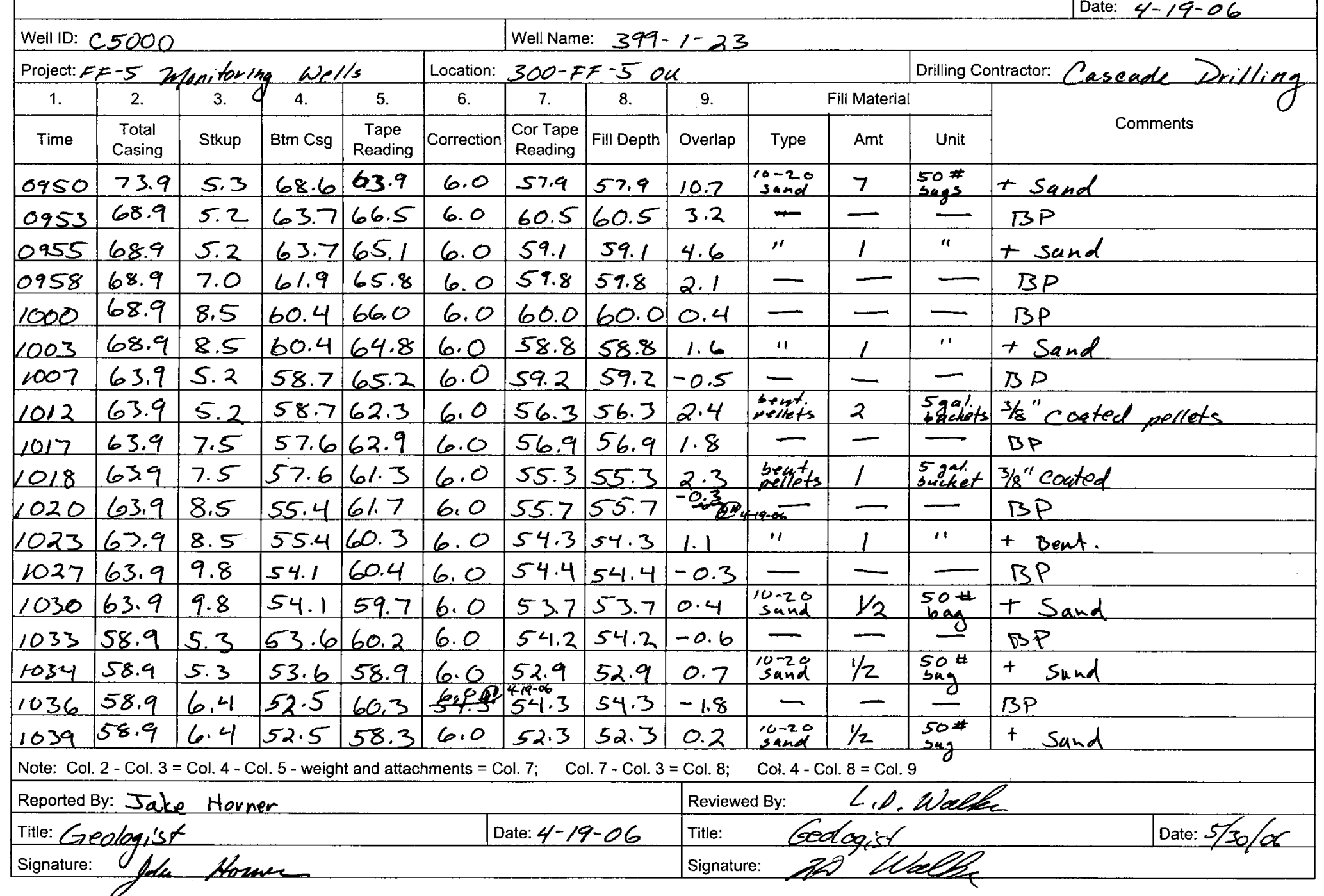




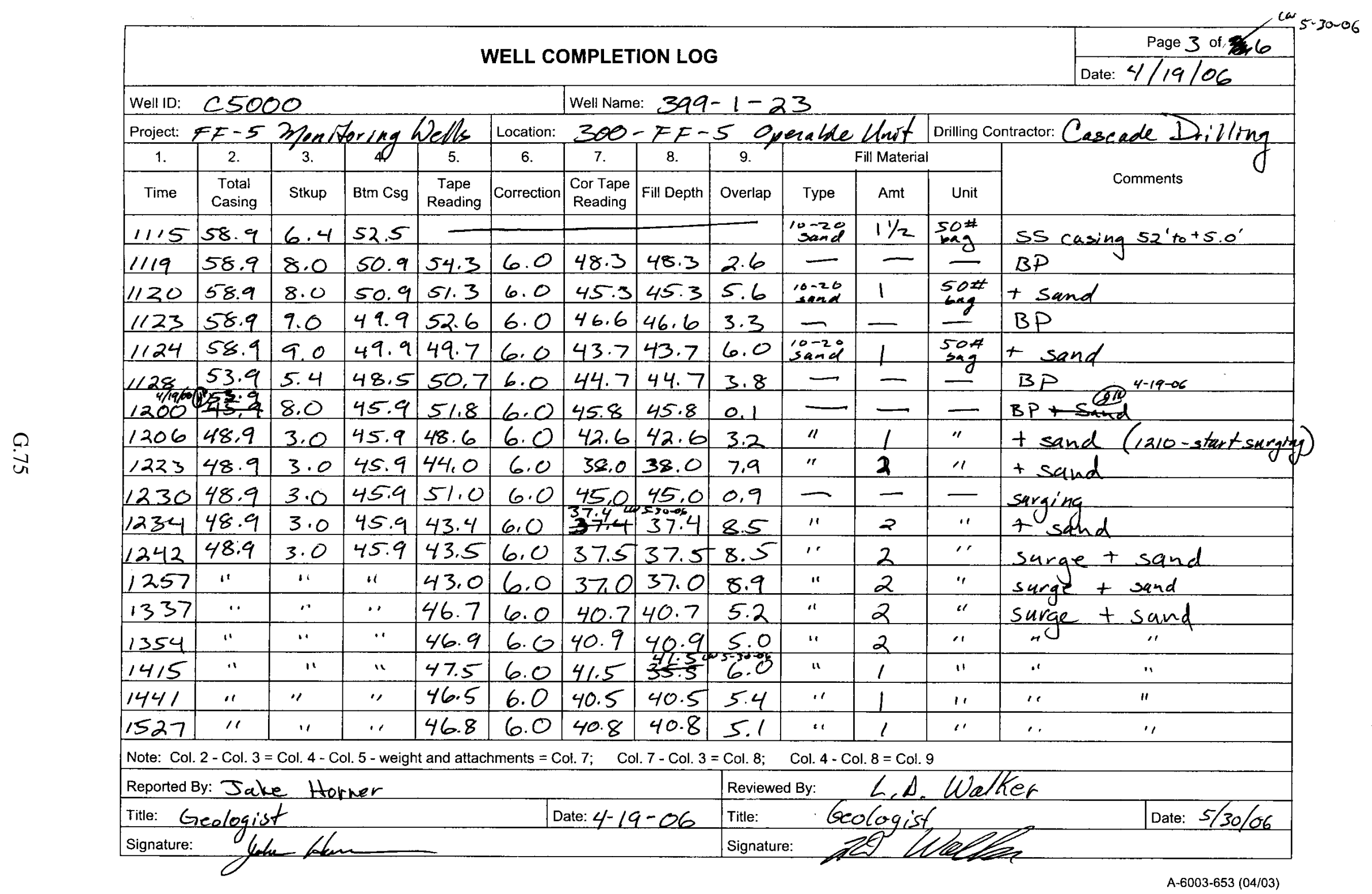




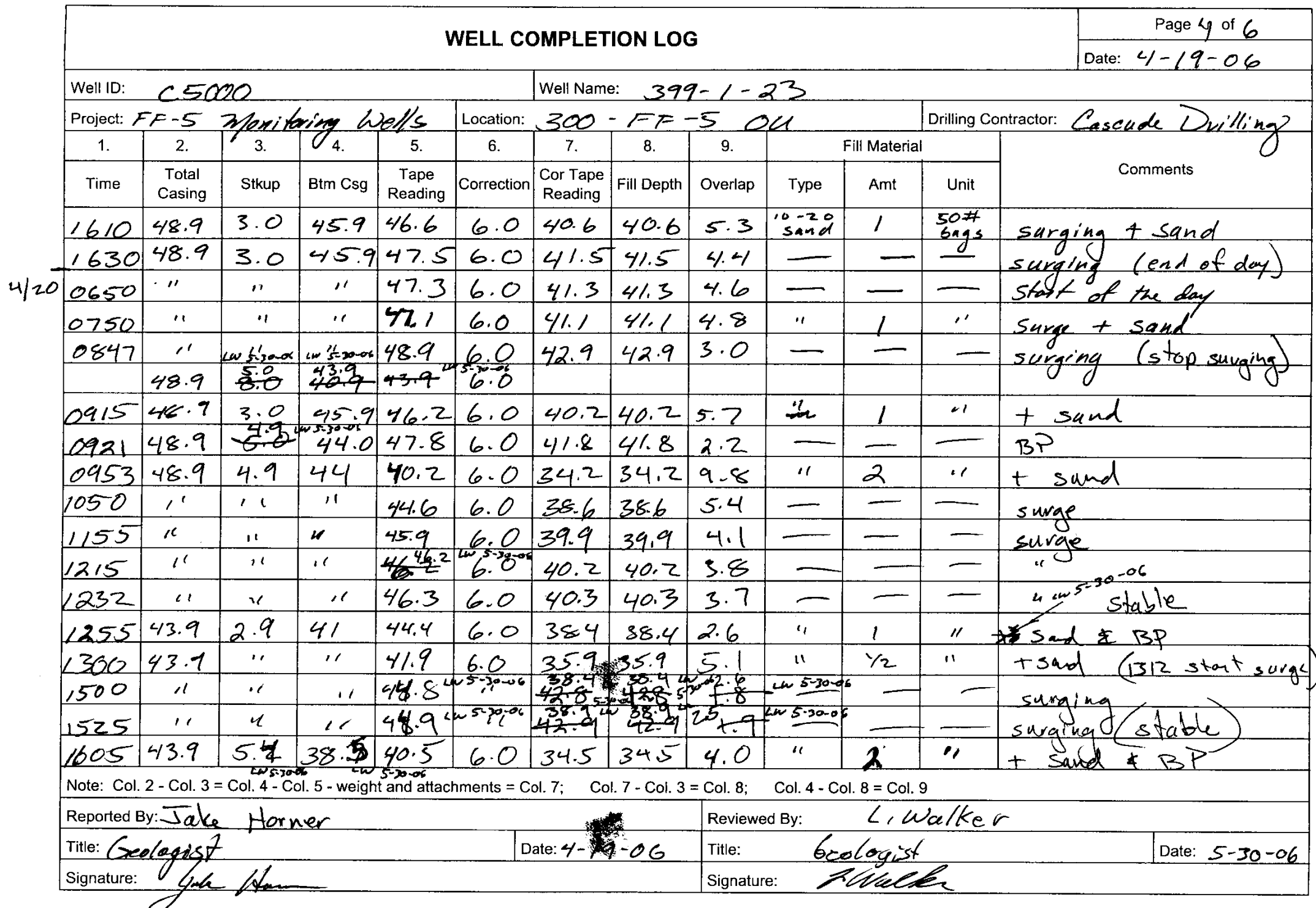




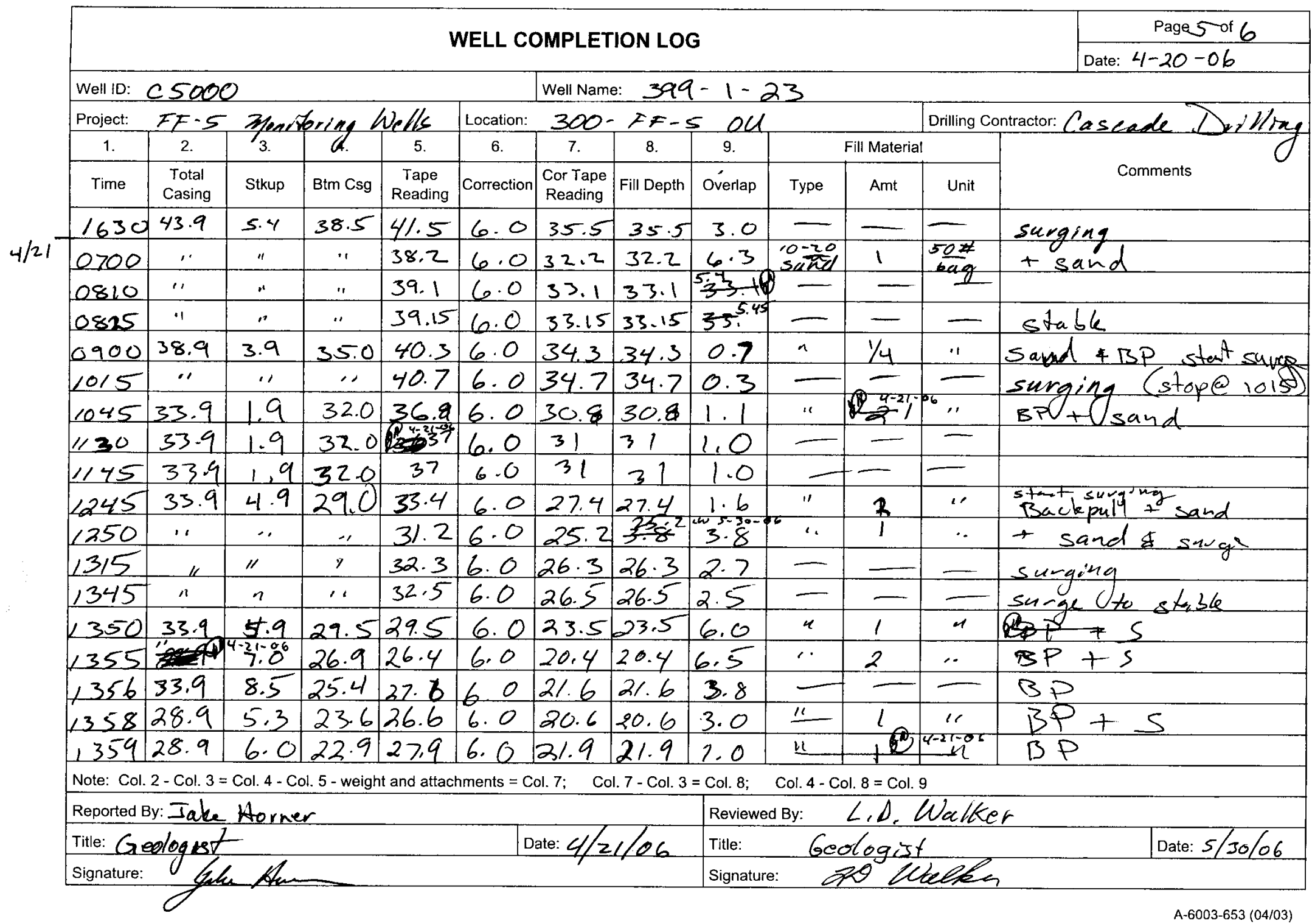




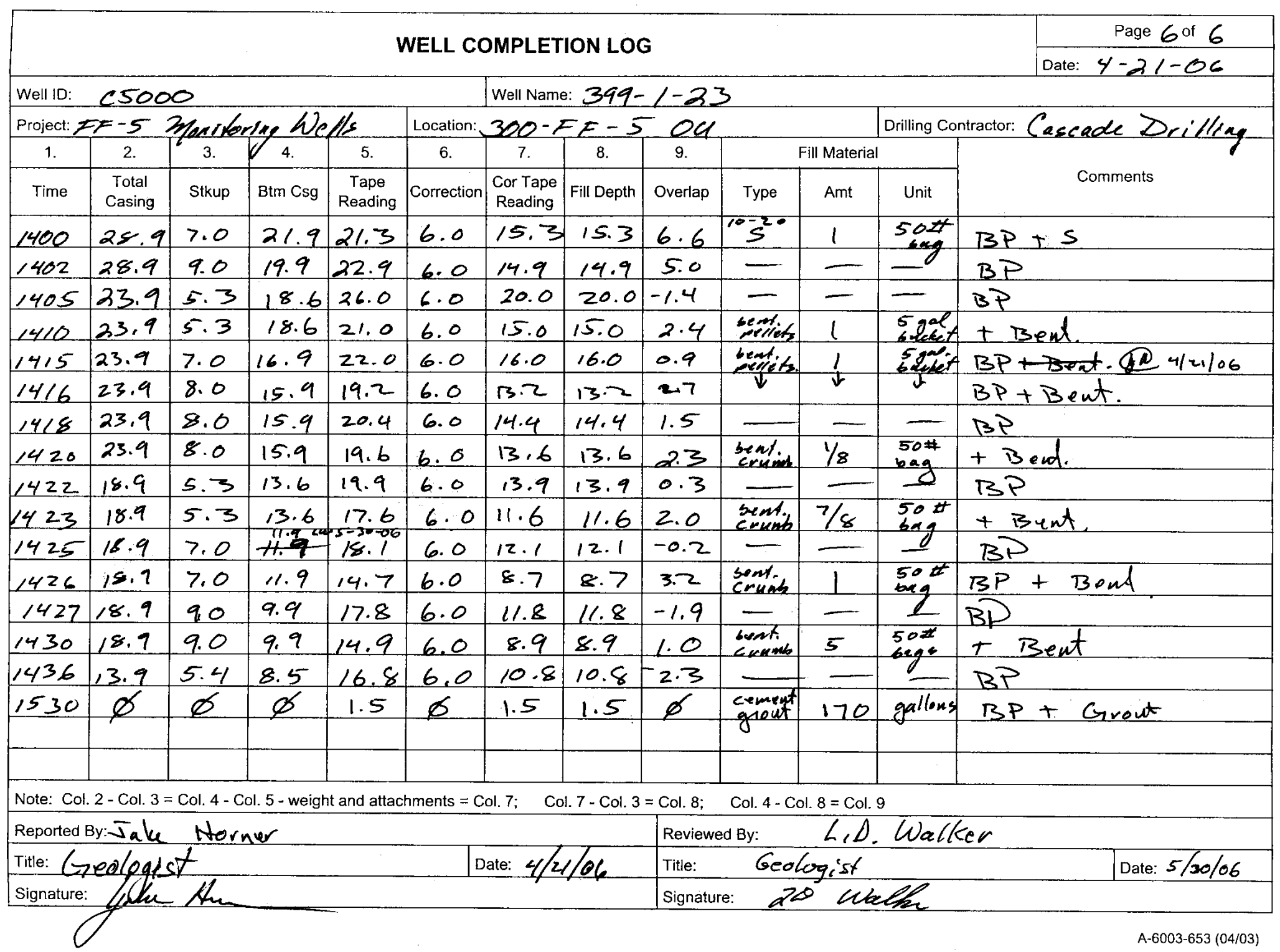




\section{Well C5001}

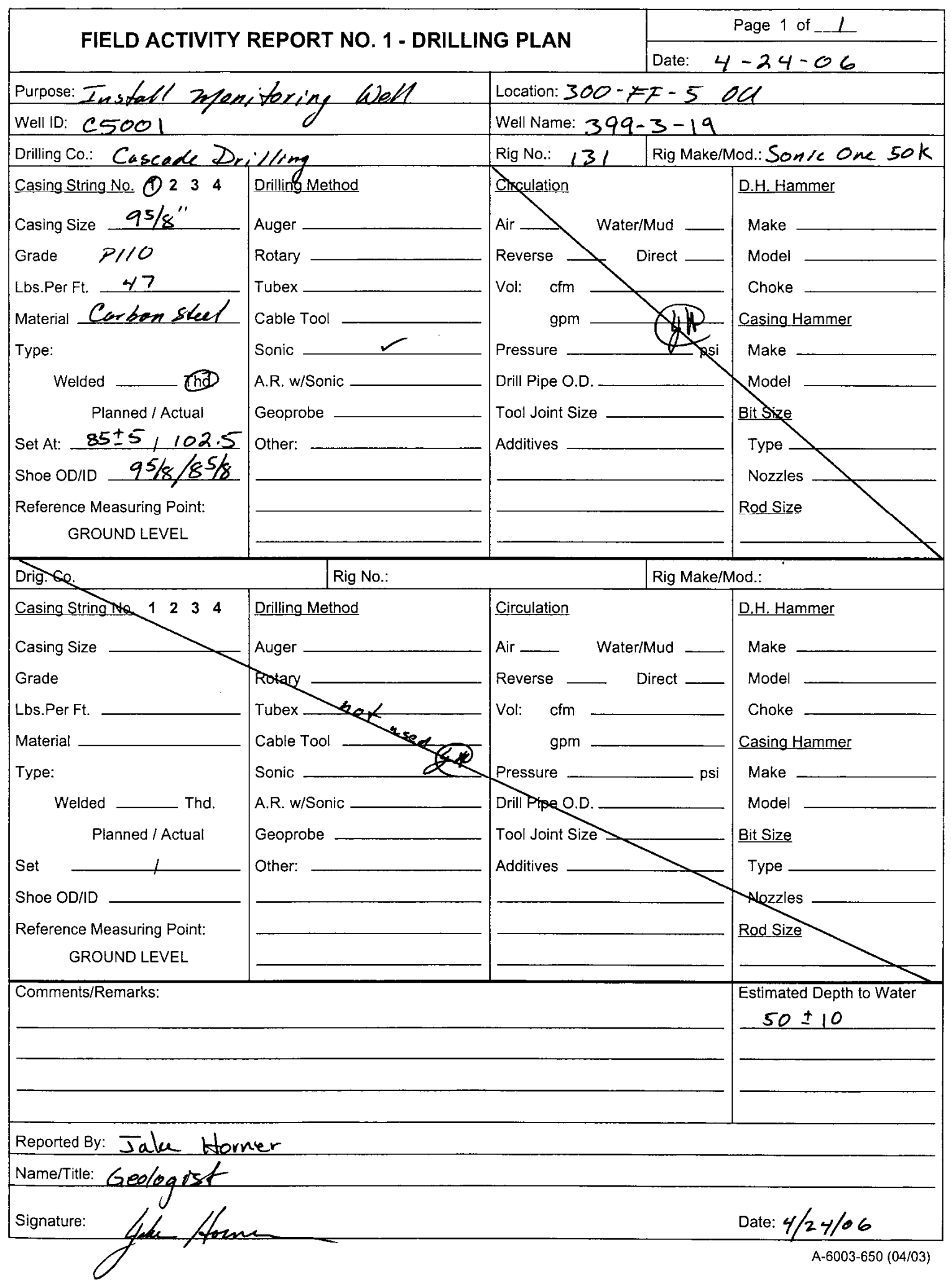




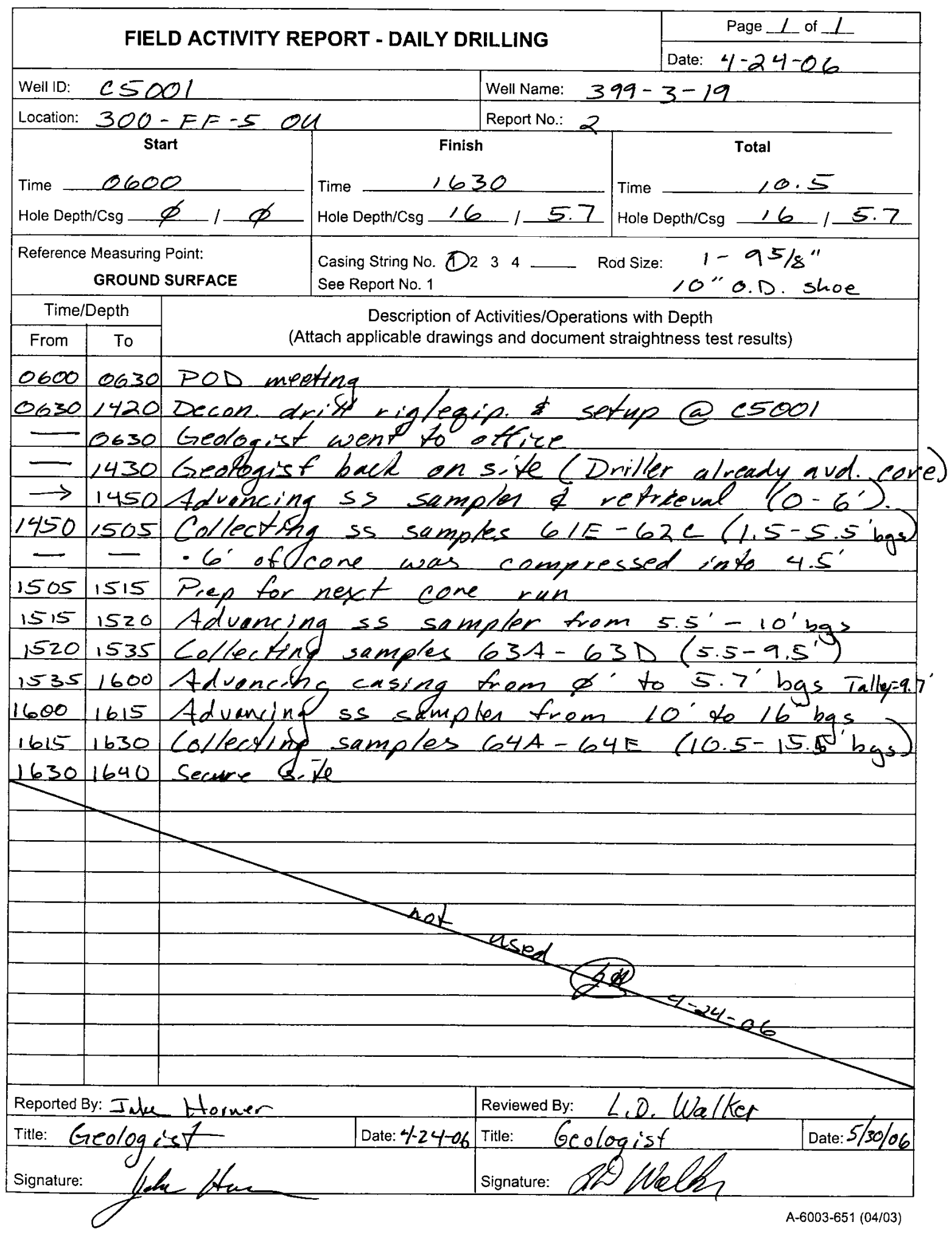




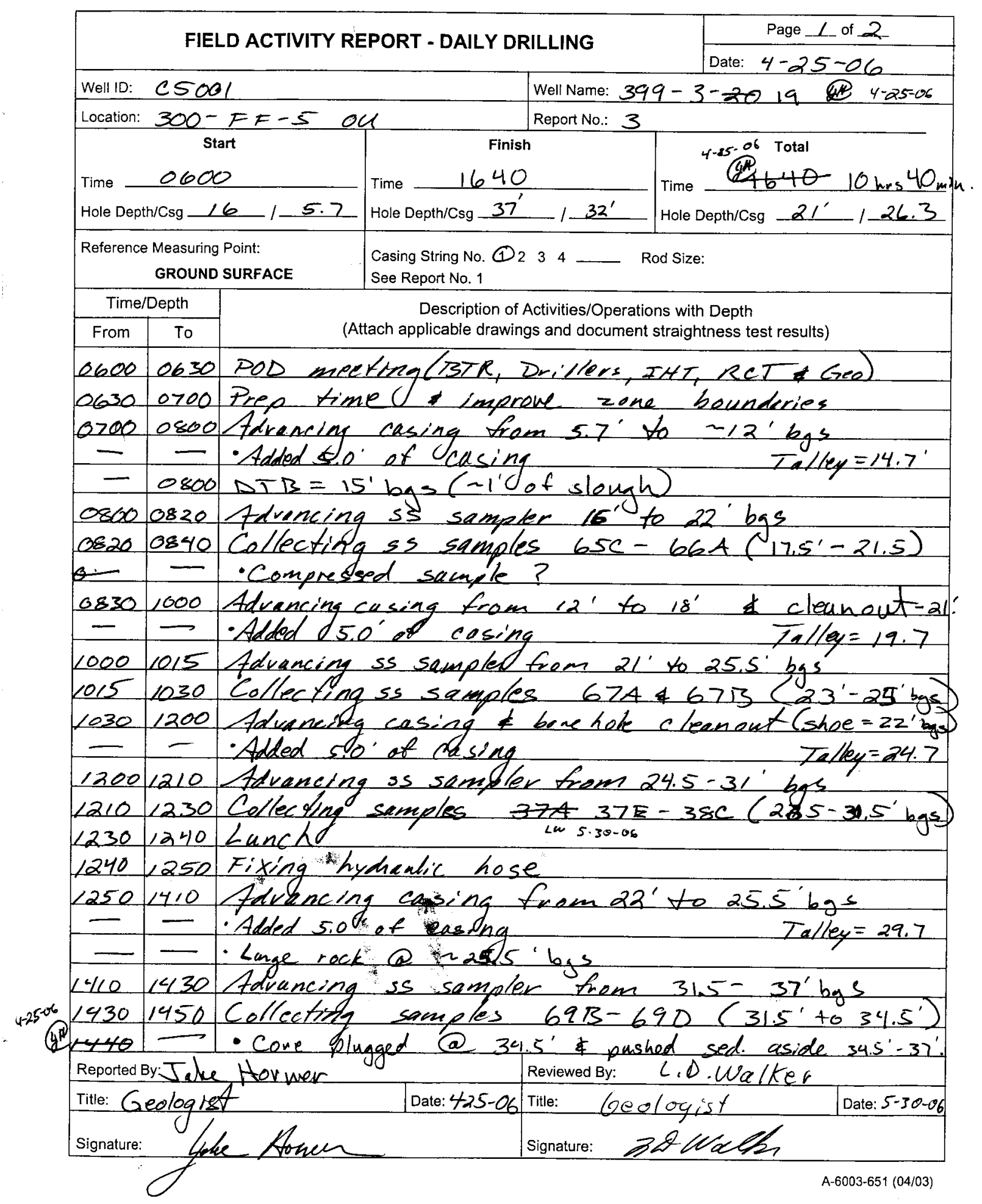




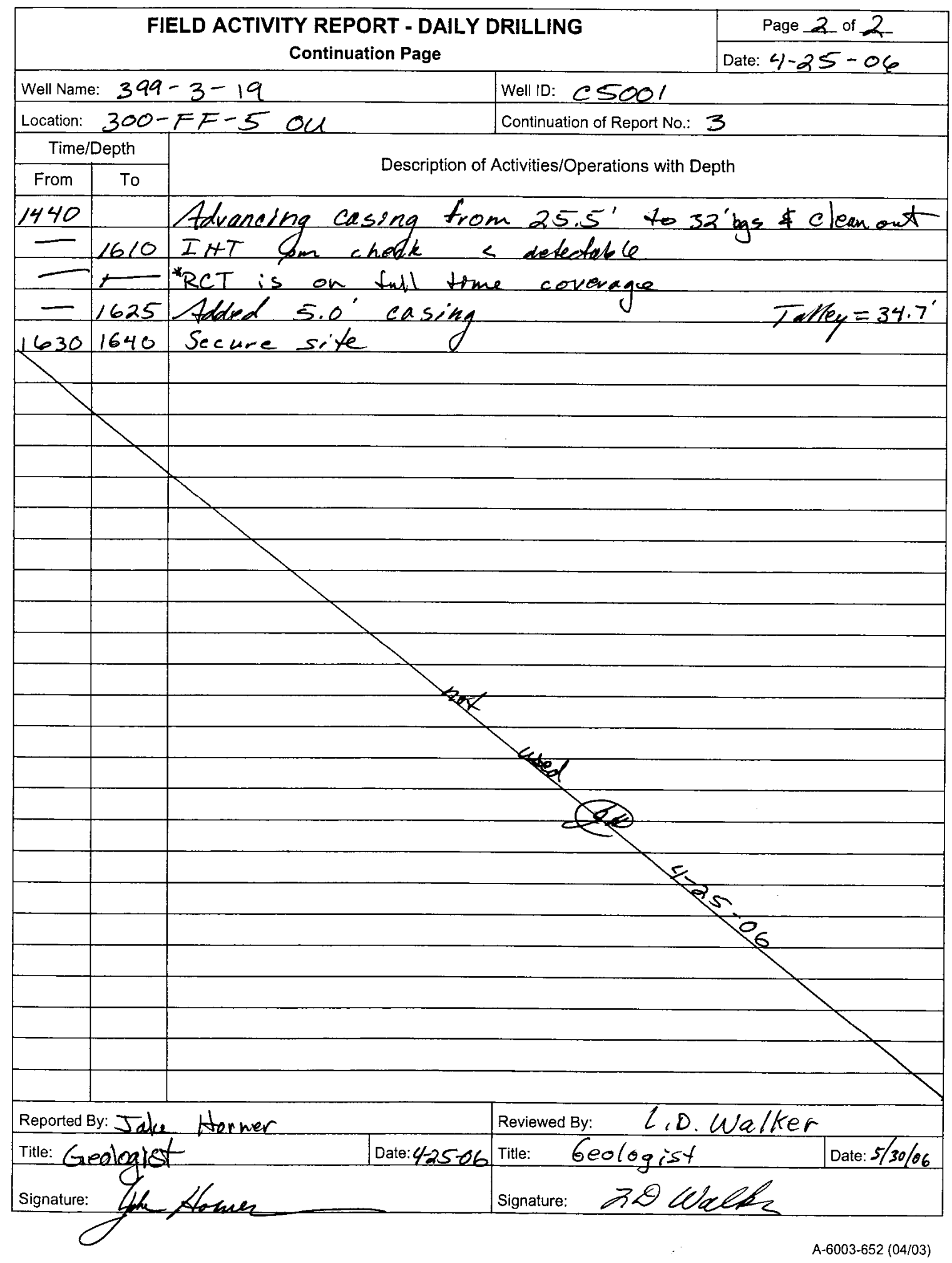




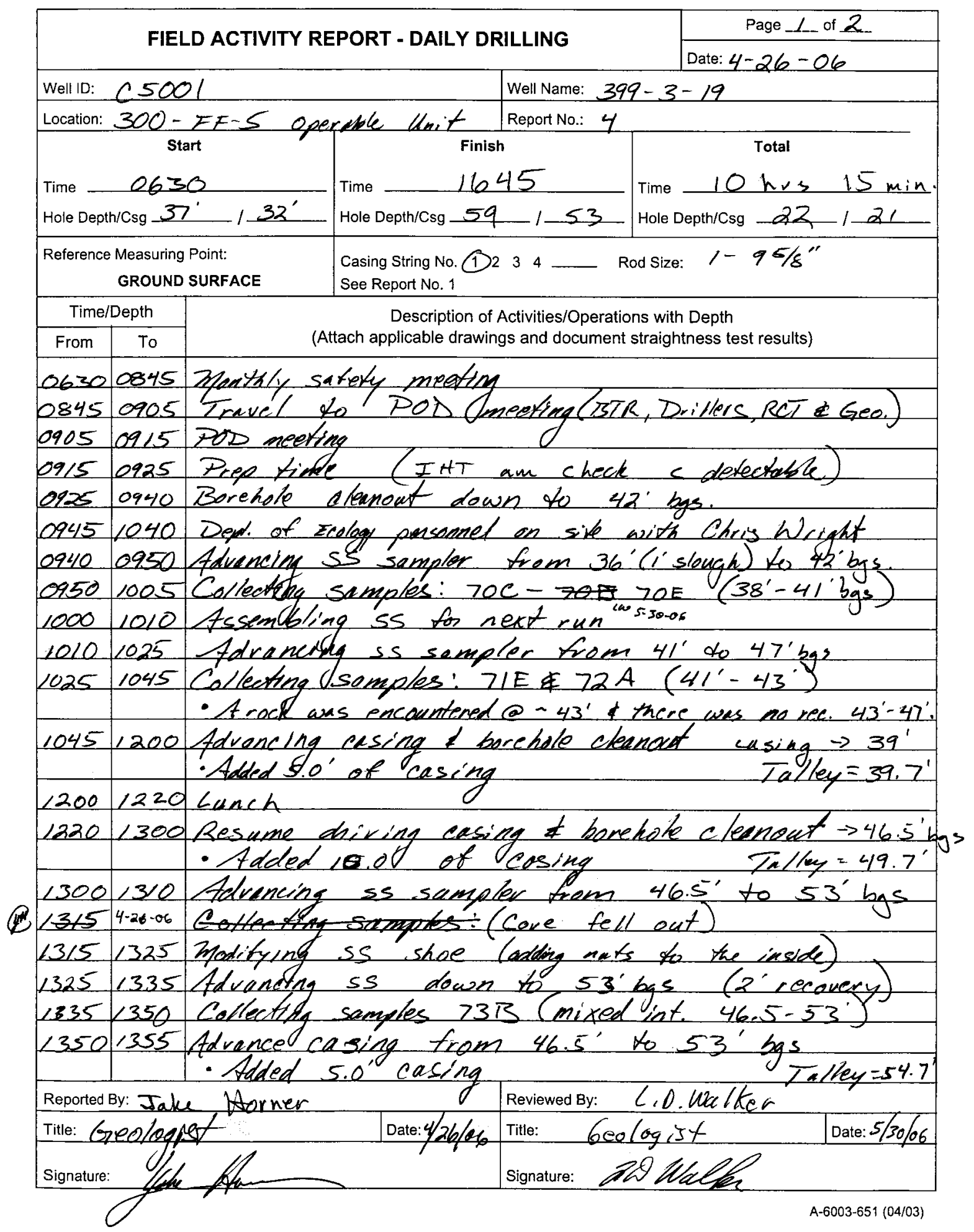




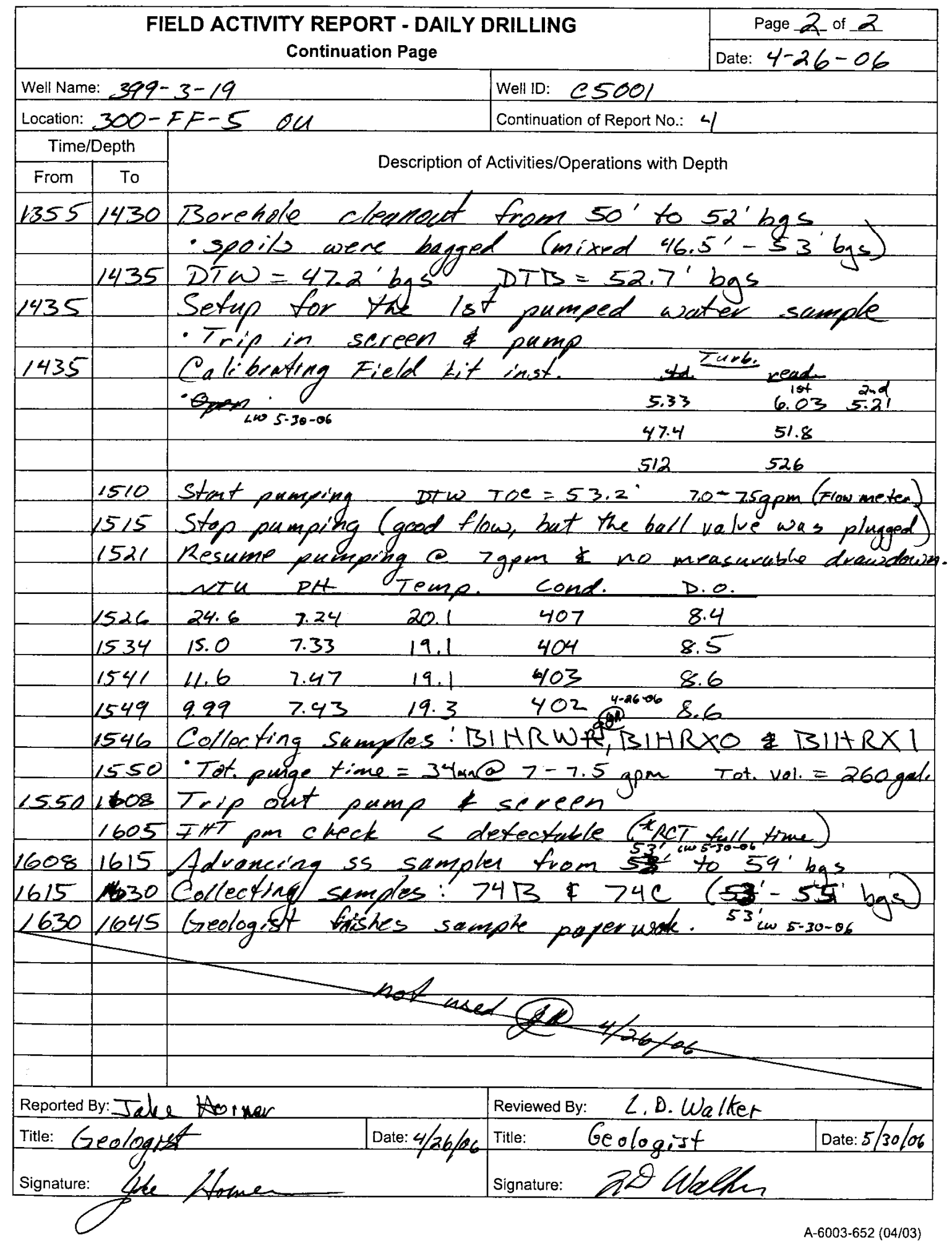




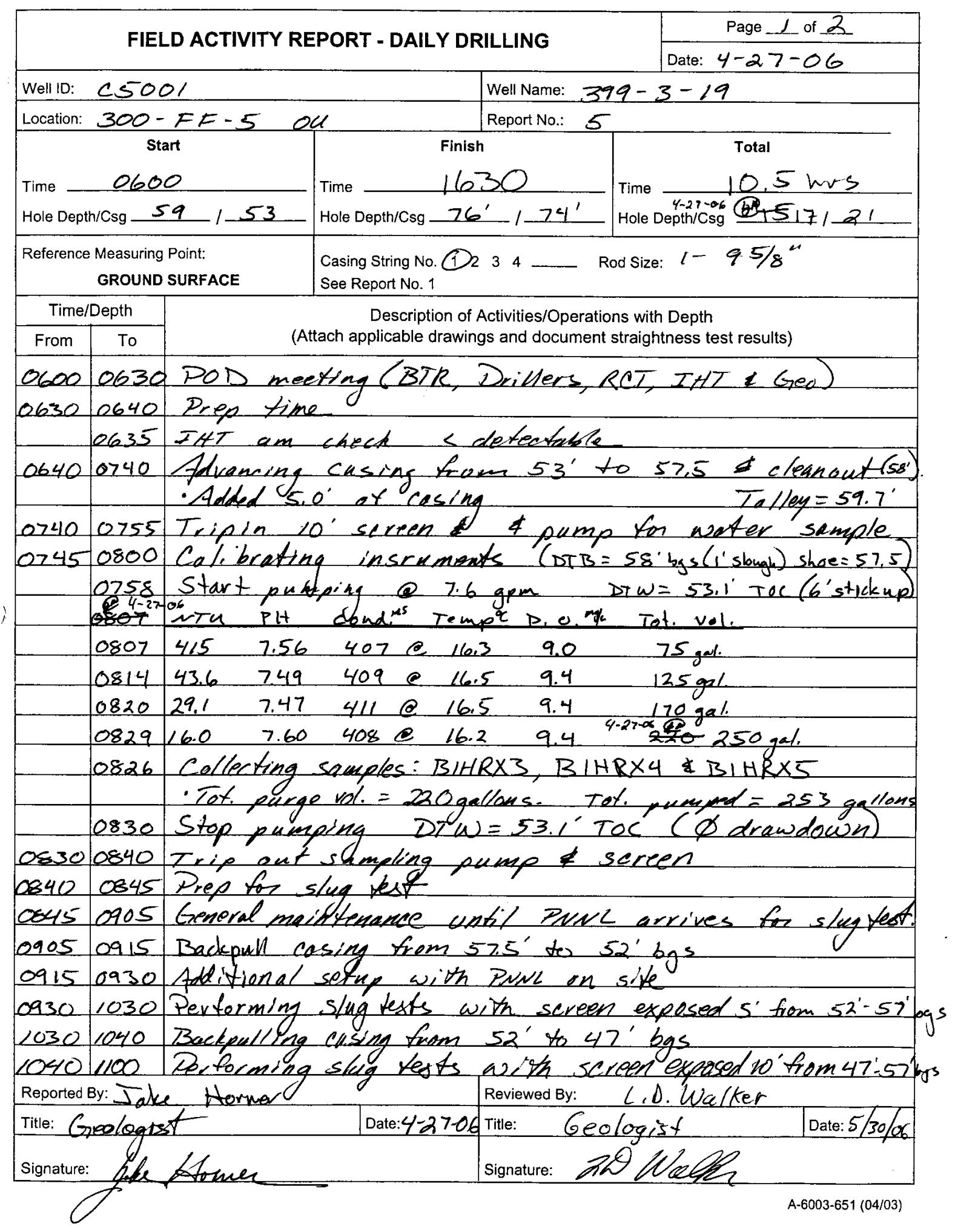




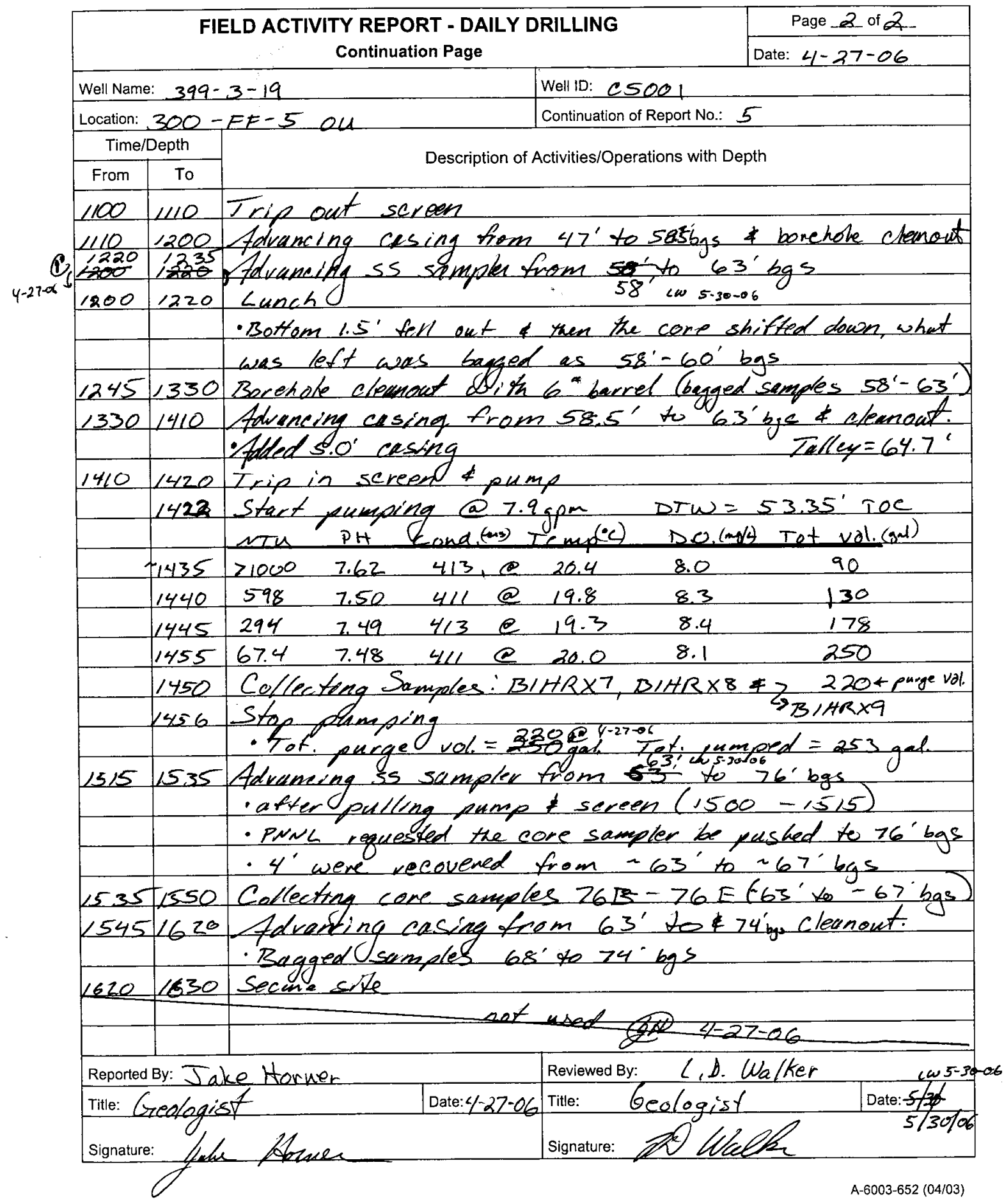




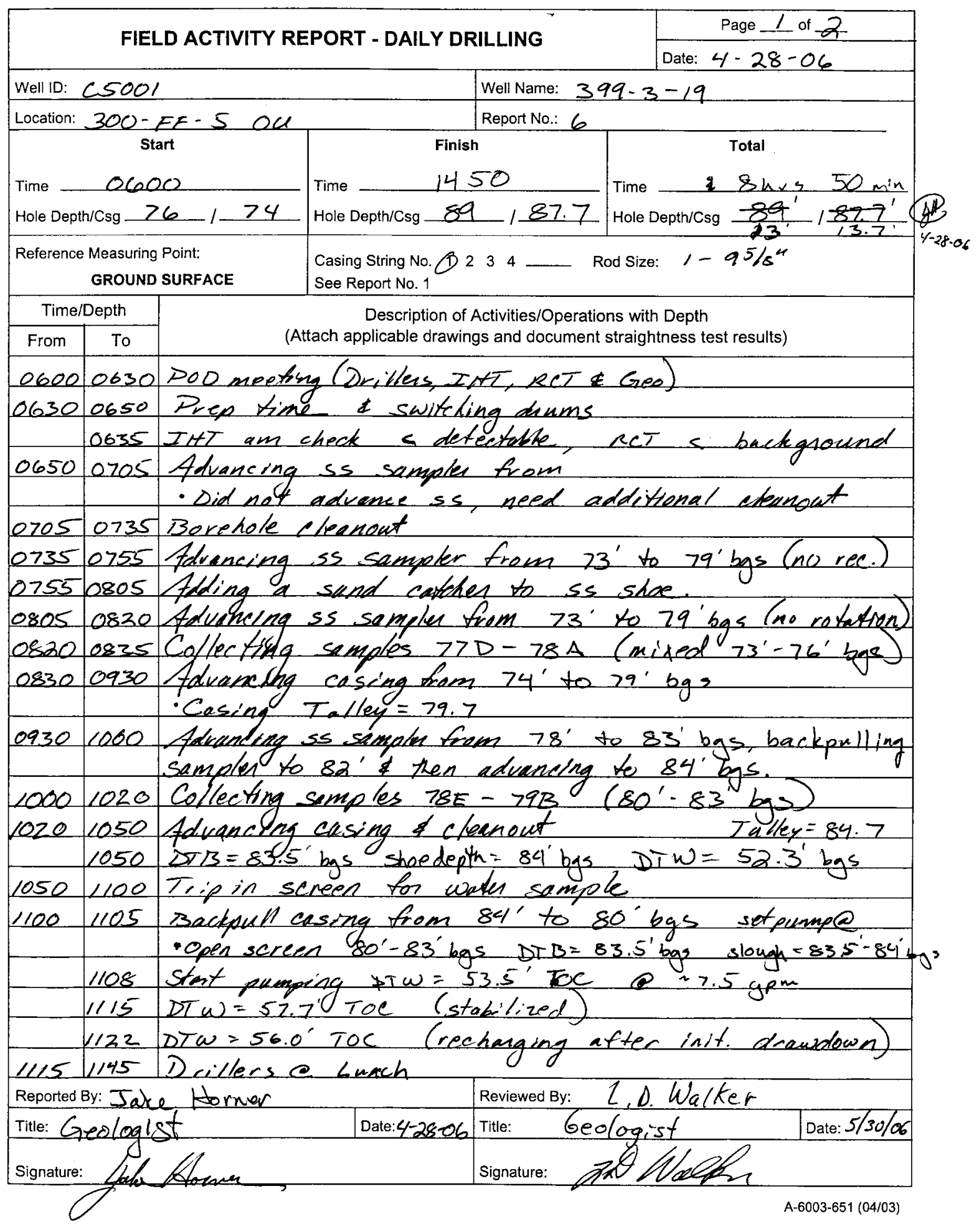




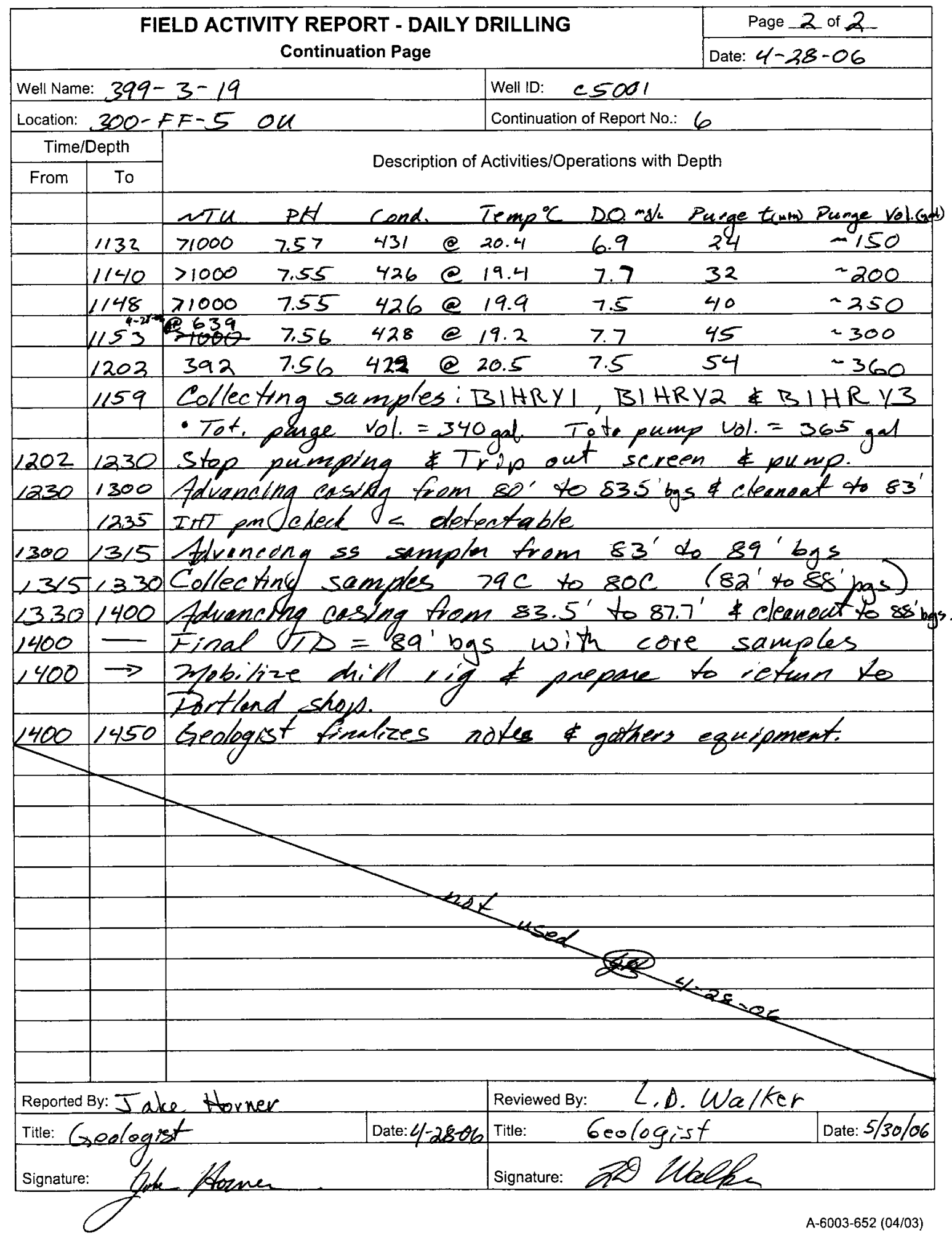




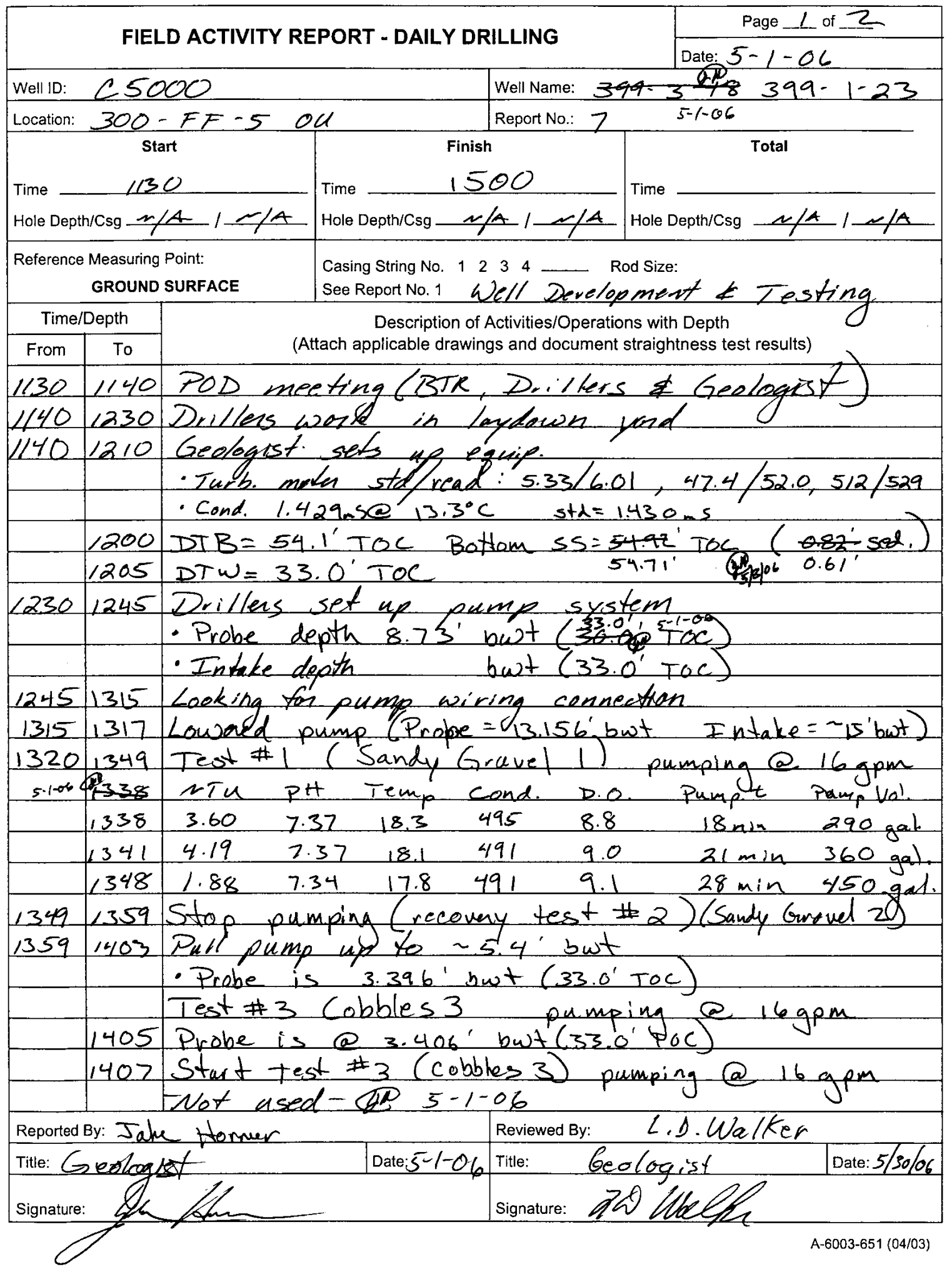




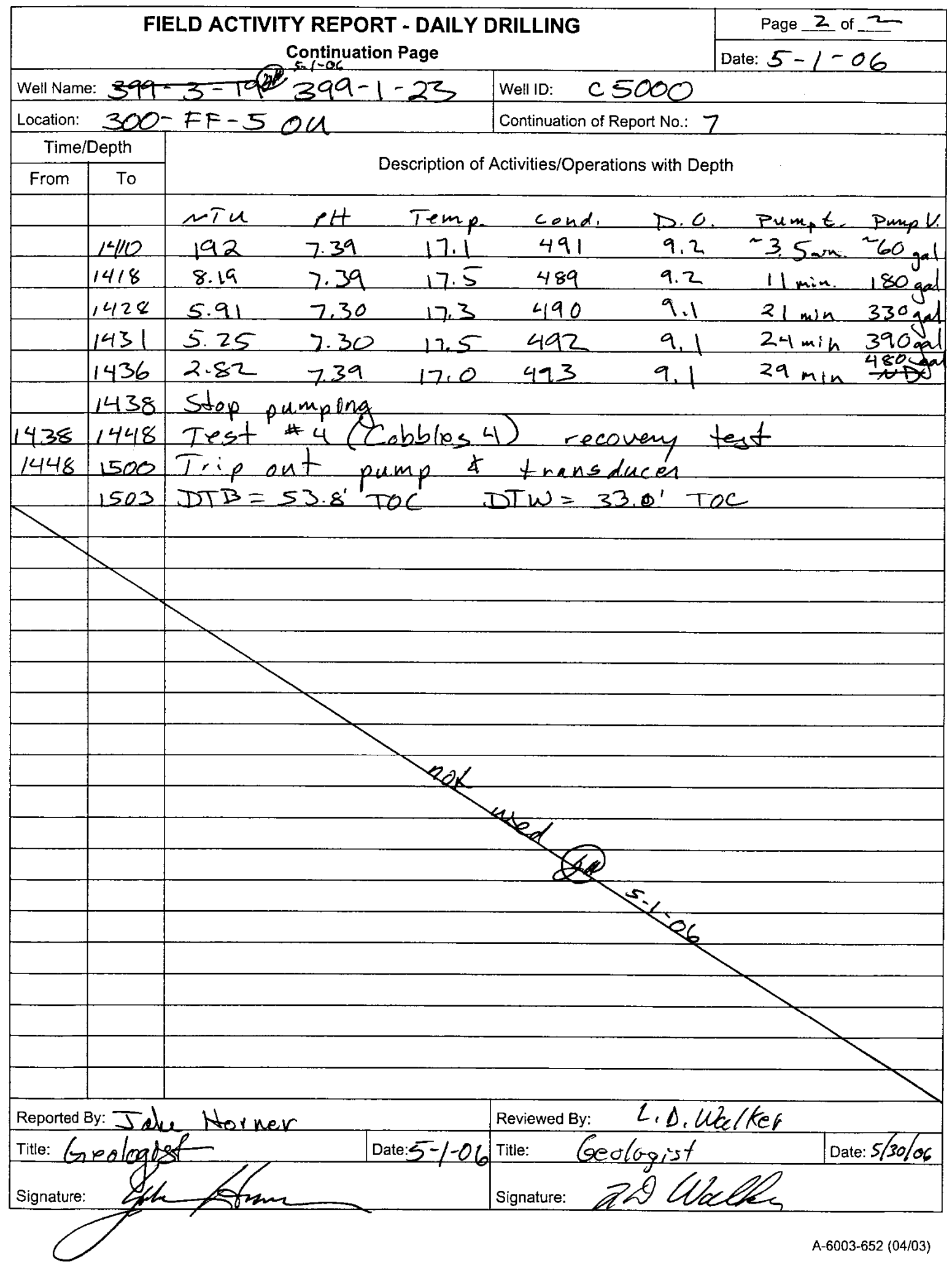




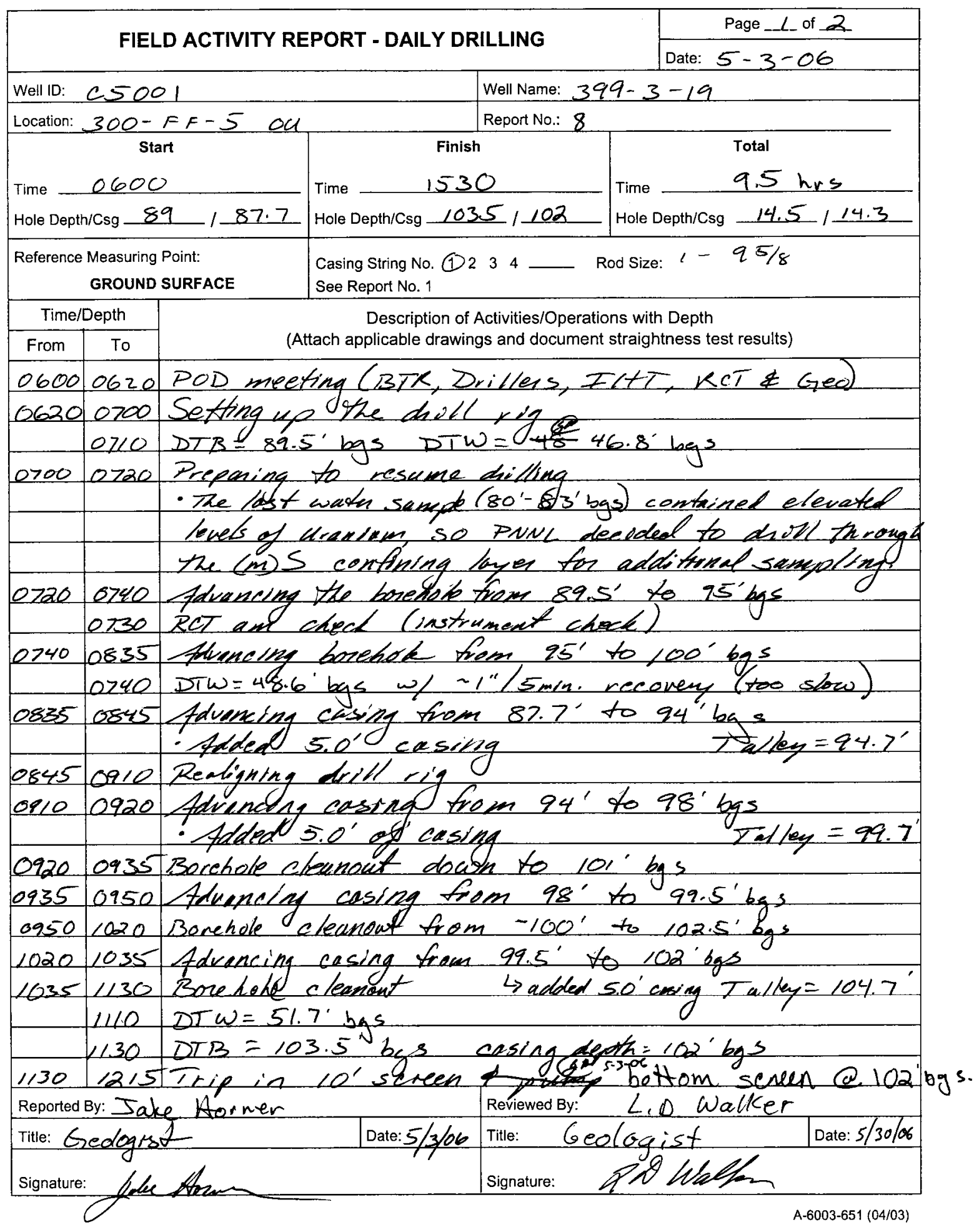




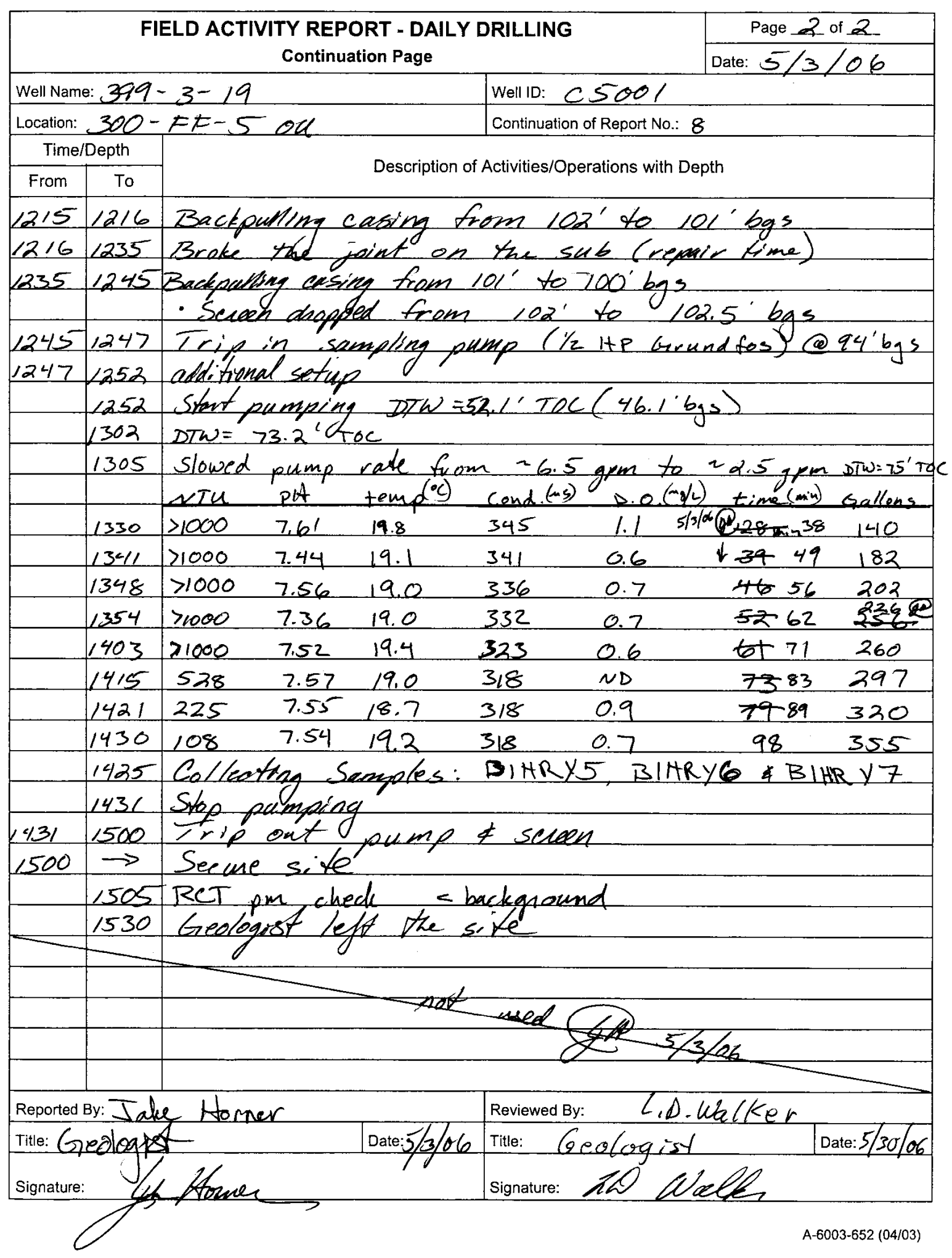




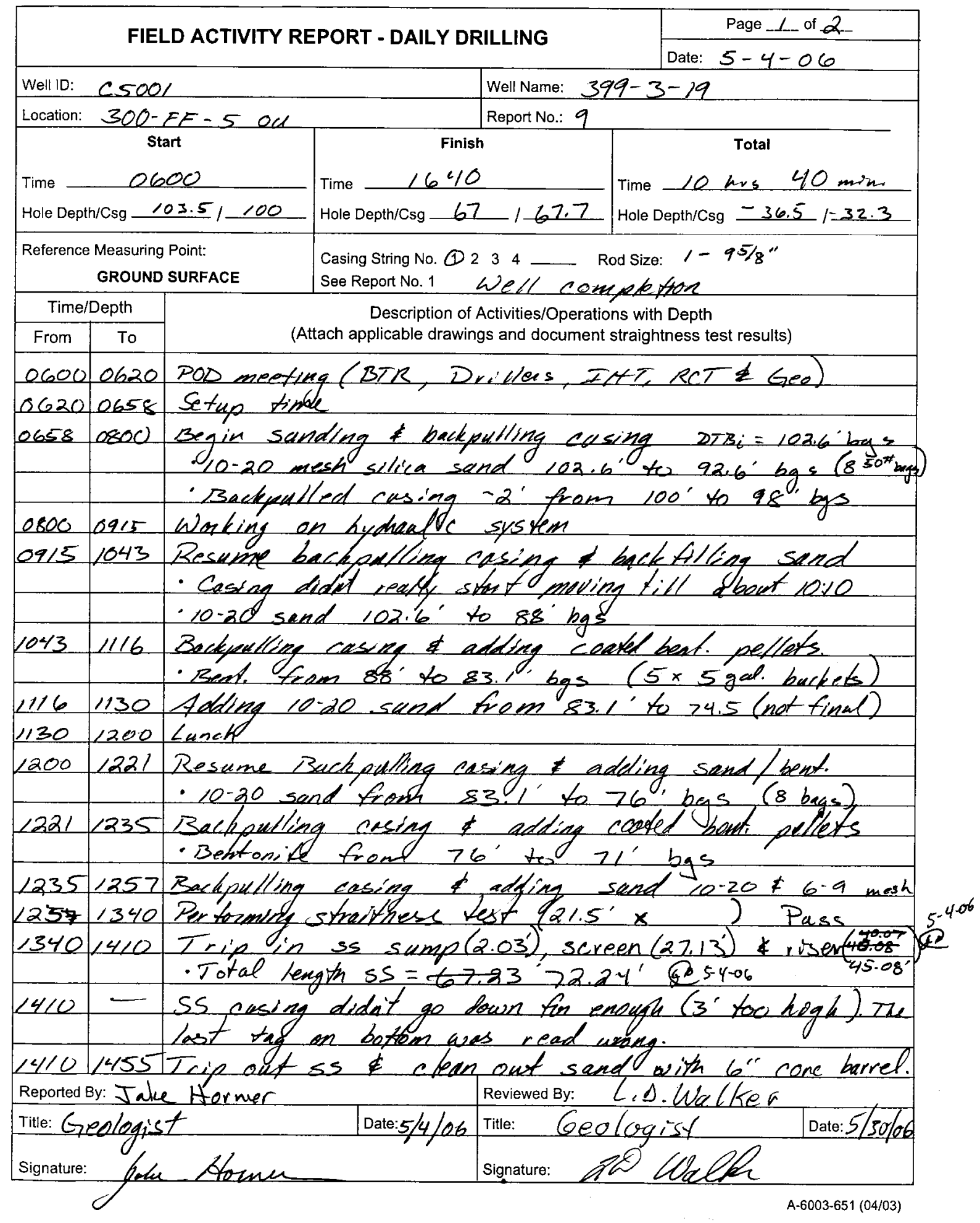




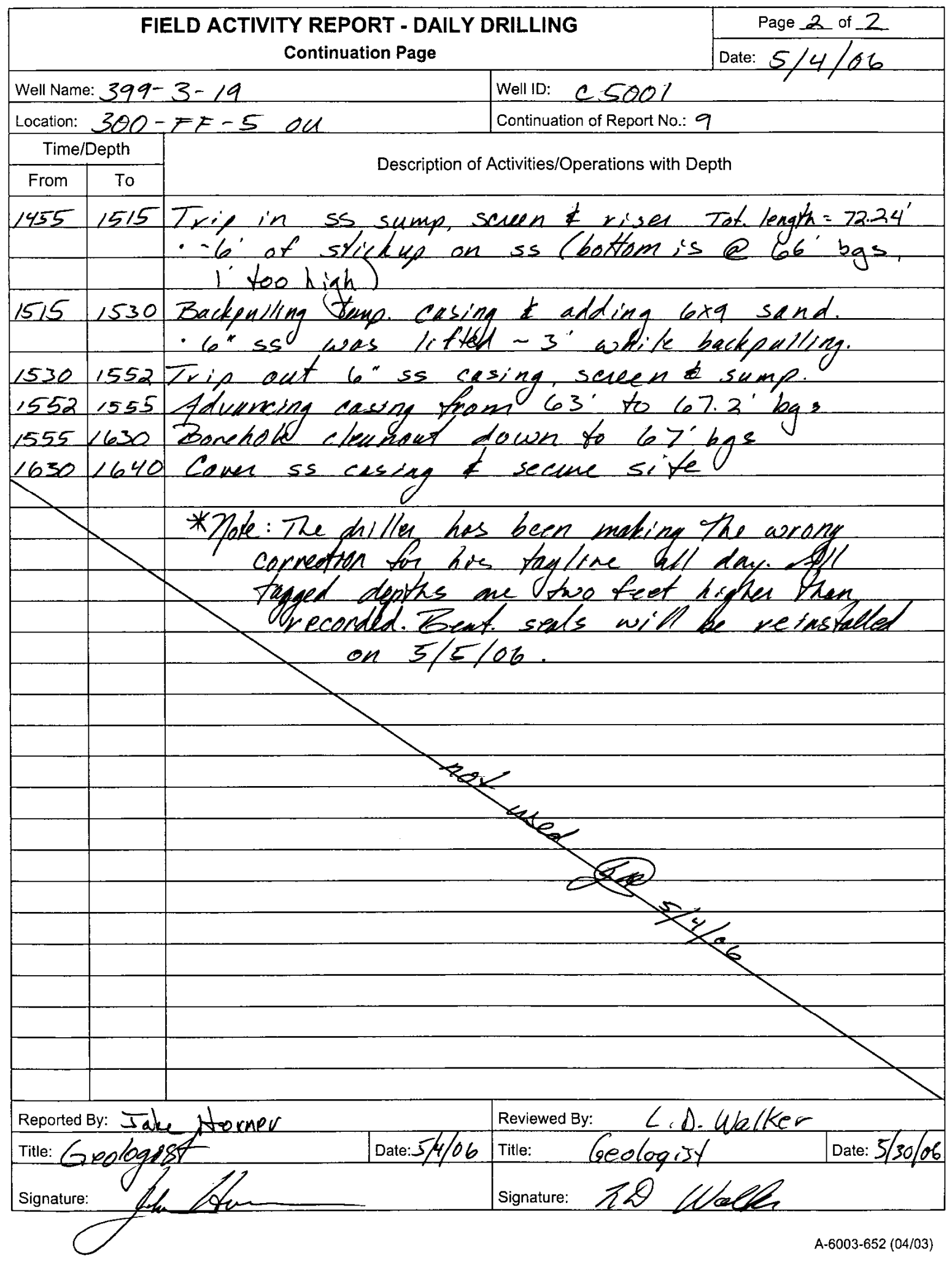




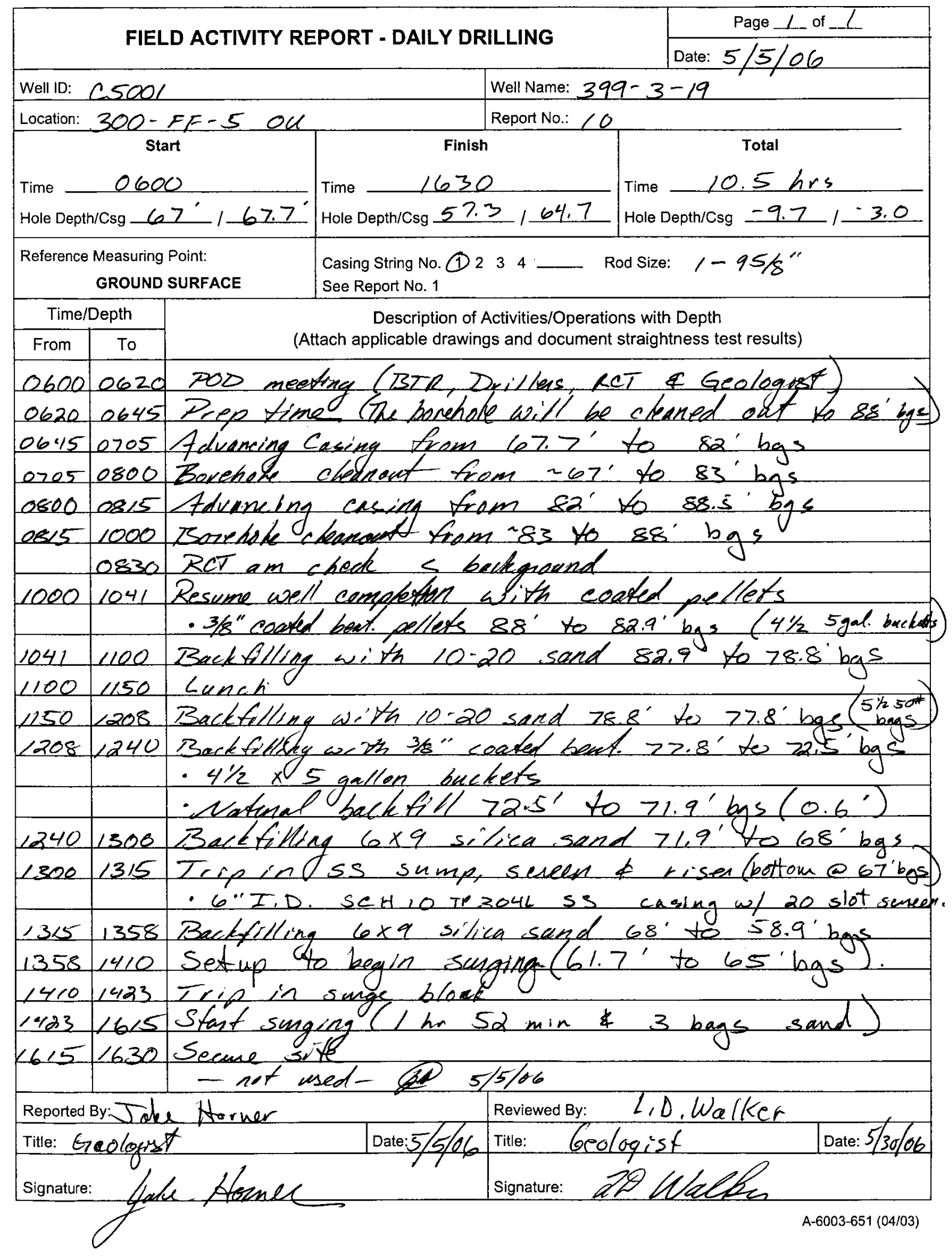




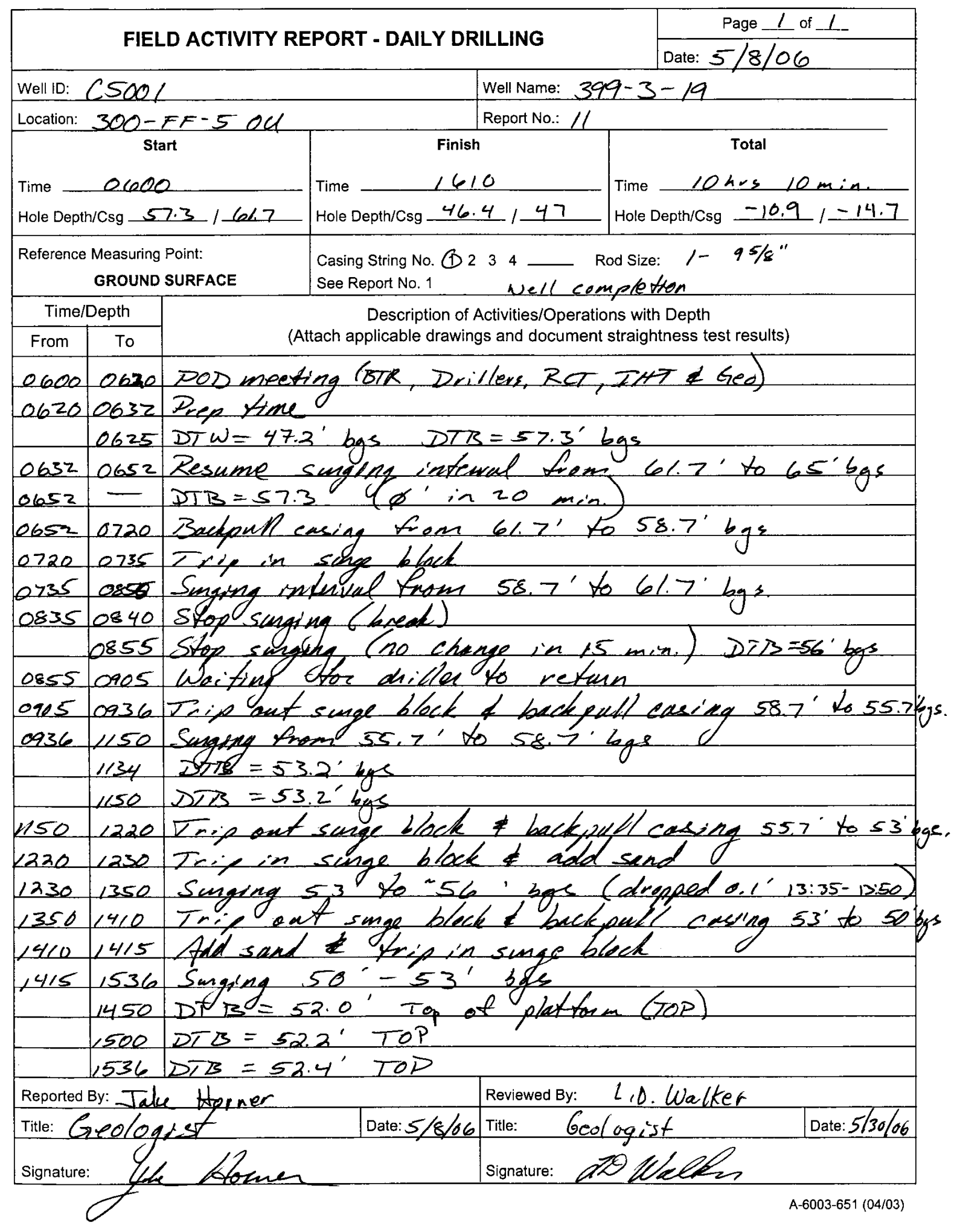




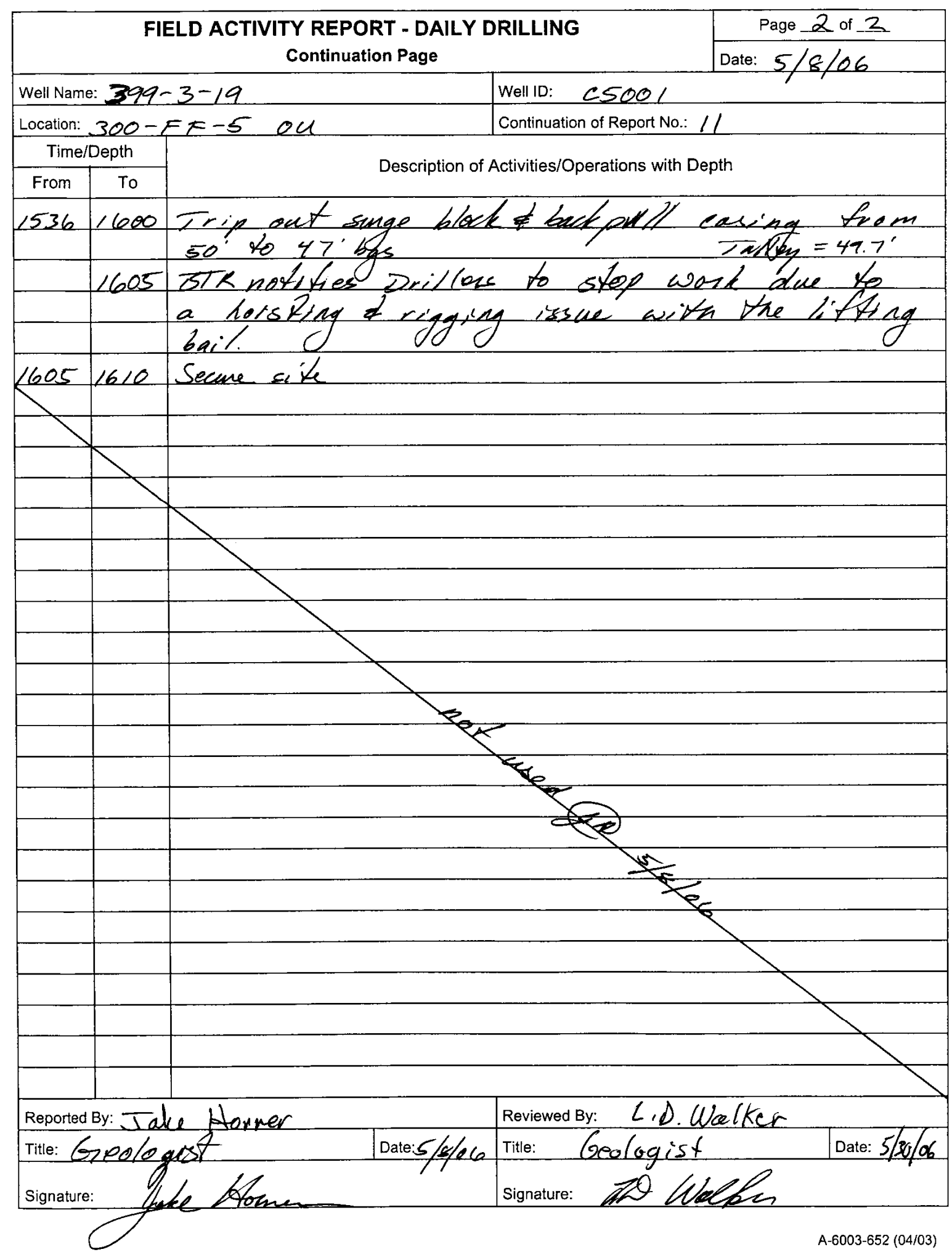




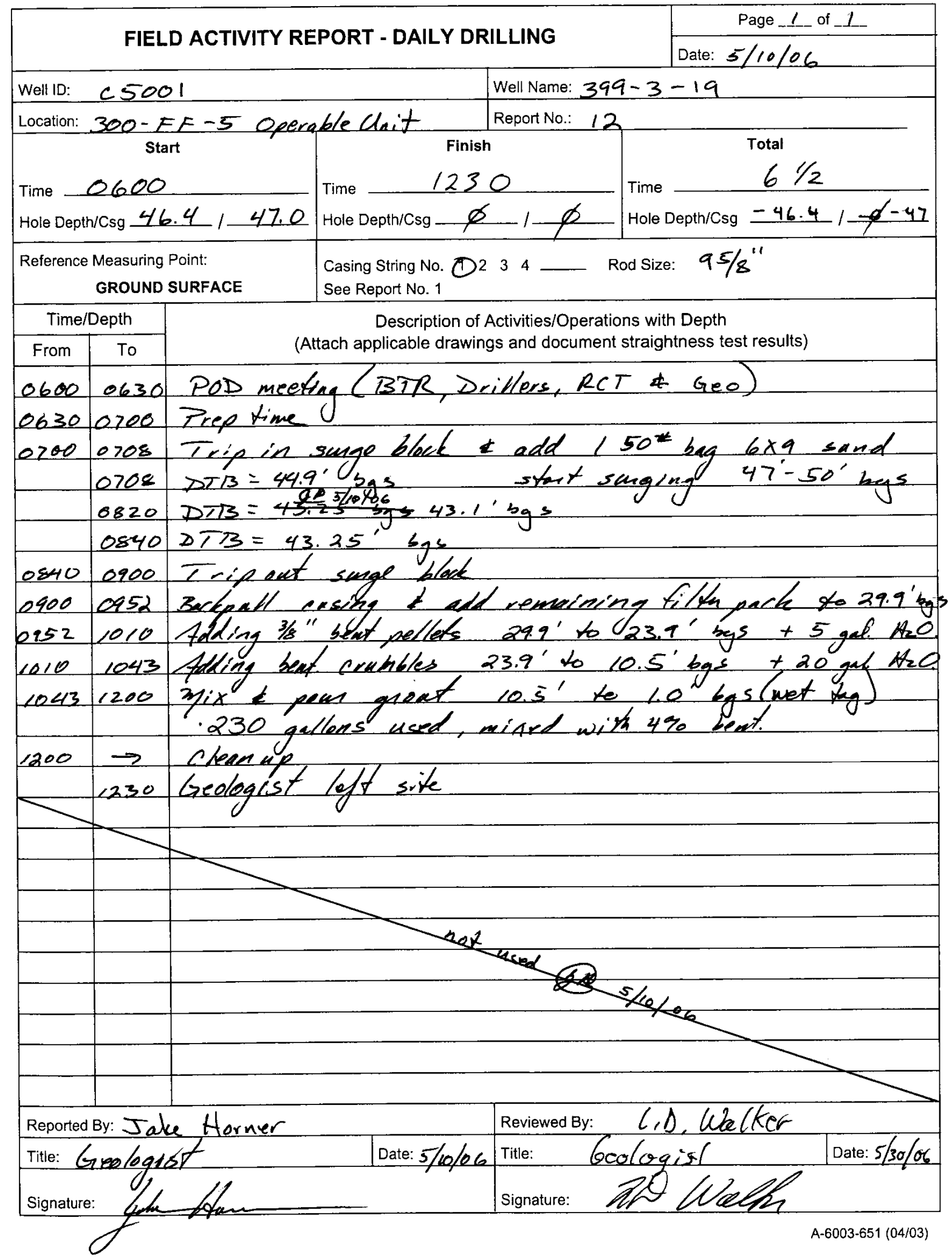




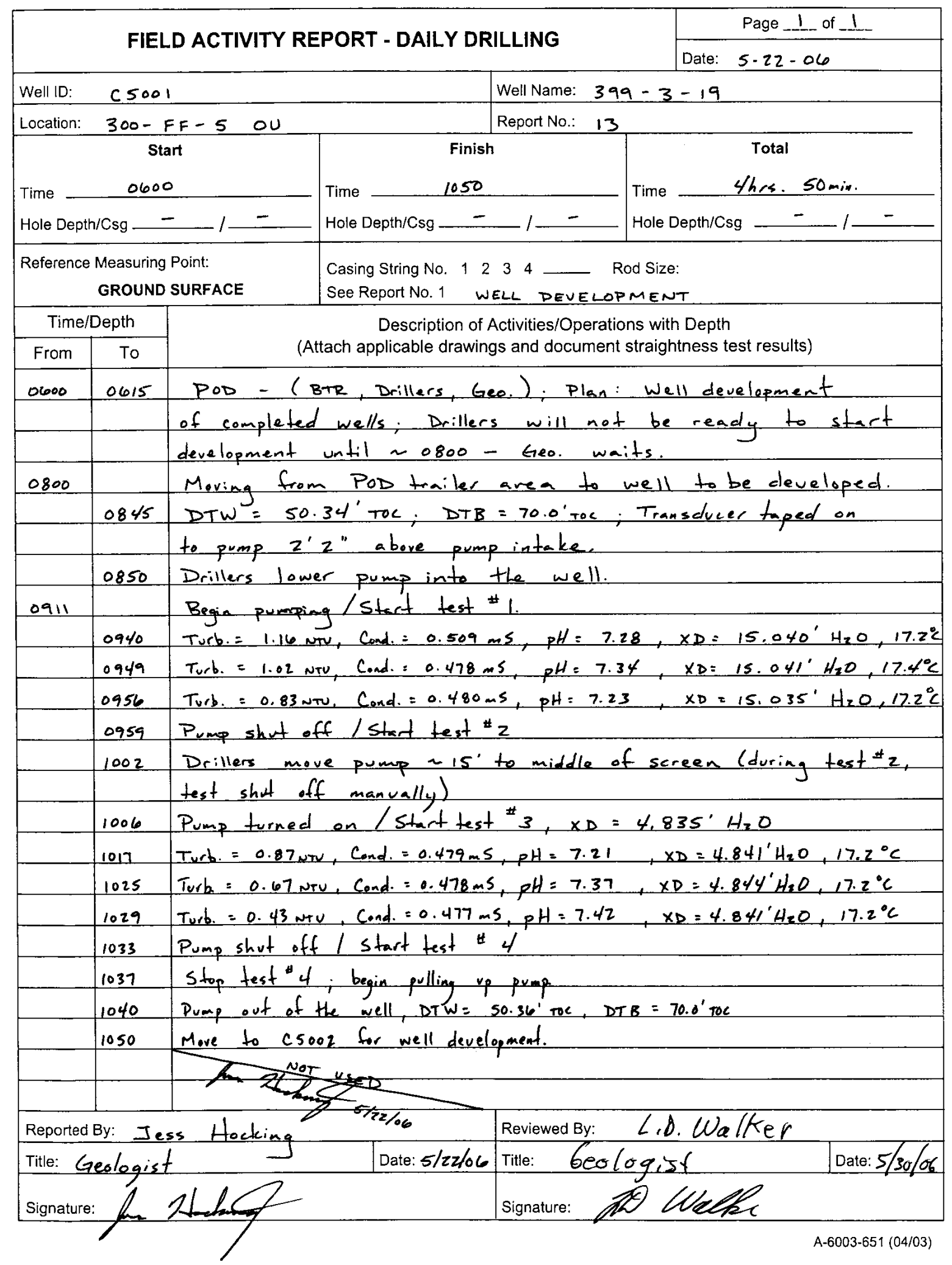




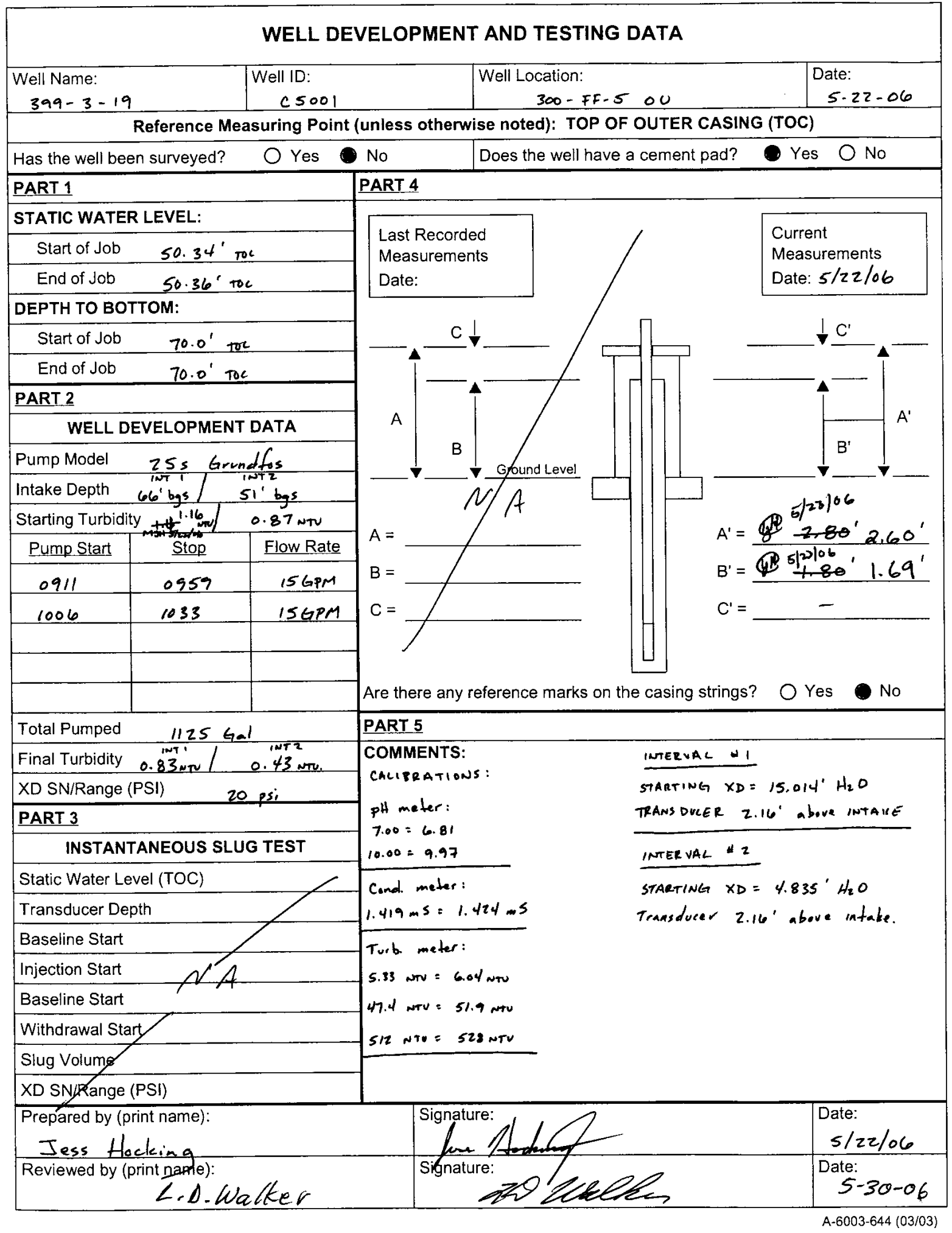




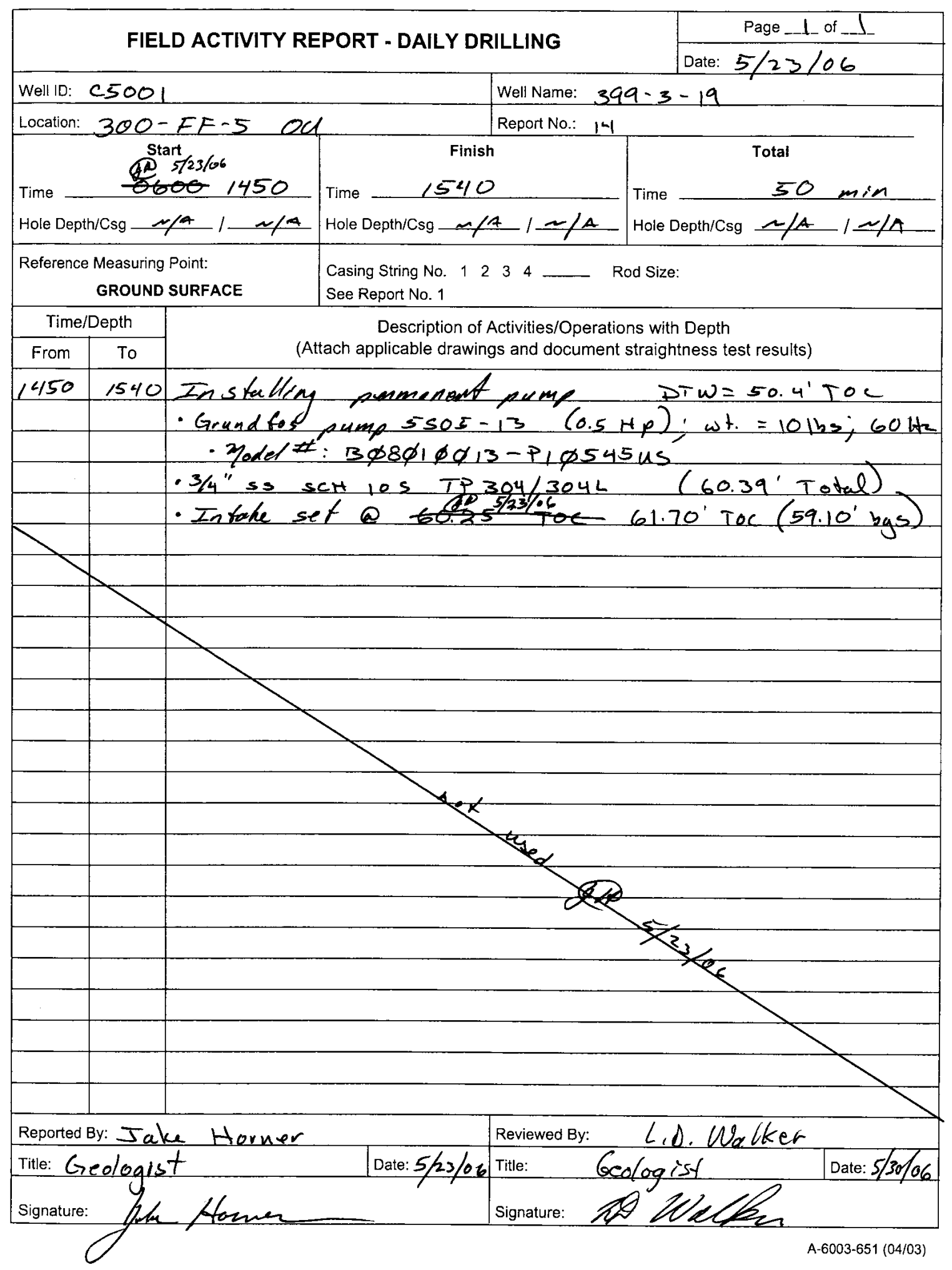




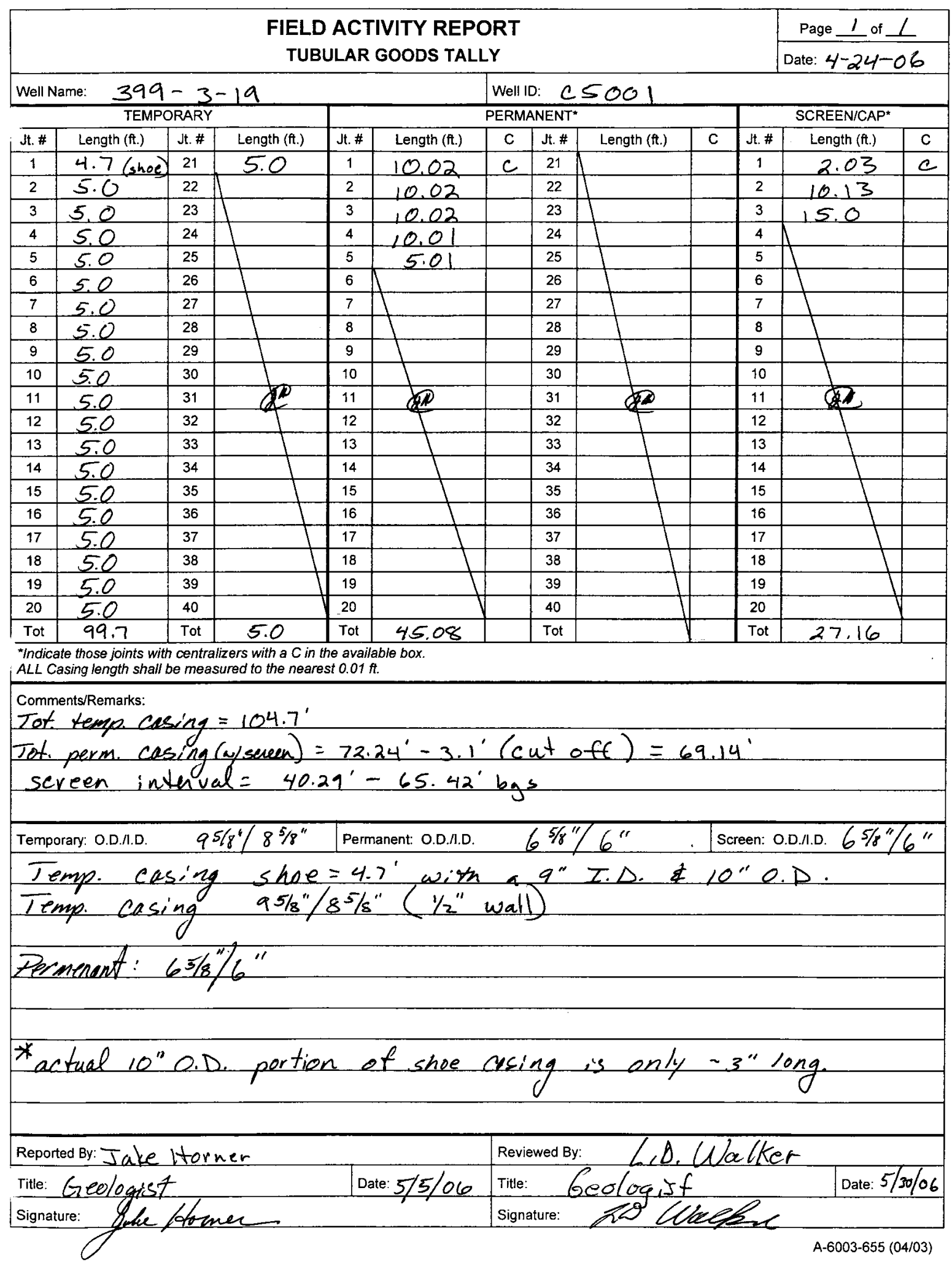




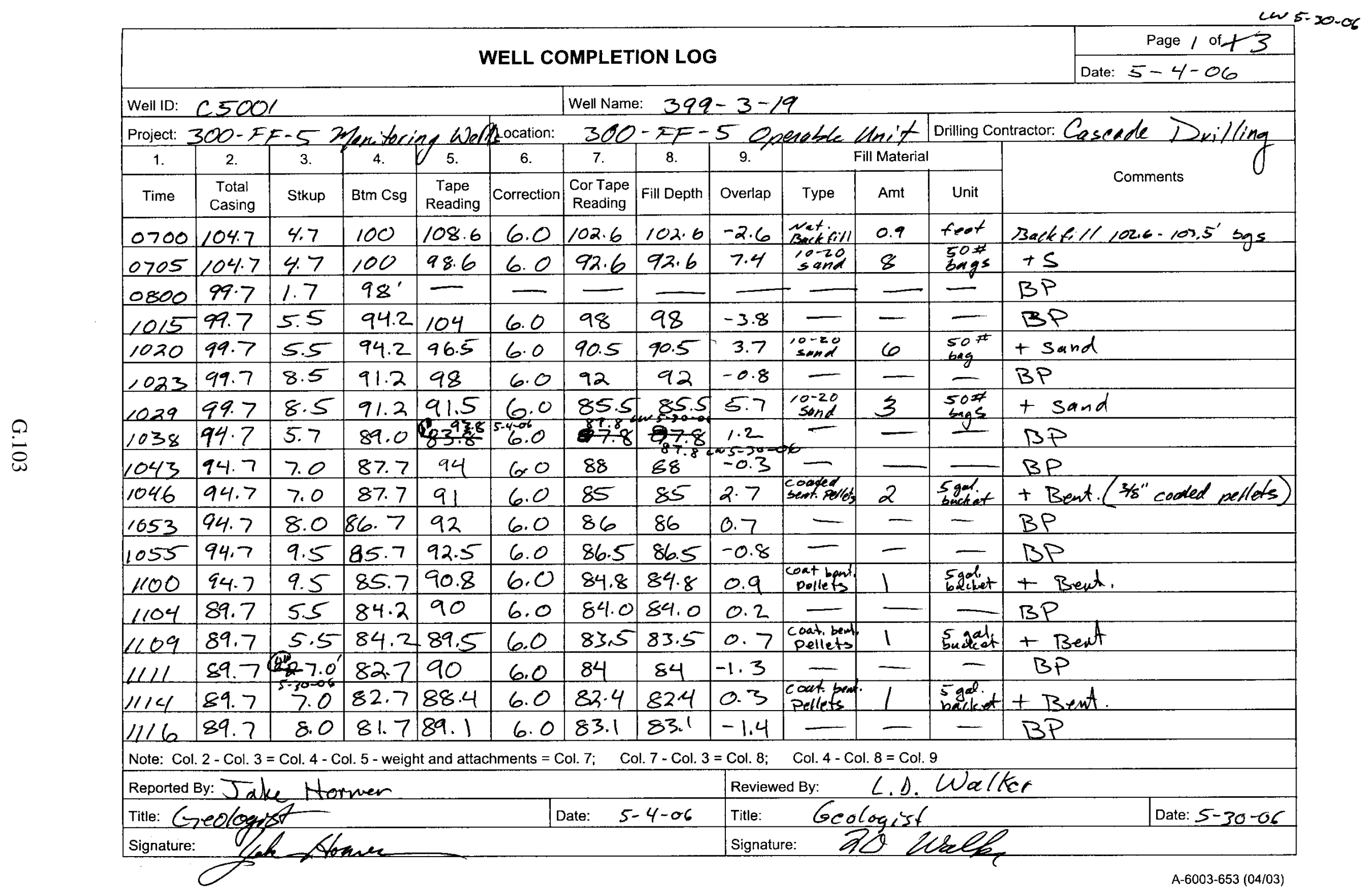




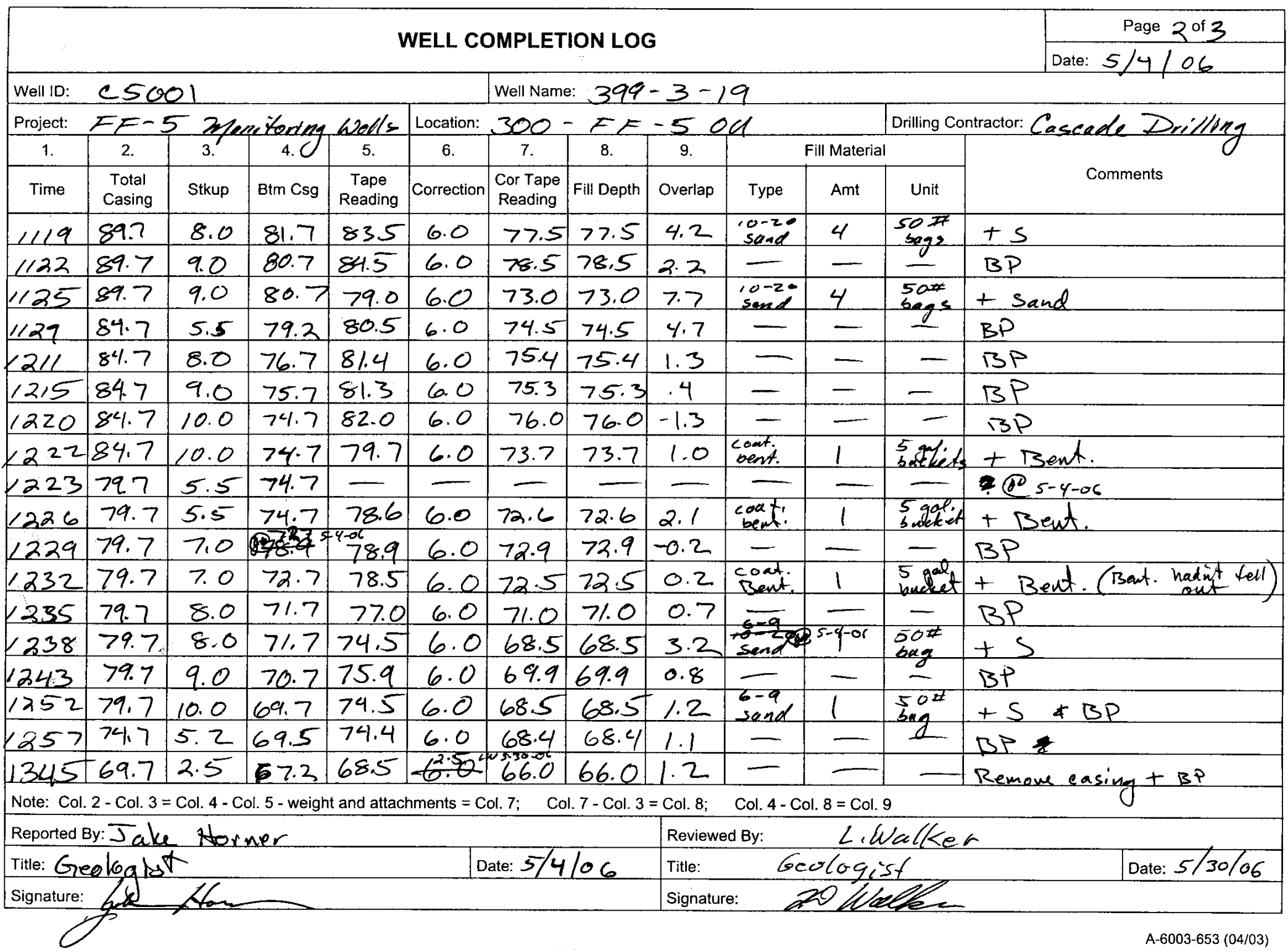




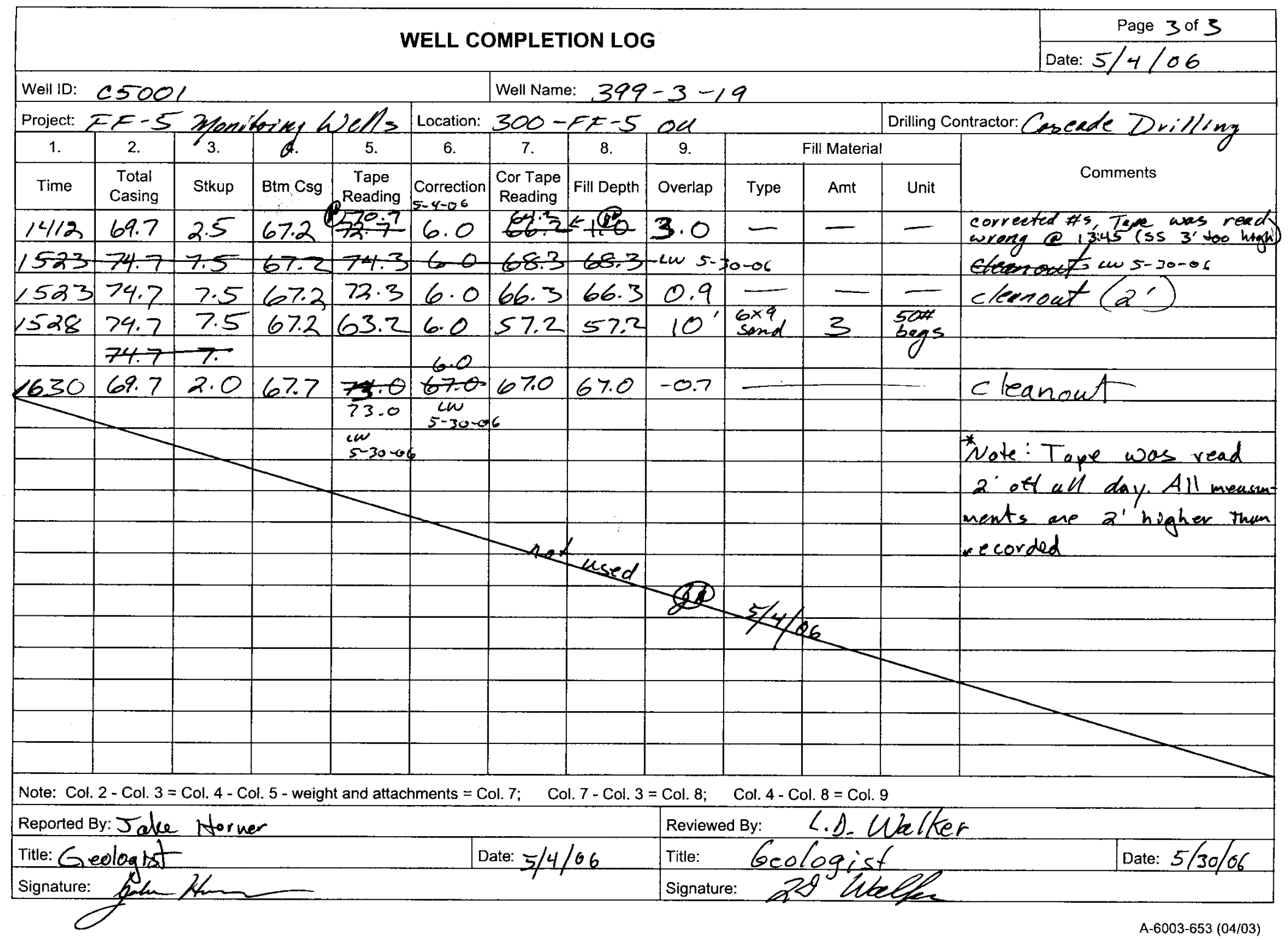




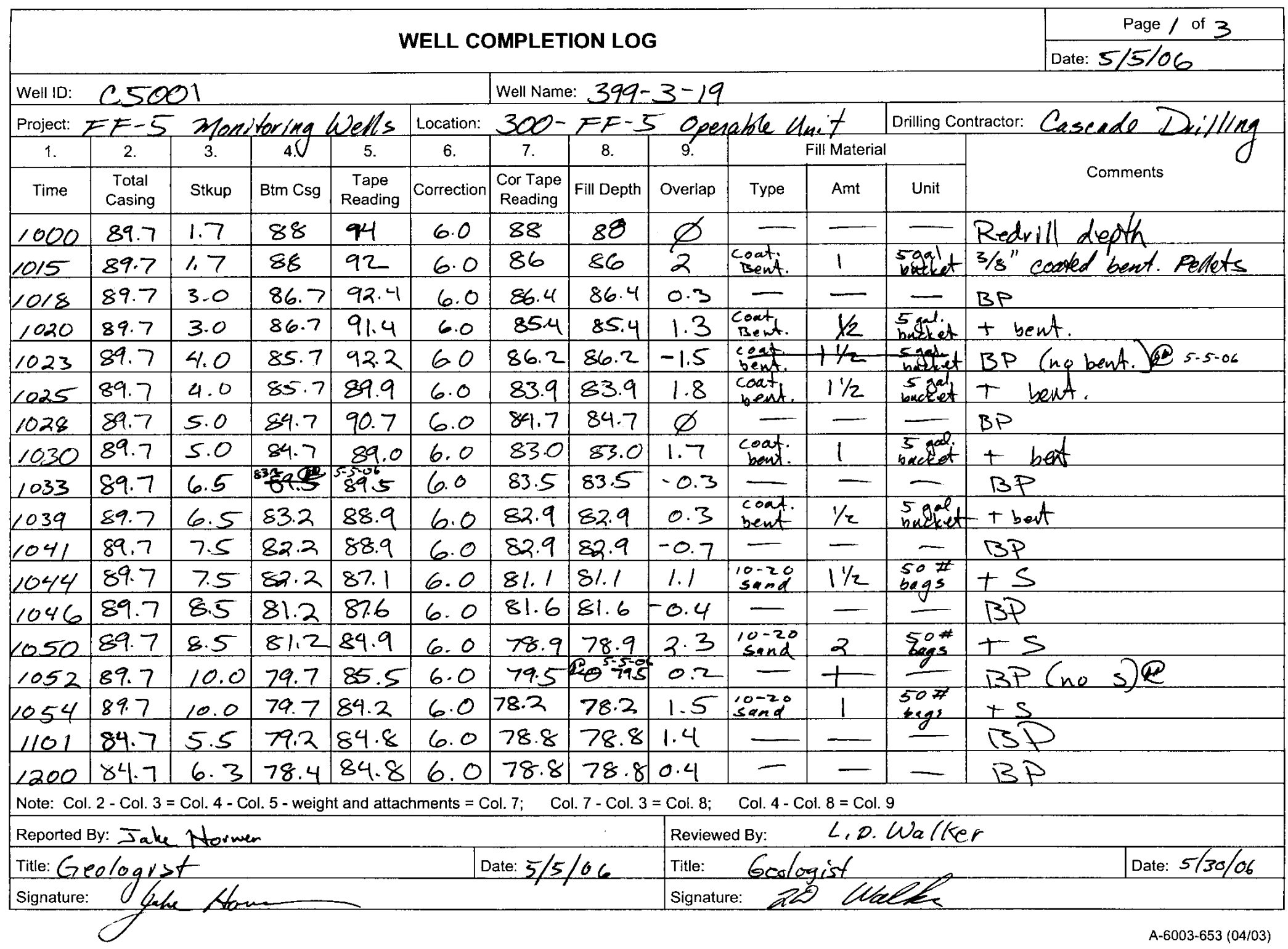




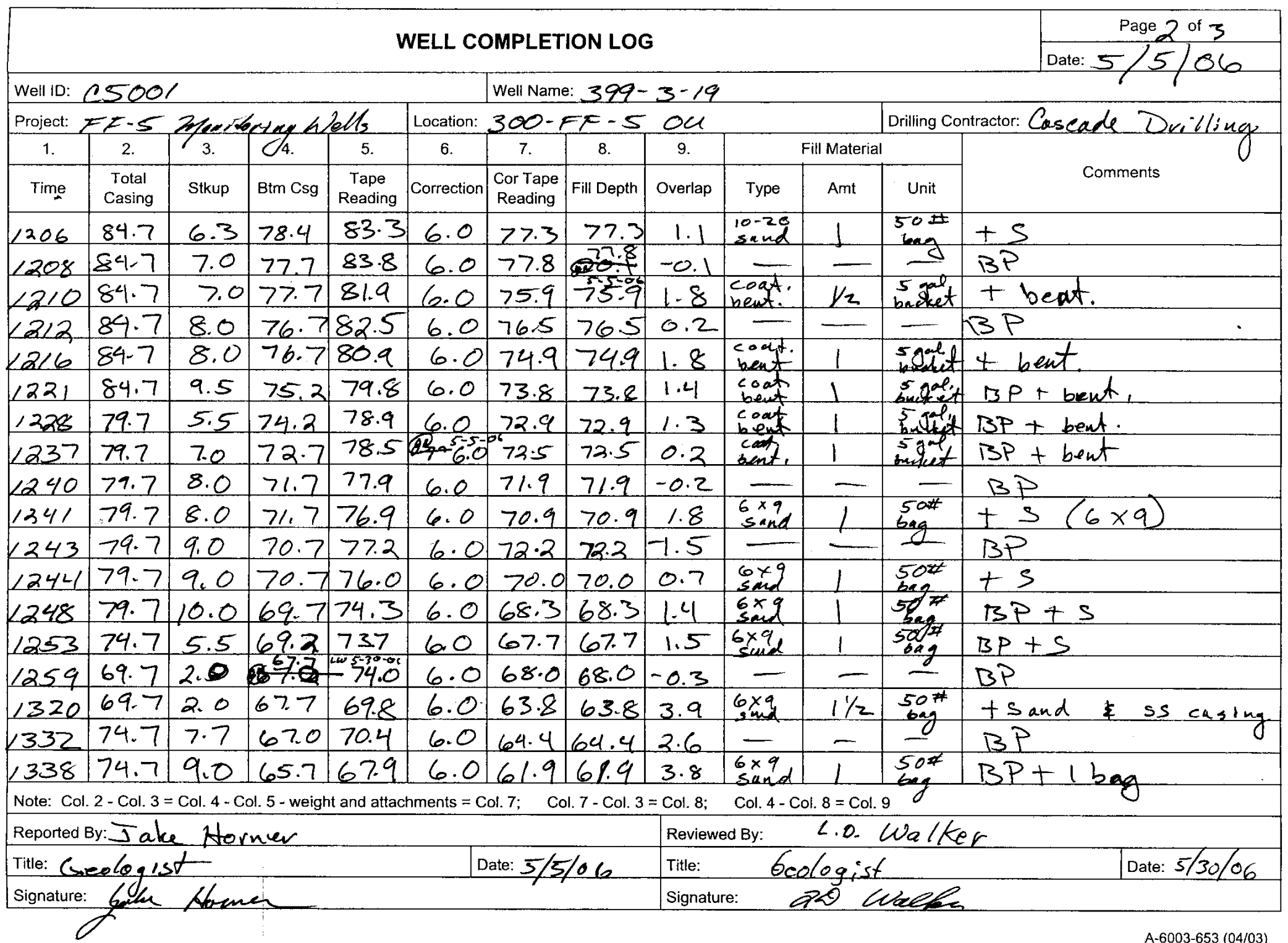




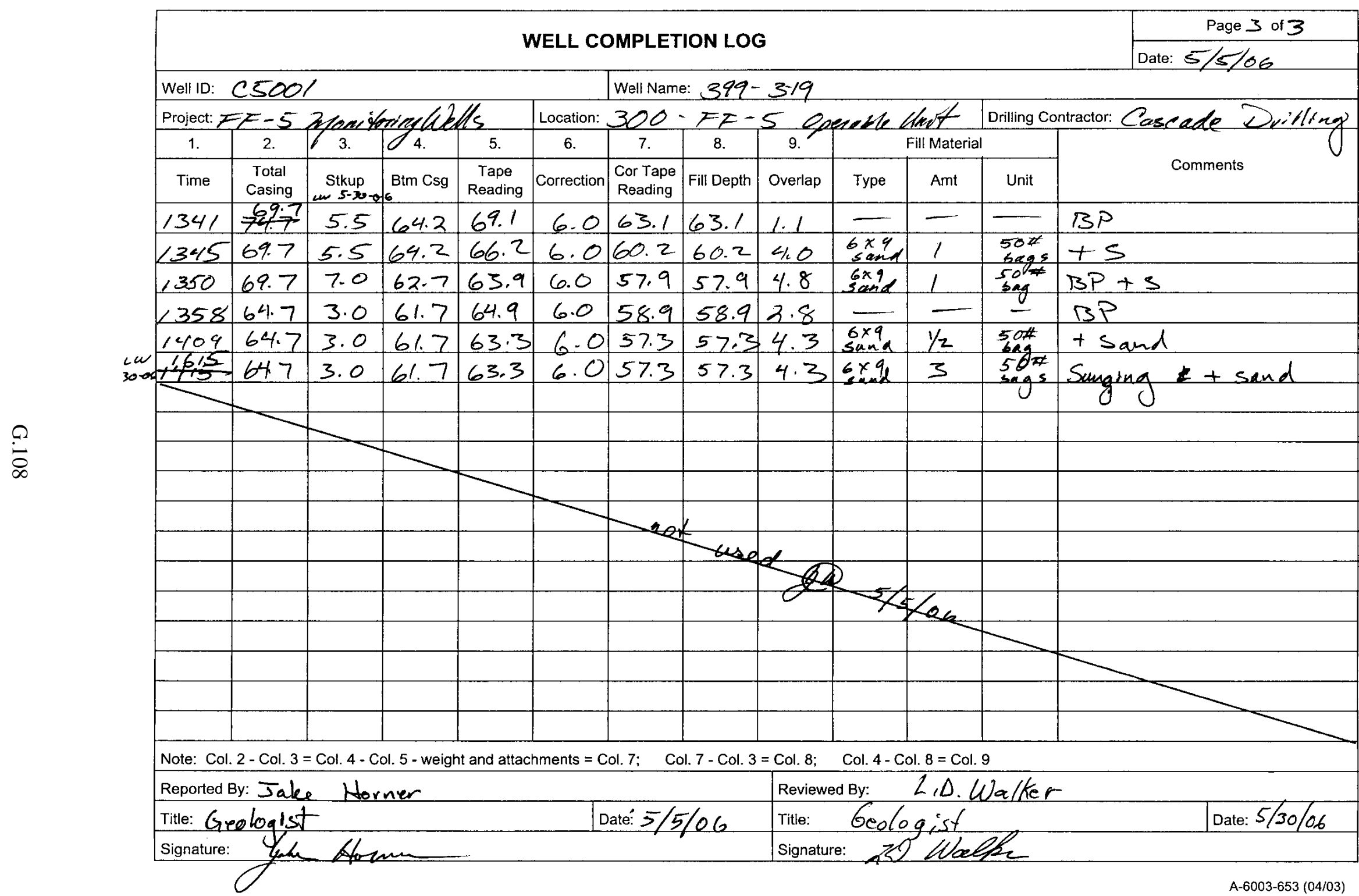




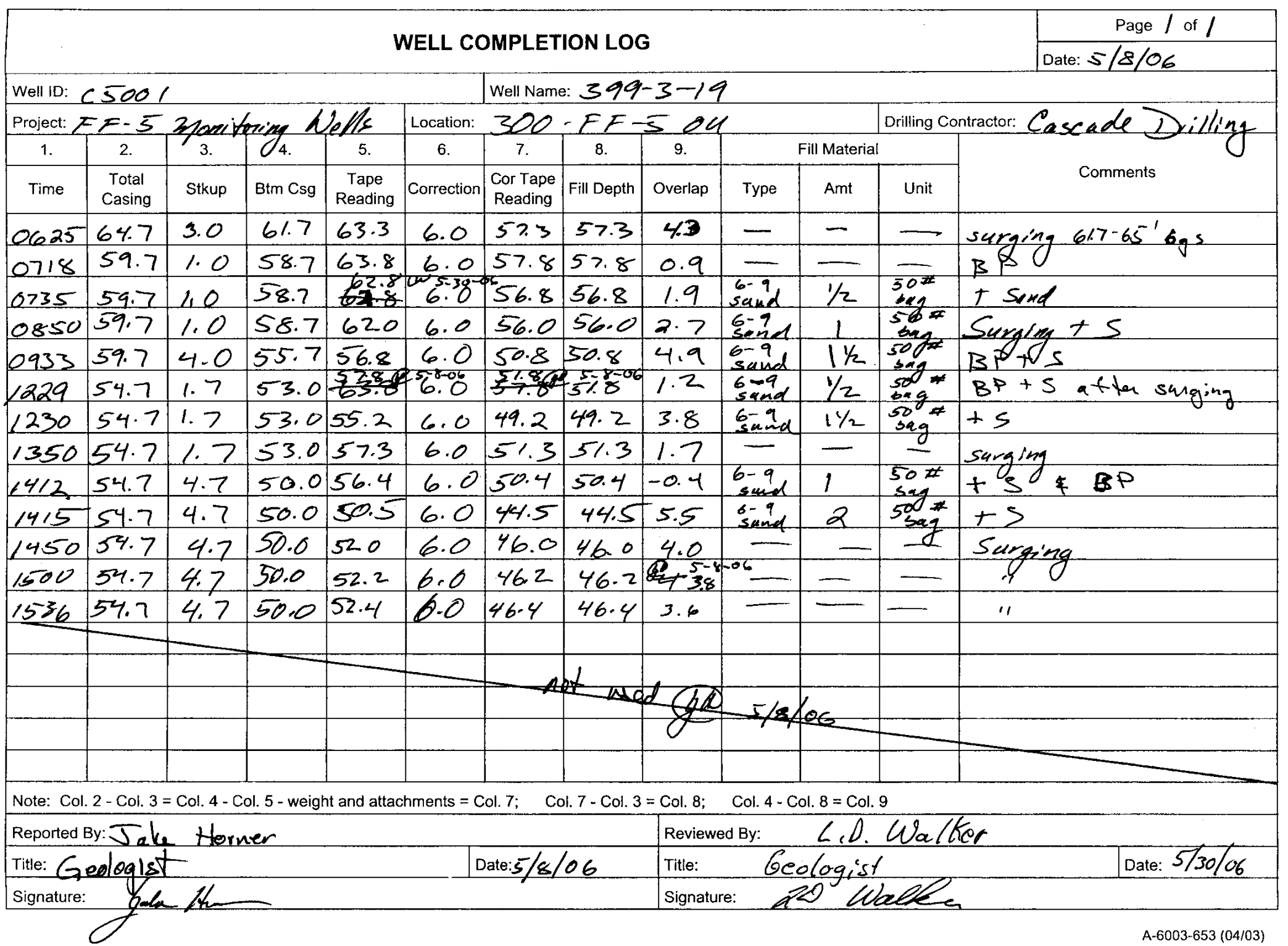


Well ID: 05001

Well Name: $399-3-19$

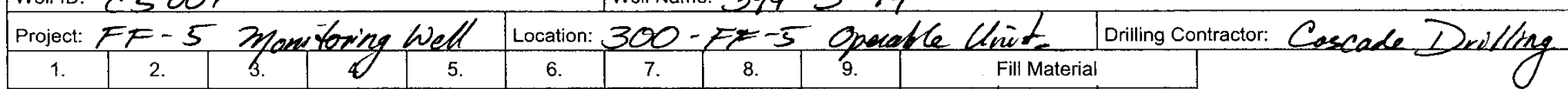

\begin{tabular}{|c|c|c|c|c|c|c|c|c|c|c|c|c|}
\hline & & & & & & & & & \multicolumn{3}{|c|}{ Fill Materıal } & \multirow[b]{2}{*}{ Comments } \\
\hline Time & $\begin{array}{c}\text { Total } \\
\text { Casing }\end{array}$ & Stkup & Btm Csg & $\begin{array}{c}\text { Tape } \\
\text { Reading }\end{array}$ & Correction & $\begin{array}{l}\text { Cor Tape } \\
\text { Reading }\end{array}$ & Fill Depth & Overlap & Type & Amt & Unit & \\
\hline 0708 & 49.7 & $2 \cdot 7$ & 47.0 & 50.9 & 6.0 & 44.9 & 44.9 & 2.1 & $\begin{array}{l}6-9 \\
\text { sand }\end{array}$ & 1 & $\begin{array}{l}507 \\
\text { sag }\end{array}$ & + s (stant sunging) \\
\hline 0721 & 49.7 & 2.7 & 47.0 & 49.0 & 6.0 & 43.0 & 43.0 & 4.0 & $\begin{array}{l}6-9 \\
\sin d\end{array}$ & 1 & 50.4 & sunglug +5 \\
\hline 0840 & 49.7 & 2.7 & 47.0 & $-492=$ & 5.510100 & $4 z^{2}$ & $0 \frac{5100}{2}$ & 3.8 & saind & 1 & 500 & suraina $+S$ \\
\hline 9909 & 49.7 & 2.7 & 47.0 & 46.9 & 6.0 & 40.9 & 40.9 & 6.1 & s-gued & 1 & $\begin{array}{l}507 \\
\text { bag }\end{array}$ & +50 \\
\hline 0912 & 49.7 & 5.5 & 44.2 & 46.4 & 6.0 & 40.4 & 40.4 & 3.8 & $6-9$ & 1 & sale & $B P+S$ \\
\hline 0915 & 49.7 & 8.0 & 41.7 & 48.1 & 6.0 & 42.1 & $4 \pi .1$ & -0.4 & - & - & $\underline{d}$ & $B P$ \\
\hline 0917 & 49.7 & 8.0 & 41.7 & 42.9 & 6.0 & 36.9 & 36.9 & 4.8 & $\sin \alpha$ & 2 & 504 & +5 \\
\hline & $4^{24} 4^{2}$ & 5.5 .5 & 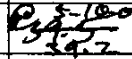 & $\sim D$ & 60 & - & - & - & - & - & 2 & $B P$ \\
\hline 0927 & 44.7 & $5 \cdot 5$ & 39.2 & 46.9 & 6.0 & 40.9 & 40.9 & -1.1 & - & - & - & $B P$ \\
\hline 0930 & 44.7 & 5.5 & 39.2 & 40.6 & 6.0 & 34.6 & 34.6 & 4.6 & 6 sund & 3 & 5047 & $+s$ \\
\hline 0932 & 44.7 & 8.0 & 36.7 & 42.9 & 36.96 & 36.9 & 36.9 & -0.2 & - & - & $\underline{7}$ & $B P$ \\
\hline 0933 & 44.7 & 8.0 & 36.7 & 37.0 & 6.0 & 31.0 & 31.0 & 5.7 & $\begin{array}{l}6-9 \\
\text { send }\end{array}$ & 2 & 50.7 & $+s$ \\
\hline 0937 & 39.7 & 5.5 & 34.2 & 394 & 6.0 & 33.4 & 33.4 & 0.8 & - & - & - & $B P$ \\
\hline 0938 & 39.7 & 5.5 & 34.2 & 36.5 & 6.0 & 30.5 & 30.5 & 3.7 & $\begin{array}{l}6-9 \\
\operatorname{sen} \alpha\end{array}$ & 1 & 5027 & $T S$ \\
\hline 0942 & 39.7 & 7.5 & 32.2 & 38.3 & 6.0 & 32.3 & 32.3 & 0.1 & - & - & -1 & $B P$ \\
\hline 0946 & 39.7 & 7.5 & 32.2 & $32.8^{-61}$ & 6.0 & $\frac{26.8}{26.84}$ & $\begin{array}{l}0.50-06 \\
26.8\end{array}$ & 5.4 & s-a & 3 & 50 s.tt & +5 \\
\hline 0952 & 54.7 & 5.5 & 29.2 & 35.9 & 6.0 & 29.9 & 29.9 & -0.7 & - & - & 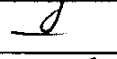 & $B P$ \\
\hline 0959 & 34.7 & 5.5 & 29.2 & 28.7 & 6.0 & 23.9 & 22.9 & 6.3 & 3 bent $^{2 \text { sent }}$ & 2 & 5 gale & + Bent per \\
\hline
\end{tabular}
Note: Col. $2-$ Col. $3=$ Col. $4-$ Col. 5 - weight and attachments $=$ Col. $7 ; \quad$ Col. $7-$ Col. $3=$ Col. $8 ; \quad$ Col. $4-$ Col. $8=$ Col. 9

\begin{tabular}{|c|c|c|c|}
\hline Reported By:Jake Horner & & L.D. Walker & \\
\hline Title: Geologlst & Date: $5 / 10 / 06$ & Geologist & Date: $5 / 30 / 06$ \\
\hline Signature: Gele Homm & & $200^{\circ}$ Nale & \\
\hline
\end{tabular}




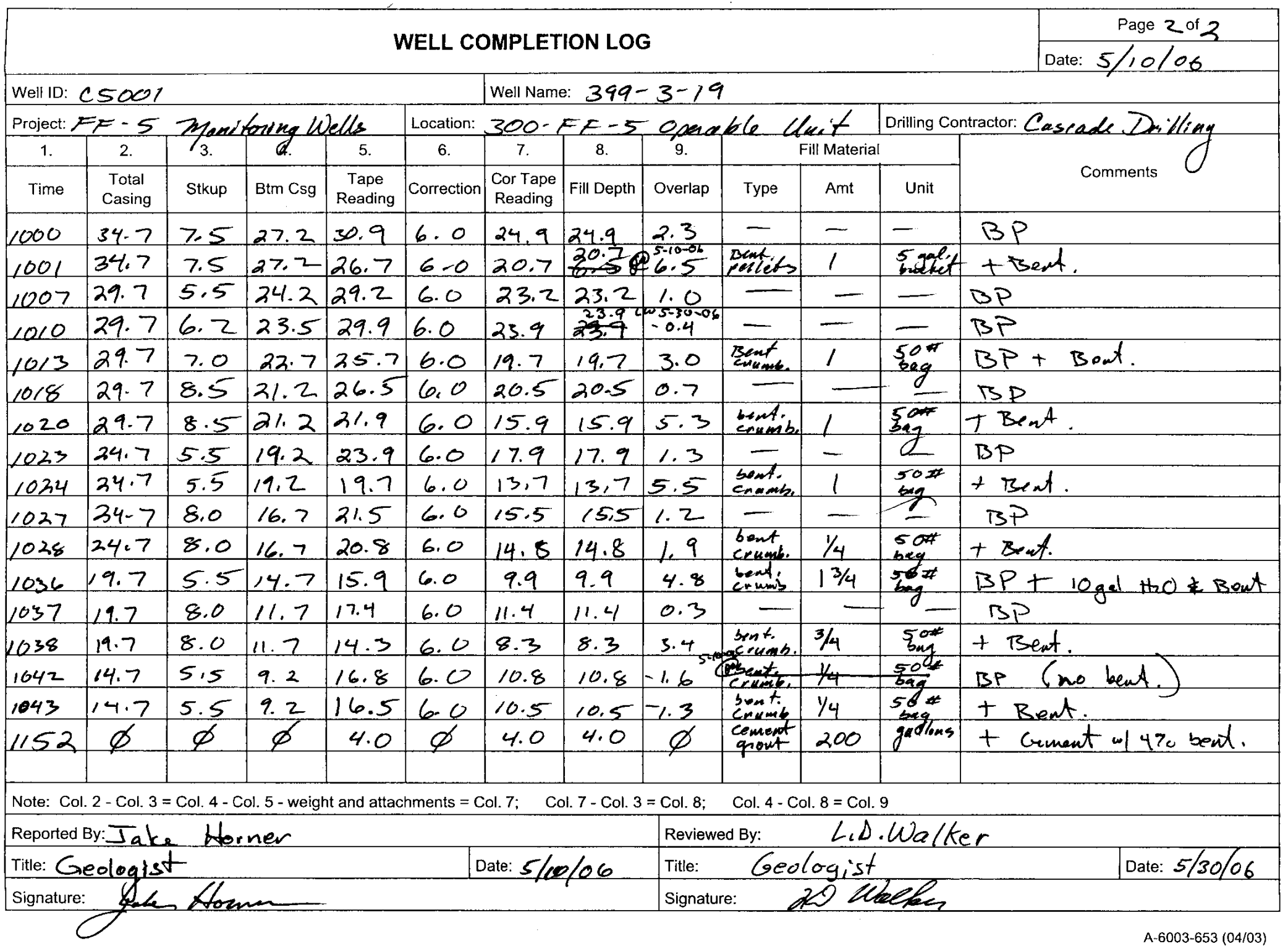




\section{Well C5002}

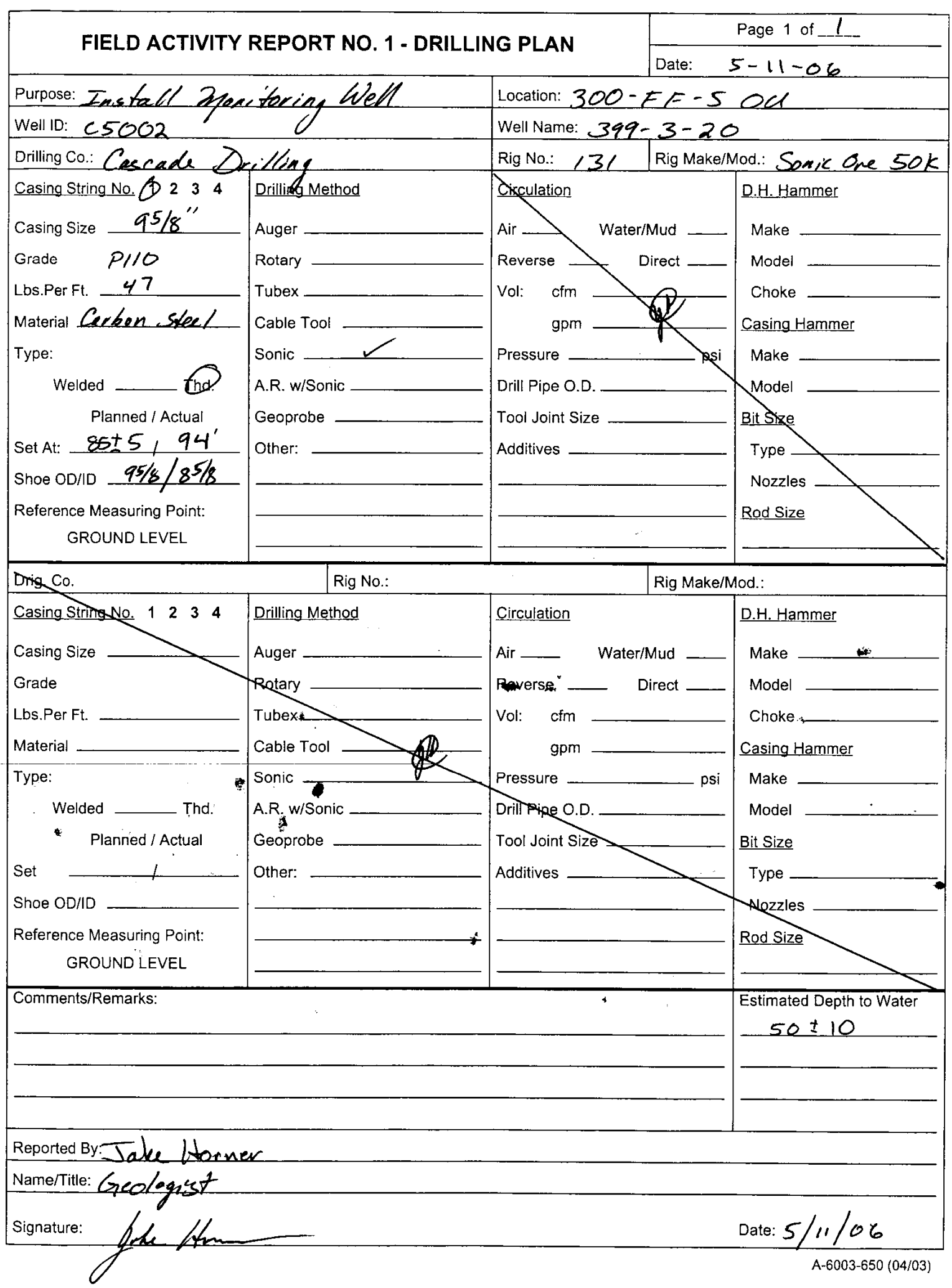




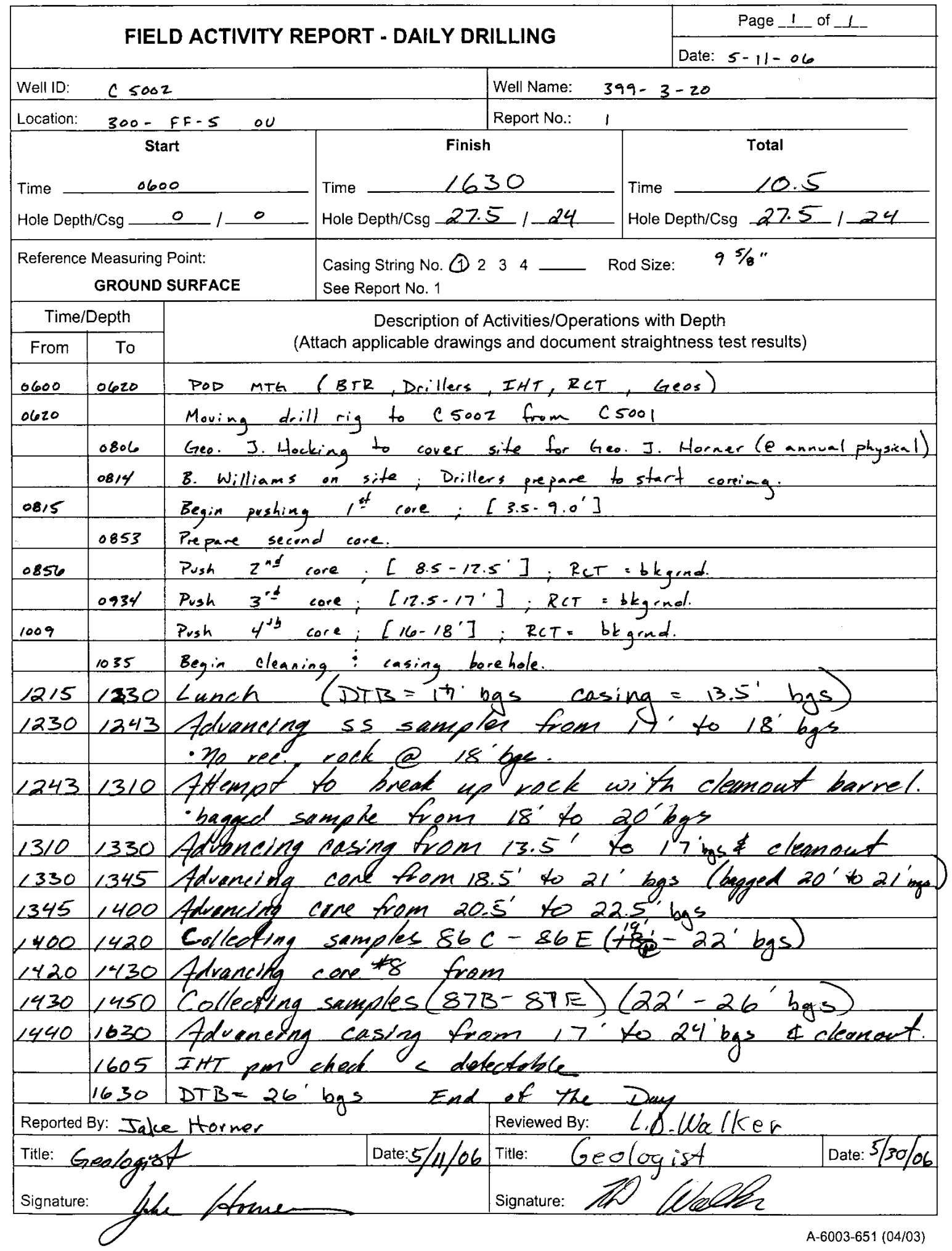




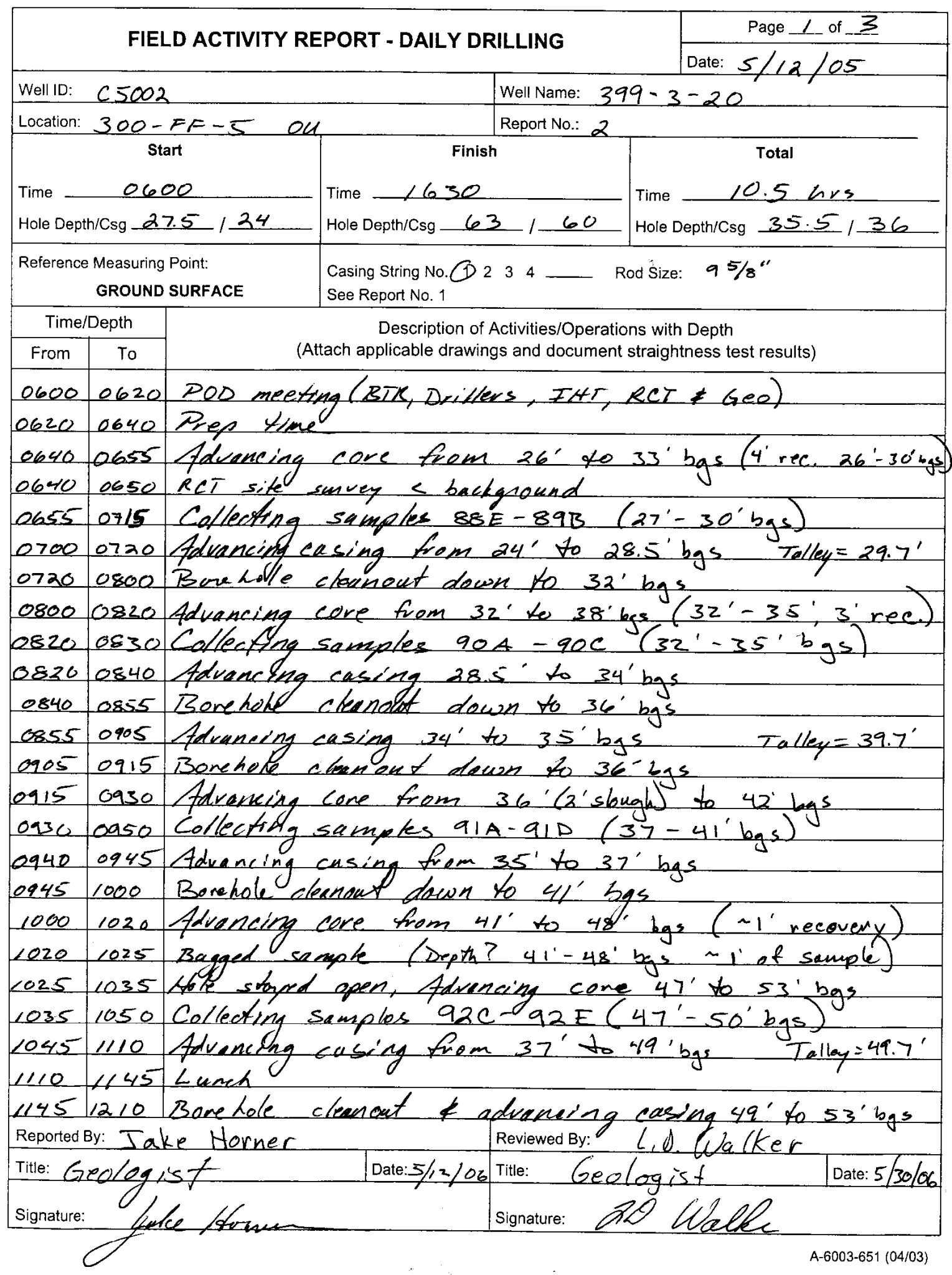




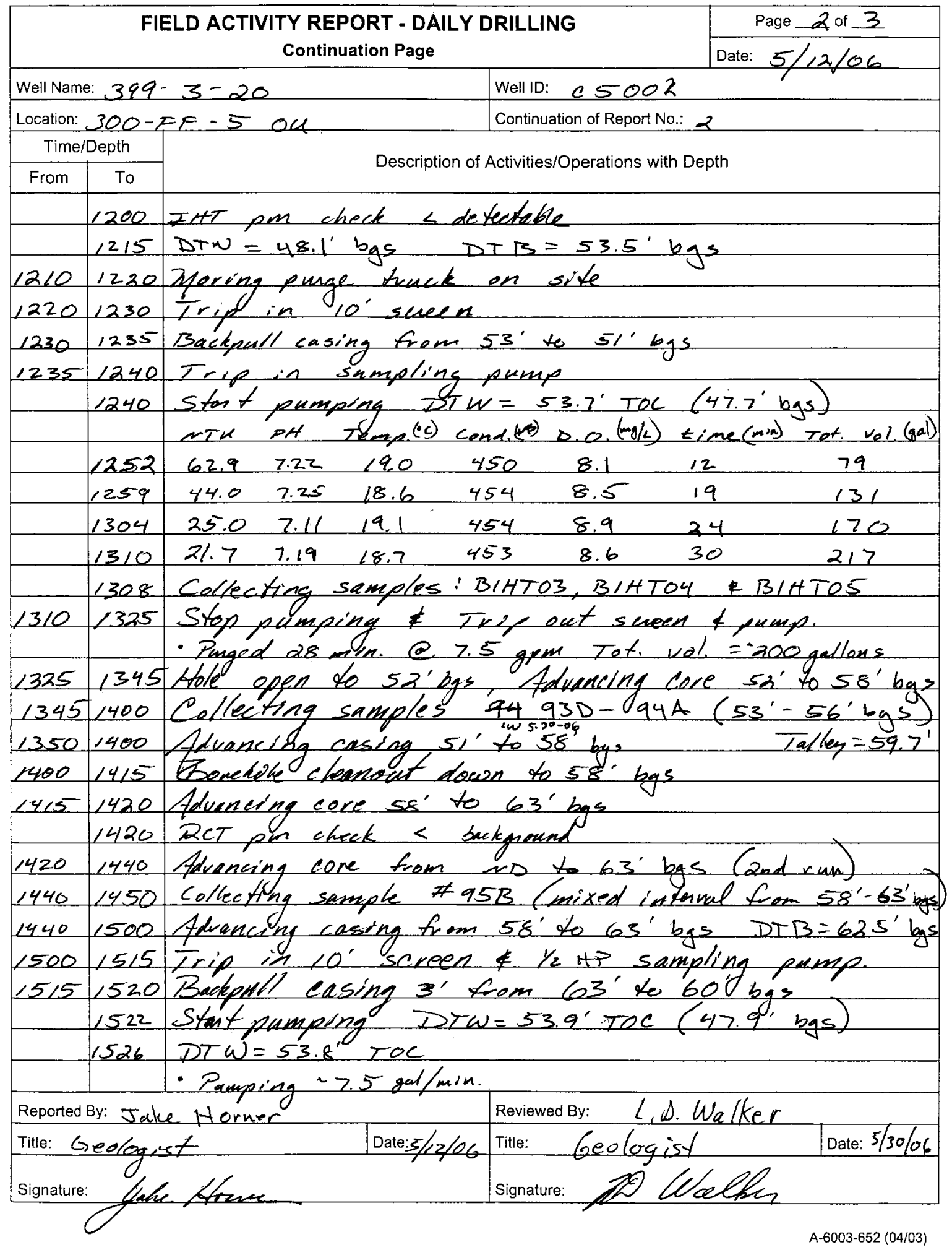




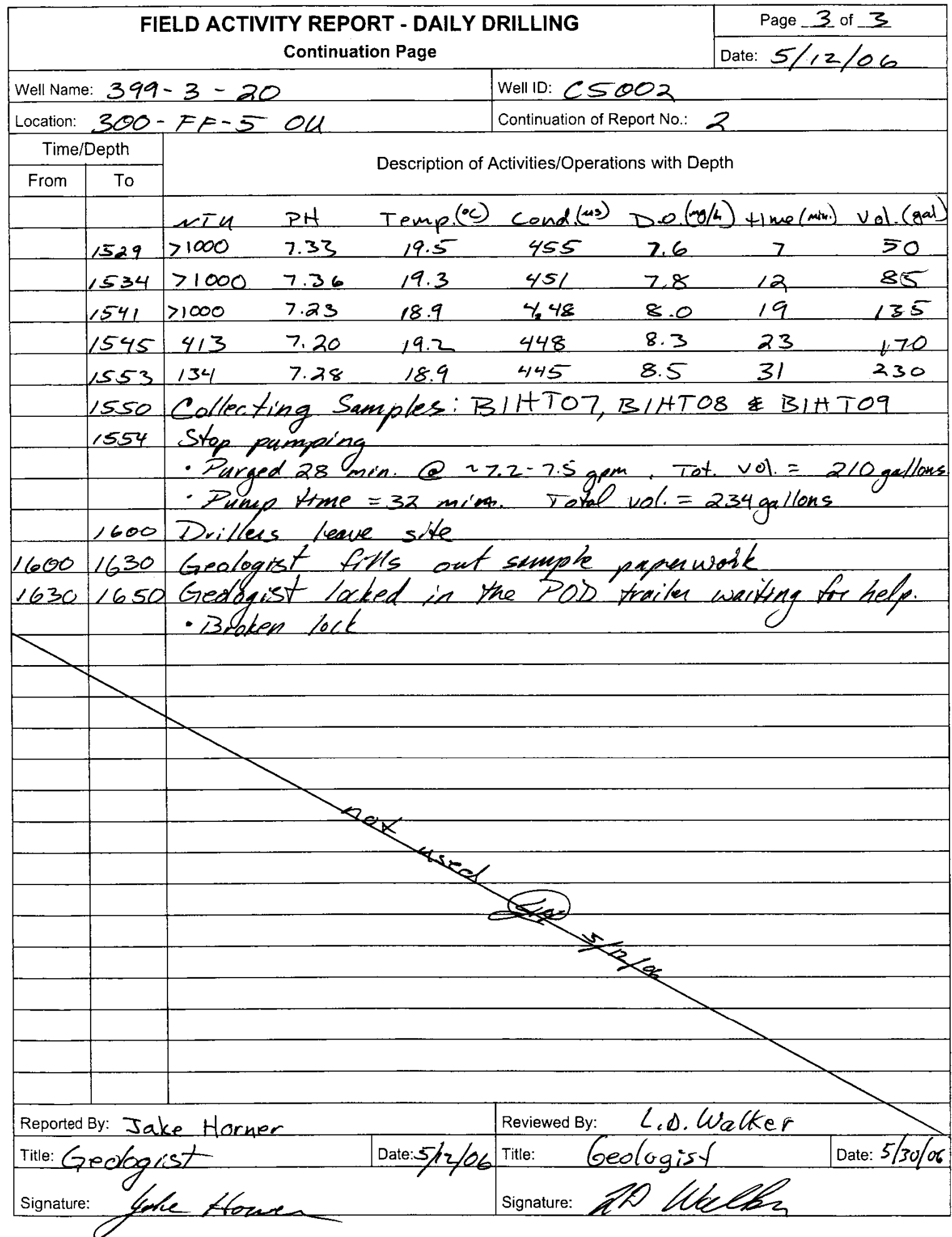

A-6003-652 (04/03) 


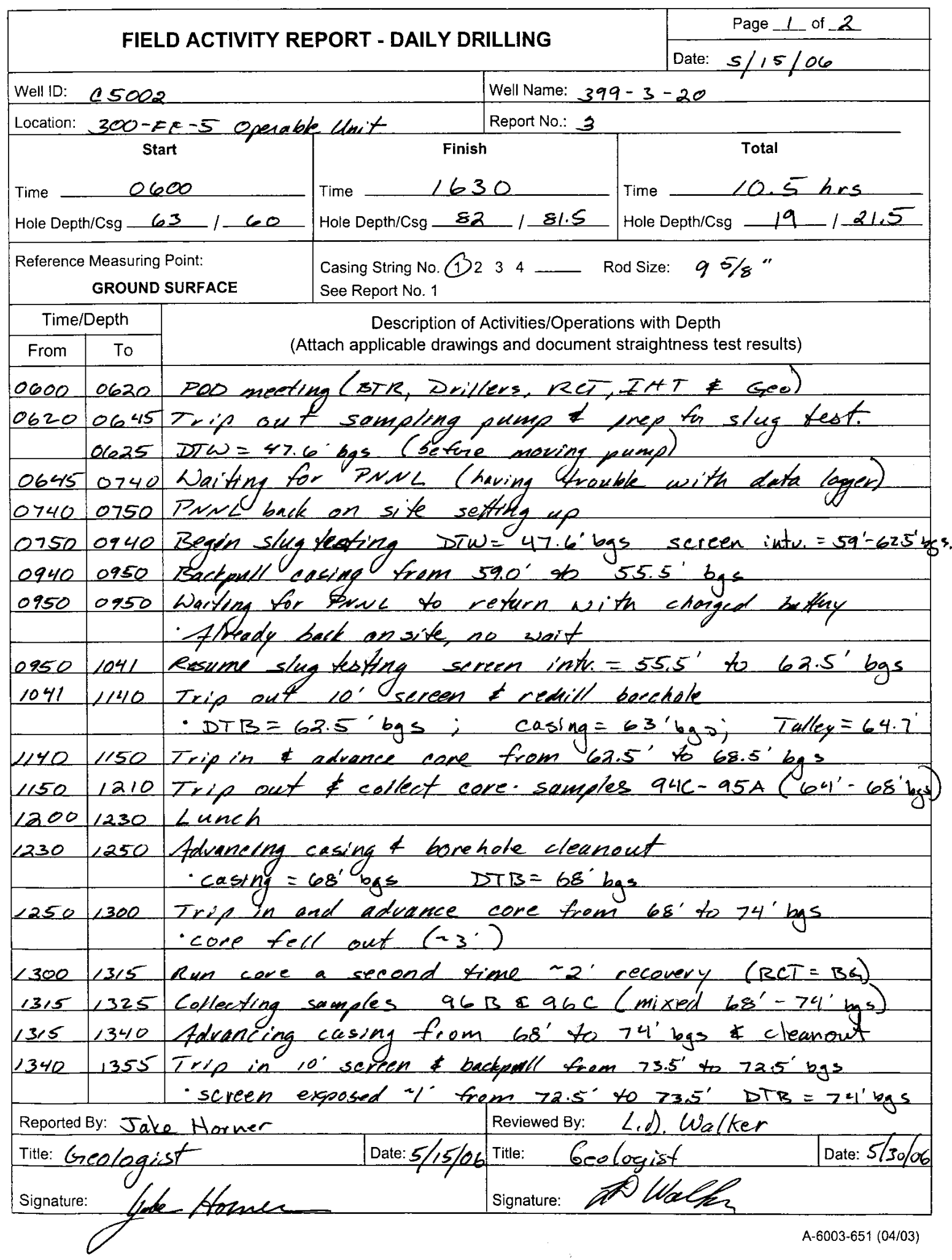




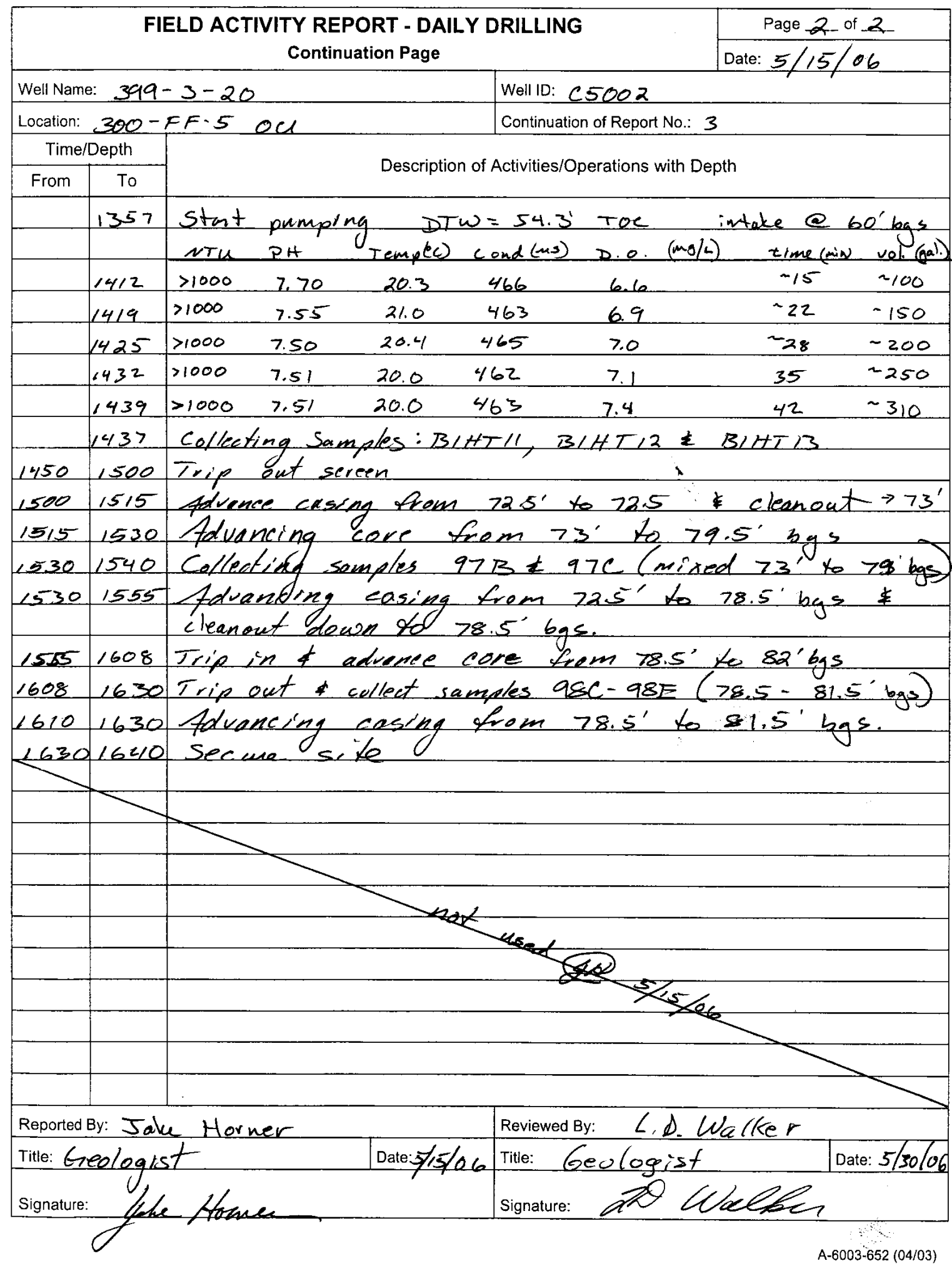




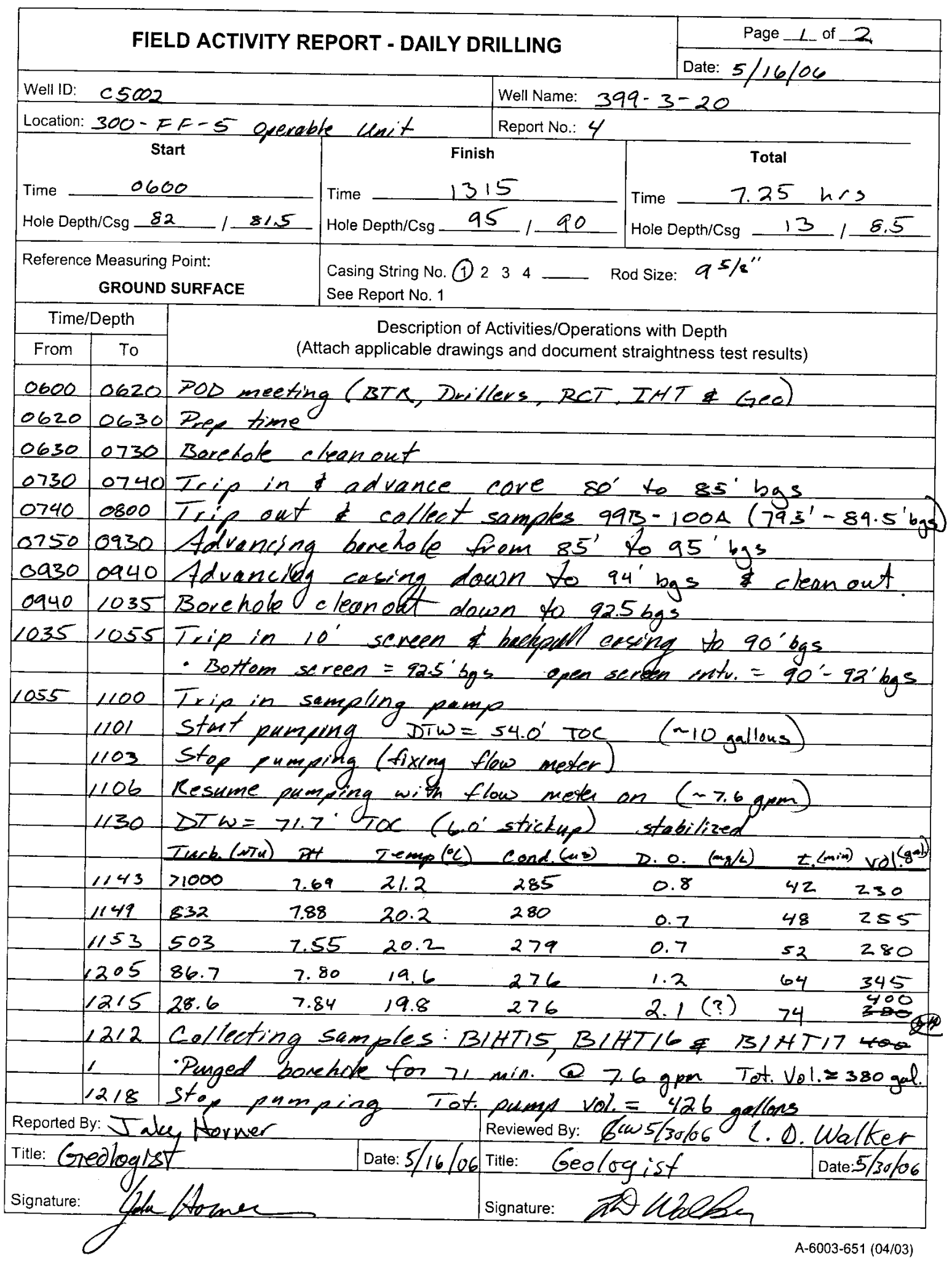




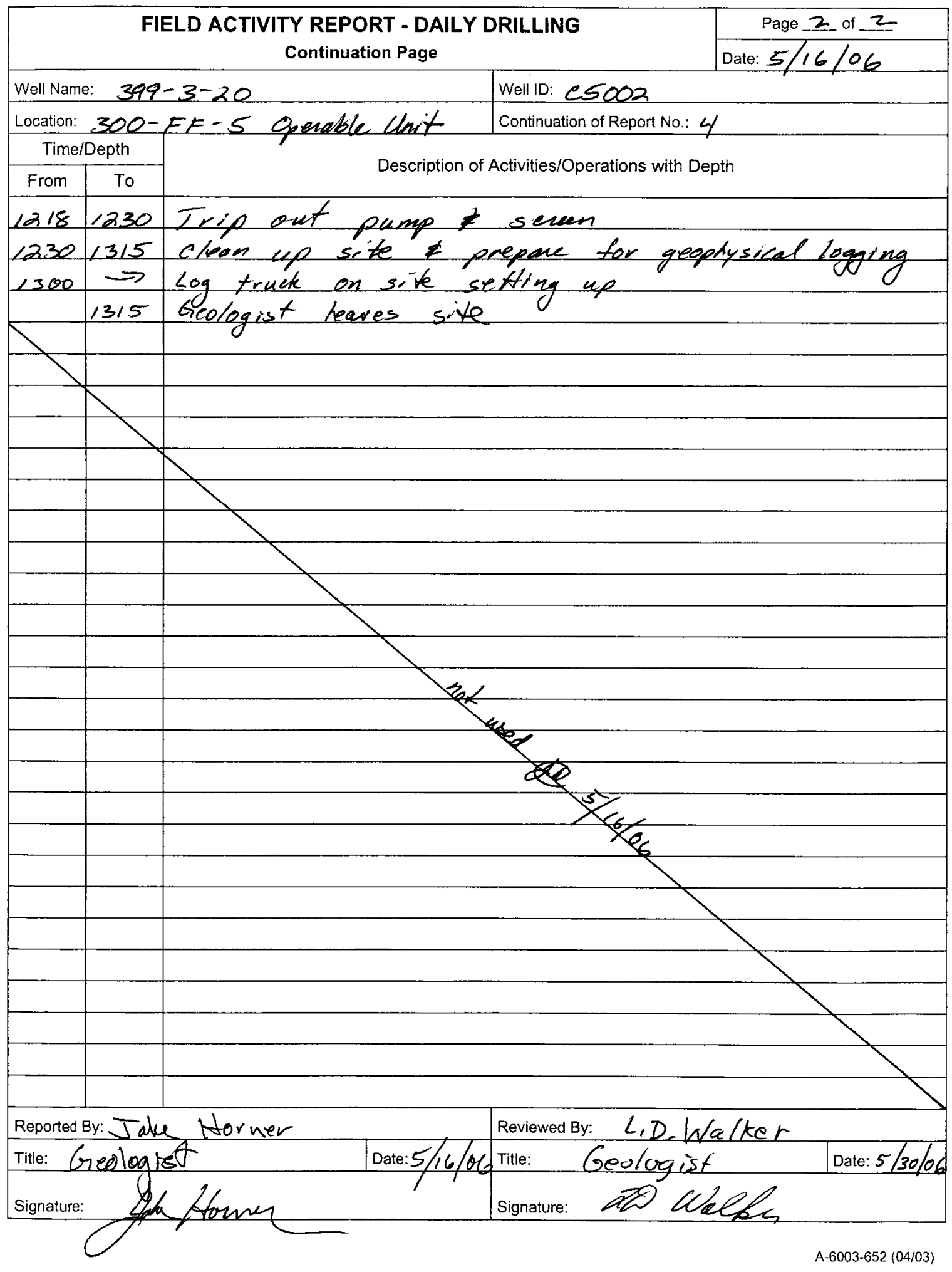

G.120 


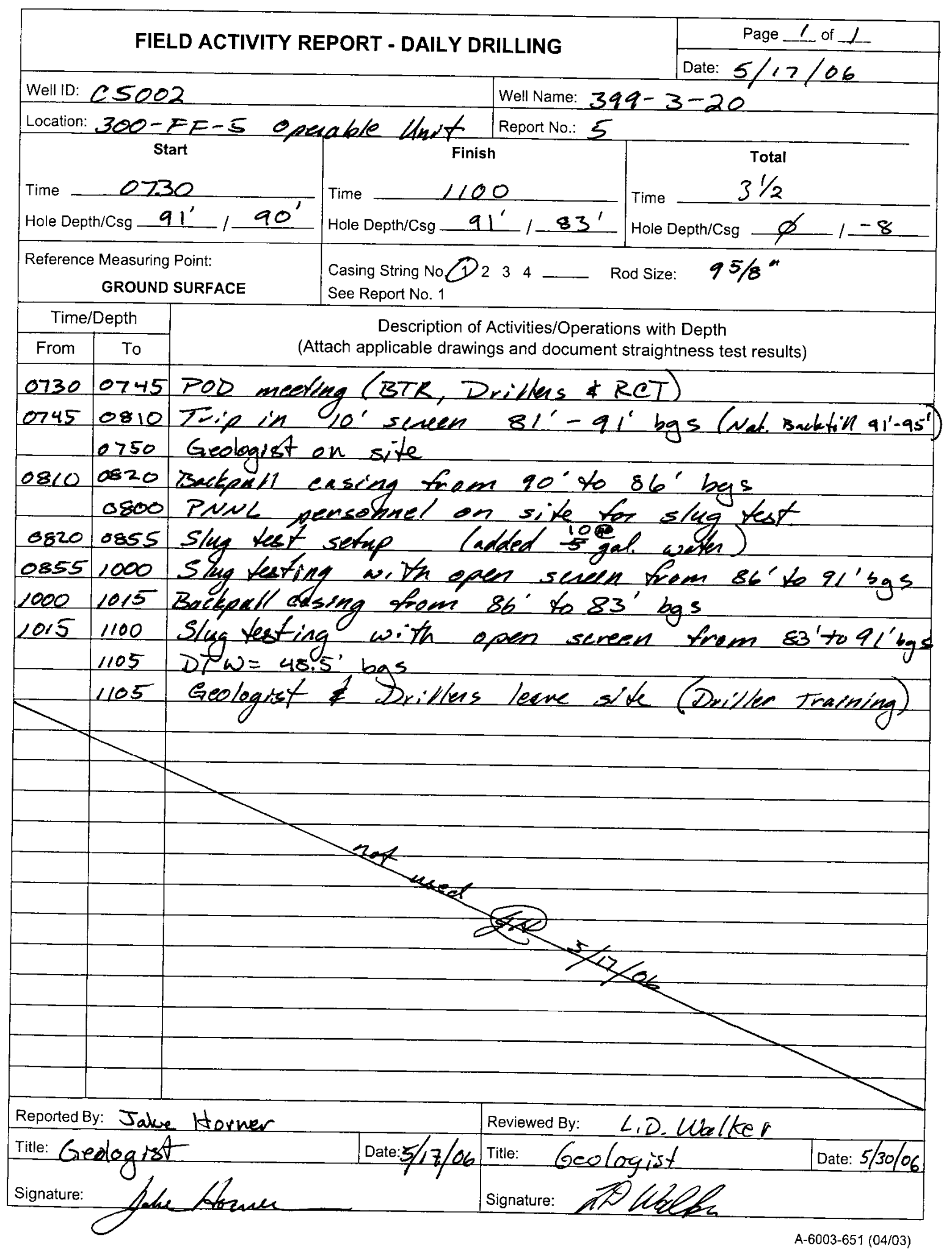




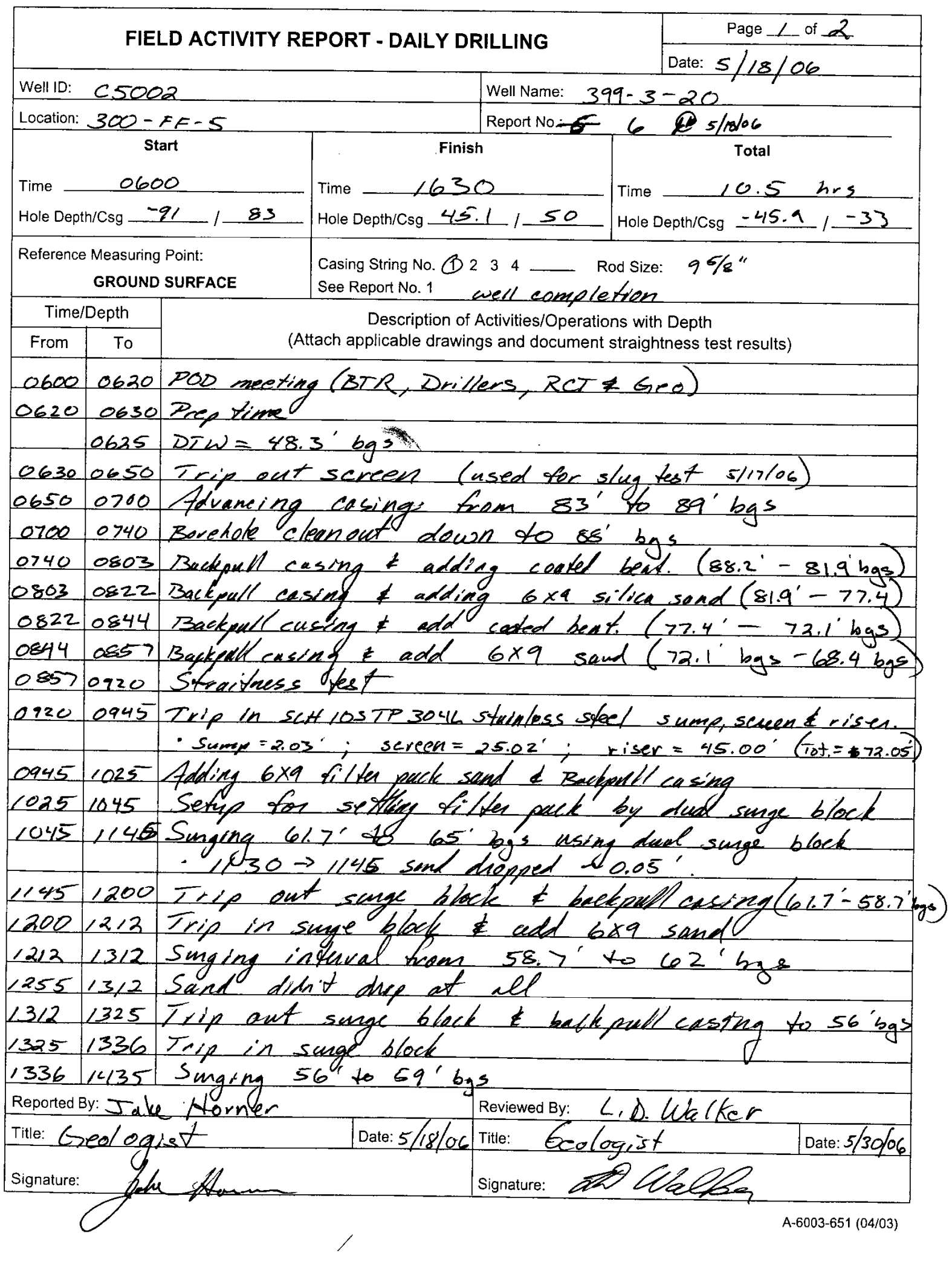




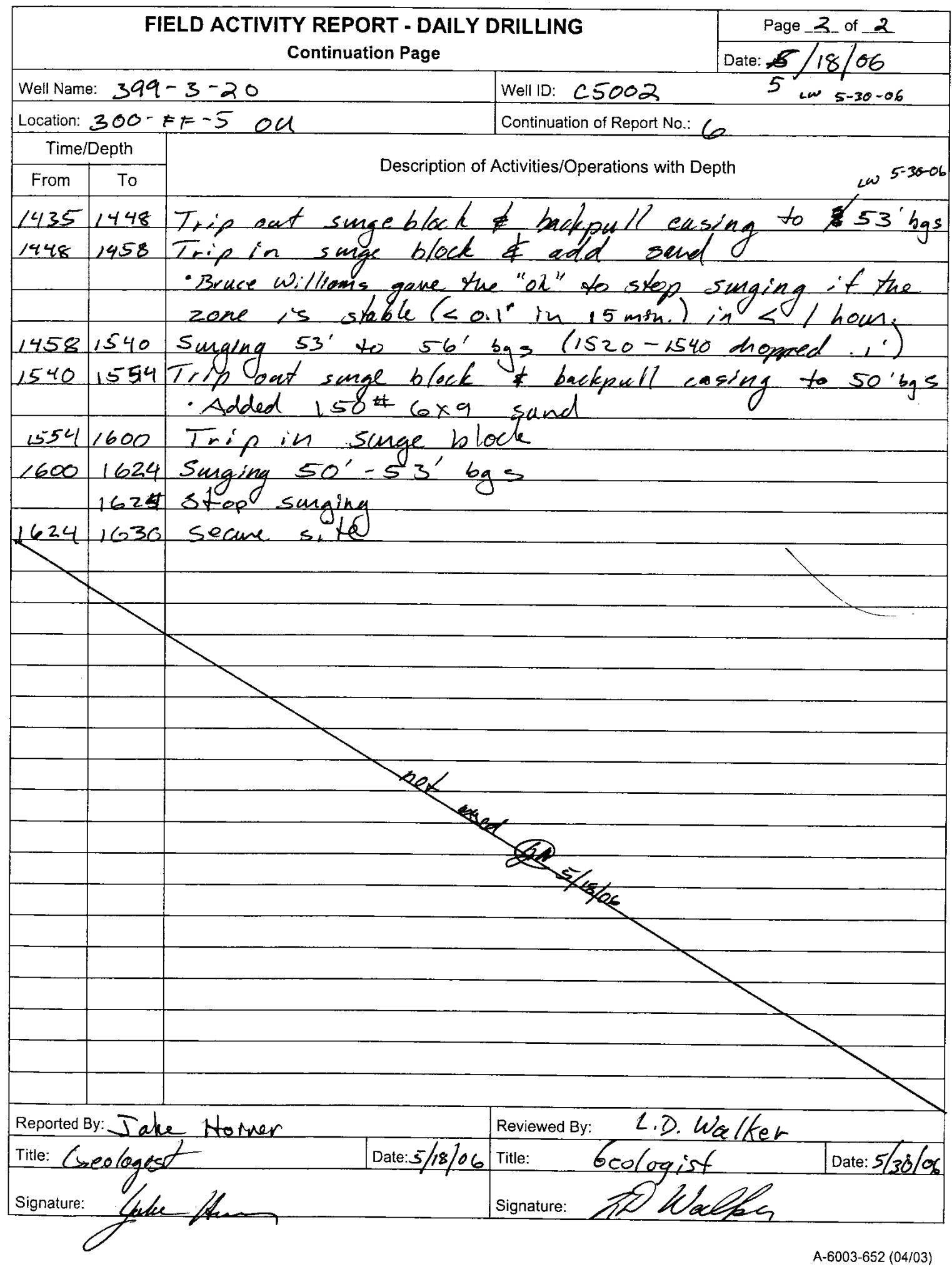

G.123 


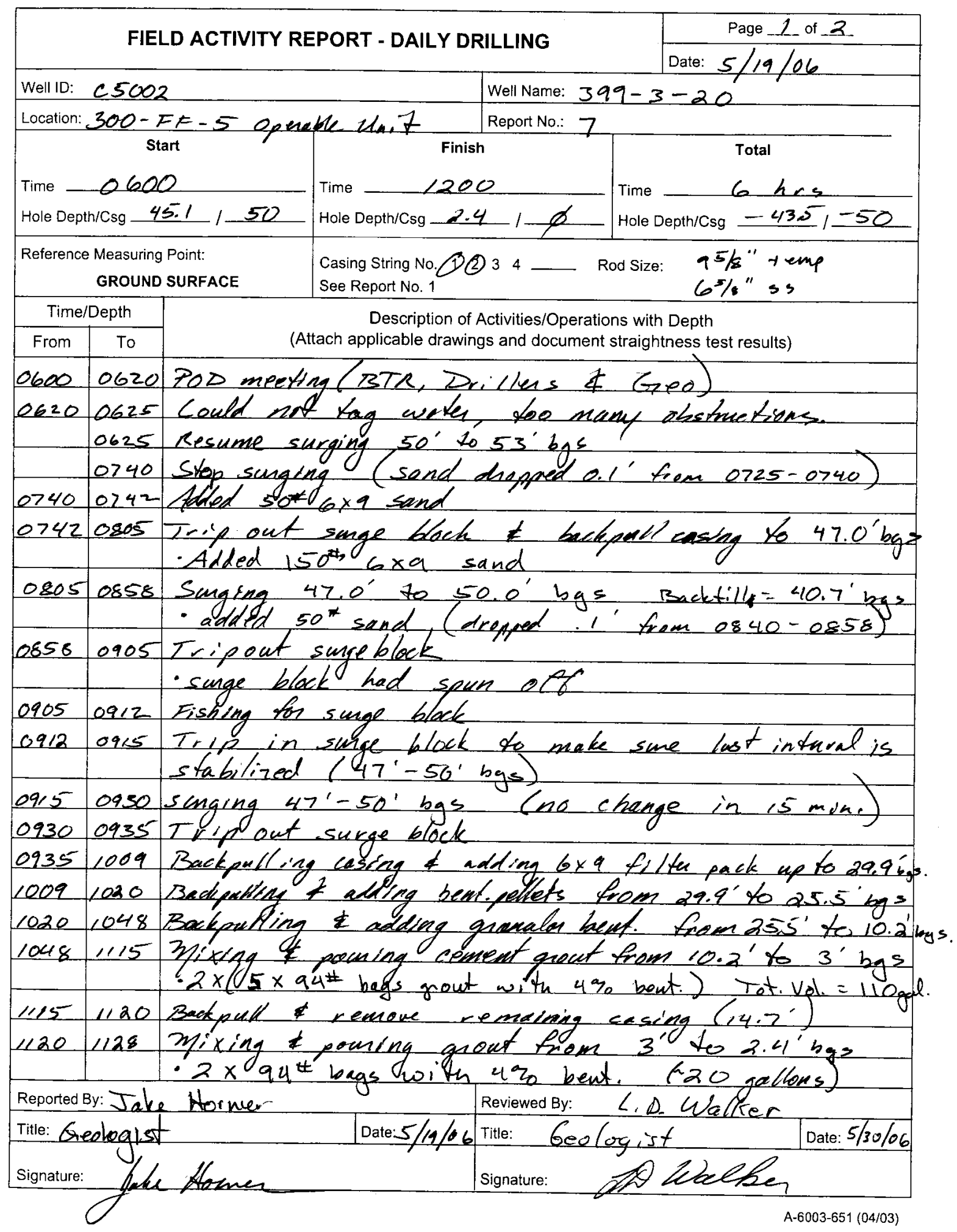




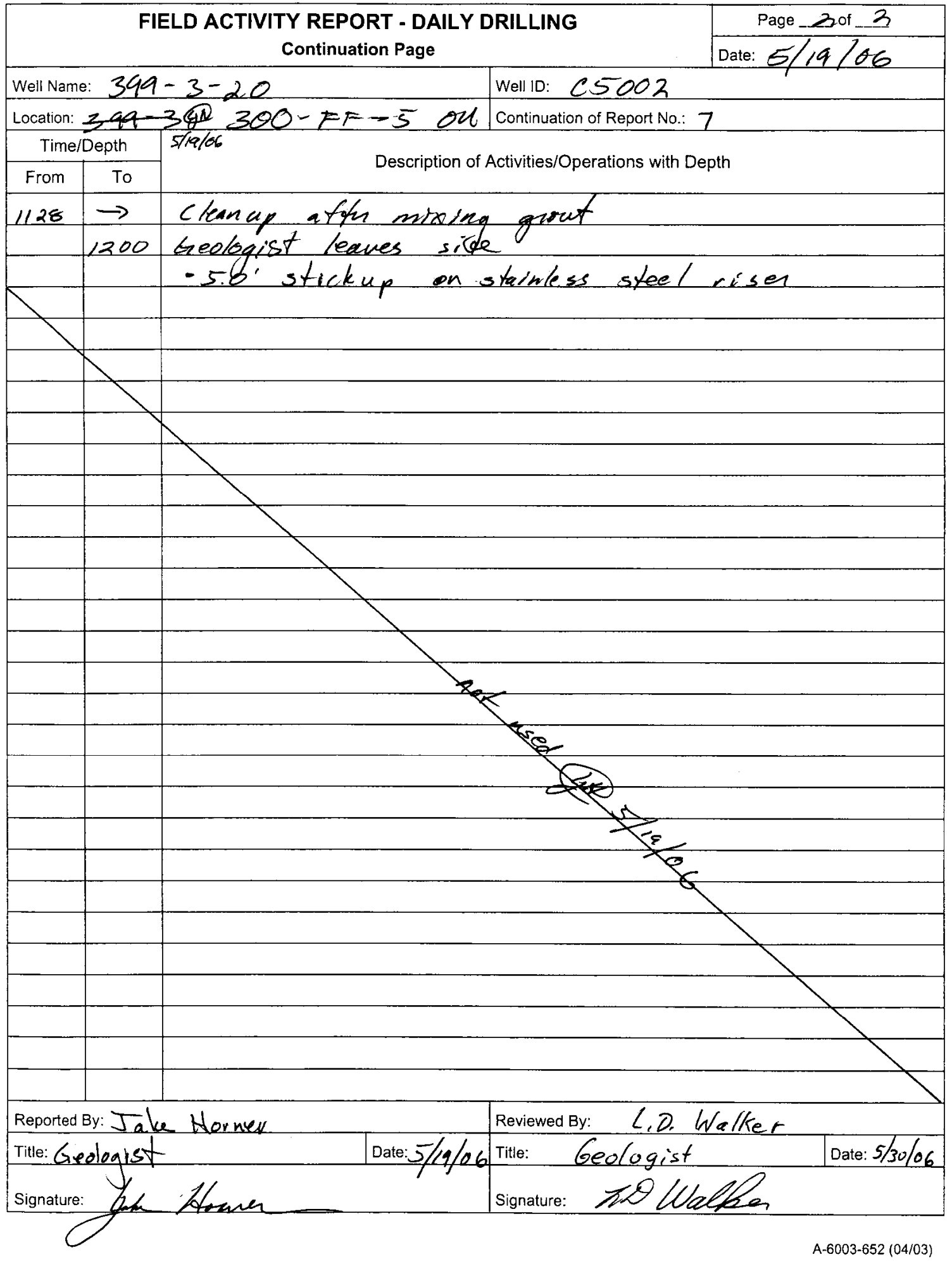




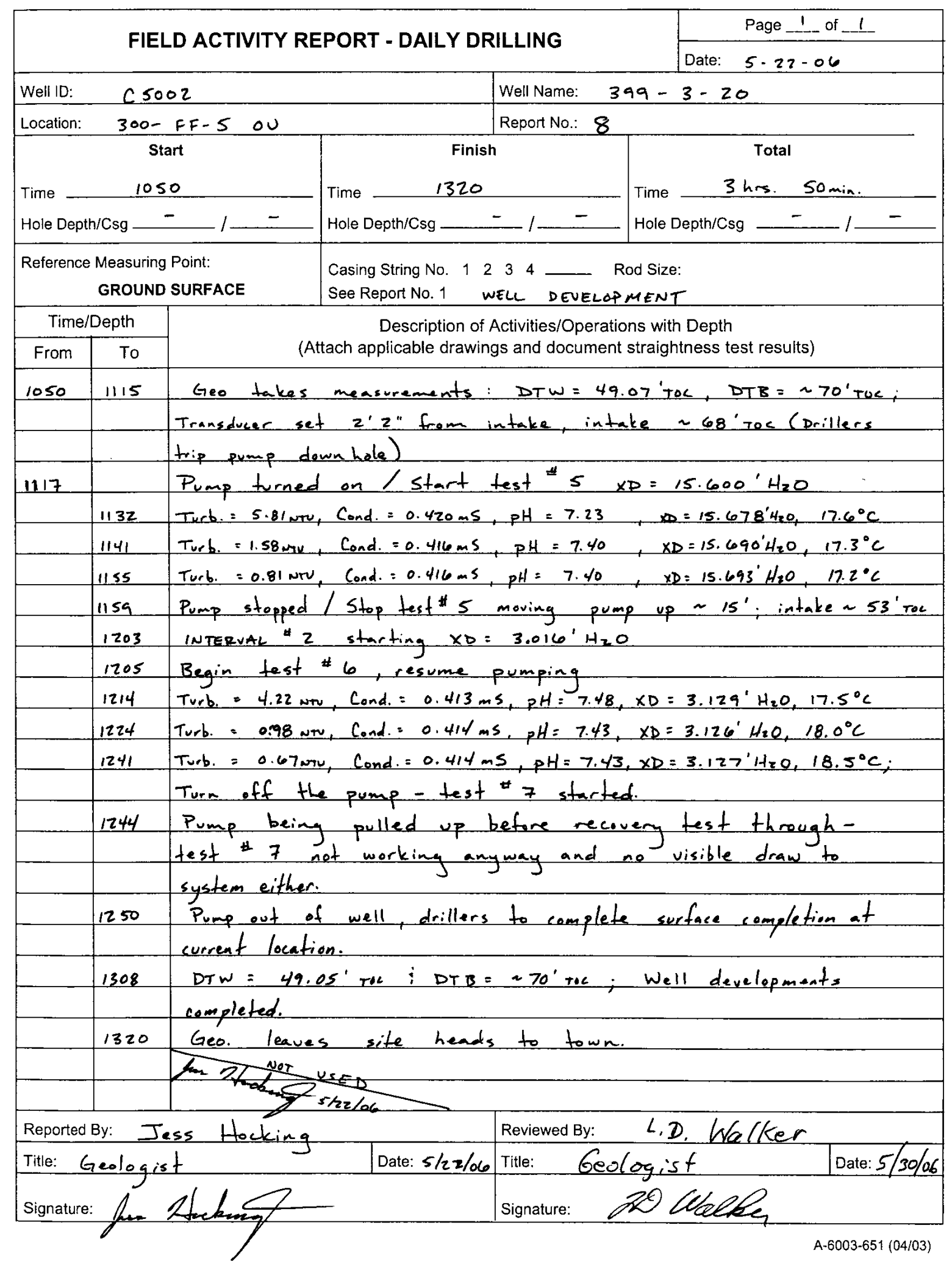




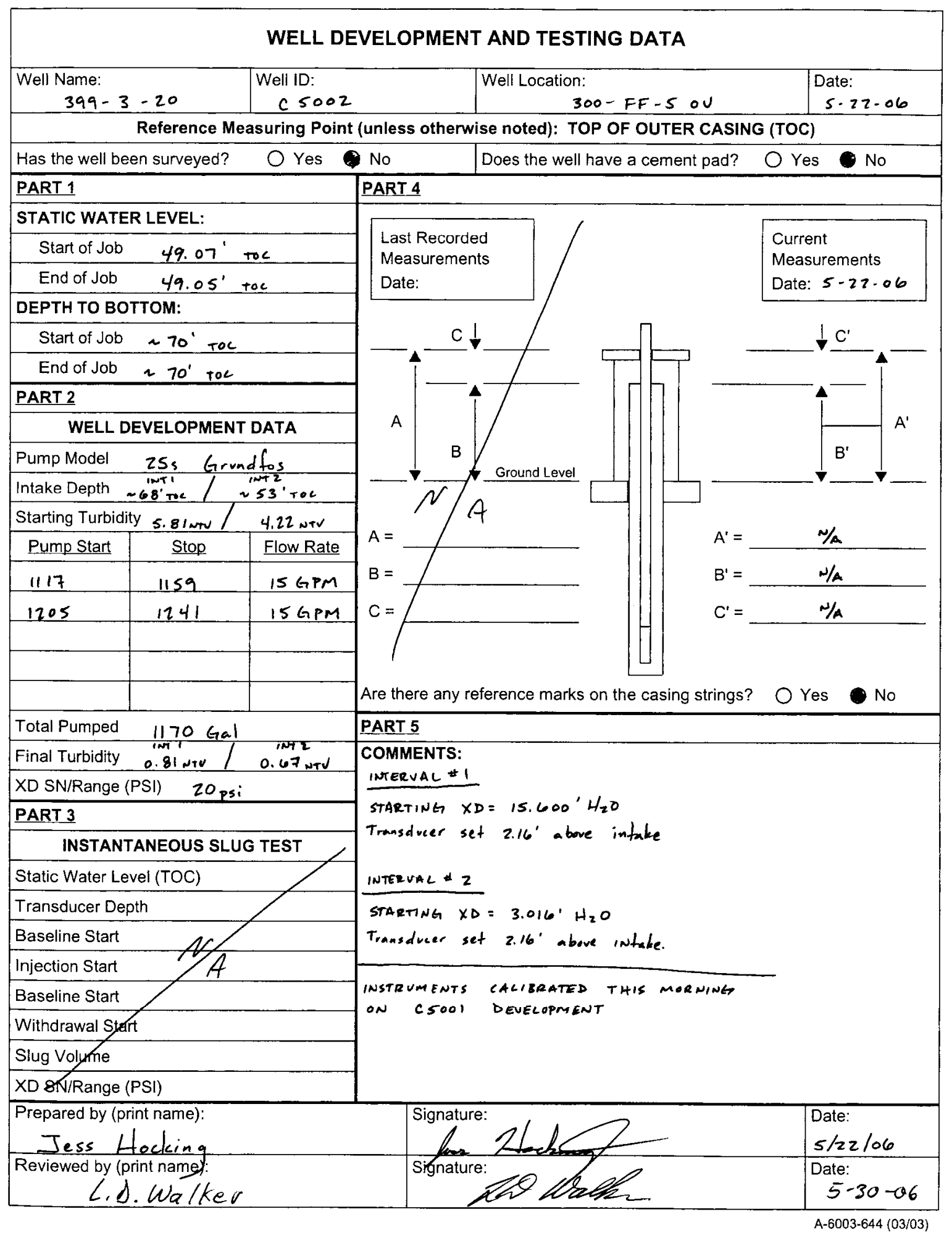




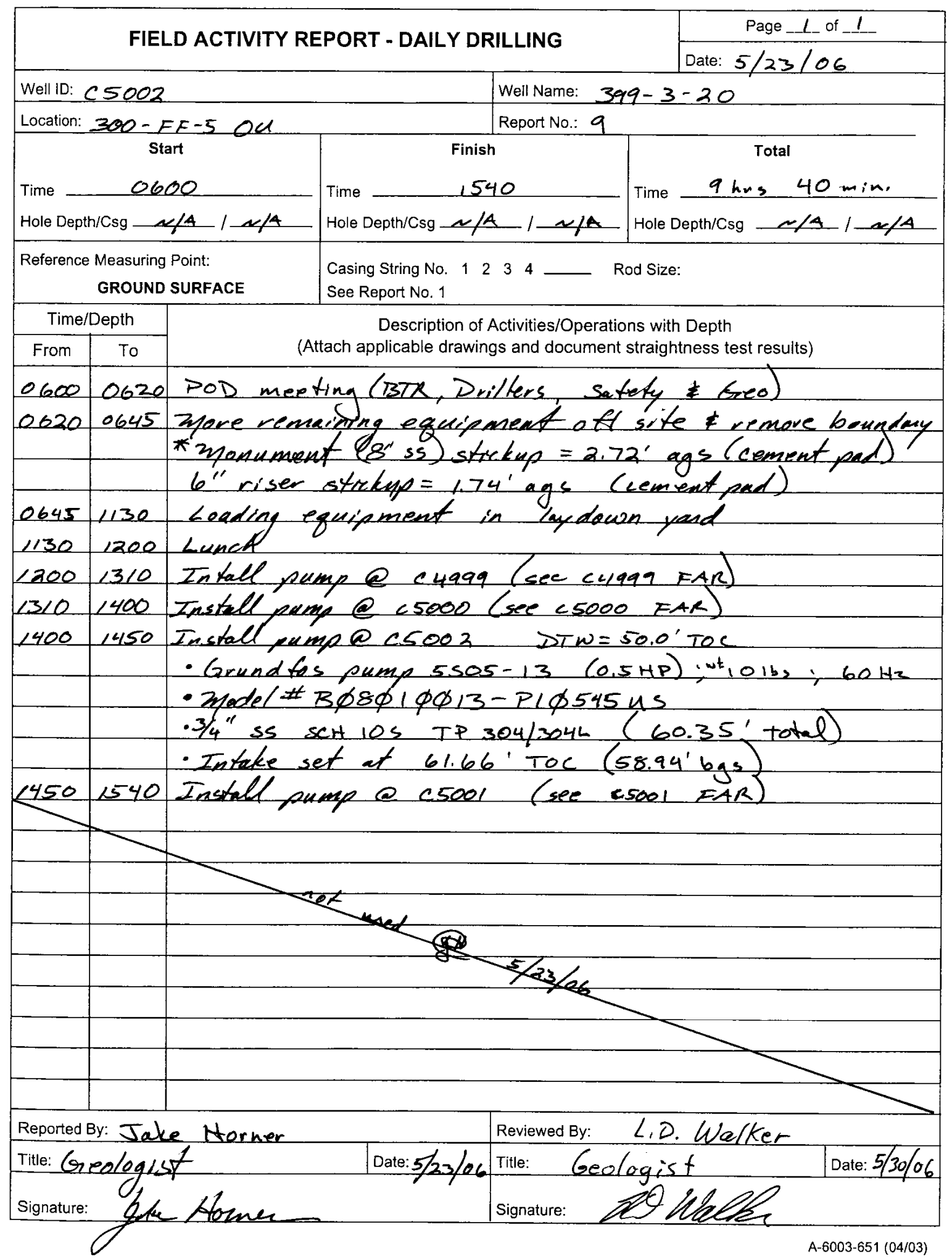




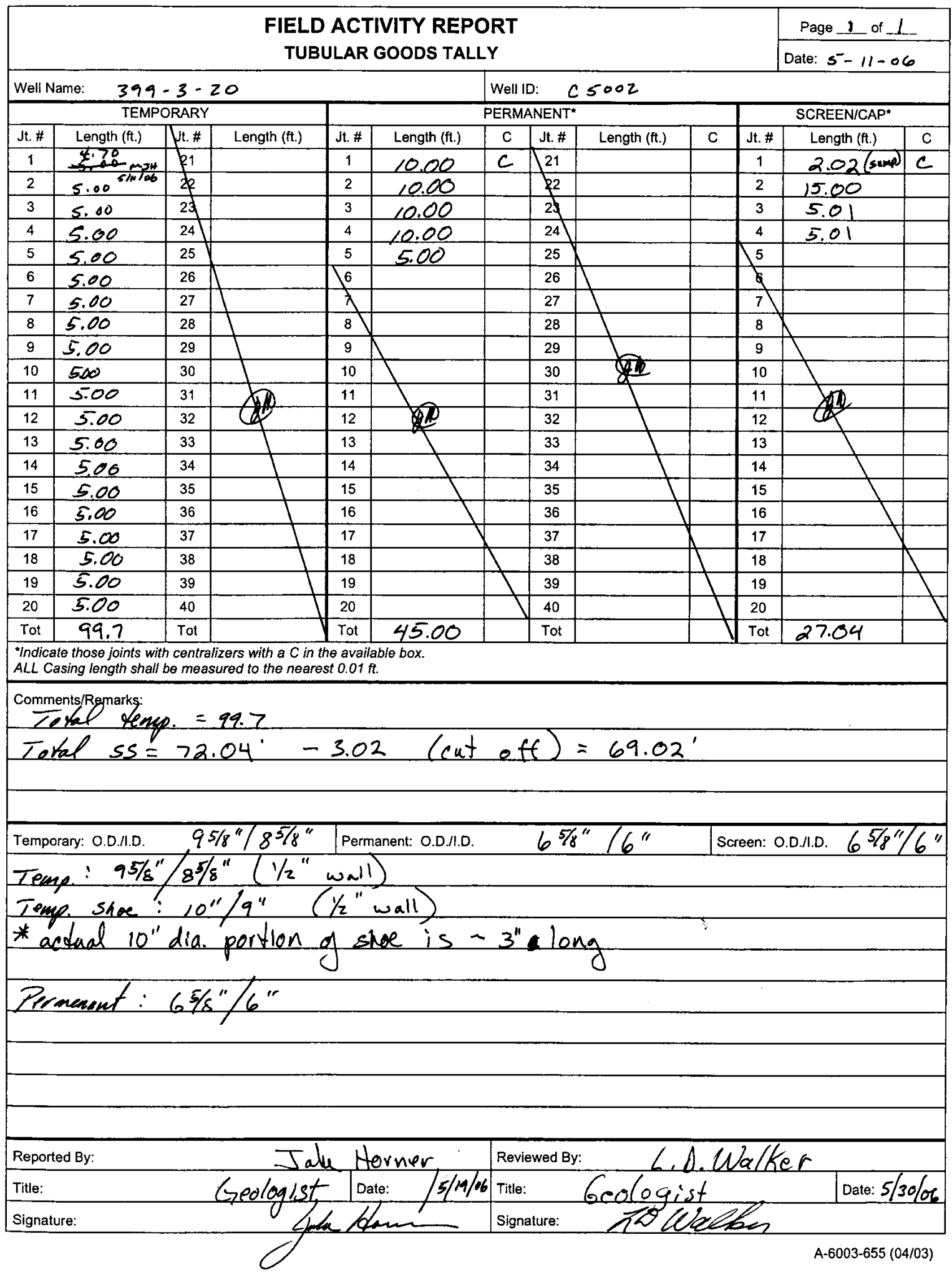




\begin{tabular}{|c|c|c|c|c|c|c|c|c|c|c|c|c|c|}
\hline \multirow{2}{*}{\multicolumn{12}{|c|}{ WELL COMPLETION LOG }} & \multirow{3}{*}{\multicolumn{2}{|c|}{$\begin{array}{r}\text { Page } / \text { of } 3 \\
\text { Date: } 5 / 18 / 06\end{array}$}} \\
\hline & & & & & & & & & & & & & \\
\hline \multirow{2}{*}{$\begin{array}{l}\text { Well ID: } \\
\text { Project: }\end{array}$} & \multicolumn{5}{|c|}{$C 5002$} & \multicolumn{6}{|c|}{ Well Name: $399 \cdot 3-20$} & & \\
\hline & \multirow{2}{*}{$\frac{E F-5}{2}$} & \multicolumn{3}{|c|}{ Moniforing Wells } & \multicolumn{6}{|c|}{ Location: $300-7 F-5$ Qperable unit } & \multicolumn{3}{|c|}{ Drilling Contractor: Cascede Dillix a } \\
\hline 1. & & 3 & $\checkmark$ & 5. & 6. & 7. & 8. & 9. & \multicolumn{3}{|c|}{ Fill Material } & \multirow{2}{*}{\multicolumn{2}{|c|}{ Comments }} \\
\hline Time & $\begin{array}{c}\text { Total } \\
\text { Casing } \\
\end{array}$ & Stkup & Btm Csg & $\begin{array}{c}\text { Tape } \\
\text { Reading } \\
\end{array}$ & Correction & \begin{tabular}{|l|}
$\begin{array}{l}\text { Cor Tape } \\
\text { Reading }\end{array}$ \\
\end{tabular} & Fill Depth & Overlap & Type & Amt & Unit & & \\
\hline 0740 & 81.7 & 0.7 & 89.0 & 94.2 & 6.0 & 88.2 & 88.2 & 0.8 & Farkitid & 6.8 & feet & stut depth & \\
\hline $0>42$ & 89.7 & 0.7 & 89.0 & 91.0 & 6.0 & 85.0 & 85.0 & 4.0 & $\begin{array}{l}3 \text { cooat. } \\
\text { bint. }\end{array}$ & 1.5 & $\begin{array}{l}5 \text { geqit } \\
\text { baket }\end{array}$ & $+3 / 8^{\prime \prime}$ coat. & bent. \\
\hline 0745 & 89.7 & $2 \cdot 5$ & 87.2 & 91.9 & 6.0 & 85.9 & 85.9 & 1.3 & $=$ & - & - & $D P$ & \\
\hline 0747 & 89.7 & 2.5 & 87.2 & 91.3 & 6.0 & 85.3 & 85.3 & 1.9 & coat: & 0.5 & $\begin{array}{l}5 \text { gall } \\
\text { Snaket }\end{array}$ & + Bent. & \\
\hline & $9^{87} 7^{4}$ & $4.0^{5.30-\infty}$ & 85.7 & 91.9 & 6.0 & 85.9 & 85.9 & -0.2 & - & - & - & SSP & \\
\hline 0754 & 89.7 & 4.0 & 85.7 & 88.9 & 6.0 & 82.9 & 82.9 & 2.8 & $\begin{array}{l}\text { Coat. } \\
\text { stent. }\end{array}$ & 2 & 5 gall & + Bent & \\
\hline 0800 & 81.7 & 5.5 & 84.2 & 89.9 & 6.0 & 83.9 & 83.9 & 0.3 & - & - & - & $B P$ & \\
\hline 0802 & 81.7 & 5.5 & $\$ 4.2$ & 88.0 & 6.0 & 82.0 & 82.0 & 2.2 & Coat. & 1 & 5 gal. & + Bent. & \\
\hline 0803 & 84.7 & 2.0 & 82.7 & 87.9 & 6.0 & 81.9 & 81.9 & -0.2 & - & - & & $B P$ & \\
\hline 0804 & 84.7 & 2.0 & 82.7 & 86.0 & 6.0 & 80.0 & 80.0 & 2.7 & $\begin{array}{l}6 \times 9 \\
\text { sand }\end{array}$ & 1 & $\begin{array}{c}100 \pm \\
\text { bag }\end{array}$ & +5 & \\
\hline 0805 & 84.7 & 3.0 & 81.7 & 87.0 & 60 & 81.0 & 81.0 & 0.7 & - & $=$ & - & $B P$ & \\
\hline 0808 & 84.7 & 3.0 & 81.7 & 85.4 & 6.0 & 79.4 & 79.4 & $2 \cdot 3$ & $\begin{array}{l}6 \times 9 \\
\text { sand }\end{array}$ & 1 & $\begin{array}{l}1007 \\
\operatorname{sug}\end{array}$ & $+s$ & \\
\hline 0810 & 84.7 & 4.7 & 80.0 & 85.1 & 6.0 & 79.1 & 79.1 & 0.9 & - & - & - & $D P$ & \\
\hline 0813 & 84.7 & 4.7 & 80.0 & 82.6 & 6.0 & 76.6 & 76.6 & 3.4 & $\begin{array}{l}6 \times 9 \\
\text { sand }\end{array}$ & 2 & $\begin{array}{l}50 \# \\
609\end{array}$ & $+5_{5-18-06}$ & \\
\hline 0817 & 84.7 & 5.7 & 79.0 & 83.1 & 6.0 & 77.1 & 77.1 & 1.9 & $\frac{6 \times 9}{\sin x}$ & 22 & $\frac{-506}{6,4}$ & $9+3 p$ & ad \\
\hline 0820 & 84.7 & 5.7 & 79.0 & 81.8 & 6.0 & 75.8 & 75.8 & 3.2 & $\begin{array}{l}6 \times 9 \\
\text { sind }\end{array}$ & 1 & 5004 & +5 & \\
\hline 0822 & 84.7 & 7.2 & $>7.0$ & 834 & 6.0 & 77.4 & 77.4 & -0.4 & - & - & - & $B P$ & \\
\hline 0825 & 84.7 & 7.2 & 77.0 & 80.7 & 6.0 & 74.7 & 74.7 & $2 \cdot 3$ & $\begin{array}{l}\text { coat. } \\
\text { sent. }\end{array}$ & 1 & sabuet & $+B$ & \\
\hline \multicolumn{14}{|c|}{ Note: Col. $2-$ Col. $3=$ Col. $4-$ Col. $5-$ weight and attachments $=$ Col. $7 ; \quad$ Col. 7 - Col. $3=$ Col. $8 ; \quad$ Col. $4-$ Col. $8=$ Col. 9} \\
\hline \multicolumn{8}{|c|}{ Reported By: Jake Hornev } & \multicolumn{6}{|c|}{ Reviewed By: $\quad L C$. Walker } \\
\hline \multirow{2}{*}{\multicolumn{8}{|c|}{ Title: Gedogist }} & \multicolumn{4}{|c|}{ Title: Geologist } & & Date: $5 / 30 / 06$ \\
\hline & & & & & & & & Signature & & $29 \quad 1$ & 10 & & \\
\hline
\end{tabular}


WELL COMPLETION LOG

Page 2 of 3

Well ID: 25002

Well Name: $399-3-20$

Project: FF-5 manitaring Wells Location: 300-FF-5 Opereble Unit Driling Contractor: Cascede Drilling

\begin{tabular}{|c|c|c|c|c|c|c|c|c|c|c|c|c|}
\hline 1. & 2. & 3. & 4. & 5. & 6. & 7. & 8. & 9. & \multicolumn{3}{|c|}{ Fill Material } & \multirow{2}{*}{ Comments } \\
\hline \multirow{2}{*}{ Time } & $\begin{array}{c}\text { Total } \\
\text { Casing }\end{array}$ & Stkup & Btm Csg & $\begin{array}{c}\text { Tape } \\
\text { Reading }\end{array}$ & Correction & $\begin{array}{c}\text { Cor Tape } \\
\text { Reading }\end{array}$ & $\begin{array}{c}\text { Fill Depth } \\
5-18-06\end{array}$ & Overlap & Type & Amt & Unit & \\
\hline
\end{tabular}

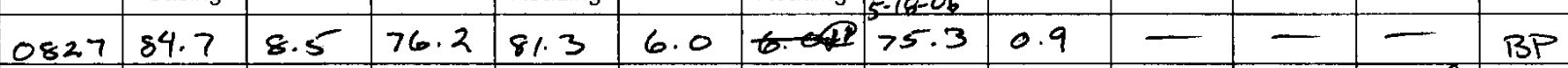

\begin{tabular}{|l|l|l|l|l|l|l|l|l|l|l|l|l}
\hline 0829 & 84.7 & 8.5 & 76.2 & 79.5 & 6.0 & 73.5 & 73.5 & 2.7 & coot. & 1 & bendef +13 \\
\hline
\end{tabular}

\begin{tabular}{l|l|l|l|l|l|l|l|l|l|l|l|l|l|l|l}
083, & 84.7 & 9.0 & 75.7 & 79.9 & 6.0 & 73.9 & 73.9 & 1.8 & - & - & $-13 P$ \\
\hline
\end{tabular}

\begin{tabular}{l|l|l|l|l|l|l|l|l|l|l|l|l|l}
083384.7 & 9.0 & 75.7 & 78.4 & 6.0 & 72.4 & 72.4 & 3.3 & coat. 1 & 5 gent. 1 is
\end{tabular}

\begin{tabular}{ll|l|l|l|l|l|l|l|l|l}
0838 & 79.7 & 5.2 & 74.5 & 78.6 & 6.0 & 72.6 & 72.6 & 1.9 & - & -1
\end{tabular}

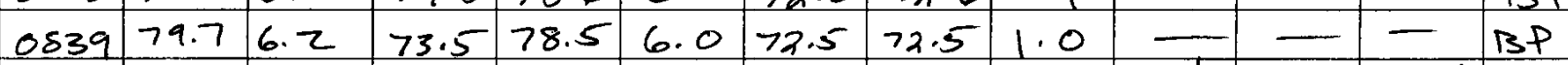

\begin{tabular}{l|l|l|l|l|l|l|l|l|l|l|l}
0841 & 79.7 & 6.2 & 73.5 & 78.1 & 6.0 & 72.1 & 72.1 & 1.4 & cont. & $1 / 3$ & 5 galient $+B$
\end{tabular}

\begin{tabular}{|c|c|c|}
\hline 0844 & 79.7 & 7. \\
\hline
\end{tabular}

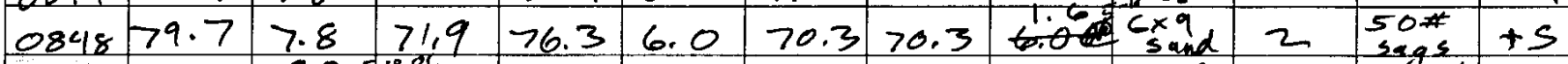

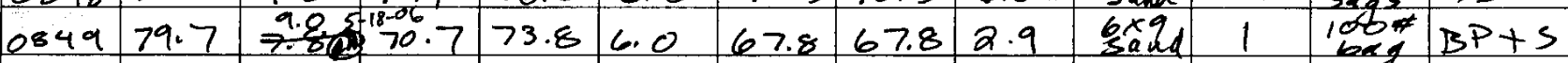

$085374.75 .5699 .274 .166 .068 .168 .11 .1-B P$

\begin{tabular}{l|l|l|l|l|l|l|l|l|l|}
0857 & 74.7 & 6.5 & 68.2 & 74.4 & 6.0 & 68.4 & 68.4 & -0.2
\end{tabular}

\begin{tabular}{lll|l|l|l|l|l|l|l|l}
0955 & 69.7 & 2.5 & 68.2 & 71.5 & 6.0 & 65.5 & 65.5 & 2.7
\end{tabular}

\begin{tabular}{ll|l|l|l|l|l|l|l|l|}
1000 & 697 & 3.0 & 66.7 & 72.4 & 6.0 & 66.4 & 66.4 & 0.3
\end{tabular}

\begin{tabular}{l|l|l|l|l|l|l|l|l|l}
1003 & 69.7 & 3.0 & 66.7 & 67.2 & 6.0 & 61.2 & 61.2 & 5.5
\end{tabular}

\begin{tabular}{l|l|l|l|l|l|l|l|l}
1006 & 69.7 & 3.5 & 66.2 & 68.5 & 6.0 & 62.5 & 62.5 & 3.7
\end{tabular}

\begin{tabular}{|l|l|l|l|l|l|l|l|l|}
1010 & 69.7 & 5.5 & 64.2 & 69.8 & 6.0 & 63.8 & 63.8
\end{tabular}

Note: Col. 2 - Col. $3=$ Col. 4 - Col. 5 - weight and attachments $=$ Col. $7 ; \quad$ Col. $7-$ Col. $3=$ Col. $8 ; \quad$ Col. $4-$ Col. $8=$ Col. 9

Reported By: Jake Horner

Title: Geologist

Signature:

\begin{tabular}{l|l} 
& Reviewed By: L.D. Walker \\
\hline & Tite: Gedogist \\
& Signature: NLO Clat
\end{tabular}




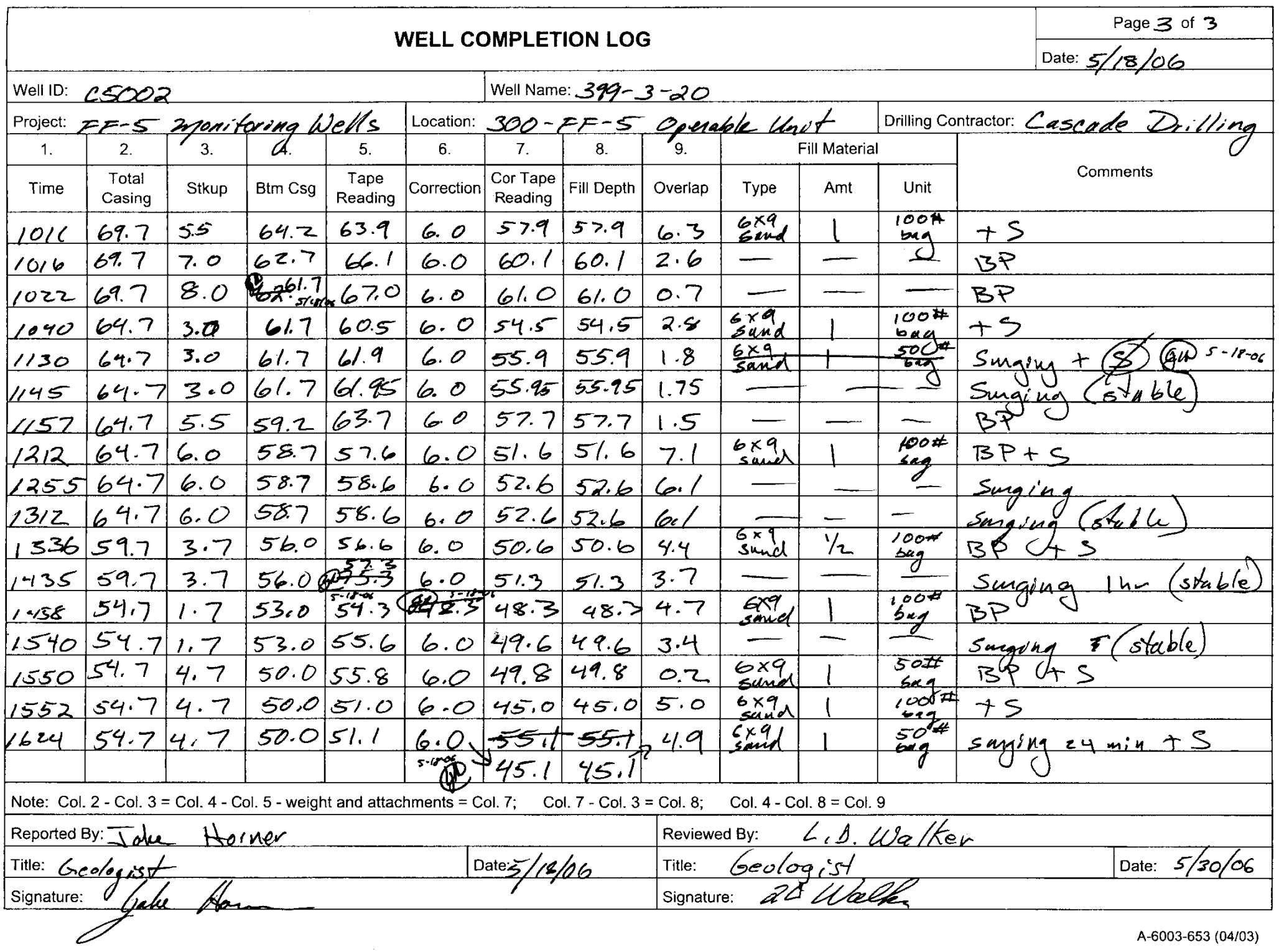




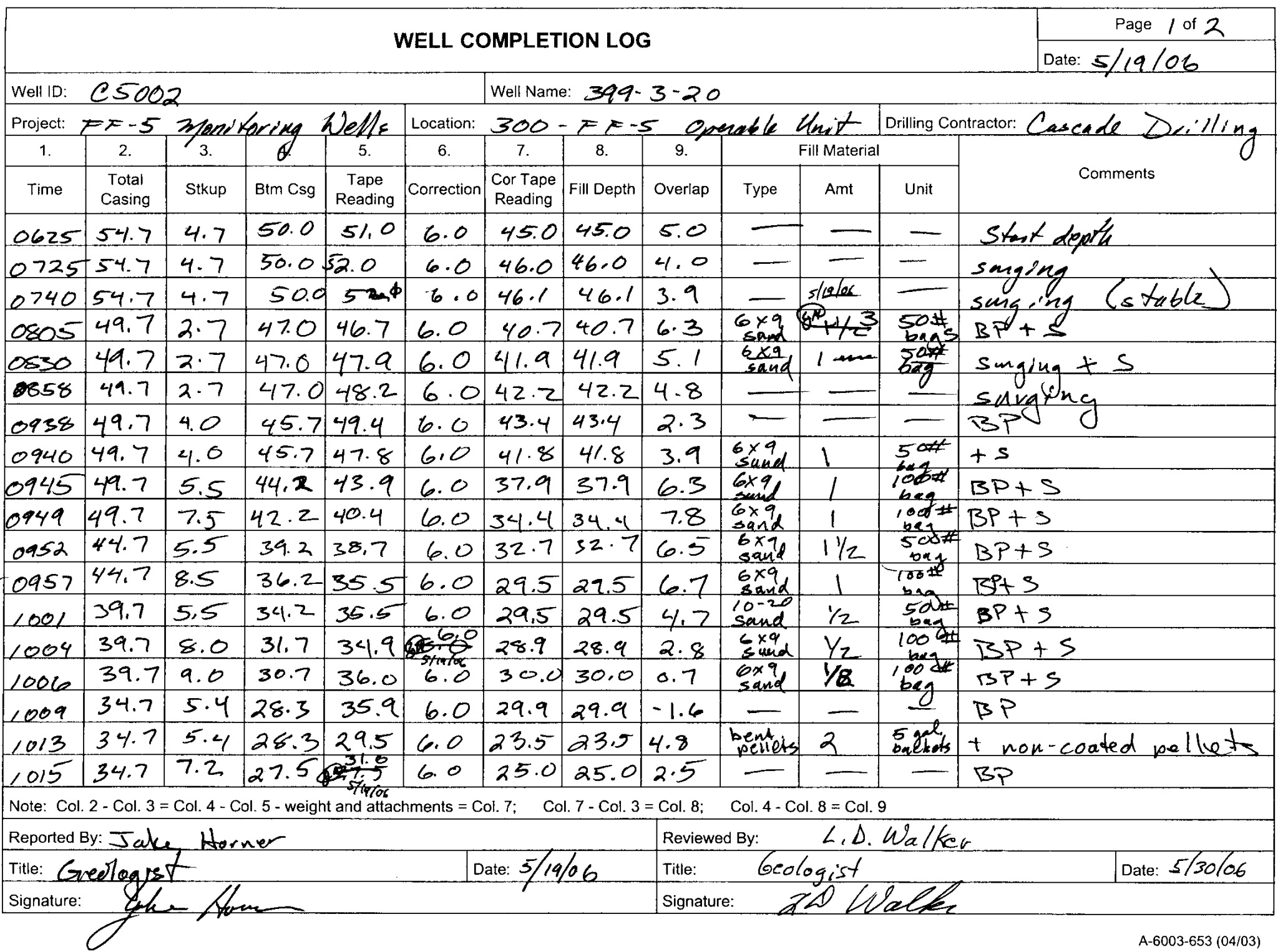




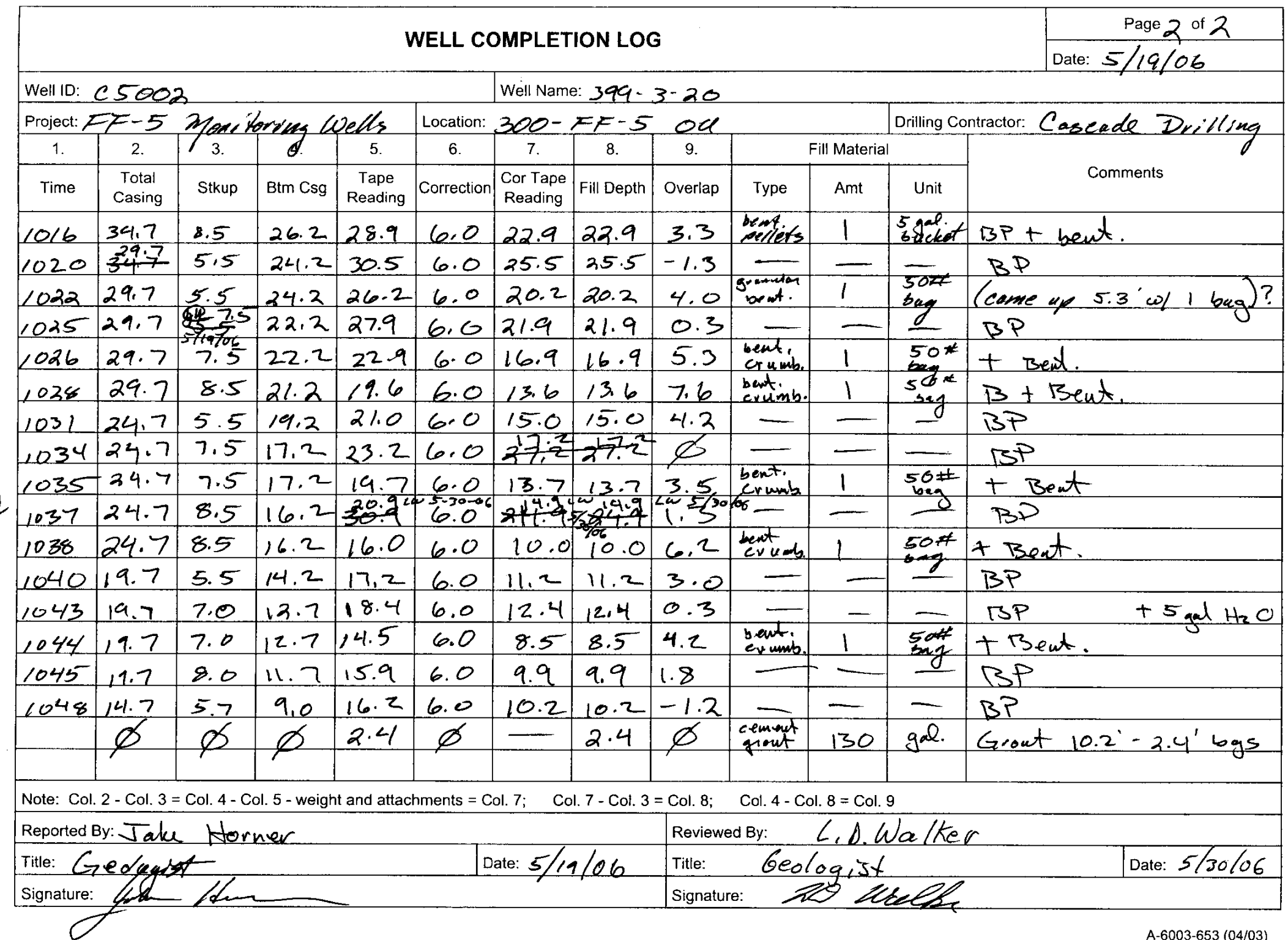




\section{Construction Surveillance Reports}

\section{Well C4999}

Page 1 of 2

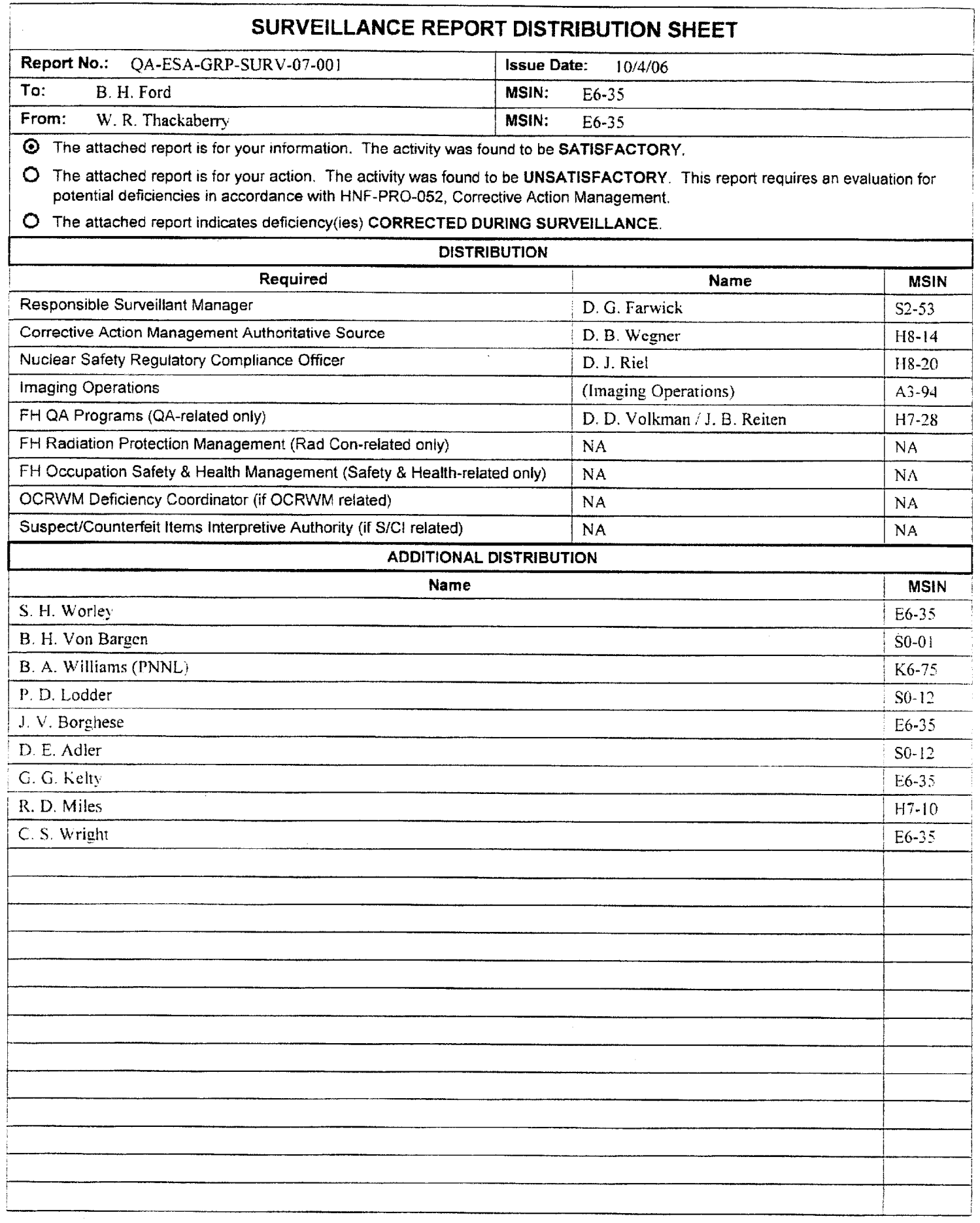


Page 2 of 2

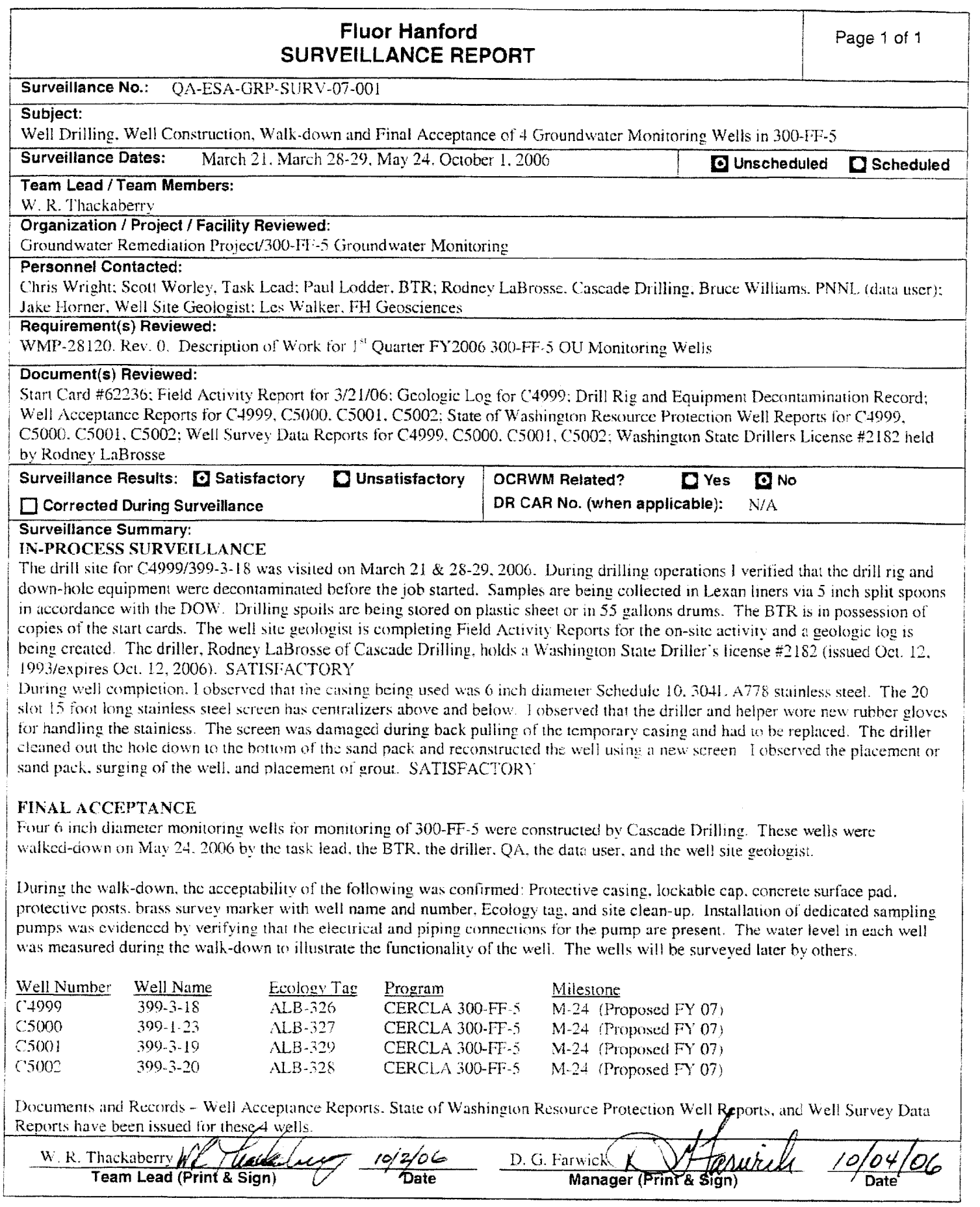




\section{Distribution}

No. of

Copies

ONSITE

20 DOE Richland Operations Office

K. M. Thompson (20P)

A6-38

6 Fluor Hanford, Inc.

J. V. Borghese (P/3CD)

J. W. Lindberg (P)

L. C. Swanson (P)

B. A. Williams (3P)
No. of

Copies

18 Pacific Northwest National Laboratory

B. N. Bjornstad (P) K6-81

C. F. Brown (P) P7-22

M. D. Freshley (P) K9-33

D. C. Lanigan (P) K6-75

R. E. Peterson (P) K6-75

M. L. Rockhold (P) K9-36

R. J. Serne (P) P7-22

R. M. Smith (P/5CD) K6-96

F. A. Spane (P) K6-96

P. D. Thorne (P) K6-96

W. Um (P) P7-22

V. R. Vermeul (P) K6-96

A. L. Ward (P) K9-33

M. D. Williams (P) K6-96

S. B. Yabusaki (P) K9-36

J. M. Zachara (P) K8-96

Hanford Technical Library (2P) P8-55
$\mathrm{CD}=\mathrm{CD}-\mathrm{ROM}$

$\mathrm{P}=$ Paper Copy plus CD-ROM inside 